Floods of

August 1940

in the

Southeastern States

Prepared by W A T E R R E OUR C E B R A CH

GEOLOGICAL S URVEY WATER - S UPPLY PA PER 1066

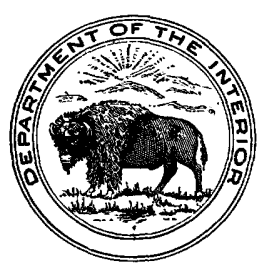


UNITED STATES DEPARTMENT OF THE INTERIOR

J. A. Krug, Secretary

GEOLOGICAL SURVEY

W. E. Wrather, Director

FOR SALE BY

SUPERINTENDENT OF DOCUMENTS, U. S. GOVERNMENT PRIN'TING OFFICE WASHINGTON 25, D. C.

Price $\$ 2.75$ 


\section{CONTENTS}

Fage

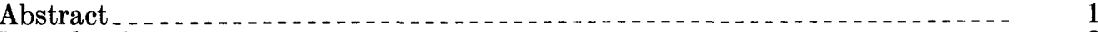

Introduction

Administration and personnel

Acknowledgments . . .

General features of the storms and floods

Mid-August storm . . .

Late-August storm

Mid-August flood

Late-August flood

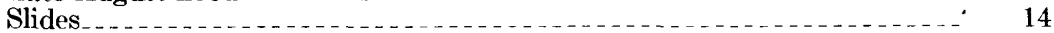

Damage . . .

Meteorologic and hydrologic conditions .

Antecedent conditions

Precipitation ...

Mid-August storm 20

Precipitation records 20

Distribution of precipitation $\ldots$

Late-August storm .

Area-depth-duration relations

Measurement of flood discharges

Stages and discharges at stream-gaging stations

Explanation of data $\ldots \ldots$

Definitions of terms

Gaging-station records

Station description

Mean discharge

Gage height and discharge at indicated times

James River Basin . . 81

Jackson River at Falling Spring, Va.

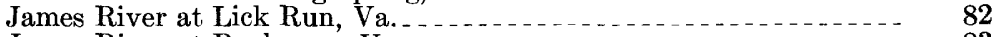

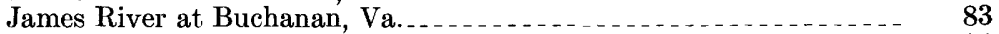

James River at Holcombs Rock, Va...... 84

James River at Bent Creek, Va...... 86

James River at Scottsville, Va..... 87

James River at Cartersville, Va. . . .

James River near Richmond, Va............ 90

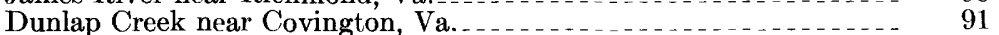

Potts Creek near Covington, Va..... 92

Cowpasture River near Clifton Forge, Va... 93

Craig Creek at Parr, Va..... 95

Meadow Creek at Newcastle, Va.

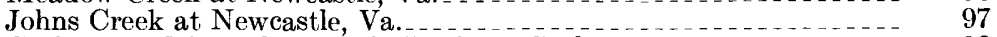

Calfpasture River above Mill Creek, at Goshen, Va. .

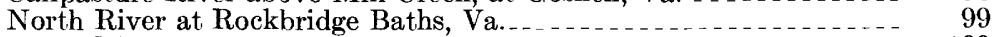

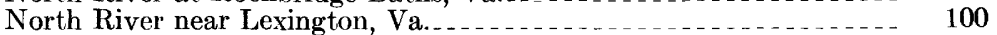

North River near Buena Vista, Va...................... 101

Kerrs Creek near Lexington, Va.

Buffalo River near Norwood, Va...... 104

Tye River near Lovingston, Va...... 105

Hardware River below Briery Run, near Scottsville, Va.......... 106

Slate River near Arvonia, Va......... 107

Rivanna River at Palmyra, Va. 108

Willis River at Flanagan Mills, Va......... 109

James River \& Kanawha Canal near Richmond, Va. . .

Appomattox River at Farmville, Va. . .

Appomattox River at Mattoax, Va._. $\ldots \ldots \ldots \ldots \ldots$

Appomattox River near Petersburg, Va.

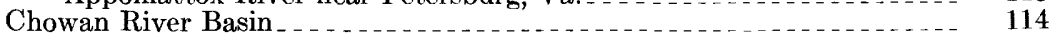

Nottoway River near Stony Creek, Va.

Meherrin River near Lawrenceville, Va. 116

Roanoke River Basin $\ldots \ldots \ldots 17$

Roanoke River at Roanoke, Va. 117

Roanoke River at Niagara, Va....... 119 
Stages and discharges at stream-gaging stations-Continued

Roanoke River Basin-Continued

Roanoke River near Toshes, Va.

- Roanoke River at Altavista, Va. .

Roanoke River at Brookneal, Va. . .

Roanoke River near Clover, Va.

Roanoke River at Clarksville, Va.

Roanoke River at Roanoke Rapids, N. C.

Roanoke River near Scotland Neck, N. C.

Blackwater River near Union Hall, Va.

Pigg River near Toshes, Va.

Snow Creek at Sago, Va.

Goose Creek near Huddleston, Va. .

Otter River near Evington, Va.

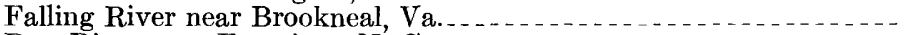

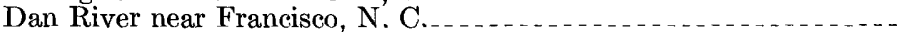

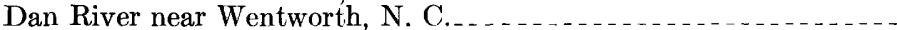

Dan River at Leaksville, N. C. . . . . . .

Dan River at Danville, Va.

Dan River at South Boston, Va.

Mayo River near Price, N. C. .

North Mayo River near Spencer, Va.

Smith River at Bassett, Va.

Smith River at Martinsville, Va.

Smith River at Spray, N. C....

Sandy River near Danville, Va.

Banister River at Halifax, Va.

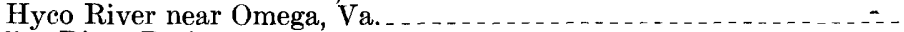

Pamlico River Basin

Tar River near Tar River, N. C

Tar River near Nashville, N. C.

Tar River at Tarboro, N. C.

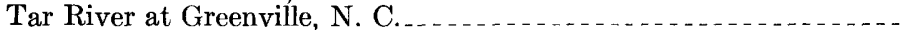

Fishing Creek near Enfield, N. C.

Neuse River Basin

Fno River at Hillsboro N. C.

Neuse River near Northside, N. $\mathrm{C}$

Neuse River near Clayton, N. C.

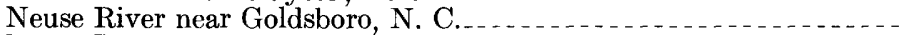

Neuse River at Kinston, N. C.

Flat River at Bahama, N. C. . .

Flat River at dam near Bahama, N. C.

Dial Creek near Bahama, N. C.

Middle Creek near Clayton, N. C. . . . . . . . . . . . . . . .

Iittle River near Princeton, N. C.

Contentnea Creek near Wilson, N. C.

Contentnea Creek at Hookerton, N. C. . . . . . . . . .

Cape Fear River Basin

Haw River near Benaja, N. C.......................... 167

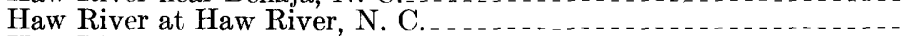

Haw River near Pittsboro, N. C.

Cape Fear River at Lillington, N. C.

Cape Fear River at Fayetteville, N. C. . . .

Cape Fear River at lock 3 near Tarheel, N. C.

Reedy Fork near Gibsonville, N. C.

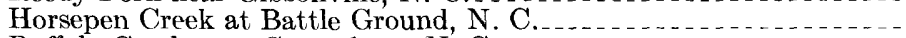

Buffalo Creek near Greensboro, N. C. C.

North Buffalo Creek near Greensboro, N. C. . . . . . . . . . . . . .

West Fork Deep River near High Point, N. C.

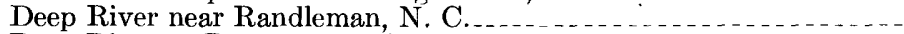

Deep River at Ramseur, N. C.

Deep River at Moncure, N. C

East Fork Deep River near High Point, N. C. 175

Muddy Creek near Archdale, N. C.

Bear Creek at Robbins, N. C. .

Lower Little River at Manchester, N. C. 
Stages and discharges at stream-gaging stations-Continued

Capє Fear River Basin-Continued

Lower Little River at Linden, N. C.

Rockfish Creek near Hope Mills, N. C. .

Northeast Cape Fear River near Chinquapin, N. C. . _ _

Waccamaw River Basin

Waccamaw River at Freeland, N. C.

Middle Swamp near Elkton, N. C.

Beaverdam Swamp at Lebanon, N. C.

Pee Dee River Basin

Yadkin River at Patterson, N. C.

Yadkin River at Wilkesboro, N. C.

Yadkin River at Yadkin College, N. C.

Yadkin River at High Rock Reservoir, at High Rock

Yadkin River at Narrows Reservoir, near Badin, N. C.

Pee Dee River at Tillery Reservoir, near Norwood, N. C. . . . . . . .

Pee Dee River near Ansonville, N. C.

Pee Dee River at Blewett Reservoir, near Rockingham, N. C. . .

Pee Dee River near Rockingham, N. C. . . .

Pee Dee River near Mars Bluff, S. C.

Reddies River at North Wilkesboro, N. C. .

Fisher River near Copeland, N. C.

Little Yadkin River near Donnaha, N. C.

Forbush Creek near Yadkinville, N. C.

Reedy Creek near Yadkin College, N. C.

Dutchman Creek near Cornatzer, N. C.

South Yadkin River near Mocksville, N. C.

South Yadkin River at Cooleemee, N. C. . .

Rocky River at Turnersburg, N. C.

Third Creek at Cleveland, N. C.

Abbotts Creek at Lexington $\mathrm{N}$.

Fourmile Branch near Southmont

Uwharrie River near Trinity, N. C.

Uwharrie River near Eldorado, N. C.

Rocky River near Norwood, N. C.

Richardson Creek near Marshville, N. C.

Brown Creek near Polkton, N. C.

Little Brown Creek near Polkton, N. C.

Mountain Creek near Ellerbe, N. C. . . .

North Fork Jones Creek near Wadesboro, N. C.

Juniper Creek near Cheraw, S. C. . . .

Lynches River at Effingham, S. C.

Little Pee Dee River near Dillon, S. C.

Drowning Creek near Hoffman, N. C.

Lumber River at Boardman, N. C. . .

Deep Creek near Roseland, N. C. .

Little Raft Swamp at Red Springs, N. C.

Black River at Kingstree, S. C. .

Santee River Basin

Catawba River at Bridgewater Reservoir, near Bridgewater, N. C.-- 219

Catawba River at Rhodhiss Reservoir, at Rhodhiss, N. C. . . . . 221

Catawba River at Oxford Reservoir, near Taylorsville, N. C. . ... 223

Catawba River at Lookout Shoals Reservoir, near Catawba, N. C.-- 225

Catawba River at Catawba, N. C. . . . . . . . .

Catawba River at Mountain Island Reservoir, near Mount Holly, N.C. 229

Catawba River at Catawba Reservoir, near Rock Hill, S. C..... 231

Catawba River at Fishing Creek Reservoir, near Great Falls, S. C.-- 233

Catawba River at Rocky Creek Reservoir, near Great Falls, S. C.-- 235

Wateree River at Wateree Reservoir, near Camden, S. C. . . . . . 237

Wateree River near Camden, S. C. . 239

Santee River at Ferguson, S. C. 239

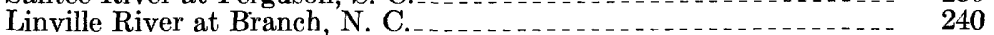

Little Sugar Creek near Charlotte, N. C.

Broad River near Chimney Rock, N. C.

Broad River near Boiling Springs, N. C. .

Broad River near Gaffney, S. C. 244 
Stages and discharges at stream-gaging stations - Continued

Santee River Basin-Continued

Broad River near Carlisle, S. C.

Broad River at Richtex, S. C.

Green River near Mill Spring, N. C.

Second Broad River at Cliffside, N. C................. 248

First Broad River near Lawndale, N. C. . . .

North Pacolet River at Fingerville, S. C. . _ _ _ _ _ _ _ _ 251

Pacolet River near Fingerville, S. C.

Pacolet River near Clifton, S. C.

South Pacolet River Reservoir near Fingerville, S. C. ........... 253

North Tyger River near Moore, S. C. _. _ .

Tyger River near Woodruff, S. C. . $\ldots \ldots \ldots \ldots \ldots$

Middle Tyger River at Lyman, S. C. $\ldots$

South Tyger River near Reidville, S. C. $\ldots \ldots \ldots \ldots \ldots$

South Tyger River near Woodruff, S. C. _........ 258

Fair Forest Creek near Union, S. C.

Enoree River near Enoree, S. C. . . . .

Saluda River near Pelzer, S. C.

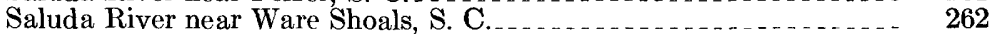

Lake Greenwood near Chappells, S. C...... $\ldots \ldots \ldots \ldots$

Saluda River at Chappells, S. C.

Saluda River near Silverstreet, S. C.

Lake Murray near Columbia, S. C. . . . . . . . . . . . . . . . . 266

Saluda River near Columbia, S. C.

Reedy River near Ware Shoals, S. C. . $\ldots \ldots \ldots$

Edisto River Basin .........

South Fork Edisto River near Montmorenci, S. C. $\ldots \ldots \ldots . . . . . .269$

South Fork Edisto River near Denmark, S. C. . . _ _ _ _ _ _ _ _ 269

Edisto River near Givhans, S. C.

North Fork Edisto River at Orangeburg, S. C.

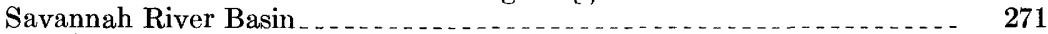

Chattooga River near Clayton, Ga.

Tugaloo River near Hartwell, Ga.......... 272

Savannah River near Calhoun Falls, S. C..............................

Savannah River at Augusta, Ga................................. 276

Savannah River at Burtons Ferry Bridge, near Millhaven, Ga.... . . 277

Savannah River near Clyo, Ga._. . . . . . . . . . . . . . . . . . 278

Keowee River near Newry, S. C.

Seneca River near Anderson, S. C. . .

Broad River near Bell, Ga.. . . . . . . . . . . . . . . . . . . . 283

Little River near Mount Carmel, S. C. . . . . . . . . . . . . . . . . 284

Stevens Creek near Modoc, S. C.

Brier Creek at Millhaven, Ga........................... 286

Ogeechee River Basin

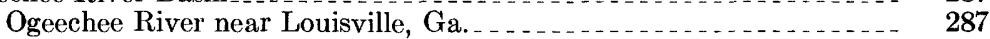

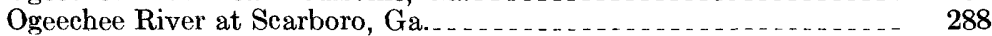

Ogeechee River near Eden, Ga. ......................... 288

Canoochee River near Claxton, Ga.................. 289

Altamaha River Basin . . . .

Oconee River near Greensboro, Ga....... 289

Oconee River at Milledgeville, Ga. . . .

Oconee River at Dublin, Ga........................... 290

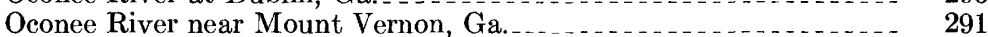

Middle Oconee River near Athens, Ga................ 291

Ohoopee River near Reidsville, Ga.................. 292

Apalachicola River Basin ............................ 292

Chattahoochee River near Leaf, Ga............................ 292

Chattahoochee River near Gainesville, Ga.................. 293

Chattahoochee River near Vinings, Ga................ 295

Chattahoochee River near Whitesburg, Ga............ 295

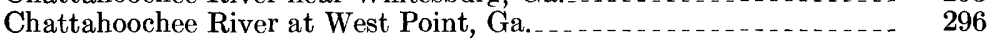

Soque River near Demorest, Ga.

Sweetwater Creek near Austell, Ga.......... 299 
Stages and discharges at stream-gaging stations-Continued

Kanawha River Basin. .300

South Fork New River near Jefferson, N. C.

New River near Galax, Va......... 301

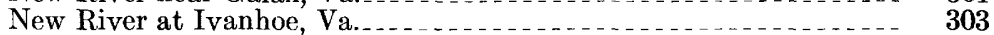

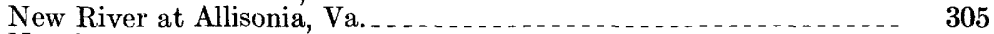

New River at Radford, Va:_... 306

New River at Eggleston, Va.

New River at Glenlyn, Va............ 309

New River near Hinton, W. Va.

New River at Caperton, W. Va.

Kanawha River at Kanawha Falls, W. Va.

Kanawha River at Charleston, W. Va...... 313

North Fork New River at Crumpler, N. C.

Reed Creek at Grahams Forge, Va. 315

Big Reed Island Creek near Allisonia, Va._... 316

Little River at Graysonton, Va..... 318

Walker Creek at Bane, Va..... 319

Wolf Creek near Narrows, Va....... 321

Bluestone River at Lilly, W. Va.

Greenbrier River at Hilldale, W. Va.

Gauley River above Belva, W. Va.

Elk River at Queen Shoals, W. Va........ 325

Tennessee River Basin.

French Broad River at Rosman, N. C.

French Broad River at Calvert, N. C.

French Broad River at Blantyre, N. C.

French Broad River at Bent Creek, N. C.

French Broad River at Asheville, N. C.

French Broad River at Hot Springs, N. C.

French Broad River near Newport, Tenn.

French Broad River at Dandridge, Tenn........ 338

Tennessee River at Knoxville, Tenn......... 340

Tennessee River at Loudon, Tenn.

Chickamauga Reservoir near Chattanooga, Tenn.

Tennessee River at Chattanooga, Tenn.

Davidson River near Brevard, N. C.... 345

South Fork Mills River at The Pink Beds, N. C.

Mills River near Mills River, N. C.

Mud Creek at Naples, N. C.

Swannanoa River at Biltmore, N. C.

North Fork Swannanoa River near Black Mountain, N. C...... 354

Beetree Creek near Swannanoa, N. C. .

Ivy River near Marshall, N. C.

Big Laurel Creek near Stackhouse, N. C..... 360

Pigeon River at Canton, N. C.

Pigeon River near Hepco, N. C..... 363

Pigeon River at Hartford, Tenn. 365

Jonathan Creek near Cove Creek, N. C. 366

Cataloochee Creek near Cataloochee, N. C. 368

North Toe River at Altapass, N. C.

Nolichucky River at Poplar, N. C. .

Nolichucky River at Embreeville, Tenn................ 374

Nolichucky River at Greeneville Dam, near Greeneville, Tenn. . . . . 376

Nolichucky River near Morristown, Tenn................... 377

South Toe River at Newdale, N. C..

Cane River near Sioux, N. C.

Little Pigeon River at Sevierville, Tenn.

South Fork Holston River at Vestal, Va.

South Fork Holston River at Bluff City, Tenn. . .

South Fork Holston River at Kingsport, Tenn.

Holston River near Rogersville, Tenn....... 388

Holston River near Morristown, Tenn..... 389

Holston River near Jefferson City, Tenn.... 390

Holston River at Strawberry Plains, Tenn.

Middle Fork Holston River near Meadowview, Va........... 392 
Stages and discharges at stream-gaging stations-Continued

Tennessee River Basin-Continued

Watauga River near Sugar Grove, N. C.

Watauga River at Stump Knob, Tenn.

Watauga River at Butler Tenn.

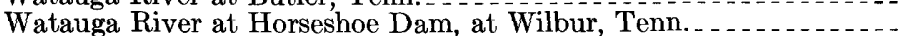

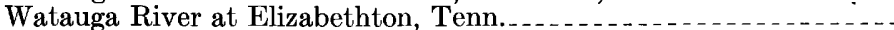

Elk Creek near Elk Park, N. C.

Roan Creek at Butler, Tenn.

Doe River at Elizabethton, Tenn.

North Fork Holston River near Saltville, Va..................

North Fork Holston River near Gate City, Va. . . . . . . . . . .

Little River near Walland, Tenn.

Little Tennessee River at Iotla, N. C.

Little Tennessee River at Judson, N. C.

Little Tennessee River near Fontana, N. C.

Little Tennessee River at Calderwood, Tenn...................

Little Tennessee River at McGhee, Tenn.

Cullasaja Creek at Highlands, N. C

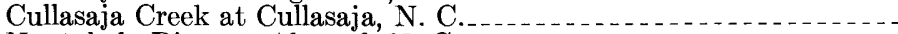

Nantahala River at Almond, N. C.

Tuckasegee River at Tuckasegee, N. C.

Tuckasegee River at Dillsboro, N. C.

Tuckasegee River at Bryson City, N. C.

Scott Creek at Sylva, N. C. . .

Oconalufty River at Cherokee, N. C.

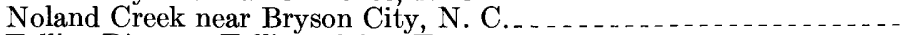

Tellico River at Tellico Plains, Tenn.

Clinch River at Cleveland, Va.

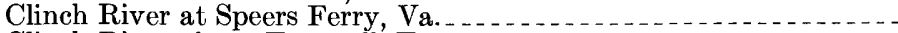

Clinch River above Tazewell, Tenn.

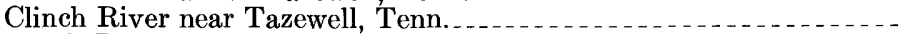

Norris Reservoir at Norris Dam, Tenn.

Clinch River below Norris Dam, Tenn.

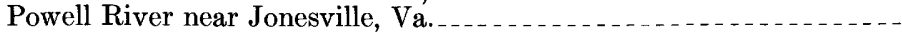

Emory River at Oakdale, Tenn.

Hiwassee River below Hayesville, N. C.

Hiwassee River above Murphy, N. C.

Hiwassee Reservoir at Hiwassee Dam, N. C.

Hiwassee River at Hiwassee Dam, N. C. . . . . . . . . . . . . . .

Hiwassee River near Reliance, Tenn. . . . . . . .

Valley River at Tomotla, N. C.

Nottely River near Ivylog, Ga.

Nottely River near Ranger, N. C.

Blue Ridge Reservoir, near Blue Ridge, Ga.

Parksville Reservoir at Parksville, Tenn.

Ocoee River at Parksville, Tenn.

South Chickamauga Creek near Chickamauga, Tenn.

Maximum discharges at stream-measurement stations for the floods of Augustig40 449

Unit discharges

Storage

Rainfall and runoff studies

Methods of analysis

Discussion of results

Variation of rainfall-runoff relations during mid-August storm

Concentration of discharge

Inventory

Comparisons of maximum rainfall rates and volumes with maximum flood discharges and volumes

Base flow and ground-water levels 


\section{ILLUSTRATIONS}

Tage

PLATE 1. Index map showing area covered by report and areas of high runoff .

2. Map showing path of mid-August storm

3. Highway bridges destroyed in North Carolina: $A$, Bridge over Lost Cove Creek near Edgemont, Caldwell County; $B$, Bridge on U. S. Highway 421, Wilkes County

4. $A$, Debris left by Johns River at Collettsville, N. C.; $B$, Agricultural damage on New River near Galax, Va.

5. Farm lands ruined by flood debris, Wilson Creek, N. C.: $A$, Bottom land covered with boulders washed down by flood; $B$, Sand carried down from Brown Mountain Beach and upper Wilson Creek

6. Flood crest of James River at Richmond, Va., August 18, 1940: $A$, Emergency levees erected to protect lower part of city; $B$, Airplane view of flooded industrial area.

7. $A$, Flood of August 14, 1940, on Yadkin River at Elkin, N. C.; $B$, Washout on Southern Railway near Icard, N. C. . . . . . . .

8. $A$, Flood on Savannah River at Augusta, Ga.; $B$, Flood on New River passing Claytor Dam near Radford, Va.

9. Flood damage along Watauga River, Tenn.: $A$, Bridge, track, and roadbed of Linville Valley Railroad destroyed; $B$, Wilbur Powerhouse at Horseshoe Dam

10. A, Late-August floods on Swannanoa River at Biltmore, N. C.; $B$, Remains of powerhouse at Dillsboro, N. C.

11. Late-August floods in North Carolina: $A$, French Broad River at Marshall; $B$, Tuckasegee River at Bryson City

12. A, Canton, N. C., manufacturing plant damaged by mid-August flood; $B$, Cleaning up after the flood in Elizabethton, Tenn.....

13. A, Highway bridge destroyed on Tuckasegee River; $B$, $C$, Slide in Wilkes County, N. C.

14. Highways damaged by flood: $A$, State Route 195 on left bank of Meherrin River near Branchville, Va.; B, U. S. Highway 19-23 along Hominy Creek near Canton, N. C. .

15. Repairing Asheville's water-supply line.

16. Isohyetal map of southeastern States showing total storm precipitation August 10-17, 1940 . .

17. Isohyetal map of southeastern States showing total storm precip:tation August 28-31, $1940 \ldots$

18. Reaches used for slope-area measurements: $A$, Elk Creek at Elkville, N. C. ; $B$, West Fork Lewis Fork near Champion, N. C.

19. Recording gage on Catawba River at Catawba, N. C.: A, Scene January 4, 1935; $B$, Scene August 14, 1940

20. Map of southeastern States showing location of flood discharges listed in tables 12,13 , and $14 \ldots$ In pocket

21. Map showing generalized values of infiltration index, in inches per hour, August 10-17, 1940

22. Map showing generalized values of infiltration index, in inches per hour, August 28-31, 1940

Figure 1. Daily precipitation at selected precipitation stations, July 1 to September 30, 1940 ................

2. Water levels of Kurfee well, Mocksville, N. C., 1937-40 ......

3. Cumulative precipitation at selected stations for storm period, August 10-17, 1940 . . . . . . . .

4. Hourly precipitation at selected stations, August 10-17, 1940

5. Hourly precipitation at selected precipitation stations, August 2831,1940

6. Area-depth relations for various centers of precipitation during mid-August storm . . . . . . . . . . . . . . . .

7. Graphs of discharge at various stream-gaging stations on James River

8. Graphs of discharge at various stream-gaging stations on tributaries of James River

9. Graphs of discharge at various stream-gaging stations in Roanoke River Basin 
10. Graphs of discharge at various stream-gaging stations in Chowan and Pamlico River Basins _... . . . . . . . . . . . . . . . . . .

11. Graphs of discharge at various stream-gaging stations in Neuse River Basin

12. Graphs of discharge at various stream-gaging stations in Cape

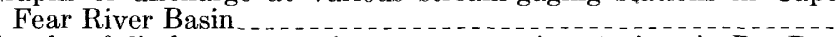

13. Graphs of discharge at various stream-gaging stations in Pee Dee River Basin .......................................

14. Graphs of discharge at various stream-gaging stations in Santee River Basin

15. Graphs of discharge at various stream-gaging stations in Savannah River Basin

16. Graphs of discharge at various stream-gaging stations in Kanawha River Basin

17. Graphs of discharge at various stream-gaging stations on French Broad and Tennessee Rivers . . . . . . . . . . . . . . . . . . . . .

18. Graphs of discharge at various stream-gaging stations in Holston River Basin

19. Graphs of discharge at various stream-gaging stations on tributaries of French Broad River

20. Graphs of discharges at various stream-gaging stations in Little Tennessee River Basin . . . . . . . . . . . . . . . . . .

21. Relation of unit discharge to size of drainage basin _........

22. Diagram showing contents, outflow, and computed inflow at Bridgewater Reservoir near Bridgewater, N. C. . . . . . . .

23. Diagram showing contents, outflow, and computed inflow at Lake Murray near Columbia, S. C.

24. Discharge hydrograph of Goose Creek near Huddleston, Va., showing method of analysis used to obtain runoff associated with storm of August 10-17, 1940 .

25. Discharge hydrograph of French Broad River at Rosman, N. C., showing method of analysis used to obtain runoff associated with storms of August 1940 .

26. Chart showing total rainfall and direct runoff for mid-August storm, in relation to indicated infiltration indices. . . . . .

27. Chart showing total rainfall and direct runoff for late-August storm in relation to indicated infiltration indices . . . .

28. Mean rainfall-runoff relation, mid-August storm

29. Mean rainfall-runoff relation, late-August storm, and comparison with mid-August storm

30. Cumulative direct runoff in relation to cumulative rainfall for selected basins in Virginia and North Carolina, mid-August storm

31. Relation between concentration ratio and lag, mid-August flood -

32. Hydrograph of Sweetwater Creek near Austell, Ga., August 12-16, 1940

33. Chart showing volumes of runoff in relation to drainage areas and maximum rainfall, mid-August flood.

34. Hydrograph of water level in Freuler well near Roanoke Rapids,

35. Hydrograph of water level in Baldwin well at Blantyre, N. C., August-November 1940 .

\section{TABLES}

TABLE 1. Estimates of loss and damage caused by the floods of August 1940 -

2. Monthly precipitation and departure from normal, March to August 1940 , by States.

3. Monthly mean temperature and departure from normal, March to August 1940, by States

4. Estimated base flow at selected gaging stations for period August 110 in various years .

5. Daily preoipitation, August 10-19, 1940

6. Daily precipitation, August 28-31, 1940 
7. Area enclosed within indicated isohyetal lines for various storm

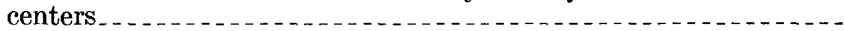

8. Depth of mean precipitation in relation to areal extent for notable storms

9. Maximum precipitation over indicated areas, during indicated periods, for storm of August 10-17, 1940

10. Maximum recorded precipitation during indicated periods, storm of August 10-17, 1940

11. Maximum recorded precipitation during indicated periods, storm of August 28-31, 1940

12. Summary of flood discharges in Potomac, Rappahannock, and York River Basins for the flood of August, 1940

13. Summary of flood discharges in south Atlantic slope and eastern Gulf of Mexico basins for the floods of August 1940

14. Summary of flood discharges in Kanawha, Big Sandy, and Tennessee River Basins for the floods of August 1940

15. Principal storage reservoirs in the indicated drainage basins

16. Rainfall and associated direct runoff of floods of August 1940 . . -

17. Rainfall and associated direct runoff on selected streams having several peak flows during the mid-August flood

18. Inventory of rainfall and runoff, mid-August flood

19. Inventory of rainfall and runoff, late-August flood

20. Average base flow in second-feet per square mile, by drainage basins_

21. Water levels in wells in North Carolina during flood periods ..... .

22. Flood-crest stages of mid-August flood

23. Flood-crest stages of late-August flood . . . . . . . . . .

24. Annual maximum daily mean and momentary peak discharges at gaging stations on New River, W. Va.

25. Annual maximum daily mean and momentary peak gage heights and discharges for Kanawha River at Kanawha Falls, W. Va.......

26. Flood-crest stages, in feet, at stations on French Broad River when stage was 12 feet or more at Dandridge, Tenn.

498

499

504

504

507

530

537

538

539

27. Flood-crest stages, in feet, at stations on Tennessee River during years in which stage was 35.0 feet or more at Chattanooga, Tenn.-

28. Flood-crest stages, in feet, at stations on Nolichucky River when stage was 7.5 feet or more at Embreeville, Tenn

29. Flood-crest stages, in feet, at stations on Holston River when stage was 13.0 feet or more at Rogersville, Tenn.

30. Flood-crest stages, in feet, at stations on the Watauga River when stage was 10.0 feet or more at Elizabethton, Tenn.

31. Flood-crest stages, in feet, at stations on Little Tennessee and Hiwassee Rivers when stage was 20.0 feet or more on Little Tennessee River at McGhee, Tenn.

32. Flood-crest stages, in feet, at stations on Clinch River when stage was 30 feet or more at Ćlinton, 10 feet or more near Tazewell, or 12 feet or more above Tazewell

33. Flood-crest stages, in feet, at stations on Toccoa and Ocoee Rivers, when stage exceeded 7.0 feet at Dial, Ga. 


\title{
FLOODS OF AUGUST 1940 IN THE SOUTHEASTERN STATES
}

\author{
Prepared by the Water Resources Branch ${ }^{1}$
}

ABSTRACT
During August 1940 the southeastern States experienced two major floods that took the lives of 30 to 40 persons and eaused damage of about $\$ 30,000,000$. Chese floods exceeded all known floods on Roanoke River since settlement began in 1607 and all known floods in western North Carolina except on some streams where the floods of July 1916 were greater.

The first flood resulted from the hurricane storm of August 10-17, which in the coastal area caused the death of about 20 persons and damage amounting to about $\$ 3,000,000$. The storm followed a roughly semicircular path, noving inland from the vicinity of Beaufort, S. C., and Savannah, Ga., to the Appalachian Mountains, northward along the mountains, then eastward to the coast near Norfolk, Va. Precipitation greater than 15 inches was measured at many points and averaged 10 inches over an area of about 35,000 square miles. The resulting flood flows were most severe in the Roanoke, Catawba, Yadkin, Nolichucky, Watauga, and New Rivers. Peak discharges of at least 1,400 secondfeet per square mile came from several drainage areas of more than 50 square miles. The highest discharge observed was 280,000 second-feet on Roanoke River at Clarksville, Va.

The second flood resulted from the storm of August 28-31, which covered a much smaller area in western North Carolina and eastern Tennessee. Precipitation of about 24 hours' duration, varying from 8 to 13 inches, was measured in the Blue Ridge. Exceptionally high peak discharges occurred in small drainage areas. The floods in the headwaters of the French Broad, Little Tennessee, and upper Savannah River Basins were generally greater than those in mid-August.

An outstanding feature of both streams was the large number of slides of earth on the steeper hillsides, more than 200 being reported within an area of about 150 square miles.

Precipitation records for about 650 stations during the mid-August storm and for about 400 stations during the late-August storm are given in this report. Isohyetal maps based on these records are also given, and pertinent results of analysis are presented.

The report contains records of stream flow at about 300 gaging stations within or adjacent to the flood area in sufficient detail for defining the hydrograph of the flood rise. Records for more than 20 reservoirs are included, and several of them are analyzed to show the effect of storage on the flood flow.

Peak discharges of streams at about $\mathbf{1} 00$ miscellaneous points are combined with a summary of peak discharges at gaging stations and reservoirs, where available previous maximum discharges are also shown. A map showing the locations of measurements is included. Studies of peak-discharge rates indicate the occurrence of point rainfalls of intensity greater than any recorded.

\footnotetext{
1 This report represents the combined effort of many engineers of the Water Resources Branch. Those responsible for its preparation are noted under Administration and personnel (p. 5 ).
} 
Special studies of rainfall-runoff relations are described. Two drainage basins of about 65 square miles had a direct-runoff volume of 11 inches; direct runoff of Roanoke River at Scotland Neck, N. C. (8,700 square miles) was 4.7 inches. Maps showing generalized values of the infiltration index are given for both storms. The effect of the storms on base flow and ground-water levels is discussed.

Flood-crest stages are given for more than 2,700 miles of river in the James, Chowan, Roanoke, Pamlico, Pee Dee, Kanawha, and Tennessee River Basins for the mid-August flood, and for more than 600 miles of river in the Tennessee River Basin for the late-August flood.

Records of previous flood in the Roanoke, Kanawha, and Tennessee River Basins are given for selected gaging stations.

\section{IN'TRODUCTION}

Two storms, a West Indian hurricane in mid-August and a local storm in late August, produced floods in North Carolina and adjacent States that exceeded all those previously known on Roanoke River since white settlement in 1607 and all those previously known in western North Carolina except the floods of July 1916 on some streams.

The hurricane storm moved inland on August 11, 1940, in the vicinity of Beaufort, S. C., and Savannah, Ga., where the high winds smashed and wrecked many buildings, uprooted and broke trees, and caused a tide higher than any experienced since 1934 . Damage amounting to about $\$ 3,000,000$ and the loss of about 20 lives were reported as resulting from the hurricane winds in the coastal area. ${ }^{1}$ As the hurricane proceeded inland with decreasing intensity, it eurved northward along the Appalachian Mountains, thence eastward, and on August 16 passed out into the Atlantic Ocean south of Norfolk, Va. The late-August storm was local in the headwaters of the Little Tennesee and French Broad Rivers. The observed precipitation of both storms was not record breaking in total amount or intensity; but the rain fell on the steep slopes of the Appalachian Mountains, and in many places the storm tended to progress downstream from the headwaters in a manner favorable to a maximum concentration of runoff. Consequently, it produced floods which in more populous and developed areas would undoubtedly have caused damages and losses that would have been as spectacular as and would have ranked with other great disastrous floods of the country.

Rates of flood discharge were extraordinary and are among the highest of record in the region. In the headwaters the floods rushed down the steep slopes of the Appalachian Mountains and by erosion or deposition of debris destroyed substantial areas of farm lands adjacent to the streams and ripped out highways, bridges, railroads, and other improvements along the banks. Slides, of which 200 were

\footnotetext{
${ }^{1}$ U. S. Weather Bur., Monthly Weather Rev., vol. 68, No. 8, p. 218, August 1940.
} 
reported on one area of 150 square miles in the headwaters of the West Fork Pigeon River and East Fork Tuckasegee River, caused great damage and considerable loss of life. In the lower reaches of the larger streams great damage was inflicted, ehiefly by inundation, on industrial plants, agricultural lands, public utilities, and homes. Loss and damage resulting from the floods have been estimated as 30 to 40 lives and about $\$ 30,000,000$. Injury on the lower reaches of Yadkin and Catawba Rivers was greatly reduced by the moderating effect of numerous storage reservoirs on each stream.

The floods of August 1940, coming only 24 years after the great flood of July 1916, have again impressed those who viewed the ravages of the floods with the magnitude of the problems of flood control. The design of protective or preventive measures requires adequate records of the great floods that have occurred in the past and hence are likely to occur in the future:

The Geological Survey, operating through several local district offices, maintains as a part of the regular Nation-wide stream-gaging program about 300 stream-gaging stations within the area affected by the floods of August 1940. These stations have been maintained largely in cooperation with States and municipalities and generally for periods beginning several years prior to the August floods. Thus the Survey has obtained and published systematic records of the stage and flow of the streams from drought to extraordinary floods.

Immediately after the floods of August 1940 the Geological Survey began to investigate comprehensively the flood flow of the streams throughout the affected area. The Tennessee Valley Authority assembled and published in a complete report information relating to precipitation, flood discharge, and damage in the Tennessee River Basin. The Corps of Engineers, War Department, the Forest Service and Soil Conservation Service, Department of Agriculture, the Weather Bureau, Department of Commerce, and various private companies have cooperated in the collection and assembly of all available information relative to the precipitation that oceurred in the midAugust storm outside the Tennessee River Basin. Most of these data on rainfall have been printed by the Weather Bureau and are available for examination at offices of the Weather Bureau and of the Corps of Engineers. The Geological Survey has published in WaterSupply Papers 891,892 , and 893 the daily mean diseharge during the flood periods at the regular gaging stations. Some of those records have been revised in succeeding Water-Supply Papers. The present report contains all pertinent revisions appearing in annual reports on Surface Water Supply of the United States through 1945.

The Corps of Engineers has prepared a series of isohyetal maps to show the precipitation for varying intervals during the mid-August 
storm period. These maps are available for examination in the office of the Chief of Engineers, War Department, Washington, D. C., or in the office of the District Engineer, Corps of Engineers, Norfolk, Va.

At the Coweeta and Bent Creek Experimental Forests in North Carolina and the Work Center of the Appalachian Forest Experiment Station at Copperhill, Tenn., the Forest Service has collected numerous detailed measurements of rainfall, runoff, ground-water levels, and soil loss. The station was in operation during the floods of August 1940. Daily rainfall amounts at selected rain gages have been furnished by the Forest Service and are published in tables 5 and 6 , but for other climatologic and hydrologic information, a written request should be made to the Appalachian Forest Experiment Station, Asheville, N. C.

The Soil Conservation Service has made many measurements of rainfall, runoff, and erosion from plots and small eatchment areas during August 1940 at experimental and demonstration projects in Virginia, North Carolina, South Carolina, and Georgia. A list of these projects follows:

Danville Demonstration Project, near Chatham, Va.

Virginia Agricultural Experiment Station, near Blacksburg, Va.

Soil Conseravtion Experiment Station, near Statesville, N. C.

High Point Demonstration Project, High Point, N. C.

Soil Conservation Experiment Station, near Raleigh, N. C.

South Carolina Agricultural Experiment Station, Clemson, S. C.

Soil Conservation Experiment Station, near Spartanburg, S. C.

Sedimentation Station, near Greenville, S. C.

Southern Piedmont Experiment Station, near Watkinsville, Ga.

Daily rainfall measurements at these projects during the midAugust and late-August storms have been furnished by the Soil Conservation Service and are included in tables 5 and 6 of this report. A compilation of rainfall, runoff, and soil-loss data for the period 1934-40 at the High Point Demonstration Project has been published by the Soil Conservation Service. ${ }^{2}$ Cardwell and Dickerson have published rainfall and runoff data for the mid-August flood at the Danville Experiment Station, including the results of their studies of rainfall and runoff. ${ }^{3}$

For other climatologic and hydrologic information collected at the above-mentioned projects, written request should be made to the Chief, Soil Conservation Service, Washington, D. C.

For many of the recent great floods the Geological Survey has assembled and published for a given flood a single volume containing all

\footnotetext{
${ }^{2}$ Potter, W. D., and Love, S. K., Hydrologic studies at the High Point Demonstration Project, SCS-NC-1, High Point, N. C.: U. S. Dept. Agr., Soil Cons. Service Tech. Pub. 48, March 1942. [Processed.]

${ }^{3}$ Cardwell, D. W., and Dickerson, W. E., Runoff from terraced areas under conditions of extreme flood: Am. Geophys. Union Trans., p. 856-862, 1941.
} 


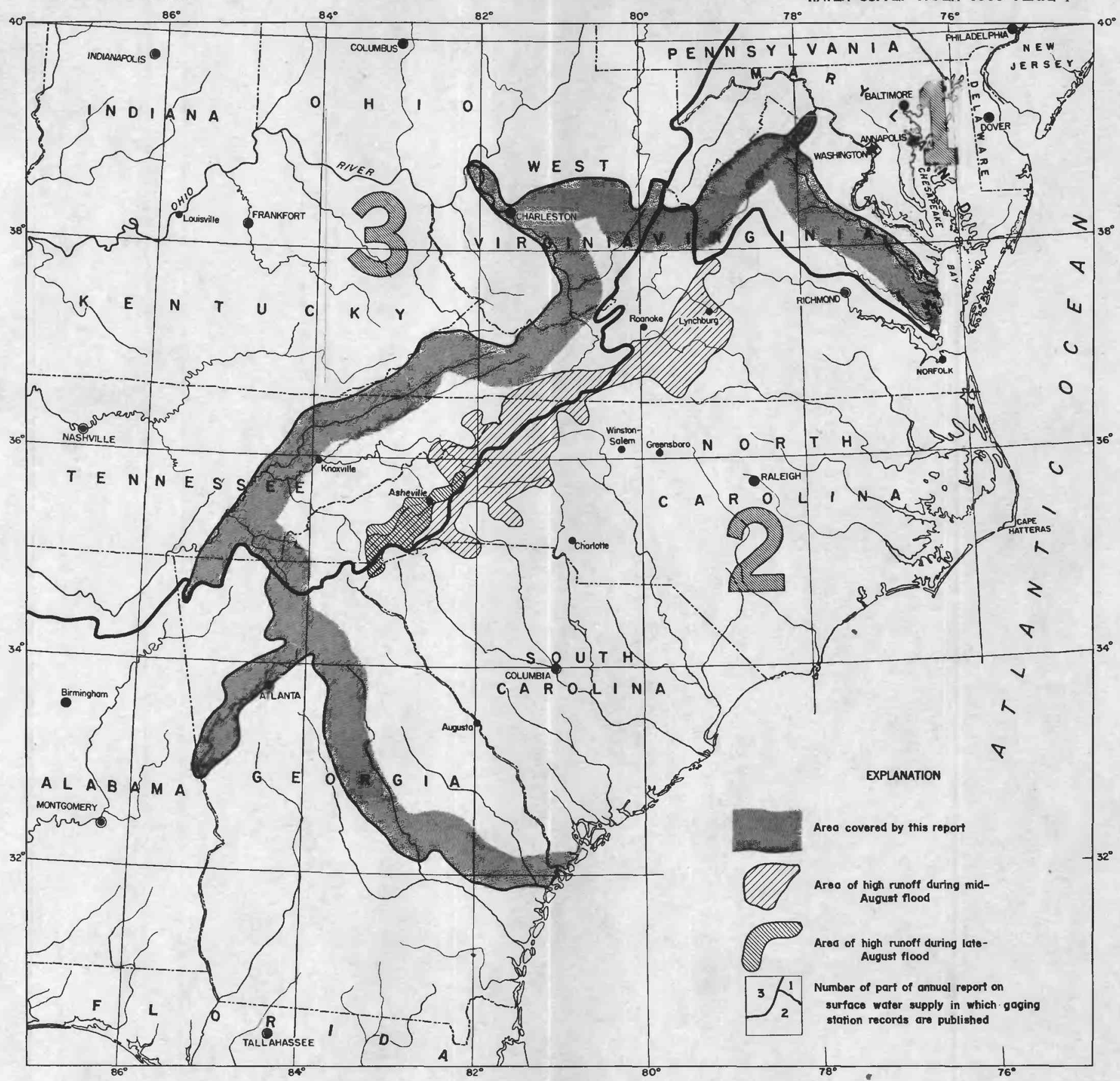

INDEX MAP SHOWING AREA COVERED BY REPORT AND AREAS OF HIGH RUNOFF 

available data and information relative to that flood. Similar procedure would have been desirable in connection with the floods of August 1940, but limitations imposed by the war made it necessary to include in this report only data that have not been made readily available in other publications. This report contains all the basic information relating to stages and discharges collected at the regular stream-gaging stations, the results of flood-flow measurements made at points where regular gaging stations were not being maintained, detailed records of the operation of storage reservoirs in the Pee Dee and Santee River Basins, basic meteorologic and hydrologic information not readily available elsewhere, and the results of analyses of rainfall and runoff. The area covered by the report is shown on plate 1 .

The major part of this report was prepared within a short period after the floods; thus most of the descriptive material was written while the facts were still fresh. Publication of the report was delayed because of the war, thus providing an unusual opportunity to include the results of later studies. In this flood, as in almost all major floods, great changes occurred in many stream channels during the highest part of the flood. Stage-discharge relations at many gaging stations, which had required several years of observation to define, were destroyed. Only a few of them could be redefined during the recession of the flood. In the years since August 1940 other smaller floods have provided opportunity on many streams to secure additional information. The records in this report make use of information available up to the time the computations for the 1945 annual report were made. This report should therefore prove to be less subject to revision and thus have more permanent value than if it had been published immediately after the 1940 flood.

\section{ADMINISTRATION AND PERSONNEL}

The field and office work incident to the preparation of this report were performed by the Water Resourees Branch of the Geological Survey under the general administrative direction of G. L. Parker, chief hydraulic engineer. The actual field work and collection and tabulation of the basic information for stages and discharges were done in the Division of Surface Water, R. G. Kasel, chief. This work was performed by the district engineers and their staffs at Asheville, N. C., Atlanta, Ga., Charlottesville, Va., Chattanooga, Tenn., Columbia, S. C., and Charleston, W. Va.

The general organization of special features of the work and the compilation of the report were supervised or conducted by the Division of Water Utilization, R. W. Davenport, chief. The organization of the report in its early stages was the work of Hollister Johnson, 
hydraulic engineer, who also furnished helpful advice and assistance in evaluating flood discharges at gaging stations and at miscellaneous points. W. B. Langbein, hydraulic engineer, prepared the section "Rainfall and runoff studies" and made the hydrologic analyses and interpretations contained therein. The report was reviewed and arranged for publication by W. S. Eisenlohr, Jr., hydraulic engineer. Many other members of the staff of the Geological Survey made valuable contributions to this work.

\section{ACKNOWLEDGMENTS}

The Geological Survey, acting through its district field offices, cooperates with State and municipal agencies in the several districts. Acknowledgment is made to the cooperating agencies for participation in the systematic collection of the records of river discharge that form the broad base for the specific flood information and in the maintenance of field organizations in which engineers trained for investigation of this kind are available for the special studies related to the collection of the field data and the preparation of the report.

Information appearing in this report has been obtained from many sources, including individuals, corporations, and local, State, and Federal governmental organizations. Financial cooperation in connection with the regular stream-gaging program of the Geological Survey in the areas covered by this report has been received from the following agencies: In Georgia from the Department of Mines, Mining and Geology, Division of Conservation; in North Carolina from the State Department of Conservation and Development; in South Carolina from the State Highway Department, the City of Spartanburg Board of Public Works, and the town of Duncan; in Tennessee from the Division of Geology, the Tennessee Department of Conservation, and the State Department of Public Health; in Virginia from the Virginia Conservation Commission; and in West Virginia from the State Public Service Commission and the State Geological and Economic Survey. The work in the Tennessee River Basin was done also in cooperation with the Tennessee Valley Authority.

Federal agencies to whom acknowledgment is made for financial cooperation, services rendered, or data furnished include the Corps of Engineers, the Tennessee Valley Authority, the Weather Bureau, and the Department of Agriculture, particularly the Flood Control Advisory Committee, the Forest Service, the Soil Conservation Service, and the Bureau of Agricultural Economies.

Funds in the amount of $\$ 8,000$ received from the Soil Conservation Service made possible an increase in the scope of the work to include the measurement of peak discharges on a greater number of 


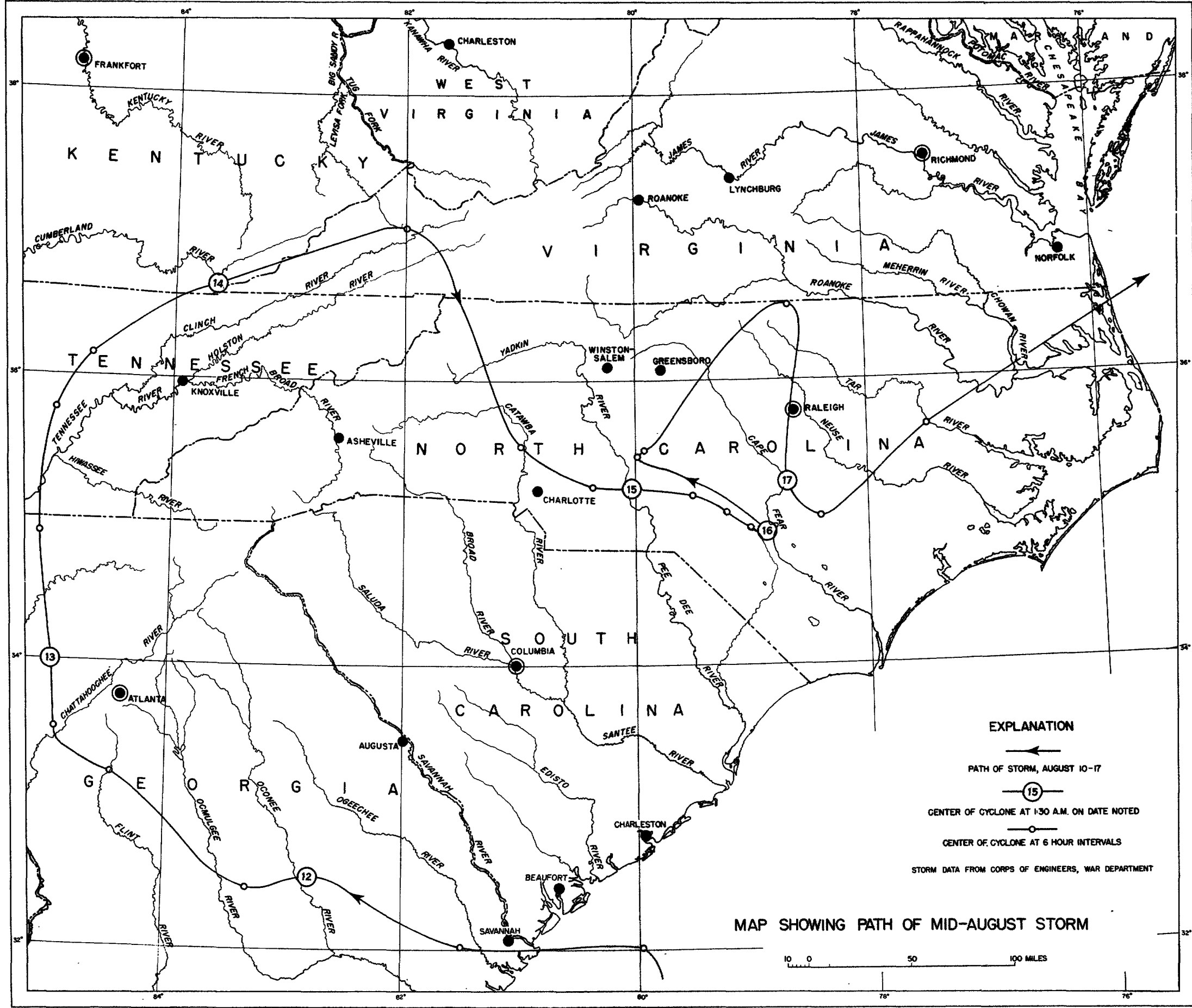


streams than would have been possible otherwise. The Norfolk, Va., and Charleston, S. C., districts, Corps of Engineers, furnished field parties for surveys for the measurement of peak discharges on streams in the Roanoke River Basin and Yadkin River Basin, respectively, as did the Tennessee Valley Authority for the Tennessee River Basin. Field parties were also made available by the Forest Service and the Flood Control Advisory Committee of the Department of Agriculture for surveys for the measurement of peak discharges of streams in Virginia and North Carolina, respectively.

Assistance in collecting records was also rendered by various individuals, corporations, organizations, and municipalities. Acknowledgments for all such contributions are given at appropriate places in the report insofar as practicable.

\section{GENERAL FEATURES OF THE STORMS AND FLOODS}

Two storms at the middle and end of August 1940 were the cause of unusual floods over a wide area in the southeastern United States.

\section{MID-AUGUST STORM}

The first or mid-August storm developed as a hurricane in the Atlantic Ocean about August 8. This hurricane, the worst in the affected coastal area since August 27, 1893, struck the coast at Savannah, Ga., with great violence during the afternoon of August 11. As it proceeded inland, following the path shown in plate 2, the hurricane abated rapidly in severity, with the result that damage was confined to a relatively small area adjacent to the coast. The center of heaviest precipitation of this storm crossed the coast line on August 11 at Beaufort, S. C., and, following a roughly semicircular path, moved inland up the Savannah River Basin across the Appalachian Mountains and adjoining areas in North Carolina, and then down the Roanoke River Basin, passing out to sea south of Norfolk, Va., about August 16. Precipitation greater than 15 inches for the entire storm and 8 inches during a single day was measured at numerous points.

The 2-day storm of July 1916 over North Carolina and South Carolina is the most outstanding previous storm of record; it caused stages and discharges on streams in the area which generally exceeded any previously known and which in some places were unsurpassed by the floods of August 1940. The Weather Bureau ${ }^{4}$ described the 1916 storm and subsequent flood as follows:

The great rainfall over the western and southern portions of North Carolina during July and particularly the downpour in the Blue Ridge Mountains on the

${ }^{4}$ U. S. Weather Bur., Climatological data, North Carolina Section, July 1916. 
15th-16th far exceeds previous records for this section. In some respects it was the most extraordinary rainfall of which there is any authentic record in this country. All streams from the upper Yadkin to the French Broad were decidedly above their previous high water marks, and no such destructive flood damage has ever been experienced before in this section.

Comparison of the two storms is significant. On areas smaller than 5,000 square miles the average rainfall in the storms of August 1940 was less than that observed during the 2-day storm of July 1916, but on areas larger than 5,000 square miles it exceeded that recorded in the earlier storm. An average rainfall of 10 inches was observed over about 11,000 square miles during the storm of July 1916 and over about 35,000 square miles during the storm of August 10-17, 1940. The average precipitation for the day of maximum rainfall, August 13, 1940, was generally slightly less than that recorded in the earlier storm for the day of maximum rainfall, July 15, 1916. The intensities of hourly precipitation recorded during the storm of August 1940 were not especially unusual, but the evidence of excessive runoff from small mountainous areas suggests intensities greater than those that were recorded. The major part of the precipitation occurred during a period of about 40 hours in the region first struck by the storm, but this period increased to about 70 hours as the storm progressed.

The period preceding the storm had been unusually dry in North Carolina, so that stream flow at the beginning of the storm was generally low. In contrast, the Weather Bureau reported in reference to the storm of 1916 that "the soil was thoroughly soaked prior to July 15."

\section{LATE-AUGUST STORM}

The second or late-August storm occurred August 28-31 in the vicinity of the Blue Ridge in North Carolina and was a comparatively local meteorological disturbance centered in the Little Tennessee and French Broad River Basins. Precipitation varying from 8 to 13 inches was measured on the western slopes of the Blue Ridge for periods of 20 to 30 hours and in general produced more rain for short periods in certain areas than the mid-August storm. The amounts of rainfall recorded at any station in periods from 2 hours to 1 day were greater during the late-August storm. There was more rain on the day of maximum rainfall in the late-August storm than in the mid-August storm for areas less than about 2,000 square miles.

\section{MID-AUGUST FLOOD}

Both storms caused floods that in many places exceeded all those previously known. In the streams draining the south Atlantic slopes the floods resulting from the mid-August storm, with very few exceptions, exceeded those occurring at the end of the month. The 


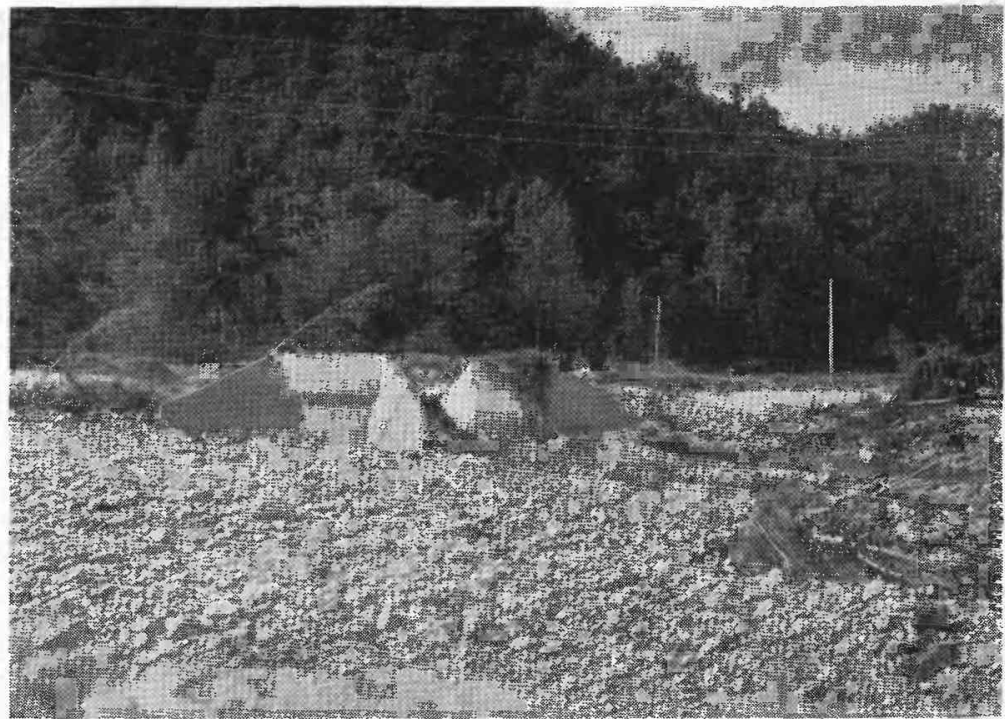

A. BRIDGE OVER LOST COVE CREEK AT JUNCTION WITH WILSON CREEK, NEAR EDGEMONT, CALDWELL COUNTY.

High water was about 5 feet over piers as they now stand. Courtesy H. J. Loughead, U.S. Forest Service

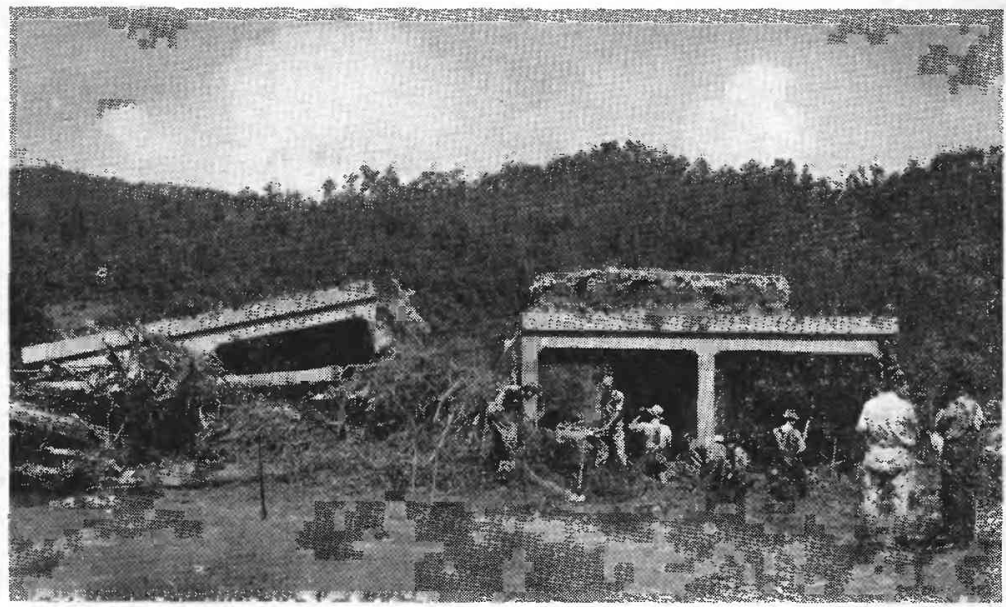

B. BRIDGE ON U.S. HIGHWAY 421, WILKES COUNTY.

Courtesy North Carolina State Highway Commission.

HIGHWAY BRIDGES DESTROYED IN NORTH CAROLINA. 


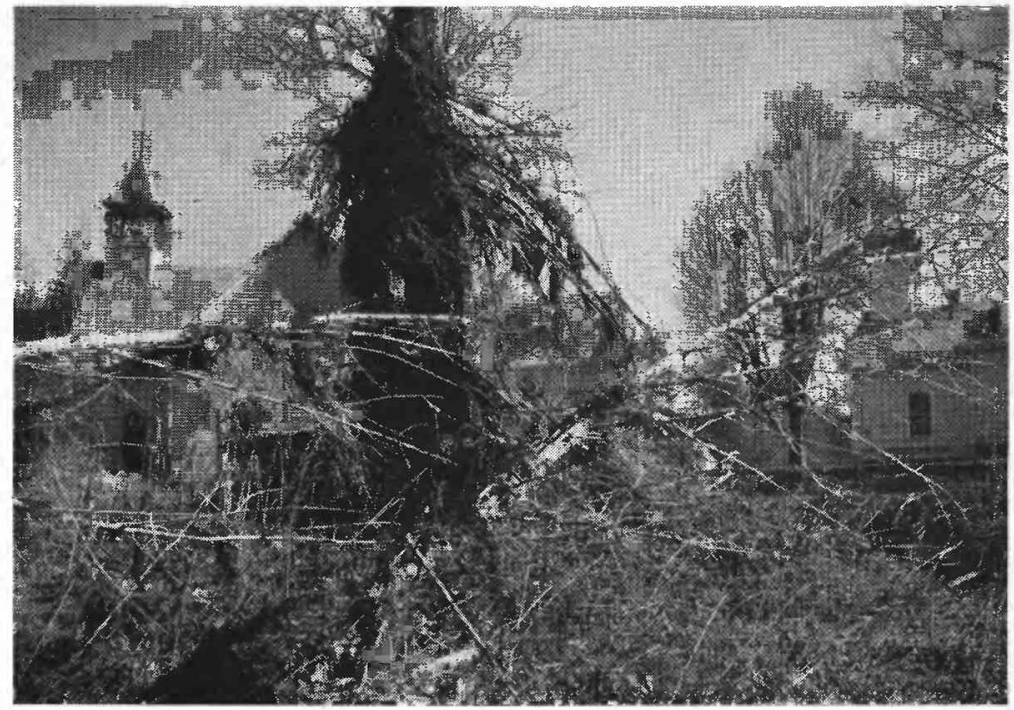

A. DEBRIS LEFT BY JOHNS RIVER AT COLIETTSVILIE. N. C

In background, Rocky Springs Baptist Church rests on lot of Adventist Church after heing floated from its own foundation. Courtesy U.S. Soil Conservation Service.

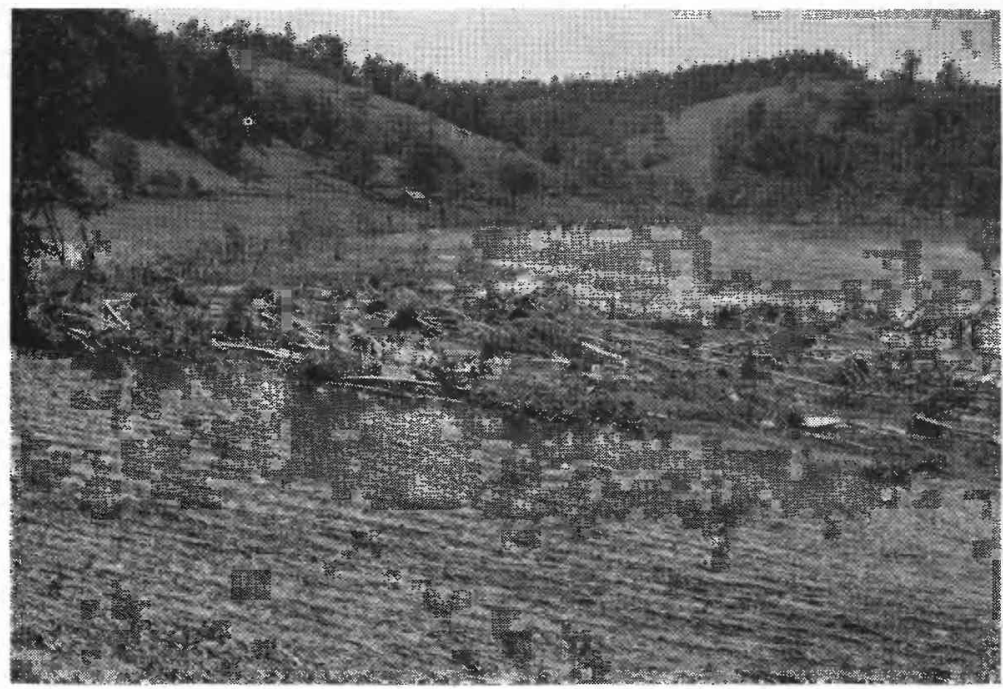

B. AGRIGULTURAL DAMAgE ON NEW RIVER NEAR GALAX, VA.

Courtesy Corps of Engineers, War Department, Huntington, W. Va. 
floods were most severe on the headwaters of Catawba and Yadkin Rivers on the eastern slopes of the Blue Ridge. The shaded area on plate 1 showing areas of high runoff conforms generally to areas tributary to those gaging stations or measuring points where the peak discharge exceeded 100 second-feet per square mile. The upper Yadkin River Basin appears to have received some of the greatest highway damage, as "highway officials estimated that 90 percent of the secondary road bridges in Ashe, Watauga, [and] Wilkes [Counties] and the northern part of Caldwell County in North Carolina were lost. Damage to main roads was not so extensive but was serious at many points, and several bridges were damaged. Railroads lost many embankments and were buried by landslides at numerous points. On the Southern Railway between Asheville and Salisbury, a distance of about 140 miles, there were 13 slides, one being 33 feet deep and 700 feet long." (See pl. 3.) Floods in streams tributary to Ohio River were most severe in the headwaters of the Nolichucky, Watauga, and New Rivers on the western slopes of the Blue Ridge.

The very steep slopes of the mountains undoubtedly were contributing factors to the high rates of runoff in the areas where they occurred. The highest rates occurred in the vicinity of Grandfather Mountain and Blowing Rock. Peak discharges of 1,400 second-feet per square mile or more were delivered by drainage areas of more than 50 square miles on the headwaters of Catawba and Yadkin Rivers. Unit discharges were not so great on the western slopes, but on one stream 1,100 second-feet per square mile came from about 33 square miles. Both floods were characterized by the large masses of floating debris brought down from the mountain areas. (See pl. 4,A.) Agricultural damage was quite extensive in many valleys, not only because of destroyed crops (pl. 4,B), but also because of topsoil washed away from some fields and deposition of sterile sand and gravel on others (pl. 5). Many gaging stations were seriously damaged or lost completely, owing to changes in the stream channels or battering by heavy drift.

Streams draining into the Atlantic Ocean north of the James River Basin did not experience severe floods, except in the Potomac River Basin on the headwaters of Shenandoah River. On James River the flood was the greatest of record at Scottsville and on several tributaries, including Appomattox River. At other points on lower James River and many tributaries, stages and discharges were nearly as great as during the flood of March 1936. On Appomattox River maximum discharges were about one and a half to two times those observed in the past 15 years and exceeded the highest stages recorded by about 2.5 feet at Farmville, Va., 5.3 feet at Mattoax, Va., and 3.3

\footnotetext{
s Engineering News-Record, vol. 125, p. 253, Aug. 22, 1940.
} 
feet near Petersburg, Va. In the Chowan River Basin discharges were more than twice those previously recorded at gaging stations on the Nottoway River since 1930 and on the Meherrin River since 1928.

The downstream path of the storm and the timing of rainfall was such as to aggravate the floods in the lower James and Roanoke River Basins. Most streams in the upper James River Basin were at their highest stages on August 15 and 16. The flood erest on the main river occurred progressively later as the flood wave moved downstream, eresting at Richmond at 8:30 a.m. August 18. (See pl. 6.) The lower tributaries were in flood on August 16, 17, and 18, debouching at near-maximum rates at times nearly coincident with the crest on the main river. A similar condition existed in the Roanoke Basin, where the floods on the upper Roanoke and Dan Rivers were approximately coincident at their confluence.

Roanoke River and practically all its tributaries reached stages and discharges at the Geological Survey gaging stations greater than previously observed. At Old Gaston, N. C., the river reached a stage of 21.48 feet as compared with stages of about 19 feet, about 15 feet, 16.2 feet, and 13.94 feet reached by the floods of 1877, 1889, 1912, and January 1936, respectively. At the plant of the Virginia Electric \& Power Co. at Roanoke Rapids, N. C., the crest stage was reported as being 10 feet higher than that reached during the 1912 flood. On the basis of research by the Corps of Engineers ${ }^{6}$ the mid-August flood was the greatest known on this river since the first white settlement was established in Virginia in 1607. Floods in the Pamlico, Neuse, Cape Fear, and Waccamaw River Basins were not severe and were considerably less than previously recorded at gaging stations.

On the headwaters of Yadkin River above Donnaha, N. C., the mid-August flood exceeded by a wide margin all previously known floods. (See pl. 7,A.) Discharges were especially large on the headwater tributaries on the north side of the basin. The peak discharge of Elk Creek near Elkville, N. C., was 70,000 second-feet from 50 square miles. The high rates of discharge of nearby streams computed by various methods corroborated the especially high computed discharge of Elk Creek. All bridges over Yadkin River above North Wilkesboro, N. C., were swept away. At the gaging station at Wilkesboro, N. C., the flood reached a stage of 37.6 feet, 3.1 feet higher than that of July 1916. The flood discharge of Pee Dee River in South Carolina was very extensively modified by the operation of storage reservoirs on Yadkin River at High Rock, Badin, and Mount Gilead, N. C., and on Pee Dee River near Rockingham, N. C. At the Geological Survey gaging station on Pee Dee River at Rockingham, N. C., the crest stage was 13.46 feet, as compared with 31.28 feet in 1908 .

${ }^{6}$ See 74th Cong., 1st sess., H. Doc. 65. 

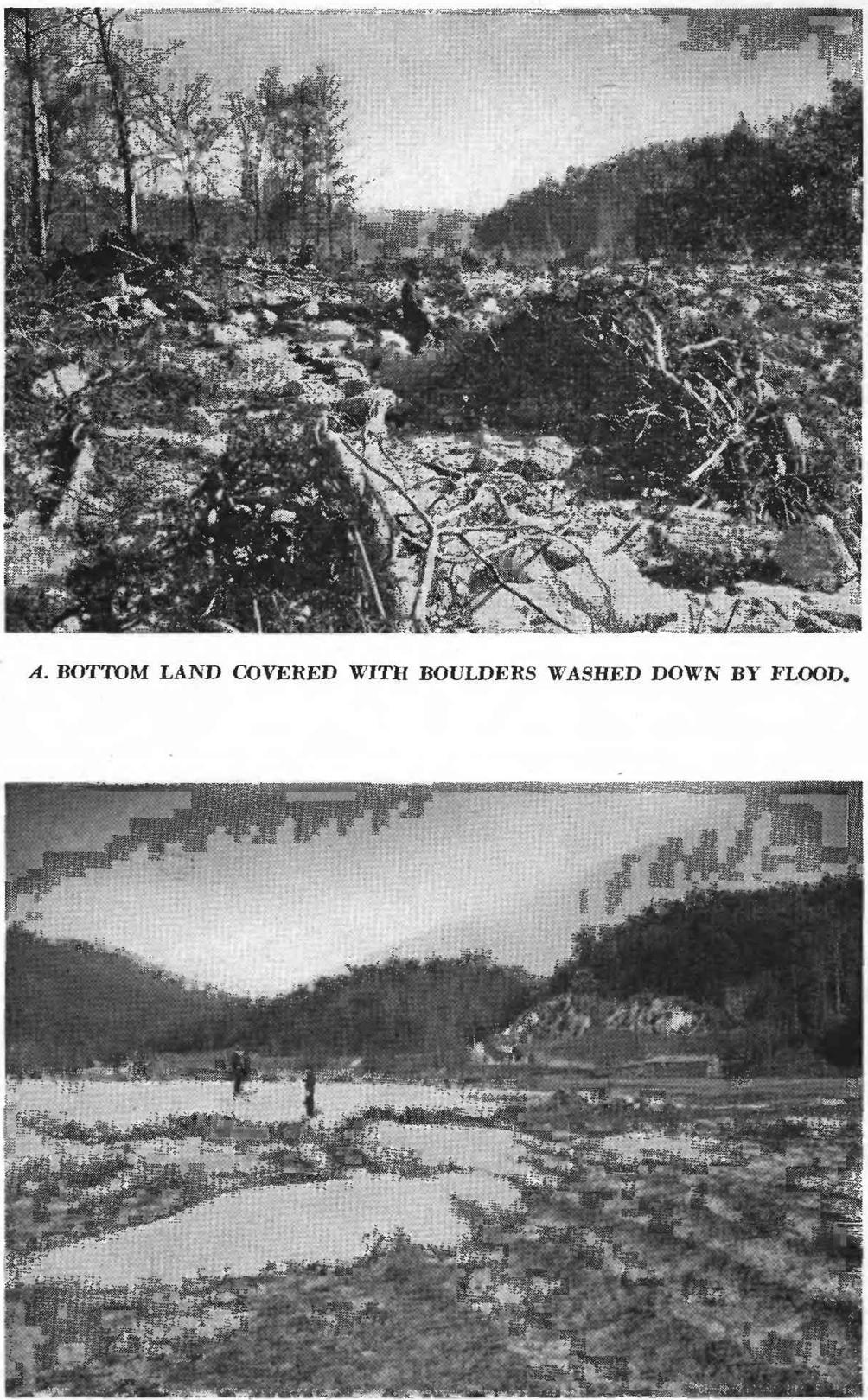

B. SAND CARRIED DOWN FROM BROWN MOUNTAIN BEACH AND UPPER WILSON CREEK.

Sand in center of picture is about 3 feet deep.

FARM LANDS RUINED BY FLOOD DEBRIS, WILSON CREEK NEAR ADOKA, BELOW BROWN MOUNTAIN BEACH, N. C.

Courtesy U.S. Soil Conservation Service. 


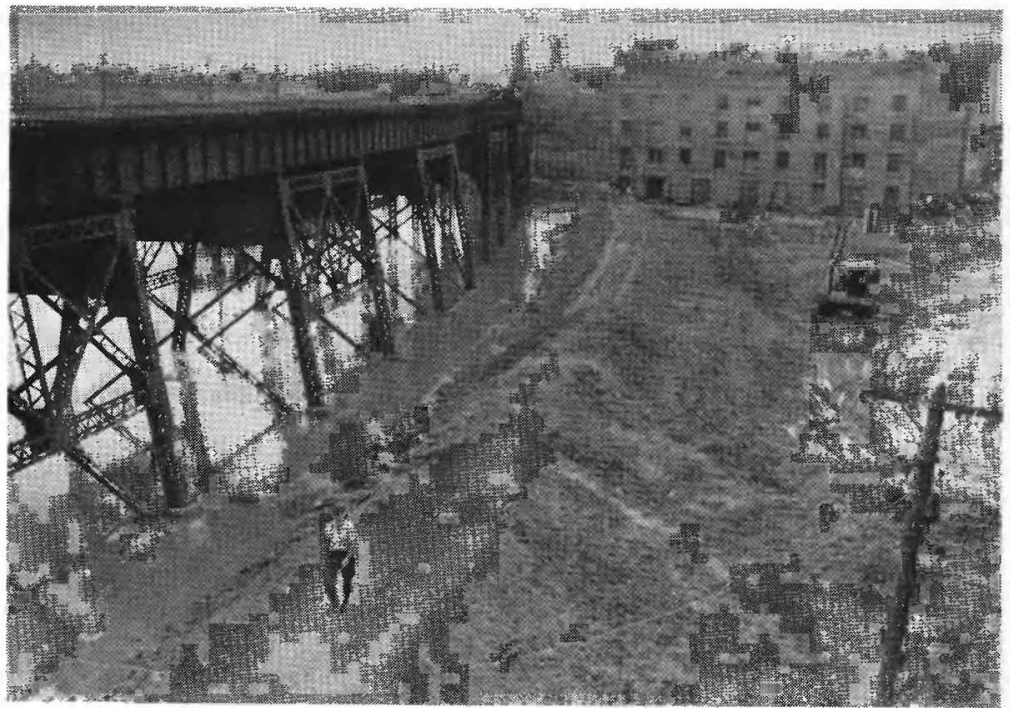

A. EMERGENCY LEVEES ERECTED TO PROTECT LOWER PART OF CITY.

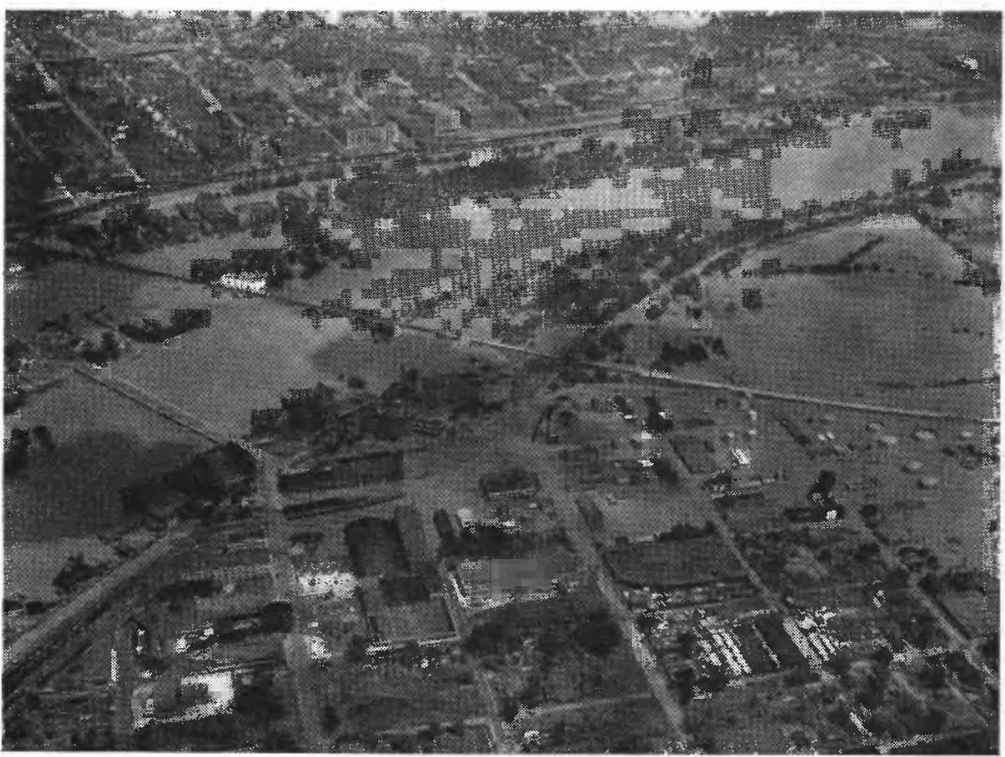

B. AIRPLANE VIEW OF FLOODED INDUSTRIAL AREA.

FLOOD CREST OF JAMES RIVER AT RICHMOND, VA., AUGUST 18, 1940. Courtesy Corps of Engineers, War Department, Norfolk, Va. 
In the headwaters of Catawba River in the Santee River Basin occurred some of the most intense runoff of the flood. (See pl. 7,B.) The peak discharge of Wilson Creek at Brown Mountain Beach, near Adako, N. C., was computed to be 99,000 second-feet from 66 square miles, or 1,500 second-feet per square mile. (See pl. 5.) This unusual unit discharge is also corroborated by measurements on nearby streams.

On Catawba and Wateree Rivers the Duke Power Co. operates nine reservoirs and power plants. During the mid-Angust flood the operation of the upper reservoir at Bridgewater reduced the peak discharge from about 142,000 second-feet to about 43,700 second-feet. Water was being stored at a rate of over 120,000 second-feet for more than. 1 hour. At Rhodhiss Reservoir, the next reservoir downstream, the peak contribution of 43,700 second-feet flowing out of the Bridgewater Reservoir was increased to about 168,000 second-feet by the very intense runoff from Wilson Creek and other streams that entered the reservoir from the north. By the storage of water the maximum outflow from Rhodhiss Reservoir was reduced to 104,000 second-feet. From 8 p.m. to midnight August 13, water was being stored at an average rate greater than 100,000 second-feet. The magnitude of the effect of storage in the other seven reservoirs and ponds was not so great as for the upper two reservoirs, but contributed greatly to the reduction of the flood diseharges.

The storage in these reservoirs undoubtedly prevented a very severe and destructive flood in South Carolina. Generally all tributaries to Catawba River above Catawba, N. C., experienced floods greater than those of July 1916. At and downstream from Catawba, N. C., the magnitude of the flood of July 1916 was claimed to have been increased by the failure of a dike at the power development at Lookout Shoals. At the Geological Survey gaging station at Catawba, N. C., a stage of 36.8 feet was reached on August 14, as eompared with a stage of 44.1 feet on July 16, 1916. At the Weather Bureau gage near Camden, S. C., on Wateree River, a maximum stage of 30.5 feet was recorded on August 16, about 9 feet lower than that of July 18,1916 , which was measured $11 / 2$ miles downstream.

Floods on many streams in South Carolina and Georgia were severe but in general did not exceed previously known floods. (See pl. 8,A.) The high winds of the hurricane caused considerable damage and loss of life in the vicinity of Charleston, S. C., and Savannah, Ga. Many buildings were smashed, and trees were uprooted or broken off above ground. The records of the Coast and Geodetic Survey show that at Charleston, S. C., the hurricane tide reached a stage of 10.7 feet above mean low water on August 11, 1.6 feet above the previous high, which occurred on May 28, 1934. Records began in 1921. 
On New River and many of its tributaries there occurred the greatest floods of record in the headwaters in North Carolina and Virginia. (See pl. 8,B.) At Crumpler, N. C., North Fork New River reached a stage of 23.0 feet on August 14, as compared with stages of 17.6 feet during the flood of 1878 and 16.4 feet during the flood of July 1916 . South Fork New River near Jefferson, N. C., on August 14 reached a stage of 22.5 feet, which was the highest known since 1892 and 4.5 feet above that of the flood of July 1916. All but two bridges in the New River Basin in North Carolina were reported to have been washed out by the flood. The flood was also reported to be particularly severe on Chestnut Creek near Galax, Va.

In the Tennessee River Basin floods were most severe on those tributaries draining the west slopes of the Blue Ridge. In the Clinch River Basin, floods on many tributaries above Norris Dam approached the magnitude of previous floods, but storage of water in Norris Reservoir materially reduced flows downstream. On North Fork Holston River and South Fork Holston River the floods generally did not surpass those previously recorded. On Watauga River at and above Butler, Tenn., the flood was the greatest known, and discharges from headwater areas exceeded 1,000 second-feet per square mile from areas greater than 30 square miles. Damage along Watauga River was the greatest on any stream in the Tennessee River Basin. (See pl. 9) At Elizabethton, Tenn., on August 14, 1940, the river reached a stage of 20.9 , only 1.1 feet lower than that reached in the record flood of February 1902.

In the Nolichucky River Basin the floods were the highest in recent years. Of the tributaries, the floods were the greatest of record on South Toe and Cane Rivers. In the French Broad River Basin above Asheville, N. C., the flood of August 13 generally exceeded that of August 30, although the August floods were generally less than previously known floods except in the Hominy Creek and Pigeon River Basins. In the Hiwassee River Basin the flood of August 13 was greater than that of August 30 but generally not outstanding. Along Tennessee River below Chattanooga, Tenn., the August floods were not serious because of the regulating effect of the reservoirs upstream.

\section{LATE-AUGUST FLOOD}

Precipitation during the late-August storm was neither so great for the total storm period nor covered so extensive an area as during the mid-August storm. Owing to the shorter storm period, however, precipitation was more intense, so that in drainage basins near the storm centers the resulting floods were generally greater than those that resulted from the mid-August storm. The basins principally affected were those of French Broad, Little Tennessee, and upper 


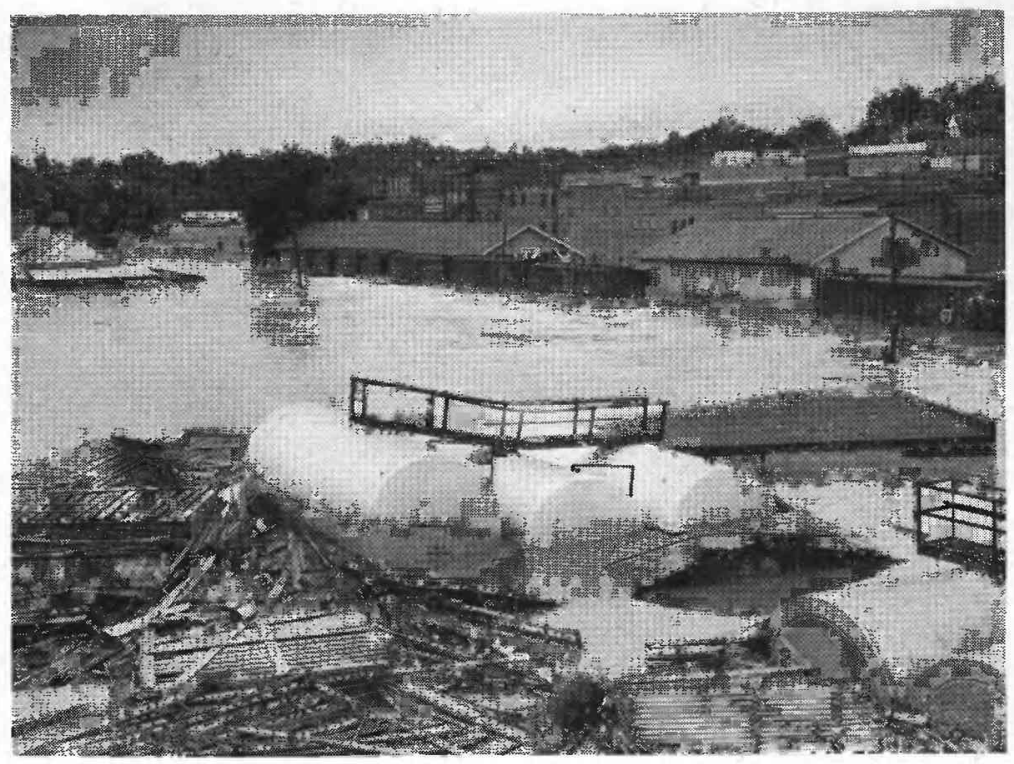

A. FLOOD OF AUGUST 14, 1940, ON YADKIN RIVER AT ELKIN, N. C.

Courtesy Winston-Salem (N.C.) Journal and Sentinel.

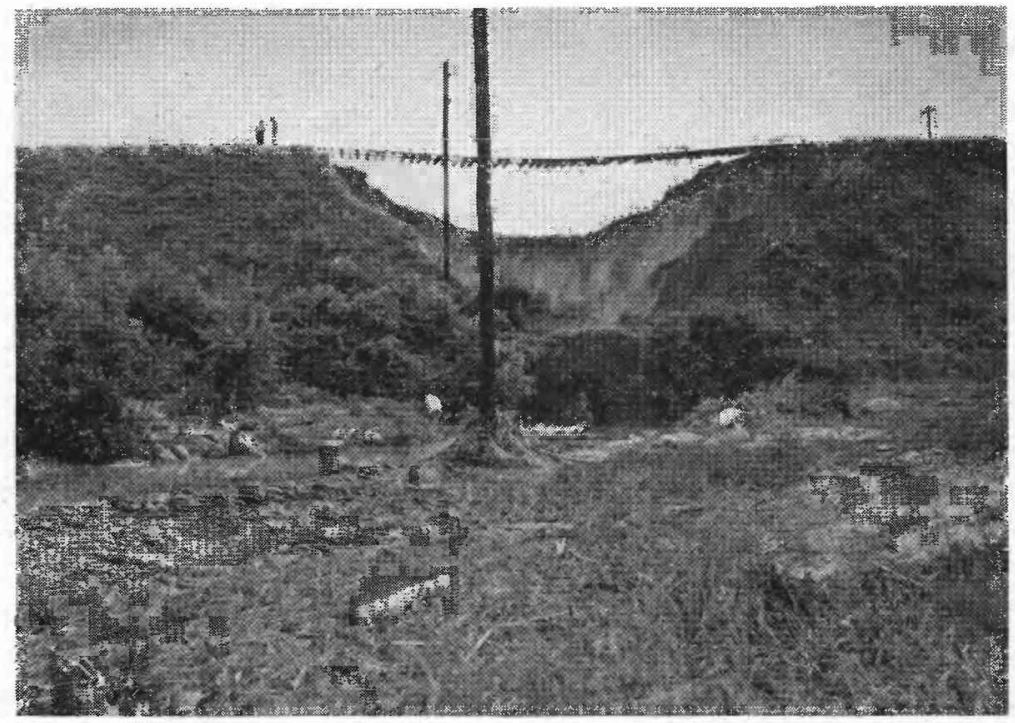

B. WASHOUT ON SOUTHERN RAILWAY NEAR ICARD, N.C.

Caused by inability of culvert to pass the great volume of water. Courtesy H. J. Loughead, U.S. Forest Service. 


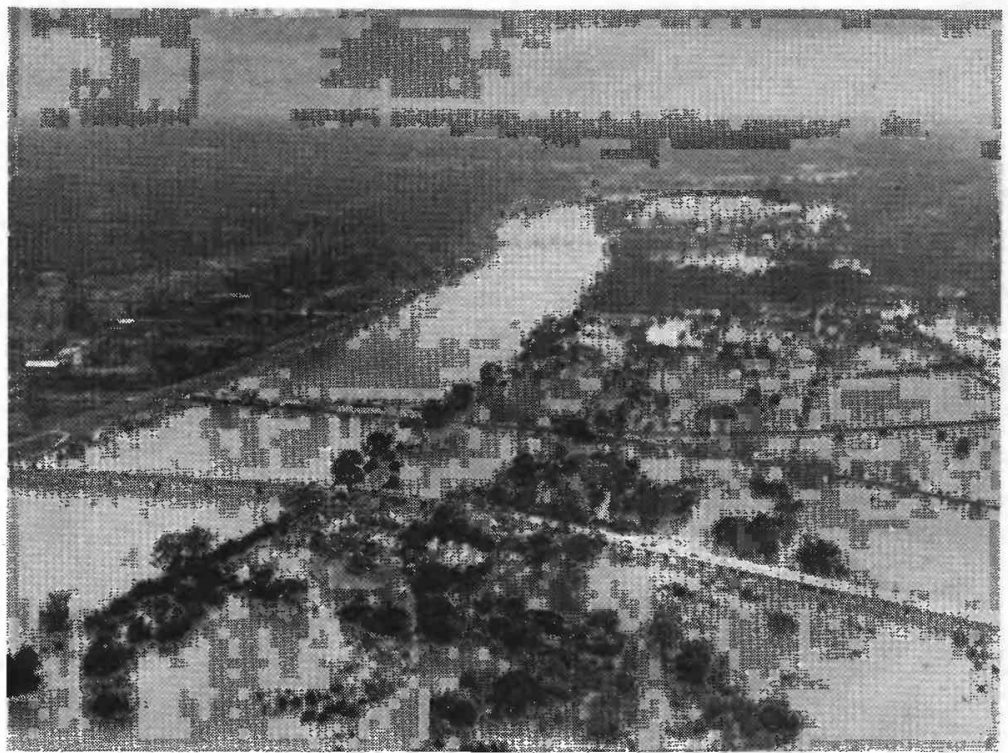

A. FLOOD ON SAVANNAH RIVER AT AUGUSTA, GA.

Courtesy Frank J. Christian, Augusta, Ga.

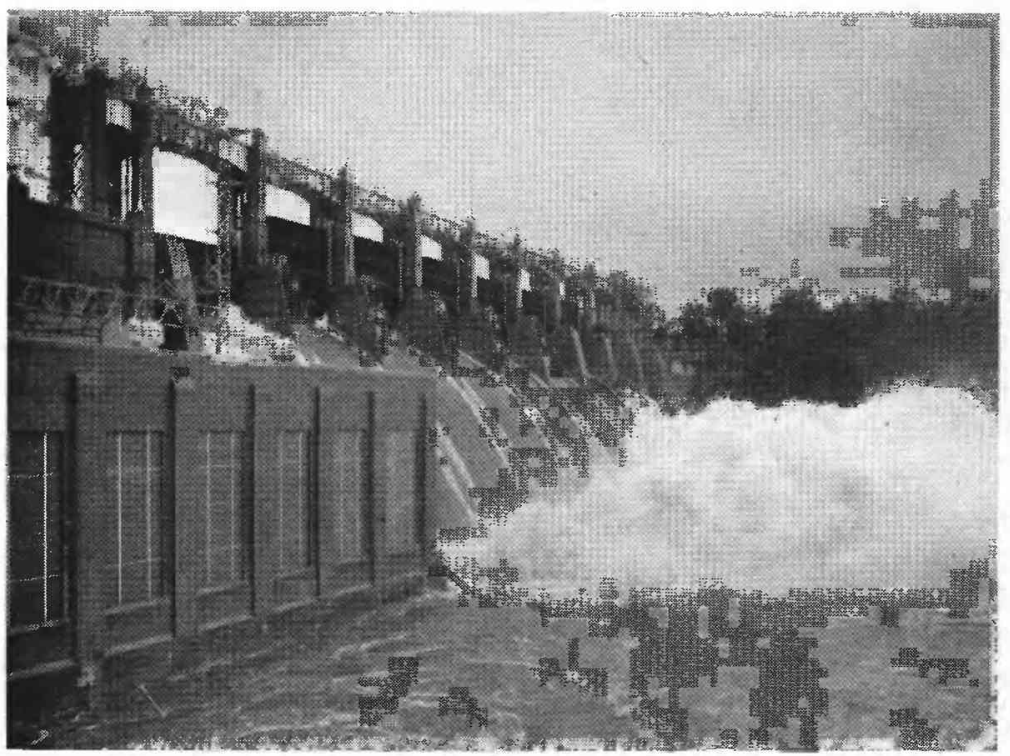

B. FLOOD ON NEW RIVER PASSING CLAYTOR DAM NEAR RADFORD, VA.

Discharge about 200,000 second-feet. Photograph by David C. Kent, Pulaski, Va. 
Savannah Rivers. The towns of Biltmore, Canton, Clyde, Cullowhee, Dillsboro, Enka, and Marshall, N. C., were severely damaged, and the business section of Bryson City, N. C., was deeply flooded. (See pls. 10 and 11.) The manufacturing plant of the Champion Paper \& Fibre Co. at Canton was especially hard hit, as it had just recovered from the mid-August flood. (See pl. 12,A.) Material damages in Jackson County, N. C., were estimated at $\$ 500,000 .^{7}$

At the plant of the American Enka Corp., at Enka, about 10,000 electric motors and their switch boxes were drowned out and had to be reconditioned. Mud covered the entire plant, in some places nearly a. foot thick. (See pl. 12,B.) Total damages were estimated at more than half a million dollars.

On French Broad River the late-August flood exceeded the midAugust flood at all gaging stations except three in North Carolina, but it was much less than the flood of July 1916. Flood heights at Marshall, N. C., were about the same as during the 1916 flood, but this is believed to be due to channel encroachments rather than to greater discharge, as flood heights in 1916 were greater both upstream and downstream from the town. ${ }^{8}$ On some of the tributaries, however, principally Hominy Creek and Mills, Ivy, and Pigeon Rivers, the late-August flood was the largest known.

Two slope-area measurements were made by the Geological Survey and one was made by the Tennessee Valley Authority on small streams in the headwaters of Pigeon River. These measurements indicated peak discharges of about 10,000 second-feet per square mile from drainage areas of 0.4 and 1.3 square miles. No great accuracy is claimed for these measurements, as they were made under difficult conditions. They indicate the extremely high rates of runoff that can come from intense rains on small areas.

The late-August flood in the Little Tennessee River Basin was particularly severe. It exceeded the mid-August flood generally and was the greatest flood of record at several points on Little Tennessee River and on Cullasaja Creek and Tuckasegee River above Dillsboro. On Tuckasegee River and Cullasaja Creek, discharges were 11/2 to 2 times greater than those previously recorded. Only two bridges were left in place on Tuckasegee River. (See pl. 13,A.) The peak discharge at Dillsboro, N. C., amounted to 52,600 second-feet from nearly 350 square miles.

The flood in the Savannah River Basin was not particularly outstanding, although it exceeded the mid-August flood in Chattooga and Tugaloo Rivers.

\footnotetext{
7 Asheville (N. C.) Times, Aug. 31, 1940.

8 Tennessee Valley Authority, Floods of August 1940 in the Tennessee River Basin, pp. 259, 263, 1940. [Processed. Supplement to Precipitation in Tennessee River Basin, October 1940.]
} 


\section{SLIDES}

One of the outstanding features connected with the storms of August 1940 was the great number of large landslides. These slides were conspicuous and contributed greatly to the devastation and death wrought by the floods. These slides occurred near the centers of both storms and they had many other characteristies in common. They occurred in shallow soils on steep slopes, surface exposures were toward the storm's path, and the areas tributary to the point of outbreak were amazingly small. They generally originated near the top of the mountain, usually about 300 to 400 feet from the top, and at a point where the slope changed from the relatively flat top to the steeper mountainside. The outbreaks are reported to have had the appearance of originating from eruptive forees, and the dislodged material was carried long distances. The slides were apparently caused by a high water content in the zone between the earth mantle and the steep underlying rock surfaces of the mountain slopes. Many of the larger slides continued on down the mountainsides into the stream valleys below, making a clean sweep of everything in their paths. (See pl. 13,B,C.) They emptied thousands of tons of soil and rock into the valley stream, which then became a mud-boulder flow, increasing the flood's destructiveness.

The slides varied in size from 6 or 8 feet wide and 40 or 50 feet long to 200 or 300 feet wide and a quarter to half a mile long. During the mid-August storm they occurred chiefly in the Blue Ridge from North Fork Catawba River northward to the north side of the Yadkin River Basin on the Atlantic slope and in the headwaters of Elk Creek and Watauga and New Rivers in the Ohio River Basin. During the late-August storm they occurred principally in the upper Pigeon and Tuckasegee River Basins, more than 200 occurring within an area of about 150 square miles. Similar slides are reported in most accounts of the flood of 1916 .

Measurements of soil eroded from experimental plots were made at several projects of the Soil Conservation Service. (For a list of these projects see p. 4.)

\section{DAMAGE}

A list of estimated damage and losses arising from the floods of August 1940 is given in table 1. These data were furnished by the Corps of Engineers, except for the Tennessee River Basin, which were taken from the report of the Tennessee Valley Authority. ${ }^{9}$

The estimated number of deaths of persons caused by the floods varies between 30 and 40 . Twenty-six persons are reported to have lost their lives in North Carolina.

\footnotetext{
Op. cit.
} 


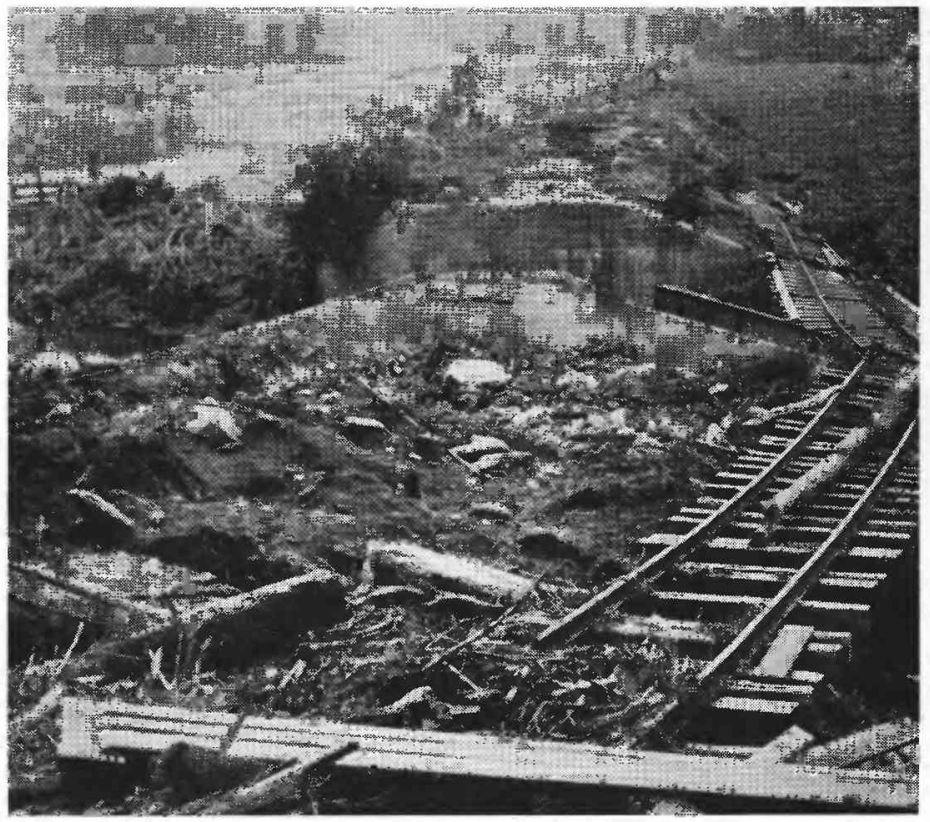

A. BRIDGE, TRACK, AND ROADBED OF LINVILLE VALLEY RAILROAD DESTROYEN

Courtesy Harrison Studio, Johnson City, Tenn.

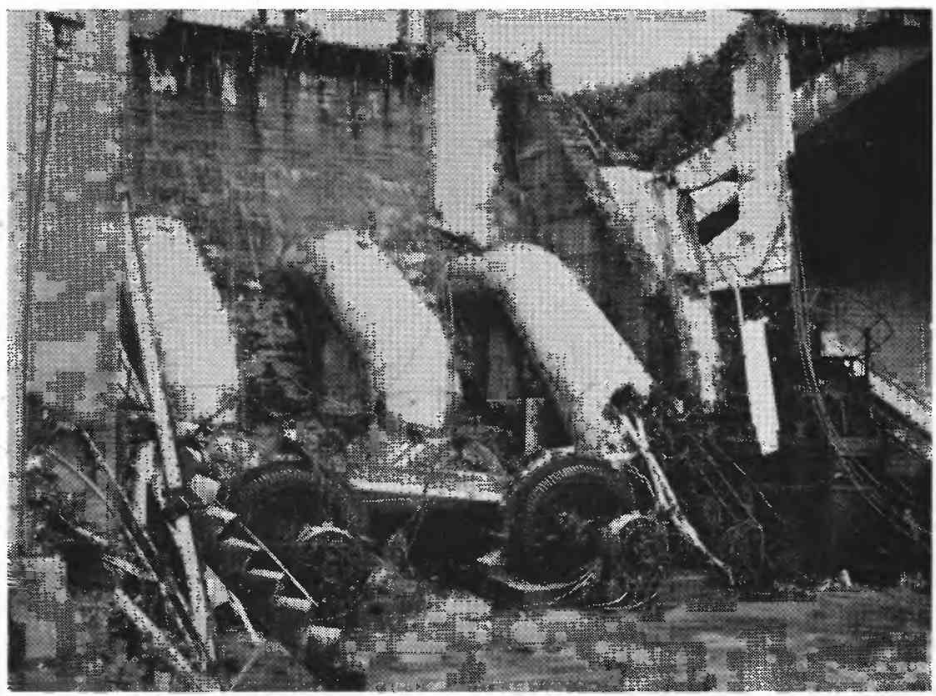

B. WILBUR POWERHOUSE AT HORSESHOE DAM.

Water in the reservoir rose more than 5 feet above the concrete wall near the top of the picture and destroyed walls and roof of powerhouse, with heavy damage to equipment. Courtesy East Tennessee Lighi \& Power Co.

FLOOD DAMAGE ALONG WATAUGA RIVER, TENN. $804331-49-3$ 


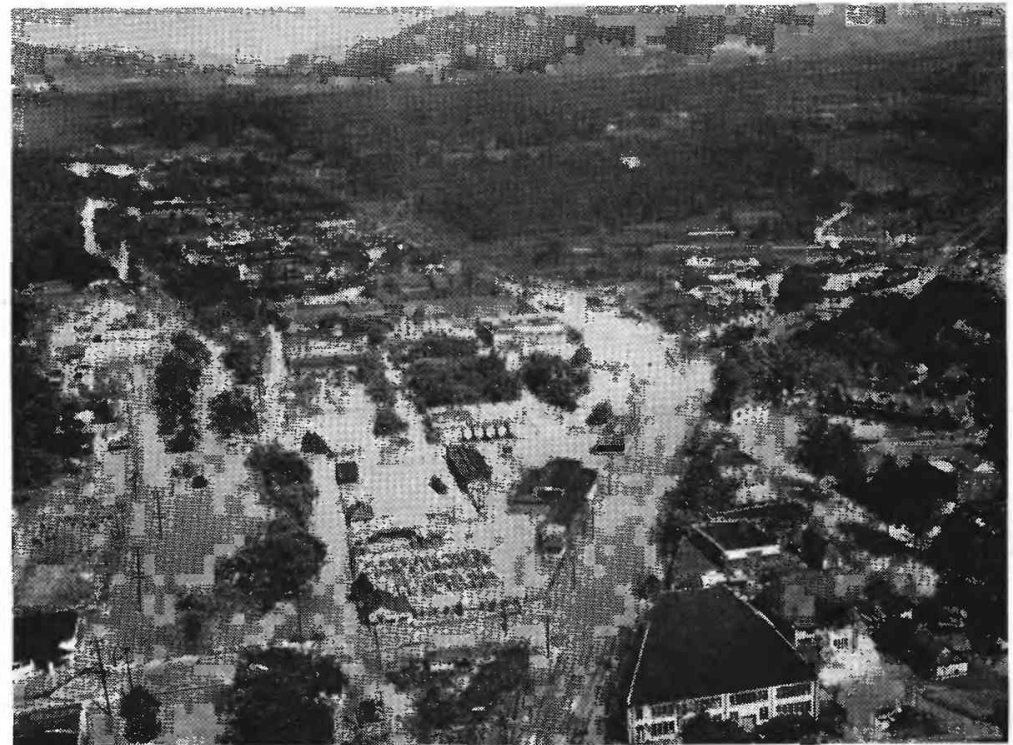

A. LATE-AUGUST FLOODS ON SWANNANOA RIVER AT BILTMORE, N. C. Courtesy Asheville (N.C.) Citizen-Times.

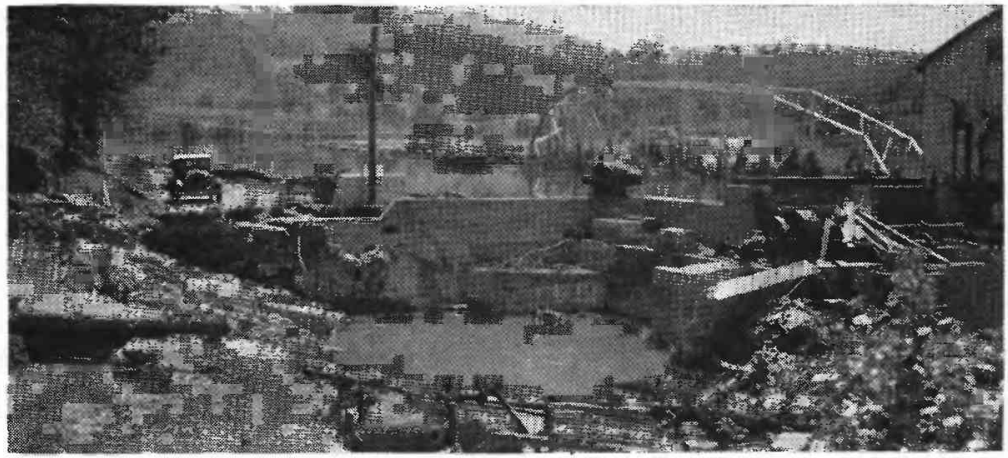

\section{B. REMAINS OF POWERHOUSE AT DILLSBORO, N.C.}

Bridge over Tuckasegee River in background was turned $90^{\circ}$ out of line. Courtesy Tennessee Valley Autbority. 
TABLE 1.-Estimates of loss and damage, in dollars, caused by the floods of August 1940

\begin{tabular}{|c|c|c|c|c|c|}
\hline & \multicolumn{4}{|c|}{ Type of loss } & \multirow{2}{*}{ Total } \\
\hline $\begin{array}{c}\text { Drainage } \\
\text { basin }\end{array}$ & Agricultural & Urban & $\begin{array}{l}\text { Communi- } \\
\text { cations and } \\
\text { utilities }\end{array}$ & $\begin{array}{l}\text { Miscel- } \\
\text { laneous }\end{array}$ & \\
\hline $\begin{array}{l}\text { James } \\
\text { Chowan } \\
\text { Roanoke. } \\
\text { Pamlico } \\
\text { Neuse }^{1} \\
\text { Pee Dee } \\
\text { Santee. }\end{array}$ & $\begin{array}{r}605,000 \\
550,900 \\
2,803,500 \\
557,226 \\
-430,000^{-} \\
200,000 \\
7,324,600 \\
446,000 \\
10,000 \\
1,195,000 \\
686,800\end{array}$ & $\begin{array}{r}171,800 \\
185,900 \\
1,676,200 \\
23,200 \\
2,82 \\
135,000 \\
929,665 \\
45,350 \\
700 \\
21,074,500 \\
2,049,000\end{array}$ & $\begin{array}{r}139,200 \\
222,100 \\
740,800 \\
3,280 \\
0,000 \\
1,241,000 \\
415,284 \\
138,060 \\
20,900 \\
901,085 \\
1,547,200\end{array}$ & \begin{tabular}{r}
$\begin{array}{r}27,000 \\
3,100 \\
57,000 \\
17,600\end{array}$ \\
\hdashline $1, \mathbf{3 2 6}, 695$ \\
4,500 \\
-2
\end{tabular} & $\begin{array}{r}943,000 \\
962,000 \\
5,277,500 \\
601,306 \\
3, \overline{250}, 000 \\
1,576,000 \\
9,996, \overline{244} \\
629,410 \\
31,600 \\
3,175,085 \\
4,283,000\end{array}$ \\
\hline Total $\ldots \ldots$ & $14,809,026$ & \multicolumn{2}{|c|}{$14,480,224$} & $1,435,895$ & $30,725,145$ \\
\hline
\end{tabular}

${ }^{1}$ Damage minor; no estimate prepared.

${ }^{2}$ Includes $\$ 200,000$ loss to navigation interests.

Highway damage alone was estimated at about $\$ 750,000$ in Virginia and $\$ 2,600,000$ in North Carolina. (See pl. 14.) Public water supplies were damaged and service was interrupted in a number of communities (see pl. 15), but apparently there were no outstanding losses of this nature.

Six gaging stations and six measuring cableways were lost by the Geological Survey during the flood.

\section{METEOROLOGIC AND HYDROLOGIC CONDITIONS}

As an aid to engineers and others who may desire to study the basic causes of floods and the remedial measures for protection from them, an effort has been made to present in this report basic data relating to the meteorologic and hydrologic conditions pertinent to the two floods of August 1940. The meteorologic data presented herein have been analyzed and used as a basis for the study of runoff during the floods of August 10-17 and 28-31. The data for the mid-August flood have been studied more extensively than those for the lateAugust flood; however, an attempt has been made to collect and publish all available precipitation data for both floods.

The unusual meteorologic events causing the mid-August flood were associated with the West Indian hurricane, which struck the coast about 4 p.m. August 11 near Savannah, Ga., and moved inland across Georgia, eastern Tennessee, southwestern Virginia, and North Carolina, where its identity was lost about August 15. Precipitation not directly associated with the hurricane also occurred at many points throughout the storm area, August 10-17. In general, the centers of greatest precipitation were in the Blue Ridge of North Carolina and Virginia, although a center on the Atlantic coast at Swansboro, N. C., and another at Keysville, Va., were observed.

Following the mid-August storm by about 2 weeks, the storm of 
August 28-31 again deluged the Blue Ridge area of North Carolina and Georgia with rainfall only slightly less than experienced during the first storm. This storm was rather limited in extent and duration, the principal rainfall occurring in 24 hours instead of 2 or 3 days, as in the mid-August storm. This second storm deposited maximum totals of 12 to 13 inches in 20 to 28 hours, as compared with 17 to 19 inches in 40 to 50 hours during the mid-August storm.

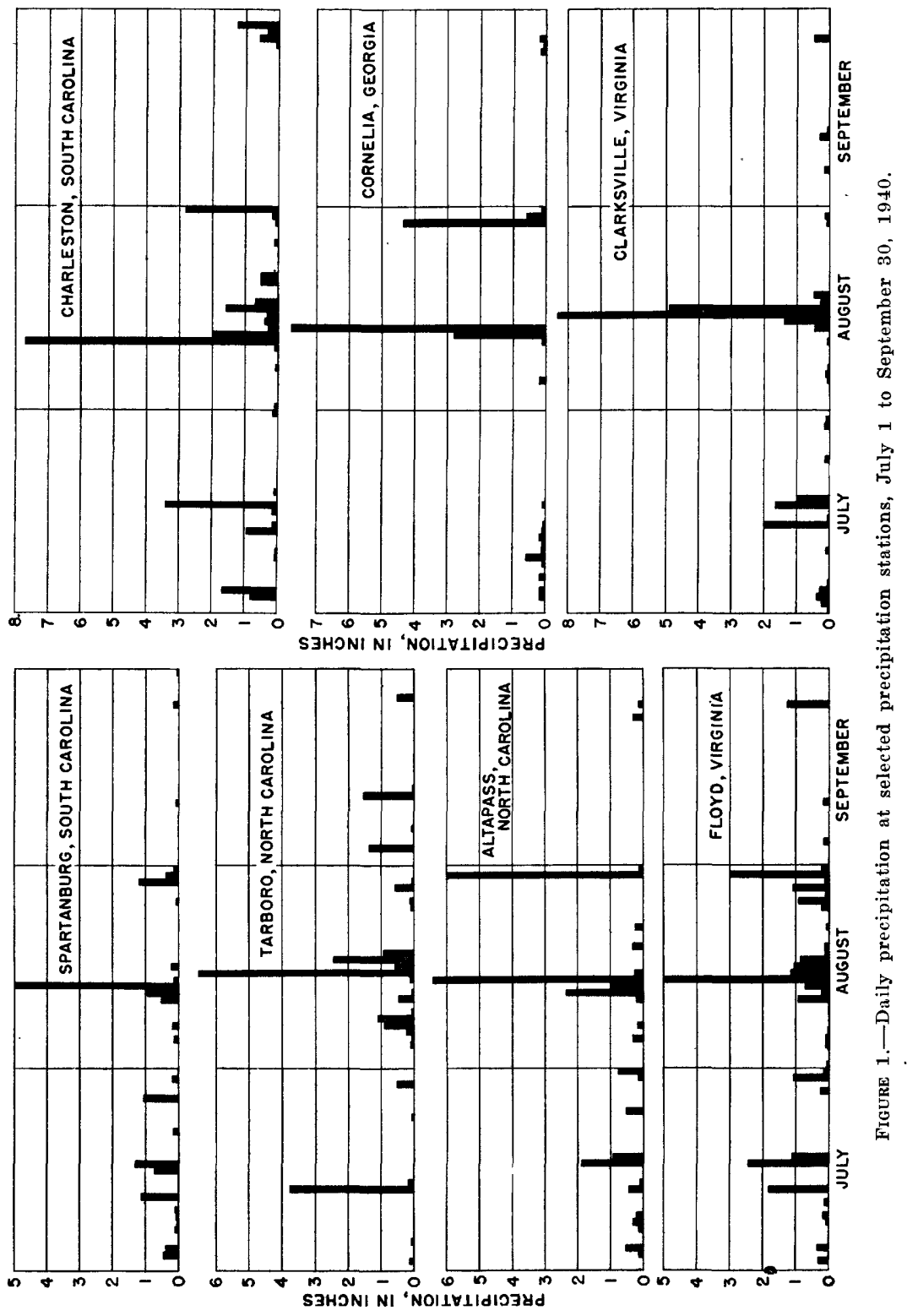




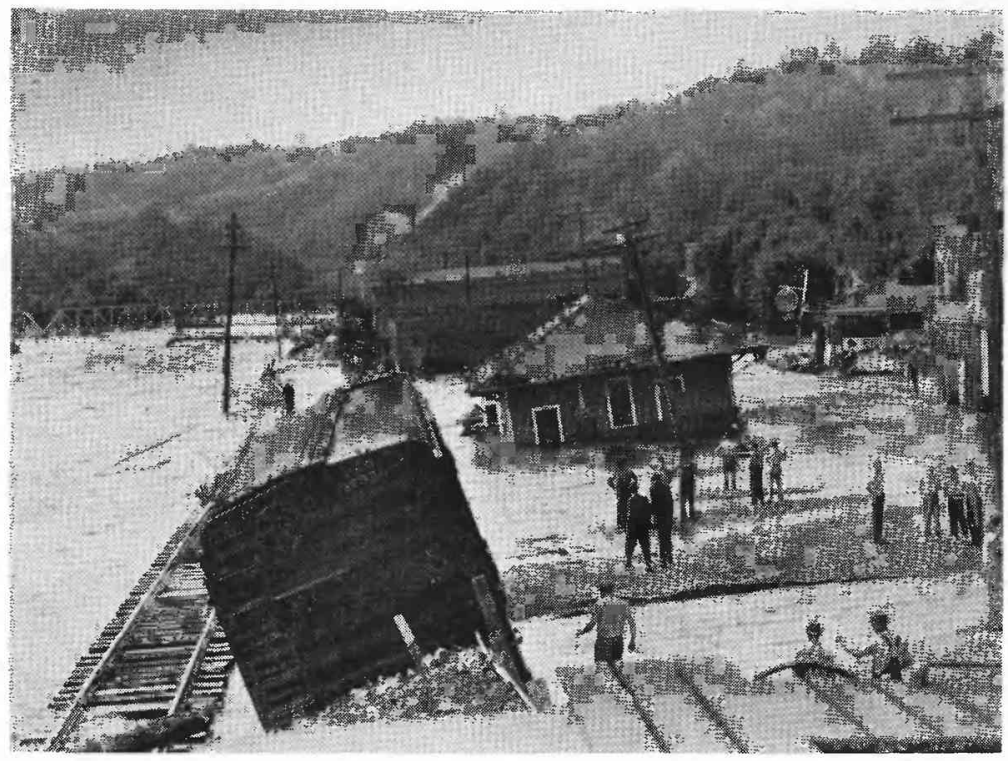

A. FRENCH BROAD RIVER AT MARSHALL.

Courtesy Asheville (N.C.) Citizen-Times.

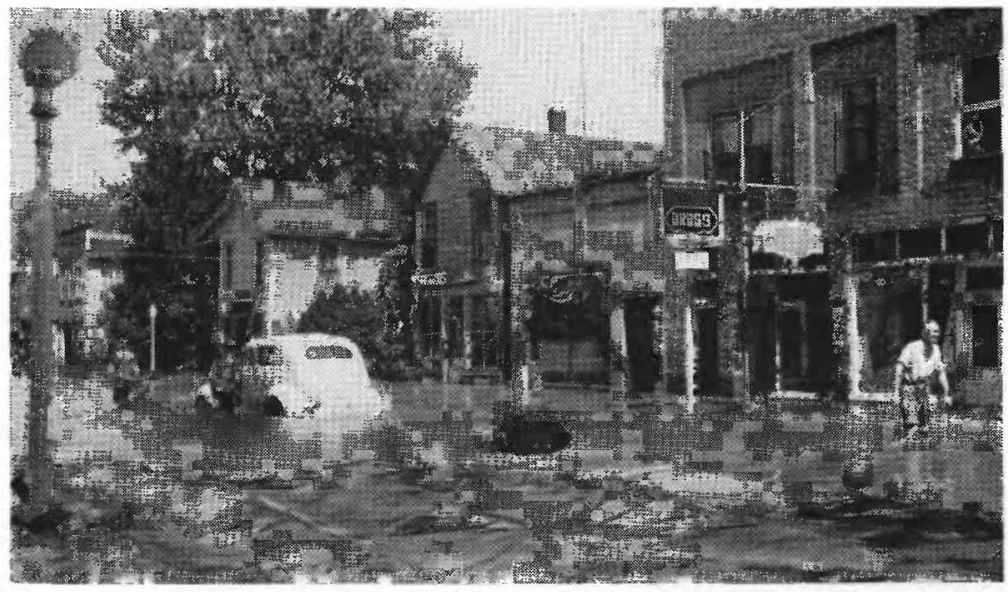

B. TUCKASEGEE RIVER AT BRYSON CITY.

About an hour and a half after the crest of the flood. Courtesy Tennessee Valley Authority.

\section{LATE-AUGUST FLOODS IN NORTH CAROLINA.}




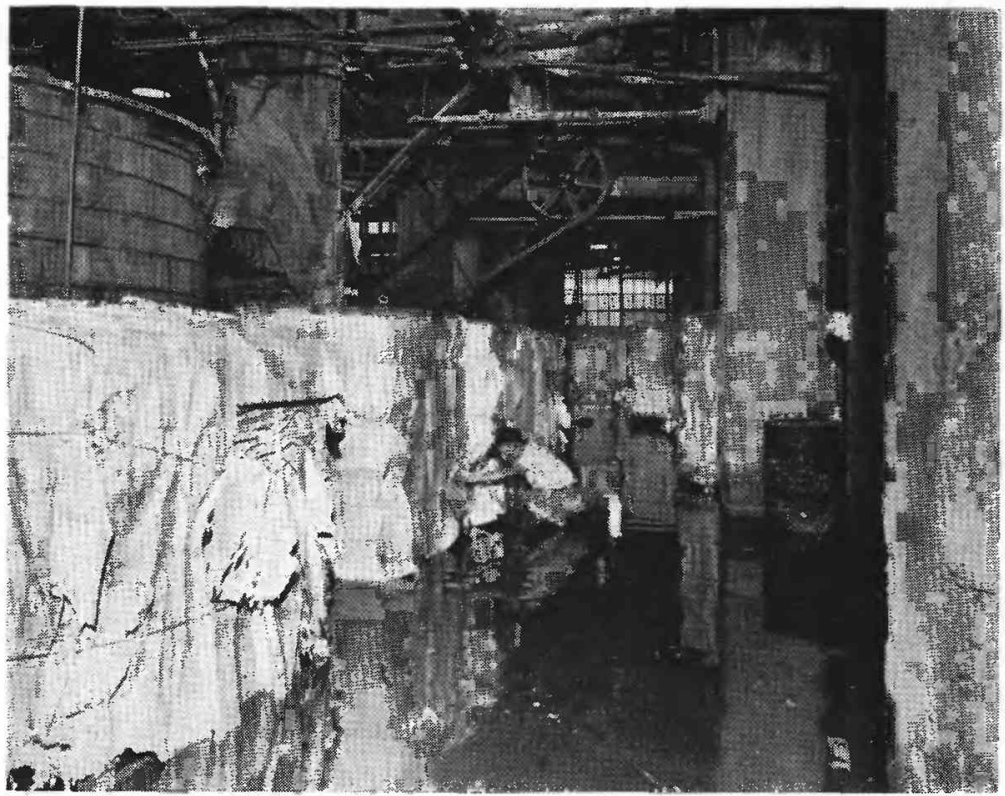

A. CANTON, N.C., PLANT OF CHAMPION PAPER \& FIBER CO. DAMAGED BY MID-AUGUST FLOOD.

Late-August flood was 3 feet above the floodmark shown in this plant. Courtesy Frank Clodfelter, Asheville N.C.) Citizen-Times.

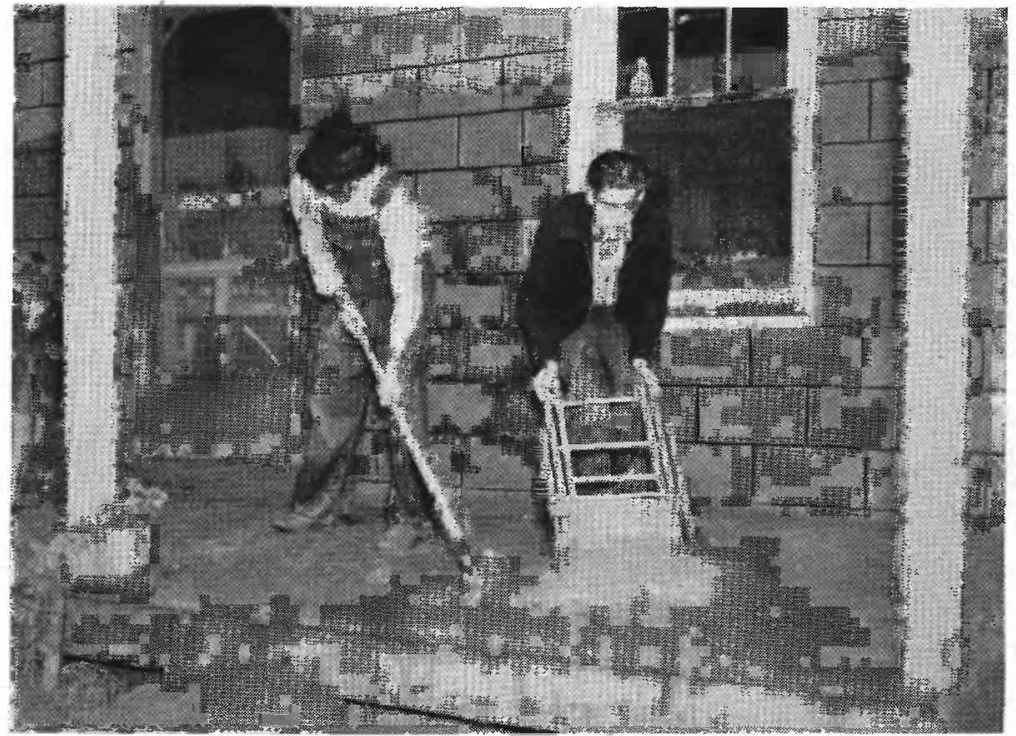

B. CLEANING UP AFTER THE FLOOD IN THE RIO VISTA SECTION OF ELIZABETHTON, TENN: Mud deposits such as these were typical of much of the flood area. Courtesy Knoxville (Tenn.) News-Sentinel. 


\section{ANTECEDENT CONDITIONS}

To a considerable extent the foundation of a flood may be laid by the meteorologic events during the period preceding the directly causative storm. In summer, factors of primary importance are soil moisture and ground-water levels, which influence the rate of infiltration into the soil and the space available for storage within the soil and as ground water. As direct measurements of soil moisture are not generally available, indirect methods of evaluating this factor, based on pertinent antecedent elimatologic data, must be used. The continuation of below-normal rainfall in combination with above-normal temperatures would be indicative of below-normal soil moisture and hence a soil conducive to greater retention. Ordinarily ground-water levels would tend to be relatively low under these circumstances. Monthly variations from normal precipitation and temperature, based on Weather Bureau records, afford a basis for evaluating such conditions and are presented in tables 2 and 3 for use in studying seasonal conditions prior to both floods. Figure 1 shows daily precipitation for July to September 1940 and indicates conditions immediately prior to as well as during and following the storms.

Owing to the broad areal extent of the mid-August storm and the variety of weather conditions in the several States affected, antecedent conditions varied considerably. This was indicated by.cumulative departures from normal for both precipitation and temperature. Cumulative deficiency in precipitation for the 5 months previous to the storm existed in all of the five States except Virginia and was greatest in North Carolina and South Carolina, being 4.2 inches and 5.9 inches, respectively. (See table 2.) As North Carolina was most affected by the storm and resulting flood, this below-normal precipitation had the effect of producing a below-normal soil moisture and hence of reducing the flood runoff to some extent. For this same period the precipitation in Georgia and eastern Tennessee was only slightly below normal and in Virginia was slightly above normal.

State-wide mean temperatures prior to the storm were below normal. (See table 3.) As this condition has a tendency to reduce soilmoisture losses, it tended to offset partly the deficiencies resulting from deficient precipitation. 
TABLE 2.-Monthly precipitation and departure from normal, in inches, March to August 1940 , by States

\begin{tabular}{|c|c|c|c|c|c|c|c|c|c|}
\hline \multirow[b]{2}{*}{ State } & \multicolumn{3}{|c|}{ March } & \multicolumn{3}{|c|}{ April } & \multicolumn{3}{|c|}{ May } \\
\hline & $\begin{array}{c}\text { Pre- } \\
\text { cipi- } \\
\text { tation }\end{array}$ & $\begin{array}{c}\text { Depar- } \\
\text { ture from } \\
\text { normal }\end{array}$ & $\begin{array}{c}\text { Cumula- } \\
\text { tive de- } \\
\text { parture } \\
\text { from } \\
\text { normal }\end{array}$ & $\begin{array}{c}\text { Pre- } \\
\text { cipi- } \\
\text { tation }\end{array}$ & $\begin{array}{c}\text { Depar- } \\
\text { ture from } \\
\text { normal }\end{array}$ & $\begin{array}{l}\text { Cumula- } \\
\text { tive de- } \\
\text { parture } \\
\text { from } \\
\text { normal }\end{array}$ & $\begin{array}{c}\text { Pre- } \\
\text { cipi- } \\
\text { tation }\end{array}$ & $\begin{array}{c}\text { Depar- } \\
\text { ture from } \\
\text { normal }\end{array}$ & $\begin{array}{l}\text { Cumula- } \\
\text { tive de- } \\
\text { parture } \\
\text { from } \\
\text { normal }\end{array}$ \\
\hline $\begin{array}{l}\text { Virginia } \\
\text { North Carolina } \\
\text { Eastern Tennessee. } \\
\text { South Carolina } \\
\text { Georgia. }\end{array}$ & $\begin{array}{l}2.58 \\
3.12 \\
4.91 \\
3.38 \\
4.03 \\
\end{array}$ & $\begin{array}{l}-1.10 \\
-1.06 \\
-\quad .39 \\
-\quad .45 \\
-\quad .77 \\
\end{array}$ & $\begin{array}{l}-1.10 \\
-1.06 \\
-\quad .39 \\
-.45 \\
-\quad .77 \\
\end{array}$ & $\begin{array}{l}4.34 \\
3.46 \\
4.04 \\
2.07 \\
3.03 \\
\end{array}$ & $\begin{array}{r}+0.98 \\
-.15 \\
-.30 \\
-1.21 \\
-.80 \\
\end{array}$ & $\begin{array}{l}-0.12 \\
-1.21 \\
-1.69 \\
-1.66 \\
-1.57 \\
\end{array}$ & $\begin{array}{l}4.43 \\
3.81 \\
3.02 \\
2.84 \\
2.14 \\
\end{array}$ & $\begin{array}{r}+0.72 \\
-.25 \\
-1.08 \\
-. .72 \\
-1.29 \\
\end{array}$ & $\begin{array}{l}+0.60 \\
-1.46 \\
-1.77 \\
-2.38 \\
-2.86 \\
\end{array}$ \\
\hline \multirow[b]{2}{*}{ State } & \multicolumn{3}{|c|}{ June } & \multicolumn{3}{|c|}{ July } & \multicolumn{3}{|c|}{ August } \\
\hline & $\begin{array}{l}\text { Pre- } \\
\text { cipi- } \\
\text { tation }\end{array}$ & $\begin{array}{c}\text { Depar- } \\
\text { turefrom } \\
\text { normal }\end{array}$ & $\begin{array}{c}\text { Cumula- } \\
\text { tive de- } \\
\text { parture } \\
\text { from } \\
\text { normal }\end{array}$ & $\begin{array}{c}\text { Pre- } \\
\text { cipi- } \\
\text { tation }\end{array}$ & $\begin{array}{c}\text { Depar- } \\
\text { ture from } \\
\text { normal }\end{array}$ & $\begin{array}{l}\text { Cumula- } \\
\text { tive de- } \\
\text { parture } \\
\text { from } \\
\text { normal }\end{array}$ & $\begin{array}{c}\text { Pre- } \\
\text { cipi- } \\
\text { tation }\end{array}$ & $\begin{array}{c}\text { Depar- } \\
\text { ture from } \\
\text { normal }\end{array}$ & $\begin{array}{l}\text { Cumula- } \\
\text { tive de- } \\
\text { parture } \\
\text { from } \\
\text { normal }\end{array}$ \\
\hline $\begin{array}{l}\text { Virginia } \\
\text { North Carolina } \\
\text { Eastern Tennessee } \\
\text { South Carolina } \\
\text { Georgia }\end{array}$ & $\begin{array}{l}3.87 \\
3.56 \\
4.78 \\
3.45 \\
4.68\end{array}$ & $\begin{array}{l}-0.32 \\
-1.11 \\
+\quad .22 \\
-1.28 \\
+\quad .25\end{array}$ & $\begin{array}{l}+0.28 \\
-2.57 \\
-1.55 \\
-3.66 \\
-2.61\end{array}$ & $\begin{array}{l}5.16 \\
4.26 \\
5.26 \\
3.60 \\
6.69\end{array}$ & $\begin{array}{l}+0.56 \\
-1.63 \\
+\quad .34 \\
-2.22 \\
+\quad .92\end{array}$ & $\begin{array}{l}+0.84 \\
-4.20 \\
-1.21 \\
-5.88 \\
-1.69\end{array}$ & $\begin{array}{r}9.19 \\
10.57 \\
5.00 \\
10.22 \\
7.09\end{array}$ & $\begin{array}{l}+4.71 \\
+5.38 \\
+.62 \\
+4.45 \\
+1.80\end{array}$ & $\begin{array}{l}+5.55 \\
+1.18 \\
+\quad .59 \\
-1.43 \\
+\quad .11 \\
\end{array}$ \\
\hline
\end{tabular}

TABLE 3.-Monthly mean temperature and departure from normal, in degrees Fahrenheit, March to August 1940, by States

\begin{tabular}{|c|c|c|c|c|c|c|c|c|c|}
\hline \multirow[b]{2}{*}{ State } & \multicolumn{3}{|c|}{ March } & \multicolumn{3}{|c|}{ April } & \multicolumn{3}{|c|}{ May } \\
\hline & Mean & $\begin{array}{c}\text { Depar- } \\
\text { ture from } \\
\text { normal }\end{array}$ & \begin{tabular}{|c|} 
Cumula- \\
tive de- \\
parture \\
from \\
normal
\end{tabular} & Mean & $\begin{array}{c}\text { Depar- } \\
\text { ture from } \\
\text { normal }\end{array}$ & $\begin{array}{l}\text { Cumula- } \\
\text { tive de- } \\
\text { parture } \\
\text { from } \\
\text { normal }\end{array}$ & Mean & $\begin{array}{c}\text { Depar- } \\
\text { ture from } \\
\text { normal }\end{array}$ & $\begin{array}{l}\text { Cumula- } \\
\text { tive de- } \\
\text { parture } \\
\text { from } \\
\text { normal }\end{array}$ \\
\hline $\begin{array}{l}\text { Virginia } \\
\text { North Carolina } \\
\text { Eastern Tennessee } \\
\text { South Carolina } \\
\text { Georgia }\end{array}$ & $\begin{array}{l}42.3 \\
47.0 \\
45.8 \\
51.6 \\
53.9 \\
\end{array}$ & $\begin{array}{l}-3.5 \\
-3.0 \\
-2.5 \\
-3.2 \\
-2.4 \\
\end{array}$ & $\begin{array}{l}-3.5 \\
-3.0 \\
-2.5 \\
-3.2 \\
-2.4 \\
\end{array}$ & $\begin{array}{l}52.2 \\
56.3 \\
56.2 \\
60.6 \\
61.6 \\
\end{array}$ & $\begin{array}{l}-2.2 \\
-1.6 \\
-1.2 \\
-1.6 \\
-1.7 \\
\end{array}$ & $\begin{array}{l}-5.7 \\
-4.6 \\
-3.7 \\
-4.8 \\
-4.1 \\
\end{array}$ & $\begin{array}{r}63.4 \\
65.4 \\
63.1 \\
68.4 \\
69.3 \\
\end{array}$ & $\begin{array}{l}-0.7 \\
-1.4 \\
-2.8 \\
-2.5 \\
-2.2 \\
\end{array}$ & $\begin{array}{l}-6.4 \\
-6.0 \\
-6.5 \\
-7.3 \\
-6.3 \\
\end{array}$ \\
\hline \multirow[b]{2}{*}{ State } & \multicolumn{3}{|c|}{ June } & \multicolumn{3}{|c|}{ July } & \multicolumn{3}{|c|}{ August } \\
\hline & Mean & $\begin{array}{c}\text { Depar- } \\
\text { ture from } \\
\text { normal }\end{array}$ & $\begin{array}{c}\text { Cumula- } \\
\text { tive de- } \\
\text { parture } \\
\text { from } \\
\text { normal }\end{array}$ & Mean & $\begin{array}{c}\text { Depar- } \\
\text { ture from } \\
\text { normal }\end{array}$ & $\begin{array}{l}\text { Cumula- } \\
\text { tive de- } \\
\text { parture } \\
\text { from } \\
\text { normal }\end{array}$ & Mean & $\begin{array}{c}\text { Depar- } \\
\text { ture from } \\
\text { normal }\end{array}$ & $\begin{array}{l}\text { Cumula- } \\
\text { tive de- } \\
\text { parture } \\
\text { from } \\
\text { normal }\end{array}$ \\
\hline $\begin{array}{l}\text { Virginia } \\
\text { North Carolina } \\
\text { Eastern Tennessee } \\
\text { South Carolina } \\
\text { Georgia }\end{array}$ & $\begin{array}{l}72.9 \\
75.3 \\
73.4 \\
78.3 \\
77.9\end{array}$ & $\begin{array}{r}+1.2 \\
+1.3 \\
0.9 \\
+\quad .2 \\
\end{array}$ & $\begin{array}{l}-5.2 \\
-4.7 \\
-6.5 \\
-6.4 \\
-6.5\end{array}$ & $\begin{array}{l}74.3 \\
75.9 \\
74.9 \\
79.6 \\
78.5 \\
\end{array}$ & $\begin{array}{l}-1.1 \\
-1.0 \\
-1.7 \\
-1.2 \\
-1.5\end{array}$ & $\begin{array}{l}-6.3 \\
-5.7 \\
-8.2 \\
-6.6 \\
-8.0\end{array}$ & $\begin{array}{l}72.7 \\
75.4 \\
75.4 \\
78.5 \\
79.9 \\
\end{array}$ & $\begin{array}{r}-1.4 \\
-. .5 \\
0 . \\
-\quad .4 \\
+\quad .4\end{array}$ & $\begin{array}{l}-7.7 \\
-6.2 \\
-8.2 \\
-7.0 \\
-7.6 \\
\end{array}$ \\
\hline
\end{tabular}

Ground-water levels are indicative of storage space in the ground; they also reflect the cumulative effects of excesses or deficiencies in precipitation and thus indirectly indicate relative soil-moisture conditions. Figure 2 shows ground-water levels in the Kurfee well, at Mocksville, N. C., in the Yadkin River Basin. This well reflects, in general, the relative water levels in the region of greater runoff during the mid-August storm. It can be noted that the level immediately prior to the storm was somewhat lower than during the corresponding periods of 1937, 1938, and 1939 but did not approach the lowest levels recorded at this well. The water level in the Baldwin 


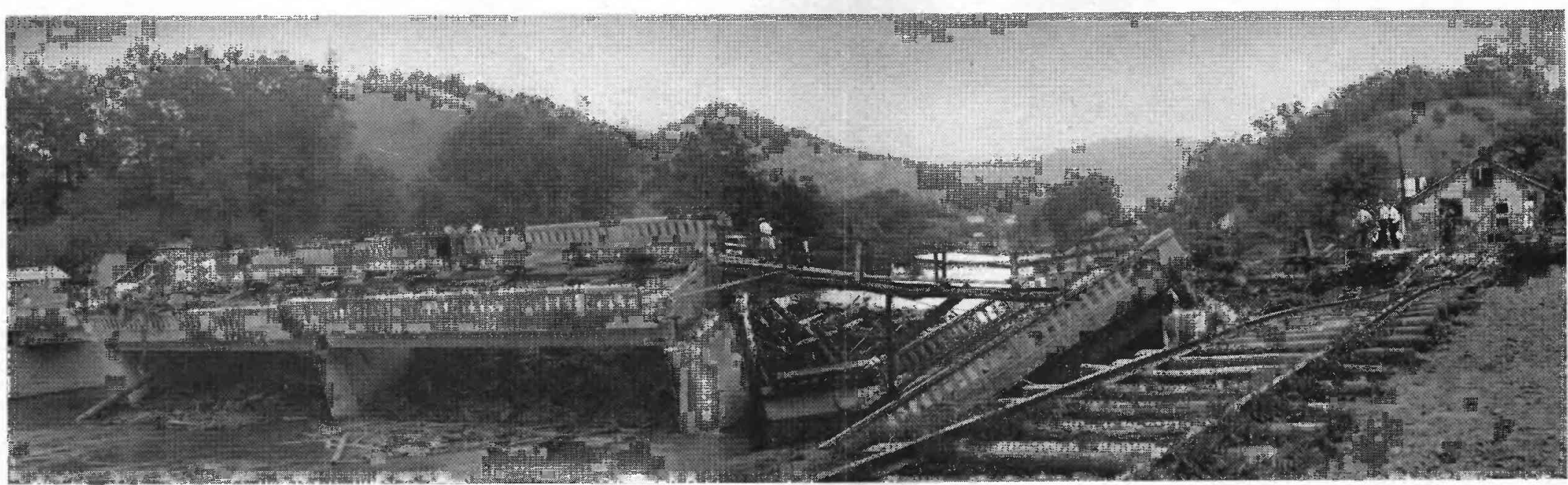

A. HIGHWAY BRIDGE DESTROYED ON TUCKASEGEE RIVER.

This bridge near Cullowhee, N.C., is one of many on Tuckasegee River destroyed by the flood of August 30. Courtesy Tennessee Valley Authority.
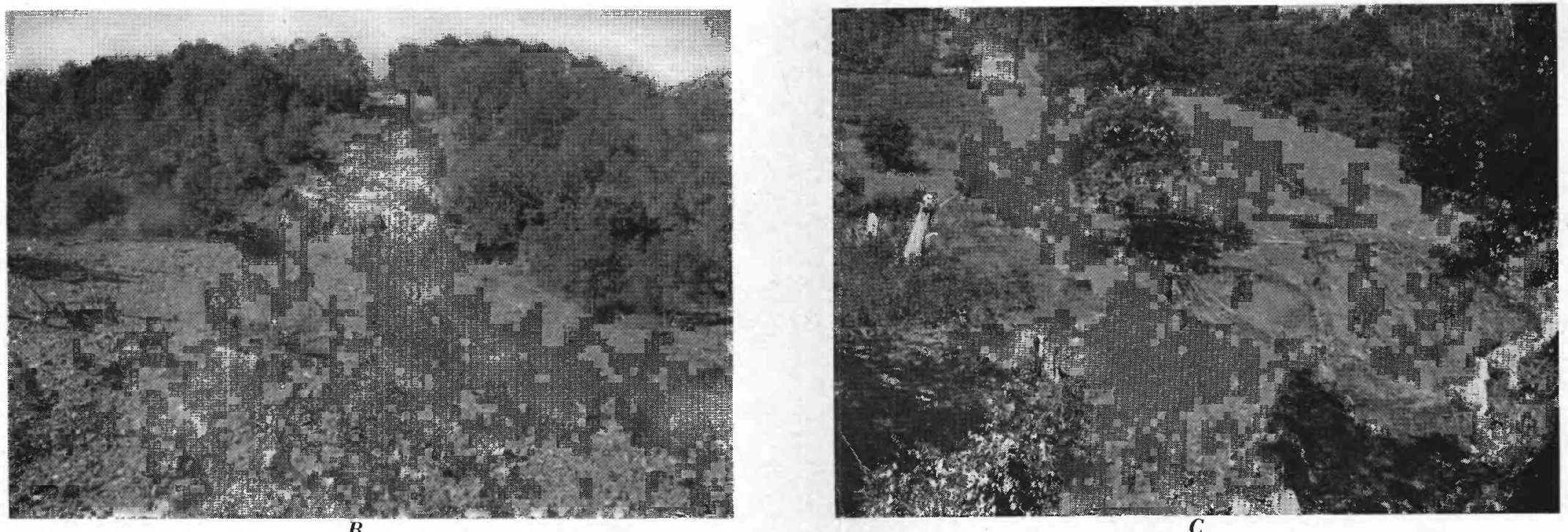

LARGE SLIDE ON LEFT FORK STONY FORK IN WILKES COUNTY, N. C.

Typical of many slides in the Deep Gap region. Note stream in lower right corner of $C$ and toe of slide from which some material has been removed. $B$ is a view of upper part of slide from Typical of many slides in the Deep Gap region. Note stream in lower right corner
top of debris prle shown in C. Courtesy $\mathrm{H}$. J. Loughead, U.S. Forest Service. 



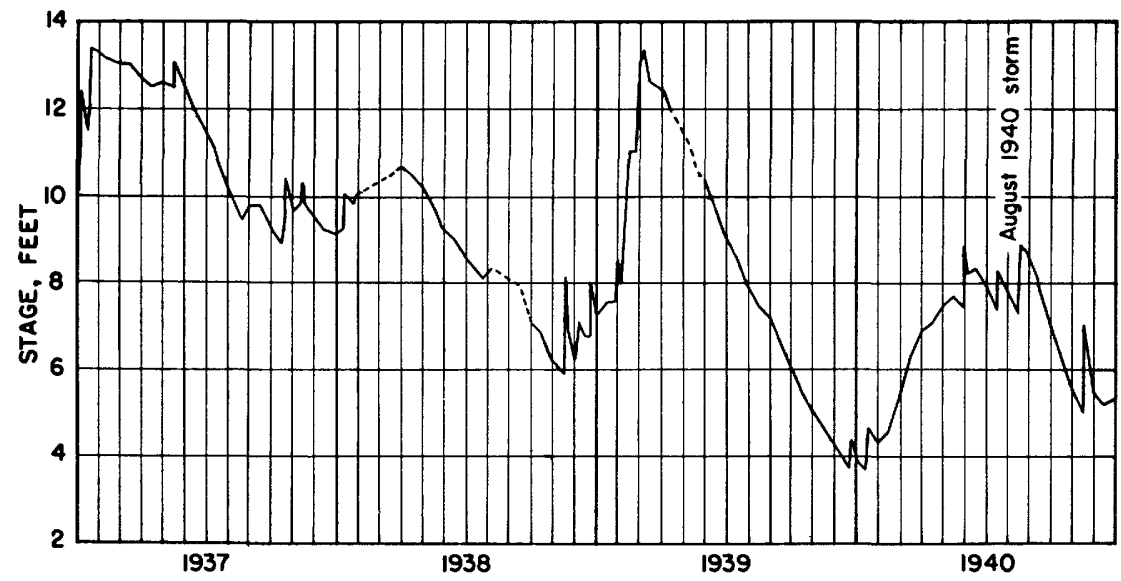

Figure 2.-Water levels of Kurfee well, Mocksville, N. C., 1937-40.

well, at Blantyre, N. C., in the upper French Broad River Basin stood at 5.49 feet on August 10; the normal stage in August in this well is $7+$ feet. The water level in well 33, of the Tyger River area near Spartanburg, S. C., was at a stage of 7.78 feet on August 12 ; normal is about 10.8 feet.

Another indirect measure of soil-moisture conditions and groundwater levels is base flow or ground-water effluent as measured by the natural flow in stream channels during periods of no direct runoff. When direct runoff has ceased subsequent to periods of rainfall, the flow of streams consists essentially of outflow from ground water. Further discharge during periods of no rainfall drains water stored in the zone of saturation and reduces the ground-water level correspondingly. The base flow for the first 10 days of August as estimated for various years is given in table 4 to afford comparison with the conditions prior to the 1940 mid-August flood. On this basis, it is apparent that soil-moisture conditions varied considerably over the area effected by the storms. Conditions in the upper Roanoke and Yadkin River Basins were generally somewhat below normal but were much higher than in 1932, one of the drought years for this region. The base flow in the Neuse and French Broad River Basins was subnormal and approached the conditions prevailing in 1932. For the Roanoke and French Broad River Basins, the base flow preceding the July 1916 flood has also been shown. The comparison of base flows in the French Broad River Basin suggests that soil-moisture conditions were apparently more conducive to direct runoff in July 1916 than in 1940 .

The late-August flood, following within 2 weeks of the first flood, may have been increased to some extent by inerements to soil mois- 
TABLE 4.-Estimated base flow, in second-feet, at selected gaging stations for period August 1-10 in various years

\begin{tabular}{|c|c|c|c|c|}
\hline Year & $\begin{array}{c}\text { Roanoke River at } \\
\text { Roanoke, Va. }\end{array}$ & $\begin{array}{c}\text { Neuse River } \\
\text { near } \\
\text { Clayton, N. C. }\end{array}$ & $\begin{array}{c}\text { Yadkin River at } \\
\text { Yadkin College, } \\
\text { N. C. }\end{array}$ & $\begin{array}{c}\text { French Broad } \\
\text { River at } \\
\text { Asheville, N. C. }\end{array}$ \\
\hline $\begin{array}{l}1940 \\
1939 \\
1938 \\
1936 \\
1932 \\
1925 \\
1916(\mathrm{July} 1 \mathrm{1} 10 \text { ) }\end{array}$ & $\begin{array}{r}120-130 \\
130-150 \\
200-250 \\
80-85 \\
40-50 \\
110-120\end{array}$ & $\begin{array}{l}180-200 \\
400-500 \\
400-450 \\
500-600 \\
100-120\end{array}$ & $\begin{array}{l}1,550-1,600 \\
1,550-1,600 \\
2,000-2,200 \\
1,400-1,500 \\
1,000-1,100\end{array}$ & $\begin{array}{r}650-700 \\
950-1,000 \\
1,600-1,700 \\
-1,100-1,200 \\
350-400 \\
1,600-1,700\end{array}$ \\
\hline
\end{tabular}

ture resulting from the mid-August storm. However, from an inspection of numerous discharge hydrographs for gaging stations in this area, it was noted that the base flow receded soon after the first flood to a comparatively low stage, so that the stage before the second flood at the end of August was not much greater than before the first flood.

\section{PRECIPITATION}

MID-AUGUST STORM

PRECIPITATION RECORDS

Precipitation records at nearly 650 stations were collected and used for the study of rainfall and runoff. The records have been furnished by governmental agencies, power companies, municipalities, corporations, and many individuals, whose cooperation is hereby acknowledged and to whom individual credit is given in the tabulations.

A compilation of rainfall data for this storm, made by the Corps of Engineers in their district office at Norfolk, Va., and furnished to the Geological Survey through the Chief of Engineers, has formed a basis for the records presented in table 5 . Numerous records published by the hydrologic units of the Weather Bureau, in cooperation with the Corps of Engineers, Soil Conservation Service, Forest Service, Flood Control Advisory Committee, and Bureau of Agricultural Economics, were assembled in this compilation, so that preparation of table 5 was greatly facilitated. Some records have been added, particularly data published by the Tennessee Valley Authority and data for miscellaneous stations maintained by the Weather Bureau. The isohyetal map presented as plate 16 has been prepared on the basis of a similar map prepared by the Corps of Engineers. However, data for the rainfall stations added by the Geological Survey have necessitated considerable revision, particularly in the Tennessee River Basin.

The daily precipitation at all stations from August 10 to 19, inclusive, is reported in table 5, with appropriate footnotes indicating the time of measurement, source of the record, and other information 


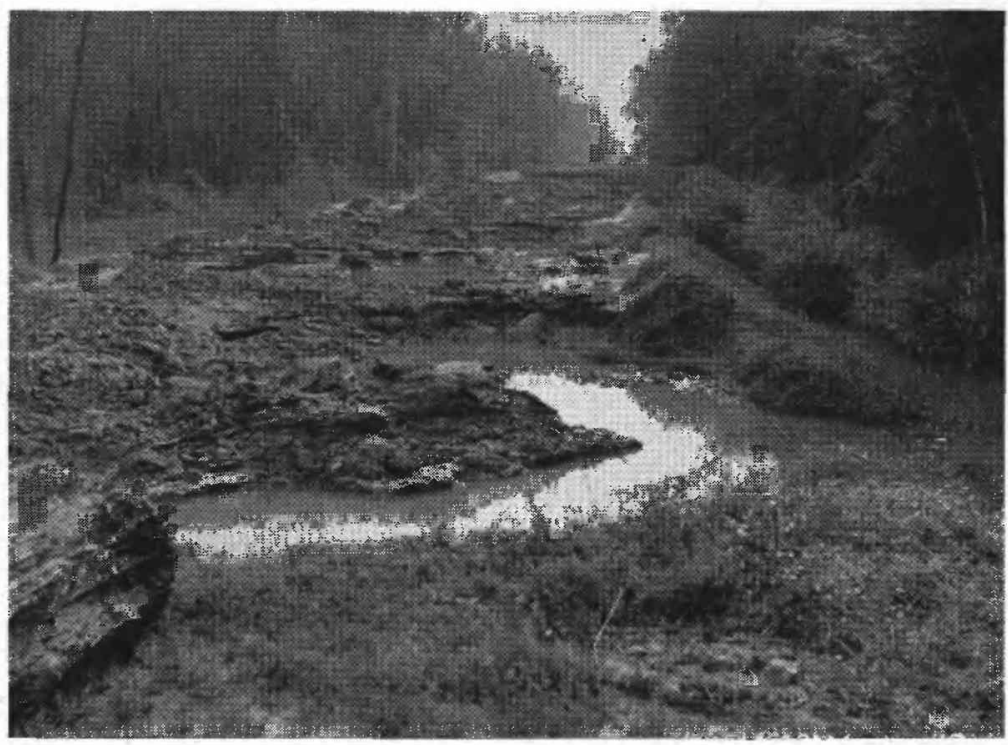

A. STATE ROUTE 195 ON LEFT BANK OF MEHERRIN RIVER NEAR BRANCHVILLE, VA. Courtesy Corps of Engineers, War Department, Norfolk, Va.

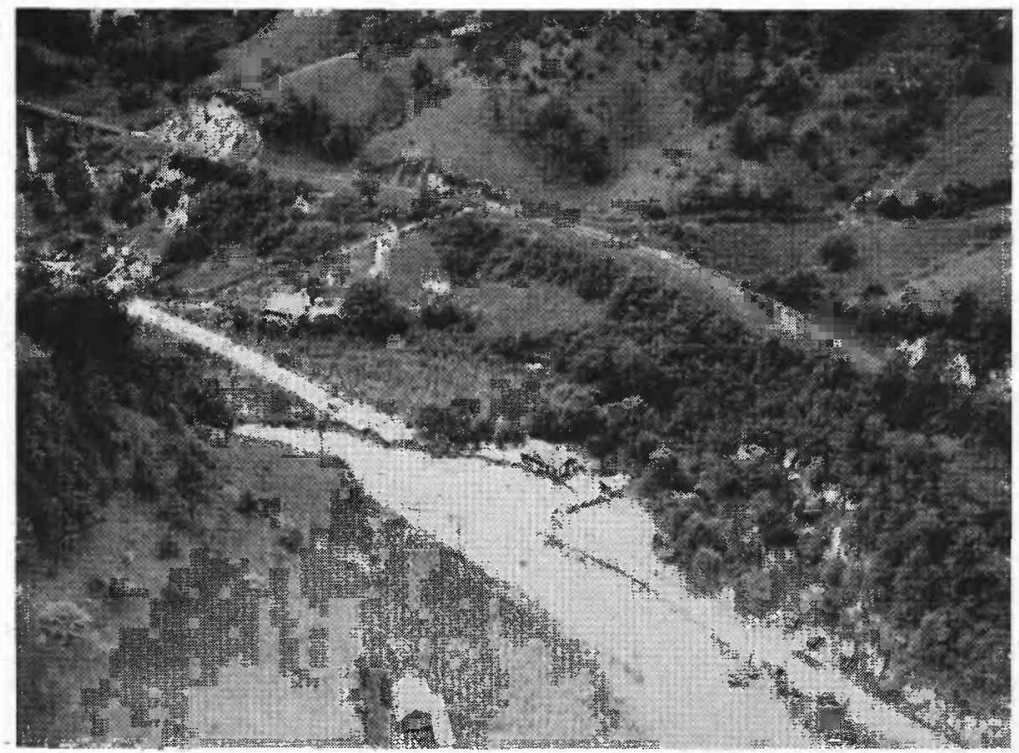

B. U.S. HIGHWAY 19-23 ALONG HOMINY CREEK NEAR CANTON, N.C.

Courtesy Asheville (N.C.) Citizen-Times. 


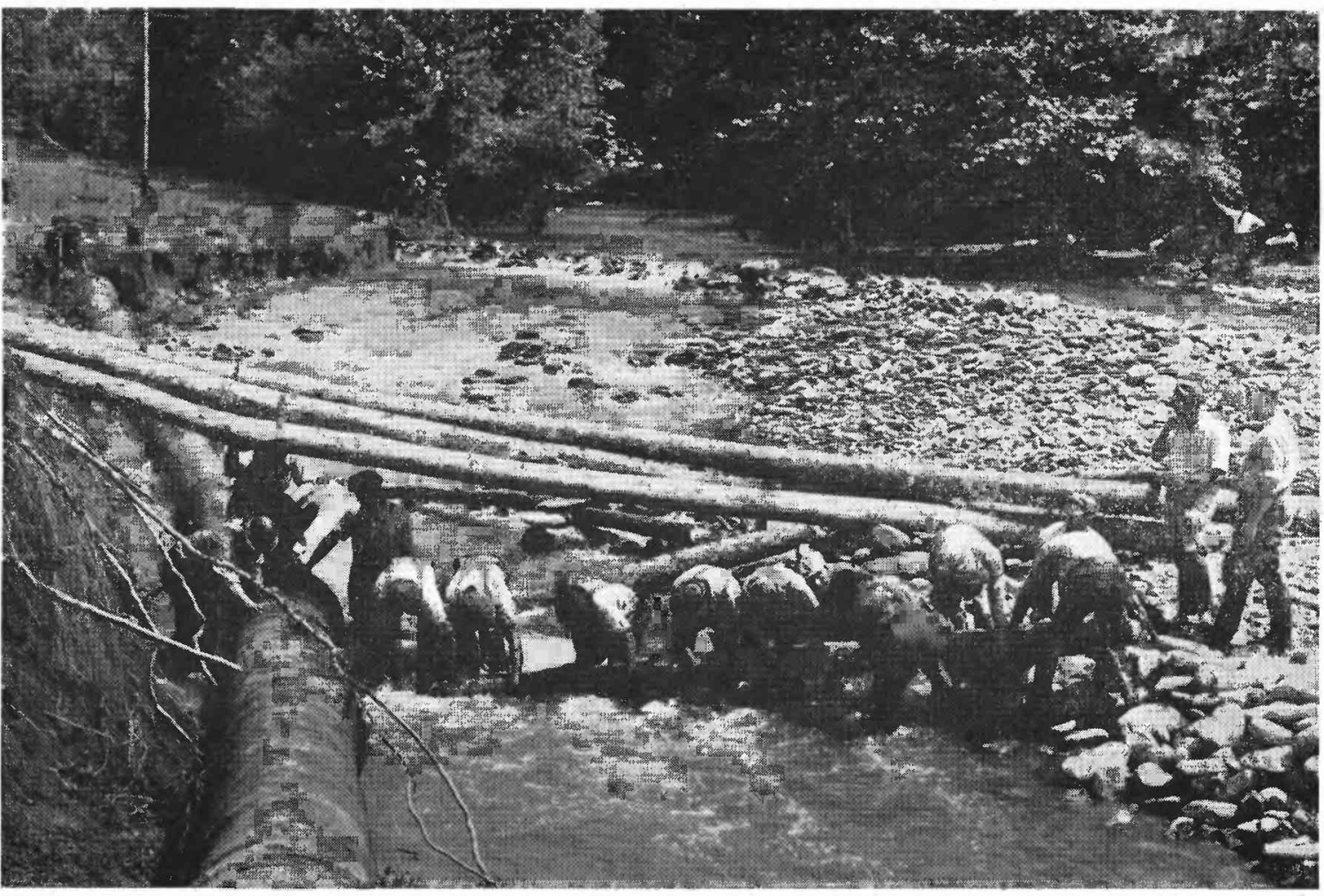

REPAIRING ASHEVILLE'S WATER-SUPPLY LINE.

This main meter line of the city of Asheville sagged and broke when Beetree Creek cut away the bank. Courtesy Frank Clodfelter, Asheville (N.C.) Citizen-Times. 
pertinent to the record. All data were furnished by the Weather Bureau, except as otherwise noted.

The last column in table 5 lists the total storm precipitation during the period between 6 a.m. August 10 and midnight August 17, which embraces the major storm. For stations in the compilation by the Corps of Engineers, the total for the stations that were read once or twice daily have been obtained from mass curves based on recording gage records (such as shown in fig. 3) at nearby stations and observers' notes as to times of beginning and ending of rain. There was generally no rain from the afternoon of August 9 to the morning of August 10 , and except for scattered showers in the mountainous areas of North Carolina and Virginia on August 18 and 19, the rain had ceased by midnight of August 17. The distribution of precipitation at selected recording gages in the storm area is shown in figure 4. From inspection of the hourly records the following rules were formulated for combining daily records that were not in the compilation by the Corps of Engineers, so as to show on as uniform a basis as possible all rainfall from 6 a.m. August 10 to midnight August 17:

1. For gages read in the afternoon, the precipitation records for August 10-17, inclusive, were totaled.

2. For gages read at midnight, the records for August 10-17, inclusive, were totaled.

3. For gages read at 1:30 a.m. and recorded for the preceding day, the records for August 10-17, inclusive, were totaled.

4. For gages read in the morning and recorded for the day read, the records for August 11-18, inclusive, were totaled. 
TABLE 5.-Daily precipitation, in inches, August 10-19, 1940

[Measured in morning except as noted; M, missing; NR, no record; $\mathrm{Tr}$, less than 0.01 inch]

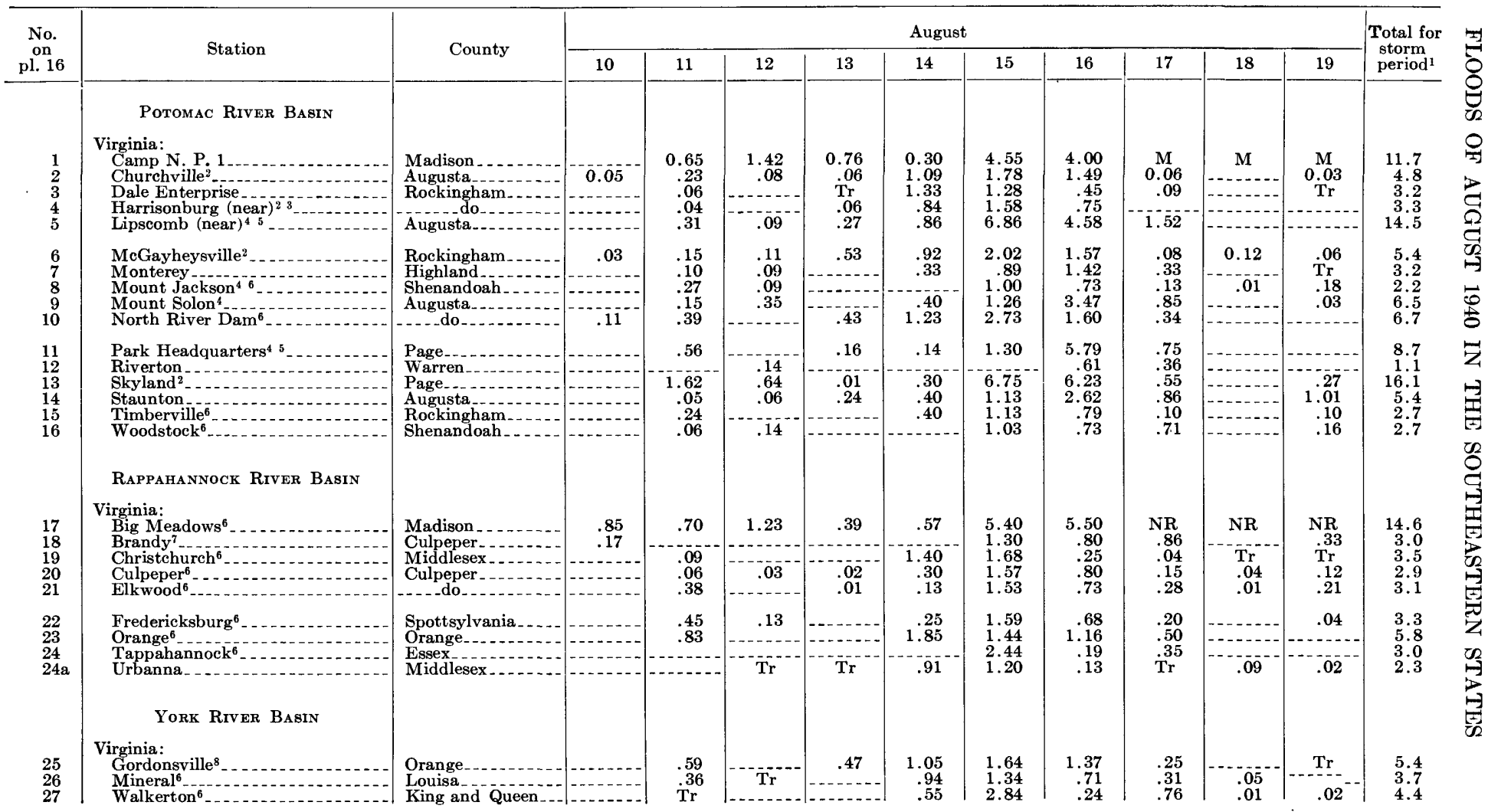




\begin{tabular}{|c|c|c|c|c|c|c|c|c|c|c|c|c|c|}
\hline & $\begin{array}{l}\text { JAMEs RIVER BASIN } \\
\text { Virginia: } \\
\text { Afton } \\
\text { Appomattox } \\
\text { Augusta Springs } \\
\text { Balcony Falls } \\
\text { Barbours Creek }{ }^{4}-\end{array}$ & $\begin{array}{l}\text { Nelson } \\
\text { Appomattox } \\
\text { Augusta } \\
\text { Rockbridge } \\
\text { Craig }\end{array}$ & & .26 & $\begin{array}{l}.23 \\
.38 \\
.73 \\
.65 \\
.08\end{array}$ & $\begin{array}{l}\mathrm{Tr} \\
.02 \\
.26 \\
.30\end{array}$ & $\begin{array}{r}.68 \\
.71 \\
.50 \\
1.97 \\
2.00\end{array}$ & $\begin{array}{r}1.43 \\
5.96 \\
1.19 \\
3.24 \\
.70\end{array}$ & $\begin{array}{l}4.42 \\
3.50 \\
3.24 \\
2.61 \\
.77\end{array}$ & $\begin{array}{r}2.64 \\
.43 \\
1.10 \\
1.75 \\
.35\end{array}$ & $\begin{array}{l}.12 \\
.23 \\
.20 \\
\mathrm{Tr}\end{array}$ & $\begin{array}{c}\mathrm{Tr} \\
.30 \\
.08\end{array}$ & $\begin{array}{r}9.8 \\
11.2 \\
7.2 \\
10.5 \\
4.6\end{array}$ \\
\hline & $\begin{array}{l}\text { luff } \\
\text { lsta. } \\
\text { Sanatorium } \\
\text { ssville (near) }\end{array}$ & Fluvanna.. & & $\begin{array}{l}.02 \\
.08 \\
.05 \\
.20 \\
.14\end{array}$ & $\begin{array}{l}.06 \\
.24 \\
.10 \\
.58 \\
\operatorname{Tr}\end{array}$ & $\begin{array}{l}.17 \\
.05 \\
.12 \\
.32 \\
.30\end{array}$ & $\begin{array}{l}1.33 \\
1.10 \\
.89 \\
3.88 \\
1.24\end{array}$ & $\begin{array}{l}2.8 \\
2.7 \\
1.9 \\
2.9 \\
2 .\end{array}$ & $\begin{array}{r}1.86 \\
1.70 \\
2.20 \\
1.25 \\
.97\end{array}$ & $\begin{array}{r}.42 \\
.67 \\
1.01 \\
.25 \\
.28\end{array}$ & $\begin{array}{l}\mathrm{Tr} \\
.05 \\
.01 \\
\mathrm{Tr}\end{array}$ & $\begin{array}{c}.02 \\
.20 \\
\operatorname{Tr}\end{array}$ & $\begin{array}{l}6.7 \\
6.6 \\
6.3 \\
9.4 \\
5.4\end{array}$ \\
\hline & $\begin{array}{l}\text { Clifton Forge. } \\
\text { Columbia } \\
\text { Covington } \\
\text { Cumberland.- } \\
\text { Deerfield (near) }{ }^{4} \\
\end{array}$ & $\begin{array}{l}\text { Alleghany } \\
\text { Fluvanna... } \\
\text { Alleghany } \\
\text { Cumberland... } \\
\text { Augusta }\end{array}$ & .10 & $\mathrm{Tr}$ & $\begin{array}{r}.24 \\
.37 \\
.70^{-}\end{array}$ & $\frac{.05}{10}$ & $\begin{array}{l}1.19 \\
1.48 \\
1.05 \\
1.46 \\
1.00\end{array}$ & $\begin{array}{l}2.10 \\
2.99 \\
.86 \\
4.00 \\
1.55\end{array}$ & $\begin{array}{r}.67 \\
2.56 \\
.24 \\
1.79 \\
.90\end{array}$ & \begin{tabular}{r}
.18 \\
.29 \\
\hdashline .50 \\
1.22
\end{tabular} & $\begin{array}{l}.14 \\
.12\end{array}$ & $\begin{array}{r}.15 \\
\end{array}$ & $\begin{array}{l}4.1 \\
7.7 \\
2.7 \\
6.9 \\
5.5\end{array}$ \\
\hline & (near) (Woodson's & Alb & & & & .48 & & .44 & .75 & 1.70 & .44 & $\operatorname{Tr}$ & 3.8 \\
\hline & 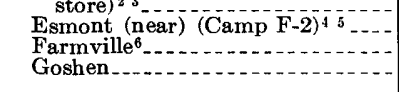 & $\begin{array}{l}\text { Albemarle....... } \\
\text { Prince Edward } \\
\text { Rockbridge....... }\end{array}$ & .02 & .19 & .35 & .10 & $\begin{array}{l}2.00 \\
1.03 \\
4.97 \\
.34\end{array}$ & $\begin{array}{l}1.06 \\
2.25 \\
4.25 \\
1.42\end{array}$ & $\begin{array}{l}1.88 \\
2.50 \\
1.76 \\
1.92\end{array}$ & $\begin{array}{l}.04 \\
.85 \\
.24 \\
.24\end{array}$ & & .03 & $\begin{array}{r}5.1 \\
7.2 \\
11.5 \\
3.9\end{array}$ \\
\hline $77 \mathrm{a}$ & $\begin{array}{l}\text { Hopewell } \\
\text { Hot Springs, } \\
\text { Hydraulic (near) } \\
\text { Ivy Depot (near) (Baker) } \\
\text { Jordan Mines (near) }{ }^{2}\end{array}$ & $\begin{array}{l}\text { Prince George } \\
\text { Bath } \\
\text { Albemarie........... } \\
\text { Alleghany }\end{array}$ & $\mathrm{Tr}$ & $\frac{.15}{.11}$ & $\begin{array}{l}.42 \\
.12 \\
.45 \\
.17\end{array}$ & $\begin{array}{r}\mathbf{T r} \\
.06 \\
\hdashline . \overline{3} \overline{6}\end{array}$ & $\begin{array}{l}111 \\
1.14 \\
(10) \\
(10) \\
2.66\end{array}$ & $\begin{array}{l}5.56 \\
1.71 \\
3.06 \\
4.56 \\
.92\end{array}$ & $\begin{array}{r}2.23 \\
2.43 \\
1.88 \\
2.63 \\
.54\end{array}$ & $\begin{array}{r}1.00 \\
.48 \\
.04 \\
.21\end{array}$ & $\begin{array}{l}\mathrm{Tr} \\
.01\end{array}$ & .06 & $\begin{array}{r}10.0 \\
6.4 \\
5.1 \\
7.8 \\
4.6\end{array}$ \\
\hline & $\begin{array}{l}\text { Kerrs Creek } \\
\text { Lynchburg } \\
\text { Lynchburg (airport) } \\
\text { McDowell } \\
\text { Millboro Springs }\end{array}$ & 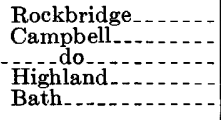 & $\begin{array}{l}.01 \\
.14\end{array}$ & $\begin{array}{l}.07 \\
.15 \\
.32 \\
.35\end{array}$ & $\begin{array}{l}.05 \\
\mathrm{Tr} \\
\mathrm{Tr} \\
.20 \\
.12\end{array}$ & $\begin{array}{l}.02 \\
.60 \\
.54 \\
.20\end{array}$ & $\begin{array}{l}1.10 \\
3.83 \\
5.02 \\
1.15 \\
1.69\end{array}$ & $\begin{array}{l}1.56 \\
1.51 \\
2.14 \\
2.77 \\
1.59\end{array}$ & $\begin{array}{r}3.37 \\
2.56 \\
2.13 \\
1.95 \\
.78\end{array}$ & $\begin{array}{r}.37 \\
.09 \\
.18 \\
1.55 \\
.03\end{array}$ & $\operatorname{Tr}$ & $\begin{array}{l}\mathrm{Tr} \\
.02\end{array}$ & $\begin{array}{r}6.5 \\
8.7 \\
10.5 \\
8.0 \\
4.4\end{array}$ \\
\hline & $\begin{array}{l}\text { Monoco (near) (Camp E-18) }{ }^{4}{ }^{5} \\
\text { Montebello } \\
\text { Moores Creek Dam }\end{array}$ & $\begin{array}{l}\text { Amberst.-.-- } \\
\text { Nelson } \\
\text { Rockbridge }\end{array}$ & & $\begin{array}{l}.07 \\
.30\end{array}$ & $\begin{array}{r}.54 \\
1.01\end{array}$ & $\begin{array}{r}.29 \\
.28\end{array}$ & $\begin{array}{l}1.7 .8 \\
.65 \\
2.10\end{array}$ & $\begin{array}{l}1.92 \\
2.25 \\
1.86\end{array}$ & $\begin{array}{l}2.84 \\
4.25 \\
1.60\end{array}$ & $\begin{array}{r}.95 \\
1.70\end{array}$ & .44 & .04 & $\begin{array}{r}8.4 \\
10.9 \\
5.6\end{array}$ \\
\hline
\end{tabular}

1 Total is for storm period 6 a.m. Aug. 10 to 12 p.m. Aug. 17 and is not the total of

recorded daily values August $10-17$.

3 Record furnished by Soil Conservation Service.

5 Precipitation ma dis the mornice.

${ }^{6}$ Precipitation measured in the afternoon.

Department

8 Precipitation measured at 1:30 a.m.; total is then recorded for previous day.

0 Precipitation included in the following measurement. 


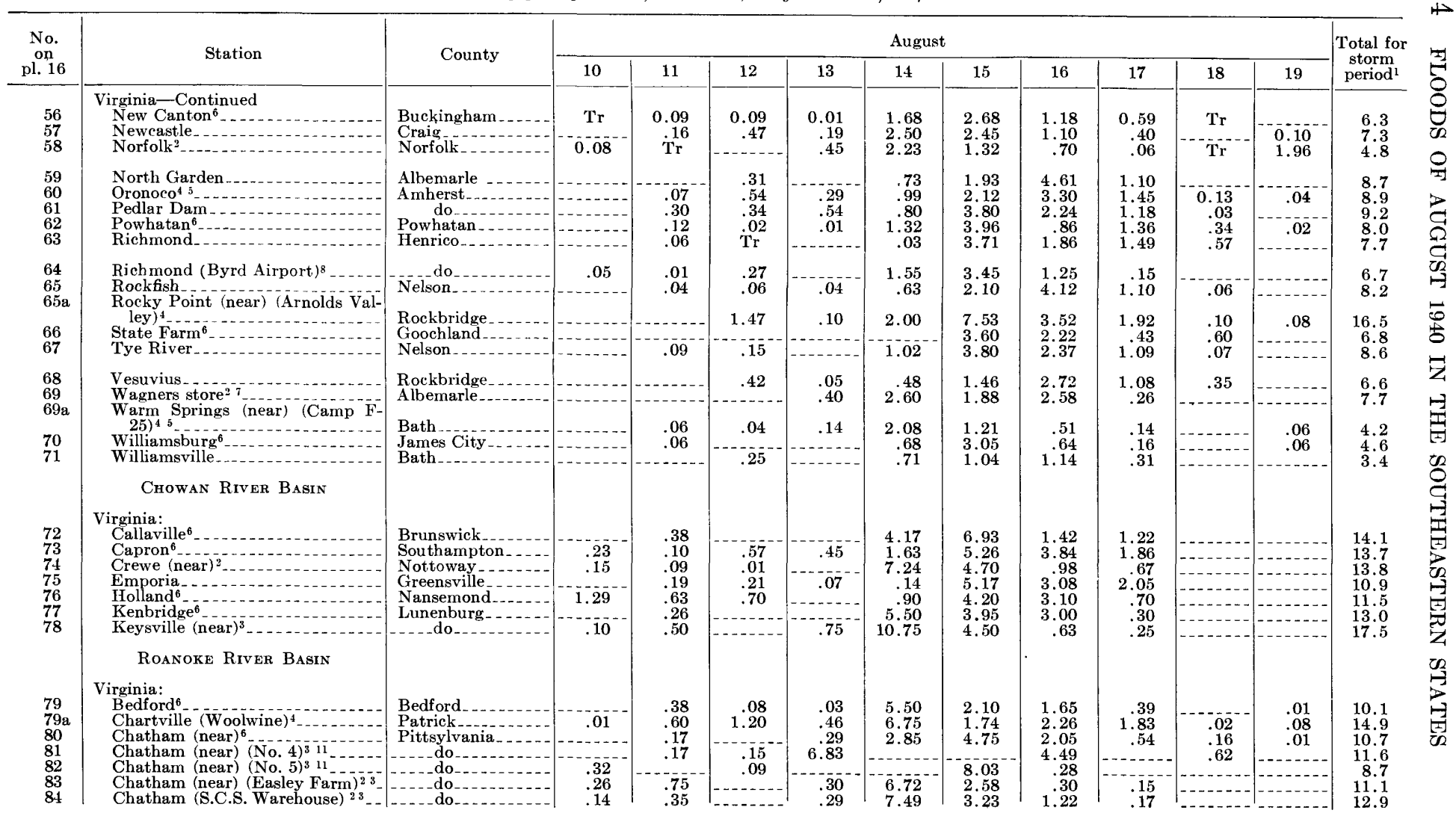




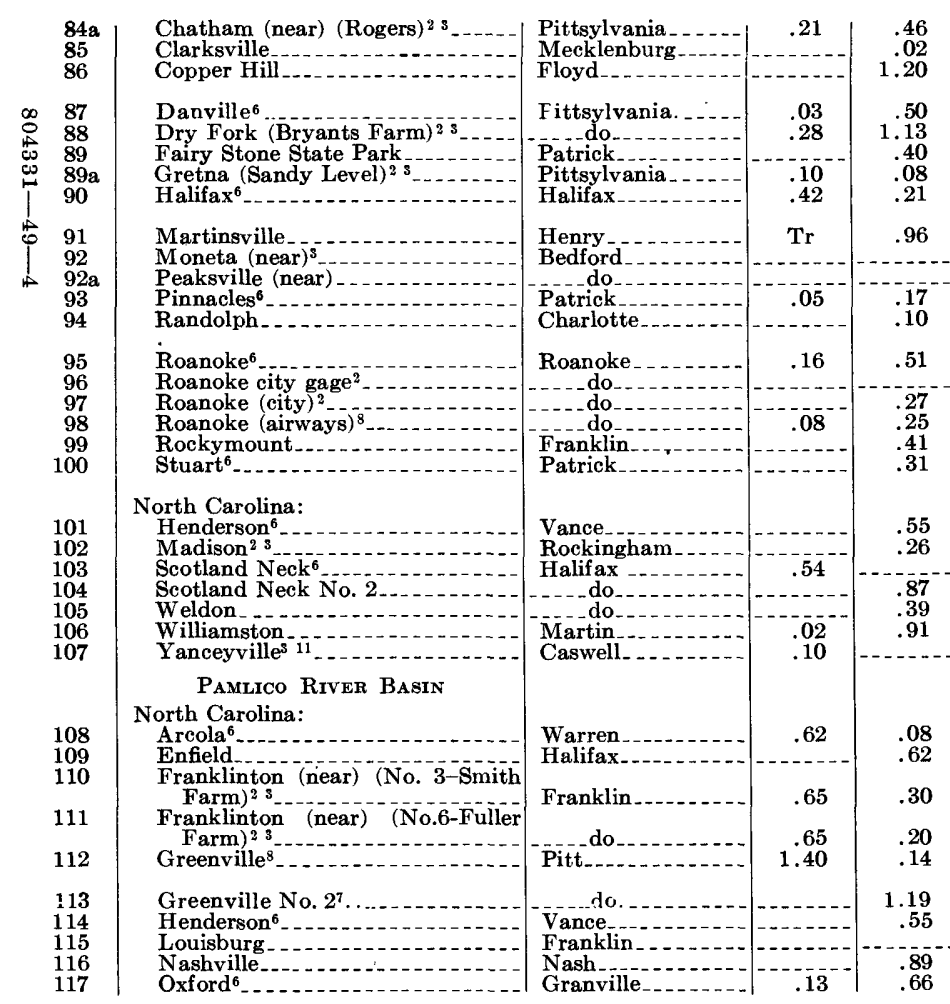

1 Total is for storm period 6 a.m. Aug. 10 to 12 p.m. Aug. 17 and is not the total of

recorded daily values August 10-17. Record furnished by Soil Conservation Service.

Precipitation measured in the morning and the evening.

\begin{tabular}{|c|c|c|c|c|c|c|c|c|}
\hline 1.15 & $\begin{array}{l}.37 \\
.43 \\
.50\end{array}$ & $\begin{array}{l}6.86 \\
1.35 \\
6.70\end{array}$ & $\begin{array}{l}1.93 \\
8.27 \\
2.70\end{array}$ & $\begin{array}{r}.23 \\
4.78 \\
3.52\end{array}$ & $\begin{array}{r}.56 \\
.23 \\
1.26\end{array}$ & .43 & & $\begin{array}{l}10.4 \\
15.5 \\
17.0\end{array}$ \\
\hline $\begin{array}{l}.07 \\
.07 \\
.25\end{array}$ & $\begin{array}{l}.03 \\
.26 \\
.53 \\
.39 \\
.22\end{array}$ & $\begin{array}{l}3.83 \\
7.48 \\
3.38 \\
8.68 \\
5.02\end{array}$ & $\begin{array}{l}1.57 \\
3.09 \\
1.33 \\
2.52 \\
4.11\end{array}$ & $\begin{array}{r}.24 \\
.48 \\
1.14 \\
.88 \\
.92\end{array}$ & $\begin{array}{r}.19 \\
.71 \\
.05 \\
.34\end{array}$ & .04 & & $\begin{array}{r}6.4 \\
13.4 \\
6.9 \\
12.8 \\
11.1\end{array}$ \\
\hline .04 & $\begin{array}{r}.07 \\
.50\end{array}$ & $\begin{array}{l}5.46 \\
3.00 \\
2.55\end{array}$ & $\begin{array}{l}1.66 \\
2.52 \\
3.10\end{array}$ & $\begin{array}{r}.47 \\
.60 \\
1.25\end{array}$ & .14 & .02 & & $\begin{array}{l}8.8 \\
6.6 \\
8.4\end{array}$ \\
\hline $\begin{array}{l}1.02 \\
.20\end{array}$ & $\begin{array}{l}.42 \\
.46\end{array}$ & $\begin{array}{r}6.00 \\
.46\end{array}$ & $\begin{array}{l}. .10 \\
1.19 \\
6.90\end{array}$ & $\begin{array}{r}1.25 \\
.35 \\
126.38\end{array}$ & $\begin{array}{r}1.00 \\
12.46 \\
12.40\end{array}$ & $\begin{array}{r}1.15 \\
12.10\end{array}$ & 0 & $\begin{array}{r}8.4 \\
9.8 \\
15.0\end{array}$ \\
\hline $\begin{array}{l}.11 \\
.39 \\
.55 \\
.56 \\
.47 \\
.58\end{array}$ & $\begin{array}{r}.51 \\
1.47 \\
.95 \\
1.13 \\
.28 \\
.60\end{array}$ & $\begin{array}{l}5.36 \\
5.76 \\
5.59 \\
5.43 \\
2.38 \\
5.26\end{array}$ & $\begin{array}{r}2.50 \\
3.12 \\
(10) \\
1.56 \\
1.78 \\
.53\end{array}$ & $\begin{array}{r}1.45 \\
1.34 \\
(10) \\
.33 \\
2.80 \\
.41\end{array}$ & $\begin{array}{r}.14 \\
.04 \\
2.06 \\
.01 \\
.60 \\
.07\end{array}$ & $\begin{array}{c}.0 \\
.19\end{array}$ & $\begin{array}{l}.02 \\
.07\end{array}$ & $\begin{array}{r}10.7 \\
12.1 \\
9.4 \\
9.4 \\
8.7 \\
7.9\end{array}$ \\
\hline $\begin{array}{l}.04 \\
.41\end{array}$ & $\begin{array}{l}.02 \\
.30 \\
.34\end{array}$ & $\begin{array}{l}3.11 \\
4.75 \\
3.65\end{array}$ & $\begin{array}{r}2.83 \\
.13 \\
6.13\end{array}$ & $\begin{array}{r}.73 \\
1.29 \\
1.65\end{array}$ & $\begin{array}{r}.03 \\
.10 \\
1.35\end{array}$ & & & $\begin{array}{r}7.3 \\
7.2 \\
13.7\end{array}$ \\
\hline $\begin{array}{l}.57 \\
.01 \\
.10\end{array}$ & $\begin{array}{l}\mathrm{Tr} \\
.01\end{array}$ & $\begin{array}{r}.12 \\
.37\end{array}$ & $\begin{array}{l}5.22 \\
3.07 \\
5.37\end{array}$ & $\begin{array}{r}2.74 \\
2.75 \\
1.09 \\
.94\end{array}$ & $\begin{array}{r}.32 \\
.78 \\
.21 \\
.94\end{array}$ & .81 & $06^{--}$ & $\begin{array}{l}9.7 \\
9.9 \\
6.6 \\
7.4\end{array}$ \\
\hline $\begin{array}{l}.24 \\
.40\end{array}$ & $\begin{array}{l}\mathrm{Tr} \\
.17\end{array}$ & $\begin{array}{r}2.70 \\
-\end{array}$ & $\begin{array}{r}.60 \\
5.25\end{array}$ & $\begin{array}{l}3.77 \\
1.07\end{array}$ & $\begin{array}{r}.09 \\
1.46\end{array}$ & $\begin{array}{l}\operatorname{Tr} \\
.45\end{array}$ & & $\begin{array}{l}8.1 \\
9.4\end{array}$ \\
\hline & & 6.40 & 3.75 & 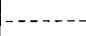 & & & & 11.1 \\
\hline & $\stackrel{05}{\mathrm{Tr}}$ & $\begin{array}{l}5.15 \\
1.11\end{array}$ & $\begin{array}{r}4.00 \\
.92\end{array}$ & $\begin{array}{r}.10 \\
1.26\end{array}$ & .32 & $\mathrm{Tr}$ & & $\begin{array}{r}10.2 \\
5.2\end{array}$ \\
\hline $\begin{array}{l}.18 \\
.04 \\
.05 \\
.70\end{array}$ & $\begin{array}{l}.02 \\
\operatorname{Tr} \\
.10\end{array}$ & $\begin{array}{r}3.11 \\
.20 \\
.10 \\
2.45\end{array}$ & $\begin{array}{l}1.18 \\
2.83 \\
3.23 \\
6.03 \\
1.40\end{array}$ & $\begin{array}{l}1.02 \\
.73 \\
2.00 \\
2.91 \\
1.27\end{array}$ & $\begin{array}{r}.75 \\
.03 \\
\operatorname{Tr} \\
1.38 \\
.13\end{array}$ & $\begin{array}{c}.27 \\
-.39\end{array}$ & & $\begin{array}{r}4.6 \\
7.3 \\
5.5 \\
12.0 \\
6.1\end{array}$ \\
\hline
\end{tabular}

- Precipitation measured in the afternoon.

7 Record furnished by Corps of Engineers, War Department.

${ }^{3}$ Precipitation measured at $1: 30$ a.m.; total is then recorded for previous day. Precipitation included in following measurement.

12 Precipitation estimated on basis of nearby stations. 
TABLE 5.-Daily precipitation, in inches, August 10-19, 1940-Continued

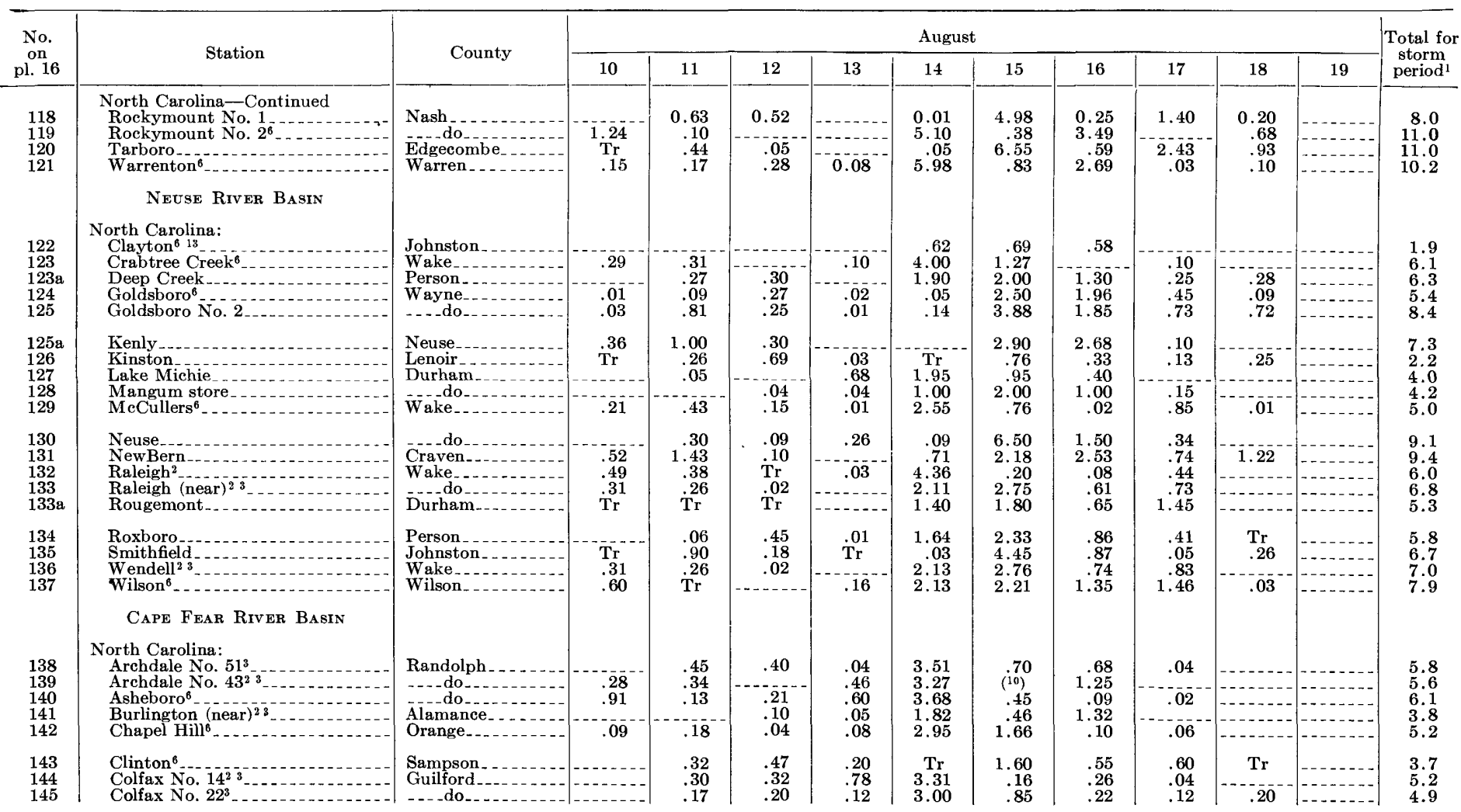




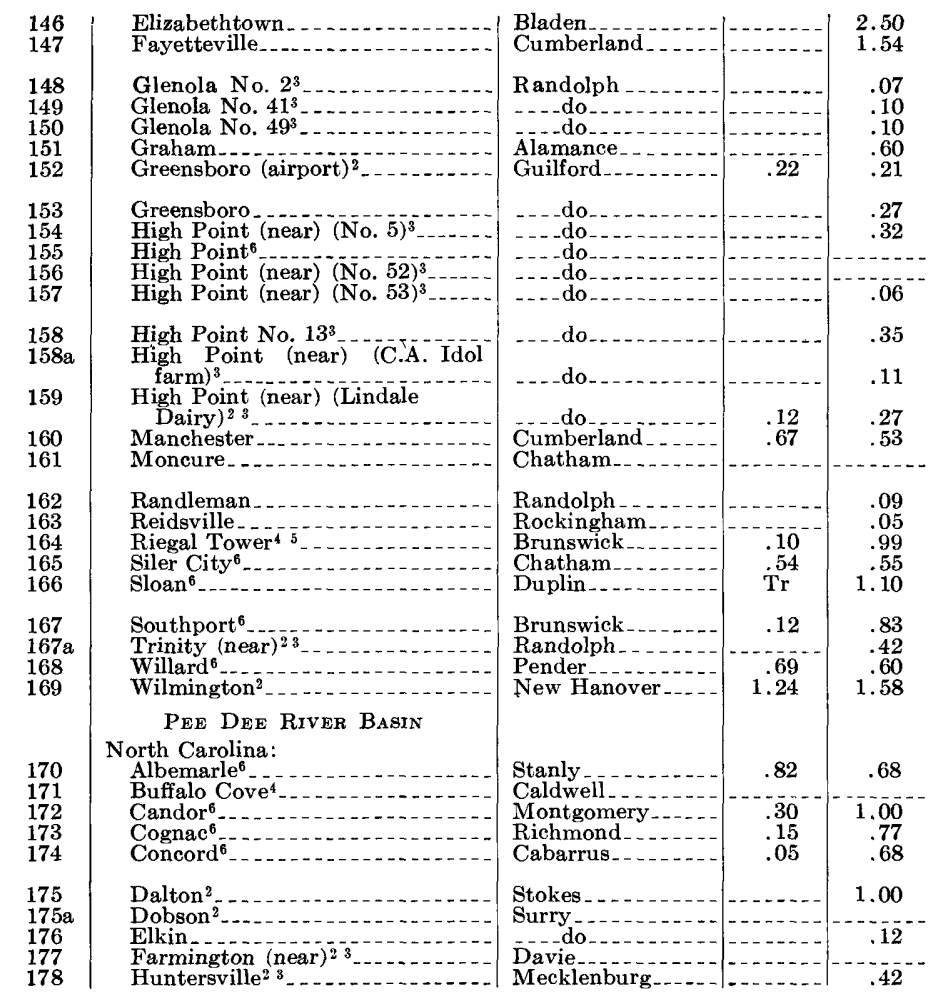

1 Total is for storm period 6 a.m. Aug. 10 to 12 p.m. Aug. 17 and is not the total of

${ }_{2}$ Recording gage; precipitation is for the 24-hour period, midnight to midnight.

Dil Conservation Service.

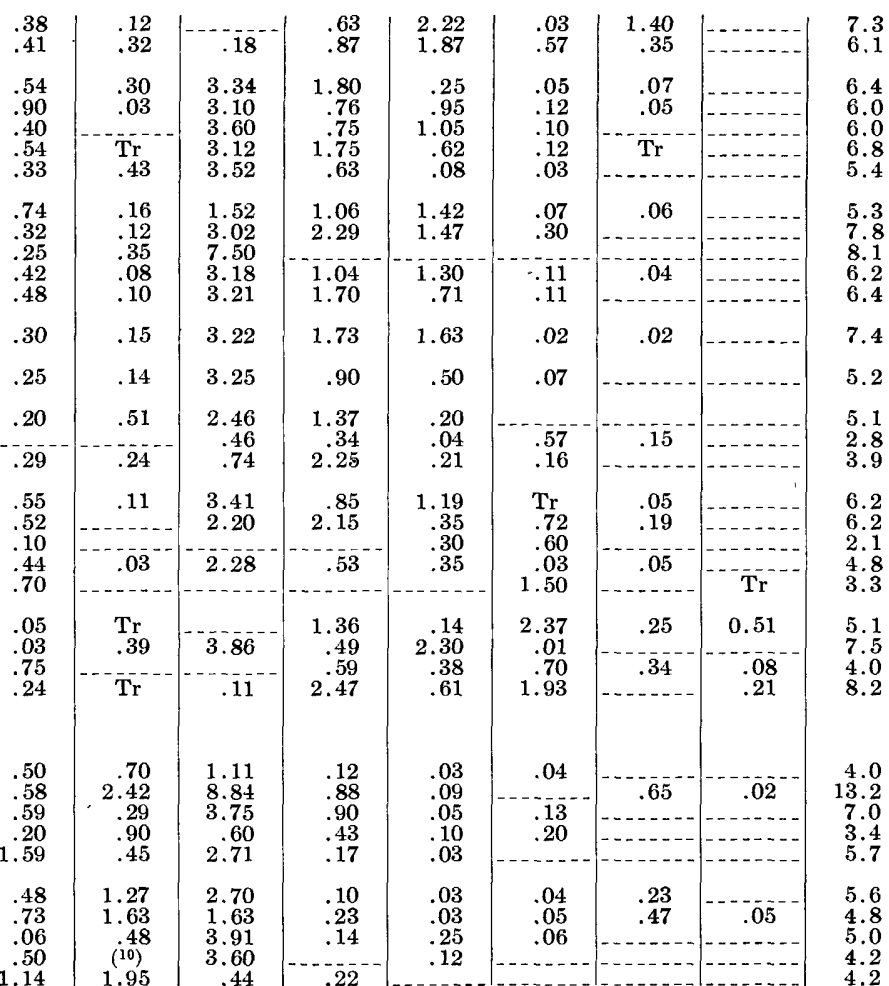

5 Precipitation measured in the morning and the evening. 10 Precipitation measured in the afternoon.

Precipitation included in following mal urement. 
TABLE 5.-Daily precipitation, in inches, August 10-19, 1940-Continued

\begin{tabular}{|c|c|c|c|c|c|c|c|c|c|c|c|c|c|}
\hline \multirow{2}{*}{$\begin{array}{l}\text { No. } \\
\text { on } \\
\text { pl. } 16\end{array}$} & \multirow{2}{*}{ Station } & \multirow{2}{*}{ County } & \multicolumn{10}{|c|}{ August } & \multirow{2}{*}{$\begin{array}{l}\text { Total for } \\
\text { storm } \\
\text { period }\end{array}$} \\
\hline & & & 10 & 11 & 12 & 13 & 14 & 15 & 16 & 17 & 18 & 19 & \\
\hline $\begin{array}{l}179 \\
180 \\
181 \\
182 \\
183\end{array}$ & $\begin{array}{l}\text { North Carolina-Continued } \\
\text { Kilby's Gap }{ }^{6}-\text { Con }^{2} \\
\text { Lexington (near) } \\
\text { Lexington } \\
\text { Lumberton } \\
\text { Mocksville }\end{array}$ & 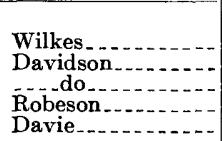 & \begin{tabular}{c}
0.03 \\
.23 \\
.06 \\
\hdashline.- .2 \\
\end{tabular} & $\begin{array}{r}0.19 \\
.56 \\
.20 \\
1.30 \\
.60\end{array}$ & $\begin{array}{r}1.16 \\
.22 \\
.47 \\
1.10\end{array}$ & $\begin{array}{r}1.81 \\
.52 \\
.30 \\
.70 \\
2.47\end{array}$ & $\begin{array}{r}8.00 \\
6.56 \\
4.00 \\
.02 \\
.43\end{array}$ & $\begin{array}{r}0.20 \\
.15 \\
.08 \\
1.20 \\
.63\end{array}$ & $\begin{array}{l}0.18 \\
.85 \\
.50 \\
.05\end{array}$ & $\begin{array}{c}\text { Tr } \\
0.40 \\
.60 \\
-\end{array}$ & 0.35 & & $\begin{array}{r}11.9 \\
8.2 \\
6.4 \\
4.3 \\
5.3\end{array}$ \\
\hline $\begin{array}{l}183 \mathrm{a} \\
184 \\
185 \\
186 \\
187\end{array}$ & $\begin{array}{l}\text { Monroe }^{6} \\
\text { Mount Airy } \\
\text { Mount Gilead } \\
\text { Mount Pleasant } \\
\text { North Wilkesboro (near) }\end{array}$ & $\begin{array}{l}\text { Union } \\
\text { Surry } \\
\text { Montgomery } \\
\text { Cabarrus.... } \\
\text { Wilkes.... }\end{array}$ & \begin{tabular}{c|}
.20 \\
.24 \\
.10
\end{tabular} & $\begin{array}{r}.15 \\
1.68 \\
.44 \\
.09\end{array}$ & $\begin{array}{r}.64 \\
.93 \\
.90 \\
.59 \\
1.66\end{array}$ & $\begin{array}{r}.35 \\
.34 \\
2.22 \\
.72 \\
3.50\end{array}$ & $\begin{array}{r}1.10 \\
3.00 \\
.33 \\
2.14 \\
2.60\end{array}$ & $\begin{array}{l}\mathrm{Tr} \\
.37 \\
.08 \\
.13 \\
.14\end{array}$ & $\begin{array}{l}\mathrm{Tr} \\
.07 \\
.33 \\
.05\end{array}$ & \begin{tabular}{l}
$\mathrm{Tr}$ \\
.36 \\
\hdashline .11
\end{tabular} & .11 & 0.03 & $\begin{array}{l}2.4 \\
5.1 \\
5.5 \\
4.3 \\
8.2\end{array}$ \\
\hline $\begin{array}{l}188 \\
189 \\
190 \\
191 \\
192\end{array}$ & $\begin{array}{l}\text { North Wilkesboro } \\
\text { Pinehurst }^{6} \\
\text { Red Springs } \\
\text { Rockingham } \\
\text { Salisbury (near) }\end{array}$ & $\begin{array}{l}\text { Moore } \\
\text { Robeson } \\
\text { Richmond } \\
\text { Rowan }\end{array}$ & $\begin{array}{l}.08 \\
.05 \\
.05 \\
.37\end{array}$ & $\begin{array}{r}.38 \\
2.40 \\
1.50 \\
.87 \\
.05\end{array}$ & $\begin{array}{r}1.54 \\
.60 \\
.40 \\
1.48 \\
.48\end{array}$ & $\begin{array}{r}2.15 \\
.70 \\
.40 \\
.87 \\
1.40\end{array}$ & $\begin{array}{r}4.50 \\
.70 \\
.22 \\
.70 \\
2.07\end{array}$ & $\begin{array}{r}.34 \\
1.20 \\
.97 \\
.25\end{array}$ & $\begin{array}{l}.40 \\
.10 \\
.08 \\
.32 \\
.25\end{array}$ & $\begin{array}{l}.06 \\
.47 \\
.86 \\
.05\end{array}$ & .09 & .02 & $\begin{array}{l}9.5 \\
5.7 \\
3.1 \\
6.1 \\
4.9\end{array}$ \\
\hline $\begin{array}{l}193 \\
194 \\
195 \\
196 \\
197\end{array}$ & $\begin{array}{l}\text { Salisbury }{ }^{6} \\
\text { Settle }{ }^{6} \\
\text { Southern Pines } \\
\text { Statesville }{ }^{6}-{ }^{6} \\
\text { Trinity No. } 50^{2}{ }_{3}^{3}\end{array}$ & $\begin{array}{l}\text { Iredell } \\
\text { Moore } \\
\text { Iredell } \\
\text { Randolph.'. }\end{array}$ & $\begin{array}{l}.20 \\
.07 \\
.10 \\
.21\end{array}$ & $\begin{array}{r}.29 \\
1.87 \\
.20 \\
.58\end{array}$ & $\begin{array}{l}.66 \\
.53 \\
.75 \\
.69 \\
.20\end{array}$ & $\begin{array}{l}.78 \\
.62 \\
.33 \\
.85 \\
.34\end{array}$ & $\begin{array}{l}2.58 \\
2.63 \\
.86 \\
3.05 \\
4.93\end{array}$ & $\begin{array}{r}2.27 \\
.10 \\
.50 \\
.25 \\
1.04\end{array}$ & $\begin{array}{l}.20 \\
.37 \\
.08 \\
.08\end{array}$ & $\begin{array}{l}\mathrm{Tr} \\
.12\end{array}$ & $\begin{array}{l}.15 \\
\mathrm{Tr} \\
.12 \\
.14\end{array}$ & $\begin{array}{l}\mathrm{Tr} \\
.03\end{array}$ & $\begin{array}{l}6.7 \\
4.6 \\
4.6 \\
5.1 \\
7.4\end{array}$ \\
\hline $\begin{array}{l}198 \\
199 \\
200 \\
201 \\
202\end{array}$ & $\begin{array}{l}\text { Trinity No. } 4^{6}{ }^{2}{ }^{3} \\
\text { Trinity No. } 3^{3} \\
\text { Troy Court House } \\
\text { Wadesboro (near) (Briggs farm) } \\
\text { Wadesboro (near) }{ }^{2}{ }^{3}{ }^{3} 11 \\
\text { Wad }\end{array}$ & $\begin{array}{l}\text { Montgomery } \\
\text { Anson } \\
- \text { do do }\end{array}$ & $\begin{array}{l}.28 \\
.50 \\
.30\end{array}$ & $\begin{array}{r}.46 \\
.01 \\
1.20 \\
1.06 \\
1.06\end{array}$ & $\begin{array}{l}.30 \\
.72 \\
.17 \\
.56 \\
.90\end{array}$ & $\begin{array}{l}.31 \\
.23 \\
.57 \\
.25 \\
.58\end{array}$ & $\begin{array}{l}6.06 \\
3.30 \\
2.33 \\
1.01 \\
\mathbf{3 . 5 2}\end{array}$ & $\begin{array}{l}.54 \\
.94 \\
.57 \\
. .04\end{array}$ & $\begin{array}{l}.04 \\
.73 \\
.77 \\
.20\end{array}$ & $\begin{array}{l}.02 \\
.36 \\
.10 \\
.10\end{array}$ & $\begin{array}{l}.04 \\
.04\end{array}$ & & $\begin{array}{l}8.0 \\
6.3 \\
5.7 \\
3.4 \\
6.7\end{array}$ \\
\hline $\begin{array}{l}203 \\
204 \\
205\end{array}$ & $\begin{array}{l}\text { Wadesboro } \\
\text { Winston-Salem } \\
\text { Yadkinville }{ }^{2} 4\end{array}$ & $\begin{array}{l}\text { Forsyth } \\
\text { Yadkin }\end{array}$ & $\begin{array}{l}.41 \\
.01 \\
.26\end{array}$ & $\begin{array}{r}2.40 \\
.07 \\
.09\end{array}$ & $\begin{array}{l}.59 \\
.31 \\
.38\end{array}$ & $\begin{array}{r}.84 \\
.22 \\
1.49\end{array}$ & $\begin{array}{l}1.33 \\
3.37 \\
3.46\end{array}$ & $\begin{array}{r}.04 \\
1.39 \\
.34\end{array}$ & $\begin{array}{l}.41 \\
.09\end{array}$ & $\begin{array}{l}.07 \\
.27\end{array}$ & & .04 & $\begin{array}{l}6.0 \\
5.5 \\
6.3\end{array}$ \\
\hline $\begin{array}{l}206 \\
207 \\
208 \\
210 \\
211\end{array}$ & $\begin{array}{l}\text { South Carolina: } \\
\text { Bishopville } \\
\text { Cheraw } \\
\text { Choppee } \\
\text { Darlington } \\
\text { Effingham }\end{array}$ & $\begin{array}{l}\text { Lee } \\
\text { Chesterfield } \\
\text { Georgetown } \\
\text { Darlington... } \\
\text { Florence........ }\end{array}$ & \begin{tabular}{c}
$: 40$ \\
\hdashline $.14^{-1}$ \\
\hdashline-0 \\
-0
\end{tabular} & $\begin{array}{c}.59 \\
.23 \\
1.54 \\
.43 \\
\mathrm{Tr}\end{array}$ & $\begin{array}{r}.40 \\
.75 \\
1.00 \\
.74 \\
.92\end{array}$ & $\begin{array}{r}.04 \\
.70 \\
1.10 \\
2.30 \\
1.51\end{array}$ & $\begin{array}{r}1.45 \\
.45 \\
.79 \\
.85\end{array}$ & $\begin{array}{r}.04 \\
1.53 \\
.90 \\
3.67 \\
3.14\end{array}$ & $\begin{array}{l}.04 \\
.11 \\
.64 \\
.37\end{array}$ & $\begin{array}{r}.15 \\
.25 \\
.41 \\
.12 \\
1.54\end{array}$ & $\begin{array}{ll}.02 \\
.02\end{array}$ & $\begin{array}{l}\operatorname{Tr} \\
-0 \overline{3}^{--}\end{array}$ & $\begin{array}{l}3.1 \\
4.0 \\
5.7 \\
8.4 \\
8.4\end{array}$ \\
\hline $\begin{array}{l}212 \\
213 \\
214\end{array}$ & $\begin{array}{l}\text { Florence } \\
\text { Florence (airport) } \\
\text { Juniper Creek Dam }{ }^{2}\end{array}$ & Chesterfield & $\mid \begin{array}{c}.51 \\
.52\end{array}$ & $\begin{array}{l}.40 \\
.53 \\
.24\end{array}$ & $\begin{array}{r}.61 \\
1.71 \\
.43\end{array}$ & $\begin{array}{r}2.59 \\
.52 \\
.39\end{array}$ & $\begin{array}{l}.14 \\
6.06 \\
2.22\end{array}$ & $\begin{array}{r}6.68 \\
.32\end{array}$ & $\begin{array}{l}.15 \\
.94 \\
.12\end{array}$ & $\begin{array}{r}1.31 \\
.07\end{array}$ & .03 & .03 & $\begin{array}{r}11.9 \\
10.7 \\
3.9\end{array}$ \\
\hline
\end{tabular}




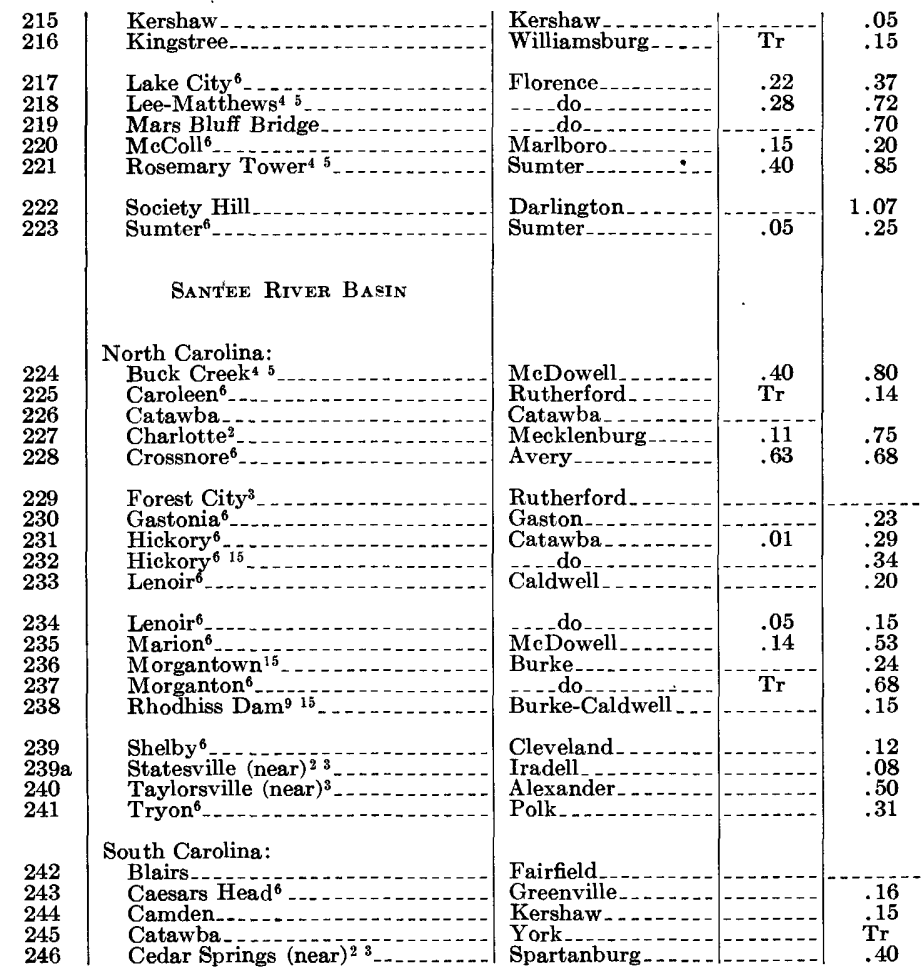

1 Total is for storm period 6 a.m. Aug. 10 to 12 p.m. Aug. 17 and is not the total of recorded daily values Aug. $10-17$

2 Recording gage; precipitation is for the 24-hour period, midnight to midnight. Record furnished by Soil Conservation Service

5 Precipitation measured in the morning and the evening.

\begin{tabular}{|c|c|c|c|c|c|c|c|c|}
\hline $\begin{array}{r}.74 \\
1.30\end{array}$ & $\begin{array}{l}.55 \\
.27\end{array}$ & $\begin{array}{l}.36 \\
.25\end{array}$ & $\begin{array}{l}1.39 \\
2.00\end{array}$ & $\begin{array}{l}.07 \\
.06\end{array}$ & $\begin{array}{c}\mathrm{Tr} \\
1.00\end{array}$ & ${ }^{-} 1.00^{-}$ & .02 & $\begin{array}{l}3.2 \\
6.0\end{array}$ \\
\hline $\begin{array}{r}.98 \\
.88 \\
1.00 \\
2.80 \\
3.94\end{array}$ & $\begin{array}{r}.60 \\
1.06 \\
3.55 \\
1.10 \\
.02\end{array}$ & $\begin{array}{l}1.55 \\
1.80 \\
1.10 \\
1.13 \\
1.84\end{array}$ & $\begin{array}{r}.08 \\
1.18 \\
2.45 \\
.60 \\
.52\end{array}$ & $\begin{array}{r}.02 \\
.04 \\
.42 \\
\end{array}$ & $\begin{array}{l}.30 \\
.67 \\
.98 \\
.09 \\
.20\end{array}$ & $\begin{array}{l}.04 \\
.02\end{array}$ & $\begin{array}{l}-- \\
-- \\
--\end{array}$ & $\begin{array}{l}4.1 \\
6.6 \\
9.9 \\
6.5 \\
7.8\end{array}$ \\
\hline 1.54 & .02 & $\begin{array}{l}2.10 \\
2.07\end{array}$ & .44 & $\begin{array}{r}3.25 \\
.10\end{array}$ & $\begin{array}{l}.40 \\
.44\end{array}$ & & & $\begin{array}{l}6.8 \\
4.9\end{array}$ \\
\hline $\begin{array}{r}2.50 \\
.21 \\
.07 \\
.61 \\
4.71\end{array}$ & $\begin{array}{r}9.60 \\
3.12 \\
2.12 \\
.91 \\
8.98\end{array}$ & $\begin{array}{l}3.05 \\
2.71 \\
4.06 \\
2.00 \\
\text { Tr }\end{array}$ & $\begin{array}{l}.09 \\
.03 \\
.02 \\
\text { Tr }\end{array}$ & $\begin{array}{l}.16 \\
.04 \\
\mathrm{Tr}\end{array}$ & $\begin{array}{l}.42 \\
.20\end{array}$ & $\begin{array}{l}\mathrm{Tr} \\
.08 \\
\mathrm{Tr}\end{array}$ & & $\begin{array}{r}16.4 \\
6.3 \\
6.9 \\
4.6 \\
15.0\end{array}$ \\
\hline $\begin{array}{r}.31 \\
.51 \\
1.33 \\
1.72 \\
1.48\end{array}$ & $\begin{array}{l}1.07 \\
1.07 \\
1.92 \\
9.33 \\
2.97\end{array}$ & $\begin{array}{r}8.65 \\
1.71 \\
7.92 \\
.68 \\
5.40\end{array}$ & $\begin{array}{l}.43 \\
.02 \\
.19 \\
.08\end{array}$ & $\begin{array}{l}.36 \\
.80 \\
.88 \\
.10\end{array}$ & $\begin{array}{l}.12 \\
.12 \\
.11 \\
.30 \\
.92\end{array}$ & $\begin{array}{l}.95 \\
.78 \\
.15\end{array}$ & & $\begin{array}{r}10.6 \\
4.0 \\
12.6 \\
13.3 \\
11.1\end{array}$ \\
\hline $\begin{array}{l}1.30 \\
1.19 \\
1.32 \\
1.78 \\
1.17\end{array}$ & $\begin{array}{l}2.05 \\
8.20 \\
1.95 \\
2.96 \\
9.72\end{array}$ & $\begin{array}{r}4.55 \\
.35 \\
8.15 \\
6.10 \\
.23\end{array}$ & $\begin{array}{l}.11 \\
.07 \\
.08 \\
.08 \\
.07\end{array}$ & .18 & \begin{tabular}{l}
.60 \\
.07 \\
\hdashline $\mathrm{Tr}$ \\
.54
\end{tabular} & $\begin{array}{l}.10 \\
.01 \\
.22 \\
.88\end{array}$ & & $\begin{array}{l}10.6 \\
11.7 \\
11.6 \\
12.1\end{array}$ \\
\hline $\begin{array}{r}.32 \\
1.09 \\
.82 \\
.75\end{array}$ & $\begin{array}{l}1.06 \\
3.53 \\
1.91 \\
7.15\end{array}$ & $\begin{array}{r}4.55 \\
.65 \\
7.13 \\
1.13\end{array}$ & $\begin{array}{r}.03 \\
.14 \\
\hdashline .28\end{array}$ & $\begin{array}{l}.05 \\
.34\end{array}$ & $\begin{array}{l}.09 \\
.04\end{array}$ & $\begin{array}{c}.30 \\
-1.47 \\
.08\end{array}$ & $\begin{array}{l}.09 \\
.03 \\
.03\end{array}$ & $\begin{array}{r}5.9 \\
11.8 \\
9.7\end{array}$ \\
\hline $\begin{array}{r}.87 \\
1.69 \\
.71 \\
.49 \\
.72\end{array}$ & $\begin{array}{r}1.60 \\
9.50 \\
.74 \\
.61 \\
4.53\end{array}$ & $\begin{array}{r}.92 \\
.40 \\
.30 \\
1.13\end{array}$ & \begin{tabular}{r}
.12 \\
\hdashline 2.47 \\
.32
\end{tabular} & $\begin{array}{l}\mathrm{Tr} \\
.01 \\
.03\end{array}$ & $\begin{array}{l}.03 \\
.02\end{array}$ & .07 & $\ldots$ & 3. \\
\hline
\end{tabular}

- Precipitation measured in the afternoon.

9 Precipitation measured at midnight.

11 Precipitation measured after each rain.

15 Record furnished by Duke Power $\mathrm{C} o$. 
TABLE 5.-Daily precipitation, in inches, August 10-19, 1940-Continued

\begin{tabular}{|c|c|c|c|c|c|c|c|c|c|c|c|c|c|}
\hline \multirow{2}{*}{$\begin{array}{c}\text { No. } \\
\text { on } \\
\text { pl. } 16\end{array}$} & \multirow{2}{*}{ Station } & \multirow{2}{*}{ County } & \multicolumn{10}{|c|}{ August } & \multirow{2}{*}{$\begin{array}{l}\text { Total for } \\
\text { storm } \\
\text { period }\end{array}$} \\
\hline & & & 10 & 11 & 12 & 13 & 14 & 15 & 16 & 17 & 18 & 19 & \\
\hline $\begin{array}{l}247 \\
248 \\
249 \\
249 \mathrm{a} \\
249 \mathrm{~b}\end{array}$ & $\begin{array}{l}\text { South Carolina-Continued } \\
\text { Chappells } \\
\text { Cherokee (near) } \\
\text { Chester }{ }^{6} \text { (nill } \\
\text { Collins Mear })^{3} \\
\text { Collins Mill (near) }{ }^{3}\end{array}$ & $\begin{array}{l}\text { Newberry } \\
\text { Spartanburg } \\
\text { Chester } \\
\text { Spartanburg. }\end{array}$ & 0.01 & $\begin{array}{r}0.12 \\
.32 \\
.22 \\
\\
\end{array}$ & $\begin{array}{r}4.72 \\
.60 \\
.80 \\
.42 \\
2.00\end{array}$ & $\begin{array}{l}5.23 \\
4.34 \\
1.06 \\
2.76 \\
7.85\end{array}$ & $\begin{array}{r}1.17 \\
1.47 \\
.93 \\
8.29 \\
2.68\end{array}$ & 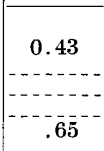 & $\begin{array}{l}0.03 \\
1.32\end{array}$ & $\mathrm{~T}_{\mathrm{r}}$ & $\begin{array}{r}0.01 \\
.05\end{array}$ & & $\begin{array}{r}11.7 \\
8.0 \\
3.0 \\
11.5 \\
13.2\end{array}$ \\
\hline $\begin{array}{l}250 \\
251 \\
252 \\
253 \\
254\end{array}$ & $\begin{array}{l}\text { Columbia } \\
\text { Crescent } \\
\text { Duncan (near) } \\
\text { Fairforest (near) } \\
\text { Fairforest (near) }{ }^{3}{ }^{3}\end{array}$ & $\begin{array}{l}\text { Richland } \ldots \\
\text { Spartanburg. } \\
-\ldots \text { do } \\
-\ldots \text { do }\end{array}$ & $\frac{.04}{(10)^{-1}}$ & $\begin{array}{l}.16 \\
.46 \\
.58 \\
.15\end{array}$ & $\begin{array}{r}1.41 \\
.30 \\
.84 \\
.60 \\
.62\end{array}$ & $\begin{array}{l}.03 \\
2.70 \\
6.27 \\
6.70 \\
4.28\end{array}$ & $\begin{array}{r}.24 \\
7.60 \\
.29 \\
.20 \\
3.91\end{array}$ & \begin{tabular}{c}
$\mathrm{Tr}$ \\
.36 \\
\hdashline .29
\end{tabular} & $\operatorname{Tr}$ & $\operatorname{Tr}$ & & & $\begin{array}{r}1.9 \\
11.0 \\
7.9 \\
8.1 \\
9.2\end{array}$ \\
\hline $\begin{array}{l}255 \\
256 \\
257 \\
258 \\
259\end{array}$ & $\begin{array}{l}\text { Fairmount }{ }^{3} \\
\text { Ferguson } \\
\text { Fountain Inn (near) } \\
\text { Gaston Shoals }{ }^{3} \\
\text { Goldville }^{3}\end{array}$ & 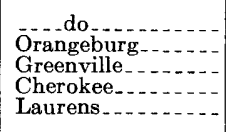 & 01 & $\begin{array}{l}.20 \\
.08 \\
.50 \\
.08\end{array}$ & $\begin{array}{r}.25 \\
3.20 \\
6.00 \\
.17 \\
1.02\end{array}$ & $\begin{array}{l}3.85 \\
.90 \\
1.95 \\
4.14 \\
3.90\end{array}$ & $\begin{array}{r}4.28 \\
.30 \\
-3.00 \\
2.74\end{array}$ & $\begin{array}{c}1.90 \\
-\end{array}$ & $\begin{array}{r}.04 \\
.47\end{array}$ & & & & $\begin{array}{l}8.6 \\
6.5 \\
8.4 \\
7.9 \\
7.7\end{array}$ \\
\hline $\begin{array}{l}260 \\
261 \\
262 \\
263 \\
264\end{array}$ & $\begin{array}{l}\text { Greenville }^{2} \\
\text { Greenwood (near) } \\
\text { Greenwood } \\
\text { Greer (near) }{ }^{2}{ }_{3}^{3} \\
\text { Greer (near) }{ }^{3}\end{array}$ & $\begin{array}{l}\text { Greenville } \ldots . . . . \\
\text { Greenwood } \\
\text { Greenville............ } \\
\text { Spartanburg }\end{array}$ & .04 & .52 & $\begin{array}{r}2.04 \\
1.80 \\
1.65 \\
1.30 \\
.80\end{array}$ & $\begin{array}{l}4.29 \\
8.00 \\
7.42 \\
(10) \\
6.65\end{array}$ & $\begin{array}{l}.23 \\
1.30 \\
2.11 \\
9.15 \\
3.53\end{array}$ & $\begin{array}{l}.13 \\
.04\end{array}$ & -1 & & & & $\begin{array}{r}7.1 \\
11.2 \\
11.2 \\
11.1 \\
11.0\end{array}$ \\
\hline $\begin{array}{l}265 \\
266 \\
267 \\
268 \\
269\end{array}$ & $\begin{array}{l}\text { Heath Springs } \\
\text { Highland } \\
\text { Inman }^{2}{ }^{3} \\
\text { Lancaster }^{3} \\
\text { Landrum }^{6}\end{array}$ & 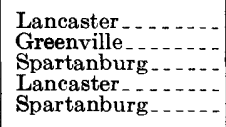 & 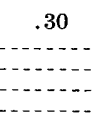 & $\begin{array}{l}.32 \\
.10 \\
.30 \\
.72 \\
.31\end{array}$ & $\begin{array}{l}.55 \\
.25 \\
.90 \\
.33 \\
.74\end{array}$ & $\begin{array}{r}.17 \\
4.25 \\
11.80 \\
.42 \\
6.83\end{array}$ & $\begin{array}{r}2.14 \\
4.25 \\
.30 \\
.64 \\
1.81\end{array}$ & $\begin{array}{l}.05 \\
.09 \\
-.03 \\
.59\end{array}$ & .02 & & .81 & & $\begin{array}{r}3.6 \\
8.9 \\
13.3 \\
2.1 \\
10.2\end{array}$ \\
\hline $\begin{array}{l}270 \\
271 \\
272 \\
273 \\
274\end{array}$ & $\begin{array}{l}\text { Laurens } \\
\text { Little Mountain } \\
\text { Locust (near) }{ }^{2}{ }^{6} \\
\text { Locust (near) } \\
\text { Moore (near) }\end{array}$ & 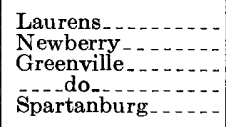 & $\begin{array}{l}.15 \\
.02 \\
.02\end{array}$ & $\begin{array}{l}.52 \\
.35 \\
.60 \\
.03\end{array}$ & $\begin{array}{r}1.51 \\
2.10 \\
1.41 \\
.85 \\
.86\end{array}$ & $\begin{array}{l}5.55 \\
2.25 \\
5.64 \\
4.40 \\
5.10\end{array}$ & $\begin{array}{l}.11 \\
2.50 \\
.41 \\
2.61 \\
2.30\end{array}$ & $\begin{array}{l}.18 \\
.28\end{array}$ & 1.09 & & & $\begin{array}{l}-- \\
-- \\
--\end{array}$ & $\begin{array}{l}7.7 \\
7.4 \\
8.1 \\
8.1 \\
9.6\end{array}$ \\
\hline $\begin{array}{l}275 \\
276 \\
277 \\
278 \\
279\end{array}$ & $\begin{array}{l}\text { Moore (near) }{ }^{2}{ }^{3} \\
\text { Newberry } \\
\text { Newberry }(\text { near })^{3} \\
\text { O'Neal (near) } \\
\text { Pelham }{ }^{2}{ }^{3}{ }^{3}\end{array}$ & 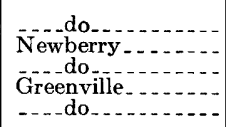 & $\begin{array}{l}.06 \\
.06\end{array}$ & $\begin{array}{l}.48 \\
1.33 \\
.45 \\
.51\end{array}$ & $\begin{array}{l}.56 \\
1.74 \\
4.50 \\
(10) \\
1.53\end{array}$ & $\begin{array}{l}5.92 \\
2.81 \\
1.00 \\
7.60 \\
\mathbf{3 . 6 2}\end{array}$ & $\begin{array}{r}.20 \\
.89 \\
.32 \\
.32\end{array}$ & (n) & 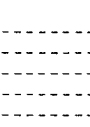 & & & & $\begin{array}{l}7.2 \\
6.8 \\
5.6 \\
8.4 \\
5.6\end{array}$ \\
\hline $\begin{array}{l}280 \\
281\end{array}$ & $\begin{array}{l}\text { Pelzer } \\
\text { Rimini-... }\end{array}$ & $\begin{array}{l}\text { Anderson... } \\
\text { Sumter.... }\end{array}$ & & .08 & $\begin{array}{r}.66 \\
2.00\end{array}$ & 5.68 & 1.07 & $\begin{array}{l}.08 \\
.55\end{array}$ & & & .18 & & $\begin{array}{l}7.8 \\
2.6\end{array}$ \\
\hline
\end{tabular}




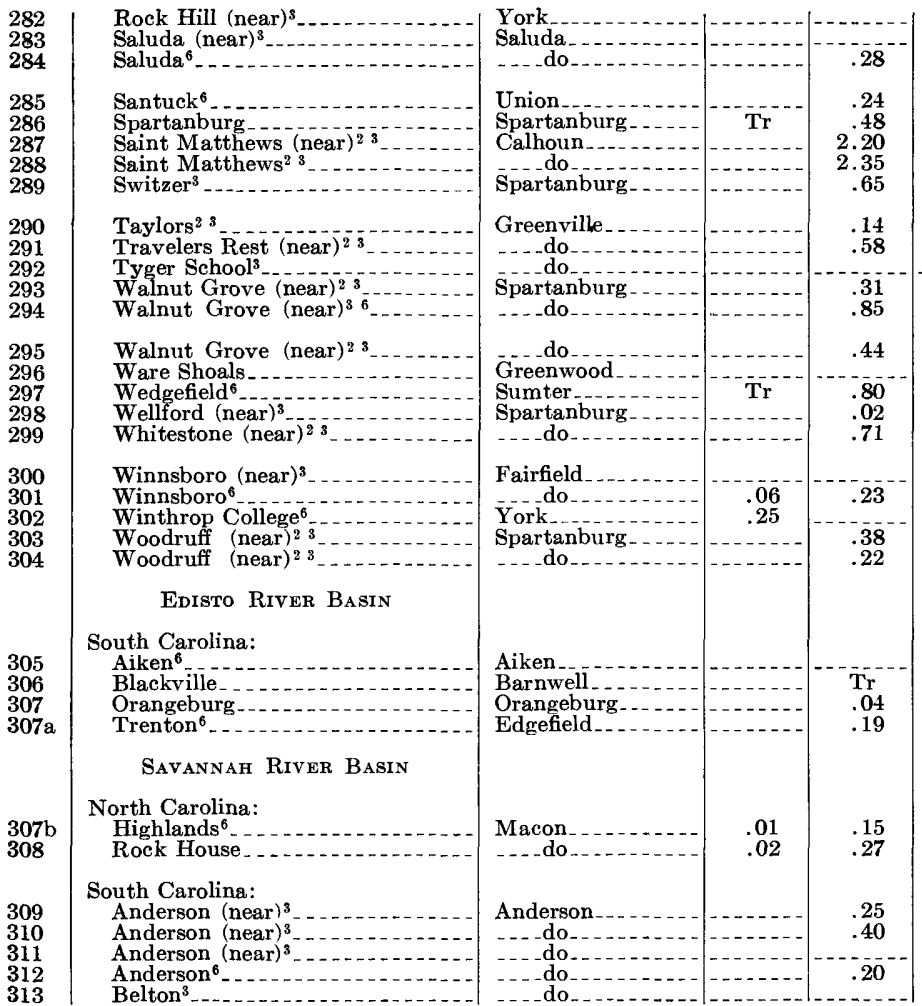

1 Total is for storm period 6 a.m. Aug. 10 to 12 p.m. Aug. 17 and is not the total of 2 Recording gage; precipitation is for the 24-hour period, midnignt to midnight.

Recording gage; precipitation is for the 24-hour

\begin{tabular}{|c|c|c|c|c|c|c|c|}
\hline $\begin{array}{l}1.11 \\
4.00 \\
3.15\end{array}$ & $\begin{array}{r}.83 \\
2.10 \\
4.48\end{array}$ & $\begin{array}{r}.66 \\
2.82 \\
.90\end{array}$ & $\begin{array}{l}.02 \\
.73 \\
-\end{array}$ & $\mid \begin{array}{l}--- \\
--- \\
--\end{array}$ & - & $\begin{array}{l}-- \\
-- \\
--\end{array}$ & $\begin{array}{r}0.33 \\
.22\end{array}$ \\
\hline $\begin{array}{r}.52 \\
.95 \\
1.77 \\
1.85 \\
6.16\end{array}$ & $\begin{array}{r}1.91 \\
5.00 \\
.22 \\
.15 \\
2.25\end{array}$ & $\begin{array}{l}.98 \\
.11 \\
.52 \\
.20\end{array}$ & $\begin{array}{l}10 \\
\mathrm{Tr} \\
-.-\end{array}$ & $\begin{array}{l}.02 \\
.20\end{array}$ & $\begin{array}{c}0.13 \\
.04\end{array}$ & $\begin{array}{l}19 \\
10\end{array}$ & $\begin{array}{l}.13 \\
.15\end{array}$ \\
\hline $\begin{array}{l}1.00 \\
1.62\end{array}$ & $\begin{array}{l}5.20 \\
3.43\end{array}$ & $\begin{array}{r}.06 \\
.27\end{array}$ & & & & & \\
\hline $\begin{array}{l}1 . \overline{1} \\
3.85\end{array}$ & $\begin{array}{l}1.19 \\
4.08 \\
1.40\end{array}$ & $\begin{array}{r}6.82 \\
.50 \\
.15\end{array}$ & $\begin{array}{l}.37 \\
.16\end{array}$ & .40 & & & -1 \\
\hline $\begin{array}{r}.93 \\
3.38\end{array}$ & $\begin{array}{l}4.60 \\
5.97\end{array}$ & $\begin{array}{r}.22 \\
1.22\end{array}$ & $\begin{array}{r}1.42 \\
.02\end{array}$ & & & .05 & \\
\hline $\begin{array}{r}.85 \\
.86 \\
(10)\end{array}$ & $\begin{array}{c}3.67 \\
(10)\end{array}$ & $\begin{array}{l}3.85 \\
6.72 \\
6.50\end{array}$ & $\begin{array}{l}.12 \\
.44\end{array}$ & - & .05 & $\mathrm{Tr}$ & .22 \\
\hline $\begin{array}{r}.73 \\
1.32 \\
.67 \\
1.10 \\
1.13\end{array}$ & $\begin{array}{r}1.19 \\
.63 \\
.41 \\
5.40 \\
5.02\end{array}$ & $\begin{array}{r}1.81 \\
2.14 \\
1.20 \\
.10\end{array}$ & $\begin{array}{l}.41 \\
.20\end{array}$ & & $\begin{array}{c}.19 \\
\operatorname{Tr} \\
.10 \\
-\end{array}$ & & \\
\hline $\begin{array}{l}2.41 \\
3.60 \\
4.20 \\
2.45\end{array}$ & $\begin{array}{l}1.69 \\
1.51 \\
.45 \\
2.65\end{array}$ & $\begin{array}{r}.01 \\
.07 \\
1.60\end{array}$ & $\begin{array}{l}.15 \\
.75 \\
.22\end{array}$ & $-\cdots$ & $\begin{array}{l}.42 \\
.47\end{array}$ & .01 & $\begin{array}{l}.05 \\
.23 \\
.39 \\
.04\end{array}$ \\
\hline $\begin{array}{l}2.91 \\
4.03\end{array}$ & 9.68 & .06 & & L & 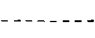 & _. & - \\
\hline $\begin{array}{r}5.00 \\
6.80 \\
2.45 \\
5.23 \\
.78\end{array}$ & $\begin{array}{r}.90 \\
1.70 \\
5.10 \\
6.32 \\
8.75\end{array}$ & $\begin{array}{l}.25 \\
.85 \\
.35 \\
.43\end{array}$ & & & 01 & $\cdots$ & 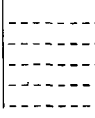 \\
\hline
\end{tabular}

6 Precipitation measured in the afternoon

10 Precipitation included in the following measurement. 
TABLE 5.-Daily precipitation, in inches, August 10-19, 1940-Continued

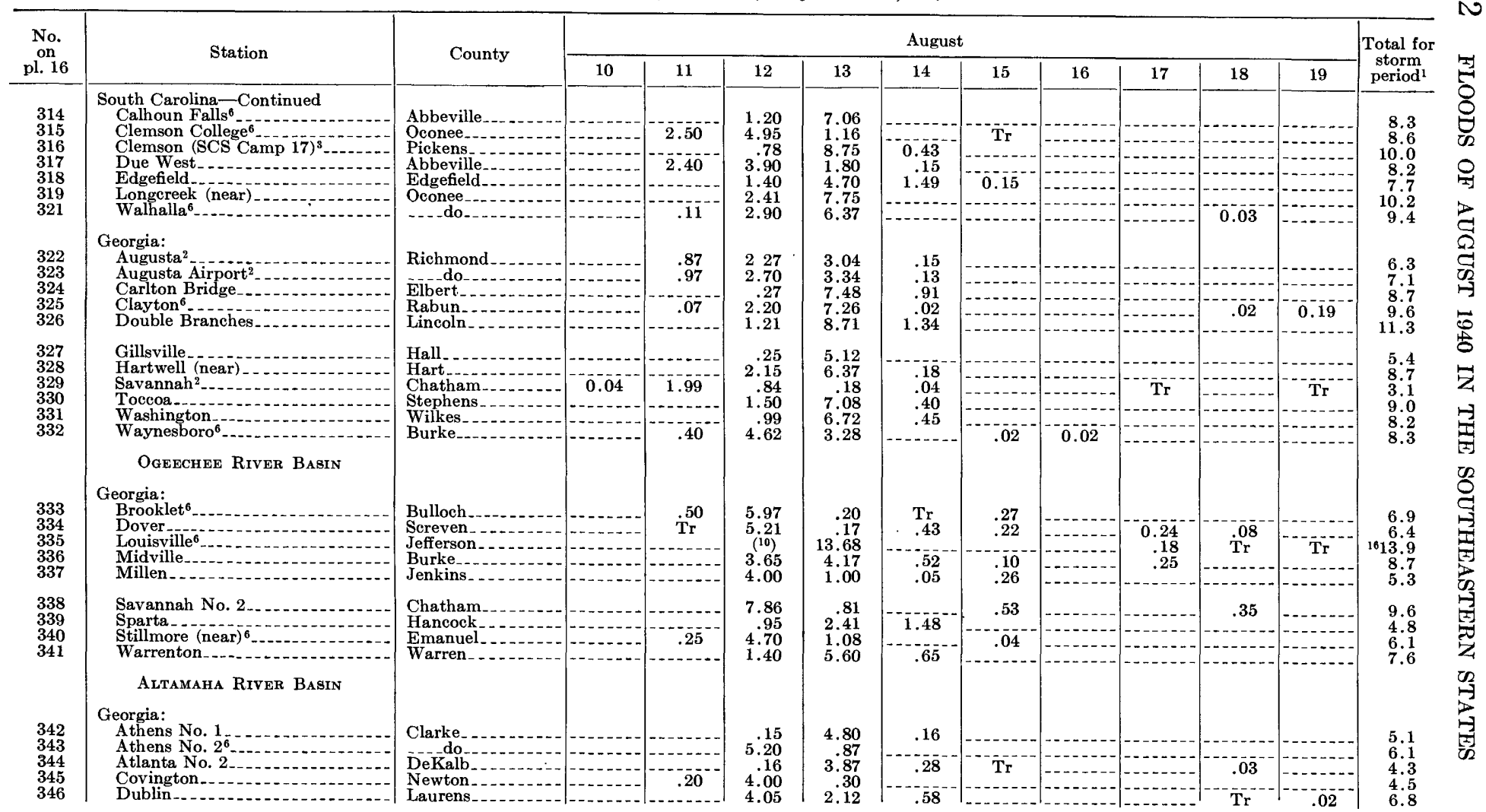




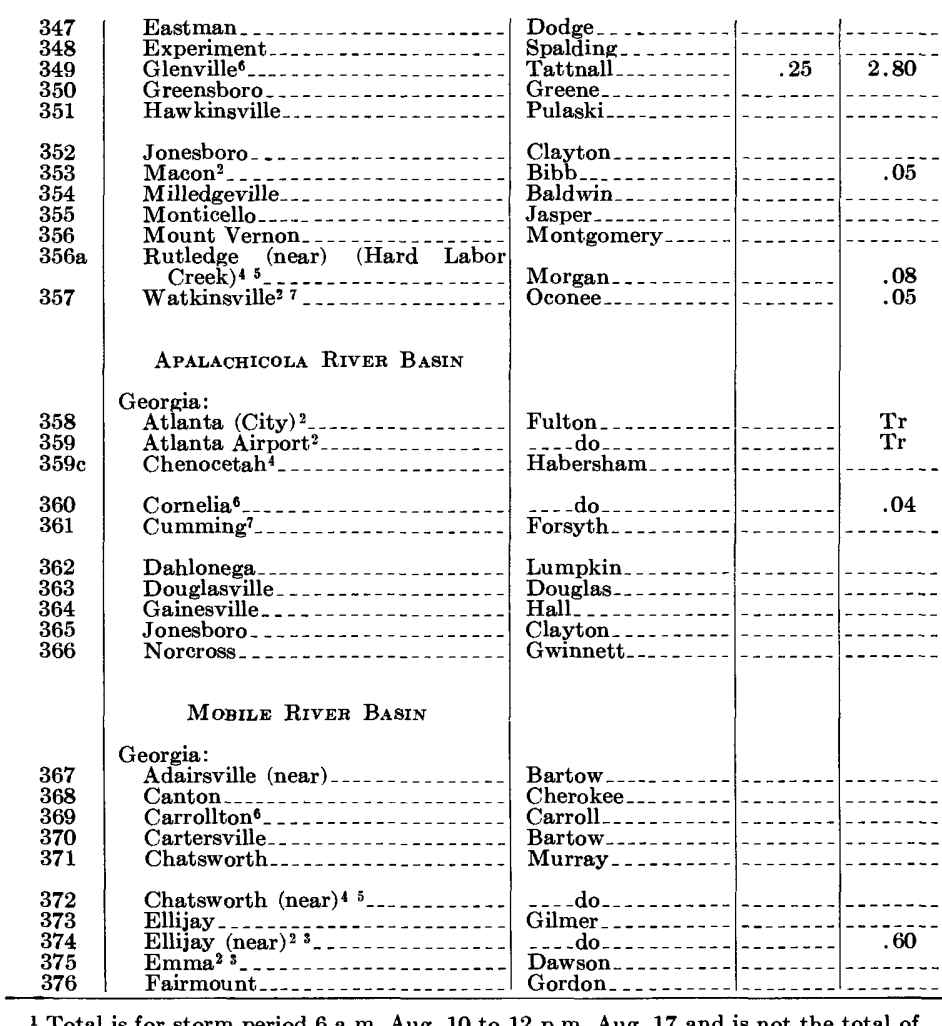

1 Total is for storm period 6 a.m. Aug. 10 to 12 p.m. Aug. 17 and is not the total of recorded daily values Aug. 10-17.

2 Recording gage; precipitation is for the 24-hour period, midnight to midnight.

Record furnished by Soil Conservation Service.
4 Record furnished by U. S. Forest Service.

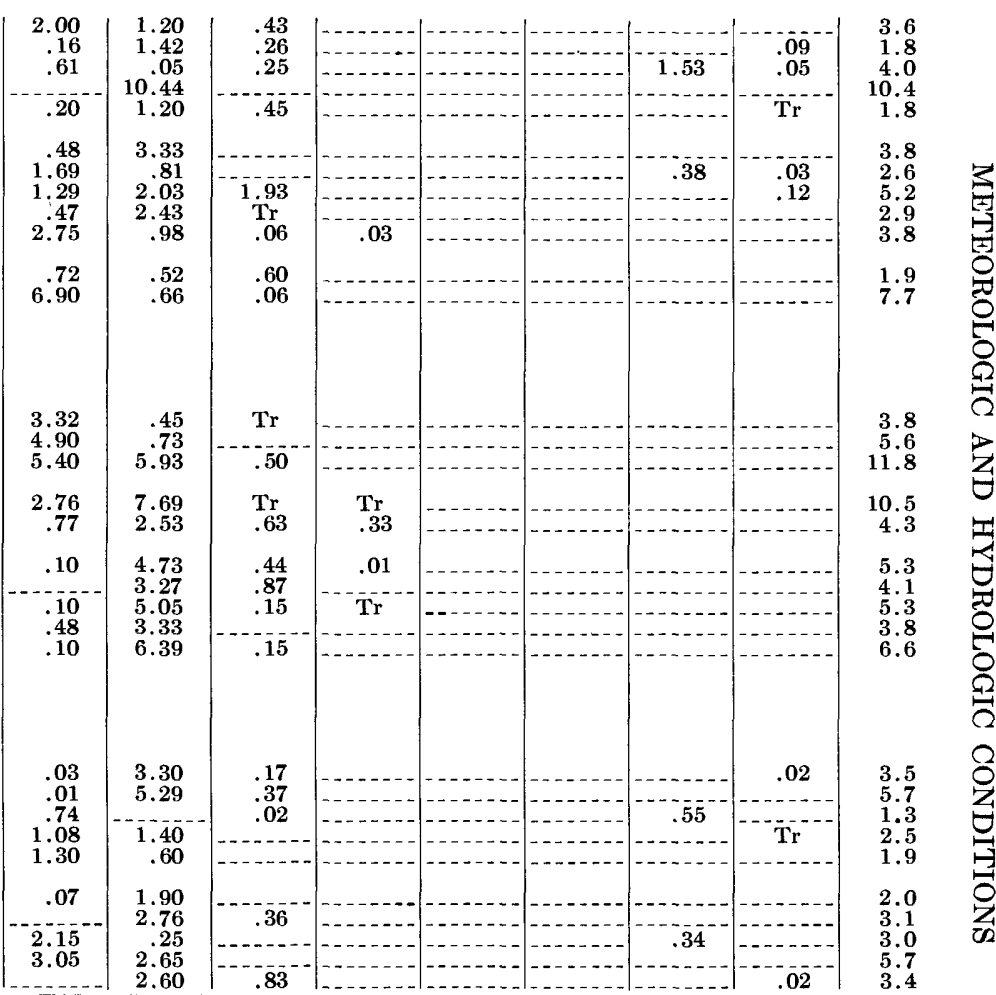

5 Precipitation measured in the morning and the evening.

6 Precipitation measured in the afternoon.

7 Record furnished by Corps of Engineers, War Department.

10 Precipitation included in the following measurement.

16 Partly estimated. 
TABLE 5.-Daily precipitation, in inches, August 10-19, 1940-Continued

\begin{tabular}{|c|c|c|c|c|c|c|c|c|c|c|c|c|c|}
\hline \multirow{2}{*}{$\begin{array}{l}\text { No. } \\
\text { on } \\
\text { pl. } 16\end{array}$} & \multirow{2}{*}{ Station } & \multirow{2}{*}{ County } & \multicolumn{10}{|c|}{ August } & \multirow{2}{*}{$\begin{array}{l}\text { Total for } \\
\text { storm } \\
\text { period }^{1} \\
\end{array}$} \\
\hline & & & 10 & 11 & 12 & 13 & 14 & 15 & 16 & 17 & 18 & 19 & \\
\hline $\begin{array}{l}377 \\
378 \\
379 \\
380 \\
381\end{array}$ & $\begin{array}{l}\text { Georgia-Continued } \\
\text { Jasper } \\
\text { Jasper }(\text { near })^{2} \\
\text { Oakman } \\
\text { Taylorsilile } \\
\text { Woodstock }\end{array}$ & $\begin{array}{l}\text { Pickens } \\
\text { Gordon } \\
\text { Bartow } \\
\text { Cherokee. }\end{array}$ & $\ldots$ & 2.55 & 1.34 & \begin{tabular}{l}
4.10 \\
\hdashline 2.35 \\
3.12 \\
5.07
\end{tabular} & $\begin{array}{r}0.61 \\
1.16 \\
.11 \\
.06\end{array}$ & \begin{tabular}{c}
0.08 \\
\hdashline$-1 .-$ \\
$-1 .-1$
\end{tabular} & -- & - & 0.04 & $\begin{array}{r}0.33 \\
- \\
\end{array}$ & $\begin{array}{l}4.8 \\
5.0 \\
2.5 \\
3.1 \\
5.1\end{array}$ \\
\hline $\begin{array}{l}382 \\
383 \\
384 \\
385 \\
386 \\
387\end{array}$ & 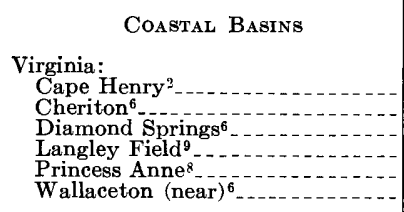 & $\begin{array}{l}\text { Princess Anne } \\
\text { Northampton--..- } \\
\text { Princess Anne.--. } \\
\text { Elizabeth City } \\
\text { Princess Anne } \\
\text { Norfolk }\end{array}$ & $\begin{array}{l}\operatorname{Tr} \\
0.02 \\
.47 \\
.47\end{array}$ & .02 & -1 & $\operatorname{Tr}$ & $\begin{array}{r}1.69 \\
.18 \\
.84 \\
1.81 \\
2.64 \\
1.89\end{array}$ & $\begin{array}{r}1.92 \\
1.96 \\
4.53 \\
2.66 \\
1.51 \\
.85\end{array}$ & $\begin{array}{l}0.58 \\
.10 \\
.49 \\
.59 \\
.45 \\
.85\end{array}$ & $\begin{array}{r}0.09 \\
.08 \\
.05 \\
\mathrm{Tr} \\
.13\end{array}$ & \begin{tabular}{c}
.14 \\
\hdashline .53 \\
\hdashline $\mathbf{T r}$
\end{tabular} & $\begin{array}{l}1.39 \\
.45 \\
2.10 \\
.07 \\
2.01 \\
.35\end{array}$ & $\begin{array}{l}4.3 \\
2.3 \\
6.0 \\
5.1 \\
4.6 \\
3.7\end{array}$ \\
\hline $\begin{array}{l}388 \\
389 \\
390 \\
391 \\
392\end{array}$ & 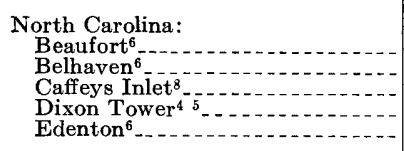 & $\begin{array}{l}\text { Carteret } \\
\text { Beaufort } \\
\text { Currituck } \\
\text { Onslow } \\
\text { Chowan }\end{array}$ & $\begin{array}{r}1.13 \\
.90 \\
.43 \\
.03\end{array}$ & $\begin{array}{r}.11 \\
.10 \\
.02 \\
. . .-\end{array}$ & .08 & .08 & $\begin{array}{r}.14 \\
1.25 \\
3.20 \\
1.26 \\
.12\end{array}$ & $\begin{array}{l}2.00 \\
2.00 \\
1.57 \\
1.99 \\
1.35\end{array}$ & $\begin{array}{r}.38 \\
1.10 \\
.09 \\
1.90 \\
.39\end{array}$ & $\begin{array}{r}.45 \\
.40 \\
1.14 \\
.55 \\
1.63\end{array}$ & 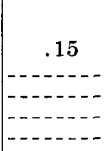 & $\begin{array}{l}.01 \\
.50 \\
.45\end{array}$ & $\begin{array}{l}4.5 \\
5.8 \\
6.0 \\
5.9 \\
3.6\end{array}$ \\
\hline $\begin{array}{l}393 \\
394 \\
395 \\
396 \\
397\end{array}$ & $\begin{array}{l}\text { Elizabeth City }{ }^{6} \\
\text { Hatteras }{ }^{2} \\
\text { Manteo } 6 \\
\text { New Holland }{ }^{6}{ }^{6} \\
\text { Newport }{ }^{5}\end{array}$ & $\begin{array}{l}\text { Pasquotank } \\
\text { Dare } \\
\text { Hyde } \\
\text { Carteret }\end{array}$ & $\begin{array}{l}.10 \\
1.69 \\
1.00\end{array}$ & $\begin{array}{l}.04 \\
.07 \\
.06\end{array}$ & $\begin{array}{l}\mathrm{Tr} \\
\mathrm{Tr}_{\mathrm{r}} \\
.05 \\
.03\end{array}$ & $\begin{array}{r}.08 \\
.01 \\
1.62 \\
.05 \\
.14\end{array}$ & $\begin{array}{r}.73 \\
1.24 \\
2.24 \\
.50 \\
.08\end{array}$ & $\begin{array}{l}1.34 \\
1.06 \\
4.32 \\
.47 \\
2.10\end{array}$ & $\begin{array}{r}2.35 \\
.75 \\
-.42 \\
.85\end{array}$ & $\begin{array}{l}.38 \\
.56 \\
.48 \\
.04 \\
.45\end{array}$ & \begin{tabular}{c}
.47 \\
.03 \\
\hdashline .05
\end{tabular} & $\begin{array}{r}.35 \\
1.10 \\
1.52 \\
.02 \\
.06\end{array}$ & $\begin{array}{l}4.9 \\
3.8 \\
8.7 \\
3.2 \\
4.8\end{array}$ \\
\hline $\begin{array}{l}398 \\
399 \\
400\end{array}$ & $\begin{array}{l}\text { Oregon Inlet }^{8} \\
\text { Swansboro } \\
\text { Wenona }{ }^{6}\end{array}$ & $\begin{array}{l}\text { Dare } \\
\text { Onslow } \\
\text { Washington.-..... }\end{array}$ & $\begin{array}{r}.90 \\
1.42\end{array}$ & 3.40 & $\begin{array}{r}2.20 \\
.78\end{array}$ & $\begin{array}{r}1.40 \\
.50 \\
.01\end{array}$ & $\begin{array}{r}1.00 \\
.30 \\
.11\end{array}$ & $\begin{array}{l}1.25 \\
9.06 \\
3.23\end{array}$ & $\begin{array}{r}.70 \\
2.50 \\
1.01\end{array}$ & $\begin{array}{r}1.04 \\
.70 \\
.06\end{array}$ & .09 & 1.05 & $\begin{array}{r}5.5 \\
19.6 \\
6.6\end{array}$ \\
\hline $\begin{array}{l}401 \\
402 \\
403 \\
403 a \\
404\end{array}$ & $\begin{array}{l}\text { South Carolina: } \\
\text { Beaufort (near) } \\
\text { Charleston }{ }^{2} \\
\text { Charleston Airport } \\
\text { Conway } \\
\text { Georgetown } 6\end{array}$ & 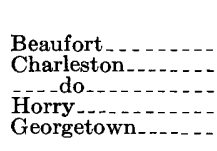 & $\begin{array}{l}.24 \\
.03 \\
.41 \\
.19 \\
.03\end{array}$ & $\begin{array}{r}10.84 \\
7.66 \\
7.88 \\
.08 \\
.96\end{array}$ & $\begin{array}{r}.32 \\
1.94 \\
1.99 \\
1.64 \\
.92\end{array}$ & $\begin{array}{r}.84 \\
.25 \\
.48 \\
.43 \\
1.03\end{array}$ & $\begin{array}{l}.35 \\
.35 \\
.78 \\
.08 \\
.08\end{array}$ & $\begin{array}{r}.27 \\
.01 \\
.20 \\
2.08\end{array}$ & $\begin{array}{c}1.55 \\
.31 \\
.46 \\
.02\end{array}$ & $\begin{array}{l}.04 \\
.64 \\
.04 \\
.06 \\
.27\end{array}$ & $\begin{array}{c}.78 \\
.16\end{array}$ & $\begin{array}{c}\mathbf{T r} \\
\mathbf{T r} \\
.17\end{array}$ & $\begin{array}{r}12.6 \\
12.7 \\
11.9 \\
3.9 \\
5.4\end{array}$ \\
\hline $\begin{array}{l}405 \\
406 \\
407\end{array}$ & $\begin{array}{l}\text { Miley } 6 \\
\text { Myrtle Beach } \\
\text { Pinopolis }\end{array}$ & $\begin{array}{l}\text { Hampton.... } \\
\text { Horry } \\
\text { Berkeley }\end{array}$ & $\begin{array}{l}.20 \\
.08 \\
.20\end{array}$ & $\begin{array}{l}2.50 \\
.84 \\
5.00\end{array}$ & $\begin{array}{l}8.36 \\
.24 \\
1.00\end{array}$ & .33 & $\begin{array}{r}.08 \\
.05 \\
1.00\end{array}$ & $\begin{array}{l}.75 \\
.50 \\
.20\end{array}$ & 1.14 & $\begin{array}{r}.01 \\
2.00 \\
.22\end{array}$ & 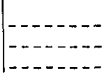 & .08 & $\begin{array}{r}12.2 \\
4.8 \\
8.0\end{array}$ \\
\hline
\end{tabular}




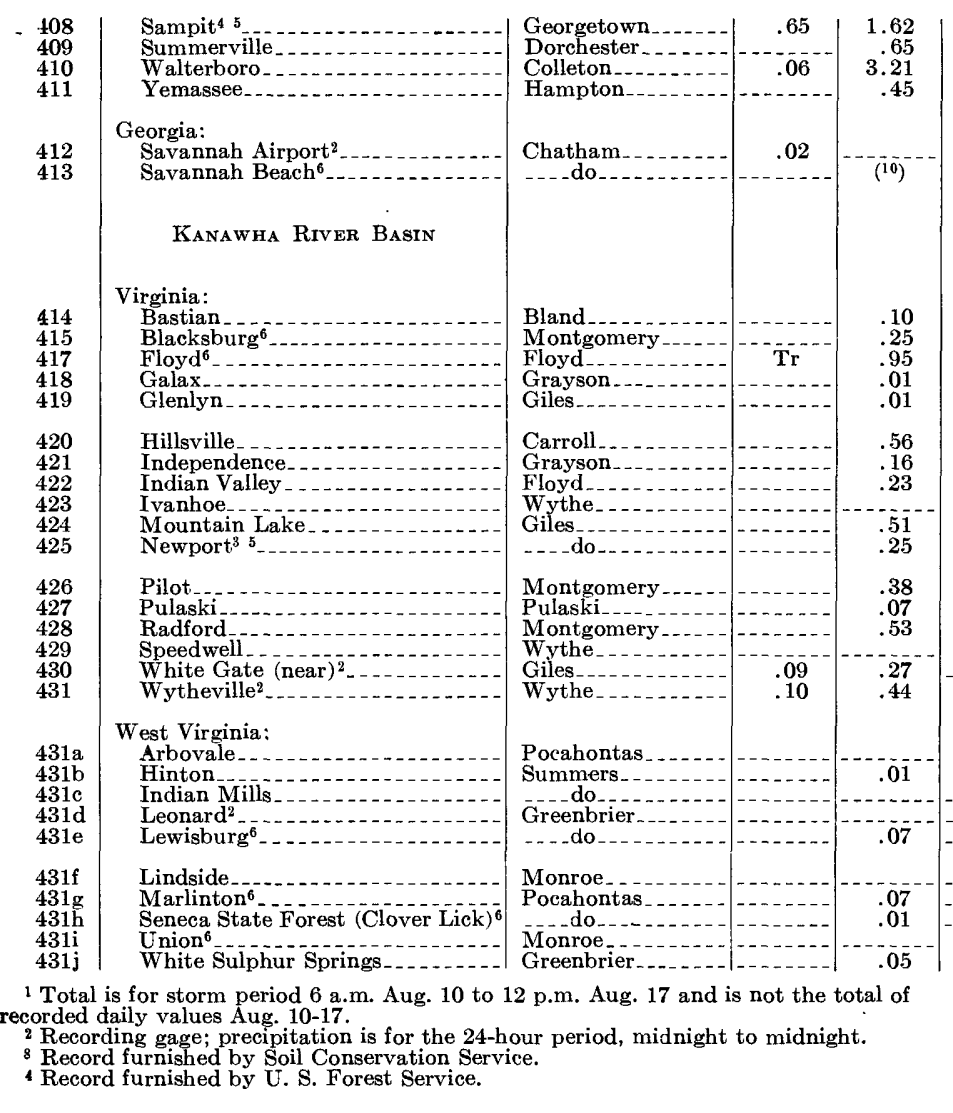

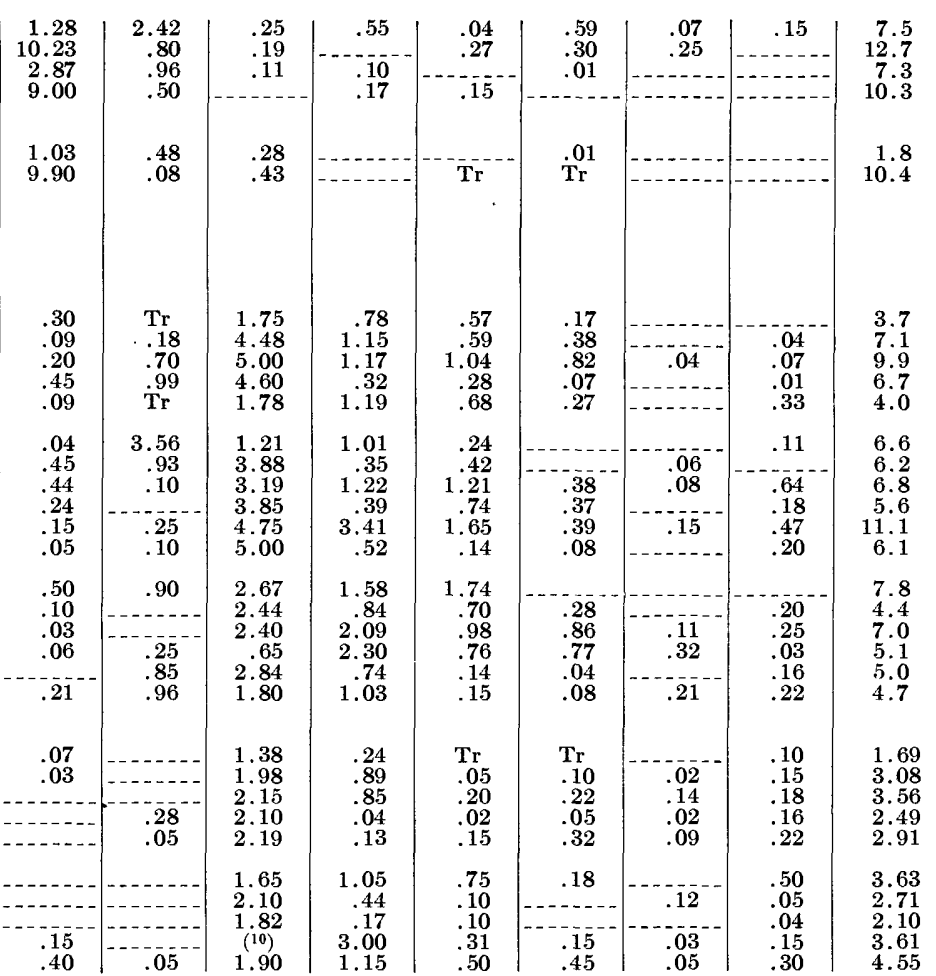

${ }^{5}$ Precipitation measured in the morning and the evening.

8 Precipitation measured at 1:30 a.m.; total is then recorded for previous day.

10 Precipitation included in the following measurement. 
TABLE 5.-Daily precipitation, in inches, August 10-19, 1940-Continued

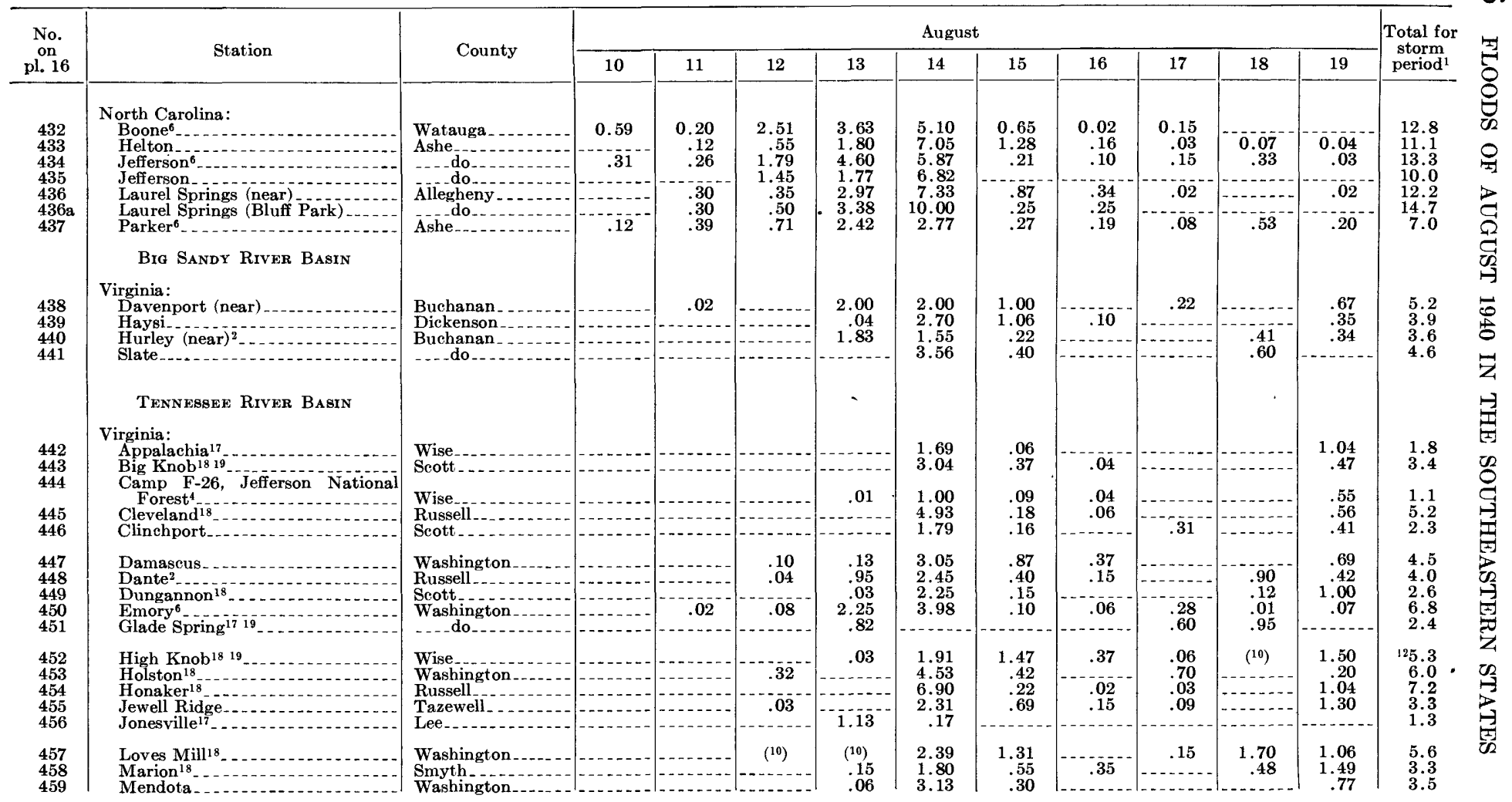




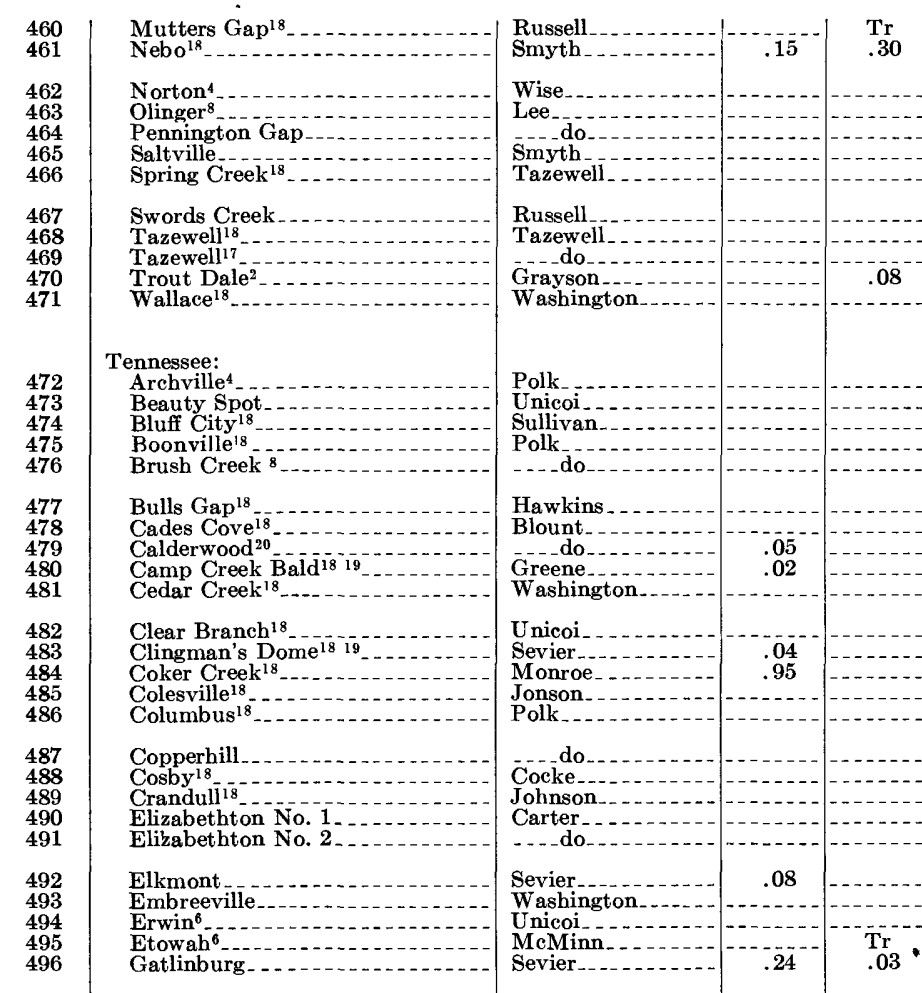

Total is for storm period 6 a.m. Aug. 10 to 12 p.m. Aug. 17 and is not the total of recorded daily values Aug. 10-17.

Recording gage; precipitation is for the 24-hour period, midnight to midnight.

1 Record furnished by U. S. Forest Service.

10 Precipitation tncluded in the following measurement.

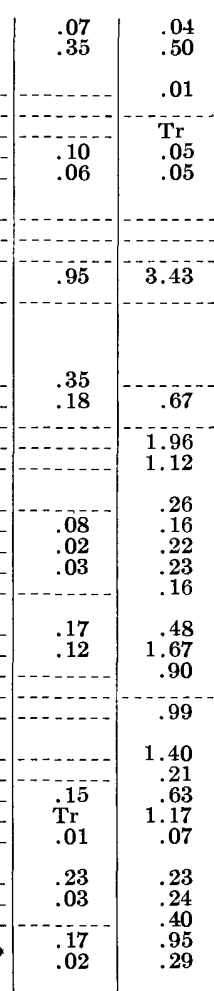

\begin{tabular}{|c|c|}
\hline $\begin{array}{r}5.43 \\
.70\end{array}$ & $\begin{array}{r}1.64 \\
.60\end{array}$ \\
\hline $\begin{array}{r}1.00 \\
1.44\end{array}$ & .09 \\
\hline 1.61 & .18 \\
\hline 4.20 & 1.01 \\
\hline & \\
\hline 3.60 & .42 \\
\hline 1.55 & .84 \\
\hline 1.80 & .75 \\
\hline $\begin{array}{l}2.33 \\
4.03\end{array}$ & $\begin{array}{r}.36 \\
2.01\end{array}$ \\
\hline 2,00 & \\
\hline 2.80 & 1.10 \\
\hline 2.05 & .30 \\
\hline .36 & .32 \\
\hline & \\
\hline 1.12 & .18 \\
\hline .89 & .29 \\
\hline $\begin{array}{r}.96 \\
1.81\end{array}$ & $\begin{array}{r}.32 \\
1.62\end{array}$ \\
\hline 2.38 & .28 \\
\hline 1.25 & .25 \\
\hline 5.33 & $2 . \overline{3} 5$ \\
\hline $\begin{array}{l}1.10 \\
3.00\end{array}$ & $\begin{array}{r}.30 \\
1.00\end{array}$ \\
\hline .32 & -- \\
\hline .27 & .04 \\
\hline .63 & 1.11 \\
\hline 1.42 & .817 \\
\hline 1.64 & 1.66 \\
\hline 1.03 & 1.10 \\
\hline 1.45 & .20 \\
\hline $\begin{array}{r}1.80 \\
.50\end{array}$ & $=-1$ \\
\hline .59 & .54 \\
\hline
\end{tabular}

\begin{tabular}{|c|c|c|c|}
\hline $\begin{array}{l}.58 \\
.55\end{array}$ & $\begin{array}{l}.04 \\
.40\end{array}$ & $\begin{array}{l}\mathrm{Tr} \\
.30\end{array}$ & $\begin{array}{l}1.24 \\
1.00\end{array}$ \\
\hline .04 & & & $\begin{array}{r}.55 \\
72\end{array}$ \\
\hline $\begin{array}{l}.04 \\
.25\end{array}$ & $\mathrm{Tr}$ & & $\begin{array}{l}.95 \\
.95 \\
.92\end{array}$ \\
\hline $\begin{array}{l}.11 \\
.30\end{array}$ & .22 & & .68 \\
\hline $\begin{array}{l}.30 \\
.10\end{array}$ & $\begin{array}{l}.26 \\
.59\end{array}$ & $51^{-1}$ & .34 \\
\hline .70 & $\begin{array}{l}.19 \\
.20\end{array}$ & $0 \overrightarrow{04}$ & $\begin{array}{l}.33 \\
.25\end{array}$ \\
\hline & -1 & & .20 \\
\hline & - - - - & 01 & \\
\hline $\begin{array}{l}.66 \\
.04\end{array}$ & $\begin{array}{l}.28 \\
.12\end{array}$ & 07 & $\begin{array}{r}.29 \\
.52 \\
.14\end{array}$ \\
\hline $\begin{array}{l}.05 \\
.12\end{array}$ & $\begin{array}{l}.14 \\
.02\end{array}$ & & $\begin{array}{l}.53 \\
.60\end{array}$ \\
\hline - - & .11 & .08 & .16 \\
\hline .04 & & & $\begin{array}{r}.26 \\
.35\end{array}$ \\
\hline $\begin{array}{r}.94 \\
.14\end{array}$ & $\mathrm{Tr}$ & 4 & רירי \\
\hline .09 & & & .19 \\
\hline $\begin{array}{l}.02 \\
.13\end{array}$ & $\begin{array}{l}\mathrm{Tr} \\
.02\end{array}$ & & $\begin{array}{l}.20 \\
.25\end{array}$ \\
\hline & & $\mathrm{Tr}$ & 18 \\
\hline
\end{tabular}

12 Precipitation estimated on basis of nearby stations. ${ }_{17}$ Record furnished by Virginia Agricultural Experiment Station. Record furnished by Tennessee Valley Authority.

19 Recording gage; daily total for 24 hours ending in morning.
20 Record furnished by Aluminum Company of America. 
TABLE 5.-Daily precipitation, in inches, August 10-19, 1940-Continued

\begin{tabular}{|c|c|c|c|c|c|c|c|c|c|c|c|c|c|}
\hline \multirow{2}{*}{$\begin{array}{l}\text { No. } \\
\text { on } \\
\text { pl. } 16\end{array}$} & \multirow{2}{*}{ Station } & \multirow{2}{*}{ County } & \multicolumn{10}{|c|}{ August } & \multirow{2}{*}{$\begin{array}{l}\text { Total for } \\
\text { storm } \\
\text { period }^{1}\end{array}$} \\
\hline & & & 10 & 11 & 12 & 13 & 14 & 15 & 16 & 17 & 18 & 19 & \\
\hline $\begin{array}{l}497 \\
498 \\
499 \\
500 \\
501\end{array}$ & 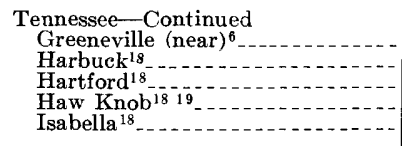 & \begin{tabular}{|l|} 
Greene \\
Polk \\
Cocke \\
Monroe. \\
Polk
\end{tabular} & 0.01 & & $\begin{array}{c}\operatorname{Tr} \\
\operatorname{Tr} \\
0.07^{--}\end{array}$ & $\begin{array}{r}1.15 \\
1.60 \\
.15 \\
.96 \\
1.34\end{array}$ & $\begin{array}{r}0.37 \\
.99 \\
.70 \\
4.05 \\
.31\end{array}$ & $\begin{array}{r}0.06 \\
.32 \\
.80 \\
2.22 \\
.11\end{array}$ & $\begin{array}{l}0.20 \\
\operatorname{Tr}^{04}\end{array}$ & $\mathrm{Tr}$ & & $\begin{array}{r}0.19 \\
.19 \\
.33 \\
.62 \\
.15\end{array}$ & $\begin{array}{l}1.8 \\
2.9 \\
1.6 \\
7.3 \\
1.8\end{array}$ \\
\hline $\begin{array}{l}502 \\
503 \\
504 \\
505 \\
506\end{array}$ & $\begin{array}{l}\text { Jearoldstown } 18 \\
\text { Johnson City } 18^{18} \\
\text { Johnson City Veterans Hospital } \\
\text { Kingsport }^{18} \\
\text { Lick Creek }^{18}\end{array}$ & 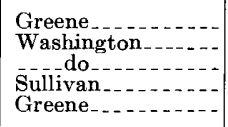 & & $\overrightarrow{\mathbf{T r}}$ & .01 & $\begin{array}{l}.33 \\
.15 \\
.13 \\
.03 \\
.40\end{array}$ & $\begin{array}{l}2.13 \\
2.42 \\
2.38 \\
2.71 \\
1.27\end{array}$ & $\begin{array}{l}.21 \\
.30 \\
.22 \\
.10 \\
.08\end{array}$ & $\begin{array}{l}.03 \\
.12 \\
.04 \\
.06\end{array}$ & $\begin{array}{l}0.04 \\
\mathrm{Tr} \\
.04 \\
.19 \\
.29\end{array}$ & 0.10 & $\begin{array}{r}.18 \\
.27 \\
.12 \\
1.07 \\
.19\end{array}$ & $\begin{array}{l}2.7 \\
3.0 \\
2.9 \\
3.1 \\
2.0\end{array}$ \\
\hline $\begin{array}{l}507 \\
508 \\
509 \\
510 \\
511\end{array}$ & $\begin{array}{l}\text { Limestone }{ }^{18} \\
\text { Little Chucky } \\
\text { Mountain City }{ }^{18}{ }^{18} \\
\text { Mount LeConte } \\
\text { Ocoee No. } 2^{18}\end{array}$ & $\begin{array}{l}\text { Washingtor } \\
\text { Greene_... } \\
\text { Johnson } \\
\text { Sevier } \\
\text { Polk }\end{array}$ & $(01$ & 0.06 & $\begin{array}{c}.60 \\
.20 \\
-2 .-1.2\end{array}$ & $\begin{array}{r}.21 \\
.15 \\
.52 \\
.86 \\
1.07\end{array}$ & $\begin{array}{r}1.30 \\
.91 \\
2.78 \\
2.04 \\
.73\end{array}$ & $\begin{array}{r}1.66 \\
4.80 \\
.06\end{array}$ & $\begin{array}{l}.05 \\
.17^{-1} \\
.18\end{array}$ & $\begin{array}{l}.15 \\
.04\end{array}$ & & $\begin{array}{l}.20 \\
.30 \\
.66 \\
.96 \\
.19\end{array}$ & $\begin{array}{l}1.7 \\
1.1 \\
5.8 \\
8.2 \\
1.9\end{array}$ \\
\hline $\begin{array}{l}512 \\
513 \\
514 \\
515 \\
516\end{array}$ & 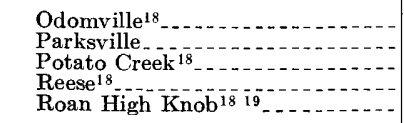 & 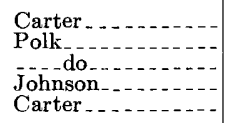 & & $\begin{array}{l}.04 \\
.37\end{array}$ & $\begin{array}{l}.04 \\
.29 \\
.83\end{array}$ & $\begin{array}{l}.41 \\
.91 \\
1.52 \\
1.53 \\
2.95\end{array}$ & $\begin{array}{r}1.95 \\
.36 \\
.34 \\
4.63 \\
3.67\end{array}$ & $\begin{array}{r}.28 \\
.12 \\
.91 \\
1.00\end{array}$ & $\begin{array}{r}.12 \\
1.01 \\
.24\end{array}$ & $.19^{9}$ & .04 & $\begin{array}{l}.34 \\
.02 \\
.24 \\
.26 \\
.83\end{array}$ & $\begin{array}{l}2.8 \\
1.3 \\
2.0 \\
8.6 \\
9.5\end{array}$ \\
\hline $\begin{array}{l}517 \\
518 \\
519 \\
520 \\
521\end{array}$ & $\begin{array}{l}\text { Sassafras Knob }{ }^{18}{ }^{19} \\
\text { Servilla }{ }^{18} \\
\text { Snake Mountain } \\
\text { Stansbury Gap }{ }^{18}{ }_{19}^{19} \\
\text { Stone Mountain }{ }^{18}\end{array}$ & $\begin{array}{l}\text { Polk } \\
\text { Johnson- } \\
\text { Polk } \\
\text { Carter }\end{array}$ & & .36 & 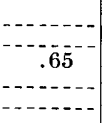 & $\begin{array}{r}2.20 \\
1.13 \\
1.15 \\
1.44 \\
.43\end{array}$ & $\begin{array}{r}1.53 \\
.46 \\
4.00 \\
.38 \\
1.38\end{array}$ & $\begin{array}{l}.32 \\
.29 \\
1.56 \\
.09 \\
.92\end{array}$ & .05 & $.42^{-11}$ & $41^{-}$ & $\begin{array}{l}.04 \\
.11 \\
.03 \\
.32\end{array}$ & $\begin{array}{l}4.1 \\
1.9 \\
8.4 \\
1.9 \\
3.6\end{array}$ \\
\hline $\begin{array}{l}522 \\
523 \\
524 \\
525 \\
526\end{array}$ & $\begin{array}{l}\text { Tellico } \\
\text { Tellico Plains } \\
\text { Tri-City Airport }{ }^{2} \\
\text { Turtletown } 18 \\
\text { Wolf Creek }{ }^{18}\end{array}$ & 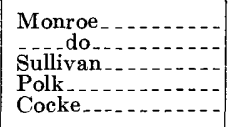 & $\begin{array}{r}.43 \\
-.4 \\
\end{array}$ & .05 & \begin{tabular}{c|}
${ }^{(10)}$ \\
.34 \\
\hdashline-14 \\
-0
\end{tabular} & $\begin{array}{r}.16 \\
.56 \\
2.13 \\
.37 \\
.16\end{array}$ & $\begin{array}{l}(10) \\
.94 \\
.35 \\
.65 \\
.91\end{array}$ & $\begin{array}{l}1.20 \\
.42 \\
.21\end{array}$ & .21 & & $\begin{array}{l}.15 \\
.14 \\
.46\end{array}$ & .08 & $\begin{array}{l}1.4 \\
2.2 \\
2.5 \\
1.4 \\
2.0\end{array}$ \\
\hline $\begin{array}{l}\mathbf{5 2 7} \\
\mathbf{5 2 8} \\
\mathbf{5 2 9} \\
\mathbf{5 3 0} \\
\mathbf{5 3 1}\end{array}$ & 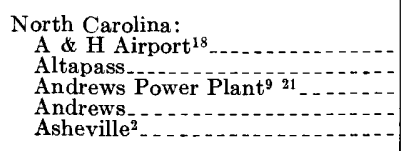 & $\begin{array}{l}\text { Henderson } \\
\text { Mitchell } \\
\text { Clay } \\
\text { Cherokee } \\
\text { Bu c combe }\end{array}$ & .01 & $\begin{array}{l}.20 \\
.02 \\
.36\end{array}$ & $\begin{array}{r}.86 \\
2.35 \\
.25 \\
.03 \\
1.24\end{array}$ & $\begin{array}{l}2.00 \\
.95 \\
1.45 \\
.78 \\
3.62\end{array}$ & $\begin{array}{r}2.01 \\
6.40 \\
.11 \\
.94 \\
.50\end{array}$ & $\begin{array}{l}.23^{-} \\
\mathbf{T r}\end{array}$ & 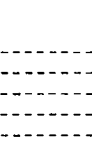 & & .07 & $\begin{array}{l}.50 \\
.31 \\
.02 \\
.02\end{array}$ & $\begin{array}{r}4.9 \\
10.1 \\
1.8 \\
1.8 \\
5.7\end{array}$ \\
\hline 532 & Asheville No. 2.... & .....do... & & .04 & .92 & 1.29 & 2.98 & .50 & $\operatorname{Tr}$ & & & .01 & 5.7 \\
\hline
\end{tabular}




\begin{tabular}{|c|c|c|c|c|c|c|}
\hline $\begin{array}{l}\mathbf{5 3 3} \\
\mathbf{5 3 4} \\
\mathbf{5 3 5} \\
\mathbf{5 3 6}\end{array}$ & $\begin{array}{l}\text { Bakersville } \\
\text { Banners Elk } \\
\text { Barnardsville } \\
\text { Beaverdam Creek }\end{array}$ & $\begin{array}{l}\text { Mitchell } \\
\text { Avery } \\
\text { Buncombe } \\
\text { Cherokee......... }\end{array}$ & $\begin{array}{r}.30 \\
-\end{array}$ & $\begin{array}{l}.45 \\
.05 \\
0 .+2\end{array}$ & $\begin{array}{r}.54 \\
2.77 \\
.51\end{array}$ & $\begin{array}{r}1.62 \\
8.50 \\
1.39 \\
.89\end{array}$ \\
\hline $\begin{array}{l}537 \\
538 \\
539 \\
540 \\
541\end{array}$ & $\begin{array}{l}\text { Beetree Dam } 19{ }^{22} \\
\text { Beetree Gap }{ }^{19}{ }_{22} \\
\text { Bent Creek }{ }^{4} 9^{2} \\
\text { Big Pine'18 } \\
\text { Blue Ridge Post Office }\end{array}$ & $\begin{array}{l}\text { Buncombe } \\
\text { Madison } \\
\text { Henderson. }\end{array}$ & .03 & $\begin{array}{l}.27 \\
.61 \\
.07 \\
.11 \\
.27\end{array}$ & $\begin{array}{r}1.12 \\
2.19 \\
.59 \\
.44 \\
.20\end{array}$ & $\begin{array}{l}4.54 \\
3.13 \\
2.22 \\
.33 \\
5.15\end{array}$ \\
\hline $\begin{array}{l}542 \\
542 \mathrm{a} \\
543 \\
544 \\
545\end{array}$ & $\begin{array}{l}\text { Boiling Spring }{ }^{18} \\
\text { Brasstown }{ }^{4} \\
\text { Bryson City }{ }^{18} \\
\text { Cane River }{ }^{18} \\
\text { Canton }\end{array}$ & $\begin{array}{l}\text { Cherokee.- } \\
\text { Clay } \\
\text { Swain } \\
\text { Yancey.-- } \\
\text { Haywood- }\end{array}$ & .02 & $\begin{array}{r}.10 \\
.32\end{array}$ & $\begin{array}{r}.07 \\
.02 \\
.80 \\
2.03\end{array}$ & $\begin{array}{l}1.10 \\
1.88 \\
.95 \\
1.28 \\
2.00\end{array}$ \\
\hline $\begin{array}{l}546 \\
547 \\
548\end{array}$ & $\begin{array}{l}\text { Cataloochee Ranch } \\
\text { Cedar Mountain } \\
\text { Celo }^{18}\end{array}$ & $\begin{array}{l}\text { Transylyania.... } \\
\text { Yancey }\end{array}$ & .05 & $\begin{array}{r}.46 \\
.15 \\
1.78\end{array}$ & $\begin{array}{r}.98 \\
.70 \\
4.20\end{array}$ & $\begin{array}{l}3.34 \\
6.97 \\
3.50\end{array}$ \\
\hline $\begin{array}{l}549 \\
550\end{array}$ & $\begin{array}{l}\text { Chambers Mountain (near } \\
\text { Clyde) } \\
\text { Cheoah }^{10}\end{array}$ & $\begin{array}{l}\text { Haywood } \\
\text { Graham }\end{array}$ & & .20 & $\begin{array}{l}.60 \\
.03\end{array}$ & $\begin{array}{r}1.81 \\
.45\end{array}$ \\
\hline $\begin{array}{l}551 \\
552 \\
553 \\
554 \\
555\end{array}$ & $\begin{array}{l}\text { Cody Store }{ }^{18} \\
\text { Coleman Dam Site } \\
\text { Cove Creek }{ }^{18} \\
\text { Coweeta No. } 1^{4}{ }^{19} \\
\text { Coxcombe Mountain } 18\end{array}$ & $\begin{array}{l}\text { Madison } \\
\text { Cherokee. } \\
\text { Haywood } \\
\text { Macon } \\
\text { Buncombe..... }\end{array}$ & & .11 & $\begin{array}{l}.16 \\
1.09\end{array}$ & $\begin{array}{l}.75 \\
1.07 \\
1.48 \\
3.55 \\
2.98\end{array}$ \\
\hline $\begin{array}{l}556 \\
557 \\
558 \\
559 \\
560\end{array}$ & $\begin{array}{l}\text { Cullowhee } \\
\text { Daybook } \\
\text { Dicks Creek } \\
\text { Dix Creek } 18 \\
\text { Doggett Gap }{ }^{18}\end{array}$ & $\begin{array}{l}\text { Jackson } \\
\text { Yancey } \\
\text { Jackson } \\
\text { Haywood } \\
\text { Madison }\end{array}$ & & $\begin{array}{c}. \mathrm{Tr} \\
.07 \\
.45 \\
.28\end{array}$ & $\begin{array}{r}.46 \\
.63 \\
\mathrm{Tr} \\
2.15 \\
.40\end{array}$ & $\begin{array}{l}2.83 \\
2.19 \\
1.60 \\
6.87 \\
1.37\end{array}$ \\
\hline $\begin{array}{l}561 \\
562 \\
563 \\
564 \\
565\end{array}$ & $\begin{array}{l}\text { Eaglenest Mountain }{ }^{18} \\
\text { Erastus } \\
\text { Fie Branch } \\
\text { Flat Top Mountain } \\
\text { Franklin }\end{array}$ & $\begin{array}{l}\text { Haywood } \\
\text { Jackson } \\
\text { Haywood } \\
\text { Yancey } \\
\text { Macon }\end{array}$ & .20 & $\begin{array}{l}.25 \\
.05 \\
.49 \\
.05\end{array}$ & $\begin{array}{l}.90 \\
.92 \\
.54 \\
.27 \\
.75\end{array}$ & $\begin{array}{l}2.75 \\
6.76 \\
2.95 \\
.71 \\
2.25\end{array}$ \\
\hline $\begin{array}{l}566 \\
567 \\
568 \\
569 \\
570\end{array}$ & $\begin{array}{l}\text { Garren Creek }{ }^{18} \\
\text { Glade Gap }^{18}{ }_{19} \\
\text { Hayesville } \\
\text { Haywood Gap } \\
\text { Hendersonville }\end{array}$ & $\begin{array}{l}\text { Buncombe... } \\
\text { Clay } \\
\text { Jackson } \\
\text { Henderson... }\end{array}$ & $\begin{array}{l}.02 \\
.07\end{array}$ & $\begin{array}{r}.29 \\
.21\end{array}$ & $\begin{array}{r}2.18 \\
.53 \\
-2.00 \\
1.55\end{array}$ & $\begin{array}{l}6.80 \\
3.55 \\
1.70 \\
8.54 \\
5.53\end{array}$ \\
\hline
\end{tabular}

\begin{tabular}{|c|c|c|c|c|c|c|}
\hline $\begin{array}{l}.00 \\
.25 \\
.41\end{array}$ & $\begin{array}{l}.32 \\
.31 \\
.60\end{array}$ & $\begin{array}{l}.08 \\
.35 \\
.14\end{array}$ & $\mid$\begin{tabular}{c}
.10 \\
\hdashline-10
\end{tabular} & - & .30 & $\begin{array}{r}5.7 \\
12.9 \\
4.5 \\
3.0\end{array}$ \\
\hline & $\begin{array}{l}.03 \\
.42 \\
.03 \\
.39 \\
.10\end{array}$ & $\begin{array}{l}.13 \\
.06\end{array}$ & $\begin{array}{l}.17 \\
.21 \\
.03 \\
.18\end{array}$ & & $\begin{array}{c}.01 \\
.08 \\
.04 \\
.47\end{array}$ & $\begin{array}{r}10.4 \\
9.8 \\
6.2 \\
3.2 \\
9.6\end{array}$ \\
\hline $\begin{array}{l}60 \\
34 \\
50 \\
23\end{array}$ & $\begin{array}{l}.19 \\
.02 \\
.22\end{array}$ & & $\mathrm{Tr}$ & & $\begin{array}{l}.08 \\
.28 \\
.01\end{array}$ & $\begin{array}{l}3.0 \\
2.3 \\
2.5 \\
4.6 \\
4.6\end{array}$ \\
\hline 12 & $\begin{array}{l}.55 \\
.05\end{array}$ & $\operatorname{Tr}$ & & & $\begin{array}{r}.45 \\
-.0\end{array}$ & $\begin{array}{r}6.5 \\
12.4 \\
13.6\end{array}$ \\
\hline .95 & $\begin{array}{r}.20 \\
.38\end{array}$ & .10 & & & $\begin{array}{l}.13 \\
.18\end{array}$ & $\begin{array}{l}4.2 \\
1.8\end{array}$ \\
\hline 67 & $\begin{array}{l}.20 \\
.65 \\
.22\end{array}$ & .08 & & & $\begin{array}{l}.64 \\
.20 \\
.93 \\
.08 \\
.44\end{array}$ & $\begin{array}{l}2.4 \\
1.9 \\
3.2 \\
5.6 \\
7.4\end{array}$ \\
\hline $\begin{array}{l}.05 \\
.97 \\
.70 \\
.72\end{array}$ & $\begin{array}{l}.06 \\
.14 \\
.71\end{array}$ & .01 & & .11 & $\begin{array}{l}.05 \\
.29 \\
.32 \\
.03 \\
.24\end{array}$ & $\begin{array}{r}3.5 \\
5.9 \\
3.3 \\
11.3 \\
5.7\end{array}$ \\
\hline $\begin{array}{l}.30 \\
.26 \\
.09\end{array}$ & $\begin{array}{l}.12 \\
.09 \\
.32 \\
.45\end{array}$ & $.15^{--}$ & .18 & & $\begin{array}{l}.18 \\
.74 \\
.46\end{array}$ & $\begin{array}{l}5.6 \\
9.0 \\
5.6 \\
5.1 \\
3.1\end{array}$ \\
\hline .8 & .25 & $.02^{--}$ & $\begin{array}{l}.50 \\
.01\end{array}$ & $\cdots \overline{7}$ & $\begin{array}{l}.15 \\
.08 \\
.09 \\
.\end{array}$ & $\begin{array}{r}13.4 \\
7.0 \\
2.6 \\
13.3 \\
7.7\end{array}$ \\
\hline
\end{tabular}

1 Total is for storm period 6 a.m. Aug. 10 to 12 p.m. Aug. 17 and is not the total of

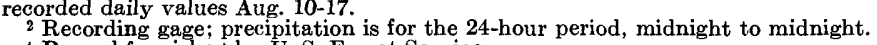
4 Recording gage; precipitation is for the 24 . 
TABLE 5.-Daily precipitation, in inches, August 10-19, 1940-Continued

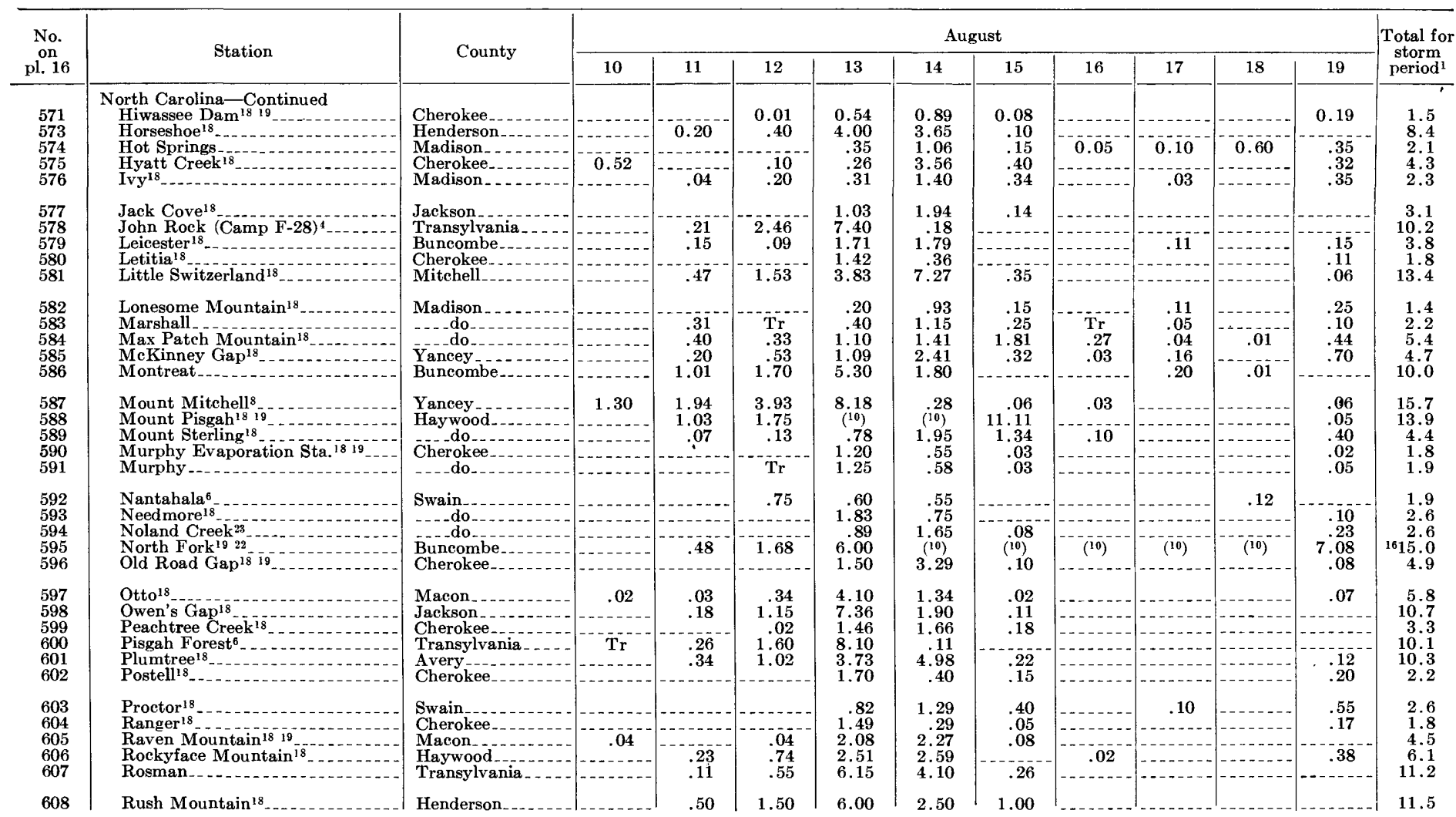




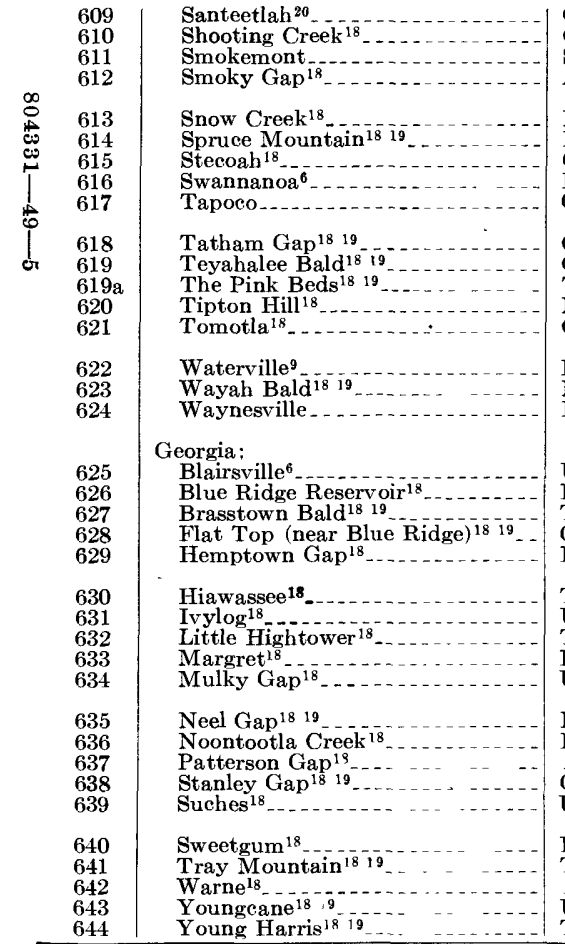

\begin{tabular}{|c|c|c|c|}
\hline Graham .. - & .98 & & .04 \\
\hline Swain & & & .06 \\
\hline Avery & & 22 & .68 \\
\hline Mitchell_ & & 0 & .65 \\
\hline Haywood. & & 34 & .93 \\
\hline Graham $_{-. .}$ & & 10 & .03 \\
\hline Buncombe_ & .80 & 1.40 & 2.70 \\
\hline Granam-- & & & \\
\hline Cherokee. & .03 & & \\
\hline Graham -- & .32 & & .07 \\
\hline Transylvania & .02 & 38 & 1.68 \\
\hline Mitchell... & & 66 & .39 \\
\hline & & & \\
\hline Haywood & & 01 & .10 \\
\hline $\begin{array}{l}\text { Macon } \\
\text { Haywood }\end{array}$ & .02 & .49 & $\begin{array}{l}.08 \\
1.70\end{array}$ \\
\hline Union & & & .89 \\
\hline Fannin & & & \\
\hline Towns $\ldots$ & & .04 & .59 \\
\hline $\begin{array}{l}\text { Gilmer } \\
\text { Fannin }\end{array}$ & -1 & & .02 \\
\hline Towns & & & 80 \\
\hline Union.-- & & & .02 \\
\hline Towns _. & & & .10 \\
\hline Fannin & & & .04 \\
\hline Union & & & .19 \\
\hline Lumpkin & & .02 & .90 \\
\hline Fannin... & & & .12 \\
\hline Gilmer & & & \\
\hline Union & & & .30 \\
\hline Fannin & & & \\
\hline Towns ....... & & .03 & .72 \\
\hline $\begin{array}{l}\text { Union } \\
\text { Towne }\end{array}$ & (10) & $(0)$ & $\begin{array}{l}(10) \\
1.0\end{array}$ \\
\hline
\end{tabular}

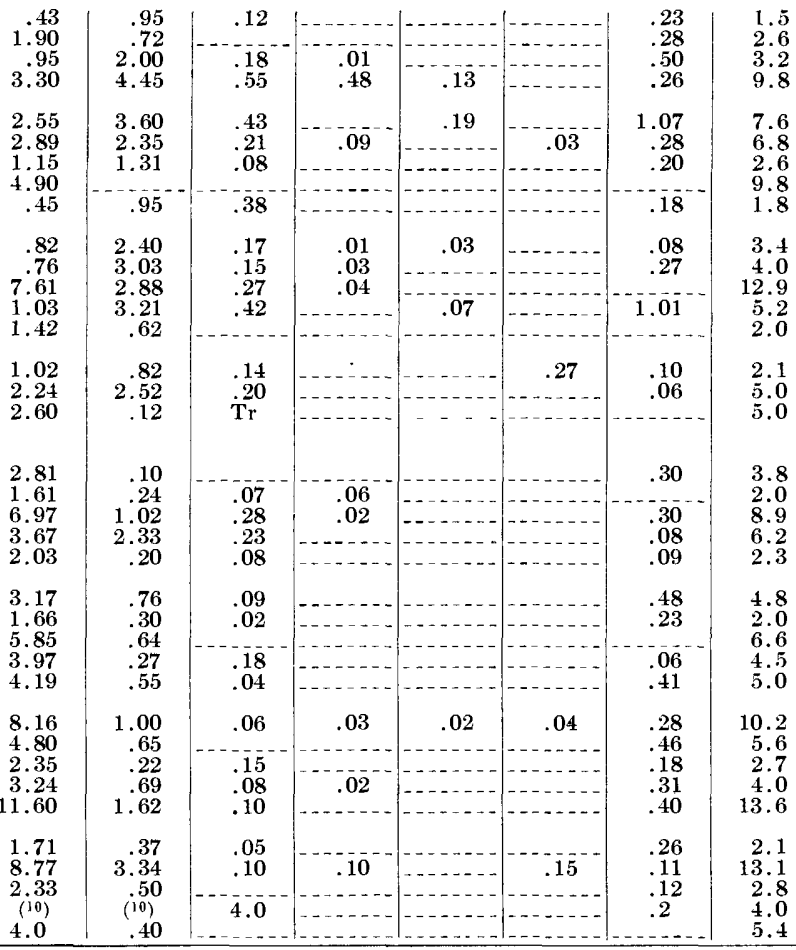

16 Partly estimated.

19 Recording gage; daily total for 24 hours ending in morning.

${ }^{20}$ Record furnished by Aluminum Company of America.

${ }^{22}$ Record furnished by city of Asheville. N. C.

${ }^{3}$ Record furnished by P, G. Rust. 


\section{DISTRIBUTION OF PRECIPITATION}

The total precipitation during the period August 10-17, based on data listed in table 5, is shown on plate 16. Several areas of rainfall concentration, or storm centers, defined by this map, indicate the variability of the storm rainfall over comparatively short distances. There is a well-defined series of storm centers along the Appalachian Mountains, extending from the vicinity of Blue Ridge, Ga., in a northeasterly direction to the vicinity of Luray, Va., showing the orographic influence on the storm precipitation. This is not a continuous ridge of high precipitation but rather a series of storm centers with relatively low precipitation intervening. Total precipitation for the storm period varied from 13 to 16 inches as a maximum and from 6 to 8 inches as a minimum for the mountainous area. Along the coastal plain there are two centers, one between Beaufort and Charleston, S. C., and another near Swansboro, N. C., where there was a total precipitation of more than 19 inches, the maximum observed for the storm. Other major centers of precipitation were located around Keysville, Va., and Louisville, Ga.

A factor of importance to the Tennessee Valley region was the sharp westward decrease in precipitation in the vicinity of the North Carolina-Tennessee boundary. Many of the tributaries of Tennessee River in North Carolina rose to high stages. On some of the headwater streams with drainage areas of less than 100 square miles, the peak runoff rates rank with the greatest experienced in the eastern United States. Owing to the rapid decrease in precipitation in the downstream direction, the relative magnitude of the floods decreased progressively. The volume of flood flow from the mountainous areas was sufficient, however, to produce flood stages along the entire length of Holston and French Broad Rivers. On Tennessee River. flood stages occurred downstream as far as Chickamauga Reservoir, but below this point the combined effect of reservoir regulation and decreased rainfall reduced the peak discharges to minor rises.

On the rivers affected by the storm of August 10-17 the distribution of precipitation relative to time was a decisive factor in producing peak stages and discharges. The path of the center of the storm has been indicated on plate 2 .

In general on August 11 and 12 the storm erossed the Coastal Plain and Piedmont areas of Georgia and South Carolina and moved up the rivers. To the extent that the runoff from some of the downstream tributaries would reach tidewater in advance of the flood runoff from the headwaters, the peak discharges downstream were reduced. In the mountainous areas affected by the storm where the drainage basins are comparatively small, broad-areal timing is, of course, not critical in producing high rates of runoff. 


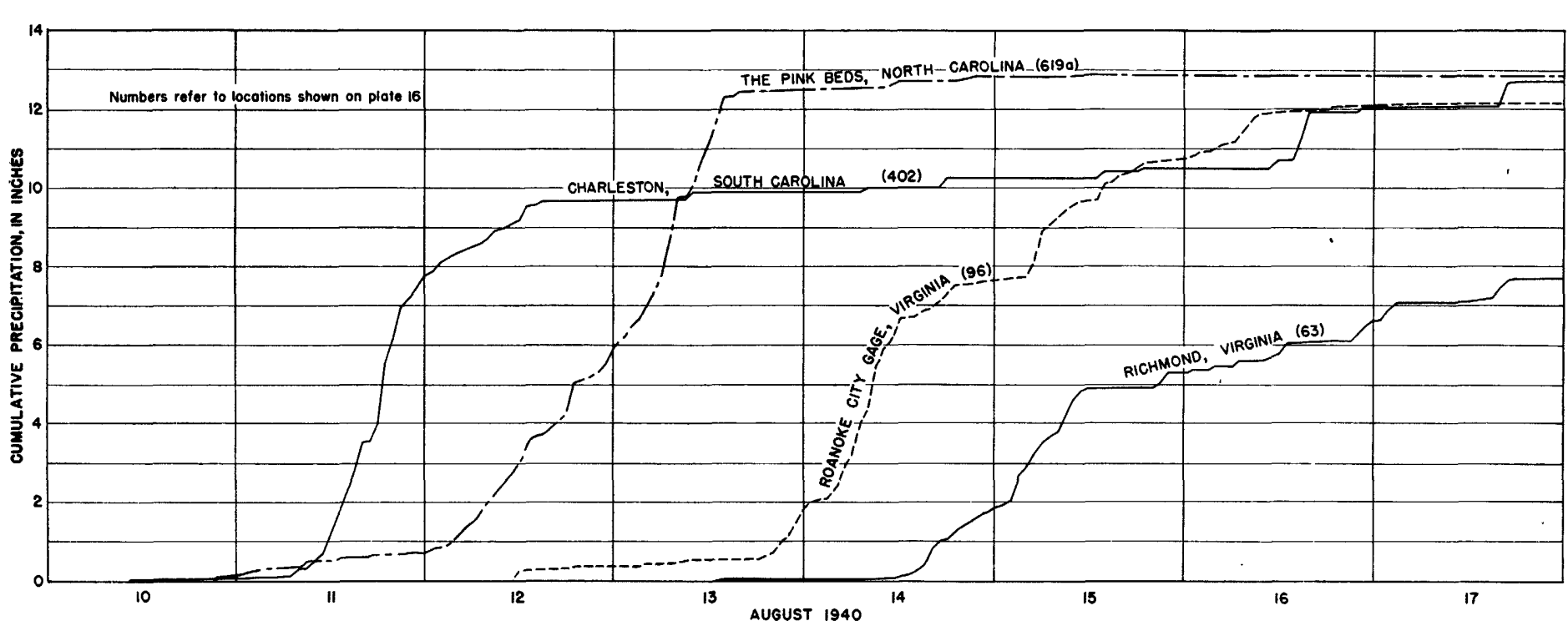

FIGURE 3.-Cumulative precipitation, in inches, at selected stations for storm period, August 10-17, 1940. 
On August 14 and 15 the storm reversed its direction of travel and moved eastward down the various streams flowing into the Atlantic Ocean in Virginia and North Carolina. On Roanoke River, especially, this critical direction of the storm and resulting timing of rainfall served to produce the highest flood in more than 300 years on the lower portion of the main stem of the river.

Cumulative precipitation graphs based on records of recording rain gages at four selected stations are shown in figure 3 to illustrate the distribution of rainfall during the storm. Hourly precipitation at these stations and four additional stations is shown in figure 4. Of particular interest is the difference between the time of occurrence
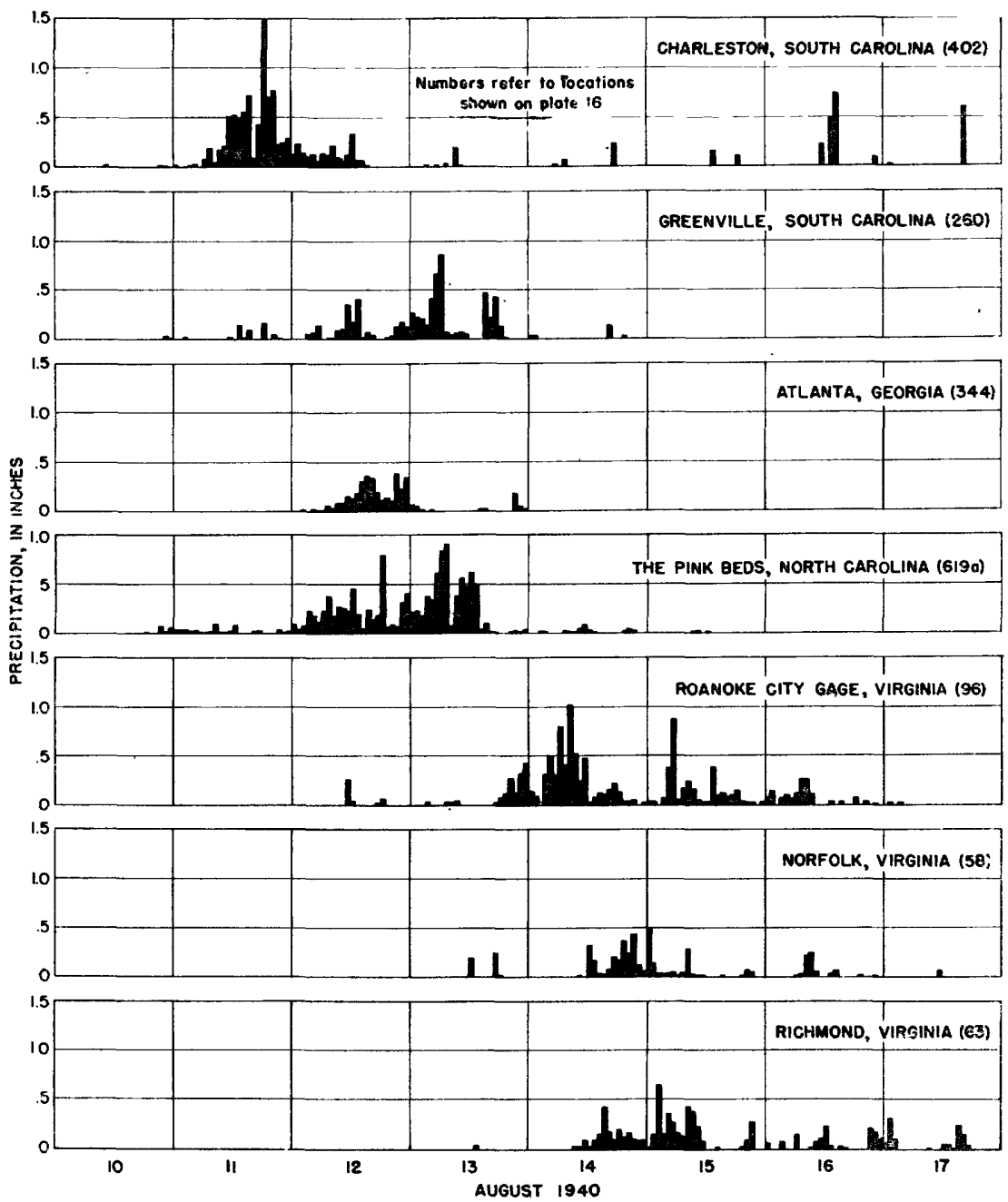

Figure 4.-Hourly precipitation, in inches, at selected stations, August 10-17. 1940. 
of the major rainfall at the various stations. The arrival of the storm can be traced from southern South Carolina westward, thence northward along the mountains of North Carolina, and thence eastward through Virginia and northeastern North Carolina. There was a lag of about 3 days between the beginning of flood-producing rainfall at Beaufort, S. C., where the storm first erossed the coast, and Richmond, Va., about where the storm passed out to sea. The lag of about 24 hours between the rainfall at Roanoke, Va., and Richmond, Va., is especially important, as during this period the storm was progressing downstream over the Roanoke River Basin, so that the peak discharges from the longer downstream tributaries tended to synchronize with the peak on the main stem.

As the storm traveled over the land, it diminished in intensity and apparently was dispersed over a great area. At Charleston, S. C., about $9 \frac{1}{2}$ inches of rain fell in 30 hours, and at The Pink Beds, N. C., 12 inches fell in about 40 hours, during the most intense part of the storm, whereas at Richmond, Va., the major storm precipitation continued for 60 to 70 hours. These rates were fairly typical, the storm being most concentrated during the time it was over Georgia, South Carolina, and western North Carolina, and somewhat more spread out by the time it reached Virginia and eastern North Carolina.

\section{LATE-A UGUS'T STTORM}

The storm of August 28-31, 1940, was rather local, the principal area of heavy precipitation being along the Blue Ridge in North Carolina. Total rainfall was slightly less than for the mid-August storm, but it fell mostly in a period of about 24 hours, whereas in the earlier storm the slightly greater amount was distributed over several days.

There was rain on 4 days, August 28-31, inclusive, but intense rainfall did not begin until the morning of August 29, the time ranging from midnight to noon. Generally, rainfall thereafter was practically continuous until August 30, when it ended as abruptly as it had started. Except for an occasional shower noted at several gages on August 31, precipitation had ceased by noon of August 30. Figure 5 indicates intensities observed during this storm.

The daily precipitation at all stations August 28-31, inclusive, is reported in table 6 with appropriate footnotes indicating the time of measurement, source of the record, and other information pertinent to the record. All data were furnished by the Weather Bureau, except as noted. The rain gages are numbered to agree with the corresponding record for the mid-August flood in table 5. The last column in table 6 lists the total precipitation during the period between 12 :01 a.m. August 28 and 12 p.m. August 31, termed either the storm 

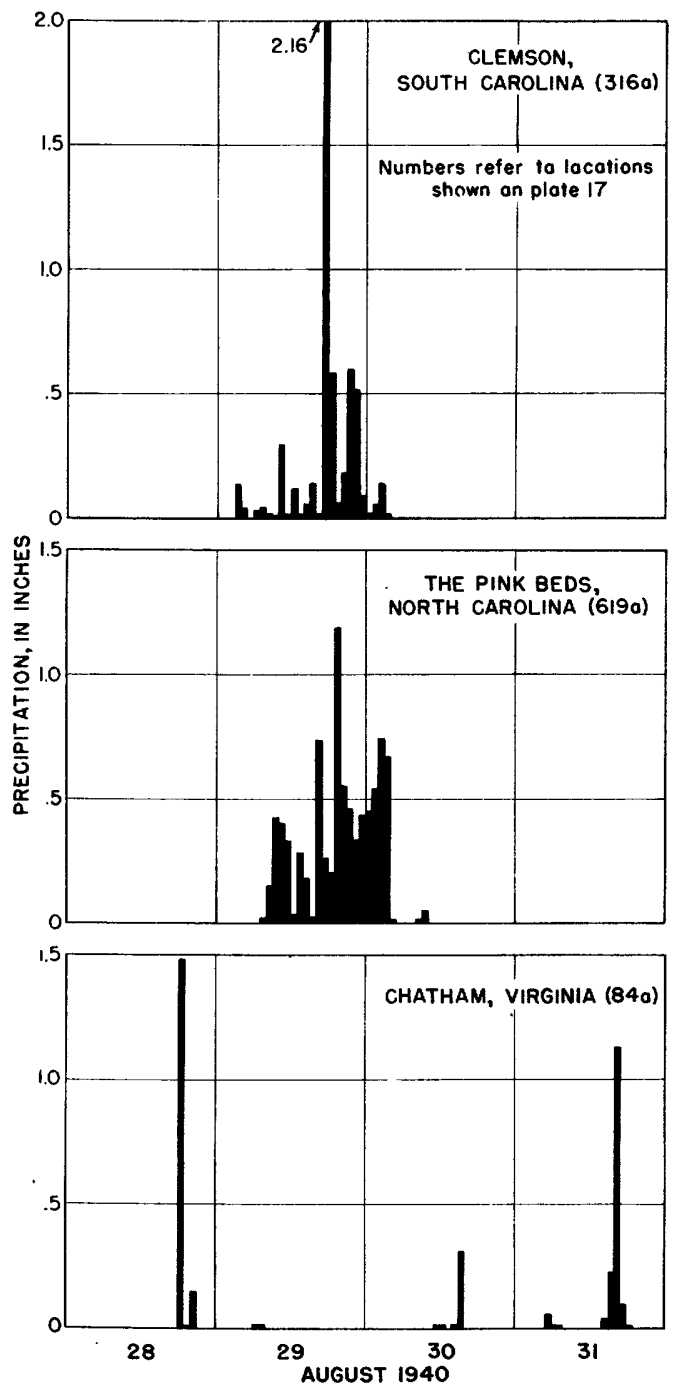

FIGURE 5.-Hourly precipitation, in inches, at selected precipitation stations, August $28-31,1940$.

of August 28-31 or the late-August storm. From inspection of the hourly records (not published in this report) the following rules were adopted for combining the daily records so as to exclude all rain not occurring within the storm period as defined:

1. For gages read in the afternoon all preeipitation measurements on August 28-31 were added.

2. For gages read at midnight all precipitation measurements on August 28-31 were added.

3. For gages read in the morning and recorded for the day read, records for August 28-September 1 were added. 
The total precipitation given in table 6 was plotted on a $1: 1,000,000$ scale base map in proper locations, and lines of equal precipitation were drawn to conform to the points so plotted. The resultant isohyetal map is presented on full scale as plate 17 .

On plate 17 there are four storm centers indicated, fairly evenly spaced alqng the crest of the Blue Ridge in North Carolina. The sharp decrease in rainfall on both sides of the mountain indicates the probable effect of physiographic characteristics of the storm-affected area. Practically the entire area that experienced more than 6 inches of rainfall was in the mountains of North Carolina. 
TABLE 6.-Daily precipitation, in inches, August 28-91, 1940

[Measured in morning except as noted; M, missing; NR, no record; Tr, less than 0.01 inch]

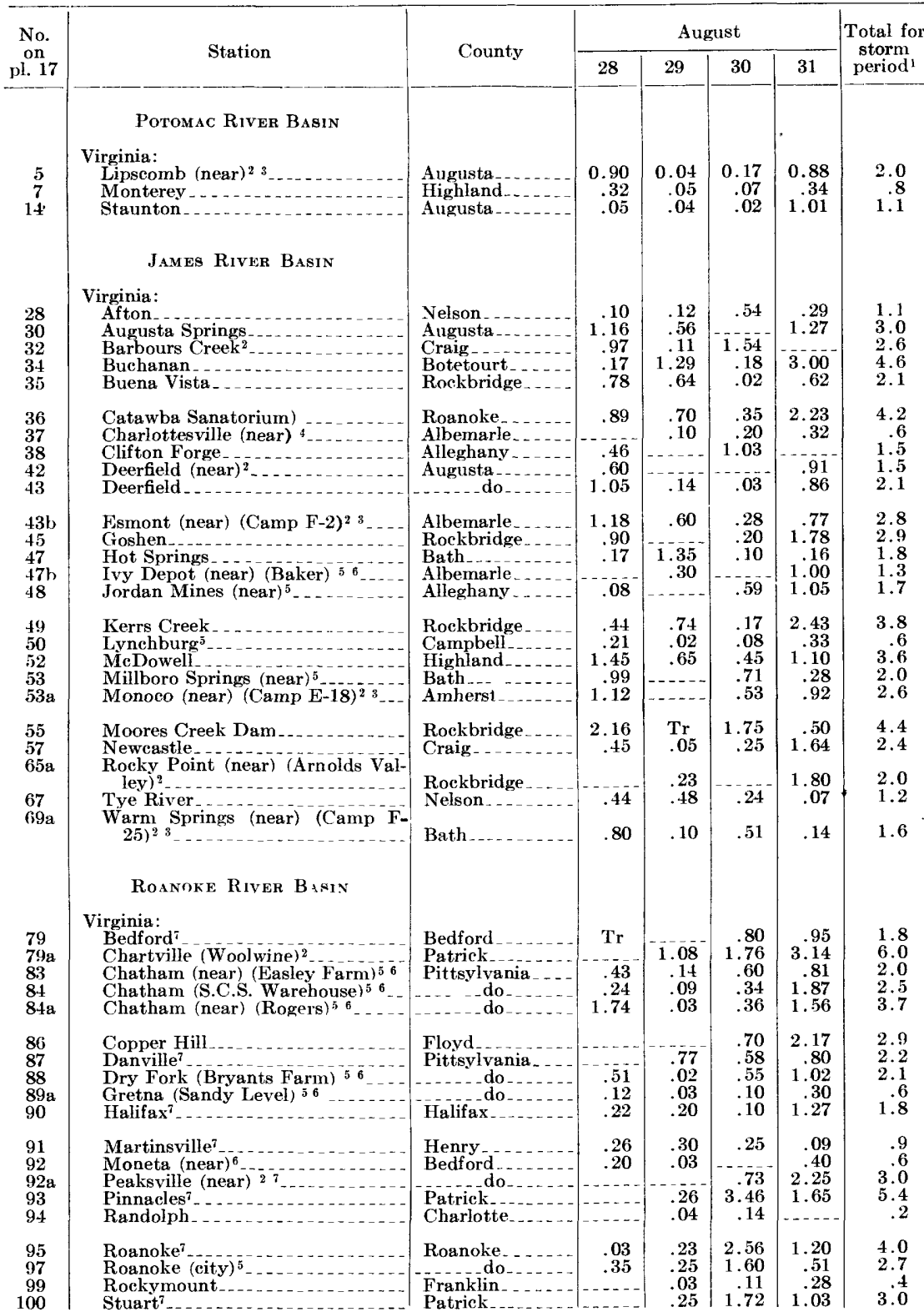

1 Total is for storm period 12.01 a.m. Aug. 28 to $12 \mathrm{p.m}$. Aug. 31 and is not necessarily equal to the total of recorded daily values Aug. 28-31.

2 Record furnished by U. S. Forest Service.

3 Precipitation measured in the morning and the evening.

4 Precipitation measured at midnight.

5 Recording gage; precipitation is for the 24-hour period, midnight to midnight.

- Record furnished by Soil Conservation Service.

7 Precipitation measured in the afternoon. 
TABLE 6.-Daily precipitation, in inches, August 28-91, 1940-Continued

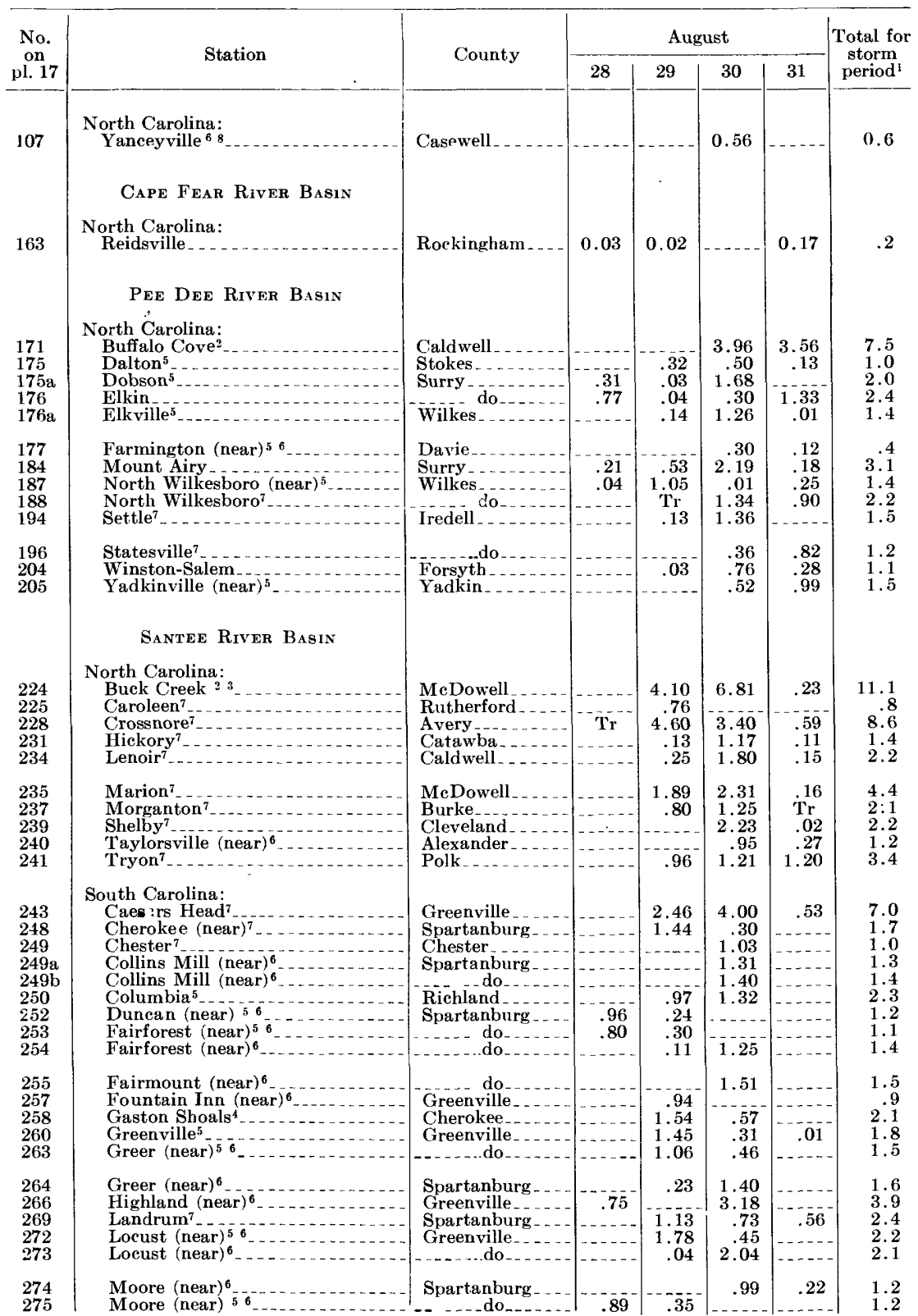

1 Total is for storm period 12:01 a.m. Aug. 28 to 12 p.m. Aug. 31 and is not necessarily equal to the total of recorded daily values Aug. 28-31.

2 Record furnished by U.S. Forest Service.

3 Precipitation measured in the morning and the evening.

4 Precipitation measured at midnight.

5 Recording gage; precipitation is for the 24 -hour period, midnight to midnight.

- Record furnished by Soil Conservation Service.

7 Precipitation measured in the afternoon.

8 Precipitation measured after each rain. 
FLOODS OF AUGUST 1940 IN THE SOUTHEASTERN STATES

TABLE 6.-Daily precipitation, in inches, August 28-31, 1940-Continued

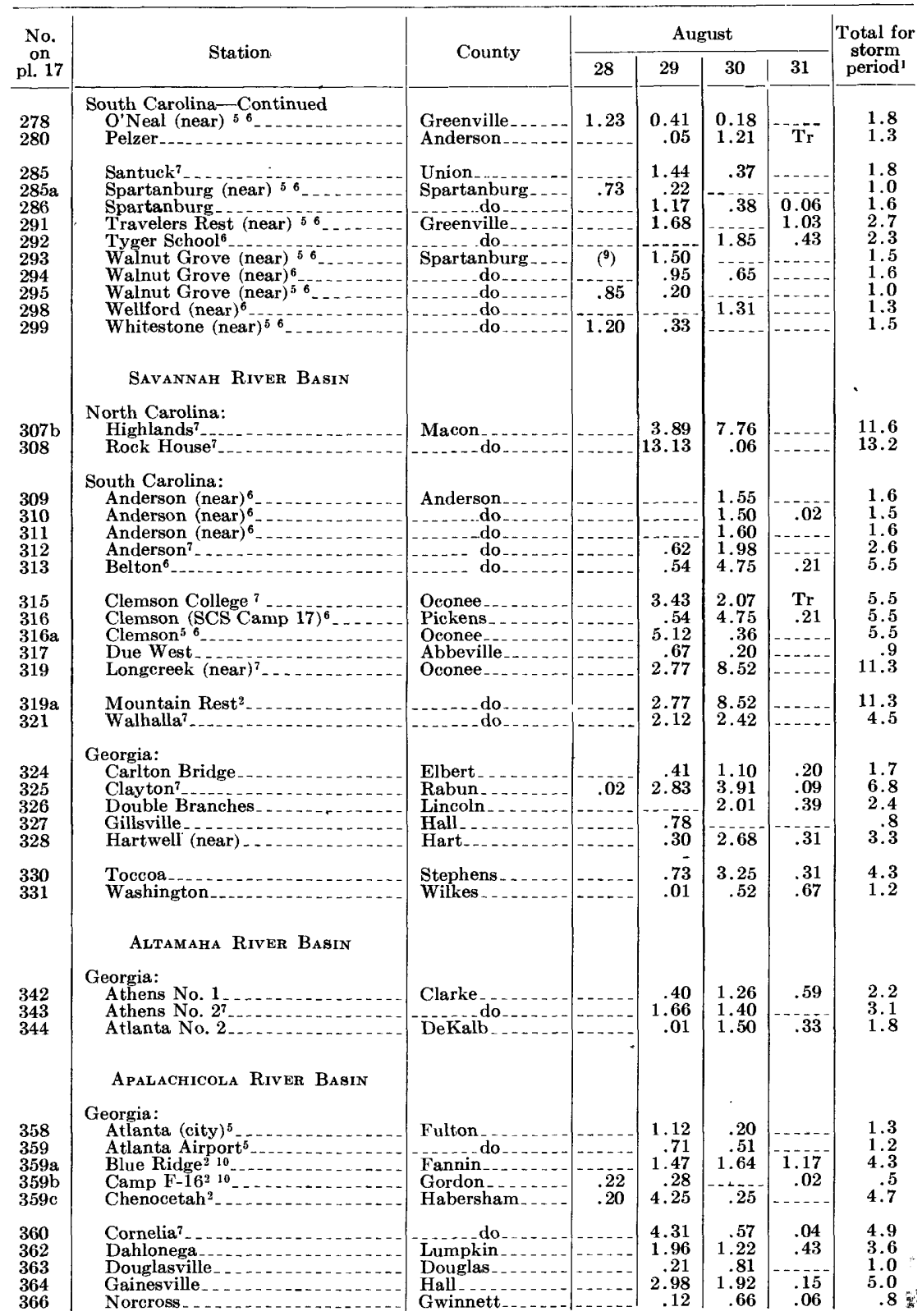

1 Total is for storm period 12:01 a.m. Aug. 28 to 12 p.m. Aug. 31 and is not necessarily equal to the total of recorded daily values Aug. 28-31.

2 Record furnished by U. S. Forest Service.

5 Recording gage; precipitation is for the 24 -hour period, midnight to midnight.

6 Record furnished by Soil Conservation Service.

7 Precipitation measured in the afternoon.

9 Precipitation included in the following measurement.

10 Station is in central standard time zone. 
TABLE 6.-Daily precipitation, in inches, August 28-31, 1940-Continued

\begin{tabular}{|c|c|c|c|c|c|c|c|}
\hline \multirow{2}{*}{$\begin{array}{l}\text { No. } \\
\text { on } \\
\text { pl. } 17\end{array}$} & \multirow{2}{*}{ Station } & \multirow{2}{*}{ County } & \multicolumn{4}{|c|}{ August } & \multirow{2}{*}{$\begin{array}{l}\text { Total for } \\
\text { storm } \\
\text { period }^{1}\end{array}$} \\
\hline & & & 28 & 29 & 30 & 31 & \\
\hline $\begin{array}{l}367 \\
367 \mathrm{a} \\
367 \mathrm{~b} \\
368 \\
370\end{array}$ & $\begin{array}{l}\quad \text { MobIte RIVER Basin } \\
\text { Georgia: } \\
\text { Adairsville (near) } \\
\text { Beaverdale } 10 \\
\text { Canton } 10 \\
\text { Canton } \\
\text { Cartersville }\end{array}$ & $\begin{array}{l}\text { Bartow } \\
\text { Whitfield } \\
\text { Cherokee }\end{array}$ & \begin{tabular}{r|}
0.49 \\
.24 \\
\hdashline .34
\end{tabular} & $\begin{array}{r}0.11 \\
1.52 \\
1.09 \\
.23 \\
1.09\end{array}$ & $\begin{array}{r}1.35 \\
1.05 \\
.14 \\
.86 \\
.11\end{array}$ & \begin{tabular}{c}
0.06 \\
.05 \\
\hdashline .17 \\
..--
\end{tabular} & $\begin{array}{l}2.0 \\
1.9 \\
1.2 \\
1.3 \\
1.5\end{array}$ \\
\hline $\begin{array}{l}370 \mathrm{a} \\
371 \\
372 \\
372 \mathrm{a} \\
372 \mathrm{~b}\end{array}$ & $\begin{array}{l}\text { Cedartown } \\
\text { Chatsworth } \\
\text { Chatsworth }(\mathrm{near})^{2}{ }^{2}{ }^{10} \\
\text { Cunningham } \\
\text { Dalton } 810\end{array}$ & $\begin{array}{l}\text { Polk } \\
\text { Murray } \\
\text { Floyd } \\
\text { Whitfield. }\end{array}$ & $\begin{array}{r}.91 \\
.30 \\
.24 \\
-.39\end{array}$ & $\begin{array}{r}.80 \\
.40 \\
.26 \\
1.17 \\
1.14\end{array}$ & $\begin{array}{r}.51 \\
.50 \\
-.96 \\
1.20\end{array}$ & \begin{tabular}{c}
$\operatorname{Tr}$ \\
1.05 \\
\hdashline 1.84
\end{tabular} & $\begin{array}{l}2.2 \\
2.2 \\
.5 \\
2.1 \\
4.6\end{array}$ \\
\hline $\begin{array}{l}373 \\
374 \\
374 \mathrm{a} \\
375 \\
376\end{array}$ & 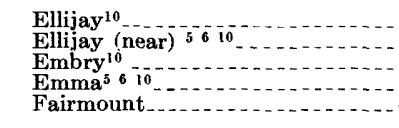 & $\begin{array}{l}\text { Gilmer } \\
\text { Paulding } \\
\text { Dawson } \\
\text { Gordon. }\end{array}$ & $\begin{array}{r}.37 \\
.15 \\
1.35 \\
.06\end{array}$ & $\begin{array}{r}1.02 \\
.46 \\
.53 \\
.05 \\
.24\end{array}$ & $\begin{array}{l}.85 \\
.33 \\
.61 \\
.05 \\
.27\end{array}$ & $\begin{array}{r}.37 \\
.48 \\
1.10-\end{array}$ & $\begin{array}{l}2.2 \\
1.3 \\
1.6 \\
1.4 \\
1.7\end{array}$ \\
\hline $\begin{array}{l}377 \\
378 \\
378 \mathrm{a} \\
378 \mathrm{~b} \\
379\end{array}$ & $\begin{array}{l}\text { Jasper } \\
\text { Jasper }(\text { near) } \\
\text { LaFayette }^{5}{ }^{5}{ }^{6}{ }_{10} \\
\text { LaFayette } \\
\text { Oakman }\end{array}$ & Pickens & $\begin{array}{r}.91 \\
.51 \\
1.40 \\
.22\end{array}$ & $\begin{array}{l}2.21 \\
-42 \\
.90 \\
.17\end{array}$ & $\begin{array}{r}1.57 \\
.77 \\
-.41\end{array}$ & \begin{tabular}{c}
.67 \\
\hdashline .10 \\
\hdashline .10 \\
\end{tabular} & $\begin{array}{r}4.4 \\
1.7 \\
112.3 \\
2.3 \\
.9\end{array}$ \\
\hline $\begin{array}{l}379 \mathrm{a} \\
379 \mathrm{~b} \\
379 \mathrm{c} \\
379 \mathrm{~d} \\
379 \mathrm{e}\end{array}$ & $\begin{array}{l}\text { Resaca } \\
\text { Rome } \\
\text { Rome (near) }{ }^{6} \mathbf{8}^{8} 10^{2} \\
\text { Summerville } \\
\text { Tallapoosa }\end{array}$ & $\begin{array}{l}\text { Floyd } \\
\text { Chattooga } \\
\text { Haralson }\end{array}$ & $\begin{array}{r}.15 \\
2.05 \\
.94 \\
.08\end{array}$ & $\begin{array}{r}.42 \\
.18 \\
1.17 \\
.32 \\
1.77\end{array}$ & $\begin{array}{r}.43 \\
.21 \\
.96 \\
.87 \\
1.04\end{array}$ & \begin{tabular}{c}
1.04 \\
.03 \\
\hdashline .08 \\
.14
\end{tabular} & $\begin{array}{l}2.0 \\
2.5 \\
2.1 \\
2.2 \\
3.0\end{array}$ \\
\hline $\begin{array}{l}380 \\
380 a \\
381\end{array}$ & $\begin{array}{l}\text { Taylorsville } \\
\text { Whitfield }{ }^{6} \\
\text { Woodstock }\end{array}$ & $\begin{array}{l}\text { Bartow } \\
\text { Whitfield } \\
\text { Cherokee....... }\end{array}$ & $\begin{array}{c}1.05 \\
(9) \\
-\end{array}$ & $\begin{array}{r}1.40 \\
1.25 \\
.01\end{array}$ & $\begin{array}{r}.50 \\
.17 \\
1.20\end{array}$ & -1.83 & $\begin{array}{l}3.0 \\
1.4 \\
3.0\end{array}$ \\
\hline $\begin{array}{l}415 \\
417 \\
418 \\
419 \\
420\end{array}$ & $\begin{array}{l}\quad \text { Kanawha RIVER Basin } \\
\text { Virginia: } \\
\text { Blacksburg } \\
\text { Floyd } \\
\text { Galax } \\
\text { Glenlyn } \\
\text { Hillsville }\end{array}$ & $\begin{array}{l}\text { Montgomery } \\
\text { Floyd } \\
\text { Grayson } \\
\text { Giles_. } \\
\text { Carroll }\end{array}$ & $\begin{array}{c}\mathrm{Tr} \\
1.03 \\
.19 \\
.09\end{array}$ & $\begin{array}{r}\text { Tr } \\
.07 \\
.32 \\
1.52 \\
.34\end{array}$ & $\begin{array}{r}1.25 \\
2.97 \\
3.47 \\
.09 \\
.49\end{array}$ & $\begin{array}{r}.14 \\
.15 \\
2.65 \\
2.96\end{array}$ & $\begin{array}{l}1.4 \\
4.2 \\
4.0 \\
2.3 \\
3.9\end{array}$ \\
\hline $\begin{array}{l}421 \\
422 \\
423 \\
425 \\
426\end{array}$ & $\begin{array}{l}\text { Independence..... } \\
\text { Indian Valley } \\
\text { Ivanhoe } \\
\text { Newport }{ }^{3} 6 \\
\text { Pilot. }\end{array}$ & $\begin{array}{l}\text { Grayson... } \\
\text { Floyd } \\
\text { Wythe... } \\
\text { Giles } \\
\text { Montgomery }\end{array}$ & \begin{tabular}{c}
.02 \\
\hdashline .03 \\
\hdashline-0 \\
-0
\end{tabular} & $.5 \overline{3}$ & $\begin{array}{r}2.60 \\
.53 \\
-.29\end{array}$ & $\begin{array}{c}1.55 \\
1.96 \\
3.21 \\
1.14\end{array}$ & $\begin{array}{r}4.2 \\
2.5 \\
124.0 \\
.0 \\
1.6\end{array}$ \\
\hline $\begin{array}{l}427 \\
428 \\
429 \\
430 \\
431\end{array}$ & $\begin{array}{l}\text { Pulaski } \\
\text { Radford } \\
\text { Speedwell } \\
\text { White Gate (near) } \\
\text { Wytheville }{ }^{5} \text { (n) }\end{array}$ & 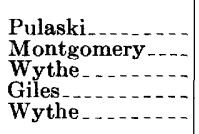 & $\begin{array}{l}.01 \\
.17\end{array}$ & $\begin{array}{l}.02 \\
.19 \\
.06 \\
.11 \\
.08\end{array}$ & $\begin{array}{l}.34 \\
.08 \\
.55 \\
.96 \\
.61\end{array}$ & \begin{tabular}{r|}
1.44 \\
1.73 \\
1.13 \\
.06
\end{tabular} & $\begin{array}{r}1.8 \\
132.5 \\
1.7 \\
1.1 \\
.9\end{array}$ \\
\hline $\begin{array}{l}432 \\
433 \\
433 a \\
434 \\
436\end{array}$ & 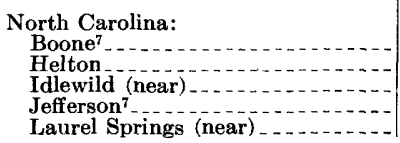 & $\begin{array}{l}\text { Watauga } \\
\text { Ashe }\end{array}$ & $\begin{array}{l}.27 \\
.05 \\
\mathrm{Tr}\end{array}$ & $\begin{array}{r}.90 \\
.04 \\
-.26 \\
.04\end{array}$ & $\begin{array}{l}\mathbf{5 . 5 5} \\
1.39 \\
3.70 \\
7.90 \\
\mathbf{2 . 4 4}\end{array}$ & $\begin{array}{r}.55 \\
.35 \\
2.55 \\
.39 \\
2.00\end{array}$ & $\begin{array}{l}7.3 \\
1.8 \\
6.3 \\
8.6 \\
4.5\end{array}$ \\
\hline
\end{tabular}

1 Total is for storm period 12:01 a.m. Aug. 28 to 12 p.m. Aug. 31 and is not necessarily equal to the total of recorded daily values Aug. 28-31

${ }^{2}$ Record furnished by U.S. Forest Service.

3 Precipitation measured in the morning and the evening.

5 Recording gage; precipitation is for the 24-hour period, midnight to midnight.

6 Record furnished by Soil Conservation Service.

7 Precipitation measured in the afternoon.

8 Precipitation measured after each rain.

9 Precipitation included in the following measurement.

10 Station is in central standard time zone.

11 Includes 1.35 inches measured Aug. 27.

12 Includes 0.21 inch measured Sept. 1.

13 Includes 0.53 inch measured Sept. 1 . 
FLOODS OF AUGUST 1940 IN THE SOUTHEASTERN STATES

TABLE 6.-Daily precipitation, in inches, August 28-31, 1940-Continued

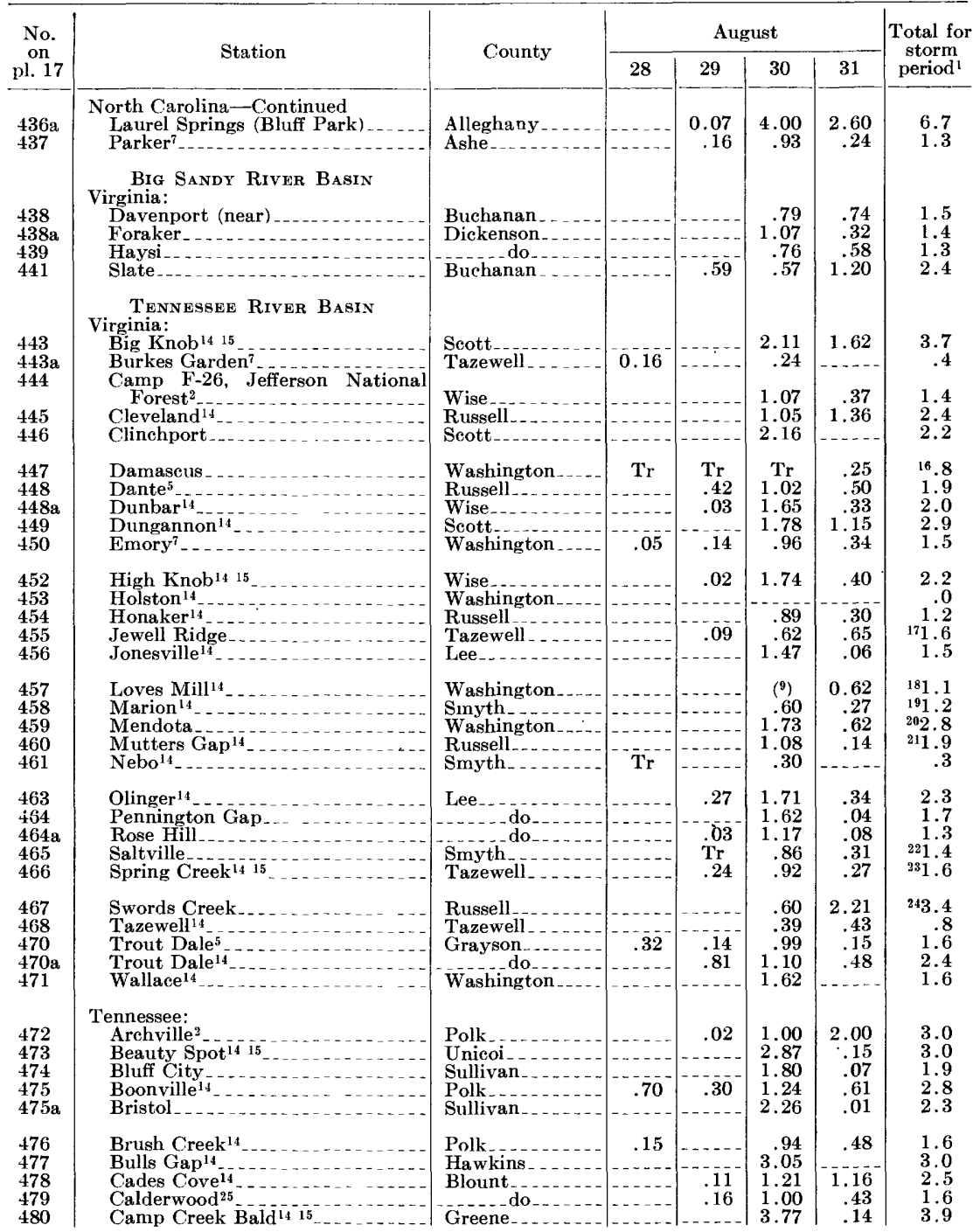

1 Total is for storm period 12:01 a.m. Aug. 28 to 12 p.m. Aug. 31 and is not necessarily equal to the total of recorded daily values Aug. 28-31.

${ }_{2}$ Record furnished by U. S. Forest Service.

5 Recording gage; precipitation is for the 24-hour period, midnight to midnight.

7 Precipitation measured in the afternoon.

9 Precipitation included in the following measurement.

14 Record furnished by Tennessee Valley Authority.

15 Recording gage; daily total for 24 hours ending in morning.

16 Includes 0.50 inch measured Sept. 1.

17 Includes 0.26 inch measured Sept. 1 .

${ }_{18}$ Includes 0.45 inch measured Sept. 1 .

19 Includes 0.33 inch measured Sept. 1 .

${ }^{20}$ Includes 0.41 inch measured Sept. 1.

21 Includes 0.71 inch measured Sept. 1.

32 Includes 0.22 inch measured Sept. 1.

${ }^{23}$ Includes 0.15 inch measured Sept. 1 .

${ }^{24}$ Includes 0.55 inch measured Sept. 1 .

25 Record furnished by Aluminum Company of America. 
TABLE 6.-Daily precipitation, in inches, August 28-31, 1940-Continued

\begin{tabular}{|c|c|c|c|c|c|c|c|}
\hline \multirow{2}{*}{$\begin{array}{l}\text { No. } \\
\text { on } \\
\text { pl.17 }\end{array}$} & \multirow{2}{*}{ Station } & \multirow{2}{*}{ County } & \multicolumn{4}{|c|}{ August } & \multirow{2}{*}{$\begin{array}{l}\text { Total for } \\
\text { storm } \\
\text { period }^{1}\end{array}$} \\
\hline & & & 28 & 29 & 30 & 31 & \\
\hline $\begin{array}{l}480 a \\
481 \\
481 a \\
481 b \\
482\end{array}$ & $\begin{array}{l}\text { Tennessee-Continued } \\
\text { Catlettsburg }{ }^{14} \\
\text { Cedar Creek } \\
\text { Charleston } \\
\text { Chattanooga } \\
\text { Clear Branch }\end{array}$ & $\begin{array}{l}\text { Sevier. } \\
\text { Washington } \\
\text { Bradley } \\
\text { Hamilton } \\
\text { Unicoi }\end{array}$ & 0.26 & $\begin{array}{c}0.05 \\
-.15 \\
1.36 \\
-2--\end{array}$ & $\begin{array}{l}1.71 \\
2.47 \\
.91 \\
\mathrm{Tr}_{\mathrm{r}} \\
2.93\end{array}$ & $\begin{array}{r}0.23 \\
.02 \\
.06 \\
-.15\end{array}$ & $\begin{array}{l}2.0 \\
2.5 \\
1.1 \\
1.6 \\
3.1\end{array}$ \\
\hline $\begin{array}{l}483 \\
483 \mathrm{a} \\
484 \\
485 \\
486\end{array}$ & $\begin{array}{l}\text { Clingman's Dome }{ }^{14}{ }^{15} \\
\text { Clinton } \\
\text { Coker Creek }{ }^{4}-{ }^{4} \\
\text { Colesville }{ }^{4} \\
\text { Columbus }\end{array}$ & $\begin{array}{l}\text { Sevier.--- } \\
\text { Anderson_- } \\
\text { Monroe.- } \\
\text { Johnson.- } \\
\text { Polk }\end{array}$ & & $\begin{array}{l}.39 \\
.01 \\
.30 \\
.04 \\
.28\end{array}$ & $\begin{array}{r}6.68 \\
.74 \\
1.00 \\
.87 \\
.40\end{array}$ & \begin{tabular}{c}
.18 \\
$\mathrm{Tr}$ \\
.78 \\
\hdashline 1.96
\end{tabular} & $\begin{array}{l}7.2 \\
.8 \\
2.1 \\
.9 \\
2.6\end{array}$ \\
\hline $\begin{array}{l}487 \\
487 \mathrm{a} \\
488 \\
489 \\
489 \mathrm{a}\end{array}$ & $\begin{array}{l}\text { Copperhill } \\
\text { Copperhill No. }{ }^{14} \\
\text { Cosby } \\
\text { Cranduld } \\
\text { Dandridge... }\end{array}$ & $\begin{array}{l}\text { Cocke... } \\
\text { Johnson. } \\
\text { Jefferson. }\end{array}$ & .10 & \begin{tabular}{c}
.27 \\
.39 \\
\hdashline-1 \\
\hdashline.--
\end{tabular} & $\begin{array}{l}1.23 \\
1.10 \\
2.63 \\
.60 \\
2.20\end{array}$ & $\begin{array}{c}.56 \\
.54 \\
.14\end{array}$ & $\begin{array}{l}2.2 \\
1.5 \\
3.2 \\
.6 \\
2.3\end{array}$ \\
\hline $\begin{array}{l}489 \mathrm{~b} \\
489 \mathrm{c} \\
490 \\
491 \\
492\end{array}$ & $\begin{array}{l}\text { Decatur } \\
\text { Dunlap } \\
\text { Elizabethton No. } 1 \\
\text { Elizabethton No. } 2 \\
\text { Elkmont }\end{array}$ & $\begin{array}{l}\text { Meigs } \\
\text { Sequatchie } \\
\text { Carter } \\
\text { Sevier do. }\end{array}$ & .03 & $\begin{array}{r}1.92 \\
.75 \\
.52 \\
-.10\end{array}$ & $\begin{array}{l}.01 \\
1.80 \\
1.06 \\
1.70 \\
2.04\end{array}$ & $\begin{array}{l}.02 \\
.23 \\
.07 \\
.45\end{array}$ & $\begin{array}{l}2.0 \\
2.6 \\
1.8 \\
1.8 \\
2.6\end{array}$ \\
\hline $\begin{array}{l}493 \\
494 \\
494 a \\
496 \\
497\end{array}$ & $\begin{array}{l}\text { Embreeville } \\
\text { Erwin }^{7} \\
\text { Flat Gap } \text { Gap }^{14} \\
\text { Gatlinburg } \\
\text { Greeneville (near) } \\
\text { Gre }\end{array}$ & $\begin{array}{l}\text { Washingto } \\
\text { Unicoi_-. } \\
\text { Hawkins . } \\
\text { Sevier.... } \\
\text { Greene... }\end{array}$ & & $\begin{array}{r}. \overline{18} \\
1.99\end{array}$ & $\begin{array}{l}2.25 \\
3.40 \\
1.93 \\
2.62 \\
1.37\end{array}$ & $\begin{array}{l}.05 \\
.25 \\
.34 \\
. .34\end{array}$ & $\begin{array}{l}2.3 \\
3.6 \\
1.9 \\
3.1 \\
3.4\end{array}$ \\
\hline $\begin{array}{l}498 \\
499 \\
500 \\
501 \\
502\end{array}$ & $\begin{array}{l}\text { Harbuck }^{14} \\
\text { Hartford } 14 \\
\text { Haw Knob }{ }^{14} 15^{14} \\
\text { Isabella } \\
\text { Jearoldstown }\end{array}$ & $\begin{array}{l}\text { Polk } \\
\text { Cocke_... } \\
\text { Monroe } \\
\text { Polk } \\
\text { Greene... }\end{array}$ & 08 & $\begin{array}{l}.75 \\
.55 \\
.25\end{array}$ & $\begin{array}{l}1.14 \\
2.80 \\
2.25 \\
1.73 \\
2.68\end{array}$ & $\begin{array}{l}.55 \\
.52 \\
.06 \\
.67 \\
.04\end{array}$ & $\begin{array}{l}2.5 \\
3.3 \\
2.9 \\
2.7 \\
2.7\end{array}$ \\
\hline $\begin{array}{l}502 \mathrm{a} \\
503 \\
504 \\
505 \\
505 \mathrm{a}\end{array}$ & $\begin{array}{l}\text { Jefferson City } \text { (near) }^{5} \\
\text { Johnson City }{ }^{14} \\
\text { Johnson City Veterans Hospital } \\
\text { Kingsport } \\
\text { Kingston }\end{array}$ & $\begin{array}{l}\text { Jefferson } . . \\
\text { Washington } \\
\text { Sullivan } \\
\text { Roane }\end{array}$ & & \begin{tabular}{|l}
1.61 \\
$-\cdots-1$ \\
\hdashline$-1-2$ \\
\hdashline$-1-1$
\end{tabular} & $\begin{array}{l}.09 \\
1.78 \\
1.82 \\
2.40 \\
1.95\end{array}$ & $\begin{array}{l}.07 \\
.18 \\
. . .-\end{array}$ & $\begin{array}{l}1.7 \\
1.8 \\
2.0 \\
2.4 \\
2.0\end{array}$ \\
\hline $\begin{array}{l}506 \\
507 \\
508 \\
508 \mathrm{a} \\
508 \mathrm{~b}\end{array}$ & $\begin{array}{l}\text { Lick Creek }{ }^{1415} \\
\text { Limestone }{ }^{14} \\
\text { Little Chucky } \\
\text { Little War Gap }{ }^{14} \\
\text { Loudon }\end{array}$ & $\begin{array}{l}\text { Greene } \\
\text { Washington } \\
\text { Greene } \\
\text { Hawkins . - } \\
\text { Loudon . . }\end{array}$ & 5 & 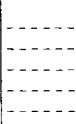 & $\begin{array}{r}2.47 \\
2.20 \\
3.51 \\
2.43 \\
.45\end{array}$ & $\begin{array}{l}.04 \\
.03 \\
.06 \\
.25 \\
1.99\end{array}$ & $\begin{array}{l}2.5 \\
2.2 \\
3.6 \\
2.7 \\
2.4\end{array}$ \\
\hline $\begin{array}{l}508 \mathrm{c} \\
508 \mathrm{~d} \\
508 \mathrm{e} \\
508 \mathrm{f} \\
509\end{array}$ & $\begin{array}{l}\text { MeGhee } \\
\text { Morgan Springs } \\
\text { Morristown (near) } \\
\text { Morristown } \\
\text { Mountain City } 14\end{array}$ & $\begin{array}{l}\text { Monroe } . .- \\
\text { Rhea } \\
\text { Hamblen.- } \\
\text { Johnson }\end{array}$ & & $\begin{array}{r}.11 \\
1.26 \\
-1.74 \\
-\cdots\end{array}$ & $\begin{array}{r}.90 \\
1.69 \\
2.26 \\
.97 \\
.96\end{array}$ & $\begin{array}{r}2.34 \\
.30 \\
.05 \\
- \\
\hdashline-0 .-\end{array}$ & $\begin{array}{l}3.4 \\
3.2 \\
2.3 \\
2.7 \\
1.0\end{array}$ \\
\hline $\begin{array}{l}510 \\
510 \mathrm{a} \\
511 \\
512 \\
513\end{array}$ & $\begin{array}{l}\text { Mount Le Conte't } \\
\text { Newport } \\
\text { Ocoee No. }{ }^{14}{ }^{14} \\
\text { Odomville }{ }^{14} \\
\text { Parksville } 2\end{array}$ & $\begin{array}{l}\text { Sevier } \\
\text { Cocke } \\
\text { Polk } \\
\text { Carter } \\
\text { Polk }\end{array}$ & $\begin{array}{l}.05 \\
.05\end{array}$ & $\begin{array}{l}.64 \\
.08 \\
.04 \\
\end{array}$ & $\begin{array}{r}3.54 \\
2.15 \\
.55 \\
1.46 \\
.43\end{array}$ & $\begin{array}{r}.78 \\
.08 \\
1.94 \\
.10 \\
.21\end{array}$ & $\begin{array}{r}5.0 \\
2.3 \\
2.6 \\
1.6 \\
.7\end{array}$ \\
\hline $\begin{array}{l}513 a \\
514 \\
515 \\
516 \\
516 a\end{array}$ & $\begin{array}{l}\text { Pittman Center }{ }^{4} \\
\text { Potato Creek }{ }^{14} \\
\text { Reese }^{14} \text { Hoan High Knob } \\
\text { Rogersville } \\
\text { Rogen }\end{array}$ & 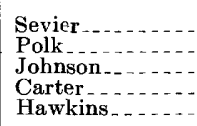 & $\begin{array}{r}.20 \\
.09 \\
.21\end{array}$ & $\begin{array}{r}.26 \\
-10 \\
-.10\end{array}$ & $\begin{array}{r}(9) \\
1.74 \\
1.20 \\
.3 .29 \\
2.40\end{array}$ & $\begin{array}{r}2.75 \\
.51 \\
.11 \\
.60 \\
.03\end{array}$ & $\begin{array}{l}3.0 \\
2.6 \\
1.3 \\
4.2 \\
2.4\end{array}$ \\
\hline $\begin{array}{l}517 \\
518 \\
519 \\
519 a \\
520\end{array}$ & $\begin{array}{l}\text { Sassafras Knob } 14{ }^{15} \\
\text { Servilla } \\
\text { Snake Mountain } \\
\text { Sneedville (near) } \\
\text { Stansbury Gap }{ }^{14}{ }^{14} \\
\text { Sta }\end{array}$ & $\begin{array}{l}\text { Polk } \\
\text { Johnson-_. } \\
\text { Hancock } \\
\text { Polk }\end{array}$ & .05 & $\begin{array}{r}.15 \\
.09 \\
.05 \\
2.17\end{array}$ & $\begin{array}{r}1.01 \\
.41 \\
1.45 \\
1.70 \\
.46\end{array}$ & $\begin{array}{r}.56 \\
1.25 \\
1.38 \\
\hdashline-2\end{array}$ & $\begin{array}{l}1.7 \\
1.7 \\
2.9 \\
1.8 \\
2.7\end{array}$ \\
\hline
\end{tabular}

1 Total is for storm period 12:01 a.m. Aug. 28 to 12 p.m. Aug. 31 and is not necessarily equal to the total of recorded daily values Aug. 28-31.

5 Recording gage; precipitation is for the 24 -hour period, midnight to midnight.

7 Precipitation measured in the afternoon.

9 recipitation included in the following measurement.

14 Record furnished by Tennessee Valley Authority.

15 Recording gage; daily total for 24 hours ending in morning. 
54 FLOODS OF AUGUST 1940 IN THE SOUTHEASTERN STATES

TABLE 6.-Daily precipitation, in inches, August 28-31, 1940-Continued

\begin{tabular}{|c|c|c|c|c|c|c|c|}
\hline \multirow{2}{*}{$\begin{array}{l}\text { No. } \\
\text { on } \\
\text { pl.17 }\end{array}$} & \multirow{2}{*}{ Station } & \multirow{2}{*}{ County } & \multicolumn{4}{|c|}{ August } & \multirow{2}{*}{$\begin{array}{l}\text { Total for } \\
\text { storm } \\
\text { period }^{1}\end{array}$} \\
\hline & & & 28 & 29 & 30 & 31 & \\
\hline $\begin{array}{l}521 \\
521 \mathrm{a} \\
521 \mathrm{~b} \\
522 \\
523\end{array}$ & $\begin{array}{l}\text { Tennessee-Continued } \\
\text { Stone Mountain }{ }^{14}-\ldots \\
\text { Stoney Point }{ }^{14} \\
\text { Tazewell (near) } \\
\text { Tellico }{ }^{2} \\
\text { Tellico Plains....... }\end{array}$ & $\begin{array}{l}\text { Carter - } \\
\text { Hawkins - } \\
\text { Claiborne } \\
\text { Monroe_- }\end{array}$ & & 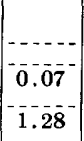 & $\begin{array}{r}2.19 \\
1.97 \\
.92 \\
(9) \\
.83\end{array}$ & $\begin{array}{c}0.48 \\
.05 \\
1.48 \\
-\end{array}$ & $\begin{array}{l}2.7 \\
2.0 \\
1.0 \\
1.5 \\
2.1\end{array}$ \\
\hline $\begin{array}{l}524 \\
525 \\
525 \mathrm{a} \\
526\end{array}$ & $\begin{array}{l}\text { Tri-City Airport } \\
\text { Turtletown } \\
\text { White Pine } \\
\text { Wolf Creek } \\
\text { Wh }^{14}\end{array}$ & $\begin{array}{l}\text { Sullivan } \\
\text { Polk } \\
\text { Jefferson } \\
\text { Cocke }\end{array}$ & 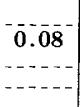 & $\left|\begin{array}{c}-7 \overline{7} \\
-\cdots-1 \\
-\cdots-\end{array}\right|$ & $\begin{array}{r}2.26 \\
.83 \\
2.14 \\
3.43\end{array}$ & 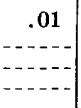 & $\begin{array}{l}2.3 \\
1.7 \\
2.1 \\
3.4\end{array}$ \\
\hline $\begin{array}{l}\mathbf{5 2 7} \\
528 \\
529 \\
530 \\
531\end{array}$ & $\begin{array}{l}\text { North Carolina: } \\
\text { A \& H Airport } 14 \\
\text { Altapass } \\
\text { Andrews Power Plant } \\
\text { Andrews } \\
\text { Asheville } 5 \text { (5) }\end{array}$ & $\begin{array}{l}\text { Henderson } \\
\text { Mitchell... } \\
\text { Clay } \\
\text { Cherokee- } \\
\text { Buncombe }\end{array}$ & & $\begin{array}{l}-.44 \\
.48 \\
4.70\end{array}$ & $\begin{array}{l}7.55 \\
6.00 \\
.36 \\
1.41 \\
2.08\end{array}$ & $\left|\begin{array}{c}-.05 \\
\hdashline .19 \\
\mathbf{T r}\end{array}\right|$ & $\begin{array}{l}7.6 \\
6.0 \\
2.8 \\
2.1 \\
6.8\end{array}$ \\
\hline $\begin{array}{l}\mathbf{5 3 3} \\
\mathbf{5 3 4} \\
\mathbf{5 3 5} \\
\mathbf{5 3 6} \\
\mathbf{5 3 7}\end{array}$ & $\begin{array}{l}\text { Bakersville14 } \\
\text { Banners Elk } \\
\text { Barnardsville } \\
\text { Beaverdam Creek } \\
\text { Beetree Dam }{ }^{15}{ }^{27}\end{array}$ & $\begin{array}{l}\text { Mitchell } \\
\text { Avery } \\
\text { Buncombe.- } \\
\text { Cherokee- } \\
\text { Buncombe. }\end{array}$ & $\begin{array}{c}.78 \\
.03 \\
\end{array}$ & $\begin{array}{c}.70 \\
4.42 \\
-.52 \\
-.52 \\
--.-\end{array}$ & $\begin{array}{l}3.50 \\
2.27 \\
5.15 \\
1.09 \\
7.26\end{array}$ & $\begin{array}{c}1.00 \\
.14 \\
.10\end{array}$ & $\begin{array}{l}5.2 \\
7.5 \\
5.2 \\
1.8 \\
7.4\end{array}$ \\
\hline $\begin{array}{l}\mathbf{5 3 8} \\
\mathbf{5 3 9} \\
\mathbf{5 4 0} \\
\mathbf{5 4 1} \\
\mathbf{5 4 2}\end{array}$ & $\begin{array}{l}\text { Beetree Gap }{ }^{15} \\
\text { Bent Creek } \\
\text { Big Pine }{ }^{14} \\
\text { Blue Ridge Post Office } \\
\text { Boiling Spring }{ }^{14}\end{array}$ & $\begin{array}{l}\text { Madison-- } \\
\text { Henderson } \\
\text { Cherokee }\end{array}$ & $\begin{array}{l}06 \\
---\end{array}$ & \begin{tabular}{|c|}
.02 \\
.03 \\
1.68
\end{tabular} & $\begin{array}{l}7.08 \\
8.84 \\
5.66 \\
6.00 \\
1.12\end{array}$ & $\begin{array}{l}.07 \\
-.63 \\
.10 \\
.53\end{array}$ & $\begin{array}{l}7.2 \\
8.8 \\
6.4 \\
6.1 \\
3.3\end{array}$ \\
\hline $\begin{array}{l}542 \mathrm{a} \\
543 \\
544 \\
545 \\
546\end{array}$ & $\begin{array}{l}\text { Brasstown }{ }^{2} \\
\text { Bryson City } \\
\text { Cane River }{ }^{14} \\
\text { Canton } 4 \\
\text { Cataloochee Ranch }\end{array}$ & $\begin{array}{l}\text { Clay } \\
\text { Swain } \\
\text { Yancey } \\
\text { Haywood.- }\end{array}$ & & $\begin{array}{r}.95 \\
.31 \\
-3.37 \\
.18\end{array}$ & $\begin{array}{l}1.12 \\
4.50 \\
2.77 \\
2.99 \\
5.28\end{array}$ & $\begin{array}{l}.29 \\
.55 \\
.05 \\
.02 \\
.28\end{array}$ & $\begin{array}{r}2.4 \\
5.4 \\
2.8 \\
6.4 \\
236.2\end{array}$ \\
\hline $\begin{array}{l}547 \\
548 \\
549\end{array}$ & $\begin{array}{l}\text { Cedar Mountain }{ }^{14} \\
\text { Celo }^{14} \\
\text { Chambers Mountain (near }\end{array}$ & $\begin{array}{l}\text { Transylvania } . . . \\
\text { Yancey } \ldots . . . .-\end{array}$ & .49 & $\begin{array}{l}.09 \\
.25\end{array}$ & 7.62 & .35 & $\begin{array}{l}8.6 \\
6.5\end{array}$ \\
\hline $\begin{array}{l}550 \\
551\end{array}$ & $\begin{array}{l}\text { Clyde) }^{14}{ }^{15} \\
\text { Cheoah } \\
\text { Cody Store }\end{array}$ & $\begin{array}{l}\text { Haywood } \\
\text { Graham }-\ldots . . . \\
\text { Madison...... }\end{array}$ & & $\begin{array}{c}.07 \\
-0\end{array}$ & $\begin{array}{r}5.06 \\
.99 \\
4.96\end{array}$ & $\begin{array}{l}.56 \\
.34\end{array}$ & $\begin{array}{l}5.1 \\
1.6 \\
5.3\end{array}$ \\
\hline $\begin{array}{l}552 \\
553 \\
554 \\
555 \\
556\end{array}$ & $\begin{array}{l}\text { Coleman Dam Site }{ }^{14} \\
\text { Cove Creek }^{14} \\
\text { Coweeta No. } \text { 1 }^{2} 15 \\
\text { Coxcombe Mountain } \\
\text { Cullowhee }^{7}\end{array}$ & $\begin{array}{l}\text { Cherokee..... } \\
\text { Haywood.-. } \\
\text { Macon } \\
\text { Buncombe-.-- } \\
\text { Jackson }\end{array}$ & .01 & \begin{tabular}{c}
.67 \\
\hdashline 1.25 \\
2.60
\end{tabular} & $\begin{array}{l}.79 \\
4.10 \\
4.13 \\
4.20 \\
3.03\end{array}$ & $\begin{array}{l}.50 \\
.18 \\
.03 \\
.05 \\
-\cdots\end{array}$ & $\begin{array}{l}2.0 \\
4.3 \\
5.4 \\
4.3 \\
5.6\end{array}$ \\
\hline $\begin{array}{l}\mathbf{5 5 7} \\
\mathbf{5 5 8} \\
\mathbf{5 5 9} \\
\mathbf{5 6 0} \\
\mathbf{5 6 1}\end{array}$ & $\begin{array}{l}\text { Daybook }{ }^{14} \\
\text { Dicks Creek } \\
\text { Dix Creek }{ }^{14} \\
\text { Doggett Gap }{ }^{14} \\
\text { Eaglenest Mountain }\end{array}$ & 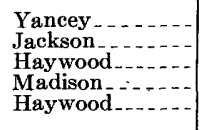 & $\begin{array}{c}.02 \\
-.01 \\
.07\end{array}$ & $\begin{array}{l}.02 \\
.55 \\
.20 \\
.08 \\
.11\end{array}$ & $\begin{array}{l}3.56 \\
4.78 \\
8.05 \\
6.08 \\
5.35\end{array}$ & $\begin{array}{l}.08 \\
.09 \\
.03 \\
.51 \\
.42\end{array}$ & $\begin{array}{r}3.7 \\
5.4 \\
8.3 \\
6.7 \\
5.9\end{array}$ \\
\hline $\begin{array}{l}562 \\
563 \\
564 \\
565 \\
566\end{array}$ & $\begin{array}{l}\text { Erastus }^{14} \\
\text { Fie Branch } \\
\text { Flat Top Mountain }{ }^{14} \\
\text { Franklin } \\
\text { Garren Creek }{ }^{14}\end{array}$ & $\begin{array}{l}\text { Jackson } \\
\text { Haywood } \\
\text { Yancey }-\ldots . . . \\
\text { Macon } \\
\text { Buncombe }\end{array}$ & & $\begin{array}{r}.89 \\
.04 \\
-8.70 \\
.05\end{array}$ & $\begin{array}{l}7.31 \\
5.30 \\
5.35 \\
.04 \\
5.50\end{array}$ & $\begin{array}{r}.30 \\
.39 \\
.03\end{array}$ & $\begin{array}{r}8.2 \\
285.9 \\
5.7 \\
8.7 \\
5.6\end{array}$ \\
\hline $\begin{array}{l}\mathbf{5 6 7} \\
568 \\
569 \\
\mathbf{5 7 0} \\
\mathbf{5 7 1}\end{array}$ & 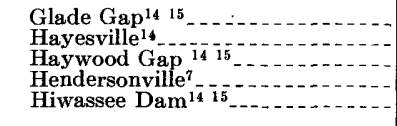 & 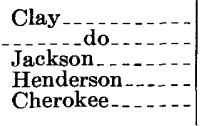 & ${ }^{(9)}$ & $\begin{array}{l}2.72 \\
(9) \\
1.02 \\
4.77 \\
\left({ }^{9}\right)\end{array}$ & $\begin{array}{r}.95 \\
2.66 \\
10.86 \\
2.22 \\
(9)\end{array}$ & $\begin{array}{r}.04 \\
.19 \\
.06 \\
.51 \\
1.85\end{array}$ & $\begin{array}{r}3.7 \\
2.8 \\
12.0 \\
7.5 \\
1.8\end{array}$ \\
\hline
\end{tabular}

1 Total is for storm period 12:01 a.m. Aug. 28 to 12 p.m. Aug. 31 and is not necessarily equal to the total of recorded daily values Aug. 28-31.

2 Record furnished by U. S. Forest Service.

4 Precipitation measured at midnight.

Recording gage; precipitation is for the 24-hour period, midnight to midnight.

7 Precipitation measured in the afternoon.

9 Precipitation included in following measurement.

14 Record furnished by Tennessee Valley Authority.

15 Recording gage; daily total for 24 hours ending in morning.

23 Includes 0.15 inch measured Sept. 1.

${ }^{25}$ Record furnished by Aluminum Company of America.

26 Record furnished by Nantahala Power Co.

27 Record furnished by city of Asheville, N. C.

28 Includes 0.28 inch measured Sept. 1 
TABLE 6.-Daily precipitation, in inches, August 28-81, 1940-Continued

\begin{tabular}{|c|c|c|c|c|c|c|c|}
\hline \multirow{2}{*}{$\begin{array}{c}\text { No } \\
\text { on } \\
\text { pl.17 }\end{array}$} & \multirow{2}{*}{ Station } & \multirow{2}{*}{ County } & \multicolumn{4}{|c|}{ August } & \multirow{2}{*}{$\begin{array}{c}\text { Total for } \\
\text { storm } \\
\text { period }\end{array}$} \\
\hline & & & 28 & 29 & 30 & 31 & \\
\hline $\begin{array}{l}\mathbf{5 7 2} \\
\mathbf{5 7 3} \\
\mathbf{5 7 4} \\
\mathbf{5 7 5} \\
\mathbf{5 7 6}\end{array}$ & $\begin{array}{l}\text { North Carolina-Continued } \\
\text { Hiwassee Dam No. 214 } \\
\text { Horseshoe }{ }^{14} \\
\text { Hot Springs } \\
\text { Hyatt Creek }{ }^{14} \\
\text { Ivy }^{14}\end{array}$ & $\begin{array}{l}\text { Cherokee } \\
\text { Henderson } \\
\text { Madison } \ldots . . . . . . .- \\
\text { Cherokee } \\
\text { Madison }\end{array}$ & $\begin{array}{c}\mathrm{Tr} \\
-\overline{0.45} \\
-----\end{array}$ & 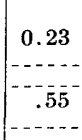 & $\begin{array}{l}1.00 \\
6.00 \\
4.70 \\
-4.05\end{array}$ & $\begin{array}{r}0.41 \\
.05 \\
.63 \\
-. .-- \\
-.-.--\end{array}$ & $\begin{array}{l}1.6 \\
6.0 \\
5.3 \\
1.0 \\
4.0\end{array}$ \\
\hline $\begin{array}{l}\mathbf{5 7 7} \\
\mathbf{5 7 8} \\
\mathbf{5 7 9} \\
\mathbf{5 8 0} \\
\mathbf{5 8 1}\end{array}$ & $\begin{array}{l}\text { Jack Cove }{ }^{14} \\
\text { John Rock (Camp F-28) } \\
\text { Leicester }{ }^{14} \\
\text { Letitia }{ }^{14} \\
\text { Little Switzerland }{ }^{14}\end{array}$ & 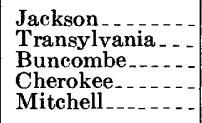 & 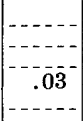 & $\begin{array}{r}.12 \\
2.48 \\
-1.20^{-} \\
.40\end{array}$ & $\begin{array}{r}3.80 \\
4.84 \\
7.97 \\
.60 \\
9.70\end{array}$ & $\begin{array}{l}.05 \\
.23 \\
.34 \\
.50 \\
.14\end{array}$ & $\begin{array}{r}4.0 \\
7.6 \\
8.3 \\
2.3 \\
10.2\end{array}$ \\
\hline $\begin{array}{l}\mathbf{5 8 2} \\
\mathbf{5 8 3} \\
\mathbf{5 8 4} \\
\mathbf{5 8 5} \\
\mathbf{5 8 6}\end{array}$ & $\begin{array}{l}\text { Lonesome Mountain }{ }^{14} \\
\text { Marshall } \\
\text { Max Pateh Mountain } \\
\text { MeKinney Gap }{ }^{14} \\
\text { Montreat }\end{array}$ & $\mid \begin{array}{l}\text { Madison } \ldots \ldots \\
\text { Yancey } \\
\text { Buncombe }\end{array}$ & 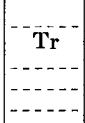 & 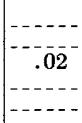 & $\begin{array}{l}4.25 \\
6.05 \\
3.92 \\
4.20 \\
7.00\end{array}$ & $\begin{array}{c}.17 \\
\mathrm{Tr} \\
.48 \\
.07 \\
-. .-\end{array}$ & $\begin{array}{l}4.4 \\
6.1 \\
4.4 \\
4.3 \\
7.0\end{array}$ \\
\hline $\begin{array}{l}\mathbf{5 8 7} \\
\mathbf{5 8 8} \\
\mathbf{5 8 9} \\
\mathbf{5 9 0} \\
\mathbf{5 9 1}\end{array}$ & $\begin{array}{l}\text { Mount Mitchell } \\
\text { Mount Pisgah } 14 \text { 15 } \\
\text { Mount Sterling }{ }^{14} \\
\text { Murphy Evaporation Station } \\
\text { Murphy }\end{array}$ & $\begin{array}{l}\text { Yancey } \\
\text { Haywood } \\
\text { Cherokee } \\
\end{array}$ & 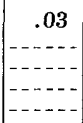 & $\begin{array}{c}9.74 \\
.14 \\
--. \overline{6} \\
.95\end{array}$ & $\begin{array}{l}2.36 \\
(9) \\
4.50 \\
1.12 \\
1.07\end{array}$ & $\begin{array}{r}.02 \\
11.14 \\
.42 \\
.87 \\
.98\end{array}$ & $\begin{array}{r}12.2 \\
11.3 \\
4.9 \\
2.8 \\
3.0\end{array}$ \\
\hline $\begin{array}{l}\mathbf{5 9 2} \\
\mathbf{5 9 3} \\
\mathbf{5 9 4} \\
\mathbf{5 9 5} \\
\mathbf{5 9 6}\end{array}$ & $\begin{array}{l}\text { Nantahala } \\
\text { Needmore } 14 \\
\text { Noland Creek }{ }^{29} \\
\text { North Fork }{ }^{27} \\
\text { Old Road Gap }{ }^{14}{ }_{15}\end{array}$ & \begin{tabular}{|} 
Swain \\
\hdashline Buncombe.... \\
Cherokee.....
\end{tabular} & 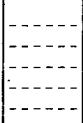 & $\begin{array}{r}2.15 \\
.75 \\
.38 \\
.04 \\
.45\end{array}$ & $\begin{array}{l}.60 \\
3.89 \\
3.86 \\
8.44 \\
3.10\end{array}$ & $\begin{array}{c}.05 \\
.12 \\
.16 \\
-.---\end{array}$ & $\begin{array}{l}2.8 \\
4.7 \\
4.4 \\
8.6 \\
3.6\end{array}$ \\
\hline $\begin{array}{l}597 \\
598 \\
599 \\
600 \\
601\end{array}$ & $\begin{array}{l}\text { Otto }{ }^{14} \\
\text { Owen's Gap }^{14} \\
\text { Peachtree Creek }{ }^{14} \\
\text { Pisgah Forest }^{7} \\
\text { Plumtree }\end{array}$ & $\begin{array}{l}\text { Macon } \\
\text { Jackson } \\
\text { Cherokee....... } \\
\text { Transylvania } \\
\text { Avery }\end{array}$ & 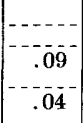 & $\begin{array}{r}.51 \\
.38 \\
.90 \\
1.58 \\
-.---\end{array}$ & $\begin{array}{l}9.42 \\
9.34 \\
1.55 \\
3.80 \\
5.12\end{array}$ & $\begin{array}{l}.01 \\
.05 \\
.29 \\
.32 \\
.21\end{array}$ & $\begin{array}{l}9.9 \\
9.8 \\
2.8 \\
5.7 \\
5.4\end{array}$ \\
\hline $\begin{array}{l}602 \\
603 \\
604 \\
603 \\
606\end{array}$ & $\begin{array}{l}\text { Postell }^{14} \\
\text { Proctor }^{14} \\
\text { Ranger } \\
\text { Raven Mountain } 14 \text { 15 } \\
\text { Rockyface Mountain }\end{array}$ & $\begin{array}{l}\text { Cherokee..... } \\
\text { Swain } \\
\text { Cherokee...... } \\
\text { Macon } \\
\text { Haywood...... }\end{array}$ & $\begin{array}{c}.05 \\
-. \overline{0}- \\
-01 \\
-.---\end{array}$ & $\begin{array}{r}.40 \\
.62 \\
.77 \\
.06 \\
-.--\end{array}$ & $\begin{array}{r}1.11 \\
2.07 \\
.72 \\
7.13 \\
7.25\end{array}$ & $\begin{array}{c}.23 \\
.60 \\
.04 \\
-.---\end{array}$ & $\begin{array}{r}1.6 \\
2.9 \\
2.1 \\
7.2 \\
309.2\end{array}$ \\
\hline $\begin{array}{l}607 \\
608 \\
609 \\
610 \\
611\end{array}$ & $\begin{array}{l}\text { Rosman } \\
\text { Rush Mountain } \\
\text { Santeetlah' } 25 \\
\text { Shooting Creek }{ }^{14} \\
\text { Smokemont }\end{array}$ & 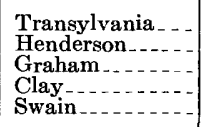 & $\left|\begin{array}{l}--\cdots-- \\
------ \\
------ \\
-\cdots--- \\
------\end{array}\right|$ & $\begin{array}{r}.55 \\
.30 \\
.04 \\
1.07 \\
.15\end{array}$ & $\begin{array}{l}6.84 \\
6.50 \\
1.34 \\
1.83 \\
4.60\end{array}$ & $\begin{array}{l}.12 \\
.30 \\
.23 \\
.07 \\
.32\end{array}$ & $\begin{array}{l}7.5 \\
7.1 \\
1.6 \\
3.0 \\
5.1\end{array}$ \\
\hline $\begin{array}{l}612 \\
613 \\
614 \\
615 \\
616\end{array}$ & $\begin{array}{l}\text { Smoky Gap }{ }^{14} \\
\text { Snow Creek }{ }^{14} \\
\text { Spruce Mountain }{ }^{14} 15 \\
\text { Stecoah }^{14} \\
\text { Swannanoa }\end{array}$ & $\begin{array}{l}\text { Avery } \\
\text { Mitchell } \\
\text { Haywood } \\
\text { Graham } \ldots \ldots \\
\text { Buncombe } \ldots \ldots\end{array}$ & $\left|\begin{array}{c}.22 \\
------ \\
------ \\
----- \\
-----\end{array}\right|$ & $\begin{array}{r}.19 \\
.10 \\
.09 \\
3.40\end{array}$ & $\begin{array}{l}3.85 \\
5.05 \\
4.23 \\
2.53 \\
4.10\end{array}$ & $\begin{array}{c}.28 \\
.10 \\
.18 \\
.07 \\
-.--\end{array}$ & $\begin{array}{l}4.4 \\
5.3 \\
4.5 \\
2.7 \\
7.5\end{array}$ \\
\hline $\begin{array}{l}617 \\
618 \\
619 \\
619 a \\
620 \\
621\end{array}$ & $\begin{array}{l}\text { Tapoco } \\
\text { Tatham Gap } 14 \text { 15 } \\
\text { Teyahalee Bal } 11^{14} 15 \\
\text { The Pink Beds }{ }^{14} 15 \\
\text { Tipton Hill } \\
\text { Tomotla }\end{array}$ & 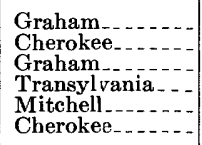 & 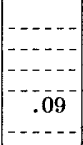 & $\begin{array}{r}.07 \\
.25 \\
.40 \\
.02 \\
.06 \\
1.68\end{array}$ & $\begin{array}{l}.99 \\
1.49 \\
1.77 \\
8.38 \\
3.76 \\
1.12\end{array}$ & $\begin{array}{l}.56 \\
.02 \\
.10 \\
.07 \\
.06 \\
.53\end{array}$ & $\begin{array}{l}1.6 \\
1.8 \\
2.3 \\
8.5 \\
4.0 \\
3.3\end{array}$ \\
\hline $\begin{array}{l}622 \\
623 \\
624\end{array}$ & $\begin{array}{l}\text { Waterville } \\
\text { Wayah Bald } 14 \text { is } 15 \\
\text { Waynesville. }\end{array}$ & $\begin{array}{l}\text { Haywood } \\
\text { Macon } \\
\text { Haywood } \\
\text { Hay }\end{array}$ & $\left|\begin{array}{c}----- \\
----- \\
-----\end{array}\right|$ & $\begin{array}{r}2.47 \\
.60 \\
3.01\end{array}$ & $\begin{array}{l}1.00 \\
4.02 \\
2.82\end{array}$ & $\begin{array}{c}.07 \\
.05\end{array}$ & $\begin{array}{l}3.5 \\
4.7 \\
5.9\end{array}$ \\
\hline
\end{tabular}

1 Total is for storm period 12:01 a.m. Aug. 28 to 12 p.m. Aug. 31 and is not necessarily equal to the total of recorded daily values Aug. 28-31.

2 Record furnished by U. S. Forest Service.

4 Precipitation measured at midnight.

7 Precipitation measured in the afternoon.

9 Precipitation measured at midnight.

14 Record furnished by Tennessee Valley Authority.

15 Recording gage; daily total for 24 hours ending in morning.

25 Record furnished by Aluminum Company of America.

27 Record furnished by city of Asheville, N. C.

${ }^{29}$ Record furnished by P. G. Rust.

so Includes 1.94 inch measured Sept. 1. 
FLOODS OF AUGUST 1940 IN THE SOUTHEASTERN STATES

TABLE 6.-Daily precipitation, in inches, August 28-31, 1940-Continued

\begin{tabular}{|c|c|c|c|c|c|c|c|}
\hline \multirow{2}{*}{$\begin{array}{l}\text { No. } \\
\text { on } \\
\text { pl.17 }\end{array}$} & \multirow{2}{*}{ Station } & \multirow{2}{*}{ County } & \multicolumn{4}{|c|}{ August } & \multirow{2}{*}{$\begin{array}{l}\text { Total for } \\
\text { storm } \\
\text { period }^{1}\end{array}$} \\
\hline & & & 28 & 29 & 30 & 31 & \\
\hline $\begin{array}{l}625 \\
626 \\
627 \\
628 \\
629\end{array}$ & $\begin{array}{l}\text { Georgia: } \\
\text { Blairsville } \\
\text { Blue Ridge Reservoir }{ }^{14} \\
\text { Brasstown Bald } 14 \text { 15 } \\
\text { Flat Top (near Blue Ridge) } \\
\text { Hemptown Gap }{ }^{14}\end{array}$ & $\begin{array}{l}\text { Union }-.- \\
\text { Fannin } \\
\text { Towns.-. } \\
\text { Gilmer.-- } \\
\text { Fannin }-.\end{array}$ & $\begin{array}{l}0.03 \\
.35\end{array}$ & $\begin{array}{r}3.00 \\
.45 \\
.79 \\
.10 \\
1.12\end{array}$ & $\begin{array}{r}0.25 \\
.97 \\
2.46 \\
1.04 \\
.50\end{array}$ & $\begin{array}{l}0.18 \\
.02 \\
.02 \\
.11\end{array}$ & $\begin{array}{l}3.2 \\
1.6 \\
3.3 \\
1.5 \\
1.7\end{array}$ \\
\hline $\begin{array}{l}630 \\
631 \\
632 \\
633 \\
634\end{array}$ & $\begin{array}{l}\text { Hiawassee }^{14} \\
\text { Ivylog } \\
\text { Little Hightower } \\
\text { Margret } \\
\text { Mulky Gap }{ }^{14}\end{array}$ & $\begin{array}{l}\text { Towns } \\
\text { Union...- } \\
\text { Towns.-. } \\
\text { Fannin.-. } \\
\text { Union... }\end{array}$ & 1.40 & $\begin{array}{r}1.17 \\
.77 \\
1.09 \\
1.85 \\
1.20\end{array}$ & $\begin{array}{r}2.13 \\
3.92 \\
.67 \\
1.40\end{array}$ & $\begin{array}{c}.11 \\
.06 \\
.56\end{array}$ & $\begin{array}{l}3.3 \\
2.3 \\
5.1 \\
1.5 \\
3.2\end{array}$ \\
\hline $\begin{array}{l}635 \\
636 \\
637 \\
638 \\
639\end{array}$ & $\begin{array}{l}\text { Neel Gap } 14 \text { 15 } \\
\text { Noontootla Creek } \\
\text { Patterson Gap } \\
\text { Stanley Gap }{ }^{14}{ }^{14} \\
\text { Suches }^{14}\end{array}$ & $\begin{array}{l}\text { Lumpkin }_{-} \\
\text {Fannin } \\
\text { Gilmer-_. } \\
\text { Union }\end{array}$ & .20 & $\begin{array}{r}1.73 \\
.46 \\
.44 \\
.31 \\
1.47\end{array}$ & $\begin{array}{r}2.24 \\
.64 \\
.32 \\
.60 \\
1.64\end{array}$ & $\begin{array}{r}.71 \\
.20 \\
.03 \\
1.17\end{array}$ & $\begin{array}{l}4.7 \\
1.1 \\
1.2 \\
.9 \\
4.3\end{array}$ \\
\hline $\begin{array}{l}640 \\
641 \\
642 \\
643 \\
644\end{array}$ & $\begin{array}{l}\text { Sweetginm } \\
\text { Tray Mountain } \\
\text { Warne }{ }^{14} \\
\text { Youngeane } \\
\text { Young Harris }\end{array}$ & $\begin{array}{l}\text { Fannin } \\
\text { Towns } \\
\text { Union } \\
\end{array}$ & .06 & $\begin{array}{l}.61 \\
.66 \\
.45 \\
.2 \\
-. .\end{array}$ & $\begin{array}{l}.76 \\
4.91 \\
1.55 \\
.8 \\
2.4\end{array}$ & \begin{tabular}{r}
1.62 \\
.79 \\
1.50 \\
\hdashline \\
\end{tabular} & $\begin{array}{l}3.0 \\
6.4 \\
3.5 \\
1.0 \\
2.4 \\
\end{array}$ \\
\hline
\end{tabular}

${ }^{1}$ Total is for storm period 12:01 a.m. Aug. 28 to 12 p.m. Aug. 31 and is not necessarily equal to the total for recorded daily values Aug. 28-31.

${ }^{4}$ Record furnished by Tennessee Valley Authority.

15 Recording gage; daily total for 24 hours ending in morning.

\section{AREA-DEP'TH-DURATION RELATIONS}

The areas within the various isohyetal lines shown on plates 16 and 17 for the mid-August and late-August storms, respectively, have been measured by planimeter. The total areas (within continuous isohyetal lines) over which the precipitation was greater than the indicated amounts were approximately as given in table 7 for the most prominent centers.

TABLE 7.-Area, in square miles, enclosed within indicated isohyetal lines for various storm centers

\begin{tabular}{|c|c|c|c|c|c|}
\hline \multirow{2}{*}{$\begin{array}{l}\text { Isohyetal } \\
\text { line }\end{array}$} & \multicolumn{2}{|c|}{ Mid-August storm } & \multicolumn{3}{|c|}{ Late-August storm } \\
\hline & $\begin{array}{l}\text { Center at } \\
\text { Swansboro, } \\
\text { N. C. }\end{array}$ & $\begin{array}{c}\text { Center at } \\
\text { Keysville, } \\
\text { Va. }\end{array}$ & $\begin{array}{l}\text { Center at } \\
\text { Rock House, } \\
\text { N. C. }\end{array}$ & $\begin{array}{l}\text { Center at } \\
\text { Mount Mit- } \\
\text { chell, N. C. }\end{array}$ & $\begin{array}{l}\text { Center at } \\
\text { Crossmore, } \\
\text { N. C. }\end{array}$ \\
\hline $\begin{array}{l}\text { 19-inch } \\
17 \text {-inch } \\
15 \text {-inch } \\
13 \text {-inch } \\
12 \text {-inch } \\
10 \text {-inch } \\
\text { 8-inch } \\
\text { 6-inch } \\
\text { 4-inch }\end{array}$ & $\begin{array}{r}24 \\
80 \\
240 \\
420 \\
530 \\
860 \\
1,270 \\
2,040 \\
\left({ }^{2}\right)\end{array}$ & $\begin{array}{r}0 \\
64 \\
688 \\
2,480 \\
3,980 \\
9,100 \\
18,600 \\
54,200 \\
128,000\end{array}$ & $\begin{array}{r}6 \\
88 \\
478 \\
1,472 \\
3,700 \\
10,100\end{array}$ & $\begin{array}{r}0 \\
4 \\
80 \\
200 \\
(1) \\
(1)\end{array}$ & $\begin{array}{r}0 \\
0 \\
0 \\
92 \\
700 \\
(1)\end{array}$ \\
\hline
\end{tabular}

${ }^{1}$ Merged with center at Rock House, N. C.

2 Merged with center at Keyṣville, Va.

The mean precipitation within the isohyetals about each storm center was computed and then plotted as shown in figure 6 . An enveloping curve is drawn to show the relation between the greatest mean precipitation with respect to area enclosed within a continuous isohyetal. From this enveloping curve selected points were read to 


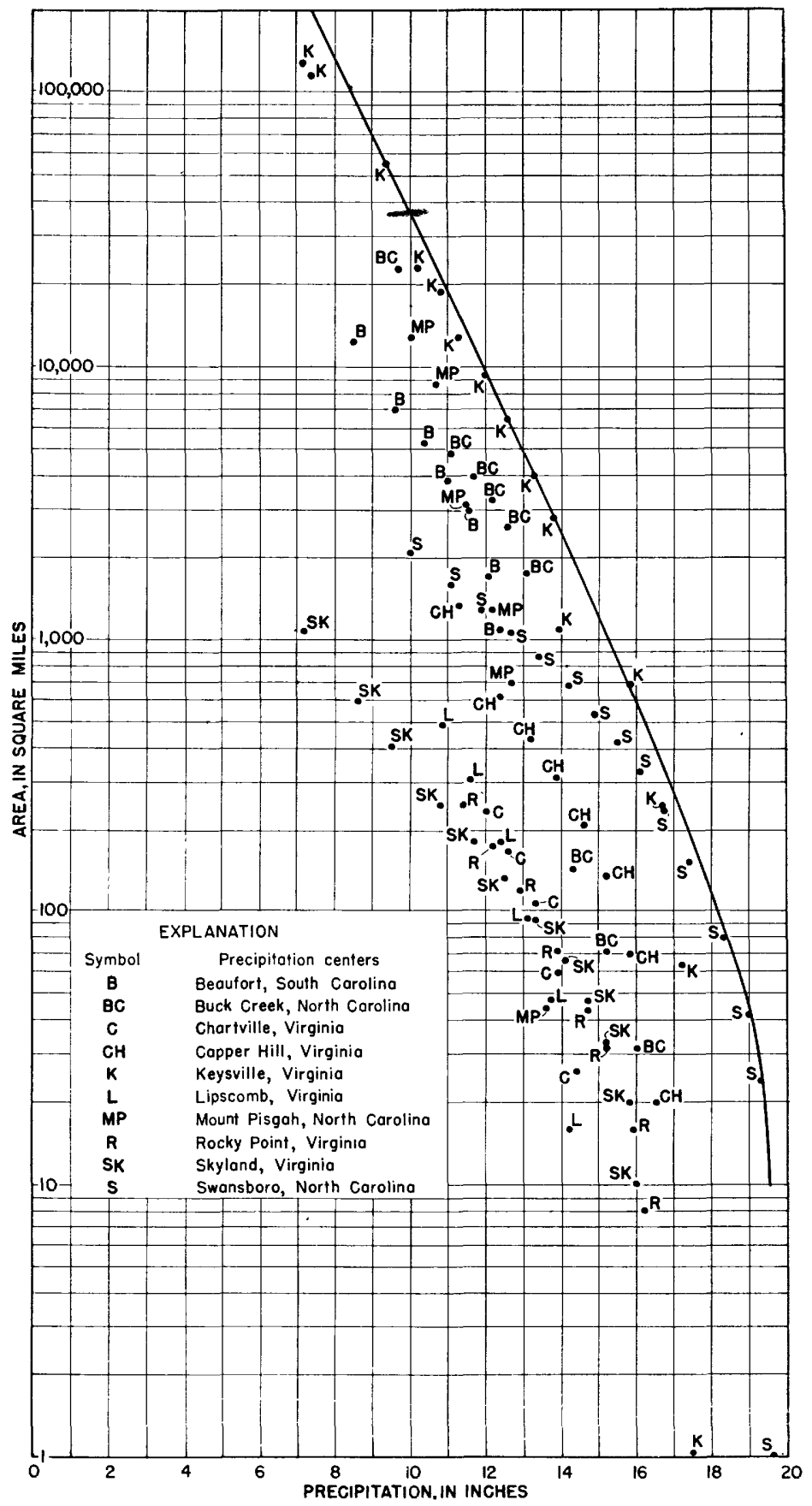

Figur: 6.-Area-depth relations for various centers of precipitation during mid-August storm. $804331-49-6$ 
TABLE 8.-Depth of mean precipitation in relation to areal extent for notable storms

\begin{tabular}{|c|c|c|c|c|c|c|c|c|c|c|c|c|}
\hline \multirow{2}{*}{ Date of storm } & \multirow{2}{*}{$\begin{array}{l}\text { Center } \\
\text { of } \\
\text { storm }\end{array}$} & \multicolumn{10}{|c|}{ Average rainfall, in inches, over indicated area, in square miles } & \multirow{2}{*}{ Duration } \\
\hline & & 1 & 500 & 1,000 & 2,000 & 4,000 & 6,000 & 10,000 & 20,000 & 40,000 & 60,000 & \\
\hline 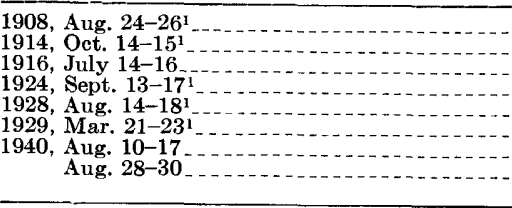 & 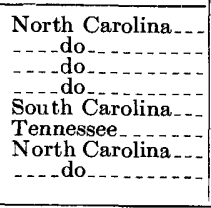 & $\begin{array}{l}15.6 \\
11.3 \\
123.2 \\
14.8 \\
13.4 \\
10.3 \\
19.6 \\
13.2\end{array}$ & $\begin{array}{r}13.9 \\
8.5 \\
118.4 \\
13.7 \\
11.8 \\
9.5 \\
16.2 \\
11.3\end{array}$ & $\begin{array}{r}13.1 \\
7.5 \\
117.1 \\
13.0 \\
11.1 \\
8.9 \\
15.2 \\
10.5\end{array}$ & $\begin{array}{r}12.2 \\
6.9 \\
115.5 \\
12.1 \\
10.2 \\
8.2 \\
14.3 \\
9.4\end{array}$ & $\begin{array}{r}11.6 \\
6.1 \\
113.7 \\
11.2 \\
9.3 \\
7.5 \\
13.3 \\
8.2\end{array}$ & $\begin{array}{r}11.3 \\
5.5 \\
112.5 \\
10.5 \\
8.8 \\
7.0 \\
12.7 \\
7.4\end{array}$ & $\begin{array}{c}10.5 \\
\begin{array}{c}11.9 \\
6.3\end{array}\end{array}$ & 29.2 & 9.8 & ${ }^{2} 6.0^{--}$ & $\begin{array}{l}3 \\
2 \\
2 \\
4 \\
4 \\
2 \\
6 \\
2\end{array}$ \\
\hline
\end{tabular}

12 From Miami Conservancy District report "Storm rainfall of eastern United States, revised."

From Tennessee Valley Authority processed report "Floods of August 1940 in Tennessee River Basin." 
enable comparison with other storms in the region on a depth-area basis as reported by the Miami Conservancy District. ${ }^{10}$ The results are given in table 8 .

The mid-August storm is listed as of 6-day duration, though at some locations most of the rain fell in two or three consecutive days. The other storms are of 2- to 4-day duration. Comparisons have already been made with the hurricane of July 1916, a 2-day rainstorm, which deposited greater depths of rain than the mid-August storm over areas smaller than 5,000 square miles. Over larger areas the rainfall during the mid-August storm was the greater. For point rainfall (=1 square mile) the mid-August storm was exceeded only by that of July 1916. For rainfall on 6,000 square miles the midAugust storm was the greatest of all the storms listed. However, the comparison is faulty because the mid-August storm was of longer duration.

The rainfall depths of the storm of August 28-31, 1940, were exceeded by those of all but two storms-October 1914 and March 1929.

The Corps of Engineers prepared a series of isohyetal maps showing rainfall during the mid-August storm by 6 -hour periods. These maps were planimetered by the Corps of Engineers in the same way as the isohyetal maps of total storm rainfall. Table 9 is a summary of the results, giving the maximum rainfall over indicated areas, for selected rainfall periods.

TABLE 9.-Maximum precipitation, in inches, over indicated areas, during indicated periods, for storm of August 10-17, 1940

[Analysis by Corps of Engineers, War Department]

\begin{tabular}{|c|c|c|c|c|c|c|c|}
\hline \multirow{2}{*}{$\begin{array}{l}\text { Period } \\
\text { (hours) }\end{array}$} & \multicolumn{7}{|c|}{ Area (square miles) } \\
\hline & 10 & 100 & 1,000 & 5,000 & 10,000 & 124,000 & ${ }^{2} 120,000$ \\
\hline $\begin{array}{r}64 \\
486 \text { (total storm) } \\
124\end{array}$ & $\begin{array}{r}37.1 \\
39.7 \\
{ }^{4} 11.5 \\
{ }^{4} 16.3 \\
{ }^{5} 19.6\end{array}$ & $\begin{array}{r}36.2 \\
38.7 \\
310.6 \\
415.7 \\
517.8\end{array}$ & $\begin{array}{r}34.6 \\
37.2 \\
310.1 \\
413.7 \\
415.5\end{array}$ & $\begin{array}{r}42.9 \\
44.9 \\
47.5 \\
411.0 \\
413.5\end{array}$ & $\begin{array}{r}42.3 \\
44.0 \\
46.4 \\
49.6 \\
412.3\end{array}$ & $\begin{array}{r}1.6 \\
2.7 \\
4.6 \\
7.4 \\
10.3\end{array}$ & 7.5 \\
\hline
\end{tabular}

${ }^{1}$ Within 7 -inch isot yetal, centering at Keysville.

2 Whole storm area.

3 Center at Beaufort, S. C.

${ }^{4}$ Center at Keysville, Va.

5 Center at Swansboro, N. C.

The maximum precipitation during the mid-August storm, 19.6 inches, was recorded at Swansboro, N. C., during a period of 186 hours. The maximum storm precipitation recorded during shorter periods is listed in table 10.

Similar data for the late-August storm are given in table 11. It will be observed that the amounts of short-period rainfall (that is, 2 hours to 1 day) were generally greater during the late-August storm. For

\footnotetext{
${ }^{10}$ Storm rainfall of eastern United States: Miami Conservancy District Tech. Repts., pt. 5 (revised), pp. 280-281, Dayton, Ohio, 1936.
} 
TABLE 10.-Maximum recorded precipitation during indicated periods, storm of August 10-17, 1940

\begin{tabular}{|c|c|c|c|c|}
\hline $\begin{array}{l}\text { Period } \\
\text { (hours) }\end{array}$ & Name of station & $\begin{array}{l}\text { No. on } \\
\text { pl. } 16\end{array}$ & Date & $\begin{array}{c}\text { Amount } \\
\text { (inches) }\end{array}$ \\
\hline $\begin{array}{r}1 \\
2 \\
3 \\
4 \\
6 \\
12 \\
24\end{array}$ & $\begin{array}{l}\text { Lexington, N.C. (near) } \\
\text { Gretna (Sandy Level), Va } \\
\text { Watkinsville, Ga. do } \\
\text { Inman, S.C. }\end{array}$ & $\begin{array}{l}180 \\
89 a \\
89 a \\
89 a \\
357 \\
267 \\
267\end{array}$ & 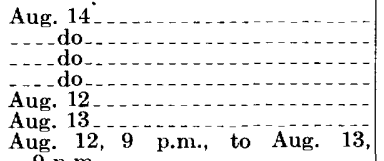 & $\begin{array}{r}2.75 \\
3.90 \\
4.32 \\
4.42 \\
5.21 \\
8.35 \\
12.04\end{array}$ \\
\hline $\begin{array}{r}48 \\
1186\end{array}$ & $\begin{array}{l}\text { Keysville, Va. (near) } \\
\text { Swansboro, N.C. }\end{array}$ & $\begin{array}{r}78 \\
399\end{array}$ & $\begin{array}{l}\text { Aug. } 14-15,6 \text { a.m., to Aug. 17, } \\
\text { Aug. } 10,6 \text { p.m. } \\
\text { } 12 \text {. }\end{array}$ & $\begin{array}{l}15.25 \\
19.6\end{array}$ \\
\hline
\end{tabular}

1 Storm period.

periods longer than 1 day the amounts for the mid-August storm were greater. In general, it is a characteristic of maximum rainstorms that short-period maxima are associated with storms of small areal distribution and long-period maxima with storms of wider distribution. The behavior of the two August storms conformed to this rule.

TABLE 11.-Maximum recorded precipitation during indicated periods, storm of Aurust 28-31, 1940

\begin{tabular}{|c|c|c|c|c|}
\hline $\begin{array}{l}\text { Period } \\
\text { (hours) }\end{array}$ & Name of station & $\begin{array}{l}\text { No. on } \\
\text { pl. } 17\end{array}$ & Date & $\begin{array}{c}\text { Amount } \\
\text { (inches) }\end{array}$ \\
\hline 1 & $\left\{\begin{array}{l}\text { Mount Pisgah, N.C. } \\
\text { Clemson, S.C. }\end{array}\right.$ & $\begin{array}{l}588 \\
316 a\end{array}$ & $\begin{array}{l}\text { August } 30 \\
\text { August } 29\end{array}$ & $\begin{array}{r}12.53 \\
2.16\end{array}$ \\
\hline 2 & $\left\{\begin{array}{l}\text { Mount Pisgah, N.C. } \\
\text { North Fork, N.C. }\end{array}\right.$ & $\begin{array}{l}588 \\
595\end{array}$ & August 30 & $\begin{array}{r}14.49 \\
3.13\end{array}$ \\
\hline 3 & $\left\{\begin{array}{l}\text { Mount Pisgah, N.C. } \\
\text { Haywood Gap, N.C. }\end{array}\right.$ & $\begin{array}{l}588 \\
569\end{array}$ & _... do do & $\begin{array}{r}16.24 \\
4.00\end{array}$ \\
\hline 4 & $\left\{\begin{array}{l}\text { Mount Pisgah, N.C. - } \\
\text { Haywood Gap, N.C. }\end{array}\right.$ & $\begin{array}{l}588 \\
569\end{array}$ & $\begin{array}{l}\text { do } \\
\text { August } 29-30\end{array}$ & $\begin{array}{l}16.56 \\
5.03\end{array}$ \\
\hline 6 & $\left\{\begin{array}{l}\text { Mount Pisgah, N.C. - } \\
\text { Haywood Gap, N.C. }\end{array}\right.$ & $\begin{array}{l}588 \\
569\end{array}$ & $\begin{array}{l}\text { August } 30 \\
\text { August } 29-30 .\end{array}$ & $\begin{array}{r}7.14 \\
6.08\end{array}$ \\
\hline 12 & Haywood Gap, N.C. & 569 & _. _do_- & 8.95 \\
\hline 24 & Rock House, N.C. - & 308 & August 29 & 13.13 \\
\hline 48 & $\ldots$. $\mathrm{do}_{-}$ & 308 & August $29-30 \ldots$ & 13.19 \\
\hline${ }^{2} 96$ & _. . do do. & 308 & August $28-31$ & 13.2 \\
\hline
\end{tabular}

1 From the part of the record where distribution was estimated.

2 Storm period.

Rainfall amounts of less than 24 hours' duration in tables 10 and 11 are based on observations at recording rain gages only. For durations of 24 hours and longer the records at all stations were examined. Differences between depths of precipitation listed in table 10 and those given in table 9 for 10 square miles (equivalent to point rainfall) may be due to one of the following differences in methods of preparation: (1) The Corps of Engineers prepared mass curves of precipitation at all stations, which are understood to have been based on observers' notes and comparisons with nearby recording gages in order to inter- 


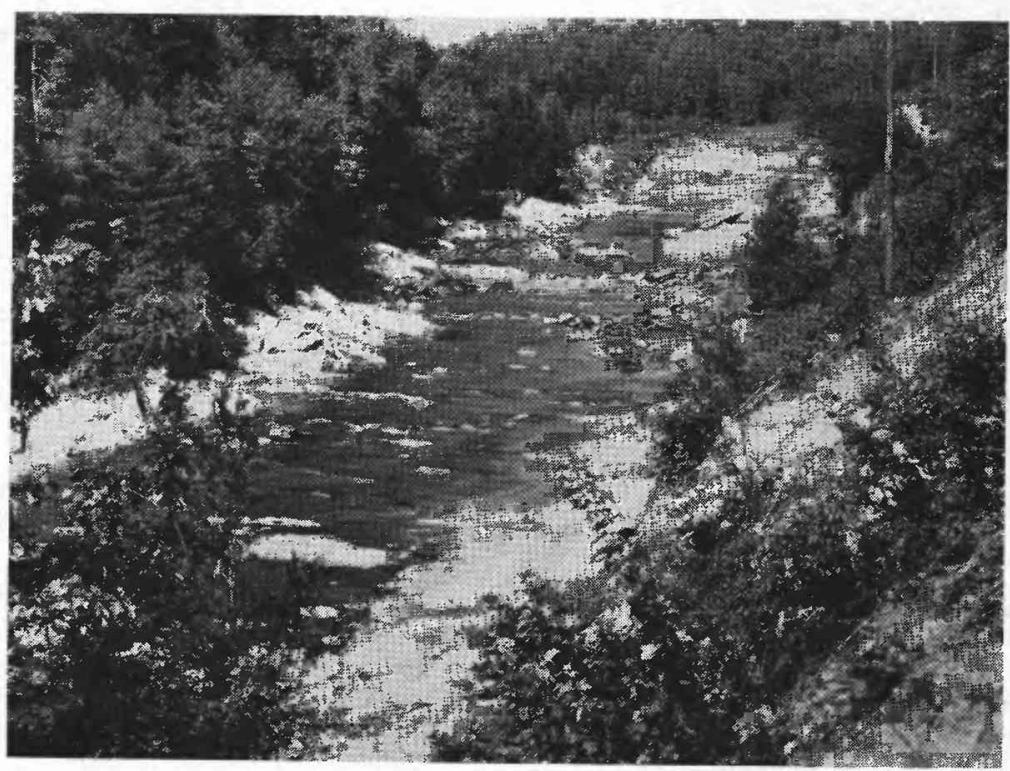

A. ELK CREEK AT ELKVILLE, N.C.

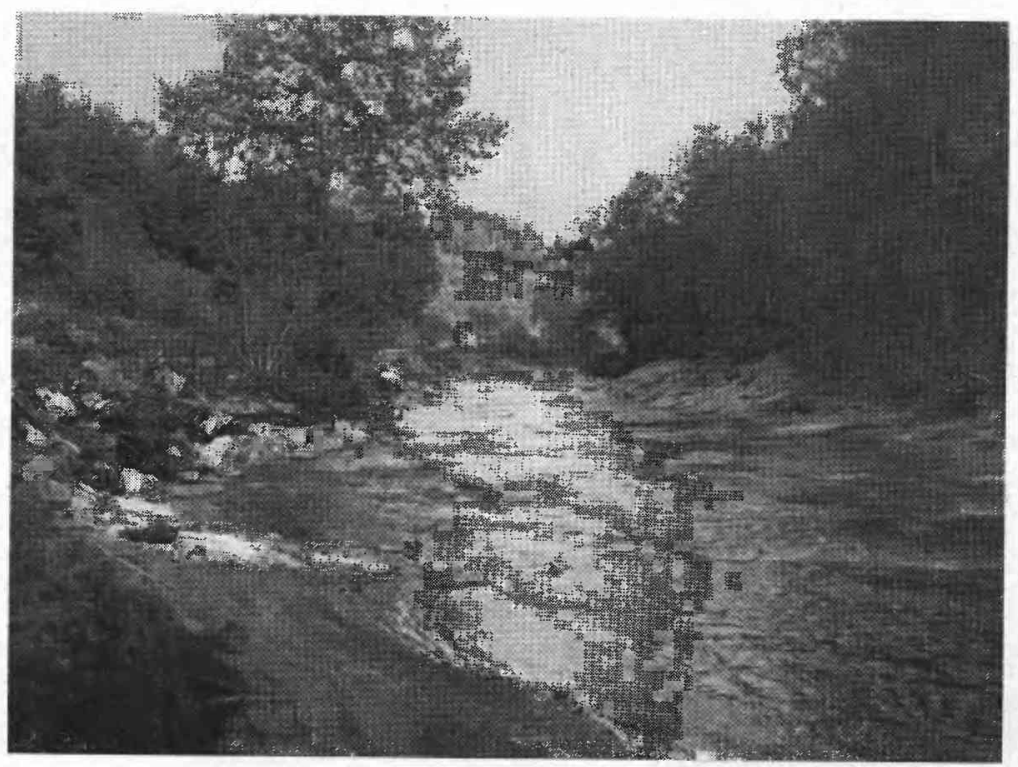

B. WEST FORK LEWIS FORK NEAR CHAMPION, N.C.

REACHES USED FOR SLOPE-AREA MEASUREMENTS.

Conrtesy U.S. Soil Conservatiou Service. 


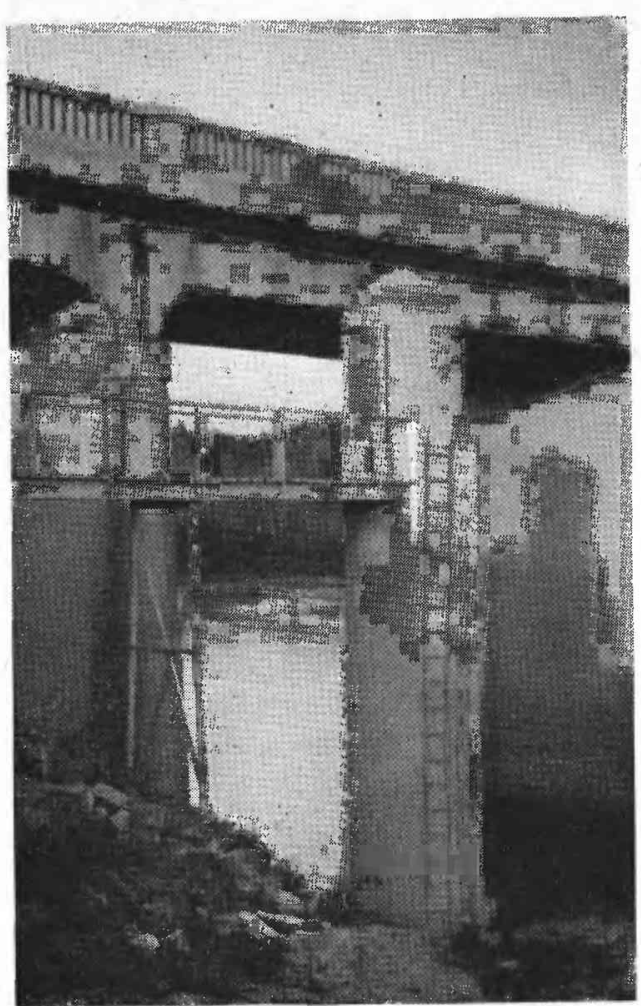

A. SCENE JANUARY 4, 1935.

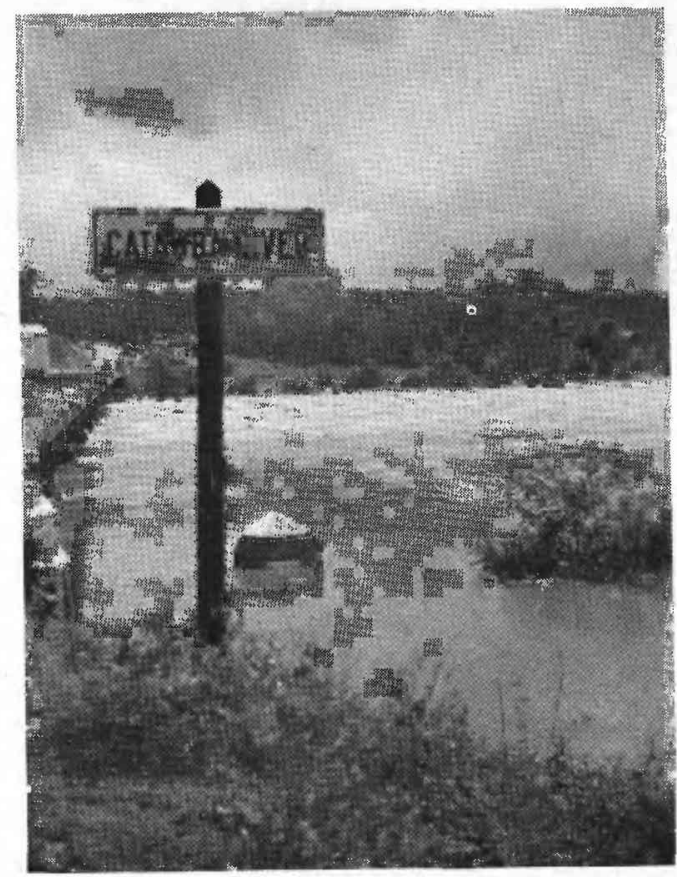

B. SCENE AUGUST 14, 1940. RECORDING GAGE ON CATAWBA RIVER AT CATAWBA, N.C. 
polate periods of intense precipitation at nonrecording stations where generally only once-daily measurements of catch are made. (2) The Corps of Engineers used 6-hour periods by definite clock hours. This would tend to eliminate more intense 6 -hour periods that might straddle the selected 6-hour periods.

As point rainfalls, the amounts listed in the foregoing tables are not impressive in comparison with recorded torrential rainstorms in the region. For example, at Guinea, Va., on August 24, 1906, the Weather Bureau reports a rainfall of 9.25 inches in only 30 minutes. A rainfall of 9.0 inches in $31 / 2$ hours was recorded at Ellsworth, N. C., on August 4, 1880. At Altapass, N. C., on July 15-16, 1916, 22.22 inches of rain fell in 24 hours. At Falkland, N. C., August 4-5, 1894, there was 13.55 inches of rain in 24 hours. At Carters Bluff, Tenn. (near Elizabethton), on the night of June 13-14, 1924, about 1' inches of rain fell in $3 \frac{1}{2}$ hours. These rare torrential rains were, however, local in coverage and quite different in character from the two August storms, which were relatively broad in areal extent.

In general it might be concluded that for storms of comparable duration no records of precipitation were broken during August 1940 with respect either to volume over broad areas or to local intensity.

\section{MEASUREMENT OF FLOOD DISCHARGES}

The evaluation of the peak discharge of a major flood is frequently a difficult problem. At regular stream-gaging stations the discharge is usually obtained from the gage-height record by means of a stagedischarge relation defined by current-meter measurements. (See Definitions of terms, pp. 62-63.) During major floods, however, it is often impossible to obtain current-meter measurements. This may be for several reasons. Many streams rise and fall so rapidly that there is insufficient time to make a current-meter measurement near the crest stage. Means of transportation and communication often fail, so that engineers cannot reach the places of measurement. Even if an engineer is fortunate in reaching a measuring point during a major flood, floating debris or inundation or destruction of the bridge or cableway from which the measurement would be made often prevents his obtaining a current-meter measurement. These happened at many points in the southeastern States during the floods of August 1940.

It is often important to know the flood discharge of streams at points other than at gaging stations. For such points, and at gaging stations under conditions described above, special methods of evaluating flood discharge must be used. The special methods chiefly used are slope-area, contracted opening, dam computation, and, at gaging stations, extension of rating curve. A general description of these 
methods will be found in "Stream-gaging procedure." 11 Detailed description of slope-area methods, with illustrative examples, will be found in recent flood reports, particularly Water-Supply Papers 773-E, 796-G, and 816. Views of two reaches used for slope-area measurements are shown in plate 18 of the present report. WaterSupply Paper 816 contains'also a detailed description and example of the contracted-opening method. The reports cited do not include all the refinements and small changes that have been made as a result of experience since those reports were prepared, but they set forth the basic principles of present Geological Survey practice.

The Norfolk district, Corps of Engineers, made extensive studies of rainfall and runoff in the Roanoke River Basin for the mid-August flood, the results of which were made available to the Geological Survey. These have been utilized in evaluating the flood discharges given herein for some gaging stations. Several records of flood discharge presented in this report have been computed from the rate of storage in reservoirs.

\section{S'TAGES AND DISCHARGES A'T STREAM-GAGING STATIONS}

\section{EXPLANATION OF DATA \\ DEFINITIONS OF TERMS}

Stream-gaging terms and units of measurement as used in this report are defined as follows:

"Stage" or "gage height" is the elevation of the water surface above the arbitrary datum, or "zero," of the gage. It may be obtained directly by reading the elevation of the water surface on the graduated scale of a staff gage or by measuring down from a fixed point with a chain or wire-weight gage; or it may be obtained indirectly from the scale of a water-stage recorder graph. Gage heights are usually expressed in feet and hundredths.

"Discharge" signifies the rate of flow of a stream past a given point, such as a gaging station, and is usually given in second-feet; it can also be the total volume of such flow. Measurements of discharge are usually made by a current meter, using equipment and methods developed by the Geological Survey through many years of experience. For flood flows they are sometimes made using methods referred to in the preceding section. (See p. 61.)

"Stage-discharge relation" is the relation between gage height and discharge, by which it is possible to obtain the discharge of a stream from the observed gage heights. The permanency and accuracy of definition of that relation determine the accuracy of the discharge

\footnotetext{
${ }^{11}$ Corbett, D. M., and others, Stream-gaging procedure, a manual describing methods and practices of the Geological Survey: U. S. Geol. Survey Water-Supply Paper 888, pp. 98-109, 1943.
} 
record obtained. Auxiliary gages are often used when the stagedischarge relation is a function of other elements of flow conditions, such as the slope of the water surface or the rate of its rise and fall.

"Control" is a term used to designate a feature downstream from the gage that determines the stage-discharge relation at the gage. This feature may be a natural section, a reach of the channel, or an artificial structure.

"Runoff" is the volume of flow from a drainage area into a stream during a given period of time.

"Second-feet" is an abbreviation for "cubic feet per second." A second-foot is the rate of flow equivalent to a stream whose channel is 1 square foot in cross-sectional area and whose average velocity is 1 foot per second.

"Second-foot-day" is the volume of water represented by a flow of 1 second-foot for 24 hours. It is equivalent to 86,400 eubic feet, 1.983471 acre-feet, or 646,317 gallons and represents a runoff of 0.0372 inch from 1 square mile.

An "acre-foot" is the quantity of water required to cover 1 acre to the depth of 1 foot and is equivalent to 43,560 eubic feet. The term is commonly used in connection with storage of water.

"Second-feet per square mile" is the average number of cubic feet of water flowing per second from each square mile of area drained, on the assumption that the runoff is distributed uniformly in regard to both time and area.

"Runoff in inches" is the depth to which an area would be covered if all the water draining from it in a given period were uniformly distributed on its surface. It is used for comparing runoff with rainfall, which is usually expressed in inches.

\section{GAGING-STATION RECORDS}

The base data collected at stream-gaging stations consist of records of stage, measurements of discharge, and general information used to supplement those records. From these data the records of daily flow are obtained. Peak stages are obtained from floodmarks at the station if they have not been previously observed or recorded. For flood periods it is customary to plot readings of nonrecording gages and construct thereon a hydrograph to obtain gage heights for times other than when the gage was read and thereby increase the accuracy of the daily discharge record.

During major floods, parts of gage-height records are occasionally lost, as through submergence or destruction of the gage itself. (See pl. 19.) Under such conditions, it is often possible to obtain a fair record of gage height and discharge from studies of meteorological information and runoff at gaging stations upstream, downstream, or on adjacent streams, interpreted in the light of an intimate knowl- 
edge of the peculiar local conditions inherent to a particular gaging station. As Geological Survey engineers usually have access to more of such information than would normally be available to other users of the records, they have made estimates for all periods of missing record pertinent to this report that could be made with reasonable accuracy.

A major flood such as the one described in this report frequently makes substantial changes in stream channels, the effect of which cannot be completely determined until measurements have been obtained at stages greater than normal high water. When such measurements are obtained it sometimes becomes necessary to make revisions in previously published records. The present report contains all revisions published in the annual reports on surface water supply of the United States through 1945. Any revisions of records made necessary in the light of future information will be published in subsequent water-supply papers.

Records of daily mean discharge for the entire 1940 water year at regular gaging stations in the area covered by this report will be found in the reports on Surface Water Supply of the United States. 1940, Parts 1, 2, and 3, published as Water-Supply Papers 891, 892, and 893. The area covered by each part is shown in plate 1 . Such records, however, are generally insufficient for the detailed analyses involved in flood studies, which require knowledge of the rate of discharge and the corresponding stage at much more frequent intervals. To provide such detailed information is one of the principal aims of this report. Therefore, on succeeding pages will be found detailed records for stream-gaging stations and for other points in the flood area for which the same type of information is available. Such information consists of a description of the place for which the record is given, details concerning the collection and computation of the record, daily mean discharge for the months of August and September 1940, and monthly figures of mean and total runoff. Also given for most stations is a table of gage height and discharge at indicated times to enable a user of the record to plot a reasonably accurate flood hydrograph of stage or discharge.

Information of this nature provides a basis for studies of the behavior of flood crests, including the concourse of crests from different tributaries, the progress of flood crests throughout a river system, and other features useful in deriving the elements necessary for forecasting flood heights and for appraising the characteristics of different basins in the shedding of flood waters. It furnishes basic information for the consideration of the feasibility of detention reservoirs, channel improvement, forest management, soil treatment, flood forecasting, and other measures, with respect to their merits for 
mitigating damage and losses caused by floods. Moreover, in view of the record-setting character of the floods of August 1940, it is important that full and authentic information concerning them be available for reference and guidance in connection with future urban and industrial development, with highway and bridge construction, and especially with the design of hydraulic structures in their relation to flood channels of streams.

In general, records of gaging stations published in this report relate to streams on which floods occurred or which are adjacent to the margins of the flood areas and so serve to define the extent of the floods. The principal river basins are arranged from north to south along the Atlantic coast and Gulf of Mexico, followed by the principal tributaries of the Ohio River. Under each basin the records of streams are arranged in downstream order, as in other Geological Survey water-supply papers. Records for the main stream are given first, followed by records for the tributaries in regular order from source to mouth, all the records for each tributary basin being given before those of the next basin below.

\section{STATION DESCRIPTION}

Location.-The statement of location includes the sea-level elevation of the gage datum, if known.

Drainage-area.-The area given represents the total area contributing to the flow at the gaging station. When part of the area does not contribute directly to the flood flow a statement concerning that fact is usually given.

Gage-height record.-Under gage-height record is given the method used to obtain the record during the flood period, including the type of gage from which it was obtained. Where for some reason the gageheight record is incomplete, the missing periods are noted, and the methods, if any, used to supply the missing part are stated.

Discharge record.--The first statement concerning discharge records usually deals with the definition of the stage-discharge relation, because of its influence on the accuracy of the discharge record. Where for ease of computation certain limits of gage height were used in computing the discharge, the limits are given. Other methods that may have been used in computing or estimating the discharge are described.

Maxima.-Under maxima are given first the maximum stage and discharge that occurred during August 1940 and the time or times of their occurrence. On streams where two floods occurred in August, the information given here is for the higher flood only, but the maxima for both floods, where significant, will be found as part of the tables "Gage height and discharge at indicated times" and in table 13 or 
14. Next under maxima are given data concerning the greatest previous flood during the period of gaging-station operation; the calendar years covering such a period or periods precede the statement. The period January to July 1940 is not included in the "previous flood" period unless during that period a flood occurred which was greater than the August flood. A further statement is added if there are other important floods to be described, whether they occurred during the period of gaging-station record or not. Flood stages and discharges are usualy indicated as being the "maximum observed" if they were not derived from a continuous record of gage height or discharge or a floodmark, or if they were not estimated.

Remarks.-Miscellaneous notes and comments essential or helpful to an understanding of the record are included as remarks.

\section{MEAN DISCHARGE}

The first table under each gaging station gives the daily and monthly mean discharge, in second-feet, and the monthly runoff, expressed as the depth in inches over the tributary drainage area, adjusted for artificial storage when appropriate, if the required information was available. These data are given for the months of August and September 1940, thereby giving, in addition to the record for both flood periods, sufficient records before and after the flood periods to show the relation of the floods to the prevalent lowwater flow.

GAGE HEIGHT AND DISCHARGE AT INDICATED TIMES

For many types of flood studies, a discharge hydrograph for the flood period is necessary. An adequate hydrograph can occasionally be obtained by plotting the daily mean discharge at noon and connecting the points thus obtained with a smooth curve. Usually, however, such points are insufficient for a proper delineation of the hydrograph. Therefore, following the table of daily discharge is a table giving gage height and discharge at indicated times. This table, used with the table of mean discharge, will make possible the construction of a reasonably accurate hydrograph of discharge for the entire period and of itself will yield a gage-height graph for the major part of the flood rise. Most of the gage heights in these tables were obtained from graphs made by water-stage recorders or graphs based on frequent readings of a nonrecording gage. Some are estimates that are believed to be of sufficient accuracy to warrant their inclusion; the manner of obtaining them is described under "gage-height record."

Figures 7 to 20 give selected hydrographs for the main stream and important tributaries of most of the principal river basins. They show graphically the relation between the mid-August and late-August flonds, also something of the runoff characteristies of the different basins. 


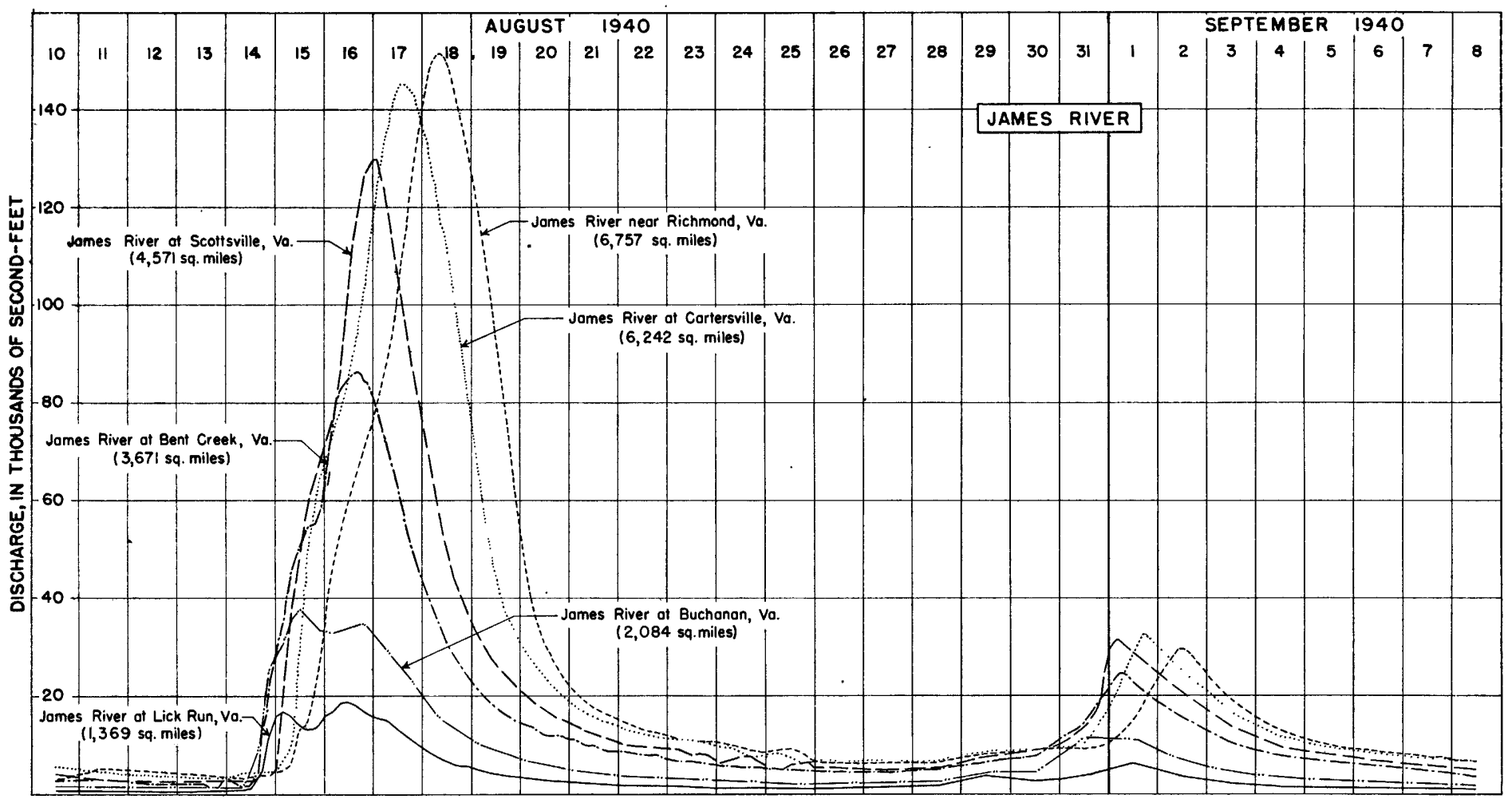

年

FIGURE 7.-Graphs of discharge at various stream-gaging stations on James River. 


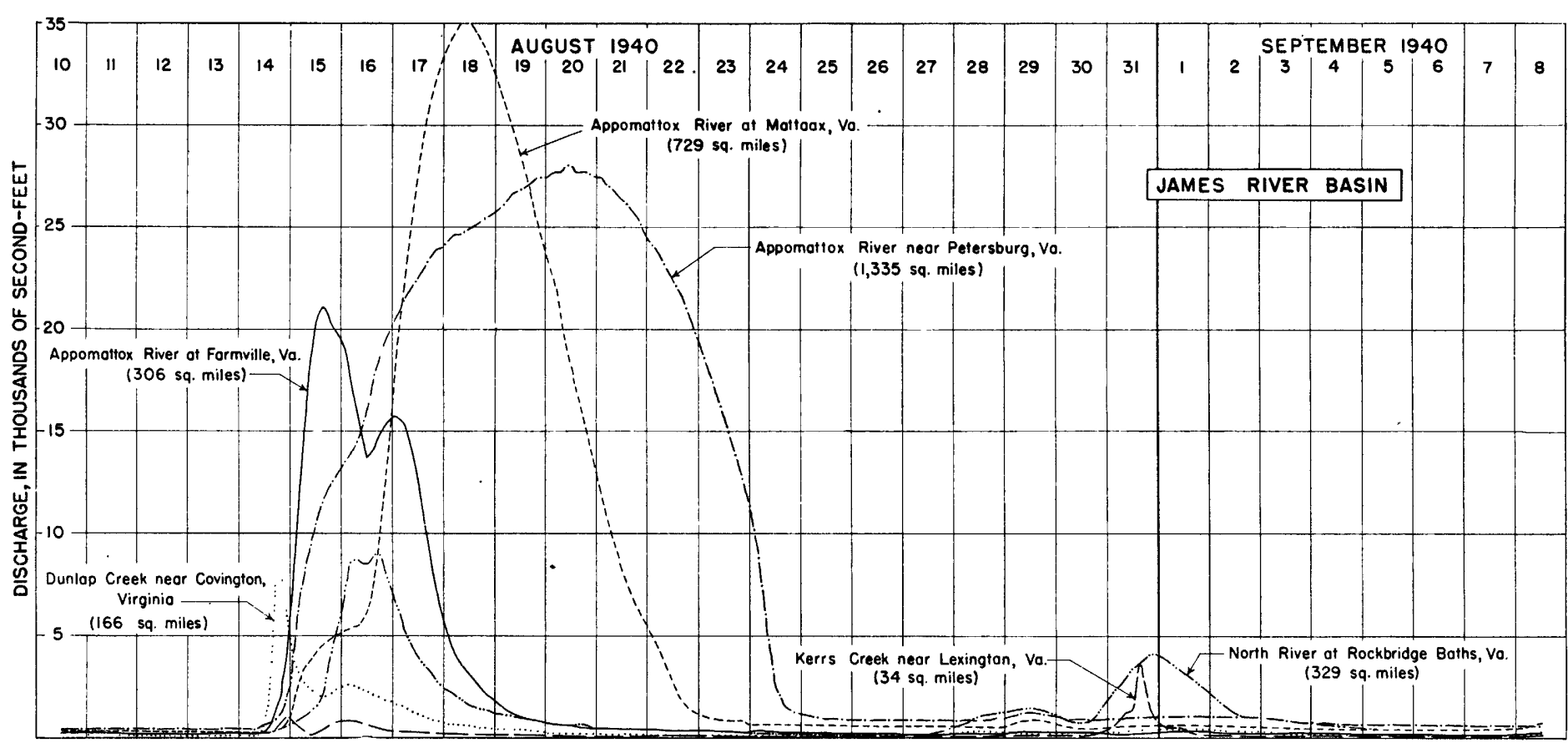




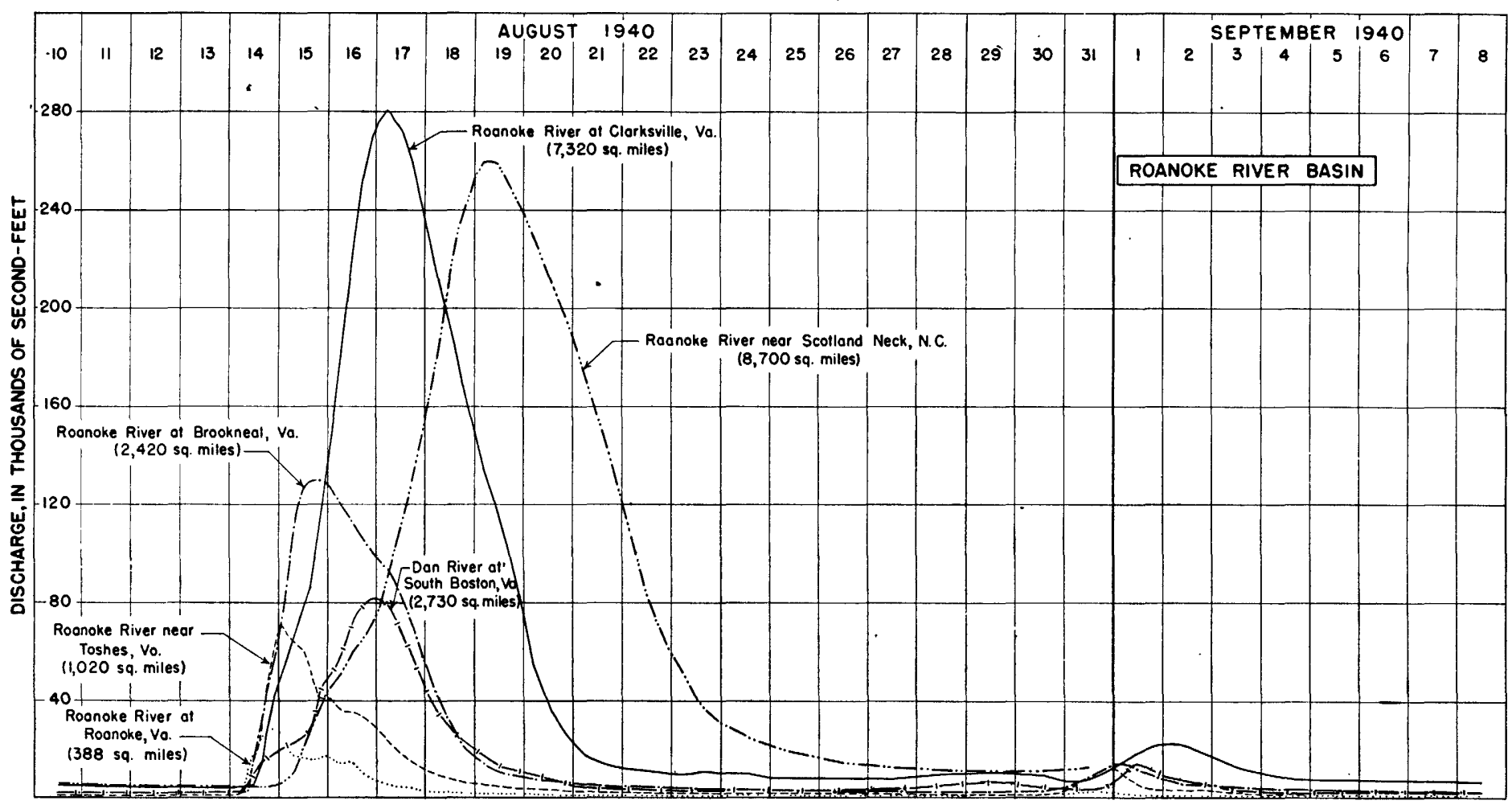




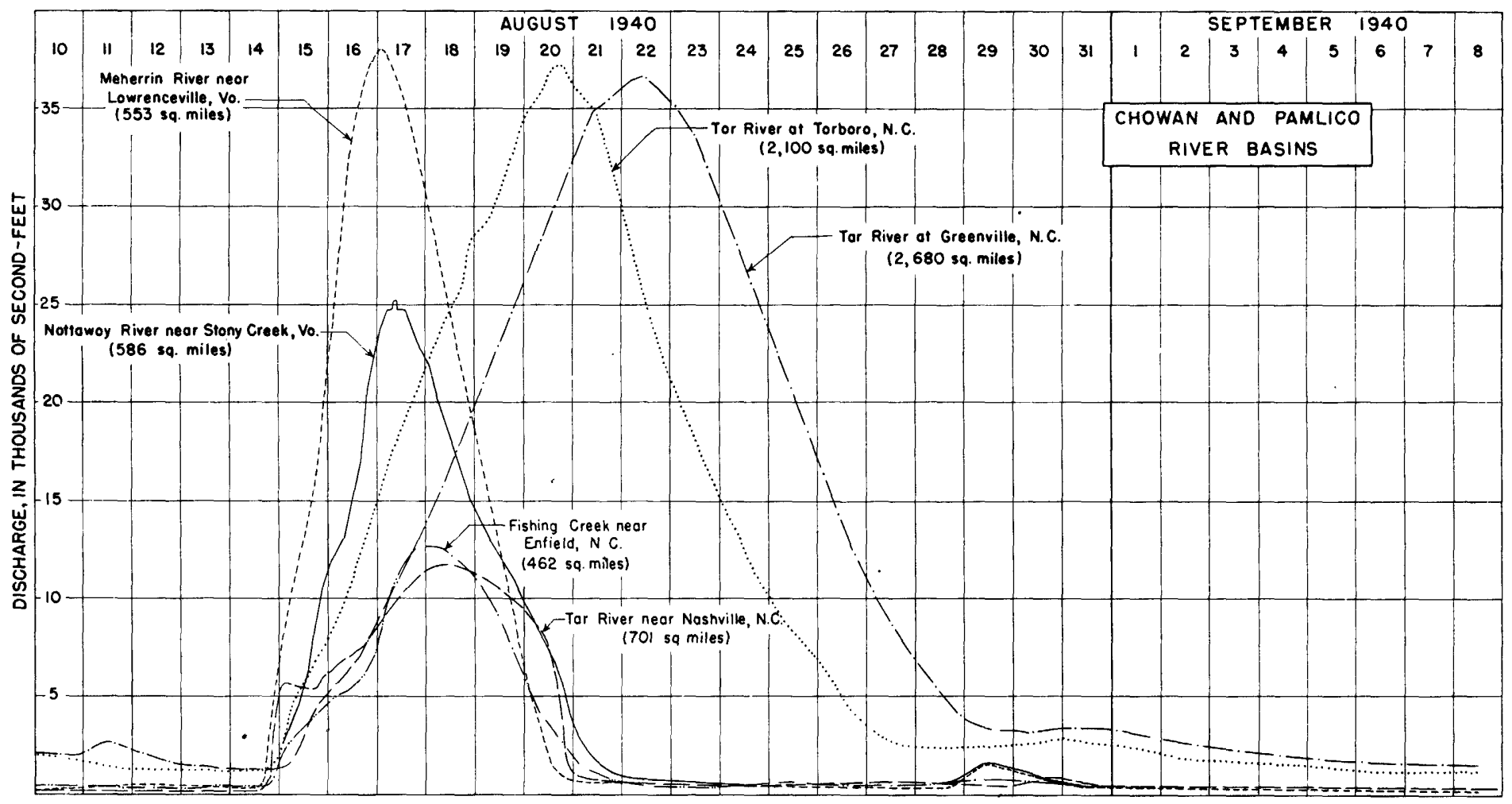




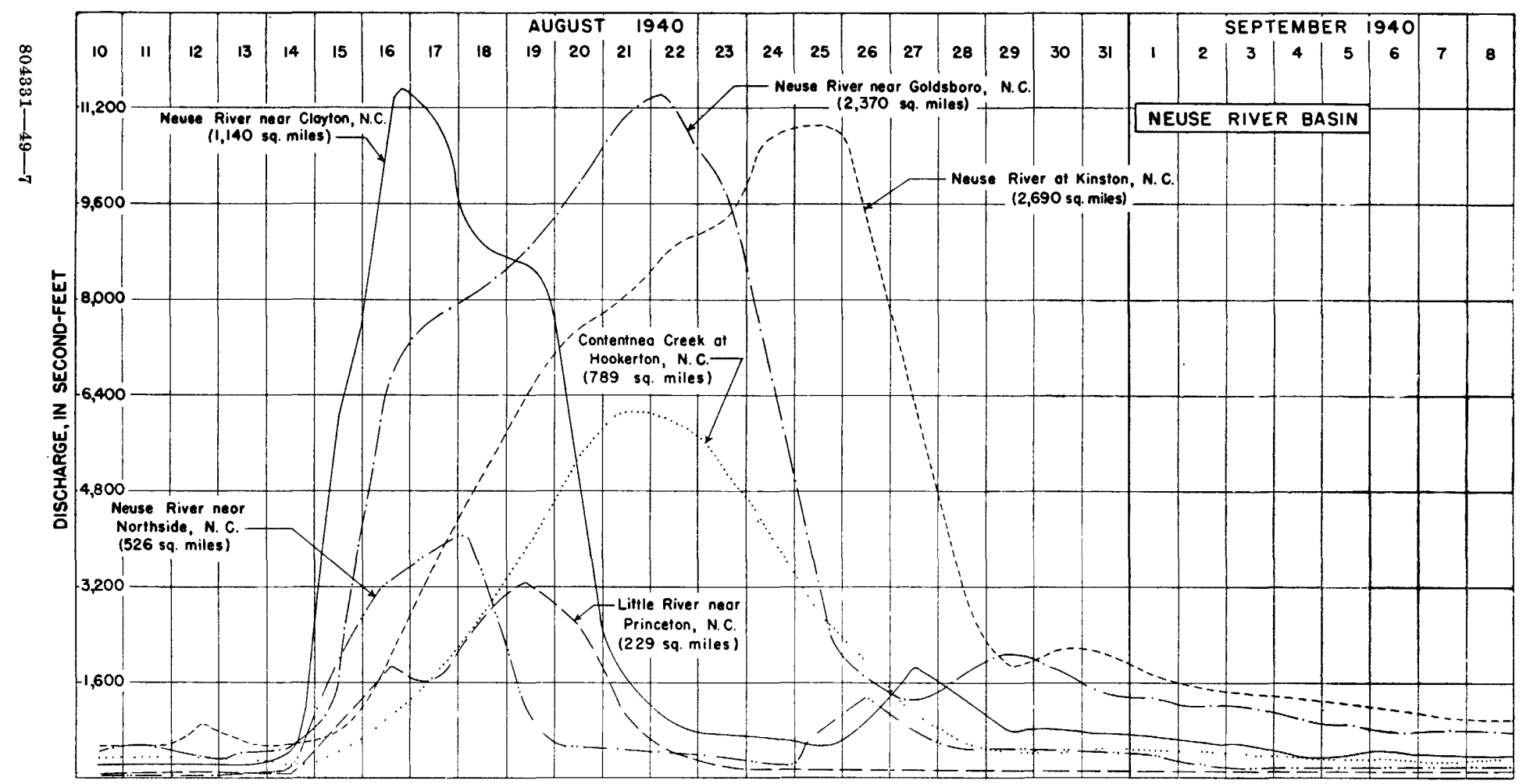

年

Frgure 11.-Graphs of discharge at various stream-gaging stations in Neuse River Basin. 


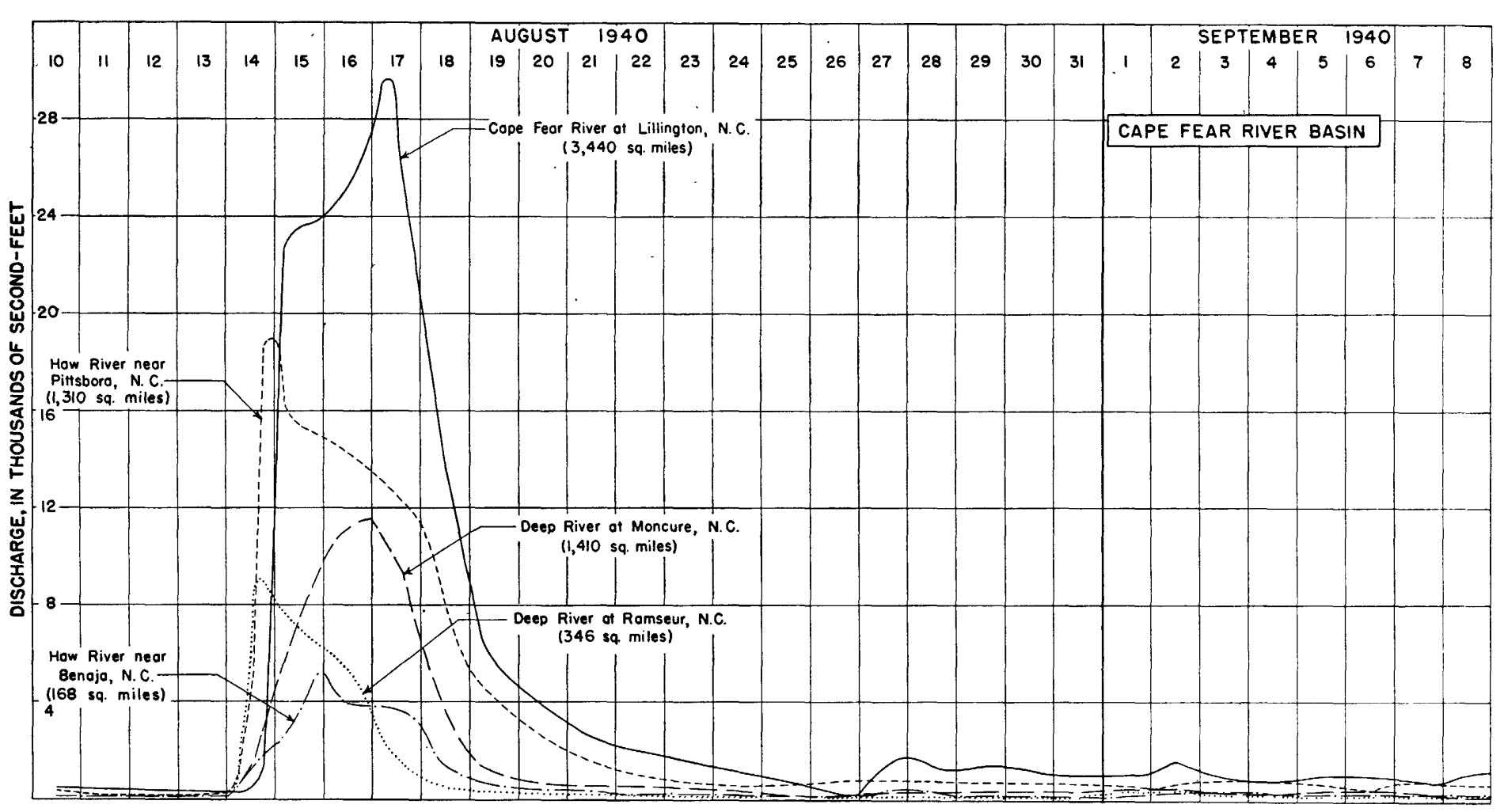




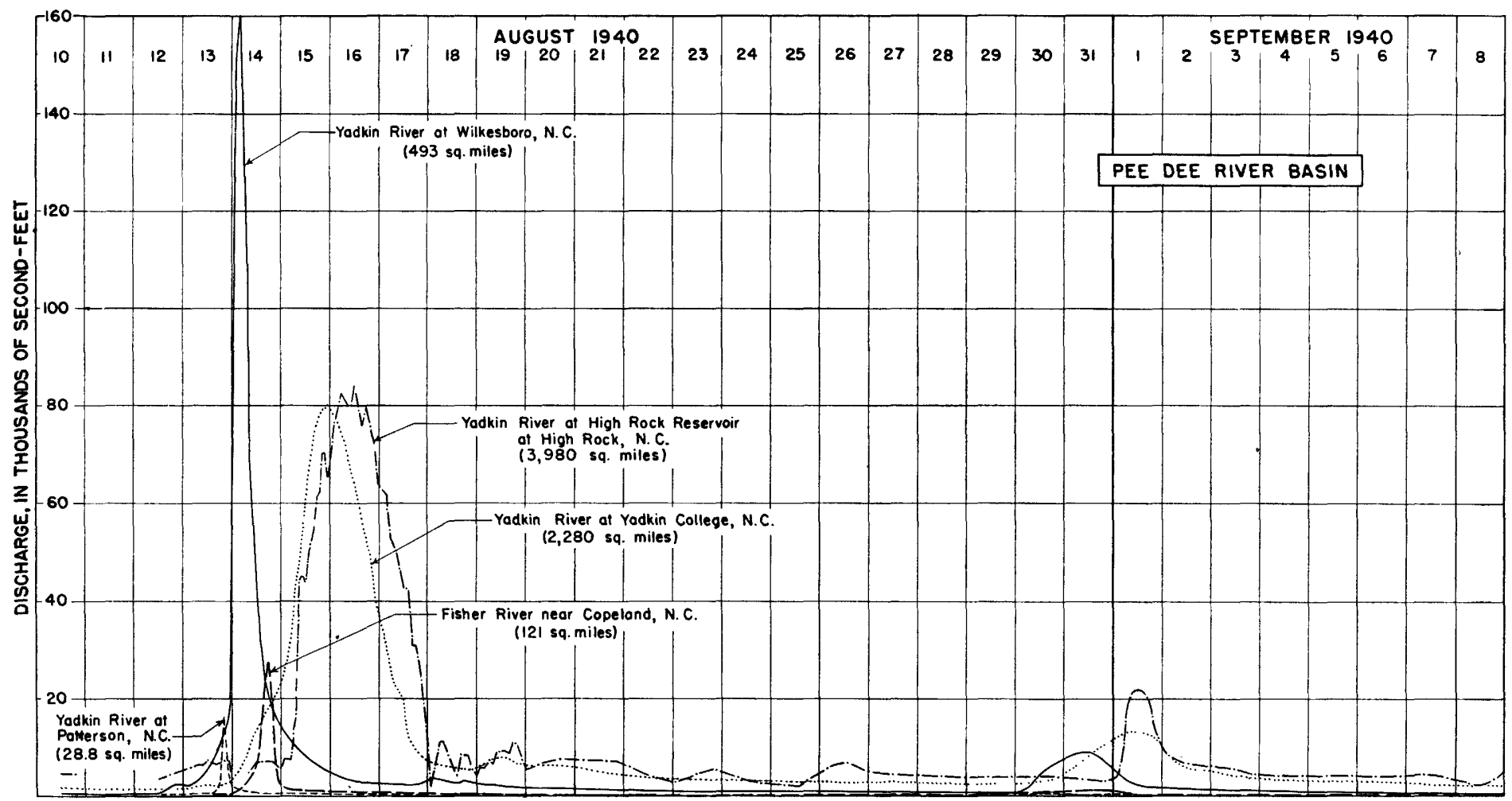

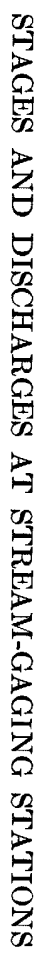

Figure 13.-Graphs of discharge at varions stream-gaging stations in Pee Dee River Basin. 


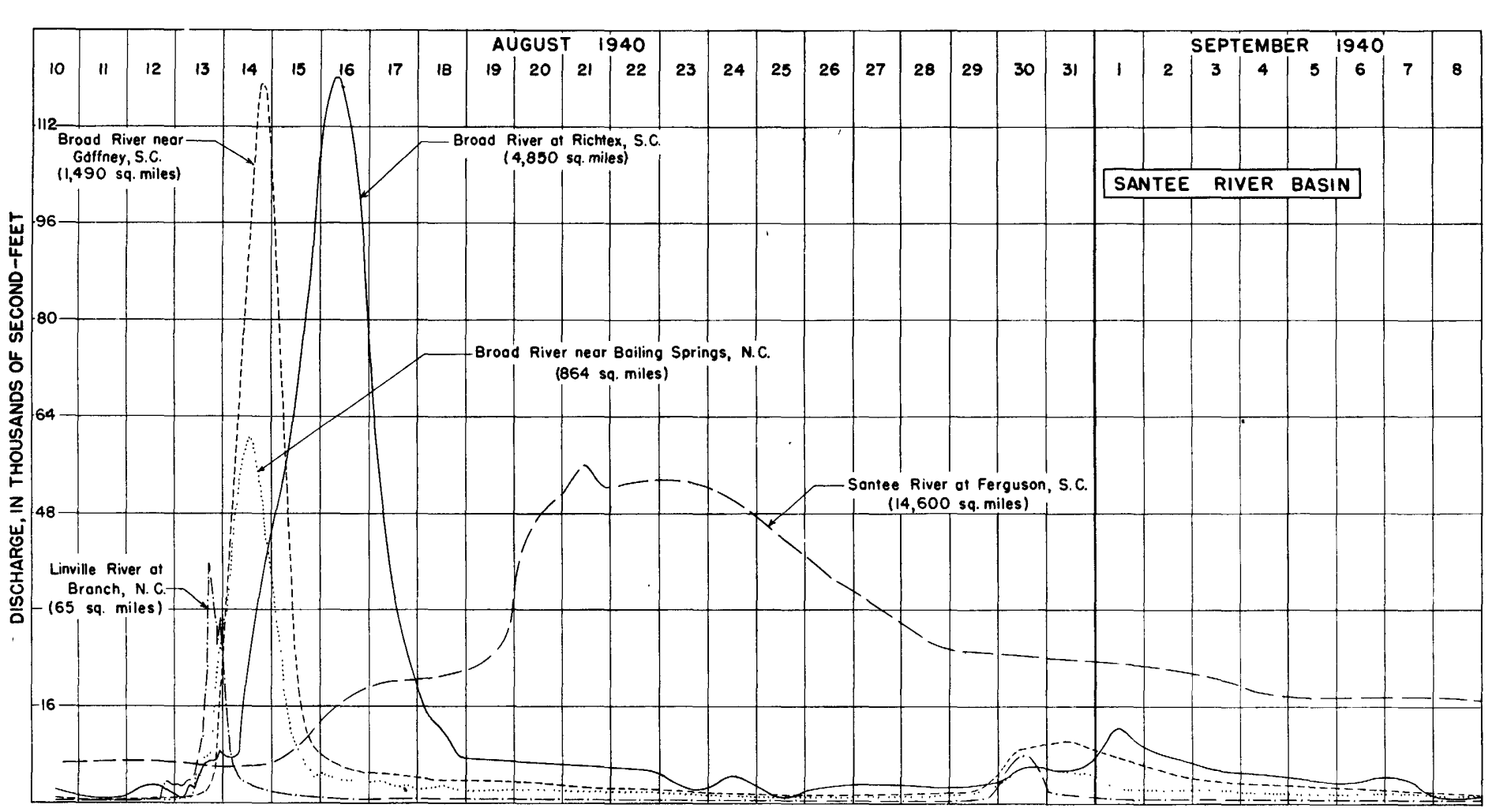




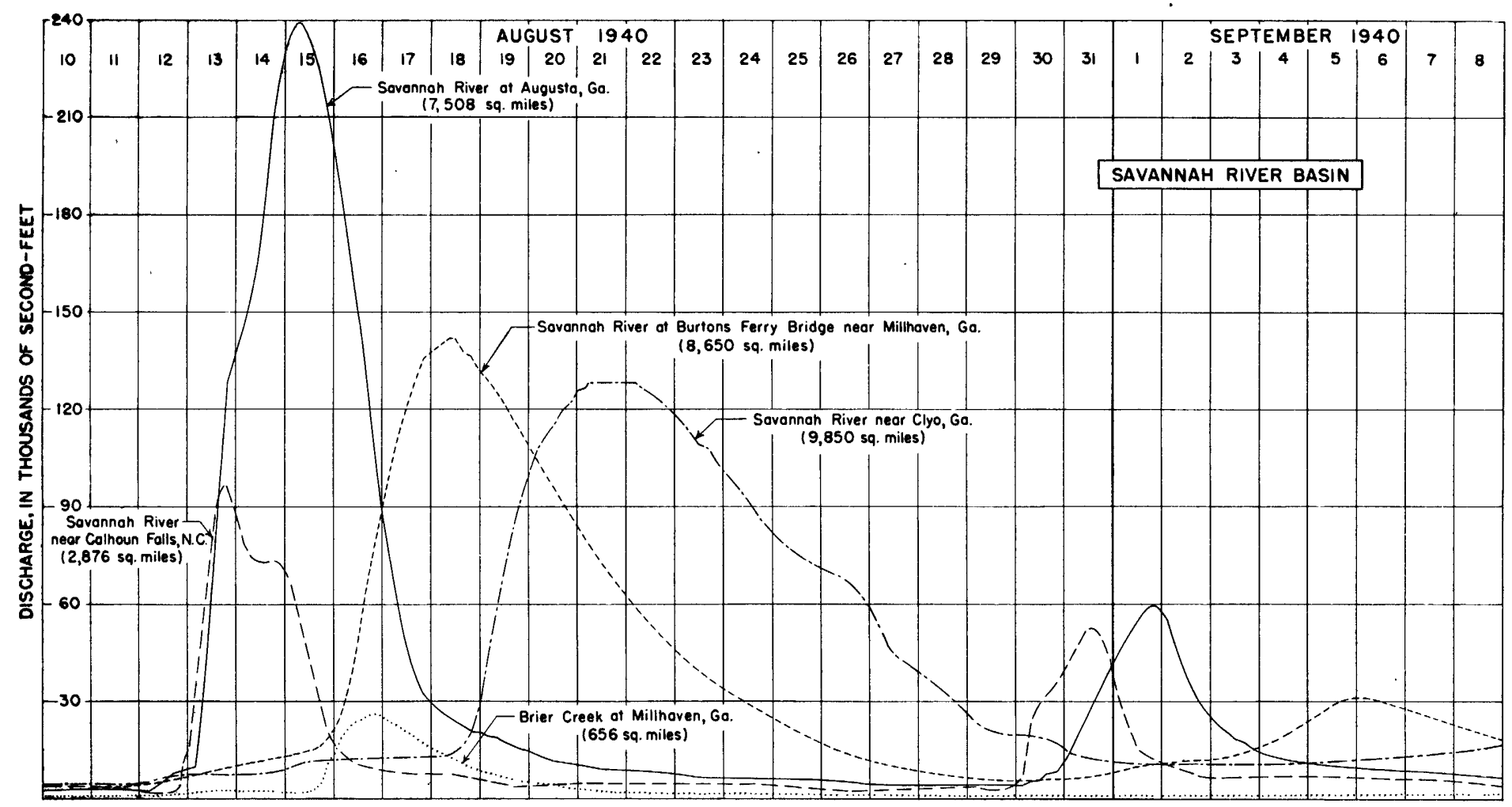

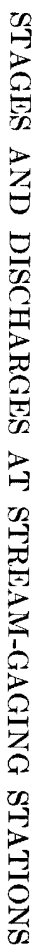

FIGURE 15.- Grap's of disciarge at various stream-gaging stations in Savannah River Barin. 


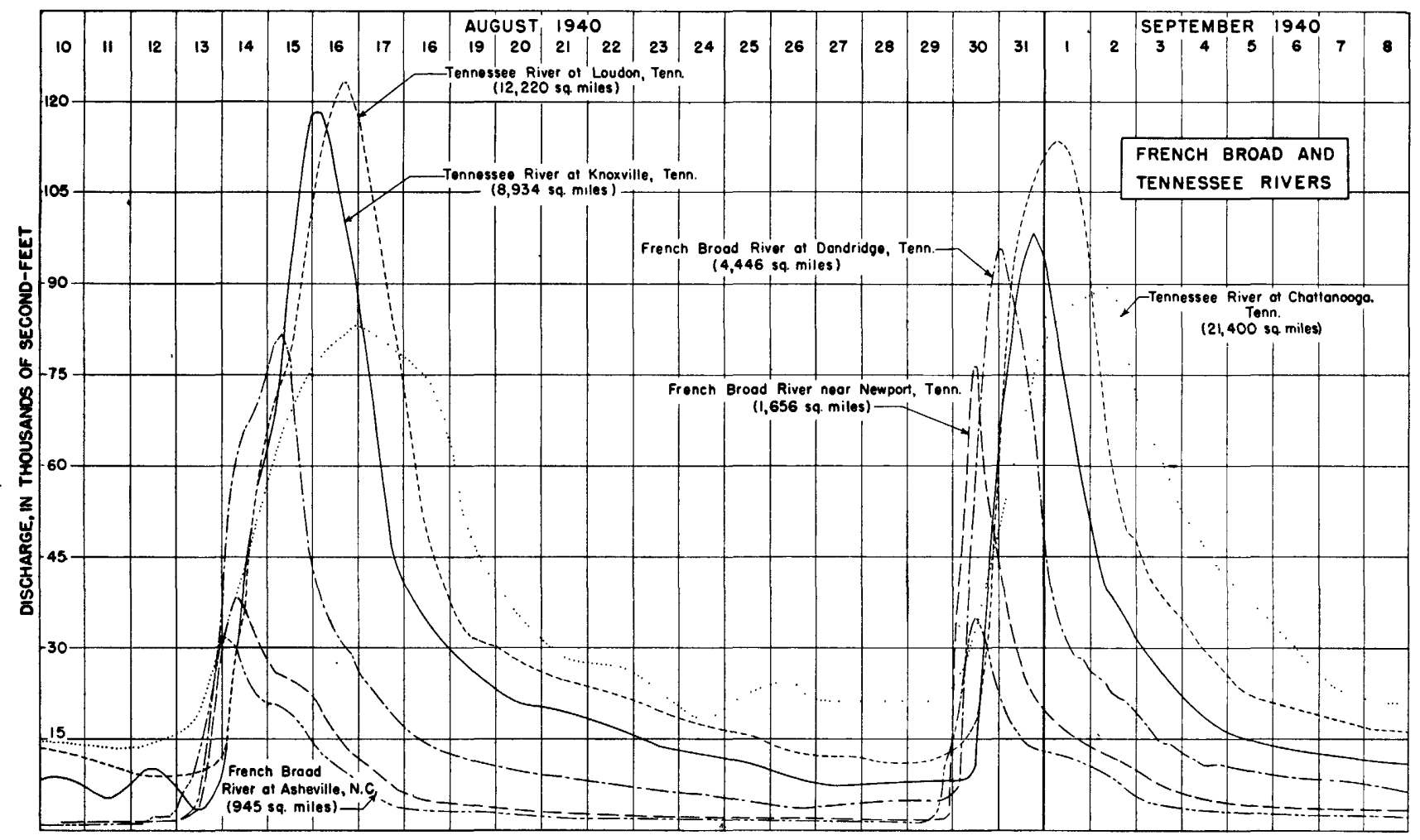

是

FIGURE 17.-Graphs of discharge at various stream-gaging stations on French Broad and Tennessee Rivers. 


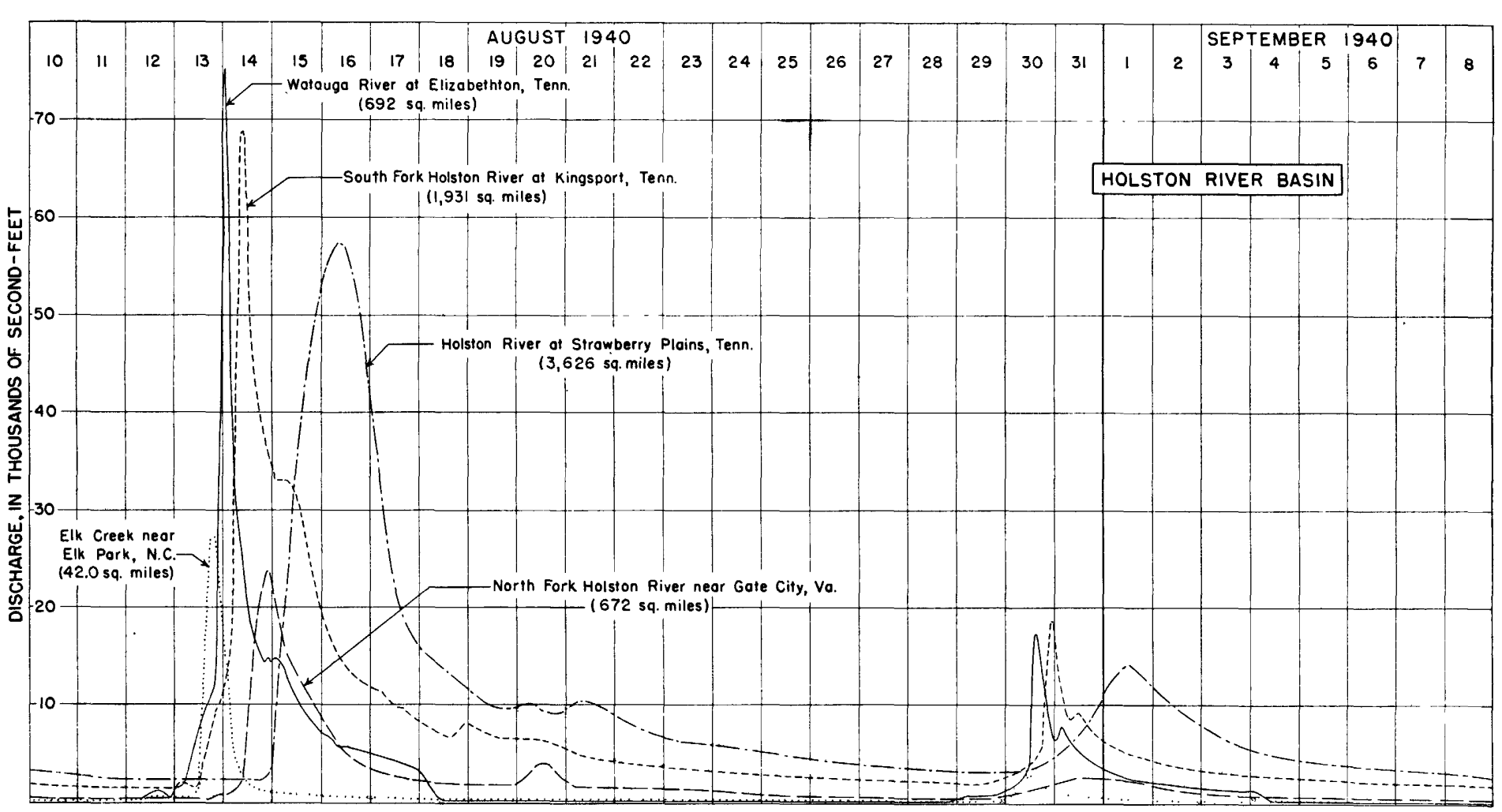




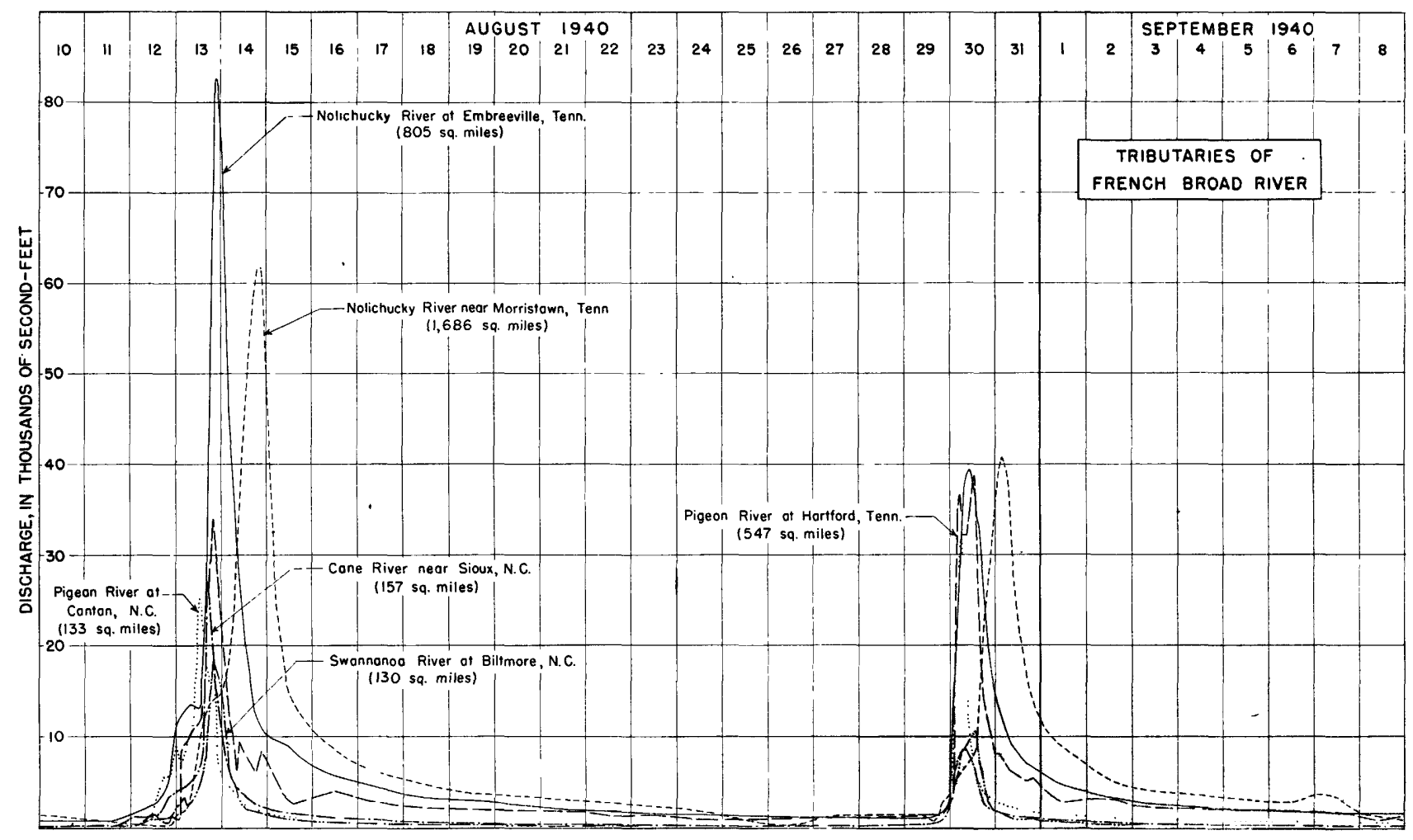




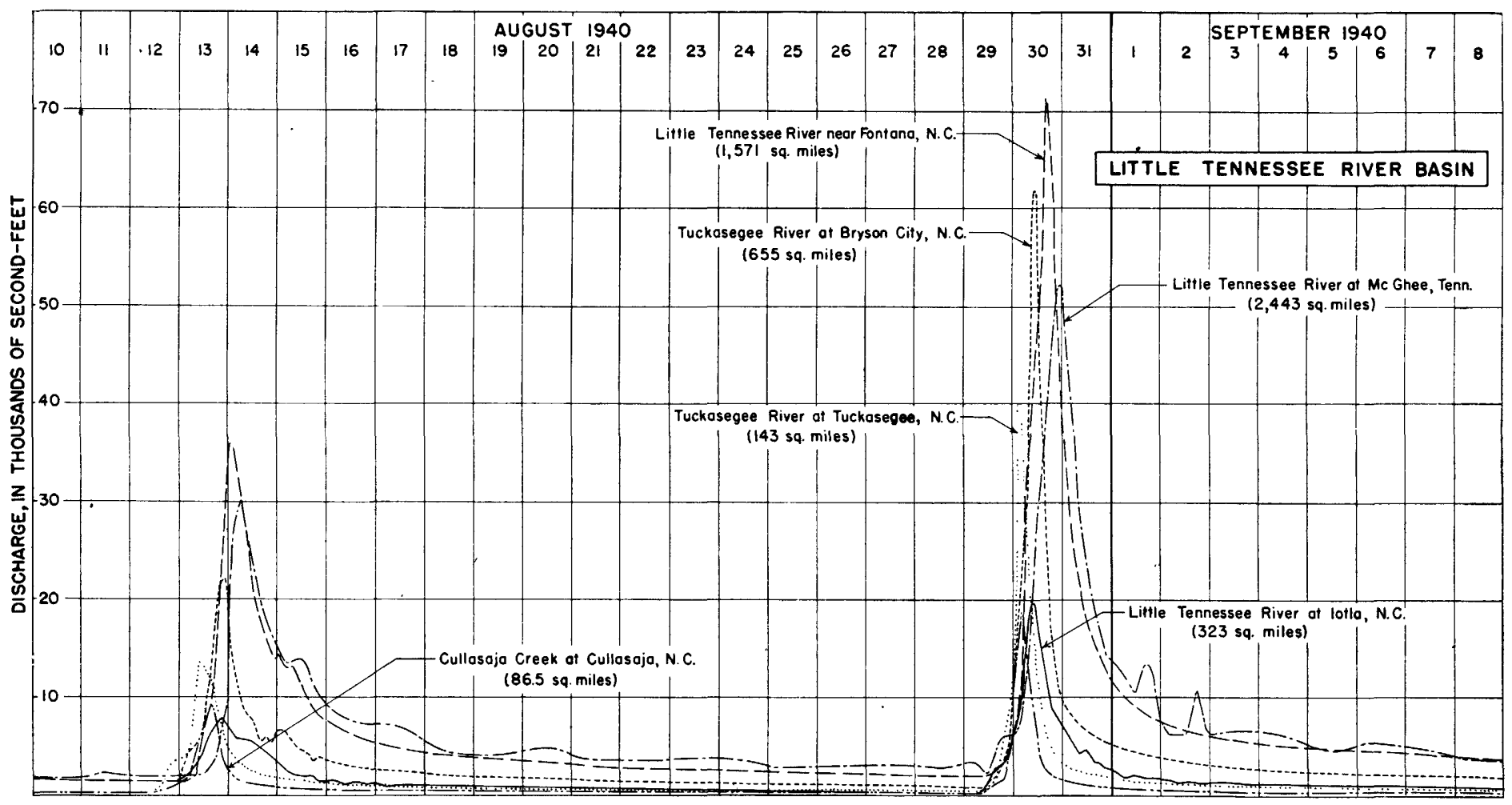




\section{JAMES RIVER BASIN}

\section{JACKSON RIVER AT FALLING SPRING, VA.}

Lochtion.-Lat. $37^{\circ} 52^{\prime} 36^{\prime \prime}$, long. $79^{\circ} 58^{\prime} 39^{\prime \prime}$, at Smith Bridge, 1 mile south of Falling Spring, Alleghany County, and $1 \frac{112}{2}$ miles downstream from Falling Springs Creek. Datum of gage is 1,333.49 feet above mean sea level (levels by Corps of Engineers, War Department).

Drainage area.-409 square miles.

GAGE-HEIGHT RECORD.-Water-stage recorder graph.

Discharge RECORD.--Stage-discharge relation defined by current-meter measurements up to 9,000 second-feet and extended to erest gage height of March 1936 on basis of velocity-area studies and comparison of peak discharge and total runoff of flood at this station with those for other stations in James River Basin. Gage heights used to half-tenths between 4.6 and 7.6 feet; hundredths below and tenths above these limits.

МАхтм $4 .-1940$ : Discharge during flood period, 4,030 second-feet 4 a.m. Aug. 16 (gage height, 8.72 feet).

1925-40: Discharge, 24,700 second-feet Mar. 17, 1936 (gage height, 14.74 feet).

Mean discharge, in second-feet, 1940

\begin{tabular}{|c|c|c|c|c|c|c|c|c|c|c|c|}
\hline${ }^{'}$ Day & Aug. & Sept. & Day & Aug. & Sept. & Day & Aug. & Sept. & Day & Aug. & Sept. \\
\hline $\begin{array}{l}1 \\
2 \\
3 \\
4 \\
5 \\
5 \\
6 \\
7 \\
8\end{array}$ & $\begin{array}{r}884 \\
530 \\
378 \\
310 \\
275 \\
275 \\
2,100 \\
779\end{array}$ & $\begin{array}{r}1,650 \\
1,030 \\
730 \\
572 \\
463 \\
398 \\
351 \\
313\end{array}$ & $\begin{array}{r}9 \\
10 \\
11 \\
12 \\
13 \\
14 \\
15 \\
16\end{array}$ & $\begin{array}{r}490 \\
.364 \\
304 \\
272 \\
254 \\
1,060 \\
2,710 \\
3,600\end{array}$ & $\begin{array}{l}295 \\
286 \\
269 \\
244 \\
226 \\
213 \\
202 \\
190\end{array}$ & $\begin{array}{l}17 \\
18 \\
19 \\
20 \\
21 \\
22 \\
23 \\
24\end{array}$ & $\begin{array}{r}2,520 \\
1,560 \\
1,050 \\
772 \\
596 \\
490 \\
417 \\
364\end{array}$ & $\begin{array}{l}182 \\
175 \\
168 \\
162 \\
155 \\
153 \\
145 \\
143\end{array}$ & $\begin{array}{l}25 \\
26 \\
27 \\
28 \\
29 \\
30 \\
31 .\end{array}$ & $\begin{array}{r}326 \\
395 \\
502 \\
1,130 \\
1,570 \\
884 \\
856\end{array}$ & $\begin{array}{r}178 \\
182 \\
175 \\
153 \\
145 \\
138 \\
\end{array}$ \\
\hline \multicolumn{10}{|c|}{$\begin{array}{l}\text { Monthly mean discharge, in second-feet } \\
\text { Runoff, in inches }\end{array}$} & $\begin{array}{r}904 \\
2.55\end{array}$ & $\begin{array}{r}323 \\
0.88\end{array}$ \\
\hline
\end{tabular}

Gage height, in feet, and discharge, in second-feet, at indicated time, 1940

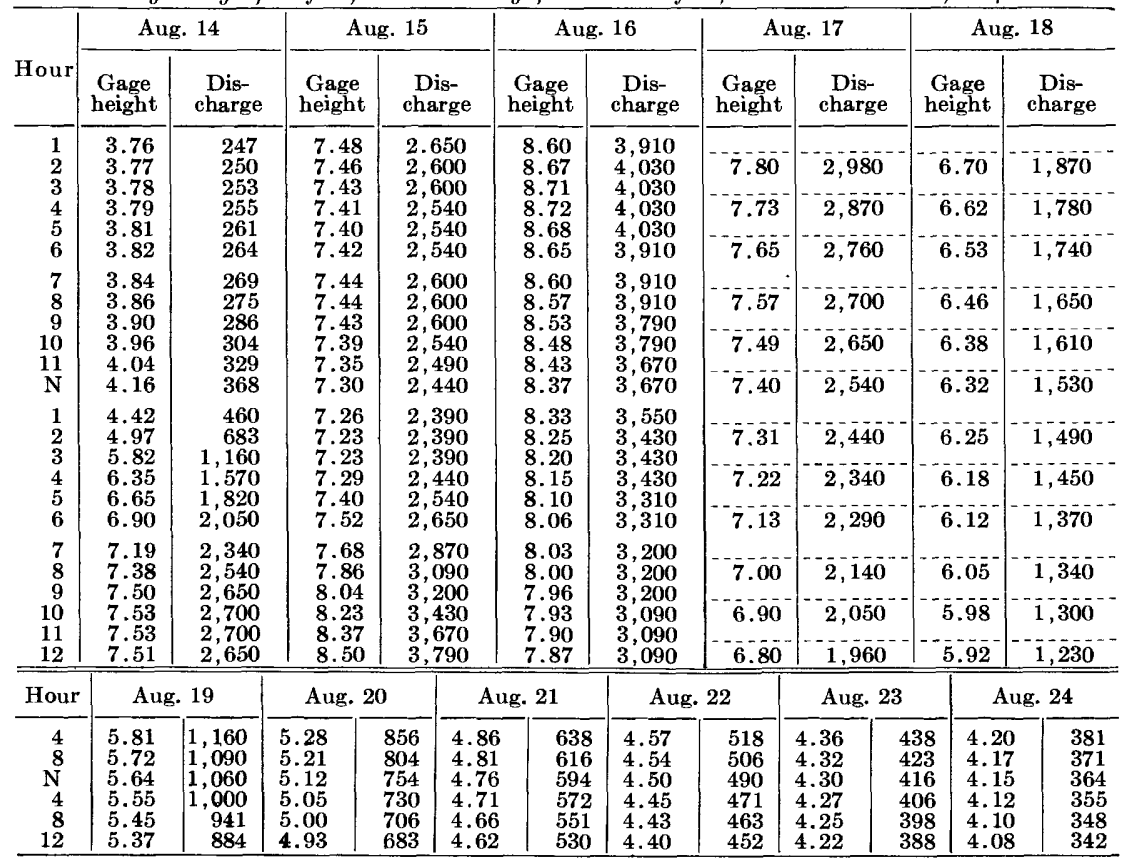


JAMES RIVER AT LICK RUN, VA.

LOCATION.-Lat. $37^{\circ} 47^{\prime}$, long. $79^{\circ} 47^{\prime}$, at highway bridge at Lick Run, Botetourt County, three-quarters of a mile downstream from confluence of Cowpasture and Jackson Rivers. Datum of gage is 978.30 feet above mean sea level (levels by Corps of Engineers, War Department).

DRAINAGE AREA.-1,369 square miles.

GAge-Height RECond.-Water-stage recorder graph.

DischARGE RECORD.- Stage-diseharge relation defined by eurrent-meter measurements up to 33,000 second-feet and extended to erest stage on basis of velocity-area studies and comparison of peak discharge and total runoff of flood of Mar. 18, 1936, at this station with those for other stations in James River Basin. Gage heights used to half-tenths between 2.5 and 5.7 feet; hundredths below and tenths above these limits.

Maxima.-August 1940: Discharge, 18,700 second-feet 10 a.m. Aug. 16 (gage height, 13.22 feet).

1925 to July 1940: Discharge, 66,600 second-feet Mar. 18, 1936 (gage height, 25.65 feet).

Stage known, about 33 feet, from floodmarks, sometime in November 1877 (discharge, about 120,000 second-feet). Flood of March 1913 reached a stage of 30.4 feet, from floodmarks (diseharge, about 98,000 second-feet).

Mean discharge, in second-feet, 1940

\begin{tabular}{|c|c|c|c|c|c|c|c|c|c|c|c|}
\hline Day & Aug. & Sept. & Day & Aug. & Sept. & Day & Aug. & Sept. & Day & Aug. & Sept. \\
\hline $\begin{array}{l}1 \\
2 \\
3 \\
4 \\
5 \\
6 \\
7 \\
8\end{array}$ & $\begin{array}{r}1,900 \\
1,750 \\
1,080 \\
845 \\
708 \\
682 \\
3,020 \\
2,350\end{array}$ & $\begin{array}{r}6,230 \\
3,670 \\
2,410 \\
1,750 \\
1,440 \\
1,190 \\
1,040 \\
905\end{array}$ & $\begin{array}{r}9 \\
10 \\
11 \\
12 \\
13 \\
14 \\
15 \\
16\end{array}$ & $\begin{array}{r}1,310 \\
938 \\
761 \\
682 \\
666 \\
4,110 \\
14,700 \\
17,400\end{array}$ & $\begin{array}{l}845 \\
816 \\
761 \\
708 \\
632 \\
589 \\
570 \\
520\end{array}$ & $\begin{array}{l}17 \\
18 \\
19 \\
20 \\
21 \\
22 \\
23 \\
24\end{array}$ & $\begin{array}{r}12,900 \\
6,710 \\
4,050 \\
2,810 \\
2,040 \\
1,600 \\
1,330 \\
1,140\end{array}$ & $\begin{array}{l}501 \\
474 \\
457 \\
440 \\
423 \\
410 \\
393 \\
385\end{array}$ & $\begin{array}{l}25 \\
26 \\
27 \\
28 \\
29 \\
30 \\
31\end{array}$ & $\begin{array}{l}1,000 \\
1,120 \\
1,520 \\
1,700 \\
3,820 \\
2,530 \\
3,820\end{array}$ & $\begin{array}{l}435 \\
488 \\
474 \\
419 \\
389 \\
377\end{array}$ \\
\hline $\begin{array}{c}\text { on } \\
\text { no }\end{array}$ & & & & & & & & & & $\begin{array}{r}3,258 \\
2.74 \\
\end{array}$ & $\begin{array}{r}1,005 \\
0.82 \\
\end{array}$ \\
\hline
\end{tabular}


JAMES RIVER BASIN

Gage height, in feet, and discharge, in second-feet, at indicated time, 1940

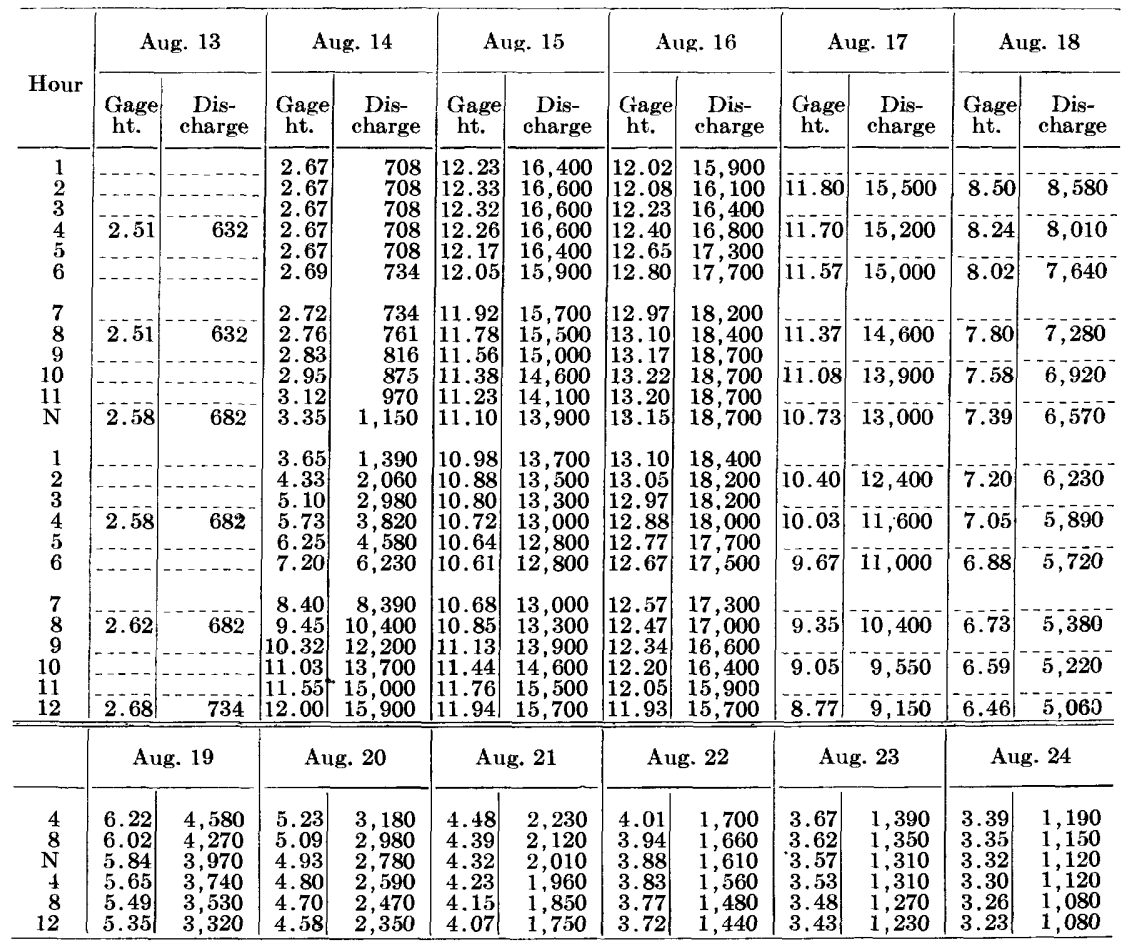

\section{JAMES RIVEK A'T BUCHANAN, VA.}

I.OCATION.-Lat. $37^{\circ} 31^{\prime} 50^{\prime \prime}$, long. $79^{\circ} 40^{\prime} 45^{\prime \prime}$, at Chesapeake and Ohio Railway station at Buchanan, Botetourt County, 300 feet upstream from bridge on U. S. Highway $11,1,000$ feet upstream from Purgatory Creek, and 11/2 miles downstream from Looney Creek. Datum of gage is 802.56 feet above mean sea level (levels by Corps of Engineers, War Department).

Drainage AREA. - 2,084 square miles.

GAGE-HEIGHT RECORD.-Water-stage recorder graph.

IISCIIARGE RECORD.-Stage-discharge relation defined by current-meter measurements up to 47,000 second-feet and extended to crest gage height of March 1913 on basis of velocity-area studies, determination of flow over dam at Balcony Falls during flood of March 1936, and comparison of peak discharge and total runoff of that flood at this station with those at other stations in James River Basin. Gage heights used to half-tenths between 3.0 and 6.0 feet; hundredths below and tenths above these limits.

M height, 16.00 feet).

1895 to July 1940: Discharge, about 105,000 second-feet Mar. 27, 1913 (gage leeight, 31 feet, from floodmarks).

Stage known, 34.9 feet, from floodmark, sometime in November 1877 (discharge, about 125,000 second-feet. 
Mean discharge, in second-feet, 1940

\begin{tabular}{|c|c|c|c|c|c|c|c|c|c|c|c|}
\hline Day & Aug. & Sept. & Day & Aug. & Sept. & Day & Aug. & Sept. & Day & Aug. & Sept. \\
\hline $\begin{array}{l}1 \\
2 \\
3 \\
4 \\
5 \\
6 \\
7 \\
8\end{array}$ & $\begin{array}{r}1,820 \\
2,450 \\
1,640 \\
1,260 \\
1,070 \\
991 \\
1,470 \\
3,970\end{array}$ & $\begin{array}{r}10,8 \\
6,8 \\
4, \\
3,1 \\
2, \\
2,1 \\
1,8 \\
1,6\end{array}$ & $\begin{array}{r}9 \\
10 \\
11 \\
12 \\
13 \\
14 \\
15 \\
16\end{array}$ & $\begin{array}{r}2,060 \\
1,430 \\
1,150 \\
1,030 \\
944 \\
9,040 \\
34,200 \\
33,400\end{array}$ & $\begin{array}{r}1,480 \\
1,380 \\
1,330 \\
1,230 \\
1,140 \\
1,070 \\
1,010 \\
964\end{array}$ & $\begin{array}{l}17 \\
18 \\
19 \\
20 \\
21 \\
22 \\
23 \\
24\end{array}$ & $\begin{array}{r}26,300 \\
14,600 \\
8,330 \\
5,350 \\
3,820 \\
3,010 \\
2,520 \\
2,140\end{array}$ & $\begin{array}{l}902 \\
870 \\
846 \\
814 \\
790 \\
758 \\
718 \\
710\end{array}$ & $\begin{array}{l}25 \\
26 \\
27 \\
28 \\
29 \\
30 \\
31\end{array}$ & $\begin{array}{r}1,880 \\
1,820 \\
2,120 \\
2,320 \\
4,070 \\
4,500 \\
11,100\end{array}$ & $\begin{array}{l}798 \\
830 \\
814 \\
782 \\
718 \\
678\end{array}$ \\
\hline \multicolumn{10}{|c|}{$\begin{array}{l}\text { Monthly mean discharge, in second-feet } \\
\text { Runoff, in inches }\end{array}$} & $\begin{array}{r}16,187 \\
3.42\end{array}$ & $\begin{array}{r}1,799 \\
0.96\end{array}$ \\
\hline
\end{tabular}

1 Discharge is different from that given in Water-Supply Paper 892. It is based on revisions not considered important enough for inclusion in other published records.

Gage height, in feet, and discharge, in second-feet, at indicated time, 1940

\begin{tabular}{|c|c|c|c|c|c|c|c|c|c|c|c|c|}
\hline \multirow{2}{*}{ Hour } & \multicolumn{2}{|c|}{ Aug. 13} & \multicolumn{2}{|c|}{ Aug. 14} & \multicolumn{2}{|c|}{ Aug. 15} & \multicolumn{2}{|c|}{ Aug. 16} & \multicolumn{2}{|c|}{ Aug. 17} & \multicolumn{2}{|c|}{ Aug. 18} \\
\hline & $\begin{array}{c}\text { Gage } \\
\text { ht. }\end{array}$ & $\begin{array}{c}\text { Dis- } \\
\text { charge }\end{array}$ & $\begin{array}{c}\text { Gage } \\
\text { ht. }\end{array}$ & $\begin{array}{c}\text { Dis- } \\
\text { charge }\end{array}$ & $\begin{array}{c}\text { Gage } \\
\text { ht. }\end{array}$ & $\begin{array}{c}\text { Dis- } \\
\text { charge }\end{array}$ & $\begin{array}{c}\text { Gage } \\
\text { ht. }\end{array}$ & $\begin{array}{c}\text { Dis- } \\
\text { charge }\end{array}$ & $\begin{array}{c}\text { Gage } \\
\text { ht. }\end{array}$ & $\begin{array}{c}\text { Dis- } \\
\text { charge }\end{array}$ & $\begin{array}{c}\text { Gage } \\
\text { ht. }\end{array}$ & $\begin{array}{c}\text { Dis- } \\
\text { charge }\end{array}$ \\
\hline \multirow{3}{*}{$\begin{array}{l}1 \\
2 \\
3 \\
4 \\
5 \\
6\end{array}$} & & & \multirow{3}{*}{$\begin{array}{l}2.65 \\
2.67 \\
2.69 \\
2.71 \\
2.73 \\
2.75\end{array}$} & \multirow{3}{*}{$\begin{array}{r}955 \\
973 \\
991 \\
1,010 \\
1,030 \\
1,040\end{array}$} & \multirow{3}{*}{$\begin{array}{l}13.27 \\
13.48 \\
13.73 \\
14.05 \\
14.45 \\
14.85\end{array}$} & \multirow{3}{*}{$\begin{array}{l}28,500 \\
29,200 \\
29,800 \\
30,800 \\
32,200 \\
33,500\end{array}$} & \multirow{3}{*}{$\begin{array}{l}14.61 \\
14.55 \\
14.50 \\
14.46 \\
14.47 \\
14.54\end{array}$} & \multirow{3}{*}{$\begin{array}{l}32,800 \\
32,800 \\
32,500 \\
32,500 \\
32,500 \\
32,500\end{array}$} & 14.25 & 31,500 & 10.31 & 18,80 \\
\hline & 2.66 & $964^{-}$ & & & & & & & $13 . \overline{8}$ & 30,500 & 9.97 & 17,900 \\
\hline & & & & & & & & & 13.52 & 29,200 & 9.65 & 16,600 \\
\hline \multirow{4}{*}{$\begin{array}{r}7 \\
8 \\
9 \\
10 \\
11\end{array}$} & 2.65 & 955 & \multirow{4}{*}{$\begin{array}{l}2.78 \\
2.87 \\
2.96 \\
3.12 \\
4.05 \\
5.29\end{array}$} & \multirow{4}{*}{$\begin{array}{r}1,070 \\
1,150 \\
1,240 \\
1,380 \\
2,520 \\
4,590\end{array}$} & \multirow{4}{*}{$\begin{array}{l}15.21 \\
15.54 \\
15.74 \\
15.90 \\
15.97 \\
16.00\end{array}$} & \multirow{4}{*}{$\begin{array}{l}34,900 \\
35,900 \\
36,600 \\
37,300 \\
37,600 \\
37,600\end{array}$} & \multirow{4}{*}{$\begin{array}{l}14.60 \\
14.63 \\
14.62 \\
14.62 \\
14.63 \\
14.68\end{array}$} & \multirow{4}{*}{$\begin{array}{l}32,800 \\
32,800 \\
32,800 \\
32,800 \\
32,800 \\
33,200\end{array}$} & 13.17 & 28,200 & 9.36 & 16,000 \\
\hline & & & & & & & & & 1287 & 0 & 09 & 5100 \\
\hline & & & & & & & & & & & & \\
\hline & 2.63 & 937 & & & & & & & 12.60 & 26,200 & 8.85 & 14,200 \\
\hline \multirow{4}{*}{$\begin{array}{l}1 \\
2 \\
3 \\
4 \\
5 \\
6\end{array}$} & & & \multirow{4}{*}{$\begin{array}{l}5.84 \\
6.29 \\
6.68 \\
7.29 \\
8.50 \\
9.64\end{array}$} & \multirow{4}{*}{$\begin{array}{r}5,780 \\
6,880 \\
7,930 \\
9,600 \\
13,200 \\
16,600\end{array}$} & \multirow{4}{*}{$\mid \begin{array}{l}15.97 \\
15.87 \\
15.72 \\
15.52 \\
15.34 \\
15.18\end{array}$} & \multirow{4}{*}{$\begin{array}{l}37,600 \\
37,300 \\
36,600 \\
35,900 \\
35,200 \\
34,900\end{array}$} & \multirow{4}{*}{$\begin{array}{l}14.75 \\
14.85 \\
14.93 \\
15.04 \\
15.10 \\
15.12\end{array}$} & \multirow{4}{*}{$\begin{array}{l}33,500 \\
33,500 \\
33,900 \\
34,200 \\
34,500 \\
34,500\end{array}$} & & & & \\
\hline & & & & & & & & & .35 & & .02 & \\
\hline & 2.62 & 928 & & & & & & & 12.07 & 24,500 & 8.40 & 12,900 \\
\hline & & & & & & & & & 11.74 & 23,300 & 8.19 & 12,300 \\
\hline \multirow{5}{*}{$\begin{array}{r}7 \\
8 \\
9 \\
10 \\
11 \\
12 \\
\end{array}$} & 2.61 & 919 & \multirow{4}{*}{$\mid \begin{array}{l}10.90 \\
11.83 \\
12.48 \\
12.85 \\
13.03 \\
13.16\end{array}$} & \multirow{4}{*}{$\begin{array}{l}20,700 \\
23,600 \\
25,800 \\
26,800 \\
27,500 \\
28,200\end{array}$} & $\begin{array}{l}15.04 \\
14.94\end{array}$ & & $\left|\begin{array}{l}15.11 \\
15.08\end{array}\right|$ & & 11.37 & 22,300 & 8.01 & 11,700 \\
\hline & & & & & 14.87 & 33, & 14.98 & 34,200 & & & & \\
\hline & & & & & 14.82 & 33,500 & 14.90 & 33,900 & 11.00 & 21,000 & 7.82 & 11,100 \\
\hline & 2.65 & $955^{-}$ & & & 14.67 & 33,200 & 4.62 & 32,800 & $10 . \overline{63}$ & 19,700 & 7.66 & 10,800 \\
\hline & & g. 19 & & g. 20 & A & 21 & & & & g. 23 & & 4 \\
\hline & & & 5.9 & & 5.1 & & & & & & & \\
\hline 8 & 7.06 & & 5.8 & & 4 . & & & & & & & \\
\hline & & & & & & & & & & & & \\
\hline & & & & & & & & & & & & \\
\hline & & & .5 & & 4. & & . & & & & & \\
\hline & & & & & & & & & & & & \\
\hline
\end{tabular}

JAMES RIVER AT HOLCOMBS ROCK, VA.

Location.-Lat. $37^{\circ} 30^{\prime}$, long. $79^{\circ} 15^{\prime}$, at Holcombs Rock, Bedford County, half a mile downstream from Pedlar River. Datum of gage is 548.53 feet above mean sea level, datum of 1929.

Drainage area.- 3,250 square miles.

GAGE-HEIGHT RECORD.-Water-stage recorder graph.

DISCHARGE RECORD.--Stage-discharge relation defined by current-meter measurements up to 41,000 second-feet and extended to crest gage height of flood of March 1936 on basis of determination of peak flow over dam at Reusens and comparisons of peak discharge and total runoff of flood at this station with those for other stations in James River Basin. Gage heights used to half-tenths between 5.1 and 7.0 feet; hundredths below and tenths above these limits. 
Maxima.-1940: Discharge, 66,800 second-feet 3 p.m. Aug. 16 (gage height, 24.25 feet).

1926-39: Discharge, 115,000 second-feet Mar. 18, 1936 (gage height, 30.78 feet).

Stage known, 31.3 feet in March 1913, from floodmarks (discharge about 118,000 second-feet.

REMARKS.-Low-water flow regulated by power plants above station.

Mean discharge, in second-feet, 1940

\begin{tabular}{|c|c|c|c|c|c|c|c|c|c|c|c|}
\hline Day & Aug. & Sept. & Day & Aug. & Sept. & Day & Aug. & Sept. & Day & Aug. & Sept. \\
\hline $\begin{array}{l}1 \\
2 \\
3 \\
4 \\
5 \\
6 \\
7 \\
8\end{array}$ & $\begin{array}{l}2,180 \\
2,880 \\
2,670 \\
2,000 \\
1,590 \\
1,400 \\
1,610 \\
4,200\end{array}$ & $\begin{array}{r}19,200 \\
12,900 \\
8,320 \\
6,020 \\
4,930 \\
4,040 \\
3,220 \\
3,000\end{array}$ & $\begin{array}{r}9 \\
10 \\
11 \\
12 \\
13 \\
14 \\
15 \\
16\end{array}$ & $\begin{array}{r}3,140 \\
2,230 \\
1,800 \\
1,630 \\
1,470 \\
8,220 \\
43,300 \\
60,300\end{array}$ & $\begin{array}{l}2,510 \\
2,240 \\
2,210 \\
2,000 \\
1,990 \\
1,640 \\
1,820\end{array}$ & $\begin{array}{l}17 \\
18 \\
19 \\
20 \\
21 \\
22 \\
23 \\
24\end{array}$ & $\begin{array}{r}48,400 \\
24,600 \\
14,200 \\
9,660 \\
7,100 \\
5,620 \\
4,590 \\
3,800\end{array}$ & $\begin{array}{l}1,670 \\
1,520 \\
1,540 \\
1,380 \\
1,260 \\
1,030 \\
1,300 \\
1,280\end{array}$ & $\begin{array}{l}25 \\
26 \\
27 \\
28 \\
29 \\
30 \\
31\end{array}$ & $\begin{array}{r}3,320 \\
3,160 \\
3,020 \\
3,960 \\
6,480 \\
7,210 \\
19,100\end{array}$ & $\begin{array}{r}1,380 \\
1,530 \\
1,400 \\
1,360 \\
1,330 \\
1,260 \\
-\end{array}$ \\
\hline \multicolumn{12}{|c|}{$\begin{array}{l}\text { Monthly mean discharge, in second-feet } \\
\text { Runoff, in inches }\end{array}$} \\
\hline
\end{tabular}

Gage height, in feet, and discharge, in second-feet, at indicated time, 1940

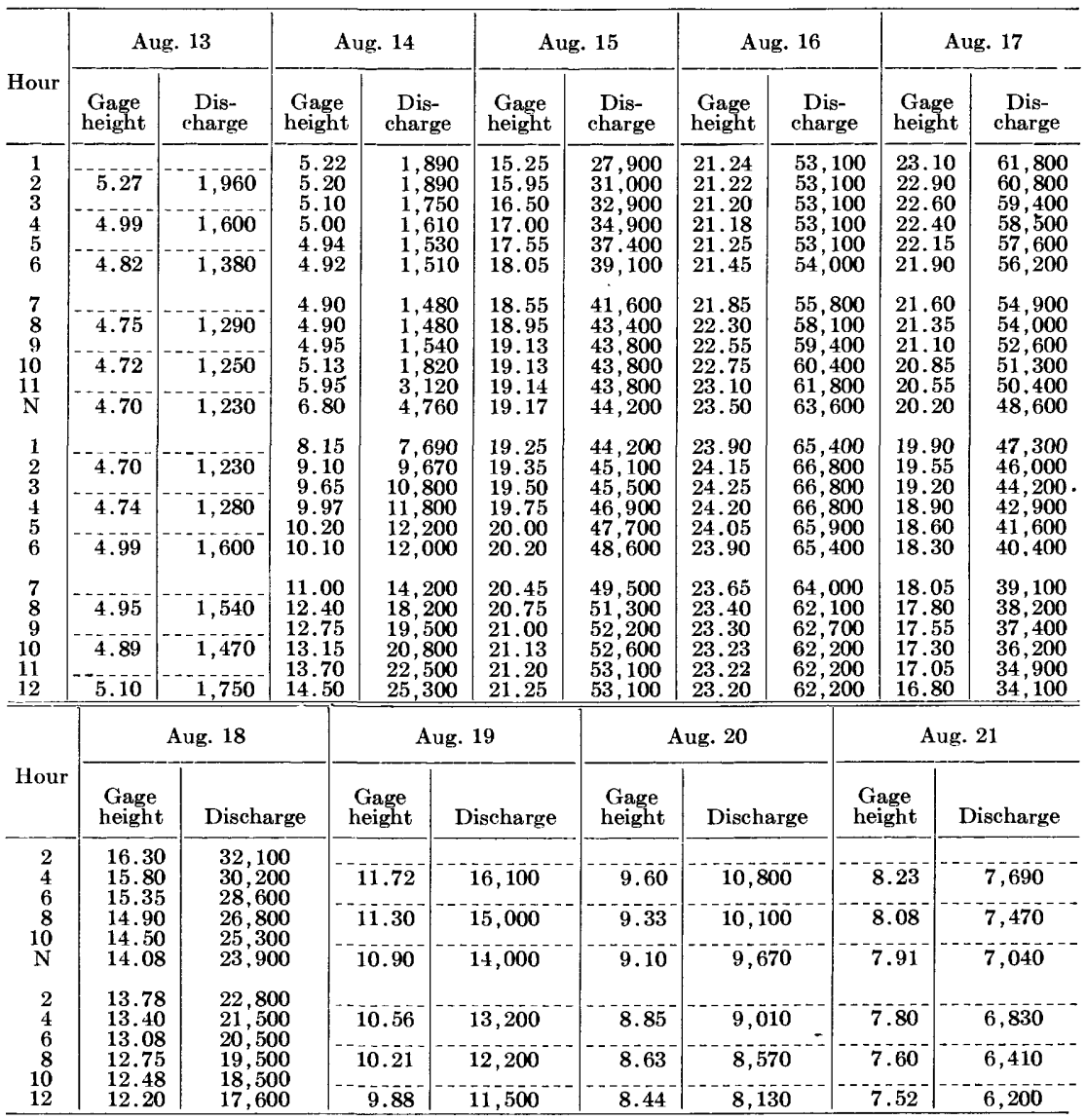


JAMES RIVER AT BENT CREEK, VA.

Location.-Lat. $37^{\circ} 32^{\prime}$, long. $78^{\circ} 50^{\prime}$, at highway bridge at town of Bent Creek, Appomattox County, 150 feet downstream from Bent Creek, and 1 mile downstream from Gladstone. Datum of gage is 381.38 feet above mean sea level datum of 1929 .

DRAINAGE AREA.- $-3,671$ square miles.

GAGE-HEIGHT RECORD.-Water-stage recorder graph.

DISCHARGE RECORD.-Stage-discharge relation defined by eurrent-meter measurements up to 45,000 second-feet and extended to erest gage height of March 1936 on basis of velocity-area studies and comparison of peak discharge and total runoff at this station with those for other stations in James River Basin. Gage heights used to half-tenths between 3.8 and 5.8 feet, to Aug. 16, between 3.7 and 5.7 feet, thereafter; hundredths below and tenths above these limits.

Maxima.-1940: Discharge, 86,200 (revised) second-feet 4:30 p.m. Aug. 16 (gage height, 19.63 feet).

1925-39: Discharge, 115,000 second-feet Mar. 18, 1936 (gage height, 23.02 feet).

Mean discharge, in second-feet, 1940

\begin{tabular}{|c|c|c|c|c|c|c|c|c|c|c|c|}
\hline Day & Aug. & Sept. & Day & Aug. & Sept. & Day & Aug. & Sept. & Day & Aug. & Sept. \\
\hline $\begin{array}{l}1 \\
2 \\
3 \\
4 \\
5 \\
6 \\
7 \\
8\end{array}$ & $\begin{array}{l}2,240 \\
2,900 \\
3,200 \\
2,800 \\
2,360 \\
2,040 \\
1,900 \\
2,520\end{array}$ & $\begin{array}{r}21,200 \\
15,300 \\
10,200 \\
7,540 \\
6,210 \\
5,320 \\
4, \mathbf{3 1 0} \\
\mathbf{3}, \mathbf{5 7 0}\end{array}$ & $\begin{array}{r}9 \\
10 \\
11 \\
12 \\
13 \\
14 \\
15 \\
16\end{array}$ & \begin{tabular}{|r|}
4,870 \\
2,550 \\
2,960 \\
2,060 \\
2,020 \\
7,190 \\
147,500 \\
181,200
\end{tabular} & $\begin{array}{l}3,500 \\
3,480 \\
2,980 \\
2,810 \\
2,780 \\
2,500 \\
2,380 \\
2,310\end{array}$ & $\begin{array}{l}17 \\
18 \\
19 \\
20 \\
21 \\
22 \\
23 \\
24\end{array}$ & $\begin{array}{r}162,700 \\
31,000 \\
18,000 \\
12,400 \\
9,420 \\
7,860 \\
6,200 \\
5,300\end{array}$ & $\begin{array}{l}2,420 \\
2,170 \\
2,020 \\
2,380 \\
2,140 \\
1,420 \\
1,320 \\
1,840\end{array}$ & $\begin{array}{l}25 \\
26 \\
27 \\
28 \\
29 \\
30 \\
31\end{array}$ & $\begin{array}{r}4,660 \\
4,260 \\
4,100 \\
4,870 \\
6,420 \\
7,700 \\
14,300\end{array}$ & $\begin{array}{l}1,960 \\
2,380 \\
1,920 \\
2,040 \\
2,260 \\
1,970\end{array}$ \\
\hline \multicolumn{11}{|c|}{$\begin{array}{l}\text { Monthly mean discharge, in second-feet. } \\
\text { Runoff, in inches. }\end{array}$} & $\begin{array}{r}4,154 \\
1.26\end{array}$ \\
\hline
\end{tabular}

${ }_{1}^{1}$ Discharge is different from that given in Water-Supply Paper 892. It is based on revisions not considered important enough for inclusion in other Water-Supply Papers. 
Gage height, in feet, and discharge, in second-feet, at indicated time, 1940

\begin{tabular}{|c|c|c|c|c|c|c|c|c|c|c|}
\hline \multirow{2}{*}{ Hour } & \multicolumn{2}{|c|}{ Aug. 13} & \multicolumn{2}{|c|}{ Aug. 14} & \multicolumn{2}{|c|}{ Aug. 15} & \multicolumn{2}{|c|}{ Aug. 16} & \multicolumn{2}{|c|}{ Aug. 17} \\
\hline & $\begin{array}{c}\text { Gage } \\
\text { height }\end{array}$ & $\begin{array}{l}\text { Dis- } \\
\text { charge }\end{array}$ & $\begin{array}{c}\text { Gage } \\
\text { height }\end{array}$ & $\begin{array}{c}\text { Dis- } \\
\text { charge }\end{array}$ & $\begin{array}{c}\text { Gage } \\
\text { height }\end{array}$ & $\begin{array}{c}\text { Dis- } \\
\text { charge }\end{array}$ & $\begin{array}{l}\text { Gage } \\
\text { height }\end{array}$ & $\begin{array}{c}\text { Dis- } \\
\text { charge }\end{array}$ & $\begin{array}{c}\text { Gage } \\
\text { height }\end{array}$ & $\begin{array}{l}\text { Dis- } \\
\text { charge }\end{array}$ \\
\hline $\begin{array}{l}1 \\
2 \\
3 \\
4 \\
5 \\
6\end{array}$ & $\begin{array}{c}3.72 \\
-3.41 \\
3.19\end{array}$ & $\begin{array}{r}2,510 \\
1,910 \\
1,510\end{array}$ & $\begin{array}{l}3.95 \\
3.83 \\
3.69 \\
3.50 \\
3.38 \\
3.28\end{array}$ & $\begin{array}{l}2,980 \\
2,780 \\
2,450 \\
2,080 \\
1,850 \\
1,670\end{array}$ & $\begin{array}{l}10.95 \\
11.60 \\
12.15 \\
12.65 \\
13.05 \\
13.45\end{array}$ & $\begin{array}{l}27,600 \\
30,800 \\
34,200 \\
36,500 \\
38,900 \\
41,300\end{array}$ & $\begin{array}{l}16.65 \\
17.15 \\
17.75 \\
18.15 \\
18.65 \\
18.95\end{array}$ & $\begin{array}{l}63,000 \\
67,500 \\
72,000 \\
75,000 \\
78,200 \\
81,400\end{array}$ & $\begin{array}{l}18.75 \\
18.55 \\
18.35 \\
18.15 \\
17.95 \\
17.80\end{array}$ & $\begin{array}{l}79,800 \\
78,200 \\
76,600 \\
75,000 \\
73,500 \\
72,000\end{array}$ \\
\hline $\begin{array}{r}7 \\
8 \\
9 \\
10 \\
11 \\
\mathrm{~N}\end{array}$ & $\begin{array}{r}3.45 \\
-3.80 \\
3.52\end{array}$ & $\begin{array}{r}1,980 \\
2,670 \\
2,120\end{array}$ & $\begin{array}{l}3.19 \\
3.12 \\
3.06 \\
3.06 \\
3.11 \\
3.25\end{array}$ & $\begin{array}{l}1,510 \\
1,390 \\
1,300 \\
1,300 \\
1,380 \\
1,620\end{array}$ & $\begin{array}{l}13.80 \\
14.05 \\
14.23 \\
14.40 \\
14.55 \\
14.75\end{array}$ & $\begin{array}{l}43,800 \\
45,100 \\
46,400 \\
47,700 \\
49,000 \\
50,300\end{array}$ & $\begin{array}{l}19.15 \\
19.20 \\
19.26 \\
19.30 \\
19.38 \\
19.46\end{array}$ & $\begin{array}{l}83,000 \\
83,000 \\
83,800 \\
83,800 \\
84,600 \\
85,400\end{array}$ & $\begin{array}{l}17.65 \\
17.50 \\
17.25 \\
17.05 \\
16.85 \\
16.60\end{array}$ & $\begin{array}{l}70,500 \\
69,800 \\
67,500 \\
66,000 \\
64,500 \\
63,000\end{array}$ \\
\hline $\begin{array}{l}1 \\
2 \\
3 \\
4 \\
5 \\
6\end{array}$ & $\begin{array}{c}3.26 \\
-3.06 \\
2.91\end{array}$ & $\begin{array}{r}1,640 \\
1,300 \\
1,060\end{array}$ & $\begin{array}{l}3.48 \\
3.80 \\
4.14 \\
4.60 \\
6.15 \\
7.55\end{array}$ & $\begin{array}{r}2,040 \\
2,670 \\
3,420 \\
4,450 \\
8,910 \\
13,600\end{array}$ & $\begin{array}{l}14.95 \\
15.15 \\
15.30 \\
15.40 \\
15.44 \\
15.45\end{array}$ & $\begin{array}{l}51,700 \\
53,100 \\
53,800 \\
54,500 \\
54,500 \\
54,500\end{array}$ & $\begin{array}{l}19.52 \\
19.56 \\
19.60 \\
19.62 \\
19.60 \\
19.56\end{array}$ & $\begin{array}{l}85,400 \\
86,200 \\
86,200 \\
86,200 \\
86,200 \\
86,200\end{array}$ & $\begin{array}{l}16.45 \\
16.20 \\
16.00 \\
15.75 \\
15.50 \\
15.25\end{array}$ & $\begin{array}{l}61,500 \\
60,100 \\
58,700 \\
57,300 \\
55,200 \\
53,100\end{array}$ \\
\hline $\begin{array}{r}7 \\
8 \\
9 \\
10 \\
11 \\
12 \\
\end{array}$ & $\begin{array}{r}3.00 \\
4.17 \\
4.08\end{array}$ & $\begin{array}{r}1,200 \\
3,420 \\
3,310\end{array}$ & $\begin{array}{r}8.20 \\
8.70 \\
9.40 \\
9.95 \\
10.28 \\
10.45 \\
\end{array}$ & $\begin{array}{l}15,700 \\
17,600 \\
20,400 \\
23,000 \\
24,300 \\
24,800\end{array}$ & $\begin{array}{l}15.46 \\
15.50 \\
15.60 \\
15.75 \\
16.00 \\
16.35\end{array}$ & $\begin{array}{l}55,200 \\
55,200 \\
55,900 \\
57,300 \\
58,700 \\
61,500\end{array}$ & $\begin{array}{l}19.51 \\
19.45 \\
19.38 \\
19.28 \\
19.18 \\
18.97\end{array}$ & $\begin{array}{l}85,400 \\
84,600 \\
84,600 \\
83,800 \\
83,000 \\
81,400\end{array}$ & $\begin{array}{l}14.95 \\
14.70 \\
14.45 \\
14.20 \\
13.95 \\
13.77\end{array}$ & $\begin{array}{l}51,700 \\
49,600 \\
47,700 \\
46,400 \\
45,100 \\
43,800\end{array}$ \\
\hline & \multicolumn{2}{|c|}{ Aug. 18} & \multicolumn{2}{|c|}{ Aug. 19} & \multicolumn{2}{|c|}{ Aug. 20} & \multicolumn{2}{|c|}{ Aug. 21} & \multicolumn{2}{|c|}{ Aug. 22} \\
\hline $\begin{array}{l}2 \\
4\end{array}$ & $\begin{array}{l}13.45 \\
13.10\end{array}$ & $\begin{array}{l}41,300 \\
39,500\end{array}$ & 9. & 20.800 & 65 & 13.60 & 3. & 10.500 & 5.95 & 8340 \\
\hline $\begin{array}{r}6 \\
8 \\
10\end{array}$ & $\begin{array}{l}12.70 \\
12.25 \\
11.85\end{array}$ & $\begin{array}{l}37,100 \\
34,200 \\
31,900\end{array}$ & $9 . \overline{15}$ & 19,600 & 7.35 & 12,900 & 6.35 & 9,570 & 5.90 & 8,040 \\
\hline $\mathrm{N}$ & 11.52 & 30,200 & 8.75 & 18,000 & 7.10 & 11,800 & $6.4 \overline{3}$ & 9,570 & $5.80^{-}$ & 7,740 \\
\hline $\begin{array}{l}2 \\
4\end{array}$ & $\begin{array}{l}11.24 \\
10.93 \\
10.62\end{array}$ & $\begin{array}{l}28,600 \\
27,200 \\
25,700\end{array}$ & 8.30 & 16,100 & 7.10 & 11,800 & 6.24 & 8,950 & 5.82 & 7,740 \\
\hline 8 & & 24 & 8.10 & 15,300 & 6.95 & 11,500 & 6.05 & 8,340 & 5.75 & 7,740 \\
\hline 12 & $\begin{array}{r}10.08 \\
9.81\end{array}$ & $\begin{array}{l}25,400 \\
22,100\end{array}$ & $\overline{7} . \overline{7}$ & $14, \overline{300}$ & 6.80 & $10, \overline{0} 0 \overline{0}$ & 6.00 & 8,340 & $\overline{5} . \overline{3}$ & $6, \overline{740}$ \\
\hline
\end{tabular}

Supp: Emental ReCord.-Aug. 16, 4:30 p m., gage height, 19.63 feet; discharge, 86,200 second-feet.

\section{JAMES RIVER AT SCOTTSUILLE, VA.}

Location.-Lat. $37^{\circ} 48^{\prime}$, long. $78^{\circ} 30^{\prime}$, at highway bridge at Scottsville, Albemarle County, 6 miles upstream from Hardware River. Datum of gage is 253.17 feet above mean sea level, datum of 1929 .

Drainage AREA.- 4,571 square miles.

GAGE-HEIGHT RECORD.-Water-stage recorder graph except for period 10 p.m. Aug. 26 to 7 p.m. Aug. 27. Gage heights partly estimated for period Aug. 1-3 when intake pipe did not function properly.

DISCHARGE RECORD.--Stage-discharge relation defined by current-meter measurements up to 103,000 second-feet; extended to crest gage height by logarithmic plotting. Gage heights used to half-tenths between 3.0 and 4.9 feet; hundredths below and tenths above these limits. Discharge for period of no gage-height record computed on basis of records for stations at Bent Creek and Cartersville.

Maxima.-1940: Discharge, 130,000 second-feet 12 p.m. Aug. 16 (gage height, 25.84 feet).

1925-39: Discharge, 126,000 second-feet Mar. 19, 1936 (gage height, 25.46 feet, from floodmarks).

Stage known, 30.7 feet in October 1870 , from information by local resident. Flood of March 1913 reached a stage of 25.16 feet, from floodmarks (discharge, 121,000 second-feet). 
Mean discharge, in second-feet, 1940

\begin{tabular}{|c|c|c|c|c|c|c|c|c|c|c|c|}
\hline Day & Aug. & Sept. & Day & Aug. & Sept. & Day & Aug. & Sept. & Day & Aug. & Sept. \\
\hline \begin{tabular}{l|}
1 \\
2 \\
3 \\
4 \\
5 \\
6 \\
7 \\
8
\end{tabular} & $\begin{array}{l}2,250 \\
2,680 \\
2,940 \\
3,400 \\
2,520 \\
2,560 \\
2,470 \\
2,140\end{array}$ & $\begin{array}{r}28,800 \\
20,800 \\
13,700 \\
9,690 \\
8,000 \\
6,790 \\
5,750 \\
4,780\end{array}$ & $\begin{array}{r}9 \\
10 \\
11 \\
12 \\
13 \\
14 \\
15 \\
16\end{array}$ & \begin{tabular}{|r|}
3,860 \\
4,000 \\
2,950 \\
2,400 \\
2,600 \\
2,880 \\
45,100 \\
1102,000
\end{tabular} & $\begin{array}{l}4,300 \\
4,150 \\
3,710 \\
3,440 \\
3,270 \\
3,340 \\
3,040 \\
2,670\end{array}$ & $\begin{array}{l}17 \\
18 \\
19 \\
20 \\
21 \\
22 \\
23 \\
24\end{array}$ & $\begin{array}{r}107,000 \\
52,200 \\
26,900 \\
17,200 \\
12,300 \\
9,650 \\
8,220 \\
6,930\end{array}$ & $\begin{array}{l}2,900 \\
2,630 \\
2,650 \\
2,500 \\
2,440 \\
2,270 \\
1,700 \\
1,750\end{array}$ & $\begin{array}{l}25 \\
26 \\
27 \\
28 \\
29 \\
30 \\
31\end{array}$ & $\begin{array}{r}5,550 \\
5,260 \\
5,000 \\
5,290 \\
7,280 \\
8,600 \\
11,200\end{array}$ & $\begin{array}{l}2,480 \\
2,770 \\
2,390 \\
2,360 \\
2,400 \\
1,950\end{array}$ \\
\hline \multicolumn{10}{|c|}{$\begin{array}{l}\text { Monthly mean discharge, in second-feet } \\
\text { Runoff, in inches }\end{array}$} & $\begin{array}{r}15,330 \\
3.86\end{array}$ & $\begin{array}{r}5,314 \\
1.29\end{array}$ \\
\hline
\end{tabular}

1 Discharge is different from that given in Water-Supply Paper 892. It is based on revisions not considered important enough to necessitate revision of daily discharge when peak was revised in WaterSupply Paper 972.

Gage height, in feet, and discharge, in second-feet, at indicated time, 1940

\begin{tabular}{|c|c|c|c|c|c|c|c|c|c|c|c|c|}
\hline \multirow{2}{*}{ Hour } & \multicolumn{2}{|c|}{ Aug. 14} & \multicolumn{2}{|c|}{ Aug. 15} & \multicolumn{2}{|c|}{ Aug. 16} & \multicolumn{2}{|c|}{ Aug. 17} & \multicolumn{2}{|c|}{ Aug. 18} & \multicolumn{2}{|c|}{ Aug. 19} \\
\hline & $\begin{array}{c}\text { Gage } \\
\text { ht. }\end{array}$ & $\begin{array}{c}\text { Dis- } \\
\text { charge }\end{array}$ & $\begin{array}{c}\text { Gage } \\
\text { ht. }\end{array}$ & $\begin{array}{c}\text { Dis- } \\
\text { charge }\end{array}$ & $\begin{array}{c}\text { Gage } \\
\text { ht. }\end{array}$ & $\begin{array}{l}\text { Dis- } \\
\text { charge }\end{array}$ & $\begin{array}{c}\text { Gage } \\
\text { ht. }\end{array}$ & $\begin{array}{c}\text { Dis- } \\
\text { charge }\end{array}$ & $\begin{array}{c}\text { Gage } \\
\text { ht. }\end{array}$ & $\begin{array}{c}\text { Dis- } \\
\text { charge }\end{array}$ & $\begin{array}{c}\text { Gage } \\
\text { ht. }\end{array}$ & $\begin{array}{c}\text { Dis- } \\
\text { charge }\end{array}$ \\
\hline \multirow{3}{*}{$\begin{array}{l}1 \\
2 \\
3 \\
4 \\
5 \\
6\end{array}$} & 3.77 & 2,700 & \multirow{3}{*}{$\begin{array}{r}6.50 \\
8.30 \\
10.00 \\
11.20 \\
12.20 \\
13.10\end{array}$} & \multirow{3}{*}{$\begin{array}{r}7,880 \\
13,000 \\
18,900 \\
23,400 \\
27,500 \\
31,400\end{array}$} & \multirow{3}{*}{$\begin{array}{l}20.20 \\
20.40 \\
20.60 \\
20.80 \\
21.15 \\
21.50\end{array}$} & \multirow{3}{*}{$\begin{array}{l}71,900 \\
73,300 \\
74,700 \\
76,200 \\
79,200 \\
81,600\end{array}$} & \multirow{3}{*}{$\begin{array}{l}25.82 \\
25.75 \\
25.65 \\
25.55 \\
25.44 \\
25.32\end{array}$} & \multirow{3}{*}{$\begin{array}{l}130,000 \\
130,000 \\
127,000 \\
127,000 \\
124,000 \\
123,000\end{array}$} & 20.20 & 71,900 & 13.53 & 33,200 \\
\hline & 3.74 & 2,700 & & & & & & & 19.55 & 67,700 & 13.15 & 31,800 \\
\hline & 3.62 & 2,480 & & & & & & & 18.85 & 62,200 & 12.80 & 30,100 \\
\hline \multirow{4}{*}{$\begin{array}{r}7 \\
8 \\
9 \\
10 \\
11 \\
\mathrm{~N}\end{array}$} & 3.46 & 2,270 & \multirow{4}{*}{$\begin{array}{l}13.80 \\
14.45 \\
15.05 \\
15.55 \\
16.15 \\
16.55\end{array}$} & \multirow{4}{*}{$\begin{array}{l}34,600 \\
37,400 \\
40,300 \\
43,300 \\
46,500 \\
48,700\end{array}$} & \multirow{4}{*}{$\begin{array}{l}21.85 \\
22.20 \\
22.60 \\
23.00 \\
23.40 \\
23.80\end{array}$} & \multirow{4}{*}{$\begin{array}{r}84,000 \\
87,600 \\
91,200 \\
95,200 \\
99,300 \\
104,000\end{array}$} & \multirow{4}{*}{$\begin{array}{l}25.16 \\
25.00 \\
24.85 \\
24.63 \\
24.43 \\
24.18\end{array}$} & \multirow{4}{*}{$\begin{array}{l}121,000 \\
118,000 \\
116,000 \\
113,000 \\
111,000 \\
108,000\end{array}$} & 18.10 & 57,600 & 12.46 & 28,800 \\
\hline & $3 . \overline{3}$ & 2,060 & & & & & & & 17.50 & 53,900 & 12.18 & 500 \\
\hline & 3.27 & & & & & & & & 85 & & 92 & \\
\hline & & & & & & & & & 0.00 & & & \\
\hline \multirow{4}{*}{$\begin{array}{l}1 \\
2 \\
3 \\
4 \\
5 \\
6\end{array}$} & 3.97 & & \multirow{4}{*}{$\begin{array}{l}17.00 \\
17.40 \\
17.80 \\
18.15 \\
18.50 \\
18.80\end{array}$} & \multirow{4}{*}{$\begin{array}{l}51,000 \\
53,300 \\
55,800 \\
58,300 \\
60,200 \\
62,200\end{array}$} & \multirow{4}{*}{\multicolumn{2}{|c|}{\begin{tabular}{|l|l|}
24.20 & 108,000 \\
24.55 & 113,000 \\
24.80 & 116,000 \\
25.03 & 118,000 \\
25.22 & 121,000 \\
25.36 & 124,000
\end{tabular}}} & \multirow{4}{*}{$\begin{array}{l}23.95 \\
23.65 \\
23.40 \\
23.10 \\
22.85 \\
22.60\end{array}$} & \multirow{4}{*}{$\begin{array}{r}106,000 \\
102,000 \\
99,300 \\
96,200 \\
93,200 \\
91,200\end{array}$} & & & & \\
\hline & & & & & & & & & & & & \\
\hline & 4.27 & 3,480 & & & & & & & 15.70 & 43,800 & 11.45 & 24,200 \\
\hline & 4.27 & 3,480 & & & & & & & 15.20 & 41,300 & $1 \overline{1} . \overline{2} \overline{3}$ & 23,400 \\
\hline \multirow{5}{*}{$\begin{array}{r}7 \\
8 \\
9 \\
10 \\
11 \\
12 \\
\end{array}$} & 4.25 & 3,480 & \multirow{4}{*}{$\begin{array}{l}19.05 \\
19.25 \\
19.42 \\
19.59 \\
19.77 \\
19.98\end{array}$} & \multirow{4}{*}{$\begin{array}{l}63,600 \\
64,900 \\
66,300 \\
67,700 \\
69,100 \\
70,500 \\
\end{array}$} & \begin{tabular}{l|l}
25.48 & \\
25.58 &
\end{tabular} & & $\left|\begin{array}{r}22.35 \\
22.10\end{array}\right|$ & & 14.75 & 39,300 & 11.00 & 22,700 \\
\hline & & & & & 25.67 & 0 & 21.80 & 84,000 & & & & \\
\hline & & & & & 25. & & $\left|\begin{array}{ll}21 & 0.20\end{array}\right|$ & & & & o & \\
\hline & 4.70 & 4,250 & & & 25.84 & 13 & 20.85 & & 13.93 & 35,000 & 0.48 & 800 \\
\hline & & Ig. 20 & $\mathrm{Au}$ & g. 21 & $\mathbf{A u}$ & tg. & & g. 2 & & g. 2 & & 5 \\
\hline & & & & & & & 6 & & 5.6 & & 5.32 & \\
\hline 4 & 10.10 & 19,200 & 8.51 & 13,600 & 7.34 & 9,920 & & & & & & \\
\hline & 9.83 & 18,100 & 8.24 & 12,600 & 7.18 & 9,640 & & & & & & \\
\hline $\mathrm{N}$ & 9.48 & 17,100 & 8.12 & 12,300 & 7.18 & 9,640 & 6.49 & 7,880 & & & 5.53 & 5,750 \\
\hline & & & & & & & & & 6. & & & \\
\hline 4 & 9.24 & 16,000 & 7.89 & 11,700 & 7.14 & 9,370 & & & & & & \\
\hline & 8.91 & $\overline{1}$ & 7.69 & 11,1 & $\overline{7.07}$ & & & & & & & \\
\hline $\begin{array}{l}10 \\
12\end{array}$ & 8.76 & 14,600 & 7.56 & 10,800 & 7.02 & 9,110 & 5.89 & 6,570 & 5.54 & 5,750 & $\begin{array}{l}5.48 \\
5.17\end{array}$ & $\begin{array}{l}5.750 \\
5,170\end{array}$ \\
\hline
\end{tabular}

JAMES RIVER A'T CARTERSVILLE, VA.

Location.-Lat. $37^{\circ} 40^{\prime}$, long. $78^{\circ} 05^{\prime}$, at highway bridge between Pemberton and Cartersville, Cumberland County, 2 miles downstream from Willis River. Datum of gage is 161.57 feet above mean sea level (levels by Corps of Engineers, War Department).

Drainage AREA.-6,242 square miles.

GAGE-HEIGHT RECORD.-Water-stage recorder graph. 
DISCHARGE RECORD.- Stage-discharge relation defined by current-meter measurements. Gage heights used to half-tenths between 1.1 and 2.6 feet; hundredths below and tenths above these limits.

Maxima.-1940: Discharge, 145,000 second-feet 3 p.m. Aug. 17 (gage height, 28.34 feet).

1899-1939: Discharge, 166,000 second-feet Mar. 19, 1936 (gage height, 28.77 feet, from floodmarks).

Mean discharge, in second-feet, 1940

\begin{tabular}{|c|c|c|c|c|c|c|c|c|c|c|c|}
\hline Day & Aug. & Sept. & Day & Aug. & Sept. & Day & Aug. & Sept. & Day & Aug. & Sept. \\
\hline 1 & 3,340 & 25,500 & 9 & 3,280 & 5,410 & 17 & 138,000 & 3,260 & 25 & 7,390 & 2,520 \\
\hline 2 & 3,500 & 25,100 & 10 & 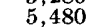 & & 18 & 110 & 3, & & & 3, \\
\hline 3 & 3,830 & 16,600 & 11 & 4,240 & 5,030 & 19 & 47,700 & 3,110 & 27 & 6,540 & 3,670 \\
\hline 4 & 4,270 & 11,700 & 12 & 3,880 & 4,450 & 20 & 24,100 & 3,080 & 28 & 6,710 & 2,840 \\
\hline 5 & 4,080 & 9,460 & 13 & 3,2 & 4,1 & 2 & 15,8 & 3,0 & 29 & 8 & 3,000 \\
\hline 6 & 3,480 & 8,010 & 14 & 3,990 & 3,9 & 22 & 12,100 & 3,0 & 30 & 9,030 & 3,020 \\
\hline 7 & 4,220 & 7,020 & 15 & 32,500 & 3,8 & 23 & 10,700 & 2,540 & 31 & 9,900 & \\
\hline 8 & 3,620 & 6,110 & 16 & 88,000 & 3,780 & 24 & 8,770 & 2,250 & & & \\
\hline \multicolumn{10}{|c|}{ Monthly mean discharge, in second-feet } & $\begin{array}{r}19,270 \\
3.56\end{array}$ & $\begin{array}{r}6,265 \\
1.12\end{array}$ \\
\hline
\end{tabular}

Gage height, in feet, and discharge, in second-feet, at indicated time, 1940

\begin{tabular}{|c|c|c|c|c|c|c|c|c|c|c|c|c|}
\hline \multirow{2}{*}{ Lour } & \multicolumn{2}{|c|}{ Aug. 14} & \multicolumn{2}{|c|}{ Aug. 15} & \multicolumn{2}{|c|}{ Aug. 16} & \multicolumn{2}{|c|}{ Aug. 17} & \multicolumn{2}{|c|}{ Aug. 18} & \multicolumn{2}{|c|}{ Aug. 19} \\
\hline & $\begin{array}{c}\text { Gage } \\
\text { ht. }\end{array}$ & $\begin{array}{l}\text { Dis- } \\
\text { charge }\end{array}$ & $\begin{array}{c}\text { Gage } \\
\text { ht. }\end{array}$ & $\begin{array}{l}\text { Dis- } \\
\text { charge }\end{array}$ & $\begin{array}{c}\text { Gage } \\
\text { ht. }\end{array}$ & $\begin{array}{l}\text { Dis- } \\
\text { charge }\end{array}$ & $\begin{array}{c}\text { Gage } \\
\text { ht. }\end{array}$ & $\begin{array}{l}\text { Dis- } \\
\text { charge }\end{array}$ & $\begin{array}{c}\text { Gage } \\
\text { ht. }\end{array}$ & $\begin{array}{c}\text { Dis- } \\
\text { charge }\end{array}$ & $\begin{array}{c}\text { Gaga } \\
\text { ht. }\end{array}$ & $\begin{array}{l}\text { Dis- } \\
\text { charge }\end{array}$ \\
\hline $\begin{array}{l}1 \\
2 \\
3 \\
4 \\
5 \\
6\end{array}$ & $\begin{array}{r}1.84 \\
1.99 \\
2.19\end{array}$ & $\begin{array}{r}3,240 \\
3,500 \\
3,840\end{array}$ & $\begin{array}{l}2.75 \\
3.00 \\
3.40 \\
3.80 \\
4.25 \\
4.70\end{array}$ & $\begin{array}{l}5,260 \\
6,010 \\
6,780 \\
7,580 \\
8,610\end{array}$ & $\begin{array}{l}19.80 \\
20.00 \\
20.33 \\
20.55 \\
20.78 \\
21.00\end{array}$ & $\begin{array}{l}00 \\
00 \\
00 \\
00 \\
00 \\
00\end{array}$ & $\begin{array}{l}26 \cdot 15 \\
26 \cdot 45 \\
26 \cdot 70 \\
26.95 \\
27.15 \\
27.40\end{array}$ & $\begin{array}{l}00 \\
00 \\
00 \\
00 \\
00 \\
00\end{array}$ & $\begin{array}{l}27.50 \\
27.35 \\
27.20 \\
27.05 \\
26.85 \\
26.65\end{array}$ & & $\begin{array}{l}20.60 \\
20.05 \\
19.50 \\
18.90 \\
18.35 \\
17.75\end{array}$ & $\begin{array}{l}73,800 \\
70,200 \\
67,400 \\
64,200 \\
61,400 \\
58,200\end{array}$ \\
\hline $\begin{array}{r}7 \\
8 \\
9 \\
10 \\
11 \\
\mathrm{~N}\end{array}$ & $\left|\begin{array}{c}2.35 \\
2.38 \\
2.37\end{array}\right|$ & $\begin{array}{r}4,100 \\
4,180 \\
4,100\end{array}$ & $\begin{array}{r}5.10 \\
5.70 \\
7.00 \\
8.50 \\
10.10 \\
11.85\end{array}$ & $\begin{array}{r}9,460 \\
10,800 \\
14,000 \\
18,400 \\
24,000 \\
30,800\end{array}$ & $\begin{array}{l}21.21 \\
21.45 \\
21.67 \\
21.91 \\
22.12 \\
22.37\end{array}$ & $\begin{array}{l}77,400 \\
78,600 \\
80,700 \\
82,100 \\
83,500 \\
85,600\end{array}$ & $\begin{array}{l}27.55 \\
27.73 \\
27.88 \\
28.02 \\
28.12 \\
28.20\end{array}$ & $\begin{array}{l}136,000 \\
138,000 \\
140,000 \\
141,000 \\
143,000 \\
144,000\end{array}$ & $\begin{array}{l}26.45 \\
26.25 \\
26.05 \\
25.80 \\
25.60 \\
25.35\end{array}$ & & $\begin{array}{l}17.15 \\
16.65 \\
16.20 \\
15.75 \\
15.30 \\
14.90\end{array}$ & $\begin{array}{l}55,200 \\
52,200 \\
50,200 \\
48,200 \\
45,900 \\
44,100\end{array}$ \\
\hline $\begin{array}{l}1 \\
2 \\
3 \\
4 \\
5 \\
6\end{array}$ & $\begin{array}{r}-\overline{2} . \overline{9} \\
2.41 \\
-2.41\end{array}$ & $\begin{array}{r}4,180 \\
4,180 \\
4,180\end{array}$ & $\begin{array}{l}13.30 \\
14.40 \\
15.40 \\
16.15 \\
16.85 \\
17.40\end{array}$ & $\begin{array}{l}37,200 \\
41,900 \\
46,400 \\
50,200 \\
53,200 \\
56,200\end{array}$ & $\begin{array}{l}22.60 \\
22.90 \\
23.13 \\
23.45 \\
23.72 \\
24.05\end{array}$ & $\begin{array}{l}87,200 \\
89,600 \\
91,200 \\
93,600 \\
96,300 \\
99,000\end{array}$ & $\begin{array}{l}28.27 \\
28.32 \\
28.34 \\
28.33 \\
28.31 \\
28.25\end{array}$ & $\begin{array}{l}14 \\
14 \\
14 \\
14 \\
14 \\
14\end{array}$ & $\begin{array}{l}25.05 \\
24.75 \\
24.45 \\
24.15 \\
23.85 \\
23.55\end{array}$ & $\begin{array}{r}108,000 \\
106,000 \\
103,000 \\
101,000 \\
97,200 \\
95,400\end{array}$ & $\begin{array}{l}14.50 \\
14.15 \\
13.85 \\
13.55 \\
13.30 \\
13.05\end{array}$ & $\begin{array}{l}42,300 \\
41,000 \\
39,300 \\
38,400 \\
37,200 \\
35,900\end{array}$ \\
\hline $\begin{array}{r}7 \\
8 \\
9 \\
10 \\
11 \\
12 \\
\end{array}$ & $\left|\begin{array}{c}-\overline{2} . \overline{43} \\
-\overline{2.45} \\
-\overline{2} . \overline{5}\end{array}\right|$ & $\begin{array}{r}4,270 \\
4,270 \\
4,540\end{array}$ & $\begin{array}{l}17.90 \\
18.30 \\
18.65 \\
18.95 \\
19.20 \\
19.50\end{array}$ & $\begin{array}{l}58,700 \\
60,800 \\
62,500 \\
64,700 \\
65,800 \\
67,400 \\
\end{array}$ & $\begin{array}{l}24.30 \\
24.60 \\
24.95 \\
25.25 \\
25.60 \\
25.90\end{array}$ & $\begin{array}{l}100 \\
100 \\
100 \\
00 \\
100 \\
100\end{array}$ & $\begin{array}{l}18 \\
10 \\
00 \\
87 \\
75 \\
65\end{array}$ & & $\mid \begin{array}{l}23.20 \\
22.85 \\
22.45 \\
22.00 \\
21.55 \\
21.10\end{array}$ & $\begin{array}{l}00 \\
300 \\
300 \\
300 \\
00 \\
300\end{array}$ & $\begin{array}{l}.82 \\
.60 \\
.40 \\
.20 \\
.02 \\
.85\end{array}$ & $\begin{array}{l}35,000 \\
34,200 \\
33,300 \\
32,500 \\
31,600 \\
30,800 \\
\end{array}$ \\
\hline & \multicolumn{2}{|c|}{ Aug. 20} & \multicolumn{2}{|c|}{ Aug. 21} & \multicolumn{2}{|c|}{ Aug. 22} & \multicolumn{2}{|c|}{ Aug. 23} & \multicolumn{2}{|c|}{ Aug. 24} & \multicolumn{2}{|c|}{ Aug. 25} \\
\hline $\begin{array}{r}2 \\
4 \\
6 \\
8 \\
10 \\
N\end{array}$ & $\begin{array}{l}11.50 \\
11.20 \\
10.88 \\
10.57 \\
10.28 \\
10.00\end{array}$ & $\begin{array}{l}29,500 \\
28,300 \\
27,100 \\
25,900 \\
24,700 \\
23,600\end{array}$ & $\begin{array}{r}\overline{8.15} \\
\overline{7.85} \\
7.57\end{array}$ & $\begin{array}{l}17,500 \\
16,300 \\
15,700\end{array}$ & $\begin{array}{l}6 . \overline{63} \\
6 . \overline{4} \overline{2} \\
\overline{6} . \overline{2} \overline{3}\end{array}$ & $\begin{array}{l}12,500 \\
12,000\end{array}$ & $\begin{array}{r}5 . \overline{78} \\
5 . \overline{82} \\
5 . \overline{8}\end{array}$ & $\begin{array}{l}11,000 \\
11,000\end{array}$ & $\begin{array}{l}5.18 \\
5.17 \\
5.12 \\
4.96 \\
4.73 \\
4.52\end{array}$ & $\begin{array}{l}9,680 \\
9,680 \\
9,460 \\
9,240 \\
8,610 \\
8,190\end{array}$ & $\begin{array}{l}4.79 \\
4.72 \\
4.56 \\
4.38 \\
4.18 \\
4.00\end{array}$ & $\begin{array}{l}8,820 \\
8,610 \\
\mathbf{8}, 400 \\
7,980 \\
7,580 \\
7,180\end{array}$ \\
\hline $\begin{array}{r}2 \\
4 \\
6 \\
8 \\
10 \\
12 \\
12 \\
\end{array}$ & $\begin{array}{l}9.77 \\
9.52 \\
9.30 \\
9.05 \\
8.83 \\
8.60\end{array}$ & $\begin{array}{l}22,900 \\
21,800 \\
21,100 \\
20,000 \\
19,400 \\
18,700\end{array}$ & $\begin{array}{r}\overline{7.28} \\
7.07 \\
6.87\end{array}$ & $\begin{array}{l}14,800 \\
14,300 \\
13,800\end{array}$ & $\begin{array}{r}6.0 \overline{2} \\
\overline{5} . \overline{90} \\
5 . \overline{84}\end{array}$ & $\begin{array}{l}11,500 \\
11,300 \\
11,000\end{array}$ & $\begin{array}{r}5.70 \\
5.46 \\
5.22\end{array}$ & $\begin{array}{r}10,800 \\
10,300 \\
9,680\end{array}$ & $\begin{array}{l}4.42 \\
4.45 \\
4.51 \\
4.60\end{array}$ & $\begin{array}{l}7,980 \\
7,980 \\
8,190 \\
8,400 \\
8,610 \\
8,820\end{array}$ & $\begin{array}{l}3.80 \\
3.60 \\
3.49 \\
3.55 \\
3.71 \\
3.80\end{array}$ & $\begin{array}{l}6,780 \\
6,390 \\
6,200 \\
6,390 \\
6,580 \\
6,780\end{array}$ \\
\hline
\end{tabular}


JAMES RIVER NEAR RICHMOND, VA.

Location.--Lat. $37^{\circ} 33^{\prime} 47^{\prime \prime}$, long. $77^{\circ} 32^{\prime} 50^{\prime \prime}$, at Westham Bridge, $13 \%$ miles downstream from Bosher Dam and 3 miles west of eity linits of Richmond, Henrico County. Datum of gage is 98.82 feet above mean sea level, datum of 1929 .

Dirainage AREa. - 6,757 square miles.

GAGE-HEIGHT RECORD.-Water-stage recorder graph except for period 9 a.m. Aug. 9

to 1 p.m. Aug. 17. Graph for period Aug. 15 to 1 p.m. Aug. 17 synthesized from partial graph and reeord for James River at Cartersville.

DISCHARGE RECORD.-Stage-discharge relation defined by eurrent-meter measurements. Gage heights used to half-tenths between 4.6 and 6.2 feet; hundredths below and tenths above these limits.

Maxima.-1940: Discharge, 151,000 second-feet 8:30 a.m. Aug. 18 (gage height, 21.80 feet).

1934-39: Discharge, 175,000 second-feet Mar. 19, 1936 (gage height, 23.42 feet).

Remarks.-Records above 100,000 second-feet include flow of James River \& Kanawha Canal.

Mean discl arge, in second-feet, 19.40

\begin{tabular}{|c|c|c|c|c|c|c|c|c|c|c|c|}
\hline Day & Aug. & Sept. & Day & Aug. & Sept. & Day & Aug. & Sept. & Day & Aug. & Sept. \\
\hline $\begin{array}{l}1 \\
2 \\
3 \\
4 \\
5 \\
6 \\
7 \\
8\end{array}$ & $\begin{array}{l}3,070 \\
2,190 \\
2,480 \\
2,710 \\
3,180 \\
2,740 \\
3,090 \\
2,850\end{array}$ & $\begin{array}{r}15,900 \\
27,200 \\
18,500 \\
12,900 \\
9,870 \\
8,240 \\
7,200 \\
6,020\end{array}$ & $\begin{array}{r}9 \\
10 \\
11 \\
12 \\
13 \\
14 \\
15 \\
16\end{array}$ & $\begin{array}{r}2,510 \\
2,400 \\
5,000 \\
4,300 \\
3,200 \\
2,800 \\
12,500 \\
58,000\end{array}$ & $\begin{array}{l}5,200 \\
4,880 \\
4,560 \\
3,950 \\
3,440 \\
3,270 \\
3,800 \\
2,880\end{array}$ & $\begin{array}{l}17 \\
18 \\
19 \\
20 \\
21 \\
22 \\
23 \\
24\end{array}$ & $\begin{array}{r}105,000 \\
144,000 \\
92,800 \\
32,400 \\
17,800 \\
13,100 \\
11,000 \\
9,560\end{array}$ & $\begin{array}{l}2,710 \\
2,510 \\
2,610 \\
2,340 \\
2,220 \\
2,150 \\
2,170 \\
1,620\end{array}$ & $\begin{array}{l}25 \\
26 \\
27 \\
28 \\
29 \\
30 \\
31\end{array}$ & $\begin{array}{l}8,480 \\
6,350 \\
6,350 \\
6,180 \\
8,070 \\
9,140 \\
9,500\end{array}$ & $\begin{array}{l}1,580 \\
2,170 \\
2,880 \\
2,580 \\
2,040 \\
2,130\end{array}$ \\
\hline \multicolumn{10}{|c|}{$\begin{array}{l}\text { observed } \\
\text { adjusted for diversion by James River \& } \\
\text { Kanawha Canal }\end{array}$} & $\begin{array}{r}19,120 \\
20,030 \\
3.41\end{array}$ & $\begin{array}{r}5,651 \\
6,550 \\
1.08\end{array}$ \\
\hline
\end{tabular}


JAMES RIVER BASIN

Gage height, in feet, and discharge, in second-feet, at indicated time, 1940

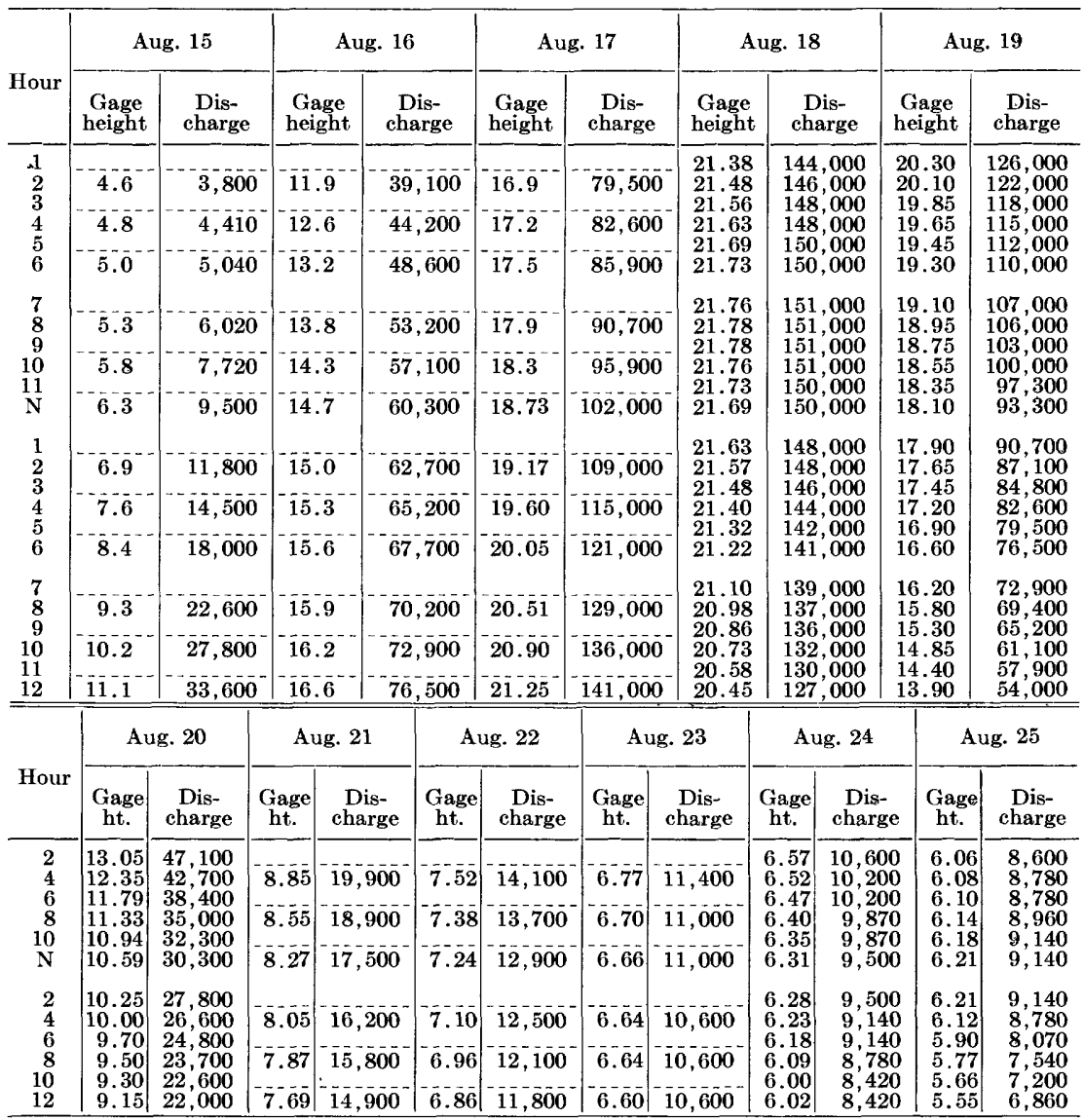

SUPPlEMENTAL RECORD.-Aug. 18, 8:30 a. m., gage height, 21.80 feet; discharge, 151,000 second-feet.

\section{DUNLAP CREEK NEAR COVINGTON, VA.}

Location.-Lat. $37^{\circ} 48^{\prime}$, long. $80^{\circ} 03^{\prime}$, at highway bridge 2 miles downstream from Ogle Creek and 3 miles west of Covington, Alleghany County. Datum of gage is 1,294.21 feet above mean sea level (levels by Corps of Engineers, War Department).

Drainage AREA.-166 square miles.

GAGE-HEIGHT RECORD.-Twice-daily readings of chain gage. Gage heights at indicated times Aug. 13-24 were obtained from graph based on floodmarks and twice-daily gage readings.

DISCHARGE RECORD.-Stage-discharge relation defined by current-meter measurements up to 4,500 second-feet and extended to crest gage height of Mar. 17, 1936, on basis of velocity-area studies and comparisons of peak discharge and total runoff of March"1936 flood at this station with those for other stations in James River Basin. Gage heights used to half-tenths between 2.0 and 3.1 feet to Aug. 14, between 2.1 and 3.3 feet thereafter; hundredths below and tenths above these limits. 


\section{FLOODS OF AUGUST 1940 IN THE SOUTHEASTERN STATES}

Maxima.-1940: Discharge, 8,050 second-feet 7 p.m. Aug. 14 (gage height, 10.3 feet, from floodmarks).

1928-39: Discharge, 8,370 second-feet Mar. 17, 1936 (gage height, 10.52 feet, from floodmarks).

Mean discharge, in second-feet, 1940

\begin{tabular}{|c|c|c|c|c|c|c|c|c|c|c|c|}
\hline Day & Aug. & Sept. & Day & Aug. & Sept. & Day & Aug. & Sept. & Day & Aug. & Sept. \\
\hline $\begin{array}{l}1 \\
2 \\
3 \\
4 \\
5 \\
6 \\
7 \\
8\end{array}$ & $\begin{array}{r}128 \\
84 \\
63 \\
52 \\
46 \\
52 \\
80 \\
53\end{array}$ & $\begin{array}{r}359 \\
204 \\
131 \\
95 \\
75 \\
66 \\
56 \\
50\end{array}$ & $\begin{array}{r}9 \\
10 \\
11 \\
12 \\
13 \\
14 \\
15 \\
16\end{array}$ & $\begin{array}{r}47 \\
42 \\
38 \\
38 \\
35 \\
2,700 \\
2,570 \\
2,210\end{array}$ & $\begin{array}{l}45 \\
45 \\
42 \\
38 \\
34 \\
32 \\
31 \\
28\end{array}$ & $\begin{array}{l}17 \\
18 \\
19 \\
20 \\
21 \\
22 \\
23 \\
24\end{array}$ & $\begin{array}{r}1,170 \\
533 \\
314 \\
202 \\
140 \\
103 \\
80 \\
70\end{array}$ & $\begin{array}{l}27 \\
26 \\
25 \\
24 \\
23 \\
23 \\
21 \\
21\end{array}$ & $\begin{array}{l}25 \\
26 \\
27 \\
28 \\
29 \\
30 \\
31\end{array}$ & $\begin{array}{r}63 \\
159 \\
177 \\
359 \\
204 \\
131 \\
321\end{array}$ & $\begin{array}{l}23 \\
26 \\
24 \\
23 \\
21 \\
20\end{array}$ \\
\hline \multicolumn{10}{|c|}{$\begin{array}{l}\text { Monthly mean discharge, in second-feet } \\
\text { Runoff, in inches }\end{array}$} & $\begin{array}{r}396 \\
2.76\end{array}$ & $\begin{array}{l}55.3 \\
0.37\end{array}$ \\
\hline
\end{tabular}

Gage height, in feet, and discharge, in second-feet, at indicated time, 1940

\begin{tabular}{|c|c|c|c|c|c|c|c|c|c|c|c|c|}
\hline \multirow{2}{*}{ Hour } & \multicolumn{2}{|c|}{ Aug. 13} & \multicolumn{2}{|c|}{ Aug. 14} & \multicolumn{2}{|c|}{ Aug. 15} & \multicolumn{2}{|c|}{ Aug. 16} & \multicolumn{2}{|c|}{ Aug. 17} & \multicolumn{2}{|c|}{ Aug. 18} \\
\hline & $\begin{array}{c}\text { Gage } \\
\text { ht. }\end{array}$ & $\begin{array}{c}\text { Dis- } \\
\text { charge }\end{array}$ & $\begin{array}{c}\text { Gage } \\
\text { ht. }\end{array}$ & $\begin{array}{c}\text { Dis- } \\
\text { charge }\end{array}$ & $\begin{array}{c}\text { Gage } \\
\text { ht. }\end{array}$ & $\begin{array}{c}\text { Dis- } \\
\text { charge }\end{array}$ & $\begin{array}{c}\text { Gage } \\
\text { ht. }\end{array}$ & $\begin{array}{l}\text { Dis- } \\
\text { charge }\end{array}$ & $\begin{array}{c}\text { Gage } \\
\text { ht. }\end{array}$ & $\begin{array}{c}\text { Dis- } \\
\text { charge }\end{array}$ & $\begin{array}{c}\text { Gage } \\
\text { ht. }\end{array}$ & $\begin{array}{c}\text { Dis- } \\
\text { charge }\end{array}$ \\
\hline \multirow{3}{*}{$\begin{array}{l}1 \\
2 \\
3 \\
4 \\
5 \\
6\end{array}$} & 1.26 & 36 & \multirow{3}{*}{$\begin{array}{l}1.32 \\
1.35 \\
1.40 \\
1.45 \\
1.50 \\
1.58\end{array}$} & \multirow{3}{*}{$\begin{array}{l}42 \\
46 \\
52 \\
59 \\
66 \\
78\end{array}$} & \multirow{3}{*}{$\begin{array}{l}7.60 \\
7.10 \\
6.90 \\
6.60 \\
6.40 \\
6.20\end{array}$} & \multirow{3}{*}{$\begin{array}{l}4,280 \\
3,690 \\
3,470 \\
3,140 \\
2,940 \\
2,740\end{array}$} & 6.02 & 2,540 & 4.90 & 1,600 & 3.45 & 665 \\
\hline & 1.26 & 36 & & & & & $6 . \overline{0}$ & $2, \overline{540}$ & 4.80 & $1, \overline{5} 20$ & $3 . \overline{4}$ & $6 \overline{6} \overline{5}$ \\
\hline & 1.26 & 36 & & & & & 6.02 & 2,540 & 4.70 & 1,450 & 3.30 & 615 \\
\hline \multirow{4}{*}{$\begin{array}{r}7 \\
8 \\
9 \\
10 \\
11 \\
\mathrm{~N}\end{array}$} & & & \multirow{4}{*}{$\begin{array}{l}1.66 \\
1.80 \\
2.00 \\
2.20 \\
2.50 \\
3.10\end{array}$} & \multirow{4}{*}{$\begin{array}{r}91 \\
117 \\
161 \\
212 \\
302 \\
528\end{array}$} & \multirow{4}{*}{$\begin{array}{l}6.08 \\
5.95 \\
5.85 \\
5.70 \\
5.65 \\
5.55\end{array}$} & \multirow{4}{*}{$\begin{array}{l}2,640 \\
2,540 \\
2,360 \\
2,270 \\
2,180 \\
2,180\end{array}$} & & & & & & \\
\hline & 1.26 & 36 & & & & & 5.90 & 2,450 & 4.55 & 1,380 & 3.25 & 592 \\
\hline & 1.25 & 34 & & & & & 5.80 & 2,360 & $4 . \overline{4}$ & 1,240 & 3.19 & 570 \\
\hline & 1.25 & 34 & & & & & 5.70 & 2,270 & 4.30 & 1,170 & 3.10 & 525 \\
\hline \multirow{4}{*}{$\begin{array}{l}1 \\
2 \\
3 \\
4 \\
5 \\
6\end{array}$} & 1,24 & 33 & \multirow{4}{*}{$\begin{array}{r}4.00 \\
5.20 \\
6.40 \\
7.90 \\
9.23 \\
10.15\end{array}$} & \multirow{4}{*}{$\begin{array}{r}990 \\
1,840 \\
2,940 \\
4,650 \\
6,410 \\
7,900\end{array}$} & \multirow{4}{*}{$\begin{array}{l}5.50 \\
5.45 \\
5.45 \\
5.45 \\
5.48 \\
5.50\end{array}$} & \multirow{4}{*}{$\begin{array}{l}2,090 \\
2,000 \\
2,000 \\
2,000 \\
2,090 \\
2,090\end{array}$} & 5.55 & 2,180 & 4.10 & 1,050 & .05 & 503 \\
\hline & & & & & & & & & & & & \\
\hline & 1.24 & 33 & & & & & 5.45 & 2,000 & 3.95 & 990 & 2.95 & 460 \\
\hline & 1.25 & $\mathbf{3} 4$ & & & & & $\overline{5.30}$ & 1,920 & 3.80 & 875 & 2.90 & 439 \\
\hline \multirow{5}{*}{$\begin{array}{r}7 \\
8 \\
9 \\
10 \\
11 \\
12 \\
\end{array}$} & 1.27 & 37 & \multirow{4}{*}{$\mid \begin{array}{r}10.30 \\
10.25 \\
10.00 \\
9.35 \\
8.60 \\
8.10\end{array}$} & \multirow{4}{*}{$\begin{array}{l}8,050 \\
7,900 \\
7,600 \\
6,700 \\
5,570 \\
4,910 \\
\end{array}$} & \multirow{4}{*}{$\begin{array}{l}5.55 \\
5.60 \\
5.68 \\
5.75 \\
5.82 \\
5.90\end{array}$} & \multirow{4}{*}{$\begin{array}{l}2,180 \\
2,180 \\
2,270 \\
2,360 \\
2,360 \\
2,450 \\
\end{array}$} & 5.20 & 1,840 & 3.70 & 820 & 2.85 & 419 \\
\hline & 1,8 & 38 & & & & & 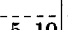 & 1 & & & 8 & 300 \\
\hline & & & & & & & 0.1 & 1,700 & . & 600 & 2.0 & \\
\hline & 1.30 & 40 & & & & & 5.00 & 1,680 & 3.50 & 715 & 2.75 & 379 \\
\hline & \multicolumn{2}{|c|}{ Aug. 19} & \multicolumn{2}{|c|}{ Aug. 20} & \multicolumn{2}{|c|}{ Aug. 21} & \multicolumn{2}{|c|}{ Aug. 22} & $\mathrm{Au}$ & . 23 & & g. 24 \\
\hline & & 359 & 2.33 & 23 & 2.1 & 16 & 1.88 & 11 & 1.7 & & 1.6 & \\
\hline 8 & 2.65 & 340 & 2.30 & & 2.0 & 15 & 1.85 & 10 & 1.7 & o & 1.6 & 74 \\
\hline $\mathrm{N}$ & 2.60 & 321 & 2.25 & & 1. & 13 & 1.82 & 102 & 1.68 & 7 & 1.62 & 69 \\
\hline $\begin{array}{l}4 \\
8\end{array}$ & $\begin{array}{l}2.50 \\
2.45\end{array}$ & 26 & 2.20 & & 1.9 & & & 9 & 1 & & 1.6 & 69 \\
\hline 12 & 2.35 & 235 & 2.10 & $\begin{array}{l}164 \\
164\end{array}$ & 1.88 & 11 & 1.75 & 90 & 1.65 & 74 & 1.60 & 66 \\
\hline
\end{tabular}

\section{POTTS CREEK NEAR COVINGTON, VA.}

LOCATION.-Lat. $37^{\circ} 44^{\prime}$, long. $80^{\circ} 02^{\prime}$, at highway bridge a quarter of a mile upstream from Hays Creek and 3 miles southwest of Covington; Alleghany County. Datum of gage is 1,257.61 feet above mean sea level (levels by Corps of Engineers, War Department).

Drainage AREA.- 158 square miles.

GAGE-HEIGHT RECORD.-Twice-daily readings of chain gage. Gage heights at indicated times Aug. 13-24 were obtained from graph based on floodmarks and twice-daily readings. 


\section{JAMES RIVER BASIN}

DISCHARGE RECORD.-Stage-discharge relation defined by current-meter measurements up to 4,000 second-feet and extended to crest gage height of January $193 \mathrm{~J}$ on basis of velocity-area studies. Gage heights used to half-tenths between 2.7 and 3.5 feet; hundredths below and tenths above these limits.

Maxima.-1940: Discharge, 5,800 second-feet 11 p.m. Aug. 14 (gage height, 7.90 feet, from floodmarks).

1928-39: Discharge observed, 9,710 second-feet Jan. 23, 1935 (gage height, 10.10 feet).

Mean discharge, in second-feet, 1940

\begin{tabular}{|c|c|c|c|c|c|c|c|c|c|c|c|}
\hline Day & Aug. & Sept. & Day & Aug. & Sept. & Day & Aug. & Sept. & Day & Aug. & Sept. \\
\hline $\begin{array}{l}1 \\
2 \\
3 \\
4 \\
5 \\
6 \\
7 \\
8\end{array}$ & $\begin{array}{l}61 \\
\mathbf{5 0} \\
42 \\
42 \\
39 \\
38 \\
38 \\
40\end{array}$ & $\begin{array}{r}436 \\
232 \\
171 \\
137 \\
113 \\
98 \\
87 \\
78\end{array}$ & $\begin{array}{r}9 \\
10 \\
11 \\
12 \\
13 \\
14 \\
15 \\
16\end{array}$ & $\begin{array}{r}35 \\
33 \\
33 \\
34 \\
43 \\
1,910 \\
3,510 \\
2,730\end{array}$ & $\begin{array}{l}74 \\
68 \\
63 \\
59 \\
58 \\
54 \\
52 \\
51\end{array}$ & $\begin{array}{l}17 \\
18 \\
19 \\
20 \\
21 \\
22 \\
23 \\
24\end{array}$ & $\begin{array}{r}1,640 \\
947 \\
584 \\
404 \\
290 \\
210 \\
168 \\
141\end{array}$ & $\begin{array}{l}46 \\
45 \\
44 \\
42 \\
40 \\
39 \\
38 \\
37\end{array}$ & $\begin{array}{l}25 \\
26 \\
27 \\
28 \\
29 \\
30 \\
31\end{array}$ & $\begin{array}{r}118 \\
146 \\
124 \\
100 \\
98 \\
130 \\
520\end{array}$ & $\begin{array}{l}42 \\
46 \\
44 \\
40 \\
37 \\
35 \\
-\end{array}$ \\
\hline \multicolumn{10}{|c|}{ Monthly mean discharge, in second-feet } & $\begin{array}{r}461 \\
3.37\end{array}$ & $\begin{array}{l}80.2 \\
0.57\end{array}$ \\
\hline
\end{tabular}

Gage height, in feet, and discharge, in second-feet, at indicated time, 1940

\begin{tabular}{|c|c|c|c|c|c|c|c|c|c|c|c|c|}
\hline \multirow{2}{*}{ Hour } & \multicolumn{2}{|c|}{ Aug. 13} & \multicolumn{2}{|c|}{ Aug. 14} & \multicolumn{2}{|c|}{ Aug. 15} & \multicolumn{2}{|c|}{ Aug. 16} & \multicolumn{2}{|c|}{ Aug. 17} & \multicolumn{2}{|c|}{ Aug. 18} \\
\hline & $\begin{array}{c}\text { Gage } \\
\text { ht. }\end{array}$ & $\begin{array}{l}\text { Dis- } \\
\text { charge }\end{array}$ & $\begin{array}{c}\text { Gage } \\
\text { ht. }\end{array}$ & $\begin{array}{c}\text { Dis- } \\
\text { charge }\end{array}$ & $\begin{array}{c}\text { Gage } \\
\text { ht. }\end{array}$ & $\begin{array}{c}\text { Dis- } \\
\text { charge }\end{array}$ & $\begin{array}{c}\text { Gage } \\
\text { ht. }\end{array}$ & $\begin{array}{c}\text { Dis- } \\
\text { charge }\end{array}$ & $\begin{array}{c}\text { Gage } \\
\text { ht. }\end{array}$ & $\begin{array}{l}\text { Dis- } \\
\text { charge }\end{array}$ & $\begin{array}{c}\text { Gage } \\
\text { ht. }\end{array}$ & $\begin{array}{c}\text { Dis- } \\
\text { charge }\end{array}$ \\
\hline \multirow{4}{*}{$\begin{array}{l}1 \\
2 \\
3 \\
4 \\
5 \\
6\end{array}$} & & & \multirow{4}{*}{$\begin{array}{l}1.90 \\
2.00 \\
2.08 \\
2.15 \\
2.25 \\
2.35\end{array}$} & \multirow{4}{*}{$\begin{array}{r}93 \\
118 \\
143 \\
167 \\
206 \\
250\end{array}$} & \multirow{4}{*}{$\begin{array}{l}7.65 \\
7.40 \\
7.15 \\
6.95 \\
6.80 \\
6.60\end{array}$} & \multirow{4}{*}{$\begin{array}{l}5,330 \\
5,030 \\
4,740 \\
4,460 \\
4,200 \\
3,950\end{array}$} & & & & & & \\
\hline & 1.58 & 37 & & & & & 5.38 & 2,680 & $4.7 \overline{5}$ & 2,140 & 3.60 & $1,150^{-}$ \\
\hline & 1.58 & 37 & & & & & $5 . \overline{4} 0$ & 2,680 & 4.60 & $1, \overline{9} 60$ & 3.55 & 1,150 \\
\hline & $\overline{1.58}$ & 37 & & & & & 5.45 & 2,680 & $4 . \overline{4}$ & $1, \overline{9} 0$ & .4 & 070 \\
\hline 7 & & & \multirow{4}{*}{$\begin{array}{l}2.45 \\
2.61 \\
2.80 \\
3.00 \\
3.25 \\
3.50\end{array}$} & \multirow{4}{*}{$\begin{array}{r}300 \\
390 \\
520 \\
670 \\
870 \\
1,070\end{array}$} & \multirow{4}{*}{$\begin{array}{l}6.45 \\
6.30 \\
6.20 \\
6.10 \\
6.05 \\
5.95\end{array}$} & \multirow{4}{*}{$\begin{array}{l}3,710 \\
3,600 \\
3,490 \\
3,380 \\
3,270 \\
3,270\end{array}$} & & & & & & \\
\hline 8 & 1.58 & 37 & & & & & 5.55 & 2,870 & 4.35 & 1,790 & 3.40 & 990 \\
\hline 10 & 1.58 & 37 & & & & & 5.65 & 2,870 & 4.25 & 1,630 & 3.35 & $950^{\circ}$ \\
\hline $\mathrm{N}$ & $1 . \overline{8}$ & 37 & & & & & 5.70 & 2,970 & 4.15 & 1,630 & 3.30 & 910 \\
\hline 1 & & & \multirow{4}{*}{$\begin{array}{l}3.80 \\
4.15 \\
4.50 \\
4.90 \\
5.40 \\
5.90\end{array}$} & \multirow{4}{*}{$\begin{array}{l}1,310 \\
1,630 \\
1,870 \\
2,230 \\
2,680 \\
3,170\end{array}$} & \multirow{4}{*}{$\begin{array}{l}5.88 \\
5.80 \\
5.75 \\
5.70 \\
5.65 \\
5.60\end{array}$} & \multirow{4}{*}{$\begin{array}{l}3,170 \\
3,070 \\
3,070 \\
2,970 \\
2,870 \\
2,870\end{array}$} & & & & & & \\
\hline 2 & 1.59 & 38 & & & & & 5.70 & 2,970 & 4.10 & 1,550 & 3.26 & 870 \\
\hline 4 & 1.60 & 39 & & & & & $\overline{5} . \overline{6}$ & 2,870 & 4.00 & 1,470 & 3.23 & $870^{-}$ \\
\hline 6 & $-\overline{1} . \overline{6} \overline{2}$ & $\overline{4} \overline{2}$ & & & & & 5.50 & 2,770 & $3 . \overline{9}$ & $1, \overline{390}$ & 3.20 & $830^{\circ}$ \\
\hline 7 & & & \multirow{4}{*}{$\begin{array}{l}6.50 \\
7.10 \\
7.60 \\
7.85 \\
7.90 \\
7.80 \\
\end{array}$} & \multirow{4}{*}{$\begin{array}{l}3,830 \\
4,600 \\
5,330 \\
5,640 \\
5,800 \\
5,640 \\
\end{array}$} & \multirow{4}{*}{$\begin{array}{l}5.55 \\
5.50 \\
5.45 \\
5.42 \\
5.40 \\
5.38 \\
\end{array}$} & \multirow{4}{*}{$\begin{array}{l}2,870 \\
2,770 \\
2,680 \\
2,680 \\
2,680 \\
2,680 \\
\end{array}$} & & & & & & \\
\hline 0 & 1.66 & 48 & & & & & 5.30 & 2,590 & 3.85 & 1,310 & 3.16 & 790 \\
\hline 10 & $1.7 \overline{5}$ & 63 & & & & & 5.10 & 2,410 & $\overline{3.75}$ & $1, \overline{3} 10$ & $\overline{3} . \overline{13}$ & 790 \\
\hline \multirow[t]{2}{*}{12} & 1.85 & 82 & & & & & 4.90 & 2,230 & 3.70 & 1,230 & 3.10 & $\overline{750}$ \\
\hline & \multicolumn{2}{|c|}{ Aug. 19} & \multicolumn{2}{|c|}{ Aug. 20} & \multicolumn{2}{|c|}{ Aug. 21} & \multicolumn{2}{|c|}{ Aug. 22} & \multicolumn{2}{|c|}{ Aug. 23} & Aug & .24 \\
\hline & 3.05 & 71 & 2.7 & 4 & & 32 & 2. & 22 & 2. & 17 & & 14 \\
\hline 8 & & & & & & & & & & & & \\
\hline $\mathrm{N}$ & 2.85 & 55 & 2.65 & 4 & 2. & 29 & 2. & 21 & 2 . & 16 & 2 & 14 \\
\hline 4 & 3 & 52 & 2.6 & & & 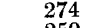 & & & & & & 13 \\
\hline 8 & & & 2. & & 2 . & 25 & & & & & & \\
\hline 1 & & 44 & 2.5 & 338 & 2.3 & 236 & 2.20 & 18 & 2 . & 15 & 2. & 13 \\
\hline
\end{tabular}

\section{COWPASTURE RIVER NEAR CLIFTON FORGE, VA.}

LOCATION.—Lat. $37^{\circ} 48^{\prime}$, long. $79^{\circ} 46^{\prime}$, at highway bridge $1 \frac{11 / 2}{2}$ miles upstream from confluence with Jackson River and 4 miles southeast of Clifton Forge, Alleghany County. Datum of gage is 1,006.93 feet above mean sea level (levels by Corps of Engineers, War Department). 
DRAINAGE AREA.-456 square miles.

GAGE-HEIGHT RECORD.-Water-stage recorder graph.

DISCHARGE RECORD.-Stage-d:scharge relation defined by current-meter measurements up to 13,000 second-feet and extended above on basis of velocity-area studies and comparison of peak discharge and total runoff of flood of Mar. 18, 1936, with those for other stations in James River Basin. Gage heights used to halftenths between 3.7 and 6.0 feet; hundredths below and tenths above these limits.

Maxima.-August 1940: Discharge, 6,120 second-feet 3 p.m. Aug. 16 (gage height, 8.21 feet).

1907-8, 1925 to July 1940: Discharge, about 34,200 second-feet Mar. 18, 1936 (gage height, 18.62 feet).

Stage known, 20.8 feet, from floodmarks, sometime in March 1913 (discharge, about 45,000 second-feet).

Mean discharge, in second-feet, 1940

\begin{tabular}{|c|c|c|c|c|c|c|c|c|c|c|c|}
\hline Day & Aug. & Sept. & Day & Aug. & Sept. & Day & Aug. & Sept. & Day & Aug. & Sept. \\
\hline $\begin{array}{l}1 \\
2 \\
3 \\
4 \\
5 \\
6 \\
7 \\
8\end{array}$ & $\begin{array}{r}724 \\
666 \\
380 \\
287 \\
240 \\
248 \\
1,120 \\
859\end{array}$ & $\begin{array}{r}2,910 \\
1,430 \\
866 \\
607 \\
476 \\
397 \\
344 \\
306\end{array}$ & $\begin{array}{r}9 \\
10 \\
11 \\
12 \\
13 \\
14 \\
15 \\
16\end{array}$ & $\begin{array}{r}476 \\
328 \\
269 \\
240 \\
263 \\
1832 \\
12,630 \\
5,650\end{array}$ & $\begin{array}{l}280 \\
276 \\
255 \\
233 \\
209 \\
199 \\
186 \\
179\end{array}$ & $\begin{array}{l}17 \\
18 \\
19 \\
20 \\
21 \\
22 \\
23 \\
24\end{array}$ & $\begin{array}{r}4,770 \\
12,190 \\
11,260 \\
818 \\
585 \\
464 \\
389 \\
336\end{array}$ & $\begin{array}{l}170 \\
160 \\
157 \\
151 \\
146 \\
143 \\
134 \\
131\end{array}$ & $\begin{array}{l}25 \\
26 \\
27 \\
28 \\
29 \\
30 \\
31\end{array}$ & $\begin{array}{r}306 \\
309 \\
384 \\
685 \\
915 \\
822 \\
1,630\end{array}$ & $\begin{array}{r}163 \\
179 \\
176 \\
148 \\
134 \\
128 \\
\end{array}$ \\
\hline \multicolumn{10}{|c|}{$\begin{array}{l}\text { Monthly mean discharge, in second-feet } \\
\text { Runoff, in inches }\end{array}$} & $\begin{array}{r}11,002 \\
12.54\end{array}$ & $\begin{array}{r}376 \\
0.92\end{array}$ \\
\hline
\end{tabular}

1 Discharge is different from that given in Water-Supply Paper 892 . It is based on revisions not considered important enough for inclusion with revised records published in Water-Supply Paper 952.

Gage height, in feet, and discharge, in second-feet, at indicated time, 1940

\begin{tabular}{|c|c|c|c|c|c|c|c|c|c|c|c|c|}
\hline \multirow{2}{*}{ Hour } & \multicolumn{2}{|c|}{ Aug. 13} & \multicolumn{2}{|c|}{ Aug. 14} & \multicolumn{2}{|c|}{ Aug. 15} & \multicolumn{2}{|c|}{ Aug. 16} & \multicolumn{2}{|c|}{ Aug. 17} & \multicolumn{2}{|c|}{ Aug. 18} \\
\hline & $\begin{array}{c}\text { Gage } \\
\text { ht. }\end{array}$ & $\begin{array}{c}\text { Dis- } \\
\text { charge }\end{array}$ & $\begin{array}{c}\text { Gage } \\
\text { ht. }\end{array}$ & $\begin{array}{c}\text { Dis- } \\
\text { charge }\end{array}$ & $\begin{array}{c}\text { Gage } \\
\text { ht. }\end{array}$ & $\begin{array}{c}\text { Dis- } \\
\text { charge }\end{array}$ & $\begin{array}{l}\text { Gage } \\
\text { ht. }\end{array}$ & $\begin{array}{c}\text { Dis- } \\
\text { charge }\end{array}$ & $\begin{array}{c}\text { Gage } \\
\text { ht. }\end{array}$ & $\begin{array}{c}\text { Dis- } \\
\text { charge }\end{array}$ & $\begin{array}{l}\text { Gage } \\
\text { ht. }\end{array}$ & $\begin{array}{c}\text { Dis- } \\
\text { charge }\end{array}$ \\
\hline \multirow{3}{*}{$\begin{array}{l}1 \\
2 \\
3 \\
4 \\
5 \\
6\end{array}$} & 2.40 & 226 & & \multirow{3}{*}{$\begin{array}{l}273 \\
269 \\
266 \\
266 \\
266 \\
266\end{array}$} & \multirow{3}{*}{$\begin{array}{l}4.84 \\
4.83 \\
4.83 \\
4.83 \\
4.86 \\
4.88\end{array}$} & \multirow{3}{*}{$\begin{array}{l}1,850 \\
1,8850 \\
1,850 \\
1,850 \\
1,850 \\
1,900\end{array}$} & \multirow{3}{*}{$\begin{array}{l}7.60 \\
7.58 \\
7.60 \\
7.70 \\
7.80 \\
7.88\end{array}$} & \multirow{3}{*}{$\begin{array}{l}5,200 \\
5,200 \\
5,200 \\
5,350 \\
5,500 \\
5,650\end{array}$} & \multirow{3}{*}{$\begin{array}{l}7.70 \\
7.80 \\
7.92 \\
8.03 \\
8.09 \\
8.12\end{array}$} & \multirow{3}{*}{$\begin{array}{l}5,350 \\
5,500 \\
5,650 \\
5,800 \\
5,960 \\
5,960\end{array}$} & 5.83 & 2,910 \\
\hline & 2.40 & 226 & & & & & & & & & 5.67 & $2,680^{-}$ \\
\hline & $\overline{2.40}$ & 226 & & & & & & & & & $\overline{5} . \overline{5}$ & 2,520 \\
\hline \multirow{3}{*}{$\begin{array}{r}7 \\
8 \\
9 \\
10 \\
11 \\
\mathrm{~N}\end{array}$} & 2.49 & 258 & & \multirow{3}{*}{$\begin{array}{l}273 \\
287 \\
309 \\
336 \\
376 \\
436\end{array}$} & \multirow{3}{*}{$\begin{array}{l}4.94 \\
5.00 \\
5.10 \\
5.18 \\
5.25 \\
5.32\end{array}$} & \multirow{3}{*}{$\begin{array}{l}1,950 \\
2,000 \\
2,100 \\
2,200 \\
2,250 \\
2,300\end{array}$} & \multirow{3}{*}{$\begin{array}{l}7.94 \\
8.00 \\
8.03 \\
8.08 \\
8.09 \\
8.11\end{array}$} & \multirow{3}{*}{$\begin{array}{l}5,650 \\
5,800 \\
5,800 \\
5,960 \\
5,960 \\
5,960\end{array}$} & \multirow{3}{*}{$\begin{array}{l}8.10 \\
8.03 \\
7.92 \\
7.79 \\
7.65 \\
7.50\end{array}$} & \multirow{3}{*}{$\begin{array}{l}5,960 \\
5,800 \\
5,650 \\
5,500 \\
5,200 \\
5,050\end{array}$} & 5.38 & 2,410 \\
\hline & $\mid-53$ & 273 & & & & & & & & & 5.25 & 2,250 \\
\hline & 2.53 & 273 & $\begin{array}{r}2.80 \\
2.94\end{array}$ & & & & & & & & 5.14 & 2,150 \\
\hline \multirow{3}{*}{$\begin{array}{l}2 \\
3 \\
4 \\
5 \\
6\end{array}$} & 2.52 & 269 & & \multirow{3}{*}{$\begin{array}{r}590 \\
845 \\
1,090 \\
1,400 \\
1,580 \\
1,620\end{array}$} & \multirow{3}{*}{$\begin{array}{l}5.38 \\
5.42 \\
5.45 \\
5.48 \\
5.54 \\
5.70\end{array}$} & \multirow{3}{*}{$\begin{array}{l}2,410 \\
2,410 \\
2,460 \\
2,520 \\
2,580 \\
2,740\end{array}$} & \multirow{3}{*}{\begin{tabular}{l|}
8.15 \\
8.19 \\
8.21 \\
8.18 \\
8.13 \\
8.07
\end{tabular}} & \multirow{3}{*}{$\begin{array}{l}6,120 \\
6,120 \\
6,120 \\
6,120 \\
5,960 \\
5,960\end{array}$} & \multirow{3}{*}{\begin{tabular}{|l|}
7.35 \\
7.20 \\
7.05 \\
6.90 \\
6.77 \\
6.66
\end{tabular}} & \multirow{3}{*}{$\begin{array}{l}4,910 \\
4,630 \\
4,350 \\
4,220 \\
4,090 \\
3,960\end{array}$} & 5.02 & 2,000 \\
\hline & 2.52 & 269 & & & & & & & & & 4.90 & $1,900^{-}$ \\
\hline & 2.54 & 276 & $\left|\begin{array}{|}4.53 \\
4.58\end{array}\right|$ & & & & & & & & 4.80 & $1,800^{\circ}$ \\
\hline \multirow{4}{*}{$\begin{array}{r}8 \\
8 \\
9 \\
10 \\
11 \\
12 \\
\end{array}$} & 256 & 284 & & \multirow{3}{*}{$\begin{array}{l}1,580 \\
1,580 \\
1,580 \\
1,660 \\
1,760 \\
1,850 \\
\end{array}$} & $\begin{array}{l}6.00 \\
6.40\end{array}$ & $\begin{array}{l}3,090 \\
3,570\end{array}$ & & & $\begin{array}{ll}6.53 \\
6.42\end{array}$ & & 4.72 & 1710 \\
\hline & 2.61 & 302 & & & 6.80 & & 7.81 & & & & $\overline{4} .6 \overline{4}$ & 1,660 \\
\hline & $\overline{2} . \overline{5} \overline{5}$ & 280 & & & $\begin{array}{l}7.57 \\
7.63\end{array}$ & & & & $\begin{array}{l}6.11 \\
6.01\end{array}$ & & -4.56 & 1,580 \\
\hline & & g. 19 & & 20 & $\mathrm{Au}$ & 21 & & g. 22 & $\mathrm{Aug}$ & 23 & & 24 \\
\hline & 4.41 & & & & & 642 & 3 & 496 & & & 2. & 48 \\
\hline 8 & & & & & & & & & & & & \\
\hline 4 & 4. & f & & & & & & & & & & \\
\hline & & 1,0 & & & & & 2. & & & & & 32 \\
\hline 12 & 3.84 & 980 & $\mid \begin{array}{l}0.70 \\
3.40\end{array}$ & 678 & 3.10 & $\begin{array}{l}510 \\
510\end{array}$ & 2.91 & 422 & 2.76 & 360 & 2.65 & 317 \\
\hline
\end{tabular}


CRAIG CRESK AT PARR, VA.

Location.-Lat. $37^{\circ} 39^{\prime} 55^{\prime \prime}$, long. $79^{\circ} 54^{\prime} 40^{\prime \prime}$, at Chesapeake and Ohio Railway bridge, 700 feet downstream from Stony Run, 0.4 mile northwest of Parr, Botetourt County, and 12 miles upstream from mouth. Datum of gage is 992.50 feet above mean sea level (levels by Corps of Engineers, War Department).

Drainage AREA.- 331 square miles.

GAGE-HEIGHT RECORD.-Water-stage recorder graph.

DISCHARGE RECORD.-Stage-discharge relation defined by current-meter measurements up to 5,000 second-feet, fairly well defined to 11,000 second-feet and extended above. Gage heights used to half-tenths between 5.9 and 8.1 feet; hundredths below and tenths above these limits.

Maxina.-1940: Discharge 15,200 second-feet 5 a.m. Aug. 15 (gage height, 15.02 feet).

1925-39: Discharge observed, 16,700 second-feet Jan. 23, 1935 (gage height, 15.85 feet).

Mean discl arqe, in second-feet, 1940

\begin{tabular}{|c|c|c|c|c|c|c|c|c|c|c|c|}
\hline Day & Aug. & Sept. & Day & Aug. & Sept. & Day & Aug. & Sept. & Day & Aug. & Sept. \\
\hline 1 & 90 & 1,320 & 9 & 77 & 191 & 17 & 4,670 & 102 & 2 & 275 & 82 \\
\hline 2 & 82 & 778 & 10 & 0 & & 1 & & & & & 0 \\
\hline$\overline{3}$ & 73 & 5 & 11 & 6 & & Is & 1,3 & 9 & & 256 & 3 \\
\hline 4 & 69 & 420 & 12 & 65 & 14 & 20 & 86 & 90 & 28 & 259 & 77 \\
\hline 5 & 66 & 344 & 13 & 75 & 13 & 21 & & 85 & & 364 & 73 \\
\hline 6 & 70 & 2 & 14 & 3,180 & 12 & 2 & & 8 & 30 & 480 & 72 \\
\hline 7 & 164 & 24 & 15 & 11,800 & 11 & 23 & 38 & 76 & 31 & 3,600 & \\
\hline 8 & 112 & 21 & 16 & 7,280 & $10^{\circ}$ & 24 & 318 & 77 & & & \\
\hline \multicolumn{12}{|c|}{$\begin{array}{l}\text { Monthly mean discharge, in second-feet } \\
\text { Runoff, in inches }\end{array}$} \\
\hline
\end{tabular}

Gage height, in feet, and discharge, in second-feet, at indicated time, 1940

\begin{tabular}{|c|c|c|c|c|c|c|c|c|c|c|c|c|}
\hline \multirow{2}{*}{ Hour } & \multicolumn{2}{|c|}{ Aug. 13} & \multicolumn{2}{|c|}{ Aug. 14} & \multicolumn{2}{|c|}{ Aug. 15} & \multicolumn{2}{|c|}{ Aug. 16} & \multicolumn{2}{|c|}{ Aug. 17} & \multicolumn{2}{|c|}{ Aug. 18} \\
\hline & $\begin{array}{c}\text { Gage } \\
\text { ht. }\end{array}$ & $\begin{array}{c}\text { Dis- } \\
\text { charge }\end{array}$ & $\begin{array}{c}\text { Gage } \\
\text { ht. }\end{array}$ & $\begin{array}{c}\text { Dis- } \\
\text { charge }\end{array}$ & $\begin{array}{c}\text { Gage } \\
\text { ht. }\end{array}$ & $\begin{array}{c}\text { Dis- } \\
\text { charge }\end{array}$ & $\begin{array}{c}\text { Gage } \\
\text { ht. }\end{array}$ & $\begin{array}{c}\text { Dis- } \\
\text { charge }\end{array}$ & $\begin{array}{c}\text { Gage } \\
\text { ht. }\end{array}$ & $\underset{\text { cha }}{\mathrm{D}}$ & $\begin{array}{c}\text { Gage } \\
\text { ht. }\end{array}$ & $\begin{array}{l}\text { Dis- } \\
\text { charge }\end{array}$ \\
\hline \multirow{5}{*}{$\begin{array}{l}1 \\
2 \\
3 \\
4 \\
5 \\
6\end{array}$} & & & \multirow{5}{*}{$\begin{array}{l}3.83 \\
3.84 \\
3.86 \\
3.88 \\
3.90 \\
3.93\end{array}$} & \multirow{5}{*}{$\begin{array}{r}85 \\
86 \\
90 \\
93 \\
96 \\
102\end{array}$} & \multirow{5}{*}{$\begin{array}{l}13.80 \\
14.35 \\
14.75 \\
14.95 \\
15.02 \\
14.95\end{array}$} & \multirow{5}{*}{$\begin{array}{l}13,000 \\
14,100 \\
14,800 \\
15,200 \\
15,200 \\
15,200\end{array}$} & \multirow{5}{*}{$\begin{array}{l}10.68 \\
10.63 \\
10.58 \\
10.56 \\
10.55 \\
10.58\end{array}$} & \multirow{5}{*}{$\begin{array}{l}7,670 \\
7,510 \\
7,510 \\
7,510 \\
7,510 \\
7,510\end{array}$} & & & & \\
\hline & 3.73 & 70 & & & & & & & 9.40 & 5,590 & 7.76 & 3,120 \\
\hline & 3.73 & 70 & & & & & & & 9.22 & 5,270 & 7.65 & 3,000 \\
\hline & & & & & & & & & & & & \\
\hline & 3.74 & 72 & & & & & & & 9.12 & 5,110 & 7.52 & 800 \\
\hline \multirow{4}{*}{$\begin{array}{r}7 \\
8 \\
9 \\
10 \\
11 \\
\mathrm{~N}\end{array}$} & & & \multirow{4}{*}{$\begin{array}{l}3.97 \\
4.05 \\
4.20 \\
4.40 \\
4.75 \\
5.40\end{array}$} & \multirow{4}{*}{$\begin{array}{l}109 \\
126 \\
164 \\
227 \\
366 \\
700\end{array}$} & \multirow{4}{*}{$\begin{array}{l}14.70 \\
14.45 \\
14.20 \\
13.95 \\
13.65 \\
13.35\end{array}$} & \multirow{4}{*}{$\begin{array}{l}14,600 \\
14,100 \\
13,700 \\
13,400 \\
12,600 \\
12,300\end{array}$} & \multirow{4}{*}{$\begin{array}{l}10.62 \\
10.67 \\
10.72 \\
10.77 \\
10.80 \\
10.82\end{array}$} & \multirow{4}{*}{$\begin{array}{l}7,510 \\
7,670 \\
7,670 \\
7,830 \\
7,830 \\
7,830\end{array}$} & & & & \\
\hline & 3.75 & 73 & & & & & & & 9.08 & 5,110 & 7.39 & 2,670 \\
\hline & $\mathbf{3} .76$ & 74 & & & & & & & 9.04 & 4,950 & 7.28 & 2,540 \\
\hline & 3.77 & $7 \overrightarrow{6}^{-}$ & & & & & & & 8.92 & 4,790 & 7.19 & 2,420 \\
\hline \multirow{4}{*}{$\begin{array}{l}1 \\
2 \\
3 \\
4 \\
5 \\
6\end{array}$} & & & \multirow{4}{*}{$\begin{array}{l}6.25 \\
7.20 \\
8.10 \\
8.80 \\
9.30 \\
9.80\end{array}$} & \multirow{4}{*}{$\begin{array}{l}1,370 \\
2,420 \\
3,610 \\
4,640 \\
5,430 \\
6,230\end{array}$} & \multirow{4}{*}{$\begin{array}{l}13.10 \\
12.85 \\
12.55 \\
12.25 \\
12.00 \\
11.75\end{array}$} & \multirow{4}{*}{$\begin{array}{r}11,700 \\
11,200 \\
10,900 \\
10,200 \\
9,850 \\
9,510\end{array}$} & \multirow{4}{*}{\begin{tabular}{|l}
10.79 \\
10.72 \\
10.62 \\
10.50 \\
10.35 \\
10.25
\end{tabular}} & \multirow{4}{*}{$\begin{array}{l}7,830 \\
7,670 \\
7,510 \\
7,350 \\
7,190 \\
6,870\end{array}$} & & & & \\
\hline & 3.77 & 76 & & & & & & & 8.78 & 4,640 & 7.10 & 2,300 \\
\hline & 3.78 & 77 & & & & & & & 8.60 & 4,340 & 7.00 & 2,180 \\
\hline & 3.79 & 79 & & & & & & & 8.43 & 4,040 & 6.90 & 2,060 \\
\hline \multirow{5}{*}{$\begin{array}{r}7 \\
8 \\
9 \\
10 \\
11 \\
12 \\
\end{array}$} & & & \multirow{4}{*}{$\begin{array}{l}10.30 \\
10.80 \\
11.35 \\
12.00 \\
12.65 \\
13.25\end{array}$} &, 030 & & & & & & & & \\
\hline & 3.80 & 80 & & & & & 10 & & 8.26 & 3,890 & 6.82 & 1,950 \\
\hline & 3.80 & 80 & & $\begin{array}{l}8,800 \\
9,850\end{array}$ & 11.05 & 8, & $\begin{array}{l}9.92 \\
9.82\end{array}$ & 6 , & 8.08 & 3,610 & 6.73 & 1,900 \\
\hline & 3.82 & 83 & & & $\mid \begin{array}{l}10.90 \\
10.78\end{array}$ & & $\begin{array}{l}9.72 \\
9.60 \\
\end{array}$ & & 7.93 & 3,400 & 6.64 & 1,780 \\
\hline & $\mathrm{Au}$ & & $\mathrm{Au}$ & 0 & $\mathrm{Au}$ & 2. & & 22 & & 3 & $\mathrm{Au}$ & 24 \\
\hline 4 & 48 & & & 988 & 5 & & 5. & & 4.8 & & 4. & 3 \\
\hline 8 & & & & & & & & & & & & \\
\hline $\mathrm{N}$ & 22 & 0 & 5. & 8 & 5.2 & & 4. & 4 & 4. & & 4. & \\
\hline 4 & & & & & 5. & & & & & & & \\
\hline 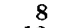 & & & & 7 & 5. & & 4. & & & & & \\
\hline 1 & & & & 71 & $\approx$ & 54 & 4 . & 42 & 4 & & 4.5 & 290 \\
\hline
\end{tabular}


MEADOW CREEK AT NEWCASTLE, VA.

LOCATION.-Lat. $37^{\circ} 29^{\prime} 35^{\prime \prime}$, long. $80^{\circ} 06^{\prime} 35^{\prime \prime}$, at south town limits of Neweastle, Craig County, 800 feet upstream from Newcastle-Salem highway bridge, and half a nile upstream from mouth. Datum of gage is $1,337.45$ feet above mean sea level (unadjusted).

DRAINAGE AREA.- -13.8 square miles.

GAGE-HEIGHT RECORD.-Water-stage recorder graph.

DISCHARGE RECORD.-Control is sharp-crested weir. Stage-discharge relation defined by current-meter measurements up to 300 second-feet and extended to crest gage height on basis of comparisons of flood records with those for Johns Creek at Newcastle and Craig Creek at Parr. Gage heights used to hundredths throughout. Maxima.-1940: Discharge, 700 second-feet 8 a.m. Aug. 16 (gage height, 4.80 feet).

1929-39: Discharge, 242 second-feet Oct. 2, 1929 (gage height, 3.64 feet, site and datum then in use).

Mean discharge, in second-feet, 1940

\begin{tabular}{r|r|r|r|r|r||r|r|r|r|r|r}
\hline Day & Aug. & Sept. & Day & Aug. & Sept. & Day & Aug. & Sept. & Day & Aug. & Sept. \\
\hline 1 & 8.1 & 88 & 9 & 5.6 & 19 & 17 & 323 & 11 & 25 & 24 & 9.0 \\
2 & 6.4 & 62 & 10 & 5.3 & 18 & 18 & 179 & 10 & 26 & 23 & 8.8 \\
3 & 6.0 & 49 & 11 & 5.7 & 16 & 19 & 101 & 10 & 27 & 26 & 8.3 \\
4 & 6.3 & 39 & 12 & 6.9 & 15 & 20 & 65 & 9.3 & 28 & 30 & 8.1 \\
5 & 6.1 & 33 & 13 & 7.4 & 14 & 21 & 50 & 9.3 & 29 & 26 & 7.9 \\
6 & 6.0 & 29 & 14 & 197 & 13 & 22 & 41 & 8.8 & 30 & 79 & 7.5 \\
7 & 5.8 & 25 & 15 & 521 & 12 & 23 & 34 & 8.6 & 31 & 148 & \\
8 & 5.8 & 21 & 16 & 526 & 12 & 24 & 30 & 8.6 & & & \\
\hline
\end{tabular}

Gage height, in feet, and discharge, in second-feet, at indicated time, 1940

\begin{tabular}{|c|c|c|c|c|c|c|c|c|c|c|c|c|}
\hline \multirow{2}{*}{ Hour } & \multicolumn{2}{|c|}{ Aug. 13} & \multicolumn{2}{|c|}{ Aug. 14} & \multicolumn{2}{|c|}{ Aug. 15} & \multicolumn{2}{|c|}{ Aug. 16} & \multicolumn{2}{|c|}{ Aug. 17} & \multicolumn{2}{|c|}{ Aug. 18} \\
\hline & $\begin{array}{c}\text { Gage } \\
\text { ht. }\end{array}$ & $\begin{array}{c}\text { Dis- } \\
\text { charge }\end{array}$ & $\begin{array}{c}\text { Gage } \\
\text { ht. }\end{array}$ & $\begin{array}{c}\text { Dis- } \\
\text { charge }\end{array}$ & $\begin{array}{l}\text { Gage } \\
\text { ht. }\end{array}$ & $\begin{array}{c}\text { Dis- } \\
\text { charge }\end{array}$ & $\begin{array}{c}\text { Gage } \\
\text { ht. }\end{array}$ & $\begin{array}{c}\text { Dis- } \\
\text { charge }\end{array}$ & $\begin{array}{l}\text { Gage } \\
\text { ht. }\end{array}$ & $\begin{array}{c}\text { Dis- } \\
\text { charge }\end{array}$ & $\begin{array}{l}\text { Gage } \\
\text { ht. }\end{array}$ & $\begin{array}{l}\text { Dis- } \\
\text { charge }\end{array}$ \\
\hline \multirow{3}{*}{$\begin{array}{l}1 \\
2 \\
3 \\
4 \\
5 \\
6\end{array}$} & 1.94 & 5.8 & 2.95 & 44 & 4.53 & 465 & 4.70 & 600 & & & & \\
\hline & 1.96 & 6.0 & $\overline{3} .1 \overline{4}$ & $6 \overline{3}$ & $-\overline{4.55}$ & 480 & 4.65 & $5 \overline{58}$ & 4.43 & 403 & $\overline{3} . \overline{3}$ & 207 \\
\hline & 1.97 & 6.2 & 3.25 & 76 & 4.45 & 415 & 4.67 & 574 & & & & \\
\hline \multirow{3}{*}{$\begin{array}{r}7 \\
8 \\
9 \\
10 \\
11 \\
\mathrm{~N}\end{array}$} & 2.00 & 6.6 & 3.45 & 106 & $\overrightarrow{4} . \overline{5} \overline{5}$ & 480 & 4.80 & 700 & 4.34 & $3 \overline{7}$ & 3.88 & 194 \\
\hline & 2.04 & 7.2 & 3.85 & 186 & 4.60 & 515 & 4.69 & 592 & $\therefore$ & & . & . \\
\hline & 1.98 & $6 . \overline{3}$ & 4.25 & 316 & 4.60 & 515 & 4.62 & $\overline{5} \overline{3} \overline{2}$ & 4.26 & 320 & 3.82 & 179 \\
\hline \multirow{3}{*}{$\begin{array}{l}1 \\
2 \\
3 \\
4 \\
5 \\
6\end{array}$} & 2.00 & $\overline{6} . \overline{6}$ & 4.20 & 295 & $4.6 \overline{5}$ & 558 & $4.5 \overline{5}$ & 480 & & & $\ldots$ & \\
\hline & 2.01 & 6.8 & $4 . \overline{15}$ & $2 \overline{7} \overline{7}$ & 4.65 & $\overline{558}$ & 4.51 & 451 & 4.14 & 273 & $3 . \overline{7}$ & 165 \\
\hline & 1.98 & 6.3 & 4.05 & 243 & 4.65 & 558 & 4.50 & 444 & & & - & . . . . . \\
\hline \multirow{4}{*}{$\begin{array}{r}7 \\
8 \\
9 \\
10 \\
11 \\
12 \\
\end{array}$} & 2.10 & 8.2 & $\begin{array}{l}4.20 \\
4.00\end{array}$ & $\begin{array}{l}295 \\
227\end{array}$ & 4.68 & 583 & 4.48 & 432 & 4.10 & 259 & 3.70 & 152 \\
\hline & 2.10 & $8 . \overline{2}$ & $\begin{array}{l}3.75 \\
4.20\end{array}$ & $\begin{array}{l}163 \\
295\end{array}$ & 4.70 & 600 & 4.49 & 438 & & & & \\
\hline & 2.62 & 24 & 4.50 & 444 & 4.70 & 600 & 4.48 & 432 & 3.98 & 221 & 3.63 & 138 \\
\hline & \multicolumn{2}{|c|}{ Aug. 19} & \multicolumn{2}{|c|}{ Aug. 20} & \multicolumn{2}{|c|}{ Aug. 21} & \multicolumn{2}{|c|}{ Aug. 22} & \multicolumn{2}{|c|}{ Aug. 23} & \multicolumn{2}{|c|}{ Aug. 24} \\
\hline $\begin{array}{r}4 \\
8 \\
\mathbf{N} \\
4 \\
8 \\
8 \\
12\end{array}$ & $\begin{array}{l}3.56 \\
3.50 \\
3.40 \\
3.32 \\
3.27 \\
3.23\end{array}$ & $\begin{array}{r}125 \\
114 \\
98 \\
86 \\
79 \\
74\end{array}$ & $\begin{array}{l}3.21 \\
3.18 \\
3.16 \\
3.12 \\
3.10 \\
3.07\end{array}$ & $\begin{array}{l}71 \\
68 \\
66 \\
61 \\
59 \\
56\end{array}$ & $\begin{array}{l}3.05 \\
3.03 \\
3.01 \\
3.00 \\
2.97 \\
2.95\end{array}$ & $\begin{array}{l}54 \\
52 \\
50 \\
49 \\
46 \\
44\end{array}$ & $\begin{array}{l}2.94 \\
2.93 \\
2.91 \\
2.89 \\
2.87 \\
2.85\end{array}$ & $\begin{array}{l}44 \\
43 \\
41 \\
39 \\
38 \\
36\end{array}$ & $\begin{array}{l}2.84 \\
2.83 \\
2.82 \\
2.80 \\
2.79 \\
2.77\end{array}$ & $\begin{array}{l}36 \\
35 \\
34 \\
33 \\
32 \\
32 \\
\end{array}$ & $\begin{array}{l}2.77 \\
2.76 \\
2.75 \\
2.71 \\
2.68 \\
2.67\end{array}$ & $\begin{array}{l}32 \\
31 \\
30 \\
28 \\
27 \\
26\end{array}$ \\
\hline
\end{tabular}

SuPPLEMENTAL ReCORD.-Aug. 14, 9:30 p.m., gage height, 4.43 feet; discharge, 403 second-feet. 


\section{JOHNS CREEK AT NEWCASTLE, VA.}

LocATION.-Lat. $37^{\circ} 30^{\prime}$, long. $80^{\circ} 06^{\prime}$, at highway bridge 800 feet northeast of town limits of Neweastle, Craig County, and 1,700 feet upstream from mouth. Datum of gage is 1,254.43 feet above mean sea level (unadjusted).

DRAINAGE AREA.-106 square miles.

GAGE-HEIGHT RECORD.-Water-stage recorder graph.

DISCHARGE RECORD.-Stage-discharge relation defined by current-meter measurements up to 3,200 second-feet and extended to crest gage height of January 1935 on basis of velocity-area studies. Gage heights used to half-tenths between 5.7 and 10.0 feet; hundredths below and tenths above these limits.

Maxima.-1940: Discharge, 4,640 second-feet 1:30 a.m. Aug. 15 (gage height, 9.53 feet).

1926-39: Discharge observed, 8,000 second-feet Jan. 23, 1935 (gage height, 10.80 feet).

Mean discharge, in second-feet, 1940

\begin{tabular}{|c|c|c|c|c|c|c|c|c|c|c|c|}
\hline Day & Aug. & Sept. & Day & Aug. & Sept. & Day & Aug. & Sept. & Day & Aug. & Sept. \\
\hline $\begin{array}{l}1 \\
2 \\
3 \\
4 \\
5 \\
6 \\
7 \\
8\end{array}$ & $\begin{array}{l}32 \\
28 \\
22 \\
21 \\
21 \\
33 \\
27 \\
20\end{array}$ & $\begin{array}{r}205 \\
144 \\
105 \\
83 \\
70 \\
60 \\
51 \\
45\end{array}$ & $\begin{array}{l}99 \\
10 \\
11 \\
12 \\
13 \\
14 \\
15 \\
16\end{array}$ & $\begin{array}{r}16 \\
14 \\
16 \\
24 \\
26 \\
12,010 \\
13,270 \\
11,940\end{array}$ & $\begin{array}{l}40 \\
39 \\
38 \\
34 \\
30 \\
29 \\
27 \\
25\end{array}$ & $\begin{array}{l}17 \\
18 \\
19 \\
20 \\
21 \\
22 \\
23 \\
24\end{array}$ & $\begin{array}{r}1,130 \\
624 \\
384 \\
258 \\
182 \\
141 \\
108 \\
85\end{array}$ & $\begin{array}{l}24 \\
23 \\
22 \\
21 \\
20 \\
18 \\
18 \\
17\end{array}$ & $\begin{array}{l}25 \\
26 \\
27 \\
28 \\
29 \\
30 \\
31\end{array}$ & $\begin{array}{r}74 \\
76 \\
67 \\
80 \\
71 \\
256 \\
366\end{array}$ & $\begin{array}{l}18 \\
22 \\
22 \\
19 \\
18 \\
18\end{array}$ \\
\hline \multicolumn{10}{|c|}{$\begin{array}{l}\text { Monthly mean discharge, in second-feet } \\
\text { Runoff, in inches }\end{array}$} & $\begin{array}{r}368 \\
4.00\end{array}$ & $\begin{array}{l}43.5 \\
0.46\end{array}$ \\
\hline
\end{tabular}

${ }^{1}$ Discharge is different from that given in Water-Supply Paper 892 . It is based on revisions not considered important enough to necessitate revision of daily discharge when peak was revised in WaterSupply Paper 972 .

Gage height, in feet, and discharge, in second-feet, at indicated time, 1940

\begin{tabular}{|c|c|c|c|c|c|c|c|c|c|c|c|c|}
\hline \multirow{2}{*}{ Hour } & \multicolumn{2}{|c|}{ Aug. 13} & \multicolumn{2}{|c|}{ Aug. 14} & \multicolumn{2}{|c|}{ Aug. 15 . } & \multicolumn{2}{|c|}{ Aug. 16} & \multicolumn{2}{|c|}{ Aug. 17} & \multicolumn{2}{|c|}{ Aug. 18} \\
\hline & $\begin{array}{c}\text { Gage } \\
\text { ht. }\end{array}$ & $\begin{array}{c}\text { Dis- } \\
\text { charge }\end{array}$ & $\begin{array}{c}\text { Gage } \\
\text { ht. }\end{array}$ & $\begin{array}{c}\text { Dis- } \\
\text { charge }\end{array}$ & $\begin{array}{c}\text { Gage } \\
\text { ht. }\end{array}$ & $\begin{array}{c}\text { Dis- } \\
\text { charge }\end{array}$ & $\begin{array}{c}\text { Gage } \\
\text { ht. }\end{array}$ & $\begin{array}{c}\text { Dis- } \\
\text { charge }\end{array}$ & $\begin{array}{c}\text { Gage } \\
\text { ht. }\end{array}$ & $\begin{array}{c}\text { Dis- } \\
\text { charge }\end{array}$ & $\begin{array}{c}\text { Gage } \\
\text { ht. }\end{array}$ & $\begin{array}{c}\text { Dis- } \\
\text { charge }\end{array}$ \\
\hline & & & & & & & 8.47 & & & & & \\
\hline 2 & 3.39 & $25^{-}$ & 5 & 70 & $\begin{array}{c}9.52 \\
9.50\end{array}$ & 4,5 & $\begin{array}{l}.7 .73 \\
8.42\end{array}$ & 0 & 7.32 & 1,460 & & \\
\hline 4 & 3.39 & 25 & $\begin{array}{l}4.10 \\
4.64\end{array}$ & $\begin{array}{r}50 \\
179\end{array}$ & 9.43 & $\begin{array}{l}4,000 \\
4,420\end{array}$ & 8.24 & 2,350 & 7.22 & 1,380 & 6.11 & 742 \\
\hline $\begin{array}{l}5 \\
6\end{array}$ & 3.39 & 25 & $\begin{array}{l}4.59 \\
4.59\end{array}$ & 17 & 9.31 & 4,090 & $\begin{array}{l}8.15 \\
8.07\end{array}$ & $\begin{array}{l}2,230 \\
2,120\end{array}$ & 7.10 & 1,310 & & \\
\hline $\begin{array}{l}7 \\
8\end{array}$ & 339 & 25 & $\begin{array}{l}4.78 \\
5.23\end{array}$ & 205 & 9.25 & & 8.00 & & 00 & & 507 & 673 \\
\hline 9 & & & 5.20 & 606 & 9.11 & $\begin{array}{l}3,690 \\
3,690\end{array}$ & 7.94 & 2,020 & & & & \\
\hline 10 & 3.40 & 26 & 7.20 & 1,380 & 9.00 & 3,490 & 7.94 & 2,020 & 6.90 & 1,170 & & \\
\hline$\stackrel{11}{N}$ & 3.38 & 25 & $\begin{array}{l}8.45 \\
9.20\end{array}$ & $\begin{array}{l}2,600 \\
3,890\end{array}$ & $\begin{array}{l}8.89 \\
8.76\end{array}$ & $\begin{array}{l}3,310 \\
3,050\end{array}$ & $\begin{array}{l}7.92 \\
7.85\end{array}$ & $\begin{array}{l}1,970 \\
1,920\end{array}$ & 6.78 & 1,110 & 5.83 & 628 \\
\hline 1 & & & 9.25 & 3,990 & 8.62 & 2,810 & 7.79 & 1,880 & & & & \\
\hline 2 & 3.38 & 25 & 8.80 & 0 & 8.50 & 2 , & 7.75 & 40 & 6.68 & 1,050 & $\cdots$ & 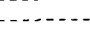 \\
\hline $\begin{array}{l}3 \\
4\end{array}$ & $3 . \overline{3}$ & 24 & $\begin{array}{l}8.50 \\
8.38\end{array}$ & $\begin{array}{l}2,670 \\
2,530\end{array}$ & $\begin{array}{l}8.40 \\
8.32\end{array}$ & $\begin{array}{l}2,530 \\
2,410\end{array}$ & $\begin{array}{l}7.70 \\
7.64\end{array}$ & $\begin{array}{l}1,790 \\
1,740\end{array}$ & $\overline{6} . \overline{58}$ & 990 & $\overline{5} . \overline{6}$ & $\overline{556}$ \\
\hline $\begin{array}{l}5 \\
6\end{array}$ & $3 . \overline{3}$ & 24 & $\begin{array}{l}8.36 \\
8.50\end{array}$ & $\begin{array}{l}2,470 \\
2,670\end{array}$ & $\begin{array}{l}8.27 \\
8.23\end{array}$ & $\begin{array}{l}2,350 \\
2,350\end{array}$ & $\begin{array}{l}7.57 \\
7.50\end{array}$ & $\begin{array}{l}1,660 \\
1,620\end{array}$ & 6.49 & $\overline{9} \overline{4} \overline{-}^{-}$ & $-\cdots$ & $\cdots$ \\
\hline 7 & & & 8.68 & 2,970 & 0. & 0 & 7. & 80 & & & & \\
\hline & 3.38 & 25 & 8.95 & & & & & & 6.41 & 890 & 5.56 & 506 \\
\hline $\begin{array}{r}9 \\
10\end{array}$ & 3.46 & 30 & $\begin{array}{l}9.20 \\
9.33\end{array}$ & $\begin{array}{l}3,890 \\
4,200\end{array}$ & $\begin{array}{l}8.27 \\
8.37\end{array}$ & $\begin{array}{l}2,350 \\
2,470\end{array}$ & $\begin{array}{l}7.36 \\
7.37\end{array}$ & $\begin{array}{l}1,500 \\
1,500\end{array}$ & 6.31 & 840 & -- & \\
\hline 11 & & & 9.42 & 4,3 & 8.44 & 2,6 & 7.37 & 1,500 & & & & \\
\hline \multirow[t]{2}{*}{12} & 3.62 & 43 & 9.50 & 4,530 & 8.49 & 2,670 & 7.37 & 1,500 & 6.23 & 815 & 5.43 & 455 \\
\hline & \multicolumn{2}{|c|}{ Aug. 19} & \multicolumn{2}{|c|}{ Aug. 20} & \multicolumn{2}{|c|}{ Aug. 21} & \multicolumn{2}{|c|}{ Aug. 22} & \multicolumn{2}{|c|}{ Aug. 23} & \multicolumn{2}{|c|}{ Aug. 24} \\
\hline 4 & $b$ & 422 & & & & & & 1 & 3. & 11 & 3.8 & $9]$ \\
\hline 8 & 5 & 4 & 4. & & & 18 & & 1 & & 11 & 3. & 8 \\
\hline N & & & 4.78 & 259 & 4.4 & 18 & 4. & 14 & 3. & 10 & 3.7 & 0 \\
\hline 18 & 5.17 & 364 & 4.7 & 241 & 4.3 & 17 & 4. & 13 & 3. & 10 & 3. & \\
\hline 0 & 5.12 & 34 & 4. & 22 & 4.32 & 16 & 4. & 13 & 3. & 100 & 3.7 & 80 \\
\hline 12 & 5.01 & 316 & 4.56 & 211 & 4.27 & 159 & 4.03 & 122 & 3.84 & 96 & 3.69 & 78 \\
\hline
\end{tabular}

SUPPLEMENTAL RECORDs.-Aug. $14,12: 30$ p.m., gage height, 9.35 feet; discharge, 4,200 second-feet. Aug. 15, 1:30 a.m., gage height, 9.53 feet; discharge, 4,640 second-feet. 
CALFPAS'TUR RIVER ABOVE MILL CREEK, A'T GOSHEN, VA.

Location.-Lat. $37^{\circ} 59^{\prime} 15^{\prime \prime}$, long. $79^{\circ} 29^{\prime} 40^{\prime \prime}$, at highway bridge at Goshen, Rockbridge County, 400 feet upstream from Mill C"reek. Datum of gage is $1,384.89$

feet above mean sea level (unadjusted).

DRAINAGE AREA.-147 square miles.

GAGE-HEIGHT RECORD.-Water-stage recorder graph.

DISCHARGE RECORD.-Stage-discharge relation defined by current-meter measurements.

Gage heights used to half-tenths between 4.7 and 6.7 feet; hundredths below and tenths above these limits.

Maxima.-August 1940: Discharge, 5,370 second-feet 8 p.m. Aug. 16 (gage height, 8.00 feet).

January 1939 to July 1940: Discharge, 7,010 second-feet May 31, 1940 (gage height, 9.03 feet).

Mean discharge, in second-feet, 1940

\begin{tabular}{|c|c|c|c|c|c|c|c|c|c|c|c|}
\hline Day & Aug. & Sept. & Day & Aug. & Sept. & Day & Aug. & Sept. & Day & Aug. & Sept. \\
\hline $\begin{array}{l}1 \\
2 \\
3 \\
4 \\
5 \\
6 \\
7 \\
8\end{array}$ & $\begin{array}{r}205 \\
123 \\
79 \\
62 \\
49 \\
44 \\
440 \\
201 \\
\end{array}$ & $\begin{array}{r}1,380 \\
584 \\
309 \\
205 \\
151 \\
120 \\
101 \\
84 \\
\end{array}$ & $\begin{array}{r}9 \\
10 \\
11 \\
12 \\
13 \\
14 \\
15 \\
, \quad 16\end{array}$ & $\begin{array}{r}123 \\
88 \\
69 \\
88 \\
116 \\
128 \\
1,070 \\
4,390 \\
\end{array}$ & $\begin{array}{l}75 \\
67 \\
60 \\
52 \\
45 \\
40 \\
36 \\
32\end{array}$ & $\begin{array}{l}17 \\
18 \\
19 \\
20 \\
21 \\
22 \\
23 \\
24\end{array}$ & $\begin{array}{r}2,440 \\
874 \\
457 \\
266 \\
181 \\
140 \\
111 \\
91\end{array}$ & $\begin{array}{l}29 \\
28 \\
26 \\
24 \\
22 \\
20 \\
19 \\
18 \\
\end{array}$ & $\begin{array}{l}25 \\
26 \\
27 \\
28 \\
29 \\
30 \\
31\end{array}$ & $\begin{array}{r}95 \\
88 \\
101 \\
368 \\
319 \\
258 \\
1,140\end{array}$ & $\begin{array}{r}20 \\
60 \\
43 \\
35 \\
29 \\
26\end{array}$ \\
\hline \multicolumn{10}{|c|}{$\begin{array}{l}\text { Monthly mean discharge, in second-feet } \\
\text { Runoff, in inches }\end{array}$} & $\begin{array}{r}458 \\
3.60\end{array}$ & $\begin{array}{r}125 \\
0.95\end{array}$ \\
\hline
\end{tabular}

Gage height, in feet, and discharge, in second-feet, at indicated time, 1940

\begin{tabular}{|c|c|c|c|c|c|c|c|c|c|c|c|c|}
\hline \multirow{2}{*}{ Hour } & \multicolumn{2}{|c|}{ Aug. 13} & \multicolumn{2}{|c|}{ Aug. 14} & \multicolumn{2}{|c|}{ Aug. 15} & \multicolumn{2}{|c|}{ Aug. 16} & \multicolumn{2}{|c|}{ Aug. 17} & \multicolumn{2}{|c|}{ Aug. 18} \\
\hline & $\begin{array}{l}\text { Gage } \\
\text { ht. }\end{array}$ & $\begin{array}{c}\text { Dis- } \\
\text { charge }\end{array}$ & $\begin{array}{l}\text { Gage } \\
\text { ht. }\end{array}$ & $\begin{array}{c}\text { Dis- } \\
\text { charge }\end{array}$ & $\begin{array}{c}\text { Gage } \\
\text { ht. }\end{array}$ & $\begin{array}{l}\text { Dis- } \\
\text { charge }\end{array}$ & $\begin{array}{l}\text { Gage } \\
\text { ht. }\end{array}$ & $\begin{array}{c}\text { Dis- } \\
\text { charge }\end{array}$ & $\begin{array}{c}\text { Gage } \\
\text { ht. }\end{array}$ & $\begin{array}{l}\text { Dis- } \\
\text { charge }\end{array}$ & $\begin{array}{c}\text { Gage } \\
\text { ht. }\end{array}$ & $\begin{array}{c}\text { Dis- } \\
\text { charge }\end{array}$ \\
\hline \multirow{3}{*}{$\begin{array}{l}1 \\
2 \\
3 \\
4 \\
5 \\
6\end{array}$} & 2.94 & 120 & 2.88 & 106 & \multirow{3}{*}{$\begin{array}{l}3.50 \\
3.65 \\
3.80 \\
3.90 \\
3.97 \\
4.02\end{array}$} & \multirow{3}{*}{$\begin{array}{l}334 \\
421 \\
518 \\
584 \\
632 \\
666\end{array}$} & \multirow{3}{*}{$\begin{array}{l}6.80 \\
7.05 \\
7.20 \\
7.32 \\
7.34 \\
7.30\end{array}$} & \multirow{3}{*}{$\begin{array}{l}3,630 \\
3,910 \\
4,190 \\
4,330 \\
4,330 \\
4,330\end{array}$} & \multirow{3}{*}{$\begin{array}{l}7.25 \\
7.03 \\
6.83 \\
6.65 \\
6.50 \\
6.35\end{array}$} & \multirow{3}{*}{$\begin{array}{l}4,190 \\
3,910 \\
3,630 \\
3,440 \\
3,240 \\
3,040\end{array}$} & 4.68 & 1,170 \\
\hline & $2 . \overline{9}$ & 120 & 2.88 & $10 \overline{6}$ & & & & & & & 4.58 & 1,080 \\
\hline & 2.94 & 120 & 2.88 & 106 & & & & & & & 4.50 & 1,020 \\
\hline \multirow{4}{*}{$\begin{array}{r}7 \\
8 \\
9 \\
10 \\
11 \\
\mathrm{~N}\end{array}$} & 2.94 & 120 & 2.88 & 106 & \multirow{4}{*}{$\begin{array}{l}4.04 \\
4.05 \\
4.06 \\
4.07 \\
4.08 \\
4.09\end{array}$} & \multirow{4}{*}{$\begin{array}{l}679 \\
686 \\
693 \\
700 \\
706 \\
713\end{array}$} & \multirow{4}{*}{$\begin{array}{l}7.22 \\
7.13 \\
7.05 \\
6.98 \\
6.94 \\
6.92\end{array}$} & \multirow{4}{*}{$\begin{array}{l}4,190 \\
4,050 \\
3,910 \\
3,910 \\
3,770 \\
3,770\end{array}$} & \multirow{4}{*}{$\begin{array}{l}6.23 \\
6.10 \\
6.00 \\
5.90 \\
5.78 \\
5.70\end{array}$} & \multirow{4}{*}{$\begin{array}{l}2,920 \\
2,720 \\
2,600 \\
2,480 \\
2,360 \\
2,240\end{array}$} & 4.42 & 956 \\
\hline & & & & & & & & & & & & \\
\hline & 2.94 & 120 & 2.89 & 108 & & & & & & & 4.34 & 892 \\
\hline & 2.93 & 118 & 2.91 & 113 & & & & & & & 4.28 & 846 \\
\hline \multirow{4}{*}{$\begin{array}{l}1 \\
2 \\
3 \\
4 \\
5 \\
6\end{array}$} & & & & & \multirow{4}{*}{$\begin{array}{l}4.09 \\
4.11 \\
4.17 \\
4.28 \\
4.48 \\
4.75\end{array}$} & \multirow{4}{*}{$\begin{array}{r}713 \\
727 \\
769 \\
846 \\
1,000 \\
1,240\end{array}$} & \multirow{4}{*}{$\begin{array}{l}6.96 \\
7.10 \\
7.30 \\
7.50 \\
7.70 \\
7.85\end{array}$} & \multirow{4}{*}{$\begin{array}{l}3,910 \\
4,050 \\
4,330 \\
4,620 \\
4,920 \\
5,070\end{array}$} & \multirow{4}{*}{$\begin{array}{l}5.60 \\
5.52 \\
5.45 \\
5.35 \\
5.28 \\
5.22\end{array}$} & \multirow{4}{*}{$\begin{array}{l}2,120 \\
2,010 \\
1,960 \\
1,840 \\
1,790 \\
1,680\end{array}$} & & \\
\hline & 2.92 & 115 & 2.92 & 115 & & & & & & & 4.22 & 804 \\
\hline & $2 . \overline{91}$ & 113 & $2 . \overline{9}$ & $12 \overline{0}$ & & & & & & & 4.16 & 762 \\
\hline & 2.91 & $11 \overline{3}$ & 2.98 & 131 & & & & & & & 4.09 & 713 \\
\hline \multirow{5}{*}{$\begin{array}{r}7 \\
8 \\
9 \\
10 \\
11 \\
12 \\
\end{array}$} & 0 & 10 & 20 & & \multirow{4}{*}{$\begin{array}{l}5.10 \\
5.40 \\
5.70 \\
6.00 \\
6.30 \\
6.58\end{array}$} & & $\because$ & 5,370 & 13 & 1, & & \\
\hline & & 110 & 3.0 & $1+5$ & & $\begin{array}{r}1,900 \\
2,240\end{array}$ & 7.96 & $\begin{array}{l}5,370 \\
5,370\end{array}$ & $\begin{array}{l}5.07 \\
5.00\end{array}$ & & 03 & 72 \\
\hline & 2.90 & 110 & 3.17 & 190 & & 2,600 & 7.88 & 5,220 & 4.91 & 1,380 & 3.97 & 632 \\
\hline & 2.89 & 108 & 3.37 & 271 & & $\begin{array}{l}2,980 \\
3,370\end{array}$ & 7.48 & $\begin{array}{l}4,920 \\
4,620\end{array}$ & $\begin{array}{l}4.85 \\
4.79\end{array}$ & $\begin{array}{l}1,330 \\
1,280\end{array}$ & $\overline{3.9}$ & 598 \\
\hline & & 19 & $\mathrm{Au}$ & $\therefore 0$ & $A_{1}$ & 21 & & 22 & & 23 & & 24 \\
\hline 4 & 3.83 & 538 & 0.40 & 299 & 3. & 19 & 3.0 & 15 & 2. & 118 & 2.84 & 97 \\
\hline 8 & 76 & & & & & & & & & & & 9 \\
\hline $\begin{array}{r}\mathrm{N} \\
4\end{array}$ & $\begin{array}{l}3.70 \\
3.64\end{array}$ & 415 & $\begin{array}{l}3.35 \\
3.32\end{array}$ & & $\begin{array}{l}3.14 \\
3.12\end{array}$ & 18 & $\begin{array}{l}3.01 \\
2.99\end{array}$ & 13 & & & 280 & 0 \\
\hline 0 & & 37 & $\begin{array}{l}3.02 \\
3.28\end{array}$ & 23 & $\begin{array}{l}0.12 \\
3.09\end{array}$ & 18 & 2.9 & 13 & 2.8 & 1 & 2.79 & $8 t$ \\
\hline 12 & & & 3.23 & 21 & 3.07 & 15 & 2.96 & 126 & 2.8 & 101 & 2.78 & \\
\hline
\end{tabular}


NORTH hIVER AT HOCKBRIDGE BATHS, VA.

Location.-Lat. $37^{\circ} 54^{\prime} 26^{\prime \prime}$, long. $79^{\circ} 25^{\prime} 20^{\prime \prime}$, at Rockbridge Baths, Rockbridge County, 700 feet upstream from highway bridge, and 1 mile upstream from Hays Creek. Datum of gage is $1,100.33$ feet above mean sea level (levels by Corps of Engineers, War Department).

Drainage AREA.-329 square miles.

GAGE-HEIGHT RECORD.-Water-stage recorder graph.

DISCHARGE RECORD.- Stage-discharge relation defined by current-meter measurements up to 16,000 second-feet and extended to crest gage height of flood of Mar. 17, 1936 by logarithmic plotting. Gage heights used to half-tenths between 3.2 and 7.9 feet; hundredths below and tenths above these limits.

Maxima.-August 1940: Discharge, 9,200 second-feet 5 p.m. Aug. 16 (gage height, 8.45 feet).

1928 to July 1940: Discharge, 33,000 second-feet Mar. 17, 1936 (gage height, 13.07 feet).

\begin{tabular}{|c|c|c|c|c|c|c|c|c|c|c|c|}
\hline Day & Aug. & Sept. & Day & Aug. & Sept. & Day & Aug. & Sept. & Day & Aug. & Sept. \\
\hline $\begin{array}{l}1 \\
2 \\
3 \\
4 \\
5 \\
6 \\
7 \\
8\end{array}$ & $\begin{array}{l}412 \\
248 \\
169 \\
138 \\
117 \\
107 \\
542 \\
321\end{array}$ & $\begin{array}{r}3,160 \\
1,320 \\
766 \\
522 \\
388 \\
308 \\
252 \\
215\end{array}$ & $\begin{array}{r}9 \\
10 \\
11 \\
12 \\
13 \\
14 \\
15 \\
16\end{array}$ & $\begin{array}{r}199 \\
152 \\
125 \\
141 \\
196 \\
279 \\
12,230 \\
8,550\end{array}$ & $\begin{array}{r}190 \\
175 \\
155 \\
133 \\
120 \\
110 \\
103 \\
96\end{array}$ & $\begin{array}{l}17 \\
18 \\
19 \\
20 \\
21 \\
22 \\
23 \\
24\end{array}$ & $\begin{array}{r}4,360 \\
1,670 \\
917 \\
584 \\
414 \\
322 \\
265 \\
218\end{array}$ & $\begin{array}{l}85 \\
83 \\
76 \\
72 \\
70 \\
64 \\
61 \\
57\end{array}$ & $\begin{array}{l}25 \\
26 \\
27 \\
28 \\
29 \\
30 \\
31\end{array}$ & $\begin{array}{r}235 \\
228 \\
248 \\
1,040 \\
1,300 \\
812 \\
3,100\end{array}$ & $\begin{array}{r}72 \\
105 \\
96 \\
81 \\
72 \\
66\end{array}$ \\
\hline on & & & & & & & & & & $\begin{array}{r}956 \\
3.36\end{array}$ & $\begin{array}{r}302 \\
1.02\end{array}$ \\
\hline
\end{tabular}

${ }^{1}$ Discharge is different from that given in Water-Supply Paper 892. It is based on revisions not considered important enough for inclusion with revised records published in Water-Supply Paper 972.

Gage height, in feet, and discharge, in second-feet, at indicated time, 1940

\begin{tabular}{|c|c|c|c|c|c|c|c|c|c|c|c|c|}
\hline \multirow[b]{2}{*}{ Hot'r } & \multicolumn{2}{|c|}{ Aug. 13} & \multicolumn{2}{|c|}{ Aug. 14} & \multicolumn{2}{|c|}{ Aug. 15} & \multicolumn{2}{|c|}{ Aug. 16} & \multicolumn{2}{|c|}{ Aug. 17} & \multicolumn{2}{|c|}{ Aug. 18} \\
\hline & $\begin{array}{c}\text { Gage } \\
\text { ht. }\end{array}$ & $\begin{array}{c}\text { Dis- } \\
\text { rharge }\end{array}$ & $\begin{array}{l}\text { Gage } \\
\text { ht. }\end{array}$ & $\begin{array}{c}\text { Dis- } \\
\text { charge }\end{array}$ & $\begin{array}{c}\text { Gage } \\
\text { ht. }\end{array}$ & $\begin{array}{l}\text { Dis- } \\
\text { charge }\end{array}$ & $\begin{array}{c}\text { Gage } \\
\text { ht. }\end{array}$ & $\begin{array}{c}\text { Dis- } \\
\text { charge }\end{array}$ & $\begin{array}{c}\text { Gage } \\
\text { ht. }\end{array}$ & $\begin{array}{c}\text { Dis- } \\
\text { charge }\end{array}$ & $\begin{array}{l}\text { Gage } \\
\text { ht. }\end{array}$ & $\begin{array}{c}\text { Dis- } \\
\text { charge }\end{array}$ \\
\hline \multirow{5}{*}{$\begin{array}{l}1 \\
2 \\
3 \\
4 \\
5 \\
6\end{array}$} & & & & & \multirow{5}{*}{$\begin{array}{l}2.85 \\
2.95 \\
3.09 \\
3.25 \\
3.43 \\
3.58\end{array}$} & \multirow{5}{*}{$\begin{array}{r}617 \\
672 \\
754 \\
858 \\
995 \\
1,100\end{array}$} & \multirow{5}{*}{\begin{tabular}{|l|}
7.75 \\
7.97 \\
8.15 \\
8.25 \\
8.31 \\
8.33
\end{tabular}} & \multirow{5}{*}{$\begin{array}{l}7,280 \\
8,000 \\
8,600 \\
8,600 \\
8,900 \\
8,900\end{array}$} & \multirow{5}{*}{$\begin{array}{l}7.65 \\
7.50 \\
7.35 \\
7.20 \\
7.08 \\
6.95\end{array}$} & \multirow{5}{*}{$\begin{array}{l}7,020 \\
6,650 \\
6,290 \\
5,940 \\
5,720 \\
5,400\end{array}$} & & \multirow[b]{2}{*}{2,260} \\
\hline & $1 . \overline{9}$ & 206 & 1.87 & 187 & & & & & & & 4.90 & \\
\hline & $1 . \overline{9}$ & 206 & $1 . \overline{87}$ & 187 & & & & & & & 4.75 & 2,100 \\
\hline & & & & & & & & & & & & \\
\hline & 1.92 & 202 & 1.87 & 187 & & & & & & & 4.60 & 1,950 \\
\hline 7 & & & & & \multirow{4}{*}{$\begin{array}{l}3.67 \\
3.72 \\
3.76 \\
3.80 \\
3.84 \\
3.92\end{array}$} & \multirow{4}{*}{$\begin{array}{l}1,140 \\
1,170 \\
1,200 \\
1,240 \\
1,280 \\
1,320\end{array}$} & \multirow{4}{*}{$\begin{array}{l}8.30 \\
8.27 \\
8.23 \\
8.20 \\
8.18 \\
8.17\end{array}$} & \multirow{4}{*}{$\begin{array}{l}8,900 \\
8,900 \\
8,600 \\
8,600 \\
8,600 \\
8,600\end{array}$} & \multirow{4}{*}{$\begin{array}{l}6.85 \\
6.74 \\
6.62 \\
6.50 \\
6.36 \\
6.25\end{array}$} & \multirow{4}{*}{$\begin{array}{l}5,200 \\
5,000 \\
4,700 \\
4,500 \\
4,220 \\
4,040\end{array}$} & & \\
\hline $\begin{array}{l}8 \\
9\end{array}$ & 1.91 & 199 & 1.87 & 187 & & & & & & & 4.48 & 1,850 \\
\hline 10 & 1.90 & $19 \overline{6}$ & 1.91 & $199^{-}$ & & & & & & & $4 . \overline{37}$ & 1,700 \\
\hline $\mathrm{N}$ & 1.90 & 196 & 1.98 & 222 & & & & & & & 4.25 & 1,620 \\
\hline \multirow{4}{*}{$\begin{array}{l}1 \\
2 \\
3 \\
4 \\
5 \\
6\end{array}$} & & & & & \multirow{4}{*}{$\begin{array}{l}4.03 \\
4.18 \\
4.35 \\
4.70 \\
5.15 \\
5.60\end{array}$} & \multirow{4}{*}{$\begin{array}{l}1,440 \\
1,570 \\
1,700 \\
2,050 \\
2,550 \\
3,110\end{array}$} & \multirow{4}{*}{$\begin{array}{l}8.16 \\
8.18 \\
8.28 \\
8.40 \\
8.45 \\
8.43\end{array}$} & \multirow{4}{*}{$\begin{array}{l}8,600 \\
8,600 \\
8,900 \\
9,200 \\
9,200 \\
9,200\end{array}$} & \multirow{4}{*}{$\begin{array}{l}6.10 \\
5.97 \\
5.85 \\
5.73 \\
5.65 \\
5.55\end{array}$} & \multirow{4}{*}{$\begin{array}{l}3,800 \\
3,580 \\
3,440 \\
3,300 \\
3,180 \\
3,040\end{array}$} & & \\
\hline & $|1.90|$ & 196 & 2.08 & 255 & & & & & & & 4.14 & 1,520 \\
\hline & 1.89 & 193 & 2.19 & 296 & & & & & & & $\overline{4} . \overline{0}$ & $\overline{1}, \overline{4} \overrightarrow{4} \overline{0}$ \\
\hline & 1.88 & 190 & 2.30 & 342 & & & & & & & 3.92 & 1,320 \\
\hline \multirow{5}{*}{$\begin{array}{r}7 \\
8 \\
9 \\
10 \\
11 \\
12 \\
\end{array}$} & & & & & \multirow{4}{*}{$\begin{array}{l}6.10 \\
6.50 \\
6.80 \\
7.05 \\
7.25 \\
7.50\end{array}$} & 3,800 & 8.40 & 9,200 & 5.45 & 2,920 & & \\
\hline & 1. & 187 & & 412 & & & & & 5.38 & 2,850 & 3.83 & 80 \\
\hline & 1.87 & $18 \overline{7}$ & 2.62 & 496 & & 5,610 & 8.05 & 8,000 & 5.22 & 2,610 & $3.7 \overline{6}$ & 1,200 \\
\hline & 1.87 & 187 & $2 . \overline{7}$ & $\overline{5} \overline{7} \overline{4}$ & & 6,650 & $\begin{array}{l}7.90 \\
7.77\end{array}$ & 7,280 & $\begin{array}{l}5.14 \\
5.07\end{array}$ & 2,430 & 3.68 & 1,170 \\
\hline & $\mathrm{Au}$ & 19 & Aug & & $\mathrm{Au}$ & g. 21 & $\mathrm{Au}$ & g. 22 & & g. 23 & & . 24 \\
\hline 4 & 3.56 & 1,060 & 2.93 & 661 & 2 & 4 & 2.2 & 3 & 2. & 28 & 2. & 228 \\
\hline 8 & & 99 & & & & 4 & & & & & & 222 \\
\hline $\mathbf{N}$ & 3.33 & 92 & 2.78 & 580 & 2.46 & 4 & 2.2 & 3 & 2. & 2 & & 215 \\
\hline 4 & 3.22 & 82 & 2.72 & 54 & 2. & & 2 . & & 2. & 2 & & 212 \\
\hline 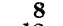 & & 7 & 2 & & 2.37 & & 2.2 & & 2. & 2 & & 209 \\
\hline 12 & & 70 & & 4 & $\overline{2} .33$ & 356 & 2.20 & 300 & 2.0 & 238 & 1.9 & 202 \\
\hline
\end{tabular}




\section{FLOODS OF AUGUST 1940 IN THE SOUTHEASTERN STATES \\ NORTH RIVER NEAR LEXINGTON, VA.}

Location.-Lat. $37^{\circ} 48^{\prime} 49^{\prime \prime}$, long. $79^{\circ} 26^{\prime} 42^{\prime \prime}$, 300 yards upstream from Lime Kiln highway bridge, a quarter of a mile downstream from Kerrs Creek, and 21/2 miles upstream from Lexington, Rockbridge County. Datum of gage is 906.56 feet above mean sea level (levels by Corps of Engineers, War Department).

DRAINAGE AREA. -487 square miles.

GAGE-HEIGHT RECORD.-Water-stage recorder graph.

DISCHARGE RECORD.-Stage-discharge relation defined by currènt-meter measurements up to 9,000 second-feet and extended to erest gage height of March 1936 on basis of velocity-area studies and comparisons of peak discharge and total runoff at this station with those for other stations in James River Basin. Gage heights used to half-tenths between 3.9 and 6.6 feet; hundredths below and tenths above these limits.

MnXima.-August 1940: Discharge, 10,600 second-feet 9:30 a.m. Aug. 16 (gage height, 12.33 feet).

1925 to July 1940: Discharge, 40,000 second-feet Mar. 18, 1936 (gage height, 23.58 feet, from floodmarks).

Mean discl arge, in second-feet, 1940

\begin{tabular}{|c|c|c|c|c|c|c|c|c|c|c|c|}
\hline Day & Aug. & Sept. & Day & Aug. & Sept. & Day & Aug. & Sept. & Day & Aug. & Sept. \\
\hline $\begin{array}{l}1 \\
2 \\
3 \\
4 \\
5 \\
6 \\
7 \\
8\end{array}$ & $\begin{array}{l}529 \\
370 \\
255 \\
211 \\
188 \\
190 \\
553 \\
448\end{array}$ & $\begin{array}{r}4,510 \\
2,110 \\
1,260 \\
905 \\
714 \\
596 \\
506 \\
440\end{array}$ & $\begin{array}{r}9 \\
10 \\
11 \\
12 \\
13 \\
14 \\
15 \\
16\end{array}$ & $\begin{array}{r}296 \\
226 \\
190 \\
188 \\
260 \\
476 \\
2,210 \\
9,310\end{array}$ & $\begin{array}{l}398 \\
370 \\
336 \\
303 \\
282 \\
265 \\
248 \\
236\end{array}$ & $\begin{array}{l}17 \\
18 \\
19 \\
20 \\
21 \\
22 \\
23 \\
24\end{array}$ & $\begin{array}{r}6,870 \\
2,840 \\
1,570 \\
1,010 \\
748 \\
591 \\
485 \\
412\end{array}$ & $\begin{array}{l}223 \\
211 \\
202 \\
193 \\
188 \\
176 \\
168 \\
163\end{array}$ & $\begin{array}{l}25 \\
26 \\
27 \\
28 \\
29 \\
30 \\
31\end{array}$ & $\begin{array}{r}419 \\
398 \\
435 \\
1,240 \\
1,849 \\
1,310 \\
4,940\end{array}$ & $\begin{array}{l}302 \\
229 \\
217 \\
188 \\
176 \\
165 \\
-\end{array}$ \\
\hline \multicolumn{10}{|c|}{$\begin{array}{l}\text { Monthly mean discharge, in second-feet } \\
\text { Runoff, in inches }\end{array}$} & $\begin{array}{r}1,323 \\
3.14\end{array}$ & $\begin{array}{r}543 \\
1.24\end{array}$ \\
\hline
\end{tabular}


JAMES RIVER BASIN

Gage height, in feet, and discharge, in second-feet, at indicated time, 1940

\begin{tabular}{|c|c|c|c|c|c|c|c|c|c|c|c|c|}
\hline \multirow{2}{*}{ Hour } & \multicolumn{2}{|c|}{ Aug. 13} & \multicolumn{2}{|c|}{ Aug. 14} & \multicolumn{2}{|c|}{ Aug. 15} & \multicolumn{2}{|c|}{ Aug. 16} & \multicolumn{2}{|c|}{ Aug. 17} & \multicolumn{2}{|c|}{ Aug. 18} \\
\hline & $\begin{array}{c}\text { Gage } \\
\text { ht. }\end{array}$ & $\begin{array}{c}\text { Dis- } \\
\text { charge }\end{array}$ & $\begin{array}{c}\text { Gage } \\
\text { ht. }\end{array}$ & $\begin{array}{c}\text { Dis- } \\
\text { charge }\end{array}$ & $\begin{array}{c}\text { Gage } \\
\text { ht. }\end{array}$ & $\begin{array}{c}\text { Dis- } \\
\text { charge }\end{array}$ & $\begin{array}{c}\text { Gage } \\
\text { ht. }\end{array}$ & $\begin{array}{c}\text { Dis- } \\
\text { charge }\end{array}$ & $\begin{array}{c}\text { Gage } \\
\text { ht. }\end{array}$ & $\begin{array}{c}\text { Dig- } \\
\text { charge }\end{array}$ & $\begin{array}{l}\text { Gage } \\
\text { ht. }\end{array}$ & $\begin{array}{c}\text { Dis- } \\
\text { charge }\end{array}$ \\
\hline \multirow{4}{*}{$\begin{array}{l}1 \\
2 \\
3 \\
4 \\
5 \\
6\end{array}$} & & & & & \multirow{4}{*}{$\begin{array}{l}4.10 \\
4.15 \\
4.24 \\
4.32 \\
4.38 \\
4.46\end{array}$} & \multirow{4}{*}{$\begin{array}{l}795 \\
822 \\
878 \\
905 \\
960 \\
990\end{array}$} & \multirow{4}{*}{$\begin{array}{r}9.65 \\
9.85 \\
10.15 \\
10.50 \\
10.95 \\
11.35\end{array}$} & \multirow{4}{*}{$\begin{array}{l}6,640 \\
6,920 \\
7,480 \\
7,900 \\
8,650 \\
9,250\end{array}$} & \multirow{4}{*}{$\begin{array}{l}11.96 \\
11.94 \\
11.85 \\
11.70 \\
11.50 \\
11.20\end{array}$} & \multirow{4}{*}{$\begin{array}{r}10,200 \\
10,000 \\
9,850 \\
9,700 \\
9,400 \\
8,950\end{array}$} & & \\
\hline & 2.85 & 242 & 2.91 & 261 & & & & & & & 7.40 & 3,770 \\
\hline & $2 . \overline{87}$ & $24 \overline{8}$ & $\overline{2.9 \overline{1}}$ & 261 & & & & & & & $\overline{7.18}$ & $\overline{3}, \overline{3} 0$ \\
\hline & $\overline{2} . \overline{90}$ & 258 & $\overline{2} . \overline{9}$ & 265 & & & & & & & 7.00 & 3,290 \\
\hline \multirow{4}{*}{$\begin{array}{r}7 \\
8 \\
9 \\
10 \\
11 \\
N\end{array}$} & & & & & \multirow{4}{*}{$\begin{array}{l}4.58 \\
4.72 \\
4.90 \\
5.10 \\
5.23 \\
5.32\end{array}$} & \multirow{4}{*}{$\begin{array}{l}1,080 \\
1,150 \\
1,290 \\
1,430 \\
1,550 \\
1,590\end{array}$} & \multirow{4}{*}{$\left|\begin{array}{l}11.70 \\
12.00 \\
12.30 \\
12.32 \\
12.15 \\
12.00\end{array}\right|$} & \multirow{4}{*}{$\begin{array}{r}9,700 \\
10,200 \\
10,600 \\
10,600 \\
10,500 \\
10,200\end{array}$} & \multirow{4}{*}{$\begin{array}{r}10.85 \\
10.55 \\
10.25 \\
9.95 \\
9.70 \\
9.45\end{array}$} & \multirow{4}{*}{$\begin{array}{l}8,350 \\
8,050 \\
7,480 \\
7,200 \\
6,780 \\
6,360\end{array}$} & & \\
\hline & 2.92 & 265 & 2.96 & 278 & & & & & & & 6.82 & 3,060 \\
\hline & $\overline{2} . \overline{3}$ & $\overline{2} \overline{6}$ & $\overline{3.0 \overline{3}}$ & 303 & & & & & & & 6,67 & $2, \overline{950}$ \\
\hline & $2 . \overline{93}$ & 268 & $\overline{3}, \overline{1}$ & 328 & & & & & & & 6.52 & 2730 \\
\hline \multirow{4}{*}{$\begin{array}{l}1 \\
\mathbf{2} \\
\mathbf{3} \\
\mathbf{4} \\
\mathbf{5} \\
\mathbf{6}\end{array}$} & & & & & \multirow{4}{*}{$\begin{array}{l}5.38 \\
5.45 \\
5.55 \\
5.75 \\
6.15 \\
6.60\end{array}$} & \multirow{4}{*}{$\begin{array}{l}1,670 \\
1,710 \\
1,800 \\
1,980 \\
2,360 \\
2,840\end{array}$} & \multirow{4}{*}{$\begin{array}{l}11.93 \\
11.92 \\
11.85 \\
11.75 \\
11.65 \\
11.53\end{array}$} & \multirow{4}{*}{$\begin{array}{r}10,000 \\
10,000 \\
9,850 \\
9,850 \\
9,550 \\
9,400\end{array}$} & \multirow{4}{*}{$\begin{array}{l}9.27 \\
9.10 \\
8.90 \\
8.70 \\
8.55 \\
8.35\end{array}$} & \multirow{4}{*}{$\begin{array}{l}6,220 \\
5,940 \\
5,680 \\
5,420 \\
5,290 \\
5,030\end{array}$} & & \\
\hline & 2.93 & 268 & 3.60 & 538 & & & & & & & 6.39 & 2,620 \\
\hline & 2.92 & 265 & $3 . \overline{2}$ & $6 \overline{88}$ & & & & & & & $6 . \overline{27}$ & $\overline{2}, 460$ \\
\hline & $\overline{2} . \overline{1}$ & $\overline{2} \overline{1} \overline{1}$ & $\overline{3} . \overline{9}$ & $7 \overline{4}$ & & & & & & & 6.14 & $\overline{2}, \overline{3} 00$ \\
\hline \multirow{5}{*}{$\begin{array}{r}8 \\
9 \\
10 \\
11 \\
12 \\
\end{array}$} & & & & & \multirow{4}{*}{$\begin{array}{l}7.15 \\
7.75 \\
8.20 \\
8.65 \\
9.00 \\
9.35\end{array}$} & & 11.48 & 9,400 & 8.20 & 4 & & \\
\hline & 2.91 & 261 & 4.10 & 79 & & 4,250 & & & & & 6.02 & 2,210 \\
\hline & 2.91 & 261 & 4.07 & 768 & & 290 & 11.75 & 0 & 7.80 & & $\overline{5} . \overline{9}$ & 2,110 \\
\hline & 2.91 & 261 & 4.06 & 768 & & $\begin{array}{r}5,810 \\
6,360 \\
\end{array}$ & .93 & & 7.60 & & 5.78 & 2,020 \\
\hline & $\mathrm{Au}$ & 19 & $\mathrm{Au}$ & 20 & $\mathrm{Aug}$ & 21 & $\mathrm{Au}$ & g. 22 & $\mathrm{Au}$ & 23 & & 24 \\
\hline & 5.57 & & 4. & & & & & & & & & 45 \\
\hline 8 & .42 & & 4.5 & 05 & & & & & & & & \\
\hline $\mathrm{N}$ & & 1,550 & $\mathbf{4 . 4 7}$ & 990 & 4.00 & 74 & 3. & & & & & 410 \\
\hline 4 & 5.14 & 1,470 & 43 & 96 & 3 . & & & & 3. & & 3. & 402 \\
\hline & & & & 9 & 3.9 & & & & & & 3. & 394 \\
\hline 1 & & & & & 3.8 & 657 & 3.59 & 533 & 3.39 & 444 & 3.25 & 386 \\
\hline
\end{tabular}

Supplemental Record.-Aug. 16, 9:30 a.m., gage height, 12.33 feet; discharge, 10,600 second-feet.

\section{NORTH RIVER NEAR BUENA VISTA, VA.}

Location.-Lat. $37^{\circ} 45^{\prime} 45^{\prime \prime}$, long. $79^{\circ} 23^{\prime} 30^{\prime \prime}$, half a mile downstream from South River and $2 \frac{1}{2}$ miles northwest of Buena Vista, Rockbridge County. Datum of gage is 846.58 feet above mean sea level, datum of 1929 .

Drainage AREa.-649 square miles.

GAGE-HEIGHT RECORD.-Water-stage recorder graph.

DISCHARGE RECORD.-Stage-discharge relation defined by current-meter measurements. Gage heights used to half-tenths between 3.2 and 6.0 feet; hundredths below and tenths above these limits.

MaX.IMA.-August 1940: Discharge, 14,700 second-feet 10:30 a.m. Aug. 16 (gage height, 13.36 feet).

1939 to July 1940: Discharge, 12,900 second-feet May 31, 1940 (gage height, 12.55 feet).

Stage known, about 22 feet Mar. 18 or 19, 1936, from information by local residents (discharge not determined). 
Mean discharge, in second-feet, 1940

\begin{tabular}{|c|c|c|c|c|c|c|c|c|c|c|c|}
\hline Day & Aug. & Sept. & Day & Aug. & Sept. & Day & Aug. & Sept. & Day & Aug. & Sept. \\
\hline 1 & 59 & 5,470 & 9 & 36 & 5 & 17 & 9,270 & 32 & 25 & & 407 \\
\hline 2 & & 2,5 & 10 & & & 18 & 14,0 & & 26 & & \\
\hline 3 & & 1,5 & 11 & 25 & & 19 & 2,3 & 30 & 27 & & 312 \\
\hline 4 & 283 & 1,110 & 12 & 25 & 43 & 20 & 1,440 & 286 & 28 & 1,640 & 274 \\
\hline 5 & 257 & 890 & 13 & 32 & 40 & 21 & 1,050 & 28 & 29 & 2,19 & 257 \\
\hline 6 & 286 & 769 & 14 & 72 & 37 & 22 & 851 & 269 & 30 & 1,5 & 246 \\
\hline 7 & 557 & 680 & 15 & 13,050 & 36 & 23 & 722 & 255 & 31 & 5,420 & \\
\hline 8 & 5 & 616 & 16 & 12,700 & 346 & 24 & 620 & 252 & & & \\
\hline \multicolumn{12}{|c|}{$\begin{array}{l}\text { Monthly mean discharge, in second-feet } \\
\text { Runoff, in inches }\end{array}$} \\
\hline
\end{tabular}

1 Discharge is different from that given in Water-Supply Paper 892. It is based on revisions not considered important enough for inclusion with revised records published in Water-Supply Paper 952.

Gage height, in feet, and discharge, in second-feet, at indicated time, 1940

\begin{tabular}{|c|c|c|c|c|c|c|c|c|c|c|c|c|}
\hline \multirow{2}{*}{ Hour } & \multicolumn{2}{|c|}{ Aug. 13} & \multicolumn{2}{|c|}{ Aug. 14} & \multicolumn{2}{|c|}{ Aug. 15} & \multicolumn{2}{|c|}{ Aug. 16} & \multicolumn{2}{|c|}{ Aug. 17} & \multicolumn{2}{|c|}{ Aug. 18} \\
\hline & $\begin{array}{c}\text { Gage } \\
\text { ht. }\end{array}$ & $\begin{array}{c}\text { Dis- } \\
\text { charge }\end{array}$ & $\begin{array}{c}\text { Gage } \\
\text { ht. }\end{array}$ & $\begin{array}{c}\text { Dis- } \\
\text { charge }\end{array}$ & $\begin{array}{c}\text { Gage } \\
\text { ht. }\end{array}$ & $\begin{array}{l}\text { Dis- } \\
\text { charge }\end{array}$ & $\begin{array}{c}\text { Gage } \\
\text { ht. }\end{array}$ & $\begin{array}{c}\text { Dis- } \\
\text { charge }\end{array}$ & $\begin{array}{c}\text { Gage } \\
\text { ht. }\end{array}$ & $\begin{array}{l}\text { Dis- } \\
\text { charge }\end{array}$ & $\begin{array}{c}\text { Gage } \\
\text { ht. }\end{array}$ & $\begin{array}{c}\text { Dis- } \\
\text { charge }\end{array}$ \\
\hline \multirow{5}{*}{$\begin{array}{l}1 \\
2 \\
3 \\
4 \\
5 \\
6\end{array}$} & & & & & \multirow{5}{*}{$\begin{array}{l}4.48 \\
4.48 \\
4.52 \\
4.56 \\
4.65 \\
4.74\end{array}$} & \multirow{5}{*}{$\begin{array}{l}1,140 \\
1,140 \\
1,140 \\
1,170 \\
1,230 \\
1,300\end{array}$} & \multirow{5}{*}{$\begin{array}{l}10.45 \\
10.65 \\
10.85 \\
11.15 \\
11.50 \\
12.00\end{array}$} & \multirow{5}{*}{$\begin{array}{r}8,660 \\
9,020 \\
9,380 \\
10,100 \\
10,700 \\
11,700\end{array}$} & \multirow{5}{*}{$\begin{array}{l}12.67 \\
12.64 \\
12.60 \\
12.50 \\
12.35 \\
12.10\end{array}$} & \multirow{5}{*}{$\begin{array}{l}13,100 \\
12,900 \\
12,900 \\
12,700 \\
12,500 \\
11,900\end{array}$} & & \multirow[b]{2}{*}{5,130} \\
\hline & 2.58 & 300 & 2.73 & 346 & & & & & & & 8.25 & \\
\hline & 2.63 & 315 & $2.7 \overline{5}$ & $3 \overrightarrow{52}$ & & & & & & & 8.03 & 4,850 \\
\hline & & & & & & & & & & & & \\
\hline & 2.63 & 315 & 2.76 & 355 & & & & & & & 7.83 & 4,570 \\
\hline \multirow{4}{*}{$\begin{array}{r}7 \\
8 \\
9 \\
10 \\
11 \\
\mathrm{~N}\end{array}$} & & & & & \multirow{4}{*}{$\begin{array}{l}4.88 \\
5.00 \\
5.20 \\
5.37 \\
5.50 \\
5.63\end{array}$} & \multirow{4}{*}{$\begin{array}{l}1,400 \\
1,470 \\
1,630 \\
1,770 \\
1,920 \\
2,080\end{array}$} & \multirow{4}{*}{$\begin{array}{l}12.50 \\
13.05 \\
13.28 \\
13.35 \\
13.34 \\
13.28\end{array}$} & \multirow{4}{*}{$\begin{array}{l}12,700 \\
13,800 \\
14,500 \\
14,700 \\
14,500 \\
14,500\end{array}$} & \multirow{4}{*}{$\begin{array}{l}11.75 \\
11.50 \\
11.20 \\
10.95 \\
10.70 \\
10.50\end{array}$} & \multirow{4}{*}{$\begin{array}{r}11,300 \\
10,700 \\
10,100 \\
9,760 \\
9,200 \\
8,840\end{array}$} & & \\
\hline & 2.68 & 330 & 2.84 & 382 & & & & & & & 7.63 & 4,310 \\
\hline & 2.70 & 336 & $\overline{2} . \overline{5}$ & 420 & & & & & & & 7.46 & $4,180^{-}$ \\
\hline & $2 . \overline{1}$ & 339 & 3.25 & 534 & & & & & & & 7.30 & 3,940 \\
\hline \multirow{4}{*}{$\begin{array}{l}2 \\
3 \\
4 \\
5 \\
6\end{array}$} & & & & & \multirow{4}{*}{$\begin{array}{l}5.78 \\
6.00 \\
6.20 \\
6.40 \\
6.85 \\
7.60\end{array}$} & \multirow{4}{*}{$\begin{array}{l}2,240 \\
2,460 \\
2,700 \\
2,940 \\
3,380 \\
4,310\end{array}$} & \multirow{4}{*}{$\begin{array}{l}13.20 \\
13.16 \\
13.18 \\
13.13 \\
13.05 \\
12.90\end{array}$} & \multirow{4}{*}{$\begin{array}{l}14,200 \\
14,200 \\
14,200 \\
14,000 \\
13,800 \\
13,600\end{array}$} & \multirow{4}{*}{$\begin{array}{r}10.30 \\
10.10 \\
9.90 \\
9.74 \\
9.55 \\
9.40\end{array}$} & \multirow{4}{*}{$\begin{array}{l}8,480 \\
8,120 \\
7,780 \\
7,440 \\
7,270 \\
6,950\end{array}$} & & \\
\hline & 2.72 & 342 & 3.80 & 769 & & & & & & & 7.14 & 3,710 \\
\hline & $\overline{2} . \overline{7}$ & 342 & 4.37 & 1,050 & & & & & & & 7.00 & $3,600^{-}$ \\
\hline & 2.70 & 336 & 4.58 & 1,200 & & & & & & & 6.84 & 3,380 \\
\hline & & & & & & & 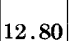 & & & & & \\
\hline 8 & 2.69 & $33 \overline{3}$ & 4.80 & 1,330 & & 6,010 & 12.70 & 13,100 & 9.10 & & 6.70 & 3,280 \\
\hline 10 & 2.68 & 330 & 4.66 & 1,230 & .65 & & $\begin{array}{l}12.69 \\
12.65\end{array} \mid$ & & 8.8 & & 6.57 & 3,180 \\
\hline 11 & $=70$ & 336 & 4.51 & & $9 \Omega_{-1}$ & & 12.66 & 13 , & 8.6 & 5,7 & & \\
\hline & 80 & 350 & . & & 1 & & & & & & & \\
\hline & $\mathrm{Au}$ & 9 & $\mathrm{Au}$ & 20 & $\mathrm{Au}$ & 1 & $\mathrm{Al}$ & 22 & Aus & 23 & & 24 \\
\hline & 6.20 & 00 & .2 & 1 , & 1.7. & 1 , & & & & 76 & 3.5 & 63 \\
\hline 8 & 6.02 & & $\therefore$ & 1,550 & 4.4 & 1,0 & 4. & & & & & 637 \\
\hline $\mathrm{N}$ & 5.83 & & 4.9 & & 4. & 1,0 & & & & & & 61 \\
\hline & 5.65 & & & & 4.2 & 99 & & & & & & 61 \\
\hline & & & & 1,260 & 4.19 & 96 & & 81 & & & 3.4 & 590 \\
\hline 12 & 5.32 & 1 , & 4.5 & 1,200 & 4.13 & 942 & 3.82 & 769 & 3.5 & 658 & 3.37 & 574 \\
\hline
\end{tabular}

Supplemental Record.-Aug. 16, $10: 30$ a.m., gage height, 13.36 feet; discharge, 14,700 second-feet.

KERRS CREEK NEAR LEXINGTON, VA.

Location.-Lat. $37^{\circ} 49^{\prime} 33^{\prime \prime}$, long. $79^{\circ} 26^{\prime} 28^{\prime \prime}$, at highway bridge $11 / 4$ miles upstream from mouth and $21 / 2$ miles north of Lexington, Rockbridge County. Datum of gage is $972.0+$ feet above mean sea level (levels by Corps of Engineers, War Department).

Drainage area.-34 square miles.

GAGE-HEIGHT RECORD.-Twice-daily readings of chain gage. Gage heights at indicated times Aug. 13-24 were obtained from graph based on floodmark and twicedaily gage readings. 
DISCHARGE RECORD.-Stage-discharge relation defined by eurrent-meter measurements up to 800 second-feet and extended to crest gage height of Mareh 1936 flood on basis of velocity-area studies and comparison of peak discharge and total runoff of flood at this station with those for other stations in James River Basin. Gage heights used to half-tenths between 5.4 and 6.6 feet; hundredths below and tenths above these limits. The record includes revised discharge published in Water-Supply Paper 1052.

Maxima.-1940: Discharge observed, 3,660 second-feet 4 p.m. Aug. 31 (gage height, 10.07 feet).

1927-39: Discharge observed, about 7,600 second-feet Mar. 17, 1936 (gage height, 12.82 feet, from floodmark).

Mean discharge, in second-feet, 1940

\begin{tabular}{|c|c|c|c|c|c|c|c|c|c|c|c|}
\hline Day & Aug. & Sept. & Day & Aug. & Sept. & Day & Aug. & Sept. & Day & Aug. & Sept. \\
\hline $\begin{array}{l}1 \\
2 \\
3 \\
4 \\
5 \\
6 \\
7 \\
8\end{array}$ & $\begin{array}{l}13 \\
13 \\
13 \\
13 \\
12 \\
31 \\
15 \\
12\end{array}$ & $\begin{array}{r}353 \\
128 \\
66 \\
55 \\
46 \\
35 \\
31 \\
32\end{array}$ & $\begin{array}{r}9 \\
10 \\
11 \\
12 \\
13 \\
14 \\
15 \\
16\end{array}$ & $\begin{array}{r}12 \\
12 \\
12 \\
12 \\
12 \\
275 \\
485 \\
655\end{array}$ & $\begin{array}{l}27 \\
25 \\
26 \\
26 \\
22 \\
22 \\
23 \\
20\end{array}$ & $\begin{array}{l}17 \\
18 \\
19 \\
20 \\
21 \\
22 \\
23 \\
24\end{array}$ & $\begin{array}{r}249 \\
155 \\
70 \\
42 \\
33 \\
26 \\
24 \\
23\end{array}$ & $\begin{array}{l}20 \\
18 \\
18 \\
18 \\
17 \\
17 \\
16 \\
16\end{array}$ & $\begin{array}{l}25 \\
26 \\
27 \\
28 \\
29 \\
30 \\
31\end{array}$ & $\begin{array}{r}20 \\
24 \\
20 \\
29 \\
28 \\
114 \\
1,400\end{array}$ & $\begin{array}{r}46 \\
20 \\
18 \\
18 \\
18 \\
17 \\
\end{array}$ \\
\hline \multicolumn{10}{|c|}{$\begin{array}{l}\text { Monthly mean discharge, in second-feet. } \\
\text { Runoff, in inches }\end{array}$} & $\begin{array}{r}124 \\
4.22\end{array}$ & $\begin{array}{l}40.5 \\
1.33\end{array}$ \\
\hline
\end{tabular}

Gage height, in feet, and discharge, in second-feet, at indicated time, 1940

\begin{tabular}{|c|c|c|c|c|c|c|c|c|c|c|c|c|}
\hline \multirow{2}{*}{ Hou } & \multicolumn{2}{|c|}{ Aug. 14} & \multicolumn{2}{|c|}{ Aug. 15} & \multicolumn{2}{|c|}{ Aug. 16} & \multicolumn{2}{|c|}{ Aug. 17} & \multicolumn{2}{|c|}{ Aug. 18} & \multicolumn{2}{|c|}{ Aug. 19} \\
\hline & $\begin{array}{c}\text { Gage } \\
\text { ht. }\end{array}$ & $\begin{array}{c}\text { Dis- } \\
\text { charge }\end{array}$ & $\begin{array}{c}\text { Gage } \\
\text { ht. }\end{array}$ & $\begin{array}{c}\text { Dis- } \\
\text { charge }\end{array}$ & $\begin{array}{c}\text { Gage } \\
\text { ht. }\end{array}$ & $\begin{array}{c}\text { Dis- } \\
\text { charge }\end{array}$ & $\begin{array}{c}\text { Gage } \\
\text { ht. }\end{array}$ & $\begin{array}{c}\text { Dis- } \\
\text { charge }\end{array}$ & $\begin{array}{l}\text { Gage } \\
\text { ht. }\end{array}$ & $\begin{array}{c}\text { Dis- } \\
\text { charge }\end{array}$ & $\begin{array}{c}\text { Gage } \\
\text { ht. }\end{array}$ & $\begin{array}{c}\text { Dis- } \\
\text { charge }\end{array}$ \\
\hline \multirow{4}{*}{$\begin{array}{l}1 \\
2 \\
3 \\
4 \\
5 \\
6\end{array}$} & \multirow{4}{*}{\begin{tabular}{|l|}
4.35 \\
4.35 \\
4.35 \\
4.36 \\
4.36 \\
4.36
\end{tabular}} & \multirow{4}{*}{$\begin{array}{l}12 \\
12 \\
12 \\
13\end{array}$} & \multirow{4}{*}{\begin{tabular}{|l|}
6.90 \\
6.65 \\
6.35 \\
6.00 \\
5.70 \\
5.40 \\
\end{tabular}} & \multirow{4}{*}{$\begin{array}{l}880 \\
710 \\
555 \\
385 \\
276 \\
186\end{array}$} & 7.05 & 940 & $5 . \overline{5}$ & 292 & 5.25 & $\mathbf{1 4 5}$ & & \\
\hline & & & & & & & & & & & & \\
\hline & & & & & 6.95 & 880 & 5.70 & 276 & 5.15 & 120 & 5.05 & 97 \\
\hline & & & & & 6.90 & 880 & 5.70 & 276 & $\overline{5} . \overline{15}$ & 120 & - & \\
\hline \multirow{5}{*}{$\begin{array}{r}7 \\
8 \\
9 \\
10 \\
11 \\
\mathrm{~N}\end{array}$} & \multirow{5}{*}{\begin{tabular}{|l|}
4.36 \\
4.37 \\
4.37 \\
4.37 \\
$\mathbf{4 . 4 0}$ \\
$\mathbf{4 . 4 7}$
\end{tabular}} & \multirow{5}{*}{$\begin{array}{l}13 \\
13 \\
13 \\
13 \\
14\end{array}$} & \multirow{5}{*}{\begin{tabular}{|l|}
5.20 \\
5.15 \\
5.12 \\
5.15 \\
5.18 \\
5.25
\end{tabular}} & \multirow{5}{*}{$\begin{array}{l}132 \\
120 \\
113 \\
120 \\
127 \\
145\end{array}$} & & & & & & & & \\
\hline & & & & & 6.80 & 820 & 5.65 & 260 & 5.15 & 120 & $4 . \overline{9}$ & 67 \\
\hline & & & & & 6.70 & $\overline{7} \overline{6} \overline{5}$ & 5.70 & 276 & $-\overline{5} .20$ & $\overline{13} \overline{2}$ & & \\
\hline & & & & & & & & & & & & \\
\hline & & & & & 6.60 & 682 & 5.70 & 276 & 5.30 & 158 & 4.85 & 60 \\
\hline \multirow{4}{*}{$\begin{array}{l}1 \\
2 \\
3 \\
4 \\
5 \\
6\end{array}$} & \multirow{4}{*}{$\begin{array}{l}4.57 \\
4.77 \\
4.97 \\
5.30 \\
5.60 \\
6.05\end{array}$} & \multirow{4}{*}{$\begin{array}{r}25 \\
48 \\
80 \\
158 \\
245 \\
405\end{array}$} & \multirow{4}{*}{$\begin{array}{l}5.50 \\
5.70 \\
5.95 \\
6.20 \\
6.40 \\
6.55\end{array}$} & \multirow{4}{*}{$\begin{array}{l}215 \\
276 \\
360 \\
465 \\
580 \\
655\end{array}$} & & & & & & & & \\
\hline & & & & & 6.45 & 605 & 5.65 & 260 & 5.45 & 200 & & \\
\hline & & & & & $6 . \overline{30}$ & $5 \overline{3} 2$ & 5.60 & 245 & 5.50 & $2 \overline{15}$ & 4.80 & 52 \\
\hline & & & & & $\overline{6} . \overline{1} \overline{5}$ & $\overline{44} \overline{5}$ & $\overline{5} . \overline{50}$ & $\overline{2} \overline{1} \overline{5}$ & $-\overline{5.45}$ & 200 & & \\
\hline \multirow{5}{*}{$\begin{array}{r}7 \\
8 \\
9 \\
10 \\
11 \\
12\end{array}$} & \multirow{5}{*}{$\begin{array}{l}6.45 \\
7.00 \\
7.25 \\
7.40 \\
7.30 \\
7.20\end{array}$} & \multirow{5}{*}{$\begin{array}{r}605 \\
940 \\
1,060 \\
1,200 \\
1,130 \\
1,060\end{array}$} & \multirow{5}{*}{$\left|\begin{array}{l}6.70 \\
6.80 \\
6.90 \\
7.00 \\
7.05 \\
7.05\end{array}\right|$} & \multirow{5}{*}{$\begin{array}{l}765 \\
820 \\
880 \\
940 \\
940 \\
940\end{array}$} & & & & & & & & \\
\hline & & & & & $6 . \overline{0}$ & 405 & 5.45 & 200 & 5.30 & 158 & 4.80 & 52 \\
\hline & & & & & 5.90 & 342 & $5 . \overline{3} 5$ & 172 & $5 . \overline{25}$ & 145 & --1 &.-- \\
\hline & & & & & & & & & & & & \\
\hline & & & & & & 325 & 5.30 & 158 & .2 & 132 & 4.80 & 5 \\
\hline
\end{tabular}

$804331-49-9$ 
104 FLOODS OF AUGUST 1940 IN THE SOUTHEASTERN STATES

Gage height, in feet, and discharge, in second-feet, at indicated time, 1940

\begin{tabular}{|c|c|c|c|c|c|c|c|c|}
\hline \multirow{2}{*}{ Hour } & \multicolumn{2}{|c|}{ Aug. 30} & \multicolumn{2}{|c|}{ Aug. 31} & \multicolumn{2}{|c|}{ Sept. 1} & \multicolumn{2}{|c|}{ Sept. 2} \\
\hline & $\begin{array}{l}\text { Gage } \\
\text { height }\end{array}$ & Discharge & $\begin{array}{l}\text { Gage } \\
\text { height }\end{array}$ & Discharge & $\begin{array}{l}\text { Gage } \\
\text { height }\end{array}$ & Discharge & $\begin{array}{l}\text { Gage } \\
\text { height }\end{array}$ & Discharge \\
\hline $\begin{array}{l}1 \\
2 \\
3 \\
4 \\
5 \\
6\end{array}$ & 4.60 & (28 & $\begin{array}{l}6.32 \\
6.47 \\
6.60 \\
6.70 \\
6.82 \\
6.95\end{array}$ & $\begin{array}{l}555 \\
630 \\
710 \\
765 \\
820 \\
940\end{array}$ & 6 & & 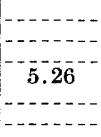 & $\mid \begin{array}{c}-160 \\
-160\end{array}$ \\
\hline $\begin{array}{r}7 \\
8 \\
9 \\
10 \\
11 \\
\mathrm{~N}\end{array}$ & $\begin{array}{c}4.63 \\
4.70\end{array}$ & 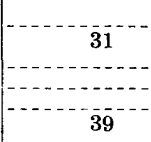 & $\begin{array}{l}7.06 \\
7 \cdot 18 \\
7 \cdot 30 \\
7 \cdot 40 \\
7.50 \\
7.60\end{array}$ & $\begin{array}{l}1,000 \\
1,060 \\
1,130 \\
1,200 \\
1,270 \\
1,340\end{array}$ & \begin{tabular}{l}
$-\overline{5.92}$ \\
\hdashline $5.7 \overline{2}^{-}$
\end{tabular} & $\begin{array}{c}-385^{-1} \\
-310\end{array}$ & \begin{tabular}{l}
$-\overline{5.26}$ \\
\hdashline 5.16
\end{tabular} & $\begin{array}{c}-\ldots 160^{-1} \\
-125\end{array}$ \\
\hline $\begin{array}{l}1 \\
2 \\
3 \\
4 \\
5 \\
6\end{array}$ & 4 & 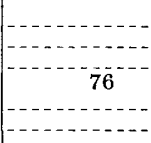 & $\begin{array}{r}7.75 \\
8.70 \\
10.00 \\
10.07 \\
9.20 \\
8.40\end{array}$ & $\begin{array}{l}1,500 \\
2,270 \\
3,540 \\
3,660 \\
2,740 \\
2,000\end{array}$ & 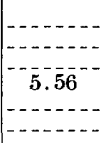 & 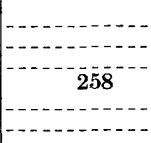 & 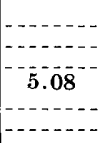 & $\begin{array}{r}-104 \\
-104\end{array}$ \\
\hline $\begin{array}{r}7 \\
8 \\
9 \\
10 \\
11 \\
12\end{array}$ & $\begin{array}{c}5.50 \\
6.18\end{array}$ & $\mid \begin{array}{r}-\cdots \\
242 \\
-\cdots \\
-\cdots\end{array}$ & $\begin{array}{l}7.95 \\
7.55 \\
7.30 \\
7.05 \\
6.88 \\
6.65\end{array}$ & $\begin{array}{r}1,660 \\
1,340 \\
1,130 \\
940 \\
880 \\
710\end{array}$ & \begin{tabular}{l}
$-\overline{5.43}$ \\
\hdashline$-\overline{-}$ \\
5.32
\end{tabular} & $\mid \begin{array}{r}-\ldots 12 \\
\cdots \ldots \\
-180\end{array}$ & \begin{tabular}{|c|}
$-\overline{5.02}$ \\
$4.9 \overline{9}^{-}$
\end{tabular} & 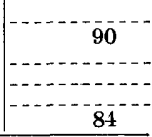 \\
\hline
\end{tabular}

BUFFALO RIVER NEAR NORWOOD, VA.

Location.-Lat. $37^{\circ} 38^{\prime}$, long. $78^{\circ} 53^{\prime}, 1$ mile downstream from Tye River, 3 miles upstream from Rucker Run, and $4 \frac{1}{2}$ miles upstream from mouth at Norwood, Nelson County. Datum of gage is 400.77 feet above mean sea level, datum of 1929.

Drain AGE AREA. - 360 square miles.

GAGE-HEIGHT RECORD.-Water-stage recorder graph except for period 8 a.m. Aug. 17 to 10 a.m. Aug. 18 where gage heights were obtained from graph based on many slope gage readings.

DISCHARGE RECORD.-Stage-discharge relation defined by current-meter measurements up to 13,000 second-feet and extended to erest gage height by logarithmic plotting. Gage heights used to half-tenths between 4.0 and 5.5 feet; hundredths below and tenths above these limits.

Maxima.-August 1940: Discharge, 25,600 second-feet $12 \mathrm{~m}$. Aug. 16 (gage height, 15.25 feet).

March to July 1940: Discharge, 2,900 second-feet Apr. 9 (gage height, 4.77 feet).

Mean discharge, in second-feet, 1940

\begin{tabular}{|c|c|c|c|c|c|c|c|c|c|c|c|}
\hline Day. & Aug. & Sept. & Day & Aug. & Sept. & Day & Aug. & Sept. & Day & Aug. & Sept. \\
\hline $\begin{array}{l}1 \\
2 \\
3 \\
4 \\
5 \\
6 \\
7 \\
8\end{array}$ & $\begin{array}{l}281 \\
210 \\
192 \\
188 \\
192 \\
205 \\
210 \\
231\end{array}$ & $\begin{array}{r}2,470 \\
1,410 \\
1,070 \\
892 \\
766 \\
706 \\
610 \\
555\end{array}$ & $\begin{array}{l}9 \\
10 \\
11 \\
12 \\
13 \\
14 \\
15 \\
16\end{array}$ & $\begin{array}{r}181 \\
162 \\
162 \\
281 \\
398 \\
1,330 \\
9,840 \\
21,300\end{array}$ & $\begin{array}{l}520 \\
478 \\
439 \\
408 \\
381 \\
367 \\
354 \\
340\end{array}$ & $\begin{array}{l}17 \\
18 \\
19 \\
20 \\
21 \\
22 \\
23 \\
24\end{array}$ & $\begin{array}{r}10,100 \\
4,020 \\
2,410 \\
1,700 \\
1,320 \\
1,080 \\
916 \\
772\end{array}$ & $\begin{array}{l}322 \\
310 \\
299 \\
293 \\
276 \\
266 \\
256 \\
251\end{array}$ & $\begin{array}{l}25 \\
26 \\
27 \\
28 \\
29 \\
30 \\
31\end{array}$ & $\begin{array}{r}706 \\
666 \\
638 \\
1,220 \\
1,010 \\
726 \\
2,150\end{array}$ & $\begin{array}{l}367 \\
354 \\
266 \\
251 \\
246 \\
236\end{array}$ \\
\hline \multicolumn{10}{|c|}{$\begin{array}{l}\text { Monthly mean discharge, in second-feet } \\
\text { Runoff, in inches }\end{array}$} & $\begin{array}{r}2,090 \\
6.70\end{array}$ & $\begin{array}{r}525 \\
1.63\end{array}$ \\
\hline
\end{tabular}


JAMES RIVER BASIN

Gage height, in feet, and discharge, in second-feet, at indicated time, 1940

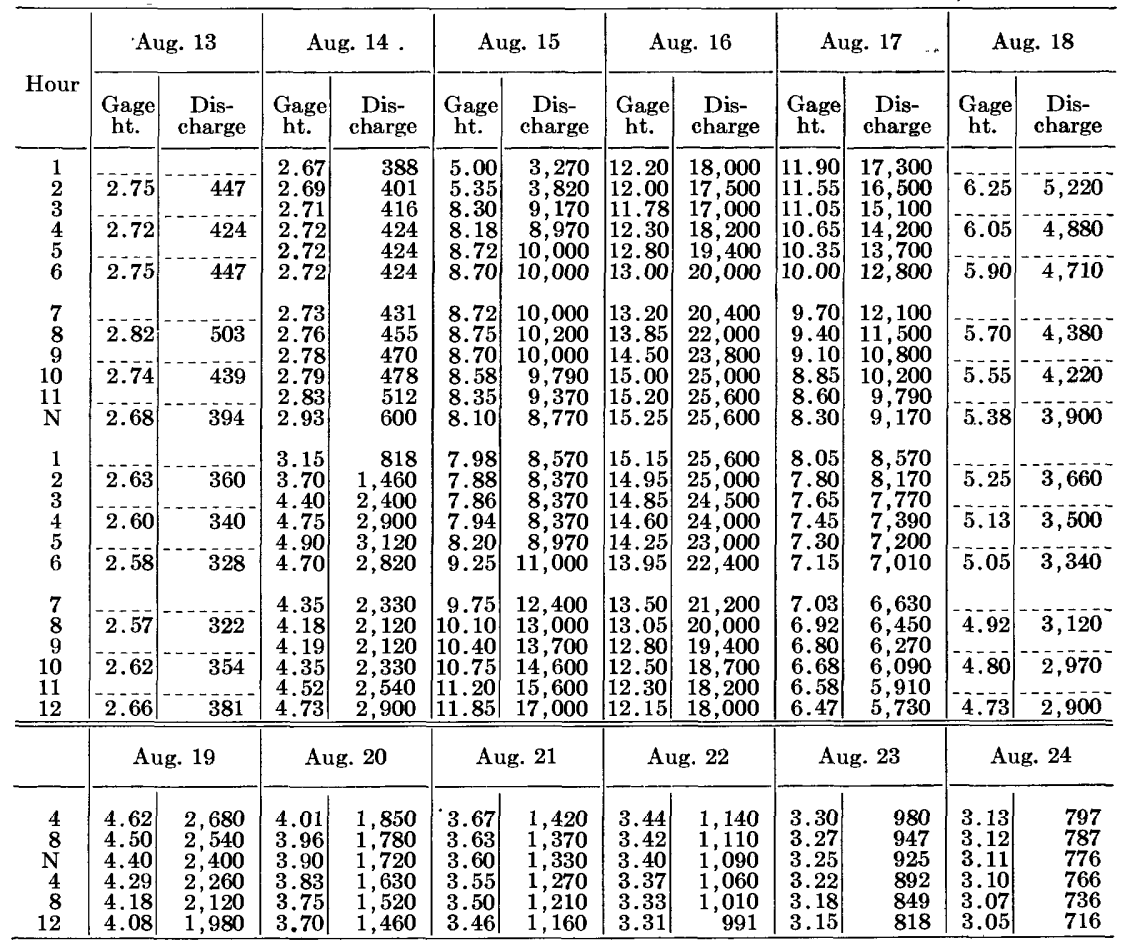

SUPPLEMENTAL RECORD.-Aug. 15, 4:30 a.m., gage height, 9.14 feet; discharge, 10,800 second-feet.

\section{TYE RIVER NEAR LOVINGSTON, VA.}

Location.-Lat. $37^{\circ} 43^{\prime}$, long. $78^{\circ} 58^{\prime}$, at highway bridge 2 miles downstream from Hat Creek, 4 miles upstream from Piney River, and 6 miles southwest of Lovingston, Nelson County. Datum of gage is 578.39 feet above mean sea level, datum of 1929.

Drainage area.-92 square miles.

GAGE-HEIGHT RECORD.-Water-stage recorder graph.

DISCHARGE RECORD.-Stage-discharge relation defined by current-meter measurements up to 7,500 second-feet. Gage heights used to half-tenths between 3.1 and 5.3 feet; hundredths below and tenths above these limits.

Maxima.-1940: Discharge, 7,700 second-feet 1:30 p.m. Aug. 16 (gage height, 11.94 feet).

1938-39 : Discharge, 6,900 second-feet Aug. 19, 1939 (gage height, 11.13 feet).

Mean discharge, in second-feet, 1940

\begin{tabular}{|c|c|c|c|c|c|c|c|c|c|c|c|}
\hline Day & Aug. & Sept. & Day & Aug. & Sept. & Day & Aug. & Sept. & Day & Aug. & Sept. \\
\hline $\begin{array}{l}1 \\
2 \\
3 \\
4 \\
5 \\
6 \\
7 \\
8\end{array}$ & $\begin{array}{l}84 \\
52 \\
50 \\
44 \\
44 \\
52 \\
46 \\
36\end{array}$ & $\begin{array}{l}670 \\
431 \\
338 \\
285 \\
252 \\
224 \\
200 \\
181\end{array}$ & $\begin{array}{r}9 \\
10 \\
11 \\
12 \\
13 \\
14 \\
15 \\
16\end{array}$ & $\begin{array}{r}36 \\
28 \\
49 \\
102 \\
98 \\
394 \\
3,040 \\
6,140\end{array}$ & $\begin{array}{l}167 \\
154 \\
139 \\
130 \\
121 \\
114 \\
106 \\
102\end{array}$ & $\begin{array}{l}17 \\
18 \\
19 \\
20 \\
21 \\
22 \\
23 \\
24\end{array}$ & $\begin{array}{r}3,210 \\
1,380 \\
849 \\
606 \\
466 \\
385 \\
324 \\
275\end{array}$ & $\begin{array}{l}98 \\
92 \\
88 \\
85 \\
81 \\
76 \\
72 \\
72\end{array}$ & $\begin{array}{l}25 \\
26 \\
27 \\
28 \\
29 \\
30 \\
31\end{array}$ & $\begin{array}{l}249 \\
243 \\
224 \\
291 \\
234 \\
230 \\
808\end{array}$ & $\begin{array}{r}118 \\
94 \\
78 \\
72 \\
69 \\
66\end{array}$ \\
\hline \multicolumn{10}{|c|}{$\begin{array}{l}\text { Monthly mean discharge, in second-feet } \\
\text { Runoff, in inches }\end{array}$} & $\begin{array}{r}647 \\
8.10\end{array}$ & $\begin{array}{r}159 \\
1.93\end{array}$ \\
\hline
\end{tabular}




\section{FLOODS OF AUGUST 1940 IN THE SOUTHEASTERN STATES}

Gage height, in feet, and discharge, in second-feet, at indicated time, 1940

\begin{tabular}{|c|c|c|c|c|c|c|c|c|c|c|c|c|}
\hline \multirow{2}{*}{ Hour } & \multicolumn{2}{|c|}{ Aug. 13} & \multicolumn{2}{|c|}{ Aug. 14} & \multicolumn{2}{|c|}{ Aug. 15} & \multicolumn{2}{|c|}{ Aug. 16} & \multicolumn{2}{|c|}{ Aug. 17} & \multicolumn{2}{|c|}{ Aug. 18} \\
\hline & $\begin{array}{l}\text { Gage } \\
\text { ht. }\end{array}$ & $\begin{array}{c}\text { Dis- } \\
\text { charge }\end{array}$ & $\begin{array}{c}\text { Gage } \\
\text { ht. }\end{array}$ & $\begin{array}{c}\text { Dis- } \\
\text { charge }\end{array}$ & $\begin{array}{c}\text { Gage } \\
\text { ht. }\end{array}$ & $\begin{array}{c}\text { Dis- } \\
\text { charge }\end{array}$ & $\begin{array}{c}\text { Gage } \\
\text { ht. }\end{array}$ & $\begin{array}{c}\text { Dis- } \\
\text { charge }\end{array}$ & $\begin{array}{c}\text { Gage } \\
\text { ht. }\end{array}$ & & $\begin{array}{c}\text { Gage } \\
\text { ht. }\end{array}$ & $\begin{array}{c}\text { Dis- } \\
\text { charge }\end{array}$ \\
\hline \multirow{4}{*}{$\begin{array}{l}1 \\
2 \\
3 \\
4 \\
5 \\
6\end{array}$} & $1 . \overline{5}$ & 96 & \multirow{4}{*}{$\begin{array}{l}1.77 \\
1.79 \\
1.82 \\
1.84 \\
1.84 \\
1.84\end{array}$} & \multirow{4}{*}{$\begin{array}{l}102 \\
106 \\
115 \\
120 \\
120 \\
120\end{array}$} & \multirow{4}{*}{$\begin{array}{l}3.37 \\
3.42 \\
3.45 \\
3.70 \\
3.98 \\
4.20\end{array}$} & \multirow{4}{*}{$\begin{array}{r}692 \\
715 \\
738 \\
860 \\
1,010 \\
1,120\end{array}$} & \multirow{4}{*}{$\begin{array}{l}9.30 \\
9.05 \\
8.85 \\
8.70 \\
8.60 \\
8.45\end{array}$} & \multirow{4}{*}{$\begin{array}{l}5,120 \\
4,850 \\
4,670 \\
4,580 \\
4,490 \\
4,310\end{array}$} & \multirow{4}{*}{$\begin{array}{l}9.65 \\
9.40 \\
9.10 \\
8.80 \\
8.50 \\
8.20\end{array}$} & \multirow{4}{*}{$\begin{array}{l}5,400 \\
5,210 \\
4,940 \\
4,670 \\
4,400 \\
4,130\end{array}$} & 5.18 & 1,740 \\
\hline & 10 & & & & & & & & & & & 16 \\
\hline & 1.74 & 94 & & & & & & & & & 5.07 & 1,640 \\
\hline & 1.74 & 94 & & & & & & & & & 4.95 & 1,570 \\
\hline \multirow{3}{*}{$\begin{array}{r}7 \\
8 \\
\mathbf{9} \\
10 \\
11 \\
\mathbf{N}\end{array}$} & 1.78 & 104 & \multirow{4}{*}{$\begin{array}{l}1.85 \\
1.87 \\
1.90 \\
1.95 \\
2.00 \\
2.10\end{array}$} & \multirow{4}{*}{$\begin{array}{l}123 \\
129 \\
137 \\
152 \\
167 \\
199\end{array}$} & \multirow{4}{*}{\begin{tabular}{|l|}
4.55 \\
4.85 \\
5.07 \\
5.13 \\
5.17 \\
5.35
\end{tabular}} & \multirow{4}{*}{$\begin{array}{l}1,330 \\
1,510 \\
1,640 \\
1,700 \\
1,700 \\
1,880\end{array}$} & \multirow{4}{*}{$\begin{array}{r}8.50 \\
8.95 \\
9.70 \\
11.00 \\
11.65 \\
11.75\end{array}$} & \multirow{4}{*}{$\begin{array}{l}4,400 \\
4,850 \\
5,500 \\
6,800 \\
7,400 \\
7,600\end{array}$} & \multirow{4}{*}{$\begin{array}{l}7.85 \\
7.55 \\
7.30 \\
7.10 \\
6.95 \\
6.75\end{array}$} & \multirow{4}{*}{$\begin{array}{l}3,770 \\
3,590 \\
3,340 \\
3,180 \\
3,100 \\
2,940\end{array}$} & 4.84 & 1,510 \\
\hline & - & 106 & & & & & & & & & 4.72 & 1,420 \\
\hline & . & 00 & & & & & & & & & & 360 \\
\hline & 1.6 & & & & & & & & & & & \\
\hline \multirow{4}{*}{$\begin{array}{l}1 \\
2 \\
3 \\
4 \\
5 \\
6\end{array}$} & 1.75 & 96 & \multirow{4}{*}{$\begin{array}{l}2.30 \\
2.80 \\
3.08 \\
3.20 \\
3.70 \\
3.85\end{array}$} & \multirow{4}{*}{$\begin{array}{l}266 \\
452 \\
571 \\
625 \\
860 \\
935\end{array}$} & \multirow{4}{*}{$\begin{array}{l}6.00 \\
6.50 \\
6.95 \\
7.55 \\
8.15 \\
9.00\end{array}$} & \multirow{4}{*}{$\begin{array}{l}2,300 \\
2,700 \\
3,100 \\
3,590 \\
4,130 \\
4,850\end{array}$} & \multirow{4}{*}{$\begin{array}{l}11.90 \\
11.85 \\
11.55 \\
11.28 \\
11.18 \\
11.18\end{array}$} & \multirow{4}{*}{$\begin{array}{l}7,700 \\
7,600 \\
7,400 \\
7,100 \\
7,000 \\
7,000\end{array}$} & \multirow{4}{*}{$\begin{array}{l}6.55 \\
6.40 \\
6.25 \\
6.10 \\
5.97 \\
5.85\end{array}$} & & $\overline{4} . \overline{50}$ & $\overline{1}, \overline{300}$ \\
\hline & 175 & 96 & & & & & & & & & 4.38 & 1,240 \\
\hline & & & & & & & & & & 2, & & \\
\hline & 1.75 & 96 & & & & & & & & 2,160 & 4.27 & 1,150 \\
\hline 8 & & $0 ?$ & & 835 & & & & & 5. & & & \\
\hline 8 & & 92 & $\begin{array}{l}3.53 \\
3.45\end{array}$ & $\begin{array}{l}785 \\
738\end{array}$ & 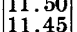 & $\begin{array}{l}7,300 \\
7,200\end{array}$ & 10.97 & & & & & \\
\hline & 1.77 & 102 & 3.38 & & & & & & 5.4 & & 4.10 & 1,060 \\
\hline 1 & 1.77 & 102 & 3.35 & & $\begin{array}{r}10.40 \\
9.70\end{array}$ & & 10.00 & & 5.32 & & $4.0 \overline{3}$ & 1,040 \\
\hline & & 9 & A & 0 & A & 21 & & 22 & & 23 & & 24 \\
\hline $\begin{array}{r}4 \\
8 \\
N \\
4 \\
8 \\
8 \\
12\end{array}$ & $\begin{array}{l}3.90 \\
3.80 \\
3.68 \\
3.54 \\
3.42 \\
3.35 \\
\end{array}$ & $\begin{array}{l}960 \\
910 \\
860 \\
785 \\
715 \\
692\end{array}$ & $\begin{array}{l}3.29 \\
3.23 \\
3.16 \\
3.07 \\
3.01 \\
2.97\end{array}$ & $\begin{array}{l}670 \\
648 \\
602 \\
567 \\
540 \\
523\end{array}$ & $\begin{array}{l}2.93 \\
2.88 \\
2.84 \\
2.78 \\
2.72 \\
2.68\end{array}$ & $\begin{array}{l}470 \\
446 \\
424 \\
409\end{array}$ & $\begin{array}{l}2.66 \\
2.64 \\
2.61 \\
2.56 \\
2.60 \\
2.55\end{array}$ & $\begin{array}{l}402 \\
394 \\
384 \\
366 \\
380 \\
362\end{array}$ & $\begin{array}{l}2.50 \\
2.48 \\
2.45 \\
2.40 \\
2.35 \\
2.33\end{array}$ & $\begin{array}{l}345 \\
338 \\
328 \\
311 \\
294 \\
288 \\
\end{array}$ & $\begin{array}{l}2.32 \\
2.31 \\
2.29 \\
2.25 \\
2.28 \\
2.26\end{array}$ & $\begin{array}{l}285 \\
281 \\
275 \\
262 \\
272 \\
265 \\
\end{array}$ \\
\hline
\end{tabular}

SuPPLEMENTAL RECORD.-Aug. 16, 1:30 p.m., gage height, 11.94 feet; discharge, 7,700 second-feet.

\section{HARDWARE RIVER BELOW BRIERY RUN, NEAR SCOTTSVILLE, VA.}

LOCATION.-Lat. $37^{\circ} 49^{\prime}$, long. $78^{\circ} 28^{\prime}$, at highway bridge half. a mile downstream from Briery Run, 2 miles northeast of Scottsville, Albemarle County, and 9 miles upstream from mouth. Datum of gage is $\mathbf{2 9 4 . 9 5}$ feet above mean sea level. Drainage AREa.- 116 square miles.

GAGE-HEIGHT RECORD.-Water-stage recorder graph.

DISCHARGE RECORD.-Stage-discharge relation defined by current-meter measurements. Gage heights used to half-tenths between 3.2 and 4.4 feet to Aug. 16 and between 3.3 and 4.5 feet thereafter; hundredths below and tenths above these limits.

Maxima.-1940: Discharge, 4,250 second-feet 11 p.m. Aug. 16 (gage height, 13.73 feet).

1938-39 : Discharge, 1,370 second-feet Feb. 11, 1939 (gage height, 10.04 feet).

Mean discharge, in second-feet, 1940

\begin{tabular}{|c|c|c|c|c|c|c|c|c|c|c|c|}
\hline Day & Aug. & Sept. & Day & Aug. & Sept. & Day & Aug. & Sept. & Day & Aug. & Sept. \\
\hline $\begin{array}{l}1 \\
2 \\
3 \\
4 \\
5 \\
6 \\
7 \\
8\end{array}$ & $\begin{array}{l}\mathbf{5 4} \\
\mathbf{4 9} \\
\mathbf{4 7} \\
47 \\
\mathbf{4 9} \\
\mathbf{5 2} \\
\mathbf{5 7} \\
48\end{array}$ & $\begin{array}{r}376 \\
164 \\
133 \\
119 \\
109 \\
104 \\
97 \\
92\end{array}$ & $\begin{array}{r}9 \\
10 \\
11 \\
12 \\
13 \\
14 \\
15 \\
16\end{array}$ & $\begin{array}{r}44 \\
42 \\
44 \\
52 \\
-\quad 50 \\
84 \\
\mathbf{9 7 6} \\
3,920\end{array}$ & $\begin{array}{l}94 \\
83 \\
79 \\
77 \\
73 \\
72 \\
69 \\
69\end{array}$ & $\begin{array}{l}17 \\
18 \\
19 \\
20 \\
21 \\
22 \\
23 \\
24\end{array}$ & $\begin{array}{r}2,690 \\
700 \\
382 \\
260 \\
201 \\
173 \\
154 \\
141\end{array}$ & $\begin{array}{l}66 \\
65 \\
64 \\
63 \\
60 \\
59 \\
57 \\
57\end{array}$ & $\begin{array}{l}25 \\
26 \\
27 \\
28 \\
29 \\
30 \\
31\end{array}$ & $\begin{array}{l}133 \\
133 \\
132 \\
133 \\
120 \\
126 \\
196\end{array}$ & $\begin{array}{r}81 \\
81 \\
63 \\
60 \\
59 \\
57 \\
-\end{array}$ \\
\hline \multicolumn{10}{|c|}{$\begin{array}{l}\text { Monthly mean discharge, in second-feet } \\
\text { Runoff, in inches }\end{array}$} & $\begin{array}{r}364 \\
3.62\end{array}$ & 90.1 \\
\hline
\end{tabular}


JAMES RIVER BASIN

Gage height, in feet, and discharge, in second-feet, at indicated time, 1940

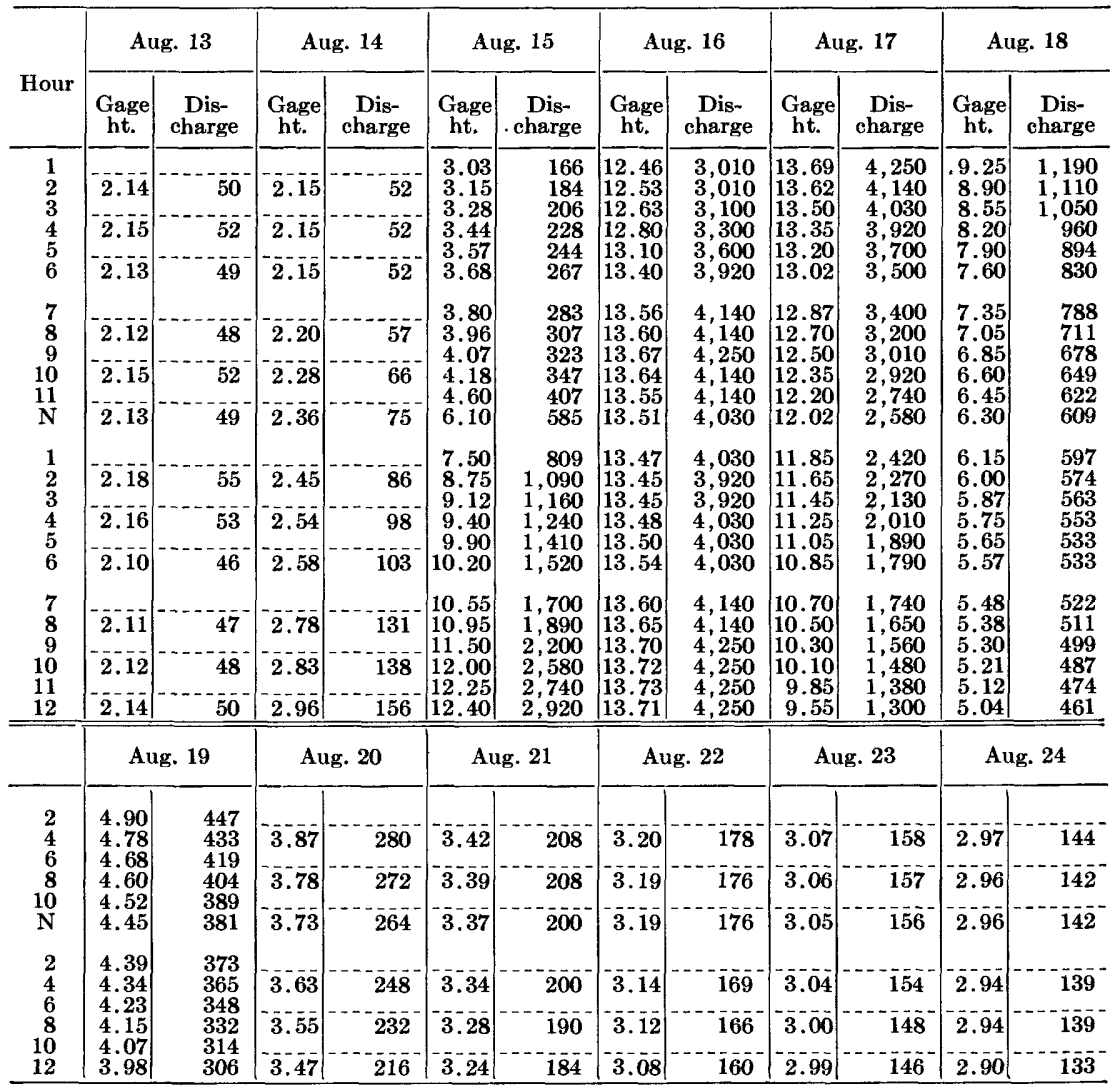

\section{SLATE RIVER NEAR ARVONIA, VA.}

Location.-Lat. $37^{\circ} 42^{\prime}$, long. $78^{\circ} 21^{\prime}$, at Bumpers Bridge, 1 mile upstream from Hunt Creek, 2 miles upstream from mouth, and 2 miles north of Arvonia, Buckingham County. Datum of gage is 238.78 feet above mean sea level (levels by Corps of Engineers, War Department).

Drain AGe AREA. - 235 square miles.

GAGE-HEIGHT RECORD.-Water-stage recorder graph except for Aug. 23-26.

DISCHARGe RECORD.-Stage-discharge relation defined by current-meter measurements up to 5,500 second-feet and extended to erest gage height of September 1935 on basis of velocity-area studies. Gage heights used to half-tenths between 4.3 and 6.4 feet; hundredths below and tenths above these limits. Discharge Aug. 23-26 computed on basis of records for Willis River at Flanagan Mills and James River at Scottsville and Cartersville.

Maxima.-1940: Discharge, 5,880 second-feet $12 \mathrm{~m}$. Aug. 16 (gage height, 13.62 feet).

1926-39: Discharge, about 13,600 second-feet Sept. 6, 1935 (gage height, 22.18 feet from floodmarks). 
Mean discharge, in second-feet, 1940

\begin{tabular}{|c|c|c|c|c|c|c|c|c|c|c|c|}
\hline Day & Aug. & Sept. & Day & Aug. & Sept. & Day & Aug. & Sept. & Day & Aug. & Sept. \\
\hline $\begin{array}{l}1 \\
2 \\
3 \\
4 \\
5 \\
6 \\
7 \\
8\end{array}$ & $\begin{array}{r}73 \\
58 \\
54 \\
57 \\
53 \\
194 \\
134 \\
72\end{array}$ & $\begin{array}{r}170 \\
146 \\
124 \\
116 \\
111 \\
109 \\
94 \\
93\end{array}$ & $\begin{array}{r}99 \\
10 \\
11 \\
12 \\
13 \\
14 \\
15 \\
16\end{array}$ & $\begin{array}{r}62 \\
54 \\
51 \\
66 \\
69 \\
258 \\
3,650 \\
5,440\end{array}$ & $\begin{array}{l}89 \\
86 \\
86 \\
84 \\
82 \\
85 \\
84 \\
85\end{array}$ & $\begin{array}{l}17 \\
18 \\
19 \\
20 \\
21 \\
22 \\
23 \\
24\end{array}$ & $\begin{array}{r}4,170 \\
926 \\
367 \\
243 \\
187 \\
165 \\
250 \\
200\end{array}$ & $\begin{array}{l}81 \\
81 \\
78 \\
77 \\
75 \\
71 \\
69 \\
67\end{array}$ & $\begin{array}{l}25 \\
26 \\
27 \\
28 \\
29 \\
30 \\
31\end{array}$ & $\begin{array}{l}150 \\
150 \\
149 \\
925 \\
311 \\
208 \\
183\end{array}$ & $\begin{array}{r}104 \\
174 \\
94 \\
85 \\
80 \\
80\end{array}$ \\
\hline \multicolumn{10}{|c|}{$\begin{array}{l}\text { Monthly mean discharge, in second-feet } \\
\text { Runoff, in inches }\end{array}$} & $\begin{array}{r}611 \\
3.00\end{array}$ & $\begin{array}{l}95.3 \\
0.45\end{array}$ \\
\hline
\end{tabular}

Gage height, in feet, and discharge, in second-feet, at indicated time, 1940

\begin{tabular}{|c|c|c|c|c|c|c|c|c|c|c|}
\hline \multirow{2}{*}{ Hour } & \multicolumn{2}{|c|}{ Aug. 13} & \multicolumn{2}{|c|}{ Aug. 14} & \multicolumn{2}{|c|}{ Aug. 15} & \multicolumn{2}{|c|}{ Aug. 16} & \multicolumn{2}{|c|}{ Aug. 17} \\
\hline & $\begin{array}{c}\text { Gage } \\
\text { height }\end{array}$ & $\begin{array}{c}\text { Dis- } \\
\text { charge }\end{array}$ & $\begin{array}{c}\text { Gage } \\
\text { height }\end{array}$ & $\begin{array}{c}\text { Dis- } \\
\text { charge }\end{array}$ & $\begin{array}{c}\text { Gage } \\
\text { height }\end{array}$ & $\begin{array}{l}\text { Dis- } \\
\text { charge }\end{array}$ & $\begin{array}{c}\text { Gage } \\
\text { height }\end{array}$ & $\begin{array}{c}\text { Dis- } \\
\text { charge }\end{array}$ & $\begin{array}{c}\text { Gage } \\
\text { height }\end{array}$ & $\begin{array}{l}\text { Dis- } \\
\text { charge }\end{array}$ \\
\hline $\begin{array}{l}1 \\
2 \\
3 \\
4 \\
5 \\
6\end{array}$ & $\begin{array}{l}2.77^{-} \\
2.76 \\
2.74\end{array}$ & $\begin{array}{l}7 \overrightarrow{4} \\
\overline{73} \\
\overline{1}\end{array}$ & $\begin{array}{l}2.64 \\
2.68 \\
2.71\end{array}$ & 62 & $\begin{array}{r}7.60 \\
8.40 \\
9.05 \\
9.95 \\
10.45 \\
10.65\end{array}$ & $\begin{array}{l}1,760 \\
2,220 \\
2,580 \\
3,220 \\
3,490 \\
3,630\end{array}$ & $\begin{array}{l}12.25 \\
12.35 \\
12.45 \\
12.55 \\
13.10 \\
13.25\end{array}$ & $\begin{array}{l}4,800 \\
4,950 \\
4,950 \\
5,100 \\
5,480 \\
5,560\end{array}$ & $\begin{array}{l}12.50 \\
12.44 \\
12.38 \\
12.32 \\
12.28 \\
12.25\end{array}$ & $\begin{array}{l}5,020 \\
4,950 \\
4,950 \\
4.880 \\
4,880 \\
4,800\end{array}$ \\
\hline $\begin{array}{r}7 \\
8 \\
9 \\
10 \\
11 \\
\mathrm{~N}\end{array}$ & $\begin{array}{l}2.73 \\
2.72 \\
2.73\end{array}$ & $\begin{array}{l}70 \\
69 \\
70\end{array}$ & $\begin{array}{c}2.74 \\
2.76 \\
2.83\end{array}$ & 83 & $\begin{array}{l}10.70 \\
10.75 \\
10.80 \\
10.78 \\
10.65 \\
10.60\end{array}$ & $\begin{array}{l}3,700 \\
3,770 \\
3,770 \\
3,770 \\
3,630 \\
3,630\end{array}$ & $\begin{array}{l}13.35 \\
13.43 \\
13.50 \\
13.58 \\
13.61 \\
13.62\end{array}$ & $\begin{array}{l}5,720 \\
5,720 \\
5,800 \\
5,880 \\
5,880 \\
5,880\end{array}$ & $\begin{array}{l}12.20 \\
12.17 \\
12.13 \\
12.09 \\
12.02 \\
11.95\end{array}$ & $\begin{array}{l}4,800 \\
4,800 \\
4,720 \\
4,720 \\
4,650 \\
4,650\end{array}$ \\
\hline $\begin{array}{l}1 \\
2 \\
3 \\
4 \\
5 \\
6\end{array}$ & $\begin{array}{r}2.80 \\
2.70 \\
2.62\end{array}$ & 67 & $\begin{array}{l}2.93 \\
3.33 \\
4.05\end{array}$ & $\begin{array}{l}92 \\
151 \\
296\end{array}$ & $\begin{array}{l}10.65 \\
10.85 \\
11.07 \\
11.20 \\
11.25 \\
11.35\end{array}$ & $\begin{array}{l}3,630 \\
3,770 \\
3,980 \\
4,050 \\
4,050 \\
4,200\end{array}$ & $\begin{array}{l}13.61 \\
13.53 \\
13.40 \\
13.25 \\
13.10 \\
13.00\end{array}$ & $\begin{array}{l}5,880 \\
5,800 \\
5,720 \\
5,560 \\
5,480 \\
5,400\end{array}$ & $\begin{array}{l}11.80 \\
11.70 \\
11.50 \\
11.30 \\
11.00 \\
10.65\end{array}$ & $\begin{array}{l}4,500 \\
4,420 \\
4,280 \\
4,120 \\
3,910 \\
3,630\end{array}$ \\
\hline $\begin{array}{r}7 \\
8 \\
9 \\
10 \\
11 \\
12 \\
\end{array}$ & $\begin{array}{c}2.73 \\
2.67 \\
2.64\end{array}$ & $\begin{array}{r}70 \\
64 \\
62\end{array}$ & $\begin{array}{l}4.85 \\
5.80 \\
6.85\end{array}$ & $\begin{array}{r}536 \\
902 \\
1,350 \\
\end{array}$ & $\begin{array}{l}11.40 \\
11.48 \\
11.55 \\
11.65 \\
11.90 \\
12.05 \\
\end{array}$ & $\begin{array}{l}4,200 \\
4,280 \\
4,350 \\
4,350 \\
4,580 \\
4,650 \\
\end{array}$ & $\begin{array}{l}12.92 \\
12.92 \\
12.80 \\
12.70 \\
12.63 \\
12.55 \\
\end{array}$ & $\begin{array}{l}5,320 \\
5,320 \\
5,250 \\
5,180 \\
5,100 \\
5,100 \\
\end{array}$ & $\begin{array}{r}10.25 \\
9.85 \\
9.35 \\
8.85 \\
8.40 \\
8.00 \\
\end{array}$ & $\begin{array}{l}3,350 \\
3,090 \\
2,830 \\
2,460 \\
2,220 \\
1,980 \\
\end{array}$ \\
\hline 12 & \multicolumn{2}{|c|}{ Aug. 18} & \multicolumn{2}{|c|}{ Aug. 19} & \multicolumn{2}{|c|}{ Aug. 20} & \multicolumn{2}{|c|}{ Aug. 21} & \multicolumn{2}{|c|}{ Aug. 22} \\
\hline $\begin{array}{r}2 \\
4 \\
6 \\
8 \\
10 \\
\mathrm{~N}\end{array}$ & $\begin{array}{l}7.30 \\
6.75 \\
6.35 \\
6.05 \\
5.80 \\
5.55\end{array}$ & $\begin{array}{r}1,600 \\
1,350 \\
1,140 \\
1,010 \\
902 \\
800\end{array}$ & $\begin{array}{l}4.62 \\
4.54 \\
4.46 \\
4.40 \\
4.34 \\
4.28\end{array}$ & $\begin{array}{l}450 \\
434 \\
403 \\
388 \\
374 \\
355\end{array}$ & $\begin{array}{l}3.98 \\
3.94 \\
3.90 \\
3.87 \\
3.85 \\
3.81\end{array}$ & $\begin{array}{l}279 \\
270 \\
261 \\
254 \\
250 \\
241\end{array}$ & $\begin{array}{l}3.61 \\
3.60 \\
3.58 \\
3.56 \\
3.55 \\
3.54\end{array}$ & $\begin{array}{l}200 \\
198 \\
194 \\
190 \\
188 \\
187\end{array}$ & $\begin{array}{l}3.43 \\
3.42 \\
3.42 \\
3.42 \\
3.43 \\
3.44\end{array}$ & $\begin{array}{l}167 \\
165 \\
165 \\
165 \\
167 \\
169\end{array}$ \\
\hline $\begin{array}{r}2 \\
4 \\
6 \\
8 \\
10 \\
12 \\
\end{array}$ & $\begin{array}{l}5.35 \\
5.20 \\
5.05 \\
4.93 \\
4.82 \\
4.70\end{array}$ & $\begin{array}{l}721 \\
664 \\
608 \\
572 \\
518 \\
484 \\
\end{array}$ & $\begin{array}{l}4.24 \\
4.22 \\
4.17 \\
4.08 \\
4.07 \\
4.02\end{array}$ & $\begin{array}{l}344 \\
338 \\
326 \\
303 \\
301 \\
289\end{array}$ & $\begin{array}{l}3.79 \\
3.75 \\
3.71 \\
3.70 \\
3.69 \\
3.64\end{array}$ & $\begin{array}{l}237 \\
228 \\
220 \\
218 \\
216 \\
206\end{array}$ & $\begin{array}{l}3.54 \\
3.52 \\
3.47 \\
3.47 \\
3.50 \\
3.47 \\
\end{array}$ & $\begin{array}{l}187 \\
183 \\
174 \\
174 \\
179 \\
174 \\
\end{array}$ & $\begin{array}{l}3.39 \\
3.39 \\
3.40 \\
3.35 \\
3.41 \\
\mathbf{3 . 5 7} \\
\end{array}$ & $\begin{array}{l}160 \\
160 \\
162 \\
154 \\
164 \\
192 \\
\end{array}$ \\
\hline
\end{tabular}

Supplemental ReCond.-Aug. 16, 7:30 p. m., gage height, 12.98 feet; discharge, 5,400 second-feet.

RIVANNA RIVER AT PALMYRA, VA.

Location.-Lat. $37^{\circ} 51^{\prime}$, long. $78^{\circ} 16^{\prime}, 200$ feet downstream from highway bridge at Palmyra, Fluvanna County, half a mile upstream from Cunningham Creek, and 15 miles upstream from mouth. Datum of gage is 210.36 feet above mean sea level.

DRAINAGE AREA.-675 square miles.

GAGE-HEIGHT RECORD.-Water-stage recorder graph.

DISCHARGE RECORD.-Stage-discharge relation defined by current-meter measurements. Gage heights used to half-tenths between 3.1 and 4.4 feet; hundredths below and tenths above these limits. 
Maxima.-1940: Discharge, 16,300 second-feet 3:30 p.m. Aug. 17 (gage height, 21.78 feet).

1934-39: Discharge, 56,700 second-feet Apr. 26, 1937 (gage height, 33.35 feet, from floodmarks).

Mean discharge, in second-feet, 1940

\begin{tabular}{|c|c|c|c|c|c|c|c|c|c|c|c|}
\hline Day & Aug. & Sept. & Day & Aug. & Sept. & Day & Aug. & Sept. & Day & Aug. & Sept. \\
\hline $\begin{array}{l}1 \\
2 \\
3 \\
4 \\
5 \\
6 \\
6 \\
7 \\
8\end{array}$ & $\begin{array}{l}481 \\
386 \\
320 \\
290 \\
275 \\
290 \\
564 \\
332\end{array}$ & $\begin{array}{r}, 570 \\
828 \\
613 \\
514 \\
458 \\
428 \\
392 \\
386\end{array}$ & $\begin{array}{r}99 \\
10 \\
11 \\
12 \\
13 \\
14 \\
15 \\
16\end{array}$ & $\begin{array}{r}255 \\
227 \\
209 \\
275 \\
277 \\
468 \\
3,970 \\
11,100\end{array}$ & $\begin{array}{l}745 \\
525 \\
434 \\
380 \\
344 \\
320 \\
308 \\
302\end{array}$ & $\begin{array}{l}17 \\
18 \\
19 \\
20 \\
21 \\
22 \\
23 \\
24\end{array}$ & $\begin{array}{r}15,500 \\
7,020 \\
2,640 \\
1,820 \\
1,360 \\
1,100 \\
918 \\
747\end{array}$ & $\begin{array}{l}290 \\
285 \\
275 \\
270 \\
260 \\
255 \\
231 \\
231\end{array}$ & $\begin{array}{l}25 \\
26 \\
27 \\
28 \\
29 \\
30 \\
31\end{array}$ & $\begin{array}{l}657 \\
635 \\
618 \\
586 \\
530 \\
514 \\
630\end{array}$ & $\begin{array}{l}290 \\
481 \\
326 \\
270 \\
255 \\
245\end{array}$ \\
\hline \multicolumn{10}{|c|}{$\begin{array}{l}\text { Monthly mean discharge, in second-feet } \\
\text { Runoff, in inches }\end{array}$} & $\begin{array}{r}1,774 \\
3.03\end{array}$ & $\begin{array}{r}417 \\
0.69\end{array}$ \\
\hline
\end{tabular}

Gage height, in feet, and discharge, in second-feet, at indicated time, 1940

\begin{tabular}{|c|c|c|c|c|c|c|c|c|c|c|c|c|}
\hline \multirow[b]{2}{*}{ Hour } & \multicolumn{2}{|c|}{ Aug. 13} & \multicolumn{2}{|c|}{ Aug. 14} & \multicolumn{2}{|c|}{ Aug. 15} & \multicolumn{2}{|c|}{ Aug. 16} & \multicolumn{2}{|c|}{ Aug. 17} & \multicolumn{2}{|c|}{ Aug. 18} \\
\hline & $\begin{array}{c}\text { Gage } \\
\text { ht. }\end{array}$ & $\begin{array}{c}\text { Dis- } \\
\text { charge }\end{array}$ & $\begin{array}{c}\text { Gage } \\
\text { ht. }\end{array}$ & $\begin{array}{c}\text { Dis- } \\
\text { charge }\end{array}$ & $\begin{array}{c}\text { Gage } \\
\text { ht. }\end{array}$ & $\begin{array}{c}\text { Dis- } \\
\text { charge }\end{array}$ & $\begin{array}{c}\text { Gage } \\
\text { ht. }\end{array}$ & $\begin{array}{c}\text { Dis- } \\
\text { charge }\end{array}$ & $\begin{array}{c}\text { Gage } \\
\text { ht. }\end{array}$ & $\begin{array}{c}\text { Dis- } \\
\text { charge }\end{array}$ & $\begin{array}{c}\text { Gage } \\
\text { ht. }\end{array}$ & $\begin{array}{c}\text { Dis- } \\
\text { charge }\end{array}$ \\
\hline $\begin{array}{l}1 \\
2 \\
3 \\
4 \\
5 \\
6\end{array}$ & $\begin{array}{r}-2.43 \\
-\overline{2} . \overline{40} \\
2.37\end{array}$ & 2908 & $\begin{array}{r}2 . \overline{5} 5 \\
\overline{2} . \overline{3} \\
\overline{2} . \overline{7}\end{array}$ & 486 & $\begin{array}{l}3.40 \\
3.45 \\
3.50 \\
3.62 \\
3.80 \\
4.00\end{array}$ & $\begin{array}{r}855 \\
892 \\
910 \\
965 \\
1,080 \\
1,180\end{array}$ & $\begin{array}{l}15.03 \\
15.03 \\
15.18 \\
15.50 \\
15.95 \\
16.40\end{array}$ & $\begin{array}{l}7,630 \\
7,630 \\
7,780 \\
8,020 \\
8,420 \\
8,770\end{array}$ & $\begin{array}{l}20.80 \\
20.88 \\
20.97 \\
21.05 \\
21.10 \\
21.18\end{array}$ & $\begin{array}{l}14,400 \\
14,600 \\
14,800 \\
14,800 \\
15,000 \\
15,200\end{array}$ & $\begin{array}{l}20.50 \\
20.15 \\
19.75 \\
19.20 \\
18.60 \\
17.70\end{array}$ & $\begin{array}{l}13,900 \\
13,400 \\
12,800 \\
11,900 \\
11,100 \\
10,100\end{array}$ \\
\hline $\begin{array}{r}7 \\
8 \\
9 \\
10 \\
11 \\
\mathrm{~N}\end{array}$ & $\begin{array}{r}\overline{2.36} \\
\overline{2} . \overline{35} \\
\overline{2} . \overline{3} \overline{5}\end{array}$ & $\begin{array}{l}270 \\
265\end{array}$ & $\begin{array}{r}2.70 \\
2.58 \\
2.5 \overline{7}\end{array}$ & $\begin{array}{l}470 \\
398\end{array}$ & $\begin{array}{l}4.12 \\
4.25 \\
4.55 \\
5.10 \\
5.70 \\
7.50\end{array}$ & $\begin{array}{r}1,240 \\
1,320 \\
1,520 \\
1,790 \\
2,120 \\
3,110\end{array}$ & $\mid \begin{array}{l}16.90 \\
17.30 \\
17.70 \\
18.10 \\
18.60 \\
18.95\end{array}$ & $\begin{array}{r}9,230 \\
9,630 \\
10,100 \\
10,500 \\
11,100 \\
11,600\end{array}$ & $\begin{array}{l}21.24 \\
21.32 \\
21.40 \\
21.48 \\
21.56 \\
21.63\end{array}$ & $\begin{array}{l}15,200 \\
15,300 \\
15,500 \\
15,700 \\
15,900 \\
15,900\end{array}$ & \begin{tabular}{|l|}
16.70 \\
15.40 \\
14.30 \\
13.40 \\
12.50 \\
11.75
\end{tabular} & $\begin{array}{l}9,040 \\
7,940 \\
7,140 \\
6,540 \\
5,960 \\
5,520\end{array}$ \\
\hline $\begin{array}{l}1 \\
2 \\
3 \\
4 \\
5 \\
6\end{array}$ & $\begin{array}{r}2.35 \\
2.34 \\
2.34\end{array}$ & $\begin{array}{l}2 \overline{6} 5 \\
260 \\
260\end{array}$ & $\begin{array}{r}2.57 \\
2.61 \\
2.66\end{array}$ & 41392 & $\begin{array}{r}9.30 \\
10.40 \\
11.60 \\
12.40 \\
13.40 \\
14.50\end{array}$ & $\begin{array}{l}4,100 \\
4,700 \\
5,400 \\
5,890 \\
6,540 \\
7,280\end{array}$ & $\left|\begin{array}{l}19.30 \\
19.50 \\
19.70 \\
19.85 \\
20.00 \\
20.08\end{array}\right|$ & $\begin{array}{l}12,100 \\
12,400 \\
12,600 \\
12,800 \\
13,100 \\
13,300\end{array}$ & $\mid \begin{array}{l}21.69 \\
21.74 \\
21.77 \\
21.77 \\
21.75 \\
21.69\end{array}$ & $\begin{array}{l}16,100 \\
16,100 \\
16,300 \\
16,300 \\
16,300 \\
16,100\end{array}$ & \begin{tabular}{|r|}
11.10 \\
10.55 \\
10.00 \\
9.60 \\
9.25 \\
8.95
\end{tabular} & $\begin{array}{l}5,100 \\
4,820 \\
4,480 \\
4,260 \\
4,040 \\
3,940\end{array}$ \\
\hline $\begin{array}{r}7 \\
8 \\
9 \\
10 \\
11 \\
12\end{array}$ & $\begin{array}{r}-\overline{3} \overline{3} \\
2.35 \\
\overline{2} . \overline{56}\end{array}$ & $2 \overline{255}$ & $\left|\begin{array}{r}2 . \overline{5} \\
-\overline{3.00} \\
-3 . \overline{30}\end{array}\right|$ & $63 \overline{4}$ & $\begin{array}{l}15.15 \\
15.60 \\
15.75 \\
15.63 \\
15.43 \\
15.20\end{array}$ & $\begin{array}{l}7,780 \\
8,100 \\
8,260 \\
8,100 \\
7,940 \\
7,780\end{array}$ & $\left|\begin{array}{l}20.18 \\
20.28 \\
20.39 \\
20.50 \\
20.62 \\
20.70\end{array}\right|$ & $\begin{array}{l}13,400 \\
13,600 \\
13,700 \\
13,900 \\
14,100 \\
14,300\end{array}$ & $\begin{array}{l}21.61 \\
21.50 \\
21.38 \\
21.22 \\
21.05 \\
20.77\end{array}$ & $\begin{array}{l}15,900 \\
15,700 \\
15,500 \\
15,200 \\
14,800 \\
14,400\end{array}$ & $\begin{array}{l}8.70 \\
8.45 \\
8.25 \\
8.10 \\
7.95 \\
7.82\end{array}$ & $\begin{array}{l}3,770 \\
3,600 \\
3,500 \\
3,440 \\
3,380 \\
3,280\end{array}$ \\
\hline
\end{tabular}

\begin{tabular}{|c|c|c|c|c|c|c|c|c|c|c|c|c|}
\hline \multirow{4}{*}{$\begin{array}{r}2 \\
4 \\
6 \\
8 \\
10 \\
\mathrm{~N}\end{array}$} & \multicolumn{2}{|c|}{ Aug. 19} & \multicolumn{2}{|c|}{ Aug. 20} & \multicolumn{2}{|c|}{ Aug. 21} & \multicolumn{2}{|c|}{ Aug. 22} & \multicolumn{2}{|c|}{ Aug. 23} & \multicolumn{2}{|c|}{ Aug. 24} \\
\hline & $\begin{array}{l}7.55 \\
7.32\end{array}$ & $\begin{array}{l}3,160 \\
3,000\end{array}$ & 5.58 & 2,060 & 4.54 & 1,460 & 3.97 & $1, \overline{1}=0$ & 3.63 & 992 & 3.31 & 800 \\
\hline & 6.90 & 2,78 & 5.34 & 1,900 & 4.40 & 1,400 & 3.89 & 1,130 & 3.56 & 938 & 3.27 & 772 \\
\hline & 6.57 & 2,620 & 5.14 & 1,790 & 4.28 & 1,350 & 3.82 & 1,080 & 3.49 & 910 & 3.21 & 745 \\
\hline $\begin{array}{l}2 \\
4\end{array}$ & $\begin{array}{l}6.43 \\
6.30\end{array}$ & $\begin{array}{l}2,500 \\
2,450\end{array}$ & 4.93 & 1,680 & 4.19 & 1,300 & 3.76 & 1,050 & 3.4 & 892 & .16 & $\mathbf{7 1 8}$ \\
\hline & $\begin{array}{l}6 . \\
6 .\end{array}$ & 2,2 & 4.80 & 1,620 & 4.12 & 1,240 & 3.76 & 1,050 & 3.39 & $\overline{8} \overline{5} \overline{5}$ & 3.12 & 690 \\
\hline $\begin{array}{l}14 \\
12\end{array}$ & $\begin{array}{l}5.90 \\
5.78\end{array}$ & $\begin{array}{l}2,230 \\
2,180\end{array}$ & 4.70 & 1,570 & 4.05 & 1,210 & $3.7 \overline{2}$ & 1.020 & 3.36 & $8 \overline{8} \overline{8}$ & 3.10 & 690 \\
\hline
\end{tabular}

Supplemental ReCoRD.-Aug. 17, 3:30 p. m., gage height, 21.78 feet; discharge 16,300 second-feet.

WILLIS RIVER AT FLANAGAN MILLS, VA.

LOCATION.-Lat. $37^{\circ} 40^{\prime}$, long. $78^{\circ} 11^{\prime}$, at highway bridge a quarter of a mile downstream from Flanagan Mills, Cumberland County, half a mile downstream from Trices Lake, and 4 miles downstream from Reynolds Creek. Datum of gage is 178.98 feet above mean sea level (levels by Corps of Engineers, War Department). 


\section{FLOODS OF AUGUST 1940 IN THE SOUTHEASTERN STATES}

DRAINAGE AREA.-247 square miles.

GAGE-HEIGHT RECORD.-Water-stage recorder graph.

DISCHARGE RECORD.-Stage-discharge relation defined by current-meter measurements up to 5,800 second-feet and extended to crest gage height of Apr. 27, 1937, on basis of velocity-area studies with backwater correction. Gage heights used to half-tenths between 4.9 and 6.6 feet to Aug. 17, between 4.8 and 6.4 feet thereafter; hundredths below and tenths above these limits.

Maxima.-1940: Discharge, 7,380 second-feet $12 \mathrm{~m}$. to 2 p.m. Aug. 17 (gage height, 21.94 feet).

1926-35, 1936-39: Discharge, 9,580 second-feet Apr. 27, 1937 (gage height, 23.86 feet, from floodmarks).

Mean discharge, in second-feet, 1940

\begin{tabular}{|c|c|c|c|c|c|c|c|c|c|c|c|}
\hline Day & Aug. & Sept. & Day & Aug. & Sept. & Day & Aug. & Sept. & Day & Aug. & Sept. \\
\hline $\begin{array}{l}1 \\
2 \\
3 \\
4 \\
5 \\
6 \\
7 \\
8\end{array}$ & $\begin{array}{r}104 \\
144 \\
87 \\
67 \\
68 \\
73 \\
94 \\
86\end{array}$ & $\begin{array}{l}186 \\
167 \\
148 \\
128 \\
120 \\
117 \\
113 \\
103\end{array}$ & $\begin{array}{r}9 \\
10 \\
11 \\
12 \\
13 \\
14 \\
15 \\
16\end{array}$ & $\begin{array}{r}76 \\
68 \\
60 \\
60 \\
64 \\
102 \\
1,300 \\
5,120\end{array}$ & $\begin{array}{c}106 \\
102 \\
102 \\
103 \\
94 \\
94 \\
87 \\
87\end{array}$ & \begin{tabular}{|r|}
17 \\
18 \\
19 \\
-20 \\
21 \\
22 \\
23 \\
24
\end{tabular} & $\begin{array}{r}7,280 \\
5,780 \\
2,510 \\
1,360 \\
336 \\
239 \\
341 \\
242\end{array}$ & $\begin{array}{l}92 \\
87 \\
87 \\
87 \\
86 \\
80 \\
75 \\
80\end{array}$ & $\begin{array}{l}25 \\
26 \\
27 \\
28 \\
29 \\
30 \\
31\end{array}$ & $\begin{array}{l}186 \\
180 \\
180 \\
501 \\
919 \\
303 \\
226\end{array}$ & $\begin{array}{r}87 \\
161 \\
128 \\
103 \\
86 \\
83\end{array}$ \\
\hline \multicolumn{10}{|c|}{$\begin{array}{l}\text { Monthly mean discharge, in second-feet } \\
\text { Runoff, in inches }\end{array}$} & $\begin{array}{r}908 \\
4.24\end{array}$ & $\begin{array}{r}106 \\
0.48\end{array}$ \\
\hline
\end{tabular}

Gage height, in feet, and discharge, in second-feet, at indicated time, 1940

\begin{tabular}{|c|c|c|c|c|c|c|c|c|c|c|c|c|}
\hline \multirow{2}{*}{ Hour } & \multicolumn{2}{|c|}{ Aug. 13} & \multicolumn{2}{|c|}{ Aug. 14} & \multicolumn{2}{|c|}{ Aug. 15} & \multicolumn{2}{|c|}{ Aug. 16} & \multicolumn{2}{|c|}{ Aug. 17} & \multicolumn{2}{|c|}{ Aug. 18} \\
\hline & $\begin{array}{c}\text { Gage } \\
\text { ht. }\end{array}$ & $\begin{array}{c}\text { Dis- } \\
\text { charge }\end{array}$ & $\begin{array}{c}\text { Gage } \\
\text { ht. }\end{array}$ & $\begin{array}{c}\text { Dis- } \\
\text { charge }\end{array}$ & $\begin{array}{c}\text { Gage } \\
\text { ht. }\end{array}$ & $\begin{array}{c}\text { Dis- } \\
\text { charge }\end{array}$ & $\begin{array}{c}\text { Gage } \\
\text { ht. }\end{array}$ & $\begin{array}{c}\text { Dis- } \\
\text { charge }\end{array}$ & $\begin{array}{c}\text { Gage } \\
\text { ht. }\end{array}$ & $\begin{array}{c}\text { Dis- } \\
\text { charge }\end{array}$ & $\begin{array}{c}\text { Gage } \\
\text { ht. }\end{array}$ & $\begin{array}{c}\text { Dis- } \\
\text { charge }\end{array}$ \\
\hline $\begin{array}{l}1 \\
2\end{array}$ & 3.68 & 60 & 3.74 & 63 & 7.00 & & $\begin{array}{l}14.30 \\
14.70\end{array}$ & $\begin{array}{l}2,200 \\
2,380\end{array}$ & $\begin{array}{l}21.50 \\
21.58\end{array}$ & $\begin{array}{l}7,120 \\
7,200\end{array}$ & $\begin{array}{l}21.35 \\
21.25\end{array}$ & $\begin{array}{l}7,040 \\
6,950\end{array}$ \\
\hline $\begin{array}{l}3 \\
4\end{array}$ & 3.68 & 60 & 3.74 & 63 & 9 & $\begin{array}{ll}44 \\
36\end{array}$ & 10 & & $\begin{array}{l}65 \\
72 \\
\end{array}$ & $\begin{array}{l}90 \\
90\end{array}$ & 10 & 80 \\
\hline $\begin{array}{l}5 \\
6\end{array}$ & 3.68 & 60 & 3.81 & 67 & $\begin{array}{r}9.75 \\
10.90\end{array}$ & $\begin{array}{l}1,090 \\
1,130\end{array}$ & $\left|\begin{array}{l}16.15 \\
16.70\end{array}\right|$ & $\begin{array}{l}3,210 \\
3,550\end{array}$ & $\left|\begin{array}{l}21.75 \\
21.79\end{array}\right|$ & 7,290 & $|20.65|$ & $\begin{array}{l}6,700 \\
6,610\end{array}$ \\
\hline $\begin{array}{l}7 \\
8\end{array}$ & 3.68 & 60 & 3.85 & 69 & $\left|\begin{array}{c|}10.30 \\
10.55\end{array}\right|$ & & $\mid \begin{array}{l}17.30 \\
17.75 \\
70.75\end{array}$ & & $\begin{array}{l}21.83 \\
21.86 \\
0.89\end{array}$ & & 20.50 & , 520 \\
\hline $\begin{array}{r}9 \\
10\end{array}$ & 3.71 & 62 & 3.87 & 70 & $\left|\begin{array}{|c}10.70 \\
10.85\end{array}\right|$ & & & & $\mid \begin{array}{l}21.88 \\
21.91\end{array}$ & & & $\begin{array}{l}70 \\
80\end{array}$ \\
\hline$\stackrel{11}{N}$ & 3.84 & 68 & 3.99 & 78 & $\left|\begin{array}{l}11.00 \\
11.20\end{array}\right|$ & $\begin{array}{l}1,350 \\
1,380\end{array}$ & $\left|\begin{array}{c}19.05 \\
19.40\end{array}\right|$ & $\begin{array}{l}5,340 \\
5,590\end{array}$ & $\left|\begin{array}{l|}21.93 \\
21.94\end{array}\right|$ & $\begin{array}{l}7,380 \\
7,380\end{array}$ & $\begin{array}{l}19.75 \\
19.50\end{array}$ & $\begin{array}{l}6,020 \\
5,840\end{array}$ \\
\hline $\begin{array}{l}1 \\
2\end{array}$ & 3.87 & 70 & 4.03 & 81 & & & & & & $\begin{array}{l}7,380 \\
7,380\end{array}$ & & \\
\hline 3 & 3.81 & 67 & 4.15 & 92 & $\left|\begin{array}{c}11.95 \\
12.20\end{array}\right|$ & $\begin{array}{l}1,520 \\
1,570\end{array}$ & 20.25 & $\begin{array}{l}6,270 \\
6,440\end{array}$ & $\left|\begin{array}{l}21.94 \\
21.93\end{array}\right|$ & $\begin{array}{l}7,290 \\
7,290\end{array}$ & & 340 \\
\hline $\begin{array}{l}5 \\
6\end{array}$ & 3.85 & 69 & 4.18 & 94 & $\left|\begin{array}{|c}12.45 \\
12.65\end{array}\right|$ & $\begin{array}{l}1,620 \\
1,670\end{array}$ & 20.80 & $\begin{array}{l}6,610 \\
6,700\end{array}$ & $\left|\begin{array}{l}21.92 \\
21.89\end{array}\right|$ & $\begin{array}{l}7,290 \\
7,290\end{array}$ & $\left|\begin{array}{|c|}18.40 \\
18.18\end{array}\right|$ & $\begin{array}{l}5,160 \\
5,000\end{array}$ \\
\hline & 3.78 & 65 & 4.45 & 122 & & & & & & & & \\
\hline 11 & 3.73 & 62 & 5.05 & 200 & $\left|\begin{array}{r}13.20 \\
13.45\end{array}\right|$ & & $\left|\begin{array}{l}21.17 \\
21.26\end{array}\right|$ & & $\left|\begin{array}{l}21.75 \\
21.67\end{array}\right|$ & & & $\begin{array}{l}570 \\
400\end{array}$ \\
\hline \multirow{2}{*}{1} & $3.78 \mid$ & 65 & 6.20 & 388 & $\mid$\begin{tabular}{|}
13.70 \\
14.00
\end{tabular} & $\begin{array}{l}1,960 \\
2,100\end{array}$ & $\left|\begin{array}{l}21.35 \\
21.43\end{array}\right|$ & & $\left|\begin{array}{l}21.57 \\
21.47\end{array}\right|$ & & $\begin{array}{l}17.00 \\
16.75\end{array}$ & \\
\hline & \multicolumn{2}{|c|}{ Aug. 19} & \multicolumn{2}{|c|}{ Aug. 20} & \multicolumn{2}{|c|}{ Aug. 21} & \multicolumn{2}{|c|}{ Aug. 22} & \multicolumn{2}{|c|}{ Aug. 23} & \multicolumn{2}{|c|}{ Aug. 24} \\
\hline $\begin{array}{r}2 \\
4 \\
6 \\
8 \\
10 \\
\mathrm{~N}\end{array}$ & $\mid$\begin{tabular}{l|}
16.30 \\
15.85 \\
15.42 \\
15.00 \\
14.65 \\
14.35
\end{tabular} & $\begin{array}{l}3,720 \\
3,380 \\
3,040 \\
2,720 \\
2,440 \\
2,320\end{array}$ & \begin{tabular}{|l|}
12.80 \\
12.62 \\
12.42 \\
12.20 \\
11.95 \\
11.65
\end{tabular} & $\begin{array}{l}1,670 \\
1,640 \\
1,590 \\
1,570 \\
1,520 \\
1,470\end{array}$ & \begin{tabular}{l|}
6.92 \\
6.68 \\
6.52 \\
6.40 \\
6.28 \\
6.20
\end{tabular} & $\begin{array}{l}\mathbf{4 2 7} \\
397 \\
367 \\
352 \\
\mathbf{3 3 1} \\
\mathbf{3 2 4}\end{array}$ & $\begin{array}{l}5.77 \\
5.73 \\
5.69 \\
5.65 \\
5.61 \\
5.58\end{array}$ & $\begin{array}{l}261 \\
254 \\
247 \\
247 \\
240 \\
233\end{array}$ & $\begin{array}{l}5.52 \\
5.58 \\
5.73 \\
6.10 \\
6.65 \\
6.95\end{array}$ & $\begin{array}{l}226 \\
233 \\
254 \\
310 \\
382 \\
427\end{array}$ & $\begin{array}{l}5.90 \\
5.80 \\
5.73 \\
5.67 \\
5.65 \\
5.66\end{array}$ & $\begin{array}{l}282 \\
268 \\
254 \\
247 \\
247 \\
247\end{array}$ \\
\hline $\begin{array}{r}2 \\
4 \\
6 \\
8 \\
10 \\
12\end{array}$ & $\left|\begin{array}{l}14.05 \\
13.82 \\
13.60 \\
13.35 \\
13.17 \\
13.00\end{array}\right|$ & $\begin{array}{l}2,100 \\
2,000 \\
1,920 \\
1,840 \\
1,780 \\
1,720\end{array}$ & $\left|\begin{array}{r}11.30 \\
10.80 \\
10.00 \\
8.95 \\
7.95 \\
7.30\end{array}\right|$ & $\begin{array}{r}1,400 \\
1,290 \\
1,100 \\
808 \\
600 \\
492\end{array}$ & \begin{tabular}{l|}
6.10 \\
6.06 \\
5.98 \\
5.92 \\
5.87 \\
5.82
\end{tabular} & $\begin{array}{l}310 \\
303 \\
289 \\
282 \\
275 \\
268\end{array}$ & \begin{tabular}{|l|}
5.55 \\
5.54 \\
5.54 \\
5.52 \\
5.50 \\
5.49
\end{tabular} & $\begin{array}{l}233 \\
226 \\
226 \\
226 \\
226 \\
219\end{array}$ & $\left|\begin{array}{l}7.08 \\
7.00 \\
6.80 \\
6.50 \\
6.23 \\
6.04\end{array}\right|$ & $\begin{array}{l}459 \\
443 \\
412 \\
367 \\
324 \\
296\end{array}$ & $\begin{array}{l}5.62 \\
5.55 \\
5.50 \\
5.39 \\
5.35 \\
5.33\end{array}$ & $\begin{array}{l}240 \\
233 \\
226 \\
206 \\
206 \\
199\end{array}$ \\
\hline
\end{tabular}


JAMES RIVER \& KANAWHA CANAL NEAR RICHMOND, VA.

LOCATION.-Lat. $37^{\circ} 33^{\prime} 52^{\prime \prime}$, long. $77^{\circ} 34^{\prime} 28^{\prime \prime}$, at canal bridge 400 feet downstream from head gates, 1,200 feet north of north end of Bosher Dam on James River, $1 \frac{1}{2}$ miles upstream from Westham Bridge, and $4 \frac{1}{2}$ miles west of city limits of Richmond, Henrico County. Datum of gage is 106.07 feet above mean sea level, datum of 1929.

GAGE-HEIGHT RECORD.-Water-stage recorder graph.

DISCHARGE RECORD.-Stage-discharge relation defined by current-meter measurements up to 1,100 second-feet and extended above. Canal merges with river during extreme floods. Gage heights used to half-tenths between 2.3 and 4.0 feet; hundredths below and tenths above these limits.

Maxima.-1940: Gage height, 19.40 feet $7: 30$ a.m. Aug. 18 (discharge not determined but may have been about 4,000 second-feet).

1936-39: Discharge not determined.

REMarks.-Canal diverts around station on James River near Richmond except during extreme floods.

Mean discharge, in second-feet, 1940

\begin{tabular}{|c|c|c|c|c|c|c|c|c|c|c|c|}
\hline Day & Aug. & Sept. & Day & Aug. & Sept. & Day & Aug. & Sept. & Day & Aug. & Sept. \\
\hline $\begin{array}{l}1 \\
2 \\
3 \\
4 \\
5 \\
6 \\
7 \\
8\end{array}$ & $\begin{array}{l}948 \\
908 \\
928 \\
928 \\
948 \\
928 \\
948 \\
928\end{array}$ & $\begin{array}{l}404 \\
948 \\
988 \\
988 \\
988 \\
988 \\
968 \\
948\end{array}$ & $\begin{array}{r}99 \\
10 \\
11 \\
12 \\
13 \\
14 \\
15 \\
16\end{array}$ & $\begin{array}{l}908 \\
948 \\
988 \\
928 \\
928 \\
928 \\
968 \\
968\end{array}$ & $\begin{array}{l}988 \\
968 \\
968 \\
948 \\
928 \\
851 \\
357 \\
948\end{array}$ & $\begin{array}{l}17 \\
18 \\
19 \\
20 \\
21 \\
22 \\
23 \\
24\end{array}$ & $\begin{array}{r}2,370 \\
3,860 \\
2,090 \\
988 \\
988 \\
988 \\
988 \\
\mathbf{8 8 8}\end{array}$ & $\begin{array}{l}928 \\
928 \\
928 \\
928 \\
908 \\
908 \\
908 \\
888\end{array}$ & $\begin{array}{l}25 \\
26 \\
27 \\
28 \\
29 \\
30 \\
31\end{array}$ & $\begin{array}{r}366 \\
948 \\
988 \\
968 \\
968 \\
1,010 \\
926\end{array}$ & $\begin{array}{l}888 \\
908 \\
948 \\
928 \\
908 \\
908\end{array}$ \\
\hline \multicolumn{10}{|c|}{ Monthly mean discharge, in second-feet } & 1,108 & 900 \\
\hline
\end{tabular}

APPOMATTOX RIVER AT FARMVILLE, VA.

LocAtion.-Lat. $37^{\circ} 18^{\prime}$, long. $78^{\circ} 23^{\prime}$, at highway bridge 1,000 feet north of town limits of Farmville, Prince Edward County, and 11/4 miles downstream from Buffalo Creek. Datum of gage is 281.93 feet above mean sea level, datum of 1929 . Drainage ARea.-306 square miles.

GAGE-HEIGHT RECORD.-Water-stage recorder graph.

Discharge RECORD.-Stage-discharge relation defined by current-meter measurements up to 12,000 second-feet and extended to crest gage height on basis of logarithmic plotting and peak flow for stations downstream. Gage heights used to half-tenths between 4.3 and 6.5 feet; hundredths below and tenths above these limits.

Maxima.-1940: Discharge, 21,000 second-feet 4 p.m. Aug. 15 (gage height, 23.60 feet).

1926-39: Discharge observed, 13,900 second-feet Aug. 12, 1928 (gage height, 21.10 feet).

Mean discharge, in second-feet, 1940

\begin{tabular}{|c|c|c|c|c|c|c|c|c|c|c|c|}
\hline Day & Aug. & Sept. & Day & Aug. & Sept. & Day & Aug. & Sept. & Day & Aug. & Sept. \\
\hline $\begin{array}{l}1 \\
2 \\
3 \\
4 \\
5 \\
6 \\
7 \\
8\end{array}$ & $\begin{array}{l}214 \\
141 \\
120 \\
114 \\
112 \\
124 \\
182 \\
136\end{array}$ & $\begin{array}{l}296 \\
234 \\
191 \\
176 \\
171 \\
166 \\
158 \\
152\end{array}$ & $\begin{array}{r}9 \\
10 \\
11 \\
12 \\
13 \\
14 \\
15 \\
16\end{array}$ & $\begin{array}{r}112 \\
100 \\
106 \\
116 \\
107 \\
1,010 \\
17,000 \\
15,800\end{array}$ & $\begin{array}{l}149 \\
146 \\
146 \\
144 \\
140 \\
132 \\
135 \\
136\end{array}$ & $\begin{array}{l}17 \\
18 \\
19 \\
20 \\
21 \\
22 \\
23 \\
24\end{array}$ & $\begin{array}{r}11,900 \\
3,250 \\
1,070 \\
516 \\
359 \\
304 \\
278 \\
254\end{array}$ & $\begin{array}{l}130 \\
130 \\
128 \\
127 \\
124 \\
122 \\
122 \\
118\end{array}$ & $\begin{array}{l}25 \\
26 \\
27 \\
28 \\
29 \\
30 \\
31\end{array}$ & $\begin{array}{l}238 \\
234 \\
234 \\
227 \\
384 \\
289 \\
234\end{array}$ & $\begin{array}{l}127 \\
168 \\
132 \\
126 \\
125 \\
124 \\
-\end{array}$ \\
\hline \multicolumn{12}{|c|}{$\begin{array}{l}\text { Monthly mean discharge, in second-feet } \\
\text { Runoff, in inches } \ldots\end{array}$} \\
\hline
\end{tabular}


FLOODS OF AUGUST 1940 IN THE SOUTHEASTERN STATES

Gage height, in feet, and discharge, in second-feet, at indicated time, 1940

\begin{tabular}{|c|c|c|c|c|c|c|c|c|c|c|c|c|}
\hline \multirow{2}{*}{ Hour } & \multicolumn{2}{|c|}{ Aug. 14} & \multicolumn{2}{|c|}{ Aug. 15} & \multicolumn{2}{|c|}{ Aug. 16} & \multicolumn{2}{|c|}{ Aug. 17} & \multicolumn{2}{|c|}{ Aug. 18} & \multicolumn{2}{|c|}{ Aug. 19} \\
\hline & $\begin{array}{c}\text { Gage } \\
\text { ht. }\end{array}$ & $\begin{array}{c}\text { Dis- } \\
\text { charge }\end{array}$ & $\begin{array}{c}\text { Gage } \\
\text { ht. }\end{array}$ & $\begin{array}{c}\text { Dis- } \\
\text { charge }\end{array}$ & $\begin{array}{c}\text { Gage } \\
\text { ht. }\end{array}$ & $\begin{array}{c}\text { Dis- } \\
\text { charge }\end{array}$ & $\begin{array}{c}\text { Gage } \\
\text { ht. }\end{array}$ & $\begin{array}{c}\text { Dis- } \\
\text { charge }\end{array}$ & $\begin{array}{c}\text { Gage } \\
\text { ht. }\end{array}$ & $\begin{array}{c}\text { Dis- } \\
\text { charge }\end{array}$ & $\begin{array}{c}\text { Gage } \\
\text { ht. }\end{array}$ & $\begin{array}{c}\text { Dis- } \\
\text { charge }\end{array}$ \\
\hline \multirow{3}{*}{$\begin{array}{l}1 \\
2 \\
3 \\
4 \\
5 \\
6\end{array}$} & \multirow{3}{*}{$\begin{array}{l}3.98 \\
3.98 \\
4.01 \\
4.13 \\
4.13 \\
4.39\end{array}$} & \multirow{3}{*}{$\begin{array}{l}107 \\
107 \\
110 \\
122 \\
122 \\
151\end{array}$} & \multirow{3}{*}{$\begin{array}{l}17.23 \\
18.33 \\
19.20 \\
20.01 \\
20.67 \\
21.25\end{array}$} & \multirow{3}{*}{\begin{tabular}{|r}
6,500 \\
8,260 \\
9,890 \\
11,500 \\
13,000 \\
14,200
\end{tabular}} & \multirow{3}{*}{$\left|\begin{array}{l}23.04 \\
22.97 \\
22.83 \\
22.62 \\
22.40 \\
22.16\end{array}\right|$} & \multirow{3}{*}{$\begin{array}{l}19,100 \\
19,100 \\
18,500 \\
17,900 \\
17,300 \\
16,700\end{array}$} & 21.81 & 15,700 & 16.15 & 5,150 & 12.11 & 1,590 \\
\hline & & & & & & & 21.74 & 15,400 & $1 \overline{15} . \overline{6}$ & 4,460 & $\overline{11} . \overline{5}$ & $\overline{1}, \overline{4} \mathbf{2} 0$ \\
\hline & & & & & & & $\overline{2} \overline{1} . \overline{5} \overline{8}$ & 15,200 & $\overline{\mathbf{1}} \overline{\mathrm{5}} . \overline{\mathrm{i}}$ & $\overline{4}, 040$ & $\overline{1} \overline{1} . \overline{1}$ & 1,280 \\
\hline \multirow{3}{*}{$\begin{array}{r}7 \\
8 \\
9 \\
10 \\
11 \\
\text { N }\end{array}$} & \multirow{3}{*}{\begin{tabular}{|l|}
4.39 \\
4.40 \\
4.56 \\
4.49 \\
4.87 \\
5.60
\end{tabular}} & \multirow{3}{*}{$\begin{array}{l}151 \\
151 \\
169 \\
163 \\
208 \\
310\end{array}$} & \multirow{3}{*}{$\left|\begin{array}{l}21.80 \\
22.20 \\
22.55 \\
22.84 \\
23.06 \\
23.28\end{array}\right|$} & \multirow{3}{*}{$\begin{array}{l}15,700 \\
16,700 \\
17,900 \\
18,500 \\
19,400 \\
20,000\end{array}$} & \multirow{3}{*}{$\left|\begin{array}{l}21.94 \\
21.74 \\
21.54 \\
221.35 \\
21.16 \\
21.04\end{array}\right|$} & \multirow{3}{*}{$\begin{array}{l}15,900 \\
15,400 \\
14,900 \\
14,700 \\
14,200 \\
13,700\end{array}$} & 21.31 & 14,400 & 14.84 & 3,650 & 10.56 & 1,150 \\
\hline & & & & & & & $\overline{2} \overline{0} \overline{9} \overline{5}$ & $\overline{13}, \overline{7} 0 \overline{0}$ & 14.57 & $3, \overline{380}$ & 10.20 & $\overline{1}, \overline{0} \overline{0} \overline{0}$ \\
\hline & & & & & & & $2 \overline{0} \overline{4} \overline{8}$ & 12,600 & $\overline{14} .3 \overline{2}$ & 3,040 & $9.9 \overline{3}$ & $9 \overline{9}$ \\
\hline \multirow{4}{*}{$\begin{array}{l}1 \\
2 \\
3 \\
4 \\
5 \\
6\end{array}$} & \multirow{4}{*}{$\mid$\begin{tabular}{r|}
5.79 \\
6.75 \\
8.25 \\
9.16 \\
10.18 \\
11.26
\end{tabular}} & \multirow{4}{*}{$\begin{array}{r}340 \\
508 \\
800 \\
1,040 \\
1,310 \\
1,620\end{array}$} & \multirow{4}{*}{$\mid \begin{array}{l}23.46 \\
23.54 \\
23.58 \\
23.60 \\
23.58 \\
23.52\end{array}$} & \multirow{4}{*}{$\begin{array}{l}20,700 \\
20,700 \\
21,000 \\
21,000 \\
21,000 \\
20,700\end{array}$} & \multirow{4}{*}{$\left|\begin{array}{l}21.00 \\
21.01 \\
21.06 \\
21.21 \\
22.35 \\
21.46\end{array}\right|$} & \multirow{4}{*}{$\begin{array}{l}13,700 \\
13,700 \\
13,900 \\
14,200 \\
17,300 \\
14,900\end{array}$} & .93 & & 4.06 & 0 & 64 & 920 \\
\hline & & & & & & & & 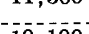 & 50 & , & & \\
\hline & & & & & & & 19.31 & 10,100 & $\mid 3.79$ & 2,490 & 9.37 & 872 \\
\hline & & & & & & & $8.6 \overline{7}$ & 8,960 & 13.52 & 2,250 & $9.1 \overline{4}$ & 800 \\
\hline \multirow{5}{*}{$\begin{array}{r}7 \\
8 \\
9 \\
10 \\
11 \\
12 \\
\end{array}$} & \multirow{4}{*}{\begin{tabular}{|}
12.40 \\
13.02 \\
13.53 \\
14.26 \\
15.20 \\
16.28 \\
\end{tabular}} & \multirow{4}{*}{$\begin{array}{r}1,990 \\
2,250 \\
2,560 \\
3,200 \\
4,040 \\
5,270 \\
\end{array}$} & & 20,400 & $\left|\begin{array}{l}21.55 \\
0.1\end{array}\right|$ & 15 & 18 & & & & & \\
\hline & & & $\left|\begin{array}{l}25.30 \\
23.18\end{array}\right|$ & $\begin{array}{l}20 \\
19\end{array}$ & $\left|\begin{array}{l}21.02 \\
21.68\end{array}\right|$ & $\begin{array}{l}10,200 \\
15,400\end{array}$ & 10.02 & 0 & 10. & 10 & .92 & \\
\hline & & & $\left|\begin{array}{l}23.15 \\
23\end{array}\right|$ & & $\mid$\begin{tabular}{|c|}
21.73 \\
91.78
\end{tabular} & 15 & 17.35 & , 800 & 12.92 & ,920 & 8.72 & 712 \\
\hline & & & & & & & $|\overline{1} \overline{6} . \overline{7}|$ & $\overline{5}, 790$ & $|\overline{1} \overline{2} . \overline{5} \overline{6}|$ & 1,780 & $8 . \overline{5} \overline{5}$ & $6 \overline{6}-$ \\
\hline & $\mathrm{Au}$ & 20 & & g. 21 & & g. 22 & & .23 & & g. 24 & & 25 \\
\hline 2 & & 646 & 7.00 & 386 & 6.54 & 318 & 6.32 & 282 & 6.16 & 261 & 6.03 & 240 \\
\hline & & & 6.96 & 378 & 6.48 & 303 & 6.39 & 296 & $6 . \overline{17}$ & $26 \overline{1}$ & $6 . \overline{0}$ & $240^{-}$ \\
\hline $\mathbf{N}$ & 7.72 & & 6.81 & $\overline{3} \overline{5} \overline{5}$ & 6.47 & 303 & 6.29 & 282 & 6.12 & 254 & 6.00 & $24 \overline{0}^{-}$ \\
\hline $\begin{array}{l}2 \\
4\end{array}$ & & $\begin{array}{l}490 \\
472\end{array}$ & 6.73 & 340 & 6.43 & 296 & 6.26 & 275 & 6.10 & 254 & 5.98 & 234 \\
\hline 10 & & & 6.66 & 332 & 6.40 & $296^{-}$ & $6.2 \overline{3}$ & 268 & 6.07 & 247 & 5.97 & 234 \\
\hline 12 & & & 6.59 & 325 & 6.34 & $28 \overline{9}^{-}$ & 6.06 & $24 \overline{7}$ & 6.05 & 247 & $\overline{5} . \overline{9}$ & $23 \overline{4}$ \\
\hline
\end{tabular}

\section{APPOMATTOX RIVER AT MATTOAX, VA.}

Location.-Lat. $37^{\circ} 25^{\prime}$, long. $77^{\circ} 52^{\prime}$, at Southern Railway bridge at Mattoax, Amelia County, half a mile upstream from Skinquarter Creek. Datum of gage is 174.49 feet above mean sea level.

DRAINAGE AREA. - 729 square miles.

GAGE-HEIGHT RECORD.-Water-stage recorder graph except from 10 a.m. Aug. 17 to $12 \mathrm{~m}$. Sept. 4. Gage heights Aug. 17-25 obtained from graph based on floodmark, many chain gage readings, and comparison with records for other stations in James River Basin. Gage height Aug. 26 from gage reading. No gageheight record Aug. 27 to Sept. 3. Gage heights given to tenths from 10 a.m. Aug. 17 to 12 p.m. Aug. 25.

DISCHARGE RECORD.-Stage-discharge relation defined by currunt-meter measurements up to 20,000 second-feet and extended to erest gage height by logarithmic plotting on basis of comparisons of flood records with those for other stations on Appomattox River. Gage heights used to half-tenths between 5.5 and 7.7 feet; hundredths below and tenths above these limits. Discharge for period Aug. 27 to Sept. 3 computed on basis of records for stations at Farmville and near Petersburg. 
Maxima.-1940: Discharge, 35,000 second-feet 8 a.m. to $12 \mathrm{~m}$. Aug. 18 (gage height, 35.3 feet, from floodmark).

1900-1905, 1926-39: Discharge, 20,100 second-feet Apr. 28, 1937 (gage height, 29.97 feet).

Mean discharge, in second-feet, 1940

\begin{tabular}{|c|c|c|c|c|c|c|c|c|c|c|c|}
\hline Day & Aug. & Sept. & Day & Aug. & Sept. & Day & Aug. & Sept. & Day & Aug. & Sept. \\
\hline $\begin{array}{l}1 \\
2 \\
3 \\
4 \\
5 \\
6 \\
7 \\
8\end{array}$ & $\begin{array}{l}916 \\
474 \\
332 \\
265 \\
257 \\
306 \\
340 \\
395\end{array}$ & $\begin{array}{l}650 \\
550 \\
470 \\
434 \\
414 \\
395 \\
376 \\
358\end{array}$ & $\begin{array}{r}9 \\
10 \\
11 \\
12 \\
13 \\
14 \\
15 \\
16\end{array}$ & $\begin{array}{r}323 \\
257 \\
226 \\
218 \\
234 \\
336 \\
3,830 \\
7,840\end{array}$ & $\begin{array}{l}349 \\
332 \\
332 \\
332 \\
332 \\
314 \\
298 \\
298\end{array}$ & $\begin{array}{l}17 \\
18 \\
19 \\
20 \\
21 \\
22 \\
23 \\
24\end{array}$ & $\begin{array}{r}26,600 \\
34,300 \\
28,600 \\
18,300 \\
8,640 \\
2,920 \\
905 \\
684\end{array}$ & $\begin{array}{l}289 \\
289 \\
273 \\
273 \\
265 \\
257 \\
249 \\
241\end{array}$ & $\begin{array}{l}25 \\
26 \\
27 \\
28 \\
29 \\
30 \\
31\end{array}$ & $\begin{array}{l}614 \\
557 \\
520 \\
500 \\
750 \\
600 \\
520\end{array}$ & $\begin{array}{l}273 \\
289 \\
349 \\
298 \\
265 \\
257\end{array}$ \\
\hline \multicolumn{10}{|c|}{$\begin{array}{l}\text { Monthly mean discharge, in second-feet } \\
\text { Runoff, in inches }\end{array}$} & $\begin{array}{r}4,566 \\
7.22\end{array}$ & $\begin{array}{r}337 \\
0.52\end{array}$ \\
\hline
\end{tabular}

Gage height, in feet, and discharge, in second-feet, at indicated time, 1940

\begin{tabular}{|c|c|c|c|c|c|c|c|c|c|c|c|c|}
\hline \multirow{2}{*}{ Hour } & \multicolumn{2}{|c|}{ Aug. 14} & \multicolumn{2}{|c|}{ Aug. 15} & \multicolumn{2}{|c|}{ Aug. 16} & \multicolumn{2}{|c|}{ Aug. 17} & \multicolumn{2}{|c|}{ Aug. 18} & \multicolumn{2}{|c|}{ Aug. 19} \\
\hline & $\begin{array}{c}\text { Gage } \\
\text { ht. }\end{array}$ & $\begin{array}{c}\text { Dis- } \\
\text { charge }\end{array}$ & $\begin{array}{c}\text { Gage } \\
\text { ht. }\end{array}$ & $\begin{array}{c}\text { Dis- } \\
\text { charge }\end{array}$ & $\begin{array}{c}\text { Gage } \\
\text { ht. }\end{array}$ & $\begin{array}{c}\text { Dis- } \\
\text { charge }\end{array}$ & $\begin{array}{c}\text { Gage } \\
\text { ht. }\end{array}$ & $\begin{array}{c}\text { Dis- } \\
\text { charge }\end{array}$ & $\begin{array}{c}\text { Gage } \\
\text { ht. }\end{array}$ & $\begin{array}{c}\text { Dis- } \\
\text { charge }\end{array}$ & $\begin{array}{l}\text { Gage } \\
\text { ht. }\end{array}$ & $\begin{array}{c}\text { Dis- } \\
\text { charge }\end{array}$ \\
\hline $\begin{array}{r}2 \\
4 \\
6 \\
8 \\
10 \\
\mathrm{~N}\end{array}$ & $\begin{array}{l}6.19 \\
6.17 \\
6.15 \\
6.14 \\
6.26 \\
6.23\end{array}$ & $\begin{array}{l}257 \\
249 \\
249 \\
249 \\
265 \\
265\end{array}$ & $\begin{array}{l}12.00 \\
14.76 \\
16.26 \\
17.22 \\
17.94 \\
18.62\end{array}$ & $\begin{array}{l}1,730 \\
2,710 \\
3,270 \\
3,610 \\
3,890 \\
4,170\end{array}$ & $\begin{array}{l}20.97 \\
21.16 \\
21.36 \\
21.61 \\
22.00 \\
22.64\end{array}$ & $\begin{array}{l}5,180 \\
5,280 \\
5,380 \\
5,480 \\
5,710 \\
6,090\end{array}$ & $\begin{array}{l}29.60 \\
30.47 \\
31.20 \\
31.85 \\
32.5 \\
33.0\end{array}$ & $\begin{array}{l}18,400 \\
20,800 \\
22,700 \\
24,300 \\
26,400 \\
27,800\end{array}$ & $\begin{array}{l}35.0 \\
35.1 \\
35.2 \\
35.3 \\
35.3 \\
35.3\end{array}$ & $\begin{array}{l}34,000 \\
34,300 \\
34,700 \\
35,000 \\
35,000 \\
35,000\end{array}$ & $\begin{array}{l}34.4 \\
34.2 \\
34.0 \\
33.8 \\
33.6 \\
33.3\end{array}$ & $\begin{array}{l}32,100 \\
31,400 \\
30,800 \\
30,200 \\
29,600 \\
28,700\end{array}$ \\
\hline $\begin{array}{r}2 \\
4 \\
6 \\
8 \\
10 \\
12 \\
\end{array}$ & $\begin{array}{l}6.21 \\
6.31 \\
6.57 \\
7.20 \\
8.12 \\
9.44 \\
\end{array}$ & $\begin{array}{l}257 \\
273 \\
314 \\
434 \\
622 \\
943 \\
\end{array}$ & $\mid \begin{array}{l}19.21 \\
19.60 \\
19.97 \\
20.30 \\
20.58 \\
20.79\end{array}$ & $\begin{array}{l}4,410 \\
4,570 \\
4,730 \\
4,850 \\
4,980 \\
5,080 \\
\end{array}$ & $\begin{array}{l}23.51 \\
24.50 \\
25.51 \\
26.62 \\
27.68 \\
28.70\end{array}$ & $\begin{array}{r}6,860 \\
8,200 \\
9,750 \\
11,700 \\
13,900 \\
16,100 \\
\end{array}$ & $\begin{array}{l}33.4 \\
33.8 \\
34.0 \\
34.3 \\
34.6 \\
34.8\end{array}$ & $\begin{array}{l}29,000 \\
30,200 \\
30,800 \\
31,800 \\
32,700 \\
33,400 \\
\end{array}$ & \begin{tabular}{|l|}
35.2 \\
35.1 \\
35.0 \\
34.9 \\
34.8 \\
$\mathbf{3 4 . 6}$ \\
\end{tabular} & $\begin{array}{l}34,700 \\
34,300 \\
34,000 \\
33,700 \\
33,400 \\
32,700\end{array}$ & $\begin{array}{l}33.1 \\
32.8 \\
32.5 \\
32.2 \\
31.9 \\
31.6 \\
\end{array}$ & $\begin{array}{l}28,100 \\
27,200 \\
26,400 \\
25,500 \\
24,600 \\
23,800 \\
\end{array}$ \\
\hline & \multicolumn{2}{|c|}{ Aug. 20} & \multicolumn{2}{|c|}{ Aug. 21} & \multicolumn{2}{|c|}{ Aug. 22} & \multicolumn{2}{|c|}{ Aug. 23} & \multicolumn{2}{|c|}{ Aug. 24} & \multicolumn{2}{|c|}{ Aug. 25} \\
\hline $\begin{array}{r}2 \\
4 \\
6 \\
8 \\
10 \\
\mathbf{N}\end{array}$ & $\begin{array}{l}31.3 \\
31.0 \\
30.7 \\
30.3 \\
29.9 \\
29.6\end{array}$ & $\begin{array}{l}22,900 \\
22,100 \\
21,300 \\
20,200 \\
19,100 \\
18,400\end{array}$ & $\begin{array}{l}26.8 \\
26.4 \\
26.0 \\
25.5 \\
25.0 \\
24.6\end{array}$ & $\begin{array}{r}12,100 \\
11,300 \\
10,600 \\
9,750 \\
8,950 \\
8,350\end{array}$ & $\begin{array}{l}20.9 \\
20.0 \\
19.0 \\
17.6 \\
16.4 \\
15.0\end{array}$ & $\begin{array}{l}4,980 \\
4,610 \\
4,210 \\
3,650 \\
3,190 \\
2,680\end{array}$ & $\begin{array}{r}10.2 \\
10.0 \\
9.9 \\
9.7 \\
9.6 \\
9.5\end{array}$ & $\begin{array}{r}1,080 \\
1,020 \\
997 \\
943 \\
916 \\
890\end{array}$ & $\begin{array}{l}8.9 \\
8.8 \\
8.8 \\
8.7 \\
8.7 \\
8.6\end{array}$ & $\begin{array}{l}739 \\
715 \\
715 \\
691 \\
691 \\
668\end{array}$ & $\begin{array}{l}8.5 \\
8.5 \\
8.5 \\
8.5 \\
8.5 \\
8.4\end{array}$ & $\begin{array}{l}645 \\
645 \\
645 \\
645 \\
645 \\
622\end{array}$ \\
\hline $\begin{array}{r}2 \\
4 \\
6 \\
8 \\
10 \\
12\end{array}$ & $\begin{array}{l}29.2 \\
28.8 \\
28.4 \\
28.0 \\
27.6 \\
27.2\end{array}$ & $\begin{array}{l}17,400 \\
16,400 \\
15,400 \\
14,500 \\
13,700 \\
12,800\end{array}$ & $\begin{array}{l}24.2 \\
23.7 \\
23.2 \\
22.8 \\
22.2 \\
21.6\end{array}$ & $\begin{array}{l}7,770 \\
7,100 \\
6,540 \\
6,230 \\
5,830 \\
5,480\end{array}$ & $\begin{array}{l}13.9 \\
12.8 \\
11.9 \\
11.2 \\
10.8 \\
10.4\end{array}$ & $\begin{array}{l}2,280 \\
1,900 \\
1,600 \\
1,370 \\
1,250 \\
1,140\end{array}$ & $\begin{array}{l}9.4 \\
9.3 \\
9.2 \\
9.1 \\
9.0 \\
8.9\end{array}$ & $\begin{array}{l}864 \\
838 \\
818 \\
788 \\
763 \\
739\end{array}$ & $\begin{array}{l}8.6 \\
8.6 \\
8.6 \\
8.5 \\
8.5 \\
8.5\end{array}$ & $\begin{array}{l}668 \\
668 \\
668 \\
645 \\
645 \\
645\end{array}$ & $\begin{array}{l}8.3 \\
8.2 \\
8.2 \\
8.2 \\
8.2 \\
8.2\end{array}$ & $\begin{array}{l}600 \\
578 \\
578 \\
578 \\
578 \\
578\end{array}$ \\
\hline
\end{tabular}

APPOMATTOX RIVER NEAR PETERSBURG, VA.

LocAtion.-Lat. $37^{\circ} 14^{\prime}$, long. $77^{\circ} 33^{\prime}$, 11/2 miles upstream from Wallace Creek, $21 / 2$ miles upstream from dam of Virginia Electric \& Power Co., and 7 miles west of Petersburg, Dinwiddie County.

DraINAge AREA.-1,335 square miles.

GAGE-HEIGHT RECORD.-Water-stage recorder graph except for Sept. 13-14.

DISCHARGE RECORD.-Stage-discharge relation defined by current-meter measurements: Gage heights used to half-tenths between 4.0 and 5.8 feet; hundredths below and tenths above these limits.

Maxima.-1940: Discharge, 28,000 second-feet 10 a.m. to 12 m. Aug. 20 (gage height, 18.15 feet).

1927-39: Discharge, 18,800 second-feet Apr. 30, 1937 (gage height, 14.85 feet, from floodmarks). 


\section{FLOODS OF AUGUST 1940 IN THE SOUTHEASTERN STATES}

Mean discharge, in second-feet, 1940

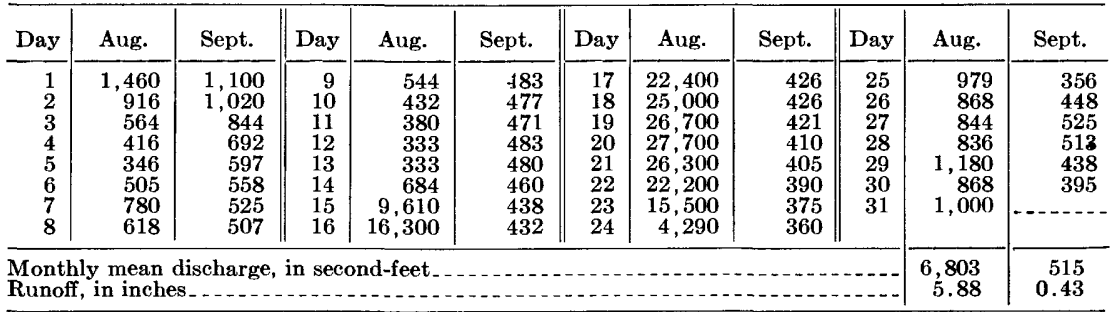

Gage height, in feet, and discharge, in second-feet, at indicated time, 1940

\begin{tabular}{|c|c|c|c|c|c|c|c|c|c|c|c|c|}
\hline \multirow{2}{*}{ Hour } & \multicolumn{2}{|c|}{ Aug. 14} & \multicolumn{2}{|c|}{ Aug. 15} & \multicolumn{2}{|c|}{ Aug. 16} & \multicolumn{2}{|c|}{ Aug. 17} & \multicolumn{2}{|c|}{ Aug. 18} & \multicolumn{2}{|c|}{ Aug. 19} \\
\hline & \begin{tabular}{|c|} 
Gage \\
ht.
\end{tabular} & $\begin{array}{c}\text { Dis- } \\
\text { charge }\end{array}$ & $\begin{array}{c}\text { Gage } \\
\text { ht. }\end{array}$ & $\begin{array}{c}\text { Dis- } \\
\text { charge }\end{array}$ & $\begin{array}{c}\text { Gage } \\
\text { ht. }\end{array}$ & $\begin{array}{c}\text { Dis- } \\
\text { eharge }\end{array}$ & $\begin{array}{c}\text { Gage } \\
\text { ht. }\end{array}$ & $\begin{array}{c}\text { Dis- } \\
\text { charge }\end{array}$ & $\begin{array}{c}\text { Gage } \\
\text { ht. }\end{array}$ & $\begin{array}{c}\text { Dis- } \\
\text { charge }\end{array}$ & \begin{tabular}{|c|} 
Gage \\
ht.
\end{tabular} & $\begin{array}{c}\text { Dis- } \\
\text { charge }\end{array}$ \\
\hline $\begin{array}{r}2 \\
4 \\
6 \\
8 \\
10 \\
\mathrm{~N}\end{array}$ & \begin{tabular}{l|}
2.95 \\
2.96 \\
2.97 \\
2.98 \\
2.98 \\
3.00
\end{tabular} & $\begin{array}{l}338 \\
342 \\
346 \\
351 \\
351 \\
360\end{array}$ & \begin{tabular}{|r|}
6.70 \\
8.72 \\
9.76 \\
10.30 \\
10.68 \\
11.15
\end{tabular} & $\begin{array}{r}3,840 \\
6,380 \\
7,950 \\
8,730 \\
9,400 \\
10,400\end{array}$ & \begin{tabular}{|l|}
12.65 \\
12.78 \\
12.92 \\
13.09 \\
13.32 \\
13.70
\end{tabular} & $\begin{array}{l}13,400 \\
13,900 \\
14,100 \\
14,500 \\
15,000 \\
16,000\end{array}$ & \begin{tabular}{|l|}
15.60 \\
15.73 \\
15.88 \\
16.01 \\
16.13 \\
16.23
\end{tabular} & $\begin{array}{l}20,800 \\
21,000 \\
21,500 \\
21,800 \\
22,100 \\
22,400\end{array}$ & $\begin{array}{l}16.92 \\
16.96 \\
17.00 \\
17.05 \\
17.09 \\
17.13\end{array}$ & $\begin{array}{l}24,300 \\
24,600 \\
24,600 \\
24,600 \\
24,900 \\
24,900\end{array}$ & \begin{tabular}{|l|}
17.48 \\
17.54 \\
17.60 \\
17.66 \\
17.72 \\
17.78
\end{tabular} & $\begin{array}{l}26,000 \\
26,000 \\
26,300 \\
27,600 \\
26,600 \\
26,800\end{array}$ \\
\hline $\begin{array}{r}2 \\
4 \\
6 \\
8 \\
10 \\
12\end{array}$ & $\begin{array}{l}3.08 \\
3.26 \\
3.60 \\
4.18 \\
4.80 \\
5.53\end{array}$ & $\begin{array}{r}400 \\
501 \\
740 \\
1,230 \\
1,800 \\
2,550 \\
\end{array}$ & \begin{tabular}{|}
11.60 \\
11.84 \\
12.06 \\
12.23 \\
12.38 \\
12.51
\end{tabular} & $\begin{array}{l}11,200 \\
11,700 \\
12,300 \\
12,500 \\
13,000 \\
13,200\end{array}$ & \begin{tabular}{|l|}
14.07 \\
14.46 \\
14.78 \\
15.00 \\
15.24 \\
15.43
\end{tabular} & $\begin{array}{l}16,900 \\
17,900 \\
18,700 \\
19,200 \\
19,700 \\
20,200\end{array}$ & \begin{tabular}{|l|}
16.35 \\
16.49 \\
16.60 \\
16.71 \\
16.79 \\
16.85 \\
\end{tabular} & $\begin{array}{l}22,900 \\
23,200 \\
23,500 \\
23,800 \\
24,000 \\
24,000\end{array}$ & \begin{tabular}{|l|}
17.17 \\
17.22 \\
17.26 \\
17.31 \\
17.37 \\
17.43
\end{tabular} & $\begin{array}{l}25,200 \\
25,200 \\
25,400 \\
25,400 \\
25,700 \\
25,700\end{array}$ & \begin{tabular}{|l|}
17.83 \\
17.88 \\
17.93 \\
17.98 \\
18.02 \\
18.05
\end{tabular} & $\begin{array}{l}26,800 \\
27,100 \\
27,100 \\
27,400 \\
27,400 \\
27,400\end{array}$ \\
\hline & \multicolumn{2}{|c|}{ Aug. 20} & \multicolumn{2}{|c|}{ Aug. 21} & \multicolumn{2}{|c|}{ Aug. 22} & \multicolumn{2}{|c|}{ Aug. 23} & \multicolumn{2}{|c|}{ Aug. 24} & \multicolumn{2}{|c|}{ Aug. 25} \\
\hline $\begin{array}{r}2 \\
4 \\
6 \\
8 \\
10 \\
\mathrm{~N}\end{array}$ & \begin{tabular}{|}
18.09 \\
18.11 \\
18.13 \\
18.14 \\
18.15 \\
18.15
\end{tabular} & $\begin{array}{l}27,700 \\
27,700 \\
27,700 \\
27,700 \\
28,000 \\
28,000\end{array}$ & \begin{tabular}{|c|}
17.99 \\
17.93 \\
17.87 \\
17.80 \\
17.73 \\
17.65
\end{tabular} & $\begin{array}{l}27,400 \\
27,100 \\
27,100 \\
26,800 \\
26,600 \\
26,300\end{array}$ & \begin{tabular}{|l|}
16.90 \\
16.76 \\
16.63 \\
16.49 \\
116.34 \\
16.18
\end{tabular} & $\begin{array}{l}24,300 \\
24,000 \\
23,500 \\
23,200 \\
22,600 \\
22,400\end{array}$ & \begin{tabular}{|l|}
14.80 \\
14.58 \\
14.34 \\
14.09 \\
13.85 \\
13.58
\end{tabular} & $\begin{array}{l}18,700 \\
18,200 \\
17,400 \\
16,900 \\
16,200 \\
15,700\end{array}$ & \begin{tabular}{|r|}
11.09 \\
10.50 \\
9.45 \\
7.94 \\
6.48 \\
5.47
\end{tabular} & $\begin{array}{r}10,200 \\
9,050 \\
7,360 \\
5,320 \\
3,600 \\
2,450\end{array}$ & \begin{tabular}{|l|}
4.04 \\
4.00 \\
3.97 \\
3.93 \\
3.90 \\
3.87
\end{tabular} & $\begin{array}{r}1,100 \\
1,060 \\
1,040 \\
1,000 \\
980 \\
956\end{array}$ \\
\hline $\begin{array}{r}2 \\
4 \\
6 \\
8 \\
10 \\
12\end{array}$ & \begin{tabular}{|}
18.14 \\
18.13 \\
18.11 \\
18.09 \\
18.06 \\
18.03
\end{tabular} & $\begin{array}{l}27,700 \\
27,700 \\
27,700 \\
27,700 \\
27,700 \\
27,400\end{array}$ & $\mid \begin{array}{l}17.56 \\
17.46 \\
17.36 \\
17.26 \\
17.15 \\
17.03\end{array}$ & $\begin{array}{l}26,300 \\
26,000 \\
25,700 \\
25,400 \\
25,200 \\
24,600\end{array}$ & $\mid \begin{array}{l}16.01 \\
15.83 \\
15.65 \\
15.46 \\
15.27 \\
15.06\end{array}$ & $\begin{array}{l}21,800 \\
21,300 \\
20,800 \\
20,500 \\
20,000 \\
19,500\end{array}$ & $\left|\begin{array}{l}13.30 \\
13.01 \\
12.71 \\
12.39 \\
12.04 \\
11.66\end{array}\right|$ & $\begin{array}{l}15,000 \\
14,300 \\
13,600 \\
13,000 \\
12,100 \\
11,400\end{array}$ & $\begin{array}{l}4.88 \\
4.54 \\
4.35 \\
4.23 \\
4.15 \\
4.09\end{array}$ & $\begin{array}{l}1,900 \\
1,550 \\
1,360 \\
1,280 \\
1,180 \\
1,140\end{array}$ & \begin{tabular}{|l|}
3.85 \\
3.84 \\
3.82 \\
3.81 \\
3.80 \\
3.79
\end{tabular} & $\begin{array}{l}940 \\
932 \\
916 \\
908 \\
900 \\
892\end{array}$ \\
\hline
\end{tabular}

\section{CHOWAN RIVER BASIN}

\section{NOTTOWAY RIVER NEAR STONY CREEK, VA.}

Location.-Lat. $36^{\circ} 54^{\prime} 00^{\prime \prime}$, long. $77^{\circ} 24^{\prime} 00^{\prime \prime}$, at bridge on Petersburg-Emporia highway 2 miles upstream from Island Swamp Creek and $31 / 2$ miles south of town of Stony Creek, Sussex County.

Drainage AREA.- 586 square miles.

GAGE-HEIGHT RECORD.-Water-stage recorder graph except from 8 a.m. Aug. 22 to 1 p.m. Aug. 27 and from 10 p.m. Aug. 28 to 3 p.m. Sept. 4.

DischaRge RECORD.-Stage-discharge relation defined by current-meter measurements up to 13,000 second-feet and extended to erest gage height by logarithmic plotting on basis of comparison of flood records with those for Meherrin River near Lawrenceville and those for stations on Appomattox River. Gage heights used to half-tenths between 3.1 and 5.0 feet; hundredths below and tenths above these limits. Discharge for periods of no gage-height record computed on basis of records for Meherrin River near Lawrenceville.

Maxima.-1940: Discharge, 25,200 second-feet 9 a.m. Aug. 17 (gage height, 23.66 feet).

1930-39: Discharge, 11,500 second-feet Apr. 28, 1937 (gage height, 20.00 feet). 
CHOWAN RIVER BASIN

Mean discharge, in second-feet, 1940

\begin{tabular}{|c|c|c|c|c|c|c|c|c|c|c|c|}
\hline Day & Aug. & Sept. & Day & Aug. & Sept.. & Day & Aug. & Sept. & Day & Aug. & Sept. \\
\hline $\begin{array}{l}1 \\
2 \\
3 \\
4 \\
5 \\
6 \\
7 \\
8\end{array}$ & $\begin{array}{l}250 \\
232 \\
224 \\
152 \\
130 \\
129 \\
208 \\
183\end{array}$ & $\begin{array}{l}500 \\
450 \\
400 \\
330 \\
294 \\
276 \\
267 \\
258\end{array}$ & $\begin{array}{r}9 \\
10 \\
11 \\
12 \\
13 \\
14 \\
15 \\
16\end{array}$ & $\begin{array}{r}189 \\
148 \\
130 \\
159 \\
224 \\
272 \\
5,980 \\
15,900\end{array}$ & $\begin{array}{l}241 \\
241 \\
267 \\
294 \\
285 \\
250 \\
232 \\
224\end{array}$ & $\begin{array}{l}17 \\
18 \\
19 \\
20 \\
21 \\
22 \\
23 \\
24\end{array}$ & $\begin{array}{r}24,000 \\
18,200 \\
12,300 \\
7,200 \\
1,810 \\
800 \\
600 \\
500\end{array}$ & $\begin{array}{l}224 \\
216 \\
208 \\
203 \\
198 \\
190 \\
178 \\
170\end{array}$ & $\begin{array}{l}25 \\
26 \\
27 \\
28 \\
29 \\
30 \\
31\end{array}$ & $\begin{array}{r}450 \\
440 \\
450 \\
520 \\
1,500 \\
1,000 \\
500\end{array}$ & $\begin{array}{l}267 \\
224 \\
224 \\
192 \\
176 \\
170\end{array}$ \\
\hline \multicolumn{10}{|c|}{$\begin{array}{l}\text { Monthly mean discharge, in second-feet } \\
\text { Runoff, in inches }\end{array}$} & $\begin{array}{r}3,057 \\
6.02\end{array}$ & $\begin{array}{r}255 \\
0.49\end{array}$ \\
\hline
\end{tabular}

Gage height, in feet, and discharge, in second-feet, at indicated time, 1940

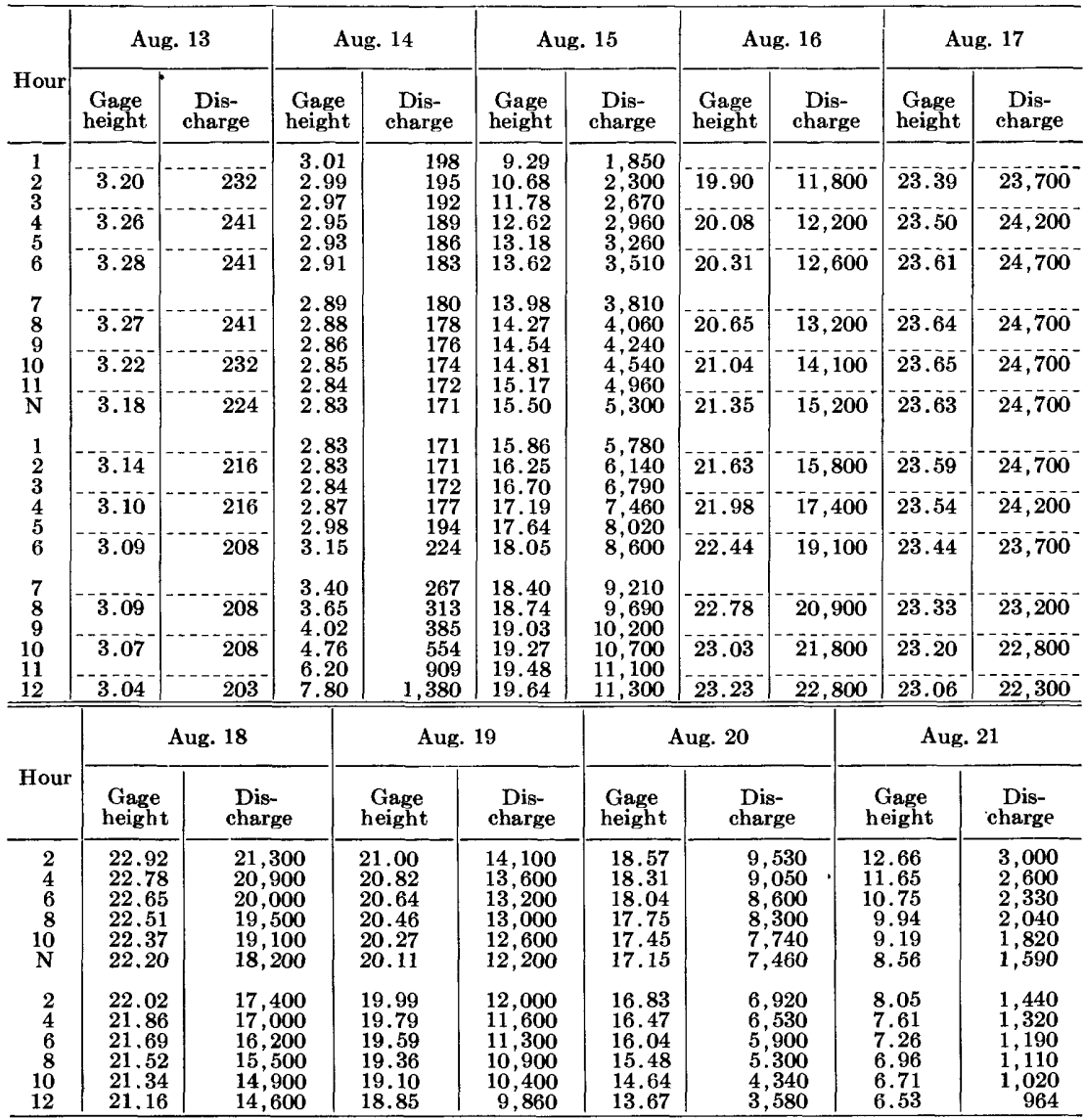

SUPPLEMENTAL RECORD.-Aug. 17, 9 a. m., gage height, 23.66 feet; discharge, 25,200 second-feet. 


\section{FLOODS OF AUGUST 1940 IN THE SOUTHEASTERN STATES}

\section{MEHERRIN RIVER NEAR LAWRENCEVILLE, VA.}

Location.-Lat. $36^{\circ} 43^{\prime} 00^{\prime \prime}$, long. $77^{\circ} 50^{\prime} 00^{\prime \prime}$, at Gholson Bridge, 1 mile upstream from Allen Creek and 3 miles southeast of Lawrenceville, Brunswick County. Datum of gage is 136.56 feet above mean sea level, datum of 1929, supplementary adjustment of 1936 .

DRAINAGE AREA.-553 square miles.

GAGE-HEIGHT RECORD.-Water-stage recorder graph except for periods 10 a.m. Aug. 15 to 5 p.m. Aug. 27, 1 p.m. Sept. 1 to 4 p.m. Sept. 6, 4 p.m. Sept. 8 to 9 a.m. Sept. 12, and 9 a.m. Sept. 16 to 4 p.m. Sept. 17. Gage heights Aug. 15-24 obtained from graph based on floodmark and twice-daily gage readings. Chain gage read twice daily Aug. 25-27.

DISCHARGE RECORD.-Stage-discharge relation defined by current-meter measurements up to 13,000 second-feet and extended to crest gage height on basis of logarithmic plotting, unit hydrograph, and velocity-area studies, and comparisons of flood records with those for Nottoway River near Stony Creek. Gage heights used to half-tenths between 3.0 and 4.4 feet; hundredths below and tenths above these limits. Discharge for periods of no gage-height record computed on basis of records for Nottoway River near Stony Creek.

Maxima.-1940: Discharge, 38,000 second-feet 2 a.m. Aug. 17 (gage height, 42,0 feet, from floodmark).

1928-39: Discharge, 17,300 second-feet Apr. 27, 1937 (gage height, 30.92 feet, from floodmarks).

Remarks.-The District Engineer, Corps of Engineers, War Department, Norfolk, Va., furnished data and computations used as factors in the determination of stage-discharge relation.

Mean discharge, in second-feet, 1940

\begin{tabular}{|c|c|c|c|c|c|c|c|c|c|c|c|}
\hline Day & Aug. & Sept. & Day & Aug. & Sept. & Day & Aug. & Sept. & Day & Aug. & Sept. \\
\hline $\begin{array}{l}1 \\
2 \\
3 \\
4 \\
5 \\
6 \\
7 \\
8\end{array}$ & $\begin{array}{l}254 \\
175 \\
148 \\
134 \\
129 \\
254 \\
201 \\
251\end{array}$ & $\begin{array}{l}450 \\
350 \\
300 \\
260 \\
250 \\
240 \\
230 \\
220\end{array}$ & $\begin{array}{r}9 \\
10 \\
11 \\
12 \\
13 \\
14 \\
15 \\
16\end{array}$ & $\begin{array}{r}172 \\
142 \\
150 \\
143 \\
195 \\
1,180 \\
13,200 \\
31,900\end{array}$ & $\begin{array}{l}210 \\
200 \\
210 \\
220 \\
225 \\
204 \\
187 \\
180\end{array}$ & $\begin{array}{l}17 \\
18 \\
19 \\
20 \\
21 \\
22 \\
23 \\
24\end{array}$ & $\begin{array}{r}35,300 \\
24,600 \\
12,500 \\
2,640 \\
638 \\
518 \\
459 \\
399\end{array}$ & $\begin{array}{l}170 \\
169 \\
169 \\
163 \\
165 \\
154 \\
134 \\
154\end{array}$ & $\begin{array}{l}25 \\
26 \\
27 \\
28 \\
29 \\
30 \\
31\end{array}$ & $\begin{array}{r}374 \\
364 \\
364 \\
377 \\
1,460 \\
1,070 \\
485\end{array}$ & $\begin{array}{l}136 \\
166 \\
134 \\
150 \\
146 \\
127\end{array}$ \\
\hline \multicolumn{10}{|c|}{$\begin{array}{l}\text { Monthly mean discharge, in second-feet } \\
\text { Runoff, in inches }\end{array}$} & $\begin{array}{r}4,199 \\
8.75\end{array}$ & $\begin{array}{r}202 \\
0.41\end{array}$ \\
\hline
\end{tabular}


Gage height, in feet, and discharge, in second-feet, at indicated time, 1940

\begin{tabular}{|c|c|c|c|c|c|c|c|c|c|c|c|c|}
\hline \multirow{2}{*}{ Hour } & \multicolumn{2}{|c|}{ Aug. 13} & \multicolumn{2}{|c|}{ Aug. 14} & \multicolumn{2}{|c|}{ Aug. 15} & \multicolumn{2}{|c|}{ Aug. 16} & \multicolumn{2}{|c|}{ Aug. 17} & \multicolumn{2}{|c|}{ Aug. 18} \\
\hline & $\begin{array}{c}\text { Gage } \\
\text { ht. }\end{array}$ & $\begin{array}{c}\text { Dis- } \\
\text { charge }\end{array}$ & $\begin{array}{c}\text { Gage } \\
\text { ht. }\end{array}$ & $\begin{array}{c}\text { Dis- } \\
\text { charge }\end{array}$ & $\begin{array}{c}\text { Gage } \\
\text { ht. }\end{array}$ & $\begin{array}{c}\text { Dis- } \\
\text { charge }\end{array}$ & $\begin{array}{c}\text { Gage } \\
\text { ht. }\end{array}$ & $\begin{array}{c}\text { Dis- } \\
\text { charge }\end{array}$ & $\begin{array}{c}\text { Gage } \\
\text { ht. }\end{array}$ & $\begin{array}{c}\text { Dis- } \\
\text { charge }\end{array}$ & $\begin{array}{c}\text { Gage } \\
\text { ht. }\end{array}$ & $\begin{array}{c}\text { Dis- } \\
\text { charge }\end{array}$ \\
\hline \multirow{4}{*}{$\begin{array}{l}1 \\
2 \\
3 \\
4 \\
5 \\
6\end{array}$} & \multirow{4}{*}{$\begin{array}{l}2.48 \\
2.50 \\
2.51 \\
2.54 \\
2.60 \\
2.66\end{array}$} & \multirow{4}{*}{$\begin{array}{l}149 \\
152 \\
154 \\
158 \\
168 \\
179\end{array}$} & \multirow{4}{*}{$\begin{array}{l}2.59 \\
2.58 \\
2.56 \\
2.55 \\
2.54 \\
2.53\end{array}$} & \multirow{4}{*}{$\begin{array}{l}166 \\
165 \\
162 \\
160 \\
158 \\
157\end{array}$} & \multirow{4}{*}{$\begin{array}{l}21.05 \\
22.35 \\
23.68 \\
24.30 \\
24.64 \\
25.00\end{array}$} & \multirow{4}{*}{$\begin{array}{r}6,480 \\
7,660 \\
8,900 \\
9,530 \\
9,860 \\
10,300\end{array}$} & & & & & & \\
\hline & & & & & & & 34.6 & 23 & 42.0 & 38 & 38.0 & 2 \\
\hline & & & & & & & 36.1 & 26,000 & 41.9 & 37,800 & 37.5 & 28,600 \\
\hline & & & & & & & $\overline{37} . \overline{2}$ & 28,000 & $\overline{4} \overline{1} . \overline{7}$ & $\overline{37}, 300$ & $3 \overline{7} . \overline{0}$ & $\overline{2}, \overline{600}$ \\
\hline \multirow{4}{*}{$\begin{array}{r}7 \\
8 \\
9 \\
10 \\
11 \\
\mathrm{~N}\end{array}$} & \multirow{4}{*}{$\begin{array}{l}2.74 \\
2.91 \\
2.91 \\
2.93 \\
2.94 \\
2.95\end{array}$} & \multirow{4}{*}{$\begin{array}{l}193 \\
224 \\
224 \\
228 \\
230 \\
232\end{array}$} & \multirow{4}{*}{$\begin{array}{l}2.52 \\
2.62 \\
2.58 \\
2.55 \\
2.54 \\
2.53\end{array}$} & \multirow{4}{*}{$\begin{array}{l}155 \\
172 \\
165 \\
160 \\
158 \\
157\end{array}$} & \multirow{4}{*}{$\begin{array}{l}25.36 \\
25.76 \\
26.12 \\
26.4 \\
26.8 \\
27.2\end{array}$} & \multirow{4}{*}{$\begin{array}{l}10,700 \\
11,200 \\
11,500 \\
11,800 \\
12,300 \\
12,700\end{array}$} & & & & & & \\
\hline & & & & & & & 38.3 & 30,100 & 41.5 & 36,800 & 36.5 & 26,700 \\
\hline & & & & & & & 39.2 & 31,900 & $4 \overline{1} . \overline{3}$ & 36,400 & 35.9 & 25,600 \\
\hline & & & & & & & $\overline{39} . \overline{9}$ & 33,300 & $4 \overline{1} .0$ & $\overline{3}, \overline{7} 0 \overline{0}$ & $\overline{\mathbf{3}} \overline{\mathbf{5}} . \overline{3}$ & $2 \overline{4}, 500$ \\
\hline \multirow{4}{*}{$\begin{array}{l}1 \\
2 \\
3 \\
4 \\
5 \\
6\end{array}$} & \multirow{4}{*}{$\begin{array}{l}2.94 \\
2.92 \\
2.90 \\
2.87 \\
2.84 \\
2.83\end{array}$} & \multirow{4}{*}{$\begin{array}{l}230 \\
226 \\
222 \\
217 \\
211 \\
209\end{array}$} & \multirow{4}{*}{$\begin{array}{l}2.39 \\
2.48 \\
2.90 \\
3.78 \\
5.00 \\
7.96\end{array}$} & \multirow{4}{*}{$\begin{array}{r}135 \\
149 \\
222 \\
406 \\
675 \\
1,490\end{array}$} & \multirow{4}{*}{$\begin{array}{l}27.6 \\
28.0 \\
28.4 \\
28.9 \\
29.4 \\
29.8\end{array}$} & \multirow{4}{*}{$\begin{array}{l}13,200 \\
13,700 \\
14,200 \\
14,800 \\
15,400 \\
15,900\end{array}$} & & & & & & \\
\hline & & & & & & & 40.5 & 34,600 & 40.7 & 35,000 & 34.7 & 23,500 \\
\hline & & & & & & & $4 \overline{1} . \overline{0}$ & $3 \overline{5}, \overline{700}$ & $40 . \overline{4}$ & $\overline{34}, \overline{4} 00$ & $\overline{34} .1$ & 22,500 \\
\hline & & & & & & & $-\overline{4} \overline{1.3}$ & 36,400 & 40.0 & 33,500 & $-\overline{3} . \overline{5}$ & $21, \overline{500}$ \\
\hline \multirow{5}{*}{$\begin{array}{r}7 \\
8 \\
9 \\
10 \\
11 \\
12 \\
\end{array}$} & & 206 & .85 & 2,690 & 30.5 & 16 & & & & & & \\
\hline & $\begin{array}{l}76 \\
72\end{array}$ & $\begin{array}{l}197 \\
190\end{array}$ & $\left|\begin{array}{l}14.80 \\
16.42\end{array}\right|$ & 700 & $\left\{\begin{array}{l}31.0 \\
31\end{array}\right.$ & & 41.6 & & 39 & & 9 & \\
\hline & 6 & 162 & 17.58 & 4,670 & 32.2 & & $4 \overrightarrow{1} \cdot \overline{7}$ & 37,300 & 39.0 & 31,500 & 32.3 & 19,600 \\
\hline & $\begin{array}{l}2.58 \\
2.59\end{array}$ & $16 t$ & .750 & & $\begin{array}{l}32.8 \\
33.4\end{array}$ & & $\overline{4} \overline{1.9}$ & 37,800 & $-\overline{38.5}$ & 30,500 & 31.6 & 18,500 \\
\hline & $\mathrm{Au}$ & g. 19 & $\mathbf{A u}$ & ח & Aug & 5. 21 & & g. 22 & $\mathbf{A u}$ & 3 & & 4 \\
\hline 2 & 30.9 & & 1 & & & & & & & & & \\
\hline 0 & $\begin{array}{l}30.2 \\
29.5\end{array}$ & & 1 & & 5.1 & 700 & 4.4 & 538 & 2 & 494 & 3.9 & 428 \\
\hline 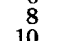 & & & & & 4.9 & 652 & 4.3 & 516 & 4.1 & $47 \overline{2}$ & $\overline{3} . \overline{8}$ & 406 \\
\hline & & & 10.0 & 2,110 & $4 . \overline{8}$ & 629 & $4 . \overline{3}$ & 516 & $4 . \overline{0}$ & 450 & $\overrightarrow{3} \cdot \overline{7}$ & 385 \\
\hline 2 & 26.2 & & & & & & & & & & & \\
\hline 4 & $\begin{array}{l}25.4 \\
24.4\end{array}$ & & 58 & 1,03 & 4.7 & 606 & $\overline{0}$ & 516 & 4.0 & 45 & 3.7 & 385 \\
\hline 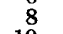 & & & 5. & 80 & $4 . \overline{6}$ & 583 & 4.2 & $\overline{4} \overline{9}$ & $3 . \overline{9}$ & 428 & 3.7 & 385 \\
\hline 12 & & & 5 & 750 & $4 . \overline{5}$ & 560 & $4 . \overline{2}$ & $49 \overline{4}$ & $3 . \overline{9}$ & 428 & 3.7 & $\overline{\mathbf{3}} \overline{\mathbf{5}} \overline{-}$ \\
\hline
\end{tabular}

ROANOKE RIVER BASIN

\section{ROANOKE RIVER AT ROANOKE, VA.}

Location.-Lat. $37^{\circ} 15^{\prime} 30^{\prime \prime}$, long. $79^{\circ} 56^{\prime} 20^{\prime \prime}$, at Walnut Street Bridge in Roanoke, Roanoke County, 3 miles upstream from Tinker Creek. Datum of gage is $\mathbf{9 0 6 . 8 4}$ feet above mean sea level (levels by Corps of Engineers, War Department).

Drainage AREa. - 388 square miles.

GAGE-HEIGHT RECORD.-Water-stage recorder graph.

DISCHARGE RECORD.--Stage-discharge relation defined by current-meter measurements up to 5,500 second-feet and extended to crest gage height by logarithmic plotting on basis of slope-area measurement, unit-hydrograph and flood-routing studies, and other comparisons with flood records for stations in Roanoke River Basin. Gage heights used to half-tenths between 2.5 and 4.5 feet; hundredths below and tenths above these limits.

Maxima.-1940: Discharge, 28,000 second-feet 10:30 p.m. Aug. 14 (gage height, 18.25 feet).

1896-1939: Discharge observed, 16,900 second-feet Aug. 6, 1901 (gage height, 14.34 feet).

The flood of August 1928 exceeded that of 1901 but was less than that of August 1940, according to local information; erest not recorded by gage observer. 


\section{FLOODS OF AUGUST 1940 IN THE SOUTHEASTERN STATES}

Remarks.-The District Engineer, Corps of Engineers, War Department, Norfolk, Va., cooperated in completing field work for determination of flood flow by slope-area method and in furnishing computed flood records by the unit-hydrograph and flood-routing methods used as a factor in determination of stagedischarge relation.

Mean discharge, in second-feet, 1940

\begin{tabular}{|c|c|c|c|c|c|c|c|c|c|c|c|}
\hline Day & Aug. & Sept. & Day & Aug. & Sept. & Day & Aug. & Sept. & Day & Aug. & Sept. \\
\hline $\begin{array}{l}1 \\
2 \\
3 \\
4 \\
5 \\
6 \\
7 \\
8\end{array}$ & $\begin{array}{l}193 \\
154 \\
129 \\
121 \\
124 \\
128 \\
126 \\
307\end{array}$ & $\begin{array}{r}1,290 \\
848 \\
646 \\
532 \\
483 \\
426 \\
388 \\
360\end{array}$ & $\begin{array}{r}9 \\
10 \\
11 \\
12 \\
13 \\
14 \\
15 \\
16\end{array}$ & $\begin{array}{r}173 \\
132 \\
145 \\
258 \\
251 \\
14,700 \\
18,200 \\
12,800\end{array}$ & $\begin{array}{l}338 \\
329 \\
320 \\
294 \\
278 \\
266 \\
258 \\
254\end{array}$ & $\begin{array}{l}17 \\
18 \\
19 \\
20 \\
21 \\
22 \\
23 \\
24\end{array}$ & $\begin{array}{r}4,750 \\
2,190 \\
1,350 \\
944 \\
744 \\
634 \\
555 \\
483\end{array}$ & $\begin{array}{l}243 \\
235 \\
228 \\
224 \\
213 \\
206 \\
199 \\
193\end{array}$ & $\begin{array}{l}26 \\
26 \\
27 \\
28 \\
29 \\
30 \\
31\end{array}$ & $\begin{array}{r}447 \\
426 \\
412 \\
397 \\
442 \\
1,710 \\
2,910\end{array}$ & $\begin{array}{l}206 \\
235 \\
199 \\
186 \\
179 \\
176\end{array}$ \\
\hline \multicolumn{10}{|c|}{$\begin{array}{l}\text { Monthly mean discharge, in second-feet, } \\
\text { Runoff, in inches }\end{array}$} & $\begin{array}{r}2,140 \\
6.36\end{array}$ & $\begin{array}{r}341 \\
0.98\end{array}$ \\
\hline
\end{tabular}

Gage height, in feet, and discharge, in second-feet, at indicated time, 1940

\begin{tabular}{|c|c|c|c|c|c|c|c|c|c|c|c|c|}
\hline \multirow{2}{*}{ Hour } & \multicolumn{2}{|c|}{ Aug. 13} & \multicolumn{2}{|c|}{ Aug. 14} & \multicolumn{2}{|c|}{ Aug. 15} & \multicolumn{2}{|c|}{ Aug. 16} & \multicolumn{2}{|c|}{ Ang. 17} & \multicolumn{2}{|c|}{ Aug. 18} \\
\hline & $\begin{array}{c}\text { Gage } \\
\text { ht. }\end{array}$ & $\begin{array}{c}\text { Dis- } \\
\text { charge }\end{array}$ & $\begin{array}{c}\text { Gage } \\
\text { ht. }\end{array}$ & $\begin{array}{c}\text { Dis- } \\
\text { charge }\end{array}$ & $\begin{array}{c}\text { Gage } \\
\text { ht. }\end{array}$ & $\begin{array}{c}\text { Dis- } \\
\text { charge }\end{array}$ & $\begin{array}{c}\text { Gage } \\
\text { ht. }\end{array}$ & $\begin{array}{c}\text { Dis- } \\
\text { charge }\end{array}$ & $\begin{array}{c}\text { Gage } \\
\text { ht. }\end{array}$ & $\begin{array}{c}\text { Dis- } \\
\text { charge }\end{array}$ & $\begin{array}{c}\text { Gage } \\
\text { ht. }\end{array}$ & $\begin{array}{c}\text { Dis- } \\
\text { charge }\end{array}$ \\
\hline \multirow{5}{*}{$\begin{array}{l}1 \\
2 \\
3 \\
4 \\
5 \\
6\end{array}$} & & & \multirow{5}{*}{$\begin{array}{l}1.73 \\
2.20 \\
2.65 \\
2.87 \\
2.93 \\
3.30\end{array}$} & \multirow{5}{*}{$\begin{array}{r}442 \\
706 \\
1,000 \\
1,140 \\
1,220 \\
1,490\end{array}$} & \multirow{5}{*}{$\begin{array}{l}17.82 \\
17.36 \\
16.75 \\
15.98 \\
15.24 \\
14.60\end{array}$} & \multirow{5}{*}{$\begin{array}{l}26,900 \\
25,900 \\
24,400 \\
22,400 \\
20,400 \\
19,100\end{array}$} & \multirow{5}{*}{$\begin{array}{l}13.36 \\
13.15 \\
12.93 \\
12.70 \\
12.52 \\
12.33\end{array}$} & \multirow{5}{*}{$\begin{array}{l}16,500 \\
16,000 \\
15,400 \\
15,000 \\
14,600 \\
14,200\end{array}$} & & & \multirow[b]{2}{*}{4.75} & \multirow[b]{2}{*}{2.850} \\
\hline & 1.31 & $2 \overline{5} \overline{4}$ & & & & & & & & 6,640 & & \\
\hline & 1.29 & 246 & & & & & & & 7.40 & & 4.59 & 2,650 \\
\hline & & & & & & & & & \multirow{2}{*}{$\overline{7} . \overline{15}$} & & \multirow{2}{*}{$4 . \overline{4}$} & \multirow{2}{*}{$2, \overline{500}$} \\
\hline & 1.27 & 239 & & & & & & & & 5,660 & & \\
\hline \multirow{4}{*}{$\begin{array}{r}7 \\
8 \\
9 \\
10 \\
11 \\
\mathrm{~N}\end{array}$} & 1.30 & & \multirow{4}{*}{$\begin{array}{r}4.20 \\
6.10 \\
8.60 \\
11.00 \\
12.25 \\
13.22\end{array}$} & \multirow{4}{*}{$\begin{array}{r}2,270 \\
4,270 \\
7,660 \\
11,700 \\
14,000 \\
16,000\end{array}$} & \multirow{4}{*}{$\begin{array}{l}14.02 \\
13.69 \\
13.50 \\
13.34 \\
13.36 \\
13.41\end{array}$} & \multirow{4}{*}{$\begin{array}{l}17,700 \\
17,100 \\
16,700 \\
16,200 \\
16,500 \\
16,500\end{array}$} & \multirow{4}{*}{$\begin{array}{l}12.20 \\
12.17 \\
12.29 \\
12.42 \\
12.57 \\
12.64\end{array}$} & & & & & \\
\hline & 1.30 & & & & & & & $\begin{array}{l}14,000 \\
14,200\end{array}$ & & & & \\
\hline & 1.29 & 246 & & & & & & 14,400 & 6.67 & 5,010 & 4.17 & 2,220 \\
\hline & $1 . \overline{2} \overline{7}$ & $2 \overline{3} \overline{9}$ & & & & & & $\begin{array}{l}14,800 \\
14,800\end{array}$ & 6.42 & 4,630 & 4.03 & 2,140 \\
\hline 1 & & & 1 & & 0 & & 3 & 14.400 & & & & \\
\hline 2 & 1.28 & 243 & & & 16 & & $\mid 12.02$ & & 6.17 & 4,390 & 3.93 & 2,040 \\
\hline 4 & 1.25 & $\overline{2} \overline{3} \overline{2}$ & $\left|\begin{array}{l}16.20 \\
17.07\end{array}\right|$ & 100 & $\left|\begin{array}{l}13.06 \\
12.98\end{array}\right|$ & $\begin{array}{c}90 \\
00\end{array}$ & $\left|\begin{array}{l}11.50 \\
10.96\end{array}\right|$ & $\begin{array}{l}600 \\
700\end{array}$ & 5.86 & 4,030 & 3.82 & $1, \overline{9} 10^{-}$ \\
\hline $\begin{array}{l}5 \\
6\end{array}$ & 1.24 & 228 & \begin{tabular}{|l}
17.52 \\
17.76
\end{tabular} \mid & & $\left|\begin{array}{l}12.97 \\
12.96\end{array}\right|$ & $\begin{array}{l}15 \\
15\end{array}$ & $\left|\begin{array}{l}10.47 \\
10.12\end{array}\right|$ & $\begin{array}{l}10,800 \\
10,100\end{array}$ & 5.61 & $3,690^{-}$ & $3.7 \overline{2}$ & 1,820 \\
\hline 7 & & & $\mid 17.77$ & & .99 & & .84 & & & & & \\
\hline 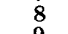 & 1.29 & 246 & 17.92 & & 13.10 & & 9.60 & & 5.37 & $\mathbf{3}, \mathbf{4 7 0}$ & 3.67 & 1,780 \\
\hline 10 & 1.39 & $2 \overline{8} \overline{6}$ & 18 & $\begin{array}{l}27, \\
28,\end{array}$ & $\mid \begin{array}{ll}13 & 29 \\
13 & .48\end{array}$ & & $\begin{array}{l}9.32 \\
9.01\end{array}$ & 50 & 5.14 & 3,150 & 3.55 & $1,690^{-}$ \\
\hline & $-\overline{5}$ & 346 & & & 13.53 & & 871 & & & & 346 & 1610 \\
\hline & & & & & & & & & & & & \\
\hline & & & & 20 & & . 21 & $\mathrm{Au}$ & & & & & \\
\hline 4 & 3.38 & & & 040 & 2. & & 2. & 6 & 2. & & & \\
\hline 8 & & & & 9 & & & & & & & & \\
\hline $\mathbf{N}$ & 3.12 & & & 93 & 2. & & 2.0 & & & & & \\
\hline 4 & 3.0 & & & & & & & & & & & 47 \\
\hline & & & .4 & 8 & 2 & & & & & & & \\
\hline 10 & 78 & & 2. & 0 & 2.1 & $0 \pi$ & 2.0 & & 1.0 & & & 45 \\
\hline
\end{tabular}

SuPPLEMENTAL RECORD.-Aing. 14, 10:30 p. m., gage height, 18.25 feet; discharge, 28 000 second-feet. 
ROANOKE RIVER AT NIAGARA, VA.

LOCATION.-Lat. $37^{\circ} 15^{\prime} 18^{\prime \prime}$, long. $79^{\circ} 52^{\prime} 18^{\prime \prime}$, 200 feet downstream from power plant of Appalachian Electric Power Co. at Niagara, Roanoke County, and 2 miles downstream from Tinker Creek. Datum of gage is 820.15 feet above mean sea level (levels by Corps of Engineers, War Department).

Drainage area.- 511 square miles.

GAGE-HEIGHT RECORD.-Water-stage recorder not operating Aug. 1 to Sept. 9. Gage heights Aug. 14-19 obtained to tenths from graph based on floodmark, unithydrograph and flood-routing studies, and comparisons with flood records for other stations in Roanoke River Basin. No gage heights Aug. 1-13, Aug. 20 to Sept. 9.

DISCHARGE RECORD.-Stage-discharge relation defined by current-meter measurements up to 12,000 second-feet and extended to crest gage height by logarithmic plotting on basis of velocity-area studies, unit-hydrograph and flood-routing studies, and other comparisons with flood records for stations in Roanoke River Basin. Gage heights used to tenths throughout. Discharge for periods Aug. 1-13 and Aug. 20 to Sept. 9 computed on basis of output of Niagara power plant and records for stations at Roanoke and near Toshes.

Maxima.-1940: Discharge, 35,000 second-feet about 8 to 10 p.m. Aug. 14 (gage height, 17.5 feet, from floodmark).

1926-39: Discharge, 34,400 second-feet Aug. 16, 1928 (gage height, 17.36 feet).

Remarks.-The District Engineer, Corps of Engineers, War Department, Norfolk, Va., furnished computed flood records by the unit-hydrograph and flood-routing methods used as a factor in determination of stage-discharge relation and in preparation of graph.

Mean discharge, in second-feet, 1940

\begin{tabular}{|c|c|c|c|c|c|c|c|c|c|c|c|}
\hline Day & Aug. & Sept. & Day & Aug. & Sept. & Day & Aug. & Sept. & Day & Aug. & Sept. \\
\hline $\begin{array}{l}1 \\
2 \\
3 \\
4 \\
5 \\
6 \\
6 \\
7 \\
8\end{array}$ & $\begin{array}{l}320 \\
230 \\
200 \\
170 \\
170 \\
310 \\
200 \\
430\end{array}$ & $\begin{array}{r}2,400 \\
1,400 \\
1,100 \\
910 \\
780 \\
740 \\
680 \\
600\end{array}$ & $\begin{array}{r}9 \\
10 \\
11 \\
12 \\
13 \\
14 \\
15 \\
16\end{array}$ & $\begin{array}{r}240 \\
230 \\
190 \\
350 \\
310 \\
19,600 \\
24,400 \\
18,200\end{array}$ & $\begin{array}{l}\mathbf{5 7 0} \\
533 \\
522 \\
474 \\
\mathbf{4 4 2} \\
\mathbf{4 3 8} \\
\mathbf{4 2 0} \\
\mathbf{4 1 4}\end{array}$ & $\begin{array}{l}17 \\
18 \\
19 \\
20 \\
21 \\
22 \\
23 \\
24\end{array}$ & $\begin{array}{r}7,090 \\
3,300 \\
2,010 \\
1,300 \\
1,100 \\
\mathbf{9 4 0} \\
\mathbf{8 6 0} \\
\mathbf{7 9 0}\end{array}$ & $\begin{array}{l}356 \\
366 \\
352 \\
325 \\
339 \\
304 \\
307 \\
293\end{array}$ & $\begin{array}{l}25 \\
26 \\
27 \\
28 \\
29 \\
30 \\
31\end{array}$ & $\begin{array}{r}720 \\
720 \\
680 \\
600 \\
740 \\
1,500 \\
4,100\end{array}$ & $\begin{array}{l}328 \\
356 \\
310 \\
268 \\
269 \\
298 \\
-\end{array}$ \\
\hline \multicolumn{10}{|c|}{$\begin{array}{l}\text { Monthly mean discharge, in second-feet } \\
\text { Runoff, in inches. }\end{array}$} & $\begin{array}{r}2,968 \\
6.70\end{array}$ & $\begin{array}{r}563 \\
1.23\end{array}$ \\
\hline
\end{tabular}

Gage height, in feet, and discharge, in second-feet, at indicated time, 1940

\begin{tabular}{|c|c|c|c|c|c|c|c|c|c|c|c|c|}
\hline \multirow{2}{*}{ Hour } & \multicolumn{2}{|c|}{ Aug. 14} & \multicolumn{2}{|c|}{ Aug. 15} & \multicolumn{2}{|c|}{ Aug. 16} & \multicolumn{2}{|c|}{ Aug. 17} & \multicolumn{2}{|c|}{ Aug. 18} & \multicolumn{2}{|c|}{ Aug. 19} \\
\hline & $\begin{array}{c}\text { Gage } \\
\text { ht. }\end{array}$ & $\begin{array}{c}\text { Dis- } \\
\text { charge }\end{array}$ & $\begin{array}{c}\text { Gage } \\
\text { ht. }\end{array}$ & $\begin{array}{l}\text { Dis- } \\
\text { charge }\end{array}$ & $\begin{array}{c}\text { Gage } \\
\text { ht. }\end{array}$ & $\begin{array}{c}\text { Dis- } \\
\text { charge }\end{array}$ & $\begin{array}{c}\text { Gage } \\
\text { ht. }\end{array}$ & $\begin{array}{c}\text { Dis- } \\
\text { charge }\end{array}$ & $\begin{array}{c}\text { Gage } \\
\text { ht. }\end{array}$ & $\begin{array}{c}\text { Dis- } \\
\text { charge }\end{array}$ & $\begin{array}{c}\text { Gage } \\
\text { ht. }\end{array}$ & $\begin{array}{c}\text { Dis- } \\
\text { charge }\end{array}$ \\
\hline $\begin{array}{r}2 \\
4 \\
6 \\
8 \\
10 \\
\mathbf{N}\end{array}$ & $\begin{array}{r}5.0 \\
6.3 \\
8.5 \\
10.9 \\
13.3 \\
15.0\end{array}$ & $\begin{array}{r}1,470 \\
2,490 \\
4,700 \\
9,080 \\
16,000 \\
22,500\end{array}$ & $\begin{array}{l}17.1 \\
16.6 \\
16.0 \\
15.2 \\
14.6 \\
14.6\end{array}$ & $\begin{array}{l}32,600 \\
30,000 \\
27,000 \\
23,400 \\
20,900 \\
20,900\end{array}$ & $\begin{array}{l}15.0 \\
15.0 \\
14.9 \\
14.6 \\
14.2 \\
13.9\end{array}$ & $\begin{array}{l}22,500 \\
22,500 \\
22,100 \\
20,900 \\
19,300 \\
18,200\end{array}$ & $\begin{array}{r}11.3 \\
10.9 \\
10.6 \\
10.3 \\
10.1 \\
9.9\end{array}$ & $\begin{array}{r}10,100 \\
9,080 \\
8,380 \\
7,710 \\
7,280 \\
6,870\end{array}$ & $\begin{array}{r}7.9 \\
7.5 \\
7.1\end{array}$ & $\begin{array}{c}4,040 \\
3,630 \\
3,230\end{array}$ & $\begin{array}{r}6.0 \\
5.8 \\
5.7\end{array}$ & $\begin{array}{l}2,230 \\
2,070 \\
1,990\end{array}$ \\
\hline $\begin{array}{r}2 \\
4 \\
6 \\
8 \\
10 \\
12 \\
\end{array}$ & $\begin{array}{l}15.9 \\
16.7 \\
17.3 \\
17.5 \\
17.5 \\
17.4\end{array}$ & $\begin{array}{l}26,600 \\
30,500 \\
33,800 \\
35,000 \\
35,000 \\
34,400\end{array}$ & \begin{tabular}{|l|}
15.0 \\
15.2 \\
15.0 \\
14.8 \\
14.5 \\
14.7
\end{tabular} & $\begin{array}{l}22,500 \\
23,400 \\
22,500 \\
21,700 \\
20,500 \\
21,300\end{array}$ & \begin{tabular}{|l|}
13.7 \\
13.5 \\
13.1 \\
12.7 \\
12.2 \\
11.7
\end{tabular} & $\begin{array}{l}17,400 \\
16,800 \\
15,400 \\
14,100 \\
12,600 \\
11,200\end{array}$ & $\begin{array}{l}9.6 \\
9.4 \\
9.1 \\
8.9 \\
8.7 \\
8.4\end{array}$ & $\begin{array}{l}6,290 \\
5,930 \\
5,450 \\
5,170 \\
4,920 \\
4,590\end{array}$ & $\begin{array}{r}6.7 \\
6.4 \\
6.2 \\
\end{array}$ & $\begin{array}{r}2,850 \\
2,580 \\
2,400\end{array}$ & $\begin{array}{r}5.6 \\
5.5 \\
5.3\end{array}$ & $\begin{array}{r}1,910 \\
1,830 \\
1,680 \\
\end{array}$ \\
\hline
\end{tabular}

$804331-49-10$ 
ROANOKE RIVER NEAR TOSHES, VA.

LoCATION.—Lat. $37^{\circ} 02^{\prime} 03^{\prime \prime}$, long. $79^{\circ} 31^{\prime} 18^{\prime \prime}, 1 \%$ miles downstream from Witchers Creek, 3 miles upstream from Pigg River, and 5 miles northwest of Toshes, Pittsylvania County. Datum of gage is 588.99 feet above mean sea level (levels by Corps of Engineers, War Department).

DranNAGE AREA.- 1,020 square miles.

GAGE-HEIGHT RECORD.-Water-stage recorder graph except for periods 11 p.m. Aug. 14 to 8 a.m. Aug. 15 when float was stopped by recorder shelf at stage of 26.62 feet, and Aug. 22-30, Sept. 4-22. Synthetic graph was drawn for crest stages based on high-water mark in gage house and extension of rising and receding recorder graphs.

DISCHARGE RECORD.-Stage-discharge relation defined by current-meter measurements up to 31,000 second-feet and extended to erest gage height by logarithmic plotting on basis of unit-hydrograph and flood-routing studies, and other comparisons with flood records for stations in Roanoke River Basin. Gage heights used to half-tenths between 2.4 and 4.0 feet; hundredths below and tenths above these limits. Discharge for period when intake was stopped computed on basis of records for stations at Niagara and Altavista.

Maxima.-1940: Discharge, 70,000 second-feet 1.30 a.m. Aug. 15 (gage height, 27.36 feet, from floodmark).

1925-39 : Discharge, 29,500 second-feet Oct. 19, 1937 (gage height, 20.45 feet).

REMARKs.-The District Engineer, Corps of Engineers, War Department, Norfolk, Va., furnished computed flood records by the unit-hydrograph and flood-routing methods used as a factor in determination of stage-discharge relation.

Mean discharge, in second-feet, 1940

\begin{tabular}{|c|c|c|c|c|c|c|c|c|c|c|c|}
\hline Day & Aug. & Sept. & Day & Aug. & Sept. & Day & Aug. & Sept. & Day & Aug. & Sept. \\
\hline $\begin{array}{l}1 \\
2 \\
3 \\
4 \\
5 \\
6 \\
7 \\
8\end{array}$ & $\begin{array}{r}750 \\
698 \\
535 \\
493 \\
480 \\
487 \\
864 \\
1,460\end{array}$ & $\begin{array}{l}6,130 \\
3,430 \\
2,440 \\
1,800 \\
1,600 \\
1,400 \\
1,300 \\
1,200\end{array}$ & $\begin{array}{r}9 \\
10 \\
11 \\
12 \\
13 \\
14 \\
15 \\
16\end{array}$ & $\begin{array}{r}1,100 \\
630 \\
600 \\
825 \\
987 \\
22,000 \\
55,500 \\
34,600\end{array}$ & $\begin{array}{r}1,150 \\
1,100 \\
1,000 \\
960 \\
920 \\
880 \\
850 \\
830\end{array}$ & $\begin{array}{l}17 \\
18 \\
19 \\
20 \\
21 \\
22 \\
23 \\
24\end{array}$ & $\begin{array}{r}19,000 \\
8,350 \\
4,790 \\
3,270 \\
2,400 \\
2,000 \\
1,800 \\
1,600\end{array}$ & $\begin{array}{l}810 \\
780 \\
750 \\
730 \\
730 \\
710 \\
690 \\
682\end{array}$ & $\begin{array}{l}25 \\
26 \\
27 \\
28 \\
29 \\
30 \\
31\end{array}$ & $\begin{array}{l}1,500 \\
1,400 \\
1,300 \\
1,200 \\
1,300 \\
1,400 \\
8,550\end{array}$ & $\begin{array}{r}840 \\
878 \\
758 \\
690 \\
660 \\
652 \\
\end{array}$ \\
\hline \multicolumn{10}{|c|}{$\begin{array}{l}\text { Monthly mean discharge, in second-feet } \\
\text { Runoff, in inchess }\end{array}$} & $\begin{array}{r}5,867 \\
6.63\end{array}$ & 1,245 \\
\hline
\end{tabular}


Gage height, in feet, and discharge, in second-feet, at indicated time, 1940

\begin{tabular}{|c|c|c|c|c|c|c|c|c|}
\hline \multirow{2}{*}{ Hour } & \multicolumn{2}{|c|}{ Aug. 13} & \multicolumn{2}{|c|}{ Aug. 14} & \multicolumn{2}{|c|}{ Aug. 15} & \multicolumn{2}{|c|}{ Aug. 16} \\
\hline & $\begin{array}{c}\text { Gage } \\
\text { height }\end{array}$ & Discharge & $\begin{array}{c}\text { Gage } \\
\text { height }\end{array}$ & Discharge & $\begin{array}{c}\text { Gage } \\
\text { height }\end{array}$ & Discharge & $\begin{array}{c}\text { Gage } \\
\text { height }\end{array}$ & Discharge \\
\hline \multirow{4}{*}{$\begin{array}{l}1 \\
2 \\
3 \\
4 \\
5 \\
6\end{array}$} & & & \multirow{4}{*}{$\begin{array}{l}2.27 \\
2.30 \\
2.34 \\
2.44 \\
2.64 \\
2.88\end{array}$} & \multirow{4}{*}{$\begin{array}{r}848 \\
870 \\
900 \\
982 \\
1,140 \\
1,340\end{array}$} & \multirow{4}{*}{$\begin{array}{l}27.35 \\
27.35 \\
27.26 \\
27.11 \\
26.97 \\
26.82\end{array}$} & \multirow{4}{*}{$\begin{array}{l}70,000 \\
70,000 \\
69,200 \\
67,500 \\
66,700 \\
65,100\end{array}$} & & \\
\hline & 2.47 & 982 & & & & & 23.26 & 39,900 \\
\hline & 2.45 & $982^{-}$ & & & & & $2 \overline{2} . \overline{9}-$ & 38,000 \\
\hline & $\overline{2} . \overline{44}$ & $982^{-}$ & & & & & $22 . \overline{5}$ & $\overline{\mathbf{3}}, \overline{6} \mathbf{6 0} \overline{0}^{--}$ \\
\hline \multirow{4}{*}{$\begin{array}{r}7 \\
8 \\
9 \\
10 \\
11 \\
\mathrm{~N}\end{array}$} & & & \multirow{4}{*}{$\begin{array}{r}3.33 \\
4.00 \\
5.20 \\
8.00 \\
11.15 \\
13.10\end{array}$} & \multirow{4}{*}{$\begin{array}{r}1,700 \\
2,260 \\
3,430 \\
6,980 \\
11,800 \\
14,900\end{array}$} & \multirow{4}{*}{$\begin{array}{l}26.70 \\
26.60 \\
26.50 \\
26.39 \\
26.28 \\
26.17\end{array}$} & \multirow{4}{*}{$\begin{array}{l}64,300 \\
63,600 \\
62,700 \\
61,900 \\
61,100 \\
60,300\end{array}$} & & \\
\hline & 2.54 & 1,060 & & & & & 22.32 & 35,400 \\
\hline & 2.57 & 1,060 & & & & & 22.15 & 35,000 \\
\hline & 2.56 & 1,060 & & & & & 22.20 & 35,000 \\
\hline \multirow{4}{*}{$\begin{array}{l}1 \\
2 \\
3 \\
4 \\
5 \\
6\end{array}$} & 2.52 & 1,020 & \multirow{4}{*}{$\begin{array}{l}14.85 \\
16.45 \\
18.20 \\
20.40 \\
22.00 \\
23.30\end{array}$} & \multirow{4}{*}{$\begin{array}{l}17,800 \\
21,000 \\
24,600 \\
29,500 \\
34,200 \\
39,900\end{array}$} & \multirow{4}{*}{$\begin{array}{l}25.98 \\
25.67 \\
25.30 \\
24.90 \\
24.50 \\
24.09\end{array}$} & \multirow{4}{*}{$\begin{array}{l}58,700 \\
56,300 \\
53,200 \\
50,200 \\
47,400 \\
\mathbf{4 4 , 6 0 0}\end{array}$} & 22.16 & 35,000 \\
\hline & $0^{-}$ & 100 & & & & & & , \\
\hline & 2.49 & 1,020 & & & & & 21.87 & 800 \\
\hline & 2.45 & 982 & & & & & 21.48 & 32,200 \\
\hline \multirow{5}{*}{$\begin{array}{r}7 \\
8 \\
9 \\
10 \\
11 \\
12 \\
\end{array}$} & 2.38 & 930 & \multirow{4}{*}{$\begin{array}{l}24.30 \\
25.17 \\
25.67 \\
26.25 \\
26.73 \\
27.18 \\
\end{array}$} & \multirow{4}{*}{$\begin{array}{l}46,000 \\
52,500 \\
56,300 \\
60,300 \\
64,300 \\
68,400 \\
\end{array}$} & \multirow{4}{*}{$\begin{array}{l}23.74 \\
23.50 \\
23.42 \\
23.45 \\
23.47 \\
23.46 \\
\end{array}$} & \multirow{4}{*}{$\begin{array}{l}42,200 \\
41,000 \\
40,400 \\
40,400 \\
41,000 \\
41,000 \\
\end{array}$} & 21.33 & 31,600 \\
\hline & -1 & $-\overline{-1}$. & & & & & 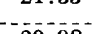 & \\
\hline & 2.29 & 862 & & & & & 20.98 & 30,800 \\
\hline & 2.25 & 832 & & & & & 20.28 & 29,300 \\
\hline & \multicolumn{2}{|c|}{ Aug. 17} & \multicolumn{2}{|c|}{ Aug. 18} & \multicolumn{2}{|c|}{ Aug. 19} & \multicolumn{2}{|c|}{ Aug. 20} \\
\hline \multirow{4}{*}{$\begin{array}{r}2 \\
4 \\
6 \\
8 \\
10 \\
\mathrm{~N}\end{array}$} & 19.40 & 27,300 & 10.7 & \multirow{4}{*}{$\begin{array}{r}11,000 \\
10,200 \\
9,750 \\
9,150 \\
8,550 \\
8,100\end{array}$} & & & & \\
\hline & $\begin{array}{l}18.38 \\
17.55\end{array}$ & $\begin{array}{l}25,100 \\
23,400\end{array}$ & $\begin{array}{r}10.2 \\
9.9\end{array}$ & & $\begin{array}{l}6.9 \\
6.8\end{array}$ & $\begin{array}{l}5,490 \\
5,360\end{array}$ & 5.4 & 3,650 \\
\hline & 16.60 & 21,400 & 9.5 & & 6.6 & 5, & 5.2 & 3,430 \\
\hline & $\begin{array}{l}15.73 \\
14.88\end{array}$ & $\begin{array}{l}19,600 \\
18,000\end{array}$ & $\begin{array}{l}9.1 \\
8.8\end{array}$ & & $\begin{array}{l}6.4 \\
6.3\end{array}$ & 20 & 5.0 & $3,210^{-}$ \\
\hline 2 & 14.16 & 16,800 & 8.5 & 7,6 & 6.2 & & & \\
\hline $\begin{array}{l}\mathbf{4} \\
\mathbf{6}\end{array}$ & $\begin{array}{l}13.52 \\
12.92\end{array}$ & $\begin{array}{l}15,600 \\
14,500\end{array}$ & $\begin{array}{l}8.2 \\
7.9\end{array}$ & $\begin{array}{l}7,260 \\
6,840\end{array}$ & $\begin{array}{l}6.0 \\
5.9\end{array}$ & $\begin{array}{l}4, \\
4,\end{array}$ & 4.9 & 10 \\
\hline $\begin{array}{r}8 \\
10\end{array}$ & $\begin{array}{l}12.2 \\
11.7\end{array}$ & $\begin{array}{l}13,400 \\
12,600\end{array}$ & $\begin{array}{l}7.7 \\
7.5\end{array}$ & $\begin{array}{l}6,560 \\
6,280\end{array}$ & $\begin{array}{l}5.8 \\
5.7\end{array}$ & $\begin{array}{l}4,120 \\
4,000\end{array}$ & 4.7 & 2,910 \\
\hline 12 & 11.1 & 11,600 & 7.3 & 6,010 & 5.6 & 3,880 & 4.5 & 2,710 \\
\hline
\end{tabular}

SUPPLEMENTAL RECORD.-Aug. 15, 1:30 a. m., gage height, 27.36 feet; discharge, 70,000 second-feet.

\section{ROANOKE RIVER AT ALTAVISTA, VA.}

LOCATION.-Lat. $37^{\circ} 06^{\prime} 21^{\prime \prime}$, long. $79^{\circ} 17^{\prime} 38^{\prime \prime}$, at highway bridge a quarter of a mile south of Altavista, Campbell County, half a mile downstream from Sycamore Creek, and $31 / 2$ miles upstream from Otter River. Datum of gage is 503.25 feet above mean sea level (levels by Corps of Engineers, War Department).

Drainage area.-1,802 square miles.

GAGE-HEIGHT RECORD.-Water-stage recorder graph, except for period 4 p.m. Aug. 14 to 7 a.m. Aug. 16, where record was based on floodmark and comparison with flood records for other stations in Roanoke River. Basin.

DISCHARGE RECORD.-Stage-discharge relation defined by current-meter measurements up to 41,000 second-feet and extended to erest gage height by logarithmic plotting on basis of unit-hydrograph and flood-routing studies, and other comparisons with flood records for stations in Roanoke River Basin. Gage heights used to half-tenths between 3.1 and 5.0 feet; hundredths below and tenths above these limits.

Maxima.-1940: Discharge, 105,000 second-feet 6 a.m. Aug. 15 (gage height, 40.08 feet, from floodmark).

1930-39: Discharge, 57,000 second-feet Oct. 20, 1937 (gage height, 31.27 feet). 
REMarks.-The Distriet Engineer, Corps of Engineers, War Department, Norfolk, Va., furnished computed flood records by the unit-hydrograph and flood-routing methods used as a factor in determination of stage-diseharge relation.

Mean discharge, in second-feet, 1940

\begin{tabular}{|c|c|c|c|c|c|c|c|c|c|c|c|}
\hline Day & Aug. & Sept. & Day & Aug. & Sept. & Day & Aug. & Sept. & Day & Aug. & Sept. \\
\hline $\begin{array}{l}1 \\
2 \\
3 \\
4 \\
5 \\
6 \\
7 \\
8\end{array}$ & $\begin{array}{r}1,940 \\
1,460 \\
1,100 \\
968 \\
939 \\
\mathbf{9 6 8} \\
1,610 \\
1,570\end{array}$ & $\begin{array}{l}8,600 \\
4,660 \\
3,400 \\
2,740 \\
2,500 \\
2,260 \\
2,100 \\
1,940\end{array}$ & $\begin{array}{r}9 \\
10 \\
11 \\
12 \\
13 \\
14 \\
15 \\
16\end{array}$ & $\begin{array}{r}2,100 \\
1,160 \\
\mathbf{9 9 9} \\
1,300 \\
1,740 \\
30,200 \\
98,300 \\
69,800\end{array}$ & $\begin{array}{l}1,820 \\
1,700 \\
1,660 \\
1,580 \\
1,500 \\
1,460 \\
1,420 \\
1,380\end{array}$ & $\begin{array}{l}17 \\
18 \\
19 \\
20 \\
21 \\
22 \\
23 \\
24\end{array}$ & $\begin{array}{r}42,700 \\
13,900 \\
7,140 \\
4,790 \\
3,760 \\
3,310 \\
2,820 \\
2,420\end{array}$ & $\begin{array}{l}1,340 \\
1,260 \\
1,260 \\
1,230 \\
1,230 \\
1,200 \\
1,130 \\
1,130\end{array}$ & $\begin{array}{l}25 \\
26 \\
27 \\
28 \\
29 \\
30 \\
31\end{array}$ & $\begin{array}{l}2,340 \\
2,180 \\
2,020 \\
1,980 \\
2,020 \\
2,100 \\
7,020\end{array}$ & $\begin{array}{r}1,300 \\
1,660 \\
1,340 \\
1,160 \\
1,130 \\
1,100 \\
\end{array}$ \\
\hline \multicolumn{10}{|c|}{$\begin{array}{l}\text { Monthly mean discharge, in second-feet } \\
\text { Runoff, in inches }\end{array}$} & $\begin{array}{r}10,210 \\
6.54\end{array}$ & $\begin{array}{r}1,940 \\
1.20\end{array}$ \\
\hline
\end{tabular}

Gage height, in feet, and discharge, in second-feet, at indicated time, 1940

\begin{tabular}{|c|c|c|c|c|c|c|c|c|}
\hline \multirow{2}{*}{ Hour } & \multicolumn{2}{|c|}{ Aug. 13} & \multicolumn{2}{|c|}{ Aug. 14} & \multicolumn{2}{|c|}{ Aug. 15} & \multicolumn{2}{|c|}{ Aug. 16} \\
\hline & $\begin{array}{c}\text { Gage } \\
\text { height }\end{array}$ & Discharge & $\begin{array}{c}\text { Gage } \\
\text { height }\end{array}$ & Discharge & $\begin{array}{c}\text { Gage } \\
\text { height }\end{array}$ & Discharge & $\begin{array}{c}\text { Gage } \\
\text { height }\end{array}$ & Discharge \\
\hline 1 & 4.97 & 1,980 & \multirow{4}{*}{$\begin{array}{l}4.54 \\
4.54 \\
4.55 \\
4.57 \\
4.59 \\
4.67\end{array}$} & \multirow{4}{*}{$\begin{array}{l}1,660 \\
1,660 \\
1,660 \\
1,660 \\
1,700 \\
1,740\end{array}$} & \multirow{4}{*}{$\begin{array}{l}39.4 \\
39.6 \\
39.8 \\
39.9 \\
40.0 \\
40.08\end{array}$} & \multirow{4}{*}{$\begin{array}{l}101,000 \\
102,000 \\
103,000 \\
104,000 \\
104,000 \\
105,000\end{array}$} & $36.1^{--}$ & $80,600^{--}$ \\
\hline $\begin{array}{l}3 \\
4\end{array}$ & 4.91 & 1,940 & & & & & $\overline{3} 5 . \overline{5}$ & $7 \overline{7}, 200$ \\
\hline 5 & & & & & & & & 0,200 \\
\hline 6 & 4.80 & 1,860 & & & & & $\mathbf{3 5 . 0}$ & 74,500 \\
\hline 7 & & & \multirow{4}{*}{$\begin{array}{r}4.92 \\
5.38 \\
6.75 \\
8.40 \\
11.50 \\
18.50\end{array}$} & \multirow{4}{*}{$\begin{array}{r}1,940 \\
2,340 \\
3,490 \\
\mathbf{4}, \mathbf{9 3 0} \\
\mathbf{7}, \mathbf{9 8 0} \\
18,800\end{array}$} & \multirow{4}{*}{$\begin{array}{l}40.0 \\
40.0 \\
39.9 \\
39.8 \\
39.6 \\
39.5\end{array}$} & \multirow{4}{*}{$\begin{array}{l}104,000 \\
104,000 \\
104,000 \\
103,000 \\
102,000 \\
101,000\end{array}$} & & \\
\hline 8 & 4.69 & 1,780 & & & & & 34.62 & 72,400 \\
\hline 10 & $4.61^{-}$ & 1,700 & & & & & 34.26 & 70,900 \\
\hline$\stackrel{11}{N}$ & $\overrightarrow{4.53}$ & 1,660 & & & & & $\overline{3} \overline{3} \overline{\mathbf{9}}$ & $68,800^{-}$ \\
\hline 1 & & & \multirow{4}{*}{$\begin{array}{l}21.90 \\
24.10 \\
25.40 \\
26.7 \\
28.6 \\
30.3\end{array}$} & \multirow{4}{*}{$\begin{array}{l}26,600 \\
32,200 \\
35,900 \\
39,900 \\
46,500 \\
52,900\end{array}$} & \multirow{4}{*}{$\begin{array}{l}39.4 \\
39.2 \\
39.0 \\
38.8 \\
38.6 \\
38.3\end{array}$} & \multirow{4}{*}{$\begin{array}{r}101,000 \\
99,300 \\
98,000 \\
96,800 \\
95,600 \\
93,800\end{array}$} & & \\
\hline 2 & 4.49 & 1,620 & & & & & 33.57 & 67,400 \\
\hline 4 & 4.48 & 1,620 & & & & & 33.20 & $6 \overline{5}, \overline{00}$ \\
\hline $\begin{array}{l}5 \\
6\end{array}$ & 4.49 & 1,620 & & & & & 32.93 & 64,000 \\
\hline 7 & & & \multirow{4}{*}{$\begin{array}{l}32.2 \\
34.0 \\
35.9 \\
37.2 \\
38.3 \\
38.9 \\
\end{array}$} & \multirow{4}{*}{$\begin{array}{l}60,900 \\
69,300 \\
79,400 \\
87,200 \\
93,800 \\
97,400 \\
\end{array}$} & \multirow{4}{*}{$\begin{array}{l}38.1 \\
37.8 \\
37.6 \\
37.3 \\
37.0 \\
36.7 \\
\end{array}$} & \multirow{4}{*}{$\begin{array}{l}\mathbf{9 2}, 600 \\
90,800 \\
\mathbf{8 9}, 600 \\
\mathbf{8 7}, \mathbf{8 0 0} \\
\mathbf{8 6}, 000 \\
\mathbf{8 4}, \mathbf{2 0 0} \\
\end{array}$} & & \\
\hline $\begin{array}{l}8 \\
9\end{array}$ & 4.51 & 1,620 & & & & & 32.64 & 62,700 \\
\hline 10 & 4.48 & 1,620 & & & & & 32.35 & 61,800 \\
\hline \multirow[t]{2}{*}{12} & 4.51 & 1,620 & & & & & 32.00 & 60,000 \\
\hline & \multicolumn{2}{|c|}{ Aug. 17} & \multicolumn{2}{|c|}{ Aug. 18} & \multicolumn{2}{|c|}{ Aug. 19} & \multicolumn{2}{|c|}{ Aug. 20} \\
\hline $\begin{array}{r}2 \\
4 \\
6 \\
8 \\
10 \\
\mathrm{~N}\end{array}$ & $\begin{array}{l}31.57 \\
30.93 \\
30.33 \\
29.57 \\
28.66 \\
27.65\end{array}$ & $\begin{array}{l}58,300 \\
55,300 \\
52,900 \\
50,200 \\
46,800 \\
42,900\end{array}$ & $\begin{array}{l}19.42 \\
18.40 \\
17.50 \\
16.63 \\
15.88 \\
15.30\end{array}$ & $\begin{array}{l}20,800 \\
18,600 \\
16,800 \\
15,000 \\
13,800 \\
12,700\end{array}$ & $\begin{array}{l}12.50 \\
12.21 \\
11.92 \\
11.65 \\
11.44 \\
11.21\end{array}$ & $\begin{array}{l}8,600 \\
8,300 \\
7,900 \\
7,600 \\
7,300 \\
7,000\end{array}$ & $\begin{array}{l}9.95 \\
9.81 \\
9.68 \\
9.56 \\
9.45 \\
9.34\end{array}$ & $\begin{array}{l}5,500 \\
5,350 \\
5,200 \\
5,000 \\
4,870 \\
4,730\end{array}$ \\
\hline $\begin{array}{r}2 \\
4 \\
6 \\
8 \\
10 \\
12 \\
\end{array}$ & $\begin{array}{l}26.55 \\
25.45 \\
24.30 \\
23.10 \\
21.90 \\
20.64\end{array}$ & $\begin{array}{l}39,600 \\
35,900 \\
32,700 \\
29,600 \\
26,600 \\
23,500\end{array}$ & $\begin{array}{l}14.75 \\
14.27 \\
13.77 \\
13.54 \\
13.21 \\
12.81 \\
\end{array}$ & $\begin{array}{r}11,900 \\
11,200 \\
10,500 \\
9,900 \\
9,500 \\
9,100\end{array}$ & $\begin{array}{l}11.00 \\
10.81 \\
10.60 \\
10.41 \\
10.24 \\
10.09\end{array}$ & $\begin{array}{l}6,800 \\
6,550 \\
6,300 \\
6,100 \\
5,850 \\
5,700 \\
\end{array}$ & $\begin{array}{l}9.23 \\
9.12 \\
9.01 \\
8.91 \\
8.81 \\
8.72 \\
\end{array}$ & $\begin{array}{l}4,600 \\
4,500 \\
4,370 \\
4,270 \\
4,180 \\
4,100 \\
\end{array}$ \\
\hline
\end{tabular}


ROANOKE HIVER AT BROOKNEAL, VA.

LOCATION.-Lat. $37^{\circ} 02^{\prime} 22^{\prime \prime}$, long. $78^{\circ} 56^{\prime} 41^{\prime \prime}$, at highway bridge at Virginian Railway station at Brookneal, Campbell County, $23 \%$ miles upstream from Falling River. Datum of gage is 352.02 feet above mean sea level, datum of 1929 , supplementary adjustment of 1936 .

Drainage AREA. - 2,420 square miles.

GAGE-HEIGHT RECORD.-Water-stage recorder graph except for period 6 a.m. Aug. 15 to Sept. 30. Gage heights to tenths 6 a.m. Aug. 15 to 12 p.m. Aug. 19 and to tenths and half-tenths Aug. 20-21 were obtained from graph based on floodmark, several slope gage readings, unit-hydrograph and flood-routing studies, and comparison with flood records for other stations in the Roanoke River Basin. Gage heights subsequent to Aug. 21 obtained from twice-daily slope gage readings except for periods of no gage-height record Aug. 22-25, 27, 28, Sept. 1, 8.

DISCHARGE RECORD.-Stage-diseharge relation defined by current-meter measurements up to 44,000 second-feet and extended to erest gage height by logarithmic plotting on basis of slope-area measurement, unit-hydrograph and flood-routing studies, and other comparisons with flood records for stations in Roanoke River Basin. Gage heights Aug. 13 to 5 a.m. Aug. 15, and Aug. 21 used to half-tenths between 3.4 and 5.4 feet; tenths above these limits. Discharge for periods of no gage-height record computed on basis of records for stations at Altavista and Clover.

Maxima.-1940: Discharge, 130,000 second-feet about 7 p.m. Aug. 15 (gage height, 46.0 feet, from floodmark).

1923-39: Diseharge, 76,300 second-feet Aug. 12, 1928 (gage height, 37.15 feet).

Remarks.-The District Engineer, Corps of Engineers, War Department, Norfolk, Va., cooperated in completing field work for determination of flood flow by slopearea method and in furnishing computed flood records by the unit-hydrograph and flood-routing methods used as a factor in determination of stage-discharge relation and in preparation of stage graph during flood period.

Mean discharge, in second-feet, 1940

\begin{tabular}{|c|c|c|c|c|c|c|c|c|c|c|c|}
\hline Day & Aug. & Sept. & Day & Aug. & Sept. & Day & Aug. & Sept. & Day & Aug. & Sept. \\
\hline $\begin{array}{l}1 \\
2 \\
3 \\
4 \\
5 \\
6 \\
7 \\
8\end{array}$ & $\begin{array}{l}2,840 \\
2,000 \\
1,560 \\
1,350 \\
1,320 \\
1,320 \\
1,530 \\
2,000\end{array}$ & $\begin{array}{r}12,000 \\
5,930 \\
4,260 \\
3,450 \\
3,030 \\
2,790 \\
2,710 \\
2,500\end{array}$ & $\begin{array}{r}9 \\
10 \\
11 \\
12 \\
13 \\
14 \\
15 \\
16\end{array}$ & $\begin{array}{r}2,210 \\
1,720 \\
1,380 \\
1,410 \\
1,910 \\
20,800 \\
112,000 \\
113,000\end{array}$ & $\begin{array}{l}2,330 \\
2,190 \\
2,120 \\
2,050 \\
1,980 \\
1,840 \\
1,840 \\
1,780\end{array}$ & $\begin{array}{l}17 \\
18 \\
19 \\
20 \\
21 \\
22 \\
23 \\
24\end{array}$ & $\begin{array}{r}80,600 \\
33,100 \\
11,600 \\
6,890 \\
5,120 \\
4,300 \\
3,600 \\
3,300\end{array}$ & $\begin{array}{l}1,780 \\
1,720 \\
1,600 \\
1,660 \\
1,660 \\
1,540 \\
1,540 \\
1,510\end{array}$ & $\begin{array}{l}25 \\
26 \\
27 \\
28 \\
29 \\
30 \\
31\end{array}$ & $\begin{array}{l}3,100 \\
2,950 \\
2,700 \\
2,600 \\
2,550 \\
3,030 \\
8,520\end{array}$ & $\begin{array}{r}1,540 \\
2,120 \\
1,910 \\
1,660 \\
1,600 \\
1,540\end{array}$ \\
\hline \multicolumn{10}{|c|}{$\begin{array}{l}\text { Monthly mean discharge, in second-feet, } \\
\text { Runoff, in inches }\end{array}$} & $\begin{array}{r}14,270 \\
6.80\end{array}$ & 2,539 \\
\hline
\end{tabular}


124 FLOODS OF AUGUST 1940 IN THE SOUTHEASTERN STATES

Gage height, in feet, and discharge, in second-feet, at indicated time, 1940

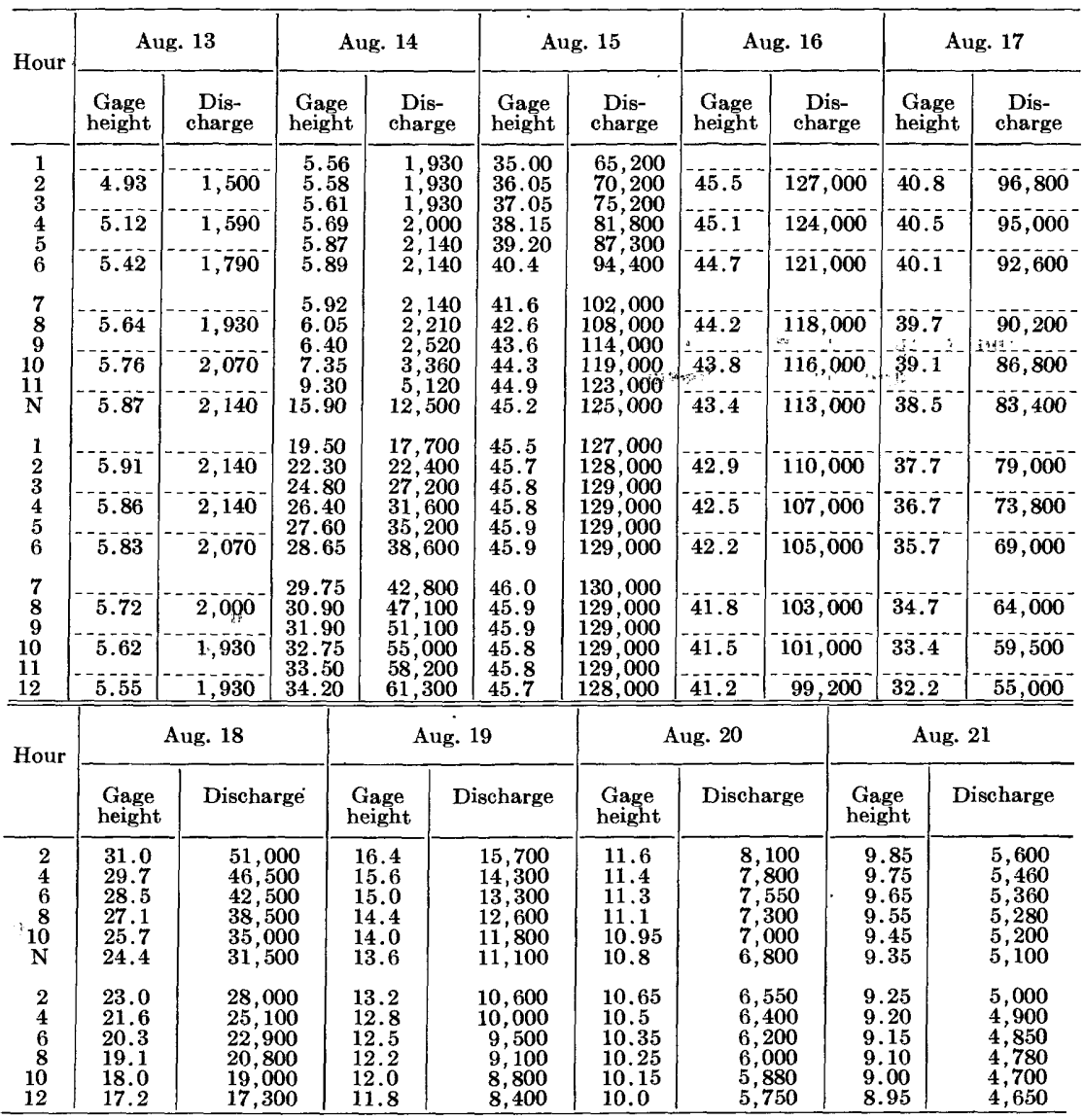

ROANOKE RIVER NEAR CLOVER, VA.

Location.-Lat. $36^{\circ} 50^{\prime} 17^{\prime \prime}$, long. $78^{\circ} 40^{\prime} 02^{\prime \prime}$, at highway bridge $3 \frac{1}{2}$ miles downstream from Roanoke Creek and 6 miles east of Clover, Halifax County. Datum of gage is 302.91 feet above mean sea level, datum of 1929, supplementary adjustment of 1936 .

Drainage AREA.- 3,230 square miles.

GAGE-HEIGHT RECORD.-Water-stage recorder graph except for period 3 a.m. Aug. 16 to Aug. 30. Gage heights Aug. 16-21 obtained from graph based on floodmarks, 2 gage readings, unit-hydrograph and flood-routing studies, and comparison of flood records with those for other stations in Roanoke River Basin. No gageheight record Aug. 22-30.

DISCHARGE RECORD.--Stage-discharge relation defined by current-meter measurements up to 70,000 second-feet and extended to erest gage height by logarithmic plotting on basis of slope-area measurement, unit-hydrograph and flood-routing studies, and other comparisons with flood records for stations in Roanoke River Basin. Gage heights used to half-tenths between 1.9 and 3.8 feet; hundredths below and tenths above these limits. Discharge for period of no gage-height record computed on basis of records for stations at Brookneal and Clarksville. 
MaXima.-1940: Discharge, 160,000 second-feet 6 p.m. Aug. 16 (gage height, 37.15 feet, from floodmark).

1929-39: Discharge observed, 56,400 second-feet Mar. 19, 1936 (gage height, 23.49 feet), but peak discharge of flood of Oct. 20 or 21,1937 , may have been as great.

ReMarKs.-The District Engineer, Corps of Engineers, War Department, Norfolk, Va., furnished computed flood records by the unit-hydrograph and flood-routing methods used as a factor in determination of stage-discharge relation and in preparation of stage graph during flood period.

Mean discharge, in second-feet, 1940

\begin{tabular}{|c|c|c|c|c|c|c|c|c|c|c|c|}
\hline Day & Aug. & Sept. & Day & Aug. & Sept. & Day & Aug. & Sept. & Day & Aug. & Sept. \\
\hline $\begin{array}{l}1 \\
2 \\
3 \\
4 \\
5 \\
6 \\
7 \\
8\end{array}$ & $\begin{array}{l}5,590 \\
2,650 \\
2,090 \\
1,760 \\
1,580 \\
1,580 \\
1,850 \\
2,390\end{array}$ & $\begin{array}{l}9,990 \\
9,840 \\
5,950 \\
4,750 \\
4,080 \\
3,860 \\
3,530 \\
3,310\end{array}$ & $\begin{array}{r}9 \\
10 \\
11 \\
12 \\
13 \\
14 \\
15 \\
16\end{array}$ & $\begin{array}{r}2,190 \\
2,540 \\
1,850 \\
1,760 \\
1,810 \\
7,630 \\
58,100 \\
147,000\end{array}$ & $\begin{array}{l}3,090 \\
2,980 \\
2,870 \\
2,700 \\
2,600 \\
2,490 \\
2,390 \\
2,340\end{array}$ & $\begin{array}{l}17 \\
18 \\
19 \\
20 \\
21 \\
22 \\
23 \\
24\end{array}$ & $\begin{array}{r}137,000 \\
89,000 \\
41,400 \\
13,300 \\
7,550 \\
5,800 \\
4,900 \\
4,600\end{array}$ & $\begin{array}{l}2,290 \\
2,190 \\
2,140 \\
2,090 \\
2,040 \\
2,040 \\
1,940 \\
1,900\end{array}$ & $\begin{array}{l}25 \\
26 \\
27 \\
28 \\
29 \\
30 \\
31\end{array}$ & $\begin{array}{l}4,300 \\
4,000 \\
3,800 \\
3,500 \\
3,400 \\
3,600 \\
3,860\end{array}$ & $\begin{array}{r}1,850 \\
2,040 \\
2,490 \\
2,140 \\
1,940 \\
1,900 \\
\end{array}$ \\
\hline \multicolumn{10}{|c|}{$\begin{array}{l}\text { Monthly mean diseharge, in second-feet } \\
\text { Runoff, in inehes }\end{array}$} & $\begin{array}{r}18,460 \\
6.60\end{array}$ & $\begin{array}{r}3,192 \\
1.10\end{array}$ \\
\hline
\end{tabular}

Gage height, in feet, and discharge, in second-feet, at indicated time, 1940

\begin{tabular}{|c|c|c|c|c|c|c|c|c|c|c|c|}
\hline \multirow{2}{*}{ Hour } & \multicolumn{2}{|c|}{ Aug. 13} & \multicolumn{2}{|c|}{ Aug. 14} & \multicolumn{2}{|c|}{ Aug. 15} & \multicolumn{3}{|c|}{ Aug. 16} & \multicolumn{2}{|c|}{ Aug. 17} \\
\hline & $\begin{array}{c}\text { Gage } \\
\text { height }\end{array}$ & $\begin{array}{c}\text { Dis- } \\
\text { charge }\end{array}$ & $\begin{array}{c}\text { Gage } \\
\text { height }\end{array}$ & $\begin{array}{c}\text { Dis- } \\
\text { charge }\end{array}$ & $\begin{array}{c}\text { Gage } \\
\text { height }\end{array}$ & $\begin{array}{l}\text { Dis- } \\
\text { charge }\end{array}$ & $\begin{array}{c}\text { Gage } \\
\text { height }\end{array}$ & \multicolumn{2}{|c|}{$\begin{array}{c}\text { Dis- } \\
\text { charge }\end{array}$} & $\begin{array}{c}\text { Gage } \\
\text { height }\end{array}$ & $\begin{array}{c}\text { Dis- } \\
\text { charge }\end{array}$ \\
\hline 1 & $2 . \overline{7}$ & 1,720 & \multirow{4}{*}{$\begin{array}{l}3.30 \\
3.35 \\
3.40 \\
3.43 \\
3.47 \\
3.49\end{array}$} & \multirow{4}{*}{$\begin{array}{l}2,240 \\
2,290 \\
2,340 \\
2,390 \\
2,390 \\
2,440\end{array}$} & \multirow{4}{*}{$\begin{array}{l}16.96 \\
17.35 \\
17.78 \\
18.21 \\
18.67 \\
19.20\end{array}$} & \multirow{4}{*}{$\begin{array}{l}23,700 \\
25,000 \\
26,200 \\
27,600 \\
29,500 \\
31,400\end{array}$} & \multirow{4}{*}{$\begin{array}{l}32.92 \\
33.40 \\
33.80 \\
34.3 \\
34.6 \\
34.9\end{array}$} & \multirow{4}{*}{\multicolumn{2}{|c|}{$\begin{array}{l}119,000 \\
124,000 \\
127,000 \\
132,000 \\
134,000 \\
138,000\end{array}$}} & 36.5 & 154,000 \\
\hline $\begin{array}{l}3 \\
4\end{array}$ & $27 \overline{7}$ & 1.720 & & & & & & & & $\overline{3} \overline{3}, \overline{3}$ & 152000 \\
\hline 5 & $--=-$ & & & & & & & & & & \\
\hline 6 & 2.77 & 1,720 & & & & & & & & 35.9 & 148,000 \\
\hline 7 & & & \multirow{4}{*}{$\begin{array}{l}3.51 \\
3.53 \\
3.54 \\
3.59 \\
3.67 \\
3.78\end{array}$} & \multirow{4}{*}{$\begin{array}{l}2,440 \\
2,490 \\
2,490 \\
2,540 \\
2,600 \\
2,760\end{array}$} & 19.77 & 34,000 & \multirow{4}{*}{$\begin{array}{l}35.2 \\
35.5 \\
35.8 \\
36.0 \\
36.2 \\
36.4\end{array}$} & \multirow{4}{*}{\multicolumn{2}{|c|}{$\begin{array}{l}140,000 \\
144,000 \\
146,000 \\
148,000 \\
150,000 \\
152,000\end{array}$}} & & \\
\hline 8 & 2.77 & 1,720 & & & 20.45 & 36,800 & & & & 35.7 & 146,000 \\
\hline 10 & 2.77 & 1,720 & & & 21.98 & $\begin{array}{l}40,000 \\
44,500\end{array}$ & & & & $\overline{3} \overline{5} . \overline{3}$ & 142,000 \\
\hline 11 & 2.78 & 1,760 & & & $\begin{array}{l}22.70 \\
23.48\end{array}$ & $\begin{array}{l}48,000 \\
52,300\end{array}$ & & & & 34.9 & 138,000 \\
\hline 1 & 280 & 1760 & \multirow{4}{*}{$\begin{array}{r}4.70 \\
6.65 \\
8.30 \\
9.55 \\
10.70 \\
11.95\end{array}$} & \multirow{4}{*}{$\begin{array}{r}3,750 \\
5,950 \\
7,990 \\
9,680 \\
11,100 \\
13,000\end{array}$} & 24.25 & 56,200 & \multirow{4}{*}{$\begin{array}{l}36.6 \\
36.7 \\
36.9 \\
37.0 \\
37.1 \\
37.15\end{array}$} & \multirow{4}{*}{\multicolumn{2}{|c|}{$\begin{array}{l}154,000 \\
156,000 \\
158,000 \\
158,000 \\
160,000 \\
160,000\end{array}$}} & & \\
\hline 3 & 2.80 & & & & $\begin{array}{l}20.10 \\
25.80\end{array}$ & $\begin{array}{l}61,800 \\
65,800\end{array}$ & & & & & 000 \\
\hline 4 & 2.82 & 1,760 & & & 26.55 & 70,700 & & & & 34.1 & 130,000 \\
\hline 6 & 2.88 & 1,850 & & & 28.1 & $\begin{array}{l}75,600 \\
81,900\end{array}$ & & & & $3 \overline{3} . \overline{7}$ & 126,000 \\
\hline 7 & & & \multirow{4}{*}{$\begin{array}{l}13.05 \\
14.00 \\
14.78 \\
15.46 \\
15.98 \\
16.54\end{array}$} & \multirow{4}{*}{$\begin{array}{l}14,600 \\
16,500 \\
18,200 \\
19,800 \\
21,000 \\
22,300 \\
\end{array}$} & 28.90 & 86,800 & \multirow{4}{*}{$\begin{array}{l}37.1 \\
37.1 \\
37.0 \\
37.0 \\
36.9 \\
36.9 \\
\end{array}$} & \multirow{4}{*}{\multicolumn{2}{|c|}{$\begin{array}{l}160,000 \\
160,000 \\
158,000 \\
158,000 \\
158,000 \\
158,000\end{array}$}} & & \\
\hline 8 & 2.98 & 1,940 & & & 29.80 & & & & & 33.3 & 000 \\
\hline 10 & 3.11 & 2,040 & & & 31.30 & 10 & & & & 32.8 & 118,000 \\
\hline $\begin{array}{l}11 \\
12\end{array}$ & $\overline{3} . \overline{2} \overline{4}$ & 2,190 & & & $\begin{array}{l}31.90 \\
32.40\end{array}$ & & & & & $\overline{32} . \overline{3}$ & 114,000 \\
\hline \multirow{2}{*}{ Hour } & \multicolumn{3}{|c|}{ Aug. 18} & \multicolumn{2}{|c|}{ Aug. 19} & & ug. 20 & & & $\mathrm{Au}$ & \\
\hline & $\begin{array}{c}\text { Gage } \\
\text { height }\end{array}$ & Disch & arge & $\begin{array}{c}\text { Gage } \\
\text { height }\end{array}$ & Discharge & $\begin{array}{c}\text { Gage } \\
\text { height }\end{array}$ & Dise & rge & & & Discharge \\
\hline $\begin{array}{r}2 \\
4 \\
6 \\
8 \\
10 \\
\mathrm{~N}\end{array}$ & $\begin{array}{l}31.9 \\
31.4 \\
30.9 \\
30.3 \\
29.8 \\
29.2\end{array}$ & $\begin{array}{r}110, \\
106, \\
102 \\
97 \\
93 \\
88,\end{array}$ & $\begin{array}{l}00 \\
0 \\
0 \\
0 \\
0 \\
0\end{array}$ & $\begin{array}{l}24.8 \\
24.1 \\
23.3 \\
22.6 \\
21.8 \\
21.0\end{array}$ & $\begin{array}{l}59,800 \\
55,600 \\
51,200 \\
47,500 \\
43,500 \\
39,600\end{array}$ & $\begin{array}{l}15.2 \\
14.5 \\
13.7 \\
13.0 \\
12.3 \\
11.6\end{array}$ & & & & $\begin{array}{l}.8 \\
.6 \\
.4 \\
1 \\
.0 \\
.8\end{array}$ & $\begin{array}{l}8,640 \\
8,380 \\
8,120 \\
7,750 \\
7,630 \\
7,390\end{array}$ \\
\hline $\begin{array}{r}2 \\
4 \\
6 \\
8 \\
10 \\
12\end{array}$ & $\begin{array}{l}28.6 \\
28.0 \\
27.4 \\
26.8 \\
26.1 \\
25.5\end{array}$ & & $\begin{array}{l}700 \\
500 \\
300 \\
100 \\
600 \\
000\end{array}$ & $\begin{array}{l}20.2 \\
19.4 \\
18.6 \\
17.7 \\
16.9 \\
16.0\end{array}$ & $\begin{array}{l}35,800 \\
32,300 \\
29,100 \\
25,900 \\
23,400 \\
21,000\end{array}$ & $\begin{array}{r}11.1 \\
10.5 \\
10.1 \\
9.7 \\
9.4 \\
9.1\end{array}$ & & & & $\begin{array}{l}.7 \\
.6 \\
.5 \\
.3 \\
.2 \\
.1\end{array}$ & $\begin{array}{l}7,270 \\
7,150 \\
7,030 \\
6,790 \\
6,670 \\
6,550\end{array}$ \\
\hline
\end{tabular}




\section{FLOODS OF AUGUST 1940 IN THE SOUTHEASTERN STATES}

\section{ROANOKE RIVER AT CLARKSVILLE, VA.}

Location.-At mouth of Dan River. Gage is water-stage recorder, lat. $36^{\circ} 37^{\prime} 40^{\prime \prime}$, long. $78^{\circ} 33^{\prime} 04^{\prime \prime}$, at highway bridge in Clarksville, Mecklenburg County, 500 feet upstream from Dan River. Datum of gage is 258.23 feet above mean sea level, datum of 1929.

Drain age AREA.-7,320 square miles (including that of Dan River).

GAGE-HEIGHT RECORD.-Water-stage recorder graph. Intake stopped Aug. 1-4.

Discharge RECORD.-Includes flow of Dan River. Stage-discharge relation defined by current-meter measurements up to 270,000 second-feet. Gage heights used to half-tenths between 2.2 and 4.3 feet; hundredths below and tenths above these limits. Discharge for period when intake was stopped computed on basis of records for other stations in the basin.

Maxima.-1940: Discharge, 280,000 second-feet 6 a.m. Aug. 17 (gage height, 26.66 feet).

1934-39: Discharge, 114,000 second-feet Jan. 21, 1936 (gage height, 16.88 feet).

Remarks.-The District Engineer, Corps of Engineers, War Department, Norfolk, Va, cooperated in completing field work for determination of flood flow by slope-area method. Gage-height record collected in cooperation with the U. S. Weather Bureau.

Mean discharge, in second-feet, 1940

\begin{tabular}{|c|c|c|c|c|c|c|c|c|c|c|c|}
\hline Day & Aug. & Sept. & Day & Aug. & Sept. & Day & Aug. & Sept. & Day & Aug. & Sept. \\
\hline $\begin{array}{l}1 \\
2 \\
3 \\
4 \\
5 \\
6 \\
7 \\
8\end{array}$ & $\begin{array}{r}18,000 \\
11,000 \\
6,400 \\
4,400 \\
3,700 \\
3,450 \\
3,450 \\
3,580\end{array}$ & $\begin{array}{r}18,500 \\
21,200 \\
12,600 \\
8,860 \\
7,630 \\
7,630 \\
6,810 \\
6,490\end{array}$ & $\begin{array}{r}9 \\
10 \\
11 \\
12 \\
13 \\
14 \\
15 \\
16\end{array}$ & $\begin{array}{r}3,960 \\
4,230 \\
4,100 \\
3,450 \\
3,240 \\
14,100 \\
79,300 \\
212,000\end{array}$ & $\begin{array}{l}\mathbf{5}, 860 \\
\mathbf{5}, 860 \\
\mathbf{5}, 250 \\
\mathbf{5}, 250 \\
4,800 \\
4,510 \\
4,660 \\
\mathbf{4}, \mathbf{5 1 0}\end{array}$ & $\begin{array}{l}17 \\
18 \\
19 \\
20 \\
21 \\
22 \\
23 \\
24\end{array}$ & $\begin{array}{r}267,000 \\
192,000 \\
114,000 \\
42,000 \\
15,400 \\
11,200 \\
10,300 \\
9,750\end{array}$ & $\begin{array}{l}4,100 \\
3,960 \\
3,960 \\
3,960 \\
3,960 \\
3,700 \\
3,830 \\
3,450\end{array}$ & $\begin{array}{l}25 \\
26 \\
27 \\
28 \\
29 \\
30 \\
31\end{array}$ & $\begin{array}{r}8,320 \\
8,680 \\
7,970 \\
9,810 \\
11,000 \\
9,430 \\
8,680\end{array}$ & $\begin{array}{l}3,580 \\
3,580 \\
4,370 \\
4,510 \\
3,830 \\
3,960\end{array}$ \\
\hline \multicolumn{12}{|c|}{$\begin{array}{l}\begin{array}{l}\text { Monthly mean discharge, in second-feet } \\
\text { Runoff, in inches. }\end{array} \\
\end{array}$} \\
\hline
\end{tabular}


ROANOKE RIVER BASIN

Gage height, in feet, and discharge, in second-feet, at indicated time, 1940

\begin{tabular}{|c|c|c|c|c|c|c|c|c|c|c|c|c|}
\hline \multirow{2}{*}{ Hour } & \multicolumn{2}{|c|}{ Aug. 13} & \multicolumn{2}{|c|}{ Aug. 14} & \multicolumn{2}{|c|}{ Ang. 15} & \multicolumn{2}{|c|}{ Aug. 16} & \multicolumn{2}{|c|}{ Aug. 17} & \multicolumn{2}{|c|}{ Aug. 18} \\
\hline & $\begin{array}{c}\text { Gage } \\
\text { lit. }\end{array}$ & c & & & & e & $\begin{array}{c}\text { Gage } \\
\text { ht. }\end{array}$ & $\begin{array}{c}\text { D } \\
\text { cha }\end{array}$ & $\begin{array}{c}\text { Gage } \\
\text { ht. }\end{array}$ & & & \\
\hline $\begin{array}{l}1 \\
2 \\
3 \\
4 \\
5 \\
6\end{array}$ & 2.28 & $\begin{array}{l}3,330 \\
3,330\end{array}$ & \begin{tabular}{l|}
2.28 \\
2.30 \\
2.33 \\
2.36 \\
2.40
\end{tabular} & $\begin{array}{l}\mathbf{3}, 4 \\
\mathbf{3}, 4 \\
3,5 \\
3,5 \\
3,7\end{array}$ & $\mid \begin{array}{l}10.71 \\
10.99 \\
11.17 \\
11.36 \\
11.60 \\
11.95\end{array}$ & $\begin{array}{l}47 \\
50 \\
51 \\
53 \\
55 \\
59\end{array}$ & \multicolumn{2}{|c|}{\begin{tabular}{|l|l|}
18.70 & 140,000 \\
19.18 & 147,000 \\
19.65 & 153,000 \\
20.10 & 161,000 \\
20.58 & 169,000 \\
21.05 & 175,000
\end{tabular}} & \multicolumn{2}{|c|}{\begin{tabular}{|l|l|}
26.41 & 274,000 \\
26.50 & 276,000 \\
26.58 & 278,000 \\
26.62 & 278,000 \\
26.65 & 278,000 \\
26.66 & 280,000
\end{tabular}} & \multicolumn{2}{|c|}{\begin{tabular}{|l|l|}
24.31 & 233,000 \\
24.11 & 229,000 \\
23.90 & 225,000 \\
23.69 & 222,000 \\
23.48 & 218,000 \\
23.26 & 214,000
\end{tabular}} \\
\hline $\begin{array}{r}7 \\
8 \\
9 \\
10 \\
11 \\
N\end{array}$ & $\begin{array}{r}2.20 \\
2.19\end{array}$ & $\begin{array}{l}3, \overline{3}, 210 \\
3,190 \\
3,190\end{array}$ & $\begin{array}{l}2.45 \\
2.51 \\
2.57 \\
2.64 \\
2.70 \\
2.82\end{array}$ & $\begin{array}{l}3,830 \\
3,960 \\
4,100 \\
4,370 \\
4,510 \\
4,800\end{array}$ & $\mid \begin{array}{l}12.47 \\
12.72 \\
12.96 \\
13.17 \\
13.37 \\
13.55\end{array}$ & $\begin{array}{l}64,000 \\
66,000 \\
69,000 \\
71,200 \\
73,400 \\
75,600\end{array}$ & \multicolumn{2}{|c|}{\begin{tabular}{|l|l|l}
21.48 & 184,000 \\
21.88 & 190,000 \\
22.24 & 195,000 \\
22.65 & 202,000 \\
23.13 & 211,000 \\
23.50 & 218,000
\end{tabular}} & \multicolumn{2}{|c|}{\begin{tabular}{|l|l}
26.65 & 278,000 \\
26.62 & 278,000 \\
26.57 & 278,000 \\
26.51 & 276,000 \\
26.44 & 274,000 \\
26.35 & 274,000
\end{tabular}} & $\left|\begin{array}{l}23.04 \\
22.84 \\
22.63 \\
22.43 \\
22.23 \\
22.02\end{array}\right|$ & $\begin{array}{l}209,000 \\
206,000 \\
202,000 \\
199,000 \\
195,000 \\
192,000\end{array}$ \\
\hline $\begin{array}{l}1 \\
2 \\
3 \\
4 \\
5 \\
6\end{array}$ & $\overline{2}$ & 210 & $\begin{array}{l}3.20 \\
3.90 \\
4.60 \\
5.50 \\
6.65 \\
7.48\end{array}$ & $\begin{array}{r}6,020 \\
8,320 \\
11,000 \\
14,800 \\
20,200 \\
25,000\end{array}$ & \begin{tabular}{|l|}
13.74 \\
13.92 \\
14.15 \\
14.39 \\
14.75 \\
15.40
\end{tabular} & $\begin{array}{l}76,700 \\
78,900 \\
82,400 \\
84,800 \\
89,600 \\
96,800\end{array}$ & \multicolumn{2}{|c|}{\begin{tabular}{|l|l|}
23.87 & 225,000 \\
24.18 & 231,000 \\
24.48 & 236,000 \\
24.76 & 242,000 \\
25.03 & 246,000 \\
25.29 & 252,000
\end{tabular}} & \multicolumn{2}{|c|}{\begin{tabular}{|l|l}
26.25 & 270,000 \\
26.15 & 270,000 \\
26.04 & 266,000 \\
25.92 & 264,000 \\
25.77 & 262,000 \\
25.62 & 258,000 \\
25.60 & 258.00
\end{tabular}} & \multicolumn{2}{|c|}{\begin{tabular}{|l|l}
21.82 & 189,000 \\
21.61 & 185,000 \\
21.38 & 182,000 \\
21.16 & 178,000 \\
20.95 & 175,000 \\
20.72 & 170,000
\end{tabular}} \\
\hline \multirow[t]{2}{*}{$\begin{array}{r}7 \\
8 \\
9 \\
10 \\
11 \\
12 \\
\end{array}$} & $\begin{array}{r}2.21 \\
2.22 \\
-2.24 \\
2\end{array}$ & $\begin{array}{r}3,210 \\
3,210 \\
3,330 \\
\end{array}$ & $\begin{array}{r}8.20 \\
8.80 \\
9.30 \\
9.75 \\
10.08 \\
10.40 \\
\end{array}$ & $\begin{array}{l}29,200 \\
33,100 \\
36,600 \\
40,400 \\
42,800 \\
45,200 \\
\end{array}$ & \multicolumn{2}{|c|}{\begin{tabular}{|l|l}
15.80 & 102,000 \\
16.22 & 107,000 \\
16.70 & 113,000 \\
17.20 & 120,000 \\
17.75 & 127,000 \\
18.20 & 133,000 \\
\end{tabular}} & \multicolumn{2}{|c|}{\begin{tabular}{|l|l|}
25.51 & 256,000 \\
25.70 & 260,000 \\
25.91 & 264,000 \\
26.06 & 268,000 \\
26.21 & 270,000 \\
26.31 & 272,000 \\
\end{tabular}} & \multicolumn{2}{|c|}{\begin{tabular}{|l|l|}
25.44 & 254,000 \\
25.27 & 252,000 \\
25.10 & 248,000 \\
24.90 & 244,000 \\
24.71 & 240,000 \\
24.51 & 236,000 \\
\end{tabular}} & \multicolumn{2}{|c|}{\begin{tabular}{|l|l|l}
20.52 & 167,000 \\
20.30 & 164,000 \\
20.09 & 161,000 \\
19.87 & 158,000 \\
19.65 & 153,000 \\
19.42 & 150,000 \\
\end{tabular}} \\
\hline & \multicolumn{2}{|c|}{ Aug. 19} & \multicolumn{2}{|c|}{ Aug. 20} & \multicolumn{2}{|c|}{ Aug. 2} & \multicolumn{2}{|c|}{ Aug. 22} & & 1g. 23 & & 24 \\
\hline 2 & .98 & $\begin{array}{l}0 \\
0\end{array}$ & & & & & 4.83 & 11,800 & 4.24 & 9,620 & 4.35 & 10,200 \\
\hline & & & $\begin{array}{l}11.28 \\
10.65\end{array}$ & & $\begin{array}{l}6.00 \\
5.75\end{array}$ & & 4.74 & 11,400 & 4.32 & 9,810 & 4.35 & 10,200 \\
\hline & & & $\begin{array}{l}0.10 \\
9.60\end{array}$ & & $\begin{array}{l}5.57 \\
5.42\end{array}$ & $\begin{array}{l}15,300 \\
14,400\end{array}$ & 4.66 & 11,400 & 4.48 & 10,600 & 4.32 & 9,810 \\
\hline 2 & & & $\begin{array}{l}9.1 \\
8.7\end{array}$ & & & & $\begin{array}{ll}4 & 57\end{array}$ & 11,000 & 4.56 & 11,000 & 4.23 & 9,620 \\
\hline & & & & & & & 4.46 & 10,600 & $4.5 \overline{4}$ & 10,600 & 4.14 & 9,240 \\
\hline & & & & & & & 1.32 &, 8 & .4 & 10,200 & $\mid .02$ & 8,680 \\
\hline
\end{tabular}

\section{ROANOKE RIVER AT ROANOKE RAPIDS, N. C.}

Location.-Lat. $36^{\circ} 28^{\prime} 15^{\prime \prime}$, long. $77^{\circ} 38^{\prime} 05^{\prime \prime}$, 11/2 miles downstream from State highway bridge at city of Roanoke Rapids, Halifax County. Datum of gage is 43.83 feet above mean sea level, datum of 1929, supplementary adjustment of 1936. Auxiliary gage on highway bridge at Weldon, Halifax County. Datum of auxiliary gage is $\mathbf{1 6 . 0 2}$ feet above mean sea level, datum of 1929 , supplementary adjustment of 1936 .

Drainage AREA. - 8,410 square miles.

GAGE-HEIGHT RECORD.-Water-stage recorder graph, except for period 10 a.m. Aug. 17 to 10 a.m. Aug. 22 where record is from graph based on floodmarks, several readings of staff gage, and shape of graph based on frequent readings of staff gage or readings referred to reference points at Weldon, N. C.

DISCHARGE RECORD. - Stage-discharge relation defined by current-meter measurements up to 260,000 second-feet. Gage heights used to half-tenths between 2.4 and 5.3 feet; hundredths below and tenths above these limits. Percent submergence was a factor in computing discharge from 6 a.m. Aug. 15 to 2 a.m. Aug. 23.

MaXima.-1940: Discharge, 261,000 second-feet 10:30 a.m. Aug. 18 (gage height, 39.0 feet, from floodmarks).

1911-39: Discharge, 158,000 second-feet Mar. 18, 1912 (gage height, 16.2 feet, former site and datum, from graph based on gage readings). 


\section{FLOODS OF AUGUST 1940 IN THE SOUTHEASTERN STATES}

Weather Bureau records at Weldon, $3 \frac{1}{2}$ miles downstream from this station, show observed stages on Nov. 26, 1877, and Mar. 18, 1912, to be lower by about 4.5 feet and 7.5 feet, respectively, than that observed Aug. 18, 1940. For records of previous floods at Old Gaston, 9 miles upstream, see that section of this report.

REMARKS.-Flood runoff not affected by artificial storage.

Mean discharge, in second-feet, 1940

\begin{tabular}{|c|c|c|c|c|c|c|c|c|c|c|c|}
\hline Day & Aug. & Sept. & Day & Aug. & Sept. & Day & Aug. & Sept. & Day & Aug. & Sept. \\
\hline $\begin{array}{l}1 \\
2 \\
3 \\
4 \\
5 \\
6 \\
7 \\
8\end{array}$ & $\begin{array}{r}11,000 \\
15,400 \\
8,470 \\
5,500 \\
4,000 \\
3,660 \\
3,900 \\
3,700\end{array}$ & $\begin{array}{r}9,450 \\
21,600 \\
18,700 \\
12,500 \\
9,100 \\
7,800 \\
7,800 \\
6,900\end{array}$ & $\begin{array}{r}9 \\
10 \\
11 \\
12 \\
13 \\
14 \\
15 \\
16\end{array}$ & $\begin{array}{r}3,800 \\
4,420 \\
4,760 \\
4,310 \\
3,700 \\
4,330 \\
63,300 \\
106,000\end{array}$ & $\begin{array}{l}6,600 \\
6,170 \\
6,460 \\
5,500 \\
5,380 \\
5,000 \\
4,640 \\
4,760\end{array}$ & $\begin{array}{l}17 \\
18 \\
19 \\
20 \\
21 \\
22 \\
23 \\
24\end{array}$ & $\mid \begin{array}{r}209,000 \\
254,000 \\
205,000 \\
133,000 \\
47,200 \\
15,600 \\
12,400 \\
11,300\end{array}$ & $\begin{array}{l}4,640 \\
4,100 \\
4,100 \\
4,000 \\
4,000 \\
3,900 \\
3,800 \\
3,900\end{array}$ & $\begin{array}{l}25 \\
26 \\
27 \\
28 \\
29 \\
30 \\
31\end{array}$ & $\begin{array}{r}10,500 \\
9,280 \\
9,450 \\
8,760 \\
10,500 \\
12,100 \\
10,200\end{array}$ & $\begin{array}{l}3,510 \\
3,600 \\
3,600 \\
4,100 \\
4,530 \\
4,000\end{array}$ \\
\hline \multicolumn{10}{|c|}{$\begin{array}{l}\text { Monthly mean diseharge, in second-feet } \\
\text { Runoff, in inches }\end{array}$} & $\begin{array}{r}38,990 \\
\mathbf{5 . 3 4}\end{array}$ & $\begin{array}{r}6,471 \\
0.86\end{array}$ \\
\hline
\end{tabular}

Gage height, in feet, and discharge, in second-feet, at indicated time, 1940

\begin{tabular}{|c|c|c|c|c|c|c|c|c|c|c|c|c|}
\hline \multirow{2}{*}{ Hour } & \multicolumn{2}{|c|}{ Aug. 14} & \multicolumn{2}{|c|}{ Aug. 15} & \multicolumn{2}{|c|}{ Aug. 16} & \multicolumn{2}{|c|}{ Aug. 17} & \multicolumn{2}{|c|}{ Aug. 18} & \multicolumn{2}{|c|}{ Aug. 19} \\
\hline & $\begin{array}{c}\text { Gage } \\
\text { ht. }\end{array}$ & $\begin{array}{c}\text { Dis- } \\
\text { charge }\end{array}$ & $\begin{array}{c}\text { Gage } \\
\text { ht. }\end{array}$ & $\begin{array}{c}\text { Dis- } \\
\text { charge }\end{array}$ & $\begin{array}{c}\text { Gage } \\
\text { ht. }\end{array}$ & $\begin{array}{c}\text { Dis- } \\
\text { charge }\end{array}$ & $\begin{array}{c}\text { Gage } \\
\text { ht. }\end{array}$ & $\begin{array}{c}\text { Dis- } \\
\text { charge }\end{array}$ & $\begin{array}{c}\text { Gage } \\
\text { ht. }\end{array}$ & $\begin{array}{c}\text { Dis- } \\
\text { charge }\end{array}$ & $\begin{array}{c}\text { Gage } \\
\text { ht. }\end{array}$ & $\begin{array}{c}\text { Dis- } \\
\text { charge }\end{array}$ \\
\hline \multirow{3}{*}{$\begin{array}{l}1 \\
2 \\
3 \\
4 \\
5 \\
6\end{array}$} & 3.78 & 3,7 & \multirow{3}{*}{$\begin{array}{r}9.99 \\
10.50 \\
12.15 \\
12.35 \\
12.60 \\
13.70\end{array}$} & \multirow{3}{*}{$\begin{array}{l}27,200 \\
30,000 \\
40,400 \\
41,800 \\
43,200 \\
50,700\end{array}$} & 19.27 & 85 & 29.25 & 159,000 & 38.4 & 252, & 37.6 & 235 \\
\hline & $\overline{3} . \overline{3}$ & 3,600 & & & $19 . \overline{64}$ & 86,400 & $\overline{30 . \overline{4}}$ & $\overline{1} \overline{3}, 000$ & $\overline{3} \overline{8} \cdot \overline{6}$ & $\overline{2} \overline{5}, 0 \overline{0}$ & $3 \overline{7} . \overline{2}$ & $\overline{2} \overline{\overline{7}}, 00 \overline{0}$ \\
\hline & 3.65 & 3,420 & & & 20.10 & 89,000 & $\overline{31.65}$ & 184,000 & $\overline{38} . \overline{8}$ & 258,000 & $36 . \overline{9}$ & $\overline{2} \overline{2}, 000$ \\
\hline \multirow{3}{*}{$\begin{array}{r}7 \\
8 \\
9 \\
10 \\
11 \\
N\end{array}$} & 3.61 & 3,320 & \multirow{3}{*}{$\begin{array}{l}13.75 \\
14.20 \\
14.85 \\
15.30 \\
15.75 \\
16.70\end{array}$} & \multirow{3}{*}{$\begin{array}{l}50,900 \\
53,400 \\
58,000 \\
60,600 \\
64,400 \\
71,700\end{array}$} & 20.60 & 91,800 & 32.80 & 196,000 & 38.9 & 259,000 & 36.5 & 219,000 \\
\hline & $\overline{3} \overline{1}$ & 3,140 & & & $2 \overline{1} . \overline{2}$ & 95,900 & $\overline{3} \overline{3} . \overline{7}$ & 207,000 & 39.0 & 261,000 & $\overline{3} \overline{1} .1$ & $2 \overline{14}, 000$ \\
\hline & $\overline{3} . \overline{4}$ & 3,230 & & & $\overline{2} 2 . \overline{0}$ & 101,000 & $\overline{34.6}$ & 215,000 & 39.0 & 261,000 & $\overline{35.6}$ & 205,000 \\
\hline \multirow{3}{*}{$\begin{array}{l}1 \\
2 \\
3 \\
4 \\
5 \\
6\end{array}$} & 3.55 & 3,230 & \multirow{3}{*}{$\begin{array}{l}16.97 \\
17.20 \\
17.35 \\
17.54 \\
17.67 \\
17.95\end{array}$} & \multirow{3}{*}{$\begin{array}{l}74,300 \\
75,200 \\
76,100 \\
76,900 \\
77,700 \\
80,200\end{array}$} & 22.80 & 106,000 & 35.4 & 222,000 & 38.9 & 259,000 & 35.1 & 200,000 \\
\hline & $\overline{3.67}$ & 3,420 & & & $\overline{2} \overline{3} . \overline{0}$ & 112,000 & $\overline{36.2}$ & 230,000 & 38.8 & $\overline{2} \overline{8}, 000$ & $3 \overline{4} . \overline{7}$ & 192,000 \\
\hline & $\overline{3.78}$ & 3,700 & & & $\overline{24} . \overline{5}$ & 119,000 & $3 \overline{6} . \overline{7}$ & $\overline{2} 36,000$ & $3 \overline{8} . \overline{6}$ & $\overline{25}, 000$ & 34.2 & 187,000 \\
\hline \multirow{3}{*}{$\begin{array}{r}7 \\
8 \\
9 \\
10 \\
11 \\
12\end{array}$} & $\overline{3} . \overline{3}$ & 4,000 & \multirow{3}{*}{$\begin{array}{l}18.20 \\
18.39 \\
18.56 \\
18.72 \\
18.85 \\
19.00\end{array}$} & \multirow{3}{*}{$\begin{array}{l}81,000 \\
82,600 \\
83,300 \\
83,200 \\
84,000 \\
84,700\end{array}$} & 25.50 & 127,000 & 37.2 & 240,000 & 38.4 & 249,000 & $\mathbf{3} 3 . \overline{7}$ & $18 \overline{2}, 000$ \\
\hline & 4.05 & 4,200 & & & 26.72 & 137,000 & 37.7 & 246,000 & 38.1 & $\overline{24} \overline{5}, 000$ & 33.1 & $\overline{17} \overline{3}, 000$ \\
\hline & 9.00 & 22,200 & & & $|\overline{27} . \overline{9} \overline{5}|$ & 149,000 & $\overrightarrow{3} \overline{8} . \overrightarrow{1}$ & 248,000 & $\overline{37} \cdot \overline{9}$ & $\overline{2} \overline{3}, 000$ & $\overrightarrow{32.6}$ & $1 \overline{6}, 000$ \\
\hline
\end{tabular}

\begin{tabular}{|c|c|c|c|c|c|c|c|c|c|c|c|c|}
\hline \multirow{7}{*}{$\begin{array}{r}2 \\
4 \\
6 \\
8 \\
10 \\
\mathbf{N}\end{array}$} & \multicolumn{2}{|c|}{ Aug. 20} & \multicolumn{2}{|c|}{ Aug. 21} & \multicolumn{2}{|c|}{ Aug. 22} & \multicolumn{2}{|c|}{ Aug. 23} & \multicolumn{2}{|c|}{ Aug. 24} & \multicolumn{2}{|c|}{ Aug. 25} \\
\hline & 32. & 160,000 & 24. & 90,900 & 11.3 & 16,400 & 7.04 & 13,500 & 6.32 & 10,900 & & \\
\hline & 31.5 & 156,000 & 23 & 82,000 & 10.6 & & 6.94 & 13,300 & 6.34 & 10,900 & 6.33 & 10,900 \\
\hline & 30.9 & 149 & 21.8 & 70 & 10.0 & 15 & 6.87 & 13,300 & 6.39 & 11,300 & & \\
\hline & 30.3 & 142,000 & 20.6 & 58,600 & 9.5 & 17,000 & 6.80 & 12,900 & 6.42 & 11,300 & 6.29 & 10,900 \\
\hline & 29.7 & 137,000 & 19.2 & 46,100 & 9.0 & 17,100 & 6.75 & 12,900 & 6.45 & 11,300 & & 50 \\
\hline & 29. & 134,000 & 18 & 37,500 & 8.5 & 16,200 & 6.67 & 12,500 & 6.51 & 11,700 & 6.22 & 10,500 \\
\hline 2 & 28.5 & 129,000 & 16.9 & 33,200 & 8.25 & 15 , & 6.62 & 12,100 & 6.54 & 11,700 & & \\
\hline 1 & 27.9 & 123 & 15 & & 7.93 & & 6.55 & & 6.52 & & 6.13 & 10,200 \\
\hline 6 & 27.2 & 118,000 & 14.7 & 24,800 & 7.67 & 15,100 & 6.49 & 11,700 & 6.45 & 11,300 & & \\
\hline $\begin{array}{r}8 \\
10\end{array}$ & $\begin{array}{l}26.5 \\
25.7\end{array}$ & $\begin{array}{l}114,000 \\
105,000\end{array}$ & $\begin{array}{l}13.7 \\
12.8\end{array}$ & $\begin{array}{l}20,000 \\
17,400\end{array}$ & $\begin{array}{l}7.40 \\
7.26\end{array}$ & $\begin{array}{l}14,400 \\
14,300\end{array}$ & $\begin{array}{l}6.43 \\
6.37\end{array}$ & $\begin{array}{l}11,300 \\
11,300\end{array}$ & $\begin{array}{l}6.42 \\
6.40\end{array}$ & $\begin{array}{l}11,300 \\
11,300\end{array}$ & .02 & 9,800 \\
\hline 12 & 24.9 & 98,200 & 12.0 & 16,100 & 7.13 & 13,800 & 6.34 & 10,900 & 6.36 & 11,300 & 5.95 & 9,800 \\
\hline
\end{tabular}

Supplemental Reconds.-Aug. 15, 6:30 a.m., gage height 13.34 feet; diseharge, 47,700 second-feet. Aug. 18, 10:30 a.m., gage height, 39.0 feet; discharge, 261,000 second-feet.

ROANOKE RIVER NEAR SCOTLAND NECK, N. C.

LoCATION.-Lat. $36^{\circ} 12^{\prime} 30^{\prime \prime}$, long. $77^{\circ} 23^{\prime} 10^{\prime \prime}$, at bridge on U. S. Highway 258,1 mile downstream from tributary on right, 3 miles downstream from Bridgers 
Creek, and 5\%/4 miles north of Scotland Neck, Halifax County. Auxiliary gage is at Atlantic Coast Line Railroad bridge $81 / 4$ miles downstream (site of old station at Neal, N. C.). Datum of both gages is 5.77 feet above mean sea level, sea level datum of 1929, supplementary adjustment of 1936 .

Drainage AREA.- 8,700 square miles.

GAGE-HEIGHT RECORD.—Graphs based on wire-weight gage readings Aug. 15-29 and Sept. 3-12, and auxiliary staff gage readings from 3 p.m. Aug. 19 to Aug. 26. Corps of Engineers, War Department, furnished records Aug. 16 to $12 \mathrm{~m}$. Aug. 19 from graph based on readings of auxiliary staff gage at Caledonia Farm above Scotland Neck. No gage-height record Aug. 1-14, Aug. 30 to Sept. 2, and Sept. 13-30.

DISCHARGE RECORD.-Stage-discharge relation defined by current-meter measurements up to.241,000 second-feet. Discharge computed by using fall as a factor. Discharge for periods of no gage-height record based on records for station at Roanoke Rapids. Discharge Aug. 15 to $12 \mathrm{~m}$. Aug. 19 furnished by Corps of Engineers, War Department.

Maxima.-1940: Discharge, 260,000 second-feet 8 a.m. Aug. 19. Gage height observed, 41.98 feet 2 p.m. Aug. 19.

1930-39: Stage observed, 35.1 feet Jan. 24, 1936 (from unpublished United States Weather Bureau records adjusted to present datum, discharge not determined).

The following data on major flood stages (adjusted to present datum) were furnished by North Carolina State Highway Commission: About 37.8 feet 1877, 36.8 feet Mareh 1912, 34.9 feet 1919, 32.9 feet 1924 (discharges not determined). REMARKs.-Flood runoff not affected by artificial storage.

Mean discharge, in second-feet, 1940

\begin{tabular}{r|r|r||r|r|r||r|r|r||r|r|r}
\hline Day & Aug. & Sept. & Day & Aug. & Sept. & Day & Aug. & Sept. & Day & Aug. & Sept. \\
\hline 1 & 11,000 & 11,000 & 9 & 4,000 & 6,900 & 17 & 111,000 & 5,000 & 25 & 19,300 & 4,200 \\
2 & 13,000 & 15,000 & 10 & 4,200 & 6,420 & 18 & 208,000 & 5,000 & 26 & 15,300 & 3,800 \\
3 & 15,000 & 18,100 & 11 & 4,600 & 6,840 & 19 & 253,000 & 4,400 & 27 & 13,000 & 3,800 \\
4 & 8,000 & 14,900 & 12 & 4,600 & 6,320 & 20 & 215,000 & 4,400 & 28 & 11,900 & 3,800 \\
5 & 5,500 & 12,200 & 13 & 4,200 & 5,500 & 21 & 156,000 & 4,200 & 29 & 11,500 & 4,400 \\
6 & 4,000 & 10,000 & 14 & 3,800 & 5,500 & 22 & 86,300 & 4,200 & 30 & 11,000 & 4,800 \\
7 & 4,000 & 8,290 & 15 & 20,400 & 5,500 & 23 & 42,800 & 4,200 & 31 & 13,000 & $-\ldots$ \\
8 & 4,000 & 7,570 & 16 & 56,200 & 5,000 & 24 & 26,200 & 4,000 & & \\
\hline
\end{tabular}

Gage height, in feet, and discharge, in second-feet, at indicated time, 1940

\begin{tabular}{|c|c|c|c|c|c|c|c|c|c|c|c|c|}
\hline \multirow{2}{*}{ Hour } & \multicolumn{2}{|c|}{ Aug. 15} & \multicolumn{2}{|c|}{ Aug. 16} & \multicolumn{2}{|c|}{ Aug. 17} & \multicolumn{2}{|c|}{ Aug. 18} & \multicolumn{2}{|c|}{ Aug. 19} & \multicolumn{2}{|c|}{ Aug. 20} \\
\hline & $\begin{array}{c}\text { Gage } \\
\text { ht. }\end{array}$ & $\begin{array}{c}\text { Dis- } \\
\text { charge }\end{array}$ & $\begin{array}{c}\text { Gage } \\
\text { bt. }\end{array}$ & $\begin{array}{c}\text { Dis- } \\
\text { charge }\end{array}$ & $\begin{array}{c}\text { Gage } \\
\text { ht. }\end{array}$ & $\begin{array}{c}\text { Dis- } \\
\text { charge }\end{array}$ & $\begin{array}{l}\text { Gage } \\
\text { ht. }\end{array}$ & $\begin{array}{l}\text { Dis- } \\
\text { charge }\end{array}$ & $\begin{array}{c}\text { Gage } \\
\text { ht. }\end{array}$ & $\begin{array}{c}\text { Dis- } \\
\text { charge }\end{array}$ & $\begin{array}{c}\text { Gage } \\
\text { ht. }\end{array}$ & $\begin{array}{c}\text { Dis- } \\
\text { charge }\end{array}$ \\
\hline \multirow[t]{2}{*}{$\begin{array}{r}4 \\
8 \\
N \\
4 \\
8 \\
12 \\
\end{array}$} & $\begin{array}{l}10.6 \\
11.9 \\
14.4 \\
17.5 \\
22.5 \\
28.7 \\
\end{array}$ & $\begin{array}{r}6,200 \\
11,700 \\
19,400 \\
26,500 \\
35,500 \\
42,000 \\
\end{array}$ & $\begin{array}{l}29.5 \\
30.0 \\
30.6 \\
31.1 \\
31.7 \\
32.2 \\
\end{array}$ & $\begin{array}{l}46,500 \\
51,000 \\
55,500 \\
60,000 \\
66,000 \\
74,000 \\
\end{array}$ & $\begin{array}{l}32.7 \\
33.3 \\
34.0 \\
34.7 \\
35.5 \\
36.5 \\
\end{array}$ & $\begin{array}{r}84,000 \\
97,000 \\
109,000 \\
123,000 \\
138,000 \\
154,000 \\
\end{array}$ & $\begin{array}{l}37.6 \\
38.72 \\
39.61 \\
40.47 \\
41.00 \\
41.41 \\
\end{array}$ & $\begin{array}{l}170,000 \\
191,000 \\
213,000 \\
231,000 \\
242,000 \\
253,000 \\
\end{array}$ & $\begin{array}{l}41.68 \\
41.88 \\
41.97 \\
41.98 \\
41.90 \\
41.76 \\
\end{array}$ & $\begin{array}{l}000 \\
000 \\
000 \\
000 \\
000 \\
000 \\
\end{array}$ & $\begin{array}{l}41.60 \\
41.37 \\
41.12 \\
40.84 \\
40.53 \\
40.19 \\
\end{array}$ & \\
\hline & \multicolumn{2}{|c|}{ Aug. 21} & \multicolumn{2}{|c|}{ Aug. 22} & \multicolumn{2}{|c|}{ Aug. 23} & \multicolumn{2}{|c|}{ Aug. 24} & \multicolumn{2}{|c|}{ Aug. 25} & \multicolumn{2}{|c|}{ Aug. 26} \\
\hline \multirow{4}{*}{$\begin{array}{r}4 \\
6 \\
8 \\
N \\
4 \\
6 \\
8 \\
12\end{array}$} & 39.8 & 177,000 & & & & & & & & & & 16 \\
\hline & 39. & $\begin{array}{l}166,000 \\
157,000\end{array}$ & 35.72 & 83,300 & $3 \overline{2} .60$ & $4 \overline{1}, 400$ & $\overline{2} \overline{9} . \overline{80}$ & $\overline{2} \overline{5}, \overline{900}$ & $\overline{2} \overline{4} . \overline{8}$ & 19,000 & $\overline{2} \overline{5} . \overline{0} \overline{0}$ & 15,200 \\
\hline & & & $3 \overline{4} . \overline{\mathrm{A}}$ & 69,600 & $\mathbf{3} \overline{1.83}$ & 35,100 & $\overline{2} \overline{9} . \overline{2} \overline{1}$ & $2 \overline{3}, 600$ & 26.87 & 18,200 & $2 \overline{4} .4$ & 14,400 \\
\hline & 38. & & $|34.16|$ & $-\overline{5}, \overline{300}$ & 31.11 & 31,400 & 28.66 & $-\overline{1}, \overline{900}$ & $|\overline{26} \overline{24}|$ & $\overline{17}, \overline{100}$ & $|23.9|$ & 13,900 \\
\hline
\end{tabular}




\section{BLACKWATER RIVER NEAR UNION HALL, VA.}

LOCATION.-Lat. $37^{\circ} 02^{\prime} 35^{\prime \prime}$, long. $79^{\circ} 41^{\prime} 07^{\prime \prime}$, at highway bridge at Kemps Ford, 3 miles upstream from Gills Creek and 3 miles north of Union Hall, Franklin County. Datum of gage is 693.13 feet above mean sea level (levels by Corps of Engineers, War Department).'

DraINAGE AREA.-208 square miles.

GAGE-HEIGHT RECORD.-Water-stage recorder graph.

DISCHARGE RECORD.-Stage-discharge relation defined by current-meter measurements up to 6,500 second-feet and extended to erest gage height by logarithmic plotting on basis of unit-hydrograph and flood-routing studies, and other comparisons with flood records for stations in Roanoke River Basin. Gage heights used to half-tenths between 3.2 to 4.8 feet; hundredths below and tenths above these limits.

Maxima.-1940: Discharge, 19,700 second-feet 8:30 p.m. Aug. 14 (gage height, 19.52 feet).

1925-39 : Discharge, 17,900 second-feet Aug. 19, 1939 (gage height, 18.50 feet).

Remarks.-The District Engineer, Corps of Engineers, War Department, Norfolk, - Va., furnished computed flood records by the unit-hydrograph and flood-routing methods used as a factor in determination of stage-discharge relation.

The Flood Control Advisory Committee, Department of Agriculture, furnished field party and equipment to obtain field data for determination of flood flows by the slope-area method on Blackwater River near Rockymount, Maggotty Creek at Boone's Mill, and Gills Creek near Union Hall.

Mean discharge, in second-feet, 1940

\begin{tabular}{|c|c|c|c|c|c|c|c|c|c|c|c|}
\hline Day & Aug. & Sept. & Day & Aug. & Sept. & Day & Aug. & Sept. & Day & Aug. & Sept. \\
\hline $\begin{array}{l}1 \\
2 \\
3 \\
4 \\
5 \\
6 \\
7 \\
8\end{array}$ & $\begin{array}{l}186 \\
154 \\
137 \\
137 \\
143 \\
168 \\
260 \\
566\end{array}$ & $\begin{array}{r}1,500 \\
704 \\
517 \\
438 \\
386 \\
386 \\
327 \\
306\end{array}$ & $\begin{array}{r}9 \\
10 \\
11 \\
12 \\
13 \\
14 \\
15 \\
16\end{array}$ & $\begin{array}{r}247 \\
161 \\
175 \\
354 \\
269 \\
10,200 \\
13,400 \\
9,440\end{array}$ & $\begin{array}{l}293 \\
280 \\
268 \\
252 \\
243 \\
235 \\
227 \\
223\end{array}$ & $\begin{array}{l}17 \\
18 \\
19 \\
20 \\
21 \\
22 \\
23 \\
24\end{array}$ & $\begin{array}{r}3,570 \\
1,510 \\
983 \\
732 \\
599 \\
523 \\
490 \\
420\end{array}$ & $\begin{array}{l}216 \\
212 \\
208 \\
204 \\
201 \\
197 \\
189 \\
186\end{array}$ & $\begin{array}{l}25 \\
26 \\
27 \\
28 \\
29 \\
30 \\
31\end{array}$ & $\begin{array}{r}386 \\
399 \\
367 \\
345 \\
414 \\
390 \\
1,610\end{array}$ & $\begin{array}{l}256 \\
268 \\
197 \\
182 \\
179 \\
175\end{array}$ \\
\hline \multicolumn{10}{|c|}{$\begin{array}{l}\text { Monthly mean discharge, in second-feet } \\
\text { Runoff, in inches }\end{array}$} & $\begin{array}{r}1,572 \\
8.72\end{array}$ & $\begin{array}{r}315 \\
1.68\end{array}$ \\
\hline
\end{tabular}


ROANOKE RIVER BASIN

Gage height, in feet, and discharge, in second-feet, at indicated time, 1940

\begin{tabular}{|c|c|c|c|c|c|c|c|c|c|c|c|c|}
\hline \multirow{2}{*}{ Hour } & \multicolumn{2}{|c|}{ Aug. 13} & \multicolumn{2}{|c|}{ Aug. 14} & \multicolumn{2}{|c|}{ Aug. 15} & \multicolumn{2}{|c|}{ Aug. 16} & \multicolumn{2}{|c|}{ Aug. 17} & \multicolumn{2}{|c|}{ Aug. 18} \\
\hline & $\begin{array}{c}\text { Gage } \\
\text { ht. }\end{array}$ & $\begin{array}{l}\text { Dis- } \\
\text { charge }\end{array}$ & $\begin{array}{c}\text { Gage } \\
\text { ht. }\end{array}$ & $\begin{array}{c}\text { Dis- } \\
\text { charge }\end{array}$ & $\begin{array}{c}\text { Gage } \\
\text { ht. }\end{array}$ & $\begin{array}{c}\text { Dis- } \\
\text { charge }\end{array}$ & $\begin{array}{c}\text { Gage } \\
\text { ht. }\end{array}$ & $\begin{array}{c}\text { Dis- } \\
\text { charge }\end{array}$ & $\begin{array}{c}\text { Gage } \\
\text { ht. }\end{array}$ & $\begin{array}{c}\text { Dis- } \\
\text { charge }\end{array}$ & $\begin{array}{c}\text { Gage } \\
\text { ht. }\end{array}$ & $\begin{array}{c}\text { Dis- } \\
\text { charge }\end{array}$ \\
\hline $\begin{array}{l}1 \\
\mathbf{2} \\
\mathbf{3} \\
\mathbf{4} \\
\mathbf{5} \\
\mathbf{6}\end{array}$ & $\begin{array}{r}2.42 \\
2.41 \\
2.43\end{array}$ & $\begin{array}{l}280 \\
276 \\
285\end{array}$ & $\begin{array}{l}2.45 \\
2.71 \\
3.13 \\
3.27 \\
3.40 \\
3.50\end{array}$ & $\begin{array}{l}293 \\
409 \\
617 \\
678 \\
756 \\
808\end{array}$ & $\begin{array}{l}18.59 \\
18.68 \\
18.78 \\
18.76 \\
18.55 \\
18.18\end{array}$ & $\begin{array}{l}18,100 \\
18,300 \\
18,400 \\
18,400 \\
18,100 \\
17,400\end{array}$ & $\begin{array}{l}13.89 \\
13.62 \\
13.27 \\
13.13 \\
13.18 \\
13.40\end{array}$ & $\begin{array}{r}10,400 \\
9,940 \\
9,520 \\
9,250 \\
9,380 \\
9,660\end{array}$ & $\begin{array}{l}9.44 \\
9.25 \\
9.12 \\
8.87 \\
8.70 \\
8.48\end{array}$ & $\begin{array}{l}5,110 \\
4,930 \\
4,840 \\
4,660 \\
4,480 \\
4,300\end{array}$ & $\begin{array}{r}5.40 \\
5.23 \\
5.04\end{array}$ & $\begin{array}{r}1,910 \\
1,780 \\
1,660\end{array}$ \\
\hline $\begin{array}{r}7 \\
8 \\
9 \\
10 \\
11 \\
\mathrm{~N}\end{array}$ & $\begin{array}{r}2.40 \\
2.39 \\
2.44\end{array}$ & $\begin{array}{r}272 \\
268 \\
289\end{array}$ & $\begin{array}{r}3.83 \\
5.55 \\
8.55 \\
11.50 \\
13.53 \\
15.00\end{array}$ & $\begin{array}{r}998 \\
2,050 \\
4,390 \\
7,270 \\
9,800 \\
12,000\end{array}$ & $\begin{array}{l}17.72 \\
17.15 \\
16.55 \\
15.95 \\
15.45 \\
15.00\end{array}$ & $\begin{array}{l}16,500 \\
15,600 \\
14,600 \\
13,600 \\
12,600 \\
12,000\end{array}$ & $\begin{array}{l}13.90 \\
14.38 \\
14.52 \\
14.53 \\
14.65 \\
14.71\end{array}$ & $\begin{array}{l}10,400 \\
11,100 \\
11,200 \\
11,200 \\
11,400 \\
11,600\end{array}$ & $\begin{array}{l}8.32 \\
8.23 \\
8.20 \\
8.23 \\
8.16 \\
7.94\end{array}$ & $\begin{array}{l}4,120 \\
4,030 \\
4,030 \\
4,030 \\
4,030 \\
3,790\end{array}$ & $\begin{array}{r}4.88 \\
4.78 \\
4.67\end{array}$ & $\begin{array}{r}1,600 \\
1,540 \\
1,450\end{array}$ \\
\hline $\begin{array}{l}1 \\
2 \\
3 \\
4 \\
5 \\
6\end{array}$ & $\begin{array}{r}2 . \overline{43} \\
2 . \overline{4} 0 \\
2 . \overline{3} 5\end{array}$ & 285 & $\begin{array}{l}16.44 \\
17.67 \\
17.94 \\
17.90 \\
17.98 \\
18.45\end{array}$ & $\begin{array}{l}14,300 \\
16,500 \\
16,800 \\
16,800 \\
17,000 \\
17,700\end{array}$ & $\begin{array}{l}14.75 \\
14.40 \\
14.05 \\
13.87 \\
13.67 \\
13.53\end{array}$ & $\begin{array}{r}11,700 \\
11,100 \\
10,500 \\
10,400 \\
10,100 \\
9,800\end{array}$ & $\begin{array}{l}14.45 \\
13.98 \\
13.72 \\
13.37 \\
13.00 \\
12.55\end{array}$ & $\begin{array}{r}11,100 \\
10,500 \\
10,100 \\
9,660 \\
9,120 \\
8,600\end{array}$ & $\begin{array}{l}7.63 \\
7.30 \\
7.00 \\
6.77 \\
6.54 \\
6.45\end{array}$ & $\begin{array}{l}3,550 \\
3,310 \\
3,070 \\
2,910 \\
2,680 \\
2,610\end{array}$ & $\begin{array}{r}4.58 \\
4.48 \\
4.38\end{array}$ & $\begin{array}{l}1, \overline{4} \mathbf{2 0} \\
1, \overline{3} 60 \\
1,300\end{array}$ \\
\hline $\begin{array}{r}7 \\
8 \\
9 \\
10 \\
11 \\
12 \\
\end{array}$ & $\begin{array}{r}2.32 \\
2.32 \\
2.36\end{array}$ & 239 & $\left|\begin{array}{l}19.13 \\
19.40 \\
19.48 \\
19.27 \\
18.90 \\
18.65\end{array}\right|$ & $\begin{array}{l}19,000 \\
19,500 \\
19,700 \\
19,300 \\
18,600 \\
18,100\end{array}$ & $\mid \begin{array}{l}13.32 \\
13.26 \\
13.60 \\
13.85 \\
13.95 \\
14.00\end{array}$ & $\begin{array}{r}9,520 \\
9,520 \\
9,940 \\
10,200 \\
10,500 \\
10,500 \\
\end{array}$ & $\mid \begin{array}{r}12.14 \\
11.67 \\
11.08 \\
10.62 \\
10.07 \\
9.67\end{array}$ & $\begin{array}{l}7,980 \\
7,500 \\
6,830 \\
6,300 \\
5,800 \\
5,400 \\
\end{array}$ & $\begin{array}{l}6.25 \\
6.13 \\
5.98 \\
5.83 \\
5.72 \\
5.60\end{array}$ & $\begin{array}{l}2,470 \\
2,400 \\
2,330 \\
2,190 \\
2,120 \\
2,050 \\
\end{array}$ & $\begin{array}{r}4.28 \\
4.23 \\
4.15 \\
\end{array}$ & $\begin{array}{l}1,240 \\
1,220 \\
1,160\end{array}$ \\
\hline & & 19 & $\mathbf{A u}$ & g. 20 & & Ig. 21 & & 22 & & g. 20 & & g. 24 \\
\hline $\begin{array}{r}4 \\
8 \\
N \\
4 \\
8 \\
12 \\
\end{array}$ & $\begin{array}{l}4.02 \\
3.89 \\
3.82 \\
3.73 \\
3.64 \\
3.56\end{array}$ & $\begin{array}{r}1,080 \\
1,020 \\
970 \\
942 \\
\mathbf{8 8 8} \\
\mathbf{8 3 4} \\
\end{array}$ & $\begin{array}{l}3.47 \\
3.38 \\
3.33 \\
3.30 \\
3.25 \\
3.21\end{array}$ & $\begin{array}{l}782 \\
756 \\
730 \\
704 \\
678 \\
652\end{array}$ & $\begin{array}{l}3.17 \\
3.12 \\
3.07 \\
3.06 \\
3.04 \\
3.01\end{array}$ & $\begin{array}{l}637 \\
612 \\
\mathbf{5 8 7} \\
\mathbf{5 8 2} \\
\mathbf{5 7 2} \\
\mathbf{5 5 7}\end{array}$ & $\begin{array}{l}2.98 \\
2.95 \\
2.93 \\
2.92 \\
2.90 \\
2.94\end{array}$ & $\begin{array}{l}\mathbf{5 4 2} \\
\mathbf{5 2 7} \\
\mathbf{5 1 7} \\
\mathbf{5 1 2} \\
\mathbf{5 0 2} \\
\mathbf{5 2 2}\end{array}$ & $\begin{array}{l}2.94 \\
2.93 \\
2.88 \\
2.83 \\
2.81 \\
2.79\end{array}$ & $\begin{array}{l}522 \\
517 \\
492 \\
467 \\
457 \\
447 \\
\end{array}$ & $\begin{array}{l}2.77 \\
2.75 \\
2.72 \\
2.71 \\
2.70 \\
2.69\end{array}$ & $\begin{array}{l}438 \\
428 \\
414 \\
409 \\
404 \\
399 \\
\end{array}$ \\
\hline
\end{tabular}

Supplemental Reconds.-Aug. 14, 8.30 p.m., gage height, 19.52 feet; discharge, 19,700 second-feet. Aug. 16, 11:30 a.m., gage height, 14.74 feet; discharge, 11,600 second-feet.

PIGG RIVER NEAR TOSHES, VA.

Location.-Lat. $36^{\circ} 59^{\prime} 01^{\prime \prime}$, long. $79^{\circ} 30^{\prime} 52^{\prime \prime}$, half a mile downstream from Fryingpan Creek and 1.7 miles northwest of Toshes, Pittsylvania County. Datum of gage is 602.55 feet above mean sea level (levels by Corps of Engineers, War Department).

DRAINAGE AREA.-394 square miles.

GAGE-HEIGHT RECORD.-Water-stage recorder graph except for periods 3 p.m. Aug. 14 to 1 p.m. Aug. 24 (recorder submerged) and Sept. 26, 27. Gage heights Aug. 14-20 obtained from graph based on floodmark, unit-hydrograph and floodrouting studies, and comparisons with records for other stations in Roanoke River Basin. No gage-height record Aug. 21-23, Sept. 26, 27.

DISCHARGE RECORD.-Stage-discharge relation defined by current-meter measurements up to 11,000 second-feet and extended to crest gage height by logarithmic plotting on basis of unit-hydrograph and flood-routing studies, and other comparisons with flood records for stations in Roanoke River Basin. Gage heights used to half-tenths between 4.2 and 5.9 feet; hundredths below and tenths above these limits. Diseharge for Aug. 21-23, Sept. 26, 27, computed on basis of records for Blackwater River near Union Hall and Roanoke River near Toshes and at Altavista.

Maxima.-1940: Discharge, 34,300 second-feet 8 a.m. Aug. 15 (gage height, 32.5 feet, from floodmark).

1930-39: Discharge, 15,400 second-feet Oct. 20, 1937 (gage height, 22.23 feet). 
Remarks.-The District Engineer, Corps of Engineers, War Department, Norfolk, Va., furnished computed flood records by the unit-hydrograph and flood-routing methods used as a factor in determination of stage-discharge relation and in preparation of stage graphs during flood period.

The Flood Control Advisory Committee, Department of Agriculture, furnished field party and equipment to obtain field data for determination of flood flow over dam on Pigg River near Glade Hill.

Mean discharge, in second-feet, 1940

\begin{tabular}{|c|c|c|c|c|c|c|c|c|c|c|c|}
\hline Day & Aug. & Sept. & Day & Aug. & Sept. & Day & Aug. & Sept. & Day & Aug. & Sept. \\
\hline $\begin{array}{l}1 \\
2 \\
3 \\
4 \\
5 \\
6 \\
7 \\
8\end{array}$ & $\begin{array}{l}768 \\
385 \\
304 \\
289 \\
281 \\
356 \\
560 \\
332\end{array}$ & $\begin{array}{l}744 \\
448 \\
385 \\
361 \\
343 \\
340 \\
329 \\
320\end{array}$ & $\begin{array}{r}9 \\
10 \\
11 \\
12 \\
13 \\
14 \\
15 \\
16\end{array}$ & $\begin{array}{r}332 \\
261 \\
276 \\
566 \\
377 \\
12,400 \\
26,200 \\
17,900\end{array}$ & $\begin{array}{l}315 \\
304 \\
302 \\
291 \\
276 \\
281 \\
286 \\
281\end{array}$ & $\begin{array}{l}17 \\
18 \\
19 \\
20 \\
21 \\
22 \\
23 \\
24\end{array}$ & $\begin{array}{r}7,140 \\
1,870 \\
1,170 \\
858 \\
700 \\
600 \\
530 \\
481\end{array}$ & $\begin{array}{r}268 \\
.268 \\
266 \\
268 \\
256 \\
247 \\
247 \\
242\end{array}$ & $\begin{array}{l}25 \\
26 \\
27 \\
28 \\
29 \\
30 \\
31\end{array}$ & $\begin{array}{l}464 \\
448 \\
432 \\
416 \\
464 \\
432 \\
708\end{array}$ & $\begin{array}{r}281 \\
350 \\
300 \\
259 \\
256 \\
254 \\
\end{array}$ \\
\hline \multicolumn{10}{|c|}{$\begin{array}{l}\text { Monthly mean discharge, in second-feet } \\
\text { Runoff, in inches }\end{array}$} & $\begin{array}{r}2,526 \\
7.39\end{array}$ & $\begin{array}{r}312 \\
0.88\end{array}$ \\
\hline
\end{tabular}

Gage height, in feet, and discharge, in second-feet, at indicated time, 1940

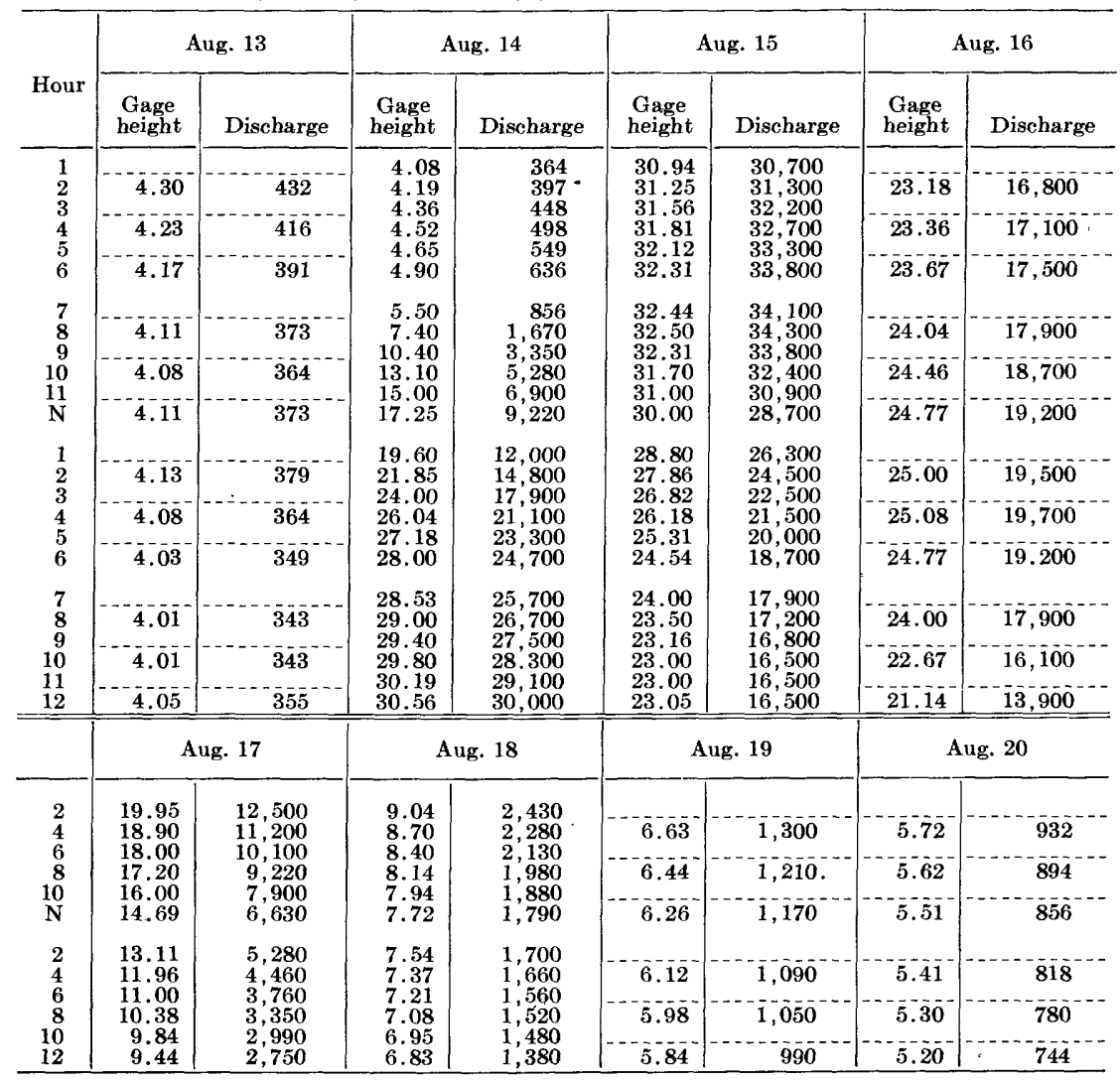


SNOW CREEK AT SAGO, VA.

Location.-Lat. $36^{\circ} 53^{\prime} 50^{\prime \prime}$, long. $79^{\circ} 39^{\prime} 05^{\prime \prime}$, at highway bridge 200 feet downstream from First Fork and three-quarters of a mile northwest of Sago, Franklin County. Datum of gage is 706.20 feet above mean sea level, datum of 1929.

Drainage AREA.-60 square miles.

GAGE-HEIGHT RECORD.-Water-stage recorder graph, except Aug. 19-22.

DISCHARGE RECORD. - Stage-discharge relation defined by current-meter measurements up to 2,200 second-feet and extended to erest gage height by logarithmic plotting on basis of velocity-area studies and comparisons with flood records of other stations in Roanoke River Basin. Gage heights used to half-tenths between 3.0 and 4.7 feet; hundredths below and tenths above these limits. Discharge for period when intake was stopped computed on basis of record for Pigg River near Toshes.

Maxima.-1940: Dischàrge, 12,000 second-feet 5 p.m. Aug. 14 (gage height, 22.98 feet).

1934-39 : Daily mean discharge, 1,700 second-feet (estimated) Jan. 19, 1936.

Mean discharge, in second-feet, 1940

\begin{tabular}{|c|c|c|c|c|c|c|c|c|c|c|c|}
\hline Day & Aug. & Sept. & Day & Aug. & Sept. & Day & Aug. & Sept. & Day & Aug. & Sept. \\
\hline $\begin{array}{l}1 \\
2 \\
3 \\
4 \\
5 \\
6 \\
7 \\
8\end{array}$ & $\begin{array}{r}277 \\
114 \\
92 \\
87 \\
84 \\
174 \\
118 \\
87\end{array}$ & $\begin{array}{l}89 \\
74 \\
70 \\
67 \\
66 \\
67 \\
62 \\
60\end{array}$ & $\begin{array}{r}9 \\
10 \\
11 \\
12 \\
13 \\
14 \\
15 \\
16\end{array}$ & $\begin{array}{r}84 \\
77 \\
86 \\
98 \\
72 \\
4,180 \\
1,860 \\
11,040\end{array}$ & $\begin{array}{l}61 \\
58 \\
57 \\
52 \\
50 \\
49 \\
48 \\
46\end{array}$ & $\begin{array}{l}17 \\
18 \\
19 \\
20 \\
21 \\
22 \\
23 \\
24\end{array}$ & $\begin{array}{r}261 \\
172 \\
150 \\
130 \\
110 \\
100 \\
109 \\
95\end{array}$ & $\begin{array}{l}43 \\
43 \\
43 \\
41 \\
39 \\
37 \\
36 \\
36\end{array}$ & $\begin{array}{l}25 \\
26 \\
27 \\
28 \\
29 \\
30 \\
31\end{array}$ & $\begin{array}{l}92 \\
90 \\
96 \\
88 \\
89 \\
88 \\
97\end{array}$ & $\begin{array}{l}42 \\
41 \\
36 \\
36 \\
35 \\
34\end{array}$ \\
\hline \multicolumn{10}{|c|}{$\begin{array}{l}\text { Monthly mean discharge, in second-feet } \\
\text { Runoff, in inchess }\end{array}$} & $\begin{array}{r}332 \\
6.38\end{array}$ & $\begin{array}{l}50.6 \\
0.94\end{array}$ \\
\hline
\end{tabular}

1 Discharge is different from that given in Water-Supply Paper 892. It is based on revisions not considered important enough for inclusion with revised records published in Water-Supply Paper 972.

Gage height, in feet, and discharge, in second-feet, at indicated time, 1940

\begin{tabular}{|c|c|c|c|c|c|c|c|c|c|c|c|c|}
\hline \multirow{2}{*}{ Hour } & \multicolumn{2}{|c|}{ Aug. 13} & \multicolumn{2}{|c|}{ Aug. 14} & \multicolumn{2}{|c|}{ Aug. 15} & \multicolumn{2}{|c|}{ Aug. 16} & \multicolumn{2}{|c|}{ Aug. 17} & \multicolumn{2}{|c|}{ Aug. 18} \\
\hline & $\begin{array}{c}\text { Gage } \\
\text { ht. }\end{array}$ & $\begin{array}{c}\text { Dis- } \\
\text { charge }\end{array}$ & $\begin{array}{c}\text { Gage } \\
\text { ht. }\end{array}$ & $\begin{array}{c}\text { Dis- } \\
\text { charge }\end{array}$ & $\begin{array}{c}\text { Gage } \\
\text { ht. }\end{array}$ & $\begin{array}{c}\text { Dis- } \\
\text { charge }\end{array}$ & $\begin{array}{c}\text { Gage } \\
\text { ht. }\end{array}$ & $\begin{array}{l}\text { Dis- } \\
\text { charge }\end{array}$ & $\begin{array}{c}\text { Gage } \\
\text { ht. }\end{array}$ & $\begin{array}{l}\text { Dis- } \\
\text { charge }\end{array}$ & $\begin{array}{c}\text { Gage } \\
\text { ht. }\end{array}$ & $\begin{array}{c}\text { Dis- } \\
\text { charge }\end{array}$ \\
\hline $\begin{array}{l}1 \\
2\end{array}$ & $2.5 \overline{2}$ & 74 & $\begin{array}{l}2.70 \\
2.90\end{array}$ & $\begin{array}{r}88 \\
106\end{array}$ & $\begin{array}{l}15.85 \\
15.35\end{array}$ & $\begin{array}{l}2,550 \\
2,370\end{array}$ & $13 . \overline{3}$ & 1,800 & 5.70 & 357 & 4.27 & 212 \\
\hline 4 & 2.50 & 72 & 陌 & 250 & 14.42 & $\begin{array}{l}2,1000 \\
1,980\end{array}$ & $\overline{\mathbf{1}} \overline{\mathrm{3}} . \overline{\mathrm{s}}$ & 1,700 & 5.40 & 325 & 4.12 & 198 \\
\hline $\begin{array}{l}5 \\
6\end{array}$ & 2.49 & 72 & $\begin{array}{l}5.00 \\
6.90\end{array}$ & $\begin{array}{l}295 \\
500\end{array}$ & $\begin{array}{l}13.98 \\
13.50\end{array}$ & $\begin{array}{l}1,840 \\
1,670\end{array}$ & 12.80 & 1.460 & $-\overline{5} . \overline{12}$ & 295 & $3 . \overline{9}$ & 184 \\
\hline $\begin{array}{l}7 \\
8\end{array}$ & 2.48 & 71 & \begin{tabular}{|}
11.25 \\
13.40
\end{tabular} \mid & $\begin{array}{l}1,120 \\
1,640\end{array}$ & $\begin{array}{l}12.95 \\
12.48\end{array} \mid$ & & $1 \overline{1} . \overline{3}$ & 1,210 & 4.85 & 265 & 3.89 & 176 \\
\hline $\begin{array}{r}9 \\
10\end{array}$ & $\overline{2} . \overline{8}$ & 71 & $\begin{array}{l}15.20 \\
16.10\end{array}$ & $\begin{array}{l}2,290 \\
2,680\end{array}$ & $\left|\begin{array}{l}12.70 \\
13.23\end{array}\right|$ & $\begin{array}{l}1,440 \\
1,580\end{array}$ & 10.70 & 1,040 & 4.69 & 250 & 3.84 & $17 \overline{1}$ \\
\hline $\begin{array}{l}11 \\
\mathrm{~N}\end{array}$ & 2.48 & 71 & $\left|\begin{array}{l}16.75 \\
17.70\end{array}\right|$ & $\begin{array}{l}3,030 \\
3,520\end{array}$ & \begin{tabular}{|}
13.33 \\
13.42
\end{tabular} \mid & $\begin{array}{l}1,610 \\
1,640\end{array}$ & 9.95 & 927 & 4.53 & 235 & 3.78 & 166 \\
\hline $\begin{array}{l}1 \\
2\end{array}$ & $\overline{2} . \overline{48}$ & 71 & $\left|\begin{array}{l}18.75 \\
20.00\end{array}\right|$ & $\begin{array}{l}4,460 \\
6,100\end{array}$ & & & 9.39 & 833 & 4.42 & 225 & 3.75 & 162 \\
\hline $\begin{array}{l}3 \\
4\end{array}$ & 2.49 & 72 & & $\begin{array}{r}8,600 \\
10,700\end{array}$ & $\begin{array}{l}13.90 \\
14.06\end{array}$ & $\begin{array}{l}1,800 \\
1,880\end{array}$ & 8.85 & 749 & 4.34 & 216 & $3 . \overline{70}$ & 158 \\
\hline $\begin{array}{l}5 \\
6\end{array}$ & $\overline{2.49}$ & $\overline{7}$ & $\left|\begin{array}{l}22.98 \\
22.50\end{array}\right|$ & $\begin{array}{l}12,000 \\
10,900\end{array}$ & $\begin{array}{l}14.19 \\
14.18\end{array}$ & $\begin{array}{l}1,910 \\
1,910\end{array}$ & 8.03 & 637 & 4.42 & 225 & 3.62 & $153^{-}$ \\
\hline 7 & 2.47 & 70 & $\begin{array}{l}21.20 \\
19.80\end{array}$ & $\begin{array}{l}8,200 \\
5,780\end{array}$ & $\begin{array}{l}14.21 \\
14.32\end{array}$ & 1,9 & 7.23 & 524 & 4.35 & 216 & $3 . \overline{5}$ & 148 \\
\hline $\begin{array}{r}9 \\
10\end{array}$ & $2 . \overline{4}$ & 70 & & & 14 & & 6.60 & 456 & $\overline{4 . \overline{3}}$ & 220 & $\overline{3} . \overline{6}$ & 148 \\
\hline $\begin{array}{l}11 \\
12\end{array}$ & $-\overline{2} . \overline{52}$ & $7 \overline{4}$ & $\left|\begin{array}{l}17.05 \\
16.40\end{array}\right|$ & $\begin{array}{l}3,130 \\
2,830\end{array}$ & $\left|\begin{array}{l}14.32 \\
14.15\end{array}\right|$ & $\begin{array}{l}1,940 \\
1,910\end{array}$ & 6.10 & 401 & $4 . \overline{3} 1$ & 216 & 3.56 & 148 \\
\hline
\end{tabular}




\section{GOOSE CREEK NEAR HUDDLESTON, VA.}

LocATION.-Lat. $37^{\circ} 10^{\prime}$, long. $79^{\circ} 32^{\prime}$, a quarter of a mile upstream from Haden Bridge, three-eighths of a mile upstream from Rockeastle Creek, and 4 miles upstream from Huddleston, Bedford County. Datum of gage is 592.91 feet above mean sea level, datum of 1929, supplementary adjustment of 1936 .

DrainaGe AREA.-187 square miles.

GAGE-HEIGHT RECORD.-Water-stage recorder graph.

DischARGE RECORD.-Stage-discharge relation defined by current-meter measurements up to 6,400 second-feet and extended to erest gage height by logarithmic plotting on basis of unit-hydrograph and flood-routing studies, and other comparisons with flood records for stations in Roanoke River Basin. Gage heights used to half-tenths between 2.6 and 4.2 feet to Aug. 14, between 2.8 and 4.4 feet thereafter; hundredths below and tenths above these limits.

Maxima.-1940: Discharge, 12,700 second-feet 5 p.m. Aug. 14 (gage height, 21.90 feet).

1930-39: Discharge, 17,200 second-feet Oct. 19, 1937 (gage height, 25.75 feet, from floodmarks).

Remarks.-The District Engineer, Corps of Engineers, War Department, Norfolk, Va., furnished computed flood records by the unit-hydrograph and flood-routing methods used as a factor in determination' of stage-discharge relation.

The Flood Control Advisory Committee, Department of Agriculture, furnished field party and equipment to obtain fleld data for determination of flood flow by slope-area method of Goose Creek at Joppa Mill.

Mean discharge, in second-feet, 1940

\begin{tabular}{|c|c|c|c|c|c|c|c|c|c|c|c|}
\hline Day & Aug. & Sept. & Day & Aug. & Sept. & Day & Aug. & Sept. & Day & Aug. & Sept. \\
\hline $\begin{array}{l}1 \\
2 \\
3 \\
4 \\
5 \\
6 \\
7 \\
8\end{array}$ & $\begin{array}{r}124 \\
106 \\
90 \\
88 \\
88 \\
104 \\
249 \\
124\end{array}$ & $\begin{array}{l}794 \\
464 \\
357 \\
310 \\
279 \\
253 \\
231 \\
217\end{array}$ & $\begin{array}{r}9 \\
10 \\
11 \\
12 \\
13 \\
14 \\
15 \\
16\end{array}$ & $\begin{array}{r}99 \\
83 \\
90 \\
122 \\
97 \\
15,510 \\
5,240 \\
4,780\end{array}$ & $\begin{array}{l}211 \\
200 \\
192 \\
181 \\
171 \\
165 \\
157 \\
146\end{array}$ & $\begin{array}{l}17 \\
18 \\
19 \\
20 \\
21 \\
22 \\
23 \\
24\end{array}$ & $\begin{array}{r}12,140 \\
945 \\
641 \\
495 \\
414 \\
478 \\
367 \\
319\end{array}$ & $\begin{array}{r}141 \\
136 \\
131 \\
126 \\
118 \\
111 \\
109 \\
99\end{array}$ & $\begin{array}{l}25 \\
26 \\
27 \\
28 \\
29 \\
30 \\
31\end{array}$ & $\begin{array}{r}302 \\
287 \\
276 \\
265 \\
253 \\
267 \\
1,370\end{array}$ & $\begin{array}{r}211 \\
157 \\
111 \\
104 \\
101 \\
99\end{array}$ \\
\hline \multicolumn{10}{|c|}{$\begin{array}{l}\text { Monthly mean discharge, in second-feet, } \\
\text { Runoff, in inchess }\end{array}$} & $\begin{array}{r}833 \\
5.13\end{array}$ & $\begin{array}{r}203 \\
1.22\end{array}$ \\
\hline
\end{tabular}

${ }^{1}$ Discharge is different from that given in Water-Supply Paper 892. It is based on revisions not considered important enough for inclusion with revised records published in Water-Supply Paper 972. 
ROANOKE RIVER BASIN

Gage height, in feet, and discharge, in second-feet, at indicated time, 1940

\begin{tabular}{|c|c|c|c|c|c|c|c|c|c|c|c|c|}
\hline \multirow{2}{*}{ Hour } & \multicolumn{2}{|c|}{ Aug. 13} & \multicolumn{2}{|c|}{ Aug. 14} & \multicolumn{2}{|c|}{ Aug. 15} & \multicolumn{2}{|c|}{ Aug. 16} & \multicolumn{2}{|c|}{ Aug. 17} & \multicolumn{2}{|c|}{ Aug. 18} \\
\hline & $\begin{array}{c}\text { Gage } \\
\text { ht. }\end{array}$ & $\begin{array}{l}\text { Dis- } \\
\text { charge }\end{array}$ & $\begin{array}{c}\text { Gage } \\
\text { ht. }\end{array}$ & $\begin{array}{c}\text { Dis- } \\
\text { charge }\end{array}$ & $\begin{array}{c}\text { Gage } \\
\text { ht. }\end{array}$ & $\begin{array}{c}\text { Dis- } \\
\text { charge }\end{array}$ & $\begin{array}{l}\text { Gage } \\
\text { ht. }\end{array}$ & $\begin{array}{l}\text { Dis- } \\
\text { charge }\end{array}$ & $\begin{array}{c}\text { Gage } \\
\text { ht. }\end{array}$ & $\begin{array}{l}\text { Dis- } \\
\text { charge }\end{array}$ & $\begin{array}{c}\text { Gage } \\
\text { ht. }\end{array}$ & $\begin{array}{c}\text { Dis- } \\
\text { charge }\end{array}$ \\
\hline 1 & 160 & & & & 13.47 & & 1.45 & 4,350 & 10.42 & & & \\
\hline 3 & 1.60 & 04 & $\begin{array}{l}1.63 \\
1.68\end{array}$ & $\begin{array}{l}112 \\
124\end{array}$ & $\left|\begin{array}{l}12.17 \\
10.94\end{array}\right|$ & $\begin{array}{l}4,820 \\
4,080\end{array}$ & $\begin{array}{r}10.49 \\
9.62\end{array}$ & $\begin{array}{l}3,860 \\
3,360\end{array}$ & $\left|\begin{array}{l}9.92 \\
9.25\end{array}\right|$ & $\begin{array}{l}3,520 \\
3,150\end{array}$ & 4.97 & 0 \\
\hline 4 & $1 . \overline{59}$ & 102 & 1.74 & 139 & $\begin{array}{r}9.92 \\
0.57\end{array}$ & 3,520 & 9.09 & 3,100 & 8.98 & 3,050 & 4.81 & 1,080 \\
\hline $\begin{array}{l}5 \\
6\end{array}$ & 1.59 & 102 & $\begin{array}{l}1.80 \\
1.93\end{array}$ & $\begin{array}{l}155 \\
190\end{array}$ & $\begin{array}{r}9.57 \\
10.40\end{array}$ & $\begin{array}{l}3,360 \\
3,800\end{array}$ & $\begin{array}{r}9.52 \\
10.82\end{array}$ & $\begin{array}{l}3,300 \\
4,020\end{array}$ & $\begin{array}{l}8.42 \\
8.10\end{array}$ & $\begin{array}{l}2,750 \\
2,600\end{array}$ & 4.72 & 1,040 \\
\hline 7 & & & 2.17 & 258 & 10.74 & 3,960 & 12.68 & 5,120 & 7.67 & 2,400 & & \\
\hline $\begin{array}{l}8 \\
9\end{array}$ & 1.58 & 99 & 2.77 & 426 & 10.58 & 3,910 & 13.44 & 5.5 & 7.42 & & 4.61 & 1,010 \\
\hline 10 & $\overline{1.57}$ & 97 & $\begin{array}{l}4.37 \\
8.32\end{array}$ & $\begin{array}{r}948 \\
2,700\end{array}$ & $\left|\begin{array}{l}10.80 \\
12.07\end{array}\right|$ & $\begin{array}{l}4,020 \\
4,760\end{array}$ & $\begin{array}{l}.78 \\
. .17\end{array}$ & $\begin{array}{l}5,820 \\
6,080\end{array}$ & $\begin{array}{l}7.21 \\
6.96\end{array}$ & $\begin{array}{l}2,160 \\
2,070\end{array}$ & 4.48 & $\overline{970} \overline{0}$ \\
\hline 11 & & & 12.52 & 5,000 & 13.47 & 5,620 & 14.21 & 6,080 & 6.82 & 1,980 & & \\
\hline $\mathbf{N}$ & 1.56 & 95 & 15.02 & 6,630 & 14.06 & 6,020 & 14.00 & 5, & 6.58 & 1,890 & 4.40 & 934 \\
\hline 1 & & & 17.52 & 8,550 & 14.11 & 6,020 & 13.70 & 5,760 & 6.43 & 1,800 & & \\
\hline $\begin{array}{l}2 \\
3\end{array}$ & 1.56 & 95 & 18.80 & 9,720 & 13.95 & 5,950 & .45 & & 6.25 & & 4.30 & 898 \\
\hline 4 & 1.56 & 95 & 21.24 & 12,000 & 13.59 & 5,690 & 12.52 & 5,000 & 6.04 & 1,620 & 4.20 & 862 \\
\hline $\begin{array}{l}5 \\
6\end{array}$ & 1.55 & 92 & $\begin{array}{l}21.90 \\
21.47\end{array}$ & $\begin{array}{l}12,700 \\
12,300\end{array}$ & $\begin{array}{l}13.61 \\
13.65\end{array}$ & $\begin{array}{l}5,690 \\
5,690\end{array}$ & $\begin{array}{l}11.75 \\
10.90\end{array}$ & $\begin{array}{l}4,580 \\
4,080\end{array}$ & $\begin{array}{l}5.96 \\
5.89\end{array}$ & $\begin{array}{l}1,620 \\
1,580\end{array}$ & 4.11 & 828 \\
\hline \multirow{6}{*}{$\begin{array}{r}8 \\
9 \\
10 \\
11 \\
12 \\
\end{array}$} & & & 20.47 & 11,300 & 13.47 & 5,620 & 10.42 & 3,800 & 5.79 & 1,530 & & \\
\hline & 1.55 & 92 & 19.30 & 10,200 & 13.38 & 5,5 & 10.24 & 3, & 5.69 & 1 , & $|4.02|$ & 794 \\
\hline & $-1, \overline{5} 5$ & 92 & \begin{tabular}{|l|}
18.22 \\
17.12
\end{tabular} & $\begin{array}{l}9,180 \\
8,230\end{array}$ & $\left|\begin{array}{l}13.19 \\
12.95\end{array}\right|$ & $\begin{array}{l}5,430 \\
5,300\end{array}$ & $\begin{array}{l}10.37 \\
10.40\end{array}$ & & $\begin{array}{l}5.59 \\
5.51\end{array}$ & 1, & $-\overline{3} \cdot \overline{94} \mid$ & $777^{-}$ \\
\hline & & & 15.87 & 7270 & 12.87 & 5,240 & 0.47 & 3 & 5.40 & 1,3 & & \\
\hline & 1.57 & 97 & & & 12.33 & & 10.59 & & 5.30 & 1,300 & 3.85 & 743 \\
\hline & \multicolumn{2}{|c|}{ Aug. 19} & \multicolumn{2}{|c|}{ Aug. 20} & \multicolumn{2}{|c|}{ Aug. 21} & \multicolumn{2}{|c|}{ Aug. 22} & \multicolumn{2}{|c|}{ Aug. 23} & \multicolumn{2}{|c|}{ Aug. 24} \\
\hline \multirow{4}{*}{$\begin{array}{r}2 \\
4 \\
6 \\
8 \\
10 \\
\mathrm{~N}\end{array}$} & 3.80 & 726 & & 59 & & & & & & 20 & 53 & 5 \\
\hline & $\begin{array}{l}3.75 \\
3.66\end{array}$ & $\begin{array}{l}709 \\
675\end{array}$ & 8 & 5 & 39 & 434 & 3 & 383 & 2.70 & 89 & & 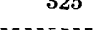 \\
\hline & 3.64 & 675 & 3.14 & 512 & 2.84 & 419 & 2.72 & 380 & 2.68 & 368 & 2.51 & 319 \\
\hline & $\begin{array}{l}3.00 \\
3.56\end{array}$ & 6 & 3.09 & 496 & 2.85 & 419 & $2 . \overline{1}$ & 377 & 2.65 & 360 & 2.50 & 316 \\
\hline \multirow{4}{*}{$\begin{array}{r}2 \\
4 \\
6 \\
8 \\
10 \\
12 \\
\end{array}$} & $\begin{array}{l}3.50 \\
3.47\end{array}$ & 624 & & & & & & & & & & \\
\hline & $\begin{array}{l}3.47 \\
3.41\end{array}$ & $\begin{array}{l}608 \\
592\end{array}$ & 3.06 & 480 & 2.80 & 404 & 3.01 & 464 & 2.61 & 348 & 2.50 & 316 \\
\hline & 3.3 & 5 & 2.98 & 464 & 2.78 & 398 & 4.15 & 845 & 2.60 & 345 & 2.48 & 310 \\
\hline & $\begin{array}{l}5.02 \\
3.26 \\
\end{array}$ & 544 & 2.90 & 434 & $\overline{2.7} \overline{5}$ & $389^{-}$ & 2.93 & $449^{-}$ & $2 . \overline{5} \overline{7}$ & $3 \overline{3} 6$ & 2.50 & 316 \\
\hline
\end{tabular}

SUPPLEMENTAL RECORDS-Aug, 15, $12: 30$ p.m. gage height, 14.16 feet, discharge, 6.080 second-feet Aug. 22, 3 p.m., gage height, 2.71 feet, discharge, 377 second-feet; 6 p.m., gage height, 4.12 feet, discharge, 828 second-feet; 10 p.m., gage height, 3.25 feet, discharge, 544 second-feet.

\section{O'TTER RIVER NEAR EVINGTON, VA.}

Location.-Lat. $37^{\circ} 13^{\prime}$, long. $79^{\circ} 18^{\prime}$, at highway bridge 2 miles upstream from Flat Creek and 2 miles southwest of Evington, Campbell County. Datum of gage is 544.02 feet above mean sea level.

Drainage AREa.-325 square miles.

GAGE-HEIGHT RECORD.-Water-stage recorder graph.

DISCHARGE RECORD.- Stage-discharge relation defined by current-meter measurements up to 6,600 second-feet and extended to erest gage height by logarithmic plotting on basis of unit-hydrograph and flood-routing studies, and other comparisons with flood records for stations in Roanoke River Basin. Gage heights used to half-tenths between 2.7 and 4.5 feet; hundredths below and tenths above these limits.

Maxima.-1940: Discharge, 24,400 second-feet 5 p.m. Aug. 14 (gage height, 22.42 feet).

1936-39: Discharge, 27,500 second-feet Oct. 19, 1937, Aug. 19, 1939 (gage height, 23.1 feet). 


\section{FLOODS OF AUGUST 1940 IN THE SOUTHEASTERN STATES}

Remarks.-The District Engineer, Corps of Engineers, War Department, Norfolk, Va., furnished computed flood records by the unit-hydrograph and flood-routing methods used as a factor in determination of stage-discharge relation.

The Flood Control Coordinating Committee, Department of Agriculture, furnished field party and equipment to obtain data for determinations of flood flow by slope-area method on Otter River near Bedford and Little Otter River near Bedford.

Mean discharge, in second-feet, 1940

\begin{tabular}{|c|c|c|c|c|c|c|c|c|c|c|c|}
\hline Day & Aug. & Sept. & Day & Aug. & Sept. & Day & Aug. & Sept. & Day & Aug. & Sept. \\
\hline $\begin{array}{l}1 \\
2 \\
3 \\
4 \\
5 \\
5 \\
6 \\
7 \\
8\end{array}$ & $\begin{array}{l}165 \\
134 \\
116 \\
111 \\
112 \\
113 \\
160 \\
119\end{array}$ & $\begin{array}{r}, 220 \\
652 \\
514 \\
449 \\
398 \\
360 \\
336 \\
312\end{array}$ & $\begin{array}{r}9 \\
10 \\
11 \\
12 \\
13 \\
14 \\
15 \\
16\end{array}$ & $\begin{array}{r}112 \\
92 \\
88 \\
142 \\
127 \\
10,300 \\
10,400 \\
8,220\end{array}$ & $\begin{array}{l}300 \\
285 \\
271 \\
260 \\
245 \\
239 \\
230 \\
228\end{array}$ & $\begin{array}{l}17 \\
18 \\
19 \\
20 \\
21 \\
22 \\
23 \\
24\end{array}$ & $\begin{array}{r}4,410 \\
1,620 \\
999 \\
736 \\
604 \\
527 \\
473 \\
415\end{array}$ & $\begin{array}{l}220 \\
210 \\
204 \\
200 \\
194 \\
180 \\
172 \\
174\end{array}$ & $\begin{array}{l}25 \\
26 \\
27 \\
28 \\
29 \\
30 \\
31\end{array}$ & $\begin{array}{r}385 \\
385 \\
372 \\
372 \\
436 \\
\mathbf{3 6 0} \\
1,180\end{array}$ & $\begin{array}{l}289 \\
318 \\
208 \\
194 \\
189 \\
181\end{array}$ \\
\hline \multicolumn{10}{|c|}{$\begin{array}{l}\text { Monthly mean discharge, in second-feet } \\
\text { Runoff, in inches }\end{array}$} & $\begin{array}{r}1,412 \\
5.00\end{array}$ & $\begin{array}{r}308 \\
1.06\end{array}$ \\
\hline
\end{tabular}

Gage height, in feet, and discharge, in second-feet, at indicated time, 1940

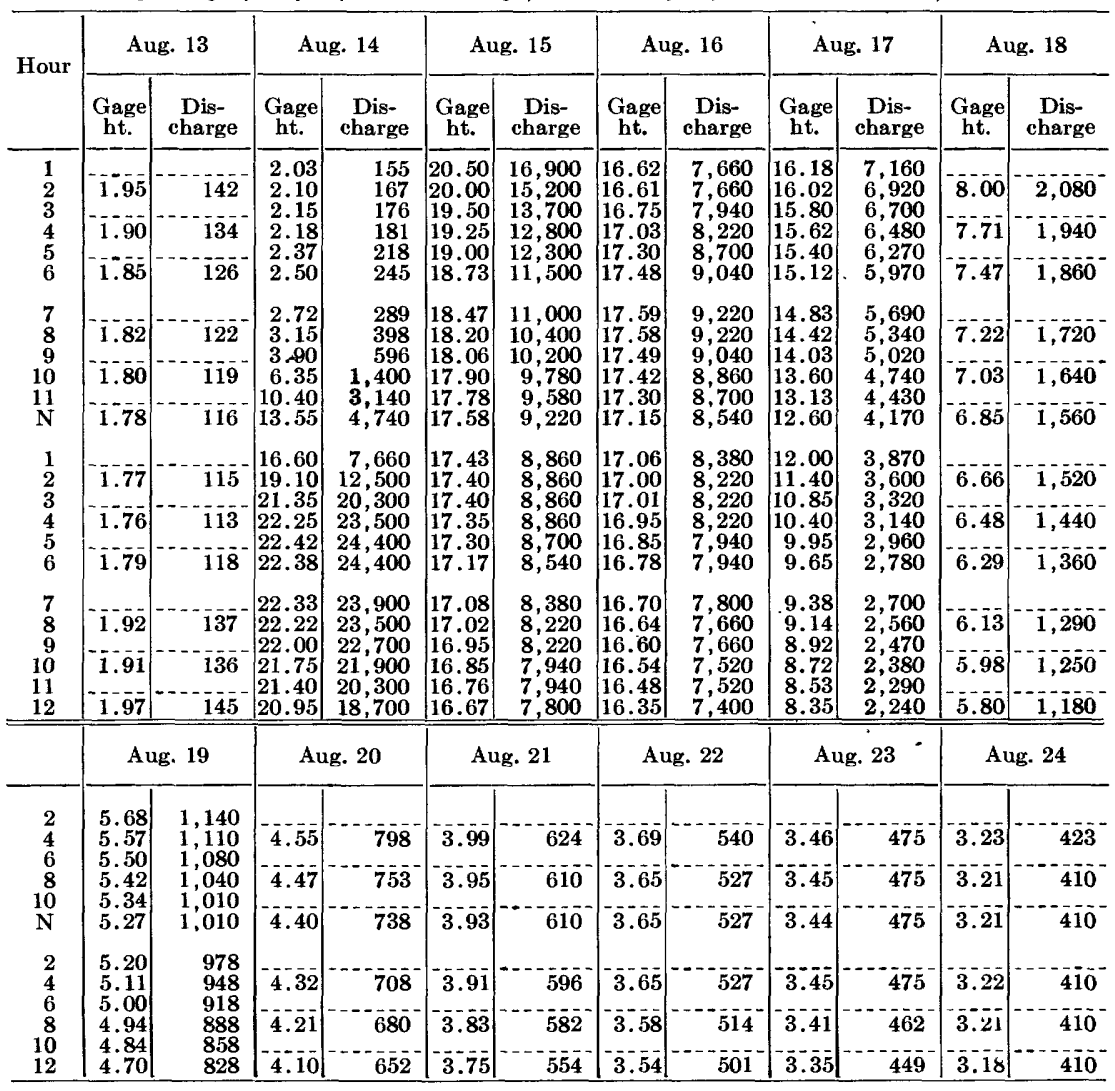


FALLING RIVER NEAR BROOKNEAL, VA.

Location.-Lat. $37^{\circ} 04^{\prime} 54^{\prime \prime}$, long. $78^{\circ} 56^{\prime} 07^{\prime \prime}$, 300 feet downstream from Hat Creek and $2 \frac{1}{4}$ miles north of Brookneal, Campbell County. Datum of gage is 378.69 feet above mean sea level, datum of 1929 .

DRAINAGE AREA.-228 square miles.

GAGE-HEIGHT RECORD.-Water-stage recorder graph, except for period 12 p.m. Aug. 14 to $12 \mathrm{~m}$. Aug. 21 where gage heights, generally to tenths, were obtained from graph based on floodmark, one gage reading, unit-hydrograph and flood-routing studies, and comparisons of flood records with those for other stations in Roanoke River Basin.

DISCHARGE RECORD.-Computed by shifting-control method. Stage-discharge relation defined by current-meter measurements up to 7,000 second-feet and extended to erest gage height by logarithmic plotting on basis of unit-hydrograph and flood-routing studies, and other comparisons with flood records for stations in Roanoke River Basin. Gage heights used to half-tenths between 6.1 and 6.6 feet; hundredths below and tenths above these limits, except for computed graph where gage heights were used as given.

Maxima.-1940: Discharge, 23,000 second-feet 3 a.m. Aug. 15 (gage height, 29.35 feet, from floodmarks).

1935-39: Discharge, 20,400 second-feet Mar. 17 or 18, 1936 (gage height 28.0 feet, from floodmarks).

REMarks.-The District Engineer, Corps of Engineers, War Department, Norfolk, Va., furnished computed flood records by the unit-hydrograph and flood-routing methods used as a factor in determination of stage-discharge relation and in preparation of a stage graph.

The Flood Control Advisory Committee, Department of Agriculture, furnished field party and equipment to obtain field data for determination of flood flow by the slope-area method at Naruna.

Mean discharge, in second-feet, 1940

\begin{tabular}{|c|c|c|c|c|c|c|c|c|c|c|c|}
\hline Day & Aug. & Sept. & Day & Aug. & Sept. & Day & Aug. & Sept. & Day & Aug. & Sept. \\
\hline $\begin{array}{l}1 \\
2 \\
3 \\
4 \\
5 \\
6 \\
7 \\
8\end{array}$ & $\begin{array}{r}117 \\
101 \\
97 \\
94 \\
94 \\
175 \\
298 \\
146\end{array}$ & $\begin{array}{l}214 \\
162 \\
151 \\
145 \\
157 \\
166 \\
135 \\
131\end{array}$ & $\begin{array}{r}9 \\
10 \\
11 \\
12 \\
13 \\
14 \\
15 \\
16\end{array}$ & $\begin{array}{r}96 \\
87 \\
100 \\
104 \\
96 \\
7,420 \\
13,500 \\
9,070\end{array}$ & $\begin{array}{l}131 \\
128 \\
124 \\
122 \\
117 \\
115 \\
114 \\
117\end{array}$ & $\begin{array}{l}17 \\
18 \\
19 \\
20 \\
21 \\
22 \\
23 \\
24\end{array}$ & $\begin{array}{r}3,040 \\
986 \\
512 \\
350 \\
282 \\
252 \\
231 \\
210\end{array}$ & $\begin{array}{l}112 \\
112 \\
111 \\
109 \\
106 \\
103 \\
100 \\
100\end{array}$ & $\begin{array}{l}25 \\
26 \\
27 \\
28 \\
29 \\
30 \\
31\end{array}$ & $\begin{array}{l}201 \\
201 \\
189 \\
184 \\
255 \\
206 \\
194\end{array}$ & $\begin{array}{l}106 \\
126 \\
106 \\
104 \\
104 \\
103\end{array}$ \\
\hline \multicolumn{10}{|c|}{$\begin{array}{l}\text { Monthly mean discharge, in second-feet } \\
\text { Runoff, in inches }\end{array}$} & $\begin{array}{r}1,254 \\
6.34\end{array}$ & $\begin{array}{r}124 \\
0.61\end{array}$ \\
\hline
\end{tabular}


138 FLOODS OF AUGUST 1940 IN THE SOUTHEASTERN STATES

Gage height, in feet, and discharge, in second-feet, at indicated time, 1940

\begin{tabular}{|c|c|c|c|c|c|c|c|c|c|c|c|c|}
\hline \multirow{2}{*}{ Hour } & \multicolumn{2}{|c|}{ Aug. 13} & \multicolumn{2}{|c|}{ Ang. 14} & \multicolumn{2}{|c|}{ Aug: 15} & \multicolumn{2}{|c|}{ Aug. 16} & \multicolumn{2}{|c|}{ Aug. 17} & \multicolumn{2}{|c|}{ Aug. 18} \\
\hline & $\begin{array}{c}\text { Gage } \\
\text { ht. }\end{array}$ & $\begin{array}{c}\text { Dis- } \\
\text { charge }\end{array}$ & $\begin{array}{c}\text { Gage } \\
\text { ht. }\end{array}$ & $\begin{array}{c}\text { Dis- } \\
\text { charge }\end{array}$ & $\begin{array}{c}\text { Gage } \\
\text { ht. }\end{array}$ & $\begin{array}{l}\text { Dis- } \\
\text { charge }\end{array}$ & $\begin{array}{c}\text { Cage } \\
\text { ht. }\end{array}$ & $\begin{array}{c}\text { Dis- } \\
\text { charge }\end{array}$ & $\begin{array}{l}\text { Gage } \\
\text { ht. }\end{array}$ & $\begin{array}{c}\text { Dis- } \\
\text { charge }\end{array}$ & $\begin{array}{c}\text { Gage } \\
\text { ht. }\end{array}$ & $\begin{array}{c}\text { Dis- } \\
\text { charge }\end{array}$ \\
\hline \multirow{3}{*}{$\begin{array}{l}1 \\
2 \\
3 \\
4 \\
5 \\
6\end{array}$} & 4.19 & 93 & \multirow{3}{*}{$\begin{array}{l}4.25 \\
4.26 \\
4.31 \\
4.33 \\
4.48 \\
5.20\end{array}$} & \multirow{3}{*}{$\begin{array}{l}101 \\
103 \\
111 \\
114 \\
141 \\
330\end{array}$} & \multirow{3}{*}{$\begin{array}{l}28.9 \\
29.3 \\
29.35 \\
29.2 \\
28.9 \\
28.5\end{array}$} & \multirow{3}{*}{$\begin{array}{r}22,000 \\
22,800 \\
23,000 \\
22,600 \\
22,000 \\
21,300\end{array}$} & $\overline{17} .9$ & 6,610 & $17.3^{-1}$ & 6,100 & & \\
\hline & $-\overline{4} . \overline{8}$ & 92 & & & & & 18.7 & $7, \overline{340}$ & 16.0 & 5,090 & 7.0 & 1,180 \\
\hline & 4.18 & 92 . & & & & & 19.6 & 8,260 & $\mathbf{1} \times \mathbf{6}$ & 4,110 & 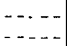 & 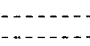 \\
\hline \multirow{4}{*}{$\begin{array}{r}7 \\
8 \\
9 \\
10 \\
11 \\
\mathrm{~N}\end{array}$} & 4.18 & 92 & \multirow{4}{*}{$\begin{array}{r}5.57 \\
5.91 \\
6.25 \\
7.00 \\
9.20 \\
14.40\end{array}$} & \multirow{4}{*}{$\begin{array}{r}466 \\
640 \\
854 \\
1,220 \\
1,880 \\
3,970\end{array}$} & \multirow{4}{*}{$\begin{array}{l}27.7 \\
27.0 \\
26.0 \\
25.2 \\
24.2 \\
23.3\end{array}$} & \multirow{4}{*}{$\begin{array}{l}19,900 \\
18,700 \\
17,000 \\
15,700 \\
14,200 \\
12,900\end{array}$} & 20.4 & 9,160 & 13.1 & 3,190 & 6.8 & 1,100 \\
\hline & & & & & & & & & & & & \\
\hline & 4.17 & 91 & & & & & 21.2 & 10,100 & 11.8 & 2,670 & 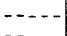 & \\
\hline & $4 . \overline{17}$ & 91 & & & & & 217 & 10,800 & 10.7 & 2,320 & 6.5 & $9 \overline{6} 6$ \\
\hline \multirow{4}{*}{$\begin{array}{l}1 \\
2 \\
3 \\
4 \\
5 \\
6\end{array}$} & 4.17 & 91 & \multirow{4}{*}{$-\mid \begin{array}{l}20.80 \\
23.25 \\
23.23 \\
23.55 \\
24.35 \\
25.10\end{array}$} & \multirow{4}{*}{$\begin{array}{r}9,640 \\
12,800 \\
12,800 \\
13,200 \\
14,400 \\
15,400\end{array}$} & \multirow{4}{*}{$\begin{array}{l}22.3 \\
21.4 \\
20.3 \\
19.2 \\
18.2 \\
17.1\end{array}$} & \multirow{4}{*}{$\begin{array}{r}11,600 \\
10,400 \\
9,040 \\
7,840 \\
6.880 \\
5,940\end{array}$} & 21.9 & 11,000 & 9.8 & 2,050 & & \\
\hline & & & & & & & & & & & & \\
\hline & 4.17 & 91 & & & & & 21.8 & 10,900 & 9.0 & 1,820 & 6.3 & 854 \\
\hline & $\overline{4 . \overline{17}}$ & 91 & & & & & 21.3 & 10,200 & $8 . \overline{5}^{-}$ & 1,690 & & \\
\hline \multirow{5}{*}{$\begin{array}{r}7 \\
8 \\
9 \\
10 \\
11 \\
12 \\
\end{array}$} & $4.3 \overline{9}$ & 124 & \multirow{4}{*}{$\begin{array}{l}25.32 \\
25.25 \\
25.17 \\
25.37 \\
25.90 \\
27.8\end{array}$} & \multirow{4}{*}{$\begin{array}{l}15,900 \\
15,700 \\
15,600 \\
15,900 \\
16,700 \\
20,100\end{array}$} & \multirow{4}{*}{$\begin{array}{l}16.6 \\
16.4 \\
16.3 \\
16.4 \\
16.7 \\
17.1 \\
\end{array}$} & \multirow{4}{*}{$\begin{array}{l}5,540 \\
5,380 \\
5,300 \\
5,380 \\
5,620 \\
5,940 \\
\end{array}$} & 20.6 & 9,400 & 8.0 & 1,540 & 6.2 & 792 \\
\hline & 431 & 11 & & & & & 108 & 8480 & 78 & 1480 & & \\
\hline & & & & & & & & & & & & \\
\hline & 4.27 & 104 & & & & & 18.7 & 7,340 & 7.5 & 1 , & 6.0 & 6 \\
\hline & \multicolumn{2}{|c|}{ Aug. 19} & \multicolumn{2}{|c|}{ Aug. 20} & \multicolumn{2}{|c|}{ Aug. 21} & \multicolumn{2}{|c|}{ Aug. 22} & \multicolumn{2}{|c|}{ Aug. 23} & \multicolumn{2}{|c|}{ Aug. 2} \\
\hline $\begin{array}{r}4 \\
8 \\
8 \\
4 \\
8 \\
12 \\
12\end{array}$ & $\begin{array}{l}5.9 \\
5.8 \\
5.7 \\
5.6 \\
5.5 \\
5.5\end{array}$ & $\begin{array}{l}604 \\
550 \\
501 \\
457 \\
417 \\
417\end{array}$ & $\begin{array}{l}5.4 \\
5.4 \\
5.3 \\
5.2 \\
5.2 \\
5.2\end{array}$ & $\begin{array}{l}380 \\
380 \\
346 \\
314 \\
314 \\
314\end{array}$ & $\begin{array}{l}5.1 \\
5.1 \\
5.10 \\
5.10 \\
5.06 \\
5.02\end{array}$ & $\begin{array}{l}284 \\
284 \\
284 \\
284 \\
272 \\
261\end{array}$ & $\begin{array}{l}5.00 \\
4.99 \\
5.00 \\
4.99 \\
4.97 \\
4.93\end{array}$ & $\begin{array}{l}255 \\
252 \\
255 \\
252 \\
247 \\
235\end{array}$ & $\begin{array}{l}4.92 \\
4.93 \\
4.93 \\
4.92 \\
4.90 \\
4.85\end{array}$ & $\begin{array}{l}233 \\
235 \\
235 \\
233 \\
227 \\
214\end{array}$ & $\begin{array}{l}4.84 \\
4.84 \\
4.84 \\
4.84 \\
4.83 \\
4.81\end{array}$ & $\begin{array}{l}211 \\
211 \\
211 \\
211 \\
209 \\
204\end{array}$ \\
\hline
\end{tabular}

DAN RIVER NEAR FRANCISCO, N. C.

Location.-Lat. $36^{\circ} 30^{\prime} 15^{\prime \prime}$, long. $80^{\circ} 20^{\prime} 55^{\prime \prime}$, at county highway bridge just downstream from Georges Mill, 3 miles east of Francisco, Stokes County, and 7.9 miles downstream from Little Dan River.

DrainaGE AREA. - 124 square niles.

GAGE-HEIGHT RECORD.-Water-stage recorder graph.

DISCHARGE RECORD.-Stage-discharge relation defined by current-meter measurements up to 8,300 second-feet. Gage heights used to half-tenths between 2.9 and 5.1 feet; hundredths below and tenths above these. limits.

Maxima.-1940: Discharge, 7,630 second-feet 10:30 a.m. Aug. 14 (gage height, 9.40 feet).

1924-39: Discharge, 12,400 second-feet Oct. 19, 1937 (gage height, 12.45 feet).

REMarKs.-Flood runoff not affected by artificial storage.

Mean discharge, in second-feet, 1940

\begin{tabular}{|c|c|c|c|c|c|c|c|c|c|c|c|}
\hline Day & Aug. & Sept. & Day & Aug. & Sept. & Day & Aug. & Sept. & Day & Aug. & Sept. \\
\hline $\begin{array}{l}1 \\
2 \\
3 \\
4 \\
5 \\
6 \\
7 \\
8\end{array}$ & $\begin{array}{l}158 \\
135 \\
126 \\
122 \\
114 \\
152 \\
136 \\
124\end{array}$ & $\begin{array}{l}495 \\
366 \\
315 \\
286 \\
311 \\
290 \\
251 \\
231\end{array}$ & $\begin{array}{r}9 \\
10 \\
11 \\
12 \\
13 \\
14 \\
15 \\
16\end{array}$ & $\begin{array}{r}120 \\
116 \\
122 \\
124 \\
146 \\
4,500 \\
1,520 \\
1,170\end{array}$ & $\begin{array}{l}226 \\
225 \\
223 \\
212 \\
193 \\
188 \\
184 \\
186\end{array}$ & $\begin{array}{l}17 \\
18 \\
19 \\
20 \\
21 \\
22 \\
23 \\
24\end{array}$ & $\begin{array}{l}931 \\
682 \\
604 \\
431 \\
368 \\
334 \\
309 \\
280\end{array}$ & $\begin{array}{l}177 \\
178 \\
175 \\
170 \\
164 \\
153 \\
153 \\
153\end{array}$ & $\begin{array}{l}25 \\
26 \\
27 \\
28 \\
29 \\
30 \\
31\end{array}$ & $\begin{array}{r}265 \\
266 \\
245 \\
253 \\
270 \\
791 \\
1,030\end{array}$ & $\begin{array}{l}203 \\
215 \\
165 \\
153 \\
146 \\
147\end{array}$ \\
\hline \multicolumn{10}{|c|}{$\begin{array}{l}\text { Monthly mean discharge, in second-feet } \\
\text { Runoff, in inches }\end{array}$} & $\begin{array}{r}514 \\
4.78\end{array}$ & $\begin{array}{r}218 \\
1.96\end{array}$ \\
\hline
\end{tabular}


ROANOKE RIVER BASIN

Gage height, in feet, and discharge, in second-feet, at indicated time, 1940

\begin{tabular}{|c|c|c|c|c|c|c|c|c|c|c|c|c|}
\hline \multirow{2}{*}{ Hour } & \multicolumn{2}{|c|}{ Aug. 12} & \multicolumn{2}{|c|}{ Aug. 13} & \multicolumn{2}{|c|}{ Aug. 14} & \multicolumn{2}{|c|}{ Aug. 15} & \multicolumn{2}{|c|}{ Aug. 16} & \multicolumn{2}{|c|}{ Aug. 17} \\
\hline & $\begin{array}{c}\text { Gage } \\
\text { ht. }\end{array}$ & $\begin{array}{l}\text { Dis- } \\
\text { charge }\end{array}$ & $\begin{array}{c}\text { Gage } \\
\text { ht. }\end{array}$ & $\begin{array}{l}\text { Dis- } \\
\text { charge }\end{array}$ & $\begin{array}{c}\text { Gage } \\
\text { ht. }\end{array}$ & $\begin{array}{c}\text { Dis- } \\
\text { charge }\end{array}$ & $\begin{array}{c}\text { Gage } \\
\text { ht. }\end{array}$ & $\begin{array}{l}\text { Dis- } \\
\text { charge }\end{array}$ & $\begin{array}{c}\text { Gage } \\
\text { ht. }\end{array}$ & $\begin{array}{l}\text { Dis- } \\
\text { charge }\end{array}$ & $\begin{array}{c}\text { Gage } \\
\text { ht. }\end{array}$ & $\begin{array}{l}\text { Dis- } \\
\text { charge }\end{array}$ \\
\hline $\begin{array}{l}1 \\
2 \\
3 \\
4 \\
5 \\
6\end{array}$ & $\begin{array}{r}-\overline{1} . \overline{9} \\
-\overline{1} . \overline{\mathbf{9}} \\
-1 . \overline{4} \overline{1}\end{array}$ & $\begin{array}{r}-114^{-} \\
116^{-}\end{array}$ & $\begin{array}{l}1.55 \\
1.55 \\
1.55 \\
1.54 \\
1.52 \\
1.50\end{array}$ & $\begin{array}{l}150 \\
150 \\
150 \\
148 \\
143 \\
138\end{array}$ & $\begin{array}{l}1.88 \\
2.27 \\
3.03 \\
4.00 \\
4.92 \\
6.24\end{array}$ & $\begin{array}{r}245 \\
397 \\
790 \\
1,480 \\
2,350 \\
3,690\end{array}$ & $\begin{array}{l}4.93 \\
4.73 \\
4.57 \\
4.43 \\
4.34 \\
4.29\end{array}$ & $\begin{array}{l}2,400 \\
2,200 \\
2,000 \\
1,900 \\
1,800 \\
1,750\end{array}$ & $\begin{array}{l}3.68 \\
3.68 \\
3.65 \\
3.59 \\
3.59 \\
3.61\end{array}$ & $\begin{array}{l}1,230 \\
1,230 \\
1,190 \\
1,160 \\
1,160 \\
1,160\end{array}$ & $\begin{array}{l}3.40 \\
3.37 \\
3.32 \\
3.27 \\
3.25 \\
3.29\end{array}$ & $\begin{array}{r}1,010 \\
\mathbf{9 7 8} \\
\mathbf{9 4 5} \\
\mathbf{9 1 2} \\
\mathbf{9 1 2} \\
\mathbf{9 4 5}\end{array}$ \\
\hline $\begin{array}{r}7 \\
8 \\
9 \\
10 \\
11 \\
\mathrm{~N}\end{array}$ & $\mid \begin{array}{c}-\overrightarrow{1} . \overline{4} \overline{1} \\
-\overline{1} . \overline{45} \\
-\overline{1} . \overline{53}\end{array}$ & $\begin{array}{r}118 \\
127 \\
145\end{array}$ & $\begin{array}{l}1.48 \\
1.55 \\
1.56 \\
1.53 \\
1.52 \\
1.51\end{array}$ & $\begin{array}{l}134 \\
150 \\
152 \\
145 \\
143 \\
140\end{array}$ & $\begin{array}{l}7.06 \\
8.44 \\
8.84 \\
9.34 \\
9.30 \\
9.15\end{array}$ & $\begin{array}{l}4,720 \\
6,330 \\
6,850 \\
7,500 \\
7,500 \\
7,370\end{array}$ & $\begin{array}{l}4.21 \\
4.14 \\
4.11 \\
4.04 \\
3.96 \\
3.91\end{array}$ & $\begin{array}{l}1,660 \\
1,620 \\
1,570 \\
1,520 \\
1,440 \\
1,390\end{array}$ & $\begin{array}{l}3.64 \\
3.65 \\
3.65 \\
3.66 \\
3.68 \\
3.66\end{array}$ & $\begin{array}{l}1,190 \\
1,190 \\
1,190 \\
1,190 \\
1,230 \\
1,190\end{array}$ & $\begin{array}{l}3.31 \\
3.35 \\
3.37 \\
3.40 \\
3.40 \\
3.40\end{array}$ & $\begin{array}{r}945 \\
978 \\
978 \\
1,010 \\
1,010 \\
1,010\end{array}$ \\
\hline $\begin{array}{l}1 \\
2 \\
3 \\
4 \\
5 \\
6\end{array}$ & $\mid \begin{array}{c}1.47 \\
-1 . \overline{45} \\
-1.41\end{array}$ & $\begin{array}{r}131 \\
118\end{array}$ & $\begin{array}{l}1.49 \\
1.46 \\
1.43 \\
1.44 \\
1.44 \\
1.44\end{array}$ & $\begin{array}{l}136 \\
129 \\
123 \\
125 . \\
125 \\
125\end{array}$ & $\begin{array}{l}9.00 \\
8.58 \\
8.27 \\
8.83 \\
8.02 \\
7.73\end{array}$ & $\begin{array}{l}7,110 \\
6,590 \\
6,200 \\
6,850 \\
5,810 \\
5,440 .\end{array}$ & $\begin{array}{l}3.85 \\
3.78 \\
3.70 \\
3.64 \\
3.62 \\
3.62\end{array}$ & $\begin{array}{l}1,350 \\
1,310 \\
1,230 \\
1,190 \\
1,160 \\
1,160\end{array}$ & $\begin{array}{l}3.64 \\
3.64 \\
3.66 \\
3.66 \\
3.64 \\
3.62\end{array}$ & $\begin{array}{l}1,190 \\
1,190 \\
1,190 \\
1,190 \\
1,190 \\
1,160\end{array}$ & $\begin{array}{l}3.38 \\
3.36 \\
3.35 \\
3.31 \\
3.29 \\
3.24\end{array}$ & $\begin{array}{r}1,010 \\
978 \\
978 \\
945 \\
945 \\
912\end{array}$ \\
\hline $\begin{array}{r}7 \\
8 \\
9 \\
10 \\
11 \\
12 \\
\end{array}$ & $\left|\begin{array}{r}1.40 \\
1.46 \\
1.55\end{array}\right|$ & $\begin{array}{l}116 \\
12 \overline{9}^{-} \\
150\end{array}$ & $\begin{array}{l}1.47 \\
1.47 \\
1.60 \\
1.71 \\
1.73 \\
1.75\end{array}$ & $\begin{array}{l}131 \\
131 \\
162 \\
191 \\
197 \\
203 \\
\end{array}$ & $\begin{array}{l}7.36 \\
6.86 \\
6.31 \\
5.78 \\
5.43 \\
5.15 \\
\end{array}$ & $\begin{array}{l}5,080 \\
4,480 \\
3,800 \\
3,250 \\
2,850 \\
2,650 \\
\end{array}$ & $\begin{array}{l}3.62 \\
3.62 \\
3.62 \\
3.64 \\
3.69 \\
3.68\end{array}$ & $\begin{array}{l}1,160 \\
1,160 . \\
1,160 \\
1,190 \\
1,230 \\
1,230 \\
\end{array}$ & $\begin{array}{l}3.62 \\
3.57 \\
3.52 \\
3.51 \\
3.56 \\
3.48 \\
\end{array}$ & $\begin{array}{l}1,160 \\
1,120 \\
1,080 \\
1,080 \\
1,120 \\
1,080 \\
\end{array}$ & $\begin{array}{l}3.19 \\
3.11 \\
3.07 \\
3.04 \\
2.99 \\
2.97\end{array}$ & $\begin{array}{l}880 \\
820 \\
790 \\
790 \\
760 \\
732 \\
\end{array}$ \\
\hline$\stackrel{12}{\longrightarrow}$ & \multicolumn{2}{|c|}{ Aug. 18} & \multicolumn{2}{|c|}{ Aug. 19} & \multicolumn{2}{|c|}{ Aug. 20} & \multicolumn{6}{|c|}{ SUPPLEMENTAL RECORDS } \\
\hline $\begin{array}{r}2 \\
4 \\
6 \\
8 \\
10 \\
\mathrm{~N}\end{array}$ & $\begin{array}{l}2.92 \\
2.86 \\
2.77 \\
2.74 \\
2.72 \\
2.70\end{array}$ & $\begin{array}{l}705 \\
683 \\
635 \\
620 \\
610 \\
600\end{array}$ & $\begin{array}{l}2.92 \\
2.89 \\
2.84 \\
2.79 \\
2.72 \\
2.70\end{array}$ & $\begin{array}{l}705 \\
700 \\
672 \\
645 \\
610 \\
600\end{array}$ & $\begin{array}{l}2.41 \\
2.44 \\
2.38 \\
2.33 \\
2.34 \\
2.33\end{array}$ & $\begin{array}{l}460 \\
473 \\
446 \\
424 \\
428 \\
424\end{array}$ & $\begin{array}{l}\text { Aug. } \\
\text { Aug. }\end{array}$ & $\begin{array}{r}14,10 \\
18,7 p \\
9 \text { p. }\end{array}$ & a.m. & & $\begin{array}{l}9.40 \\
2.91 \\
3.20\end{array}$ & $\begin{array}{r}7,630 \\
705 \\
880\end{array}$ \\
\hline $\begin{array}{r}2 \\
4 \\
6 \\
8 \\
10 \\
12 \\
\end{array}$ & $\begin{array}{l}2.68 \\
2.66 \\
2.81 \\
3.35 \\
3.12 \\
2.88\end{array}$ & $\begin{array}{l}590 \\
580 \\
656 \\
978 \\
820 \\
694 \\
\end{array}$ & $\begin{array}{l}2.67 \\
2.67 \\
2.58 \\
2.53 \\
2.51 \\
2.47\end{array}$ & $\begin{array}{l}585 \\
585 \\
540 \\
515 \\
505 \\
486 \\
\end{array}$ & $\begin{array}{l}2.32 \\
2.34 \\
2.34 \\
2.29 \\
2.27 \\
2.26\end{array}$ & $\begin{array}{l}419 \\
428 \\
428 \\
406 \\
397 \\
393\end{array}$ & & & & & & \\
\hline
\end{tabular}

DAN RIVER NEAR WENTWORTH, N. C.

Location.-Lat. $36^{\circ} 24^{\prime} 45^{\prime \prime}$, long. $79^{\circ} 49^{\prime} 45^{\prime \prime}$, at Settles Bridge, $31 / 2$ miles north of

Wentworth, Rockingham County, and 71/2 miles downstream from Mayo River.

DraiNAGE AREA. - 1,050 square miles.

GAGE-HEIGHT RECORD.-Water-stage recorder graph.

DISCHARGE RECORD.- -Stage-discharge relation defined by current-meter measurements up to 16,500 second-feet and extended to crest gage height on basis of determination of flood flow by slope-area method and flood runoff comparisons. Shifting-control method used Aug. 19 to Sept. 30. Gage heights used to half-tenths between 1.9 and 4.0 feet; hundredths below and tenths above these limits.

Maxima.-1940: Discharge, 50,200 second-feet 10-12 a.m. Aug. 15 (gage height, 26.9 feet).

REMARKs.-Flood runoff not affected by artificial storage. 
Mean discharge, in second-feet, 1940

\begin{tabular}{|c|c|c|c|c|c|c|c|c|c|c|c|}
\hline Day & Aug. & Sept. & Day & Aug. & Sept. & Day & Aug. & Sept. & Day & Aug. & Sept. \\
\hline $\begin{array}{l}1 \\
2 \\
3 \\
4 \\
5 \\
6 \\
7 \\
8\end{array}$ & $\begin{array}{r}1,430 \\
968 \\
788 \\
698 \\
720 \\
655 \\
930 \\
742\end{array}$ & $\begin{array}{r}1,980 \\
1,260 \\
1,040 \\
945 \\
878 \\
1,140 \\
900 \\
788\end{array}$ & $\begin{array}{r}9 \\
10 \\
11 \\
12 \\
13 \\
14 \\
15 \\
16\end{array}$ & $\begin{array}{r}635 \\
555 \\
515 \\
1,040 \\
953 \\
10,700 \\
40,900 \\
15,200\end{array}$ & $\begin{array}{l}765 \\
742 \\
742 \\
720 \\
675 \\
655 \\
635 \\
655\end{array}$ & $\begin{array}{l}17 \\
18 \\
19 \\
20 \\
21 \\
22 \\
23 \\
24\end{array}$ & $\begin{array}{l}7,060 \\
3,080 \\
3,480 \\
1,920 \\
1,480 \\
1,330 \\
1,260 \\
1,130\end{array}$ & $\begin{array}{l}635 \\
615 \\
635 \\
615 \\
\mathbf{5 9 5} \\
\mathbf{5 7 5} \\
\mathbf{5 7 5} \\
\mathbf{5 3 5}\end{array}$ & $\begin{array}{l}25 \\
26 \\
27 \\
28 \\
29 \\
30 \\
31\end{array}$ & $\begin{array}{r}1,010 \\
1,040 \\
1,450 \\
1,130 \\
1,060 \\
1,080 \\
2,480\end{array}$ & $\begin{array}{l}\mathbf{5 5 5} \\
\mathbf{7 6 5} \\
\mathbf{6 7 5} \\
\mathbf{5 7 5} \\
\mathbf{5 7 5} \\
\mathbf{5 7 5}\end{array}$ \\
\hline 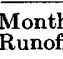 & & & & & & & & & & $\begin{array}{r}3,465 \\
3.80\end{array}$ & $\begin{array}{r}767 \\
0.82\end{array}$ \\
\hline
\end{tabular}

Gage height, in feet, and discharge, in second-feet, at indicated time, 1940

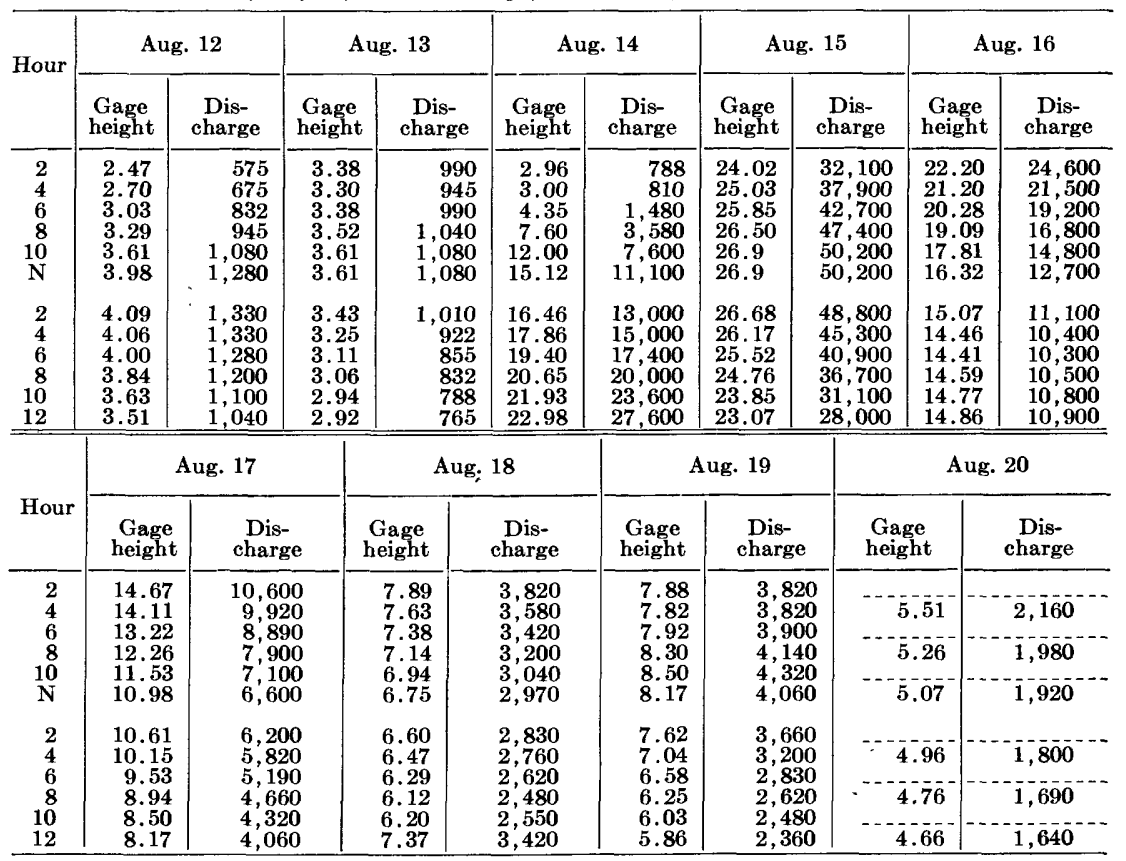

Supplemental ReCord.-Aug. 18, 9 p.m., gage height, 6.06 feet; discharge, 2,480 second-feet.

DAN RIVER AT LEAKSVILLE, N. C.

Location.-Lat. $36^{\circ} 29^{\prime} 05^{\prime \prime}$, long. $79^{\circ} 45^{\prime} 30^{\prime \prime}$, at Leaksville, Rockingham County, half a mile downstream from State highway bridge and half a mile upstream from Smith River. Datum of gage is 490.33 feet above mean sea level, datum of 1929.

Drainage AREA.-1,150 square miles.

GAGE-HEIGHT RECORD.-Water-stage recorder graph.

DISCHARGE RECORD.-Stage-discharge relation defined by current-meter measurements up to 28,000 second-feet. Gage heights used to half-tenths between 2.0 and 3.4 feet; hundredths below and tenths above these limits. During floods this station is subject to backwater from Smith River or from channel storage downstream. From 1 p.m. Aug. 14 to 4 a.m. Aug. 17 the discharge has been adjusted for backwater on basis of records for station at Wentworth. 
Maxima.-1940: Discharge, about 43,000 second-feet 12-2 p.m. Aug. 15; gage height, 28.26 feet $6: 30$ a.m. Aug. 15 .

1929-39: Gage height, 27.90 feet Oct. 20, 1937 (discharge not determined owing to backwater).

REMARKs.-Flood runoff not affected by artificial storage.

Mean discharge, in second-feet, 1940

\begin{tabular}{|c|c|c|c|c|c|c|c|c|c|c|c|}
\hline Day & Aug. & Sept. & Day & Aug. & Sept. & Day & Aug. & Sept. & Day & Aug. & Sept. \\
\hline $\begin{array}{l}1 \\
2 \\
3 \\
4 \\
5 \\
6 \\
7 \\
8\end{array}$ & $\begin{array}{r}1,680 \\
1,060 \\
852 \\
742 \\
768 \\
735 \\
930 \\
865\end{array}$ & $\begin{array}{r}2,430 \\
1,420 \\
1,160 \\
1,030 \\
962 \\
1,160 \\
1,030 \\
865\end{array}$ & $\begin{array}{r}9 \\
10 \\
11 \\
12 \\
13 \\
14 \\
15 \\
16\end{array}$ & $\begin{array}{r}702 \\
605 \\
545 \\
1,030 \\
1,060 \\
10,600 \\
38,600 \\
20,800\end{array}$ & $\begin{array}{l}839 \\
794 \\
806 \\
806 \\
754 \\
709 \\
690 \\
702\end{array}$ & $\begin{array}{l}17 \\
18 \\
19 \\
20 \\
21 \\
22 \\
23 \\
24\end{array}$ & $\begin{array}{l}8,910 \\
3,900 \\
3,720 \\
2,240 \\
1,710 \\
1,480 \\
1,420 \\
1,220\end{array}$ & $\begin{array}{l}683 \\
657 \\
664 \\
664 \\
644 \\
569 \\
581 \\
563\end{array}$ & $\begin{array}{l}25 \\
26 \\
27 \\
28 \\
29 \\
30 \\
31\end{array}$ & $\begin{array}{l}1,120 \\
1,420 \\
1,920 \\
1,320 \\
1,350 \\
1,160 \\
3,050\end{array}$ & $\begin{array}{l}569 \\
735 \\
747 \\
599 \\
593 \\
587\end{array}$ \\
\hline & & & & & & & & & & $\begin{array}{r}3,791 \\
3.80 \\
\end{array}$ & $\begin{array}{r}834 \\
0.81 \\
\end{array}$ \\
\hline
\end{tabular}

Gage height, in feet, and discharge, in second-feet, at indicated time, 1940

\begin{tabular}{|c|c|c|c|c|c|c|c|c|c|c|c|c|c|}
\hline \multirow{2}{*}{ Hour } & \multicolumn{2}{|c|}{ Aug. 12} & \multicolumn{4}{|c|}{ Aug. 13} & \multicolumn{2}{|c|}{ Aug. 14} & \multicolumn{3}{|c|}{ Aug. 15} & \multicolumn{2}{|c|}{ Aug. 16} \\
\hline & $\begin{array}{c}\text { Gage } \\
\text { height }\end{array}$ & $\begin{array}{c}\text { Dis- } \\
\text { charge }\end{array}$ & $\begin{array}{l}\text { Ga } \\
\text { heig }\end{array}$ & & Di & & $\begin{array}{c}\text { Gage } \\
\text { height }\end{array}$ & $\begin{array}{c}\text { Dis- } \\
\text { charge }\end{array}$ & $\begin{array}{c}\text { Gage } \\
\text { height }\end{array}$ & & & $\underset{\text { heig }}{\text { Gag }}$ & $\begin{array}{c}\text { Dis- } \\
\text { charge }\end{array}$ \\
\hline \multirow{4}{*}{$\begin{array}{l}1 \\
2 \\
3 \\
4 \\
5 \\
6\end{array}$} & & & \multirow{4}{*}{\multicolumn{2}{|c|}{$\begin{array}{c}-\cdots \\
-\cdots 7 \\
-\cdots\end{array}$}} & \multirow{4}{*}{\multicolumn{2}{|c|}{1,090}} & \multirow{4}{*}{$\begin{array}{l}2.03 \\
2.03 \\
2.05 \\
2.18 \\
2.49 \\
3.45\end{array}$} & \multirow{4}{*}{$\begin{array}{r}898 \\
898 \\
898 \\
995 \\
1,190 \\
1,780\end{array}$} & & \multirow{2}{*}{\multicolumn{2}{|c|}{31,000}} & \multirow[b]{2}{*}{23.63} & \\
\hline & 1.71 & 676 & & & & & & & 27.32 & & & & 32,500 \\
\hline & 1.74 & 696 & & & & & & & $\overline{28.00}$ & \multicolumn{2}{|c|}{$\overline{35,000}$} & $\overline{2} \overline{2} . \overline{9}$ & 29,000 \\
\hline & $1 . \overline{7}$ & $6 \overline{6}$ & & & & & & & $\overline{28 .} \overline{2}$ & \multicolumn{2}{|c|}{38,000} & 22.26 & $\overline{27}, \overline{000}$ \\
\hline \multirow{3}{*}{$\begin{array}{r}7 \\
8 \\
9 \\
10 \\
11 \\
\mathrm{~N}\end{array}$} & 1.86 & 774 & \multicolumn{2}{|c|}{$-\overline{2} . \overline{25}$} & \multicolumn{2}{|c|}{1,030} & $\begin{array}{l}4.50 \\
5.80\end{array}$ & \multirow{3}{*}{$\begin{array}{r}2,560 \\
3,580 \\
4,800 \\
6,400 \\
8,750 \\
11,000\end{array}$} & 28.08 & \multicolumn{2}{|c|}{$4 \overline{1}, 000$} & 21.61 & 25,000 \\
\hline & 2.04 & $\overline{89} \overline{8}$ & \multicolumn{2}{|c|}{ - } & \multicolumn{2}{|c|}{$-1-1$} & $\begin{array}{l}7.15 \\
8.78\end{array}$ & & $\overline{2} \overline{7} . \overline{5} \bar{s}^{-}$ & \multicolumn{2}{|c|}{$-\overline{42}, \overline{500}$} & 20.82 & $\overline{2}, 000$ \\
\hline & 2.25 & 1,030 & \multicolumn{2}{|c|}{2.37} & \multicolumn{2}{|c|}{1,090} & $\begin{array}{l}10.95 \\
12.80\end{array}$ & & 27.23 & \multicolumn{2}{|c|}{43,000} & 19.84 & 20,000 \\
\hline \multirow{3}{*}{\begin{tabular}{l|}
1 \\
2 \\
3 \\
4 \\
5 \\
6
\end{tabular}} & $2.5 \overline{3}$ & $1,220^{-}$ & --- & -- & & & $\begin{array}{l}14.35 \\
15.36\end{array}$ & $\begin{array}{l}12,000 \\
13,000\end{array}$ & 26.79 & $4 \overline{3}$ & & 18.94 & 17,000 \\
\hline & $2 . \overline{6}$ & $1, \overline{3} 50$ & 2 & & $\overline{1}$, & & $\begin{array}{l}16.10 \\
17.35\end{array}$ & $\begin{array}{l}14,000 \\
15,000\end{array}$ & 26.20 & $\overline{4} \overline{2}$ & & 17.83 & 14,500 \\
\hline & 2.81 & $1,380^{-}$ & & & & & $\begin{array}{l}18.92 \\
19.90\end{array}$ & $\begin{array}{l}16,000 \\
17,500\end{array}$ & $\overline{25.73}$ & $\overline{4} \overline{1}$ & & 16.64 & 13,300 \\
\hline $\begin{array}{l}7 \\
8\end{array}$ & 2.80 & $1,380^{-}$ & 2 & & & $\overline{6} \overline{2}-$ & $\begin{array}{l}20.70 \\
21.58\end{array}$ & $\begin{array}{l}19,000 \\
20,000\end{array}$ & 25.35 & & & 15.50 & 13,000 \\
\hline 9 & $-7-\overline{7}-$ & $1-5=$ & & & & & 22.50 & 21,000 & $-8 x^{-0}$ & & & 1477 & $-\overline{1}-\overline{1}$ \\
\hline $\begin{array}{l}10 \\
11\end{array}$ & 2.75 & $1,300_{-}$ & & & & & $\begin{array}{l}23.55 \\
24.96\end{array}$ & 23,000 & 24.89 & & & 14.7 & 100 \\
\hline 12 & $2.6 \overline{2}$ & 1,260 & 2. & & & 98 & 25.88 & & $24.3 \overline{3}$ & & & 14.48 & 13,000 \\
\hline & & Aug. 17 & & & & ig. & & & ug. 19 & & & $\mathrm{Au}_{\mathrm{s}}$ & \\
\hline & $\begin{array}{c}\text { Gage } \\
\text { height }\end{array}$ & Disch & arge & & $\begin{array}{l}\text { Gage } \\
\text { peight }\end{array}$ & & ischarge & $\begin{array}{c}\text { Gage } \\
\text { height }\end{array}$ & Discl & & & & Discharge \\
\hline $\begin{array}{r}2 \\
4 \\
6 \\
8 \\
10 \\
\mathrm{~N}\end{array}$ & $\begin{array}{l}14.18 \\
13.63 \\
12.90 \\
12.22 \\
11.41 \\
10.63\end{array}$ & $\begin{array}{r}12, \\
12, \\
11, \\
10, \\
9, \\
8,\end{array}$ & $\begin{array}{l}500 \\
000 \\
100 \\
200 \\
190 \\
310\end{array}$ & & $\begin{array}{r}7.09 \\
6.38 \\
5.99\end{array}$ & & $\begin{array}{l}4,710 \\
4,080 \\
3,740\end{array}$ & $\begin{array}{l}5.34 \\
5.97 \\
6.22 \\
6.25 \\
6.40 \\
6.63\end{array}$ & & & & $\begin{array}{l}.63 \\
.41 \\
.30 \\
.29 \\
.19 \\
.09\end{array}$ & $\begin{array}{l}2,640 \\
2,420 \\
2,340 \\
2,340 \\
2,270 \\
2,200\end{array}$ \\
\hline $\begin{array}{r}2 \\
4 \\
6 \\
8 \\
10 \\
12\end{array}$ & $\begin{array}{r}10.19 \\
9.72 \\
9.17 \\
8.88 \\
8.32 \\
7.80\end{array}$ & $\begin{array}{l}7, \\
7, \\
6, \\
6, \\
5 \\
5,\end{array}$ & $\begin{array}{l}870 \\
320 \\
800 \\
500\end{array}$ & & $\begin{array}{l}5.67 \\
5.27 \\
5.13\end{array}$ & & $\begin{array}{c}3,500 \\
3,180^{-} \\
3,020\end{array}$ & $\begin{array}{l}6.71 \\
6.57 \\
6.01 \\
5.69 \\
5.32 \\
4.87\end{array}$ & & & & $\begin{array}{l}.95 \\
.86 \\
.82 \\
.80 \\
.82 \\
.67\end{array}$ & $\begin{array}{l}2,130 \\
2,060 \\
2,060 \\
1,990 \\
2,060 \\
1,920\end{array}$ \\
\hline
\end{tabular}




\section{2}

DAN RIVER AT DA NVILLE, VA.

Location.-Lat. $36^{\circ} 35^{\prime} 15^{\prime \prime}$, long. $79^{\circ} 22^{\prime} 55^{\prime \prime}$, at Southern Railway bridge in Danville, Pittsylvania County, 1,000 feet upstream from Fall Creek. Datum of gage is 379.41 feet above mean sea level, datum of 1929 .

Drain AGE AREA.-2,050 square miles.

GAGE-HEIGHT RECORD.-Water-stage recorder graph.

DISCHARGE RECORD.-Stage-discharge relation defined by current-meter measurements up to 56,000 second-feet and extended to crest gage height by logarithmic plotting on basis of computation of flow over dam $3 \frac{1}{2}$ miles upstream and comparisons with flood records for other stations in Roanoke River Basin. Gage heights used to half-tenths between 3.6 and 5.1 feet; hundredths below and tenths above these limits. Rating curve not applicable Aug, 2-12 and affected by backwater from debris Aug. 18 to Sept. 30; discharge computed on basis of records for station at South Boston and stations upstream.

Maxima.-1940: Discharge, 75,000 second-feet 6:30 p.m. Aug. 15 (gage height, 20.96 feet).

1934-39: Discharge, 54,100 second-feet Oct. 21, 1937 (gage height, 18.34 feet).

Mean discharge, in second-feet, 1940

\begin{tabular}{|c|c|c|c|c|c|c|c|c|c|c|c|}
\hline Day & Aug. & Sept. & Day & Aug. & Sept. & Day & Aug. & Sept. & Day & Aug. & Sept. \\
\hline $\begin{array}{l}1 \\
2 \\
3 \\
4 \\
5 \\
5 \\
6 \\
7 \\
8\end{array}$ & $\begin{array}{l}3,760 \\
2,000 \\
1,300 \\
1,200 \\
1,200 \\
1,300 \\
1,200 \\
1,600\end{array}$ & $\begin{array}{l}8,000 \\
3,000 \\
2,500 \\
2,200 \\
2,000 \\
1,900 \\
1,900 \\
1,700\end{array}$ & \begin{tabular}{r|}
9 \\
10 \\
11 \\
12 \\
13 \\
14 \\
15 \\
16
\end{tabular} & $\begin{array}{r}1,500 \\
1,100 \\
950 \\
1,100 \\
1,750 \\
11,200 \\
64,800 \\
54,700\end{array}$ & $\begin{array}{l}1,800 \\
1,600 \\
1,500 \\
1,450 \\
1,400 \\
1,300 \\
1,200 \\
1,400\end{array}$ & $\begin{array}{l}17 \\
18 \\
19 \\
20 \\
21 \\
22 \\
23 \\
24\end{array}$ & $\begin{array}{r}24,800 \\
9,300 \\
6,920 \\
4,890 \\
3,200 \\
2,800 \\
2,800 \\
2,300\end{array}$ & $\begin{array}{l}1,300 \\
1,250 \\
1,200 \\
1,300 \\
1,100 \\
1,150 \\
1,200 \\
1,150\end{array}$ & $\begin{array}{l}25 \\
26 \\
27 \\
28 \\
29 \\
30 \\
31\end{array}$ & $\begin{array}{l}2,300 \\
2,500 \\
4,700 \\
3,500 \\
3,600 \\
2,900 \\
5,500\end{array}$ & $\begin{array}{r}1,150 \\
1,200 \\
1,500 \\
1,300 \\
1,350 \\
1,100 \\
\\
\end{array}$ \\
\hline \multicolumn{10}{|c|}{$\begin{array}{l}\text { Monthly mean discharge, in second-feet } \\
\text { Runoff, in inches }\end{array}$} & $\begin{array}{r}7,505 \\
4.22\end{array}$ & $\begin{array}{r}1,737 \\
0.94\end{array}$ \\
\hline
\end{tabular}


ROANOKE RIVER BASIN

Gage height, in feet, and discharge, in second-feet, at indicated time, 1940

\begin{tabular}{|c|c|c|c|c|c|c|c|c|}
\hline \multirow{2}{*}{ Hour } & \multicolumn{2}{|c|}{ Aug. 13} & \multicolumn{2}{|c|}{ Aug. 14} & \multicolumn{2}{|c|}{ Aug. 15} & \multicolumn{2}{|c|}{ Aug. 16} \\
\hline & $\begin{array}{c}\text { Gage } \\
\text { height }\end{array}$ & Discharge & $\begin{array}{c}\text { Gage } \\
\text { height }\end{array}$ & Discharge & $\begin{array}{c}\text { Gage } \\
\text { height }\end{array}$ & Discharge & $\begin{array}{c}\text { Gage } \\
\text { height }\end{array}$ & Discharge \\
\hline $\begin{array}{l}1 \\
2 \\
3 \\
4 \\
5 \\
6\end{array}$ & $\begin{array}{l}2.78 \\
3.16 \\
3.10 \\
3.10 \\
3.13 \\
3.09\end{array}$ & $\begin{array}{l}1,220 \\
1,910 \\
1,790 \\
1,790 \\
1,850 \\
1,770\end{array}$ & $\begin{array}{l}2.53 \\
2.87 \\
2.93 \\
2.87 \\
2.84 \\
2.85\end{array}$ & $\begin{array}{r}893 \\
1,370 \\
1,470 \\
1,370 \\
1,320 \\
1,340\end{array}$ & $\begin{array}{l}16.32 \\
16.85 \\
17.27 \\
17.55 \\
17.82 \\
18.27\end{array}$ & $\begin{array}{l}47,000 \\
49,700 \\
52,400 \\
54,100 \\
55,300 \\
58,300\end{array}$ & $\begin{array}{l}20.39 \\
20.21 \\
20.02 \\
19.82 \\
19.65 \\
19.46\end{array}$ & $\begin{array}{l}69,800 \\
68,500 \\
67,300 \\
66,100 \\
64,900 \\
63,700\end{array}$ \\
\hline $\begin{array}{c}7 \\
8 \\
9 \\
10^{\circ} \\
11 \\
\mathrm{~N}\end{array}$ & $\begin{array}{l}3.15 \\
3.17 \\
3.29 \\
3.27 \\
3.28 \\
3.27\end{array}$ & $\begin{array}{l}1,890 \\
1,930 \\
2,170 \\
2,130 \\
2,150 \\
2,130\end{array}$ & $\begin{array}{l}2.74 \\
3.02 \\
4.37 \\
5.49 \\
5.77 \\
5.97\end{array}$ & $\begin{array}{l}1,160 \\
1,640 \\
4590 \\
7,460 \\
8,240 \\
8,760\end{array}$ & $\begin{array}{l}18.72 \\
18.94 \\
19.12 \\
19.29 \\
19.42 \\
19.58\end{array}$ & $\begin{array}{l}60,700 \\
61,900 \\
63,100 \\
64,300 \\
64,900 \\
66,100\end{array}$ & $\begin{array}{l}19.22 \\
18.99 \\
18.74 \\
18.45 \\
18.07 \\
17.72\end{array}$ & $\begin{array}{l}62,500 \\
61,300 \\
59,500 \\
57,700 \\
55,300 \\
53,600\end{array}$ \\
\hline $\begin{array}{l}1 \\
2 \\
3 \\
4 \\
5 \\
6 \\
6\end{array}$ & $\begin{array}{l}3.24 \\
3.22 \\
3.18 \\
3.08 \\
3.07 \\
3.05\end{array}$ & $\begin{array}{l}2,070 \\
2,030 \\
1,950 \\
1,750 \\
1,730 \\
1,700\end{array}$ & $\begin{array}{l}6.12 \\
6.65 \\
7.52 \\
8.15 \\
8.48 \\
8.94\end{array}$ & $\begin{array}{r}9,030 \\
10,400 \\
12,900 \\
15,000 \\
15,900 \\
17,100\end{array}$ & $\begin{array}{l}19.84 \\
20.22 \\
20.55 \\
20.70 \\
20.90 \\
20.94\end{array}$ & $\begin{array}{l}67,300 \\
69,800 \\
72,400 \\
73,000 \\
74,400 \\
74,400\end{array}$ & $\begin{array}{l}17.42 \\
17.27 \\
17.15 \\
16.80 \\
16.49 \\
16.17\end{array}$ & $\begin{array}{l}51,900 \\
50,800 \\
50,200 \\
48,600 \\
47,000 \\
44,800\end{array}$ \\
\hline $\begin{array}{r}7 \\
8 \\
9 \\
10 \\
11 \\
12 \\
\end{array}$ & $\begin{array}{l}2.91 \\
2.88 \\
2.89 \\
2.88 \\
2.75 \\
2.73 \\
\end{array}$ & $\begin{array}{l}1,440 \\
1,390 \\
1,400 \\
1,390 \\
1,180 \\
1,140 \\
\end{array}$ & $\begin{array}{r}9.47 \\
10.22 \\
11.02 \\
12.27 \\
13.92 \\
15.47 \\
\end{array}$ & $\begin{array}{l}19,000 \\
21,200 \\
23,900 \\
28,400 \\
34,600 \\
42,600 \\
\end{array}$ & $\begin{array}{l}20.95 \\
20.90 \\
20.79 \\
20.69 \\
20.61 \\
20.52 \\
\end{array}$ & $\begin{array}{l}75,000 \\
74,400 \\
73,700 \\
73,000 \\
72,400 \\
71,800 \\
\end{array}$ & $\begin{array}{l}15.90 \\
15.72 \\
15.60 \\
15.60 \\
15.54 \\
15.49 \\
\end{array}$ & $\begin{array}{l}43,600 \\
42,600 \\
42,000 \\
42,000 \\
41,500 \\
41,500 \\
\end{array}$ \\
\hline \multirow{2}{*}{ Hour } & \multicolumn{2}{|c|}{ Aug. 17} & \multicolumn{2}{|c|}{ Aug. 18} & \multicolumn{2}{|c|}{ Aug. 19} & \multicolumn{2}{|c|}{ Aug. 20} \\
\hline & $\begin{array}{c}\text { Gage } \\
\text { height }\end{array}$ & Discharge & $\begin{array}{c}\text { Gage } \\
\text { height }\end{array}$ & Discharge & $\begin{array}{l}\text { Gage } \\
\text { height }\end{array}$ & Discharge & $\begin{array}{c}\text { Gage } \\
\text { height }\end{array}$ & Discharge \\
\hline \multirow{3}{*}{$\begin{array}{l}1 \\
2 \\
3 \\
4 \\
5 \\
6\end{array}$} & \multirow{3}{*}{$\begin{array}{l}15.35 \\
14.93 \\
14.60 \\
14.27 \\
13.99 \\
13.67\end{array}$} & \multirow{3}{*}{$\begin{array}{l}40,500 \\
38,500 \\
37,000 \\
35,000 \\
34,200 \\
32,600\end{array}$} & 7.35 & $11,800^{-}$ & 6.22 & 6,600 & 6.19 & $6,600^{-}$ \\
\hline & & & 7.13 & 11,200 & 6.14 & 6,600 & 6.10 & 6,300 \\
\hline & & & 6.96 & 10,700 & 6.06 & 6,700 & $5 . \overline{9}$ & 5,900 \\
\hline \multirow{4}{*}{$\begin{array}{r}7 \\
8 \\
9 \\
10 \\
11 \\
\mathrm{~N}\end{array}$} & \multirow{4}{*}{$\begin{array}{l}13.32 \\
12.95 \\
12.54 \\
12.22 \\
11.79 \\
11.29\end{array}$} & \multirow{4}{*}{$\begin{array}{l}31,400 \\
29,900 \\
28,400 \\
27,400 \\
26,000 \\
24,200\end{array}$} & 6.82 & 10,400 & 6.14 & 6,900 & 5.85 & 5,400 \\
\hline & & & & 980 & 60 & & $-5-1-$ & \\
\hline & & & 6.64 & & 6.01 & 7,000 & 5.65 & 4,800 \\
\hline & & & 6.57 & 9,200 & 6.11 & 7,000 & 5.50 & 4,400 \\
\hline \multirow{3}{*}{$\begin{array}{l}1 \\
2 \\
3 \\
4 \\
5 \\
6\end{array}$} & \multirow{3}{*}{$\begin{array}{r}10.89 \\
10.48 \\
10.05 \\
9.57 \\
9.18 \\
8.74\end{array}$} & \multirow{3}{*}{$\begin{array}{l}22,900 \\
21,200 \\
20,000 \\
18,400 \\
17,400 \\
15,900\end{array}$} & 6.49 & 8,700 & 6.24 & 7,100 & 5.49 & 4,200 \\
\hline & & & 6.36 & 8,200 & 6.22 & $\overline{7}, \overline{200}$ & $5 . \overline{44}$ & 4,100 \\
\hline & & & 6.27 & 7,700 & 6.26 & 7,100 & $5 . \overline{4}$ & 4,000 \\
\hline \multirow{3}{*}{$\begin{array}{r}7 \\
8 \\
9 \\
10 \\
11 \\
12 \\
\end{array}$} & \multirow{3}{*}{$\begin{array}{l}8.33 \\
8.07 \\
7.92 \\
7.85 \\
7.69 \\
7.56 \\
\end{array}$} & \multirow{3}{*}{$\begin{array}{l}14,700 \\
13,800 \\
13,500 \\
13,200 \\
12,900 \\
12,400 \\
\end{array}$} & 6.25 & 7,300 & 6.34 & 7,100 & $5 . \overline{4}$ & 3,900 \\
\hline & & & 6.15 & 7,000 & 6.35 & $\overline{7}, 000$ & 5.37 & 3,800 \\
\hline & & & 6.22 & $6,800^{--}$ & 6.24 & 6,800 & 5.20 & 3,700 \\
\hline
\end{tabular}

Supplemental Record.-Aug. 15, 6:30 p.m., gage height, 20.96 feet; discharge, 75,000 second-feet. 


\section{FLOODS OF AUGUST 1940 IN THE SOUTHEASTERN STATES}

DAN RIVER AT SOUTh BOSTON, VA.

LocAtion.-Lat. $36^{\circ} 41^{\prime} 37^{\prime \prime}$, long. $78^{\circ} 54^{\prime} 09^{\prime \prime}$, at Norfolk \& Western Railway bridge at South Boston, Halifax County, 1 mile downstream from Lawson Creek and 6 miles upstream from Banister River. Datum of gage is 299.23 feet above mean sea level, datum of 1929 , supplementary adjustment of 1936 .

DranNage area. - 2,730 square miles.

GAGE-HEIGHT RECORD.-Water-stage recorder graph except for period Aug. 1 to 3 p.m. Aug. 21. Gage heights Aug. 14 to 3 p.m. Aug. 21 were obtained from graph based on occasional gage readings, floodmarks, and comparisons with flood records for other stations in Roanoke River Basin. No gage-height record Aug. 1-13.

DisChARGE RECORD.-Stage-discharge relation defined by current-meter measurements up to 68,000 second-feet and extended to crest gage height by logarithmic plotting on basis of slope-area measurement and comparison with flood records for other stations in Roanoke River Basin. Discharge for Aug. 1-13 computed on basis of records for Dan River at Danville and Roanoke River at Clarksville.

Maxima.-1940: Diseharge, 81,000 second-feet 12 p.m. Aug. 16 (gage height, 31.8 feet, from floodmark).

1900-1907, 1923-39: Discharge, 51,000 seeond-feet Jan. 21, 1936 (gage height, 28.5 feet, from floodmarks).

Remarks.-The District Engineer, Corps of Engineers, War Department, Norfolk, Va., cooperated in completing field work for determination of flood flow by slope-area method.

Mean discharge, in second-feet, 1940

\begin{tabular}{|c|c|c|c|c|c|c|c|c|c|c|c|}
\hline Day & Aug. & Sept. & Day & Aug. & Sept. & Day & Aug. & Sept. & Day & Aug. & Sept. \\
\hline $\begin{array}{l}1 \\
2 \\
3 \\
4 \\
5 \\
6 \\
7 \\
8\end{array}$ & $\begin{array}{r}11,000 \\
5,000 \\
2,500 \\
1,700 \\
1,500 \\
1,300 \\
1,500 \\
1,400\end{array}$ & $\begin{array}{r}10,400 \\
5,980 \\
3,610 \\
2,920 \\
2,580 \\
2,720 \\
2,410 \\
2,320\end{array}$ & $\begin{array}{r}9 \\
10 \\
11 \\
12 \\
13 \\
14 \\
15 \\
16\end{array}$ & $\begin{array}{r}1,700 \\
1,600 \\
1,500 \\
1,400 \\
2,000 \\
9,910 \\
29,500 \\
68,300\end{array}$ & $\begin{array}{l}2,110 \\
2,070 \\
1,960 \\
1,930 \\
1,860 \\
1,800 \\
1,670 \\
1,390\end{array}$ & $\begin{array}{l}17 \\
18 \\
19 \\
20 \\
21 \\
22 \\
23 \\
24\end{array}$ & $\begin{array}{r}66,500 \\
29,600 \\
14,300 \\
8,030 \\
4,690 \\
3,720 \\
3,730 \\
3,520\end{array}$ & $\begin{array}{l}1,660 \\
1,560 \\
1,540 \\
1,490 \\
1,520 \\
1,430 \\
1,260 \\
1,350\end{array}$ & $\begin{array}{l}25 \\
26 \\
27 \\
28 \\
29 \\
30 \\
31\end{array}$ & $\begin{array}{l}3,400 \\
2,890 \\
3,850 \\
5,160 \\
6,170 \\
4,190 \\
3,900\end{array}$ & $\begin{array}{r}1,300 \\
1,410 \\
1,490 \\
1,680 \\
1,520 \\
1,240 \\
\end{array}$ \\
\hline \multicolumn{10}{|c|}{$\begin{array}{l}\text { Monthly mean discharge, in second-feet } \\
\text { Runoff, in inches }\end{array}$} & $\begin{array}{r}9,854 \\
4.16\end{array}$ & 2,273 \\
\hline
\end{tabular}


ROANOKE RIVER BASIN

Gage height, in feet, and discharge, in second-feet, at indicated time, 1940

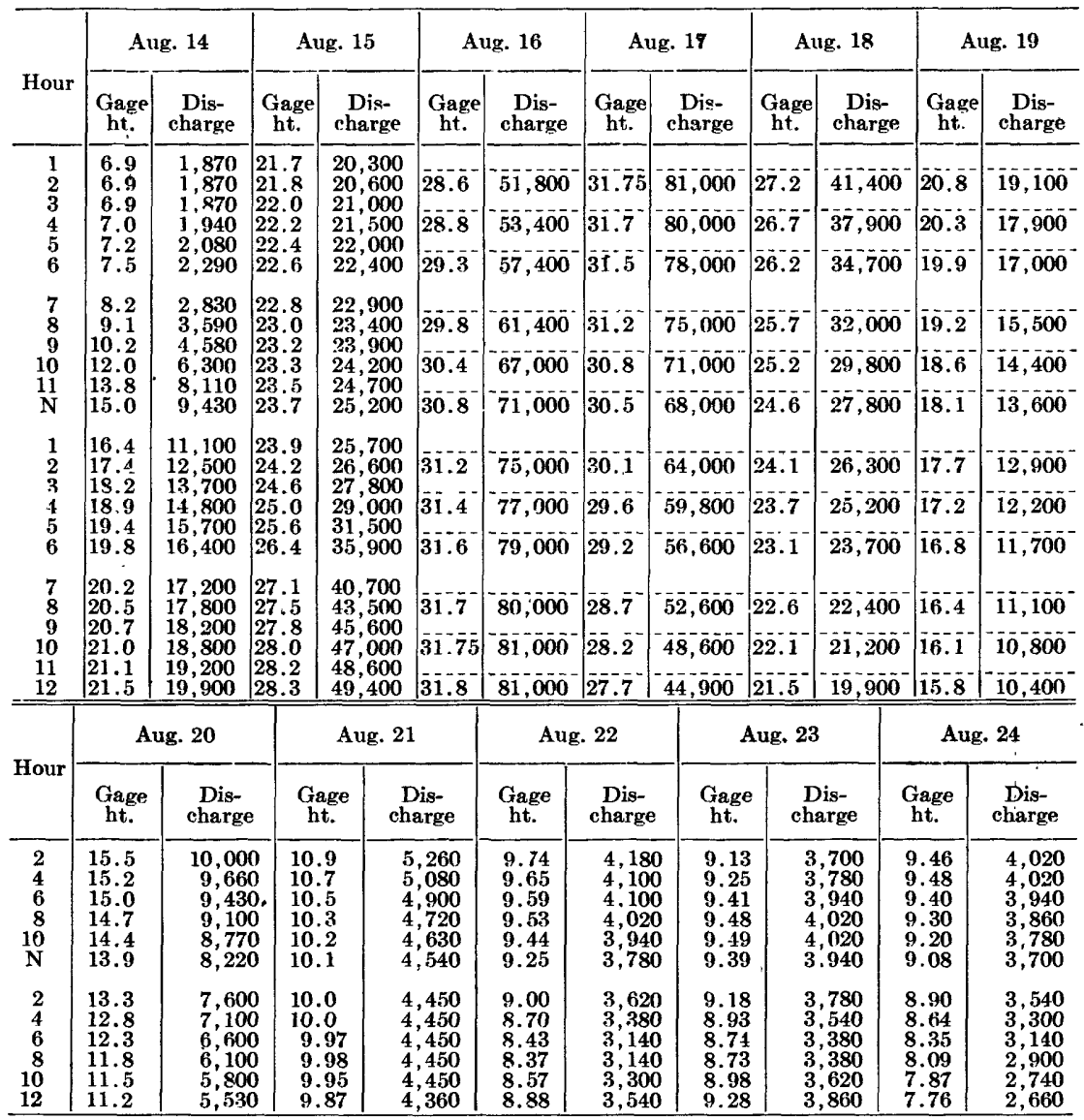

MAYO RIVER NEAR PRICE, N. C.

LocATION.-Lat. $36^{\circ} 32^{\prime} 00^{\prime \prime}$, long. $79^{\circ} 59^{\prime} 30^{\prime \prime}$, just downstream from Anglins Bridge, three-quarters of a mile downstream from State line and 4 miles west of Price, Rockingham County.

Drainage AREa.-260 square miles.

GAGE-HEIGHT RECORD.-Water-stage recorder graph.

DISCHARGE RECORD.- Stage-discharge relation defined by current-meter measurements up to 8,000 second-feet and extended logarithmically to crest gage height. Gage heights used to half-tenths between 2.8 and 5.8 feet; hundredths below and tenths above these limits.

Maxima.-1940: Discharge, 19,000 second-feet 5 p.m. Aug. 14 (gage height, 11.00 feet).

1929-39 : Discharge, :30,000 second-feet Oet. 19, 1937 (gage height, 14.00 feet).

REMARKs.-Flood runoff not affected by artificial storage. 
Mean discharge, in second-feet, 1940

\begin{tabular}{|c|c|c|c|c|c|c|c|c|c|c|c|}
\hline Day & Aug. & Sept. & Day & Aug. & Sept. & Day & Aug. & Sept. & Day & Aug. & Sept. \\
\hline $\begin{array}{l}1 \\
2 \\
3 \\
4 \\
5 \\
6 \\
7 \\
8\end{array}$ & $\begin{array}{l}362 \\
266 \\
229 \\
209 \\
203 \\
203 \\
424 \\
240\end{array}$ & $\begin{array}{l}465 \\
376 \\
336 \\
314 \\
297 \\
293 \\
273 \\
266\end{array}$ & $\begin{array}{r}9 \\
10 \\
11 \\
12 \\
13 \\
14 \\
15 \\
16\end{array}$ & $\begin{array}{r}209 \\
185 \\
197 \\
361 \\
271 \\
9,300 \\
4,390 \\
2,470\end{array}$ & $\begin{array}{l}258 \\
250 \\
254 \\
240 \\
232 \\
229 \\
226 \\
226\end{array}$ & $\begin{array}{l}17 \\
18 \\
19 \\
20 \\
21 \\
22 \\
23 \\
24\end{array}$ & $\begin{array}{r}1,320 \\
1,280 \\
1,180 \\
612 \\
497 \\
405 \\
405 \\
367\end{array}$ & $\begin{array}{l}215 \\
215 \\
215 \\
209 \\
206 \\
197 \\
191 \\
194\end{array}$ & $\begin{array}{l}25 \\
26 \\
27 \\
28 \\
29 \\
30 \\
31\end{array}$ & $\begin{array}{l}340 \\
499 \\
727 \\
507 \\
464 \\
438 \\
667\end{array}$ & $\begin{array}{r}203 \\
250 \\
203 \\
197 \\
197 \\
191 \\
\end{array}$ \\
\hline in & inc & . & & & & & & & & $\begin{array}{r}943 \\
4.18\end{array}$ & $\begin{array}{r}247 \\
1.06\end{array}$ \\
\hline
\end{tabular}

Gage height, in feet, and discharge, in second-feet, at indicated time, 1940

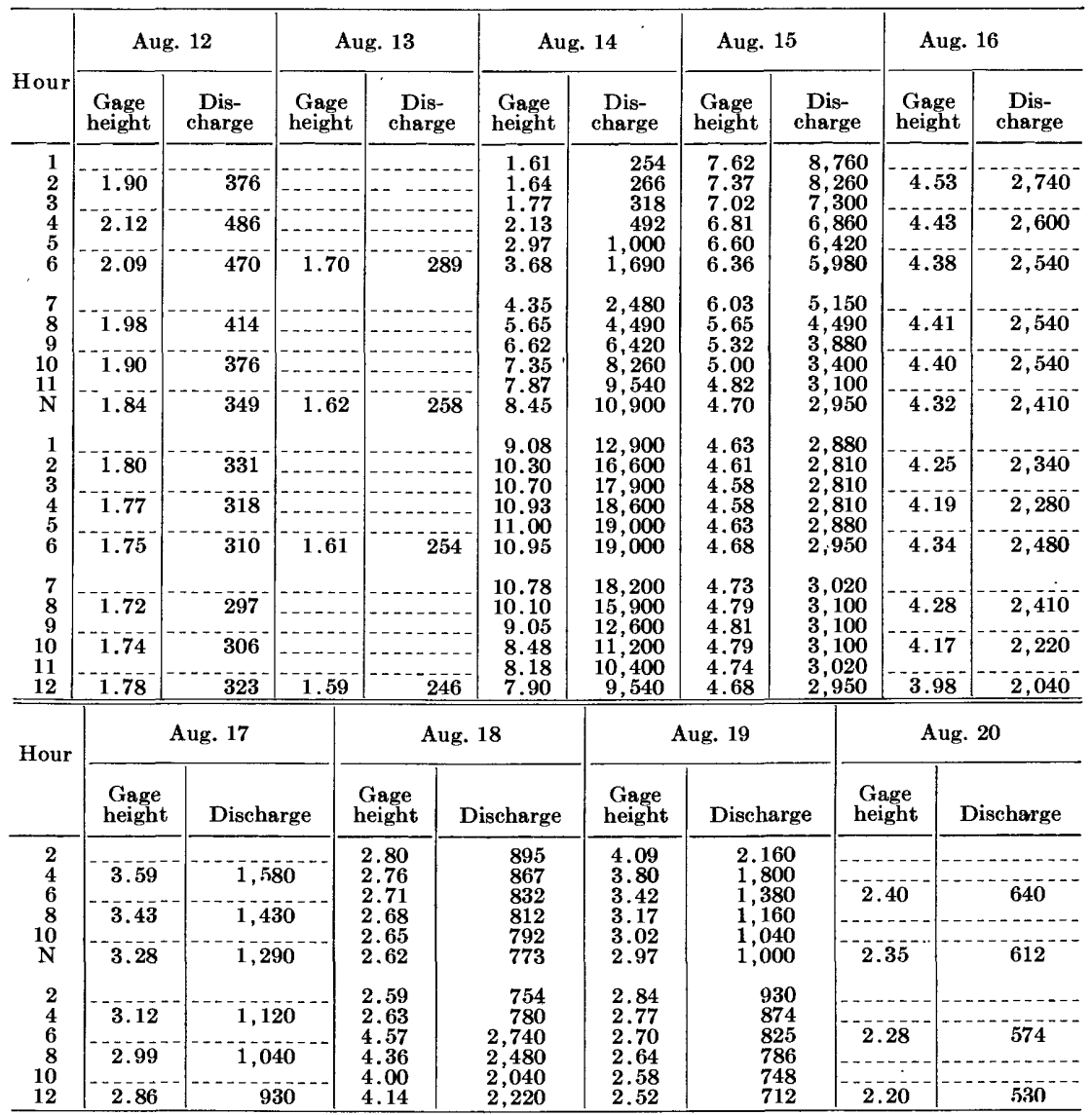

Supplemental RECORD.-Aug. 18, 3:30 p.m., gage height, 2.57 feet; discharge, 742 second-feet.

\section{NORTH MAYO RIVER NEAR SPENCER, VA.}

Location.-Lat. $36^{\circ} 34^{\prime} 05^{\prime \prime}$, long. $79^{\circ} 59^{\prime} 15^{\prime \prime}$, 800 feet downstream from highway bridge at Moores Mill, 2 miles downstream from Horse Pasture Creek, and 4 miles southeast of Spencer, Henry County. Datum of gage is 730.94 feet above mean sea level (from levels by Corps of Engineers, War Department).

Drainage ARea.-108 square miles.

GAGE-HEIGHT RECORD.-Water-stage recorder graph. 
DischaRGE RECORD.-Stage-discharge relation defined by current-meter measurements up to 6,500 second-feet and extended to erest gage height by logarithmic plotting on basis of velocity-area study for flood of Oetober 1937, and comparison with flood records for other stations in Dan River Basin. Gage heights used to half-tenths between 3.3 and 5.3 feet; hundredths below and tenths above these limits.

Maxima.-1940: Discharge, 6,800 second-feet 3 p.m. Aug. 14 (gage height, 10.11 feet).

1928-39 : Discharge, 14,300 second-feet Oct. 19, 1937 (gage height, 14.33 feet).

Mean discharge, in second-feet, 1940

\begin{tabular}{|c|c|c|c|c|c|c|c|c|c|c|c|}
\hline Day & Aug. & Sept. & Day & Aug. & Sept. & Day & Aug. & Sept. & Day & Aug. & Sept. \\
\hline $\begin{array}{l}\mathbf{1} \\
\mathbf{2} \\
\mathbf{3} \\
\mathbf{4} \\
5 \\
\mathbf{6} \\
\mathbf{7} \\
\mathbf{8}\end{array}$ & $\begin{array}{r}162 \\
117 \\
97 \\
88 \\
88 \\
116 \\
165 \\
114\end{array}$ & $\begin{array}{r}164 \\
136 \\
122 \\
115 \\
110 \\
105 \\
101 \\
98\end{array}$ & $\begin{array}{r}9 \\
10 \\
11 \\
12 \\
13 \\
14 \\
15 \\
16\end{array}$ & $\begin{array}{r}90 \\
74 \\
86 \\
157 \\
93 \\
3,430 \\
1,760 \\
\mathbf{8 7 3}\end{array}$ & $\begin{array}{l}94 \\
94 \\
94 \\
90 \\
87 \\
85 \\
85 \\
83\end{array}$ & $\begin{array}{l}17 \\
18 \\
19 \\
20 \\
21 \\
22 \\
23 \\
24\end{array}$ & $\begin{array}{l}431 \\
429 \\
389 \\
207 \\
169 \\
165 \\
187 \\
131\end{array}$ & $\begin{array}{l}81 \\
81 \\
81 \\
79 \\
77 \\
75 \\
73 \\
75\end{array}$ & $\begin{array}{l}25 \\
26 \\
27 \\
28 \\
29 \\
30 \\
31\end{array}$ & $\begin{array}{l}120 \\
337 \\
601 \\
247 \\
260 \\
188 \\
234\end{array}$ & $\begin{array}{r}85 \\
96 \\
79 \\
77 \\
75 \\
73 \\
\end{array}$ \\
\hline \multicolumn{10}{|c|}{$\begin{array}{l}\text { Monthly mean discharge, in second-feet } \\
\text { Runoff, in inches }\end{array}$} & $\begin{array}{r}374 \\
3.99\end{array}$ & $\begin{array}{l}92.3 \\
0.95\end{array}$ \\
\hline
\end{tabular}

Gage height, in feet, and discharge, in second-feet, at indicated time, 1940

\begin{tabular}{|c|c|c|c|c|c|c|c|c|c|c|c|c|}
\hline \multirow[b]{2}{*}{ Hour } & \multicolumn{2}{|c|}{ Aug. 13} & \multicolumn{2}{|c|}{ Aug. 14} & \multicolumn{2}{|c|}{ Aug. 15} & \multicolumn{2}{|c|}{ Aug. 16} & \multicolumn{2}{|c|}{ Aug. 17} & \multicolumn{2}{|c|}{ Aug. 18} \\
\hline & $\begin{array}{c}\text { Gage } \\
\text { ht. }\end{array}$ & $\begin{array}{c}\text { Dis- } \\
\text { charge }\end{array}$ & $\begin{array}{c}\text { Gage } \\
\text { ht. }\end{array}$ & $\begin{array}{l}\text { Dis- } \\
\text { charge }\end{array}$ & $\begin{array}{c}\text { Gage } \\
\text { ht. }\end{array}$ & $\begin{array}{c}\text { Dis- } \\
\text { charge }\end{array}$ & $\begin{array}{c}\text { Gage } \\
\text { ht. }\end{array}$ & $\begin{array}{c}\text { Dis- } \\
\text { charge }\end{array}$ & $\begin{array}{c}\text { Gage } \\
\text { ht. }\end{array}$ & $\begin{array}{c}\text { Dis- } \\
\text { charge }\end{array}$ & $\begin{array}{c}\text { Gage } \\
\text { ht. }\end{array}$ & $\begin{array}{c}\text { Dis- } \\
\text { charge }\end{array}$ \\
\hline \multirow{4}{*}{$\begin{array}{l}1 \\
2 \\
3 \\
4 \\
5 \\
6\end{array}$} & $1.8 \overline{3}$ & 97 & \multirow{4}{*}{$\begin{array}{l}1.82 \\
1.86 \\
1.96 \\
2.26 \\
2.48 \\
2.97\end{array}$} & \multirow{4}{*}{$\begin{array}{r}95 \\
104 \\
130 \\
215 \\
285 \\
461\end{array}$} & \multirow{4}{*}{$\begin{array}{l}8.22 \\
7.78 \\
7.43 \\
7.15 \\
6.67 \\
6.30\end{array}$} & \multirow{4}{*}{$\begin{array}{l}4,260 \\
3,820 \\
3,420 \\
3,240 \\
2,820 \\
2,500\end{array}$} & 3.98 & & 3.35 & 612 & 2.52 & 289 \\
\hline & $--\overline{8}$ & & & & & & & & & & & - - \\
\hline & 1.82 & 5 & & & & & 3.91 & 876 & 3.17 & 533 & 8 & j \\
\hline & 1.81 & 92 & & & & & 3.93 & 902 & 3.05 & $48 \overline{4}$ & $\overline{2} . \overline{4} \overline{7}$ & $27 \overline{2}$ \\
\hline \multirow{4}{*}{$\begin{array}{r}7 \\
8 \\
9 \\
10 \\
11 \\
\mathrm{~N}\end{array}$} & & & \multirow{4}{*}{$\begin{array}{l}3.45 \\
4.10 \\
4.60 \\
5.03 \\
5.80 \\
7.90\end{array}$} & \multirow{4}{*}{$\begin{array}{r}672 \\
1,010 \\
1,310 \\
1,600 \\
2,130 \\
3,930\end{array}$} & \multirow{4}{*}{\begin{tabular}{|l|}
5.72 \\
5.15 \\
4.75 \\
4.47 \\
4.25 \\
4.13
\end{tabular}} & \multirow{4}{*}{$\begin{array}{l}2,030 \\
1,640 \\
1,360 \\
1,180 \\
1,060 \\
1,010\end{array}$} & & & & & & \\
\hline & 1.80 & 90 & & & & & 3.96 & 902 & 2.97 & 453 & 2.45 & 266 \\
\hline & $\overline{1.81}$ & $\overline{9} \overline{2}$ & & & & & $\overline{3 . \overline{9}}$ & 902 & $2 . \overline{9}$ & 434 & $\overline{2} . \overline{4}$ & $260^{-}$ \\
\hline & $\overline{1.82}$ & 95 & & & & & $\overline{3.90}$ & 876 & 2.85 & 407 & $\overline{2} . \overline{1}$ & $2 \overline{53}$ \\
\hline \multirow{4}{*}{$\begin{array}{l}1 \\
2 \\
3 \\
4 \\
5 \\
6\end{array}$} & & & \multirow{4}{*}{$\begin{array}{r}9.35 \\
9.96 \\
10.11 \\
10.00 \\
9.84 \\
9.72\end{array}$} & \multirow{4}{*}{$\begin{array}{l}5,780 \\
6,650 \\
6,800 \\
6,650 \\
6.350 \\
6,200\end{array}$} & \multirow{4}{*}{\begin{tabular}{|l|}
4.08 \\
4.04 \\
4.03 \\
4.08 \\
4.02 \\
4.10
\end{tabular}} & \multirow{4}{*}{$\begin{array}{l}980 \\
954 \\
954 \\
980 \\
928 \\
980\end{array}$} & & & & & & \\
\hline & 1.82 & 95 & & & & & 3.82 & 824 & 2.78 & 381 & 2.39 & 247 \\
\hline & $\overline{1.81}$ & $\overline{9}$ & & & & & $-\overline{3.8 \overline{2}}$ & $8 \overline{2} \overline{4}$ & $\overline{2.7 \overline{4}}$ & 366 & 3.00 & 464 \\
\hline & 1.80 & 90 & & & & & $\overline{3.86}$ & 850 & $\overline{2.68}$ & $\overline{34} \overline{5}$ & $\overline{3.55}$ & 703 \\
\hline \multirow{5}{*}{$\begin{array}{r}7 \\
8 \\
9 \\
10 \\
11 \\
12 \\
\end{array}$} & & & \multirow{4}{*}{$\begin{array}{l}9.70 \\
9.70 \\
9.60 \\
9.35 \\
9.04 \\
8.66 \\
\end{array}$} & \multirow{4}{*}{$\begin{array}{l}6,200 \\
6,200 \\
6,060 \\
5,780 \\
5,240 \\
4,850\end{array}$} & \multirow{4}{*}{\begin{tabular}{|l|}
4.20 \\
4.27 \\
4.28 \\
4.26 \\
4.27 \\
4.17 \\
\end{tabular}} & & & & & & & \\
\hline & 1.80 & 90 & & & & 1,060 & 3.92 & 876 & 2.64 & 330 & 3.83 & 850 \\
\hline & 1.80 & 90 & & & & $\begin{array}{l}1,090 \\
1,060\end{array}$ & $\overline{3.85}$ & 850 & 2.60 & $\overline{316}$ & $3.6 \overline{7}$ & 750 \\
\hline & $1 . \overline{80}$ & 90 & & & & $\begin{array}{l}1,060 \\
1,010\end{array}$ & $3.6 \overline{2}$ & 726 & $-\overline{2} . \overline{56}$ & 302 & $-\overline{3.59}$ & $72 \overline{6}$ \\
\hline & & g. 19 & & g. 20 & $\mathrm{Au}$ & g. 21 & & g. 22 & & 23 & & 24 \\
\hline & 3.52 & 0 & & & & & & & & & & \\
\hline 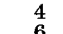 & & & 2.32 & 224 & 2.15 & 173 & 2.08 & 152 & 2.46 & 269 & 2.02 & 136 \\
\hline 8 & 2.81 & $\begin{array}{l}400 \\
392\end{array}$ & 2.28 & $21 \overline{2}$ & $|\overline{2} . \overline{15}|$ & $17 \overline{3}$ & $2 . \overline{07}$ & 150 & $2 . \overline{23}$ & $\overline{19} \overline{7}$ & $\overline{2.00}$ & 130 \\
\hline $\mathrm{N}^{10}$ & 2.64 & 3 & 2.26 & 206 & $\overline{2.14}$ & 170 & 2.07 & 150 & $\overline{2} .13$ & 167 & 2.00 & 130 \\
\hline $\begin{array}{l}2 \\
4\end{array}$ & 2.58 & 309 & $? 24$ & $? 00$ & I & 107 & & 17 & $a$ & 5 & & 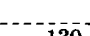 \\
\hline 6 & 2.49 & $\begin{array}{l}292 \\
279\end{array}$ & 2.24 & 200 & 2.13 & 167 & 2.06 & 147 & 2.09 & 155 & 2.00 & 130 \\
\hline 8 & 2.45 & 26 & 2.21 & $191^{\circ}$ & 2.12 & 164 & 2.22 & 194 & 2.06 & 147 & 1.99 & 128 \\
\hline $\begin{array}{l}10 \\
12\end{array}$ & $\begin{array}{l}2.41 \\
2.37\end{array}$ & $\begin{array}{l}25 \\
25\end{array}$ & 2.17 & 179 & $|\overline{2.09}|$ & $\overline{1} \overline{5} \overline{5}$ & $\overline{2} . \overline{36}$ & 237 & $-\overline{2.04}$ & $14 \overline{1}$ & $\overline{1} . \overline{97}$ & $1 \overline{2}$ \\
\hline
\end{tabular}

Supplemental Records.-Aug. 18, 3 p.m., gage height, 2.38 feet; discharge, 244 second-feet. Aug. 22 , 6 p.m., gage height, 2.20 feet; discharge, 188 second-feet; 10 p.m., gage height, 2.21 feet; discharge, 191 second-feet. Aug. 23, 2 a.m., gage height, 2.50 feet; discharge, 282 second-feet. 


\section{FLOODS OF AUGUST 1940 IN THE SOUTHEASTERN STATES \\ SMITH RIVER AT BASSETT, VA.}

LOCATION.-Lat. $36^{\circ} 46^{\prime} 15^{\prime \prime}$, long. $80^{\circ} 00^{\prime} 00^{\prime \prime}$, at highway bridge at north edge of North Bassett, 1 mile northwest of Bassett, Henry County, and 21/2 miles downstream from Town Creek. Datum of gage is $\mathbf{7 5 3 . 0 9}$ feet above mean sea level (levels by Corps of Engineers, War Department).

Drainage aRea.-253 square miles.

GAGE-HEIGHT RECORD.-Water-stage recorder graph.

DISCHARGE RECORD.-Stage-diseharge relation defined by current-meter measurements up to 24,000 second-feet. Gage heights used to half-tenths between 3.2 and 5.1 feet; hundredths below and tenths above these limits.

Maxima.-1940: Discharge, 26,600 second-feet 5 p.m. Aug. 14 (gage height, 18.28 feet).

1939 : Discharge, 23,300 second-feet Aug. 18 (gage height, 16.93 feet).

Stage known, about 22.9 feet Oct. 19, 1937, from information furnished by local residents (discharge, 38,200 second-feet, from rating curve extended above 24,000 second-feet on basis of backwater studies and comparisons of flood records with those for Smith River at Martinsville).

Mean discharge, in second-feet, 1940

\begin{tabular}{|c|c|c|c|c|c|c|c|c|c|c|c|}
\hline Day & Aug. & Sept. & Day & Aug. & Sept. & Day & Aug. & Sept. & Day & Aug. & Sept. \\
\hline $\begin{array}{l}1 \\
2 \\
3 \\
4 \\
5 \\
6 \\
7 \\
8\end{array}$ & $\begin{array}{l}312 \\
251 \\
226 \\
226 \\
238 \\
264 \\
347 \\
246\end{array}$ & $\begin{array}{l}940 \\
704 \\
597 \\
533 \\
498 \\
465 \\
437 \\
410\end{array}$ & $\begin{array}{r}9 \\
10 \\
11 \\
12 \\
13 \\
14 \\
15 \\
16\end{array}$ & $\begin{array}{r}221 \\
198 \\
256 \\
451 \\
350 \\
11,600 \\
4,500 \\
4,670\end{array}$ & $\begin{array}{l}394 \\
384 \\
384 \\
352 \\
337 \\
332 \\
322 \\
322\end{array}$ & $\begin{array}{l}17 \\
18 \\
19 \\
20 \\
21 \\
22 \\
23 \\
24\end{array}$ & $\begin{array}{r}2,580 \\
1,390 \\
1,110 \\
798 \\
638 \\
654 \\
\mathbf{5 7 4} \\
\mathbf{4 9 3}\end{array}$ & $\begin{array}{l}307 \\
297 \\
297 \\
292 \\
278 \\
269 \\
255 \\
255\end{array}$ & $\begin{array}{l}25 \\
26 \\
27 \\
28 \\
29 \\
30 \\
31\end{array}$ & $\begin{array}{r}487 \\
635 \\
634 \\
628 \\
714 \\
1,570 \\
1,870\end{array}$ & $\begin{array}{l}389 \\
342 \\
269 \\
260 \\
251 \\
242 \\
-\end{array}$ \\
\hline \multicolumn{10}{|c|}{$\begin{array}{l}\text { Monthly mean discharge, in second-feet } \\
\text { Runoff, in inches }\end{array}$} & $\begin{array}{r}1,262 \\
5.75\end{array}$ & $\begin{array}{r}380 \\
1.67\end{array}$ \\
\hline
\end{tabular}


Gage height, in feet, and discharge, in second-feet, at indicated time, 1940

\begin{tabular}{|c|c|c|c|c|c|c|c|c|c|c|c|c|}
\hline \multirow[b]{2}{*}{ Hour } & \multicolumn{2}{|c|}{ Aug. 13} & \multicolumn{2}{|c|}{ Aug. 14} & \multicolumn{2}{|c|}{ Aug. 15} & \multicolumn{2}{|c|}{ Aug. 16} & \multicolumn{2}{|c|}{ Aug. 17} & \multicolumn{2}{|c|}{ Aug. 18} \\
\hline & $\begin{array}{c}\text { Gage } \\
\text { ht. }\end{array}$ & $\begin{array}{l}\text { Dis- } \\
\text { charge }\end{array}$ & $\begin{array}{c}\text { Gage } \\
\text { ht. }\end{array}$ & $\begin{array}{l}\text { Dis- } \\
\text { charge }\end{array}$ & $\begin{array}{l}\text { Gage } \\
\text { ht. }\end{array}$ & $\begin{array}{l}\text { Dis- } \\
\text { charge }\end{array}$ & $\begin{array}{c}\text { Gage } \\
\text { ht. }\end{array}$ & $\begin{array}{c}\text { Dis- } \\
\text { charge }\end{array}$ & $\begin{array}{c}\text { Gage } \\
\text { ht. }\end{array}$ & $\begin{array}{c}\text { Dis- } \\
\text { charge }\end{array}$ & $\begin{array}{l}\text { Gage } \\
\text { ht. }\end{array}$ & $\begin{array}{c}\text { Dis- } \\
\text { charge }\end{array}$ \\
\hline \multirow{4}{*}{$\begin{array}{l}1 \\
2 \\
3 \\
4 \\
5 \\
6\end{array}$} & & & \multirow{4}{*}{$\begin{array}{l}2.17 \\
2.21 \\
2.28 \\
2.50 \\
3.10 \\
3.78\end{array}$} & \multirow{4}{*}{$\begin{array}{r}\mathbf{3 2 7} \\
\mathbf{3 4 7} \\
\mathbf{3 8 4} \\
\mathbf{5 0 4} \\
\mathbf{8 7 0} \\
1,390\end{array}$} & \multirow{4}{*}{$\begin{array}{l}8.37 \\
7.77 \\
7.32 \\
6.93 \\
6.63 \\
6.38\end{array}$} & \multirow{4}{*}{$\begin{array}{l}6,500 \\
5,650 \\
4,990 \\
4,480 \\
4,120 \\
3,890\end{array}$} & \multirow{4}{*}{$\begin{array}{l}7.78 \\
8.15 \\
7.92 \\
7.66 \\
7.49 \\
7.29\end{array}$} & \multirow{4}{*}{$\begin{array}{l}5,650 \\
6,210 \\
5,790 \\
5,510 \\
5,250 \\
4,990\end{array}$} & & & & \\
\hline & 2.12 & $\mathbf{3 4 7}$ & & & & & & & $\overline{5.65}$ & 3,040 & 4.10 & 1,630 \\
\hline & $\overline{\mathbf{2}} . \overline{10}$ & $\overline{\mathbf{3}} \overline{\mathbf{3}}$ & & & & & & & $\overline{5} . \overline{8}$ & $\overline{3}, \overline{140}$ & 4.02 & $1, \overline{5} 50$ \\
\hline & 2.07 & 322 & & & & & & & 0.70 & 3,240 & 3.95 & 1,510 \\
\hline \multirow{5}{*}{$\begin{array}{r}7 \\
8 \\
9 \\
10 \\
11 \\
\mathbf{N}\end{array}$} & & & \multirow{5}{*}{$\begin{array}{r}5.10 \\
6.70 \\
8.85 \\
10.90 \\
13.80 \\
16.30\end{array}$} & \multirow{5}{*}{$\begin{array}{r}2,540 \\
4,240 \\
7,100 \\
10,600 \\
16,400 \\
21,900\end{array}$} & \multirow{5}{*}{$\begin{array}{l}6.19 \\
6.04 \\
5.91 \\
5.79 \\
5.82 \\
6.25\end{array}$} & \multirow{5}{*}{$\begin{array}{l}3,670 \\
3,450 \\
3,340 \\
3,240 \\
3,240 \\
3,670\end{array}$} & \multirow{5}{*}{$\begin{array}{l}7.10 \\
6.94 \\
6.80 \\
6.70 \\
6.68 \\
6.74\end{array}$} & \multirow{5}{*}{$\begin{array}{l}4,730 \\
4,480 \\
4,360 \\
4,240 \\
4,240 \\
4,240\end{array}$} & & & & \\
\hline & 2.06 & 317 & & & & & & & $\overline{5} . \overline{4}$ & 3,140 & 3.89 & 1,470 \\
\hline & 2.05 & 312 & & & & & & & $\overline{5} . \overline{4} \overline{2}$ & 2,840 & $-\overline{3} . \overline{83}$ & $\overline{1}, \overline{\mathbf{4}} \mathbf{3}$ \\
\hline & & & & & & & & & 5.7 & & & \\
\hline & 2.21 & 394 & & & & & & & 5.17 & 2,640 & 3.78 & \\
\hline \multirow{4}{*}{$\begin{array}{l}1 \\
2 \\
3 \\
4 \\
5 \\
6\end{array}$} & 091 & 304 & \multirow{4}{*}{$\begin{array}{l}17.03 \\
16.83 \\
16.55 \\
17.50 \\
18.28 \\
17.48\end{array}$} & \multirow{4}{*}{$\begin{array}{l}23,500 \\
23,000 \\
22,600 \\
24,700 \\
26,600 \\
24,700\end{array}$} & \multirow{4}{*}{$\begin{array}{l}6.80 \\
7.33 \\
7.47 \\
7.44 \\
7.22 \\
7.08\end{array}$} & \multirow{4}{*}{$\begin{array}{r}4,360 \\
4,990 \\
5,250 \\
5,120 \\
4,860 \\
4,730\end{array}$} & \multirow{4}{*}{$\begin{array}{l}6.82 \\
6.96 \\
7.22 \\
7.50 \\
7.72 \\
7.55\end{array}$} & \multirow{4}{*}{$\begin{array}{r}4,360 \\
\mathbf{4}, 600 \\
\mathbf{4}, \mathbf{8 6 0} \\
\mathbf{5}, \mathbf{2 5 0} \\
\mathbf{5}, \mathbf{5 1 0} \\
\mathbf{5}, \mathbf{3 8 0}\end{array}$} & A & & & \\
\hline & & 94 & & & & & & & 4.94 & & 73 & 350 \\
\hline & $2.1 \overline{7}$ & 373 & & & & & & & 4.78 & 2,260 & $3.6 \overline{7}$ & 1,270 \\
\hline & 2.13 & $\overline{3} \overline{2}$ & & & & & & & 4.63 & 2,120 & $\overline{3} .62$ & 1,230 \\
\hline \multirow{5}{*}{$\begin{array}{r}7 \\
8 \\
9 \\
10 \\
11 \\
12 \\
\end{array}$} & & & 15.30 & 700 & 7.02 & 4,600 & 7.00 & & & & & \\
\hline & & 347 & $\mid \begin{array}{l}13.27 \\
11.30\end{array}$ & 15 & $\begin{array}{l}6.97 \\
6.90\end{array}$ & $\begin{array}{l}4,600 \\
4,480\end{array}$ & $\begin{array}{l}6.45 \\
6.12\end{array}$ & 3 , & 42 & 10 & .57 & 90 \\
\hline & 2.12 & $\mathbf{3 4 7}$ & 10.00 & 9,060 & 6.80 & 4,360 & 5.90 & 3,340 & 4.30 & 1,810 & $\overline{3} .54$ & 1,190 \\
\hline & 2.15 & 363 & $\begin{array}{l}\mathbf{Y} .55 \\
8.93\end{array}$ & & 7.08 & & & 3,140 & 4.19 & $1, \overline{7} 20$ & 3.70 & $1, \overline{3} 10$ \\
\hline & & 9 & & 20 & & 21 & Au & g. 22 & $\mathrm{Au}$ & 23 & & 24 \\
\hline 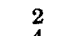 & 3.89 & 70 & & & & & & & & & & \\
\hline 4 & 3.65 & 1,270 & 3.10 & 870 & 2.75 & 650 & 2.67 & 603 & $\overrightarrow{2} . \overline{6}$ & 591 & 2.48 & 493 \\
\hline $\begin{array}{r}0 \\
8\end{array}$ & & & $\overline{3} . \overline{0}$ & $8 \overline{49}$ & 2.74 & 644 & $\overline{2} . \overline{6}$ & 603 & 2.65 & $\overline{5} \overline{9} \overline{1}$ & 2.48 & $49 \overline{3}-$ \\
\hline $\mathrm{N}$ & & & $\overline{3.05}$ & $\mathbf{8 3 5}$ & 2.73 & $63 \overline{8}$ & $2.6 \overline{7}$ & 603 & 2.62 & 574 & $2 . \overline{48}$ & 493 \\
\hline 2 & 3.38 & 880 & & & & & & & & & & \\
\hline 4 & &, 040 & 2.91 & 746 & 2.72 & 632 & 2.66 & 597 & 2.60 & 562 & 2.49 & 498 \\
\hline 8 & & 975 & 2.83 & 698 & 2.71 & 626 & $\overline{3} . \overline{1}$ & $89 \overline{1}$ & $\overline{2} . \overline{5} \overline{7}$ & $\overline{\mathbf{5}} \overline{\mathbf{4}} \overline{5}$ & $2 . \overline{47}$ & 487 \\
\hline $\begin{array}{l}10 \\
12\end{array}$ & & & 2.77 & 662 & 2.69 & 614 & $\mathbf{2 . 7 4}$ & 644 & 2.52 & 516 & 2.44 & 470 \\
\hline
\end{tabular}

SUPPLEMENTAL RECoRDs,-Aug. 17, 7 a.m., gage height, 5.80 feet; discharge, 3,240 second-feet. Aug. 20 2 p.m., gage height, 3.00 feet; discharge, 800 second-feet. Aug. 22,6 p.m., gage height, 2.66 feet; discharge 597 second-feet.

\section{SMITH RIVER A'T MARTINSVILLE, VA.}

Location.-Lat. $36^{\circ} 39^{\prime} 45^{\prime \prime}$, long. $70^{\circ} 52^{\prime} 55^{\prime \prime}, 2$ miles south of Martinsville, Henry County, and 3 miles downstream from Grassy Creek. Datum of gage is 656.86 feet above mean sea level (levels by Corps of Engineers, War Department).

Drainage AREA.- -374 square miles.

GAGE-HEIGHT RECORD.-Water-stage recorder graph.

DISCHARGE RECORD.-Stage-discharge relation defined by current-meter measurements up to 4,800 second-feet and extended to crest gage height on basis of computations of flow over dam at gage heights 16.76 feet and 21.50 feet. Gage heights used to half-tenths between 3.7 and 5.8 feet; hundredths below and tenths above these limits.

Maxima.-1940: Discharge, 34,200 second-feet 9 p.m. Aug. 14 (gage height, 19.50 feet).

1929-39: Discharge, 39,000 second-feet Oct. 19, 1937 (gage height, 21.50 feet). REMARKs.-Flow regulated by dam and power plant 1,000 feet upstream. 
Mean discharge, in second-feet, 1940

\begin{tabular}{|c|c|c|c|c|c|c|c|c|c|c|c|}
\hline Day & Aug. & Sept. & Day & Aug. & Sept. & Day & Aug. & Sept. & Day & Aug. & Sept. \\
\hline $\begin{array}{l}1 \\
2 \\
3 \\
4 \\
5 \\
6 \\
7 \\
8\end{array}$ & $\begin{array}{l}485 \\
350 \\
304 \\
245 \\
362 \\
332 \\
404 \\
468\end{array}$ & $\begin{array}{r}1,120 \\
778 \\
674 \\
632 \\
596 \\
548 \\
510 \\
436\end{array}$ & $\begin{array}{r}9 \\
10 \\
11 \\
12 \\
13 \\
14 \\
15 \\
16\end{array}$ & $\begin{array}{r}296 \\
286 \\
250 \\
555 \\
381 \\
18,500 \\
8,630 \\
5,900\end{array}$ & $\begin{array}{l}522 \\
470 \\
456 \\
450 \\
408 \\
414 \\
347 \\
462\end{array}$ & $\begin{array}{l}17 \\
18 \\
19 \\
20 \\
21 \\
22 \\
23 \\
24\end{array}$ & $\begin{array}{r}3,010 \\
1,570 \\
1,220 \\
949 \\
719 \\
704 \\
717 \\
602\end{array}$ & $\begin{array}{l}382 \\
394 \\
384 \\
384 \\
412 \\
318 \\
339 \\
353\end{array}$ & $\begin{array}{l}25 \\
26 \\
27 \\
28 \\
29 \\
30 \\
31\end{array}$ & $\begin{array}{r}531 \\
886 \\
836 \\
1,010 \\
994 \\
1,330 \\
2,290\end{array}$ & $\begin{array}{l}421 \\
508 \\
379 \\
352 \\
309 \\
386 \\
-\end{array}$ \\
\hline \multicolumn{10}{|c|}{$\begin{array}{l}\text { Monthly mean discharge, in second-feet. } \\
\text { Runoff, in inches }\end{array}$} & $\begin{array}{r}1,778 \\
5.48\end{array}$ & $\begin{array}{r}471 \\
1.41\end{array}$ \\
\hline
\end{tabular}

Gage height, in feet, and discharge, in second-feet, at indicated time, 1940

\begin{tabular}{|c|c|c|c|c|c|c|c|c|}
\hline \multirow{2}{*}{ Hour } & \multicolumn{2}{|c|}{ Aug. 13} & \multicolumn{2}{|c|}{ Aug. 14} & \multicolumn{2}{|c|}{ Aug. 15} & \multicolumn{2}{|c|}{ Aug. 16} \\
\hline & $\begin{array}{l}\text { Gage } \\
\text { height }\end{array}$ & Discharge & $\begin{array}{l}\text { Gage } \\
\text { height }\end{array}$ & Discharge & $\begin{array}{l}\text { Gage } \\
\text { height }\end{array}$ & Discharge & $\begin{array}{l}\text { Gage } \\
\text { height }\end{array}$ & Discharge \\
\hline $\begin{array}{l}1 \\
2 \\
3 \\
4 \\
5 \\
6\end{array}$ & $\begin{array}{l}2.37 \\
2.30 \\
2.15 \\
2.14 \\
2.13 \\
2.14\end{array}$ & $\begin{array}{l}327 \\
295 \\
232 \\
228 \\
224 \\
228\end{array}$ & $\begin{array}{l}2.28 \\
2.23 \\
2.20 \\
2.26 \\
2.38 \\
3.00\end{array}$ & $\begin{array}{l}286 \\
265 \\
252 \\
278 \\
332 \\
686\end{array}$ & $\begin{array}{r}15.40 \\
13.60 \\
11.60 \\
8.88 \\
8.75 \\
7.14\end{array}$ & $\begin{array}{r}24,700 \\
20,600 \\
16,000 \\
10,000 \\
9,800 \\
6,320\end{array}$ & $\begin{array}{l}7.01 \\
7.01 \\
7.13 \\
7.38 \\
7.88 \\
7.67\end{array}$ & $\begin{array}{l}6,130 \\
6,130 \\
6,320 \\
6,920 \\
7,920 \\
7,520\end{array}$ \\
\hline $\begin{array}{r}7 \\
8 \\
9 \\
10 \\
11 \\
\mathbf{N}\end{array}$ & $\begin{array}{l}2.19 \\
2.60 \\
2.65 \\
2.66 \\
2.66 \\
2.66\end{array}$ & $\begin{array}{l}248 \\
442 \\
469 \\
474 \\
474 \\
474\end{array}$ & $\begin{array}{r}5.45 \\
7.02 \\
9.10 \\
9.25 \\
12.85 \\
15.15\end{array}$ & $\begin{array}{r}3,480 \\
6,130 \\
10,400 \\
10,600 \\
18,700 \\
24,300\end{array}$ & $\begin{array}{l}7.22 \\
7.02 \\
6.45 \\
6.37 \\
6.32 \\
6.30\end{array}$ & $\begin{array}{l}6,520 \\
6,130 \\
5,020 \\
5,020 \\
4,850 \\
4,850\end{array}$ & $\begin{array}{l}7.30 \\
7.25 \\
6.65 \\
7.17 \\
6.97 \\
6.35\end{array}$ & $\begin{array}{l}\mathbf{6}, \mathbf{7 2 0} \\
\mathbf{6}, 520 \\
5,380 \\
\mathbf{6}, 520 \\
\mathbf{6}, 130 \\
5,020\end{array}$ \\
\hline $\begin{array}{l}1 \\
2 \\
3 \\
4 \\
5 \\
6\end{array}$ & $\begin{array}{l}2.65 \\
2.65 \\
2.65 \\
2.65 \\
2.60 \\
2.56\end{array}$ & $\begin{array}{l}469 \\
469 \\
469 \\
469 \\
442 \\
421\end{array}$ & $\begin{array}{l}16.40 \\
17.70 \\
18.47 \\
18.71 \\
18.80 \\
18.91\end{array}$ & $\begin{array}{l}27,000 \\
30,000 \\
31,800 \\
32,300 \\
32,500 \\
32,800\end{array}$ & $\begin{array}{l}6.33 \\
6.45 \\
6.70 \\
7.62 \\
7.54 \\
7.52\end{array}$ & $\begin{array}{l}4,850 \\
5,020 \\
5,560 \\
7,320 \\
7,120 \\
7,120\end{array}$ & $\begin{array}{l}6.44 \\
6.46 \\
6.47 \\
6.49 \\
6.56 \\
6.80\end{array}$ & $\begin{array}{l}5,020 \\
5,200 \\
5,200 \\
5,200 \\
5,380 \\
5,750\end{array}$ \\
\hline $\begin{array}{r}7 \\
8 \\
9 \\
10 \\
11 \\
12 \\
\end{array}$ & $\begin{array}{l}2.40 \\
2.45 \\
2.55 \\
2.54 \\
2.55 \\
2.40\end{array}$ & $\begin{array}{l}341 \\
366 \\
416 \\
411 \\
416 \\
341 \\
\end{array}$ & $\begin{array}{l}19.12 \\
19.35 \\
19.50 \\
19.18 \\
18.65 \\
17.42 \\
\end{array}$ & $\begin{array}{l}33,200 \\
34,000 \\
34,200 \\
33,500 \\
32,100 \\
29,300 \\
\end{array}$ & $\begin{array}{l}7.37 \\
7.31 \\
7.20 \\
6.80 \\
7.34 \\
7.05 \\
\end{array}$ & $\begin{array}{l}6,920 \\
6,720 \\
6,520 \\
5,750 \\
6,720 \\
6,130 \\
\end{array}$ & $\begin{array}{l}6.89 \\
7.07 \\
6.92 \\
6.35 \\
6.20 \\
5.43 \\
\end{array}$ & $\begin{array}{l}5,940 \\
6,320 \\
5,940 \\
5,020 \\
4,680 \\
3,480 \\
\end{array}$ \\
\hline \multicolumn{7}{|c|}{ SuPPLEMENTAL RECORDS } & & \\
\hline \multicolumn{7}{|c|}{$\begin{array}{l}\text { Aug. 14, 6:05 a.m. } \\
\text { 9:15 a.m. } \\
\text { 9:30 a.m. } \\
\text { Aug. 15, 4:20 a.m. } \\
\text { Aug. 16, 5:30 a.m. }\end{array}$} & $\begin{array}{l}5.00 \\
9.46 \\
8.95 \\
9.12 \\
7.99\end{array}$ & $\begin{array}{r}2,840 \\
11,300 \\
10,200 \\
10,400 \\
8,120\end{array}$ \\
\hline
\end{tabular}

SMITH RIVER AT SPRAY, N. C.

Location.—Lat. $36^{\circ} 31^{\prime} 47^{\prime \prime}$, long. $79^{\circ} 46^{\prime} 08^{\prime \prime}, 0.9$ mile south of State line, 1 mile downstream from Stuart Creek, and 1 mile north of Spray, Rockingham County. Datum of gage is 539.56 feet above mean sea level, datum of 1929, supplementary adjustment of 1936 .

Drainage area. 538 square miles.

GAGE-HEIGHT RECORD.-Water-stage recorder graph.

DISCHARGE RECORD.- Stage-discharge relation defined by current-meter measurements up to 8,000 second-feet and extended to crest gage height on basis of computation of flood flow over Spray Cotton Mill dam 11/2 miles downstream. Gage heights used to half-tenths between 3.4 and 5.1 feet; hundredths below and tenths above these limits. 
Maxima.-1940: Discharge, 45,600 second-feet 1 a.m. Aug. 15 (gage height, 19.28 feet).

Other flood-peak discharges over Spray Cotton Mill dam have been computed as follows: 33,000 second-feet Oct. 20, 1937, 19,000 second-feet Aug. 19, 1939.

Remarks.-Flood runoff affected very little, if any at all, by power plant at Martinsville, Va.

Mean discharge, in second-feet, 1940

\begin{tabular}{|c|c|c|c|c|c|c|c|c|c|c|c|}
\hline Day & Aug. & Sept. & Day & Aug. & Sept. & Day & Aug. & Sept. & Day & Aug. & Sept. \\
\hline $\begin{array}{l}1 \\
2 \\
3 \\
4 \\
5 \\
6 \\
7 \\
8\end{array}$ & $\begin{array}{l}948 \\
519 \\
384 \\
347 \\
434 \\
368 \\
524 \\
594 \\
\end{array}$ & $\begin{array}{r}1,480 \\
956 \\
808 \\
713 \\
696 \\
686 \\
577 \\
518\end{array}$ & $\begin{array}{r}9 \\
10 \\
11 \\
12 \\
13 \\
14 \\
15 \\
16\end{array}$ & $\begin{array}{r}385 \\
333 \\
346 \\
671 \\
521 \\
15,400 \\
23,300 \\
8,130\end{array}$ & $\begin{array}{l}589 \\
532 \\
502 \\
532 \\
486 \\
440 \\
414 \\
508\end{array}$ & $\begin{array}{l}17 \\
18 \\
19 \\
20 \\
21 \\
22 \\
23 \\
24\end{array}$ & $\begin{array}{r}4,300 \\
2,150 \\
1,670 \\
1,070 \\
894 \\
\mathbf{8 8 4} \\
\mathbf{9 1 0} \\
\mathbf{7 0 9}\end{array}$ & $\begin{array}{l}473 \\
454 \\
450 \\
455 \\
432 \\
406 \\
421 \\
399\end{array}$ & $\begin{array}{l}25 \\
26 \\
27 \\
28 \\
29 \\
30 \\
31\end{array}$ & $\begin{array}{r}627 \\
976 \\
1,620 \\
1,050 \\
1,670 \\
1,040 \\
2,690\end{array}$ & $\begin{array}{l}482 \\
622 \\
476 \\
408 \\
388 \\
459\end{array}$ \\
\hline \multicolumn{10}{|c|}{$\begin{array}{l}\text { Monthly mean discharge, in second-feet } \\
\text { Runoff, in inches }\end{array}$} & $\begin{array}{r}2,434 \\
5.22\end{array}$ & $\begin{array}{r}559 \\
1.16\end{array}$ \\
\hline
\end{tabular}

Gage height, in feet, and discharge, in second-feet, at indicated time, 1940

\begin{tabular}{|c|c|c|c|c|c|c|c|c|c|c|c|c|}
\hline \multirow{2}{*}{ Hour } & \multicolumn{2}{|c|}{ Aug. 12} & \multicolumn{2}{|c|}{ Aug. 13} & \multicolumn{2}{|c|}{ Aug. 14} & \multicolumn{2}{|c|}{ Aug. 15} & \multicolumn{2}{|c|}{ Aug. 16} & \multicolumn{2}{|c|}{ Aug. 17} \\
\hline & $\begin{array}{c}\text { Gage } \\
\text { ht. }\end{array}$ & $\begin{array}{c}\text { Dis- } \\
\text { charge }\end{array}$ & $\begin{array}{c}\text { Gage } \\
\text { ht. }\end{array}$ & $\begin{array}{c}\text { Dis- } \\
\text { charge }\end{array}$ & $\begin{array}{c}\text { Gage } \\
\text { ht. }\end{array}$ & $\begin{array}{c}\text { Dis- } \\
\text { charge }\end{array}$ & $\begin{array}{c}\text { Gage } \\
\text { ht. }\end{array}$ & $\begin{array}{c}\text { Dis- } \\
\text { charge }\end{array}$ & $\begin{array}{c}\text { Gage } \\
\text { ht. }\end{array}$ & $\begin{array}{c}\text { Dis- } \\
\text { charge }\end{array}$ & $\begin{array}{c}\text { Gage } \\
\text { ht. }\end{array}$ & $\begin{array}{l}\text { Dis- } \\
\text { charge }\end{array}$ \\
\hline \multirow{5}{*}{$\begin{array}{l}1 \\
2 \\
3 \\
4 \\
5 \\
6\end{array}$} & \multirow{5}{*}{$\begin{array}{l}1.97 \\
1.97 \\
1.97 \\
2.35 \\
2.67 \\
2.73\end{array}$} & \multirow{5}{*}{$\begin{array}{l}228 \\
228 \\
228 \\
420 \\
634 \\
678\end{array}$} & \multirow{5}{*}{$\begin{array}{l}2.75 \\
2.68 \\
2.64 \\
2.61 \\
2.58 \\
2.55\end{array}$} & \multirow{5}{*}{$\begin{array}{l}692 \\
641 \\
613 \\
592 \\
571 \\
550\end{array}$} & \multirow{5}{*}{$\begin{array}{l}2.60 \\
2.56 \\
2.53 \\
2.60 \\
2.90 \\
3.45\end{array}$} & \multirow{5}{*}{$\begin{array}{r}\mathbf{5 8 5} \\
\mathbf{5 5 7} \\
\mathbf{5 3 6} \\
\mathbf{5 8 5} \\
\mathbf{8 0 5} \\
\mathbf{1}, \mathbf{2 3 0}\end{array}$} & \multirow{5}{*}{$\begin{array}{l}19.28 \\
19.21 \\
19.05 \\
18.72 \\
18.32 \\
17.60\end{array}$} & \multirow{5}{*}{$\begin{array}{l}45,600 \\
45,200 \\
44,200 \\
42,900 \\
41,100 \\
38,000\end{array}$} & & & & \\
\hline & & & & & & & & & 9.13 & 9,150 & 7.66 & 6,440 \\
\hline & & & & & & & & & 800 & 150 & 6 on & 110 \\
\hline & & & & & & & & & 8.98 & 8,950 & 6.90 & 5,110 \\
\hline & & & & & & & & & $8 . \overline{8}$ & 8,550 & 6.42 & 4,380 \\
\hline \multirow{5}{*}{$\begin{array}{r}8 \\
9 \\
10 \\
11\end{array}$} & \multirow{5}{*}{$\begin{array}{l}2.72 \\
2.70 \\
2.70 \\
2.71 \\
2.74 \\
2.77\end{array}$} & \multirow{5}{*}{$\begin{array}{l}670 \\
655 \\
655 \\
662 \\
685 \\
708\end{array}$} & \multirow{5}{*}{$\begin{array}{l}2.52 \\
2.48 \\
2.42 \\
2.36 \\
2.29 \\
2.23\end{array}$} & \multirow{5}{*}{$\begin{array}{l}529 \\
502 \\
463 \\
426 \\
384 \\
352\end{array}$} & \multirow{5}{*}{$\begin{array}{l}4.15 \\
4.80 \\
6.15 \\
7.80 \\
9.03 \\
9.95\end{array}$} & \multirow{5}{*}{$\begin{array}{r}1,840 \\
2,480 \\
4,100 \\
6,620 \\
8,950 \\
11,200\end{array}$} & \multirow{5}{*}{\begin{tabular}{|}
16.75 \\
15.83 \\
14.85 \\
13.78 \\
12.86 \\
12.09
\end{tabular}} & \multirow{5}{*}{$\begin{array}{l}34,400 \\
30,200 \\
26,200 \\
22,500 \\
19,400 \\
16,900\end{array}$} & & & & \\
\hline & & & & & & & & & 9.04 & 8,950 & 6.29 & 4,240 \\
\hline & & & & & & & & & 9.13 & 9,150 & 6.11 & 3,970 \\
\hline & & & & & & & & & & & & \\
\hline & & & & & & & & & 8.75 & 8,550 & 6.08 & 3,970 \\
\hline \multirow{5}{*}{$\begin{array}{l}1 \\
2 \\
3 \\
4 \\
5 \\
6\end{array}$} & & 768 & 2.18 & 325 & .63 & 12 & 11.48 & 0 & & & & \\
\hline & 2.94 & 835 & 2.14 & 305 & .28 & & 10.92 & 00 & 8.54 & 7,950 & 6.41 & 4,380 \\
\hline & $\begin{array}{l}2.99 \\
3.00\end{array}$ & $\begin{array}{l}872 \\
880\end{array}$ & $\begin{array}{l}2.14 \\
2.35\end{array}$ & $\begin{array}{l}305 \\
420\end{array}$ & $\begin{array}{l}12.00 \\
13.27\end{array}$ & $\begin{array}{l}16,600 \\
20,800\end{array}$ & $\begin{array}{ll}10.36 \\
10.00\end{array} \mid$ & & 8.14 & & 5.88 & 10 \\
\hline & 2.98 & 865 & 2.55 & 550 & 14.25 & 23,900 & $\begin{array}{r}9.78 \\
9.78\end{array}$ & 10,700 & & & & \\
\hline & & & 2.61 & 592 & 15.10 & 27,400 & 9.64 & 10,200 & 7.94 & 6,800 & 5.86 & 3,710 \\
\hline 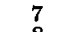 & 2.94 & 835 & 2.62 & 599 & 15.99 & 31 & 9.71 & 00 & & & & \\
\hline 8 & 2.93 & 828 & 2.62 & 599 & $\mid 16.81$ & 34 & 9.78 & 10,700 & 7.88 & 6,800 & 5.77 & 3,590 \\
\hline 9 & 2.92 & $\begin{array}{l}820 \\
812\end{array}$ & 2.62 & 599 & $\left|\begin{array}{l}17.76 \\
18.61\end{array}\right|$ & 38 & $\begin{array}{l}9.85 \\
9.76\end{array}$ & 10,700 & & & 537 & \\
\hline 19 & $\begin{array}{l}2.81 \\
2.89\end{array}$ & 708 & $\begin{array}{l}2.00 \\
2.63\end{array}$ & $\begin{array}{l}000 \\
606\end{array}$ & $\begin{array}{l}10.01 \\
19.00\end{array}$ & 44 & $\begin{array}{l}8.00 \\
9.55\end{array}$ & 10,200 & 0. & 70 & 0.01 & 20 \\
\hline 1 & 8.83 & & 2.63 & 606 & 10 - & & & 9,950 & 8.13 & 7,180 & 5.23 & 2,900 \\
\hline & & 8 & $\mathrm{Au}$ & 9 & & g. 20 & & & LEI & 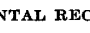 & DS & \\
\hline 2 & 5.16 & 00 & 3.9 & 1,620 & 2.9 & 718 & Aug & 6 , & & & 9. & 9,350 \\
\hline 4 & 4.94 & 2,620 & 3.9 & 0 & 3.05 & & Aug. & 7, & & & 5.7 & 3,590 \\
\hline 6 & 4.50 & 2,170 & 3.9 & 1,620 & 3.49 & 1,220 & & 71 & & & 5.92 & 3,710 \\
\hline 8 & & 120 & 3.8 & 1,580 & 3.47 & 1,180 & Aug. & $19,2: 3$ & .m. & & 4.41 & 2,070 \\
\hline $\mathbf{1 0}$ & $\begin{array}{l}4.47 \\
4.45\end{array}$ & $\begin{array}{l}2,120 \\
2,120\end{array}$ & $\begin{array}{l}3.98 \\
4.13\end{array}$ & $\begin{array}{l}1,670 \\
1,820\end{array}$ & $\begin{array}{l}3.45 \\
3.37\end{array}$ & $\begin{array}{l}1,180 \\
1,100\end{array}$ & & $\begin{array}{l}5: 30 \\
7: 30\end{array}$ & m. & & $\begin{array}{l}3.84 \\
5.40\end{array}$ & $\begin{array}{l}1,540 \\
3,120\end{array}$ \\
\hline 2 & 4.46 & 2,120 & 4.37 & 2,020 & 3.23 & 986 & Aug. & $20, \quad 3$ a & & & 2.84 & 665 \\
\hline 4 & 4.22 & 1,870 & 4.16 & & 3.32 & 1,060 & & 11 a.r & & & 3.44 & 1,180 \\
\hline $\begin{array}{l}6 \\
8\end{array}$ & 4.05 & 1,720 & 3.9 & 1,620 & 3.33 & 1,070 & & & & & & \\
\hline 10 & $\begin{array}{l}4.10 \\
4.28\end{array}$ & $\begin{array}{l}1,770 \\
1,970\end{array}$ & $\begin{array}{l}4.3 \\
3.5\end{array}$ & $\begin{array}{l}2,020 \\
1,310\end{array}$ & $\begin{array}{l}3.67 \\
3.43\end{array}$ & $\begin{array}{l}1,360 \\
1,180\end{array}$ & & & & & & \\
\hline 12 & 4.02 & 1,670 & 3.28 & 1,030 & 3.12 & 892 & & & & & & \\
\hline
\end{tabular}

$804331-49-12$ 


\section{SANDY RIVER NEAR DANVILLE, VA.}

Location.-Lat. $36^{\circ} 37^{\prime} 05^{\prime \prime}$, long. $79^{\circ} 30^{\prime} 00^{\prime \prime}, 800$ feet downstream from bridge on road between Callahans store and Mount Cross, a quarter of a mile downstream from Hickory Forest Creek, 6 miles northwest of Danville, Pittsylvania County, and 6 miles upstream from mouth. Datum of gage is 454.81 feet above mean sea level (unadjusted).

DRAINAGE AREA.- 113 square miles.

GAGE-HEIGHT RECORD.-Water-stage recorder graph.

DISCHARGE RECORD.-Stage-discharge relation defined by current-meter measurements up to 1,000 second-feet and extended to crest gage height by logarithmic plotting on basis of slope-area measurement, unit-hydrograph and flood-routing studies, and other comparison with flood records for stations in Roanoke River Basin. Gage heights used to half-tenths between 5.0 and 6.5 feet; hundredths below and tenths above these limits.

Maxima.-1940: Discharge, 23,000 second-feet 9 p.m. Aug. 14 (gage height, 17.38 feet).

1929-39: Discharge, 7,140 second-feet Sept. 7, 1934 (gage height, 11.60 feet). REMarks.-The District Engineer, Corps of Engineers, War Department, Norfolk, Va., furnished computed flood records by the unit-hydrograph and flood-routing methods used as a factor in determination of stage-discharge relation.

Mean discharge, in second-feet, 1940

\begin{tabular}{|c|c|c|c|c|c|c|c|c|c|c|c|}
\hline Day & Aug. & Sept. & Day & Aug. & Sept. & Day & Aug. & Sept. & Day & Aug. & Sept. \\
\hline $\begin{array}{l}1 \\
2 \\
3 \\
4 \\
5 \\
6 \\
7 \\
8\end{array}$ & $\begin{array}{l}56 \\
45 \\
42 \\
42 \\
43 \\
42 \\
41 \\
38\end{array}$ & $\begin{array}{r}275 \\
139 \\
106 \\
90 \\
76 \\
77 \\
69 \\
64\end{array}$ & $\begin{array}{r}9 \\
10 \\
11 \\
12 \\
13 \\
14 \\
15 \\
16\end{array}$ & $\begin{array}{r}36 \\
36 \\
40 \\
61 \\
43 \\
5,850 \\
6,050 \\
1,870\end{array}$ & $\begin{array}{l}64 \\
63 \\
62 \\
56 \\
58 \\
56 \\
57 \\
54\end{array}$ & $\begin{array}{l}17 \\
18 \\
19 \\
20 \\
21 \\
22 \\
23 \\
24\end{array}$ & $\begin{array}{r}1620 \\
268 \\
149 \\
109 \\
94 \\
114 \\
190 \\
108\end{array}$ & $\begin{array}{l}\mathbf{5 6} \\
\mathbf{5 5} \\
\mathbf{5 5} \\
\mathbf{5 3} \\
\mathbf{5 3} \\
\mathbf{5 1} \\
\mathbf{5 2} \\
\mathbf{5 1}\end{array}$ & $\begin{array}{l}25 \\
26 \\
27 \\
28 \\
29 \\
30 \\
31\end{array}$ & $\begin{array}{l}178 \\
140 \\
103 \\
126 \\
177 \\
133 \\
355\end{array}$ & $\begin{array}{l}58 \\
57 \\
49 \\
52 \\
52 \\
51\end{array}$ \\
\hline \multicolumn{10}{|c|}{$\begin{array}{l}\text { Monthly mean discharge, in second-feet } \\
\text { Ru off, in inches }\end{array}$} & $\begin{array}{r}555 \\
5.61\end{array}$ & $\begin{array}{l}70.4 \\
0.70\end{array}$ \\
\hline
\end{tabular}

1 Discharge is different from that given in Water-Supply Paper 892. It is based on revisions not considered important enough for inclusion with revised records published in Water-Supply Paper $\mathbf{9 7 2}$. 
ROANOKE RIVER BASIN

Gage height, in feet, and discharge, in second-feet, at indicated time, 1940

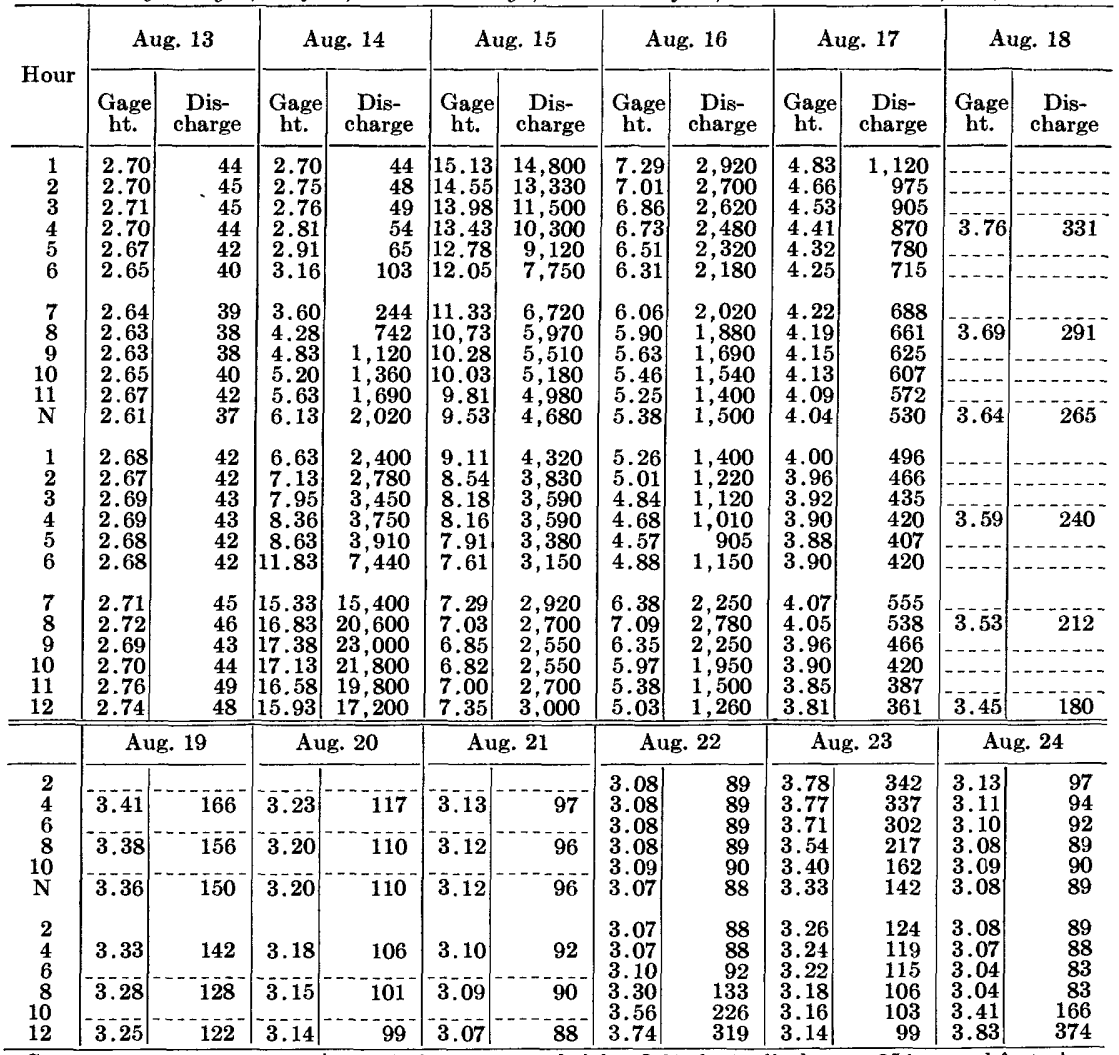

SUPPLEMENTAL RECORDs.-Aug. 22, 9 p.m., gage height, 3.62 feet; discharge, 254 second-feet. Aug. 24, 11 p. m., gage height, 3.96 feet; discharge, 466 second-feet.

BANISTER RIVEK AT HALIFAX, VA.

Location.-Lat. $36^{\circ} 45^{\prime} 30^{\prime \prime}$, long. $78^{\circ} 54^{\prime} 05^{\prime \prime}, 1,000$ feet downstream from Terrible Creek, 1 mile north of Halifax, Halifax County, and 10 miles upstream from mouth. Datum of gage is 318.54 feet above mean sea level (levels by Corps of Engineers, War Department).

DraINAGE AREa.-552 square miles.

GAGE-HEIGHT RECORD.-Water-stage recorder graph except for periods Aug. 15-20 (recorder submerged) and Sept. 15-20. Gage heights for the period Aug. 15-20 were obtained from graph based on floodmarks, gage readings, and comparisons with flood records for nearby stations. No gage-height record Sept. 15-20.

DISCHARGE RECORD.--Stage-discharge relation defined by current-meter measurements up to 11,000 second-feet and extended to crest gage heights by logarithmic plotting on basis of comparisons with flood records for other stations in Roanoke River Basin. Gage heights used to half-tenths between 1.7 and 3.6 feet to Aug. 16, between 1.8 and 3.6 feet thereafter; hundredths below and tenths above these limits.

Maxima.-1940: Discharge, 34,000 second-feet 9 a.m. Aug. 16 (gage height, 37.8 feet, from floodmarks).

1928-29: Discharge, 19,000 second-feet June 22, 1938 (gage height, 31.22 feet, from floodmarks). 


\section{FLOODS OF AUGUST 1940 IN THE SOUTHEASTERN STATES}

Remarks.-The Flood Control Advisory Committee, Department of Agrieulture, furnished a field party and equipment to obtain field data for determination of flood flow by the slope-area method on Banister River at Riceville in headwaters. Flow regulated by power plant half a mile upstream.

Mean discharge, in second-feet, 1940

\begin{tabular}{|c|c|c|c|c|c|c|c|c|c|c|c|}
\hline Day & Aug. & Sept. & Day & Aug. & Sept. & Day & Aug. & Sept. & Day & Aug. & Sept. \\
\hline $\begin{array}{l}1 \\
2 \\
3 \\
4 \\
5 \\
6 \\
7 \\
8\end{array}$ & $\begin{array}{l}688 \\
778 \\
154 \\
146 \\
273 \\
229 \\
192 \\
191\end{array}$ & $\begin{array}{r}1,510 \\
2,270 \\
1,090 \\
692 \\
634 \\
710 \\
666 \\
665\end{array}$ & $\begin{array}{r}9 \\
10 \\
11 \\
12 \\
13 \\
14 \\
15 \\
16\end{array}$ & $\begin{array}{r}202 \\
198 \\
150 \\
292 \\
523 \\
14,170 \\
119,400 \\
30,200\end{array}$ & $\begin{array}{r}655 \\
525 \\
403 \\
309 \\
83 \\
327 \\
300 \\
300\end{array}$ & $\begin{array}{l}17 \\
18 \\
19 \\
20 \\
21 \\
22 \\
23 \\
24\end{array}$ & $\begin{array}{r}15,000 \\
6,200 \\
2,560 \\
1,080 \\
759 \\
676 \\
687 \\
610\end{array}$ & $\begin{array}{r}60 \\
60 \\
190 \\
150 \\
163 \\
152 \\
225 \\
320\end{array}$ & $\begin{array}{l}25 \\
26 \\
27 \\
28 \\
29 \\
30 \\
31\end{array}$ & $\begin{array}{l}\mathbf{5 5 7} \\
\mathbf{5 5 4} \\
\mathbf{5 3 5} \\
\mathbf{5 1 0} \\
\mathbf{5 8 4} \\
\mathbf{9 9 8} \\
\mathbf{9 8 5}\end{array}$ & $\begin{array}{l}232 \\
292 \\
330 \\
223 \\
295 \\
583\end{array}$ \\
\hline \multicolumn{10}{|c|}{$\begin{array}{l}\text { Monthly mean discharge, in second-feet, } \\
\text { Runoff, in inches }\end{array}$} & $\begin{array}{r}2,906 \\
6.06\end{array}$ & $\begin{array}{r}480 \\
0.97\end{array}$ \\
\hline
\end{tabular}

1 Discharge is different from that given in Water-Supply Paper 892. It is based on revisions not con sidered important enough for inclusion with revised records published in Water-Supply Paper 972.

Gage height, in feet, and discharge, in second-feet, at indicated time, 1940

\begin{tabular}{|c|c|c|c|c|c|c|c|c|c|c|c|c|}
\hline \multirow{2}{*}{ Hour } & \multicolumn{2}{|c|}{ Aug. 13} & \multicolumn{2}{|c|}{ Aug. 14} & \multicolumn{2}{|c|}{ Aug. 15} & \multicolumn{2}{|c|}{ Aug. 16} & \multicolumn{2}{|c|}{ Aug. 17} & \multicolumn{2}{|c|}{ Aug. 18} \\
\hline & $\begin{array}{c}\text { Gage } \\
\text { ht. }\end{array}$ & $\begin{array}{c}\text { Dis- } \\
\text { charge }\end{array}$ & $\begin{array}{c}\text { Gage } \\
\text { ht. }\end{array}$ & $\begin{array}{c}\text { Dis- } \\
\text { charge }\end{array}$ & $\begin{array}{c}\text { Gage } \\
\text { ht. }\end{array}$ & $\begin{array}{c}\text { Dis- } \\
\text { charge }\end{array}$ & $\begin{array}{c}\text { Gage } \\
\text { ht. }\end{array}$ & $\begin{array}{c}\text { Dis- } \\
\text { charge }\end{array}$ & $\begin{array}{c}\text { Gage } \\
\text { ht. }\end{array}$ & $\begin{array}{c}\text { Dis- } \\
\text { charge }\end{array}$ & $\begin{array}{c}\text { Gage } \\
\text { ht. }\end{array}$ & $\begin{array}{c}\text { Dis- } \\
\text { charge }\end{array}$ \\
\hline $\begin{array}{l}1 \\
2 \\
3 \\
4 \\
5 \\
6\end{array}$ & $\begin{array}{r}1.23 \\
.82 \\
.63 \\
.56 \\
.52 \\
.51\end{array}$ & $\begin{array}{r}130 \\
80 \\
60 \\
53 \\
\mathbf{4 9} \\
\mathbf{4 8}\end{array}$ & $\begin{array}{r}1.10 \\
.74 \\
.62 \\
.59 \\
.58 \\
.61\end{array}$ & $\begin{array}{r}113 \\
71 \\
59 \\
56 \\
55 \\
58\end{array}$ & $\begin{array}{l}27.75 \\
28.22 \\
28.50 \\
28.80 \\
29.05 \\
29.2\end{array}$ & $\begin{array}{l}15,100 \\
15,500 \\
15,800 \\
16,200 \\
16,400 \\
16,600\end{array}$ & $\begin{array}{l}36.5 \\
36.8 \\
37.0 \\
37.2 \\
37.4 \\
37.5\end{array}$ & $\begin{array}{l}29,400 \\
30,300 \\
31,000 \\
31,700 \\
32,400 \\
32,800\end{array}$ & $\begin{array}{l}33.1 \\
32.6 \\
32.0 \\
31.5 \\
31.0 \\
30.4\end{array}$ & $\begin{array}{l}21,700 \\
20,900 \\
20,000 \\
19,400 \\
18,800 \\
18,100\end{array}$ & $\begin{array}{l}22.2 \\
21.9 \\
21.5 \\
21.2 \\
20.9 \\
20.6\end{array}$ & $\begin{array}{l}9,000 \\
8,700 \\
8,300 \\
8,000 \\
7,710 \\
7,440\end{array}$ \\
\hline $\begin{array}{r}7 \\
8 \\
9 \\
10 \\
11 \\
\mathrm{~N}\end{array}$ & $\begin{array}{l}2.10 \\
3.76 \\
4.40 \\
4.49 \\
4.51 \\
4.51\end{array}$ & $\begin{array}{l}258 \\
580 \\
712 \\
734 \\
734 \\
734\end{array}$ & $\begin{array}{r}.68 \\
.80 \\
3.80 \\
5.16 \\
6.35 \\
10.90\end{array}$ & $\begin{array}{r}65 \\
78 \\
580 \\
898 \\
1,190 \\
2,410\end{array}$ & $\begin{array}{l}29.4 \\
29.6 \\
29.8 \\
30.0 \\
30.2 \\
30.5\end{array}$ & $\begin{array}{l}16,900 \\
17,100 \\
17,400 \\
17,600 \\
17,800 \\
18,200\end{array}$ & $\begin{array}{l}37.6 \\
37.7 \\
37.8 \\
37.7 \\
37.7 \\
37.6\end{array}$ & $\begin{array}{l}33,200 \\
33,600 \\
34,000 \\
33,600 \\
33,600 \\
33,200\end{array}$ & $\begin{array}{l}29.8 \\
29.3 \\
28.7 \\
28.1 \\
27.6 \\
27.2\end{array}$ & $\begin{array}{l}17,400 \\
16,800 \\
16,100 \\
15,400 \\
14,900 \\
14,400\end{array}$ & $\begin{array}{l}20.3 \\
20.0 \\
19.7 \\
19.4 \\
19.1 \\
18.8\end{array}$ & $\begin{array}{l}7,170 \\
6,900 \\
6,660 \\
6,430 \\
6,220 \\
6,010\end{array}$ \\
\hline $\begin{array}{l}1 \\
2 \\
3 \\
4 \\
5 \\
6\end{array}$ & $\begin{array}{l}4.51 \\
4.53 \\
4.60 \\
4.53 \\
4.51 \\
4.62\end{array}$ & $\begin{array}{l}734 \\
734 \\
756 \\
734 \\
734 \\
756\end{array}$ & $\begin{array}{l}13.80 \\
14.76 \\
15.65 \\
17.15 \\
18.80 \\
20.20\end{array}$ & $\begin{array}{l}3,390 \\
3,770 \\
4,150 \\
4,990 \\
6,010 \\
7,080\end{array}$ & $\begin{array}{l}30.8 \\
31.2 \\
31.6 \\
32.0 \\
32.5 \\
33.0\end{array}$ & $\begin{array}{l}18,600 \\
19,000 \\
19,500 \\
20,000 \\
20,700 \\
21,500\end{array}$ & $\begin{array}{l}37.5 \\
37.4 \\
37.1 \\
36.8 \\
36.5 \\
36.2\end{array}$ & $\begin{array}{l}32,800 \\
32,400 \\
31,400 \\
30,300 \\
29,400 \\
28,500\end{array}$ & $\begin{array}{l}26.8 \\
26.4 \\
26.0 \\
25.6 \\
25.2 \\
24.8\end{array}$ & $\begin{array}{l}14,000 \\
13,500 \\
13,100 \\
12,700 \\
12,200 \\
11,800\end{array}$ & $\begin{array}{l}18.6 \\
18.3 \\
18.1 \\
17.9 \\
17.6 \\
17.4\end{array}$ & $\begin{array}{l}5,870 \\
5,660 \\
5,530 \\
5,410 \\
5,230 \\
5,110\end{array}$ \\
\hline $\begin{array}{r}7 \\
8 \\
9 \\
10 \\
11 \\
12\end{array}$ & $\begin{array}{l}4.78 \\
4.82 \\
4.87 \\
4.99 \\
3.30 \\
1.85\end{array}$ & $\begin{array}{l}802 \\
802 \\
826 \\
850 \\
476 \\
218\end{array}$ & $\mid \begin{array}{l}21.90 \\
23.60 \\
24.80 \\
25.85 \\
26.60 \\
27.20\end{array}$ & $\begin{array}{r}8,700 \\
10,500 \\
11,800 \\
12,900 \\
13,800 \\
14,400\end{array}$ & \begin{tabular}{|l|}
33.5 \\
34.0 \\
34.6 \\
35.1 \\
35.6 \\
36.1
\end{tabular} & $\begin{array}{l}22,400 \\
23,300 \\
24,500 \\
25,600 \\
26,900 \\
28,200\end{array}$ & $\begin{array}{l}35.8 \\
35.4 \\
35.0 \\
34.5 \\
34.0 \\
33.6\end{array}$ & $\begin{array}{l}27,400 \\
26,400 \\
25,400 \\
24,300 \\
23,300 \\
22,600\end{array}$ & $\begin{array}{l}24.4 \\
24.0 \\
23.6 \\
23.2 \\
22.9 \\
22.6\end{array}$ & $\begin{array}{r}11,300 \\
10,900 \\
10,500 \\
10,000 \\
9,700 \\
9,400\end{array}$ & $\begin{array}{l}17.0 \\
16.8 \\
16.6 \\
16.3 \\
16.0 \\
15.7\end{array}$ & $\begin{array}{l}4,870 \\
4,750 \\
4,650 \\
4,500 \\
4,350 \\
4,200\end{array}$ \\
\hline
\end{tabular}

\begin{tabular}{|c|c|c|c|c|c|c|c|c|c|c|c|c|}
\hline & \multicolumn{2}{|c|}{ Aug. 19} & \multicolumn{2}{|c|}{ Aug. 20} & \multicolumn{2}{|c|}{ Aug. 21} & \multicolumn{2}{|c|}{ Aug. 22} & \multicolumn{2}{|c|}{ Aug. 23} & \multicolumn{2}{|c|}{ Aug. 24} \\
\hline \multirow{5}{*}{$\begin{array}{r}2 \\
4 \\
6 \\
8 \\
10 \\
\mathbf{N}\end{array}$} & 15.0 & 3,850 & 7.2 & 1,360 & 5.1 & 814 & & & & & & \\
\hline & 14.3 & 3,570 & 6.9 & 1,280 & 5.0 & 814 & 4.46 & 678 & 4.45 & 678 & 4.23 & 634 \\
\hline & $\begin{array}{l}13.6 \\
12.7\end{array}$ & $\begin{array}{l}3,310 \\
2,990\end{array}$ & $\begin{array}{l}6.6 \\
6.4\end{array}$ & $\begin{array}{l}1,200 \\
1,150\end{array}$ & $\begin{array}{l}4.95 \\
4.9\end{array}$ & $\begin{array}{l}790 \\
766\end{array}$ & $4 . \overline{4}$ & 678 & 4.50 & 678 & 4.17 & 612 \\
\hline & 12.0 & 2,740 & 6.2 & 1,100 & 4.8 & 766 & & & & & & \\
\hline & 11. & 2,420 & 5.9 & 1,030 & 4.77 & 744 & 4.43 & 678 & 4.67 & 722 & 4.13 & 612 \\
\hline 2 & 10.1 & 2,150 & 5.8 & 1,010 & 4.73 & 744 & & & & & & \\
\hline 4 & 9.4 & 1,950 & 5.6 & 958 & 4.70 & 722 & 4.38 & 656 & 4.59 & 700 & 4.08 & 590 \\
\hline$\stackrel{0}{8}$ & $\begin{array}{l}8.8 \\
8.3\end{array}$ & $\begin{array}{l}1,780 \\
1,640\end{array}$ & $\begin{array}{l}5.5 \\
5.4\end{array}$ & $\begin{array}{l}934 \\
910\end{array}$ & $\begin{array}{l}4.66 \\
4.63\end{array}$ & $\begin{array}{l}722 \\
722\end{array}$ & $4 . \overline{4}$ & $-6 \overline{8}$ & 4.44 & $\overline{67} \overline{8}$ & 4.03 & 590 \\
\hline $\begin{array}{l}10 \\
12\end{array}$ & \begin{tabular}{|l|}
7.9 \\
7.6
\end{tabular} & $\begin{array}{l}1,540 \\
1,460\end{array}$ & $\begin{array}{l}5.3 \\
5.2\end{array}$ & $\begin{array}{l}886 \\
862\end{array}$ & $\begin{array}{l}4.60 \\
4.57\end{array}$ & $\begin{array}{l}722 \\
700\end{array}$ & 4.42 & 678 & 431 & 656 & 4.00 & 590 \\
\hline & & & & & & & & & & & & \\
\hline
\end{tabular}

HYCO RIVER NEAR OMEGA, VA.

LOCATiON.-Lat. $36^{\circ} 38^{\prime}$, long. $78^{\circ} 48^{\prime}$, at highway bridge $1 \frac{1 / 2}{2}$ miles upstream from Hilly Creek, $2 \frac{1}{2}$ miles south of Omega, Halifax County, and 7 miles upstream from mouth. Datum of gage is 294.45 feet above mean sea level, datum of 1929 , supplementary adjustment of 1936. 
Drainage AREA.-338 square miles.

GAGE-HEIGHT RECORD.-Water-stage recorder graph.

DISCHARGE RECORD.-Stage-discharge relation defined by current-meter measurements up to 6,800 second-feet and extended to crest gage height by logarithmic plotting. Gage heights used to half-tenths between 3.1 and 4.6 feet to Aug. 17, between 3.3 and 4.7 thereafter; hundredths below and tenths above these limits. Maxima.-1940: Discharge, 9,280 second-feet 8:30 a.m. Aug. 17 (gage height, 25.65 feet).

1934-39: Discharge, 11,000 second-feet Sept. 8, 1934 (gage height, 27.50 feet).

Mean discharge, in second-feet, 1940

\begin{tabular}{r|r|r||r|r|r||r|r|r||r|r|r}
\hline Day & Aug. & \multicolumn{1}{|c|}{ Sept. } & Day & Aug. & Sept. & Day & Aug. & Sept. & Day & Aug. & Sept. \\
\hline 1 & 27 & 202 & 9 & 12 & 51 & 17 & 9,120 & 41 & 25 & 528 & 42 \\
2 & 22 & 103 & 10 & 12 & 49 & 18 & 7,230 & 38 & 26 & 617 & 45 \\
3 & 16 & 78 & 11 & 20 & 55 & 19 & 3,010 & 37 & 27 & 238 & 51 \\
4 & 16 & 66 & 12 & 16 & 115 & 20 & 295 & 36 & 28 & 433 & 35 \\
5 & 13 & 113 & 13 & 22 & 87 & 21 & 178 & 34 & 29 & 532 & 32 \\
6 & 13 & 121 & 14 & 1,090 & 58 & 22 & 133 & 31 & 30 & 238 & 28 \\
7 & 16 & 66 & 15 & 12,920 & 48 & 23 & 113 & 27 & 31 & 160 & - \\
8 & 13 & 56 & 16 & 7,090 & 44 & 24 & 93 & 26 & & & \\
\hline
\end{tabular}

Discharge is different from that given in Water-Supply Paper 892. It is based on revisions not considered important enough for inclusion with revised records published in Water-Supply Paper 972.

Gage height, in feet, and discharge, in second-feet, at indicated time, 1940

\begin{tabular}{|c|c|c|c|c|c|c|c|c|c|c|c|c|}
\hline \multirow{2}{*}{ Hour } & \multicolumn{2}{|c|}{ Aug. 13} & \multicolumn{2}{|c|}{ Aug. 14} & \multicolumn{2}{|c|}{ Aug. 15} & \multicolumn{2}{|c|}{ Aug. 16} & \multicolumn{2}{|c|}{ Aug. 17} & \multicolumn{2}{|c|}{ Aug. 18} \\
\hline & $\begin{array}{c}\text { Gage } \\
\text { ht. }\end{array}$ & $\begin{array}{c}\text { Dis- } \\
\text { charge }\end{array}$ & $\begin{array}{c}\text { Gage } \\
\text { ht. }\end{array}$ & $\begin{array}{c}\text { Dis- } \\
\text { charge }\end{array}$ & $\begin{array}{c}\text { Gage } \\
\text { ht. }\end{array}$ & $\begin{array}{c}\text { Dis- } \\
\text { charge }\end{array}$ & $\begin{array}{c}\text { Gage } \\
\text { ht. }\end{array}$ & $\begin{array}{c}\text { Dis- } \\
\text { charge }\end{array}$ & $\begin{array}{c}\text { Gage } \\
\text { ht. }\end{array}$ & $\begin{array}{c}\text { Dis- } \\
\text { charge }\end{array}$ & $\begin{array}{c}\text { Gage } \\
\text { ht. }\end{array}$ & $\begin{array}{c}\text { Dis- } \\
\text { charge }\end{array}$ \\
\hline $\begin{array}{l}1 \\
2 \\
3 \\
4 \\
5 \\
6\end{array}$ & $\begin{array}{r}1.77 \\
1.85 \\
1.89\end{array}$ & $\begin{array}{l}17 \\
24 \\
27\end{array}$ & $\begin{array}{l}1.86 \\
1.87 \\
1.87 \\
1.87 \\
1.88 \\
1.88\end{array}$ & $\begin{array}{l}24 \\
25 \\
25 \\
25 \\
26 \\
26\end{array}$ & $\begin{array}{l}12.68 \\
12.65 \\
12.60 \\
12.56 \\
12.55 \\
12.57\end{array}$ & $\begin{array}{l}2,110 \\
2,080 \\
2,080 \\
2,080 \\
2,080 \\
2,080\end{array}$ & $\begin{array}{l}19.65 \\
20.10 \\
20.40 \\
20.70 \\
20.95 \\
21.20\end{array}$ & $\begin{array}{l}4.960 \\
5,270 \\
5,480 \\
5,690 \\
5,900 \\
6,040\end{array}$ & $\begin{array}{l}25.39 \\
25.46 \\
25.52 \\
25.56 \\
25.60 \\
25.63\end{array}$ & $\begin{array}{l}9,120 \\
9,200 \\
9,200 \\
9,280 \\
9,280 \\
9,280\end{array}$ & $\begin{array}{l}24.60 \\
24.48 \\
24.38 \\
24.28 \\
24.17 \\
24.07\end{array}$ & $\begin{array}{l}8,480 \\
8,400 \\
8,320 \\
8,240 \\
8,160 \\
8,080\end{array}$ \\
\hline $\begin{array}{r}7 \\
8 \\
9 \\
10 \\
11 \\
\text { N }\end{array}$ & $\begin{array}{r}1.90 \\
1.88 \\
1.86\end{array}$ & 28 & $\begin{array}{r}1.90 \\
-1.92 \\
2.08 \\
2.53 \\
7.50 \\
11.50\end{array}$ & $\begin{array}{r}28 \\
30 \\
47 \\
99 \\
888 \\
1,790\end{array}$ & $\begin{array}{l}12.57 \\
12.59 \\
12.67 \\
13.35 \\
14.40 \\
15.00\end{array}$ & $\begin{array}{l}2,080 \\
2,080 \\
2,110 \\
2,300 \\
2,590 \\
2,770\end{array}$ & $\begin{array}{l}21.42 \\
21.65 \\
21.88 \\
22.13 \\
22.40 \\
22.65\end{array}$ & $\begin{array}{l}6,180 \\
6,320 \\
6,530 \\
6,670 \\
6,880 \\
7,020\end{array}$ & $\begin{array}{l}25.64 \\
25.64 \\
25.64 \\
25.63 \\
25.62 \\
25.59\end{array}$ & $\begin{array}{l}9,280 \\
9,280 \\
9,280 \\
9,280 \\
9,280 \\
9,280\end{array}$ & $\begin{array}{l}23.94 \\
23.78 \\
23.63 \\
23.45 \\
23.25 \\
23.07\end{array}$ & $\begin{array}{l}7,930 \\
7,860 \\
7,720 \\
7,580 \\
7,440 \\
7,370\end{array}$ \\
\hline $\begin{array}{l}1 \\
2 \\
3 \\
4 \\
5 \\
6\end{array}$ & $\begin{array}{r}1.85 \\
1.83 \\
1.81\end{array}$ & 22 & $\begin{array}{l}12.25 \\
11.82 \\
11.67 \\
11.77 \\
12.00 \\
12.20\end{array}$ & $\begin{array}{l}1,970 \\
1,870 \\
1,840 \\
1,870 \\
1,920 \\
1,970\end{array}$ & $\begin{array}{l}15.15 \\
15.15 \\
15.30 \\
16.25 \\
16.93 \\
17.43\end{array}$ & $\begin{array}{l}2,830 \\
2,830 \\
2,860 \\
3,140 \\
3,370 \\
3,660\end{array}$ & $\begin{array}{l}22.97 \\
23.25 \\
23.55 \\
23.86 \\
24.12 \\
24.35\end{array}$ & $\begin{array}{l}7,300 \\
7,440 \\
7,720 \\
7,930 \\
8,080 \\
8,320\end{array}$ & $\begin{array}{l}25.56 \\
25.52 \\
25.47 \\
25.43 \\
25.35 \\
25.27\end{array}$ & $\begin{array}{l}9,280 \\
9,200 \\
9,200 \\
9,120 \\
9,120 \\
9,040\end{array}$ & $\mid \begin{array}{l}22.87 \\
22.70 \\
22.50 \\
22.29 \\
22.08 \\
21.84\end{array}$ & $\begin{array}{l}7,230 \\
7,090 \\
6,950 \\
6,810 \\
6,670 \\
6,460\end{array}$ \\
\hline $\begin{array}{r}7 \\
8 \\
9 \\
10 \\
11 \\
12\end{array}$ & $\left|\begin{array}{r}1.80 \\
-1.80 \\
1.84\end{array}\right|$ & $\begin{array}{l}19 \\
19 \\
23\end{array}$ & $\begin{array}{l}12.40 \\
12.58 \\
12.75 \\
12.82 \\
12.78 \\
12.74\end{array}$ & $\begin{array}{l}2,030 \\
2,080 \\
2,140 \\
2,140 \\
2,140 \\
2,110\end{array}$ & $\begin{array}{l}17.90 \\
18.23 \\
18.48 \\
18.75 \\
19.05 \\
19.35\end{array}$ & $\begin{array}{l}3,980 \\
4,140 \\
4,300 \\
4,480 \\
4,600 \\
4,840\end{array}$ & $\begin{array}{l}24.54 \\
24.75 \\
24.93 \\
25.08 \\
25.20 \\
25.32\end{array}$ & $\begin{array}{l}8,400 \\
8,640 \\
8,720 \\
8,880 \\
8,960 \\
9,040\end{array}$ & $\mid \begin{array}{l}25.20 \\
25.12 \\
25.02 \\
24.91 \\
24.80 \\
24.70\end{array}$ & $\begin{array}{l}8,960 \\
8,880 \\
8,800 \\
8,720 \\
8,640 \\
8,560\end{array}$ & $\left|\begin{array}{l}21.60 \\
21.37 \\
21.15 \\
20.90 \\
20.48 \\
20.17\end{array}\right|$ & $\begin{array}{l}6,320 \\
6,180 \\
6,040 \\
5,830 \\
5,550 \\
5,340\end{array}$ \\
\hline
\end{tabular}

\begin{tabular}{|c|c|c|c|c|c|c|c|c|c|c|c|c|}
\hline & \multicolumn{2}{|c|}{ Aug. 19} & \multicolumn{2}{|c|}{ Aug. 20} & \multicolumn{2}{|c|}{ Aug. 21} & \multicolumn{2}{|c|}{ Aug. 22} & \multicolumn{2}{|c|}{ Aug. 23} & \multicolumn{2}{|c|}{ Aug. 24} \\
\hline 2 & 19.55 & 4,960 & 4.63 & 393 & 3.45 & 209 & & & & & & \\
\hline 4 & 19.03 & 4,600 & 4.44 & 361 & 3.39 & 202 & 2.97 & 143 & 2.78 & 119 & 2.62 & 99 \\
\hline $\begin{array}{l}6 \\
8\end{array}$ & $\begin{array}{l}18.50 \\
17.95\end{array}$ & $\begin{array}{l}4,300 \\
4,030\end{array}$ & $\begin{array}{l}4.30 \\
4.18\end{array}$ & $\begin{array}{l}337 \\
321\end{array}$ & $\begin{array}{l}3.34 \\
3.30\end{array}$ & $\begin{array}{l}195 \\
188\end{array}$ & $2 . \overline{9}$ & 138 & $2 . \overline{7}$ & 115 & $\overline{2} . \overline{5}$ & 96 \\
\hline $\begin{array}{l}10 \\
\mathrm{~N}\end{array}$ & $\begin{array}{l}17.42 \\
16.68\end{array}$ & $\begin{array}{l}3,660 \\
3,300\end{array}$ & $\begin{array}{l}4.06 \\
3.96\end{array}$ & $\begin{array}{l}298 \\
282\end{array}$ & $\begin{array}{l}3.25 \\
3.21\end{array}$ & $\begin{array}{l}181 \\
175\end{array}$ & 2.89 & 133 & 2.72 & 111 & 2.57 & 93 \\
\hline 2 & 15.65 & 2,960 & 3.86 & 268 & 3.1 & 170 & & & & & & \\
\hline 4 & 13.70 & 2,390 & 3.77 & 252 & 3.1 & 164 & 2.85 & 128 & 2.70 & 109 & 2.53 & 89 \\
\hline $\begin{array}{l}6 \\
8\end{array}$ & $\left|\begin{array}{r}10.45 \\
7.77\end{array}\right|$ & $\begin{array}{r}1,500 \\
938\end{array}$ & $\begin{array}{l}3.68 \\
3.62\end{array}$ & 245 & 3.10 & 160 & 282 & 124 & 268 & 107 & 251 & $86-$ \\
\hline 10 & 6. & 617 & $\begin{array}{l}3.02 \\
3.56\end{array}$ & 223 & $\begin{array}{l}3.00 \\
3.03\end{array}$ & $\begin{array}{l}150 \\
151\end{array}$ & & & 2.00 & & & \\
\hline 12 & 4.9 & 449 & 3.50 & 216 & 3.01 & 148 & 2.80 & 121 & 2.66 & 104 & 2.50 & 85 \\
\hline
\end{tabular}

SUPPLEMENTAL RECORD.-Aug. 17, 8:30 a.m., gage height, 25.65 feet; discharge, 9,280 second-feet. 


\section{FLOODS OF AUGUST 1940 IN THE SOUTHEASTERN STATES}

\section{PAMLICO RIVER BASIN \\ TAR RIVER NEAR TAR RIVER, N. C.}

LOCATION.-Lat. $36^{\circ} 12^{\prime}$, long. $78^{\circ} 34^{\prime}$, at bridge on State Highway 562, 11/4 miles upstream from Fishing Creek, 21/2 miles east of town of Tar River, Granville County, and 8 miles south of Oxford.

Drainage AREA.-161 square miles.

GAGE-HEIGHT RECORD.-Water-stage recorder graph except for periods Aug. 4-12, and 8 p.m. Aug. 14 to 4 a.m. Aug. 15, when the recorder intake was partly obstructed, for which the graph was reconstructed.

DISCHARGE RECORD. - Stage-discharge record defined by current-meter measurements. Gage heights used to half-tenths between 3.5 and 5.7 feet; hundredths below and tenths above these limits. Discharge for periods of no gage-height record based on recorded range in gage height, weather records, and records for nearby streams.

Maxima.-August 1940: Discharge, 2,050 second-feet 10 to 10:30 a.m. Aug. 16 (gage height, 7.38 feet).

1939 to July 1940: Discharge, 5,550 second-feet May 25, 1940 (gage height, 11.9 feet).

REMARKs.-Flood runoff not affected by artificial storage.

Mean discharge, in second-feet, 1940

\begin{tabular}{r|r|r|r|r|r||r|r|r||r|r|r}
\hline Day & Aug. & Sept. & Day & Aug. & Sept. & Day & Aug. & Sept. & Day & Aug. & Sept. \\
\hline 1 & 13 & 38 & 9 & 17 & 21 & 17 & 493 & 19 & 25 & 208 & 11 \\
2 & 34 & 31 & 10 & 12 & 19 & 18 & 200 & 13 & 26 & 365 & 8.3 \\
3 & 13 & 26 & 11 & 15 & 107 & 19 & 101 & 12 & 27 & 86 & 6.6 \\
4 & 11 & 23 & 12 & 7 & 48 & 20 & 57 & 13 & 28 & 53 & 7.7 \\
5 & 10 & 22 & 13 & 10 & 32 & 21 & 41 & 11 & 29 & 142 & 7.2 \\
6 & 12 & 46 & 14 & 401 & 20 & 22 & 37 & 8.9 & 30 & 71 & 5.7 \\
7 & 15 & 46 & 15 & 930 & 20 & 23 & 30 & 12 & 31 & 59 & \\
8 & 22 & 33 & 16 & 1,700 & 13 & 24 & 24 & 11 & & & \\
\hline
\end{tabular}

Gage height, in feet, and discharge, in second-feet, at indicated time, 1940

\begin{tabular}{|c|c|c|c|c|c|c|c|c|c|c|c|c|}
\hline \multirow{2}{*}{ Hour } & \multicolumn{2}{|c|}{ Aug. 14} & \multicolumn{2}{|c|}{ Aug. 15} & \multicolumn{2}{|c|}{ Aug. 16} & \multicolumn{2}{|c|}{ Aug. 17} & \multicolumn{2}{|c|}{ Aug. 18} & \multicolumn{2}{|c|}{ Aug. 19} \\
\hline & $\begin{array}{c}\text { Gage } \\
\text { ht. }\end{array}$ & $\begin{array}{c}\text { Dis- } \\
\text { charge }\end{array}$ & $\begin{array}{c}\text { Gage } \\
\text { ht. }\end{array}$ & $\begin{array}{l}\text { Dis- } \\
\text { charge }\end{array}$ & $\begin{array}{c}\text { Gage } \\
\text { ht. }\end{array}$ & $\begin{array}{c}\text { Dis- } \\
\text { charge }\end{array}$ & $\begin{array}{c}\text { Gage } \\
\text { ht. }\end{array}$ & $\begin{array}{c}\text { Dis- } \\
\text { charge }\end{array}$ & $\begin{array}{c}\text { Gage } \\
\text { ht. }\end{array}$ & $\begin{array}{c}\text { Dis- } \\
\text { charge }\end{array}$ & $\begin{array}{c}\text { Gage } \\
\text { ht. }\end{array}$ & $\begin{array}{c}\text { Dis- } \\
\text { charge }\end{array}$ \\
\hline \multirow{4}{*}{$\begin{array}{l}1 \\
2 \\
3 \\
4 \\
5 \\
6\end{array}$} & \multirow{4}{*}{$\begin{array}{l}1.05 \\
1.04 \\
1.02 \\
1.02 \\
1.01 \\
1.00\end{array}$} & \multirow{4}{*}{$\begin{array}{l}13 \\
13 \\
12 \\
12 \\
12 \\
12\end{array}$} & & & & & & & & & & \\
\hline & & & 6.65 & $1,620^{\circ}$ & 6.35 & 1,520 & 4.95 & 847 & 2.98 & 216 & & \\
\hline & & & 6.50 & 1,570 & $-\overline{6.7 \overline{7}}$ & 1,720 & 4.71 & 751 & 3.02 & 230 & 2.72 & $\overline{13} \overline{1}$ \\
\hline & & & 6.08 & 1,370 & $\overline{7} . \overline{0} \overline{8}$ & 1,880 & 4.46 & 661 & 3.00 & 223 & & \\
\hline \multirow{5}{*}{$\begin{array}{r}7 \\
8 \\
9 \\
10 \\
11 \\
\mathrm{~N}\end{array}$} & \multirow{5}{*}{\begin{tabular}{|l|}
1.00 \\
1.01 \\
1.01 \\
1.02 \\
1.03 \\
1.14
\end{tabular}} & \multirow{5}{*}{$\begin{array}{l}12 \\
12 \\
12 \\
12 \\
12 \\
16\end{array}$} & & & & & & & & & & \\
\hline & & & 5.40 & 1,040 & 7.29 & 2,000 & 4.16 & 568 & 2.94 & 203 & 2.64 & 110 \\
\hline & & & 4.60 & 714 & $7 . \overline{38}$ & 2,050 & $3 . \overline{8}$ & 496 & $2 . \overline{3}$ & 200 & & \\
\hline & & & & & & & & & & & & \\
\hline & & & 3.93 & 510 & 7.34 & 2,000 & 3.65 & 426 & 2.94 & 203 & 2.56 & 97 \\
\hline \multirow{4}{*}{$\begin{array}{l}1 \\
2 \\
3 \\
4 \\
5 \\
6\end{array}$} & \multirow{4}{*}{$\begin{array}{l}1.55 \\
2.34 \\
2.77 \\
2.94 \\
3.06 \\
4.45\end{array}$} & \multirow{4}{*}{$\begin{array}{r}36 \\
77 \\
147 \\
203 \\
243 \\
661\end{array}$} & & & & & & & & & & \\
\hline & & & 3.59 & 412 & 7.17 & 1,940 & 3.47 & 375 & 2.94 & 203 & & \\
\hline & & & 3.59 & 412 & 6.94 & 1,780 & 3.34 & 336 & 2.93 & $20 \theta$ & 2.44 & 85 \\
\hline & & & 3.90 & 496 & 6.65 & 1,620 & 3.24 & 304 & 2.90 & 190 & & \\
\hline 7 & 5.61 & & & & & & & & & & & \\
\hline $\begin{array}{l}8 \\
9\end{array}$ & & & 4.28 & 612 & 6.34 & 1,470 & 3.15 & 274 & 2.86 & 177 & 2.31 & 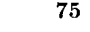 \\
\hline 10 & & 320 & 5.17 & $9 \overline{2} \overline{2}^{-}$ & 5.93 & 1,270 & 3.07 & $24 \overline{7}$ & 2.83 & 167 & & \\
\hline 12 & $\begin{array}{l}0.00 \\
6.68\end{array}$ & $\begin{array}{l}1,620 \\
1,670\end{array}$ & $\overline{\mathbf{5}} . \overline{\mathbf{8}}$ & $1, \overline{230}$ & $\overline{5} . \overline{4} \overline{1}$ & 1,040 & $\overline{3.00}$ & $2 \overline{2} \overline{3}$ & 2.78 & 150 & $\overline{2} . \overline{2} \overline{1}$ & 69 \\
\hline
\end{tabular}

( 3 p.m. gage height, 4.57 feet, discharge, 696 second-feet. Aug. 16, 10:30 a.m., gage height, 7.38 feet, discharge, 2.050 second-feet. 
TAR RIVER NEAR NASHVILLE, N. C.

Location.-Lat. $35^{\circ} 51^{\prime} 00^{\prime \prime}$, long. $77^{\circ} 55^{\prime} 50^{\prime \prime}$, at Cockrell Bridge on Nashville-Wilson road, 5 miles upstream from Sapony Creek and 10 miles south of Nashville, Nash County.

Drainage AREa.-701 square miles.

GAGE-HEIGHT RECORD.-Water-stage recorder graph.

DISCHARGE RECORD.- Stage-discharge relation defined by eurrent-meter measurements up to 15,500 second-feet. Gage heights used to half-tenths between 3.4 and 4.9 feet; hundredths below and tenths above these limits.

Maxima.-1940: Discharge, 11,700 second-feet 8 a.m. Aug. 18 (gage height, 17.37 feet).

1928-39 : Discharge, 16,900 second-feet Dec. 3, 1934 (gage height, 20.8 feet). REMARKs.-Flood runoff not affected by artificial storage.

Mean discharge, in second-feet, 1940

\begin{tabular}{r|r|r||r|r|r||r|r|r|r|r|r}
\hline Day & Aug. & Sept. & Day & Aug. & Sept. & Day & Aug. & Sept. & Day & Aug. & Sept. \\
\hline 1 & 363 & 484 & 9 & 282 & 262 & 17 & 10,100 & 206 & 25 & 393 & 159 \\
2 & 181 & 371 & 10 & 211 & 240 & 18 & 11,500 & 197 & 26 & 522 & 227 \\
3 & 141 & 326 & 11 & 326 & 408 & 19 & 10,400 & 187 & 27 & 691 & 171 \\
4 & 125 & 279 & 12 & 436 & 359 & 20 & 6,510 & 187 & 28 & 602 & 171 \\
5 & 128 & 276 & 13 & 405 & 374 & 21 & 751 & 174 & 29 & 491 & 165 \\
6 & 137 & 344 & 14 & 908 & 268 & 22 & 522 & 171 & 30 & 682 & 147 \\
7 & 283 & 333 & 15 & 5,520 & 230 & 23 & 438 & 162 & 31 & 637 &..-- \\
8 & 390 & 294 & 16 & 7,180 & 206 & 24 & 400 & 153 & & & \\
\hline
\end{tabular}

Gage height, in feet, and discharge, in second-feet, at indicated time, 1940

\begin{tabular}{|c|c|c|c|c|c|c|c|c|}
\hline \multirow{2}{*}{ Hour } & \multicolumn{2}{|c|}{ Aug. 14} & \multicolumn{2}{|c|}{ Aug. 15} & \multicolumn{2}{|c|}{ Aug. 16} & \multicolumn{2}{|c|}{ Aug. 17} \\
\hline & $\begin{array}{l}\text { Gage } \\
\text { height }\end{array}$ & Discharge & $\begin{array}{c}\text { Gage } \\
\text { height }\end{array}$ & Discharge & $\begin{array}{c}\text { Gage } \\
\text { height }\end{array}$ & Discharge & $\begin{array}{c}\text { Gage } \\
\text { height }\end{array}$ & Discharge \\
\hline \multirow{4}{*}{$\begin{array}{l}1 \\
2 \\
3 \\
4 \\
5 \\
6\end{array}$} & \multirow{4}{*}{$\begin{array}{l}2.96 \\
2.95 \\
2.93 \\
2.91 \\
2.89 \\
2.88\end{array}$} & \multirow{4}{*}{$\begin{array}{l}330 \\
\mathbf{3 2 6} \\
\mathbf{3 1 9} \\
\mathbf{3 1 2} \\
\mathbf{3 0 4} \\
\mathbf{3 0 1}\end{array}$} & & & & & & \\
\hline & & & 12.05 & 5,600 & 12.83 & 6,330 & & $\ldots$ \\
\hline & & & 12.11 & 5,690 & 13.01 & 6,530 & $15 . \overline{4}$ & 9,200 \\
\hline & & & 12.04 & 5,600 & 13.16 & 6,730 & & \\
\hline \multirow{4}{*}{$\begin{array}{r}7 \\
8 \\
9 \\
10 \\
11 \\
\text { N }\end{array}$} & \multirow{4}{*}{$\begin{array}{l}2.87 \\
2.85 \\
2.83 \\
2.82 \\
2.80 \\
2.79\end{array}$} & \multirow{4}{*}{$\begin{array}{l}297 \\
290 \\
283 \\
279 \\
272 \\
268\end{array}$} & & & & & & \\
\hline & & & 11.94 & 5,510 & 13.30 & 6,830 & 15.91 & 9,680 \\
\hline & & & 11.83 & 5,420 & 13.44 & 6,930 & $-\overline{-}$ & - \\
\hline & & & $1 \overline{1.75}$ & 5,420 & $13 . \overline{58}$ & 7,130 & 16.32 & 10,200 \\
\hline \multirow{4}{*}{$\begin{array}{l}1 \\
2 \\
3 \\
4 \\
5 \\
6\end{array}$} & \multirow{4}{*}{$\begin{array}{l}3.00 \\
3.22 \\
3.39 \\
3.46 \\
3.51 \\
3.86\end{array}$} & \multirow{4}{*}{$\begin{array}{l}344 \\
428 \\
496 \\
520 \\
540 \\
687\end{array}$} & & & & & & \\
\hline & & & 11.68 & 5,330 & 13.76 & 7,330 & & \\
\hline & & & 11.67 & 5,330 & 13.93 & 7,430 & 16.65 & 10,600 \\
\hline & & & 11.67 & $5, \overline{3} 30$ & 14.11 & 7,630 & & \\
\hline \multirow{5}{*}{$\begin{array}{r}7 \\
8 \\
9 \\
10 \\
11 \\
12 \\
\end{array}$} & \multirow{4}{*}{$\begin{array}{r}4.25 \\
5.04 \\
7.40 \\
9.42 \\
10.68 \\
11.34 \\
\end{array}$} & \multirow{4}{*}{$\begin{array}{r}860 \\
1,200 \\
2,380 \\
3,580 \\
4,510 \\
4,990 \\
\end{array}$} & 1189 & 5.510 & 14.32 & 7830 & 1704 & 11.100 \\
\hline & & & & 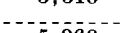 & & & & \\
\hline & & & 12.37 & 5,960 & 14.55 & 8,160 & & - \\
\hline & & & 12.61 & 6,140 & 14.79 & 8,380 & 17.23 & 11,400 \\
\hline & \multicolumn{2}{|c|}{ Aug. 18} & \multicolumn{2}{|c|}{ Aug. 19} & \multicolumn{2}{|c|}{ Aug. 20} & \multicolumn{2}{|c|}{ Aug. 21} \\
\hline \multirow{4}{*}{$\begin{array}{r}2 \\
4 \\
6 \\
8 \\
10 \\
\mathrm{~N}\end{array}$} & & & & & \multirow{4}{*}{$\begin{array}{l}15.51 \\
15.33 \\
15.12 \\
14.85 \\
14.55 \\
14.12\end{array}$} & \multirow{4}{*}{$\begin{array}{l}9,200 \\
8,960 \\
8,720 \\
8,380 \\
8,160 \\
7,630\end{array}$} & \multirow{4}{*}{$\begin{array}{l}4.48 \\
4.28 \\
4.16 \\
4.06 \\
3.99 \\
3.93\end{array}$} & \multirow{4}{*}{$\begin{array}{l}970 \\
882 \\
816 \\
772 \\
750 \\
729\end{array}$} \\
\hline & 17.34 & 11,600 & 16.86 & 11,000 & & & & \\
\hline & 17.37 & 11,700 & 16.69 & 10,700 & & & & \\
\hline & $17 . \overline{35}$ & $11, \overline{700}$ & 16.48 & 10,400 & & & & \\
\hline 2 & & & & & 13.46 & 7,030 & 3.87 & 687 \\
\hline 4 & 17.28 & 11,600 & 16.24 & 10,100 & 12.37 & 5,960 & 3.82 & 666 \\
\hline 8 & 17.17 & 11,400 & 15.98 & $9,800^{-}$ & $\begin{array}{r}10.00 \\
8.03\end{array}$ & $\begin{array}{l}4,4500 \\
2,700\end{array}$ & $\begin{array}{l}3.70 \\
3.72\end{array}$ & $\begin{array}{l}645 \\
624\end{array}$ \\
\hline $\begin{array}{l}10 \\
12\end{array}$ & 17.03 & 11,100 & 15.67 & 9,440 & 4.87 & $\begin{array}{l}1,630 \\
1,130\end{array}$ & $\begin{array}{l}3.67 \\
3.63\end{array}$ & $\begin{array}{l}603 \\
603\end{array}$ \\
\hline
\end{tabular}




\section{FLOODS OF AUGUST 1940 IN THE SOUTHEASTERN STATES}

TAR RIVER AT TARBORO, N. C.

LOCATION.-Lat. $35^{\circ} 53^{\prime} 40^{\prime \prime}$, long. $77^{\circ} 32^{\prime} 00^{\prime \prime}$, at highway bridge at Tarboro, Edgecombe County, $61 / 2$ miles downstream from Fishing Creek. Datum of gage is 10.37 feet above mean sea level, datum of 1929 , supplementary adjustment of 1936 .

Drainage AREA.-2,100 square miles.

GAGE-HEIGHT RECORD.-Water-stage recorder graph except for Aug. 1-6, where graph was based on United States Weather Bureau once-daily staff gage readings.

DISCHARGE RECORD.-Stage-discharge relation defined by current-meter measurements up to 38,000 second-feet. Gage heights used to half-tenths between 2.0 and 3.5 feet; hundredths below and tenths above these limits.

Maxima.-1940: Discharge, 37,200 second-feet 6 to 8 p.m. Aug. 20 (gage height, 31.77 feet).

1896-1900, 1931-39: Discharge, 23,800 second-feet Dee. 6, 1934 (gage height, 27.38 feet).

Stage known, 34.2 feet, present datum, July 27, 1919 (discharge, 52,800 second-feet).

REMARKs.-Flood runoff not affected by artificial storage.

Mean discharge, in second-feet, 1940

\begin{tabular}{|c|c|c|c|c|c|c|c|c|c|c|c|}
\hline Day & Aug. & Sept. & Day & Aug. & Sept. & Day & Aug. & Sept. & Day & Aug. & Sept. \\
\hline $\begin{array}{l}1 \\
2 \\
3 \\
4 \\
5 \\
6 \\
7 \\
8\end{array}$ & $\begin{array}{l}\mathbf{5 5 7} \\
475 \\
491 \\
625 \\
\mathbf{5 2 4} \\
475 \\
491 \\
\mathbf{9 7 3}\end{array}$ & $\begin{array}{l}2,400 \\
1,800 \\
1,710 \\
1,510 \\
1,310 \\
1,110 \\
1,190 \\
1,190\end{array}$ & $\begin{array}{r}9 \\
10 \\
11 \\
12 \\
13 \\
14 \\
15 \\
16\end{array}$ & $\begin{array}{r}1,420 \\
1,820 \\
1,380 \\
1,200 \\
1,200 \\
1,280 \\
5,400 \\
11,100\end{array}$ & $\begin{array}{r}\mathbf{9 5 2} \\
952 \\
1,030 \\
1,270 \\
1,310 \\
1,230 \\
1,070 \\
\mathbf{9 3 3}\end{array}$ & $\begin{array}{l}17 \\
18 \\
19 \\
20 \\
21 \\
22 \\
23 \\
24\end{array}$ & $\begin{array}{l}18,500 \\
24,700 \\
30,900 \\
36,100 \\
33,900 \\
25,300 \\
18,200 \\
12,500\end{array}$ & $\begin{array}{l}838 \\
749 \\
698 \\
634 \\
604 \\
589 \\
516 \\
502\end{array}$ & $\begin{array}{l}25 \\
26 \\
27 \\
28 \\
29 \\
30 \\
31\end{array}$ & $\begin{array}{l}8,340 \\
5,060 \\
2,810 \\
2,420 \\
2,490 \\
2,710 \\
2,720\end{array}$ & $\begin{array}{l}516 \\
502 \\
544 \\
574 \\
516 \\
460\end{array}$ \\
\hline \multicolumn{10}{|c|}{$\begin{array}{l}\text { Monthly mean discharge, in second-feet } \\
\text { Runoff, in inches }\end{array}$} & $\begin{array}{r}8,260 \\
4.53\end{array}$ & $\begin{array}{r}974 \\
0.52\end{array}$ \\
\hline
\end{tabular}

Gage height, in feet, and discharge, in second-feet, at indicated time, 1940

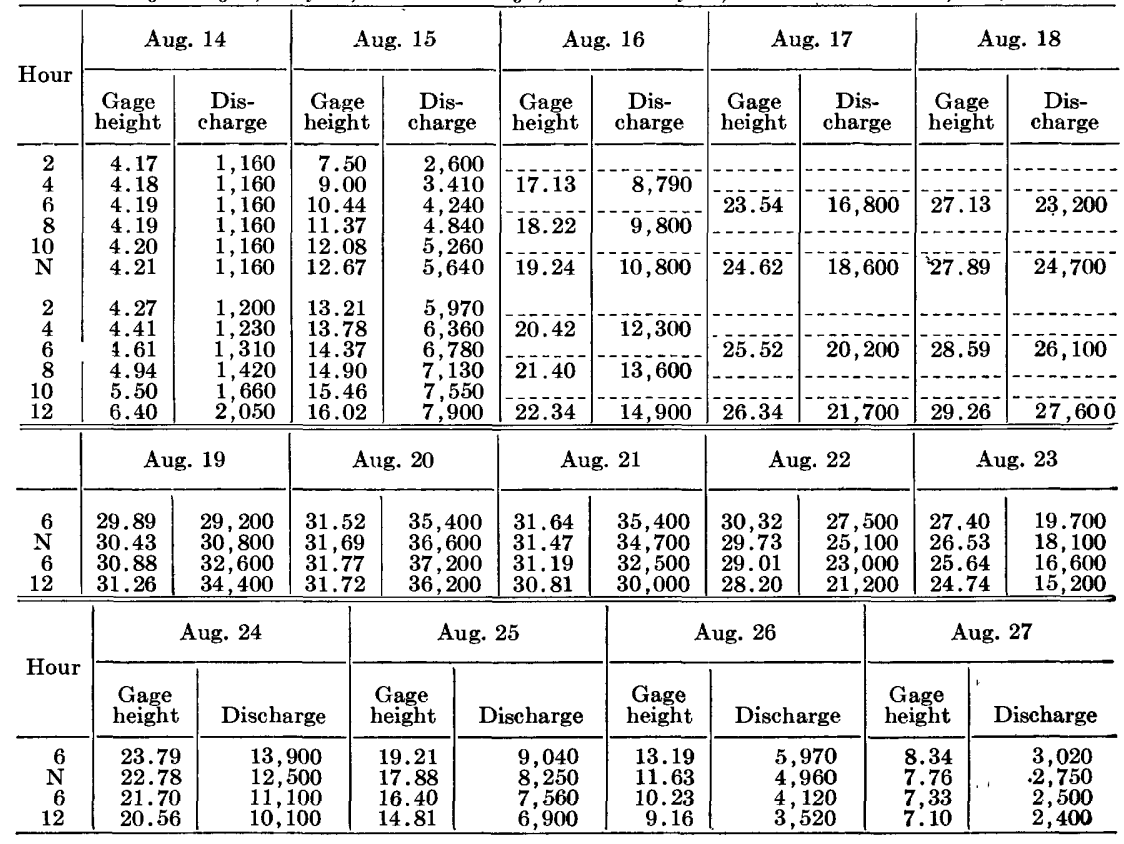


TAR RIVER A'T GREENVILLE, N. C.

Location.-Lat. $35^{\circ} 37^{\prime} 00^{\prime \prime}$, long. $77^{\circ} 22^{\prime} 30^{\prime \prime}$, at bridge on State Highway 11, about 600 feet below Atlantic Coast Line Railroad bridge at Greenville, Pitt County. Datum of gage is 2.38 feet below mean sea level, datum of 1929 , supplementary adjustment of 1936 .

Drain AGE AREA.-2,680 square miles.

GAGE-HEIGHT RECORD.-Water-stage recorder graph except for Aug. 10-11, for which period there is no gage height record.

DISCHARGE RECORD.-Stage-discharge relation defined by current-meter measurements up to 36,000 second-feet. This relation is affected by tide, but current-meter measurements made Aug. 21, 22, 23, and 24 define the relation throughout the flood peak. Gage heights used to half-tenths between 3.6 and 5.2 feet; hundredths below and tenths above these limits. Discharge for period of no gage-height record based on reeord for station at Tarboro.

Maxima.-1940: Discharge, 36,500 second-feet 6-8 a.m. Aug. 22 (gage height, 22.07 feet).

1905-39: Gage height, 24.5 feet July 28, 1919 (from U. S. Weather Bureau records, discharge not determined).

ReMARKs.-Flood runoff not affected by artificial storage. Because of serious tide effect this gage is not being maintained as a regular discharge station.

Mean discharge, in second-feet, 1940

\begin{tabular}{|c|c|c|c|c|c|c|c|c|c|c|c|}
\hline Day & Aug. & Sept. & Day & Aug. & Sept. & Day & Aug. & Sept. & Day & Aug. & Sept. \\
\hline $\begin{array}{l}1 \\
2 \\
3 \\
4 \\
5 \\
6 \\
7 \\
8\end{array}$ & $\begin{array}{r}416 \\
960 \\
1,020 \\
1,060 \\
840 \\
690 \\
650 \\
900\end{array}$ & $\begin{array}{l}3,120 \\
2,720 \\
2,260 \\
2,100 \\
1,880 \\
1,660 \\
1,540 \\
1,510\end{array}$ & $\begin{array}{r}99 \\
10 \\
11 \\
12 \\
13 \\
14 \\
15 \\
16\end{array}$ & $\begin{array}{l}1,340 \\
2,000 \\
2,400 \\
1,840 \\
1,400 \\
1,240 \\
3,020 \\
6,670\end{array}$ & $\begin{array}{r}1,230 \\
990 \\
1,160 \\
1,510 \\
1,770 \\
1,730 \\
1,440 \\
1,400\end{array}$ & $\begin{array}{l}17 \\
18 \\
19 \\
20 \\
21 \\
22 \\
23 \\
24\end{array}$ & $\begin{array}{l}11,200 \\
16,800 \\
23,000 \\
29,400 \\
34,700 \\
36,200 \\
33,300 \\
27,300\end{array}$ & $\begin{array}{r}1,370 \\
1,300 \\
1,120 \\
930 \\
750 \\
635 \\
756 \\
680\end{array}$ & $\begin{array}{l}25 \\
26 \\
27 \\
28 \\
29 \\
30 \\
31\end{array}$ & $\begin{array}{r}20,700 \\
14,000 \\
8,820 \\
5,300 \\
3,400 \\
3,290 \\
3,350\end{array}$ & $\begin{array}{r}495 \\
630 \\
990 \\
1,090 \\
1,020 \\
1,200\end{array}$ \\
\hline \multicolumn{10}{|c|}{$\begin{array}{l}\text { Monthly mean discharge, in second-feet } \\
\text { Runoff, in inches. }\end{array}$} & $\begin{array}{r}9,587 \\
4.12\end{array}$ & $\begin{array}{r}1,366 \\
0.57\end{array}$ \\
\hline
\end{tabular}

Gage height, in feet, and discharge, in second-feet, at indicated time, 1940

\begin{tabular}{|c|c|c|c|c|c|c|c|c|c|c|c|c|}
\hline \multirow{2}{*}{ Hour } & \multicolumn{2}{|c|}{ Aug. 14} & \multicolumn{2}{|c|}{ Aug. 15} & \multicolumn{2}{|c|}{ Aug. 16} & \multicolumn{2}{|c|}{ Aug. 17} & \multicolumn{2}{|c|}{ Aug. 18} & \multicolumn{2}{|c|}{ Aug. 19} \\
\hline & $\begin{array}{c}\text { Gage } \\
\text { ht. }\end{array}$ & $\begin{array}{c}\text { Dis- } \\
\text { charge }\end{array}$ & $\begin{array}{c}\text { Gage } \\
\text { ht. }\end{array}$ & $\begin{array}{c}\text { Dis- } \\
\text { charge }\end{array}$ & $\begin{array}{c}\text { Gage } \\
\text { ht. }\end{array}$ & $\begin{array}{c}\text { Dis- } \\
\text { charge }\end{array}$ & $\begin{array}{c}\text { Gage } \\
\text { ht. }\end{array}$ & $\begin{array}{c}\text { Dis- } \\
\text { charge }\end{array}$ & $\begin{array}{c}\text { Gage } \\
\text { ht. }\end{array}$ & $\begin{array}{c}\text { Dis- } \\
\text { charge }\end{array}$ & $\begin{array}{c}\text { Gage } \\
\text { ht. }\end{array}$ & $\begin{array}{c}\text { Dis- } \\
\text { charge }\end{array}$ \\
\hline \multirow{5}{*}{$\begin{array}{r}4 \\
8 \\
N \\
4 \\
8 \\
12 \\
\end{array}$} & 4.23 & 1,200 & \multirow{4}{*}{\begin{tabular}{|r|}
14.65 \\
15.27 \\
6.47 \\
7.69 \\
8.56 \\
9.13 \\
\end{tabular}} & \multirow{4}{*}{$\begin{array}{l}1,480 \\
1,960 \\
2,880 \\
3,880 \\
4,690 \\
5,160 \\
\end{array}$} & \multirow{4}{*}{$\mid \begin{array}{r}9.56 \\
10.04 \\
10.46 \\
11.02 \\
11.55 \\
12.16\end{array}$} & \multirow{4}{*}{$\begin{array}{l}5,650 \\
6,050 \\
6,550 \\
7,100 \\
7,820 \\
8,580 \\
\end{array}$} & 13.35 & 10,300 & 16.20 & 15,700 & 18.50 & 22,000 \\
\hline & 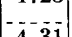 & 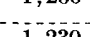 & & & & & & & & & & -0 \\
\hline & 4.31 & 1,230 & & & & & $\mid 14.44$ & 12,000 & 16.98 & 17,700 & $|19.19|$ & 24,100 \\
\hline & $4 . \overline{45}$ & 1,340 & & & & & $|\overline{15} . \mathbf{3 6}|$ & 13,900 & $|\overline{17} . \overline{75}|$ & 19,900 & $\mid \overline{19} . \overline{83}$ & 26,100 \\
\hline & \multicolumn{2}{|c|}{ Aug. 20} & \multicolumn{2}{|c|}{ Aug. 21} & \multicolumn{2}{|c|}{ Aug. 22} & \multicolumn{2}{|c|}{ Aug. 23} & \multicolumn{2}{|c|}{ Aug. 24} & \multicolumn{2}{|c|}{ Aug. 25} \\
\hline \multirow{5}{*}{$\begin{array}{r}6 \\
8 \\
\mathrm{~N} \\
4 \\
6 \\
12 \\
\end{array}$} & 20.26 & 28,000 & 21.56 & 34,000 & 22.07 & 36,500 & 21.74 & 34,500 & 20.53 & 28,800 & & \\
\hline & $\overline{20.64}$ & 29,200 & $2 \overline{1} . \overline{7} \overline{5}$ & 35,000 & $\overline{2} .06$ & $\overline{3} 6, \overline{50}$ & $2 \overline{1} . \overline{5}$ & $3 \overline{3}, 500$ & 20.11 & $\overline{27}, \overline{200}$ & & \\
\hline & $\overline{2} \overline{1.00}$ & 31,000 & 21.90 & 35,500 & $\overline{22.01}$ & 36,000 & $|\overline{2} \overline{1} . \overline{3}|$ & 32,000 & 19.66 & $2 \overline{5}$ & & \\
\hline & 21.31 & 32,500 & 22.01 & 36,000 & 21.90 & $\begin{array}{r}30,500 \\
35,500 \\
\end{array}$ & $|20.90|$ & 30,600 & $\begin{array}{l}19.00 \\
19.16\end{array}$ & & 16.82 & 17,200 \\
\hline & \multicolumn{2}{|c|}{ Aug. 26} & \multicolumn{2}{|c|}{ Aug. 27} & \multicolumn{2}{|c|}{ Aug. 28} & \multicolumn{2}{|c|}{ Aug. 29} & \multicolumn{2}{|c|}{ Aug. 30} & \multicolumn{2}{|c|}{ Aug. 31} \\
\hline \multirow{4}{*}{$\begin{array}{r}6 \\
8 \\
N \\
4 \\
6 \\
12\end{array}$} & & & & & 9.97 & 6,050 & 7.28 & 3,540 & & & & \\
\hline & 15 & 000 & 12 & 0 & $1 \overline{6}$ & 5,260 & 7.02 & 3,280 & & & 9 & \\
\hline & $14 . \overline{9}$ & 12,900 & $\overline{1} 1 . \overline{7} \overline{5}$ & 8,060 & & & 1.02 & 300 & 7.06 & 3,360 & 7.08 & 3,360 \\
\hline & $\mid 13.89$ & 11,100 & $\overline{10.7 \overline{6}}$ & 6,880 & $\begin{array}{l}8.50 \\
7.74\end{array}$ & $\begin{array}{l}4,500 \\
3,880\end{array}$ & $\begin{array}{l}0.92 \\
6.97\end{array}$ & $\begin{array}{l}3,200 \\
3,280\end{array}$ & 7.08 & 3,360 & 7.02 & $3, \overline{280}$ \\
\hline
\end{tabular}

1 Estimated from partial record.

SUPPl EMENTAL RECORD.-Aug. 22, 8 a.m., gage height, 22.07 feet; discharge, 36,500 second-feet. 
FISHING CREEK NEÁR ENFIELD, N. C.

Location.-Lat. $36^{\circ} 08^{\prime} 55^{\prime \prime}$, long. $77^{\circ} 41^{\prime} 45^{\prime \prime}$, at bridge on U. S. Highway $301,2,000$ feet. downstream from Atlantic Coast Line Railroad bridge, 2 miles southwest of Enfield, Halifax County, and 4\%/4 miles downstream from Rocky Creek.

Drain AGE AREA.- 462 square miles.

GAGE-HEIGHT RECORD.-Water-stage recorder graph.

DisCHARGE RECORD.-Stage-discharge relation defined by current-meter measurements up to 11,300 second-feet. Shifting-control method used Sept. 23-30. Gage heights used to half-tenths between 1.6 and 3.2 feet; hundredths below and tenths above these limits.

Maxima.-1940: Discharge, 12,600 second-feet 1-4 a.m. Aug. 18 (gage height, 17.72 feet).

1923-39: Discharge, 12,600 second-feet Dec. 2, 1934 (gage height, 17.66 feet). 1910-39: Stage known, 21.0 feet April 19, 1910 (from U. S. Weather Bureau records, discharge not determined). Flood of July 24, 1919, reached a stage of 19.6 feet (discharge 20,300 second-feet).

RemarKs.-Flood runoff not affected by artificial storage.

Mean discharge, in second-feet, 1940

\begin{tabular}{|c|c|c|c|c|c|c|c|c|c|c|c|}
\hline Day & Aug. & Sept. & Day & Aug. & Sept. & Day & Aug. & Sept. & Day & Aug. & Sept. \\
\hline $\begin{array}{l}1 \\
2 \\
3 \\
4 \\
5 \\
6 \\
6 \\
7 \\
8\end{array}$ & $\begin{array}{r}338 \\
212 \\
145 \\
120 \\
117 \\
118 \\
178 \\
1,530\end{array}$ & $\begin{array}{l}358 \\
308 \\
278 \\
250 \\
239 \\
332 \\
302 \\
234\end{array}$ & $\begin{array}{r}9 \\
10 \\
11 \\
12 \\
13 \\
14 \\
15 \\
16\end{array}$ & $\begin{array}{r}1,000 \\
390 \\
351 \\
292 \\
390 \\
505 \\
3,310 \\
5,670\end{array}$ & $\begin{array}{l}228 \\
228 \\
358 \\
308 \\
266 \\
239 \\
206 \\
195\end{array}$ & $\begin{array}{l}17 \\
18 \\
19 \\
20 \\
21 \\
22 \\
23 \\
24\end{array}$ & $\begin{array}{r}11,100 \\
12,100 \\
8,770 \\
3,760 \\
1,090 \\
481 \\
372 \\
\mathbf{3 7 0}\end{array}$ & $\begin{array}{l}178 \\
168 \\
173 \\
173 \\
168 \\
162 \\
162 \\
147\end{array}$ & $\begin{array}{l}25 \\
26 \\
27 \\
28 \\
29 \\
30 \\
31\end{array}$ & $\begin{array}{l}577 \\
453 \\
382 \\
543 \\
808 \\
668 \\
532\end{array}$ & $\begin{array}{l}147 \\
152 \\
137 \\
142 \\
132 \\
142\end{array}$ \\
\hline \multicolumn{10}{|c|}{$\begin{array}{l}\text { Monthly mean discharge, in second-feet } \\
\text { Runoff, in inches. }\end{array}$} & $\begin{array}{r}1,828 \\
4.56\end{array}$ & $\begin{array}{r}217 \\
0.52\end{array}$ \\
\hline
\end{tabular}

Gage height, in feet, and discharge, in second-feet, at indicated time, 1940

\begin{tabular}{|c|c|c|c|c|c|c|c|c|c|c|}
\hline \multirow{2}{*}{ Hour } & \multicolumn{2}{|c|}{ Aug. 14} & \multicolumn{2}{|c|}{ Aug. 15} & \multicolumn{2}{|c|}{ Aug. 16} & \multicolumn{2}{|c|}{ Aug. 17} & \multicolumn{2}{|c|}{ Aug. 18} \\
\hline & $\begin{array}{c}\text { Gage } \\
\text { height }\end{array}$ & $\begin{array}{c}\text { Dis- } \\
\text { charge }\end{array}$ & $\begin{array}{c}\text { Gage } \\
\text { height }\end{array}$ & $\begin{array}{c}\text { Dis- } \\
\text { charge }\end{array}$ & $\begin{array}{c}\text { Gage } \\
\text { height }\end{array}$ & $\begin{array}{c}\text { Dis- } \\
\text { charge }\end{array}$ & $\begin{array}{c}\text { Gage } \\
\text { height }\end{array}$ & $\begin{array}{c}\text { Dis- } \\
\text { charge }\end{array}$ & $\begin{array}{c}\text { Gage } \\
\text { height }\end{array}$ & $\begin{array}{c}\text { Dis- } \\
\text { charge }\end{array}$ \\
\hline \multirow{4}{*}{$\begin{array}{r}2 \\
4 \\
6 \\
8 \\
10 \\
\mathbf{N}\end{array}$} & \multirow{4}{*}{$\begin{array}{l}3.75 \\
\mathbf{3 . 6 6} \\
\mathbf{3 . 5 7} \\
\mathbf{3 . 4 7} \\
\mathbf{3 . 3 8} \\
\mathbf{3 . 3 0}\end{array}$} & \multirow{4}{*}{$\begin{array}{l}429 \\
416 \\
403 \\
390 \\
377 \\
364\end{array}$} & \multirow{4}{*}{$\begin{array}{l}11.53 \\
12.28 \\
12.67 \\
12.94 \\
13.19 \\
13.43\end{array}$} & \multirow{4}{*}{$\begin{array}{l}2,110 \\
2,540 \\
2,780 \\
2,910 \\
3,120 \\
3,270\end{array}$} & & & & & \multirow[b]{2}{*}{$17.72^{-}$} & \multirow[b]{2}{*}{12,600} \\
\hline & & & & & 14.80 & 5,010 & 16.55 & 9,260 & & \\
\hline & & & & & 14.89 & 5,210 & $17.09^{-}$ & 10,700 & $1 \overline{7} .69$ & 12,600 \\
\hline & & & & & 15.00 & 5,420 & 17.41 & $1 \overline{1}, 600$ & 17.63 & 12,200 \\
\hline \multirow{5}{*}{$\begin{array}{r}2 \\
4 \\
6 \\
8 \\
10 \\
12 \\
\end{array}$} & \multirow{4}{*}{$\begin{array}{l}3.36 \\
3.71 \\
4.01 \\
4.69 \\
7.00 \\
9.85 \\
\end{array}$} & \multirow{4}{*}{$\begin{array}{r}377 \\
416 \\
455 \\
550 \\
904 \\
1,530 \\
\end{array}$} & \multirow{4}{*}{$\begin{array}{l}13.65 \\
13.93 \\
14.17 \\
14.36 \\
14.52 \\
14.63 \\
\end{array}$} & \multirow{4}{*}{$\begin{array}{l}3,430 \\
3,710 \\
4,040 \\
4,310 \\
4,470 \\
4,640 \\
\end{array}$} & & & & & \multirow[b]{2}{*}{17.54} & \multirow{2}{*}{11,900} \\
\hline & & & & & 15.17 & 5,840 & 17.56 & 12,200 & & \\
\hline & & & & & 15.51 & 6,510 & 17.67 & 12,600 & 17.40 & 11,600 \\
\hline & & & & & 15.92 & $\overline{7}, \overline{450}$ & 17.71 & 12,600 & 17.22 & 11,000 \\
\hline & \multicolumn{2}{|c|}{ Aug. 19} & \multicolumn{2}{|c|}{ Aug. 20} & \multicolumn{2}{|c|}{ Aug. 21} & \multicolumn{2}{|c|}{ Aug. 22} & \multicolumn{2}{|c|}{ Aug. 23} \\
\hline \multirow{3}{*}{$\begin{array}{r}4 \\
6 \\
8 \\
\mathbf{N}\end{array}$} & \multirow{2}{*}{16.91} & \multirow{2}{*}{$\mathbf{1 0}, \mathbf{1 0 0}$} & 14.85 & 5,010 & 9.71 & 1,500 & & & & \\
\hline & & & & 4310 & 86 & 1240 & 4.79 & 517 & & 38 \\
\hline & 16.48 & 8,990 & 13.84 & 3,610 & $\begin{array}{l}0.00 \\
7.52\end{array}$ & $\begin{array}{l}1,240 \\
1,000\end{array}$ & $4.40^{-}$ & 462 & 3.74 & $371^{-}$ \\
\hline 4 & & & 13.24 & 3,120 & 6.66 & 843 & & & & \\
\hline $\begin{array}{l}6 \\
8\end{array}$ & 15 & 7,450 & 12.32 & & 5.92 & 697 & 19 & 436 & 3.62 & 358 \\
\hline 12 & 15.31 & 6,060 & 11.04 & 1,920 & 5.37 & 610 & $3.97^{-}$ & 410 & 3.47 & 345 \\
\hline
\end{tabular}




\section{FLOODS OF AUGUST 1940 IN THE SOUTHEASTERN STATES 161}

\section{NEUSE RIVER BASIN \\ ENO RIVER AT HILLSBORO, N. C.}

Location.-Lat. $36^{\circ} 04^{\prime} 20^{\prime \prime}$, long. $79^{\circ} 06^{\prime} 30^{\prime \prime}$, 1,000 feet downstream from U. $S$. Highway 70 at Hillsboro, Orange County, and 2 miles downstream from Sevenmile Creek.

DRAINAgE AREA.-66.5 square miles.

GAGE-HEIGHT RECORD.-Water-stage recorder graph.

DISCHARGE RECORD.- Stage-discharge relation defined by current-meter measurements up to 5,700 second-feet. Shifting-control method used Sept. 22-30. Gage heights used to half-tenths between 3.6 and 4.3 feet Aug. 1-14 and between 3.5 and 4.6 feet Aug. 15 to Sept. 30; hundredths below and tenths above these limits.

Maxma.-August 1940: Discharge, 1,680 second-feet 5 p.m. Aug. 14 (gage height, 10.90 feet).

1927 to July 1940: Discharge, 6,750 second-feet Oct. 2, 1929 (gage height, 18.0 feet, from graph based on gage readings).

REMARKS.-Flood runoff not affected by artificial storage.

Mean discharge, in second-feet, 1940

\begin{tabular}{|c|c|c|c|c|c|c|c|c|c|c|c|}
\hline Day & Aug. & Sept. & Day & Aug. & Sept. & Day & Aug. & Sept. & Day & Aug. & Sept. \\
\hline $\begin{array}{l}1 \\
2 \\
3 \\
4 \\
5 \\
6 \\
7 \\
8\end{array}$ & $\begin{array}{r}7.8 \\
7.5 \\
6.9 \\
6.9 \\
6.9 \\
12 \\
8.6 \\
6.9\end{array}$ & $\begin{array}{l}17 \\
15 \\
14 \\
14 \\
13 \\
13 \\
12 \\
12\end{array}$ & $\begin{array}{r}9 \\
10 \\
11 \\
12 \\
13 \\
14 \\
15 \\
16\end{array}$ & $\begin{array}{c}6.3 \\
6.3 \\
7.8 \\
10 \\
9.6 \\
584 \\
244 \\
214\end{array}$ & $\begin{array}{c}11 \\
12 \\
18 \\
14 \\
12 \\
10 \\
10 \\
9.3\end{array}$ & $\begin{array}{l}17 \\
18 \\
19 \\
20 \\
21 \\
22 \\
23 \\
24\end{array}$ & $\begin{array}{r}160 \\
71 \\
46 \\
30 \\
23 \\
21 \\
20 \\
19\end{array}$ & $\begin{array}{l}9.0 \\
8.6 \\
8.3 \\
7.9 \\
7.6 \\
6.8 \\
5.8 \\
5.1\end{array}$ & $\begin{array}{l}25 \\
26 \\
27 \\
28 \\
29 \\
30 \\
31\end{array}$ & $\begin{array}{l}30 \\
49 \\
41 \\
25 \\
21 \\
19 \\
17\end{array}$ & $\begin{array}{l}6.2 \\
6.8 \\
5.8 \\
5.4 \\
5.8 \\
5.4\end{array}$ \\
\hline \multicolumn{10}{|c|}{$\begin{array}{l}\text { Monthly mean discharge, in second-feet } \\
\text { Runoff, in inches }\end{array}$} & $\begin{array}{l}56.0 \\
0.97\end{array}$ & $\begin{array}{l}10.0 \\
0.17\end{array}$ \\
\hline
\end{tabular}

NEUSE RIVER NEAR NORTHSIDE, $N$. C.

Location.-Lat. $36^{\circ} 02^{\prime} 25^{\prime \prime}$, long. $78^{\circ} 45^{\prime} 05^{\prime \prime}$, at Fish Dam Bridge, 11/2 miles downstream from Seaboard Railway bridge and 2 miles south of Northside, Granville County. Datum of gage is 226.32 feet above mean sea level (from levels by Corps of Engineers, War Department).

DrainaGe AREa.-526 square miles.

GAGE-HEIGHT RECORD.-Water-stage recorder graph.

DischaRge RECORD.-Stage-discharge relation well defined up to 700 second-feet and poorly defined between 700 and 27,000 second-feet by current-meter measurements. Affected by changing stage and backwater during floods. Gage heights used to half-tenths between 2.2 and 4.1 feet; hundredths below and tenths above these limits.

Maxima.-August 1940: Discharge, 4,050 second-feet 3 a.m. Aug. 18 (gage height, 16.50 feet).

1927 to July 1940: Discharge, 26,600 second-feet Oct. 3, 1929 (gage height, 28.64 feet).

REMARKS.-Flood runoff not affected by artificial storage.

Mean discharge, in second-feet, 1940

\begin{tabular}{|c|c|c|c|c|c|c|c|c|c|c|c|}
\hline Day & Aug. & Sept. & Day & Aug. & Sept. & Day & Aug. & Sept. & Day & Aug. & Sept. \\
\hline $\begin{array}{l}1 \\
2 \\
3 \\
4 \\
5 \\
6 \\
7 \\
8\end{array}$ & $\begin{array}{l}63 \\
48 \\
38 \\
32 \\
31 \\
31 \\
46 \\
48\end{array}$ & $\begin{array}{l}384 \\
240 \\
164 \\
167 \\
162 \\
164 \\
158 \\
129\end{array}$ & $\begin{array}{r}9 \\
10 \\
11 \\
12 \\
13 \\
14 \\
15 \\
16\end{array}$ & $\begin{array}{r}44 \\
32 \\
32 \\
34 \\
34 \\
167 \\
2,000 \\
3,200\end{array}$ & $\begin{array}{r}133 \\
156 \\
153 \\
168 \\
172 \\
145 \\
76 \\
74\end{array}$ & $\begin{array}{l}17 \\
18 \\
19 \\
20 \\
21 \\
22 \\
23 \\
24\end{array}$ & $\begin{array}{r}3,800 \\
3,400 \\
1,000 \\
519 \\
445 \\
427 \\
375 \\
226\end{array}$ & $\begin{array}{l}78 \\
80 \\
78 \\
76 \\
73 \\
73 \\
66 \\
68\end{array}$ & $\begin{array}{l}25 \\
26 \\
27 \\
28 \\
29 \\
30 \\
31\end{array}$ & $\begin{array}{r}750 \\
1,200 \\
750 \\
519 \\
519 \\
454 \\
418\end{array}$ & $\begin{array}{l}66 \\
57 \\
48 \\
45 \\
44 \\
42\end{array}$ \\
\hline Ion & hes & & & & & & & & & $\begin{array}{r}667 \\
1.46\end{array}$ & $\begin{array}{r}118 \\
0.25\end{array}$ \\
\hline
\end{tabular}


NEUSE RIVER NEAR CLAYTON, N. C.

Location.-Lat. $35^{\circ} 38^{\prime} 55^{\prime \prime}$, long. $78^{\circ} 24^{\prime} 30^{\prime \prime}$, at bridge 3 miles east of Clayton, Johnston County. Datum of gage is $\mathbf{1 2 8 . 1 2}$ feet above mean sea level (levels by Corps of Engineers, War Department).

Drainage area.- 1,140 square miles.

GAGE-HEIGHT RECORD.-Water-stage recorder graph except for period Aug. 10-22, for which there is no record.

DISCHARGE RECORD.-Dtage-discharge relation defined by current-meter measurements up to 14,200 second-feet and extended to the 1929 erest gage height on basis of flood runoff comparisons. Shifting-control method used Sept. 11-30. Gage heights used to half-tenths between 2.5 and 4.2 feet; hundredths below and tenths above these limits. Discharge for period of no gage-height record based on weather records, recorded range in gage height, and records for United States Weather Bureau river stations at Smithfield and Neuse.

Maxima.-1940: Discharge, 11,500 second-feet Aug. 16 (gage height, 14.6 feet, from recorded range in gage height).

1927-39: Discharge, 22,000 second-feet Oct. 3, 1929 (gage height, 21.62 feet). REMARKs.-Flood runoff not affected by artificial storage.

Mean discharge, in second-feet, 1940

\begin{tabular}{|c|c|c|c|c|c|c|c|c|c|c|c|}
\hline Day & Aug. & Sept. & Day & Aug. & Sept. & Day & Aug. & Sept. & Day & Aug. & Sept \\
\hline $\begin{array}{l}1 \\
2 \\
3 \\
4 \\
5 \\
6 \\
7 \\
8\end{array}$ & $\begin{array}{l}214 \\
207 \\
207 \\
189 \\
179 \\
185 \\
177 \\
541\end{array}$ & $\begin{array}{l}688 \\
604 \\
535 \\
385 \\
366 \\
438 \\
389 \\
\mathbf{3 5 8}\end{array}$ & $\begin{array}{r}9 \\
10 \\
11 \\
12 \\
13 \\
14 \\
15 \\
16\end{array}$ & $\begin{array}{r}386 \\
220 \\
240 \\
240 \\
220 \\
600 \\
6,000 \\
10,000\end{array}$ & $\begin{array}{l}325 \\
317 \\
475 \\
397 \\
347 \\
354 \\
328 \\
277\end{array}$ & $\begin{array}{l}17 \\
18 \\
19 \\
20 \\
21 \\
22 \\
23 \\
24\end{array}$ & $\begin{array}{c}11,000 \\
9,000 \\
8,500 \\
5,000 \\
1,600 \\
900 \\
714 \\
663\end{array}$ & $\begin{array}{l}243 \\
227 \\
219 \\
227 \\
219 \\
219 \\
196 \\
205\end{array}$ & $\begin{array}{l}25 \\
26 \\
27 \\
28 \\
29 \\
30 \\
31\end{array}$ & $\begin{array}{r}600 \\
979 \\
1,660 \\
1,370 \\
850 \\
\mathbf{8 2 2} \\
\mathbf{7 4 0}\end{array}$ & $\begin{array}{r}196 \\
273 \\
232 \\
205 \\
189 \\
173 \\
\end{array}$ \\
\hline \multicolumn{10}{|c|}{$\begin{array}{l}\text { Monthly mean discharge, in seeond-feet } \\
\text { Runoff, in inches }\end{array}$} & $\begin{array}{r}2,071 \\
2.09\end{array}$ & $\begin{array}{r}320 \\
0.31\end{array}$ \\
\hline
\end{tabular}

NEUSE RIVER NEAR GOLDSBORO, N. C.

Location.-Lat. $35^{\circ} 20^{\prime} 40^{\prime \prime}$, long. $78^{\circ} 01^{\prime} 35^{\prime \prime}$, a quarter of a mile upstream from bridge on State Highway 40, 21/2 miles upstream from Stoney Creek, and 3 miles south of Goldsboro, Wayne County. Datum of gage is 44.66 feet above mean sea level, datum of 1929, supplementary adjustment of 1936 .

Drain age area.-2,370 square miles.

GAGE-HEIGHT RECORD.-Water-stage recorder graph.

Discharge RECORD.-Stage-discharge relation defined by current-meter measurements up to 25,500 second-feet for 1940 and up to 38,400 second-feet for 1929. During the periods of rapidly changing stage the rate of change in stage was used as a factor in computing the discharge. Gage heights used to half-tenths between 2.4 and 4.1 feet; hundredths below and tenths above these limits.

Maxima.-1940: Discharge, 11,400 second-feet 4 a.m. Aug. 22; gage height, 19.18 feet 11 a.m. Aug. 22.

1930-39: Discharge, 26,300 second-feet Apr. 11, 1936; gage height, 25.3 feet Apr. 11, 1936.

Discharge known, 38,600 second-feet Oct. 5, 1929 (gage height, 25.3 feet, former site and datum).

REMARKs.-Flood runoff not affected by artificial storage. 
Mean discharge, in second-feet, 1940

\begin{tabular}{|c|c|c|c|c|c|c|c|c|c|c|c|}
\hline Day & Aug. & Sept, & Day & Aug. & Sept. & Day & Aug. & Sept. & Day & Aug. & Sept. \\
\hline $\begin{array}{l}1 \\
2 \\
3 \\
4 \\
5 \\
6 \\
7 \\
8\end{array}$ & $\begin{array}{l}363 \\
366 \\
300 \\
271 \\
252 \\
230 \\
227 \\
265\end{array}$ & $\begin{array}{r}1,340 \\
1,200 \\
1,160 \\
998 \\
875 \\
755 \\
775 \\
755 \\
\end{array}$ & $\begin{array}{r}9 \\
10 \\
11 \\
12 \\
13 \\
14 \\
15 \\
16\end{array}$ & $\begin{array}{r}252 \\
457 \\
539 \\
387 \\
414 \\
516 \\
1,710 \\
6,460 \\
\end{array}$ & $\begin{array}{l}695 \\
655 \\
636 \\
695 \\
795 \\
795 \\
755 \\
695 \\
\end{array}$ & $\begin{array}{l}17 \\
18 \\
19 \\
20 \\
21 \\
22 \\
23 \\
24\end{array}$ & $\begin{array}{r}7,690 \\
8,180 \\
8,850 \\
9,910 \\
11,100 \\
11,200 \\
9,920 \\
6,850 \\
\end{array}$ & $\begin{array}{l}636 \\
539 \\
466 \\
445 \\
404 \\
397 \\
363 \\
360 \\
\end{array}$ & $\begin{array}{l}25 \\
26 \\
27 \\
28 \\
29 \\
30 \\
31 \\
\end{array}$ & $\begin{array}{l}3,250 \\
1,700 \\
1,340 \\
1,700 \\
2,010 \\
1,830 \\
1,420\end{array}$ & $\begin{array}{r}353 \\
346 \\
356 \\
387 \\
377 \\
337 \\
\end{array}$ \\
\hline \multicolumn{10}{|c|}{$\begin{array}{l}\text { Monthly mean discharge, in second-feet } \\
\text { Runoff, in inches }\end{array}$} & $\begin{array}{r}3,224 \\
1.57\end{array}$ & $\begin{array}{r}645 \\
0.30\end{array}$ \\
\hline
\end{tabular}

\section{NEUSE RIVER AT KINSTON, N. C.}

LOCATION.-Lat. $35^{\circ} 15^{\prime} 30^{\prime \prime}$, long. $77^{\circ} 35^{\prime} 10^{\prime \prime}$, at Kinston, Lenoir County, two blocks downstream from bridge on State Highway 11. Datum of gage is 10.80 feet above mean sea level (North Carolina Highway surveys).

DRAINAGE AREA.-2,690 square miles.

GAGE-HEIGHT RECORD.-Water-stage recorder graph.

DischARGE RECORD.- - Stage-discharge relation defined by current-meter measurements up to 36,200 second-feet. Gage heights used to half-tenths between 2.4 and 4.3 feet; hundredths below and tenths above these limits.

Maxima.-1940: Discharge, 10,900 second-feet 6 a.m. Aug. 25 (gage height, 16.14 feet).

1930-39: Discharge, 24,400 second-feet April 14, 1936 (gage height, 20.9 feet).

Stagè known, 25.0 feet July 1919 (discharge, about 39,000 seeond-feet).

REMARKs.-Flood runoff not affected by artificial storage.

Mean discharge, in second-feet, 1940

\begin{tabular}{|c|c|c|c|c|c|c|c|c|c|c|c|}
\hline Day & Aug. & Sept. & Day & Aug. & Sept. & Day & Aug. & Sept. & Day & Aug. & Sept. \\
\hline $\begin{array}{l}1 \\
2 \\
3 \\
4 \\
5 \\
6 \\
7 \\
8\end{array}$ & $\begin{array}{l}349 \\
382 \\
463 \\
416 \\
394 \\
388 \\
496 \\
696\end{array}$ & $\begin{array}{r}1,710 \\
1,510 \\
1,410 \\
1,320 \\
1,230 \\
1,140 \\
1,000 \\
960\end{array}$ & $\begin{array}{r}9 \\
10 \\
11 \\
12 \\
13 \\
14 \\
15 \\
16\end{array}$ & $\begin{array}{r}715 \\
530 \\
513 \\
735 \\
638 \\
565 \\
766 \\
1,900\end{array}$ & $\begin{array}{l}938 \\
875 \\
835 \\
815 \\
815 \\
895 \\
915 \\
895\end{array}$ & $\begin{array}{l}17 \\
18 \\
19 \\
20 \\
21 \\
22 \\
23 \\
24\end{array}$ & $\begin{array}{r}3,580 \\
5,060 \\
6,510 \\
7,500 \\
8,040 \\
8,860 \\
9,300 \\
10,700\end{array}$ & $\begin{array}{l}835 \\
795 \\
715 \\
638 \\
601 \\
565 \\
530 \\
513\end{array}$ & $\begin{array}{l}25 \\
26 \\
27 \\
28 \\
29 \\
30 \\
31\end{array}$ & $\begin{array}{r}10,900 \\
9,450 \\
6,260 \\
3,140 \\
1,960 \\
2,110 \\
2,060\end{array}$ & $\begin{array}{l}480 \\
463 \\
463 \\
480 \\
480 \\
496\end{array}$ \\
\hline Run & & & & & & & & & & $\begin{array}{r}3,399 \\
1.46\end{array}$ & $\begin{array}{r}844 \\
0.35\end{array}$ \\
\hline
\end{tabular}

FLAT TIVER AT BAHAMA, N. C.

Location.-Lat. $36^{\circ} 11^{\prime} 25^{\prime \prime}$, long. $78^{\circ} 53^{\prime} 00^{\prime \prime}$, at head of Lake Michie, $11 / 1$ miles upstream from county highway bridge, $1 \frac{11 / 2}{2}$ miles upstream from Dial Creek, and $1 \frac{1}{2}$ miles north of Bahama, Durham County. Datum of gage is 255.05 feet above mean sea level.

Drainage AREA.-150 square miles.

GAGE-HEIGHT RECORD.-Water-stage recorder graph.

DISCHARGE RECORD.-Stage-discharge relation defined by current-meter measurements up to 13,000 second-feet. Gage heights used to half-tenths between 5.0 and 7.0 feet; hundredths below and tenths above these limits.

Maxima-August 1940: Discharge, 4,000 second-feet 8:30 p.m. Aug. 14 (gage height, 6.97 feet).

1925 to July 1940: Discharge, 16,000 second-feet July 26, 1938, based on records for nearby streams.

REMARKs.-Flood runoff not affected by artificial storage. 
Mean discharge, in second-feet, 1940

\begin{tabular}{|c|c|c|c|c|c|c|c|c|c|c|c|}
\hline Day & Aug. & Sept. & Day & Aug. & Sept. & Day & Aug. & Sept. & Day & Aug. & Sept. \\
\hline $\begin{array}{l}1 \\
2 \\
3 \\
4 \\
5 \\
6 \\
7 \\
8\end{array}$ & $\begin{array}{l}21 \\
27 \\
26 \\
23 \\
21 \\
20 \\
18 \\
18\end{array}$ & $\begin{array}{l}53 \\
48 \\
43 \\
36 \\
37 \\
36 \\
34 \\
31\end{array}$ & $\begin{array}{r}9 \\
10 \\
11 \\
12 \\
13 \\
14 \\
15 \\
16\end{array}$ & $\begin{array}{r}24 \\
16 \\
12 \\
13 \\
14 \\
1,510 \\
1,710 \\
1,520\end{array}$ & $\begin{array}{l}30 \\
30 \\
86 \\
65 \\
46 \\
34 \\
30 \\
28\end{array}$ & $\begin{array}{l}17 \\
18 \\
19 \\
20 \\
21 \\
22 \\
23 \\
24\end{array}$ & $\begin{array}{r}1,320 \\
222 \\
123 \\
82 \\
64 \\
56 \\
50 \\
46\end{array}$ & $\begin{array}{l}24 \\
23 \\
24 \\
21 \\
20 \\
19 \\
18 \\
18\end{array}$ & $\begin{array}{l}25 \\
26 \\
27 \\
28 \\
29 \\
30 \\
31\end{array}$ & $\begin{array}{r}1,060 \\
386 \\
157 \\
200 \\
92 \\
73 \\
62\end{array}$ & $\begin{array}{l}16 \\
12 \\
14 \\
12 \\
12 \\
14\end{array}$ \\
\hline & $\begin{array}{l}\text { mear } \\
\text { incl }\end{array}$ & & & & & & & & & $\begin{array}{r}290 \\
2.23\end{array}$ & $\begin{array}{l}30.5 \\
0.23\end{array}$ \\
\hline
\end{tabular}

FLAT RIVER AT DAM, NEAR BAHAMA, N. C.

LOCATION.-Lat. $36^{\circ} 09^{\prime} 05^{\prime \prime}$, long. $78^{\circ} 50^{\prime} 55^{\prime \prime}$, just downstream from Durham municipal dam at old Tilley mill site, 3 miles southeast of Bahama, Durham County, and 4 miles upstream from confluence with Eno River.

Drainage AREA. - 171 square miles.

GAGE-HEIGHT RECORD.-Water-stage recorder graph except for Sept. 3, 4, 6-8, 11-16, for which periods the graph was completed on basis of record from water-stage recorder at the power-plant tailrace a short distance upstream.

DISCHARGE RECORD.-Stage-discharge relation defined by current-meter measurements up to 3,800 second-feet and extended to the 1938 erest gage height on basis of computations of flow over Durham municipal dam and through power plant for gage heights 13.6, 14.6, 16.7, and 19.5 feet. Gage heights used to half-tenths between 3.1 and 4.7 feet; hundredths below and tenths above these limits.

Maxima.-August 1940: Discharge, 3,020 second-feet 3 a.m. Aug. 16 (gage height, 9.28 feet).

1927 to July 1940: Discharge, 18,600 second-feet July 26, 1938 (gage height, 19.50 feet).

Remarks.-Flood runoff affected by storage in Durham Reservoir (Lake Michie), which has a usable capacity of 13,810 acre-feet. A daily average of about 10 second-feet is diverted from Lake Michie for Durham water supply.

Mean discharge, in second-feet, 1940

\begin{tabular}{|c|c|c|c|c|c|c|c|c|c|c|c|}
\hline Day & Aug. & Sept. & Day & Aug. & Sept. & Day & Aug. & Sept. & Day & Aug. & Sept. \\
\hline $\begin{array}{l}1 \\
2 \\
3 \\
4 \\
5 \\
6 \\
7 \\
8\end{array}$ & $\begin{array}{l}7.4 \\
8.4 \\
7.9 \\
7.4 \\
6.3 \\
4.2 \\
4.2 \\
4.2\end{array}$ & $\begin{array}{r}242 \\
78 \\
89 \\
99 \\
97 \\
95 \\
85 \\
79 \\
\end{array}$ & \begin{tabular}{r|}
9 \\
10 \\
11 \\
12 \\
13 \\
14 \\
15 \\
16
\end{tabular} & $\begin{array}{r}4.2 \\
4.7 \\
4.2 \\
4.2 \\
4.2 \\
105 \\
754 \\
1,700\end{array}$ & $\begin{array}{r}98 \\
104 \\
88 \\
110 \\
100 \\
46 \\
30 \\
41\end{array}$ & $\begin{array}{l}17 \\
18 \\
19 \\
20 \\
21 \\
22 \\
23 \\
24\end{array}$ & $\begin{array}{r}1 ; 410 \\
341 \\
270 \\
294 \\
294 \\
310 \\
193 \\
94 \\
\end{array}$ & $\begin{array}{l}35 \\
41 \\
41 \\
41 \\
43 \\
45 \\
38 \\
43\end{array}$ & $\begin{array}{l}25 \\
26 \\
27 \\
28 \\
29 \\
30 \\
31\end{array}$ & $\begin{array}{l}209 \\
394 \\
280 \\
276 \\
285 \\
285 \\
279\end{array}$ & $\begin{array}{l}35 \\
25 \\
25 \\
24 \\
18 \\
25\end{array}$ \\
\hline \multicolumn{10}{|c|}{$\begin{array}{l}\text { Monthly mean discharge, in second-feet, } \\
\text { Runoff, in inches. }\end{array}$} & $\begin{array}{r}253 \\
1.71\end{array}$ & $\begin{array}{l}65.3 \\
0.43\end{array}$ \\
\hline
\end{tabular}

DIAL CREEK NEAR BAHAMA, N. C.

LOCATION.-Lat. $36^{\circ} 10^{\prime} 50^{\prime \prime}$, long. $78^{\circ} 51^{\prime} 55^{\prime \prime}$, three-eighths of a mile upstream from mouth and Lake Michie, and 3 miles northeast of Bahama, Durham County.

Drainage AREA.- 4.9 square miles.

GAGE-HEIGHT RECORD.-Water-stage recorder graph except for periods Aug. 20-26 and Sept. 24-29, when recorder clock was stopped.

DISCHARGE RECORD.-Stage-discharge relation defined by current-meter measurements up to 60 second-feet and extended on basis of computation of flow for gage heights 3.0, 3.5, 4.0, and 4.5 feet over $90^{\circ} \mathrm{V}$-notehed weir and irregular masonry control. Gage heights used to half-tenths between 3.7 and 7.0 feet; hundredths 
below and tenths above these limits. Discharge for periods of no gage-height record based on recorded range in gage heights, weather records, and records for nearby streams.

Maxima.-August 1940: Discharge, 130 second-feet $3: 30$ p.m. Aug. 14 (gage height, 3.22 feet).

1925 to July 1940: Discharge, 1,270 second-feet May 24, 1940 (gage height, 7.60 feet).

REMARKS.-Flood runoff not affected by artificial storage.

Mean discharge, in second-feet, 1940

\begin{tabular}{|c|c|c|c|c|c|c|c|c|c|c|c|}
\hline Day & Aug. & Sept. & Day & Aug. & Sept. & Day & Aug. & Sept. & Day & Aug. & Sept. \\
\hline $\begin{array}{l}1 \\
2 \\
3 \\
4 \\
5 \\
6 \\
7 \\
8\end{array}$ & $\begin{array}{r}0.95 \\
.60 \\
.55 \\
.52 \\
.52 \\
.52 \\
.46 \\
.43\end{array}$ & $\begin{array}{r}1.41 \\
1.12 \\
1.04 \\
.97 \\
1.64 \\
1.68 \\
1.08 \\
.90\end{array}$ & $\begin{array}{r}9 \\
10 \\
11 \\
12 \\
13 \\
14 \\
15 \\
16\end{array}$ & $\begin{array}{l}.39 \\
.31 \\
.63 \\
.46 \\
.46 \\
33 \\
21 \\
12\end{array}$ & $\begin{array}{r}.84 \\
1.19 \\
1.25 \\
.97 \\
.84 \\
.74 \\
.68 \\
.68\end{array}$ & $\begin{array}{l}17 \\
18 \\
19 \\
20 \\
21 \\
22 \\
23 \\
24\end{array}$ & $\begin{array}{l}5.9 \\
4.36 \\
2.52 \\
1.7 \\
1.5 \\
1.3 \\
1.3 \\
1.2\end{array}$ & $\begin{array}{l}.68 \\
.66 \\
.63 \\
.60 \\
.55 \\
.48 \\
.35 \\
.30\end{array}$ & $\begin{array}{l}25 \\
26 \\
27 \\
28 \\
29 \\
30 \\
31\end{array}$ & $\begin{array}{c}20 \\
6.0 \\
3.42 \\
2.49 \\
1.94 \\
1.79 \\
1.54\end{array}$ & $\begin{array}{l}.34 \\
.34 \\
.30 \\
.30 \\
.34 \\
.33\end{array}$ \\
\hline \multicolumn{10}{|c|}{ Monthly mean discharge, in second-feet. } & $\begin{array}{l}4.19 \\
0.98\end{array}$ & $\begin{array}{r}.774 \\
0.18\end{array}$ \\
\hline
\end{tabular}

MIDDLE CREEK NEAR CLAYTON, N. C.

Location.-Lat. $35^{\circ} 34^{\prime} 10^{\prime \prime}$, long. $78^{\circ} 35^{\prime} 30^{\prime \prime}$, at bridge on State Highway 50 a quarter of a mile upstream from Buffalo Branch, $31 / 4$ miles downstream from county line, and $9 \frac{1}{1}$ miles southwest of Clayton, Johnston County.

Drainage AREA, - 80.7 square miles.

GAGE-HEIGHT RECORD.-Water-stage recorder graph.

DISCHARGE RECORD.-Stage-discharge relation defined by current-meter measurements up to 450 second-feet. Shifting-control method used Sept. 25-30. Gage heights used to half-tenths between 2.7 and 4.4 feet; hundredths below and tenths above these limits.

Maxima.-August 1940: Discharge, -360 second-feet 5:30 a.m. Aug. 18 (gage height, 5.07 feet).

1939 to July 1940: Discharge, 577 second-feet Apr. 22, 1940 (gage height, 6.51 feet).

REMARKs.-Flood runoff not affected by artificial storage.

Mean discharge, in second-feet, 1940

\begin{tabular}{|c|c|c|c|c|c|c|c|c|c|c|c|}
\hline Day & Aug. & Sept. & Day & Aug. & Sept. & Day & Aug. & Sept. & Day & Aug. & Sept. \\
\hline $\begin{array}{l}1 \\
2 \\
3 \\
4 \\
5 \\
6 \\
7 \\
8\end{array}$ & $\begin{array}{l}3.1 \\
2.2 \\
3.1 \\
3.8 \\
3.0 \\
2.0 \\
2.5 \\
2.3\end{array}$ & $\begin{array}{c}12 \\
11 \\
9.8 \\
8.9 \\
11 \\
17 \\
16 \\
12\end{array}$ & $\begin{array}{r}99 \\
10 \\
11 \\
12 \\
13 \\
14 \\
15 \\
16\end{array}$ & $\begin{array}{r}14 \\
6.6 \\
4.7 \\
4.4 \\
6.4 \\
9.4 \\
148 \\
97\end{array}$ & $\begin{array}{c}11 \\
9.0 \\
42 \\
26 \\
16 \\
14 \\
13 \\
11\end{array}$ & $\begin{array}{l}17 \\
18 \\
19 \\
20 \\
21 \\
22 \\
23 \\
24\end{array}$ & $\begin{array}{r}240 \\
286 \\
85 \\
34 \\
21 \\
19 \\
16 \\
16\end{array}$ & \begin{tabular}{c|}
8.7 \\
11 \\
10 \\
12 \\
9.4 \\
8.7 \\
7.8 \\
6.0
\end{tabular} & $\begin{array}{l}25 \\
26 \\
27 \\
28 \\
29 \\
30 \\
31\end{array}$ & $\begin{array}{l}20 \\
20 \\
15 \\
16 \\
15 \\
16 \\
14\end{array}$ & $\begin{array}{c}6.5 \\
8.7 \\
15 \\
10 \\
6.7 \\
6.7\end{array}$ \\
\hline \multicolumn{10}{|c|}{$\begin{array}{l}\text { Monthly mean discharge, in second-feet, } \\
\text { Runoff, in inches }\end{array}$} & $\begin{array}{l}37.0 \\
0.53\end{array}$ & $\begin{array}{l}12.2 \\
0.17\end{array}$ \\
\hline
\end{tabular}

LITIUL RIVER NEAR PRINCETON, N. C.

LoCATION.-Lat. $35^{\circ} 30^{\prime} 40^{\prime \prime}$, long. $78^{\circ} 09^{\prime} 30^{\prime \prime}$, a quarter of a mile upstream from county bridge, three-quarters of a mile upstream from Little Creek, and 3 miles north of Princeton, Johnston County.

Drainage area.-229 square miles. 


\section{FLOODS OF AUGUST 1940 IN THE SOUTHEASTERN STATES}

GAGE-HEIGHT RECORD.-Water-stage recorder graph.

DischaRge RECORD.- Stage-discharge relation defined by current-meter measurements up to 3,300 second-feet. Gage heights used to half-tenths between 2.4 and 3.2 feet; hundredths below and tenths above these limits.

Maxima.-1940: Discharge, 3,270 second-feet 9 a.m. Aug. 19 (gage height, 11.70 feet).

1930-39: Discharge, 4,030 second-feet Dec. 2, 1934 (gage height, 12.68 feet).

Stage known, 14.90 feet sometime in September 1924 (discharge not determined).

REMARKs.-Flood runoff not affected by artificial storage.

Mean discharge, in second-feet, 1940

\begin{tabular}{|c|c|c|c|c|c|c|c|c|c|c|c|}
\hline Day & Aug. & Sept. & Day & Aug. & Sept. & Day & Aug. & Sept. & Day & Aug. & Sept. \\
\hline $\begin{array}{l}1 \\
2 \\
3 \\
4 \\
5 \\
6 \\
7 \\
8\end{array}$ & $\begin{array}{l}19 \\
18 \\
18 \\
18 \\
37 \\
34 \\
31 \\
24\end{array}$ & $\begin{array}{r}111 \\
132 \\
106 \\
97 \\
87 \\
87 \\
65 \\
78\end{array}$ & $\begin{array}{r}9 \\
10 \\
11 \\
12 \\
13 \\
14 \\
15 \\
16\end{array}$ & $\begin{array}{r}26 \\
42 \\
34 \\
82 \\
72 \\
78 \\
848 \\
1,710\end{array}$ & $\begin{array}{r}102 \\
77 \\
89 \\
75 \\
105 \\
110 \\
77 \\
84\end{array}$ & $\begin{array}{l}17 \\
18 \\
19 \\
20 \\
21 \\
22 \\
23 \\
24\end{array}$ & $\begin{array}{r}1,710 \\
2,660 \\
3,190 \\
2,510 \\
972 \\
406 \\
187 \\
128\end{array}$ & $\begin{array}{l}\mathbf{6 5} \\
\mathbf{5 4} \\
\mathbf{5 0} \\
\mathbf{5 2} \\
\mathbf{5 0} \\
\mathbf{3 8} \\
\mathbf{5 1} \\
\mathbf{5 5}\end{array}$ & $\begin{array}{l}25 \\
26 \\
27 \\
28 \\
29 \\
30 \\
31\end{array}$ & $\begin{array}{r}98 \\
105 \\
105 \\
86 \\
84 \\
103 \\
102\end{array}$ & $\begin{array}{l}56 \\
54 \\
51 \\
48 \\
27 \\
47\end{array}$ \\
\hline \multicolumn{10}{|c|}{$\begin{array}{l}\text { Monthly mean discharge, in second-feet, } \\
\text { Runoff, in inches }\end{array}$} & $\begin{array}{r}501 \\
2.52\end{array}$ & $\begin{array}{l}72.7 \\
0.35\end{array}$ \\
\hline
\end{tabular}

CONTENTNEA CREEK NEAR WILSON, N. C.

Location.-Lat. $35^{\circ} 41^{\prime} 15^{\prime \prime}$, long. $77^{\circ} 56^{\prime} 50^{\prime \prime}$, at bridge on U. S. Highway 301, just downstream from municipal power plant, 1 mile upstream from Atlantic Coast Line Railroad bridge, and 3 miles southwest of Wilson, Wilson County.

DraINAGE AREA.-236 square miles.

GAGE-HEIGHT RECORD.-Water-stage recorder graph.

DISCHARGE RECORD.-Stage-discharge relation defined by current-meter measurements up to 4,700 second-feet. Gage heights used to half-tenths between 2.6 and 3.4 feet; hundredths below and tenths above these limits. Shifting-control method used Aug. 1-14, Aug. 21 to Sept. 11, and Sept. 13-30.

Maxima.-1940: Discharge, 4,830 second-feet $\dot{6}: 30$ p.m. Aug. 17 (gage height, 13.80 feet).

1930-39: Discharge, 4,820 second-feet Jan. 31, 1937 (gage height, 13.37 feet).

Stage known, about 24.3 feet sometime in September 1924 .

REMARKs.-Flood runoff practically unaffected by artificial storage. About 1.8 second-feet diverted for Wilson, N. C., water supply.

Mean discharge, in second-feet, 1940

\begin{tabular}{|c|c|c|c|c|c|c|c|c|c|c|c|}
\hline Day & Aug. & Sept. & Day & Aug. & Sept. & Day & Aug. & Sept. & Day & Aug. & Sept. \\
\hline $\begin{array}{l}1 \\
2 \\
3 \\
4 \\
5 \\
6 \\
7 \\
8\end{array}$ & $\begin{array}{l}13 \\
12 \\
12 \\
12 \\
12 \\
11 \\
11 \\
12\end{array}$ & $\begin{array}{r}96 \\
86 \\
103 \\
88 \\
47 \\
107 \\
161 \\
109\end{array}$ & $\begin{array}{r}9 \\
10 \\
11 \\
12 \\
13 \\
14 \\
15 \\
16\end{array}$ & $\begin{array}{r}15 \\
158 \\
36 \\
25 \\
23 \\
93 \\
892 \\
2,110\end{array}$ & $\begin{array}{r}143 \\
26 \\
134 \\
92 \\
123 \\
94 \\
19 \\
62\end{array}$ & $\begin{array}{l}17 \\
18 \\
19 \\
20 \\
21 \\
22 \\
23 \\
24\end{array}$ & $\begin{array}{r}4,090 \\
3,870 \\
2,750 \\
1,710 \\
900 \\
420 \\
261 \\
164\end{array}$ & $\begin{array}{l}66 \\
67 \\
24 \\
24 \\
65 \\
19 \\
19 \\
74\end{array}$ & $\begin{array}{l}25 \\
26 \\
27 \\
28 \\
29 \\
30 \\
31\end{array}$ & $\begin{array}{r}31 \\
251 \\
31 \\
243 \\
31 \\
92 \\
172\end{array}$ & $\begin{array}{l}84 \\
73 \\
64 \\
76 \\
15 \\
15\end{array}$ \\
\hline \multicolumn{10}{|c|}{$\begin{array}{l}\text { Monthly mean discharge, in second-feet } \\
\text { Runoff, in inches }\end{array}$} & $\begin{array}{r}596 \\
2.91\end{array}$ & $\begin{array}{l}72.5 \\
0.34\end{array}$ \\
\hline
\end{tabular}

CONTENTNEA CREEK A'T hoOKERTON, N. C.

Location.-Lat. $35^{\circ} 25^{\prime} 40^{\prime \prime}$, long. $77^{\circ} 35^{\prime} 05^{\prime \prime}$, at Hookerton, Green County, about 300 feet downstream from highway bridge and $2 \frac{1}{2}$ miles upstream from Wheat Swamp Creek. 
Drainage AREa.-789 square miles.

GAGE-HEIGHT RECORD.-Water-stage recorder graph.

DISCHARGE RECORD.-Stage-discharge relation defined by current-meter measurements up to 6,100 second-feet for 1940 and up to 7,200 second-feet for 1929. Gage heights used to half-tenths between 3.2 and 4.7 feet; hundredths below and tenths above these limits.

Maxima.-1940: Discharge, 6,100 second-feet 8 p.m. Aug. 21 (gage height, 15.23 feet).

1928-39: Discharge, 11,100 second-feet Oct. 6, 1929 (gage height, 18.9 feet).

Stage known, 23.3 feet sometime in September 1928.

REMARKs.-Flood runoff not affected by artificial storage.

Mean discharge, in second-feet, 1940

\begin{tabular}{r|r|r|r|r|r|r|r|r|r|r|r}
\hline Day & Aug. & Sept. & Day & Aug. & Sept. & Day & Aug. & Sept. & Day & Aug. \\
\hline 1 & 76 & 459 & 9 & 488 & 288 & 17 & 1,700 & 236 & 25 & 2,830 & 134 \\
2 & 68 & 445 & 10 & 320 & 340 & 18 & 2,750 & 190 & 26 & 1,930 & 116 \\
3 & 64 & 375 & 11 & 340 & 274 & 19 & 3,930 & 177 & 27 & 1,080 & 129 \\
4 & 62 & 320 & 12 & 340 & 288 & 20 & 5,350 & 170 & 28 & 610 & 143 \\
5 & 60 & 294 & 13 & 294 & 361 & 21 & 6,100 & 164 & 29 & 445 & 143 \\
6 & 60 & 288 & 14 & 236 & 375 & 22 & 5,950 & 138 & 30 & 417 & 143 \\
7 & 430 & 274 & 15 & 428 & 314 & 23 & 5,200 & 125 & 31 & 488 & $\ldots$ \\
8 & 659 & 248 & 16 & 980 & 268 & 24 & 4,060 & 138 & & \\
\hline
\end{tabular}

\section{CAPE FEAR RIVER BASIN \\ HAW RIVER NEAR BENAJA, N. C.}

Location.-Lat. $36^{\circ} 14^{\prime} 55^{\prime \prime}$, long. $79^{\circ} 33^{\prime} 45^{\prime \prime}$, at site of old High Rock Mill, 500 feet upstream from county-road crossing, half a mile upstream from county line, and 6 miles east of Benaja, Rockingham County.

Drainage area.-168 square miles.

GAGE-HEIGHT RECORD.-Water-stage recorder graph except for Aug. 1-28 and Sept. 8-11, when recorder clock was stopped.

DischaRge RECORD.-Stage-discharge relation defined by current-meter measurements up to 3,200 second-feet. Gage heights used to half-tenths between 2.7 and 4.5 feet; hundredths below and tenths above these limits. Shifting-control method used Aug. 29 and Sept. 1-4. Discharge for periods of no gage-height record based on recorded range in gage heights, weather records, discharge measurements on Aug. 28 and Sept. 11, and records for nearby streams.

Maxima.-1940: Discharge, 5,200 second-feet about 11 p.m. Aug. 15 (gage height, 13.7 feet, from floodmarks).

1928-39: Discharge, 5,020 second-feet Oct. 3, 1929 (gage height, 13.54 feet).

Flood of July 1916 reached a stage of about 17.5 feet, from floodmark on tree about 500 feet below gage (discharge not determined).

REMARKS.-Flood runoff not affected by artificial storage.

Mean discharge, in second-feet, 194?

\begin{tabular}{|c|c|c|c|c|c|c|c|c|c|c|c|}
\hline Day & Aug. & Sept. & Day & Aug. & Sept. & Day & Aug. & Sept. & Day & Aug. & Sept. \\
\hline 1 & 100 & 162 & 9 & 70 & 140 & 17 & $3, \mathrm{EO}$ & 63 & 25 & 120 & 51 \\
\hline 2 & 110 & 289 & 10 & 50 & 110 & 18 & 1,500 & 58 & 26 & 150 & 53 \\
\hline 3 & 130 & 290 & 11 & 42 & 85 & 19 & 600 & 52 & 27 & 220 & $5)$ \\
\hline 4 & 80 & 135 & 12 & 55 & 105 & 20 & 400 & 53 & 28 & 300 & 51 \\
\hline 5 & 50 & 85 & 13 & 75 & 82 & 21 & 280 & 52 & 29 & 192 & 48 \\
\hline 6 & 70 & 88 & 14 & 1,200 & 68 & 22 & 200 & 53 & 30 & 105 & 42 \\
\hline 7 & 100 & 135 & 15 & 3,200 & 61 & $\overline{2}$ & 160 & 42 & 31 & 108 & \\
\hline 8 & 120 & 160 & 16 & 4,000 & 54 & 24 & 140 & 51 & & & \\
\hline \multirow{2}{*}{\multicolumn{10}{|c|}{ Monthly mean discharge, in second-feet }} & 565 & 92.3 \\
\hline & & & & & & & & & & 3.88 & 0.61 \\
\hline
\end{tabular}

$804331-49-13$ 


\section{HAW RIVER A'T HAW RIVER, N. C.}

Location.-Lat. $36^{\circ} 05^{\prime} 35^{\prime \prime}$, long. $79^{\circ} 21^{\prime} 40^{\prime \prime}$, at town of Haw River, Alamance County, 400 feet downstream from Southern Railway bridge and 3 miles downstream from Stony Creek.

Drainage AREa. - 599 square miles.

GAGE-HEIGHT RECORD.-Water-stage recorder graph.

DISCHARGE RECORD. - Stage-discharge relation defined by current-meter measurements up to 11,800 second-feet. Gage heights used to half-tenths between 3.1 and 4.9 feet; hundredths below and tenths above these limits.

Maxima.-1940: Discharge, 12,700 second-feet 5 a.m. Aug. 16 (gage height, 20.37 feet).

1928-39: Discharge, 17,000 second-feet Feb. 28, 1929 (gage height, 23.96 feet).

REMARKS.-Flood runoff affected only slightly by artificial storage.

Mean discharge, in second-feet, 1940

\begin{tabular}{|c|c|c|c|c|c|c|c|c|c|c|c|}
\hline Day & Aug. & Sept. & Day & Aug. & Sept. & Day & Aug. & Sept. & Day & Aug. & Sept. \\
\hline $\begin{array}{l}1 \\
2 \\
3 \\
4 \\
5 \\
6 \\
7 \\
8\end{array}$ & $\begin{array}{l}284 \\
323 \\
190 \\
134 \\
191 \\
129 \\
164 \\
247\end{array}$ & $\begin{array}{l}344 \\
395 \\
545 \\
455 \\
359 \\
444 \\
440 \\
395\end{array}$ & $\begin{array}{r}9 \\
10 \\
11 \\
12 \\
13 \\
14 \\
15 \\
16\end{array}$ & $\begin{array}{r}175 \\
78 \\
56 \\
251 \\
211 \\
5,820 \\
8,840 \\
11,300\end{array}$ & $\begin{array}{l}425 \\
443 \\
822 \\
410 \\
380 \\
264 \\
172 \\
239\end{array}$ & $\begin{array}{l}17 \\
18 \\
19 \\
20 \\
21 \\
22 \\
23 \\
24\end{array}$ & $\begin{array}{r}6,880 \\
3,380 \\
1,480 \\
1,000 \\
743 \\
490 \\
326 \\
230\end{array}$ & \begin{tabular}{|r|r|}
189 \\
186 \\
239 \\
164 \\
48 \\
42 \\
199 \\
106
\end{tabular} & $\begin{array}{l}25 \\
26 \\
27 \\
28 \\
29 \\
30 \\
31\end{array}$ & $\begin{array}{l}348 \\
498 \\
517 \\
489 \\
470 \\
429 \\
395\end{array}$ & \begin{tabular}{|l}
190 \\
189 \\
148 \\
130 \\
109 \\
220 \\
\end{tabular} \\
\hline \multicolumn{10}{|c|}{$\begin{array}{l}\text { Monthly mean discharge, in second-feet } \\
\text { Runoff, in inches }\end{array}$} & $\begin{array}{r}1,486 \\
2.86\end{array}$ & 0.54 \\
\hline
\end{tabular}

HAW RIVER NEAR PITTSBORO, N. C.

Location.—Lat. $35^{\circ} 41^{\prime} 00^{\prime \prime}$, long. $79^{\circ} 05^{\prime} 40^{\prime \prime}$, about 100 feet upstream from Robinsons Creek, 2 miles downstream from bridge on State Highway 90, and 5 miles east of Pittsboro, Chatham County. Datum of gage is 180.06 feet above mean sea level (levels by Corps of Engineers, War Dapartment).

Drainage AREa.- $-1,310$ square miles.

GAGE-HEIGHT RECORD.-Water-stage recorder graph except for period Aug. 17 to Sept. 11.

DISCHARGE RECORD.-Stage-discharge relation defined by eurrent-meter measurements up to 47,000 second-feet. Gage heights used to half-tenths between 3.7 and 5.4 feet; hundredths below and tenths above these limits. Discharge for period of no gage-height record based on weather records and records for station at Haw River.

Maxima.-1940: Discharge, 18,900 second-feet 11 p.m. Aug. 14 (gage height, 14.68 feet).

1928-39 : Discharge, 47,300 second-feet Oct. 2, 1929 (gage height, 22.1 feet).

Flood of August 1908 reached a stage of about 32.1 feet, from floodmarks on highway bridge (discharge, 98,000 second-feet). Flood of 1865 is believed to have reached a stage 1 foot higher than that of August 1908 (discharge not determined).

ReMARKs.-Flood runoff only slightly affected by artificial storage. 
CAPE FEAR RIVER BASIN

Mean discharge, in second-feet, 1940

\begin{tabular}{|c|c|c|c|c|c|c|c|c|c|c|c|}
\hline Day & Aug. & Sept. & Day & Aug. & Sept. & Day & Aug. & Sept. & Day & Aug. & Sept. \\
\hline $\begin{array}{l}1 \\
2 \\
3 \\
4 \\
5 \\
6 \\
7 \\
8\end{array}$ & $\begin{array}{r}247 \\
238 \\
265 \\
159 \\
65 \\
121 \\
252 \\
313\end{array}$ & $\begin{array}{l}600 \\
600 \\
750 \\
750 \\
650 \\
500 \\
750 \\
600\end{array}$ & $\begin{array}{r}9 \\
10 \\
11 \\
12 \\
13 \\
14 \\
15 \\
16\end{array}$ & $\begin{array}{r}286 \\
308 \\
196 \\
98 \\
149 \\
4,890 \\
15,500 \\
14,200\end{array}$ & $\begin{array}{r}600 \\
600 \\
1,300 \\
908 \\
523 \\
502 \\
219 \\
205\end{array}$ & $\begin{array}{l}17 \\
18 \\
19 \\
20 \\
21 \\
22 \\
23 \\
24\end{array}$ & $\begin{array}{r}12,500 \\
8,000 \\
4,200 \\
2,600 \\
1,600 \\
1,000 \\
700 \\
600\end{array}$ & $\begin{array}{r}495 \\
296 \\
276 \\
261 \\
256 \\
134 \\
69 \\
42\end{array}$ & $\begin{array}{l}25 \\
26 \\
27 \\
28 \\
29 \\
30 \\
31\end{array}$ & $\begin{array}{l}550 \\
750 \\
750 \\
700 \\
700 \\
700 \\
650\end{array}$ & $\begin{array}{r}104 \\
247 \\
270 \\
270 \\
139 \\
53 \\
- \\
\end{array}$ \\
\hline \multicolumn{10}{|c|}{$\begin{array}{l}\text { Monthly mean discharge, in second-feet } \\
\text { Runoff, in inches }\end{array}$} & $\begin{array}{r}2,364 \\
2.08\end{array}$ & $\begin{array}{r}432 \\
0.37\end{array}$ \\
\hline
\end{tabular}

CAPE FEAR RIVER AT LILLINGTON, N. C.

LOCATION.-Lat. $35^{\circ} 24^{\prime} 25^{\prime \prime}$, long. $78^{\circ} 48^{\prime} 45^{\prime \prime}$, at highway bridge just downstream from Norfolk Southern Railway bridge at Lillington, Harnett County, and 1 mile downstream from Neill Creek. Datum of gage is 105.71 feet above mean sea level (levels by Corps of Engineers, War Department).

Drainage area.- 3,440 square miles.

GAGE-HEIGHT RECORD.-Water-stage recorder graph except Aug. 20-23, when recorder clock was stopped. Recorder graph completed from partial record Aug. 24, Sept. 23, 24, 26, 29, 30.

DISCHARGE RECORD.-Stage-discharge relation defined by current-meter measurements up to 77,000 second-feet. Gage heights used to half-tenths between 2.6 and 4.7 feet; hundredths below and tenths above these limits.

Maxima.-August 1940: Discharge, 29,600 second-feet 8 a.m. Aug. 17 (gage height, 13.87 feet).

1923 to July 1940: Discharge, 101,000 second-feet Oct. 2, 1929 (gage height, 27.55 feet).

REMARKs.-Flood runoff only slightly affected by artificial storage.

Mean discharge, in second-feet, 1940

\begin{tabular}{|c|c|c|c|c|c|c|c|c|c|c|c|}
\hline Day & Aug. & Sept. & Day & Aug. & Sept. & Day & Aug. & Sept. & Day & Aug. & Sept. \\
\hline $\begin{array}{l}1 \\
2 \\
3 \\
4 \\
5 \\
6 \\
7 \\
7 \\
8\end{array}$ & $\begin{array}{l}485 \\
146 \\
442 \\
274 \\
168 \\
167 \\
242 \\
397\end{array}$ & $\begin{array}{r}990 \\
1,360 \\
1,020 \\
792 \\
960 \\
991 \\
777 \\
1,080\end{array}$ & $\begin{array}{r}9 \\
10 \\
11 \\
12 \\
13 \\
14 \\
15 \\
16\end{array}$ & $\begin{array}{r}374 \\
462 \\
362 \\
268 \\
240 \\
1,080 \\
23,000 \\
25,400\end{array}$ & $\begin{array}{r}570 \\
740 \\
1,020 \\
1,310 \\
1,100 \\
586 \\
532 \\
442\end{array}$ & $\begin{array}{l}17 \\
18 \\
19 \\
20 \\
21 \\
22 \\
23 \\
24\end{array}$ & $\begin{array}{r}26,600 \\
13,800 \\
6,000 \\
4,000 \\
2,600 \\
2,000 \\
1,500 \\
1,140\end{array}$ & $\begin{array}{l}582 \\
386 \\
411 \\
360 \\
322 \\
329 \\
253 \\
209\end{array}$ & $\begin{array}{l}25 \\
26 \\
27 \\
28 \\
29 \\
30 \\
31\end{array}$ & $\begin{array}{r}722 \\
306 \\
1,240 \\
1,400 \\
1,340 \\
1,200 \\
970\end{array}$ & $\begin{array}{l}352 \\
161 \\
428 \\
360 \\
306 \\
228\end{array}$ \\
\hline \multicolumn{10}{|c|}{$\begin{array}{l}\text { Monthly mean discharge, in second-feet } \\
\text { Runoff, in inches }\end{array}$} & $\begin{array}{r}3,817 \\
1.28\end{array}$ & $\begin{array}{r}632 \\
0.20\end{array}$ \\
\hline
\end{tabular}

CAPE FEAR RIVER A'T FAYETTEVILLE, N. C.

Location.-Lat. $35^{\circ} 02^{\prime} 50^{\prime \prime}$, long. $78^{\circ} 51^{\prime} 35^{\prime \prime}$, at highway bridge at Fayetteville, Cumberland County, just downstream from Cross Creek, 7 miles upstream from Rockfish Creek, and about 20 miles upstream from lock 3. Datum of gage is 20.23 feet above mean sea level (levels by Corps of Engineers, War Department).

Drainage AREa. $-4,370$ square miles.

GAGE-HEIGHT RECORD.-Water-stage recorder graph.

DISCHARGE RECORD.-Stage-discharge relation for low and medium stages unsatisfactory owing to backwater from lock 3 and diurnal fluctuations from power plants upstream and on Rockfish Creek. Discharge record Aug. 1-16 and Aug. 20 to Sept. 30 based on records for stations at lock 3 and Rockfish Creek near Hope Mills. 


\section{FLOODS OF AUGUST 1940 IN THE SOUTHEASTERN STATES}

Stage-discharge relation from 10,000 to 39,000 second-feet, which ineludes fall between Fayetteville and lock 3 as a factor, defined by current-meter measurements and used for Aug. 17-19.

A stage-discharge relation defined by current-meter measurements for medium and high stages up to 111,000 second-feet was used prior to completion of lock 3 in August 1935.

Maxima.-August 1940: Discharge, 28,500 second-feet 5 p.m. Aug. 17 (gage height, 32.25 feet).

1889-1903, 1928-July 1940: Discharge, 110,000 second-feet Oet. 4, 1929 (gage height, 63.43 feet).

Stage known, about 68.0 feet Aug. 29, 1908, from flood crest, as witnessed by local residents (discharge, about 133,000 second-feet).

REMARKS.-Flood runoff affected only slightly by artificial storage.

Mean discharge, in second-feet, 1940

\begin{tabular}{|c|c|c|c|c|c|c|c|c|c|c|c|}
\hline Day & Aug. & Sept. & Day & Aug. & Sept. & Day & Aug. & Sept. & Day & Aug. & Sept. \\
\hline $\begin{array}{l}1 \\
2 \\
3 \\
4 \\
5 \\
6 \\
7 \\
8\end{array}$ & $\begin{array}{l}301 \\
532 \\
281 \\
364 \\
300 \\
233 \\
201 \\
235\end{array}$ & $\begin{array}{r}971 \\
1,260 \\
1,220 \\
1,000 \\
875 \\
1,080 \\
1,090 \\
866\end{array}$ & $\begin{array}{r}9 \\
10 \\
11 \\
12 \\
13 \\
14 \\
15 \\
16\end{array}$ & $\begin{array}{r}462 \\
498 \\
624 \\
572 \\
449 \\
554 \\
14,200 \\
24,700\end{array}$ & $\begin{array}{r}939 \\
845 \\
981 \\
1,440 \\
1,330 \\
1,090 \\
657 \\
321\end{array}$ & $\begin{array}{l}17 \\
18 \\
19 \\
20 \\
21 \\
22 \\
23 \\
24\end{array}$ & $\begin{array}{r}27,800 \\
21,300 \\
10,600 \\
4,370 \\
2,740 \\
1,860 \\
1,510 \\
1,250\end{array}$ & $\begin{array}{l}555 \\
635 \\
476 \\
430 \\
418 \\
320 \\
336 \\
229\end{array}$ & $\begin{array}{l}25 \\
26 \\
27 \\
28 \\
29 \\
30 \\
31\end{array}$ & $\begin{array}{r}1,090 \\
404 \\
411 \\
1,460 \\
1,490 \\
1,230 \\
1,340\end{array}$ & $\begin{array}{l}254 \\
391 \\
203 \\
513 \\
378 \\
302 \\
-\end{array}$ \\
\hline $\begin{array}{l}\text { Hon } \\
\text { Run }\end{array}$ & & & & & & & & & & $\begin{array}{r}3,979 \\
1.05\end{array}$ & $\begin{array}{r}714 \\
0.18\end{array}$ \\
\hline
\end{tabular}

CAPE FEAR RIVER AT LOCK 3, NEAR TARHERL, N. C.

LocATION.-Lat. $34^{\circ} 50^{\prime} 00^{\prime \prime}$, long. $78^{\circ} 48^{\prime} 30^{\prime \prime}$, just above lock 3,1 mile downstream from county line, and 7 miles north of Tarheel, Bladen County. Datum of gage is 29.75 feet above mean sea level (levels by Corps of Engineers, War Department).

DRAINAGE AREA. $-4,810$ square miles.

GAGE-HEIGHT RECORD.-Water-stage recorder graph.

DiSCHARGE RECORD.-Stage-discharge relation defined by current-meter measurements up to 23,000 second-feet. Submergence, determined from readings of auxiliary staff gages just below lock 3 , is generally a factor in eomputing the discharge above 10,000 second-feet. Above 23,000 second-feet the submergence effect has not yet been defined, and discharge is based on records for stations at Fayetteville and Rockfish Creek near Hope Mills. Gage heights used to half-tenths between 1.8 and 4.2 feet; hundredths below and tenths above these limits.

Maxima.-August 1940: Daily discharge, 27,100 second-feet Aug. 17; gage height, 16.49 feet 2 a.m. Aug. 18.

1937 to July 1940: Gage height, 24.0 feet July 28, 1938 (discharge not determined).

REMARKS.-Flood runoff affected only slightly by artificial storage.

Mean discharge, in second-feet, 1940

\begin{tabular}{r|r|r||r|r|r||r|r|r|r|r|r}
\hline Day & Aug. & \multicolumn{1}{c|}{ Sept. } & Day & Aug. & Sept. & Day & Aug. & Sept. & Day & Aug. & Sept. \\
\hline 1 & 468 & 1,160 & 9 & 565 & 1,170 & 17 & 27,100 & 720 & 25 & 1,310 & 420 \\
2 & 668 & 1,280 & 10 & 636 & 1,050 & 18 & 23,900 & 876 & 26 & 910 & 585 \\
3 & 439 & 1,510 & 11 & 899 & 1,280 & 19 & 14,800 & 764 & 27 & 615 & 496 \\
4 & 420 & 1,340 & 12 & 945 & 1,550 & 20 & 6,890 & 699 & 28 & 1,430 & 575 \\
5 & 486 & 1,140 & 13 & 864 & 1,660 & 21 & 3,590 & 626 & 29 & 1,660 & 545 \\
6 & 496 & 1,280 & 14 & 899 & 1,460 & 22 & 2,720 & 496 & 30 & 1,530 & 525 \\
7 & 420 & 1,320 & 15 & 8,740 & 934 & 23 & 1,960 & 486 & 31 & 1,510 & \\
8 & 411 & 1,050 & 16 & 23,200 & 742 & 24 & 1,450 & 515 & & & \\
\hline
\end{tabular}


REEDY FORK NEAR GIBSONVILLE, N. C.

Location.-Lat. $36^{\circ} 10^{\prime} 30^{\prime \prime}$, long. $79^{\circ} 37^{\prime} 00^{\prime \prime}$, a quarter of a mile downstream from Huffines Mill, 11/4 miles upstream from Buffalo Creek, and 6 miles northwest of Gibsonville, Guilford County.

Drainage AREa.-133 square miles.

GAGE-HEIGHT RECORD.-Water-stage recorder graph.

DISCHARGE RECORD.-Stage-discharge relation defined by current-meter measurements up to 1,400 second-feet. Gage heights used to half-tenths between 2.8 and 4.6 feet; hundredths below and tenths above these limits.

Maxima.-1940: Discharge, 4,130 second-feet 4 p.m. Ang. 15 (gage height, 12.70 feet).

1928-39: Discharge, 4,390 second-feet Jan. 20, 1936 (gage height, 13.28 feet).

Flood of July 1916 reached a stage of 17.90 feet, from reference marks witnessed by landowner (discharge, 8,640 second-feet).

REMarks.-Flood runoff affected slightly by Greensboro reservoir, 14 miles upstream, where about 11 second-feet is diverted for water supply.

Mean discharge, in second-feet, 1940

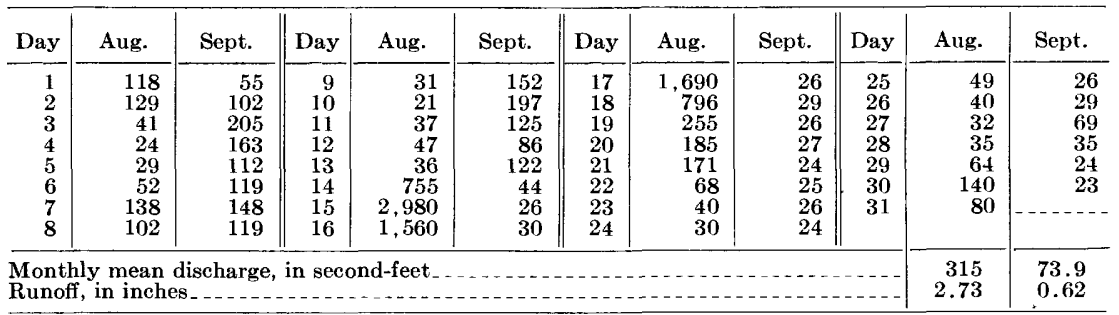

HORSEPEN CREEK AT BATTLE GROUND, N. C.

LocAtion.-Lat. $36^{\circ} 08^{\prime} 30^{\prime \prime}$, long. $79^{\circ} 51^{\prime} 20^{\prime \prime}$, at bridge on U. S. Highway 411 , threequarters of a mile north of Battle Ground, Guilford County, and about $2 \frac{1}{2}$ miles upstream from mouth.

Drainage AREA.-15.9 square miles.

GAGE-HEIGHT RECORD.-Water-stage recorder graph.

DISCHARGE RECORD.- Stage-discharge relation defined by current-meter measurements up to 330 second-feet. Gage heights used to half-tenths above 1.9 feet Aug. 1-14, and above 2.2 feet Aug. 15 to Sept. 30; hundredths below these limits. Maxima.-1940: Diseharge, 820 second-feet 11:30 a.m. Aug. 14 (gage height, 6.64 feet).

1925-31, 1934-39: Discharge, 980 second-feet Jan. 19, 1936 (gage height, 7.07 feet).

REMARKs.-Flood runoff not affected by artificial storage.

Mean discharge, in second-feet, 1940

\begin{tabular}{|c|c|c|c|c|c|c|c|c|c|c|c|}
\hline Day & Aug. & Sept. & Day & Aug. & Sept. & Day & Aug. & Sept. & Day & Aug. & Sept. \\
\hline $\begin{array}{l}1 \\
2 \\
3 \\
4 \\
5 \\
6 \\
7 \\
8\end{array}$ & $\begin{array}{l}19 \\
4.3 \\
4.2 \\
4.2 \\
6.3 \\
4.8 \\
3.9 \\
4\end{array}$ & $\begin{array}{c}79 \\
12 \\
8.8 \\
7.3 \\
13 \\
22 \\
8.1 \\
6.8\end{array}$ & $\begin{array}{r}9 \\
10 \\
11 \\
12 \\
13 \\
14 \\
15 \\
16\end{array}$ & $\begin{array}{c}3.7 \\
4 \\
7 \\
8.6 \\
7.5 \\
464 \\
243 \\
272\end{array}$ & $\begin{array}{l}6.2 \\
15 \\
11 \\
6.8 \\
6.2 \\
6 \\
5.7 \\
5.5\end{array}$ & $\begin{array}{l}17 \\
18 \\
19 \\
20 \\
21 \\
22 \\
23 \\
24\end{array}$ & $\begin{array}{r}53 \\
28 \\
17 \\
12 \\
9.9 \\
8.8 \\
7.7 \\
7.3\end{array}$ & $\begin{array}{l}5.2 \\
5.2 \\
5.2 \\
5.2 \\
4.8 \\
4.6 \\
4.5 \\
4.5\end{array}$ & $\begin{array}{l}25 \\
26 \\
27 \\
28 \\
29 \\
30 \\
31\end{array}$ & $\begin{array}{c}11 \\
12 \\
28 \\
13 \\
7.5 \\
27 \\
58\end{array}$ & $\begin{array}{l}5 \\
4.8 \\
4.6 \\
4.5 \\
4.5 \\
4.1\end{array}$ \\
\hline $\mathbf{T}$ & & & & & & & & & & $\begin{array}{l}43.9 \\
3.18\end{array}$ & $\begin{array}{l}9.54 \\
0.67\end{array}$ \\
\hline
\end{tabular}




\section{HUFFALO CREEK NEAR GREENSBORO, N. C.}

Location.-Lat. $36^{\circ} 03^{\prime} 30^{\prime \prime}$, long. $79^{\circ} 43^{\prime} 35^{\prime \prime}$, at MeConnell road crossing, 3 miles east of Greensboro, Guilford County, and 6 miles upstream from North Buffalo Creek.

Drainage AREA.- 32.8 square miles.

GAGE-HEIGHT RECORD.-Water-stage recorder graph.

DISCHARGE RECORD.-Stage-discharge relation defined by current-meter measurements up to 1,960 second-feet. Gage heights used to half-tenths above and hundredths below 7.1 feet. Shifting-control method used Sept. 19-30.

Maxima.-1940: Diseharge, 1,060 second-feet 10 p.m. Aug. 14 (gage height, 7.32 feet).

1928-39: Discharge, 2,680 second-feet Feb. 28, 1929 (gage height, 8.74 feet). REMARKS.-Flood runoff not affected by artificial storage.

Mean discharge, in second-feet, 1940

\begin{tabular}{r|r|r|r|r|r||r|r|r||r|r|r}
\hline Day & Aug. & \multicolumn{1}{|c|}{ Sept. } & Day & Aug. & Sept. & Day & Aug. & Sept. & Day & Aug. & Sept. \\
\hline 1 & 5.7 & 9.3 & 9 & 5.0 & 6.7 & 17 & 413 & 5.6 & 25 & 7.3 & 5.5 \\
2 & 5.9 & 7.8 & 10 & 5.1 & 10 & 18 & 64 & 5.6 & 26 & 44 & 6.5 \\
3 & 5.4 & 7.4 & 11 & 6.5 & 17 & 19 & 19 & 5.8 & 27 & 13 & 5.8 \\
4 & 4.8 & 7.2 & 12 & 11 & 9.0 & 20 & 12 & 5.8 & 28 & 13 & 5.2 \\
5 & 5.0 & 18 & 13 & 11 & 7.3 & 21 & 10 & 5.7 & 29 & 8.5 & 4.6 \\
6 & 6.4 & 82 & 14 & 471 & 6.7 & 22 & 10 & 4.7 & 30 & 8.8 & 4.4 \\
7 & 5.7 & 10 & 15 & 488 & 5.9 & 23 & 8.5 & 4.7 & 31 & 16 &.-- \\
8 & 5.2 & 7.2 & 16 & 306 & 5.7 & 24 & 7.9 & 4.8 & & \\
\hline
\end{tabular}

\section{NORTH BUFFALO CREEK NEAR GREENSBORO, N. C.}

Location.-Lat. $36^{\circ} 07^{\prime} 10^{\prime \prime}$, long. $79^{\circ} 42^{\prime} 35^{\prime \prime}$, at county highway bridge, 3 miles upstream from mouth and 6 miles northeast of Greensboro, Guilford County.

Drainage AREa.- -36.4 square miles.

GAGE-HEIGHT RECORD.-Water-stage recorder graph.

DiSCHARGE RECORD. - Stage-discharge relation defined by current-meter measurements up to 1,050 second-feet. Gage heights used to half-tenths between 4.1 and 5.1 feet; hundredths below and tenths above these limits.

Maxima.-1940: Discharge, 1,200 second-feet 1 p.m. Aug. 14 (gage height, 8.89 feet).

1928-39: Discharge, 1,750 second-feet Jan. 19, 1936 (gage height, 11.38 feet).

Remarks.-Flood runoff not affected by artificial storage.

Mean discharge, in second-feet, 1940

\begin{tabular}{|c|c|c|c|c|c|c|c|c|c|c|c|}
\hline Day & Aug. & Sept. & Day & Aug. & Sept. & Day & Aug. & Sept. & Day & Aug. & Sept. \\
\hline $\begin{array}{l}1 \\
2 \\
3 \\
4 \\
5 \\
6 \\
7 \\
8\end{array}$ & $\begin{array}{c}15 \\
12 \\
9.9 \\
8.7 \\
15 \\
20 \\
14 \\
14\end{array}$ & $\begin{array}{r}15 \\
18 \\
18 \\
17 \\
26 \\
218 \\
24 \\
17\end{array}$ & $\begin{array}{r}9 \\
10 \\
11 \\
12 \\
13 \\
14 \\
15 \\
16\end{array}$ & $\begin{array}{r}9.9 \\
12 \\
28 \\
42 \\
31 \\
845 \\
429 \\
418\end{array}$ & $\begin{array}{l}18 \\
51 \\
40 \\
22 \\
18 \\
16 \\
15 \\
16\end{array}$ & $\begin{array}{l}17 \\
18 \\
19 \\
20 \\
21 \\
22 \\
23 \\
24\end{array}$ & $\begin{array}{r}151 \\
40 \\
28 \\
23 \\
21 \\
16 \\
15 \\
13\end{array}$ & $\begin{array}{c}15 \\
15 \\
14 \\
14.0 \\
9.9 \\
8.7 \\
13 \\
15\end{array}$ & $\begin{array}{l}25 \\
26 \\
27 \\
28 \\
29 \\
30 \\
31\end{array}$ & $\begin{array}{l}13 \\
53 \\
34 \\
45 \\
27 \\
21 \\
19\end{array}$ & $\begin{array}{c}17 \\
18 \\
14 \\
11 \\
8.3 \\
12\end{array}$ \\
\hline \multicolumn{12}{|c|}{ 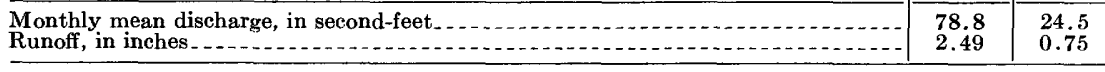 } \\
\hline
\end{tabular}




\section{WEST FORK DEEP RIVER NEAR HIGH POINT, N. C.}

LOCATION.-Lat. $36^{\circ} 00^{\prime} 15^{\prime \prime}$, long. $79^{\circ} 58^{\prime} 40^{\prime \prime}$, a quarter of a mile upstream from State highway bridge at head of High Point Reservoir, about 2 miles northwest of Jamestown, and 31/2 miles northeast of High Point, Guilford County.

DRAINAGE AREA.- -32.1 square miles.

GAGE-HEIGHT RECORD.-Water-stage recorder graph.

DISCHARGE RECORD. - Stage-discharge relation defined by current-meter measurements up to 2,000 second-feet. Gage heights used to half-tenths between 5.0 and 5.9 feet; hundredths below and tenths above these limits.

Maxima.-August 1940: Discharge, 2,370 second-feet 8:30 a.m. Aug. 14 (gage height, 12.74 feet).

1923-26, 1928 to July 1940: Discharge, 2,880 second-feet Jan. 19, 1936 (gage height, 13.84 feet).

REMARKS.-Flood runoff not affected by artificial storage.

Mean discharge, in second-feet, 1940

\begin{tabular}{|c|c|c|c|c|c|c|c|c|c|c|c|}
\hline Day & Aug. & Sept. & Day & Aug. & Sept. & Day & Aug. & Sept. & Day & Aug. & Sept. \\
\hline $\begin{array}{l}1 \\
2 \\
3 \\
4 \\
5 \\
6 \\
7 \\
8\end{array}$ & $\begin{array}{r}21 \\
8.8 . \\
7.5 \\
7.8 \\
10.8 \\
8.6 \\
7.0 \\
7.3\end{array}$ & $\begin{array}{c}35 \\
16 \\
15 \\
14 \\
15 \\
30 \\
14 \\
9.9\end{array}$ & \begin{tabular}{r|r}
9 \\
10 \\
11 \\
12 \\
13 \\
14 \\
15 \\
16
\end{tabular} & $\begin{array}{c}6.6 \\
6.1 \\
7.8 \\
8.8 \\
11 \\
1,310 \\
386 \\
218\end{array}$ & $\begin{array}{l}9.3 \\
57 \\
51 \\
15 \\
12 \\
10 \\
9.6 \\
9.3\end{array}$ & $\begin{array}{l}17 \\
18 \\
19 \\
20 \\
21 \\
22 \\
23 \\
24\end{array}$ & $\begin{array}{l}46 \\
27 \\
19 \\
15 \\
13 \\
12 \\
12 \\
11\end{array}$ & $\begin{array}{l}8.8 \\
8.8 \\
8.6 \\
8.6 \\
8.0 \\
7.5 \\
7.3 \\
7.5\end{array}$ & $\begin{array}{l}25 \\
26 \\
27 \\
28 \\
29 \\
30 \\
31\end{array}$ & $\begin{array}{c}17 \\
13 \\
10 \\
9.9 \\
14 \\
18 \\
164\end{array}$ & $\begin{array}{l}9.1 \\
8.6 \\
7.5 \\
7.5 \\
7.3 \\
6.8\end{array}$ \\
\hline \multicolumn{10}{|c|}{$\begin{array}{l}\text { Monthly mean discharge, in second-feet } \\
\text { Runoff, in inches }\end{array}$} & $\begin{array}{l}78.5 \\
2.82\end{array}$ & $\begin{array}{l}14.5 \\
0.50\end{array}$ \\
\hline
\end{tabular}

\section{DEEP RIVER NEAR RANDLEMAN, N. C.}

Location.-Lat. $35^{\circ} 54^{\prime} 10^{\prime \prime}$, long. $79^{\circ} 51^{\prime} 15^{\prime \prime}$, 500 feet downstream from county bridge at Coltrane Mill, half a mile south of Guilford County line, and 7 miles north of Randleman, Randolph County. Datum of gage is 638.11 feet above mean sea level (levels by Corps of Engineers, War Department).

DRAINAGE AREA.-124 square miles.

GAGE-HEIGHT RECORD.-Water-stage recorder graph except for periods Aug. 21-25, 27, 29, when intake was obstructed. Graph for Aug. 26, 28, and 30 based on partial record.

DISCHARGE RECORD.-Stage-discharge relation defined by current-meter measurements up to 7,100 second-feet. Gage heights used to half-tenths between 3.7 and 5.0 feet; hundredths below and tenths above these limits. Discharge for periods of no gage-height record based on records for station at Ramseur.

Maxima.-August 1940 : Discharge, 5,590 second-feet 3 a.m. Aug. 15 (gage height, 19.88 feet).

1928 to July 1940 : Discharge, 8,470 second-feet Feb. 28, 1929 (gage height, 23.9 feet).

REMarKs.-Flood runoff affected slightly by High Point Reservoir.

Mean discharge, in second-feet, 1940

\begin{tabular}{|c|c|c|c|c|c|c|c|c|c|c|c|}
\hline Day & Aug. & Sept. & Day & Aug. & Sept. & Day & Aug. & Sept. & Day & Aug. & Sept. \\
\hline $\begin{array}{l}1 \\
2 \\
3 \\
4 \\
5 \\
5 \\
6 \\
7 \\
8\end{array}$ & $\begin{array}{l}32 \\
20 \\
38 \\
14 \\
12 \\
28 \\
15 \\
36\end{array}$ & $\begin{array}{r}336 \\
83 \\
62 \\
36 \\
32 \\
48 \\
41 \\
27\end{array}$ & $\begin{array}{r}9 \\
10 \\
11 \\
12 \\
13 \\
14 \\
15 \\
16\end{array}$ & $\begin{array}{c}12 \\
9.2 \\
18 \\
42 \\
30 \\
2,540 \\
2,620 \\
2,000\end{array}$ & $\begin{array}{r}44 \\
38 \\
127 \\
69 \\
36 \\
38 \\
15 \\
34\end{array}$ & $\begin{array}{l}17 \\
18 \\
19 \\
20 \\
21 \\
22 \\
23 \\
24\end{array}$ & $\begin{array}{r}367 \\
173 \\
106 \\
74 \\
55 \\
50 \\
30 \\
44\end{array}$ & $\begin{array}{l}37 \\
9.0 \\
18 \\
20 \\
15 \\
16 \\
30 \\
25\end{array}$ & $\begin{array}{l}25 \\
26 \\
27 \\
28 \\
29 \\
30 \\
31\end{array}$ & $\begin{array}{r}55 \\
98 \\
55 \\
74 \\
55 \\
111 \\
142\end{array}$ & $\begin{array}{c}31 \\
37 \\
20 \\
19 \\
9.7 \\
23\end{array}$ \\
\hline \multicolumn{10}{|c|}{$\begin{array}{l}\text { Monthly mean discharge, in second-feet. } \\
\text { Runoff, in inches }\end{array}$} & $\begin{array}{r}289 \\
2.69\end{array}$ & $\begin{array}{l}45.9 \\
0.41\end{array}$ \\
\hline
\end{tabular}




\section{FLOODS OF AUGUST 1940 IN THE SOUTHEASTERN STATES}

DEEP RIVER AT RAMSEUR, N.C.

Location.-Lat. $35^{\circ} 44^{\prime} 10^{\prime \prime}$, long. $79^{\circ} 38^{\prime} 40^{\prime \prime}, 2,000$ feet downstream from railroad station at Ramseur, Randolph County, and 11/2 miles downstream from Sandy Creek. Datum of gage is $\$ 19.50$ feet above mean sea level (levels by Corps of Engineers, War Department).

Drainage AREA.- -346 square miles.

GAGE-HEIGHT RECORD.-Water-stage recorder graph.

DISCHARGE RECORD.-Stage-discharge relation defined by current-meter measurements up to 17,000 second-feet and extended above on basis of slope-area measurement in 1945. Gage heights used to half-tenths between 2.4 and 4.8 feet; hundredths below and tenths above these limits.

Maxima.-August 1940: Discharge, 9,050 second-feet 5 p.m. Aug. 14 (gage height, 14.53 feet).

1922 to July 1940: Discharge, 22,400 second-feet Sept. 19, 1928 (gage height, 25.44 feet).

Flood of August 1901 reached a stage of 28.75 feet, from reference mark in mill 1,500 feet above gage (discharge, 30,000 second-feet).

REMARKs.-Flood runoff practically unaffected by artificial storage.

Mean discharge, in second-feet, 1940

\begin{tabular}{|c|c|c|c|c|c|c|c|c|c|c|c|}
\hline Day & Aug. & Sept. & Day & Aug. & Sept. & Day & Aug. & Sept. & Day & Aug. & Sept. \\
\hline $\begin{array}{l}1 \\
2 \\
3 \\
4 \\
5 \\
6 \\
7 \\
8\end{array}$ & $\begin{array}{r}115 \\
135 \\
23 \\
26 \\
86 \\
80 \\
75 \\
91\end{array}$ & $\begin{array}{r}389 \\
255 \\
144 \\
136 \\
117 \\
135 \\
72 \\
74\end{array}$ & $\begin{array}{r}9 \\
10 \\
11 \\
12 \\
13 \\
14 \\
15 \\
16\end{array}$ & $\begin{array}{r}66 \\
33 \\
31 \\
46 \\
46 \\
5,460 \\
5,900 \\
5,180\end{array}$ & $\begin{array}{r}153 \\
103 \\
72 \\
89 \\
36 \\
16 \\
18 \\
128\end{array}$ & $\begin{array}{l}17 \\
18 \\
19 \\
20 \\
21 \\
22 \\
23 \\
24\end{array}$ & $\begin{array}{r}1,660 \\
481 \\
300 \\
208 \\
167 \\
155 \\
83 \\
125\end{array}$ & $\begin{array}{r}127 \\
111 \\
116 \\
95 \\
62 \\
25 \\
55 \\
85\end{array}$ & $\begin{array}{l}25 \\
26 \\
27 \\
28 \\
29 \\
30 \\
31\end{array}$ & $\begin{array}{l}143 \\
186 \\
133 \\
125 \\
127 \\
112 \\
154\end{array}$ & $\begin{array}{r}51 \\
46 \\
58 \\
21 \\
3 \\
6\end{array}$ \\
\hline $\begin{array}{l}\text { on } \\
\text { un }\end{array}$ & inc & & & & & & & & & $\begin{array}{r}695 \\
2.32\end{array}$ & $\begin{array}{l}93.3 \\
0.30\end{array}$ \\
\hline
\end{tabular}

DEEP RIVER AT MONCURE, N. C.

Location.-Lat. $35^{\circ} 36^{\prime} 25^{\prime \prime}$, long. $79^{\circ} 05^{\prime} 10^{\prime \prime}, 1 \frac{1}{2}$ miles northwest of Moncure, Chatham County. Datum of gage is 185.88 feet above mean sea level (levels by Corps of Engineers, War Department).

Drainage AREA.- 1,410 square miles.

GAGE-HEIGHT RECORD.-Water-stage recorder graph.

DISCHARGE RECORD.-Stage-discharge relation defined by current-meter measurements up to 16,500 second-feet. Gage heights used to half-tenths between 3.3 and 6.1 feet; hundredths below and tenths above these linits.

Maxima.-August 1940: Discharge, 11,500 second-feet 11 p.m. Aug. 16 (gage height, 6.64 feet).

1898-99, 1930 to July 1940: Discharge, 27,000 second-feet Apr. 7, 1936 (gage height, 10.47 feet).

REMARKS.-Flood runoff practically unaffected by artificial storage.

Mean discharge, in second-feet, 1940

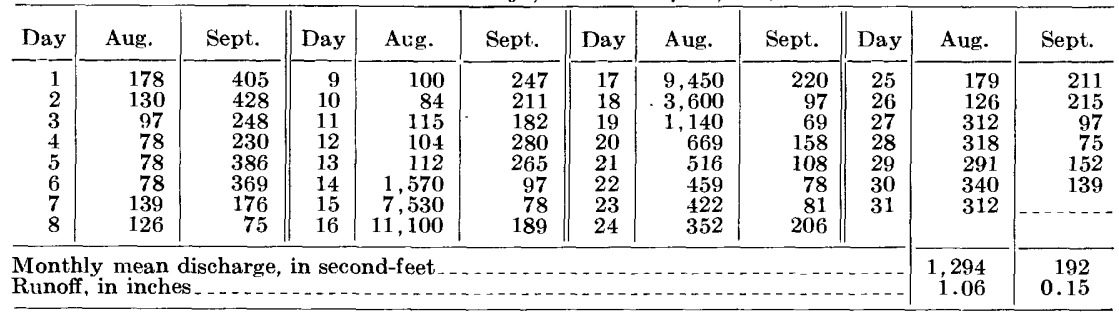


EAST FORK DERP RIVER NEAR HIGH POINT, N. C.

Location.-Lat. $36^{\circ} 02^{\prime} 15^{\prime \prime}$, long. $79^{\circ} 56^{\prime} 45^{\prime \prime}$, at highway bridge a quarter of a mile upstream from High Point Reservoir and 6 miles northeast of High Point, Guilford County.

Drainage AREA.- -14.2 square miles.

GAGE-HEIGHT RECORD.-Water-stage recorder graph.

Discharge record.- Stage-discharge relation defined by current-meter measurements up to 1,550 second-feet. Gage heights used to half-tenths between 3.4 and 3.7 feet; hundredths below and tenths above these limits.

Maxima.-1940: Discharge, 2,520 second-feet $7: 45$ a.m. Aug. 14 (gage height, 5.84 feet)

1928-39; Discharge, 2,170 second-feet Jan. 19, 1936, Aug. 24, 1939 ; gage height, 7.5 feet June 8, 1934 (affected by backwater from trash on bridge piers). Remarks.-Flood runoff not affected by artificial storage.

Mean discharge, in second-feet, 1940

\begin{tabular}{|c|c|c|c|c|c|c|c|c|c|c|c|}
\hline Day & Aug. & Sept. & Day & Aug. & Sept. & Day & Aug. & Sept. & Day & Aug. & Sept. \\
\hline $\begin{array}{l}1 \\
2 \\
3 \\
4 \\
5 \\
6 \\
7 \\
8\end{array}$ & $\begin{array}{r}16 \\
4.8 \\
4.8 \\
4.8 \\
7.8 \\
5.1 \\
4.6 \\
4.6\end{array}$ & $\begin{array}{c}25 \\
9.2 \\
7.1 \\
6.8 \\
11 \\
10 \\
6.3 \\
6.0\end{array}$ & $\begin{array}{r}9 \\
10 \\
11 \\
12 \\
13 \\
14 \\
15 \\
16\end{array}$ & $\begin{array}{r}4.4 \\
4.4 \\
5.5 \\
6.7 \\
11 \\
\mathbf{7 4 1} \\
93 \\
62\end{array}$ & $\begin{array}{l}5.7 \\
41 \\
12 \\
7.3 \\
6.3 \\
6.0 \\
5.7 \\
5.5\end{array}$ & $\begin{array}{l}17 \\
18 \\
19 \\
20 \\
21 \\
22 \\
23 \\
24\end{array}$ & $\begin{array}{c}19 \\
12 \\
9.2 \\
7.3 \\
6.8 \\
6.5 \\
6.0 \\
6.0\end{array}$ & $\begin{array}{l}5.3 \\
5.1 \\
5.1 \\
5.1 \\
4.8 \\
4.6 \\
4.6 \\
46\end{array}$ & $\begin{array}{l}25 \\
26 \\
27 \\
28 \\
23 \\
30 \\
31\end{array}$ & $\begin{array}{c}8.7 \\
6.5 \\
6.0 \\
5.7 \\
5.5 \\
15 \\
141\end{array}$ & $\begin{array}{l}5.5 \\
5.1 \\
4.8 \\
4.8 \\
4.6 \\
4.6 \\
\end{array}$ \\
\hline \multicolumn{10}{|c|}{$\begin{array}{l}\text { Aonthly mean discharge, in second-feet } \\
\text { uunoff, in inches }\end{array}$} & $\begin{array}{l}40.1 \\
3.25\end{array}$ & $\begin{array}{l}7.98 \\
0.63\end{array}$ \\
\hline
\end{tabular}

MUDDY CREEK NEAR ARCHDALE, N. C.

Location.-Lat. $35^{\circ} 52^{\prime} 35^{\prime \prime}$, long. $79^{\circ} 52^{\prime} 45^{\prime \prime}$, 600 feet upstream from county highway bridge, 2 miles east of Glenola brick plant, 3 miles southwest of Coltrane Mill, and 7 miles southeast of Archdale, Randolph County.

Drainage ARea. - 16.2 square miles.

GAGE-HEIGHT RECORD.-Water-stage recorder graph.

DISCHARGE RECORD.-Stage-discharge relation defined by current-meter measurements up to 1,700 second-feet. Gage heights used to half-tenths between 2.8 and 3.8 feet; hundredths below and tenths above these limits.

Maxima.-August 1940: Discharge, 1,240 second-feet $12 \mathrm{~m}$. Aug. 14 (gage height, 8.00 feet).

1934 to July 1940: Discharge, 2,180 second-feet June 28, 1938 (gage height, 10.46 feet).

Remarks.-Flood runoff not affected by artificial storage.

Mean discharge, in second-feet, 1940

\begin{tabular}{r|r|r||r|r|r||r|r|r||r|r|r}
\hline Day & Aug. & Sept. & Day & Aug. & Sept. & Day & Aug. & Sept. & Day & Aug. & Sept. \\
\hline 1 & 1.1 & 5.6 & 9 & .54 & 1.6 & 17 & 46 & 1.1 & 25 & 3.2 & 1.7 \\
2 & .79 & 3.8 & 10 & .49 & 1.4 & 18 & 19 & 1.0 & 26 & 3.2 & .85 \\
3 & .64 & 2.9 & 11 & 1.4 & 3.3 & 19 & 12 & 1.0 & 27 & 2.6 & .79 \\
4 & .72 & 2.3 & 12 & 3.0 & 2.2 & 20 & 8.0 & 1.0 & 28 & 2.3 & .79 \\
5 & .85 & 2.0 & 13 & 2.3 & 1.6 & 21 & 6.1 & .94 & 29 & 5.9 & .72 \\
6 & .94 & 2.6 & 14 & 433 & 1.3 & 22 & 5.1 & .85 & 30 & 31 & .72 \\
7 & .72 & 2.2 & 15 & 120 & 1.3 & 23 & 4.0 & .72 & 31 & 14 & \\
8 & .59 & 1.7 & 16 & 198 & 1.2 & 24 & 3.6 & .64 & & & \\
\hline
\end{tabular}

BEAR CREEK A'T ROBBINS, N. C.

Location.-Lat. $35^{\circ} 25^{\prime} 40^{\prime \prime}$, long. $79^{\circ} 35^{\prime} 40^{\prime \prime}$, just below Cabin Creek, half a mile west of Robbins, Moore County. 
Drainage AREa.-134 square miles.

GAGE-HEIGHT RECORD.-Water-stage recorder graph.

Discharge RECORD.-Stage-discharge relation defined by current-meter measurements up to 5,500 second-feet. Gage heights used to half-tenths between 4.7 and 6.3 feet; hundredths below and tenths above these limits.

Maxima.-August 1940: Discharge 3,420 second-feet 6 p.m. Aug. 14 (gage height 10.08 feet).

ReMarKs.-Flood runoff unaffected by artificial storage.

Mean discharge, in second-feet, 1940

\begin{tabular}{|c|c|c|c|c|c|c|c|c|c|c|c|}
\hline Day & Aug. & Sept. & Day & Aug. & Sept. & Day & Aug. & Sept. & Day & Aug. & Sept. \\
\hline $\begin{array}{l}1 \\
2 \\
3 \\
4 \\
5 \\
6 \\
6 \\
7 \\
8\end{array}$ & $\begin{array}{l}1.8 \\
1.5 \\
3.2 \\
2.6 \\
1.2 \\
1.4 \\
1.5 \\
1.7\end{array}$ & $\begin{array}{l}6.8 \\
7.5 \\
6.4 \\
4.1 \\
5.4 \\
5.1 \\
5.8 \\
5.1\end{array}$ & $\begin{array}{r}9 \\
10 \\
11 \\
12 \\
13 \\
14 \\
15 \\
16\end{array}$ & $\begin{array}{r}1.5 \\
1.2 \\
2.0 \\
2.8 \\
27 \\
1,340 \\
965 \\
380\end{array}$ & $\begin{array}{l}4.5 \\
4.5 \\
5.8 \\
6.1 \\
5.4 \\
6.1 \\
4.8 \\
3.6\end{array}$ & $\begin{array}{l}17 \\
18 \\
19 \\
20 \\
21 \\
22 \\
23 \\
24\end{array}$ & $\begin{array}{r}183 \\
78 \\
51 \\
30 \\
24 \\
19 \\
15 \\
17\end{array}$ & $\begin{array}{l}5.8 \\
6.1 \\
3.8 \\
3.4 \\
3.6 \\
3.8 \\
3.6 \\
3.0\end{array}$ & $\begin{array}{l}25 \\
26 \\
27 \\
28 \\
29 \\
30 \\
31\end{array}$ & $\begin{array}{c}11 \\
9.4 \\
11 \\
9.4 \\
7.1 \\
8.3 \\
7.5\end{array}$ & $\begin{array}{r}32 \\
7.5 \\
4.8 \\
2.6 \\
2.4 \\
3.4\end{array}$ \\
\hline \multicolumn{10}{|c|}{$\begin{array}{l}\text { Monthly mean discharge, in second-feet } \\
\text { Runoff, in inches }\end{array}$} & $\begin{array}{r}104 \\
0.89\end{array}$ & $\begin{array}{l}5.76 \\
0.05\end{array}$ \\
\hline
\end{tabular}

LOWER LITTLE RIVER AT MANCHESTER, N. C.

Location.-Lat. $35^{\circ} 11^{\prime} 40^{\prime \prime}$, long. $78^{\circ} 59^{\prime} 15^{\prime \prime}$, at bridge on State Highway 24 at Manchester, Cumberland County, 11/4 miles downstream from Atlantic Coast Line Railroad and 12 miles southwest of Linden.

Drainage AREA. - 348 square miles.

GAGE-HEIGHT RECORD.-Water-stage recorder graph.

DISCHARGE RECORD.-Stage-discharge relation defined by current-meter measurements up to 2,550 second-feet. Gage heights used to half-tenths between 1.9 and 3.7 feet; hundredths below and tenths above these limits.

Maxima.-August 1940: Discharge, 289 second-feet 1 p.m. Aug. 16 (gage height, 2.49 feet). Flow regulated.

1938 to July 1940: Discharge, 2,960 second-feet Mar. 3, 1939 (gage height, 12.77 feet).

REMARKs.-Flood runoff practically unaffected by artificial storage except for small rises.

Mean discharge, in second-feet, 1940

\begin{tabular}{|c|c|c|c|c|c|c|c|c|c|c|c|}
\hline Day & Aug. & Sept. & Day & Aug. & Sept. & Day & Aug. & Sept. & Day & Aug. & Sept. \\
\hline $\begin{array}{l}1 \\
2 \\
3 \\
4 \\
5 \\
6 \\
7 \\
8\end{array}$ & $\begin{array}{l}28 \\
30 \\
33 \\
35 \\
\mathbf{3 4} \\
\mathbf{3 4} \\
\mathbf{3 4} \\
40\end{array}$ & $\begin{array}{l}44 \\
43 \\
51 \\
50 \\
50 \\
51 \\
51 \\
40\end{array}$ & $\begin{array}{r}9 \\
10 \\
11 \\
12 \\
13 \\
14 \\
15 \\
16\end{array}$ & $\begin{array}{r}34 \\
33 \\
33 \\
64 \\
99 \\
168 \\
280 \\
280\end{array}$ & $\begin{array}{l}42 \\
53 \\
76 \\
62 \\
53 \\
52 \\
42 \\
45\end{array}$ & $\begin{array}{l}17 \\
18 \\
19 \\
20 \\
21 \\
22 \\
23 \\
24\end{array}$ & $\begin{array}{r}180 \\
188 \\
175 \\
157 \\
106 \\
73 \\
80 \\
71\end{array}$ & $\begin{array}{l}50 \\
52 \\
52 \\
49 \\
40 \\
41 \\
39 \\
44\end{array}$ & $\begin{array}{l}25 \\
26 \\
27 \\
28 \\
29 \\
30 \\
31\end{array}$ & $\begin{array}{l}54 \\
67 \\
66 \\
68 \\
63 \\
64 \\
51\end{array}$ & $\begin{array}{l}36 \\
40 \\
33 \\
31 \\
36 \\
38\end{array}$ \\
\hline \multicolumn{10}{|c|}{$\begin{array}{l}\text { Monthly mean discharge, in second-feet } \\
\text { Runoff, in inches }\end{array}$} & $\begin{array}{r}87.8 \\
0.29\end{array}$ & $\begin{array}{l}46.2 \\
0.15\end{array}$ \\
\hline
\end{tabular}

LOWER LITTLE RIVER AT LINDEN, N. C.

Location.-Lat. $35^{\circ} 16^{\prime} 00^{\prime \prime}$, long. $78^{\circ} 46^{\prime} 40^{\prime \prime}$, at bridge on State Highway $21,13 / 4$ miles west of Linden, Cumberland County, 2 miles upstream from Stewart Creek, and $4 \frac{1}{2}$ miles upstream from mouth. Datum of gage is 71.37 feet above mean sea level (levels by Corps of Engineers, War Department).

DratNage ARea.-460 square miles.

GAGE-HEIGHT RECORD.-Water-stage recorder graph except for period Sept. 12-26. DISCHARGE RECORD.-Stage-discharge relation defined by current-meter measurements up to 4,100 second-feet. Several current-meter measurements have been made between 1,700 and 10,100 second-feet during periods of backwater from Cape 
Fear River. Gage heights used to half-tenths between 3.8 and 5.2 feet Aug. 1 to Sept. 11, and between 4.2 and 5.6 feet Sept. 12-30; hundredths below and tenths above these limits. Discharge for period of no gage-height record based on weather records and records for station at Manchester.

Maxima.-August 1940: Discharge, 383 second-feet 2 a.m. Aug. 16 (gage height, 3.66 feet). Flow regulated.

1928 to July 1940: Discharge, 10,300 second-feet Oct. 2, 1929, based on eurrent-meter measurements during period of backwater from Cape Fear River; gage height, 35.5 feet Oct. 4, 1929 (affected by backwater from Cape Fear River).

Stage known, 37.3 feet Sept. 21, 1928, during period of backwater from Cape Fear River (discharge, 13,000 second-feet, estimated).

REMARKS.-Flood runoff practically unaffected by artificial storage except for small rises.

Mean discharge, in second-feet, 1940

\begin{tabular}{|c|c|c|c|c|c|c|c|c|c|c|c|}
\hline Day & Aug. & Sept. & Day & Aug. & Sept. & Day & Aug. & Sept. & Day & Aug. & Sept. \\
\hline $\begin{array}{l}1 \\
2 \\
3 \\
4 \\
5 \\
6 \\
7 \\
8\end{array}$ & $\begin{array}{l}31 \\
32 \\
35 \\
43 \\
47 \\
45 \\
43 \\
45\end{array}$ & $\begin{array}{l}67 \\
51 \\
59 \\
63 \\
61 \\
61 \\
63 \\
64\end{array}$ & $\begin{array}{r}9 \\
10 \\
11 \\
12 \\
13 \\
14 \\
15 \\
16\end{array}$ & $\begin{array}{r}51 \\
41 \\
49 \\
59 \\
117 \\
190 \\
314 \\
\mathbf{3 7 0}\end{array}$ & $\begin{array}{r}40 \\
55 \\
102 \\
85 \\
75 \\
70 \\
70 \\
50\end{array}$ & $\begin{array}{l}17 \\
18 \\
19 \\
20 \\
21 \\
22 \\
23 \\
24\end{array}$ & $\begin{array}{r}312 \\
259 \\
240 \\
224 \\
189 \\
126 \\
93 \\
107\end{array}$ & $\begin{array}{l}65 \\
65 \\
65 \\
65 \\
60 \\
55 \\
46 \\
50\end{array}$ & $\begin{array}{l}25 \\
26 \\
27 \\
28 \\
29 \\
30 \\
31\end{array}$ & $\begin{array}{r}103 \\
95 \\
96 \\
107 \\
105 \\
96 \\
74\end{array}$ & $\begin{array}{r}55 \\
46 \\
47 \\
35 \\
40 \\
34 \\
-0\end{array}$ \\
\hline \multicolumn{10}{|c|}{$\begin{array}{l}\text { Monthly mean discharge, in second-feet } \\
\text { Runoff, in inches }\end{array}$} & $\begin{array}{r}121 \\
0.30\end{array}$ & $\begin{array}{l}58.8 \\
0.14\end{array}$ \\
\hline
\end{tabular}

ROCKFISH CREEK NEAR HOPE MLLS, N. C.

Lochtion.-At mouth of Little Rockfish Creek. Gage is water-stage recorder, lat. $34^{\circ} 58^{\prime}$, long. $78^{\circ} 55^{\prime}$, at bridge on U. S. Highway 301 , just upstream from Little Rockfish Creek, $13 / 4$ miles east of town of Hope Mills, Cumberland County, and $5 \%$ miles upstream from mouth.

Drainage AREA.-284 square miles, including that of Little Rockfish Creek.

GAGE-HEIGHT RECORD.-Water-stage recorder graph.

DISCHARGE RECORD.-Includes flow of Little Rockfish Creek. Stage-discharge relation defined by current-meter measurements up to 1,200 second-feet. Current-meter measurements have been made between 1,100 and 1,420 second-feet during periods of backwater from Cape Fear River. Gage heights used to half-tenths between 5.2 and 6.4 feet; hundredths below and tenths above these limits.

Maxima.-August 1940: Discharge, 791 second-feet 12:30 p.m. Aug. 16 (gage height, 7.20 feet). Flow regulated.

1928-31, 1939 to July 1940: Discharge, 5,200 second-feet, estimated, Oct. 3, 1929, at site 4 miles downstream during period of backwater from Cape Fear River.

REMARKS.-Flood runoff practically unaffected by artificial storage except for small rises.

Mean discharge, in second-feet, 1940

\begin{tabular}{|c|c|c|c|c|c|c|c|c|c|c|c|}
\hline Day & Aug. & Sept. & Day & Aug. & Sept. & Day & Aug. & Sept. & Day & Aug. & Sept. \\
\hline 1 & 127 & 32 & 9 & 118 & 169 & 17 & 329 & 208 & 25 & 28 & 139 \\
\hline 2 & 96 & 140 & 10 & & & 18 & 20 & & & 129 & 137 \\
\hline 3 & 23 & 182 & 11 & 28 & 232 & 19 & 368 & 16 & 2 & 144 & 151 \\
\hline 4 & 26 & 172 & 12 & 313 & 164 & 20 & 319 & 162 & 2 & 140 & 60 \\
\hline 5 & 126 & 143 & 13 & 295 & 24 & 21 & 279 & 61 & 29 & 127 & 40 \\
\hline 6 & 128 & 210 & 14 & 345 & 112 & 22 & 284 & 34 & 30 & 137 & 176 \\
\hline 7 & 144 & 99 & 15 & 447 & 65 & 23 & 145 & 138 & 31 & 55 & \\
\hline 8 & 126 & 47 & 16 & 492 & 224 & 24 & 26 & 139 & & & \\
\hline \multicolumn{10}{|c|}{$\begin{array}{l}\text { Monthly mean discharge, in second-feet } \\
\text { Runoff, in inches }\end{array}$} & 191 & 140 \\
\hline
\end{tabular}




\section{NORThEAST CAPE FEAR RIVER NEAR CHINQUAPIN, N. C.}

LOCATION.-Lat. $34^{\circ} 49^{\prime}$, long. $77^{\circ} 50^{\prime}$, 1,000 feet downstream from bridge on State Highway 41, half a mile downstream from Muddy Creek, and 11/4 miles west of Chinquapin, Duplin County.

DRAINAGE AREA.-600 square miles.

GAGE-HEIGHT RECORD.-Graph based on one to four staff-gage readings a day Aug. 1-3, 5-15. Water-stage recorder graph Aug. 23 to Sept. 30. No record Aug. 4, 16-22.

DISCHARGE RECORD.-Stage-discharge relation defined by current-meter measurements up to 2,800 second-feet. Gage heights used to half-tenths between 2.2 and 3.6 feet Aug. 1-22 and between 2.4 and 3.8 feet Aug. 23 to Sept. 30; hundredths below and tenths above these limits. Discharge during periods of no gage-height record based on weather records and characteristic shape of hydrograph.

Maxima.-1940: Discharge, 1,700 second-feet about 4 a.m. Aug. 23 (gage height, 8.3 feet, based on partial record).

REMARKS.-Flood runoff not affected by artificial storage.

Mean discharge, in second-feet, 1940

\begin{tabular}{|c|c|c|c|c|c|c|c|c|c|c|c|}
\hline Day & Aug. & Sept. & Day & Aug. & Sept. & Day & Aug. & Sept. & Day & Aug. & Sept. \\
\hline $\begin{array}{l}1 \\
2 \\
3 \\
4 \\
5 \\
6 \\
7 \\
8\end{array}$ & $\begin{array}{r}17 \\
17 \\
16 \\
20 \\
25 \\
22 \\
45 \\
103\end{array}$ & $\begin{array}{l}65 \\
58 \\
52 \\
44 \\
41 \\
43 \\
49 \\
58\end{array}$ & $\begin{array}{r}9 \\
10 \\
11 \\
12 \\
13 \\
14 \\
15 \\
16\end{array}$ & $\begin{array}{l}155 \\
173 \\
140 \\
137 \\
136 \\
103 \\
136 \\
220\end{array}$ & $\begin{array}{l}58 \\
50 \\
41 \\
36 \\
39 \\
42 \\
38 \\
38 \\
\end{array}$ & $\begin{array}{l}17 \\
18 \\
19 \\
20 \\
21 \\
22 \\
23 \\
24\end{array}$ & $\begin{array}{r}320 \\
440 \\
600 \\
850 \\
1,200 \\
1,600 \\
1,660 \\
1,340 \\
\end{array}$ & $\begin{array}{l}37 \\
32 \\
29 \\
29 \\
28 \\
24 \\
22 \\
22\end{array}$ & $\begin{array}{l}25 \\
26 \\
27 \\
28 \\
29 \\
30 \\
31\end{array}$ & $\begin{array}{r}854 \\
490 \\
281 \\
172 \\
118 \\
90 \\
75\end{array}$ & $\begin{array}{r}20 \\
17 \\
16 \\
18 \\
21 \\
25 \\
\end{array}$ \\
\hline \multicolumn{10}{|c|}{$\begin{array}{l}\text { Monthly mean discharge, in second-feet } \\
\text { Runoff, in inches }\end{array}$} & $\begin{array}{r}373 \\
0.72\end{array}$ & $\begin{array}{l}36.4 \\
0.07\end{array}$ \\
\hline
\end{tabular}

\section{WACCAMAW RIVER BASIN \\ WACCAMAW RIVER AT FREELAND, N. C.}

LOCATION.-Lat. $34^{\circ} 05^{\prime} 45^{\prime \prime}$, long. $78^{\circ} 32^{\prime} 50^{\prime \prime}$, at bridge on State Highway 130,1 mile southwest of Freeland, Brunswick County, and about 7 miles downstream from mouth of White Marsh.

DrainAGE AREA.-667 square miles.

GAGE-HEIGHT RECORD.-Gage-height record from mean of twice-daily readings of staff gage.

DISCHARGE RECORD.-Stage-discharge relation defined by current-meter measurements up to 1,860 second-feet. Gage heights used to half-tenths between 1.2 and 2.3 feet; hundredths below and tenths above these limits.

Maxima.-August 1940: Discharge, 398 second-feet 6:15 p.m. Aug. 21 and 6:25 a.m. Aug. 22 (gage height, 6.58 feet).

1939 to July 1940: Discharge, 1,910 second-feet Feb. 23, 24, 1940 (gage height, 13.15 feet).

REMARKS.-Flood runoff affected materially by storage in Lake Waccamaw and large swamps.

Mean discharge, in second-feet, 1940

\begin{tabular}{|c|c|c|c|c|c|c|c|c|c|c|c|}
\hline Day & Aug. & Sept. & Day & Aug. & Sept. & Day & Aug. & Sept. & Day & Aug. & Sept. \\
\hline $\begin{array}{l}1 \\
2 \\
3 \\
4 \\
5 \\
6 \\
7 \\
8\end{array}$ & $\begin{array}{l}19 \\
22 \\
23 \\
23 \\
24 \\
23 \\
26 \\
39\end{array}$ & $\begin{array}{r}254 \\
222 \\
176 \\
141 \\
113 \\
93 \\
81 \\
72\end{array}$ & $\begin{array}{r}9 \\
10 \\
11 \\
12 \\
13 \\
14 \\
15 \\
16\end{array}$ & $\begin{array}{r}53 \\
50 \\
50 \\
93 \\
155 \\
169 \\
162 \\
183\end{array}$ & $\begin{array}{l}63 \\
53 \\
41 \\
37 \\
31 \\
28 \\
24 \\
20\end{array}$ & $\begin{array}{l}17 \\
18 \\
19 \\
20 \\
21 \\
22 \\
23 \\
24\end{array}$ & $\begin{array}{l}238 \\
318 \\
358 \\
374 \\
398 \\
398 \\
382 \\
350\end{array}$ & $\begin{array}{c}18 \\
16 \\
14 \\
12 \\
11 \\
9.5 \\
8.1 \\
7.0\end{array}$ & $\begin{array}{l}25 \\
26 \\
27 \\
28 \\
29 \\
30 \\
31\end{array}$ & $\begin{array}{l}310 \\
278 \\
278 \\
294 \\
310 \\
302 \\
286\end{array}$ & $\begin{array}{r}6.2 \\
5.1 \\
4.3 \\
3.9 \\
4.7 \\
4.1 \\
\end{array}$ \\
\hline \multicolumn{10}{|c|}{$\begin{array}{l}\text { Monthly mean discharge, in second-feet, } \\
\text { Runoff, in inches }\end{array}$} & $\begin{array}{r}193 \\
0.33\end{array}$ & $\begin{array}{l}52.4 \\
0.09\end{array}$ \\
\hline
\end{tabular}


MIDDLE SWAMP NEAR ELKTON, N. C.

Lochtion.-Lat. $34^{\circ} 27^{\prime} 25^{\prime \prime}$, long. $78^{\circ} 33^{\prime} 30^{\prime \prime}$, at bridge on State Highway 211 and 2 miles east of Elkton, Bladen County.

Drainage AREA. - 3.7 square miles.

GAGE-HEIGHT RECORD.-Water-stage recorder graph except for Aug. 1-8 and 10-16, when recorder elock was stopped.

DISCHARge RECORD. - Stage-discharge relation defined by current-meter measurements up to 84 second-feet. Discharge for periods of no gage-height record based on

recorded range in gage heights, weather records, and records for nearby streams. Maxima.-1940: Discharge, 56 second-feet 7 p.m. Aug. 17 (gage height, 3.29 feet). REMarKs.-Flood runoff not affected by artificial storage.

Mean discharge, in second-feet, 1940

\begin{tabular}{|c|c|c|c|c|c|c|c|c|c|c|c|}
\hline Day & Aug. & Sept. & Day & Aug. & Sept. & Day & Aug. & Sept. & Day & Aug. & Sept. \\
\hline $\begin{array}{l}1 \\
2 \\
3 \\
4 \\
5 \\
6 \\
7 \\
8\end{array}$ & $\begin{array}{l}0 \\
0 \\
0 \\
0 \\
0 \\
0 \\
1 \\
0\end{array}$ & & $\begin{array}{r}9 \\
10 \\
11 \\
12 \\
13 \\
14 \\
15 \\
16\end{array}$ & $\begin{array}{l}0 \\
0 \\
1 \\
1 \\
.5 \\
.5 \\
0 \\
0\end{array}$ & & $\begin{array}{l}17 \\
18 \\
19 \\
20 \\
21 \\
22 \\
23 \\
24\end{array}$ & $\begin{array}{r}13 \\
14 \\
5.8 \\
1.5 \\
.5 \\
.2 \\
.1 \\
0\end{array}$ & & $\begin{array}{l}25 \\
26 \\
27 \\
28 \\
29 \\
30 \\
31\end{array}$ & $\begin{array}{l}0 \\
0 \\
0 \\
0 \\
0 \\
0 \\
0\end{array}$ & \\
\hline $\begin{array}{l}\text { Mont } \\
\text { Runo }\end{array}$ & $\mathrm{n}$ i & 0 & & & & & & & - & $\begin{array}{l}1.26 \\
0.39\end{array}$ & $\begin{array}{l}0 \\
0\end{array}$ \\
\hline
\end{tabular}

Gage height, in feet, and discharge, in second-feet, at indicated time, 1940

\begin{tabular}{|c|c|c|c|c|c|c|c|c|c|c|c|c|}
\hline \multirow{2}{*}{ Hour } & \multicolumn{2}{|c|}{ Aug. 17} & \multicolumn{2}{|c|}{ Aug. 18} & \multicolumn{2}{|c|}{ Aug. 19} & \multicolumn{2}{|c|}{ Aug. 20} & \multicolumn{2}{|c|}{ Aug. 21} & \multicolumn{2}{|c|}{ Aug. 22} \\
\hline & $\begin{array}{c}\text { Gage } \\
\text { ht. }\end{array}$ & $\begin{array}{l}\text { Dis- } \\
\text { charge }\end{array}$ & $\begin{array}{c}\text { Gage } \\
\text { ht. }\end{array}$ & $\begin{array}{c}\text { Dis- } \\
\text { charge }\end{array}$ & $\begin{array}{c}\text { Gage } \\
\text { ht. }\end{array}$ & $\begin{array}{c}\text { Dis- } \\
\text { charge }\end{array}$ & $\begin{array}{c}\text { Gage } \\
\text { ht. }\end{array}$ & $\begin{array}{c}\text { Dis- } \\
\text { charge }\end{array}$ & $\begin{array}{c}\text { Gage } \\
\text { ht. }\end{array}$ & $\begin{array}{l}\text { Dis- } \\
\text { charge }\end{array}$ & $\begin{array}{c}\text { Gage } \\
\text { ht. }\end{array}$ & $\begin{array}{l}\text { Dis- } \\
\text { charge }\end{array}$ \\
\hline 2 & $\overline{1} 1.02$ & 0 . & & & & & & & & & & \\
\hline 4 & 11.01 & & 2.68 & 19 & & & & & & & & \\
\hline $\begin{array}{l} \pm \\
6\end{array}$ & 11.00 & 0 & 2.00 & & $\overline{2} .09$ & 7.5 & 1.60 & 2.0 & $1 \overline{1} . \overline{3} 3$ & 0.6 & $1 . \overline{2} 2$ & 0.3 \\
\hline 8 & $\begin{array}{lll}1 & 1 & 0 \\
1 & 0 & 0\end{array}$ & 0 & 2.44 & 14 & $\ldots$ & 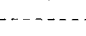 & $\ldots$ & $-\infty$ & $\ldots-\cdots$ & - & $\ldots$ & $\ldots \ldots$ \\
\hline $\mathrm{N}$ & {$\left[\begin{array}{l}.99 \\
1.30\end{array}\right]$} & .8 & 2.36 & 12 & 1.95 & $\overline{5} . \overline{7}$ & 1.51 & $1 . \overline{4}$ & 1.30 & $\overline{5}$ & 1.19 & .2 \\
\hline 2 & 1.51 & 1.8 & {$\left[\begin{array}{ll}2 & 33\end{array}\right.$} & 12 & & & & & & & & \\
\hline $\begin{array}{l}4 \\
6\end{array}$ & $\begin{array}{l}1.90 \\
3.25\end{array}$ & 52 & & & 1.80 & 3.8 & 1.43 & 1.0 & $1 . \overline{2}$ & 4 & 1.15 & 1 \\
\hline 8 & 3.23 & 50 & 2.28 & 11 & & & & & & & & \\
\hline $\begin{array}{l}10 \\
12\end{array}$ & $\begin{array}{l}3.05 \\
2.92\end{array}$ & $\begin{array}{l}34 \\
27\end{array}$ & 2.22 & 9.7 & $1 . \overline{68}$ & 2.6 & $1 . \overline{3}$ & .8 & $1, \overline{2}$ &.$\overline{3}$ & 1.13 & 1 \\
\hline
\end{tabular}

1 Estimated.

SuPPLEMENTAL ReCords.-Aug. 17, 1 p.m., gage height, 1.61 feet, discharge, 2.5 second-feet; 3 p.m., gage height, 1.49 feet, discharge, 1.6 second-feet; 7 p.m., gage height, 3.29 feet, discharge, 56 second-feet.

\section{HEAVERDAM SWAMP AT LEBANON, N. C.}

Lochtion.-Lat. $34^{\circ} 14^{\prime} 15^{\prime \prime}$, long. $78^{\circ} 44^{\prime} 50^{\prime \prime}$, at bridge on U. S. Highway 701 half a mile upstream from Big Pond Branch and 1 mile north of Lebanon, Columbus County.

Drainage AREA.-21.3 square miles.

GAGE-HEIGHT RECORD.-Water-stage recorder graph.

DISCHARGE RECORD.-Stage-discharge relation defined by current-meter measurements up to 170 second-feet and extended logarithmically to erest gage height.

Maxima.-August 1940: Discharge, 18 second-feet 8 a.m. Aug. 19 (gage height, 2.89 feet).

May to July 1940: Discharge, 102 second-feet June 3 (gage height, 4.09 feet). REMARKS.-Flood runoff affected slightly by regulation in small mill ponds. 
Mean discharge, in second-feet, 1940

\begin{tabular}{r|r|r|r|r|r||r|r|r||r|r|r}
\hline Day & Aug. & Sept. & Day & Aug. & Sept. & Day & Aug. & Sept. & Day & Aug. & Sept. \\
\hline 1 & 0 & 2.0 & 9 & 0 & 0 & 17 & 1.1 & 0 & 25 & 5.8 & 0 \\
2 & 0 & .6 & 10 & 0 & 1.2 & 18 & 8.6 & 0 & 26 & 1.9 & 0 \\
3 & 0 & 0 & 11 & 0 & 2.7 & 19 & 15 & 0 & 27 & 1.4 & 0 \\
4 & 0 & 1.8 & 12 & 0 & .9 & 20 & 13 & 0 & 28 & 2.2 & 0 \\
5 & 0 & 1.7 & 13 & 0 & 0 & 21 & 6.9 & 0 & 29 & 3.5 & 0 \\
6 & 0 & .5 & 14 & 0 & 0 & 22 & 3.3 & 0 & 30 & 4.7 & 0 \\
7 & 0 & 1.0 & 15 & 0 & 0 & 23 & 2.0 & 0 & 31 & 1.3 &..-- \\
8 & 0 & 1.2 & 16 & .2 & 0 & 24 & 2.8 & .0 & & & \\
\hline
\end{tabular}

\section{PEE DEE RIVER BASIN}

YADKIN RIVER AT PATWERSON, N. C.

Location.-Lat. $39^{\circ} 59^{\prime} 30^{\prime \prime}$, long. $81^{\circ} 33^{\prime} 32^{\prime \prime}, 200$ feet upstream from bridge on State Highway 268 and half a mile south of Patterson, Caldwell County.

DratNAGE AREA.—28.8 square miles.

GAGE-HEIGHT RECORD.-Water-stage recorder graph. The lower intake was plugged Aug. 2-11, and the graph for part of each day was synthesized.

DISCHARGE RECORD.- - Stage-discharge relation defined by current-meter measurements up to 1,000 second-feet but poorly, owing to a shifting bed load of sand, and extended to crest gage height on basis of computation of flood flow over mill dam 1 mile above gage. Gage heights used to half-tenths between 3.0 and 7.2 feet Aug. 1-13, between 2.0 and 3.6 feet Aug. 14-30, and between 2.6 and 4.0 feet Aug. 31 to Sept: 30; hundredths below and tenths above these limits. Shifting-control method used Aug. 1-12, Aug. 30 to Sept. 30.

Maxima.-1940: Discharge, 16,200 second.feet 8 p.m. Aug. 13 (gage height, 12.70 feet).

REMARKS.-Flood runoff not affected by artificial storage.

Mean discharge, in second-feet, 1940

\begin{tabular}{|c|c|c|c|c|c|c|c|c|c|c|c|}
\hline Day & Aug. & Sept. & Day & Aug. & Sept. & Day & Aug. & Sept. & Day & Aug. & Sept. \\
\hline $\begin{array}{l}1 \\
2 \\
3 \\
4 \\
5 \\
6 \\
7 \\
8\end{array}$ & $\begin{array}{r}36 \\
26 \\
25 \\
+\quad 20 \\
30 \\
28 \\
29 \\
32\end{array}$ & $\begin{array}{r}120 \\
81 \\
63 \\
53 \\
57 \\
53 \\
46 \\
44\end{array}$ & $\begin{array}{r}9 \\
10 \\
11 \\
12 \\
13 \\
14 \\
15 \\
16\end{array}$ & $\begin{array}{r}26 \\
25 \\
23 \\
56 \\
2,130 \\
895 \\
364 \\
214\end{array}$ & $\begin{array}{l}42 \\
41 \\
39 \\
38 \\
36 \\
36 \\
35 \\
29\end{array}$ & $\begin{array}{l}17 \\
18 \\
19 \\
20 \\
21 \\
22 \\
23 \\
24\end{array}$ & $\begin{array}{r}149 \\
127 \\
103 \\
85 \\
78 \\
76 \\
66 \\
71\end{array}$ & $\begin{array}{l}32 \\
32 \\
32 \\
32 \\
32 \\
30 \\
30 \\
30\end{array}$ & $\begin{array}{l}25 \\
26 \\
27 \\
28 \\
29 \\
30 \\
31\end{array}$ & $\begin{array}{r}61 \\
56 \\
50 \\
54 \\
66 \\
670 \\
358\end{array}$ & $\begin{array}{l}40 \\
32 \\
29 \\
25 \\
26 \\
28\end{array}$ \\
\hline \multicolumn{10}{|c|}{$\begin{array}{l}\text { Monthly mean discharge, in second-feet } \\
\text { Runoff, in inches }\end{array}$} & $\begin{array}{r}194 \\
7.79\end{array}$ & $\begin{array}{l}41.4 \\
1.61\end{array}$ \\
\hline
\end{tabular}


Gage height, in feet, and discharge, in second-feet, at indicated time, 1940

\begin{tabular}{|c|c|c|c|c|c|c|c|c|c|c|c|c|}
\hline \multirow{2}{*}{ Hour } & \multicolumn{2}{|c|}{ Aug. 12} & \multicolumn{2}{|c|}{ Aug. 13} & \multicolumn{2}{|c|}{ Aug. 14} & \multicolumn{2}{|c|}{ Aug. 15} & \multicolumn{2}{|c|}{ Aug. 16} & \multicolumn{2}{|c|}{ Aug. 17} \\
\hline & $\begin{array}{c}\text { Gage } \\
\text { height }\end{array}$ & $\begin{array}{c}\text { Dis- } \\
\text { charge }\end{array}$ & $\begin{array}{c}\text { Gage } \\
\text { height }\end{array}$ & $\begin{array}{l}\text { Dis- } \\
\text { charge }\end{array}$ & $\begin{array}{c}\text { Gage } \\
\text { height }\end{array}$ & $\begin{array}{c}\text { Dis- } \\
\text { charge }\end{array}$ & $\begin{array}{r}\text { Gage } \\
\text { height }\end{array}$ & $\begin{array}{c}\text { Dis- } \\
\text { charge }\end{array}$ & $\begin{array}{c}\text { Gage } \\
\text { height }\end{array}$ & $\begin{array}{c}\text { Dis- } \\
\text { charge }\end{array}$ & $\begin{array}{c}\text { Gage } \\
\text { height }\end{array}$ & $\begin{array}{c}\text { Dis- } \\
\text { charge }\end{array}$ \\
\hline $\begin{array}{l}1 \\
2 \\
3 \\
4 \\
5 \\
6\end{array}$ & $\begin{array}{r}0.75 \\
.72 \\
.72 \\
.72 \\
.72 \\
.72\end{array}$ & $\begin{array}{l}30 \\
28 \\
28 \\
28 \\
28 \\
28\end{array}$ & $\begin{array}{l}2.09 \\
2.04 \\
2.31 \\
2.36 \\
2.32 \\
2.29\end{array}$ & $\begin{array}{l}229 \\
219 \\
280 \\
293 \\
282 \\
275\end{array}$ & $\begin{array}{l}4.23 \\
3.87 \\
3.79 \\
3.49 \\
3.29 \\
3.06\end{array}$ & $\begin{array}{l}1,740 \\
1,580 \\
1,520 \\
1,360 \\
1,240 \\
1,120\end{array}$ & $\mid$\begin{tabular}{c}
1.64 \\
\hdashline 1.64 \\
\hdashline
\end{tabular} & 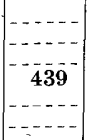 & $\mid \begin{array}{c}\cdots \\
1.17 \\
-\cdots\end{array}$ & $\mid \begin{array}{c}\cdots \\
248 \\
\cdots \\
\cdots\end{array}$ & $\begin{array}{l}0.93 \\
0.93 \\
-10\end{array}$ & 164 \\
\hline $\begin{array}{r}7 \\
8 \\
9 \\
10 \\
11 \\
N\end{array}$ & $\begin{array}{l}.84 \\
.83 \\
.83 \\
.83 \\
.83 \\
.83\end{array}$ & $\begin{array}{l}37 \\
36 \\
36 \\
36 \\
36 \\
36\end{array}$ & $\begin{array}{l}2.17 \\
2.19 \\
2.19 \\
2.25 \\
2.33 \\
2.50\end{array}$ & $\begin{array}{l}246 \\
251 \\
251 \\
265 \\
285 \\
331\end{array}$ & $\begin{array}{l}2.87 \\
2.69 \\
2.55 \\
2.46 \\
2.33 \\
2.24\end{array}$ & $\begin{array}{r}1,020 \\
940 \\
865 \\
815 \\
765 \\
715\end{array}$ & $\begin{array}{l}1.54 \\
1.44\end{array}$ & $\mid$\begin{tabular}{c}
$-\overline{396}$ \\
\hdashline-6 \\
\hdashline$\overline{354}$
\end{tabular} & $\begin{array}{c}1 . \overline{11} \\
1.07\end{array}$ & 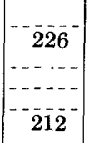 & $\begin{array}{c}.90 \\
.88\end{array}$ & $\mid \begin{array}{c}154 \\
148\end{array}$ \\
\hline $\begin{array}{l}1 \\
2 \\
3 \\
4 \\
5 \\
6\end{array}$ & $\begin{array}{r}.83 \\
.88 \\
.88 \\
.85 \\
.85 \\
1.02\end{array}$ & $\begin{array}{l}36 \\
41 \\
41 \\
38 \\
38 \\
55\end{array}$ & $\begin{array}{l}2.59 \\
3.37 \\
3.73 \\
4.14 \\
5.30 \\
5.98\end{array}$ & $\begin{array}{r}358 \\
638 \\
825 \\
1,020 \\
1,800 \\
2,490\end{array}$ & $\begin{array}{l}2.14 \\
2.08 \\
2.04 \\
1.99 \\
1.92 \\
1.93\end{array}$ & $\begin{array}{l}668 \\
645 \\
622 \\
596 \\
564 \\
568\end{array}$ & \begin{tabular}{c}
$\cdots$ \\
\hdashline 1.36 \\
\hdashline-1 \\
\hdashline-1
\end{tabular} & $\mid$\begin{tabular}{c}
$-\ldots$. \\
$-\cdots$ \\
$-\overline{3} 2 \overline{2}^{-}$ \\
\hdashline$-\cdots$
\end{tabular} & $\mid$\begin{tabular}{c}
1. \\
\hdashline 1.03 \\
\hdashline \\
\hdashline
\end{tabular} & 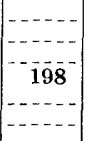 & 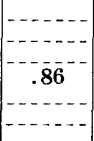 & $\mid \begin{array}{c}\cdots \\
\cdots \\
\cdots \\
\cdots \\
\cdots\end{array}$ \\
\hline $\begin{array}{r}7 \\
8 \\
9 \\
10 \\
11 \\
12 \\
\end{array}$ & $\begin{array}{l}1.36 \\
1.50 \\
1.49 \\
1.45 \\
1.62 \\
1.73 \\
\end{array}$ & $\begin{array}{l}102 \\
123 \\
122 \\
116 \\
142 \\
161 \\
\end{array}$ & $\begin{array}{r}6.42 \\
12.70 \\
10.50 \\
8.49 \\
6.35 \\
5.24 \\
\end{array}$ & $\begin{array}{r}2,950 \\
16,200 \\
10,700 \\
6,320 \\
3,330 \\
2,360 \\
\end{array}$ & $\begin{array}{l}1.92 \\
1.89 \\
1.87 \\
1.86 \\
1.83 \\
1.78 \\
\end{array}$ & $\begin{array}{l}564 \\
550 \\
542 \\
537 \\
524 \\
501 \\
\end{array}$ & \begin{tabular}{|c|}
$1.2 \overline{8}^{--}$ \\
\hdashline $1.2 \overline{2}^{-}$
\end{tabular} & $\mid \begin{array}{c}-290 \\
267\end{array}$ & \begin{tabular}{c}
.99 \\
\hdashline .95 \\
95
\end{tabular} & $\left|\begin{array}{c}-184 \\
-170\end{array}\right|$ & \begin{tabular}{c}
$.84^{-}$ \\
\hdashline $.82^{-}$ \\
\end{tabular} & \begin{tabular}{|c}
$1 \overline{35}$ \\
$12 \overline{9}$ \\
\end{tabular} \\
\hline & \multicolumn{2}{|c|}{ Aug. 18} & \multicolumn{2}{|c|}{ Aug. 19} & \multicolumn{2}{|c|}{ Aug. 20} & \multicolumn{6}{|c|}{ SUPPLEMENTAL RECORDS } \\
\hline $\begin{array}{r}4 \\
8 \\
N \\
4 \\
8 \\
12\end{array}$ & $\begin{array}{r}0.80 \\
.79 \\
.78 \\
.81 \\
.88 \\
.80\end{array}$ & $\begin{array}{l}123 \\
120 \\
117 \\
126 \\
148 \\
123\end{array}$ & $\begin{array}{r}0.76 \\
.74 \\
.73 \\
.72 \\
.69 \\
.67\end{array}$ & $\begin{array}{r}111 \\
106 \\
103 \\
100 \\
91 \\
86\end{array}$ & $\begin{array}{r}0.67 \\
.66 \\
.67 \\
.68 \\
.66 \\
.65\end{array}$ & $\begin{array}{l}86 \\
84 \\
86 \\
89 \\
84 \\
81\end{array}$ & \multicolumn{4}{|l|}{ Aug. 12, } & $\begin{array}{r}0.86 \\
.96 \\
2.24\end{array}$ & $\begin{array}{r}39 \\
49 \\
263\end{array}$ \\
\hline
\end{tabular}

YADKIN RIVER A'T WILKESBORO, N. C.

Location.-Lat. $36^{\circ} 09^{\prime}$, long. $81^{\circ} 09^{\prime}$, at highway bridge connecting North Wilkesboro and Wilkesboro, Wilkes County, just downstream from Reddies River. Datum of gage is 942.35 feet above mean sea level, datum of 1929 , supplementary adjustment of 1936 .

Drainage area. - 493 square miles.

GAGE-HEIGHT RECORD.-Water-stage recorder graph except for periods 12 p.m. Aug. 13 to 12 m. Aug. 16, 12 p.m. Aug. 17 to 10 a.m. Aug. 18, and 9 a.m. to 7 p.m. Aug. 30. Graph for Aug. 13-16 completed from floodmark and information on time water receded to low point in highway and to bankful stage near station. Graph for Aug. 17-18 completed from floodmark. Graph for Aug. 30 completed from engineers' notes and records for stations at Patterson, Yadkin College, and Reddies River at North Wilkesboro.

DISCHARGE RECORD.- Stage-discharge relation defined by current-meter measurements up to 18,000 second-feet and extended to crest gage height on basis of the mean of two determinations of flood-flow by slope-area method. Shifting-control method used Sept. 2-30.

Maxima.-1940: Discharge, 160,000 second-feet about 3:30 a.m. Aug. 14 (gage height, 37.6 feet, from floodmarks).

1903-9, 1920-39: Discharge, 29,000 second-feet, revised, Oct. 2, 1929 (gage height, 24.0 feet, from graph based on gage readings).

The flood of July 1916 reached a stage of 34.5 feet, from flood reference mark cut in old steel highway bridge (discharge, 116,000 second-feet).

REMARKs.-Flood runoff not affected by artificial storage. 
Mean discharge, in second-feet, 1940

\begin{tabular}{|c|c|c|c|c|c|c|c|c|c|c|c|}
\hline Day & Aug. & Sept. & Day & Aug. & Sept. & Day & Aug. & Sept. & Day & Aug. & Sept. \\
\hline $\begin{array}{l}1 \\
2 \\
3 \\
4 \\
5 \\
6 \\
7 \\
8\end{array}$ & $\begin{array}{r}864 \\
480 \\
398 \\
370 \\
452 \\
458 \\
715 \\
1,060\end{array}$ & $\begin{array}{r}2,830 \\
1,820 \\
1,460 \\
1,220 \\
1,120 \\
1,050 \\
985 \\
920\end{array}$ & $\begin{array}{r}9 \\
10 \\
11 \\
12 \\
13 \\
14 \\
15 \\
16\end{array}$ & $\begin{array}{r}546 \\
420 \\
442 \\
1,160 \\
8,480 \\
66,900 \\
8,470 \\
3,450\end{array}$ & $\begin{array}{l}855 \\
842 \\
822 \\
777 \\
751 \\
725 \\
712 \\
686\end{array}$ & $\begin{array}{l}17 \\
18 \\
19 \\
20 \\
21 \\
22 \\
23 \\
24\end{array}$ & $\begin{array}{l}2,400 \\
3,150 \\
2,110 \\
1,570 \\
1,360 \\
1,260 \\
1,180 \\
1,080\end{array}$ & $\begin{array}{l}654 \\
642 \\
648 \\
630 \\
600 \\
582 \\
570 \\
564\end{array}$ & $\begin{array}{l}25 \\
26 \\
27 \\
28 \\
29 \\
30 \\
31\end{array}$ & $\begin{array}{r}1,050 \\
1,150 \\
985 \\
1,020 \\
855 \\
4,570 \\
8,310\end{array}$ & $\begin{array}{l}686 \\
624 \\
564 \\
552 \\
522 \\
516\end{array}$ \\
\hline \multicolumn{10}{|c|}{$\begin{array}{l}\text { Monthly mean discharge, in second-feet } \\
\text { Runoff, in inches }\end{array}$} & $\begin{array}{c}4,088 \\
9.56\end{array}$ & $\begin{array}{r}864 \\
1.95\end{array}$ \\
\hline
\end{tabular}

Gage height, in feet, and discharge, in second-feet, at indicated time, 1940

\begin{tabular}{|c|c|c|c|c|c|c|c|c|c|c|}
\hline \multirow{2}{*}{ Hour } & \multicolumn{2}{|c|}{ Aug. 11} & \multicolumn{2}{|c|}{ Aug. 12} & \multicolumn{2}{|c|}{ Aug. 13} & \multicolumn{2}{|c|}{ Aug. 14} & \multicolumn{2}{|c|}{ Aug. 15} \\
\hline & $\begin{array}{c}\text { Gage } \\
\text { height }\end{array}$ & $\begin{array}{l}\text { Dis- } \\
\text { charge }\end{array}$ & $\begin{array}{c}\text { Gage } \\
\text { height }\end{array}$ & $\begin{array}{l}\text { Dis- } \\
\text { charge }\end{array}$ & $\begin{array}{c}\text { Gage } \\
\text { height }\end{array}$ & $\begin{array}{l}\text { Dis- } \\
\text { charge }\end{array}$ & $\begin{array}{c}\text { Gage } \\
\text { height }\end{array}$ & $\begin{array}{l}\text { Dis- } \\
\text { charge }\end{array}$ & $\begin{array}{c}\text { Gage } \\
\text { height }\end{array}$ & $\begin{array}{l}\text { Dis- } \\
\text { charge }\end{array}$ \\
\hline 1 & & & & & 4.89 & 2.260 & 35.9 & 136,000 & 16.28 & 13.500 \\
\hline 2 & & & 2.24 & 447 & 3.82 & 2,180 & 37.0 & 151,000 & 15.75 & 12,900 \\
\hline 3 & & & & & 4.75 & 2,180 & 37.55 & 160,000 & $15: 15$ & 12,200 \\
\hline 4 & 2.16 & 403 & 2.27 & 464 & 4.77 & 2,180 & 37.55 & 160,000 & 14.70 & 11,700 \\
\hline 5 & $-\ldots--$ & $\ldots \ldots$ & & $\ldots \ldots$ & 5.12 & 2,400 & 37.0 & 151,000 & 14.17 & 11,100 \\
\hline 6 & $\ldots \ldots$ & $\ldots$ & 2.31 & 486 & 5.74 & 2,860 & 35.9 & 136,000 & 13.73 & 10,500 \\
\hline 7 & & & & & 6.33 & 3,330 & 34.1 & 111,000 & 13.29 & 10,100 \\
\hline 8 & 2.22 & 436 & 2.32 & 492 & 6.63 & 3,570 & 32.2 & 87,700 & 12.87 & 9,640 \\
\hline 9 & $\ldots-\ldots$ & $\ldots \ldots$ & $----\overline{0}=-$ & $=-\cdots$ & 6.93 & 3,820 & 30.4 & 69,600 & 12.50 & 9,200 \\
\hline 10 & $-\ldots-\ldots$ & $\ldots \ldots$ & 2.37 & 522 & 7.56 & 4,410 & 29.1 & 58,800 & 12.11 & 8,760 \\
\hline 11 & $--\overline{0}-\overline{7}$ & $---1--50^{-}$ & $--\overline{0}-\overline{1}$ & $-\cdots-\cdots \bar{c}-\overline{0}$ & 8.30 & 5,020 & 27.8 & 49,800 & 11.72 & 8,340 \\
\hline $\mathrm{N}$ & 2.27 & 464 & 2.61 & 666 & 9.00 & 5.650 & 26.5 & 42,000 & 11.35 & 8,020 \\
\hline 1 & - & - & & & 9.38 & 6,030 & 25.5 & 36,500 & 11.00 & 7,600 \\
\hline 2 & $---\ldots$ & $\ldots$ & 3.21 & 1,050 & 9.87 & 6,500 & 24.5 & 31,500 & 10.62 & 7,200 \\
\hline 3 & $--\overline{0} \overline{9}-$ & $460^{-}$ & $-\overline{3}-80$ & 540 & 10.52 & 7,100 & 23.5 & 27,000 & 10.28 & 6,900 \\
\hline $\begin{array}{l}4 \\
5\end{array}$ & $\begin{array}{c}2.28 \\
-\end{array}$ & $\begin{array}{c}469 \\
-\end{array}$ & 3.89 & 1,040 & $\begin{array}{l}11.52 \\
12.50\end{array}$ & $\begin{array}{l}8,120 \\
9,200\end{array}$ & $\begin{array}{l}22.55 \\
21.7\end{array}$ & $\begin{array}{l}23,800 \\
21,400\end{array}$ & $\begin{array}{r}10.00 \\
9.72\end{array}$ & $\begin{array}{l}6,600 \\
6,320\end{array}$ \\
\hline 6 & $-\ldots-\cdots$ & $---\ldots \ldots$ & 4.46 & 1,960 & 13.55 & 10,400 & 20.8 & 19,300 & 9.47 & 6,120 \\
\hline 7 & & & & & 14.43 & 11,300 & 20.05 & 18,000 & 9.18 & 5,840 \\
\hline 8 & 2.26 & 458 & 5.10 & 2,400 & 15.65 & 12,700 & 19.45 & 17,200 & 8.88 & 5,560 \\
\hline 9 & & $\ldots$ & ----- & & 16.90 & 14,200 & 18.8 & 16,500 & 8.67 & 5,380 \\
\hline 10 & $\ldots \ldots$ & ---- & 5.23 & 2,480 & 18.30 & 15,900 & 18.15 & 15,800 & 8.48 & 5,200 \\
\hline 11 & $-\overline{2}-\overline{3}$ & $-\cdots+-149^{-}$ & $-x^{4}$ & --5320 & & 18,200 & 17.55 & 15,100 & 8.32 & 5,020 \\
\hline 1 & L. & & 30 & 2,2 & 32 & 500 & & 200 & 8.09 & 4,840 \\
\hline
\end{tabular}

\begin{tabular}{|c|c|c|c|c|c|c|c|c|c|c|}
\hline & \multicolumn{2}{|c|}{ Aug. 16} & \multicolumn{2}{|c|}{ Aug. 17} & \multicolumn{2}{|c|}{ Aug. 18} & \multicolumn{2}{|c|}{ Aug. 19} & \multicolumn{2}{|c|}{ Aug. 20} \\
\hline 2 & 7.74 & 4,500 & 5.29 & 2,560 & 6.88 & 3,820 & & & & \\
\hline 4 & 7.33 & 4,160 & 5.19 & 2,480 & 6.85 & 3,730 & $-\cdots=-\cdots$ & 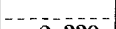 & & \\
\hline 6 & 7.00 & 3,900 & 5.11 & 2,400 & 6.69 & 3,650 & 5.00 & 2,330 & 4.06 & 1,640 \\
\hline 8 & 6.71 & 3,650 & 5.02 & 2,330 & 6.38 & 3,410 & $-\ldots . .$. & $\ldots \ldots$ & $\ldots \ldots$ & $\ldots \ldots$ \\
\hline 10 & 6.47 & 3,490 & 4.95 & 2,330 & 6.06 & 3,170 & 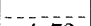 & -------- & ------ & $---\frac{1}{-150}$ \\
\hline $\mathbf{N}$ & 6.26 & 3,330 & 4.87 & 2,260 & 5.74 & 2,860 & 4.72 & 2,100 & 3.94 & 1,570 \\
\hline 2 & 6.13 & 3,170 & 4.82 & 2,180 & 5.49 & 2,700 & -- & $\ldots-\ldots-\ldots$ & $-\ldots$ & --- \\
\hline 4 & 5.89 & 3,010 & 4.75 & 2,180 & 5.48 & 2,700 & -- & ----7 & $--\bar{a}-\bar{c}$ & \\
\hline 6 & 5.77 & 2,930 & 4.72 & 2,100 & 6.10 & 3,170 & 4.44 & 1,880 & 3.85 & 1,500 \\
\hline 8 & 5.57 & 2,780 & 4.89 & 2,260 & 5.72 & 2,860 & $\ldots$ & - . - - - & $\ldots \ldots$ & $\ldots$ \\
\hline 10 & 5.52 & 2,700 & 5.35 & 2,630 & 5.41 & 2,630 & $\ldots-\overline{1}$ & $-\cdots-\overline{1}-$ & $-\overline{\mathbf{3}} \overline{\mathbf{7}}-\overline{-}$ & $-\cdots$ \\
\hline 12 & & 2 & & 3,650 & & 2,560 & 4.17 & 1,710 & 3.73 & 1,430 \\
\hline
\end{tabular}

SUPPlemental ReCoRds.-Aug, 12, 9:30 p.m, 5.27 feet, 2,560 second-feet; Aug, 14, 3:30 a.m., 37.6 feet, 160,000 second-feet; Aug. 16, 6:45 p.m., 5.35 feet, 2,630 second-feet; Aug. 18, 3 p.m., 5.40 feet. 2,630 second-feet.

YADKIN RIVER AT YADKIN COLLEGE, N. C.

Location.-Lat. $35^{\circ} 51^{\prime} 25^{\prime \prime}$, long. $80^{\circ} 23^{\prime} 25^{\prime \prime}$, at State highway bridge, $1 \frac{1}{2}$ miles south of Yadkin College, Davidson County, and $61 / 4$ miles downstream from Reedy Creek.

DRAINAGE AREA. $-2,280$ square miles.

GAGE-HEIGHT RECORD.-Water-stage recorder graph except for period Aug. 20-26. DISCHARGE RECORD. - Stage-discharge relation defined by current-meter measurements up to 71,000 second-feet for 1940 and up to 45,000 second-feet for 1929 . Gage 
heights used to half-tenths between 1.3 and 2.7 feet; hundredths below and tenths above these limits.

Maxima.-1940: Discharge, 80,200 second-feet 10:30 p.m. Aug. 15 (gage height, 33.75 feet).

1928-39: Discharge, 67,800 second-feet Oct. 3, 1929 (gage height, 29.8 feet).

Stage known, 35.0 feet sometime in July 1916, from floodmarks (discharge not determined).

REMARKs.-Flood runoff not affected by artificial storage.

Mean discharge, in second-feet, 1940

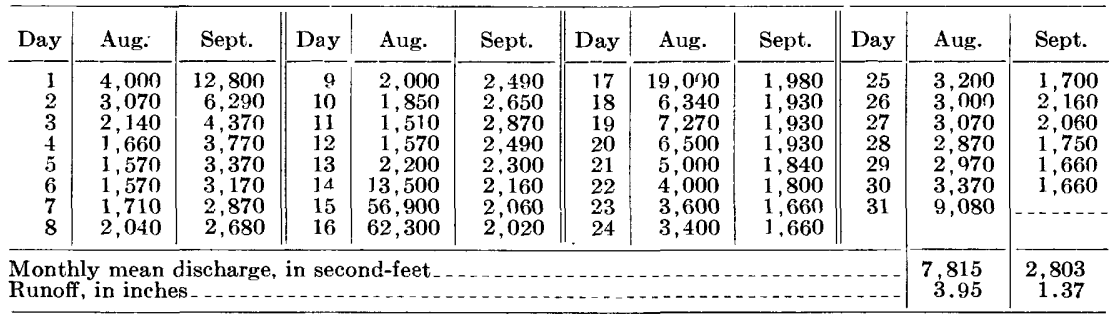

Gage height, in feet, and discharge, in second-feet, at indicated time, 1940

\begin{tabular}{|c|c|c|c|c|c|c|c|c|}
\hline \multirow{2}{*}{ Hour } & \multicolumn{2}{|c|}{ Aug. 13} & \multicolumn{2}{|c|}{ Aug. 14} & \multicolumn{2}{|c|}{ Aug. 15} & \multicolumn{2}{|c|}{ Aug. 16} \\
\hline & $\begin{array}{l}\text { Gage } \\
\text { height }\end{array}$ & Discharge & $\begin{array}{l}\text { Gage } \\
\text { height }\end{array}$ & Discharge & $\begin{array}{c}\text { Gage } \\
\text { height }\end{array}$ & Discharge & $\begin{array}{l}\text { Gage } \\
\text { height }\end{array}$ & Discharge \\
\hline $\begin{array}{r}2 \\
4 \\
6 \\
8 \\
10 \\
\mathrm{~N}\end{array}$ & $\begin{array}{l}1.95 \\
2.02 \\
2.14 \\
2.19 \\
2.17 \\
2.23\end{array}$ & $\begin{array}{l}1,850 \\
1,900 \\
2,040 \\
2,090 \\
2,040 \\
2,140\end{array}$ & $\begin{array}{r}4.45 \\
5.80 \\
7.50 \\
9.55 \\
11.80 \\
13.35\end{array}$ & $\begin{array}{r}4,270 \\
5,670 \\
7,450 \\
9,760 \\
12,400 \\
14,300\end{array}$ & $\begin{array}{l}20.10 \\
21.75 \\
23.65 \\
25.72 \\
27.55 \\
29.55\end{array}$ & $\begin{array}{l}26,800 \\
31,400 \\
37,100 \\
44,800 \\
52,400 \\
60,900\end{array}$ & $\begin{array}{l}33.45 \\
33.08 \\
32.52 \\
31.84 \\
31.08 \\
30.27\end{array}$ & $\begin{array}{l}78,200 \\
76,700 \\
74,000 \\
70,800 \\
67,600 \\
64,000\end{array}$ \\
\hline $\begin{array}{r}2 \\
4 \\
6 \\
8 \\
10 \\
12\end{array}$ & $\begin{array}{l}2.30 \\
2.37 \\
2.47 \\
2.56 \\
2.76 \\
3.30\end{array}$ & $\begin{array}{l}2,180 \\
2,230 \\
2,330 \\
2,420 \\
2,670 \\
3,170 \\
\end{array}$ & $\begin{array}{l}14.62 \\
15.69 \\
16.48 \\
17.12 \\
17.86 \\
18.89\end{array}$ & $\begin{array}{l}15,900 \\
17,600 \\
19,000 \\
20,100 \\
21,600 \\
23,800\end{array}$ & $\begin{array}{l}31.15 \\
32.35 \\
33.17 \\
33.60 \\
33.74 \\
33.70\end{array}$ & $\begin{array}{l}68,100 \\
73,500 \\
77,200 \\
79,200 \\
79,700 \\
79,700 \\
\end{array}$ & $\begin{array}{l}29.40 \\
28.45 \\
27.45 \\
26.35 \\
25.20 \\
24.00\end{array}$ & $\begin{array}{l}60,000 \\
55,600 \\
51,600 \\
47,600 \\
42,800 \\
38,500 \\
\end{array}$ \\
\hline
\end{tabular}

\begin{tabular}{|c|c|c|c|c|c|c|}
\hline \multirow{2}{*}{ Hour } & \multicolumn{2}{|c|}{ Aug. 17} & \multicolumn{2}{|c|}{ Aug. 18} & \multicolumn{2}{|c|}{ Aug. 19} \\
\hline & $\begin{array}{c}\text { Gage } \\
\text { height }\end{array}$ & Discharge & $\begin{array}{l}\text { Gage } \\
\text { height }\end{array}$ & Discharge & $\begin{array}{l}\text { Gage } \\
\text { height }\end{array}$ & Discharge \\
\hline 2 & 22.83 & 34,400 & & & & \\
\hline $\begin{array}{l}4 \\
6\end{array}$ & $\begin{array}{l}21.53 \\
20.13\end{array}$ & $\begin{array}{l}30,500 \\
26,800\end{array}$ & 7.12 & 6,980 & 6.97 & 6,870 \\
\hline 8 & 18.52 & 22,800 & 6.73 & 6,540 & 7.87 & 7,860 \\
\hline $\begin{array}{l}10 \\
N\end{array}$ & $\begin{array}{l}17.56 \\
16.58\end{array}$ & $\begin{array}{l}21,000 \\
19,200\end{array}$ & 6.43 & 6,210 & 8.18 & 8,190 \\
\hline 2 & 12.31 & 13,000 & & & & \\
\hline 4 & 10.58 & 10,900 & 6.14 & 5,880 & 7.68 & 7,640 \\
\hline $\begin{array}{l}0 \\
8\end{array}$ & $\begin{array}{l}9.48 \\
8.63\end{array}$ & $\begin{array}{l}9,620 \\
8,630\end{array}$ & 5.92 & 5,660 & 7.05 & $6,870^{-}$ \\
\hline $\begin{array}{l}10 \\
12\end{array}$ & $\begin{array}{l}8.07 \\
7.69\end{array}$ & $\begin{array}{l}8,080 \\
7,640\end{array}$ & 6.06 & $5, \overline{880}$ & 6.73 & 6,540 \\
\hline
\end{tabular}

SuPPLEMENTAL RECORD.-Aug. 15, 10:30 p.m., 33.75 feet; 80,200 second-feet.

YADKIN RIVER A'T HIGH ROCK RESERVOIR, A'T HIGH ROCK, N. C.

Location.-Lat. $35^{\circ} 35^{\prime} 50^{\prime \prime}$, long. $80^{\circ} 14^{\prime} 00^{\prime \prime}$, at High Rock Dam, half a mile west of High Rock, Davidson County, and 2 miles upstream from Lick Creek. Datum of gage is 31.32 feet below mean sea level, datum of 1929 .

Drainage ARea. - 3,980 square miles.

GAGE-HEIGHT RECORD.-WWater-stage recorder graph.

DISCHARGE RECORD.-Record of outflow based on formula established for similar 


\section{FLOODS OF AUGUST 1940 IN THE SOUTHEASTERN STATES}

gates and manufacturers' ratings for turbines. Record of inflow based on outflow and change in contents.

Maxima.-1940: Inflow, 85,835 second-feet 12 m. Aug. 16; outflow, 86,965 secondfeet 7 a.m. Aug. 16 (reservoir gage height, 654.29 feet); reservoir gage height, 655.00 feet 2 a.m. to 6 p.m. Aug. 19 (contents, 11,090,000,000 cubic feet).

1919-39: Outflow, 113,030 second-feet 7 a.m. Oct. 3, 1929 (reservoir gage height, 652.55 feet); inflow during same flood, 121,300 second-feet.

Stage known, 612.1 feet July 1916, from floodmarks at site of gaging station a quarter of a mile below High Rock Dam (discharge uncertain; flgure previously published believed to be too high).

Remarks.-Reservoir, first put into operation Nov: 7, 1927, has a total storage capacity of 11,090,000,000 eubic feet below 655.00 feet (top of gates) and a storage capacity under normal operation of 10,230,000,000 cubic feet. Records furnished by Aluminum Company of America.

High Rock Reservoir, gage height and contents at midnight and mean outflow, 1940

\begin{tabular}{|c|c|c|c|c|c|c|}
\hline \multirow{2}{*}{ Day } & \multicolumn{3}{|c|}{ August } & \multicolumn{3}{|c|}{ September } \\
\hline & $\begin{array}{c}\text { Gage } \\
\text { height } \\
\text { (feet) }\end{array}$ & $\begin{array}{l}\text { Contents } \\
\text { (million } \\
\text { cubic feet) }\end{array}$ & $\begin{array}{l}\text { Outflow } \\
\text { (second- } \\
\text { feet) }\end{array}$ & $\begin{array}{c}\text { Gage } \\
\text { height } \\
\text { (feet) }\end{array}$ & $\begin{array}{l}\text { Contents } \\
\text { (million } \\
\text { cubic feet) }\end{array}$ & $\begin{array}{l}\text { Outflow } \\
\text { (second- } \\
\text { feet) }\end{array}$ \\
\hline $\begin{array}{l}1 \\
2 \\
3 \\
4 \\
5\end{array}$ & $\begin{array}{l}650.33 \\
650.15 \\
650.25 \\
650.53 \\
650.10\end{array}$ & $\begin{array}{l}8,272 \\
8,172 \\
8,228 \\
8,382 \\
8,145\end{array}$ & $\begin{array}{r}4,556 \\
4,534 \\
1,836 \\
78 \\
4,640\end{array}$ & $\begin{array}{l}654.95 \\
654.98 \\
654.90 \\
654.83 \\
654.73\end{array}$ & $\begin{array}{l}11,058 \\
11,077 \\
11,025 \\
10,980 \\
10,914\end{array}$ & $\begin{array}{r}16,656 \\
7,762 \\
5,942 \\
4,608 \\
4,460\end{array}$ \\
\hline $\begin{array}{r}6 \\
7 \\
8 \\
9 \\
10\end{array}$ & $\begin{array}{l}649.65 \\
649.37 \\
649.10 \\
648.79 \\
648.85\end{array}$ & $\begin{array}{l}7,906 \\
7,759 \\
7,618 \\
7,459 \\
7,489\end{array}$ & $\begin{array}{l}4,625 \\
3,845 \\
3,845 \\
3,890 \\
1,901\end{array}$ & $\begin{array}{l}654.72 \\
654.65 \\
654.62 \\
654.26 \\
654.08\end{array}$ & $\begin{array}{l}10,908 \\
10,862 \\
10,843 \\
10,609 \\
10,492\end{array}$ & $\begin{array}{l}4,320 \\
4,022 \\
3,280 \\
5,665 \\
4,385\end{array}$ \\
\hline $\begin{array}{l}11 \\
12 \\
13 \\
14 \\
15\end{array}$ & $\begin{array}{l}649.13 \\
648.92 \\
648.57 \\
652.77 \\
654.30\end{array}$ & $\begin{array}{r}7,634 \\
7,524 \\
7,348 \\
9,677 \\
10,635\end{array}$ & $\begin{array}{r}0 \\
3,749 \\
4,923 \\
5,067 \\
42,477\end{array}$ & $\begin{array}{l}653.99 \\
653.76 \\
653.49 \\
653.40 \\
653.11\end{array}$ & $\begin{array}{r}10,434 \\
10,290 \\
10,122 \\
10,065 \\
9,884\end{array}$ & $\begin{array}{l}4,285 \\
4,255 \\
4,325 \\
3,145 \\
4,230\end{array}$ \\
\hline $\begin{array}{l}16 \\
17 \\
18 \\
19 \\
20\end{array}$ & $\begin{array}{l}654.46 \\
654.74 \\
654.98 \\
654.98 \\
654.86\end{array}$ & $\begin{array}{l}10,739 \\
10,921 \\
11,077 \\
11,077 \\
10,999\end{array}$ & $\begin{array}{r}77,920 \\
41,664 \\
7,208 \\
8,339 \\
7,043\end{array}$ & $\begin{array}{l}652.66 \\
652.35 \\
652.20 \\
652.01 \\
651.74\end{array}$ & $\begin{array}{l}9,611 \\
9,425 \\
9,335 \\
9,221 \\
9,065\end{array}$ & $\begin{array}{l}5,272 \\
4,257 \\
3,025 \\
3,280 \\
3,519\end{array}$ \\
\hline $\begin{array}{l}21 \\
22 \\
23 \\
24 \\
25\end{array}$ & $\begin{array}{l}654.88 \\
654.83 \\
654.76 \\
654.82 \\
654.90\end{array}$ & $\begin{array}{l}11,012 \\
10,980 \\
10,934 \\
10,973 \\
11,025\end{array}$ & $\begin{array}{l}7,645 \\
4,590 \\
4,480 \\
3,415 \\
2,855\end{array}$ & $\begin{array}{l}651.71 \\
652.00 \\
651.75 \\
651.46 \\
651.19\end{array}$ & $\begin{array}{l}9,048 \\
9,215 \\
9,071 \\
8,905 \\
8,749\end{array}$ & $\begin{array}{r}2,315 \\
0 \\
3,492 \\
3,670 \\
3,628\end{array}$ \\
\hline $\begin{array}{l}26 \\
27 \\
28 \\
29 \\
30 \\
31\end{array}$ & $\begin{array}{l}654.53 \\
654.40 \\
654.19 \\
654.00 \\
653.91 \\
654.66\end{array}$ & $\begin{array}{l}10,784 \\
10,700 \\
10,564 \\
10,440 \\
10,384 \\
10,869\end{array}$ & $\begin{array}{l}6,243 \\
4,582 \\
4,420 \\
4,475 \\
4,515 \\
3,880\end{array}$ & $\begin{array}{r}650.99 \\
650.80 \\
650.84 \\
651.10 \\
650.63 \\
-\end{array}$ & $\begin{array}{l}8,634 \\
8,530 \\
8,552 \\
8,698 \\
8,436\end{array}$ & $\begin{array}{r}3,300 \\
3,320 \\
1,800 \\
0 \\
4,590\end{array}$ \\
\hline & & & & & August & September \\
\hline \multicolumn{5}{|c|}{$\begin{array}{l}\text { Change in contents, equivalent, in second-feet } \\
\text { Monthly mean outflow, in second-feet } \\
\text { Monthly mean inflow, in second-feet } \\
\text { Runoff, depth in inches, corresponding to inflow }\end{array}$} & $\begin{array}{r}+986 \\
9,137 \\
10,123 \\
2.93\end{array}$ & $\begin{array}{r}-939 \\
4,227 \\
3,288 \\
.92\end{array}$ \\
\hline
\end{tabular}


High Rock Reservoir, gage height, contents, and mean inflow and outflow for preceding hour, at indicated time, 1940

\begin{tabular}{|c|c|c|c|c|c|c|c|c|}
\hline \multirow{2}{*}{ Hour } & \multicolumn{4}{|c|}{ Aug. 13} & \multicolumn{4}{|c|}{ Aug. 14} \\
\hline & $\begin{array}{c}\text { Gage } \\
\text { height } \\
\text { (feet) }\end{array}$ & $\begin{array}{c}\text { Contents } \\
\text { (million } \\
\text { cubic feet) }\end{array}$ & $\begin{array}{l}\text { Inflow } \\
\text { (second- } \\
\text { feet) }\end{array}$ & $\begin{array}{l}\text { Outflow } \\
\text { (second- } \\
\text { feet) }\end{array}$ & $\begin{array}{c}\text { Gage } \\
\text { height } \\
\text { (feet) }\end{array}$ & $\begin{array}{c}\text { Contents } \\
\text { (million } \\
\text { cubic feet) }\end{array}$ & $\begin{array}{l}\text { Inflow } \\
\text { (second- } \\
\text { feet) }\end{array}$ & $\begin{array}{l}\text { Outflow } \\
\text { (second- } \\
\text { feet) }\end{array}$ \\
\hline $\begin{array}{l}1 \\
2 \\
3 \\
4 \\
5 \\
5 \\
6\end{array}$ & - & $\begin{array}{l}-- \\
--- \\
--- \\
-- \\
--\end{array}$ & $\begin{array}{l}1,440 \\
1,440 \\
1,440 \\
2,880 \\
2,880 \\
1,440\end{array}$ & $\begin{array}{c}0 \\
0 \\
0 \\
0 \\
0 \\
0 \\
0\end{array}$ & 648.80 & \begin{tabular}{c}
$\mathbf{7}, \mathbf{4 6 4}$ \\
\hdashline$\overline{7}, 806$ \\
10
\end{tabular} & $\begin{array}{r}7,200 \\
8,640 \\
17,300 \\
40,300 \\
26,400 \\
29,300\end{array}$ & $\begin{array}{l}0 \\
0 \\
0 \\
0 \\
0 \\
0\end{array}$ \\
\hline $\begin{array}{r}7 \\
8 \\
9 \\
10 \\
11 \\
\mathrm{~N}\end{array}$ & - & & $\begin{array}{l}4,920 \\
5,130 \\
3,670 \\
2,230 \\
2,230 \\
3,180\end{array}$ & $\begin{array}{l}\mathbf{4}, 920 \\
6, \mathbf{5 7 0} \\
6, \mathbf{5 5 0} \\
6, \mathbf{5 5 0} \\
6, \mathbf{5 5 0} \\
\mathbf{7}, \mathbf{5 0 0}\end{array}$ & $\begin{array}{l}649.87^{--} \\
650.27\end{array}$ & $\begin{array}{c}8,02 \overline{2} \\
-\overline{8}, \overline{2} 3 \overline{8}^{-}\end{array}$ & $\begin{array}{l}25,240 \\
26,460 \\
27,850 \\
24,710 \\
30,210 \\
27,110\end{array}$ & $\begin{array}{l}4,740 \\
7,410 \\
7,350 \\
7,110 \\
7,110 \\
7,110\end{array}$ \\
\hline $\begin{array}{l}1 \\
2 \\
3 \\
4 \\
4 \\
5 \\
6\end{array}$ & & & $\begin{array}{l}3,180 \\
1,560 \\
120 \\
2,670 \\
3,000 \\
3,030\end{array}$ & $\begin{array}{l}7,500 \\
7,320 \\
7,320 \\
6,990 \\
7,320 \\
7,350\end{array}$ & $650.70^{-1}$ & $\begin{array}{c}8, \overline{4} \overline{5} \\
-8,8 \overline{3}\end{array}$ & $\begin{array}{l}31,810 \\
25,550 \\
30,150 \\
53,220 \\
41,920 \\
41,890\end{array}$ & $\begin{array}{l}7,110 \\
7,050 \\
7,050 \\
7,020 \\
7,020 \\
6,990\end{array}$ \\
\hline \multirow[t]{2}{*}{$\begin{array}{r}7 \\
8 \\
9 \\
10 \\
11 \\
12 \\
\end{array}$} & $\cdots$ & 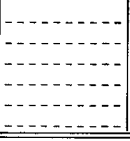 & $\begin{array}{l}1,590 \\
5,910 \\
3,030 \\
3,030 \\
5,310 \\
6,480 \\
\end{array}$ & $\begin{array}{l}\mathbf{7}, \mathbf{3 5 0} \\
7, \mathbf{3 5 0} \\
\mathbf{7}, \mathbf{3 5 0} \\
\mathbf{7}, \mathbf{3 5 0} \\
6,750 \\
\mathbf{3}, 600 \\
\end{array}$ & 652.06 & \begin{tabular}{|c|}
$-\overline{9}, \mathbf{2 5 1}$ \\
$-\overline{9}, \mathbf{6 7} \overline{7}^{-}$
\end{tabular} & $\begin{array}{l}40,290 \\
43,600 \\
36,140 \\
44,040 \\
45,740 \\
48,680 \\
\end{array}$ & $\begin{array}{l}6,990 \\
7,200 \\
7,640 \\
7,640 \\
7,640 \\
5,580 \\
\end{array}$ \\
\hline & \multicolumn{4}{|c|}{ Aug. 15} & \multicolumn{4}{|c|}{ Aug. 16} \\
\hline $\begin{array}{l}1 \\
2 \\
3 \\
4 \\
5 \\
5 \\
6\end{array}$ & $\begin{array}{c}653.24 \\
653.66 \\
654.06\end{array}$ & $\begin{array}{c}9,965 \\
10,228 \\
10,479^{-}\end{array}$ & $\begin{array}{l}43,330 \\
50,920 \\
43,980 \\
44,010 \\
43,950 \\
49,020\end{array}$ & $\begin{array}{r}6,930 \\
7,620 \\
7,680 \\
7,710 \\
7,650 \\
14,320\end{array}$ & $654.30^{--}$ & 10,635 & $\begin{array}{l}73,645 \\
76,185 \\
81,080 \\
80,095 \\
82,320 \\
84,495\end{array}$ & $\begin{array}{l}73,645 \\
76,185 \\
79,255 \\
80,095 \\
82,320 \\
86,320\end{array}$ \\
\hline $\begin{array}{r}7 \\
8 \\
9 \\
10 \\
11 \\
\mathrm{~N}\end{array}$ & $\begin{array}{l}654.22 \\
654.22 \\
654.22\end{array}$ & $\begin{array}{c}10,583 \\
10,583 \\
10,583\end{array}$ & $\begin{array}{l}32,420 \\
41,780 \\
43,880 \\
45,050 \\
45,050 \\
43,650\end{array}$ & $\begin{array}{l}16,020 \\
28,980 \\
43,880 \\
45,050 \\
45,050 \\
43,650\end{array}$ & 654.36 & $10,674^{-1}$ & $\begin{array}{l}85,140 \\
82,760 \\
81,750 \\
85,515 \\
84,835 \\
85,835\end{array}$ & $\begin{array}{l}86,965 \\
80,935 \\
79,925 \\
80,035 \\
83,010 \\
84,010\end{array}$ \\
\hline $\begin{array}{l}1 \\
2 \\
3 \\
4 \\
5 \\
6\end{array}$ & $\begin{array}{c}654.23 \\
654.23 \\
654.23\end{array}$ & $\begin{array}{c}10,590^{-} \\
10,590^{-} \\
10,590^{-1}\end{array}$ & $\begin{array}{l}45,630 \\
\mathbf{5 1}, \mathbf{5 7 5} \\
\mathbf{5 3}, 410 \\
\mathbf{5 3}, 890 \\
\mathbf{5 4}, \mathbf{8 3 0} \\
61,160\end{array}$ & $\begin{array}{l}45,630 \\
49,750 \\
53,410 \\
53,890 \\
54,830 \\
61,160\end{array}$ & 654.41 & $10,706^{-}$ & $\begin{array}{r}84,010 \\
80,035 \\
77,675 \\
80,970 \\
79,140 \\
79,875\end{array}$ & $\begin{array}{l}84,010 \\
80,035 \\
77,675 \\
75,490 \\
75,490 \\
79,875\end{array}$ \\
\hline $\begin{array}{r}7 \\
8 \\
9 \\
10 \\
11 \\
12 \\
\end{array}$ & $\begin{array}{l}654.23 \\
654.20^{-} \\
654.30^{-1}\end{array}$ & $\begin{array}{c}10,590^{-} \\
10,570^{-} \\
10,635 \\
\end{array}$ & $\begin{array}{l}63,985 \\
68,435 \\
66,610 \\
67,235 \\
74,595 \\
76,510 \\
\end{array}$ & $\begin{array}{l}62,160 \\
70,260 \\
70,260 \\
69,060 \\
65,465 \\
67,380 \\
\end{array}$ & 654.46 & $10, \mathbf{7} \overline{9}$ & $\begin{array}{l}76,975 \\
75,490 \\
72,970 \\
75,820 \\
69,570 \\
67,410 \\
\end{array}$ & $\begin{array}{l}78,800 \\
75,490 \\
72,970 \\
72,170 \\
65,920 \\
63,760 \\
\end{array}$ \\
\hline
\end{tabular}


186 FLOODS OF AUGUST 1940 IN THE SOUTHEASTERN STATES

High Rock Reservoir, gage height, contents, and mean inflow and outflow for preceding hour, at indicated time, 1940-Continued

\begin{tabular}{|c|c|c|c|c|c|c|c|c|}
\hline \multirow[b]{2}{*}{ Hour } & \multicolumn{4}{|c|}{ Aug. 17} & \multicolumn{4}{|c|}{ Aug. 18} \\
\hline & $\begin{array}{l}\text { Gage } \\
\text { height } \\
\text { (feet) }\end{array}$ & $\begin{array}{c}\text { Contents } \\
\text { (million } \\
\text { cubic feet) }\end{array}$ & $\begin{array}{l}\text { Inflow } \\
\text { (second- } \\
\text { feet) }\end{array}$ & $\begin{array}{l}\text { Outflow } \\
\text { (second- } \\
\text { feet) }\end{array}$ & $\begin{array}{l}\text { Gage } \\
\text { height } \\
\text { (feet) }\end{array}$ & $\begin{array}{c}\text { Contents } \\
\text { (million } \\
\text { cubic feet) }\end{array}$ & $\begin{array}{l}\text { Inflow } \\
\text { (second- } \\
\text { feet) }\end{array}$ & $\begin{array}{l}\text { Outflow } \\
\text { (second- } \\
\text { feet) }\end{array}$ \\
\hline $\begin{array}{l}1 \\
2 \\
3 \\
4 \\
5 \\
6\end{array}$ & $\mid \begin{array}{c}-\ldots \ldots \\
-6.5 \\
654.53\end{array}$ & $\mid$\begin{tabular}{c}
$\ldots \ldots$ \\
\hdashline 10,784
\end{tabular} & $\begin{array}{l}65,615 \\
66,925 \\
61,250 \\
63,165 \\
60,280 \\
56,510\end{array}$ & $\begin{array}{l}63,790 \\
65,100 \\
64,250 \\
61,340 \\
56,630 \\
52,860\end{array}$ & $\begin{array}{c}---1---- \\
------- \\
654.97\end{array}$ & $\begin{array}{c}\ldots \ldots \\
-11,070\end{array}$ & $\begin{array}{r}14,025 \\
12,850 \\
14,025 \\
12,080 \\
8,975 \\
15,040\end{array}$ & $\begin{array}{r}3,075 \\
1,900 \\
3,075 \\
6,600 \\
8,975 \\
11,390\end{array}$ \\
\hline $\begin{array}{r}7 \\
8 \\
9 \\
10 \\
11 \\
\mathrm{~N}\end{array}$ & $\mid$\begin{tabular}{c}
$-\cdots$ \\
\hdashline$-\ldots \ldots$ \\
\hdashline 654.60
\end{tabular} & $\mid$\begin{tabular}{c}
$-\ldots \ldots$ \\
\hdashline 10,830
\end{tabular} & $\begin{array}{l}54,560 \\
52,735 \\
50,910 \\
48,515 \\
45,440 \\
46,255\end{array}$ & $\begin{array}{l}50,910 \\
50,910 \\
50,910 \\
46,690 \\
43,615 \\
42,605\end{array}$ & 65 & $\mid$\begin{tabular}{c}
$-\cdots-\ldots$ \\
\hdashline$-\cdots$ \\
\hdashline$-11, \overline{0} 58$
\end{tabular} & $\begin{array}{r}7,810 \\
11,460 \\
10,365 \\
6,075 \\
8,465 \\
6,820\end{array}$ & $\begin{array}{r}11,460 \\
11,460 \\
10,365 \\
7,900 \\
6,640 \\
6,820\end{array}$ \\
\hline $\begin{array}{l}1 \\
2 \\
3 \\
4 \\
5 \\
6\end{array}$ & $\mid$\begin{tabular}{c}
$-\ldots$ \\
\hdashline-1. \\
\hdashline 654.61
\end{tabular} & $\mid$\begin{tabular}{c}
$-\ldots$ \\
\hdashline-1, \\
\hdashline 10,836
\end{tabular} & $\begin{array}{l}44,430 \\
40,780 \\
39,050 \\
34,330 \\
30,880 \\
32,705\end{array}$ & $\begin{array}{l}42,605 \\
42,605 \\
39,050 \\
34,330 \\
30,880 \\
30,880\end{array}$ & 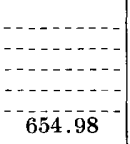 & $\mid$\begin{tabular}{c}
$-\cdots$ \\
\hdashline$-1 \overline{0}, \overline{7}$
\end{tabular} & $\begin{array}{r}7,180 \\
6,065 \\
9,010 \\
10,255 \\
8,430 \\
8,430\end{array}$ & $\begin{array}{l}7,180 \\
4,240 \\
7,185 \\
8,430 \\
8,430 \\
8,430\end{array}$ \\
\hline $\begin{array}{r}7 \\
8 \\
9 \\
10 \\
11 \\
12 \\
\end{array}$ & 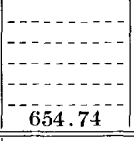 & \begin{tabular}{|c|}
$\ldots \ldots$ \\
\hdashline$\ldots$ \\
$10,92 \overline{1}$
\end{tabular} & $\begin{array}{l}30,305 \\
26,130 \\
25,605 \\
21,645 \\
20,025 \\
19,960 \\
\end{array}$ & $\begin{array}{r}28,480 \\
26,130 \\
23,780 \\
19,820 \\
12,725 \\
9,010 \\
\end{array}$ & 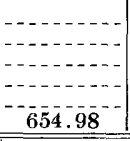 & $\mid$\begin{tabular}{|c|} 
\\
\hdashline \\
\hdashline
\end{tabular} & $\begin{array}{l}6,605 \\
8,415 \\
6,930 \\
5,450 \\
6,965 \\
4,380 \\
\end{array}$ & $\begin{array}{l}8,430 \\
8,415 \\
6,930 \\
5,450 \\
5,140 \\
4,380 \\
\end{array}$ \\
\hline & \multicolumn{4}{|c|}{ Aug. 19} & & & & \\
\hline $\begin{array}{l}1 \\
2 \\
3 \\
4 \\
5 \\
6\end{array}$ & $65 \overline{50}$ & $\mid$ & $\begin{array}{l}7,895 \\
7,895 \\
6,070 \\
6,070 \\
7,300 \\
7,300\end{array}$ & $\begin{array}{l}6,070 \\
6,070 \\
6,070 \\
6,070 \\
7,300 \\
7,300\end{array}$ & & & & \\
\hline $\begin{array}{r}7 \\
8 \\
9 \\
10 \\
11 \\
\mathrm{~N}\end{array}$ & $\mid$\begin{tabular}{c}
$-\ldots \ldots$ \\
\hdashline 655.00
\end{tabular} & $\mid$\begin{tabular}{c}
$\ldots$ \\
\hdashline$-1 \overline{0} 0$
\end{tabular} & $\begin{array}{l}5,415 \\
6,840 \\
8,005 \\
9,230 \\
9,230 \\
9,230\end{array}$ & $\begin{array}{l}5,415 \\
6,840 \\
8,005 \\
9,230 \\
9,230 \\
9,230\end{array}$ & . & & & \\
\hline $\begin{array}{l}1 \\
2 \\
3 \\
4 \\
5 \\
6\end{array}$ & $\mid \begin{array}{c}-\ldots \ldots \\
655.00\end{array}$ & (11,090 & $\begin{array}{r}9,230 \\
9,230 \\
9,230 \\
8,855 \\
11,060 \\
11,060\end{array}$ & $\begin{array}{r}9,230 \\
9,230 \\
9,230 \\
8,855 \\
11,060 \\
11,060\end{array}$ & & & & \\
\hline $\begin{array}{r}7 \\
8 \\
9 \\
10 \\
11 \\
12\end{array}$ & $\mid$\begin{tabular}{c}
$-\ldots-1$ \\
\hdashline-1, \\
\hdashline 654.98
\end{tabular} & $\mid$ & $\begin{array}{l}9,235 \\
8,590 \\
9,800 \\
8,820 \\
6,415 \\
7,275\end{array}$ & $\begin{array}{r}11,060 \\
10,415 \\
9,800 \\
8,820 \\
8,240 \\
5,450\end{array}$ & & & & \\
\hline
\end{tabular}

Note.-First flood gate opened between 5 and 6 a.m. Aug. 15 .

YADKIN RIVER A'T NARROWS RESERVOIR, NEAR BADIN, N. C.

Location.-Lat. $35^{\circ} 25^{\prime} 00^{\prime \prime}$, long. $80^{\circ} 05^{\prime} 30^{\prime \prime}$, at Narrows Dam, $1 \frac{1 / 2}{2}$ miles northeast of Badin, Stanly County, 21/2 miles upstream from Falls Dam, and 4 miles upstream from Uwharrie River. Datum of gage is 31.63 feet below mean sea level, datum of 1929 .

Drainage area.-4,160 square miles.

GAGE-HEIGHT RECORD.-Water-stage recorder graph.

Discharge RECORD.-Record of outflow based on formula established for similar spillways and gates and manufacturers' ratings for turbines.

Maxima.-1940: Daily mean outflow, 82,483 second-feet Aug. 16; reservoir gage 
height, 541.10 feet Aug. 18-20 (contents, 10,524,000,000 cubic feet).

1917-39: Discharge, 113,200 second-feet 7 a.m. Oct. 3, 1929 (reservoir gage height, 540 feet).

REMARKs.-Reservoir, first put in use Aug. 6, 1917, has a total storage capacity of $10,498,000,000$ cubic feet below 541.00 feet (top of gates) and a storage capacity under normal operation of $6,748,000,000$ cubic feet. River also affected by storage in High Rock Reservoir upstream having a storage capacity under normal operation of 10,230,000,000 cubic feet. Records furnished by Aluminum Company of America.

Narrows Reservoir, gage height and contents at midnight and mean outflow, 19.40

\begin{tabular}{|c|c|c|c|c|c|c|}
\hline \multirow{2}{*}{ Day } & \multicolumn{3}{|c|}{ August } & \multicolumn{3}{|c|}{ September } \\
\hline & $\begin{array}{c}\text { Gage } \\
\text { height } \\
\text { (feet) }\end{array}$ & $\begin{array}{l}\text { Contents } \\
\text { (million } \\
\text { cubic feet) }\end{array}$ & $\begin{array}{l}\text { Outflow } \\
\text { (second- } \\
\text { feet) }\end{array}$ & $\begin{array}{c}\text { Gage } \\
\text { height } \\
\text { (feet) }\end{array}$ & $\begin{array}{c}\text { Contents } \\
\text { (million } \\
\text { eubic feet) }\end{array}$ & $\begin{array}{l}\text { Outflow } \\
\text { (second- } \\
\text { feet) }\end{array}$ \\
\hline $\begin{array}{l}1 \\
2 \\
3 \\
4 \\
5\end{array}$ & $\begin{array}{l}533.75 \\
534.11 \\
534.21 \\
533.79 \\
533.76\end{array}$ & $\begin{array}{l}8,850 \\
8,929 \\
8,951 \\
8,859 \\
8,852\end{array}$ & $\begin{array}{l}3,578 \\
3,525 \\
1,830 \\
1,850 \\
3,562\end{array}$ & $\begin{array}{l}540.97 \\
541.10 \\
541.08 \\
540.94 \\
540.71\end{array}$ & $\begin{array}{l}10,492 \\
10,524 \\
10,519 \\
10,485 \\
10,432\end{array}$ & $\begin{array}{r}13,655 \\
8,833 \\
6,012 \\
5,010 \\
5,120\end{array}$ \\
\hline $\begin{array}{r}6 \\
7 \\
8 \\
9 \\
10\end{array}$ & $\begin{array}{l}534.12 \\
534.26 \\
534.23 \\
534.19 \\
534.28\end{array}$ & $\begin{array}{l}8,931 \\
8,962 \\
8,956 \\
8,947 \\
8,967\end{array}$ & $\begin{array}{l}3,865 \\
3,770 \\
3,860 \\
3,815 \\
1,874\end{array}$ & $\begin{array}{l}540.47 \\
540.36 \\
540.14 \\
540.36 \\
540.07\end{array}$ & $\begin{array}{l}10,375 \\
10,350 \\
10,297 \\
10,350 \\
10,281\end{array}$ & $\begin{array}{l}5,150 \\
4,175 \\
4,055 \\
4,890 \\
5,150\end{array}$ \\
\hline $\begin{array}{l}11 \\
12 \\
13 \\
14 \\
15\end{array}$ & $\begin{array}{l}533.84 \\
533.73 \\
534.47 \\
535.70 \\
539.00\end{array}$ & $\begin{array}{r}8,870 \\
8,846 \\
9,008 \\
9,282 \\
10,035\end{array}$ & $\begin{array}{r}1,840 \\
3,175 \\
2,969 \\
2,821 \\
28,042\end{array}$ & $\begin{array}{l}539.82 \\
539.47 \\
539.16 \\
538.72 \\
538.74\end{array}$ & $\begin{array}{r}10,224 \\
10,143 \\
10,072 \\
9,971 \\
9,975\end{array}$ & $\begin{array}{l}5,110 \\
5,200 \\
5,190 \\
4,530 \\
3,860\end{array}$ \\
\hline $\begin{array}{l}16 \\
17 \\
18 \\
19 \\
20\end{array}$ & $\begin{array}{l}539.92 \\
540.67 \\
541.10 \\
541.10 \\
541.10\end{array}$ & $\begin{array}{l}10,247 \\
10,422 \\
10,524 \\
10,524 \\
10,524\end{array}$ & $\begin{array}{r}82,483 \\
49,300 \\
7,137 \\
8,577 \\
7,322\end{array}$ & $\begin{array}{l}538.85 \\
538.53 \\
537.92 \\
537.36 \\
537.00\end{array}$ & $\begin{array}{r}10,000 \\
9,927 \\
9,787 \\
9,658 \\
9,575\end{array}$ & $\begin{array}{l}5,055 \\
5,350 \\
5,135 \\
4,655 \\
4,595\end{array}$ \\
\hline $\begin{array}{l}21 \\
22 \\
23 \\
24 \\
25\end{array}$ & $\begin{array}{l}541.05 \\
541.06 \\
540.95 \\
540.65 \\
540.26\end{array}$ & $\begin{array}{l}10,512 \\
10,514 \\
10,488 \\
10,418 \\
10,326\end{array}$ & $\begin{array}{l}5,181 \\
4,830 \\
4,940 \\
4,160 \\
4,250\end{array}$ & $\begin{array}{l}536.65 \\
535.66 \\
534.86 \\
534.56 \\
534.32\end{array}$ & $\begin{array}{l}9,496 \\
9,274 \\
9,094 \\
9,028 \\
8,975\end{array}$ & $\begin{array}{l}3,785 \\
3,270 \\
4,620 \\
4.495 \\
4,420\end{array}$ \\
\hline \multirow[t]{2}{*}{$\begin{array}{l}26 \\
27 \\
28 \\
29 \\
30 \\
31\end{array}$} & $\begin{array}{l}540.72 \\
540.64 \\
540.40 \\
540.22 \\
539.80 \\
539.84\end{array}$ & $\begin{array}{l}10,435 \\
10,415 \\
10,359 \\
10,317 \\
10,219 \\
10,228\end{array}$ & $\begin{array}{l}4,800 \\
5,120 \\
5,130 \\
5,195 \\
5,210 \\
4,405\end{array}$ & $\begin{array}{l}534.04 \\
533.90 \\
533.66 \\
532.92 \\
533.00 \\
\end{array}$ & $\begin{array}{l}8,914 \\
8,883 \\
8,830 \\
8,667 \\
8,685\end{array}$ & $\begin{array}{l}4,320 \\
3,705 \\
2,630 \\
2,520 \\
3,225\end{array}$ \\
\hline & & & & & August & September \\
\hline \multicolumn{5}{|c|}{$\begin{array}{l}\text { Change in contents, equivalent, in second-feet } \\
\text { Monthly mean outflow, in second-feet }\end{array}$} & $\begin{array}{r}+547 \\
8,981\end{array}$ & $\begin{array}{l}-595 \\
4,924\end{array}$ \\
\hline
\end{tabular}

PEE DEE RIVER A' ThLLEY RESERVOIR, NEAR NORWOOD, N. C.

Location.-Lat. $35^{\circ} 12^{\prime} 10^{\prime \prime}$, long. $80^{\circ} 03^{\prime} 10^{\prime \prime}$, in power plant at left end of Tillery Dam, an eighth of a mile above Norfolk Southern R. R. bridge, 4 miles east of Norwood, Stanly County, and $3 \%$ miles upstream from Rocky River. Datum of gage is 38.71 feet above mean sea level, datum of 1929 (levels by Corps of Engineers, War Department).

Drainage AREa.-4,600 square miles.

GAGE-HEIGHT RECORD.-Water-stage recorder graph.

DISCHARGE RECORD.-Record of outflow based on formula for gates and manufacturers' ratings for turbines. 


\section{8}

FLOODS OF AUGUST 1940 IN THE SOUTHEASTERN STATES

Maxima.-1940: Daily mean outflow, 83,800 second-feet Aug. 16; reservoir gage height, 241.3 feet, 5-9 p.m. Aug. 17 (contents, estimated, 6,400,000,000 eubic feet).

1896-99: Discharge (not determined) about Mar. 20, 1899; gage washed out. REMARKs.-Reservoir, first put in use in 1928, has a total usable eapacity of 5,960,000,000 cubic feet between 200.5 feet (minimum draw-down) and 239.5 feet (top of spill gates) and a storage capacity under normal operation of 360,000,000 cubic feet above 238.0 feet. River also affected by storage in High Rock and Narrows Reservoirs upstream having a combined storage capacity under normal operation of $16,978,000,000$ cubic feet. A small reservoir of unknown capacity at Falls Dam, a short distance below Narrows Dam, affects the stream only slightly. Basic data furnished by Carolina Power \& Light Co.

Tillery Reservoir, gage height and contents at midnight and mean outflow, 1940

\begin{tabular}{|c|c|c|c|c|c|c|}
\hline \multirow{2}{*}{ Day } & \multicolumn{3}{|c|}{ August } & \multicolumn{3}{|c|}{ September } \\
\hline & $\begin{array}{c}\text { Gage } \\
\text { height } \\
\text { (feet) }\end{array}$ & $\begin{array}{c}\text { Contents } \\
\text { (million } \\
\text { cubic feet) }\end{array}$ & $\begin{array}{l}\text { Outflow } \\
\text { (second- } \\
\text { feet) }\end{array}$ & $\begin{array}{l}\text { Gage } \\
\text { height } \\
\text { (feet) }\end{array}$ & $\begin{array}{c}\text { Contents } \\
\text { (million } \\
\text { cubic feet) }\end{array}$ & $\begin{array}{l}\text { Outflow } \\
\text { (second- } \\
\text { feet) }\end{array}$ \\
\hline $\begin{array}{l}1 \\
2 \\
3 \\
4 \\
5\end{array}$ & $\begin{array}{l}236.5 \\
236.4 \\
237.1 \\
237.7 \\
237.4\end{array}$ & $\begin{array}{l}5.270 \\
5,248 \\
5,402 \\
5,534 \\
5,468\end{array}$ & $\begin{array}{r}4,060 \\
3,610 \\
139 \\
370 \\
4,210\end{array}$ & $\begin{array}{l}239.4 \\
238.7 \\
236.8 \\
236.8 \\
236.9\end{array}$ & $\begin{array}{l}\mathbf{5}, 934 \\
5,758 \\
5,336 \\
5,336 \\
5,358\end{array}$ & $\begin{array}{r}10,100 \\
10,600 \\
11,200 \\
5,020 \\
4,950\end{array}$ \\
\hline $\begin{array}{r}6 \\
7 \\
8 \\
9 \\
10\end{array}$ & $\begin{array}{l}236.9 \\
236.9 \\
237.3 \\
237.9 \\
238.6\end{array}$ & $\begin{array}{l}5,358 \\
5,358 \\
5,446 \\
5,578 \\
5,734\end{array}$ & $\begin{array}{r}4,990 \\
3,600 \\
2,800 \\
2,300 \\
231\end{array}$ & $\begin{array}{l}237.1 \\
236.6 \\
237.1 \\
237.3 \\
237.2\end{array}$ & $\begin{array}{l}5,402 \\
5,292 \\
5,402 \\
5,446 \\
5,424\end{array}$ & $\begin{array}{l}4,840 \\
5,450 \\
2,660 \\
4,260 \\
5,500\end{array}$ \\
\hline $\begin{array}{l}11 \\
12 \\
13 \\
14 \\
15\end{array}$ & $\begin{array}{l}238.7 \\
238.4 \\
237.5 \\
236.6 \\
238.9\end{array}$ & $\begin{array}{l}5,758 \\
5,688 \\
5,490 \\
5,292 \\
5,806\end{array}$ & $\begin{array}{r}1,850 \\
4,310 \\
5,320 \\
6,700 \\
30,000\end{array}$ & $\begin{array}{l}237.2 \\
237.4 \\
237.4 \\
237.0 \\
238.4\end{array}$ & $\begin{array}{l}5,424 \\
5,468 \\
5,468 \\
5,380 \\
5,688\end{array}$ & $\begin{array}{l}5,030 \\
4,640 \\
5,100 \\
5,640 \\
324\end{array}$ \\
\hline $\begin{array}{l}16 \\
17 \\
18 \\
19 \\
20\end{array}$ & $\begin{array}{l}240.8 \\
240.7 \\
239.2 \\
239.5 \\
239.2\end{array}$ & $\begin{array}{r}16,275 \\
16,250 \\
5,882 \\
5,960 \\
5,882\end{array}$ & $\begin{array}{r}83,800 \\
53,100 \\
12,200 \\
8,090 \\
8,920\end{array}$ & $\begin{array}{l}238.4 \\
238.3 \\
238.6 \\
238.5 \\
237.8\end{array}$ & $\begin{array}{l}5,688 \\
5,666 \\
5,734 \\
5,710 \\
5,556\end{array}$ & $\begin{array}{l}4,830 \\
5,640 \\
4,090 \\
5,030 \\
6,230\end{array}$ \\
\hline $\begin{array}{l}21 \\
22 \\
23 \\
24 \\
25\end{array}$ & $\begin{array}{l}238.1 \\
236.5 \\
236.7 \\
237.6 \\
238.2\end{array}$ & $\begin{array}{l}5,622 \\
5,270 \\
5,314 \\
5,512 \\
5,644\end{array}$ & $\begin{array}{l}7,930 \\
8,600 \\
4,330 \\
2,120 \\
2,790\end{array}$ & $\begin{array}{l}238.2 \\
238.3 \\
238.0 \\
237.5 \\
238.0\end{array}$ & $\begin{array}{l}5,644 \\
5,666 \\
5,600 \\
5,490 \\
5,600\end{array}$ & $\begin{array}{l}2,860 \\
3,010 \\
5,370 \\
5,730 \\
3,220\end{array}$ \\
\hline $\begin{array}{l}26 \\
27 \\
28 \\
29 \\
30 \\
31\end{array}$ & $\begin{array}{l}238.0 \\
238.1 \\
238.2 \\
238.2 \\
238.3 \\
237.9\end{array}$ & $\begin{array}{l}5,600 \\
5,622 \\
5,644 \\
5,644 \\
5,666 \\
5,578\end{array}$ & $\begin{array}{l}\mathbf{5}, 300 \\
4,720 \\
4,770 \\
5,080 \\
5,420 \\
5,530\end{array}$ & $\begin{array}{l}238.4 \\
238.2 \\
238.5 \\
238.6 \\
238.1\end{array}$ & $\begin{array}{l}5,688 \\
5,644 \\
5,710 \\
5,734 \\
5,622\end{array}$ & $\begin{array}{l}2,960 \\
4,090 \\
1,910 \\
2,090 \\
4,250 \\
\end{array}$ \\
\hline \multirow{2}{*}{\multicolumn{5}{|c|}{$\begin{array}{l}\text { Change in contents, equivalent, in second-feet } \\
\text { Monthly mean outflow, in second-feet }\end{array}$}} & August & September \\
\hline & & & & & $\begin{array}{r}+99 \\
9,590\end{array}$ & $\begin{array}{r}+17 \\
4,890\end{array}$ \\
\hline
\end{tabular}

1 Approximate contents.

Supplemental RECORD.-July 31 midnight, gage height, 236.7 feet; contents, 5,314 million cubic feet. 
PEE DEE RIVER BASIN

Tillery Reservoir, gage height and comtents at indicated time, 1940

\begin{tabular}{|c|c|c|c|c|c|c|}
\hline \multirow{2}{*}{ Hour } & \multicolumn{2}{|c|}{ Aug. 14} & \multicolumn{2}{|c|}{ Aug. 15} & \multicolumn{2}{|c|}{ Aug. 16} \\
\hline & $\begin{array}{l}\text { Gage } \\
\text { height } \\
\text { (feet) }\end{array}$ & $\begin{array}{l}\text { Contents } \\
\text { (million } \\
\text { cubic feet) }\end{array}$ & $\begin{array}{l}\text { Gage } \\
\text { height } \\
\text { (feet) }\end{array}$ & $\begin{array}{l}\text { Contents } \\
\text { (million } \\
\text { cubic feet) }\end{array}$ & $\begin{array}{l}\text { Gage } \\
\text { height } \\
\text { (feet) }\end{array}$ & $\begin{array}{l}\text { Contents } \\
\text { (million } \\
\text { cubic feet) }\end{array}$ \\
\hline $\begin{array}{l}1 \\
2 \\
3 \\
4 \\
5 \\
6\end{array}$ & $\begin{array}{l}237.5 \\
237.5 \\
237.5 \\
237.5 \\
237.5 \\
237.6\end{array}$ & $\begin{array}{l}5,490 \\
5,490 \\
5,490 \\
5,490 \\
5,490 \\
5,512\end{array}$ & $\begin{array}{l}236.6 \\
236.6 \\
236.7 \\
236.7 \\
236.8 \\
236.9\end{array}$ & $\begin{array}{l}5,292 \\
5,292 \\
5,314 \\
5,314 \\
5,336 \\
5,358\end{array}$ & $\begin{array}{l}239.1 \\
239.1 \\
239.2 \\
239.3 \\
239.4 \\
239.5\end{array}$ & $\begin{array}{l}\mathbf{5}, \mathbf{8 5 6} \\
\mathbf{5}, \mathbf{8 5 6} \\
\mathbf{5}, \mathbf{8 8 2} \\
\mathbf{5}, \mathbf{9 0 8} \\
\mathbf{5}, \mathbf{9 3 4} \\
\mathbf{5}, 960\end{array}$ \\
\hline $\begin{array}{r}7 \\
8 \\
9 \\
10 \\
11 \\
\mathrm{~N}\end{array}$ & $\begin{array}{l}237.6 \\
237.6 \\
237.5 \\
237.4 \\
237.4 \\
237.3\end{array}$ & $\begin{array}{l}5,512 \\
5,512 \\
5,490 \\
5,468 \\
5,468 \\
5,446\end{array}$ & $\begin{array}{l}236.9 \\
236.9 \\
237.0 \\
237.2 \\
237.5 \\
237.6\end{array}$ & $\begin{array}{l}5,358 \\
5,358 \\
5,380 \\
5,424 \\
5,490 \\
5,512\end{array}$ & $\begin{array}{l}239.6 \\
239.7 \\
239.8 \\
239.9 \\
240.0 \\
240.1\end{array}$ & $\begin{array}{r}15,980 \\
6,000 \\
6,025 \\
6,050 \\
6,075 \\
{ }^{1} 6,075 \\
{ }^{1} 6,100\end{array}$ \\
\hline $\begin{array}{l}1 \\
2 \\
3 \\
4 \\
5 \\
6\end{array}$ & $\begin{array}{l}237 \cdot 2 \\
237 \cdot 2 \\
237 \cdot 1 \\
237.0 \\
237.0 \\
236.9\end{array}$ & $\begin{array}{l}5,424 \\
5,424 \\
5,402 \\
5,380 \\
5,380 \\
5,358\end{array}$ & $\begin{array}{l}237.8 \\
237.9 \\
238.0 \\
238.1 \\
238.2 \\
238.2\end{array}$ & $\begin{array}{l}5,556 \\
5,578 \\
5,600 \\
5,622 \\
5,644 \\
5,644\end{array}$ & $\begin{array}{l}240.2 \\
240.2 \\
240.3 \\
240.4 \\
240.4 \\
240.4\end{array}$ & $\begin{array}{r}6,125 \\
16,125 \\
16,150 \\
{ }^{1} 6,175 \\
{ }^{1} 6,175 \\
16,175\end{array}$ \\
\hline \multirow[t]{2}{*}{$\begin{array}{r}7 \\
8 \\
9 \\
10 \\
11 \\
12 \\
\end{array}$} & $\begin{array}{l}236.8 \\
236.8 \\
236.8 \\
236.7 \\
236.7 \\
236.6 \\
\end{array}$ & $\begin{array}{l}\mathbf{5}, 336 \\
\mathbf{5}, \mathbf{3 3 6} \\
\mathbf{5}, \mathbf{3 3 6} \\
\mathbf{5}, \mathbf{3 1 4} \\
\mathbf{5}, \mathbf{3 1 4} \\
\mathbf{5}, \mathbf{2 9 2} \\
\end{array}$ & $\begin{array}{l}238.3 \\
238.4 \\
238.6 \\
238.7 \\
238.8 \\
238.9 \\
\end{array}$ & $\begin{array}{l}5,666 \\
5,688 \\
5,734 \\
5,758 \\
5,782 \\
5,806 \\
\end{array}$ & $\begin{array}{l}240.5 \\
240.6 \\
240.6 \\
240.7 \\
240.8 \\
240.8 \\
\end{array}$ & $\begin{array}{r}16,200 \\
{ }^{1} 6,225 \\
16,225 \\
16,250 \\
16,275 \\
16,275 \\
\end{array}$ \\
\hline & \multicolumn{2}{|c|}{ Aug. 17} & \multicolumn{2}{|c|}{ Aug. 18} & \multicolumn{2}{|c|}{ Aug. 19} \\
\hline $\begin{array}{l}1 \\
2 \\
3 \\
4 \\
5 \\
6\end{array}$ & $\begin{array}{l}240.9 \\
240.9 \\
240.9 \\
241.0 \\
241.0 \\
241.1\end{array}$ & $\begin{array}{c}16,300 \\
16,300 \\
16,300 \\
16,325 \\
{ }^{1} 6,325 \\
16,350\end{array}$ & $\begin{array}{l}240.6 \\
240.3 \\
240.2 \\
239.9 \\
239.7 \\
239.5\end{array}$ & $\begin{array}{r}16,225 \\
16,150 \\
16,125 \\
16,050 \\
16,000 \\
5,960\end{array}$ & $\begin{array}{l}239.2 \\
239.2 \\
239.3 \\
239.3 \\
239.3 \\
239.3\end{array}$ & $\begin{array}{l}5,882 \\
5,882 \\
5,908 \\
5,908 \\
5,908 \\
5,908\end{array}$ \\
\hline $\begin{array}{r}7 \\
8 \\
9 \\
10 \\
11 \\
\mathrm{~N}\end{array}$ & $\begin{array}{l}241.1 \\
241.1 \\
241.1 \\
241.1 \\
241.1 \\
241.1\end{array}$ & $\begin{array}{r}16,350 \\
16,350 \\
{ }^{1} 6,350 \\
{ }^{1} 6,350 \\
{ }^{1} 6,350 \\
16,350\end{array}$ & $\begin{array}{l}239.4 \\
239.3 \\
239.3 \\
239.4 \\
239.4 \\
239.4\end{array}$ & $\begin{array}{l}5,934 \\
5,908 \\
5,908 \\
5,934 \\
5,934 \\
5,934\end{array}$ & $\begin{array}{l}239.3 \\
239.3 \\
239.3 \\
239.3 \\
239.3 \\
239.3\end{array}$ & $\begin{array}{l}\mathbf{5}, 908 \\
\mathbf{5}, 908 \\
\mathbf{5}, 908 \\
\mathbf{5}, 908 \\
\mathbf{5}, 908 \\
\mathbf{5}, 908\end{array}$ \\
\hline $\begin{array}{l}1 \\
2 \\
3 \\
4 \\
5 \\
6\end{array}$ & $\begin{array}{l}241.1 \\
241.1 \\
241.1 \\
241.1 \\
241.3 \\
241.3\end{array}$ & $\begin{array}{r}16,350 \\
16,350 \\
16,350 \\
{ }^{1} 6,350 \\
{ }^{1} 6,400 \\
{ }^{1} 6,400\end{array}$ & $\begin{array}{l}239.4 \\
239.5 \\
239.4 \\
239.4 \\
239.3 \\
239.3\end{array}$ & $\begin{array}{l}5,934 \\
5,960 \\
5,934 \\
5,934 \\
5,908 \\
5,908\end{array}$ & $\begin{array}{l}239.3 \\
239.3 \\
239.3 \\
239.3 \\
239.3 \\
239.4\end{array}$ & $\begin{array}{l}5,908 \\
5,908 \\
5,908 \\
5,908 \\
5,908 \\
5,934\end{array}$ \\
\hline $\begin{array}{r}7 \\
8 \\
9 \\
10 \\
11 \\
12 \\
\end{array}$ & $\begin{array}{l}241.3 \\
241.3 \\
241.3 \\
241.1 \\
240.9 \\
240.7 \\
\end{array}$ & $\begin{array}{l}16,400 \\
16,400 \\
16,400 \\
16,350 \\
16,300 \\
16,250\end{array}$ & $\begin{array}{l}239.3 \\
239.3 \\
239.4 \\
239.3 \\
239.3 \\
239.2 \\
\end{array}$ & $\begin{array}{l}5,908 \\
5,908 \\
5,934 \\
5,908 \\
5,908 \\
5,882 \\
\end{array}$ & $\begin{array}{l}239.4 \\
239.4 \\
239.4 \\
239.4 \\
239.5 \\
239.5 \\
\end{array}$ & $\begin{array}{l}5,934 \\
5,934 \\
5,934 \\
5,934 \\
5,960 \\
5,960\end{array}$ \\
\hline
\end{tabular}

1 Approximate contents.

PEE DEE RIVER NEAR ANSONVILLE, N. C.

Location.-Lat. $35^{\circ} 05^{\prime} 25^{\prime \prime}$, long. $79^{\circ} 59^{\prime} 55^{\prime \prime}$, in bridge pier on State Highway 109,1 mile downstream from Brown Creek and 6 miles east of Ansonville, Anson County.

DRAINAGE AREA.-6,330 square miles.

GAGE-HEIGHT RECORD.-Water-stage recorder graph.

DISCHARGE RECORD. - Stage-discharge relation defined by current-meter measurements up to 73,000 second-feet. Discharge for periods of changing stage were computed using rate of change of stage as a factor where necessary.

MAXima.-1940: Discharge, 78,700 second-feet 11 p.m. Aug. 16 (gage height, 28.20

- feet); gage height, 28.27 feet 1 a.m. Aug. 17. 
1938-39: Discharge, 67,600 second-feet Mar. 1, 1939 (gage height, 26.26 feet).

Stage known, 41.3 feet sometime in 1908, from State Highway Department records (discharge not determined). State Highway Department records also give 37.3 feet for flood of Sept. 19, 1928, and 31.3 feet for flood of March 1929 (discharges not determined).

Remarks.-Flow affected by storage in High Rock, Narrows, and Tillery Reservoirs (combined storage capacity under normal operation, 17,338,000,000 cubic feet). Large diurnal fluctuation caused by power plant above station.

Mean discharge, in second-feet, 1940

\begin{tabular}{r|r|r||r|r|r||r|r|r|r|r|r}
\hline Day & Aug. & Sept. & Day & Aug. & Sept. & Day & Aug. & Sept. & Day & Aug. & Sept. \\
\hline 1 & 4,980 & 8,220 & 9 & 2,410 & 4,090 & 17 & 64,900 & 5,790 & 25 & 2,820 & 4,820 \\
2 & 3,900 & 12,700 & 10 & 972 & 4,980 & 18 & 20,400 & 4,060 & 26 & 4,630 & 2,040 \\
3 & 1,070 & 12,600 & 11 & 1,180 & 5,900 & 19 & 8,440 & 5,030 & 27 & 4,840 & 4,140 \\
4 & 460 & 6,720 & 12 & 4,160 & 4,820 & 20 & 9,510 & 6,070 & 28 & 5,070 & 2,800 \\
5 & 2,880 & 5,010 & 13 & 7,280 & 5,260 & 21 & 8,070 & 4,210 & 29 & 5,340 & 1,710 \\
6 & 5,310 & 5,050 & 14 & 11,900 & 5,390 & 22 & 8,980 & 2,480 & 30 & 5,400 & 3,410 \\
7 & 3,810 & 5,020 & 15 & 27,600 & 1,850 & 23 & 5,910 & 4,290 & 31 & 5,890 & $-\cdots$ \\
8 & 3,100 & 4,220 & 16 & 71,300 & 3,500 & 24 & 2,670 & 6,050 & & \\
\hline
\end{tabular}

Gage height, in feet, ant discharge, in second-feet, at indicated time, 1940

\begin{tabular}{|c|c|c|c|c|c|c|c|c|c|c|}
\hline \multirow{2}{*}{ Hour } & \multicolumn{2}{|c|}{ Aug. 11} & \multicolumn{2}{|c|}{ Aug. 12} & \multicolumn{2}{|c|}{ Aug. 13} & \multicolumn{2}{|c|}{ Aug. 14} & \multicolumn{2}{|c|}{ Aug. 15} \\
\hline & $\begin{array}{l}\text { Gage } \\
\text { height }\end{array}$ & $\begin{array}{c}\text { Dis- } \\
\text { charge }\end{array}$ & $\begin{array}{c}\text { Gage } \\
\text { height }\end{array}$ & $\begin{array}{c}\text { Dis- } \\
\text { oharge }\end{array}$ & $\begin{array}{c}\text { Gage } \\
\text { height }\end{array}$ & $\begin{array}{c}\text { Dis- } \\
\text { charge }\end{array}$ & $\begin{array}{c}\text { Gage } \\
\text { height }\end{array}$ & $\begin{array}{c}\text { Dis- } \\
\text { charge }\end{array}$ & $\begin{array}{c}\text { Gage } \\
\text { height }\end{array}$ & $\begin{array}{c}\text { Dis- } \\
\text { charge }\end{array}$ \\
\hline \multirow{5}{*}{$\begin{array}{l}1 \\
2 \\
3 \\
4 \\
5 \\
6\end{array}$} & \multirow{5}{*}{$\begin{array}{l}5.29 \\
5.29 \\
5.32 \\
5.42 \\
5.54 \\
5.57\end{array}$} & \multirow{5}{*}{$\begin{array}{r}312 \\
294 \\
344 \\
471 \\
516 \\
513\end{array}$} & \multirow{5}{*}{$\begin{array}{l}7.97 \\
7.98 \\
7.80 \\
7.53 \\
7.23 \\
6.98\end{array}$} & \multirow{5}{*}{$\begin{array}{l}3,040 \\
2,860 \\
2,370 \\
1,970 \\
1,600 \\
1,370\end{array}$} & & & & & & \\
\hline & & & & & 11.47 & 8,700 & 10.78 & 7,560 & 14.73 & 16,800 \\
\hline & & & & & 10.68 & 6,900 & 10.19 & 5,960 & 14.22 & 15,200 \\
\hline & & & & & 9.95 & 5.750 & 946 & 0 & 369 & 14100 \\
\hline & & & & & & & & & & \\
\hline \multirow{4}{*}{$\begin{array}{r}7 \\
8 \\
9 \\
10 \\
11 \\
\mathrm{~N}\end{array}$} & \multirow{4}{*}{$\begin{array}{l}5.54 \\
5.50 \\
5.44 \\
5.40 \\
5.33 \\
5.29\end{array}$} & \multirow{4}{*}{$\begin{array}{l}468 \\
420 \\
368 \\
336 \\
287 \\
270\end{array}$} & \multirow{4}{*}{$\begin{array}{l}6.76 \\
6.56 \\
6.40 \\
6.25 \\
6.10 \\
5.99\end{array}$} & \multirow{4}{*}{$\begin{array}{r}1,180 \\
1,050 \\
966 \\
866 \\
773 \\
764\end{array}$} & & & 3 & & 326 & \\
\hline & & & & & & & & & & 00 \\
\hline & & & & & 9.28 & 5,320 & 10.30 & 8,610 & 13.80 & 16,400 \\
\hline & & & & & 9.97 & 6,890 & 12.40 & 13,100 & 14.85 & 19,800 \\
\hline \multirow{4}{*}{$\begin{array}{l}1 \\
2 \\
3 \\
4 \\
5 \\
6\end{array}$} & \multirow{4}{*}{$\begin{array}{l}5.24 \\
5.25 \\
6.40 \\
7.33 \\
7.80 \\
7.88\end{array}$} & \multirow{4}{*}{$\begin{array}{r}243 \\
618 \\
2,070 \\
2,800 \\
3,010 \\
2,830\end{array}$} & \multirow{4}{*}{$\begin{array}{r}6.90 \\
8.25 \\
9.04 \\
9.42 \\
9.76 \\
10.12\end{array}$} & \multirow{4}{*}{$\begin{array}{l}2,860 \\
4,470 \\
5,290 \\
5,710 \\
6,490 \\
7,100\end{array}$} & & & & & & \\
\hline & & & & & 10.78 & 8,500 & 13.40 & 15,000 & 16.86 & 27,800 \\
\hline & & & & & 10.92 & 7,910 & 14.10 & 16,900 & 18.46 & $3 \overline{3}, 000$ \\
\hline & & & & & 10.82 & 7,870 & 14.52 & 17,500 & 20.10 & 39,300 \\
\hline \multirow{5}{*}{$\begin{array}{r}7 \\
8 \\
9 \\
10 \\
11 \\
12 \\
\end{array}$} & \multirow{4}{*}{$\begin{array}{l}7.72 \\
7.50 \\
7.31 \\
7.28 \\
7.36 \\
7.70\end{array}$} & \multirow{4}{*}{$\begin{array}{l}2,270 \\
2,010 \\
1,890 \\
2,030 \\
2,320 \\
2,960\end{array}$} & & \multirow{4}{*}{$\begin{array}{l}7,580 \\
8,050 \\
8,390 \\
8,910 \\
9,680 \\
9,950\end{array}$} & & & & & & \\
\hline & & & 10.71 & & 10.82 & 7,870 & 14.68 & 17,700 & 21.57 & 45,400 \\
\hline & & & $\begin{array}{l}10.90 \\
11.10\end{array}$ & & 10.83 & 7,870 & 14.74 & 17,700 & 22.90 & 52,500 \\
\hline & & & $\begin{array}{l}11.38 \\
11.60\end{array}$ & & 10.84 & 7,870 & 14.79 & 17,800 & 23.94 & 56,900 \\
\hline & \multicolumn{2}{|c|}{ Aug. 16} & \multicolumn{2}{|c|}{ Aug. 17} & \multicolumn{2}{|c|}{ Aug. 18} & & 19 & & 20 \\
\hline 2 & 24 & 66 & 24 & & 21.9 & & 11.57 & & 11.86 & 00 \\
\hline 4 & & & & & & & & & & \\
\hline 6 & 25.80 & & & & & & 10. & & 11 & \\
\hline 8 & & & & & & & & & & \\
\hline 10 & & & & & & & & & & \\
\hline $\mathrm{N}$ & & & & 100 & & & & & 11.39 & 9,130 \\
\hline & & & & & & & & & 11.40 & 9,130 \\
\hline 4 & 27.62 & & 26.17 & & & & & & & 9,130 \\
\hline 6 & 27. & & & & & & & & & \\
\hline 8 & & & & & 11 . & & & & & \\
\hline 10 & 28 & 78,70 & 23.74 & & 11. & & 11 & & & 9,130 \\
\hline 12 & & 78,000 & 22.78 & 44,400 & 11.53 & 9,440 & 11.47 & 9,350 & 11.39 & 9,130 \\
\hline
\end{tabular}

SupPLEMENTAL ReCORDs.-Aug. 16, 11 p.m., 28.20 feet, 78,700 second-feet; Aug. 17, 1 a.m., 28.27 feet 77,800 second-feet. 
PEE DEE RIVER AT BLEWETT RESGRVOIR, NEAR ROCKINGHAM, N. C.

Location.-Lat. $34^{\circ} 59^{\prime} 20^{\prime \prime}$, long. $79^{\circ} 52^{\prime} 35^{\prime \prime}$, in power plant at right end of Blewett Dam, 51/2 miles downstream from Mountain Creek, and 7 miles northwest of Rockingham, Richmond County. Datum of gage is 39.04 feet above mean sea level, datum of 1929 (levels by Corps of Engineers, War Department).

Drainage AREa.-6,830 square miles.

GAGE-HEIGHT RECORD.-Hourly readings of electric indicating gage.

DISCHARGE RECORD.--Record of outflow based on formula for spillways and manufacturers' ratings for turbines.

Maxima.-1940: Daily mean outflow, 82,800 second-feet Aug. 17; reservoir gage height, 141.8 feet 1 a.m. to 3 p.m. Aug. 17 (contents, estimated, 2,130,000,000 eubic feet).

REMARKS.- Reservoir, first put in use in 1911, has a total usable capacity of 1,850 , 000,000 cubic feet between 120.0 feet (minimum drawdown) and 139.0 feet (top of flashboards) and a storage eapacity under normal operation of 300,000,000 eubic feet above 136.0 feet. River also affected by storage in High Rock, Narrows, and Tillery Reservoirs upstream having a combined storage eapacity under normal operation of $17,338,000,000$ cubic feet. Basic data furnished by Carolina Power and Light Company.

Blewett Reservoir, gage height and contents at midnight and mean outflow, 1940

\begin{tabular}{|c|c|c|c|c|c|c|}
\hline \multirow{2}{*}{ Day } & \multicolumn{3}{|c|}{ August } & \multicolumn{3}{|c|}{ September } \\
\hline & $\begin{array}{c}\text { Gage } \\
\text { height } \\
\text { (feet) }\end{array}$ & $\begin{array}{l}\text { Contents } \\
\text { (million } \\
\text { cubic feet) }\end{array}$ & $\begin{array}{l}\text { Outflow } \\
\text { (second- } \\
\text { feet) }\end{array}$ & $\begin{array}{c}\text { Gage } \\
\text { height } \\
\text { (feet) }\end{array}$ & $\begin{array}{l}\text { Contents } \\
\text { (million } \\
\text { cubic feet) }\end{array}$ & $\begin{array}{l}\text { Outflow } \\
\text { (second- } \\
\text { feet) }\end{array}$ \\
\hline $\begin{array}{l}1 \\
2 \\
3 \\
4 \\
5\end{array}$ & $\begin{array}{l}137.2 \\
136.8 \\
137.6 \\
137.5 \\
136.1\end{array}$ & $\begin{array}{l}1,670 \\
1,630 \\
1,710 \\
1,700 \\
1,560\end{array}$ & $\begin{array}{r}5,360 \\
4,390 \\
972 \\
347 \\
3,800\end{array}$ & $\begin{array}{l}139.7 \\
139.9 \\
139.9 \\
138.9 \\
137.5\end{array}$ & $\begin{array}{r}11,920 \\
11,940 \\
11,940 \\
1,840 \\
1,700\end{array}$ & $\begin{array}{r}6,030 \\
11,700 \\
11,100 \\
8,780 \\
5,790\end{array}$ \\
\hline $\begin{array}{r}6 \\
7 \\
8 \\
9 \\
10\end{array}$ & $\begin{array}{l}137.1 \\
136.1 \\
135.9 \\
135.1 \\
136.3\end{array}$ & $\begin{array}{l}1,660 \\
1,560 \\
1,540 \\
1,460 \\
1,580\end{array}$ & $\begin{array}{r}4,400 \\
5,510 \\
3,690 \\
3,480 \\
0\end{array}$ & $\begin{array}{l}136.8 \\
137.1 \\
137.4 \\
136.5 \\
136.8\end{array}$ & $\begin{array}{l}1,630 \\
1,660 \\
1,690 \\
1,600 \\
1,630\end{array}$ & $\begin{array}{l}6,310 \\
4,640 \\
4,900 \\
4,880 \\
4,860\end{array}$ \\
\hline $\begin{array}{l}11 \\
12 \\
13 \\
14 \\
15\end{array}$ & $\begin{array}{l}135.9 \\
134.6 \\
135.0 \\
138.3 \\
140.1\end{array}$ & $\begin{array}{r}1,540 \\
1,410 \\
1,450 \\
1,780 \\
11,960\end{array}$ & $\begin{array}{r}1,700 \\
5,530 \\
7,180 \\
7,220 \\
19,800\end{array}$ & $\begin{array}{l}137.8 \\
137.8 \\
138.2 \\
138.5 \\
137.2\end{array}$ & $\begin{array}{l}1,730 \\
1,730 \\
1,770 \\
1,800 \\
1,670\end{array}$ & $\begin{array}{l}4,870 \\
4,900 \\
4,900 \\
4,920 \\
4,920\end{array}$ \\
\hline $\begin{array}{l}16 \\
17 \\
18 \\
19 \\
20\end{array}$ & $\begin{array}{l}141.7 \\
140.9 \\
136.6 \\
135.8 \\
135.8\end{array}$ & $\begin{array}{r}12,120 \\
12,040 \\
1,610 \\
1,530 \\
1,530\end{array}$ & $\begin{array}{l}49,500 \\
82,800 \\
38,100 \\
10,800 \\
10,600\end{array}$ & $\begin{array}{l}135.7 \\
136.6 \\
136.7 \\
137.1 \\
137.8\end{array}$ & $\begin{array}{l}1,520 \\
1,610 \\
1,620 \\
1,660 \\
1,730\end{array}$ & $\begin{array}{l}4,830 \\
4,900 \\
4,870 \\
4,870 \\
4,880\end{array}$ \\
\hline $\begin{array}{l}21 \\
22 \\
23 \\
24 \\
25\end{array}$ & $\begin{array}{l}135.6 \\
135.8 \\
134.4 \\
134.7 \\
137.2\end{array}$ & $\begin{array}{l}1,510 \\
1,530 \\
1,390 \\
1,420 \\
1,670\end{array}$ & $\begin{array}{r}9.530 \\
9,490 \\
8,500 \\
2,550 \\
0\end{array}$ & $\begin{array}{l}137.8 \\
136.4 \\
135.9 \\
137.1 \\
137.7\end{array}$ & $\begin{array}{l}1,730 \\
1,590 \\
1,540 \\
1,660 \\
1,720\end{array}$ & $\begin{array}{l}4,920 \\
4,690 \\
4,840 \\
4,860 \\
4,930\end{array}$ \\
\hline \multirow[t]{2}{*}{$\begin{array}{l}26 \\
27 \\
28 \\
29 \\
30 \\
31\end{array}$} & $\begin{array}{l}137.7 \\
137.7 \\
137.8 \\
137.8 \\
137.9 \\
138.2\end{array}$ & $\begin{array}{r}1,720 \\
, 1,720 \\
1,730 \\
1,730 \\
1,740 \\
1,770\end{array}$ & $\begin{array}{l}3,800 \\
4,900 \\
4,900 \\
5,490 \\
5,830 \\
5,830\end{array}$ & $\begin{array}{r}135.5 \\
135.1 \\
136.0 \\
136.7 \\
136.7\end{array}$ & $\begin{array}{l}1,500 \\
1,460 \\
1,550 \\
1,620 \\
1,620\end{array}$ & $\begin{array}{r}4,900 \\
4,780 \\
2,550 \\
799 \\
3,500 \\
-\end{array}$ \\
\hline & & & & & August & September \\
\hline \multicolumn{5}{|c|}{$\begin{array}{l}\text { Change in contents, equivalent, in second-feet } \\
\text { Monthly mean outflow, in second-feet }\end{array}$} & $\begin{array}{r}+37 \\
10,500\end{array}$ & $\begin{array}{r}-58 \\
5,290\end{array}$ \\
\hline
\end{tabular}

\footnotetext{
1 Approximate contents.
}

SuPPLEMENTAL RECORD.-July 31 midnight, gage height, 137.2 feet; contents, 1,670 million cubic feet. 
FLOODS OF AUGUST 1940 IN THE SOUTHEASTERN STATES

Blewett Reservoir, gage height and contents at indicated time, 1940

\begin{tabular}{|c|c|c|c|c|c|c|}
\hline \multirow{2}{*}{ Hour } & \multicolumn{2}{|c|}{ Aug. 14} & \multicolumn{2}{|c|}{ Aug. 15} & \multicolumn{2}{|c|}{ Aug. 16} \\
\hline & $\begin{array}{l}\text { Gage } \\
\text { height } \\
\text { (feet) }\end{array}$ & $\begin{array}{c}\text { Contents } \\
\text { (million } \\
\text { cubic feet) }\end{array}$ & $\begin{array}{l}\text { Gage } \\
\text { height } \\
\text { (feet) }\end{array}$ & $\begin{array}{c}\text { Contents } \\
\text { (million } \\
\text { cubic feet) }\end{array}$ & $\begin{array}{l}\text { Gage } \\
\text { height } \\
\text { (feet) }\end{array}$ & $\begin{array}{l}\text { Contents } \\
\text { (million } \\
\text { cubic feet) }\end{array}$ \\
\hline $\begin{array}{l}1 \\
2 \\
3 \\
4 \\
5 \\
6\end{array}$ & $\begin{array}{l}135.0 \\
135.0 \\
135.1 \\
135.2 \\
135.2 \\
135.2\end{array}$ & $\begin{array}{l}1,450 \\
1,450 \\
1,460 \\
1,470 \\
1,470 \\
1,470\end{array}$ & $\begin{array}{l}138.5 \\
138.8 \\
138.9 \\
139.0 \\
139.0 \\
139.1\end{array}$ & $\begin{array}{r}1,800 \\
1,830 \\
1,840 \\
1,850 \\
1,850 \\
11,860\end{array}$ & $\begin{array}{l}140.3 \\
140.4 \\
140.6 \\
140.7 \\
140.8 \\
140.8\end{array}$ & $\begin{array}{l}11,980 \\
11,990 \\
12,010 \\
12,020 \\
12,030 \\
12,030\end{array}$ \\
\hline $\begin{array}{r}7 \\
8 \\
9 \\
10 \\
11 \\
\mathrm{~N}\end{array}$ & $\begin{array}{l}135.2 \\
135.2 \\
135.1 \\
135.1 \\
135.0 \\
135.0\end{array}$ & $\begin{array}{l}1,470 \\
1,470 \\
1,460 \\
1,460 \\
1,450 \\
1,450\end{array}$ & $\begin{array}{l}139.1 \\
139.1 \\
139.0 \\
138.8 \\
138.7 \\
138.6\end{array}$ & $\begin{array}{r}11,860 \\
11,860 \\
1,850 \\
1,830 \\
1,820 \\
1,810\end{array}$ & $\begin{array}{l}140.9 \\
141.0 \\
141.1 \\
141.1 \\
141.2 \\
141.2\end{array}$ & $\begin{array}{l}12,040 \\
12,050 \\
12,060 \\
12,060 \\
12,070 \\
12,070\end{array}$ \\
\hline $\begin{array}{l}1 \\
\mathbf{2} \\
3 \\
4 \\
\mathbf{5} \\
\mathbf{6}\end{array}$ & $\begin{array}{l}135.0 \\
135.1 \\
135.4 \\
135.8 \\
136.0 \\
136.4\end{array}$ & $\begin{array}{l}1,450 \\
1,460 \\
1,490 \\
1,530 \\
1,550 \\
1,590\end{array}$ & $\begin{array}{l}138.6 \\
138.6 \\
138.7 \\
138.9 \\
139.0 \\
139.3\end{array}$ & $\begin{array}{r}1,810 \\
1,810 \\
1,820 \\
1,840 \\
1,850 \\
11,880\end{array}$ & $\begin{array}{l}141.2 \\
141.2 \\
141.2 \\
141.3 \\
141.3 \\
141.4\end{array}$ & $\begin{array}{l}12,070 \\
12,070 \\
12,070 \\
12,080 \\
12,080 \\
12,090\end{array}$ \\
\hline \multirow[t]{2}{*}{$\begin{array}{r}7 \\
8 \\
9 \\
10 \\
11 \\
12 \\
\end{array}$} & $\begin{array}{l}136.7 \\
137.2 \\
137.6 \\
137.8 \\
138.0 \\
138.3 \\
\end{array}$ & $\begin{array}{r}1,620 \\
1,670 \\
1,710 \\
1,730 \\
1,750 \\
1,780 \\
\end{array}$ & $\begin{array}{l}139.5 \\
139.7 \\
139.8 \\
139.9 \\
140.0 \\
140.1 \\
\end{array}$ & $\begin{array}{r}11,900 \\
11,920 \\
11,930 \\
11,940 \\
11,950 \\
11,960 \\
\end{array}$ & $\begin{array}{l}141.5 \\
141.5 \\
141.6 \\
141.6 \\
141.7 \\
141.7 \\
\end{array}$ & $\begin{array}{l}12,100 \\
12,100 \\
12,110 \\
12,110 \\
12,120 \\
12,120 \\
\end{array}$ \\
\hline & \multicolumn{2}{|c|}{ Aug. 17} & \multicolumn{2}{|c|}{ Aug. 18} & \multicolumn{2}{|c|}{ Aug. 19} \\
\hline $\begin{array}{l}1 \\
2 \\
3 \\
4 \\
4 \\
5 \\
6\end{array}$ & $\begin{array}{l}141.8 \\
141.8 \\
141.8 \\
141.8 \\
141.8 \\
141.8\end{array}$ & $\begin{array}{l}12,130 \\
12,130 \\
12,130 \\
12,130 \\
12,130 \\
12,130\end{array}$ & $\begin{array}{l}140.7 \\
140.6 \\
140.5 \\
140.3 \\
140.1 \\
139.9\end{array}$ & $\begin{array}{r}12,020 \\
12,010 \\
12,000 \\
11,980 \\
11,960 \\
11,940\end{array}$ & $\begin{array}{l}136.5 \\
136.4 \\
136.3 \\
136.3 \\
136.2 \\
136.1\end{array}$ & $\begin{array}{l}1,600 \\
1,590 \\
1,580 \\
1,580 \\
1,570 \\
1,560\end{array}$ \\
\hline $\begin{array}{r}7 \\
8 \\
9 \\
10 \\
11 \\
\mathrm{~N}\end{array}$ & $\begin{array}{l}141.8 \\
141.8 \\
141.8 \\
141.8 \\
141.8 \\
141.8\end{array}$ & $\begin{array}{l}12,130 \\
12,130 \\
12,130 \\
12,130 \\
12,130 \\
12,130\end{array}$ & $\begin{array}{l}139.7 \\
139.6 \\
139.4 \\
139.2 \\
139.0 \\
138.6\end{array}$ & $\begin{array}{r}11,920 \\
11,910 \\
11,890 \\
11,870 \\
1,850 \\
1,810\end{array}$ & $\begin{array}{l}136.0 \\
136.0 \\
135.8 \\
135.8 \\
135.8 \\
135.7\end{array}$ & $\begin{array}{l}1,550 \\
1,550 \\
1,530 \\
1,530 \\
1,530 \\
1,520\end{array}$ \\
\hline $\begin{array}{l}1 \\
2 \\
3 \\
4 \\
5 \\
5 \\
6\end{array}$ & $\begin{array}{l}141.8 \\
141.8 \\
141.8 \\
141.7 \\
141.6 \\
141.6\end{array}$ & $\begin{array}{l}12,130 \\
12,130 \\
12,130 \\
12,120 \\
12,110 \\
12,110\end{array}$ & $\begin{array}{l}138.4 \\
138.2 \\
138.0 \\
137.9 \\
137.7 \\
137.6\end{array}$ & $\begin{array}{l}1,790 \\
1,770 \\
1,750 \\
1,740 \\
1,720 \\
1,710\end{array}$ & $\begin{array}{l}135.7 \\
135.7 \\
135.7 \\
135.7 \\
135.7 \\
135,7\end{array}$ & $\begin{array}{r}1,520 \\
1,520 \\
1,520 \\
1,520 \\
1,520 \\
1,520\end{array}$ \\
\hline $\begin{array}{r}7 \\
8 \\
9 \\
10 \\
11 \\
12\end{array}$ & $\begin{array}{l}141.6 \\
141.6 \\
141.6 \\
141.6 \\
141.6 \\
140.9\end{array}$ & $\begin{array}{l}12,110 \\
12,110 \\
12,110 \\
12,110 \\
12,110 \\
12,040\end{array}$ & $\begin{array}{l}137.3 \\
137.1 \\
136.9 \\
136.8 \\
136.7 \\
136.6\end{array}$ & $\begin{array}{l}1,680 \\
1,660 \\
1,640 \\
1,630 \\
1,620 \\
1,610\end{array}$ & $\begin{array}{l}135.7 \\
135.7 \\
135.7 \\
135.7 \\
135.7 \\
135.8\end{array}$ & $\begin{array}{r}1,520 \\
1,520 \\
1,520 \\
1,520 \\
1,520 \\
1,530\end{array}$ \\
\hline
\end{tabular}

1 Approximate contents.

PEE DEE RIVER NEAR ROCKINGHAM, N. C.

Location.-Lat. $34^{\circ} 56^{\prime} 10^{\prime \prime}$, long. $79^{\circ} 51^{\prime} 10^{\prime \prime}$, at State highway bridge, 1 mile upstream from Falling Creek, 4 miles downstream from Blewett Falls hydroelectric plant, and 6 miles west of Rockingham, Richmond County. Datum of gage is 120.68 feet above mean sea level, datum of 1929 .

DRAINAGE AREA.-6,870 square miles.

GAGE-HEIGHT RECORD.-Water-stage recorder graph.

DISCHARGE RECORD.--Stage-discharge relation defined by eurrent-meter measurements up to 193,000 second-feet. Gage heights used to half-tenths between 3.0 and 5.3 feet; hundredths below and tenths above these limits. 
Maxima.-1940: Discharge, 84,000 second-feet $7: 30$ to 8 a.m. Aug. 17 (gage height, 13.46 feet).

1927-39 : Diseharge, 212,000 second-feet Sept. 19, 1928 (gage height, 25.38 feet).

Stage known, 31.28 feet sometime in 1908, from State Highway Department records (discharge, 276,000 second-feet).

Remarks.-Flow affected by storage in High Rock, Narrows, Tillery, and Blewett Reservoirs (combined storage capacity under normal operation, 17,638,000,000 cubic feet). Large diurnal fluctuation caused by power plant above station.

Mean discharge, in second-feet, 1940

\begin{tabular}{|c|c|c|c|c|c|c|c|c|c|c|c|}
\hline Day & Aug. & Sept. & Day & Aug. & Sept. & Day & Aug. & Sept. & Day & Aug. & Sept. \\
\hline $\begin{array}{l}1 \\
2 \\
3 \\
4 \\
5 \\
6 \\
7 \\
8\end{array}$ & $\begin{array}{r}5,440 \\
4,970 \\
1,250 \\
664 \\
3,620 \\
4,150 \\
5,880 \\
3,980\end{array}$ & $\begin{array}{r}6,010 \\
12,400 \\
12,200 \\
9,820 \\
7,220 \\
6,600 \\
5,020 \\
5,270\end{array}$ & $\begin{array}{r}9 \\
10 \\
11 \\
12 \\
13 \\
14 \\
15 \\
16\end{array}$ & $\begin{array}{r}3,700 \\
534 \\
1,170 \\
5,610 \\
7,430 \\
8,560 \\
24,500 \\
66,700\end{array}$ & $\begin{array}{l}5,270 \\
5,270 \\
5,270 \\
5,270 \\
5,270 \\
5,270 \\
5,270 \\
5,090\end{array}$ & $\begin{array}{l}17 \\
18 \\
19 \\
20 \\
21 \\
22 \\
23 \\
24\end{array}$ & $\begin{array}{r}79,900 \\
39,500 \\
11,000 \\
10,200 \\
9,200 \\
8,980 \\
8,750 \\
3,570\end{array}$ & $\begin{array}{l}5,090 \\
5,090 \\
5,090 \\
5,270 \\
5,270 \\
5,090 \\
5,090 \\
5,090\end{array}$ & $\begin{array}{l}25 \\
26 \\
27 \\
28 \\
29 \\
30 \\
31\end{array}$ & $\begin{array}{r}169 \\
3,410 \\
5,270 \\
5,270 \\
5,640 \\
6,010 \\
6,010\end{array}$ & $\begin{array}{l}5,090 \\
5,090 \\
4,920 \\
3,570 \\
1,040 \\
2,740\end{array}$ \\
\hline \multicolumn{12}{|c|}{$\begin{array}{l}\text { Monthly mean discharge, in second-feet } \\
\text { Runoff, in inches } \ldots\end{array}$} \\
\hline
\end{tabular}

Gage height, in feet, and discharge, in second-feet, at indicated time, 1940

\begin{tabular}{|c|c|c|c|c|c|c|c|c|c|c|}
\hline \multirow{2}{*}{ Hour } & \multicolumn{2}{|c|}{ Aug. 11} & \multicolumn{2}{|c|}{ Aug. 12} & \multicolumn{2}{|c|}{ Aug. 13} & \multicolumn{2}{|c|}{ Aug. 14} & \multicolumn{2}{|c|}{ Aug. 15} \\
\hline & $\begin{array}{c}\text { Gage } \\
\text { height }\end{array}$ & $\begin{array}{c}\text { Dis- } \\
\text { charge }\end{array}$ & $\begin{array}{c}\text { Gage } \\
\text { height }\end{array}$ & $\begin{array}{c}\text { Dis- } \\
\text { charge }\end{array}$ & $\begin{array}{c}\text { Gage } \\
\text { height }\end{array}$ & $\begin{array}{c}\text { Dis- } \\
\text { charge }\end{array}$ & $\begin{array}{c}\text { Gage } \\
\text { height }\end{array}$ & $\begin{array}{c}\text { Dis- } \\
\text { charge }\end{array}$ & $\begin{array}{c}\text { Gage } \\
\text { height }\end{array}$ & $\begin{array}{c}\text { Dis- } \\
\text { charge }\end{array}$ \\
\hline $\begin{array}{l}1 \\
2 \\
3 \\
4 \\
5 \\
6\end{array}$ & $\begin{array}{r}0.63 \\
.62 \\
.61 \\
.61 \\
.61 \\
.61\end{array}$ & $\begin{array}{l}172 \\
170 \\
169 \\
169 \\
169 \\
169\end{array}$ & $\begin{array}{l}3.24 \\
3.14 \\
3.31 \\
3.24 \\
2.96 \\
2.64\end{array}$ & $\begin{array}{l}5,270 \\
4,920 \\
5,450 \\
5,270 \\
4,260 \\
3,200\end{array}$ & & & 3.81 & $\begin{array}{l}7,430 \\
7,430\end{array}$ & $\begin{array}{c}5.45 \\
5.94 \\
6.42\end{array}$ & $\begin{array}{r}15,700 \\
18,900 \\
22,200\end{array}$ \\
\hline $\begin{array}{r}7 \\
8 \\
9 \\
10 \\
11 \\
\mathrm{~N}\end{array}$ & $\begin{array}{l}.63 \\
.63 \\
.64 \\
.64 \\
.64 \\
.64\end{array}$ & $\begin{array}{l}172 \\
172 \\
174 \\
174 \\
174 \\
174\end{array}$ & $\begin{array}{l}2.50 \\
2.85 \\
3.23 \\
3.38 \\
3.44 \\
3.46\end{array}$ & $\begin{array}{l}2,780 \\
3,890 \\
5,270 \\
5,820 \\
6,010 \\
6,010\end{array}$ & 3.80 & $\overline{7}, 430$ & $\begin{array}{l}3.81 \\
3.79\end{array}$ & 7,430 & $\begin{array}{l}6.43 \\
6.33 \\
6.19\end{array}$ & $\begin{array}{r}22,200 \\
21,500 \\
20,900\end{array}$ \\
\hline $\begin{array}{l}1 \\
2 \\
3 \\
4 \\
5 \\
6\end{array}$ & $\begin{array}{l}.64 \\
.65 \\
.66 \\
.69 \\
.75 \\
.81\end{array}$ & $\begin{array}{l}174 \\
176 \\
177 \\
182 \\
197 \\
213\end{array}$ & $\begin{array}{l}3.46 \\
3.46 \\
3.45 \\
3.48 \\
3.50 \\
3.49\end{array}$ & $\begin{array}{l}6,010 \\
6,010 \\
6,010 \\
6,200 \\
6,200 \\
6,200\end{array}$ & & & $\begin{array}{l}3.88 \\
4.13\end{array}$ & $\begin{array}{l}7,860 \\
8,980\end{array}$ & $\begin{array}{c}6.16 \\
6.32 \\
6.83\end{array}$ & $\begin{array}{r}20,900 \\
21,500 \\
25,100\end{array}$ \\
\hline $\begin{array}{r}7 \\
8 \\
9 \\
10 \\
11 \\
12 \\
\end{array}$ & $\begin{array}{l}1.15 \\
2.91 \\
3.30 \\
3.40 \\
3.44 \\
3.47 \\
\end{array}$ & $\begin{array}{r}370 \\
4,090 \\
5,450 \\
5,820 \\
6,010 \\
6,010 \\
\end{array}$ & $\begin{array}{l}3.48 \\
3.49 \\
3.61 \\
3.72 \\
3.76 \\
3.78 \\
\end{array}$ & $\begin{array}{l}6,200 \\
6,200 \\
6,600 \\
7,010 \\
7,220 \\
7,430 \\
\end{array}$ & $3.81^{-}$ & 7,430 & 5.13 & 14,200 & $\begin{array}{r}7.92 \\
8.77^{-} \\
9.53^{-}\end{array}$ & $\begin{array}{r}33,500 \\
41,000 \\
47,000 \\
\end{array}$ \\
\hline & \multicolumn{2}{|c|}{ Aug. 16} & \multicolumn{2}{|c|}{ Aug. 17} & \multicolumn{2}{|c|}{ Aug. 18} & \multicolumn{2}{|c|}{ Aug. 19} & \multicolumn{2}{|c|}{ Aug. 20} \\
\hline $\begin{array}{r}4 \\
8 \\
\mathrm{~N}\end{array}$ & $\begin{array}{l}10.60 \\
11.29 \\
11.88\end{array}$ & $\begin{array}{l}56,700 \\
63,000 \\
68,500\end{array}$ & $\begin{array}{l}13.30 \\
13.46 \\
13.42\end{array}$ & $\begin{array}{l}82,000 \\
84,000 \\
83,000\end{array}$ & $\begin{array}{r}10.92 \\
9.73 \\
8.39\end{array}$ & $\begin{array}{l}59,300 \\
48,800 \\
37,700\end{array}$ & $\begin{array}{l}4.96 \\
4.70 \\
4.37\end{array}$ & $\begin{array}{r}13,000 \\
11,600 \\
9,900\end{array}$ & $\begin{array}{l}4.32 \\
4.43 \\
4.50\end{array}$ & $\begin{array}{r}9,660 \\
10,400 \\
10,600\end{array}$ \\
\hline $\begin{array}{r}4 \\
8 \\
12\end{array}$ & $\begin{array}{l}12.40 \\
12.70 \\
12.93\end{array}$ & $\begin{array}{l}73,200 \\
76,100 \\
78,000\end{array}$ & $\begin{array}{l}13.24 \\
12.72 \\
11.94\end{array}$ & $\begin{array}{l}81,000 \\
76,100 \\
68,500\end{array}$ & $\begin{array}{l}7.20 \\
6.25 \\
5.46\end{array}$ & $\begin{array}{l}28,100 \\
20,900 \\
16,300\end{array}$ & $\begin{array}{l}4.20 \\
4.21 \\
4.27\end{array}$ & $\begin{array}{l}9,200 \\
9,200 \\
9,430\end{array}$ & $\begin{array}{l}4.44 \\
4.41 \\
4.39\end{array}$ & $\begin{array}{l}10,400 \\
10,100 \\
10,100\end{array}$ \\
\hline
\end{tabular}

SUPPLEMENTAL RECORD.-Aug. 17, $7: 30$ a.m., 13.46 feet, 84,000 second-feet.

PEE DEE RIVER NEAR MARS BLUFF, S. C.

Location.-Lat. $34^{\circ} 11^{\prime}$, long. $79^{\circ} 34^{\prime}$, at bridge on U. S. Highway 76,2 miles downstream from Atlantic Coast Line Railroad bridge, 4.6 miles east of Mars 
Bluff, Florence County, and 10 miles downstream from Black Creek. Datum of gage is 23.46 feet (1942 revision) above mean sea level, datum of 1929 , supplementary adjustment of 1936 .

Drainage AReA. $-8,870$ square miles.

GAGE-HEIGHT RECORD.-Water-stage recorder graph.

DISCHARGE RECORD.--Stage-discharge relation defined by current-meter measurements up to 48,000 second-feet and extended to crest gage height by logarithmic plotting.

Maxima.-1940: Discharge, 35,300 second-feet 8 a.m. Aug. 22 (gage height, 22.35 feet).

1939 : Discharge, 66,700 second-feet Mar. 6 (gage height, 25.61 feet).

Stage known, 31.6 feet (present datum) Sept. 23, 1928, from records of U. S. Weather Bureau (discharge not determined).

REMARKs.-Flow regulated by power plants above station in North Carolina. Natural storage in large swampy areas.

Mean discharge, in second-feet, 1940

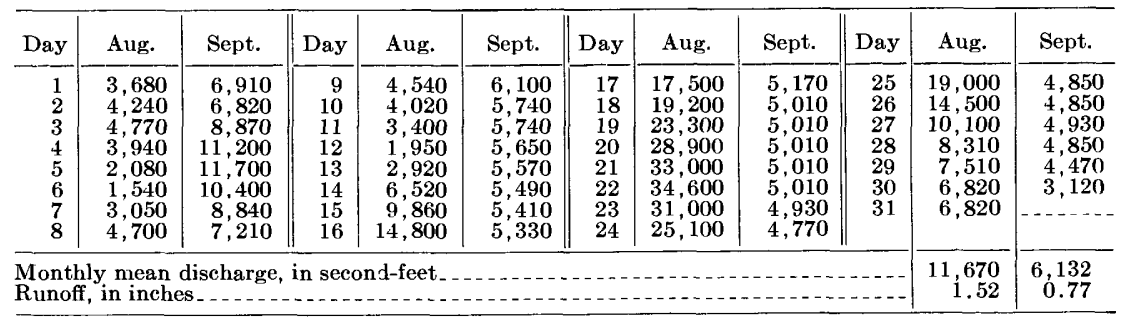

REDDIES RIVER AT NORTH WILKESBORO, N. C.

LocATION.-Lat. $36^{\circ} 10^{\prime} 25^{\prime \prime}$, long. $81^{\circ} 10^{\prime} 10^{\prime \prime}$, 11/4 miles northwest of North Wilkesboro, Wilkes County, and $1 \frac{1}{2}$ miles upstream from mouth. Datum of gage is 978.62 feet above mean sea level, datum of 1929, supplementary adjustment of 1936.

Drainage AREA.-93.9 square miles.

GAGE-HEIGHT RECORD.-Water-stage recorder graph except for period Sept. 2-30.

DischARgE RECORD.-Stage-discharge relation defined by current-meter measurements up to 2,100 second-feet and extended logarithmically to erest gage height on basis of computation of flood flow over dam about $1 \frac{1}{2}$ miles below station and verified by a determination by slope-area method. Gage heights used to half-tenths between 2.7 and 5.0 feet Aug. 1-13, and between 2.5 and 4.9 feet Aug. 14 to Sept. 30; hundredths below and tenths above these limits. Discharge for period of no gage-height record based on records for nearby streams.

Maxima.-1940: Discharge, 27,000 second-feet 2:45 a.m. Aug. 14 (gage height, 22.02 feet).

REMARKs.-Flood runoff not affected by artificial storage.

Mean discharge, in second-feet, 1940

\begin{tabular}{r|r|r|r|r|r||r|r|r|r|r|r}
\hline Day & Aug. & \multicolumn{1}{|c|}{ Sept. } & Day & Aug. & Sept. & Day & Aug. & Sept. & Day & Aug. & Sept. \\
\hline 1 & 130 & 388 & 9 & 68 & 140 & 17 & 395 & 110 & 25 & 184 & 120 \\
2 & 84 & 280 & 10 & 64 & 140 & 18 & 360 & 110 & 26 & 171 & 110 \\
3 & 72 & 240 & 11 & 73 & 130 & 19 & 286 & 110 & 27 & 153 & 100 \\
4 & 72 & 200 & 12 & 257 & 130 & 20 & 232 & 110 & 28 & 145 & 95 \\
5 & 86 & 180 & 13 & 2,810 & 130 & 21 & 213 & 100 & 29 & 137 & 95 \\
6 & 77 & 170 & 14 & 7600 & 120 & 22 & 196 & 100 & 30 & 1,390 & 90 \\
7 & 84 & 160 & 15 & 897 & 120 & 23 & 196 & 100 & 31 & 980 & -167 \\
8 & 81 & 150 & 16 & 522 & 120 & 24 & 167 & 95 & & \\
\hline
\end{tabular}


PEE DEE RIVER BASIN

Gage height, in feet, and discharge, in second-fect, at indicated time, 1940

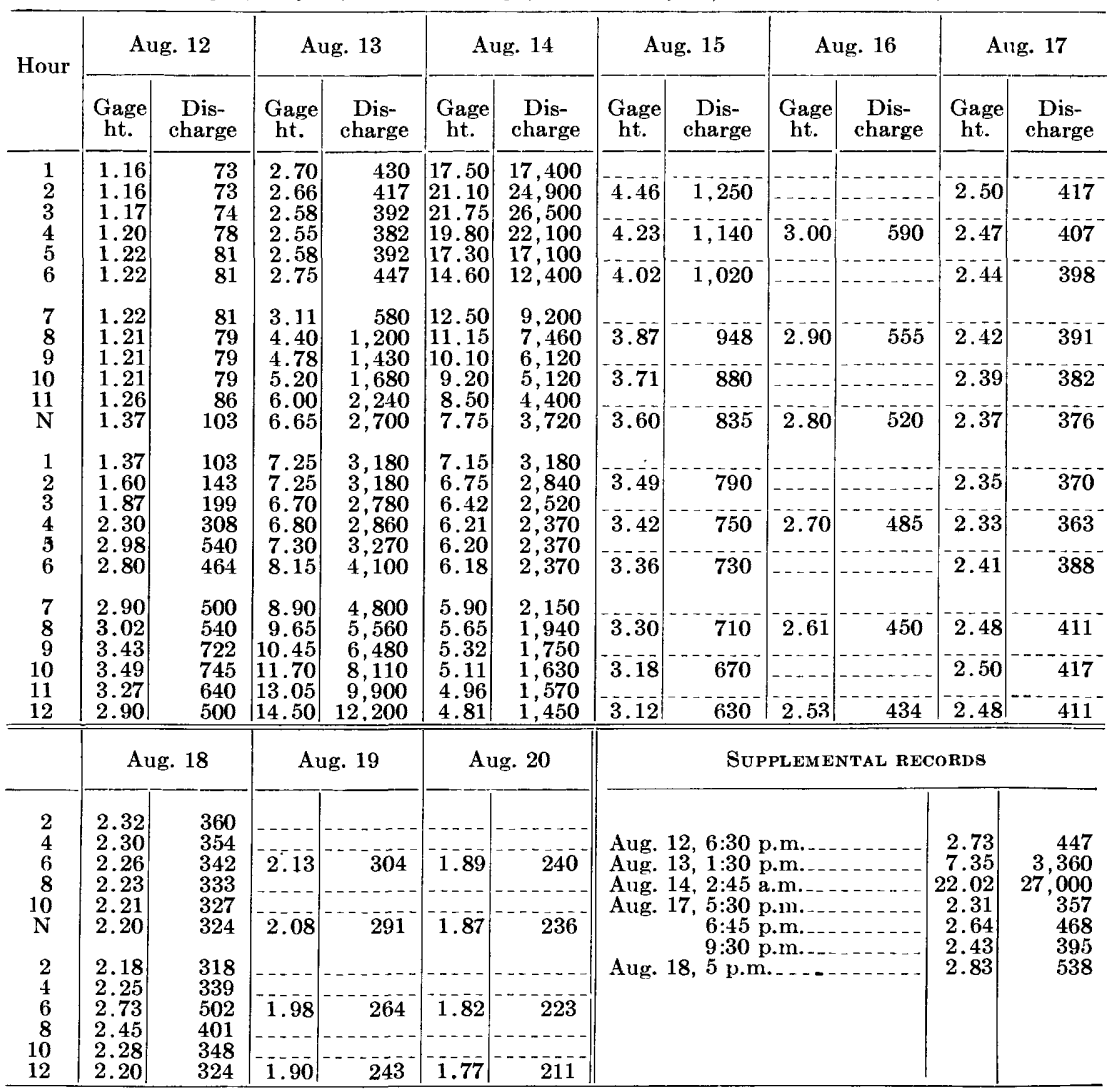

FISHER RIVER NEAR COPELAND, N. C.

Location.-Lat. $36^{\circ} 19^{\prime} 55^{\prime \prime}$, long. $80^{\circ} 40^{\prime} 30^{\prime \prime}$, 300 feet upstream from bridge on State Highway 268, about half a mile upstream from Cody Creek, and 2 miles west of Copeland, Surry County.

DRAINAGE AREA.-121 square miles.

GAGE-HEIGHT RECORD.-Water-stage recorder graph except for periods 4 p.m. Aug. 14 to 12 m. Aug. 18, 6 to 12 p.m. Aug. 18, and 9 p.m. Aug. 30 to 6 a.m. Aug. 31. Graph for Aug. 14-18 completed on basis of floodmarks, observer's or engineer's once-daily gage readings Aug. 15-18, and records for nearby streams. Graph for Aug. 30-31 completed on basis of flood-graph characteristics.

DISCHARGE RECORD.-Dtage-discharge relation defined by current-meter measurements up to 5,800 second-feet and extended logarithmically to erest gage height on basis of two determinations of flood flow by slope-area method. Gage heights used to half-tenths between 3.7 and 5.5 feet; hundredths below and tenths above these limits.

Maxima.-1940: Discharge, 27,300 second-feet about 5 p.m. Aug. 14 (gage height, 18.4 feet, from floodmarks).

1931-39: Discharge, 10,500 second-feet Oct. 19, 1937 (gage height, 13.59 feet).

REMARKs.-Flood runoff not affected by artificial storage. 
Mean discharge, in second-feet, 1940

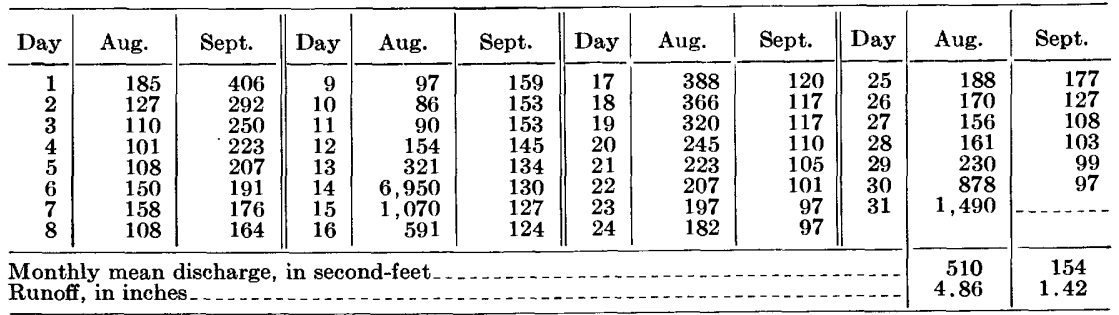

\section{LITTLE YADKIN RIVER NGAR DONNAHA, N. C.}

Location.-Lat. $36^{\circ} 15^{\prime} 40^{\prime \prime}$, long. $80^{\circ} 26^{\prime} 35^{\prime \prime}$, at county highway bridge just upstream from Spainhour Mill, 11/4 miles upstream from mouth, and 2 miles northwest of Donnaha, Forsyth County.

Drain AGe AREa.-59.7 square miles.

GAGE-HEIGHT RECORD.-Water-stage recorder graph except Sept. 1-13.

Discharge RECORD.-Stage-discharge relation defined by current-meter measurements up to 3,470 second-feet. A current-meter measurement was made Aug. 14, 1940 at the time of maximum discharge, but a much higher stage occurred shortly afterward, eaused by backwater from the Yadkin River. Discharge during this backwater period (Aug. 14-15) is based on a slope-area determination, records for nearby streams, and a study of probable flow from channel and groundwater storage. Shifting-control also used owing to unstable stream-bed conditions. Gage heights used to half-tenths between 3.0 and 4.2 feet; hundredths below and tenths above these limits. Discharge for period of no gage-height record, Sept. 1-13, based on records for nearby streams.

Maxima.-1940: Discharge, 3,470 second-feet 11 a.m. Aug. 14 (gage height, 10.57 feet); gage height, 11.54 feet $8: 30$ p.m. Aug. 14 .

Remarks.-Flood flow not affected by artificial storage.

Mean discharge, in second-feet, 1940

\begin{tabular}{|c|c|c|c|c|c|c|c|c|c|c|c|}
\hline Day & Aug. & Sept. & Day & Aug. & Sept. & Day & Aug. & Sept. & Day & Aug. & Sept. \\
\hline $\begin{array}{l}1 \\
2 \\
3 \\
4 \\
5 \\
6 \\
7 \\
8\end{array}$ & $\begin{array}{l}44 \\
29 \\
23 \\
22 \\
32 \\
22 \\
18 \\
15\end{array}$ & $\begin{array}{l}44 \\
36 \\
32 \\
30 \\
30 \\
28 \\
26 \\
26\end{array}$ & \begin{tabular}{r|}
9 \\
10 \\
11 \\
12 \\
13 \\
14 \\
15 \\
16
\end{tabular} & $\begin{array}{r}13 \\
11 \\
26 \\
92 \\
48 \\
2,640 \\
367 \\
134\end{array}$ & $\begin{array}{l}24 \\
24 \\
24 \\
22 \\
22 \\
22 \\
22 \\
21\end{array}$ & $\begin{array}{l}17 \\
18 \\
19 \\
20 \\
21 \\
22 \\
23 \\
24\end{array}$ & $\begin{array}{r}99 \\
195 \\
178 \\
50 \\
39 \\
35 \\
34 \\
35\end{array}$ & $\begin{array}{l}18 \\
19 \\
19 \\
18 \\
16 \\
16 \\
14 \\
14\end{array}$ & $\begin{array}{l}25 \\
26 \\
27 \\
28 \\
29 \\
30 \\
31\end{array}$ & $\begin{array}{l}37 \\
40 \\
35 \\
36 \\
39 \\
98 \\
56\end{array}$ & $\begin{array}{l}19 \\
23 \\
15 \\
15 \\
15 \\
15\end{array}$ \\
\hline \multicolumn{10}{|c|}{$\begin{array}{l}\text { Monthly mean discharge, in second-feet. } \\
\text { Runoff, in inches }\end{array}$} & $\begin{array}{r}147 \\
2.83\end{array}$ & $\begin{array}{l}22.3 \\
0.42\end{array}$ \\
\hline
\end{tabular}


PEE DEE RIVER BASIN

Gage height, in feet, and discharge, in second-feet, at indicated time, 1940

\begin{tabular}{|c|c|c|c|c|c|c|c|c|c|c|}
\hline \multirow{2}{*}{ Hour } & \multicolumn{2}{|c|}{ Aug. 11} & \multicolumn{2}{|c|}{ Aug. 12} & \multicolumn{2}{|c|}{ Aug. 13} & \multicolumn{2}{|c|}{ Aug. 14} & \multicolumn{2}{|c|}{ Aug. 15} \\
\hline & $\begin{array}{c}\text { Gage } \\
\text { height }\end{array}$ & $\begin{array}{l}\text { Dis- } \\
\text { charge }\end{array}$ & $\begin{array}{c}\text { Gage } \\
\text { height }\end{array}$ & $\begin{array}{c}\text { Dis- } \\
\text { charge }\end{array}$ & $\begin{array}{c}\text { Gage } \\
\text { height }\end{array}$ & $\begin{array}{l}\text { Dis- } \\
\text { charge }\end{array}$ & $\begin{array}{l}\text { Gage } \\
\text { height }\end{array}$ & $\begin{array}{l}\text { Dis- } \\
\text { charge }\end{array}$ & $\begin{array}{l}\text { Gage } \\
\text { height }\end{array}$ & $\begin{array}{c}\text { Dis- } \\
\text { charge }\end{array}$ \\
\hline $\begin{array}{l}1 \\
2 \\
3 \\
4 \\
5 \\
6\end{array}$ & $\begin{array}{r}0.50 \\
.50 \\
.50 \\
.50 \\
.50 \\
.50\end{array}$ & $\begin{array}{l}12 \\
12 \\
12 \\
12 \\
12 \\
12\end{array}$ & $\begin{array}{l}1.90 \\
1.75 \\
1.60 \\
1.46 \\
1.33 \\
1.19\end{array}$ & $\begin{array}{r}193 \\
167 \\
144 \\
122 \\
104 \\
83\end{array}$ & $\begin{array}{r}1.28 \\
1.17 \\
1.04 \\
.94 \\
.88 \\
.83\end{array}$ & $\begin{array}{l}99 \\
86 \\
71 \\
60 \\
53 \\
48\end{array}$ & $\begin{array}{l}2.44 \\
4.25 \\
6.95 \\
8.62 \\
9.15 \\
9.60\end{array}$ & $\begin{array}{r}325 \\
1,120 \\
2,320 \\
2,950 \\
3,150 \\
3,250\end{array}$ & $\begin{array}{l}8.13 \\
7.10 \\
6.05 \\
5.20 \\
4.32 \\
3.70\end{array}$ & $\begin{array}{l}740 \\
660 \\
580 \\
520 \\
480 \\
450\end{array}$ \\
\hline $\begin{array}{r}7 \\
8 \\
9 \\
10 \\
11 \\
\text { N }\end{array}$ & $\begin{array}{l}.50 \\
.50 \\
.51 \\
.51 \\
.51 \\
.51\end{array}$ & $\begin{array}{l}12 \\
12 \\
13 \\
13 \\
13 \\
13\end{array}$ & $\begin{array}{r}1.07 \\
.99 \\
.92 \\
.87 \\
.84 \\
.80\end{array}$ & $\begin{array}{l}67 \\
58 \\
50 \\
44 \\
41 \\
37\end{array}$ & $\begin{array}{l}.80 \\
.77 \\
.75 \\
.74 \\
.72 \\
.71\end{array}$ & $\begin{array}{l}45 \\
42 \\
40 \\
39 \\
37 \\
36\end{array}$ & $\begin{array}{l}10.00 \\
10.00 \\
10.20 \\
10.45 \\
10.57 \\
10.32\end{array}$ & $\begin{array}{l}3,340 \\
3,340 \\
3,390 \\
3,430 \\
3,470 \\
3,410\end{array}$ & $\begin{array}{l}3.42 \\
3.18 \\
3.01 \\
2.88 \\
2.74 \\
2.65\end{array}$ & $\begin{array}{l}420 \\
390 \\
370 \\
350 \\
330 \\
320\end{array}$ \\
\hline $\begin{array}{l}1 \\
2 \\
3 \\
4 \\
5 \\
6\end{array}$ & $\begin{array}{l}.52 \\
.52 \\
.53 \\
.53 \\
.52 \\
.66\end{array}$ & $\begin{array}{l}14 \\
14 \\
14 \\
14 \\
14 \\
14 \\
24\end{array}$ & $\begin{array}{r}.78 \\
.76 \\
.75 \\
.74 \\
.72 \\
1.23\end{array}$ & $\begin{array}{l}35 \\
33 \\
32 \\
31 \\
29 \\
89\end{array}$ & $\begin{array}{l}.70 \\
.70 \\
.69 \\
.69 \\
.68 \\
.68\end{array}$ & $\begin{array}{r}\mathbf{3 5} \\
\mathbf{3 5} \\
\mathbf{3 4} \\
\mathbf{3 4} \\
\mathbf{3 3} \\
\mathbf{3 3}\end{array}$ & $\begin{array}{r}10.40 \\
10.18 \\
9.65 \\
9.22 \\
9.46 \\
10.23\end{array}$ & $\begin{array}{l}3,430 \\
3,390 \\
3,250 \\
3,150 \\
3,200 \\
3,300\end{array}$ & $\begin{array}{l}2.56 \\
2.46 \\
2.38 \\
2.28 \\
2.21 \\
2.15\end{array}$ & $\begin{array}{l}300 \\
280 \\
270 \\
260 \\
247 \\
233\end{array}$ \\
\hline $\begin{array}{r}7 \\
8 \\
9 \\
10 \\
11 \\
12 \\
\end{array}$ & $\begin{array}{r}.66 \\
.60 \\
.68 \\
1.30 \\
1.34 \\
1.83 \\
\end{array}$ & $\begin{array}{r}24 \\
19 \\
26 \\
99 \\
105 \\
181 \\
\end{array}$ & $\begin{array}{l}1.61 \\
1.75 \\
1.53 \\
1.48 \\
1.43 \\
1.40\end{array}$ & $\begin{array}{l}146 \\
167 \\
133 \\
125 \\
118 \\
115\end{array}$ & $\begin{array}{r}.68 \\
.68 \\
.69 \\
.72 \\
.82 \\
1.24 \\
\end{array}$ & $\begin{array}{l}33 \\
33 \\
34 \\
37 \\
47 \\
94 \\
\end{array}$ & $\begin{array}{r}10.95 \\
11.45 \\
11.48 \\
10.84 \\
9.95 \\
9.10 \\
\end{array}$ & $\begin{array}{r}3,300 \\
2,800 \\
1,550 \\
1,160 \\
960 \\
840 \\
\end{array}$ & $\begin{array}{l}2.12 \\
2.11 \\
2.12 \\
2.08 \\
1.98 \\
1.94\end{array}$ & $\begin{array}{l}227 \\
224 \\
227 \\
216 \\
196 \\
188\end{array}$ \\
\hline
\end{tabular}

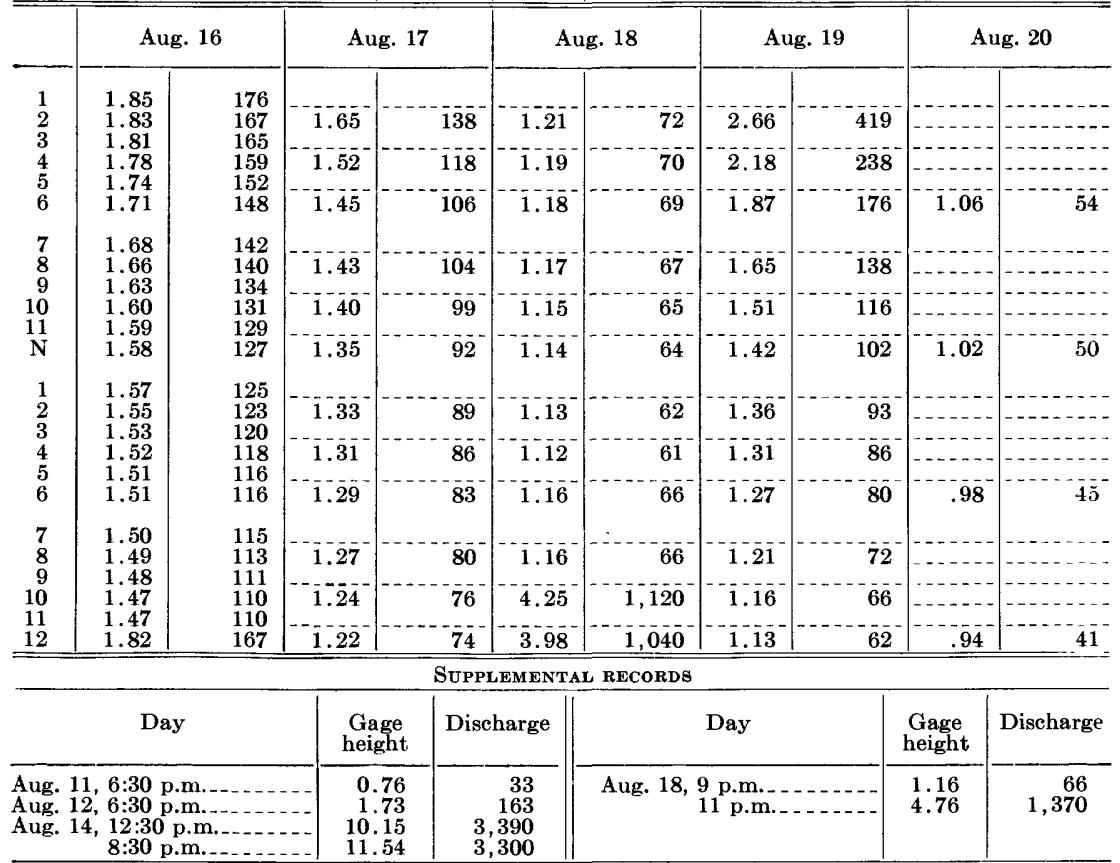

FORBUSH CREEK NEAR YADKINVILLE, N. C.

LoCATION.-Lat. $36^{\circ} 08^{\prime} 00^{\prime \prime}$, long. $80^{\circ} 32^{\prime} 45^{\prime \prime}, 600$ feet upstream from eounty highway bridge, three-quarters of a mile north of Forbush Church, $4 \frac{1}{2}$ miles upstream from mouth, and 6 miles east of Yadkinville, Yadkin County.

DraiNAGE AREA.-21.7 square miles.

GAGE-HEIGHT RECORD.-Water-stage recorder graph. 
DISCHARGE RECORD.-Stage-discharge relation defined by current-meter measurements up to 700 second-feet. Gage heights used to half-tenths between 2.3 and 4.0 feet; hundredths below and tenths above these limits.

Maxima.-1940: Discharge, 819 second-feet 6:15 a.m. Aug. 14 (gage height, 7.84 feet).

Remarks.-Flood runoff not affected by artificial storage.

Mean discharge, in second-feet, 1940

\begin{tabular}{|c|c|c|c|c|c|c|c|c|c|c|c|}
\hline Day & Aug. & Sept. & Day & Aug. & Sept. & Day & Aug. & Sept. & Day & Aug. & Sept. \\
\hline $\begin{array}{l}1 \\
2 \\
3 \\
4 \\
5 \\
6 \\
7 \\
8\end{array}$ & $\begin{array}{c}13 \\
14 \\
13 \\
9.1 \\
13 \\
9.1 \\
13 \\
8.4\end{array}$ & $\begin{array}{r}12 \\
13 \\
13 \\
7.4 \\
9.4 \\
9.6 \\
6.7 \\
8.2\end{array}$ & $\begin{array}{r}9 \\
10 \\
11 \\
12 \\
13 \\
14 \\
15 \\
16\end{array}$ & $\begin{array}{c}9.7 \\
11 \\
9.1 \\
21 \\
21 \\
503 \\
60 \\
39\end{array}$ & $\begin{array}{r}8.2 \\
7.8 \\
11 \\
6 \\
7.3 \\
9.4 \\
5.5 \\
7.6\end{array}$ & $\begin{array}{l}17 \\
18 \\
19 \\
20 \\
21 \\
22 \\
23 \\
24\end{array}$ & $\begin{array}{l}26 \\
34 \\
30 \\
15 \\
15 \\
13 \\
14 \\
11\end{array}$ & $\begin{array}{l}5.3 \\
6.4 \\
8.5 \\
7 \\
7.3 \\
5 \\
6.3 \\
5.8\end{array}$ & $\begin{array}{l}25 \\
26 \\
27 \\
28 \\
29 \\
30 \\
31\end{array}$ & $\begin{array}{c}12 \\
13 \\
14 \\
9.9 \\
9 \\
17 \\
18\end{array}$ & $\begin{array}{c}12 \\
6.7 \\
7.2 \\
9.6 \\
5.6 \\
5.8 \\
-\end{array}$ \\
\hline \multicolumn{10}{|c|}{$\begin{array}{l}\text { Monthly mean discharge, in second-feet } \\
\text { Runoff, in inches }\end{array}$} & $\begin{array}{l}32.8 \\
1.74\end{array}$ & $\begin{array}{l}8.02 \\
0.41\end{array}$ \\
\hline
\end{tabular}

Gage height, in feet, and discharge, in second-feet, at indicated time, 1940

\begin{tabular}{|c|c|c|c|c|c|c|c|c|}
\hline \multirow{2}{*}{ Hour } & \multicolumn{2}{|c|}{ Aug. 13} & \multicolumn{2}{|c|}{ Aug. 14} & \multicolumn{2}{|c|}{ Aug. 15} & \multicolumn{2}{|c|}{ Aug. 16} \\
\hline & $\begin{array}{l}\text { Gage } \\
\text { height }\end{array}$ & Discharge & $\begin{array}{l}\text { - Gage } \\
\text { height }\end{array}$ & Discharge & $\begin{array}{l}\text { Gage } \\
\text { height }\end{array}$ & Discharge & $\begin{array}{l}\text { Gage } \\
\text { height }\end{array}$ & Discharge \\
\hline $\begin{array}{l}1 \\
2 \\
3 \\
4 \\
5 \\
6\end{array}$ & $\begin{array}{r}0.87 \\
.83 \\
.87 \\
.93 \\
.92 \\
.90\end{array}$ & $\begin{array}{l}16 \\
14 \\
16 \\
19 \\
18 \\
17\end{array}$ & $\begin{array}{l}3.45 \\
4.55 \\
5.75 \\
6.46 \\
7.56 \\
7.84\end{array}$ & $\begin{array}{l}256 \\
403 \\
559 \\
650 \\
793 \\
819\end{array}$ & $\begin{array}{l}1.98 \\
1.88 \\
1.81 \\
1.74 \\
1.69 \\
1.64\end{array}$ & $\begin{array}{l}96 \\
88 \\
83 \\
77 \\
73 \\
69\end{array}$ & $\begin{array}{l}1.30 \\
1.33 \\
1.32 \\
1.32 \\
1.32 \\
1.29\end{array}$ & $\begin{array}{l}43 \\
45 \\
44 \\
44 \\
44 \\
42\end{array}$ \\
\hline $\begin{array}{r}7 \\
8 \\
9 \\
10 \\
11 \\
\mathrm{~N}\end{array}$ & $\begin{array}{l}.89 \\
.88 \\
.88 \\
.87 \\
.87 \\
.87\end{array}$ & $\begin{array}{l}17 \\
16 \\
16 \\
16 \\
16 \\
16\end{array}$ & $\begin{array}{l}7.68 \\
7.23 \\
6.90 \\
6.67 \\
6.56 \\
6.33\end{array}$ & $\begin{array}{l}806 \\
741 \\
702 \\
676 \\
663 \\
624\end{array}$ & $\begin{array}{l}1.60 \\
1.56 \\
1.53 \\
1.52 \\
1.51 \\
1.45\end{array}$ & $\begin{array}{l}66 \\
63 \\
60 \\
60 \\
59 \\
54\end{array}$ & $\begin{array}{l}1.27 \\
1.25 \\
1.24 \\
1.23 \\
1.22 \\
1.22\end{array}$ & $\begin{array}{l}41 \\
40 \\
39 \\
38 \\
37 \\
37\end{array}$ \\
\hline $\begin{array}{l}1 \\
2 \\
3 \\
4 \\
5 \\
6\end{array}$ & $\begin{array}{l}.87 \\
.88 \\
.88 \\
.88 \\
.89 \\
.89\end{array}$ & $\begin{array}{l}16 \\
16 \\
16 \\
16 \\
17 \\
17\end{array}$ & $\begin{array}{l}6.01 \\
5.97 \\
6.23 \\
6.54 \\
6.15 \\
4.45\end{array}$ & $\begin{array}{l}585 \\
585 \\
611 \\
650 \\
611 \\
377\end{array}$ & $\begin{array}{l}1.48 \\
1.38 \\
1.45 \\
1.44 \\
1.42 \\
1.42\end{array}$ & $\begin{array}{l}56 \\
49 \\
54 \\
53 \\
52 \\
52\end{array}$ & $\begin{array}{l}1.31 \\
1.29 \\
1.23 \\
1.14 \\
1.24 \\
1.25\end{array}$ & $\begin{array}{l}44 \\
42 \\
38 \\
32 \\
39 \\
40\end{array}$ \\
\hline $\begin{array}{r}7 \\
8 \\
9 \\
10 \\
11 \\
12\end{array}$ & $\begin{array}{r}.89 \\
.89 \\
.90 \\
.96 \\
1.30 \\
2.83\end{array}$ & $\begin{array}{r}17 \\
17 \\
17 \\
21 \\
43 \\
184\end{array}$ & $\begin{array}{l}3.10 \\
2.93 \\
2.62 \\
2.40 \\
2.21 \\
2.08\end{array}$ & $\begin{array}{l}214 \\
196 \\
157 \\
136 \\
117 \\
105\end{array}$ & $\begin{array}{l}1.40 \\
1.33 \\
1.28 \\
1.27 \\
1.23 \\
1.24\end{array}$ & $\begin{array}{l}50 \\
45 \\
42 \\
41 \\
38 \\
39\end{array}$ & $\begin{array}{l}1.28 \\
1.18 \\
1.14 \\
1.14 \\
1.10 \\
1.05\end{array}$ & $\begin{array}{l}42 \\
35 \\
32 \\
32 \\
29 \\
26\end{array}$ \\
\hline
\end{tabular}

Supplemental Records.-Aug. 14, 1:30 p.m., gage height, 5.93 feet; discharge, 572 second-feet; 4:30 p.m., gage height, 6.62 feet, discharge, 663 second-feet.

\section{REEDY CREEK NEAR YADKIN COLLEGE, N. C.}

Locatron.-Lat. $35^{\circ} 54^{\prime} 45^{\prime \prime}$, long. $80^{\circ} 20^{\prime} 05^{\prime \prime}$, at bridge on State Highway 703 about 700 feet upstream from Huffines Creek and 4 miles northeast of Yadkin College, Davidson County.

Drainage AREA.- 13.3 square miles.

GAGE-HEIGHT RECORD.-Water-stage recorder graph.

DISCHARGE RECORD.- Stage-discharge relation defined by current-meter measurements up to 380 second-feet and extended logarithmically to crest gage height. Shifting-control method used Sept. 1-30.

Maxima.-1940: Discharge, 738 seeond-feet 10:30 a.m. Aug. 14 (gage height, 5.46 feet).

REMARKS.-Flood runoff not affected by artificial storage. 
PEE DEE RIVER BASIN

Mean discharge, in second-feet, 1940

\begin{tabular}{|c|c|c|c|c|c|c|c|c|c|c|c|}
\hline Day & Aug. & Sept. & Day & Aug. & Sept. & Day & Aug. & Sept. & Day & Aug. & Sept. \\
\hline $\begin{array}{l}1 \\
2 \\
3 \\
4 \\
5 \\
6 \\
7 \\
8\end{array}$ & $\begin{array}{l}4.1 \\
3.5 \\
3.1 \\
3.5 \\
3.8 \\
3.5 \\
3.1 \\
2.8\end{array}$ & $\begin{array}{r}34 \\
4.5 \\
3.8 \\
3.5 \\
3.6 \\
8.4 \\
3.8 \\
3.3\end{array}$ & $\begin{array}{r}9 \\
10 \\
11 \\
12 \\
13 \\
14 \\
15 \\
16\end{array}$ & $\begin{array}{c}2.8 \\
2.7 \\
4.5 \\
6.9 \\
5.8 \\
329 \\
109 \\
43\end{array}$ & $\begin{array}{c}3.1 \\
10 \\
18 \\
4.1 \\
3.3 \\
3.1 \\
3.0 \\
3.0\end{array}$ & $\begin{array}{l}17 \\
18 \\
19 \\
20 \\
21 \\
22 \\
23 \\
24\end{array}$ & $\begin{array}{c}57 \\
9.6 \\
6.4 \\
5.2 \\
4.9 \\
4.7 \\
4.5 \\
5.3\end{array}$ & $\begin{array}{l}2.8 \\
2.8 \\
2.8 \\
2.8 \\
2.7 \\
2.7 \\
2.5 \\
2.7\end{array}$ & $\begin{array}{l}25 \\
26 \\
27 \\
28 \\
29 \\
30 \\
31\end{array}$ & $\begin{array}{c}6.2 \\
4.3 \\
3.9 \\
3.8 \\
5.9 \\
18 \\
28\end{array}$ & $\begin{array}{l}3.9 \\
3.1 \\
2.8 \\
2.8 \\
2.7 \\
2.5\end{array}$ \\
\hline \multicolumn{10}{|c|}{$\begin{array}{l}\text { Monthly mean discharge, in second-feet } \\
\text { Runoff, in inches }\end{array}$} & $\begin{array}{l}22.5 \\
1.95\end{array}$ & $\begin{array}{l}5.07 \\
0.43\end{array}$ \\
\hline
\end{tabular}

Gage height, in feet, and discharge, in second-feet, at indicated time, 1940

\begin{tabular}{|c|c|c|c|c|c|c|c|c|c|c|}
\hline \multirow{2}{*}{ Hour } & \multicolumn{2}{|c|}{ Aug. 13} & \multicolumn{2}{|c|}{ Aug. 14} & \multicolumn{2}{|c|}{ Aug. 15} & \multicolumn{2}{|c|}{ Aug. 16} & \multicolumn{2}{|c|}{ Aug. 17} \\
\hline & $\begin{array}{c}\text { Gage } \\
\text { height }\end{array}$ & $\begin{array}{c}\text { Dis- } \\
\text { charge }\end{array}$ & $\begin{array}{c}\text { Gage } \\
\text { height }\end{array}$ & $\begin{array}{c}\text { Dis- } \\
\text { charge }\end{array}$ & $\begin{array}{c}\text { Gage } \\
\text { height }\end{array}$ & $\begin{array}{c}\text { Dis- } \\
\text { charge }\end{array}$ & $\begin{array}{c}\text { Gage } \\
\text { height }\end{array}$ & $\begin{array}{c}\text { Dis- } \\
\text { charge }\end{array}$ & $\begin{array}{c}\text { Gage } \\
\text { height }\end{array}$ & $\begin{array}{c}\text { Dis- } \\
\text { charge }\end{array}$ \\
\hline $\begin{array}{l}1 \\
2 \\
3 \\
4 \\
5 \\
6\end{array}$ & $\begin{array}{l}1.06 \\
1.03 \\
1.01 \\
.99 \\
.98 \\
.96\end{array}$ & $\begin{array}{l}7.5 \\
6.8 \\
6.3 \\
5.9 \\
5.7 \\
5.3\end{array}$ & $\begin{array}{l}1.52 \\
2.01 \\
2.84 \\
3.55 \\
4.14 \\
4.87\end{array}$ & $\begin{array}{r}21 \\
35 \\
65 \\
100 \\
140 \\
343\end{array}$ & 4.19 & $14 \overline{5}^{-}$ & $\begin{array}{l}2.36 \\
2.26 \\
2.16 \\
2.08 \\
2.03 \\
2.01\end{array}$ & $\begin{array}{l}46 \\
43 \\
40 \\
37 \\
36 \\
35\end{array}$ & $\begin{array}{r}3.28 \\
3.14 \\
3.13 \\
3.33\end{array}$ & $\begin{array}{l}-\overline{86} \\
79 \\
78 \\
-88\end{array}$ \\
\hline $\begin{array}{r}7 \\
8 \\
9 \\
10 \\
11 \\
\mathrm{~N}\end{array}$ & $\begin{array}{l}.95 \\
.95 \\
.95 \\
.95 \\
.96 \\
.97\end{array}$ & $\begin{array}{l}5.1 \\
5.1 \\
5.1 \\
5.1 \\
5.3 \\
5.5\end{array}$ & $\begin{array}{l}5.42 \\
5.29 \\
5.35 \\
5.43 \\
5.40 \\
5.21\end{array}$ & $\begin{array}{l}706 \\
603 \\
650 \\
714 \\
690 \\
547\end{array}$ & 3.73 & 110 & $\begin{array}{l}2.00 \\
1.98 \\
1.99 \\
2.03 \\
2.03 \\
2.06\end{array}$ & $\begin{array}{l}35 \\
34 \\
35 \\
36 \\
36 \\
37\end{array}$ & $\begin{array}{c}3.33 \\
3.26 \\
-3.01 \\
-2.68\end{array}$ & $\begin{array}{l}88 \\
85 \\
72 \\
58\end{array}$ \\
\hline $\begin{array}{l}1 \\
2 \\
3 \\
4 \\
5 \\
6\end{array}$ & $\begin{array}{l}.97 \\
.97 \\
.97 \\
.98 \\
.98 \\
.98\end{array}$ & $\begin{array}{l}5.5 \\
5.5 \\
5.5 \\
5.7 \\
5.7 \\
5.7\end{array}$ & $\begin{array}{l}5.00 \\
4.85 \\
4.81 \\
4.77 \\
4.76 \\
4.95\end{array}$ & $\begin{array}{l}410 \\
333 \\
314 \\
296 \\
292 \\
384\end{array}$ & $\begin{array}{r}-3.50 \\
-3.32\end{array}$ & 88 & $\begin{array}{l}2.13 \\
2.28 \\
2.35 \\
2.30 \\
2.22 \\
2.17\end{array}$ & $\begin{array}{l}39 \\
43 \\
46 \\
44 \\
42 \\
40\end{array}$ & $\begin{array}{c}2.37 \\
2.11 \\
1.87\end{array}$ & $\begin{array}{l}\overline{4} \overline{6}^{-} \\
-\overline{38} \\
31\end{array}$ \\
\hline $\begin{array}{r}7 \\
8 \\
9 \\
10 \\
11 \\
12\end{array}$ & $\begin{array}{r}.98 \\
.98 \\
.98 \\
.97 \\
.97 \\
1.10\end{array}$ & $\begin{array}{l}5.7 \\
5.7 \\
5.7 \\
5.5 \\
5.5 \\
8.5\end{array}$ & $\begin{array}{l}4.83 \\
4.70 \\
4.57 \\
4.48 \\
4.39 \\
4.33\end{array}$ & $\begin{array}{l}323 \\
266 \\
220 \\
194 \\
174 \\
164 \\
\end{array}$ & $\begin{array}{r}2.98 \\
2.50\end{array}$ & 51 & $\begin{array}{l}2.13 \\
2.11 \\
2.10 \\
2.35 \\
3.33 \\
3.55\end{array}$ & $\begin{array}{r}39 \\
38 \\
38 \\
46 \\
88 \\
100\end{array}$ & $\begin{array}{c}1.65 \\
1.49 \\
1.36\end{array}$ & $\frac{24}{16}$ \\
\hline
\end{tabular}

SUPPlemental RecoRds,-Aug. 14, 10:30 a.m., gage height, 5.46 feet; discharge, 738 second-feet. Aug. 16, $9: 30$ p.m., gage height, 2.10 feet; discharge, 38 second-feet.

DUTCHMAN CREEK NEAR CORNATZER, N. C.

LoCATION.—Lat. $35^{\circ} 55^{\prime} 50^{\prime \prime}$, long. $80^{\circ} 30^{\prime} 10^{\prime \prime}$, at bridge on county highway 100 feet downstream from Cedar Creek and $1 \frac{1}{2}$ miles west of Cornatzer, Davie County.

DRAINAGE AREA. - 83.6 square miles.

GAGE-HEIGHT RECORD.-Water-stage recorder graph.

DISCHARGE RECORD.-Stage-discharge relation defined by current-meter measurements up to 2,450 second-feet. Change in channel storage was a factor in computing discharge from 12 p.m. Aug. 13 to $12 \mathrm{~m}$. Aug. 18. Gage heights used to halftenths between 1.6 and 7.2 feet; hundredths below and tenths above these limits.

Maxima.-1940: Discharge, 3,300 second-feet 3 a.m. Aug. 15 (gage height, 10.58 feet); gage height, 10.63 feet 4 a.m. Aug. 15.

REMARKs.-Flood runoff not affected by artificial storage.

$804331-49-15$ 
Mean discharge, in second-feet, 1940

\begin{tabular}{|c|c|c|c|c|c|c|c|c|c|c|c|}
\hline Day & Aug. & Sept. & Day & Aug. & Sept. & Day & Aug. & Sept. & Day & Aug. & Sept. \\
\hline $\begin{array}{l}1 \\
2 \\
3 \\
4 \\
5 \\
6 \\
7 \\
8\end{array}$ & $\begin{array}{l}31 \\
24 \\
21 \\
20 \\
22 \\
22 \\
56 \\
24\end{array}$ & $\begin{array}{l}56 \\
29 \\
24 \\
22 \\
21 \\
24 \\
24 \\
21\end{array}$ & $\begin{array}{r}9 \\
10 \\
11 \\
12 \\
12 \\
13 \\
14 \\
15 \\
16\end{array}$ & $\begin{array}{r}20 \\
18 \\
19 \\
26 \\
53 \\
1,400 \\
2,150 \\
460\end{array}$ & $\begin{array}{l}21 \\
32 \\
42 \\
22 \\
20 \\
19 \\
19 \\
18\end{array}$ & $\begin{array}{l}17 \\
18 \\
19 \\
20 \\
21 \\
22 \\
23 \\
24\end{array}$ & $\begin{array}{r}112 \\
65 \\
51 \\
40 \\
34 \\
31 \\
29 \\
27\end{array}$ & $\begin{array}{l}18 \\
17 \\
17 \\
17 \\
16 \\
15 \\
14 \\
14\end{array}$ & $\begin{array}{l}25 \\
26 \\
27 \\
28 \\
29 \\
30 \\
31\end{array}$ & $\begin{array}{l}30 \\
30 \\
26 \\
24 \\
23 \\
24 \\
45\end{array}$ & $\begin{array}{l}17 \\
44 \\
21 \\
18 \\
17 \\
16\end{array}$ \\
\hline uno & . & & & & & & & & & $\begin{array}{r}160 \\
2.20\end{array}$ & $\begin{array}{l}22.5 \\
0.30\end{array}$ \\
\hline
\end{tabular}

Gage height, in feet, and discharge, in second-feet, at indicated time, 1940

\begin{tabular}{|c|c|c|c|c|c|c|c|c|c|c|}
\hline \multirow{2}{*}{ Hour } & \multicolumn{2}{|c|}{ Aug. 13} & \multicolumn{2}{|c|}{ Aug. 14} & \multicolumn{2}{|c|}{ Aug. 15} & \multicolumn{2}{|c|}{ Aug. 16} & \multicolumn{2}{|c|}{ Aug. 17} \\
\hline & $\begin{array}{l}\text { Gage } \\
\text { height }\end{array}$ & $\begin{array}{l}\text { Dis- } \\
\text { charge }\end{array}$ & $\begin{array}{l}\text { Gage } \\
\text { height }\end{array}$ & $\begin{array}{l}\text { Dis- } \\
\text { charge }\end{array}$ & $\begin{array}{c}\text { Gage } \\
\text { height }\end{array}$ & $\begin{array}{l}\text { Dis- } \\
\text { charge }\end{array}$ & $\begin{array}{c}\text { Gage } \\
\text { height }\end{array}$ & $\begin{array}{l}\text { Dis- } \\
\text { charge }\end{array}$ & $\begin{array}{c}\text { Gage } \\
\text { height }\end{array}$ & $\begin{array}{l}\text { Dis- } \\
\text { charge }\end{array}$ \\
\hline 1 & 1.27 & 50 & $\begin{array}{l}2.06 \\
3.80\end{array}$ & 180 & $10.37^{-}$ & 3,250 & & $\mid \begin{array}{l}-\cdots-- \\
-\cdots-\cdots\end{array}$ & - & -...... \\
\hline $\begin{array}{l}3 \\
4 \\
5\end{array}$ & $1 . \overline{27}$ & 50 & $\begin{array}{l}5.39 \\
5.84\end{array}$ & $\begin{array}{l}640 \\
770\end{array}$ & $10.6 \overline{3}$ & 3,290 & 5.81 & 660 & 3.17 & $138^{---}$ \\
\hline $\begin{array}{l}5 \\
6\end{array}$ & $1 . \overline{2} \overline{3}$ & 48 & $\begin{array}{l}6.21 \\
6.62\end{array}$ & $\begin{array}{r}910 \\
1,060\end{array}$ & $10 \cdot 44$ & 3,050 & 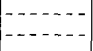 & - & - - - & - \\
\hline $\begin{array}{l}7 \\
8 \\
9\end{array}$ & $1 . \overline{2} 6$ & - & $\begin{array}{l}6.89 \\
7.12 \\
7.30\end{array}$ & $\begin{array}{l}1,160 \\
1,280 \\
1,360\end{array}$ & 10.07 & 2,800 & 5.34 & $--\overline{5} \overline{2}$ & $2 . \overline{7} 6$ & 118 \\
\hline 10 & $1 . \overline{35}$ & 54 & 7.49 & 1,460 & 9.60 & 2,550 & - & 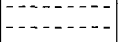 & $\mid-\cdots$ & (-n) \\
\hline 11 & 1.46 & $---\overline{59}$ & $\begin{array}{l}7.66 \\
7.79\end{array}$ & $\begin{array}{l}1,540 \\
1,580\end{array}$ & 9.09 & 2,180 & $-\overline{5.13}$ & $460^{---}$ & $--\overline{2.48}$ & 106 \\
\hline 1 & $-4 \overline{3}^{-}$ & - & 7.88 & 1,640 & 855 & $-\cdots \overline{1} 86$ & & -- & -- & -- \\
\hline $\begin{array}{l}2 \\
3\end{array}$ & 1.43 & 58 & $\begin{array}{l}7.94 \\
7.96\end{array}$ & $\begin{array}{l}1,640 \\
1,640\end{array}$ & 8.55 & 1,860 & $-\cdots$ & --- & $\cdots$ & $-\cdots-$ \\
\hline$\frac{4}{5}$ & 1.39 & 56 & $\begin{array}{l}7.94 \\
7.92\end{array}$ & 1,620 & 8.03 & 1,600 & 4.72 & $\mathbf{3 4 0}$ & 2.29 & 96 \\
\hline 6 & $\overline{1.35}$ & $\overline{5} \overline{4}$ & 8.06 & $\begin{array}{l}1,020 \\
1,800\end{array}$ & $\overline{7} . \overline{5} \overline{5}$ & 1,360 & 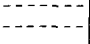 & 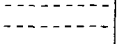 & 年- & 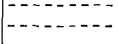 \\
\hline $\begin{array}{l}7 \\
8\end{array}$ & 1.30 & 51 & $\begin{array}{l}8.19 \\
8.28\end{array}$ & $\begin{array}{l}1,800 \\
1,840\end{array}$ & 7.10 & 1,140 & 4.27 & $260^{----}$ & $-\overline{2} . \overline{11}$ & $-\cdots$ \\
\hline $\begin{array}{r}9 \\
10\end{array}$ & $1 . \overline{28}$ & $---50^{---}$ & $\begin{array}{l}8.42 \\
8.58\end{array}$ & $\begin{array}{l}1,960 \\
2,060\end{array}$ & $-\overline{6} . \overline{72}$ & $9 \overline{9} 0$ & ---1 & 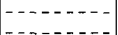 & $-\cdots----$ & 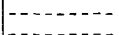 \\
\hline 11 & $-\overrightarrow{1}-\overrightarrow{5} \overline{7}-$ & & & 2,280 & & -10 & & $---0=---$ & & 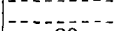 \\
\hline 12 & 1.57 & 66 & & 2,600 & 6.40 & 860 & 3.72 & 178 & 1.94 & 80 \\
\hline
\end{tabular}

SUPPI EMENTAL RECORDs.-Aug. 15, 3 a.m., gage height, 10.58 feet; discharge, 3,300 second-feet.

SOUTH YADKIN RIVER NEAR MOCKSVILLE, N. C.

Location.—Lat. $35^{\circ} 50^{\prime} 40^{\prime \prime}$, long. $80^{\circ} 39^{\prime} 45^{\prime \prime}$, at highway bridge 1 mile upstream from Little Creek, $41 / 2$ miles upstream from Hunting Creek, and 51/4 miles southwest of Mocksville, Davie County.

DRAINAGE AREA. - 313 square miles.

GAGE-HEIGHT RECORD.-Water-stage recorder graph.

DISCHARGE RECORD.-Stage-discharge relation defined by current-meter measurements up to 1,900 second-feet and extended logarithmically to erest gage height. Shifting-control method used Aug. 18 to Sept. 30. Gage heights used to halftenths between 3.0 and 4.5 feet; hundredths below and tenths above these limits.

Maxima.-1940: Discharge, 4,600 second-feet 11:30 p.m. Aug. 15 (gage height, 12.34 feet).

1938-39: Discharge, 3,110 second-feet Mar. 1, 1939 (gage height, 9.33 feet).

Stage known, 22.6 feet, from flood reference mark eut by local resident in tree near gage, sometime in October 1929 (discharge not determined).

REMARKS.-Flood runoff not affected by artificial storage. 
PEE DEE RIVER BASIN

Mean discharge, in second-feet, 1940

\begin{tabular}{|c|c|c|c|c|c|c|c|c|c|c|c|}
\hline Day & Aug. & Sept. & Day & Aug. & Sept. & Day & Aug. & Sept. & Day & Aug. & Sept. \\
\hline $\begin{array}{l}1 \\
2 \\
\mathbf{3} \\
\mathbf{4} \\
\mathbf{5} \\
\mathbf{6} \\
\mathbf{7} \\
8\end{array}$ & $\begin{array}{r}210 \\
171 \\
111 \\
98 \\
102 \\
114 \\
297 \\
121\end{array}$ & $\begin{array}{l}579 \\
255 \\
196 \\
173 \\
161 \\
312 \\
197 \\
154\end{array}$ & $\begin{array}{r}9 \\
10 \\
11 \\
12 \\
13 \\
14 \\
15 \\
16\end{array}$ & $\begin{array}{r}106 \\
95 \\
97 \\
178 \\
420 \\
2,200 \\
3,680 \\
3,920\end{array}$ & $\begin{array}{l}143 \\
164 \\
159 \\
135 \\
129 \\
125 \\
123 \\
121\end{array}$ & $\begin{array}{l}17 \\
18 \\
19 \\
20 \\
21 \\
22 \\
23 \\
24\end{array}$ & $\begin{array}{r}1,010 \\
545 \\
486 \\
370 \\
300 \\
264 \\
234 \\
223\end{array}$ & $\begin{array}{l}120 \\
118 \\
118 \\
118 \\
112 \\
111 \\
106 \\
106\end{array}$ & $\begin{array}{l}25 \\
26 \\
27 \\
28 \\
29 \\
30 \\
31\end{array}$ & $\begin{array}{l}215 \\
215 \\
198 \\
183 \\
170 \\
178 \\
548\end{array}$ & $\begin{array}{c}114 \\
125 \\
121 \\
114 \\
107 \\
102\end{array}$ \\
\hline \multicolumn{10}{|c|}{$\begin{array}{l}\text { Monthly mean discharge, in second-feet } \\
\text { Runoff, in inches }\end{array}$} & $\begin{array}{r}550 \\
2.03\end{array}$ & $\begin{array}{r}157 \\
0.56\end{array}$ \\
\hline
\end{tabular}

Gage height, in feet, and discharge, in second-feet, at indicated time, 1940

\begin{tabular}{|c|c|c|c|c|c|c|c|c|}
\hline \multirow{2}{*}{ Hour } & \multicolumn{2}{|c|}{ Aug. 13} & \multicolumn{2}{|c|}{ Aug. 14} & \multicolumn{2}{|c|}{ Aug. 15} & \multicolumn{2}{|c|}{ Aug. 16} \\
\hline & $\begin{array}{c}\text { Gage } \\
\text { height }\end{array}$ & Discharge & $\begin{array}{c}\text { Gage } \\
\text { height }\end{array}$ & Discharge & $\begin{array}{c}\text { Gage } \\
\text { height }\end{array}$ & Discharge & $\begin{array}{c}\text { Gage } \\
\text { height }\end{array}$ & Discharge \\
\hline \multirow{4}{*}{$\begin{array}{l}1 \\
2 \\
3 \\
4 \\
5 \\
6\end{array}$} & & & \multirow{4}{*}{$\begin{array}{l}3.54 \\
4.09 \\
5.11 \\
7.18 \\
7.17 \\
7.06\end{array}$} & \multirow{4}{*}{$\begin{array}{r}650 \\
870 \\
1,270 \\
2,160 \\
2,160 \\
2,120\end{array}$} & & & & \\
\hline & 2.78 & & & & 9.22 & 3,060 & 12.26 & 4,600 \\
\hline & 2.90 & $4 \overline{15}$ & & & 9.28 & 3,110 & 12.08 & 4,500 \\
\hline & 3.01 & $\overline{4} \overline{5} \overline{0}$ & & & 9.34 & 3,110 & 11.87 & 4,400 \\
\hline 7 & & & \multirow{4}{*}{$\begin{array}{l}7.05 \\
7.04 \\
7.05 \\
7.10 \\
7.18 \\
7.26\end{array}$} & \multirow{4}{*}{$\begin{array}{l}2,080 \\
2,080 \\
2,080 \\
2,120 \\
2,160 \\
2,210\end{array}$} & & & & \\
\hline $\begin{array}{l}8 \\
9\end{array}$ & 3.03 & 468 & & & 9.48 & 3,200 & 11.61 & 4,250 \\
\hline 10 & 3.05 & 468 & & & 9.71 & 3,300 & 11.46 & 4,200 \\
\hline $\begin{array}{l}11 \\
\mathbf{N}\end{array}$ & 2.95 & 432 & & & 10.05 & 3,450 & 11.21 & 4,050 \\
\hline \multirow{4}{*}{$\begin{array}{l}1 \\
2 \\
3 \\
4 \\
5 \\
6\end{array}$} & 97 & 404 & \multirow{4}{*}{$\begin{array}{l}7.34 \\
7.45 \\
7.53 \\
7.58 \\
7.49 \\
7.49\end{array}$} & \multirow{4}{*}{$\begin{array}{l}2,210 \\
2,260 \\
2,300 \\
2,340 \\
2,300 \\
2,300\end{array}$} & $10-5 \overline{5}$ & 3770 & 53 & 300 \\
\hline & 2.87 & 404 & & & 10.51 & 3,700 & 10.93 & 3,900 \\
\hline & 2.83 & 390 & & & 11.17 & 4,050 & 10.65 & 3,750 \\
\hline & 2.83 & 390 & & & 11.69 & 4,300 & 10.27 & 3,600 \\
\hline \multirow{5}{*}{$\begin{array}{r}7 \\
8 \\
9 \\
10 \\
11 \\
12 \\
\end{array}$} & & & \multirow{4}{*}{$\begin{array}{l}7.49 \\
9.66 \\
9.86 \\
9.51 \\
9.32 \\
9.23 \\
\end{array}$} & \multirow{4}{*}{$\begin{array}{l}2,300 \\
3,300 \\
3,400 \\
3,200 \\
3,110 \\
3,060 \\
\end{array}$} & & & & \\
\hline & 2.83 & 390 & & & 12.09 & 4,500 & 9.73 & 3,300 \\
\hline & $2 . \overline{3}$ & $4 \overline{2} \overline{6}$ & & & 12.29 & 4,600 & 8.99 & 2,980 \\
\hline & 3.19 & 520 & & & 12.33 & 4,600 & $\overline{7} . \overline{86}$ & 2,480 \\
\hline & \multicolumn{2}{|c|}{ Aug. 17} & \multicolumn{2}{|c|}{ Aug. 18} & \multicolumn{2}{|c|}{ Aug. 19} & \multicolumn{2}{|c|}{ Aug. 20} \\
\hline \multirow{4}{*}{$\begin{array}{r}2 \\
4 \\
6 \\
8 \\
10 \\
\mathrm{~N}\end{array}$} & \multirow{4}{*}{$\begin{array}{l}6.28 \\
5.20 \\
4.78 \\
4.50 \\
4.25 \\
4.05\end{array}$} & \multirow{4}{*}{$\begin{array}{r}1,760 \\
1,310 \\
1,150 \\
1,030 \\
910 \\
830\end{array}$} & & & & & & \\
\hline & & & 3.36 & 590 & 3.18 & 538 & 2.77 & 401 \\
\hline & & & 3.27 & $\overline{5} \overline{5} \overline{5}^{-}$ & 3.08 & 502 & $2.7 \overline{2}$ & 384 \\
\hline & & & $\overline{3} . \overline{22}$ & $\overline{\mathbf{5}} \overline{8} \overline{8}$ & $3.0 \mathrm{1}^{-}$ & $4 \overline{68}$ & 2.68 & $3 \overline{7} 0$ \\
\hline 2 & & & & & & & & \\
\hline 4 & 3.79 & 750 & 3.19 & 520 & 3.00 & 468 & 2.63 & 353 \\
\hline $\begin{array}{r}6 \\
8\end{array}$ & $\begin{array}{l}3.69 \\
3.60\end{array}$ & $\begin{array}{l}710 \\
670\end{array}$ & 3.14 & 502 & $2 . \overline{9}$ & $4 \overline{68}$ & $\overline{2} . \overline{59}$ & $3 \overline{3}$ \\
\hline $\begin{array}{l}10 \\
12\end{array}$ & $\begin{array}{l}3.53 \\
3.46\end{array}$ & $\begin{array}{l}650 \\
610\end{array}$ & 3.18 & 520 & 2.86 & 422 & $2 . \overline{55}$ & 326 \\
\hline
\end{tabular}

Supplemental RECORDs.-Aug. 14, 4:30 a.m. gage height, 7.25 feet, discharge, 2,160 second-feet: 8:45 p.m., gage height, 9.96 feet, discharge, 3,450 second-feet. Aug. 15, 11:30 p.m., gage height, 12.34 feet, discharge, 4,600 second-feet. 
SOUTH YADKIN RIVER AT COOLEEMEE, N. C.

LoCATION.-Lat. $35^{\circ} 48^{\prime} 30^{\prime \prime}$, long. $80^{\circ} 33^{\prime} 45^{\prime \prime}$, just downstream from tailrace of Erwin Cotton Mills at Cooleemee, Davie County, and 21/4 miles downstream from Bear Creek. Datum of gage is 624.57 feet above mean sea level, datum of 1929 supplementary adjustment of 1.936 (levels by Corps of Engineers, War Department).

DRAINAGE AREA.-569 square miles.

GAGE-HEIGHT RECORD.-Water-stage recorder graph except for Aug. 1-5, when recorder elock was stopped.

DISCHARGE RECORD.--Stage-discharge relation defined by current-meter measurements up to 7,400 second-feet for 1940 , up to 4,600 second-feet for 1929, and extended to erest gage height on basis of a rough computation of flood flow over Erwin Cotton Mills dam. Discharge during period of no gage-height record, Aug. 1-5, based on recorded range in gage heights, weather records, and records for station near Mocksville.

Maxima.-1940: Discharge, 8,230 second-feet 2 a.m. Aug. 16 (gage height, 20.62 feet).

1928-39: Discharge, 24,800 second-feet Oct. 3, 1929 (gage height, 32.25 feet). REMARKS.-Flood runoff practically unaffected by artificial storage.

Mean discharge, in second-feet, 1940

\begin{tabular}{|c|c|c|c|c|c|c|c|c|c|c|c|}
\hline Day & Aug. & Sept. & Day & Aug. & Sept. & Day & Aug. & Sept. & Day & Aug. & Sept. \\
\hline $\begin{array}{l}1 \\
2 \\
3 \\
4 \\
5 \\
6 \\
7 \\
8\end{array}$ & $\begin{array}{r}340 \\
300 \\
260 \\
80 \\
300 \\
192 \\
427 \\
324\end{array}$ & $\begin{array}{r}1,370 \\
548 \\
468 \\
318 \\
342 \\
460 \\
394 \\
279\end{array}$ & $\begin{array}{r}9 \\
10 \\
11 \\
12 \\
13 \\
14 \\
15 \\
16\end{array}$ & $\begin{array}{r}131 \\
248 \\
69 \\
389 \\
613 \\
3,570 \\
6,780 \\
7,680\end{array}$ & $\begin{array}{l}366 \\
249 \\
373 \\
240 \\
246 \\
312 \\
148 \\
244\end{array}$ & $\begin{array}{l}17 \\
18 \\
19 \\
20 \\
21 \\
22 \\
23 \\
24\end{array}$ & $\begin{array}{r}3,950 \\
1,140 \\
1,180 \\
828 \\
542 \\
495 \\
459 \\
387\end{array}$ & $\begin{array}{r}221 \\
217 \\
204 \\
210 \\
255 \\
82 \\
262 \\
187\end{array}$ & $\begin{array}{l}25 \\
26 \\
27 \\
28 \\
29 \\
30 \\
31\end{array}$ & $\begin{array}{l}250 \\
451 \\
390 \\
294 \\
322 \\
289 \\
868\end{array}$ & $\begin{array}{r}174 \\
278 \\
242 \\
247 \\
93 \\
270 \\
\end{array}$ \\
\hline \multicolumn{10}{|c|}{$\begin{array}{l}\text { Monthly mean discharge, in second-feet } \\
\text { Runoff, in inches }\end{array}$} & $\begin{array}{r}1,082 \\
2.19\end{array}$ & $\begin{array}{r}310 \\
0.61\end{array}$ \\
\hline
\end{tabular}


PEE DEE RIVER BASIN

Gage height, in feet, and discharge, in second-feet, at indicated time, 1940

\begin{tabular}{|c|c|c|c|c|c|c|c|c|c|c|c|}
\hline \multirow{2}{*}{ Hour } & \multicolumn{2}{|c|}{ Aug. 11} & \multicolumn{3}{|c|}{ Aug. 12} & \multicolumn{2}{|c|}{ Aug. 13} & \multicolumn{2}{|c|}{ Aug. 14} & \multicolumn{2}{|c|}{ Aug. 15} \\
\hline & $\begin{array}{c}\text { Gage } \\
\text { height }\end{array}$ & $\begin{array}{c}\text { Dis- } \\
\text { charge }\end{array}$ & $\begin{array}{c}\text { Gage } \\
\text { height }\end{array}$ & \multicolumn{2}{|c|}{$\begin{array}{l}\text { Dis- } \\
\text { charge }\end{array}$} & $\begin{array}{c}\text { Gage } \\
\text { height }\end{array}$ & $\begin{array}{l}\text { Dis- } \\
\text { charge }\end{array}$ & $\begin{array}{c}\text { Gage } \\
\text { height }\end{array}$ & $\begin{array}{l}\text { Dis- } \\
\text { charge }\end{array}$ & $\begin{array}{c}\text { Gage } \\
\text { height }\end{array}$ & $\begin{array}{l}\text { Dis- } \\
\text { charge }\end{array}$ \\
\hline $\begin{array}{l}1 \\
2 \\
3 \\
4 \\
5 \\
6\end{array}$ & $\begin{array}{r}0.67 \\
.68 \\
.68 \\
.68 \\
.68 \\
.68\end{array}$ & $\begin{array}{l}21 \\
22 \\
22 \\
22 \\
22 \\
22\end{array}$ & $\begin{array}{l}1.49 \\
1.53 \\
1.59 \\
1.64 \\
1.68 \\
2.49\end{array}$ & \multicolumn{2}{|c|}{$\begin{array}{l}205 \\
217 \\
236 \\
252 \\
265 \\
569\end{array}$} & $\begin{array}{l}2.13 \\
2.13 \\
2.14 \\
2.14 \\
2.15 \\
2.17\end{array}$ & $\begin{array}{l}420 \\
420 \\
424 \\
424 \\
428 \\
436\end{array}$ & $\begin{array}{l}4.00 \\
5.58 \\
7.39 \\
8.53 \\
8.91 \\
9.10\end{array}$ & $\begin{array}{l}1,260 \\
1,850 \\
2,480 \\
2,890 \\
3,040 \\
3,120\end{array}$ & $\begin{array}{r}14.92 \\
15.76 \\
16.37\end{array}$ & $\begin{array}{r}5,440 \\
5,840 \\
6,120\end{array}$ \\
\hline $\begin{array}{r}7 \\
8 \\
9 \\
10 \\
11 \\
\mathrm{~N}\end{array}$ & $\begin{array}{l}.68 \\
.68 \\
.68 \\
.68 \\
.68 \\
.68\end{array}$ & $\begin{array}{l}22 \\
22 \\
22 \\
22 \\
22 \\
22\end{array}$ & $\begin{array}{l}2.28 \\
2.21 \\
2.19 \\
2.18 \\
2.17 \\
2.16\end{array}$ & \multicolumn{2}{|c|}{$\begin{array}{l}479 \\
451 \\
443 \\
439 \\
436 \\
432\end{array}$} & $\begin{array}{l}2.18 \\
2.18 \\
2.21 \\
2.54 \\
2.60 \\
2.64\end{array}$ & $\begin{array}{l}439 \\
439 \\
451 \\
591 \\
619 \\
642\end{array}$ & $\begin{array}{r}9.37 \\
9.73 \\
10.54 \\
10.85 \\
10.93 \\
10.96\end{array}$ & $\begin{array}{l}3,230 \\
3,350 \\
3,650 \\
3,760 \\
3,800 \\
3,840\end{array}$ & $\begin{array}{r}16.90 \\
17.14 \\
17.69\end{array}$ & $\begin{array}{r}6,350 \\
6,450 \\
6,750\end{array}$ \\
\hline $\begin{array}{l}1 \\
2 \\
3 \\
4 \\
5 \\
6\end{array}$ & $\begin{array}{r}.68 \\
.69 \\
.75 \\
.96 \\
1.18 \\
1.27\end{array}$ & $\begin{array}{r}22 \\
23 \\
31 \\
66 \\
117 \\
141\end{array}$ & $\begin{array}{l}2.16 \\
2.15 \\
2.14 \\
2.13 \\
2.12 \\
2.11\end{array}$ & \multicolumn{2}{|c|}{$\begin{array}{l}432 \\
428 \\
424 \\
420 \\
417 \\
413\end{array}$} & $\begin{array}{l}2.72 \\
2.81 \\
2.88 \\
2.92 \\
2.93 \\
2.94\end{array}$ & $\begin{array}{l}666 \\
714 \\
762 \\
762 \\
786 \\
786\end{array}$ & $\begin{array}{l}11.01 \\
11.07 \\
11.13 \\
11.21 \\
11.38 \\
11.82\end{array}$ & $\begin{array}{l}3,840 \\
3,880 \\
3,880 \\
3,920 \\
4,000 \\
4,160\end{array}$ & $\begin{array}{l}18.24 \\
18.82 \\
19.40\end{array}$ & $\begin{array}{r}7,000 \\
7, \overline{7} 00 \\
7,600\end{array}$ \\
\hline $\begin{array}{r}7 \\
8 \\
9 \\
10 \\
11 \\
12 \\
\end{array}$ & $\begin{array}{l}1.33 \\
1.38 \\
1.41 \\
1.43 \\
1.45 \\
1.47 \\
\end{array}$ & $\begin{array}{l}158 \\
172 \\
181 \\
187 \\
193 \\
199 \\
\end{array}$ & $\begin{array}{l}2.11 \\
2.11 \\
2.11 \\
2.11 \\
2.12 \\
2.12\end{array}$ & & $\begin{array}{l}413 \\
413 \\
413 \\
413 \\
417 \\
417 \\
\end{array}$ & $\begin{array}{l}2.94 \\
2.93 \\
2.91 \\
2.71 \\
2.95 \\
3.50 \\
\end{array}$ & $\begin{array}{r}786 \\
786 \\
762 \\
666 \\
786 \\
1,040 \\
\end{array}$ & $\begin{array}{l}12.00 \\
12.28 \\
12.70 \\
13.20 \\
13.66 \\
14.07 \\
\end{array}$ & $\begin{array}{l}4,240 \\
4,360 \\
4,520 \\
4,720 \\
4,930 \\
5,100 \\
\end{array}$ & $\begin{array}{r}19.87 \\
20.31 \\
20.53 \\
\end{array}$ & $\begin{array}{r}7,850 \\
8,060 \\
8,180 \\
\end{array}$ \\
\hline 12 & \multicolumn{2}{|c|}{ Aug. 16} & \multicolumn{3}{|c|}{ Aug. 17} & \multicolumn{2}{|c|}{ Aug. 18} & \multicolumn{2}{|c|}{ Aug. 19} & \multicolumn{2}{|c|}{ Aug. 20} \\
\hline $\begin{array}{r}2 \\
4 \\
6 \\
8 \\
10 \\
\mathbf{N}\end{array}$ & $\begin{array}{l}20.62 \\
20.54 \\
20.37 \\
20.18 \\
19.91 \\
19.64\end{array}$ & $\begin{array}{l}8,230 \\
8,180 \\
8,120 \\
8,010 \\
7,850 \\
7,700\end{array}$ & $\begin{array}{l}16.61 \\
15.57 \\
14.44 \\
13.28 \\
12.22 \\
10.84\end{array}$ & & $\begin{array}{l}210 \\
750 \\
230 \\
770 \\
320 \\
760\end{array}$ & $\begin{array}{l}4.66 \\
4.50 \\
4.33 \\
4.20 \\
1.51 \\
1.73\end{array}$ & $\begin{array}{r}1,540 \\
1,460 \\
1,380 \\
1,340 \\
211 \\
281\end{array}$ & $\begin{array}{l}4.05 \\
4.01 \\
3.96 \\
3.99 \\
3.95 \\
3.77\end{array}$ & $\begin{array}{l}1,260 \\
1,260 \\
1,260 \\
1,260 \\
1,260 \\
1,170\end{array}$ & $\begin{array}{r}3.40 \\
3.26 \\
3.20\end{array}$ & $\begin{array}{l}996 \\
927 \overline{7} \\
904\end{array}$ \\
\hline $\begin{array}{r}2 \\
4 \\
6 \\
8 \\
10 \\
12 \\
\end{array}$ & $\begin{array}{l}19.42 \\
19.22 \\
18.94 \\
18.66 \\
18.10 \\
17.41 \\
\end{array}$ & $\begin{array}{l}7,600 \\
7,500 \\
7,350 \\
7,250 \\
6,950 \\
6,600 \\
\end{array}$ & $\begin{array}{l}9.84 \\
8.88 \\
7.83 \\
6.74 \\
5.78 \\
5.10 \\
\end{array}$ & & $\begin{array}{r}380 \\
, 040 \\
620 \\
, 220 \\
, 920 \\
, 680 \\
\end{array}$ & $\begin{array}{l}2.93 \\
4.05 \\
4.15 \\
4.10 \\
4.06 \\
4.06 \\
\end{array}$ & $\begin{array}{r}786 \\
1,260 \\
1,340 \\
1,300 \\
1,300 \\
1,300 \\
\end{array}$ & $\begin{array}{l}3.70 \\
3.66 \\
3.64 \\
3.62 \\
3.58 \\
3.52 \\
\end{array}$ & $\begin{array}{l}1,130 \\
1,110 \\
1,110 \\
1,090 \\
1,090 \\
1,040 \\
\end{array}$ & $\begin{array}{r}2.79 \\
2.58 \\
2.54 \\
\end{array}$ & 610 \\
\hline \multicolumn{12}{|c|}{ SUPPLEMENTAL RECORDS } \\
\hline \multicolumn{3}{|c|}{ Day } & \multicolumn{2}{|c|}{$\begin{array}{c}\text { Gage } \\
\text { height }\end{array}$} & \multicolumn{2}{|c|}{ Discharge } & & Day & & $\begin{array}{c}\text { Gage } \\
\text { height }\end{array}$ & Discharge \\
\hline $\begin{array}{l}\text { Aug. } \\
\text { Aug. } \\
\text { Aug. }\end{array}$ & $\begin{array}{l}5: 30 \\
9: 30 \\
9 \text { a.m }\end{array}$ & a & & & & & $\begin{array}{r}\text { Aug. } 19,6 \\
9 \\
9 \\
\text { Aug. } 20, \\
5\end{array}$ & $\begin{array}{l}\text { a.m. } \\
\text { n.m.-. } \\
\text { m... } \\
\text { m. }\end{array}$ & \begin{tabular}{|c|}
..- \\
$\cdots$ \\
$\cdots$
\end{tabular} & $\begin{array}{l}4.40 \\
4.11 \\
3.15 \\
2.63\end{array}$ & $\begin{array}{r}1,420 \\
1,300 \\
881 \\
642 \\
\end{array}$ \\
\hline
\end{tabular}

ROCKY RIVER AT TURNERSBURG, N. C.

Location.-Lat. $35^{\circ} 54^{\prime} 35^{\prime \prime}$, long. $80^{\circ} 48^{\prime} 10^{\prime \prime}$, 500 feet downstream from bridge on

U. S. Highway 21 at Turnersburg, Iredell County, and 1 mile downstream from Mud Creek.

DRAINAGE AREA.-85.5 square miles.

GAGE-HEIGHT RECORD.-Water-stage recorder graph.

DISCHARGE RECORD.—Stage-discharge relation defined by current-meter measurements up to 3,350 second-feet.

Maxima.-1940: Discharge, 2,840 second-feet 11 p.m. Aug. 14 (gage height, 8.05 feet).

ReMarks.-Flood runoff not affected by artificial storage. 
Mean discharge, in second-feet, 1940

\begin{tabular}{|c|c|c|c|c|c|c|c|c|c|c|c|}
\hline Day & Aug. & Sept. & Day & Aug. & Sept. & Day & Aug. & Sept. & Day & Aug. & Sept. \\
\hline 1 & 57 & 92 & 9 & 36 & 50 & 17 & 180 & 40 & 25 & & \\
\hline 2 & 40 & 68 & 10 & 34 & 47 & 18 & 154 & 41 & 26 & 64 & 43 \\
\hline$\overline{3}$ & 36 & 61 & 11 & 39 & 46 & 19 & 126 & 41 & 27 & 62 & 43 \\
\hline 4 & 34 & 58 & 12 & 129 & 45 & 20 & 97 & 40 & 28 & 57 & 38 \\
\hline 5 & 43 & 55 & 13 & 199 & 43 & 21 & 82 & 39 & 29 & 53 & 36 \\
\hline 6 & 55 & 69 & 14 & 1,880 & 44 & 22 & 75 & 35 & 30 & 75 & 38 \\
\hline 7 & 68 & 55 & 15 & 969 & 41 & 23 & 70 & 37 & 31 & & \\
\hline 8 & 40 & 48 & 16 & 291 & 44 & 24 & 67 & 37 & & & \\
\hline \multicolumn{10}{|c|}{$\begin{array}{l}\text { Monthly mean discharge, in second-feet } \\
\text { Runoff, in inches }\end{array}$} & $\begin{array}{r}175 \\
2.36\end{array}$ & $\begin{array}{l}47.2 \\
0.62\end{array}$ \\
\hline
\end{tabular}

Gage height, in feet, and discharge, in second-feet, at indicated time, 1940

\begin{tabular}{|c|c|c|c|c|c|c|c|c|}
\hline \multirow{2}{*}{ Hour } & \multicolumn{2}{|c|}{ Aug. 11} & \multicolumn{2}{|c|}{ Aug. 12} & \multicolumn{2}{|c|}{ Aug. 13} & \multicolumn{2}{|c|}{ Aug. 14} \\
\hline & $\begin{array}{l}\text { Gage } \\
\text { height }\end{array}$ & Discharge & $\begin{array}{l}\text { Gage } \\
\text { height }\end{array}$ & Discharge & $\begin{array}{l}\text { Gage } \\
\text { height }\end{array}$ & Discharge & $\begin{array}{l}\text { Gage } \\
\text { height }\end{array}$ & Discharge \\
\hline $\begin{array}{l}1 \\
2 \\
3 \\
4 \\
\mathbf{5} \\
6\end{array}$ & $\begin{array}{l}1.80 \\
1.81 \\
1.80 \\
1.80 \\
1.80 \\
1.79\end{array}$ & $\begin{array}{l}37 \\
38 \\
37 \\
37 \\
37 \\
36\end{array}$ & $\begin{array}{l}1.88 \\
1.89 \\
1.90 \\
1.91 \\
1.91 \\
1.91\end{array}$ & $\begin{array}{l}44 \\
45 \\
46 \\
47 \\
47 \\
47\end{array}$ & $\begin{array}{l}2.62 \\
2.56 \\
2.50 \\
2.45 \\
2.41 \\
2.40\end{array}$ & $\begin{array}{l}163 \\
149 \\
136 \\
126 \\
118 \\
116\end{array}$ & $\begin{array}{l}4.38 \\
4.95 \\
5.12 \\
5.20 \\
5.32 \\
5.49\end{array}$ & $\begin{array}{r}810 \\
1,060 \\
1,140 \\
1,190 \\
1,240 \\
1,340\end{array}$ \\
\hline $\begin{array}{r}7 \\
8 \\
9 \\
10 \\
11 \\
\mathrm{~N}\end{array}$ & $\begin{array}{l}1.80 \\
1.80 \\
1.80 \\
1.79 \\
1.78 \\
1.78\end{array}$ & $\begin{array}{l}37 \\
37 \\
37 \\
36 \\
35 \\
35\end{array}$ & $\begin{array}{l}1.97 \\
1.91 \\
1.88 \\
1.93 \\
2.08 \\
1.94\end{array}$ & $\begin{array}{l}53 \\
47 \\
44 \\
49 \\
66 \\
50\end{array}$ & $\begin{array}{l}2.40 \\
2.37 \\
2.45 \\
2.55 \\
2.66 \\
2.85\end{array}$ & $\begin{array}{l}116 \\
111 \\
126 \\
147 \\
172 \\
222\end{array}$ & $\begin{array}{l}5.78 \\
5.85 \\
6.00 \\
6.14 \\
6.39 \\
6.59\end{array}$ & $\begin{array}{l}1,500 \\
1,500 \\
1,610 \\
1.660 \\
1,840 \\
1,950\end{array}$ \\
\hline $\begin{array}{l}1 \\
2 \\
3 \\
4 \\
5 \\
6\end{array}$ & $\begin{array}{l}1.78 \\
1.78 \\
1.80 \\
1.81 \\
1.81 \\
1.93\end{array}$ & $\begin{array}{l}35 \\
35 \\
37 \\
38 \\
38 \\
49\end{array}$ & $\begin{array}{l}2.08 \\
2.61 \\
2.55 \\
2.98 \\
3.07 \\
3.03\end{array}$ & $\begin{array}{r}66 \\
160 \\
147 \\
260 \\
288 \\
276\end{array}$ & $\begin{array}{l}3.01 \\
2.98 \\
2.89 \\
2.85 \\
2.89 \\
2.92\end{array}$ & $\begin{array}{l}269 \\
260 \\
233 \\
222 \\
233 \\
242\end{array}$ & $\begin{array}{l}6.77 \\
6.89 \\
7.01 \\
7.03 \\
7.46 \\
7.28\end{array}$ & $\begin{array}{l}2,070 \\
2,130 \\
2,190 \\
2,190 \\
2,510 \\
2,380\end{array}$ \\
\hline \multirow[t]{2}{*}{$\begin{array}{r}7 \\
8 \\
9 \\
10 \\
11 \\
12 \\
\end{array}$} & $\begin{array}{l}1.92 \\
1.87 \\
1.89 \\
1.88 \\
1.86 \\
1.86 \\
\end{array}$ & $\begin{array}{l}48 \\
43 \\
45 \\
44 \\
42 \\
42 \\
\end{array}$ & $\begin{array}{l}2.98 \\
2.98 \\
2.96 \\
2.89 \\
2.78 \\
2.69 \\
\end{array}$ & $\begin{array}{l}260 \\
260 \\
254 \\
233 \\
203 \\
180 \\
\end{array}$ & $\begin{array}{l}2.91 \\
2.88 \\
2.89 \\
2.97 \\
3.20 \\
3.60 \\
\end{array}$ & $\begin{array}{l}239 \\
230 \\
233 \\
257 \\
332 \\
480 \\
\end{array}$ & $\begin{array}{l}7.33 \\
7.51 \\
7.75 \\
7.98 \\
8.05 \\
7.96 \\
\end{array}$ & $\begin{array}{l}2,380 \\
2,510 \\
2,700 \\
2,840 \\
2,840 \\
2,840 \\
\end{array}$ \\
\hline & \multicolumn{2}{|c|}{ Aug. 15} & \multicolumn{2}{|c|}{ Aug. 16} & \multicolumn{2}{|c|}{ Aug. 17} & \multicolumn{2}{|c|}{ Aug. 18} \\
\hline $\begin{array}{l}1 \\
2 \\
3 \\
4 \\
5 \\
6\end{array}$ & $\begin{array}{l}7.68 \\
7.32 \\
6.91 \\
6.36 \\
5.75 \\
5.20\end{array}$ & $\begin{array}{l}2,630 \\
2,380 \\
2,130 \\
1,840 \\
1,500 \\
1,190\end{array}$ & $\begin{array}{l}3.35 \\
3.31 \\
3.27 \\
3.24 \\
3.22 \\
3.19\end{array}$ & $\begin{array}{l}386 \\
372 \\
357 \\
346 \\
339 \\
329\end{array}$ & - & $\mid \begin{array}{l}-\cdots \\
-\cdots \\
-\cdots \\
-\cdots\end{array}$ & $\begin{array}{r}-\overline{2} . \overline{55} \\
-\overline{2} . \overline{57} \\
-\overline{2} . \overline{60}\end{array}$ & $\begin{array}{c}147 \\
151\end{array}$ \\
\hline $\begin{array}{r}7 \\
8 \\
9 \\
10 \\
11 \\
\mathrm{~N}\end{array}$ & $\begin{array}{l}4.76 \\
4.47 \\
4.30 \\
4.19 \\
4.13 \\
4.03\end{array}$ & $\begin{array}{l}971 \\
833 \\
767 \\
724 \\
702 \\
660\end{array}$ & $\begin{array}{l}3.16 \\
3.13 \\
3.11 \\
3.08 \\
3.07 \\
3.03\end{array}$ & $\begin{array}{l}318 \\
308 \\
301 \\
292 \\
288 \\
276\end{array}$ & 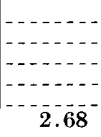 & \begin{tabular}{c}
$-\ldots \ldots$ \\
\hdashline$-177^{-}$
\end{tabular} & \begin{tabular}{c}
$-\overline{2} . \overline{58}$ \\
\hdashline$\overline{2} . \overline{54}$ \\
$-\overline{2} . \overline{52}$
\end{tabular} & $\begin{array}{c}154 \\
1455^{--}\end{array}$ \\
\hline $\begin{array}{l}1 \\
2 \\
3 \\
4 \\
5 \\
6\end{array}$ & $\begin{array}{l}3.95 \\
3.86 \\
3.76 \\
3.67 \\
3.59 \\
3.55\end{array}$ & $\begin{array}{l}618 \\
578 \\
538 \\
499 \\
476 \\
461\end{array}$ & $\begin{array}{l}3.02 \\
3.00 \\
2.98 \\
2.97 \\
2.95 \\
2.92\end{array}$ & $\begin{array}{l}272 \\
266 \\
260 \\
257 \\
251 \\
242\end{array}$ & 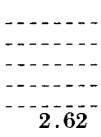 & $\begin{array}{c}-16-1 \\
-163\end{array}$ & $\begin{array}{c}-\overline{2.56} \\
-\overline{2.67} \\
-\overline{2.66}\end{array}$ & $\begin{array}{c}149^{--} \\
17 \overline{5}^{--}\end{array}$ \\
\hline $\begin{array}{r}7 \\
8 \\
9 \\
10 \\
11 \\
12 \\
\end{array}$ & $\begin{array}{l}3.55 \\
3.51 \\
3.45 \\
3.39 \\
3.39 \\
3.39\end{array}$ & $\begin{array}{l}461 \\
446 \\
423 \\
400 \\
400 \\
400\end{array}$ & $\begin{array}{l}2.91 \\
2.94 \\
2.93 \\
2.93 \\
2.90 \\
2.85\end{array}$ & $\begin{array}{l}239 \\
248 \\
245 \\
245 \\
236 \\
222\end{array}$ & 2.57 & $\mid \begin{array}{c}-15 \\
-15\end{array}$ & $\begin{array}{r}-\overline{2} . \overline{6} \\
-\overline{2} . \overline{5} \overline{7} \\
-\overline{2.53}\end{array}$ & $\begin{array}{c}163^{--} \\
151^{-} \\
143^{3}\end{array}$ \\
\hline
\end{tabular}

Supplemental RECORDs-Aug, 11, 6:30 p.m gage height, 2.00 feet; discharge, 56 second-feet, Aug. 12 , 6.30 a.m., gage height, 2.06 feet; discharge, 63 second-f eet. Aug. 16, 8:30 p.m., gage height, 3.02 feet; discharge, 272 second-feet. Aug. 18, 5 p.m., gage height, 2.69 feet; discharge, 180 second-feet. 
THIRD CREEK AT CLEVELAND, N. C.

Location.-Lat. $35^{\circ} 44^{\prime} 40^{\prime \prime}$, long. $80^{\circ} 40^{\prime} 55^{\prime \prime}$, at county road bridge $3 / 4$ mile north of Cleveland, Rowan County, and 7 miles upstream from Fourth Creek.

Drainage AREa.-87.4 square miles.

GAGE-HEIGHT RECORD.-Water-stage recorder graph except Aug. 1-4.

DISCHARGE RECORD.-Stage-discharge relation defined by current-meter measurements up to 1,130 second-feet. Gage heights used to half-tenths between 2.3 and 4.8 feet; hundredths below and tenths above these limits. Shifting-control method used from $12 \mathrm{~m}$. Aug. 17 to Sept. 6. Discharge for period of no gage-height record, Aug. 1-4, based on records for nearby streams.

Maxima.-1940: Discharge, 1,380 second-feet 9:30 p.m. Aug. 14 (gage height, 8.91 feet).

REMARKs.-Flood runoff not affected by artificial storage.

Mean discharge, in second-feet, 1940

\begin{tabular}{|c|c|c|c|c|c|c|c|c|c|c|c|}
\hline Day & Aug. & Sept. & Day & Aug. & Sept. & Day & Aug. & Sept. & Day & Aug. & Sept. \\
\hline $\begin{array}{l}1 \\
2 \\
3 \\
4 \\
5 \\
6 \\
7 \\
8\end{array}$ & $\begin{array}{l}30 \\
28 \\
26 \\
26 \\
33 \\
30 \\
35 \\
28\end{array}$ & $\begin{array}{r}68 \\
44 \\
41 \\
38 \\
38 \\
166 \\
44 \\
36\end{array}$ & $\begin{array}{r}9 \\
10 \\
11 \\
12 \\
13 \\
14 \\
15 \\
16\end{array}$ & $\begin{array}{r}27 \\
26 \\
28 \\
40 \\
97 \\
1,150 \\
848 \\
443\end{array}$ & $\begin{array}{r}33 \\
142 \\
87 \\
41 \\
35 \\
33 \\
31 \\
30\end{array}$ & $\begin{array}{l}17 \\
18 \\
19 \\
20 \\
21 \\
22 \\
23 \\
24\end{array}$ & $\begin{array}{r}162 \\
102 \\
84 \\
64 \\
57 \\
51 \\
56 \\
54\end{array}$ & $\begin{array}{l}28 \\
28 \\
28 \\
28 \\
27 \\
27 \\
26 \\
26\end{array}$ & $\begin{array}{l}25 \\
26 \\
27 \\
28 \\
29 \\
30 \\
31\end{array}$ & $\begin{array}{l}46 \\
44 \\
41 \\
41 \\
39 \\
45 \\
80\end{array}$ & $\begin{array}{l}62 \\
79 \\
31 \\
29 \\
28 \\
27\end{array}$ \\
\hline \multicolumn{10}{|c|}{$\begin{array}{l}\text { Monthly mean discharge, in second-feet } \ldots \ldots \\
\text { Runoff, in inches }\end{array}$} & $\begin{array}{r}125 \\
1.65\end{array}$ & $\begin{array}{l}46.0 \\
0.59\end{array}$ \\
\hline
\end{tabular}

Gage height, in feet, and discharge, in second-feet, at indicated time, 1940

\begin{tabular}{|c|c|c|c|c|c|c|c|c|c|c|}
\hline \multirow{2}{*}{ Hour } & \multicolumn{2}{|c|}{ Aug. 13} & \multicolumn{2}{|c|}{ Aug. 14} & \multicolumn{2}{|c|}{ Aug. 15} & \multicolumn{2}{|c|}{ Aug. 16} & \multicolumn{2}{|c|}{ Aug. 17} \\
\hline & $\begin{array}{l}\text { Gage } \\
\text { ht. }\end{array}$ & $\begin{array}{l}\text { Dis- } \\
\text { charge }\end{array}$ & $\begin{array}{l}\text { Gage } \\
\text { ht. }\end{array}$ & $\begin{array}{l}\text { Dis- } \\
\text { charge }\end{array}$ & $\begin{array}{l}\text { Gage } \\
\text { ht. }\end{array}$ & $\begin{array}{c}\text { Dis- } \\
\text { charge }\end{array}$ & $\begin{array}{c}\text { Gage } \\
\text { ht. }\end{array}$ & $\begin{array}{l}\text { Dis- } \\
\text { charge }\end{array}$ & $\begin{array}{c}\text { Gage } \\
\text { ht. }\end{array}$ & $\begin{array}{c}\text { Dis- } \\
\text { charge }\end{array}$ \\
\hline $\begin{array}{l}1 \\
2 \\
3 \\
4 \\
5 \\
6\end{array}$ & $\begin{array}{l}1.95 \\
1.94 \\
1.91 \\
1.90 \\
1.90 \\
1.92\end{array}$ & $\begin{array}{l}82 \\
82 \\
79 \\
78 \\
78 \\
80\end{array}$ & $\begin{array}{l}5.10 \\
7.15 \\
7.94 \\
8.23 \\
8.32 \\
8.32\end{array}$ & $\begin{array}{r}521 \\
965 \\
1,130 \\
1,200 \\
1,220 \\
1,220\end{array}$ & $\begin{array}{l}8.80 \\
8.71 \\
8.81 \\
8.73 \\
8.70 \\
8.65\end{array}$ & $\begin{array}{l}1,350 \\
1,320 \\
1,350 \\
1,320 \\
1,320 \\
1,300\end{array}$ & $\begin{array}{l}3.67 \\
3.58 \\
3.50 \\
3.43 \\
3.38 \\
3.35\end{array}$ & $\begin{array}{l}272 \\
265 \\
250 \\
243 \\
236 \\
229\end{array}$ & 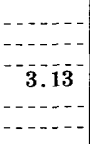 & 202 \\
\hline $\begin{array}{r}7 \\
8 \\
9 \\
10 \\
11 \\
\mathrm{~N}\end{array}$ & $\begin{array}{l}1.95 \\
1.97 \\
2.06 \\
2.14 \\
2.20 \\
2.22\end{array}$ & $\begin{array}{r}82 \\
84 \\
92 \\
100 \\
105 \\
107\end{array}$ & $\begin{array}{l}8.32 \\
8.28 \\
8.24 \\
8.20 \\
8.22 \\
8.14\end{array}$ & $\begin{array}{l}1,220 \\
1,220 \\
1,200 \\
1,200 \\
1,200 \\
1,180\end{array}$ & $\begin{array}{l}8.56 \\
8.38 \\
8.09 \\
7.77 \\
7.23 \\
6.65\end{array}$ & $\begin{array}{r}1,300 \\
1,250 \\
1,180 \\
1,100 \\
965 \\
830\end{array}$ & $\begin{array}{l}3.53 \\
6.34 \\
7.04 \\
7.04 \\
6.87 \\
6.55\end{array}$ & $\begin{array}{l}258 \\
764 \\
919 \\
919 \\
896 \\
830\end{array}$ & $\begin{array}{r}2.88 \\
2.69\end{array}$ & $\begin{array}{c}17 \overline{3} \\
152\end{array}$ \\
\hline $\begin{array}{l}1 \\
2 \\
3 \\
4 \\
5 \\
6\end{array}$ & $\begin{array}{l}2.22 \\
2.22 \\
2.24 \\
2.24 \\
2.25 \\
2.25\end{array}$ & $\begin{array}{l}107 \\
107 \\
109 \\
109 \\
110 \\
110\end{array}$ & $\begin{array}{l}8.07 \\
8.01 \\
8.04 \\
7.88 \\
7.76 \\
7.60\end{array}$ & $\begin{array}{l}1,180 \\
1,150 \\
1,150 \\
1,130 \\
1,100 \\
1,060\end{array}$ & $\begin{array}{l}6.06 \\
5.65 \\
5.25 \\
4.94 \\
4.74 \\
4.49\end{array}$ & $\begin{array}{l}722 \\
619 \\
540 \\
483 \\
456 \\
411\end{array}$ & $\begin{array}{l}5.80 \\
5.18 \\
4.80 \\
4.52 \\
4.27 \\
4.06\end{array}$ & $\begin{array}{l}659 \\
540 \\
465 \\
411 \\
368 \\
335\end{array}$ & 2.52 & $13 \overline{7}$ \\
\hline $\begin{array}{r}7 \\
8 \\
9 \\
10 \\
11 \\
12\end{array}$ & $\begin{array}{l}2.22 \\
2.19 \\
2.15 \\
2.14 \\
2.23 \\
2.58\end{array}$ & $\begin{array}{l}107 \\
104 \\
100 \\
100 \\
108 \\
142\end{array}$ & $\begin{array}{l}8.13 \\
8.71 \\
8.89 \\
8.88 \\
8.80 \\
8.78\end{array}$ & $\begin{array}{l}1,180 \\
1,320 \\
1,380 \\
1,380 \\
1,350 \\
1,350\end{array}$ & $\begin{array}{l}4.33 \\
4.19 \\
4.08 \\
3.97 \\
3.86 \\
3.78\end{array}$ & $\begin{array}{l}386 \\
360 \\
343 \\
319 \\
303 \\
295\end{array}$ & $\begin{array}{l}3.86 \\
3.70 \\
3.96 \\
3.86 \\
3.70 \\
3.55\end{array}$ & $\begin{array}{l}303 \\
280 \\
319 \\
303 \\
280 \\
258\end{array}$ & $\begin{array}{r}2.38 \\
2.28\end{array}$ & $12 \overline{3}^{-}$ \\
\hline
\end{tabular}

Supplemental ReCORDs.-Aug. 14, 9:30 p.m., gage height, 8.91 feet; discharge, 1,380 second-feet Aug. 16, 9:30 a.m., gage height, 7.08 feet; discharge, 942 second-feet.

ABBOT'S CREEK AT LEXINGTON, N. C.

Location.-Lat. $35^{\circ} 48^{\prime} 30^{\prime \prime}$, long. $80^{\circ} 14^{\prime} 10^{\prime \prime}$, about 1,000 feet upstream from first bridge below U. S. Highway 64 and $1 \frac{1}{2}$ miles southeast of Lexington, Davidson County. 


\section{FLOODS OF AUGUST 1940 IN THE SOUTHEASTERN STATES}

DRAINAGE AREA.-174 square miles (includes small unnamed tributary between gage and highway bridge below gage).

GAGE-HEIGHT RECORD.-Water-stage recorder graph.

DISCHARGE RECORD.-Stage-discharge relation defined by current-meter measurements up to 6,200 second-feet. Gage heights used to half-tenths between 3.9 and 5.2 feet; hundredths below and tenths above these limits. Shifting-control method used Aug. 28-29, Sept. 9-10, 14-30.

Maxima.-1940: Discharge, 6,820 second-feet 4 a.m. Aug. 15 (gage height, 16.92 feet).

Remarks.-Flood runoff practically unaffected by artificial storage. The cities of Thomasville and Lexington divert their water supplies above the station, and Lexington sewage is returned below the station.

Mean discharge, in second-feet, 1940

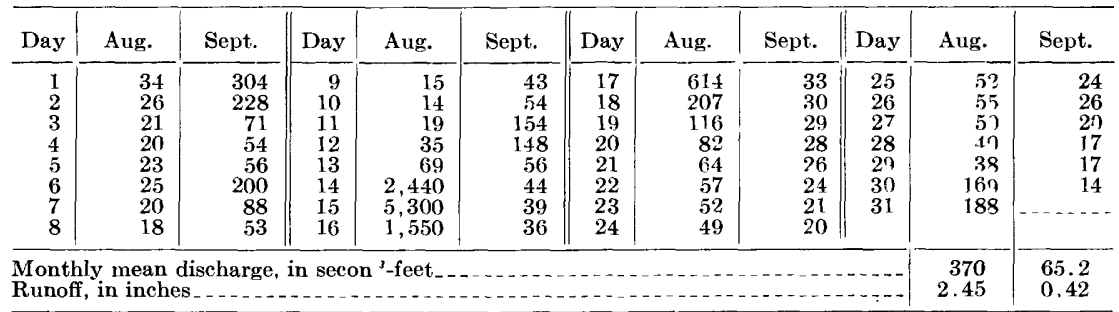

Gage height, in feet, and discharge, in second-feet, at indicated time, 1940

\begin{tabular}{|c|c|c|c|c|c|c|c|c|c|c|c|c|}
\hline \multirow{2}{*}{ Hour } & \multicolumn{2}{|c|}{ Aug. 13} & \multicolumn{2}{|c|}{ Aug. 14} & \multicolumn{2}{|c|}{ Aug. 15} & \multicolumn{2}{|c|}{ Aug. 16} & \multicolumn{2}{|c|}{ Aug. 17} & \multicolumn{2}{|c|}{ Aug. 18} \\
\hline & $\begin{array}{c}\text { Gage } \\
\text { ht. }\end{array}$ & $\begin{array}{c}\text { Dis- } \\
\text { charge }\end{array}$ & $\begin{array}{c}\text { Gage } \\
\text { ht. }\end{array}$ & $\begin{array}{c}\text { Dis- } \\
\text { charge }\end{array}$ & $\begin{array}{c}\text { Gage } \\
\text { ht. }\end{array}$ & $\begin{array}{c}\text { Dis- } \\
\text { charge }\end{array}$ & $\begin{array}{c}\text { Gage } \\
\text { ht. }\end{array}$ & $\begin{array}{c}\text { Dis- } \\
\text { charge }\end{array}$ & $\begin{array}{c}\text { Gage } \\
\text { ht. }\end{array}$ & $\begin{array}{c}\text { Dis- } \\
\text { charge }\end{array}$ & $\begin{array}{c}\text { Gage } \\
\text { ht. }\end{array}$ & $\begin{array}{c}\text { Dis- } \\
\text { charge }\end{array}$ \\
\hline 1 & 2.23 & 36 & 3.11 & 152 & 6.47 & 6,400 & 12.22 & 3,120 & & & & \\
\hline 2 & 2.46 & 56 & & 152 & 3.72 & 6,600 & 12.11 & 3,070 & & & & \\
\hline 3 & 2.82 & 102 & 3.86 & 353 & .88 & 6,820 & 11.53 & 2,810 & & & & \\
\hline $\begin{array}{l}4 \\
5\end{array}$ & $\begin{array}{l}2.92 \\
2.92\end{array}$ & $\begin{array}{l}118 \\
118\end{array}$ & $\begin{array}{l}6.19 \\
6.27\end{array}$ & $\begin{array}{l}1,050 \\
1,080\end{array}$ & $\left|\begin{array}{l}16.92 \\
16.88\end{array}\right|$ & $\begin{array}{l}6,820 \\
6,820\end{array}$ & $\left|\begin{array}{l}11.00 \\
10.41\end{array}\right|$ & $\begin{array}{l}2,620 \\
2,400\end{array}$ & 5.62 & 870 & & \\
\hline 6 & 2.87 & 110 & 6.88 & 1,260 & 16.79 & 6,710 & 9.80 & 2,190 & & & 3.47 & 242 \\
\hline 7 & 2.82 & 102 & 7.70 & 1,510 & 16.65 & 6,500 & 9.17 & 1,990 & & & & \\
\hline 8 & 2.75 & 92 & 8.1 & 1,660 & 3.49 & 6,400 & 8.50 & 1,760 & 5.22 & 750 & & \\
\hline 9 & 2.70 & 84 & 8.36 & 1,730 & 16.27 & 6 & 7.85 & 1,540 & & & & \\
\hline 10 & 2.64 & 76 & 8.46 & 1,760 & 16.06 & 6,000 & 7.26 & 1,380 & & & & \\
\hline 11 & 2.60 & 71 & 8.74 & 1,820 & 15.82 & 5,700 & 6.73 & 1,200 & & & & \\
\hline & 2.55 & 66 & 9.19 & 1,990 & $|15.59|$ & 5,510 & 6.34 & 1,080 & 4.70 & 600 & 3.30 & 195 \\
\hline 1 & 2.52 & 62 & 9.75 & 2,190 & .34 & 5,220 & 6.06 & 1,020 & & & & \\
\hline 2 & 2.49 & 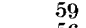 & 10. & & & 5 , & 5.83 & 930 & & & 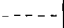 & \\
\hline 3 & 2.46 & 56 & 10.79 & 2,550 & 14.85 & 4,770 & 5.69 & 90 & & & & \\
\hline 4 & 2.43 & 53 & $\mid \begin{array}{l}13.10 \\
13\end{array}$ & 3,580 & $\left|\begin{array}{l}14.59 \\
14.98\end{array}\right|$ & $\begin{array}{l}4,600 \\
4,360\end{array}$ & 5.64 & $\begin{array}{l}870 \\
870\end{array}$ & 4.23 & 466 & & \\
\hline 6 & $\begin{array}{l}2.41 \\
2.40\end{array}$ & $\begin{array}{l}51 \\
50\end{array}$ & $\left|\begin{array}{l}13.85 \\
13.58\end{array}\right|$ & $\begin{array}{l}4,000 \\
3,880\end{array}$ & $\left|\begin{array}{l}14.28 \\
14.01\end{array}\right|$ & $\begin{array}{l}4,360 \\
4,140\end{array}$ & $\begin{array}{l}5.62 \\
5.65\end{array}$ & $\begin{array}{l}870 \\
870\end{array}$ & & & 3.16 & $163^{-}$ \\
\hline & 2.40 & 50 & 13. & 3 & $1:$ & 3 & $5 . ?$ & 900 & & & & \\
\hline 8 & 2.39 & 50 & 13.7 & 4,000 & 13.42 & 3,750 & 5.84 & 930 & 3.93 & 380 & & \\
\hline 9 & $\begin{array}{r}2.39 \\
2.30\end{array}$ & 50 & 14.28 & 4,360 . & 13.11 & 3,580 & 5.85 & 930 & $\cdots$ & &.- & \\
\hline 10 & 2.38 & 49 & 14.90 & 4,8 & 12.79 & 3,4 & 5.8 & 960 & & & -- & \\
\hline 11 & & 49 & 15.50 & 5,420 & 12.46 & 3,260 & 5.8 & 9 & & & & \\
\hline 12 & 2.52 & 62 & $|1.6 .07|$ & 6,000 & $|12.12|$ & 3,070 & 5.85 & 930 & 3.71 & 310 & 3.06 & 143 \\
\hline
\end{tabular}

SUPPlemENTAL RECORDs--Aug. 14, 4:30 a.m., gage height, 6.80 feet; discharge, 1,230 second-feet. Aug. 16, 12:30 a.m., gage height, 12.06 feet; discharge 3,070 second-feet; 1:30 a.m., gage height 12.28 feet; discharge, 3,160 second-feet.

FOURMILE BRANCH NEAR SOUTHMON'T, N. C.

Location.-Lat. $35^{\circ} 40^{\prime} 00^{\prime \prime}$, long. $80^{\circ} 10^{\prime} 25^{\prime \prime}$, at county highway bridge, 1,600 feet upstream from Flat Swamp Creek, and 5 miles east of Southmont, Davidson County.

Drainage AREa.-19.4 square miles.

GAGE-HEIGHT RECORD.-Water-stage recorder graph. 
DISCHARGE RECORD. - Stage-discharge relation defined by current-meter measurements up to 360 second-feet and extended to erest gage height on basis of determination of flood flow by slope-area method. Gage heights used to half-tenths above and hundredths below 2.3 feet.

Maxima.-1940: Discharge, 1,800 second-feet 8 a.m. Aug. 14 (gage height, 6.95 feet).

REMARKs.-Flood runoff not affected by artificial storage.

Mean discharge, in second-feet, 1940

\begin{tabular}{|c|c|c|c|c|c|c|c|c|c|c|c|}
\hline Day & Aug. & Sept. & Day & Aug. & Sept. & Day & Aug. & Sept. & Day & Aug. & Sept. \\
\hline $\begin{array}{l}1 \\
2 \\
3 \\
4 \\
5 \\
6 \\
7 \\
8\end{array}$ & $\begin{array}{r}0.34 \\
.24 \\
.15 \\
.10 \\
.10 \\
.06 \\
.01\end{array}$ & $\begin{array}{l}1.5 \\
.98 \\
.56 \\
.42 \\
.34 \\
.34 \\
.31 \\
.28\end{array}$ & $\begin{array}{r}9 \\
10 \\
11 \\
12 \\
13 \\
14 \\
15 \\
16\end{array}$ & \begin{tabular}{c}
0 \\
$\quad .11$ \\
.24 \\
.39 \\
\multicolumn{2}{c}{.49} \\
664 \\
139 \\
31
\end{tabular} & $\begin{array}{l}.24 \\
.22 \\
.30 \\
.42 \\
.24 \\
.18 \\
.16\end{array}$ & $\begin{array}{l}17 \\
18 \\
19 \\
20 \\
21 \\
22 \\
23 \\
24\end{array}$ & $\begin{array}{c}13 \\
8.1 \\
5.0 \\
2.7 \\
1.7 \\
1.4 \\
1.1 \\
.83\end{array}$ & $\begin{array}{l}.10 \\
.09 \\
.07 \\
.05 \\
.02 \\
0 \\
0 \\
0\end{array}$ & $\begin{array}{l}25 \\
26 \\
27 \\
28 \\
29 \\
30 \\
31\end{array}$ & $\begin{array}{r}.77 \\
.56 \\
.48 \\
.42 \\
.39 \\
.75 \\
2.3\end{array}$ & $\begin{array}{l}0 \\
0 \\
0 \\
0 \\
0 \\
0\end{array}$ \\
\hline & & & & & & & & & & $\begin{array}{l}28.2 \\
1.68\end{array}$ & $\begin{array}{l}.237 \\
0.01\end{array}$ \\
\hline
\end{tabular}

Gage height, in feet, and discharge, in second-feet, at indicated time, 1940

\begin{tabular}{|c|c|c|c|c|c|c|c|}
\hline \multirow{2}{*}{ Hour } & \multicolumn{2}{|c|}{ Aug. 14} & \multicolumn{2}{|c|}{ Aug. 15} & \multicolumn{3}{|c|}{ Aug. 16} \\
\hline & $\begin{array}{l}\text { Gage } \\
\text { height }\end{array}$ & Discharge & $\begin{array}{c}\text { Gage } \\
\text { height }\end{array}$ & Discharge & $\begin{array}{l}\text { Gage } \\
\text { height }\end{array}$ & Dis & ge \\
\hline $\begin{array}{l}1 \\
2 \\
3 \\
4 \\
5 \\
6\end{array}$ & $\begin{array}{r}0.37 \\
.45 \\
.62 \\
1.10 \\
3.65 \\
5.18\end{array}$ & $\begin{array}{c}1.3 \\
2.3 \\
6.1 \\
25 \\
298 \\
768\end{array}$ & $\begin{array}{l}4.94 \\
4.35 \\
3.75 \\
2.86 \\
2.23 \\
1.99\end{array}$ & $\begin{array}{l}662 \\
454 \\
315 \\
188 \\
123 \\
100\end{array}$ & $\begin{array}{l}1.31 \\
1.28 \\
1.25 \\
1.24 \\
1.23 \\
1.23\end{array}$ & & $\begin{array}{l}40 \\
37 \\
35 \\
34 \\
34 \\
34\end{array}$ \\
\hline $\begin{array}{r}7 \\
8 \\
9 \\
10 \\
11 \\
\mathrm{~N}\end{array}$ & $\begin{array}{l}6.02 \\
6.95 \\
6.50 \\
5.76 \\
5.05 \\
4.64\end{array}$ & $\begin{array}{r}1,170 \\
1,800 \\
1,490 \\
1,040 \\
703 \\
550\end{array}$ & $\begin{array}{l}1.87 \\
1.77 \\
1.68 \\
1.61 \\
1.54 \\
1.49\end{array}$ & $\begin{array}{l}89 \\
80 \\
72 \\
66 \\
60 \\
\mathbf{5 5}\end{array}$ & $\begin{array}{l}1.23 \\
1.28 \\
1.34 \\
1.34 \\
1.30 \\
1.27\end{array}$ & & $\begin{array}{l}34 \\
37 \\
42 \\
42 \\
39 \\
37\end{array}$ \\
\hline $\begin{array}{l}1 \\
2 \\
3 \\
4 \\
5 \\
6\end{array}$ & $\begin{array}{l}4.47 \\
4.14 \\
3.55 \\
2.27 \\
1.90 \\
2.90\end{array}$ & $\begin{array}{r}484 \\
400 \\
281 \\
127 \\
92 \\
193\end{array}$ & $\begin{array}{l}1.44 \\
1.40 \\
1.37 \\
1.34 \\
1.33 \\
1.48\end{array}$ & $\begin{array}{l}51 \\
48 \\
45 \\
42 \\
42 \\
54\end{array}$ & $\begin{array}{l}1.23 \\
1.19 \\
1.16 \\
1.13 \\
1.09 \\
1.07\end{array}$ & & $\begin{array}{l}34 \\
31 \\
29 \\
27 \\
25 \\
24\end{array}$ \\
\hline $\begin{array}{r}7 \\
8 \\
9 \\
9 \\
10 \\
11 \\
12\end{array}$ & $\begin{array}{l}4.50 \\
6.20 \\
6.56 \\
6.24 \\
6.32 \\
5.73\end{array}$ & $\begin{array}{r}499 \\
1,290 \\
1,520 \\
1,320 \\
1,350 \\
1,040\end{array}$ & $\begin{array}{l}1.45 \\
1.40 \\
1.40 \\
1.39 \\
1.35 \\
1.33\end{array}$ & $\begin{array}{l}52 \\
48 \\
48 \\
47 \\
43 \\
42\end{array}$ & $\begin{array}{r}1.04 \\
1.01 \\
.99 \\
.97 \\
.95 \\
.93\end{array}$ & . & $\begin{array}{l}22 \\
21 \\
20 \\
19 \\
18 \\
17\end{array}$ \\
\hline
\end{tabular}

Supplemental Record.-Aug. 14, 8:30 p.m., gage height, 6.63 feet; discharge 1,600 senond-feet.

UWHARRIE RIVER NEAR TRINITY, N. C.

Location.-Lat. $35^{\circ} 52^{\prime} 00^{\prime \prime}$, long. $79^{\circ} 59^{\prime} 20^{\prime \prime}$, 500 feet downstream from county highway bridge and 2 miles south of Trinity, Randolph County.

DRAINAGE AREA.- 11.3 square miles.

GAGE-HEIGHT RECORD.-Water-stage recorder graph.

DisCHARGE RECORD. - Stage-discharge relation defined by current-meter measurements up to 1,500 second-feet. Gage heights used to half-tenths between 3.2 and 5.0 feet; hundredths below and tenths above these limits.

Maxima.-1940: Discharge, 2,140 second-feet 7:30 p.m. Aug. 14 (gage height, 6.88 feet).

1934-39: Discharge, 1,540 second-feet Oct. 8, 1936 (gage height, 5.7 feet). Remarks.-Flood runoff not affected by artificial storage. 
FLOODS OF AUGUST 1940 IN THE SOUTHEASTERN STATES

Mean discharge, in second-feet, 1940

\begin{tabular}{|c|c|c|c|c|c|c|c|c|c|c|c|}
\hline Day & Aug. & Sept. & Day & Aug. & Sept. & Day & Aug. & Sept. & Day & Aug. & Sept. \\
\hline $\begin{array}{l}1 \\
2 \\
3 \\
4 \\
5 \\
6 \\
7 \\
8\end{array}$ & $\begin{array}{r}1.1 \\
.76 \\
.76 \\
.76 \\
1.3 \\
.92 \\
.76 \\
.69\end{array}$ & $\begin{array}{l}3.8 \\
2.9 \\
2.6 \\
2.3 \\
2.3 \\
2.8 \\
2.0 \\
1.8\end{array}$ & $\begin{array}{r}99 \\
10 \\
11 \\
12 \\
13 \\
14 \\
15 \\
16\end{array}$ & $\begin{array}{c}.63 \\
.56 \\
4.4 \\
3.2 \\
2.8 \\
515 \\
98 \\
52\end{array}$ & $\begin{array}{l}1.7 \\
2.3 \\
3.3 \\
2.1 \\
1.7 \\
1.5 \\
1.5 \\
1.5\end{array}$ & $\begin{array}{l}17 \\
18 \\
19 \\
20 \\
21 \\
22 \\
23 \\
24\end{array}$ & $\begin{array}{r}17 \\
9.7 \\
7.1 \\
5.2 \\
4.3 \\
3.5 \\
6.1 \\
3.8\end{array}$ & $\begin{array}{l}1.4 \\
1.3 \\
1.3 \\
1.3 \\
1.2 \\
1.1 \\
1.0 \\
1.1\end{array}$ & $\begin{array}{l}25 \\
26 \\
27 \\
28 \\
29 \\
30 \\
31\end{array}$ & $\begin{array}{r}3.3 \\
3.1 \\
2.6 \\
2.4 \\
5.0 \\
19 \\
5.9\end{array}$ & $\begin{array}{r}1.3 \\
1.2 \\
1.0 \\
1.0 \\
.92 \\
.84 \\
\end{array}$ \\
\hline \multicolumn{10}{|c|}{$\begin{array}{l}\text { Monthly mean discharge, in second-feet } \\
\text { Runoff, in inches }\end{array}$} & 25.2 & $\begin{array}{l}1.74 \\
0.17\end{array}$ \\
\hline
\end{tabular}

Gage height, in feet, and discharge, in second-feet, at indicated time, 1940

\begin{tabular}{|c|c|c|c|c|c|c|c|c|}
\hline \multirow{2}{*}{ Hour } & \multicolumn{2}{|c|}{ Aug. 13} & \multicolumn{2}{|c|}{ Aug. 14} & \multicolumn{2}{|c|}{ Aug. 15} & \multicolumn{2}{|c|}{ Aug. 16} \\
\hline & $\begin{array}{l}\text { Gage } \\
\text { height }\end{array}$ & Discharge & $\begin{array}{l}\text { Gage } \\
\text { height }\end{array}$ & Discharge & $\begin{array}{l}\text { Gage } \\
\text { height }\end{array}$ & - Discharge & $\begin{array}{c}\text { Gage } \\
\text { height }\end{array}$ & Discharge \\
\hline $\begin{array}{l}\mathbf{1} \\
\mathbf{2} \\
\mathbf{3} \\
\mathbf{4} \\
\mathbf{5} \\
\mathbf{6}\end{array}$ & $\begin{array}{r}0.77 \\
.74 \\
.73 \\
.71 \\
.69 \\
.68\end{array}$ & $\begin{array}{l}3.2 \\
2.6 \\
2.5 \\
2.1 \\
1.9 \\
1.7\end{array}$ & $\begin{array}{l}1.17 \\
1.60 \\
1.95 \\
2.60 \\
3.65 \\
4.16\end{array}$ & $\begin{array}{r}17 \\
54 \\
108 \\
252 \\
609 \\
816\end{array}$ & $\begin{array}{l}1.91 \\
1.83 \\
1.79 \\
1.74 \\
1.69 \\
1.64\end{array}$ & $\begin{array}{r}101 \\
87 \\
80 \\
73 \\
66 \\
59\end{array}$ & $\begin{array}{l}1.58 \\
1.55 \\
1.53 \\
1.51 \\
1.51 \\
1.50\end{array}$ & $\begin{array}{l}\mathbf{5 2} \\
\mathbf{4 8} \\
\mathbf{4 6} \\
\mathbf{4 4} \\
\mathbf{4 4} \\
\mathbf{4 3}\end{array}$ \\
\hline $\begin{array}{r}7 \\
8 \\
9 \\
10 \\
11 \\
\mathbf{N}\end{array}$ & $\begin{array}{l}.68 \\
.67 \\
.67 \\
.67 \\
.67 \\
.66\end{array}$ & $\begin{array}{l}1.7 \\
1.6 \\
1.6 \\
1.6 \\
1.6 \\
1.5\end{array}$ & $\begin{array}{l}4.85 \\
4.90 \\
3.95 \\
3.22 \\
2.62 \\
2.18\end{array}$ & $\begin{array}{r}1,130 \\
1,150 \\
732 \\
441 \\
258 \\
152\end{array}$ & $\begin{array}{l}1.59 \\
1.54 \\
1.50 \\
1.47 \\
1.43 \\
1.41\end{array}$ & $\begin{array}{l}\mathbf{5 3} \\
\mathbf{4 7} \\
\mathbf{4 3} \\
\mathbf{4 0} \\
\mathbf{3 6} \\
\mathbf{3 4}\end{array}$ & $\begin{array}{l}1.47 \\
1.44 \\
1.42 \\
1.39 \\
1.38 \\
1.57\end{array}$ & $\begin{array}{l}\mathbf{4 0} \\
\mathbf{3 7} \\
\mathbf{3 5} \\
\mathbf{3 2} \\
\mathbf{3 1} \\
\mathbf{5 1}\end{array}$ \\
\hline $\begin{array}{l}1 \\
2 \\
3 \\
4 \\
5 \\
6\end{array}$ & $\begin{array}{l}.66 \\
.66 \\
.66 \\
.90 \\
.81 \\
.88\end{array}$ & $\begin{array}{l}1.5 \\
1.5 \\
1.5 \\
6.2 \\
4.0 \\
5.7\end{array}$ & $\begin{array}{l}1.90 \\
1.72 \\
1.62 \\
1.53 \\
1.64 \\
3.55\end{array}$ & $\begin{array}{r}99 \\
\mathbf{7 0} \\
\mathbf{5 7} \\
46 \\
\mathbf{5 9} \\
\mathbf{5 7 0}\end{array}$ & $\begin{array}{l}1.89 \\
2.71 \\
2.54 \\
2.33 \\
2.20 \\
2.10\end{array}$ & $\begin{array}{r}97 \\
284 \\
236 \\
184 \\
156 \\
136\end{array}$ & $\begin{array}{l}2.60 \\
2.10 \\
1.67 \\
1.53 \\
1.46 \\
1.40\end{array}$ & $\begin{array}{r}252 \\
136 \\
63 \\
46 \\
39 \\
\mathbf{3 3}\end{array}$ \\
\hline $\begin{array}{r}7 \\
8 \\
9 \\
10 \\
11 \\
12 \\
\end{array}$ & $\begin{array}{l}.85 \\
.83 \\
.79 \\
.77 \\
.77 \\
.78\end{array}$ & $\begin{array}{l}5.0 \\
4.5 \\
3.5 \\
3.2 \\
3.2 \\
3.3\end{array}$ & $\begin{array}{l}6.30 \\
6.60 \\
5.16 \\
3.03 \\
2.27 \\
2.05\end{array}$ & $\begin{array}{r}1,840 \\
1,990 \\
1,290 \\
384 \\
171 \\
126\end{array}$ & $\begin{array}{l}2.03 \\
1.96 \\
1.82 \\
1.74 \\
1.68 \\
1.63\end{array}$ & $\begin{array}{r}123 \\
110 \\
85 \\
73 \\
64 \\
58\end{array}$ & $\begin{array}{l}1.37 \\
1.34 \\
1.32 \\
1.30 \\
1.28 \\
1.27\end{array}$ & $\begin{array}{l}\mathbf{3 1} \\
\mathbf{2 8} \\
\mathbf{2 7} \\
\mathbf{2 5} \\
\mathbf{2 4} \\
\mathbf{2 3}\end{array}$ \\
\hline
\end{tabular}

SUPPLEMENTAL RECORDS-Aug. 14, 7:30 a.m., gage height, 5.12 feet, discharge, 1,250 second-feet; $4: 30$ p.m., gage height, 1.50 feet, discharge, 43 second-feet; $7: 30$ p.m., gage height, 6.88 feet, discharge, 2,140 second-feet.

UWHARRIE RIVER NEAR EIDORADO, N. C.

LOCATION.-Lat. $35^{\circ} 25^{\prime} 25^{\prime \prime}$, long. $80^{\circ} 00^{\prime} 40^{\prime \prime}$, a quarter of a mile upstream from State Highway 109, 1 mile upstream from MeLeans Creek, and 3 miles south of Eldorado, Montgomery County.

DrAINAGE AREA.- 347 square miles.

GAGE-HEIGHT RECORD.-Water-stage recorder graph.

DISCHARGE RECORD. - Stage-discharge relation defined by cur; ent-meter measurements up to 5,500 second-feet.

Maxima.-1940: Discharge, 4,810 second-feet 4:30 p.m. Aug. 15 (gage height, 8.75 feet).

1938-39: Discharge, 9,400 second-feet Aug. 18, 1939 (gage height 13.70 feet).

Stage known, 22.2 feet sometime in August 1928, from flood reference mark established by local resident (discharge not determined).

REMARKs.-Flood runoff not affected by artificial storage. 
PEE DEE RIVER BASIN

Mean discharge, in second-feet, 1940

\begin{tabular}{|c|c|c|c|c|c|c|c|c|c|c|c|}
\hline Day & Aug. & Sept. & Day & Aug. & Sept. & Day & Aug. & Sept. & Day & Aug. & Sept. \\
\hline $\begin{array}{l}1 \\
2 \\
3 \\
4 \\
5 \\
6 \\
7 \\
8\end{array}$ & $\begin{array}{r}35 \\
38 \\
39 \\
33 \\
11 \\
9 \\
25 \\
26\end{array}$ & $\begin{array}{r}126 \\
74 \\
55 \\
42 \\
37 \\
41 \\
28 \\
31\end{array}$ & $\begin{array}{r}9 \\
10 \\
11 \\
12 \\
13 \\
14 \\
15 \\
16\end{array}$ & $\begin{array}{r}22 \\
15 \\
17 \\
15 \\
44 \\
947 \\
4,220 \\
1,350\end{array}$ & $\begin{array}{l}19 \\
41 \\
19 \\
32 \\
34 \\
38 \\
29 \\
11\end{array}$ & $\begin{array}{l}17 \\
18 \\
19 \\
20 \\
21 \\
22 \\
23 \\
24\end{array}$ & $\begin{array}{r}706 \\
238 \\
146 \\
99 \\
74 \\
62 \\
52 \\
48\end{array}$ & $\begin{array}{r}18 \\
20 \\
22 \\
12 \\
23 \\
27 \\
11 \\
9\end{array}$ & $\begin{array}{l}25 \\
26 \\
27 \\
28 \\
29 \\
30 \\
31\end{array}$ & $\begin{array}{r}52 \\
48 \\
42 \\
38 \\
40 \\
36 \\
204\end{array}$ & $\begin{array}{l}39 \\
21 \\
34 \\
19 \\
25 \\
12\end{array}$ \\
\hline \multicolumn{10}{|c|}{$\begin{array}{l}\text { Monthly mean discharge, in second-feet } \\
\text { Runoff, in inches }\end{array}$} & $\begin{array}{r}282 \\
0.94\end{array}$ & $\begin{array}{l}31.6 \\
0.10\end{array}$ \\
\hline
\end{tabular}

Gage height, in feet, and discharge, in second-feet, at indicated time, 1940

\begin{tabular}{|c|c|c|c|c|c|c|c|c|c|c|}
\hline \multirow{2}{*}{ Hour } & \multicolumn{3}{|c|}{ Aug. 14} & \multicolumn{2}{|c|}{ Aug. 15} & \multicolumn{3}{|c|}{ Aug. 16} & \multicolumn{2}{|c|}{ Aug. 17} \\
\hline & $\begin{array}{l}\text { Gage } \\
\text { height }\end{array}$ & \multicolumn{2}{|c|}{ Discharge } & $\begin{array}{c}\text { Gage } \\
\text { height }\end{array}$ & Discharge & $\begin{array}{c}\text { Gage } \\
\text { height }\end{array}$ & \multicolumn{2}{|c|}{ Discharge } & $\begin{array}{l}\text { Gage } \\
\text { height }\end{array}$ & Discharge \\
\hline \multirow{3}{*}{$\begin{array}{l}1 \\
2 \\
3 \\
4 \\
5 \\
6\end{array}$} & \multirow{3}{*}{$\begin{array}{l}1.33 \\
1.51 \\
1.55 \\
1.55 \\
1.57 \\
1.57\end{array}$} & \multirow{3}{*}{\multicolumn{2}{|c|}{$\begin{array}{l}48 \\
77 \\
84 \\
84 \\
88 \\
88\end{array}$}} & 7.23 & 3,450 & 5.95 & & 480 & 3.31 & $725^{-}$ \\
\hline & & & & 7.53 & 3,700 & 4.97 & & 700 & 3.82 & $9 \overline{9}$ \\
\hline & & & & 7.81 & 3,960 & 4.54 & & 440 & 3.92 & 1,050 \\
\hline \multirow{3}{*}{$\begin{array}{r}7 \\
8 \\
9 \\
10 \\
11 \\
\mathrm{~N}\end{array}$} & \multirow{3}{*}{$\begin{array}{l}1.56 \\
1.54 \\
1.53 \\
1.53 \\
1.56 \\
1.95\end{array}$} & \multirow{3}{*}{\multicolumn{2}{|c|}{$\begin{array}{r}86 \\
83 \\
81 \\
81 \\
86 \\
178\end{array}$}} & 8.08 & 4,220 & 4.45 & & 380 & 3.85 & 1,020 \\
\hline & & & & 8.31 & 4,380 & $4.41^{-}$ & & 340 & 3.66 & 912 \\
\hline & & & & 8.49 & 4,560 & 4.30 & & 280 & $3 . \overline{4}$ & 775 \\
\hline \multirow{4}{*}{$\begin{array}{l}1 \\
2 \\
3 \\
4 \\
5 \\
6\end{array}$} & \multirow{4}{*}{$\begin{array}{l}2.62 \\
3.09 \\
3.40 \\
3.92 \\
4.65 \\
5.30\end{array}$} & \multirow{4}{*}{\multicolumn{2}{|c|}{$\begin{array}{r}408 \\
620 \\
775 \\
1,050 \\
1,500 \\
1,940\end{array}$}} & & & & & 190 & & 675 \\
\hline & & & & 8.63 & 4,640 & 4.12 & & 160 & 3.18 & 675 \\
\hline & & & & 8.73 & 4,720 & 3.88 & & 050 & $2 . \overline{98}$ & 566 \\
\hline & & & & 8.72 & 4,720 & 3.63 & & 912 & 2.80 & 485 \\
\hline \multirow{4}{*}{$\begin{array}{r}7 \\
8 \\
9 \\
10 \\
11 \\
12 \\
\end{array}$} & $\begin{array}{l}5.77 \\
6.11\end{array}$ & \multirow{4}{*}{\multicolumn{2}{|c|}{$\begin{array}{l}2,320 \\
2,560 \\
2,800 \\
2,960 \\
3,120 \\
3,200 \\
\end{array}$}} & 8.57 & 4,640 & 3.40 & & 775 & 2.66 & 424 \\
\hline & 6.37 & & & $0-$ & -1 & 2 & & 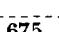 & 055 & 380 \\
\hline & $\begin{array}{l}0.09 \\
6.78\end{array}$ & & & 0.10 & 4,300 & 0.18 & & 0.0 & 2.00 & 300 \\
\hline & & & & 7.25 & 3,450 & 3.06 & & 605 & 2.42 & $33 \overline{2}$ \\
\hline \multirow{2}{*}{ Hour } & \multicolumn{4}{|c|}{ Aug. 18} & \multicolumn{3}{|c|}{ Aug. 19} & \multicolumn{3}{|c|}{ Aug. 20} \\
\hline & \multicolumn{2}{|c|}{ Gage height } & \multicolumn{2}{|c|}{ Discharge } & Gage height & \multicolumn{2}{|c|}{ Discharge } & \multicolumn{2}{|c|}{ Gage height } & Discharge \\
\hline $\begin{array}{r}2 \\
4 \\
6 \\
8 \\
10 \\
\mathrm{~N}\end{array}$ & & $\frac{2.25}{2.13}$ & & 272 & $\begin{array}{l}1.89 \\
1.87 \\
1.85 \\
1.83 \\
1.82 \\
1.81\end{array}$ & & $\begin{array}{l}161 \\
156 \\
151 \\
146 \\
143 \\
141\end{array}$ & & $\begin{array}{l}1.67 \\
1.61 \\
1.56 \\
1.56 \\
1.58 \\
1.60\end{array}$ & $\begin{array}{r}109 \\
96 \\
86 \\
86 \\
90 \\
94\end{array}$ \\
\hline $\begin{array}{r}2 \\
4 \\
6 \\
8 \\
10 \\
12\end{array}$ & & $\frac{2.02}{1.92}$ & & $\begin{array}{l}198 \\
170\end{array}$ & $\begin{array}{l}1.80 \\
1.83 \\
1.84 \\
1.81 \\
1.77 \\
1.72\end{array}$ & & $\begin{array}{l}138 \\
146 \\
148 \\
141 \\
131 \\
120\end{array}$ & & $\begin{array}{l}1.61 \\
1.61 \\
1.65 \\
1.69 \\
1.68 \\
1.64\end{array}$ & $\begin{array}{r}96 \\
96 \\
104 \\
113 \\
111 \\
102\end{array}$ \\
\hline
\end{tabular}

Supplemental RECORD.-Aug. 15, 4:30 p.m., gage height, 8.75 feet; discharge, 4,810 second-feet.

ROCKY HIVER NEAR NORWOOD, N. C.

Location.-Lat. $35^{\circ} 08^{\prime} 40^{\prime \prime}$, long. $80^{\circ} 10^{\prime} 45^{\prime \prime}$, at Hyatts Ford, 1,000 feet downstream from Lanes Creek, and 6 miles southwest of Norwood, Stanly County. Datum of gage is 212.91 feet above mean sea level, datum of 1929 (levels by Corps of Engineers, War Department).

Drainage AREa.- $-1,370$ square miles.

GAGE-HEIGHT RECORD.-Water-stage recorder graph. 
DISCHARGE RECORD.-Stage-discharge relation defined by eurrent-meter measurements up to 70,000 second-feet and extended above on basis of slope-area measurement in 1945. Gage heights used to half-tenths between 2.3 and 4.3 feet; hundredths below and tenths above these limits.

Maxima.-August 1940: Diseharge, 8,500 second-feet 8 p.m. Aug. 15 (gage height, 8.21 feet).

1929 to July 1940: Discharge, 56,400 second-feet (revised) Apr. 7, 1936 (gage height, about 32.0 feet, from floodmarks).

Stage known, about 35 feet sometime in August 1908, from flood reference mark as witnessed by local resident (discharge estimated, 67,600 second-feet (revised)).

REMARKs.-Flood runoff not affected by artificial storage.

Mean discharge, in second-feet, 1940

\begin{tabular}{|c|c|c|c|c|c|c|c|c|c|c|c|}
\hline Day & Aug. & Sept. & Day & Aug. & Sept. & Day & Aug. & Sept. & Day & Aug. & Sept. \\
\hline 1 & 84 & 701 & 9 & 62 & 146 & 17 & 1,400 & 69 & 25 & 164 & 47 \\
\hline 2 & 69 & 482 & 10 & 55 & 100 & 18 & 760 & 5 & 26 & 149 & 5 \\
\hline 3 & 75 & 224 & 11 & 63 & 82 & 19 & 436 & 60 & 27 & 130 & 60 \\
\hline 4 & 71 & 149 & 12 & 1,140 & 71 & 20 & 297 & 64 & 28 & 105 & 8 \\
\hline 5 & 59 & 119 & 13 & 1,310 & 98 & 21 & 228 & 59 & 29 & 102 & 55 \\
\hline 6 & 60 & 184 & 14 & 4,120 & 94 & 22 & 200 & 60 & 30 & 105 & 47 \\
\hline 7 & 98 & 300 & 15 & 7,730 & 80 & 23 & 177 & 54 & 31 & 132 & \\
\hline 8 & $75^{\circ}$ & 193 & 16 & 4,310 & 66 & 24 & 168 & 59 & & & \\
\hline \multicolumn{10}{|c|}{$\begin{array}{l}\text { Monthly mean discharge, in second-feet } \\
\text { Runoff, in inches. }\end{array}$} & $\begin{array}{r}772 \\
0.65\end{array}$ & $\begin{array}{r}130 \\
0.11\end{array}$ \\
\hline
\end{tabular}

Gage height, in feet, and discharge, in second-feet, at indicated time, 1940

\begin{tabular}{|c|c|c|c|c|c|c|c|c|c|c|c|c|}
\hline \multirow{2}{*}{ Hour } & \multicolumn{2}{|c|}{ Aug. 12} & \multicolumn{2}{|c|}{ Aug. 13} & \multicolumn{2}{|c|}{ Aug. 14} & \multicolumn{2}{|c|}{ Aug. 15} & \multicolumn{2}{|c|}{ Aug. 16} & \multicolumn{2}{|c|}{ Aug. 17} \\
\hline & $\begin{array}{c}\text { Gage } \\
\text { ht. }\end{array}$ & $\begin{array}{l}\text { Dis- } \\
\text { charge }\end{array}$ & $\begin{array}{c}\text { Gage } \\
\text { ht. }\end{array}$ & $\begin{array}{l}\text { Dis- } \\
\text { charge }\end{array}$ & $\begin{array}{c}\text { Gage } \\
\text { ht. }\end{array}$ & $\begin{array}{l}\text { Dis- } \\
\text { charge }\end{array}$ & $\begin{array}{c}\text { Gage } \\
\text { ht. }\end{array}$ & $\begin{array}{l}\text { Dis- } \\
\text { charge }\end{array}$ & $\begin{array}{c}\text { Gage } \\
\text { ht. }\end{array}$ & $\begin{array}{c}\text { Dis- } \\
\text { charge }\end{array}$ & $\begin{array}{c}\text { Gage } \\
\text { ht. }\end{array}$ & $\begin{array}{c}\text { Dis- } \\
\text { charge }\end{array}$ \\
\hline 1 & 0 & 98 & 93 & 1,600 & .27 & 01 & & & & & & \\
\hline 2 & & 127 & & & & & 6.83 & 6,400 & 7.91 & 8,050 & 3.15 & 1,780 \\
\hline 3 & .84 & 197 & 6 & 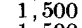 & 2.24 & & & & & & & \\
\hline $\begin{array}{l}4 \\
5\end{array}$ & $\begin{array}{l}1.16 \\
1.66\end{array}$ & 320 & 3 & 500 & 2.34 & 1,070 & 7.05 & 6,700 & 7.62 & 7,600 & 3.35 & 1,980 \\
\hline 6 & 2.00 & 800 & 2.87 & 1,500 & 3.45 & 2,080 & $\overline{7} . \overline{28}$ & 7,150 & 7.05 & 6,700 & 3.07 & 1,680 \\
\hline 7 & 2.13 & 894 & 2.87 & 0 & 3.94 & 2 & & & & & & \\
\hline 8 & 2.04 & & 2.85 & & 4.45 & 3 & 7.50 & 7,450 & 6.37 & 5,800 & 2.94 & 1,600 \\
\hline $\begin{array}{r}9 \\
10\end{array}$ & 2.27 & $\begin{array}{r}786 \\
1,010\end{array}$ & $\begin{array}{l}2.82 \\
2.77\end{array}$ & $\begin{array}{l}1,460 \\
1,420\end{array}$ & $\begin{array}{l}4.79 \\
4.89\end{array}$ & $\begin{array}{l}3,610 \\
3,730\end{array}$ & 7.74 & 7,750 & 5.56 & 4,650 & 2.75 & 1,420 \\
\hline 11 & 2.78 & 1,460 & 2.71 & 1,370 & 5.12 & 3,990 & & & & & $0-\overline{0}$ & \\
\hline & 2.82 & 1,460 & 2.65 & 1,320 & 5.92 & 5,070 & 7.91 & 8,050 & 4.70 & 3,490 & 2.58 & 1,280 \\
\hline 1 & 2.85 & 1,500 & 2.59 & 1 & 6.18 & 5 & & & & & & \\
\hline $\begin{array}{l}2 \\
3\end{array}$ & 2.99 & 40 & .5 & 1,19 & 6.41 & 5 & 8.03 & 8,200 & 4.04 & 2,720 & 2.49 & 1,190 \\
\hline 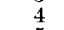 & 3.16 & 1,780 & 2.44 & o & 6.56 & 6 , & $8 . \overline{12}$ & $8, \overline{350}$ & $3 . \overline{7}$ & 2,180 & 2.46 & 1,150 \\
\hline 5 & $\begin{array}{l}3.23 \\
3.24\end{array}$ & $\begin{array}{l}880 \\
880\end{array}$ & $\begin{array}{l}2.42 \\
2.42\end{array}$ & 1,110 & 6.55 & 6,100 & 8.18 & 8,500 & $-\overline{3} . \overline{2} \overline{7}$ & 1.880 & $2, \overline{4} 5$ & 150 \\
\hline & & & & & & & & & & & & \\
\hline 8 & $\begin{array}{l}3.08 \\
2.99\end{array}$ & & 2. & & $\begin{array}{l}0 . \\
6 .\end{array}$ & & $8.2 \overline{1}$ & $8, \overline{500}$ & $\overline{3} . \overline{18}$ & 1,830 & $\overline{2.45}$ & 1,150 \\
\hline 9 & 2.82 & & 2.37 & 1,0 & 6.52 & 5,950 & & & & & & \\
\hline 10 & 2.75 & 1,420 & 2.35 & 1,070 & 6.54 & 5,950 & 8.20 & 8,500 & 3.16 & 1,780 & 2.42 & 1,110 \\
\hline $\begin{array}{l}11 \\
12\end{array}$ & $\begin{array}{l}2.80 \\
2.89\end{array}$ & $\begin{array}{l}1,460 \\
1,550\end{array}$ & $\begin{array}{l}2.33 \\
2.30\end{array}$ & $\begin{array}{l}1,070 \\
1,030\end{array}$ & $\begin{array}{l}6.57 \\
6.62\end{array}$ & $\begin{array}{l}6,100 \\
6,100\end{array}$ & 8.11 & 8,350 & 3.00 & 1,640 & $2 . \overline{3}$ & 1,070 \\
\hline
\end{tabular}

Supplemental ReCoRds.-Aug. 11, 12 p.m., gage height, 0.34 feet; discharge, 69 second-feet. Aug. 17, 5 a.m., gage height, 3.35 feet; discharge, 1,980 second-feet.

RICHARDSON CREEK NEAR MARSHVILLE, N. C.

Location.-Lat. $35^{\circ} 05^{\prime} 55^{\prime \prime}$, long. $80^{\circ} 23^{\prime} 05^{\prime \prime}$, at bridge on State Highway 205 , a quarter of a mile downstream from Goodman Branch, three-quarters of a mile upstream from Niggerhead Creek, and 71/2 miles north of Marshville, Union County.

DRAINAGE AREA. -170 square miles.

GAGE-HEIGHT RECORD.-Water-stage recorder graph. 
Discharge RECORD.-Stage-discharge relation defined by current-meter measurements up to 1,900 second-feet. Gage heights used to half-tenths between 2.8 and 5.0 feet; hundredths below and tenths above these limits.

Maxima.-Angust 1940: Discharge, 129 second-feet 12 to $12: 30$ a.m. Aug. 15 (gage height, 1.90 feet).

April to July 1940: Daily discharge, 200 second-feet July 18 (estimated, recorder not operating properly).

REMarks.-There is a small reservoir about 13 miles above station where the eity of Monroe diverts its water supply.

Mean discharge, in second-feet, 1940

\begin{tabular}{|c|c|c|c|c|c|c|c|c|c|c|c|}
\hline Day & Aug. & Sept. & Day & Aug. & 'Sept. & Day & Aug. & Sept. & Day & Aug. & Sept. \\
\hline $\begin{array}{l}1 \\
2 \\
3 \\
4 \\
5 \\
6 \\
7 \\
8\end{array}$ & $\begin{array}{c}28 \\
17 \\
5.1 \\
2.5 \\
1.7 \\
1.4 \\
1.2 \\
.85\end{array}$ & $\begin{array}{c}75 \\
25 \\
9.3 \\
5.1 \\
2.9 \\
3.7 \\
2.9 \\
1.8\end{array}$ & $\begin{array}{r}9 \\
10 \\
11 \\
12 \\
13 \\
14 \\
15 \\
16\end{array}$ & $\begin{aligned} & .65 \\
& .45 \\
& .9 \\
& 3.6 \\
& 3.3 \\
& 64 \\
& 92 \\
& 92 \\
& 32\end{aligned}$ & $\begin{array}{c}1.5 \\
1.3 \\
1.2 \\
1.1 \\
.95 \\
.85 \\
.75 \\
.65\end{array}$ & $\begin{array}{l}17 \\
18 \\
19 \\
20 \\
21 \\
22 \\
23 \\
24\end{array}$ & $\begin{array}{r}13 \\
6.0 \\
3.0 \\
1.9 \\
1.5 \\
1.3 \\
1.4 \\
1.3\end{array}$ & $\begin{array}{l}.55 \\
.55 \\
.45 \\
.35 \\
.25 \\
.25 \\
.15 \\
.15\end{array}$ & $\begin{array}{l}25 \\
26 \\
27 \\
28 \\
29 \\
30 \\
31\end{array}$ & $\begin{array}{c}1.2 \\
1.1 \\
.95 \\
.85 \\
.65 \\
.65 \\
.65\end{array}$ & $\begin{array}{l}0 \\
0 \\
0 \\
0 \\
0 \\
0\end{array}$ \\
\hline \multicolumn{10}{|c|}{$\begin{array}{l}\text { Monthly mean discharge, in second-feet, } \\
\text { Runoff, in inches }\end{array}$} & $\begin{array}{l}9.36 \\
0.06\end{array}$ & $\begin{array}{l}4.56 \\
0.03\end{array}$ \\
\hline
\end{tabular}

Gage height, in feet, and discharge, in second-feet, at indicated time, 1940

\begin{tabular}{|c|c|c|c|c|c|c|c|c|c|c|}
\hline \multirow{2}{*}{ Hour } & \multicolumn{2}{|c|}{ Aug. 14} & \multicolumn{2}{|c|}{ Aug. 15} & \multicolumn{2}{|c|}{ Aug. 16} & \multicolumn{2}{|c|}{ Aug. 17} & \multicolumn{2}{|c|}{ Aug. 18} \\
\hline & $\begin{array}{c}\text { Gage } \\
\text { height }\end{array}$ & $\begin{array}{c}\text { Dis- } \\
\text { charge }\end{array}$ & $\begin{array}{c}\text { Gage } \\
\text { height }\end{array}$ & $\begin{array}{c}\text { Dis- } \\
\text { charge }\end{array}$ & $\begin{array}{c}\text { Gage } \\
\text { height }\end{array}$ & $\begin{array}{c}\text { Dis- } \\
\text { charge }\end{array}$ & $\begin{array}{c}\text { Gage } \\
\text { height }\end{array}$ & $\begin{array}{c}\text { Dis- } \\
\text { charge }\end{array}$ & $\begin{array}{c}\text { Gage } \\
\text { height }\end{array}$ & $\begin{array}{c}\text { Dis- } \\
\text { charge }\end{array}$ \\
\hline $\begin{array}{l}2 \\
4\end{array}$ & 1.13 & 2.9 & $\begin{array}{l}1.86 \\
1.78\end{array}$ & 121 & & & & & $\ldots$ & $-\ldots$ \\
\hline 6 & 1.22 & 7.7 & $\begin{array}{l}1.70 \\
1.70\end{array}$ & $\begin{array}{r}80 \\
89\end{array}$ & 1.46 & 41 & 1.28 & 12 & & \\
\hline 8 & 1.64 & 77 & 1.64 & 77 & $\ldots$ & $=-1$ & $\ldots$ & & -- & 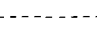 \\
\hline$\stackrel{10}{N}$ & $\begin{array}{l}1.62 \\
1.57\end{array}$ & $\begin{array}{l}73 \\
63\end{array}$ & $\begin{array}{l}1.61 \\
1.68\end{array}$ & $\begin{array}{l}71 \\
85\end{array}$ & 1.39 & 28 & 1.26 & 11 & 1. 18 & 5.1 \\
\hline 2 & 1.55 & 59 & 1.81 & 111 & & & & & & 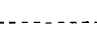 \\
\hline $\begin{array}{l}4 \\
6\end{array}$ & $\begin{array}{l}1.64 \\
1.74\end{array}$ & $\begin{array}{l}77 \\
97\end{array}$ & $\begin{array}{l}1.79 \\
1.73\end{array}$ & $\begin{array}{r}107 \\
95\end{array}$ & 135 & 22 & 131 & 16 & -- & 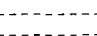 \\
\hline $\begin{array}{l}0 \\
8\end{array}$ & $\begin{array}{l}1.84 \\
1.82\end{array}$ & 113 & 1.66 & 81 & & & & & & \\
\hline 10 & 1.88 & 125 & 1.61 & 71 & - & - & & & & \\
\hline 12 & 1.90 & 129 & 1.56 & 61 & 1.31 & 16 & 1.25 & 10 & 1.15 & 3.7 \\
\hline
\end{tabular}

SUPPLEMENTAL RECORD.-Aug. 15, 12:30 a.m., gage height, 1.90 feet; discharge, 129 second-feet.

hrown CRERK NEAR POLKTON, N. C.

Location.-Lat. $35^{\circ} 02^{\prime} 15^{\prime \prime}$, long. $80^{\circ} 08^{\prime} 45^{\prime \prime}$, at Medley Mill, just downstream from bridge on State Highway 742, 31/2 miles downstream from Little Brown Creek, and 4 miles northeast of Polkton, Anson County.

JRAINAGE AREA.-110 square miles.

GAGE-HEIGHT RECORD.-None, except water-stage recorder graph for Sept. 25-26.

Discharge RECORD, - Stage-discharge relation defined by current-meter measurements up to 2,900 second-feet. Discharge for periods of no gage-height record, Aug. 1 to Sept. 24, Sept. 27-30, based on floodmarks, weather records, recorded range in gage heights, and records for nearby streams.

Maxima.-1940: Discharge, 535 second-feet Aug. 14 (gage height, 6.17 feet, from floodmarks).

1937-39: Discharge, 3,960 second-feet July 21, 1939 (gage height, 12.50 feet).

Stages known, 16.4 feet sometime in August 1908 (discharge 12,500 secondfeet), 15.7 feet sometime in July 1916 (discharge 10,400 second-feet), and 15.0 


\section{FLOODS OF AUGUST 1940 IN THE SOUTHEASTERN STATES}

feet sometime in September 1928 (discharge 8,500 second-feet), from flood reference marks as witnessed by owner of Medley Mill.

Remarks.-Flood runoff not affected by artificial storage.

Mean discharge, in second-feet, 1940

\begin{tabular}{r|r|r||r|r|r||r|r|r||r|r|r}
\hline Day & Aug. & Sept. & Day & Aug. & Sept. & Day & Aug. & Sept. & Day & Aug. & Sept. \\
\hline 1 & 0.1 & 25 & 9 & 0 & 2.0 & 17 & 200 & 1.0 & 25 & 2.0 & .79 \\
2 & .1 & 14 & 10 & 0 & 1.8 & 18 & 50 & 1.0 & 26 & 1.6 & .72 \\
3 & .1 & 8.0 & 11 & 0 & 1.6 & 19 & 20 & .9 & 27 & 1.2 & .7 \\
4 & .1 & 5.0 & 12 & 10 & 1.4 & 20 & 12 & .9 & 28 & 1.1 & .7 \\
5 & 0 & 4.0 & 13 & 10 & 1.4 & 21 & 8.0 & .9 & 29 & 1.0 & .6 \\
6 & 0 & 7.0 & 14 & 200 & 1.2 & 22 & 5.0 & .8 & 30 & 10 & .6 \\
7 & 0 & 4.0 & 15 & 450 & 1.2 & 23 & 4.0 & .8 & 31 & 60 &..- \\
8 & 0 & 3.0 & 16 & 300 & 1.0 & 24 & 3.0 & .8 & & & \\
\hline
\end{tabular}
Monthly mean discharge, in second-feet.
Runoff, in inches

LITTLE HROWN CREEK NEAR POLKTON, N. C.

Location.-Lat. $34^{\circ} 58^{\prime} 45^{\prime \prime}$, long. $80^{\circ} 11^{\prime} 20^{\prime \prime}, 1$ mile southwest of State convict eamp on U. S. Highway 74, 11/2 niles upstream from mouth, and 2 miles southeast of Polkton, Anson County.

Drainage AREa.-13.5 square miles.

GAGE-HEIGHT RECORD.-Water-stage recorder graph except Aug. 15-19, when recorder elock was stopped.

DISCHARGE RECORD. - Stage-discharge relation defined by current-meter measurements up to 410 second-feet. Discharge for period of no gage-height record, Aug. 15-19, based on recorded range in gage heights, weather records, and records for nearby streams.

Maxima.-1940: Discharge, 668 second-feet 3 p.m. Aug. 14 (gage height, 3.83 feet). 1935-39: Discharge, 2,200 second-feet July 21, 1939 (gage height, 7.04 feet).

REMARKs.-Flood runoff practically unaffected by artificial storage.

Mean discharge, in second-feet, 1940

\begin{tabular}{|c|c|c|c|c|c|c|c|c|c|c|c|}
\hline Day & Aug. & Sept. & Day & Aug. & Sept. & Day & Aug. & Sept. & Day & Aug. & Sept. \\
\hline $\begin{array}{l}1 \\
2 \\
3 \\
4 \\
5 \\
6 \\
7 \\
8\end{array}$ & $\begin{array}{l}0 \\
0 \\
0 \\
0 \\
0 \\
0 \\
0 \\
0\end{array}$ & $\begin{array}{l}0.18 \\
.09 \\
.05 \\
.04 \\
.03 \\
.03 \\
.03 \\
.02\end{array}$ & $\begin{array}{r}9 \\
10 \\
11 \\
12 \\
13 \\
14 \\
15 \\
16\end{array}$ & $\begin{array}{c}0 \\
0 \\
0 \\
.06 \\
2.5 \\
151 \\
20 \\
8.0\end{array}$ & $\begin{array}{l}.02 \\
.02 \\
.02 \\
.01 \\
.01 \\
.01 \\
0 \\
0\end{array}$ & $\begin{array}{l}17 \\
18 \\
19 \\
20 \\
21 \\
22 \\
23 \\
24\end{array}$ & $\begin{array}{c}3.0 \\
1.4 \\
.90 \\
.36 \\
.16 \\
.07 \\
.05 \\
.04\end{array}$ & $\begin{array}{l}0 \\
0 \\
0 \\
0 \\
0 \\
0 \\
0 \\
0\end{array}$ & $\begin{array}{l}25 \\
26 \\
27 \\
28 \\
29 \\
30 \\
31\end{array}$ & $\begin{array}{r}.04 \\
.03 \\
.03 \\
.03 \\
.03 \\
5.8 \\
.55\end{array}$ & $\begin{array}{l}0 \\
0 \\
0 \\
0 \\
0 \\
0\end{array}$ \\
\hline \multicolumn{10}{|c|}{$\begin{array}{l}\text { Monthly mean discharge, in second-feet } \\
\text { Runoff, in inches }\end{array}$} & $\begin{array}{l}6.26 \\
0.53\end{array}$ & $\begin{array}{l}0.019 \\
0 \\
0002\end{array}$ \\
\hline
\end{tabular}


Gage height, in feet, and discharge, in second-feet, at indicated time, 1940

\begin{tabular}{|c|c|c|c|c|c|c|c|c|}
\hline \multirow{2}{*}{ Hour } & \multicolumn{2}{|c|}{ Aug. 11} & \multicolumn{2}{|c|}{ Aug. 12} & \multicolumn{2}{|c|}{ Aug. 13} & \multicolumn{2}{|c|}{ Aug. 14} \\
\hline & $\begin{array}{l}\text { Gage } \\
\text { height }\end{array}$ & Discharge & $\begin{array}{l}\text { Gage } \\
\text { height }\end{array}$ & Discharge & $\begin{array}{l}\text { Gage } \\
\text { height }\end{array}$ & Discharge & $\begin{array}{l}\text { Gage } \\
\text { height }\end{array}$ & Discharge \\
\hline $\begin{array}{l}1 \\
2 \\
3 \\
4 \\
5 \\
6\end{array}$ & 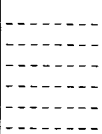 & 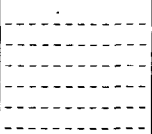 & 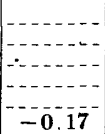 & 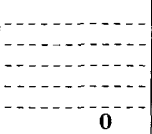 & $\begin{array}{r}0.22 \\
.19 \\
.18 \\
.18 \\
.18 \\
.18\end{array}$ & $\begin{array}{r}0.29 \\
.21 \\
.18 \\
.18 \\
.18 \\
.18\end{array}$ & $\begin{array}{r}0.42 \\
.39 \\
.38 \\
.37 \\
.36 \\
.40\end{array}$ & $\begin{array}{l}1.7 \\
1.4 \\
1.3 \\
1.2 \\
1.1 \\
1.5\end{array}$ \\
\hline $\begin{array}{r}7 \\
8 \\
9 \\
10 \\
11 \\
\mathbf{N}\end{array}$ & 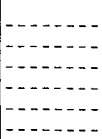 & 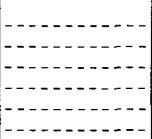 & 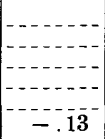 & 负 & $\begin{array}{l}.17 \\
.17 \\
.24 \\
.30 \\
.30 \\
.28\end{array}$ & $\begin{array}{l}.16 \\
.16 \\
.35 \\
.60 \\
.60 \\
.50\end{array}$ & $\begin{array}{l}1.52 \\
2.39 \\
2.13 \\
2.06 \\
1.91 \\
1.99\end{array}$ & $\begin{array}{r}21 \\
116 \\
73 \\
64 \\
47 \\
56\end{array}$ \\
\hline $\begin{array}{l}1 \\
2 \\
3 \\
4 \\
5 \\
6\end{array}$ & \begin{tabular}{l}
-1. \\
\hdashline-0.25 \\
-0
\end{tabular} & 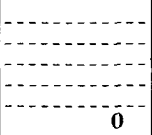 & 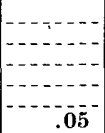 & 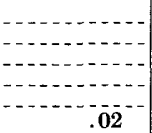 & $\begin{array}{r}.24 \\
.28 \\
.32 \\
.52 \\
.68 \\
1.04\end{array}$ & $\begin{array}{r}.35 \\
.50 \\
.73 \\
3.0 \\
5.6 \\
12\end{array}$ & $\begin{array}{l}2.29 \\
3.17 \\
3.83 \\
3.57 \\
3.71 \\
2.99\end{array}$ & $\begin{array}{r}97 \\
372 \\
668 \\
542 \\
600 \\
\mathbf{3 0 0}\end{array}$ \\
\hline $\begin{array}{r}7 \\
8 \\
9 \\
10 \\
11 \\
12\end{array}$ & 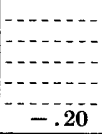 & 西 & $\begin{array}{r}. \overline{20} \\
-.24 \\
.2 \overline{4} \\
\hdashline .2 \overline{2}\end{array}$ & $\begin{array}{c}.2 \overline{3} \\
.3 \overline{5} \\
-29\end{array}$ & $\begin{array}{l}.99 \\
.82 \\
.69 \\
.61 \\
.54 \\
.48\end{array}$ & $\begin{array}{r}11 \\
7.8 \\
5.7 \\
4.5 \\
3.3 \\
2.4\end{array}$ & $\begin{array}{l}2.45 \\
2.32 \\
2.40 \\
2.51 \\
2.43 \\
2.28\end{array}$ & $\begin{array}{r}129 \\
103 \\
118 \\
142 \\
125 \\
96\end{array}$ \\
\hline
\end{tabular}

MOUNTAIN CREGK NEAR ELLERBE, N. C.

Location.-Lat. $35^{\circ} 06^{\prime}$, long. $79^{\circ} 48^{\prime}$, at bridge on State Highway 73 , half a mile downstream from Baldwin Mill, 31/4 miles upstream from Little Mountain Creek, and 5 miles northwest of Ellerbe, Richmond County.

Drainage AREA.-33.4 square miles.

GAGE-HEIGHT RECORD.-Water-stage recorder graph.

DISCHARGE RECORD.-Stage-discharge relation defined by current-meter measurements up to 135 second-feet. Gage heights used to half-tenths above and hundredths below 2.3 feet.

Maxima.-August 1940: Discharge, 175 second-feet. 7 p.m. Aug. 14 (gage height, 2.94 feet).

April to July 1940: Discharge, 196 second-feet Apr. 13 (gage height, 3.13 feet).

REMARKS.-Flood runoff for small rises only slightly affected by artificial storage.

Mean discharge, in second-feet, 1940

\begin{tabular}{|c|c|c|c|c|c|c|c|c|c|c|c|}
\hline Day & Aug. & Sept. & Day & Aug. & Sept. & Day & Aug. & Sept. & Day & Aug. & Sept. \\
\hline $\begin{array}{l}1 \\
2 \\
3 \\
4 \\
5 \\
6 \\
7 \\
8\end{array}$ & $\begin{array}{l}2.3 \\
1.2 \\
1.8 \\
.4 \\
1.5 \\
2.5 \\
3.6 \\
3.2\end{array}$ & $\begin{array}{l}2.1 \\
6.4 \\
6.9 \\
4.4 \\
2.6 \\
5.9 \\
4.7 \\
1.5\end{array}$ & $\begin{array}{r}9 \\
10 \\
11 \\
12 \\
13 \\
14 \\
15 \\
16\end{array}$ & $\begin{array}{l}1.4 \\
1.5 \\
2.5 \\
22 \\
21 \\
77 \\
81 \\
61\end{array}$ & $\begin{array}{l}3.3 \\
4.7 \\
4.0 \\
5.3 \\
1.2 \\
3.5 \\
1.7 \\
1.8\end{array}$ & $\begin{array}{l}17 \\
18 \\
19 \\
20 \\
21 \\
22 \\
23 \\
24\end{array}$ & $\begin{array}{c}60 \\
28 \\
21 \\
14 \\
14 \\
10 \\
7.6 \\
7.0\end{array}$ & $\begin{array}{l}5.5 \\
2.4 \\
3.5 \\
2.4 \\
1.9 \\
1.2 \\
4.2 \\
2.2\end{array}$ & $\begin{array}{l}25 \\
26 \\
27 \\
28 \\
29 \\
30 \\
31\end{array}$ & $\begin{array}{l}4.1 \\
7.7 \\
5.6 \\
4.9 \\
4.7 \\
5.2 \\
8.3\end{array}$ & $\begin{array}{r}4.0 \\
4.1 \\
1.7 \\
1.5 \\
2.1 \\
.4\end{array}$ \\
\hline \multicolumn{10}{|c|}{$\begin{array}{l}\text { Monthly mean discharge, in second-feet } \\
\text { Runoff, in inches }\end{array}$} & $\begin{array}{l}15.7 \\
0.54\end{array}$ & $\begin{array}{l}3.20 \\
0.11\end{array}$ \\
\hline
\end{tabular}


FLOODS OF AUGUST 1940 IN THE SOUTHEASTERN STATES

Gage height, in feet, and discharge, in second-feet, at indicated time, 1940

\begin{tabular}{|c|c|c|c|c|c|c|c|c|c|c|}
\hline \multirow{2}{*}{ Hour } & \multicolumn{2}{|c|}{ Aug. 14} & \multicolumn{2}{|c|}{ Aug. 15} & \multicolumn{2}{|c|}{ Aug. 16} & \multicolumn{2}{|c|}{ Aug. 17} & \multicolumn{2}{|c|}{ Aug. 18} \\
\hline & $\begin{array}{c}\text { Gage } \\
\text { height }\end{array}$ & $\begin{array}{c}\text { Dis- } \\
\text { charge }\end{array}$ & $\begin{array}{c}\text { Gage } \\
\text { height }\end{array}$ & $\begin{array}{c}\text { Dis- } \\
\text { charge }\end{array}$ & $\begin{array}{l}\text { Gage } \\
\text { height }\end{array}$ & $\begin{array}{l}\text { Dis- } \\
\text { charge }\end{array}$ & $\begin{array}{c}\text { Gage } \\
\text { height }\end{array}$ & $\begin{array}{c}\text { Dis- } \\
\text { charge }\end{array}$ & $\begin{array}{c}\text { Gage } \\
\text { height }\end{array}$ & $\begin{array}{c}\text { Dis- } \\
\text { charge }\end{array}$ \\
\hline $\begin{array}{l}1 \\
2 \\
3 \\
4 \\
5 \\
6\end{array}$ & $\begin{array}{r}0.76 \\
.75 \\
.75 \\
.75 \\
.87 \\
.95\end{array}$ & $\begin{array}{r}7.7 \\
7.3 \\
7.3 \\
7.3 \\
13 \\
17\end{array}$ & $\begin{array}{l}2.82 \\
2.64 \\
2.41 \\
2.19 \\
1.99 \\
1.83\end{array}$ & $\begin{array}{r}160 \\
145 \\
122 \\
103 \\
87 \\
74\end{array}$ & $\begin{array}{l}1.78 \\
1.69 \\
1.62 \\
1.55 \\
1.49 \\
1.45\end{array}$ & $\begin{array}{l}70 \\
63 \\
58 \\
54 \\
49 \\
46\end{array}$ & $\begin{array}{r}2.43 \\
2.06 \\
1.77\end{array}$ & $\begin{array}{r}126 \\
70\end{array}$ & 1.17 & $\overline{2} \overline{9}$ \\
\hline $\begin{array}{r}7 \\
8 \\
9 \\
10 \\
11 \\
\mathrm{~N}\end{array}$ & $\begin{array}{l}1.09 \\
1.05 \\
1.02 \\
1.33 \\
1.38 \\
1.71\end{array}$ & $\begin{array}{l}24 \\
22 \\
21 \\
39 \\
42 \\
65\end{array}$ & $\begin{array}{l}1.71 \\
1.60 \\
1.52 \\
1.48 \\
1.44 \\
1.41\end{array}$ & $\begin{array}{l}65 \\
57 \\
51 \\
49 \\
46 \\
44\end{array}$ & $\begin{array}{l}1.41 \\
1.37 \\
1.34 \\
1.32 \\
1.30 \\
1.29\end{array}$ & $\begin{array}{l}44 \\
41 \\
39 \\
38 \\
37 \\
36\end{array}$ & $\begin{array}{r}1.61 \\
-1.50 \\
1.40\end{array}$ & 58 & 1. 16 & 29 \\
\hline $\begin{array}{l}1 \\
2 \\
3 \\
4 \\
5 \\
6\end{array}$ & $\begin{array}{l}1.83 \\
1.90 \\
1.81 \\
2.37 \\
2.68 \\
2.74\end{array}$ & $\begin{array}{r}74 \\
80 \\
73 \\
118 \\
150 \\
155\end{array}$ & $\begin{array}{l}1.37 \\
1.29 \\
1.39 \\
1.90 \\
1.96 \\
2.00\end{array}$ & $\begin{array}{l}41 \\
36 \\
42 \\
80 \\
85 \\
88\end{array}$ & $\begin{array}{l}1.28 \\
1.28 \\
1.38 \\
1.31 \\
1.22 \\
1.19\end{array}$ & $\begin{array}{l}36 \\
36 \\
42 \\
38 \\
32 \\
30\end{array}$ & $\begin{array}{r}1.30 \\
1.34 \\
1.33\end{array}$ & 37 & 1.13 & 27 \\
\hline $\begin{array}{r}7 \\
8 \\
9 \\
10 \\
11 \\
12\end{array}$ & $\begin{array}{l}2.94 \\
2.87 \\
2.87 \\
.2 .89 \\
2.90 \\
2.88\end{array}$ & $\begin{array}{l}175 \\
165 \\
165 \\
170 \\
170 \\
170\end{array}$ & $\begin{array}{l}2.07 \\
2.14 \\
2.04 \\
1.96 \\
1.94 \\
1.86\end{array}$ & $\begin{array}{l}94 \\
99 \\
91 \\
85 \\
83 \\
77\end{array}$ & $\begin{array}{l}1.90 \\
2.35 \\
2.20 \\
2.35 \\
2.60 \\
2.64\end{array}$ & $\begin{array}{r}80 \\
118 \\
104 \\
118 \\
140 \\
145\end{array}$ & $\begin{array}{c}1.30 \\
1.28 \\
1.28\end{array}$ & $\begin{array}{r}37 \\
-36 \\
36\end{array}$ & 1.05 & 22 \\
\hline
\end{tabular}

NORTH FORK JONES CREEK NEAR WADESBORO, N. C.

LOCATION.-Lat. $34^{\circ} 55^{\prime} 20^{\prime \prime}$, long. $80^{\circ} 04^{\prime} 05^{\prime \prime}$, 300 feet downstream from county highway bridge, $31 / 2$ miles south of Wadesboro, Anson County, and $5 \frac{1}{2}$ miles upstream from confluence with South Fork.

DRAINAGE AREA.-10.0 square miles.

GAGE-HEIGHT RECORD.-Water-stage recorder graph except Aug. 6-8 and Aug. 14 to Sept. 25.

DISCHARGE RECORD.- Stage-discharge relation defined by current-meter measurements up to 320 second-feet and extended to 1937 and 1939 erest gage heights on basis of computation of flood-flow over conerete control.

Maxima.-1940: Discharge, 219 second-feet Aug. 14 (gage height, 2.48 feet, from recorded range in stage).

1935-39: Discharge, 2,410 second-feet June 4, 1937 and July 20, 1939; gage height, 6.39 feet June 4, 1937.

REMARKs.-Flood runoff unaffected by artificial storage except for small rises, which might be slightly affected by a small reservoir a short distance above station where Wadesboro diverts about 0.3 second-foot for water supply.

Mean discharge, in second-feet, 1940

\begin{tabular}{|c|c|c|c|c|c|c|c|c|c|c|c|}
\hline Day & Aug. & Sept. & Day & Aug. & Sept. & Day & Aug. & Sept. & Day & Aug. & Sept. \\
\hline $\begin{array}{l}1 \\
2 \\
3 \\
4 \\
5 \\
6 \\
7 \\
8\end{array}$ & $\begin{array}{r}0.2 \\
.2 \\
.2 \\
.2 \\
.2 \\
.2 \\
.2 \\
.2\end{array}$ & $\begin{array}{r}1.0 \\
.6 \\
.4 \\
.3 \\
.2 \\
.2 \\
.2 \\
.2\end{array}$ & $\begin{array}{r}9 \\
10 \\
11 \\
12 \\
13 \\
14 \\
15 \\
16\end{array}$ & $\begin{array}{r}.2 \\
.3 \\
1.0 \\
2.5 \\
1.3 \\
80 \\
40 \\
25\end{array}$ & $\begin{array}{l}.2 \\
.2 \\
.2 \\
.2 \\
.2 \\
.2 \\
.2 \\
.2\end{array}$ & $\begin{array}{l}17 \\
18 \\
19 \\
20 \\
21 \\
22 \\
23 \\
24\end{array}$ & $\begin{array}{r}10 \\
5.0 \\
2.0 \\
1.0 \\
.8 \\
.6 \\
.5 \\
.4\end{array}$ & $\begin{array}{l}.2 \\
.2 \\
.2 \\
.2 \\
.2 \\
.2 \\
.2 \\
.2\end{array}$ & $\begin{array}{l}25 \\
26 \\
27 \\
28 \\
29 \\
30 \\
31\end{array}$ & $\begin{array}{r}.4 \\
.4 \\
.4 \\
.4 \\
.4 \\
17 \\
5.0\end{array}$ & $\begin{array}{l}.2 \\
.2 \\
.2 \\
.2 \\
.2 \\
.2\end{array}$ \\
\hline \multicolumn{10}{|c|}{$\begin{array}{l}\text { Monthly mean discharge, in second-feet } \\
\text { Runoff, in inches }\end{array}$} & $\begin{array}{l}6.33 \\
0.73\end{array}$ & $\begin{array}{l}0.25 \\
0.03\end{array}$ \\
\hline
\end{tabular}

JUNIPER CREEK NEAR CHERA W, S. C.

Location.-Lat. $34^{\circ} 39^{\prime}$, long. $79^{\circ} 54^{\prime}$, at spillway of Eureka Lake Dam, 11/2 miles 
upstream from mouth and $3 \frac{1}{2}$ miles south of Cheraw, Chesterfield County.

DraiNAGE AREA.-64 square miles.

GAGE-HEIGHT RECORD.-Water-stage recorder graph.

DISCHARGE RECORD.-Stage-discharge relation defined by current-meter measurements.

Shifting-control method used Aug. 1-31.

Maxima.-1940: Discharge, 256 second-feet 4-7 a.m. Aug. 16 (gage height, 1.06 feet.) REMARKs.--Runoff slightly affeeted by artificial storage in Eureka Lake.

Mean discharge, in second-feet, 1940

\begin{tabular}{|c|c|c|c|c|c|c|c|c|c|c|c|}
\hline Day & Aug. & Sept. & Day & Aug. & Sept. & Day & Aug. & Sept. & Day & Aug. & Sept. \\
\hline $\begin{array}{l}1 \\
2 \\
3 \\
4 \\
5 \\
6 \\
7 \\
8\end{array}$ & $\begin{array}{r}8.6 \\
9.7 \\
9.7 \\
11.4 \\
14.5 \\
15.2 \\
21.6 \\
29.2\end{array}$ & & $\begin{array}{r}9 \\
10 \\
11 \\
12 \\
13 \\
14 \\
15 \\
16\end{array}$ & $\begin{array}{c}28.3 \\
25.6 \\
31 \\
47 \\
68 \\
100 \\
194 \\
243\end{array}$ & & $\begin{array}{l}17 \\
18 \\
19 \\
20 \\
21 \\
22 \\
23 \\
24\end{array}$ & $\begin{array}{c}211 \\
159 \\
112 \\
68 \\
41 \\
32 \\
26.5 \\
23.2\end{array}$ & & $\begin{array}{l}25 \\
26 \\
27 \\
28 \\
29 \\
30 \\
31\end{array}$ & $\begin{array}{l}22.4 \\
20.1 \\
19.4 \\
18.6 \\
17.9 \\
30 \\
57\end{array}$ & \\
\hline \multicolumn{10}{|c|}{$\begin{array}{l}\text { Monthiy mean discharge, in second-feet } \\
\text { Runoff, in inches }\end{array}$} & $\begin{array}{l}55.3 \\
1.00\end{array}$ & \\
\hline
\end{tabular}

LYNCHES RIVER AT EFFINGHAM, S. C.

LoCAtion.-Lat. $34^{\circ} 03^{\prime}$, long. $79^{\circ} 45^{\prime}$, at steel bridge on U. S. Highway 52, 75 feet upstream from Atlantic Coast Line Railroad bridge and 1 mile south of Effingham, Florence County. Datum of gage is 58.49 feet above mean sea level, datum of 1929, supplementary adjustment of 1936 .

Drain AGE AREA.-1,030 square miles. (1942 revision).

GAGE-HEIGHT RECORD.-Water-stage recorder graph.

DISCHARGE RECORD.- Stage-discharge relation defined by current-meter measurements up to 9,900 second-feet and extended to erest gage height.

Maxima.-1940: Discharge, 1,980 second-feet 10 p.m. Aug. 18 (gage-height, 9.43 feet).

1929-39: Discharge observed, 15,200 second-feet Oct. 7, 1929 (gage height, 19.25 feet).

1891-1929: Stage known, 20.0 feet Aug. 30, 1908, from records of U. S. Weather Bureau (discharge, 18,000 second-feet).

REMARKs.-Runoff not affected by artificial storage or diversion. Natural storage in swampy area.

Mean discharge, in second-feet, 1940

\begin{tabular}{|c|c|c|c|c|c|c|c|c|c|c|c|}
\hline Day & Aug. & Sept. & Day & Aug. & Sept. & Day & Aug. & Sept. & Day & Aug. & Sept. \\
\hline $\begin{array}{l}1 \\
2 \\
3 \\
4 \\
5 \\
6 \\
7 \\
8 \\
\end{array}$ & $\begin{array}{l}156 \\
154 \\
162 \\
198 \\
210 \\
210 \\
198 \\
204\end{array}$ & $\begin{array}{l}258 \\
258 \\
288 \\
370 \\
434 \\
451 \\
342 \\
334 \\
\end{array}$ & $\begin{array}{r}9 \\
10 \\
11 \\
12 \\
13 \\
14 \\
15 \\
16\end{array}$ & $\begin{array}{r}192 \\
204 \\
272 \\
320 \\
313 \\
436 \\
1,670 \\
1,770 \\
\end{array}$ & $\begin{array}{l}312 \\
284 \\
312 \\
319 \\
291 \\
256 \\
242 \\
235 \\
\end{array}$ & $\begin{array}{l}17 \\
18 \\
19 \\
20 \\
21 \\
22 \\
23 \\
24 \\
\end{array}$ & $\begin{array}{l}1, \\
1, \\
1, \\
1, \\
1, \\
1, \\
1,\end{array}$ & $\begin{array}{l}222 \\
216 \\
202 \\
196 \\
190 \\
183 \\
183 \\
176 \\
\end{array}$ & $\begin{array}{l}20 \\
26 \\
27 \\
28 \\
29 \\
30 \\
31\end{array}$ & $\begin{array}{l}764 \\
417 \\
348 \\
318 \\
295 \\
280 \\
272\end{array}$ & $\begin{array}{l}170 \\
167 \\
162 \\
164 \\
170 \\
183\end{array}$ \\
\hline \multicolumn{12}{|c|}{$\begin{array}{l}\text { Monthly mean discharge, in second-feet } \\
\text { Runoff, in inches }\end{array}$} \\
\hline
\end{tabular}

LITTLE PEW DEE RIVER NEAR DILLON, S. C.

Location.-Lat. $34^{\circ} 24^{\prime}$, long. $79^{\circ} 20^{\prime}$, at bridge on State Highway 9, 1.1 miles east of Dillon, Dillon County, and 3 miles upstream from Maple Swamp.

DRAINAGE AREA.-524 square miles.

GAGE-HEIGHT RECORD.-Wire-weight gage read twice daily to hundredths except $804331-49-16$ 


\section{FLOODS OF AUGUST 1940 IN THE SOUTHEASTERN STATES}

Aug. 23. Record for Aug. 14, 15 obtained from graph based on twice-daily gage readings. Record for Aug. 23 obtained from graph based on record for adjacent days.

DISCHARGE RECORD.-Stage-discharge relation defined by current-meter measurements up to 2,400 second-feet and extended to crest gage height by logarithmic plotting.

Maxima.-August 1940: Discharge observed, 797 second-feet 6 p.m. Aug. 19 (gage height, 7.94 feet).

1939 to July 1940: Discharge, 2,910 second-feet July 24, 1939 (gage height, 10.18 feet, from graph based on gage readings).

REMARKs.-Runoff not affected by artificial storage or diversion. Natural storage in swampy areas.

Mean discharge, in second-feet, 1940

\begin{tabular}{|c|c|c|c|c|c|c|c|c|c|c|c|}
\hline Day & Aug. & Sept. & Day & Aug. & Sept. & Day & Aug. & Sept. & Day & Aug. & Sept. \\
\hline $\begin{array}{l}1 \\
2 \\
3 \\
4 \\
5 \\
6 \\
7 \\
8\end{array}$ & $\begin{array}{l}70 \\
83 \\
70 \\
70 \\
70 \\
64 \\
74 \\
72\end{array}$ & $\begin{array}{l}170 \\
162 \\
155 \\
155 \\
158 \\
170 \\
190 \\
148\end{array}$ & $\begin{array}{r}9 \\
10 \\
11 \\
12 \\
13 \\
14 \\
15 \\
16\end{array}$ & $\begin{array}{r}74 \\
83 \\
107 \\
134 \\
162 \\
208 \\
468 \\
670\end{array}$ & $\begin{array}{r}120 \\
107 \\
110 \\
113 \\
110 \\
101 \\
104 \\
95\end{array}$ & $\begin{array}{l}17 \\
18 \\
19 \\
20 \\
21 \\
22 \\
23 \\
24\end{array}$ & $\begin{array}{l}775 \\
775 \\
775 \\
720 \\
575 \\
470 \\
346 \\
262\end{array}$ & $\begin{array}{r}92 \\
101 \\
116 \\
130 \\
134 \\
124 \\
107 \\
107\end{array}$ & $\begin{array}{l}25 \\
26 \\
27 \\
28 \\
29 \\
30 \\
31\end{array}$ & $\begin{array}{l}218 \\
210 \\
186 \\
170 \\
158 \\
158 \\
166\end{array}$ & $\begin{array}{r}113 \\
120 \\
127 \\
127 \\
101 \\
95\end{array}$ \\
\hline \multicolumn{10}{|c|}{$\begin{array}{l}\text { Monthly mean discharge, in second-feet } \\
\text { Runoff, in inches }\end{array}$} & $\begin{array}{r}272 \\
0.60\end{array}$ & $\begin{array}{r}125 \\
0.27\end{array}$ \\
\hline
\end{tabular}

DROWNING CREEK NEAR HOFFMAN, N. C.

(Head of Lumber River)

Location.-Lat. $35^{\circ} 03^{\prime} 35^{\prime \prime}$, long. $79^{\circ} 29^{\prime} 35^{\prime \prime}$, at bridge on U. S. Highway 1 , about three-quarters of a mile downstream from Deep Creek, about 1 mile upstream from Seaboard Railway bridge, and 4 miles northeast of Hoffman, Richmond County.

Drainage ARea. -178 square miles.

GAGE-HEIGHT RECORD.-Water-stage recorder graph.

DISCHARGE RECORD. - Stage-discharge relation defined by current-meter measurements up to 600 second-feet. Gage heights used to half-tenths between 2.3 and 5.5 feet; hundredths below and tenths above these limits.

Maxima.-August 1940: Discharge, 354 second-feet 9 a.m. Aug. 18 (gage height, 5.07 feet).

1939 to July 1940: Discharge, 435 second-feet Feb. 22, 1940 (gage height, 5.28 feet).

REMARKs.-Flood runoff not affected by artificial storage.

Mean discharge, in second-feet, 1940

\begin{tabular}{|c|c|c|c|c|c|c|c|c|c|c|c|}
\hline Day & Aug. & Sept. & Day & Aug. & Sept. & Day & Aug. & Sept. & Day & Aug. & Sept. \\
\hline $\begin{array}{l}1 \\
2 \\
3 \\
4 \\
5 \\
6 \\
7 \\
8\end{array}$ & $\begin{array}{l}32 \\
30 \\
29 \\
30 \\
35 \\
38 \\
58 \\
64\end{array}$ & $\begin{array}{l}71 \\
59 \\
54 \\
50 \\
47 \\
50 \\
53 \\
49\end{array}$ & $\begin{array}{r}9 \\
10 \\
11 \\
12 \\
13 \\
14 \\
15 \\
16\end{array}$ & $\begin{array}{r}47 \\
39 \\
60 \\
151 \\
210 \\
226 \\
260 \\
316\end{array}$ & $\begin{array}{l}44 \\
41 \\
41 \\
53 \\
50 \\
44 \\
42 \\
41\end{array}$ & $\begin{array}{l}17 \\
18 \\
19 \\
20 \\
21 \\
22 \\
23 \\
24\end{array}$ & $\begin{array}{r}350 \\
350 \\
316 \\
206 \\
114 \\
89 \\
77 \\
70\end{array}$ & $\begin{array}{l}40 \\
40 \\
39 \\
38 \\
38 \\
37 \\
34 \\
33\end{array}$ & $\begin{array}{l}25 \\
26 \\
27 \\
28 \\
29 \\
30 \\
31\end{array}$ & $\begin{array}{l}64 \\
60 \\
55 \\
52 \\
50 \\
51 \\
65\end{array}$ & $\begin{array}{l}52 \\
62 \\
55 \\
47 \\
52 \\
46\end{array}$ \\
\hline \multicolumn{10}{|c|}{$\begin{array}{l}\text { Monthly mean discharge, in second-feet } \\
\text { Runoff, in inches }\end{array}$} & $\begin{array}{r}116 \\
0.75\end{array}$ & $\begin{array}{l}46.7 \\
0.29\end{array}$ \\
\hline
\end{tabular}




\section{LUMBER RIVER AT BOARDMAN, N. C.}

Location.-Lat. $34^{\circ} 26^{\prime} 40^{\prime \prime}$, long. $78^{\circ} 56^{\prime} 35^{\prime \prime}$, at State highway bridge, 1 mile downstream from Atlantic Coast Line Railroad bridge at Boardman, Columbus County, and 11/2 miles downstream from Big Swamp. Datum of gage is 72.05 feet above mean sea level, datum of 1929 (levels by Corps of Engineers, War Department).

Drainage AREa.-1,220 square miles.

GAGE-HEIGHT RECORD.-Graph based on twice-daily wire-weight gage readings Aug. 11-28. Mean of twice-daily readings used Aug. 1-10 and Aug. 29 to Sept. 30.

DISCHARGE RECORD.-Stage-discharge relation defined by current-meter measurements up to 7,300 second-feet and extended to 1928 crest stage on basis of estimate of flood flow by area-velocity method. Changing stage is a factor in computing discharge above 700 second-feet. Gage heights used to tenths.

Maxima.-August 1940: Discharge, 763 second-feet 12 m. Aug. 20 (gage height, 4.00 feet).

1929 to July 1940: Discharge, 12,600 second-feet Mar. 4, 1939 (gage height, 10.35 feet).

Stage known, 11.8 feet sometime in August 1928, from flood reference mark as witnessed by local resident (discharge, estimated, 25,000 second-feet).

REMARKs.-Flood runoff not affected by artificial storage.

Mean discharge, in second-feet, 1940

\begin{tabular}{|c|c|c|c|c|c|c|c|c|c|c|c|}
\hline Day & Aug. & Sept. & Day & Aug. & Sept. & Day & Aug. & Sept. & Day & Aug. & Sept. \\
\hline $\begin{array}{l}1 \\
2 \\
3 \\
4 \\
5 \\
6 \\
7 \\
8\end{array}$ & $\begin{array}{l}145 \\
156 \\
167 \\
167 \\
167 \\
178 \\
190 \\
240\end{array}$ & $\begin{array}{l}254 \\
240 \\
226 \\
226 \\
226 \\
240 \\
240 \\
214\end{array}$ & $\begin{array}{r}9 \\
10 \\
11 \\
12 \\
13 \\
14 \\
15 \\
16\end{array}$ & $\begin{array}{l}226 \\
190 \\
202 \\
240 \\
300 \\
334 \\
372 \\
448\end{array}$ & $\begin{array}{l}214 \\
202 \\
202 \\
214 \\
202 \\
202 \\
202 \\
202\end{array}$ & $\begin{array}{l}17 \\
18 \\
19 \\
20 \\
21 \\
22 \\
23 \\
24\end{array}$ & $\begin{array}{l}\mathbf{5 1 6} \\
638 \\
729 \\
760 \\
\mathbf{7 3 8} \\
\mathbf{7 0 2} \\
686 \\
668\end{array}$ & $\begin{array}{l}190 \\
190 \\
178 \\
178 \\
167 \\
156 \\
156 \\
145\end{array}$ & $\begin{array}{l}25 \\
26 \\
27 \\
28 \\
29 \\
30 \\
31\end{array}$ & $\begin{array}{l}668 \\
656 \\
623 \\
558 \\
414 \\
\mathbf{3 4 8} \\
\mathbf{2 8 4}\end{array}$ & $\begin{array}{l}145 \\
145 \\
134 \\
134 \\
145 \\
156\end{array}$ \\
\hline \multicolumn{10}{|c|}{$\begin{array}{l}\text { Monthly mean discharge, in second-feet } \\
\text { Runoff, in inches }\end{array}$} & $\begin{array}{r}410 \\
0.39\end{array}$ & $\begin{array}{r}191 \\
0.17\end{array}$ \\
\hline
\end{tabular}

DEEP CREEK NEAR ROSELAND, N. C.

LOCATION.-Lat. $35^{\circ} 07^{\prime} 20^{\prime \prime}$, long. $79^{\circ} 32^{\prime} 25^{\prime \prime}$, at county highway bridge, 2 miles southwest of Roseland, Moore County, 21/2 miles upstream from Horse Creek, and about 7 miles west of Aberdeen.

DRAINAGE AREA.-18.9 square miles.

GAGE-HEIGHT RECORD.-Water-stage recorder graph.

DISCHARGE RECORD.- Stage-discharge relation defined by current-meter measurements up to 47 second-feet.

Maxima.-1940: Discharge, 47 second-feet 11 p.m. Aug. 15 (gage height, 2.79 feet). REMARKS.-Flood runoff not affected by artificial storage.

Mean discharge, in second-feet, 1940

\begin{tabular}{|c|c|c|c|c|c|c|c|c|c|c|c|}
\hline Day & Aug. & Sept. & Day & Aug. & Sept. & Day & Aug. & Sept. & Day & Aug. & Sept. \\
\hline $\begin{array}{l}1 \\
2 \\
3 \\
4 \\
5 \\
6 \\
7 \\
8\end{array}$ & $\begin{array}{l}\mathbf{5 . 9} \\
5.9 \\
5.9 \\
6.3 \\
7.3 \\
6.9 \\
9.7 \\
9.9\end{array}$ & $\begin{array}{l}9.7 \\
8.3 \\
8.1 \\
7.9 \\
7.5 \\
9.3 \\
8.5 \\
7.5\end{array}$ & $\begin{array}{r}9 \\
10 \\
11 \\
12 \\
13 \\
14 \\
15 \\
16\end{array}$ & $\begin{array}{l}7.1 \\
7.1 \\
25 \\
34 \\
25 \\
28 \\
40 \\
45\end{array}$ & $\begin{array}{l}7.1 \\
6.9 \\
7.1 \\
7.7 \\
7.1 \\
7.1 \\
6.9 \\
6.9\end{array}$ & $\begin{array}{l}17 \\
18 \\
19 \\
20 \\
21 \\
22 \\
23 \\
24\end{array}$ & $\begin{array}{c}34 \\
25 \\
15 \\
12 \\
11 \\
9.7 \\
9.3 \\
8.7\end{array}$ & $\begin{array}{l}6.9 \\
7.1 \\
6.7 \\
6.5 \\
6.3 \\
6.1 \\
6.1 \\
6.3\end{array}$ & $\begin{array}{l}25 \\
26 \\
27 \\
28 \\
29 \\
30 \\
\mathbf{3 1}\end{array}$ & $\begin{array}{r}8.3 \\
8.1 \\
7.9 \\
7.5 \\
7.5 \\
8.9 \\
10\end{array}$ & $\begin{array}{l}7.9 \\
8.5 \\
77.9 \\
7.7 \\
7.5\end{array}$ \\
\hline \multicolumn{10}{|c|}{$\begin{array}{l}\text { Monthly mean discharge, in second-feet } \\
\text { Runoff, in inches }\end{array}$} & $\begin{array}{l}14.6 \\
0.89\end{array}$ & $\begin{array}{l}7.44 \\
0.44\end{array}$ \\
\hline
\end{tabular}


LITTLE RAFT SWAMP AT RED SPRINGS, N. C.

LoCATION.-Lat. $34^{\circ} 49^{\prime} 50^{\prime \prime}$, long. $79^{\circ} 10^{\prime} 55^{\prime \prime}$, at bridge on State Highway 71 , at Red Springs, Robeson County, half a mile upstream from Atlantic Coast Line Railroad crossing, and three-quarters of a mile downstream from Graham Pond.

DRAINAGE AREA.-23.1 square miles.

GAGE-HEIGHT RECORD.-Water-stage recorder graph except for Sept. 20-30.

DISCHARGE RECORD.- Stage-discharge relation defined by current-meter measurements

up to 30 second-feet. Discharge for period of no gage-height record, Sept. 20-30, based on records for nearby streams.

Maxima.-1940: Discharge, 32 second-feet 2 a.m. Aug. 13 (gage height, 2.14 feet). REMARKs.-Flood runoff not affected by artificial storage.

Mean discharge, in second-feet, 1940

\begin{tabular}{r|r|r|r|r|r|r|r|r|r|r|r}
\hline Day & Aug. & Sept. & Day & Aug. & Sept. & Day & Aug. & Sept. & Day & Aug. \\
\hline 1 & 2.5 & 2.8 & 9 & 4.4 & 1.9 & 17 & 14 & 2.0 & 25 & 4.2 & 1.5 \\
2 & 5.7 & 2.6 & 10 & 4.5 & 2.1 & 18 & 16 & 2.0 & 26 & 3.7 & 1.5 \\
3 & 7.0 & 2.5 & 11 & 12 & 2.1 & 19 & 12 & 2.0 & 27 & 4.0 & 1.5 \\
4 & 5.8 & 2.3 & 12 & 25 & 2.1 & 20 & 11 & 2 & 28 & 3.4 & 1.5 \\
5 & 4.9 & 2.2 & 13 & 28 & 2.1 & 21 & 7.8 & 2 & 29 & 3.1 & 2 \\
6 & 4.1 & 2.1 & 14 & 18 & 2.1 & 22 & 6.6 & 2 & 30 & 3.0 & 2 \\
7 & 4.0 & 2.0 & 15 & 20 & 2.0 & 23 & 5.6 & 2 & 31 & 2.9 & -1.5 \\
8 & 4.0 & 2.0 & 16 & 17 & 1.9 & 24 & 4.8 & 1.5 & \\
\hline
\end{tabular}

HLACK RIVER AT KINGSTREF, S. C.

LOCATION.-Lat. $33^{\circ} 40^{\prime}$, long. $79^{\circ} 50^{\prime}$, at highway bridge at Kingstree, Williamsburg County, a quarter of a mile downstream from Broad Swamp. Datum of gage is 25.66 feet above mean sea level, datum of 1929, supplementary adjustment of 1936.

Drainage AREA.-1,260 square miles (1945 revision).

GAGE-HEIGHT RECORD.-Water-stage recorder graph.

DISCHARGE RECORD. - Stage-discharge relation defined by current-meter measurements up to 9,900 second-feet and extended to erest stage.

Maxima.-August 1940: Discharge, 376 second-feet 11 p.m. Aug. 25 (gage height, 4.03 feet).

1929 to July 1940 : Discharge, 12,200 second-feet Mar. 4, 1939 (gage height, 13.21 feet).

1893-1929: Stage known, 18.0 feet Sept. 21, 1928, from records of United States Weather Bureau (discharge, 41,600 second-feet).

REMARKs.- Runoff not affected by artificial storage or diversion. Natural storage in large swampy areas.

Mean discharge, in second-feet, 1940

\begin{tabular}{|c|c|c|c|c|c|c|c|c|c|c|c|}
\hline Day & Aug. & Sept. & Day & Aug. & Sept. & Day & Aug. & Sept. & Day & Aug. & Sept. \\
\hline $\begin{array}{l}1 \\
2 \\
3 \\
4 \\
5 \\
6 \\
7 \\
8\end{array}$ & $\begin{array}{l}6 \\
5 \\
5 \\
5 \\
8 \\
8 \\
6 \\
6\end{array}$ & $\begin{array}{r}153 \\
126 \\
106 \\
91 \\
80 \\
72 \\
65 \\
58\end{array}$ & $\begin{array}{r}9 \\
10 \\
11 \\
12 \\
13 \\
14 \\
15 \\
16\end{array}$ & $\begin{array}{r}6 \\
6 \\
8 \\
10 \\
11 \\
15 \\
70 \\
158\end{array}$ & $\begin{array}{l}51 \\
45 \\
42 \\
44 \\
57 \\
66 \\
61 \\
54\end{array}$ & $\begin{array}{l}17 \\
18 \\
19 \\
20 \\
21 \\
22 \\
23 \\
24\end{array}$ & $\begin{array}{l}216 \\
222 \\
227 \\
239 \\
245 \\
257 \\
296 \\
338\end{array}$ & $\begin{array}{l}48 \\
44 \\
40 \\
40 \\
38 \\
36 \\
34 \\
31\end{array}$ & $\begin{array}{l}25 \\
26 \\
27 \\
28 \\
29 \\
30 \\
31\end{array}$ & $\begin{array}{l}368 \\
368 \\
354 \\
310 \\
263 \\
222 \\
183\end{array}$ & $\begin{array}{r}28 \\
24 \\
22 \\
23 \\
24 \\
20 \\
-\end{array}$ \\
\hline \multicolumn{10}{|c|}{$\begin{array}{l}\text { Monthly mean discharge, in second-feet } \\
\text { Runoff, in inches, }\end{array}$} & $\begin{array}{r}143 \\
0.13\end{array}$ & $\begin{array}{l}54.1 \\
0.05\end{array}$ \\
\hline
\end{tabular}




\section{SANTEE RIVER BASIN}

\section{CATAWBA RIVER AT BRIDGEWATER RESERVOIR, NEAR BRIDGEWA'TER, N. C.}

Location.-Lat. $35^{\circ} 44^{\prime} 40^{\prime \prime}$, long. $81^{\circ} 50^{\prime} 35^{\prime \prime}$, at intake tower in Paddy-Linville division of Bridgewater Dam, 2 miles northeast of Bridgewater, Burke County. Datum of gage is 1,100 feet above mean sea level (levels by Duke Power Co.).

Drainage ARea. - 380 square miles.

GAGE-HEIGHT RECORD.- - Staff gage read to tenths hourly. Adjusted gage heights Aug. 12-16 taken from graph based on hourly readings.

DISCHARGE RECORD.-Record of outflow based on formula for spillways and manufacturer's ratings for turbines. Record of inflow based on outflow and change in contents.

Maxima.-1940: Mean inflow, 141,760 second-feet for hour ending 9 p.m. Aug. 13; outflow, 43,700 second-feet 2 to 3 a.m. Aug. 14; reservoir gage height, 106.1 feet 2 to 3 a.m. Aug. 14 (total contents, 14,402,000,000 eubic feet).

ReMARKs.-Reservoir, first put in use May 5, 1919, is in two divisions, one on Catawba River and one on Paddy Creek and Linville River, connected by a canal; it has a total storage capacity of 12,582,000,000 eubic feet below 100 feet gage height (erest of spillways). Storage capacity under normal operation is 10,506,000,000 enbic feet above gage height of 60 feet in Catawba division and 20 feet in Paddy-Linville division. Records furnished by Duke Power Co.

Bridgewater Reservoir, gage height and contents at midnight and mean outflow, 1940

\begin{tabular}{|c|c|c|c|c|c|c|c|c|c|c|c|c|c|}
\hline \multirow[b]{2}{*}{ Day } & \multicolumn{3}{|c|}{ August } & \multicolumn{3}{|c|}{ September } & \multirow[b]{2}{*}{ Day } & \multicolumn{3}{|c|}{ August } & \multicolumn{3}{|c|}{ September } \\
\hline & $\begin{array}{c}\text { Gage } \\
\text { height } \\
\text { (feet) }\end{array}$ & \begin{tabular}{|l|} 
Con- \\
tents \\
(mil- \\
lion \\
cubic \\
feet) \\
\end{tabular} & $\begin{array}{l}\text { Out- } \\
\text { flow } \\
\text { (sec- } \\
\text { ond- } \\
\text { feet) }\end{array}$ & $\begin{array}{c}\text { Gage } \\
\text { height } \\
\text { (feet) }\end{array}$ & $\begin{array}{l}\text { Con- } \\
\text { tents } \\
\text { (mil- } \\
\text { lion } \\
\text { cubic } \\
\text { feet) }\end{array}$ & $\begin{array}{l}\text { Out- } \\
\text { flow } \\
\text { (sec- } \\
\text { ond- } \\
\text { feet) }\end{array}$ & & $\left|\begin{array}{c}\text { Gage } \\
\text { height } \\
\text { (feet) }\end{array}\right|$ & $\begin{array}{l}\text { Con- } \\
\text { tents } \\
\text { (mil- } \\
\text { lion } \\
\text { cubic } \\
\text { feet) }\end{array}$ & $\begin{array}{l}\text { Out- } \\
\text { flow } \\
\text { (sec- } \\
\text { ond- } \\
\text { feet) }\end{array}$ & $\left|\begin{array}{c}\text { Gage } \\
\text { height } \\
\text { (feet) }\end{array}\right|$ & $\begin{array}{c}\text { Con- } \\
\text { tents } \\
\text { (mil- } \\
\text { lion } \\
\text { cubic } \\
\text { feet) }\end{array}$ & $\begin{array}{l}\text { Out- } \\
\text { flow } \\
\text { (sec- } \\
\text { ond- } \\
\text { feet) }\end{array}$ \\
\hline $\begin{array}{l}1 \\
2 \\
3 \\
4 \\
5\end{array}$ & $\begin{array}{l}93.6 \\
93.6 \\
93.6 \\
93.6 \\
93.7\end{array}$ & $\begin{array}{l}10,865 \\
10,865 \\
10,865 \\
10,865 \\
10,890\end{array}$ & $\begin{array}{r}340 \\
160 \\
0 \\
200 \\
0\end{array}$ & $\begin{array}{r}101.3 \\
100.8 \\
100.4 \\
100.0 \\
99.7\end{array}$ & $\begin{array}{l}12,955 \\
12,810 \\
12,696 \\
12,582 \\
12,497\end{array}$ & $\begin{array}{l}6,310 \\
4,810 \\
3,320 \\
2,370 \\
2,040\end{array}$ & $\begin{array}{l}16 \\
17 \\
18 \\
19 \\
20\end{array}$ & $\begin{array}{r}100.9 \\
100.5 \\
100.4 \\
100.1 \\
99.9\end{array}$ & $\mid \begin{array}{l}12,839 \\
12,725 \\
12,696 \\
12,610 \\
12,554\end{array}$ & $\begin{array}{l}5,900 \\
3,620 \\
1,980 \\
2,380 \\
1,430\end{array}$ & $\begin{array}{l}96.0 \\
95.5 \\
94.9 \\
94.3 \\
93.8\end{array}$ & $\mid \begin{array}{l}11,487 \\
11,355 \\
11,199 \\
11,044 \\
10,916\end{array}$ & $\begin{array}{l}1,810 \\
2,060 \\
2,150 \\
2,100 \\
1,750\end{array}$ \\
\hline $\begin{array}{r}6 \\
7 \\
8 \\
9 \\
10\end{array}$ & $\begin{array}{l}93.5 \\
93.4 \\
93.3 \\
93.2 \\
93.1\end{array}$ & $\begin{array}{l}10,840 \\
10,814 \\
10,789 \\
10,764 \\
10,739\end{array}$ & $\begin{array}{l}540 \\
550 \\
510 \\
410 \\
330\end{array}$ & $\begin{array}{l}99.3 \\
99.1 \\
99.2 \\
99.0 \\
98.5\end{array}$ & $\mid \begin{array}{l}12,385 \\
12,329 \\
12,357 \\
12,301 \\
12,163\end{array}$ & $\begin{array}{r}2,040 \\
1,590 \\
320 \\
1,540 \\
2,020\end{array}$ & $\begin{array}{l}21 \\
22 \\
23 \\
24 \\
25\end{array}$ & $\begin{array}{l}99.7 \\
99.5 \\
99.3 \\
99.2 \\
99.1\end{array}$ & $\begin{array}{l}12,497 \\
12,441 \\
12,385 \\
12,357 \\
12,329\end{array}$ & $\begin{array}{r}1,280 \\
1,370 \\
1,350 \\
560 \\
1,000\end{array}$ & $\begin{array}{c}93.8 \\
93.7 \\
93.5 \\
93.3 \\
93.2\end{array}$ & $\begin{array}{l}10,916 \\
10,890 \\
10,840 \\
10,789 \\
10,764\end{array}$ & $\begin{array}{r}770 \\
350 \\
1,140 \\
770 \\
860\end{array}$ \\
\hline $\begin{array}{l}11 \\
12 \\
13 \\
14 \\
15\end{array}$ & $\begin{array}{r}93.2 \\
93.8 \\
105.8 \\
102.9 \\
101.7\end{array}$ & $\begin{array}{l}10,764 \\
10,916 \\
14,308 \\
13,424 \\
13,071\end{array}$ & $\begin{array}{r}470 \\
0 \\
5,120 \\
28,950 \\
11,400\end{array}$ & $\begin{array}{l}98.1 \\
97.6 \\
97.1 \\
96.6 \\
96.4\end{array}$ & $\begin{array}{l}12,053 \\
11,916 \\
11,781 \\
11,647 \\
11,593\end{array}$ & $\begin{array}{l}2.050 \\
2,060 \\
2,100 \\
1,750 \\
1,080\end{array}$ & $\begin{array}{l}26 \\
27 \\
28 \\
29 \\
30 \\
31\end{array}$ & $\begin{array}{r}98.8 \\
98.3 \\
97.8 \\
98.2 \\
102.7 \\
102.0\end{array}$ & $\mid \begin{array}{l}12,246 \\
12,108 \\
11,971 \\
12,080 \\
13,365 \\
13,158\end{array}$ & $\begin{array}{r}1,710 \\
2,100 \\
2,110 \\
2,110 \\
8,460 \\
11,770\end{array}$ & \begin{tabular}{|c|}
93.0 \\
92.8 \\
92.8 \\
92.8 \\
92.7 \\
$-\cdots$
\end{tabular} & $\begin{array}{l}10,713 \\
10,663 \\
10,663 \\
10,663 \\
10,638\end{array}$ & $\begin{array}{l}710 \\
810 \\
180 \\
350 \\
620\end{array}$ \\
\hline \multirow{2}{*}{\multicolumn{11}{|c|}{$\begin{array}{l}\text { Change in contents, equivalent, in second-feet } \\
\text { Monthly mean outflow, in second-feet } \\
\text { Monthly mean inflow, in second-feet. } \\
\text { Runoff, depth in inches, corresponding to inflow }\end{array}$}} & August & \multicolumn{2}{|c|}{ September } \\
\hline & & & & & & & & & & & $\begin{array}{l}+856 \\
3,165 \\
4,021 \\
12.22\end{array}$ & \multicolumn{2}{|c|}{$\begin{array}{r}-972 \\
1,728 \\
756 \\
2.22 \\
\end{array}$} \\
\hline
\end{tabular}

SUPPLEMENTAL RECORD,-July 31, midnight, gage height, 93.6 feet; contents, 10,865 million cubic feet. 


\section{FLOODS OF AUGUST 1940 IN THE SOUTHEASTERN STATES}

Bridgewater Reservoir, gage height, contents, mean inflow for preceding hour, and outflow, at indicated time, 1940

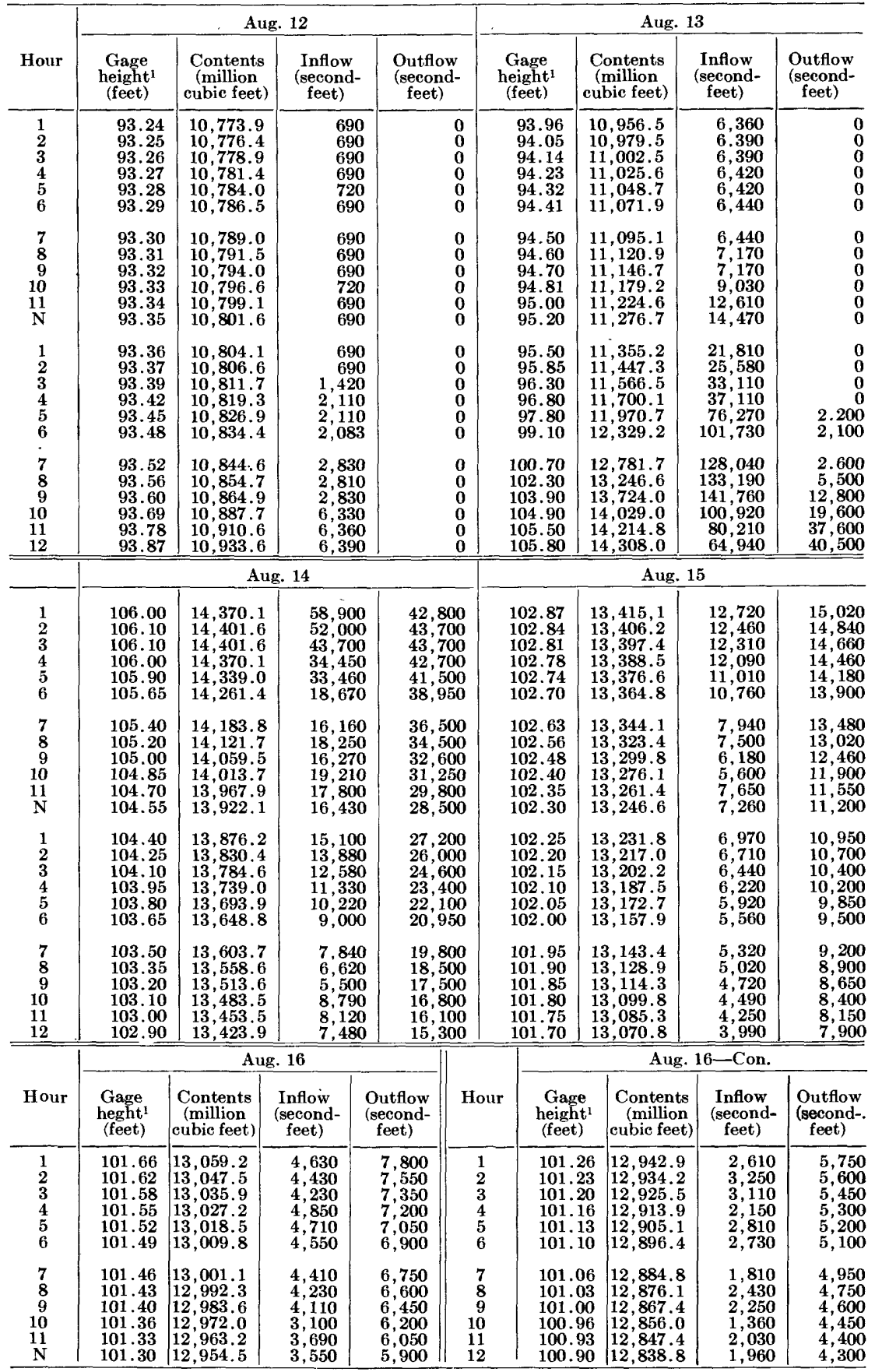

1 Gage heights from graph based on hourly observations.

SUPPLEMENTAL RECoRD.-Aug. 11, 12 p.m., gage height, 93.23 feet; contents 10,771.4 million cubic feet. 


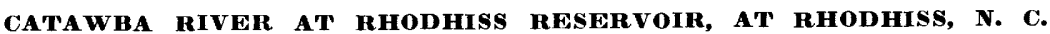

Location.-Lat. $35^{\circ} 46^{\prime} 30^{\prime \prime}$, long. $81^{\circ} 26^{\prime} 25^{\prime \prime}$, at powerhouse forebay at Rhodhiss Dam, three-quarters of a mile west of Rhodhiss, Caldwell County, and 2 miles upstream from Carolina \& Northwestern Railway bridge. Datum of gage is 895.0 feet above mean sea level (levels by Duke Power Co.).

DRAINAGE AREA.- $-1,088$ square miles.

GAGE-HEIGHT RECORD.- Staff gage read to tenths hourly. Adjusted gage heights Aug. 12-16 taken from graph based on hourly readings.

DISCHARge RECORD.-Record of outflow based on formula for spillway and manufacturer's ratings for turbines. Record of inflow based on outflow and change in contents.

Maxima.-1940: Mean inflow, 167,740 second-feet for hour ending 12 p.m. Aug. 13; outflow, 104,000 second-feet 4 a.m. Ang. 14; reservoir gage height, 110.1 feet 4 to 6 a.m. Aug. 14 (contents, 3,560,000,000 eubic feet above gage height 85.0 feet).

REMARKs.-Reservoir, first put in use Feb. 18, 1925, has a storage capacity under normal operation of $1,717,000,000$ cubie feet between gage heights 85.0 and 100.0 feet (crest of spillway). River also affected by storage in Bridgewater Reservoir upstream having a storage capacity under normal operation of 10,506,000,000 eubic feet. Records furnished by Duke Power Co.

Rhodhiss Reservoir, gage height and contents at midnight and mean outflow, 1940

\begin{tabular}{|c|c|c|c|c|c|c|c|c|c|c|c|c|c|}
\hline \multirow[b]{2}{*}{ Day } & \multicolumn{3}{|c|}{ August } & \multicolumn{3}{|c|}{ September } & \multirow[b]{2}{*}{ Day } & \multicolumn{3}{|c|}{ August } & \multicolumn{3}{|c|}{ September } \\
\hline & $\begin{array}{c}\text { Gage } \\
\text { height } \\
\text { (feet) }\end{array}$ & $\begin{array}{l}\text { Con- } \\
\text { tents } \\
\text { (mil- } \\
\text { lion } \\
\text { cubic } \\
\text { feet) }\end{array}$ & $\begin{array}{l}\text { Out- } \\
\text { flow } \\
\text { (sec- } \\
\text { ond- } \\
\text { feet) }\end{array}$ & $\begin{array}{c}\text { Gage } \\
\text { height } \\
\text { (feet) }\end{array}$ & \begin{tabular}{|l} 
Con- \\
tents \\
(mil- \\
lion \\
cubic \\
feet)
\end{tabular} & $\begin{array}{l}\text { Out- } \\
\text { flow } \\
\text { (sec- } \\
\text { ond- } \\
\text { feet) }\end{array}$ & & $\underset{\substack{\text { Gage } \\
\text { height } \\
\text { (feet) }}}{\mid}$ & $\begin{array}{l}\text { Con- } \\
\text { tents } \\
\text { (mil- } \\
\text { lion } \\
\text { cubic } \\
\text { feet) }\end{array}$ & $\begin{array}{l}\text { Out- } \\
\text { flow } \\
\text { (sec- } \\
\text { ond- } \\
\text { feet) }\end{array}$ & $\begin{array}{c}\text { Gage } \\
\text { height } \\
\text { (feet) }\end{array}$ & $\begin{array}{l}\text { Con- } \\
\text { tents } \\
\text { (mil- } \\
\text { lion } \\
\text { cubic } \\
\text { feet) }\end{array}$ & $\begin{array}{l}\text { Out- } \\
\text { flow } \\
\text { (sec- } \\
\text { ond- } \\
\text { feet) }\end{array}$ \\
\hline $\begin{array}{l}1 \\
2 \\
3 \\
4 \\
5\end{array}$ & $\begin{array}{l}90.2 \\
89.7 \\
90.1 \\
90.5 \\
90.0\end{array}$ & $\begin{array}{l}477 \\
427 \\
467 \\
508 \\
457\end{array}$ & \begin{tabular}{r|r|}
1,090 \\
1,090 \\
0 \\
0 \\
1,190
\end{tabular} & \begin{tabular}{|r|}
101.7 \\
100.8 \\
100.2 \\
99.9 \\
99.5
\end{tabular} & \begin{tabular}{|l|}
1,986 \\
1,842 \\
1,748 \\
1,702 \\
1,641
\end{tabular} & $\begin{array}{l}9,430 \\
7,200 \\
5,590 \\
4,200 \\
3,930\end{array}$ & $\begin{array}{l}16 \\
17 \\
18 \\
19 \\
20\end{array}$ & $\begin{array}{r}101.1 \\
100.8 \\
100.6 \\
99.9 \\
99.0\end{array}$ & $\begin{array}{l}1,889 \\
1,842 \\
1,811 \\
1,702 \\
1,567\end{array}$ & $\begin{array}{r}10,000 \\
5,990 \\
4,050 \\
5,400 \\
4,440\end{array}$ & \begin{tabular}{|l|}
96.2 \\
95.7 \\
95.9 \\
96.0 \\
95.7
\end{tabular} & $\begin{array}{l}1,177 \\
1,112 \\
1,137 \\
1,150 \\
1,112\end{array}$ & $\begin{array}{l}3,360 \\
3,270 \\
2,500 \\
2,850 \\
3,000\end{array}$ \\
\hline $\begin{array}{r}6 \\
7 \\
8 \\
9 \\
10\end{array}$ & $\begin{array}{l}89.4 \\
89.5 \\
89.5 \\
89.3 \\
89.7\end{array}$ & $\begin{array}{l}398 \\
408 \\
408 \\
388 \\
427\end{array}$ & $\begin{array}{r}1,200 \\
1,090 \\
980 \\
1,070 \\
0\end{array}$ & \begin{tabular}{|l|}
99.1 \\
99.3 \\
99.2 \\
98.0 \\
97.5
\end{tabular} & $\begin{array}{l}1,582 \\
1,611 \\
1,597 \\
1,422 \\
1,352\end{array}$ & $\begin{array}{l}3,780 \\
2,410 \\
1,600 \\
3,830 \\
3,640\end{array}$ & $\begin{array}{l}21 \\
22 \\
23 \\
24 \\
25\end{array}$ & $\begin{array}{l}98.1 \\
97.5 \\
96.7 \\
97.9 \\
98.6\end{array}$ & $\begin{array}{l}1,436 \\
1,352 \\
1,243 \\
1,408 \\
1,509\end{array}$ & $\begin{array}{r}3,480 \\
3,350 \\
3,420 \\
220 \\
880\end{array}$ & \begin{tabular}{|l|}
96.0 \\
96.7 \\
96.5 \\
95.8 \\
95.3
\end{tabular} & $\begin{array}{l}1,150 \\
1,243 \\
1,216 \\
1,124 \\
1,060\end{array}$ & $\begin{array}{r}1,080 \\
0 \\
1,800 \\
2,320 \\
2,000\end{array}$ \\
\hline $\begin{array}{l}11 \\
12 \\
13 \\
14 \\
15\end{array}$ & $\begin{array}{r}90.7 \\
90.8 \\
107.1 \\
105.8 \\
102.2\end{array}$ & $\begin{array}{r}528 \\
539 \\
2,959 \\
2,708 \\
2,069\end{array}$ & $\begin{array}{r}0 \\
1,330 \\
5,810 \\
79,820 \\
25,200\end{array}$ & \begin{tabular}{|l|}
96.6 \\
95.8 \\
95.0 \\
96.3 \\
96.9
\end{tabular} & $\begin{array}{l}1,230 \\
1,124 \\
1,022 \\
1,190 \\
1,270\end{array}$ & $\begin{array}{l}4,100 \\
3,830 \\
3,820 \\
1,050 \\
1,110\end{array}$ & $\begin{array}{l}26 \\
27 \\
28 \\
29 \\
30 \\
31 \\
\end{array}$ & $\begin{array}{r}98.0 \\
97.0 \\
96.7 \\
97.1 \\
103.6 \\
102.5 \\
\end{array}$ & $\begin{array}{l}1,422 \\
1,283 \\
1,243 \\
1,297 \\
2,307 \\
2,119 \\
\end{array}$ & $\mid \begin{array}{r}3,400 \\
4,130 \\
3,460 \\
2,760 \\
10,400 \\
18,640\end{array}$ & $\begin{array}{r}95.1 \\
94.7 \\
95.5 \\
96.1 \\
95.4 \\
-2 \\
\end{array}$ & $\begin{array}{r}1,035 \\
985 \\
1,086 \\
1,163 \\
1,073 \\
- \\
\end{array}$ & $\begin{array}{r}1,470 \\
1,690 \\
0 \\
0 \\
1,840 \\
\\
\end{array}$ \\
\hline \multirow{2}{*}{\multicolumn{12}{|c|}{$\begin{array}{l}\text { Change in contents, equivalent, in second-feet } \\
\text { Monthly mean outflow, in second-feet }\end{array}$}} & $\begin{array}{l}\text { Au- } \\
\text { gust }\end{array}$ & $\begin{array}{l}\text { Sep- } \\
\text { tember }\end{array}$ \\
\hline & & & & & & & & & & & & $\begin{array}{r}+609 \\
6,577\end{array}$ & $\begin{array}{r}-404 \\
2,090 \\
\end{array}$ \\
\hline
\end{tabular}

SUPPLEMENTAL RECORD,-July 31, midnight, gage height, 90.3 feet; contents, 488 million cubic feet. 
Khodhiss Reservoir, gage height, contents, mean inflow for preceding hour, and outflow, at indicated time, 1940

\begin{tabular}{|c|c|c|c|c|c|c|c|c|c|}
\hline \multirow[b]{2}{*}{ Hour } & \multicolumn{5}{|c|}{ Aug. 12} & \multicolumn{4}{|c|}{ Aug. 13} \\
\hline & $\begin{array}{c}\text { Gage } \\
\text { height }{ }^{1} \\
\text { (feet) }\end{array}$ & $\begin{array}{l}\text { Contents } \\
\text { (million } \\
\text { cubic feet) }\end{array}$ & $\begin{array}{l}\text { Inflow } \\
\text { (second } \\
\text { feet) }\end{array}$ & $\begin{array}{l}\text { Out } \\
\text { (sec } \\
\text { fe }\end{array}$ & & $\begin{array}{c}\text { Gage } \\
\text { height }{ }^{1} \\
\text { (feet) }\end{array}$ & $\begin{array}{c}\text { Contents } \\
\text { (million } \\
\text { cubic feet) }\end{array}$ & $\begin{array}{l}\text { Inflow } \\
\text { (second- } \\
\text { feet) }\end{array}$ & $\begin{array}{l}\text { Outflow } \\
\text { (second- } \\
\text { feet) }\end{array}$ \\
\hline $\begin{array}{l}1 \\
2 \\
3 \\
4 \\
5 \\
6\end{array}$ & $\begin{array}{l}90.75 \\
90.80 \\
90.85 \\
90.90 \\
90.95 \\
90.97\end{array}$ & $\begin{array}{l}533.6 \\
538.8 \\
544.1 \\
549.4 \\
554.7 \\
556.8\end{array}$ & $\begin{array}{l}1,4 \\
1,4 \\
1,4 \\
1,4 \\
1,4 \\
1,2\end{array}$ & & $\begin{array}{l}0 \\
0 \\
0 \\
0 \\
0 \\
0\end{array}$ & $\begin{array}{l}90.90 \\
91.00 \\
91.10 \\
91.20 \\
91.30 \\
91.40\end{array}$ & $\begin{array}{l}549.4 \\
560.0 \\
570.6 \\
581.3 \\
592.0 \\
602.7\end{array}$ & $\begin{array}{l}2,940 \\
2,940 \\
2,940 \\
2,970 \\
2,970 \\
3,520\end{array}$ & $\begin{array}{r}0 \\
0 \\
0 \\
0 \\
0 \\
1,100\end{array}$ \\
\hline $\begin{array}{r}7 \\
8 \\
9 \\
10 \\
11 \\
\mathrm{~N}\end{array}$ & $\begin{array}{l}90.98 \\
90.99 \\
91.00 \\
91.00 \\
90.96 \\
90.90\end{array}$ & $\begin{array}{l}557.9 \\
558.9 \\
560.0 \\
560.0 \\
555.8 \\
549.4\end{array}$ & $\begin{array}{r}1,56 \\
1,68 \\
2,01 \\
1,85 \\
68 \\
84\end{array}$ & & & $\begin{array}{l}91.50 \\
91.60 \\
91.65 \\
91.70 \\
91.80 \\
91.90\end{array}$ & $\begin{array}{l}613.5 \\
624.3 \\
629.8 \\
635.2 \\
646.1 \\
657.0\end{array}$ & $\begin{array}{l}4,050 \\
4,130 \\
2,750 \\
2,730 \\
4,230 \\
4,380\end{array}$ & $\begin{array}{l}1,000 \\
1,250 \\
1,200 \\
1,250 \\
1,150 \\
1,550\end{array}$ \\
\hline $\begin{array}{l}1 \\
2 \\
3 \\
4 \\
5 \\
6\end{array}$ & $\begin{array}{l}90.85 \\
90.80 \\
90.76 \\
90.73 \\
90.71 \\
90.70\end{array}$ & $\begin{array}{l}544.1 \\
538.8 \\
534.6 \\
531.5 \\
529.4 \\
528.3\end{array}$ & $\begin{array}{r}1,3 \\
1,1 \\
1,7 \\
2,0 \\
1,4 \\
9\end{array}$ & & & $\begin{array}{l}92.00 \\
92.30 \\
92.60 \\
92.90 \\
93.40 \\
93.80\end{array}$ & $\begin{array}{l}668.0 \\
701.4 \\
735.2 \\
769.5 \\
827.6 \\
875.0\end{array}$ & $\begin{array}{r}4,480 \\
10,630 \\
10,770 \\
10,880 \\
17,640 \\
16,540\end{array}$ & $\begin{array}{l}1,300 \\
1,400 \\
1,350 \\
1,350 \\
1,650 \\
5,100\end{array}$ \\
\hline $\begin{array}{r}7 \\
8 \\
9 \\
10 \\
11 \\
12 \\
\end{array}$ & $\begin{array}{l}90.68 \\
90.66 \\
90.64 \\
90.65 \\
90.70 \\
90.80 \\
\end{array}$ & $\begin{array}{l}526.2 \\
524.1 \\
522.0 \\
523.1 \\
528.3 \\
538.8 \\
\end{array}$ & $\begin{array}{r}80 \\
99 \\
92 \\
1,51 \\
1,99 \\
2,92 \\
\end{array}$ & & $\begin{array}{r}00 \\
0 \\
0 \\
\end{array}$ & $\begin{array}{r}94.70 \\
96.50 \\
99.50 \\
102.10 \\
104.80 \\
107.10 \\
\end{array}$ & $\begin{array}{r}984.6 \\
1,216.2 \\
1,641.1 \\
2,052.0 \\
2,522.0 \\
2,959.0 \\
\end{array}$ & $\begin{array}{r}35,690 \\
69,680 \\
122,530 \\
121,840 \\
153,110 \\
167,740 \\
\end{array}$ & $\begin{array}{r}5,400 \\
5,300 \\
3,700 \\
11,700 \\
33,400 \\
59,300 \\
\end{array}$ \\
\hline 12 & \multicolumn{5}{|c|}{ Aug. 14} & \multicolumn{4}{|c|}{ Aug. 15} \\
\hline $\begin{array}{l}1 \\
2 \\
3 \\
4 \\
5 \\
6\end{array}$ & $\begin{array}{l}108.6 \\
109.5 \\
109.9 \\
110.1 \\
110.1 \\
110.1\end{array}$ & $\begin{array}{l}3,260.0 \\
3,440.0 \\
3,520.0 \\
3,560.0 \\
3,560.0 \\
3,560.0\end{array}$ & $\begin{array}{l}153,51 \\
137,40 \\
119,62 \\
113,36 \\
103,85 \\
103,75\end{array}$ & $\begin{array}{r}80, \\
94, \\
100, \\
104, \\
103, \\
103,\end{array}$ & & $\begin{array}{l}105.6 \\
105.4 \\
105.2 \\
105.0 \\
104.8 \\
104.6\end{array}$ & $\begin{array}{l}2,670.0 \\
2,633.0 \\
2,595.0 \\
2,558.0 \\
2,522.0 \\
2,486.0\end{array}$ & $\begin{array}{l}32,490 \\
30,470 \\
28,190 \\
26,320 \\
24,400 \\
22,450\end{array}$ & $\begin{array}{l}41,800 \\
39,700 \\
37,800 \\
35,400 \\
33,400 \\
31,500\end{array}$ \\
\hline $\begin{array}{r}7 \\
8 \\
9 \\
10 \\
11 \\
\mathrm{~N}\end{array}$ & $\begin{array}{l}110.0 \\
109.8 \\
109.5 \\
109.3 \\
109.0 \\
108.8\end{array}$ & $\begin{array}{l}3,540.0 \\
3,500.0 \\
3,440.0 \\
3,400.0 \\
3,340.0 \\
3,300.0\end{array}$ & $\begin{array}{l}97,99 \\
91,44 \\
82,93 \\
84,74 \\
75,28 \\
76,88\end{array}$ & $\begin{array}{r}103 \\
101 \\
97 \\
94 \\
89 \\
86\end{array}$ & & $\begin{array}{l}104.6 \\
104.5 \\
104.5 \\
104.1 \\
103.8 \\
103.7\end{array}$ & $\begin{array}{l}2,486.0 \\
2,468.0 \\
2,468.0 \\
2,395.0 \\
2,342.0 \\
2,325.0\end{array}$ & $\begin{array}{r}31,000 \\
26,000 \\
31,650 \\
9,670 \\
11,830 \\
19,880\end{array}$ & $\begin{array}{l}30,500 \\
31,500 \\
31,800 \\
28,100 \\
25,000 \\
24,200\end{array}$ \\
\hline $\begin{array}{l}1 \\
2 \\
3 \\
4 \\
5 \\
6\end{array}$ & $\begin{array}{l}108.6 \\
108.3 \\
108.0 \\
107.7 \\
107.5 \\
107.2\end{array}$ & $\begin{array}{l}3,260.0 \\
3,200.0 \\
3,140.0 \\
3,079.0 \\
3,039.0 \\
2,979.0\end{array}$ & $\begin{array}{l}73,8 \\
64,6 \\
60,2 \\
55,7 \\
58,1 \\
49,3\end{array}$ & & & $\begin{array}{l}103.5 \\
103.4 \\
103.2 \\
103.0 \\
102.9 \\
102.8\end{array}$ & $\begin{array}{l}2,290.0 \\
2,273.0 \\
2,238.0 \\
2,203.0 \\
2,186.0 \\
2,169.0\end{array}$ & $\begin{array}{l}13,580 \\
17,330 \\
11,630 \\
10,580 \\
14,480 \\
13,630\end{array}$ & $\begin{array}{l}22,400 \\
21,700 \\
21,000 \\
19,600 \\
18,800 \\
17,900\end{array}$ \\
\hline $\begin{array}{r}7 \\
8 \\
9 \\
10 \\
11 \\
12 \\
\end{array}$ & $\begin{array}{l}107.0 \\
106.7 \\
106.5 \\
106.2 \\
106.0 \\
105.8 \\
\end{array}$ & $\begin{array}{l}2,939.0 \\
2,881.0 \\
2,842.0 \\
2,784.0 \\
2,745.0 \\
2,708.0\end{array}$ & $\begin{array}{l}51,5 \\
43,34 \\
45,5 \\
36,54 \\
38,12 \\
35,62 \\
\end{array}$ & & & & $\begin{array}{l}2,169.0 \\
2,136.0 \\
2,119.0 \\
2,102.0 \\
2,085.0 \\
2,069.0\end{array}$ & $\begin{array}{r}17,650 \\
8,030 \\
11,480 \\
10,730 \\
10,080 \\
9,260 \\
\end{array}$ & $\begin{array}{l}17,400 \\
17,000 \\
15,400 \\
15,500 \\
14,100 \\
13,300 \\
\end{array}$ \\
\hline \multirow[b]{2}{*}{ Hour } & \multicolumn{4}{|c|}{ Aug. 16} & \multicolumn{5}{|c|}{ Aug. 16-Con. } \\
\hline & $\begin{array}{c}\text { Gage } \\
\text { height, } \\
\text { (feet) }\end{array}$ & $\begin{array}{c}\text { Contents } \\
\text { (million } \\
\text { cubic feet) }\end{array}$ & $\begin{array}{l}\text { Inflow } \\
\text { (second- } \\
\text { feet) }\end{array}$ & $\begin{array}{l}\text { Outflow } \\
\text { (second- } \\
\text { feet) }\end{array}$ & Hour & $\begin{array}{r}\text { Gag } \\
\text { heigl } \\
\text { (fee }\end{array}$ & \begin{tabular}{|c|c} 
Contents \\
tmillion \\
cubic feet)
\end{tabular} & $\begin{array}{c}\text { Inflow } \\
\text { (second- } \\
\text { feet) }\end{array}$ & $\begin{array}{c}\text { Outflow } \\
\text { (second- } \\
\text { feet) }\end{array}$ \\
\hline $\begin{array}{l}1 \\
2 \\
3 \\
4 \\
5 \\
6\end{array}$ & $\begin{array}{l}102.2 \\
102.1 \\
102.1 \\
102.0 \\
102.0 \\
101.9\end{array}$ & $\begin{array}{l}2,069.0 \\
2,052.0 \\
2,052.0 \\
2,035.0 \\
2,035.0 \\
2,019.0\end{array}$ & $\begin{array}{r}13,350 \\
8,030 \\
12,500 \\
7,480 \\
11,900 \\
7,260\end{array}$ & $\begin{array}{l}13,000 \\
12,500 \\
12,500 \\
11,900 \\
11,900 \\
11,500\end{array}$ & $\begin{array}{l}1 \\
2 \\
3 \\
4 \\
5 \\
5 \\
6\end{array}$ & $\begin{array}{l}10 \\
10 \\
10 \\
10 \\
10 \\
10\end{array}$ & $\begin{array}{l}1,954.0 \\
1,954.0 \\
1,938.0 \\
1,922.0 \\
1,922.0 \\
1,905.0\end{array}$ & $\begin{array}{l}9,800 \\
9,700 \\
4,960 \\
4,610 \\
9,000 \\
4,330\end{array}$ & $\begin{array}{r}10,000 \\
9,400 \\
9,400 \\
8,700 \\
9,300 \\
8,800\end{array}$ \\
\hline $\begin{array}{r}7 \\
8 \\
9 \\
10 \\
11 \\
\mathrm{~N} \\
\end{array}$ & $\begin{array}{l}101.8 \\
101.8 \\
101.7 \\
101.6 \\
101.6 \\
101.5 \\
\end{array}$ & $\begin{array}{l}2,003.0 \\
2,003.0 \\
1,986.0 \\
1,970.0 \\
1,970.0 \\
1,954.0\end{array}$ & $\begin{array}{r}6,510 \\
11,050 \\
6,780 \\
6,560 \\
10,600 \\
5,610\end{array}$ & $\begin{array}{r}10,400 \\
11,700 \\
11,300 \\
10,700 \\
10,500 \\
9,600 \\
\end{array}$ & $\begin{array}{r}7 \\
8 \\
9 \\
10 \\
11 \\
12 \\
\end{array}$ & $\begin{array}{l}101 \\
101 \\
101 \\
101 \\
101 \\
101\end{array}$ & $\begin{array}{l}1,905.0 \\
1,905.0 \\
1,889.0 \\
1,889.0 \\
1,889.0 \\
1,889.0\end{array}$ & $\begin{array}{l}8,750 \\
8,750 \\
3,860 \\
7,500 \\
7,000 \\
7,150\end{array}$ & $\begin{array}{l}8,700 \\
8,800 \\
7,800 \\
7,200 \\
6,800 \\
7,500 \\
\end{array}$ \\
\hline
\end{tabular}

Gage heights from graph based on hourly observations.

SUPPLEMENTAL RECORD.-Aug. 11, 12 p.m., gage height 90.70 feet; contents 528.3 million cubic feet. 
CATAWBA RIVER AT OXFORD RESERVOIR, NEAR TAYLORSVILLE, N. C.

Location.-Lat. $35^{\circ} 49^{\prime}$, long. $81^{\circ} 12^{\prime}$, at powerhouse forebay at Oxford Dam, 2 miles upstream from Lower Little River, and 7 miles south of Taylorsville, Alexander County. Datum of gage is 835.0 feet above mean sea level (levels by Duke Power Co.).

DRAINAGE AREA.-1,310 square miles.

GAGE-HEIGHT RECORD.-Staff gage read to tenths hourly. Adjusted gage heights Aug. 12-16 taken from graph based on hourly readings.

DISCHARGE RECORD.-Record of outflow based on formula for flood gates and manufacturer's rating for turbines. Record of inflow based on outflow and change in contents.

Maxima.-1940: Mean inflow, 183,620 second-feet for hour ending 4 a.m. Aug. 14; outflow, 158,060 second-feet 5 a.m. Aug. 14; reservoir gage height, 104.7 feet 4 to 5 a.m. Aug. 14 (total contents, 6,381,000,000 cubic feet).

REMARKS.-Reservoir, first put in use Apr. 5, 1928, has a total storage capacity of $5,553,000,000$ cubic feet below gage height of 100.0 feet (top of flood gates in closed position) and a storage capacity under normal operation of 2,278,000,000 cubic feet between gage heights 85.0 and 100.0 feet. River also affected by storage in Bridgewater and Rhodhiss Reservoirs upstream having a combined storage capacity under normal operation of 12,223,000,000 cubic feet. Records furnished by Duke Power Co.

Oxford Reservoir, gage height and contents, at midnight, 1940

\begin{tabular}{|c|c|c|c|c|c|c|c|c|c|}
\hline \multirow[b]{2}{*}{ Day } & \multicolumn{2}{|c|}{ August } & \multicolumn{2}{|c|}{ September } & \multirow[b]{2}{*}{ Day } & \multicolumn{2}{|c|}{ August } & \multicolumn{2}{|c|}{ September } \\
\hline & $\begin{array}{l}\text { Gage } \\
\text { height } \\
\text { (feet) }\end{array}$ & $\begin{array}{c}\text { Contents } \\
\text { (million } \\
\text { cubic feet) }\end{array}$ & $\begin{array}{l}\text { Gage } \\
\text { height } \\
\text { (feet) }\end{array}$ & $\begin{array}{c}\text { Contents } \\
\text { (million } \\
\text { cubic feet) }\end{array}$ & & $\begin{array}{l}\text { Gage } \\
\text { height } \\
\text { (feet) }\end{array}$ & $\begin{array}{c}\text { Contents } \\
\text { (million } \\
\text { cubic feet) }\end{array}$ & $\begin{array}{l}\text { Gage } \\
\text { height } \\
\text { (feet) }\end{array}$ & $\begin{array}{c}\text { Contents } \\
\text { (million } \\
\text { cubic } \\
\text { feet) }\end{array}$ \\
\hline $\begin{array}{l}1 \\
2 \\
3 \\
4 \\
5\end{array}$ & $\begin{array}{l}93.8 \\
93.8 \\
93.8 \\
93.5 \\
93.4\end{array}$ & $\begin{array}{l}1,240 \\
1,240 \\
1,240 \\
1,193 \\
1,178\end{array}$ & $\begin{array}{l}99.9 \\
99.9 \\
99.6 \\
99.6 \\
99.6\end{array}$ & $\begin{array}{l}2,290 \\
2,260 \\
2,206 \\
2,206 \\
2,206\end{array}$ & $\begin{array}{l}16 \\
17 \\
18 \\
19 \\
20\end{array}$ & $\begin{array}{l}99.0 \\
99.8 \\
98.7 \\
99.5 \\
99.5\end{array}$ & $\begin{array}{l}2,101 \\
2,242 \\
2,048 \\
2,189 \\
2,189\end{array}$ & $\begin{array}{l}97.6 \\
97.1 \\
96.3 \\
96.0 \\
95.6\end{array}$ & $\begin{array}{l}1,859 \\
1,775 \\
1,641 \\
1,592 \\
1,527\end{array}$ \\
\hline $\begin{array}{r}6 \\
7 \\
8 \\
9 \\
10\end{array}$ & $\begin{array}{l}93.3 \\
93.0 \\
92.7 \\
92.8 \\
92.8\end{array}$ & $\begin{array}{l}1,162 \\
1,116 \\
1,070 \\
1,085 \\
1,085\end{array}$ & $\begin{array}{l}99.5 \\
99.4 \\
99.4 \\
99.0 \\
98.7\end{array}$ & $\begin{array}{l}2,180 \\
2,171 \\
2,171 \\
2,101 \\
2,049\end{array}$ & $\begin{array}{l}21 \\
22 \\
23 \\
24 \\
25\end{array}$ & $\begin{array}{l}99.7 \\
99.7 \\
99.6 \\
99.1 \\
99.3\end{array}$ & $\begin{array}{l}2,224 \\
2,224 \\
2,206 \\
2,118 \\
2,153\end{array}$ & $\begin{array}{l}95.5 \\
95.5 \\
95.1 \\
95.4 \\
95.7\end{array}$ & $\begin{array}{l}1,510 \\
1,510 \\
1,446 \\
1,494 \\
1,543\end{array}$ \\
\hline $\begin{array}{l}11 \\
12 \\
13 \\
14 \\
15\end{array}$ & $\begin{array}{r}92.6 \\
92.7 \\
100.0 \\
99.2 \\
99.9\end{array}$ & $\begin{array}{l}1,055 \\
1,070 \\
2,278 \\
2,136 \\
2,260\end{array}$ & $\begin{array}{l}98.5 \\
98.2 \\
98.0 \\
97.7 \\
97.7\end{array}$ & $\begin{array}{l}2,014 \\
1,962 \\
1,927 \\
1,876 \\
1,876\end{array}$ & $\begin{array}{l}26 \\
27 \\
28 \\
29 \\
30 \\
31 \\
\end{array}$ & $\begin{array}{l}99.5 \\
99.6 \\
99.6 \\
99.5 \\
99.9 \\
99.9 \\
\end{array}$ & $\begin{array}{l}2,189 \\
2,206 \\
2,206 \\
2,189 \\
2,260 \\
2,260 \\
\end{array}$ & $\begin{array}{r}95.6 \\
95.4 \\
95.4 \\
95.4 \\
95.3 \\
\end{array}$ & $\begin{array}{r}1,527 \\
1,494 \\
1,494 \\
1,494 \\
1,478 \\
\end{array}$ \\
\hline 15 & & & & & & & & August & $\begin{array}{c}\text { Sep- } \\
\text { tember }\end{array}$ \\
\hline \multicolumn{8}{|c|}{ Change in contents, equivalent, in second-feet } & +381 & -302 \\
\hline
\end{tabular}

Supplemental RECord.- July 31, midnight, gage height, 93.8 feet; contents, 1,240 million cubic feet. 
Oxford Reservoir, gage height, contents, mean inflow for preceding hour, and outflow, at indicated time, 1940

\begin{tabular}{|c|c|c|c|c|c|c|c|c|c|}
\hline \multirow[b]{2}{*}{ Hour } & \multicolumn{5}{|c|}{ Aug. 12} & \multicolumn{4}{|c|}{ Aug. 13} \\
\hline & $\begin{array}{c}\text { Gage } \\
\text { height' } \\
\text { (feet) }\end{array}$ & $\begin{array}{c}\text { Contents } \\
\text { (million } \\
\text { cubic feet) }\end{array}$ & $\begin{array}{l}\text { Inflow } \\
\text { (second- } \\
\text { feet) }\end{array}$ & \multicolumn{2}{|c|}{$\begin{array}{l}\text { Outflow } \\
\text { (second- } \\
\text { feet) }\end{array}$} & $\begin{array}{c}\text { Gage } \\
\text { height } \\
\text { (feet) }\end{array}$ & $\begin{array}{c}\text { Contents } \\
\text { (million } \\
\text { cubic feet) }\end{array}$ & $\begin{array}{l}\text { Inflow } \\
\text { (second- } \\
\text { feet) }\end{array}$ & $\begin{array}{l}\text { Outflow } \\
\text { (second- } \\
\text { feet) }\end{array}$ \\
\hline $\begin{array}{l}1 \\
2 \\
3 \\
4 \\
5 \\
6\end{array}$ & $\begin{array}{l}92.52 \\
92.54 \\
92.56 \\
92.57 \\
92.58 \\
92.60\end{array}$ & $\begin{array}{r}1,042.6 \\
1,045.7 \\
1,048.7 \\
1,050.2 \\
1,051.8 \\
1,054.8\end{array}$ & $\begin{array}{l}8 \\
8 \\
8 \\
4 \\
4 \\
8\end{array}$ & $\begin{array}{l}30 \\
60 \\
30 \\
20 \\
40 \\
30\end{array}$ & $\begin{array}{l}0 \\
0 \\
0 \\
0 \\
0 \\
0\end{array}$ & $\begin{array}{l}92.65 \\
92.66 \\
92.67 \\
92.68 \\
92.69 \\
92.70\end{array}$ & $\begin{array}{r}1,062.4 \\
1,063.9 \\
1,065.4 \\
1,067.0 \\
1,068.5 \\
1,070.0\end{array}$ & $\begin{array}{r}420 \\
420 \\
420 \\
440 \\
420 \\
420\end{array}$ & $\begin{array}{l}0 \\
0 \\
0 \\
0 \\
0 \\
0\end{array}$ \\
\hline $\begin{array}{r}7 \\
8 \\
9 \\
10 \\
11 \\
\mathrm{~N}\end{array}$ & $\begin{array}{l}92.60 \\
92.57 \\
92.54 \\
92.50 \\
92.46 \\
92.42\end{array}$ & $\begin{array}{r}1,054.8 \\
1,050.2 \\
1,045.7 \\
1,039.6 \\
1,033.6 \\
1,027.5\end{array}$ & $\begin{array}{l}1,350 \\
1,520 \\
1,650 \\
1,210 \\
1,230 \\
1,210\end{array}$ & \multicolumn{2}{|c|}{$\begin{array}{l}2,700 \\
2,900 \\
2,900 \\
2,900 \\
2,900 \\
2,900\end{array}$} & $\begin{array}{l}92.71 \\
92.72 \\
92.73 \\
92.74 \\
92.75 \\
92.76\end{array}$ & $\begin{array}{l}1,071.5 \\
1,073.0 \\
1,074.6 \\
1,076.1 \\
1,077.6 \\
1,079.1\end{array}$ & $\begin{array}{l}1,770 \\
3,120 \\
3,240 \\
3,320 \\
3,320 \\
3,320\end{array}$ & $\begin{array}{l}2,700 \\
2,700 \\
2,900 \\
2,900 \\
2,900 \\
2,900\end{array}$ \\
\hline $\begin{array}{l}1 \\
2 \\
3 \\
4 \\
5 \\
6\end{array}$ & $\begin{array}{l}92.40 \\
92.45 \\
92.50 \\
92.55 \\
92.60 \\
92.605\end{array}$ & $\begin{array}{l}1,024.5 \\
1,032.1 \\
1,039.6 \\
1,047.2 \\
1,054.8 \\
1,055.6\end{array}$ & $\begin{array}{l}1,570 \\
4,010 \\
3,930 \\
3,910 \\
3,710 \\
1,670\end{array}$ & \multicolumn{2}{|c|}{$\begin{array}{l}1,900 \\
1,900 \\
1,800 \\
1,800 \\
1,400 \\
1,500\end{array}$} & $\begin{array}{l}92.77 \\
92.78 \\
92.79 \\
92.80 \\
92.84 \\
92.88\end{array}$ & $\begin{array}{r}1,080.6 \\
1,082.2 \\
1,083.7 \\
1,085.2 \\
1,091.3 \\
1,097.4\end{array}$ & $\begin{array}{l}3,120 \\
2,940 \\
2,920 \\
2,970 \\
4,240 \\
4,390\end{array}$ & $\begin{array}{l}2,500 \\
2,500 \\
2,500 \\
2,600 \\
2,500 \\
2,900\end{array}$ \\
\hline $\begin{array}{r}7 \\
8 \\
9 \\
10 \\
11 \\
12 \\
\end{array}$ & $\begin{array}{l}92.610 \\
92.615 \\
92.62 \\
92.625 \\
92.63 \\
92.64 \\
\end{array}$ & $\begin{array}{l}1,056.3 \\
1,057.1 \\
1,057.8 \\
1,058.6 \\
1,059.4 \\
1,060.9\end{array}$ & \multicolumn{3}{|c|}{$\begin{array}{r}1,690 \\
1,920 \\
2,040 \\
1,770 \\
870 \\
420 \\
\end{array}$} & $\begin{array}{r}92.92 \\
93.00 \\
93.50 \\
94.70 \\
97.60 \\
100.0 \\
\end{array}$ & $\begin{array}{l}1,103.6 \\
1,115.8 \\
1,193.0 \\
1,381.6 \\
1,859.1 \\
2,277.8 \\
\end{array}$ & $\begin{array}{r}4,570 \\
6,190 \\
24,240 \\
55,190 \\
135,540 \\
119,310 \\
\end{array}$ & $\begin{array}{l}2,800 \\
2,800 \\
2,800 \\
2,800 \\
3,000 \\
3,000 \\
\end{array}$ \\
\hline & \multicolumn{5}{|c|}{ Aug. 14} & \multicolumn{4}{|c|}{ Aug. 15} \\
\hline $\begin{array}{l}1 \\
2 \\
3 \\
4 \\
5 \\
6\end{array}$ & $\begin{array}{l}101.1 \\
102.0 \\
103.6 \\
104.7 \\
104.7 \\
104.3\end{array}$ & $\begin{array}{l}2,467.0 \\
2,620.0 \\
2,908.0 \\
3,106.0 \\
3,106.0 \\
3,034.0\end{array}$ & $\begin{array}{r}76,700 \\
106,340 \\
180,600 \\
183,620 \\
148,250 \\
136,360\end{array}$ & \multicolumn{2}{|c|}{$\begin{array}{r}45,280 \\
82,400 \\
118,790 \\
138,450 \\
158,060 \\
154,650\end{array}$} & $\begin{array}{l}98.8 \\
98.8 \\
98.8 \\
98.8 \\
98.8 \\
98.8\end{array}$ & $\begin{array}{l}2,065 \cdot 7 \\
2,065 \cdot 7 \\
2,065 \cdot 7 \\
2,065 \cdot 7 \\
2,065 \cdot 7 \\
2,065 \cdot 7\end{array}$ & $\begin{array}{l}37,260 \\
48,480 \\
40,650 \\
40,650 \\
35,710 \\
28,940\end{array}$ & $\begin{array}{l}56,300 \\
40,650 \\
40,650 \\
40,650 \\
30,770 \\
27,120\end{array}$ \\
\hline $\begin{array}{r}7 \\
8 \\
9 \\
10 \\
11 \\
\text { N }\end{array}$ & $\begin{array}{l}103.7 \\
103.0 \\
102.7 \\
102.0 \\
101.4 \\
100.7\end{array}$ & $\begin{array}{l}2,926.0 \\
2,800.0 \\
2,746.0 \\
2,620.0 \\
2,518.0 \\
2,398.3\end{array}$ & $\begin{array}{l}122,850 \\
113,680 \\
130,600 \\
107,600 \\
110,070 \\
100,810\end{array}$ & \multicolumn{2}{|c|}{$\begin{array}{l}151,060 \\
146,300 \\
144,890 \\
140,310 \\
136,500 \\
131,610\end{array}$} & $\begin{array}{l}99.0 \\
99.0 \\
99.1 \\
99.2 \\
99.3 \\
99.3\end{array}$ & $\begin{array}{l}2,100.7 \\
2,100.7 \\
2,118.2 \\
2,135.8 \\
2,153.4 \\
2,153.4\end{array}$ & $\begin{array}{l}36,870 \\
27,120 \\
29,150 \\
26,420 \\
26,580 \\
21,810\end{array}$ & $\begin{array}{l}27,170 \\
27,070 \\
21,510 \\
21,560 \\
21,810 \\
21,810\end{array}$ \\
\hline $\begin{array}{l}1 \\
2 \\
3 \\
4 \\
5 \\
6\end{array}$ & $\begin{array}{l}100.3 \\
100.1 \\
100.0 \\
100.0 \\
100.0 \\
100.0\end{array}$ & $\begin{array}{l}2,329.5 \\
2,295.0 \\
2,277.8 \\
2,277.8 \\
2,277.8 \\
2,277.8\end{array}$ & $\begin{array}{r}101,540 \\
92,700 \\
87,510 \\
77,360 \\
65,010 \\
70,250\end{array}$ & \multicolumn{2}{|c|}{$\begin{array}{r}109,700 \\
94,860 \\
89,710 \\
65,010 \\
65,010 \\
75,500\end{array}$} & $\begin{array}{l}99.3 \\
99.3 \\
99.4 \\
99.4 \\
99.4 \\
99.4\end{array}$ & $\begin{array}{l}2,153 \cdot 4 \\
2,153 \cdot 4 \\
2,171 \cdot 1 \\
2,171 \cdot 1 \\
2,171 \cdot 1 \\
2,171 \cdot 1\end{array}$ & $\begin{array}{l}21,810 \\
21,810 \\
26,760 \\
21,870 \\
21,870 \\
21,870\end{array}$ & $\begin{array}{l}21,810 \\
21,810 \\
21,870 \\
21,870 \\
21,870 \\
21,870\end{array}$ \\
\hline $\begin{array}{r}7 \\
8 \\
9 \\
10 \\
11 \\
12 \\
\end{array}$ & $\begin{array}{r}100.0 \\
99.7 \\
99.4 \\
99.3 \\
99.2 \\
99.2 \\
\end{array}$ & $\begin{array}{l}2,277.8 \\
2,224.3 \\
2,171.1 \\
2,153.4 \\
2,135.8 \\
2,135.8 \\
\end{array}$ & $\begin{array}{l}75,400 \\
60,030 \\
54,200 \\
55,500 \\
52,320 \\
57,110\end{array}$ & \multicolumn{2}{|c|}{$\begin{array}{l}75,300 \\
74,480 \\
63,470 \\
57,370 \\
57,060 \\
57,160 \\
\end{array}$} & $\begin{array}{l}99.4 \\
99.4 \\
99.4 \\
99.5 \\
99.7 \\
99.9 \\
\end{array}$ & $\begin{array}{l}2,171.1 \\
2,171 \cdot 1 \\
2,171 \cdot 1 \\
2,188.8 \\
2,224.3 \\
2,259.9 \\
\end{array}$ & $\begin{array}{l}21,870 \\
16,750 \\
11,640 \\
13,590 \\
14,960 \\
14,440 \\
\end{array}$ & $\begin{array}{r}21,870 \\
11,640 \\
11,640 \\
5,700 \\
4,500 \\
4,600 \\
\end{array}$ \\
\hline \multirow[b]{2}{*}{ Hour } & \multicolumn{4}{|c|}{ Aug. 16} & & \multicolumn{4}{|c|}{ Aug. $16-$ Con. } \\
\hline & $\underset{c}{\begin{array}{c}\text { Gage } \\
\text { height } \\
\text { (feet) }\end{array}}$ & $\begin{array}{c}\text { Contents } \\
\text { (million } \\
\text { cubic feet) }\end{array}$ & $\begin{array}{c}\text { Inflow } \\
\text { (second- } \\
\text { feet) }\end{array}$ & $\begin{array}{l}\text { Outflow } \\
\text { (second- } \\
\text { feet) }\end{array}$ & Hour & $\begin{array}{c}\begin{array}{c}\text { Gage } \\
\text { height } \\
\text { (feet) }\end{array} \\
\text { (f) }\end{array}$ & $\begin{array}{c}\text { Contents } \\
\text { (million } \\
\text { cubic feet) }\end{array}$ & $\begin{array}{c}\text { Inflow } \\
\text { (second- } \\
\text { feet) }\end{array}$ & $\begin{array}{l}\text { Outflow } \\
\text { (second- } \\
\text { feet) }\end{array}$ \\
\hline $\begin{array}{l}1 \\
2 \\
3 \\
4 \\
5 \\
5 \\
6\end{array}$ & $\begin{array}{r}100.00 \\
100.00 \\
100.00 \\
99.93 \\
99.86 \\
99.80\end{array}$ & $\begin{array}{l}2,277.8 \\
2,277.8 \\
2,277.8 \\
2,265.3 \\
2,252.8 \\
2,242.1\end{array}$ & $\begin{array}{l}12,800 \\
10,900 \\
13,770 \\
13,580 \\
13,830 \\
14,050\end{array}$ & $\begin{array}{l}11,050 \\
10,750 \\
16,800 \\
17,300 \\
17,300 \\
16,750\end{array}$ & $\begin{array}{l}1 \\
\mathbf{2} \\
\mathbf{3} \\
4 \\
\mathbf{5} \\
\mathbf{6}\end{array}$ & $\begin{array}{l}99.20 \\
99.10 \\
99.09 \\
99.08 \\
99.06 \\
99.04\end{array}$ & $\begin{array}{l}2,135.8 \\
2,118.2 \\
2,116.5 \\
2,114.7 \\
2,111.2 \\
2,107.7\end{array}$ & $\begin{array}{r}12,610 \\
9,680 \\
10,380 \\
9,950 \\
9,830 \\
9,750\end{array}$ & $\begin{array}{l}17,500 \\
11,650 \\
10,050 \\
10,850 \\
10,750 \\
10,700\end{array}$ \\
\hline $\begin{array}{r}7 \\
8 \\
9 \\
10 \\
11 \\
\mathrm{~N}\end{array}$ & $\begin{array}{l}99.74 \\
99.66 \\
99.58 \\
99.50 \\
99.40 \\
99.30\end{array}$ & $\begin{array}{l}2,231.4 \\
2,217.2 \\
2,203.0 \\
2,188.8 \\
2,171 \cdot 1 \\
2,153.4\end{array}$ & $\begin{array}{l}13,700 \\
12,560 \\
13,060 \\
13,640 \\
12,680 \\
12,650\end{array}$ & $\begin{array}{l}16,600 \\
16,400 \\
17,600 \\
17,550 \\
17,650 \\
17,500\end{array}$ & $\begin{array}{r}7 \\
8 \\
9 \\
10 \\
11 \\
12\end{array}$ & $\begin{array}{l}99.03 \\
99.02 \\
99.01 \\
99.00 \\
99.00 \\
99.00\end{array}$ & $\begin{array}{l}2,106.0 \\
2,104.2 \\
2,102.5 \\
2,100.7 \\
2,100.7 \\
2,100.7\end{array}$ & $\begin{array}{r}9,980 \\
9,700 \\
9,730 \\
9,600 \\
10,050 \\
10,100\end{array}$ & $\begin{array}{l}10,200 \\
10,200 \\
10,200 \\
10,000 \\
10,100 \\
10,100\end{array}$ \\
\hline
\end{tabular}

1 Gage heights from graph based on hourly observations.

SUPPLEM ENTAL RECORD.- Aug. 11, 12 p.m., gage height, 92.5 feet; contents, 1,039.6 million cubic feet. 


\section{CA'TAWHA RIVER A'T LOOKOUT SHOALS RESERVOIR,} NEAR CATAWHA, N. C.

Loca'tion.-Lat. $35^{\circ} 46^{\prime}$, long. $81^{\circ} 06^{\prime}$, at powerhouse forebay at Lookout Shoals Dam, 4 miles upstream from bridge on U. S. Highways 64 and 70 , and $4 \frac{1}{4}$ miles north of Catawba, Catawba County. Datum of gage is 738.0 feet above mean sea level (levels by Duke Power Co.).

Drainage AREa.-1,449 square miles.

GAGE-HEIGHT RECORD.- Staff gage read to tenths hourly. Adjusted gage heights Aug. 12-16 taken from graph based on hourly readings.

DISCHARGE RECORD.-Record of outflow based on formula for spillway and manufacturer's ratings for turbines. Record of inflow based on outflow and change in contents.

Maxima.-1940: Mean inflow, 191,230 second-feet for hour ending 6 a.m. Aug. 14; outflow, 177,400 second-feet 6 a.m. Aug. 14 ; reservoir gage height, 114.4 feet 6 to 8 a.m. Aug. 14 (total contents, 2,183,000,000 cubic feet).

1915-40: Discharge 180,000 second-feet July 16, 1916, just prior to failure of earth dike.

Remarks.-Reservoir, first put in use Dee. 2, 1915, has a total storage capacity of $1,355,000,000$ cubic feet below gage height of 100.0 feet (crest of spillway) and a storage capacity of $474,000,000$ cubic feet under normal operation between gage heights 90.0 and 100.0 feet. River affected by storage in Bridgewater, Rhodhiss, and Oxford Reservoirs upstream which have a combined storage capacity under normal operation of 14,501,000,000 cubic feet. Records furnished by Duke Power Co.

Lookout Shoals Reservoir, gage height and contents at midnight, 1940

\begin{tabular}{|c|c|c|c|c|c|c|c|c|c|}
\hline \multirow{2}{*}{ Day } & \multicolumn{2}{|c|}{ August } & \multicolumn{2}{|c|}{ September } & \multirow[b]{2}{*}{ Day } & \multicolumn{2}{|c|}{ August } & \multicolumn{2}{|c|}{ September } \\
\hline & $\begin{array}{c}\text { Gage } \\
\text { height } \\
\text { (feet) }\end{array}$ & $\begin{array}{l}\text { Contents } \\
\text { (million } \\
\text { cubic feet) }\end{array}$ & $\begin{array}{c}\text { Gage } \\
\text { height } \\
\text { (feet) }\end{array}$ & $\begin{array}{l}\text { Contents } \\
\text { (million } \\
\text { cubic feet) }\end{array}$ & & $\begin{array}{l}\text { Gage } \\
\text { height } \\
\text { (feet) }\end{array}$ & $\begin{array}{c}\text { Contents } \\
\text { (million } \\
\text { cubic feet) }\end{array}$ & $\begin{array}{l}\text { Gage } \\
\text { height } \\
\text { (feet) }\end{array}$ & $\begin{array}{l}\text { Contents } \\
\text { (million } \\
\text { cubic } \\
\text { feet) }\end{array}$ \\
\hline $\begin{array}{l}1 \\
2 \\
3 \\
4 \\
5\end{array}$ & $\begin{array}{l}97.2 \\
97.2 \\
97.1 \\
98.1 \\
98.1\end{array}$ & $\begin{array}{l}326 \\
326 \\
321 \\
373 \\
373\end{array}$ & $\begin{array}{l}101.9 \\
101.2 \\
101.0 \\
100.2 \\
100.2\end{array}$ & $\begin{array}{l}577 \\
539 \\
528 \\
485 \\
485\end{array}$ & $\begin{array}{l}16 \\
17 \\
18 \\
19 \\
20\end{array}$ & $\begin{array}{l}102.3 \\
101.0 \\
102.1 \\
100.6 \\
100.8\end{array}$ & $\begin{array}{l}598 \\
528 \\
588 \\
506 \\
517\end{array}$ & $\begin{array}{l}97.5 \\
97.5 \\
97.9 \\
95.9 \\
97.6\end{array}$ & $\begin{array}{l}342 \\
342 \\
363 \\
261 \\
347\end{array}$ \\
\hline $\begin{array}{r}6 \\
7 \\
8 \\
9 \\
10\end{array}$ & $\begin{array}{l}98.1 \\
98.2 \\
98.0 \\
97.4 \\
97.1\end{array}$ & $\begin{array}{l}373 \\
379 \\
368 \\
337 \\
321\end{array}$ & $\begin{array}{l}99.6 \\
99.1 \\
97.9 \\
98.7 \\
99.0\end{array}$ & $\begin{array}{l}453 \\
426 \\
363 \\
405 \\
421\end{array}$ & $\begin{array}{l}21 \\
22 \\
23 \\
24 \\
25\end{array}$ & $\begin{array}{l}99.9 \\
99.8 \\
99.4 \\
97.6 \\
97.4\end{array}$ & $\begin{array}{l}469 \\
463 \\
442 \\
347 \\
337\end{array}$ & $\begin{array}{l}98.2 \\
98.0 \\
99.0 \\
98.3 \\
97.1\end{array}$ & $\begin{array}{l}379 \\
368 \\
421 \\
384 \\
321\end{array}$ \\
\hline $\begin{array}{l}11 \\
12 \\
13 \\
14 \\
15\end{array}$ & $\begin{array}{r}97.7 \\
97.9 \\
98.9 \\
107.9 \\
102.6\end{array}$ & $\begin{array}{l}352 \\
363 \\
416 \\
916 \\
615\end{array}$ & $\begin{array}{l}99.3 \\
99.5 \\
99.0 \\
97.2 \\
97.4\end{array}$ & $\begin{array}{l}437 \\
448 \\
421 \\
326 \\
337\end{array}$ & $\begin{array}{l}26 \\
27 \\
28 \\
29 \\
30 \\
31\end{array}$ & $\begin{array}{r}98.5 \\
99.8 \\
100.3 \\
100.0 \\
103.0 \\
103.5 \\
\end{array}$ & $\begin{array}{l}394 \\
463 \\
490 \\
474 \\
637 \\
665 \\
\end{array}$ & $\begin{array}{r}96.8 \\
97.4 \\
97.5 \\
97.8 \\
97.5 \\
\\
\end{array}$ & $\begin{array}{r}306 \\
337 \\
342 \\
358 \\
342 \\
\end{array}$ \\
\hline & & & & & & & & August & $\begin{array}{c}\text { Sep- } \\
\text { tember }\end{array}$ \\
\hline Chang & onten & equivale & n sece & 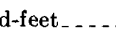 & & & $\ldots$ & +128 & -125 \\
\hline
\end{tabular}

SuPPLEMFNTAL RECORD.-July 31, midnight, gage height, 97.1 feet; contents, 321 million cubic feet. 


\section{FLOODS OF AUGUST 1940 IN THE SOUTHEASTERN STATES}

Lookout Shoals Reservoir, gage height, contents, mean inflow for preceling hour, and outflsw, at indicated time, 1940

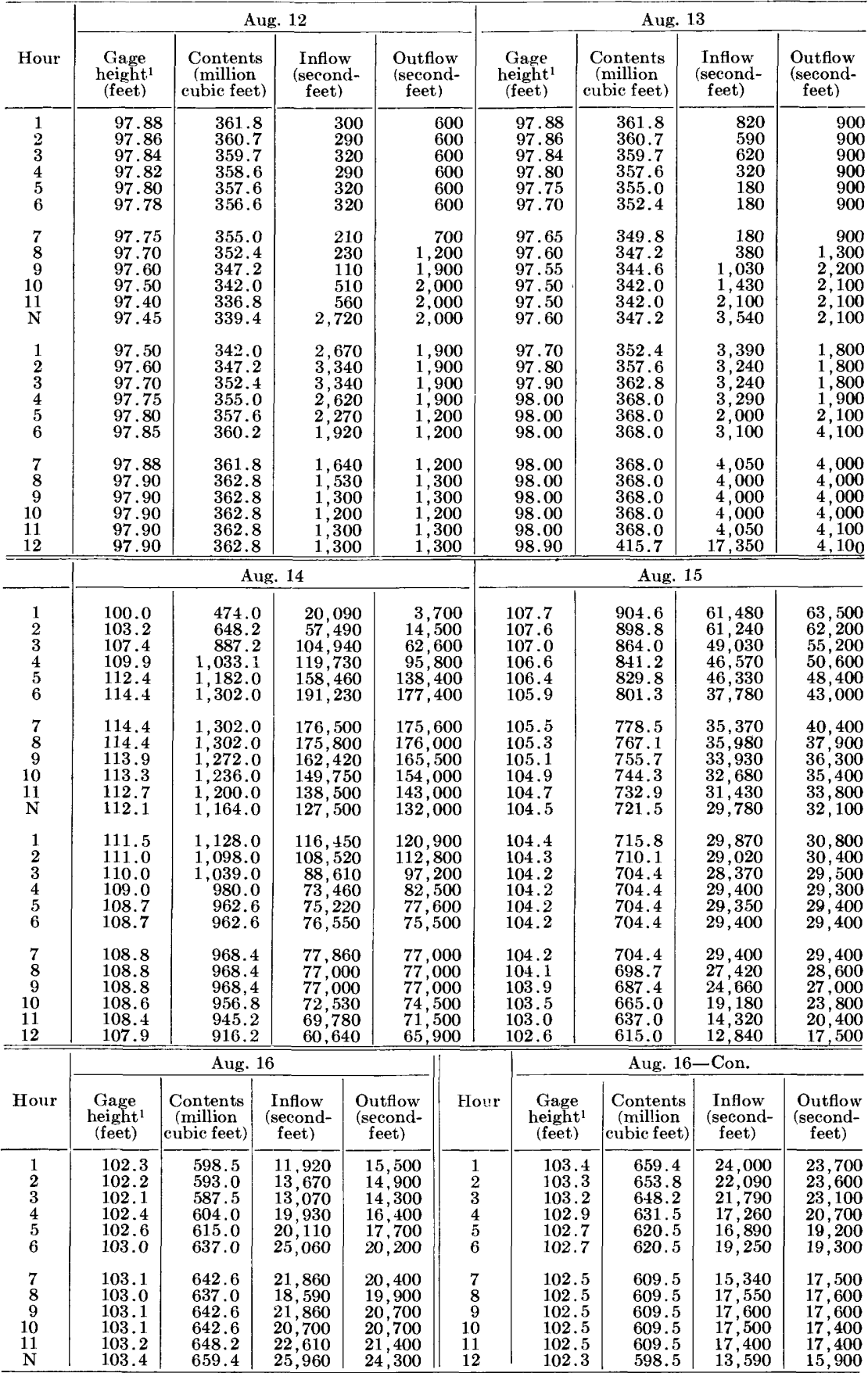

1 Gage heights from graph based on hourly observations.

SUPPLEMENTAL RECORD.--Aug. 11, 12 p.m., gage height, 97.88 feet; centents, 361.8 million cubic feet. 
CATAWBA RIVER AT CATAWBA, N. C.

LoCATION.-Lat. $35^{\circ} 42^{\prime} 50^{\prime \prime}$, long. $81^{\circ} 04^{\prime} 10^{\prime \prime}$, just downstream from bridge on U. S. Highway 70, a quarter of a mile upstream from Lyle Creek, half a mile upstream from Southern Railway bridge, and 1 mile northeast of Catawba, Catawba County. Datum of gage is 746.49 feet above mean sea level, datum of 1929, supplementary adjustment of 1936 .

Drainage AREA.-1,535 square miles, 1942 revision (including that of Lyle Creek). GAGE-HEIGHT RECORD.-Water-stage recorder graph except for periods 6 a.m. to 3 p.m. Aug. 14, 4-8 a.m., 1-3 p.m. and 5-7 p.m. Aug. 15, 6 a.m. to 12 p.m. Aug. 16, 1-7 a.m. Aug. 23, 7-8 a.m. Aug. 24, 1-7 a.m. Sept. 1, 11 a.m. Sept. 2 to 7 a.m. Sept. 3, and 1-7 a.m. Sept. 15 when recorder clock was stopped after being; submerged by the flood. Gage-height graph for these periods partly estimated on basis of United States Weather Bureau gage reading at 8 a.m. and floodmark plotted to time of crest as reported by gage observer on Aug. 14, recorded range in gage heights and engineers' notes on Aug. 15, six gage readings on Aug. 16, and recorded range in gage heights on other days. No gage-height record of value for Aug. 17-22 and Sept. 4-14.

Discharge RECORD.- Stage-discharge relation defined for present site by currentmeter measurements up to 23,000 second-feet and extended to crest gage height on basis of computation of flow at gage heights 25.0 and 36.8 feet by Duke Power Co. at their Lookout Shoals plant about 4 miles upstream. Stage-discharge relation defined for site at Southern Railway bridge, half a mile downstream, by current-meter measurements up to 10,000 second-feet and extended above. Gage heights used to half-tenths between 4.0 and 5.7 feet; hundredths below and tenths above these limits. Discharge record for periods of no gage-height record, Aug. 17-22, Sept. 4-14, furnished by Duke Power Co. as computed for their Lookout Shoals power plant.

Maxima.-1940: Discharge, 177,000 second-feet 11:30 a.m. Aug. 14 (gage height, 36.8 feet, from floodmarks).

1896-1902, 1934-39: Discharge observed, 81,500 second-feet May 22, 1901 (gage height, 29.0 feet, former site and datum).

Stage known, 44.1 feet July 16, 1916, affected by failure of earth dike at Lookout Shoals Dam, from levels of State Bridge Department (discharge not determined).

REMARKS.-Flow affected by storage in Bridgewater, Rhodhiss, Oxford, and Lookout Shoals Reservoirs (combined storage capacity under normal operation, 14,975,000,000 cubic feet).

Mean discharge, in second-feet, 1940

\begin{tabular}{r|r|r|r|r|r|r|r|r|r|r|r}
\hline Day & Aug. & Sept. & Day & Aug. & Sept. & Day & Aug. & Sept. & Day & Aug. & Sept. \\
\hline $\mathbf{1}$ & $\mathbf{1 , 6 6 0}$ & $\mathbf{9}, 430$ & 9 & 1,450 & 3,930 & 17 & 10,600 & 4,290 & 25 & 829 & 2,390 \\
2 & 1,200 & 7,580 & 10 & 494 & 4,070 & 18 & 9,410 & 4,290 & 26 & 2,580 & 2,120 \\
3 & 472 & 6,760 & 11 & 140 & 4,210 & 19 & 8,900 & 4,290 & 27 & 3,520 & 1,650 \\
4 & 136 & 5,360 & 12 & 1,450 & 4,280 & 20 & 5,260 & 3,360 & 28 & 3,740 & 650 \\
5 & 1,300 & 4,320 & 13 & 2,750 & 4,340 & 21 & 4,840 & 1,260 & 29 & 3,520 & 136 \\
6 & 1,670 & 4,090 & 14 & 101,000 & 2,490 & 22 & 3,760 & 412 & 30 & 5,740 & 1,890 \\
7 & 1,660 & 3,020 & 15 & 31,900 & 1,310 & 23 & 3,390 & 2,160 & 31 & 19,000 & $-\ldots$ \\
8 & 1,550 & 2,350 & 16 & 13,200 & 3,520 & 24 & 3,280 & 2,010 & & & \\
\hline
\end{tabular}


228 FLOODS OF AUGUST 1940 IN THE SOUTHEASTERN STATES

Gage height, in feet, and discharge, in second-feet, at indicated time, 1940

\begin{tabular}{|c|c|c|c|c|c|c|c|c|c|c|}
\hline \multirow{2}{*}{ Hour } & \multicolumn{2}{|c|}{ Aug. 12} & \multicolumn{2}{|c|}{ Aug. 13} & \multicolumn{2}{|c|}{ Aug. 14} & \multicolumn{2}{|c|}{ Aug. 15} & \multicolumn{2}{|c|}{ Aug. 16} \\
\hline & $\begin{array}{c}\text { Gage } \\
\text { height }\end{array}$ & $\begin{array}{l}\text { Dis- } \\
\text { charge }\end{array}$ & $\begin{array}{c}\text { Gage } \\
\text { height }\end{array}$ & $\begin{array}{c}\text { Dis- } \\
\text { charge }\end{array}$ & $\begin{array}{c}\text { Gage } \\
\text { height }\end{array}$ & $\begin{array}{c}\text { Dis- } \\
\text { charge }\end{array}$ & $\begin{array}{l}\text { Gage } \\
\text { height }\end{array}$ & $\begin{array}{l}\text { Dis- } \\
\text { charge }\end{array}$ & $\begin{array}{c}\text { Gage } \\
\text { height }\end{array}$ & $\begin{array}{c}\text { Dis- } \\
\text { charge }\end{array}$ \\
\hline $\begin{array}{l}1 \\
2 \\
3 \\
4 \\
5 \\
6\end{array}$ & $\begin{array}{l}2.29 \\
2.65 \\
3.05 \\
3.12 \\
3.12 \\
3.14\end{array}$ & $\begin{array}{l}142 \\
295 \\
565 \\
630 \\
630 \\
650\end{array}$ & $\begin{array}{l}3.86 \\
\mathbf{3 . 6 8} \\
3.61 \\
\mathbf{3 . 5 7} \\
\mathbf{3 . 5 8} \\
\mathbf{3 . 6 4}\end{array}$ & $\begin{array}{l}1,470 \\
1,250 \\
1,160 \\
1,110 \\
1,130 \\
1,200\end{array}$ & $\begin{array}{r}7.62 \\
9.20 \\
16.70 \\
23.70 \\
28.30 \\
31.4\end{array}$ & $\begin{array}{r}7,250 \\
9,940 \\
26,100 \\
55,800 \\
89,700 \\
120,000\end{array}$ & $\begin{array}{l}24.60 \\
23.90 \\
23.10 \\
22.3 \\
21.5 \\
20.8\end{array}$ & $\begin{array}{l}60,900 \\
56,800 \\
52,800 \\
48,800 \\
44,800 \\
41,600\end{array}$ & $\begin{array}{r}10.30 \\
9.40 \\
9.10 \\
9.30 \\
9.90 \\
10.6\end{array}$ & $\begin{array}{r}11,800 \\
10,300 \\
9,770 \\
10,100 \\
11,100 \\
12,400\end{array}$ \\
\hline $\begin{array}{r}7 \\
8 \\
9 \\
10 \\
11 \\
\text { N }\end{array}$ & $\begin{array}{l}3.16 \\
3.21 \\
3.40 \\
4.05 \\
4.46 \\
4.52\end{array}$ & $\begin{array}{r}\mathbf{6 7 0} \\
\mathbf{7 2 0} \\
\mathbf{9 2 0} \\
\mathbf{1 , 7 2 0} \\
\mathbf{2}, \mathbf{2 6 0} \\
\mathbf{2}, \mathbf{3 3 0}\end{array}$ & $\begin{array}{l}3.66 \\
3.72 \\
4.00 \\
4.55 \\
4.69 \\
4.72\end{array}$ & $\begin{array}{l}1,220 \\
1,290 \\
1,650 \\
2,400 \\
2,620 \\
2,620\end{array}$ & $\begin{array}{l}33.2 \\
35.0 \\
35.9 \\
36.50 \\
36.75 \\
36.75\end{array}$ & $\begin{array}{l}138,000 \\
158,000 \\
168,000 \\
174,000 \\
177,000 \\
177,000\end{array}$ & $\begin{array}{l}20.0 \\
19.50 \\
18.70 \\
18.00 \\
17.23 \\
16.50\end{array}$ & $\begin{array}{l}38,000 \\
35,800 \\
32,600 \\
30,100 \\
27,600 \\
25,500\end{array}$ & $\begin{array}{l}11.1 \\
11.5 \\
11.8 \\
12.0 \\
12.25 \\
12.5\end{array}$ & $\begin{array}{l}13,300 \\
14,000 \\
14,600 \\
15,000 \\
15,400 \\
16,000\end{array}$ \\
\hline $\begin{array}{l}1 \\
2 \\
3 \\
4 \\
4 \\
5 \\
6\end{array}$ & $\begin{array}{l}4.53 \\
4.22 \\
4.40 \\
4.46 \\
4.50 \\
4.52\end{array}$ & $\begin{array}{l}2,400 \\
1,910 \\
2,190 \\
2,260 \\
2,330 \\
2,330\end{array}$ & $\begin{array}{l}4.58 \\
4.72 \\
4.84 \\
4.88 \\
4.86 \\
5.00\end{array}$ & $\begin{array}{l}2,470 \\
2,620 \\
2,840 \\
2,920 \\
2,840 \\
3,070\end{array}$ & $\begin{array}{l}36.4 \\
33.8 \\
31.4 \\
29.70 \\
28.70 \\
27.70\end{array}$ & $\begin{array}{r}173,000 \\
144,000 \\
120,000 \\
103,000 \\
93,300 \\
84,300\end{array}$ & $\begin{array}{l}15.80 \\
15.50 \\
15.30 \\
15.05 \\
14.95 \\
14.9\end{array}$ & $\begin{array}{l}23,700 \\
23,000 \\
22,500 \\
21,800 \\
21,800 \\
21,600\end{array}$ & $\begin{array}{l}12.6 \\
12.7 \\
12.65 \\
12.5 \\
12.2 \\
11.8\end{array}$ & $\begin{array}{l}16,200 \\
16,400 \\
16,200 \\
16,000 \\
15,400 \\
14,600\end{array}$ \\
\hline $\begin{array}{r}7 \\
8 \\
9 \\
10 \\
11 \\
12\end{array}$ & $\begin{array}{l}4.26 \\
4.15 \\
4.10 \\
4.07 \\
4.03 \\
3.96\end{array}$ & $\begin{array}{l}1,980 \\
1,840 \\
1,780 \\
1,720 \\
1,720 \\
1,600\end{array}$ & $\begin{array}{l}5.90 \\
6.10 \\
6.18 \\
6.34 \\
6.98 \\
7.72\end{array}$ & $\begin{array}{l}4,450 \\
4,780 \\
4,940 \\
5,100 \\
6,260 \\
7,420\end{array}$ & $\begin{array}{l}27.28 \\
26.98 \\
26.68 \\
26.12 \\
25.56 \\
25.00\end{array}$ & $\begin{array}{l}81,000 \\
78,600 \\
76,200 \\
71,400 \\
67,800 \\
63,600\end{array}$ & $\begin{array}{l}14.9 \\
14.72 \\
14.20 \\
13.45 \\
12.45 \\
11.45\end{array}$ & $\begin{array}{l}21,600 \\
21,100 \\
19,900 \\
18,000 \\
15,800 \\
13,900\end{array}$ & $\begin{array}{r}11.1 \\
10.5 \\
10.0 \\
9.5 \\
9.2 \\
\mathbf{8 . 9}\end{array}$ & $\begin{array}{r}13,300 \\
12,200 \\
11,300 \\
10,400 \\
9,940 \\
9,430\end{array}$ \\
\hline
\end{tabular}

SUPPLEMENTAL RECORD.-Aug. 14, 11:30 a.m., gage height, 36.8 feet (from floodmark), discharge, 177,000 second-feet. 


\section{CATAWHA RIVER AT MOUNTAIN ISLAND RESERVOIR,}

NEAR MOUN'T HOLLY, N. C.

Location.-Lat. $35^{\circ} 20^{\prime}$, long. $80^{\circ} 59^{\prime}$, at powerhouse forebay at Mountain Island Dam, 11/2 miles downstream from State Highway 16, and 3 miles northeast of Mount Holly, Gaston County. Datum of gage is 548.0 feet above mean sea level (levels by Duke Power Co.).

Drainage AREa.- 1,860 square miles.

GAGE-HEIGHT RECORD.-Dtaff gage read to tenths hourly. Adjusted gage heights Ang. 12-16 taken from graph based on hourly readings.

Discharge RECORD.- - Record of outflow based on formula for spillway and manufacturer's rating for turbines. Record of inflow based on outflow and change in contents.

Maxima.-1940: Mean inflow, 124,230 second-feet for hour ending 1 a.m. Aug. 15; outflow, 117,200 second-feet 6 a.m. Aug. 15; reservoir gage height, 109.6 feet 5 to 8 a.m. Aug. 15 (contents, 3,444,000,000 cubic feet).

REMARKs.--Reservoir, first put in use Dec. 16, 1923, has a total storage capacity of $1,826,000,000$ cubic feet between gage heights of about 76.0 and 100.0 feet (crest of spillway) and a usable storage capacity of 1,132,000,00 cubic feet between gage heights 90.0 and 100.0 feet. River affected by storage in Bridgewater, Rhodhiss, Oxford, and Lookout Shoals Reservoirs upstream having a combined capacity under normal operation of $14,975,00,000$ cubic feet. Records furnished by Duke Power Co.

Mountain Island Reservoir, gage height and contents at midnight, 1940

\begin{tabular}{|c|c|c|c|c|c|c|c|c|c|}
\hline \multirow[b]{2}{*}{ Day } & \multicolumn{2}{|c|}{ August } & \multicolumn{2}{|c|}{ September } & \multirow[b]{2}{*}{ Day } & \multicolumn{2}{|c|}{ August } & \multicolumn{2}{|c|}{ September } \\
\hline & $\begin{array}{c}\text { Gage } \\
\text { height } \\
\text { (feet) }\end{array}$ & $\begin{array}{c}\text { Contents } \\
\text { (million } \\
\text { cubic feet) }\end{array}$ & $\begin{array}{c}\text { Gage } \\
\text { height } \\
\text { (feet) }\end{array}$ & $\begin{array}{c}\text { Contents } \\
\text { (million } \\
\text { cubic feet) }\end{array}$ & & $\begin{array}{c}\text { Gage } \\
\text { height } \\
\text { (feet) }\end{array}$ & $\begin{array}{c}\text { Contents } \\
\text { (million } \\
\text { cubic feet) }\end{array}$ & $\begin{array}{c}\text { Gage } \\
\text { height } \\
\text { (feet) }\end{array}$ & $\begin{array}{l}\text { Contents } \\
\text { (million } \\
\text { cubi } \\
\text { feet) }\end{array}$ \\
\hline $\begin{array}{l}1 \\
2 \\
3 \\
4 \\
5\end{array}$ & $\begin{array}{l}96.1 \\
96.3 \\
97.0 \\
97.0 \\
95.3\end{array}$ & $\begin{array}{l}1,321 \\
1,345 \\
1,430 \\
1,430 \\
1,228\end{array}$ & $\begin{array}{r}101.8 \\
100.1 \\
99.6 \\
98.8 \\
97.7\end{array}$ & $\begin{array}{l}2,089 \\
1,839 \\
1,771 \\
1,663 \\
1,519\end{array}$ & $\begin{array}{l}16 \\
17 \\
18 \\
19 \\
20\end{array}$ & $\begin{array}{r}102.0 \\
101.0 \\
100.6 \\
99.8 \\
99.2\end{array}$ & $\begin{array}{l}2,120 \\
1,969 \\
1,911 \\
1,799 \\
1,716\end{array}$ & $\begin{array}{l}96.1 \\
95.1 \\
94.7 \\
95.2 \\
95.7\end{array}$ & $\begin{array}{l}1,321 \\
1,204 \\
1,160 \\
1,216 \\
1,274\end{array}$ \\
\hline $\begin{array}{r}6 \\
7 \\
8 \\
9 \\
10\end{array}$ & $\begin{array}{l}94.5 \\
94.2 \\
93.9 \\
94.1 \\
95.2\end{array}$ & $\begin{array}{l}1,138 \\
1,105 \\
1,072 \\
1,094 \\
1,216\end{array}$ & $\begin{array}{l}97.0 \\
99.1 \\
99.5 \\
97.7 \\
97.0\end{array}$ & $\begin{array}{l}1,430 \\
1,703 \\
1,758 \\
1,519 \\
1,430\end{array}$ & $\begin{array}{l}21 \\
22 \\
23 \\
24 \\
25\end{array}$ & $\begin{array}{l}98.5 \\
96.6 \\
95.4 \\
97.5 \\
98.5\end{array}$ & $\begin{array}{l}1,623 \\
1,381 \\
1,239 \\
1,494 \\
1,623\end{array}$ & $\begin{array}{l}97.0 \\
97.2 \\
95.9 \\
96.0 \\
95.5\end{array}$ & $\begin{array}{l}1,430 \\
1,455 \\
1,297 \\
1,309 \\
1,250\end{array}$ \\
\hline $\begin{array}{l}11 \\
12 \\
13 \\
14 \\
15\end{array}$ & $\begin{array}{r}95.7 \\
94.8 \\
95.2 \\
109.0 \\
105.5\end{array}$ & $\begin{array}{l}1,274 \\
1,171 \\
1,216 \\
3,330 \\
2,690\end{array}$ & $\begin{array}{l}96.1 \\
94.8 \\
94.2 \\
96.9 \\
98.0\end{array}$ & $\begin{array}{l}1,321 \\
1,171 \\
1,105 \\
1,418 \\
1,557\end{array}$ & $\begin{array}{l}26 \\
27 \\
28 \\
29 \\
30 \\
31 \\
\end{array}$ & $\begin{array}{r}95.2 \\
92.8 \\
92.9 \\
93.8 \\
92.1 \\
101.9 \\
\end{array}$ & $\begin{array}{r}1,216 \\
958 \\
968 \\
1,062 \\
888 \\
2,104 \\
\end{array}$ & $\begin{array}{l}95.7 \\
95.1 \\
96.0 \\
96.1 \\
94.2\end{array}$ & $\begin{array}{l}1,274 \\
1,204 \\
1,307 \\
1,321 \\
1,105\end{array}$ \\
\hline \multirow{2}{*}{\multicolumn{8}{|c|}{ Change in contents, equivalent, in second-feet. }} & August & $\begin{array}{c}\text { Sep- } \\
\text { tember }\end{array}$ \\
\hline & & & & & & & & +314 & -385 \\
\hline
\end{tabular}

SUPPLEMENTAL RECORD.- July 31, midnight, gage height, 95.6 feet; contents, 1,262 million cubic feet. 
Mountain Island Reservoir, gage height, contents, mean inflow for preceding hour, and outflow, at indicated time, 1940

\begin{tabular}{|c|c|c|c|c|c|c|c|c|c|}
\hline \multirow[b]{2}{*}{ Hour } & \multicolumn{5}{|c|}{ Aug. 12} & \multicolumn{4}{|c|}{ Aug. 13} \\
\hline & $\begin{array}{c}\text { Gage } \\
\text { height' } \\
\text { (feet) }\end{array}$ & $\begin{array}{l}\text { Contents } \\
\text { (million } \\
\text { cubic feet) }\end{array}$ & $\begin{array}{l}\text { Inflow } \\
\text { (second } \\
\text { feet) }\end{array}$ & $\begin{array}{l}\text { Out } \\
\text { (sec } \\
\text { fee }\end{array}$ & & $\begin{array}{l}\text { Gage } \\
\text { height }^{1} \\
\text { (feet) }\end{array}$ & $\begin{array}{c}\text { Contents } \\
\text { (million } \\
\text { cubic feet) }\end{array}$ & $\begin{array}{l}\text { Inflow } \\
\text { (second- } \\
\text { feet) }\end{array}$ & $\begin{array}{l}\text { Outflow } \\
\text { (second- } \\
\text { feet) }\end{array}$ \\
\hline $\begin{array}{l}1 \\
2 \\
3 \\
4 \\
5 \\
6\end{array}$ & $\begin{array}{l}95.68 \\
95.72 \\
95.76 \\
95.80 \\
95.86 \\
95.90\end{array}$ & $\begin{array}{l}1,271.2 \\
1,275.8 \\
1,280.4 \\
1,285.0 \\
1,291.9 \\
1,296.5\end{array}$ & $\begin{array}{l}1,28 \\
1.28 \\
1,28 \\
1,28 \\
1,92 \\
2,23\end{array}$ & & $\begin{array}{l}0 \\
0 \\
0 \\
0 \\
0 \\
0\end{array}$ & $\begin{array}{l}94.85 \\
94.90 \\
94.95 \\
95.00 \\
95.10 \\
95.15\end{array}$ & $\begin{array}{l}1,176.5 \\
1,182.0 \\
1,187.5 \\
1,193.0 \\
1,204.5 \\
1,210.3\end{array}$ & $\begin{array}{l}1,530 \\
1,530 \\
1,530 \\
1,530 \\
3,190 \\
1,610\end{array}$ & $\begin{array}{l}0 \\
0 \\
0 \\
0 \\
0 \\
0\end{array}$ \\
\hline $\begin{array}{r}7 \\
8 \\
9 \\
10 \\
11 \\
\mathrm{~N}\end{array}$ & $\begin{array}{l}95.87 \\
95.80 \\
95.69 \\
95.57 \\
95.45 \\
95.34\end{array}$ & $\begin{array}{l}1,293.1 \\
1,285.0 \\
1,272.4 \\
1,258.6 \\
1,244.8 \\
1,232.1\end{array}$ & $\begin{array}{r}1,46 \\
90 \\
30 \\
37 \\
42 \\
62\end{array}$ & $\begin{array}{l}0 \\
0 \\
0 \\
0 \\
0\end{array}$ & & $\begin{array}{l}95.20 \\
95.25 \\
95.30 \\
95.30 \\
95.30 \\
95.30\end{array}$ & $\begin{array}{l}1,216.0 \\
1,221.8 \\
1,227.5 \\
1,227.5 \\
1,227.5 \\
1,227.5\end{array}$ & $\begin{array}{l}2,880 \\
4,710 \\
5,380 \\
3,950 \\
3,650 \\
3,050\end{array}$ & $\begin{array}{l}2,600 \\
3,600 \\
4,000 \\
3,900 \\
3,400 \\
2,700\end{array}$ \\
\hline $\begin{array}{l}1 \\
2 \\
3 \\
4 \\
5 \\
6\end{array}$ & $\begin{array}{l}95.23 \\
95.13 \\
95.03 \\
94.93 \\
94.85 \\
94.80\end{array}$ & $\begin{array}{l}1,219.5 \\
1,208.0 \\
1,196.5 \\
1,185.3 \\
1,176.5 \\
1,171.0\end{array}$ & $\begin{array}{l}25 \\
31 \\
26 \\
24 \\
41 \\
87\end{array}$ & & & & $\begin{array}{l}1,227.5 \\
1,231.0 \\
1,234.4 \\
1,237.9 \\
1,239.0 \\
1,239.0\end{array}$ & $\begin{array}{l}2,450 \\
2,870 \\
2,540 \\
2,720 \\
2,260 \\
2,750\end{array}$ & $\begin{array}{l}2,200 \\
1,600 \\
1,600 \\
1,900 \\
2,000 \\
3,500\end{array}$ \\
\hline $\begin{array}{r}7 \\
8 \\
9 \\
10 \\
11 \\
12 \\
\end{array}$ & $\begin{array}{l}94.80 \\
94.76 \\
94.71 \\
94.70 \\
94.74 \\
94.80 \\
\end{array}$ & $\begin{array}{l}1,171.0 \\
1,166.6 \\
1,161.1 \\
1,160.0 \\
1,164.4 \\
1,170.0 \\
\end{array}$ & $\begin{array}{r}1,95 \\
73 \\
1,42 \\
1,89 \\
1,67 \\
1,83 \\
\end{array}$ & & $\begin{array}{r}00 \\
00 \\
00 \\
00 \\
0 \\
0 \\
\end{array}$ & & $\begin{array}{l}1,239.0 \\
1,239.0 \\
1,236.7 \\
1,234.4 \\
1,227.5 \\
1,216.0 \\
\end{array}$ & $\begin{array}{l}3,500 \\
3,750 \\
3,260 \\
3,010 \\
2,930 \\
3,160 \\
\end{array}$ & $\begin{array}{l}3,500 \\
4,000 \\
3,800 \\
3,500 \\
6,200 \\
6,500 \\
\end{array}$ \\
\hline 12 & \multicolumn{5}{|c|}{ Aug. 14} & \multicolumn{4}{|c|}{ Aug. 15} \\
\hline $\begin{array}{l}1 \\
2 \\
3 \\
4 \\
5 \\
6\end{array}$ & $\begin{array}{l}95.2 \\
95.2 \\
95.2 \\
95.2 \\
95.3 \\
95.4\end{array}$ & $\begin{array}{l}1,216.0 \\
1,216.0 \\
1,216.0 \\
1,216.0 \\
1,227.5 \\
1,239.0\end{array}$ & $\begin{array}{l}6,450 \\
6,600 \\
6,800 \\
6,800 \\
9,990 \\
9,890\end{array}$ & \multicolumn{2}{|c|}{$\begin{array}{l}6,400 \\
6,800 \\
6,800 \\
6,800 \\
6,800 \\
6,600\end{array}$} & $\begin{array}{l}109.3 \\
109.4 \\
109.5 \\
109.5 \\
109.6 \\
109.6\end{array}$ & $\begin{array}{l}3,387.0 \\
3,406.0 \\
3,425.0 \\
3,425.0 \\
3,444.0 \\
3,444.0\end{array}$ & $\begin{array}{l}124,230 \\
117,730 \\
119,730 \\
115,400 \\
121,530 \\
117,150\end{array}$ & $\begin{array}{l}111,400 \\
113,500 \\
115,400 \\
115,400 \\
117,100 \\
117,200\end{array}$ \\
\hline $\begin{array}{r}7 \\
8 \\
9 \\
10 \\
11 \\
\mathrm{~N}\end{array}$ & $\begin{array}{l}95.6 \\
95.8 \\
96.3 \\
97.0 \\
98.1 \\
99.1\end{array}$ & $\begin{array}{l}1,262.0 \\
1,285.0 \\
1,344.6 \\
1,430.0 \\
1,568.5 \\
1,703.5\end{array}$ & $\begin{array}{l}11,590 \\
11,090 \\
22,560 \\
30,670 \\
46,020 \\
45,200\end{array}$ & \multicolumn{2}{|c|}{$\begin{array}{l}3,800 \\
5,600 \\
6,400 \\
7,500 \\
7,600 \\
7,800\end{array}$} & & & $\begin{array}{r}116,950 \\
116,850 \\
105,740 \\
97,020 \\
85,340 \\
96,620\end{array}$ & $\begin{array}{l}116,700 \\
117,000 \\
115,600 \\
110,100 \\
102,800 \\
101,000\end{array}$ \\
\hline $\begin{array}{l}1 \\
2 \\
3 \\
4 \\
5 \\
6\end{array}$ & $\begin{array}{l}100.2 \\
101.5 \\
102.6 \\
103.5 \\
104.4 \\
105.2\end{array}$ & $\begin{array}{l}1,853.0 \\
2,042.5 \\
2,216.0 \\
2,360.0 \\
2,504.0 \\
2,636.0\end{array}$ & $\begin{array}{l}49,480 \\
63,490 \\
65,690 \\
65,350 \\
74,000 \\
78,870\end{array}$ & \multicolumn{2}{|c|}{$\begin{array}{r}8,100 \\
13,600 \\
21,400 \\
29,300 \\
38,700 \\
45,700\end{array}$} & & & $\begin{array}{l}81,870 \\
82,590 \\
74,470 \\
70,300 \\
71,350 \\
62,300\end{array}$ & $\begin{array}{l}94,400 \\
91,900 \\
87,600 \\
83,000 \\
79,700 \\
74,900\end{array}$ \\
\hline $\begin{array}{r}7 \\
8 \\
9 \\
10 \\
11 \\
12 \\
\end{array}$ & $\begin{array}{l}106.3 \\
107.0 \\
107.6 \\
108.1 \\
108.6 \\
109.0 \\
\end{array}$ & $\begin{array}{l}2,834.0 \\
2,960.0 \\
3,068.0 \\
3,159.0 \\
3,254.0 \\
3,330.0\end{array}$ & $\begin{array}{l}108,800 \\
102,800 \\
108,250 \\
112,030 \\
120,340 \\
122,410\end{array}$ & \multicolumn{2}{|c|}{$\begin{array}{r}61,900 \\
73,700 \\
82,800 \\
90,700 \\
97,200 \\
105,400\end{array}$} & & $\begin{array}{l}2,906.0 \\
2,852.0 \\
2,798.0 \\
2,726.0 \\
2,690.0 \\
2,690.0\end{array}$ & & $\begin{array}{l}70,200 \\
65,900 \\
61,700 \\
56,200 \\
52,500 \\
51,500 \\
\end{array}$ \\
\hline \multirow[b]{2}{*}{ Hour } & \multicolumn{4}{|c|}{ Aug. 16} & & \multicolumn{4}{|c|}{ Aug. $16-C$ on. } \\
\hline & $\begin{array}{c}\begin{array}{c}\text { Gage } \\
\text { height } \\
\text { (feet) }\end{array} \\
\text { (f) }\end{array}$ & $\begin{array}{c}\text { Contents } \\
\text { (million } \\
\text { cubic feet) }\end{array}$ & $\begin{array}{l}\text { Inflow } \\
\text { (second- } \\
\text { feet) }\end{array}$ & $\begin{array}{l}\text { Outflow } \\
\text { (second- } \\
\text { feet) }\end{array}$ & Hour & $\begin{array}{r}\text { Gage } \\
\text { height } \\
\text { (feet) }\end{array}$ & $\begin{array}{c}\text { Contents } \\
\text { (million } \\
\text { cubic feet) }\end{array}$ & $\begin{array}{c}\text { Inflow } \\
\text { (second- } \\
\text { feet) }\end{array}$ & $\begin{array}{l}\text { Outflow } \\
\text { (second- } \\
\text { feet) }\end{array}$ \\
\hline $\begin{array}{l}1 \\
2 \\
3 \\
4 \\
5 \\
6\end{array}$ & $\begin{array}{l}105.1 \\
104.8 \\
104.6 \\
104.3 \\
104.2 \\
104.0\end{array}$ & $\begin{array}{l}2,618.0 \\
2,568.0 \\
2,536.0 \\
2,488.0 \\
2,472.0 \\
2,440.0\end{array}$ & $\begin{array}{l}29,350 \\
31,460 \\
33,560 \\
26,120 \\
32,460 \\
25,710\end{array}$ & $\begin{array}{l}47,200 \\
43,500 \\
41,400 \\
37,500 \\
36,300 \\
32,900\end{array}$ & $\begin{array}{l}1 \\
2 \\
3 \\
4 \\
5 \\
6\end{array}$ & $\begin{array}{l}102.4 \\
102.2 \\
102.1 \\
102.0 \\
102.0 \\
102.0\end{array}$ & $\begin{array}{l}2,152.0 \\
2,136.0 \\
2,120.0 \\
2,120.0 \\
2,120.0\end{array}$ & $\begin{array}{l}12,010 \\
10,560 \\
14,960 \\
14,760 \\
17,550 \\
16,000\end{array}$ & $\begin{array}{l}19,300 \\
19,600 \\
19,200 \\
19,200 \\
15,900 \\
16,100\end{array}$ \\
\hline $\begin{array}{r}7 \\
8 \\
9 \\
10 \\
11 \\
\mathrm{~N}\end{array}$ & $\begin{array}{l}103.9 \\
103.6 \\
103.3 \\
103.0 \\
102.8 \\
102.6\end{array}$ & $\begin{array}{l}2,424.0 \\
2,376.0 \\
2,328.0 \\
2,280.0 \\
2,248.0 \\
2,216.0\end{array}$ & $\begin{array}{l}26,810 \\
16,220 \\
15,770 \\
14,120 \\
16,260 \\
14,410\end{array}$ & $\begin{array}{l}29,600 \\
29,500 \\
28,700 \\
26,200 \\
24,100 \\
22,500\end{array}$ & $\begin{array}{r}7 \\
8 \\
9 \\
10 \\
11 \\
12\end{array}$ & $\begin{array}{l}102.0 \\
102.0 \\
102.0 \\
102.0 \\
102.0 \\
102.0\end{array}$ & $\begin{array}{l}2,120.0 \\
2,120.0 \\
2,120.0 \\
2,120.0 \\
2,120.0 \\
2,120.0\end{array}$ & $\begin{array}{l}16,000 \\
16,500 \\
17,000 \\
16,300 \\
15,800 \\
16,100\end{array}$ & $\begin{array}{l}15,900 \\
17,100 \\
16,900 \\
15,700 \\
15,900 \\
16,300\end{array}$ \\
\hline
\end{tabular}

${ }^{1}$ Gage heights from graph based on hourly observations.

SUPPLEM ENTAL RECORD.-Aug. 11, 12 p.m., gage height, 95.64 feet; contents, 1,266.6 million cubic feet. 
CATAWBA RIVER AT CATAWBA ReSGRVOIR, NeAR ROCK hILL, S. C.

LoCATION.-Lat. $35^{\circ} 01^{\prime}$, long. $81^{\circ} 00^{\prime}$, at powerhouse forebay at Catawba Dam, 6 miles north of Rock Hill, York County, and 10 miles upstream from Sugar Creek. Datum of gage is 470.0 feet above mean sea level (levels by Duke Power Co.).

Drainage area.-3,020 square miles.

GAGE-HEIGHT RECORD.-Staff gage read to tenths hourly. Adjusted gage heights Aug. 12-16 taken from graph based on hourly readings.

DISCHARGE RECORD.-Record of outflow based on formula for spillway and manufacturer's rating for turbines. Record of inflow based on outflow and change in contents.

Maxima.-1940: Mean inflow, 169,160 second-feet for hour ending 9 a.m. Aug. 15; outflow, 138,640 second-feet 2 p.m. Aug. 15; reservoir gage height, 100.0 feet 1 p.m. Aug. 15 to 7 p.m. Aug. 16 (contents, 6,542,000,000 cubic feet).

1895-1903: Discharge, 151,000 second-feet May 23, 1901.

REMARKS.-Reservoir, first put in use Aug. 8, 1925, has a storage eapacity of $6,542,000,000$ cubic feet under normal operation between gage heights 85.0 and 100.0 feet (top of flood gates in closed position). River affected by storage in Bridgewater, Rhodhiss, Oxford, Lookout Shoals, and Mountain Island Reservoirs upstream having a combined capacity under normal operation of $16,107,000,000$ cubic feet. Records furnished by Duke Power Co.

Catawba Reservoir, gage height and contents at midnight, 1940

\begin{tabular}{|c|c|c|c|c|c|c|c|c|c|}
\hline \multirow[b]{2}{*}{ Day } & \multicolumn{2}{|c|}{ August } & \multicolumn{2}{|c|}{ September } & \multirow[b]{2}{*}{ Day } & \multicolumn{2}{|c|}{ August } & \multicolumn{2}{|c|}{ September } \\
\hline & $\begin{array}{c}\text { Gage } \\
\text { height } \\
\text { (feet) }\end{array}$ & $\begin{array}{c}\text { Contents } \\
\text { (million } \\
\text { cubic feet) }\end{array}$ & $\begin{array}{c}\text { Gage } \\
\text { height } \\
\text { (feet) }\end{array}$ & $\left|\begin{array}{c}\text { Contents } \\
\text { (million } \\
\text { cubicfeet) }\end{array}\right|$ & & $\begin{array}{c}\text { Gage } \\
\text { height } \\
\text { (feet) }\end{array}$ & $\begin{array}{c}\text { Contents } \\
\text { (million } \\
\text { cubic feet) }\end{array}$ & $\begin{array}{c}\text { Gage } \\
\text { height } \\
\text { (feet) }\end{array}$ & $\begin{array}{c}\text { Contents } \\
\text { (million } \\
\text { cubic } \\
\text { feet) }\end{array}$ \\
\hline $\begin{array}{l}1 \\
2 \\
3 \\
4 \\
5\end{array}$ & $\begin{array}{l}95.0 \\
95.0 \\
94.9 \\
94.7 \\
94.8\end{array}$ & $\begin{array}{l}4,022 \\
4,022 \\
3,975 \\
3,882 \\
3,929\end{array}$ & $\begin{array}{r}100.0 \\
99.6 \\
99.9 \\
99.7 \\
99.6\end{array}$ & $\begin{array}{l}6,542 \\
6,327 \\
6,488 \\
6,381 \\
6,327\end{array}$ & $\begin{array}{l}16 \\
17 \\
18 \\
19 \\
20\end{array}$ & $\begin{array}{l}99.9 \\
99.8 \\
99.5 \\
99.9 \\
99.7\end{array}$ & $\begin{array}{l}6,488 \\
6,434 \\
6,274 \\
6,488 \\
6,381\end{array}$ & $\begin{array}{l}97.2 \\
96.8 \\
96.2 \\
95.6 \\
95.0\end{array}$ & $\begin{array}{l}5,086 \\
4,887 \\
4,594 \\
4,305 \\
4,022\end{array}$ \\
\hline $\begin{array}{r}6 \\
7 \\
8 \\
9 \\
10\end{array}$ & $\begin{array}{l}95.0 \\
95.1 \\
95.2 \\
95.3 \\
95.2\end{array}$ & $\begin{array}{l}4,022 \\
4,069 \\
4,116 \\
4,163 \\
4,116\end{array}$ & $\begin{array}{l}99.4 \\
99.0 \\
99.1 \\
99.0 \\
98.8\end{array}$ & $\begin{array}{l}6,220 \\
6,009 \\
6,061 \\
6,009 \\
5,904\end{array}$ & $\begin{array}{l}21 \\
22 \\
23 \\
24 \\
25\end{array}$ & $\begin{array}{l}99.8 \\
99.6 \\
99.6 \\
99.6 \\
99.5\end{array}$ & $\begin{array}{l}6,434 \\
6,327 \\
6,327 \\
6,327 \\
6,274\end{array}$ & $\begin{array}{l}94.5 \\
94.2 \\
93.9 \\
93.7 \\
93.5\end{array}$ & $\begin{array}{l}3,790 \\
3,652 \\
3,516 \\
3,427 \\
3,338\end{array}$ \\
\hline $\begin{array}{l}11 \\
12 \\
13 \\
14 \\
15\end{array}$ & $\begin{array}{r}95.1 \\
95.2 \\
95.5 \\
94.7 \\
100.0\end{array}$ & $\begin{array}{l}4,069 \\
4,116 \\
4,258 \\
3,882 \\
6,542\end{array}$ & $\begin{array}{l}98.4 \\
98.2 \\
98.0 \\
97.9 \\
97.7\end{array}$ & $\begin{array}{l}5,696 \\
5,592 \\
5,489 \\
5,439 \\
5,337\end{array}$ & $\begin{array}{l}26 \\
27 \\
28 \\
29 \\
30 \\
31 \\
\end{array}$ & $\begin{array}{l}99.3 \\
98.9 \\
98.3 \\
97.8 \\
97.9 \\
98.4 \\
\end{array}$ & $\begin{array}{l}6,167 \\
5,956 \\
5,644 \\
5,388 \\
5,439 \\
5,696\end{array}$ & $\begin{array}{l}93.2 \\
92.9 \\
92.7 \\
92.5 \\
92.4 \\
\\
\end{array}$ & \begin{tabular}{r}
3,203 \\
3,071 \\
2,984 \\
2,897 \\
2,854 \\
\hdashline \\
\end{tabular} \\
\hline & & & & & & & & August & $\begin{array}{c}\text { Sep- } \\
\text { tember }\end{array}$ \\
\hline \multicolumn{8}{|c|}{ Change in contents, equivalent, in second-feet } & +608 & $-1,096$ \\
\hline
\end{tabular}

Supplemental ReCoRd.-July 31, midnight, gage height, 95.1 feet; contents, 4,069 million cubic feet. $804331-49-17$ 
Catawba Reservoir, gage height, contents, mean inflow for preceding hour, and outflow, at indicated time, 1940

\begin{tabular}{|c|c|c|c|c|c|c|c|c|c|}
\hline \multirow[b]{2}{*}{ Hour } & \multicolumn{5}{|c|}{ Aug. 12} & \multicolumn{4}{|c|}{ Aug. 13} \\
\hline & $\begin{array}{c}\text { Gage } \\
\text { height } \text { (f }^{\prime} \\
\text { (feet) }\end{array}$ & $\begin{array}{c}\text { Contents } \\
\text { (million } \\
\text { cubic feet) }\end{array}$ & $\begin{array}{l}\text { Inflow } \\
\text { (second- } \\
\text { feet) }\end{array}$ & \multicolumn{2}{|c|}{$\begin{array}{l}\text { Outflow } \\
\text { (second- } \\
\text { feet) }\end{array}$} & $\begin{array}{c}\text { Gage } \\
\text { height }{ }^{1} \\
\text { (feet) }\end{array}$ & $\begin{array}{c}\text { Contents } \\
\text { (million } \\
\text { cubic feet) }\end{array}$ & $\begin{array}{l}\text { Inflow } \\
\text { (second- } \\
\text { feet) }\end{array}$ & $\begin{array}{l}\text { Outflow } \\
\text { (sscond- } \\
\text { feet) }\end{array}$ \\
\hline $\begin{array}{l}1 \\
2 \\
3 \\
4 \\
5 \\
6\end{array}$ & $\begin{array}{l}95.10 \\
95.095 \\
95.09 \\
95.085 \\
95.08 \\
95.075\end{array}$ & $\begin{array}{l}4,068.8 \\
4,066.5 \\
4,064.1 \\
4,061 \cdot 8 \\
4,059.4 \\
4,057.1\end{array}$ & $\begin{array}{l}\mathbf{6 0 0} \\
\mathbf{5 6 0} \\
\mathbf{5 3 0} \\
\mathbf{5 6 0} \\
\mathbf{5 3 0} \\
\mathbf{5 6 0}\end{array}$ & \multicolumn{2}{|c|}{$\begin{array}{l}1,200 \\
1,200 \\
1,200 \\
1,200 \\
1,200 \\
1,200\end{array}$} & $\begin{array}{l}95.20 \\
95.20 \\
95.20 \\
95.20 \\
95.21 \\
95.22\end{array}$ & $\begin{array}{l}4,115.8 \\
4,115.8 \\
4,115.8 \\
4,115.8 \\
4,120.5 \\
4,125.2\end{array}$ & $\begin{array}{l}1,200 \\
1,200 \\
1,200 \\
1,200 \\
2,510 \\
2,510\end{array}$ & $\begin{array}{l}1,200 \\
1,200 \\
1,200 \\
1,200 \\
1,200 \\
1,200\end{array}$ \\
\hline $\begin{array}{r}7 \\
8 \\
9 \\
10 \\
11 \\
\mathrm{~N}\end{array}$ & $\begin{array}{l}95.07 \\
95.063 \\
95.054 \\
95.043 \\
95.032 \\
95.021\end{array}$ & \begin{tabular}{|r|r}
$4,054.8$ \\
$4,051.5$ \\
$4,047.3$ \\
$4,042.1$ \\
$4,037.0$ \\
$4,031.8$
\end{tabular} & $\begin{array}{r}560 \\
430 \\
330 \\
60 \\
80 \\
60\end{array}$ & \multicolumn{2}{|c|}{$\begin{array}{l}1,200 \\
1,500 \\
1,500 \\
1,500 \\
1,500 \\
1,500\end{array}$} & $\begin{array}{l}95.23 \\
95.24 \\
95.25 \\
95.26 \\
95.27 \\
95.28\end{array}$ & $\begin{array}{l}4,130.0 \\
4,134.7 \\
4,139.4 \\
4,144.1 \\
4,148.8 \\
4,153.6\end{array}$ & $\begin{array}{l}2,530 \\
2,510 \\
2,510 \\
2,510 \\
2,510 \\
2,530\end{array}$ & $\begin{array}{l}1,200 \\
1,200 \\
1,200 \\
1,200 \\
1,200 \\
1,200\end{array}$ \\
\hline $\begin{array}{l}1 \\
2 \\
3 \\
4 \\
5 \\
5 \\
6\end{array}$ & $\begin{array}{l}95.01 \\
\mathbf{9 5 . 0 0} \\
\mathbf{9 5 . 0 2} \\
\mathbf{9 5 . 0 4} \\
\mathbf{9 5 . 0 6} \\
\mathbf{9 5 . 0 8}\end{array}$ & $\begin{array}{l}4,026.7 \\
4,022.0 \\
4,031.4 \\
4,040.7 \\
4,050.1 \\
4,059.4\end{array}$ & $\begin{array}{r}80 \\
190 \\
4,110 \\
4,080 \\
4,110 \\
4,080\end{array}$ & \multicolumn{2}{|c|}{$\begin{array}{l}1,500 \\
1,500 \\
1,500 \\
1,500 \\
1,500 \\
1,500\end{array}$} & $\begin{array}{l}95.29 \\
95.30 \\
95.32 \\
95.34 \\
95.36 \\
95.38\end{array}$ & $\begin{array}{l}4,158.3 \\
4,163.0 \\
4,172.4 \\
4,181.8 \\
4,191.3 \\
4,200.7\end{array}$ & $\begin{array}{l}2,510 \\
2,510 \\
3,810 \\
3,810 \\
4,540 \\
6,310\end{array}$ & $\begin{array}{l}1,200 \\
1,200 \\
1,200 \\
1,200 \\
2,600 \\
4,800\end{array}$ \\
\hline \multirow[t]{2}{*}{$\begin{array}{r}7 \\
8 \\
9 \\
10 \\
11 \\
12 \\
\end{array}$} & $\begin{array}{l}95.10 \\
95.12 \\
95.14 \\
95.16 \\
95.18 \\
95.20 \\
\end{array}$ & $\begin{array}{l}4,068.8 \\
4,078.2 \\
4,087.6 \\
4,097.0 \\
4,106.4 \\
4,115.8 \\
\end{array}$ & $\begin{array}{l}4,1 \\
4,1 \\
4,1 \\
4,1 \\
3,9 \\
3,8 \\
\end{array}$ & & & $\begin{array}{l}95.40 \\
95.42 \\
95.44 \\
95.46 \\
95.48 \\
95.50 \\
\end{array}$ & $\begin{array}{l}4,210.1 \\
4,219.6 \\
4,229.1 \\
4,238.5 \\
4,248.0 \\
4,257.5 \\
\end{array}$ & $\begin{array}{l}6,310 \\
5,340 \\
5,440 \\
5,410 \\
6,390 \\
7,640 \\
\end{array}$ & $\begin{array}{l}2,600 \\
2,800 \\
2,800 \\
2,800 \\
4,700 \\
5,300 \\
\end{array}$ \\
\hline & \multicolumn{5}{|c|}{ Aug. 14} & \multicolumn{4}{|c|}{ Aug. 15} \\
\hline $\begin{array}{l}1 \\
2 \\
3 \\
4 \\
5 \\
6 \\
6\end{array}$ & $\begin{array}{l}95.55 \\
95.60 \\
95.65 \\
95.70 \\
95.80 \\
95.80\end{array}$ & $\begin{array}{l}4,281.3 \\
4,305.1 \\
4,328.9 \\
4,352.7 \\
4,400.6 \\
4,400.6\end{array}$ & $\begin{array}{l}12,5 \\
13,1 \\
13,1 \\
13,1 \\
30,7 \\
28,5\end{array}$ & $\begin{array}{r}6, \\
6, \\
6, \\
6, \\
28, \\
28,\end{array}$ & & $\begin{array}{l}95.1 \\
95.5 \\
96.0 \\
96.5 \\
97.0 \\
97.5\end{array}$ & $\begin{array}{l}4,068.8 \\
4,257.5 \\
4,496.6 \\
4,739.4 \\
4,985.7 \\
5,235.6\end{array}$ & $\begin{array}{l}121,730 \\
123,530 \\
138,750 \\
141,160 \\
143,700 \\
146,220\end{array}$ & $\begin{array}{l}70,480 \\
71,740 \\
72,910 \\
74,530 \\
76,030 \\
77,580\end{array}$ \\
\hline $\begin{array}{r}7 \\
8 \\
9 \\
10 \\
11 \\
\mathrm{~N}\end{array}$ & $\begin{array}{l}95.70 \\
95.50 \\
95.30 \\
95.10 \\
94.90 \\
94.70\end{array}$ & $\begin{array}{l}4,352.7 \\
4,257.5 \\
4,163.0 \\
4,068.8 \\
3,975.3 \\
3,882.3\end{array}$ & $\begin{array}{l}26, \\
25, \\
31, \\
37, \\
41, \\
42,\end{array}$ & $\begin{array}{l}50, \\
54, \\
60, \\
65, \\
68,\end{array}$ & & $\begin{array}{l}98.0 \\
98.6 \\
99.2 \\
99.6 \\
99.8 \\
99.9\end{array}$ & $\begin{array}{l}5,489.3 \\
5,798.7 \\
6,113.7 \\
6,326 \cdot 8 \\
6,434 \cdot 3 \\
6,488 \cdot 3\end{array}$ & $\begin{array}{l}148,670 \\
165,680 \\
169,160 \\
148,770 \\
132,140 \\
126,200\end{array}$ & $\begin{array}{r}78,810 \\
80,680 \\
82,640 \\
96,520 \\
108,040 \\
114,350\end{array}$ \\
\hline $\begin{array}{l}1 \\
2 \\
3 \\
4 \\
5 \\
6 \\
6\end{array}$ & $\begin{array}{l}94.40 \\
94.30 \\
94.10 \\
94.00 \\
93.90 \\
93.90\end{array}$ & $\begin{array}{l}3,743.8 \\
3,697.9 \\
3,606.5 \\
3,561.1 \\
3,515.8 \\
3,515.8\end{array}$ & $\begin{array}{l}28, \\
54, \\
41, \\
53, \\
53, \\
65,\end{array}$ & & & & $\begin{array}{l}6,542.5 \\
6,542.5 \\
6,542.5 \\
6,542.5 \\
6,542.5 \\
6,542.5\end{array}$ & $\begin{array}{l}133,650 \\
130,740 \\
137,440 \\
136,490 \\
136,490 \\
130,950\end{array}$ & $\begin{array}{l}122,840 \\
138,640 \\
136,240 \\
136,740 \\
136,240 \\
125,650\end{array}$ \\
\hline $\begin{array}{r}7 \\
8 \\
9 \\
10 \\
11 \\
12 \\
\end{array}$ & $\begin{array}{l}93.90 \\
94.00 \\
94.10 \\
94.20 \\
94.50 \\
94.70 \\
\end{array}$ & $\begin{array}{l}3,515.8 \\
3,561.1 \\
3,606.5 \\
3,652.2 \\
3,789.8 \\
3,882.3 \\
\end{array}$ & $\begin{array}{r}65, \\
78, \\
78, \\
79 \\
106, \\
94, \\
\end{array}$ & & & & $\begin{array}{l}6,542.5 \\
6,542.5 \\
6,542.5 \\
6,542.5 \\
6,542.5 \\
6,542.5 \\
\end{array}$ & $\begin{array}{r}117,050 \\
108,700 \\
106,830 \\
104,620 \\
97,550 \\
90,570 \\
\end{array}$ & $\begin{array}{r}108,450 \\
108,950 \\
104,720 \\
104,520 \\
90,570 \\
90,570 \\
\end{array}$ \\
\hline \multirow[b]{2}{*}{ Hour } & \multicolumn{4}{|c|}{ Aug. 16} & & \multicolumn{4}{|c|}{ Aug. 16-Con. } \\
\hline & $\begin{array}{c}\text { Gage } \\
\text { height! } \\
\text { (feet) }\end{array}$ & $\begin{array}{c}\text { Contents } \\
\text { (million } \\
\text { cubic feet) }\end{array}$ & $\begin{array}{c}\text { Inflow } \\
\text { (second- } \\
\text { feet) }\end{array}$ & $\begin{array}{l}\text { Outflow } \\
\text { (second- } \\
\text { feet) }\end{array}$ & & $\begin{array}{c}\text { Gage } \\
\text { height } \\
\text { (feet) }\end{array}$ & $\begin{array}{c}\text { Contents } \\
\text { (million } \\
\text { cubic feet) }\end{array}$ & 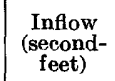 & $\begin{array}{l}\text { Outflow } \\
\text { (second- } \\
\text { feet) }\end{array}$ \\
\hline $\begin{array}{l}1 \\
2 \\
3 \\
4 \\
5 \\
6\end{array}$ & $\begin{array}{l}100.00 \\
100.00 \\
100.00 \\
100.00 \\
100.00 \\
100.00\end{array}$ & $\begin{array}{l}6,542.5 \\
6,542.5 \\
6,542.5 \\
6,542.5 \\
6,542.5 \\
6,542.5\end{array}$ & $\begin{array}{l}83,170 \\
75,420 \\
75,070 \\
68,580 \\
61,980 \\
61,880\end{array}$ & $\begin{array}{l}75,770 \\
75,070 \\
75,070 \\
62,080 \\
61,880 \\
61,880\end{array}$ & $\begin{array}{l}1 \\
2 \\
3 \\
4 \\
5 \\
6\end{array}$ & $\begin{array}{l}100 \\
100 \\
100\end{array}$ & $\begin{array}{r}42.5 \\
42.5 \\
42.5 \\
42.5 \\
42.5\end{array}$ & $\begin{array}{l}41,040 \\
40,240 \\
39,490 \\
36,760 \\
31,830 \\
29,010\end{array}$ & $\begin{array}{l}40,990 \\
39,490 \\
39,490 \\
34,030 \\
29,620 \\
28,400\end{array}$ \\
\hline $\begin{array}{r}7 \\
8 \\
9 \\
10 \\
11 \\
\mathrm{~N}\end{array}$ & $\begin{array}{l}100.00 \\
100.00 \\
100.00 \\
100.00 \\
100.00 \\
100.00\end{array}$ & $\begin{array}{l}6,542.5 \\
6,542.5 \\
6,542.5 \\
6,542.5 \\
6,542.5 \\
6,542.5\end{array}$ & $\begin{array}{l}56,690 \\
\mathbf{4 6}, 920 \\
\mathbf{4 2}, 220 \\
\mathbf{3 9}, \mathbf{4 5 0} \\
36,790 \\
\mathbf{3 8}, \mathbf{9 4 0}\end{array}$ & $\begin{array}{l}51,510 \\
42,320 \\
42,120 \\
36,790 \\
36,790 \\
41,090\end{array}$ & $\begin{array}{r}7 \\
8 \\
9 \\
10 \\
11 \\
12 \\
\end{array}$ & $\begin{array}{r}100.0 \\
99.9 \\
99.9 \\
99.9 \\
99.9 \\
99.9\end{array}$ & $\begin{array}{l}6,542.5 \\
6,531.7 \\
6,520.8 \\
6,510.0 \\
6,499.1 \\
6,488.3\end{array}$ & $\begin{array}{l}24,700 \\
18,010 \\
17,980 \\
17,900 \\
17,760 \\
15,990\end{array}$ & $\begin{array}{l}21,010 \\
21,010 \\
21,000 \\
20,800 \\
20,790 \\
17,190\end{array}$ \\
\hline
\end{tabular}

\footnotetext{
1 Gage heights from graph based on hourly observations.
}

SUPPLEMENTAL RECORD.-Aug. 11, 12 p.m., gage heights, 95.10 feet; contents, $4,068.8$ million cubic feet. 
CATAWBA RIVER AT FISHING CREEK RESERVOIR,

NEAR GREAT FALLS, S. C.

LOCATION.-Lat. $34^{\circ} 36^{\prime}$, long. $80^{\circ} 53^{\prime}$, at powerhouse forebay at Fishing Creek Dam, $21 / 2$ miles north of Great Falls, Chester County. Datum of gage is 316.85 feet above mean sea level (levels by Duke Power Co.). Some Duke Power Co. records for this station, not published herein, are referred to a datum 8.85 feet lower. Drainage AREA. - 3,810 square miles.

GAGE-HEIGHT RECORD.- Staff gage read to tenths hourly. Adjusted gage heights Aug. 12-16 taken from graph based on hourly readings.

DISCHARGE RECORD.-Record of outflow based on formula for flood gates and manufacturer's ratings for turbines. Record of inflow based on outflow and change in contents.

Maxima.-1940: Mean inflow, 110,180 second-feet for hour ending 5 a.m. Aug. 16; outflow, 115,490 second-feet 7 a.m. Aug. 16; reservoir gage height, 99.8 feet, 1, 5, and 6 a.m. Aug. 16 (contents, 1,601,000,000 cubic feet).

REMARKs.-Reservoir, first put in use Nov. 22,1916 , has a storage capacity of 1,630 ,000,000 cubic feet under normal operation between gage heights of 85.0 and 100.0 feet (top of flood gates in closed position). River affected by storage in Bridgewater, Rhodhiss, Oxford, Lookout Shoals, Mountain Island, and Catawba Reservoirs upstream having a combined capacity under normal operation of 22,649,000,000 cubic feet. Records furnished by Duke Power Co.

Fishing Creek Reservoir, gage height and contents at midnight, 1940

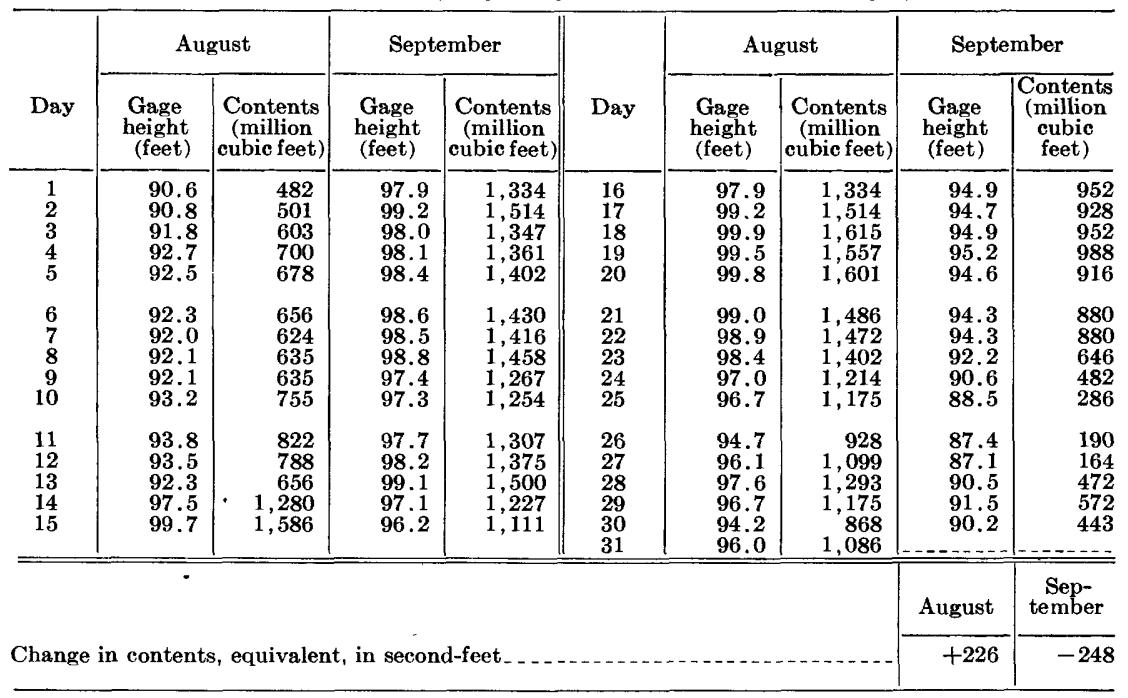

SupPLEME NTAL RECORD.-July 31, midnight, gage height, 90.6 feet; contents, 482 million cubic feet. 


\section{FLOODS OF AUGUST 1940 IN THE SOUTHEASTERN STATES}

Fishing Creek Reservoir, gage height, contents, mean inflow for preceding hour, and outflow, at indicated time, 1940

\begin{tabular}{|c|c|c|c|c|c|c|c|c|c|c|}
\hline \multirow[b]{2}{*}{ Hour } & \multicolumn{6}{|c|}{ Aug. 12} & \multicolumn{4}{|c|}{ Aug." 13} \\
\hline & $\begin{array}{c}\text { Gage } \\
\text { height }^{1} \\
\text { (feet) }\end{array}$ & $\begin{array}{c}\text { Contents } \\
\text { (million } \\
\text { cubic feet) }\end{array}$ & \multicolumn{2}{|c|}{$\begin{array}{l}\text { Inflow } \\
\text { (second- } \\
\text { feet) }\end{array}$} & \multicolumn{2}{|c|}{$\begin{array}{l}\text { Outflow } \\
\text { (second- } \\
\text { feet) }\end{array}$} & $\begin{array}{l}\text { Gage } \\
\text { height }{ }^{1} \\
\text { (feet) }\end{array}$ & $\begin{array}{c}\text { Contents } \\
\text { (million } \\
\text { cubic feet) }\end{array}$ & $\begin{array}{l}\text { Inflow } \\
\text { (second- } \\
\text { feet) }\end{array}$ & $\begin{array}{l}\text { Outflow } \\
\text { (second- } \\
\text { feet) }\end{array}$ \\
\hline $\begin{array}{l}1 \\
2 \\
3 \\
4 \\
5 \\
6\end{array}$ & $\begin{array}{l}93.84 \\
93.88 \\
93.92 \\
93.96 \\
94.00 \\
94.00\end{array}$ & $\begin{array}{l}826.7 \\
831.5 \\
836.1 \\
840.7 \\
845.3 \\
845.3\end{array}$ & \multicolumn{2}{|c|}{$\begin{array}{l}1,280 \\
1,280 \\
1,280 \\
1,280 \\
1,280 \\
1,100\end{array}$} & \multicolumn{2}{|c|}{$\begin{array}{r}0 \\
0 \\
0 \\
0 \\
0 \\
, 200\end{array}$} & $\begin{array}{l}93.55 \\
93.60 \\
93.65 \\
93.70 \\
93.75 \\
93.80\end{array}$ & $\begin{array}{l}793.9 \\
799.5 \\
805.2 \\
810.9 \\
816.6 \\
822.3\end{array}$ & $\begin{array}{l}1,580 \\
1,560 \\
1,580 \\
1,580 \\
1,580 \\
2,130\end{array}$ & $\begin{array}{r}0 \\
0 \\
0 \\
0 \\
0 \\
1,100\end{array}$ \\
\hline $\begin{array}{r}7 \\
8 \\
9 \\
10 \\
11 \\
\mathrm{~N}\end{array}$ & $\begin{array}{l}93.98 \\
93.96 \\
93.94 \\
93.92 \\
93.89 \\
93.82\end{array}$ & $\begin{array}{l}843.0 \\
840.7 \\
838.4 \\
836.1 \\
832.7 \\
824.6\end{array}$ & \multicolumn{2}{|c|}{$\begin{array}{r}1,340 \\
960 \\
1,180 \\
1,610 \\
1,890 \\
1,000\end{array}$} & \multicolumn{2}{|c|}{$\begin{array}{l}1,750 \\
1,450 \\
2,200 \\
2,300 \\
3,350 \\
3,150\end{array}$} & $\begin{array}{l}93.80 \\
93.77 \\
93.70 \\
93.60 \\
93.45 \\
93.30\end{array}$ & $\begin{array}{l}822.3 \\
818.9 \\
810.9 \\
799.5 \\
782.6 \\
765.8\end{array}$ & $\begin{array}{l}1,100 \\
1,160 \\
1,930 \\
2,080 \\
1,460 \\
1,430\end{array}$ & $\begin{array}{l}1,100 \\
3,100 \\
5,200 \\
5,300 \\
7,000 \\
5,200\end{array}$ \\
\hline $\begin{array}{l}1 \\
2 \\
3 \\
4 \\
5 \\
6\end{array}$ & $\begin{array}{l}93.78 \\
93.74 \\
93.70 \\
93.66 \\
93.63 \\
93.60\end{array}$ & $\begin{array}{l}820.0 \\
815.5 \\
810.9 \\
806.3 \\
802.9 \\
799.5\end{array}$ & \multicolumn{2}{|c|}{$\begin{array}{r}990 \\
1,030 \\
1,840 \\
1,820 \\
1,560 \\
1,060\end{array}$} & \multicolumn{2}{|c|}{$\begin{array}{l}1,400 \\
3,150 \\
3,100 \\
3,100 \\
1,900 \\
2,100\end{array}$} & $\begin{array}{l}93.20 \\
93.15 \\
93.10 \\
93.00 \\
92.90 \\
92.80\end{array}$ & $\begin{array}{l}754.6 \\
749.0 \\
743.5 \\
732.4 \\
721.4 \\
710.5\end{array}$ & $\begin{array}{r}1,340 \\
2,790 \\
3,470 \\
1,220 \\
\mathbf{9 9 0} \\
1,320\end{array}$ & $\begin{array}{l}3,700 \\
5,000 \\
5,000 \\
3,600 \\
4,500 \\
4,200\end{array}$ \\
\hline $\begin{array}{r}7 \\
8 \\
9 \\
10 \\
11 \\
12 \\
\end{array}$ & $\begin{array}{l}93.58 \\
93.55 \\
93.52 \\
93.50 \\
93.50 \\
93.50 \\
\end{array}$ & $\begin{array}{l}797.2 \\
793.9 \\
790.5 \\
788.2 \\
788.2 \\
788.2 \\
\end{array}$ & \multicolumn{2}{|c|}{$\begin{array}{l}1,310 \\
1,330 \\
1,660 \\
1,560 \\
1,530 \\
1,250 \\
\end{array}$} & \multicolumn{2}{|c|}{$\begin{array}{l}1,800 \\
2,700 \\
2,500 \\
1,900 \\
1,150 \\
1,350 \\
\end{array}$} & $\begin{array}{l}92.70 \\
92.60 \\
92.50 \\
92.40 \\
92.30 \\
92.20 \\
\end{array}$ & $\begin{array}{l}699.6 \\
688.7 \\
677.9 \\
667.1 \\
656.4 \\
645.7 \\
\end{array}$ & $\begin{array}{r}720 \\
470 \\
950 \\
1,250 \\
1,830 \\
2,330 \\
\end{array}$ & $\begin{array}{l}3,300 \\
3,700 \\
4,200 \\
4,300 \\
5,300 \\
5,300 \\
\end{array}$ \\
\hline 12 & \multicolumn{6}{|c|}{ Aug. 14} & \multicolumn{4}{|c|}{ Aug. 15} \\
\hline $\begin{array}{l}1 \\
2 \\
3 \\
4 \\
5 \\
6\end{array}$ & $\begin{array}{l}92.10 \\
92.00 \\
92.00 \\
92.00 \\
92.00 \\
92.00\end{array}$ & $\begin{array}{l}635.1 \\
624.5 \\
624.5 \\
624.5 \\
624.5 \\
624.5\end{array}$ & \multicolumn{2}{|c|}{$\begin{array}{l}2,060 \\
1,210 \\
3,350 \\
3,050 \\
2,650 \\
4,300\end{array}$} & \multicolumn{2}{|c|}{$\begin{array}{l}4,700 \\
3,600 \\
3,100 \\
3,000 \\
2,300 \\
6,300\end{array}$} & $\begin{array}{l}97.7 \\
97.9 \\
98.1 \\
98.3 \\
98.6 \\
98.9\end{array}$ & $\begin{array}{l}1,306.8 \\
1,333.8 \\
1,361.0 \\
1,388.4 \\
1,429.9 \\
1,471.9\end{array}$ & $\begin{array}{l}48,920 \\
49,700 \\
50,710 \\
51,410 \\
55,810 \\
57,060\end{array}$ & $\begin{array}{l}41,700 \\
42,700 \\
43,600 \\
44,000 \\
44,560 \\
46,220\end{array}$ \\
\hline $\begin{array}{r}7 \\
8 \\
9 \\
10 \\
11 \\
\mathbf{N}\end{array}$ & $\begin{array}{l}92.00 \\
92.00 \\
92.10 \\
92.20 \\
92.30 \\
92.80\end{array}$ & $\begin{array}{l}624.5 \\
624.5 \\
635.1 \\
645.7 \\
656.4 \\
710.5\end{array}$ & \multicolumn{2}{|c|}{$\begin{array}{r}4,600 \\
2,900 \\
5,840 \\
7,540 \\
9,070 \\
21,230\end{array}$} & \multicolumn{2}{|c|}{$\begin{array}{l}2,900 \\
2,900 \\
2,900 \\
6,300 \\
5,900 \\
6,500\end{array}$} & & $\begin{array}{l}1,514.4 \\
1,514.4 \\
1,471.9 \\
1,457.9 \\
1,443.9 \\
1,443.9\end{array}$ & $\begin{array}{l}61,540 \\
60,970 \\
56,390 \\
63,610 \\
63,240 \\
66,930\end{array}$ & $\begin{array}{l}53,230 \\
68,720 \\
67,680 \\
67,320 \\
66,930 \\
66,930\end{array}$ \\
\hline $\begin{array}{l}1 \\
2 \\
3 \\
4 \\
5 \\
6\end{array}$ & $\begin{array}{l}93.50 \\
94.40 \\
95.40 \\
96.00 \\
96.30 \\
96.40\end{array}$ & $\begin{array}{r}788.2 \\
891.8 \\
1,011.7 \\
1,086.0 \\
1,123.9 \\
1,136.6\end{array}$ & \multicolumn{2}{|c|}{$\begin{array}{l}27,830 \\
34,930 \\
39,760 \\
35,130 \\
40,860 \\
42,180\end{array}$} & \multicolumn{2}{|c|}{$\begin{array}{r}6,000 \\
6,300 \\
6,600 \\
22,380 \\
38,280 \\
39,020\end{array}$} & $\begin{array}{l}98.7 \\
98.8 \\
98.9 \\
99.0 \\
99.2 \\
99.4\end{array}$ & $\begin{array}{l}1,443.9 \\
1,457.9 \\
1,471.9 \\
1,486.0 \\
1,514.4 \\
1,543.0\end{array}$ & $\begin{array}{l}66,380 \\
70,460 \\
70,040 \\
69,750 \\
74,680 \\
75,290\end{array}$ & $\begin{array}{l}65,830 \\
67,320 \\
64,980 \\
66,670 \\
66,920 \\
67,770\end{array}$ \\
\hline $\begin{array}{r}7 \\
8 \\
9 \\
10 \\
11 \\
12 \\
\end{array}$ & $\begin{array}{l}96.50 \\
96.70 \\
96.90 \\
97.10 \\
97.30 \\
97.50 \\
\end{array}$ & $\begin{array}{r}1,149.4 \\
1,175.1 \\
1,201.0 \\
1,227.2 \\
1,253.5 \\
1,280.1 \\
\end{array}$ & \multicolumn{2}{|c|}{$\begin{array}{l}43,050 \\
47,240 \\
47,370 \\
47,290 \\
46,560 \\
47,340 \\
\end{array}$} & \multicolumn{2}{|c|}{$\begin{array}{l}39,960 \\
40,240 \\
40,120 \\
39,900 \\
38,600 \\
41,300 \\
\end{array}$} & $\begin{array}{l}99.5 \\
99.4 \\
99.4 \\
99.4 \\
99.6 \\
99.7 \\
\end{array}$ & $\begin{array}{r}1,557.4 \\
1,543.0 \\
1,543.0 \\
1,543.0 \\
1,571.8 \\
1,586.3 \\
\end{array}$ & $\begin{array}{r}81,550 \\
84,200 \\
88,960 \\
89,310 \\
97,940 \\
100,260 \\
\end{array}$ & $\begin{array}{r}87,340 \\
89,060 \\
88,860 \\
89,760 \\
90,120 \\
102,340 \\
\end{array}$ \\
\hline \multirow[b]{2}{*}{ Hour } & \multicolumn{5}{|c|}{ Aug. 16} & & \multicolumn{4}{|c|}{ Aug. 16-Con. } \\
\hline & $\begin{array}{c}\text { Gage } \\
\text { height }^{1} \\
\text { (feet) }\end{array}$ & $\begin{array}{c}\text { Contents } \\
\text { (million } \\
\text { cubic feet) }\end{array}$ & $\begin{array}{l}\text { Inflow } \\
\text { (second- } \\
\text { feet) }\end{array}$ & & & Hour & $\begin{array}{r}\text { Gage } \\
\text { height } \\
\text { (feet) }\end{array}$ & $\begin{array}{c}\text { Contents } \\
\text { (million } \\
\text { cubic feet) }\end{array}$ & $\begin{array}{l}\text { Inflow } \\
\text { (second- } \\
\text { feet) }\end{array}$ & $\begin{array}{l}\text { Outflow } \\
\text { (second- } \\
\text { feet) }\end{array}$ \\
\hline $\begin{array}{l}1 \\
2 \\
3 \\
4 \\
5 \\
5 \\
6\end{array}$ & $\begin{array}{l}99.8 \\
99.7 \\
99.7 \\
99.7 \\
99.8 \\
99.8\end{array}$ & $\begin{array}{l}1,600.8 \\
1,586.3 \\
1,586.3 \\
1,586.3 \\
1,600.8 \\
1,600.8\end{array}$ & $\begin{array}{l}109,400 \\
103,670 \\
106,950 \\
106,550 \\
110,180 \\
108,200\end{array}$ & & & $\begin{array}{l}1 \\
2 \\
3 \\
4 \\
5 \\
6\end{array}$ & $\begin{array}{l}98.9 \\
99.1 \\
99.2 \\
99.0 \\
98.9 \\
99.0\end{array}$ & $\begin{array}{l}1,471.9 \\
1,500.2 \\
1,514.4 \\
1,486.0 \\
1,471.9 \\
1,486.0\end{array}$ & $\begin{array}{l}\mathbf{9 3}, \mathbf{9 2 0} \\
\mathbf{9 0}, 780 \\
\mathbf{8 7}, \mathbf{7 9 0} \\
\mathbf{7 6}, \mathbf{8 7 0} \\
\mathbf{7 4}, 540 \\
\mathbf{7 3}, \mathbf{3 8 0}\end{array}$ & $\begin{array}{l}83,040 \\
84,660 \\
84,860 \\
72,050 \\
66,870\end{array}$ \\
\hline $\begin{array}{r}7 \\
8 \\
9 \\
10 \\
11 \\
\mathbf{N}\end{array}$ & $\begin{array}{l}99.5 \\
99.3 \\
99.2 \\
99.0 \\
98.7 \\
98.6 \\
\end{array}$ & $\begin{array}{l}1,557.4 \\
1,528.7 \\
1,514.4 \\
1,486.0 \\
1,443.9 \\
1,429.9 \\
\end{array}$ & $\begin{array}{r}100,890 \\
106,310 \\
108,750 \\
104,030 \\
98,660 \\
91,570 \\
\end{array}$ & & & $\begin{array}{r}7 \\
8 \\
9 \\
10 \\
11 \\
12\end{array}$ & $\begin{array}{l}98 . \\
98 \\
98 \\
98 \\
98 \\
97\end{array}$ & $\begin{array}{l}1,471.9 \\
1,457.9 \\
1,416.0 \\
1,374.7 \\
1,347.4 \\
1,333.8\end{array}$ & $\begin{array}{l}62,350 \\
62,460 \\
55,010 \\
53,280 \\
53,050 \\
54,100\end{array}$ & $\begin{array}{l}67,020 \\
66,280 \\
63,210 \\
58,060 \\
57,700 \\
\end{array}$ \\
\hline
\end{tabular}

1 Gage heights from graph based on hourly observations.

SUPPLEMENTAL RECORD.-Aug. 11, 12 p.m., gage height, 93.80 feet; contents 822.3 million cubic feet. 


\section{CATAWBA RIVER AT ROCKY CREEK RESERVOIR,}

NEAR GREAT FALLS, S. C.

LOCATION.-Lat. $34^{\circ} 32^{\prime}$, long. $80^{\circ} 52^{\prime}$, at powerhouse forebay at Rocky Creek Dam, 3 miles southeast of Great Falls, Chester County. Datum of gage is $\mathbf{1 8 4 . 8 5}$ feet above mean sea level (levels by Duke Power Co.). Some Duke Power Co. records for this station, not published herein, are referred to a datum 8.85 feet lower.

Drainage AREA.-4,360 square miles.

GAGE-HEIGHT RECORD.--Staff gage read to tenths hourly. Adjusted gage heights Aug.

12-16 taken from graph based on hourly readings.

Discharge RECORD-Record of outflow based on formula for spillway and flood gates and manufacturer's ratings for turbines. Record of inflow based on outflow and change in contents.

Maxima.-1940: Mean inflow, 114,940 second-feet for hours ending 9 and 10 a.m.

Aug. 16; outflow, 115,310 second-feet 7 a.m. Aug. 16; reservoir gage height, 106.0 feet 4 to 7 a.m. Aug. $16^{\circ}$ (contents $632,000,000$ cubie feet).

1909-39 : Discharge, 382,000 second-feet July 1916.

REMARKs.- Reservoir, first put in use Apr. 28, 1909, has a total storage eapacity of $419,000,000$ cubic feet between gage heights 85.0 and 100.0 feet (erest of spillway) and a storage capacity of $163,000,000$ cubic feet under normal operation between gage heights 95.0 and 100.0 feet. River affected by storage in Bridgewater, Rhodhiss, Oxford, Lookout Shoals, Mountain Island, Catawba, and Fishing Creek Reservoirs upstream having a combined capacity under normal operation of 24,279,000,000 cubic feet. Records furnished by Duke Power Co.

Rocky Creek Reservoir, gage height and contents at midnight, 1940

\begin{tabular}{|c|c|c|c|c|c|c|c|c|c|}
\hline \multirow[b]{2}{*}{ Day } & \multicolumn{2}{|c|}{ August } & \multicolumn{2}{|c|}{ September } & \multirow[b]{2}{*}{ Day } & \multicolumn{2}{|c|}{ August } & \multicolumn{2}{|c|}{ September } \\
\hline & $\begin{array}{c}\text { Gage } \\
\text { height } \\
\text { (feet) }\end{array}$ & $\begin{array}{c}\text { Contents } \\
\text { (million } \\
\text { cubic feet) }\end{array}$ & $\begin{array}{c}\text { Gage } \\
\text { height } \\
\text { (feet) }\end{array}$ & $\mid \begin{array}{c}\text { Contents } \\
\text { (million } \\
\text { cubic feet) }\end{array}$ & & $\begin{array}{c}\text { Gage } \\
\text { height } \\
\text { (feet) }\end{array}$ & $\begin{array}{c}\text { Contents } \\
\text { (million } \\
\text { cubic feet) }\end{array}$ & $\begin{array}{c}\text { Gage } \\
\text { height } \\
\text { (feet) }\end{array}$ & $\begin{array}{l}\text { Contents } \\
\text { (million } \\
\text { cubic } \\
\text { feet) }\end{array}$ \\
\hline $\begin{array}{l}1 \\
2 \\
3 \\
4 \\
5\end{array}$ & $\begin{array}{l}98.5 \\
98.4 \\
98.0 \\
98.0 \\
97.6\end{array}$ & $\begin{array}{l}368 \\
365 \\
351 \\
351 \\
338\end{array}$ & $\begin{array}{r}97.8 \\
100.9 \\
96.9 \\
97.2 \\
97.4\end{array}$ & $\begin{array}{l}345 \\
450 \\
316 \\
325 \\
332\end{array}$ & $\begin{array}{l}16 \\
17 \\
18 \\
19 \\
20\end{array}$ & $\begin{array}{r}102.6 \\
99.3 \\
99.0 \\
99.6 \\
98.8\end{array}$ & $\begin{array}{l}510 \\
395 \\
385 \\
405 \\
378\end{array}$ & $\begin{array}{l}97.1 \\
97.2 \\
97.3 \\
96.8 \\
98.0\end{array}$ & $\begin{array}{l}322 \\
325 \\
329 \\
313 \\
351\end{array}$ \\
\hline $\begin{array}{r}6 \\
7 \\
8 \\
9 \\
10\end{array}$ & $\begin{array}{l}97.0 \\
97.1 \\
98.3 \\
97.9 \\
97.9\end{array}$ & $\begin{array}{l}319 \\
322 \\
361 \\
348 \\
348\end{array}$ & $\begin{array}{l}97.3 \\
97.5 \\
97.8 \\
96.6 \\
97.1\end{array}$ & $\begin{array}{l}329 \\
335 \\
345 \\
306 \\
322\end{array}$ & $\begin{array}{l}21 \\
22 \\
23 \\
24 \\
25\end{array}$ & $\begin{array}{l}97.6 \\
97.5 \\
97.5 \\
98.2 \\
97.7\end{array}$ & $\begin{array}{l}\mathbf{3 3 8} \\
335 \\
\mathbf{3 3 5} \\
\mathbf{3 5 8} \\
\mathbf{3 4 1}\end{array}$ & $\begin{array}{l}98.4 \\
98.6 \\
97.5 \\
98.1 \\
97.2\end{array}$ & $\begin{array}{l}\mathbf{3 6 5} \\
\mathbf{3 7 1} \\
\mathbf{3 3 5} \\
\mathbf{3 5 4} \\
\mathbf{3 2 5}\end{array}$ \\
\hline $\begin{array}{l}11 \\
12 \\
13 \\
14 \\
15\end{array}$ & $\begin{array}{r}97.9 \\
98.0 \\
96.8 \\
97.8 \\
105.0\end{array}$ & $\begin{array}{l}348 \\
351 \\
313 \\
345 \\
596\end{array}$ & $\begin{array}{l}96.7 \\
95.8 \\
96.3 \\
97.6 \\
97.9\end{array}$ & $\begin{array}{l}309 \\
281 \\
297 \\
338 \\
348\end{array}$ & $\begin{array}{l}26 \\
27 \\
28 \\
29 \\
30 \\
31 \\
\end{array}$ & $\begin{array}{l}97.0 \\
95.8 \\
95.5 \\
97.9 \\
99.1 \\
96.6 \\
\end{array}$ & $\begin{array}{l}319 \\
281 \\
272 \\
348 \\
388 \\
306 \\
\end{array}$ & $\begin{array}{l}97.4 \\
97.8 \\
97.8 \\
97.8 \\
98.0\end{array}$ & $\begin{array}{l}332 \\
345 \\
345 \\
345 \\
351\end{array}$ \\
\hline \multirow{2}{*}{\multicolumn{8}{|c|}{ Change in contents, equivalent, in second-feet }} & August & $\begin{array}{c}\text { Sep- } \\
\text { tember }\end{array}$ \\
\hline & & & & & & & & -3.73 & +17.4 \\
\hline
\end{tabular}

SuPPLEMENTAL RECoRD.-July 31, midnight, gage height, 96.9 feet; contents, 316 milhon cubic feet 


\section{FLOODS OF AUGUST 1940 IN THE SOUTHEASTERN STATES}

Rocky Creek Reservoir, gage height, contents, mean inflow for preceding hour, and outflow, at indicated time, 1940

\begin{tabular}{|c|c|c|c|c|c|c|c|c|c|c|}
\hline \multirow[b]{2}{*}{ Hour } & \multicolumn{6}{|c|}{ Aug. 12} & \multicolumn{4}{|c|}{ Aug. 13} \\
\hline & $\begin{array}{c}\text { Gage } \\
\text { height }^{1} \\
\text { (feet) }\end{array}$ & $\begin{array}{l}\text { Contents } \\
\text { (million } \\
\text { cubic feet) }\end{array}$ & \multicolumn{2}{|c|}{$\begin{array}{l}\text { Inflow } \\
\text { (second- } \\
\text { feet) }\end{array}$} & \multicolumn{2}{|c|}{$\begin{array}{l}\text { Outflow } \\
\text { (second- } \\
\text { feet) }\end{array}$} & $\begin{array}{c}\text { Gage } \\
\text { height }{ }^{1} \\
\text { (feet) }\end{array}$ & $\begin{array}{c}\text { Contents } \\
\text { (million } \\
\text { cubic feet) }\end{array}$ & $\begin{array}{l}\text { Inflow } \\
\text { (second- } \\
\text { feet) }\end{array}$ & $\begin{array}{c}\text { Outflow } \\
\text { (second- } \\
\text { feet) }\end{array}$ \\
\hline $\begin{array}{l}1 \\
2 \\
3 \\
4 \\
5 \\
6\end{array}$ & $\begin{array}{l}97.91 \\
97.92 \\
97.93 \\
97.94 \\
97.90 \\
97.80\end{array}$ & $\begin{array}{l}348.1 \\
348.4 \\
348.8 \\
349.1 \\
347.8 \\
344.6\end{array}$ & \multicolumn{2}{|c|}{$\begin{array}{r}80 \\
80 \\
110 \\
80 \\
340 \\
410\end{array}$} & \multicolumn{2}{|c|}{$\begin{array}{r}0 \\
0 \\
0 \\
0 \\
400 \\
200\end{array}$} & $\begin{array}{l}98.04 \\
98.08 \\
98.12 \\
98.16 \\
98.20 \\
98.24\end{array}$ & $\begin{array}{l}352.4 \\
353.7 \\
355.1 \\
356.4 \\
357.8 \\
359.2\end{array}$ & $\begin{array}{l}390 \\
360 \\
390 \\
360 \\
390 \\
390\end{array}$ & $\begin{array}{l}0 \\
0 \\
0 \\
0 \\
0 \\
0\end{array}$ \\
\hline $\begin{array}{r}7 \\
8 \\
9 \\
10 \\
11 \\
\mathrm{~N}\end{array}$ & $\begin{array}{l}97.70 \\
97.90 \\
98.00 \\
98.10 \\
98.30 \\
98.50\end{array}$ & $\begin{array}{l}341.4 \\
347.8 \\
351.0 \\
354.4 \\
361.2 \\
368.0\end{array}$ & \multicolumn{2}{|c|}{$\begin{array}{r}210 \\
2,780 \\
1,890 \\
2,090 \\
3,190 \\
4,540\end{array}$} & \multicolumn{2}{|c|}{$\begin{array}{l}1,000 \\
1,000 \\
1,000 \\
1,300 \\
1,300 \\
4,000\end{array}$} & $\begin{array}{l}98.30 \\
98.30 \\
98.30 \\
98.30 \\
98.10 \\
98.00\end{array}$ & $\begin{array}{l}361.2 \\
361.2 \\
361.2 \\
361.2 \\
354.4 \\
351.0\end{array}$ & $\begin{array}{r}560 \\
1,300 \\
2,600 \\
2,600 \\
3,210 \\
5,460\end{array}$ & $\begin{array}{r}0 \\
2,600 \\
2,600 \\
2,600 \\
7,600 \\
5,200\end{array}$ \\
\hline $\begin{array}{l}1 \\
2 \\
3 \\
4 \\
5 \\
6\end{array}$ & $\begin{array}{l}98.30 \\
98.10 \\
98.00 \\
97.90 \\
97.70 \\
97.60\end{array}$ & $\begin{array}{l}361.2 \\
354.4 \\
351.0 \\
347.8 \\
341.4 \\
338.2\end{array}$ & \multicolumn{2}{|c|}{$\begin{array}{l}2,060 \\
1,560 \\
2,060 \\
2,110 \\
1,220 \\
2,110\end{array}$} & \multicolumn{2}{|c|}{$\begin{array}{l}3,900 \\
3,000 \\
3,000 \\
3,000 \\
3,000 \\
3,000\end{array}$} & $\begin{array}{l}97.90 \\
97.80 \\
97.60 \\
97.40 \\
97.40 \\
97.30\end{array}$ & $\begin{array}{l}347.8 \\
344.6 \\
338.2 \\
331.8 \\
331.8 \\
328.6\end{array}$ & $\begin{array}{l}3,210 \\
2,110 \\
1,220 \\
1,220 \\
3,000 \\
3,260\end{array}$ & $\begin{array}{l}3,000 \\
3,000 \\
3,000 \\
3,000 \\
3,000 \\
5,300\end{array}$ \\
\hline $\begin{array}{r}7 \\
8 \\
9 \\
10 \\
11 \\
12 \\
\end{array}$ & $\begin{array}{l}97.60 \\
97.60 \\
97.60 \\
97.60 \\
97.80 \\
98.00 \\
\end{array}$ & $\begin{array}{l}338.2 \\
338.2 \\
338.2 \\
338.2 \\
344.6 \\
351.0 \\
\end{array}$ & \multicolumn{2}{|c|}{$\begin{array}{l}2,800 \\
2,600 \\
2,600 \\
2,400 \\
2,880 \\
1,780 \\
\end{array}$} & \multicolumn{2}{|c|}{$\begin{array}{r}2,600 \\
2,600 \\
2,600 \\
2,200 \\
0 \\
0 \\
\end{array}$} & $\begin{array}{l}97.30 \\
97.30 \\
97.10 \\
96.90 \\
96.90 \\
96.80 \\
\end{array}$ & $\begin{array}{l}328.6 \\
328.6 \\
322.2 \\
315.8 \\
315.8 \\
312.6 \\
\end{array}$ & $\begin{array}{l}5,300 \\
6,300 \\
5,020 \\
4,520 \\
4,900 \\
2,610 \\
\end{array}$ & $\begin{array}{l}5,300 \\
7,300 \\
6,300 \\
6,300 \\
3,500 \\
3,500 \\
\end{array}$ \\
\hline & \multicolumn{6}{|c|}{ Aug. 14} & \multicolumn{4}{|c|}{ Aug. 15} \\
\hline $\begin{array}{l}1 \\
2 \\
3 \\
4 \\
5 \\
6\end{array}$ & $\begin{array}{l}96.8 \\
96.9 \\
97.0 \\
97.1 \\
97.2 \\
97.1\end{array}$ & $\begin{array}{l}312.6 \\
315.8 \\
319.0 \\
322.2 \\
325.4 \\
322.2\end{array}$ & \multicolumn{2}{|c|}{$\begin{array}{l}3,650 \\
4,090 \\
3,590 \\
3,390 \\
3,490 \\
3,110\end{array}$} & \multicolumn{2}{|c|}{$\begin{array}{l}3,800 \\
2,600 \\
2,800 \\
2,200 \\
3,000 \\
5,000\end{array}$} & $\begin{array}{r}98.0 \\
98.5 \\
99.4 \\
99.8 \\
100.2 \\
100.2\end{array}$ & $\begin{array}{l}351.0 \\
368.0 \\
398.6 \\
412.2 \\
425.8 \\
425.8\end{array}$ & $\begin{array}{l}42,920 \\
45,900 \\
49,730 \\
45,670 \\
46,740 \\
44,670\end{array}$ & $\begin{array}{l}41,380 \\
40,980 \\
41,480 \\
42,300 \\
43,620 \\
45,720\end{array}$ \\
\hline $\begin{array}{r}7 \\
8 \\
9 \\
10 \\
11 \\
N\end{array}$ & $\begin{array}{l}97.0 \\
96.8 \\
96.5 \\
96.4 \\
96.2 \\
96.3\end{array}$ & $\begin{array}{l}319.0 \\
312.6 \\
303.0 \\
299.8 \\
293.4 \\
296.6\end{array}$ & \multicolumn{2}{|c|}{$\begin{array}{l}\mathbf{5}, 110 \\
\mathbf{5}, 250 \\
4,450 \\
6,290 \\
\mathbf{5}, 390 \\
\mathbf{8}, 090\end{array}$} & \multicolumn{2}{|c|}{$\begin{array}{l}7,000 \\
7,050 \\
7,200 \\
7,150 \\
7,200 \\
7,200\end{array}$} & $\begin{array}{l}100.2 \\
100.7 \\
100.7 \\
102.2 \\
102.4 \\
102.4\end{array}$ & $\begin{array}{l}425.8 \\
442.8 \\
442.8 \\
495.2 \\
502.4 \\
502.4\end{array}$ & $\begin{array}{l}46,770 \\
54,040 \\
50,860 \\
72,750 \\
68,590 \\
67,700\end{array}$ & $\begin{array}{l}47,820 \\
50,810 \\
50,910 \\
65,480 \\
67,700 \\
67,700\end{array}$ \\
\hline $\begin{array}{l}1 \\
2 \\
3 \\
4 \\
5 \\
6\end{array}$ & $\begin{array}{l}96.0 \\
95.7 \\
95.6 \\
95.6 \\
95.0 \\
96.1\end{array}$ & $\begin{array}{l}287.0 \\
278.0 \\
275.0 \\
275.0 \\
257.0 \\
290.2\end{array}$ & \multicolumn{2}{|c|}{$\begin{array}{r}4,530 \\
4,750 \\
5,770 \\
5,900 \\
5,170 \\
23,670\end{array}$} & \multicolumn{2}{|c|}{$\begin{array}{r}7,200 \\
7,300 \\
5,900 \\
5,900 \\
14,440 \\
14,460\end{array}$} & $\begin{array}{l}102.4 \\
102.7 \\
102.7 \\
102.7 \\
102.8 \\
102.8\end{array}$ & $\begin{array}{l}\mathbf{5 0 2 . 4} \\
\mathbf{5 1 3 . 2} \\
\mathbf{5 1 3 . 2} \\
\mathbf{5 1 3 . 2} \\
\mathbf{5 1 6 . 8} \\
\mathbf{5 1 6 . 8}\end{array}$ & $\begin{array}{l}67,630 \\
71,530 \\
68,880 \\
68,260 \\
69,870 \\
69,470\end{array}$ & $\begin{array}{l}67,550 \\
69,510 \\
68,260 \\
68,260 \\
69,470 \\
69,470\end{array}$ \\
\hline $\begin{array}{r}7 \\
8 \\
9 \\
10 \\
11 \\
12 \\
\end{array}$ & $\begin{array}{l}97.6 \\
98.2 \\
98.0 \\
98.0 \\
98.0 \\
97.8 \\
\end{array}$ & $\begin{array}{l}338.2 \\
357.8 \\
351.0 \\
351.0 \\
351.0 \\
344.6 \\
\end{array}$ & \multicolumn{2}{|c|}{$\begin{array}{l}39,870 \\
44,780 \\
38,830 \\
41,380 \\
41,380 \\
39,360 \\
\end{array}$} & \multicolumn{2}{|c|}{$\begin{array}{l}38,620 \\
40,060 \\
41,380 \\
41,380 \\
41,380 \\
40,900\end{array}$} & $\begin{array}{l}102.8 \\
104.2 \\
104.3 \\
104.4 \\
105.0 \\
105.0 \\
\end{array}$ & $\begin{array}{l}516.8 \\
567.2 \\
570.8 \\
574.4 \\
596.0 \\
596.0 \\
\end{array}$ & $\begin{array}{r}68,820 \\
91,470 \\
89,150 \\
91,270 \\
100,670 \\
98,300 \\
\end{array}$ & $\begin{array}{l}68,170 \\
86,760 \\
89,510 \\
91,040 \\
98,300 \\
98,300 \\
\end{array}$ \\
\hline \multirow[b]{2}{*}{ Hour } & \multicolumn{5}{|c|}{ Aug. 16} & & \multicolumn{4}{|c|}{ Aug. 16-Con. } \\
\hline & $\begin{array}{c}\text { Gage } \\
\text { height }^{1} \\
\text { (feet) }\end{array}$ & $\begin{array}{c}\text { Contents } \\
\text { (million } \\
\text { cubic feet) }\end{array}$ & $\begin{array}{l}\text { Inflow } \\
\text { (second- } \\
\text { feet) }\end{array}$ & & $\begin{array}{l}\text { low } \\
\text { nd- } \\
\text { t) }\end{array}$ & Hour & $\begin{array}{c}\text { Gage } \\
\text { height }{ }^{\text {(feet) }}\end{array}$ & $t^{1} \mid \begin{array}{c}\text { Contents } \\
\text { (million } \\
\text { cubic feet) }\end{array}$ & $\begin{array}{l}\text { Inflow } \\
\text { (second- } \\
\text { feet) }\end{array}$ & $\begin{array}{l}\text { Outflow } \\
\text { (second- } \\
\text { feet) }\end{array}$ \\
\hline $\begin{array}{l}1 \\
2 \\
3 \\
4 \\
5 \\
6\end{array}$ & $\begin{array}{l}105.6 \\
105.7 \\
105.9 \\
106.0 \\
106.0 \\
106.0\end{array}$ & $\begin{array}{l}617.6 \\
621.2 \\
628.4 \\
632.0 \\
632.0 \\
632.0\end{array}$ & $\begin{array}{l}108,970 \\
109,490 \\
113,110 \\
114,490 \\
114,110 \\
114,110\end{array}$ & & $\begin{array}{l}340 \\
350 \\
360 \\
110 \\
110 \\
110\end{array}$ & $\begin{array}{l}1 \\
2 \\
3 \\
4 \\
5 \\
6\end{array}$ & $\begin{array}{l}104.7 \\
104.5 \\
104.4 \\
104.4 \\
104.3 \\
104.3\end{array}$ & $\begin{array}{l}\mathbf{5 8 5 . 2} \\
\mathbf{5 7 8 . 0} \\
\mathbf{5 7 4 . 4} \\
\mathbf{5 7 4 . 4} \\
\mathbf{5 7 0 . 8} \\
\mathbf{5 7 0 . 8}\end{array}$ & $\begin{array}{l}94,810 \\
91,600 \\
90,290 \\
90,590 \\
89,130 \\
89,610\end{array}$ & $\begin{array}{l}95,150 \\
92,050 \\
90,540 \\
90,640 \\
89,610 \\
89,610\end{array}$ \\
\hline $\begin{array}{r}7 \\
8 \\
9 \\
10 \\
11 \\
\mathbf{N}\end{array}$ & $\begin{array}{l}106.0 \\
105.8 \\
105.8 \\
105.8 \\
105.5 \\
105.3\end{array}$ & $\begin{array}{l}632.0 \\
624.8 \\
624.8 \\
624.8 \\
614.0 \\
606.8\end{array}$ & $\begin{array}{l}114,710 \\
113,120 \\
114,940 \\
114,940 \\
109,320 \\
106,070\end{array}$ & & $\begin{array}{l}310 \\
940 \\
940 \\
940 \\
690 \\
460\end{array}$ & $\begin{array}{r}7 \\
8 \\
9 \\
10 \\
11 \\
12\end{array}$ & $\begin{array}{l}103.3 \\
103.0 \\
102.8 \\
102.6 \\
102.6 \\
102.6\end{array}$ & $\begin{array}{l}534.8 \\
524.0 \\
516.8 \\
509.6 \\
509.6 \\
509.6\end{array}$ & $\begin{array}{l}72,680 \\
70,870 \\
68,770 \\
66,570 \\
65,980 \\
64,680\end{array}$ & $\begin{array}{l}75,760 \\
71,970 \\
69,570 \\
67,580 \\
64,380 \\
64,980\end{array}$ \\
\hline
\end{tabular}

1 Gage heights from graph based on hourly observations.

SUPPLEMENTAL RECORD.-Aug. 11, 12 p.m., gage height, 97.9 feet; contents, 347.8 million cubic feet. 
WATEREE RIVER AT WATEREE RESERVOIR, NEAR CAMDEN, S. C.

Location.-Lat. $34^{\circ} 20^{\prime}$, long. $80^{\circ} 42^{\prime}$, at powerhouse forebay at Wateree Dam, 1 mile upstream from Sawneys Creek, and $7 \frac{1}{2}$ miles northwest of Camden, Kershaw County. Datum of gage is 126.85 feet above mean sea level (levels by Duke Power Co.). Some Duke Power Co. records for this_station, not published herein, are referred to a datum 8.85 feet lower.

DrainAGE AREA.-4,750 square miles.

GAGE-HEIGHT RECORD.-Staff gage read to tenths hourly. Adjusted gage heights Aug. 12-16 taken from graph based on hourly readings.

DISCHARGE RECORD.-Record of outflow based on formula for spillway and manufacturer's ratings for turbines. Record of inflow based on outflow and change in contents.

Maxima.-1940: Mean inflow, 132,200 second-feet for hour ending 8 a.m. Aug. 16; outflow, 85,040 second-feet 3 p.m. Aug. 16; reservoir gage height, 106.30 feet 2 p.m. Aug. 16 (contents 11,621,000,000 cubic feet).

REMARKS.-Reservoir, first put in use Oct. 7, 1919, has a storage capacity of $7,626,000,000$ cubic feet under normal operation between gage heights. of 84.0 and 100.0 feet (crest of spillway). River affected by storage in Bridgewater, Rhodhiss, Oxford, Lookout Shoals, Mountain Island, Catawba, Fishing Creek, and Rocky Creek Reservoirs upstream having a combined storage capacity under normal operation of $24,442,000,000$ cubic feet. Records furnished by Duke Power Co.

Wateree Reservoir, gage height and contents at midnight, 1940

\begin{tabular}{|c|c|c|c|c|c|c|c|c|c|}
\hline \multirow[b]{2}{*}{ Day } & \multicolumn{2}{|c|}{ August } & \multicolumn{2}{|c|}{ September } & \multirow[b]{2}{*}{ Day } & \multicolumn{2}{|c|}{ August } & \multicolumn{2}{|c|}{ September } \\
\hline & $\begin{array}{c}\text { Gage } \\
\text { height } \\
\text { (feet) }\end{array}$ & $\begin{array}{c}\text { Contents } \\
\text { (million } \\
\text { cubic feet) }\end{array}$ & $\begin{array}{c}\text { Gage } \\
\text { height } \\
\text { (feet) }\end{array}$ & $\begin{array}{c}\text { Contents } \\
\text { (million } \\
\text { cubic feet) }\end{array}$ & & $\begin{array}{c}\text { Gage } \\
\text { height } \\
\text { (feet) }\end{array}$ & $\begin{array}{c}\text { Contents } \\
\text { (million } \\
\text { cubic feet) }\end{array}$ & $\begin{array}{c}\text { Gage } \\
\text { height } \\
\text { (feet) }\end{array}$ & $\begin{array}{c}\text { Contents } \\
\text { (million } \\
\text { cubic } \\
\text { feet) }\end{array}$ \\
\hline $\begin{array}{l}1 \\
2 \\
3 \\
4 \\
5\end{array}$ & $\begin{array}{l}95.1 \\
94.9 \\
94.6 \\
94.6 \\
94.5\end{array}$ & $\begin{array}{l}4,884 \\
4,780 \\
4,625 \\
4,625 \\
4,574\end{array}$ & $\begin{array}{l}96.7 \\
98.1 \\
99.2 \\
99.1 \\
99.1\end{array}$ & $\begin{array}{l}5,738 \\
6,518 \\
7,152 \\
7,094 \\
7,094\end{array}$ & $\begin{array}{l}16 \\
17 \\
18 \\
19 \\
20\end{array}$ & $\begin{array}{l}106.1 \\
103.3 \\
102.4 \\
101.0 \\
100.9\end{array}$ & $\begin{array}{r}11,487 \\
9,662 \\
9,092 \\
8,222 \\
8,161\end{array}$ & $\begin{array}{l}96.4 \\
96.2 \\
96.1 \\
96.0 \\
95.9\end{array}$ & $\begin{array}{l}5,575 \\
5,467 \\
5,413 \\
5,359 \\
5,306\end{array}$ \\
\hline $\begin{array}{r}6 \\
7 \\
8 \\
9 \\
10\end{array}$ & $\begin{array}{l}94.5 \\
94.3 \\
93.9 \\
93.6 \\
93.2\end{array}$ & $\begin{array}{l}4,574 \\
4,472 \\
4,269 \\
4,118 \\
3,920\end{array}$ & $\begin{array}{l}99.3 \\
99.3 \\
99.3 \\
99.1 \\
98.7\end{array}$ & $\begin{array}{l}7,211 \\
7,211 \\
7,211 \\
7,094 \\
6,862\end{array}$ & $\begin{array}{l}21 \\
22 \\
23 \\
24 \\
25\end{array}$ & $\begin{array}{r}100.1 \\
99.5 \\
98.9 \\
98.3 \\
98.3\end{array}$ & $\begin{array}{l}7,685 \\
7,329 \\
6,978 \\
6,633 \\
6,633\end{array}$ & $\begin{array}{l}95.6 \\
95.8 \\
95.7 \\
95.4 \\
95.0\end{array}$ & $\begin{array}{l}5,146 \\
5,253 \\
5,199 \\
5,040 \\
4,832\end{array}$ \\
\hline $\begin{array}{l}11 \\
12 \\
13 \\
14 \\
15\end{array}$ & $\begin{array}{r}93.2 \\
93.1 \\
93.3 \\
94.7 \\
102.3\end{array}$ & $\begin{array}{l}3,920 \\
3,871 \\
3,969 \\
4,676 \\
9,029\end{array}$ & $\begin{array}{l}98.3 \\
97.5 \\
96.5 \\
95.9 \\
96.3\end{array}$ & $\begin{array}{l}6,633 \\
6,180 \\
5,629 \\
5,306 \\
5,521\end{array}$ & $\begin{array}{l}26 \\
27 \\
28 \\
29 \\
30 \\
31 \\
\end{array}$ & $\begin{array}{l}97.9 \\
97.2 \\
96.3 \\
95.9 \\
96.1 \\
96.7 \\
\end{array}$ & $\begin{array}{l}6,405 \\
6,013 \\
\mathbf{5}, 521 \\
\mathbf{5}, 306 \\
\mathbf{5}, 413 \\
\mathbf{5 , 7 3 8} \\
\end{array}$ & $\begin{array}{l}94.8 \\
94.4 \\
94.1 \\
94.1 \\
93.8\end{array}$ & $\begin{array}{r}4,728 \\
4,522 \\
4,370 \\
4,370 \\
4,218 \\
\\
\end{array}$ \\
\hline \multirow{2}{*}{\multicolumn{8}{|c|}{ Change in contents, equivalent, in second-feet }} & August & $\begin{array}{c}\text { Sep- } \\
\text { tember }\end{array}$ \\
\hline & & & & & & & & +299 & -586 \\
\hline
\end{tabular}

Supplemental Recond.-July 31, midnight, gage height, 95.2 feet; contents, 4,936 million cubic feet. 


\section{FLOODS OF AUGUST 1940 IN THE SOUTHEASTERN STATES}

Wateree Reservoir, gage height, contents, mean inflow for preceding hour, and outflow, at indicated time, 1940

\begin{tabular}{|c|c|c|c|c|c|c|c|c|c|}
\hline \multirow[b]{2}{*}{ Hour } & \multicolumn{5}{|c|}{ Aug. 12} & \multicolumn{4}{|c|}{ Aug. 13} \\
\hline & $\begin{array}{c}\text { Gage } \\
\text { height' } \\
\text { (feet) }\end{array}$ & $\begin{array}{c}\text { Contents } \\
\text { (million } \\
\text { cubic feet) }\end{array}$ & $\begin{array}{l}\text { Inflo } \\
\text { (seco } \\
\text { feet }\end{array}$ & $\begin{array}{l}\text { Out } \\
\text { (sec } \\
\text { fe }\end{array}$ & & $\begin{array}{c}\text { Gage } \\
\text { height }{ }^{1} \\
\text { (feet) }\end{array}$ & $\begin{array}{c}\text { Contents } \\
\text { (million } \\
\text { cubic feet) }\end{array}$ & $\begin{array}{l}\text { Inflow } \\
\text { (second- } \\
\text { feet) }\end{array}$ & $\begin{array}{l}\text { Outflow } \\
\text { (second- } \\
\text { feet) }\end{array}$ \\
\hline $\begin{array}{l}1 \\
2 \\
3 \\
4 \\
5 \\
6\end{array}$ & $\begin{array}{l}93.12 \\
93.14 \\
93.16 \\
93.18 \\
93.20 \\
93.20\end{array}$ & $\begin{array}{l}3,880.6 \\
3,890.5 \\
3,900.3 \\
3,910.2 \\
3,920.0 \\
3,920.0\end{array}$ & $\begin{array}{l}2, \\
2, \\
2, \\
2, \\
2, \\
1,\end{array}$ & & $\begin{array}{l}0 \\
0 \\
0 \\
0 \\
0 \\
00\end{array}$ & $\begin{array}{l}93.04 \\
93.05 \\
93.06 \\
93.07 \\
93.08 \\
93.09\end{array}$ & $\begin{array}{l}3,841 \cdot 3 \\
3,846.3 \\
3,851.2 \\
3,856.1 \\
3,861.0 \\
3,865.9\end{array}$ & $\begin{array}{l}1,360 \\
1,390 \\
1,360 \\
1,360 \\
1,360 \\
2,910\end{array}$ & $\begin{array}{r}0 \\
0 \\
0 \\
0 \\
0 \\
3,100\end{array}$ \\
\hline $\begin{array}{r}7 \\
8 \\
9 \\
10 \\
11 \\
\mathbf{N}\end{array}$ & $\begin{array}{l}93.19 \\
93.18 \\
93.16 \\
93.14 \\
93.12 \\
93.10\end{array}$ & $\begin{array}{l}3,915.1 \\
3,910.2 \\
3,900.3 \\
3,890.4 \\
3,880.6 \\
3,870.8\end{array}$ & $\begin{array}{r}1,5 \\
2,2 \\
2,0 \\
2,1 \\
2,1 \\
9\end{array}$ & & & $\begin{array}{l}93.09 \\
93.10 \\
93.11 \\
93.12 \\
93.13 \\
93.14\end{array}$ & $\begin{array}{l}3,865.9 \\
3,870.8 \\
3,875.7 \\
3,880.6 \\
3,885.6 \\
3,890.5\end{array}$ & $\begin{array}{l}2,750 \\
3,760 \\
3,760 \\
3,760 \\
4,990 \\
4,960\end{array}$ & $\begin{array}{l}2,400 \\
2,400 \\
2,400 \\
2,400 \\
4,800 \\
2,400\end{array}$ \\
\hline $\begin{array}{l}1 \\
2 \\
3 \\
4 \\
5 \\
6\end{array}$ & $\begin{array}{l}93.09 \\
93.08 \\
93.07 \\
93.06 \\
93.05 \\
93.04\end{array}$ & $\begin{array}{l}3,865.9 \\
3,861.0 \\
3,856.1 \\
3,851.2 \\
3,846.3 \\
3,841.3\end{array}$ & $\begin{array}{r}1,0 \\
1,0 \\
1,0 \\
1,0 \\
5 \\
1\end{array}$ & & & $\begin{array}{l}93.15 \\
93.16 \\
93.17 \\
93.18 \\
93.19 \\
93.20\end{array}$ & $\begin{array}{l}3,895.4 \\
3,900.3 \\
3,905.2 \\
3,910.2 \\
3,915.1 \\
3,920.0\end{array}$ & $\begin{array}{l}3,760 \\
3,760 \\
3,760 \\
3,790 \\
3,310 \\
3,810\end{array}$ & $\begin{array}{l}2,400 \\
2,400 \\
2,400 \\
2,400 \\
1,500 \\
3,400\end{array}$ \\
\hline \multirow[t]{2}{*}{$\begin{array}{r}7 \\
8 \\
9 \\
10 \\
11 \\
12 \\
\end{array}$} & $\begin{array}{l}93.03 \\
93.02 \\
93.01 \\
93.01 \\
93.02 \\
93.03 \\
\end{array}$ & $\begin{array}{l}3,836.4 \\
3,831.5 \\
3,826.6 \\
3,826.6 \\
3,831.5 \\
3,836.4 \\
\end{array}$ & $\begin{array}{r}1 \\
5 \\
1,0 \\
1,2 \\
1,3 \\
1,3 \\
\end{array}$ & & $\begin{array}{r}00 \\
00 \\
00 \\
0 \\
0 \\
0 \\
\end{array}$ & $\begin{array}{l}93.21 \\
93.22 \\
93.23 \\
93.24 \\
93.24 \\
93.25 \\
\end{array}$ & $\begin{array}{l}3,924.9 \\
3,929.9 \\
3,934.8 \\
3,939.8 \\
3,939.8 \\
3,944.7 \\
\end{array}$ & $\begin{array}{l}4,960 \\
5,640 \\
7,410 \\
8,790 \\
4,900 \\
4,510 \\
\end{array}$ & $\begin{array}{l}3,800 \\
4,700 \\
7,400 \\
7,400 \\
2,400 \\
3,900 \\
\end{array}$ \\
\hline & \multicolumn{5}{|c|}{ Aug. 14} & \multicolumn{4}{|c|}{ Aug. 15} \\
\hline $\begin{array}{l}1 \\
2 \\
3 \\
4 \\
5 \\
6 \\
6\end{array}$ & $\begin{array}{l}93.25 \\
93.26 \\
93.28 \\
93.30 \\
93.37 \\
93.45\end{array}$ & $\begin{array}{l}3,944.7 \\
3,949.6 \\
3,959.5 \\
3,969.4 \\
4,004.1 \\
4,043.7\end{array}$ & $\begin{array}{r}2,6 \\
2,0 \\
2,7 \\
2,7 \\
9,6 \\
12,3\end{array}$ & & $\begin{array}{r}00 \\
0 \\
0 \\
0 \\
0 \\
00\end{array}$ & $\begin{array}{l}94.95 \\
95.20 \\
95.45 \\
95.70 \\
96.00 \\
\mathbf{9 6 . 3 5}\end{array}$ & $\begin{array}{l}4,805.7 \\
4,935.9 \\
5,067.1 \\
5,199.3 \\
5,359.2 \\
5,547.5\end{array}$ & $\begin{array}{l}40,440 \\
38,820 \\
39,440 \\
39,720 \\
47,420 \\
55,360\end{array}$ & $\begin{array}{l}2,300 \\
3,000 \\
3,000 \\
3,000 \\
3,000 \\
3,100\end{array}$ \\
\hline $\begin{array}{r}7 \\
8 \\
9 \\
10 \\
11 \\
\mathrm{~N}\end{array}$ & $\begin{array}{l}93.50 \\
93.54 \\
93.56 \\
93.57 \\
93.58 \\
93.59\end{array}$ & $\begin{array}{l}4,068.6 \\
4,088.5 \\
4,098.5 \\
4,103.5 \\
4,108.4 \\
4,113.4\end{array}$ & $\begin{array}{l}11, \\
14, \\
14, \\
14, \\
14, \\
14,1\end{array}$ & & & $\begin{array}{l}96.60 \\
96.85 \\
97.10 \\
97.40 \\
97.70 \\
98.10\end{array}$ & $\begin{array}{l}5,683.0 \\
5,819.6 \\
5,957.1 \\
6,123.5 \\
6,291.7 \\
6,518.2\end{array}$ & $\begin{array}{l}41,940 \\
45,840 \\
48,490 \\
56,920 \\
57,820 \\
74,020\end{array}$ & $\begin{array}{r}5,500 \\
10,300 \\
10,300 \\
11,100 \\
11,100 \\
11,100\end{array}$ \\
\hline $\begin{array}{l}1 \\
2 \\
3 \\
4 \\
5 \\
6\end{array}$ & $\begin{array}{l}93.60 \\
93.61 \\
93.62 \\
93.63 \\
93.64 \\
93.65\end{array}$ & $\begin{array}{l}4,118.4 \\
4,123.4 \\
4,128.4 \\
4,133.4 \\
4,138.4 \\
4,143.4\end{array}$ & $\begin{array}{l}12,9 \\
12,5 \\
12,9 \\
11,7 \\
10,9 \\
12,0\end{array}$ & $\begin{array}{r}10, \\
11, \\
11, \\
9, \\
9, \\
11,\end{array}$ & & $\begin{array}{r}98.50 \\
98.85 \\
99.20 \\
99.50 \\
99.80 \\
100.10\end{array}$ & $\begin{array}{l}6,747.1 \\
6,949.0 \\
7,152.7 \\
7,328.9 \\
7,506.5 \\
7,685.0\end{array}$ & $\begin{array}{l}74,680 \\
67,180 \\
67,680 \\
60,040 \\
60,080 \\
60,340\end{array}$ & $\begin{array}{r}11,100 \\
11,100 \\
11,100 \\
11,100 \\
10,400 \\
11,120\end{array}$ \\
\hline $\begin{array}{r}7 \\
8 \\
9 \\
10 \\
11 \\
12 \\
\end{array}$ & $\begin{array}{l}93.70 \\
93.80 \\
93.90 \\
94.10 \\
94.40 \\
94.70 \\
\end{array}$ & $\begin{array}{l}4,168.4 \\
4,218.5 \\
4,268.7 \\
4,369.7 \\
4,522.3 \\
4,676.3 \\
\end{array}$ & $\begin{array}{l}18, \\
25, \\
24, \\
38, \\
50, \\
48, \\
\end{array}$ & $\begin{array}{r}10 \\
11 \\
9 \\
11 \\
4 \\
6 \\
\end{array}$ & & $\begin{array}{l}100.50 \\
100.85 \\
101.20 \\
101.60 \\
102.00 \\
102.30 \\
\end{array}$ & $\begin{array}{l}7,922.8 \\
8,130.9 \\
8,344.0 \\
8,592.0 \\
8,840.0 \\
9,029.0 \\
\end{array}$ & $\begin{array}{l}77,830 \\
71,120 \\
74,700 \\
87,240 \\
88,470 \\
71,610 \\
\end{array}$ & $\begin{array}{l}12,410 \\
14,210 \\
16,810 \\
19,890 \\
19,270 \\
18,960 \\
\end{array}$ \\
\hline \multirow[b]{2}{*}{ I } & \multicolumn{4}{|c|}{ Aug. 16} & & \multicolumn{4}{|c|}{ Aug. 16-Con. } \\
\hline & $\begin{array}{c}\text { Gage } \\
\text { height }{ }^{1} \\
\text { (feet) }\end{array}$ & $\begin{array}{c}\text { Contents } \\
\text { (million } \\
\text { cubic feet) }\end{array}$ & $\begin{array}{l}\text { Inflow } \\
\text { (second- } \\
\text { feet) }\end{array}$ & $\begin{array}{l}\text { Outflow } \\
\text { (second- } \\
\text { feet) }\end{array}$ & Hour & $\underset{\substack{\text { Gage } \\
\text { height }{ }^{1}}}{\text { (feet) }}$ & $\mid \begin{array}{c}\text { Contents } \\
\text { (million } \\
\text { cubic feet) }\end{array}$ & $\begin{array}{l}\text { Inflow } \\
\text { (second- } \\
\text { feet) }\end{array}$ & $\begin{array}{l}\text { Outflow } \\
\text { (second- } \\
\text { feet) }\end{array}$ \\
\hline $\begin{array}{l}1 \\
2 \\
3 \\
4 \\
5 \\
5 \\
6\end{array}$ & $\begin{array}{l}102.80 \\
103.30 \\
103.70 \\
104.05 \\
104.40 \\
104.70\end{array}$ & $\begin{array}{r}9,344.0 \\
9,662.0 \\
9,918.0 \\
10,142.5 \\
10,370.0 \\
10,565.0\end{array}$ & $\begin{array}{r}108,830 \\
114,680 \\
103,150 \\
99,850 \\
105,120 \\
102,480\end{array}$ & $\begin{array}{l}23,690 \\
29,020 \\
35,050 \\
39,940 \\
43,920 \\
52,700\end{array}$ & $\begin{array}{l}1 \\
2 \\
3 \\
4 \\
5 \\
6\end{array}$ & $\begin{array}{l}106.20 \\
106.30 \\
106.28 \\
106.26 \\
106.24 \\
106.22\end{array}$ & $\begin{array}{l}11,554.0 \\
11,621.0 \\
11,607.6 \\
11,594.2 \\
11,580.8 \\
11,567.4\end{array}$ & $\begin{array}{r}100,250 \\
102,160 \\
81,050 \\
81,140 \\
80,780 \\
80,480\end{array}$ & $\begin{array}{l}82,620 \\
84,490 \\
85,040 \\
84,680 \\
84,330 \\
84,070\end{array}$ \\
\hline $\begin{array}{r}7 \\
8 \\
9 \\
10 \\
11 \\
\mathbf{N}\end{array}$ & $\begin{array}{l}105.00 \\
105.37 \\
105.60 \\
105.80 \\
105.95 \\
106.10 \\
\end{array}$ & $\begin{array}{l}10,760.0 \\
11,004.0 \\
11,156.0 \\
11,288.0 \\
11,387.0 \\
11,487.0\end{array}$ & $\begin{array}{l}111,080 \\
132,200 \\
111,760 \\
108,990 \\
102,670 \\
106,630\end{array}$ & $\begin{array}{l}61,110 \\
67,730 \\
71,350 \\
73,290 \\
77,050 \\
80,650\end{array}$ & $\begin{array}{r}7 \\
8 \\
9 \\
10 \\
11 \\
12\end{array}$ & $\begin{array}{l}106.20 \\
106.18 \\
106.16 \\
106.14 \\
106.12 \\
106.10\end{array}$ & $\begin{array}{l}11,554.0 \\
11,540.6 \\
11,527.2 \\
11,513.8 \\
11,500.4 \\
11,487.0\end{array}$ & $\begin{array}{l}79,800 \\
79,410 \\
78,720 \\
76,220 \\
72,920\end{array}$ & $\begin{array}{l}83,720 \\
83,330 \\
82,930 \\
81,940 \\
77,940 \\
75,350\end{array}$ \\
\hline
\end{tabular}

\footnotetext{
1 Gage heights from graph based on hourly observations.
}

SuPPLeMENTAL RECoRD.-Aug. 11, 12 p.m., gage height, 93.1 feet; contenta, 3,870 million cubic feet. 
WATEREE RIVER NEAR CAMDEN, S. C.

Location.-Lat. $34^{\circ} 14^{\prime} 50^{\prime \prime}$, long. $80^{\circ} 39^{\prime} 20^{\prime \prime}$, at bridge on U. S. Highway 1,500 feet downstream from Twentyfivemile Creek, 5,000 feet upstream from Seaboard Railway bridge, 3 miles southwest of Camden, Kershaw County, and 7 miles downstream from Wateree Dam. Datum of gage is 119.36 feet (revised) above mean sea level, datum of 1929, supplementary adjustment of 1936 .

Drainage area.-5,070 square miles (1942 revision).

GAGE-HEIGHT RECORD.-Water-stage recorder graph.

DISCHARGE RECORD.-Stage-discharge relation defined by current-meter measurements up to 130,000 second-feet.

Maxima.-1940: Discharge, 89,000 second-feet 11 p.m. Aug. 16 (gage height, 30.50 feet).

1903-10, 1929-39: Discharge, 198,000 second-feet (estimated) Aug. 26, 1908 (gage height, 39.7 feet, at site $1 \frac{112}{2}$ miles downstream, from records of U. S. Weather Bureau).

1891-1940: Stage known, 40.4 feet July 18, 1916, at site 11/2 miles downstream, from records of U. S. Weather Bureau (discharge uncertain, figure previously published believed to be too small).

REMARKS.-Flood discharge affected by artificial storage in Wateree Reservoir (capacity, 7,626,000,000 eubic feet) and other reservoirs on the Catawba River in North and South Carolina.

Mean discharge, in second-feet, 1940

\begin{tabular}{|c|c|c|c|c|c|c|c|c|c|c|c|}
\hline Day & Aug. & Sept. & Day & Aug. & Sept. & Day & Aug. & Sept. & Day & Aug. & Sept. \\
\hline $\begin{array}{l}1 \\
2 \\
3 \\
4 \\
5 \\
6 \\
7 \\
8\end{array}$ & $\begin{array}{r}1,980 \\
2,140 \\
1,800 \\
447 \\
1,420 \\
2,030 \\
2,880 \\
3,060\end{array}$ & $\begin{array}{r}416 \\
2,820 \\
5,900 \\
7,280 \\
8,090 \\
7,750 \\
6,130 \\
2,490\end{array}$ & $\begin{array}{l}9 \\
10 \\
11 \\
12 \\
13 \\
14 \\
15 \\
16\end{array}$ & $\begin{array}{r}3,550 \\
2,400 \\
560 \\
2,050 \\
2,380 \\
7,840 \\
9,980 \\
54,600\end{array}$ & $\begin{array}{r}5,950 \\
9,990 \\
10,900 \\
11,700 \\
12,300 \\
11,200 \\
1,660 \\
5,780\end{array}$ & $\begin{array}{l}17 \\
18 \\
19 \\
20 \\
21 \\
22 \\
23 \\
24\end{array}$ & $\begin{array}{l}61,000 \\
26,600 \\
17,500 \\
13,600 \\
13,400 \\
12,600 \\
12,200 \\
10,800\end{array}$ & $\begin{array}{l}9,260 \\
9,500 \\
8,780 \\
9,360 \\
7,840 \\
2,030 \\
5,880 \\
8,270\end{array}$ & $\begin{array}{l}25 \\
26 \\
27 \\
28 \\
29 \\
30 \\
31\end{array}$ & $\begin{array}{r}4,020 \\
8,670 \\
11,800 \\
12,800 \\
11,100 \\
7,570 \\
2,210\end{array}$ & $\begin{array}{r}8,330 \\
7,570 \\
6,650 \\
2,440 \\
461 \\
4,190 \\
\end{array}$ \\
\hline \multicolumn{10}{|c|}{$\begin{array}{l}\text { Monthly mean discharge, in second-feet. } \\
\text { Runoff, in inches }\end{array}$} & $\begin{array}{r}10,480 \\
2.38\end{array}$ & $\begin{array}{r}6,697 \\
1.47\end{array}$ \\
\hline
\end{tabular}

SANTEE RIVER A'T FERGUSON, S. C.

Locatron.-Lat. $33^{\circ} 26^{\prime} 15^{\prime \prime}$, long. $80^{\circ} 16^{\prime} 20^{\prime \prime}$, at-Ferguson, Orangeburg County, 4 miles downstream from Eutaw Creek. Datum of gage is 42.30 feet above mean sea level, datum of 1929, supplementary adjustment of 1936 .

Drainage AREa. - 14,600 square miles (1944 revision); 2,420 square miles affected by storage in Lake Murray.

GAGE-HEIGHT RECORD.-Water-stage recorder graph.

DISCHARGE RECORD.--Stage-discharge relation defined by current-meter measurements up to 260,000 second-feet and extended to crest gage height.

Maxima.-1940: Discharge, 56,000 second-feet 10 a.m. Aug. 21 (gage height, 14.07 feet).

1907-39: Discharge observed, 368,000 second-feet July 22, 1916 (gage height, 24.5 feet).

REMARKs.-Flood discharge affected by artificial storage in Lake Murray on Saluda River and other reservoirs on the Broad and Catawba-Wateree Rivers in North and South Carolina; also by natural storage in large swampy areas above station. 
Mean discharge, in second-feet, 1940

\begin{tabular}{|c|c|c|c|c|c|c|c|c|c|c|c|}
\hline Day & Aug. & Sept. & Day & Aug. & Sept. & Day & Aug. & Sept. & Day & Aug. & Sept. \\
\hline $\begin{array}{l}1 \\
2 \\
3 \\
4 \\
5 \\
6 \\
7 \\
8\end{array}$ & $\begin{array}{l}4,700 \\
5,200 \\
5,300 \\
5,400 \\
4,900 \\
3,970 \\
3,370 \\
4,700\end{array}$ & $\begin{array}{l}22,800 \\
22,200 \\
20,500 \\
18,100 \\
17,200 \\
17,400 \\
17,600 \\
17,200\end{array}$ & $\begin{array}{l}9 \\
10 \\
11 \\
12 \\
13 \\
14 \\
15 \\
16\end{array}$ & $\begin{array}{r}6,120 \\
6,670 \\
6,890 \\
6,780 \\
6,010 \\
6,010 \\
9,210 \\
16,700\end{array}$ & $\begin{array}{l}14,900 \\
10,300 \\
11,700 \\
15,300 \\
16,300 \\
17,200 \\
17,400 \\
16,100\end{array}$ & $\begin{array}{l}17 \\
18 \\
19 \\
20 \\
21 \\
22 \\
23 \\
24\end{array}$ & $\begin{array}{l}19,500 \\
20,900 \\
24,100 \\
47,000 \\
53,000 \\
53,000 \\
53,000 \\
50,000\end{array}$ & $\begin{array}{l}12,800 \\
12,800 \\
15,500 \\
16,300 \\
16,300 \\
16,300 \\
15,300 \\
11,200\end{array}$ & $\begin{array}{l}25 \\
26 \\
27 \\
28 \\
29 \\
30 \\
31\end{array}$ & $\begin{array}{l}44,000 \\
38,000 \\
32,500 \\
27,200 \\
25,000 \\
24,100 \\
23,400\end{array}$ & $\begin{array}{r}9,960 \\
12,200 \\
13,900 \\
13,900 \\
13,300 \\
10,400\end{array}$ \\
\hline \multicolumn{10}{|c|}{$\begin{array}{l}\text { Monthly mean discharge, in second-feet } \\
\text { Runoff, in inches }\end{array}$} & $\begin{array}{r}20,540 \\
1.62\end{array}$ & $\begin{array}{r}15,410 \\
1.18\end{array}$ \\
\hline
\end{tabular}

LINVILLE RIVER AT BRANCH, N. C.

Location.-Lat. $35^{\circ} 47^{\prime} 50^{\prime \prime}$, long. $81^{\circ} 53^{\prime} 20^{\prime \prime}$, at highway bridge at Branch, Burke County, and a quarter of a mile upstream from Bridgewater Reservoir (Lake James).

Drainage Area.-65 square miles.

GAGE-HEIGHT RECORD.-Water-stage recorder graph except for Sept. 15-19. Recorder graph Sept. 10-14 reconstructed slightly because of partly obstructed intake pipe.

DISCHARGE RECORD.- Stage-discharge relation defined by current-meter measurements up to 1,900 second-feet and extended to crest gage height on basis of determination of flood flow by slope-area method. Gage heights used to half-tenths between 3.9 and 10.2 feet; hundredths below and tenths above these limits. Discharge for period of no gage-height record, Sept. 15-19, based on records for North Toe River at Altapass, N. C.

Maxima.-1940: Discharge, 39,500 second-feet 5 p.m. Aug. 13 (gage height, 11.4 feet).

1922-39: Discharge, 8,350 second-feet Aug. 15, 1928 (gage height, about 7.5 feet).

The flood of July 1916 reached a stage about 0.4 foot lower than that of Aug. 13,1940 , or about 11.0 feet gage height, from testimony of local resident (discharge, 34,600 second-feet).

REMARKS.-Flood runoff not affected by artificial storage.

Mean discharge, in second-feet, 1940

\begin{tabular}{|c|c|c|c|c|c|c|c|c|c|c|c|}
\hline Day & Aug. & Sept. & Day & Aug. & Sept. & Day & Aug. & Sept. & Day & Aug. & Sept. \\
\hline \begin{tabular}{l|}
1 \\
2 \\
3 \\
4 \\
5 \\
6 \\
7 \\
8
\end{tabular} & $\begin{array}{r}74 \\
59 \\
54 \\
52 \\
57 \\
74 \\
102 \\
76\end{array}$ & $\begin{array}{l}617 \\
349 \\
263 \\
220 \\
192 \\
166 \\
148 \\
134\end{array}$ & \begin{tabular}{r|}
9 \\
10 \\
11 \\
12 \\
13 \\
14 \\
15 \\
16
\end{tabular} & $\begin{array}{r}61 \\
54 \\
80 \\
1,110 \\
14,000 \\
4,410 \\
1,230 \\
642\end{array}$ & $\begin{array}{l}125 \\
120 \\
117 \\
114 \\
110 \\
108 \\
100 \\
100\end{array}$ & $\begin{array}{l}17 \\
18 \\
19 \\
20 \\
21 \\
22 \\
23 \\
24\end{array}$ & $\begin{array}{l}420 \\
321 \\
252 \\
189 \\
172 \\
158 \\
143 \\
130\end{array}$ & $\begin{array}{l}95 \\
95 \\
95 \\
93 \\
91 \\
89 \\
86 \\
84\end{array}$ & $\begin{array}{l}25 \\
26 \\
27 \\
28 \\
29 \\
30 \\
31\end{array}$ & $\begin{array}{r}124 \\
117 \\
114 \\
122 \\
727 \\
6,970 \\
1,520\end{array}$ & $\begin{array}{l}86 \\
86 \\
84 \\
84 \\
78 \\
76\end{array}$ \\
\hline \multicolumn{10}{|c|}{$\begin{array}{l}\text { Monthly mean discharge, in second-feet } \\
\text { Runoff, in inchess }\end{array}$} & $\begin{array}{l}1,084 \\
19.23\end{array}$ & $\begin{array}{r}140 \\
2.41\end{array}$ \\
\hline
\end{tabular}


Gage height, in feet, and discharge, in second-feet, at indicated time, 1940

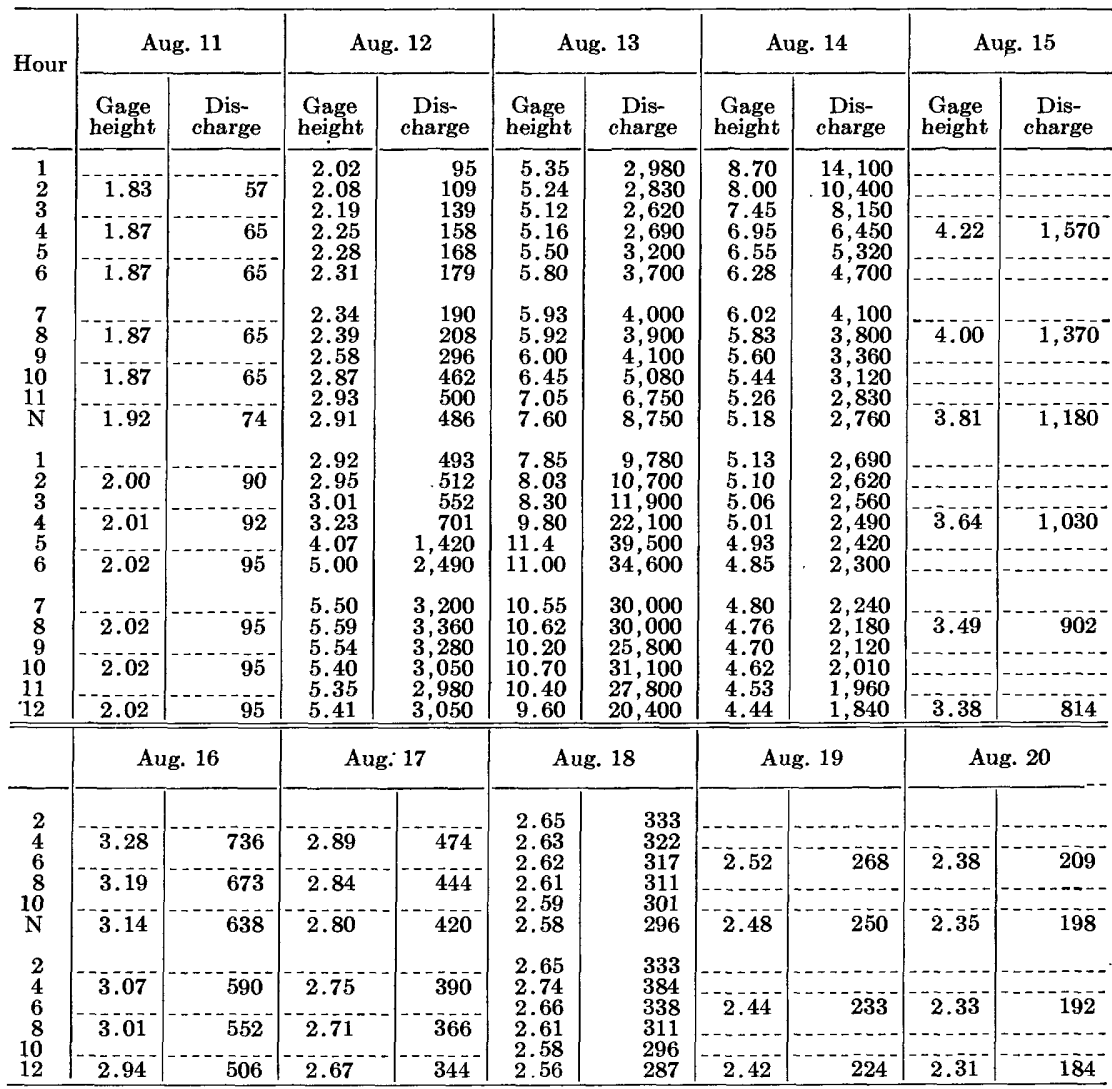

SuPPLEMENTAL RECoRDs.-Aug. 13, 3:30 a.m. gage height, 5.08 feet, discharge, 2,620 second-feet: 6:45 p.m., gage height, 10.26 feet, discharge, 26,800 second-feet; $7: 30$ p.m., gage height, 10.68 feet, discharge, 31,100 second-feet; 10:30 p.m., gage height, 11.07 feet, discharge, 35,800 second-feet.

LITTLE SUGAR CREEK NEAR CHARLO'TE, N. C.

Location.-Lat. $35^{\circ} 09^{\prime} 15^{\prime \prime}$, long. $80^{\circ} 51^{\prime} 10^{\prime \prime}$, just upstream from sewage-disposal plant of eity of Charlotte, a quarter of a mile downstream from Brier Creek, and 5 miles south of Charlotte, Mecklenburg County. Datum of gage is 571.6 feet above mean sea level (city of Charlotte datum).

Drainage AREA.-41.4 square miles.

GAGE-HEIGHT RECORD.-Water-stage recorder graph.

DischARGE RECORD.-Stage-discharge relation defined by current-meter measurements up to 2,000 second-feet and extended above by area-velocity method. Gage heights used to half-tenths between 3.0 and 4.6 feet; hundredths below and tenths above these limits.

Maxima.-1940: Discharge, 2,230 second-feet 4 a.m. Aug. 14 (gage height, 8.75 feet).

1924-39: Discharge, 8,370 second-feet Apr. 6, 1936 (gage height, 16.2 feet, from floodmarks).

REMARKS.-Flood runoff not affected by artificial storage. 
Mean discharge, in second-feet, 1940

\begin{tabular}{|c|c|c|c|c|c|c|c|c|c|c|c|}
\hline Day & Aug. & Sept. & Day & Aug. & Sept. & Day & Aug. & Sept. & Day & Aug. & Sept. \\
\hline $\begin{array}{l}1 \\
2 \\
3 \\
4 \\
5 \\
6 \\
7 \\
8\end{array}$ & $\begin{array}{l}7.8 \\
7.4 \\
6.9 \\
6.5 \\
7.8 \\
7.8 \\
7.4 \\
6.9\end{array}$ & $\begin{array}{l}22 \\
11 \\
11 \\
10 \\
10 \\
12 \\
9.5 \\
8.9\end{array}$ & $\begin{array}{r}9 \\
10 \\
11 \\
12 \\
13 \\
14 \\
15 \\
16\end{array}$ & $\begin{array}{r}6.5 \\
6.9 \\
21 \\
46 \\
42 \\
554 \\
187 \\
41\end{array}$ & $\begin{array}{r}8.9 \\
9.5 \\
9.5 \\
8.3 \\
7.8 \\
7.8 \\
7.4 \\
8.3\end{array}$ & $\begin{array}{l}17 \\
18 \\
19 \\
20 \\
21 \\
22 \\
23 \\
24\end{array}$ & $\begin{array}{l}44 \\
28 \\
20 \\
14 \\
13 \\
11 \\
11 \\
11\end{array}$ & $\begin{array}{l}7.8 \\
8.9 \\
7.8 \\
7.4 \\
7.4 \\
6.5 \\
6.9 \\
7.4\end{array}$ & $\begin{array}{l}25 \\
26 \\
27 \\
28 \\
29 \\
30 \\
31\end{array}$ & $\begin{array}{l}10 \\
11 \\
10 \\
9.5 \\
10 \\
26 \\
23\end{array}$ & $\begin{array}{r}9.6 \\
6.9 \\
6.1 \\
6.1 \\
5.6 \\
6.9 \\
\end{array}$ \\
\hline \multicolumn{10}{|c|}{$\begin{array}{l}\text { Monthly mean discharge, in second-feet } \\
\text { Runoff, in inches }\end{array}$} & $\begin{array}{l}39.2 \\
1.09\end{array}$ & $\begin{array}{l}8.77 \\
0.24\end{array}$ \\
\hline
\end{tabular}

Gage height, in feet, and discharge, in second-feet, at indicated time, 1940

\begin{tabular}{|c|c|c|c|c|c|c|c|c|}
\hline \multirow{2}{*}{ Hour } & \multicolumn{2}{|c|}{ Aug. 13} & \multicolumn{2}{|c|}{ Aug. 14} & \multicolumn{2}{|c|}{ Aug. 15} & \multicolumn{2}{|c|}{ Aug. 17} \\
\hline & $\begin{array}{c}\text { Gage } \\
\text { height }\end{array}$ & Discharge & $\begin{array}{l}\text { Gage } \\
\text { height }\end{array}$ & Discharge & $\begin{array}{l}\text { Gage } \\
\text { height }\end{array}$ & Discharge & $\begin{array}{l}\text { Gage } \\
\text { height }\end{array}$ & Discharge \\
\hline $\begin{array}{l}1 \\
2 \\
3 \\
4 \\
5 \\
6\end{array}$ & $\begin{array}{l}1.87 \\
1.85 \\
1.82 \\
1.82 \\
1.82 \\
1.85\end{array}$ & $\begin{array}{l}20 \\
18 \\
16 \\
16 \\
16 \\
18\end{array}$ & $\begin{array}{l}1.94 \\
2.70 \\
6.0 \\
8.75 \\
7.3 \\
6.1\end{array}$ & $\begin{array}{r}26 \\
171 \\
1,010 \\
2,230 \\
1,500 \\
1,040\end{array}$ & $\begin{array}{l}4.60 \\
4.65 \\
4.66 \\
4.12 \\
2.99 \\
2.65\end{array}$ & $\begin{array}{l}668 \\
668 \\
690 \\
554 \\
246 \\
160\end{array}$ & $\begin{array}{l}2.02 \\
2.01 \\
2.00 \\
1.99 \\
1.98 \\
1.97\end{array}$ & $\begin{array}{l}36 \\
34 \\
33 \\
32 \\
31 \\
30\end{array}$ \\
\hline $\begin{array}{r}7 \\
8 \\
9 \\
10 \\
11 \\
N\end{array}$ & $\begin{array}{l}2.34 \\
2.27 \\
2.26 \\
2.24 \\
2.27 \\
2.26\end{array}$ & $\begin{array}{l}90 \\
76 \\
74 \\
71 \\
76 \\
74\end{array}$ & $\begin{array}{l}5.45 \\
4.77 \\
4.42 \\
4.10 \\
3.35 \\
2.77\end{array}$ & $\begin{array}{l}850 \\
710 \\
624 \\
554 \\
354 \\
188\end{array}$ & $\begin{array}{l}2.51 \\
2.43 \\
2.37 \\
2.32 \\
2.29 \\
2.25\end{array}$ & $\begin{array}{r}127 \\
110 \\
97 \\
86 \\
80 \\
72\end{array}$ & $\begin{array}{l}1.97 \\
1.96 \\
1.96 \\
1.95 \\
1.94 \\
1.94\end{array}$ & $\begin{array}{l}30 \\
29 \\
29 \\
28 \\
26 \\
26\end{array}$ \\
\hline $\begin{array}{r}1 \\
-2 \\
3 \\
4 \\
4 \\
5 \\
6\end{array}$ & $\begin{array}{l}2.25 \\
2.19 \\
2.13 \\
2.07 \\
2.02 \\
1.98\end{array}$ & $\begin{array}{l}72 \\
61 \\
52 \\
43 \\
36 \\
31\end{array}$ & $\begin{array}{l}2.55 \\
2.45 \\
2.37 \\
2.37 \\
2.56 \\
2.89\end{array}$ & $\begin{array}{r}136 \\
114 \\
97 \\
97 \\
139 \\
219\end{array}$ & $\begin{array}{l}2.23 \\
2.21 \\
2.18 \\
2.17 \\
2.17 \\
2.15\end{array}$ & $\begin{array}{l}69 \\
65 \\
60 \\
58 \\
58 \\
55\end{array}$ & $\begin{array}{l}1.94 \\
1.94 \\
1.94 \\
1.95 \\
1.95 \\
2.07\end{array}$ & $\begin{array}{l}26 \\
26 \\
26 \\
28 \\
28 \\
43\end{array}$ \\
\hline $\begin{array}{r}7 \\
8 \\
9 \\
10 \\
11 \\
12 \\
\end{array}$ & $\begin{array}{l}1.96 \\
1.94 \\
1.91 \\
1.89 \\
1.88 \\
1.88 \\
\end{array}$ & $\begin{array}{l}29 \\
26 \\
23 \\
21 \\
20 \\
20\end{array}$ & $\begin{array}{l}3.52 \\
4.91 \\
4.67 \\
3.96 \\
4.17 \\
4.53 \\
\end{array}$ & $\begin{array}{l}400 \\
730 \\
690 \\
518 \\
566 \\
646 \\
\end{array}$ & $\begin{array}{l}2.12 \\
2.10 \\
2.08 \\
2.06 \\
2.05 \\
2.03 \\
\end{array}$ & $\begin{array}{l}50 \\
47 \\
44 \\
41 \\
40 \\
37 \\
\end{array}$ & $\begin{array}{l}2.24 \\
2.36 \\
2.26 \\
2.19 \\
2.19 \\
2.39 \\
\end{array}$ & $\begin{array}{r}71 \\
95 \\
74 \\
61 \\
61 \\
101 \\
\end{array}$ \\
\hline
\end{tabular}

BROAD RIVER NEAR CHIMNEY ROCK, N. C.

LOCATION.—Lat. $35^{\circ} 25^{\prime} 35^{\prime \prime}$, long. $82^{\circ} 10^{\prime} 45^{\prime \prime}, 1,000$ feet downstream from Lake Lure Dam and 3 miles east of Chimney Rock, Rutherford County.

Drainage AREa. - 97 square miles.

GAGE-HEIGHT RECORD.-Water-stage recorder graph.

DISCHARgE RECORD.-Stage-discharge relation defined by current-meter measurements up to 4,200 second-feet and extended above on basis of computation of flood flow over Lake Lure Dam and through power plant at gage heights 16.8 and 12.2 feet. Gage heights used to half-tenths between 3.2 and 5.2 feet; hundredths below and tenths above these limits.

Maxima.-1940: Discharge, 17,300 second-feet 2 p.m. Aug. 13 (gage height, 12.20 feet).

1907-9, 1927-39: Discharge, 26,000 second-feet Aug. 15, 1928 (gage height, 16.8 feet).

REMARKs.-Flood runoff affected only slightly by artificial storage in Lake Lure. 
SANTEE RIVER BASIN

Mean discharge, in second-feet, 1940

\begin{tabular}{|c|c|c|c|c|c|c|c|c|c|c|c|}
\hline Day & Aug. & Sept. & Day & Aug. & Sept. & Day & Aug. & Sept. & Day & Aug. & Sept. \\
\hline $\begin{array}{l}1 \\
2 \\
3 \\
4 \\
5 \\
6 \\
7 \\
8\end{array}$ & $\begin{array}{c}86 \\
4.2 \\
4.2 \\
4.2 \\
85 \\
89 \\
87 \\
91\end{array}$ & $\begin{array}{l}558 \\
518 \\
504 \\
426 \\
342 \\
336 \\
343 \\
178\end{array}$ & $\begin{array}{l}9 \\
10 \\
11 \\
12 \\
13 \\
14 \\
15 \\
16\end{array}$ & $\begin{array}{r}244 \\
46 \\
93 \\
353 \\
6,430 \\
1,390 \\
869 \\
572\end{array}$ & $\begin{array}{c}187 \\
257 \\
88 \\
156 \\
159 \\
155 \\
3.9 \\
152\end{array}$ & $\begin{array}{l}17 \\
18 \\
19 \\
20 \\
21 \\
22 \\
23 \\
24\end{array}$ & $\begin{array}{l}472 \\
504 \\
504 \\
468 \\
497 \\
298 \\
131 \\
167\end{array}$ & \begin{tabular}{c|}
155 \\
148 \\
148 \\
84 \\
83 \\
3.5 \\
238 \\
355
\end{tabular} & $\begin{array}{l}25 \\
26 \\
27 \\
28 \\
29 \\
30 \\
31\end{array}$ & $\begin{array}{r}174 \\
134 \\
153 \\
150 \\
310 \\
1,450 \\
773\end{array}$ & $\begin{array}{c}360 \\
82 \\
86 \\
86 \\
3.7 \\
84 \\
\end{array}$ \\
\hline \multicolumn{10}{|c|}{$\begin{array}{l}\text { Monthly mean discharge, in second-feet } \\
\text { Runoff, in inches. }\end{array}$} & $\begin{array}{r}537 \\
6.38\end{array}$ & $\begin{array}{r}209 \\
2.41\end{array}$ \\
\hline
\end{tabular}

Gage height, in feet, and discharge, in second-feet, at indicated time, 1940

\begin{tabular}{|c|c|c|c|c|c|c|c|c|c|c|c|c|}
\hline \multirow{2}{*}{ Hour } & \multicolumn{2}{|c|}{ Aug. 11} & \multicolumn{2}{|c|}{ Aug. 12} & \multicolumn{2}{|c|}{ Aug. 13} & \multicolumn{2}{|c|}{ Aug. 14} & \multicolumn{2}{|c|}{ Aug. 15} & \multicolumn{2}{|c|}{ Aug. 16} \\
\hline & $\begin{array}{c}\text { Gage } \\
\text { ht. }\end{array}$ & $\begin{array}{c}\text { Dis- } \\
\text { charge }\end{array}$ & $\begin{array}{c}\text { Gage } \\
\text { ht. }\end{array}$ & $\begin{array}{c}\text { Dis- } \\
\text { charge }\end{array}$ & $\begin{array}{c}\text { Gage } \\
\text { ht. }\end{array}$ & $\begin{array}{c}\text { Dis- } \\
\text { charge }\end{array}$ & $\begin{array}{c}\text { Gage } \\
\text { ht. }\end{array}$ & $\begin{array}{c}\text { Dis- } \\
\text { charge }\end{array}$ & $\begin{array}{c}\text { Gage } \\
\text { ht. }\end{array}$ & $\begin{array}{c}\text { Dis- } \\
\text { charge }\end{array}$ & $\begin{array}{c}\text { Gage } \\
\text { ht. }\end{array}$ & $\begin{array}{c}\text { Dis- } \\
\text { charge }\end{array}$ \\
\hline $\begin{array}{l}1 \\
2 \\
3 \\
4 \\
5 \\
6\end{array}$ & \begin{tabular}{r|}
0.52 \\
.52 \\
.52 \\
.52 \\
.52 \\
.52
\end{tabular} & $\begin{array}{l}5.1 \\
5.1 \\
5.1 \\
5.1 \\
5.1\end{array}$ & $\begin{array}{r}0.52 \\
.52 \\
.52 \\
.52 \\
.52 \\
.52\end{array}$ & $\begin{array}{l}5.1 \\
5.1 \\
5.1 \\
5.1 \\
5.1\end{array}$ & $\begin{array}{l}2.29 \\
2.29 \\
2.30 \\
2.30 \\
2.43 \\
2.44\end{array}$ & $\begin{array}{l}628 \\
628 \\
635 \\
635 \\
721 \\
728\end{array}$ & $\begin{array}{l}4.56 \\
4.15 \\
3.90 \\
3.90 \\
3.47 \\
3.17\end{array}$ & $\begin{array}{l}3,420 \\
2,760 \\
2,400 \\
2,400 \\
1,820 \\
1,480\end{array}$ & $\begin{array}{r}2.66 \\
2.64 \\
2.62\end{array}$ & $\begin{array}{l}984 \\
96 \overline{6} \\
948\end{array}$ & $\begin{array}{r}2.33 \\
-2.3 \overline{3} \\
\overline{2} . \overline{3} \overline{3}\end{array}$ & $\begin{array}{l}712 \\
712\end{array}$ \\
\hline $\begin{array}{r}7 \\
8 \\
9 \\
10 \\
11 \\
\mathbf{N}\end{array}$ & $\begin{array}{r}.52 \\
.52 \\
.52 \\
.52 \\
.52 \\
1.47\end{array}$ & $\begin{array}{r}5.1 \\
5.1 \\
5.1 \\
5.1 \\
5.1 \\
190\end{array}$ & $\begin{array}{l}1.27 \\
1.78 \\
1.78 \\
1.78 \\
1.78 \\
1.78\end{array}$ & $\begin{array}{l}121 \\
325 \\
325 \\
325 \\
325 \\
325\end{array}$ & $\begin{array}{r}2.46 \\
2.47 \\
2.52 \\
7.30 \\
10.04 \\
10.05\end{array}$ & $\begin{array}{r}742 \\
749 \\
784 \\
8,260 \\
13,200 \\
13,200\end{array}$ & $\begin{array}{l}3.17 \\
2.59 \\
2.61 \\
2.63 \\
2.64 \\
2.65\end{array}$ & $\begin{array}{r}1,480 \\
922 \\
939 \\
957 \\
966 \\
975\end{array}$ & $\begin{array}{l}2.60 \\
2.59 \\
2.57\end{array}$ & $\begin{array}{l}930 \\
922 \\
904\end{array}$ & $\begin{array}{r}2.16 \\
-2.04 \\
2.04\end{array}$ & $\begin{array}{l}587 \\
504 \\
504\end{array}$ \\
\hline $\begin{array}{l}1 \\
2 \\
3 \\
4 \\
5 \\
6\end{array}$ & $\begin{array}{l}1.78 \\
1.78 \\
1.78 \\
1.78 \\
1.78 \\
1.78\end{array}$ & $\begin{array}{l}325 \\
325 \\
325 \\
325 \\
325 \\
325\end{array}$ & $\begin{array}{l}1.93 \\
2.11 \\
2.11 \\
2.16 \\
2.29 \\
2.29\end{array}$ & $\begin{array}{l}408 \\
516 \\
516 \\
546 \\
628 \\
628\end{array}$ & $\begin{array}{r}10.36 \\
12.20 \\
10.75 \\
10.30 \\
9.70 \\
9.05\end{array}$ & $\begin{array}{l}13,900 \\
17,300 \\
14,700 \\
13,700 \\
12,600 \\
11,300\end{array}$ & $\begin{array}{l}2.67 \\
2.68 \\
2.70 \\
2.71 \\
2.71 \\
2.71\end{array}$ & $\begin{array}{r}993 \\
1,000 \\
1,020 \\
1,030 \\
1,030 \\
1,030\end{array}$ & $\begin{array}{r}2.55 \\
-2.53 \\
2.34\end{array}$ & $\begin{array}{c}888 \\
870 \\
7 \overline{2} 0\end{array}$ & $\begin{array}{r}2.04 \\
2.04 \\
2.04\end{array}$ & $\begin{array}{l}504 \\
504 \\
504\end{array}$ \\
\hline $\begin{array}{r}7 \\
8 \\
9 \\
10 \\
11 \\
12\end{array}$ & $\begin{array}{l}.69 \\
.58 \\
.54 \\
.53 \\
.53 \\
.52\end{array}$ & $\begin{array}{r}12 \\
7.3 \\
5.8 \\
5.5 \\
5.5 \\
5.1\end{array}$ & $\begin{array}{l}2.29 \\
2.29 \\
2.29 \\
2.29 \\
2.29 \\
2.29\end{array}$ & $\begin{array}{l}628 \\
628 \\
628 \\
628 \\
628 \\
628\end{array}$ & $\begin{array}{l}6.78 \\
6.78 \\
6.58 \\
5.42 \\
3.57 \\
3.95\end{array}$ & $\begin{array}{l}7,360 \\
7,360 \\
7,000 \\
4,900 \\
1,820 \\
2,410\end{array}$ & $\begin{array}{l}2.70 \\
2.70 \\
2.70 \\
2.69 \\
2.68 \\
2.68\end{array}$ & $\begin{array}{l}1,020 \\
1,020 \\
1,020 \\
1,010 \\
1,000 \\
1,000\end{array}$ & $\begin{array}{r}2.3 \overline{4} \\
2.34 \\
2 . \overline{3} 3\end{array}$ & $\begin{array}{l}720 \\
720 \\
712\end{array}$ & $\begin{array}{r}2.04 \\
2,04 \\
2.04\end{array}$ & 504 \\
\hline
\end{tabular}

BROAD RIVER NEAR BOLLING SPHINGS, N. C.

Location.-Lat. $35^{\circ} 12^{\prime} 35^{\prime \prime}$, long. $81^{\circ} 41^{\prime} 55^{\prime \prime}$, half a mile upstream from Sandy Run Creek and 31/2 miles southwest of Boiling Springs, Cleveland County.

Drainage AREa.-864 square miles.

GAGE-HEIGHT RECORD.-Water-stage recorder graph.

DISCHARGE RECORD.-Stage-discharge relation defined by current-meter measurements up to 58,200 second-feet. Gage heights used to half-tenths between 2.6 and 4.2 feet; hundredths below and tenths above these limits.

Maxima.-1940: Discharge, 60,400 second-feet 12:30 to 1 p.m. Aug. 14 (gage height, 22.10 feet).

1925-39: Discharge, 73,300 second-feet Aug. 16, 1928 (gage height, 24.3 feet, present datum).

REMARKs.-Flood runoff affected only slightly by artificial storage. 


\section{FLOODS OF AUGUST 1940 IN THE SOUTHEASTERN STATES}

Mean discharge, in second-feet, 1940

\begin{tabular}{|c|c|c|c|c|c|c|c|c|c|c|c|}
\hline Day & Aug. & Sept. & Day & Aug. & Sept. & Day & Aug. & Sept. & Day & Aug. & Sept. \\
\hline $\begin{array}{l}1 \\
2 \\
3 \\
4 \\
5 \\
6 \\
7 \\
8\end{array}$ & $\begin{array}{l}472 \\
406 \\
278 \\
175 \\
194 \\
662 \\
550 \\
668\end{array}$ & $\begin{array}{r}2,950 \\
1,910 \\
1,970 \\
1,620 \\
1,450 \\
1,360 \\
1,330 \\
968\end{array}$ & $\begin{array}{r}9 \\
10 \\
11 \\
12 \\
13 \\
14 \\
15 \\
16\end{array}$ & $\begin{array}{r}680 \\
489 \\
283 \\
357 \\
7,740 \\
49,000 \\
13,300 \\
3,790\end{array}$ & $\begin{array}{r}946 \\
1,480 \\
1,500 \\
1,050 \\
980 \\
931 \\
620 \\
568\end{array}$ & $\begin{array}{l}17 \\
18 \\
19 \\
20 \\
21 \\
22 \\
23 \\
24\end{array}$ & $\begin{array}{l}2,810 \\
2,340 \\
1,990 \\
2, C 50 \\
1,720 \\
1,670 \\
1,360 \\
1,190\end{array}$ & $\begin{array}{r}1,070 \\
1,040 \\
950 \\
944 \\
1,030 \\
694 \\
502 \\
872\end{array}$ & $\begin{array}{l}25 \\
26 \\
27 \\
28 \\
29 \\
30 \\
31\end{array}$ & $\begin{array}{r}1,010 \\
946 \\
1,130 \\
1,120 \\
1,620 \\
5,360 \\
5,050\end{array}$ & $\begin{array}{r}1,080 \\
1,050 \\
806 \\
826 \\
472 \\
478 \\
\end{array}$ \\
\hline in & & & & & & & & & & $\begin{array}{r}3,562 \\
4.75\end{array}$ & $\begin{array}{r}1,115 \\
1.44\end{array}$ \\
\hline
\end{tabular}

Gage height, in feet, and discharge, in second-feet, at indicated time, 1940

\begin{tabular}{|c|c|c|c|c|c|c|c|c|c|c|c|c|}
\hline \multirow{2}{*}{ Hour } & \multicolumn{2}{|c|}{ Aug. 12} & \multicolumn{2}{|c|}{ Aug. 13} & \multicolumn{2}{|c|}{ Aug. 14} & \multicolumn{2}{|c|}{ Aug. 15} & \multicolumn{2}{|c|}{ Aug. 16} & \multicolumn{2}{|c|}{ Aug. 17} \\
\hline & $\begin{array}{c}\text { Gage } \\
\text { ht. }\end{array}$ & $\begin{array}{c}\text { Dis- } \\
\text { charge }\end{array}$ & $\begin{array}{c}\text { Gage } \\
\text { ht. }\end{array}$ & $\begin{array}{c}\text { Dis- } \\
\text { charge }\end{array}$ & $\begin{array}{c}\text { Gage } \\
\text { ht. }\end{array}$ & $\begin{array}{c}\text { Dis- } \\
\text { charge }\end{array}$ & $\begin{array}{c}\text { Gage } \\
\text { ht. }\end{array}$ & $\begin{array}{c}\text { Dis- } \\
\text { charge }\end{array}$ & $\begin{array}{c}\text { Gage } \\
\text { ht. }\end{array}$ & $\begin{array}{c}\text { Dis- } \\
\text { charge }\end{array}$ & $\begin{array}{c}\text { Gage } \\
\text { ht. }\end{array}$ & $\begin{array}{c}\text { Dis- } \\
\text { charge }\end{array}$ \\
\hline $\begin{array}{l}1 \\
2\end{array}$ & & & $\begin{array}{l}1.83 \\
1.82\end{array}$ & $\begin{array}{l}566 \\
557\end{array}$ & $\left|\begin{array}{l}16.15 \\
17.05\end{array}\right|$ & $\begin{array}{l}32,000 \\
35,000\end{array}$ & $\begin{array}{l}16.60 \\
15.80\end{array} \mid$ & $\begin{array}{l}33,500 \\
30,500\end{array}$ & & & 4.30 & 3,390 \\
\hline 3 & & & $\begin{array}{l}1.02 \\
1.79\end{array}$ & 532 & 17.95 & 39,000 & 15.05 & 27,700 & & & 7.00 & 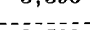 \\
\hline $\begin{array}{l}4 \\
5\end{array}$ & 1.38 & 221 & 1.76 & 506 & 18.77 & 42,600 & 14.15 & 25,100 & 4.96 & 4,310 & 4.39 & 3,520 \\
\hline $\begin{array}{l}5 \\
6\end{array}$ & - & & $\begin{array}{l}1.76 \\
1.78\end{array}$ & $\begin{array}{l}506 \\
523\end{array}$ & 19.45 & $\begin{array}{l}45,500 \\
48,600\end{array}$ & $\left|\begin{array}{l}13.15 \\
12.10\end{array}\right|$ & $\begin{array}{l}22,100 \\
18,900\end{array}$ & 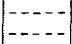 & & 4.30 & 3,390 \\
\hline 7 & & & 1.85 & 582 & 20.50 & 51,300 & 11.00 & 16 & & & & \\
\hline $\begin{array}{l}8 \\
9\end{array}$ & 1.37 & 215 & 2.13 & 828 & 21.00 & 54,100 & 9.95 & 13,600 & 4.71 & 3,910 & 4.13 & 3,200 \\
\hline 10 & & & 4.60 & 3,600 & $\mid \begin{array}{l}21.00 \\
21.60\end{array}$ & 57,500 & $\begin{array}{l}9.23 \\
8.70\end{array}$ & 10,600 & -- & & 4.04 & 3,060 \\
\hline 11 & & & 6.10 & 5,860 & 21.88 & 59,200 & 8.30 & 9,800 & & & & \\
\hline $\mathbf{N}$ & 1.58 & 360 & 6.90 & 7,180 & 22.05 & 59,800 & 7.90 & 9,010 & 4.52 & 3,650 & 3,90 & 2,880 \\
\hline 1 & & & 6.97 & 7,350 & 22.10 & 400 & 7.55 & 8,450 & & & & \\
\hline 2 & & & 6.87 & 80 & & & 7.25 & 50 & $\ldots$ & & 3.85 & 2,820 \\
\hline 4 & 1.63 & $\overline{39}$ & $\begin{array}{r}7.05 \\
7.17\end{array}$ & $\begin{array}{l}7,350 \\
7,710\end{array}$ & $\left|\begin{array}{l}21.80 \\
21.45\end{array}\right|$ & $\begin{array}{l}58,600 \\
56,300\end{array}$ & $\begin{array}{l}6.95 \\
6.65\end{array}$ & $\begin{array}{l}7,410 \\
6,740\end{array}$ & 4.39 & 3,520 & 3.20 & 2,050 \\
\hline $\begin{array}{l}5 \\
6\end{array}$ & $\ldots$ & & $\begin{array}{l}7.25 \\
7.50\end{array}$ & $\begin{array}{l}7,710 \\
8,250\end{array}$ & $\left|\begin{array}{l}21.00 \\
20.75\end{array}\right|$ & $\begin{array}{l}54,100 \\
53,000\end{array}$ & $\begin{array}{l}6.42 \\
6.18\end{array}$ & $\begin{array}{l}6,420 \\
6,100\end{array}$ & $-\cdots-$ & & $-\overline{3.89}$ & 2,880 \\
\hline & & & 9.10 & 11,500 & 20.20 & 0 & 5.98 & 5 & & & & \\
\hline 8 & 1.82 & 557 & 12.02 & & 19.65 & & 5.79 & 5,470 & 4.29 & 3,390 & 3.10 & 1,940 \\
\hline $\begin{array}{r}9 \\
10\end{array}$ & $\cdots$ & & 12.75 & 20,900 & 19.10 & $\cdot 44,000$ & 5.65 & 5,170 & $-\cdots$ & -- & 17 & 0 \\
\hline $\begin{array}{l}10 \\
11\end{array}$ & & & $\left|\begin{array}{l}13.95 \\
14.58\end{array}\right|$ & $\begin{array}{l}24,500 \\
26,400\end{array}$ & $\mid \begin{array}{l}18.60 \\
18.00\end{array}$ & $\begin{array}{l}41,700 \\
39,000\end{array}$ & $\begin{array}{l}5.52 \\
5.40\end{array}$ & $\begin{array}{l}5,020 \\
4,870\end{array}$ & & & 7 & 0 \\
\hline 12 & 1.82 & 557 & 15.45 & 29,100 & $|17.30|$ & 36,200 & $\mid 5.28$ & 4,730 & 4.16 & 3,200 & 3.22 & 2,050 \\
\hline
\end{tabular}

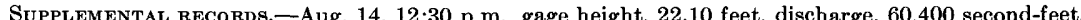
Aug. 17, 12:30 p.m., gage height, 3.80 feet, discharge, 2,760 second-feet; $4: 30$ p.m., gage height, 3.06 feet, discharge, 1,880 second-feet; 5 p.m., gage height, 3.30 feet, discharge, 2,160 second-feet: $6: 15$ p.m., gage height, 3.90 feet, discharge, 2,880 second-feet.

\section{BROAD RIVER NGAR GAFFNEY, S. C.}

Locatron.-Lat. $35^{\circ} 05^{\prime} 20^{\prime \prime}$, long. $81^{\circ} 34^{\prime} 20^{\prime \prime}$, at bridge on U. S. Highway $29,0.3$ mile upstream from Cherokee Creek, 4.4 miles downstream from Gaston Shoals Dam, and 4.5 miles east of Gaffney, Cherokee County.

DrAINAGE AREA.-1,490 square miles (1943 revision).

GAGE-HEIGHT RECORD.-Water-stage recorder graph except for periods Aug. 3-13, 11 a.m. Aug. 30 to $12 \mathrm{~m}$. Sept. 9, record for which was computed on basis of power-plant operation records, weather records, and records for station near Carlisle.

DISCHARGE RECORD.-Stage-discharge relation defined by current-meter measurements up to 14,000 second-feet and extended to crest gage height on basis of determination of flood flow over Gaston Shoals Dam.

Maxima.-1940: Discharge, 119,000 second-feet $7: 30$ p.m. Aug. 14 (gage height, 19.78 feet).

1896-99, 1938-39 : Discharge, observed, 25,400 second-feet Mar. 19, 1899 (gage height, 12.20 feet, site and datum then in use). 
REMARKS.-Flood discharge not appreciably affected by artificial storage or diversion. Flow regulated during medium and low stages by power plants above station.

Mean discharge, in second-feet, 1940

\begin{tabular}{|c|c|c|c|c|c|c|c|c|c|c|c|}
\hline Day & Aug. & Sept. & Day & Aug. & Sept. & Day & Aug. & Sept. & Day & Aug. & Sept. \\
\hline $\begin{array}{l}1 \\
2 \\
3 \\
4 \\
5 \\
6 \\
7 \\
8\end{array}$ & $\begin{array}{l}766 \\
696 \\
550 \\
480 \\
460 \\
500 \\
950 \\
900\end{array}$ & $\begin{array}{l}7,500 \\
4,800 \\
3,600 \\
3,000 \\
2,600 \\
2,200 \\
1,800 \\
1,200\end{array}$ & $\begin{array}{r}9 \\
10 \\
11 \\
12 \\
13 \\
14 \\
15 \\
16\end{array}$ & $\begin{array}{r}1,000 \\
700 \\
600 \\
500 \\
3,000 \\
80,600 \\
36,000 \\
6,000\end{array}$ & $\begin{array}{r}1,100 \\
2,130 \\
2,610 \\
1,580 \\
1,270 \\
1,340 \\
962 \\
926\end{array}$ & $\begin{array}{l}17 \\
18 \\
19 \\
20 \\
21 \\
22 \\
23 \\
24\end{array}$ & $\begin{array}{l}4,550 \\
3,670 \\
3,370 \\
3,150 \\
2,390 \\
2,170 \\
1,840 \\
1,530\end{array}$ & $\begin{array}{r}1,290 \\
1,230 \\
1,180 \\
1,010 \\
1,310 \\
972 \\
825 \\
985\end{array}$ & $\begin{array}{l}25 \\
26 \\
27 \\
28 \\
29 \\
30 \\
31\end{array}$ & $\begin{array}{l}1,330 \\
1,270 \\
1,340 \\
1,310 \\
1,990 \\
8,500 \\
9,500\end{array}$ & $\begin{array}{r}1,520 \\
1,440 \\
953 \\
866 \\
820 \\
602 \\
\end{array}$ \\
\hline & & & & & & & & & & $\begin{array}{r}5,858 \\
4.53\end{array}$ & $\begin{array}{r}1,787 \\
1.34\end{array}$ \\
\hline
\end{tabular}

Gage height, in feet, and discharge, in second-feet, at indicated time, 1940

\begin{tabular}{|c|c|c|c|c|c|c|}
\hline \multirow{2}{*}{ Hour } & \multicolumn{2}{|c|}{ Aug. 14} & \multicolumn{2}{|c|}{ Aug. 15} & \multicolumn{2}{|c|}{ Aug. 16} \\
\hline & $\begin{array}{c}\text { Gage } \\
\text { height }\end{array}$ & Discharge & $\begin{array}{l}\text { Gage } \\
\text { height }\end{array}$ & Discharge & $\begin{array}{l}\text { Gage } \\
\text { height }\end{array}$ & Discharge \\
\hline $\begin{array}{l}1 \\
2 \\
3 \\
4 \\
5 \\
6\end{array}$ & $\begin{array}{l}11.60 \\
12.84 \\
13.33 \\
13.73 \\
14.17 \\
14.64\end{array}$ & $\begin{array}{l}26,600 \\
35,200 \\
39,000 \\
42,500 \\
46,400 \\
51,100\end{array}$ & $\begin{array}{l}18.29 \\
17.82 \\
17.22 \\
16.60 \\
16.03 \\
15.40\end{array}$ & $\begin{array}{l}96,000 \\
89,400 \\
81,200 \\
73,100 \\
66,300 \\
59,100\end{array}$ & $\begin{array}{l}6.42 \\
6.30 \\
6.21 \\
6.13 \\
6.05 \\
5.98\end{array}$ & $\begin{array}{l}7,600 \\
7,310 \\
7,090 \\
6,900 \\
6,710 \\
6,540\end{array}$ \\
\hline $\begin{array}{r}7 \\
8 \\
9 \\
10 \\
11 \\
\mathrm{~N}\end{array}$ & $\begin{array}{l}15.10 \\
15.57 \\
16.07 \\
16.57 \\
17.03 \\
17.53\end{array}$ & $\begin{array}{l}55,800 \\
61,000 \\
66,700 \\
72,700 \\
78,700 \\
85,300\end{array}$ & $\begin{array}{l}14.70 \\
13.96 \\
13.21 \\
12.40 \\
11.61 \\
10.71\end{array}$ & $\begin{array}{l}51,700 \\
44,500 \\
38,100 \\
32,000 \\
26,700 \\
21,900\end{array}$ & $\begin{array}{l}\mathbf{5 . 9 2} \\
\mathbf{5 . 8 7} \\
\mathbf{5 . 8 0} \\
\mathbf{5 . 7 6} \\
\mathbf{5 . 7 0} \\
\mathbf{5 . 6 7}\end{array}$ & $\begin{array}{l}6,400 \\
6,280 \\
6,110 \\
6,010 \\
5,870 \\
5,800\end{array}$ \\
\hline $\begin{array}{l}1 \\
2 \\
3 \\
4 \\
5 \\
6\end{array}$ & $\begin{array}{l}18.09 \\
18.58 \\
18.89 \\
19.21 \\
19.52 \\
19.67\end{array}$ & $\begin{array}{r}93,200 \\
100,000 \\
105,000 \\
110,000 \\
115,000 \\
117,000\end{array}$ & $\begin{array}{l}9.97 \\
9.28 \\
8.74 \\
8.22 \\
7.85 \\
7.58\end{array}$ & $\begin{array}{l}18,800 \\
16,100 \\
14,200 \\
12,600 \\
11,400 \\
10,700\end{array}$ & $\begin{array}{l}\mathbf{5 . 5 7} \\
\mathbf{5 . 5 3} \\
\mathbf{5 . 4 9} \\
\mathbf{5 . 5 2} \\
\mathbf{5 . 5 2} \\
\mathbf{5 . 4 8}\end{array}$ & $\begin{array}{l}5,560 \\
5,470 \\
5,380 \\
5,450 \\
5,450 \\
5,350\end{array}$ \\
\hline $\begin{array}{r}7 \\
8 \\
9 \\
10 \\
11 \\
12\end{array}$ & $\begin{array}{l}19.74 \\
19.73 \\
19.62 \\
19.40 \\
19.08 \\
18.70\end{array}$ & $\begin{array}{l}119,000 \\
118,000 \\
117,000 \\
113,000 \\
108,000 \\
102,000\end{array}$ & $\begin{array}{l}7.38 \\
7.08 \\
6.94 \\
6.88 \\
6.69 \\
6.55\end{array}$ & $\begin{array}{r}10,100 \\
9,320 \\
8,950 \\
8,800 \\
8,300 \\
7,940\end{array}$ & $\begin{array}{l}5.44 \\
5.31 \\
5.46 \\
5.51 \\
5.43 \\
5.36\end{array}$ & $\begin{array}{l}5,260 \\
4,960 \\
5,310 \\
5,420 \\
5,240 \\
5,080\end{array}$ \\
\hline
\end{tabular}

Supplemental RECoRd.-Aug. 14, 7:30 p.m., gage height, 19.78 feet; discharge, 119,000 second-feet.

BROAD RIVER NEAR CARLISLE, S. C.

Location.-Lat. $34^{\circ} 36^{\prime}$, long. $81^{\circ} 25^{\prime}$, at bridge on State Highway 7,2 miles upstream from Sandy River, 2 miles downstream from Seaboard Railway bridge, $21 / 2$ miles east of Carlisle, Union County, and 5 miles downstream from Neals Shoals Dam. Datum of gage is 290.70 feet above mean sea.level, datum of 1929, supplementary adjustment of 1936 .

Drainage AREA.-2,790 square miles.

GAGE-HEIGHT RECORD.-Water-stage recorder graph.

DISCHARGE RECORD.-Stage-discharge relation defined by current-meter measurements up to 34,000 second-feet and extended to crest gage height on basis of determination of flood flow over Neals Shoals Dam.

Maxima.-1940: Discharge, 103,000 second-feet 4:30 p.m. Aug. 15 (gage height, 29.41 feet).

1938-39: Discharge, 34,900 second-feet Mar. 1, 1939 (gage height, 16.27 feet). 


\section{FLOODS OF AUGUST 1940 IN THE SOUTHEASTERN STATES}

REMARKs.-Flood discharge not appreciably affected by artificial storage or diversion. Flow regulated during medium and low stages by power plants above station.

Mean discharge, in second-feet, 1940

\begin{tabular}{|c|c|c|c|c|c|c|c|c|c|c|c|}
\hline Day & Aug. & Sept. & Day & Aug. & Sept. & Day & Aug. & Sept. & Day & Aug. & Sept. \\
\hline $\begin{array}{l}1 \\
2 \\
3 \\
4 \\
5 \\
6 \\
7 \\
8\end{array}$ & $\begin{array}{r}1,050 \\
1,730 \\
702 \\
92 \\
958 \\
1,190 \\
1,010 \\
1,110\end{array}$ & $\begin{array}{l}7, \\
5, \\
4 \\
3, \\
2, \\
3, \\
1, \\
1,\end{array}$ & $\begin{array}{l}9 \\
10 \\
11 \\
12 \\
13 \\
14 \\
15 \\
16\end{array}$ & $\begin{array}{r}1,620 \\
672 \\
95 \\
1,240 \\
2,990 \\
29,100 \\
85,500 \\
43,900\end{array}$ & $\begin{array}{r}2,560 \\
2,080 \\
2,320 \\
3,360 \\
2,740 \\
1,240 \\
503 \\
1,690\end{array}$ & $\begin{array}{l}18 \\
19 \\
20 \\
21 \\
22 \\
23 \\
24\end{array}$ & $\begin{array}{l}7,740 \\
5,640 \\
4,940 \\
4,740 \\
4,640 \\
2,920 \\
2,690 \\
1,780\end{array}$ & $\begin{array}{r}1,730 \\
1,680 \\
1,840 \\
1,140 \\
193 \\
1,630 \\
1,520\end{array}$ & $\begin{array}{l}25 \\
26 \\
27 \\
28 \\
29 \\
30 \\
31\end{array}$ & $\begin{array}{r}1,100 \\
2,340 \\
2,190 \\
1,960 \\
2,160 \\
6,150 \\
11,100\end{array}$ & $\begin{array}{r}1,330 \\
1,750 \\
2,190 \\
1,210 \\
221 \\
1,380 \\
\end{array}$ \\
\hline \multicolumn{10}{|c|}{$\begin{array}{l}\text { Monthly mean discharge, in second-feet } \\
\text { Runoff, in inches }\end{array}$} & 7,5 & $\begin{array}{r}2,143 \\
0.86\end{array}$ \\
\hline
\end{tabular}

Gage height, in feet, and discharge, in second-feet, at indicated time, 1940

\begin{tabular}{|c|c|c|c|c|c|c|c|c|c|c|}
\hline \multirow{2}{*}{ Hour } & \multicolumn{2}{|c|}{ Aug. 13} & \multicolumn{2}{|c|}{ Aug. 14} & \multicolumn{2}{|c|}{ Aug. 15} & \multicolumn{2}{|c|}{ Aug. 16} & \multicolumn{2}{|c|}{ Aug. 17} \\
\hline & $\begin{array}{c}\text { Gage } \\
\text { height }\end{array}$ & $\begin{array}{l}\text { Dis- } \\
\text { charge }\end{array}$ & $\begin{array}{c}\text { Gage } \\
\text { height }\end{array}$ & $\begin{array}{l}\text { Dis- } \\
\text { charge }\end{array}$ & $\begin{array}{l}\text { Gage } \\
\text { height }\end{array}$ & $\begin{array}{l}\text { Dis- } \\
\text { charge }\end{array}$ & $\begin{array}{l}\text { Gage } \\
\text { height }\end{array}$ & $\begin{array}{l}\text { Dis- } \\
\text { charge }\end{array}$ & $\begin{array}{l}\text { Gage } \\
\text { height }\end{array}$ & $\begin{array}{l}\text { Dis- } \\
\text { charge }\end{array}$ \\
\hline $\begin{array}{l}1 \\
2 \\
3 \\
4 \\
5 \\
6\end{array}$ & $\begin{array}{l}2.73 \\
2.54 \\
2.25 \\
2.00 \\
1.85 \\
1.72\end{array}$ & $\begin{array}{r}1,380 \\
1,140 \\
807 \\
565 \\
440 \\
342\end{array}$ & $\begin{array}{r}6.44 \\
7.22 \\
8.08 \\
9.52 \\
10.59 \\
11.32\end{array}$ & $\begin{array}{r}8,510 \\
10,200 \\
12,100 \\
15,600 \\
18,300 \\
20,200\end{array}$ & $\begin{array}{l}21.02 \\
21.73 \\
22.43 \\
23.25 \\
24.02 \\
24.57\end{array}$ & $\begin{array}{l}53,300 \\
56,800 \\
60,400 \\
64,600 \\
68,800 \\
71,800\end{array}$ & $\begin{array}{l}26.94 \\
26.29 \\
25.79 \\
25.18 \\
24.49 \\
23.83\end{array}$ & $\begin{array}{l}86,200 \\
82,000 \\
79,000 \\
75,400 \\
71,400 \\
67,800\end{array}$ & 6.71 & 9,100 \\
\hline $\begin{array}{r}7 \\
8 \\
9 \\
10 \\
11 \\
\mathrm{~N}\end{array}$ & $\begin{array}{l}1.64 \\
1.58 \\
1.80 \\
3.40 \\
3.76 \\
4.33\end{array}$ & $\begin{array}{r}289 \\
251 \\
400 \\
2,400 \\
3,060 \\
4,200\end{array}$ & $\begin{array}{l}12.16 \\
12.94 \\
13.44 \\
13.89 \\
14.25 \\
14.65\end{array}$ & $\begin{array}{l}22,500 \\
24,700 \\
26,100 \\
27,400 \\
28,500 \\
29,700\end{array}$ & $\begin{array}{l}25.10 \\
25.28 \\
26.78 \\
27.35 \\
27.93 \\
28.33\end{array}$ & $\begin{array}{l}74,900 \\
76,000 \\
85,100 \\
88,800 \\
92,600 \\
95,300\end{array}$ & $\begin{array}{l}23.11 \\
22.35 \\
21.53 \\
20.63 \\
19.49 \\
18.18\end{array}$ & $\begin{array}{l}63,800 \\
60,000 \\
55,800 \\
51,500 \\
46,500 \\
41,400\end{array}$ & $\begin{array}{c}-1.81 \\
-5.42\end{array}$ & $\begin{array}{r}7,160 \\
6,380\end{array}$ \\
\hline $\begin{array}{l}1 \\
2 \\
3 \\
4 \\
5 \\
6\end{array}$ & $\begin{array}{l}4.54 \\
4.60 \\
4.60 \\
4.60 \\
4.60 \\
4.60\end{array}$ & $\begin{array}{l}4,620 \\
4,740 \\
4,740 \\
4,740 \\
4,740 \\
4,740\end{array}$ & $\begin{array}{l}15.04 \\
15.47 \\
16.04 \\
16.56 \\
16.94 \\
17.31\end{array}$ & $\begin{array}{l}30,900 \\
32,200 \\
34,100 \\
35,700 \\
37,000 \\
38,300\end{array}$ & $\begin{array}{l}28.70 \\
28.95 \\
29.13 \\
29.40 \\
29.40 \\
29.34\end{array}$ & $\begin{array}{r}97,900 \\
99,600 \\
101,000 \\
103,000 \\
103,000 \\
102,000\end{array}$ & $\begin{array}{l}16.82 \\
15.37 \\
13.93 \\
12.42 \\
11.16 \\
10.08\end{array}$ & $\begin{array}{l}36,600 \\
31,900 \\
27,600 \\
23,200 \\
19,800 \\
17,000\end{array}$ & $\begin{array}{c}5.33 \\
6.07\end{array}$ & $\frac{6,200}{7,690}$ \\
\hline $\begin{array}{r}7 \\
8 \\
9 \\
10 \\
11 \\
12\end{array}$ & $\begin{array}{l}4.60 \\
4.60 \\
4.60 \\
4.65 \\
4.78 \\
5.55\end{array}$ & $\begin{array}{l}4,740 \\
4,740 \\
4,740 \\
4,840 \\
5,100 \\
6,640\end{array}$ & $\begin{array}{l}17.69 \\
18.17 \\
18.69 \\
19.22 \\
19.74 \\
20.43\end{array}$ & $\begin{array}{l}39,600 \\
41,400 \\
43,300 \\
45,400 \\
47,500 \\
50,600\end{array}$ & $\begin{array}{l}29.18 \\
28.98 \\
28.68 \\
28.31 \\
27.90 \\
27.43\end{array}$ & $\begin{array}{r}101,000 \\
99,900 \\
97,800 \\
95,200 \\
92,400 \\
89,300\end{array}$ & $\begin{array}{l}9.42 \\
8.84 \\
8.39 \\
8.03 \\
7.71 \\
7.47\end{array}$ & $\begin{array}{l}15,300 \\
14,000 \\
12,900 \\
12,000 \\
11,300 \\
10,800\end{array}$ & $\begin{array}{c}6.25 \\
6.16\end{array}$ & $\begin{array}{r}8,090 \\
--\overline{7}, 890\end{array}$ \\
\hline
\end{tabular}

SuPPLEMENTAL RECORD.-Aug. 15, 4:30 p.m., gage height, 29.41 feet; discharge, 103,000 second-feet.

BROAD RIVER AT RICHTEX, S. C.

Location.-Lat. $34^{\circ} 11^{\prime}$, long. $81^{\circ} 12^{\prime}$, 1 mile upstream from Little River and Richtex, Fairfield County, and 11 miles downstream from Parr Shoals Dam. Datum of gage is 184.84 feet above mean sea level, datum of 1929 , supplementary adjustment of 1936 .

Drainage ARea.—4,850 square miles (1943 revision).

GAGE-HEIGHT RECORD.-Water-stage recorder graph.

DISCHARGE REC0RD.- Stage-discharge relation defined by current-meter measurements up to 80,000 second-feet and extended to crest gage height on basis of determinations of flood flows over. Parr Shoals Dam.

Maxima.-1940: Discharge, 120,000 second-feet 8 a.m. Aug. 16 (gage height, 21.08 feet).

1925-39: Discharge, 228,000 second-feet Oct. 3, 1929 (gage height, 30.7 feet, from floodmarks). 
REMARKS.-Flood diseharge not appreciably affected by artificial storage or diversion. Flow regulated by power plants above station during low and medium stages.

Mean discharge, in second-feet, 1940

\begin{tabular}{r|r|r||r|r|r||r|r|r||r|r|r}
\hline Day & Aug. & \multicolumn{1}{|c|}{ Sept. } & Day & Aug. & Sept. & Day & Aug. & Sept. & Day & Aug. & Sept. \\
\hline 1 & 1,730 & 10,800 & 9 & 1,440 & 2,680 & 17 & 39,900 & 1,940 & 25 & 1,190 & 2,050 \\
2 & 1,030 & 7,690 & 10 & 2,080 & 2,710 & 18 & 12,100 & 1,330 & 26 & 2,580 & 1,420 \\
3 & 1,960 & 5,550 & 11 & 535 & 2,530 & 19 & 7,030 & 2,200 & 27 & 3,050 & 1,740 \\
4 & 389 & 4,480 & 12 & 2,120 & 3,290 & 20 & 6,280 & 1,840 & 28 & 2,600 & 2,040 \\
5 & 645 & 3,760 & 13 & 4,270 & 3,490 & 21 & 5,900 & 2,400 & 29 & 2,780 & 516 \\
6 & 1,410 & 3,460 & 14 & 22,600 & 2,750 & 22 & 5,410 & 671 & 30 & 5,170 & 1,220 \\
7 & 1,550 & 3,200 & 15 & 71,300 & 606 & 23 & 2,940 & 1,050 & 31 & 5,490 & $-\ldots$ \\
8 & 1,410 & 672 & 16 & 109,000 & 1,580 & 24 & 3,400 & 2,720 & & \\
\hline
\end{tabular}

Gage height, in feet, and discharge, in second-feet, at indicated time, 1940

\begin{tabular}{|c|c|c|c|c|c|c|c|c|c|c|c|c|}
\hline \multirow{2}{*}{ Hour } & \multicolumn{2}{|c|}{ Aug. 13} & \multicolumn{2}{|c|}{ Aug. 14} & \multicolumn{2}{|c|}{ Aug. 15} & \multicolumn{2}{|c|}{ Aug. 16} & \multicolumn{2}{|c|}{ Aug. 17} & \multicolumn{2}{|c|}{ Aug. 18} \\
\hline & $\begin{array}{c}\text { Gage } \\
\text { ht. }\end{array}$ & cl & & $\begin{array}{c}\text { Dis } \\
\text { charg }\end{array}$ & & $\underset{c h}{D}$ & e & $\begin{array}{r}\mathrm{Di} \\
\text { ehai }\end{array}$ & & & ge & $\begin{array}{c}\text { Dis- } \\
\text { charge }\end{array}$ \\
\hline \multirow[t]{4}{*}{$\begin{array}{l}1 \\
2\end{array}$} & & & \multirow{4}{*}{\begin{tabular}{|l|}
3.60 \\
3.59 \\
3.50 \\
3.50 \\
3.51 \\
3.54 \\
\end{tabular}} & \multirow{4}{*}{$\begin{array}{l}7,400 \\
7,370 \\
7,, 100 \\
7,100 \\
7,130 \\
7,220\end{array}$} & \multirow{4}{*}{$\begin{array}{l}11.95 \\
12.19 \\
12.44 \\
12.69 \\
12.97 \\
13.24\end{array}$} & \multirow{4}{*}{\begin{tabular}{|l}
46,500 \\
48,000 \\
49,700 \\
51,300 \\
53,100 \\
54,900
\end{tabular}} & \multirow{4}{*}{$\begin{array}{l}20.17 \\
20.42 \\
20.63 \\
20.79 \\
20.93 \\
21.02\end{array}$} & \multirow{4}{*}{$\begin{array}{l}111,000 \\
113,000 \\
115,000 \\
117,000 \\
118,000 \\
119,000\end{array}$} & \multirow{4}{*}{$\begin{array}{l}16.04 \\
15.41 \\
14.76 \\
14.10 \\
13.46 \\
12.84\end{array}$} & \multirow{4}{*}{$\begin{array}{l}74,100 \\
69,700 \\
65,100 \\
60,500 \\
56,300 \\
52,300\end{array}$} & 6.08 & 5 \\
\hline & & & & & & & & & & & 577 & \\
\hline & & & & & & & & & & & 5.77 & \\
\hline & & & & & & & & & & & 5.50 & 50 \\
\hline \multirow{4}{*}{$\begin{array}{r}7 \\
8 \\
9 \\
10 \\
11 \\
\mathrm{~N}\end{array}$} & & & & & \multirow{4}{*}{$\begin{array}{l}13.54 \\
13.83 \\
14.13 \\
14.44 \\
14.77 \\
15.14\end{array}$} & \multirow{4}{*}{$\begin{array}{l}56,800 \\
58,700 \\
60,700 \\
62,900 \\
65,200 \\
67,800\end{array}$} & \multirow{4}{*}{$\left|\begin{array}{l}21.07 \\
21.08 \\
21.07 \\
22.03 \\
20.94 \\
20.81\end{array}\right|$} & \multirow{4}{*}{$\begin{array}{l}120,000 \\
120,000 \\
120,000 \\
119,000 \\
118,000 \\
117,000\end{array}$} & \multirow{4}{*}{$\begin{array}{r}12.27 \\
11.74 \\
11.25 \\
10.78 \\
10.36 \\
9.92\end{array}$} & \multirow{4}{*}{$\begin{array}{l}48,600 \\
45,200 \\
42,300 \\
39,500 \\
37,000 \\
34,600\end{array}$} & & \\
\hline & & & & & & & & & & & 5.27 & 13,200 \\
\hline & & & & & & & & & & & 5.26 & 13,200 \\
\hline & & & & & & & & & & & 4.99 & 12,200 \\
\hline \multirow{4}{*}{$\begin{array}{l}1 \\
2 \\
3 \\
4 \\
5 \\
6\end{array}$} & 2.88 & 5,8 & 91 _ & 24 & \multirow{4}{*}{$\begin{array}{l}15.51 \\
15.92 \\
16.34 \\
16.76 \\
17.19 \\
17.59\end{array}$} & \multirow{4}{*}{$\begin{array}{l}70,400 \\
73,200 \\
76,400 \\
79,500 \\
82,900 \\
86,300\end{array}$} & \multirow{4}{*}{\begin{tabular}{|l|}
20.67 \\
20.48 \\
20.26 \\
20.01 \\
19.72 \\
19.38
\end{tabular}} & \multirow{4}{*}{$\begin{array}{l}116,000 \\
114,000 \\
112,000 \\
109,000 \\
106,000 \\
103,000\end{array}$} & \multirow{4}{*}{$\begin{array}{l}9.64 \\
9.37 \\
9.04 \\
8.68 \\
8.40 \\
8.14\end{array}$} & \multirow{4}{*}{$\begin{array}{l}83,100 \\
31,600 \\
29,800 \\
28,000 \\
26,600 \\
25,300\end{array}$} & & \\
\hline & & & & & & & & & & & 4.71 & 11,100 \\
\hline & & & & & & & & & & & 4.41 & 10,100 \\
\hline & & & & & & & & & & & $4.1 \overline{1}$ & $9,160^{-}$ \\
\hline \multirow{4}{*}{$\begin{array}{r}7 \\
8 \\
9 \\
10 \\
11 \\
12\end{array}$} & & & & & \multirow{4}{*}{$\left|\begin{array}{l}18.00 \\
18.44 \\
18.85 \\
19.23 \\
19.57 \\
19.89\end{array}\right|$} & \multirow{4}{*}{$\begin{array}{r}90,000 \\
94,200 \\
98,100 \\
102,000 \\
105,000 \\
108,000\end{array}$} & \multirow{4}{*}{$\left|\begin{array}{l}19.00 \\
18.64 \\
18.18 \\
17.70 \\
17.18 \\
16.63\end{array}\right|$} & & & & & \\
\hline & & & & & & & & & & & 3.93 & 8, \\
\hline & & & & & & & & & & & 4.01 & $8,710^{-}$ \\
\hline & & & & & & & & & & & 3.81 & $8,050^{-}$ \\
\hline
\end{tabular}

GREEN RIVER NEAR MILL SPRING, N. C.

LOCATION.--Lat. $35^{\circ} 20^{\prime} 10^{\prime \prime}$, long. $82^{\circ} 04^{\prime} 50^{\prime \prime}$, at abandoned ford $11 / 2$ miles northeast of Pea Ridge Church, about 2 miles downstream from Walnut Creek and 51/4 miles northeast of Mill Spring, Polk County.

DraINAGE AREA.- 174 square miles.

GAGE-HEIGHT RECORD.-Water-stage recorder graph.

DisCHARGE RECORD.-Stage-discharge relation defined by current-meter measurements up to 2,700 second-feet and extended logarithmically to crest gage height on basis of computation of flood flow over dam and through wheels at Turner Shoals power plant, about 4 miles above station. Gage heights used to halftenths between 3.2 and 3.8 feet; hundredths below and tenths above these limits.

Maxima.-1940: Discharge, 10,800 second-feet 8:30 p.m. Aug. 13 (gage height, 22.15 feet).

Stage known, 24.2 feet sometime in July 1916, from flood reference mark placed by local resident (discharge not determined).

$804331-49-18$ 


\section{FLOODS OF AUGUST 1940 IN THE SOUTHEASTERN STATES}

REMARKs.-Flood runoff affected by storage in Lake Summit, about 25 miles upstream, which has a total storage capacity of $211,015,000$ cubic feet and a usable storage capacity of 110,580,000 cubic feet, and in Turner Shoals Reservoir, about 4 miles upstream, which has a total storage capacity of about 519,547,000 cubic feet and a usable storage capacity of $153,875,000$ cubic feet.

Mean discharge, in second-feet, 1940

\begin{tabular}{r|r|r||r|r|r||r|r|r|r|r|r}
\hline Day & Aug. & \multicolumn{1}{|c|}{ Sept. } & Day & \multicolumn{1}{c|}{ Aug. } & Sept. & Day & Aug. & Sept. & Day & Aug. & Sept. \\
\hline 1 & 76 & 748 & 9 & 51 & 740 & 17 & 587 & 444 & 25 & 60 & 244 \\
2 & 35 & 815 & 10 & 34 & 671 & 18 & 327 & 347 & 26 & 285 & 255 \\
3 & 35 & 554 & 11 & 34 & 385 & 19 & 825 & 345 & 27 & 330 & 296 \\
4 & 34 & 464 & 12 & 221 & 324 & 20 & 472 & 568 & 28 & 345 & 93 \\
5 & 429 & 357 & 13 & 4,880 & 296 & 21 & 434 & 328 & 29 & 422 & 43 \\
6 & 210 & 478 & 14 & 4,650 & 142 & 22 & 402 & 58 & 30 & 1,540 & 456 \\
7 & 260 & 153 & 15 & 1,420 & 51 & 23 & 404 & 220 & 31 & 1,420 & $-\ldots$ \\
8 & 310 & 111 & 16 & 1,080 & 418 & 24 & 103 & 299 & & & \\
\hline
\end{tabular}

Gage height, in feet, and discharge, in second-feet, at indicated time, 1940

\begin{tabular}{|c|c|c|c|c|c|c|c|c|c|c|}
\hline \multirow{2}{*}{ Hour } & \multicolumn{2}{|c|}{ Aug. 12} & \multicolumn{2}{|c|}{ Aug. 13} & \multicolumn{2}{|c|}{ Aug. 14} & \multicolumn{2}{|c|}{ Aug. 15} & \multicolumn{2}{|c|}{ Aug. 16} \\
\hline & $\begin{array}{c}\text { Gage } \\
\text { height }\end{array}$ & $\begin{array}{c}\text { Dis- } \\
\text { charge }\end{array}$ & $\begin{array}{c}\text { Gage } \\
\text { height }\end{array}$ & $\begin{array}{l}\text { Dis- } \\
\text { charge }\end{array}$ & $\begin{array}{c}\text { Gage } \\
\text { height }\end{array}$ & $\begin{array}{c}\text { Dis- } \\
\text { charge }\end{array}$ & $\begin{array}{c}\text { Gage } \\
\text { height }\end{array}$ & $\begin{array}{l}\text { Dis- } \\
\text { charge }\end{array}$ & $\begin{array}{l}\text { Gage } \\
\text { height }\end{array}$ & $\begin{array}{l}\text { Dis- } \\
\text { charge }\end{array}$ \\
\hline \multirow{5}{*}{$\begin{array}{l}1 \\
2 \\
3 \\
4 \\
5 \\
6\end{array}$} & \multirow{5}{*}{$\begin{array}{l}1.51 \\
1.51 \\
1.51 \\
1.51 \\
1.50 \\
1.50\end{array}$} & \multirow{5}{*}{$\begin{array}{l}36 \\
36 \\
36 \\
36 \\
35 \\
35\end{array}$} & \multirow{5}{*}{$\begin{array}{l}2.07 \\
1.97 \\
1.93 \\
1.97 \\
1.91 \\
1.92\end{array}$} & \multirow{5}{*}{$\begin{array}{l}167 \\
134 \\
123 \\
134 \\
117 \\
120\end{array}$} & \multirow{5}{*}{$\begin{array}{l}19.82 \\
19.15 \\
18.45 \\
17.70 \\
16.84 \\
15.95\end{array}$} & \multirow{5}{*}{$\begin{array}{l}9,380 \\
9,020 \\
8,570 \\
8,180 \\
7,690 \\
7,250\end{array}$} & \multirow[b]{2}{*}{5.64} & \multirow[b]{2}{*}{1,970} & \multirow[b]{2}{*}{3.68} & \multirow[b]{2}{*}{1,120} \\
\hline & & & & & & & & & & \\
\hline & & & & & & & \multirow{2}{*}{$-\overline{5} .05$} & 1700 & \multirow{2}{*}{3.67} & \multirow{2}{*}{1,090} \\
\hline & & & & & & & & 1,700 & & \\
\hline & & & & & & & $4 . \overline{7}$ & 1,560 & 3.62 & 1,070 \\
\hline \multirow{4}{*}{$\begin{array}{r}7 \\
8 \\
9 \\
10 \\
11 \\
\mathrm{~N}\end{array}$} & 1.50 & 35 & 2.20 & 6 & \multirow{4}{*}{$\begin{array}{r}14.94 \\
13.83 \\
12.65 \\
11.30 \\
9.87 \\
8.80\end{array}$} & \multirow{4}{*}{$\begin{array}{l}6,640 \\
6,040 \\
5,400 \\
4,750 \\
4,050 \\
3,500\end{array}$} & & & \multirow[b]{2}{*}{3.62} & \multirow[b]{2}{*}{1,070} \\
\hline & & 9 & 3.55 & 1. 0 & & & 4.47 & 1,480 & & \\
\hline & 1.50 & $\begin{array}{l}53 \\
35\end{array}$ & $\begin{array}{l}3.20 \\
8.90\end{array}$ & 3,550 & & & $4 . \overline{3} \overline{3}^{-}$ & $1, \overline{380}$ & 3.60 & $1,070^{-}$ \\
\hline & $\begin{array}{l}1.50 \\
1.93\end{array}$ & $\begin{array}{r}35 \\
123\end{array}$ & $\begin{array}{l}10.62 \\
11.32\end{array}$ & $\begin{array}{l}4,400 \\
4,750\end{array}$ & & & 417 & 1.340 & 3.60 & 1070 \\
\hline \multirow{4}{*}{$\begin{array}{l}1 \\
2 \\
3 \\
4 \\
5 \\
6\end{array}$} & & & & & \multirow{5}{*}{$\begin{array}{l}7.95 \\
7.31 \\
6.84 \\
6.51 \\
6.22 \\
5.93\end{array}$} & \multirow{5}{*}{$\begin{array}{l}3,100 \\
2,750 \\
2,510 \\
2,380 \\
2,240 \\
2,100\end{array}$} & & & & \multirow{2}{*}{1,070} \\
\hline & 2.44 & & 13.00 & 5,6 & & & 4.08 & 1,300 & 3.58 & \\
\hline & $\begin{array}{l}2.56 \\
2.48\end{array}$ & $\begin{array}{l}401 \\
354\end{array}$ & $\begin{array}{l}14.15 \\
16.67\end{array}$ & $\begin{array}{l}6,2 \\
7,6\end{array}$ & & & 4.02 & 1,250 & 3.57 & 1,040 \\
\hline & $\begin{array}{l}2.63 \\
2.72\end{array}$ & & $\begin{array}{l}18.50 \\
20.10\end{array}$ & $\begin{array}{l}8,620 \\
9,560\end{array}$ & & & 3.88 & 1,200 & 3.56 & 1,040 \\
\hline & & & & & & & & & & \\
\hline $\begin{array}{l}7 \\
8\end{array}$ & $\begin{array}{l}2.75 \\
2.77\end{array}$ & $\begin{array}{l}525 \\
539\end{array}$ & $\begin{array}{l}21.76 \\
22.14\end{array}$ & $\begin{array}{l}10,600 \\
10,800\end{array}$ & $\begin{array}{l}5.76 \\
5.70\end{array}$ & $\begin{array}{l}2,060 \\
2,020\end{array}$ & $3.80^{-}$ & 1,160 & 3.68 & 1,120 \\
\hline $\begin{array}{r}9 \\
10\end{array}$ & $\begin{array}{l}2.78 \\
2.66\end{array}$ & $\begin{array}{l}546 \\
464\end{array}$ & 22.03 & 10,700 & 5.61 & $\begin{array}{l}1,970 \\
970\end{array}$ & 3 & & 3.65 & \\
\hline 11 & 2.43 & 3 & 21 . & & 5 & $\begin{array}{l}1,9 \\
2,0\end{array}$ & 3. & 1,120 & & 1,090 \\
\hline 12 & & 2 & 0. & 0 & & 2,150 & 3.69 & 1,120 & 3.64 & 1,090 \\
\hline
\end{tabular}

Sirpplemental Recond.-Aug. 13, 8:30 p.m., gage height, 22.15 feet; discharge 10,800 second-feet

\section{SECOND BROAD RIVER AT CLIFWSIDE, N. C.}

Location.-Lat. $35^{\circ} 14^{\prime} 15^{\prime \prime}$, long. $81^{\circ} 46^{\prime} 25^{\prime \prime}$, at Cliffside, Rutherford County, 2 miles upstream from mouth.

DRAINAGE AREA.—211 square miles.

GAGE-HEIGHT RECORD.-Water-stage recorder graph.

DISCHARGE RECORD.- Stage-discharge relation defined by current-meter measurements up to 9,100 second-feet and extended to crest gage height on basis of computation of flood flow over Cliffside Mills Dam, about a quarter of a mile upstream. Gage heights used to half-tenths between 2.5 and 4.6 feet; hundredths below and tenths above these limits.

Maxima.-1940: Discharge, 15,000 second-feet 1 p.m. Ang. 14 (gage height, 17.93 feet).

1925-39: Discharge, 14,500 second-feet Aug. 16, 1928 (gage height, 17.26 feet).

REMARKS.-Flood runoff not affected by artificial storage. 
SANTEE RIVER BASIN

Mean discharge, in second-feet, 1940

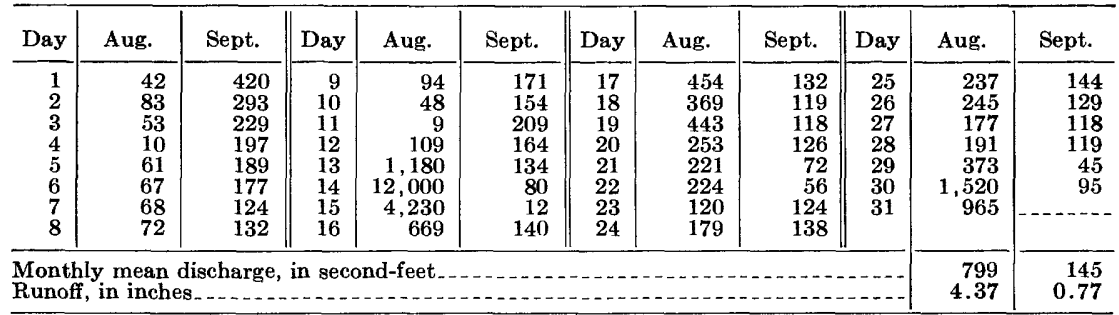

Gage height, in feet, and discharge, in second-feet, at indicated time, 1940

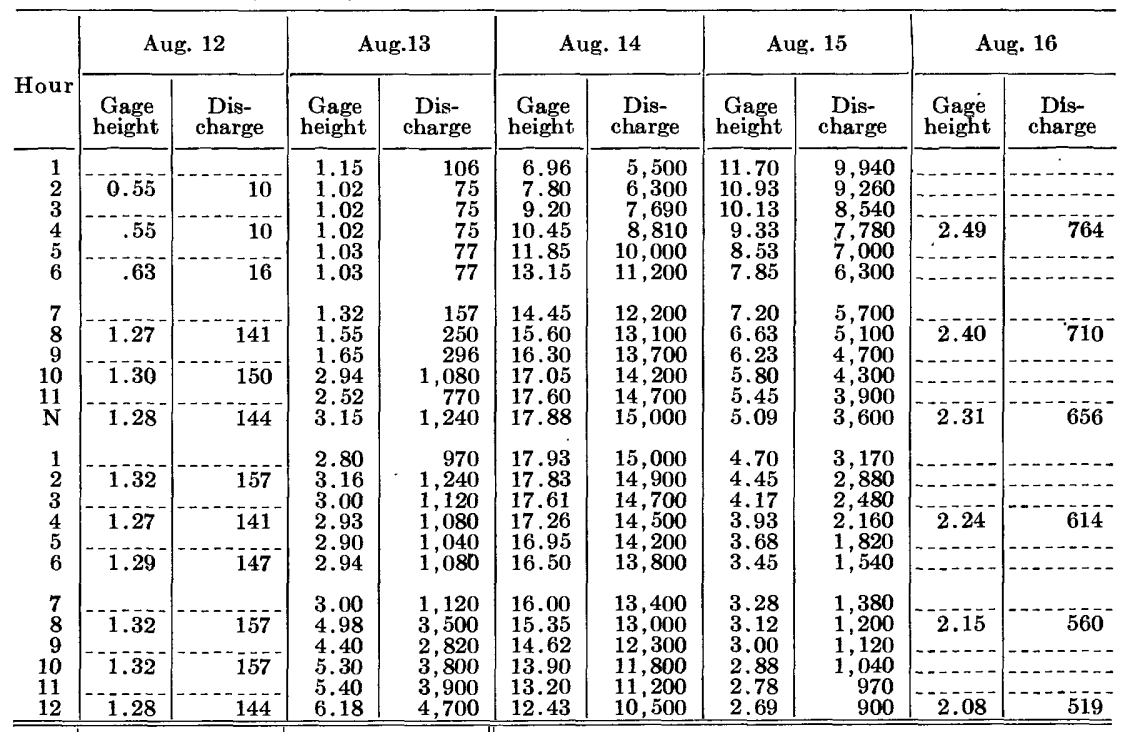

\begin{tabular}{|c|c|c|c|c|c|c|c|}
\hline \multirow{2}{*}{$\begin{array}{r}\text { Hour } \\
6 \\
6 \\
5 \\
6 \\
12\end{array}$} & \multicolumn{2}{|c|}{ Aug. 17} & \multicolumn{2}{|c|}{ Aug. 18} & \multicolumn{3}{|l|}{ SUPPLEMENTAL RECORDS } \\
\hline & $\begin{array}{l}2.02 \\
1.93 \\
1.92 \\
1.88\end{array}$ & $\begin{array}{l}486 \\
436 \\
431 \\
410\end{array}$ & $\begin{array}{l}1.82 \\
1.81 \\
1.77 \\
1.70\end{array}$ & $\begin{array}{l}380 \\
375 \\
355 \\
320\end{array}$ & $\begin{aligned} \text { Aug. } 12,1: 45 \text { p.m. } \\
\text { Aug. 13, } 12: 15 \text { p.m. } \\
\text { 12:45 p.m. } \\
\text { Aug. 17, } 12: 15 \text { p.m.m. } \\
\text { Aun. }\end{aligned}$ & $\begin{array}{l}1.39 \\
3.24 \\
2.75 \\
5.15 \\
1.75\end{array}$ & $\begin{array}{r}182 \\
1,340 \\
935 \\
3,700 \\
345\end{array}$ \\
\hline
\end{tabular}

FIRST BROAD RIVER NEAR LAWNDALE, N. C.

Location.-Lat. $35^{\circ} 22^{\prime} 50^{\prime \prime}$, long. $81^{\circ} 32^{\prime} 40^{\prime \prime}$, 500 feet downstream from dam at Double Shoals, about one-eighth of a mile upstream from Barnes Creek, and

$2 \frac{1}{2}$ miles southeast of Lawndale, Cleveland County.

DratNAGE AREA.-198 square miles (1942 revision).

GAGE-HEIGHT RECORD.-Water-stage recorder graph.

DISCHARGE RECORD.- Stage-discharge relation defined by current-meter measurements up to 8,300 second-feet and extended above on basis of records for nearby streams. The flood of Aug. 13-14 deposited large quantities of sand in the river and upset the normal stage-discharge relation very seriously from Aug. 13 to Sept. 3.0. The result of a slope-area determination of the discharge at erest gage height was valueless because of sand movement. Shifting-control method used 3-8 p.m. Ang. 13 and 8 p.m. Aug. 14 to Sept. 30 based on four eurrentmeter measurements. Gage heights used to half-tenths between 3.1 and 4.5 feet; hundredths below and tenths above these limits. 
Maxima.-1940: Diseharge, 32,500 seeond-feet 6 a.m. Aug. 14 (gage height, 37.8 feet).

The flood of July 1916 reached a stage about 0.03 foot higher than that of Aug. 14, 1940, from flood reference mark placed by local resident (discharge not determined).

REMARKS.-Runoff for major floods not affected by artificial storage. Reeords of diseharge above 10,000 second-feet are of doubtful accuracy because of poor definition of stage-discharge relation.

Mean discharge, in second-feet, 1940

\begin{tabular}{r|r|r|r|r|r||r|r|r|r|r|r}
\hline Day & Aug. & \multicolumn{1}{|c|}{ Sept. } & Day & Aug. & Sept. & Day & Aug. & Sept. & Day & Aug. & Sept. \\
\hline 1 & 88 & 352 & 9 & 53 & 111 & 17 & 594 & 40 & 25 & 195 & 72 \\
2 & 71 & 226 & 10 & 51 & 244 & 18 & 715 & 82 & 26 & 179 & 66 \\
3 & 54 & 177 & 11 & 53 & 286 & 19 & 657 & 78 & 27 & 163 & 55 \\
4 & 42 & 172 & 12 & 181 & 86 & 20 & 329 & 74 & 28 & 135 & 55 \\
5 & 57 & 159 & 13 & 3,500 & 101 & 21 & 246 & 70 & 29 & 378 & 46 \\
6 & 55 & 134 & 14 & 19,900 & 132 & 22 & 189 & 58 & 30 & 2,200 & 57 \\
7 & 88 & 121 & 15 & 981 & 100 & 23 & 166 & 81 & 31 & 1,070 & \\
8 & 103 & 97 & 16 & 604 & 93 & 24 & 201 & 62 & & \\
\hline
\end{tabular}

Gage height, in feet, and discharge, in second-feet, at indicated time, 1940

\begin{tabular}{|c|c|c|c|c|c|c|c|c|c|c|c|c|}
\hline \multirow{2}{*}{ Hour } & \multicolumn{2}{|c|}{ Aug. 12} & \multicolumn{2}{|c|}{ Aug. 13} & \multicolumn{2}{|c|}{ Aug. 14} & \multicolumn{2}{|c|}{ Aug. 15} & \multicolumn{2}{|c|}{ Aug. 16} & \multicolumn{2}{|c|}{ Aug. 17} \\
\hline & $\begin{array}{c}\text { Gage } \\
\text { ht. }\end{array}$ & $\begin{array}{c}\text { Dis- } \\
\text { charge }\end{array}$ & $\begin{array}{c}\text { Gage } \\
\text { ht. }\end{array}$ & $\begin{array}{c}\text { Dis- } \\
\text { charge }\end{array}$ & $\begin{array}{c}\text { Gage } \\
\text { ht. }\end{array}$ & $\begin{array}{c}\text { Dis- } \\
\text { charge }\end{array}$ & $\begin{array}{c}\text { Gage } \\
\text { ht. }\end{array}$ & $\begin{array}{c}\text { Dis- } \\
\text { charge }\end{array}$ & $\begin{array}{c}\text { Gage } \\
\text { ht. }\end{array}$ & $\begin{array}{c}\text { Dis- } \\
\text { charge }\end{array}$ & $\begin{array}{c}\text { Gage } \\
\text { ht. }\end{array}$ & $\begin{array}{c}\text { Dis- } \\
\text { charge }\end{array}$ \\
\hline \multirow{4}{*}{$\begin{array}{l}1 \\
2 \\
3 \\
4 \\
5 \\
6\end{array}$} & & & \multirow{4}{*}{$\begin{array}{l}2.03 \\
1.98 \\
1.92 \\
1.91 \\
1.92 \\
1.75\end{array}$} & \multirow{4}{*}{$\begin{array}{l}230 \\
209 \\
185 \\
181 \\
185 \\
129\end{array}$} & \multirow{4}{*}{$\mid \begin{array}{l}30.40 \\
31.95 \\
33.80 \\
35.65 \\
37.10 \\
37.8\end{array}$} & \multirow{4}{*}{$\begin{array}{l}22,500 \\
24,600 \\
26,900 \\
29,400 \\
31,500 \\
32,500\end{array}$} & \multirow{4}{*}{\begin{tabular}{|}
5.45 \\
5.02 \\
4.80 \\
4.50 \\
4.38 \\
4.30
\end{tabular}} & \multirow{4}{*}{$\begin{array}{l}1,660 \\
1,420 \\
1,300 \\
1,140 \\
1,080 \\
1,030\end{array}$} & & & & \multirow[b]{2}{*}{628} \\
\hline & 1.77 & 135 & & & & & & & 3.63 & 644 & 3.68 & \\
\hline & $1 . \overline{7} \overline{5}$ & 129 & & & & & & & 3.56 & $604^{-}$ & $3.6 \overline{6}$ & 619 \\
\hline & 1.70 & 115 & & & & & & & 3.52 & 580 & 3.63 & 606 \\
\hline 7 & 177 & 125 & \multirow{4}{*}{$\begin{array}{l}2.10 \\
2.36 \\
2.33 \\
2.40 \\
2.53 \\
2.57\end{array}$} & \multirow{4}{*}{$\begin{array}{l}260 \\
393 \\
376 \\
415 \\
488 \\
512\end{array}$} & \multirow{4}{*}{$\begin{array}{l}37.50 \\
36.75 \\
35.60 \\
34.10 \\
32.50 \\
31.00\end{array}$} & \multirow{4}{*}{$\begin{array}{l}32,100 \\
31,100 \\
29,400 \\
27,300 \\
25,200 \\
23,300\end{array}$} & \multirow{4}{*}{\begin{tabular}{|}
4.24 \\
4.20 \\
4.16 \\
4.12 \\
4.09 \\
4.07
\end{tabular}} & \multirow{4}{*}{$\begin{array}{r}1,000 \\
979 \\
957 \\
935 \\
919 \\
908\end{array}$} & 358 & & 250 & \\
\hline$\stackrel{8}{9}$ & 1.77 & 135 & & & & & & & 3.58 & 601 & 3.58 & 582 \\
\hline 10 & 1.98 & 209 & & & & & & & 3.56 & 586 & 3.52 & 555 \\
\hline $\mathbf{N}$ & $\overline{1} . \overline{9}$ & 189 & & & & & & & 3.54 & 564 & $\overline{3} . \overline{4} \overline{6}$ & 528 \\
\hline 1 & 186 & 163 & \multirow{4}{*}{$\begin{array}{l}3.35 \\
4.90 \\
6.93 \\
5.85 \\
6.95 \\
7.10\end{array}$} & \multirow{4}{*}{$\begin{array}{r}998 \\
2,040 \\
3,060 \\
2,210 \\
2,820 \\
2,910\end{array}$} & \multirow{4}{*}{$\left|\begin{array}{l}29.30 \\
27.75 \\
26.10 \\
24.50 \\
22.90 \\
21.10\end{array}\right|$} & \multirow{4}{*}{$\begin{array}{l}21,100 \\
19,300 \\
17,200 \\
15,400 \\
13,600 \\
11,800\end{array}$} & \multirow{4}{*}{$\begin{array}{l}4.11 \\
4.10 \\
4.06 \\
3.98 \\
3.91 \\
3.99\end{array}$} & \multirow{4}{*}{$\begin{array}{l}930 \\
917 \\
895 \\
845 \\
811 \\
844\end{array}$} & 207 & 70 & , I & \\
\hline 3 & 1.86 & 163 & & & & & & & 3.5 & 578 & .41 & 506 \\
\hline 4 & 1.81 & 146 & & & & & & & 3.62 & 601 & 3.39 & 498 \\
\hline $\begin{array}{l}0 \\
6\end{array}$ & 1.88 & 170 & & & & & & & $\overline{3} . \overline{65}$ & 614 & $\overline{3} . \overline{3}$ & 493 \\
\hline $\begin{array}{l}7 \\
8\end{array}$ & 2.27 & 344 & \multirow{4}{*}{$\mid \begin{array}{r}7.00 \\
14.50 \\
20.70 \\
25.00 \\
27.70 \\
29.20\end{array}$} & $\begin{array}{l}2,850 \\
6,530\end{array}$ & $\begin{array}{l}18.90 \\
16.10\end{array}$ & $\begin{array}{l}9,760 \\
7,490\end{array}$ & $\begin{array}{l}3.95 \\
3.75\end{array}$ & $\begin{array}{l}824 \\
720\end{array}$ & 3.67 & 624 & 3.38 & 493 \\
\hline 9 & & & & 11,400 & 13.55 & 5,840 & 3.51 & 606 & & & & \\
\hline 10 & 2.14 & 279 & & 15,900 & 11.10 & 4,540 & 3.65 & 666 & 3.67 & 624 & 3.45 & 524 \\
\hline $\begin{array}{l}11 \\
12\end{array}$ & $\overline{2.05}$ & 238 & & $\begin{array}{l}19,100 \\
21,000\end{array}$ & $\begin{array}{l}8.70 \\
6.40\end{array}$ & $\begin{array}{l}3,430 \\
2,190\end{array}$ & $\begin{array}{l}3.81 \\
3.60\end{array}$ & $\begin{array}{l}742 \\
635\end{array}$ & 3.68 & 628 & 5.50 & 1,560 \\
\hline Hour & $\mathbf{A u}$ & g. 18 & & Ig. 19 & & & Sur & EMENTA & RECO & RDS & 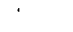 & \\
\hline 2 & 5.50 & 1,560 & 4.8 & 1,220 & Al & $5: 4$ & m. & & & & 1.9 & \\
\hline 4 & 4.35 & 959 & 4.50 & 1,040 & & & & & & & 1.69 & 113 \\
\hline 6 & 3.85 & 706 & 4.10 & 828 & & $3: 4$ & & & & & 5.57 & 2,040 \\
\hline 8 & 3.54 & 564 & 3.7 & 6 & & $4: 4$ & . & & & & 7.4 & 3,070 \\
\hline 10 & 3.42 & 51 & 3.6 & 6 & & & & & & & 7.45 & 3,100 \\
\hline $\mathrm{M}$ & & 488 & 3.4 & 533 & & $6: 45$ & n. & & & & 6.78 & 2,730 \\
\hline 2 & 3.34 & 475 & 3.3 & 493 & $\begin{array}{l}\text { Aug. } \\
\text { Aug. }\end{array}$ & $18,12: 4$ & II. & & & & $\begin{array}{l}0.00 \\
5.95\end{array}$ & 1,810 \\
\hline 4 & 3.27 & 446 & 3.3 & 467 & & & & & & & & 688 \\
\hline 8 & 3. & 48 & 3.3 & 458 & Aug. & $19,1: 30$ & t.m. & & & & 4.92 & 1,250 \\
\hline 10 & $\begin{array}{l}3.23 \\
3.80\end{array}$ & 68 & 3 & 40 & & & & & & & & \\
\hline 12 & 4.60 & 1,090 & 3.15 & 396 & & & & & & & & \\
\hline
\end{tabular}


NORTH PACOLET RIVER A'T FINGERVILLE, S. C.

Location.-Lat. $35^{\circ} 07^{\prime}$, long. $81^{\circ} 59^{\prime}$, at McMillin Mill, about 400 feet downstream from Obed Creek and 1 mile south of Fingerville, Spartanburg County. Datum of gage is 715.56 feet above mean sea level, datum of 1929, supplementary adjustment of 1936 .

DraINAGE AREA.- -116 square miles.

GAGE-HEIGHT RECORD.-Water-stage recorder graph.

DiSCHARGE RECORD. - Stage-discharge relation defined by current-meter measurements up to 850 second-feet and extended to erest gage height on basis of determination of flood flow over dam 2 miles upstream.

Maxima.-1940: Discharge, 12,500 second-feet 1:15 a.m. Aug. 14 (gage height, 27.13 feet).

1929-39: Discharge, 7,290 second-feet Oct. 17, 1936 (gage height, 21.23 feet), from rating curve extended above 1,100 second-feet.

REMARKs.-Flood discharge not affected by artificial storage or regulation. Some diurnal fluctuation at low and medium stages caused by mills upstream.

Mean discharge, in second-feet, 1940

\begin{tabular}{|c|c|c|c|c|c|c|c|c|c|c|c|}
\hline Day & Aug. & Sept. & Day & Aug. & Sept. & Day & Aug. & Sept. & Day & Aug. & Sept. \\
\hline $\begin{array}{l}1 \\
2 \\
3 \\
4 \\
5 \\
6 \\
7 \\
8\end{array}$ & $\begin{array}{l}52 \\
51 \\
51 \\
40 \\
52 \\
49 \\
75 \\
83\end{array}$ & $\begin{array}{r}182 \\
146 \\
120 \\
114 \\
105 \\
104 \\
109 \\
91\end{array}$ & $\begin{array}{r}9 \\
10 \\
11 \\
12 \\
13 \\
14 \\
15 \\
16\end{array}$ & $\begin{array}{r}59 \\
54 \\
48 \\
71 \\
3,310 \\
6,450 \\
1,080 \\
571\end{array}$ & $\begin{array}{r}93 \\
101 \\
97 \\
86 \\
88 \\
99 \\
78 \\
76\end{array}$ & $\begin{array}{l}17 \\
18 \\
19 \\
20 \\
21 \\
22 \\
23 \\
24\end{array}$ & $\begin{array}{l}428 \\
332 \\
282 \\
176 \\
152 \\
144 \\
125 \\
134\end{array}$ & $\begin{array}{l}80 \\
79 \\
82 \\
75 \\
90 \\
58 \\
69 \\
69\end{array}$ & $\begin{array}{l}25 \\
26 \\
27 \\
28 \\
29 \\
30 \\
31\end{array}$ & $\begin{array}{l}105 \\
112 \\
102 \\
111 \\
164 \\
446 \\
292\end{array}$ & $\begin{array}{r}80 \\
91 \\
69 \\
91 \\
63 \\
69 \\
\end{array}$ \\
\hline \multicolumn{10}{|c|}{$\begin{array}{l}\text { Monthly mean discharge, in second-feet } \\
\text { Runoff, in inches }\end{array}$} & $\begin{array}{r}490 \\
4.86\end{array}$ & $\begin{array}{l}91.8 \\
0.88\end{array}$ \\
\hline
\end{tabular}

Gage height, in feet, and discharge, in second-feet, at indicated time, 1940

\begin{tabular}{|c|c|c|c|c|c|c|c|c|c|c|}
\hline \multirow{2}{*}{ Hour } & \multicolumn{2}{|c|}{ Aug. 13} & \multicolumn{2}{|c|}{ Aug. 14} & \multicolumn{2}{|c|}{ Aug. 15} & \multicolumn{2}{|c|}{ Aug. 16} & \multicolumn{2}{|c|}{ Aug. 17} \\
\hline & $\begin{array}{r}\text { Gage } \\
\text { height }\end{array}$ & $\begin{array}{c}\text { Dis- } \\
\text { charge }\end{array}$ & $\begin{array}{c}\text { Gage } \\
\text { height }\end{array}$ & $\begin{array}{c}\text { Dis- } \\
\text { charge }\end{array}$ & $\begin{array}{c}\text { Gage } \\
\text { height }\end{array}$ & $\begin{array}{c}\text { Dis- } \\
\text { charge }\end{array}$ & $\begin{array}{c}\text { Gage } \\
\text { height }\end{array}$ & $\begin{array}{c}\text { Dis- } \\
\text { charge }\end{array}$ & $\begin{array}{c}\text { Gage } \\
\text { height }\end{array}$ & $\begin{array}{c}\text { Dis- } \\
\text { charge }\end{array}$ \\
\hline $\begin{array}{l}1 \\
2 \\
3 \\
4 \\
5 \\
6\end{array}$ & $\begin{array}{l}3.37 \\
3.54 \\
3.90 \\
4.01 \\
4.15 \\
4.44\end{array}$ & $\begin{array}{l}102 \\
133 \\
204 \\
227 \\
256 \\
319\end{array}$ & $\begin{array}{l}27.10 \\
27.04 \\
26.62 \\
26.16 \\
25.62 \\
24.99\end{array}$ & $\begin{array}{l}12,400 \\
12,400 \\
12,100 \\
11,700 \\
10,900 \\
10,100\end{array}$ & $\begin{array}{l}9.49 \\
9.23 \\
9.26 \\
8.94 \\
8.90 \\
8.58\end{array}$ & $\begin{array}{l}1,540 \\
1,450 \\
1,460 \\
1,350 \\
1,340 \\
1,220\end{array}$ & $\begin{array}{l}7.10 \\
6.93 \\
6.83 \\
6.75 \\
6.62 \\
6.57\end{array}$ & $\begin{array}{l}744 \\
696 \\
668 \\
646 \\
611 \\
598\end{array}$ & $\begin{array}{l}7.17 \\
6.74 \\
6.38 \\
6.21 \\
6.05 \\
5.99\end{array}$ & $\begin{array}{l}764 \\
644 \\
548 \\
504 \\
464 \\
448\end{array}$ \\
\hline $\begin{array}{r}7 \\
8 \\
9 \\
10 \\
11 \\
\text { N }\end{array}$ & $\begin{array}{l}5.40 \\
7.62 \\
7.43 \\
8.77 \\
9.10 \\
9.71\end{array}$ & $\begin{array}{r}553 \\
1,240 \\
1,170 \\
1,640 \\
1,760 \\
2,000\end{array}$ & $\begin{array}{l}24.35 \\
23.52 \\
22.81 \\
21.94 \\
21.00 \\
20.18\end{array}$ & $\begin{array}{l}9,300 \\
8,370 \\
7,590 \\
7,020 \\
6,440 \\
5,650\end{array}$ & $\begin{array}{l}8.40 \\
8.19 \\
8.13 \\
8.07 \\
8.06 \\
7.94\end{array}$ & $\begin{array}{r}1,160 \\
1,090 \\
1,070 \\
1,040 \\
1,040 \\
999\end{array}$ & $\begin{array}{l}6.50 \\
6.45 \\
6.36 \\
6.32 \\
6.25 \\
6.18\end{array}$ & $\begin{array}{l}\mathbf{5 7 9} \\
566 \\
543 \\
532 \\
514 \\
496\end{array}$ & $\begin{array}{l}\mathbf{5 . 9 2} \\
\mathbf{5 . 8 6} \\
5.83 \\
\mathbf{5 . 7 9} \\
\mathbf{5 . 7 7} \\
\mathbf{5 . 6 4}\end{array}$ & $\begin{array}{l}431 \\
416 \\
409 \\
400 \\
395 \\
364\end{array}$ \\
\hline $\begin{array}{l}1 \\
2 \\
3 \\
4 \\
5 \\
5\end{array}$ & $\begin{array}{r}10.03 \\
10.25 \\
10.10 \\
9.91 \\
12.17 \\
14.30\end{array}$ & $\begin{array}{l}2,130 \\
2,220 \\
2,160 \\
2,080 \\
3,050 \\
4,080\end{array}$ & $\begin{array}{l}19.32 \\
18.39 \\
17.43 \\
16.52 \\
15.48 \\
14.42\end{array}$ & $\begin{array}{l}5,160 \\
4,650 \\
4,140 \\
3,690 \\
3,190 \\
2,710\end{array}$ & $\begin{array}{l}7.93 \\
7.88 \\
7.85 \\
7.85 \\
7.79 \\
7.70\end{array}$ & $\begin{array}{l}\mathbf{9 9 6} \\
978 \\
968 \\
968 \\
947 \\
920\end{array}$ & $\begin{array}{l}5.70 \\
5.72 \\
6.01 \\
6.08 \\
5.95 \\
5.91\end{array}$ & $\begin{array}{l}378 \\
383 \\
454 \\
471 \\
438 \\
428\end{array}$ & $\begin{array}{l}\mathbf{5 . 6 5} \\
\mathbf{5 . 6 6} \\
\mathbf{5 . 6 4} \\
\mathbf{5 . 6 3} \\
\mathbf{5 . 6 2} \\
\mathbf{5 . 6 0}\end{array}$ & $\begin{array}{l}366 \\
\mathbf{3 6 9} \\
\mathbf{3 6 4} \\
\mathbf{3 6 2} \\
360 \\
\mathbf{3 5 5}\end{array}$ \\
\hline \begin{tabular}{r|}
7 \\
8 \\
9 \\
10 \\
11 \\
12
\end{tabular} & $\begin{array}{l}17.16 \\
21.99 \\
24.32 \\
25.82 \\
26.47 \\
26.80\end{array}$ & $\begin{array}{r}5,640 \\
8,700 \\
10,300 \\
11,400 \\
11,900 \\
12,200\end{array}$ & $\begin{array}{l}13.52 \\
12.71 \\
12.06 \\
11.42 \\
10.76 \\
10.13\end{array}$ & $\begin{array}{l}2,530 \\
2,200 \\
2,140 \\
1,890 \\
1,640 \\
1,590\end{array}$ & $\begin{array}{l}7.66 \\
7.54 \\
7.46 \\
7.36 \\
7.29 \\
7.19\end{array}$ & $\begin{array}{l}908 \\
872 \\
848 \\
819 \\
799 \\
770\end{array}$ & $\begin{array}{l}5.87 \\
5.90 \\
6.89 \\
7.23 \\
7.39 \\
7.48\end{array}$ & $\begin{array}{l}419 \\
426 \\
685 \\
782 \\
828 \\
854\end{array}$ & $\begin{array}{l}5.58 \\
5.56 \\
5.54 \\
\mathbf{5 . 5 2} \\
\mathbf{5 . 5 0} \\
\mathbf{5 . 4 8}\end{array}$ & $\begin{array}{l}350 \\
346 \\
341 \\
337 \\
332 \\
328\end{array}$ \\
\hline
\end{tabular}

SUPPLEMENTAL RECORD.-Aug. 14, 1:15 a.m., gage height, 27.13 feet; discharge, 12,500 second-feet.

PACOLET RIVER NEAR FINGERVILLE, S. C.

Location.-Lat. $35^{\circ} 07^{\prime}$, long. $81^{\circ} 58^{\prime}, 100$ feet upstream from county highway bridge, a quarter of a mile downstream from confluence of North and South 


\section{FLOODS OF AUGUST 1940 IN THE SOUTHEASTERN STATES}

Pacolet Rivers, and 21/2 miles southeast of Fingerville, Spartanburg County. Datum of gage is 706.33 feet above mean sea level, datum of 1929, supplementary adjustment of 1936 .

DrAIN AGE AREA.-212 square miles; 92 square miles affected by storage in South Pacolet River Reservoir.

GAGE-HEIGHT RECORD.-Water-stage recorder graph except for periods of doubtful gage-height record, Aug. 3, 4, 10, 11, Sept. 22, 29, record for which was computed on basis of records for North Pacolet River at Fingerville.

DischaRge RECORD.-Stage-discharge relation defined by current-meter measurements up to 9,600 second-feet and extended to erest gage height on basis of velocityarea studies.

Maxima.-1940: Discharge, 22,800 second-feet 1:45 a.m. Aug. 14 (gage height, 22.43 feet).

1929-39: Discharge, 11,300 second-feet Oct. 17, 1936 (gage height, 13.63 feet).

Remarks.-Flood discharge affected by storage in South Pacolet River Reservoir.

For information on storage see records for South Pacolet River Reservoir near Fingerville, S. C.

Mean discharge, in second-feet, 1940

\begin{tabular}{|c|c|c|c|c|c|c|c|c|c|c|c|}
\hline Day & Aug. & Sept. & Day & Aug. & Sept. & Day & Aug. & Sept. & Day & Aug. & Sept. \\
\hline & 114 & 252 & & 97 & 160 & 17 & 660 & 147 & & & 128 \\
\hline 2 & $\begin{array}{l}114 \\
102\end{array}$ & 213 & 10 & $\begin{array}{l}95 \\
55\end{array}$ & $\begin{array}{l}164 \\
164\end{array}$ & $\begin{array}{l}17 \\
18\end{array}$ & $\begin{array}{l}003 \\
403\end{array}$ & $\begin{array}{l}145 \\
147\end{array}$ & 26 & & 138 \\
\hline 3 & 50 & 196 & 11 & 50 & $\begin{array}{l}167 \\
167\end{array}$ & $\begin{array}{l}19 \\
19\end{array}$ & 531 & 149 & 27 & 171 & $\begin{array}{l}109 \\
\end{array}$ \\
\hline 4 & 40 & 188 & 12 & 123 & 156 & 20 & 387 & 131 & 28 & 177 & 93 \\
\hline 5 & 97 & 176 & 13 & $\begin{array}{r}3,660 \\
\end{array}$ & 141 & 21 & 242 & 92 & 29 & 236 & 65 \\
\hline 6 & 102 & 175 & 14 & 13,500 & 101 & 22 & 213 & 60 & $\begin{array}{l}30 \\
31\end{array}$ & 523 & \\
\hline $\begin{array}{l}7 \\
8\end{array}$ & $\begin{array}{l}122 \\
128\end{array}$ & $\begin{array}{l}179 \\
157\end{array}$ & $\begin{array}{l}15 \\
16\end{array}$ & $\begin{array}{l}2,280 \\
1,040\end{array}$ & $\begin{array}{r}85 \\
142\end{array}$ & 23 & $\begin{array}{l}196 \\
200\end{array}$ & ${ }_{121}^{134}$ & 31 & & \\
\hline \multirow{2}{*}{\multicolumn{10}{|c|}{$\begin{array}{l}\text { Monthly mean discharge, in second-feet. } \\
\text { Runoff, in inches }\end{array}$}} & 846 & 142 \\
\hline & & & & & & & & & & 4.60 & 0.75 \\
\hline
\end{tabular}

Gage height, in feet, and discharge, in second-feet, at indicated time, 1940

\begin{tabular}{|c|c|c|c|c|c|c|c|c|c|c|}
\hline \multirow{2}{*}{ Hour } & \multicolumn{2}{|c|}{ Aug. 13} & \multicolumn{2}{|c|}{ Aug. 14} & \multicolumn{2}{|c|}{ Aug. 15} & \multicolumn{2}{|c|}{ Aug. 16} & \multicolumn{2}{|c|}{ Aug. 17} \\
\hline & $\begin{array}{c}\text { Gage } \\
\text { height }\end{array}$ & $\begin{array}{l}\text { Dis- } \\
\text { charge }\end{array}$ & $\begin{array}{c}\text { Gage } \\
\text { height }\end{array}$ & $\begin{array}{l}\text { Dis- } \\
\text { charge }\end{array}$ & $\begin{array}{c}\text { Gage } \\
\text { height }\end{array}$ & $\begin{array}{l}\text { Dis- } \\
\text { charge }\end{array}$ & $\begin{array}{l}\text { Gage } \\
\text { height }\end{array}$ & $\begin{array}{c}\text { Dis- } \\
\text { charge }\end{array}$ & $\begin{array}{l}\text { Gage } \\
\text { height }\end{array}$ & $\begin{array}{c}\text { Dis- } \\
\text { charge }\end{array}$ \\
\hline $\begin{array}{l}1 \\
2 \\
3 \\
4 \\
5 \\
6\end{array}$ & $\begin{array}{r}0.75 \\
.82 \\
.99 \\
1.15 \\
1.30 \\
1.38\end{array}$ & $\begin{array}{l}166 \\
185 \\
235 \\
290 \\
346 \\
378\end{array}$ & $\begin{array}{l}22.32 \\
22.40 \\
22.20 \\
21.80 \\
21.22 \\
20.51\end{array}$ & $\begin{array}{l}22,600 \\
22,700 \\
22,400 \\
21,900 \\
21,100 \\
20,100\end{array}$ & $\begin{array}{l}6.35 \\
6.13 \\
5.84 \\
5.59 \\
5.38 \\
5.13\end{array}$ & $\begin{array}{l}3,720 \\
3,520 \\
3,270 \\
3,070 \\
2,900 \\
2,700\end{array}$ & $\begin{array}{l}3.25 \\
3.14 \\
3.05 \\
2.97 \\
2.87 \\
2.80\end{array}$ & $\begin{array}{l}1,380 \\
1,310 \\
1,260 \\
1,210 \\
1,150 \\
1,100\end{array}$ & $\begin{array}{l}2.93 \\
2.67 \\
2.42 \\
2.26 \\
2.12 \\
2.04\end{array}$ & $\begin{array}{r}1,220 \\
1,060 \\
914 \\
826 \\
750 \\
710\end{array}$ \\
\hline $\begin{array}{r}7 \\
8 \\
9 \\
10 \\
11 \\
\mathrm{~N}\end{array}$ & $\begin{array}{l}1.60 \\
2.68 \\
3.57 \\
3.48 \\
3.94 \\
3.99\end{array}$ & $\begin{array}{r}472 \\
1,030 \\
1,590 \\
1,530 \\
1,840 \\
1,870\end{array}$ & $\begin{array}{l}19.75 \\
18.91 \\
18.07 \\
17.17 \\
16.12 \\
15.12\end{array}$ & $\begin{array}{l}19,000 \\
17,900 \\
16,900 \\
15,700 \\
14,400 \\
13,200\end{array}$ & $\begin{array}{l}4.95 \\
4.77 \\
4.59 \\
4.46 \\
4.35 \\
4.25\end{array}$ & $\begin{array}{l}2,560 \\
2,420 \\
2,290 \\
2,200 \\
2,120 \\
2,060\end{array}$ & $\begin{array}{l}2.76 \\
2.69 \\
2.62 \\
2.56 \\
2.49 \\
2.43\end{array}$ & $\begin{array}{r}\mathbf{1}, 080 \\
\mathbf{1}, 040 \\
\mathbf{9 9 7} \\
\mathbf{9 6 1} \\
\mathbf{9 2 0} \\
\mathbf{8 8 6}\end{array}$ & $\begin{array}{l}1.98 \\
1.92 \\
1.88 \\
1.86 \\
1.85 \\
1.81\end{array}$ & $\begin{array}{l}680 \\
650 \\
631 \\
622 \\
617 \\
598\end{array}$ \\
\hline $\begin{array}{l}1 \\
2 \\
3 \\
4 \\
5 \\
6\end{array}$ & $\begin{array}{l}4.19 \\
4.31 \\
4.63 \\
4.62 \\
4.65 \\
5.22\end{array}$ & $\begin{array}{l}2,010 \\
2,100 \\
2,320 \\
2,310 \\
2,340 \\
2,780\end{array}$ & $\begin{array}{r}14.03 \\
13.08 \\
12.18 \\
11.27 \\
10.52 \\
9.81\end{array}$ & $\begin{array}{r}11,800 \\
10,700 \\
9,710 \\
8,710 \\
7,880 \\
7,100\end{array}$ & $\begin{array}{l}4.15 \\
4.06 \\
4.00 \\
3.93 \\
3.86 \\
3.78\end{array}$ & $\begin{array}{l}1,980 \\
1,920 \\
1,880 \\
1,830 \\
1,780 \\
1,730\end{array}$ & $\begin{array}{l}2.24 \\
2.05 \\
2.27 \\
2.32 \\
2.23 \\
2.22\end{array}$ & $\begin{array}{l}782 \\
685 \\
798 \\
826 \\
776 \\
771\end{array}$ & $\begin{array}{l}1.74 \\
1.77 \\
1.78 \\
1.76 \\
1.74 \\
1.75\end{array}$ & $\begin{array}{l}564 \\
578 \\
583 \\
574 \\
564 \\
569\end{array}$ \\
\hline $\begin{array}{r}7 \\
8 \\
9 \\
10 \\
11 \\
12\end{array}$ & $\begin{array}{r}5.93 \\
7.00 \\
11.73 \\
17.50 \\
20.49 \\
21.73\end{array}$ & $\begin{array}{r}3,340 \\
4,300 \\
9,210 \\
16,100 \\
20,000 \\
21,800\end{array}$ & $\begin{array}{l}9.22 \\
8.63 \\
8.02 \\
7.51 \\
7.09 \\
6.71\end{array}$ & $\begin{array}{l}6,470 \\
5,880 \\
5,270 \\
4,760 \\
4,380 \\
4,040\end{array}$ & $\begin{array}{l}3.75 \\
3.68 \\
3.57 \\
3.51 \\
3.43 \\
3.33\end{array}$ & $\begin{array}{l}1,710 \\
1,660 \\
1,590 \\
1,550 \\
1,500 \\
1,430\end{array}$ & $\begin{array}{l}2.18 \\
2.79 \\
3.10 \\
2.95 \\
3.11 \\
3.10\end{array}$ & $\begin{array}{r}750 \\
1,100 \\
1,280 \\
1,200 \\
1,290 \\
1,280\end{array}$ & $\begin{array}{l}1.72 \\
1.71 \\
1.39 \\
1.29 \\
1.41 \\
1.36\end{array}$ & $\begin{array}{l}\mathbf{5 5 5} \\
550 \\
407 \\
366 \\
\mathbf{4 1 5} \\
\mathbf{3 9 4}\end{array}$ \\
\hline
\end{tabular}

SUPPLEMENTAL RECORD.-Aug. 14, 1:45 a.m., gage height, 22.43 feet; discharge, 22,800 second-feet. 
PAColet river neAr ChIFTON, S. C.

Location.-Lat. $34^{\circ} 58^{\prime}$, long. $81^{\circ} 48^{\prime}, 1$ mile downstream from dam at Clifton Mill 2, 1.5 miles southeast of Clifton, Spartanburg County, 2.2 miles upstream from Lawson Fork, and 2.5 miles northeast of Glendale.

Drainage AREA.-320 square miles; 92 square miles affected by storage in South Pacolet River Reservoir.

GAGE-HEIGHT RECORD.-Water-stage recorder graph.

DischARGE RECORD.- - Stage-discharge relation defined by current-meter measurements up to 4,400 second-feet; extended to peak stage on basis of determination of flood flow over dam at Clifton Mill 2. Shifting-control method used Aug. 15-31. Maxima.-Discharge, 26,800 second-feet $12 \mathrm{~m}$., Aug. 14 (gage height, 21.19 feet). Remarks.-Flood discharge affected by storage in South Pacolet River Reservoir.

For information on storage see records for South Pacolet River Reservoir near Fingerville, S. C. Low and medium flow regulated by power plants above station.

Mean discharge, in second-feet, 1940

\begin{tabular}{|c|c|c|c|c|c|c|c|c|c|c|c|}
\hline Day & Aug. & Sept. & Day & Aug. & Sept. & Day & Aug. & Sept. & Day & Aug. & Sept. \\
\hline $\begin{array}{l}1 \\
2 \\
3 \\
4 \\
5 \\
6 \\
7 \\
8\end{array}$ & $\begin{array}{r}147 \\
126 \\
149 \\
53 \\
111 \\
121 \\
121 \\
149\end{array}$ & & $\begin{array}{r}9 \\
10 \\
11 \\
12 \\
13 \\
14 \\
15 \\
16\end{array}$ & $\begin{array}{r}136 \\
114 \\
53 \\
177 \\
3,030 \\
18,200 \\
3,070 \\
1,370\end{array}$ & & $\begin{array}{l}17 \\
18 \\
19 \\
20 \\
21 \\
22 \\
23 \\
24\end{array}$ & $\begin{array}{l}926 \\
594 \\
700 \\
513 \\
365 \\
271 \\
260 \\
261\end{array}$ & & $\begin{array}{l}25 \\
26 \\
27 \\
28 \\
29 \\
30 \\
31\end{array}$ & $\begin{array}{l}222 \\
225 \\
225 \\
214 \\
330 \\
718 \\
466\end{array}$ & \\
\hline \multicolumn{10}{|c|}{$\begin{array}{l}\text { Monthly mean discharge, in second-feet } \\
\text { Runoff, in inches. }\end{array}$} & $\begin{array}{r}1,078 \\
3.88\end{array}$ & \\
\hline
\end{tabular}

Gage height, in feet, and discharge, in second-feet, at indicated time, 1940

\begin{tabular}{|c|c|c|c|c|c|c|}
\hline \multirow{2}{*}{ Hour } & \multicolumn{2}{|c|}{ Aug. 13} & \multicolumn{2}{|c|}{ Aug. 14} & \multicolumn{2}{|c|}{ Aug. 15} \\
\hline & $\begin{array}{l}\text { Gage } \\
\text { height }\end{array}$ & Discharge & $\begin{array}{l}\text { Gage } \\
\text { height }\end{array}$ & Discharge & $\begin{array}{c}\text { Gage } \\
\text { height }\end{array}$ & Discharge \\
\hline $\begin{array}{l}1 \\
2 \\
3 \\
4 \\
5 \\
6\end{array}$ & $\begin{array}{r}0.75 \\
.80 \\
1.03 \\
1.49 \\
1.62 \\
1.99\end{array}$ & $\begin{array}{r}42 \\
50 \\
106 \\
301 \\
384 \\
697\end{array}$ & $\begin{array}{r}6.83 \\
9.96 \\
13.07 \\
15.20 \\
16.17 \\
17.77\end{array}$ & $\begin{array}{r}5,660 \\
9,660 \\
14,000 \\
17,200 \\
18,700 \\
21,200\end{array}$ & $\begin{array}{r}10.36 \\
9.77 \\
8.68 \\
7.25 \\
6.16 \\
5.88\end{array}$ & $\begin{array}{l}8,660 \\
7,890 \\
6,510 \\
4,800 \\
3,600 \\
3,300\end{array}$ \\
\hline $\begin{array}{r}7 \\
8 \\
9 \\
10 \\
11 \\
\mathrm{~N}\end{array}$ & $\begin{array}{l}2.39 \\
5.28 \\
3.50 \\
5.04 \\
5.25 \\
4.74\end{array}$ & $\begin{array}{l}1,050 \\
3,890 \\
2,070 \\
3,630 \\
3,860 \\
3,310\end{array}$ & $\begin{array}{l}18.65 \\
19.46 \\
20.16 \\
20.69 \\
21.05 \\
21.19\end{array}$ & $\begin{array}{l}22,600 \\
23,900 \\
25,100 \\
26,000 \\
26,600 \\
26,800\end{array}$ & $\begin{array}{l}5.68 \\
5.55 \\
5.37 \\
5.07 \\
4.91 \\
4.83\end{array}$ & $\begin{array}{l}3,090 \\
2,960 \\
2,780 \\
2,480 \\
2,320 \\
2,240\end{array}$ \\
\hline $\begin{array}{l}\mathbf{1} \\
2 \\
3 \\
\mathbf{4} \\
5 \\
\mathbf{6}\end{array}$ & $\begin{array}{l}4.40 \\
4.06 \\
4.39 \\
4.20 \\
3.84 \\
5.96\end{array}$ & $\begin{array}{l}2,960 \\
2,620 \\
2,940 \\
2,760 \\
2,400 \\
4,640\end{array}$ & $\begin{array}{l}20.36 \\
19.29 \\
18.20 \\
17.09 \\
15.90 \\
14.59\end{array}$ & $\begin{array}{l}25,400 \\
23,600 \\
21,900 \\
20,100 \\
18,300 \\
16,300\end{array}$ & $\begin{array}{l}4.48 \\
4.35 \\
4.09 \\
4.75 \\
4.44 \\
4.35\end{array}$ & $\begin{array}{l}1,910 \\
1,780 \\
1,550 \\
2,160 \\
1,870 \\
1,780\end{array}$ \\
\hline $\begin{array}{r}7 \\
8 \\
9 \\
10 \\
11 \\
12\end{array}$ & $\begin{array}{l}7.35 \\
8.06 \\
8.15 \\
7.37 \\
6.97 \\
6.80\end{array}$ & $\begin{array}{l}6,290 \\
7,180 \\
7,290 \\
6,310 \\
5,830 \\
5,620\end{array}$ & $\begin{array}{l}13.74 \\
12.92 \\
12.40 \\
11.81 \\
11.30 \\
10.81\end{array}$ & $\begin{array}{l}15,000 \\
13,800 \\
13,000 \\
12,200 \\
11,500 \\
10,800\end{array}$ & $\begin{array}{l}4.34 \\
4.32 \\
2.16 \\
4.37 \\
4.51 \\
4.42\end{array}$ & $\begin{array}{r}1,780 \\
\times 1,760 \\
1,100 \\
1,800 \\
1,940 \\
1,850\end{array}$ \\
\hline
\end{tabular}

\section{SOUTH PACOLET RIVER RESERVOIR NEAR FINGERVILLE, S. C.}

Location.-Lat. 3 a $^{\circ} 07^{\prime}$, long. $81^{\circ} 59^{\prime}$, at highway bridge across South .Pacolet River Reservoir, 1 mile upstream from dam and $1 \%$ miles south of Fingerville, Spartanburg County. Datum of gage is 761.18 feet above mean sea level, datum of 1929, supplementary adjustment of 1936 . 


\section{FLOODS OF AUGUST 1940 IN THE SOUTHEASTERN STATES}

Drainage area.-92 square miles.

GAGE-HEIGHT RECORD.-Water-stage recorder graph.

Maxima.-1940: Gage height, 17.58 feet 2 a.m. Aug. 14 (contents, 1,179,000,000 gallons).

1930-39: Gage height, 17.68 feet Oet. 19, 1937 (contents, 1,192,000,000 gallons).

Remarks.-Usable capacity, $879,000,000$ gallons between gage heights 0.0 foot (draw-down limit) and 15.0 feet (top of flashboards). City of Spartanburg diverts about 5,000,000 gallons daily from reservoir for municipal use. Figures given herein represent usable contents.

Gage height, and contents, 1940

\begin{tabular}{|c|c|c|c|c|c|c|c|c|c|}
\hline \multirow{2}{*}{ Day } & \multicolumn{2}{|c|}{ August } & \multicolumn{2}{|c|}{ September } & \multirow{2}{*}{ Day } & \multicolumn{2}{|c|}{ August } & \multicolumn{2}{|c|}{ September } \\
\hline & $\begin{array}{c}\text { Gage } \\
\text { height } \\
\text { (feet) }\end{array}$ & $\begin{array}{l}\text { Contents } \\
\text { (million } \\
\text { gallons) }\end{array}$ & $\begin{array}{c}\text { Gage } \\
\text { height } \\
\text { (feet) }\end{array}$ & $\begin{array}{l}\text { Contents } \\
\text { (million } \\
\text { gallons) }\end{array}$ & & $\begin{array}{c}\text { Gage } \\
\text { height } \\
\text { (feet) }\end{array}$ & $\begin{array}{c}\text { Contents } \\
\text { (million } \\
\text { gallons) }\end{array}$ & $\begin{array}{c}\text { Gage } \\
\text { height } \\
\text { (feet) }\end{array}$ & $\begin{array}{l}\text { Contents } \\
\text { (million } \\
\text { gallons) }\end{array}$ \\
\hline $\begin{array}{l}1 \\
2 \\
3 \\
4 \\
5\end{array}$ & $\begin{array}{l}6.67 \\
6.22 \\
6.21 \\
6.44 \\
6.45\end{array}$ & $\begin{array}{l}265 \\
241 \\
241 \\
253 \\
253\end{array}$ & $\begin{array}{l}10.92 \\
10.95 \\
10.83 \\
10.62 \\
10.41\end{array}$ & $\begin{array}{l}\mathbf{5 2 9} \\
\mathbf{5 3 1} \\
\mathbf{5 2 3} \\
\mathbf{5 0 8} \\
\mathbf{4 9 3}\end{array}$ & $\begin{array}{l}16 \\
17 \\
18 \\
19 \\
20\end{array}$ & $\begin{array}{l}12.65 \\
11.98 \\
11.94 \\
12.02 \\
10.82\end{array}$ & $\begin{array}{l}663 \\
609 \\
606 \\
612 \\
522\end{array}$ & $\begin{array}{l}8.68 \\
8.26 \\
7.77 \\
7.23 \\
6.69\end{array}$ & $\begin{array}{l}381 \\
355 \\
326 \\
296 \\
266\end{array}$ \\
\hline $\begin{array}{r}6 \\
7 \\
8 \\
9 \\
10\end{array}$ & $\begin{array}{l}6.27 \\
6.07 \\
6.01 \\
6.01 \\
6.15\end{array}$ & $\begin{array}{l}\mathbf{2 4 4} \\
\mathbf{2 3 3} \\
230 \\
\mathbf{2 3 0} \\
\mathbf{2 3 8}\end{array}$ & $\begin{array}{r}10.20 \\
9.97 \\
9.70 \\
9.38 \\
9.08\end{array}$ & $\begin{array}{l}479 \\
463 \\
445 \\
424 \\
405\end{array}$ & $\begin{array}{l}21 \\
22 \\
23 \\
24 \\
25\end{array}$ & $\begin{array}{r}10.12 \\
10.06 \\
9.96 \\
9.82 \\
9.63\end{array}$ & $\begin{array}{l}473 \\
469 \\
463 \\
453 \\
441\end{array}$ & $\begin{array}{l}6.90 \\
7.35 \\
7.30 \\
6.75 \\
6.65\end{array}$ & $\begin{array}{l}277 \\
302 \\
299 \\
269 \\
264\end{array}$ \\
\hline $\begin{array}{l}11 \\
12 \\
13 \\
14 \\
15\end{array}$ & $\begin{array}{r}6.46 \\
6.70 \\
9.80 \\
16.18 \\
13.49\end{array}$ & $\begin{array}{r}254 \\
267 \\
452 \\
1,007 \\
735\end{array}$ & $\begin{array}{l}8.81 \\
8.40 \\
7.99 \\
8.24 \\
8.70\end{array}$ & $\begin{array}{l}389 \\
364 \\
339 \\
\mathbf{3 5 4} \\
\mathbf{3 8 1}\end{array}$ & $\begin{array}{l}26 \\
27 \\
28 \\
29 \\
30 \\
31\end{array}$ & $\begin{array}{r}9.41 \\
9.16 \\
8.98 \\
8.78 \\
9.74 \\
10.64\end{array}$ & $\begin{array}{l}426 \\
410 \\
399 \\
386 \\
448 \\
509\end{array}$ & $\begin{array}{l}6.62 \\
6.48 \\
6.79 \\
7.27 \\
7.32\end{array}$ & $\begin{array}{l}262 \\
255 \\
271 \\
298 \\
301\end{array}$ \\
\hline \multirow{2}{*}{\multicolumn{8}{|c|}{ Change in contents, equivalent, in second-feet. }} & August & $\begin{array}{c}\text { Sep- } \\
\text { tember }\end{array}$ \\
\hline & & & & & & & & +12.2 & -11.5 \\
\hline
\end{tabular}

Gage height, in feet, and contents in millions of gallons, at indicated time, 1940

\begin{tabular}{|c|c|c|c|c|c|c|c|c|}
\hline \multirow{2}{*}{ Hour } & \multicolumn{2}{|c|}{ Aug. 13} & \multicolumn{2}{|c|}{ Aug. 14} & \multicolumn{2}{|c|}{ Aug. 15} & \multicolumn{2}{|c|}{ Aug. 16} \\
\hline & $\begin{array}{c}\text { Gage } \\
\text { height }\end{array}$ & Contents & $\begin{array}{c}\text { Gage } \\
\text { height }\end{array}$ & Contents & $\begin{array}{c}\text { Gage } \\
\text { height }\end{array}$ & Contents & $\begin{array}{c}\text { Gage } \\
\text { height }\end{array}$ & Contents \\
\hline $\begin{array}{l}1 \\
2 \\
3 \\
4 \\
5 \\
6\end{array}$ & $\begin{array}{l}6.78 \\
6.79 \\
6.82 \\
6.86 \\
6.93 \\
7.04\end{array}$ & $\begin{array}{l}271 \\
271 \\
273 \\
275 \\
279 \\
285\end{array}$ & 17.51 & 1,169 & $13 . \overline{3}$ & $75 \overline{6}^{-}$ & 12.90 & 684 \\
\hline $\begin{array}{r}7 \\
8 \\
9 \\
10 \\
11 \\
\mathrm{~N}\end{array}$ & $\begin{array}{l}7.13 \\
7.23 \\
7.37 \\
7.81 \\
8.38 \\
9.08\end{array}$ & $\begin{array}{l}290 \\
296 \\
303 \\
329 \\
362 \\
405\end{array}$ & $\begin{array}{r}17.05 \\
16.27\end{array}$ & 1,111 & $13.4 \overline{2}$ & 728 & 12.76 & $6 \overline{2}^{-6}$ \\
\hline $\begin{array}{l}1 \\
2 \\
3 \\
4 \\
5 \\
6\end{array}$ & $\begin{array}{r}9.87 \\
10.34 \\
10.66 \\
10.94 \\
11.18 \\
11.44\end{array}$ & $\begin{array}{l}\mathbf{4 5 7} \\
\mathbf{4 8 9} \\
\mathbf{5 1 1} \\
\mathbf{5 3 1} \\
\mathbf{5 4 8} \\
\mathbf{5 6 8}\end{array}$ & 15.50 & $\mathbf{9 3 2}$ & 13.18 & 708 & 12.50 & $650^{-1 .}$ \\
\hline $\begin{array}{r}7 \\
8 \\
9 \\
10 \\
11 \\
12\end{array}$ & $\begin{array}{l}11.86 \\
12.58 \\
13.58 \\
15.27 \\
17.04 \\
17.44\end{array}$ & $\begin{array}{r}600 \\
657 \\
743 \\
907 \\
1,109 \\
1,160\end{array}$ & $\begin{array}{r}14.86 \\
14.29\end{array}$ & $86 \overline{5}^{-}$ & 13.00 & $6 \overline{2}$ & $\begin{array}{r}-1 \overline{2} . \overline{34} \\
12 . \overline{5} 1\end{array}$ & $\begin{array}{l}637^{-1} \\
-651\end{array}$ \\
\hline
\end{tabular}


NOR'TH TYGER RIVER NEAR MOORE, S. C.

LocATION.-Lat. $34^{\circ} 48^{\prime}$, long. $81^{\circ} 58^{\prime}$, at Ott Shoals, $11 / 4$ miles upstream from Wards Creek, $2 \frac{1}{2}$ miles southeast of Moore, Spartanburg County, and 37/8 miles upstream from eonfluence of North and South Tyger Rivers. Datum of gage is 564.79 feet above mean sea level, datum of 1929, supplementary adjustment of 1936.

Drainage ARea.- 162 square miles.

GAGE-HEIGHT RECORD.-Water-stage recorder graph.

DiSCHARGE RECORD.-Stage-diseharge relation defined by current-meter measurements up to 7,800 second-feet and extended to erest gage height on basis of velocityarea studies.

Maxima.-1940: Discharge, 12,300 seeond-feet 3:45 p.m. Aug. 14 (gage height, 7.15 feet).

1934-39: Discharge, 8,640 second-feet Apr. 7, 1936 (gage height, 6.15 feet). REMARKs.-Flòd discharge not affected by artificial storage or diversion. Some diurnal fluctuation eaused by power plants above station.

Mean discharge, in second-feet, 1940

\begin{tabular}{|c|c|c|c|c|c|c|c|c|c|c|c|}
\hline Day & Aug. & Sept. & Day & Aug. & Sept. & Day & Aug. & Sept. & Day & Aug. & Sept. \\
\hline $\begin{array}{l}1 \\
2 \\
3 \\
4 \\
5 \\
6 \\
7 \\
8\end{array}$ & $\begin{array}{l}77 \\
72 \\
54 \\
32 \\
59 \\
72 \\
64 \\
46\end{array}$ & $\begin{array}{r}151 \\
159 \\
128 \\
98 \\
88 \\
106 \\
87 \\
47\end{array}$ & $\begin{array}{r}9 \\
10 \\
11 \\
12 \\
13 \\
14 \\
15 \\
16\end{array}$ & $\begin{array}{r}48 \\
51 \\
28 \\
69 \\
1,090 \\
9,340 \\
3,700 \\
902\end{array}$ & $\begin{array}{l}87 \\
98 \\
82 \\
75 \\
73 \\
63 \\
40 \\
81\end{array}$ & $\begin{array}{l}17 \\
18 \\
19 \\
20 \\
21 \\
22 \\
23 \\
24\end{array}$ & $\begin{array}{l}416 \\
223 \\
205 \\
164 \\
124 \\
139 \\
135 \\
111\end{array}$ & $\begin{array}{l}80 \\
73 \\
76 \\
74 \\
61 \\
37 \\
68 \\
75\end{array}$ & $\begin{array}{l}25 \\
26 \\
27 \\
28 \\
29 \\
30 \\
31\end{array}$ & $\begin{array}{r}74 \\
114 \\
123 \\
99 \\
122 \\
222 \\
182\end{array}$ & $\begin{array}{r}67 \\
60 \\
69 \\
54 \\
30 \\
53 \\
\\
\end{array}$ \\
\hline \multicolumn{10}{|c|}{$\begin{array}{l}\text { Monthly mean discharge, in second-feet } \\
\text { Runoff, in inches }\end{array}$} & $\begin{array}{r}586 \\
4.17\end{array}$ & $\begin{array}{l}78.0 \\
0.54\end{array}$ \\
\hline
\end{tabular}

Gage height, in feet, and discharge, in second-feet, at indicated time, 1940

\begin{tabular}{|c|c|c|c|c|c|c|c|c|}
\hline \multirow{2}{*}{ Hour } & \multicolumn{2}{|c|}{ Aug. 13} & \multicolumn{2}{|c|}{ A ug. 14} & \multicolumn{2}{|c|}{ Aug. 15} & \multicolumn{2}{|c|}{ Aug. 16} \\
\hline & $\begin{array}{l}\text { Gage } \\
\text { height }\end{array}$ & Discharge & $\begin{array}{c}\text { Gage } \\
\text { height }\end{array}$ & Discharge & $\begin{array}{c}\text { Gage } \\
\text { height }\end{array}$ & Discharge & $\begin{array}{c}\text { Gage } \\
\text { height }\end{array}$ & Discharge \\
\hline $\begin{array}{l}1 \\
2 \\
3 \\
4 \\
5 \\
6\end{array}$ & $\begin{array}{l}1.13 \\
1.16 \\
1.26 \\
1.32 \\
1.41 \\
1.63\end{array}$ & $\begin{array}{l}106 \\
115 \\
150 \\
174 \\
213 \\
329\end{array}$ & $\begin{array}{l}4.60 \\
4.92 \\
5.37 \\
5.47 \\
5.68 \\
5.85\end{array}$ & $\begin{array}{l}4,350 \\
5,080 \\
6,210 \\
6,490 \\
7,100 \\
7,630\end{array}$ & $\begin{array}{l}5.75 \\
5.71 \\
5.49 \\
5.33 \\
5.18 \\
4.98\end{array}$ & $\begin{array}{l}7,320 \\
7,190 \\
6,540 \\
6,100 \\
5,710 \\
5,220\end{array}$ & $\begin{array}{l}2.77 \\
2.71 \\
2.65 \\
2.60 \\
2.55 \\
2.50\end{array}$ & $\begin{array}{l}1,320 \\
1,260 \\
1,200 \\
1,140 \\
1,100 \\
1,050\end{array}$ \\
\hline $\begin{array}{r}7 \\
8 \\
9 \\
10 \\
11 \\
\text { N }\end{array}$ & $\begin{array}{l}1.89 \\
2.32 \\
2.48 \\
2.36 \\
2.36 \\
2.37\end{array}$ & $\begin{array}{r}513 \\
883 \\
1,030 \\
920 \\
920 \\
929\end{array}$ & $\begin{array}{l}6.01 \\
6.18 \\
6.39 \\
6.61 \\
6.77 \\
6.92\end{array}$ & $\begin{array}{r}8,150 \\
8,740 \\
9,480 \\
10,300 \\
10,900 \\
11,400\end{array}$ & $\begin{array}{l}4.76 \\
4.65 \\
4.49 \\
4.31 \\
4.16 \\
3.98\end{array}$ & $\begin{array}{l}4,710 \\
4,460 \\
4,110 \\
3,730 \\
3,430 \\
3,080\end{array}$ & $\begin{array}{l}2.45 \\
2.41 \\
2.38 \\
2.34 \\
2.31 \\
2.27\end{array}$ & $\begin{array}{r}1,000 \\
965 \\
938 \\
901 \\
874 \\
838\end{array}$ \\
\hline $\begin{array}{l}1 \\
2 \\
3 \\
4 \\
5 \\
6\end{array}$ & $\begin{array}{l}2.38 \\
2.39 \\
2.40 \\
2.42 \\
2.47 \\
2.57\end{array}$ & $\begin{array}{r}938 \\
947 \\
956 \\
975 \\
1,020 \\
1,120\end{array}$ & $\begin{array}{l}7.06 \\
7.10 \\
7.13 \\
7.10 \\
7.06 \\
6.93\end{array}$ & $\begin{array}{l}11,900 \\
12,100 \\
12,200 \\
12,100 \\
11,900 \\
11,500\end{array}$ & $\begin{array}{l}3.88 \\
3.74 \\
3.62 \\
3.50 \\
3.38 \\
3.29\end{array}$ & $\begin{array}{l}2,890 \\
2,640 \\
2,430 \\
2,240 \\
2,060 \\
1,940\end{array}$ & $\begin{array}{l}2.24 \\
2.21 \\
2.18 \\
2.15 \\
2.13 \\
2.10\end{array}$ & $\begin{array}{l}812 \\
785 \\
759 \\
732 \\
715 \\
689\end{array}$ \\
\hline $\begin{array}{r}7 \\
8 \\
9 \\
10 \\
11 \\
12 \\
\end{array}$ & $\begin{array}{l}3.06 \\
3.24 \\
3.50 \\
3.82 \\
4.13 \\
4.39\end{array}$ & $\begin{array}{l}1,650 \\
1,870 \\
2,240 \\
2,790 \\
3,370 \\
3,900\end{array}$ & $\begin{array}{l}6.85 \\
6.70 \\
6.59 \\
6.42 \\
6.21 \\
6.05\end{array}$ & $\begin{array}{r}11,200 \\
10,600 \\
10,200 \\
9,590 \\
8,840 \\
8,290\end{array}$ & $\begin{array}{l}3.20 \\
3.12 \\
3.04 \\
2.95 \\
2.88 \\
2.82 \\
\end{array}$ & $\begin{array}{l}1,820 \\
1,720 \\
1,620 \\
1,520 \\
1,440 \\
1,370 \\
\end{array}$ & $\begin{array}{l}2.08 \\
2.05 \\
2.06 \\
2.22 \\
2.17 \\
2.14\end{array}$ & $\begin{array}{l}672 \\
646 \\
655 \\
794 \\
750 \\
724 \\
\end{array}$ \\
\hline
\end{tabular}

Supplemental ReCond.-Aug. 14, 3:45 p.m., gage height, 7.15 feet; discharge, 12,300 second-feet. 


\section{TYGER RIVER NEAR WOODRUFF, S. C.}

Location.-Lat. $34^{\circ} 45^{\prime}$, long. $81^{\circ} 55^{\prime}$, at Nesbitts Bridge, half a mile downstream from confluence of North and South Tyger Rivers and 61/2 miles east of Woodruff, Spartanburg County. Datum of gage is $\mathbf{4 8 9 . 4 4}$ feet above mean sea level, datun of 1929 , supplementary adjustment of 1936 .

DraINAGE AREA.-351 square miles.

GAGE-HEIGHT RECORD.-Water-stage recorder graph.

DISCHARGE RECORD.- Stage-discharge relation defined by eurrent-meter measurements up to 11,000 second-feet and extended to erest gage height on basis of rating curves for North Tyger River near Moore and South Tyger River near Woodruff.

Maxima.-1940: Discharge, 19,200 second-feet 4 p.m. Aug. 14 (gage height, 13.27 feet).

Oetober 1929 to 1939: Discharge, 17,100 second-feet Apr. 6, 1936 (gage height, 13.16 feet).

Stage known, about 20.0 feet, during flood of August 1928 (discharge not determined). Flood of September 1929 reached a stage of 14.65 feet, from floodmarks (discharge, 19,600 second-feet).

Remarks.-Flood discharge not affected by artificial storage or diversion. Flow regulated by power plants above station during low and medium stages.

Mean discharge, in second-feet, 1940

\begin{tabular}{|c|c|c|c|c|c|c|c|c|c|c|c|}
\hline Day & Aug. & Sept. & Day & Aug. & Sept. & Day & Aug. & Sept. & Day & Aug. & Sept. \\
\hline $\begin{array}{l}1 \\
2 \\
3 \\
4 \\
5 \\
6 \\
7 \\
8\end{array}$ & $\begin{array}{r}155 \\
106 \\
92 \\
112 \\
136 \\
218 \\
108 \\
86\end{array}$ & $\begin{array}{l}270 \\
451 \\
490 \\
273 \\
222 \\
192 \\
175 \\
146\end{array}$ & $\begin{array}{r}9 \\
10 \\
11 \\
12 \\
13 \\
14 \\
15 \\
16\end{array}$ & $\begin{array}{r}75 \\
86 \\
116 \\
180 \\
2,980 \\
15,200 \\
7,120 \\
1,850\end{array}$ & $\begin{array}{l}172 \\
210 \\
128 \\
146 \\
220 \\
202 \\
134 \\
164\end{array}$ & $\begin{array}{l}17 \\
18 \\
19 \\
20 \\
21 \\
22 \\
23 \\
24\end{array}$ & $\begin{array}{l}898 \\
410 \\
379 \\
455 \\
358 \\
286 \\
301 \\
218\end{array}$ & $\begin{array}{r}144 \\
108 \\
106 \\
106 \\
98 \\
122 \\
132 \\
163\end{array}$ & $\begin{array}{l}25 \\
26 \\
27 \\
28 \\
29 \\
30 \\
31\end{array}$ & $\begin{array}{l}196 \\
254 \\
305 \\
196 \\
200 \\
342 \\
398\end{array}$ & $\begin{array}{r}106 \\
90 \\
98 \\
165 \\
124 \\
133\end{array}$ \\
\hline \multicolumn{10}{|c|}{$\begin{array}{l}\text { Monthly mean discharge, in second-feet } \\
\text { Runoff, in inches. }\end{array}$} & $\begin{array}{r}1,091 \\
3.58\end{array}$ & $\begin{array}{r}176 \\
0.56\end{array}$ \\
\hline
\end{tabular}

Gage height, in feet, and discharge, in second-feet, at indicated time, 1940

\begin{tabular}{|c|c|c|c|c|c|c|c|c|c|c|}
\hline \multirow{2}{*}{ Hour } & \multicolumn{2}{|c|}{ Aug. 13} & \multicolumn{2}{|c|}{ Aug. 14} & \multicolumn{2}{|c|}{ Aug. 15} & \multicolumn{2}{|c|}{ Aug. 16} & \multicolumn{2}{|c|}{ Aug. 17} \\
\hline & $\begin{array}{l}\text { Gage } \\
\text { height }\end{array}$ & $\begin{array}{c}\text { Dis- } \\
\text { charge }\end{array}$ & $\begin{array}{c}\text { Gage } \\
\text { height }\end{array}$ & $\begin{array}{c}\text { Dis- } \\
\text { charge }\end{array}$ & $\begin{array}{c}\text { Gage } \\
\text { height }\end{array}$ & $\begin{array}{l}\text { Dis- } \\
\text { charge }\end{array}$ & $\begin{array}{c}\text { Gage } \\
\text { height }\end{array}$ & $\begin{array}{c}\text { Dis- } \\
\text { charge }\end{array}$ & $\begin{array}{c}\text { Gage } \\
\text { height }\end{array}$ & $\begin{array}{l}\text { Dis- } \\
\text { charge }\end{array}$ \\
\hline $\begin{array}{l}1 \\
2 \\
3 \\
4 \\
5 \\
6\end{array}$ & $\begin{array}{l}2.42 \\
2.57 \\
2.66 \\
2.79 \\
2.99 \\
3.19\end{array}$ & $\begin{array}{l}291 \\
373 \\
429 \\
520 \\
686 \\
876\end{array}$ & $\begin{array}{l}7.26 \\
7.70 \\
8.15 \\
8.85 \\
9.60 \\
9.98\end{array}$ & $\begin{array}{r}6,900 \\
7,780 \\
8,720 \\
10,000 \\
11,700 \\
12,600\end{array}$ & $\begin{array}{r}10.83 \\
10.52 \\
10.20 \\
9.88 \\
9.47 \\
9.14\end{array}$ & $\begin{array}{l}14,000 \\
13,200 \\
12,500 \\
11,800 \\
10,800 \\
10,100\end{array}$ & $\begin{array}{l}5.11 \\
4.92 \\
4.80 \\
4.69 \\
4.63 \\
4.53\end{array}$ & $\begin{array}{l}3,000 \\
2,720 \\
2,550 \\
2,400 \\
2,320 \\
2,190\end{array}$ & $\begin{array}{c}3.76 \\
3.64 \\
3.53\end{array}$ & $\begin{array}{l}1,310 \\
1,180 \\
1,060\end{array}$ \\
\hline $\begin{array}{r}7 \\
8 \\
9 \\
10 \\
11 \\
\mathrm{~N}\end{array}$ & $\begin{array}{l}3.64 \\
4.45 \\
5.41 \\
5.60 \\
5.49 \\
5.29\end{array}$ & $\begin{array}{l}1,340 \\
2,340 \\
3,770 \\
4,070 \\
3,890 \\
3,570\end{array}$ & $\begin{array}{l}10.58 \\
11.20 \\
11.45 \\
11.82 \\
12.10 \\
12.35\end{array}$ & $\begin{array}{l}13,700 \\
15,200 \\
15,700 \\
16,300 \\
17,000 \\
17,600\end{array}$ & $\begin{array}{l}8.66 \\
8.33 \\
7.95 \\
7.61 \\
7.42 \\
7.29\end{array}$ & $\begin{array}{l}9,050 \\
8,360 \\
7,580 \\
6,900 \\
6,520 \\
6,280\end{array}$ & $\begin{array}{l}4.40 \\
4.33 \\
4.26 \\
4.17 \\
4.11 \\
4.05\end{array}$ & $\begin{array}{l}2,020 \\
1,930 \\
1,840 \\
1,730 \\
1,660 \\
1,590\end{array}$ & $\begin{array}{c}3.47 \\
3.40 \\
3.35\end{array}$ & $\begin{array}{l}1,000 \\
93 \overline{5} \\
885\end{array}$ \\
\hline $\begin{array}{l}1 \\
2 \\
3 \\
4 \\
5 \\
6\end{array}$ & $\begin{array}{l}5.15 \\
4.95 \\
4.97 \\
5.01 \\
5.20 \\
5.61\end{array}$ & $\begin{array}{l}3,360 \\
3,060 \\
3,080 \\
3,140 \\
3,430 \\
4,090\end{array}$ & $\begin{array}{l}12.63 \\
12.87 \\
13.12 \\
13.27 \\
13.20 \\
12.97\end{array}$ & $\begin{array}{l}18,000 \\
18,500 \\
19,100 \\
19,200 \\
19,100 \\
18,500\end{array}$ & $\begin{array}{l}6.80 \\
6.71 \\
6.66 \\
6.25 \\
6.38 \\
5.86\end{array}$ & $\begin{array}{l}5,360 \\
5,200 \\
5,110 \\
4,400 \\
4,620 \\
3,770\end{array}$ & $\begin{array}{l}4.01 \\
3.95 \\
3.90 \\
3.87 \\
3.84 \\
3.79\end{array}$ & $\begin{array}{l}1,540 \\
1,470 \\
1,410 \\
1,380 \\
1,340 \\
1,290\end{array}$ & $\begin{array}{c}3.32 \\
3.24 \\
3.11\end{array}$ & 880 \\
\hline $\begin{array}{r}7 \\
8 \\
9 \\
10 \\
11 \\
12 \\
\end{array}$ & $\begin{array}{l}5.71 \\
6.05 \\
6.50 \\
6.38 \\
6.57 \\
6.95\end{array}$ & $\begin{array}{l}4,250 \\
4,820 \\
5,630 \\
5,410 \\
5,760 \\
6,480\end{array}$ & $\begin{array}{l}12.89 \\
12.89 \\
12.64 \\
12.26 \\
11.92 \\
11.45\end{array}$ & $\begin{array}{l}18,300 \\
18,300 \\
18,100 \\
17,200 \\
16,500 \\
15,400\end{array}$ & $\begin{array}{l}5.85 \\
5.70 \\
5.55 \\
5.39 \\
5.22 \\
5.19\end{array}$ & $\begin{array}{l}3,750 \\
3,510 \\
3,280 \\
3,040 \\
2,790 \\
2,750\end{array}$ & $\begin{array}{l}3.75 \\
3.71 \\
3.66 \\
4.43 \\
4.47 \\
4.13\end{array}$ & $\begin{array}{l}1,240 \\
1,200 \\
1,150 \\
2,060 \\
2,110 \\
1,690\end{array}$ & $\begin{array}{c}2.99 \\
2.90 \\
2.83\end{array}$ & $\begin{array}{l}5 \overline{59} \\
491^{-}\end{array}$ \\
\hline
\end{tabular}


MIDDLE TYGER RIVER AT LYMAN, S. C.

Location.-Lat. $34^{\circ} 56^{\prime} 35^{\prime \prime}$, long. $82^{\circ} 08^{\prime} 00^{\prime \prime}$, at Lyman, Spartanburg County, 200 feet upstream from bridge on U. S. Highway 29, 600 feet downstream from

Southern Railway bridge, and three-quarters of a mile northeast of Duncan.

Drainage AREA.-68.3 square miles.

GAGE-HEIGHT RECORD.-Water-stage recorder graph.

Discharge RECORD.-Artificial control of masonry. Stage-discharge relation defined by current-meter measurements up to 2,900 second-feet and extended to crest gage height on basis of determination of flood flow over dam.

Maxima.-1940: Discharge, 4,800 second-feet 12:30 a.m. Aug. 14 (gage height, 16.16 feet).

1938-39: Discharge, 2,730 second-feet Aug. 18, 1939 (gage height, 9.28 feet). REMARKs.-Flood discharge not affected by artificial storage or diversion.

Mean discharge, in second-feet, 1940

\begin{tabular}{|c|c|c|c|c|c|c|c|c|c|c|c|}
\hline Day & Aug. & Sept. & Day & Aug. & Sept. & Day & Aug. & Sept. & Day & Aug. & Sept. \\
\hline $\begin{array}{l}1 \\
2 \\
3 \\
4 \\
5 \\
6 \\
7 \\
8\end{array}$ & $\begin{array}{l}27 \\
24 \\
21 \\
24 \\
23 \\
26 \\
27 \\
29\end{array}$ & $\begin{array}{l}95 \\
57 \\
49 \\
45 \\
41 \\
40 \\
37 \\
39\end{array}$ & $\begin{array}{r}9 \\
10 \\
11 \\
12 \\
13 \\
14 \\
15 \\
16\end{array}$ & $\begin{array}{r}26 \\
20 \\
26 \\
40 \\
1,730 \\
3,110 \\
566 \\
187\end{array}$ & $\begin{array}{l}36 \\
36 \\
32 \\
32 \\
33 \\
28 \\
31 \\
29\end{array}$ & $\begin{array}{l}17 \\
18 \\
19 \\
20 \\
21 \\
22 \\
23 \\
25\end{array}$ & $\begin{array}{r}105 \\
82 \\
65 \\
59 \\
53 \\
48 \\
45 \\
48\end{array}$ & $\begin{array}{l}30 \\
27 \\
28 \\
29 \\
28 \\
30 \\
26 \\
28\end{array}$ & $\begin{array}{l}25 \\
26 \\
27 \\
28 \\
29 \\
30 \\
31\end{array}$ & $\begin{array}{r}41 \\
37 \\
38 \\
42 \\
48 \\
151 \\
100\end{array}$ & $\begin{array}{l}28 \\
31 \\
28 \\
28 \\
26 \\
21\end{array}$ \\
\hline \multicolumn{10}{|c|}{$\begin{array}{l}\text { Monthly mean diseharge, in second-feet } \\
\text { Runoff, in inches }\end{array}$} & $\begin{array}{r}222 \\
3.75\end{array}$ & $\begin{array}{l}34.9 \\
0.57\end{array}$ \\
\hline
\end{tabular}

Gage height, in feet, and discharge, in second-feet, at indicated time, 1940

\begin{tabular}{|c|c|c|c|c|c|c|c|c|}
\hline \multirow{2}{*}{ Hour } & \multicolumn{2}{|c|}{ Aug. 13} & \multicolumn{2}{|c|}{ Aug. 14} & \multicolumn{2}{|c|}{ Aug. 15} & \multicolumn{2}{|c|}{ Aug. 16} \\
\hline & $\begin{array}{c}\text { Gage } \\
\text { height }\end{array}$ & Discharge & $\begin{array}{c}\text { Gage } \\
\text { height }\end{array}$ & Discharge & $\begin{array}{c}\text { Gage } \\
\text { height }\end{array}$ & Discharge & $\begin{array}{c}\text { Gage } \\
\text { height }\end{array}$ & Discharge \\
\hline $\begin{array}{l}1 \\
2 \\
3 \\
4 \\
5 \\
6\end{array}$ & $\begin{array}{l}1.46 \\
1.57 \\
1.84 \\
1.98 \\
2.05 \\
2.14\end{array}$ & $\begin{array}{r}43 \\
53 \\
84 \\
105 \\
116 \\
131\end{array}$ & $\begin{array}{l}16.14 \\
15.92 \\
15.45 \\
14.90 \\
14.39 \\
13.90\end{array}$ & $\begin{array}{l}4,790 \\
4,730 \\
4,580 \\
4,420 \\
4,270 \\
4,120\end{array}$ & $\begin{array}{l}5.13 \\
4.94 \\
4.76 \\
4.61 \\
4.45 \\
4.30\end{array}$ & $\begin{array}{r}1,050 \\
963 \\
886 \\
823 \\
760 \\
702\end{array}$ & $\begin{array}{c}2.84 \\
2.74 \\
2.64\end{array}$ & ${ }^{24} 7^{2} \overline{9}^{2}$ \\
\hline $\begin{array}{r}7 \\
8 \\
9 \\
10 \\
11 \\
\mathbf{N}\end{array}$ & $\begin{array}{l}2.69 \\
4.15 \\
5.05 \\
5.04 \\
5.46 \\
5.90\end{array}$ & $\begin{array}{r}236 \\
648 \\
1,010 \\
1,010 \\
1,200 \\
1,400\end{array}$ & $\begin{array}{l}13.38 \\
12.86 \\
12.30 \\
11.79 \\
11.26 \\
10.73\end{array}$ & $\begin{array}{l}3,960 \\
3,810 \\
3,640 \\
3,490 \\
3,330 \\
3,170\end{array}$ & $\begin{array}{l}4.17 \\
4.07 \\
3.97 \\
3.88 \\
3.80 \\
3.69\end{array}$ & $\begin{array}{l}655 \\
620 \\
586 \\
556 \\
530 \\
495\end{array}$ & $\begin{array}{c}2.56 \\
2.49 \\
2.43\end{array}$ & $\begin{array}{l}210^{-} \\
196^{-}\end{array}$ \\
\hline $\begin{array}{l}1 \\
2 \\
3 \\
4 \\
5 \\
6\end{array}$ & $\begin{array}{l}6.30 \\
6.60 \\
6.73 \\
7.35 \\
8.70 \\
9.85\end{array}$ & $\begin{array}{l}1,580 \\
1,710 \\
1,770 \\
2,020 \\
2,520 \\
2,900\end{array}$ & $\begin{array}{r}10.28 \\
9.75 \\
9.17 \\
8.63 \\
8.12 \\
7.61\end{array}$ & $\begin{array}{l}3,030 \\
2,880 \\
2,680 \\
2,500 \\
2,320 \\
2,120\end{array}$ & $\begin{array}{l}3.60 \\
3.52 \\
3.47 \\
3.40 \\
3.35 \\
3.30\end{array}$ & $\begin{array}{l}468 \\
444 \\
430 \\
410 \\
396 \\
382\end{array}$ & $\begin{array}{c}2.38 \\
2.32 \\
2.20\end{array}$ & $\begin{array}{l}174^{-} \\
164 \\
14 \overline{2}^{-}\end{array}$ \\
\hline $\begin{array}{r}7 \\
8 \\
9 \\
10 \\
11 \\
12\end{array}$ & $\begin{array}{l}11.50 \\
12.74 \\
14.25 \\
15.28 \\
15.83 \\
16.14\end{array}$ & $\begin{array}{l}3,400 \\
3,770 \\
4,220 \\
4,530 \\
4,700 \\
4,790\end{array}$ & $\begin{array}{l}7.14 \\
6.68 \\
6.24 \\
5.88 \\
5.59 \\
5.36\end{array}$ & $\begin{array}{l}1,940 \\
1,750 \\
1,550 \\
1,390 \\
1,260 \\
1,150\end{array}$ & $\begin{array}{l}3.24 \\
3.19 \\
3.14 \\
3.08 \\
3.02 \\
2.97\end{array}$ & $\begin{array}{l}366 \\
353 \\
340 \\
325 \\
311 \\
299\end{array}$ & $\begin{array}{c}2.04 \\
1.98 \\
2.12\end{array}$ & $\begin{array}{l}11 \overline{4} \\
105 \\
12 \overline{8}\end{array}$ \\
\hline
\end{tabular}

SuPPLemental Record.-Aug. 14, 12:30 a.m., gage height, 16.16 feet; discharge, 4,800 second-feet.

SOUTH TYGER RIVER NEAR REIDVILLE, S. C.

Lochtion.-Lat. $34^{\circ} 52^{\prime} 35^{\prime \prime}$, long. $82^{\circ} 05^{\prime} 10^{\prime \prime}, 0.4$ mile upstream from county highway bridge, 1.2 miles downstream from Berry Shoals, 1.8 miles northeast of Reidville, Spartanburg County, and 4 miles upstream from Bens Creek. Datum of gage is 626.28 feet above mean sea level, datum of 1929 , supple- 


\section{FLOODS OF AUGUST 1940 IN THE SOUTHEASTERN STATES}

mentary adjustment of 1936 .

DRAINAGE AREA.- -106 square miles.

GAGE-HEIGHT RECORD.-Water-stage recorder graph.

DISCHARGE RECORD.- Stage discharge relation defined by current-meter measurements.

Maхima.-1940: Discharge, 5,510 second-feet 8:30 p.m. Aug. 13 (gage height, 12.68 feet).

1934-39: Discharge, 6,080 second-feet Apr. 6, 1936 (gage height, 13.66 feet). Remarks.-Flood discharge not affected by artificial storage or diversion. Flow regulated by power plants above station during low and medium stages.

Mean discharge, in second-feet, 1940

\begin{tabular}{|c|c|c|c|c|c|c|c|c|c|c|c|}
\hline Day & Aug. & Sept. & Day & Aug. & Sept. & Day & Aug. & Sept. & Day & Aug. & Sept. \\
\hline $\begin{array}{l}1 \\
2 \\
3 \\
4 \\
5 \\
6 \\
7 \\
8\end{array}$ & \begin{tabular}{c|}
12 \\
.7 .7 \\
56 \\
64 \\
92 \\
20 \\
9.9 \\
9.4
\end{tabular} & $\begin{array}{r}122 \\
361 \\
153 \\
123 \\
69 \\
14 \\
80 \\
61\end{array}$ & $\begin{array}{r}9 \\
10 \\
11 \\
12 \\
13 \\
14 \\
15 \\
16\end{array}$ & $\begin{array}{r}9.4 \\
58 \\
64 \\
53 \\
2,350 \\
3,240 \\
1,020 \\
410\end{array}$ & $\begin{array}{r}105 \\
20 \\
10 \\
148 \\
113 \\
76 \\
62 \\
62\end{array}$ & $\begin{array}{l}17 \\
18 \\
19 \\
20 \\
21 \\
22 \\
23 \\
24\end{array}$ & $\begin{array}{r}178 \\
67 \\
155 \\
194 \\
94 \\
115 \\
36 \\
81\end{array}$ & $\begin{array}{c}9.9 \\
9.9 \\
9.9 \\
11 \\
57 \\
62 \\
75 \\
9.4\end{array}$ & $\begin{array}{l}25 \\
26 \\
27 \\
28 \\
29 \\
30 \\
31\end{array}$ & $\begin{array}{r}71 \\
153 \\
77 \\
16 \\
22 \\
84 \\
115\end{array}$ & $\begin{array}{c}9.9 \\
9.9 \\
70 \\
72 \\
64 \\
80 \\
\end{array}$ \\
\hline $\begin{array}{c}\text { on } \\
\text { un }\end{array}$ & & & & & & & & & & $\begin{array}{r}288 \\
3.14\end{array}$ & $\begin{array}{l}71.0 \\
0.75\end{array}$ \\
\hline
\end{tabular}

Gage height, in feet, and discharge, in second-feet, at indicated time, 1940

\begin{tabular}{|c|c|c|c|c|c|c|c|c|}
\hline \multirow{2}{*}{ Hour } & \multicolumn{2}{|c|}{ Aug. 13} & \multicolumn{2}{|c|}{ Aug. 14} & \multicolumn{2}{|c|}{ Aug. 15} & \multicolumn{2}{|c|}{ Aug. 16} \\
\hline & $\begin{array}{c}\text { Gage } \\
\text { height }\end{array}$ & Discharge & $\begin{array}{c}\text { Gage } \\
\text { height }\end{array}$ & Discharge & $\begin{array}{c}\text { Gage } \\
\text { height }\end{array}$ & Discharge & $\begin{array}{c}\text { Gage } \\
\text { height }\end{array}$ & Discharge \\
\hline $\begin{array}{l}1 \\
2 \\
3 \\
4 \\
5 \\
6\end{array}$ & $\begin{array}{l}0.88 \\
1.14 \\
1.29 \\
1.37 \\
1.47 \\
1.67\end{array}$ & $\begin{array}{r}20 \\
47 \\
67 \\
78 \\
95 \\
133\end{array}$ & $\begin{array}{l}11.39 \\
11.64 \\
11.77 \\
11.61 \\
11.15 \\
10.45\end{array}$ & $\begin{array}{l}4,800 \\
4,940 \\
5,010 \\
4,930 \\
4,670 \\
4,290\end{array}$ & $\begin{array}{l}5.90 \\
5.87 \\
5.65 \\
5.47 \\
5.25 \\
4.95\end{array}$ & $\begin{array}{l}1,820 \\
1,800 \\
1,700 \\
1,600 \\
1,500 \\
1,340\end{array}$ & $\begin{array}{l}3.15 \\
2.9 \overline{3}^{-6} \\
2.67^{-1}\end{array}$ & $\begin{array}{r}576 \\
496 \\
409\end{array}$ \\
\hline $\begin{array}{r}7 \\
8 \\
9 \\
10 \\
11 \\
\mathrm{~N}\end{array}$ & $\begin{array}{l}2.30 \\
3.36 \\
3.30 \\
5.09 \\
4.42 \\
3.84\end{array}$ & $\begin{array}{r}293 \\
655 \\
632 \\
1,420 \\
1,100 \\
846\end{array}$ & $\begin{array}{l}9.65 \\
9.01 \\
8.45 \\
8.02 \\
7.75 \\
7.53\end{array}$ & $\begin{array}{l}3,850 \\
3,500 \\
3,190 \\
2,950 \\
2,800 \\
2,680\end{array}$ & $\begin{array}{l}4.77 \\
4.55 \\
4.35 \\
4.18 \\
4.03 \\
3.91\end{array}$ & $\begin{array}{r}1,260 \\
1,160 \\
1,070 \\
\mathbf{9 9 6} \\
928 \\
\mathbf{8 7 4}\end{array}$ & $\begin{array}{l}2.57 \\
2.55 \\
2.5 \overline{3}^{-}\end{array}$ & $\begin{array}{l}376 \\
370 \\
364\end{array}$ \\
\hline $\begin{array}{l}1 \\
2 \\
3 \\
4 \\
5 \\
6\end{array}$ & $\begin{array}{r}3.36 \\
6.90 \\
10.75 \\
11.80 \\
12.21 \\
12.38\end{array}$ & $\begin{array}{r}655 \\
2,340 \\
4,450 \\
5,030 \\
5,260 \\
5,350\end{array}$ & $\begin{array}{l}7.40 \\
7.36 \\
7.39 \\
7.29 \\
7.43 \\
7.17\end{array}$ & $\begin{array}{l}2,610 \\
2,590 \\
2,600 \\
2,550 \\
2,630 \\
2,480\end{array}$ & $\begin{array}{l}3.82 \\
3.75 \\
3.83 \\
3.73 \\
3.64 \\
3.55\end{array}$ & $\begin{array}{l}838 \\
810 \\
842 \\
802 \\
766 \\
730\end{array}$ & 2.60 & $\begin{array}{c}364 \\
386 \\
383\end{array}$ \\
\hline $\begin{array}{r}7 \\
8 \\
9 \\
10 \\
11 \\
12 \\
\end{array}$ & $\begin{array}{l}12.44 \\
12.17 \\
12.40 \\
11.50 \\
11.14 \\
11.18\end{array}$ & $\begin{array}{l}5,380 \\
5,230 \\
5,360 \\
4,860 \\
4,670 \\
4,690\end{array}$ & $\begin{array}{l}7.07 \\
6.94 \\
6.82 \\
6.64 \\
6.58 \\
6.32 \\
\end{array}$ & $\begin{array}{l}2,430 \\
2,360 \\
2,290 \\
2,190 \\
2,160 \\
2,030\end{array}$ & $\begin{array}{l}3.44 \\
3.35 \\
2.81 \\
2.20 \\
2.45 \\
2.65\end{array}$ & $\begin{array}{l}687 \\
652 \\
455 \\
265 \\
338 \\
402 \\
\end{array}$ & $\begin{array}{l}2.63 \\
2.64 \\
2.62 \\
\end{array}$ & $\begin{array}{l}396 \\
399^{-1} \\
393^{-1}\end{array}$ \\
\hline
\end{tabular}

SUPPLEMENTAL RECORD.-Aug. 13, 8:30 p.m., gage height, 12.68 feet; discharge, 5,510 second-feet.

\section{SOUTH TYGER RIVER NEAR WOODRUFF, S. C.}

Location.-Lat. $34^{\circ} 45^{\prime}$, long. $81^{\circ} 56^{\prime}$, at Chesnee Shoals, three-eighths of a mile upstream from confluence of North and South Tyger Rivers and 5\%/4 miles east of Woodruff, Spartanburg County. Datum of gage is 508.35 feet above mean sea level, datum of 1929 , supplementary adjustment of 1936 .

DRAINAGE AREA. - 174 square miles.

GAGE-HEIGHT RECORD.-Water-stage recorder graph.

DisCHARGE RECORD.-Artificial control of concrete. Stage-discharge relation defined 
by current-meter measurements up to 2,500 second-feet and extended above by velocity-area studies.

Maxima.-1940: Discharge, 6,960 second-feet 1:45 p.m. Aug. 14 (gage height, 8.18 feet).

1934-39: Discharge, 9,510 second-feet Apr. 6, 1936 (gage height, 9.78 feet). REMARKs.-Flood discharge not affected by artificial storage or diversion. Flow regulated by power plants above station during low and medium stages.

Mean discharge, in second-feet, 1940

\begin{tabular}{|c|c|c|c|c|c|c|c|c|c|c|c|}
\hline Day & Aug. & Sept. & Day & Aug. & Sept. & Day & Aug. & Sept. & Day & Aug. & Sept. \\
\hline $\begin{array}{l}1 \\
2 \\
3 \\
4 \\
5 \\
6 \\
7 \\
8\end{array}$ & $\begin{array}{r}68 \\
28 \\
28 \\
76 \\
84 \\
137 \\
35 \\
30\end{array}$ & $\begin{array}{r}120 \\
257 \\
297 \\
149 \\
121 \\
79 \\
67 \\
88\end{array}$ & $\begin{array}{r}9 \\
10 \\
11 \\
12 \\
13 \\
14 \\
15 \\
16\end{array}$ & $\begin{array}{r}28 \\
29 \\
79 \\
113 \\
1,590 \\
5,600 \\
2,890 \\
873\end{array}$ & $\begin{array}{r}97 \\
98 \\
39 \\
72 \\
142 \\
129 \\
90 \\
97\end{array}$ & $\begin{array}{l}17 \\
18 \\
19 \\
20 \\
21 \\
22 \\
23 \\
24\end{array}$ & $\begin{array}{l}438 \\
177 \\
177 \\
248 \\
211 \\
152 \\
162 \\
105\end{array}$ & $\begin{array}{l}53 \\
32 \\
32 \\
31 \\
33 \\
82 \\
87 \\
68\end{array}$ & $\begin{array}{l}25 \\
26 \\
27 \\
28 \\
29 \\
30 \\
31\end{array}$ & $\begin{array}{r}130 \\
149 \\
172 \\
105 \\
71 \\
113 \\
199\end{array}$ & $\begin{array}{l}31 \\
29 \\
33 \\
96 \\
81 \\
90\end{array}$ \\
\hline \multicolumn{10}{|c|}{$\begin{array}{l}\text { Monthly mean discharge, in second-feet } \\
\text { Runoff, in inches }\end{array}$} & $\begin{array}{r}461 \\
3.06\end{array}$ & $\begin{array}{l}90.7 \\
0.58\end{array}$ \\
\hline
\end{tabular}

Gage height, in feet, and discharge, in second-feet, at indicated time, 1940

\begin{tabular}{|c|c|c|c|c|c|c|c|c|}
\hline \multirow{2}{*}{ Hour } & \multicolumn{2}{|c|}{ Aug. 13} & \multicolumn{2}{|c|}{ Aug. 14} & \multicolumn{2}{|c|}{ Aug. 15} & \multicolumn{2}{|c|}{ Aug. 16} \\
\hline & $\begin{array}{c}\text { Gage } \\
\text { height }\end{array}$ & Discharge & $\begin{array}{c}\text { Gage } \\
\text { height }\end{array}$ & Discharge & $\begin{array}{c}\text { Gage } \\
\text { height }\end{array}$ & Discharge & $\begin{array}{c}\text { Gage } \\
\text { height }\end{array}$ & Discharge \\
\hline \multirow{4}{*}{$\begin{array}{l}1 \\
2 \\
3 \\
4 \\
5 \\
6\end{array}$} & \multirow{4}{*}{$\begin{array}{l}2.24 \\
2.35 \\
2.41 \\
2.56 \\
2.71 \\
2.99\end{array}$} & \multirow{4}{*}{$\begin{array}{l}147 \\
175 \\
192 \\
243 \\
300 \\
426\end{array}$} & \multirow{4}{*}{$\begin{array}{l}5.66 \\
5.86 \\
6.03 \\
6.34 \\
6.55 \\
6.95\end{array}$} & \multirow{4}{*}{$\begin{array}{l}3,180 \\
3,480 \\
3,740 \\
4,200 \\
4,520 \\
5,120\end{array}$} & 6.48 & 4,410 & & \\
\hline & & & & & $-\frac{1}{1}=$ & 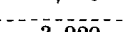 & & \\
\hline & & & & & 6.15 & 3,920 & & \\
\hline & & & & & 5.90 & 3,540 & 3.93 & 1,060 \\
\hline \multirow{4}{*}{$\begin{array}{r}7 \\
8 \\
9 \\
10 \\
11 \\
\mathrm{~N}\end{array}$} & \multirow{4}{*}{$\begin{array}{l}3.39 \\
3.96 \\
4.56 \\
4.76 \\
4.75 \\
4.70\end{array}$} & \multirow{4}{*}{$\begin{array}{r}648 \\
1,090 \\
1,690 \\
1,920 \\
1,900 \\
1,840\end{array}$} & \multirow{4}{*}{$\begin{array}{l}7.33 \\
7.65 \\
7.92 \\
8.05 \\
8.12 \\
\mathbf{8 . 0 7}\end{array}$} & \multirow{4}{*}{$\begin{array}{l}5,680 \\
6,160 \\
6,570 \\
6,760 \\
6,870 \\
6,800\end{array}$} & & & & \\
\hline & & & & & 5.67 & 3,200 & & \\
\hline & & & & & $\overline{5} . \overline{5} \overline{5}$ & 3,020 & 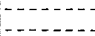 & \\
\hline & & & & & 5.37 & 2,740 & 3.53 & $752^{---}$ \\
\hline \multirow{4}{*}{$\begin{array}{l}1 \\
2 \\
3 \\
4 \\
5 \\
6\end{array}$} & \multirow{4}{*}{$\begin{array}{l}4.64 \\
4.61 \\
4.65 \\
4.86 \\
5.01 \\
5.28\end{array}$} & \multirow{4}{*}{$\begin{array}{l}1,780 \\
1,740 \\
1,790 \\
2,040 \\
2,230 \\
2,610\end{array}$} & \multirow{4}{*}{$\begin{array}{l}8.12 \\
8.13 \\
8.05 \\
8.04 \\
7.81 \\
7.77\end{array}$} & \multirow{4}{*}{$\begin{array}{l}6,870 \\
6,880 \\
6,760 \\
6,750 \\
6,400 \\
6,340\end{array}$} & & & & \\
\hline & & & & & 5.22 & 2,520 & $\ldots$ & \\
\hline & & & & & 5.08 & $\overline{2}, \overline{3} 30$ & $-\cdots$ & -- \\
\hline & & & & & 4.94 & $\overline{2}, 140$ & $\overline{3} . \overline{3} \overline{1}$ & $613^{--}$ \\
\hline \multirow{4}{*}{$\begin{array}{r}7 \\
8 \\
9 \\
10 \\
11 \\
12\end{array}$} & \multirow{4}{*}{$\begin{array}{l}5.25 \\
5.28 \\
5.34 \\
5.46 \\
5.48 \\
5.61\end{array}$} & \multirow{4}{*}{$\begin{array}{l}2,570 \\
2,610 \\
2,700 \\
2,880 \\
2,910 \\
3,100\end{array}$} & \multirow{4}{*}{$\begin{array}{l}7.62 \\
7.42 \\
7.22 \\
7.00 \\
6.77 \\
6.72\end{array}$} & \multirow{4}{*}{$\begin{array}{l}6,120 \\
5,820 \\
5,520 \\
5,190 \\
4,840 \\
4,770\end{array}$} & & & & \\
\hline & & & & & 4.80 & 1,960 & & \\
\hline & & & & & 4.64 & 1,780 & . & 1 \\
\hline & & & & & 4.45 & 1,570 & 3.23 & 566 \\
\hline
\end{tabular}

SUPPLEMENTAL RECORD.-Aug. 14, 1:45 p.m., gage height, 8.18 feet; discharge, 6,960 second-feet.

FAIR FOREST CREEK NEAR UNION, S. C.

Location.-Lat. $34^{\circ} 41^{\prime}$, long. $81^{\circ} 41^{\prime}$, at bridge on State Highway 92, 0.3 mile downstream from Buffalo Creek and 4.3 miles southwest of Union, Union County. Datum of gage is 393.91 feet above mean sea level, datum of 1929 , supplementary adjustment of 1936 .

Drainage AREa.-183 square miles.

GAGE-HEIGHT RECORD.-Water-stage recorder graph.

DISCHARGE RECORD.-Stage-discharge relation defined by current-meter measurements up to 4,300 second-feet and extended to crest gage height by velocity-area studies and logarithmic plotting. 


\section{FLOODS OF AUGUST 1940 IN THE SOUTHEASTERN STATES}

Maxima.-1940: Discharge, 7,520 second-feet $9: 15$ a.m. Aug. 14 (gage height, 7.15 feet).

REMARKS.-Flood discharge not affected by storage or diversion.

Mean discharge, in second-feet, 1940

\begin{tabular}{|c|c|c|c|c|c|c|c|c|c|c|c|}
\hline Day & Aug. & Sept. & Day & Aug. & Sept. & Day & Aug. & Sept. & Day & Aug. & Sept. \\
\hline $\begin{array}{l}1 \\
2 \\
3 \\
4 \\
5 \\
6 \\
7 \\
8\end{array}$ & $\begin{array}{l}43 \\
30 \\
24 \\
21 \\
28 \\
27 \\
24 \\
21\end{array}$ & $\begin{array}{l}76 \\
60 \\
53 \\
49 \\
48 \\
46 \\
44 \\
42\end{array}$ & $\begin{array}{r}9 \\
10 \\
11 \\
12 \\
13 \\
14 \\
15 \\
16\end{array}$ & $\begin{array}{r}25 \\
21 \\
21 \\
51 \\
1,850 \\
5,570 \\
2,510 \\
433\end{array}$ & $\begin{array}{r}38 \\
38 \\
42 \\
37 \\
34 \\
\mathbf{3 4} \\
\mathbf{3 4} \\
\mathbf{3 4}\end{array}$ & $\begin{array}{l}17 \\
18 \\
19 \\
20 \\
21 \\
22 \\
23 \\
24\end{array}$ & $\begin{array}{r}306 \\
203 \\
110 \\
83 \\
70 \\
64 \\
60 \\
57\end{array}$ & $\begin{array}{l}33 \\
33 \\
33 \\
36 \\
32 \\
31 \\
28 \\
28\end{array}$ & $\begin{array}{l}25 \\
26 \\
27 \\
28 \\
29 \\
30 \\
31\end{array}$ & $\begin{array}{r}53 \\
51 \\
51 \\
49 \\
96 \\
288 \\
149\end{array}$ & $\begin{array}{r}31 \\
32 \\
28 \\
26 \\
26 \\
25 \\
-2\end{array}$ \\
\hline $\begin{array}{l}\text { on } \\
\text { in }\end{array}$ & & & & & & & & & & $\begin{array}{r}400 \\
2.52\end{array}$ & $\begin{array}{l}37.7 \\
0.23\end{array}$ \\
\hline
\end{tabular}

Gage height, in feet, and discharge, in second-feet, at indicated time, 1940

\begin{tabular}{|c|c|c|c|c|c|c|c|c|c|c|c|c|}
\hline \multirow{2}{*}{ Hour } & \multicolumn{2}{|c|}{ Aug. 12} & \multicolumn{2}{|c|}{ Aug. 13} & \multicolumn{2}{|c|}{ Aug. 14} & \multicolumn{2}{|c|}{ Aug. 15} & \multicolumn{2}{|c|}{ Aug. 16} & \multicolumn{2}{|c|}{ Aug. 17} \\
\hline & $\begin{array}{l}\text { Gage } \\
\text { ht. }\end{array}$ & $\begin{array}{c}\text { Dis- } \\
\text { charge }\end{array}$ & $\begin{array}{c}\text { Gage } \\
\text { ht. }\end{array}$ & $\begin{array}{c}\text { Dis- } \\
\text { charge }\end{array}$ & $\begin{array}{c}\text { Gage } \\
\text { ht. }\end{array}$ & $\begin{array}{c}\text { Dis- } \\
\text { charge }\end{array}$ & $\begin{array}{c}\text { Gage } \\
\text { ht. }\end{array}$ & $\begin{array}{c}\text { Dis- } \\
\text { charge }\end{array}$ & $\begin{array}{c}\text { Gage } \\
\text { ht. }\end{array}$ & $\begin{array}{c}\text { Dis- } \\
\text { charge }\end{array}$ & $\begin{array}{c}\text { Gage } \\
\text { ht. }\end{array}$ & $\begin{array}{l}\text { Dis- } \\
\text { charge }\end{array}$ \\
\hline $\begin{array}{l}1 \\
2\end{array}$ & 1.92 & 25 & $\begin{array}{l}2.21 \\
2.24\end{array}$ & $\begin{array}{l}70 \\
78\end{array}$ & $\begin{array}{l}5.87 \\
5.90\end{array}$ & $\begin{array}{l}4,400 \\
4,470\end{array}$ & $\begin{array}{l}5.74 \\
5.69\end{array}$ & $\begin{array}{l}4,120 \\
4,010\end{array}$ & 3.43 & 774 & $\begin{array}{l}2.82 \\
2.96\end{array}$ & $\begin{array}{l}338 \\
431\end{array}$ \\
\hline $\begin{array}{l}3 \\
4\end{array}$ & $1.9 \overline{9}$ & 26 & $\begin{array}{l}2.32 \\
2.54\end{array}$ & $\begin{array}{r}99 \\
181\end{array}$ & $\begin{array}{l}6.10 \\
6.54\end{array}$ & $\begin{array}{l}4,930 \\
5,990\end{array}$ & $\begin{array}{l}5.61 \\
5.55\end{array}$ & $\begin{array}{l}3,830 \\
3,710\end{array}$ & $3 . \overline{30}$ & 674 & $\begin{array}{l}3.01 \\
3.02\end{array}$ & $\begin{array}{l}465 \\
472\end{array}$ \\
\hline 5 & & & 2.71 & 270 & 6.85 & 6,740 & 5.50 & 3,610 & & & 3.02 & 472 \\
\hline 6 & 1.94 & 27 & 2.92 & 404 & 6.94 & 6,970 & 5.42 & 3,450 & 3.18 & 586 & 3.01 & 465 \\
\hline 7 & & & 3.19 & 593 & 7.01 & 7,160 & 5.37 & 3,350 & & & 2.96 & 431 \\
\hline $\begin{array}{l}8 \\
9\end{array}$ & 1.97 & 1 & $\begin{array}{l}3.85 \\
4.50\end{array}$ & $\begin{array}{l}1,150 \\
1,910\end{array}$ & $\begin{array}{l}6.63 \\
7.08\end{array}$ & $\begin{array}{l}6,200 \\
7,340\end{array}$ & $\begin{array}{l}5.28 \\
5.19\end{array}$ & $\begin{array}{l}3,170 \\
3,010\end{array}$ & 3.05 & 493 & $\begin{array}{l}2.86 \\
2.77\end{array}$ & $\begin{array}{l}364 \\
307\end{array}$ \\
\hline 10 & 2.04 & 40 & 4.84 & 2,410 & 6.84 & 6,710 & 5.10 & 2,850 & 2.94 & 417 & 2.71 & 270 \\
\hline $\begin{array}{l}11 \\
\mathbf{N}\end{array}$ & 2.14 & 57 & $\begin{array}{l}4.96 \\
4.82\end{array}$ & $\begin{array}{l}2,610 \\
2,380\end{array}$ & $\begin{array}{l}6.70 \\
6.79\end{array}$ & $\begin{array}{l}6,370 \\
6,590\end{array}$ & $\begin{array}{l}5.00 \\
4.90\end{array}$ & $\begin{array}{l}2,670 \\
2,510\end{array}$ & 2.85 & 358 & $\begin{array}{l}2.67 \\
2.66\end{array}$ & $\begin{array}{l}248 \\
242\end{array}$ \\
\hline 1 & & & 4.81 & 2,370 & 6.61 & 6,1 & 4.79 & 2,340 & & & 2.64 & 23 \\
\hline 2 & 2.18 & 64 & 4.86 & 2,450 & 6.54 & & 4. & & 2.78 & 313 & 2.64 & \\
\hline 3 & & & 4.96 & 2,610 & 6. & & t. & & & & & 226 \\
\hline 4 & 2.21 & 70 & 4.94 & 2,570 & 6.35 & 5,530 & 4.43 & 1,820 & 2.73 & 282 & 2.63 & 226 \\
\hline 5 & $2 . \overline{2}$ & 76 & $\begin{array}{l}4.82 \\
4.78\end{array}$ & $\begin{array}{l}2,380 \\
2,320\end{array}$ & $\begin{array}{l}6.19 \\
6.15\end{array}$ & $\begin{array}{l}5,150 \\
5,050\end{array}$ & $\begin{array}{l}4.31 \\
4.20\end{array}$ & $\begin{array}{l}1,660 \\
1,530\end{array}$ & 2.69 & 258 & $\begin{array}{l}2.64 \\
2.64\end{array}$ & $\begin{array}{l}231 \\
231\end{array}$ \\
\hline & & & 4.89 & 2,490 & 6.02 & 4. & 4.0 & 1,400 & & & 2.65 & 23 \\
\hline$\therefore$ & 2.23 & 76 & 4.91 & 2,530 & 5.91 & 4,490 & 3.98 & 1,280 & 2.65 & 236 & 2.65 & 23 \\
\hline $\mathbf{9}$ & 221 & $70^{-}$ & 5.1 & 2,940 & $\begin{array}{r}5.88 \\
5.84\end{array}$ & $\begin{array}{l}4,430 \\
4,340\end{array}$ & $\begin{array}{l}3.88 \\
3.78\end{array}$ & 1,180 & 64 & 231 & 2.66 & 242 \\
\hline 11 & & & 5.71 & 4,050 & $\begin{array}{r}3.84 \\
5.83\end{array}$ & 4,320 & 3.6 & $\begin{array}{r}1,080 \\
987\end{array}$ & 2.04 & & 2.68 & $\begin{array}{l}250 \\
253\end{array}$ \\
\hline 12 & 2.21 & 70 & 5.79 & 4,230 & 5.78 & 4,210 & 3.5 & 906 & 2.64 & 231 & 2.69 & 258 \\
\hline
\end{tabular}

SUPPLEMENTAL RECORDS.-Aug. 13, 11:15 a.m., gage height, 4.99 feet, discharge, 2,650 second-feet; 2:30 p.m., gage height, 5.02 feet, discharge, 2,710 second-feet. Aug. 14, 9:15 a.m., gage height, 7.15 feet, discharge, 7,520 second-feet.

ENOREF RIVER NEAR ENOREE, S. C.

Location.-Lat. $34^{\circ} 36^{\prime}$, long. $81^{\circ} 54^{\prime}$, half a mile upstream from Yarboroughs Bridge, three-quarters of a mile upstream from Warrior Creek, and 4 miles southeast of Enoree, Spartanburg County. Datum of gage is 448.07 feet above mean sea level, datum of 1929, supplementary adjustment of 1936.

DRAINAGE AREA.-307 square miles.

GAGE-HEIGHT RECORD.-Water-stage recorder graph.

DISCHARGE RECORD.-Stage-discharge relation defined by current-meter measurements up to 17,000 second-feet and extended above by logarithmic plotting.

Maxima.-1940: Discharge, 12,800 second-feet $12 \mathrm{~m}$. Aug. 14 (gage height, 6.86 feet).

1929-39: Discharge, 30,000 second-feet Oct. 2, 1929 (gage height, 10.5 feet, from floodmark). 
REMARKs.-Flood discharge not affected by artificial storage or diversion. Flow regulated by power plants above station during low and medium stages.

Mean discharge, in second-feet, 1940

\begin{tabular}{r|r|r||r|r|r||r|r|r||r|r|r}
\hline Day & \multicolumn{1}{|c|}{ Aug. } & \multicolumn{1}{|c|}{ Sept. } & Day & \multicolumn{1}{c|}{ Aug. } & Sept. & Day & Aug. & Sept. & Day & Aug. & Sept. \\
\hline 1 & 64 & 303 & 9 & 106 & 133 & 17 & 554 & 105 & 25 & 206 & 97 \\
2 & 71 & 215 & 10 & 64 & 133 & 18 & 380 & 100 & 26 & 164 & 93 \\
3 & 52 & 154 & 11 & 90 & 132 & 19 & 330 & 108 & 27 & 260 & 85 \\
4 & 50 & 154 & 12 & 231 & 124 & 20 & 276 & 99 & 28 & 122 & 107 \\
5 & 71 & 148 & 13 & 4,100 & 88 & 21 & 224 & 127 & 29 & 122 & 35 \\
6 & 219 & 148 & 14 & 10,800 & 128 & 22 & 215 & 102 & 30 & 362 & 62 \\
7 & 124 & 156 & 15 & 5,820 & 79 & 23 & 215 & 83 & 31 & 421 & $-\ldots$ \\
8 & 235 & 128 & 16 & 1,160 & 108 & 24 & 200 & 92 & & & \\
\hline
\end{tabular}

Gage height, in feet, and discharge, in second-feet, at indicated time, 1940

\begin{tabular}{|c|c|c|c|c|c|c|c|c|c|c|}
\hline \multirow{2}{*}{ Hour } & \multicolumn{2}{|c|}{ Aug. 12} & \multicolumn{2}{|c|}{ Aug. 13} & \multicolumn{2}{|c|}{ Aug. 14} & \multicolumn{2}{|c|}{ Aug. 15} & \multicolumn{2}{|c|}{ Aug. 16} \\
\hline & $\begin{array}{l}\text { Gage } \\
\text { height }\end{array}$ & $\begin{array}{l}\text { Dis- } \\
\text { charge }\end{array}$ & $\begin{array}{l}\text { Gage } \\
\text { height }\end{array}$ & $\begin{array}{l}\text { Dis- } \\
\text { charge }\end{array}$ & $\begin{array}{l}\text { Gage } \\
\text { height }\end{array}$ & $\begin{array}{c}\text { Dis- } \\
\text { charge }\end{array}$ & $\begin{array}{c}\text { Gage } \\
\text { height }\end{array}$ & $\begin{array}{l}\text { Dis- } \\
\text { charge }\end{array}$ & $\begin{array}{c}\text { Gage } \\
\text { height }\end{array}$ & $\begin{array}{c}\text { Dis- } \\
\text { charge }\end{array}$ \\
\hline $\begin{array}{r}1 \\
2 \\
3 \\
4 \\
5 \\
6\end{array}$ & $\begin{array}{l}1.81 \\
1.80 \\
1.77 \\
1.75 \\
1.75 \\
1.74\end{array}$ & $\begin{array}{l}95 \\
91 \\
82 \\
76 \\
76 \\
74\end{array}$ & $\begin{array}{l}2.58 \\
2.64 \\
2.72 \\
2.83 \\
2.91 \\
3.09\end{array}$ & $\begin{array}{r}738 \\
818 \\
931 \\
1,100 \\
1,230 \\
1,530\end{array}$ & $\begin{array}{l}5.75 \\
5.89 \\
5.73 \\
5.86 \\
5.99 \\
6.12\end{array}$ & $\begin{array}{l}8,600 \\
9,100 \\
8,540 \\
9,000 \\
9,460 \\
9,940\end{array}$ & $\begin{array}{l}5.99 \\
5.91 \\
5.77 \\
5.67 \\
5.58 \\
5.50\end{array}$ & $\begin{array}{l}9,460 \\
9,180 \\
8,680 \\
8,320 \\
8,010 \\
7,740\end{array}$ & $\begin{array}{r}\overline{3.37} \\
-\overline{3} . \overline{18} \\
\overline{3.00}\end{array}$ & $\begin{array}{c}2,100 \\
1,750 \\
1,430\end{array}$ \\
\hline $\begin{array}{r}7 \\
8 \\
9 \\
10 \\
11 \\
\mathbf{N}\end{array}$ & $\begin{array}{l}1.74 \\
1.74 \\
1.74 \\
1.75 \\
1.76 \\
1.79\end{array}$ & $\begin{array}{l}74 \\
74 \\
74 \\
76 \\
79 \\
88\end{array}$ & $\begin{array}{l}3.55 \\
3.88 \\
4.14 \\
4.26 \\
4.31 \\
4.45\end{array}$ & $\begin{array}{l}2,400 \\
3,110 \\
3,730 \\
4,040 \\
4,170 \\
4,540\end{array}$ & $\begin{array}{l}6.24 \\
6.42 \\
6.52 \\
6.65 \\
6.82 \\
6.86\end{array}$ & $\begin{array}{l}10,400 \\
11,100 \\
11,500 \\
12,000 \\
12,700 \\
12,800\end{array}$ & $\begin{array}{l}5.39 \\
5.30 \\
5.19 \\
5.08 \\
4.94 \\
4.86\end{array}$ & $\begin{array}{l}7,370 \\
7,070 \\
6,720 \\
6,370 \\
5,940 \\
5,700\end{array}$ & $\mid \begin{array}{r}-\overline{2}, \overline{86} \\
-\overline{2.7 \overline{7}} \\
2 . \overline{7} \overline{0}\end{array}$ & $\begin{array}{r}1,190 \\
1,050 \\
946\end{array}$ \\
\hline $\begin{array}{l}1 \\
2 \\
3 \\
4 \\
5 \\
6\end{array}$ & $\begin{array}{l}1.90 \\
2.04 \\
2.08 \\
2.07 \\
2.05 \\
2.07\end{array}$ & $\begin{array}{l}132 \\
217 \\
244 \\
237 \\
224 \\
237\end{array}$ & $\begin{array}{l}4.54 \\
4.63 \\
4.55 \\
4.65 \\
4.66 \\
4.96\end{array}$ & $\begin{array}{l}4,780 \\
5,030 \\
4,810 \\
5,090 \\
5,120 \\
6,000\end{array}$ & $\begin{array}{l}6.78 \\
6.69 \\
6.71 \\
6.68 \\
6.53 \\
6.52\end{array}$ & $\begin{array}{l}12,500 \\
12,100 \\
12,200 \\
12,100 \\
11,500 \\
11,500\end{array}$ & $\begin{array}{l}4.75 \\
4.65 \\
4.51 \\
4.41 \\
4.30 \\
4.18\end{array}$ & $\begin{array}{l}5,380 \\
5,090 \\
4,700 \\
4,430 \\
4,140 \\
3,830\end{array}$ & $\mid \begin{array}{c}-\overline{2} . \overline{65} \\
-\overline{2} . \overline{59} \\
-\overline{2} . \overline{58}\end{array}$ & $\begin{array}{c}\mathbf{8} \overline{3} \\
\overline{7} \overline{9} \overline{1} \\
\overline{7} \overline{7} \overline{7}\end{array}$ \\
\hline $\begin{array}{r}7 \\
8 \\
9 \\
10 \\
11 \\
12 \\
\end{array}$ & $\begin{array}{l}2.19 \\
2.35 \\
2.46 \\
2.53 \\
2.56 \\
2.56\end{array}$ & $\begin{array}{l}333 \\
489 \\
613 \\
700 \\
738 \\
738 \\
\end{array}$ & $\begin{array}{l}4.99 \\
5.28 \\
5.26 \\
5.31 \\
5.53 \\
5.55 \\
\end{array}$ & $\begin{array}{l}6,090 \\
7,010 \\
6,940 \\
7,100 \\
7,840 \\
7,910 \\
\end{array}$ & $\begin{array}{l}6.52 \\
6.43 \\
6.28 \\
6.25 \\
6.15 \\
6.09 \\
\end{array}$ & $\begin{array}{r}11,500 \\
11,100 \\
10,500 \\
10,400 \\
10,000 \\
9,820\end{array}$ & $\begin{array}{l}4.06 \\
3.97 \\
3.86 \\
3.76 \\
3.66 \\
3.56\end{array}$ & $\begin{array}{l}3,530 \\
3,320 \\
3,070 \\
2,840 \\
2,630 \\
2,420\end{array}$ & $\begin{array}{r}-\overline{2.56} \\
-2.54 \\
2 . \overline{53}\end{array}$ & $\begin{array}{l}750 \\
725 \\
712\end{array}$ \\
\hline
\end{tabular}

SALUDA RIVER NEAR PELZER, S. C.

LOCATION.-Lat. $34^{\circ} 40^{\prime}$, long. $82^{\circ} 28^{\prime}$, half a mile downstream from Hurricane Creek and 2 miles north of Pelzer, Anderson County. Datum of gage is 727.75 feet above mean sea level (from partly adjusted network of levels).

Drainage AREA. - 405 square miles.

GAGE-HEIGHT RECORD.-Water-stage recorder graph.

DISCHARGE RECORD.—Stage-discharge relation defined by current-meter measurements up to 12,000 second-feet.

Maxima.-1940: Discharge, 9,920 second-feet 6 a.m. Aug. 14 (gage height, 8.31 feet).

1929-39: Discharge, 13,300 second-feet Apr. 7, 1936 (gage height, 10.26 feet). REMARKS.-Flood runoff not affected by artificial storage or diversion. Diurnal fluctuation caused by power plants above station. 
Mean discharge, in second-feet, 1940

\begin{tabular}{|c|c|c|c|c|c|c|c|c|c|c|c|}
\hline Day & Aug. & Sept. & Day & Aug. & Sept. & Day & Aug. & Sept. & Day & Aug. & Sept. \\
\hline $\begin{array}{l}1 \\
2 \\
3 \\
4 \\
5 \\
6 \\
7 \\
8\end{array}$ & $\begin{array}{l}218 \\
208 \\
214 \\
201 \\
230 \\
189 \\
215 \\
216\end{array}$ & $\begin{array}{r}2,320 \\
1,470 \\
1,020 \\
578 \\
605 \\
568 \\
558 \\
458\end{array}$ & $\begin{array}{r}9 \\
10 \\
11 \\
12 \\
13 \\
14 \\
15 \\
16\end{array}$ & $\begin{array}{r}202 \\
208 \\
216 \\
330 \\
3,660 \\
8,490 \\
6,250 \\
2,680\end{array}$ & $\begin{array}{l}469 \\
473 \\
472 \\
312 \\
382 \\
391 \\
262 \\
374\end{array}$ & $\begin{array}{l}17 \\
18 \\
19 \\
20 \\
21 \\
22 \\
23 \\
24\end{array}$ & $\begin{array}{r}1,250 \\
1,090 \\
720 \\
641 \\
537 \\
514 \\
409 \\
411\end{array}$ & $\begin{array}{l}372 \\
352 \\
314 \\
316 \\
344 \\
.241 \\
320 \\
312\end{array}$ & $\begin{array}{l}25 \\
26 \\
27 \\
28 \\
29 \\
30 \\
31\end{array}$ & $\begin{array}{r}404 \\
411 \\
306 \\
368 \\
426 \\
938 \\
2,460\end{array}$ & $\begin{array}{l}284 \\
292 \\
300 \\
332 \\
294 \\
267\end{array}$ \\
\hline \multicolumn{10}{|c|}{$\begin{array}{l}\text { Monthly mean discharge, in second-feet } \\
\text { Runoff, in inches }\end{array}$} & $\begin{array}{r}1,117 \\
3.18\end{array}$ & $\begin{array}{r}502 \\
1.38\end{array}$ \\
\hline
\end{tabular}

Gage height, in feet, and discharge, in second-feet, at indicated time, 1940

\begin{tabular}{|c|c|c|c|c|c|c|c|c|c|c|}
\hline \multirow{2}{*}{ Hour } & \multicolumn{2}{|c|}{ Aug. 12} & \multicolumn{2}{|c|}{ Aug. 13} & \multicolumn{2}{|c|}{ Aug. 14} & \multicolumn{2}{|c|}{ Aug. 15} & \multicolumn{2}{|c|}{ Aug. 16} \\
\hline & $\begin{array}{c}\text { Gage } \\
\text { height }\end{array}$ & $\begin{array}{l}\text { Dis- } \\
\text { charge }\end{array}$ & $\begin{array}{c}\text { Gage } \\
\text { height }\end{array}$ & $\begin{array}{c}\text { Dis- } \\
\text { charge }\end{array}$ & $\begin{array}{c}\text { Gage } \\
\text { height }\end{array}$ & $\begin{array}{l}\text { Dis- } \\
\text { charge }\end{array}$ & $\begin{array}{c}\text { Gage } \\
\text { height }\end{array}$ & $\begin{array}{l}\text { Dis- } \\
\text { charge }\end{array}$ & $\begin{array}{c}\text { Gage } \\
\text { height }\end{array}$ & $\begin{array}{l}\text { Dis- } \\
\text { charge }\end{array}$ \\
\hline $\begin{array}{l}1 \\
2 \\
3 \\
4 \\
5 \\
5 \\
6\end{array}$ & $\begin{array}{r}1.27 \\
1.14 \\
1.05 \\
1.00 \\
.99 \\
1.12\end{array}$ & $\begin{array}{r}152 \\
105 \\
78 \\
64 \\
62 \\
99\end{array}$ & $\begin{array}{l}2.10 \\
2.22 \\
2.35 \\
2.78 \\
3.05 \\
3.27\end{array}$ & $\begin{array}{r}637 \\
735 \\
851 \\
1,290 \\
1,620 \\
1,900\end{array}$ & $\begin{array}{l}7.78 \\
7.99 \\
8.15 \\
8.26 \\
8.30 \\
8.31\end{array}$ & $\begin{array}{l}9,020 \\
9,370 \\
9,640 \\
9,830 \\
9,900 \\
9,920\end{array}$ & $\begin{array}{l}6.50 \\
6.51 \\
6.50 \\
6.51 \\
6.52 \\
6.44\end{array}$ & $\begin{array}{l}6,840 \\
6,860 \\
6,840 \\
6,860 \\
6,870 \\
6,740\end{array}$ & \begin{tabular}{c}
$-\cdots$ \\
\hdashline$-\cdots$ \\
\hdashline-24
\end{tabular} & $\mid$\begin{tabular}{c}
- \\
$-\cdots$ \\
\hdashline \\
\hdashline, 250
\end{tabular} \\
\hline $\begin{array}{r}7 \\
8 \\
9 \\
10 \\
11 \\
\mathrm{~N}\end{array}$ & $\begin{array}{l}1.36 \\
1.81 \\
1.81 \\
1.78 \\
1.78 \\
1.71\end{array}$ & $\begin{array}{l}188 \\
430 \\
430 \\
411 \\
411 \\
367\end{array}$ & $\begin{array}{l}3.49 \\
3.69 \\
3.70 \\
3.87 \\
4.09 \\
4.40\end{array}$ & $\begin{array}{l}2,190 \\
2,460 \\
2,470 \\
2,710 \\
3,020 \\
3,490\end{array}$ & $\begin{array}{l}8.28 \\
8.22 \\
8.13 \\
7.98 \\
7.83 \\
7.61\end{array}$ & $\begin{array}{l}9,870 \\
9,760 \\
9,610 \\
9,360 \\
9,100 \\
8,730\end{array}$ & $\begin{array}{l}6.51 \\
6.55 \\
6.51 \\
6.52 \\
6.41 \\
6.34\end{array}$ & $\begin{array}{l}6,860 \\
6,920 \\
6,860 \\
6,870 \\
6,700 \\
6,580\end{array}$ & 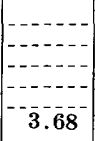 & $\mid$ \\
\hline $\begin{array}{l}1 \\
2 \\
3 \\
4 \\
5 \\
6\end{array}$ & $\begin{array}{l}1.72 \\
1.69 \\
1.61 \\
1.57 \\
1.66 \\
1.76\end{array}$ & $\begin{array}{l}373 \\
355 \\
310 \\
\mathbf{2 8 8} \\
\mathbf{3 3 8} \\
\mathbf{3 9 8}\end{array}$ & $\begin{array}{l}4.58 \\
4.90 \\
5.22 \\
5.10 \\
4.84 \\
4.95\end{array}$ & $\begin{array}{l}3,770 \\
4,280 \\
4,790 \\
4,600 \\
4,180 \\
4,360\end{array}$ & $\begin{array}{l}7.46 \\
7.19 \\
7.10 \\
7.06 \\
6.95 \\
6.79\end{array}$ & $\begin{array}{l}8,470 \\
8,010 \\
7,860 \\
7,790 \\
7,600 \\
7,330\end{array}$ & $\begin{array}{l}6.37 \\
6.26 \\
6.09 \\
6.04 \\
5.95 \\
5.86\end{array}$ & $\begin{array}{l}6,630 \\
6,460 \\
6,180 \\
6.100 \\
5,960 \\
5,820\end{array}$ & \begin{tabular}{|l}
$-\cdots$ \\
\hdashline-1. \\
\hdashline$\overline{3} \mathbf{3 5}$
\end{tabular} & | \\
\hline $\begin{array}{r}7 \\
8 \\
9 \\
10 \\
11 \\
12\end{array}$ & $\begin{array}{l}1.78 \\
1.90 \\
1.98 \\
2.03 \\
2.10 \\
2.01\end{array}$ & $\begin{array}{l}411 \\
490 \\
547 \\
584 \\
637 \\
569 \\
\end{array}$ & $\begin{array}{l}5.44 \\
6.04 \\
6.56 \\
6.93 \\
7.27 \\
7.53\end{array}$ & $\begin{array}{l}\mathbf{5}, \mathbf{1 4 0} \\
6,100 \\
6,940 \\
7,570 \\
8,150 \\
8,590\end{array}$ & $\begin{array}{l}6.68 \\
6.67 \\
6.56 \\
6.55 \\
6.50 \\
6.44 \\
\end{array}$ & $\begin{array}{l}7,150 \\
7,130 \\
6,940 \\
6,920 \\
6,840 \\
6,740 \\
\end{array}$ & $\begin{array}{l}5.68 \\
5.56 \\
5.43 \\
5.31 \\
5.12 \\
4.99 \\
\end{array}$ & $\begin{array}{l}\mathbf{5}, 530 \\
5,340 \\
5,130 \\
4,940 \\
4,630 \\
4,420 \\
\end{array}$ & 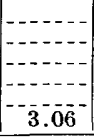 & 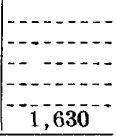 \\
\hline
\end{tabular}

SALUDA RIVER NEAR WARE SHOALS, S. C.

Location.-Lat. $34^{\circ} 23^{\prime}$, long. $82^{\circ} 14^{\prime}, 2$ miles southeast of Ware Shoals, Greenwood County, 21/2 miles downstream from Ware Shoals Dam, and 5 miles upstream from Turkey Creek.

Drainage ARea. - 569 square miles.

GAGE-HEIGHT RECORD.-Water-stage recorder graph.

DISCHARGE RECORD.- Stage-discharge relation defined by current-meter measurements up to 4,200 second-feet and extended to crest gage height on basis of determination of peak flow over Ware Shoals Dam.

Maxima.-1940: Discharge, 20,600 second-feet 2:30 p.m. Aug. 13 (gage height, 20.48 feet).

1939: Discharge, 10,500 second-feet Aug. 18 (gage height, 14.29 feet).

Remarks.-Flood discharge not affected by artificial storage or diversion. Diurnal fluctuation caused by power plant above station. 
SANTEE RIVER BASIN

Mean discharge, in second-feet, 1940

\begin{tabular}{|c|c|c|c|c|c|c|c|c|c|c|c|}
\hline Day & Aug. & Sept. & Day & Aug. & Sept. & Day & Aug. & Sept. & Day & Aug. & Sept. \\
\hline $\begin{array}{l}1 \\
2 \\
3 \\
4 \\
5 \\
6 \\
7 \\
8\end{array}$ & $\begin{array}{l}152 \\
159 \\
293 \\
164 \\
383 \\
359 \\
154 \\
393\end{array}$ & $\begin{array}{r}3,120 \\
2,420 \\
1,590 \\
1,140 \\
722 \\
848 \\
668 \\
390\end{array}$ & $\begin{array}{l}99 \\
10 \\
11 \\
12 \\
13 \\
14 \\
15 \\
16\end{array}$ & $\begin{array}{r}447 \\
351 \\
156 \\
1,340 \\
12,600 \\
14,400 \\
9,210 \\
5,220\end{array}$ & $\begin{array}{l}784 \\
805 \\
649 \\
672 \\
\mathbf{5 3 5} \\
\mathbf{3 7 9} \\
\mathbf{3 4 7} \\
\mathbf{5 4 5}\end{array}$ & $\begin{array}{l}17 \\
18 \\
19 \\
20 \\
21 \\
22 \\
23 \\
24\end{array}$ & $\begin{array}{r}2,080 \\
1,610 \\
1,830 \\
1,010 \\
902 \\
805 \\
1,120 \\
741\end{array}$ & $\begin{array}{l}509 \\
323 \\
430 \\
706 \\
447 \\
330 \\
559 \\
515\end{array}$ & $\begin{array}{l}25 \\
26 \\
27 \\
28 \\
29 \\
30 \\
31\end{array}$ & $\begin{array}{r}591 \\
746 \\
632 \\
642 \\
816 \\
1,050 \\
1,340\end{array}$ & $\begin{array}{l}240 \\
250 \\
493 \\
422 \\
230 \\
462\end{array}$ \\
\hline
\end{tabular}

Gage height, in feet, and discharge, in second-feet, at indicated time, 1940

\begin{tabular}{|c|c|c|c|c|c|c|c|c|c|c|}
\hline \multirow{2}{*}{ Jour } & \multicolumn{2}{|c|}{ Aug. 12} & \multicolumn{2}{|c|}{ Aug. 13} & \multicolumn{2}{|c|}{ Aug. 14} & \multicolumn{2}{|c|}{ Aug. 15} & \multicolumn{2}{|c|}{ Aug. 16} \\
\hline & $\begin{array}{c}\text { Gage } \\
\text { height }\end{array}$ & $\begin{array}{l}\text { Dis- } \\
\text { charge }\end{array}$ & $\begin{array}{c}\text { Gage } \\
\text { height }\end{array}$ & $\begin{array}{l}\text { Dis- } \\
\text { charge }\end{array}$ & $\begin{array}{c}\text { Gage } \\
\text { height }\end{array}$ & $\begin{array}{l}\text { Dis- } \\
\text { charge }\end{array}$ & $\begin{array}{c}\text { Gage } \\
\text { height }\end{array}$ & $\begin{array}{c}\text { Dis- } \\
\text { charge }\end{array}$ & $\begin{array}{c}\text { Gage } \\
\text { height }\end{array}$ & $\begin{array}{l}\text { Dis- } \\
\text { charge }\end{array}$ \\
\hline \multirow{4}{*}{$\begin{array}{l}1 \\
2 \\
3 \\
4 \\
5 \\
6\end{array}$} & \multirow{4}{*}{$\begin{array}{l}0.99 \\
1.05 \\
1.04 \\
1.03 \\
1.08 \\
1.45\end{array}$} & \multirow{4}{*}{$\begin{array}{l}176 \\
196 \\
193 \\
189 \\
206 \\
352\end{array}$} & \multirow{4}{*}{$\begin{array}{l}3.44 \\
3.24 \\
4.43 \\
5.98 \\
9.28 \\
9.88\end{array}$} & \multirow{4}{*}{$\begin{array}{l}1,360 \\
1,250 \\
1,900 \\
2,750 \\
4,990 \\
5,550\end{array}$} & & & & & & \\
\hline & & & & & 16.80 & 14,000 & 14.95 & 11,400 & 11.80 & 7,550 \\
\hline & & & & & 16.75 & 13,900 & 14.15 & $10, \overline{300}$ & $1 \overline{17}$ & 6,870 \\
\hline & & & & & 16.91 & 14,200 & $\mathbf{1 3} . \mathbf{4 8}$ & 9,480 & 10.60 & 6,270 \\
\hline \multirow{4}{*}{$\begin{array}{r}7 \\
8 \\
9 \\
10 \\
11 \\
\text { N }\end{array}$} & \multirow{4}{*}{$\begin{array}{l}2.32 \\
3.65 \\
3.28 \\
3.36 \\
3.42 \\
3.27\end{array}$} & \multirow{4}{*}{$\begin{array}{r}760 \\
1,470 \\
1,270 \\
1,310 \\
1,350 \\
1,260\end{array}$} & \multirow{4}{*}{$\begin{array}{l}11.23 \\
13.18 \\
15.30 \\
17.48 \\
18.92 \\
19.78\end{array}$} & \multirow{4}{*}{$\begin{array}{r}6,930 \\
9,120 \\
11,800 \\
15,100 \\
17,600 \\
19,200\end{array}$} & & & & & & \\
\hline & & & & & 17.14 & 14,600 & 13.11 & 9,030 & 9.78 & 5,460 \\
\hline & & & & & 17.30 & $14,800^{-}$ & 12.97 & 8,860 & $9 . \overline{8}$ & 5,550 \\
\hline & & & & & 17.50 & 15,100 & $12 . \overline{98}$ & 8,880 & 9.77 & 5,450 \\
\hline \multirow{4}{*}{$\begin{array}{l}1 \\
2 \\
3 \\
4 \\
5 \\
6\end{array}$} & \multirow{4}{*}{$\begin{array}{l}3.13 \\
4.41 \\
5.11 \\
5.42 \\
5.50 \\
5.48\end{array}$} & \multirow{4}{*}{$\begin{array}{l}1,190 \\
1,890 \\
2.280 \\
2,450 \\
2,490 \\
2,480\end{array}$} & \multirow{4}{*}{$\begin{array}{l}20.21 \\
20.44 \\
20.46 \\
20.20 \\
19.70 \\
19.02\end{array}$} & \multirow{4}{*}{$\begin{array}{l}20,000 \\
20,500 \\
20,500 \\
20,000 \\
19,000 \\
17,800\end{array}$} & & & & & & 1 090 \\
\hline & & & & & 1 & 00 & 12.90 & 80 & 9.2 & 4, \\
\hline & & & & & 17.46 & 15,100 & 12.77 & 8,620 & 8.50 & 4,350 \\
\hline & & & & & 17.25 & 14,700 & $\overline{12.66}$ & 8,500 & $\overline{7} . \overline{7}$ & 3,810 \\
\hline & \multirow{4}{*}{$\begin{array}{l}5.36 \\
4.98 \\
4.38 \\
4.03 \\
4.00 \\
3.79\end{array}$} & \multirow{4}{*}{$\begin{array}{l}2,410 \\
2,200 \\
1,870 \\
1,680 \\
1,660 \\
1,550\end{array}$} & \multirow{4}{*}{$\begin{array}{l}18.48 \\
18.15 \\
18.00 \\
17.83 \\
17.48 \\
17.15\end{array}$} & \multirow{4}{*}{$\begin{array}{l}16,800 \\
16,200 \\
16,000 \\
15,700 \\
15,100 \\
14,600\end{array}$} & & & & & & \\
\hline & & & & & 16.86 & 14,100 & 12.54 & 8,360 & 7.58 & 3,720 \\
\hline & & & & & 16.28 & 13,200 & 12.40 & 8,210 & 6.73 & 3,200 \\
\hline & & & & & 15.65 & 12,300 & $1 \overline{15}$ & 7,940 & 6.40 & 3,000 \\
\hline
\end{tabular}

SuPPLEMENTAL RECORD.-Aug. 13, 2:30 p.m., gage height, 20.48 feet; discharge, 20,600 second-feet.

LAKE GREENWOOD NEAR CHAPPELLS, S. C.

Location.-Lat. $34^{\circ} 10^{\prime}$, long. $81^{\circ} 54^{\prime}$, at dam on Saluda River 0.7 mile upstream from Wilson Creek and 2.4 miles west of Chappells, Newberry County. Datum of gage is 400.00 feet above mean sea level, datum of 1929 .

Drainage AREA.—1,150 square miles (1943 revision).

GAGE-HEIGHT RECORD.-Water-stage recorder graph. Gage readings have been reduced to elevations above mean sea level.

Maxima.-1940: Elevation, 441.09 feet 2-8 a.m. Aug. 20 (eontents, about 8,150,000,000 eubic feet).

RemarKs.-Usable capacity, about 7,640,000,000 cubic feet between elevations 420.0 feet (draw-down limit) and $\mathbf{4 4 0 . 0}$ feet (normal reservoir level and top of spillway gates). Figures given herein represent usable contents.

$804331-49-19$ 
264 FLOODS OF AUGUST 1940 IN THE SOUTHEASTERN STATES

Daily mean elevation, in feet, and contents, in billions of cubic feet, 1940

\begin{tabular}{|c|c|c|c|c|c|c|c|c|c|}
\hline \multirow{2}{*}{ Day } & \multicolumn{2}{|c|}{ August } & \multicolumn{2}{|c|}{ September } & \multirow{2}{*}{ Day } & \multicolumn{2}{|c|}{ August } & \multicolumn{2}{|c|}{ September } \\
\hline & Elevation & Contents & Elevation & Contents & & Elevation & Contents & Elevation & Contents \\
\hline $\begin{array}{l}1 \\
2 \\
3 \\
4 \\
5\end{array}$ & $\begin{array}{l}430.84 \\
430.86 \\
430.90 \\
430.91 \\
430.97\end{array}$ & $\begin{array}{l}3.64 \\
3.64 \\
3.66 \\
3.66 \\
3.69\end{array}$ & $\begin{array}{l}440.86 \\
440.98 \\
440.67 \\
440.59 \\
440.59\end{array}$ & $\begin{array}{l}8.03 \\
8.09 \\
7.95 \\
7.92 \\
7.92\end{array}$ & $\begin{array}{l}16 \\
17 \\
18 \\
19 \\
20\end{array}$ & $\begin{array}{l}439.72 \\
440.50 \\
440.82 \\
440.99 \\
441.07\end{array}$ & $\begin{array}{l}7.51 \\
7.87 \\
8.02 \\
8.10 \\
8.14\end{array}$ & $\begin{array}{l}440.20 \\
440.19 \\
440.13 \\
440.04 \\
440.01\end{array}$ & $\begin{array}{l}7.73 \\
7.73 \\
7.70 \\
7.66 \\
7.64\end{array}$ \\
\hline $\begin{array}{r}6 \\
7 \\
8 \\
9 \\
10\end{array}$ & $\begin{array}{l}431.10 \\
431.19 \\
431.29 \\
431.39 \\
431.54\end{array}$ & $\begin{array}{l}3.74 \\
3.78 \\
3.82 \\
3.86 \\
3.91\end{array}$ & $\begin{array}{l}440.54 \\
440.41 \\
440.38 \\
440.35 \\
440.40\end{array}$ & $\begin{array}{l}7.89 \\
7.82 \\
7.81 \\
7.80 \\
7.82\end{array}$ & $\begin{array}{l}21 \\
22 \\
23 \\
24 \\
25\end{array}$ & $\begin{array}{l}441.01 \\
440.97 \\
440.92 \\
440.90 \\
440.87\end{array}$ & $\begin{array}{l}8.10 \\
8.08 \\
8.06 \\
8.05 \\
8.04\end{array}$ & $\begin{array}{l}440.01 \\
440.00 \\
439.97 \\
439.88 \\
439.75\end{array}$ & $\begin{array}{l}7.64 \\
7.64 \\
7.62 \\
7.58 \\
7.52\end{array}$ \\
\hline $\begin{array}{l}11 \\
12 \\
13 \\
14 \\
15\end{array}$ & $\begin{array}{l}431.60 \\
432.54 \\
436.40 \\
439.08 \\
439.34\end{array}$ & $\begin{array}{l}3.93 \\
4.32 \\
6.00 \\
7.22 \\
7.34\end{array}$ & $\begin{array}{l}440.39 \\
440.37 \\
440.33 \\
440.27 \\
440.23\end{array}$ & $\begin{array}{l}7.82 \\
7.81 \\
7.79 \\
7.76 \\
7.74\end{array}$ & $\begin{array}{l}26 \\
27 \\
28 \\
29 \\
30 \\
31 \\
\end{array}$ & $\begin{array}{l}440.83 \\
440.78 \\
440.70 \\
440.63 \\
440.70 \\
440.75 \\
\end{array}$ & $\begin{array}{l}8.02 \\
8.00 \\
7.96 \\
7.93 \\
7.96 \\
7.98 \\
\end{array}$ & $\begin{array}{r}439.58 \\
439.42 \\
439.35 \\
439.32 \\
439.23 \\
\end{array}$ & $\begin{array}{r}7.45 \\
7.37 \\
7.34 \\
7.33 \\
7.28 \\
- \\
\end{array}$ \\
\hline & & & & & & & & August & $\begin{array}{c}\text { Sep- } \\
\text { tember }\end{array}$ \\
\hline \multicolumn{8}{|c|}{ Change in contents, equivalent, in second-feet } & $+1,620$ & -278 \\
\hline
\end{tabular}

Elevation, in feet, and contents, in billions of cubic feet, at indicated time, 1940

\begin{tabular}{|c|c|c|c|c|c|c|c|c|c|c|}
\hline \multirow{2}{*}{ Hour } & \multicolumn{2}{|c|}{ Aug. 12} & \multicolumn{2}{|c|}{ Aug. 13} & \multicolumn{2}{|c|}{ Aug. 14} & \multicolumn{2}{|c|}{ Aug. 15} & \multicolumn{2}{|c|}{ Aug. 16} \\
\hline & $\begin{array}{c}\text { Eleva- } \\
\text { tion }\end{array}$ & $\begin{array}{l}\text { Con- } \\
\text { tents }\end{array}$ & $\begin{array}{c}\text { Eleva- } \\
\text { tion }\end{array}$ & $\begin{array}{l}\text { Con- } \\
\text { tents }\end{array}$ & $\begin{array}{c}\text { Eleva- } \\
\text { tion }\end{array}$ & $\begin{array}{l}\text { Con- } \\
\text { tents }\end{array}$ & $\begin{array}{c}\text { Eleva- } \\
\text { tion }\end{array}$ & $\begin{array}{l}\text { Con- } \\
\text { tents }\end{array}$ & $\begin{array}{c}\text { Eleva- } \\
\text { tion }\end{array}$ & $\begin{array}{l}\text { Con- } \\
\text { tents }\end{array}$ \\
\hline 2 & & & 433.90 & 4.90 & $\ldots$ & - & - - - & $-\ldots$ & $\ldots$ & $--\cdots-$ \\
\hline 4 & 431.64 & 3.95 & 434.22 & 5.04 & & & & & & \\
\hline 6 & & & 434.99 & 5.38 & 439.24 & $\overline{7} . \overline{2} 9$ & 439.64 & 7.48 & 439.42 & 7.37 \\
\hline 8 & $432: 23$ & 4.18 & 435.52 & 5.61 & -....... & ------- & 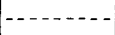 & $\ldots \ldots$ & $-\cdots-\cdots-\cdots$ & $\ldots-\cdots$ \\
\hline$\frac{10}{\mathrm{~N}}$ & $4 \overline{3} . \overline{3}$ & $-\overline{4.35}$ & $\begin{array}{l}435.98 \\
436.40\end{array}$ & $\begin{array}{l}5.81 \\
6.00\end{array}$ & $43 \overline{8} . \overline{9}$ & $-\overline{7.13}$ & 439.42 & $-\overline{7.37}$ & $-\overline{439} \overline{7} \overline{8}$ & $\overline{7.54}$ \\
\hline 2 & $--\overline{439} \overline{9} \overline{1}$ & 47 & 436.88 & 6.21 & $-\cdots-\cdots$ & & $-\cdots---\cdots$ & & $\ldots$ & -- \\
\hline $\begin{array}{l}4 \\
6\end{array}$ & $\begin{array}{c}432.91 \\
-\end{array}$ & $\begin{array}{l}4.47 \\
-. .--\end{array}$ & $\begin{array}{l}437.28 \\
437.86\end{array}$ & $\begin{array}{l}6.39 \\
6.66\end{array}$ & $-\overline{438} . \overline{86}$ & $-\overline{7} \cdot \overline{1} \overline{1}$ & $4 \overline{\mathbf{3}} . \overline{\mathbf{0}}$ & $-\overline{7.20}$ & 440.06 & $-\overline{7 .} . \overline{67}$ \\
\hline 8 & 433.22 & 4.61 & 438.44 & 6.92 & $\ldots$ &.---1 & 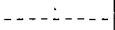 & $-\ldots-.-1$ & - & $-\ldots .-$ \\
\hline $\begin{array}{l}10 \\
12\end{array}$ & $\left|--\overline{43} \overline{3} \cdot \overline{6} \overline{8}^{-}\right|$ & $--\overline{4.80}$ & $\begin{array}{l}438.89 \\
439.10\end{array}$ & $\begin{array}{l}7.13 \\
7.23\end{array}$ & $4 \overline{39.56}$ & $-\overline{7.44}$ & $-4 \overline{3} \overline{9} \overline{4}$ & $|-\overline{7.15}|$ & $--\overline{4} \overline{0} . \overline{2} \overline{6}-$ & $-\overline{7.7} \overline{6}$ \\
\hline
\end{tabular}

SALUDA RIVER AT CHAPPEMLS, S. C.

Location.-Lat. $34^{\circ} 11^{\prime}$, long. $81^{\circ} 52$, at bridge on State Highway 39 , at Chappells, Newberry County, 7 miles downstream from Lake Greenwood Dam, and 81/4 miles upstream from Little River. Datum of gage is 363.89 feet above mean sea level, datum of 1929, supplementary adjustment of 1936 .

Drainage area.-1,350 square miles; 1,150 square miles affected by storage in Lake Greenwood since May 1940 (1943 revision).

GAGE-HEIGHT RECORD.-Water-stage recorder graph.

DISCHARGE RECORD.-Stage-diseharge relation defined by current-meter measurements up to 27,000 second-feet and extended to crest gage height on basis of velocityarea studies.

Maxima.-1940: Diseharge, 49,700 second-feet 6 p.m. Ang. 14 (gage height, 28.66 feet).

1927-39: Discharge, 63,700 second-feet Oct. 2, 1929 (gage height 31.5 feet). 1905-27: Stage known, 35.7 feet (present datum) Aug. 26, 1908, from reeords of United States Weather Bureau (discharge not determined).

REMARKs.-Flood discharge affected by storage in Lake Greenwood. For information on storage see records for Lake Greenwood near Chappells, S. C. 
SANTEE RIVER BASIN .

Mean discharge, in second-feet, 1940

\begin{tabular}{|c|c|c|c|c|c|c|c|c|c|c|c|}
\hline Day & Aug. & Sept. & Day & Aug. & Sept. & Day & Aug. & Sept. & Day & Aug. & Sept. \\
\hline $\begin{array}{l}1 \\
2 \\
3 \\
4 \\
5 \\
6 \\
6 \\
7 \\
8\end{array}$ & $\begin{array}{r}114 \\
32 \\
92 \\
88 \\
80 \\
80 \\
93 \\
88\end{array}$ & $\begin{array}{r}1,850 \\
2,640 \\
4,050 \\
1,120 \\
1,000 \\
1,480 \\
1,540 \\
564 .\end{array}$ & $\begin{array}{r}9 \\
10 \\
11 \\
12 \\
13 \\
14 \\
15 \\
16\end{array}$ & $\begin{array}{r}86 \\
85 \\
73 \\
1,270 \\
8,650 \\
43,200 \\
29,000 \\
10,300\end{array}$ & $\begin{array}{l}719 \\
864 \\
898 \\
864 \\
898 \\
661 \\
486 \\
671\end{array}$ & $\begin{array}{l}17 \\
18 \\
19 \\
20 \\
21 \\
22 \\
23 \\
24\end{array}$ & $\begin{array}{r}684 \\
898 \\
1,100 \\
1,300 \\
1,260 \\
1,180 \\
1,180 \\
966\end{array}$ & $\begin{array}{r}832 \\
832 \\
832 \\
898 \\
663 \\
400 \\
857 \\
1,180\end{array}$ & $\begin{array}{l}25 \\
26 \\
27 \\
28 \\
29 \\
30 \\
31\end{array}$ & $\begin{array}{r}800 \\
966 \\
1,040 \\
1,000 \\
1,000 \\
1,040 \\
1,900\end{array}$ & $\begin{array}{r}1,100 \\
1,080 \\
1,100 \\
810 \\
376 \\
1,160 \\
\end{array}$ \\
\hline \multicolumn{10}{|c|}{$\begin{array}{l}\text { Monthly mean discharge, in second-feet } \\
\text { Runoff, in inches }\end{array}$} & $\begin{array}{r}3,537 \\
3.02\end{array}$ & $\begin{array}{r}1,081 \\
0.89\end{array}$ \\
\hline
\end{tabular}

Gage height, in feet, and discharge, in second-feet, at indicated time, 1940

\begin{tabular}{|c|c|c|c|c|c|c|c|c|c|c|}
\hline \multirow{2}{*}{ Hour } & \multicolumn{2}{|c|}{ Aug. 12} & \multicolumn{2}{|c|}{ Aug. 13} & \multicolumn{2}{|c|}{ Aug. 14} & \multicolumn{2}{|c|}{ Aug. 15} & \multicolumn{2}{|c|}{ Aug. 16} \\
\hline & $\begin{array}{c}\text { Gage } \\
\text { height }\end{array}$ & $\begin{array}{c}\text { Dis- } \\
\text { charge }\end{array}$ & $\begin{array}{c}\text { Gage } \\
\text { height }\end{array}$ & $\begin{array}{c}\text { Dis- } \\
\text { charge }\end{array}$ & $\begin{array}{c}\text { Gage } \\
\text { height }\end{array}$ & $\begin{array}{c}\text { Dis- } \\
\text { charge }\end{array}$ & $\begin{array}{c}\text { Gage } \\
\text { height }\end{array}$ & $\begin{array}{c}\text { Dis- } \\
\text { charge }\end{array}$ & $\begin{array}{c}\text { Gage } \\
\text { height }\end{array}$ & $\begin{array}{l}\text { Dis- } \\
\text { charge }\end{array}$ \\
\hline $\begin{array}{l}1 \\
2 \\
3 \\
4 \\
5 \\
6\end{array}$ & $\begin{array}{r}0.12 \\
.11 \\
.13 \\
.14 \\
.20 \\
.60\end{array}$ & $\begin{array}{r}75 \\
74 \\
77 \\
78 \\
85 \\
139\end{array}$ & $\begin{array}{r}5.62 \\
5.64 \\
5.84 \\
6.20 \\
6.90 \\
10.00\end{array}$ & $\begin{array}{l}1,760 \\
1,770 \\
1,860 \\
2,020 \\
2,340 \\
3,820\end{array}$ & $\begin{array}{l}24.00 \\
24.80 \\
25.50 \\
26.00 \\
26.46 \\
26.82\end{array}$ & $\begin{array}{l}29,000 \\
32,300 \\
35,300 \\
37,500 \\
39,600 \\
41,200\end{array}$ & $\begin{array}{l}25.94 \\
25.50 \\
25.08 \\
24.73 \\
24.48 \\
24.26\end{array}$ & $\begin{array}{l}37,200 \\
35,300 \\
33,500 \\
32,000 \\
30,900 \\
30,000\end{array}$ & $\begin{array}{l}22.94 \\
22.52 \\
22.00 \\
21.46 \\
20.92 \\
20.33\end{array}$ & $\begin{array}{l}24,800 \\
23,300 \\
21,400 \\
19,700 \\
18,000 \\
16,300\end{array}$ \\
\hline $\begin{array}{r}7 \\
8 \\
9 \\
10 \\
11 \\
\mathbf{N}\end{array}$ & $\begin{array}{l}1.40 \\
3.10 \\
4.05 \\
4.80 \\
5.42 \\
5.88\end{array}$ & $\begin{array}{r}281 \\
765 \\
1,100 \\
1,400 \\
1,670 \\
1,880\end{array}$ & $\begin{array}{l}12.00 \\
12.80 \\
13.70 \\
14.56 \\
15.00 \\
15.40\end{array}$ & $\begin{array}{l}4,960 \\
5,520 \\
6,240 \\
6,980 \\
7,400 \\
7,800\end{array}$ & $\begin{array}{l}27.10 \\
27.30 \\
27.48 \\
27.65 \\
27.82 \\
28.06\end{array}$ & $\begin{array}{l}42,500 \\
43,400 \\
44,200 \\
45,000 \\
45,800 \\
46,900\end{array}$ & $\begin{array}{l}24.12 \\
24.00 \\
23.90 \\
23.80 \\
23.70 \\
23.61\end{array}$ & $\begin{array}{l}29,400 \\
29,000 \\
28,500 \\
28,100 \\
27,700 \\
27,400\end{array}$ & $\begin{array}{l}19.73 \\
19.12 \\
18.50 \\
17.78 \\
17.02 \\
16.20\end{array}$ & $\begin{array}{r}14,700 \\
13,200 \\
11,800 \\
10,500 \\
9,480 \\
\mathbf{8}, 600\end{array}$ \\
\hline $\begin{array}{l}1 \\
2 \\
3 \\
4 \\
5 \\
6\end{array}$ & $\begin{array}{l}6.07 \\
6.16 \\
6.21 \\
6.27 \\
6.28 \\
6.26\end{array}$ & $\begin{array}{l}1,960 \\
2,000 \\
2,020 \\
2,050 \\
2,060 \\
2,050\end{array}$ & $\begin{array}{l}15.82 \\
16.20 \\
16.50 \\
17.15 \\
17.62 \\
18.26\end{array}$ & $\begin{array}{r}8,220 \\
8,600 \\
8,900 \\
9,640 \\
10,200 \\
11,300\end{array}$ & $\begin{array}{l}28.23 \\
28.36 \\
28.48 \\
28.60 \\
28.64 \\
28.66\end{array}$ & $\begin{array}{l}47,700 \\
48,300 \\
48,900 \\
49,400 \\
49,600 \\
49,700\end{array}$ & $\begin{array}{l}23.52 \\
23.49 \\
23.46 \\
23.44 \\
23.43 \\
23.44\end{array}$ & $\begin{array}{l}27,000 \\
26,900 \\
26,800 \\
26,700 \\
26,700 \\
26,700\end{array}$ & $\begin{array}{r}15.30 \\
14.10 \\
12.80 \\
11.50 \\
10.20 \\
9.08\end{array}$ & $\begin{array}{l}7,700 \\
6,570 \\
5,520 \\
4,660 \\
3,920 \\
3,300\end{array}$ \\
\hline $\begin{array}{r}7 \\
8 \\
9 \\
10 \\
11 \\
12\end{array}$ & $\begin{array}{l}6.20 \\
6.11 \\
6.02 \\
5.94 \\
5.80 \\
5.67\end{array}$ & $\begin{array}{l}2,020 \\
1,980 \\
1,940 \\
1,900 \\
1,840 \\
1,780\end{array}$ & $\begin{array}{l}19.00 \\
19.70 \\
20.40 \\
21.20 \\
22.10 \\
23.06\end{array}$ & $\begin{array}{l}12,900 \\
14,700 \\
16,500 \\
18,900 \\
21,800 \\
25,300\end{array}$ & $\begin{array}{l}28.52 \\
28.22 \\
27.80 \\
27.40 \\
26.90 \\
26.43\end{array}$ & $\begin{array}{l}49,100 \\
47,700 \\
45,700 \\
43,800 \\
41,500 \\
39,400\end{array}$ & $\begin{array}{l}23.45 \\
23.45 \\
23.42 \\
23.40 \\
23.32 \\
23.19\end{array}$ & $\begin{array}{l}26,700 \\
26,700 \\
26,600 \\
26,600 \\
26,200 \\
25,700\end{array}$ & $\begin{array}{l}7.96 \\
7.00 \\
6.20 \\
5.50 \\
4.92 \\
4.38\end{array}$ & $\begin{array}{l}2,700 \\
2,220 \\
1,850 \\
1,540 \\
1,310 \\
1,100\end{array}$ \\
\hline
\end{tabular}

SALUDA RIVER NEAR SILVERSTREET, S. C.

Lochtion.-Lat. $34^{\circ} 11^{\prime}$, long. $81^{\circ} 44^{\prime}, 200$ feet upstream from new Higgins Ferry Bridge on State Highway 19, 1 mile downstream from Little River, and 21/2 miles south of Silverstreet, Newberry County. Datum of gage is 345.13 feet above mean sea level (from partly adjusted network of levels).

DraiNAGE AREA.—1,620 square miles; 1,150 square miles affected by storage in Lake Greenwood since May 1940 (1943 revision).

GAGE-HEIGHT RECORD.-Water-stage recorder graph.

DISCHARGE RECORD.-Stage-discharge relation defined by current-meter measurements up to 19,000 second-feet and extended above on basis of current-meter measurements made at Chappells and near Chapin.

Maxima.-1940: Discharge, 58,300 second-feet 2:30 a.m. Aug. 15 (gage height, 30.29 feet).

1927-39: Discharge, 83,800 second-feet Oct. 3, 1929 (gage height, 33.97 feet, from floodmarks).

REMarKs.-Flood runoff affected by storage in Lake Greenwood. For information on storage see records for Lake Greenwood near Chappells, S. C. 
Mean discharge, in second-feet, 1940

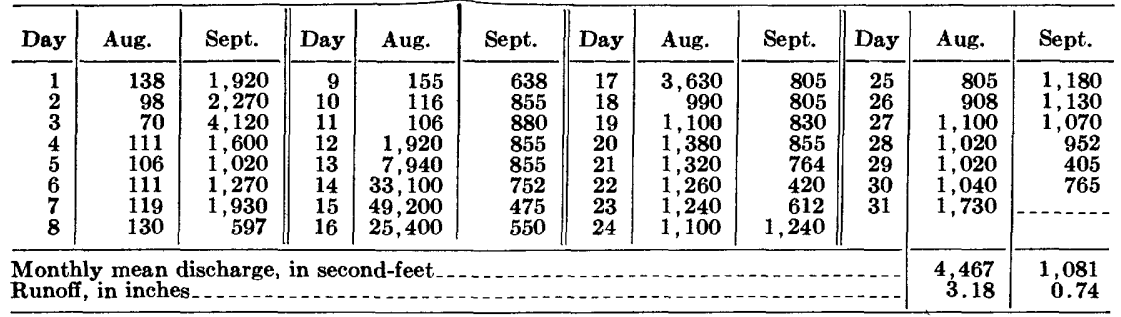

Gage height, in feet, and discharge, in second-feet, at indicated time, 1940

\begin{tabular}{|c|c|c|c|c|c|c|c|c|c|c|c|c|}
\hline \multirow[b]{2}{*}{ Hour } & \multicolumn{2}{|c|}{ Aug. 12} & \multicolumn{2}{|c|}{ Aug. 13} & \multicolumn{2}{|c|}{ Aug. 14} & \multicolumn{2}{|c|}{ Aug. 15} & \multicolumn{2}{|c|}{ Aug. 16} & \multicolumn{2}{|c|}{ Aug. 17} \\
\hline & $\begin{array}{c}\text { Gage } \\
\text { ht. }\end{array}$ & $\begin{array}{l}\text { Dis- } \\
\text { charge }\end{array}$ & $\begin{array}{c}\text { Gage } \\
\text { ht. }\end{array}$ & $\begin{array}{c}\text { Dis- } \\
\text { charge }\end{array}$ & $\begin{array}{c}\text { Gage } \\
\text { ht. }\end{array}$ & $\begin{array}{c}\text { Dis- } \\
\text { charge }\end{array}$ & $\begin{array}{c}\text { Gage } \\
\text { ht. }\end{array}$ & $\begin{array}{l}\text { Dis- } \\
\text { charge }\end{array}$ & $\begin{array}{c}\text { Gage } \\
\text { ht. }\end{array}$ & $\begin{array}{l}\text { Dis- } \\
\text { charge }\end{array}$ & $\begin{array}{c}\text { Gage } \\
\text { ht. }\end{array}$ & $\begin{array}{l}\text { Dis- } \\
\text { charge }\end{array}$ \\
\hline $\begin{array}{l}1 \\
2 \\
3 \\
4 \\
5 \\
6\end{array}$ & $\begin{array}{l}3.16 \\
3.17 \\
3.17 \\
3.18 \\
3.19 \\
3.21\end{array}$ & $\begin{array}{l}106 \\
108 \\
108 \\
111 \\
113 \\
119\end{array}$ & $\begin{array}{l}8.08 \\
8.21 \\
8.46 \\
8.72 \\
9.06 \\
9.71\end{array}$ & $\begin{array}{l}2,700 \\
2,780 \\
2,930 \\
3,080 \\
3,290 \\
3,720\end{array}$ & $\begin{array}{l}18.58 \\
18.98 \\
19.40 \\
19.92 \\
20.62 \\
21.30\end{array}$ & $\begin{array}{l}13,800 \\
14,500 \\
15,200 \\
16,200 \\
17,600 \\
19,100\end{array}$ & $\begin{array}{l}30.23 \\
30.28 \\
30.28 \\
30.23 \\
30.14 \\
30.01\end{array}$ & $\begin{array}{l}\mathbf{5 7}, 900 \\
58,300 \\
58,300 \\
57,900 \\
57,400 \\
56,500\end{array}$ & $\begin{array}{l}26.28 \\
26.11 \\
25.93 \\
25.76 \\
25.56 \\
25.36\end{array}$ & $\begin{array}{l}36,100 \\
35,300 \\
34,500 \\
33,700 \\
32,900 \\
32,000\end{array}$ & $\begin{array}{l}17.38 \\
16.64 \\
15.87 \\
14.88 \\
13.72 \\
12.40\end{array}$ & $\begin{array}{r}11,800 \\
10,700 \\
9,620 \\
8,340 \\
6,990 \\
5,740\end{array}$ \\
\hline $\begin{array}{r}7 \\
8 \\
9 \\
10 \\
11 \\
\mathbf{N}\end{array}$ & $\begin{array}{l}3.29 \\
3.35 \\
4.10 \\
5.80 \\
7.50 \\
8.75\end{array}$ & $\begin{array}{r}145 \\
167 \\
530 \\
1,430 \\
2,360 \\
3,100\end{array}$ & $\begin{array}{l}10.81 \\
12.21 \\
13.32 \\
14.30 \\
14.84 \\
15.30\end{array}$ & $\begin{array}{l}4,490 \\
5,580 \\
6,580 \\
7,640 \\
8,290 \\
8,870\end{array}$ & $\mid \begin{array}{l}22.00 \\
22.68 \\
23.37 \\
24.04 \\
24.70 \\
25.30\end{array}$ & $\begin{array}{l}20,900 \\
22,800 \\
24,900 \\
27,100 \\
29,500 \\
31,800\end{array}$ & $\left|\begin{array}{l}29.89 \\
29.69 \\
29.51 \\
29.30 \\
29.10 \\
28.89\end{array}\right|$ & $\begin{array}{l}55,800 \\
54,500 \\
53,400 \\
52,200 \\
51,000 \\
49,700\end{array}$ & $\mid \begin{array}{l}25.12 \\
24.84 \\
24.56 \\
24.29 \\
23.95 \\
23.62\end{array}$ & $\begin{array}{l}31,100 \\
30,000 \\
29,000 \\
28,000 \\
26,800 \\
25,700\end{array}$ & $\begin{array}{r}10.80 \\
9.30 \\
8.20 \\
7.26 \\
6.54 \\
6.00\end{array}$ & $\begin{array}{l}4,480 \\
3,450 \\
2,770 \\
2,230 \\
1,840 \\
1,540\end{array}$ \\
\hline $\begin{array}{l}\mathbf{1} \\
\mathbf{2} \\
\mathbf{3} \\
\mathbf{4} \\
\mathbf{5} \\
\mathbf{6}\end{array}$ & $\begin{array}{l}9.51 \\
9.85 \\
9.91 \\
9.73 \\
9.43 \\
9.12\end{array}$ & $\begin{array}{l}3,590 \\
3,810 \\
3,850 \\
3,730 \\
3,530 \\
3, \mathbf{3 3 0}\end{array}$ & $\begin{array}{l}15.72 \\
16.07 \\
16.30 \\
16.52 \\
16.74 \\
16.95\end{array}$ & $\begin{array}{r}9,420 \\
9,900 \\
10,200 \\
10,500 \\
10,800 \\
11,200\end{array}$ & $\left|\begin{array}{l}25.84 \\
26.40 \\
26.92 \\
27.38 \\
27.87 \\
28.34\end{array}\right|$ & $\begin{array}{l}34,100 \\
36,600 \\
39,200 \\
41,500 \\
44,100 \\
46,600\end{array}$ & $\begin{array}{l}28.68 \\
28.47 \\
28.27 \\
28.02 \\
27.81 \\
27.61\end{array}$ & $\begin{array}{l}48,500 \\
47,300 \\
46,200 \\
44,900 \\
43,800 \\
42,700\end{array}$ & $\left|\begin{array}{l}23.23 \\
22.84 \\
22.49 \\
22.10 \\
21 \cdot 64 \\
21.19\end{array}\right|$ & $\begin{array}{l}24,400 \\
23,200 \\
22,200 \\
21,100 \\
19,900 \\
18,800\end{array}$ & $\begin{array}{l}5.62 \\
5.34 \\
5.20 \\
5.09 \\
4.98 \\
4.88\end{array}$ & $\begin{array}{r}1,330 \\
1,180 \\
1,100 \\
1,040 \\
979 \\
924\end{array}$ \\
\hline $\begin{array}{r}7 \\
8 \\
9 \\
10 \\
11 \\
12 \\
\end{array}$ & $\begin{array}{l}8.83 \\
8.59 \\
8.39 \\
8.22 \\
8.13 \\
8.08\end{array}$ & $\begin{array}{l}3,150 \\
3,000 \\
2,880 \\
2,780 \\
2,730 \\
2,700\end{array}$ & $\mid \begin{array}{l}17.16 \\
17.37 \\
17.56 \\
17.76 \\
18.00 \\
18.30\end{array}$ & $\begin{array}{l}11,500 \\
11,800 \\
12,100 \\
12,400 \\
12,800 \\
13,300\end{array}$ & $\left|\begin{array}{l}28.71 \\
29.09 \\
29.45 \\
29.70 \\
29.96 \\
30.12\end{array}\right|$ & $\begin{array}{l}48,700 \\
50,900 \\
53,100 \\
54,600 \\
56,200 \\
57,200\end{array}$ & $\left|\begin{array}{l}27.41 \\
27.19 \\
26.99 \\
26.80 \\
26.61 \\
26.45\end{array}\right|$ & $\begin{array}{l}41,700 \\
40,500 \\
39,500 \\
38,600 \\
37,700 \\
36,900\end{array}$ & $\left|\begin{array}{l}20.74 \\
20.20 \\
19.72 \\
19.20 \\
18.62 \\
18.08\end{array}\right|$ & $\begin{array}{l}17,800 \\
16,700 \\
15,800 \\
14,900 \\
13,900 \\
12,900\end{array}$ & $\begin{array}{l}4.80 \\
4.74 \\
4.71 \\
4.70 \\
4.70 \\
4.72\end{array}$ & $\begin{array}{l}880 \\
850 \\
835 \\
830 \\
830 \\
840\end{array}$ \\
\hline
\end{tabular}

Supplemental Record.-Aug. 15, 2:30 a.m., gage height, 30.29 feet; discharge, 58,300 second-feet.

\section{LAKE MURRAY NEAR COLUMBIA, S. C.}

LOCATION.-Lat. $34^{\circ} 03^{\prime}$ long. $81^{\circ} 13^{\prime}$, about 500 feet upstream from dam on Saluda River, 10 miles upstream from mouth, and 11 miles northwest of Columbia, Richland County. Datum of gage is $\mathbf{0 . 6 4}$ foot below mean sea level, datum of 1929 , supplementary adjustment of 1936 .

Drainage area.-2,420 square miles (1943 revision).

GAGE-HEIGHT RECORD.-Water-stage recorder graph except for periods 4:30 a.m. Aug. 4 to 2 p.m. Aug. 14, 8 a.m. Aug. 27 to 11:30 a.m. Aug. 31, for which record was obtained from graph based on four gage readings daily at power plant.

Maxima.-1940: Gage height, 346.43 feet 6 a.m. Aug. 21 (contents, 45,380,000,000 cubic feet).

1929-39: Gage height, 361.51 feet Apr. 10, 1936 (contents, about 74,540,000,000 cubic feet).

REMARKs.-Usable eapacity, $71,110,000,000$ cubic feet between gage heights 300.0 feet (draw-down limit) and 360.0 feet (maximum normal lake level). Gage height of top of spillway gates, 365.0 feet. Figures given herein represent usable contents. 
SANTEE RIVER BASIN

Daily mean gage height, in feet, and contents, in billions of cubic feet, 1940

\begin{tabular}{|c|c|c|c|c|c|c|c|c|c|}
\hline \multirow{2}{*}{ Day } & \multicolumn{2}{|c|}{ August } & \multicolumn{2}{|c|}{ September } & \multirow{2}{*}{ Day } & \multicolumn{2}{|c|}{ August } & \multicolumn{2}{|c|}{ September } \\
\hline & $\begin{array}{l}\text { Gage } \\
\text { height }\end{array}$ & Contents & $\begin{array}{l}\text { Gage } \\
\text { height }\end{array}$ & Contents & & $\begin{array}{l}\text { Gage } \\
\text { height }\end{array}$ & Contents & $\begin{array}{c}\text { Gage } \\
\text { height }\end{array}$ & Contents \\
\hline $\begin{array}{l}1 \\
2 \\
3 \\
4 \\
5\end{array}$ & $\begin{array}{l}\mathbf{3 3 7} . \mathbf{9 8} \\
\mathbf{3 3 7} . \mathbf{8 9} \\
\mathbf{3 3 7} . \mathbf{8 3} \\
\mathbf{3 3 7} \cdot \mathbf{7 9} \\
\mathbf{3 3 7} \cdot \mathbf{7 4}\end{array}$ & $\begin{array}{l}\mathbf{3 3 . 1 3} \\
\mathbf{3 3} .02 \\
\mathbf{3 2 . 9 4} \\
\mathbf{3 2 . 8 9} \\
\mathbf{3 2 . 8 2}\end{array}$ & $\begin{array}{l}345.62 \\
345.70 \\
345.81 \\
345.91 \\
345.79\end{array}$ & $\begin{array}{l}44.10 \\
44.22 \\
44.39 \\
44.55 \\
44.39\end{array}$ & $\begin{array}{l}16 \\
17 \\
18 \\
19 \\
20\end{array}$ & $\begin{array}{l}\mathbf{3 4 5 . 3 3} \\
\mathbf{3 4 6 . 2 5} \\
\mathbf{3 4 6 . 3 6} \\
\mathbf{3 4 6 . 4 1} \\
\mathbf{3 4 6 . 4 1}\end{array}$ & $\begin{array}{l}43.64 \\
45.09 \\
45.27 \\
45.35 \\
45.35\end{array}$ & $\begin{array}{l}344.54 \\
344.31 \\
344.08 \\
343.85 \\
343.64\end{array}$ & $\begin{array}{l}42.42 \\
42.07 \\
41.72 \\
41.38 \\
41.07\end{array}$ \\
\hline $\begin{array}{r}6 \\
7 \\
8 \\
9 \\
10\end{array}$ & $\begin{array}{l}337 \cdot 65 \\
337.56 \\
337.49 \\
\mathbf{3 3 7} \cdot \mathbf{4 5} \\
\mathbf{3 3 7} . \mathbf{4 1}\end{array}$ & $\begin{array}{l}32.71 \\
32.59 \\
32.50 \\
32.45 \\
32.39\end{array}$ & $\begin{array}{l}345.64 \\
345.58 \\
345.61 \\
\mathbf{3 4 5} .58 \\
\mathbf{3 4 5 . 3 6}\end{array}$ & $\begin{array}{l}44.13 \\
44.03 \\
44.08 \\
44.03 \\
43.69\end{array}$ & $\begin{array}{l}21 \\
22 \\
23 \\
24 \\
25\end{array}$ & $\begin{array}{l}\mathbf{3 4 6 . 4 2} \\
\mathbf{3 4 6 . 4 2} \\
\mathbf{3 4 6 . 4 2} \\
\mathbf{3 4 6 . 4 0} \\
\mathbf{3 4 6 . 3 9}\end{array}$ & $\begin{array}{l}45.37 \\
45.37 \\
45.37 \\
45.33 \\
45.32\end{array}$ & $\begin{array}{l}343.47 \\
343.41 \\
343.33 \\
343.24 \\
343.16\end{array}$ & $\begin{array}{l}40.81 \\
40.72 \\
40.60 \\
40.47 \\
40.35\end{array}$ \\
\hline $\begin{array}{l}11 \\
12 \\
13 \\
14 \\
15\end{array}$ & $\begin{array}{l}\mathbf{3 3 7} . \mathbf{3 7} \\
\mathbf{3 3 7} .63 \\
\mathbf{3 3 8} .65 \\
\mathbf{3 4 0 . 8 4} \\
\mathbf{3 4 3 . 4 2}\end{array}$ & $\begin{array}{l}32.34 \\
32.68 \\
34.02 \\
37.01 \\
40.74\end{array}$ & $\begin{array}{l}\mathbf{3 4 5} .20 \\
\mathbf{3 4 4 . 9 8} \\
\mathbf{3 4 4} .77 \\
\mathbf{3 4 4 . 6 4} \\
\mathbf{3 4 4 . 6 4}\end{array}$ & $\begin{array}{l}43.44 \\
43.09 \\
42.77 \\
42.58 \\
42.58\end{array}$ & $\begin{array}{l}\mathbf{2 6} \\
\mathbf{2 7} \\
\mathbf{2 8} \\
\mathbf{2 9} \\
\mathbf{3 0} \\
\mathbf{3 1} \\
\end{array}$ & $\begin{array}{l}\mathbf{3 4 6 . 3 2} \\
\mathbf{3 4 6 . 1 4} \\
\mathbf{3 4 5 . 8 2} \\
\mathbf{3 4 5 . 5 9} \\
\mathbf{3 4 5} .53 \\
\mathbf{3 4 5 . 5 4} \\
\end{array}$ & $\begin{array}{l}45.20 \\
44.92 \\
44.41 \\
44.05 \\
43.96 \\
43.97 \\
\end{array}$ & $\begin{array}{r}342.99 \\
342.84 \\
\mathbf{3 4 2 . 7 4} \\
\mathbf{3 4 2 . 7 5} \\
\mathbf{3 4 2 . 7 0} \\
\end{array}$ & $\begin{array}{r}40.10 \\
39.88 \\
39.74 \\
39.75 \\
39.68 \\
\\
\end{array}$ \\
\hline & & & & & & & & August & $\begin{array}{c}\text { Sep- } \\
\text { tember }\end{array}$ \\
\hline \multicolumn{8}{|c|}{ Change in contents, equivalent, in second-feet } & $+4,050$ & $-1,730$ \\
\hline
\end{tabular}

Gage height, in feet, and content in billions of cubic feet, at indicated time, 1940

\begin{tabular}{|c|c|c|c|c|c|c|c|c|c|c|c|c|}
\hline \multirow{2}{*}{ Hour } & \multicolumn{2}{|c|}{ Aug. 12} & \multicolumn{2}{|c|}{ Aug. 13} & \multicolumn{2}{|c|}{ Aug. 14} & \multicolumn{2}{|c|}{ Aug. 15} & \multicolumn{2}{|c|}{ Aug. 16} & \multicolumn{2}{|c|}{ Aug. 17} \\
\hline & $\begin{array}{c}\text { Gage } \\
\text { height }\end{array}$ & $\begin{array}{l}\text { Con- } \\
\text { tents }\end{array}$ & $\begin{array}{c}\text { Gage } \\
\text { height }\end{array}$ & $\begin{array}{l}\text { Con- } \\
\text { tents }\end{array}$ & $\begin{array}{c}\text { Gage } \\
\text { height }\end{array}$ & $\begin{array}{l}\text { Con- } \\
\text { tents }\end{array}$ & $\begin{array}{c}\text { Gage } \\
\text { height }\end{array}$ & $\begin{array}{l}\text { Con- } \\
\text { tents }\end{array}$ & $\begin{array}{l}\text { Gage } \\
\text { height }\end{array}$ & $\begin{array}{l}\text { Con- } \\
\text { tents }\end{array}$ & $\begin{array}{c}\text { Gage } \\
\text { height }\end{array}$ & $\begin{array}{l}\text { Con- } \\
\text { tents }\end{array}$ \\
\hline $\begin{array}{r}6 \\
N \\
6 \\
12\end{array}$ & $\begin{array}{l}337.40 \\
337.60 \\
337.82 \\
\mathbf{3 3 8 . 0 8}\end{array}$ & $\begin{array}{l}32.38 \\
32.64 \\
32.93 \\
33.27\end{array}$ & $\begin{array}{l}338,16 \\
338.41 \\
339,17 \\
339.62 \\
\end{array}$ & $\begin{array}{l}\mathbf{3 3 . 3 7} \\
\mathbf{3 3 . 7 0} \\
\mathbf{3 4 . 7 2} \\
\mathbf{3 5 . 3 2}\end{array}$ & $\begin{array}{l}340.26 \\
\mathbf{3 4 0 . 8 1} \\
341.42 \\
\mathbf{3 4 2} .11\end{array}$ & $\begin{array}{l}36.20 \\
\mathbf{3 6 . 9 7} \\
\mathbf{3 7 . 8 3} \\
\mathbf{3 8 . 8 2} \\
\end{array}$ & $\begin{array}{l}\mathbf{3 4 2 . 8 5} \\
\mathbf{3 4 3 . 4 7} \\
\mathbf{3 4 4 . 0 3} \\
\mathbf{3 4 4 . 5 3}\end{array}$ & $\begin{array}{l}39.90 \\
40.81 \\
41.65 \\
42.41 \\
\end{array}$ & $\begin{array}{l}345.00 \\
345.37 \\
345.71 \\
345.98\end{array}$ & $\begin{array}{l}43.12 \\
43.70 \\
44.24 \\
44.66\end{array}$ & $\begin{array}{l}346.21 \\
346.30 \\
346.32 \\
346.34\end{array}$ & $\begin{array}{l}45.03 \\
45.17 \\
45.20 \\
45.24 \\
\end{array}$ \\
\hline
\end{tabular}

SALUDA RIVER NEAR COLUMBIA, S. C.

LocÁtion.-Lat. $34^{\circ} 01^{\prime}$, long. $81^{\circ} 06^{\prime}$, a quarter of a mile upstream from site of old Saluda mill and 2 miles upstream from mouth and from Columbia, Richland County. Datum of gage is 149.46 feet above mean sea level, datum of 1929 , supplementary adjustment of 1936 .

Drain AGe AREa.-2,510 square miles; 2,420 square miles affected by storage in Lake Murray since August 1929 (1943 revision).

GAGE-HEIGHT RECORD.-Water-stage recorder graph.

DISCHARGE RECORD.-Stage-discharge relation defined by current-meter measurements up to 39,000 second-feet and extended above on basis of discharge measurements made at Wise Ferry Bridge near Chapin, S. C.

Maxima.-1940: Discharge, 9,950 second-feet 1:15 p.m. Aug. 28 (gage height, 5.95 feet).

1925-39: Discharge, 67,000 second-feet Oct. 2, 1929 (gage height, 15.22 feet).

REMARKs.-Discharge materially affected by storage in Lake Murray and Lake Greenwood. For information on storage see records for Lake Murray near Columbia, S. C., and Lake Greenwood near Chappells, S. C. 


\section{FLOODS OF AUGUST 1940 IN THE SOUTHEASTERN STATES}

Mean discharge, in second-feet, 1940

\begin{tabular}{|c|c|c|c|c|c|c|c|c|c|c|c|}
\hline Day & Aug. & Sept. & Day & Aug. & Sept. & Day & Aug. & Sept. & Day & Aug. & Sept. \\
\hline $\begin{array}{l}1 \\
2 \\
3 \\
4 \\
5 \\
6 \\
7 \\
8\end{array}$ & $\begin{array}{r}1,400 \\
897 \\
308 \\
47 \\
1,530 \\
1,900 \\
1,930 \\
1,790\end{array}$ & $\begin{array}{r}155 \\
97 \\
954 \\
3,070 \\
3,670 \\
3,980 \\
947 \\
101\end{array}$ & $\begin{array}{r}9 \\
10 \\
11 \\
12 \\
13 \\
14 \\
15 \\
16\end{array}$ & $\begin{array}{r}1,280 \\
240 \\
54 \\
687 \\
536 \\
514 \\
840 \\
910\end{array}$ & $\begin{array}{r}3,460 \\
4,870 \\
4,260 \\
4,730 \\
4,350 \\
784 \\
586 \\
4,050\end{array}$ & $\begin{array}{l}17 \\
18 \\
19 \\
20 \\
21 \\
22 \\
23 \\
24\end{array}$ & $\begin{array}{r}289 \\
86 \\
392 \\
868 \\
1,050 \\
702 \\
1,930 \\
834\end{array}$ & $\begin{array}{r}4,920 \\
4,920 \\
4,630 \\
4,750 \\
2,760 \\
868 \\
2,330 \\
1,860\end{array}$ & $\begin{array}{l}25 \\
26 \\
27 \\
28 \\
29 \\
30 \\
31\end{array}$ & $\begin{array}{r}1,420 \\
2,790 \\
6,340 \\
7,170 \\
4,360 \\
2,760 \\
641\end{array}$ & $\begin{array}{r}3,250 \\
3,580 \\
3,520 \\
1,130 \\
379 \\
2,540 \\
\end{array}$ \\
\hline \multicolumn{10}{|c|}{$\begin{array}{l}\text { Monthly mean discharge, in second-feet } \\
\text { Runoff, in inches. }\end{array}$} & $\begin{array}{r}1,500 \\
0.69\end{array}$ & $\begin{array}{r}2,717 \\
1.21\end{array}$ \\
\hline
\end{tabular}

REEDY RIVER NEAR WARE SHOALS, S. C.

Location.-Lat. $34^{\circ} 27^{\prime}$, long. $82^{\circ} 12^{\prime}, 1 \%$ miles downstream from dam at Boyd's mill, 4.5 miles northeast of Ware Shoals, Greenwood County, and 10.5 miles upstream from Redburn Creek.

Drainage AREa.-228 square miles (1941 revision).

GAGE-HEIGHT RECORD.-Water-stage recorder graph.

DISCHARGE RECORD.- Stage-diseharge relation defined by current-meter measurements up to 2,400 second-feet and extended to crest gage height on basis of determination of peak flow over dam $13 / 4$ miles upstream.

Maxima.-1940: Discharge, 7,750 second-feet 5 a.m. Aug. 14 (gage height, 13.32 feet).

1939: Discharge, 3,560 second-feet Aug. 19 (gage height, 5.65 feet).

REMarKs.-Flood discharge not affected by artificial storage or diversion. Diurnal fluctuation caused by power plant above station.

Mean discharge, in second-feet, 1940

\begin{tabular}{|c|c|c|c|c|c|c|c|c|c|c|c|}
\hline Day & Aug. & Sept. & Day & Aug. & Sept. & Day & Aug. & Sept. & Day & Aug. & Sept. \\
\hline $\begin{array}{l}1 \\
2 \\
3 \\
4 \\
5 \\
6 \\
7 \\
8\end{array}$ & $\begin{array}{r}42 \\
53 \\
39 \\
40 \\
50 \\
60 \\
106 \\
208\end{array}$ & $\begin{array}{r}295 \\
126 \\
88 \\
185 \\
125 \\
84 \\
187 \\
21\end{array}$ & $\begin{array}{r}9 \\
10 \\
11 \\
12 \\
13 \\
14 \\
15 \\
16\end{array}$ & $\begin{array}{r}122 \\
48 \\
26 \\
207 \\
4,560 \\
7,070 \\
3,960 \\
1,430\end{array}$ & $\begin{array}{r}207 \\
111 \\
111 \\
112 \\
111 \\
61 \\
14 \\
151\end{array}$ & $\begin{array}{l}17 \\
18 \\
19 \\
20 \\
21 \\
22 \\
23 \\
24\end{array}$ & $\begin{array}{r}750 \\
306 \\
323 \\
185 \\
186 \\
17 \\
69 \\
124\end{array}$ & \begin{tabular}{r|}
133 \\
104 \\
101 \\
101 \\
47 \\
14 \\
63 \\
82
\end{tabular} & $\begin{array}{l}25 \\
26 \\
27 \\
28 \\
29 \\
30 \\
31\end{array}$ & $\begin{array}{r}80 \\
200 \\
208 \\
42 \\
197 \\
336 \\
416\end{array}$ & $\begin{array}{r}106 \\
98 \\
84 \\
50 \\
18 \\
60\end{array}$ \\
\hline \multicolumn{10}{|c|}{$\begin{array}{l}\text { Monthly mean discharge, in second-feet } \\
\text { Runoff, in inches. }\end{array}$} & $\begin{array}{r}692 \\
3.50\end{array}$ & $\begin{array}{r}102 \\
0.50\end{array}$ \\
\hline
\end{tabular}


EDISTO RIVER BASIN

Gage height, in feet, and discharge, in second-feet, at indicated time, 1940

\begin{tabular}{|c|c|c|c|c|c|c|c|c|c|c|}
\hline \multirow{2}{*}{ Hour } & \multicolumn{2}{|c|}{ Aug. 12} & \multicolumn{2}{|c|}{ Aug. 13} & \multicolumn{2}{|c|}{ Aug. 14} & \multicolumn{2}{|c|}{ Aug. 15} & \multicolumn{2}{|c|}{ Aug. 16} \\
\hline & $\begin{array}{l}\text { Gage } \\
\text { height }\end{array}$ & $\begin{array}{l}\text { Dis- } \\
\text { charge }\end{array}$ & $\begin{array}{c}\text { Gage } \\
\text { height }\end{array}$ & $\begin{array}{l}\text { Dis- } \\
\text { charge }\end{array}$ & $\begin{array}{c}\text { Gage } \\
\text { height }\end{array}$ & $\begin{array}{l}\text { Dis- } \\
\text { charge }\end{array}$ & $\begin{array}{l}\text { Gage } \\
\text { height }\end{array}$ & $\begin{array}{l}\text { Dis- } \\
\text { charge }\end{array}$ & $\begin{array}{c}\text { Gage } \\
\text { height }\end{array}$ & $\begin{array}{l}\text { Dis- } \\
\text { charge }\end{array}$ \\
\hline $\begin{array}{l}1 \\
2 \\
3 \\
4 \\
5 \\
6\end{array}$ & $\begin{array}{r}0.90 \\
.92 \\
.92 \\
.93 \\
.93 \\
.96\end{array}$ & $\begin{array}{l}22 \\
24 \\
24 \\
24 \\
24 \\
27\end{array}$ & $\begin{array}{l}2.72 \\
2.72 \\
2.74 \\
2.88 \\
3.57 \\
\mathbf{3 . 6 9}\end{array}$ & $\begin{array}{r}818 \\
818 \\
836 \\
962 \\
1,580 \\
1,690\end{array}$ & $\begin{array}{l}12.80 \\
13.01 \\
13.20 \\
13.30 \\
13.32 \\
13.30\end{array}$ & $\begin{array}{l}7,520 \\
7,610 \\
7,700 \\
7,740 \\
7,750 \\
7,740\end{array}$ & $\begin{array}{l}8.45 \\
8.19 \\
7.92 \\
7.73 \\
7.54 \\
7.61\end{array}$ & $\begin{array}{l}5,440 \\
5,300 \\
5,150 \\
5,040 \\
4,930 \\
4,970\end{array}$ & 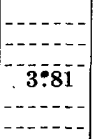 & 1,800 \\
\hline $\begin{array}{r}7 \\
8 \\
9 \\
10 \\
11 \\
N\end{array}$ & $\begin{array}{r}1.67 \\
1.76 \\
1.79 \\
1.85 \\
1.86 \\
1.82\end{array}$ & $\begin{array}{r}135 \\
-\quad 158 \\
166 \\
186 \\
189 \\
176\end{array}$ & $\begin{array}{l}4.90 \\
5.59 \\
5.94 \\
6.55 \\
7.35 \\
8.21\end{array}$ & $\begin{array}{l}2,880 \\
3,550 \\
3,850 \\
4,300 \\
4,820 \\
5,310\end{array}$ & $\begin{array}{l}13.25 \\
13.14 \\
12.99 \\
12.85 \\
12.62 \\
12.39\end{array}$ & $\begin{array}{l}7,720 \\
7,670 \\
7,600 \\
7,540 \\
7,430 \\
7,330\end{array}$ & $\begin{array}{l}7.29 \\
7.03 \\
6.79 \\
6.58 \\
6.38 \\
6.20\end{array}$ & $\begin{array}{l}4,780 \\
4,620 \\
4,460 \\
4,330 \\
4,190 \\
4,060\end{array}$ & $\begin{array}{c}3.49 \\
3.3 \overline{3}\end{array}$ & $\begin{array}{c}1, \overline{1} 10 \\
1,370\end{array}$ \\
\hline $\begin{array}{l}1 \\
2 \\
3 \\
4 \\
5 \\
6\end{array}$ & $\begin{array}{r}1.79 \\
1.78 \\
1.77 \\
1.75 \\
1.76 \\
1.86\end{array}$ & $\begin{array}{l}166 \\
164 \\
161 \\
156 \\
158 \\
189\end{array}$ & $\begin{array}{r}8.62 \\
9.46 \\
10.45 \\
10.80 \\
10.93 \\
11.22\end{array}$ & $\begin{array}{l}5,540 \\
5,960 \\
6,460 \\
6,620 \\
6,670 \\
6,800\end{array}$ & $\begin{array}{l}12.15 \\
11.90 \\
11.62 \\
11.33 \\
11.05 \\
10.75\end{array}$ & $\begin{array}{l}7,220 \\
7,110 \\
6,980 \\
6,850 \\
6,730 \\
6,590\end{array}$ & $\begin{array}{l}5.97 \\
5.77 \\
5.61 \\
5.42 \\
5.24 \\
5.07\end{array}$ & $\begin{array}{l}3,880 \\
3,710 \\
3,570 \\
3,400 \\
3,220 \\
3,050\end{array}$ & $\begin{array}{c}-1.17 \\
-3 . \\
-\end{array}$ & 1, 220 \\
\hline $\begin{array}{r}7 \\
8 \\
9 \\
10 \\
11 \\
12\end{array}$ & $\begin{array}{l}1.92 \\
2.05 \\
2.38 \\
2.50 \\
2.68 \\
2.73\end{array}$ & $\begin{array}{l}210 \\
268 \\
512 \\
620 \\
782 \\
827\end{array}$ & $\begin{array}{l}11.67 \\
11.88 \\
12.06 \\
12.13 \\
12.27 \\
12.51\end{array}$ & $\begin{array}{l}7,010 \\
7,100 \\
7,180 \\
7,210 \\
7,280 \\
7,380\end{array}$ & $\begin{array}{r}10.45 \\
10.00 \\
9.68 \\
9.36 \\
9.03 \\
8.72\end{array}$ & $\begin{array}{l}6,460 \\
6,240 \\
6,080 \\
5,920 \\
5,750 \\
5,590\end{array}$ & $\begin{array}{l}4.93 \\
4.77 \\
4.63 \\
4.49 \\
4.36 \\
4.25\end{array}$ & $\begin{array}{l}2,910 \\
2,750 \\
2,610 \\
2,470 \\
2,340 \\
2,230 \\
\end{array}$ & $\begin{array}{c}-\overline{3.02} \\
-\overline{2.91} \\
\end{array}$ & $\begin{array}{c}1,090 \\
989 \\
\end{array}$ \\
\hline
\end{tabular}

\section{EDISTO RIVER BASIN}

SOUTH FORK EDISTO MIVER NEAR MONTMORENCI, $\mathbf{c}$.

Location.-Lat. $33^{\circ} 34^{\prime} 35^{\prime \prime}$, long. $81^{\circ} 30^{\prime} 50^{\prime \prime}, 0.4$ mile upstream from Cedar Creek and

7.6 miles northeast of Montmorenci, Aiken County. Datum of gage is 250.18

feet above mean sea level, datum of 1929, supplementary adjustment of 1936 .

Drainage AREA.—198 square miles (1945 revision).

GAGE-HEIGHT RECORD.-Graph based on twice-daily readings of wire-weight gage.

DISCHARGE RECORD.-Stage-discharge relation defined by current-meter measurements.

Maxima.-1940: Discharge, 2,460 second-feet 8 a.m. Aug. 15 (gage height, 8.81 feet, from graph based on gage readings).

REMARKs.-Flood discharge not affected by artificial storage or diversion. Natural storage in swampy areas above station.

- Mean discharge, in second-feet, 1940

\begin{tabular}{|c|c|c|c|c|c|c|c|c|c|c|c|}
\hline Day & Aug. & Sept. & Day & Aug. & Sept. & Day & Aug. & Sept. & Day & Aug. & Sept. \\
\hline \begin{tabular}{l|}
1 \\
2 \\
3 \\
4 \\
5 \\
6 \\
7 \\
8
\end{tabular} & $\begin{array}{r}90 \\
94 \\
98 \\
90 \\
92 \\
102 \\
108 \\
128\end{array}$ & $\begin{array}{l}148 \\
146 \\
118 \\
108 \\
110 \\
124 \\
122 \\
108\end{array}$ & $\begin{array}{r}9 \\
10 \\
11 \\
12 \\
13 \\
14 \\
15 \\
16\end{array}$ & $\begin{array}{r}154 \\
156 \\
131 \\
204 \\
410 \\
1,280 \\
2,140 \\
1,020\end{array}$ & $\begin{array}{r}106 \\
102 \\
108 \\
108 \\
100 \\
\mathbf{9 4} \\
\mathbf{9 0} \\
\mathbf{9 2}\end{array}$ & $\begin{array}{l}17 \\
18 \\
19 \\
20 \\
21 \\
22 \\
23 \\
24\end{array}$ & $\begin{array}{l}450 \\
339 \\
256 \\
204 \\
174 \\
148 \\
136 \\
128\end{array}$ & $\begin{array}{l}94 \\
94 \\
92 \\
90 \\
86 \\
84 \\
90 \\
92\end{array}$ & $\begin{array}{l}25 \\
26 \\
27 \\
28 \\
29 \\
30 \\
31\end{array}$ & $\begin{array}{l}116 \\
118 \\
112 \\
108 \\
104 \\
114 \\
136\end{array}$ & $\begin{array}{r}88 \\
84 \\
92 \\
100 \\
116 \\
124\end{array}$ \\
\hline on & & & & & & & & & - & $\begin{array}{r}288 \\
1.68\end{array}$ & $\begin{array}{r}104 \\
0.58\end{array}$ \\
\hline
\end{tabular}

SOUTH FORK EDISTO RIVER NEAR DENMARK, S. C.

Location.-Lat. $33^{\circ} 23^{\prime} 35^{\prime \prime}$, long. $81^{\circ} 08^{\prime} 00^{\prime \prime}$, at bridge on State Highway 5, 200 feet downstream from Seaboard Railway bridge, 11/2 miles downstream from Little River, and $4 \frac{3}{4}$ miles north of Denmark, Bamberg County. Datum of gage is 155.68 feet above mean sea level, datum of 1929, supplementary adjustment of 1936 . 


\section{FLOODS OF AUGUST 1940 IN THE SOUTHEASTERN STATES}

Drainage AREa.-720 square miles.

GAGE-HEIGHT RECORD.-Water-stage recorder graph.

DISCHARGE RECORD. - Stage-discharge relation defined by current-meter measurements up to 4,800 second-feet and extended to crest gage height on basis of velocityarea studies and logarithmic plotting.

Maxima.-1940: Discharge, 2,060 second-feet 4:45 a.m. Aug. 19 (gage leight, 7.92 feet).

1931-39: Discharge, 13,500 second-feet Apr. 11, 1936 (gage height, 10.91 feet).

REMARKs.-Natural storage in large swampy areas above station.

Mean discharge, in second-feet, 1940

\begin{tabular}{|c|c|c|c|c|c|c|c|c|c|c|c|}
\hline Day & Aug. & Sept. & Day & Aug. & Sept. & Day & Aug. & Sept. & Day & Aug. & Sept. \\
\hline $\begin{array}{l}1 \\
2 \\
3 \\
4 \\
5 \\
6 \\
7 \\
8\end{array}$ & $\begin{array}{l}304 \\
337 \\
314 \\
297 \\
297 \\
308 \\
314 \\
412\end{array}$ & $\begin{array}{l}\mathbf{3 9 0} \\
\mathbf{3 7 6} \\
\mathbf{3 8 3} \\
\mathbf{3 6 9} \\
\mathbf{3 5 6} \\
\mathbf{3 5 0} \\
\mathbf{3 4 3} \\
\mathbf{3 5 6}\end{array}$ & \begin{tabular}{r|}
9 \\
10 \\
11 \\
12 \\
13 \\
14 \\
15 \\
16
\end{tabular} & $\begin{array}{r}\mathbf{3 9 7} \\
\mathbf{3 8 3} \\
\mathbf{3 9 0} \\
\mathbf{5 2 9} \\
\mathbf{8 2 0} \\
1,050 \\
1, \mathbf{1 8 0} \\
1, \mathbf{2 3 0}\end{array}$ & $\begin{array}{l}\mathbf{3 7 6} \\
\mathbf{3 7 6} \\
\mathbf{3 4 3} \\
\mathbf{3 2 5} \\
\mathbf{3 2 5} \\
\mathbf{3 2 5} \\
\mathbf{3 1 9} \\
\mathbf{3 1 4}\end{array}$ & $\begin{array}{l}17 \\
18 \\
19 \\
20 \\
21 \\
22 \\
23 \\
24\end{array}$ & $\begin{array}{r}1,090 \\
1,600 \\
2,000 \\
1,540 \\
1,180 \\
972 \\
805 \\
703\end{array}$ & $\begin{array}{l}302 \\
292 \\
287 \\
287 \\
287 \\
282 \\
282 \\
282\end{array}$ & $\begin{array}{l}25 \\
26 \\
27 \\
28 \\
29 \\
30 \\
31\end{array}$ & $\begin{array}{l}625 \\
532 \\
457 \\
404 \\
376 \\
412 \\
412\end{array}$ & $\begin{array}{r}277 \\
272 \\
272 \\
277 \\
282 \\
287 \\
\end{array}$ \\
\hline \multicolumn{10}{|c|}{$\begin{array}{l}\text { Monthly mean discharge, in second-feet. } \\
\text { Runoff, in inches }\end{array}$} & $\begin{array}{r}699 \\
1.12\end{array}$ & $\begin{array}{r}320 \\
0.50\end{array}$ \\
\hline
\end{tabular}

GDISTO RIVER NEAR GIVHANS, S. C.

Location,-Lat. $33^{\circ} 01^{\prime} 40^{\prime \prime}$, long. $80^{\circ} 23^{\prime} 30^{\prime \prime}$, at bridge on State Highway $65,2.3$ miles downstream from Four Hole Swamp, and 2.8 miles west of Givhans, Dorchester County. Datum of gage is 20.46 feet above mean sea level, datum of 1929, supplementary adjustment of 1936 .

Drainage AREA.-2,730 square miles (1945 revision).

GAGE-HEIGHT RECORD.-Water-stage recorder graph except for periods 11 p.m. Aug. 11 to 8:30 p.m. Aug. 13 and 11:30 a.m. Ang. 16 to 4 p.m. Sept. 27, which were obtained from graph based on partial record, weather records, and records for North Fork Edisto River at Orangeburg and South Fork Edisto River near Denmark.

DISCHARGE RECORD.- Stage-discharge relation defined by current-meter measurements up to 14,000 second-feet and extended to crest gage height.

Maxima.-1940: Discharge, 12,600 second-feet 12:15 a.m. Aug. 15 (gage height, 13.03 feet).

1939: Discharge, 16,900 second-feet Mar. 6, 1939 (gage height, 14.68 feet). Remarks.-Flood runoff not affected by artificial storage. Natural storage in large swampy areas. About 23,700,000 gallons a day diverted above station for Charleston water supply during August and September.

Mean discharge, in second-feet, 1940

\begin{tabular}{|c|c|c|c|c|c|c|c|c|c|c|c|}
\hline Day & Aug. & Sept. & Day & Aug. & Sept. & Day & Aug. & Sept. & Day & Aug. & Sept. \\
\hline $\begin{array}{l}1 \\
2 \\
3 \\
4 \\
5 \\
6 \\
7 \\
8\end{array}$ & $\begin{array}{l}611 \\
625 \\
597 \\
611 \\
639 \\
639 \\
639 \\
639\end{array}$ & $\begin{array}{l}2,220 \\
2,160 \\
2,060 \\
1,820 \\
1,580 \\
1,350 \\
1,18 \mathrm{C} \\
1,020\end{array}$ & $\begin{array}{r}9 \\
10 \\
11 \\
12 \\
13 \\
14 \\
15 \\
16\end{array}$ & $\begin{array}{r}667 \\
667 \\
800 \\
3,600 \\
8,540 \\
12,400 \\
12,200 \\
10,400\end{array}$ & $\begin{array}{l}958 \\
905 \\
870 \\
835 \\
\mathbf{8 3 5} \\
\mathbf{8 1 8} \\
\mathbf{7 8 4} \\
\mathbf{7 5 0}\end{array}$ & $\begin{array}{l}17 \\
18 \\
19 \\
20 \\
21 \\
22 \\
23 \\
24\end{array}$ & $\begin{array}{l}9,170 \\
8,570 \\
9,170 \\
9,370 \\
9,170 \\
8,370 \\
7,430 \\
6,350\end{array}$ & $\begin{array}{l}684 \\
668 \\
653 \\
653 \\
638 \\
638 \\
623\end{array}$ & $\begin{array}{l}25 \\
26 \\
27 \\
28 \\
29 \\
30 \\
31\end{array}$ & $\begin{array}{l}5,230 \\
4,430 \\
3,710 \\
3,140 \\
2,600 \\
2,280 \\
2,120\end{array}$ & $\begin{array}{l}623 \\
623 \\
608 \\
623 \\
653 \\
734\end{array}$ \\
\hline \multicolumn{10}{|c|}{$\begin{array}{l}\text { Monthly mean discharge, in second-feet, } \\
\text { Runoff, in inchess }\end{array}$} & $\begin{array}{r}4,690 \\
1.98\end{array}$ & $\begin{array}{r}976 \\
0.40\end{array}$ \\
\hline
\end{tabular}


NORTH FORK EDISTO RIVER AT ORA NGEBURG, S. C.

LocAtion.-Lat. $33^{\circ} 29^{\prime} 00^{\prime \prime}$, long. $80^{\circ} 52^{\prime} 25^{\prime \prime}$, at bridge on State Highway 4 at Orangeburg, Orangeburg County, 0.5 mile upstream from Atlantic Coast Line Railroad bridge and $11 / 2$ miles downstream from Caw Swamp. Datum of gage is 149.02 feet above mean sea level, datum of 1929 , supplementary adjustment of 1936 .

DrainaGe AREA.—683 square miles (1945 revision).

GAGE-HEIGHT RECORD.-Water-stage recorder graph.

DISCHARGE RECORD.-Stage-discharge relation defined by current-meter measurements. MaXima.-1940: Discharge, 2,340 second-feet 10 a.m. Aug. 19 (gage height, 8.59 feet).

1938-39: Discharge, 3,910 second-feet Mar. 3, 1939 (gage height, 9.98 feet). REMARKs.-Flood discharge not affected by artificial storage or diversion. Natural storage in swampy areas.

Mean discharge, in second-feet, 1940

\begin{tabular}{|c|c|c|c|c|c|c|c|c|c|c|c|}
\hline Day & Aug. & Sept. & Day & Aug. & Sept. & Day & Aug. & Sept. & Day & Aug. & Sept. \\
\hline $\begin{array}{l}1 \\
2 \\
3 \\
4 \\
5 \\
6 \\
7 \\
8\end{array}$ & $\begin{array}{l}274 \\
288 \\
281 \\
268 \\
268 \\
274 \\
281 \\
314\end{array}$ & $\begin{array}{l}554 \\
491 \\
448 \\
422 \\
406 \\
390 \\
382 \\
382\end{array}$ & $\begin{array}{r}9 \\
10 \\
11 \\
12 \\
13 \\
14 \\
15 \\
16\end{array}$ & $\begin{array}{r}356 \\
356 \\
363 \\
687 \\
1,340 \\
2,070 \\
1,930 \\
1,710\end{array}$ & $\begin{array}{l}374 \\
358 \\
366 \\
358 \\
342 \\
335 \\
328 \\
320\end{array}$ & $\begin{array}{l}17 \\
18 \\
19 \\
20 \\
21 \\
22 \\
23 \\
24\end{array}$ & $\begin{array}{r}1,520 \\
1,800 \\
2,300 \\
1,990 \\
1,500 \\
1,140 \\
896 \\
\mathbf{7 5 4}\end{array}$ & $\begin{array}{l}312 \\
305 \\
305 \\
305 \\
298 \\
298 \\
298 \\
\mathbf{8 9 8}\end{array}$ & $\begin{array}{l}25 \\
26 \\
27 \\
28 \\
29 \\
30 \\
31\end{array}$ & $\begin{array}{l}\mathbf{6 5 7} \\
582 \\
509 \\
\mathbf{4 5 6} \\
\mathbf{4 4 8} \\
\mathbf{5 3 6} \\
\mathbf{6 0 2}\end{array}$ & $\begin{array}{l}298 \\
298 \\
305 \\
312 \\
320 \\
312\end{array}$ \\
\hline $\mathbf{n}$ & & & & & & & & & & $\begin{array}{r}863 \\
1.46\end{array}$ & $\begin{array}{r}351 \\
0.57\end{array}$ \\
\hline
\end{tabular}

\section{SAVANNAH RIVER BASIN}

CHATTOOGA RIVER NEAR CLAYTON, GA.

Location.-Lat. $34^{\circ} 49^{\prime}$, long. $83^{\circ} 18^{\prime}$, at Rogues Ford, at bridge on U. S. Highway $76,2 \%$ miles upstream from Stekoa Creek, 7 miles southeast of Clayton, Rabun County, 9 miles downstream from War Woman Creek, and 9 miles upstream from confluence with Tallulah River to form Tugaloo River.

DRAINAGE AREA.-203 square miles.

Gage-HEIGHT RECORD.-Water-stage recorder graph except for 7 p.m. Aug. 13 to 11 a.m. Aug. 14 where it was determined by interpolation.

DISCHARGE RECORD.-Stage-discharge relation defined by current-meter measurements up to 700 second-feet and extended to erest gage height on basis of three independent slope-area determinations. Gage heights used to half-tenths between 2.6 and 4.7 feet; hundredths below and tenths above these limits.

Maxima.-1907-8, 1939-40: Discharge, 29,000 second-feet 6 a.m. Aug. 30 (gage height, 13.78 feet).

Discharge during flood of Aug. 15, 1928, 20,700 second-feet.

REMARKs.-Flood runoff not affected by storage or diversion.

Mean discharge, in second-feet, 1940

\begin{tabular}{|c|c|c|c|c|c|c|c|c|c|c|c|}
\hline Day & Aug. & Sept. & Day & Aug. & Sept. & Day & Aug. & Sept. & Day & Aug. & Sept. \\
\hline $\begin{array}{l}1 \\
2 \\
3 \\
4 \\
5 \\
6 \\
7 \\
8\end{array}$ & $\begin{array}{l}212 \\
220 \\
204 \\
188 \\
181 \\
196 \\
254 \\
237\end{array}$ & $\begin{array}{r}1,700 \\
1,360 \\
1,170 \\
1,050 \\
998 \\
953 \\
\mathbf{8 7 4} \\
\mathbf{8 0 2}\end{array}$ & $\begin{array}{r}9 \\
10 \\
11 \\
12 \\
13 \\
14 \\
15 \\
16\end{array}$ & $\begin{array}{r}232 \\
220 \\
189 \\
466 \\
9,580 \\
2,690 \\
1,390 \\
1,020\end{array}$ & $\begin{array}{l}762 \\
722 \\
674 \\
635 \\
612 \\
590 \\
568 \\
547\end{array}$ & $\begin{array}{l}17 \\
18 \\
19 \\
20 \\
21 \\
22 \\
23 \\
24\end{array}$ & $\begin{array}{l}818 \\
706 \\
635 \\
568 \\
533 \\
505 \\
472 \\
453\end{array}$ & $\begin{array}{l}519 \\
505 \\
492 \\
486 \\
466 \\
446 \\
428 \\
479\end{array}$ & $\begin{array}{l}25 \\
26 \\
27 \\
28 \\
29 \\
30 \\
31\end{array}$ & $\begin{array}{r}428 \\
403 \\
384 \\
370 \\
1,640 \\
13,900 \\
2,520\end{array}$ & $\begin{array}{l}512 \\
453 \\
409 \\
390 \\
384 \\
372\end{array}$ \\
\hline \multicolumn{10}{|c|}{$\begin{array}{l}\text { Monthly mean discharge, in second-feet. } \\
\text { Runoff, in inches }\end{array}$} & $\begin{array}{r}1,349 \\
7.67\end{array}$ & $\begin{array}{r}679 \\
3.73\end{array}$ \\
\hline
\end{tabular}


FLOODS OF AUGUST 1940 IN THE SOUTHEASTERN STATES

Gage height, in feet, and discharge, in second-feet, at indicated time, 1940

\begin{tabular}{|c|c|c|c|c|c|c|c|c|c|c|}
\hline \multirow{2}{*}{ Hour } & \multicolumn{2}{|c|}{ Aug. 12} & \multicolumn{2}{|c|}{ Aug. 13} & \multicolumn{2}{|c|}{ Aug. 14} & \multicolumn{2}{|c|}{ Aug. 15} & \multicolumn{2}{|c|}{ Aug. 16} \\
\hline & $\begin{array}{c}\text { Gage } \\
\text { height }\end{array}$ & $\begin{array}{l}\text { Dis- } \\
\text { charge }\end{array}$ & $\begin{array}{c}\text { Gage } \\
\text { height }\end{array}$ & $\begin{array}{c}\text { Dis- } \\
\text { charge }\end{array}$ & $\begin{array}{c}\text { Gage } \\
\text { height }\end{array}$ & $\begin{array}{c}\text { Dis- } \\
\text { charge }\end{array}$ & $\begin{array}{c}\text { Gage } \\
\text { height }\end{array}$ & $\begin{array}{l}\text { Dis- } \\
\text { charge }\end{array}$ & $\begin{array}{c}\text { Gage } \\
\text { height }\end{array}$ & $\begin{array}{c}\text { Dis- } \\
\text { charge }\end{array}$ \\
\hline $\begin{array}{l}1 \\
2 \\
3 \\
4 \\
5 \\
6\end{array}$ & $\begin{array}{l}1.12 \\
1.12 \\
1.13 \\
1.13 \\
.1 .14 \\
1.14\end{array}$ & $\begin{array}{l}196 \\
196 \\
200 \\
200 \\
204 \\
204\end{array}$ & $\begin{array}{l}3.34 \\
3.48 \\
3.86 \\
4.28 \\
5.25 \\
6.14\end{array}$ & $\begin{array}{l}2,090 \\
2,280 \\
2,740 \\
3,390 \\
4,840 \\
6,500\end{array}$ & $\begin{array}{l}4.94 \\
4.80 \\
4.64 \\
4.47 \\
4.35 \\
4.23\end{array}$ & $\begin{array}{l}4,330 \\
4,170 \\
3,930 \\
3,620 \\
3,460 \\
3,320\end{array}$ & 2.91 & 1,570 & $\begin{array}{r}2.43 \\
-1\end{array}$ & 1,100 \\
\hline $\begin{array}{r}7 \\
8 \\
9 \\
10 \\
11 \\
\mathrm{~N}\end{array}$ & $\begin{array}{l}1.15 \\
1.18 \\
1.20 \\
1.24 \\
1.39 \\
1.50\end{array}$ & $\begin{array}{l}208 \\
220 \\
228 \\
246 \\
317 \\
378\end{array}$ & $\begin{array}{l}6.36 \\
7.23 \\
7.87 \\
8.54 \\
9.30 \\
9.74\end{array}$ & $\begin{array}{r}7,100 \\
8,840 \\
10,500 \\
11,900 \\
14,000 \\
15,100\end{array}$ & $\begin{array}{l}4.12 \\
4.01 \\
3.91 \\
3.81 \\
3.69 \\
3.64\end{array}$ & $\begin{array}{l}3,090 \\
2,950 \\
2,810 \\
2,670 \\
2,540 \\
2,480\end{array}$ & 2.72 & 1,460 & $\begin{array}{r}2.39 \\
\end{array}$ & $\begin{array}{r}1,060 \\
1,020\end{array}$ \\
\hline $\begin{array}{l}1 \\
2 \\
3 \\
4 \\
5 \\
6\end{array}$ & $\begin{array}{l}1.54 \\
1.55 \\
1.50 \\
1.51 \\
1.64 \\
1.72\end{array}$ & $\begin{array}{l}403 \\
409 \\
378 \\
384 \\
466 \\
519\end{array}$ & $\begin{array}{l}9.92 \\
9.94 \\
9.87 \\
9.77 \\
9.51 \\
9.18\end{array}$ & $\begin{array}{l}15,700 \\
15,700 \\
15,700 \\
15,400 \\
14,600 \\
13,700\end{array}$ & $\begin{array}{l}3.55 \\
3.50 \\
3.40 \\
3.34 \\
3.29 \\
3.24\end{array}$ & $\begin{array}{l}2,340 \\
2,280 \\
2,150 \\
2,090 \\
2,030 \\
1,970\end{array}$ & 2.64 & 1,310 & 2.31 & 989 \\
\hline $\begin{array}{r}7 \\
8 \\
9 \\
10 \\
11 \\
12 \\
\end{array}$ & $\begin{array}{l}1.84 \\
1.96 \\
2.14 \\
2.40 \\
2.91 \\
3.22 \\
\end{array}$ & $\begin{array}{r}605 \\
698 \\
842 \\
1,070 \\
1,570 \\
1,910 \\
\end{array}$ & $\begin{array}{l}8.74 \\
8.15 \\
7.43 \\
6.62 \\
5.90 \\
5.20 \\
\end{array}$ & $\begin{array}{r}12,400 \\
11,200 \\
9,280 \\
7,520 \\
6,110 \\
4,840 \\
\end{array}$ & $\begin{array}{l}3.20 \\
3.16 \\
3.12 \\
3.07 \\
3.05 \\
3.01 \\
\end{array}$ & $\begin{array}{l}1,910 \\
1,850 \\
1,790 \\
1,740 \\
1,740 \\
1,680 \\
\end{array}$ & $\begin{array}{r}2.55 \\
2.48 \\
\end{array}$ & 1,210 & \begin{tabular}{|c|}
2.26 \\
2.22 \\
\end{tabular} & $\begin{array}{c}9 \overline{4} \overline{4} \\
908 \\
\end{array}$ \\
\hline & \multicolumn{2}{|c|}{ Aug. 29} & \multicolumn{2}{|c|}{ Aug. 30} & \multicolumn{2}{|c|}{ Aug. 31} & \multicolumn{2}{|c|}{ Sept. 1} & \multicolumn{2}{|c|}{ Sept. 2} \\
\hline $\begin{array}{l}1 \\
2 \\
3 \\
4 \\
5 \\
6\end{array}$ & $\begin{array}{l}1.47 \\
1.47 \\
1.47 \\
1.47 \\
1.46 \\
1.47\end{array}$ & $\begin{array}{l}\mathbf{3 6 1} \\
\mathbf{3 6 1} \\
\mathbf{3 6 1} \\
\mathbf{3 6 1} \\
\mathbf{3 5 6} \\
\mathbf{3 6 1}\end{array}$ & $\begin{array}{r}9.00 \\
11.65 \\
13.00 \\
13.43 \\
13.51 \\
13.78\end{array}$ & $\begin{array}{l}13,200 \\
20,900 \\
25,800 \\
27,400 \\
27,800 \\
29,000\end{array}$ & 4.00 & $\begin{array}{l}3,090 \\
2,950 \\
2,810\end{array}$ & 3.14 & 1,850 & 2.77 & 1,410 \\
\hline $\begin{array}{r}7 \\
8 \\
9 \\
10 \\
11 \\
\mathrm{~N}\end{array}$ & $\begin{array}{l}1.49 \\
1.53 \\
1.64 \\
1.95 \\
2.06 \\
1.93\end{array}$ & $\begin{array}{l}372 \\
397 \\
466 \\
690 \\
778 \\
674\end{array}$ & $\begin{array}{r}13.63 \\
13.00 \\
12.15 \\
11.17 \\
10.00 \\
8.67\end{array}$ & $\begin{array}{l}25,800 \\
23,000 \\
19,600 \\
16,000 \\
12,400\end{array}$ & $\begin{array}{l}3.79 \\
3.70 \\
3.64\end{array}$ & $\begin{array}{l}2,670 \\
2,540 \\
2,480\end{array}$ & 3.01 & $1,790^{-}$ & $2.7 \overline{2}$ & $1,360^{-}$ \\
\hline $\begin{array}{l}1 \\
2 \\
3 \\
4 \\
5 \\
6\end{array}$ & $\begin{array}{l}2.02 \\
2.30 \\
2.76 \\
2.71 \\
2.69 \\
3.03\end{array}$ & $\begin{array}{r}746 \\
\mathbf{9 8 0} \\
1,410 \\
1,360 \\
1,360 \\
1,740\end{array}$ & $\begin{array}{l}7.51 \\
6.74 \\
6.16 \\
5.69 \\
5.29 \\
5.11\end{array}$ & $\begin{array}{l}7,740 \\
6,700 \\
5,730 \\
5,010 \\
4,670\end{array}$ & $\begin{array}{r}3.55 \\
3.50 \\
3.46\end{array}$ & $\begin{array}{l}2,340 \\
2,280 \\
2,220\end{array}$ & 2.96 & $1,620^{-}$ & 2.66 & 1,310 \\
\hline $\begin{array}{r}7 \\
8 \\
9 \\
10 \\
11 \\
12\end{array}$ & $\begin{array}{l}3.19 \\
3.52 \\
4.90 \\
5.95 \\
6.20 \\
7.38\end{array}$ & $\begin{array}{l}1,910 \\
2,280 \\
4,330 \\
6,300 \\
6,700 \\
9,280\end{array}$ & $\begin{array}{l}4.91 \\
4.76 \\
4.63 \\
4.49 \\
4.41 \\
4.33\end{array}$ & $\begin{array}{r}4,330 \\
4,170 \\
3,930 \\
3,690 \\
3,540 \\
3,460\end{array}$ & $\begin{array}{c}3.36 \\
3.28 \\
3.22\end{array}$ & $\begin{array}{l}2,090 \\
2,030 \\
1,910\end{array}$ & 2.82 & $1,570^{-}$ & 2.59 & 1,260 \\
\hline
\end{tabular}

TUGALOO RIVER NEAR HARTWELL, GA.

Location.-Lat. $34^{\circ} 29^{\prime}$, long. $82^{\circ} 55^{\prime}$, three quarters of a mile upstream from Beaverdam Creek, 5 miles upstream from confluence with Seneca River to form Savannah River, and 10 miles north of Hartwell, Hart County.

Drainage AREA. -905 square miles; 150 square miles affected by storage in Burton and Mathis Reservoirs.

GAGE-HEIGHT RECORD.-Water-stage recorder graph.

DISCHARGE RECORD.-Stage-discharge relation defined by current-meter measurements up to 25,000 second-feet. Gage heights used to half-tenths between 3.2 and 6.2 feet; hundredths below and tenths above these limits.

Maxima.-1940: Diseharge, 28,600 second-feet 4 a.m. Aug. 31 (gage height, 10.76 feet). 
1925-27: Discharge, 15,400 second-feet Jan. 18, 1926 (gage height, 7.76 feet, datum then in use).

REMARKs.-Monthly mean discharge and runoff, in inches, adjusted for storage in Burton and Mathis Reservoirs.

Mean discharge, in second-feet, 1940

\begin{tabular}{|c|c|c|c|c|c|c|c|c|c|c|c|}
\hline Day & Aug. & Sept. & Day & Aug. & Sept. & Day & Aug. & Sept. & Day & Aug. & Sept. \\
\hline $\begin{array}{l}1 \\
2 \\
3 \\
4 \\
5 \\
6 \\
7 \\
8\end{array}$ & $\begin{array}{r}1,030 \\
955 \\
1,040 \\
246 \\
190 \\
280 \\
995 \\
885\end{array}$ & $\begin{array}{l}5,280 \\
2,350 \\
3,070 \\
2,930 \\
3,080 \\
3,030 \\
1,910 \\
1,780\end{array}$ & $\begin{array}{r}9 \\
10 \\
11 \\
12 \\
13 \\
14 \\
15 \\
16\end{array}$ & $\begin{array}{r}1,400 \\
675 \\
247 \\
2,040 \\
21,700 \\
23,700 \\
7,290 \\
3,390\end{array}$ & $\begin{array}{r}700 \\
2,060 \\
2,120 \\
2,360 \\
2,180 \\
-1,980 \\
530 \\
615\end{array}$ & $\begin{array}{l}17 \\
18 \\
19 \\
20 \\
21 \\
22 \\
23 \\
24\end{array}$ & $\begin{array}{r}3,450 \\
1,940 \\
742 \\
1,940 \\
1,910 \\
1,800 \\
2,140 \\
1,930\end{array}$ & $\begin{array}{r}1,710 \\
1,300 \\
1,560 \\
1,780 \\
.1,860 \\
460 \\
395 \\
1,430\end{array}$ & $\begin{array}{l}25 \\
26 \\
27 \\
28 \\
29 \\
30 \\
31\end{array}$ & $\begin{array}{r}500 \\
452 \\
1,210 \\
1,360- \\
2,340 \\
16,300 \\
20,600\end{array}$ & $\begin{array}{r}1,420 \\
1,890 \\
1,780 \\
1,460 \\
425 \\
365\end{array}$ \\
\hline un & & $d j$ & & & & & & & & $\begin{array}{r}4,022 \\
4,168 \\
5.32\end{array}$ & $\begin{array}{r}1,794 \\
1,651 \\
2.03\end{array}$ \\
\hline
\end{tabular}

Gage height, in feet, and discharge, in second-feet, at indicated time, 1940

\begin{tabular}{|c|c|c|c|c|c|c|c|c|c|c|c|}
\hline \multirow{2}{*}{ Hour } & \multicolumn{2}{|c|}{ Aug. 11} & \multicolumn{2}{|c|}{ Aug. 12} & \multicolumn{2}{|c|}{ Aug. 13} & \multicolumn{3}{|c|}{ Aug. 14} & \multicolumn{2}{|c|}{ Aug. 15} \\
\hline & $\begin{array}{c}\text { Gage } \\
\text { height }\end{array}$ & $\begin{array}{c}\text { Dis- } \\
\text { charge }\end{array}$ & $\begin{array}{c}\text { Gage } \\
\text { height }\end{array}$ & $\begin{array}{c}\text { Dis- } \\
\text { charge }\end{array}$ & $\begin{array}{c}\text { Gage } \\
\text { height }\end{array}$ & $\begin{array}{l}\text { Dis- } \\
\text { charge }\end{array}$ & $\begin{array}{c}\text { Gage } \\
\text { height }\end{array}$ & \multicolumn{2}{|c|}{$\begin{array}{c}\text { Dis- } \\
\text { charge }\end{array}$} & $\begin{array}{l}\text { Gage } \\
\text { height }\end{array}$ & $\begin{array}{c}\text { Dis- } \\
\text { charge }\end{array}$ \\
\hline $\begin{array}{l}1 \\
2 \\
3 \\
4 \\
5 \\
6\end{array}$ & $\begin{array}{l}2.00 \\
1.95 \\
1.90 \\
1.85 \\
1.81 \\
1.77\end{array}$ & $\begin{array}{l}390 \\
365 \\
340 \\
315 \\
295 \\
275\end{array}$ & $\begin{array}{l}1.57 \\
1.58 \\
1.59 \\
1.60 \\
1.62 \\
1.78\end{array}$ & $\begin{array}{l}190 \\
194 \\
198 \\
202 \\
210 \\
280\end{array}$ & $\begin{array}{l}6.90 \\
7.74 \\
8.44 \\
8.93 \\
9.32 \\
9.56\end{array}$ & $\begin{array}{r}9,860 \\
12,800 \\
15,700 \\
18,000 \\
20,000 \\
21,600\end{array}$ & $\begin{array}{r}9.88 \\
9.85 \\
9.88 \\
9.92 \\
9.94 \\
10.02\end{array}$ & \multicolumn{2}{|c|}{$\begin{array}{l}23,200 \\
22,700 \\
23,200 \\
23,200 \\
23,200 \\
23,800\end{array}$} & $\begin{array}{l}8.50 \\
8.17 \\
7.80 \\
7.43 \\
7.03 \\
6.67\end{array}$ & $\begin{array}{r}16,100 \\
14,800 \\
13,200 \\
11,700 \\
10,200 \\
9,180\end{array}$ \\
\hline $\begin{array}{r}7 \\
8 \\
9 \\
10 \\
11 \\
\mathbf{N}\end{array}$ & $\begin{array}{l}1.74 \\
1.72 \\
1.69 \\
1.68 \\
1.66 \\
1.65\end{array}$ & $\begin{array}{l}260 \\
250 \\
238 \\
234 \\
226 \\
222\end{array}$ & $\begin{array}{l}1.92 \\
2.10 \\
2.90 \\
3.30 \\
3.31 \\
3.37\end{array}$ & $\begin{array}{r}350 \\
\mathbf{4 4 8} \\
1,080 \\
1,520 \\
1,540 \\
1,600\end{array}$ & $\begin{array}{r}9.82 \\
9.93 \\
10.00 \\
10.02 \\
10.04 \\
10.03\end{array}$ & $\begin{array}{l}22,700 \\
23,200 \\
23,800 \\
23,800 \\
23,800 \\
23,800\end{array}$ & $\begin{array}{l}10.12 \\
10.19 \\
10.29 \\
10.32 \\
10.37 \\
10.40\end{array}$ & \multicolumn{2}{|c|}{$\begin{array}{l}24,400 \\
25,000 \\
25,600 \\
25,600 \\
26,200 \\
26,200\end{array}$} & $\begin{array}{l}6.33 \\
6.05 \\
5.81 \\
5.60 \\
5.43 \\
5.27\end{array}$ & $\begin{array}{l}7,900 \\
7,150 \\
6,440 \\
5,900 \\
5,520 \\
5,050\end{array}$ \\
\hline $\begin{array}{l}1 \\
2 \\
3 \\
4 \\
5 \\
6\end{array}$ & $\begin{array}{l}1.64 \\
1.62 \\
1.60 \\
1.60 \\
1.60 \\
1.60\end{array}$ & $\begin{array}{l}218 \\
210 \\
202 \\
202 \\
202 \\
202\end{array}$ & $\begin{array}{l}3.65 \\
4.18 \\
4.52 \\
4.61 \\
4.56 \\
4.48\end{array}$ & $\begin{array}{l}1,920 \\
2,740 \\
3,340 \\
3,520 \\
3,430 \\
3,250\end{array}$ & $\begin{array}{l}10.08 \\
10.12 \\
10.13 \\
10.19 \\
10.19 \\
10.14\end{array}$ & $\begin{array}{l}24,400 \\
24,400 \\
24,400 \\
25,000 \\
25,000 \\
24,400\end{array}$ & $\begin{array}{l}10.42 \\
10.40 \\
10.37 \\
10.25 \\
10.10 \\
10.02\end{array}$ & \multicolumn{2}{|c|}{$\begin{array}{l}26,200 \\
26,200 \\
26,200 \\
25,000 \\
24,400 \\
23,800\end{array}$} & $\begin{array}{r}5.14 \\
5.05 \\
5.03 \\
5.10 \\
5.18 \\
5.22\end{array}$ & $\begin{array}{l}4,830 \\
4,610 \\
4,610 \\
4,720 \\
4,940 \\
4,490\end{array}$ \\
\hline $\begin{array}{r}7 \\
8 \\
9 \\
10 \\
11 \\
12 \\
\end{array}$ & $\begin{array}{l}1.60 \\
1.60 \\
1.60 \\
1.59 \\
1.58 \\
1.58 \\
\end{array}$ & $\begin{array}{l}202 \\
202 \\
202 \\
198 \\
194 \\
194 \\
\end{array}$ & $\begin{array}{l}4.39 \\
4.37 \\
4.53 \\
4.95 \\
5.57 \\
6.24 \\
\end{array}$ & $\begin{array}{l}3,070 \\
3,070 \\
3,340 \\
4,200 \\
5,520 \\
7,300 \\
\end{array}$ & $\begin{array}{r}10.11 \\
10.04 \\
10.03 \\
9.94 \\
9.89 \\
9.84 \\
\end{array}$ & $\begin{array}{l}24,400 \\
23,800 \\
23,800 \\
23,200 \\
23,200 \\
22,700 \\
\end{array}$ & $\begin{array}{l}9.89 \\
9.78 \\
9.48 \\
9.28 \\
9.03 \\
8.74 \\
\end{array}$ & \multicolumn{2}{|c|}{$\begin{array}{l}23,200 \\
22,700 \\
21,000 \\
20,000 \\
18,500 \\
17,060 \\
\end{array}$} & $\begin{array}{l}5.22 \\
5.17 \\
5.07 \\
4.93 \\
4.77 \\
4.60 \\
\end{array}$ & $\begin{array}{l}4,940 \\
4,830 \\
4,610 \\
4,400 \\
4,000 \\
3,700 \\
\end{array}$ \\
\hline & \multicolumn{3}{|c|}{ Aug. 29} & \multicolumn{2}{|c|}{ Aug. 30} & \multicolumn{3}{|c|}{ Aug. 31} & & \multicolumn{2}{|c|}{ Sept. 1} \\
\hline $\begin{array}{l}1 \\
2 \\
3 \\
4 \\
5 \\
6\end{array}$ & $\begin{array}{l}3.29 \\
3.24 \\
3.16 \\
3.09 \\
3.00 \\
2.94\end{array}$ & \multicolumn{2}{|c|}{$\begin{array}{l}1,660 \\
1,600 \\
1,490 \\
1,410 \\
1,300 \\
1,240\end{array}$} & $\begin{array}{l}6.55 \\
6.74 \\
6.98 \\
7.05 \\
7.17 \\
7.28\end{array}$ & $\begin{array}{r}8,860 \\
9,180 \\
10,200 \\
10,200 \\
10,900 \\
11,300\end{array}$ & $\begin{array}{l}10.52 \\
10.60 \\
10.69 \\
10.76 \\
10.74 \\
10.59\end{array}$ & \multicolumn{2}{|c|}{$\begin{array}{l}26,800 \\
27,400 \\
28,000 \\
28,600 \\
28,000 \\
27,400\end{array}$} & & $\begin{array}{l}89 \\
\overline{7} \overline{1} \\
\overline{5}\end{array}$ & $6,7,160^{6}$ \\
\hline $\begin{array}{r}7 \\
8 \\
9 \\
10 \\
11 \\
N\end{array}$ & $\begin{array}{l}2.97 \\
3.09 \\
3.21 \\
3.29 \\
3.29 \\
3.24\end{array}$ & $\begin{array}{l}1,2 \\
1,4 \\
1,5 \\
1,8 \\
1,8 \\
1,8\end{array}$ & & $\begin{array}{l}7.41 \\
7.51 \\
7.75 \\
8.02 \\
8.18 \\
8.44\end{array}$ & $\begin{array}{l}11,700 \\
12,000 \\
13,200 \\
14,000 \\
14,800 \\
15,700\end{array}$ & $\begin{array}{r}10.46 \\
10.38 \\
10.31 \\
10.13 \\
9.92 \\
9.73\end{array}$ & $\begin{array}{l}26 \\
26 \\
25 \\
24 \\
23 \\
22\end{array}$ & & & 44 & $\begin{array}{l}5,640 \\
5,520^{-} \\
5,400\end{array}$ \\
\hline $\begin{array}{l}1 \\
2 \\
3 \\
4 \\
5 \\
6\end{array}$ & $\begin{array}{l}3.17 \\
3.06 \\
2.97 \\
2.91 \\
3.04 \\
3.10\end{array}$ & $\begin{array}{l}1, \\
1,2 \\
1,2 \\
1,2 \\
1,2 \\
1,4\end{array}$ & & $\begin{array}{l}8.69 \\
8.76 \\
8.98 \\
9.12 \\
9.28 \\
9.61\end{array}$ & $\begin{array}{l}17,100 \\
17,500 \\
18,500 \\
19,000 \\
20,000 \\
21,600\end{array}$ & $\begin{array}{l}9.48 \\
9.27 \\
9.06 \\
8.78 \\
8.52 \\
8.20\end{array}$ & $\begin{array}{l}21, \\
20, \\
19, \\
17, \\
16, \\
14,\end{array}$ & & & $\begin{array}{l}30^{-} \\
144^{-}\end{array}$ & $\begin{array}{l}5,160^{-} \\
4,830^{-400^{-1}}\end{array}$ \\
\hline $\begin{array}{r}7 \\
8 \\
9 \\
10 \\
11 \\
12\end{array}$ & $\begin{array}{l}3.16 \\
3.35 \\
5.20 \\
6.35 \\
6.62 \\
6.50\end{array}$ & $\begin{array}{l}1,4 \\
1,7 \\
4, \\
8, \\
8, \\
8,\end{array}$ & & $\begin{array}{r}9.68 \\
9.68 \\
9.98 \\
10.06 \\
10.22 \\
10.34\end{array}$ & $\begin{array}{l}22,200 \\
22,200 \\
23,800 \\
24,400 \\
25,000 \\
25,600\end{array}$ & $\begin{array}{l}7.84 \\
7.47 \\
7.10 \\
6.86 \\
6.50 \\
6.22\end{array}$ & $\begin{array}{r}13, \\
12, \\
10, \\
9, \\
8, \\
7,\end{array}$ & & & $\begin{array}{l}79 \\
71 \\
60\end{array}$ & $\begin{array}{l}4,100^{-} \\
3,900^{-}\end{array}$ \\
\hline
\end{tabular}


SAVANNAH RIVER NEAR CALHOUN FALLS, S. C.

LOCATION.-Lat. $34^{\circ} 04^{\prime}$, long. $82^{\circ} 38^{\prime}, 150$ feet upstream from bridge on State Highway 7, 1 mile downstream from Seaboard Railway bridge, 11/2 miles downstream from Rocky River, and 3 miles southwest of Calhoun Falls, Ábbeville County. Datum of gage is 363.53 feet above mean sea level, datum of 1929, supplementary adjustment of 1936 .

Drain age AREa.-2,876 square miles.

GAGE-HEIGHT RECORD.-Water-stage recorder graph.

DISCHARGE RECORD.- - Stage-discharge relation defined by current-meter measurements up to 50,000 second-feet and extended to crest gage height on basis of velocityarea studies and logarithmic plotting.

Maxima.-1940: Discharge, 96,500 second-feet 7 p.m. Aug. 13 (gage height, 11.52 feet).

1896-1903, 1930-32, 1938-39: Discharge observed, about 75,200 second-feet Feb. 14, 1900 (gage height, 19.4 feet, former site and datum).

Stage known, 28.2 feet Aug. 25, 1908, original site and datum.

A flood of 97,600 second-feet occurred Oct. 17, 1932 (gage height, 11.6 feet). REMARKs.-Flood discharge not materially affected by artificial storage. Flow regulated during medium and low stages by power plants above station.

\begin{tabular}{|c|c|c|c|c|c|c|c|c|c|c|c|}
\hline Day & Aug. & Sept. & Day & Aug. & Sept. & Day & Aug. & Sept. & Day & Aug. & Sept. \\
\hline $\begin{array}{l}1 \\
2 \\
3 \\
4 \\
5 \\
6 \\
7 \\
8\end{array}$ & $\begin{array}{l}1,800 \\
1,890 \\
1,800 \\
1,840 \\
1,110 \\
1,020 \\
1,260 \\
3,600\end{array}$ & $\begin{array}{r}19,200 \\
8,360 \\
6,730 \\
6,060 \\
6,280 \\
5,840 \\
5,490 \\
4,040\end{array}$ & $\begin{array}{r}9 \\
10 \\
11 \\
12 \\
13 \\
14 \\
15 \\
16\end{array}$ & $\begin{array}{r}2,310 \\
2,110 \\
1,650 \\
2,740 \\
68,100 \\
74,700 \\
42,200 \\
11,300\end{array}$ & $\begin{array}{l}3,170 \\
3,540 \\
4,230 \\
4,210 \\
4,300 \\
4,020 \\
2,930 \\
2,020\end{array}$ & $\begin{array}{l}17 \\
18 \\
19 \\
20 \\
21 \\
22 \\
23 \\
24\end{array}$ & $\begin{array}{l}8,080 \\
6,970 \\
4,400 \\
4,280 \\
4,300 \\
4,020 \\
4,140 \\
4,260\end{array}$ & $\begin{array}{l}2,860 \\
2,840 \\
3,070 \\
3,380 \\
3,740 \\
2,720 \\
1,410 \\
2,090\end{array}$ & $\begin{array}{l}25 \\
26 \\
27 \\
28 \\
29 \\
30 \\
31\end{array}$ & $\begin{array}{r}3,060 \\
2,180 \\
2,360 \\
2,840 \\
3,020 \\
25,200 \\
46,800\end{array}$ & $\begin{array}{r}2,850 \\
3,180 \\
3,340 \\
3,020 \\
2,410 \\
1,540 \\
--.-\end{array}$ \\
\hline \multicolumn{10}{|c|}{$\begin{array}{l}\text { Monthly mean discharge, in second-feet, } \\
\text { Runoff, in inches }\end{array}$} & $\begin{array}{r}11,140 \\
4.46\end{array}$ & $\begin{array}{r}4,296 \\
1.66 \\
\end{array}$ \\
\hline
\end{tabular}


SAVANNAH RIVER BASIN

Gage height, in feet, and discharge, in second-feet, at indicated time, 1940

\begin{tabular}{|c|c|c|c|c|c|c|c|c|c|c|}
\hline \multirow{2}{*}{ Hour } & \multicolumn{2}{|c|}{ Aug. 12} & \multicolumn{2}{|c|}{ Aug. 13} & \multicolumn{2}{|c|}{ Aug. 14} & \multicolumn{2}{|c|}{ Aug. 15} & \multicolumn{2}{|c|}{ Aug. 16} \\
\hline & $\begin{array}{c}\text { Gage } \\
\text { height }\end{array}$ & $\begin{array}{c}\text { Dis- } \\
\text { charge }\end{array}$ & $\begin{array}{c}\text { Gage } \\
\text { height }\end{array}$ & $\begin{array}{c}\text { Dis- } \\
\text { charge }\end{array}$ & $\begin{array}{c}\text { Gage } \\
\text { height }\end{array}$ & $\begin{array}{c}\text { Dis- } \\
\text { charge }\end{array}$ & $\begin{array}{c}\text { Gage } \\
\text { height }\end{array}$ & $\begin{array}{c}\text { Dis- } \\
\text { charge }\end{array}$ & $\begin{array}{c}\text { Gage } \\
\text { height }\end{array}$ & $\begin{array}{l}\text { Dis- } \\
\text { charge }\end{array}$ \\
\hline $\begin{array}{l}\mathbf{1} \\
\mathbf{2} \\
\mathbf{3} \\
\mathbf{4} \\
\mathbf{5} \\
\mathbf{6}\end{array}$ & -- & & $\begin{array}{l}4.92 \\
5.70 \\
6.04 \\
6.33 \\
6.71 \\
7.20\end{array}$ & $\begin{array}{l}20,100 \\
26,700 \\
29,800 \\
32,600 \\
36,400 \\
41,600\end{array}$ & $\begin{array}{r}10.67 \\
10.50 \\
10.36 \\
10.19 \\
10.07 \\
9.96\end{array}$ & $\begin{array}{l}85,000 \\
82,800 \\
80,900 \\
78,600 \\
76,900 \\
75,500\end{array}$ & $\begin{array}{l}9.44 \\
9.34 \\
9.20 \\
9.03 \\
8.84 \\
8.61\end{array}$ & $\begin{array}{l}68,700 \\
67,400 \\
65,600 \\
63,400 \\
61,000 \\
58,100\end{array}$ & 4.07 & 13,800 \\
\hline $\begin{array}{r}7 \\
8 \\
9 \\
10 \\
11 \\
\text { N }\end{array}$ & 1.05 & 1,240 & $\begin{array}{r}7.76 \\
8.32 \\
8.83 \\
9.34 \\
9.79 \\
10.16\end{array}$ & $\begin{array}{l}47,700 \\
54,500 \\
60,900 \\
67,400 \\
73,300 \\
78,200\end{array}$ & $\begin{array}{l}9.88 \\
9.81 \\
9.79 \\
9.74 \\
9.72 \\
9.71\end{array}$ & $\begin{array}{l}74,400 \\
73,500 \\
73,300 \\
72,600 \\
72,400 \\
72,200\end{array}$ & $\begin{array}{l}8.34 \\
8.10 \\
7.83 \\
7.57 \\
7.47 \\
7.22\end{array}$ & $\begin{array}{l}54,800 \\
51,900 \\
48,700 \\
45,700 \\
44,600 \\
41,800\end{array}$ & 3.77 & $\begin{array}{r}12,000 \\
10,300\end{array}$ \\
\hline $\begin{array}{l}1 \\
2 \\
3 \\
4 \\
5 \\
6\end{array}$ & $\begin{array}{l}1.06 \\
1.06 \\
1.07 \\
1.09 \\
1.12 \\
1.34\end{array}$ & $\begin{array}{l}1,250 \\
1,250 \\
1,270 \\
1,300 \\
1,350 \\
1,750\end{array}$ & $\begin{array}{l}10.55 \\
10.90 \\
11.08 \\
11.29 \\
11.46 \\
11.50\end{array}$ & $\begin{array}{l}83,400 \\
88,200 \\
90,600 \\
93,400 \\
95,700 \\
96,200\end{array}$ & $\begin{array}{l}9.71 \\
9.73 \\
9.73 \\
9.73 \\
9.75 \\
9.74\end{array}$ & $\begin{array}{l}72,200 \\
72,500 \\
72,500 \\
72,500 \\
72,800 \\
72,600\end{array}$ & $\begin{array}{l}6.93 \\
6.66 \\
6.39 \\
6.12 \\
5.86 \\
5.68\end{array}$ & $\begin{array}{l}38,700 \\
35,900 \\
33,200 \\
30,600 \\
28,100 \\
26,500\end{array}$ & 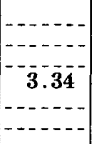 & $\begin{array}{r}9,630 \\
0\end{array}$ \\
\hline $\begin{array}{r}7 \\
8 \\
9 \\
10 \\
11 \\
12 \\
\end{array}$ & $\begin{array}{l}1.57 \\
1.94 \\
2.94 \\
3.42 \\
3.80 \\
4.30 \\
\end{array}$ & $\begin{array}{r}2,260 \\
3,300 \\
7,230 \\
9,610 \\
11,800 \\
14,800 \\
\end{array}$ & $\begin{array}{l}11.52 \\
11.41 \\
11.30 \\
11.19 \\
11.03 \\
10.85 \\
\end{array}$ & $\begin{array}{l}96,500 \\
95,000 \\
93,600 \\
92,100 \\
89,900 \\
87,500 \\
\end{array}$ & $\begin{array}{l}9.75 \\
9.72 \\
9.71 \\
9.69 \\
9.64 \\
9.57 \\
\end{array}$ & $\begin{array}{r}72,800 \\
72,400 \\
72,200 \\
72,000 \\
71,300 \\
70,400 \\
\end{array}$ & $\begin{array}{l}5.43 \\
5.22 \\
5.01 \\
4.82 \\
4.65 \\
4.50 \\
\end{array}$ & $\begin{array}{l}24,300 \\
22,500 \\
20,800 \\
19,300 \\
17,900 \\
16,800 \\
\end{array}$ & \begin{tabular}{c}
3.25 \\
\hdashline 3.11 \\
\end{tabular} & $\begin{array}{r}9,170 \\
\mathbf{8 7 0} \\
\end{array}$ \\
\hline & \multicolumn{2}{|c|}{ Aug. 29} & \multicolumn{2}{|c|}{ Aug. 30} & \multicolumn{2}{|c|}{ Aug. 31} & \multicolumn{2}{|c|}{ Sept. 1} & \multicolumn{2}{|c|}{ Sept. 2} \\
\hline $\begin{array}{l}1 \\
\mathbf{2} \\
\mathbf{3} \\
\mathbf{4} \\
\mathbf{5} \\
\mathbf{6}\end{array}$ & - & 0 & $\begin{array}{l}2.18 \\
2.30 \\
2.51 \\
2.70 \\
3.50 \\
4.59\end{array}$ & $\begin{array}{r}4,530 \\
4,970 \\
5,780 \\
6,560 \\
10,500 \\
17,500\end{array}$ & $\begin{array}{l}7.07 \\
7.18 \\
7.30 \\
7.39 \\
7.48 \\
7.58\end{array}$ & $\begin{array}{l}40,200 \\
41,400 \\
42,700 \\
43,700 \\
44,700 \\
45,800\end{array}$ & $\begin{array}{l}6.68 \\
6.44 \\
6.22 \\
5.97 \\
5.77 \\
5.54\end{array}$ & $\begin{array}{l}36,100 \\
33,700 \\
31,500 \\
29,200 \\
27,300 \\
25,300\end{array}$ & 3.41 & 9,990 \\
\hline $\begin{array}{r}7 \\
8 \\
9 \\
10 \\
11 \\
N\end{array}$ & 1.54 & 2,450 & $\begin{array}{l}5.11 \\
5.40 \\
5.60 \\
5.75 \\
5.91 \\
6.05\end{array}$ & $\begin{array}{l}21,600 \\
24,000 \\
25,800 \\
27,200 \\
28,600 \\
29,900\end{array}$ & $\begin{array}{l}7.69 \\
7.78 \\
7.87 \\
7.96 \\
8.01 \\
8.08\end{array}$ & $\begin{array}{l}47,100 \\
48,100 \\
49,200 \\
50,200 \\
50,800 \\
51,700\end{array}$ & $\begin{array}{l}5.28 \\
5.05 \\
4.84 \\
4.65 \\
4.49 \\
4.35\end{array}$ & $\begin{array}{l}23,000 \\
21,100 \\
19,400 \\
17,900 \\
16,700 \\
15,700\end{array}$ & 3.09 & $\begin{array}{r}9,170 \\
8,370\end{array}$ \\
\hline $\begin{array}{l}1 \\
2 \\
3 \\
4 \\
5 \\
6\end{array}$ & 1.62 & 2,670 & $\begin{array}{l}6.15 \\
6.22 \\
6.29 \\
6.35 \\
6.41 \\
6.48\end{array}$ & $\begin{array}{l}30,900 \\
\mathbf{3 1}, \mathbf{5 0 0} \\
\mathbf{3 2}, 200 \\
\mathbf{3 2}, \mathbf{8 0 0} \\
\mathbf{3 3}, \mathbf{4 0 0} \\
\mathbf{3 4}, \mathbf{1 0 0}\end{array}$ & $\begin{array}{l}8.08 \\
8.08 \\
8.05 \\
8.03 \\
7.99 \\
7.91\end{array}$ & $\begin{array}{l}51,700 \\
51,700 \\
51,300 \\
51,100 \\
50,600 \\
49,600\end{array}$ & $\begin{array}{l}4.22 \\
4.12 \\
4.03 \\
3.97 \\
3.90 \\
3.85\end{array}$ & $\begin{array}{l}14,800 \\
14,100 \\
13,500 \\
13,200 \\
12,800 \\
12,400\end{array}$ & $2 . \overline{87}$ & 7, \\
\hline $\begin{array}{r}7 \\
8 \\
9 \\
10 \\
11 \\
12 \\
\end{array}$ & 1.78 & $4,280^{-1}$ & $\begin{array}{l}6.54 \\
6.59 \\
6.66 \\
6.75 \\
6.85 \\
6.96\end{array}$ & $\begin{array}{l}\mathbf{3 4}, \mathbf{7 0 0} \\
\mathbf{3 5}, \mathbf{2 0 0} \\
\mathbf{3 5}, \mathbf{9 0 0} \\
\mathbf{3 6}, \mathbf{8 0 0} \\
\mathbf{3 7}, \mathbf{9 0 0} \\
\mathbf{3 9}, \mathbf{0 0 0}\end{array}$ & $\begin{array}{l}7.79 \\
7.67 \\
7.52 \\
7.33 \\
7.13 \\
6.91 \\
\end{array}$ & $\begin{array}{l}48,200 \\
46,900 \\
45,100 \\
43,000 \\
40,800 \\
38,500\end{array}$ & $\begin{array}{l}3.80 \\
3.76 \\
3.72 \\
3.68 \\
3.65 \\
3.60\end{array}$ & $\begin{array}{l}12,200 \\
11,900 \\
11,700 \\
11,400 \\
11,300 \\
11,000\end{array}$ & $\begin{array}{c}2.73 \\
2.63\end{array}$ & $\begin{array}{r}6,690 \\
6,270 \\
\end{array}$ \\
\hline
\end{tabular}

Supplemental recond.-Aug. 31, 1 :30 p.m., gage height, 8.09 feet; discharge, 51,800 second-feet. 


\section{FLOODS OF AUGUST 1940 IN THE SOUTHEASTERN STATES}

\section{SAVANNAH RIVER AT AUGUSTA, GA.}

Location.-Lat. $33^{\circ} 25^{\prime} 15^{\prime \prime}$, long. $81^{\circ} 56^{\prime} 40^{\prime \prime}$, at Butler Creek, 0.3 mile downstream from New Savannah Bluff lock and dam and 13 miles downstream from Augusta, Richmond County. Datum of gage is $\mathbf{9 7 . 0 0}$ feet above mean sea level (Corps of Engineers, War Department, bench mark). Auxiliary water-stage recorder at Fifth Street Bridge on U. S. Highway 1 at Augusta used in computation of discharge during floods. Datum of auxiliary gage is 102.56 feet above mean sea level (U. S. Weather Bureau bench mark).

Drainage area. - 7,508 square miles.

GAGE-HEIGHT RECORD.-Water-stage recorder graphs.

DISCHARGE RECORD.-Stage-discharge relation defined by current-meter measurements up to 240,000 second-feet.

Maxima.-1940: Discharge, 239,000 second-feet 6:30 a.m. Aug. 15 (gage height 29.40 feet).

1884-91, 1898-1906, 1927-32, 1938-39: Discharge, 350,000 second-feet Oet. 3, 1929 (gage height, 45.1 feet, at site and datum of present auxiliary gage), from rating curve extended above 310,000 second-feet by computation of flow over dam. Gage height, 46.3 feet Sept. 27, 1929 (at site and datum of present auxiliary gage).

REMARKs.-Flood discharge not materially affected by artificial storage or diversion. Flow regulated during medium and low stages by gates at New Savannah Bluff lock and dam, and by power plants above station. Water-stage recorder graphs and discharge measurements furnished by Corps of Engineers, War Department).

Mean discharge, in second-feet, 1940

\begin{tabular}{|c|c|c|c|c|c|c|c|c|c|c|c|}
\hline Day & Aug. & Sept. & Day & Aug. & Sept. & Day & Aug. & Sept. & Day & Aug. & Sept. \\
\hline $\begin{array}{l}1 \\
2 \\
3 \\
4 \\
5 \\
6 \\
7 \\
8\end{array}$ & $\begin{array}{l}2,130 \\
2,000 \\
1,820 \\
2,240 \\
2,260 \\
3,010 \\
1,340 \\
2,540\end{array}$ & $\begin{array}{r}53,000 \\
38,900 \\
19,000 \\
12,100 \\
9,520 \\
8,690 \\
8,040 \\
6,610\end{array}$ & $\begin{array}{r}9 \\
10 \\
11 \\
12 \\
13 \\
14 \\
15 \\
16\end{array}$ & $\begin{array}{r}3,580 \\
2,660 \\
3,130 \\
5,550 \\
67,200 \\
177,000 \\
228,000 \\
149,000\end{array}$ & $\begin{array}{l}5,650 \\
5,170 \\
4,730 \\
5,530 \\
5,530 \\
5,170 \\
4,950 \\
4,290\end{array}$ & $\begin{array}{l}17 \\
18 \\
19 \\
20 \\
21 \\
22 \\
23 \\
24\end{array}$ & $\begin{array}{r}50,800 \\
23,600 \\
16,900 \\
11,600 \\
8,990 \\
7,910 \\
6,370 \\
6,250\end{array}$ & $\begin{array}{l}3,110 \\
3,200 \\
3,880 \\
3,480 \\
4,180 \\
4,170 \\
4,080 \\
3,170\end{array}$ & $\begin{array}{l}25 \\
26 \\
27 \\
28 \\
29 \\
30 \\
31\end{array}$ & $\begin{array}{r}6,010 \\
5,320 \\
3,780 \\
3,580 \\
4,080 \\
6,080 \\
26,400\end{array}$ & $\begin{array}{l}2,670 \\
2,640 \\
3,480 \\
3,680 \\
3,580 \\
3,940\end{array}$ \\
\hline \multicolumn{10}{|c|}{$\begin{array}{l}\text { Monthly mean discharge, in second-feet } \\
\text { Runoff, in inches }\end{array}$} & $\begin{array}{r}27,130 \\
4.16\end{array}$ & $\begin{array}{r}8,205 \\
1.22\end{array}$ \\
\hline
\end{tabular}


SAVANNAH RIVER BASIN

Gage height, in feet, and discharge, in second-feet, at indicated time, 1940

\begin{tabular}{|c|c|c|c|c|c|c|c|c|c|c|}
\hline \multirow{2}{*}{ Hour } & \multicolumn{2}{|c|}{ Aug. 12} & \multicolumn{2}{|c|}{ Aug. 13} & \multicolumn{2}{|c|}{ Aug. 14} & \multicolumn{2}{|c|}{ Aug. 15} & \multicolumn{2}{|c|}{ Aug. 16} \\
\hline & $\begin{array}{c}\text { Gage } \\
\text { height }\end{array}$ & $\begin{array}{c}\text { Dis- } \\
\text { charge }\end{array}$ & $\begin{array}{c}\text { Gage } \\
\text { height }\end{array}$ & $\begin{array}{c}\text { Dis- } \\
\text { charge }\end{array}$ & $\begin{array}{c}\text { Gage } \\
\text { height }\end{array}$ & $\begin{array}{c}\text { Dis- } \\
\text { charge }\end{array}$ & $\begin{array}{c}\text { Gage } \\
\text { height }\end{array}$ & $\begin{array}{c}\text { Dis- } \\
\text { charge }\end{array}$ & $\begin{array}{c}\text { Gage } \\
\text { height }\end{array}$ & $\begin{array}{c}\text { Dis- } \\
\text { charge }\end{array}$ \\
\hline 1 & & & $\begin{array}{l}8.02 \\
8.82\end{array}$ & $\begin{array}{l}8,200 \\
9,270\end{array}$ & & & & & & \\
\hline $\begin{array}{l}3 \\
\mathbf{4}\end{array}$ & & & $\begin{array}{l}9.06 \\
9.08\end{array}$ & $\begin{array}{l}9,600 \\
\mathbf{9}, 630\end{array}$ & 26.91 & 145,000 & 29.36 & 237,000 & 28.15 & $1 \overline{8}, 000$ \\
\hline $\begin{array}{l}5 \\
6\end{array}$ & 2.95 & $\overline{\mathbf{2}} \overline{\mathbf{5}} \overline{\mathbf{3}} \overline{0}$ & $\begin{array}{r}9.40 \\
11.16\end{array}$ & $\begin{array}{l}10,100 \\
12,700\end{array}$ & $\ldots \ldots$ & $-\cdots$ & & -- & $\cdots$ & --- \\
\hline 7 & & & 16.76 & 23,800 & & & & & & \\
\hline $\begin{array}{l}8 \\
9\end{array}$ & & & $\begin{array}{l}20.14 \\
21.40\end{array}$ & $\begin{array}{l}33,600 \\
41,300\end{array}$ & 27.23 & 155,000 & 29.39 & 239,000 & 27.64 & 169,000 \\
\hline 10 & & & 22.02 & 47,000 & & & & & & $\mid-1,-1$ \\
\hline $\mathbf{N}$ & 5.09 & 4,610 & 23.2 & 62,800 & 27.72 & 171,000 & 29.30 & 234,000 & 27.10 & 150,000 \\
\hline 1 & 5.82 & 5,430 & 23.77 & 71,6 & & & & & & \\
\hline$?$ & 6.19 & & 24 & & & & & & & \\
\hline 4 & 7.48 & 7,490 & 25.19 & 99,500 & 28.28 & 193,000 & 29.13 & 227,000 & 26.44 & 131,000 \\
\hline 5 & & & 25.50 & 107,000 & & & & & & $----\div---$ \\
\hline & & & & & & & & & & \\
\hline $\begin{array}{l}7 \\
8\end{array}$ & 9.25 & 9,870 & 26.15 & 123,000 & & & & & & \\
\hline$\overline{9}$ & $\begin{array}{l}9.51 \\
9.60\end{array}$ & & $\begin{array}{l}26.32 \\
26.45\end{array}$ & $\begin{array}{l}128,000 \\
131,000\end{array}$ & 28.82 & 214,000 & 28.89 & 217,000 & 25.62 & 109,000 \\
\hline 10 & & & 26. & 134, & & & - & & - & -1 \\
\hline $\begin{array}{l}11 \\
12\end{array}$ & 9.59 & 10,300 & 26.62 & 136,000 & & & & & & \\
\hline 12 & 8.70 & 9,100 & 26.70 & 138,000 & 29.22 & 231,000 & 28.56 & 203,000 & 24.62 & 87,600 \\
\hline
\end{tabular}

\begin{tabular}{|c|c|c|c|c|c|c|c|c|}
\hline \multirow{2}{*}{ Hour } & \multicolumn{2}{|c|}{ Aug. 17} & \multicolumn{2}{|c|}{ Aug. 18} & \multicolumn{2}{|c|}{ Aug. 19} & \multicolumn{2}{|c|}{ Aug. 20} \\
\hline & $\begin{array}{c}\text { Gage } \\
\text { height }\end{array}$ & Discharge & $\begin{array}{l}\text { Gage } \\
\text { height }\end{array}$ & Discharge & $\begin{array}{c}\text { Gage } \\
\text { height }\end{array}$ & Discharge & $\begin{array}{l}\text { Gage } \\
\text { height }\end{array}$ & Discharge \\
\hline $\begin{array}{r}4 \\
8 \\
\mathrm{~N} \\
4 \\
8 \\
12\end{array}$ & $\begin{array}{l}23.78 \\
22.90 \\
21.98 \\
20.92 \\
19.92 \\
18.79\end{array}$ & $\begin{array}{l}71,900 \\
57,600 \\
26,400 \\
37,900 \\
32,400 \\
29,200\end{array}$ & $\begin{array}{l}17.97 \\
17.27 \\
16.46 \\
15.98 \\
15.33 \\
14.93\end{array}$ & $\begin{array}{l}26,900 \\
25,100 \\
23,100 \\
21,900 \\
20,400 \\
19,500\end{array}$ & $\begin{array}{l}14.57 \\
14.18 \\
13.67 \\
13.16 \\
12.68 \\
12.43\end{array}$ & $\begin{array}{l}18,700 \\
17,900 \\
16,900 \\
15,900 \\
15,100 \\
14,700\end{array}$ & $\begin{array}{r}11.89 \\
11.56 \\
10.56 \\
9.63 \\
8.45 \\
7.98 \\
\end{array}$ & $\begin{array}{r}13,800 \\
13,300 \\
11,800 \\
10,400 \\
8,760 \\
8,140 \\
\end{array}$ \\
\hline
\end{tabular}

\begin{tabular}{|c|c|c|c|c|c|c|c|c|c|c|}
\hline Hour & & 30 & & 31 & & t. 1 & & t. 2 & & t. 3 \\
\hline & & & & & & & & & & \\
\hline 2 & 4.69 & 4,170 & & & & & 22.76 & 55.500 & 16.70 & 23,600 \\
\hline 4 & 4.66 & 4,140 & 13.00 & 15,600 & 21.98 & 46,400 & $\overline{2} 2 . \overline{5}$ & 52,500 & 16.25 & 22,600 \\
\hline 6 & 4.66 & 4,140 & 14.60 & 18,800 & & & 22.17 & 48,400 & 15.88 & 21,700 \\
\hline $\begin{array}{l}7 \\
8\end{array}$ & 5.13 & 4,650 & $\begin{array}{l}15.28 \\
15.90\end{array}$ & $\begin{array}{l}20,300 \\
21,700\end{array}$ & 22.37 & 50,600 & 21.73 & 44,000 & 15.43 & 20,600 \\
\hline 10 & 5.52 & 5,080 & $\begin{array}{l}10.03 \\
17.12\end{array}$ & $\begin{array}{l}23,200 \\
24,700\end{array}$ & & & 21.25 & 40,100 & 15.10 & 19,900 \\
\hline N & 5.67 & 5,250 & 18.11 & $\begin{array}{l}20,100 \\
27,300\end{array}$ & 22.65 & 54,400 & 20.64 & 36,000 & 14.75 & 19,100 \\
\hline$\frac{1}{2}$ & 6.62 & 6,390 & 18.53 & 28,500 & & & 20.05 & 33,100 & 14.38 & 18,300 \\
\hline A & 7.54 & 7,570 & $\begin{array}{l}19 \\
19\end{array}$ & $\begin{array}{l}30,700 \\
31,700\end{array}$ & 228 & 57,400 & $19 \overline{2}$ & 31,200 & 13.78 & 17,100 \\
\hline $\begin{array}{l}5 \\
6 \\
\end{array}$ & 7.66 & 7,730 & $\begin{array}{l}19.95 \\
20.20\end{array}$ & 33,800 & & & $18 . \overline{9}$ & 29,600 & 13.17 & 16,000 \\
\hline 7 & 7.75 & 7,840 & $\begin{array}{l}20.44 \\
20.65\end{array}$ & 24,900 & 23.02 & 59,600 & 18.38 & 28,000 & 12.62 & 15,000 \\
\hline & 8.24 & $8, \overline{480}$ & $\begin{array}{r}20.83 \\
21.01\end{array}$ & & & & 17.89 & 26,700 & 12.46 & 14,700 \\
\hline 12 & 9.92 & 10,800 & $\begin{array}{l}21.17 \\
21.38\end{array}$ & $\begin{array}{l}39,500 \\
41,100\end{array}$ & $2 \overline{2} \overline{9} \overline{2}$ & 57,800 & $-\overline{17} \cdot \overline{15}$ & 24,800 & 12.20 & 14,300 \\
\hline
\end{tabular}

Supplamental Records-Aug. 15, 6:30 a.m., gage height, $29.40 \mathrm{feet;}$ discharge, 239,000 second-feet. Sept. 1, 9 p.m., gage height, 23.03 feet; discharge, 59,800 second-feet.

SAVANNAH RIVER A'T BURTONS FERRY BRIDGE, NEAR MILLHAVEN, GA.

Location.-Lat. $32^{\circ} 56^{\prime} 20^{\prime \prime}$, long. $81^{\circ} 30^{\prime} 10^{\prime \prime}$, at bridge on State Highway 73,2 miles downstream from Rocky Creek and 9 miles east of Millhaven, Screven 


\section{FLOODS OF AUGUST 1940 IN THE SOUTHEASTERN STATES}

County. Datum of gage is 52.42 feet above mean sea level (levels by Corps of

Engineers, War Department).

Drainage area.-8,650 square miles.

GAGE-HEIGHT RECORD.-Water-stage recorder graph.

DISCHARGE RECORD.-Stage-discharge relation defined by current-meter measurements.

Gage heights used to tenths.

Maxima.-1939-40: Discharge, 141,000 second-feet 9 to 11 a.m. Aug. 18 (gage height, 27.0 feet).

REMARKs.-Flood runoff not seriously affected by storage. Gage-height record and results of current-meter measurements furnished by Corps of Engineers, War Department.

Mean discharge, in second-feet, 1940

\begin{tabular}{|c|c|c|c|c|c|c|c|c|c|c|c|}
\hline Day & Aug. & Sept. & Day & Aug. & Sept. & Day & Aug. & Sept. & Day & Aug. & Sept. \\
\hline $\begin{array}{l}1 \\
2 \\
3 \\
4 \\
5 \\
6 \\
7 \\
8\end{array}$ & $\begin{array}{l}3,360 \\
3,440 \\
3,280 \\
3,120 \\
3,040 \\
3,200 \\
3,680 \\
\mathbf{3}, 440\end{array}$ & $\begin{array}{l}10,300 \\
12,100 \\
13,900 \\
19,300 \\
28,100 \\
29,300 \\
25,500 \\
20,100\end{array}$ & $\begin{array}{r}9 \\
10 \\
11 \\
12 \\
13 \\
14 \\
15 \\
16\end{array}$ & $\begin{array}{r}3,040 \\
3,920 \\
4,080 \\
5,020 \\
8,080 \\
11,900 \\
15,000 \\
51,300\end{array}$ & $\begin{array}{r}14,600 \\
10,600 \\
8,300 \\
7,060 \\
6,880 \\
6,790 \\
6,520 \\
6,160\end{array}$ & $\begin{array}{l}17 \\
18 \\
19 \\
20 \\
21 \\
22 \\
23 \\
24\end{array}$ & $\begin{array}{r}118,000 \\
138,000 \\
121,000 \\
96,400 \\
73,100 \\
53,900 \\
39,500 \\
29,600\end{array}$ & $\begin{array}{l}5,800 \\
5,080 \\
4,450 \\
4,630 \\
4,720 \\
4,810 \\
5,080 \\
4,990\end{array}$ & $\begin{array}{l}\mathbf{2 5} \\
\mathbf{2 6} \\
\mathbf{2 7} \\
\mathbf{2 8} \\
\mathbf{2 9} \\
\mathbf{3 0} \\
\mathbf{3 1}\end{array}$ & $\begin{array}{r}21,000 \\
14,000 \\
10,000 \\
7,460 \\
6,070 \\
5,620 \\
6,610\end{array}$ & $\begin{array}{r}4,540 \\
4,270 \\
3,600 \\
3,920 \\
4,360 \\
4,540 \\
-\end{array}$ \\
\hline $\mathbf{n}$ & & & & & & & & & & $\begin{array}{r}28,040 \\
3.74 \\
\end{array}$ & $\begin{array}{r}9,677 \\
1.25 \\
\end{array}$ \\
\hline
\end{tabular}

Gage height, in feet, and discharge, in second-feet, at indicated time, 1940

\begin{tabular}{|c|c|c|c|c|c|c|c|c|c|c|}
\hline \multirow{2}{*}{ Hour } & \multicolumn{2}{|c|}{ Aug. 15} & \multicolumn{2}{|c|}{ Aug. 16} & \multicolumn{2}{|c|}{ Aug. 17} & \multicolumn{2}{|c|}{ Aug. 18} & \multicolumn{2}{|c|}{ Aug. 19} \\
\hline & $\begin{array}{c}\text { Gage } \\
\text { height }\end{array}$ & $\begin{array}{c}\text { Dis- } \\
\text { charge }\end{array}$ & $\begin{array}{c}\text { Gage } \\
\text { height }\end{array}$ & $\begin{array}{l}\text { Dis- } \\
\text { charge }\end{array}$ & $\begin{array}{c}\text { Gage } \\
\text { height }\end{array}$ & $\begin{array}{l}\text { Dis- } \\
\text { charge }\end{array}$ & $\begin{array}{c}\text { Gage } \\
\text { height }\end{array}$ & $\begin{array}{c}\text { Dis- } \\
\text { charge }\end{array}$ & $\begin{array}{c}\text { Gage } \\
\text { height }\end{array}$ & $\begin{array}{c}\text { Dis- } \\
\text { charge }\end{array}$ \\
\hline \multirow{6}{*}{$\begin{array}{r}4 \\
6 \\
8 \\
\mathbf{N} \\
4 \\
6 \\
8 \\
12 \\
\end{array}$} & 12.60 & 13,400 & 16.23 & 26,000 & 24.30 & 101,000 & 26.92 & 139,000 & \multirow{2}{*}{26.20} & \multirow{2}{*}{128,000} \\
\hline & 12.78 & $\mathbf{1 3}$ & 18.00 & $\mathbf{3 7}$ & 25.10 & 112 & \multirow{3}{*}{$\begin{array}{l}26.95 \\
26.96 \\
26.85\end{array}$} & \multirow{3}{*}{$\begin{array}{l}140,000 \\
141,000 \\
137,000\end{array}$} & & \\
\hline & 12.96 & 14 & 19 & & 25 & 12 & & & $25: 80$ & 122,000 \\
\hline & & & & & & & & & \multirow{2}{*}{25.34} & \\
\hline & 13.98 & 17 & 22.30 & $\mathbf{7 6}, \mathbf{3 0 0}$ & $\overline{2} \overline{6} \overline{5} \overline{5}^{-}$ & & \multirow{2}{*}{$\begin{array}{r}26.70 \\
26.54 \\
\end{array}$} & \multirow{2}{*}{$\begin{array}{r}136,000 \\
132,000\end{array}$} & & \\
\hline & 14.92 & & & & & & & & 24.88 & 109,000 \\
\hline & \multicolumn{2}{|c|}{ Aug. 20} & \multicolumn{2}{|c|}{ Aug. 21} & \multicolumn{2}{|c|}{ Aug. 22} & \multicolumn{2}{|c|}{ Aug. 23} & \multicolumn{2}{|c|}{ Aug. 24} \\
\hline $\begin{array}{r}6 \\
N \\
6 \\
12\end{array}$ & $\begin{array}{l}24.42 \\
23.95 \\
23.46 \\
23.00\end{array}$ & $\begin{array}{r}102,000 \\
97,000 \\
90,000 \\
84,500\end{array}$ & $\begin{array}{l}22.50 \\
22.00 \\
21.50 \\
21.03\end{array}$ & $\begin{array}{l}78,500 \\
73,000 \\
67,500 \\
62,500\end{array}$ & $\begin{array}{l}20.60 \\
20.10 \\
19.58 \\
19.12\end{array}$ & $\begin{array}{l}58,500 \\
53,900 \\
49,400 \\
45,300\end{array}$ & $\begin{array}{l}18.70 \\
18.30 \\
17.98 \\
17.58\end{array}$ & $\begin{array}{l}42,100 \\
39,100 \\
37,000 \\
34,200\end{array}$ & $\begin{array}{l}17.29 \\
16.83 \\
16.45 \\
16.02\end{array}$ & $\begin{array}{l}32,300 \\
29,300 \\
27,000 \\
25,000\end{array}$ \\
\hline
\end{tabular}

\section{SAVANNAH RIVER NEAR CLYO, GA.}

Location.-Lat. $32^{\circ} 31^{\prime} 30^{\prime \prime}$, long. $81^{\circ} 15^{\prime} 45^{\prime \prime}$, at bridge on Seaboard Railway 3 miles north of Clyo, Effingham County. Datum of gage is 13.41 feet above mean sea level, datum of 1929, supplementary adjustment of 1936 .

Drainage AREA. $-9,850$ square miles.

GAGE-HEIGHT RECORD.-Graph based on twice-daily gage readings of staff gage except Aug. 18-24 where hourly gage readings were available.

DISCHARGE RECORD.-Stage-discharge relation defined by current-meter measurements up to 119,000 second-feet. Gage heights used to tenths.

Maxima.-1940: Discharge, 128,000 second-feet 6 a.m. Aug. 21 to 5 a.m. Aug. 22 (gage height, 23.6 feet).

1937-39: Discharge, 70,100 second-feet Mar. 7, 8, 1939 (gage height, 20.4 feet).

1921-40: Gage height, 29.7 feet Oct. 6, 1929 from records of U. S. Weather Bureau (discharge not determined).

REMARKs.-Flood runoff not seriously affected by headwater storage reservoirs. 
Gage-height record and results of discharge measurements furnished by Corps of Engineers, War Department.

Mean discharge, in second-feet, 1940

\begin{tabular}{|c|c|c|c|c|c|c|c|c|c|c|c|}
\hline Day & Aug. & Sept. & Day & Aug. & Sept. & Day & Aug. & Sept. & Day & Aug. & Sept. \\
\hline $\begin{array}{l}1 \\
2 \\
3 \\
4 \\
5 \\
6 \\
7 \\
8\end{array}$ & $\begin{array}{l}4,180 \\
4,000 \\
3,820 \\
3,820 \\
3,820 \\
3,640 \\
3,550 \\
3,820\end{array}$ & $\begin{array}{l}10,400 \\
10,400 \\
10,800 \\
11,200 \\
11,800 \\
12,200 \\
12,700 \\
15,000\end{array}$ & $\begin{array}{r}9 \\
10 \\
11 \\
12 \\
13 \\
14 \\
15 \\
16\end{array}$ & $\begin{array}{r}4,180 \\
3,910 \\
4,180 \\
6,200 \\
7,600 \\
9,670 \\
11,100 \\
11,800\end{array}$ & $\begin{array}{r}19,500 \\
21,600 \\
20,700 \\
18,300 \\
15,000 \\
11,800 \\
9,780 \\
8,680\end{array}$ & $\begin{array}{l}17 \\
18 \\
19 \\
20 \\
21 \\
22 \\
23 \\
24\end{array}$ & $\begin{array}{r}12,400 \\
16,100 \\
68,100 \\
114,000 \\
127,000 \\
124,000 \\
110,000 \\
91,600\end{array}$ & $\begin{array}{l}7,800 \\
7,200 \\
6,400 \\
5,710 \\
5,440 \\
5,440 \\
5,440 \\
5,620\end{array}$ & $\begin{array}{l}25 \\
26 \\
27 \\
28 \\
29 \\
30 \\
31\end{array}$ & $\begin{array}{l}73,000 \\
58,000 \\
44,700 \\
33,700 \\
25,600 \\
18,300 \\
12,700\end{array}$ & $\begin{array}{l}5,620 \\
5,440 \\
5,080 \\
4,720 \\
4,540 \\
4,810 \\
-\end{array}$ \\
\hline & & & & & & & & & & $\begin{array}{r}32,850 \\
3.85\end{array}$ & $\begin{array}{r}9,971 \\
1.13\end{array}$ \\
\hline
\end{tabular}

Gage height, in feet, and discharge, in second-feet, at indicated time, 1940

\begin{tabular}{|c|c|c|c|c|c|c|c|c|c|c|}
\hline \multirow{2}{*}{ Hour } & \multicolumn{3}{|c|}{ Aug. 18} & \multicolumn{2}{|c|}{ Aug. 19} & \multicolumn{3}{|c|}{ Aug. 20} & \multicolumn{2}{|c|}{ Aug. 21} \\
\hline & $\begin{array}{l}\text { Gage } \\
\text { height }\end{array}$ & \multicolumn{2}{|c|}{ Discharge } & $\begin{array}{l}\text { Gage } \\
\text { height }\end{array}$ & Discharge & $\begin{array}{c}\text { Gage } \\
\text { height }\end{array}$ & \multicolumn{2}{|c|}{ Discharge } & $\begin{array}{l}\text { Gage } \\
\text { height }\end{array}$ & Discharge \\
\hline \multirow{3}{*}{$\begin{array}{l}1 \\
2 \\
3 \\
4 \\
5 \\
6\end{array}$} & 11.1 & \multicolumn{2}{|c|}{12,900} & \multirow{3}{*}{$\begin{array}{l}15.7 \\
16.2 \\
16.7 \\
17.1 \\
17.6 \\
18.0\end{array}$} & \multirow{3}{*}{$\begin{array}{l}32,300 \\
35,800 \\
39,700 \\
42,900 \\
47,400 \\
51,000\end{array}$} & & \multirow{2}{*}{\multicolumn{2}{|c|}{106,000}} & & 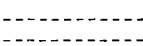 \\
\hline & 11.2 & \multicolumn{2}{|c|}{$\overline{13}, \overline{100}$} & & & $2 \overline{2} \cdot \overline{3}$ & & & 23.5 & 126,000 \\
\hline & - & \multicolumn{2}{|c|}{. } & & & (n) & \multicolumn{2}{|c|}{ 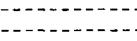 } & & 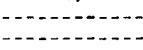 \\
\hline 7 & \multirow{2}{*}{11.4} & \multirow{2}{*}{\multicolumn{2}{|c|}{13,500}} & 18.2 & 53,000 & & \multirow{2}{*}{\multicolumn{2}{|c|}{111,000}} & & \\
\hline $\begin{array}{l}8 \\
9\end{array}$ & & & & 18.5 & 56,000 & 22.6 & & & 23.6 & 128,000 \\
\hline 10 & - - & \multicolumn{2}{|c|}{$\cdots$} & $\begin{array}{l}18.9 \\
19.2\end{array}$ & $\begin{array}{l}60,200 \\
63,500\end{array}$ & . & & & & - \\
\hline$\stackrel{11}{N}$ & $1 \overline{1} .8$ & \multicolumn{2}{|c|}{14,500} & $\begin{array}{l}19.5 \\
19.8\end{array}$ & $\begin{array}{l}67,000 \\
70,600\end{array}$ & 22.8 & \multicolumn{2}{|c|}{114,000} & 23.6 & 128,000 \\
\hline $\begin{array}{l}1 \\
2\end{array}$ & 12.0 & \multirow{2}{*}{\multicolumn{2}{|c|}{15,000}} & $\begin{array}{l}20.0 \\
20.3\end{array}$ & $\begin{array}{l}73,000 \\
76,900\end{array}$ & & & & & - \\
\hline $\mathbf{3}$ & & & & 20.5 & 79,500 & & \multirow{2}{*}{\multicolumn{2}{|c|}{119,000}} & & \\
\hline 4 & $12 . \overline{3}$ & \multicolumn{2}{|c|}{15,900} & 20.7 & 82,100 & 23.1 & & & 23.6 & 128,000 \\
\hline $\begin{array}{l}3 \\
6\end{array}$ & 12.7 & & $0^{-\cdots}$ & 21.1 & 87,700 & & & & & - \\
\hline $\begin{array}{l}7 \\
8\end{array}$ & 13.3 & & & $\begin{array}{l}21.2 \\
21.3\end{array}$ & $\begin{array}{l}89,200 \\
90,700\end{array}$ & 23.2 & & & 23.6 & 128,000 \\
\hline 10 & 14.1 & & & $\begin{array}{l}21.5 \\
21.6\end{array}$ & 95,200 & -- & & & (n) & (n- \\
\hline $\begin{array}{l}11 \\
12\end{array}$ & $15{ }^{--}$ & & & 21.7 & 96,700 & 23 & & & 6 & 128000 \\
\hline & & & 22 & & & 23 & & & Aug. & \\
\hline & & & & harge & $\begin{array}{l}\text { Gage } \\
\text { height }\end{array}$ & Disc & ge & & & Discharge \\
\hline $\begin{array}{r}4 \\
8 \\
N \\
4 \\
8 \\
12\end{array}$ & & $\begin{array}{l}6 \\
.5 \\
.4 \\
.3 \\
.2\end{array}$ & & $\begin{array}{l}, 000 \\
, 000 \\
, 000 \\
, 000 \\
, 000 \\
, 000\end{array}$ & $\begin{array}{l}22.9 \\
22.7 \\
22.5 \\
22.4 \\
22.2 \\
22.0\end{array}$ & $\begin{array}{l}116 \\
112 \\
109 \\
108 \\
104 \\
101\end{array}$ & $\begin{array}{l}000 \\
000 \\
000 \\
000 \\
000 \\
000\end{array}$ & & & $\begin{array}{l}98,200 \\
95,200 \\
92,200 \\
87,700 \\
84,900 \\
82,100\end{array}$ \\
\hline
\end{tabular}

KEOWEE RIVER NEAR NEWRY, S. C.

Location.-Lat. $34^{\circ} 44^{\prime}$, long. $82^{\circ} 53^{\prime}$, 0.4 mile upstream from Six Mile Creek, 1 mile downstream from Little River, and 1.5 miles east of Newry, Oconee County.

Drainage AREA.- 455 square miles.

GAGE-HEIGHT RECORD.-Water-stage recorder graph.

DISCHARGE RECORD.- Stage-discharge relation defined by current-meter measurements up to 20,000 second-feet; extended to peak stage by logarithmic plotting. Shifting-control method used Aug. 14 to Sept. 30. Rate of change of stage used as a factor in computing discharge Aug. 12-15, 29-31, Sept. 1.

Maxima.-Discharge, 25,200 second-feet 10 p.m. Aug. 13; maximum gage height, 24.60 feet 12 p.m. Aug. 13. 
REMARKs.-Flood discharge not affected by artificial storage or diversion. Low flow regulated by power plant above station.

Mean discharge, in second-feet, 1940

\begin{tabular}{|c|c|c|c|c|c|c|c|c|c|c|c|}
\hline Day & Aug. & Sept. & Day & Aug. & Sept. & Day & Aug. & Sept. & Day & Aug. & Sept. \\
\hline $\begin{array}{l}1 \\
2 \\
3 \\
4 \\
5 \\
6 \\
7 \\
8\end{array}$ & $\begin{array}{l}400 \\
441 \\
378 \\
357 \\
355 \\
360 \\
369 \\
407\end{array}$ & $\begin{array}{l}3,240 \\
2,560 \\
2,130 \\
1,850 \\
1,680 \\
1,540 \\
1,360 \\
1,290\end{array}$ & $\begin{array}{r}9 \\
10 \\
11 \\
12 \\
13 \\
14 \\
15 \\
16\end{array}$ & $\begin{array}{r}443 \\
379 \\
344 \\
703 \\
16,500 \\
10,600 \\
2,660 \\
1,840\end{array}$ & $\begin{array}{r}1,180 \\
1,070 \\
956 \\
871 \\
825 \\
716 \\
723 \\
728\end{array}$ & $\begin{array}{l}17 \\
18 \\
19 \\
20 \\
21 \\
22 \\
23 \\
24\end{array}$ & $\begin{array}{r}1,420 \\
1,420 \\
1,120 \\
962 \\
910 \\
868 \\
816 \\
762\end{array}$ & $\begin{array}{l}655 \\
612 \\
598 \\
578 \\
512 \\
503 \\
478 \\
473\end{array}$ & $\begin{array}{l}25 \\
26 \\
27 \\
28 \\
29 \\
30 \\
31\end{array}$ & $\begin{array}{r}828 \\
775 \\
647 \\
614 \\
4,370 \\
19,600 \\
5,340\end{array}$ & $\begin{array}{l}564 \\
514 \\
464 \\
390 \\
480 \\
489\end{array}$ \\
\hline \multicolumn{10}{|c|}{$\begin{array}{l}\text { Monthly mean discharge, in second-feet } \\
\text { Runof, in inches }\end{array}$} & $\begin{array}{r}2,483 \\
6.30\end{array}$ & $\begin{array}{r}1,001 \\
2.46\end{array}$ \\
\hline
\end{tabular}

Gage height, in feet, and discharge, in second-feet, at indicated time, 1940

\begin{tabular}{|c|c|c|c|c|c|c|c|c|c|c|c|c|}
\hline \multirow{2}{*}{ Hour } & \multicolumn{2}{|c|}{ Aug. 12} & \multicolumn{2}{|c|}{ Aug. 13} & \multicolumn{2}{|c|}{ Aug. 14} & \multicolumn{3}{|c|}{ Aug. 15} & \multicolumn{3}{|c|}{ Aug. 16} \\
\hline & $\begin{array}{c}\text { Gage } \\
\text { height }\end{array}$ & $\begin{array}{l}\text { Dis- } \\
\text { charge }\end{array}$ & $\begin{array}{c}\text { Gage } \\
\text { height }\end{array}$ & $\begin{array}{l}\text { Dis- } \\
\text { charge }\end{array}$ & $\begin{array}{l}\text { Gage } \\
\text { height }\end{array}$ & $\begin{array}{l}\text { Dis- } \\
\text { charge }\end{array}$ & $\begin{array}{c}\text { Gage } \\
\text { height }\end{array}$ & \multicolumn{2}{|c|}{$\begin{array}{l}\text { Dis- } \\
\text { charge }\end{array}$} & \multicolumn{2}{|c|}{$\begin{array}{c}\text { Gage } \\
\text { height }\end{array}$} & $\begin{array}{l}\text { Dis- } \\
\text { charge }\end{array}$ \\
\hline $\begin{array}{l}1 \\
2 \\
3 \\
4 \\
5 \\
6\end{array}$ & 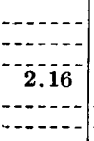 & 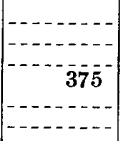 & $\begin{array}{r}4.65 \\
5.16 \\
6.09 \\
7.55 \\
9.75 \\
11.88\end{array}$ & $\begin{array}{r}2,570 \\
3,060 \\
4,130 \\
5,880 \\
8,310 \\
11,100\end{array}$ & $\begin{array}{l}24.47 \\
24.18 \\
23.77 \\
23.24 \\
22.62 \\
21.88\end{array}$ & $\begin{array}{l}23,400 \\
22,600 \\
20,800 \\
19,400 \\
18,300 \\
16,800\end{array}$ & $\mid \begin{array}{c}-\cdots \\
-1.48 \\
-\cdots\end{array}$ & \multicolumn{2}{|c|}{$\mid \begin{array}{r}-\cdots \\
-\cdots, 130 \\
-\cdots\end{array}$} & \multicolumn{2}{|c|}{4.94} & $\begin{array}{r}-1, \ldots \\
\hdashline-1,960\end{array}$ \\
\hline $\begin{array}{r}7 \\
8 \\
9 \\
10 \\
11 \\
\text { N }\end{array}$ & \begin{tabular}{c}
$-\overline{2.44}$ \\
\hdashline$-\overline{-}$ \\
2.64
\end{tabular} & $\mid$\begin{tabular}{c}
$-\cdots \overline{\mathbf{5 7 4}}$ \\
\hdashline$-\overline{\mathbf{7 3 3}}$ \\
\hdashline-1 \\
\hdashline-1
\end{tabular} & $\begin{array}{l}14.50 \\
16.70 \\
17.66 \\
18.44 \\
18.94 \\
19.24\end{array}$ & $\begin{array}{l}14,700 \\
16,800 \\
16,900 \\
17,400 \\
17,700 \\
18,000\end{array}$ & $\begin{array}{l}21.06 \\
20.05 \\
18.80 \\
17.45 \\
15.96 \\
14.64\end{array}$ & $\begin{array}{r}15,600 \\
13,600 \\
11,600 \\
9,970 \\
8,840 \\
7,870\end{array}$ & \begin{tabular}{c}
$-\overline{6.09}$ \\
\hdashline$\overline{5.80}$
\end{tabular} & -- & $\begin{array}{l}\overline{800} \\
-\cdots \\
\overline{5} \\
-\overline{0}\end{array}$ & \multicolumn{3}{|c|}{ 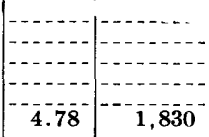 } \\
\hline $\begin{array}{l}1 \\
\mathbf{1} \\
\mathbf{3} \\
\mathbf{4} \\
\mathbf{5} \\
\mathbf{6}\end{array}$ & 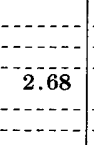 & 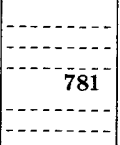 & $\begin{array}{l}19.51 \\
19.87 \\
20.31 \\
20.86 \\
21.54 \\
22.20\end{array}$ & $\begin{array}{l}18,400 \\
19,000 \\
19,800 \\
20,800 \\
21,900 \\
22,900\end{array}$ & $\begin{array}{r}13.37 \\
12.20 \\
11.24 \\
10.35 \\
9.68 \\
9.02\end{array}$ & $\begin{array}{l}6,980 \\
6,130 \\
5,840 \\
5,260 \\
4,960 \\
4,760\end{array}$ & 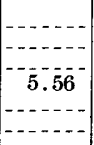 & $\begin{array}{l}--- \\
--- \\
--- \\
---\end{array}$ & 410 & 4.64 & $\begin{array}{l}--- \\
-\cdots 4 \\
--- \\
---\end{array}$ & 1, 110 \\
\hline $\begin{array}{r}7 \\
8 \\
9 \\
10 \\
11 \\
12 \\
\end{array}$ & $\begin{array}{c}-\overline{2.97} \\
4.04 \\
\end{array}$ & $\left|\begin{array}{r}-1,000 \\
-2,010\end{array}\right|$ & $\begin{array}{l}22.88 \\
23.50 \\
23.99 \\
24.37 \\
24.54 \\
24.60 \\
\end{array}$ & $\begin{array}{l}23,900 \\
24,400 \\
24,900 \\
25,200 \\
25,000 \\
24,500 \\
\end{array}$ & $\begin{array}{l}8.52 \\
8.14 \\
7.82 \\
7.55 \\
7.29 \\
7.09 \\
\end{array}$ & $\begin{array}{l}4,480 \\
4,190 \\
4,070 \\
3,850 \\
3,720 \\
3,560 \\
\end{array}$ & \begin{tabular}{|c|}
$-\overline{5} . \overline{36}$ \\
-15 \\
5.21 \\
\end{tabular} & $\begin{array}{l}--- \\
--- \\
--- \\
--- \\
\end{array}$ & $\begin{array}{l}40^{-} \\
10 \\
\end{array}$ & 4. & $\begin{array}{l}--- \\
-\cdots- \\
-\cdots- \\
-\cdots- \\
50\end{array}$ & (1,590 \\
\hline Hour & \multicolumn{3}{|c|}{ Aug. 29} & \multicolumn{2}{|c|}{ Aug. 30} & \multicolumn{3}{|c|}{ Aug. 31} & \multicolumn{4}{|c|}{ Sept. 1} \\
\hline $\begin{array}{l}1 \\
2 \\
\mathbf{3} \\
4 \\
5 \\
\mathbf{6} \\
6\end{array}$ & $\begin{array}{r}-\overline{2} . \overline{84} \\
--\overrightarrow{2} . \overline{83} \\
-2 . \overline{82}\end{array}$ & $\begin{array}{r}4 \\
3\end{array} \mid \frac{85}{84}$ & $2^{---}$ & $\begin{array}{l}19.04 \\
19.47 \\
19.81 \\
20.09 \\
20.38 \\
20.71\end{array}$ & $\begin{array}{l}18,000 \\
18,500 \\
18,800 \\
19,100 \\
19,600 \\
20,000\end{array}$ & $\begin{array}{l}15.94 \\
14.58 \\
13.35 \\
12.26 \\
11.34 \\
10.48\end{array}$ & $\begin{array}{l}8,8 \\
7,7 \\
7,1 \\
6,6 \\
6,1 \\
5,9\end{array}$ & $\begin{array}{l}30 \\
30 \\
10 \\
50 \\
90 \\
30\end{array}$ & $\begin{array}{c}---- \\
-\cdots \\
---- \\
--\overline{6}\end{array}$ & $\begin{array}{l}-.-. \\
-\cdots \\
1\end{array}$ & $\begin{array}{l}-- \\
-- \\
-- \\
--\end{array}$ & 3,480 \\
\hline $\begin{array}{r}7 \\
8 \\
9 \\
10 \\
11 \\
N\end{array}$ & $\begin{array}{r}--\overline{2} . \overline{83} \\
-\overline{2.84} \\
-2 . \overline{83}\end{array}$ & $\begin{array}{r}-\overline{85} \\
-\overline{85}\end{array}$ & 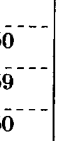 & $\begin{array}{l}21.08 \\
21.50 \\
21.93 \\
22.41 \\
22.97 \\
23.32\end{array}$ & $\begin{array}{l}20,700 \\
21,200 \\
22,300 \\
22,800 \\
23,600 \\
23,800\end{array}$ & $\begin{array}{l}9.86 \\
9.38 \\
9.01 \\
8.69 \\
8.42 \\
8.21\end{array}$ & $\begin{array}{l}5,5 \\
5,5 \\
5,4 \\
5,1 \\
5,0 \\
4,8\end{array}$ & & $\begin{array}{c}--- \\
\cdots-- \\
\cdots- \\
-\cdots \\
-\overline{6}\end{array}$ & \begin{tabular}{l}
$-\cdots-$ \\
$\overline{0}$ \\
\hdashline$-\overline{8}$
\end{tabular} & $\begin{array}{l}-- \\
-- \\
-- \\
--\end{array}$ & 3,270 \\
\hline $\begin{array}{l}1 \\
2 \\
3 \\
4 \\
5 \\
6\end{array}$ & $\begin{array}{l}2.83 \\
2.86 \\
2.99 \\
3.20 \\
4.00 \\
6.41\end{array}$ & $\begin{array}{r}85 \\
87 \\
1,02 \\
1,23 \\
2,17 \\
5,37\end{array}$ & & $\begin{array}{l}23.60 \\
23.66 \\
23.61 \\
23.43 \\
23.08 \\
22.58\end{array}$ & $\begin{array}{l}23,600 \\
23,200 \\
22,700 \\
22,000 \\
20,400 \\
19,300\end{array}$ & $\begin{array}{l}8.04 \\
7.87 \\
7.73 \\
7.60 \\
7.47 \\
7.37\end{array}$ & $\begin{array}{l}4,7 \\
4,6 \\
4,5 \\
4,4 \\
4,3 \\
4,2\end{array}$ & $\begin{array}{l}0 \\
0 \\
0 \\
0 \\
0 \\
0\end{array}$ & $\begin{array}{l}-\cdots \\
-\cdots \\
-\cdots \\
-\cdots \\
-\cdots\end{array}$ & 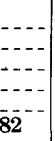 & $\begin{array}{l}--- \\
--- \\
--- \\
--- \\
---\end{array}$ & $\mathbf{3}, \mathbf{0} 50^{-\cdots}$ \\
\hline $\begin{array}{r}7 \\
8 \\
9 \\
10 \\
11 \\
12\end{array}$ & $\begin{array}{l}10.90 \\
14.17 \\
15.80 \\
17.02 \\
17.94 \\
18.58\end{array}$ & $\begin{array}{l}11,00 \\
14,30 \\
15,30 \\
16,20 \\
17,10 \\
17,70\end{array}$ & & $\begin{array}{l}22.03 \\
21.36 \\
20.46 \\
19.55 \\
18.45 \\
17.18\end{array}$ & $\begin{array}{l}18,000 \\
16,300 \\
14,900 \\
13,500 \\
12,100 \\
10,200\end{array}$ & $\begin{array}{l}7.26 \\
7.16 \\
7.10 \\
7.03 \\
6.93 \\
6.86\end{array}$ & $\begin{array}{l}4,1 \\
4,1 \\
4,0 \\
4,0 \\
3,9 \\
3,8\end{array}$ & & $\begin{array}{l}-\ldots \\
-\cdots \\
-\cdots \\
-\cdots\end{array}$ & \begin{tabular}{l|}
.--- \\
.--- \\
.--- \\
.--- \\
50
\end{tabular} & $\begin{array}{l}--- \\
--- \\
--- \\
--- \\
--\end{array}$ & $2,780^{-1}$ \\
\hline
\end{tabular}


SENECA RIVER NEAR ANDERSON, S. C.

LOCATION.-Lat. $34^{\circ} 30^{\prime}$, long. $82^{\circ} 50^{\prime}$, at highway bridge $1 \frac{11 / 2}{2}$ miles downstream from Deep Creek, 4 miles upstream from confluence of Seneca and Tugaloo Rivers, and 101/2 miles west of Anderson, Anderson County.

Drainage AREa.-1,026 square miles.

GAGE-HEIGHT RECORD.-Water-stage recorder graph.

DISCHARGE RECORD.--Stage-discharge relation defined by current-meter measurements up to 18,000 second-feet and extended to crest stage by logarithmic plotting. MaximA.-1940: Discharge, 45,600 second-feet 12:45 p.m. Aug. 14 (gage height, 18.30 feet).

1931-39: Discharge, '55,200 second-feet Oct. 1, 1936 (gage height, 20.07 feet).

Stage known, 25 feet Aug. 17, 18, 1928 (discharge, 77,000 second-feet, estimated).

REMARKs.-Flood discharge not affected by artificial storage or diversion. Flow regulated by power plant above station during low stages.

Mean discharge, in second-feet, 1940

\begin{tabular}{|c|c|c|c|c|c|c|c|c|c|c|c|}
\hline Day & Aug. & Sept. & Day & Aug. & Sept. & Day & Aug. & Sept. & Day & Aug. & Sept. \\
\hline \begin{tabular}{l|}
1 \\
2 \\
3 \\
4 \\
5 \\
6 \\
7 \\
8
\end{tabular} & $\begin{array}{l}630 \\
715 \\
698 \\
590 \\
529 \\
649 \\
670 \\
734\end{array}$ & $\begin{array}{l}5,950 \\
3,490 \\
2,810 \\
2,400 \\
2,060 \\
1,940 \\
1,870 \\
1,580\end{array}$ & $\begin{array}{r}9 \\
10 \\
11 \\
12 \\
13 \\
14 \\
15 \\
16\end{array}$ & $\begin{array}{r}661 \\
746 \\
518 \\
2,050 \\
20,300 \\
40,200 \\
14,300 \\
4,020\end{array}$ & $\begin{array}{l}1,540 \\
1,500 \\
1,440 \\
1,300 \\
1,260 \\
1,310 \\
1,100 \\
1,110\end{array}$ & $\begin{array}{l}17 \\
18 \\
19 \\
20 \\
21 \\
22 \\
23 \\
24\end{array}$ & $\begin{array}{l}3,070 \\
2,960 \\
2,470 \\
1,870 \\
1,640 \\
1,520 \\
1,490 \\
1,540\end{array}$ & $\begin{array}{r}1,130 \\
1,040 \\
1,050 \\
1,070 \\
1,390 \\
\mathbf{5 8 4} \\
\mathbf{8 4 2} \\
\mathbf{9 3 4}\end{array}$ & $\begin{array}{l}25 \\
26 \\
27 \\
28 \\
29 \\
30 \\
31\end{array}$ & $\begin{array}{r}1,290 \\
1,320 \\
1,220 \\
1,120 \\
1,760 \\
18,500 \\
23,100\end{array}$ & $\begin{array}{r}956 \\
1,080 \\
870 \\
945 \\
752 \\
808 \\
\end{array}$ \\
\hline & & & & & & & & & & $\begin{array}{r}4,932 \\
5.54\end{array}$ & $\begin{array}{r}1,537 \\
1.67\end{array}$ \\
\hline
\end{tabular}


FLOODS OF AUGUST 1940 IN THE SOUTHEASTERN STATES

Gage height, in feet, and discharge, in second-feet, at indicated time, 1940

\begin{tabular}{|c|c|c|c|c|c|c|c|c|}
\hline \multirow{2}{*}{ Hour } & \multicolumn{2}{|c|}{ Aug. 12} & \multicolumn{2}{|c|}{ Aug. 13} & \multicolumn{2}{|c|}{ Aug. 14} & \multicolumn{2}{|c|}{ Aug. 15} \\
\hline & $\begin{array}{c}\text { Gage } \\
\text { height }\end{array}$ & Discharge & $\begin{array}{c}\text { Gage } \\
\text { height }\end{array}$ & Discharge & $\begin{array}{l}\text { Gage } \\
\text { height }\end{array}$ & Discharge & $\begin{array}{c}\text { Gage } \\
\text { height }\end{array}$ & Discharge \\
\hline $\begin{array}{l}1 \\
2 \\
3 \\
4 \\
5 \\
6\end{array}$ & $\begin{array}{l}2.87 \\
2.89 \\
2.93 \\
2.90 \\
2.90 \\
2.92\end{array}$ & $\begin{array}{l}\mathbf{5 1 3} \\
\mathbf{5 3 1} \\
\mathbf{5 6 8} \\
\mathbf{5 4 0} \\
\mathbf{5 4 0} \\
\mathbf{5 5 9}\end{array}$ & $\begin{array}{r}4.90 \\
5.54 \\
7.09 \\
8.90 \\
9.97 \\
11.12\end{array}$ & $\begin{array}{r}2,980 \\
3,860 \\
6,340 \\
10,200 \\
13,000 \\
16,300\end{array}$ & $\begin{array}{l}15.32 \\
15.72 \\
16.07 \\
16.47 \\
16.97 \\
17.27\end{array}$ & $\begin{array}{l}31,600 \\
33,400 \\
35,000 \\
36,800 \\
39,000 \\
40,400\end{array}$ & $\begin{array}{l}14.78 \\
14.31 \\
13.77 \\
13.35 \\
12.96 \\
12.56\end{array}$ & $\begin{array}{l}29,400 \\
27,500 \\
25,400 \\
23,800 \\
22,400 \\
21,000\end{array}$ \\
\hline $\begin{array}{r}7 \\
8 \\
9 \\
10 \\
11 \\
\mathbf{N}\end{array}$ & $\begin{array}{l}3.13 \\
3.80 \\
4.40 \\
5.00 \\
5.29 \\
5.38\end{array}$ & $\begin{array}{r}766 \\
1,530 \\
2,300 \\
3,110 \\
3,510 \\
3,630\end{array}$ & $\begin{array}{l}11.52 \\
11.87 \\
12.24 \\
12.56 \\
12.88 \\
13.21\end{array}$ & $\begin{array}{l}17,500 \\
18,600 \\
19,900 \\
21,000 \\
22,100 \\
23,300\end{array}$ & $\begin{array}{l}17.56 \\
17.86 \\
18.03 \\
18.17 \\
18.27 \\
18.28\end{array}$ & $\begin{array}{l}41,900 \\
43,400 \\
44,200 \\
45,000 \\
45,400 \\
45,500\end{array}$ & $\begin{array}{r}12.08 \\
11.68 \\
11.30 \\
10.85 \\
10.41 \\
9.92\end{array}$ & $\begin{array}{l}19,300 \\
17,900 \\
16,800 \\
15,400 \\
14,200 \\
12,800\end{array}$ \\
\hline $\begin{array}{l}1 \\
2 \\
3 \\
4 \\
5 \\
6\end{array}$ & $\begin{array}{l}5.26 \\
4.94 \\
4.80 \\
4.84 \\
4.93 \\
4.78\end{array}$ & $\begin{array}{l}3,460 \\
3,030 \\
2,840 \\
2,890 \\
3,020 \\
2,810\end{array}$ & $\begin{array}{l}13.49 \\
13.75 \\
13.94 \\
14.03 \\
14.07 \\
14.10\end{array}$ & $\begin{array}{l}24,300 \\
25,300 \\
26,100 \\
26,400 \\
26,600 \\
26,700\end{array}$ & $\begin{array}{l}18.27 \\
18.24 \\
18.18 \\
18.06 \\
17.92 \\
17.66\end{array}$ & $\begin{array}{l}45,400 \\
45,300 \\
45,000 \\
44,400 \\
43,700 \\
42,400\end{array}$ & $\begin{array}{l}9.38 \\
8.84 \\
8.33 \\
7.87 \\
7.50 \\
7.23\end{array}$ & $\begin{array}{r}11,400 \\
10,100 \\
8,920 \\
7,910 \\
7,140 \\
6,610\end{array}$ \\
\hline \multirow[t]{2}{*}{$\begin{array}{r}7 \\
8 \\
9 \\
10 \\
11 \\
12 \\
\end{array}$} & $\begin{array}{l}4.48 \\
4.34 \\
4.31 \\
4.36 \\
4.47 \\
4.67 \\
\end{array}$ & $\begin{array}{l}2,410 \\
2,220 \\
2,180 \\
2,250 \\
2,390 \\
2,660 \\
\end{array}$ & $\begin{array}{l}14.18 \\
14.28 \\
14.40 \\
14.51 \\
14.68 \\
14.93 \\
\end{array}$ & $\begin{array}{l}27,000 \\
27,400 \\
27,900 \\
28,300 \\
29,000 \\
30,000 \\
\end{array}$ & $\begin{array}{l}17.41 \\
17.08 \\
16.60 \\
16.17 \\
15.70 \\
15.23 \\
\end{array}$ & $\begin{array}{l}41,200 \\
39,500 \\
37,400 \\
35,400 \\
33, \mathbf{3 0 0} \\
31,200 \\
\end{array}$ & $\begin{array}{l}6.99 \\
6.83 \\
6.66 \\
6.52 \\
6.42 \\
6.34 \\
\end{array}$ & $\begin{array}{l}6,150 \\
5,860 \\
5,560 \\
5,320 \\
5,150 \\
5,020 \\
\end{array}$ \\
\hline & \multicolumn{2}{|c|}{ Aug. 29} & \multicolumn{2}{|c|}{ Aug. 30} & \multicolumn{2}{|c|}{ Aug. 31} & \multicolumn{2}{|c|}{ Sept. 1} \\
\hline $\begin{array}{l}1 \\
2 \\
3 \\
4 \\
5 \\
6\end{array}$ & $\begin{array}{l}3.56 \\
3.61 \\
3.61 \\
3.50 \\
3.69 \\
3.76\end{array}$ & $\begin{array}{l}1,130 \\
1,190 \\
1,190 \\
1,060 \\
1,290 \\
1,380\end{array}$ & $\begin{array}{r}8.88 \\
9.50 \\
10.07 \\
10.51 \\
10.84 \\
11.03\end{array}$ & $\begin{array}{l}10,200 \\
11,700 \\
13,200 \\
14,500 \\
15,400 \\
16,000\end{array}$ & $\begin{array}{l}14.58 \\
14.67 \\
14.74 \\
14.78 \\
14.80 \\
14.74\end{array}$ & $\begin{array}{l}28,600 \\
29,000 \\
29,300 \\
29,400 \\
29,500 \\
29,300\end{array}$ & $\begin{array}{c}8.51^{-} \\
7.77^{-1} \\
7.26\end{array}$ & $\begin{array}{l}9,330^{-} \\
7,700^{-} \\
6,660^{-1}\end{array}$ \\
\hline $\begin{array}{r}7 \\
8 \\
9 \\
10 \\
11 \\
\mathrm{~N}\end{array}$ & $\begin{array}{l}3.68 \\
3.63 \\
3.56 \\
3.55 \\
3.56 \\
3.58\end{array}$ & $\begin{array}{l}1,280 \\
1,220 \\
1,130 \\
1,120 \\
1,130 \\
1,160\end{array}$ & $\begin{array}{l}11.10 \\
11.22 \\
11.26 \\
11.34 \\
11.45 \\
11.57\end{array}$ & $\begin{array}{l}16,200 \\
16,600 \\
16,700 \\
16,900 \\
17,200 \\
17,600\end{array}$ & $\begin{array}{l}14.70 \\
14.59 \\
14.46 \\
14.26 \\
13.96 \\
13.61\end{array}$ & $\begin{array}{l}29,100 \\
28,700 \\
28,100 \\
27,300 \\
26,100 \\
24,700\end{array}$ & $\begin{array}{c}6.90 \\
6.66 \\
6.50\end{array}$ & $\begin{array}{l}5,990^{-} \\
5,560^{-} \\
5,290^{-}\end{array}$ \\
\hline $\begin{array}{l}1 \\
2 \\
3 \\
4 \\
\mathbf{4} \\
\mathbf{5} \\
\mathbf{6}\end{array}$ & $\begin{array}{l}3.59 \\
3.60 \\
3.58 \\
3.63 \\
3.61 \\
3.63\end{array}$ & $\begin{array}{l}1,170 \\
1,180 \\
1,160 \\
1,220 \\
1,190 \\
1,220\end{array}$ & $\begin{array}{l}11.77 \\
11.96 \\
12.15 \\
12.39 \\
12.62 \\
12.92\end{array}$ & $\begin{array}{l}18,200 \\
18,900 \\
19,600 \\
20,400 \\
21,200 \\
22,300\end{array}$ & $\begin{array}{l}13.26 \\
12.93 \\
12.60 \\
12.28 \\
11.93 \\
11.60\end{array}$ & $\begin{array}{l}23,500 \\
22,300 \\
21,200 \\
20,000 \\
18,800 \\
17,700\end{array}$ & $\begin{array}{l}6.31^{-} \\
6.19^{-} \\
6.09^{-}\end{array}$ & $\begin{array}{l}4,980^{-} \\
4,780^{-} \\
4,620^{-}\end{array}$ \\
\hline $\begin{array}{r}7 \\
8 \\
9 \\
10 \\
11 \\
12 \\
\end{array}$ & $\begin{array}{l}3.66 \\
4.18 \\
4.98 \\
5.84 \\
6.85 \\
8.00\end{array}$ & $\begin{array}{l}1,250 \\
1,910 \\
3,000 \\
4,240 \\
5,900 \\
8,190 \\
\end{array}$ & $\begin{array}{l}13.11 \\
13.38 \\
13.63 \\
13.79 \\
14.18 \\
14.40\end{array}$ & $\begin{array}{l}22,900 \\
23,900 \\
24,800 \\
25,500 \\
27,000 \\
27,900 \\
\end{array}$ & $\begin{array}{r}11.23 \\
10.90 \\
10.50 \\
10.10 \\
9.75 \\
9.32 \\
\end{array}$ & $\begin{array}{l}16,600 \\
15,600 \\
14,400 \\
13,300 \\
12,400 \\
11,300\end{array}$ & $\begin{array}{l}5.96 \\
5.88 \\
5.78 \\
\end{array}$ & $\begin{array}{l}4,420^{-} \\
4,300^{-} \\
4,150^{-} \\
\end{array}$ \\
\hline
\end{tabular}

Supplemental Records-Aug, 14,12:45 p.m. gage height, 18.30 feet; discharge, 45,600 second-feet. Aug. 31, 4:30 a.m., gage height, 14.82 feet; discharge, 29,600 second-feet. 
BROAD RIVER NEAR BELL, GA.

LOCATion.-Lat. $33^{\circ} 58^{\prime}$, long. $82^{\circ} 46^{\prime}$, at bridge on State Highway 17 , half a mile downstream from Long Creek, 1 mile south of Bell's crossroads, and 12 miles southeast of Elberton, Elbert County. Datum of gage is 357.16 feet above mean sea level, datum of 1929, supplementary adjustment of 1936 .

Drain age AREa. $-1,420$ square miles.

GAGE-HEIGHT RECORD.-Water-stage recorder graph.

DISCHARGE RECORD.- Stage-discharge relation defined by current-meter measurements up to 25,000 second-feet and extended logarithmically to erest gage height. Gage heights used to half-tenths between 3.5 and 5.2 feet; hundredths below and tenths above these limits.

Maxima.-1940: Discharge, 28,400 second-feet 4 a.m. Aug. 14 (gage height, 25.10 feet).

1926-32, 1937-39: Gage height, 34.8 feet Oct. 2, 1929 (discharge uncertain).

REMARKs.-Flood runoff not affected by storage or diversion.

Mean discharge, in second-feet, 1940

\begin{tabular}{|c|c|c|c|c|c|c|c|c|c|c|c|}
\hline Day & Aug. & Sept. & Day & Aug. & Sept. & Day & Aug. & Sept. & Day & Aug. & Sept. \\
\hline $\begin{array}{l}1 \\
2 \\
3 \\
4 \\
5 \\
6 \\
7 \\
8\end{array}$ & $\begin{array}{l}\mathbf{4 6 0} \\
\mathbf{3 7 0} \\
\mathbf{3 7 5} \\
\mathbf{3 7 0} \\
\mathbf{3 0 7} \\
\mathbf{3 6 1} \\
\mathbf{3 8 0} \\
\mathbf{6 7 0}\end{array}$ & $\begin{array}{r}3,820 \\
1,510 \\
1,120 \\
925 \\
845 \\
795 \\
770 \\
720\end{array}$ & $\begin{array}{r}9 \\
10 \\
11 \\
12 \\
13 \\
14 \\
15 \\
16\end{array}$ & $\begin{array}{r}605 \\
435 \\
361 \\
1,190 \\
23,400 \\
26,100 \\
16,300 \\
3,110\end{array}$ & $\begin{array}{l}670 \\
645 \\
615 \\
575 \\
555 \\
550 \\
535 \\
505\end{array}$ & $\begin{array}{l}17 \\
18 \\
19 \\
20 \\
21 \\
22 \\
23 \\
24\end{array}$ & $\begin{array}{r}1,540 \\
1,210 \\
1,040 \\
925 \\
.820 \\
770 \\
720 \\
695\end{array}$ & $\begin{array}{l}525 \\
505 \\
490 \\
500 \\
475 \\
470 \\
410 \\
445\end{array}$ & $\begin{array}{l}25 \\
26 \\
27 \\
28 \\
29 \\
30 \\
31\end{array}$ & $\begin{array}{r}670 \\
615 \\
620 \\
575 \\
595 \\
4,720 \\
\mathbf{8}, 270\end{array}$ & $\begin{array}{l}445 \\
440 \\
430 \\
460 \\
440 \\
370\end{array}$ \\
\hline \multicolumn{10}{|c|}{$\begin{array}{l}\text { Monthly mean discharge, in second-feet } \\
\text { Runoff, in inches }\end{array}$} & $\begin{array}{r}3,180 \\
2.58\end{array}$ & $\begin{array}{r}719 \\
0.56\end{array}$ \\
\hline
\end{tabular}

Gage height, in feet, and discharge, in second-feet, at indicated time, 1940

\begin{tabular}{|c|c|c|c|c|c|c|c|c|c|c|}
\hline \multirow{2}{*}{ Hour } & \multicolumn{2}{|c|}{ Aug. 12} & \multicolumn{2}{|c|}{ Aug. 13} & \multicolumn{2}{|c|}{ Aug. 14} & \multicolumn{2}{|c|}{ Aug. 15} & \multicolumn{2}{|c|}{ Aug. 16} \\
\hline & $\begin{array}{c}\text { Gage } \\
\text { height }\end{array}$ & $\begin{array}{c}\text { Dis- } \\
\text { charge }\end{array}$ & $\begin{array}{c}\text { Gage } \\
\text { height }\end{array}$ & $\begin{array}{c}\text { Dis- } \\
\text { charge }\end{array}$ & $\begin{array}{c}\text { Gage } \\
\text { height }\end{array}$ & $\begin{array}{c}\text { Dis- } \\
\text { charge }\end{array}$ & $\begin{array}{c}\text { Gage } \\
\text { height }\end{array}$ & $\begin{array}{c}\text { Dis- } \\
\text { charge }\end{array}$ & $\begin{array}{c}\text { Gage } \\
\text { height }\end{array}$ & $\begin{array}{c}\text { Dis- } \\
\text { charge }\end{array}$ \\
\hline $\begin{array}{l}1 \\
2 \\
3 \\
4 \\
5 \\
6\end{array}$ & $\mid$\begin{tabular}{l}
-1. \\
\hdashline-12.91 \\
\hdashline-1
\end{tabular} & 1930 & $\begin{array}{l}16.80 \\
18.50 \\
19.70 \\
20.58 \\
21.30 \\
21.90\end{array}$ & $\begin{array}{l}13,100 \\
15,700 \\
17,700 \\
19,300 \\
20,600 \\
21,700\end{array}$ & $\begin{array}{l}24.93 \\
25.00 \\
25.07 \\
25.10 \\
25.06 \\
25.00\end{array}$ & $\begin{array}{l}28,000 \\
28,200 \\
28,400 \\
28,400 \\
28,400 \\
28,200\end{array}$ & $\begin{array}{l}21.66 \\
21.44 \\
21.20 \\
21.00 \\
20.77 \\
20.56\end{array}$ & $\begin{array}{l}21,300 \\
20,800 \\
20,400 \\
20,000 \\
19,600 \\
19,300\end{array}$ & $\begin{array}{r}12.20 \\
11.20 \\
10.00 \\
9.10 \\
8.30 \\
7.68\end{array}$ & $\begin{array}{l}7,500 \\
6,500 \\
5,360 \\
4,550 \\
3,850 \\
3,370\end{array}$ \\
\hline $\begin{array}{r}7 \\
8 \\
9 \\
10 \\
11 \\
\mathrm{~N}\end{array}$ & & & $\begin{array}{l}22.43 \\
22.90 \\
23.20 \\
23.48 \\
23.66 \\
23.74\end{array}$ & $\begin{array}{l}22,700 \\
23,700 \\
24,300 \\
25,000 \\
25,400 \\
25,400\end{array}$ & $\begin{array}{l}24.96 \\
24.88 \\
24.76 \\
24.64 \\
24.50 \\
24.37\end{array}$ & $\begin{array}{l}28,200 \\
28,000 \\
27,800 \\
27,300 \\
27,100 \\
26,900\end{array}$ & $\begin{array}{l}20.35 \\
20.14 \\
19.83 \\
19.62 \\
19.42 \\
19.14\end{array}$ & $\begin{array}{l}18,900 \\
18,400 \\
17,900 \\
17,500 \\
17,200 \\
16,700\end{array}$ & $\begin{array}{l}7.36 \\
7.08 \\
6.88 \\
6.70 \\
6.58 \\
6.46\end{array}$ & $\begin{array}{l}3,050 \\
2,820 \\
2,670 \\
2,520 \\
2,450 \\
2,380\end{array}$ \\
\hline $\begin{array}{l}1 \\
2 \\
3 \\
4 \\
5 \\
6\end{array}$ & $\begin{array}{l}2.95 \\
2.96 \\
2.98 \\
3.00 \\
3.04 \\
3.10\end{array}$ & $\begin{array}{l}348 \\
352 \\
361 \\
370 \\
390 \\
420\end{array}$ & $\begin{array}{l}23.76 \\
23.78 \\
23.80 \\
23.84 \\
23.90 \\
24.00\end{array}$ & $\begin{array}{l}25,600 \\
25,600 \\
25,600 \\
25,600 \\
25,800 \\
26,000\end{array}$ & $\begin{array}{l}24.20 \\
24.00 \\
23.82 \\
23.64 \\
23.45 \\
23.20\end{array}$ & $\begin{array}{l}26,400 \\
26,000 \\
25,600 \\
25,200 \\
24,700 \\
24,300\end{array}$ & $\begin{array}{l}18.90 \\
18.60 \\
18.30 \\
18.00 \\
17.66 \\
17.28\end{array}$ & $\begin{array}{l}16,300 \\
15,900 \\
15,400 \\
14,900 \\
14,400 \\
13,800\end{array}$ & $\begin{array}{l}6.34 \\
6.28 \\
6.19 \\
6.10 \\
6.04 \\
5.97\end{array}$ & $\begin{array}{l}2,310 \\
2,240 \\
2,170 \\
2,100 \\
2,040 \\
2,040\end{array}$ \\
\hline $\begin{array}{r}7 \\
8 \\
9 \\
10 \\
11 \\
12\end{array}$ & $\begin{array}{r}3.21 \\
3.65 \\
6.20 \\
10.30 \\
12.70 \\
14.90\end{array}$ & $\begin{array}{r}475 \\
695 \\
2,240 \\
5,630 \\
8,040 \\
10,600\end{array}$ & $\begin{array}{l}24.10 \\
24.24 \\
24.40 \\
24.56 \\
24.70 \\
24.84\end{array}$ & $\begin{array}{l}26,200 \\
26,400 \\
26,900 \\
27,300 \\
27,500 \\
27,800\end{array}$ & $\begin{array}{l}23.00 \\
22.76 \\
22.56 \\
22.37 \\
22.14 \\
21.88\end{array}$ & $\begin{array}{l}23,900 \\
23,500 \\
23,100 \\
22,700 \\
22,100 \\
21,700\end{array}$ & $\begin{array}{l}16.88 \\
16.40 \\
15.76 \\
15.00 \\
14.20 \\
13.20\end{array}$ & $\begin{array}{r}13,300 \\
12,600 \\
11,700 \\
10,700 \\
9,740 \\
8,590\end{array}$ & $\begin{array}{l}5.91 \\
5.85 \\
5.79 \\
5.72 \\
5.69 \\
5.63\end{array}$ & $\begin{array}{r}1,970 \\
1,970 \\
1,900 \\
1,840 \\
1,840 \\
1,780\end{array}$ \\
\hline
\end{tabular}

1 Mean for 12 hours. 


\section{FLOODS OF AUGUST 1940 IN THE SOUTHEASTERN STATES}

Gage height, in feet, and discharge, in second-feet, at indicated time, 1940-Con.

\begin{tabular}{|c|c|c|c|c|c|c|c|c|}
\hline \multirow{2}{*}{ Hour } & \multicolumn{2}{|c|}{ Aug. 29} & \multicolumn{2}{|c|}{ Aug. 30} & \multicolumn{2}{|c|}{ Aug. 31} & \multicolumn{2}{|c|}{ Sept. 1} \\
\hline & $\begin{array}{l}\text { Gage } \\
\text { height }\end{array}$ & Discharge & $\begin{array}{l}\text { Gage } \\
\text { height }\end{array}$ & Discharge & $\begin{array}{c}\text { Gage } \\
\text { height }\end{array}$ & Discharge & $\begin{array}{l}\text { Gage } \\
\text { height }\end{array}$ & Discharge \\
\hline $\begin{array}{l}1 \\
2 \\
3 \\
4 \\
5 \\
5 \\
6\end{array}$ & 13.49 & (15) & $\begin{array}{l}3.91 \\
3.99 \\
4.06 \\
4.17 \\
4.52 \\
5.47\end{array}$ & $\begin{array}{r}770 \\
820 \\
845 \\
898 \\
1,090 \\
1,710\end{array}$ & $\begin{array}{l}12.50 \\
12.56 \\
12.64 \\
12.70 \\
12.76 \\
12.81\end{array}$ & $\begin{array}{l}7,820 \\
7,930 \\
7,930 \\
8,040 \\
8,150 \\
8,150\end{array}$ & $\begin{array}{r}12.06 \\
11.72 \\
11.30 \\
10.90 \\
10.40 \\
9.86\end{array}$ & $\begin{array}{l}7,400 \\
7,000 \\
6,600 \\
6,200 \\
5,720 \\
5,270\end{array}$ \\
\hline $\begin{array}{r}7 \\
8 \\
9 \\
10 \\
11 \\
\mathrm{~N}\end{array}$ & 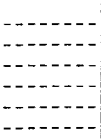 & 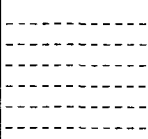 & $\begin{array}{r}6.70 \\
7.80 \\
8.70 \\
9.40 \\
9.96 \\
10.34\end{array}$ & $\begin{array}{l}2,520 \\
3,450 \\
4,190 \\
4,820 \\
5,360 \\
5,630\end{array}$ & $\begin{array}{l}12.87 \\
12.92 \\
12.98 \\
13.03 \\
13.08 \\
13.11\end{array}$ & $\begin{array}{l}8,260 \\
8,260 \\
8,370 \\
8,370 \\
8,480 \\
8,480\end{array}$ & $\begin{array}{l}9.34 \\
8.86 \\
8.42 \\
8.02 \\
7.68 \\
7.39\end{array}$ & $\begin{array}{l}\mathbf{4}, \mathbf{7 3 0} \\
\mathbf{4}, \mathbf{3 7 0} \\
3,930 \\
3,610 \\
3,370 \\
\mathbf{3}, 130\end{array}$ \\
\hline $\begin{array}{l}1 \\
\mathbf{2} \\
\mathbf{3} \\
\mathbf{4} \\
\mathbf{5} \\
\mathbf{6}\end{array}$ & $\begin{array}{l}3.50 \\
3.50 \\
3.50 \\
3.51 \\
\mathbf{3 . 5 3} \\
3.54\end{array}$ & $\begin{array}{l}570 \\
570 \\
570 \\
575 \\
585 \\
590\end{array}$ & $\begin{array}{l}10.70 \\
11.00 \\
11.24 \\
11.44 \\
11.62 \\
11.78\end{array}$ & $\begin{array}{l}6,000 \\
6,300 \\
6,500 \\
6,700 \\
6,900 \\
7,100\end{array}$ & $\begin{array}{l}13.15 \\
13.17 \\
13.19 \\
13.20 \\
13.18 \\
13.14\end{array}$ & $\begin{array}{l}\mathbf{8}, 590 \\
\mathbf{8}, 590 \\
\mathbf{8}, 590 \\
\mathbf{8}, 590 \\
\mathbf{8}, 590 \\
\mathbf{8 , 4 8 0}\end{array}$ & $\begin{array}{l}7.13 \\
6.91 \\
6.72 \\
6.53 \\
6.39 \\
6.24\end{array}$ & $\begin{array}{l}2,900 \\
2,740 \\
2,600 \\
2,450 \\
2,380 \\
2,240\end{array}$ \\
\hline $\begin{array}{r}7 \\
8 \\
9 \\
10 \\
11 \\
12 \\
12\end{array}$ & $\begin{array}{l}3.56 \\
3.64 \\
3.70 \\
3.80 \\
3.85 \\
3.86\end{array}$ & $\begin{array}{l}600 \\
645 \\
670 \\
720 \\
745 \\
745\end{array}$ & $\begin{array}{l}11.92 \\
12.05 \\
12.15 \\
12.26 \\
12.34 \\
12.42\end{array}$ & $\begin{array}{l}7,200 \\
7,300 \\
7,500 \\
7,600 \\
7,600 \\
7,710\end{array}$ & $\begin{array}{l}13.08 \\
13.02 \\
12.90 \\
12.76 \\
12.56 \\
12.34\end{array}$ & $\begin{array}{l}8,480 \\
8, \mathbf{3 7 0} \\
8,260 \\
8,150 \\
7,930 \\
7,600\end{array}$ & $\begin{array}{l}6.11 \\
6.01 \\
5.92 \\
5.82 \\
5.75 \\
5.68\end{array}$ & $\begin{array}{l}2,170 \\
2,100 \\
2,040 \\
1,970 \\
1,970 \\
1,900\end{array}$ \\
\hline
\end{tabular}

'Mean for 12 hours.

\section{LINTLE RIVER NEAR MOUNT CARMEL, S. C.}

Location.-Lat. $34^{\circ} 04^{\prime}$, long. $82^{\circ} 30^{\prime}, 480$ feet downstream from Island Ford Bridge on State Highway 721, 2.8 miles upstream from Calhoun Creek, and 4.5 miles north of Mount Carmel, McCormick County.

Drainage ARea.--217 square miles.

GAGE-HEIGHT RECORD.-Water-stage recorder graph, except for period 11 p.m. Aug. 13 to 8 a.m. Aug. 14, for which a graph was drawn based on a floodmark and comparison with stage graph of nearby stations.

DISCHARGE RECORD.- -Stage-discharge relation defined by current-meter measurements up to 13,000 second-feet; extended to peak stage by logarithmic plotting. Shifting-control method used Aug. 16 to Sept. 30.

Maxima.-Discharge, 20,800 second-feet 4 a.m. Aug. 14 (gage height, 29.60 feet, from floodmark).

Remarks.-Flood discharge not affected by artificial storage or diversion.

Mean discharge, in second-feet, 1940

\begin{tabular}{|c|c|c|c|c|c|c|c|c|c|c|c|}
\hline Day & Aug. & Sept. & Day & Aug. & Sept. & Day & Aug. & Sept. & Day & Aug. & Sept. \\
\hline $\begin{array}{l}1 \\
2 \\
3 \\
4 \\
5 \\
6 \\
7 \\
8 \\
8\end{array}$ & $\begin{array}{r}29 \\
28 \\
22 \\
20 \\
21 \\
59 \\
74 \\
139\end{array}$ & $\begin{array}{r}160 \\
104 \\
87 \\
80 \\
74 \\
73 \\
70 \\
68\end{array}$ & $\begin{array}{l}99 \\
10 \\
11 \\
12 \\
13 \\
14 \\
15 \\
16\end{array}$ & $\begin{array}{r}116 \\
55 \\
43 \\
193 \\
10,500 \\
15,200 \\
2,770 \\
419\end{array}$ & $\begin{array}{l}63 \\
60 \\
69 \\
95 \\
69 \\
64 \\
64 \\
61\end{array}$ & $\begin{array}{l}17 \\
18 \\
19 \\
20 \\
21 \\
22 \\
23 \\
24\end{array}$ & $\begin{array}{r}256 \\
184 \\
152 \\
118 \\
104 \\
99 \\
91 \\
87\end{array}$ & $\begin{array}{l}59 \\
56 \\
54 \\
54 \\
51 \\
50 \\
46 \\
43\end{array}$ & $\begin{array}{l}25 \\
26 \\
27 \\
28 \\
29 \\
30 \\
31 .\end{array}$ & $\begin{array}{r}83 \\
74 \\
69 \\
63 \\
68 \\
468 \\
\mathbf{2 4 8}\end{array}$ & $\begin{array}{l}\mathbf{4 3} \\
\mathbf{3 8} \\
\mathbf{3 8} \\
\mathbf{3 8} \\
\mathbf{3 8} \\
\mathbf{3 8}\end{array}$ \\
\hline \multicolumn{10}{|c|}{$\begin{array}{l}\text { Monthly mean discharge, in second-feet. } \\
\text { Runoff, in inches. }\end{array}$} & 1,027 & $\begin{array}{l}63.6 \\
0.33\end{array}$ \\
\hline
\end{tabular}


SAVANNAH RIVER BASIN

Gage height, in feet, and discharge, in second-feet, at indicated time, 1940

\begin{tabular}{|c|c|c|c|c|c|c|c|c|c|c|}
\hline \multirow{2}{*}{ Hour } & \multicolumn{2}{|c|}{ Aug. 12} & \multicolumn{2}{|c|}{ Aug. 13} & \multicolumn{2}{|c|}{ Aug. 14} & \multicolumn{2}{|c|}{ Aug. 15} & \multicolumn{2}{|c|}{ Aug. 16} \\
\hline & $\begin{array}{l}\text { Gage } \\
\text { height }\end{array}$ & $\begin{array}{c}\text { Dis- } \\
\text { charge }\end{array}$ & $\begin{array}{c}\text { Gage } \\
\text { height }\end{array}$ & $\begin{array}{c}\text { Dis- } \\
\text { charge }\end{array}$ & $\begin{array}{l}\text { Gage } \\
\text { height }\end{array}$ & $\begin{array}{c}\text { Dis- } \\
\text { charge }\end{array}$ & $\begin{array}{l}\text { Gage } \\
\text { height }\end{array}$ & $\begin{array}{l}\text { Dis- } \\
\text { charge }\end{array}$ & $\begin{array}{c}\text { Gage } \\
\text { height }\end{array}$ & $\begin{array}{l}\text { Dis- } \\
\text { charge }\end{array}$ \\
\hline $\begin{array}{l}1 \\
2 \\
3 \\
4 \\
5 \\
6\end{array}$ & $\begin{array}{r}0 . \overline{95} \\
.96 \\
.9 \overline{9}\end{array}$ & $\mid \begin{array}{r}-40 \\
43\end{array}$ & $\begin{array}{l}12.35 \\
15.11 \\
15.17 \\
15.37 \\
15.89 \\
16.90\end{array}$ & $\begin{array}{l}2,950 \\
4,120 \\
4,150 \\
4,240 \\
4,500 \\
5,020\end{array}$ & $\begin{array}{l}29.08 \\
29.30 \\
29.50 \\
29.60 \\
29.41 \\
29.10\end{array}$ & $\begin{array}{l}19,700 \\
20,100 \\
20,600 \\
20,800 \\
20,400 \\
19,700\end{array}$ & $\begin{array}{l}19.34 \\
18.50 \\
17.61 \\
16.78 \\
15.97 \\
15.09\end{array}$ & $\begin{array}{l}6,500 \\
5,940 \\
5,410 \\
4,950 \\
4,540 \\
4,120\end{array}$ & 3.95 & $\mid \begin{array}{r}-\cdots \\
-\cdots\end{array}$ \\
\hline $\begin{array}{r}7 \\
8 \\
9 \\
10 \\
11 \\
\text { N }\end{array}$ & $\begin{array}{c}1.06 \\
1.13\end{array}$ & $\frac{47}{55}$ & $\begin{array}{l}17.79 \\
18.47 \\
19.90 \\
21.61 \\
23.01 \\
23.93\end{array}$ & $\begin{array}{r}5,510 \\
5,920 \\
6,910 \\
8,420 \\
9,920 \\
11,100\end{array}$ & $\begin{array}{l}28.81 \\
28.56 \\
28.28 \\
27.87 \\
27.48 \\
27.03\end{array}$ & $\begin{array}{l}19,200 \\
18,600 \\
18,100 \\
17,300 \\
16,600 \\
15,800\end{array}$ & $\begin{array}{l}14.29 \\
13.50 \\
12.69 \\
12.05 \\
11.45 \\
10.83\end{array}$ & $\begin{array}{l}3,760 \\
3,410 \\
3,090 \\
2,830 \\
2,620 \\
2,400\end{array}$ & \begin{tabular}{c}
$-\overline{3} . \overline{6} \overline{6}^{-}$ \\
\hdashline$\overline{3.44}$
\end{tabular} & {$\left[\begin{array}{r}4 \overline{4} \overline{7}^{-} \\
\cdots \\
\hdashline \overline{40}\end{array}\right.$} \\
\hline $\begin{array}{l}1 \\
2 \\
3 \\
4 \\
4 \\
5 \\
6\end{array}$ & $\begin{array}{c}1.24 \\
1.38 \\
2.62\end{array}$ & $\begin{array}{r}\mathbf{8 0} \\
-98 \overline{9}\end{array}$ & $\begin{array}{l}24.72 \\
25.24 \\
25.59 \\
25.91 \\
26.14 \\
26.47\end{array}$ & $\begin{array}{l}12,100 \\
12,900 \\
13,400 \\
13,900 \\
14,300 \\
14,800\end{array}$ & $\begin{array}{l}26.56 \\
26.07 \\
25.56 \\
25.04 \\
24.52 \\
23.99\end{array}$ & $\begin{array}{l}15,000 \\
14,200 \\
13,400 \\
12,600 \\
11,800 \\
11,100\end{array}$ & $\begin{array}{r}10.32 \\
9.47 \\
8.44 \\
7.61 \\
6.82 \\
6.09\end{array}$ & $\begin{array}{l}2,220 \\
1,950 \\
1,640 \\
1,400 \\
1,190 \\
1,000\end{array}$ & $\begin{array}{r}-\overline{3} \cdot \overline{8} \\
-\cdots \\
-\cdots\end{array}$ & 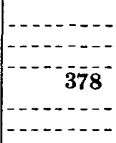 \\
\hline $\begin{array}{r}7 \\
8 \\
9 \\
10 \\
11 \\
12 \\
\end{array}$ & $\mid \begin{array}{c}-\overline{3} . \overline{82} \\
-\overline{4} . \overline{53} \\
-\overline{5.64}\end{array}$ & $\begin{array}{l}498 \overline{8} \\
64 \overline{5} \\
896 \overline{6}\end{array}$ & $\begin{array}{l}27.19 \\
27.98 \\
28.24 \\
28.37 \\
28.58 \\
28.87\end{array}$ & $\begin{array}{l}16,100 \\
17,500 \\
18,000 \\
18,300 \\
18,700 \\
19,300\end{array}$ & $\begin{array}{l}23.48 \\
22.94 \\
22.34 \\
21.70 \\
20.99 \\
20.21 \\
\end{array}$ & $\begin{array}{r}10,500 \\
9,840 \\
9,170 \\
8,510 \\
7,830 \\
7,160 \\
\end{array}$ & $\begin{array}{l}5.56 \\
5.16 \\
4.89 \\
4.66 \\
4.49 \\
4.33 \\
\end{array}$ & $\begin{array}{l}876 \\
783 \\
724 \\
673 \\
636 \\
601 \\
\end{array}$ & $\mid$\begin{tabular}{c}
$-\overline{3} . \overline{11}$ \\
\hdashline$\overline{2.97}$ \\
$-\overline{9}$
\end{tabular} & \begin{tabular}{|c}
$-\overline{349}$ \\
\hdashline$-\overline{325}$ \\
-5
\end{tabular} \\
\hline
\end{tabular}

STEVENS CREGK NEAR MODOC, S. C.

Location.-Lat. $33^{\circ} 43^{\prime} 45^{\prime \prime}$, long. $82^{\circ} 10^{\prime} 55^{\prime \prime}$, at bridge on State Highway $23,1.4$ miles east of Modoc, McCormick County, and 3.2 miles downstream from Turkey Creek.

Drainage AREA. -545 square miles (1945 revision).

GAGE-HEIGHT RECORD.-Water-stage recorder graph.

DISCHARGE RECORD.- - Stage-discharge relation defined by current-meter measurements.

Rate of change of stage used as a factor in computing discharge Aug. 12-16.

Maxima.-Discharge, 35,100 second-feet 6:30 a.m. Aug. 14; maximum gage height,

41.08 feet 9:30 a.m. Aug. 14.

REMARKs.-Flood discharge not affected by artificial storage or diversion.

Mean discharge, in second-feet, 1940

\begin{tabular}{|c|c|c|c|c|c|c|c|c|c|c|c|}
\hline Day & Aug. & Sept. & Day & Aug. & Sept. & Day & Aug. & Sept. & Day & Aug. & Sept. \\
\hline $\begin{array}{l}1 \\
2 \\
3 \\
4 \\
5 \\
6 \\
7 \\
8\end{array}$ & $\begin{array}{r}22 \\
16 \\
17 \\
11 \\
17 \\
34 \\
96 \\
\mathbf{1 6 4}\end{array}$ & & $\begin{array}{r}9 \\
10 \\
11 \\
12 \\
13 \\
14 \\
15 \\
16\end{array}$ & $\begin{array}{r}222 \\
124 \\
51 \\
372 \\
25,000 \\
31,700 \\
10,800 \\
1,000\end{array}$ & - & $\begin{array}{l}17 \\
18 \\
19 \\
20 \\
21 \\
22 \\
23 \\
24\end{array}$ & $\begin{array}{r}368 \\
238 \\
194 \\
144 \\
116 \\
97 \\
84 \\
81\end{array}$ & & $\begin{array}{l}25 \\
26 \\
27 \\
28 \\
29 \\
30 \\
31\end{array}$ & $\begin{array}{r}60 \\
64 \\
59 \\
60 \\
63 \\
41 \\
437 \\
\end{array}$ & \\
\hline \multicolumn{10}{|c|}{$\begin{array}{l}\text { Monthly mean discharge, in second-feet. } \\
\text { Runoff, in inches }\end{array}$} & $\begin{array}{r}2,311 \\
4.89\end{array}$ & \\
\hline
\end{tabular}


Gage height, in feet, and discharge, in second-feet, at indicated time, 1940

\begin{tabular}{|c|c|c|c|c|c|c|c|c|c|c|c|c|}
\hline \multirow{2}{*}{ Hour } & \multicolumn{2}{|c|}{ Aug. 12} & \multicolumn{2}{|c|}{ Aug. 13} & \multicolumn{2}{|c|}{ Aug. 14} & \multicolumn{2}{|c|}{ Aug. 15} & \multicolumn{2}{|c|}{ Aug. 16} & \multicolumn{2}{|c|}{ Aug. 17} \\
\hline & $\begin{array}{c}\text { Gage } \\
\text { ht. }\end{array}$ & $\begin{array}{l}\text { Dis- } \\
\text { charge }\end{array}$ & $\begin{array}{c}\text { Gage } \\
\text { ht. }\end{array}$ & $\begin{array}{l}\text { Dis- } \\
\text { charge }\end{array}$ & $\begin{array}{c}\text { Gage } \\
\text { ht. }\end{array}$ & $\begin{array}{c}\text { Dis- } \\
\text { charge }\end{array}$ & $\begin{array}{c}\text { Gage } \\
\text { ht. }\end{array}$ & $\begin{array}{c}\text { Dis- } \\
\text { charge }\end{array}$ & $\begin{array}{c}\text { Gage } \\
\text { ht. }\end{array}$ & $\underset{\text { chai }}{\mathrm{Di}}$ & $\begin{array}{c}\text { Gage } \\
\text { ht. }\end{array}$ & \\
\hline $\begin{array}{l}1 \\
2 \\
3 \\
4 \\
5 \\
6\end{array}$ & 0.97 & & $\begin{array}{l}15.50 \\
21.08 \\
25.60 \\
27.38 \\
28.86 \\
30.70\end{array}$ & $\begin{array}{r}7,520 \\
12,100 \\
18,000 \\
17,100 \\
19,600 \\
23,100\end{array}$ & $\begin{array}{l}39.08 \\
39.43 \\
39.80 \\
40.18 \\
40.49 \\
40.72\end{array}$ & $\begin{array}{l}33,300 \\
33,900 \\
34,600 \\
35,000 \\
35,000 \\
35,000\end{array}$ & $\begin{array}{l}35.67 \\
35.01 \\
34.27 \\
33.52 \\
32.77 \\
32.00\end{array}$ & $\begin{array}{l}21,800 \\
21,000 \\
20,000 \\
18,600 \\
17,600 \\
16,800\end{array}$ & $\begin{array}{r}10.18 \\
-8.34 \\
-6.62\end{array}$ & $\begin{array}{l}2,070^{-} \\
1,630 \\
1,280^{0}\end{array}$ & $2.5 \overline{3}$ & 428 \\
\hline $\begin{array}{r}7 \\
8 \\
9 \\
10 \\
11 \\
\text { N }\end{array}$ & 1.03 & & $\begin{array}{l}32.26 \\
33.44 \\
34.34 \\
35.10 \\
35.63 \\
36.13\end{array}$ & $\begin{array}{l}24,800 \\
25,700 \\
25,700 \\
27,200 \\
27,400 \\
28,000\end{array}$ & $\mid \begin{array}{l}40.90 \\
41.02 \\
41.07 \\
41.07 \\
41.00 \\
40.88\end{array}$ & $\begin{array}{l}35,000 \\
34,800 \\
34,600 \\
34,600 \\
33,800 \\
34,200\end{array}$ & $\mid \begin{array}{l}31.19 \\
30.40 \\
29.62 \\
28.74 \\
27.80 \\
26.90\end{array}$ & $\begin{array}{l}16,000 \\
15,000 \\
14,100 \\
12,600 \\
11,700 \\
10,900\end{array}$ & $\begin{array}{r}5 . \overline{24} \\
4.33 \\
3.86\end{array}$ & $\begin{array}{c}1,020 \\
8599^{-} \\
746^{-1}\end{array}$ & 2.26 & $\overline{3} \overline{5} \overline{8}$ \\
\hline $\begin{array}{l}1 \\
2 \\
3 \\
4 \\
5 \\
5 \\
6\end{array}$ & $\begin{array}{l}1.00 \\
1.00 \\
1.00 \\
1.00 \\
1.00 \\
1.08\end{array}$ & $\begin{array}{l}\mathbf{5 3} \\
\mathbf{5 3} \\
\mathbf{5 3} \\
\mathbf{5 3} \\
\mathbf{5 3} \\
\mathbf{6 6}\end{array}$ & $\begin{array}{l}36.50 \\
36.84 \\
37.10 \\
37.27 \\
37.46 \\
37.62\end{array}$ & $\begin{array}{l}28,700 \\
28,700 \\
28,500 \\
28,800 \\
29,100 \\
29,500\end{array}$ & $\begin{array}{l}40.70 \\
40.48 \\
40.24 \\
39.92 \\
39.56 \\
39.20\end{array}$ & $\begin{array}{l}32,500 \\
32,200 \\
33,100 \\
30,900 \\
29,700 \\
29,700\end{array}$ & $\left|\begin{array}{l}25.90 \\
24.88 \\
23.59 \\
22.20 \\
20.80 \\
19.29\end{array}\right|$ & $\begin{array}{l}8,250 \\
6,260 \\
4,800 \\
4,150 \\
3,470\end{array}$ & $\begin{array}{r}3 . \overline{6} \\
3 . \overline{38} \\
3.21\end{array}$ & $635^{-68}$ & 2.08 & 311 \\
\hline $\begin{array}{r}7 \\
8 \\
9 \\
10 \\
11 \\
12\end{array}$ & \begin{tabular}{|r|}
1.37 \\
1.77 \\
3.60 \\
6.32 \\
8.18
\end{tabular} & $\begin{array}{r}128 \\
253 \\
1,000 \\
1,900 \\
2,470 \\
4,880\end{array}$ & $\mid \begin{array}{l}37.78 \\
37.86 \\
38.05 \\
38.28 \\
38.45 \\
38.72\end{array}$ & $\begin{array}{l}29, \\
30, \\
30, \\
30,\end{array}$ & $\left|\begin{array}{l}38.80 \\
38.37 \\
37.88 \\
37.41 \\
36.89 \\
36.30\end{array}\right|$ & $\begin{array}{l}28, \\
27, \\
27, \\
25 \text {, } \\
24, \\
23,\end{array}$ & $\mid \begin{array}{l}16.66 \\
15.48 \\
14.37 \\
13.20 \\
19.12\end{array}$ & $\begin{array}{l}2,970 \\
3,010 \\
2,990 \\
2,910 \\
2,890 \\
2,460\end{array}$ & $\begin{array}{r}3.07 \\
2.90 \\
2.78\end{array}$ & $\begin{array}{l}568 \\
524 \\
493\end{array}$ & 1.94 & 274 \\
\hline
\end{tabular}

SUPPLEMENTAL RECORD.-Aug. 14, 6:30 a.m., gage height, 40.82 feet; discharge, 35,100 second-feet.

\section{BRIER CREEK AT MILLHAVEN, GA.}

Location.-Lat. $32^{\circ} 56^{\prime} 00^{\prime \prime}$, long. $81^{\circ} 39^{\prime} 05^{\prime \prime}$, at Savannah \& Atlanta Railway trestle at Millhaven, Sereven County, $81 \frac{1}{2}$ miles above Beaver Dam Creek.

DRAINAGE AREA.-656 square miles.

GAGE-HEIGHT RECORD.-Graph based on highwater mark and twice daily gage readings of staff gage.

DISCHARGE RECORD.-Stage-discharge relation defined by current-meter measurements up to 20,000 second-feet and extended to erest gage height by logarithmic plotting. Gage heights used to tenths.

Maxima.-1940: Discharge, 25,400 second-feet 7 to 9 p.m. Aug. 16 (gage height, 17.4 feet, from floodmark).

1937-39: Discharge, 5,900 second-feet Mar. 3, 5, 1939 (gage height, 12.2 feet).

REMARKS.-Flood runoff not affected by storage or diversion. Local residents state that the flood of August 1940 equaled any within their memory.

Mean discharge, in second-feet, 1940

\begin{tabular}{|c|c|c|c|c|c|c|c|c|c|c|c|}
\hline Day & Aug. & Sept. & Day & Aug. & Sept. & Day & Aug. & Sept. & Day & Aug. & Sept. \\
\hline $\begin{array}{l}1 \\
2 \\
3 \\
4 \\
5 \\
6 \\
7 \\
8\end{array}$ & $\begin{array}{l}191 \\
286 \\
298 \\
263 \\
310 \\
310 \\
286 \\
286\end{array}$ & $\begin{array}{l}568 \\
548 \\
508 \\
490 \\
472 \\
490 \\
568 \\
758\end{array}$ & $\begin{array}{r}9 \\
10 \\
11 \\
12 \\
13 \\
14 \\
15 \\
16\end{array}$ & $\begin{array}{r}274 \\
263 \\
312 \\
782 \\
1,070 \\
1,160 \\
3,740 \\
22,100\end{array}$ & $\begin{array}{l}612 \\
568 \\
490 \\
454 \\
422 \\
406 \\
390 \\
362\end{array}$ & $\begin{array}{l}17 \\
18 \\
19 \\
20 \\
21 \\
22 \\
23 \\
24\end{array}$ & $\begin{array}{r}20,300 \\
11,900 \\
6,690 \\
3,880 \\
2,440 \\
1,740 \\
1,350 \\
1,220\end{array}$ & \begin{tabular}{l||}
$\mathbf{3 4 8}$ \\
348 \\
334 \\
334 \\
322 \\
310 \\
286 \\
$\mathbf{2 8 6}$
\end{tabular} & $\begin{array}{l}25 \\
26 \\
27 \\
28 \\
29 \\
30 \\
31\end{array}$ & $\begin{array}{r}1,140 \\
1,060 \\
930 \\
784 \\
706 \\
658 \\
612\end{array}$ & $\begin{array}{l}286 \\
274 \\
274 \\
274 \\
274 \\
274\end{array}$ \\
\hline \multicolumn{10}{|c|}{$\begin{array}{l}\text { Monthly mean discharge, in second-feet. } \\
\text { Runoff, in inches }\end{array}$} & $\begin{array}{r}2,817 \\
4.95\end{array}$ & $\begin{array}{r}411 \\
0.70\end{array}$ \\
\hline
\end{tabular}


OGEECHEE RIVER BASIN

Gage height, in feet, and discharge, in second-feet, at indicated time, 1940

\begin{tabular}{|c|c|c|c|c|c|c|c|c|c|c|}
\hline \multirow{2}{*}{ Hour } & \multicolumn{2}{|c|}{ Aug. 15} & \multicolumn{2}{|c|}{ Aug. 16} & \multicolumn{2}{|c|}{ Aug. 17} & \multicolumn{2}{|c|}{ Aug. 18} & \multicolumn{2}{|c|}{ Aug. 19} \\
\hline & $\begin{array}{c}\text { Gage } \\
\text { height }\end{array}$ & $\begin{array}{c}\text { Dis- } \\
\text { charge }\end{array}$ & $\begin{array}{c}\text { Gage } \\
\text { height }\end{array}$ & $\begin{array}{c}\text { Dis- } \\
\text { charge }\end{array}$ & $\begin{array}{c}\text { Gage } \\
\text { height }\end{array}$ & $\begin{array}{c}\text { Dis- } \\
\text { charge }\end{array}$ & $\begin{array}{l}\text { Gage } \\
\text { height }\end{array}$ & $\begin{array}{c}\text { Dis- } \\
\text { charge }\end{array}$ & $\begin{array}{c}\text { Gage } \\
\text { height }\end{array}$ & $\begin{array}{c}\text { Dis- } \\
\text { charge }\end{array}$ \\
\hline \multirow{5}{*}{$\begin{array}{r}4 \\
6 \\
8 \\
\mathbf{N} \\
4 \\
6 \\
8 \\
12\end{array}$} & 6.9 & 1,260 & 16.0 & 18,200 & 17.1 & 23,700 & & & & \\
\hline & 7.2 & 1,400 & 16.7 & 21,700 & 16.8 & 22,200 & & 00 & 13.0 & \\
\hline & 8.0 & 1,800 & 17.1 & 23,700 & 16.4 & 20,200 & 14.4 & 11,700 & 12.5 & 6,550 \\
\hline & & 3,040 & & 24,800 & & 18,70 & $\overline{\mathbf{1 3}} . \overline{8}$ & 9,900 & 12.0 & 5,600 \\
\hline & $\begin{array}{l}13.0 \\
14.8\end{array}$ & $\begin{array}{r}7,700 \\
13,200\end{array}$ & $\begin{array}{l}17.4 \\
17.3\end{array}$ & $\begin{array}{l}25,400 \\
24,800\end{array}$ & $\begin{array}{l}15.7 \\
15.4\end{array}$ & $\begin{array}{l}16,800 \\
15,600\end{array}$ & $\overline{13} \overline{.5}$ & 9,000 & $\overline{11} \overline{5}$ & 4,840 \\
\hline
\end{tabular}

\section{OGEECHEE RIVER BASIN}

\section{OGEECHEE RIVER NEAR LOUISVILLE, GA.}

Location.-Lat. $32^{\circ} 58^{\prime}$, long. $82^{\circ} 23^{\prime}$, at bridge on U. S. Highway 1,1 mile downstream from Louisville \& Wadley Railroad bridge, 2 miles south of Louisville, Jefferson County, 2 miles downstream from Rocky Comfort Creek, and 2 miles upstream from Big Creek. Datum of gage is 199.24 feet above mean sea level (levels by Corps of Engineers, War Department).

DRAINAGE AREA. - 800 square miles.

GAGE-HEIGHT RECORD.- -Graph based on two or more readings daily of staff gage.

DISCHARGE RECORD.- Stage-discharge relation defined by current-meter measurements up to 17,000 second-feet and extended to crest gage height by logarithmic plotting. Gage heights used to tenths.

Maxima.-1940: Discharge, 20,600 second-feet 4 a.m. Aug. 16 (gage height, 17.6 feet, from graph based on gage readings).

1937-39: Diseharge, 12,800 second-feet May 2, 1937, Mar. 2, 1938 (gage height, 16.1 feet).

Stage known, 21.3 feet October 1929 (from data furnished by Central of Georgia Railroad); discharge not determined.

REMARKs.-Flood runoff not affected by storage or diversion.

Mean discharge, in second-feet, 1940

\begin{tabular}{|c|c|c|c|c|c|c|c|c|c|c|c|}
\hline Day & Aug. & Sept. & Day & Aug. & Sept. & Day & Aug. & Sept. & Day & Aug. & Sept. \\
\hline $\begin{array}{l}1 \\
2 \\
3 \\
4 \\
5 \\
6 \\
7 \\
8\end{array}$ & $\begin{array}{l}150 \\
160 \\
160 \\
150 \\
170 \\
180 \\
160 \\
180\end{array}$ & $\begin{array}{l}704 \\
780 \\
860 \\
840 \\
722 \\
614 \\
496 \\
432\end{array}$ & $\begin{array}{r}9 \\
10 \\
11 \\
12 \\
13 \\
14 \\
15 \\
16\end{array}$ & $\begin{array}{r}190 \\
234 \\
240 \\
625 \\
13,200 \\
13,400 \\
16,100 \\
18,900\end{array}$ & $\begin{array}{l}418 \\
404 \\
376 \\
348 \\
334 \\
306 \\
294 \\
282\end{array}$ & $\begin{array}{l}17 \\
18 \\
19 \\
20 \\
21 \\
22 \\
23 \\
24\end{array}$ & $\begin{array}{r}11,100 \\
5,290 \\
3,310 \\
2,360 \\
1,850 \\
1,520 \\
1,160 \\
940\end{array}$ & $\begin{array}{l}258 \\
258 \\
246 \\
246 \\
234 \\
234 \\
222 \\
234\end{array}$ & $\begin{array}{l}25 \\
26 \\
27 \\
28 \\
29 \\
30 \\
31\end{array}$ & $\begin{array}{l}840 \\
704 \\
632 \\
560 \\
528 \\
650 \\
668\end{array}$ & $\begin{array}{c}222 \\
222 \\
246 \\
246 \\
320 \\
390 \\
-\end{array}$ \\
\hline \multicolumn{10}{|c|}{$\begin{array}{l}\text { Monthly mean discharge, in second-feet } \\
\text { Runoff, in inches. }\end{array}$} & $\begin{array}{r}3,107 \\
4.47\end{array}$ & $\begin{array}{r}393 \\
0.55\end{array}$ \\
\hline
\end{tabular}

Gage height, in feet, and discharge, in second-feet, at indicated time, 1940

\begin{tabular}{|c|c|c|c|c|c|c|c|c|c|c|c|c|}
\hline \multirow{2}{*}{ Hour } & \multicolumn{2}{|c|}{ Aug. 12} & \multicolumn{2}{|c|}{ Aug. 13} & \multicolumn{2}{|c|}{ Aug. 14} & \multicolumn{2}{|c|}{ Aug. 15} & \multicolumn{2}{|c|}{ Aug. 16} & \multicolumn{2}{|c|}{ Aug. 17} \\
\hline & $\begin{array}{c}\text { Gage } \\
\text { ht. }\end{array}$ & $\begin{array}{c}\text { Dis- } \\
\text { charge }\end{array}$ & $\begin{array}{l}\text { Gage } \\
\text { ht. }\end{array}$ & $\begin{array}{c}\text { Dis- } \\
\text { charge }\end{array}$ & $\begin{array}{c}\text { Gage } \\
\text { ht. }\end{array}$ & $\begin{array}{c}\text { Dis- } \\
\text { charge }\end{array}$ & $\begin{array}{c}\text { Gage } \\
\text { ht. }\end{array}$ & $\begin{array}{c}\text { Dis- } \\
\text { charge }\end{array}$ & $\begin{array}{c}\text { Gage } \\
\text { ht. }\end{array}$ & $\begin{array}{c}\text { Dis- } \\
\text { charge }\end{array}$ & $\begin{array}{c}\text { Gage } \\
\text { ht. }\end{array}$ & $\begin{array}{c}\text { Dis- } \\
\text { charge }\end{array}$ \\
\hline $\begin{array}{r}4 \\
8 \\
N \\
4 \\
8 \\
12\end{array}$ & $\begin{array}{r}4.1 \\
4.6 \\
5.3 \\
6.4 \\
8.2 \\
10.8\end{array}$ & $\begin{array}{r}282 \\
348 \\
448 \\
632 \\
980 \\
1,870 \\
\end{array}$ & $\begin{array}{l}13.4 \\
15.5 \\
17.1 \\
17.4 \\
17.3 \\
17.0\end{array}$ & $\begin{array}{r}4,320 \\
9,900 \\
17,600 \\
19,400 \\
18,800 \\
17,000\end{array}$ & $\begin{array}{l}16.7 \\
16.4 \\
16.1 \\
16.0 \\
16.0 \\
16.0\end{array}$ & $\begin{array}{l}15,500 \\
14,000 \\
12,500 \\
12,000 \\
12,000 \\
12,000\end{array}$ & $\begin{array}{l}16.1 \\
16.4 \\
16.8 \\
17.2 \\
17.4 \\
17.5\end{array}$ & $\begin{array}{l}12,500 \\
14,000 \\
16,000 \\
18,200 \\
19,400 \\
20,000\end{array}$ & $\begin{array}{l}17.6 \\
17.5 \\
17.4 \\
17.2 \\
17.0 \\
16.7\end{array}$ & $\begin{array}{l}20,600 \\
20,000 \\
19,400 \\
18,200 \\
17,000 \\
15,500\end{array}$ & $\begin{array}{l}16.4 \\
16.1 \\
15.8 \\
15.4 \\
15.0 \\
14.7\end{array}$ & $\begin{array}{r}14,000 \\
12,500 \\
11,100 \\
9,500 \\
8,100 \\
7,200 \\
\end{array}$ \\
\hline
\end{tabular}




\section{OGEECHEE RIVER AT SCARBORO, GA.}

Location.-Lat. $32^{\circ} 42^{\prime} 40^{\prime \prime}$, long. $81^{\circ} 52^{\prime} 45^{\prime \prime}$, at county highway bridge at Scarboro, Jenkins County, 31/2 miles downstream from Sculls Creek, 61/2 miles upstream from Horse Creek, and 71/2 miles southeast of Millen. Datum of gage is 111.81 feet above mean sea level (levels by Corps of Engineers, War Department).

DRAINAGE AREA,-1,940 square miles.

GAGE-HEIGHT RECORD.—Graph based on twice-daily readings of staff gage.

DISCHARGE RECORD.-Stage-discharge relation defined by current-meter measurements

up to 24,000 second-feet. Gage heights used to tenths, except Aug. 17-19 when

- hundredths were used.

Maxima.-1940: Discharge, 24,600 second-feet 12 p.m. Aug. 17 (gage height, 12.8

feet, from graph based on gage readings).

1937-39: Discharge, 20,600 Mar. 5, 1938 (gage height, 12.12 feet).

REMARKS.- - Flood runoff not affected by storage or diversion.

Mean discharge, in second-feet, 1940

\begin{tabular}{|c|c|c|c|c|c|c|c|c|c|c|c|}
\hline Day & Aug. & Sept. & Day & Aug. & Sept. & Day & Aug. & Sept. & Day & Aug. & Sept. \\
\hline $\begin{array}{l}1 \\
2 \\
3 \\
4 \\
5 \\
6 \\
7 \\
8\end{array}$ & $\begin{array}{l}395 \\
395 \\
337 \\
323 \\
365 \\
410 \\
440 \\
440\end{array}$ & $\begin{array}{l}1,670 \\
1,550 \\
1,450 \\
1,350 \\
1,450 \\
1,500 \\
1,450 \\
1,400\end{array}$ & $\begin{array}{r}9 \\
10 \\
11 \\
12 \\
13 \\
14 \\
15 \\
16\end{array}$ & $\begin{array}{r}425 \\
410 \\
418 \\
699 \\
928 \\
1,310 \\
1,770 \\
11,600\end{array}$ & $\begin{array}{r}1,350 \\
1,310 \\
1,270 \\
1,190 \\
\mathbf{9 9 5} \\
\mathbf{8 5 5} \\
\mathbf{7 8 0} \\
\mathbf{7 3 0}\end{array}$ & $\begin{array}{l}17 \\
18 \\
19 \\
20 \\
21 \\
22 \\
23 \\
24\end{array}$ & $\begin{array}{r}23,100 \\
24,000 \\
22,400 \\
19,700 \\
16,200 \\
12,600 \\
9,300 \\
6,600\end{array}$ & $\begin{array}{l}690 \\
650 \\
610 \\
574 \\
556 \\
\mathbf{5 3 8} \\
504 \\
488\end{array}$ & $\begin{array}{l}25 \\
26 \\
27 \\
28 \\
29 \\
30 \\
31\end{array}$ & $\begin{array}{l}5,240 \\
4,240 \\
3,560 \\
2,820 \\
2,540 \\
2,300 \\
1,870\end{array}$ & $\begin{array}{l}488 \\
504 \\
488 \\
472 \\
472 \\
472\end{array}$ \\
\hline
\end{tabular}

Gage height, in feet, and discharge, in second-feet, at indicated time, 1940

\begin{tabular}{|c|c|c|c|c|c|c|c|c|}
\hline \multirow{2}{*}{ Hour } & \multicolumn{2}{|c|}{ Aug. 15} & \multicolumn{2}{|c|}{ Aug. 16} & \multicolumn{2}{|c|}{ Aug. 17} & \multicolumn{2}{|c|}{ Aug. 18} \\
\hline & $\begin{array}{l}\text { Gage } \\
\text { height }\end{array}$ & Discharge & $\begin{array}{l}\text { Gage } \\
\text { height }\end{array}$ & Discharge & $\begin{array}{l}\text { Gage } \\
\text { height }\end{array}$ & Discharge & $\begin{array}{c}\text { Gage } \\
\text { height }\end{array}$ & Discharge \\
\hline $\begin{array}{r}2 \\
4 \\
6 \\
8 \\
10 \\
\mathbf{N}\end{array}$ & $\begin{array}{l}6.0 \\
6.0 \\
6.1 \\
6.1 \\
6.2 \\
6.2\end{array}$ & $\begin{array}{l}1,550 \\
1,550 \\
1,610 \\
1,610 \\
1,670 \\
1,670\end{array}$ & $\begin{array}{r}7.9 \\
8.5 \\
9.0 \\
9.6 \\
10.0 \\
10.4\end{array}$ & $\begin{array}{r}3,780 \\
5,240 \\
6,600 \\
8,550 \\
10,100 \\
11,700\end{array}$ & $\begin{array}{l}12.2 \\
12.3 \\
12.4 \\
12.5 \\
12.55 \\
12.60\end{array}$ & $\begin{array}{l}21,000 \\
21,600 \\
22,200 \\
22,800 \\
23,100 \\
23,400\end{array}$ & $\begin{array}{r}12 . \overline{78} \\
-12 . \overline{7} \overline{5} \\
-12 . \overline{7} \overline{2}\end{array}$ & $\begin{array}{l}24,500 \\
24,300 \\
24,100\end{array}$ \\
\hline $\begin{array}{r}2 \\
4 \\
6 \\
8 \\
10 \\
12\end{array}$ & $\begin{array}{l}6.2 \\
6.3 \\
6.4 \\
6.6 \\
7.0 \\
7.4\end{array}$ & $\begin{array}{l}1,670 \\
1,730 \\
1,800 \\
1,940 \\
2,500 \\
2,820\end{array}$ & $\begin{array}{l}10.8 \\
11.1 \\
11.40 \\
11.6 \\
11.8 \\
12.0\end{array}$ & $\begin{array}{l}13,500 \\
15,000 \\
16,500 \\
17,500 \\
18,600 \\
20,400\end{array}$ & $\begin{array}{l}12.65 \\
12.70 \\
12.72 \\
12.76 \\
12.78 \\
12.80\end{array}$ & $\begin{array}{l}23,700 \\
24,000 \\
24,100 \\
24,400 \\
24,500 \\
24,600\end{array}$ & $\left|\begin{array}{c}--12.68 \\
-12.60 \\
--\overline{12.55}\end{array}\right|$ & $\begin{array}{c}2 \overline{3}, 900 \\
2 \overline{3}, 400 \\
-\overline{23}, 100\end{array}$ \\
\hline
\end{tabular}

\section{OGEECHEE RIVER NEAR GDEN, GA.}

Location.-Lat. $32^{\circ} 10^{\prime}$, long. $81^{\circ} 25^{\prime}, 600$ feet downstream from bridge on U. S. Highways 25, 80, and 280, 2 miles west of Eden, Effingham County, 2 miles upstream from Seaboard Railway bridge, and 3 miles upstream from Black Creek. Datum of gage is $\mathbf{1 9 . 6 4}$ feet above mean sea level (levels by Corps of Engineers, War Department).

DRAINAGE AREA.—2,650 square miles.

GAGE-HEIGHT RECORD.-Water-stage recorder graph.

DischARGE RECORD. - Stage-discharge relation defined by current-meter measurements throughout: Gage heights used to half-tenths between 0.8 feet and 2.4 feet; hundredths below and tenths above these limits.

Maxima.-1940: Discharge, 20,200 second-feet 11 a.m. to 5 p.m. Aug. 23 (gage height, 13.78 feet). 
1937-39: Discharge, 23,700 second-feet Mar. 8, 9, 1939 (gage height, 14.2 feet, at former staff gage 600 feet upstream).

Stage known, 20.0 feet in October 1929, from data furnished by Central of Georgia Railroad.

REMARKS.-Flood runoff not affected.by storage or diversion.

Mean discharge, in second-feet, 1940

\begin{tabular}{|c|c|c|c|c|c|c|c|c|c|c|c|}
\hline Day & Aug. & Sept. & Day & Aug. & Sept. & Day & A ug. & Sept. & Day & Aug. & Sept. \\
\hline $\begin{array}{l}1 \\
2 \\
3 \\
4 \\
5 \\
6 \\
7 \\
8 \\
8\end{array}$ & $\begin{array}{l}705 \\
722 \\
722 \\
640 \\
580 \\
520 \\
460 \\
565\end{array}$ & $\begin{array}{l}6,000 \\
4,900 \\
4,280 \\
3,600 \\
3,060 \\
2,690 \\
2,400 \\
2,200\end{array}$ & $\begin{array}{r}9 \\
10 \\
11 \\
12 \\
13 \\
14 \\
15 \\
16\end{array}$ & $\begin{array}{r}688 \\
758 \\
798 \\
1,590 \\
2,300 \\
3,600 \\
5,000 \\
5,150\end{array}$ & $\begin{array}{l}2,060 \\
1,8600 \\
1,740 \\
1,700 \\
1,620 \\
1,580 \\
1,540 \\
1,460\end{array}$ & $\begin{array}{l}17 \\
18 \\
19 \\
20 \\
21 \\
22 \\
23 \\
24\end{array}$ & $\begin{array}{r}4,620 \\
4,230 \\
3,940 \\
4,080 \\
7,930 \\
17,100 \\
20,100 \\
19,600\end{array}$ & $\begin{array}{r}1,380 \\
1,260 \\
1,160 \\
1,020 \\
880 \\
792 \\
722 \\
655\end{array}$ & $\begin{array}{l}25 \\
26 \\
27 \\
28 \\
29 \\
30 \\
31\end{array}$ & $\begin{array}{r}17,800 \\
15,500 \\
13,300 \\
11,200 \\
9,460 \\
8,180 \\
7,040\end{array}$ & $\begin{array}{l}\mathbf{6 2 5} \\
580 \\
580 \\
565 \\
580 \\
\mathbf{5 8 0}\end{array}$ \\
\hline \multicolumn{10}{|c|}{$\begin{array}{l}\text { Monthly mean discharge, in second-feet } \\
\text { Runoff, in inches. }\end{array}$} & $\begin{array}{r}6,093 \\
2.65\end{array}$ & $\begin{array}{r}1,802 \\
0.76\end{array}$ \\
\hline
\end{tabular}

CANOOCHEE RIVER NEAR CLAXTON, GA.

Location.-Lat. $32^{\circ} 11^{\prime} 05^{\prime \prime}$, Long. $81^{\circ} 53^{\prime} 25^{\prime \prime}$, at bridge on State Highway 73,2 miles northeast of Claxton, Evans County, and 10 miles above Lotts Creek.

Drainage AREA.- 555 square miles.

GAGE-HEIGHT RECORD.-Graph based on twice-daily staff gage readings supplemented by oceasional additional readings.

DISCHARGE RECORD.- Stage-discharge relation defined by current-meter measurements. up to 5,000 second-feet and extended to erest gage height by logarithmic plotting. Gage heights used to tenths.

Maxima.-1940: Discharge, 5,910 second-feet 10 p.m. Aug. 16 to 4 a.m. Aug. 17 (gage height, 12.9 feet, from graph based on gage readings).

1937-39 : Discharge, 7,980 second-feet Feb. 28, Mar. 1, 1939 (gage height 13.8 feet, from floodmark).

REMARKS.-Flood runoff not affected by artificial storage or diversion.

Mean discharge, in second-feet, 1940

\begin{tabular}{|c|c|c|c|c|c|c|c|c|c|c|c|}
\hline Day & Aug. & Sept. & Day & Aug. & Sept. & Day & Aug. & -Sept. & Day & Aug. & Sept. \\
\hline $\begin{array}{l}1 \\
2 \\
3 \\
4 \\
5 \\
6 \\
7 \\
8\end{array}$ & $\begin{array}{r}46 \\
107 \\
111 \\
70 \\
62 \\
53 \\
55 \\
67\end{array}$ & $\begin{array}{l}284 \\
248 \\
302 \\
398 \\
573 \\
592 \\
509 \\
398\end{array}$ & $\begin{array}{r}9 \\
10 \\
11 \\
12 \\
13 \\
14 \\
15 \\
16\end{array}$ & $\begin{array}{r}58 \\
48 \\
75 \\
674 \\
916 \\
1,150 \\
1,800 \\
4,650\end{array}$ & $\begin{array}{r}318 \\
229 \\
176 \\
115 \\
92 \\
75 \\
62 \\
58\end{array}$ & $\begin{array}{l}17 \\
18 \\
19 \\
20 \\
21 \\
22 \\
23 \\
24\end{array}$ & $\begin{array}{r}5,420 \\
3,970 \\
2,690 \\
2,000 \\
1,480 \\
1,120 \\
916 \\
826\end{array}$ & $\begin{array}{l}50 \\
46 \\
38 \\
31 \\
28 \\
28 \\
25 \\
24\end{array}$ & $\begin{array}{l}25 \\
26 \\
27 \\
28 \\
29 \\
30 \\
31\end{array}$ & $\begin{array}{l}678 \\
457 \\
428 \\
398 \\
382 \\
367 \\
335\end{array}$ & $\begin{array}{l}23 \\
25 \\
27 \\
28 \\
28 \\
31\end{array}$ \\
\hline & & & & & & & & & & $\begin{array}{r}1,013 \\
2.11\end{array}$ & $\begin{array}{r}162 \\
0.33\end{array}$ \\
\hline
\end{tabular}

\section{ALTAMAHA RIVER BASIN}

\section{OCONEE RIVER NEAR GREENSBORO, GA.}

Location.-Lat. $33^{\circ} 35^{\prime}$, long. $83^{\circ} 16^{\prime}$, at bridge on State Highway 12,1 mile downstream from Town Creek, 5 miles upstream from Apalachee River, 5 miles west of Greensboro, Greene County, and 12 miles downstream from Barnett Shoals Dam. Datum of gage is 409.82 feet above mean sea level (unadjusted).

nRAINAGE aREa.- 1,090 square miles.

GAGE-HEIGHT RECORD.-Water-stage recorder graph.

DISCHARGE RECORD.-Stage-discharge record defined by current-meter measurements. 


\section{FLOODS OF AUGUST 1940 IN THE SOUTHEASTERN STATES}

Maxima.-1940: Discharge, 12,200 second-feet 4 a.m. Aug. 14 (gage height, 19.0 feet).

1903-31, 1937-39: Gage height observed, 35.4 feet Aug. 26, 1908 (discharge uncertain).

REMARKs.-Low flow regulated by Barnett Shoals power plant.

Mean discharge, in second-feet, 1940

\begin{tabular}{|c|c|c|c|c|c|c|c|c|c|c|c|}
\hline Day & Aug. & Sept. & Day & Aug. & Sept. & Day & Aug. & Sept. & Day & Aug. & Sept. \\
\hline $\begin{array}{l}1 \\
2 \\
3 \\
4 \\
5 \\
6 \\
7 \\
8\end{array}$ & $\begin{array}{l}378 \\
376 \\
406 \\
348 \\
339 \\
368 \\
308 \\
378\end{array}$ & $\begin{array}{r}5,320 \\
4,460 \\
1,350 \\
1,010 \\
887 \\
848 \\
751 \\
672\end{array}$ & $\begin{array}{r}9 \\
10 \\
11 \\
12 \\
13 \\
14 \\
15 \\
16\end{array}$ & $\begin{array}{r}376 \\
367 \\
272 \\
1,310 \\
\mathbf{8}, \mathbf{2 1 0} \\
11,700 \\
9,420 \\
8,020\end{array}$ & $\begin{array}{l}691 \\
684 \\
618 \\
580 \\
558 \\
524 \\
521 \\
498\end{array}$ & $\begin{array}{l}17 \\
18 \\
19 \\
20 \\
21 \\
22 \\
23 \\
24\end{array}$ & $\begin{array}{r}3,060 \\
1,130 \\
939 \\
834 \\
730 \\
694 \\
648 \\
621\end{array}$ & $\begin{array}{l}532 \\
482 \\
469 \\
453 \\
463 \\
440 \\
434 \\
448\end{array}$ & $\begin{array}{l}25 \\
26 \\
27 \\
28 \\
29 \\
30 \\
31\end{array}$ & $\begin{array}{r}582 \\
568 \\
580 \\
514 \\
941 \\
\mathbf{4}, 680 \\
\mathbf{5 , 4 5 0}\end{array}$ & $\begin{array}{l}421 \\
473 \\
534 \\
432 \\
456 \\
408\end{array}$ \\
\hline & & & & & & & & & & $\begin{array}{r}2,082 \\
2,20\end{array}$ & $\begin{array}{r}881 \\
0.90 \\
\end{array}$ \\
\hline
\end{tabular}

OCONEE RIVER AT MILLEDGEVILLE, GA.

Location.-Lat. $33^{\circ} 05^{\prime}$, long. $83^{\circ} 13^{\prime}$, at Milledgeville, Baldwin County, 900 feet upstream from bridge on State Highway 24, half a mile upstream from Fishing Creek, and 4 miles downstream from partly completed Furman Shoals Dam of Georgia Power Co. Datum of gage is $\mathbf{2 3 0 . 8 4}$ feet above mean sea level, datum of 1929, supplementary adjustment of 1936 .

Drain age AREA.-2,950 square miles.

GAGE-HEIGHT RECORD.-Water-stage recorder graph.

DischARGE RECORD.- - Stage-diseharge relation defined by current-meter measurements up to 50,000 second-feet.

Maxima.-1940: Discharge, 27,400 second-feet 2 a.m. Aug. 14 (gage height, 24.4 feet).

1903-31, 1937-39: Discharge, 77,500 second-feet (possibly in error) Aug. 16, 1928 (gage height, 38.8 feet, present site and datum from records of U. S. Weather Bureau) from rating curve developed in 1937.

Mean discharge, in second-feet, 1940

\begin{tabular}{|c|c|c|c|c|c|c|c|c|c|c|c|}
\hline Day & Aug. & Sept. & Day & Aug. & Sept. & Day & Aug. & Sept. & Day & Aug. & Sept. \\
\hline $\begin{array}{l}1 \\
2 \\
3 \\
4 \\
5 \\
6 \\
7 \\
8\end{array}$ & $\begin{array}{l}952 \\
952 \\
888 \\
888 \\
855 \\
822 \\
822 \\
855\end{array}$ & $\begin{array}{l}7,940 \\
7,460 \\
5,170 \\
2,360 \\
1,920 \\
1,640 \\
1,560 \\
1,380\end{array}$ & $\begin{array}{r}9 \\
10 \\
11 \\
12 \\
13 \\
14 \\
15 \\
16\end{array}$ & $\begin{array}{r}888 \\
855 \\
822 \\
3,520 \\
15,400 \\
21,900 \\
15,800 \\
13,400\end{array}$ & $\begin{array}{r}1,230 \\
1,160 \\
1,120 \\
1,020 \\
952 \\
952 \\
888 \\
855\end{array}$ & $\begin{array}{l}17 \\
18 \\
19 \\
20 \\
21 \\
22 \\
23 \\
24\end{array}$ & $\begin{array}{r}10,200 \\
4,130 \\
2,450 \\
2,000 \\
1,760 \\
1,560 \\
1,490 \\
1,380\end{array}$ & $\begin{array}{l}855 \\
888 \\
855 \\
822 \\
790 \\
790 \\
790 \\
748\end{array}$ & $\begin{array}{l}25 \\
26 \\
27 \\
28 \\
29 \\
30 \\
31\end{array}$ & $\begin{array}{l}1,300 \\
1,230 \\
1,160 \\
1,120 \\
1,120 \\
4,100 \\
8,420\end{array}$ & $\begin{array}{l}822 \\
766 \\
822 \\
888 \\
888 \\
855\end{array}$ \\
\hline \multicolumn{10}{|c|}{$\begin{array}{l}\text { Monthly mean discharge, in second-feet } \\
\text { Runoff, in inches }\end{array}$} & $\begin{array}{r}3,969 \\
1.56\end{array}$ & $\begin{array}{r}1,640 \\
0.62\end{array}$ \\
\hline
\end{tabular}

\section{OCONEE RIVER AT DUBLIN, GA.}

Location.-Lat. $32^{\circ} 32^{\prime}$, long. $82^{\circ} 54^{\prime}$, at bridge on U. S. Highway 80 at Dublin, Laurens County. Datum of gage is 149.08 feet above mean sea level, datum of 1929 , supplementary adjustment of 1936 .

Drainage AREA. - 4,400 square miles.

GAGE-HEIGHT RECORD.-Water-stage recorder graph.

Discharge RECORD.-Stage-discharge relation defined by current-meter measurements.

Shifting-control method used Sept. 12-30. 
Maxima.-1940: Discharge, 18,800 second-feet 10 a.m. Aug. 19 (gage height, 18.0 feet).

1898-1913, 1929-39 : Discharge, 96,700 second-feet Apr. 12, 13, 1936 (gage height, 32.97 feet).

Mean discharge, in second-feet, 1940

\begin{tabular}{|c|c|c|c|c|c|c|c|c|c|c|c|}
\hline Day & Aug. & Sept. & Day & Aug. & Sept. & Day & Aug. & Sept. & Day & Aug. & Sept. \\
\hline $\begin{array}{l}1 \\
2 \\
3 \\
4 \\
5 \\
6 \\
6 \\
7 \\
8\end{array}$ & $\begin{array}{l}1,320 \\
1,740 \\
1,740 \\
1,490 \\
1,560 \\
1,520 \\
1,380 \\
1,380\end{array}$ & $\begin{array}{l}6,200 \\
7,130 \\
7,600 \\
7,500 \\
5,480 \\
\mathbf{3}, 480 \\
3,000 \\
2,680\end{array}$ & $\begin{array}{l}9 \\
10 \\
11 \\
12 \\
13 \\
14 \\
15 \\
16\end{array}$ & $\begin{array}{r}1,560 \\
1,420 \\
1,380 \\
4,520 \\
11,500 \\
12,100 \\
13,000 \\
14,000\end{array}$ & $\begin{array}{l}2,330 \\
2,050 \\
1,910 \\
1,700 \\
1,600 \\
1,460 \\
1,420 \\
1,350\end{array}$ & $\begin{array}{l}17 \\
18 \\
19 \\
20 \\
21 \\
22 \\
23 \\
24\end{array}$ & $\begin{array}{r}15,900 \\
18,000 \\
18,600 \\
17,600 \\
13,800 \\
6,950 \\
3,960 \\
3,000\end{array}$ & $\begin{array}{l}1,280 \\
1,280 \\
1,240 \\
1,210 \\
1,180 \\
1,140 \\
1,100 \\
1,070\end{array}$ & $\begin{array}{l}25 \\
26 \\
27 \\
28 \\
29 \\
30 \\
31\end{array}$ & $\begin{array}{l}\mathbf{2 , 6 1 0} \\
\mathbf{2}, 260 \\
\mathbf{2}, 120 \\
\mathbf{1}, 980 \\
\mathbf{1}, 910 \\
\mathbf{1}, \mathbf{9 8 0} \\
\mathbf{3}, 190\end{array}$ & $\begin{array}{l}1,040 \\
1,040 \\
1,070 \\
1,070 \\
1,320 \\
1,420\end{array}$ \\
\hline \multicolumn{10}{|c|}{$\begin{array}{l}\text { Monthly mean discharge, in second-feet } \\
\text { Runoff, in inches }\end{array}$} & $\begin{array}{r}5,983 \\
1.57\end{array}$ & $\begin{array}{r}2,445 \\
0.62\end{array}$ \\
\hline
\end{tabular}

OCONEE RIVER NEAR MOUN'T VERNON, GA.

LoCATION.-Lat. $32^{\circ} 12^{\prime}$, long. $82^{\circ} 38^{\prime}$, at bridge on U. S. Highway 280 , a quarter of a mile downstream from Seaboard Railway bridge, half a mile upstream from Okeewalkee Creek, 2 miles upstream from Flat Creek, and 2 miles west of Mount Vernon, Montgomery County. Datum of gage is 103.34 feet above mean sea level, datum of 1929, supplementary adjustment of 1936 .

Drain age AREa. $-5,110$ square miles.

GAGE-HEIGHT RECORD.-Water-stage recorder graph.

DISCHARGE RECORD:-Stage-discharge relation defined by current-meter measurements. Maxima.-1940: Discharge, 20,000 second-feet 8 p.m. Aug. 21 (gage height, 15.9 feet).

1937-39 : Discharge, 48,300 second-feet Mar. 6, 1939 (gage height, 20.4 feet). Mean discharge, in second-feet, 1940

\begin{tabular}{|c|c|c|c|c|c|c|c|c|c|c|c|}
\hline Day & Aug. & Sept. & Day & Aug. & Sept. & Day & Aug. & Sept. & Day & Aug. & Sept. \\
\hline $\begin{array}{l}1 \\
2 \\
\mathbf{3} \\
\mathbf{4} \\
5 \\
6 \\
\mathbf{7} \\
\mathbf{8}\end{array}$ & $\begin{array}{l}1,690 \\
2,110 \\
2,290 \\
2,170 \\
2,360 \\
2,230 \\
2,170 \\
2,050\end{array}$ & $\begin{array}{l}3,480 \\
5,390 \\
6,280 \\
6,940 \\
7,420 \\
7,300 \\
5,300 \\
3,870\end{array}$ & $\begin{array}{r}9 \\
10 \\
11 \\
12 \\
13 \\
14 \\
15 \\
16\end{array}$ & $\begin{array}{r}1,930 \\
1,930 \\
1,810 \\
3,600 \\
9,360 \\
11,300 \\
12,500 \\
14,800\end{array}$ & $\begin{array}{l}3,270 \\
2,850 \\
2,500 \\
2,230 \\
2,050 \\
1,930 \\
1,810 \\
1,690\end{array}$ & $\begin{array}{l}17 \\
18 \\
19 \\
20 \\
21 \\
22 \\
23 \\
24\end{array}$ & $\begin{array}{l}15,800 \\
16,400 \\
17,300 \\
18,800 \\
19,600 \\
19,200 \\
17,000 \\
12,800\end{array}$ & $\begin{array}{l}1,570 \\
1,510 \\
1,480 \\
1,450 \\
1,420 \\
1,390 \\
1,330 \\
1,300\end{array}$ & $\begin{array}{l}25 \\
26 \\
27 \\
28 \\
29 \\
30 \\
31\end{array}$ & $\begin{array}{l}7,180 \\
4,510 \\
3,630 \\
3,200 \\
2,990 \\
2,780 \\
2,920\end{array}$ & $\begin{array}{r}1,270 \\
1,240 \\
1,220 \\
1,220 \\
1,220 \\
1,330 \\
\end{array}$ \\
\hline \multicolumn{10}{|c|}{$\begin{array}{l}\text { Monthly mean discharge, in second-feet } \\
\text { Runoff, in inches. }\end{array}$} & $\begin{array}{r}7,691 \\
1.74\end{array}$ & $\begin{array}{r}2,775 \\
0.61\end{array}$ \\
\hline
\end{tabular}

MIDDLE OCONEE RIVER NEAR ATHENS, GA.

Location.-Lat. $33^{\circ} 55^{\prime}$, long. $82^{\circ} 23^{\prime}$, at Princeton Bridge on U. S. Highway 129 , half a mile downstream from Princeton Mill Dam, $1 \frac{1}{4} / 4$ miles upstream from Barber Creek, 2 miles south of Athens, Clarke County, and 6 miles upstream from mouth. Datum of gage is 531.30 feet above mean sea level (levels by Corps of Engineers, War Department).

Drainage AREA.-404 square miles.

GAGE-HEIGHT RECORD.-Water-stage recorder graph.

DISCHARGE RECORD.- Stage-discharge relation defined by current-meter measurements at present site. Shifting-control method used.

Max.ImA.-1940: Discharge, 5,930 second-feet 10 p.m. Aug. 14 (gage height, 20.3 feet).

1901-2, 1929-32, 1937-39: Discharge observed, 19,600 second-feet Feb. 28, 1902 (gage height, 25.5 feet, site and datum then in use). 
Mean discharge, in second-feet, 1940

\begin{tabular}{|c|c|c|c|c|c|c|c|c|c|c|c|}
\hline Day & Aug. & Sept. & Day & Aug. & Sept. & Day & Aug. & Sept. & Day & Aug. & Sept. \\
\hline $\begin{array}{l}1 \\
2 \\
3 \\
4 \\
5 \\
6 \\
7 \\
8\end{array}$ & $\begin{array}{l}175 \\
220 \\
194 \\
162 \\
152 \\
153 \\
164 \\
185\end{array}$ & $\begin{array}{r}2,190 \\
712 \\
534 \\
456 \\
418 \\
368 \\
336 \\
329\end{array}$ & $\begin{array}{r}9 \\
10 \\
11 \\
12 \\
13 \\
14 \\
15 \\
16\end{array}$ & $\begin{array}{r}174 \\
154 \\
148 \\
1,170 \\
4,470 \\
5,300 \\
3,800 \\
730\end{array}$ & $\begin{array}{l}304 \\
284 \\
268 \\
278 \\
228 \\
237 \\
234 \\
225\end{array}$ & $\begin{array}{l}17 \\
18 \\
19 \\
20 \\
21 \\
22 \\
23 \\
24\end{array}$ & $\begin{array}{l}522 \\
432 \\
382 \\
329 \\
291 \\
277 \\
260 \\
242\end{array}$ & $\begin{array}{l}215 \\
210 \\
197 \\
202 \\
195 \\
193 \\
181 \\
182\end{array}$ & $\begin{array}{l}25 \\
26 \\
27 \\
28 \\
29 \\
30 \\
31\end{array}$ & $\begin{array}{r}226 \\
221 \\
204 \\
192 \\
711 \\
2,670 \\
3,830\end{array}$ & $\begin{array}{l}226 \\
224 \\
218 \\
216 \\
180 \\
168\end{array}$ \\
\hline \multicolumn{10}{|c|}{$\begin{array}{l}\text { Monthly mean discharge, in second-feet } \\
\text { Runoff, in inches. }\end{array}$} & $\begin{array}{r}908 \\
2.59\end{array}$ & $\begin{array}{r}340 \\
0.94 \\
\end{array}$ \\
\hline
\end{tabular}

OHOOPEE RIVER NEAR REIDSVILLE, GA.

Location.-Lat. $32^{\circ} 04^{\prime}$, long. $82^{\circ} 11^{\prime}$, at Sheppard Bridge, half a mile downstream from Brazells Creek, 11/2 miles downstream from Rocky Creek, 31/2 miles west of Reidsville, Tattnall County, about 6 miles downstream from Pendleton Creek, and about 14 miles upstream from mouth.

Drain AGe AREA.-1,110 square miles.

GAGE-HEIGHT RECORD.-Staff gage read twice daily; graph based on staff-gage read-

ings used Aug. 12-27.

DISCHARGE RECORD.--Stage-discharge relation defined by current-meter measurements. Maxima.-1940: Discharge, 14,900 second-feet 12.2 p.m. Aug. 16 (gage height, 19.7 feet, from graph based on gage readings).

1903-7, 1937-39: Discharge observed, 15,100 second-feet Mar. 3, 1939 (gage height, 19.8 feet).

REMARKS.- Some diurnal fluetuation at low flow.

Mean discharge, in second-feet, 1940

\begin{tabular}{|c|c|c|c|c|c|c|c|c|c|c|c|}
\hline Day & Aug. & Sept. & Day & Aug. & Sept. & Day & Aug. & Sept. & Day & Aug. & Sept. \\
\hline $\begin{array}{l}1 \\
2 \\
3 \\
4 \\
5 \\
6 \\
7 \\
8\end{array}$ & $\begin{array}{r}104 \\
104 \\
98 \\
132 \\
140 \\
125 \\
104 \\
98\end{array}$ & $\begin{array}{r}940 \\
880 \\
940 \\
1,030 \\
1,170 \\
1,060 \\
1,030 \\
940\end{array}$ & $\begin{array}{r}9 \\
10 \\
11 \\
12 \\
13 \\
14 \\
15 \\
16\end{array}$ & $\begin{array}{r}86 \\
81 \\
98 \\
196 \\
562 \\
1,720 \\
7,980 \\
14,700\end{array}$ & $\begin{array}{l}850 \\
730 \\
646 \\
542 \\
470 \\
404 \\
342 \\
302\end{array}$ & $\begin{array}{l}17 \\
18 \\
19 \\
20 \\
21 \\
22 \\
23 \\
24\end{array}$ & $\begin{array}{r}12,100 \\
9,200 \\
6,860 \\
5,200 \\
3,950 \\
3,140 \\
2,600 \\
2,190\end{array}$ & $\begin{array}{l}265 \\
230 \\
213 \\
196 \\
188 \\
164 \\
134 \\
127\end{array}$ & $\begin{array}{l}25 \\
26 \\
27 \\
28 \\
29 \\
30 \\
31\end{array}$ & $\begin{array}{l}2,060 \\
1,730 \\
1,490 \\
1,310 \\
1,170 \\
1,170 \\
1,030\end{array}$ & $\begin{array}{l}127 \\
142 \\
134 \\
127 \\
114 \\
107\end{array}$ \\
\hline \multicolumn{10}{|c|}{$\begin{array}{l}\text { Monthly mean discharge, in second-feet } \\
\text { Runoff, in inches }\end{array}$} & $\begin{array}{r}2,630 \\
2.73\end{array}$ & $\begin{array}{r}485 \\
0.49\end{array}$ \\
\hline
\end{tabular}

Gage height, in feet, and discharge, in second-feet, at indicated time, 1940

\begin{tabular}{|c|c|c|c|c|c|c|c|c|c|c|c|c|}
\hline \multirow{2}{*}{ Hour } & \multicolumn{2}{|c|}{ Aug. 12} & \multicolumn{2}{|c|}{ Aug. 13} & \multicolumn{2}{|c|}{ Aug. 14} & \multicolumn{2}{|c|}{ Aug. 15} & \multicolumn{2}{|c|}{ Aug. 16} & \multicolumn{2}{|c|}{ Aug. 17} \\
\hline & $\begin{array}{c}\text { Gage } \\
\text { ht. }\end{array}$ & $\begin{array}{c}\text { Dis- } \\
\text { charge }\end{array}$ & $\begin{array}{l}\text { Gage } \\
\text { ht. }\end{array}$ & $\begin{array}{c}\text { Dis- } \\
\text { charge }\end{array}$ & $\begin{array}{c}\text { Gage } \\
\text { ht. }\end{array}$ & $\begin{array}{c}\text { Dis- } \\
\text { charge }\end{array}$ & $\begin{array}{c}\text { Gage } \\
\text { ht. }\end{array}$ & $\begin{array}{c}\text { Dis- } \\
\text { charge }\end{array}$ & $\begin{array}{c}\text { Gage } \\
\text { ht. }\end{array}$ & $\begin{array}{c}\text { Dis- } \\
\text { charge }\end{array}$ & $\begin{array}{c}\text { Gage } \\
\text { ht. }\end{array}$ & $\begin{array}{c}\text { Dis- } \\
\text { charge }\end{array}$ \\
\hline $\begin{array}{r}6 \\
\mathbf{N}\end{array}$ & 2.40 & 187 & 4.1 & 562 & 7.2 & 1,640 & $\begin{array}{l}12.2 \\
15.2\end{array}$ & $\begin{array}{r}4,350 \\
7,580\end{array}$ & 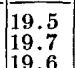 & $\begin{array}{l}14,500 \\
14,900 \\
14,700\end{array}$ & 18.7 & 12,300 \\
\hline $\begin{array}{r}6 \\
12\end{array}$ & 3.10 & 318 & $\overline{5.4}$ & $9 \overline{60}$ & $10.1^{-}$ & 3,000 & $\begin{array}{l}17.8 \\
18.9\end{array}$ & $\begin{array}{l}11,600 \\
13,700\end{array}$ & $\begin{array}{l}19.6 \\
19.4\end{array}$ & $\begin{array}{l}14,700 \\
14,300\end{array}$ & $\left|\overline{17} . \overline{8}^{-}\right|$ & 10,500 \\
\hline
\end{tabular}

\section{APALACHICOLA RIVER BASIN}

CHATTAHOOCHEE RIVER NEAR LEAF, GA.

LOCATION.-Lat. $34^{\circ} 35^{\prime}$, long. $83^{\circ} 38^{\prime}, 700$ feet upstream from bridge on State Highway $115,1 \frac{1}{2}$ miles east of Leaf, White County, 21/2 miles downstream from Blue Creek, 3 miles upstream from Soque River, and $7 \frac{1}{2}$ miles southeast of Cleveland. Datum of gage is 1,219.47 feet above mean sea level, datum of 1929, supplementary adjustment of 1936 .

Drainage RECORD.-150 square miles.

GAGE-HEIGHT RECORD.-Water-stage recorder graph.

DISCHARGE RECORD.—Stage-discharge relation defined by current-meter measurements 
up to 11,000 second-feet. Gage heights used to half-tenths between 3.2 and 5.0 feet; hundredths below and tenths above these limits.

Maxima.-1940: Discharge, 11,200 second-feet 2 p.m. Aug. 13 (gage height, 11.75 feet).

REMarKs.-Flood runoff not affected by storage or diversion. No accurate flooddischarge data available prior to August 1940.

Mean discharge, in second-feet, 1940

\begin{tabular}{rl|r||r|r|r|r|r|r||r|r|r}
\hline Day & Aug. & Sept. & Day & Aug. & Sept. & Day & Aug. & Sept. & Day & Aug. & Sept. \\
\hline 1 & 124 & 424 & 9 & 117 & 238 & 17 & 380 & 189 & 25 & 216 & 245 \\
2 & 140 & 344 & 10 & 110 & 230 & 18 & 349 & 186 & 26 & 212 & 192 \\
3 & 117 & 310 & 11 & 106 & 220 & 19 & 305 & 183 & 27 & 206 & 177 \\
4 & 114 & 292 & 12 & 468 & 212 & 20 & 266 & 183 & 28 & 196 & 171 \\
5 & 112 & 270 & 13 & 7,670 & 209 & 21 & 258 & 180 & 29 & 1,050 & 165 \\
6 & 127 & 292 & 14 & 1,370 & 206 & 22 & 262 & 174 & 30 & 1,340 & 165 \\
7 & 134 & 262 & 15 & 649 & 202 & 23 & 242 & 168 & 31 & 595 & -12 \\
8 & 124 & 250 & 16 & 464 & 195 & 24 & 230 & 228 & & & \\
\hline
\end{tabular}

Gage height, in feet, and discharge, in second-feet, at indicated time, 1940

\begin{tabular}{|c|c|c|c|c|c|c|c|c|c|c|c|c|}
\hline \multirow{2}{*}{ Hour } & \multicolumn{2}{|c|}{ Aug. 12} & \multicolumn{2}{|c|}{ Aug. 13} & \multicolumn{2}{|c|}{ Aug. 14} & \multicolumn{2}{|c|}{ Aug. 28} & \multicolumn{2}{|c|}{ Aug. 29} & \multicolumn{2}{|c|}{ Aug. 30} \\
\hline & $\begin{array}{c}\text { Gage } \\
\text { ht. }\end{array}$ & $\begin{array}{l}\text { Dis- } \\
\text { charge }\end{array}$ & $\begin{array}{c}\text { Gage } \\
\text { ht. }\end{array}$ & $\begin{array}{c}\text { Dis- } \\
\text { charge }\end{array}$ & $\begin{array}{c}\text { Gage } \\
\text { ht. }\end{array}$ & $\begin{array}{c}\text { Dis- } \\
\text { charge }\end{array}$ & $\begin{array}{c}\text { Gage } \\
\text { ht. }\end{array}$ & $\begin{array}{c}\text { Dis- } \\
\text { charge }\end{array}$ & $\begin{array}{c}\text { Gage } \\
\text { ht. }\end{array}$ & $\begin{array}{c}\text { Dis- } \\
\text { charge }\end{array}$ & $\begin{array}{c}\text { Gage } \\
\text { ht. }\end{array}$ & $\begin{array}{c}\text { Dis- } \\
\text { charge }\end{array}$ \\
\hline $\begin{array}{l}1 \\
2 \\
3 \\
4 \\
5 \\
6\end{array}$ & $\begin{array}{l}1.59 \\
1.59 \\
1.60 \\
1.61 \\
1.60 \\
1.58\end{array}$ & $\begin{array}{l}110 \\
110 \\
112 \\
114 \\
112 \\
108\end{array}$ & $\begin{array}{l}5.17 \\
7.32 \\
8.45 \\
8.99 \\
9.10 \\
9.23\end{array}$ & $\begin{array}{l}2,580 \\
4,860 \\
6,220 \\
7,000 \\
7,140 \\
7,280\end{array}$ & $\begin{array}{l}5.18 \\
4.88 \\
4.68 \\
4.45 \\
4.30 \\
4.13\end{array}$ & $\begin{array}{l}2,580 \\
2,300 \\
2,120 \\
1,900 \\
1,770 \\
1,640\end{array}$ & $\begin{array}{c}-89 \\
1.89\end{array}$ & 192 & $\begin{array}{l}1.87 \\
1.87 \\
1.87 \\
1.87 \\
1.90 \\
1.93\end{array}$ & $\begin{array}{l}186 \\
186 \\
186 \\
186 \\
195 \\
206\end{array}$ & $\begin{array}{l}5.24 \\
5.06 \\
4.85 \\
4.67 \\
4.53 \\
4.36\end{array}$ & $\begin{array}{l}2,580 \\
2,490 \\
2,260 \\
2,080 \\
1,980 \\
1,810\end{array}$ \\
\hline $\begin{array}{r}7 \\
8 \\
9 \\
10 \\
11 \\
\text { N }\end{array}$ & $\begin{array}{l}1.59 \\
1.66 \\
1.74 \\
2.07 \\
2.72 \\
2.70\end{array}$ & $\begin{array}{l}110 \\
127 \\
148 \\
258 \\
599 \\
587\end{array}$ & $\begin{array}{r}9.25 \\
9.53 \\
10.10 \\
10.67 \\
11.00 \\
11.24\end{array}$ & $\begin{array}{r}7,280 \\
7,700 \\
8,550 \\
9,450 \\
9,900 \\
10,200\end{array}$ & $\begin{array}{l}4.03 \\
3.91 \\
3.83 \\
3.73 \\
3.66 \\
3.59\end{array}$ & $\begin{array}{l}1,560 \\
1,440 \\
1,400 \\
1,320 \\
1,240 \\
1,200\end{array}$ & $1.9 \overline{2}$ & 202 & $\begin{array}{l}1.93 \\
1.94 \\
2.02 \\
2.50 \\
2.48 \\
2.58\end{array}$ & $\begin{array}{l}206 \\
209 \\
238 \\
472 \\
461 \\
518\end{array}$ & $\begin{array}{l}4.18 \\
4.02 \\
3.85 \\
3.70 \\
3.52 \\
3.39\end{array}$ & $\begin{array}{l}1,680 \\
1,520 \\
1,400 \\
1,280 \\
1,120 \\
1,050\end{array}$ \\
\hline $\begin{array}{l}1 \\
2 \\
3 \\
4 \\
5 \\
6\end{array}$ & $\begin{array}{l}2.58 \\
2.62 \\
2.73 \\
2.78 \\
2.79 \\
2.77\end{array}$ & $\begin{array}{l}\mathbf{5 1 8} \\
541 \\
605 \\
635 \\
641 \\
629\end{array}$ & 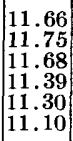 & $\begin{array}{l}11,000 \\
11,200 \\
11,000 \\
10,500 \\
10,400 \\
10,100\end{array}$ & $\begin{array}{l}3.53 \\
3.46 \\
3.41 \\
3.35 \\
3.31 \\
3.27\end{array}$ & $\begin{array}{r}1,160 \\
1,090 \\
1,050 \\
1,020 \\
980 \\
945\end{array}$ & 1.92 & 202 & $\begin{array}{l}2.82 \\
3.10 \\
3.46 \\
3.53 \\
3.60 \\
3.79\end{array}$ & $\begin{array}{r}660 \\
840 \\
1,090 \\
1,160 \\
1,200 \\
1,360\end{array}$ & $\begin{array}{l}3.28 \\
3.34 \\
3.19 \\
3.12 \\
3.04 \\
3.04\end{array}$ & $\begin{array}{r}980 \\
1,020 \\
903 \\
854 \\
801 \\
801\end{array}$ \\
\hline \begin{tabular}{r|}
7 \\
8 \\
9 \\
10 \\
11 \\
12
\end{tabular} & $\begin{array}{l}2.71 \\
2.71 \\
3.02 \\
3.40 \\
3.68 \\
4.13\end{array}$ & $\begin{array}{r}593 \\
593 \\
788 \\
1,050 \\
1,280 \\
1,640\end{array}$ & $\mid \begin{array}{r}10.50 \\
9.40 \\
7.75 \\
6.55 \\
5.92 \\
5.50\end{array}$ & $\begin{array}{l}9,150 \\
7,560 \\
5,460 \\
4,060 \\
3,300 \\
2,880\end{array}$ & $\begin{array}{l}3.23 \\
3.21 \\
3.15 \\
3.12 \\
3.09 \\
3.05\end{array}$ & $\begin{array}{l}945 \\
910 \\
875 \\
854 \\
834 \\
808\end{array}$ & 1.87 & & $\begin{array}{l}4.65 \\
5.42 \\
5.84 \\
5.84 \\
5.63 \\
5.44\end{array}$ & $\begin{array}{l}2,080 \\
2,780 \\
3,190 \\
3,190 \\
2,980 \\
2,780\end{array}$ & $\begin{array}{l}3.10 \\
3.07 \\
2.99 \\
2.95 \\
2.92 \\
2.91\end{array}$ & $\begin{array}{l}840 \\
820 \\
768 \\
742 \\
723 \\
716\end{array}$ \\
\hline
\end{tabular}

CHATTAHOOCHEE RIVER NEAR GAINESVILLE, GA.

Location.-Lat. $34^{\circ} 20^{\prime}$, long. $83^{\circ} 52^{\prime}, 1,100$ feet upstream from bridge on State Highway 53, half a mile upstream from Eddie Creek, $31 / 2$ miles downstream from Little River, 4 miles northwest of Gainesville, Hall County, and 6 miles upstream from Chestatee River. Datum of gage is 974.98 feet above mean sea level, datum of 1929 , supplementary adjustment of 1936 .

Drainage AREA. - 559 square miles (1941 revision).

GAGE-HEIGHT RECORD.-Water-stage recorder graph.

DISCHARGE RECORD.-Stage-discharge relation defined by current-meter measurements up to 20,000 second-feet and extended to erest gage height by velocity-area studies. Gage heights used to half-tenths between 2.1 and 3.7 feet; hundredths below and tenths above these limits.

Maxima.-1940: Discharge, 30,500 second-feet 3 a.m. Aug. 14 (gage height, 18.74 feet).

1901-03, 1937-39: Gage height, 28.4 feet, site and datum then in use, Dee. 29, 


\section{FLOODS OF AUGUST 1940 IN THE SOUTHEASTERN STATES}

1901 (discharge probably exceeded that of Aug. 14, 1940; previously published figure in error).

REMarKs.-Flood runoff not affected by storage or diversion.

Mean discharge, in second-feet, 1940

\begin{tabular}{|c|c|c|c|c|c|c|c|c|c|c|c|}
\hline Day & Aug. & Sept. & Day & Aug. & Sept. & Day & Aug. & Sept. & Day & Aug. & Sept. \\
\hline $\begin{array}{l}1 \\
2 \\
3 \\
4 \\
5 \\
6 \\
7 \\
8\end{array}$ & $\begin{array}{l}520 \\
535 \\
418 \\
370 \\
377 \\
439 \\
468 \\
520\end{array}$ & $\begin{array}{r}1,670 \\
1,210 \\
1,100 \\
922 \\
\mathbf{8 3 4} \\
\mathbf{7 9 4} \\
\mathbf{7 5 4} \\
\mathbf{7 1 4}\end{array}$ & $\begin{array}{r}9 \\
10 \\
11 \\
12 \\
13 \\
14 \\
15 \\
16\end{array}$ & $\begin{array}{r}411 \\
383 \\
351 \\
674 \\
13,900 \\
18,900 \\
2,980 \\
1,920\end{array}$ & $\begin{array}{l}674 \\
642 \\
618 \\
588 \\
565 \\
565 \\
542 \\
535\end{array}$ & $\begin{array}{l}17 \\
18 \\
19 \\
20 \\
21 \\
22 \\
23 \\
24\end{array}$ & $\begin{array}{r}1,450 \\
1,160 \\
1,080 \\
922 \\
826 \\
762 \\
746 \\
674\end{array}$ & $\begin{array}{l}528 \\
512 \\
505 \\
505 \\
490 \\
498 \\
453 \\
482\end{array}$ & $\begin{array}{l}25 \\
26 \\
27 \\
28 \\
29 \\
30 \\
31\end{array}$ & $\begin{array}{r}610 \\
588 \\
565 \\
542 \\
2,150 \\
6,000 \\
2,670\end{array}$ & $\begin{array}{l}\mathbf{5 5 8} \\
\mathbf{5 7 2} \\
\mathbf{4 9 8} \\
\mathbf{4 7 5} \\
\mathbf{4 4 6} \\
\mathbf{4 4 6}\end{array}$ \\
\hline & & & & & & & & & & $\begin{array}{r}2,062 \\
4.25\end{array}$ & $\begin{array}{r}656 \\
1.31\end{array}$ \\
\hline
\end{tabular}

Gage height, in feet, and discharge, in second-feet, at indicated time, 1940

\begin{tabular}{|c|c|c|c|c|c|c|c|c|c|c|}
\hline \multirow{2}{*}{ Hour } & \multicolumn{2}{|c|}{ Aug. 12} & \multicolumn{2}{|c|}{ Aug. 13} & \multicolumn{2}{|c|}{ Aug. 14} & \multicolumn{2}{|c|}{ Aug. 15} & \multicolumn{2}{|c|}{ Aug. 16} \\
\hline & $\begin{array}{c}\text { Gage } \\
\text { height }\end{array}$ & $\begin{array}{c}\text { Dis- } \\
\text { charge }\end{array}$ & $\begin{array}{c}\text { Gage } \\
\text { height }\end{array}$ & $\begin{array}{l}\text { Dis- } \\
\text { charge }\end{array}$ & $\begin{array}{c}\text { Gage } \\
\text { height }\end{array}$ & $\begin{array}{c}\text { Dis- } \\
\text { charge }\end{array}$ & $\begin{array}{c}\text { Gage } \\
\text { height }\end{array}$ & $\begin{array}{c}\text { Dis- } \\
\text { charge }\end{array}$ & $\begin{array}{c}\text { Gage } \\
\text { height }\end{array}$ & $\begin{array}{c}\text { Dis- } \\
\text { charge }\end{array}$ \\
\hline $\begin{array}{l}1 \\
2 \\
\mathbf{3} \\
\mathbf{4} \\
\mathbf{5} \\
\mathbf{6}\end{array}$ & $\begin{array}{l}1.16 \\
1.17 \\
1.17 \\
1.17 \\
1.17 \\
1.17\end{array}$ & $\begin{array}{l}363 \\
370 \\
370 \\
370 \\
370 \\
370\end{array}$ & $\begin{array}{l}4.93 \\
5.37 \\
5.95 \\
6.65 \\
7.32 \\
7.90\end{array}$ & $\begin{array}{l}4,130 \\
4,640 \\
5,240 \\
5,840 \\
6,540 \\
7,190\end{array}$ & $\begin{array}{l}18.52 \\
18.68 \\
18.74 \\
18.67 \\
18.51 \\
18.29\end{array}$ & $\begin{array}{l}29,800 \\
30,500 \\
30,500 \\
30,500 \\
29,800 \\
29,100\end{array}$ & $\begin{array}{l}4.81 \\
4.51 \\
4.35\end{array}$ & $\begin{array}{r}3,800 \\
3,470 \\
3,360\end{array}$ & $\begin{array}{l}3.41 \\
3.31 \\
3.25\end{array}$ & $\begin{array}{r}2,230 \\
2,120 \\
2,060\end{array}$ \\
\hline $\begin{array}{r}7 \\
8 \\
9 \\
10 \\
11 \\
\text { N }\end{array}$ & $\begin{array}{l}1.17 \\
1.17 \\
1.17 \\
1.17 \\
1.18 \\
1.19\end{array}$ & $\begin{array}{l}370 \\
370 \\
370 \\
370 \\
377 \\
383\end{array}$ & $\begin{array}{r}8.53 \\
9.07 \\
9.57 \\
10.00 \\
10.50 \\
11.23\end{array}$ & $\begin{array}{r}7,900 \\
8,630 \\
9,280 \\
9,830 \\
10,600 \\
11,600\end{array}$ & $\begin{array}{l}18.00 \\
17.56 \\
17.04 \\
16.50 \\
15.89 \\
15.22\end{array}$ & $\begin{array}{l}28,100 \\
26,900 \\
25,000 \\
23,600 \\
21,900 \\
20,100\end{array}$ & $\begin{array}{l}4.17 \\
4.05 \\
3.96\end{array}$ & $\begin{array}{l}3,120 \\
2,890 \\
2,890\end{array}$ & $\begin{array}{c}3.19 \\
3.13 \\
3.06\end{array}$ & $\begin{array}{r}2,010 \\
1,960 \\
1,850\end{array}$ \\
\hline \multirow{2}{*}{$\begin{array}{r}1 \\
2 \\
3 \\
4 \\
5 \\
6 \\
7 \\
7 \\
8 \\
9 \\
10 \\
11 \\
12 \\
\end{array}$} & $\begin{array}{l}1.20 \\
1.22 \\
1.24 \\
1.27 \\
1.34 \\
1.49\end{array}$ & $\begin{array}{l}390 \\
404 \\
418 \\
439 \\
490 \\
602\end{array}$ & $\begin{array}{l}11.95 \\
12.62 \\
13.21 \\
13.95 \\
14.64 \\
15.30\end{array}$ & $\begin{array}{l}13,000 \\
14,200 \\
15,400 \\
17,200 \\
18,600 \\
20,400\end{array}$ & $\begin{array}{r}14.43 \\
13.74 \\
12.78 \\
11.86 \\
10.76 \\
9.25\end{array}$ & $\begin{array}{r}18,200 \\
16,500 \\
14,600 \\
12,800 \\
11,000 \\
8,760\end{array}$ & $\begin{array}{l}3.85 \\
3.75 \\
3.73\end{array}$ & $\begin{array}{l}2,720 \\
2,620 \\
2,620\end{array}$ & $\begin{array}{r}3.02 \\
2.99\end{array}$ & $\begin{array}{l}1,800 \\
1,800 \\
1,750\end{array}$ \\
\hline & $\begin{array}{l}1.69 \\
1.92 \\
2.30 \\
2.74 \\
3.33 \\
4.12 \\
\end{array}$ & $\begin{array}{r}762 \\
958 \\
1,300 \\
1,750 \\
2,400 \\
3,240 \\
\end{array}$ & $\begin{array}{l}15.92 \\
16.58 \\
17.15 \\
17.62 \\
18.03 \\
18.31 \\
\end{array}$ & $\begin{array}{l}21,900 \\
23,900 \\
25,600 \\
26,900 \\
28,100 \\
29,100 \\
\end{array}$ & $\begin{array}{l}7.85 \\
6.95 \\
6.25 \\
5.64 \\
5.31 \\
5.11 \\
\end{array}$ & $\begin{array}{l}7,080 \\
6,240 \\
5,440 \\
4,840 \\
4,540 \\
4,340 \\
\end{array}$ & $\begin{array}{l}3.65 \\
3.54 \\
3.45\end{array}$ & 2,500 & $\begin{array}{l}2.94 \\
2.91 \\
2.85\end{array}$ & $\begin{array}{l}1,750 \\
1,700 \\
1,650\end{array}$ \\
\hline & \multicolumn{2}{|c|}{ Aug. 28} & \multicolumn{2}{|c|}{ Aug. 29} & \multicolumn{2}{|c|}{ Aug. 30} & \multicolumn{2}{|c|}{ Aug. 31} & \multicolumn{2}{|c|}{ Sept. 1} \\
\hline $\begin{array}{l}1 \\
2 \\
3 \\
4 \\
5 \\
5 \\
6\end{array}$ & 1.64 & & $\begin{array}{l}1.56 \\
1.58 \\
1.60 \\
1.65 \\
2.45 \\
3.05\end{array}$ & $\begin{array}{r}505 \\
\mathbf{5 2 0} \\
\mathbf{5 3 5} \\
\mathbf{5 7 2} \\
\mathbf{1}, \mathbf{2 6 0} \\
\mathbf{1}, \mathbf{8 5 0}\end{array}$ & $\begin{array}{l}6.54 \\
6.60 \\
6.76 \\
6.93 \\
7.14 \\
7.33\end{array}$ & $\begin{array}{l}\mathbf{5}, 640 \\
\mathbf{5}, 740 \\
5,940 \\
6,040 \\
6,240 \\
6,440\end{array}$ & $\begin{array}{r}4.38 \\
4.16 \\
4.01\end{array}$ & $\begin{array}{l}3,470 \\
3,240 \\
3,000\end{array}$ & 2.97 & 1,850 \\
\hline $\begin{array}{r}7 \\
8 \\
9 \\
10 \\
11 \\
\mathbf{N}\end{array}$ & 1.63 & $\mathbf{5 5 8}$ & $\begin{array}{l}2.64 \\
2.25 \\
2.35 \\
2.44 \\
2.51 \\
2.55\end{array}$ & $\begin{array}{l}1,450 \\
1,080 \\
1,160 \\
1,260 \\
1,300 \\
1,350\end{array}$ & $\begin{array}{l}7.54 \\
7.68 \\
7.84 \\
7.92 \\
8.00 \\
8.01\end{array}$ & $\begin{array}{l}6,640 \\
6,860 \\
6,970 \\
7,080 \\
7,190 \\
7,190\end{array}$ & $\begin{array}{c}3.85 \\
3.75 \\
3.61\end{array}$ & $\begin{array}{c}2,890 \\
2,720 \\
2,560\end{array}$ & 2.85 & 1,750 \\
\hline $\begin{array}{l}1 \\
2 \\
3 \\
4 \\
5 \\
6\end{array}$ & 1.58 & 520 & $\begin{array}{l}2.78 \\
3.02 \\
3.33 \\
3.57 \\
4.05 \\
4.37\end{array}$ & $\begin{array}{l}1,600 \\
1,800 \\
2,180 \\
2,400 \\
2,890 \\
3,360\end{array}$ & $\begin{array}{l}7.91 \\
7.76 \\
7.53 \\
7.25 \\
6.83 \\
6.43\end{array}$ & $\begin{array}{l}6,970 \\
6,640 \\
6,440 \\
\mathbf{5}, 940 \\
\mathbf{5 , 5 4 0}\end{array}$ & $\begin{array}{c}3.50 \\
3.40 \\
3.31\end{array}$ & $\begin{array}{r}2,450 \\
2,340 \\
2,230\end{array}$ & 2.65 & $1, \overline{550}$ \\
\hline $\begin{array}{r}7 \\
8 \\
9 \\
10 \\
11 \\
12 \\
\end{array}$ & $1.5 \overline{3}$ & 482 & $\begin{array}{l}4.57 \\
4.88 \\
5.25 \\
5.70 \\
6.05 \\
6.31\end{array}$ & $\begin{array}{l}3,580 \\
3,910 \\
4,240 \\
4,740 \\
5,040 \\
5,340\end{array}$ & $\begin{array}{l}6.04 \\
5.72 \\
5.40 \\
5.12 \\
4.90 \\
\mathbf{4 . 7 2}\end{array}$ & $\begin{array}{l}5,140 \\
4,840 \\
4,540 \\
4,240 \\
4,020 \\
3,800\end{array}$ & $\begin{array}{c}3.23 \\
3.15 \\
3.10 \\
\end{array}$ & $\begin{array}{l}2,180^{-} \\
2,060 \\
2,010\end{array}$ & 2.53 & $\begin{array}{l}1,500 \\
1,450 \\
\end{array}$ \\
\hline
\end{tabular}


CHATWAHOOCHEE RIVER NEAR VININGS, GA.

LOCATION.-Lat. $33^{\circ} 52^{\prime}$, long. $84^{\circ} 27^{\prime}$, at Pace Ferry .Bridge, 1 mile southeast of Vinings, Cobb County, 1 mile downstream from Rotten Wood Creek, 21/2 miles upstream from Peachtree Creek, and 8 miles northwest of Atlanta. Datum of gage is 749.60 feet above mean sea level, datum of 1929 , supplementary adjustment of 1936 (levels by Corps of Engineers, War Department).

DRAINAGE AREA.-1,450 square miles.

GAGE-HEIGHT RECORD.-Water-stage recorder graph.

DISCHARGE RECORD.—Stage-discharge relation defined by current-meter measurements up to 22,000 second-feet. Gage-heights used to half-tenths between 2.8 and 4.8 feet; tenths above and hundredths below these limits.

Maxima.-1940: Discharge, 24,200 second-feet 8 p.m. Aug. 15 (gage height, 17.48 feet).

1928-31, 1936-39: Discharge, 28,700 second-feet Sept. 28, 1929 (gage height, 18.84 feet).

ReMarKs.-Flood runoff not affected by storage in Morgan Falls Reservoir 91/2 miles upstream.

Mean discharge, in second-feet, 1940

\begin{tabular}{|c|c|c|c|c|c|c|c|c|c|c|c|}
\hline Day & Aug. & Sept. & Day & Aug. & Sept. & Day & Aug. & Sept. & Day & Aug. & Sept. \\
\hline $\begin{array}{l}1 \\
2 \\
3 \\
4 \\
5 \\
6 \\
7 \\
8\end{array}$ & $\begin{array}{r}828 \\
772 \\
1,020 \\
822 \\
716 \\
705 \\
660 \\
748\end{array}$ & $\begin{array}{l}4,190 \\
2,620 \\
2,080 \\
1,910 \\
1,660 \\
1,600 \\
1,650 \\
1,420\end{array}$ & $\begin{array}{r}9 \\
10 \\
11 \\
12 \\
13 \\
14 \\
15 \\
16\end{array}$ & $\begin{array}{r}887 \\
780 \\
678 \\
1,240 \\
12,400 \\
15,200 \\
21,800 \\
12,100\end{array}$ & $\begin{array}{l}1,380 \\
1,320 \\
1,270 \\
1,180 \\
1,150 \\
1,080 \\
1,070 \\
1,080\end{array}$ & $\begin{array}{l}17 \\
18 \\
19 \\
20 \\
21 \\
22 \\
23 \\
24\end{array}$ & $\begin{array}{l}3,340 \\
2,600 \\
2,210 \\
2,000 \\
1,800 \\
1,640 \\
1,570 \\
1,540\end{array}$ & $\begin{array}{r}1,030 \\
1,000 \\
960 \\
980 \\
940 \\
930 \\
914 \\
850\end{array}$ & $\begin{array}{l}25 \\
26 \\
27 \\
28 \\
29 \\
30 \\
31\end{array}$ & $\begin{array}{l}1,440 \\
1,270 \\
1,310 \\
1,250 \\
1,700 \\
5,350 \\
9,050\end{array}$ & $\begin{array}{r}918 \\
974 \\
1,220 \\
940 \\
931 \\
886 \\
\end{array}$ \\
\hline JI & & & & & & & & & & $\begin{array}{r}3,530 \\
2.80\end{array}$ & $\begin{array}{r}1,338 \\
1.03\end{array}$ \\
\hline
\end{tabular}

Gage height, in feet, and discharge, in second-feet, at indicated time, 1940

\begin{tabular}{|c|c|c|c|c|c|c|c|c|c|c|c|c|}
\hline \multirow{2}{*}{ Hour } & \multicolumn{2}{|c|}{ Aug. 12} & \multicolumn{2}{|c|}{ Aug. 13} & \multicolumn{2}{|c|}{ Aug. 14} & \multicolumn{2}{|c|}{ Aug. 15} & \multicolumn{2}{|c|}{ Aug. 16} & \multicolumn{2}{|c|}{ Aug. 17} \\
\hline & $\begin{array}{c}\text { Yage } \\
\text { ht. }\end{array}$ & $\begin{array}{c}\text { Dis- } \\
\text { charge }\end{array}$ & $\begin{array}{c}\text { Gage } \\
\text { ht. }\end{array} \mid$ & $\begin{array}{c}\text { Dis- } \\
\text { charge }\end{array}$ & $\begin{array}{c}\text { Gage } \\
\text { ht. }\end{array}$ & $\begin{array}{c}\text { Dis- } \\
\text { charge }\end{array}$ & $\begin{array}{c}\text { Gage } \\
\text { ht. }\end{array}$ & $\begin{array}{c}\text { Dis- } \\
\text { charge }\end{array}$ & $\begin{array}{c}\text { Gage } \\
\text { ht. }\end{array}$ & $\begin{array}{c}\text { Dis- } \\
\text { charge }\end{array}$ & $\begin{array}{c}\text { Gage } \\
\text { ht. }\end{array}$ & $\begin{array}{c}\text { Dis- } \\
\text { charge }\end{array}$ \\
\hline $\begin{array}{l}1 \\
2 \\
3 \\
4 \\
5 \\
6\end{array}$ & $\begin{array}{l}2.08 \\
2.07 \\
2.08 \\
2.12 \\
2.15 \\
2.14\end{array}$ & $\begin{array}{l}622 \\
615 \\
622 \\
652 \\
675 \\
668\end{array}$ & \begin{tabular}{|r|}
7.30 \\
8.08 \\
8.64 \\
9.07 \\
9.52 \\
10.02
\end{tabular} & $\begin{array}{r}7,550 \\
8,750 \\
9,500 \\
10,300 \\
10,900 \\
11,700\end{array}$ & 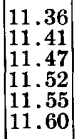 & $\begin{array}{l}13,900 \\
13,900 \\
14,100 \\
14,100 \\
14,300 \\
14,300\end{array}$ & $\begin{array}{l}13.92 \\
14.10 \\
14.31 \\
14.52 \\
14.74 \\
14.99\end{array}$ & $\begin{array}{l}18,000 \\
18,300 \\
18,700 \\
19,000 \\
19,400 \\
19,900\end{array}$ & $\begin{array}{l}16.98 \\
16.74 \\
16.35 \\
15.90 \\
15.38 \\
14.75\end{array}$ & $\begin{array}{l}23,300 \\
22,800 \\
22,200 \\
21,400 \\
20,600 \\
19,500\end{array}$ & $\begin{array}{r}4.89 \\
4.70 \\
4.52\end{array}$ & $\begin{array}{c}3,950 \\
3,650 \\
3,350\end{array}$ \\
\hline $\begin{array}{r}7 \\
8 \\
9 \\
10 \\
11 \\
\text { IN }\end{array}$ & $\begin{array}{l}2.13 \\
2.12 \\
2.10 \\
2.11 \\
2.15 \\
2.21\end{array}$ & $\begin{array}{l}660 \\
652 \\
638 \\
645 \\
675 \\
722\end{array}$ & $\begin{array}{l}10.41 \\
10.72 \\
10.94 \\
11.14 \\
11.31 \\
11.44\end{array} \mid$ & $\begin{array}{l}12,300 \\
12,800 \\
13,100 \\
13,500 \\
13,800 \\
13,900\end{array}$ & $\begin{array}{l}11.68 \\
11.75 \\
11.83 \\
11.92 \\
12.02 \\
12.12\end{array}$ & $\begin{array}{l}14,400 \\
14,600 \\
14,600 \\
14,700 \\
14,900 \\
15,100\end{array}$ & \begin{tabular}{|l|}
15.23 \\
15.50 \\
15.74 \\
16.02 \\
16.25 \\
16.50
\end{tabular} & $\begin{array}{l}20,200 \\
20,700 \\
21,100 \\
21,600 \\
21,900 \\
22,400\end{array}$ & \begin{tabular}{|r|}
14.00 \\
13.08 \\
12.25 \\
11.30 \\
10.30 \\
9.28
\end{tabular} & $\begin{array}{l}18,200 \\
16,700 \\
15,200 \\
13,800 \\
12,200 \\
10,600\end{array}$ & $\begin{array}{r}4.62 \\
-4 . \overline{52} \\
-4 . \overline{92}\end{array}$ & $\begin{array}{c}3,500 \\
3,350 \\
3,950\end{array}$ \\
\hline $\begin{array}{r}1 \\
2 \\
3 \\
14 \\
5 \\
6\end{array}$ & $\begin{array}{l}2.25 \\
2.33 \\
2.39 \\
2.45 \\
2.51 \\
2.63\end{array}$ & $\begin{array}{r}754 \\
818 \\
866 \\
914 \\
966 \\
1,080\end{array}$ & $\mid \begin{array}{l}11.53 \\
11.58 \\
11.61 \\
11.57 \\
11.47 \\
11.37\end{array}$ & $\begin{array}{l}14,100 \\
14,300 \\
14,300 \\
14,300 \\
14,100 \\
13,900\end{array}$ & $\left|\begin{array}{l}12.23 \\
12.34 \\
12.49 \\
12.65 \\
12.80 \\
12.93\end{array}\right|$ & $\begin{array}{l}15,200 \\
15,400 \\
15,700 \\
15,900 \\
16,200 \\
16,300\end{array}$ & $\begin{array}{l}16.72 \\
16.89 \\
17.04 \\
17.19 \\
17.30 \\
17.38\end{array}$ & $\begin{array}{l}22,800 \\
23,200 \\
23,300 \\
23,700 \\
23,900 \\
24,000\end{array}$ & $\begin{array}{l}8.36 \\
7.57 \\
6.86 \\
6.28 \\
5.83 \\
5.53\end{array}$ & $\begin{array}{l}9,200 \\
8,000 \\
6,950 \\
6,050 \\
5,300 \\
4,850\end{array}$ & $\begin{array}{r}4.36 \\
-4.34 \\
-4.14\end{array}$ & $\begin{array}{l}3,120 \\
3,120 \\
2,840\end{array}$ \\
\hline $\begin{array}{r}7 \\
8 \\
9 \\
10 \\
11 \\
12 \\
\end{array}$ & $\begin{array}{l}2.87 \\
3.43 \\
3.73 \\
4.30 \\
5.34\end{array}$ & $\begin{array}{l}1,320 \\
1,930 \\
2,300 \\
3,050 \\
4,550 \\
6,050 \\
\end{array}$ & $\begin{array}{l}11.27 \\
11.19 \\
11.17 \\
11.19 \\
11.23 \\
11.30\end{array}$ & $\begin{array}{l}13,800 \\
13,600 \\
13,600 \\
13,600 \\
13,600 \\
13,800\end{array}$ & $\mid \begin{array}{l}13.05 \\
13.18 \\
13.31 \\
13.44 \\
13.58 \\
13.74\end{array}$ & $\begin{array}{l}16,500 \\
16,800 \\
17,000 \\
17,200 \\
17,500 \\
17,700\end{array}$ & $\begin{array}{l}17.45 \\
17.48 \\
17.45 \\
17.42 \\
17.32 \\
17.14\end{array}$ & $\begin{array}{l}24,000 \\
24,200 \\
24,000 \\
24,000 \\
23,900 \\
23,500\end{array}$ & $\begin{array}{l}5.35 \\
5.22 \\
5.12 \\
4.98 \\
4.93 \\
4.93\end{array}$ & $\begin{array}{l}4,700 \\
4,400 \\
4,250 \\
4,100 \\
3,950 \\
3,950\end{array}$ & $\begin{array}{r}4.15 \\
4.26 \\
-4.24\end{array}$ & $\begin{array}{r}2,840 \\
2,980 \\
2,980\end{array}$ \\
\hline
\end{tabular}

$804331-49-21$ 
CHATTAHOOCHEE RIVER NEAR WHITESBURG, GA.

LOCATION.-Lat. $33^{\circ} 29^{\prime}$, long. $84^{\circ} 53^{\prime}$, at bridge on State Highway 16 , half a mile downstream from Cedar Creek, 1 mile downstream from Snake Creek, 11/2 miles upstream from Central of Georgia Railroad, $1 \%$ miles southeast of Whitesburg, Carroll County. Datum of gage is 684.06 feet above mean sea level datum of 1929 (Corps of Engineers, War Department, bench mark), levels by Corps of Engineers.

Drain AGE AREA.-2,430 square miles.

GAGE-HEIGHT RECORD.-Graph based on twice-daily readings of wire-weight gage.

DISCHARGE RECORD.-Stage-discharge relation defined by eurrent-meter measurements up to 19,000 second-feet and extended to peak discharge by logarithmic plotting and use of velocity-area curves. Gage heights used to tenths above 1.9 feet and to half-tenths below.

Maxima.-1940: Discharge, 20,800 second-feet 7 to 8 p.m. Aug. 16 (gage height, 14.5 feet, from graph based on gage readings).

1938-39: Discharge, 23,300 second-feet Feb. 28, 1939 (gage height, 15.7 feet, from graph based on gage readings).

REMARKs.- Flood runoff not affected by storage. City of Atlanta at point 40 miles upstream pumps average of 35 million gallons daily for municipal water supply, most of which is returned to stream through sewage plants.

Mean discharge, in second-feet, 1940

\begin{tabular}{|c|c|c|c|c|c|c|c|c|c|c|c|}
\hline Day & Aụg. & Sept. & Day & Aug. & Sept. & Day & Aug. & Sept. & Day & Aug. & Sept. \\
\hline $\begin{array}{l}1 \\
2 \\
3 \\
4 \\
5 \\
6 \\
7 \\
8\end{array}$ & $\begin{array}{l}1,520 \\
1,320 \\
1,220 \\
1,420 \\
1,170 \\
1,070 \\
1,120 \\
1,120\end{array}$ & $\begin{array}{l}9,020 \\
4,230 \\
3,030 \\
2,480 \\
2,370 \\
2,040 \\
2,150 \\
1,930\end{array}$ & $\begin{array}{r}99 \\
10 \\
11 \\
12 \\
13 \\
14 \\
15 \\
16\end{array}$ & $\begin{array}{r}1,120 \\
1,170 \\
1,070 \\
1,120 \\
9,680 \\
16,500 \\
17,600 \\
19,800\end{array}$ & $\begin{array}{l}1,820 \\
1,720 \\
1,720 \\
1,620 \\
1,520 \\
1,420 \\
1,320 \\
1,320\end{array}$ & $\begin{array}{l}17 \\
18 \\
19 \\
20 \\
21 \\
22 \\
23 \\
24\end{array}$ & $\begin{array}{r}13,400 \\
4,110 \\
3,270 \\
2,810 \\
2,590 \\
2,370 \\
2,150 \\
2,040\end{array}$ & $\begin{array}{l}1,320 \\
1,270 \\
1,270 \\
1,220 \\
1,170 \\
1,170 \\
1,170 \\
1,120\end{array}$ & $\begin{array}{l}25 \\
26 \\
27 \\
28 \\
29 \\
30 \\
31\end{array}$ & $\begin{array}{l}1,930 \\
1,820 \\
1,620 \\
1,720 \\
2,370 \\
3,990 \\
9,090\end{array}$ & $\begin{array}{r}1,120 \\
1,270 \\
1,320 \\
1,520 \\
1,220 \\
1,170 \\
\end{array}$ \\
\hline \multicolumn{10}{|c|}{$\begin{array}{l}\text { Monthly mean discharge, in second-feet } \\
\text { Runoff, in inches }\end{array}$} & $\begin{array}{r}4,300 \\
2,04\end{array}$ & $\begin{array}{r}1,901 \\
\mathbf{0 . 8 7}\end{array}$ \\
\hline
\end{tabular}

Gage height, in feet, and discharge, in second-feet, at indicated time, 1940

\begin{tabular}{|c|c|c|c|c|c|c|c|c|c|c|c|c|}
\hline \multirow{2}{*}{ Hou } & \multicolumn{2}{|c|}{ Aug. 12} & \multicolumn{2}{|c|}{ Aug. 13} & \multicolumn{2}{|c|}{ Aug. 14} & \multicolumn{2}{|c|}{ Aug. 15} & \multicolumn{2}{|c|}{ Aug. 16} & \multicolumn{2}{|c|}{ Aug. 17} \\
\hline & $\begin{array}{c}\text { Gage } \\
\text { ht. }\end{array}$ & $\begin{array}{c}\text { Dis- } \\
\text { charge }\end{array}$ & $\begin{array}{l}\text { Gage } \\
\text { ht. }\end{array}$ & $\begin{array}{c}\text { Dis- } \\
\text { charge }\end{array}$ & $\begin{array}{c}\text { Gage } \\
\text { ht. }\end{array}$ & $\begin{array}{c}\text { Dis- } \\
\text { charge }\end{array}$ & $\begin{array}{c}\text { Gage } \\
\text { ht. }\end{array}$ & $\begin{array}{c}\text { Dis- } \\
\text { charge }\end{array}$ & $\begin{array}{c}\text { Gage } \\
\text { ht. }\end{array}$ & $\begin{array}{c}\text { Dis- } \\
\text { charge }\end{array}$ & $\begin{array}{c}\text { Gage } \\
\text { ht. }\end{array}$ & $\begin{array}{l}\text { Dis- } \\
\text { charge }\end{array}$ \\
\hline $\begin{array}{l}1 \\
2 \\
3\end{array}$ & 1.60 & 1,020 & $\begin{array}{l}3.1 \\
3.6\end{array}$ & $\begin{array}{l}2,590 \\
3,150 \\
3,750\end{array}$ & 1.7 & 15,4 & $\begin{array}{l}12.7 \\
12.7\end{array}$ & $\begin{array}{l}17,200 \\
17,200\end{array}$ & $\begin{array}{l}13.3 \\
13.4\end{array}$ & & 14.4 & 20,600 \\
\hline 4 & 1.55 & $980^{-}$ & 4.1 & 4 & 1 & $\begin{array}{l}15,7 \\
15,7\end{array}$ & 12. & 17,200 & 13.5 & $\begin{array}{l}18,600 \\
18,800\end{array}$ & 14.3 & 20,400 \\
\hline $\begin{array}{l}5 \\
6\end{array}$ & 1.55 & 980 & 5 & 6,0 & $\begin{array}{l}12.0 \\
12.1\end{array}$ & & 12.7 & $\begin{array}{l}17,200 \\
17,200\end{array}$ & $\left|\begin{array}{l}13.6 \\
13.6\end{array}\right|$ & $\begin{array}{l}19,000 \\
19,000\end{array}$ & 14.1 & 20,000 \\
\hline 7 & $1 . \overline{55}$ & 980 & 6.5 & & $\begin{array}{l}12.1 \\
12.2\end{array}$ & & $\begin{array}{l}12.7 \\
12.8\end{array}$ & & $\begin{array}{l}13.7 \\
13.8\end{array}$ & & 13.5 & 18,800 \\
\hline 10 & $\overline{1.55}$ & $980^{-}$ & & & 12.2 & & 12 & 1 & & 00 & 23 & 500 \\
\hline 1. & & & 8.5 & 9,810 & 12.3 & & 12.8 & 17 & 14.0 & 19,800 & & \\
\hline$\lambda$ & 1.60 & 1,020 & 8.9 & 10 , & 12.4 & & 12 & 400 & 14.1 & 20,000 & 10.8 & 13,700 \\
\hline $\begin{array}{l}1 \\
2\end{array}$ & 1.60 & 1.020 & 9.3 & $\begin{array}{l}11,100 \\
11,600\end{array}$ & & & & & & & & \\
\hline 3 & & & & 12 & 12 & & $\begin{array}{l}12 \\
12\end{array}$ & & & & & \\
\hline$A$ & 1.60 & 1,020 & 10.2 & 12,700 & 12.6 & & 12.9 & & 14.3 & & 8.0 & 9,030 \\
\hline 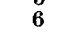 & 1.65 & 1,070 & 10.7 & 00 & $\left\{\begin{array}{l}12.6 \\
12.6\end{array}\right.$ & 10 & 13.0 & 800 & $\begin{array}{l}14.4 \\
14.4\end{array}$ & $\begin{array}{l}20,000 \\
20,600\end{array}$ & 6.6 & 6,990 \\
\hline 7 & $-\overline{8} \overline{5}$ & 1,2 & 10.9 & $\begin{array}{l}13,900 \\
14,300 \\
14\end{array}$ & 12.6 & $\begin{array}{l}17,000 \\
17,200\end{array}$ & $\begin{array}{l}13.0 \\
13.1\end{array}$ & & 14.5 & & 5.7 & 5,760 \\
\hline 10 & 2.2 & 1,620 & 11.3 & & & & & & & & 5.3 & 5,240 \\
\hline 12 & 2.6 & 2,040 & 1 & & $\begin{array}{l}12.7 \\
12.7\end{array}$ & & 3.3 & 400 & 1.4 & 20,600 & 5.0 & $4,850^{-}$ \\
\hline
\end{tabular}




\section{CHATTAHOOCHEE RIVER AT WEST ROINT, GA.}

LoCATION.-Lat. $32^{\circ} 53^{\prime}$, long. $85^{\circ} 11^{\prime}$, just downstream from Oseligee Creek and 1 mile upstream from West Point, Troup County. Datum of gage is 551.67 feet above mean sea level, datum of 1929, supplementary adjustment of 1936 .

Drannage AREa.- 3,550 square miles.

GAGE-HEIGHT RECORD.-Water-stage recorder graph.

DISCHARGE RECORD.-Stage-discharge relation defined by eurrent-meter measurements up to 50,000 second-feet. Gage heights used to half-tenths between 3.1 and 4.4 feet; hundredths below and tenths above these limits.

Maxima.-August 1940: Discharge, 20,300 second-feet 4 to 6 p.m., Aug. 17 (gage height, 11.60 feet).

1896-1910, 1912 to July 1940: Discharge, 134,000 second-feet, Dee. 10, 1919 (gage height, 30.0 feet).

REMARKs.-Flood runoff not affected by storage or diversion.

Mean discharge, in second-feet, 1940

\begin{tabular}{|c|c|c|c|c|c|c|c|c|c|c|c|}
\hline Day & Aug. & Sept. & Day & Aug. & Sept. & Day & Aug. & Sept. & Day & Aug. & Sept. \\
\hline $\begin{array}{l}1 \\
2 \\
3 \\
4 \\
5 \\
6 \\
7 \\
8\end{array}$ & $\begin{array}{l}2,200 \\
2,180 \\
1,880 \\
1,760 \\
1,880 \\
1,700 \\
1,550 \\
1,570\end{array}$ & $\begin{array}{r}10,600 \\
8,020 \\
4,340 \\
3,290 \\
2,860 \\
2,700 \\
2,440 \\
2,440\end{array}$ & $\begin{array}{r}9 \\
10 \\
11 \\
12 \\
13 \\
14 \\
15 \\
16\end{array}$ & $\begin{array}{r}1,540 \\
1,620 \\
1,730 \\
1,520 \\
1,800 \\
12,700 \\
16,700 \\
17,700\end{array}$ & $\begin{array}{l}2,220 \\
2,100 \\
2,020 \\
2,030 \\
1,840 \\
1,740 \\
1,710 \\
1,650\end{array}$ & $\begin{array}{l}17 \\
18 \\
19 \\
20 \\
21 \\
22 \\
23 \\
24\end{array}$ & $\begin{array}{r}19,700 \\
9,640 \\
4,430 \\
3,630 \\
3,120 \\
3,200 \\
2,780 \\
2,520\end{array}$ & $\begin{array}{l}1,600 \\
1,600 \\
1,520 \\
1,500 \\
1,460 \\
1,440 \\
1,420 \\
1,390\end{array}$ & $\begin{array}{l}25 \\
26 \\
27 \\
28 \\
29 \\
30 \\
31\end{array}$ & $\begin{array}{l}2,360 \\
2,250 \\
2,120 \\
2,020 \\
2,050 \\
2,950 \\
5,240\end{array}$ & $\begin{array}{r}1,470 \\
1,570 \\
1,760 \\
1,780 \\
1,830 \\
1,570\end{array}$ \\
\hline $\begin{array}{l}\text { on } \\
\text { ine }\end{array}$ & & & & & & & & & & $\begin{array}{r}4,453 \\
1.44\end{array}$ & $\begin{array}{r}2,464 \\
0.77\end{array}$ \\
\hline
\end{tabular}

Gage height, in feet, and discharge, in second-feet, at indicated time, 1940

\begin{tabular}{|c|c|c|c|c|c|c|c|c|c|c|c|c|}
\hline \multirow{2}{*}{ Hour } & \multicolumn{2}{|c|}{ Aug. 13} & \multicolumn{2}{|c|}{ Aug. 14} & \multicolumn{2}{|c|}{ Aug. 15} & \multicolumn{2}{|c|}{ Aug. 16} & \multicolumn{2}{|c|}{ Aug. 17} & \multicolumn{2}{|c|}{ Aug. 18} \\
\hline & $\begin{array}{c}\text { Gage } \\
\text { ht. }\end{array}$ & $\begin{array}{c}\text { Dis- } \\
\text { charge }\end{array}$ & $\begin{array}{c}\text { Gage } \\
\text { ht. }\end{array}$ & $\begin{array}{c}\text { Dis- } \\
\text { charge }\end{array}$ & $\begin{array}{c}\text { Gage } \\
\text { ht. }\end{array}$ & $\begin{array}{c}\text { Dis- } \\
\text { charge }\end{array}$ & $\begin{array}{c}\text { Gage } \\
\text { ht. }\end{array}$ & $\begin{array}{c}\text { Dis- } \\
\text { charge }\end{array}$ & $\begin{array}{c}\text { Gage } \\
\text { ht. }\end{array}$ & $\begin{array}{c}\text { Dis- } \\
\text { charge }\end{array}$ & $\begin{array}{c}\text { Gage } \\
\text { ht. }\end{array}$ & $\begin{array}{c}\text { Dis- } \\
\text { charge }\end{array}$ \\
\hline \multirow{4}{*}{$\begin{array}{l}1 \\
2 \\
3 \\
4 \\
5 \\
6\end{array}$} & \multirow{4}{*}{\begin{tabular}{|l|}
2.65 \\
2.64 \\
2.64 \\
2.64 \\
2.64 \\
2.64
\end{tabular}} & \multirow{4}{*}{$\begin{array}{l}1,520 \\
1,500 \\
1,500 \\
1,500 \\
1,500 \\
1,500\end{array}$} & \multirow{4}{*}{\begin{tabular}{|l|}
$\mathbf{5} .74$ \\
6.37 \\
6.86 \\
7.27 \\
7.52 \\
$\mathbf{7 . 8 8}$
\end{tabular}} & \multirow{4}{*}{$\begin{array}{r}6,880 \\
8,210 \\
9,180 \\
9,980 \\
10,400 \\
11,200\end{array}$} & \multirow{4}{*}{$\begin{array}{l}10.05 \\
10.10 \\
10.13 \\
10.18 \\
10.21 \\
10.25\end{array}$} & \multirow{4}{*}{$\begin{array}{l}16,000 \\
16,200 \\
16,200 \\
16,400 \\
16,400 \\
16,400\end{array}$} & 0.47 & 17,200 & 11.08 & 18 & \multirow{2}{*}{10.54} & \multirow{2}{*}{17,2000} \\
\hline & & & & & & & & & & & & \\
\hline & & & & & & & 10.50 & 17,200 & 11.15 & 19,100 & 9.70 & $15 ; 200$ \\
\hline & & & & & & & 10.53 & 17,200 & 11.26 & 19,400 & 8.74 & 12,900 \\
\hline \multirow{4}{*}{$\begin{array}{r}7 \\
8 \\
9 \\
10 \\
11 \\
\mathbf{N}\end{array}$} & 2.64 & 1,500 & 8.13 & 11 & \multirow{4}{*}{$\begin{array}{l}10.27 \\
10.30 \\
10.32 \\
10.34 \\
10.35 \\
10.36\end{array}$} & \multirow{4}{*}{$\begin{array}{l}16,700 \\
16,700 \\
16,700 \\
16,700 \\
17,000 \\
17,000\end{array}$} & & & & & \multirow[b]{2}{*}{7.80} & \multirow[b]{2}{*}{11,000} \\
\hline & & & & & & & 10.56 & 17,500 & 11.32 & 19,400 & & \\
\hline & 2.65 & 1,5 & 8.68 & 12,900 & & & 10.60 & 17,500 & $1 \overline{1} .40$ & 19,700 & $6 . \overrightarrow{98}$ & 9,380 \\
\hline & & & & $\begin{array}{l}13,200 \\
13,400\end{array}$ & & & 10.64 & 17,500 & 11.47 & 20,000 & 6.30 & 8,020 \\
\hline \multirow{5}{*}{$\begin{array}{l}1 \\
2 \\
3 \\
4 \\
5 \\
6\end{array}$} & & & & & \multirow{5}{*}{$\begin{array}{l}10.37 \\
10.38 \\
10.39 \\
10.40 \\
10.41 \\
10.42\end{array}$} & \multirow{5}{*}{$\begin{array}{l}17,000 \\
17,000 \\
17,000 \\
17,000 \\
17,000 \\
17,000\end{array}$} & & & & & & \multirow{2}{*}{7,260} \\
\hline & & & & & & & 10.69 & 17,700 & 11.54 & 20,000 & 5.90 & \\
\hline & 2. & & $\begin{array}{l}9.30 \\
9.39\end{array}$ & & & & 10.74 & 17,700 & 11.60 & 20,300 & 5.44 & 6,320 \\
\hline & & & & & & & & & & & & \\
\hline & 2 & & & & & & 10.80 & 18 & $|11.60|$ & 20 & 5.14 & 5,780 \\
\hline \multirow{4}{*}{$\begin{array}{r}7 \\
8 \\
9 \\
10 \\
11 \\
12 \\
\end{array}$} & 2.7 & 1 & 9.64 & & \multirow{4}{*}{$\begin{array}{l}10.42 \\
10.42 \\
10.43 \\
10.43 \\
10.43 \\
10.44 \\
\end{array}$} & \multirow{4}{*}{$\begin{array}{l}17,000 \\
17,000 \\
17,000 \\
17,000 \\
17,000 \\
17,000\end{array}$} & & & & & & \multirow[b]{2}{*}{5,420} \\
\hline & & & 9 & & & & 10.86 & 18,300 & 11.57 & 20,300 & 4.9 & \\
\hline & 3.1 & 2,3 & 0 & & & & 10.93 & 18,300 & 11.42 & 20,000 & 4.77 & 5,240 \\
\hline & $\begin{array}{l}4.17 \\
5.06\end{array}$ & $\begin{array}{l}4,070 \\
5,780\end{array}$ & 9.9 & $\begin{array}{l}15,700 \\
16,000\end{array}$ & & & 11 & 18 & $\mid 11.10$ & 18,800 & 4.64 & $4, \overline{8}$ \\
\hline & & & & & & & & & & & & \\
\hline
\end{tabular}




\section{SOQUE RIVER NEAR DEMOREST, GA.}

Location.-Lat. $83^{\circ} 35^{\prime}$, long. $34^{\circ} 34^{\prime}$, at Cannon Bridge, $2 \frac{1}{2}$ miles west of Demorest, Habersham County, 3 miles downstream from Habersham Mill dam, and 3 miles upstream from mouth. Datum of gage is $1,152.16$ feet above mean sea level, datum of 1929, supplementary adjustment of 1936 .

DRAINAGE AREA.- 156 square miles.

GAGE-HEIGHT RECORD.-Water-stage recorder graph.

DISCHARGE RECORD.- Stage-discharge relation defined by current-meter measurements up to 11,900 second-feet. Gage heights used to half-tenths between 2.8 and 4.3 feet; hundredths below and tenths above these limits.

Maxima.-1940: Discharge, 11,900 second-feet $12 \mathrm{~m}$. Aug. 13 (gage height, 20.04 feet).

1904-9, 1929-31: Discharge, 9,500 second-feet Aug. 18, 1906 (gage height, 17.0 feet).

Discharge known, 14,400 second-feet July 21 or 22, 1938 (gage height, 22.8 feet from floodmark).

REMARKs.-Storage capacity of reservoir at Habersham Mills insufficient to eause regulation of flood runoff.

Mean discharge, in second-feet, 1940

\begin{tabular}{r|r|r|r|r|r||r|r|r||r|r|r}
\hline Day & Aug. & Sept. & Day & Aug. & Sept. & Day & Aug. & Sept. & Day & Aug. & Sept. \\
\hline 1 & 117 & 360 & 9 & 110 & 210 & 17 & 295 & 161 & 25 & 184 & 177 \\
2 & 116 & 332 & 10 & 81 & 190 & 18 & 266 & 162 & 26 & 198 & 165 \\
3 & 86 & 279 & 11 & 102 & 184 & 19 & 259 & 160 & 27 & 176 & 157 \\
4 & 104 & 245 & 12 & 684 & 173 & 20 & 225 & 159 & 28 & 169 & 129 \\
5 & 127 & 235 & 13 & 9,190 & 172 & 21 & 214 & 161 & 29 & 1,000 & 149 \\
6 & 109 & 216 & 14 & 2,280 & 156 & 22 & 222 & 133 & 30 & 2,150 & 165 \\
7 & 152 & 186 & 15 & 535 & 167 & 23 & 210 & 166 & 31 & 567 & \\
8 & 117 & 202 & 16 & 372 & 177 & 24 & 175 & 149 & & & \\
\hline
\end{tabular}

Gage height, in feet, and discharge, in second-feet, at indicated time, 1940

\begin{tabular}{|c|c|c|c|c|c|c|c|c|}
\hline \multirow{2}{*}{ Hour } & \multicolumn{2}{|c|}{ Aug. 12} & \multicolumn{2}{|c|}{ Aug. 13} & \multicolumn{2}{|c|}{ Aug. 14} & \multicolumn{2}{|c|}{ Aug. 15} \\
\hline & $\begin{array}{l}\text { Gage } \\
\text { height }\end{array}$ & $\begin{array}{c}\text { Dis- } \\
\text { charge }\end{array}$ & $\begin{array}{l}\text { Gage } \\
\text { height }\end{array}$ & $\begin{array}{c}\text { Dis- } \\
\text { charge }\end{array}$ & $\begin{array}{l}\text { Gage } \\
\text { height }\end{array}$ & $\begin{array}{c}\text { Dis- } \\
\text { charge }\end{array}$ & $\begin{array}{l}\text { Gage } \\
\text { height }\end{array}$ & $\begin{array}{c}\text { Dis- } \\
\text { charge }\end{array}$ \\
\hline $\begin{array}{l}1 \\
2 \\
3 \\
4 \\
5 \\
5 \\
6\end{array}$ & $\begin{array}{l}1.43 \\
1.43 \\
1.43 \\
1.43 \\
1.44 \\
1.44\end{array}$ & $\begin{array}{l}106 \\
106 \\
106 \\
106 \\
108 \\
108\end{array}$ & $\begin{array}{l}7.50 \\
10.65 \\
14.20 \\
15.75 \\
16.95 \\
18.15\end{array}$ & $\begin{array}{r}2,850 \\
4,790 \\
7,350 \\
8,550 \\
\mathbf{9}, 500 \\
10,500\end{array}$ & $\begin{array}{r}12.32 \\
11.62 \\
10.84 \\
10.15 \\
9.50 \\
8.80\end{array}$ & $\begin{array}{l}5,960 \\
5,470 \\
4,920 \\
4,530 \\
4,080 \\
\mathbf{3}, 630\end{array}$ & $\begin{array}{c}-1.04 \\
-3.04\end{array}$ & 6 \\
\hline $\begin{array}{r}7 \\
8 \\
9 \\
10 \\
11 \\
\text { N }\end{array}$ & $\begin{array}{l}1.45 \\
1.80 \\
1.92 \\
1.97 \\
3.15 \\
3.41\end{array}$ & $\begin{array}{l}110 \\
189 \\
220 \\
234 \\
648 \\
752\end{array}$ & $\begin{array}{l}18.75 \\
18.71 \\
18.78 \\
19.25 \\
19.78 \\
20.04\end{array}$ & $\begin{array}{l}10,900 \\
10,900 \\
10,900 \\
11,300 \\
11,700 \\
11,900\end{array}$ & $\begin{array}{l}8.02 \\
7.47 \\
6.95 \\
5.22 \\
4.78 \\
4.53\end{array}$ & $\begin{array}{l}3,150 \\
2,850 \\
2,560 \\
1,590 \\
1,400 \\
1,250\end{array}$ & 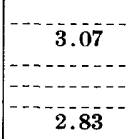 & 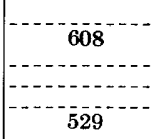 \\
\hline $\begin{array}{l}1 \\
2 \\
3 \\
4 \\
\mathbf{4} \\
\mathbf{6} \\
\mathbf{6}\end{array}$ & $\begin{array}{l}3.54 \\
3.88 \\
4.00 \\
3.98 \\
4.01 \\
\mathbf{3 . 9 8}\end{array}$ & $\begin{array}{r}816 \\
974 \\
1,020 \\
1,020 \\
1,020 \\
1,020\end{array}$ & $\begin{array}{l}19.82 \\
19.50 \\
19.05 \\
18.44 \\
17.86 \\
17.20\end{array}$ & $\begin{array}{r}11,700 \\
11,500 \\
11,100 \\
10,600 \\
10,200 \\
9,660\end{array}$ & $\begin{array}{l}4.29 \\
4.14 \\
4.02 \\
3.82 \\
3.80 \\
3.63\end{array}$ & $\begin{array}{r}1,160 \\
1,090 \\
1,020 \\
928 \\
928 \\
860\end{array}$ & $\begin{array}{c}-\cdots \\
2.74 \\
\cdots \\
\cdots\end{array}$ & 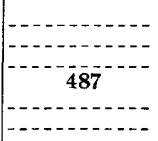 \\
\hline $\begin{array}{r}7 \\
8 \\
9 \\
10 \\
11 \\
12\end{array}$ & $\begin{array}{l}4.40 \\
4.69 \\
4.76 \\
4.90 \\
5.04 \\
5.26 \\
\end{array}$ & $\begin{array}{l}1,200 \\
1,350 \\
1,400 \\
1,440 \\
1,490 \\
1,650\end{array}$ & $\begin{array}{l}16.55 \\
15.93 \\
15.20 \\
14.46 \\
13.75 \\
13.00\end{array}$ & $\begin{array}{l}9,180 \\
8,620 \\
8,100 \\
7,580 \\
7,050 \\
6,450\end{array}$ & $\begin{array}{l}\mathbf{3 . 5 3} \\
\mathbf{3 . 5 3} \\
\mathbf{3 . 4 3} \\
\mathbf{3 . 3 1} \\
\mathbf{3 . 2 0} \\
\mathbf{3 . 1 4} \\
\end{array}$ & $\begin{array}{l}816 \\
816 \\
773 \\
710 \\
668 \\
648 \\
\end{array}$ & 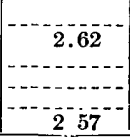 & 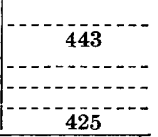 \\
\hline
\end{tabular}


APALACHICOLA RIVER BASIN

Gage height, in feet, and discharge, in second-feet, at indicated time, 1940-Con.

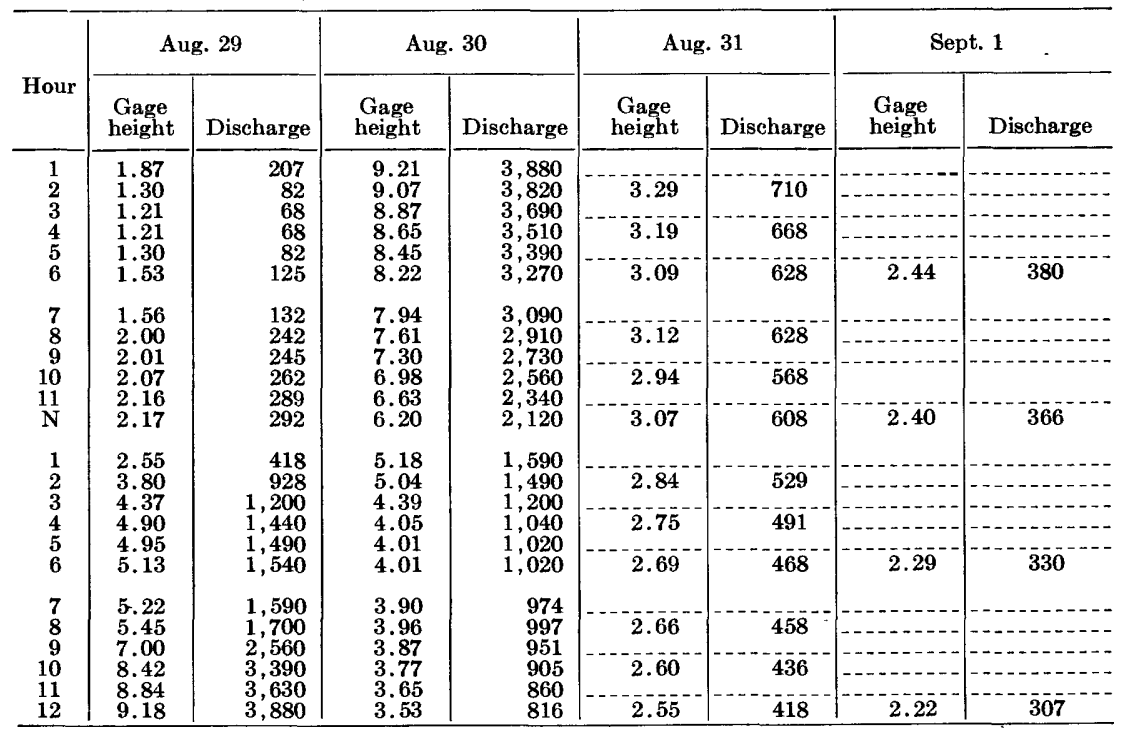

\section{SWEETWATER CREEK NEAR AUSTELI, GA.}

Location.-Lat. $33^{\circ} 46^{\prime}$, long. $84^{\circ} 37^{\prime}$, at Blair Bridge, 3 miles southeast of Austell, Cobb County, and about 51/2 miles upstream from mouth. Datum of gage is 857.01 feet above mean sea level, datum of 1929, supplementary adjustment of 1936.

Drainage ARea.-246 square miles.

GAGE-HEIGHT RECORD.-Water-stage recorder graph.

DISCHARGE RECORD.- Stage-discharge relation defined by current-meter measurements up to 6,500 second-feet. Gage heights used to half-tenths between 2.1 and 3.5 feet; hundredths below and tenths above these limits.

Maxima.-August 1940: Discharge, 2,280 second-feet 12 p.m. Aug. 13 (gage-height, 7.76 feet).

1904-05, 1913, 1937 to July 1940: Discharge, 6,640 second-feet Apr. 9, 1938 (gage-height, 16.18 feet).

Flood of July 8,1916 , reached stage of 20.0 feet from information by local residents.

REMARKs.-Flood runoff not affected by storage or diversion.

Mean discharge, in second-feet, 1940

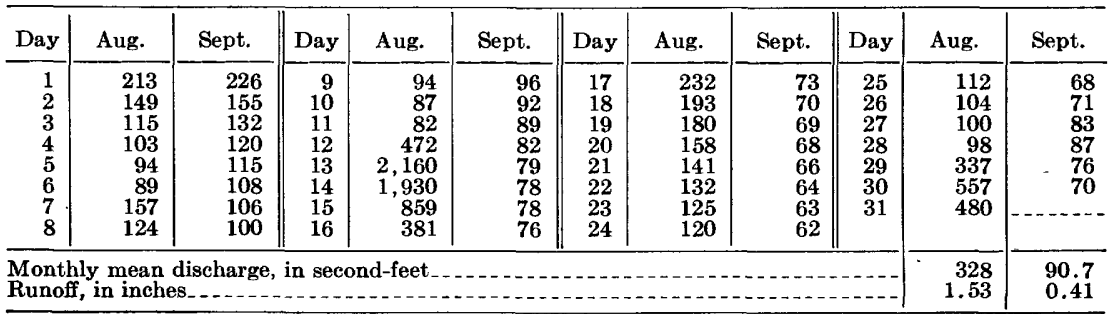


Gage height, in feet, and discharge, in second-feet, at indicated time, 1940

\begin{tabular}{|c|c|c|c|c|c|c|c|c|c|c|}
\hline \multirow{2}{*}{ Hour } & \multicolumn{2}{|c|}{ Aug. 12} & \multicolumn{2}{|c|}{ Aug. 13} & \multicolumn{2}{|c|}{ Aug. 14} & \multicolumn{2}{|c|}{ Aug. 15} & \multicolumn{2}{|c|}{ Aug. 16} \\
\hline & $\begin{array}{c}\text { Gage } \\
\text { height }\end{array}$ & $\begin{array}{c}\text { Dis- } \\
\text { charge }\end{array}$ & $\begin{array}{c}\text { Gage } \\
\text { height }\end{array}$ & $\begin{array}{c}\text { Dis- } \\
\text { charge }\end{array}$ & $\begin{array}{c}\text { Gage } \\
\text { height }\end{array}$ & $\begin{array}{c}\text { Dis- } \\
\text { charge }\end{array}$ & $\begin{array}{c}\text { Gage } \\
\text { height }\end{array}$ & $\begin{array}{c}\text { Dis- } \\
\text { charge }\end{array}$ & $\begin{array}{c}\text { Gage } \\
\text { height }\end{array}$ & $\begin{array}{c}\text { Dis- } \\
\text { charge }\end{array}$ \\
\hline $\begin{array}{l}1 \\
2 \\
3 \\
4 \\
5 \\
6\end{array}$ & $\begin{array}{r}0.76 \\
.76 \\
.75 \\
.75 \\
.75 \\
.74\end{array}$ & $\begin{array}{l}79 \\
79 \\
78 \\
78 \\
78 \\
77\end{array}$ & $\begin{array}{l}7.40 \\
7.43 \\
7.44 \\
7.43 \\
7.42 \\
7.43\end{array}$ & $\begin{array}{l}2,130 \\
2,130 \\
2,130 \\
2,130 \\
2,130 \\
2,130\end{array}$ & $\begin{array}{l}7.74 \\
7.72 \\
7.68 \\
7.65 \\
7.61 \\
7.57\end{array}$ & $\begin{array}{l}2,240 \\
2,240 \\
2,240 \\
2,200 \\
2,200 \\
2,200\end{array}$ & $\begin{array}{l}5.00 \\
4.85 \\
4.64 \\
4.49 \\
4.34 \\
4.18\end{array}$ & $\begin{array}{l}1,300 \\
1,230 \\
1,160 \\
1,130 \\
1,070 \\
1,030\end{array}$ & $\begin{array}{l}2.64 \\
2.59 \\
2.54 \\
2.49 \\
2.44 \\
2.37\end{array}$ & $\begin{array}{l}542 \\
526 \\
510 \\
495 \\
480 \\
450\end{array}$ \\
\hline $\begin{array}{r}7 \\
8 \\
9 \\
10 \\
11 \\
\text { N }\end{array}$ & $\begin{array}{l}.74 \\
.75 \\
.75 \\
.76 \\
.78 \\
.80\end{array}$ & $\begin{array}{l}77 \\
78 \\
78 \\
79 \\
82 \\
84\end{array}$ & $\begin{array}{l}7.43 \\
7.43 \\
7.42 \\
7.44 \\
7.45 \\
7.45\end{array}$ & $\begin{array}{l}2,130 \\
2,130 \\
2,130 \\
2,130 \\
2,130 \\
2,130\end{array}$ & $\begin{array}{l}7.53 \\
7.47 \\
7.41 \\
7.32 \\
7.23 \\
7.12\end{array}$ & $\begin{array}{l}2,160 \\
2,160 \\
2,130 \\
2,090 \\
2,060 \\
2,020\end{array}$ & $\begin{array}{l}4.03 \\
3.92 \\
3.81 \\
3.70 \\
3.59 \\
3.51\end{array}$ & $\begin{array}{l}970 \\
938 \\
906 \\
874 \\
842 \\
810\end{array}$ & $\begin{array}{l}2.32 \\
2.26 \\
2.20 \\
2.15 \\
2.09 \\
2.04\end{array}$ & $\begin{array}{l}435 \\
420 \\
406 \\
392 \\
374 \\
360\end{array}$ \\
\hline $\begin{array}{l}1 \\
2 \\
3 \\
4 \\
5 \\
6\end{array}$ & $\begin{array}{r}.84 \\
.89 \\
.97 \\
1.16 \\
1.85 \\
2.90\end{array}$ & $\begin{array}{r}89 \\
96 \\
108 \\
139 \\
307 \\
619\end{array}$ & $\begin{array}{l}7.48 \\
7.52 \\
7.54 \\
7.58 \\
7.61 \\
7.63\end{array}$ & $\begin{array}{l}2,160 \\
2,160 \\
2,160 \\
2,200 \\
2,200 \\
2,200\end{array}$ & $\begin{array}{l}7.00 \\
6.88 \\
6.74 \\
6.58 \\
6.42 \\
6.25\end{array}$ & $\begin{array}{l}1,980 \\
1,950 \\
1,880 \\
1,840 \\
1,770 \\
1,700\end{array}$ & $\begin{array}{l}3.43 \\
3.35 \\
3.28 \\
3.21 \\
3.12 \\
3.06\end{array}$ & $\begin{array}{l}794 \\
762 \\
746 \\
714 \\
682 \\
666\end{array}$ & $\begin{array}{l}2.00 \\
1.96 \\
1.92 \\
1.89 \\
1.86 \\
1.83\end{array}$ & $\begin{array}{l}349 \\
338 \\
327 \\
318 \\
310 \\
301\end{array}$ \\
\hline $\begin{array}{r}7 \\
8 \\
9 \\
10 \\
11 \\
12 \\
\end{array}$ & $\begin{array}{l}4.13 \\
5.20 \\
6.22 \\
6.70 \\
7.12 \\
7.33\end{array}$ & $\begin{array}{l}1,000 \\
1,360 \\
1,700 \\
1,880 \\
2,020 \\
2,090\end{array}$ & $\begin{array}{l}7.65 \\
7.68 \\
7.71 \\
7.74 \\
7.74 \\
7.76\end{array}$ & $\begin{array}{l}2,200 \\
2,240 \\
2,240 \\
2,240 \\
2,240 \\
2,280\end{array}$ & $\begin{array}{l}6.08 \\
5.89 \\
5.72 \\
5.53 \\
5.34 \\
5.17 \\
\end{array}$ & $\begin{array}{l}1,660 \\
1,600 \\
1,530 \\
1,460 \\
1,390 \\
1,360 \\
\end{array}$ & $\begin{array}{l}2.99 \\
2.92 \\
2.86 \\
2.80 \\
2.75 \\
2.69\end{array}$ & $\begin{array}{l}650 \\
619 \\
604 \\
588 \\
572 \\
557 \\
\end{array}$ & $\begin{array}{l}1.81 \\
1.78 \\
1.75 \\
1.73 \\
1.71 \\
1.69 \\
\end{array}$ & $\begin{array}{l}296 \\
288 \\
280 \\
274 \\
269 \\
263 \\
\end{array}$ \\
\hline
\end{tabular}

\section{KANAWHA RIVER BASIN}

SOUTH FORK NEW RIVER NEAR JEFFERSON, N. C.

LOCATION.-Lat. $36^{\circ} 23^{\prime} 35^{\prime \prime}$, long. $81^{\circ} 24^{\prime} 35^{\prime \prime}, 400$ feet upstream from highway bridge, a quarter of a mile downstream from Bear Creek, and 4 miles southeast of Jefferson, Ashe County.

DRAINAGE AREA.-207 square miles.

GAGE-HeIGHT RECORD.-Water-stage recorder graph Aug. 1 to 3 a.m. Aug. 14. Recorder house was tipped over by the flood on Aug. 14. Staff gage read twice daily Aug. 21-29 and Sept. 4-30. Graph based on gage readings used Aug. 21, 28, 29. No gage-height record from 3 a.m. Aug. 14 to Aug. 20 and Aug. 30 to Sept. 3 ; gage heights for the period 3 a.m. Aug. 14 to Aug. 16 were computed from estimated discharge.

DischARGE RECORD.- Stage-discharge relation defined by current-meter measurements up to 1,900 second-feet and extended to slope-area measurement for crest gage height. The 1940 rating verifies the 1935 extension reasonably well. Gage heights used to half-tenths between 3.3 and 5.4 feet prior to Aug. 14; hundredths below and tenths above these limits. Subsequent to Aug. 14 gage heights used to halftenths below 3.3 feet and tenths above. Discharge for periods of no gage-height record is based on records for nearby streams.

Maxima.-1940: Discharge, 52,800 second-feet 3 a.m. Aug. 14 (gage height, 22.50 feet).

1924-26, 1928-39: Discharge, 6,930 second-feet Jan. 9, 1935 (gage height, 8.50 feet, from graph based on gage readings).

1892-1924: Stage known, 18.0 feet July 15, 1916, from flood reference marks as witnessed by local residents (discharge, 35,200 second-feet).

REMARKs.-Flood runoff not affected by artificial storage. 
KANAWHA RIVER BASIN

301

Mean discharge, in second-feet, 1940

\begin{tabular}{|c|c|c|c|c|c|c|c|c|c|c|c|}
\hline Day & Aug. & Sept. & Day & Aug. & Sept. & Day & Aug. & Sept. & Day & Aug. & Sept. \\
\hline $\begin{array}{l}1 \\
2 \\
3 \\
4 \\
5 \\
6 \\
7 \\
8\end{array}$ & $\begin{array}{l}632 \\
430 \\
336 \\
304 \\
340 \\
367 \\
627 \\
435\end{array}$ & $\begin{array}{r}3,200 \\
2,000 \\
1,400 \\
1,160 \\
1,040 \\
920 \\
840 \\
780\end{array}$ & $\begin{array}{r}9 \\
10 \\
11 \\
12 \\
13 \\
14 \\
15 \\
16\end{array}$ & $\begin{array}{r}326 \\
287 \\
413 \\
1,330 \\
8,920 \\
27,700 \\
5,610 \\
3,060\end{array}$ & $\begin{array}{l}\mathbf{7 3 0} \\
\mathbf{7 3 0} \\
695 \\
630 \\
600 \\
\mathbf{5 7 0} \\
\mathbf{5 7 0} \\
\mathbf{5 4 2}\end{array}$ & $\begin{array}{l}17 \\
18 \\
19 \\
20 \\
21 \\
22 \\
23 \\
24\end{array}$ & $\begin{array}{r}2,200 \\
1,800 \\
1,400 \\
1,200 \\
1,060 \\
920 \\
802 \\
730\end{array}$ & $\begin{array}{l}513 \\
513 \\
513 \\
486 \\
459 \\
433 \\
433 \\
433\end{array}$ & $\begin{array}{l}25 \\
26 \\
27 \\
28 \\
29 \\
30 \\
31\end{array}$ & $\begin{array}{r}695 \\
695 \\
630 \\
630 \\
630 \\
8,500 \\
8,000\end{array}$ & $\begin{array}{l}459 \\
433 \\
407 \\
407 \\
384 \\
360\end{array}$ \\
\hline on & & & & & & & & & & $\begin{array}{l}2,613 \\
14.55 \\
\end{array}$ & $\begin{array}{r}755 \\
4.07 \\
\end{array}$ \\
\hline
\end{tabular}

Gage height, in feet, and discharge, in second-feet, at indicated time, 1940

\begin{tabular}{|c|c|c|c|c|c|c|c|c|c|c|c|c|}
\hline \multirow{2}{*}{ our } & \multicolumn{2}{|c|}{ Aug. 11} & \multicolumn{2}{|c|}{ Aug. 12} & \multicolumn{2}{|c|}{ Aug. 13} & \multicolumn{2}{|c|}{ Aug. 14} & \multicolumn{2}{|c|}{ Aug. 15} & \multicolumn{2}{|c|}{ Aug. 16} \\
\hline & $\begin{array}{c}\text { Gage } \\
\text { ht. }\end{array}$ & $\begin{array}{l}\text { Dis- } \\
\text { charge }\end{array}$ & $\begin{array}{l}\text { Gage } \\
\text { ht. }\end{array}$ & $\begin{array}{c}\text { Dis- } \\
\text { charge }\end{array}$ & $\begin{array}{c}\text { Gage } \\
\text { ht. }\end{array}$ & $\begin{array}{c}\text { Dis- } \\
\text { charge }\end{array}$ & $\begin{array}{c}\text { Gage } \\
\text { ht. }\end{array}$ & $\begin{array}{c}\text { Dis- } \\
\text { charge }\end{array}$ & $\begin{array}{c}\text { Gage } \\
\text { ht. }\end{array}$ & $\underset{\text { ch }}{\mathrm{D}}$ & $\begin{array}{c}\text { Gage } \\
\text { ht. }\end{array}$ & $\begin{array}{c}\text { Dis- } \\
\text { charge }\end{array}$ \\
\hline \multirow{3}{*}{$\begin{array}{l}1 \\
2 \\
3 \\
4 \\
5 \\
6\end{array}$} & 2,07 & 283 & \multirow{3}{*}{$\begin{array}{l}3.30 \\
3.32 \\
3.23 \\
3.03 \\
2.85 \\
2.67\end{array}$} & \multirow{3}{*}{$\begin{array}{r}1,000 \\
1,000 \\
948 \\
798 \\
676 \\
572\end{array}$} & \multirow{3}{*}{$\begin{array}{l}5.40 \\
5.35 \\
5.30 \\
5.28 \\
5.34 \\
5.35\end{array}$} & \multirow{3}{*}{$\begin{array}{l}3,030 \\
2,970 \\
2,910 \\
2,910 \\
2,970 \\
2,970\end{array}$} & 22.00 & 50,8 & & & & \\
\hline & 2.07 & 283 & & & & & 22.30 & 52,000 & & & & \\
\hline & 2.05 & 275 & & & & & 20.8 & 46,000 & 7.8 & 6,600 & 5.6 & 3,300 \\
\hline \multirow{4}{*}{$\begin{array}{r}7 \\
8 \\
9 \\
10 \\
11 \\
\mathbf{N}\end{array}$} & & & \multirow{4}{*}{$\begin{array}{l}2.49 \\
2.35 \\
2.40 \\
2.50 \\
2.67 \\
2.95\end{array}$} & \multirow{4}{*}{$\begin{array}{l}480 \\
410 \\
435 \\
485 \\
572 \\
\mathbf{7 4 1}\end{array}$} & \multirow{4}{*}{$\begin{array}{l}5.10 \\
5.90 \\
5.87 \\
5.80 \\
5.72 \\
5.78\end{array}$} & \multirow{4}{*}{$\begin{array}{l}2,690 \\
3,650 \\
3,650 \\
3,520 \\
3,390 \\
\mathbf{3}, 520\end{array}$} & & & & & & \\
\hline & 2.03 & 267 & & & & & 18.5 & 37,000 & & & & \\
\hline & $\overline{2} .08$ & $28 \overline{7}^{-}$ & & & & & 16.2 & 29,000 & & & & \\
\hline & 2.14 & 313 & & & & & 14,4 & 23,000 & 7.0 & & 5.4 & \\
\hline \multirow{5}{*}{$\begin{array}{l}1 \\
2 \\
3 \\
4 \\
5 \\
6\end{array}$} & & & \multirow{5}{*}{$\begin{array}{l}3.16 \\
3.48 \\
3.75 \\
4.05 \\
4.30 \\
4.50\end{array}$} & \multirow{5}{*}{$\begin{array}{r}895 \\
1,160 \\
1,370 \\
1,640 \\
1,870 \\
2,070\end{array}$} & \multirow{5}{*}{$\begin{array}{l}5.95 \\
6.20 \\
6.85 \\
7.40 \\
8.50 \\
9.40\end{array}$} & \multirow{5}{*}{$\begin{array}{l}3,780 \\
4,060 \\
4,950 \\
5,900 \\
7,870 \\
9,700\end{array}$} & & & & & & \\
\hline & 2.27 & $372^{-}$ & & & & & $\overline{13} . \overline{1}$ & 19,000 & & & & \\
\hline & $\overline{2} . \overline{39}$ & 430 & & & & & 12.0 & 16,000 & & & & \\
\hline & & & & & & & 11 & 1 & & & & \\
\hline & 2.52 & 495 & & & & & 11.2 & 14 & 6.4 & 0 & 5.2 & 2,800 \\
\hline \multirow{4}{*}{$\begin{array}{r}7 \\
8 \\
9 \\
10 \\
11 \\
12\end{array}$} & $\overline{2}, \overline{2}$ & 599 & \multirow{4}{*}{$\begin{array}{l}4.62 \\
4.75 \\
4.98 \\
5,20 \\
5.34 \\
5.42\end{array}$} & \multirow{4}{*}{$\begin{array}{l}2,170 \\
2,320 \\
2,580 \\
2,800 \\
2,970 \\
3,030\end{array}$} & \multirow{4}{*}{$\left|\begin{array}{l}10.50 \\
11.60 \\
13.10 \\
14.30 \\
16.80 \\
18.80\end{array}\right|$} & \multirow{4}{*}{$\begin{array}{l}12,200 \\
15,000 \\
19,100 \\
22,700 \\
30,900 \\
38,200\end{array}$} & & & & & & \\
\hline & & & & & & & 10.4 & & & & & \\
\hline & 2.95 & 741 & & & & & 9.5 & 10,000 & & & & \\
\hline & 3.20 & 925 & & & & & 9.1 & 9,000 & 5.9 & 3,700 & 5.0 & 2,600 \\
\hline
\end{tabular}

SUPPLEMENTAL RECORD.-Aug. 14, 3 a.m., gage height, 22.50 feet; discharge, 52,800 second-feet.

\section{NEW RIVER NEAR GALAX, VA.}

LOCATION.-Lat. $36^{\circ} 38^{\prime} 50^{\prime \prime}$, long. $80^{\circ} 58^{\prime} 45^{\prime \prime}$, at highway bridge 500 feet downstream from Meadow Creek, 11/8 miles southwest of Old Town, and 3 miles southwest of Galax, Carroll County. Datum of gage is 2,208.04 feet above mean sea level, datum of 1929, supplementary adjustment of 1936 .

Drainage ARea.-1,131 square miles.

GAGE-HEIGHT RECORD.-Water-stage recorder graph, except for period 5 a.m. Aug. 14 to 8 a.m. Ang. 15, where record was based on floodmark and comparison with flood records for station at Ivanhoe.

DISCHARGE RECORD.-Stage-discharge relation defined by current-meter measurements up to 30,000 seeond-feet and extended to erest gage height by logarithmic plotting on basis of computation of flood flow over dam at Fries and verified by slope-area determination. Gage heights used to half-tenths between 2.5 and 4.0 feet; hundredths below and tenths above these limits.

Maxima.-1940: Discharge, 141,000 second-feet 9:30 a.m. Aug. 14 (gage height, 25.7 feet, from floodmark).

1929-39: Discharge, 24,900 second-feet Sept. 6, 1935 (gage height, 7.38 feet).

Flood of Oet. 2, 1929, reached a stage of about 9 feet from floodmark (discharge, 33,100 second-feet). 
FLOODS OF AUGUST 1940 IN THE SOUTHEASTERN STATES

Mean discharge, in second-feet, 1940

\begin{tabular}{|c|c|c|c|c|c|c|c|c|c|c|c|}
\hline Day & Aug. & Sept. & Day & Aug. & Sept. & Day & Aug. & Sept. & Day & Aug. & Sept. \\
\hline $\begin{array}{l}1 \\
2 \\
3 \\
4 \\
5 \\
6 \\
7 \\
8\end{array}$ & $\begin{array}{l}4,010 \\
2,330 \\
1,660 \\
1,450 \\
1,360 \\
1,800 \\
3,130 \\
2,280\end{array}$ & $\begin{array}{l}8,350 \\
5,280 \\
4,000 \\
3,360 \\
3,020 \\
2,830 \\
2,620 \\
2,470\end{array}$ & $\begin{array}{r}9 \\
10 \\
11 \\
12 \\
13 \\
14 \\
15 \\
16\end{array}$ & $\begin{array}{r}1,640 \\
1,360 \\
1,280 \\
1,640 \\
7,910 \\
86,200 \\
31,800 \\
15,200\end{array}$ & $\begin{array}{l}2,300 \\
2,230 \\
2,330 \\
2,160 \\
2,030 \\
1,950 \\
1,880 \\
1,840\end{array}$ & $\begin{array}{l}17 \\
18 \\
19 \\
20 \\
21 \\
22 \\
23 \\
24\end{array}$ & $\begin{array}{l}9,890 \\
7,330 \\
6,020 \\
4,790 \\
3,830 \\
3,370 \\
3,090 \\
2,750\end{array}$ & $\begin{array}{l}1,780 \\
1,740 \\
1,720 \\
1,660 \\
1,600 \\
1,560 \\
1,490 \\
1,490\end{array}$ & $\begin{array}{l}25 \\
26 \\
27 \\
28 \\
29 \\
30 \\
31\end{array}$ & $\begin{array}{r}2,520 \\
2,350 \\
2,230 \\
2,140 \\
2,120 \\
16,100 \\
19,000\end{array}$ & $\begin{array}{l}1,540 \\
1,620 \\
1,560 \\
1,470 \\
1,430 \\
1,410\end{array}$ \\
\hline \multicolumn{10}{|c|}{ Monthly mean discharge, in second-feet } & $\begin{array}{r}8,148 \\
8.30\end{array}$ & $\begin{array}{r}2,357 \\
2.32\end{array}$ \\
\hline
\end{tabular}

Gage height, in feet, and discharge, in second-feet, at indicated time, 1940

\begin{tabular}{|c|c|c|c|c|c|c|c|c|c|c|c|c|}
\hline \multirow{2}{*}{ Hour } & \multicolumn{2}{|c|}{ Aug. 12} & \multicolumn{2}{|c|}{ Aug. 13} & \multicolumn{2}{|c|}{ Aug. 14} & \multicolumn{2}{|c|}{ Aug. 15} & \multicolumn{2}{|c|}{ Aug. 16} & \multicolumn{2}{|c|}{ Aug. 17} \\
\hline & $\begin{array}{c}\text { Gage } \\
\text { ht. }\end{array}$ & $\begin{array}{c}\text { Dis- } \\
\text { charge }\end{array}$ & $\begin{array}{c}\text { Gage } \\
\text { ht. }\end{array}$ & $\begin{array}{c}\text { Dis- } \\
\text { charge }\end{array}$ & $\begin{array}{c}\text { Gage } \\
\text { ht. }\end{array}$ & $\begin{array}{c}\text { Dis- } \\
\text { charge }\end{array}$ & $\begin{array}{c}\text { Gage } \\
\text { ht. }\end{array}$ & $\begin{array}{l}\text { Dis- } \\
\text { charge }\end{array}$ & $\begin{array}{c}\text { Gage } \\
\text { ht. }\end{array}$ & $\underset{\text { ch }}{\mathrm{D}}$ & $\begin{array}{c}\text { Gage } \\
\text { ht. }\end{array}$ & $\begin{array}{c}\text { Dis- } \\
\text { charge }\end{array}$ \\
\hline \multirow{4}{*}{$\begin{array}{l}1 \\
2 \\
3 \\
4 \\
5 \\
6\end{array}$} & 1.39 & 1,390 & \multirow{4}{*}{$\begin{array}{l}1.90 \\
1.96 \\
2.02 \\
2.09 \\
2.17 \\
2.24\end{array}$} & \multirow{4}{*}{$\begin{array}{l}2,470 \\
2,620 \\
2,770 \\
2,960 \\
3,190 \\
3,390\end{array}$} & \multirow{4}{*}{$\begin{array}{r}8.05 \\
9.00 \\
10.30 \\
12.50 \\
14.90 \\
17.80\end{array}$} & \multirow{4}{*}{$\begin{array}{l}27,900 \\
33,100 \\
40,200 \\
52,800 \\
67,100 \\
85,900\end{array}$} & \multirow{4}{*}{$\begin{array}{l}12.56 \\
12.00 \\
11.50 \\
11.06 \\
10.65 \\
10.22\end{array}$} & \multirow{4}{*}{$\begin{array}{l}53,400 \\
49,900 \\
47,000 \\
44,700 \\
41,900 \\
39,600\end{array}$} & 6.02 & 18,200 & 4.51 & 1,500 \\
\hline & 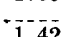 & & & & & & & & & & & \\
\hline & & & & & & & & & & & & 0 \\
\hline & 1.44 & 1,490 & & & & & & & 5.70 & 16,800 & 4.33 & 10,600 \\
\hline \multirow{4}{*}{$\begin{array}{r}7 \\
8 \\
9 \\
10 \\
11 \\
\mathrm{~N}\end{array}$} & & & \multirow{4}{*}{\begin{tabular}{|l|}
2.32 \\
2.55 \\
2.93 \\
3.22 \\
3.41 \\
3.52
\end{tabular}} & \multirow{4}{*}{$\begin{array}{l}3,630 \\
4,360 \\
5,720 \\
6,600 \\
7,310 \\
7,670\end{array}$} & \multirow{4}{*}{\multicolumn{2}{|c|}{\begin{tabular}{|l|l}
21.10 & 108,000 \\
24.50 & 132,000 \\
25.62 & 140,000 \\
25.56 & 140,000 \\
24.64 & 133,000 \\
23.65 & 126,000
\end{tabular}}} & \multirow{4}{*}{$\begin{array}{l}9.82 \\
9.46 \\
9.08 \\
8.75 \\
8.46 \\
8.16\end{array}$} & \multirow{4}{*}{$\begin{array}{l}37,400 \\
35,800 \\
33,600 \\
32,100 \\
30,500 \\
28,900\end{array}$} & & & & \\
\hline & 1.45 & 1,500 & & & & & & & 5.58 & & 4.25 &, 300 \\
\hline & $1.4 \overline{5}$ & 1,500 & & & & & & & 5.46 & 15,900 & 4.17 & 10,300 \\
\hline & $\overline{1} \overline{4} \overline{6}$ & $1, \overline{5} 20$ & & & & & & & $\overline{5}, \overline{3} \overline{5}$ & 15,400 & 4.09 & $\overline{9}, \overline{880}$ \\
\hline \multirow{4}{*}{$\begin{array}{l}1 \\
2 \\
3 \\
4 \\
5 \\
6\end{array}$} & & & \multirow{4}{*}{$\begin{array}{l}3.60 \\
3.66 \\
3.73 \\
3.80 \\
3.88 \\
4.01\end{array}$} & \multirow{4}{*}{$\begin{array}{l}8,030 \\
8,210 \\
\mathbf{8}, 580 \\
8,760 \\
\mathbf{9}, 130 \\
\mathbf{9}, 500\end{array}$} & \multirow{4}{*}{$\begin{array}{l}22.58 \\
21.43 \\
20.32 \\
19.28 \\
18.35 \\
17.40\end{array}$} & 119,000 & 7.88 & & & & & \\
\hline & 1.52 & 1,640 & & & & 00 & 7.66 & & 5.23 & 14,500 & 4.02 &, 500 \\
\hline & $\overline{1} . \overline{5}$ & 1,700 & & & & $\begin{array}{r}102,000 \\
95,600\end{array}$ & $\begin{array}{l}7.40 \\
7.23\end{array}$ & $\begin{array}{l}24 \\
23\end{array}$ & $\overline{5} . \overline{0}$ & 14,100 & $3 . \overline{94}$ & 9,320 \\
\hline & 1.54 & 1,680 & & & & $\begin{array}{l}89,800 \\
83,300\end{array}$ & $\begin{array}{l}7.08 \\
6.92\end{array}$ & $\begin{array}{l}23,400 \\
22,500\end{array}$ & 4.93 & 13,200 & 3.87 & 8,940 \\
\hline 7 & & & 4.27 & 0 & 16.60 & 7 & 6.69 & & & & & \\
\hline 8 & 1.64 & 1,880 & 4.65 & & 15.82 & & 6.56 & & 4.82 & & 3.81 & 760 \\
\hline 10 & $\overline{1} . \overline{4}$ & 2,100 & $\begin{array}{l}0.13 \\
5.64\end{array}$ & $\begin{array}{l}14, \\
16\end{array}$ & $\left|\begin{array}{l}13.05 \\
14.35\end{array}\right|$ & $\begin{array}{l}68 \\
64\end{array}$ & $\begin{array}{l}0.47 \\
6.37\end{array}$ & & $4 . \overline{1}$ & 12,300 & 3.74 & $\overline{8}, \overline{580}$ \\
\hline 1 & $1 . \overline{8}$ & $2, \overline{3} 0$ & $\begin{array}{l}6.15 \\
7.08\end{array}$ & & $\left|\begin{array}{l}13.73 \\
13.10\end{array}\right|$ & & $\begin{array}{l}6.25 \\
6.14\end{array}$ & & 4.61 & 11,900 & $3.6 \overline{7}$ & 8,210 \\
\hline & & & & 10 & & ept. 1 & & & & & & \\
\hline $\begin{array}{l}1 \\
2\end{array}$ & 1.77 & & 7.18 & & & & & & & & & \\
\hline $\begin{array}{l}2 \\
3\end{array}$ & $\begin{array}{l}1.77 \\
1.78\end{array}$ & $\begin{array}{l}2,160 \\
2,190\end{array}$ & $\begin{array}{l}7.01 \\
6.86\end{array}$ & 23 , & & & & & & & & \\
\hline 4 & 1.78 & ? 100 & 6.71 & 21,500 & $4.1 \overline{6}$ & 10,300 & & & & & & \\
\hline 6 & 1.79 & $\begin{array}{l}2,190 \\
2,210\end{array}$ & $\begin{array}{l}6.57 \\
6.48\end{array}$ & $\begin{array}{l}21,000 \\
20,600\end{array}$ & 3.98 & 9,500 & & & & & & \\
\hline 7 & 80 & 2 & & & & & & & & & & \\
\hline : & & & & & 3.86 & 8,940 & & & & & & \\
\hline 10 & & & & & $3.7 \overline{3}$ & 8,580 & & & & & & \\
\hline 1 & & & & & & -7 & & & & & & \\
\hline$\Lambda$ & & & 6.20 & & 3.59 & 8,030 & 2.80 & 5,210 & 2.43 & 3,980 & 2.22 & 3,330 \\
\hline 1 & 7.46 & & & & & & & & & & & \\
\hline $\begin{array}{l}2 \\
3\end{array}$ & 87 & & & & 3.48 & 7,670 & & & & & & \\
\hline 4 & & & & & 3.37 & 7,130 & & & & & & \\
\hline $\begin{array}{l}5 \\
6\end{array}$ & & & $\begin{array}{l}6.04 \\
5.88\end{array}$ & $\begin{array}{l}18 \\
17\end{array}$ & 3.28 & 6,950 & & & & & & \\
\hline 7 & 7.99 & & 5 & & & & & & & & & \\
\hline 8 & & & & & 3.21 & 6,600 & & & & & & \\
\hline $\mathrm{g}$ & & & $\begin{array}{l}5 . \\
4 .\end{array}$ & & 3,16 & & & & & & & \\
\hline & & & 4.7 & & & & & & & & & \\
\hline & & 900 & 4.58 & 11,900 & 3.11 & 6,250 & 2.60 & 4,530 & 2.31 & 3,600 & 2.16 & 3,160 \\
\hline
\end{tabular}

Supplemental Recorn.-Aug. 14, 9:30 a. m., gage height, 25.7 feet; discharge, 141,000 second-feet. 
NEW RIVER AT IVANHOE, VA.

Location.-Lat. $36^{\circ} 50^{\prime} 05^{\prime \prime}$, Iong. $80^{\circ} 57^{\prime} 10^{\prime \prime}$, at Ivanhoe, Wythe County, $2 \frac{1}{2}$ miles upstream from Cripple Creek. Datum of gage is $1,943.09$ feet above mean sea level, datum of 1929.

Drain AGE AREA.-1,340 square miles.

GAGE-HEIGHT RECORD.-Water-stage recorder graph except for 11 a.m. to 12:30 p.m. Aug. 14 when float was stopped by recorder shelf at stage 37.65 feet. Graph completed on basis of high-water mark in gage house and extension of rising and reeding recorder graphs. Intake pipe stopped Aug. 22-29.

DISCHARGE RECORD.-Stage-discharge relation defined by current-meter measurements up to 25,000 second-feet and extended to crest gage height by logarithmic plotting on basis of comparisons of flood records with those for other stations on New River. Gage heights Aug. 12 and 13 used to half-tenths between 3.0 and 4.8 feet; hundredths below and tenths above these limits. Gage heights Aug. 14-23, Aug. 30 to Sept. 4 used to half-tenths between 2.6 and 4.8 feet; hundredths below and tenths above these limits. Discharge for period when intake was stopped computed on basis of records for stations at Galax and Allisonia.

Maxima.-1940: Discharge, 155,000 second-feet $12 \mathrm{~m}$. Aug. 14 (gage height, 38.1 feet, from floodmarks).

1929-30: Discharge, 25,200 second-feet Sept. 6, 1935 (gage height, 13.22 feet).

Mean discharge, in second-feet, 1940

\begin{tabular}{|c|c|c|c|c|c|c|c|c|c|c|c|}
\hline Day & Aug. & Sept. & Day & Aug. & Sept. & Day & Aug. & Sept. & Day & Aug. & Sept. \\
\hline \begin{tabular}{l|}
1 \\
2 \\
3 \\
4 \\
5 \\
6 \\
7 \\
8
\end{tabular} & $\begin{array}{l}5,560 \\
2,910 \\
2,020 \\
1,680 \\
1,780 \\
2,860 \\
3,700 \\
3,030\end{array}$ & $\begin{array}{r}11,000 \\
6,300 \\
5,100 \\
3,550 \\
3,170 \\
3,160 \\
3,200 \\
2,850\end{array}$ & $\begin{array}{l}9 \\
10 \\
11 \\
12 \\
13 \\
14 \\
15 \\
16\end{array}$ & $\begin{array}{r}2,060 \\
1,890 \\
1,390 \\
1,840 \\
5,490 \\
87,600 \\
36,900 \\
17,900\end{array}$ & $\begin{array}{l}2,650 \\
2,840 \\
2,520 \\
2,640 \\
2,370 \\
2,240 \\
2,290 \\
2,170\end{array}$ & $\begin{array}{l}17 \\
18 \\
19 \\
20 \\
21 \\
22 \\
23 \\
24\end{array}$ & $\begin{array}{r}11,500 \\
8,120 \\
6,760 \\
5,240 \\
4,410 \\
4,000 \\
3,500 \\
3,200\end{array}$ & $\begin{array}{l}2,120 \\
2,040 \\
2,070 \\
2,250 \\
1,670 \\
1,860 \\
1,910 \\
1,980\end{array}$ & $\begin{array}{l}25 \\
26 \\
27 \\
28 \\
29 \\
30 \\
31\end{array}$ & $\begin{array}{r}3,000 \\
2,800 \\
2,600 \\
2,500 \\
2,500 \\
15,800 \\
23,000\end{array}$ & $\begin{array}{r}1,770 \\
1,510 \\
2,080 \\
1,970 \\
1,440 \\
1,830 \\
\end{array}$ \\
\hline \multicolumn{10}{|c|}{$\begin{array}{l}\text { Monthly mean discharge, in second-feet } \\
\text { Runoff, in inches. }\end{array}$} & $\begin{array}{r}8,953 \\
7.70\end{array}$ & $\begin{array}{r}2,818 \\
2.34\end{array}$ \\
\hline
\end{tabular}


304 FLOODS OF AUGUST 1940 IN THE SOUTHEASTERN STATES

Gage height, in feet, and discharge, in second-feet, at indicated time, 1940

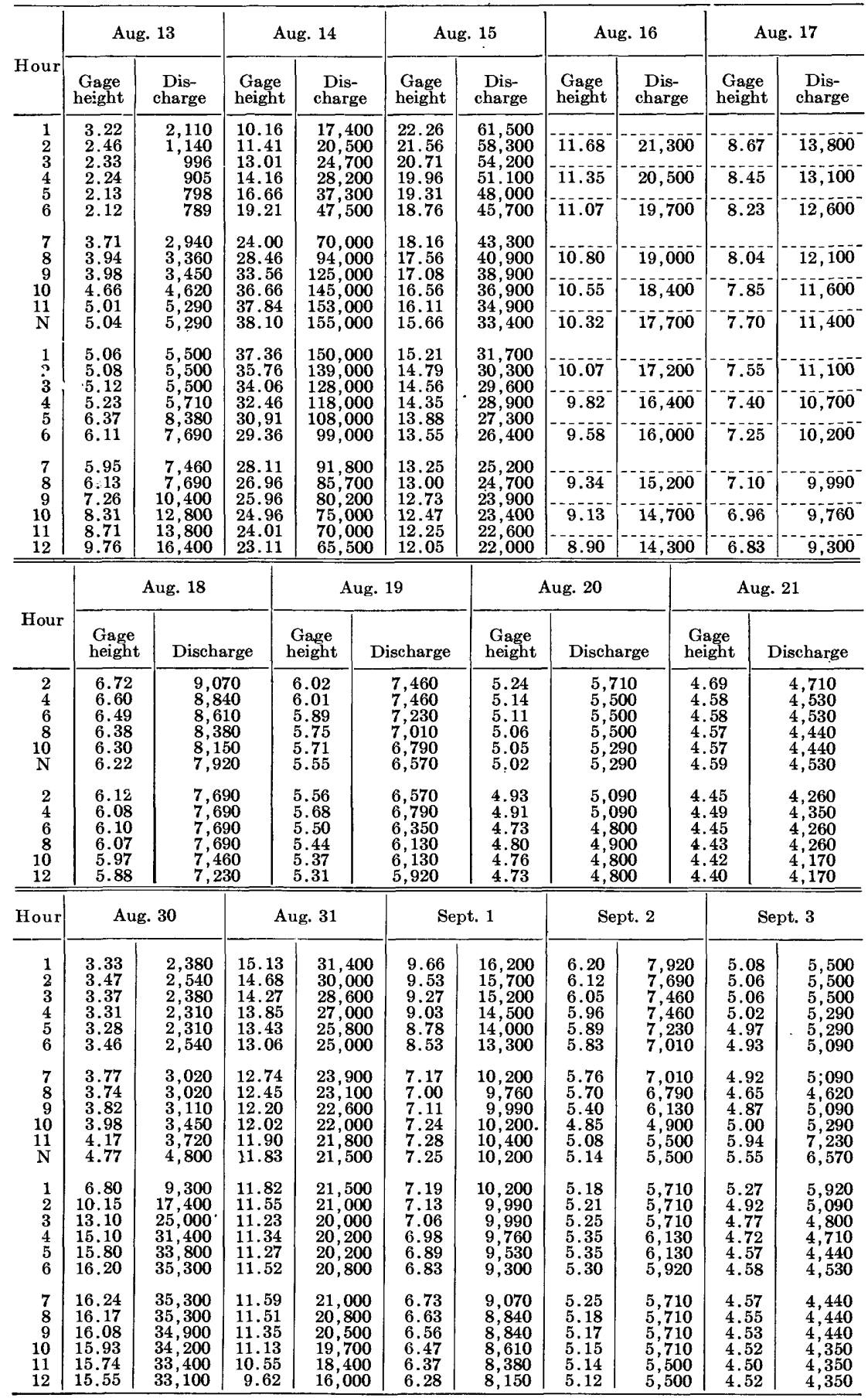

SUPPLEMENTAL RECORD.-Aug. 30, 6:30 p.m., gage height, 16.26 feet; discharge, 35,700 second-feet. 
NEW RIVER AT ALLISONIA, VA.

LocAtion.-Lat. $36^{\circ} 56^{\prime}$, long. $80^{\circ} 45^{\prime}$, a quarter of a mile downstream from Big Reed Island Creek and half a mile upstream from Allisonia, Pulaski County. Datum of gage is 1,848.36 feet above mean sea level, datum of 1929 .

DraINAGE AREA.-2,202 square miles.

GAGE-HEIGHT RECORD.-Water-stage recorder graph. Intake pipe not functioning properly Aug. 25-29, Sept. 4, 5.

DISCHARGE RECORD. - Stage-discharge relation defined by current-meter measurements up to 43,000 second-feet and extended to crest gage height by logarithmic plotting on basis of comparisons of flood records with those for other stations on New River. Gage heights used to half-tenths between 2.6 and 5.0 feet; hundredths below and tenths above these limits. Discharge for period when intake was not functioning computed on basis of records for station at Ivanhoe.

Maxima.-1940: Discharge, 185,000 second-feet 3 p.m. Aug. 14 (gage height, 23.42 feet).

1929-39: Discharge, 59,800 second-feet Oct. 2, 1929 (gage height, 11.14 feet).

Mean discharge, in second-feet, 1940

\begin{tabular}{|c|c|c|c|c|c|c|c|c|c|c|c|}
\hline Day & Aug. & Sept. & Day & Aug. & Sept. & Day & Aug. & Sept. & Day & Aug. & Sept. \\
\hline $\begin{array}{l}1 \\
2 \\
3 \\
4 \\
5 \\
6 \\
7 \\
8\end{array}$ & $\begin{array}{l}7,710 \\
4,410 \\
2,920 \\
2,560 \\
2,550 \\
2,940 \\
4,820 \\
4,370\end{array}$ & $\begin{array}{r}15,200 \\
8,500 \\
6,880 \\
5,000 \\
4,500 \\
4,460 \\
4,440 \\
3,920\end{array}$ & $\begin{array}{r}9 \\
10 \\
11 \\
12 \\
13 \\
14 \\
15 \\
16\end{array}$ & $\begin{array}{r}2,700 \\
2,440 \\
1,840 \\
2,570 \\
4,680 \\
95,000 \\
54,200 \\
27,000\end{array}$ & $\begin{array}{l}3,900 \\
4,060 \\
3,380 \\
3,820 \\
3,240 \\
3,150 \\
3,100 \\
3,070\end{array}$ & $\begin{array}{l}17 \\
18 \\
19 \\
20 \\
21 \\
22 \\
23 \\
24\end{array}$ & $\begin{array}{r}17,200 \\
11,300 \\
9,740 \\
7,830 \\
6,430 \\
5,710 \\
5,210 \\
4,720\end{array}$ & $\begin{array}{l}2,860 \\
2,830 \\
2,860 \\
2,890 \\
2,260 \\
2,520 \\
2,440 \\
2,740\end{array}$ & $\begin{array}{l}25 \\
26 \\
27 \\
28 \\
29 \\
30 \\
31\end{array}$ & $\begin{array}{r}4,300 \\
4,100 \\
3,800 \\
3,700 \\
3,700 \\
17,200 \\
31,000\end{array}$ & $\begin{array}{l}2,860 \\
2,590 \\
2,420 \\
2,420 \\
2,220 \\
2,320\end{array}$ \\
\hline \multicolumn{10}{|c|}{$\begin{array}{l}\text { Monthly mean discharge, in second-feet } \\
\text { Runoff, in inches }\end{array}$} & $\begin{array}{r}11,570 \\
6.05\end{array}$ & $\begin{array}{r}3,895 \\
1.98\end{array}$ \\
\hline
\end{tabular}

Gage height, in feet, and discharge, in second-feet, at indicated time, 1940

\begin{tabular}{|c|c|c|c|c|c|c|c|c|c|c|c|c|}
\hline \multirow{2}{*}{ Hour } & \multicolumn{2}{|c|}{ Aug. 13} & \multicolumn{2}{|c|}{ Aug. 14} & \multicolumn{2}{|c|}{ Aug. 15} & \multicolumn{2}{|c|}{ Aug. 16} & \multicolumn{2}{|c|}{ Aug. 17} & \multicolumn{2}{|c|}{ Aug. 18} \\
\hline & $\begin{array}{c}\text { Gage } \\
\text { ht. }\end{array}$ & $\begin{array}{l}\text { Dis- } \\
\text { charge }\end{array}$ & $\begin{array}{c}\text { Gage } \\
\text { ht. }\end{array}$ & $\begin{array}{c}\text { Dis- } \\
\text { charge }\end{array}$ & $\begin{array}{c}\text { Gage } \\
\text { ht. }\end{array}$ & $\begin{array}{c}\text { Dis- } \\
\text { charge }\end{array}$ & $\begin{array}{c}\text { Gage } \\
\text { ht. }\end{array}$ & $\begin{array}{c}\text { Dis- } \\
\text { charge }\end{array}$ & $\begin{array}{c}\text { Gage } \\
\text { ht. }\end{array}$ & $\begin{array}{c}\text { Dis- } \\
\text { charge }\end{array}$ & $\begin{array}{c}\text { Gage } \\
\text { ht. }\end{array}$ & $\begin{array}{c}\text { Dis- } \\
\text { charge }\end{array}$ \\
\hline \multirow{5}{*}{$\begin{array}{l}1 \\
2 \\
3 \\
4 \\
5\end{array}$} & \multirow{5}{*}{\begin{tabular}{|l|}
1.83 \\
2.05 \\
2.42 \\
2.53 \\
2.47 \\
2.32
\end{tabular}} & \multirow{5}{*}{$\begin{array}{l}2,270 \\
2,860 \\
3,990 \\
4,360 \\
4,150 \\
3,660\end{array}$} & \multirow{5}{*}{$\begin{array}{l}4.27 \\
4.72 \\
5.15 \\
5.56 \\
6.03 \\
6.75\end{array}$} & \multirow{5}{*}{$\begin{array}{l}11,300 \\
13,800 \\
16,800 \\
19,300 \\
21,800 \\
27,000\end{array}$} & \multirow{5}{*}{$\begin{array}{l}15.00 \\
14.35 \\
13.70 \\
13.15 \\
12.65 \\
12.15\end{array}$} & \multirow{5}{*}{$\begin{array}{l}93,000 \\
87,300 \\
80,600 \\
76,100 \\
70,700 \\
67,200\end{array}$} & & & & & & \\
\hline & & & & & & & 7.50 & $3 \overline{1}, 500$ & 5.78 & 20,600 & & \\
\hline & & & & & & & & & & & & \\
\hline & & & & & & & & & 35 & & & \\
\hline & & & & & & & 7.20 & 29,600 & 5.52 & 18,700 & & \\
\hline \multirow{5}{*}{$\begin{array}{r}10 \\
11 \\
\mathrm{~N}\end{array}$} & \multirow{5}{*}{$\begin{array}{l}2.13 \\
1.96 \\
1.82 \\
1.71 \\
1.63 \\
1.63\end{array}$} & \multirow{5}{*}{$\begin{array}{l}3,090 \\
2,630 \\
2,240 \\
1,960 \\
1,780 \\
1,780\end{array}$} & \multirow{5}{*}{$\begin{array}{r}7.70 \\
9.00 \\
11.05 \\
13.50 \\
15.95 \\
18.45\end{array}$} & \multirow{5}{*}{$\begin{array}{r}32,800 \\
41,700 \\
57,100 \\
78,800 \\
103,000 \\
128,000\end{array}$} & \multirow{5}{*}{$\begin{array}{r}11.72 \\
11.32 \\
10.95 \\
10.58 \\
10.25 \\
9.92\end{array}$} & \multirow{5}{*}{$\begin{array}{l}63,000 \\
59,600 \\
57,100 \\
53,900 \\
50,700 \\
48,400\end{array}$} & & & & & & \\
\hline & & & & & & & 7.07 & 28,900 & 5.43 & 18,000 & & \\
\hline & & & & & & & $6-\overline{95}$ & 28,200 & $5 . \overline{3}$ & 18,000 & & \\
\hline & & & & & & & & & & & & \\
\hline & & & & & & & 6.83 & 27,000 & 5.28 & 17,400 & $4 . \overline{20}$ & 11,100 \\
\hline \multirow{5}{*}{$\begin{array}{l}1 \\
2 \\
3 \\
4 \\
5 \\
6\end{array}$} & \multirow{5}{*}{\begin{tabular}{|l|}
2.07 \\
2.45 \\
2.83 \\
3.05 \\
3.12 \\
3.15
\end{tabular}} & \multirow{5}{*}{$\begin{array}{l}2,920 \\
4,080 \\
5,490 \\
6,230 \\
6,420 \\
6,610\end{array}$} & \multirow{5}{*}{$\begin{array}{l}21.50 \\
23.10 \\
23.42 \\
23.00 \\
22.25 \\
21.25\end{array}$} & \multirow{5}{*}{$\begin{array}{l}163,000 \\
181,000 \\
185,000 \\
180,000 \\
171,000 \\
159,000\end{array}$} & \multirow{5}{*}{$\begin{array}{l}9.62 \\
9.33 \\
9.07 \\
8.85 \\
8.64 \\
8.46\end{array}$} & \multirow{5}{*}{$\begin{array}{l}46,100 \\
43,800 \\
42,400 \\
40,300 \\
38,900 \\
38,200\end{array}$} & & & & & & \\
\hline & & & & & & & 6.67 & 26,300 & 5.17 & 16,800 & & \\
\hline & & & & & & & 6.53 & 25000 & 5.07 & 16 & & \\
\hline & & & & & & & & & & & & \\
\hline & & & & & & & 6.38 & 24,400 & 4.95 & 15,300 & & \\
\hline \multirow{5}{*}{$\begin{array}{r}7 \\
8 \\
9 \\
10 \\
11 \\
12\end{array}$} & \multirow{5}{*}{\begin{tabular}{|}
3.20 \\
3.27 \\
3.53 \\
3.72 \\
3.74 \\
3.83 \\
\end{tabular}} & \multirow{5}{*}{$\begin{array}{l}6,800 \\
7,000 \\
8,180 \\
8,810 \\
9,020 \\
9,460 \\
\end{array}$} & \multirow{5}{*}{$\mid \begin{array}{l}20.30 \\
19.15 \\
18.10 \\
17.30 \\
16.45 \\
15.70\end{array}$} & 1 & 8.8 & & & & & & & \\
\hline & & & & & 8.1 & & 6.26 & 23,700 & 4.84 & 14,700 & & \\
\hline & & & & & 8. & & 6.09 & 22,500 & 4.74 & 14,100 & & \\
\hline & & & & 107,000 & 7.8 & & & & & & & \\
\hline & & & & 100,000 & & & 5.93 & 21,200 & 4.64 & 13,500 & 3.99 & 10,100 \\
\hline
\end{tabular}




\section{FLOODS OF AUGUST 1940 IN THE SOUTHEASTERN STATES}

Gage height, in feet, and discharge, in second-feet, at indicated time, 1940-Con.

\begin{tabular}{|c|c|c|c|c|c|c|c|c|c|c|}
\hline \multirow{2}{*}{ Hour } & \multicolumn{2}{|c|}{ Aug. 30} & \multicolumn{2}{|c|}{ Aug. 31} & \multicolumn{2}{|c|}{ Sept. 1} & \multicolumn{2}{|c|}{ Sept. 2} & \multicolumn{2}{|c|}{ Sept. 3} \\
\hline & $\begin{array}{c}\text { Gage } \\
\text { height }\end{array}$ & $\begin{array}{c}\text { Dis- } \\
\text { charge }\end{array}$ & $\begin{array}{c}\text { Gage } \\
\text { height }\end{array}$ & $\begin{array}{c}\text { Dis- } \\
\text { charge }\end{array}$ & $\begin{array}{c}\text { Gage } \\
\text { height }\end{array}$ & $\begin{array}{c}\text { Dis- } \\
\text { charge }\end{array}$ & $\begin{array}{c}\text { Gage } \\
\text { height }\end{array}$ & $\begin{array}{c}\text { Dis- } \\
\text { charge }\end{array}$ & $\begin{array}{c}\text { Gage } \\
\text { height }\end{array}$ & $\begin{array}{c}\text { Dis- } \\
\text { charge }\end{array}$ \\
\hline 1 & 2.37 & 3,820 & 9.40 & 44,600 & & & & & & \\
\hline 2 & 2.39 & 3,890 & 9.17 & 43,100 & 6.00 & 21,800 & & & & \\
\hline $\begin{array}{l}3 \\
4\end{array}$ & $\begin{array}{l}2.39 \\
2.35\end{array}$ & $\begin{array}{l}3,890 \\
3,760\end{array}$ & $\begin{array}{l}8.92 \\
8.64\end{array}$ & $\begin{array}{l}41,000 \\
38,900\end{array}$ & 5.68 & 19900 & & & & \\
\hline 5 & $\begin{array}{l}2.30 \\
2.30\end{array}$ & $\begin{array}{l}3,600 \\
3,600\end{array}$ & $\begin{array}{l}8.04 \\
8.37\end{array}$ & $\begin{array}{l}38,900 \\
37,500\end{array}$ & & & & & & \\
\hline 6 & 2.27 & 3,510 & 8.12 & 35,500 & 5.50 & 18,700 & & & & \\
\hline 7 & 2.27 & 3,510 & 7.84 & 33,500 & $-1=$ & & & & & \\
\hline $\begin{array}{l}8 \\
9\end{array}$ & $\begin{array}{l}2.27 \\
2.31\end{array}$ & $\begin{array}{l}3,510 \\
3,630\end{array}$ & $\begin{array}{l}7.60 \\
7.37\end{array}$ & $\begin{array}{l}32,200 \\
30,800\end{array}$ & 5.27 & 17,400 & & & & \\
\hline 10 & 2.38 & 3,860 & 7.18 & 29,600 & 4.73 & 14,100 & $\ldots$ & & & \\
\hline$\stackrel{11}{N}$ & $\begin{array}{l}2.61 \\
2.87\end{array}$ & $\begin{array}{l}4,600 \\
5,490\end{array}$ & $\begin{array}{l}7.02 \\
6.88\end{array}$ & $\begin{array}{l}28,200 \\
27,600\end{array}$ & 4.48 & 12,600 & 3.62 & 8,390 & 3.13 & 6,610 \\
\hline 1 & 3.40 & 7,580 & 6.80 & 27,000 & & & & & & \\
\hline 2 & $\begin{array}{l}4.05 \\
4.62\end{array}$ & 10,400 & 6.75 & 27,000 & 4.52 & 12,600 & --- & & & \\
\hline $\begin{array}{l}3 \\
4\end{array}$ & $\begin{array}{l}4.62 \\
5.60\end{array}$ & $\begin{array}{l}13,200 \\
19,300\end{array}$ & 6.73 & $\begin{array}{l}26,300 \\
26,300\end{array}$ & 4.47 & 12,600 & & & & \\
\hline $\begin{array}{l}5 \\
6\end{array}$ & $\begin{array}{l}6.92 \\
7.70\end{array}$ & $\begin{array}{l}27,600 \\
32,800\end{array}$ & $\begin{array}{l}6.62 \\
6.61\end{array}$ & $\begin{array}{l}25,700 \\
25,700\end{array}$ & 4.40 & 12,100 & 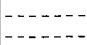 & & 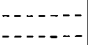 & \\
\hline 7 & 9.15 & 43,100 & 6.58 & 2 & & & & & & \\
\hline 8 & 9.47 & 400 & 6.55 & 700 & 4.30 & 11,600 & & & & \\
\hline $\begin{array}{r}9 \\
10\end{array}$ & $\begin{array}{l}9.68 \\
9.77\end{array}$ & $\begin{array}{l}4 \\
4\end{array}$ & $\begin{array}{l}6.57 \\
6.58\end{array}$ & $\begin{array}{l}25,700 \\
25,700\end{array}$ & 4.22 & $1 \overline{1}, \overline{100}$ & 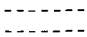 & & & \\
\hline $\begin{array}{l}11 \\
12\end{array}$ & 9.70 & 46,800 & 6.54 & 25,000 & $4-\overline{12}$ & $-\overline{10}-\overline{6}$ & 33 & 780 & 3 & \\
\hline & & & & & 4.12 & & 3.33 & 7,380 & 3.00 & 6 \\
\hline
\end{tabular}

NEW RIVER AT RADFORD, VA.

Location.-Lat. $37^{\circ} 08^{\prime}$, long. $80^{\circ} 34^{\prime}$, at Radford, Montgomery County, 2,000 feet downstream from bridge on U. S. Highway 11, 5 miles downstream from Little River, and 51/2 miles downstream from Claytor Dam. Datum of gage is 1,712.36 feet above mean sea level, datum of 1929 .

Drainage area.-2,748 square miles.

GAGE-HEIGHT RECORD.-Water-stage recorder graph.

DISCHARGE RECORD. - Stage-diseharge relation defined by eurrent-meter measurements up to 73,000 second-feet and extended to erest gage height by logarithmic plotting on basis of comparisons of flood records with those for other stations on New River and flow over Claytor Dam. Gage heights used to half-tenths between 3.1 and 4.4 feet; hundredths below and tenths above these limits.

Maxima.-1940: Discharge, 218,000 second-feet 4 p.m. Aug. 14 (gage height, 35.96 feet).

1907-15, 1939: Discharge recorded, about 138,000 second-feet May 22, 1901 (gage height, 30.2 feet, former site and datum).

The floods of Sept. 15, 1878, and July 16, 1916, reached stages of 37.4 feet and 35.7 feet, respectively, site and datum used by Geological Survey 1904-7, from reports of United States Weather Bureau (discharge not determined).

REMARKS.-Flood discharge slightly affected by operation of Claytor Dam and power plant of Appalachian Electric Power Co. 
KANAWHA RIVER BASIN

Mean discharge, in second-feet, 1940

\begin{tabular}{|c|c|c|c|c|c|c|c|c|c|c|c|}
\hline Day & Aug. & Sept. & Day & Aug. & Sept. & Day & Aug. & Sept. & Day & Aug. & Sept. \\
\hline $\begin{array}{l}1 \\
2 \\
3 \\
4 \\
5 \\
6 \\
7 \\
8\end{array}$ & $\begin{array}{l}8,420 \\
5,640 \\
3,300 \\
2,960 \\
4,120 \\
5,260 \\
4,830 \\
4,880\end{array}$ & $\begin{array}{r}18,700 \\
12,000 \\
8,710 \\
8,330 \\
6,370 \\
6,380 \\
6,140 \\
2,490\end{array}$ & $\begin{array}{r}9 \\
10 \\
11 \\
12 \\
13 \\
14 \\
15 \\
16\end{array}$ & $\begin{array}{r}4,260 \\
3,200 \\
1,160 \\
3,110 \\
5,790 \\
105,000 \\
69,200 \\
37,000\end{array}$ & $\begin{array}{l}4,970 \\
5,080 \\
4,250 \\
4,140 \\
3,910 \\
3,880 \\
1,720 \\
3,700\end{array}$ & $\begin{array}{l}17 \\
18 \\
19 \\
20 \\
21 \\
22 \\
23 \\
24\end{array}$ & $\begin{array}{r}22,000 \\
14,900 \\
12,700 \\
10,800 \\
8,210 \\
7,540 \\
8,060 \\
5,960\end{array}$ & $\begin{array}{l}4,190 \\
4,640 \\
4,630 \\
4,340 \\
3,100 \\
1,480 \\
3,830 \\
4,930\end{array}$ & $\begin{array}{l}25 \\
26 \\
27 \\
28 \\
29 \\
30 \\
31\end{array}$ & $\begin{array}{r}5,810 \\
5,260 \\
5,280 \\
5,040 \\
5,420 \\
18,000 \\
36,200\end{array}$ & $\begin{array}{l}3,520 \\
3,380 \\
3,540 \\
1,940 \\
1,040 \\
3,110\end{array}$ \\
\hline & & & & & \multicolumn{5}{|c|}{$\begin{array}{l}\text { observed } \\
\text { adjusted for storage }\end{array}$} & $\begin{array}{r}14,170 \\
14,216 \\
5.96\end{array}$ & $\begin{array}{r}4,948 \\
4,690 \\
1.91\end{array}$ \\
\hline
\end{tabular}

Gage height, in feet, and discharge, in second-feet, at indicated time, 1940

\begin{tabular}{|c|c|c|c|c|c|c|c|c|c|c|c|c|}
\hline \multirow{2}{*}{ Hour } & \multicolumn{2}{|c|}{ Aug. 12} & \multicolumn{2}{|c|}{ Aug. 13} & \multicolumn{2}{|c|}{ Aug. 14} & \multicolumn{2}{|c|}{ Aug. 15} & \multicolumn{2}{|c|}{ Aug. 16} & \multicolumn{2}{|c|}{ Aug. 17} \\
\hline & $\begin{array}{c}\text { Gage } \\
\text { ht. }\end{array}$ & $\begin{array}{c}\text { Dis- } \\
\text { charge }\end{array}$ & $\begin{array}{c}\text { Gage } \\
\text { ht. }\end{array}$ & $\begin{array}{c}\text { Dis- } \\
\text { charge }\end{array}$ & $\begin{array}{c}\text { Gage } \\
\text { ht. }\end{array}$ & $\begin{array}{c}\text { Dis- } \\
\text { charge }\end{array}$ & $\begin{array}{c}\text { Gage } \\
\text { ht. }\end{array}$ & $\begin{array}{c}\text { Dis- } \\
\text { charge }\end{array}$ & $\begin{array}{c}\text { Gage } \\
\text { ht. }\end{array}$ & $\begin{array}{c}\text { Dis- } \\
\text { eharge }\end{array}$ & $\begin{array}{c}\text { Gage } \\
\text { ht. }\end{array}$ & $\begin{array}{c}\text { Dis- } \\
\text { eharge }\end{array}$ \\
\hline $\begin{array}{l}1 \\
2 \\
3 \\
4 \\
5 \\
6\end{array}$ & $\begin{array}{l}1.78 \\
1.76 \\
1.74 \\
1.72 \\
1.72 \\
1.73\end{array}$ & $\begin{array}{l}962 \\
924 \\
886 \\
848 \\
848 \\
867\end{array}$ & \begin{tabular}{|l|}
2.25 \\
2.02 \\
1.93 \\
1.92 \\
1.90 \\
1.90
\end{tabular} & $\begin{array}{l}2,140 \\
1,520 \\
1,300 \\
1,270 \\
1,220 \\
1,220\end{array}$ & $\begin{array}{l}3.95 \\
3.95 \\
3.95 \\
3.98 \\
4.08 \\
4.75\end{array}$ & $\begin{array}{r}8,920 \\
8,920 \\
8,920 \\
9,150 \\
9,600 \\
12,500\end{array}$ & $\begin{array}{l}26.52 \\
24.70 \\
22.95 \\
21.65 \\
20.80 \\
20.25\end{array}$ & $\begin{array}{r}128,000 \\
113,000 \\
100,000 \\
89,900 \\
84,400 \\
80,500\end{array}$ & $\begin{array}{l}12.81 \\
12.88 \\
12.93 \\
12.96 \\
12.97 \\
12.71\end{array}$ & $\begin{array}{l}43,000 \\
43,400 \\
43,400 \\
43,900 \\
43,900 \\
42,600\end{array}$ & $\begin{array}{l}9.38 \\
9.22 \\
8.96 \\
8.45 \\
8.10 \\
7.95\end{array}$ & $\begin{array}{l}28,500 \\
27,800 \\
27,000 \\
24,700 \\
23,600 \\
23,200\end{array}$ \\
\hline $\begin{array}{r}7 \\
8 \\
9 \\
10 \\
11 \\
\mathrm{~N}\end{array}$ & $\begin{array}{l}1.73 \\
1.74 \\
2.00 \\
3.30 \\
3.36 \\
3.32\end{array}$ & $\begin{array}{r}867 \\
886 \\
1,470 \\
5,940 \\
6,160 \\
5,940\end{array}$ & $\begin{array}{l}1.90 \\
2.00 \\
3.00 \\
3.60 \\
3.67 \\
3.68\end{array}$ & $\begin{array}{l}1,220 \\
1,470 \\
4,730 \\
7,290 \\
7,520 \\
7,750\end{array}$ & \begin{tabular}{|r|}
5.79 \\
8.44 \\
14.88 \\
17.32 \\
19.52 \\
25.20
\end{tabular} & $\begin{array}{r}15,800 \\
24,700 \\
52,400 \\
64,200 \\
76,200 \\
117,000\end{array}$ & $\begin{array}{l}19.90 \\
19.60 \\
19.26 \\
18.90 \\
18.71 \\
18.05\end{array}$ & $\begin{array}{l}78,600 \\
76,800 \\
75,000 \\
72,600 \\
71,600 \\
67,700\end{array}$ & $\begin{array}{l}12.16 \\
11.73 \\
11.65 \\
11.45 \\
11.30 \\
11.22\end{array}$ & $\begin{array}{l}40,300 \\
38,000 \\
37,600 \\
36,700 \\
36,200 \\
35,800\end{array}$ & \begin{tabular}{|l|}
7.88 \\
7.85 \\
7.85 \\
7.85 \\
7.86 \\
7.67
\end{tabular} & $\begin{array}{l}22,800 \\
22,500 \\
22,500 \\
22,500 \\
22,800 \\
22,100\end{array}$ \\
\hline $\begin{array}{l}1 \\
2 \\
3 \\
4 \\
5\end{array}$ & $\begin{array}{l}2.96 \\
3.15 \\
3.24 \\
3.28 \\
2.90 \\
2.45\end{array}$ & $\begin{array}{l}4,580 \\
5,320 \\
5,730 \\
5,940 \\
4,350 \\
2,760\end{array}$ & $\begin{array}{l}3.55 \\
3.65 \\
3.85 \\
3.95 \\
3.96 \\
3.95\end{array}$ & $\begin{array}{l}7,060 \\
7,520 \\
8,460 \\
8,920 \\
8,920 \\
8,920\end{array}$ & $\begin{array}{l}35.48 \\
35.96 \\
35.81 \\
35.12\end{array}$ & $\begin{array}{l}140,000 \\
176,000 \\
213,000 \\
218,000 \\
216,000 \\
209,000\end{array}$ & $\begin{array}{l}17.41 \\
16.41 \\
15.31 \\
14.36 \\
13.67 \\
13.11\end{array}$ & $\begin{array}{l}64,700 \\
59,700 \\
54,200 \\
50,200 \\
47,000 \\
44,400\end{array}$ & $\begin{array}{l}11.30 \\
11.44 \\
11.17 \\
10.75 \\
10.56 \\
10.45\end{array}$ & $\begin{array}{r}36,200 \\
36,700 \\
35,800 \\
34,100 \\
33,300 \\
32,500\end{array}$ & $\begin{array}{l}7.57 \\
7.56 \\
7.47 \\
7.28 \\
7.02 \\
6.80\end{array}$ & $\begin{array}{l}21,800 \\
21,800 \\
21,400 \\
20,700 \\
19,600 \\
19,000\end{array}$ \\
\hline $\begin{array}{r}7 \\
8 \\
9 \\
10 \\
11 \\
12 \\
\end{array}$ & $\begin{array}{l}2.40 \\
2.42 \\
2.63 \\
2.98 \\
2.83 \\
2.48 \\
\end{array}$ & $\begin{array}{l}2,600 \\
2,670 \\
3,380 \\
4,650 \\
4,090 \\
2,860 \\
\end{array}$ & \begin{tabular}{|l|}
3.95 \\
3.95 \\
3.96 \\
3.95 \\
3.95 \\
3.94 \\
\end{tabular} & $\begin{array}{l}8,920 \\
8,920 \\
8,920 \\
8,920 \\
8,920 \\
8,920 \\
\end{array}$ & $\begin{array}{l}28.0 \\
27.3 \\
\end{array}$ & $\begin{array}{l}203,000 \\
198,000 \\
176,000 \\
157,000 \\
141,000 \\
135,000 \\
\end{array}$ & $\begin{array}{l}12.87 \\
12.76 \\
12.58 \\
12.56 \\
12.64 \\
12.72 \\
\end{array}$ & $\begin{array}{l}43,400 \\
43,000 \\
42,100 \\
42,100 \\
42,100 \\
42,600 \\
\end{array}$ & $\begin{array}{r}10.38 \\
10.30 \\
10.25 \\
10.18 \\
10.06 \\
9.65 \\
\end{array}$ & $\begin{array}{l}32,500 \\
32,100 \\
31,700 \\
31,700 \\
31,300 \\
29,300 \\
\end{array}$ & $\begin{array}{l}6.70 \\
6.63 \\
6.57 \\
6.53 \\
6.48 \\
6.45 \\
\end{array}$ & $\begin{array}{l}18,600 \\
18,300 \\
18,300 \\
18,000 \\
18,000 \\
17,600 \\
\end{array}$ \\
\hline
\end{tabular}

\begin{tabular}{|c|c|c|c|c|c|c|c|c|c|c|c|c|}
\hline Hour & & g. 30 & & g. 31 & & ppt. 1 & & pt. 2 & & ept. 3 & & ept. 4 \\
\hline $\begin{array}{l}1 \\
2 \\
3 \\
4 \\
5 \\
6\end{array}$ & $\begin{array}{l}2.97 \\
2.62 \\
2.35 \\
2.27 \\
2.27 \\
2.28\end{array}$ & $\begin{array}{l}4,620 \\
3,340 \\
2,440 \\
2,200 \\
2,200 \\
2,230\end{array}$ & $\begin{array}{l}14.52 \\
14.72 \\
15.00 \\
15.32 \\
15.15 \\
14.47\end{array}$ & $\begin{array}{l}50,600 \\
51,600 \\
52,900 \\
54,200 \\
53,800 \\
50,600\end{array}$ & $\begin{array}{l}8.79 \\
9.08 \\
9.17 \\
8.85 \\
8.30 \\
7.63\end{array}$ & $\begin{array}{l}26,200 \\
27,400 \\
27,800 \\
26,200 \\
24,300 \\
21,800\end{array}$ & $\begin{array}{l}5.09 \\
5.04 \\
5.01 \\
4.91 \\
4.86 \\
4.85\end{array}$ & $\begin{array}{l}13,600 \\
13,200 \\
13,200 \\
12,800 \\
12,800 \\
12,500\end{array}$ & & & & \\
\hline $\begin{array}{r}7 \\
8 \\
9 \\
10 \\
11 \\
\mathrm{~N}\end{array}$ & $\begin{array}{l}2.29 \\
2.30 \\
3.03 \\
4.00 \\
4.37 \\
5.05\end{array}$ & $\begin{array}{r}2,260 \\
2,290 \\
4,850 \\
9,150 \\
10,700 \\
13,200\end{array}$ & \begin{tabular}{|c|}
13.55 \\
12.35 \\
11.80 \\
11.22 \\
10.80 \\
10.33
\end{tabular} & $\begin{array}{l}46,600 \\
41,200 \\
38,500 \\
35,800 \\
34,100 \\
32,100\end{array}$ & $\begin{array}{l}7.39 \\
7.27 \\
7.30 \\
7.29 \\
6.96 \\
6.50\end{array}$ & $\begin{array}{l}21,000 \\
20,700 \\
20,700 \\
20,700 \\
19,600 \\
18,000\end{array}$ & $\begin{array}{l}4.90 \\
4.78 \\
4.65 \\
4.56 \\
4.55 \\
4.54\end{array}$ & $\begin{array}{l}12,800 \\
12,500 \\
11,700 \\
11,700 \\
11,700 \\
11,300\end{array}$ & 4.21 & 10,000 & 4.06 & \\
\hline $\begin{array}{l}1 \\
2 \\
3 \\
4 \\
5 \\
6\end{array}$ & $\mid \begin{array}{r}5.42 \\
5.50 \\
8.20 \\
10.10 \\
10.65 \\
10.57\end{array}$ & $\begin{array}{l}14,500 \\
14,900 \\
24,000 \\
31,300 \\
33,300 \\
33,300\end{array}$ & $\begin{array}{l}9.65 \\
9.17 \\
8.75 \\
8.70 \\
8.82 \\
8.88\end{array}$ & $\begin{array}{l}29,300 \\
27,800 \\
26,200 \\
25,900 \\
26,200 \\
26,600\end{array}$ & $\begin{array}{l}5.93 \\
5.77 \\
5.42 \\
5.33 \\
5.37 \\
5.13\end{array}$ & $\begin{array}{l}16,100 \\
15,800 \\
14,500 \\
14,200 \\
14,500 \\
13,600\end{array}$ & $\begin{array}{l}4.52 \\
4.44 \\
4.48 \\
4.59 \\
4.61 \\
4.59\end{array}$ & $\begin{array}{l}11,300 \\
10,900 \\
11,300 \\
11,700 \\
11,700 \\
11,700\end{array}$ & & & & \\
\hline $\begin{array}{r}7 \\
8 \\
9 \\
10 \\
11 \\
12\end{array}$ & $\left|\begin{array}{l}10.41 \\
10.95 \\
11.90 \\
12.65 \\
13.60 \\
14.27\end{array}\right|$ & $\begin{array}{l}32,500 \\
34,900 \\
39,000 \\
42,100 \\
46,600 \\
49,800\end{array}$ & $\begin{array}{l}8.72 \\
8.67 \\
8.65 \\
8.63 \\
8.60 \\
8.61\end{array}$ & $\begin{array}{l}25,900 \\
25,900 \\
25,500 \\
25,500 \\
25,500 \\
25,500\end{array}$ & $\begin{array}{l}5.03 \\
5.01 \\
5.00 \\
5.01 \\
5.02 \\
5.07\end{array}$ & $\begin{array}{l}13,200 \\
13,200 \\
13,200 \\
13,200 \\
13,200 \\
13,600\end{array}$ & \begin{tabular}{|l}
4.55 \\
4.55 \\
4.54 \\
4.50 \\
4.48 \\
4.40
\end{tabular} & $\begin{array}{l}11,700 \\
11,700 \\
11,300 \\
11,300 \\
11,300 \\
10,900\end{array}$ & 4.36 & & 4.05 & \\
\hline
\end{tabular}


NEW RIVER AT EGGLESTON, VA.

LOCATION.—Lat. $37^{\circ} 17^{\prime} 22^{\prime \prime}$, long. $80^{\circ} 37^{\prime} 01^{\prime \prime}$, at highway bridge at Eggleston, Giles County, 2 miles downstream from Spruce Run. Datum of gage is 1,615.59 feet above mean sea level, datum of 1929 .

Drainage AREA. - 2,941 square miles.

GAGE-HEIGHT RECORD.-Water-stage recorder graph.

DISCHARGE RECORD.-Stage-discharge relation defined by current-meter measurements up to 35,000 second-feet and extended to erest gage height by logarithmic plotting on basis of comparisons of flood records with those for other stations on New River. Gage heights used to half-tenths between 3.6 and 5.6 feet; hundredths below and tenths above these limits.

Maxima.-1940: Discharge, 219,000 second-feet 8:30 p.m. Aug. 14 (gage height, 41.16 feet).

1914-39: Discharge observed, 204,000 second-feet July 16, 1916 (gage height, 39.5 feet).

Flood of 1878 reached a stage of about 40 feet (discharge, about 209,000 second-feet).

Mean discharge, in second-feet, 1940

\begin{tabular}{|c|c|c|c|c|c|c|c|c|c|c|c|}
\hline Day & Aug. & Sept. & Day & Aug. & Sept. & Day & Aug. & Sept. & Day & Aug. & Sept. . \\
\hline $\begin{array}{l}1 \\
2 \\
3 \\
4 \\
5 \\
6 \\
7 \\
8\end{array}$ & $\begin{array}{l}8,820 \\
6,160 \\
4,460 \\
2,780 \\
3,540 \\
4,880 \\
5,960 \\
4,750\end{array}$ & $\begin{array}{r}23,100 \\
13,300 \\
9,500 \\
9,440 \\
7,060 \\
6,620 \\
6,600 \\
4,300\end{array}$ & $\begin{array}{r}9 \\
10 \\
11 \\
12 \\
13 \\
14 \\
15 \\
16\end{array}$ & $\begin{array}{r}4,170 \\
3,380 \\
2,440 \\
2,200 \\
4,360 \\
86,900 \\
91,100 \\
40,600\end{array}$ & $\begin{array}{l}3,720 \\
5,600 \\
4,340 \\
4,770 \\
4,050 \\
3,970 \\
2,960 \\
3,490\end{array}$ & $\begin{array}{l}17 \\
18 \\
19 \\
20 \\
21 \\
22 \\
23 \\
24\end{array}$ & $\begin{array}{r}25,900 \\
16,900 \\
13,600 \\
11,900 \\
9,360 \\
7,450 \\
8,540 \\
7,050\end{array}$ & $\begin{array}{l}4,060 \\
4,570 \\
5,140 \\
4,540 \\
4,180 \\
2,440 \\
3,100 \\
4,680\end{array}$ & $\begin{array}{l}25 \\
26 \\
27 \\
28 \\
29 \\
30 \\
31\end{array}$ & $\begin{array}{r}5,300 \\
6,240 \\
5,600 \\
4,900 \\
5,380 \\
12,000 \\
41,100\end{array}$ & $\begin{array}{l}4,740 \\
3,740 \\
3,540 \\
3,100 \\
1,850 \\
2,220\end{array}$ \\
\hline un & & & & & & & & & & $\begin{array}{r}14,770 \\
14,816 \\
5.81\end{array}$ & $\begin{array}{r}5,491 \\
5,233 \\
1.99\end{array}$ \\
\hline
\end{tabular}

Gage height, in feet, and discharge, in second-feet, at indicated time, 1940

\begin{tabular}{|c|c|c|c|c|c|c|c|c|c|c|c|c|}
\hline \multirow{2}{*}{ Hour } & \multicolumn{2}{|c|}{ Aug. 13} & \multicolumn{2}{|c|}{ Aug. 14} & \multicolumn{2}{|c|}{ Aug. 15} & \multicolumn{2}{|c|}{ Aug. 16} & \multicolumn{2}{|c|}{ Aug. 17} & \multicolumn{2}{|c|}{ Aug. 18} \\
\hline & $\begin{array}{c}\text { Gage } \\
\text { ht. }\end{array}$ & $\begin{array}{c}\text { Dis- } \\
\text { charge }\end{array}$ & $\begin{array}{c}\text { Gage } \\
\text { ht. }\end{array}$ & $\begin{array}{c}\text { Dis- } \\
\text { charge }\end{array}$ & $\begin{array}{c}\text { Gage } \\
\text { ht. }\end{array}$ & $\begin{array}{c}\text { Dis- } \\
\text { charge }\end{array}$ & $\begin{array}{c}\text { Gage } \\
\text { ht. }\end{array}$ & $\begin{array}{c}\text { Dis- } \\
\text { charge }\end{array}$ & $\begin{array}{c}\text { Gage } \\
\text { ht. }\end{array}$ & $\begin{array}{l}\text { Dis- } \\
\text { charge }\end{array}$ & $\begin{array}{l}\text { Gage } \\
\text { ht. }\end{array}$ & $\begin{array}{l}\text { Dis- } \\
\text { charge }\end{array}$ \\
\hline \multirow{5}{*}{$\begin{array}{l}1 \\
2 \\
3 \\
4 \\
5 \\
6\end{array}$} & \multirow{5}{*}{$\begin{array}{l}4.87 \\
4.65 \\
4.48 \\
4.42 \\
4.50 \\
4.60\end{array}$} & \multirow{5}{*}{$\begin{array}{l}4,240 \\
3,840 \\
3,550 \\
3,360 \\
3,550 \\
3,740\end{array}$} & \multirow{5}{*}{$\begin{array}{l}6.81 \\
6.82 \\
6.83 \\
6.84 \\
6.90 \\
7.07\end{array}$} & \multirow{5}{*}{$\begin{array}{l}8,970 \\
8,970 \\
8,970 \\
8,970 \\
9,260 \\
9,840\end{array}$} & \multirow{5}{*}{$\begin{array}{l}35.20 \\
33.70 \\
32.50 \\
31.25 \\
29.75 \\
27.90\end{array}$} & \multirow{5}{*}{$\begin{array}{l}169,000 \\
157,000 \\
148,000 \\
138,000 \\
128,000 \\
114,000\end{array}$} & \multirow{5}{*}{$\begin{array}{l}15.78 \\
15.78 \\
15.82 \\
15.87 \\
15.92 \\
15.95\end{array}$} & \multirow{5}{*}{$\begin{array}{l}44,700 \\
44,700 \\
44,700 \\
45,200 \\
45,200 \\
45,700\end{array}$} & \multirow{5}{*}{$\begin{array}{l}13.35 \\
13.25 \\
13.05 \\
12.83 \\
12.63 \\
12.40\end{array}$} & \multirow{5}{*}{$\begin{array}{l}33,700 \\
32,800 \\
31,900 \\
31,100 \\
30,200 \\
29,400\end{array}$} & & \\
\hline & & & & & & & & & & & 9.92 & 19,500 \\
\hline & & & & & & & & & & & & \\
\hline & & & & & & & & & & & & \\
\hline & & & & & & & & & & & $9 . \overline{7} \overline{5}$ & 19,100 \\
\hline \multirow{5}{*}{$\begin{array}{r}7 \\
8 \\
9 \\
10 \\
11 \\
\mathbf{N}\end{array}$} & \multirow{5}{*}{$\begin{array}{l}4.56 \\
4.44 \\
4.27 \\
4.08 \\
3.91 \\
3.75\end{array}$} & \multirow{5}{*}{$\begin{array}{l}3,640 \\
3,460 \\
3,080 \\
2,810 \\
2,470 \\
2,230\end{array}$} & \multirow{5}{*}{$\begin{array}{r}7.48 \\
8.13 \\
9.05 \\
10.40 \\
11.70 \\
16.00\end{array}$} & \multirow{5}{*}{$\begin{array}{l}11,000 \\
13,000 \\
16,100 \\
21,400 \\
26,500 \\
45,700\end{array}$} & \multirow{5}{*}{$\begin{array}{l}26.10 \\
24.90 \\
24.05 \\
23.45 \\
22.97 \\
22.60\end{array}$} & \multirow{5}{*}{$\begin{array}{r}102,000 \\
94,600 \\
89,200 \\
85,600 \\
83,200 \\
80,800\end{array}$} & \multirow{5}{*}{$\begin{array}{l}15.95 \\
15.92 \\
15.77 \\
15.46 \\
15.12 \\
14.90\end{array}$} & \multirow{5}{*}{$\begin{array}{l}45,700 \\
45,200 \\
44,700 \\
43,300 \\
41,400 \\
40,400\end{array}$} & \multirow{5}{*}{$\begin{array}{l}12.12 \\
11.80 \\
11.55 \\
11.37 \\
11.26 \\
11.20\end{array}$} & \multirow{5}{*}{$\begin{array}{l}28,100 \\
26,900 \\
26,100 \\
25,300 \\
24,900 \\
24,500\end{array}$} & & \\
\hline & & & & & & & & & & & 9.68 & 700 \\
\hline & & & & & & & & & & & $9-61$ & 18300 \\
\hline & & & & & & & & & & & & \\
\hline & & & & & & & & & & & 9.40 & 17,600 \\
\hline \multirow{5}{*}{$\begin{array}{l}1 \\
2 \\
3 \\
4 \\
5 \\
6\end{array}$} & \multirow{5}{*}{$\begin{array}{l}3.60 \\
3.48 \\
3.41 \\
3.47 \\
4.40 \\
5.85\end{array}$} & \multirow{5}{*}{$\begin{array}{l}2,000 \\
1,820 \\
1,720 \\
1,810 \\
3,360 \\
6,320\end{array}$} & & & & & & & 7 & & & \\
\hline & & & & & & & & & & & 9.03 & 16,100 \\
\hline & & & 29 & & & & & & & & 8.67 & 15000 \\
\hline & & & & & & & & & & & & \\
\hline & & & 25 & 00 & 19.20 & 800 & 14.25 & 37,200 & 10.85 & 22,900 & 8.50 & 14,300 \\
\hline 7 & 6. & 0 & 39 & 20 & 25 & 56 & 1 & & 10.75 & & & \\
\hline & & & & & & & & & & & 8.42 & 14,000 \\
\hline & & & & & & & & & & & & \\
\hline & & & 39.6 & & & & & & 10. & & & \\
\hline & & & & & & & & & & & 8.3 & 14 \\
\hline
\end{tabular}


Gage height, in feet, and discharge, in second-feet, at indicated time, 1940-Con.

\begin{tabular}{|c|c|c|c|c|c|c|c|c|}
\hline \multirow{2}{*}{ Hour } & \multicolumn{2}{|c|}{ Aug. 30} & \multicolumn{2}{|c|}{ Aug. 31} & \multicolumn{2}{|c|}{ Sept. 1} & \multicolumn{2}{|c|}{ Sept. 2} \\
\hline & $\begin{array}{c}\text { Gage } \\
\text { height }\end{array}$ & Discharge & $\begin{array}{c}\text { Gage } \\
\text { height }\end{array}$ & Discharge & $\begin{array}{c}\text { Gage } \\
\text { height }\end{array}$ & Discharge & $\begin{array}{c}\text { Gage } \\
\text { height }\end{array}$ & Discharge \\
\hline \multirow{4}{*}{$\begin{array}{l}1 \\
2 \\
3 \\
4 \\
5 \\
6\end{array}$} & \multirow{4}{*}{$\begin{array}{l}5.73 \\
5.52 \\
5.38 \\
5.33 \\
5.35 \\
5.36\end{array}$} & \multirow{4}{*}{$\begin{array}{l}6,080 \\
5,620 \\
5,400 \\
5,290 \\
5,290 \\
5,290\end{array}$} & \multirow{4}{*}{$\begin{array}{l}15.25 \\
15.85 \\
16.50 \\
16.97 \\
17.27 \\
17.52\end{array}$} & \multirow{4}{*}{$\begin{array}{l}41,900 \\
44,700 \\
48,200 \\
50,700 \\
52,200 \\
53,200\end{array}$} & 12.00 & 27,700 & 8.46 & 14,300 \\
\hline & & & & & 证 & 27700 & 8.40 & \\
\hline & & & & & 12.00 & 27,700 & 8.40 & 14,000 \\
\hline & & & & & 12.20 & 28,500 & 8.35 & 14,000 \\
\hline \multirow{4}{*}{$\begin{array}{r}7 \\
8 \\
9 \\
10 \\
11 \\
\mathrm{~N}\end{array}$} & \multirow{4}{*}{$\begin{array}{l}5.32 \\
5.20 \\
5.05 \\
4.90 \\
4.77 \\
4.65\end{array}$} & \multirow{4}{*}{$\begin{array}{l}5,180 \\
4,970 \\
4,660 \\
4,340 \\
4,040 \\
3,840\end{array}$} & \multirow{4}{*}{$\begin{array}{l}17.80 \\
17.82 \\
17.55 \\
17.00 \\
16.30 \\
15.60\end{array}$} & \multirow{4}{*}{$\begin{array}{l}54,700 \\
54,700 \\
53,700 \\
50,700 \\
47,200 \\
43,800\end{array}$} & & & & \\
\hline & & & & & 12.22 & 28,500 & 8.36 & 14,000 \\
\hline & & & & & 11.60 & $\overline{2} \overline{6}, \overline{1} \overline{0}$ & $\overline{8} . \overline{3} \overline{2}$ & 13,700 \\
\hline & & & & & $10 . \overline{93}$ & $2 \overline{3}, \overline{300}$ & $8 . \overline{8}$ & $\overline{1} \overline{7}, \overline{700}$ \\
\hline \multirow{4}{*}{$\begin{array}{l}1 \\
2 \\
3 \\
4 \\
5 \\
6\end{array}$} & \multirow{4}{*}{$\begin{array}{l}4.59 \\
4.62 \\
4.83 \\
6.20 \\
7.75 \\
8.85\end{array}$} & \multirow{4}{*}{$\begin{array}{r}3,740 \\
3,740 \\
4,240 \\
7,320 \\
12,000 \\
15,400\end{array}$} & \multirow{4}{*}{$\begin{array}{l}15.03 \\
14.55 \\
14.10 \\
13.68 \\
13.25 \\
12.83\end{array}$} & \multirow{4}{*}{$\begin{array}{l}40,900 \\
39,100 \\
36,800 \\
35,000 \\
32,800 \\
31,100\end{array}$} & & & $0-11$ & \\
\hline & & & & & 10.70 & 22,500 & 8.14 & 000 \\
\hline & & & & & 10.30 & 21,000 & 7.98 & 12,600 \\
\hline & & & & & 9.62 & 18,300 & 7.88 & 12,300 \\
\hline \multirow{4}{*}{$\begin{array}{r}7 \\
8 \\
9 \\
10 \\
11 \\
12\end{array}$} & \multirow{4}{*}{$\begin{array}{l}10.50 \\
12.50 \\
13.55 \\
13.88 \\
14.05 \\
14.54\end{array}$} & \multirow{4}{*}{$\begin{array}{l}21,700 \\
29,800 \\
34,500 \\
35,900 \\
36,300 \\
38,600\end{array}$} & \multirow{4}{*}{$\begin{array}{l}12.45 \\
12.25 \\
12.17 \\
12.14 \\
12.08 \\
12.04\end{array}$} & \multirow{4}{*}{$\begin{array}{l}29,400 \\
28,500 \\
28,500 \\
28,100 \\
28,100 \\
27,700\end{array}$} & & & & \\
\hline & & & & & 9.08 & 500 & 7.83 & 12,000 \\
\hline & & & & & 8.82 & 15,400 & 7.90 & 12,300 \\
\hline & & & & & $8 . \overline{57}$ & 14,700 & $\overline{7.91}$ & 12,300 \\
\hline
\end{tabular}

SupPlemental RECoRds.-Aug. 14, 8:30 p.m., gage height, 41.16 feet; discharge, 219,000 second-feet. Aug. 31, 7:30 a.m., gage height, 17.86 feet, discharge, 55,200 second-feet.

\section{NEW RIVER AT GLENLYN, VA.}

Location.-Lat. $37^{\circ} 22^{\prime} 20^{\prime \prime}$, long. $80^{\circ} 51^{\prime} 45^{\prime \prime}$, at highway bridge and power plant at Glenlyn, Giles County, a third of a mile upstream from East River. Datum of gage is 1,489.76 feet above mean sea level, datum of 1929 .

DRATNAGE AREA.- $-3,768$ square miles.

GAGE-HEIGHT RECORD.-Water-stage recorder graph.

DISCHARGE RECORD.-Stage-discharge relation defined by current-meter measurements up to 55,000 second-feet and extended by logarithmic plotting to slope-area measurement for erest gage height, and verified by comparisons of flood records with those for other stations on New River. Gage heights used to half-tenths between 3.6 and 5.7 feet; hundredths below and tenths above these limits.

Maxima.-1940: Discharge, 226,000 second-feet 12 p.m. Aug. 14 (gage height, 27.50 feet).

1927-39: Discharge, 94,400 second-feet Oct. 3, 1929 (gage height, 16.75 feet).

Mean discharge, in second-feet, 1940

\begin{tabular}{|c|c|c|c|c|c|c|c|c|c|c|c|}
\hline Day & Aug. & Sept. & Day & Aug. & Sept. & Day & Aug. & Sept. & Day & Aug. & Sept. \\
\hline $\begin{array}{l}1 \\
2 \\
3 \\
4 \\
5 \\
6 \\
7 \\
8\end{array}$ & $\begin{array}{r}10,100 \\
7,830 \\
6,130 \\
3,480 \\
3,640 \\
5,300 \\
6,380 \\
5,120\end{array}$ & $\begin{array}{r}26,300 \\
14,900 \\
11,100 \\
10,200 \\
8,130 \\
7,180 \\
7,400 \\
6,240\end{array}$ & $\begin{array}{r}9 \\
10 \\
11 \\
12 \\
13 \\
14 \\
15 \\
16\end{array}$ & $\begin{array}{r}4,980 \\
4,560 \\
3,570 \\
1,770 \\
3,700 \\
59,400 \\
126,000 \\
51,300 .\end{array}$ & $\begin{array}{l}3,220 \\
5,950 \\
5,460 \\
5,360 \\
4,490 \\
4,510 \\
4,640 \\
2,520\end{array}$ & $\begin{array}{l}17 \\
18 \\
19 \\
20 \\
21 \\
22 \\
23 \\
24\end{array}$ & $\begin{array}{r}33,000 \\
20,800 \\
15,700 \\
13,900 \\
11,300 \\
8,790 \\
9,460 \\
8,520\end{array}$ & $\begin{array}{l}4,420 \\
4,840 \\
5,480 \\
5,180 \\
5,220 \\
3,660 \\
2,220 \\
4,620\end{array}$ & $\begin{array}{l}25 \\
26 \\
27 \\
28 \\
29 \\
30 \\
31\end{array}$ & $\begin{array}{r}6,300 \\
7,120 \\
6,690 \\
5,900 \\
6,240 \\
7,950 \\
43,700\end{array}$ & $\begin{array}{r}5,610 \\
4,340 \\
4,100 \\
4,220 \\
2,700 \\
1,760 \\
\end{array}$ \\
\hline \multicolumn{10}{|c|}{ Monthly mean discharge, in second-feet } & $\begin{array}{r}16,410 \\
16,456 \\
5.04\end{array}$ & $\begin{array}{r}6,199 \\
5,941 \\
1.76\end{array}$ \\
\hline
\end{tabular}




\section{FLOODS OF AUGUST 1940 IN THE SOUTHEASTERN STATES}

Gage height, in feet, and discharge, in second-feet, at indicated time, 1940

\begin{tabular}{|c|c|c|c|c|c|c|c|c|c|c|c|c|}
\hline \multirow{2}{*}{ Hour } & \multicolumn{2}{|c|}{ Aug. 13} & \multicolumn{2}{|c|}{ Aug. 14} & \multicolumn{2}{|c|}{ Aug. 15} & \multicolumn{2}{|c|}{ Aug. 16} & \multicolumn{2}{|c|}{ Aug. 17} & \multicolumn{2}{|c|}{ Aug. 18} \\
\hline & $\begin{array}{c}\text { Gage } \\
\text { ht. }\end{array}$ & $\begin{array}{c}\text { Dis- } \\
\text { charge }\end{array}$ & $\begin{array}{c}\text { Gage } \\
\text { ht. }\end{array}$ & $\begin{array}{c}\text { Dis- } \\
\text { charge }\end{array}$ & $\begin{array}{c}\text { Gage } \\
\text { ht. }\end{array}$ & $\begin{array}{c}\text { Dis- } \\
\text { charge }\end{array}$ & $\begin{array}{c}\text { Gage } \\
\text { ht. }\end{array}$ & $\begin{array}{c}\text { Dis- } \\
\text { charge }\end{array}$ & $\begin{array}{c}\text { Gage } \\
\text { ht. }\end{array}$ & $\begin{array}{c}\text { Dis- } \\
\text { charge }\end{array}$ & $\begin{array}{c}\text { Gage } \\
\text { ht. }\end{array}$ & $\begin{array}{c}\text { Dis- } \\
\text { charge }\end{array}$ \\
\hline $\begin{array}{l}1 \\
2 \\
3 \\
4 \\
5 \\
6\end{array}$ & $\mid \begin{array}{c}-\cdots \\
-4.26\end{array}$ & 5,380 & $\begin{array}{l}4.45 \\
4.90 \\
5.13 \\
5.26 \\
5.37 \\
5.43\end{array}$ & $\begin{array}{l}6,020 \\
7,580 \\
8,520 \\
8,920 \\
9,310 \\
9,720\end{array}$ & $\mid \begin{array}{l}27.30 \\
26.80 \\
25.85 \\
24.80 \\
23.80 \\
22.90\end{array}$ & $\begin{array}{l}224,000 \\
217,000 \\
204,000 \\
191,000 \\
179,000 \\
168,000\end{array}$ & $\begin{array}{l}12.80 \\
12.53 \\
12.32 \\
12.20 \\
12.14 \\
12.10\end{array}$ & $\begin{array}{l}59,600 \\
56,900 \\
55,100 \\
54,200 \\
53,300 \\
53,300\end{array}$ & $\begin{array}{l}10.70 \\
10.60 \\
10.51 \\
10.44 \\
10.38 \\
10.30\end{array}$ & $\begin{array}{l}41,500 \\
40,700 \\
39,900 \\
39,200 \\
39,200 \\
38,400\end{array}$ & 8.01 & 22,400 \\
\hline $\begin{array}{r}7 \\
8 \\
9 \\
10 \\
11 \\
\mathrm{~N}\end{array}$ & $3 . \overline{9}$ & 4,040 & $\begin{array}{l}5.48 \\
5.52 \\
5.58 \\
5.67 \\
5.77 \\
6.12\end{array}$ & $\begin{array}{r}9,9 \\
9,9 \\
10,3 \\
10,6 \\
11,2 \\
12,5\end{array}$ & $\begin{array}{l}22.00 \\
21.00 \\
20.10 \\
19.10 \\
18.20 \\
17.30\end{array}$ & $\begin{array}{l}157 \\
145 \\
13 \\
124 \\
114 \\
104\end{array}$ & $\begin{array}{l}12.10 \\
12.12 \\
12.14 \\
12.14 \\
12.15 \\
12.13\end{array}$ & $\begin{array}{l}53,300 \\
53,300 \\
53,300 \\
53,300 \\
54,200 \\
53,300\end{array}$ & $\begin{array}{r}10.20 \\
10.08 \\
9.97 \\
9.77 \\
9.58 \\
9.40\end{array}$ & $\begin{array}{l}37,600 \\
36,900 \\
36,200 \\
34,600 \\
33,200 \\
31,700\end{array}$ & 7.78 & 21,300 \\
\hline $\begin{array}{l}1 \\
2 \\
3 \\
4 \\
5 \\
6\end{array}$ & 3.61 & $\overline{3}, \overline{500}$ & $\begin{array}{r}6.95 \\
8.25 \\
9.70 \\
11.80 \\
14.30 \\
16.50\end{array}$ & $\begin{array}{l}16,800 \\
23,700 \\
33,900 \\
50,600 \\
74,000 \\
96,000\end{array}$ & $\begin{array}{l}16.75 \\
16.35 \\
16.00 \\
15.75 \\
15.52 \\
15.30\end{array}$ & & $\begin{array}{l}12.07 \\
11.96 \\
11.82 \\
11.65 \\
11.50 \\
11.37\end{array}$ & $\begin{array}{l}53,300 \\
52,400 \\
50,600 \\
48,800 \\
47,900 \\
47,100\end{array}$ & $\begin{array}{l}9.24 \\
9.12 \\
9.00 \\
8.93 \\
8.89 \\
8.86\end{array}$ & $\begin{array}{l}30,300 \\
29,600 \\
28,900 \\
28,200 \\
28,200 \\
28,200\end{array}$ & 7.42 & 19,000 \\
\hline $\begin{array}{r}7 \\
8 \\
9 \\
10 \\
11 \\
12\end{array}$ & $|-\overline{3.47}|$ & 3,160 & $\left|\begin{array}{l}18.50 \\
22.10 \\
24.75 \\
26.30 \\
27.20 \\
27.50\end{array}\right|$ & $\begin{array}{l}118,000 \\
158,000 \\
191,000 \\
211,000 \\
223,000 \\
226,000\end{array}$ & $\begin{array}{l}15.05 \\
14.75 \\
14.40 \\
13.97 \\
13.55 \\
13.15\end{array}$ & $\begin{array}{l}81,000 \\
79,000 \\
75,000 \\
71,000 \\
67,000 \\
63,200\end{array}$ & $\begin{array}{l}11.26 \\
11.20 \\
11.16 \\
11.10 \\
10.94 \\
10.82\end{array}$ & $\begin{array}{l}46,300 \\
45,500 \\
45,500 \\
44,700 \\
43,100 \\
42,300\end{array}$ & $\begin{array}{l}8.82 \\
8.77 \\
8.72 \\
8.66 \\
8.60 \\
8.51\end{array}$ & $\begin{array}{l}27,600 \\
27,600 \\
26,900 \\
26,900 \\
26,200 \\
25,600\end{array}$ & $\mid-\overline{9}$ & 16,300 \\
\hline
\end{tabular}

\begin{tabular}{|c|c|c|c|c|c|c|c|c|c|c|c|c|}
\hline & \multicolumn{2}{|c|}{ Aug. 30} & \multicolumn{2}{|c|}{ Aug. 31} & \multicolumn{2}{|c|}{ Sept. 1} & \multicolumn{2}{|c|}{ Sept. 2} & \multicolumn{2}{|c|}{ Sept. 3} & \multicolumn{2}{|c|}{ Sept. 4} \\
\hline $\begin{array}{l}1 \\
2 \\
3 \\
4 \\
5 \\
6\end{array}$ & $\begin{array}{l}5.08 \\
5.08 \\
5.06 \\
5.00 \\
4.91 \\
4.82\end{array}$ & $\begin{array}{l}8,330 \\
8,330 \\
8,140 \\
7,950 \\
7,580 \\
7,220\end{array}$ & $\begin{array}{r}9.73 \\
10.00 \\
10.25 \\
10.60 \\
11.05 \\
11.52\end{array}$ & $\begin{array}{l}33,900 \\
36,200 \\
37,600 \\
40,700 \\
43,900 \\
47,900\end{array}$ & $\overline{8} . \overline{9}$ & 28,900 & & & & & & \\
\hline $\begin{array}{r}7 \\
8 \\
9 \\
10 \\
11 \\
\mathrm{~N}\end{array}$ & $\begin{array}{l}4.70 \\
4.62 \\
4.56 \\
4.55 \\
4.54 \\
4.53\end{array}$ & $\begin{array}{l}6,870 \\
6,520 \\
6,350 \\
6,350 \\
6,350 \\
6,350\end{array}$ & $\begin{array}{l}11.85 \\
12.07 \\
12.24 \\
12.38 \\
12.45 \\
12.36\end{array}$ & $\begin{array}{l}50,600 \\
53,300 \\
54,200 \\
56,000 \\
56,000 \\
56,000\end{array}$ & 9.05 & 28,900 & 6.58 & 14,800 & 5.94 & 11,600 & 5.84 & 11,200 \\
\hline $\begin{array}{l}1 \\
2 \\
3 \\
4 \\
5 \\
6\end{array}$ & $\begin{array}{l}4.51 \\
4.47 \\
4.43 \\
4.38 \\
4.32 \\
4.26\end{array}$ & $\begin{array}{l}6,180 \\
6,020 \\
6,020 \\
5,850 \\
5,530 \\
5,380\end{array}$ & $\begin{array}{l}12.17 \\
11.90 \\
11.48 \\
11.10 \\
10.78 \\
10.50\end{array}$ & $\begin{array}{l}54,200 \\
51,500 \\
47,900 \\
44,700 \\
42,300 \\
39,900\end{array}$ & $8 . \overline{15}$ & $2 \overline{3}, \overline{700}$ & -- & & & & $\cdots$ & 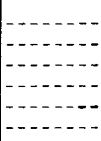 \\
\hline $\begin{array}{r}7 \\
8 \\
9 \\
10 \\
11 \\
12 \\
\end{array}$ & $\begin{array}{l}4.22 \\
4.21 \\
4.50 \\
5.94 \\
7.95 \\
9.10\end{array}$ & $\begin{array}{r}5,220 \\
5,220 \\
6,180 \\
11,600 \\
22,400 \\
29,600 \\
\end{array}$ & \begin{tabular}{|r|}
10.23 \\
10.00 \\
9.78 \\
9.54 \\
9.34 \\
9.20
\end{tabular} & $\begin{array}{l}37,600 \\
36,200 \\
34,600 \\
32,400 \\
31,000 \\
30,300\end{array}$ & 7.20 & 17,900 & 6.23 & 13,000 & 5.50 & 9,920 & $\begin{array}{l}-\cdots . . \\
-\overline{4}\end{array}$ & 9 \\
\hline
\end{tabular}

\section{NEW RIVER NEAR HINTON, W: VA.}

LOCATION.-Lat. $37^{\circ} 37^{\prime} 35^{\prime \prime}$, long. $80^{\circ} 53^{\prime} 50^{\prime \prime}, 2$ miles upstream from Greenbrier River and $3 \frac{1}{2}$ miles south of Hinton, Summers County. Datum of gage is 1,368.49 feet above mean sea level, datum of 1929 (levels by West Virginia Power Co.).

Drainage AREA.-4,600 square miles.

GAGE-HEIGHT RECORD.-Water-stage recorder graph.

DISCHARGE RECORD.- Stage-discharge relation defined by current-meter measurements up to 50,000 second-feet and extended to slope-area measurement for crest gage height.

Maxima.-1940: Discharge, 232,000 second-feet 4:45 a.m. Aug. 15 (gage height, 24.08 feet). 
1923-39: Discharge, 105,000 second-feet Oct. 3, 1929 (gage height, 17.2 feet).

Floods of Apr. 21 and May 23, 1901 reached a stage of 24.2 feet on present gage (discharge, 234,000 second-feet). Flood of 1878 probably reached a higher stage.

Remarks.-Low and medium flow regulated by Claytor Dam and power plant in Virginia, 82 miles upstream.

Mean discharge, in second-feet, 1940

\begin{tabular}{|c|c|c|c|c|c|c|c|c|c|c|c|}
\hline Day & Aug. & Sept. & Day & Aug. & Sept. & Day & Aug. & Sept. & Day & Aug. & Sept. \\
\hline $\begin{array}{l}1 \\
2 \\
3 \\
4 \\
5 \\
6 \\
7 \\
8\end{array}$ & $\begin{array}{r}11,000 \\
10,200 \\
6,900 \\
4,270 \\
3,690 \\
4,760 \\
6,150 \\
5,420\end{array}$ & $\begin{array}{r}33,400 \\
17,600 \\
12,600 \\
10,600 \\
8,800 \\
7,650 \\
7,500 \\
6,900\end{array}$ & $\begin{array}{r}9 \\
10 \\
11 \\
12 \\
13 \\
14 \\
15 \\
16\end{array}$ & $\begin{array}{r}5,020 \\
4,760 \\
3,690 \\
2,350 \\
3,000 \\
27,100 \\
153,000 \\
57,800\end{array}$ & $\begin{array}{l}3,690 \\
5,700 \\
6,000 \\
5,020 \\
4,890 \\
4,640 \\
4,520 \\
2,730\end{array}$ & $\begin{array}{l}17 \\
18 \\
19 \\
20 \\
21 \\
22 \\
23 \\
24\end{array}$ & $\begin{array}{r}39,300 \\
25,400 \\
17,100 \\
15,300 \\
12,600 \\
9,850 \\
9,150 \\
9,150\end{array}$ & $\begin{array}{l}4,150 \\
4,640 \\
5,280 \\
5,150 \\
4,890 \\
3,800 \\
2,350 \\
3,920\end{array}$ & $\begin{array}{l}25 \\
26 \\
27 \\
28 \\
29 \\
30 \\
31\end{array}$ & $\begin{array}{r}7,200 \\
7,350 \\
7,200 \\
6,750 \\
7,200 \\
7,650 \\
40,100\end{array}$ & $\begin{array}{r}5,420 \\
4,390 \\
4,040 \\
4,150 \\
2,730 \\
2,120 \\
-\end{array}$ \\
\hline \multicolumn{10}{|c|}{$\begin{array}{l}\text { Monthly mean discharge, in second-feet } \\
\text { Runoff, in inches }\end{array}$} & $\begin{array}{r}17,110 \\
4.29\end{array}$ & $\begin{array}{r}6,642 \\
1.61\end{array}$ \\
\hline
\end{tabular}

Gage height, in feet, and discharge, in second-feet, at indicated time, 1940

\begin{tabular}{|c|c|c|c|c|c|c|c|c|c|c|c|c|}
\hline \multirow{2}{*}{ Hour } & \multicolumn{2}{|c|}{ Aug. 14} & \multicolumn{2}{|c|}{ Aug. 15} & \multicolumn{2}{|c|}{ Aug. 16} & \multicolumn{2}{|c|}{ Aug. 17} & \multicolumn{2}{|c|}{ Aug. 18} & \multicolumn{2}{|c|}{ Aug. 19} \\
\hline & $\begin{array}{c}\text { Gage } \\
\text { ht. }\end{array}$ & $\begin{array}{c}\text { Dis- } \\
\text { charge }\end{array}$ & $\begin{array}{c}\text { Gage } \\
\text { ht. }\end{array}$ & $\begin{array}{c}\text { Dis- } \\
\text { charge }\end{array}$ & $\begin{array}{c}\text { Gage } \\
\text { ht. }\end{array}$ & $\begin{array}{c}\text { Dis- } \\
\text { charge }\end{array}$ & $\begin{array}{l}\text { Gage } \\
\text { ht. }\end{array}$ & $\begin{array}{l}\text { Dis- } \\
\text { charge }\end{array}$ & $\begin{array}{c}\text { Gage } \\
\text { ht. }\end{array}$ & $\begin{array}{c}\text { Dis- } \\
\text { charge }\end{array}$ & $\begin{array}{l}\text { Gage } \\
\text { ht. }\end{array}$ & $\begin{array}{c}\text { Dis- } \\
\text { charge }\end{array}$ \\
\hline \multirow{5}{*}{$\begin{array}{l}1 \\
2 \\
3 \\
4 \\
5 \\
6\end{array}$} & 3.87 & 0 & 21.60 & 179,000 & & & & & & & & \\
\hline & 3.81 & & & & $14 . \overline{5}$ & $\mathbf{7 3}, \mathbf{3 0 0}$ & 12.06 & 47,800 & & & & \\
\hline & $\begin{array}{l}3.70 \\
3.67\end{array}$ & 3, & 24.00 & 230,000 & 14.10 & 65,800 & 11.90 & 46,200 & 9.62 & $2 \overline{9}, 200$ & 7.60 & 17,600 \\
\hline & 3.62 & & & 230,000 & & & & & & & & \\
\hline & 3.5 & & 23 & 228,000 & 13.55 & 60,800 & 11.65 & 43,800 & & & & \\
\hline \multirow{5}{*}{$\begin{array}{r}7 \\
8 \\
9 \\
10 \\
11 \\
\mathrm{~N}\end{array}$} & 3.55 & 3,360 & 23.50 & 219,000 & & & & & & & & \\
\hline & & & 23.00 & & 13.20 & 57,200 & 11.48 & 43,000 & 9.37 & 28,000 & 7.52 & 17,100 \\
\hline & 4.85 & 6 , & 21.70 & 181,000 & $\overline{13} .0 \overline{7}$ & $\mathbf{5 6}, \mathbf{3 0 0}$ & 11.37 & 42,300 & & & & \\
\hline & 5.67 & 9 & 21.00 & 168,000 & & & & & & & & \\
\hline & 6.08 & 11,000 & 20.25 & 154,000 & 13.05 & 55,400 & 11.18 & 40,800 & 9.03 & 25,400 & 7.51 & 17,100 \\
\hline \multirow{5}{*}{$\begin{array}{l}1 \\
2 \\
3 \\
4 \\
5 \\
6\end{array}$} & 6.32 & & & & & & & & & & & \\
\hline & 5 & 13 & 18.95 & 133 & 13.05 & 55,400 & 10.90 & $\mathbf{3 8}, \mathbf{6 0 0}$ & & & & \\
\hline & $\begin{array}{l}6.80 \\
7.10\end{array}$ & $\begin{array}{l}14 \\
15\end{array}$ & $\begin{array}{l}18.30 \\
17.70\end{array}$ & $\begin{array}{l}12 \\
11\end{array}$ & 13.02 & 55,400 & 10.58 & $\mathbf{3 6}, \mathbf{3 0 0}$ & 8.65 & 23,000 & 7.48 & 17,100 \\
\hline & 7.40 & 16 & 17 & 10 & & & & & & & & \\
\hline & 8.00 & 1 & 16.90 & 101,000 & 12.87 & 54,500 & 10.35 & $\mathbf{3 4}, 800$ & & & & \\
\hline \multirow{4}{*}{$\begin{array}{r}7 \\
8 \\
9 \\
10 \\
11 \\
12\end{array}$} & 9.70 & 30 , & 16.60 & & & & & & & & & \\
\hline & $\left|\begin{array}{l}11.80 \\
14.00\end{array}\right|$ & $\begin{array}{l}45 \\
64\end{array}$ & & $\begin{array}{l}93,600 \\
89,400\end{array}$ & 12.60 & 51,800 & 10.10 & 32,800 & 8.32 & 21,200 & 7.47 & 17,100 \\
\hline & 16.00 & 88 & 15.90 & 86 , & 12.36 & 50,200 & 9.87 & 31,400 & & & & \\
\hline & $\begin{array}{l}18.00 \\
20.30\end{array}$ & 1 & 1 & $\begin{array}{l}84,100 \\
80,300\end{array}$ & $\overline{12} .20$ & 48,600 & 9.80 & 30,600 & $\overline{7} . \overline{9}$ & 19,600 & $7 . \overline{2}$ & 16,600 \\
\hline
\end{tabular}

Supplemental ReCORD.-Aug. 15, 4:45 a.m., gage height, 24.08 feet; discharge, 232,000 second-feet.

\section{NEW RIVER AT CAPERTON, W. VA.}

Location.-Lat. $38^{\circ} 01^{\prime} 20^{\prime \prime}$, long. $81^{\circ} 01^{\prime} 45^{\prime \prime}$, at suspension foot-bridge at Caperton, Fayette County, 2 miles southeast of Nuttallburg, Fayette County. Datum of gage is 938.44 feet above mean sea level, datum of 1929.

DrainaGe AREA. - 6,826 square miles.

GAGE-HEIGHT RECORD.-Water-stage recorder graph, except for periods 11 p.m. Aug. 15 to 11 a.m. Aug. 18 and Sept. 16-21 where record was based on those for stations near Hinton and Kanawha River at Kanawha Falls.

DISCHARGE RECORD.-Stage-discharge relation defined by current-meter measurements up to 201,000 second-feet and extended above.

Maxima.-1940: Discharge, 244,000 second-feet 9 a.m. Aug. 15 (gage height, 36.0 feet). 


\section{FLOODS OF AUGUST 1940 IN THE SOUTHEASTERN STATES}

1928-39: Discharge, 142,000 second-feet Jan. 23, 1935 (gage height, 23.60 feet).

REMARKs.-Some regulation of low flow at Claytor Dam and power plant 127 miles upstream.

Mean discharge, in second-feet, 1940

\begin{tabular}{|c|c|c|c|c|c|c|c|c|c|c|c|}
\hline Day & Aug. & Sept. & Day & Aug. & Sept. & Day & Aug. & Sept. & Day & Aug. & Sept. \\
\hline $\begin{array}{l}1 \\
2 \\
3 \\
4 \\
5 \\
6 \\
7 \\
8\end{array}$ & $\begin{array}{r}15,100 \\
15,600 \\
9,500 \\
7,500 \\
4,820 \\
4,950 \\
6,410 \\
7,780\end{array}$ & $\begin{array}{r}44,900 \\
28,400 \\
18,300 \\
12,800 \\
11,600 \\
9,200 \\
8,340 \\
8,340\end{array}$ & $\begin{array}{r}9 \\
10 \\
11 \\
12 \\
13 \\
14 \\
15 \\
16\end{array}$ & $\begin{array}{r}7,220 \\
5,870 \\
5,210 \\
4,180 \\
2,380 \\
13,100 \\
177,000 \\
89,300\end{array}$ & $\begin{array}{l}6,540 \\
4,440 \\
6,950 \\
5,870 \\
6,000 \\
5,080 \\
4,950 \\
5,080\end{array}$ & $\begin{array}{l}17 \\
18 \\
19 \\
20 \\
21 \\
22 \\
23 \\
24\end{array}$ & $\begin{array}{l}59,300 \\
36,800 \\
25,700 \\
21,200 \\
16,600 \\
12,800 \\
10,500 \\
10,800\end{array}$ & $\begin{array}{l}3,000 \\
4,600 \\
5,200 \\
5,800 \\
5,080 \\
5,210 \\
3,700 \\
2,300\end{array}$ & $\begin{array}{l}25 \\
26 \\
27 \\
28 \\
29 \\
30 \\
31\end{array}$ & $\begin{array}{r}9,200 \\
8,060 \\
8,900 \\
9,800 \\
9,200 \\
10,800 \\
35,100\end{array}$ & $\begin{array}{r}5,210 \\
5,740 \\
4,560 \\
4,310 \\
4,560 \\
3,040 \\
-\end{array}$ \\
\hline $\begin{array}{l}\text { on } \\
\text { an }\end{array}$ & & & & & & & & & & $\begin{array}{r}21,310 \\
3.60 \\
\end{array}$ & $\begin{array}{r}8,303 \\
1.36 \\
\end{array}$ \\
\hline
\end{tabular}

Gage height, in feet, and discharge, in second-feet, at indicated time, 1940

\begin{tabular}{|c|c|c|c|c|c|c|c|c|c|c|c|c|}
\hline \multirow{2}{*}{ Hour } & \multicolumn{2}{|c|}{ Aug. 14} & \multicolumn{2}{|c|}{ Aug. 15} & \multicolumn{2}{|c|}{ Aug. 16} & \multicolumn{2}{|c|}{ Aug. 17} & \multicolumn{2}{|c|}{ Aug. 18} & \multicolumn{2}{|c|}{ Aug. 19} \\
\hline & $\begin{array}{c}\text { Gage } \\
\text { ht. }\end{array}$ & $\begin{array}{c}\text { Dis- } \\
\text { charge }\end{array}$ & $\begin{array}{c}\text { Gage } \\
\text { ht. }\end{array}$ & $\begin{array}{c}\text { Dis- } \\
\text { charge }\end{array}$ & $\begin{array}{c}\text { Gage } \\
\text { ht. }\end{array}$ & $\begin{array}{c}\text { Dis- } \\
\text { charge }\end{array}$ & $\begin{array}{l}\text { Gage } \\
\text { ht. }\end{array}$ & $\begin{array}{c}\text { Dis- } \\
\text { charge }\end{array}$ & $\begin{array}{l}\text { Gage } \\
\text { ht. }\end{array}$ & $\begin{array}{c}\text { Dis- } \\
\text { charge }\end{array}$ & $\begin{array}{c}\text { Gage } \\
\text { ht. }\end{array}$ & $\begin{array}{c}\text { Dis- } \\
\text { charge }\end{array}$ \\
\hline \multirow{5}{*}{$\begin{array}{l}1 \\
2 \\
3 \\
4 \\
5 \\
6\end{array}$} & 2.95 & 16 & 13.00 & 600 & & & & & & & & \\
\hline & & & & & 21.00 & 120,000 & 14.80 & 69,900 & & & & \\
\hline & 65 & $\begin{array}{l}3,940 \\
5,080\end{array}$ & $\left|\begin{array}{l}22.00 \\
26.50\end{array}\right|$ & $\begin{array}{l}128,000 \\
165,000\end{array}$ & 20.00 & 112,000 & 14.55 & $-68, \overline{300}$ & $11 . \overline{40}$ & 43,400 & $9 . \overline{40}$ & $2 \overline{9}$ \\
\hline & 4.27 & 5,470 & 29.00 & 186,000 & & & & & & & & \\
\hline & 20 & 5,600 & 32.20 & 213,000 & 19.10 & 105,000 & 14.35 & 66,700 & & & & \\
\hline \multirow{5}{*}{$\begin{array}{c}7 \\
8 \\
9 \\
10 \\
11 \\
\text { N }\end{array}$} & 4 & 5,600 & & 2 & & & & & & & & \\
\hline & & 740 & 35.50 & 24 & 18.25 & 97,300 & 14.10 & 64,300 & 10.90 & 39,700 & 9.17 & 27,700 \\
\hline & & 50 & & & & & & & & & & \\
\hline & 497 & 7360 & 35.00 & & & & & & & & & \\
\hline & 51 & 政 & 3400 & 2 & 16.75 & 86,000 & 13.55 & 60,300 & 10.45 & 36,100 & 8.80 & 25,100 \\
\hline \multirow{4}{*}{$\begin{array}{l}1 \\
2 \\
3 \\
4 \\
5 \\
6\end{array}$} & 5.42 & 8,620 & 32.50 & 215,000 & & & & & & & & \\
\hline & $\begin{array}{l}5.80 \\
6.35\end{array}$ & $\begin{array}{r}9,8 \\
12,0\end{array}$ & $\begin{array}{l}30 \\
30\end{array}$ & & 16.15 & 81 & 13.30 & 00 & -- & & & \\
\hline & 6.75 & 13,700 & $\left|\begin{array}{l}29.000 \\
29.00\end{array}\right|$ & 186,000 & 15.65 & 76,300 & 13.00 & 55,600 & 10.04 & 33,200 & 8.60 & 23,800 \\
\hline & $\begin{array}{l}7.15 \\
7.80\end{array}$ & $\begin{array}{l}15,600 \\
18,800\end{array}$ & $\begin{array}{l}27.50 \\
26.20\end{array} \mid$ & $\begin{array}{l}174,000 \\
163,000\end{array}$ & $\overline{15} \cdot \overline{3} \overline{5}$ & $\overline{74}, \overline{700}$ & 12.70 & $\overline{53}, \overline{300}$ & & & $\cdots$ & \\
\hline \multirow{5}{*}{$\begin{array}{r}7 \\
8 \\
9 \\
10 \\
11 \\
12\end{array}$} & 8.60 & & 2 & & & & & & & & & \\
\hline & & & 24.50 & & 15.20 & 73,100 & 12.45 & 51,000 & 9.75 & 31,800 & 8.50 & 23,100 \\
\hline & & & $\begin{array}{l}23.00 \\
23.00\end{array}$ & & 15.15 & 73,100 & $\overline{12} . \overline{15}$ & 49,400 & & & . & \\
\hline & & & & & & & & & & & & \\
\hline & 10.15 & 34,600 & $|22.00|$ & 128,000 & $|15.00|$ & 71,500 & $|11.90|$ & 47,200 & 9.54 & 29,800 & 8.40 & 22,400 \\
\hline
\end{tabular}

\section{KANAWHA RIVER AT KANAWHA FALLS, W. VA.}

Location.-Lat. $38^{\circ} 08^{\prime} 20^{\prime \prime}$, long. $81^{\circ} 12^{\prime} 45^{\prime \prime}$, at toll bridge, three-quarters of a mile downstream from village of Kanawha Falls, Fayette County, 2 miles downstream from Gauley Bridge, and 2 miles downstream from confluence of New River and Gauley River. Datum of gage is 623.20 feet above mean sea level, datum of 1929 .

Drainage AREA. $-8,367$ square miles.

GAGE-HEIGHT RECORD.-Water-stage recorder graph, except for period of doubtful gage heights, Aug. 20 to Sept. 14, where record was based on those for stations on New River at Caperton and Gauley River at Belva.

DISCHARGE RECORD.-Stage-discharge relation defined by current-meter measurements up to 150,000 second-feet and extended above on basis of area-velocity studies and logarithmic plotting.

Maxima.-1940: Discharge, 248,000 second-feet 11:30 a.m. Aug. 15 (gage height, 29.60 feet). 
1877-1939: Discharge, 320,0-0 second-feet (revised) Sept. 14, 1878 (gage height, 37.8 feet, site then in use and present datum).

Mean discharge, in second-feet, 1940

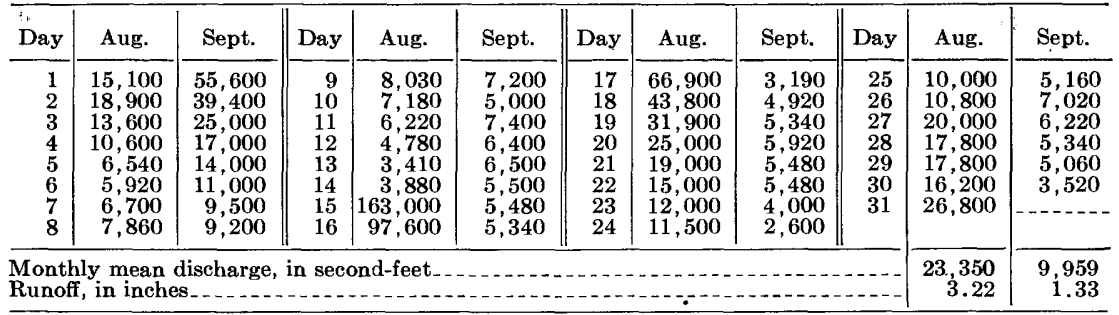

Gage height, in feet, and discharge, in second-feet, at indicated time, 1940

\begin{tabular}{|c|c|c|c|c|c|c|c|c|c|c|c|c|}
\hline \multirow{2}{*}{ our } & \multicolumn{2}{|c|}{ Aug. 14} & \multicolumn{2}{|c|}{ Aug. 15} & \multicolumn{2}{|c|}{ Aug. 16} & \multicolumn{2}{|c|}{ Aug. 17} & \multicolumn{2}{|c|}{ Aug. 18} & \multicolumn{2}{|c|}{ Aug. 19} \\
\hline & $\begin{array}{c}\text { Gage } \\
\text { ht. }\end{array}$ & $\begin{array}{c}\text { Dis- } \\
\text { charge }\end{array}$ & $\begin{array}{c}\text { Gage } \\
\text { ht. }\end{array}$ & $\begin{array}{c}\text { Dis- } \\
\text { charge }\end{array}$ & $\begin{array}{c}\text { Gage } \\
\text { ht. }\end{array}$ & $\begin{array}{c}\text { Dis- } \\
\text { charge }\end{array}$ & $\begin{array}{l}\text { Gage } \\
{ }^{n} \text { ht. }\end{array}$ & $\begin{array}{c}\text { Dis- } \\
\text { charge }\end{array}$ & ht. & $\begin{array}{c}\text { Dis- } \\
\text { charge }\end{array}$ & $\begin{array}{c}\text { Gage } \\
\text { ht. }\end{array}$ & $\begin{array}{c}\text { Dis- } \\
\text { charge }\end{array}$ \\
\hline $\begin{array}{l}1 \\
2\end{array}$ & & & $\begin{array}{l}0 \\
0\end{array}$ & & 18.30 & 128,000 & 12.88 & 78,600 & & & & \\
\hline $\begin{array}{l}3 \\
4\end{array}$ & & & $\begin{array}{l}5.70 \\
7.00\end{array}$ & 23,000 & & 1 & & & 9 & & & \\
\hline 5 & & & 12.70 & 76,800 & & & 1 & & 9. & & & 500 \\
\hline 6 & 0.75 & 2,880 & 18.80 & 134,000 & 16.80 & 114,000 & 12.28 & 73,200 & -- & - & -- & \\
\hline 7 & & & 23.00 & & & & & & 3 & & | & \\
\hline$\stackrel{\circ}{9}$ & & & $\left|\begin{array}{l}20.00 \\
27.60\end{array}\right|$ & $\begin{array}{l}200 \\
226\end{array}$ & & 10 & & 00 & 9.03 & & .32 & 200 \\
\hline 10 & & & 28.60 & 237,000 & 15.13 & 98,400 & 11.76 & 68,700 & & & & \\
\hline $\mathrm{N}$ & 1.12 & 3,640 & $\left|\begin{array}{l}29.40 \\
29.60\end{array}\right|$ & 248,000 & 14.60 & 93,900 & $\overline{1} \overline{1.57}$ & $6 \overline{6}, \overline{900}$ & 8.72 & 43,000 & 7.06 & 31,900 \\
\hline 1 & & & 29 & & & & & & & & & \\
\hline 3 & & & $\left|\begin{array}{l}28.60 \\
27.50\end{array}\right|$ & & & 00 & 32 & 00 & & & & \\
\hline 4 & & & 26.50 & 214,000 & 13.60 & 84,900 & 11.10 & 62,400 & 8.40 & 40,800 & 6.80 & 30,000 \\
\hline b & 1.49 & 4,650 & 24.45 & 191,000 & 13.25 & 81,300 & 10.92 & 60,600 & & & & \\
\hline $\begin{array}{l}7 \\
8\end{array}$ & & & $\begin{array}{l}23.50 \\
22.50\end{array}$ & 18 & 13.13 & 80,400 & 10.65 & 58,100 & 8.00 & 38,000 & 6.60 & 28,600 \\
\hline 9 & & & & & & & & & & & & \\
\hline 10 & & & 20.90 & 154 & 13.08 & 80,400 & 10.40 & 56,400 & & & ..... & \\
\hline 12 & 2.48 & 7,690 & 19 &, 000 & $|\overline{13} . \overline{0}|$ & 79,500 & $|\overline{10.13}|$ & 53,800 & 7.72 & 35,900 & $6 . \overline{4} \mid$ & $2 \overline{7}, \overline{4} 00$ \\
\hline
\end{tabular}

Supplemental ReCoRD.--Aug. 15, 11:30 a.m., gage height, 29.60 feet; discharge, 248,000 second-feet.

KANAWHA RIVER AT CHARLESTON, W. VA.

LOCATION.-Lat. $38^{\circ} 22^{\prime} 10^{\prime \prime}$, long. $81^{\circ} 42^{\prime} 05^{\prime \prime}$, at old lock $6,1.0$ mile upstream from Davis Creek, 11/2 miles downstream from Twomile Creek, 2.0 miles downstream from Patrick Street Bridge in Charleston, Kanawha County, and 3.5 miles downstream from Elk River. Datum of gage is 548.00 feet above mean sea level, datum of 1929 (levels by Corps of Engineers, War Department). Auxiliary gage used in determining slope, lat. $38^{\circ} 21^{\prime} 15^{\prime \prime}$, long. $81^{\circ} 38^{\prime} 35^{\prime \prime}$, at Kanawha Boulevard Bridge over Elk River at its mouth.

DrainAGE AREA. - 10,420 square miles at the measuring section at Patrick Street Bridge.

GAGE-HEIGHT RECORD.-Water-stage recorder graphs except for stages above $\mathbf{1 4 . 6}$ feet on the auxiliary gage. The auxiliary gage becomes submerged above 14.6 feet, and gage heights are obtained from graph based on readings obtained from wire-weight gage in the mouth of Elk River, about 300 feet upstream from recorder. Gage heights given are those for gage at old lock 6 .

DISCHARGE RECORD.-Stage-slope-discharge relation defined by current-meter meas- 


\section{FLOODS OF AUGUST 1940 IN THE SOUTHEASTERN STATES}

urements up to 214,000 second-feet. Discharge computed using fall between gages as a factor.

Maxima.-1940: Discharge, 216,000 second-feet 8 p.m. Aug. 15; gage height, 38.25 feet at 9 p.m. Aug. 15.

REMARKs.-Low flow regulated by power plants in Virginia and at London and Marmet in West Virginia.

Mean discharge, in second-feet, 1940

\begin{tabular}{|c|c|c|c|c|c|c|c|c|c|c|c|}
\hline Day & Aug. & Sept. & Day & Aug. & Sept. & Day & Aug. & Sept. & Day & Aug. & Sept. \\
\hline $\begin{array}{l}1 \\
2 \\
3 \\
4 \\
5 \\
6 \\
7 \\
8\end{array}$ & $\begin{array}{r}17,700 \\
19,800 \\
14,100 \\
8,250 \\
6,600 \\
6,600 \\
8,000 \\
9,170\end{array}$ & $\begin{array}{r}41,300 \\
25,700 \\
21,700 \\
16,200 \\
12,000 \\
10,300 \\
7,680\end{array}$ & $\begin{array}{r}9 \\
10 \\
11 \\
12 \\
13 \\
14 \\
15 \\
16\end{array}$ & $\begin{array}{r}7,220 \\
5,350 \\
3,390 \\
2,330 \\
2,330 \\
6,320 \\
130,000 \\
120,000\end{array}$ & $\begin{array}{l}5,340 \\
4,860 \\
6,330 \\
5,840 \\
5,170 \\
5,840 \\
5,840\end{array}$ & $\begin{array}{l}17 \\
18 \\
19 \\
20 \\
21 \\
22 \\
23 \\
24\end{array}$ & $\begin{array}{l}62,900 \\
41,200 \\
29,900 \\
24,400 \\
19,900 \\
15,500 \\
12,900 \\
11,700\end{array}$ & & $\begin{array}{l}25 \\
26 \\
27 \\
28 \\
29 \\
30 \\
31\end{array}$ & $\begin{array}{l}10,200 \\
12,900 \\
24,000 \\
20,200 \\
19,800 \\
17,500 \\
26,700\end{array}$ & $\begin{array}{r}9,770 \\
13,100 \\
8,650 \\
6,320 \\
3,870 \\
3,870 \\
-\end{array}$ \\
\hline \multicolumn{10}{|c|}{$\begin{array}{l}\text { Ionthly mean discharge, in second-feet } \\
\text { unoff, in inches }\end{array}$} & $\begin{array}{r}23,120 \\
2.56\end{array}$ & $\begin{array}{r}10,840 \\
1.16 \\
\end{array}$ \\
\hline
\end{tabular}

Gage height, in feet, and discharge, in second-feet, at indicated time, 1940

\begin{tabular}{|c|c|c|c|c|c|c|c|c|c|c|c|c|}
\hline \multirow{2}{*}{ Hour } & \multicolumn{2}{|c|}{ Aug. 14} & \multicolumn{2}{|c|}{ Aug. 15} & \multicolumn{2}{|c|}{ Aug. 16} & \multicolumn{2}{|c|}{ Aug. 17} & \multicolumn{2}{|c|}{ Aug. 18} & \multicolumn{2}{|c|}{ Aug. 19} \\
\hline & $\begin{array}{c}\text { Gage } \\
\text { ht. }\end{array}$ & $\begin{array}{l}\text { Dis- } \\
\text { charge }\end{array}$ & $\begin{array}{c}\text { Gage } \\
\text { ht. }\end{array}$ & $\begin{array}{c}\text { Dis- } \\
\text { charge }\end{array}$ & $\begin{array}{c}\text { Gage } \\
\text { ht. }\end{array}$ & $\begin{array}{c}\text { Dis- } \\
\text { charge }\end{array}$ & $\begin{array}{l}\text { Gage } \\
\text { ht. }\end{array}$ & $\begin{array}{l}\text { Dis- } \\
\text { charge }\end{array}$ & $\begin{array}{c}\text { Gage } \\
\text { ht. }\end{array}$ & $\underset{\text { cha }}{\mathrm{D}}$ & $\begin{array}{c}\text { Gage } \\
\text { ht. }\end{array}$ & $\underset{\text { ch }}{\mathrm{D}}$ \\
\hline \multirow{3}{*}{$\begin{array}{l}1 \\
2 \\
3 \\
4 \\
5 \\
6\end{array}$} & & & \multirow{3}{*}{$\begin{array}{l}18.60 \\
19.04 \\
19.42 \\
19.72 \\
19.95 \\
21.00\end{array}$} & \multirow{3}{*}{$\begin{array}{l}21,900 \\
25,000 \\
28,600 \\
32,400 \\
42,800 \\
57,400\end{array}$} & \multirow{3}{*}{$\begin{array}{l}37.47 \\
37.05 \\
36.60 \\
36.10 \\
35.55 \\
35.00\end{array}$} & \multirow{3}{*}{$\begin{array}{l}197,000 \\
187,000 \\
180,000 \\
170,000 \\
162,000 \\
154,000\end{array}$} & 24.88 & 69,300 & & & & \\
\hline & 17.99 & 4,860 & & & & & 24.77 & 68,900 & $\overline{22.06}$ & 43,900 & & \\
\hline & & & & & & & 24.73 & 68,500 & & & 19.84 & $\overline{31}, 000$ \\
\hline \multirow{4}{*}{$\begin{array}{r}7 \\
8 \\
9 \\
10 \\
11 \\
\mathrm{~N}\end{array}$} & & & \multirow{4}{*}{$\left|\begin{array}{l}22.35 \\
24.00 \\
25.90 \\
27.90 \\
29.50 \\
31.20\end{array}\right|$} & \multirow{4}{*}{$\begin{array}{r}73,700 \\
82,100 \\
94,900 \\
103,000 \\
119,000 \\
136,000\end{array}$} & \multirow{4}{*}{$\mid \begin{array}{l}34.43 \\
33.87 \\
33.30 \\
32.73 \\
32.20 \\
31.60\end{array}$} & \multirow{4}{*}{$\begin{array}{l}142,000 \\
137,000 \\
130,000 \\
123,000 \\
115,000 \\
110,000\end{array}$} & & & & & & \\
\hline & 17.93 & 1,850 & & & & & 24.56 & 68,600 & 21.19 & 43,700 & & \\
\hline & & & & & & & 24.40 & 66,700 & & & & \\
\hline &.$\overline{0}$ & 9,870 & & & & & 24.16 & 65,500 & 20.80 & $4 \overline{1}, 800$ & 19.63 & 30,200 \\
\hline \multirow{4}{*}{$\begin{array}{l}1 \\
2 \\
3 \\
4 \\
5 \\
5 \\
6\end{array}$} & & & \multirow{4}{*}{\multicolumn{2}{|c|}{\begin{tabular}{|l|l}
32.70 & 153,000 \\
34.00 & 173,000 \\
35.25 & 185,000 \\
36.25 & 196,000 \\
36.92 & 205,000 \\
37.50 & 211,000
\end{tabular}}} & \multirow{4}{*}{$\begin{array}{l}30.90 \\
30.20 \\
29.60 \\
29.00 \\
28.43 \\
27.88\end{array}$} & \multirow{4}{*}{$\begin{array}{r}105,000 \\
104,000 \\
98,600 \\
92,200 \\
87,000 \\
84,800\end{array}$} & & & & & & \\
\hline & & & & & & & 23.92 & 62,400 & & & & \\
\hline & 18.04 & 6,820 & & & & & $\overline{2} \overline{3} \cdot \overline{6} \overline{5}$ & 60,400 & $20 . \overline{70}$ & $\overline{38}, \overline{700}$ & & \\
\hline & & & & & & & 23.33 & 58,600 & & & $\overline{19} . \overline{20}$ & $\overline{25}, \overline{900}$ \\
\hline 7 & 18.17 & 8,510 & & & & & 23.06 & 56,100 & 20.37 & 35,900 & & \\
\hline 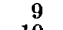 & & & & & & & & & & & & \\
\hline 1 & & & & & & & & & & & & \\
\hline & $|\overline{18} . \overline{35}|$ & 17,600 & & & & & $2 \overline{2} .6$ & 48,500 & $|20.00|$ & 33,900 & 19.18 & 25,600 \\
\hline
\end{tabular}

NORTH FORK NEW RIVER AT CRUMPLER, N. C.

LOCATION.-Lat. $36^{\circ} 31^{\prime} 30^{\prime \prime}$, long. $81^{\circ} 23^{\prime} 35^{\prime \prime}$, a quarter of a mile downstream from State highway bridge at Crumpler, Ashe County, and 6 miles upstream from confluence with South Fork.

Drainage AREA.-277 square miles.

GAGE-HEIGHT RECORD.-Recorder house and water-stage recorder were destroyed by the flood on Aug. 13. No gage-height record Aug. 1-6, 8-25, 30, Sept. 14-19. Staff gage read once or twice daily Aug. 7, 26-29, Aug. 31 to Sept. 13, Sept. 20-30. Graphs based on gage readings used Aug. 29, Aug. 31 to Sept. 5, Sept. $10,21$.

DISCHARGE RECORD.-Stage-discharge relation for 1940 defined by current-meter measurements up to 2,600 second-feet and extended logarithmically to slopearea measurement at erest gage height. Gage heights used to half-tenths be- 
tween 2.5 and 5.3 feet; hundredths below and tenths above these limits. Discharge for periods of no gage-height record is based on records for nearby streams.

Maxima.-1940: Discharge, 79,400 second-feet 2 a.m. Aug. 14 (gage height, 23.0 feet, revised, from floodmarks).

1908-16, 1928-39: Discharge, 45,000 second-feet (revised on basis of 1940 rating) July 15, 1916 (gage height, about 16.4 feet, from flood reference marks referred to 1940 floodmarks at farm buildings three-quarters of a mile above station).

Flood of 1878 reached a stage of about 17.6 feet, from flood reference marks referred to 1940 floodmarks at farm buildings three-quarters of a mile above station (discharge, 51,000 second-feet, from 1940 rating).

REMARKs.--Flood runoff not affected by artificial storage.

Mean discharge, in second-feet, 1940

\begin{tabular}{|c|c|c|c|c|c|c|c|c|c|c|c|}
\hline Day & Aug. & Sept. & Day & Aug. & Sept. & Day & Aug. & Sept. & Day & Aug. & Sept. \\
\hline $\begin{array}{l}1 \\
2 \\
3 \\
4 \\
5 \\
6 \\
7 \\
8\end{array}$ & $\begin{array}{l}850 \\
550 \\
400 \\
360 \\
400 \\
500 \\
672 \\
500\end{array}$ & $\begin{array}{l}\mathbf{9 4 6} \\
\mathbf{6 9 7} \\
\mathbf{5 9 2} \\
\mathbf{5 3 7} \\
\mathbf{6 0 2} \\
\mathbf{4 6 3} \\
\mathbf{4 3 4} \\
\mathbf{3 9 4}\end{array}$ & $\begin{array}{r}9 \\
10 \\
11 \\
12 \\
13 \\
14 \\
15 \\
16\end{array}$ & $\begin{array}{r}400 \\
340 \\
380 \\
800 \\
12,000 \\
36,000 \\
6,600 \\
3,200\end{array}$ & $\begin{array}{l}377 \\
428 \\
475 \\
377 \\
366 \\
360 \\
360 \\
350\end{array}$ & $\begin{array}{l}17 \\
18 \\
19 \\
20 \\
21 \\
22 \\
23 \\
24\end{array}$ & $\begin{array}{r}2,200 \\
1,700 \\
1,300 \\
1,100 \\
900 \\
800 \\
700 \\
600\end{array}$ & $\begin{array}{l}\mathbf{3 4 0} \\
340 \\
340 \\
323 \\
292 \\
258 \\
243 \\
238\end{array}$ & $\begin{array}{l}25 \\
26 \\
27 \\
28 \\
29 \\
30 \\
31\end{array}$ & $\begin{array}{r}500 \\
481 \\
469 \\
451 \\
452 \\
2,400 \\
1,820\end{array}$ & $\begin{array}{l}243 \\
318 \\
253 \\
234 \\
234 \\
215\end{array}$ \\
\hline \multicolumn{10}{|c|}{$\begin{array}{l}\text { Monthly mean discharge, in second-feet } \\
\text { Runoff, in inches }\end{array}$} & $\begin{array}{l}2,575 \\
10.72\end{array}$ & $\begin{array}{r}388 \\
1.56 \\
\end{array}$ \\
\hline
\end{tabular}

REED CREEK AT GRAHAMS FORGE, VA.

Location.-Lat. $36^{\circ} 56^{\prime} 20^{\prime \prime}$, long. $80^{\circ} 53^{\prime} 15^{\prime \prime}$, at highway bridge at Grahams Forge, Wythe County, 21/2 miles downstream from Glade Creek. Datum of gage is 1,924.65 feet above mean sea level, datum of 1929 .

Drainage AREA. -247 square miles.

GAGE-HEIGHT RECORD.-Water-stage recorder graph.

DISCHARGE RECORD.- Stage-discharge relation defined by current-meter measurements up to 2,300 second-feet. Gage heights used to half-tenths between 3.7 and 5.4 feet; hundredths below and tenths above these limits.

Maxima.-1940: Diseharge, 3,730 second-feet 10 p.m. Aug. 14 (gage height, 4.82 feet).

1908-16, 1927-39: Gage height observed, 12.1 feet July 16, 1916 (discharge not determined).

REMARKs.-Some regulation at low flow by mill 300 feet upstream.

Mean discharge, in second-feet, 1940

\begin{tabular}{|c|c|c|c|c|c|c|c|c|c|c|c|}
\hline Day & Aug. & Sept. & Day & Aug. & Sept. & Day & Aug. & Sept. & Day & Aug. & Sept. \\
\hline $\begin{array}{l}1 \\
2 \\
3 \\
4 \\
5 \\
6 \\
7 \\
8\end{array}$ & $\begin{array}{r}424 \\
266 \\
172 \\
133 \\
117 \\
114 \\
123 \\
112\end{array}$ & $\begin{array}{l}226 \\
186 \\
167 \\
151 \\
143 \\
153 \\
133 \\
127\end{array}$ & $\begin{array}{r}9 \\
10 \\
11 \\
12 \\
13 \\
14 \\
15 \\
16\end{array}$ & $\begin{array}{r}100 \\
88 \\
88 \\
91 \\
96 \\
1,440 \\
2,200 \\
1,820\end{array}$ & $\begin{array}{l}117 \\
117 \\
117 \\
112 \\
106 \\
106 \\
103 \\
100\end{array}$ & $\begin{array}{l}17 \\
18 \\
19 \\
20 \\
21 \\
22 \\
23 \\
24\end{array}$ & $\begin{array}{r}1,020 \\
585 \\
856 \\
663 \\
419 \\
344 \\
286 \\
244\end{array}$ & $\begin{array}{l}\mathbf{9 8} \\
\mathbf{9 5} \\
\mathbf{9 5} \\
\mathbf{9 5} \\
\mathbf{9 0} \\
\mathbf{8 8} \\
\mathbf{8 8} \\
\mathbf{8 8}\end{array}$ & $\begin{array}{l}25 \\
26 \\
27 \\
28 \\
29 \\
30 \\
31\end{array}$ & $\begin{array}{l}214 \\
198 \\
179 \\
168 \\
168 \\
385 \\
327\end{array}$ & $\begin{array}{l}\mathbf{9 0} \\
90 \\
88 \\
88 \\
85 \\
83\end{array}$ \\
\hline \multicolumn{10}{|c|}{$\begin{array}{l}\text { Monthly mean discharge, in second-feet } \\
\text { Runoff, in inches }\end{array}$} & $\begin{array}{r}434 \\
2.03\end{array}$ & $\begin{array}{r}114 \\
0.52\end{array}$ \\
\hline
\end{tabular}


316 FLOODS OF AUGUST 1940 IN THE SOUTHEASTERN STATES

Gage height, in feet, and discharge, in second-feet, at indicated time, 1940

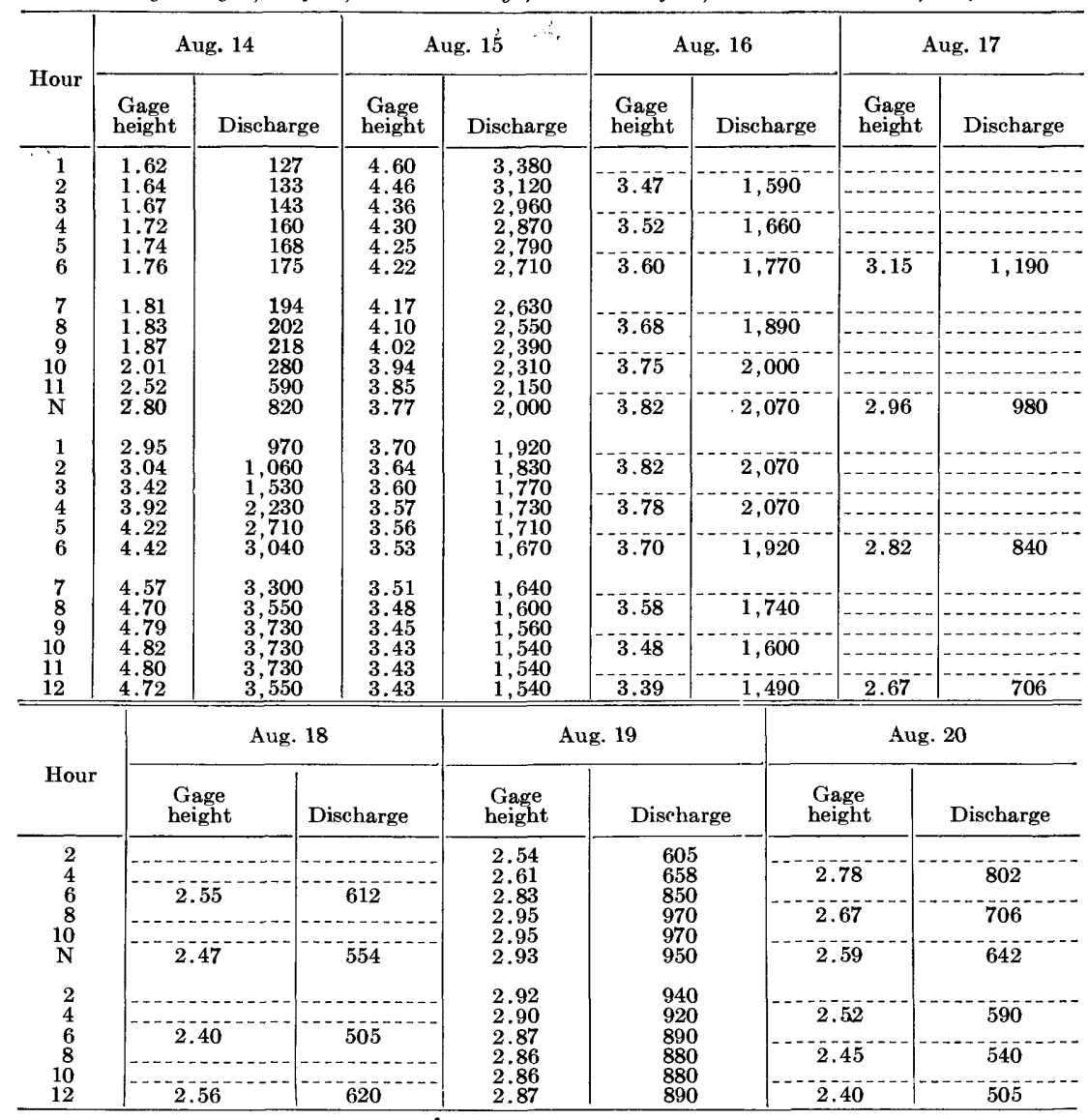

HIG REED ISLAND CREEK NEAR ALLISONIA, VA.

Location.-Lat. $36^{\circ} 53^{\prime}$, long. $80^{\circ} 44^{\prime}$, 700 feet downstream from highway bridge, $31 / 2$ miles southeast of Allisonia, Pulaski County, 4 miles upstream from Little Reed Island Creek, and 41/2 miles upstream from mouth. Datum of gage is $1,902.74$ feet above mean sea level, datum of 1929 .

Drainage AREA.-278 square miles.

GAGE-HEIGHT RECORD.-Water-stage recorder graph.

DISCHARGE RECORD.-Stage-discharge relation defined by current-meter measurements up to 2,900 second-feet and extended to erest gage height by logarithmic plotting on basis of comparisons of flood records with those for other stations in New River Basin. Gage heights used to half-tenths between 3.9 and 5.7 feet; hundredths below and tenths above these limits.

MAXima.-1940: Discharge, 20,900 second-feet 7:45 a.m. Aug. 14 (gage height, 11.70 feet).

1908-16, 1939: Gage height, 14.8 feet July 16, 1916, site and datum then in use, caused partly by backwater from New River (discharge not determined). 
KANAWHA RIVER BASIN

Mean discharge, in second-feet, 1940

\begin{tabular}{|c|c|c|c|c|c|c|c|c|c|c|c|}
\hline Day & Aug. & Sept. & Day & Aug. & Sept. & Day & Aug. & Sept. & Day & Aug. & Sept. \\
\hline 1 & 452 & 1,160 & 9 & 262 & 452 & 17 & 1,950 & 379 & 25 & & \\
\hline 2 & 340 & 747 & 10 & 245 & 452 & 18 & 1,210 & 379 & 26 & 509 & 544 \\
\hline 3 & 300 & 624 & 11 & 279 & 472 & 19 & 1,120 & 374 & 27 & 504 & 384 \\
\hline 4 & $\begin{array}{l}292 \\
296\end{array}$ & $\begin{array}{l}570 \\
580\end{array}$ & 12 & & $\begin{array}{l}427 \\
412\end{array}$ & 20 & 771 & 365 & 28 & $\begin{array}{l}493 \\
483\end{array}$ & $\begin{array}{l}360 \\
351\end{array}$ \\
\hline 6 & 296 & 514 & 14 & 12,300 & 403 & 22 & 608 & 346 & 30 & 2,600 & \\
\hline & 318 & & 15 & & & & 553 & 337 & & & \\
\hline 8 & 365 & 462 & 16 & 2,860 & 393 & 24 & 509 & 337 & & & \\
\hline \multicolumn{10}{|c|}{$\begin{array}{l}\text { Monthly mean discharge, in second-feet. } \\
\text { Runoff, in inches }\end{array}$} & $\begin{array}{r}1,234 \\
5.12\end{array}$ & $\begin{array}{r}472 \\
1.90\end{array}$ \\
\hline
\end{tabular}

Gage height, in feet, and discharge, in second-feet, at indicated time, 1940

\begin{tabular}{|c|c|c|c|c|c|c|c|c|c|c|c|c|}
\hline \multirow{2}{*}{ Iour } & \multicolumn{2}{|c|}{ Aug. 12} & \multicolumn{2}{|c|}{ Aug. 13} & \multicolumn{2}{|c|}{ Aug. 14} & \multicolumn{2}{|c|}{ Aug. 15} & \multicolumn{2}{|c|}{ Aug. 16} & \multicolumn{2}{|c|}{ Aug. 17} \\
\hline & $\begin{array}{c}\text { Gage } \\
\text { ht. }\end{array}$ & $\begin{array}{c}\text { Dis- } \\
\text { eharge }\end{array}$ & $\begin{array}{c}\text { Gage } \\
\text { ht. }\end{array}$ & $\begin{array}{c}\text { Dis- } \\
\text { charge }\end{array}$ & $\begin{array}{c}\text { Gage } \\
\text { ht. }\end{array}$ & $\begin{array}{l}\text { Dis- } \\
\text { charge }\end{array}$ & $\begin{array}{c}\text { Gage } \\
\text { ht. }\end{array}$ & $\begin{array}{l}\text { Dis- } \\
\text { charge }\end{array}$ & $\begin{array}{c}\text { Gage } \\
\text { ht. }\end{array}$ & $\begin{array}{c}\text { Dis- } \\
\text { charge }\end{array}$ & $\begin{array}{c}\text { Gage } \\
\text { ht. }\end{array}$ & $\begin{array}{c}\text { Dis- } \\
\text { charge }\end{array}$ \\
\hline \multirow{3}{*}{$\begin{array}{l}1 \\
2 \\
3 \\
4 \\
5 \\
6\end{array}$} & 2.76 & $36 \overline{7}$ & 3.12 & 562 & \multirow{3}{*}{$\begin{array}{l}3.62 \\
4.03 \\
4.25 \\
4.85 \\
6.40 \\
8.45\end{array}$} & \multirow{3}{*}{$\begin{array}{r}917 \\
1,320 \\
1,520 \\
2,200 \\
4,020 \\
7,690\end{array}$} & \multirow{3}{*}{$\begin{array}{l}7.65 \\
7.25 \\
6.90 \\
6.55 \\
6.27 \\
6.05\end{array}$} & \multirow{3}{*}{$\begin{array}{l}5,920 \\
5,210 \\
4,740 \\
4,300 \\
3,880 \\
3,490\end{array}$} & 5.89 & 3,360 & 4.63 & 1,960 \\
\hline & 2.77 & 372 & 3.05 & 520 & & & & & $5 . \overline{8}$ & 3,360 & $-\overline{4} . \overline{5}$ & $\overline{1}, \overline{900}$ \\
\hline & $2 . \overline{9}$ & $46 \overline{2}$ & 2.98 & 479 & & & & & $-\overline{5} . \overline{8} \overline{5}$ & 3,230 & $4 . \overline{6}$ & $\overline{1}, \overline{9} \overline{0}$ \\
\hline \multirow{3}{*}{$\begin{array}{r}7 \\
8 \\
9 \\
10 \\
11 \\
\mathrm{~N}\end{array}$} & 2.97 & $47 \overline{4}$ & 2.94 & 457 & \multirow{3}{*}{$\begin{array}{l}11.10 \\
11.67 \\
11.45 \\
11.53 \\
11.64 \\
11.47\end{array}$} & \multirow{3}{*}{$\begin{array}{l}17,900 \\
20,900 \\
19,400 \\
19,900 \\
20,400 \\
19,900\end{array}$} & \multirow{3}{*}{$\begin{array}{l}5.85 \\
5.68 \\
5.55 \\
5.45 \\
5.37 \\
5.30\end{array}$} & \multirow{3}{*}{$\begin{array}{l}3,230 \\
3,110 \\
2,930 \\
2,810 \\
2,690 \\
2,630\end{array}$} & 5.80 & 3,230 & 4.85 & 2,200 \\
\hline & 2.93 & 452 & 2.90 & 435 & & & & & 5.67 & 3,050 & 5.03 & 2,460 \\
\hline & $2.9 \overline{4}$ & $4 \overline{5} \overline{7}$ & 2.89 & 430 & & & & & $\overline{5} . \overline{5} 3$ & 2,930 & 4.87 & 2,200 \\
\hline \multirow{3}{*}{$\begin{array}{l}1 \\
2 \\
3 \\
4 \\
5 \\
6\end{array}$} & {$[3.17$} & $5 \overline{9}$ & 2.89 & 430 & \multirow{3}{*}{$\mid$\begin{tabular}{l|}
11.05 \\
10.67 \\
10.58 \\
10.52 \\
10.62 \\
10.68
\end{tabular}} & \multirow{3}{*}{$\begin{array}{l}17,400 \\
16,000 \\
15,600 \\
15,200 \\
15,600 \\
16,000\end{array}$} & \multirow{3}{*}{\begin{tabular}{|l|}
5.26 \\
5.27 \\
5.32 \\
5.38 \\
5.50 \\
5.65
\end{tabular}} & \multirow{3}{*}{$\begin{array}{l}2,570 \\
2.570 \\
2,630 \\
2,750 \\
2,870 \\
3,050\end{array}$} & 5.37 & 690 & $4.7 \overline{7}$ & 2,080 \\
\hline & $-\overline{3} 3$ & 696 & 2.90 & 435 & & & & & 5.25 & 2,570 & $4.6 \overline{6}$ & 1,960 \\
\hline & 3.37 & $\overline{7} \overline{4}$ & -2.98 & 479 & & & & & 5.18 & 2,510 & -4.50 & 1,790 \\
\hline \multirow{4}{*}{$\begin{array}{r}7 \\
8 \\
9 \\
10 \\
11 \\
12 \\
\end{array}$} & 3.33 & 696 & 3.08 & 538 & \multirow{3}{*}{\begin{tabular}{|r|}
10.50 \\
10.10 \\
9.57 \\
9.10 \\
8.62 \\
8.12 \\
\end{tabular}} & \multirow{3}{*}{$\begin{array}{r}15,200 \\
13,500 \\
11,600 \\
9,800 \\
8,220 \\
6,970 \\
\end{array}$} & \multirow{3}{*}{$\begin{array}{l}5.80 \\
5.96 \\
6.04 \\
6.05 \\
6.02 \\
5.94 \\
\end{array}$} & \multirow{3}{*}{$\begin{array}{l}3,230 \\
3,490 \\
3,490 \\
3,490 \\
3,490 \\
3,360 \\
\end{array}$} & 509 & 390 & 4.40 & 680 \\
\hline & 3.27 & $\overline{6} \overline{5} \overline{6}$ & 3.20 & 610 & & & & & 4.90 & 2,260 & 4.29 & $\mathrm{i}, \overline{570}$ \\
\hline & 3.21 & $6 \overline{1} \overline{6}$ & $3 . \overline{4}$ & 798 & & & & & 4.72 & 2,020 & $\mid 4.20$ & 1,470 \\
\hline & \multicolumn{2}{|c|}{ Aug. 18} & \multicolumn{2}{|c|}{ Aug. 19} & & g. 30 & & g. 31 & & pt. 1 & & pt. 2 \\
\hline 1 & & & 39 & 1220 & 2.97 & $\begin{array}{l}509 \\
509\end{array}$ & 6.87 & & 47 & 150 & & \\
\hline 3 & & & & & & 509 & 6.47 & 4,160 & & & & \\
\hline$\frac{4}{5}$ & & & 4.16 & 1,420 & $\begin{array}{l}2.97 \\
2.99\end{array}$ & $\begin{array}{l}509 \\
520\end{array}$ & $\begin{array}{l}6.22 \\
6.00\end{array}$ & $\begin{array}{l}3,750 \\
3,490\end{array}$ & 4.16 & 1,420 & & \\
\hline 6 & 4.04 & 1,320 & 4.10 & 1,370 & 3.00 & 525 & 5.78 & 3,230 & 4.07 & 1,320 & & \\
\hline 8. & & & 3.98 & 1,270 & & $\begin{array}{l}530 \\
536\end{array}$ & & & 3.98 & 1,270 & & \\
\hline 9 & & & 3.87 & $1,140^{\circ}$ & $\begin{array}{l}3.18 \\
3.32\end{array}$ & $\begin{array}{l}628 \\
713\end{array}$ & $\begin{array}{l}5.12 \\
4.93\end{array}$ & & -3.90 & 1,170 & & \\
\hline $\mathrm{N}$ & $\overline{3} . \overline{89}$ & 1,160 & 3.82 & $1,090^{-}$ & $\mid \begin{array}{l}5.44 \\
3.70\end{array}$ & 990 & $\begin{array}{l}4.81 \\
4.72\end{array}$ & 2,020 & 3.83 & 1,100 & $3 . \overline{3} 6$ & $739^{-}$ \\
\hline$\frac{1}{2}$ & & & 3.76 & 1.040 & $\begin{array}{l}5.11 \\
6.20\end{array}$ & & $\begin{array}{l}4.66 \\
4.66\end{array}$ & & 3.77 & 1,050 & & \\
\hline & $\ldots$ & $\ldots$ & $3 . \overline{3}$ & 1,020 & $\begin{array}{l}6.53 \\
6.98\end{array}$ & $\begin{array}{l}4,160 \\
4,890\end{array}$ & $\begin{array}{l}5.10 \\
4.95\end{array}$ & $\begin{array}{l}2,390 \\
2,320\end{array}$ & 3.72 & 1,010 & & \\
\hline 6 & $3.8 \overline{3}$ & 1,100 & $3 . \overline{0}$ & $990^{-}$ & 7.67 & $\begin{array}{l}0,020 \\
6,120\end{array}$ & 5.32 & 2,630 & $3.6 \overline{7}$ & 966 & & \\
\hline $\begin{array}{l}7 \\
8\end{array}$ & & & 3.6 & 966 & $\begin{array}{l}7.15 \\
6.96\end{array}$ & $\begin{array}{l}5,210 \\
4,890\end{array}$ & $\begin{array}{l}4.85 \\
4.66\end{array}$ & & $3.6 \overline{3}$ & 934 & & \\
\hline 1 & & & 3.62 & 926 & 6.98 & & 4.54 & & 3.58 & 895 & & $\ldots$ \\
\hline 12 & 3.82 & 1,090 & $-\overline{3} \overline{5}$ & 888 & $\begin{array}{l}7.0 \\
7.0\end{array}$ & $\begin{array}{l}4, \\
4\end{array}$ & $\begin{array}{l}4.4 \\
4.3\end{array}$ & $\begin{array}{l}1,740 \\
1,680\end{array}$ & $-\overline{3} . \overline{5}$ & 858 & 3.25 & 670 \\
\hline
\end{tabular}

SuPPlemental ReCORDs.-Aug. 14, $7: 45$ a.m., gage height 11.70 feet; discharge 20,900 second-feet. Aug. 30, 5:30 p.m., gage height, 7.85 feet; discharge, 6,320 second-feet. 


\section{FLOODS OF AUGUST 1940 IN THE SOUTHEASTERN STATES}

\section{LITTLE RIVER AT GRAYSONTON, VA.}

Location.-Lat. $37^{\circ} 03^{\prime}$, long. $80^{\circ} 34^{\prime}, 900$ feet downstream from highway bridge at Graysonton, Montgomery County, 7 miles south of Radford, and 7 miles upstream from mouth. Datum of gage is $1,795.43$ feet above mean sea level, datum of 1929.

Drainage AREa.-302 square miles (revised).

GAGE-HEIGHT RECORD.-Water-stage recorder graph.

DISCHARGE RECORD.- Stage-discharge relation defined by current-meter measurements up to 3,500 second-feet and extended to erest gage height by logarithmic plotting on basis of two slope-area determinations at sites upstream and comparisons of flood records with those for other stations in New River Basin. Gage heights used to half-tenths between 2.1 and 3.3 feet (Oet. 1 to Aug. 14), between 1.6 and 3.3 (Aug. 15 to Sept. 30); hundredths below and tenths above these limits.

Maxima.-1940: Diseharge, 17,700 second-feet 10 p.m. Aug. 14 (gage height, 16.44 feet).

1928-39: Discharge observed, about 13,500 second-feet Oet. 2, 1929 'gage height, 12.84 feet, former site and datum).

Mean discharge, in second-feet, 1940

\begin{tabular}{|c|c|c|c|c|c|c|c|c|c|c|c|}
\hline Day & Aug. & Sept. & Day & Aug. & Sept. & Day & Aug. & Sept. & Day & Aug. & Sept. \\
\hline $\begin{array}{l}1 \\
2 \\
3 \\
4 \\
5 \\
6 \\
7 \\
8\end{array}$ & $\begin{array}{l}301 \\
247 \\
214 \\
209 \\
222 \\
\mathbf{2 3 4} \\
282 \\
\mathbf{2 3 2}\end{array}$ & $\begin{array}{r}1,650 \\
882 \\
710 \\
644 \\
616 \\
\mathbf{5 7 2} \\
\mathbf{5 4 2} \\
\mathbf{5 2 4}\end{array}$ & $\begin{array}{r}9 \\
10 \\
11 \\
12 \\
13 \\
14 \\
15 \\
16\end{array}$ & $\begin{array}{r}212 \\
188 \\
202 \\
472 \\
488 \\
7,820 \\
8,470 \\
6,980\end{array}$ & $\begin{array}{l}508 \\
500 \\
506 \\
474 \\
461 \\
444 \\
444 \\
436\end{array}$ & $\begin{array}{l}17 \\
18 \\
19 \\
20 \\
21 \\
22 \\
23 \\
24\end{array}$ & $\begin{array}{r}3,990 \\
1,920 \\
1,260 \\
939 \\
780 \\
708 \\
658 \\
558\end{array}$ & $\begin{array}{l}426 \\
424 \\
420 \\
409 \\
402 \\
383 \\
370 \\
368\end{array}$ & $\begin{array}{l}25 \\
26 \\
27 \\
28 \\
29 \\
30 \\
31\end{array}$ & $\begin{array}{r}594 \\
660 \\
644 \\
612 \\
790 \\
2,610 \\
5,610\end{array}$ & $\begin{array}{l}\mathbf{5 2 7} \\
\mathbf{5 8 2} \\
\mathbf{4 0 4} \\
384 \\
\mathbf{3 7 6} \\
\mathbf{3 6 6}\end{array}$ \\
\hline \multicolumn{10}{|c|}{$\begin{array}{l}\text { Monthly mean discharge, in second-feet } \\
\text { Runoff, in inches }\end{array}$} & $\begin{array}{l}1,584 \\
16.05\end{array}$ & $\begin{array}{r}525 \\
11.94\end{array}$ \\
\hline
\end{tabular}

${ }^{1}$ Based on revised drainage area. 
KANAWHA RIVER BASIN

Gage height, in feet, and discharge, in second-feet, at indicated time, 1940

\begin{tabular}{|c|c|c|c|c|c|c|c|c|c|c|c|c|}
\hline \multirow{2}{*}{ u } & \multicolumn{2}{|c|}{ Aug. 12} & \multicolumn{2}{|c|}{ Aug. 13} & \multicolumn{2}{|c|}{ Aug. 14} & \multicolumn{2}{|c|}{ Aug. 15} & \multicolumn{2}{|c|}{ Aug. 16} & \multicolumn{2}{|c|}{ Aug. 17} \\
\hline & $\begin{array}{c}\text { Gage } \\
\text { ht. }\end{array}$ & $\begin{array}{l}\text { Dis- } \\
\text { charge }\end{array}$ & $\begin{array}{c}\text { Gage } \\
\text { ht. }\end{array}$ & $\begin{array}{c}\text { Dis- } \\
\text { charge }\end{array}$ & ht & $\begin{array}{c}\text { Dis- } \\
\text { charge }\end{array}$ & $\begin{array}{c}\text { Gage } \\
\text { ht. }\end{array}$ & $\begin{array}{c}\mathrm{Di} \\
\text { cha }\end{array}$ & $\begin{array}{c}\text { Gage } \\
\text { ht. }\end{array}$ & $\begin{array}{c}\mathrm{D} \\
\text { che }\end{array}$ & $\begin{array}{c}\text { Gage } \\
\text { ht. }\end{array}$ & $\begin{array}{c}\text { Dis- } \\
\text { charge }\end{array}$ \\
\hline \multirow{4}{*}{$\begin{array}{l}1 \\
2 \\
3 \\
4 \\
5 \\
6\end{array}$} & 18 & 27 & 51 & & \multirow{4}{*}{$\begin{array}{l}1.59 \\
1.68 \\
1.78 \\
1.85 \\
2.00 \\
2.37\end{array}$} & \multirow{4}{*}{$\begin{array}{r}554 \\
608 \\
668 \\
712 \\
810 \\
1,040\end{array}$} & \multirow{4}{*}{$\begin{array}{l}15.90 \\
15.55 \\
15.00 \\
14.05 \\
13.10 \\
12.00\end{array}$} & \multirow{4}{*}{$\begin{array}{l}17,000 \\
16,500 \\
15,600 \\
14,100 \\
12,800 \\
11,100\end{array}$} & \multirow{4}{*}{$\begin{array}{l}9.08 \\
9.17 \\
9.20 \\
9.22 \\
9.23 \\
9.26\end{array}$} & \multirow{4}{*}{$\begin{array}{l}7,200 \\
7,330 \\
7,330 \\
7,330 \\
7,330 \\
7,460\end{array}$} & 6.62 & \\
\hline & & & & & & & & & & & & \\
\hline & 1.21 & 335 & 1.52 & 512 & & & & & & & 6.37 & 4,120 \\
\hline & 1.30 & $38 \overline{4}$ & 1.52 & 512 & & & & & & & 6.36 & 4,120 \\
\hline 7 & & & & & \multirow{4}{*}{$\begin{array}{l}3.60 \\
7.25 \\
8.95 \\
9.67 \\
9.30 \\
8.50\end{array}$} & \multirow{4}{*}{$\begin{array}{l}1,960 \\
4,960 \\
7,070 \\
7,980 \\
7,460 \\
6,460\end{array}$} & \multirow{4}{*}{$\begin{array}{r}10.95 \\
10.00 \\
8.95 \\
8.20 \\
7.60 \\
7.30\end{array}$} & \multirow{4}{*}{$\begin{array}{l}9,740 \\
8,370 \\
7,070 \\
6,100 \\
5,400 \\
5,070\end{array}$} & \multirow{4}{*}{$\begin{array}{l}9.32 \\
9.37 \\
9.47 \\
9.59 \\
9.60 \\
9.58\end{array}$} & \multirow{4}{*}{$\begin{array}{l}7,460 \\
7,590 \\
7,720 \\
7,850 \\
7,850 \\
7,850\end{array}$} & & \\
\hline 8 & 1.36 & 418 & 1.49 & 494 & & & & & & & 6.52 & 4,220 \\
\hline 10 & $\overline{1} . \overline{4} \overline{7}$ & $\overline{4} 8 \overline{2}$ & $1 . \overline{4} \overline{3}$ & $\overline{4} \overline{8}-$ & & & & & & & $-\overline{6} . \overline{88}$ & 4,630 \\
\hline $\mathrm{N}$ & $\overline{1} . \overline{4}$ & 584 & 1.38 & 429 & & & & & & & 7.17 & 4,960 \\
\hline \multirow{4}{*}{$\begin{array}{l}1 \\
2 \\
3 \\
4 \\
5 \\
6\end{array}$} & & & 1 & & \multirow{4}{*}{$\begin{array}{r}8.07 \\
8.25 \\
9.00 \\
10.30 \\
11.95 \\
13.65\end{array}$} & \multirow{4}{*}{$\begin{array}{r}5,980 \\
6,100 \\
7,070 \\
8,760 \\
11,100 \\
13,500\end{array}$} & \multirow{4}{*}{$\mid \begin{array}{l}7.22 \\
7.36 \\
7.57 \\
7.63 \\
7.65 \\
7.70\end{array}$} & \multirow{4}{*}{$\begin{array}{l}4,960 \\
5,180 \\
5,400 \\
5,400 \\
5,400 \\
5,510\end{array}$} & \multirow{4}{*}{$\begin{array}{l}9.48 \\
9.39 \\
9.23 \\
9.05 \\
8.90 \\
8.64\end{array}$} & \multirow{4}{*}{$\begin{array}{l}7,720 \\
7,590 \\
7,330 \\
7,070 \\
6,940 \\
6,580\end{array}$} & & \\
\hline & 1 & & 1 & & & & & & & & & \\
\hline & 1.68 & 608 & 1.49 & 494 & & & & & & & $6 . \overline{5}$ & 3,920 \\
\hline & $\overline{1} . \overline{1} 1$ & $\overline{5} \overline{6}$ & $1 . \overline{5}$ & 506 & & & & & & & 5.75 & 3,530 \\
\hline 8 & & & & & & & 7.80 & & 8. & & & \\
\hline 9 & 1.53 & 518 & 1.49 & 494 & & & & & & & 5.38 & 3,170 \\
\hline 10 & 1.50 & 500 & 1.50 & 500 & 16. & 17 & 8. & & 7. & & 4.95 & 2,820 \\
\hline & 1.50 & 500 & $1 . \overline{\mathbf{6}}$ & $\overline{5} 36$ & 16. & 17 & 8.94 & & $\begin{array}{l}7.17 \\
6.92\end{array}$ & 4,630 & $\overline{4} . \overline{6} \overline{4}$ & $2, \overline{1} 10$ \\
\hline
\end{tabular}

\begin{tabular}{|c|c|c|c|c|c|c|c|c|c|c|c|c|}
\hline \multirow{6}{*}{$\begin{array}{l}1 \\
2 \\
3 \\
4 \\
5 \\
6\end{array}$} & \multicolumn{2}{|c|}{ Aug. 18} & \multicolumn{2}{|c|}{ Aug. 30} & \multicolumn{2}{|c|}{ Aug. 31} & \multicolumn{2}{|c|}{ Sept. 1} & \multicolumn{2}{|c|}{ Sept. 2} & \multicolumn{2}{|c|}{ Sept. 3} \\
\hline & & & .38 & 610 & 0.20 & 8,630 & 3.46 & 1,900 & & & & \\
\hline & & & 1.38 & & 1.20 & & 3.45 & & 2.12 & 1,000 & & \\
\hline & & & 1.40 & 621 & 11.90 & 11,000 & 3.80 & 2,050 & & & & \\
\hline & & & $\begin{array}{l}1.42 \\
1.45\end{array}$ & $\begin{array}{l}632 \\
648\end{array}$ & $\begin{array}{r}12.14 \\
11.90\end{array}$ & $\begin{array}{l}11,300 \\
11,000\end{array}$ & $\begin{array}{l}4.20 \\
4.47\end{array}$ & $\begin{array}{l}2,240 \\
2,440\end{array}$ & 2.06 & 972 & 1.64 & 755 \\
\hline & 3.88 & 2,090 & 1.47 & 658 & 11.47 & 10,400 & 4.50 & 2,440 & 1.99 & 945 & & \\
\hline 7 & & & 1.47 & 658 & 10.80 & 9,460 & 4.32 & 2,300 & & & & \\
\hline 8 & & & 1.49 & 669 & 10.00 & 70 & 4.00 & 30 & 1.93 & 918 & 1.58 & 717 \\
\hline 10 & & & $\begin{array}{l}1.49 \\
1.57\end{array}$ & $\begin{array}{l}669 \\
712\end{array}$ & $\begin{array}{l}9 \\
8\end{array}$ & & $\begin{array}{l}3.66 \\
3.36\end{array}$ & 2, & 1.89 & 800 & & \\
\hline 11 & & & 2.00 & 945 & 7 & 4,960 & 3.13 & 1,660 & & & & \\
\hline$N$ & 3.41 & 40 & 2.11 & 1,000 & 6.30 & 4,020 & 2.97 & 1,520 & 1.86 & 863 & 1.54 & 696 \\
\hline 1 & & & 2.32 & 0 & 5.58 & 50 & 2. & 1 & & & & \\
\hline 2 & & & 9.00 & 7,0 & 4.90 & 0 & 2 . & & 1.78 & 836 & & \\
\hline 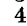 & & & 5.80 & , & $\begin{array}{l}4.85 \\
4.85\end{array}$ & 2,660 & 2.60 & & $\overline{1} . \overline{1}$ & 836 & $\overline{1.53}$ & $690^{-}$ \\
\hline & $-\overline{25}$ & $\overline{7}$ & 6.15 & 3,920 & 5.20 & 2,990 & 2.53 & 1,260 & 177 & 0 & & -- \\
\hline & & 1,740 & o. & & 0.00 & & 2.48 & 1,230 & 1.16 & 809 & & \\
\hline 7 & & & $\begin{array}{l}6.99 \\
6.90\end{array}$ & $\begin{array}{l}4,740 \\
4,630\end{array}$ & $\begin{array}{l}4.36 \\
4.12\end{array}$ & 2,370 & $\begin{array}{l}2.42 \\
2.37\end{array}$ & & 1.75 & 809 & 1.50 & 674 \\
\hline 9 & -1 & & 7.0 & & $\begin{array}{l}4.12 \\
3.95\end{array}$ & & 2.3 & & & & & \\
\hline 1 & -- & & 7.50 & 5,2 & 3.82 & 2,0 & 2.2 & i, & 1.72 & 782 & & \\
\hline $\begin{array}{l}11 \\
12\end{array}$ & 3.00 & $1, \overline{560}$ & $\begin{array}{l}8.2 b \\
9.15\end{array}$ & $\begin{array}{l}6,100 \\
7,330\end{array}$ & $\begin{array}{l}3.68 \\
3.55\end{array}$ & $\begin{array}{l}2,010 \\
1,960\end{array}$ & $\begin{array}{l}2.25 \\
2.20\end{array}$ & $\begin{array}{l}1,080 \\
1,060\end{array}$ & $\overline{1.71}$ & 782 & $\overline{1} . \overline{50}$ & $6 \overline{7} \overline{4}$ \\
\hline
\end{tabular}

\section{WALKER CREEK AT BANE, VA.}

LocAtion.-Lat. $37^{\circ} 16^{\prime} 05^{\prime \prime}$, long. $80^{\circ} 42^{\prime} 35^{\prime \prime}$, a quarter of a mile downstream from highway bridge at Bane, Giles County, a quarter of a mile downstream from Sugar Run, and 8 miles upstream from mouth. Datum of gage is 1,665.92 feet above mean sea level, datum of 1929 .

DRAINAGE AREA.—305 square miles.

GAGE-HEIGHT RECORD.-Water-stage recorder graph.

DISCHARGE RECORD.- Stage-discharge relation defined by current-meter measurements up to 2,900 second-feet and extended above by logarithmic plotting. Gage heights used to half-tenths between 5.0 and 7.0 feet; hundredths below and tenths above these limits.

Maxima.-1940: Discharge, 4,660 second-feet $12 \mathrm{~m}$. Aug. 14 (gage height, 10.08 feet). 
320 FLOODS OF AUGUST 1940 IN THE SOUTHEASTERN STATES

1938 to July 1940: Discharge, 8,020 second-feet Apr. 20, 1940 (gage height, 12.64 feet).

Stage known, about 23.5 feet, in September 1878.

Mean discharge, in second-feet, 1940

\begin{tabular}{|c|c|c|c|c|c|c|c|c|c|c|c|}
\hline Day & Aug. & Sept. & Day & Aug. & Sept. & Day & Aug. & Sept. & Day & Aug. & Sept. \\
\hline $\begin{array}{l}1 \\
2 \\
3 \\
4 \\
5 \\
6 \\
7 \\
8\end{array}$ & $\begin{array}{l}276 \\
272 \\
183 \\
152 \\
132 \\
134 \\
116 \\
114\end{array}$ & $\begin{array}{r}1,040 \\
608 \\
422 \\
319 \\
252 \\
211 \\
188 \\
170\end{array}$ & $\begin{array}{r}9 \\
10 \\
11 \\
12 \\
13 \\
14 \\
15 \\
16\end{array}$ & $\begin{array}{r}106 \\
94 \\
93 \\
95 \\
94 \\
2,430 \\
2,540 \\
2,770\end{array}$ & $\begin{array}{l}156 \\
152 \\
152 \\
142 \\
126 \\
121 \\
116 \\
110\end{array}$ & $\begin{array}{l}17 \\
18 \\
19 \\
20 \\
21 \\
22 \\
23 \\
24\end{array}$ & $\begin{array}{r}1,760 \\
1,100 \\
782 \\
583 \\
434 \\
353 \\
299 \\
248\end{array}$ & $\begin{array}{r}105 \\
102 \\
99 \\
96 \\
93 \\
90 \\
86 \\
86\end{array}$ & $\begin{array}{l}25 \\
26 \\
27 \\
28 \\
29 \\
30 \\
31\end{array}$ & $\begin{array}{l}230 \\
400 \\
402 \\
300 \\
272 \\
554 \\
918\end{array}$ & $\begin{array}{l}90 \\
94 \\
92 \\
87 \\
84 \\
83\end{array}$ \\
\hline & & & & & & & & & & $\begin{array}{r}588 \\
2.22\end{array}$ & $\begin{array}{r}186 \\
0.68\end{array}$ \\
\hline
\end{tabular}

Gage height, in feet, and discharge, in second-feet, at indicated time, 1940

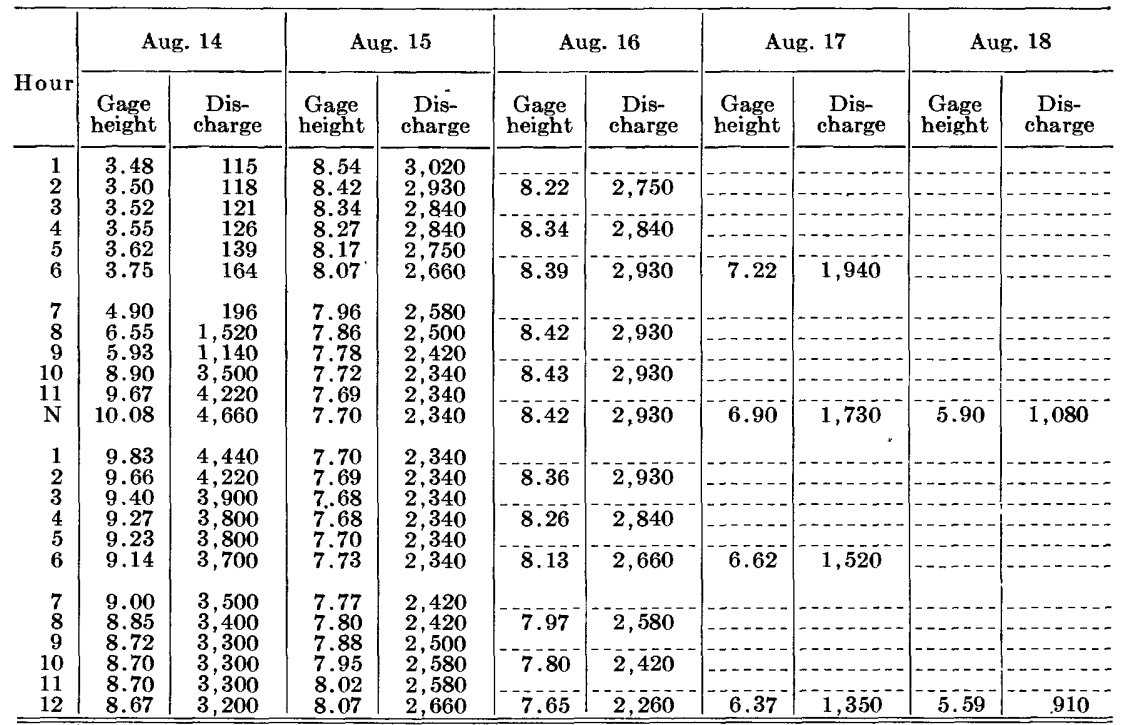

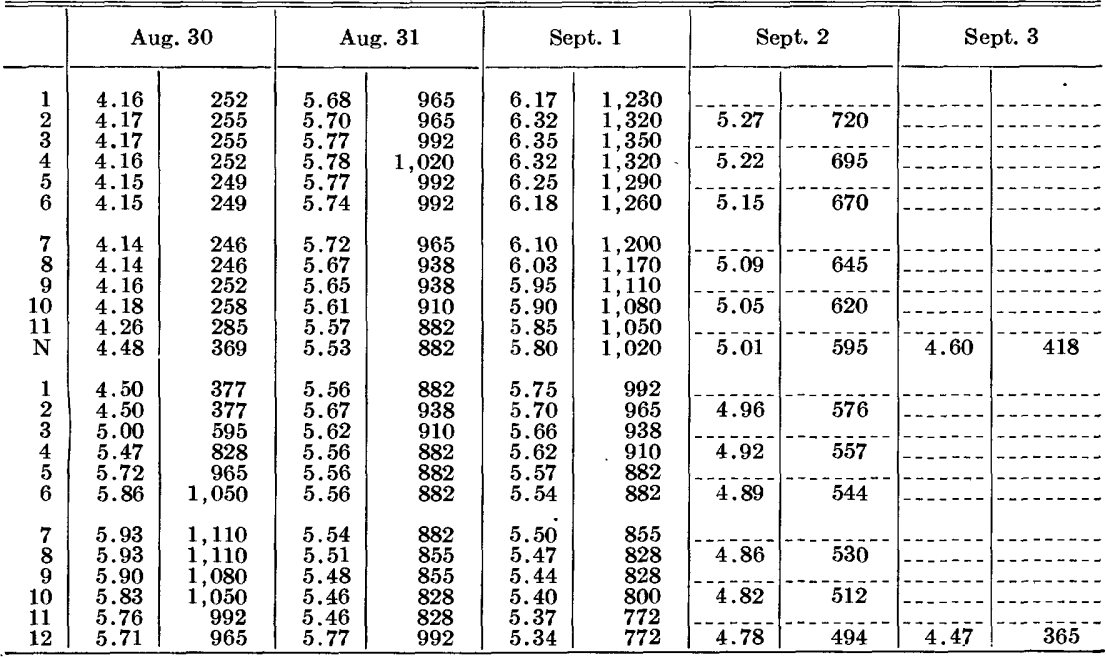


WOLF CREEK NEAR NARROWS, VA.

LOCATION.-Lat. $37^{\circ} 18^{\prime} 20^{\prime \prime}$, long. $80^{\circ} 51^{\prime} 00^{\prime \prime}$, at highway bridge 3 miles upstream from Narrows, Giles County, and $3 \frac{1}{2}$ miles upstream from mouth. Datum of gage is $1,583.83$ feet above mean sea level, datum of 1929 .

Drainage AREA.-223 square miles.

GAGE-HEIGHT RECORD.-Water-stage recorder graph except for period 9 a.m. Aug. 14 to $8: 45$ a.m. Aug. 16, when clock was stopped.

DISCHARGE RECORD.--Stage-discharge relation defined by current-meter measurements up to 2,300 second-feet. Gage heights used to half-tenths between 4.6 and 6.2 feet; hundredths below and tenths above these limits. Discharge for period of missing gage heights computed on basis of records for nearby stations.

Maxima.-August 1940: Discharge, 2,820 second-feet Ang. 15 or 16 (gage height,

7.2 feet, from erest indicated by pen on recorder chart).

1908-16, 1938 to July 1940: Gage height observed, 13.0 feet, from floodmarks, July 16, 1916 (discharge not determined).

Mean discharge, in second-feet, 1940

\begin{tabular}{|c|c|c|c|c|c|c|c|c|c|c|c|}
\hline Day & Aug. & Sept. & Day & Aug. & Sept. & Day & Aug. & Sept. & Day & Aug. & Sept. \\
\hline $\begin{array}{l}1 \\
2 \\
3 \\
4 \\
5 \\
6 \\
7 \\
8\end{array}$ & $\begin{array}{l}825 \\
404 \\
251 \\
189 \\
156 \\
136 \\
161 \\
153\end{array}$ & $\begin{array}{l}702 \\
438 \\
314 \\
244 \\
203 \\
172 \\
151 \\
136\end{array}$ & $\begin{array}{r}9 \\
10 \\
11 \\
12 \\
13 \\
14 \\
15 \\
16\end{array}$ & $\begin{array}{r}122 \\
105 \\
99 \\
97 \\
96 \\
1,000 \\
2,000 \\
2,420\end{array}$ & $\begin{array}{r}125 \\
132 \\
141 \\
120 \\
107 \\
99 \\
93 \\
88\end{array}$ & $\begin{array}{l}17 \\
18 \\
19 \\
20 \\
21 \\
22 \\
23 \\
24\end{array}$ & $\begin{array}{r}1,520 \\
980 \\
780 \\
608 \\
463 \\
387 \\
307 \\
251\end{array}$ & $\begin{array}{l}86 \\
80 \\
77 \\
75 \\
70 \\
68 \\
65 \\
65\end{array}$ & $\begin{array}{l}25 \\
26 \\
27 \\
28 \\
29 \\
30 \\
31\end{array}$ & $\begin{array}{l}240 \\
285 \\
265 \\
213 \\
233 \\
265 \\
847\end{array}$ & $\begin{array}{l}70 \\
84 \\
73 \\
66 \\
62 \\
58\end{array}$ \\
\hline \multicolumn{10}{|c|}{$\begin{array}{l}\text { Monthly mean discharge, in second-feet } \\
\text { Runoff, in inches. }\end{array}$} & $\begin{array}{r}512 \\
2.64\end{array}$ & $\begin{array}{r}142 \\
0.71\end{array}$ \\
\hline
\end{tabular}


Gage height, in feet, and discharge, in second-feet, at indicated time, 1940

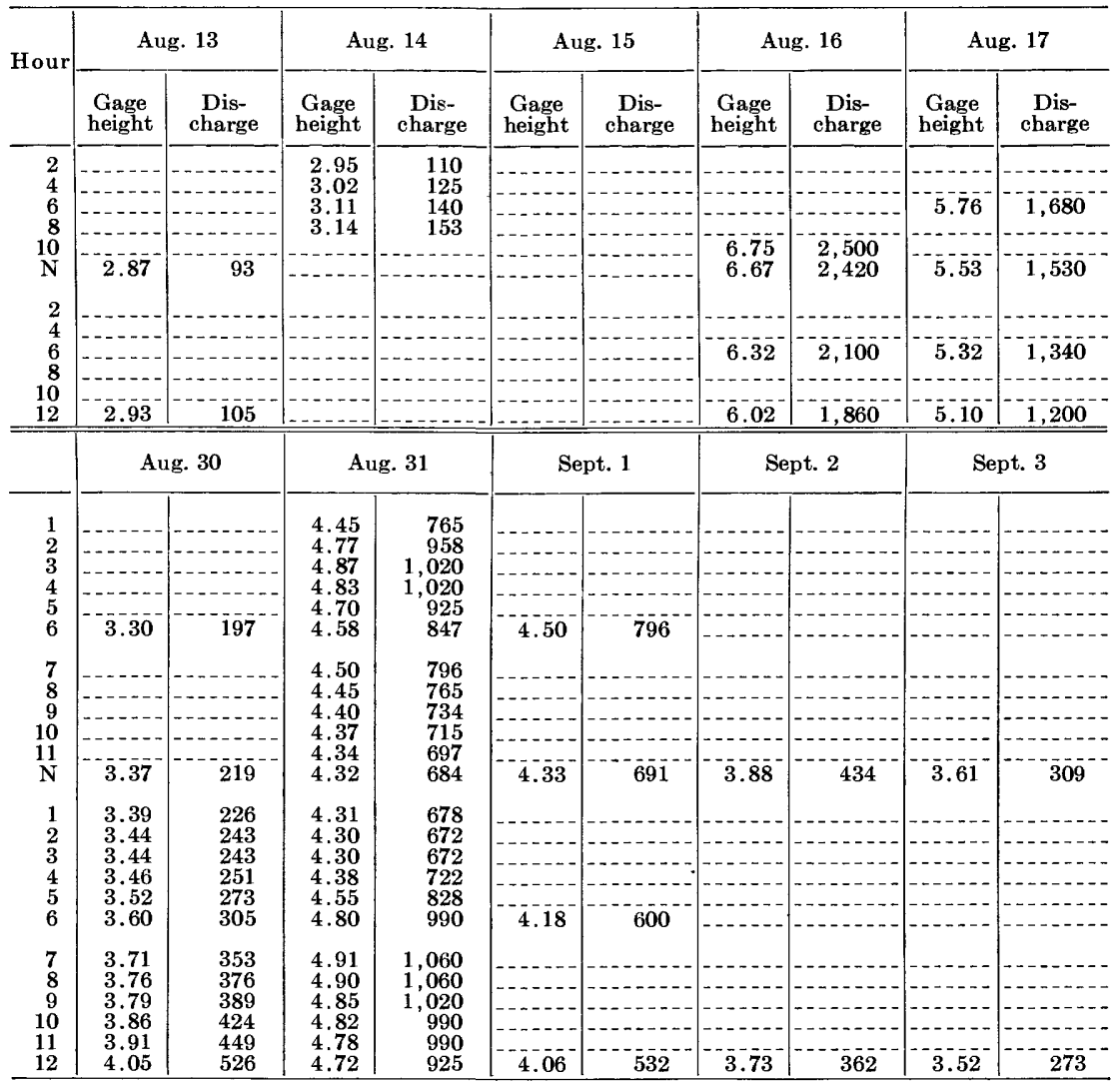

SUPPLEMENTAL RECORD.-Aug. 15 or 16, peak gage height, 7.2 feet; peak discharge, 2,820 second-feet.

\section{HLUESTONE RIVER AT LILLY, W. VA.}

Location.-Lat. $37^{\circ} 35^{\prime} 05^{\prime \prime}$, long. $80^{\circ} 57^{\prime} 55^{\prime \prime}$, at Lilly, Summers County, 1,200 feet downstream from Little Bluestone River and 5 miles upstream from mouth. Datum of gage is 1,433.7 feet above mean sea level, datum of 1929 (levels by The Virginia Power Co.).

Drainage AREa. - 438 square miles.

GAGE-HEIGHT RECORD. - Staff gage read twice daily. Graph based on gage readings used Aug. 14, 15.

DischaRGE RECORD. - Stage-discharge relation defined by current-meter measurements up to 4,500 second-feet and extended to erest gage height on basis of logarithmic plotting and area-velocity studies.

Maxima.-August 1940: Discharge, 6,400 second-feet 8 p.m. Aug. 14 (gage height, 7.05 feet, from graph based on gage readings).

1908-16, 1929 to July 1940: Discharge, 14,400 second-feet Mar. 25, 1935 (gage height, 11.0 feet, from graph based on gage readings).

REMARKs.-Flow not affected by regulation, storage, or diversion. 
KANAWHA RIVER BASIN

Mean discharge, in second-feet, 1940

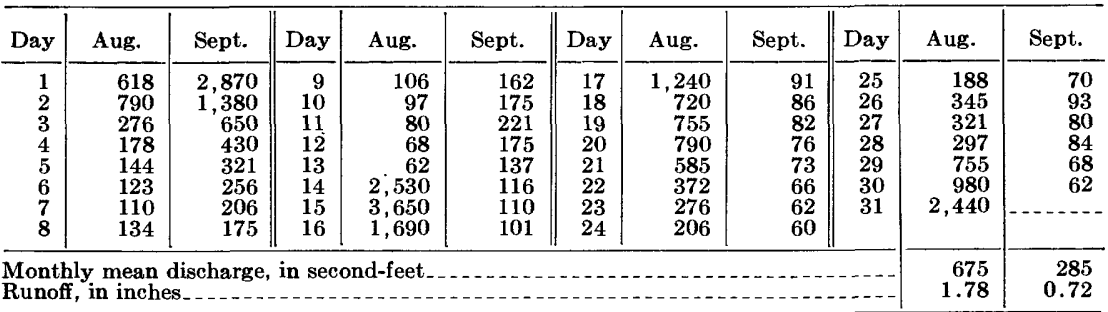

Gage height, in feet, and discharge, in second-feet, at indicated time, 1940

\begin{tabular}{|c|c|c|c|c|c|c|c|c|c|}
\hline \multirow{2}{*}{ Hour } & \multicolumn{2}{|c|}{ Aug. 14} & \multicolumn{2}{|c|}{ Aug. 15} & \multirow{2}{*}{ Hour } & \multicolumn{2}{|c|}{ Aug. 14-Con. } & \multicolumn{2}{|c|}{ Aug. 15-Con. } \\
\hline & $\begin{array}{c}\text { Gage } \\
\text { height }\end{array}$ & Discharge & $\begin{array}{c}\text { Gage } \\
\text { height }\end{array}$ & Discharge & & $\begin{array}{l}\text { Gage } \\
\text { height }\end{array}$ & Discharge & $\begin{array}{l}\text { Gage } \\
\text { height }\end{array}$ & Discharge \\
\hline $\begin{array}{r}4 \\
8 \\
N\end{array}$ & $\begin{array}{l}1.75 \\
2.00 \\
3.45\end{array}$ & $\begin{array}{r}128 \\
191 \\
1,060\end{array}$ & $\begin{array}{l}5.95 \\
5.60 \\
5.40\end{array}$ & $\begin{array}{l}4,520 \\
3,820 \\
3,490\end{array}$ & $\begin{array}{r}4 \\
8 \\
12\end{array}$ & $\begin{array}{l}6.10 \\
7.05 \\
6.60\end{array}$ & $\begin{array}{l}4,700 \\
6,400 \\
5,640\end{array}$ & $\begin{array}{l}5.20 \\
4.95 \\
4.65\end{array}$ & $\begin{array}{l}3,170 \\
2,870 \\
2,300\end{array}$ \\
\hline
\end{tabular}

\section{GREENBRIER RIVER A'T' HILLDALE, W. VA.}

Location.-Lat. $37^{\circ} 38^{\prime} 25^{\prime \prime}$, long. $80^{\circ} 48^{\prime} 20^{\prime \prime}$, at Hilldale, Summers County, opposite Howard Creek, 0.9 mile upstream from Powley Creek, 5 miles southeast of Hinton, and 5.6 miles upstream from mouth. Datum of gage is 1,388.66 feet above mean sea level, datum of 1929 (levels by Corps of Engineers, War Department).

Drainage AREA.-1,625 square miles, including area of Howard Creek.

GAGE-HEIGHT RECORD.-Water-stage recorder graph except for Aug. 1-5, and 9-14, records for which were based on those for station at Alderson and recorded range in stage.

DISCHARGE RECORD.-Stage-discharge relation defined by current-meter measurements up to 20,000 second-feet and extended above by logarithmic plotting.

Maxima.-August 1940: Discharge, 18,100 second-feet 9 a.m. Aug. 15 (gage height, 11.34 feet).

June 1936 to July 1940: Discharge, 40,000 second-feet Feb. 4, 1939 (gage height, 17.99 feet).

Stage known, 21.85 feet Mar. 18, 1936 (discharge, 60,800 second-feet), from data furnished by Corps of Engineers, War Department.

REMARKs.-Flow not affected by regulation, storage, or diversion.

Mean discharge, in second-feet, 1940

\begin{tabular}{|c|c|c|c|c|c|c|c|c|c|c|c|}
\hline Day & Aug. & Sept. & Day & Aug. & Sept. & Day & Aug. & Sept. & Day & Aug. & Sept. \\
\hline $\begin{array}{l}1 \\
2 \\
3 \\
4 \\
5 \\
6 \\
6 \\
7 \\
8\end{array}$ & $\begin{array}{r}3,500 \\
2,500 \\
2,200 \\
1,000 \\
700 \\
660 \\
884 \\
1,760\end{array}$ & $\begin{array}{r}3,550 \\
3,970 \\
2,480 \\
1,760 \\
1,300 \\
1,020 \\
839 \\
700\end{array}$ & $\begin{array}{r}9 \\
10 \\
11 \\
12 \\
13 \\
14 \\
15 \\
16\end{array}$ & $\begin{array}{r}1,400 \\
875 \\
580 \\
500 \\
410 \\
2,150 \\
14,700 \\
10,000\end{array}$ & $\begin{array}{l}636 \\
580 \\
540 \\
500 \\
472 \\
424 \\
391 \\
365\end{array}$ & $\begin{array}{l}17 \\
18 \\
19 \\
20 \\
21 \\
22 \\
23 \\
24\end{array}$ & $\begin{array}{r}6,540 \\
4,340 \\
3,200 \\
2,420 \\
1,860 \\
1,450 \\
1,170 \\
965\end{array}$ & $\begin{array}{l}332 \\
306 \\
300 \\
282 \\
276 \\
270 \\
276 \\
276\end{array}$ & $\begin{array}{l}25 \\
26 \\
27 \\
28 \\
29 \\
30 \\
31\end{array}$ & $\begin{array}{r}830 \\
767 \\
1,810 \\
2,660 \\
2,540 \\
3,690 \\
2,720\end{array}$ & $\begin{array}{l}247 \\
236 \\
288 \\
339 \\
508 \\
384 \\
-\end{array}$ \\
\hline \multicolumn{10}{|c|}{$\begin{array}{l}\text { Monthly mean discharge, in second-feet } \\
\text { Runoff, in inches. }\end{array}$} & $\begin{array}{r}2,606 \\
1.85\end{array}$ & $\begin{array}{r}795 \\
0.55\end{array}$ \\
\hline
\end{tabular}


FLOODS OF AUGUST 1940 IN THE SOUTHEASTERN STATES

Gage height, in feet, and discharge, in second-feet, at indicated time, 1940

\begin{tabular}{|c|c|c|c|c|c|c|c|c|c|c|c|c|}
\hline \multirow{2}{*}{ Hour } & \multicolumn{2}{|c|}{ Aug. 14} & \multicolumn{2}{|c|}{ Aug. 15} & \multicolumn{2}{|c|}{ Aug. 16} & \multicolumn{2}{|c|}{ Aug. 17} & \multicolumn{2}{|c|}{ Aug. 18} & \multicolumn{2}{|c|}{ Aug. 19} \\
\hline & $\begin{array}{c}\text { Gage } \\
\text { ht. }\end{array}$ & $\begin{array}{c}\text { Dis- } \\
\text { charge }\end{array}$ & $\begin{array}{c}\text { Gage } \\
\text { ht. }\end{array}$ & $\begin{array}{c}\text { Dis- } \\
\text { charge }\end{array}$ & $\begin{array}{c}\text { Gage } \\
\text { ht. }\end{array}$ & $\begin{array}{c}\text { Dis- } \\
\text { charge }\end{array}$ & $\begin{array}{c}\text { Gage } \\
\text { ht. }\end{array}$ & $\begin{array}{c}\text { Dis- } \\
\text { charge }\end{array}$ & $\begin{array}{l}\text { Gage } \\
\text { ht. }\end{array}$ & $\underset{\text { cha }}{\text { D }}$ & $\begin{array}{c}\text { Gage } \\
\text { ht. }\end{array}$ & $\begin{array}{c}\text { Dis- } \\
\text { eharge }\end{array}$ \\
\hline \multirow{4}{*}{$\begin{array}{l}1 \\
2 \\
3 \\
4 \\
5 \\
6\end{array}$} & 1.25 & 398 & \multirow{4}{*}{$\begin{array}{r}7.50 \\
8.15 \\
8.95 \\
9.65 \\
10.35 \\
10.85\end{array}$} & \multirow{4}{*}{$\begin{array}{r}9,200 \\
10,600 \\
12,400 \\
13,800 \\
15,800 \\
16,800\end{array}$} & & & & & & & & \\
\hline & -1 & & & & 8.68 & 11 , & 6.71 & & & & & \\
\hline & & & & & 8.47 & 11,300 & $\overline{6} . \overline{56}$ & 7,440 & 5.17 & 4,980 & 4.18 & 3,480 \\
\hline & $\overline{1} \overline{1} . \overline{2} \overline{5}$ & 398 & & & 8.31 & 10,900 & $6 . \overline{43}$ & 7,080 & & & -1 & \\
\hline \multirow{4}{*}{$\begin{array}{r}7 \\
8 \\
9 \\
10 \\
11 \\
\mathrm{~N}\end{array}$} & $\overline{1} \overline{3} \overline{0} \mid$ & 430 & \multirow{4}{*}{$\begin{array}{l}11.20 \\
11,33 \\
11.34 \\
11,26 \\
11.08 \\
10.95\end{array}$} & \multirow{4}{*}{$\begin{array}{l}17,800 \\
18,100 \\
18,100 \\
18,100 \\
17,600 \\
17,300\end{array}$} & 818 & & 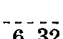 & 0 & 493 & 80 & 4.07 & 3,270 \\
\hline & & & & & & & & & & & & \\
\hline & $\overline{1} \overline{\mathbf{3}} \overline{\mathbf{5}}$ & 465 & & & 8.11 & 10,400 & 6.18 & 6,320 & & & & \\
\hline & 31.40 & 500 & & & 8.03 & 10,200 & $6 . \overline{0} 6$ & 6,540 & 4.78 & 4,340 & 3.97 & 3,140 \\
\hline \multirow{4}{*}{$\begin{array}{l}1 \\
2 \\
3 \\
4 \\
5 \\
6\end{array}$} & 11.50 & 0 & \multirow{4}{*}{$\mid \begin{array}{r}10.74 \\
10.55 \\
10,38 \\
10.22 \\
10.05 \\
9.83\end{array}$} & \multirow{4}{*}{$\begin{array}{l}16,500 \\
16,300 \\
15,800 \\
15,300 \\
14,800 \\
14,300\end{array}$} & & & & & & & & \\
\hline & 11.60 & & & & 7.90 & 10,000 & 5.95 & 6,360 & & & & \\
\hline & \begin{tabular}{|}
11.80 \\
12.50
\end{tabular} \mid & $\begin{array}{r}830 \\
1,500\end{array}$ & & & $\overline{7.74}$ & 9,600 & 5.83 & 6,000 & 4.62 & 4,040 & $\overline{\mathbf{3}} \cdot \overrightarrow{\mathrm{8}}$ & 3,020 \\
\hline & $\begin{array}{l}13.50 \\
15.00\end{array}$ & & & & $-\overline{7.55}$ & 9,400 & 5.70 & 5,820 & & & & \\
\hline \multirow{5}{*}{$\begin{array}{r}7 \\
8 \\
9 \\
10 \\
11 \\
12\end{array}$} & 5 & 5 & \multirow{5}{*}{\begin{tabular}{|l|}
9.70 \\
9.55 \\
9.42 \\
9.26 \\
9.09 \\
8.96
\end{tabular}} & \multirow{5}{*}{$\begin{array}{l}14,100 \\
13,800 \\
13,400 \\
13,100 \\
12,600 \\
12,400\end{array}$} & & & & & & & & \\
\hline & 80 & & & & 7.33 & 8,800 & 5.57 & 5,640 & 4.44 & 3,830 & $\mathbf{3 . 7 5}$ & 2,900 \\
\hline & & & & & 7.12 & 8,400 & 5.47 & 5,460 & & & & \\
\hline & 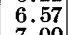 & 7.4 & & & & & $=-\overline{0} \overline{0}$ & & & & & \\
\hline & & & & & 6.90 & 8,000 & 5.37 & 5,300 & 4.32 & 3,620 & $|3.66|$ & 2,780 \\
\hline
\end{tabular}

'Computed on basis of record for station at Alderson.

\section{GAULEY RIVER ABOVE RELVA, W. VA.}

Location.-Lat. $38^{\circ} 14^{\prime} 00^{\prime \prime}$, long. $81^{\circ} 10^{\prime} 45^{\prime \prime}$, half a mile above Belva, Nicholas County, and 1 mile upstream from Twentymile Creek. Datum of gage is 669.0 feet above mean sea level, adjustment of 1912.

Drainage AREa.-1,315 square miles.

GAGE-HEIGHT RECORD. - Water-stage recorder graph except for periods of missing gage heights, Aug. 21-27, 28-31, Sept. 1-3, 5-9, records for which were based on those for station near Summersville and onee-daily readings on a Corps of Engineers, War Department, staff gage about half a mile below station.

DISCHARGE RECORD.-Stage-discharge relation defined by current-meter measurements up to 37,000 second-feet and extended above on basis of area-velocity studies and inflow and storage adjustments for station on Kanawha River at Kanawha Falls.

Maxima.-August 1940: Discharge, 9,830 second-feet 10:30 a.m. Aug. 15 (gage height, 7.07 feet). A discharge of 16,200 second-feet occurred Aug: 27 (gage height, 9.25 feet, from range line on recorded ehart) as a result of a storm centering in West Virginia.

1928 to July 1940: Discharge, 105,000 second-feet July 5, 1932 (gage height, 28.60 feet).

REMARKs.-Flow not affected by storage, regulation, or diversion.

Mean discharge, in second-feet, 1940

\begin{tabular}{|c|c|c|c|c|c|c|c|c|c|c|c|}
\hline Day & Aug. & Sept. & Day & Aug. & Sept. & Day & Aug. & Sept. & Day & Aug. & Sept. \\
\hline $\begin{array}{l}1 \\
2 \\
3 \\
4 \\
5 \\
6 \\
7 \\
8\end{array}$ & $\begin{array}{r}2,880 \\
2,960 \\
2,060 \\
1,350 \\
894 \\
615 \\
747 \\
849\end{array}$ & $\begin{array}{r}7,940 \\
5,660 \\
3,560 \\
2,500 \\
1,720 \\
1,230 \\
975 \\
755\end{array}$ & $\begin{array}{r}9 \\
10 \\
11 \\
12 \\
13 \\
14 \\
15 \\
16\end{array}$ & $\begin{array}{r}731 \\
518 \\
391 \\
299 \\
248 \\
1,060 \\
8,740 \\
6,390\end{array}$ & $\begin{array}{l}615 \\
548 \\
511 \\
504 \\
490 \\
391 \\
325 \\
283\end{array}$ & $\begin{array}{l}17 \\
18 \\
19 \\
20 \\
21 \\
22 \\
23 \\
24\end{array}$ & $\begin{array}{r}4,240 \\
2,720 \\
1,990 \\
1,720 \\
1,320 \\
975 \\
798 \\
638\end{array}$ & $\begin{array}{l}248 \\
216 \\
194 \\
174 \\
156 \\
142 \\
128 \\
120\end{array}$ & $\begin{array}{l}25 \\
26 \\
27 \\
28 \\
29 \\
30 \\
31\end{array}$ & $\begin{array}{r}490 \\
3,590 \\
12,400 \\
7,420 \\
6,260 \\
3,750 \\
4,440\end{array}$ & $\begin{array}{r}216 \\
1,110 \\
1,350 \\
755 \\
511 \\
374 \\
-\end{array}$ \\
\hline \multicolumn{10}{|c|}{$\begin{array}{l}\text { Monthly mean discharge, in second-feet } \\
\text { Runoff, in inches }\end{array}$} & $\begin{array}{r}2,693 \\
2.36\end{array}$ & $\begin{array}{r}1,123 \\
0.95\end{array}$ \\
\hline
\end{tabular}


KANAWHA RIVER BASIN

Gage height, in feet, and discharge, in second-feet, at indicated time, 1940

\begin{tabular}{|c|c|c|c|c|c|c|c|c|c|c|c|c|}
\hline \multirow{2}{*}{ Hour } & \multicolumn{2}{|c|}{ Aug. 14} & \multicolumn{2}{|c|}{ Aug. 15} & \multicolumn{2}{|c|}{ Aug. 16} & \multicolumn{2}{|c|}{ Aug. 17} & \multicolumn{2}{|c|}{ Aug. 18} & \multicolumn{2}{|c|}{ Aug 19} \\
\hline & $\begin{array}{c}\text { Gage } \\
\text { ht. }\end{array}$ & $\begin{array}{c}\text { Dis- } \\
\text { charge }\end{array}$ & $\begin{array}{c}\text { Gage } \\
\text { ht. }\end{array}$ & $\begin{array}{c}\text { Dis- } \\
\text { charge }\end{array}$ & $\begin{array}{c}\text { Gage } \\
\text { ht. }\end{array}$ & $\begin{array}{c}\text { Dis- } \\
\text { charge }\end{array}$ & $\begin{array}{c}\text { Gage } \\
\text { ht. }\end{array}$ & $\begin{array}{c}\text { Dis- } \\
\text { charge }\end{array}$ & $\begin{array}{c}\text { Gage } \\
\text { ht. }\end{array}$ & $\begin{array}{c}\text { Dis- } \\
\text { charge }\end{array}$ & $\begin{array}{c}\text { Gage } \\
\text { ht. }\end{array}$ & $\begin{array}{c}\text { Dis- } \\
\text { charge }\end{array}$ \\
\hline \multirow{5}{*}{$\begin{array}{r}1 \\
2 \\
4 \\
6 \\
8 \\
10 \\
\mathbf{N}\end{array}$} & 1.60 & 239 & \multirow{5}{*}{$\begin{array}{l}6.55 \\
6.50 \\
6.44 \\
6.50 \\
7.06 \\
7.01\end{array}$} & \multirow{5}{*}{$\begin{array}{l}8,470 \\
8,200 \\
7,940 \\
8,200 \\
9,830 \\
9,550\end{array}$} & & & \multirow{3}{*}{-5.17} & \multirow{3}{*}{4,870} & & \multirow[b]{2}{*}{$\ldots$} & & \multirow{2}{*}{$---1,-1$} \\
\hline & & & & & 9 & & & & & & & \\
\hline & & & & & & & & & 4.15 & 2,960 & 3.52 & \multirow{2}{*}{1,990} \\
\hline & 1.60 & 239 & & & $5 . \overline{9} 5$ & 6,770 & 5.03 & 4,660 & & $\ldots \ldots$ & $\ldots$ & \\
\hline & 1.62 & 248 & & & $\overline{5.73}$ & $6, \overline{2} 60$ & 4.88 & $\overline{4}, \overline{4} \overline{0}$ & $\overline{3} . \overline{9} \overline{5} \mid$ & 2,640 & $\overline{3} . \overline{4}$ & 1,920 \\
\hline \multirow{3}{*}{$\begin{array}{r}2 \\
4 \\
6 \\
8\end{array}$} & 1.63 & 252 & 6.89 & 9,2 & & & & & & & & \multirow{2}{*}{$-\overline{1}, \overline{9} 20$} \\
\hline & $\begin{array}{l}1.64 \\
1.66\end{array}$ & 257 & $\begin{array}{l}6.76 \\
6.66\end{array}$ & 9, & 5.54 & 5,780 & 4.71 & 3,940 & $\overline{3} . \overline{7} \overline{8}$ & 2,420 & $\overline{3}, \overline{4}$ & \\
\hline & $\begin{array}{l}1.00 \\
1.69\end{array}$ & 279 & 6.69 & 8,740 & $\overline{5} . \overline{\mathbf{3} 8}$ & 5,430 & $\overline{4} . \overline{5} 5$ & 3,660 & & & & \\
\hline $\begin{array}{l}10 \\
12\end{array}$ & 6.30 & $\begin{array}{l}7,680 \\
8,470\end{array}$ & $\begin{array}{l}6.59 \\
6.46\end{array}$ & 8,470 & $-\overline{5} .25$ & 5,090 & 4.38 & 3 & 3.65 & 2,200 & $|\overline{3.43}|$ & 1,920 \\
\hline & & & 6.46 & 8 , & 5.25 & 5,090 & 4.38 & & 3.05 & 2,200 & 3.45 & \\
\hline
\end{tabular}

Supplemental reconds.-Aug. 14, 11 p.m., gage height, 6.67 feet; discharge, 8,740 second-feet. Aug. 15, 10:30 a.m., gage height, 7.07 feet; discharge, 9,830 second-feet.

\section{EIK RIVER AT QUEEN SHOALS, W. VA.}

Location.- -Lat. $38^{\circ} 28^{\prime} 20^{\prime \prime}$, long. $81^{\circ} 17^{\prime} 10^{\prime \prime}$, at highway bridge at Queen Shoals, Kanawha County, 100 feet upstream from Queen Shoals Creek, and 4 miles upstream from Big Sandy Creek. Datum of gage is 604.13 feet above mean sea level, datum of 1929, Parkersburg-Uniontown supplementary adjustment of 1944.

Drainage ARea.-1,145 square miles, ineluding area of Queen Shoals Creek.

GAGE-HEIGHT RECORD.-Water-stage recorder graph.

DISCHARGE RECORD.-Stage-discharge relation defined by current-meter measurements up to 30,000 second-feet and extended above on basis of logarithmic plotting and area-velocity studies.

Maxima.-August 1940: Discharge, 164 second-feet 11 p.m. Aug. 15 (gage height, 3.96 feet). A discharge of 3,380 second-feet occurred 9 p.m. Aug. 26 (gage height, 7.78 feet) as a result of a storm centering in West Virginia.

1928 to July 1940: Discharge, 91,300 second-feet July 5, 1932 (gage height, 29.2 feet).

REMARKs.-Flow not affected by storage, regulation, or diversion.

Mean discharge, in second-feet, 1940

\begin{tabular}{|c|c|c|c|c|c|c|c|c|c|c|c|}
\hline Day & Aug. & Sept. & Day & Aug. & Sept. & Day & Aug. & Sept. & Day & Aug. & Sept. \\
\hline 1 & 687 & 956 & 9 & 221 & 228 & 17 & 148 & 132 & 25 & 121 & 1,800 \\
\hline 2 & 482 & 991 & 10 & 195 & 204 & 18 & 148 & 113 & 26 & 1,680 & 4,870 \\
\hline$\overline{3}$ & 356 & 949 & 11 & 172 & 187 & 19 & 241 & 100 & 27 & 2,440 & 2,510 \\
\hline 4 & 427 & 732 & 12 & $\begin{array}{l}150 \\
134\end{array}$ & 168 & 20 & 231 & 91 & 28 & 2,510 & 1,340 \\
\hline $\begin{array}{l}5 \\
6\end{array}$ & $\begin{array}{l}337 \\
301\end{array}$ & $\begin{array}{l}560 \\
497\end{array}$ & $\begin{array}{l}13 \\
14\end{array}$ & $\begin{array}{l}134 \\
138\end{array}$ & $\begin{array}{l}154 \\
158\end{array}$ & 21 & 193 & 81 & $\begin{array}{l}29 \\
30\end{array}$ & $\begin{array}{l}2,370 \\
9\end{array}$ & $\begin{array}{l}840 \\
570\end{array}$ \\
\hline 7 & 356 & 330 & $\begin{array}{l}15 \\
15\end{array}$ & 152 & 166 & 23 & 150 & 63 & & 1,340 & \\
\hline 8 & 266 & 266 & 16 & 162 & 152 & 24 & 132 & 57 & & & \\
\hline \multicolumn{10}{|c|}{ Monthly mean discharge, in second-feet_. } & $\begin{array}{r}591 \\
0.60\end{array}$ & $\begin{array}{r}642 \\
0.63\end{array}$ \\
\hline
\end{tabular}




\section{TENNESSEE RIVER BASIN}

\section{FRENCH BROAD RIVER AT ROSMAN, N. C.}

Location.—Lat. $35^{\circ} 08^{\prime} 20^{\prime \prime}$, long. $82^{\circ} 49^{\prime} 30^{\prime \prime}$, at bridge on State Highway 283 at Rosman, Transylvania County, half a mile upstream from East Fork. Datum of gage is 2,173.83 feet above mean sea level, datum of 1929, supplementary adjustment of 1936 .

DraINAGE AREA.-67.9 square miles.

GAGE-HEIGHT RECORD.-Water-stage recorder graph.

DISCHARGE RECORD. - Stage-discharge relation defined by current-meter measurements up to 2,300 second-feet and extended to erest gage height on basis of determination of flood flow by slope-area method. Gage heights used to half-tenths between 3.2 and 4.7 feet; hundredths below and tenths above these limits. Shifting-control method used Aug. 14 to 7 p.m. Aug. 29.

Maxima.-1940: Discharge, 9,410 second-feet 6 a.m. Aug. 30 (gage height, 11.86 feet).

1907-9, 1935-39: Discharge observed, 6,900 seeond-feet on night of Feb. 14-15, 1908 (gage height, 9.0 feet). River channel has become greatly restricted since 1908.

Stage known, 13.9 feet in July 1916, from floodmarks (diseharge not determined). Surveys by the Tennessee Valley Authority show that the flood of August 1928 reached a stage of 12.5 feet (discharge, 11,800 second-feet).

REMARKS.-Flood runoff not affected by artificial storage.

Mean discharge, in second-feet, 1940

\begin{tabular}{|c|c|c|c|c|c|c|c|c|c|c|c|}
\hline Day & Aug. & Sept. & Day & Aug. & Sept. & Day & Aug. & Sept. & Day & Aug. & Sept. \\
\hline $\begin{array}{l}1 \\
2 \\
3 \\
4 \\
5 \\
6 \\
7 \\
8\end{array}$ & $\begin{array}{l}81 \\
79 \\
76 \\
74 \\
74 \\
74 \\
74 \\
76\end{array}$ & $\begin{array}{l}546 \\
441 \\
381 \\
343 \\
333 \\
312 \\
290 \\
259\end{array}$ & $\begin{array}{r}9 \\
10 \\
11 \\
12 \\
13 \\
14 \\
15 \\
16\end{array}$ & $\begin{array}{r}104 \\
74 \\
90 \\
446 \\
3,920 \\
976 \\
524 \\
385\end{array}$ & $\begin{array}{l}228 \\
219 \\
212 \\
196 \\
187 \\
184 \\
175 \\
172\end{array}$ & $\begin{array}{l}17 \\
18 \\
19 \\
20 \\
21 \\
22 \\
23 \\
24\end{array}$ & $\begin{array}{l}320 \\
284 \\
256 \\
231 \\
219 \\
213 \\
204 \\
210\end{array}$ & $\begin{array}{l}163 \\
160 \\
157 \\
152 \\
143 \\
141 \\
138 \\
141\end{array}$ & $\begin{array}{l}25 \\
26 \\
27 \\
28 \\
29 \\
30 \\
31\end{array}$ & $\begin{array}{r}190 \\
181 \\
175 \\
167 \\
923 \\
3,240 \\
776\end{array}$ & $\begin{array}{l}166 \\
135 \\
127 \\
124 \\
121 \\
118\end{array}$ \\
\hline or & & & & & & & & & & $\begin{array}{r}475 \\
8.06\end{array}$ & $\begin{array}{r}215 \\
3.54\end{array}$ \\
\hline
\end{tabular}


TENNESSEE RIVER BASIN

Gage height; in feet, and discharge, in second-feet, at indicated time, 1940

\begin{tabular}{|c|c|c|c|c|c|c|c|c|c|c|c|c|}
\hline \multirow{2}{*}{ Hour } & \multicolumn{2}{|c|}{ Aug. 12} & \multicolumn{2}{|c|}{ Aug. 13} & \multicolumn{2}{|c|}{ Aug. 14} & \multicolumn{2}{|c|}{ Aug. 15} & \multicolumn{2}{|c|}{ Aug. 16} & \multicolumn{2}{|c|}{ Aug. 17} \\
\hline & $\begin{array}{c}\text { Gage } \\
\text { ht. }\end{array}$ & $\begin{array}{c}\text { Dis- } \\
\text { eharge }\end{array}$ & $\begin{array}{c}\text { Gage } \\
\text { ht. }\end{array}$ & $\begin{array}{c}\text { Dis- } \\
\text { charge }\end{array}$ & $\begin{array}{c}\text { Gage } \\
\text { ht. }\end{array}$ & $\begin{array}{c}\text { Dis- } \\
\text { charge }\end{array}$ & $\begin{array}{c}\text { Gage } \\
\text { ht. }\end{array}$ & $\begin{array}{c}\text { Dis- } \\
\text { charge }\end{array}$ & $\begin{array}{c}\text { Gage } \\
\text { ht. }\end{array}$ & & $\begin{array}{c}\text { Gage } \\
\text { ht. }\end{array}$ & \\
\hline $\begin{array}{l}1 \\
2 \\
3 \\
4 \\
5 \\
6\end{array}$ & $\begin{array}{l}1.98 \\
1.98 \\
1.98 \\
1.98 \\
1.99 \\
2.00\end{array}$ & $\begin{array}{l}117 \\
117 \\
120 \\
122\end{array}$ & $\begin{array}{l}4.85 \\
4.68 \\
4.70 \\
5.30 \\
5.60 \\
5.98\end{array}$ & $\begin{array}{l}1,200 \\
1,150 \\
1,150 \\
1,420 \\
1,570 \\
1,770\end{array}$ & $\begin{array}{l}5.55 \\
5.26 \\
5.04 \\
4.86 \\
4.71 \\
4.59\end{array}$ & $\begin{array}{l}1,570 \\
1,470 \\
1,330 \\
1,280 \\
1,200 \\
1,150\end{array}$ & $-\overline{3} \cdot \overline{3} \overline{2}$ & $-5 \overline{5}$ & & & & \\
\hline $\begin{array}{r}7 \\
8 \\
9 \\
10 \\
11 \\
\mathrm{~N}\end{array}$ & $\begin{array}{l}2.03 \\
2.09 \\
2.14 \\
2.19 \\
2.29 \\
2.57\end{array}$ & $\begin{array}{l}130 \\
145 \\
159 \\
172 \\
201 \\
287\end{array}$ & $\begin{array}{r}6.78 \\
8.65 \\
10.20 \\
11.16 \\
11.78 \\
11.18\end{array}$ & $\begin{array}{l}2,190 \\
3,460 \\
5,400 \\
7,340 \\
9,040 \\
7,340\end{array}$ & $\begin{array}{l}4.49 \\
4.37 \\
4.27 \\
4.17 \\
4.09 \\
4.03\end{array}$ & $\begin{array}{r}1,100 \\
1,040 \\
992 \\
948 \\
925 \\
880\end{array}$ & 3.22 & $5 \overline{5} 5$ & 2.77 & 387 & 2.59 & $32 \overline{3}$ \\
\hline $\begin{array}{l}1 \\
2 \\
3 \\
4 \\
5 \\
6\end{array}$ & $\begin{array}{l}2.70 \\
3.14 \\
3.29 \\
3.45 \\
3.65 \\
3.83\end{array}$ & $\begin{array}{l}330 \\
492 \\
555 \\
615 \\
695 \\
775\end{array}$ & $\mid \begin{array}{r}11.05 \\
10.73 \\
10.68 \\
10.60 \\
10.29 \\
9.70\end{array}$ & $\begin{array}{l}6,890 \\
6,290 \\
6,290 \\
6,100 \\
5,570 \\
4,660\end{array}$ & $\begin{array}{l}3.99 \\
3.96 \\
3.86 \\
3.80 \\
3.75 \\
3.69\end{array}$ & $\begin{array}{l}880 \\
858 \\
815 \\
795 \\
775 \\
755\end{array}$ & 3.04 & 488 & & & & \\
\hline $\begin{array}{r}7 \\
8 \\
9 \\
10 \\
11 \\
12 \\
\end{array}$ & $\begin{array}{l}3.90 \\
4.04 \\
4.15 \\
4.20 \\
4.80 \\
5.21 \\
\end{array}$ & $\begin{array}{r}795 \\
858 \\
902 \\
925 \\
1,200 \\
1,380 \\
\end{array}$ & $\begin{array}{l}9.05 \\
8.20 \\
7.40 \\
6.83 \\
6.26 \\
5.87 \\
\end{array}$ & $\begin{array}{l}3,840 \\
3,130 \\
2,550 \\
2,190 \\
1,920 \\
1,720 \\
\end{array}$ & $\begin{array}{l}3.66 \\
3.60 \\
3.55 \\
3.52 \\
3.48 \\
3.45 \\
\end{array}$ & $\begin{array}{l}735 \\
715 \\
695 \\
675 \\
655 \\
655 \\
\end{array}$ & $\left|\begin{array}{r}2.93 \\
-\end{array}\right|$ & 431 & $\mid \begin{array}{r}2 .-1 \\
2.65 \\
\end{array}$ & $3 \overline{4} 4$ & $2 . \overline{5} \overline{1}$ & 297 \\
\hline & \multicolumn{2}{|c|}{ Aug. 29} & \multicolumn{2}{|c|}{ Aug. 30} & \multicolumn{2}{|c|}{ Aug. 31} & \multicolumn{2}{|c|}{ Sept. 1} & \multicolumn{2}{|c|}{ Sept. 2} & \multicolumn{2}{|c|}{ Sept. } \\
\hline $\begin{array}{l}1 \\
2 \\
\mathbf{3} \\
\mathbf{4} \\
5 \\
\mathbf{6}\end{array}$ & $\begin{array}{l}2.05 \\
2.05 \\
2.06 \\
2.07 \\
2.11 \\
2.19\end{array}$ & $\begin{array}{l}159 \\
159 \\
162 \\
164 \\
175 \\
198\end{array}$ & $\begin{array}{r}9.05 \\
9.73 \\
10.40 \\
11.10 \\
11.73 \\
11.86\end{array}$ & $\begin{array}{l}3,840 \\
4,660 \\
5,740 \\
7,110 \\
8,700 \\
9,410\end{array}$ & $\begin{array}{c}4.21 \\
4.10^{-} \\
3.99^{-}\end{array}$ & $\begin{array}{l}925 \\
880 \\
835\end{array}$ & & & & & & \\
\hline $\begin{array}{r}7 \\
8 \\
9 \\
10 \\
11 \\
\mathrm{~N}\end{array}$ & $\begin{array}{l}2.21 \\
2.25 \\
2.31 \\
2.45 \\
2.55 \\
2.65\end{array}$ & $\begin{array}{l}204 \\
216 \\
234 \\
278 \\
310 \\
344\end{array}$ & $\begin{array}{r}10.70 \\
9.65 \\
8.65 \\
7.75 \\
7.03 \\
6.50\end{array}$ & $\begin{array}{l}6,290 \\
4,530 \\
3,460 \\
2,830 \\
2,310 \\
2,020\end{array}$ & $\begin{array}{c}4.06 \\
3.96 \\
3.82\end{array}$ & $\begin{array}{l}858 . \\
815 \\
755\end{array}$ & 3.28 & 555 & 3.02 & 446 & 2.86 & 387 \\
\hline $\begin{array}{l}1 \\
2 \\
3 \\
4 \\
5 \\
6\end{array}$ & $\begin{array}{l}2.85 \\
3.41 \\
4.10 \\
4.50 \\
5.06 \\
5.19\end{array}$ & $\begin{array}{r}416 \\
635 \\
925 \\
1,100 \\
1,380 \\
1,420\end{array}$ & $\begin{array}{l}6.12 \\
5.88 \\
5.57 \\
5.30 \\
5.11 \\
4.96\end{array}$ & $\begin{array}{l}1,820 \\
1,720 \\
1,570 \\
1,420 \\
1,330 \\
1,280\end{array}$ & $\begin{array}{c}3.75 \\
3.70 \\
3.63\end{array}$ & $\begin{array}{c}7355^{-} \\
-715 \\
695\end{array}$ & & & & & & 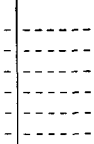 \\
\hline $\begin{array}{r}7 \\
8 \\
9 \\
10 \\
11 \\
12 \\
\end{array}$ & $\begin{array}{l}5.85 \\
6.60 \\
7.30 \\
7.71 \\
7.94 \\
8.35 \\
\end{array}$ & $\begin{array}{l}1,720 \\
2,070 \\
2,490 \\
2,760 \\
2,900 \\
3,290 \\
\end{array}$ & $\begin{array}{l}4.81 \\
4.71 \\
4.60 \\
4.48 \\
4.41 \\
4.35\end{array}$ & $\begin{array}{r}1,200 \\
1,150 \\
1,100 \\
1,060 \\
1,020 \\
992 \\
\end{array}$ & $\begin{array}{r}3 . \overline{56} \\
3.51 \\
3.47 \\
\end{array}$ & $\begin{array}{c}-\overline{6} \overline{5} \overline{5}^{-} \\
-6 \overline{3} \overline{5} \\
-615 \\
\end{array}$ & 3.10 & 476 & 2.89 & 397 & 2.77 & 354 \\
\hline
\end{tabular}

SUPPlemental RECoRds.-Aug. 12, 8:45 p.m., gage height, 4.17 feet, discharge, 902 second-feet; 11:45 p.m., gage height, 5.26 feet, discharge, 1,420 second-feet. Aug. 31, 8:30 a.m., gage height, 4.09 feet, discharge, 880 second-feet.

$804331-49-23$ 
FRENCH BROAD RIVER AT CALVERT, N. C.

Location.-Lat. $35^{\circ} 08^{\prime} 45^{\prime \prime}$, long. $82^{\circ} 48^{\prime} 05^{\prime \prime}$, at township bridge 1 mile downstream from East Fork and 1 mile southeast of railroad station at Calvert, Transylvania County. Datum of gage is 2,154.63 feet above mean sea level, datum of 1929, supplementary adjustment of 1936 .

DRAINAGE AREA.-103 square miles.

GAGE-HEIGHT RECORD.-Water-stage recorder graph.

DISCHARGE RECORD.-Stage-discharge relation defined by current-meter measurements up to 3,600 second-feet and extended to erest gage height on basis of determination of flood flow by slope-area method. Gage heights used to half-tenths between 2.1 and 3.4 feet; hundredths below and tenths abóve these limits.

Maxima.-1940: Diseharge, 12,300 second-feet 1 p.m. Aug. 13 (gage height, 11.66 feet).

1924-39: Discharge, 16,100 second-feet Aug. 15, 1928 (gage height, 13.0' feet).

Stage known, 18.3 feet in July, 1916, from flood reference mark (diseharge not determined).

REMARKS.-Flood runoff not affected by artificial storage.

Mean discharge, in second-feet, 1940

\begin{tabular}{|c|c|c|c|c|c|c|c|c|c|c|c|}
\hline Day & Aug. & Sept. & Day & Aug. & Sept. & Day & Aug. & Sept. & Day & Aug. & Sept. \\
\hline $\begin{array}{l}1 \\
2 \\
3 \\
4 \\
5 \\
6 \\
7 \\
8\end{array}$ & $\begin{array}{l}128 \\
130 \\
124 \\
119 \\
121 \\
128 \\
124 \\
128\end{array}$ & $\begin{array}{l}830 \\
670 \\
580 \\
530 \\
514 \\
475 \\
442 \\
405\end{array}$ & $\begin{array}{r}9 \\
10 \\
11 \\
12 \\
13 \\
14 \\
15 \\
16\end{array}$ & $\begin{array}{r}147 \\
121 \\
140 \\
580 \\
5,980 \\
1,710 \\
870 \\
630\end{array}$ & $\begin{array}{l}379 \\
360 \\
341 \\
323 \\
315 \\
302 \\
294 \\
282\end{array}$ & $\begin{array}{l}17 \\
18 \\
19 \\
20 \\
21 \\
22 \\
23 \\
24\end{array}$ & $\begin{array}{l}514 \\
442 \\
384 \\
346 \\
323 \\
307 \\
290 \\
294\end{array}$ & $\begin{array}{l}271 \\
267 \\
264 \\
256 \\
249 \\
238 \\
235 \\
242\end{array}$ & $\begin{array}{l}25 \\
26 \\
27 \\
28 \\
29 \\
30 \\
31\end{array}$ & $\begin{array}{r}267 \\
252 \\
245 \\
235 \\
1,150 \\
4,300 \\
1,180\end{array}$ & $\begin{array}{l}304 \\
238 \\
225 \\
221 \\
218 \\
211\end{array}$ \\
\hline \multicolumn{10}{|c|}{$\begin{array}{l}\text { Monthly mean discharge, in second-feet } \\
\text { Runoff, in inches }\end{array}$} & 7.800 & $\begin{array}{r}349 \\
3.78\end{array}$ \\
\hline
\end{tabular}


Gage height, in feet, and discharge, in second-feet, at indicated time, 1940

\begin{tabular}{|c|c|c|c|c|c|c|c|c|c|c|c|c|}
\hline \multirow{2}{*}{ Hour } & \multicolumn{2}{|c|}{ Aug. 12} & \multicolumn{2}{|c|}{ Aug. 13} & \multicolumn{2}{|c|}{ Aug. 14} & \multicolumn{2}{|c|}{ Aug. 15} & \multicolumn{2}{|c|}{ Aug. 16} & \multicolumn{2}{|c|}{ Aug. 17} \\
\hline & $\begin{array}{c}\text { Gage } \\
\text { ht. }\end{array}$ & $\begin{array}{c}\text { Dis- } \\
\text { charge }\end{array}$ & $\begin{array}{c}\text { Gage } \\
\text { ht. }\end{array}$ & $\begin{array}{c}\text { Dis- } \\
\text { charge }\end{array}$ & $\begin{array}{c}\text { Gage } \\
\text { ht. }\end{array}$ & $\begin{array}{c}\text { Dis- } \\
\text { charge }\end{array}$ & $\begin{array}{c}\text { Gage } \\
\text { ht. }\end{array}$ & $\begin{array}{l}\text { Dis- } \\
\text { charge }\end{array}$ & $\begin{array}{c}\text { Gage } \\
\text { ht. }\end{array}$ & $\begin{array}{c}\text { Dis- } \\
\text { charge }\end{array}$ & $\begin{array}{c}\text { Gage } \\
\text { ht. }\end{array}$ & $\begin{array}{l}\text { Dis- } \\
\text { charge }\end{array}$ \\
\hline $\begin{array}{l}1 \\
2 \\
3 \\
4 \\
5 \\
6\end{array}$ & $\begin{array}{r}0.86 \\
.87 \\
.87 \\
.88 \\
.89 \\
.90\end{array}$ & $\begin{array}{l}169 \\
172 \\
172 \\
174 \\
177 \\
180\end{array}$ & $\begin{array}{l}3.46 \\
3.41 \\
3.51 \\
4.15 \\
4.80 \\
5.65\end{array}$ & $\begin{array}{l}1,600 \\
1,540 \\
1,600 \\
2,010 \\
2,340 \\
2,800\end{array}$ & $\begin{array}{l}5.86 \\
5.40 \\
5.02 \\
4.67 \\
4.43 \\
4.19\end{array}$ & $\begin{array}{l}2,980 \\
2,680 \\
2,450 \\
2,280 \\
2,120 \\
2,010\end{array}$ & & & & & & \\
\hline $\begin{array}{r}7 \\
8 \\
9 \\
10 \\
11 \\
\mathrm{~N}\end{array}$ & $\begin{array}{l}.95 \\
1.00 \\
1.03 \\
1.08 \\
1.19 \\
1.40\end{array}$ & $\begin{array}{l}196 \\
211 \\
221 \\
238 \\
278 \\
369\end{array}$ & $\begin{array}{r}6.70 \\
7.70 \\
8.70 \\
9.35 \\
10.15 \\
11.22\end{array}$ & $\begin{array}{r}3,460 \\
4,150 \\
5,130 \\
6,140 \\
7,790 \\
10,600\end{array}$ & $\begin{array}{l}3.99 \\
3.84 \\
3.70 \\
3.58 \\
3.47 \\
3.37\end{array}$ & $\begin{array}{l}1,900 \\
1,780 \\
1,720 \\
1,660 \\
1,600 \\
1,500\end{array}$ & 2.28 & 875 & 1.89 & 634 & 1.68 & 519 \\
\hline $\begin{array}{l}1 \\
2 \\
3 \\
4 \\
5 \\
6\end{array}$ & $\begin{array}{l}1.54 \\
1.84 \\
2.00 \\
2.19 \\
2.34 \\
2.52\end{array}$ & $\begin{array}{l}442 \\
607 \\
695 \\
815 \\
905 \\
995\end{array}$ & $\begin{array}{l}11.66 \\
11.53 \\
11.31 \\
11.11 \\
10.87 \\
10.55\end{array}$ & $\begin{array}{r}12,300 \\
11,600 \\
10,900 \\
10,300 \\
9,680 \\
8,810\end{array}$ & $\begin{array}{l}3.32 \\
3.28 \\
3.17 \\
3.09 \\
3.01 \\
2.94\end{array}$ & $\begin{array}{l}1,480 \\
1,480 \\
1,380 \\
1,360 \\
1,300 \\
1,260\end{array}$ & & & & & & \\
\hline $\begin{array}{r}7 \\
8 \\
9 \\
10 \\
11 \\
12 \\
\end{array}$ & $\begin{array}{l}2.64 \\
2.77 \\
2.72 \\
2.85 \\
3.24 \\
3.58\end{array}$ & $\begin{array}{l}1,080 \\
1,140 \\
1,120 \\
1,200 \\
1,440 \\
1,660\end{array}$ & \begin{tabular}{|r|}
10.12 \\
9.60 \\
9.02 \\
8.30 \\
7.40 \\
6.52
\end{tabular} & $\begin{array}{l}7,560 \\
6,510 \\
5,520 \\
4,700 \\
3,930 \\
3,340 \\
\end{array}$ & $\begin{array}{l}2.89 \\
2.82 \\
2.76 \\
2.72 \\
2.68 \\
2.64\end{array}$ & $\begin{array}{l}1,240 \\
1,180 \\
1,140 \\
1,120 \\
1,120 \\
1,080\end{array}$ & 2.02 & 707 & & 558 & $1 . \overline{59}$ & \\
\hline & \multicolumn{2}{|c|}{ Aug: 29} & \multicolumn{2}{|c|}{ Aug. 30} & \multicolumn{2}{|c|}{ Aug. 31} & \multicolumn{2}{|c|}{ Sept. 1} & \multicolumn{2}{|c|}{ Sept. 2} & \multicolumn{2}{|c|}{ Sept. } \\
\hline $\begin{array}{l}1 \\
2 \\
3 \\
4 \\
5 \\
6\end{array}$ & $\begin{array}{l}1.03 \\
1.03 \\
1.03 \\
1.04 \\
1.05 \\
1.09\end{array}$ & $\begin{array}{l}221 \\
221 \\
221 \\
225 \\
228 \\
242\end{array}$ & $\begin{array}{r}8.20 \\
8.78 \\
9.20 \\
9.70 \\
10.37 \\
10.79\end{array}$ & $\begin{array}{l}4,600 \\
5,250 \\
5,810 \\
6,700 \\
8,280 \\
9,380\end{array}$ & $\begin{array}{l}3.25 \\
3.19 \\
3.12 \\
3.06 \\
3.00 \\
2.96\end{array}$ & $\begin{array}{l}1,440 \\
1,420 \\
1,360 \\
1,320 \\
1,300 \\
1,260\end{array}$ & $\mid \begin{array}{c}2 . \overline{3} 5 \\
-\end{array}$ & 905 & & & & \\
\hline $\begin{array}{r}7 \\
8 \\
9 \\
10 \\
11 \\
\mathrm{~N}\end{array}$ & $\begin{array}{l}1.20 \\
1.22 \\
1.25 \\
1.34 \\
1.50 \\
1.64\end{array}$ & $\begin{array}{l}282 \\
290 \\
302 \\
341 \\
420 \\
497\end{array}$ & $\begin{array}{r}10.75 \\
10.30 \\
9.75 \\
9.00 \\
7.88 \\
6.73\end{array}$ & $\begin{array}{l}9,380 \\
8,030 \\
6,900 \\
5,520 \\
4,320 \\
3,460\end{array}$ & $\begin{array}{l}2.92 \\
2.92 \\
2.98 \\
2.91 \\
2.84 \\
2.77\end{array}$ & $\begin{array}{l}1,240 \\
1,240 \\
1,300 \\
1,240 \\
1,200 \\
1,140\end{array}$ & $\left|\begin{array}{c}-2.28 \\
\hdashline 2.23\end{array}\right|$ & $8 \overline{4} \overline{5}$ & 1.96 & 673 & 1.81 & 590 \\
\hline $\begin{array}{l}1 \\
2 \\
3 \\
4 \\
5 \\
5 \\
6\end{array}$ & $\begin{array}{l}1.64 \\
1.84 \\
2.27 \\
2.67 \\
3.22 \\
3.80\end{array}$ & $\begin{array}{r}497 \\
607 \\
845 \\
1,080 \\
1,420 \\
1,780\end{array}$ & $\begin{array}{l}5.88 \\
5.35 \\
4.92 \\
4.60 \\
4.34 \\
4.10\end{array}$ & $\begin{array}{l}2,980 \\
2,680 \\
2,400 \\
2,230 \\
2,060 \\
1,960\end{array}$ & $\begin{array}{l}2.74 \\
2.74 \\
2.72 \\
2.67 \\
2.65 \\
2.60\end{array}$ & $\begin{array}{l}1,140 \\
1,140 \\
1,120 \\
1,080 \\
1,080 \\
1,060\end{array}$ & $\mid \begin{array}{r}2.15 \\
\hdashline-\end{array}$ & 785 & - & & $\ldots$ & \\
\hline $\begin{array}{r}7 \\
8 \\
9 \\
10 \\
11 \\
12\end{array}$ & $\begin{array}{l}4.17 \\
5.40 \\
6.55 \\
7.12 \\
7.45 \\
7.74\end{array}$ & $\begin{array}{l}2,010 \\
2,680 \\
3,400 \\
3,720 \\
3,930 \\
4.150\end{array}$ & $\begin{array}{l}3.90 \\
3.76 \\
3.63 \\
3.51 \\
3.42 \\
3.33\end{array}$ & $\begin{array}{l}1,840 \\
1,780 \\
1,660 \\
1,600 \\
1,540 \\
1,500\end{array}$ & $\begin{array}{l}2.56 \\
2.52 \\
2.49 \\
2.47 \\
2.44 \\
2.42\end{array}$ & $\begin{array}{r}1,020 \\
995 \\
995 \\
965 \\
965 \\
935\end{array}$ & $\left|\begin{array}{c}\overline{2.08} \\
\hdashline \overline{2.05}\end{array}\right|$ & 725 & 1.85 & 612 & $|-1.72|$ & 541 \\
\hline
\end{tabular}

Supplemental RECORD.-Aug. 30, $6: 30$ a.m., gage height, 10.83 feet, discharge, 9,380 second-feet.

FRENCH BROAD RIVER AT BLANTYRE, N. C.

Location.-Lat. $35^{\circ} 17^{\prime} 50^{\prime \prime}$, long. $82^{\circ} 37^{\prime} 25^{\prime \prime}$, at highway bridge 700 feet east of railroad station at Blantyre, Transylvania County, and 3 miles downstream from Little River. Datum of gage is 2,060.32 feet above mean sea level, datum of 1929, supplementary adjustment of 1936.

Drainage AREa.-296 square miles.

GAGE-HEIGHT RECORD.-Water-stage recorder graph.

DISCHARGE RECORD.-Stage-discharge relation defined by current-meter measurements up to 11,600 second-feet and extended to the 1928 erest gage height on basis of flood runoff comparisons. Gage heights used to half-tenths between 3.3 and 4.8 feet; hundredths below and tenths above these limits. 
Maxima.-1940: Discharge, 20,800 second-feet (revised) 9 a.m. Aug. 14 (gage height, 21.89 feet).

1920-39: Discharge, 26,500 second-feet Aug. 16, 1928 (gage height, 22.9 feet).

Stage known, 27.1 feet in July 1916, from floodmarks (discharge not determined). Surveys by the Tennessee Valley Authority show that the flood of June 1876 was 5 feet below that of 1916 at Penrose, 3 miles upstream.

REMARKs.-Flood runoff not affected by artificial storage.

Mean discharge, in second-feet, 1940

\begin{tabular}{|c|c|c|c|c|c|c|c|c|c|c|c|}
\hline Day & Aug. & Sept. & Day & Aug. & Sept. & Day & Aug. & Sept. & Day & Aug. & Sept. \\
\hline $\begin{array}{l}1 \\
2 \\
3 \\
4 \\
5 \\
6 \\
7 \\
8\end{array}$ & $\begin{array}{l}375 \\
310 \\
310 \\
290 \\
300 \\
310 \\
364 \\
321\end{array}$ & $\begin{array}{l}5,050 \\
2,260 \\
1,620 \\
1,400 \\
1,280 \\
1,280 \\
1,130 \\
1,040\end{array}$ & $\begin{array}{r}9 \\
10 \\
11 \\
12 \\
13 \\
14 \\
15 \\
16\end{array}$ & $\begin{array}{r}364 \\
310 \\
321 \\
832 \\
6,370 \\
18,300 \\
8,550 \\
3,090\end{array}$ & $\begin{array}{l}984 \\
926 \\
897 \\
841 \\
785 \\
757 \\
730 \\
730\end{array}$ & $\begin{array}{l}17 \\
18 \\
19 \\
20 \\
21 \\
22 \\
23 \\
24\end{array}$ & $\begin{array}{r}1,540 \\
1,250 \\
1,100 \\
955 \\
869 \\
841 \\
785 \\
813\end{array}$ & $\begin{array}{l}703 \\
651 \\
651 \\
651 \\
626 \\
564 \\
601 \\
588\end{array}$ & $\begin{array}{l}25 \\
26 \\
27 \\
28 \\
29 \\
30 \\
31\end{array}$ & $\begin{array}{r}813 \\
730 \\
677 \\
651 \\
1,200 \\
6,400 \\
9,870\end{array}$ & $\begin{array}{l}677 \\
626 \\
576 \\
564 \\
\mathbf{4 7 9} \\
\mathbf{5 1 5}\end{array}$ \\
\hline \multicolumn{10}{|c|}{ Monthly mean discharge, in second-feet } & $\begin{array}{r}2,233 \\
8.70\end{array}$ & $\begin{array}{r}1,006 \\
3.79\end{array}$ \\
\hline
\end{tabular}

Gage height, in feet, and discharge, in second-feet, at indicated time, 1940

\begin{tabular}{|c|c|c|c|c|c|c|c|c|c|c|c|c|}
\hline \multirow{2}{*}{ Hour } & \multicolumn{2}{|c|}{ Aug. 12} & \multicolumn{2}{|c|}{ Aug. 13} & \multicolumn{2}{|c|}{ Aug. 14} & \multicolumn{2}{|c|}{ Aug. 15} & \multicolumn{2}{|c|}{ Aug. 16} & \multicolumn{2}{|c|}{ Aug. 17} \\
\hline & $\begin{array}{c}\text { Gage } \\
\text { ht. }\end{array}$ & $\begin{array}{l}\text { Dis- } \\
\text { charge }\end{array}$ & $\begin{array}{c}\text { Gage } \\
\text { ht. }\end{array}$ & $\begin{array}{l}\text { Dis- } \\
\text { charge }\end{array}$ & $\begin{array}{c}\text { Gage } \\
\text { ht. }\end{array}$ & $\begin{array}{c}\text { Dis- } \\
\text { charge }\end{array}$ & $\begin{array}{c}\text { Gage } \\
\text { ht. }\end{array}$ & $\begin{array}{c}\text { Dis- } \\
\text { charge }\end{array}$ & $\begin{array}{c}\text { Gage } \\
\text { ht. }\end{array}$ & $\begin{array}{l}\text { Dis- } \\
\text { charge }\end{array}$ & $\begin{array}{c}\text { Gage } \\
\text { ht. }\end{array}$ & $\begin{array}{l}\text { Dis- } \\
\text { charge }\end{array}$ \\
\hline $\begin{array}{r}2 \\
4 \\
6 \\
8 \\
10 \\
\mathrm{~N}\end{array}$ & $\begin{array}{r}13.80 \\
13.83 \\
13.89 \\
3.97 \\
4.13 \\
4.67\end{array}$ & $\begin{array}{l}386 \\
398 \\
409 \\
420 \\
467 \\
588\end{array}$ & $\begin{array}{l}10.67 \\
11.55 \\
13.76 \\
13.95 \\
14.80 \\
15.73\end{array}$ & $\begin{array}{l}2,560 \\
2,840 \\
3,700 \\
3,780 \\
4,120 \\
4,520\end{array}$ & $\begin{array}{l}21.22 \\
21.48 \\
21.73 \\
21.88 \\
21.88 \\
21.80\end{array}$ & $\begin{array}{l}17,600 \\
18,900 \\
19,900 \\
20,800 \\
20,800 \\
20,300\end{array}$ & \begin{tabular}{l}
.---- \\
$\overline{19} . \overline{2} \overline{1}$ \\
\hdashline$\overline{18.35}$
\end{tabular} & 10,600 & $\mid$\begin{tabular}{l}
$-\ldots .$. \\
14.37 \\
\hdashline.-- \\
11.87
\end{tabular} & \begin{tabular}{c}
$-3,940$ \\
\hdashline 2,940
\end{tabular} & \begin{tabular}{l}
$-\cdots$ \\
$-\cdots-$ \\
$-\cdots-$ \\
\hdashline$\overline{7.91}$
\end{tabular} & |י \\
\hline $\begin{array}{r}2 \\
4 \\
6 \\
8 \\
10 \\
12\end{array}$ & $\begin{array}{l}5.28 \\
6.04 \\
6.82 \\
7.45 \\
8.47 \\
9.82\end{array}$ & $\begin{array}{r}757 \\
955 \\
1,190 \\
1,370 \\
1,750 \\
2,200 \\
\end{array}$ & $\begin{array}{l}16.62 \\
17.42 \\
18.43 \\
19.56 \\
20.40 \\
20.90\end{array}$ & $\begin{array}{r}5,020 \\
5,920 \\
8,330 \\
11,800 \\
14,500 \\
16,400\end{array}$ & $\mid \begin{array}{l}21.65 \\
21.41 \\
21.13 \\
20.82 \\
20.50 \\
20.18\end{array}$ & $\begin{array}{l}19,400 \\
18,500 \\
17,200 \\
16,000 \\
14,900 \\
13,800\end{array}$ & $\left|\begin{array}{l}-\cdots-\overline{17} \\
\overline{17} \overline{0} \\
\hdashline \overline{16.34}\end{array}\right|$ & 6,070 & $\mid$\begin{tabular}{c}
$-\cdots .83$ \\
$-\overline{8}$ \\
\hdashline$\overline{8.66}$
\end{tabular} & $\begin{array}{c}-1,200 \\
-1,820\end{array}$ & 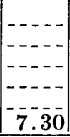 & 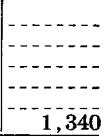 \\
\hline
\end{tabular}

\begin{tabular}{|c|c|c|c|c|c|c|c|c|c|c|c|c|}
\hline & \multicolumn{2}{|c|}{ Aug. 29} & \multicolumn{2}{|c|}{ Aug. 30} & \multicolumn{2}{|c|}{ Aug. 31} & \multicolumn{2}{|c|}{ Sept. 1} & \multicolumn{2}{|c|}{ Sept. 2} & \multicolumn{2}{|c|}{ Sept. 3} \\
\hline $\begin{array}{r}2 \\
4 \\
6 \\
8 \\
10 \\
\mathbf{N}\end{array}$ & $\begin{array}{l}4.80 \\
4.78 \\
4.79 \\
4.79 \\
4.86 \\
5.16\end{array}$ & $\begin{array}{l}626 \\
626 \\
626 \\
626 \\
651 \\
730\end{array}$ & $\begin{array}{l}14.30 \\
15.00 \\
15.55 \\
16.05 \\
16.62 \\
17.22\end{array}$ & $\begin{array}{l}3,900 \\
4,200 \\
4,470 \\
4,670 \\
5,020 \\
5,660\end{array}$ & $\begin{array}{l}19.00 \\
19.15 \\
19.27 \\
19.32 \\
19.29 \\
19.20\end{array}$ & $\begin{array}{l}10,000 \\
10,600 \\
10,900 \\
10,900 \\
10,900 \\
10,600\end{array}$ & $\mid \begin{array}{l}17.88 \\
17.62 \\
17.38 \\
17.10 \\
16.78 \\
16.38\end{array}$ & $\begin{array}{l}6,940 \\
6,240 \\
5,920 \\
5,540 \\
5,210 \\
4,890\end{array}$ & \begin{tabular}{c}
10.74 \\
\hdashline 9.65
\end{tabular} & $\begin{array}{r}2,520 \\
2,140\end{array}$ & 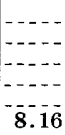 & 1,640 \\
\hline $\begin{array}{r}2 \\
4 \\
6 \\
8 \\
10 \\
12\end{array}$ & $\begin{array}{r}6.05 \\
6.98 \\
7.78 \\
9.14 \\
11.28 \\
13.30\end{array}$ & $\begin{array}{r}955 \\
1,250 \\
1,500 \\
1,960 \\
2,730 \\
3,500\end{array}$ & $\begin{array}{l}17.83 \\
18.27 \\
18.58 \\
18.70 \\
18.78 \\
18.86\end{array}$ & $\begin{array}{l}6,680 \\
8,040 \\
8,900 \\
9,180 \\
9,470 \\
9,760\end{array}$ & $\begin{array}{l}19.07 \\
18.91 \\
18.72 \\
18.52 \\
18.32 \\
18.10\end{array}$ & $\begin{array}{r}10,300 \\
9,760 \\
9,180 \\
8,620 \\
8,040 \\
7,480\end{array}$ & $\begin{array}{l}15.94 \\
15.40 \\
14.80 \\
14.14 \\
13.42 \\
12.68\end{array}$ & $\begin{array}{l}4,620 \\
4,380 \\
4,120 \\
3,820 \\
3,540 \\
3,260\end{array}$ & $\begin{array}{r}-\overline{9} . \overline{0} \\
-\overline{8.5} \overline{6}\end{array}$ & $\begin{array}{r}-1,920 \\
1,780\end{array}$ & \begin{tabular}{l}
$-\cdots$ \\
\hdashline.-- \\
$-\ldots$ \\
7.68
\end{tabular} & 1, \\
\hline
\end{tabular}

1 Partly estimated.

SUPPLEMENTAL RECORD.-Aug. 14, 9 a.m., gage height 21.89 feet, discharge, 20,800 second-feet. 
FRENCH GHOAD RIVER AT BENT CREEK, N. C.

Location.-Lat. $35^{\circ} 30^{\prime} 10^{\prime \prime}$, long. $82^{\circ} 35^{\prime} 30^{\prime \prime}$, about 50 feet downstream from Bent Creek, 6 miles upstream from Hominy Creek, and 7 miles south of Asheville, Buncombe County. Datum of gage is 1,995.95 feet above mean sea level, datum of 1929 , supplementary adjustment of 1936 .

Drainage AREA. - 676 square miles.

GAGE-HEIGHT RECORD.-Water-stage recorder graph.

DISCHARGE RECORD.-Stage-discharge relation defined by current-meter measurements up to 14,500 second-feet and extended logarithmically to crest gage height. Gage heights used to half-tenths between 3.5 and 5.5 feet; hundredths below and tenths above these limits.

Maxima.-1940: Discharge, 23,600 second-feet 6 a.m. Aug. 14 (gage height, 12.60 feet).

1934-39: Discharge, 13,200 second-feet Apr. 7, 1936 (gage height, 9.00 feet).

Stage known, about 27.3 feet July 15, 1916, from floodmarks (discharge not determined). The flood of August 1928 reached a stage of about 16.1 feet (discharge not determined).

REMARKs.-Flood runoff not affected by artificial storage.

Mean discharge, in second-feet, 1940

\begin{tabular}{|c|c|c|c|c|c|c|c|c|c|c|c|}
\hline Day & Aug. & Sept. & Day & Aug. & Sept. & Day & Aug. & Sept. & Day & Aug. & Sept. \\
\hline $\begin{array}{l}1 \\
2 \\
3 \\
4 \\
5 \\
6 \\
7 \\
8\end{array}$ & $\begin{array}{l}662 \\
751 \\
628 \\
594 \\
561 \\
594 \\
688 \\
706\end{array}$ & $\begin{array}{r}10,300 \\
6,670 \\
3,290 \\
2,650 \\
2,350 \\
2,210 \\
1,930 \\
1,860\end{array}$ & $\begin{array}{r}9 \\
10 \\
11 \\
12 \\
13 \\
14 \\
15 \\
16\end{array}$ & $\begin{array}{r}628 \\
628 \\
619 \\
1,050 \\
7,920 \\
21,300 \\
16,800 \\
8,940\end{array}$ & $\begin{array}{l}1,800 \\
1,670 \\
1,600 \\
1,500 \\
1,440 \\
1,400 \\
1,340 \\
1,300\end{array}$ & $\begin{array}{l}17 \\
18 \\
19 \\
20 \\
21 \\
22 \\
23 \\
24\end{array}$ & $\begin{array}{l}3,790 \\
2,350 \\
2,140 \\
1,670 \\
1,480 \\
1,360 \\
1,310 \\
1,240\end{array}$ & $\begin{array}{l}1,290 \\
1,220 \\
1,220 \\
1,170 \\
1,160 \\
1,100 \\
1,060 \\
1,080\end{array}$ & $\begin{array}{l}25 \\
26 \\
27 \\
28 \\
29 \\
30 \\
31\end{array}$ & $\begin{array}{r}1,270 \\
1,150 \\
1,090 \\
1,060 \\
3,070 \\
15,200 \\
12,700\end{array}$ & $\begin{array}{r}1,140 \\
1,180 \\
1,060 \\
1,030 \\
983 \\
910\end{array}$ \\
\hline \multicolumn{10}{|c|}{$\begin{array}{l}\text { Monthly mean discharge, in second-feet } \\
\text { Runoff, in inches }\end{array}$} & $\begin{array}{r}3,676 \\
6.27\end{array}$ & $\begin{array}{r}1,964 \\
3.24\end{array}$ \\
\hline
\end{tabular}




\section{FLOODS OF AUGUST 1940 IN THE SOUTHEASTERN STATES}

Gage height, in feet, and discharge, in second-feet, at indicated time, 1940

\begin{tabular}{|c|c|c|c|c|c|c|c|c|c|c|c|c|}
\hline \multirow{2}{*}{ Hour } & \multicolumn{2}{|c|}{ Aug. 12} & \multicolumn{2}{|c|}{ Aug. 13} & \multicolumn{2}{|c|}{ Aug. 14} & \multicolumn{2}{|c|}{ Aug. 15} & \multicolumn{2}{|c|}{ Aug. 16} & \multicolumn{2}{|c|}{ Aug. 17} \\
\hline & $\begin{array}{c}\text { Gage } \\
\text { ht. }\end{array}$ & $\begin{array}{l}\text { Dis- } \\
\text { charge }\end{array}$ & $\begin{array}{c}\text { Gage } \\
\text { ht. }\end{array}$ & $\begin{array}{l}\text { Dis- } \\
\text { charge }\end{array}$ & $\begin{array}{c}\text { Gage } \\
\text { ht. }\end{array}$ & $\begin{array}{c}\text { Dis- } \\
\text { charge }\end{array}$ & $\begin{array}{c}\text { Gage } \\
\text { ht. }\end{array}$ & $\begin{array}{l}\text { Dis- } \\
\text { charge }\end{array}$ & $\begin{array}{c}\text { Gage } \\
\text { ht. }\end{array}$ & $\underset{\text { cha }}{\mathrm{Di}}$ & $\begin{array}{c}\text { Gage } \\
\text { ht. }\end{array}$ & $\begin{array}{c}\text { Dis- } \\
\text { charge }\end{array}$ \\
\hline \multirow{4}{*}{$\begin{array}{l}1 \\
2 \\
3 \\
4 \\
5 \\
6\end{array}$} & & & \multirow{4}{*}{\begin{tabular}{|l|}
14.22 \\
14.38 \\
14.55 \\
14.80 \\
15.00 \\
15.14 \\
\end{tabular}} & \multirow{4}{*}{$\begin{array}{l}2,650 \\
2,960 \\
3,200 \\
3,630 \\
3,980 \\
4,250\end{array}$} & \multirow{4}{*}{$\begin{array}{l}11.45 \\
11.95 \\
12.25 \\
12.50 \\
12.58 \\
12.60\end{array}$} & \multirow{4}{*}{$\begin{array}{l}19,800 \\
21,700 \\
22,300 \\
23,300 \\
23,600 \\
23,600\end{array}$} & & & & & & \\
\hline & 2.67 & 733 & & & & & & & & & & \\
\hline & 2.68 & 742 & & & & & 11.30 & 19,500 & 8.13 & 10,500 & 5.62 & 5,100 \\
\hline & 2.68 & 742 & & & & & & & & & & \\
\hline \multirow{4}{*}{$\begin{array}{r}8 \\
9 \\
10 \\
11 . \\
\mathrm{N}\end{array}$} & & & \multirow{4}{*}{$\begin{array}{r}15.30 \\
15.48 \\
15.65 \\
5.83 \\
6.20 \\
6.56\end{array}$} & \multirow{4}{*}{$\begin{array}{l}4,530 \\
4,910 \\
5,100 \\
5,500 \\
6,300 \\
7,140\end{array}$} & \multirow{4}{*}{$\begin{array}{l}12.57 \\
12.46 \\
12.37 \\
12.25 \\
12.10 \\
11.94\end{array}$} & \multirow{4}{*}{$\begin{array}{l}23,600 \\
23,300 \\
23,000 \\
22,300 \\
22,000 \\
21,400\end{array}$} & & & & & & \\
\hline & 2.69 & 751 & & & & & 10.98 & 18,600 & 7.75 & 9,820 & 5.00 & 3,980 \\
\hline & $-\overline{2} . \overline{7}$ & 769 & & & & & & & & & & \\
\hline & 12.81 & 860 & & & & & 10.55 & 17,400 & 7.38 & 8,890 & 4.63 & 3,380 \\
\hline 1 & & & \multirow{5}{*}{$\begin{array}{l}6.91 \\
7.20 \\
7.50 \\
7.90 \\
8.23 \\
8.40\end{array}$} & \multirow{5}{*}{$\begin{array}{r}7,780 \\
8,440 \\
9,120 \\
10,100 \\
10,800 \\
11,300\end{array}$} & \multirow{5}{*}{$\begin{array}{l}11.80 \\
11.67 \\
11.55 \\
11.48 \\
11.43 \\
11.42\end{array}$} & \multirow{5}{*}{$\begin{array}{l}21,000 \\
20,700 \\
20,400 \\
20,100 \\
19,800 \\
19,800\end{array}$} & & & & & & \\
\hline $\begin{array}{l}1 \\
2\end{array}$ & 12.90 & 950 & & & & & & & & & & \\
\hline $\begin{array}{l}3 \\
4\end{array}$ & 13.00 & 1,060 & & & & & 9.9 & & 7.05 & 8.000 & 4.43 & $3,040^{-}$ \\
\hline 5 & $\mid \begin{array}{c}0.00 \\
---10\end{array}$ & & & & & & & & & & & \\
\hline 6 & 13.12 & 1,190 & & & & & & & & & & \\
\hline \multirow{5}{*}{$\begin{array}{r}7 \\
8 \\
9 \\
10 \\
11 \\
12 \\
\end{array}$} & & & \multirow{4}{*}{$\begin{array}{r}8.47 \\
8.56 \\
9.20 \\
9.70 \\
10.30 \\
10.87\end{array}$} & 00 & .43 & 00 & & & & & & \\
\hline & 3.30 & & & $\begin{array}{r}11,800 \\
13,400\end{array}$ & 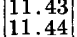 & $\begin{array}{l}19,800 \\
19,800\end{array}$ & 9.35 & & 6.70 & & 28 & \\
\hline & $3.6 \overline{3}$ & 1,860 & & 14,800 & $\mid \begin{array}{l}11.44 \\
11.45\end{array}$ & 19,800 & & & & & & \\
\hline & 4.00 & 2,350 & & & $\left|\begin{array}{ll}11 & .46 \\
11 & .47\end{array}\right|$ & & 8.65 & 11,800 & $6 . \overline{2}$ & 6,300 & 4.16 & $2,580^{-}$ \\
\hline & $\mathrm{A}$ & 9 & & 18 & $\mathrm{Au}$ & $g$ & & $\mathrm{pp}$ & & ep & & \\
\hline 1 & 2.96 & & 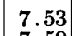 & & .23 & & & & & & & \\
\hline $\begin{array}{l}2 \\
3\end{array}$ & & & 7.59 & & 10.00 & & & & $\ldots$ & & & \\
\hline $\begin{array}{l}3 \\
4 \\
4\end{array}$ & $\begin{array}{l}2.95 \\
2.95\end{array}$ & $\begin{array}{l}1,000 \\
1,000\end{array}$ & $\begin{array}{r}7.95 \\
8.60\end{array}$ & & $\begin{array}{l}9.80 \\
9.67\end{array}$ & $\begin{array}{l}15 \\
14\end{array}$ & 8.34 & 11,000 & 7.10 & 8,220 & 4.81 & 3,630 \\
\hline 5 & 2.95 & 000 & 9.35 & & 9.52 & & 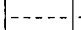 &.- & ---- & $\ldots \ldots$ & $\ldots$ & $\ldots$ \\
\hline 6 & & 1,00 & & & 9.35 & & & & & & & \\
\hline 8 & 2.94 & & & & & & & & & & & \\
\hline $\begin{array}{l}8 \\
9\end{array}$ & & & & & 9. & & 8.25 & & 6.82 & 60 & 66 & \\
\hline 10 & & & & & & & -- & & $\cdots+1$ & & & \\
\hline 11 & & & & & 8.75 & & & & & & & \\
\hline $\mathrm{N}$ & 2 & & 70 & & 8.66 & 12 & 8.08 & 500 & 6.50 & 6,930 & 4.56 & 3,200 \\
\hline 1 & 3.02 & &, 00 & & 85 & & & & & & & \\
\hline $\begin{array}{l}2 \\
3\end{array}$ & & & & & & & & & & & & \\
\hline 4 & 4.40 & 2960 & .90 & & $\begin{array}{l}8.48 \\
8.44\end{array}$ & & $\overline{7} . \overline{85}$ & 9,820 & 6.04 & 5,900 & 4.48 & 3,120 \\
\hline 5 & & 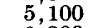 & 4 & & 8.41 & & & & & & & \\
\hline 6 & & & 8 & 18,900 & 8.39 & 11,300 & & & & & & \\
\hline 7 & 6.45 & & & & 8. & & & & & & & \\
\hline 8 & & & & & & & 7.57 & 9,350 & 5.51 & 4,910 & 4.41 & 2,960 \\
\hline 9 & & 8. & 1 & & 8. & & & & & & $-\infty$ & \\
\hline 1 & & & & & 8. & & & & & & & \\
\hline 12 & & 8 , & 10.42 & 16,800 & 8.36 & 11 & 7.35 & 8,890 & 5.07 & 4,070 & 4.34 & 2,880 \\
\hline
\end{tabular}

' Partly estimated. 
FRENCH BROAD RIVLR AT ASHEVILLE, N. C.

Location.-Lat. $35^{\circ} 36^{\prime} 25^{\prime \prime}$; long. $82^{\circ} 34^{\prime} 30^{\prime \prime}$, at Bingham School Bridge at Asheville, Buncombe County, 21/4 miles downstream from Southern Railway station and 3 miles downstream from Swannanoa River. Datum of gage is 1,950.28 feet above mean sea level, datum of 1929, supplementary adjustment of 1936 .

Drainage area.-945 square miles.

GAGE-HEIGHT RECORD.-Water-stage recorder graph.

DISCHARGE RECORD.-Stage-discharge relation defined by current-meter measurements up to 43,000 second-feet and extended logarithmically to the 1916 crest gage height. Gage heights used to half-tenths between 1.8 and 3.7 feet; hundredths below and tenths above these limits.

Maxima.-1940: Discharge, 34,800 second-feet $12 \mathrm{~m}$. Aug. 30 (gage height, 12.15 feet).

1895-1901, 1903-39: Discharge, 110,000 second-feet July 16, 1916 (gage height, 23.1 feet, from floodmarks).

Surveys by the Tennessee Valley Authority show that the flood of June 1876 reached a stage of 18 feet, from floodmarks.

REMarKs.-Flood runoff not affected by artificial storage.

Mean discharge, in second-feet, 1940

\begin{tabular}{|c|c|c|c|c|c|c|c|c|c|c|c|}
\hline Day & Aug. & Sept. & Day & Aug. & Sept. & Day & Aug. & Sept. & Day & Aug. & Sept. \\
\hline $\begin{array}{l}1 \\
2 \\
3 \\
4 \\
5 \\
6 \\
7 \\
8\end{array}$ & $\begin{array}{l}775 \\
852 \\
742 \\
700 \\
670 \\
700 \\
797 \\
830\end{array}$ & $\begin{array}{r}11,800 \\
8,300 \\
4,260 \\
3,290 \\
2,860 \\
2,690 \\
2,450 \\
2,220\end{array}$ & $\begin{array}{r}9 \\
10 \\
11 \\
12 \\
13 \\
14 \\
15 \\
16\end{array}$ & $\begin{array}{r}720 \\
731 \\
731 \\
1,710 \\
14,700 \\
25,800 \\
18,500 \\
10,800\end{array}$ & $\begin{array}{l}2,080 \\
1,980 \\
1,910 \\
1,750 \\
1,670 \\
1,600 \\
1,530 \\
1,480\end{array}$ & $\begin{array}{l}17 \\
18 \\
19 \\
20 \\
21 \\
22 \\
23 \\
24\end{array}$ & $\begin{array}{l}5,290 \\
3,110 \\
2,770 \\
2,300 \\
1,980 \\
1,820 \\
1,740 \\
1,640\end{array}$ & $\begin{array}{l}1,430 \\
1,380 \\
1,360 \\
1,340 \\
1,280 \\
1,220 \\
1,140 \\
1,170\end{array}$ & $\begin{array}{l}25 \\
26 \\
27 \\
28 \\
29 \\
30 \\
31\end{array}$ & $\begin{array}{r}1,640 \\
1,490 \\
1,410 \\
1,340 \\
4,210 \\
27,300 \\
16,000\end{array}$ & $\begin{array}{l}1,190 \\
1,280 \\
1,170 \\
1,130 \\
1,100 \\
1,000\end{array}$ \\
\hline on & & & & & & & & & & $\begin{array}{r}4,961 \\
6.05\end{array}$ & $\begin{array}{r}2,302 \\
2.72\end{array}$ \\
\hline
\end{tabular}


334 FLOODS OF AUGUST 1940 IN THE SOUTHEASTERN STATES

Gage height, in feet, and discharge, in second-feet, at indicated time, 1940

\begin{tabular}{|c|c|c|c|c|c|c|c|c|c|c|c|c|}
\hline \multirow[b]{2}{*}{ a } & \multicolumn{2}{|c|}{ Aug. 12} & \multicolumn{2}{|c|}{ Aug. 13} & \multicolumn{2}{|c|}{ Aug. 14} & \multicolumn{2}{|c|}{ Aug. 15} & \multicolumn{2}{|c|}{ Aug. 16} & \multicolumn{2}{|c|}{ Aug. 17} \\
\hline & $\begin{array}{c}\text { Gage } \\
\text { ht. }\end{array}$ & $\begin{array}{c}\text { Dis- } \\
\text { charge }\end{array}$ & $\begin{array}{l}\text { iage } \\
\text { ht. }\end{array}$ & $\begin{array}{c}\text { Dis- } \\
\text { charge }\end{array}$ & $\begin{array}{c}\text { Gage } \\
\text { ht. }\end{array}$ & $\begin{array}{c}\text { Dis- } \\
\text { charge }\end{array}$ & $\begin{array}{c}\text { Gage } \\
\text { ht. }\end{array}$ & & $\begin{array}{c}\text { Gage } \\
\text { ht. }\end{array}$ & & $\begin{array}{c}\text { Gage } \\
\text { ht. }\end{array}$ & \\
\hline $\begin{array}{l}1 \\
2 \\
3 \\
4 \\
5 \\
6\end{array}$ & $\begin{array}{l}0.95 \\
1.04 \\
1.08 \\
1.09 \\
1.14 \\
1.22\end{array}$ & $\begin{array}{r}885 \\
988 \\
1,040 \\
1,050 \\
1,110 \\
1,210\end{array}$ & $\begin{array}{l}2.77 \\
3.14 \\
3.52 \\
3.92 \\
4.30 \\
4.57\end{array}$ & $\begin{array}{l}3,560 \\
4,360 \\
5,110 \\
5,990 \\
6,910 \\
7,620\end{array}$ & $\begin{array}{l}11.65 \\
11.64 \\
11.59 \\
11.47 \\
11.33 \\
11.10\end{array}$ & $\begin{array}{l}31,800 \\
31,800 \\
31,800 \\
31,300 \\
30,400 \\
29,500\end{array}$ & 8.91 & 20 & 6.50 & 12 & 3 & 140 \\
\hline $\begin{array}{r}7 \\
8 \\
9 \\
10 \\
11 \\
\mathrm{~N}\end{array}$ & $\begin{array}{l}1.27 \\
1.30 \\
1.35 \\
1.46 \\
1.79 \\
1.81\end{array}$ & $\begin{array}{l}1,270 \\
1,310 \\
1,380 \\
1,520 \\
1,980 \\
2,000\end{array}$ & $\begin{array}{l}4.60 \\
4.70 \\
4.90 \\
5.40 \\
\mathbf{5 . 9 2} \\
\mathbf{6 . 4 5}\end{array}$ & $\begin{array}{r}7,620 \\
7,860 \\
8,350 \\
9,640 \\
11,000 \\
12,500\end{array}$ & $\begin{array}{l}10.88 \\
10.69 \\
10.54 \\
10.43 \\
10.25 \\
10.08\end{array}$ & $\begin{array}{l}28,600 \\
27,700 \\
26,900 \\
26,400 \\
25,600 \\
25,200\end{array}$ & 8.75 & 18,800 & 6.07 & 11,600 & $\mathbf{3} .88$ & $990^{-}$ \\
\hline $\begin{array}{l}1 \\
2 \\
3 \\
4 \\
5 \\
6\end{array}$ & $\begin{array}{l}1.77 \\
1.73 \\
1.73 \\
1.75 \\
1.77 \\
1.88\end{array}$ & $\begin{array}{l}1,960 \\
1,900 \\
1,900 \\
1,920 \\
1,960 \\
2,150\end{array}$ & $\begin{array}{l}7.02 \\
7.50 \\
8.03 \\
8.36 \\
8.70 \\
9.10\end{array}$ & $\begin{array}{l}14,300 \\
15,800 \\
17,400 \\
18,800 \\
19,800 \\
21,300\end{array}$ & $\begin{array}{l}9.95 \\
9.81 \\
9.67 \\
9.55 \\
9.42 \\
9.30\end{array}$ & $\begin{array}{l}24,800 \\
24,000 \\
23,600 \\
23,200 \\
22,400 \\
22,000\end{array}$ & 8.07 & & 5.41 & 10 & 3.07 & 150 \\
\hline $\begin{array}{r}7 \\
8 \\
9 \\
10 \\
11 \\
12\end{array}$ & $\begin{array}{l}1.90 \\
1.89 \\
1.97 \\
2.10 \\
2.26 \\
2.50 \\
\end{array}$ & $\begin{array}{l}2,150 \\
2,150 \\
2,220 \\
2,450 \\
2,690 \\
3,110 \\
\end{array}$ & $\begin{array}{r}9.45 \\
10.05 \\
10.90 \\
11.35 \\
11.54 \\
11.62\end{array}$ & $\begin{array}{l}22,400 \\
24,800 \\
28,600 \\
30,900 \\
31,300 \\
31,800 \\
\end{array}$ & $\begin{array}{l}9.20 \\
9.13 \\
9.07 \\
9.02 \\
8.99 \\
8.96 \\
\end{array}$ & $\begin{array}{l}21,700 \\
21,300 \\
21,300 \\
20,900 \\
20,900 \\
20,900 \\
\end{array}$ & $\left|\begin{array}{r}7.61 \\
\hdashline 7.04\end{array}\right|$ & $\begin{array}{l}16,200 \\
14,300 \\
\end{array}$ & 5.09 & 8,850 & $\begin{array}{r}2.87 \\
-2.7 \overline{2} \\
\end{array}$ & $3,470^{-}$ \\
\hline & \multicolumn{2}{|c|}{ Aug. 29} & \multicolumn{2}{|c|}{ Aug. 30} & \multicolumn{2}{|c|}{ Aug. 31} & \multicolumn{2}{|c|}{ Sept. 1} & \multicolumn{2}{|c|}{ Sept. 2} & \multicolumn{2}{|c|}{ Sept. 3} \\
\hline $\begin{array}{l}1 \\
2 \\
3 \\
4 \\
5 \\
6\end{array}$ & $\begin{array}{l}1.31 \\
1.29 \\
1.28 \\
1.25 \\
1.24 \\
1.24\end{array}$ & $\begin{array}{l}1,320 \\
1,300 \\
1,280 \\
1,240 \\
1,230 \\
1,230\end{array}$ & $\begin{array}{r}7.40 \\
7.69 \\
8.25 \\
9.00 \\
10.35 \\
10.35\end{array}$ & $\begin{array}{l}15, \\
16, \\
18, \\
20, \\
26, \\
26,\end{array}$ & $\begin{array}{l}9.13 \\
8.92 \\
8.76 \\
8.61 \\
8.44 \\
8.25\end{array}$ & $\begin{array}{l}21,300 \\
20,500 \\
20,200 \\
19,500 \\
18,800 \\
18,100\end{array}$ & $\begin{array}{r}6.42 \\
- \\
-\end{array}$ & 500 & 5.46 & 910 & 3.36 & $780^{-}$ \\
\hline $\begin{array}{r}7 \\
8 \\
9 \\
10 \\
11 \\
\mathrm{~N}\end{array}$ & $\begin{array}{l}1.24 \\
1.24 \\
1.25 \\
1.26 \\
1.27 \\
1.28\end{array}$ & $\begin{array}{l}1,230 \\
1,230 \\
1,240 \\
1,260 \\
1,270 \\
1,280\end{array}$ & $\begin{array}{l}10.62 \\
11.15 \\
11.58 \\
11.90 \\
12.08 \\
12.15\end{array}$ & $\begin{array}{l}27,300 \\
29,900 \\
31,800 \\
33,300 \\
34,300 \\
34,800\end{array}$ & $\begin{array}{l}8.02 \\
7.84 \\
7.66 \\
7.55 \\
7.41 \\
7.29\end{array}$ & $\begin{array}{l}16,800 \\
16,500 \\
16,200 \\
15,500 \\
15,200\end{array}$ & 6.24 & 11,900 & $\overline{4} . \overline{98}$ & 8,600 & 3.16 & 360 \\
\hline $\begin{array}{l}1 \\
2 \\
3 \\
4 \\
5 \\
6\end{array}$ & $\begin{array}{l}1.32 \\
1.38 \\
1.55 \\
2.50 \\
3.55 \\
4.25\end{array}$ & $\begin{array}{l}1,340 \\
1,410 \\
1,640 \\
3,110 \\
5,220 \\
6,680\end{array}$ & $\begin{array}{l}12.12 \\
12.03 \\
11.94 \\
11.80 \\
11.60 \\
11.25\end{array}$ & $\begin{array}{l}33,800 \\
33,300 \\
32,800 \\
31,800 \\
29,900\end{array}$ & $\begin{array}{l}7.12 \\
7.02 \\
6.90 \\
6.84 \\
6.77 \\
6.74\end{array}$ & & 6.08 & 11,600 & 4.60 & 7,620 & 2.93 & 3,950 \\
\hline $\begin{array}{r}7 \\
8 \\
9 \\
10 \\
11 \\
12\end{array}$ & $\begin{array}{l}5.10 \\
5.76 \\
6.32 \\
6.57 \\
6.80 \\
7.07\end{array}$ & $\begin{array}{r}8,850 \\
10,700 \\
12,200 \\
13,100 \\
13,700 \\
14,600\end{array}$ & $\begin{array}{r}10.80 \\
10.36 \\
10.00 \\
9.76 \\
9.52 \\
9.32\end{array}$ & $\begin{array}{l}24, \\
22,\end{array}$ & $\begin{array}{l}6.69 \\
6.65 \\
6.60 \\
6.56 \\
6.55 \\
6.52\end{array}$ & $\begin{array}{l}13, \\
13, \\
13, \\
13, \\
12\end{array}$ & $5 . \overline{8}$ & 10,700 & $\begin{array}{r}4.18 \\
3.72\end{array}$ & 6,680 & $\begin{array}{r}\overline{2} . \overline{85} \\
\overline{2.77}\end{array}$ & $\begin{array}{r}3,760 \\
-3,560\end{array}$ \\
\hline
\end{tabular}


FRENCH BROAD RIVER AT HOT SPRINGS, N. C.

Location.-Lat. $35^{\circ} 53^{\prime} 45^{\prime \prime}$, long. $82^{\circ} 49^{\prime} 10^{\prime \prime}$, at Hot Springs, Madison County, a quarter of a mile upstream from bridge on U.S. Highways 25 and 70 and half a mile upstream from Spring Creek. Datum of gage is 1,311.55 feet above mean sea level, datum of 1929, supplementary adjustment of 1936 .

DraINAGE AREA.-1,567 square miles.

GAGE-HEIGHT RECORD.-Water-stage recorder graph except 11 p.m. Aug. 31 to 9 a.m. Sept. 6, record for which is from graph based on records for station near Newport, Tenn.

DISCHARGE RECORD. - Stage-discharge relation defined by eurrent-meter measurements up to 34,000 second-feet and extended to crest gage height on basis of determination of flood flow by slope-area method. Gage heights used to lialf-tenths between 4.3 and 6.0 feet; hundredths below and tenths above these limits. Shiftingcontrol method used to correct for apparent backwater effect 2 a.m. Aug. 14 to 8 p.m. Aug. 15 and 2 p.m. Aug. 30 to 6 p.m. Sept. 1.

Maxima.-1940: Discharge, 75,900 second-feet 7:30 a.m. Aug. 30 (gage height, 16.1 feet).

1934-39: Discharge, 38,600 second-feet Jan. 19, 1936 (gage height, 8.75 feet).

Stage known, about 19.3 feet in July 1916, derived from floodmarks a quarter of a mile downstream (discharge not determined).

REMARKS.-Flood runoff not affected by artificial storage.

Mean discharge, in second-feet, 1940

\begin{tabular}{|c|c|c|c|c|c|c|c|c|c|c|c|}
\hline Day & Aug. & Sept. & Day & Aug. & Sept. & Day & Aug. & Sept. & Day & Aug. & Sept. \\
\hline $\begin{array}{l}1 \\
2 \\
3 \\
4 \\
5 \\
6 \\
7 \\
8\end{array}$ & $\begin{array}{r}1,110 \\
980 \\
1,000 \\
860 \\
840 \\
940 \\
1,820 \\
1,170\end{array}$ & $\begin{array}{r}13,800 \\
10,400 \\
6,280 \\
4,070 \\
3,590 \\
3,260 \\
3,080 \\
2,760\end{array}$ & $\begin{array}{r}9 \\
10 \\
11 \\
12 \\
13 \\
14 \\
15 \\
16\end{array}$ & $\begin{array}{r}1,110 \\
920 \\
920 \\
1,270 \\
12,900 \\
30,700 \\
21,300 \\
13,600\end{array}$ & $\begin{array}{l}2,550 \\
2,580 \\
2,490 \\
2,210 \\
2,100 \\
1,990 \\
1,920 \\
1,790\end{array}$ & $\begin{array}{l}17 \\
18 \\
19 \\
20 \\
21 \\
22 \\
23 \\
24\end{array}$ & $\begin{array}{l}7,730 \\
4,190 \\
3,590 \\
2,950 \\
2,490 \\
2,290 \\
2,120 \\
1,990\end{array}$ & $\begin{array}{l}1,790 \\
1,690 \\
1,640 \\
1,620 \\
1,590 \\
1,520 \\
1,460 \\
1,430\end{array}$ & $\begin{array}{l}25 \\
26 \\
27 \\
28 \\
29 \\
30 \\
31\end{array}$ & $\begin{array}{r}1,940 \\
1,860 \\
1,720 \\
1,660 \\
6,780 \\
49,900 \\
22,200\end{array}$ & $\begin{array}{l}1,480 \\
1,550 \\
1,500 \\
1,400 \\
1,300 \\
1,200\end{array}$ \\
\hline \multicolumn{10}{|c|}{$\begin{array}{l}\text { Monthly mean discharge, in second-feet } \\
\text { Runoff, in inches }\end{array}$} & $\begin{array}{r}6,608 \\
4.86\end{array}$ & $\begin{array}{r}2,868 \\
2.04\end{array}$ \\
\hline
\end{tabular}




\section{FLOODS OF AUGUST 1940 IN THE SOUTHEASTERN STATES}

Gage height, in feet, and discharge, in second-feet, at indicated time, 1940

\begin{tabular}{|c|c|c|c|c|c|c|c|c|c|c|c|c|}
\hline \multirow[b]{2}{*}{ Hour } & \multicolumn{2}{|c|}{ Aug. 12} & \multicolumn{2}{|c|}{ Aug. 13} & \multicolumn{2}{|c|}{ Aug. 14} & \multicolumn{2}{|c|}{ Aug. 15} & \multicolumn{2}{|c|}{ Aug. 16} & \multicolumn{2}{|c|}{ Aug. 17} \\
\hline & $\begin{array}{c}\text { Gage } \\
\text { ht. }\end{array}$ & $\begin{array}{c}\text { Dis- } \\
\text { charge }\end{array}$ & $\begin{array}{c}\text { Gage } \\
\text { ht. }\end{array}$ & $\begin{array}{c}\text { Dis- } \\
\text { charge }\end{array}$ & $\begin{array}{c}\text { Gage } \\
\text { ht. }\end{array}$ & $\begin{array}{l}\text { Dis- } \\
\text { charge }\end{array}$ & $\begin{array}{c}\text { Gage } \\
\text { ht. }\end{array}$ & $\begin{array}{c}\text { Dis } \\
\text { char }\end{array}$ & $\begin{array}{c}\text { Gage } \\
\text { ht. }\end{array}$ & $\begin{array}{l}\text { Dis- } \\
\text { charge }\end{array}$ & $\begin{array}{c}\text { Gage } \\
\text { ht. }\end{array}$ & $\begin{array}{c}\text { Dis- } \\
\text { charge }\end{array}$ \\
\hline \multirow{5}{*}{$\begin{array}{r}2 \\
4 \\
6 \\
8 \\
10 \\
\mathrm{~N}\end{array}$} & & & \multirow{5}{*}{$\begin{array}{l}3.33 \\
3.42 \\
3.51 \\
3.69 \\
4.19 \\
4.62\end{array}$} & \multirow{5}{*}{$\begin{array}{l}2,830 \\
3,120 \\
3,440 \\
4,150 \\
6,540 \\
8,850\end{array}$} & \multirow{5}{*}{$\begin{array}{l}\mathbf{8 . 8 7} \\
\mathbf{9 . 0 6} \\
\mathbf{9 . 0 7} \\
\mathbf{9 . 0 3} \\
\mathbf{8 . 8 7} \\
\mathbf{8 . 6 5}\end{array}$} & \multirow{5}{*}{$\begin{array}{l}36,500 \\
37,100 \\
37,100 \\
34,700 \\
32,200 \\
30,300\end{array}$} & & \multirow{2}{*}{22,900} & & \multirow{3}{*}{15,600} & & \multirow{2}{*}{$-1-1$} \\
\hline & -5 & & & & & & 6.94 & & & & & \\
\hline & 2.56 & 900 & & & & & 6 & & 5.64 & & 4.68 & 9,450 \\
\hline & & & & & & & & & & & & \\
\hline & 2.56 & 900 & & & & & 6.70 & 21,500 & 5.30 & 13,200 & 4.42 & 7,690 \\
\hline \multirow{4}{*}{$\begin{array}{l}1 \\
2 \\
3 \\
4 \\
5 \\
6\end{array}$} & \multirow{4}{*}{$\begin{array}{l}2.57 \\
2.61 \\
2.68 \\
2.79 \\
2.80 \\
2.89\end{array}$} & \multirow{4}{*}{$\begin{array}{r}920 \\
1,010 \\
1,150 \\
1,390 \\
1,410 \\
1,620\end{array}$} & & & & \multirow[b]{2}{*}{28,400} & & & & \multirow[b]{2}{*}{$-\cdots---\cdots$} & \multirow{2}{*}{\multicolumn{2}{|c|}{$\cdots$}} \\
\hline & & & 4.82 & $10, C$ & 8.36 & & & & & & & \\
\hline & & & 5.60 & 15,200 & 8.15 & 27,700 & $6 . \overline{50}$ & 20,800 & & & & \\
\hline & & & $\overline{6} . \overline{6} \overline{5}$ & 22,200 & $\overline{7} . \overline{9} \overline{2}$ & 26,400 & & & $\overline{5.07}$ & 11,600 & 4.10 & $6,070^{-}$ \\
\hline 7 & 2.95 & 1,760 & & & & & & & & & & \\
\hline $\begin{array}{l}8 \\
9\end{array}$ & $\begin{array}{l}2.95 \\
2.98\end{array}$ & $\begin{array}{l}1,760 \\
1,840\end{array}$ & 7.55 & 29,000 & 7.62 & 25,000 & 6.29 & 19,400 & & & & \\
\hline 10 & 3.16 & 2,320 & 7.90 & 31,000 & $\overline{7} \cdot \mathbf{3} \overline{7}$ & 24,300 & & & & & & \\
\hline 12 & $\begin{array}{l}3.20 \\
3.30 \\
\end{array}$ & 2,730 & $\overline{8} \cdot \overline{34}$ & 33,500 & $\overline{7} .17$ & 23,600 & $6 . \overline{05}$ & $18,000^{-}$ & 4.86 & 10,400 & 3.88 & $5,000^{-}$ \\
\hline
\end{tabular}

\begin{tabular}{|c|c|c|c|c|c|c|c|c|c|c|c|c|}
\hline \multirow[b]{2}{*}{$\begin{array}{l}1 \\
2 \\
3 \\
4 \\
5 \\
6\end{array}$} & \multicolumn{2}{|c|}{ Aug. 29} & \multicolumn{2}{|c|}{ Aug. 30} & \multicolumn{2}{|c|}{ Aug. 31} & \multicolumn{2}{|c|}{ Sept. 1} & \multicolumn{2}{|c|}{ Sept. 2} & \multicolumn{2}{|c|}{ Sept. 3} \\
\hline & $\begin{array}{l}2.82 \\
2.84 \\
2.86 \\
2.87 \\
2.87 \\
2.87\end{array}$ & $\begin{array}{l}1,460 \\
1,500 \\
1,550 \\
1,570 \\
1,570 \\
1,570\end{array}$ & $\begin{array}{r}8.76 \\
9.00 \\
9.50 \\
11.75 \\
12.82 \\
13.60\end{array}$ & $\begin{array}{l}36,500 \\
37,700 \\
40,700 \\
53,400 \\
58,900 \\
63,300\end{array}$ & $\mathbf{7 . 7 7}$ & 29,000 & 5.60 & 14,600 & 5.00 & 11,300 & 4.32 & 7,130 \\
\hline $\begin{array}{r}7 \\
8 \\
9 \\
10 \\
11 \\
\text { N }\end{array}$ & $\begin{array}{l}2.87 \\
2.87 \\
2.87 \\
2.89 \\
2.89 \\
2.90\end{array}$ & $\begin{array}{l}1,570 \\
1,570 \\
1,570 \\
1,620 \\
1,620 \\
1,640\end{array}$ & $\begin{array}{l}15.60 \\
15.90 \\
14.75 \\
13.67 \\
12.61 \\
12.00\end{array}$ & $\begin{array}{l}\mathbf{7 3}, 400 \\
\mathbf{7 4}, 900 \\
69,400 \\
63,800 \\
\mathbf{5 7}, 800 \\
\mathbf{5 4}, 500\end{array}$ & 7.11 & 23,600 & 5.41 & 13,600 & 4.86 & 10,400 & 4.12 & 6,170 \\
\hline $\begin{array}{l}1 \\
2 \\
3 \\
4 \\
5 \\
6\end{array}$ & $\begin{array}{l}2.90 \\
2.95 \\
2.99 \\
3.11 \\
3.43 \\
3.82\end{array}$ & $\begin{array}{l}1,640 \\
1,760 \\
1,860 \\
2,180 \\
3,160 \\
4,720\end{array}$ & $\begin{array}{l}11.48 \\
11.12 \\
10.86 \\
10.65 \\
10.44 \\
10.23\end{array}$ & $\begin{array}{l}51,800 \\
49,000 \\
47,400 \\
45,200 \\
44,000 \\
43,000\end{array}$ & 6.30 & 18,000 & 5.26 & 12,900 & 4.71 & 9,450 & $\mid \begin{array}{c}-\cdots \\
-\cdots \\
-3.93\end{array}$ & 5,230 \\
\hline $\begin{array}{r}7 \\
8 \\
9 \\
10 \\
11 \\
12\end{array}$ & $\begin{array}{l}5.42 \\
6.27 \\
6.59 \\
7.08 \\
7.68 \\
8.15\end{array}$ & $\begin{array}{l}13,900 \\
20,100 \\
22,200 \\
25,700 \\
29,600 \\
32,900\end{array}$ & \begin{tabular}{|r|}
10.02 \\
9.95 \\
9.65 \\
9.55 \\
9.04 \\
8.66
\end{tabular} \mid & $\begin{array}{l}41,800 \\
41,300 \\
40,100 \\
38,900 \\
37,100 \\
35,300\end{array}$ & 6.04 & \begin{tabular}{|c}
17,000 \\
15,600
\end{tabular} & $-\overline{5} \cdot \overline{13} \mid$ & $\overline{12,300}$ & $\begin{array}{l}-\cdots . \\
4.56\end{array}$ & 8.560 & $\left|\begin{array}{c}\mid \cdots \\
\mathbf{3 . 8 0}\end{array}\right|$ & 4,630 \\
\hline
\end{tabular}

Supplemen'ral ReCords.-Aug. 14, 5:30 a.m., gage height, 9.07 feet, discharge, 37,100 second-feet. Aug. 30, $7: 30$ a.m., gage height, 16.1 feet, discharge, 75,900 second-feet. 


\section{FRENCH BROAD RIVER NEAR NGWPORT, TENN.}

Location.-Lat. $35^{\circ} 58^{\prime} 54^{\prime \prime}$, long. $83^{\circ} 09^{\prime} 40^{\prime \prime}$, at bridge on State Highway 35 at Oldtown, 1\%/4 miles northeast of Newport, Cocke County, and 4 miles upstream from Pigeon River. Datum of gage is 1,011.61 feet above mean sea level, datum of 1929, supplementary adjustment of 1936 .

Drainage AREA.-1,858 square miles.

GAGE-HEIGHT RECORD.-Water-stage recorder graph.

DISCHARGE RECORD.-Stage-discharge relation defined by current-meter measurements up to 75,800 second-feet. Gage heights used to half-tenths between 2.8 and 4.6 feet; hundredths below and tenths above these limits.

Maxima.-1940: Discharge, 76,300 second-feet 12 m. Aug. 30 (gage height, 19.25 feet).

1900-1905, 1907, 1920-39: Discharge observed, 62,200 second-feet (subject to large error) Apr. 8, 1903 (gage height, 12.0 feet, former datum); gage height, 13.45 feet Aug. 16, 1928.

Floods of Feb. 28, 1902 and July 17, 1916 reached stages of about 23 feet (discharge 101,000 second-feet) and 22.5 feet (discharge 97,000 second-feet) respectively, present datum, from floodmarks.

REMarKs.-Flood runoff probably affected slightly by storage in small lakes and ponds.

Mean discharge, in second-feet, 1940

\begin{tabular}{|c|c|c|c|c|c|c|c|c|c|c|c|}
\hline Day & Aug. & Sept. & Day & Aug. & Sept. & Day & Aug. & Sept. & Day & Aug. & Sept. \\
\hline $\begin{array}{l}1 \\
2 \\
3 \\
4 \\
5 \\
6 \\
7 \\
8\end{array}$ & $\begin{array}{r}1,450 \\
1,180 \\
1,090 \\
994 \\
890 \\
1,010 \\
3,480 \\
1,640\end{array}$ & $\begin{array}{r}16,500 \\
12,000 \\
7,720 \\
5,150 \\
4,170 \\
3,680 \\
3,550 \\
3,250\end{array}$ & $\begin{array}{r}9 \\
10 \\
11 \\
12 \\
13 \\
14 \\
15 \\
16\end{array}$ & $\begin{array}{r}1,370 \\
1,100 \\
1,030 \\
1,010 \\
8,060 \\
33,500 \\
24,600 \\
16,000\end{array}$ & $\begin{array}{l}2,990 \\
2,850 \\
2,950 \\
2,650 \\
2,420 \\
2,320 \\
2,210 \\
2,130\end{array}$ & $\begin{array}{l}17 \\
18 \\
19 \\
20 \\
21 \\
22 \\
23 \\
24\end{array}$ & $\begin{array}{l}8,690 \\
4,580 \\
3,790 \\
3,160 \\
2,650 \\
2,450 \\
2,180 \\
2,010\end{array}$ & $\begin{array}{l}2,010 \\
1,950 \\
1,860 \\
1,810 \\
1,790 \\
1,740 \\
1,670 \\
1,590\end{array}$ & $\begin{array}{l}25 \\
26 \\
27 \\
28 \\
29 \\
30 \\
31\end{array}$ & $\begin{array}{r}1,900 \\
1,850 \\
1,670 \\
1,620 \\
2,560 \\
54,400 \\
29,000\end{array}$ & $\begin{array}{l}1,590 \\
1,660 \\
1,660 \\
1,500 \\
1,420 \\
1,360\end{array}$ \\
\hline \multicolumn{10}{|c|}{$\begin{array}{l}\text { Monthly mean discharge, in second-feet } \\
\text { Runoff, in inches }\end{array}$} & $\begin{array}{r}7,126 \\
4.42\end{array}$ & $\begin{array}{r}3,338 \\
2.00\end{array}$ \\
\hline
\end{tabular}




\section{FLOODS OF AUGUST 1940 IN THE SOUTHEASTERN STATES}

Gage height, in feet, and discharge, in second feet, at indicated time, 1940

\begin{tabular}{|c|c|c|c|c|c|c|c|c|c|c|c|c|}
\hline \multirow{2}{*}{ Hour } & \multicolumn{2}{|c|}{ Aug. 13} & \multicolumn{2}{|c|}{ Aug. 14} & \multicolumn{2}{|c|}{ Aug. 15} & \multicolumn{2}{|c|}{ Aug. 16} & \multicolumn{2}{|c|}{ Aug. 17} & \multicolumn{2}{|c|}{ Aug. 18} \\
\hline & $\begin{array}{c}\text { Gage } \\
\text { ht. }\end{array}$ & $\begin{array}{l}\text { Dis- } \\
\text { charge }\end{array}$ & $\begin{array}{c}\text { Gage } \\
\text { ht. }\end{array}$ & $\begin{array}{l}\text { Dis- } \\
\text { charge }\end{array}$ & $\begin{array}{c}\text { Gage } \\
\text { ht. }\end{array}$ & $\begin{array}{l}\text { Dis- } \\
\text { charge }\end{array}$ & $\begin{array}{c}\text { Gage } \\
\text { ht. }\end{array}$ & $\begin{array}{l}\text { Dis- } \\
\text { charge }\end{array}$ & $\begin{array}{c}\text { Gage } \\
\text { ht. }\end{array}$ & $\begin{array}{l}\text { Dis- } \\
\text { charge }\end{array}$ & $\begin{array}{c}\text { Gage } \\
\text { ht. }\end{array}$ & $\begin{array}{l}\text { Dis- } \\
\text { charge }\end{array}$ \\
\hline $\begin{array}{l}1 \\
2 \\
3 \\
4 \\
5 \\
6\end{array}$ & $\begin{array}{l}1.93 \\
2.08 \\
2.23 \\
2.32 \\
2.43 \\
2.69\end{array}$ & $\begin{array}{l}1,200 \\
1,440 \\
1,690 \\
1,860 \\
2,060 \\
2,580\end{array}$ & $\mid \begin{array}{ll}11 & .06 \\
11 & .32 \\
11 & .57 \\
11 & .87 \\
12 & .20 \\
12 & .47\end{array}$ & $\begin{array}{l}30,900 \\
31,800 \\
33,200 \\
34,600 \\
36,100 \\
37,500\end{array}$ & $\begin{array}{r}10.20 \\
10.10 \\
10.03 \\
9.93 \\
9.90 \\
9.85\end{array}$ & $\begin{array}{l}26,900 \\
26,500 \\
26,100 \\
25,700 \\
25,700 \\
25,300\end{array}$ & $\begin{array}{l}8.75 \\
8.63 \\
8.52 \\
8.37 \\
8.26 \\
8.14\end{array}$ & $\begin{array}{l}21,200 \\
20,500 \\
20,100 \\
19,700 \\
19,400 \\
18,600\end{array}$ & $\begin{array}{l}6.05 \\
5.97 \\
5.89 \\
5.82 \\
5.73 \\
5.66\end{array}$ & $\begin{array}{l}11,300 \\
11,300 \\
10,900 \\
10,600 \\
10,300 \\
10,300\end{array}$ & 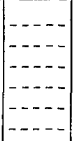 & 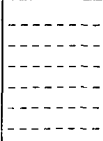 \\
\hline $\begin{array}{r}7 \\
8 \\
9 \\
10 \\
11 \\
\mathrm{~N}\end{array}$ & $\begin{array}{l}2.86 \\
2.92 \\
2.97 \\
3.01 \\
3.09 \\
3.20\end{array}$ & $\begin{array}{l}2,920 \\
3,030 \\
3,140 \\
3,250 \\
3,480 \\
3,710\end{array}$ & $\begin{array}{l}12.57 \\
12.57 \\
12.50 \\
12.46 \\
12.37 \\
12.25\end{array}$ & $\begin{array}{l}38,000 \\
38,000 \\
37,500 \\
37,500 \\
37,000 \\
36,100\end{array}$ & $\begin{array}{l}9.82 \\
9.79 \\
9.76 \\
9.76 \\
9.76 \\
9.70\end{array}$ & $\begin{array}{l}25,300 \\
25,300 \\
25,300 \\
25,300 \\
25,300 \\
24,800\end{array}$ & $\begin{array}{l}7.90 \\
7.75 \\
7.64 \\
7.52 \\
7.38 \\
7.27\end{array}$ & $\begin{array}{l}17,900 \\
17,500 \\
16,800 \\
16,400 \\
16,100 \\
15,800\end{array}$ & $\begin{array}{l}5.59 \\
5.53 \\
5.48 \\
5.41 \\
5.33 \\
5.25\end{array}$ & $\begin{array}{l}9,920 \\
9,590 \\
9,590 \\
9,260 \\
8,940 \\
8,630\end{array}$ & \begin{tabular}{c}
$-\cdots$ \\
$\cdots-\cdots$ \\
\hdashline$\overline{3} .68$
\end{tabular} & 4,490 \\
\hline $\begin{array}{l}1 \\
2 \\
3 \\
4 \\
5 \\
6\end{array}$ & $\begin{array}{l}3.33 \\
3.62 \\
4.36 \\
4.98 \\
5.42 \\
5.86\end{array}$ & $\begin{array}{r}4,060 \\
4,640 \\
6,540 \\
8,400 \\
9,630 \\
11,300\end{array}$ & $\begin{array}{l}12.07 \\
11.88 \\
11.71 \\
11.50 \\
11.34 \\
11.16\end{array}$ & $\begin{array}{l}35,600 \\
34,600 \\
33,700 \\
32,700 \\
31,800 \\
31,300\end{array}$ & $\begin{array}{l}9.67 \\
9.65 \\
9.57 \\
9.53 \\
9.47 \\
9.42\end{array}$ & $\begin{array}{l}24,800 \\
24,400 \\
24,400 \\
24,000 \\
24,000 \\
23,600\end{array}$ & $\begin{array}{l}7.14 \\
7.03 \\
6.90 \\
6.80 \\
6.70 \\
6.60\end{array}$ & $\begin{array}{l}15,000 \\
14,700 \\
14,400 \\
14,000 \\
13,700 \\
13,300\end{array}$ & $\begin{array}{l}5.18 \\
5.09 \\
5.00 \\
4.90 \\
4.81 \\
4.70\end{array}$ & $\begin{array}{l}8,630 \\
8,320 \\
8,010 \\
7,710 \\
7,410 \\
7,110\end{array}$ & 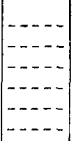 & 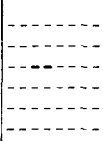 \\
\hline $\begin{array}{r}7 \\
8 \\
9 \\
10 \\
11 \\
12 \\
\end{array}$ & $\begin{array}{r}6.55 \\
7.55 \\
8.65 \\
9.57 \\
10.27 \\
10.70 \\
\end{array}$ & $\begin{array}{l}13,600 \\
17,200 \\
20,800 \\
24,500 \\
27,400 \\
29,100 \\
\end{array}$ & $\mid \begin{array}{l}11.05 \\
10.92 \\
10.85 \\
10.61 \\
10.47 \\
10.39\end{array}$ & $\begin{array}{l}30,400 \\
30,000 \\
29,500 \\
28,600 \\
28,200 \\
27,800 \\
\end{array}$ & $\begin{array}{l}9.34 \\
9.30 \\
9.20 \\
9.10 \\
8.97 \\
8.87 \\
\end{array}$ & $\begin{array}{l}23,200 \\
23,200 \\
22,800 \\
22,400 \\
22,000 \\
21,600 \\
\end{array}$ & $\begin{array}{l}6.51 \\
6.42 \\
6.35 \\
6.27 \\
6.20 \\
6.12 \\
\end{array}$ & $\begin{array}{l}13,000 \\
12,600 \\
12,600 \\
12,300 \\
12,000 \\
11,600\end{array}$ & $\begin{array}{l}4.60 \\
4.50 \\
4.42 \\
4.41 \\
4.36 \\
4.25 \\
\end{array}$ & $\begin{array}{l}6,820 \\
6.540 \\
6,270 \\
6,270 \\
6,140 \\
5,870 \\
\end{array}$ & \begin{tabular}{|c|}
$-\cdots$ \\
\hdashline$-\cdots$ \\
\hdashline-1.49 \\
\hdashline
\end{tabular} & 4,020 \\
\hline
\end{tabular}

\begin{tabular}{|c|c|c|c|c|c|c|c|c|c|c|c|c|}
\hline & \multicolumn{2}{|c|}{ Aug. 29} & \multicolumn{2}{|c|}{ Aug. 30} & \multicolumn{2}{|c|}{ Aug. 31} & \multicolumn{2}{|c|}{ Sept. 1} & \multicolumn{2}{|c|}{ Sept. 2} & \multicolumn{2}{|c|}{ Sept. 3} \\
\hline $\begin{array}{l}1 \\
2 \\
3 \\
4 \\
5 \\
6\end{array}$ & \begin{tabular}{l|}
2.28 \\
2.27 \\
2.26 \\
2.23 \\
2.19 \\
2.19
\end{tabular} & $\begin{array}{l}1,610 \\
1,590 \\
1,570 \\
1,520 \\
1,450 \\
1,450\end{array}$ & $\left|\begin{array}{l}10.55 \\
11.70 \\
12.70 \\
13.55 \\
14.23 \\
14.85\end{array}\right|$ & $\begin{array}{l}28,600 \\
33,700 \\
38,500 \\
43,100 \\
46,400 \\
49,700\end{array}$ & $\begin{array}{l}13.70 \\
13.30 \\
12.89 \\
12.58 \\
12.28 \\
11.92\end{array}$ & $\begin{array}{l}43,700 \\
41,600 \\
39,500 \\
38,000 \\
36,500 \\
34,600\end{array}$ & $\begin{array}{l}8.30 \\
8.22 \\
8.19 \\
8.13 \\
8.04 \\
7.92\end{array}$ & $\begin{array}{l}19,400 \\
19,000 \\
19,000 \\
18,600 \\
18,200 \\
17,900\end{array}$ & $\begin{array}{l}6.77 \\
6.72 \\
6.67 \\
6.61 \\
6.57 \\
6.51\end{array}$ & $\begin{array}{l}14,000 \\
13,700 \\
13,700 \\
13,300 \\
13,300 \\
13,000\end{array}$ & 5.23 & 8,630 \\
\hline $\begin{array}{r}7 \\
8 \\
9 \\
10 \\
11 \\
\mathrm{~N}\end{array}$ & $\begin{array}{l}2.12 \\
2.11 \\
2.12 \\
2.14 \\
2.18 \\
2.23\end{array}$ & $\begin{array}{l}1,340 \\
1,330 \\
1,340 \\
1,370 \\
1,440 \\
1,520\end{array}$ & $\begin{array}{l}15.60 \\
16.50 \\
17.40 \\
18.30 \\
19.01 \\
19.25\end{array}$ & $\begin{array}{l}54,300 \\
59,600 \\
65,100 \\
70,700 \\
75,000 \\
76,300\end{array}$ & $\begin{array}{l}11.60 \\
11.27 \\
10.97 \\
10.73 \\
10.48 \\
10.30\end{array}$ & $\begin{array}{l}33,200 \\
31,800 \\
30,400 \\
29,100 \\
28,200 \\
27,400\end{array}$ & $\begin{array}{l}7.87 \\
7.70 \\
7.59 \\
7.50 \\
7.42 \\
7.37\end{array}$ & $\begin{array}{l}17,900 \\
17,200 \\
16,800 \\
16,400 \\
16,100 \\
16,100\end{array}$ & $\begin{array}{l}6.47 \\
6.42 \\
6.36 \\
6.30 \\
6.25 \\
6.21\end{array}$ & $\begin{array}{l}13,000 \\
12,600 \\
12,600 \\
12,300 \\
12,000 \\
12,000\end{array}$ & 4.85 & 7,560 \\
\hline $\begin{array}{l}1 \\
2 \\
3 \\
4 \\
5 \\
6\end{array}$ & $\begin{array}{l}2.26 \\
2.27 \\
2.28 \\
2.29 \\
2.32 \\
2.38\end{array}$ & $\begin{array}{l}1,570 \\
1,590 \\
1,610 \\
1,620 \\
1,670 \\
1,780\end{array}$ & $\begin{array}{l}18.95 \\
18.30 \\
17.50 \\
16.75 \\
16.20 \\
15.68\end{array}$ & $\begin{array}{l}75,000 \\
70,700 \\
65,700 \\
61,400 \\
57,800 \\
54,900\end{array}$ & $\begin{array}{r}10.06 \\
9.82 \\
9.62 \\
9.46 \\
9.28 \\
9.13\end{array}$ & $\begin{array}{l}26,500 \\
25,300 \\
24,400 \\
24,000 \\
23,200 \\
22,400\end{array}$ & $\begin{array}{l}7.33 \\
7.27 \\
7.25 \\
7.22 \\
7.18 \\
7.13\end{array}$ & $\begin{array}{l}15,800 \\
15,800 \\
15,400 \\
15,400 \\
15,400 \\
15,000\end{array}$ & $\begin{array}{l}6.17 \\
6.12 \\
6.07 \\
6.02 \\
5.97 \\
5.92\end{array}$ & $\begin{array}{l}12,000 \\
11,600 \\
11,600 \\
11,300 \\
11,300 \\
10,900\end{array}$ & 4.54 & 6,680 \\
\hline $\begin{array}{r}7 \\
8 \\
9 \\
10 \\
11 \\
12\end{array}$ & $\begin{array}{l}2.41 \\
2.45 \\
2.48 \\
2.62 \\
6.80 \\
9.20\end{array}$ & $\begin{array}{r}1,830 \\
1,900 \\
1,950 \\
2,210 \\
14,000 \\
22,800\end{array}$ & $\mid \begin{array}{l}15.25 \\
14.95 \\
14.62 \\
14,37 \\
14.15 \\
13.93\end{array}$ & $\begin{array}{l}52,000 \\
50,800 \\
48,600 \\
47,500 \\
46,400 \\
44,800\end{array}$ & $\begin{array}{l}9.00 \\
8.86 \\
8.72 \\
8.60 \\
8.52 \\
8.41\end{array}$ & $\begin{array}{l}22,000 \\
21,600 \\
20,900 \\
20,500 \\
20,100 \\
19,700\end{array}$ & $\begin{array}{l}7.08 \\
7.03 \\
6.98 \\
6.94 \\
6.89 \\
6.84\end{array}$ & $\begin{array}{l}15,000 \\
14,700 \\
14,700 \\
14,400 \\
14,400 \\
14,000\end{array}$ & $\begin{array}{l}5.86 \\
5.81 \\
5.75 \\
5.70 \\
5.64 \\
5.59\end{array}$ & $\begin{array}{r}10,900 \\
10,600 \\
10,600 \\
10,300 \\
9.920 \\
9.920\end{array}$ & $|-\overline{4} . \overline{3} 0|$ & 6,000 \\
\hline
\end{tabular}

SUPPLEMENTAL RECORD.-Aug. 14, 7:30 a.m., gage height, 12.59 feet; discharge, 38,000 second-feet. 


\section{FRENCH BROAD RIVER AT DANDRIDGE, TENN.}

Location.-Lat. $36^{\circ} 00^{\prime} 53^{\prime \prime}$, long. $83^{\circ} 24^{\prime} 43^{\prime \prime}$, at highway bridge at Dandridge, Jefferson County. Datum of gage is 903.33 feet above mean sea level, datum of 1929, supplementary adjustment of 1936 .

Drain AGe AREA. - 4,446 square miles.

GAGE-HEIGHT RECORD.-Water-stage recorder graph.

DISCHARGE RECORD.-Stage-discharge relation defined by current-meter measurements up to 87,200 second-feet. Gage heights used to half-tenths between 0.7 foot and 2.4 feet; hundredths below and tenths above these limits.

Maxima.-1940: Discharge, 95,600 second-feet 1 a.m. Aug. 31 (gage height, 20.93 feet).

1918-39: Discharge observed, 84,500 second-feet Apr. 2, 1920 (gage height, 18.7 feet).

Flood of May 21, 1901, reached a stage of 28.0 feet (discharge not determined).

Stages of 32 feet in May 1875 or 1876 and 40 feet in March 1867 are said to have occurred.

REMARKs.-Flood runoff probably affected slightly by storage in small reservoirs upstream.

Mean discharge, in second-feet, 1940

\begin{tabular}{|c|c|c|c|c|c|c|c|c|c|c|c|}
\hline Day & Aug. & Sept. & Day & Aug. & Sept. & Day & Aug. & Sept. & Day & Aug. & Sept. \\
\hline 1 & 9,350 & 32,900 & 9 & 4,960 & 4,460 & 17 & 21,100 & 4,350 & 25 & 4,670 & 3,880 \\
\hline 2 & 7,360 & 22,500 & 10 & 990 & 5,240 & 18 & 13,900 & 4,230 & 26 & 3,590 & 4,230 \\
\hline 3 & 4,710 & 15,300 & 11 & 2,490 & 6,140 & 19 & 10,900 & 3,990 & 27 & 4,080 & 3,420 \\
\hline 4 & 2,980 & 11,100 & 12 & 1,840 & 5,210 & 20 & 9,460 & 3,760 & 28 & 4,600 & 3,310 \\
\hline 5 & 1,920 & 9,590 & 13 & 11,100 & 5,210 & 21 & 8,260 & 3,640 & 2 & 4,740 & 2,350 \\
\hline 6 & 2,870 & 8,560 & 14 & 62,500 & 5,340 & 22 & 7,460 & 2,980 & 30 & 54,200 & 2,030 \\
\hline 7 & 7,080 & 8,000 & 15 & 68,400 & 4,840 & 23 & 6,460 & 2,270 & 31 & 78,100 & \\
\hline 8 & 6,270 & 6,650 & 16 & 33,200 & 3,530 & 24 & 5,890 & 3,530 & & & \\
\hline \multicolumn{10}{|c|}{$\begin{array}{l}\text { Monthly mean discharge, in second-feet } \\
\text { Runoff, in inches }\end{array}$} & $\begin{array}{r}15,110 \\
3.92\end{array}$ & $\begin{array}{r}6,751 \\
1.69\end{array}$ \\
\hline
\end{tabular}


340 FLOODS OF AUGUST 1940 IN THE SOUTHEASTERN STATES

Gage height, in feet, and discharge, in second-feet, at indicated time, 1940

\begin{tabular}{|c|c|c|c|c|c|c|c|c|c|c|c|c|}
\hline \multirow{2}{*}{ Hour } & \multicolumn{2}{|c|}{ Aug. 13} & \multicolumn{2}{|c|}{ Aug. 14} & \multicolumn{2}{|c|}{ Aug. 15} & \multicolumn{2}{|c|}{ Aug. 16} & \multicolumn{2}{|c|}{ Aug. 17} & \multicolumn{2}{|c|}{ Aug. 18} \\
\hline & $\begin{array}{c}\text { Gage } \\
\text { ht! }\end{array}$ & $\begin{array}{c}\text { Dis- } \\
\text { charge }\end{array}$ & $\begin{array}{c}\text { Gage } \\
\text { ht. }\end{array}$ & $\begin{array}{c}\text { Dis- } \\
\text { charge }\end{array}$ & $\begin{array}{c}\text { Gage } \\
\text { ht. }\end{array}$ & $\begin{array}{c}\text { Dis- } \\
\text { charge }\end{array}$ & $\begin{array}{c}\text { Gage } \\
\text { ht. }\end{array}$ & $\begin{array}{c}\text { Dis- } \\
\text { charge }\end{array}$ & $\begin{array}{c}\text { Gage } \\
\text { ht. }\end{array}$ & $\begin{array}{c}\text { Dis- } \\
\text { charge }\end{array}$ & $\begin{array}{l}\text { Gage } \\
\text { ht. }\end{array}$ & $\begin{array}{c}\text { Dis- } \\
\text { charge }\end{array}$ \\
\hline $\begin{array}{l}\mathbf{1} \\
\mathbf{2} \\
\mathbf{3} \\
\mathbf{4} \\
\mathbf{5} \\
\mathbf{6}\end{array}$ & $\begin{array}{r}0.17 \\
.23 \\
.38 \\
.52 \\
.63 \\
.68\end{array}$ & $\begin{array}{l}1,630 \\
1,730 \\
2,010 \\
2,290 \\
2,510 \\
2,620\end{array}$ & $\begin{array}{l}11.67 \\
12.50 \\
13.14 \\
13.76 \\
14.28 \\
14.67\end{array}$ & $\begin{array}{l}42,000 \\
45,800 \\
48,800 \\
52,400 \\
55,100 \\
57,300\end{array}$ & $\begin{array}{l}17.95 \\
18.15 \\
18.30 \\
18.46 \\
18.60 \\
18.70\end{array}$ & $\begin{array}{l}77,000 \\
78.300 \\
78,900 \\
80,200 \\
80,800 \\
81,400\end{array}$ & $\mid \begin{array}{l}11.60 \\
11.42 \\
11.22 \\
11.03 \\
10.87 \\
10.68\end{array}$ & $\begin{array}{l}41,500 \\
40,600 \\
39,700 \\
38,800 \\
38,300 \\
37,500\end{array}$ & $\begin{array}{r}-.-- \\
7.58 \\
7.3 \overline{1}\end{array}$ & 24,400 & - - & 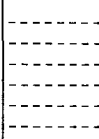 \\
\hline $\begin{array}{r}7 \\
8 \\
9 \\
10 \\
11 \\
\mathrm{~N}\end{array}$ & $\begin{array}{r}.78 \\
.99 \\
1.23 \\
1.45 \\
1.64 \\
1.90\end{array}$ & $\begin{array}{l}2,870 \\
3,310 \\
3,880 \\
4,350 \\
4,840 \\
5,470\end{array}$ & $\begin{array}{l}15.04 \\
15.35 \\
15.60 \\
15.82 \\
16.00 \\
16.14\end{array}$ & $\begin{array}{l}59,000 \\
61,300 \\
62,400 \\
63,600 \\
64,800 \\
65,400\end{array}$ & $\begin{array}{l}18.73 \\
18.70 \\
18.60 \\
18.42 \\
18.15 \\
17.82\end{array}$ & $\begin{array}{l}81,400 \\
81,400 \\
80,800 \\
79,500 \\
78,300 \\
75,800\end{array}$ & $\mid$\begin{tabular}{r|}
10.49 \\
10.25 \\
10.07 \\
9.86 \\
9.69 \\
9.57
\end{tabular} & $\begin{array}{l}36,600 \\
35,300 \\
34,800 \\
34,000 \\
33,100 \\
32,700\end{array}$ & $6 . \overline{8}$ & 21,600 & 4.69 & 13,700 \\
\hline $\begin{array}{l}1 \\
\mathbf{2} \\
\mathbf{3} \\
\mathbf{4} \\
\mathbf{5} \\
\mathbf{6}\end{array}$ & $\begin{array}{l}2.57 \\
3.50 \\
4.38 \\
4.94 \\
5.31 \\
5.69\end{array}$ & $\begin{array}{r}7,360 \\
9,930 \\
12,700 \\
14,400 \\
15,800 \\
17,200\end{array}$ & $\begin{array}{l}16.23 \\
16.30 \\
16.40 \\
16.49 \\
16.60 \\
16.71\end{array}$ & $\begin{array}{l}66,000 \\
66,600 \\
67,200 \\
67,800 \\
68,400 \\
69,000\end{array}$ & $\begin{array}{l}17.38 \\
16.80 \\
16.22 \\
15.68 \\
15.06 \\
14.47\end{array}$ & $\begin{array}{l}73,300 \\
69,700 \\
66,000 \\
63,000 \\
59,500 \\
56,200\end{array}$ & $\begin{array}{l}9.41 \\
9.26 \\
9.15 \\
9.02 \\
8.88 \\
8.74\end{array}$ & $\begin{array}{l}31,800 \\
31,400 \\
31,000 \\
30,200 \\
29,700 \\
28,900\end{array}$ & $\begin{array}{r}6.40 \\
6.26\end{array}$ & 19,800 & & 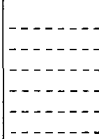 \\
\hline $\begin{array}{r}7 \\
8 \\
9 \\
10 \\
11 \\
12 \\
\end{array}$ & $\begin{array}{r}6.30 \\
7.22 \\
8.14 \\
9.01 \\
9.84 \\
10.73 \\
\end{array}$ & $\begin{array}{l}19,400 \\
22,800 \\
26,400 \\
30,200 \\
33,600 \\
37,500 \\
\end{array}$ & $\begin{array}{l}16.86 \\
17.02 \\
17.17 \\
17.35 \\
17.52 \\
17.72\end{array}$ & $\begin{array}{l}70,300 \\
70,900 \\
72,100 \\
73,300 \\
74,000 \\
75,200 \\
\end{array}$ & $\begin{array}{l}13.90 \\
13.34 \\
12.90 \\
12.49 \\
12.11 \\
11.83\end{array}$ & $\begin{array}{l}52,900 \\
49,800 \\
47,800 \\
45,800 \\
43,900 \\
42,500 \\
\end{array}$ & $\begin{array}{l}8.61 \\
8.46 \\
8.33 \\
8.22 \\
8.11 \\
7.98 \\
\end{array}$ & \begin{tabular}{|l}
28,500 \\
28,000 \\
27,200 \\
26,800 \\
26,400 \\
26,000 \\
\end{tabular} & $\overline{5} . \overline{3}$ & $\begin{array}{l}18,600 \\
17,200\end{array}$ & 4.18 & 12,100 \\
\hline & \multicolumn{2}{|c|}{ Aug. 30} & \multicolumn{2}{|c|}{ Aug. 31} & \multicolumn{2}{|c|}{ Sept. 1} & \multicolumn{2}{|r|}{ Sept. 2} & \multicolumn{2}{|c|}{ Sept. 3} & \multicolumn{2}{|c|}{ Sept. } \\
\hline $\begin{array}{l}\mathbf{1} \\
2 \\
3 \\
4 \\
5 \\
\mathbf{6}\end{array}$ & $\begin{array}{l}2.00 \\
2.03 \\
2.15 \\
3.06 \\
6.05 \\
8.21\end{array}$ & $\begin{array}{r}5,730 \\
5,860 \\
6,140 \\
8,770 \\
18,300 \\
26,800\end{array}$ & $\begin{array}{l}20.93 \\
20.90 \\
20.71 \\
20.55 \\
20.33 \\
20.05\end{array}$ & $\begin{array}{l}95,600 \\
95,600 \\
94,200 \\
93,600 \\
91,600 \\
89,700\end{array}$ & $\begin{array}{l}12.55 \\
12.05 \\
11.59 \\
11.18 \\
10.82 \\
10.45\end{array}$ & $\begin{array}{l}46,300 \\
43,400 \\
41,500 \\
39,700 \\
37,900 \\
36,100\end{array}$ & $\begin{array}{l}7.99 \\
7.92 \\
7.83 \\
7.76 \\
7.70 \\
7.65\end{array}$ & $\begin{array}{l}26,000 \\
25,600 \\
25,200 \\
25,200 \\
24,800 \\
24,400\end{array}$ & $\begin{array}{r}-\overline{6} . \overline{4} \\
5.70\end{array}$ & 18,300 & 4.07 & $-1 \overline{1}, 800$ \\
\hline $\begin{array}{r}7 \\
8 \\
9 \\
10 \\
11 \\
\mathrm{~N}\end{array}$ & $\begin{array}{r}9.62 \\
10.90 \\
12.23 \\
13.25 \\
14.14 \\
14.95\end{array}$ & $\begin{array}{l}32,700 \\
38,300 \\
44,400 \\
49,300 \\
54,000 \\
59,000\end{array}$ & $\begin{array}{l}19.75 \\
19.55 \\
19.25 \\
19.10 \\
18.83 \\
18.60\end{array}$ & $\begin{array}{l}88,400 \\
87,100 \\
84,600 \\
83,900 \\
82,000 \\
80,800\end{array}$ & $\begin{array}{r}10.15 \\
9.92 \\
9.70 \\
9.53 \\
9.36 \\
9.16\end{array}$ & $\begin{array}{l}35,300 \\
34,000 \\
33,100 \\
32,300 \\
31,800 \\
31,000\end{array}$ & $\begin{array}{l}7.58 \\
7.46 \\
7.33 \\
7.16 \\
7.05 \\
6.96\end{array}$ & $\begin{array}{l}24,400 \\
24,000 \\
23,200 \\
22,800 \\
22,000 \\
22,000\end{array}$ & 5.33 & $\mid \begin{array}{c}\overline{15}, 800 \\
14,400\end{array}$ & $\overline{3} . \overline{7}$ & 10,800 \\
\hline $\begin{array}{l}1 \\
2 \\
3 \\
4 \\
5 \\
6\end{array}$ & $\begin{array}{l}15.75 \\
16.48 \\
17.34 \\
17.95 \\
18.55 \\
19.05\end{array}$ & $\begin{array}{l}63,600 \\
67,800 \\
72,700 \\
77,000 \\
80,800 \\
83,300\end{array}$ & $\begin{array}{l}18.25 \\
18,05 \\
17.73 \\
17.41 \\
16.93 \\
16.50\end{array}$ & $\begin{array}{l}78,300 \\
77,000 \\
75,200 \\
73,300 \\
70,300 \\
67,800\end{array}$ & $\begin{array}{l}8.98 \\
8.79 \\
8.64 \\
8.55 \\
8.50 \\
8.48\end{array}$ & $\begin{array}{l}30,200 \\
29,300 \\
28,500 \\
28,500 \\
28,000 \\
28,000\end{array}$ & $\begin{array}{l}6.90 \\
6.85 \\
6.85 \\
6.87 \\
6.86 \\
6.77\end{array}$ & $\begin{array}{l}21,600 \\
21,300 \\
21,300 \\
21,600 \\
21,600 \\
21,300\end{array}$ & $\mid \begin{array}{r}-\overline{4.69} \\
-\overline{4.77}\end{array}$ & $\begin{array}{l}13, \overline{700} \\
14,000\end{array}$ & $\overline{3} . \overline{8} \overline{1}$ & 10,800 \\
\hline $\begin{array}{r}7 \\
8 \\
9 \\
10 \\
11 \\
12\end{array}$ & $\begin{array}{l}19.52 \\
20.02 \\
20.35 \\
20.60 \\
20.80 \\
20.90\end{array}$ & $\begin{array}{l}86,500 \\
89,700 \\
92,300 \\
93,600 \\
94,900 \\
95,600\end{array}$ & $\begin{array}{l}16,06 \\
15.55 \\
14.95 \\
14.35 \\
13.72 \\
13.10\end{array}$ & $\begin{array}{l}65,400 \\
62,400 \\
59,000 \\
55,600 \\
51,900 \\
48,800\end{array}$ & $\begin{array}{l}8.47 \\
8.46 \\
8.38 \\
8.25 \\
8.13 \\
8.03\end{array}$ & $\begin{array}{l}28,000 \\
28,000 \\
27,600 \\
26,800 \\
26,400 \\
26,000\end{array}$ & $\begin{array}{l}6.68 \\
6.57 \\
6.45 \\
6.34 \\
6.26 \\
6.23\end{array}$ & $\begin{array}{l}20,500 \\
19,800 \\
19,400 \\
19,400 \\
19,000\end{array}$ & $4 . \overline{59}$ & $\begin{array}{l}1 \overline{3}, 400 \\
12,400\end{array}$ & 3.66 & $-10,500$ \\
\hline
\end{tabular}


TENNESSEE RIVER AT KNOXVILLE, TENN.

Lochtion.-Lat. $35^{\circ} 57^{\prime} 47^{\prime \prime}$, long. $83^{\circ} 54^{\prime} 27^{\prime \prime}$, at old city pumping plant at Knoxville, Knox County, three-eighths of a mile upstream from First Creek, half a mile upstream from Gay Street Bridge, and 4 miles downstream from confluence of French Broad and Holston Rivers. Datum of gage is 797.68 feet above mean sea level, datum of 1929 , supplementary adjustment of 1936 .

Drainage area.-8,934 square miles, including that of First Creek.

GAGE-HEIGHT RECORD.-Water-stage recorder graph except for period 6:30 p.m. Aug. 31 to 7:30 a.m. Sept. 2, record for which was based on one telemark reading and shape of graph for nearby stations.

DISCHARGE RECORD.-Stage-discharge relation defined by current-meter measurements up to 122,000 second-feet. Gage heights used to half-tenths below 3.0 feet; tenths above this limit.

MАхімА.-1940: Discharge, 118,000 second-feet 2 a.m. Aug. 16 (gage height, 23.90 feet).

1899-1939: Discharge observed, 195,000 second-feet Mar. 1, 1902 (36.0 feet present site and datum) from rating curve extended above 130,000 secondfeet.

Stage known, 45.8 feet (present site and datum, from high-water profile by Corps of Engineers, War Department, and Tennessee Valley Authority) Mar. 10, 1867 (discharge, 270,000 second-feet).

REMarKs.-Flood runoff doubtless affected by storage in several lakes and ponds and large overflow areas.

Mean discharge, in second-feet, 1940

\begin{tabular}{|c|c|c|c|c|c|c|c|c|c|c|c|}
\hline Day & Aug. & Sept. & Day & Aug. & Sept. & Day & Aug. & Sept. & Day & Aug. & Sept. \\
\hline $\begin{array}{l}1 \\
2 \\
3 \\
4 \\
5 \\
6 \\
7 \\
8\end{array}$ & $\begin{array}{r}30,700 \\
23,100 \\
16,100 \\
10,100 \\
7,600 \\
6,140 \\
8,950 \\
10,300\end{array}$ & $\begin{array}{l}71,800 \\
38,600 \\
26,600 \\
18,200 \\
14,800 \\
13,100 \\
11,800 \\
10,900\end{array}$ & $\begin{array}{r}9 \\
10 \\
11 \\
12 \\
13 \\
14 \\
15 \\
16\end{array}$ & $\begin{array}{r}8,950 \\
7,780 \\
6,140 \\
5,010 \\
4,630 \\
38,300 \\
90,600 \\
106,000\end{array}$ & $\begin{array}{l}8,250 \\
7,260 \\
8,340 \\
8,340 \\
7,960 \\
7,780 \\
7,420 \\
6,580\end{array}$ & $\begin{array}{l}17 \\
18 \\
19 \\
20 \\
21 \\
22 \\
23 \\
24\end{array}$ & $\begin{array}{l}60,000 \\
34,200 \\
26,000 \\
21,400 \\
19,300 \\
17,100 \\
14,000 \\
12,200\end{array}$ & $\begin{array}{l}5,740 \\
6,140 \\
6,140 \\
5,740 \\
5,490 \\
5,140 \\
4,720 \\
4,160\end{array}$ & $\begin{array}{l}25 \\
26 \\
27 \\
28 \\
29 \\
30 \\
31\end{array}$ & $\begin{array}{r}10,900 \\
8,630 \\
7,340 \\
7,660 \\
8,010 \\
23,100 \\
87,100\end{array}$ & $\begin{array}{l}5,250 \\
6,140 \\
5,490 \\
5,140 \\
4,920 \\
4,080\end{array}$ \\
\hline \multicolumn{10}{|c|}{$\begin{array}{l}\text { Monthly mean discharge, in second-feet } \\
\text { Runoff, in inches }\end{array}$} & $\begin{array}{r}23,790 \\
3.07\end{array}$ & $\begin{array}{r}11,400 \\
1.42\end{array}$ \\
\hline
\end{tabular}




\section{FLOODS OF AUGUST 1940 IN THE SOUTHEASTERN STATES}

Gage height, in feet, and discharge, in second-feet, at indicated time, 1940

\begin{tabular}{|c|c|c|c|c|c|c|c|c|c|c|c|c|}
\hline \multirow{2}{*}{ Hour } & \multicolumn{2}{|c|}{ Aug. 13} & \multicolumn{2}{|c|}{ Aug. 14} & \multicolumn{2}{|c|}{ Aug. 15} & \multicolumn{2}{|c|}{ Aug. 16} & \multicolumn{2}{|c|}{ Aug. 17} & \multicolumn{2}{|c|}{ Aug. 18} \\
\hline & $\begin{array}{c}\text { Gage } \\
\text { ht. }\end{array}$ & $\begin{array}{c}\text { Dis- } \\
\text { charge }\end{array}$ & $\begin{array}{c}\text { Gage } \\
\text { ht. }\end{array}$ & $\begin{array}{c}\text { Dis- } \\
\text { charge }\end{array}$ & $\begin{array}{c}\text { Gage } \\
\text { ht. }\end{array}$ & $\begin{array}{c}\text { Dis- } \\
\text { charge }\end{array}$ & $\begin{array}{c}\text { Gage } \\
\text { ht. }\end{array}$ & $\begin{array}{c}\text { Dis- } \\
\text { charge }\end{array}$ & $\begin{array}{c}\text { Gage } \\
\text { ht. }\end{array}$ & & $\begin{array}{c}\text { Gage } \\
\text { ht. }\end{array}$ & \\
\hline $\begin{array}{l}1 \\
2 \\
3 \\
4 \\
5 \\
6\end{array}$ & \begin{tabular}{|c|}
.-- \\
.- \\
-60 \\
0.60 \\
-
\end{tabular} & 4,430 & $\begin{array}{l}1.60 \\
2.50 \\
3.25 \\
3.90 \\
4.60 \\
5.30\end{array}$ & $\begin{array}{r}6,900 \\
10,500 \\
13,900 \\
16,900 \\
19,700 \\
22,600\end{array}$ & $\begin{array}{l}13.95 \\
14.20 \\
14.45 \\
14.80 \\
15.20 \\
15.70\end{array}$ & $\begin{array}{l}64,100 \\
65,100 \\
66,200 \\
68,200 \\
70,300 \\
72,900\end{array}$ & \begin{tabular}{|}
23.85 \\
23.90 \\
23.90 \\
23.85 \\
23.75 \\
23.55
\end{tabular} & $\begin{array}{l}118,000 \\
118,000 \\
118,000 \\
118,000 \\
118,000 \\
117,000\end{array}$ & \begin{tabular}{|l|}
$-\ldots$ \\
16.60 \\
\hdashline- \\
-
\end{tabular} & $0^{-}$ & & \\
\hline $\begin{array}{r}7 \\
8 \\
9 \\
10 \\
11 \\
\mathrm{~N}\end{array}$ & --- & & $\begin{array}{l}6.00 \\
6.80 \\
7.50 \\
8.20 \\
8.80 \\
9.40\end{array}$ & $\begin{array}{l}25,700 \\
29,300 \\
32,600 \\
35,900 \\
38,700 \\
41,500\end{array}$ & $\begin{array}{l}16.25 \\
16.80 \\
17.30 \\
18.00 \\
18.50 \\
19.10\end{array}$ & 0 & $\begin{array}{l}23.35 \\
23.10 \\
22.85 \\
22.60 \\
22.30 \\
22.00\end{array}$ & $\begin{array}{l}115,000 \\
114,000 \\
112,000 \\
111,000 \\
109,000 \\
108,000\end{array}$ & $\begin{array}{l}\overline{14.60} \\
12.70\end{array}$ & 50 & 7.64 & \\
\hline $\begin{array}{l}1 \\
2 \\
3 \\
4 \\
5 \\
6\end{array}$ & .70 & $4,620^{\circ}$ & $\begin{array}{r}9.90 \\
10.35 \\
10.80 \\
11.20 \\
11.70 \\
12.00\end{array}$ & $\begin{array}{l}43,900 \\
46,200 \\
48,100 \\
50,100 \\
52,500 \\
54,000\end{array}$ & $\begin{array}{l}19.70 \\
20.20 \\
20.75 \\
21.20 \\
21.65 \\
22.05\end{array}$ & $\begin{array}{r}94,600 \\
97,400 \\
101,000 \\
103,000 \\
105,000 \\
108,000\end{array}$ & $\begin{array}{l}21.75 \\
21.45 \\
21.20 \\
20.90 \\
20.65 \\
20.35\end{array}$ & $\begin{array}{r}106,000 \\
104,000 \\
103,000 \\
101,000 \\
99,700 \\
98,500\end{array}$ & $\mid \begin{array}{l}\cdots \\
11.15 \\
\cdots\end{array}$ & 50,100 & & \\
\hline $\begin{array}{r}7 \\
8 \\
9 \\
10 \\
11 \\
12 \\
\end{array}$ & $|-\overline{1.60}|$ & $6,900^{-}$ & $\mid \begin{array}{r}12.35 \\
12.70 \\
13.00 \\
13.30 \\
13.50 \\
13.75\end{array}$ & $\begin{array}{l}\mathbf{5 6}, 000 \\
\mathbf{5 7}, 500 \\
59,000 \\
60,500 \\
61,500 \\
63,000 \\
\end{array}$ & \begin{tabular}{|}
22.45 \\
22.80 \\
23.10 \\
23.40 \\
23.60 \\
23.75
\end{tabular} & $\begin{array}{l}11 \\
11 \\
11 \\
11 \\
\end{array}$ & \begin{tabular}{|l|}
20.05 \\
19.70 \\
19.40 \\
19.10 \\
18.75 \\
18.40
\end{tabular} & $\begin{array}{l}96,300 \\
94,600 \\
92,900 \\
91,300 \\
89,600 \\
87,400\end{array}$ & 9.25 & 40,600 & 7.00 & \\
\hline & \multicolumn{2}{|c|}{ Aug. 30} & \multicolumn{2}{|c|}{ Aug. 31} & \multicolumn{2}{|c|}{ Sept. 1} & \multicolumn{2}{|c|}{ Sept. 2} & \multicolumn{2}{|c|}{ Sept. 3} & \multicolumn{2}{|c|}{ Sept. 4} \\
\hline $\begin{array}{l}1 \\
2 \\
3 \\
4 \\
5 \\
6\end{array}$ & $\begin{array}{l}2.01 \\
2.02 \\
2.02 \\
2.02 \\
2.03 \\
2.04\end{array}$ & $\begin{array}{l}\mathbf{8}, \mathbf{3 4 0} \\
\mathbf{8}, \mathbf{3 4 0} \\
\mathbf{8}, \mathbf{3 4 0} \\
\mathbf{8}, \mathbf{3 4 0} \\
\mathbf{8}, 540 \\
\mathbf{8 , 5 4 0}\end{array}$ & \begin{tabular}{|l|}
14.05 \\
14.65 \\
15.20 \\
15.80 \\
16.30 \\
16.80
\end{tabular} & $\begin{array}{l}64,100 \\
67,200 \\
70,300 \\
73,400 \\
76,100 \\
78,800\end{array}$ & \begin{tabular}{|l|}
19.40 \\
19.12 \\
18.80 \\
18.46 \\
18.00 \\
17.60
\end{tabular} & & $\begin{array}{r}11.00 \\
10.70 \\
10.40 \\
10.10 \\
9.78 \\
9.46\end{array}$ & $\begin{array}{l}43,400 \\
42,000\end{array}$ & $6.7 \overline{1}$ & 28,800 & 4.64 & 19,700 \\
\hline $\begin{array}{r}7 \\
8 \\
9 \\
10 \\
11 \\
\mathrm{~N}\end{array}$ & $\begin{array}{l}2.06 \\
2.10 \\
2.15 \\
2.25 \\
2.39 \\
2.56\end{array}$ & $\begin{array}{r}8,540 \\
8,740 \\
8,950 \\
9,380 \\
10,100 \\
10,800\end{array}$ & \begin{tabular}{|l|}
17.30 \\
17.70 \\
18.20 \\
18.60 \\
18.95 \\
19.25
\end{tabular} & $\begin{array}{l}86,400 \\
88,500 \\
90,700 \\
\mathbf{9 1}, 800\end{array}$ & \begin{tabular}{|l|}
17.16 \\
16.78 \\
16.39 \\
16.02 \\
15.66 \\
15.30
\end{tabular} & & $\begin{array}{l}9.15 \\
9.00 \\
8.90 \\
8.80 \\
8.68 \\
8.56\end{array}$ & & 6.21 & 26,600 & 4.16 & 18,100 \\
\hline $\begin{array}{l}1 \\
\mathbf{2} \\
\mathbf{3} \\
\mathbf{4} \\
\mathbf{5} \\
\mathbf{6}\end{array}$ & $\begin{array}{l}2.90 \\
4.32 \\
5.50 \\
6.67 \\
7.90 \\
9.00\end{array}$ & $\begin{array}{l}18,500 \\
23,500 \\
28,800 \\
34,500 \\
39,600\end{array}$ & $\left|\begin{array}{l}19.50 \\
19,75 \\
19.95 \\
20.05 \\
20.15 \\
20,25\end{array}\right|$ & $\begin{array}{l}00 \\
00 \\
00 \\
00 \\
00\end{array}$ & $\left|\begin{array}{l}14.97 \\
14.60 \\
14.28 \\
13.90 \\
13,60 \\
13.26\end{array}\right|$ & & $\begin{array}{l}8.48 \\
8.36 \\
8.25 \\
8.15 \\
8.03 \\
7.92\end{array}$ & $\begin{array}{l}35,900 \\
35,900 \\
34,900 \\
34,500\end{array}$ & 5.70 & 24,400 & $3 . \overline{7}$ & 16,500 \\
\hline $\begin{array}{r}7 \\
8 \\
9 \\
10 \\
11 \\
12\end{array}$ & $\begin{array}{r}9.80 \\
10.60 \\
11.40 \\
12.20 \\
12.80 \\
13.40\end{array}$ & $\begin{array}{l}43,400 \\
47,200 \\
51,000 \\
55,000 \\
58,000 \\
61,000\end{array}$ & $\begin{array}{l}20.28 \\
20.25 \\
20.17 \\
20.03 \\
19.86 \\
19.60\end{array}$ & $\begin{array}{l}98 \\
97 \\
97 \\
96 \\
95 \\
94\end{array}$ & $\left|\begin{array}{l|}12.95 \\
12.60 \\
12.30 \\
11.96 \\
11.62 \\
11.30\end{array}\right|$ & $\begin{array}{l}\mathbf{5 9} \\
\mathbf{5 7} \\
\mathbf{5 5} \\
\mathbf{5 4} \\
\mathbf{5 2} \\
\mathbf{5 0}\end{array}$ & $\begin{array}{l}7.80 \\
7.66 \\
7.54 \\
7.43 \\
7.33 \\
7.22\end{array}$ & $\begin{array}{l}33,500 \\
32,600 \\
32,100 \\
31,600 \\
31,200\end{array}$ & - & 22,200 & \begin{tabular}{c}
$-\cdots-$ \\
\hdashline $\mathbf{3} 8$ \\
$-\overline{8}$
\end{tabular} & $\overline{15}, \overline{7} 00$ \\
\hline
\end{tabular}

TENNESSEE RIVER AT LOUDON, TENN.

Location.-Lat. $35^{\circ} 44^{\prime} 33^{\prime \prime}$, long. $84^{\circ} 19^{\prime} 56^{\prime \prime}$, at bridge on U. S. Highway 11 at Loudon, Loudon County, 93/4 miles downstream from Little Tennessee River. Datum of gage is 726.29 feet above mean sea level, datum of 1929, supplementary adjustment of 1936 .

DRAINAGE AREA.- $-12,220$ square miles.

GAGE-HEIGHT RECORD.-Water-stage recorder graph except for 3 a.m. to $12 \mathrm{~m}$. Aug. 31, where it was determined by the shape of the graph at beginning and end of period.

DISCHARǴ RECORD.-Stage-discharge relation defined by current-meter measurements up to 151,000 second-feet. Gage heights used to half-tenths between 2.5 and 4.8 feet; hundredths below and tenths above these limits. 
Maxima.-1940: Discharge, 123,000 second-feet 4 p.m. Aug. 16 (gage height, 19.86 feet).

1922-39: Discharge, 169,000 second-feet Mar. 28, 1936 (gage height, 25.75 feet).

Flood of Mar. 5,1917 , reached a stage of 32.9 feet, present site and datum (diseharge, 225,000 second-feet).

The United States Weather Bureau reports stages of 49.7 feet Mar. 10 or 11 , 1867, 42.7 feet Feb. 27, 1875, and 34.9 feet Mar. 31, 1886 (all referred to gage at present site and datum). Flood of Mar. 31, 1886, may have reached a higher stage; no readings were obtained after Mar. 31.

REMARKS.-Flood runoff not appreciably affected by storage or regulation.

Mean discharge, in second-feet, 1940

\begin{tabular}{|c|c|c|c|c|c|c|c|c|c|c|c|}
\hline Day & Aug. & Sept. & Day & Aug. & Sept. & Day & Aug. & Sept. & Day & Aug. & Sept. \\
\hline $\begin{array}{l}1 \\
2 \\
3 \\
4 \\
5 \\
6 \\
7 \\
8\end{array}$ & $\begin{array}{l}27,400 \\
34,600 \\
21,600 \\
15,500 \\
11,200 \\
10,500 \\
10,800 \\
13,700\end{array}$ & $\begin{array}{r}108,000 \\
62,700 \\
39,700 \\
29,300 \\
21,800 \\
19,900 \\
17,800 \\
16,100\end{array}$ & \begin{tabular}{r|}
9 \\
10 \\
11 \\
12 \\
13 \\
14 \\
15 \\
16
\end{tabular} & $\begin{array}{r}13,400 \\
12,600 \\
10,500 \\
8,720 \\
9,360 \\
38,000 \\
81,300 \\
117,000\end{array}$ & $\begin{array}{l}14,300 \\
12,300 \\
12,600 \\
13,700 \\
12,600 \\
12,600 \\
12,000 \\
11,200\end{array}$ & $\begin{array}{l}17 \\
18 \\
19 \\
20 \\
21 \\
22 \\
23 \\
24\end{array}$ & $\begin{array}{l}95,400 \\
50,100 \\
31,400 \\
27,700 \\
24,500 \\
22,500 \\
19,700 \\
17,100\end{array}$ & $\begin{array}{r}10,500 \\
10,300 \\
10,500 \\
10,000 \\
10,000 \\
9,540 \\
7,520 \\
8,180\end{array}$ & $\begin{array}{l}25 \\
26 \\
27 \\
28 \\
29 \\
30 \\
31\end{array}$ & $\begin{array}{l}15,500 \\
12,800 \\
12,100 \\
11,200 \\
12,000 \\
26,200 \\
95,800\end{array}$ & $\begin{array}{l}8,180 \\
8,850 \\
9,540 \\
8,400 \\
7,300 \\
6,460\end{array}$ \\
\hline \multicolumn{12}{|c|}{$\begin{array}{l}\text { Monthly mean discharge, in second-feet. } \\
\text { Runoff, in inches. }\end{array}$} \\
\hline
\end{tabular}

Gage height, in feet, and discharge, in second-feet, at indicated time, 1940

\begin{tabular}{|c|c|c|c|c|c|c|c|c|c|c|c|c|}
\hline \multirow{2}{*}{ Hour } & \multicolumn{2}{|c|}{ Aug. 14} & \multicolumn{2}{|c|}{ Aug. 15} & \multicolumn{2}{|c|}{ Aug. 16} & \multicolumn{2}{|c|}{ Aug. 17} & \multicolumn{2}{|c|}{ Aug. 18} & \multicolumn{2}{|c|}{ Aug. 19} \\
\hline & $\begin{array}{c}\text { Gage } \\
\text { ht. }\end{array}$ & $\begin{array}{c}\text { Dis- } \\
\text { charge }\end{array}$ & $\begin{array}{l}\text { Gage } \\
\text { ht. }\end{array}$ & $\begin{array}{c}\text { Dis- } \\
\text { charge }\end{array}$ & $\begin{array}{c}\text { Gage } \\
\text { ht. }\end{array}$ & $\begin{array}{l}\text { Dis- } \\
\text { charge }\end{array}$ & $\begin{array}{c}\text { Gage } \\
\text { ht. }\end{array}$ & $\begin{array}{c}\text { Dis- } \\
\text { charge }\end{array}$ & $\begin{array}{l}\text { Gage } \\
\text { ht. }\end{array}$ & $\begin{array}{c}\text { Dis- } \\
\text { charge }\end{array}$ & $\begin{array}{c}\text { Gage } \\
\text { ht. }\end{array}$ & $\begin{array}{c}\text { Dis- } \\
\text { charge }\end{array}$ \\
\hline \multirow{4}{*}{$\begin{array}{r}2 \\
4 \\
6 \\
8 \\
10 \\
\mathbf{N}\end{array}$} & 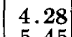 & 1 & & & & & & & & & & \\
\hline & $\begin{array}{l}5.45 \\
6.42\end{array}$ & & 13.02 & 71,100 & 18.40 & 111,000 & 2,12 & 109 & 11107 & & & \\
\hline & 7.08 & 30,000 & 13.44 & 74,000 & 19.22 & 117,000 & $-\cdots$ & 108 & 1.00 & & & \\
\hline & 8.00 & $\begin{array}{l}32,600 \\
36,000\end{array}$ & 13.99 & 78,300 & 19.69 & 121,000 & 16.52 & 96,800 & 9.80 & 48,500 & $\overline{7.22}$ & 30,600 \\
\hline \multirow{5}{*}{$\begin{array}{r}2 \\
4 \\
6 \\
8 \\
10 \\
12 \\
\end{array}$} & 8.89 & 42,200 & & & & & & & & & & \\
\hline & 9.80 & 48 & 15.04 & 85,700 & 19.86 & 123,000 & & & 887 & & & \\
\hline & $\begin{array}{l}10.51 \\
11.12\end{array}$ & $\begin{array}{l}53,400 \\
57,600\end{array}$ & $\overline{1} \overline{6} . \overline{13}$ & 93,800 & 19.72 & 121,000 & & & $\begin{array}{r}8.87 \\
-\therefore-.-\end{array}$ & & & \\
\hline & $\left|\begin{array}{l}11.69 \\
12.17\end{array}\right|$ & $\begin{array}{l}61,800 \\
65,300\end{array}$ & 17.30 & 103,000 & $\overline{19} . \overline{24}$ & 117,000 & $\overline{12.5 \overline{1}} \mid$ & 67,500 & $8 . \overline{2}$ & $\overline{37}, \overline{4} 0 \overline{0}$ & 7.10 & 30,000 \\
\hline & \multicolumn{2}{|c|}{ Aug. 30} & \multicolumn{2}{|c|}{ Aug. 31} & \multicolumn{2}{|c|}{ Sept. 1} & \multicolumn{2}{|c|}{ Sept. 2} & \multicolumn{2}{|c|}{ Sept. 3} & \multicolumn{2}{|c|}{ Sept. 4} \\
\hline \multirow{4}{*}{$\begin{array}{r}2 \\
4 \\
6 \\
8 \\
10 \\
\mathbf{N}\end{array}$} & & & 13.00 & 00 & & & & & & & & \\
\hline & & & 14.30 & 80,500 & 18.57 & 113,000 & 14.25 & 79,800 & & & & \\
\hline & $\begin{array}{r}4.67 \\
\ldots . . .\end{array}$ & 14,600 & $\begin{array}{l}15.28 \\
16.00\end{array}$ & $\begin{array}{l}87,900 \\
93,100\end{array}$ & 18.65 & 113,000 & 12.50 & 67,500 & .94 & & & \\
\hline & 5.20 & 17,900 & $\mid \begin{array}{l}16.57 \\
17.07\end{array}$ & $\begin{array}{r}97,500 \\
101,000\end{array}$ & $\overline{18 . \overline{4}}$ & $11 \overline{2}, 000$ & $\overline{11} . \overline{17}$ & $\overline{58}, \overline{30} \overline{0}$ & 8.45 & 38,700 & 6.96 & 29,300 \\
\hline \multirow{4}{*}{$\begin{array}{r}2 \\
4 \\
6 \\
8 \\
10 \\
12\end{array}$} & 6 & & & & & & & & & & & \\
\hline & & & 17.60 & 105,000 & {$[\overline{17} . \overline{9}$} & 108,000 & 10.32 & 52,000 & & & & \\
\hline & $\begin{array}{l}8.40 \\
9.20\end{array}$ & $\begin{array}{l}38,700 \\
44,300\end{array}$ & $\overline{18.0} \overline{1}$ & 108,000 & $\overline{17} . \overline{15}$ & $1 \overline{0} \overline{2}, 000$ & $9 . \overline{9}$ & 48,500 & & & & \\
\hline & 10.28 & $\begin{array}{l}52,000 \\
61,100\end{array}$ & $3 . \overline{37}$ & 111,000 & 15.94 & 2,400 & 9.68 & 47,800 & $7 . \overline{7}$ & 34,600 & $6 . \overline{36}$ & $\overline{2} 5, \overline{4} 00$ \\
\hline
\end{tabular}

SuPPLEMENTAL RECORD.-Sept. 1, 7 a.m., gage height, 18.66 feet; discharge, 113,000 second-feet.

\section{CHICKAMAUGA RESERVOIR NEAR CHATTANOOGA, TENN.}

Location.--Lat. $35^{\circ} 06^{\prime} 07^{\prime \prime}$, long. $85^{\circ} 13^{\prime} 42^{\prime \prime}$, at Chickamauga Dam on Tennesseo River, 1,000 feet upstream from North Chickamauga Creek, 1,500 feet upstream from Southern Railway bridge, and $53 / 4$ miles northeast of Chattanooga, Hamilton County. Datum of gage is mean sea level, datum of 1929, supplementary adjustment of 1936 . 
Drainage AREA.-20,790 square miles.

GAGE-HEIGHT RECORD.-Water-stage recorder graph.

STORAGE RECORD.-Figures represent total capacity or contents for level pool.

REMARKs. - Controlled storage, between elevations 673.00 (minimum pool) and

685.44 feet (top of gates) is 376,900 acre-feet. Records furnished by the Tennessee Valley Authority. Chickamauga Reservoir is drawn down in advance of floods.

\begin{tabular}{|c|c|c|c|c|c|c|c|c|c|}
\hline \multirow{2}{*}{ Day } & \multicolumn{2}{|c|}{ August } & \multicolumn{2}{|c|}{ September } & \multirow{2}{*}{ Day } & \multicolumn{2}{|c|}{ August-Con. } & \multicolumn{2}{|c|}{ September-Con. } \\
\hline & $\begin{array}{c}\text { Ele- } \\
\text { vation } \\
\text { (feet) }\end{array}$ & $\begin{array}{l}\text { Contents } \\
\text { (thousand } \\
\text { acre-feet) }\end{array}$ & $\begin{array}{l}\text { Ele- } \\
\text { vation } \\
\text { (feet) }\end{array}$ & $\begin{array}{l}\text { Contents } \\
\text { (thousand } \\
\text { acre-feet) }\end{array}$ & & $\begin{array}{l}\text { Ele- } \\
\text { vation } \\
\text { (feet) }\end{array}$ & $\begin{array}{l}\text { Contents } \\
\text { (thousand } \\
\text { acre-feet) }\end{array}$ & $\begin{array}{c}\text { Ele- } \\
\text { vation } \\
\text { (feet) }\end{array}$ & $\begin{array}{l}\text { Contents } \\
\text { (thousand } \\
\text { acre-feet) }\end{array}$ \\
\hline $\begin{array}{l}1 \\
2 \\
3 \\
4 \\
5\end{array}$ & $\begin{array}{l}681.40 \\
682.19 \\
682.38 \\
682.23 \\
682.00\end{array}$ & $\begin{array}{l}559.6 \\
586.1 \\
592.6 \\
\mathbf{5 8 7 . 4} \\
\mathbf{5 7 9 . 5}\end{array}$ & $\begin{array}{l}681.73 \\
682.76 \\
682.30 \\
681.92 \\
681.52\end{array}$ & $\begin{array}{l}570.6 \\
605.7 \\
589.8 \\
576.9 \\
563.6\end{array}$ & $\begin{array}{l}16 \\
17 \\
18 \\
19 \\
20\end{array}$ & $\begin{array}{l}679.32 \\
681.89 \\
682.45 \\
682.32 \\
682.21\end{array}$ & $\begin{array}{l}494.1 \\
575.9 \\
595.0 \\
590.5 \\
586.7\end{array}$ & $\begin{array}{l}681.19 \\
681.14 \\
681.10 \\
681.02 \\
681.00\end{array}$ & $\begin{array}{l}552.7 \\
551.0 \\
549.7 \\
547.1 \\
546.4\end{array}$ \\
\hline $\begin{array}{r}6 \\
7 \\
8 \\
9 \\
10\end{array}$ & $\begin{array}{l}681.90 \\
681.67 \\
681.45 \\
681.38 \\
681.24\end{array}$ & $\begin{array}{l}\mathbf{5 7 6 . 2} \\
568.6 \\
561.3 \\
559.0 \\
\mathbf{5 5 4 . 3}\end{array}$ & $\begin{array}{l}681.21 \\
681.20 \\
681.07 \\
681.00 \\
681.06\end{array}$ & $\begin{array}{l}553.4 \\
553.0 \\
548.7 \\
546.4 \\
548.4\end{array}$ & $\begin{array}{l}21 \\
22 \\
23 \\
24 \\
25\end{array}$ & $\begin{array}{l}682.27 \\
682.28 \\
682.35 \\
682.52 \\
682.31\end{array}$ & $\begin{array}{l}588.8 \\
589.2 \\
591.6 \\
597.4 \\
590.2\end{array}$ & $\begin{array}{l}680.93 \\
681.20 \\
681.32 \\
681.03 \\
680.82\end{array}$ & $\begin{array}{l}544.2 \\
553.0 \\
557.0 \\
547.4 \\
540.7\end{array}$ \\
\hline $\begin{array}{l}11 \\
12 \\
13 \\
14 \\
15\end{array}$ & $\begin{array}{l}681.22 \\
681.21 \\
680.48 \\
678.62 \\
677.78\end{array}$ & $\begin{array}{l}553.7 \\
553.4 \\
529.9 \\
473.4 \\
449.3\end{array}$ & $\begin{array}{l}681.14 \\
681.16 \\
681.15 \\
681.04 \\
681.15\end{array}$ & $\begin{array}{l}551.0 \\
551.7 \\
551.4 \\
547.7 \\
551.4\end{array}$ & $\begin{array}{l}26 \\
27 \\
28 \\
29 \\
30 \\
31\end{array}$ & $\begin{array}{l}681.91 \\
681.60 \\
681.35 \\
681.37 \\
680.62 \\
680.12 \\
\end{array}$ & $\begin{array}{l}\mathbf{5 7 6 . 5} \\
\mathbf{5 6 6 . 3} \\
\mathbf{5 5 8 . 0} \\
\mathbf{5 5 8 . 6} \\
\mathbf{5 3 4 . 4} \\
\mathbf{5 1 8 . 5} \\
\end{array}$ & $\begin{array}{l}680.47 \\
680.46 \\
680.40 \\
680.40 \\
680.37\end{array}$ & $\begin{array}{l}\mathbf{5 2 9 . 6} \\
\mathbf{5 2 9 . 3} \\
\mathbf{5 2 7 . 4} \\
\mathbf{5 2 7 . 4} \\
\mathbf{5 2 6 . 4}\end{array}$ \\
\hline \multirow{2}{*}{\multicolumn{8}{|c|}{ Change in contents, equivalent, in second-feet $\ldots \ldots \ldots$}} & August & $\begin{array}{c}\text { Sep- } \\
\text { tember }\end{array}$ \\
\hline & & & & & & & & -598 & +133 \\
\hline
\end{tabular}

TENNESSEE hIVER AT CHATTANOOGA, TENN.

Location.-Lat. $35^{\circ} 05^{\prime} 12^{\prime \prime}$, long. $85^{\circ} 16^{\prime} 43^{\prime \prime}$, near southeast corner of Meadow Lake Country Club golf course, half a mile downstream from South Chickamauga Creek, 3 miles downstream, from Chickamauga Dam, and 31/2 miles upstream from Walnut Street Bridge in Chattanooga, Hamilton County. Auxiliary waterstage recorder at Citico Bar, 21/4 miles downstream and 11/4 miles upstream from Walnut Street Bridge. Datum of gages is 621.12 feet above mean sea level, datum of 1929, supplementary adjustment of 1936 .

DRAINAGE AREA.--21,400 square miles.

GAGE-HEIGHT RECORD.-Water-stage recorder graph.

Discharge RECORD.- - Slope-stage-discharge relation defined by current-meter measurements up to 185,000 second-feet. Gage height used to tenths throughout.

Maxima.-1940: Discharge, 89,400 second-feet at 10 a.m. Sept. 2 (gage height, 21.03 feet); gage height, 21.07 feet $12: 15$ p.m. Sept. 2.

1874-1939: Discharge observed, 410,000 second-feet Mar. 1, 1875 (gage height, 53.8 feet), from rating curve extended above 250,000 second-feet.

Stage known, 57.9 feet present datum, Mar. 11, 1867 (discharge, about 459, 000 second-feet) at Walnut Street.

REMARKs.-Flow regulated by operation of power plants and storage at Norris, Parksville, Hiwassee, and Chickamauga Reservoirs. 
Mean discharge, in second-feet, 1940

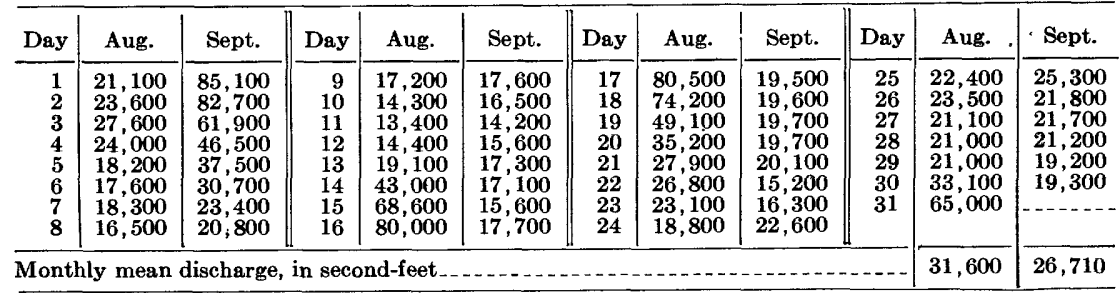

DAVIDSON RIVER NEAR BREVARD, N. C.

Location.-Lat. $35^{\circ} 16^{\prime} 23^{\prime \prime}$, long. $82^{\circ} 42^{\prime} 21^{\prime \prime}, 150$ feet upstream from bridge on State Highway 280, 2.0 miles upstream from mouth, 2.1 miles downstream from Avery Creek, and $31 \frac{1}{2}$ miles northeast of Brevard, Transylvania County. Datum of gage is 2,115.13 feet above mean sea level, datum of 1929, supplementary adjustment of 1936 .

DRAINAGE AREA.-40.4 square miles.

GAGE-HEIGHT RECORD.-Water-stage recorder graph.

DISCHARGE RECORD. - Stage-discharge relation defined by current-meter measurements up to 1,300 second-feet and extended to crest gage height on basis of determination of flood flow by slope-area method. Gage heights used to half-tenths between 2.0 and 5.3 feet; hundredths below and tenths above these limits. Rating for 1928 defined by current-meter measurements up to 360 second-feet and extended to erest gage height on basis of flood runoff comparisons.

Maxima.-1940: Discharge, 6,100 second-feet 10:30 a.m. Aug. 13 (gage height, 9.20 feet).

1920-39: Discharge, 8,400 second-feet Aug. 15, 1928 (gage height, 11.8 feet).

Surveys by the Tennessee Valley Authority show that the floods of June 1876, July 1916, and Oetober 1918 reached stages of 11.9 feet, 10.3 feet, and 10.9 feet, respectively, from flood profiles.

ReMarKs.-Flood runoff not affected by artificial storage. In 1938 a canal was put in service to deliver water to Ecusta Paper Corp. from the river at a point a short distance below the gage. This and improved channel conditions doubtless increased the flood-flow capacity of the river.

Mean discharge, in second-feet, 1940

\begin{tabular}{r|r|r||r|r|r||r|r|r|r|r|r}
\hline Day & Aug. & \multicolumn{1}{|c|}{ Sept. } & Day & Aug. & Sept. & Day & Aug. & Sept. & Day & Aug. & Sept. \\
\hline 1 & 51 & 294 & 9 & 61 & 125 & 17 & 197 & 83 & 25 & 92 & 85 \\
2 & 47 & 239 & 10 & 49 & 120 & 18 & 171 & 92 & 26 & 82 & 66 \\
3 & 46 & 203 & 11 & 75 & 114 & 19 & 150 & 87 & 27 & 76 & 64 \\
4 & 43 & 180 & 12 & 389 & 108 & 20 & 134 & 79 & 28 & 71 & 63 \\
5 & 45 & 165 & 13 & 2,500 & 102 & 21 & 119 & 74 & 29 & 522 & 63 \\
6 & 61 & 154 & 14 & 602 & 96 & 22 & 104 & 71 & 30 & 1,660 & 60 \\
7 & 62 & 144 & 15 & 319 & 92 & 23 & 97 & 69 & 31 & 408 & \\
8 & 49 & 133 & 16 & 239 & 88 & 24 & 119 & 71 & & & \\
\hline
\end{tabular}




\section{FLOODS OF AUGUST 1940 IN THE SOUTHEASTERN STATES}

Gage height, in feet, and discharge, in second-feet, at indicated time, 1940

\begin{tabular}{|c|c|c|c|c|c|c|c|c|c|c|c|c|}
\hline \multirow{2}{*}{ Hour } & \multicolumn{2}{|c|}{ Aug. 12} & \multicolumn{2}{|c|}{ Aug. 13} & \multicolumn{2}{|c|}{ Aug. 14} & \multicolumn{2}{|c|}{ Aug. 15} & \multicolumn{2}{|c|}{ Aug. 16} & \multicolumn{2}{|c|}{ Aug. 17} \\
\hline & $\begin{array}{c}\text { Gage } \\
\text { ht. }\end{array}$ & $\begin{array}{c}\text { Dis- } \\
\text { charge }\end{array}$ & $\begin{array}{c}\text { Gage } \\
\text { ht. }\end{array}$ & $\begin{array}{c}\text { Dis- } \\
\text { charge }\end{array}$ & $\begin{array}{c}\text { Gage } \\
\text { ht. }\end{array}$ & $\begin{array}{c}\text { Dis- } \\
\text { charge }\end{array}$ & $\begin{array}{c}\text { Gage } \\
\text { ht. }\end{array}$ & $\begin{array}{c}\text { Dis- } \\
\text { charge }\end{array}$ & $\begin{array}{c}\text { Gage } \\
\text { ht. }\end{array}$ & $\begin{array}{l}\text { Dis- } \\
\text { charge }\end{array}$ & $\begin{array}{c}\text { Gage } \\
\text { ht. }\end{array}$ & $\begin{array}{c}\text { Dis- } \\
\text { charge }\end{array}$ \\
\hline \multirow{5}{*}{$\begin{array}{l}1 \\
2 \\
3 \\
4 \\
5 \\
6\end{array}$} & 0.99 & 97 & 3.15 & 748 & & & & & & & & \\
\hline & & $y$ & & & 3.48 & 920 & & & & & & \\
\hline & $\begin{array}{l}.98 \\
.98 \\
\end{array}$ & $\begin{array}{l}96 \\
96\end{array}$ & $\begin{array}{l}0.00 \\
3.78\end{array}$ & $\begin{array}{r}970 \\
1,070\end{array}$ & $-\overline{3.26} \mid$ & $\overline{7} \overline{9} \overline{5}$ & & & & & & \\
\hline & 1.00 & $\begin{array}{r}99 \\
-99\end{array}$ & 3.76 & 1,040 & & & & & & & & \\
\hline & 1.03 & 104 & 3.96 & 1,140 & 3.08 & 725 & & & & & & \\
\hline \multirow{5}{*}{$\begin{array}{r}7 \\
8 \\
9 \\
10 \\
11 \\
\mathrm{~N}\end{array}$} & 1.08 & 113 & 4.65 & 1,5 & & & & & & & & \\
\hline & $\begin{array}{l}1.13 \\
1.19\end{array}$ & 123 & 5.85 & 2,4 & 2.95 & 658 & & & & & & \\
\hline & $\begin{array}{l}1.19 \\
1.25\end{array}$ & $\begin{array}{l}134 \\
146\end{array}$ & $\begin{array}{l}7.30 \\
8.80\end{array}$ & $\begin{array}{l}3,880 \\
5,600\end{array}$ & $-\overline{2} . \overline{8}$ & $\overline{5} \overline{90}$ & & & & & & \\
\hline & $\begin{array}{l}1.41 \\
1.63\end{array}$ & & $\begin{array}{l}8.85 \\
7.88\end{array}$ & 5,6 & $2.7 \overline{2}$ & 554 & 201 & 18 & 60 & 41 & & - \\
\hline & & & & & 2.12 & & 6.01 & 518 & 1.09 & 241 & 1.51 & 0 \\
\hline \multirow{4}{*}{$\begin{array}{l}1 \\
2 \\
3 \\
4 \\
5 \\
6\end{array}$} & $\begin{array}{l}2.07 \\
2.34\end{array}$ & $\begin{array}{l}332 \\
414\end{array}$ & $\begin{array}{l}7.55 \\
7.74\end{array}$ & 4,20 & & & & & & & & \\
\hline & 2.52 & $\begin{array}{l}414 \\
477\end{array}$ & 8.00 & $\begin{array}{l}4,510 \\
4.640\end{array}$ & 2.61 & 509 & & & & & & \\
\hline & $\begin{array}{l}2.69 \\
2.72\end{array}$ & $\begin{array}{l}541 \\
554\end{array}$ & $\begin{array}{l}7.30 \\
6.36\end{array}$ & $\begin{array}{l}3,880 \\
2,990\end{array}$ & 2.53 & 480 & - & & & & & \\
\hline & & & 5.67 & 2,380 & $2 . \overline{4}$ & $4 \overline{5} \overline{2}$ & - & & & & & \\
\hline $\begin{array}{l}7 \\
8\end{array}$ & $\begin{array}{l}2.74 \\
3.10\end{array}$ & $\begin{array}{l}563 \\
725\end{array}$ & 5,05 & $\begin{array}{l}1,8 \\
1,5\end{array}$ & 2.37 & 424 & & & & & & \\
\hline 9 & 3.81 & 1,070 & 4.36 & & & & & & & & & \\
\hline 10 & & 1,120 & .10 & 1,2 & 2.32 & 407 & & & & & & \\
\hline $\begin{array}{l}11 \\
12 \\
\end{array}$ & $\begin{array}{l}3.76 \\
3.37\end{array}$ & 840 & $\begin{array}{l}3.90 \\
3.73\end{array}$ & $\begin{array}{l}1,120 \\
1,040 \\
\end{array}$ & $2 . \overline{27} \mid$ & 391 & 1.81 & 268 & 1.57 & 213 & $1 . \overline{4} \overline{1}$ & $17 \overline{9}$ \\
\hline
\end{tabular}

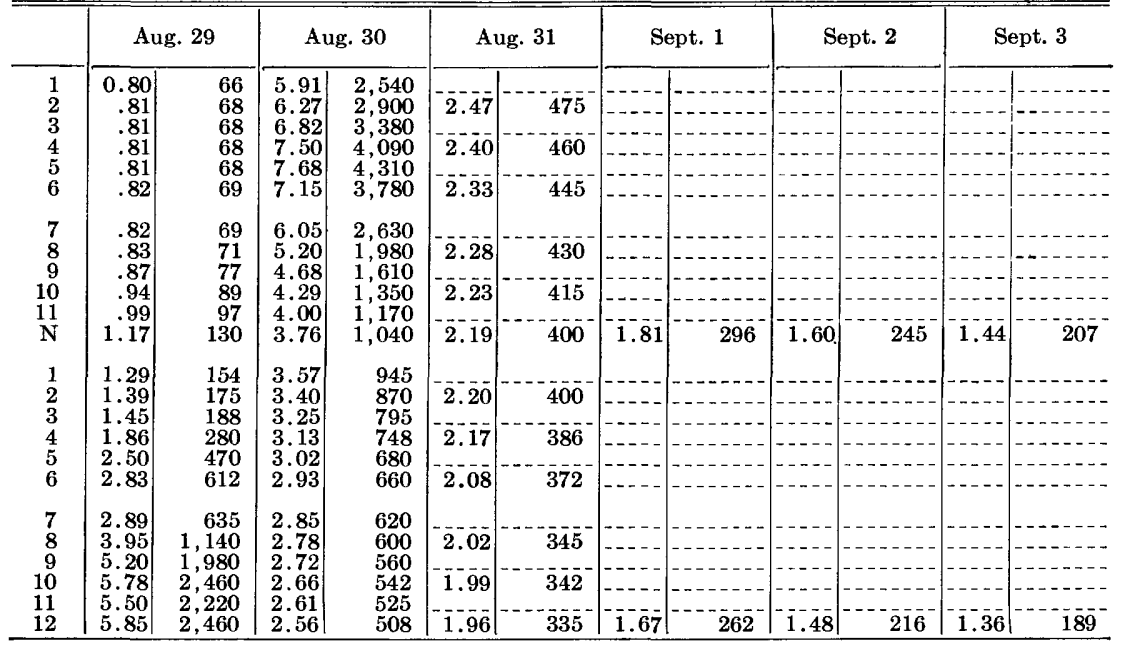

SUPplemental RECORDs.-Aug. 12, 4:30 p.m., gage height, 2.77 feet, discharge, 576 second-feet. Aug. 13, 1:30 a.m., gage height, 3.13 feet, discharge, 748 second-feet; $10: 30$ a.m., gage height, 9.20 feet, discharge, 6,100 second-feet; 2:30 p.m., gage height, 8.10 feet, discharge, 4,760 second-feet. Aug. 31, 3 p.m., gage height, 2.23 feet, discharge, 415 second-feet. 


\section{SOUTH FORK MILLS RIVER AT THE PINK BEDS, $\mathbf{N}$. C.}

Location.-Lat. $35^{\circ} 21^{\prime} 50^{\prime \prime}$, long. 82 $44^{\prime} 30^{\prime \prime}$, at The Pink Beds in Pisgah National Forest, 400 feet downstream from Thompson Creek and 9 miles north of Brevard, Transylvania County. Datum of gage is $3,138.38$ feet above mean sea level.

DRAINAGE AREA. - 9.99 square miles.

GAGE-HEIGHT RECORD.-Water-stage recorder graph.

DISCHARGE RECORD.- Stage-discharge relation defined by current-meter measurements up to 425 second-feet and extended to the 1928 crest gage height on basis of computation of flow over two sharp-crested weirs and their abutments just below the gage. Gage heights used to half-tenths between 4.8 and 7.4 feet; hundredths below and tenths above these limits.

Maxima.-1940: Discharge, 1,610 second-feet 2 p.m. Aug. 13 (gage height, 7.16 feet).

1926-39: Discharge, 2,220 second-feet Aug. 15, 1928 (gage height, 8.0 feet). REMARKs.-Flood runoff not affected by artificial storage.

Mean discharge, in second-feet, 1940

\begin{tabular}{r|r|r|r|r|r||r|r|r|r|r|r}
\hline Day & \multicolumn{1}{c|}{ Aug. } & Sept. & Day & Aug. & Sept. & Day & Aug. & Sept. & Day & Aug. & Sept. \\
\hline 1 & 12 & 91 & 9 & 17 & 34 & 17 & 80 & 23 & 25 & 35 & 22 \\
2 & 12 & 73 & 10 & 15 & 33 & 18 & 66 & 25 & 26 & 32 & 18 \\
3 & 11 & 62 & 11 & 28 & 32 & 19 & 56 & 23 & 27 & 30 & 17 \\
4 & 11 & 54 & 12 & 278 & 30 & 20 & 49 & 21 & 28 & 28 & 17 \\
5 & 12 & 49 & 13 & 900 & 28 & 21 & 45 & 20 & 29 & 204 & 16 \\
6 & 34 & 45 & 14 & 280 & 27 & 22 & 42 & 19 & 30 & 487 & 16 \\
7 & 20 & 41 & 15 & 146 & 25 & 23 & 38 & 19 & 31 & 132 & $-\ldots$ \\
8 & 14 & 37 & 16 & 104 & 24 & 24 & 38 & 19 & & \\
\hline
\end{tabular}


348 FLOODS OF AUGUST 1940 IN THE SOUTHEASTERN STATES

Gage height, in feet, and discharge, in second-feet, at indicated time, 1940

\begin{tabular}{|c|c|c|c|c|c|c|c|c|c|c|c|c|}
\hline \multirow{2}{*}{ Hour } & \multicolumn{2}{|c|}{ Aug. 12} & \multicolumn{2}{|c|}{ Aug. 13} & \multicolumn{2}{|c|}{ Aug. 14} & \multicolumn{2}{|c|}{ Aug. 15} & \multicolumn{2}{|c|}{ Aug. 16} & \multicolumn{2}{|c|}{ Aug. 17} \\
\hline & $\begin{array}{c}\text { Gage } \\
\text { ht. }\end{array}$ & $\begin{array}{l}\text { Dis- } \\
\text { charge }\end{array}$ & $\begin{array}{c}\text { Gage } \\
\text { ht. }\end{array}$ & $\begin{array}{l}\text { Dis- } \\
\text { charge }\end{array}$ & $\begin{array}{c}\text { Gage } \\
\text { ht. }\end{array}$ & $\begin{array}{l}\text { Dis- } \\
\text { eharge }\end{array}$ & $\begin{array}{c}\text { Gage } \\
\text { ht. }\end{array}$ & $\begin{array}{l}\text { Dis- } \\
\text { charge }\end{array}$ & $\begin{array}{c}\text { Gage } \\
\text { ht. }\end{array}$ & $\begin{array}{c}\text { Dis- } \\
\text { charge }\end{array}$ & $\begin{array}{c}\text { Gage } \\
\text { ht. }\end{array}$ & $\begin{array}{c}\text { Dis- } \\
\text { charge }\end{array}$ \\
\hline $\begin{array}{l}1 \\
2 \\
3 \\
4 \\
5 \\
6\end{array}$ & $\begin{array}{l}2.68 \\
2.70 \\
2.77 \\
2.94 \\
3.17 \\
3.39\end{array}$ & $\begin{array}{l}30 \\
31 \\
37 \\
51 \\
73 \\
98\end{array}$ & $\begin{array}{l}4.96 \\
4.98 \\
5.00 \\
5.05 \\
5.09 \\
5.17\end{array}$ & $\begin{array}{l}486 \\
504 \\
504 \\
522 \\
541 \\
560\end{array}$ & 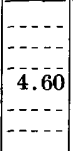 & & $\mid$\begin{tabular}{l}
---- \\
\hdashline$-\cdots$ \\
\hdashline$-\overline{-}$ \\
\hdashline$\overline{3} . \overline{80}$
\end{tabular} & $\mid$\begin{tabular}{c}
$-\cdots$ \\
$-\cdots$ \\
\hdashline-160
\end{tabular} & $\begin{array}{l}-- \\
-- \\
-- \\
-- \\
-- \\
--\end{array}$ & 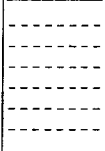 & 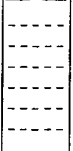 & 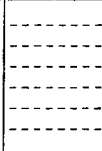 \\
\hline $\begin{array}{r}7 \\
8 \\
9 \\
10 \\
11 \\
\text { N }\end{array}$ & $\begin{array}{l}3.58 \\
3.84 \\
4.01 \\
4.23 \\
4.33 \\
4.44\end{array}$ & $\begin{array}{l}123 \\
168 \\
204 \\
260 \\
289 \\
321\end{array}$ & $\begin{array}{l}5.53 \\
6.00 \\
6.80 \\
6.94 \\
6.89 \\
6.75\end{array}$ & $\begin{array}{r}722 \\
928 \\
1,380 \\
1,480 \\
1,440 \\
1,350\end{array}$ & $\begin{array}{r}-\overline{4} . \overline{38} \\
-.-\overline{2} \\
\hdashline 4 . \overline{1}\end{array}$ & 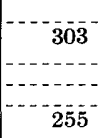 & 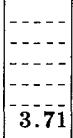 & 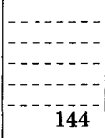 & $\mid$\begin{tabular}{l}
$-\cdots$ \\
$-\cdots-$ \\
\hdashline-- \\
\hdashline$-\overline{3}$ \\
\hdashline$\overline{4}$
\end{tabular} & $\mid \begin{array}{r}-\cdots \\
\hdashline-10 \\
\hdashline-104\end{array}$ & 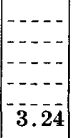 & 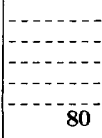 \\
\hline $\begin{array}{l}1 \\
2 \\
\mathbf{3} \\
\mathbf{4} \\
5 \\
\mathbf{6} \\
\mathbf{6}\end{array}$ & $\begin{array}{l}4.56 \\
4.57 \\
4.54 \\
4.58 \\
4.62 \\
4.74\end{array}$ & $\begin{array}{l}358 \\
361 \\
351 \\
364 \\
376 \\
414\end{array}$ & $\begin{array}{l}6.90 \\
7.16 \\
7.00 \\
6.50 \\
6.10 \\
5.81\end{array}$ & $\begin{array}{r}1,440 \\
1,610 \\
1,510 \\
1,200 \\
978 \\
833\end{array}$ & $\begin{array}{c}----- \\
-\overline{4} .08 \\
---- \\
-\cdots\end{array}$ & - & $\mid$\begin{tabular}{l}
----- \\
----- \\
\hdashline--- \\
\hdashline--- \\
$3.6 \overline{2}$
\end{tabular} & $\mid \begin{array}{r}-\cdots \\
\hdashline-129 \\
\hdashline-1 .\end{array}$ & 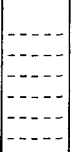 & 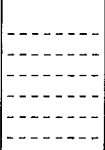 & 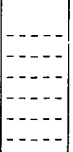 & 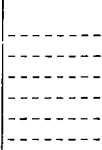 \\
\hline $\begin{array}{r}7 \\
8 \\
9 \\
10 \\
11 \\
12 \\
\end{array}$ & $\begin{array}{l}5.00 \\
5.08 \\
5.02 \\
4.97 \\
4.92 \\
4.96\end{array}$ & $\begin{array}{l}504 \\
541 \\
504 \\
486 \\
468 \\
486\end{array}$ & $\begin{array}{l}5.60 \\
5.43 \\
5.29 \\
5.16 \\
5.04 \\
4.93\end{array}$ & $\begin{array}{l}743 \\
679 \\
618 \\
560 \\
522 \\
486 \\
\end{array}$ & $\mid$\begin{tabular}{c}
$-\overline{3.98}$ \\
\hdashline$-\overline{3}$ \\
\hdashline
\end{tabular} & 198 & $\left|\begin{array}{|c}-\cdots-- \\
-\cdots \\
-\cdots- \\
\hdashline-\overline{3} 7\end{array}\right|$ & 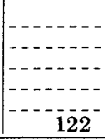 & 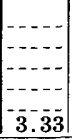 & 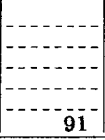 & 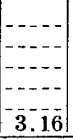 & 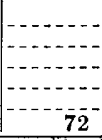 \\
\hline
\end{tabular}

\begin{tabular}{|c|c|c|c|c|c|c|c|c|c|c|c|c|}
\hline & \multicolumn{2}{|c|}{ Aug. 29} & \multicolumn{2}{|c|}{ Aug. 30} & \multicolumn{2}{|c|}{ Aug. 31} & \multicolumn{2}{|c|}{ Sept. 1} & \multicolumn{2}{|c|}{ Sept. 2} & \multicolumn{2}{|c|}{ Sept. 3} \\
\hline $\begin{array}{l}1 \\
2 \\
3 \\
4 \\
5 \\
6\end{array}$ & $\begin{array}{l}2.64 \\
2.66 \\
2.67 \\
2.68 \\
2.68 \\
2.68\end{array}$ & $\begin{array}{l}27 \\
28 \\
29 \\
30 \\
30 \\
30\end{array}$ & $\begin{array}{l}5.59 \\
5.66 \\
6.05 \\
6.34 \\
6.28 \\
5.94\end{array}$ & $\begin{array}{r}743 \\
765 \\
953 \\
1,110 \\
1,080 \\
904\end{array}$ & 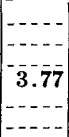 & $\begin{array}{r}-15 \overline{5} \\
-\cdots\end{array}$ & 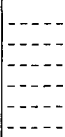 & 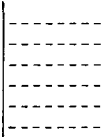 & 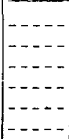 & 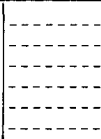 & $\mid \begin{array}{l}-\cdots \\
-\cdots- \\
-\cdots- \\
-\cdots- \\
-\cdots- \\
-\cdots-\end{array}$ & 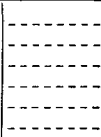 \\
\hline $\begin{array}{r}7 \\
8 \\
9 \\
10 \\
11 \\
\text { N }\end{array}$ & $\begin{array}{l}2.70 \\
2.71 \\
2.75 \\
2.87 \\
3.16 \\
3.40\end{array}$ & $\begin{array}{l}31 \\
32 \\
35 \\
45 \\
72 \\
99\end{array}$ & $\begin{array}{l}5.55 \\
5.27 \\
5.05 \\
4.86 \\
4.72 \\
4.58\end{array}$ & $\begin{array}{l}722 \\
599 \\
522 \\
451 \\
408 \\
364\end{array}$ & $\begin{array}{r}-\overline{3.68} \\
---- \\
----- \\
-\overline{3} . \overline{62}\end{array}$ & \begin{tabular}{c}
$-13 \overline{9}$ \\
\hdashline$-1 \overline{2}$
\end{tabular} & \begin{tabular}{l}
$-\cdots$ \\
$-\cdots$ \\
\hdashline$-\overline{-}$ \\
\hdashline$\overline{3} \overline{2}$ \\
$-\overline{-}$
\end{tabular} & 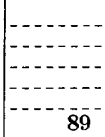 & $\begin{array}{l}----- \\
----- \\
----- \\
-\cdots-- \\
-\overline{\mathbf{3}} \mathbf{1 7}\end{array}$ & 正 & $\begin{array}{l}-\cdots \\
-\overline{3.07}\end{array}$ & 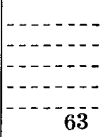 \\
\hline $\begin{array}{l}1 \\
2 \\
3 \\
4 \\
5 \\
6\end{array}$ & $\begin{array}{l}3.79 \\
4.04 \\
3.82 \\
3.63 \\
3.72 \\
4.26\end{array}$ & $\begin{array}{l}158 \\
212 \\
164 \\
131 \\
146 \\
269\end{array}$ & $\begin{array}{l}4.45 \\
4.35 \\
4.28 \\
4.21 \\
4.14 \\
4.09\end{array}$ & $\begin{array}{l}324 \\
294 \\
274 \\
255 \\
236 \\
224\end{array}$ & $\begin{array}{r}-\overline{3} . \overline{5} \overline{5} \\
-\cdots \\
-\cdots\end{array}$ & $\begin{array}{r}119 \\
\hdashline\end{array}$ & 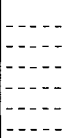 & 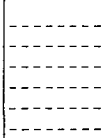 & $\begin{array}{l}----- \\
----- \\
----- \\
----- \\
----- \\
-----\end{array}$ & 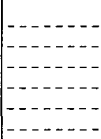 & 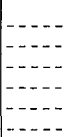 & 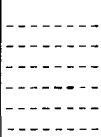 \\
\hline $\begin{array}{r}7 \\
8 \\
9 \\
10 \\
11 \\
12\end{array}$ & $\begin{array}{l}4.57 \\
4.60 \\
5.10 \\
5.69 \\
5.84 \\
5.68\end{array}$ & $\begin{array}{l}361 \\
370 \\
541 \\
\mathbf{7 8 7} \\
857 \\
\mathbf{7 8 7} \\
\end{array}$ & $\begin{array}{l}4.04 \\
4.00 \\
3.96 \\
3.93 \\
3.89 \\
3.87\end{array}$ & $\begin{array}{l}212 \\
202 \\
193 \\
187 \\
178 \\
174 \\
\end{array}$ & $\left|\begin{array}{c}-\overline{3.48} \\
\hdashline \overline{3} . \overline{4}\end{array}\right|$ & $\begin{array}{l}109 \\
106\end{array}$ & $\begin{array}{l}-\cdots \\
-. . \\
-\overline{3} \\
-\overline{2}\end{array}$ & 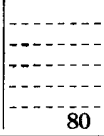 & $\mid \begin{array}{l}-\cdots-- \\
-\cdots-- \\
----- \\
---- \\
-\overline{3} . \overline{12}\end{array}$ & $\mid$\begin{tabular}{l}
$-\cdots$ \\
\hdashline$-\cdots$ \\
\hdashline$-\cdots$
\end{tabular} & \begin{tabular}{l}
$-\cdots$ \\
\hdashline.- \\
$-\cdots$ \\
$\mathbf{3 . 0 2}$
\end{tabular} & (58 \\
\hline
\end{tabular}


MILLS RIVER NEAR MILLS RIVER, N. C.

Location.-Lat. $35^{\circ} 23^{\prime} 45^{\prime \prime}$, long. $82^{\circ} 35^{\prime} 25^{\prime \prime}$, at ford $1 \frac{1}{2}$ miles downstream from confluence of North and South Forks, 2 miles upstream from village. of Mills River, Henderson County, and $41 / 2$ miles northwest of Horseshoe. Datum of gage is 2,088.47 feet (revised) above mean sea level, datum of 1929 , supplementary adjustment of 1936 .

Drainage AREa.-66.7 square miles.

GAGE-HEIGHT RECORD.-Water-stage recorder graph.

DischARGE RECORD.- Stage-discharge relation defined by current-meter measurements up to 2,600 second-feet and extended to erest gage height on basis of studies by Tennessee Valley Authority. Gage heights used to half-tenths between 3.7 and 4.7 feet; hundredths below and tenths above these limits.

Maxima.-1940: Discharge, 10,000 second-feet 7 a.m. Aug. 30 (gage height, 13.62 feet).

1924-26, 1934-39: Discharge, 3,560 second-feet Jan. 9, 1935 (gage height, 8.36 feet); gage height, 8.38 feet Oct. 16, 1936.

Surveys by the Tennessee Valley Authority show that the floods of June 1876, July 1916, and August 1928 reached stages of 12 feet, 12.5 feet, and 13.5 feet, respectively, from flood profiles.

Remarks.-Flood runoff not affected by artificial storage.

Mean discharge, in second-feet, 1940

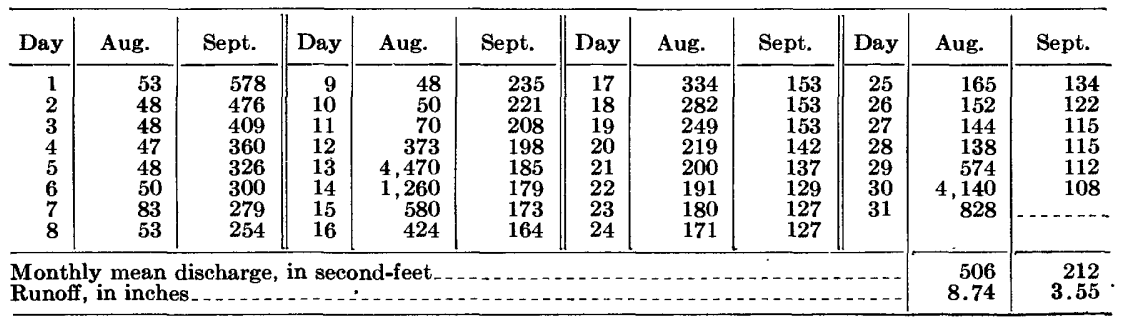


350 FLOODS.OF AUGUST 1940 IN THE SOUTHEASTERN STATES

Gage height, in feet, and discharge, in second-feet, at indicated time, 1940

\begin{tabular}{|c|c|c|c|c|c|c|c|c|c|c|c|c|}
\hline \multirow{2}{*}{ Hour } & \multicolumn{2}{|c|}{ Aug. 12} & \multicolumn{2}{|c|}{ Aug. 13} & \multicolumn{2}{|c|}{ Aug. 14} & \multicolumn{2}{|c|}{ Aug. 15} & \multicolumn{2}{|c|}{ Aug. 16} & \multicolumn{2}{|c|}{ Aug. 17} \\
\hline & $\underset{\text { ht: }}{\text { Gage }}$ & $\begin{array}{l}\text { Dis- } \\
\text { charge }\end{array}$ & $\begin{array}{c}\text { Gage } \\
\text { ht. }\end{array}$ & $\begin{array}{l}\text { Dis- } \\
\text { charge }\end{array}$ & $\begin{array}{c}\text { Gage } \\
\text { ht. }\end{array}$ & $\begin{array}{l}\text { Dis- } \\
\text { charge }\end{array}$ & $\begin{array}{c}\text { Gage } \\
\text { ht. }\end{array}$ & $\begin{array}{l}\text { Dis- } \\
\text { charge }\end{array}$ & $\begin{array}{c}\text { Gage } \\
\text { ht. }\end{array}$ & $\begin{array}{l}\text { Dis- } \\
\text { charge }\end{array}$ & $\begin{array}{c}\text { Gage } \\
\text { ht. }\end{array}$ & $\begin{array}{l}\text { Dis- } \\
\text { charge }\end{array}$ \\
\hline $\begin{array}{l}1 \\
2 \\
3 \\
4 \\
5 \\
6\end{array}$ & $\begin{array}{l}1.89 \\
1.90 \\
1.90 \\
1.90 \\
1.90 \\
1.90\end{array}$ & $\begin{array}{l}91 \\
93 \\
93 \\
93 \\
93 \\
93\end{array}$ & $\begin{array}{l}4.02 \\
4.04 \\
4.09 \\
4.08 \\
4.16 \\
4.24\end{array}$ & $\begin{array}{l}1,100 \\
1,130 \\
1,160 \\
1,160 \\
1,190 \\
1,250\end{array}$ & $\begin{array}{l}6.52 \\
5.95 \\
5.35 \\
4.85 \\
4.75 \\
4.55\end{array}$ & $\begin{array}{l}2,550 \\
2,270 \\
1,920 \\
1,570 \\
1,570 \\
1,430\end{array}$ & \begin{tabular}{c}
$-\cdots--$ \\
\hdashline$\overline{3} \cdot \overline{3} \mathbf{3}$ \\
\hdashline--- \\
\hdashline---
\end{tabular} & 663 & $\begin{array}{c} \\
----- \\
----- \\
---- \\
---- \\
----- \\
-----\end{array}$ & 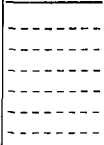 & $\mid \begin{array}{l}---- \\
---- \\
----- \\
----- \\
---- \\
--\end{array}$ & 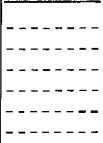 \\
\hline $\begin{array}{r}7 \\
8 \\
9 \\
10 \\
11 \\
\mathrm{~N}\end{array}$ & $\begin{array}{l}1.91 \\
1.92 \\
1.95 \\
2.00 \\
2.09 \\
2.17\end{array}$ & $\begin{array}{r}95 \\
98 \\
104 \\
116 \\
138 \\
160\end{array}$ & $\begin{array}{l}4.41 \\
4.85 \\
5.80 \\
6.95 \\
8.00 \\
9.50\end{array}$ & $\begin{array}{l}1,340 \\
1,570 \\
2,150 \\
2,850 \\
3,480 \\
4,810\end{array}$ & $\begin{array}{l}4.42 \\
4.27 \\
4.19 \\
4.08 \\
4.03 \\
4.00\end{array}$ & $\begin{array}{l}1,340 \\
1,250 \\
1,220 \\
1,160 \\
1,130 \\
1,100\end{array}$ & $\left|\begin{array}{c}-\overline{3} . \overline{24} \\
--\overline{1} \\
-\overline{3} . \overline{15}\end{array}\right|$ & \begin{tabular}{c}
$-\cdots \overline{612}$ \\
\hdashline$-\overline{562}$ \\
\hdashline$-\bar{c}$
\end{tabular} & 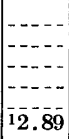 & $\begin{array}{r}-\cdots \\
-\cdots \\
-\cdots \\
-\cdots\end{array}$ & 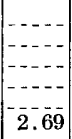 & 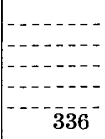 \\
\hline $\begin{array}{l}1 \\
2 \\
3 \\
4 \\
5 \\
6\end{array}$ & $\begin{array}{l}2.38 \\
2.77 \\
3.00 \\
3.13 \\
3.25 \\
3.30\end{array}$ & $\begin{array}{l}223 \\
371 \\
482 \\
552 \\
618 \\
645\end{array}$ & $\begin{array}{l}11.10 \\
12.20 \\
12.95 \\
13.15 \\
13.08 \\
12.75\end{array}$ & $\begin{array}{r}6,650 \\
8,060 \\
9,160 \\
9,440 \\
9,300 \\
8,880\end{array}$ & $\begin{array}{l}3.92 \\
3.94 \\
3.84 \\
3.82 \\
3.77 \\
3.70\end{array}$ & $\begin{array}{r}1,040 \\
1,070 \\
1,000 \\
970 \\
935 \\
900\end{array}$ & $\mid$\begin{tabular}{l}
.--- \\
\hdashline-10 \\
-10 \\
$-\cdots$
\end{tabular} & 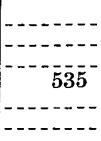 & $\begin{array}{l}----- \\
----- \\
----- \\
----- \\
----- \\
-----\end{array}$ & $\begin{array}{l}--- \\
--- \\
--- \\
--- \\
--- \\
---\end{array}$ & $\mid \begin{array}{l}----- \\
----- \\
---- \\
----- \\
--\cdots-- \\
-----\end{array}$ & 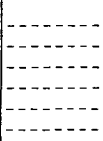 \\
\hline $\begin{array}{r}7 \\
8 \\
9 \\
10 \\
11 \\
12 \\
\end{array}$ & $\begin{array}{l}3.36 \\
3.44 \\
3.60 \\
3.78 \\
3.86 \\
4.01\end{array}$ & $\begin{array}{r}681 \\
729 \\
830 \\
970 \\
1,000 \\
1,100 \\
\end{array}$ & $\begin{array}{r}12.30 \\
11.68 \\
10.65 \\
9.55 \\
8.55 \\
7.40\end{array}$ & $\begin{array}{l}8,190 \\
7,410 \\
6,050 \\
4,910 \\
3,960 \\
3,090 \\
\end{array}$ & $\begin{array}{l}3.65 \\
3.58 \\
3.55 \\
3.51 \\
3.45 \\
3.44\end{array}$ & $\begin{array}{l}865 \\
817 \\
798 \\
772 \\
735 \\
729 \\
\end{array}$ & $\mid$\begin{tabular}{c}
13.04 \\
\hdashline$\overline{0}$ \\
$\mathbf{3} .00$
\end{tabular} & $\begin{array}{r}-5 \overline{3} \\
-482^{-} \\
\end{array}$ & \begin{tabular}{|l|}
$-\cdots--$ \\
$--\cdots-$ \\
$-\cdots--$ \\
$-\overline{2} . \overline{7}$
\end{tabular} & $\begin{array}{r}-1 \\
\hdashline \mathbf{3 7} \\
\\
\hdashline\end{array}$ & $\left|\begin{array}{|c}-\cdots-- \\
-\cdots--- \\
-\cdots-- \\
----- \\
-\overline{2}-\overline{59}\end{array}\right|$ & $\begin{array}{r}- \\
- \\
\hdashline \\
\hdashline\end{array}$ \\
\hline
\end{tabular}

\begin{tabular}{|c|c|c|c|c|c|c|c|c|c|c|c|c|}
\hline \multirow[b]{2}{*}{$\begin{array}{l}1 \\
2 \\
3 \\
4 \\
5 \\
6\end{array}$} & \multicolumn{2}{|c|}{ Aug. 29} & \multicolumn{2}{|c|}{ Aug. 30} & \multicolumn{2}{|c|}{ Aug. 31} & \multicolumn{2}{|c|}{ Sept. 1} & \multicolumn{2}{|c|}{ Sept. 2} & \multicolumn{2}{|c|}{ Sept. 3} \\
\hline & $\begin{array}{l}2.06 \\
2.06 \\
2.06 \\
2.06 \\
2.06 \\
2.06\end{array}$ & $\begin{array}{l}131 \\
131 \\
131 \\
131 \\
131 \\
131\end{array}$ & $\begin{array}{r}8.05 \\
8.35 \\
8.82 \\
9.40 \\
10.45 \\
12.70\end{array}$ & $\begin{array}{l}3,480 \\
3,790 \\
4,140 \\
4,710 \\
5,810 \\
8,740\end{array}$ & $\begin{array}{r}3.90 \\
\overline{3} . \overline{80} \\
\overline{3} . \overline{74}\end{array}$ & $\begin{array}{r}1, \overline{040} \overline{0}^{-} \\
\hdashline \overline{970} \overline{0}^{-}\end{array}$ & $\mid \begin{array}{l}--\cdots-- \\
----- \\
----- \\
----- \\
----- \\
-\cdots---\end{array}$ & 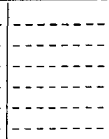 & $\mid \begin{array}{c}---\cdots \\
----- \\
----- \\
-\cdots-- \\
----- \\
-----\end{array}$ & 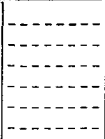 & $\begin{array}{l}---- \\
-\cdots-- \\
---- \\
---- \\
---n \\
-----\end{array}$ & 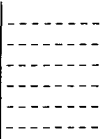 \\
\hline $\begin{array}{r}7 \\
8 \\
9 \\
10 \\
11 \\
\text { N }\end{array}$ & $\begin{array}{l}2.06 \\
2.08 \\
2.11 \\
2.12 \\
2.15 \\
2.22\end{array}$ & $\begin{array}{l}131 \\
136 \\
144 \\
146 \\
154 \\
174\end{array}$ & $\left|\begin{array}{r}13.62 \\
13.35 \\
12.57 \\
11.49 \\
10.20 \\
9.17\end{array}\right|$ & $\begin{array}{r}10,000 \\
9,720 \\
8,600 \\
7,150 \\
5,570 \\
4,510\end{array}$ & $\begin{array}{r}\overline{3.66} \\
\overline{3.59} \\
\overline{3.55}\end{array}$ & $\mid \begin{array}{r}8 \overline{8} \overline{2} \\
-\overline{82} \overline{4} \\
-\overline{79} \overline{8}\end{array}$ & 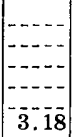 & $\mid \begin{array}{l}-\cdots \\
-\cdots- \\
-\cdots \overline{5}\end{array}$ & $\mid$\begin{tabular}{l}
$-\cdots$ \\
$-\cdots$ \\
\hdashline$-\cdots$ \\
\hdashline 2.98
\end{tabular} & 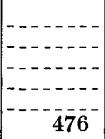 & $\begin{array}{l}----- \\
---- \\
---- \\
--- \\
2 . \overline{84}\end{array}$ & $\begin{array}{r}-\cdots \\
-\cdots \\
\hdashline-10 \\
\hdashline-10\end{array}$ \\
\hline $\begin{array}{l}1 \\
2 \\
3 \\
4 \\
5 \\
6\end{array}$ & $\begin{array}{l}2.52 \\
2.87 \\
3.10 \\
3.32 \\
3.56 \\
3.44\end{array}$ & $\begin{array}{l}270 \\
417 \\
535 \\
657 \\
804 \\
729\end{array}$ & $\begin{array}{l}7.95 \\
7.02 \\
6.37 \\
5.82 \\
5.37 \\
5.02\end{array}$ & $\begin{array}{l}3,480 \\
2,850 \\
2,490 \\
2,150 \\
1,920 \\
1,690\end{array}$ & $\begin{array}{r}\overline{3} . \overline{50} \\
\overline{3} . \overline{49} \\
\overline{3} . \overline{4} \overline{3}\end{array}$ & $\begin{array}{r}\overline{7} \overline{6} \overline{5}^{-} \\
-\overline{7} \overline{9} \overline{9}^{-} \\
\hdashline \overline{7} \overline{3}\end{array}$ & 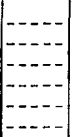 & 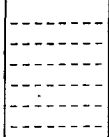 & $\mid \begin{array}{l}-\cdots-- \\
----- \\
----- \\
---- \\
----- \\
-----\end{array}$ & 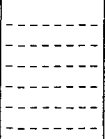 & 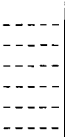 & 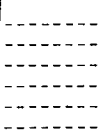 \\
\hline $\begin{array}{r}7 \\
8 \\
9 \\
10 \\
11 \\
12\end{array}$ & $\begin{array}{l}3.55 \\
3.81 \\
4.10 \\
4.72 \\
6.55 \\
7.50\end{array}$ & $\begin{array}{r}798 \\
970 \\
1,160 \\
1,520 \\
2,610 \\
3,150 \\
\end{array}$ & $\begin{array}{l}4.72 \\
4.47 \\
4.32 \\
4.16 \\
4.08 \\
4.01\end{array}$ & $\begin{array}{l}1,520 \\
1,370 \\
1,280 \\
1,190 \\
1,160 \\
1,100\end{array}$ & $\begin{array}{r}\overline{3} \cdot \overline{3} \overline{9} \\
-\overline{\mathbf{3}} \cdot \overline{\mathbf{3} 5} \\
-\overline{\mathbf{3}} \overline{\mathbf{3}} \overline{\mathbf{3}}\end{array}$ & $\begin{array}{r}69 \overline{9} \\
-\overline{675} \\
-6 \overline{5}\end{array}$ & 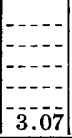 & 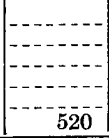 & $\left|\begin{array}{l}----- \\
----- \\
----- \\
\hdashline---- \\
2.90\end{array}\right|$ & 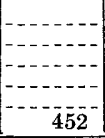 & $\begin{array}{c}-\cdots- \\
-\overline{2} . \overline{7}\end{array}$ & $\begin{array}{r}-1 .-1 \\
-378\end{array}$ \\
\hline
\end{tabular}

${ }^{1}$ Partly estimated. 


\section{MUD CREEK AT NAPLES, N. C.}

Location.-Lat. $35^{\circ} 22^{\prime} 51^{\prime \prime}$, long. $82^{\circ} 29^{\prime} 53^{\prime \prime}$, at bridge on old Asheville-Hendersonville highway just downstream from Byers Creek, 0.8 mile south of Naples, Henderson County, and 2.2 miles upstream from mouth. Datum of gage is $2,047.48$ feet above mean sea level, datum of 1929 , supplementary adjustment of 1936.

Drainage AREA.-109 square miles.

GAGE-HEIGHT RECORD.-Water-stage recorder graph except for Aug. 10 to 5 p.m. Aug. 13, where gage heights were obtained from estimated discharge, and 4 p.m. Sept. 1 to 6 p.m. Sept. 3, where recorder graph was completed from characteristic shape of record.

Discharge RECORD.-Stage-discharge relation defined by current-meter measurements up to 9,200 second-feet. Backwater from French Broad River is a factor in computing the discharge during floods. Gage heights used to half-tenths between 2.4 and 4.3 feet; hundredths below and tenths above these limits. Discharge for Aug. 10 to 5 p.m. Aug. 13 estimated from records for nearby streams.

Maxima.--1940: Discharge, 10,800 second-feet 11-12 p.m. Aug. 13 (gage height, 13.07 feet).

1907, 1938-39: Discharge, 1,520 second-feet Mar. 1, 1939 (gage height, 8.47 feet); gage height, 8.53 feet Aug. 19, 1939.

Surveys by the Tennessee Valley Authority show that the floods of July 1916 and August 1928 reached stages of 21 feet and 15 feet, respectively.

REMARKs.-Flood runoff slightly affected by numerous small artificial ponds above station.

Mean discharge, in second-feet, 1940

\begin{tabular}{|c|c|c|c|c|c|c|c|c|c|c|c|}
\hline Day & Aug. & Sept. & Day & Aug. & Sept. & Day & Aug. & Sept. & Day & Aug. & Sept. \\
\hline $\begin{array}{l}1 \\
2 \\
3 \\
4 \\
5 \\
6 \\
7 \\
8\end{array}$ & $\begin{array}{r}72 \\
177 \\
86 \\
73 \\
69 \\
66 \\
72 \\
132\end{array}$ & $\begin{array}{r}1,090 \\
560 \\
331 \\
251 \\
218 \\
213 \\
182 \\
164\end{array}$ & $\begin{array}{r}9 \\
10 \\
11 \\
12 \\
13 \\
14 \\
15 \\
16\end{array}$ & $\begin{array}{r}76 \\
65 \\
75 \\
396 \\
3,920 \\
4,950 \\
1,240 \\
620\end{array}$ & $\begin{array}{l}160 \\
150 \\
142 \\
132 \\
129 \\
126 \\
122 \\
117\end{array}$ & $\begin{array}{l}17 \\
18 \\
19 \\
20 \\
21 \\
22 \\
23 \\
24\end{array}$ & $\begin{array}{l}345 \\
306 \\
352 \\
229 \\
196 \\
171 \\
163 \\
145\end{array}$ & $\begin{array}{r}112 \\
111 \\
109 \\
110 \\
103 \\
101 \\
97 \\
101\end{array}$ & $\begin{array}{l}25 \\
26 \\
27 \\
28 \\
29 \\
30 \\
31\end{array}$ & $\begin{array}{r}142 \\
132 \\
137 \\
126 \\
702 \\
3,820 \\
2,560\end{array}$ & $\begin{array}{r}113 \\
101 \\
96 \\
95 \\
92 \\
91\end{array}$ \\
\hline \multicolumn{10}{|c|}{$\begin{array}{l}\text { Monthly mean discharge, in second-feet, } \\
\text { Runoff, in inches }\end{array}$} & $\begin{array}{r}697 \\
7.37\end{array}$ & $\begin{array}{r}184 \\
1.88\end{array}$ \\
\hline
\end{tabular}


FLOODS OF AUGUST 1940 IN THE SOUTHEASTERN STATES

Gage height, in feet, and discharge, in second-feet, at indicated time, 1940

\begin{tabular}{|c|c|c|c|c|c|c|c|c|c|c|c|c|}
\hline \multirow{2}{*}{ Hour } & \multicolumn{2}{|c|}{ Aug. 12} & \multicolumn{2}{|c|}{ Aug. 13} & \multicolumn{2}{|c|}{ Aug. 14} & \multicolumn{2}{|c|}{ Aug. 15} & \multicolumn{2}{|c|}{ Aug. 16} & \multicolumn{2}{|c|}{ Aug. 17} \\
\hline & $\begin{array}{c}\text { Gage } \\
\text { ht. }\end{array}$ & $\begin{array}{c}\text { Dis- } \\
\text { charge }\end{array}$ & $\begin{array}{c}\text { Gage } \\
\text { ht. }\end{array}$ & $\begin{array}{l}\text { Dis- } \\
\text { charge }\end{array}$ & $\begin{array}{c}\text { Gage } \\
\text { ht. }\end{array}$ & $\begin{array}{c}\text { Dis- } \\
\text { charge }\end{array}$ & $\begin{array}{c}\text { Gagee } \\
\text { ht. }\end{array}$ & $\begin{array}{c}\text { Dis- } \\
\text { charge }\end{array}$ & $\begin{array}{c}\text { Gage } \\
\text { ht. }\end{array}$ & $\underset{\text { ch }}{D}$ & $\begin{array}{c}\text { Gage } \\
\text { ht. }\end{array}$ & $\begin{array}{c}\text { Dis- } \\
\text { charge }\end{array}$ \\
\hline \multirow{4}{*}{$\begin{array}{l}1 \\
2 \\
3 \\
4 \\
5 \\
6\end{array}$} & & & -2 & & 13.03 & & & & & & & \\
\hline & $-\overline{1 . \overline{7}}$ & 100 & 8.27 & 1,500 & $\left|\begin{array}{l}12.91 \\
12.76\end{array}\right|$ & $\begin{array}{r}10,000 \\
9,640\end{array}$ & & & & & & \\
\hline & $\ldots$ & $\ldots . .$. & $\cdots$ & $\ldots$ & 12.60 & 8,880 & $9 . \overline{45}$ & 1,820 & 6.20 & 702 & 3.64 & 390 \\
\hline & $\overline{1.90}$ & 120 & 8.89 & 1,900 & $\left|\begin{array}{l}12.40 \\
12.20\end{array}\right|$ & $\begin{array}{l}7,880 \\
6,950\end{array}$ & $\cdots--$ & & & & & \\
\hline \multirow{4}{*}{$\begin{array}{r}7 \\
8 \\
9 \\
10 \\
11 \\
\mathrm{~N}\end{array}$} & & 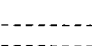 & & & 12.00 & 6,230 & 06 & & & & & \\
\hline & $\overline{1.99}$ & 130 & $9 . \overline{19}$ & 2,200 & $\begin{array}{l}11.80 \\
11.58\end{array}$ & $\begin{array}{l}5,560 \\
4,990\end{array}$ & 9.06 & 410 & 5.78 & & 3.51 & 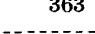 \\
\hline & $\ldots$ & 年 & - & & $\begin{array}{ll}1 & 1.39 \\
1 & 2\end{array}$ & 4,440 & & & & & & \\
\hline & $2.6 \overline{6}$ & 220 & 9.46 & 2,500 & 11.04 & $\begin{array}{l}3,940 \\
3,630\end{array}$ & $-\overline{8.58}$ & 1,120 & 5.37 & 639 & $\overline{3} . \overline{4}$ & $\overline{3} \overline{4}$ \\
\hline \multirow{4}{*}{$\begin{array}{l}1 \\
2 \\
3 \\
4 \\
5 \\
6\end{array}$} & & & & & 10 & 30 & & & & & & \\
\hline & 3.69 & 400 & $\overline{9} . \overline{7} 0$ & $\overline{2}, \overline{800}$ & $\begin{array}{l}10.74 \\
10.62\end{array} \mid$ & 3,070 & & & & & & \\
\hline & 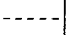 & & & & 10.50 & 2,930 & 7.89 & 900 & 4.90 & 597 & 3.28 & 327 \\
\hline & $4 . \overline{95}$ & $65 \overline{0}$ & 10.50 & $\overline{3}, \overline{9} \overline{0}$ & $\begin{array}{l}10.38 \\
10.27\end{array}$ & $\begin{array}{l}2,800 \\
2,670\end{array}$ & ---- & & & & & \\
\hline \multirow{5}{*}{$\begin{array}{r}7 \\
8 \\
9 \\
10 \\
11 \\
12\end{array}$} & & & 68 & 30 & 10.17 & & & & & & & 0 \\
\hline & 6.10 & 900 & $\left|\begin{array}{l}12.60 \\
13.00\end{array}\right|$ & $\begin{array}{r}8,8 \\
10,4\end{array}$ & $\begin{array}{r}10.08 \\
9.99\end{array}$ & $\begin{array}{l}2,430 \\
2,310\end{array}$ & 7.21 & $8 r$ & 31 & & .13 & 80 \\
\hline & -- & & 13.06 & 10 , & 9.90 & 2,210 & - & & --1 & & 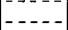 & \\
\hline & $\overline{7} \cdot \overline{30}$ & 1,200 & $\left|\begin{array}{l}13.07 \\
13.07\end{array}\right|$ & $\begin{array}{l}10, \\
10,\end{array}$ & $\begin{array}{l}9.82 \\
9.75\end{array}$ & $\begin{array}{l}2 \\
2\end{array}$ & $6 . \overline{6}$ & 744 & 3.87 & 428 & $\overline{2} . \overline{9} \overline{7}$ & 266 \\
\hline & \multicolumn{2}{|c|}{ Aug. 29} & \multicolumn{2}{|c|}{ Aug. 30} & \multicolumn{2}{|c|}{ Aug. 31} & \multicolumn{2}{|c|}{ Sept. 1} & \multicolumn{2}{|c|}{ Sept. 2} & \multicolumn{2}{|c|}{ Sept. 3} \\
\hline \multirow[b]{4}{*}{$\mathbf{N}$} & & & 9.19 & 2,210 & & & & & & & & \\
\hline & 1.88 & 118 & $\begin{array}{l}9.44 \\
9.86\end{array}$ & $\begin{array}{l}2,430 \\
3,070\end{array}$ & 10.13 & & .91 & 80 & 4.95 & 660 & 3.48 & $\mathbf{3 6 3}$ \\
\hline & & & 10.16 & & 9.72 & 2,800 & 7.29 & 1,200 & & & $\ldots--$ & \\
\hline & 2.10 & 143 & $\begin{array}{l}10.47 \\
10.70\end{array}$ & $\begin{array}{l}3,940 \\
4,270\end{array}$ & 9.38 & 2,430 & $-\overline{6} \overline{7} \overline{0}$ & 1,040 & 4.42 & 537 & $-\overline{3.29}$ & 327 \\
\hline \multirow{8}{*}{$\begin{array}{r}1 \\
2 \\
3 \\
4 \\
5 \\
6 \\
7 \\
8 \\
9 \\
10 \\
11 \\
12\end{array}$} & 2.19 & 154 & & & & & & & & & & \\
\hline & 2.30 & 168 & 10.86 & 4,620 & $\ldots$ & & & & & & & \\
\hline & 6.00 & 77 & 10.97 & 4,800 & 9.10 & 2,110 & 6.19 & 923 & & & -- & \\
\hline & 8.70 & & $10 . \overline{8}$ & 4,800 & - & & & & 4.07 & 467 & 3.11 & 292 \\
\hline & $\begin{array}{l}8.75 \\
8.83\end{array}$ & & 10.91 & 4,620 & 8.80 & $\overline{1}, \overline{8} \overline{2} \overline{-}$ & $-\overline{5} . \overline{81}$ & $\overline{8} \overline{1} \overline{1}^{-}$ & & &.- & \\
\hline & $\begin{array}{l}8.91 \\
8.99\end{array}$ & & $\overline{10.7 \overline{5}}$ & 4 & 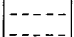 & & & & & & & \\
\hline & & & 56 & - & 8.49 & 1550 & 5. & & 275 & 0 & 800 & $55^{-}$ \\
\hline & & & b6) & & 3.42 & 0 & 5.45 & 44 & 3.75 & 410 & 2.991 & 275 \\
\hline
\end{tabular}

Supplemental ReCORD.-Aug. 30, 5 p.m., gage height, 10.99 feet, discharge, 4,800 second-feet. 
SWANNANOA RIVER AT BILTMORE, N. C.

Location.-Lat. $35^{\circ} 33^{\prime} 55^{\prime \prime}$, long. $82^{\circ} 32^{\prime} 35^{\prime \prime}$, at Biltmore, Buncombe County, 100 feet downstream from Biltmore Avenue Bridge, 200 feet upstream from Southern Railway bridge, and $1 \frac{1}{2}$ miles upstream from mouth. Datum of gage is $1,976, .58$ feet above mean sea level, datum of 1929, supplementary adjustment of 1936.

Drainage AREa.-130 square miles.

GAGE-HEIGHT RECORD.-Water-stage recorder graph.

DISGHARGE RECORD.-Artificial control is of masonry. Stage-diseharge relation for 1940 is defined by eurrent-meter measurements up to 63,000 second-feet and extended to crest gage height on basis of determination of Aug. 13 and Aug. 30, 1940, flood flows over dam at reereation park 3 miles upstream, as computed by the Tennessee Valley Authority. The relation for 1923 was extended above 1,300 second-feet and is verified by the 1940 rating when allowance is made for the effect of a control built in 1935. Gage heights used to helf-tenths between 3.2 and 4.8 feet; hundredths below and tenths above these limits.

Maxima.-1940: Discharge, 18,400 second-feet $7: 30$ p.m. Aug. 13 (gage height, 19.00 feet).

1920-26, 1934-39: Discharge, 4,690 second-feet May 29, 1923 (gage height, 8.2 feet).

Stage known, 21.5 feet July 1916, from floodmarks (discharge not determined). The flood of Aug. 16, 1928, reached a stage of 18.74 feet, from floodmarks (discharge not determined). Researeh by the Tennessee Valley Authority shows that a flood in April 1791 probably reached a stage about 5 feet higher than that of July 1916. Extremely high stages are subject to backwater from the French Broad River.

Remarks.-Flood runoff practically unaffected by artificial storage. Monthly flow adjusted for storage (in Beetree Reservoir, eapacity 700,000,000 gallons) and diversion (from North Fork Swannanoa River) for water supply of eity of Asheville.

Mean discharge, in second-feet, 1940

\begin{tabular}{r|r|r|r|r|r||r|r|r|r|r|r}
\hline Day & Aug. & Sept. & Day & Aug. & Sept. & Day & Aug. & Sept. & Day & Aug. & Sept. \\
\hline 1 & 68 & 677 & 9 & 54 & 178 & 17 & 525 & 97 & 25 & 132 & 77 \\
2 & 58 & 558 & 10 & 58 & 187 & 18 & 390 & 93 & 26 & 114 & 72 \\
3 & 56 & 392 & 11 & 69 & 193 & 19 & 313 & 90 & 27 & 103 & 77 \\
4 & 61 & 329 & 12 & 878 & 146 & 20 & 264 & 97 & 28 & 97 & 77 \\
5 & 50 & 290 & 13 & 7,560 & 141 & 21 & 196 & 88 & 29 & 738 & 73 \\
6 & 58 & 256 & 14 & 3,920 & 134 & 22 & 181 & 84 & 30 & 6,420 & 66 \\
7 & 60 & 219 & 15 & 998 & 118 & 23 & 161 & 77 & 31 & 1,270 & $-\ldots$ \\
8
\end{tabular}


354 FLOODS OF AUGUST 1940 IN THE SOUTHEASTERN STATES

Gage height, in feet, and discharge, in second-feet, at indicated time, 1940

\begin{tabular}{|c|c|c|c|c|c|c|c|c|c|c|c|c|}
\hline \multirow{2}{*}{ our } & \multicolumn{2}{|c|}{ Aug. 12} & \multicolumn{2}{|c|}{ Aug. 13} & \multicolumn{2}{|c|}{ Aug. 14} & \multicolumn{2}{|c|}{ Aug. 15} & \multicolumn{2}{|c|}{ Aug. 16} & \multicolumn{2}{|c|}{ Aug. 17} \\
\hline & $\begin{array}{c}\text { Gage } \\
\text { ht. }\end{array}$ & $\begin{array}{c}\text { Dis- } \\
\text { charge }\end{array}$ & $\begin{array}{c}\text { Gage } \\
\text { ht. }\end{array}$ & $\begin{array}{c}\text { Dis- } \\
\text { charge }\end{array}$ & $\begin{array}{c}\text { Gage } \\
\text { ht. }\end{array}$ & $\begin{array}{c}\text { Dis- } \\
\text { charge }\end{array}$ & $\begin{array}{c}\text { Gage } \\
\text { ht. }\end{array}$ & $\begin{array}{c}\text { Dis- } \\
\text { charge }\end{array}$ & $\begin{array}{c}\text { Gage } \\
\text { ht. }\end{array}$ & $\begin{array}{c}\text { Dis- } \\
\text { charge }\end{array}$ & $\begin{array}{c}\text { Gage } \\
\text { ht. }\end{array}$ & chr \\
\hline \multirow{4}{*}{$\begin{array}{l}1 \\
2 \\
3 \\
4 \\
5 \\
6\end{array}$} & & & $\begin{array}{l}.83 \\
.19\end{array}$ & & & & 56 & & & & & \\
\hline & & & & & 0 & & & & & & & \\
\hline & & & 7.40 & & 2.50 & & $4 . \overline{34}$ & 1,190 & 3.40 & 700 & 3.18 & 96 \\
\hline & $\begin{array}{l}2.72 \\
2.75\end{array}$ & $\begin{array}{l}414 \\
428\end{array}$ & $\begin{array}{l}6.57 \\
6.38\end{array}$ & 2,3 & $\begin{array}{r}10.58 \\
9.27\end{array}$ & & 4.22 & 1,110 & & & & \\
\hline \multirow{4}{*}{$\begin{array}{r}7 \\
8 \\
9 \\
10 \\
11 \\
\mathrm{~N}\end{array}$} & 86 & 480 & 6.42 & 90 & 2 & 30 & & & & & & \\
\hline & & & & & & & 4.12 & 1,060 & 3.27 & 628 & .11 & 564 \\
\hline & .02 & , 2200 & $\begin{array}{l}7.34 \\
8.11\end{array}$ & $\begin{array}{l}0 \\
0\end{array}$ & $\begin{array}{l}7.55 \\
6.50\end{array}$ & $\begin{array}{l}3,120 \\
2,450\end{array}$ & 4.03 & 1,030 & & & & \\
\hline & $\begin{array}{l}3.90 \\
3.80\end{array}$ & $\begin{array}{l}1,060 \\
1,000\end{array}$ & $\begin{array}{r}8.85 \\
10.05\end{array}$ & $\begin{array}{l}0 \\
0\end{array}$ & $\begin{array}{l}5.60 \\
5.99\end{array}$ & $\begin{array}{l}1,910 \\
2,150\end{array}$ & 3.94 & 975 & 3.22 & 605 & 3.03 & 528 \\
\hline \multirow{5}{*}{$\begin{array}{l}1 \\
2 \\
3 \\
4 \\
5 \\
6\end{array}$} & 3.7 & & & & & & & & & & & \\
\hline & 3.69 & 945 & 11. & & & & 3.87 & 925 & & & & \\
\hline & $\begin{array}{l}3.65 \\
3.62\end{array}$ & $\begin{array}{l}915 \\
885\end{array}$ & $\begin{array}{l}12.46 \\
13.55\end{array} \mid$ & & 8 & & & & 3,16 & & & \\
\hline & \begin{tabular}{|}
3.62 \\
3.72
\end{tabular} & $\begin{array}{l}885 \\
945\end{array}$ & $\begin{array}{l}13.55 \\
14.40\end{array}$ & & $\begin{array}{l}5.56 \\
5.38\end{array}$ & & 3.79 & 900 & 3.16 & 587 & 95 & \\
\hline & 3.78 & 1,000 & 168 & 14,0 & 598 & & 3.68 & 850 & & & & \\
\hline \multirow{6}{*}{$\begin{array}{r}7 \\
8 \\
9 \\
10 \\
11 \\
12 \\
\end{array}$} & 3.91 & 1,060 & 18.85 & 3,000 & 5.16 & 1,670 & & & & & & \\
\hline & $4.05 \mid$ & 160 & $\begin{array}{l}18.97 \\
18.60\end{array}$ & & & & 3.60 & 800 & 3.08 & 551 & 2.90 & 1 \\
\hline & 53 & 0 & & & $\begin{array}{l}4.92 \\
4.86\end{array}$ & & $\overline{3} . \overline{5}$ & 775 & & & & \\
\hline & 8 & 年 & .03 & & 4.80 & & & & & & & \\
\hline & 32 & & 46 & & 4 & & 3.50 & 750 & 3.10 & 560 & 2.82 & 37 \\
\hline & \multicolumn{2}{|c|}{ Aug. 29} & \multicolumn{2}{|c|}{ Aug. 30} & \multicolumn{2}{|c|}{ Aug. 31} & \multicolumn{2}{|c|}{ Sept. 1} & \multicolumn{2}{|c|}{ Sept. 2} & \multicolumn{2}{|c|}{ Sept. 3} \\
\hline \multirow{4}{*}{$\begin{array}{l}1 \\
2 \\
3 \\
4 \\
5 \\
6\end{array}$} & & & 8.44 & & .50 & 50 & & & & & & \\
\hline & & & $\begin{array}{l}8 \\
9\end{array}$ & & & & 3.56 & 775 & .27 & 628 & & \\
\hline & & & 11.70 & 5, & $\begin{array}{l}0.39 \\
5.28\end{array}$ & & $\overline{3} . \overline{5} \overline{2}$ & $750^{-}$ & 3.29 & $650^{-}$ & & \\
\hline & $1 . \overline{7} \overline{2}$ & 84 & 14 & & $\begin{array}{l}5.00 \\
4.62\end{array}$ & $\begin{array}{l}1,550 \\
1,330\end{array}$ & 3.48 & 750 & 3.29 & 650 & 2.77 & 415 \\
\hline \multirow{4}{*}{$\begin{array}{r}7 \\
8 \\
9 \\
10 \\
11 \\
\mathrm{~N}\end{array}$} & & & & & & & & & & & & \\
\hline & & & & & & & 3.43 & 725 & 3.28 & 650 & & \\
\hline & $\ldots$ & & & & & & 3.39 & 700 & 3.25 & 628 & & \\
\hline & 1.80 & 99 & $\begin{array}{l}1 \\
1\end{array}$ & & 18 & & 335 & 675 & 321 & 605 & 2.73 & 399 \\
\hline \multirow{5}{*}{$\begin{array}{l}1 \\
2 \\
3 \\
\mathbf{4} \\
\mathbf{5} \\
\mathbf{6}\end{array}$} & 1 & 105 & & & & & & & & & & \\
\hline & 1.96 & 134 & 22 & & & & 3.31 & 650 & 3.01 & 520 & & \\
\hline & $\begin{array}{l}3.07 \\
3.90\end{array}$ & $\begin{array}{l}546 \\
950\end{array}$ & 14 & & & & 3.25 & 28 & 94 & 489 & & \\
\hline & $\begin{array}{l}5.90 \\
4.04\end{array}$ & 1,030 & 10 & & $\begin{array}{l}3.99 \\
4.05\end{array}$ & & 3.25 & 28 & 94. & 489 & & \\
\hline & 3.92 & & & 3 & 4. & 1,030 & 3.19 & 600 & 2.90 & 471 & $2 . \overline{6}$ & 374 \\
\hline \multirow{5}{*}{$\begin{array}{r}7 \\
8 \\
9 \\
10 \\
11 \\
12 \\
\end{array}$} & 5 & 550 & 7. & 3 & 4 & & & & & & & \\
\hline & & & & & & 1, & 3.18 & 596 & 2.89 & 467 & & \\
\hline & $\begin{array}{l}0.02 \\
6.57\end{array}$ & 2,510 & 6. & & & 950 & $\overline{3.11}$ & 564 & 2.84 & 445 & & \\
\hline & $\begin{array}{l}7.20 \\
7.47\end{array}$ & $\begin{array}{l}2,870 \\
3,060\end{array}$ & $\begin{array}{l}6.10 \\
5.62\end{array}$ & $\begin{array}{l}2,210 \\
1,910\end{array}$ & $\begin{array}{l}3.83 \\
3.70\end{array}$ & $\begin{array}{l}925 \\
850\end{array}$ & 3.11 & 564 & $\overline{2} . \overline{7} \overline{7}$ & 415 & 2.61 & 49 \\
\hline & & & & & & & & & & & & $4 x^{2}$ \\
\hline
\end{tabular}

SUPPLEMENTAL RECORDS

\begin{tabular}{|c|c|c|c|c|c|}
\hline Day & $\begin{array}{c}\text { Gage } \\
\text { height }\end{array}$ & Discharge & Day & $\begin{array}{c}\text { Gage } \\
\text { height }\end{array}$ & Discharge \\
\hline $\begin{array}{r}\text { Aug. 13, } 7: 30 \text { p.m. } \\
\text { Aug. 14, 10:30 a.m. } \\
12: 30 \text { p.m. }\end{array}$ & $\begin{array}{r}19.00 \\
5.32 \\
6.00\end{array}$ & $\begin{array}{r}18,400 \\
1,730 \\
2,150\end{array}$ & $\begin{array}{rr}\text { Aug. 29, } 4: 30 \text { p.m. } \\
\text { 5:30 p.m. } \\
\text { 9:45 p.m. } \\
\text { Aug. 30, 1:30 p.m. } \\
\end{array}$ & $\begin{array}{r}4.19 \\
3.60 \\
6.49 \\
15.34 \\
\end{array}$ & $\begin{array}{r}1,110 \\
800 \\
2,450 \\
11,200 \\
\end{array}$ \\
\hline
\end{tabular}


NOR'H FORK SWANNANOA RIVER NEAR BLACK MOUNTAIN, N. C.

Location.-Lat. $35^{\circ} 39^{\prime} 25^{\prime \prime}$, long. $82^{\circ} 21^{\prime} 05^{\prime \prime}$, a quarter of a mile downstream from emergency pumping plant of Asheville Water Department, 3 miles downstream from forks of North Fork, and 3 miles northwest of Black Mountain, Buncombe County. Datum of gage is $2,428.03$ feet above mean sea level, datum of 1929 , supplementary adjustment of 1936 .

DraINAGE AREA.-23.8 square miles.

GAGE-HEIGHT RECORD.-Water-stage recorder graph.

DISCHARGE RECORD.-Artificial control is of concrete. Stage-discharge relation for 1940 defined by current-meter measurements up to 600 second-feet and extended to crest gage height on basis of determination of flood flow by slope-area method verified by computation of flow over Asheville Water Department dam on Right Hand Fork $31 / 2$ miles above station. The relation for 1928 was defined by current-meter measurements up to 700 second-feet and extended to 1928 crest gage height on basis of runoff comparisons. Changes in overflow channels eliminate the probability of close agreement with the 1940 rating. Shifting-control method used Aug. 17-27. Gage heights used to half-tenths between 4.3 and 6.7 feet; hundredths below and tenths above these limits.

Maxima.-1940: Discharge, 8,200 second-feet 12 m. Aug. 13 (gage height, 8.55 feet).

1926-39: Discharge, 5,050 second-feet Aug. 15, 1928 (gage height, 7.04 feet). REMARKS.-Flood runoff not materially affected by diversion or artificial storage. Monthly flow adjusted for diversions of city of Asheville for water supply.

Mean discharge, in second-feet, 1940

\begin{tabular}{|c|c|c|c|c|c|c|c|c|c|c|c|}
\hline Day & Aug. & Sept. & Day & Aug. & Sept. & Day & Aug. & Sept. & Day & Aug. & Sept. \\
\hline 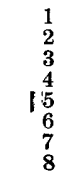 & $\begin{array}{l}28 \\
19 \\
15 \\
13 \\
14 \\
22 \\
23 \\
17\end{array}$ & $\begin{array}{r}223 \\
162 \\
131 \\
110 \\
91 \\
82 \\
71 \\
63\end{array}$ & $\begin{array}{r}9 \\
10 \\
11 \\
12 \\
13 \\
14 \\
15 \\
16\end{array}$ & $\begin{array}{r}32 \\
20 \\
112 \\
814 \\
3,820 \\
976 \\
350 \\
236\end{array}$ & $\begin{array}{l}\mathbf{5 5} \\
\mathbf{5 7} \\
\mathbf{4 7} \\
\mathbf{3 9} \\
\mathbf{3 7} \\
\mathbf{3 7} \\
\mathbf{3 2} \\
\mathbf{2 7}\end{array}$ & $\begin{array}{l}17 \\
18 \\
19 \\
20 \\
21 \\
22 \\
23 \\
24\end{array}$ & $\begin{array}{r}189 \\
150 \\
124 \\
106 \\
86 \\
72 \\
63 \\
57\end{array}$ & $\begin{array}{l}25 \\
23 \\
22 \\
20 \\
19 \\
17 \\
16 \\
16\end{array}$ & $\begin{array}{l}25 \\
26 \\
27 \\
28 \\
29 \\
30 \\
31\end{array}$ & $\begin{array}{r}49 \\
41 \\
34 \\
32 \\
653 \\
2,120 \\
406\end{array}$ & $\begin{array}{l}16 \\
17 \\
15 \\
14 \\
13 \\
12\end{array}$ \\
\hline \multicolumn{10}{|c|}{$\begin{array}{l}\text { Monthly mean discharge, in second-feet } \begin{array}{l}\text { observed } \\
\text { adjusted } \\
\text { Runoff, in inches, adjusted. }\end{array}\end{array}$} & $\begin{array}{r}345 \\
354 \\
17.13\end{array}$ & $\begin{array}{l}50.3 \\
61.8 \\
2.90\end{array}$ \\
\hline
\end{tabular}




\section{FLOODS OF AUGUST 1940 IN THE SOUTHEASTERN STATES}

Gage height, in feet, and discharge, in second-feet, at indicated time, 1940

\begin{tabular}{|c|c|c|c|c|c|c|c|c|c|c|c|c|}
\hline \multirow{2}{*}{ Hour } & \multicolumn{2}{|c|}{ Aug. 12} & \multicolumn{2}{|c|}{ Aug. 13} & \multicolumn{2}{|c|}{ Aug. 14} & \multicolumn{2}{|c|}{ Aug. 15} & \multicolumn{2}{|c|}{ Aug. 16} & \multicolumn{2}{|c|}{ Aug. 17} \\
\hline & $\begin{array}{c}\text { Gage } \\
\text { ht. }\end{array}$ & $\begin{array}{c}\text { Dis- } \\
\text { charge }\end{array}$ & $\begin{array}{c}\text { Gage } \\
\text { ht. }\end{array}$ & $\begin{array}{l}\text { Dis- } \\
\text { charge }\end{array}$ & $\begin{array}{c}\text { Gage } \\
\text { ht. }\end{array}$ & $\begin{array}{c}\text { Dis- } \\
\text { charge }\end{array}$ & $\begin{array}{c}\text { Gage } \\
\text { ht. }\end{array}$ & $\begin{array}{c}\text { Dis- } \\
\text { charge }\end{array}$ & $\begin{array}{c}\text { Gage } \\
\text { ht. }\end{array}$ & $\begin{array}{c}\text { Dis- } \\
\text { charge }\end{array}$ & $\begin{array}{c}\text { Gage } \\
\text { ht. }\end{array}$ & $\begin{array}{c}\text { Dis- } \\
\text { charge }\end{array}$ \\
\hline $\begin{array}{l}1 \\
2 \\
3 \\
4 \\
5 \\
6\end{array}$ & $\begin{array}{l}2.68 \\
2.85 \\
3.05 \\
3.54 \\
3.54 \\
3.35\end{array}$ & $\begin{array}{l}322 \\
440 \\
777 \\
777 \\
635\end{array}$ & $\begin{array}{l}4.12 \\
4.15 \\
4.32 \\
4.72 \\
4.79 \\
5.00\end{array}$ & $\begin{array}{l}1,290 \\
1,340 \\
1,500 \\
1,950 \\
2,070 \\
2,310\end{array}$ & $\begin{array}{l}4.67 \\
4.51 \\
4.36 \\
4.23 \\
4.12 \\
4.02\end{array}$ & $\begin{array}{l}1,890 \\
1,720 \\
1,560 \\
1,450 \\
1,300 \\
1,210\end{array}$ & $2 . \overline{98}$ & 428 & $\begin{array}{r}2.62 \\
-\end{array}$ & 242 & & \\
\hline $\begin{array}{r}7 \\
8 \\
9 \\
10 \\
11 \\
\mathrm{~N}\end{array}$ & $\begin{array}{l}3.24 \\
3.16 \\
3.15 \\
3.13 \\
3.11 \\
3.13\end{array}$ & $\begin{array}{l}561 \\
509 \\
502 \\
490 \\
476\end{array}$ & $\begin{array}{l}5.58 \\
5.38 \\
5.07 \\
5.05 \\
6.10 \\
8.55\end{array}$ & $\begin{array}{l}3,110 \\
2,830 \\
2,380 \\
2,380 \\
3,850 \\
8,200\end{array}$ & $\begin{array}{l}3.93 \\
3.84 \\
3.77 \\
3.69 \\
3.63 \\
3.57\end{array}$ & $\begin{array}{r}1,150 \\
1,070 \\
1,010 \\
942 \\
894 \\
848\end{array}$ & $\begin{array}{r}2.90 \\
2.81\end{array}$ & 380 & 2.60 & 233 & 2.47 & 188 \\
\hline $\begin{array}{l}\mathbf{1} \\
\mathbf{2} \\
\mathbf{3} \\
\mathbf{4} \\
\mathbf{5} \\
\mathbf{6}\end{array}$ & $\begin{array}{l}3.28 \\
3.52 \\
3.53 \\
3.62 \\
3.71 \\
3.88\end{array}$ & $\begin{array}{r}587 \\
761 \\
769 \\
842 \\
919 \\
1,070\end{array}$ & $\begin{array}{l}7.96 \\
8.12 \\
7.25 \\
6.80 \\
8.10 \\
8.00\end{array}$ & $\begin{array}{l}7,100 \\
7,280 \\
5,670 \\
4,990 \\
7,280 \\
7,100\end{array}$ & $\begin{array}{l}3.52 \\
3.48 \\
3.42 \\
3.37 \\
3.32 \\
3.27\end{array}$ & $\begin{array}{l}810 \\
780 \\
735 \\
698 \\
660 \\
623\end{array}$ & \begin{tabular}{c}
- \\
\hdashline .76 \\
\hdashline
\end{tabular} & 307 & $\overline{2} . \overline{5}$ & 210 & & \\
\hline $\begin{array}{r}7 \\
8 \\
9 \\
10 \\
11 \\
12 \\
\end{array}$ & $\begin{array}{l}4.02 \\
4.30 \\
4.43 \\
4.46 \\
4.33 \\
4.13\end{array}$ & $\begin{array}{l}1,210 \\
1,500 \\
1,660 \\
1,660 \\
1,560 \\
1,340\end{array}$ & $\begin{array}{l}6.83 \\
6.05 \\
5.66 \\
5.38 \\
5.12 \\
4.85\end{array}$ & $\begin{array}{l}4,990 \\
3,780 \\
3,180 \\
2,830 \\
2,440 \\
2,130\end{array}$ & $\begin{array}{l}3.24 \\
3.20 \\
3.17 \\
3.14 \\
3.11 \\
3.08\end{array}$ & $\begin{array}{l}602 \\
573 \\
553 \\
532 \\
512 \\
492\end{array}$ & $2 . \overline{70}$ & 278 & $\begin{array}{r}\mathbf{2 . 6 7} \\
\overline{2.59}\end{array}$ & 264 & 2.38 & $15 \overline{9}$ \\
\hline
\end{tabular}

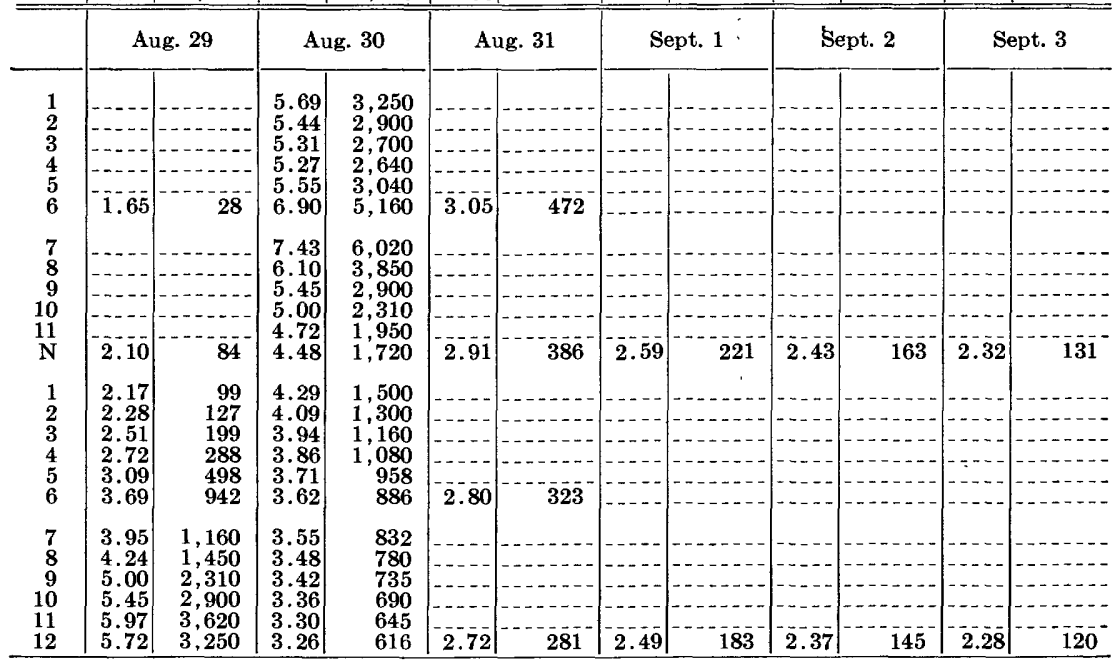

Supplemental ReCords.-Aug. 13, 5:30 p.m., gage height, 8.42 feet; discharge, 7,820 second-feet" Aug. 30, 6:30 a.m., gage height, 7.72 feet; discharge, 6,560 second-feet. 
BEETREE CREEK NEAR SWANNANOA, N. C.

Location.- Lat. $35^{\circ} 39^{\prime} 15^{\prime \prime}$, long. $82^{\circ} 24^{\prime} 20^{\prime \prime}, 200$ feet upstream from upper intake to Asheville water supply, 1,000 feet upstream from Beetree Reservoir, and 4 miles north of Swannanoa, Buncombe County. Datum of gage is 2,728.39 feet above mean sea level, datum of 1929, supplementary adjustment of 1936 . Drainage AREA.-5.46 square miles.

GAGE-HEIGHT RECORD.-Water-stage recorder graph. Recorder graph valueless Sept. 23-30, when debris was being removed from weir basin.

DIScharge RECORD.-Artificial control is 1-foot Cippoletti weir in masonry dam. Stage-discharge relation defined by current-meter measurements up to 150 second-feet and extended above on basis of computation of the flow over control at half-foot stage intervals and at peak stage. The floods filled the weir basin with debris, eausing a large shift in stage-discharge relation Aug. 13 and necessitated estimates of discharge $12 \mathrm{~m}$. Aug. 30 to Sept. 3 and Sept. 23-30 and the use of shifting-control method Sept. 4-22. The estimates of discharge are based on weather records and records for nearby streams. Gage heights Aug. 1 to 3 p.m. Aug. 13 used to half-tenths above and hundredths below 4.3 feet. Gage heights 3 p.m. Aug. 13 to Sept. 30 used to half-tenths between 3.1 and 4.0 feet; hundredths below and tenths above these limits.

Maxima.-1940: Discharge, 1,370 second-feet 3 p.m. Aug. 13 (gage height, 6.20 feet).

1926-39: Discharge, 830 second-feet Aug. 15, 1928 (gage height, 5.40 feet). REMARKs.-Flood runoff not affected by artificial storage.

Mean discharge, in second-feet, 1940

\begin{tabular}{|c|c|c|c|c|c|c|c|c|c|c|c|}
\hline Day & Aug. & Sept. & Day & Aug. & Sept. & Day & Aug. & Sept. & Day & Aug. & Sept. \\
\hline $\begin{array}{l}1 \\
2 \\
3 \\
4 \\
5 \\
5 \\
6 \\
7 \\
8\end{array}$ & $\begin{array}{l}3.8 \\
3.15 \\
2.85 \\
2.75 \\
3.15 \\
3.5 \\
4.35 \\
3.3\end{array}$ & $\begin{array}{l}61 \\
44 \\
34 \\
26 \\
22 \\
20 \\
16 \\
14\end{array}$ & $\begin{array}{r}9 \\
10 \\
11 \\
12 \\
13 \\
14 \\
15 \\
16\end{array}$ & $\begin{array}{c}3.55 \\
3.2 \\
7.8 \\
97 \\
528 \\
169 \\
82 \\
57\end{array}$ & $\begin{array}{c}13 \\
20 \\
12 \\
11 \\
9.6 \\
8.6 \\
8.2 \\
8.0\end{array}$ & $\begin{array}{l}17 \\
18 \\
19 \\
20 \\
21 \\
22 \\
23 \\
24\end{array}$ & $\begin{array}{l}44 \\
33 \\
26 \\
21 \\
19 \\
16 \\
14 \\
13\end{array}$ & $\begin{array}{l}7.5 \\
7.2 \\
7.2 \\
7.5 \\
7.2 \\
7.2 \\
7.0 \\
7.5\end{array}$ & $\begin{array}{l}25 \\
26 \\
27 \\
28 \\
29 \\
30 \\
31\end{array}$ & $\begin{array}{r}12 \\
11 \\
10 \\
10 \\
156 \\
448 \\
107\end{array}$ & $\begin{array}{l}8.0 \\
7.0 \\
6.5 \\
6.0 \\
5.0 \\
4.0\end{array}$ \\
\hline \multicolumn{10}{|c|}{$\begin{array}{l}\text { Monthly mean discharge, in second-feet. } \\
\text { Runoff, in inches }\end{array}$} & $\begin{array}{r}61.8 \\
13.04\end{array}$ & $\begin{array}{l}14.1 \\
2.88\end{array}$ \\
\hline
\end{tabular}


358 FLOODS OF AUGUST 1940 IN THE SOUTHEASTERN STATES

Gage height, in feet, and discharge, in second-feet, at indicated time, 1940

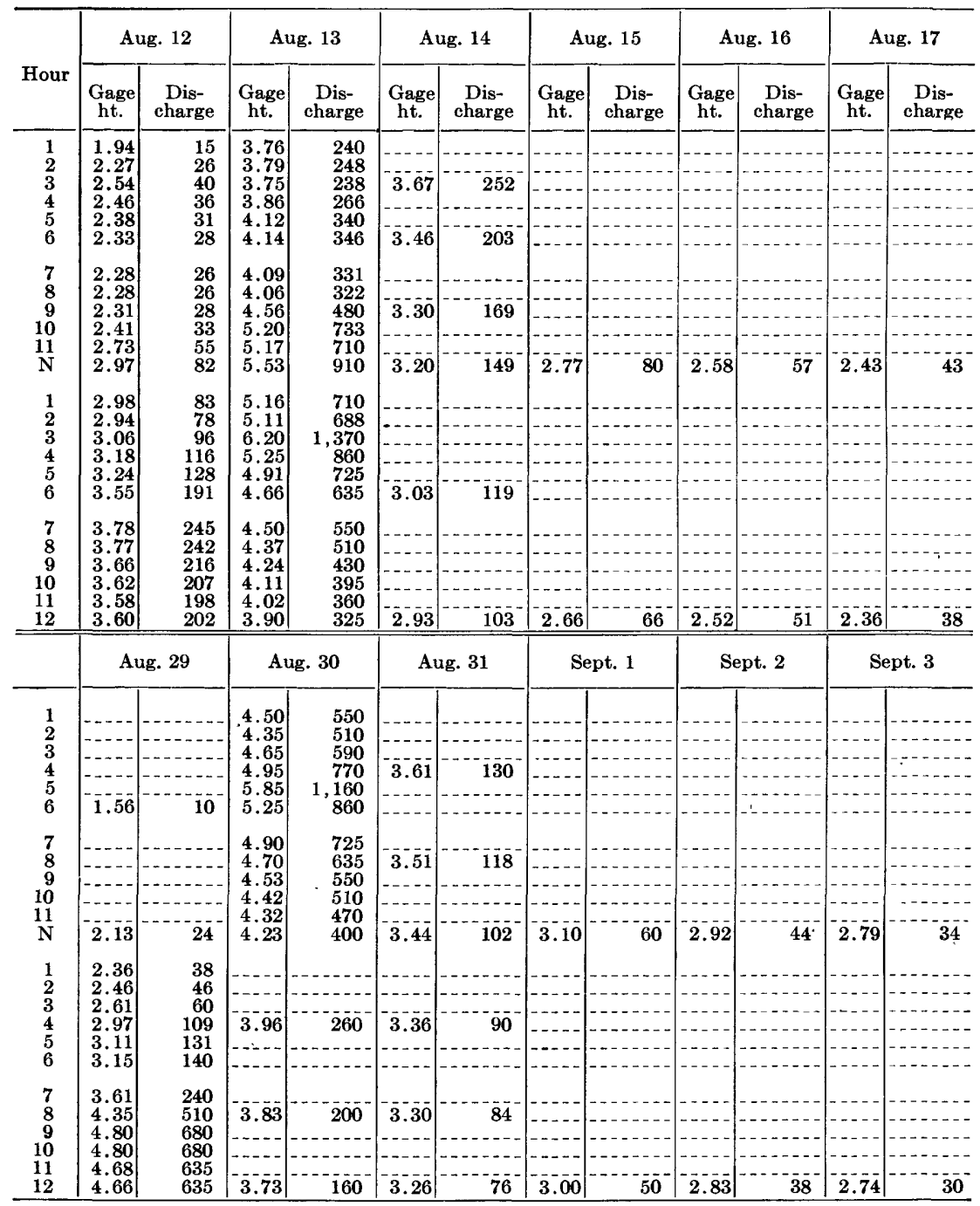


IVY RIVER NEAR MARSHALL, N. C.

Location.-Lat. $35^{\circ} 46^{\prime} 05^{\prime \prime}$, long. $82^{\circ} 37^{\prime} 15^{\prime \prime}$, 300 feet downstream from county bridge, 1.8 miles upstream from mouth, and 4 miles southeast of Marshall, Madison County. Datum of gage is 1,700.41 feet above mean sea level, datum of 1929 , supplementary adjustment of 1936 .

Drainage AREA.-158 square miles.

GAGE-HEIGHT RECORD.-Water-stage recorder graph.

DischaRGE RECORD.--Stage-discharge relation defined by current-meter measurements up to 2,500 second-feet and extended to the 1940 crest gage height on basis of determination of flood flow by slope-area method. This rating verifies the 1936 extension. Shifting-control method used Aug. 1 to 1 p.m. Aug. 13. Gage heights used to half-tenths between 3.7 and 6.5 feet; hundredths below and tenths above these limits.

Maxima.-1940: Discharge, 8,880 second-feet 5:30 a.m. Aug. 30 (gage height, 12.67 feet).

1934-39: Discharge, 5,850 second-feet Aug. 8, 1936 (gage height, 10.68 feet). REMarks.-Flood runoff not affected by artificial storage.

Mean discharge, in second-feet, 1940

\begin{tabular}{|c|c|c|c|c|c|c|c|c|c|c|c|}
\hline Day & Aug. & Sept. & Day & Aug. & Sept. & Day & Aug. & Sept. & Day & Aug. & Sept. \\
\hline $\begin{array}{l}1 \\
2 \\
3 \\
4 \\
5 \\
6 \\
7 \\
8\end{array}$ & $\begin{array}{r}97 \\
70 \\
63 \\
59 \\
58 \\
82 \\
125 \\
69\end{array}$ & $\begin{array}{l}485 \\
331 \\
244 \\
195 \\
162 \\
141 \\
127 \\
113\end{array}$ & $\begin{array}{r}9 \\
10 \\
11 \\
12 \\
13 \\
14 \\
15 \\
16\end{array}$ & $\begin{array}{r}57 \\
51 \\
51 \\
272 \\
2,460 \\
1,460 \\
647 \\
441\end{array}$ & $\begin{array}{r}103 \\
102 \\
103 \\
86 \\
80 \\
73 \\
69 \\
67\end{array}$ & $\begin{array}{l}17 \\
18 \\
19 \\
20 \\
21 \\
22 \\
23 \\
24\end{array}$ & $\begin{array}{l}383 \\
304 \\
248 \\
190 \\
158 \\
151 \\
122 \\
108\end{array}$ & $\begin{array}{l}62 \\
59 \\
58 \\
56 \\
53 \\
50 \\
50 \\
48\end{array}$ & $\begin{array}{l}25 \\
26 \\
27 \\
28 \\
29 \\
30 \\
31\end{array}$ & $\begin{array}{r}97 \\
90 \\
84 \\
76 \\
435 \\
+, 340 \\
918\end{array}$ & $\begin{array}{r}50 \\
57 \\
50 \\
48 \\
46 \\
44 \\
\end{array}$ \\
\hline n & & & & & & & & & & $\begin{array}{r}444 \\
3.24 \\
\end{array}$ & $\begin{array}{r}107 \\
0.76 \\
\end{array}$ \\
\hline
\end{tabular}

$804331-49-25$ 
360 FLOODS OF AUGUST 1940 IN THE SOUTHEASTERN STATES

Gage height, in feet, and discharge, in second-feet, at indicated time, 1940

\begin{tabular}{|c|c|c|c|c|c|c|c|c|c|c|c|c|}
\hline \multirow{2}{*}{ Hour } & \multicolumn{2}{|c|}{ Aug. 12} & \multicolumn{2}{|c|}{ Aug. 13} & \multicolumn{2}{|c|}{ Aug. 14} & \multicolumn{2}{|c|}{ Aug. 15} & \multicolumn{2}{|c|}{ Aug. 16} & \multicolumn{2}{|c|}{ Aug. 17} \\
\hline & $\begin{array}{c}\text { Gage } \\
\text { ht. }\end{array}$ & $\begin{array}{l}\text { Dis- } \\
\text { charge }\end{array}$ & $\begin{array}{c}\text { Gage } \\
\text { ht. }\end{array}$ & $\begin{array}{l}\text { Dis- } \\
\text { charge }\end{array}$ & $\begin{array}{c}\text { Gage } \\
\text { ht. }\end{array}$ & $\begin{array}{l}\text { Dis- } \\
\text { charge }\end{array}$ & $\begin{array}{c}\text { Gage } \\
\text { ht. }\end{array}$ & $\begin{array}{l}\text { Dis- } \\
\text { charge }\end{array}$ & $\begin{array}{c}\text { Gage } \\
\text { ht. }\end{array}$ & $\begin{array}{l}\text { Dis- } \\
\text { charge }\end{array}$ & $\begin{array}{c}\text { Gage } \\
\text { ht. }\end{array}$ & $\begin{array}{c}\text { Dis- } \\
\text { charge }\end{array}$ \\
\hline $\begin{array}{l}1 \\
2 \\
3 \\
4 \\
5 \\
6\end{array}$ & $\begin{array}{l}2.58 \\
2.62 \\
2.68 \\
2.72 \\
2.76 \\
2.82\end{array}$ & $\begin{array}{l}56 \\
60 \\
68 \\
73 \\
78 \\
88\end{array}$ & $\begin{array}{l}4.86 \\
4.85 \\
4.82 \\
5.06 \\
5.33 \\
5.10\end{array}$ & $\begin{array}{r}663 \\
685 \\
685 \\
829 \\
1,020 \\
908\end{array}$ & $\begin{array}{r}-\overline{6.95} \\
-\overline{6.42} \\
-\overline{6.07}\end{array}$ & $\begin{array}{c}-\overline{2}, 430 \\
1, \overline{930} \\
1,660\end{array}$ & 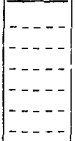 & 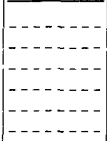 & $\mid$\begin{tabular}{c|}
$-\cdots$ \\
$-\cdots$ \\
$-\cdots$ \\
$-\cdots$ \\
$-\cdots$ \\
$-\cdots$
\end{tabular} & 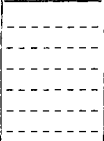 & $\mid \begin{array}{l}-\cdots \\
-\cdots- \\
---\end{array}$ & 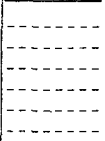 \\
\hline $\begin{array}{r}7 \\
8 \\
9 \\
10 \\
11 \\
\mathbf{N}\end{array}$ & $\begin{array}{l}2.84 \\
2.87 \\
2.94 \\
3.42 \\
3.56 \\
3.63\end{array}$ & $\begin{array}{r}90 \\
95 \\
106 \\
197 \\
228 \\
245\end{array}$ & $\begin{array}{l}5.29 \\
5.39 \\
5.53 \\
5.87 \\
5.93 \\
5.90\end{array}$ & $\begin{array}{l}1,050 \\
1,140 \\
1,260 \\
1,490 \\
1,560 \\
1,520\end{array}$ & $\left|\begin{array}{r}-\overline{5.80} \\
-\overline{5.64} \\
-\overline{5.61}\end{array}\right|$ & $\begin{array}{c}1,490 \\
1, \overline{380} \\
-\overline{1}, \overline{350}\end{array}$ & $\mid$\begin{tabular}{l}
$-\cdots$ \\
\hdashline$-\cdots$ \\
\hdashline 4.29
\end{tabular} & $\mid$\begin{tabular}{l}
$-\cdots$ \\
$\cdots \cdots$ \\
\hdashline-14
\end{tabular} & $\mid$\begin{tabular}{l}
..- \\
\hdashline$-\cdots$ \\
\hdashline$\overline{3} . \overline{3}$
\end{tabular} & $\mid \begin{array}{r}-\cdots \\
-\cdots \\
\hdashline-138\end{array}$ & $\mid$\begin{tabular}{l}
$-\cdots$ \\
$-\cdots$ \\
\hdashline$-\overline{-}$ \\
\hdashline$\overline{\mathbf{3} 7}$
\end{tabular} & $\mid \begin{array}{c}-\ldots \ldots \\
-\cdots \\
-\cdots \\
-380\end{array}$ \\
\hline $\begin{array}{l}1 \\
2 \\
3 \\
4 \\
5 \\
6\end{array}$ & $\begin{array}{l}3.68 \\
3.73 \\
3.78 \\
3.90 \\
4.11 \\
4.62\end{array}$ & $\begin{array}{l}258 \\
270 \\
283 \\
315 \\
377 \\
542\end{array}$ & $\begin{array}{l}5.89 \\
6.60 \\
7.65 \\
8.60 \\
9.07 \\
9.82\end{array}$ & $\begin{array}{l}1,520 \\
2,090 \\
2,970 \\
3,970 \\
4,510 \\
5,280\end{array}$ & $\begin{array}{r}\overline{5.49} \\
-\overline{5.2 \overline{9}} \\
-\overline{5.07}\end{array} \mid$ & \begin{tabular}{r}
$-1,290$ \\
\hdashline 1,170 \\
1,020
\end{tabular} & 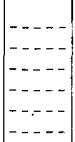 & 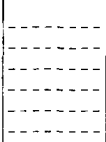 & $\left|\begin{array}{c}---- \\
---- \\
---- \\
-\cdots- \\
-\cdots- \\
-\cdots\end{array}\right|$ & 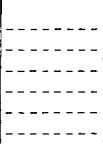 & 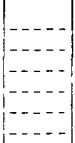 & 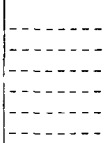 \\
\hline $\begin{array}{r}7 \\
8 \\
9 \\
10 \\
11 \\
12 \\
\end{array}$ & $\begin{array}{l}4.62 \\
4.59 \\
4.57 \\
4.54 \\
4.59 \\
4.71\end{array}$ & $\begin{array}{l}561 \\
561 \\
542 \\
542 \\
561 \\
600 \\
\end{array}$ & $\begin{array}{r}9.82 \\
10.32 \\
9.85 \\
8.90 \\
8.10 \\
7.55\end{array}$ & $\begin{array}{l}5,280 \\
5,860 \\
5,280 \\
4,290 \\
3,470 \\
2,970\end{array}$ & $\begin{array}{r}-4 . \overline{89} \\
-4 . \overline{84} \\
4.74\end{array}$ & $\mid \begin{array}{r}93 \overline{5} \\
90 \overline{8} \\
-\overline{85} 5\end{array}$ & 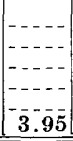 & $\begin{array}{r}-\cdots \\
\cdots \\
\cdots \\
-\cdots\end{array}$ & $\left|\begin{array}{|c|}\mid \cdots \\
\hdashline-\cdots \\
\hdashline \overline{3} \mathbf{6}\end{array}\right|$ & $\begin{array}{r}-\ldots . . \\
\mathbf{4 3 8}\end{array}$ & 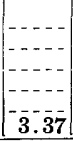 & 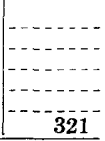 \\
\hline & \multicolumn{2}{|c|}{ Aug. 29} & \multicolumn{2}{|c|}{ Aug. 30} & \multicolumn{2}{|c|}{ Aug. 31} & \multicolumn{2}{|c|}{ Sept. 1} & \multicolumn{2}{|c|}{ Sept. 2} & \multicolumn{2}{|c|}{ Sept. 3} \\
\hline $\begin{array}{l}1 \\
2 \\
3 \\
\mathbf{3} \\
\mathbf{4} \\
5 \\
\mathbf{6}\end{array}$ & $\mid$\begin{tabular}{c}
$-\cdots .-$ \\
$-\cdots$ \\
\hdashline..-- \\
$-\overline{2} .13$
\end{tabular} & $6 \overline{8}^{-}$ & $\begin{array}{r}8.00 \\
8.22 \\
8.87 \\
10.50 \\
12.50 \\
12.30\end{array}$ & $\begin{array}{l}3,370 \\
3,570 \\
4,290 \\
6,100 \\
8,620 \\
\mathbf{8}, \mathbf{3 6 0}\end{array}$ & $\left|\begin{array}{c}-\cdots-- \\
-\cdots- \\
----- \\
-\overline{5} . \overline{16}\end{array}\right|$ & 1, & - & $\mid \begin{array}{l}------ \\
------- \\
------- \\
----\cdots--- \\
----\cdots--\end{array}$ & 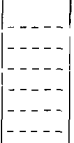 & 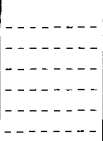 & $\left|\begin{array}{c}----- \\
----- \\
----- \\
---\cdots \\
-----\end{array}\right|$ & 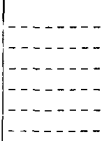 \\
\hline $\begin{array}{r}7 \\
8 \\
9 \\
10 \\
11 \\
\text { N }\end{array}$ & $\left|\begin{array}{c}-. .-- \\
-\cdots--- \\
-\cdots-. \\
-\overline{2} . \overline{15}\end{array}\right|$ & 70 & $\begin{array}{r}11.68 \\
11.87 \\
12.04 \\
11.80 \\
10.75 \\
9.10\end{array}$ & $\begin{array}{l}7,580 \\
7,840 \\
7,970 \\
7,710 \\
6,460 \\
4,510\end{array}$ & 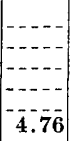 & $\mid \begin{array}{r}------- \\
--\cdots---- \\
--\cdots--- \\
------- \\
---\overline{85} \overline{5}\end{array}$ & 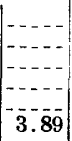 & 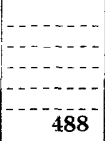 & $\mid$\begin{tabular}{c|}
$-\cdots$ \\
\hdashline$-\cdots$ \\
\hdashline$-\overline{3}$ \\
-1
\end{tabular} & $--\overline{\mathbf{3}} \overline{\mathbf{3}} \overline{\mathbf{5}}^{-}$ & $\left|\begin{array}{l}--\cdot- \\
----- \\
----- \\
--\cdots- \\
-\overline{3} . \overline{10}\end{array}\right|$ & $\mid \begin{array}{r}\ldots- \\
-\cdots- \\
-\cdots-\cdots \\
-\cdots-\cdots \\
-\cdots-\overline{250}\end{array}$ \\
\hline $\begin{array}{l}1 \\
2 \\
3 \\
4 \\
\mathbf{5} \\
\mathbf{5} \\
\mathbf{6}\end{array}$ & $\begin{array}{l}2.20 \\
2.26 \\
2.40 \\
2.80 \\
3.00 \\
3.13\end{array}$ & $\begin{array}{r}77 \\
86 \\
108 \\
182 \\
226 \\
258\end{array}$ & $\begin{array}{l}8.35 \\
7.90 \\
7.46 \\
7.15 \\
6.86 \\
6.62\end{array}$ & $\begin{array}{l}3,770 \\
3,270 \\
2,880 \\
2,610 \\
2,340 \\
2,090\end{array}$ & 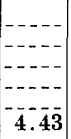 & - & 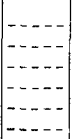 & 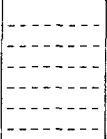 & 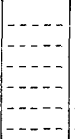 & 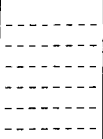 & 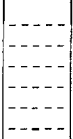 & 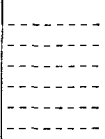 \\
\hline $\begin{array}{r}7 \\
8 \\
9 \\
10 \\
11 \\
12\end{array}$ & $\begin{array}{l}3.50 \\
4.05 \\
5.20 \\
6.65 \\
7.57 \\
7.84\end{array}$ & $\begin{array}{r}358 \\
542 \\
1,110 \\
2,090 \\
2,970 \\
3,170\end{array}$ & $\begin{array}{l}6.41 \\
6.22 \\
6.05 \\
5.93 \\
5.87 \\
5.74\end{array}$ & $\begin{array}{l}1,930 \\
1,770 \\
1,660 \\
1,600 \\
1,520 \\
1,460\end{array}$ & $\left|\begin{array}{c}-\cdots- \\
\hdashline-.- \\
\hdashline-.- \\
\hdashline-\overline{18}\end{array}\right|$ & $\mid \begin{array}{c}\cdots \\
\cdots \cdots \\
\cdots \cdots\end{array}$ & 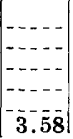 & 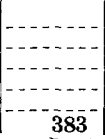 & $\left|\begin{array}{c}--.- \\
-\cdots- \\
-\cdots- \\
-\overline{\mathbf{3}}\end{array}\right|$ & $\mid$\begin{tabular}{c}
$-\cdots$ \\
$-\cdots$ \\
$\cdots$ \\
\hdashline$-\cdots$ \\
\hdashline$-\overline{270}$
\end{tabular} & $\left|\begin{array}{c}-\cdots- \\
-\cdots-- \\
---- \\
-\overline{2.92}\end{array}\right|$ & 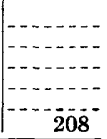 \\
\hline
\end{tabular}

Supplemental RECORD.-Aug. 30, 5:30 a.m., gage height, 12.67 feet; discharge, 8,880 second-feet! 


\section{BIG LAUREL CREEK NEAR STACKHOUSE, N. C.}

Location.-Lat. $35^{\circ} 55^{\prime} 05^{\prime \prime}$, long. $82^{\circ} 45^{\prime} 45^{\prime \prime}$; midway between Big Hurricane and Little Hurricane Creeks, 50 feet west of State Highway 208, and 3 miles north of Stackhouse, Madison County. Datum of gage is 1,595.68 feet above mean sea level, datum of 1929 , supplementary adjustment of 1936 .

DrainAgE AREA.-126 square miles.

GAGE-HEIGHT RECORD.-Water-stage recorder graph.

DISCHARGE RECORD.-Stage-discharge relation defined by current-meter measurements up to 4,500 second-feet and extended to the 1935 crest gage height. Gage heights used to half-tenths between 3.7 and 5.5 feet; hundredths below and tenths above these limits.

Maxima.-1940: Discharge, 4,920 second-feet 8 a.m. Aug. 30 (gage height, 6.66 feet).

1934-39: Discharge, 7,260 second-feet Mar. 25, 1935 (gage height, 7.94 feet). REMARKs.-Flood runoff not affected by artificial storage.

Mean discharge, in second-feet, 1940

\begin{tabular}{|c|c|c|c|c|c|c|c|c|c|c|c|}
\hline Day & Aug. & Sept. & Day & Aug. & Sept. & Day & Aug. & Sept. & Day & Aug. & Sept. \\
\hline $\begin{array}{l}1 \\
2 \\
3 \\
4 \\
5 \\
6 \\
7 \\
8\end{array}$ & $\begin{array}{r}169 \\
117 \\
96 \\
82 \\
80 \\
148 \\
772 \\
258\end{array}$ & $\begin{array}{l}432 \\
291 \\
215 \\
172 \\
148 \\
129 \\
121 \\
108\end{array}$ & $\begin{array}{r}9 \\
10 \\
11 \\
12 \\
13 \\
14 \\
15 \\
16\end{array}$ & $\begin{array}{l}235 \\
153 \\
124 \\
110 \\
273 \\
473 \\
634 \\
462\end{array}$ & $\begin{array}{r}104 \\
129 \\
113 \\
92 \\
84 \\
80 \\
75 \\
72\end{array}$ & $\begin{array}{l}17 \\
18 \\
19 \\
20 \\
21 \\
22 \\
23 \\
24\end{array}$ & $\begin{array}{l}319 \\
235 \\
231 \\
184 \\
156 \\
146 \\
121 \\
106\end{array}$ & $\begin{array}{l}67 \\
65 \\
64 \\
62 \\
59 \\
56 \\
54 \\
55\end{array}$ & $\begin{array}{l}25 \\
26 \\
27 \\
28 \\
29 \\
30 \\
31\end{array}$ & $\begin{array}{r}98 \\
92 \\
88 \\
80 \\
337 \\
2,980 \\
\mathbf{8 6 4}\end{array}$ & $\begin{array}{r}77 \\
84 \\
59 \\
54 \\
52 \\
49 \\
-\end{array}$ \\
\hline \multicolumn{10}{|c|}{$\begin{array}{l}\text { Monthly mean discharge, in second-feet } \\
\text { Runoff, in inches }\end{array}$} & $\begin{array}{r}330 \\
3.02 \\
\end{array}$ & $\begin{array}{r}107 \\
0.95 \\
\end{array}$ \\
\hline
\end{tabular}

Gage height, in feet, and discharge, in second-feet, at indicated time, 1940

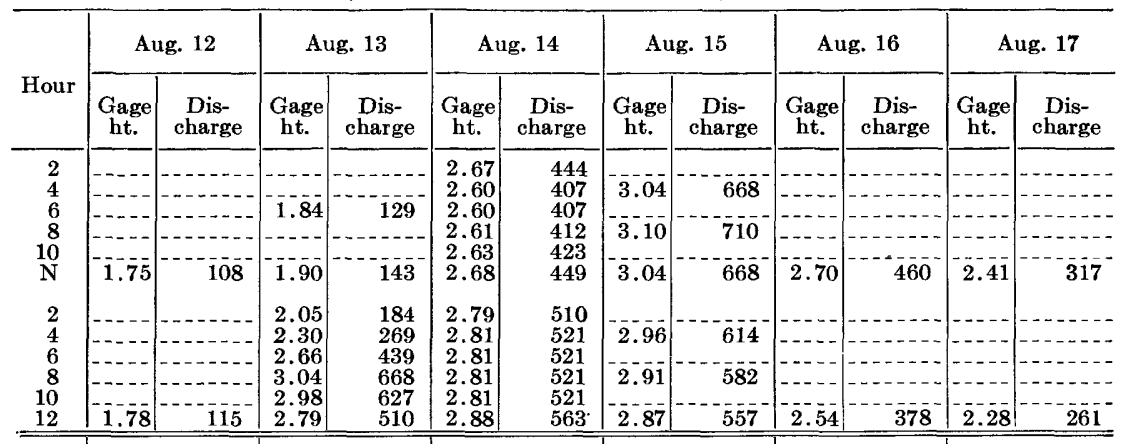

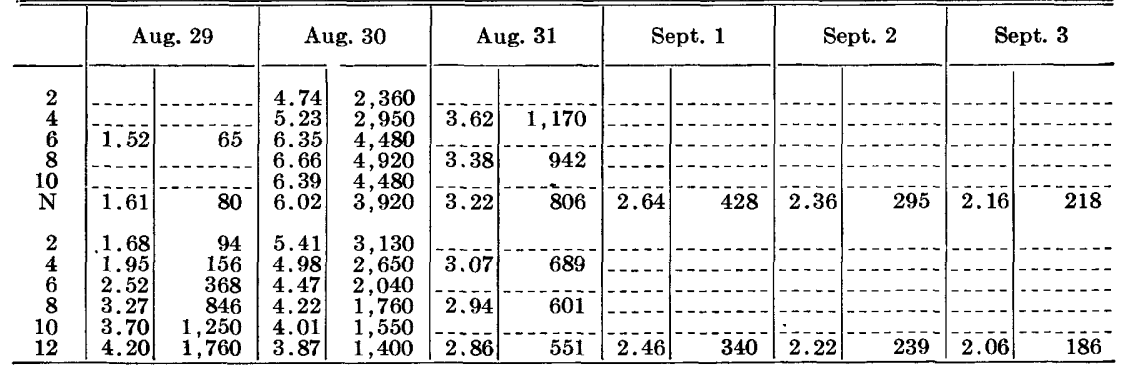




\section{PIGEON RIVER AT CANTON, N. C.}

LOCATION.-Lat. $35^{\circ} 31^{\prime} 50^{\prime \prime}$, long. $82^{\circ} 50^{\prime} 30^{\prime \prime}$, a third of a mile upstream from State Highway bridge at Canton, Haywood County. Datum of gage is 2,572.22 feet above mean sea level, datum of 1929 , supplementary adjustment of 1936 .

Drainage AREa.-133 square miles.

GAGE-HEIGHT RECORD.-Water-stage recorder graph except from 5:30 to 7:30 a.m. Aug. 30, for which a graph based on recorder record and floodmark in gage well was used.

DISCHARGE RECORD.-Stage-discharge relation defined by current-meter measurements up to 24,500 second-feet and extended logarithmically to crest gage height. Shifting-control method used 8 p.m. Aug. 13 to 2 a.m. Aug. 30. Gage heights used to half-tenths between 2.5 and 4.5 feet; hundredths below and tenths above these limits.

Maxima.-1940: Discharge, 31,600 second-feet 6:30 a.m. Aug. 30 (gage height, 20.75 feet, from floodmark).

1907-9, 1928-39: Discharge, 8,690 second-feet Jan. 30, 1939 (gage height, 9.45 feet).

Surveys by the Tennessee Valley Authority show that the floods of June 1876 and September 1893 reached a stage of 18 feet and that of August 1928 reached 16 feet, from flood profiles.

REMARKs.-Flood runoff not affected by artificial storage

Mean discharge, in second-feet, 1940

\begin{tabular}{|c|c|c|c|c|c|c|c|c|c|c|c|}
\hline Day & Aug. & Sept. & Day & Aug. & Sept. & Day & Aug. & Sept. & Day & Aug. & Sept. \\
\hline 1 & 180 & 1,480 & 9 & 392 & 437 & 17 & 980 & 288 & 25 & 386 & 216 \\
\hline 2 & 164 & $\begin{array}{l}1,130 \\
130\end{array}$ & 10 & 244 & 411 & 18 & 890 & 274 & 26 & 350 & 205 \\
\hline 3 & 152 & 913 & 11 & 345 & 390 & 19 & 676 & 267 & 27 & 324 & 197 \\
\hline 4 & 138 & 766 & 12 & 3,100 & 357 & 20 & 589 & 257 & 28 & 299 & 197 \\
\hline 5 & 138 & 658 & 13 & 12,800 & 337 & 21 & 522 & 250 & 29 & 1,620 & 205 \\
\hline 6 & 148 & 580 & 14 & 3,310 & 318 & 22 & 473 & 237 & $\begin{array}{l}30 \\
31\end{array}$ & 11,200 & 197 \\
\hline 8 & $\begin{array}{l}208 \\
147\end{array}$ & $\begin{array}{l}547 \\
482\end{array}$ & $\begin{array}{l}15 \\
16\end{array}$ & $\begin{array}{l}1,740 \\
1,220\end{array}$ & $\begin{array}{l}299 \\
296\end{array}$ & $\begin{array}{l}23 \\
24\end{array}$ & $\begin{array}{l}440 \\
454\end{array}$ & $\begin{array}{l}234 \\
225\end{array}$ & & & \\
\hline \multicolumn{10}{|c|}{ Monthly mean discharge, in second-feet } & 1,476 & 422 \\
\hline
\end{tabular}


Gage height, in feet, and discharge, in second-feet, at indicated time, 1940

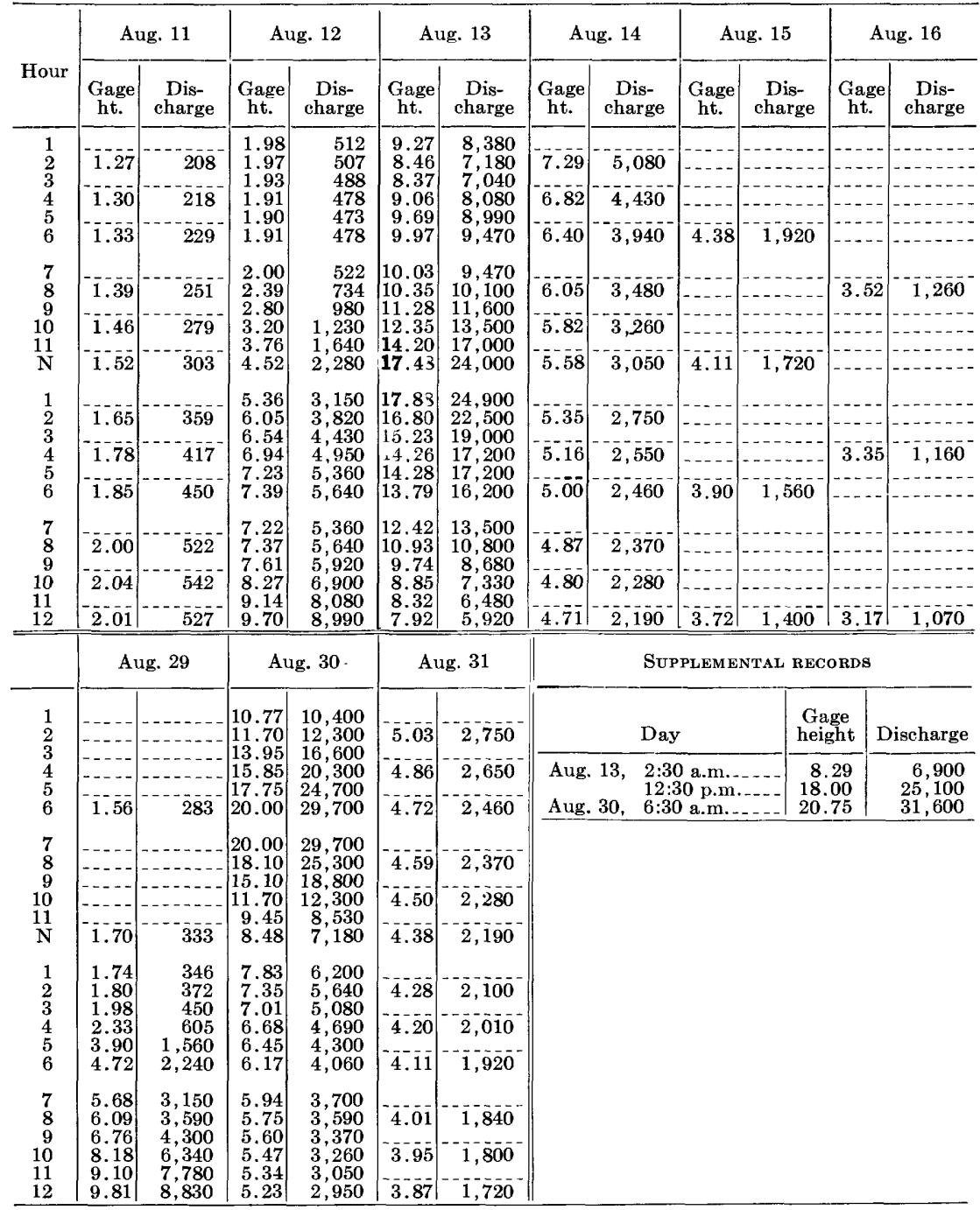


PIGEON RIVER NEAR HEPCo, N. C.

LOCATION.-Lat. $35^{\circ} 38^{\prime} 15^{\prime \prime}$, long. $82^{\circ} 59^{\prime} 15^{\prime \prime}$, three-quarters of a mile downstream from Jonathan Creek and 21/2 miles upstream from Fines Creek and from Hepco, Haywood County. Datum of gage is 2,335.95 feet above mean sea level, datum of 1929, supplementary adjustment of 1936 .

Drain AGE AREA.- 350 square miles.

GAGE-HEIGHT RECORD.-Water-stage recorder graph except for 2-11 p.m. Aug. 13 and Aug. 29 to noon Aug. 30, where graph based on floodmarks in gage house and records for stations at Canton and Waterville power plant and for tributary streams was used, and Aug. 23-28, where only fragmentary recorder graph was available.

DischARge RECORD.-Stage-discharge relation defined by current-meter measurements up to 10,600 second-feet and extended to crest gage height on basis of determination of flood flows by slope-area method at gage heights 14.94 feet and 15.82 feet. Shifting-control method used Aug. 17 to 6 p.m. Aug. 29. Gage heights used to half-tenths between 2.4 and 5.7 feet; hundredths below and tenths above these limits.

Maxima.-1940: Discharge, 32,700 second-feet about 10:30 a.m. Aug. 30 (gage height, 15.82 feet, from floodmarks in gage house).

1927-39: Discharge, 21,900 second-feet Aug. 16, 1928 (gage height, 12.63 feet).

Surveys by the Tennessee Valley Authority show that the floods of June 1876 and February 1902 reached a stage of about 18 feet, from flood profiles. REMARKs.-Flood runoff not affected by artificial storage.

Mean discharge, in second-feet, 1940

\begin{tabular}{|c|c|c|c|c|c|c|c|c|c|c|c|}
\hline Day & Aug. & Sept. & Day & Aug. & Sept. & Day & Aug. & Sept. & Day & Aug. & Sept. \\
\hline 1 & 445 & 2,170 & 9 & 521 & 839 & 17 & 1,760 & 614 & 25 & & 504 \\
\hline 2 & 394 & 1,900 & 10 & 458 & & 18 & 1,470 & 583 & 26 & 650 & 486 \\
\hline 3 & 373 & 1,470 & 11 & & 808 & 19 & 1,240 & 573 & 27 & 600 & 454 \\
\hline 4 & 365 & 1,470 & 12 & 2,540 & 722 & 20 & 1,100 & 558 & 28 & & 445 \\
\hline 5 & 353 & 1,170 & 13 & 17,100 & 694 & 21 & 968 & 538 & 29 & 1,420 & 458 \\
\hline 6 & 365 & 935 & 14 & 6,490 & 66 & 22 & 870 & 519 & 30 & 16,400 & 450 \\
\hline 8 & $\begin{array}{ll}476 \\
386\end{array}$ & $\begin{array}{r}1,000 \\
935\end{array}$ & 16 & $\begin{array}{l}3,250 \\
2,300\end{array}$ & 640 & $\begin{array}{l}23 \\
24\end{array}$ & $\begin{array}{l}850 \\
850\end{array}$ & $\begin{array}{l}504 \\
500\end{array}$ & & & \\
\hline \multicolumn{10}{|c|}{ Monthly mean discharge, in second-feet } & $\begin{array}{r}2,246 \\
7.40\end{array}$ & $\begin{array}{r}803 \\
2.56\end{array}$ \\
\hline
\end{tabular}


TENNESSEE RIVER BASIN

Gage height, in feet, and discharge, in second-feet, at indicated time, 1940

\begin{tabular}{|c|c|c|c|c|c|c|c|c|c|c|}
\hline \multirow{2}{*}{ Hour } & \multicolumn{2}{|c|}{ Aug. 12} & \multicolumn{2}{|c|}{ Aug. 13} & \multicolumn{2}{|c|}{ Aug. 14} & \multicolumn{2}{|c|}{ Aug. 15} & \multicolumn{2}{|c|}{ Aug. 16} \\
\hline & $\begin{array}{c}\text { Gage } \\
\text { height }\end{array}$ & $\begin{array}{c}\text { Dis- } \\
\text { charge }\end{array}$ & $\begin{array}{c}\text { Gage } \\
\text { height }\end{array}$ & $\begin{array}{c}\text { Dis- } \\
\text { charge }\end{array}$ & $\begin{array}{c}\text { Gage } \\
\text { height }\end{array}$ & $\begin{array}{l}\text { Dis- } \\
\text { charge }\end{array}$ & $\begin{array}{c}\text { Gage } \\
\text { height }\end{array}$ & $\begin{array}{c}\text { Dis- } \\
\text { charge }\end{array}$ & $\begin{array}{l}\text { ge } \\
\text { ht }\end{array}$ & $\begin{array}{c}\text { Dis- } \\
\text { charge }\end{array}$ \\
\hline $\begin{array}{l}1 \\
2 \\
3 \\
4 \\
5 \\
6\end{array}$ & 2.60 & 808 & $\begin{array}{l}7.61 \\
8.01 \\
8.68 \\
8.64 \\
8.45 \\
8.14\end{array}$ & $\begin{array}{r}7,740 \\
8,680 \\
10,500 \\
10,200 \\
9,690 \\
8,930\end{array}$ & $\begin{array}{l}9.30 \\
8.70 \\
8.40 \\
8.07 \\
7.79 \\
7.55\end{array}$ & $\begin{array}{r}12,100 \\
10,500 \\
9,690 \\
8,930 \\
8,200 \\
7,740\end{array}$ & $\overline{5} . \overline{37}$ & 3,580 & 4.53 & 2,470 \\
\hline $\begin{array}{r}7 \\
8 \\
9 \\
10 \\
11 \\
\mathrm{~N}\end{array}$ & 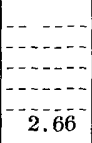 & 839 & $\begin{array}{r}8.03 \\
8.56 \\
9.29 \\
9.86 \\
10.25 \\
10.52\end{array}$ & $\begin{array}{r}8,680 \\
10,200 \\
12,100 \\
13,800 \\
14,700 \\
15,600\end{array}$ & $\begin{array}{l}7.38 \\
7.17 \\
7.02 \\
6.86 \\
6.74 \\
6.62\end{array}$ & $\begin{array}{l}7,300 \\
6,880 \\
6,470 \\
6,270 \\
5,880 \\
5,690\end{array}$ & $-\overline{5} 1 \overline{2}^{-}$ & 3,210 & 4.38 & 2,290 \\
\hline \multirow{3}{*}{$\begin{array}{r}1 \\
2 \\
3 \\
4 \\
5 \\
6 \\
7 \\
8 \\
9 \\
10 \\
11 \\
12 \\
\end{array}$} & $\begin{array}{l}2.85 \\
3.50 \\
4.08 \\
4.67 \\
5.34 \\
5.88\end{array}$ & $\begin{array}{r}968 \\
1,430 \\
1,970 \\
2,600 \\
3,580 \\
4,460\end{array}$ & $\begin{array}{l}11.10 \\
12.20 \\
13.08 \\
13.80 \\
14.48 \\
14.90\end{array}$ & $\begin{array}{l}17,300 \\
20,600 \\
23,400 \\
25,700 \\
28,100 \\
29,500\end{array}$ & $\begin{array}{r}6.42^{-} \\
6.28 \\
6.12\end{array}$ & $\begin{array}{l}5,320 \\
5,140 \\
4,800\end{array}$ & 4.89 & 2,930 & 4.23 & 2,120 \\
\hline & $\begin{array}{l}6.30 \\
6.74 \\
7.08 \\
7.37 \\
7.42 \\
7.49 \\
\end{array}$ & $\begin{array}{l}5,140 \\
5,880 \\
6,670 \\
7,300 \\
7,300 \\
7,520 \\
\end{array}$ & $\begin{array}{l}14.87 \\
14.35 \\
13.65 \\
12.72 \\
11.50 \\
10.14 \\
\end{array}$ & $\begin{array}{l}29,500 \\
27,800 \\
25,100 \\
22,200 \\
18,500 \\
14,400 \\
\end{array}$ & $\begin{array}{r}5.76 \\
5.41^{-} \\
5.43 \\
\end{array}$ & $\begin{array}{r}4,300 \\
3,660 \\
3,740 \\
\end{array}$ & 4.69 & 2,660 & 4.09 & 1,970 \\
\hline & \multicolumn{2}{|c|}{ Aug. 29} & \multicolumn{2}{|c|}{ - Aug. 30} & \multicolumn{2}{|c|}{ Aug. 31} & \multicolumn{2}{|c|}{ Sept. 1} & \multicolumn{2}{|c|}{ Sept. 2} \\
\hline $\begin{array}{l}1 \\
2 \\
3 \\
4 \\
5 \\
6\end{array}$ & ${ }^{2.27}$ & 533 & $\begin{array}{l}10.00 \\
11.70 \\
13.00 \\
12.97 \\
12.93 \\
12.88\end{array}$ & $\begin{array}{l}14,100 \\
19,100 \\
23,100 \\
23,100 \\
22,800 \\
22,800\end{array}$ & $\begin{array}{l}6.25 \\
6.03 \\
5.92\end{array}$ & $\begin{array}{r}4,970 \\
4,630 \\
4,460\end{array}$ & 4.37 & 2,240 & & \\
\hline $\begin{array}{r}7 \\
8 \\
9 \\
10 \\
11\end{array}$ & & & $\begin{array}{l}12.83 \\
12.81 \\
13.50 \\
15.40 \\
15.40\end{array}$ & $\begin{array}{l}22,500 \\
22,500 \\
24,800 \\
31,200 \\
31,200\end{array}$ & $\begin{array}{l}5.81 \\
5.72\end{array}$ & $4,4,300$ & 4.25 & 2,120 & & \\
\hline $\mathrm{N}$ & 2.37 & 588 & 13.80 & 25,700 & 5.59 & $3,980^{-}$ & 4.34 & 2,240 & 4.31 & 2,180 \\
\hline $\begin{array}{l}1 \\
2 \\
3\end{array}$ & $2.60^{-}$ & 722 & $\begin{array}{r}12.27 \\
10.90 \\
9.07\end{array}$ & $\begin{array}{l}20, \\
16, \\
11,\end{array}$ & 5.56 & 3,900 & -1 & & & \\
\hline $\begin{array}{l}4 \\
5\end{array}$ & $3.03^{-}$ & $1,030^{-}$ & 8.32 & $\begin{array}{r}9,430 \\
7,970\end{array}$ & $5 . \overline{4}$ & 3,740 & 4.30 & $2,180^{\circ}$ & & \\
\hline 6 & 3.58 & 1,470 & 7. & 7 ;', & $4.92^{-}$ & 2,930 & - - - & & & \\
\hline $\begin{array}{l}7 \\
8 \\
9\end{array}$ & 4.32 & 2,180 & $\begin{array}{l}7.16 \\
6.91\end{array}$ & & 4.66 & $2,600^{\circ}$ & 4.20 & 2,070 & & \\
\hline $\begin{array}{l}10 \\
11\end{array}$ & 5.57 & $\overline{3}, \overline{9} 00$ & 7 & & $4.57^{-}$ & $\overline{2}, \overline{4} \overline{7}$ & $---\overline{-}$ & & & \\
\hline 12 & $7.90^{-1}$ & 8,440 & 6.50 & 5,500 & $4.50^{-}$ & 2,410 & 4.10 & 1,970 & 3.45 & 1,390 \\
\hline
\end{tabular}

SUPPLEMENTAL RECORDs.-Aug. 13, 6:30 p.m., gage height, 14.94 feet; discharge, 29,500 second-feet. Aug. 30, 10:30 a.m., gage height, 15.82 feet; discharge, 32,700 second-feet.

\section{PIGEON RIVER A'T HARTFORD, TENN.}

Location.-Lat. $35^{\circ} 48^{\prime} 52^{\prime \prime}$, long. $83^{\circ} 08^{\prime} 42^{\prime \prime}$, 600 feet downstream from highway bridge at Hartford, Cocke County, and 4.5 miles downstream from Big Creek and North Carolina-Tennessee State line. Datum of gage is 1,245.74 feet above mean sea level, datum of 1929, supplementary adjustment of 1936 .

Drainage AREA.-547 square miles.

GAGE-HEIGHT RECORD.-Water-stage recorder graph.

DISCHARGE RECORD.-Stage-discharge relation defined by current-meter measurements up to 28,800 second-feet. Gage heights used to half-tenths between 3.3 and 5.1 feet; hundredths below and tenths above these limits. 


\section{FLOODS OF AUGUST 1940 IN THE SOUTHEASTERN STATES}

Maxima.-1940: Discharge, 38,600 second-feet 1:30 p.m. Aug. 30 (gage height, 12.79 feet).

1925-39: Discharge, 25,500 second-feet Jan. 19, 1936 (gage height, 10.68 feet).

REMARKS.-Regulation of flood flow caused by operation of gates at Waterville dam of Carolina Power \& Light Co. 4.5 miles upstream.

Mean discharge, in second-feet, 1940

\begin{tabular}{|c|c|c|c|c|c|c|c|c|c|c|c|}
\hline Day & Aug. & Sept. & Day & Aug. & Sept. & Day & Aug. & Sept. & Day & Aug. & Sept. \\
\hline 1 & 718 & 350 & 9 & 764 & 1,320 & 17 & 2,780 & 1,120 & 25 & 788 & 813 \\
\hline$\overline{2}$ & & & 10 & & & 18 & & & & & \\
\hline 3 & 202 & 2,110 & 11 & 93 & 1,370 & 19 & 2,090 & 970 & 27 & 1,240 & 690 \\
\hline 4 & 75 & 2,130 & 12 & 637 & 1,300 & 20 & 1,7 & 656 & 28 & 1,180 & 115 \\
\hline 5 & 629 & 1,9 & 13 & 15,400 & 1,2 & 21 & 1,7 & 100 & 29 & 1,370 & 83 \\
\hline 6 & 630 & 1,790 & 14 & 9,860 & 1,040 & 22 & 1,480 & 91 & 30 & 22,100 & 706 \\
\hline 7 & 756 & 1,620 & 15 & 5,7 & 828 & 23 & 1,460 & 880 & 31 & 6,330 & $\ldots$ \\
\hline 8 & 758 & 860 & 16 & 3,660 & 1,150 & 24 & 926 & 819 & & & \\
\hline \multicolumn{10}{|c|}{$\begin{array}{l}\text { Monthly mean discharge, in second-feet } \\
\text { Runoff, in inches }\end{array}$} & $\begin{array}{r}2,881 \\
6.07\end{array}$ & $\begin{array}{r}1,183 \\
2.41\end{array}$ \\
\hline
\end{tabular}

Gage height, in feet, and discharge, in second-feet, at indicated time, 1940

\begin{tabular}{|c|c|c|c|c|c|c|c|c|c|c|c|c|}
\hline \multirow{2}{*}{ Hour } & \multicolumn{2}{|c|}{ Aug. 12} & \multicolumn{2}{|c|}{ Aug. 13} & \multicolumn{2}{|c|}{ Aug. 14} & \multicolumn{2}{|c|}{ Aug. 29} & \multicolumn{2}{|c|}{ Aug. 30} & \multicolumn{2}{|c|}{ Aug. 31} \\
\hline & $\begin{array}{c}\text { Gage } \\
\text { ht. }\end{array}$ & $\begin{array}{l}\text { Dis- } \\
\text { charge }\end{array}$ & $\begin{array}{c}\text { Gage } \\
\text { ht. }\end{array}$ & $\begin{array}{l}\text { Dis- } \\
\text { charge }\end{array}$ & $\begin{array}{c}\text { Gage } \\
\text { ht. }\end{array}$ & $\begin{array}{c}\text { Dis- } \\
\text { charge }\end{array}$ & $\begin{array}{c}\text { Gage } \\
\text { ht. }\end{array}$ & $\begin{array}{l}\text { Dis- } \\
\text { charge }\end{array}$ & $\begin{array}{c}\text { Gage } \\
\text { ht. }\end{array}$ & $\begin{array}{c}\text { Dis- } \\
\text { charge }\end{array}$ & $\begin{array}{c}\text { Gage } \\
\text { ht. }\end{array}$ & $\begin{array}{l}\text { Dis- } \\
\text { charge }\end{array}$ \\
\hline $\begin{array}{l}1 \\
2 \\
3 \\
4 \\
5 \\
6\end{array}$ & $\begin{array}{l}1.20 \\
1.21 \\
1.21 \\
1.22 \\
1.22 \\
1.22\end{array}$ & $\begin{array}{l}88 \\
89 \\
90 \\
92 \\
92 \\
92\end{array}$ & $\begin{array}{l}2.57 \\
2.66 \\
2.23 \\
6.90 \\
6.92 \\
6.99\end{array}$ & $\begin{array}{r}853 \\
937 \\
572 \\
9,120 \\
9,120 \\
9,440\end{array}$ & $\begin{array}{l}9.89 \\
9.60 \\
9.21 \\
7.85 \\
7.14 \\
7.18\end{array}$ & $\begin{array}{r}21,300 \\
19,800 \\
17,900 \\
12,200 \\
9,760 \\
10,100\end{array}$ & $\begin{array}{l}2.63 \\
2.58 \\
2.55 \\
2.55 \\
2.54 \\
2.53\end{array}$ & $\begin{array}{l}908 \\
862 \\
835 \\
835 \\
826 \\
817\end{array}$ & $\begin{array}{r}4.16 \\
4.67 \\
6.05 \\
11.85 \\
12.47 \\
12.47\end{array}$ & $\begin{array}{r}2,970 \\
3,800 \\
6,500 \\
32,200 \\
36,700 \\
36,700\end{array}$ & \begin{tabular}{|l|}
6.58 \\
6.57 \\
6.54 \\
6.52 \\
6.49 \\
6.30
\end{tabular} & $\begin{array}{l}8,200 \\
8,200 \\
7,900 \\
7,900 \\
7,900 \\
7,220\end{array}$ \\
\hline $\begin{array}{r}7 \\
8 \\
9 \\
10 \\
11 \\
\mathrm{~N}\end{array}$ & $\begin{array}{l}1.23 \\
1.23 \\
2.10 \\
3.16 \\
3.06 \\
3.07\end{array}$ & $\begin{array}{r}94 \\
94 \\
475 \\
1,490 \\
1,360 \\
1,370\end{array}$ & $\begin{array}{l}7.46 \\
7.45 \\
7.53 \\
7.53 \\
7.43 \\
7.60\end{array}$ & $\begin{array}{l}11,100 \\
10,800 \\
11,100 \\
11,100 \\
10,800 \\
11,500\end{array}$ & $\begin{array}{l}7.11 \\
5.75 \\
6.99 \\
6.95 \\
6.67 \\
6.55\end{array}$ & $\begin{array}{l}9,760 \\
6,000 \\
9,440 \\
9,440 \\
8,500 \\
8,200\end{array}$ & $\begin{array}{l}2.54 \\
2.56 \\
2.75 \\
3.32 \\
3.43 \\
3.36\end{array}$ & $\begin{array}{r}826 \\
844 \\
1,020 \\
1,670 \\
1,880 \\
1,740\end{array}$ & $\begin{array}{l}11.85 \\
11.78 \\
11.77 \\
11.98 \\
12.00 \\
12.52\end{array}$ & $\begin{array}{l}32,200 \\
32,200 \\
32,200 \\
33,400 \\
33,400 \\
36,700\end{array}$ & $\begin{array}{l}6.04 \\
5.94 \\
6.01 \\
6.00 \\
5.80 \\
5.72\end{array}$ & $\begin{array}{l}6,500 \\
6,240 \\
6,500 \\
6,500 \\
6,000 \\
5,780\end{array}$ \\
\hline $\begin{array}{l}1 \\
2 \\
3 \\
4 \\
5 \\
6\end{array}$ & $\begin{array}{l}3.11 \\
2.90 \\
2.94 \\
2.66 \\
2.12 \\
1.85\end{array}$ & $\begin{array}{r}1,420 \\
1,180 \\
1,220 \\
938 \\
490 \\
310\end{array}$ & $\begin{array}{r}8.27 \\
8.64 \\
9.06 \\
9.54 \\
10.46 \\
11.08\end{array}$ & $\begin{array}{l}14,100 \\
15,300 \\
17,500 \\
19,300 \\
24,500 \\
27,900\end{array}$ & $\begin{array}{l}6.31 \\
6.44 \\
6.16 \\
6.11 \\
5.89 \\
5.94\end{array}$ & $\begin{array}{l}7,220 \\
7,600 \\
7,040 \\
6,760 \\
6,240 \\
6,240\end{array}$ & $\begin{array}{l}3.43 \\
2.98 \\
3.34 \\
3.17 \\
2.95 \\
2.93\end{array}$ & $\begin{array}{l}1,880 \\
1,270 \\
1,740 \\
1,500 \\
1,240 \\
1,210\end{array}$ & $\begin{array}{r}12.62 \\
12.50 \\
11.40 \\
10.00 \\
8.03 \\
8.30\end{array}$ & $\begin{array}{l}37,300 \\
36,700 \\
29,700 \\
21,800 \\
13,000 \\
14,100\end{array}$ & $\begin{array}{l}5.88 \\
5.72 \\
5.43 \\
5.48 \\
5.72 \\
5.70\end{array}$ & $\begin{array}{l}6,240 \\
5,780 \\
5,160 \\
5,360 \\
5,780 \\
5,780\end{array}$ \\
\hline $\begin{array}{r}7 \\
8 \\
9 \\
10 \\
11 \\
12\end{array}$ & $\begin{array}{l}1.87 \\
2.00 \\
2.25 \\
3.03 \\
2.91 \\
2.57\end{array}$ & $\begin{array}{r}322 \\
405 \\
588 \\
1,330 \\
1,190 \\
853\end{array}$ & $\left|\begin{array}{l}11.75 \\
11.90 \\
11.10 \\
11.10 \\
10.10 \\
10.05\end{array}\right|$ & $\begin{array}{l}31,600 \\
32,800 \\
27,900 \\
27,900 \\
22,400 \\
21,800\end{array}$ & $\begin{array}{l}6.00 \\
6.55 \\
6.70 \\
6.63 \\
6.30 \\
6.27\end{array}$ & $\begin{array}{l}6,500 \\
8,200 \\
8,500 \\
8,200 \\
7,220 \\
7,220\end{array}$ & $\begin{array}{l}2.96 \\
3.13 \\
3.63 \\
3.73 \\
3.66 \\
3.85\end{array}$ & $\begin{array}{l}1,250 \\
1,450 \\
2,180 \\
2,330 \\
2,180 \\
2,490\end{array}$ & $\begin{array}{l}7.77 \\
7.68 \\
7.30 \\
7.18 \\
7.07 \\
6.60\end{array}$ & $\begin{array}{r}12,200 \\
11,900 \\
10,400 \\
10,100 \\
9,760 \\
8,200\end{array}$ & $\begin{array}{l}5.68 \\
5.62 \\
5.63 \\
5.45 \\
5.09 \\
5.03\end{array}$ & $\begin{array}{l}5,780 \\
5,560 \\
5,560 \\
5,160 \\
4,580 \\
4,490\end{array}$ \\
\hline
\end{tabular}

Supplamental ReCords.-Aug. 13, 7:30 p.m., gage height, 12.10 feet; discharge, 34,100 second-feet. Aug. 30, 1:30 p.m., gage height, 12.79 feet; discharge, 38,600 second-feet. 
JONATHAN CREEK NEAR COVE CREEK, N. C.

Location.-Lat. $35^{\circ} 37^{\prime} 40^{\prime \prime}$, long. $83^{\circ} 00^{\prime} 00^{\prime \prime}, 1,500$ feet downstream from ford, three-quarters of a mile upstream from mouth, and 2 miles downstream from Cove Creek and Cove Creek post office, Haywood County. Datum of gage is 2,383.89 feet above mean sea level, datum of 1929, supplementary adjustment of 1936 .

DRAINAGE AREA.-65.3 square miles.

GAGE-HEIGHT RECORD.-Water-stage recorder graph.

DISCIIARGE RLCORD.-Stage-diseharge relation defined by current-meter measurements up to 1,350 second-feet and extended to erest gage height on basis of logarithmie plotting, giving some weight to a determination of flood flow by slope-area method. Gage heights used to half-tenths between 2.8 and 5.3 feet; hundredths below and tenths above these limits.

Maxima.-1940: Discharge, 3,200 second-feet 4 a.m. Aug. 30 (gage height, 7.51 feet).

1930-39: Discharge, 2,270 second-feet Jan. 19, 1936 (gage height, 6.20 feet). Remarks.--Flood runoff not affected by artificial storage.

- Mean discharge, in second-feet, 1940

\begin{tabular}{r|r|r||r|r|r|r|r|r|r|r|r}
\hline Day & Aug. & \multicolumn{1}{|c|}{ Sept. } & Day & Aug. & Sept. & Day & Aug. & Sept. & Day & Aug. & Sept. \\
\hline 1 & 99 & 358 & 9 & 75 & 154 & 17 & 261 & 105 & 25 & 124 & 96 \\
2 & 91 & 293 & 10 & 72 & 180 & 18 & 225 & 104 & 26 & 116 & 89 \\
3 & 84 & 251 & 11 & 92 & 154 & 19 & 212 & 102 & 27 & 110 & 83 \\
4 & 81 & 228 & 12 & 257 & 137 & 20 & 181 & 96 & 28 & 104 & 81 \\
5 & 79 & 210 & 13 & 1,100 & 128 & 21 & 163 & 95 & 29 & 466 & 79 \\
6 & 86 & 191 & 14 & 720 & 122 & 22 & 154 & 91 & 30 & 1,540 & 77 \\
7 & 104 & 177 & 15 & 427 & 117 & 23 & 142 & 89 & 31 & 514 & \\
8 & 80 & 165 & 16 & 317 & 110 & 24 & 141 & 88 & & \\
\hline
\end{tabular}


368 FLOODS OF AUGUST 1940 IN THE SOUTHEASTERN STATES

Gage height, in feet, and discharge, in second-feet, at indicated time, 1940

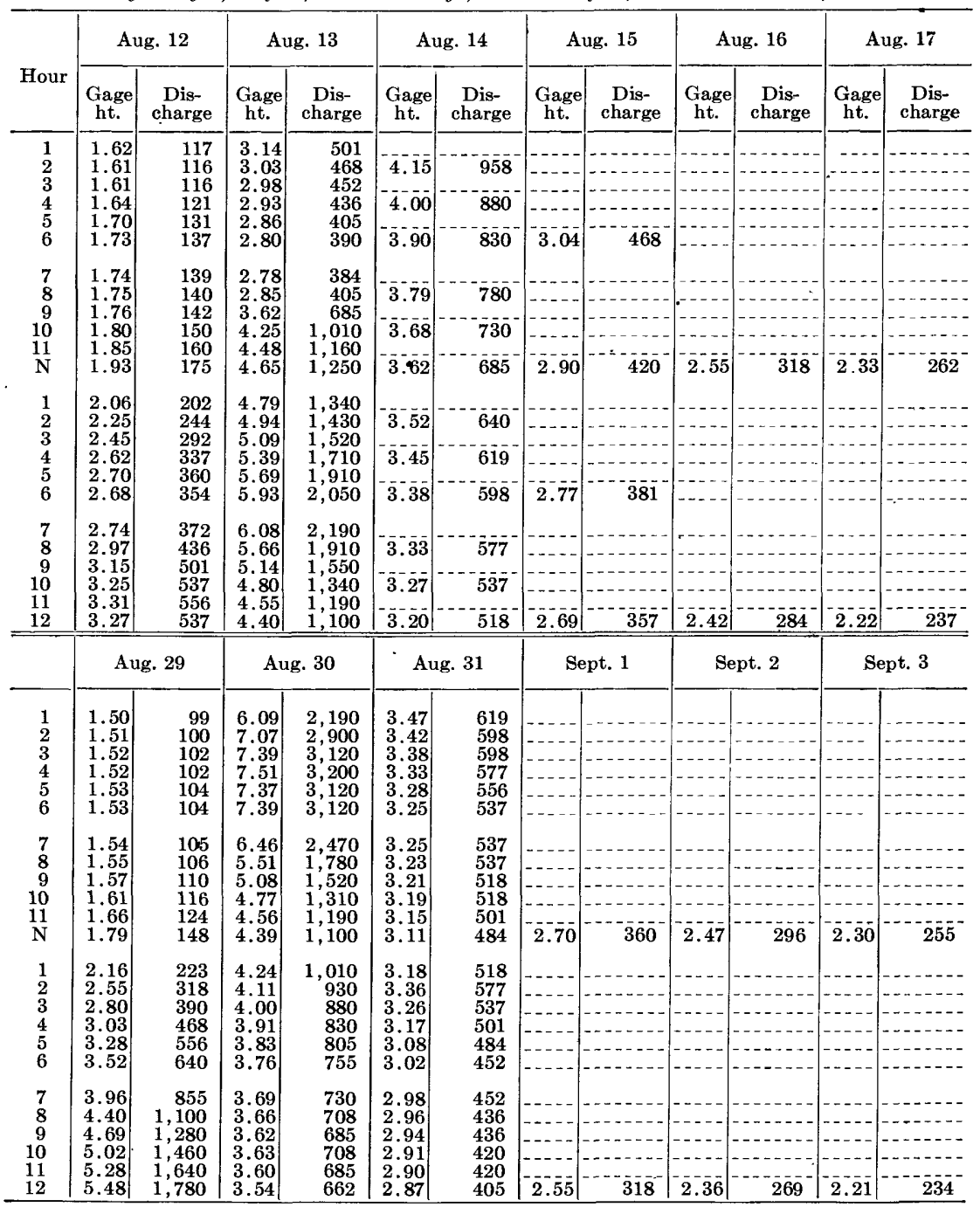


CATALOOCHEE CREEK NEAR CATALOOCHEE, N. C.

Location.-Lat. $35^{\circ} 39^{\prime} 55^{\prime \prime}$, long. $83^{\circ} 04^{\prime} 50^{\prime \prime}$, at bridge on State Highway 284, just upstream from Little Cataloochee Creek and 2 miles north of Cataloochee, Haywood County. Datum of gage is $2,457.48$ feet above mean sea level, datum of 1929.

DrAINAGE AREA. -49.2 square miles.

GAGE-HEIGHT RECORD.-Water-stage recorder graph.

DISCHARGE RECORD.-Artificial control is concrete. Stage-discharge relation defined by current-meter measurements up to 1,500 second-feet and extended to erest gage height logarithmically, allowing for slight over-bank flow. Shifting-control method used from 2 p.m. Aug. 30 to Sept. 30. Gage heights used to half-tenths above and hundredths below 4.1 feet.

Maxima.-1940: Discharge, 3,390 second-feet 3 a.m. Aug. 30 (gage height, 7.01 feet).

1934-39: Discharge, 2,700 second-feet Jan. 19, 1936 (gage height, 6.64 feet). REMARKs.-Flood runoff not affected by artificial storage.

Mean discharge, in second-feet, 1940

\begin{tabular}{|c|c|c|c|c|c|c|c|c|c|c|c|}
\hline Day & Aug: & Sept. & Day & Aug. & Sept. & Day & Aug. & Sept. & Day & Aug. & Sept. \\
\hline $\begin{array}{l}1 \\
2 \\
3 \\
4 \\
5 \\
6 \\
7 \\
8\end{array}$ & $\begin{array}{r}105 \\
94 \\
90 \\
82 \\
80 \\
86 \\
80 \\
73\end{array}$ & $\begin{array}{l}312 \\
246 \\
204 \\
178 \\
154 \\
137 \\
122 \\
112\end{array}$ & $\begin{array}{r}9 \\
10 \\
11 \\
12 \\
13 \\
14 \\
15 \\
16\end{array}$ & $\begin{array}{r}71 \\
68 \\
80 \\
133 \\
742 \\
589 \\
455 \\
320\end{array}$ & $\begin{array}{r}101 \\
124 \\
101 \\
88 \\
84 \\
82 \\
76 \\
73\end{array}$ & $\begin{array}{l}17 \\
18 \\
19 \\
20 \\
21 \\
22 \\
23 \\
24\end{array}$ & $\begin{array}{l}249 \\
217 \\
196 \\
163 \\
145 \\
137 \\
122 \\
119\end{array}$ & $\begin{array}{l}\mathbf{6 9} \\
\mathbf{6 8} \\
\mathbf{6 6} \\
\mathbf{6 2} \\
\mathbf{6 2} \\
\mathbf{5 9} \\
\mathbf{5 7} \\
\mathbf{5 7}\end{array}$ & $\begin{array}{l}25 \\
26 \\
27 \\
28 \\
29 \\
30 \\
31\end{array}$ & $\begin{array}{r}108 \\
98 \\
92 \\
86 \\
252 \\
1,310 \\
459\end{array}$ & $\begin{array}{l}62 \\
56 \\
53 \\
51 \\
49 \\
48 \\
-\end{array}$ \\
\hline \multicolumn{10}{|c|}{$\begin{array}{l}\text { Monthly mean discharge, in second-feet. } \\
\text { Runoff, in inches }\end{array}$} & $\begin{array}{r}223 \\
5.22\end{array}$ & $\begin{array}{r}100 \\
2.28\end{array}$ \\
\hline
\end{tabular}




\section{FLOODS OF AUGUST 1940 IN THE SOUTHEASTERN STATES}

Gage height, in feet, and discharge, in second-feet, at indicated time, 1940

\begin{tabular}{|c|c|c|c|c|c|c|c|c|c|c|c|c|}
\hline \multirow[b]{2}{*}{ Hour } & \multicolumn{2}{|c|}{ Aug. 12} & \multicolumn{2}{|c|}{ Aug. 13} & \multicolumn{2}{|c|}{ Aug. 14} & \multicolumn{2}{|c|}{ Aug. 15} & \multicolumn{2}{|c|}{ Aug. 16} & \multicolumn{2}{|c|}{ Aug. 17} \\
\hline & $\begin{array}{c}\text { Gage } \\
\text { ht. }\end{array}$ & $\begin{array}{l}\text { Dis- } \\
\text { charge }\end{array}$ & $\begin{array}{c}\text { Gage } \\
\text { ht. }\end{array}$ & $\begin{array}{l}\text { Dis- } \\
\text { charge }\end{array}$ & $\begin{array}{c}\text { Gage } \\
\text { ht. }\end{array}$ & $\begin{array}{l}\text { Dis- } \\
\text { charge }\end{array}$ & $\begin{array}{c}\text { Gage } \\
\text { ht. }\end{array}$ & $\begin{array}{c}\text { Dis- } \\
\text { charge }\end{array}$ & $\begin{array}{c}\text { Gage } \\
\text { ht. }\end{array}$ & $\begin{array}{c}\text { Dis- } \\
\text { charge }\end{array}$ & $\begin{array}{c}\text { Gage } \\
\text { ht. }\end{array}$ & $\begin{array}{c}\text { Dis- } \\
\text { charge }\end{array}$ \\
\hline 1 & $\ldots$ & -- & 3.11 & 274 & & & & & & & & \\
\hline 2 & & & 3.11 & 2 & 4.04 & $6 \overline{7} \overline{7}$ & & & & & & \\
\hline $\begin{array}{l}5 \\
4\end{array}$ & - & $\ldots$ & $\begin{array}{l}3.14 \\
3.15\end{array}$ & $\begin{array}{l}284 \\
288\end{array}$ & 4.00 & 655 & $\ldots$ & & & & & \\
\hline $\begin{array}{l}5 \\
6\end{array}$ & 2.44 & 84 & $\begin{array}{l}3.15 \\
3.15\end{array}$ & $\begin{array}{l}288 \\
288\end{array}$ & 3.98 & 645 & -- & & & & & \\
\hline 7 & & & 3.22 & 312 & & & & & & & & \\
\hline $\begin{array}{l}8 \\
9\end{array}$ & & & $\begin{array}{l}3.50 \\
4.16\end{array}$ & 420 & $3 . \overline{9} 3$ & 620 & & & & & & \\
\hline 10 & & & $\begin{array}{l}4.42 \\
4.42\end{array}$ & 880 & 3.89 & 600 &.- & & ---- & & & \\
\hline $\mathrm{N}$ & 2.48 & 92 & $\begin{array}{l}4 .+1 \\
4.30\end{array}$ & 820 & $\overline{3} . \overline{8} \overline{3}$ & 570 & $\overline{3} . \overline{5}$ & 452 & 3.24 & 319 & 3.04 & $24 \overline{9}$ \\
\hline $\begin{array}{l}1 \\
2\end{array}$ & 2,51 & 98 & 4.33 & 850 & 380 & $=555$ & & & & & & \\
\hline 3 & & & $\begin{array}{l}4.70 \\
5.05\end{array}$ & $\begin{array}{l}1,070 \\
1,320\end{array}$ & 0.00 & 050 & & & & & & \\
\hline $\begin{array}{l}4 \\
5\end{array}$ & 2.63 & 127 & 5.12 & 1,360 & 3.75 & 532 & & & & & & \\
\hline 6 & 2.64 & 129 & 4.80 & 1,140 & 3.72 & 519 & -- & & & & $\cdots-$ & - \\
\hline $\begin{array}{l}7 \\
8\end{array}$ & 3.00 & 235 & 4.65 & 1,040 & 372 & 519 & & & & & & \\
\hline 9 & & & 4.43 & 910 & & & & & & & & \\
\hline $\begin{array}{l}10 \\
11\end{array}$ & 3.22 & 312 & $\begin{array}{l}4.34 \\
4.23\end{array}$ & 850 & 3.75 & 532 & & & & & & \\
\hline 12 & $|\overline{3} . \overline{13}|$ & $280^{-}$ & $\begin{array}{l}4.20 \\
4.16\end{array}$ & 738 & $\overline{3} . \overline{8}$ & $5 \overline{4} 6$ & $\overline{3} . \overline{3} \overline{7}$ & 368 & $\overline{3} . \overline{1}$ & 280 & 2.97 & 226 \\
\hline
\end{tabular}

\begin{tabular}{|c|c|c|c|c|c|c|c|c|c|c|c|c|}
\hline \multirow{5}{*}{$\begin{array}{l}1 \\
2 \\
3 \\
4 \\
5 \\
6\end{array}$} & \multicolumn{2}{|c|}{ Aug. 29} & \multicolumn{2}{|c|}{ Aug. 30} & \multicolumn{2}{|c|}{ Aug. 31} & \multicolumn{2}{|c|}{ Sept. 1} & \multicolumn{2}{|c|}{ Sept. 2} & \multicolumn{2}{|c|}{ Sept. 3} \\
\hline & & & $\begin{array}{l}5.08 \\
6.10\end{array}$ & $\begin{array}{l}1,360 \\
2,240\end{array}$ & 3.87 & 56 & & & & & & \\
\hline & $\ldots$ & --- & 7.01 & 3,390 & & & & & & & & \\
\hline & & $\cdots-1$ & $\begin{array}{l}6.70 \\
6.22\end{array}$ & 2,960 & 3.80 & 532 & $-\ldots$ & & & & -- & \\
\hline & 2.44 & 84 & 5.86 & 1,990 & $3 . \overline{4}$ & 501 & & & -- & & $\mid \begin{array}{l}-\cdots \\
-\cdots-1\end{array}$ & - \\
\hline $\begin{array}{l}7 \\
8\end{array}$ & & & $\begin{array}{l}5.51 \\
5.30\end{array}$ & $\begin{array}{l}1,680 \\
1,520\end{array}$ & 3.70 & 483 & & & & & & \\
\hline $\begin{array}{r}9 \\
10\end{array}$ & & & 5.10 & 1,360 & 0.10 & (100 & & & & & & \\
\hline 11 & & & $\begin{array}{l}4.90 \\
4.75\end{array}$ & $\begin{array}{l}1,210 \\
1,100\end{array}$ & 3.67 & 470 & & & & & & \\
\hline $\mathbf{N}$ & 2.56 & 110 & 4.65 & 1,040 & 3.64 & 456 & 3.28 & 312 & 3.09 & 246 & 2.96 & 205 \\
\hline 1 & 2.67 & 137 & 4.5 & 94 & & & & & & & & \\
\hline $\begin{array}{l}2 \\
3\end{array}$ & $\begin{array}{l}3.00 \\
3.23\end{array}$ & 235 & $\begin{array}{l}4.41 \\
4.32\end{array}$ & 880 & 3.64 & 456 & & & & & & \\
\hline 4 & 3.27 & 330 & $\begin{array}{l}4.32 \\
4.25\end{array}$ & $\begin{array}{l}820 \\
765\end{array}$ & 3.56 & 420 & -... - & $\ldots$ &.-- & & & \\
\hline 5 & $\begin{array}{l}3.30 \\
3.32\end{array}$ & 340 & 4.17 & 73 & & & -1 & & $\ldots$ & & 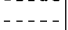 & \\
\hline 0 & 3.32 & 48 & 4.10 & 88 & 3.50 & 396 & & & $\cdots$ & & $\cdots-$ & -- \\
\hline 7 & 3.35 & 360 & 4.2 & 76 & & & & & & & & \\
\hline$y$ & 41 . & 3 & 4.2 & 738 & 3.46 & 380 & & & & & & \\
\hline 10 & 4.00 & 65 & 4.07 & 672 & $3 . \overline{3}$ & $3 \overline{6}$ & - & & -- & & & - \\
\hline $\begin{array}{l}11 \\
12\end{array}$ & $\begin{array}{l}4.29 \\
4.65\end{array}$ & 820 & 4.0 & 630 & & & & & & & & \\
\hline 玨 & 4.60 & 1,040 & 3.95 & 600 & 3.411 & 360 & 3.17 & 274 & 3.02 & 223 & 2.90 & 187 \\
\hline
\end{tabular}

SUPPLEMENTAL RECORDs.-Aug. 13, 10:30 a.m., gage height, 4.45 feet, discharge, 910 second-feet; $3: 30$ p.m., gage height, 5.12 feet, discharge, 1,360 second-feet. Aug. 30, 6:30·p.m., gage height, 4.08 feet, discharge, 677 second-feet. 
NORTH TOE RIVER AT ALTAPASS, N. C.

LoCATION.-Lat. $35^{\circ} 53^{\prime} 59^{\prime \prime}$, long. $82^{\circ} 01^{\prime} 50^{\prime \prime}, 0.1$ mile upstream from Rose Creek and about 1 mile northwest of Altapass, Mitchell County. Datum of gage is 2,542.91 feet above mean sea level, datum of 1929, supplementary adjustment of 1936 .

Drainage AREa.-104 square miles (1943 revision).

GAGE-HEIGHT RECORD.-Water-stage recorder graph except 8:30-10 p.m. Aug. 13, when recorder float was stopped by gage house floor and for which period the graph was completed on basis of floodmark in gage house, and Sept. 14-20, 23-30, when elock was stopped.

Discharge RECORD.-Stage-discharge relation defined by current-meter measurements up to 1,600 second-feet and extended logarithmically to crest gage height on basis of determination of flood flow by slope-area method. Gage heights used to half-tenths between 2.8 and 4.6 feet Aug. 1-13 and between 3.2 and 4.8 feet Aug. 14 to Sept. 30; hundredths below and tenths above these limits. Discharge for periods of no gage-height record based on recorded range in gage heights and records for nearby streams.

Maxima.-1940: Discharge, 22,200 second-feet 9 p.m. Aug. 13 (gage height, 19.5 feet, from floodmark).

1934-39: Discharge, 4,450 second-feet Jan. 9, 1935 (gage height, 11.75 feet, site and datum then in use).

Surveys by the Tennessee Valley Authority show that the flood of July 1916 reached a stage of 24 feet, from floodmarks, and flood of May 1901 reached a stage of 23 feet, from local residents' comparison with 1916 flood.

ReMarKs.-Flood runoff not affected by artificial storage.

Mean discharge, in second-feet, 1940

\begin{tabular}{|c|c|c|c|c|c|c|c|c|c|c|c|}
\hline Day & Aug. & Sept. & Day & Aug. & Sept. & Day & Aug. & Sept. & Day & Aug. & Sept. \\
\hline 1 & 98 & 705 & 9 & 86 & 23 & 17 & 646 & 160 & 25 & 224 & 130 \\
\hline 2 & 8 & & 10 & & & 18 & & & & & \\
\hline 3 & 81 & 46 & 11 & 10 & 21 & 19 & & & 2 & 205 & 120 \\
\hline 4 & 79 & 370 & 12 & 730 & 19 & 20 & 3 & 15 & 2 & 239 & 110 \\
\hline 5 & 9 & 3 & 13 & 8,3 & 19 & 21 & & 14 & 2 & 562 & 110 \\
\hline 6 & 98 & $3 n$ & 14 & 4,78 & 19 & 22 & 30 & 14 & 30 & 3,760 & 110 \\
\hline 7 & 161 & 27 & 15 & 1,3 เ0 & 18 & 23 & 265 & 130 & 31 & 1,200 & \\
\hline 8 & 105 & 253 & 16 & 871 & 170 & 24 & 241 & 130 & & & \\
\hline \multicolumn{10}{|c|}{$\begin{array}{l}\text { Monthly mean discharge, in second-feet } \\
\text { Runoff, in inches. }\end{array}$} & $\begin{array}{r}861 \\
9.54\end{array}$ & $\begin{array}{r}224 \\
2.40\end{array}$ \\
\hline
\end{tabular}


FLOODS OF AUGUST 1940 IN THE SOUTHEASTERN STATES

Gage height, in feet, and discharge, in second-feet, at indicated time, 1940

\begin{tabular}{|c|c|c|c|c|c|c|c|c|c|c|}
\hline \multirow{2}{*}{ Hour } & \multicolumn{2}{|c|}{ Aug. 12} & \multicolumn{2}{|c|}{ Aug. 13} & \multicolumn{2}{|c|}{ Aug. 14} & \multicolumn{2}{|c|}{ Aug. 15} & \multicolumn{2}{|c|}{ Aug. 16} \\
\hline & $\begin{array}{c}\text { Gage } \\
\text { height }\end{array}$ & $\begin{array}{c}\text { Dis- } \\
\text { charge }\end{array}$ & $\begin{array}{c}\text { Gage } \\
\text { height }\end{array}$ & $\begin{array}{l}\text { Dis- } \\
\text { charge }\end{array}$ & $\begin{array}{c}\text { Gage } \\
\text { height }\end{array}$ & $\begin{array}{c}\text { Dis- } \\
\text { charge }\end{array}$ & $\begin{array}{c}\text { Gage } \\
\text { height }\end{array}$ & $\begin{array}{c}\text { Dis- } \\
\text { charge }\end{array}$ & $\begin{array}{c}\text { Gage } \\
\text { height }\end{array}$ & $\begin{array}{c}\text { Dis- } \\
\text { charge }\end{array}$ \\
\hline $\begin{array}{l}1 \\
2 \\
3 \\
4 \\
5 \\
6\end{array}$ & $\begin{array}{l}1.47 \\
1.48 \\
1.54 \\
1.62 \\
1.77 \\
1.89\end{array}$ & $\begin{array}{l}123 \\
126 \\
142 \\
164 \\
206 \\
243\end{array}$ & $\begin{array}{l}5.13 \\
5.11 \\
5.12 \\
5.13 \\
5.23 \\
5.42\end{array}$ & $\begin{array}{l}1,880 \\
1,880 \\
1,880 \\
1,880 \\
1,950 \\
2,090\end{array}$ & $\begin{array}{r}16.73 \\
14.32 \\
11.85 \\
10.44 \\
9.51 \\
8.80\end{array}$ & $\begin{array}{r}16,800 \\
12,600 \\
8,780 \\
6,980 \\
5,920 \\
5,150\end{array}$ & $\begin{array}{c}4.89 \\
4.72 \\
4.57\end{array}$ & $\begin{array}{r}1,740 \\
1,620 \\
1,520\end{array}$ & & - \\
\hline $\begin{array}{r}7 \\
8 \\
9 \\
10 \\
11 \\
N\end{array}$ & $\begin{array}{l}1.86 \\
1.87 \\
2.02 \\
2.27 \\
2.35 \\
2.36\end{array}$ & $\begin{array}{l}234 \\
237 \\
286 \\
374 \\
404 \\
407\end{array}$ & $\begin{array}{l}5.63 \\
5.90 \\
6.20 \\
6.56 \\
7.14 \\
7.79\end{array}$ & $\begin{array}{r}2,230 \\
2,460 \\
2,700 \\
-\overline{3}, 020 \\
3,470 \\
4,130\end{array}$ & $\begin{array}{l}8.23 \\
7.77 \\
7.35 \\
6.99 \\
6.69 \\
6.51\end{array}$ & $\begin{array}{l}4,530 \\
4,130 \\
3,740 \\
3,380 \\
3,110 \\
2,940\end{array}$ & $\begin{array}{c}4.42 \\
4.30^{-} \\
4.24\end{array}$ & $\begin{array}{r}1,420 \\
1,360 \\
1,320\end{array}$ & 3.48 & 880 \\
\hline $\begin{array}{l}1 \\
2 \\
3 \\
4 \\
5 \\
6\end{array}$ & $\begin{array}{l}2.45 \\
.2 .53 \\
2.81 \\
3.09 \\
3.67 \\
4.17\end{array}$ & $\begin{array}{r}440 \\
470 \\
580 \\
720 \\
1,010 \\
1,290\end{array}$ & $\begin{array}{r}8.21 \\
8.58 \\
9.56 \\
11.70 \\
14.78 \\
18.22\end{array}$ & $\begin{array}{r}4,530 \\
4,930 \\
6,030 \\
8,640 \\
13,400 \\
19,600\end{array}$ & $\begin{array}{l}6.37 \\
6.23 \\
6.07 \\
5.91 \\
5.82 \\
5.75\end{array}$ & $\begin{array}{l}2,860 \\
2,700 \\
2,620 \\
2,460 \\
2,380 \\
2,380\end{array}$ & $\begin{array}{c}4.12 \\
4.02 \\
-3.93\end{array}$ & $\begin{array}{r}1,230 \\
1,170 \\
1,140\end{array}$ & & \\
\hline \multirow[t]{2}{*}{$\begin{array}{r}7 \\
8 \\
9 \\
10 \\
11 \\
12 \\
\end{array}$} & $\begin{array}{l}4.53 \\
4.78 \\
5.10 \\
5.25 \\
5.27 \\
5.22\end{array}$ & $\begin{array}{l}1,520 \\
1,670 \\
1,880 \\
1,950 \\
2,020 \\
1,950\end{array}$ & $\begin{array}{l}18.06 \\
18.45 \\
19.5 \\
18.93 \\
18.56 \\
18.13\end{array}$ & $\begin{array}{l}19,400 \\
20,000 \\
22,200 \\
21,000 \\
20,400 \\
19,400\end{array}$ & $\begin{array}{l}5.69 \\
5.64 \\
5.50 \\
5.36 \\
5.23 \\
5.09\end{array}$ & $\begin{array}{l}2,300 \\
2,230 \\
2,160 \\
2,090 \\
1,950 \\
1,880\end{array}$ & $\begin{array}{c}3.87 \\
3.80 \\
3.74\end{array}$ & $\begin{array}{l}1,080 \\
1,050 \\
1,020\end{array}$ & 3.27 & 74 \\
\hline & \multicolumn{2}{|c|}{ Aug. 29} & \multicolumn{2}{|c|}{ Aug. 30} & \multicolumn{2}{|c|}{ Aug. 31} & \multicolumn{2}{|c|}{ Sept. 1} & \multicolumn{2}{|c|}{ Sept. 2} \\
\hline $\begin{array}{l}1 \\
2 \\
3 \\
4 \\
5 \\
6\end{array}$ & 1.85 & $19 \overline{9}$ & $\begin{array}{l}5.92 \\
6.15 \\
6.44 \\
6.68 \\
6.95 \\
7.45\end{array}$ & $\begin{array}{l}2,460 \\
2,700 \\
2,860 \\
3,110 \\
3,380 \\
3,740\end{array}$ & $\begin{array}{r}4.85 \\
4.61 \\
4.40\end{array}$ & $\begin{array}{r}1,680 \\
1,550 \\
1,420\end{array}$ & 3.34 & 798 & $\begin{array}{r}2.87 \\
\end{array}$ & 562 \\
\hline $\begin{array}{r}7 \\
8 \\
9 \\
10 \\
11 \\
\mathrm{~N}\end{array}$ & $1.8 \overline{8}$ & $20 \overline{5}$ & $\begin{array}{r}8.20 \\
9.30 \\
9.82 \\
9.90 \\
10.07 \\
9.72\end{array}$ & $\begin{array}{l}4,530 \\
5,700 \\
6,260 \\
6,380 \\
6,620 \\
6,140\end{array}$ & $\begin{array}{l}4.22 \\
4.06 \\
3.94\end{array}$ & $\begin{array}{r}1,290 \\
1,200 \\
1,140\end{array}$ & 3.25 & $\overline{745}$ & $\begin{array}{c}-\overline{2} .84^{-} \\
2.80^{-}\end{array}$ & 548 \\
\hline $\begin{array}{l}1 \\
2 \\
3 \\
4 \\
5 \\
6\end{array}$ & $\begin{array}{l}1.90 \\
1.97 \\
2.13 \\
2.28 \\
2.83 \\
3.00\end{array}$ & $\begin{array}{l}210 \\
230 \\
278 \\
328 \\
544 \\
620\end{array}$ & $\begin{array}{l}9.00 \\
8.33 \\
7.83 \\
7.32 \\
6.85 \\
6.32\end{array}$ & $\begin{array}{l}5,370 \\
4,630 \\
4,130 \\
3,650 \\
3,200 \\
2,780\end{array}$ & $\begin{array}{c}3.83 \\
3.73 \\
3.63\end{array}$ & $\begin{array}{r}1,080 \\
1,020 \\
962\end{array}$ & $\mathbf{3 . 0 7}$ & $6 \overline{5} 5$ & 2.74 & 506 \\
\hline $\begin{array}{r}7 \\
8 \\
9 \\
10 \\
11 \\
12\end{array}$ & $\begin{array}{l}3.07 \\
3.48 \\
4.48 \\
5.42 \\
5.90 \\
5.94\end{array}$ & $\begin{array}{r}655 \\
880 \\
1,480 \\
2,090 \\
2,460 \\
2,460\end{array}$ & $\begin{array}{l}5.92 \\
5.60 \\
5.36 \\
5.16 \\
5.00 \\
4.82\end{array}$ & $\begin{array}{l}2,460 \\
2,230 \\
2,090 \\
1,950 \\
1,810 \\
1,680\end{array}$ & $\begin{array}{c}3.57 \\
3.50 \\
3.44\end{array}$ & 808 & $\begin{array}{c}2.98 \\
2.92\end{array}$ & 584 & \begin{tabular}{c}
$\overline{2} . \overline{6} \overline{7}$ \\
\hdashline$\overline{2} .6 \overline{3}$
\end{tabular} & $4 \overline{8}$ \\
\hline
\end{tabular}

SUPPLEMENTAL RECORDs.-Aug. 13, 6:30 p.m., gage height, 18.33 feet, discharge, 19,800 second-feet. Aug. 29, $5: 30$ p.m., gage height, 3.06 feet, discharge, 650 second-feet; $6: 30$ p.m., gage height, 2.97 feet, discharge, 606 second-feet. 
NOLICHUCKY RIVER AT POPLAR, N. C.

Location.-Lat. $36^{\circ} 04^{\prime} 25^{\prime \prime}$, long. $82^{\circ} 20^{\prime} 20^{\prime \prime}$, at Poplar, Mitchell County, 4 miles downstream from Cane River and 6 miles upstream from State line. Datum of gage is $1,971.96$ feet above mean sea level, datum of 1929 , supplementary adjustment of 1936 .

DRAINAGE AREA.-608 square miles.

GAGE-HEIGHT RECORD.-Water-stage recorder graph. Recorder graph reconstructed from 11 p.m. Aug. 30 to 11 a.m. Aug. 31 owing to partly obstructed intake.

DISCHARGE RECORD.-Stage-discharge relation defined by current-meter measurements up to 16,000 second-feet and extended to crest gage height on basis of determination of flood flow by slope-area method. Gage heights used to half-tenths between 2.7 and 4.5 feet prior to Aug. 14 and between 3.0 and 4.5 feet subsequently; hundredths below and tenths above these limits.

Maxima.-1940: Discharge, 74,500 second-feet 7 p.m. Aug. 13 (gage height, 19.70 feet).

1925-39: Discharge, 41,400 second-feet (revised) Aug. 16, 1928 (gage height, 14.7 feet).

Floods of 1901 and 1916 reached a stage slightly over 21 feet, from flood. marks (discharge not determined).

REMARKs.-Flood runoff not affected by artificial storage.

Mean discharge, in second-feet, 1940

\begin{tabular}{|c|c|c|c|c|c|c|c|c|c|c|c|}
\hline Day & Aug. & Sept. & Day & Aug. & Sept. & Day & Aug. & Sept. & Day & Aug. & Sept. \\
\hline $\begin{array}{l}1 \\
2 \\
3 \\
4 \\
5 \\
6 \\
7 \\
8\end{array}$ & $\begin{array}{l}948 \\
670 \\
510 \\
449 \\
456 \\
559 \\
970 \\
700\end{array}$ & $\begin{array}{l}4,060 \\
3,010 \\
2,420 \\
2,080 \\
1,810 \\
1,630 \\
1,470 \\
1,310\end{array}$ & $\begin{array}{r}9 \\
10 \\
11 \\
12 \\
13 \\
14 \\
15 \\
16\end{array}$ & $\begin{array}{r}518 \\
478 \\
809 \\
5,070 \\
33,200 \\
23,600 \\
7,190 \\
4,440\end{array}$ & $\begin{array}{r}1,230 \\
1,190 \\
1,140 \\
1,010 \\
\mathbf{9 5 5} \\
915 \\
\mathbf{8 4 7} \\
\mathbf{8 2 9}\end{array}$ & $\begin{array}{l}17 \\
18 \\
19 \\
20 \\
21 \\
22 \\
23 \\
24\end{array}$ & $\begin{array}{l}3,420 \\
2,740 \\
2,620 \\
2,080 \\
1,710 \\
1,630 \\
1,400 \\
1,250\end{array}$ & $\begin{array}{l}802 \\
741 \\
732 \\
732 \\
698 \\
641 \\
633 \\
649\end{array}$ & $\begin{array}{l}25 \\
26 \\
27 \\
28 \\
29 \\
30 \\
31\end{array}$ & $\begin{array}{r}1,120 \\
1,090 \\
998 \\
965 \\
2,070 \\
23,500 \\
6,970\end{array}$ & $\begin{array}{l}690 \\
707 \\
649 \\
576 \\
545 \\
537\end{array}$ \\
\hline in & & & & & & & & & & $\begin{array}{r}4,327 \\
8.20\end{array}$ & $\begin{array}{r}1,175 \\
2.16\end{array}$ \\
\hline
\end{tabular}




\section{FLOODS OF AUGUST 1940 IN THE SOUTHEASTERN STATES}

Gage height, in feet, and discharge, in second-feet, at indicated time, 1949

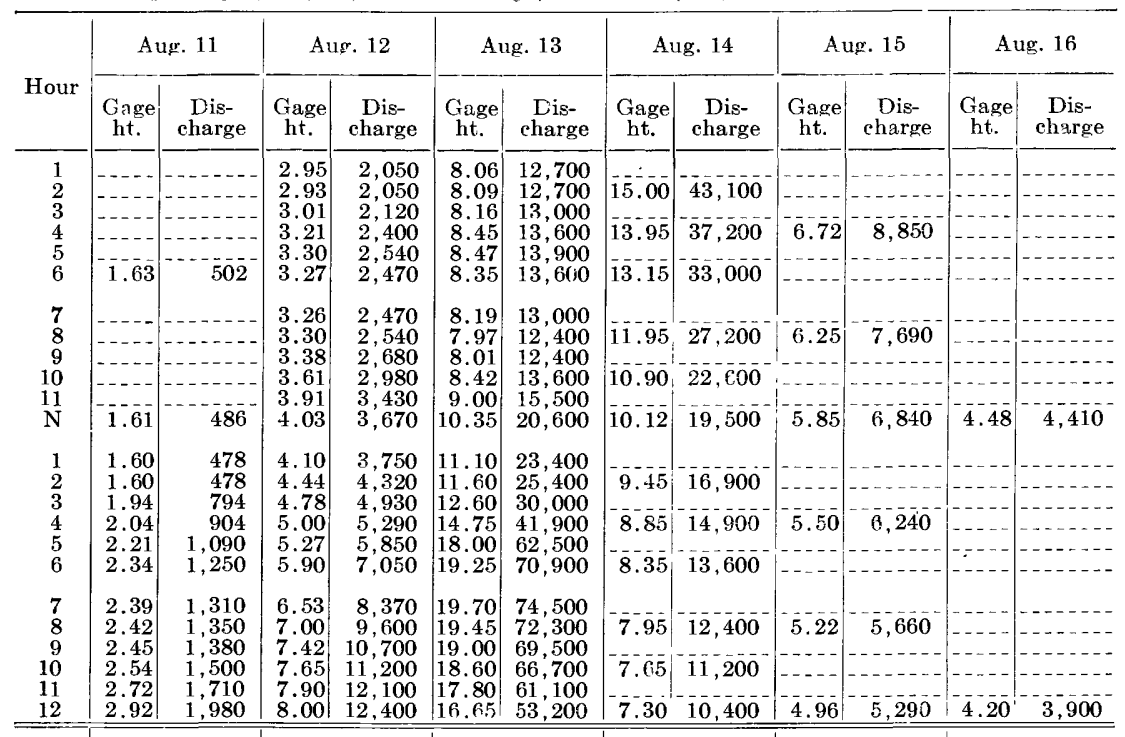

\begin{tabular}{|c|c|c|c|c|c|c|c|c|c|c|c|c|}
\hline \multirow{6}{*}{$\begin{array}{l}1 \\
2 \\
3 \\
4 \\
5 \\
6\end{array}$} & \multicolumn{2}{|c|}{ Aug. 29} & \multicolumn{2}{|c|}{ Aug. 30} & \multicolumn{2}{|c|}{ Aug. 31} & \multicolumn{2}{|c|}{ Sept. 1} & \multicolumn{2}{|c|}{ Sept. 2} & \multicolumn{2}{|c|}{ Sept. 3} \\
\hline & 2.23 & 998 & 9.75 & 18,300 & & & & & & & & \\
\hline & 2.20 & 965 & 10.60 & 21,400 & $\overline{7} . \overline{0}$ & 9,600 & & & & & & \\
\hline & 2.18 & & 11.50 & 25,000 & & & & & & & & \\
\hline & $\begin{array}{l}2.17 \\
2.17\end{array}$ & $\begin{array}{l}935 \\
935\end{array}$ & $\begin{array}{l}12.08 \\
12.35\end{array} \mid$ & $\begin{array}{l}27,700 \\
29,000\end{array}$ & 6.64 & 8,610 & & & & & & \\
\hline & 2.19 & 955 & 12.65 & 30,000 & 6.33 & 7,910 & & & & & & \\
\hline 7 & 2.22 & 987 & 12.92 & 31,500 & & & & & & & & \\
\hline 8 & 2.22 & 987 & 13.07 & 32 & 6.08 & 7,470 & & & & & & \\
\hline $\begin{array}{r}9 \\
10\end{array}$ & $\begin{array}{l}2.23 \\
2.24\end{array}$ & $\begin{array}{r}998 \\
1,010\end{array}$ & $\begin{array}{l}12.98 \\
12.72\end{array}$ & $\begin{array}{l}32,000 \\
30,500\end{array}$ & 5.87 & 7,050 & & & & & & \\
\hline$\stackrel{11}{\mathrm{~N}}$ & $\begin{array}{l}2.25 \\
2.26\end{array}$ & $\begin{array}{l}1,020 \\
1,030\end{array}$ & $\begin{array}{l}12.52 \\
12.47\end{array} \mid$ & $\begin{array}{l}29,500 \\
29,500\end{array}$ & $5, \overline{7}$ & 6640 & 4.25 & 3980 & 3.64 & 3020 & $3 . \overline{2}$ & 2460 \\
\hline 1 & 2.28 & & & & & & & & & & & \\
\hline 2 & 2.33 & 10 & 12.17 & & 5.52 & 6,240 & & & & & & \\
\hline 3 & 2.36 & 1,140 & 11.50 & 25 & & & & & & & & \\
\hline 4 & 2.44 & 1,240 & 10.80 & 22,2 & 5.37 & 6,040 & & & & & & - \\
\hline 6 & 2.66 & $\begin{array}{l}1,400 \\
1,520\end{array}$ & $\left|\begin{array}{r}10.53 \\
9.85\end{array}\right|$ & $\begin{array}{l}20,000 \\
18,300\end{array}$ & 5.24 & 5,660 & & & & & & \\
\hline 7 & 2.90 & 50 & 9.45 & 1 & & & & & & & & \\
\hline 0 & & & 9.00 & & 5.11 & 5,470 & & & & & & \\
\hline $\begin{array}{r}9 \\
10\end{array}$ & $\begin{array}{l}3.57 \\
4.70\end{array}$ & $\begin{array}{l}2,860 \\
4,750\end{array}$ & $\begin{array}{l}8.58 \\
8.20\end{array}$ & $\begin{array}{l}14,200 \\
13,000\end{array}$ & 4.90 & 5,110 & & & & & & \\
\hline 11 & 7.40 & 10,700 & 7.84 & 11,800 & & & & & & & & \\
\hline 12 & 8.90 & 15,200 & 7.50 & 10,900 & 4.76 & 4,930 & 3.86 & 3,340 & 3.42 & 2,620 & 3.12 & 2,150 \\
\hline
\end{tabular}




\section{NOLICHUCKY RIVER AT WMBREEVILLE, TENN.}

LOCATION.-Lat. $36^{\circ} 10^{\prime} 35^{\prime \prime}$, long. $82^{\circ} 27^{\prime} 27^{\prime \prime}, 2,000$ feet upstream from bridge on State Highway 81 at Embreeville, Washington County, 3 miles northwest of Erwin, and 51/4 miles downstream from North Indian Creek. Datum of gage is $1,519.30$ feet above mean sea level, datum of 1929 , supplementary adjustment of 1936 .

DRAINAGE AREA. - 805 square miles.

GAGE-HEIGHT RECORD.-Water-stage recorder graph.

DISCHARGE RECORD.-Stage-discharge relation defined by current-meter measurements up to 47,600 second-feet and extended to crest gage height on basis of determination of flood flow by slope-area method. Gage heights used to half-tenths between 2.7 and 5.2 feet; hundredths below and tenths above these limits.

Maxima.-1940: Discharge, 82,500 second-feet 9:30 p.m. Aug. 13 (gage height, 18.57 feet).

1920-39: Discharge, 36,600 second-feet Mar. 26, 1935 (gage height, 10.69 feet).

ReMarks.-Flood runoff not affected by artificial storage.

Mean discharge, in second-feet, 1940

\begin{tabular}{|c|c|c|c|c|c|c|c|c|c|c|c|}
\hline Day & Aug. & Sept. & Day & Aug. & Sept. & Day & Aug. & Sept. & Day & Aug. & Sept. \\
\hline 1 & 1,510 & 4,780 & 9 & 927 & 1,380 & 17 & 4,370 & 922 & 25 & 1,320 & 780 \\
\hline 2 & 1,050 & 3,400 & 10 & 772 & 1,350 & 18 & 3,330 & 855 & 26 & 1,260 & 844 \\
\hline 3 & 814 & 2,690 & 11 & 804 & 1,300 & 19 & 3,120 & 833 & 27 & 1,060 & 740 \\
\hline 4 & 720 & 2,260 & 12 & 3,590 & 1,160 & 20 & 2,480 & 822 & 28 & 1,080 & 673 \\
\hline 5 & 664 & 1,980 & 13 & 30,700 & 1,100 & 21 & 2,060 & 780 & 29 & 1,380 & 637 \\
\hline 6 & 1,050 & 1,790 & 14 & 27,900 & 1,060 & 22 & 1,860 & 740 & 30 & 27,200 & 628 \\
\hline 7 & 2,290 & 1,620 & 15 & 8,730 & 970 & 23 & 1,610 & 720 & 31 & 9,030 & \\
\hline 8 & 1,280 & 1,470 & 16 & 5,770 & 958 & 24 & 1,430 & 730 & & & \\
\hline \multicolumn{10}{|c|}{$\begin{array}{l}\text { Monthly mean discharge, in second-feet } \\
\text { Runoff, in inches }\end{array}$} & $\begin{array}{r}4,876 \\
6.98\end{array}$ & $\begin{array}{r}1,332 \\
1.85\end{array}$ \\
\hline
\end{tabular}

$804331-49-26$ 
376 FLOODS OF AUGUST 1940 IN THE SOUTHEASTERN STATES

Gage height, in feet, and discharge, in second-feet, at indicated time, 1940

\begin{tabular}{|c|c|c|c|c|c|c|c|c|c|c|c|c|}
\hline \multirow{2}{*}{ Hour } & \multicolumn{2}{|c|}{ Aug. 12} & \multicolumn{2}{|c|}{ Aug. 13} & \multicolumn{2}{|c|}{ Aug. 14} & \multicolumn{2}{|c|}{ Aug. 15} & \multicolumn{2}{|c|}{ Aug. 16} & \multicolumn{2}{|c|}{ Aug. 17} \\
\hline & $\begin{array}{c}\text { Gage } \\
\text { ht. }\end{array}$ & $\begin{array}{c}\text { Dis- } \\
\text { charge }\end{array}$ & $\begin{array}{c}\text { Gage } \\
\text { ht. }\end{array}$ & $\begin{array}{c}\text { Dis- } \\
\text { charge }\end{array}$ & $\begin{array}{c}\text { Gage } \\
\text { ht. }\end{array}$ & $\begin{array}{c}\text { Dis- } \\
\text { charge }\end{array}$ & $\begin{array}{c}\text { Gage } \\
\text { ht. }\end{array}$ & $\begin{array}{c}\text { Dis- } \\
\text { charge }\end{array}$ & $\begin{array}{c}\text { Gage } \\
\text { ht. }\end{array}$ & $\begin{array}{l}\text { Dis- } \\
\text { charge }\end{array}$ & $\begin{array}{c}\text { Gage } \\
\text { ht. }\end{array}$ & $\begin{array}{c}\text { Dis- } \\
\text { charge }\end{array}$ \\
\hline \multirow{5}{*}{$\begin{array}{l}1 \\
2 \\
3 \\
4 \\
5 \\
6\end{array}$} & 4 & 1 & 38 & 800 & .45 & 9,0 & & & & & & \\
\hline & & & & & & & $5 . \overline{34}$ & 10,000 & & & & \\
\hline & & 15 & 5.87 & 1 & 50 & 52,200 & & & & & & \\
\hline & & 1,7 & 5.89 & 12,700 & $\begin{array}{l}12.50 \\
11.75\end{array}$ & 46,600 & 5.27 & 9,820 & & & & \\
\hline & 2.43 & 2,05 & 6.02 & 13,100 & 11.07 & 39,000 & 5.20 & 9,620 & & & & \\
\hline \multirow{5}{*}{$\begin{array}{r}7 \\
8 \\
9 \\
10 \\
11 \\
\mathrm{~N}\end{array}$} & 2.44 & 2,07 & 6.12 & 1 & 10.52 & 35,800 & & & & & & \\
\hline & 1 & & & & & & 5.15 & 9,420 & & & & \\
\hline & $\begin{array}{l}2.63 \\
2.66\end{array}$ & 2,4 & 6.07 & 13 & 9.32 & 29,300 & 5 & 0 & & & & \\
\hline & $\begin{array}{l}2.00 \\
2.66\end{array}$ & $\begin{array}{l}2,4 \\
2,4\end{array}$ & $\begin{array}{l}0.93 \\
5.88\end{array}$ & $\begin{array}{l}12,7 \\
12,7\end{array}$ & $\begin{array}{l}8.70 \\
8.12\end{array}$ & 23,1 & 0.11 & & & & & \\
\hline & 2.66 & 2,480 & 5.97 & 13,100 & 7.78 & 21,600 & 5.04 & 9,040 & 4.07 & 5,660 & 3.60 & 4,440 \\
\hline \multirow{5}{*}{$\begin{array}{l}1 \\
2 \\
3 \\
4 \\
5 \\
6\end{array}$} & 2.69 & 2,540 & 6.32 & 1 & 7.30 & 1 & & & & & & \\
\hline & 2.79 & 2,7 & 6.97 & & 7.00 & & & & & & & \\
\hline & 3.02 & 3,190 & 7.95 & 22 , & 6.58 & 15,800 & $=$ & & & & & \\
\hline & $\begin{array}{l}3.1 \\
3.2\end{array}$ & $\begin{array}{l}3,5 \\
3,6\end{array}$ & $\begin{array}{l}8.45 \\
9.70\end{array}$ & $\begin{array}{l}24, \\
31\end{array}$ & $\begin{array}{l}6.40 \\
6.13\end{array}$ & $\begin{array}{l}14,8 \\
13,\end{array}$ & 4.75 & 0 & & & & \\
\hline & 3.52 & 0 & 11.70 & 42,200 & 5.92 & 12,600 & & & & & & \\
\hline \multirow{5}{*}{$\begin{array}{r}7 \\
8 \\
9 \\
10 \\
11 \\
12 .\end{array}$} & 3.70 & 4,860 & 16.00 & 66 & 5.78 & & & & & & & \\
\hline & 3.88 & 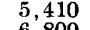 & 17.8 & & & & 4.61 & 7,410 & & & & \\
\hline & $\begin{array}{l}4.30 \\
4.82\end{array}$ & $\begin{array}{l}0,800 \\
8,360\end{array}$ & $\begin{array}{l}18.48 \\
18.45\end{array}$ & $\begin{array}{l}81, \\
81,\end{array}$ & $\begin{array}{l}\mathbf{5 . 5 6} \\
\mathbf{5 . 4 7}\end{array}$ & $\begin{array}{l}11,8 \\
10,8\end{array}$ & & & & & & \\
\hline & 5.28 & 10,200 & 18.00 & 78 , & 5.38 & & & & & & & \\
\hline & 5.51 & 11,000 & 17.54 & 75,700 & 5.33 & 10,000 & 4.43 & 6,900 & 3.80 & 4,970 & 3.29 & 3,710 \\
\hline
\end{tabular}

\begin{tabular}{|c|c|c|c|c|c|c|c|c|c|c|c|c|}
\hline \multirow{5}{*}{$\begin{array}{l}1 \\
2 \\
3 \\
4 \\
5 \\
6\end{array}$} & \multicolumn{2}{|c|}{ Aug. 29} & \multicolumn{2}{|c|}{ Aug. 30} & \multicolumn{2}{|c|}{ Aug. 31} & \multicolumn{2}{|c|}{ Sept. 1} & \multicolumn{2}{|c|}{ Sept. 2} & \multicolumn{2}{|c|}{ Sept. 3} \\
\hline & & & 5.23 & 9,820 & & & & & & & & \\
\hline & & & $\begin{array}{l}6.60 \\
7.14\end{array}$ & 15,800 & 6.11 & 13,500 & & & & & & \\
\hline & & & 8.14 & 23,100 & 5.78 & 12,100 & & & & & & \\
\hline & & & $\begin{array}{l}9.06 \\
9.78\end{array}$ & $\begin{array}{l}28,300 \\
32,000\end{array}$ & 5.50 & 10,800 & & & & & & \\
\hline & & & 10.45 & 35,200 & & & & & & & & \\
\hline 8 & $\cdots$ & & 10.77 & 37 & 5.12 & 9,230 & $\ldots-1$, & & & & & \\
\hline 10 & & & $\begin{array}{l}11.11 \\
11,23\end{array}$ & $\begin{array}{l}39,000 \\
39,500\end{array}$ & $4 . \overline{9}$ & $8, \overline{6} 60$ & & & & & & \\
\hline N & $\overline{1.86}$ & 1110 & 11.08 & 39,000 & 480 & 8480 & 30 & 700 & 316 & 70 & 080 & 8 \\
\hline I & & & 10 & & & & & & & & & \\
\hline 2 & & & 10.30 & 34 & & & & & & $\ldots$ & $\ldots$ & - \\
\hline 4 & $\cdots$ & 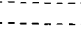 & $\begin{array}{r}10.30 \\
9.92\end{array}$ & $\begin{array}{l}34,700 \\
32,500\end{array}$ & 4.57 & 7,240 & & & & & & \\
\hline $\begin{array}{l}5 \\
6\end{array}$ & $2 . \overline{8}$ & 1,400 & $\begin{array}{l}9.34 \\
8.66\end{array}$ & $\begin{array}{l}29,300 \\
26,200\end{array}$ & $\begin{array}{l}-- \\
---\end{array}$ & & & & & & -- & \\
\hline $\begin{array}{l}7 \\
8\end{array}$ & & & $\begin{array}{l}8.06 \\
7.71\end{array}$ & $\begin{array}{l}23,100 \\
21,100\end{array}$ & 4.38 & 6,740 & & & & & & \\
\hline 9 & & & 7.18 & 18,600 & & & & & & & & \\
\hline 10 & & & 6.90 & 17,200 & - & & & & & & & - \\
\hline 12 & 3.40 & 3,950 & 6.41 & 14,800 & $4 . \overline{19}$ & $6,110^{-}$ & $\overline{3} . \overline{3} \overline{8}$ & 3,950 & $\overline{2} . \overline{9}$ & $3,050^{-}$ & $\overline{2} . \overline{7}$ & 2,450 \\
\hline
\end{tabular}

SUPPLEMENTARY RECORD.-Aug. 13, 9:30 p.m., gage height, 18.57 feet; diseharge, 82,500 second-feet.

NOLICHUCKY RIVER A'T GREENEVILLE DAM, NEAR GREENEVILLE, TENN.

Location.-Lat. $36^{\circ} 03^{\prime} 55^{\prime \prime}$, long. $82^{\circ} 52^{\prime} 01^{\prime \prime}$, at dam of East Tennessee Power \& Light Co., 300 feet upstream from bridge on State Highway 70, 7 miles south of Greeneville, Greene County, and 22 miles upstream from Morristown gage. Datum of gage 1,175.5 feet above mean sea level (levels by East Tennessee Power \& Light Co.).

Drainage AREa.-1,183 square miles.

GAGE-HEIGHT RECORD.-Head-water gage readings hourly, Aug. 13-15.

DISCHARGE RECORD.- - Stage-discharge relation based on determination of flow over dam. Discharge, Aug. 13 to $12 \mathrm{~m}$. Aug. 14 based on flow over dam plus diseharge through turbines. Secondary flashboards at 72.0 feet assumed to be down at 
9 a.m. Aug. 13. Main flashboards at 70.0 feet were washed out at 3 a.m. Aug. 14 . Discharges for indicated time Aug. 12 and 1 p.m. Aug. 14 to Aug. 17 were computed on basis of records for stations at Embreeville and near Morristown. Maxima.-1940: Discharge, 73,500 second-feet 8 a.m. Aug. 14 (gage height, 80.0 feet).

1903-8, 1919-25: Discharge observed, about 73,500 second-feet Jan. 23, 1906 . (gage height, 19.3 feet, at site 8 miles upstream and datum then in use).

REMARKs.-Crest of spillway is at gage height of 65 feet. Gage readings furnished by East Tennessee Power \& Light Co.

Gage height, in feet, and discharge, in second-feet, at indicated time, 1940

\begin{tabular}{|c|c|c|c|c|c|c|c|c|c|c|c|c|}
\hline \multirow{2}{*}{ Hour } & \multicolumn{2}{|c|}{ Aug. 12} & \multicolumn{2}{|c|}{ Aug. 13} & \multicolumn{2}{|c|}{ Aug. 14} & \multicolumn{2}{|c|}{ Aug. 15} & \multicolumn{2}{|c|}{ Aug. 16} & \multicolumn{2}{|c|}{ Aug. 17} \\
\hline & $\begin{array}{c}\text { Gage } \\
\text { ht. }\end{array}$ & $\begin{array}{l}\text { Dis- } \\
\text { charge }\end{array}$ & $\begin{array}{c}\text { Gage } \\
\text { ht. }\end{array}$ & $\begin{array}{l}\text { Dis- } \\
\text { charge }\end{array}$ & $\begin{array}{c}\text { Gage } \\
\text { ht. }\end{array}$ & $\begin{array}{l}\text { Dis- } \\
\text { charge }\end{array}$ & $\begin{array}{c}\text { Gage } \\
\text { ht. }\end{array}$ & $\begin{array}{l}\text { Dis- } \\
\text { charge }\end{array}$ & $\begin{array}{c}\text { Gage } \\
\text { ht. }\end{array}$ & $\begin{array}{l}\text { Dis- } \\
\text { charge }\end{array}$ & $\begin{array}{c}\text { Gage } \\
\text { ht. }\end{array}$ & $\begin{array}{l}\text { Dis- } \\
\text { charge }\end{array}$ \\
\hline $\begin{array}{l}1 \\
2 \\
3 \\
4 \\
5 \\
6\end{array}$ & $\mid \begin{array}{l}-\cdots- \\
-\cdots \\
-\cdots- \\
-\cdots- \\
-\cdots-\end{array}$ & 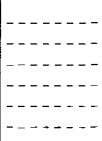 & $\begin{array}{l}71.6 \\
71.8 \\
72.1 \\
72.5 \\
72.9 \\
73.2\end{array}$ & $\begin{array}{l}1,650 \\
2,050 \\
2,580 \\
2,900 \\
3,610 \\
6,150\end{array}$ & $\begin{array}{l}76.9 \\
77.4 \\
77.7 \\
77.8 \\
79.2 \\
79.6\end{array}$ & $\begin{array}{l}600 \\
400 \\
500 \\
600 \\
000 \\
700\end{array}$ & $\begin{array}{l}72.1 \\
71.9 \\
71.7 \\
71.5 \\
71.4 \\
71.2\end{array}$ & $\begin{array}{l}15,800 \\
14,900 \\
14,200 \\
13,600 \\
13,200 \\
12,800\end{array}$ & $\begin{array}{l}-- \\
-- \\
-- \\
-- \\
--\end{array}$ & 8,600 & 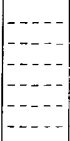 & $\mid$\begin{tabular}{l}
$\cdots$ \\
$\cdots$ \\
$\cdots$ \\
\hdashline, $\mathbf{9 5 0}$
\end{tabular} \\
\hline $\begin{array}{r}7 \\
8 \\
9 \\
10 \\
11 \\
\mathrm{~N}\end{array}$ & 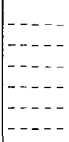 & $\begin{array}{c}-\cdots \\
-150\end{array}$ & $\begin{array}{l}73.6 \\
73.7 \\
73.7 \\
73.7 \\
73.7 \\
73.7\end{array}$ & $\begin{array}{r}8,800 \\
11,000 \\
11,000 \\
11,000 \\
11,000 \\
11,000\end{array}$ & $\begin{array}{l}80.0 \\
80.0 \\
79.9 \\
79.4 \\
79.0 \\
78.4\end{array}$ & $\begin{array}{l}73,100 \\
73,500 \\
72.900 \\
69,500 \\
66,300 \\
61,200\end{array}$ & $\begin{array}{l}71.2 \\
71.1 \\
71.1 \\
71.1 \\
71.1 \\
71.1\end{array}$ & $\begin{array}{l}12,500 \\
12,200 \\
11,900 \\
11,700 \\
11,500 \\
11,300\end{array}$ & $\mid$\begin{tabular}{c}
---- \\
--- \\
----- \\
\hdashline---- \\
----- \\
-----
\end{tabular} & $\begin{array}{c}-8.050 \\
7,600\end{array}$ & $\begin{array}{l}----- \\
----- \\
----- \\
----- \\
----- \\
---.-\end{array}$ & (י. \\
\hline $\begin{array}{l}1 \\
\mathbf{2} \\
\mathbf{3} \\
4 \\
5 \\
\mathbf{6}\end{array}$ & $\begin{array}{l}-- \\
-- \\
-- \\
-- \\
-- \\
--\end{array}$ & & $\begin{array}{l}74.2 \\
74.2 \\
74.2 \\
74.2 \\
74.3 \\
74.3\end{array}$ & $\begin{array}{l}12,800 \\
12,800 \\
12,800 \\
12,800 \\
13,000 \\
13,100\end{array}$ & $\begin{array}{l}77.9 \\
77.3 \\
76.6 \\
75.9 \\
75.4 \\
74.6\end{array}$ & $\begin{array}{l}56,200 \\
51,300 \\
46,300 \\
42,000 \\
38,100 \\
34,300\end{array}$ & $\begin{array}{l}71.0 \\
71.0 \\
70.9 \\
70.9 \\
70.8 \\
70.7\end{array}$ & $\begin{array}{l}11,100 \\
10,900 \\
10,700 \\
10,500 \\
10,300 \\
10,100\end{array}$ & 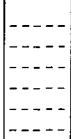 & 7,250 & $\left|\begin{array}{l}-\cdots \\
-\cdots \\
-\cdots \\
-\cdots \\
-- \\
-\end{array}\right|$ & | \\
\hline $\begin{array}{r}7 \\
8 \\
9 \\
10 \\
11 \\
12\end{array}$ & & & $\begin{array}{l}74.4 \\
74.5 \\
74.8 \\
75.2 \\
75.6 \\
76.4\end{array}$ & $\begin{array}{l}13,400 \\
13,900 \\
15,200 \\
16,600 \\
18,600 \\
21,800\end{array}$ & $\begin{array}{l}74.2 \\
73.7 \\
73.3 \\
72.9 \\
72.6 \\
72.3\end{array}$ & $\begin{array}{l}31,000 \\
28,200 \\
25,100 \\
22,100 \\
20,000 \\
17,600\end{array}$ & $\begin{array}{l}70.7 \\
70.6 \\
70.6 \\
70.5 \\
70.5 \\
70.4\end{array}$ & $\begin{array}{r}10,000 \\
9,800 \\
9,750 \\
9,500 \\
9,350 \\
9,120\end{array}$ & $\mid \begin{array}{l}----- \\
----- \\
----- \\
----- \\
--\cdots-- \\
--\cdots--\end{array}$ & $\mid \begin{array}{c}-6,850 \\
6,500\end{array}$ & $\left|\begin{array}{c|}--- \\
----- \\
----- \\
---- \\
----- \\
--\cdots--\end{array}\right|$ & $\mid$\begin{tabular}{l}
$\cdots \cdots$ \\
$\cdots \cdots$ \\
$\cdots$ \\
\hdashline$-\overline{7}, \overline{0} 0$
\end{tabular} \\
\hline Mean & 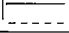 & 150 & & 10,400 & & 46,600 & & 11,700 & & 7,690 & & 5,520 \\
\hline
\end{tabular}

NOLICHUCKY RIVER NEAR MORRISTOWN, TENN.

Location.-Lat. $36^{\circ} 07^{\prime} 59^{\prime \prime}$, long. $83^{\circ} 10^{\prime} 31^{\prime \prime}$, 150 feet upstream from Jones Bridge on old Morristown-Newport road, 4 miles (revised) downstream from Bent Creek, and 9 miles southeast of Morristown, Hamblen County. Datum of gage is $1,005.44$ feet above mean sea level, datum of 1929 , supplementary adjustment of 1936 .

Drainage AREa.- 1,686 square miles.

GAGE-HEIGHT RECORD.-Water-stage recorder graph except for periods 1 a.m. Aug. 12 to 9 p.m. Aug. 13, 5 p.m. Aug. 21 to 11 a.m. Aug. 22, and 1 p.m. Aug. 22 to 10 a.m. Aug. 23, for which graph was based on study of regulation, range in stage, and several gage readings.

DISCHARGE RECORD.-Stage-discharge relation defined by current-meter measurements up to 38,800 second-feet and extended to crest gage heights on basis of study of overflow areas and by comparison of flood flows at other places in the Nolichucky River Basin. Special backwater rating curves were used for falling stages to account for backwater due to return flow of over-bank storage. Gage heights used to half-tenths between 2.9 and 4.7 feet; hundredths below and tenths above these limits.

Maxima.-1940: Discharge, 61,900 second-feet 8 p.m. Aug. 14 (gage height, 22.68 feet).

1920-39: Discharge, 56,600 second-feet Mar. 26, 1935 (gage height, 22.0 feet). 
Remarks.-Flood flows affected slightly by storage and regulation at Greeneville Dam, 22 miles upstream.

Mean discharge, in second-feet, 1940

\begin{tabular}{|c|c|c|c|c|c|c|c|c|c|c|c|}
\hline Day & Aug. & Sept. & Day & Auê. & Sept. & Day & Aug. & Sept. & Day & Aug. & Sept. \\
\hline 1 & 6,000 & 9,150 & 9 & 2,040 & 510 & 17 & 6,060 & 1,180 & 25 & 784 & 2,100 \\
\hline 2 & 3,800 & 5,520 & 10 & 1,260 & 1,450 & 18 & 4,760 & 1,180 & 26 & 332 & 1,090 \\
\hline 3 & 1,520 & $\begin{array}{l}4,100 \\
3\end{array}$ & 11 & 692 & $\begin{array}{l}1,370 \\
1000\end{array}$ & 19 & $\begin{array}{l}3,900 \\
3,600\end{array}$ & 1,160 & 27 & 1,300 & 958 \\
\hline 4 & & $\begin{array}{l}3,470 \\
3,130\end{array}$ & 12 & & $\begin{array}{l}1,500 \\
1780\end{array}$ & 20 & $\begin{array}{l}3,600 \\
2,000\end{array}$ & 1,140 & 28 & 1,430 & 878 \\
\hline 6 & 1,400 & 2,930 & $\begin{array}{l}13 \\
14\end{array}$ & $\begin{array}{r}8,200 \\
40,800\end{array}$ & 1,760 & $\begin{array}{l}21 \\
22\end{array}$ & $\begin{array}{l}3,780 \\
2,780\end{array}$ & $\begin{array}{l}1,1504 \\
904\end{array}$ & $\begin{array}{l}29 \\
30\end{array}$ & $\begin{array}{r}1,090 \\
14,200\end{array}$ & $\begin{array}{l}619 \\
219\end{array}$ \\
\hline 7 & 2,7 & 2,760 & 15 & 19,100 & 1,260 & 23 & $\overline{2}$, & 638 & & 25,700 & \\
\hline 8 & 3,120 & 1,110 & 16 & 8,720 & 742 & 24 & 1,900 & 1,120 & & & \\
\hline \multicolumn{10}{|c|}{$\begin{array}{l}\text { Monthly mean discharge, in second-feet } \\
\text { Runoff, in inehts }\end{array}$} & $\begin{array}{r}5,643 \\
3.86\end{array}$ & $\begin{array}{r}1,897 \\
1.26\end{array}$ \\
\hline
\end{tabular}

Gage height, in feet, and discharge, in second-feet, at indicated time, 1940

\begin{tabular}{|c|c|c|c|c|c|c|c|c|c|c|c|c|}
\hline \multirow{2}{*}{ Hour } & \multicolumn{2}{|c|}{ Aug. 12} & \multicolumn{2}{|c|}{ Aug. 13} & \multicolumn{2}{|c|}{ Aug. 14} & \multicolumn{2}{|c|}{ Aug. 15} & \multicolumn{2}{|c|}{ Aug. 16} & \multicolumn{2}{|c|}{ Aug. 17} \\
\hline & $\begin{array}{l}\text { Gage } \\
\text { ht. }\end{array}$ & $\begin{array}{c}\text { Dis- } \\
\text { charge }\end{array}$ & $\begin{array}{c}\text { Gage } \\
\text { ht. }\end{array}$ & $\begin{array}{c}\text { Dis- } \\
\text { charge }\end{array}$ & $\begin{array}{c}\text { Gage } \\
\text { ht. }\end{array}$ & $\begin{array}{c}\text { Dis- } \\
\text { charge }\end{array}$ & $\begin{array}{c}\text { Gage } \\
\text { ht. }\end{array}$ & $\begin{array}{c}\text { Dis- } \\
\text { charge }\end{array}$ & $\begin{array}{c}\text { Gage } \\
\text { ht. }\end{array}$ & $\begin{array}{c}\text { Dis- } \\
\text { charge }\end{array}$ & $\begin{array}{c}\text { Gage } \\
\text { ht. }\end{array}$ & $\begin{array}{c}\text { Dis- } \\
\text { charge }\end{array}$ \\
\hline \multirow{5}{*}{$\begin{array}{l}1 \\
2 \\
3 \\
4 \\
5 \\
6\end{array}$} & & 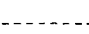 & 64 & 620 & 2.68 & 15,500 & 21.20 & 43 & & & & \\
\hline & & & & & 13.09 & & & & & & & \\
\hline & & & & $\begin{array}{l}1,660 \\
1,800\end{array}$ & $\left|\begin{array}{l}13.64 \\
14.35\end{array}\right|$ & $\begin{array}{l}17,4 \\
19\end{array}$ & $\begin{array}{l}19.85 \\
19.00\end{array} \mid$ & & & & & \\
\hline & & & 3.95 & 1,900 & 15.15 & 21, & & & & & & \\
\hline & 1.67 & 242 & 4.12 & 2,050 & 16.05 & 22,800 & 17.05 & 22,400 & 9.83 & 9,740 & & \\
\hline \multirow{4}{*}{$\begin{array}{r}7 \\
8 \\
9 \\
10 \\
11 \\
\mathrm{~N}\end{array}$} & & & 4.55 & 2,520 & 17.15 & 25,800 & 16.18 & 20,8 & & & & \\
\hline & & & & 3 & 1788 & & & & & & & \\
\hline & & & 7.68 & $\begin{array}{l}7,280 \\
6,280\end{array}$ & 19.30 & 37, & 13.67 & & & & & \\
\hline & 1.57 & 198 & $\begin{array}{l}9.00 \\
9.55\end{array}$ & $\begin{array}{l}8,300 \\
\mathbf{9}, 380\end{array}$ & $\left|\begin{array}{l}19.82 \\
20.35\end{array}\right|$ & $\begin{array}{l}40,900 \\
45,100\end{array}$ & $\left|\begin{array}{l}13.22 \\
12.80\end{array}\right|$ & \begin{tabular}{|l|l}
15,300 \\
14,700
\end{tabular} & 9.19 & 8,660 & 7.51 & 6,000 \\
\hline \multirow{5}{*}{$\begin{array}{l}1 \\
2 \\
3 \\
4 \\
5 \\
6\end{array}$} & 1.55 & 190 & 10.10 & 10,300 & 0.86 & 48 & 12.52 & 14 & & & & \\
\hline & & 182 & & & & & & & & & & \\
\hline & & 178 & $\left|\begin{array}{l}10.96 \\
11.30\end{array}\right|$ & 12, & 21 & & 12.02 & & & & $\cdots$ & \\
\hline & & $\begin{array}{l}174 \\
170\end{array}$ & $\left|\begin{array}{l}11.30 \\
11.56\end{array}\right|$ & 12,600 & 22.00 & $\begin{array}{l}56 \\
58\end{array}$ & $\begin{array}{l}11.84 \\
11.65\end{array}$ & & & & & \\
\hline & & 170 & 11,80 & 13.600 & 22.52 & 60,400 & 11.50 & 12,400 & 8.56 & 7,660 & & \\
\hline 7 & & & & & & & 1. & & & & & \\
\hline & & & & & & & & & & & & \\
\hline 10 & & & 12 & 14 & $\left|\begin{array}{l}22.62 \\
22.44\end{array}\right|$ & $\begin{array}{l}59, \\
57\end{array}$ & $\left|\begin{array}{l}11.04 \\
10.91\end{array}\right|$ & & t & & & \\
\hline 1 & & 1,220 & 12.28 & 14, & 22. & & 10.74 & & & & & \\
\hline & & & 12. & 14,800 & $|21.73|$ & 48,500 & $|10.60|$ & 10 & 8.15 & 7,020 & 7.08 & 5,480 \\
\hline
\end{tabular}

\begin{tabular}{|c|c|c|c|c|c|c|c|c|c|c|c|c|}
\hline & & 29 & & g. 30 & & g. 31 & & pt. 1 & & pt. 2 & & t. 3 \\
\hline 0 & & & & 4,860 & .33 & 500 & & & & & & \\
\hline${ }_{3}^{2}$ & & & $\begin{array}{l}7.48 \\
8.07\end{array}$ & $\begin{array}{l}6,000 \\
6,860\end{array}$ & $\begin{array}{l}19.55 \\
19.70\end{array}$ & $\begin{array}{l}39,500 \\
40,200\end{array}$ & & & & & & \\
\hline 4 & & & 8.48 & $\begin{array}{l}7,500 \\
7,080\end{array}$ & \begin{tabular}{|c|}
19.78 \\
19
\end{tabular} & 40,900 & & & & & & \\
\hline 6 & 3.50 & 1,480 & 9.04 & 8,300 & 19.73 & $\begin{array}{l}40,700 \\
39,200\end{array}$ & 10.11 & 10,100 & $7.5 \overline{7}$ & 6,140 & & \\
\hline 7 & & & 9.25 & 8,660 & 19.58 & 37,900 & 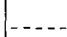 & & & & & \\
\hline $\begin{array}{l}8 \\
9\end{array}$ & & & $\begin{array}{l}9.30 \\
9.30\end{array}$ & $\begin{array}{l}8,840 \\
8,840\end{array}$ & $\mid \begin{array}{l}19.34 \\
18.90\end{array}$ & $\begin{array}{l}34, \\
30\end{array}$ & & & & & & \\
\hline 10 & & & 9.19 & 8,660 & 18.44 & 27,000 & & & & & & \\
\hline $\mathrm{N}$ & 2.82 & 930 & 8.68 & 7,820 & 17.33 & 23,000 & 9.40 & 9,020 & 6.95 & 5,350 & 5.97 & 4,140 \\
\hline 1 & 2.70 & 845 & 8.30 & 7,180 & 16.6 & 21,600 & & & & & & \\
\hline $\begin{array}{l}2 \\
3\end{array}$ & $\left|\begin{array}{r}2.60 \\
2.52\end{array}\right|$ & $\begin{array}{r}719 \\
719\end{array}$ & $\mid \begin{array}{r}9.20 \\
11.25\end{array}$ & $\begin{array}{r}8,660 \\
12,400\end{array}$ & 15. & $\begin{array}{l}20, \\
18\end{array}$ & & & & & & \\
\hline 4 & 2.47 & 686 & 13.14 & 16,300 & 14.38 & 17, & & & & & & \\
\hline $\mathrm{s}$ & $\begin{array}{l}3.40 \\
3.55\end{array}$ & $\begin{array}{r}079 \\
1,520\end{array}$ & $\left|\begin{array}{l}15.62 \\
15.66\end{array}\right|$ & $\begin{array}{l}19,400 \\
22,100\end{array}$ & $\begin{array}{l}13.82 \\
13.28\end{array}$ & $\begin{array}{l}16,300 \\
15,500\end{array}$ & 8.79 & 7,980 & 6.59 & 4,860 & & \\
\hline 7 & 4.5 & & 16. & 23 & 12.80 & 14 & & & & & & \\
\hline & & & 17. & $\begin{array}{l}25 \\
28\end{array}$ & 12.44 & 13 & & & & & & \\
\hline 10 & 5.2 & & 10.02 & & $\begin{array}{l}11.75 \\
11.75\end{array}$ & & & & & & & \\
\hline $\begin{array}{l}11 \\
12\end{array}$ & \begin{tabular}{|l|}
5.43 \\
5.77
\end{tabular} & $\begin{array}{l}3,460 \\
3,920\end{array}$ & $\left|\begin{array}{|}18.72 \\
19.11\end{array}\right|$ & $\begin{array}{l}33,600 \\
36,200\end{array}$ & $\begin{array}{l}11.47 \\
11.23\end{array}$ & $\begin{array}{l}12,400 \\
12,000\end{array}$ & 8.30 & 7,180 & 6.34 & 4,500 & 5.60 & 3,680 \\
\hline
\end{tabular}


SOUTH TOE RIVER AT NEWDALE, N, C.

Location.-Lat. $35^{\circ} 54^{\prime} 30^{\prime \prime}$, long. $82^{\circ} 11^{\prime} 30^{\prime \prime}$, at bridge on State Highway 69 at Newdale, Yancey County, 11/1 miles upstream from Little Crabtree Creek, and $61 / 4$ miles east of Burnsville. Datum of gage is $2,443.98$ feet above mean sea level, datum of 1929, supplementary adjustment of 1936 .

DRAINAGE AREA.- 60.8 square miles.

GAGE-HEIGHT RECORD,-Water-stage recorder graph.

DISCHARGE RECORD.--Stage-discharge relation defined by current-meter measurements up to 3,500 second-feet and extended to crest gage height on basis of discharge measurement at gage height 16.9 feet and contracted-opening computation for gage height of 17.4 feet. Shifting-control method used from 11 p.m. Aug. 13 to Aug. 19 and 5-10 p.m. Aug. 29. Gage heights used to half-tenths between 3.3 and 5.2 feet prior to 4 p.m. Aug. 13 and between 3.5 and 5.2 feet subsequently; hundredths below and tenths above these limits.

Maxima.-1940: Discharge, 29,400 second-feet 4 p.m. Aug. 13 (gage height, 17.4 feet).

1934-39: Discharge, 12,100 second-feet Oct. 16, 1936 (gage height, 10.15 feet) from rating curve extended logarithmically above 2,500 second-feet.

Surveys by the Tennessee Valley Authority show that the flood of July 1916 reached a stage of $14 \mathrm{feet}$, as witnessed by local resident (discharge, 20,300 second-feet, from 1940 rating).

REMARKS.-Flood runoff not affected by artificial storage.

Mean discharge, in second-feet, 1940

\begin{tabular}{r|r|r|r|r|r|r|r|r|r|r|r}
\hline Day & Aug. & Sept. & Day & Aug. & Sept. & Day & Aug. & Sept. & Day & Aug. & Sept. \\
\hline 1 & 85 & 963 & 9 & 103 & 245 & 17 & 577 & 148 & 25 & 216 & 117 \\
2 & 76 & 665 & 10 & 94 & 231 & 18 & 471 & 142 & 26 & 202 & 110 \\
3 & 69 & 516 & 11 & 736 & 216 & 19 & 407 & 139 & 27 & 192 & 101 \\
4 & 69 & 427 & 12 & 2,840 & 199 & 20 & 342 & 132 & 28 & 185 & 98 \\
5 & 85 & 378 & 13 & 11,800 & 189 & 21 & 305 & 126 & 29 & 1,710 & 95 \\
6 & 109 & 326 & 14 & 2,900 & 175 & 22 & 309 & 120 & 30 & 6,710 & 92 \\
7 & 144 & 297 & 15 & 1,140 & 168 & 23 & 256 & 117 & 31 & 1,620 &.- .1 \\
8 & 97 & 267 & 16 & 763 & 158 & 24 & 234 & 114 & & \\
\hline
\end{tabular}


380 FLOODS OF AUGUST 1940 IN THE SOUTHEASTERN STATES

Gage height, in feet, and discharge, in second-feet, at indicated time, 1940

\begin{tabular}{|c|c|c|c|c|c|c|c|c|c|c|c|c|}
\hline \multirow{2}{*}{ Hour } & \multicolumn{2}{|c|}{ Aug. 11} & \multicolumn{2}{|c|}{ Aug. 12} & \multicolumn{2}{|c|}{ Aug. 13} & \multicolumn{2}{|c|}{ Aug. 14} & \multicolumn{2}{|c|}{ Aug. 15} & \multicolumn{2}{|c|}{ Aug. 16} \\
\hline & $\begin{array}{c}\text { Gage } \\
\text { ht. }\end{array}$ & $\begin{array}{l}\text { Dis- } \\
\text { charge }\end{array}$ & $\begin{array}{c}\text { Gage } \\
\text { ht. }\end{array}$ & $\begin{array}{l}\text { Dis- } \\
\text { charge }\end{array}$ & $\begin{array}{c}\text { Gage } \\
\text { ht. }\end{array}$ & $\begin{array}{l}\text { Dis- } \\
\text { charge }\end{array}$ & $\begin{array}{c}\text { Gage } \\
\text { ht. }\end{array}$ & $\begin{array}{l}\text { Dis- } \\
\text { charge }\end{array}$ & $\begin{array}{c}\text { Gage } \\
\text { ht. }\end{array}$ & $\begin{array}{l}\text { Dis- } \\
\text { charge }\end{array}$ & $\begin{array}{c}\text { Gage } \\
\text { ht. }\end{array}$ & $\begin{array}{l}\text { Dis- } \\
\text { charge }\end{array}$ \\
\hline $\begin{array}{l}1 \\
2 \\
3 \\
4 \\
5 \\
6\end{array}$ & $\begin{array}{l}1.54 \\
1.65 \\
1.91 \\
2.05 \\
2.19 \\
2.40\end{array}$ & $\begin{array}{r}91 \\
125 \\
212 \\
268 \\
335 \\
455\end{array}$ & $\begin{array}{l}3.56 \\
3.45 \\
3.35 \\
3.28 \\
3.25 \\
3.47\end{array}$ & $\begin{array}{l}1,400 \\
1,300 \\
1,200 \\
1,140 \\
1,120 \\
1,300\end{array}$ & $\begin{array}{l}6.39 \\
5.90 \\
5.64 \\
5.41 \\
5.43 \\
5.76\end{array}$ & $\begin{array}{l}4,940 \\
4,240 \\
3,820 \\
3,550 \\
3,550 \\
4,100\end{array}$ & $\begin{array}{c}-\cdots . \overline{33} \\
-\overline{6} \\
-\overline{5.67}\end{array}$ & $\begin{array}{c}4,520 \\
-3,540\end{array}$ & 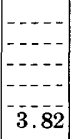 & (-. & 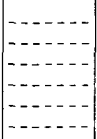 & 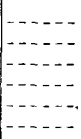 \\
\hline $\begin{array}{r}7 \\
8 \\
9 \\
10 \\
11 \\
\mathrm{~N}\end{array}$ & $\begin{array}{l}2.51 \\
2.64 \\
2.68 \\
2.71 \\
2.75 \\
2.78\end{array}$ & $\begin{array}{l}522 \\
608 \\
636 \\
658 \\
690 \\
714\end{array}$ & $\begin{array}{l}4.00 \\
4.45 \\
4.32 \\
4.18 \\
4.15 \\
4.49\end{array}$ & $\begin{array}{l}1,870 \\
2,360 \\
2,200 \\
2,090 \\
2,040 \\
2,420\end{array}$ & $\begin{array}{l}6.48 \\
7.11 \\
7.26 \\
7.11 \\
7.08 \\
8.28\end{array}$ & $\begin{array}{l}5,080 \\
5,980 \\
6,300 \\
5,980 \\
5,980 \\
7,960\end{array}$ & $\begin{array}{c}---- \\
-\overline{5.23} \\
--\overline{3} \\
\overline{4} . \overline{88}\end{array}$ & $\begin{array}{r}2,940 \\
-2,430\end{array}$ & 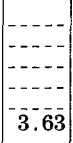 & $\mid \begin{array}{l}-\cdots \\
\cdots \\
-1,100\end{array}$ & 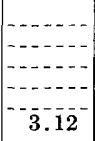 & $\mid$\begin{tabular}{l}
$\cdots$ \\
$\cdots$ \\
$\cdots$ \\
\hdashline$\overline{756}$
\end{tabular} \\
\hline $\begin{array}{l}1 \\
2 \\
3 \\
4 \\
5 \\
6\end{array}$ & $\begin{array}{l}2.76 \\
2.73 \\
2.73 \\
2.75 \\
2.87 \\
3.06\end{array}$ & $\begin{array}{l}698 \\
674 \\
674 \\
690 \\
786 \\
944\end{array}$ & $\begin{array}{l}4.88 \\
5.21 \\
5.48 \\
5.61 \\
5.68 \\
5.84\end{array}$ & $\begin{array}{l}2,900 \\
3,290 \\
3,680 \\
3,820 \\
3,960 \\
4,100\end{array}$ & $\begin{array}{l}11.16 \\
14.29 \\
17.1 \\
17.4 \\
16.9 \\
16.2\end{array}$ & $\begin{array}{l}13,700 \\
21,000 \\
28,600 \\
29,400 \\
28,000 \\
26,000\end{array}$ & $\begin{array}{r}-.-\overline{6} \\
-\overline{4} \overline{-} \\
-4.44\end{array}$ & $\begin{array}{c}2,190 \\
1,890\end{array}$ & 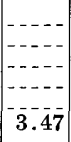 & \begin{tabular}{c}
$-\ldots \ldots$ \\
\hdashline-1. \\
\hdashline 994
\end{tabular} & 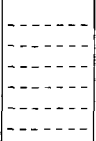 & 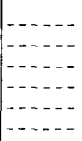 \\
\hline $\begin{array}{r}7 \\
8 \\
9 \\
10 \\
11 \\
12 \\
\end{array}$ & $\begin{array}{l}3.31 \\
3.64 \\
3.71 \\
3.61 \\
3.58 \\
3.61 \\
\end{array}$ & $\begin{array}{l}1,160 \\
1,500 \\
1,550 \\
1,450 \\
1,450 \\
1,450 \\
\end{array}$ & $\begin{array}{l}6.12 \\
6.33 \\
6.21 \\
6.05 \\
6.09 \\
6.33 \\
\end{array}$ & $\begin{array}{l}4,520 \\
4,800 \\
4,660 \\
4,380 \\
4,520 \\
4,800 \\
\end{array}$ & $\begin{array}{r}14.7 \\
13.0 \\
11.23 \\
8.97 \\
8.02 \\
7.46 \\
\end{array}$ & $\begin{array}{r}22,000 \\
17,800 \\
13,700 \\
9,230 \\
7,450 \\
6,460 \\
\end{array}$ & \begin{tabular}{|c|}
.- .24 \\
$-\overline{2}$ \\
.--- \\
4.06
\end{tabular} & $\begin{array}{r}1,670 \\
1,510\end{array}$ & 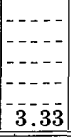 & $\begin{array}{r}-1 \\
890 \\
\end{array}$ & $\mid$\begin{tabular}{c}
$-\cdots$ \\
\hdashline-1. \\
\hdashline 2.93 \\
\end{tabular} & $\begin{array}{r}-\cdots \\
\hdashline \cdots \\
\hdashline 649 \\
\hdashline\end{array}$ \\
\hline
\end{tabular}

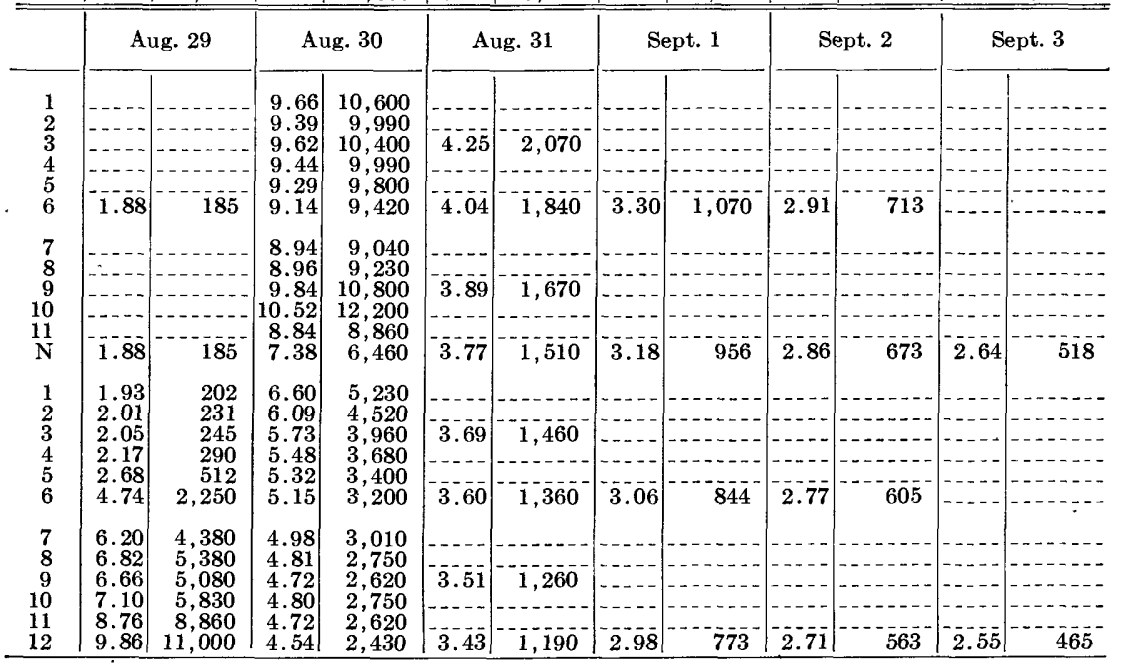




\section{CANE RIVER NEAR SIOUX, N. C.}

Location.-Lat. $36^{\circ} 00^{\prime} 52^{\prime \prime}$, long. $82^{\circ} 19^{\prime} 40^{\prime \prime}$, on State Highway $19,11 / 4$ miles east of Sioux, Yancey County, and 1.4 miles upstream from mouth. Datum of gage is 2,045.24 feet above mean sea level, datum of 1929, supplementary adjustment of 1936 .

Drain AGe AREA.- 157 square miles.

GAGE-HEIGHT RECORD.-Water-stage recorder graph except for period 11 a.m. Aug. 12 to 2 p.m. Aug. 13 for which gage heights were computed from estimated discharge.

DISCHARGE RECORD.-Stage-discharge relation defined by current-meter measurements up to 7,300 second-feet and extended to crest gage height on basis of flood flow determination by slope-area method. Gage heights used to half-tenths between 3.4 and 5.7 feet prior to Aug. 14 and between 3.7 and 5.7 feet subsequently; hundredths below and tenths above these limits. Discharge for period of no gage-height record is based on records for nearby streams.

Maxima.-1940: Discharge, 27,300 second-feet 4:30 p.m. Aug. 13 (gage height, 17.8 feet).

1934-39: Discharge, 11,400 second-feet July 15, 1934 (gage height, 12.10 feet).

Surveys by the Tennessee Valley Authority show that the floods of August 1893 and May 1901 reached a stage of 16 feet (discharge, 21,700 second-feet, from 1940 rating).

REMARKs.-Flood runoff not affected by artificial storage.

Mean discharge, in second-feet, 1940

\begin{tabular}{|c|c|c|c|c|c|c|c|c|c|c|c|}
\hline Day & Aug. & Sept. & Day & Aug. & Sept. & Day & Aug. & Sept. & Day & Aug. & Sept. \\
\hline $\begin{array}{l}1 \\
2 \\
3 \\
4 \\
5 \\
6 \\
7 \\
8\end{array}$ & $\begin{array}{l}241 \\
185 \\
161 \\
138 \\
129 \\
179 \\
346 \\
202\end{array}$ & $\begin{array}{l}957 \\
660 \\
496 \\
398 \\
343 \\
305 \\
276 \\
246\end{array}$ & $\begin{array}{r}9 \\
10 \\
11 \\
12 \\
13 \\
14 \\
15 \\
16\end{array}$ & $\begin{array}{r}171 \\
139 \\
363 \\
1,960 \\
10,200 \\
4,140 \\
1,740 \\
1,150\end{array}$ & $\begin{array}{l}234 \\
232 \\
224 \\
189 \\
179 \\
186 \\
150 \\
160\end{array}$ & $\begin{array}{l}17 \\
18 \\
19 \\
20 \\
21 \\
22 \\
23 \\
24\end{array}$ & $\begin{array}{l}854 \\
658 \\
617 \\
465 \\
390 \\
358 \\
305 \\
276\end{array}$ & $\begin{array}{l}164 \\
139 \\
138 \\
142 \\
131 \\
105 \\
110 \\
118\end{array}$ & $\begin{array}{l}25 \\
26 \\
27 \\
28 \\
29 \\
30 \\
31\end{array}$ & $\begin{array}{r}246 \\
243 \\
226 \\
209 \\
553 \\
5,510 \\
1,440\end{array}$ & $\begin{array}{r}137 \\
147 \\
131 \\
101 \\
105 \\
87\end{array}$ \\
\hline \multicolumn{10}{|c|}{$\begin{array}{l}\text { Monthly mean discharge, in second-feet } \\
\text { Runoff, in inches. }\end{array}$} & $\begin{array}{r}1,090 \\
8.01\end{array}$ & $\begin{array}{r}233 \\
1.66\end{array}$ \\
\hline
\end{tabular}




\section{FLOODS OF AUGUST 1940 IN THE SOUTHEASTERN STATES}

Gage height, in feet, and discharge, in second-feet, at indicated time, 1940

\begin{tabular}{|c|c|c|c|c|c|c|c|c|c|c|c|c|}
\hline \multirow{2}{*}{ Hour } & \multicolumn{2}{|c|}{ Aug. 11} & \multicolumn{2}{|c|}{ Aug. 12} & \multicolumn{2}{|c|}{ Aug. 13} & \multicolumn{2}{|c|}{ Aug. 14} & \multicolumn{2}{|c|}{ Aug. 15} & \multicolumn{2}{|c|}{ Aug. 16} \\
\hline & $\begin{array}{c}\text { Gege } \\
\text { ht. }\end{array}$ & $\begin{array}{c}\text { Dis- } \\
\text { charge }\end{array}$ & $\begin{array}{c}\text { Gage } \\
\text { ht. }\end{array}$ & $\begin{array}{l}\text { Dis- } \\
\text { charge }\end{array}$ & $\begin{array}{c}\text { Gage } \\
\text { ht. }\end{array}$ & $\begin{array}{c}\text { Dis- } \\
\text { charge }\end{array}$ & $\begin{array}{c}\text { Gage } \\
\text { ht. }\end{array}$ & $\begin{array}{l}\text { Dis- } \\
\text { charge }\end{array}$ & $\begin{array}{c}\text { Gage } \\
\text { ht. }\end{array}$ & $\begin{array}{l}\text { Dis- } \\
\text { charge }\end{array}$ & $\begin{array}{c}\text { Gage } \\
\text { ht. }\end{array}$ & $\begin{array}{l}\text { Dis- } \\
\text { charge }\end{array}$ \\
\hline 1 & & & 23 & 0 & 7.7 & 30 & 10.80 & 30 & & & & \\
\hline 2 & 2.12 & 163 & 14 & & 7.8 & 4 & 10.15 & & & & & \\
\hline $\begin{array}{l}3 \\
4\end{array}$ & $-\overrightarrow{2.15}$ & & & & $\begin{array}{l}7.7 \\
7.6\end{array}$ & $\begin{array}{l}4,380 \\
4,260\end{array}$ & $\begin{array}{l}9.55 \\
9.03\end{array}$ & & & & & \\
\hline 5 & & & 1 & 1,020 & 7.4 & 4,020 & 8.60 & $\begin{array}{l}5,500 \\
5,510\end{array}$ & & & & \\
\hline 6 & 2.15 & 170 & 4.02 & 955 & 8.05 & 4,800 & 8.25 & 4,990 & 5.36 & 1,940 & & \\
\hline 7 & & & 4.00 & 955 & 8.4 & 5,250 & 7.98 & 4,740 & & & & \\
\hline $\begin{array}{l}8 \\
9\end{array}$ & 2.12 & 163 & 4.17 & 1,050 & 8.7 & & 7.67 & & $\ldots$ & & & \\
\hline 10 & $\overline{2.01}$ & 139 & $\begin{array}{l}7.40 \\
5.06\end{array}$ & 7 & 9.0 & & 7.42 & & & & & \\
\hline 11 & & & 4. & 1,5 & 9.0 & 6,030 & 6.93 & 3,450 & & & & \\
\hline $\mathbf{N}$ & 1.95 & 126 & 4.8 & 1,500 & 9.0 & 6,030 & 6.82 & 3,340 & 5.12 & 1,740 & 4.28 & 1,140 \\
\hline 1 & & & 4. & 1 & 9.3 & & & & & & & \\
\hline 2 & 3.04 & 464 & & & 10.35 & & & & & & & \\
\hline 4 & 3.12 & $4 \overrightarrow{96}$ & $\begin{array}{l}4.8 \\
5.15\end{array}$ & $\begin{array}{l}1,5 \\
1,7\end{array}$ & $\begin{array}{l}11.65 \\
16.25\end{array}$ & 2 & & & & & & \\
\hline 5 & 307 & 476 & 6. & 2,520 & $|17.45|$ & 26,000 & & & & & & \\
\hline 0 & 3.07 & 476 & 6.7 & 3,230 & 16.40 & 22,900 & 6.11 & 2,620 & 4.80 & 1,500 & & \\
\hline $\begin{array}{l}7 \\
8\end{array}$ & & & 6.85 & 3,400 & 15.50 & 20 & 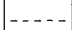 & & & & & \\
\hline $\begin{array}{l}8 \\
9\end{array}$ & 3.14 & 50 & $\begin{array}{l}6.95 \\
6.95\end{array}$ & $\begin{array}{l}3,500 \\
3,500\end{array}$ & $\left|\begin{array}{l}14.30 \\
13.65\end{array}\right|$ & 16 & -- & & & & & \\
\hline 10 & 3.68 & 780 & 7.05 & 3,6 & 13.50 & & $\cdots$ & & 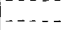 & & & \\
\hline 12 & 4.29 & 1,140 & $\begin{array}{l}7.4 \\
7.55\end{array}$ & $\begin{array}{l}4,020 \\
4,200\end{array}$ & $\left|\begin{array}{l}12.60 \\
11.65\end{array}\right|$ & $\begin{array}{l}12,600 \\
10,300\end{array}$ & $\overrightarrow{5} .68$ & 2,250 & 4.62 & 1,340 & 4.07 & 985 \\
\hline
\end{tabular}

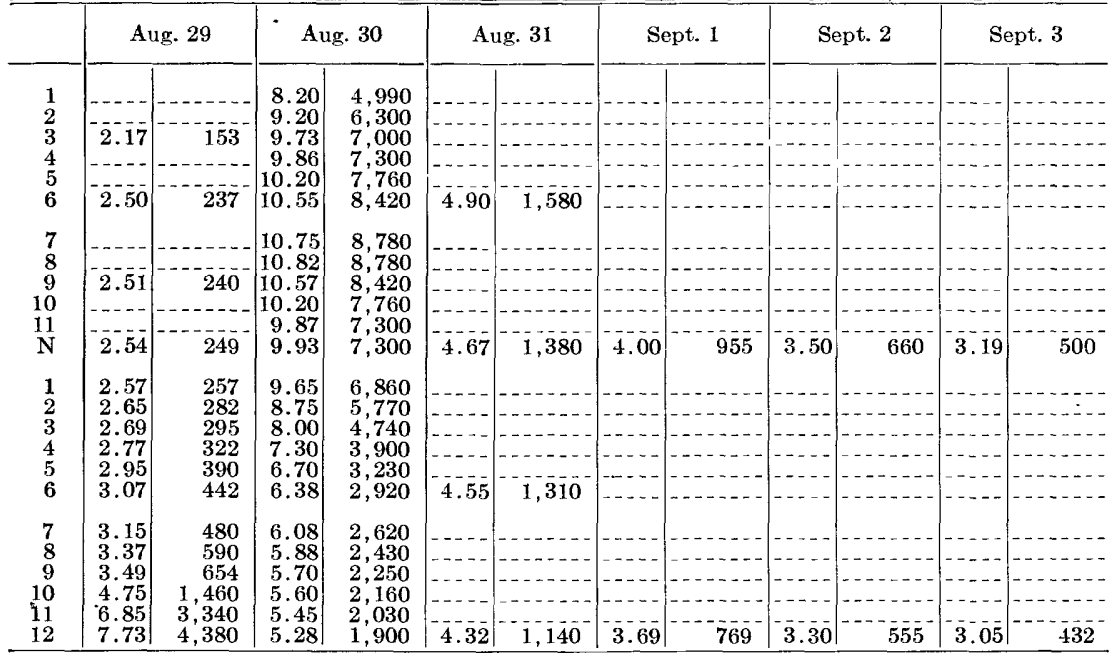

SuPplemental Records.-Aug. 11, 1 p.m., gage height, 1.94 feet; discharge, 126 second-feet. Aug. 13, 4:30 p.m., gage height, 17.8 feet; discharge, 27,300 second-feet. Aug. 30, 7:45 a.m., gage height, 10.81 feet; discharge, 8,780 second-feet. 


\section{LTTLE PIGEON RIVER AT SEVIERVILLE, TENN.}

Location.-Lat. $35^{\circ} 52^{\prime} 34^{\prime \prime}$, long. $83^{\circ} 34^{\prime} 36^{\prime \prime}$, at Eckel farmhouse, half a mile downstream from Sevierville, Sevier County, and half a mile downstream from confluence of East and West Forks. Datum of gage is 881.44 feet above mean sea level, datum of 1929 , supplementary adjustment of 1936 .

Drainage AREA. - 353 square miles.

GAGE-HEIGHT RECORD.-Water-stage recorder graph.

DISCHARGE RECORD.-Stage-discharge relation defined by current-meter measurements up to 18,400 second-feet. Gage heights 'used to half-tenths between 2.6 and $\mathbf{4 . 2}$ feet; hundredths below and tenths above these limits.

Maxima.-1940: Discharge 8,760 second-feet 12 p.m. Aug. 14 (gage height, 9.17 feet).

1920-39: Discharge, 32,000 second-feet June 29, 1928 (gage height, 15.4 feet), from rating curve extended above 20,000 second-feet.

REMARKs.-Flood runoff affected slightly by small dams above station.

Mean discharge, in second-feet, 1940

\begin{tabular}{|c|c|c|c|c|c|c|c|c|c|c|c|}
\hline Day & Aug. & Sept. & Day & Aug. & Sept. & Day & Aug. & Sept. & Day & Aug. & Sept. \\
\hline $\begin{array}{l}1 \\
2 \\
3 \\
4 \\
5 \\
6 \\
7 \\
8\end{array}$ & $\begin{array}{r}1,060 \\
436 \\
307 \\
247 \\
211 \\
207 \\
381 \\
271\end{array}$ & $\begin{array}{l}855 \\
584 \\
448 \\
366 \\
315 \\
276 \\
243 \\
219\end{array}$ & $\begin{array}{r}9 \\
10 \\
11 \\
12 \\
13 \\
14 \\
15 \\
16\end{array}$ & $\begin{array}{r}276 \\
252 \\
207 \\
193 \\
703 \\
2,130 \\
3,860 \\
1,230\end{array}$ & $\begin{array}{l}200 \\
216 \\
319 \\
221 \\
195 \\
178 \\
162 \\
151\end{array}$ & $\begin{array}{l}17 \\
18 \\
19 \\
29 \\
21 \\
22 \\
23 \\
24\end{array}$ & $\begin{array}{l}732 \\
533 \\
535 \\
481 \\
381 \\
345 \\
286 \\
252\end{array}$ & $\begin{array}{l}140 \\
133 \\
126 \\
123 \\
113 \\
110 \\
103 \\
103\end{array}$ & $\begin{array}{l}25 \\
26 \\
27 \\
28 \\
29 \\
30 \\
31\end{array}$ & $\begin{array}{r}220 \\
202 \\
182 \\
171 \\
343 \\
3,080 \\
1,750\end{array}$ & $\begin{array}{l}123 \\
249 \\
148 \\
123 \\
110 \\
110\end{array}$ \\
\hline \multicolumn{10}{|c|}{$\begin{array}{l}\text { Monthly mean discharge, in second-feet } \\
\text { Runoff, in inches }\end{array}$} & $\begin{array}{r}692 \\
2.26\end{array}$ & $\begin{array}{r}225 \\
0.71\end{array}$ \\
\hline
\end{tabular}


384 FLOODS OF AUGUST 1940 IN THE SOUTHEASTERN STATES

Gage height, in feet, and discharge, in second-feet, at indicated time, 1940

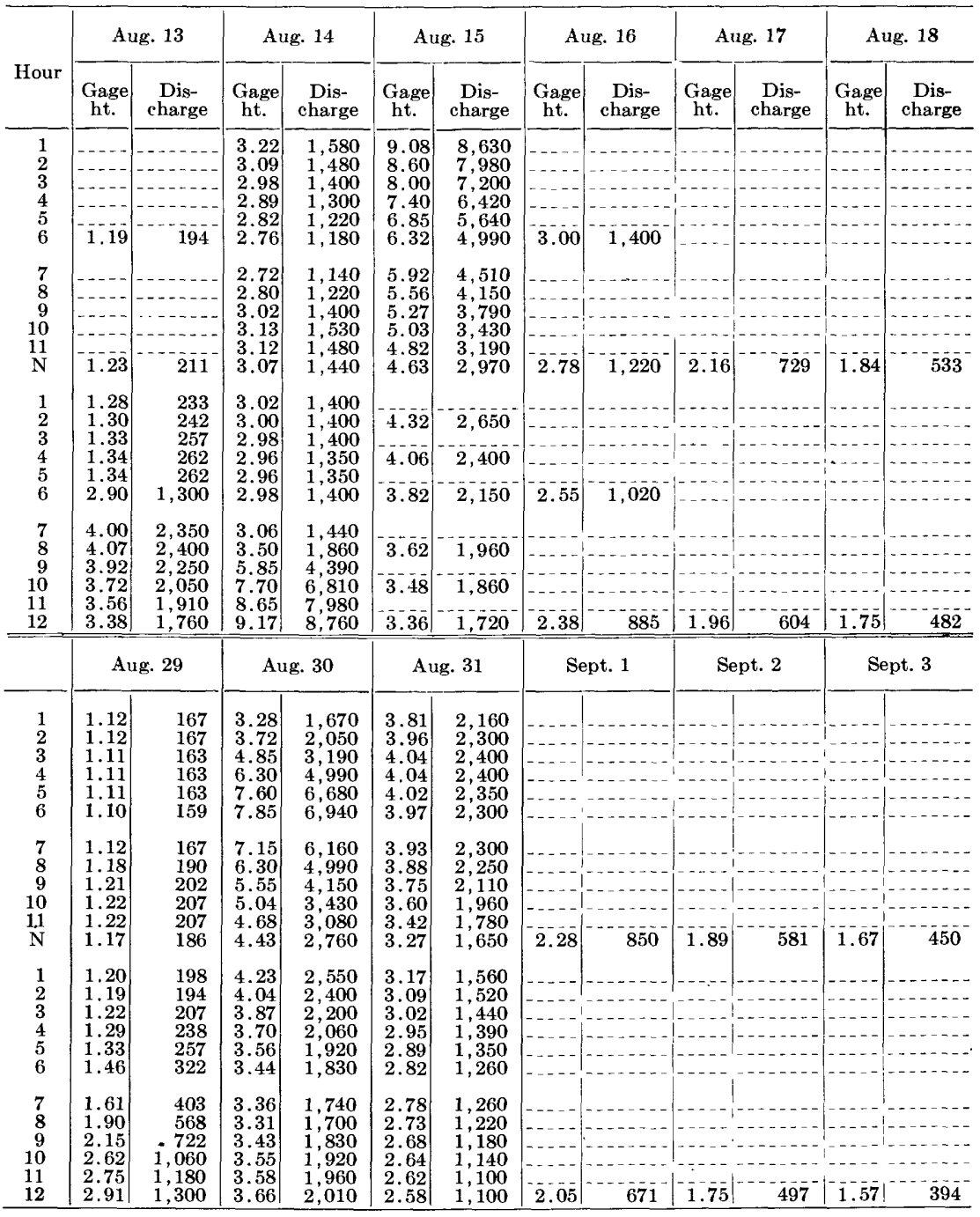

\section{SOUTH FORK HOLSTON RIVER AT VESTAL, VA.}

Location.-Lat. $36^{\circ} 39^{\prime} 06^{\prime \prime}$, long. $81^{\circ} 50^{\prime} 39^{\prime \prime}$, at highway bridge at Vestal, Washington County, three-quarters of a mile downstream from Laurel.Creek and $4 \frac{3 / 4}{4}$ miles upstream from Middle Fork Holston River. Datum of gage is 1,792.30 feet above mean sea level, datum of 1929, supplementary adjustment of 1936 .

Drainage area. - 301 square miles.

GAGE-HEIGHT RECORD.-Water-stage recorder graph.

DISCHARGE RECORD.-Stage-discharge relation defined by current-meter measurements up to 9,800 second-feet. Gage heights used to half-tenths between 4.3 and 6.6 feet; hundredths below and tenths above these limits.

Maxima.-1940: Discharge, 10,600 second-feet 6 to 7 a.m. Aug. 14 (gage height, 13.25 feet). 
1931-39 : Discharge, 10,700 second-feet Mar. 26, 1935 (gage height, 13.26 feet).

Mean discharge, in second-feet, 1940

\begin{tabular}{|c|c|c|c|c|c|c|c|c|c|c|c|}
\hline Day & Aug. & Sept. & Day & A ug. & Sept. & Day & Aug. & Sept. & Day & Aug. & Sept. \\
\hline $\begin{array}{l}1 \\
2 \\
3 \\
4 \\
5 \\
6 \\
7 \\
8\end{array}$ & $\begin{array}{r}2,190 \\
1,100 \\
708 \\
536 \\
442 \\
394 \\
363 \\
312\end{array}$ & $\begin{array}{l}552 \\
441 \\
370 \\
322 \\
293 \\
268 \\
252 \\
234\end{array}$ & $\begin{array}{l}9 \\
10 \\
11 \\
12 \\
13 \\
14 \\
15 \\
16\end{array}$ & $\begin{array}{r}272 \\
248 \\
240 \\
238 \\
1,040 \\
9,180 \\
4,790 \\
3,130\end{array}$ & $\begin{array}{l}226 \\
282 \\
264 \\
222 \\
204 \\
192 \\
186 \\
182\end{array}$ & $\begin{array}{l}17 \\
18 \\
19 \\
20 \\
21 \\
22 \\
23 \\
24\end{array}$ & $\begin{array}{r}2,080 \\
1,840 \\
1,400 \\
1,050 \\
814 \\
684 \\
572 \\
478\end{array}$ & $\begin{array}{l}170 \\
165 \\
158 \\
158 \\
150 \\
146 \\
146 \\
143\end{array}$ & $\begin{array}{l}25 \\
26 \\
27 \\
28 \\
29 \\
30 \\
31\end{array}$ & $\begin{array}{l}419 \\
\mathbf{3 7 8} \\
\mathbf{3 4 9} \\
\mathbf{3 3 7} \\
\mathbf{3 5 2} \\
\mathbf{5 0 0} \\
\mathbf{5 5 9}\end{array}$ & $\begin{array}{l}185 \\
203 \\
155 \\
146 \\
136 \\
138\end{array}$ \\
\hline \multicolumn{10}{|c|}{$\begin{array}{l}\text { Monthly mean discharge, in second-feet. } \\
\text { Runoff, in inches, }\end{array}$} & $\begin{array}{r}1,193 \\
4.57\end{array}$ & $\begin{array}{r}223 \\
0.83\end{array}$ \\
\hline
\end{tabular}

Gage height, in feet, and discharge, in second-feet, at indicated time, 1940

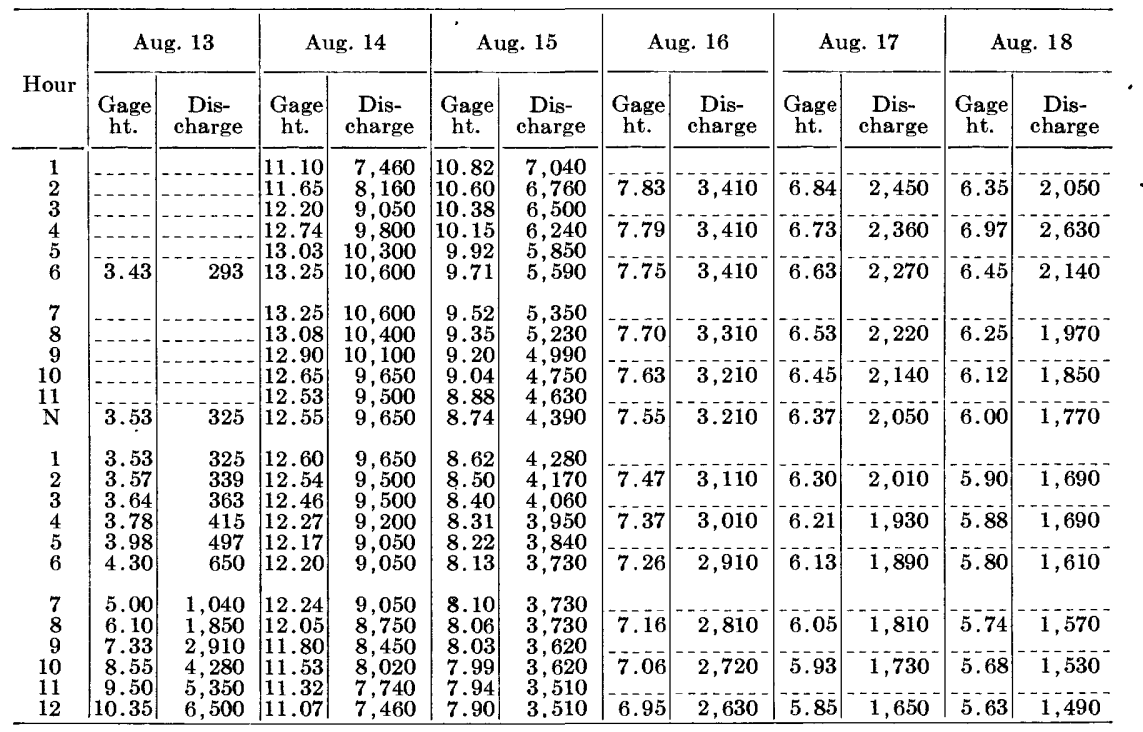

\section{SOUTH FORK HOLSTON RIVER AT BLUFW CITY, TENN.}

Location.-Lat. $36^{\circ} 28^{\prime} 38^{\prime \prime}$, long. $82^{\circ} 15^{\prime} 47^{\prime \prime}, 100$ feet upstream from bridge on U. S. Highways $11 \mathrm{E}$ and 19 at Bluff City, Sullivan County, 600 feet downstream from Southern Railway bridge, three-quarters of a mile downstream from Indian Creek, and 5 miles upstream from Beaver Creek. Datum of gage is $1,368.35$ feet above mean sea level, datum of 1929, supplementary adjustment of 1936 .

Drainage area.-813 square miles.

GAGE-HEIGHT RECORD.-Water-stage recorder graph.

DISCHARGE RECORD.- Stage-discharge relation defined by current-meter measurements up to 18,900 second-feet. Gage heights used to half-tenths between 2.2 and 4.6 feet; hundredths below and tenths above these limits.

Maxima.-1940: Discharge, 18,200 second-feet at 4 p.m. Aug. 14 and 4 a.m. Aug. 15 (gage height, 11.60 feet).

1900-1939: Discharge observed, 28,000 second-feet May 22, 1901 (gage height, 15.0 feet, former site), from rating curve extended above 5,500 secondfeet.

REMARKs.-Flood runoff probably affected slightly by storage in millponds upstream. 
Mean discharge, in second-feet, 1940

\begin{tabular}{|c|c|c|c|c|c|c|c|c|c|c|c|}
\hline Day & Aug. & Sept. & Day & Aug. & Sept. & Day & Aug. & Sept. & Day & Aug. & Sept. \\
\hline 1 & 4,310 & 1,440 & 9 & 682 & 589 & 17 & 4,640 & 471 & 25 & 1,180 & 424 \\
\hline 0 & 2,620 & 1,140 & 10 & 622 & 668 & 18 & 3,850 & 440 & 26 & 1,070 & 488 \\
\hline 3 & 1,610 & 955 & 11 & 583 & 682 & 19 & 3,670 & 424 & 27 & 992 & 434 \\
\hline 4 & 1,220 & 867 & 12 & 540 & 596 & 20 & 3,490 & 419 & 28 & 911 & 404 \\
\hline 6 & $\begin{array}{l}1,030 \\
911\end{array}$ & $\begin{array}{l}787 \\
723\end{array}$ & $\begin{array}{l}13 \\
14\end{array}$ & $\begin{array}{r}642 \\
11800\end{array}$ & $\begin{array}{l}539 \\
505\end{array}$ & $\begin{array}{l}21 \\
22\end{array}$ & $\begin{array}{l}2,280 \\
1,810\end{array}$ & $\begin{array}{l}414 \\
399\end{array}$ & $\begin{array}{l}29 \\
30\end{array}$ & $\begin{array}{r}853 \\
1.220\end{array}$ & $\begin{array}{l}379 \\
337\end{array}$ \\
\hline & 875 & 668 & 15 & 13,400 & 482 & 23 & 1,650 & 374 & & 1,390 & \\
\hline 8 & 795 & 648 & 16 & 6,480 & 440 & 24 & 1,390 & 384 & & & \\
\hline \multicolumn{10}{|c|}{$\begin{array}{l}\text { Monthly mean discharge, in second-feet } \\
\text { Runoff, in inches }\end{array}$} & $\begin{array}{r}2,533 \\
3.59\end{array}$ & $\begin{array}{r}584 \\
0.80\end{array}$ \\
\hline
\end{tabular}

Gage height, in feet, and discharge, in second-feet, at indicated time, 1940

\begin{tabular}{|c|c|c|c|c|c|c|c|c|c|c|c|c|}
\hline \multirow{2}{*}{ Hour } & \multicolumn{2}{|c|}{ Aug. 14} & \multicolumn{2}{|c|}{ Aug. 15} & \multicolumn{2}{|c|}{ Aug. 16} & \multicolumn{2}{|c|}{ Aug. 17} & \multicolumn{2}{|c|}{ Aug. 18} & \multicolumn{2}{|c|}{ Aug. 19} \\
\hline & $\begin{array}{c}\text { Gage } \\
\text { ht. }\end{array}$ & $\begin{array}{c}\text { Dis- } \\
\text { charge }\end{array}$ & $\begin{array}{c}\text { Gage } \\
\text { ht. }\end{array}$ & $\begin{array}{c}\text { Dis- } \\
\text { charge }\end{array}$ & $\begin{array}{c}\text { Gage } \\
\text { ht. }\end{array}$ & $\begin{array}{c}\text { Dis- } \\
\text { charge }\end{array}$ & ge & $\mathrm{Di}$ & $\begin{array}{c}\text { Gage } \\
\mathrm{ht.}\end{array}$ & $\begin{array}{c}\text { Dis- } \\
\text { charge }\end{array}$ & $\begin{array}{l}\text { age } \\
\text { it. }\end{array}$ & $\begin{array}{c}\begin{array}{c}\text { Dis- } \\
\text { charge }\end{array} \\
\end{array}$ \\
\hline \multirow{3}{*}{$\begin{array}{l}1 \\
2 \\
3 \\
4 \\
5 \\
6\end{array}$} & $\begin{array}{l}2.29 \\
2.40\end{array}$ & & \multirow{3}{*}{\begin{tabular}{|}
11.46 \\
11.50 \\
11.56 \\
11.60 \\
11.55 \\
11.38
\end{tabular}} & \multirow{3}{*}{$\begin{array}{l}17,900 \\
17,900 \\
18,200 \\
18,200 \\
18,200 \\
17,600\end{array}$} & \multirow{3}{*}{\begin{tabular}{|l|}
7.28 \\
7.16 \\
7.07 \\
6.99 \\
6.92 \\
6.86
\end{tabular}} & \multirow{3}{*}{$\begin{array}{l}7,800 \\
7,600 \\
7,400 \\
7,200 \\
7,020 \\
7,020\end{array}$} & \multirow{3}{*}{$\begin{array}{l}6.02 \\
6.00 \\
5.95 \\
5.90 \\
5.86 \\
5.80\end{array}$} & \multirow{3}{*}{$\begin{array}{l}5,450 \\
5,450 \\
5,450 \\
5,280 \\
5,280 \\
5,110\end{array}$} & 4.84 & 3,590 & 4.66 & 3,460 \\
\hline & & & & & & & & & 4.73 & 3,460 & 4.56 & 3,260 \\
\hline & $\begin{array}{l}3.80 \\
5.25\end{array}$ & & & & & & & & $4.6 \overline{4}$ & 3,330 & 4.53 & $3,260^{-}$ \\
\hline \multirow{4}{*}{$\begin{array}{r}7 \\
8 \\
9 \\
10 \\
11 \\
\mathrm{~N}\end{array}$} & \multirow{4}{*}{$\begin{array}{r}6.65 \\
7.72 \\
8.80 \\
9.43 \\
10.08 \\
10.62\end{array}$} & \multirow{4}{*}{$\begin{array}{r}6,480 \\
8,620 \\
11,100 \\
12,500 \\
14,200 \\
15,500\end{array}$} & \multirow{4}{*}{$\begin{array}{r}11.18 \\
10.91 \\
10.63 \\
10.33 \\
10.03 \\
9.70\end{array}$} & \multirow{4}{*}{$\begin{array}{l}17,100 \\
16,300 \\
15,500 \\
14,700 \\
14,000 \\
13,200\end{array}$} & \multirow{4}{*}{\begin{tabular}{|l|}
6.79 \\
6.71 \\
6.65 \\
6.59 \\
6.54 \\
6.50
\end{tabular}} & \multirow{4}{*}{$\begin{array}{l}6,840 \\
6,660 \\
6,480 \\
6,480 \\
6,300 \\
6,300\end{array}$} & \multirow{4}{*}{$\begin{array}{l}5.75 \\
5.70 \\
5.64 \\
5.58 \\
5.52 \\
5.47\end{array}$} & \multirow{4}{*}{$\begin{array}{l}5,110 \\
4,950 \\
4,790 \\
4,790 \\
4,630 \\
4,630\end{array}$} & 56 & & 55 & \\
\hline & & & & & & & & & 4.50 & 3,260 & 4.50 & 3,260 \\
\hline & & & & & & & & & 4.53 & 3,260 & 4.60 & 3,330 \\
\hline & & & & & & & & & 5.08 & 4,010 & 4.71 & 3,460 \\
\hline \multirow{4}{*}{$\begin{array}{l}1 \\
2 \\
3 \\
4 \\
5 \\
6\end{array}$} & \multirow{4}{*}{$\begin{array}{l}11.00 \\
11.35 \\
11.53 \\
11.60 \\
11.54 \\
11.43\end{array}$} & \multirow{4}{*}{$\begin{array}{l}16,500 \\
17,600 \\
17,900 \\
18,200 \\
17,900 \\
17,600\end{array}$} & \multirow{4}{*}{$\begin{array}{l}9.40 \\
9.12 \\
8.88 \\
8.65 \\
8.45 \\
8.26\end{array}$} & \multirow{4}{*}{$\begin{array}{r}12,500 \\
11,800 \\
11,300 \\
10,600 \\
10,200 \\
9,940\end{array}$} & \multirow{4}{*}{$\begin{array}{l}6.47 \\
6.44 \\
6.40 \\
6.37 \\
6.34 \\
6.32\end{array}$} & \multirow{4}{*}{$\begin{array}{l}6,300 \\
6,130 \\
6,130 \\
6,130 \\
5,960 \\
5,960\end{array}$} & \multirow{4}{*}{$\begin{array}{l}5.40 \\
5.35 \\
5.31 \\
5.27 \\
5.21 \\
5.18\end{array}$} & \multirow{4}{*}{$\begin{array}{r}4,470 \\
4,470 \\
4,310 \\
4,310 \\
4,160 \\
4,160\end{array}$} & & & & 770 \\
\hline & & & & & & & & & & & & \\
\hline & & & & & & & & & 1 & & .07 & 4,010 \\
\hline & & & & & & & & & 5.56 & 4,790 & 5.16 & 4,160 \\
\hline \multirow{4}{*}{$\begin{array}{r}7 \\
8 \\
9 \\
10 \\
11 \\
12\end{array}$} & \multirow{4}{*}{$\begin{array}{l}11.35 \\
11.28 \\
11.31 \\
11.35 \\
11.40 \\
11.44\end{array}$} & & $\begin{array}{l}8.10 \\
7.93\end{array}$ & & & & & & & 4.310 & 5.19 & 16 \\
\hline & & 400 & & & & & & & & & & \\
\hline & & 600 & & & & & 5. & & 5.02 & 3,870 & 5.17 & 4,160 \\
\hline & & & & & & & & & 4.83 & 3,590 & 5.14 & 4,010 \\
\hline
\end{tabular}

SOU'TH FORK HOLSTON RIVER AT KINGSPORT, TENN.

Location.-Lat. $36^{\circ} 30^{\prime} 37^{\prime \prime}$, long. $82^{\circ} 32^{\prime} 10^{\prime \prime}$, 0.5 mile downstream from Clinchfield Railroad bridge, 1 mile upstream from bridge on State Highway 81, 3 miles southeast of Kingsport postoffice, Sullivan County, and $5 \%$ miles upstream from confluence with North Fork Holston River. Datum of gage is 1,184.31 feet above mean sea level, datum of 1929, supplementary adjustment of 1936 .

DraINAGE AREA.-1,931 square miles.

GAGE-HEIGHT RECORD.-Water-stage recorder graph.

DISCHARGE RECORD.-Stage-discharge relation defined by current-meter measurements up to 67,200 second-feet. Gage heights used to half-tenths between 1.4 and 3.2 feet; hundredths below and tenths above these limits.

Maxima.-1940: Discharge, 68,800 second-feet 9:30 a.m. Aug. 14 (gage height, 18.80 feet).

1925-39 : Discharge, 45,200 second-feet Mar. 26, 1935 (gage height, 15.1, feet).

Remarks.-Flood runoff possibly affected by storage. 
Mean discharge, in second-feet, 1940

\begin{tabular}{|c|c|c|c|c|c|c|c|c|c|c|c|}
\hline Day & Aug. & Sept. & Day & Aug. & Sept. & Day & Aug. & Sept. & Day & Aug. & Sept. \\
\hline \begin{tabular}{l|}
1 \\
2 \\
3 \\
4 \\
5 \\
6 \\
7 \\
8
\end{tabular} & $\begin{array}{l}8,560 \\
5,740 \\
3,770 \\
2,740 \\
2,400 \\
2,150 \\
2,400 \\
2,400\end{array}$ & $\begin{array}{l}.5,270 \\
3,830 \\
3,080 \\
2,680 \\
2,340 \\
2,180 \\
1,940 \\
1,800\end{array}$ & $\begin{array}{r}9 \\
10 \\
11 \\
12 \\
13 \\
14 \\
15 \\
16\end{array}$ & $\begin{array}{r}1,900 \\
1,650 \\
1,420 \\
1,400 \\
4,390 \\
39,900 \\
29,200 \\
14,500\end{array}$ & $\begin{array}{l}1,700 \\
1,740 \\
1,940 \\
1,710 \\
1,500 \\
1,410 \\
1,330 \\
1,270\end{array}$ & $\begin{array}{l}17 \\
18 \\
19 \\
20 \\
21 \\
22 \\
23 \\
24\end{array}$ & $\begin{array}{r}10,200 \\
7,460 \\
6,760 \\
6,300 \\
4,620 \\
3,830 \\
3,470 \\
3,020\end{array}$ & $\begin{array}{r}1,240 \\
1,170 \\
1,140 \\
1,100 \\
1,070 \\
1,030 \\
1,010 \\
986\end{array}$ & $\begin{array}{l}25 \\
26 \\
27 \\
28 \\
29 \\
30 \\
31\end{array}$ & $\begin{array}{l}2,680 \\
2,510 \\
2,340 \\
2,100 \\
2,110 \\
6,120 \\
9,400\end{array}$ & $\begin{array}{r}1,060 \\
1,190 \\
1,130 \\
1,020 \\
951 \\
828\end{array}$ \\
\hline & & & & & & & & & & $\begin{array}{r}6,369 \\
3.80\end{array}$ & $\begin{array}{r}1,688 \\
0.98\end{array}$ \\
\hline
\end{tabular}

Gage height, in feet, and discharge, in second-feet, at indicated time, 1940

\begin{tabular}{|c|c|c|c|c|c|c|c|c|c|c|c|c|}
\hline \multirow{2}{*}{ Hour } & \multicolumn{2}{|c|}{ Aug. 13} & \multicolumn{2}{|c|}{ Aug. 14} & \multicolumn{2}{|c|}{ Aug. 15} & \multicolumn{2}{|c|}{ Aug. 16} & \multicolumn{2}{|c|}{ Aug. 17} & \multicolumn{2}{|c|}{ Aug. 18} \\
\hline & $\begin{array}{c}\text { Gage } \\
\text { ht. }\end{array}$ & $\begin{array}{c}\text { Dis- } \\
\text { charge }\end{array}$ & $\begin{array}{c}\text { Gage } \\
\text { ht. }\end{array}$ & $\begin{array}{c}\text { Dis- } \\
\text { charge }\end{array}$ & $\begin{array}{c}\text { Gage } \\
\text { ht. }\end{array}$ & $\begin{array}{c}\text { Dis- } \\
\text { charge }\end{array}$ & $\begin{array}{c}\text { Gage } \\
\text { ht. }\end{array}$ & $\begin{array}{c}\text { Dis- } \\
\text { charge }\end{array}$ & $\begin{array}{c}\text { Gage } \\
\text { ht. }\end{array}$ & $\begin{array}{c}\text { Dis- } \\
\text { charge }\end{array}$ & $\begin{array}{c}\text { Gage } \\
\text { ht. }\end{array}$ & $\begin{array}{c}\text { Dis- } \\
\text { eharge }\end{array}$ \\
\hline $\begin{array}{l}1 \\
2 \\
3 \\
4 \\
5 \\
6\end{array}$ & $\begin{array}{l}1.17 \\
1.30 \\
1.34 \\
1.34 \\
1.32 \\
1.25\end{array}$ & $\begin{array}{l}1,650 \\
1,840 \\
1,900 \\
1,900 \\
1,870 \\
1,760\end{array}$ & $\begin{array}{r}6.01 \\
6.30 \\
6.85 \\
8.02 \\
9.86 \\
12.80\end{array}$ & $\begin{array}{l}11,900 \\
12,700 \\
14,200 \\
18,000 \\
24,500 \\
35,400\end{array}$ & $\left|\begin{array}{l}12.31 \\
12.20 \\
12.17 \\
12.16 \\
12.15 \\
12.15\end{array}\right|$ & $\begin{array}{l}33,400 \\
33,000 \\
33,000 \\
33,000 \\
33,000 \\
33,000\end{array}$ & $\begin{array}{l}8.15 \\
7.97 \\
7.80 \\
7.66 \\
7.50 \\
7.36\end{array}$ & $\begin{array}{l}8,700 \\
8,000 \\
7,400 \\
7,100 \\
6,400 \\
6,100\end{array}$ & $\begin{array}{l}6.00 \\
5.95 \\
5.90 \\
5.87 \\
5.83 \\
5.78\end{array}$ & $\begin{array}{l}11,900 \\
11,900 \\
11,600 \\
11,600 \\
11,300 \\
11,300\end{array}$ & $\begin{array}{r}4.62 \\
-4.53 \\
-4.42\end{array} \mid$ & $\begin{array}{r}8,130 \\
7,880 \\
7,640\end{array}$ \\
\hline $\begin{array}{r}7 \\
8 \\
9 \\
10 \\
11 \\
\mathbf{N}\end{array}$ & $\begin{array}{r}1.16 \\
1.08 \\
1.02 \\
.98 \\
1.20 \\
1.51\end{array}$ & $\begin{array}{l}1,630 \\
1,520 \\
1,440 \\
1,380 \\
1,690 \\
2,150\end{array}$ & $\begin{array}{r}5.80 \\
.80 \\
8.65 \\
.76 \\
8.25 \\
7.35\end{array}$ & $\begin{array}{l}49, \\
61, \\
67, \\
68, \\
64,\end{array}$ & $\begin{array}{l}12.15 \\
12.17 \\
12.18 \\
12.14 \\
12.03 \\
11.85\end{array}$ & $\begin{array}{l}33,000 \\
33,000 \\
33,000 \\
32,600 \\
32,200 \\
31,400\end{array}$ & $\begin{array}{l}7.23 \\
7.11 \\
7.00 \\
6.91 \\
6.82 \\
6.72\end{array}$ & $\begin{array}{l}15,500 \\
15,200 \\
14,800 \\
14,500 \\
14,200 \\
13,900\end{array}$ & \begin{tabular}{l|}
5.72 \\
5.66 \\
5.60 \\
5.53 \\
5.48 \\
5.41
\end{tabular} & $\begin{array}{l}11,000 \\
11,000 \\
10,800 \\
10,500 \\
10,500 \\
10,200\end{array}$ & $\left|\begin{array}{r}4.31 \\
4.22 \\
-4.12\end{array}\right|$ & $\begin{array}{r}7,400 \\
7,170 \\
6,940\end{array}$ \\
\hline $\begin{array}{l}1 \\
2 \\
3 \\
4 \\
5 \\
5 \\
6\end{array}$ & $\begin{array}{l}1.90 \\
2.46 \\
2.88 \\
3.27 \\
3.75 \\
4.25\end{array}$ & $\begin{array}{l}2,830 \\
3,860 \\
4,740 \\
5,540 \\
6,580 \\
7,460\end{array}$ & $\begin{array}{l}16.27 \\
15.43 \\
14.70 \\
14.26 \\
13.95 \\
13.73\end{array}$ & $\begin{array}{l}52,200 \\
47,000 \\
43,500 \\
41,700 \\
40,400 \\
39,100\end{array}$ & $\begin{array}{l}11.63 \\
11.38 \\
11.08 \\
10.80 \\
10.50 \\
10.15\end{array}$ & $\begin{array}{l}30,700 \\
29,900 \\
28,800 \\
27,700 \\
26,600 \\
25,500\end{array}$ & $\begin{array}{l}6.64 \\
6.55 \\
6.47 \\
6.42 \\
6.36 \\
6.31\end{array}$ & $\begin{array}{l}13,600 \\
13,600 \\
13,300 \\
13,000 \\
13,000 \\
12,700\end{array}$ & $\begin{array}{l}5.34 \\
5.28 \\
5.21 \\
5.15 \\
5.08 \\
5.01\end{array}$ & $\begin{array}{l}9,940 \\
9,670 \\
9,670 \\
9,410 \\
9,150\end{array}$ & $\left|\begin{array}{c}4.03 \\
4.03 \\
4 . \overline{2} \overline{2}\end{array}\right|$ & $6,7 \overline{6}$ \\
\hline $\begin{array}{r}7 \\
8 \\
9 \\
10 \\
11 \\
12\end{array}$ & $\begin{array}{l}4.64 \\
4.95 \\
5.14 \\
5.31 \\
5.52 \\
5.78\end{array}$ & $\begin{array}{r}8,340 \\
9,250 \\
9,480 \\
9,940 \\
10,400 \\
11,100\end{array}$ & $\begin{array}{l}13.54 \\
13.36 \\
13.20 \\
12.90 \\
12.70 \\
12.50\end{array}$ & $\begin{array}{l}38,300 \\
37,900 \\
37,000 \\
35,800 \\
35,000 \\
34,200\end{array}$ & $\begin{array}{l}9.83 \\
9.56 \\
9.30 \\
9.00 \\
8.77 \\
8.55\end{array}$ & $\begin{array}{l}24,100 \\
23,400 \\
22,400 \\
21,400 \\
20,700 \\
20,000\end{array}$ & $\begin{array}{l}6.26 \\
6.21 \\
6.16 \\
6.12 \\
6.08 \\
6.03\end{array}$ & $\begin{array}{l}12,700 \\
12,400 \\
12,400 \\
12,100 \\
12,100 \\
11,900\end{array}$ & $\begin{array}{l}4.96 \\
4.90 \\
4.85 \\
4.80 \\
4.75 \\
4.70\end{array}$ & $\begin{array}{l}8,890 \\
8,630 \\
8,630 \\
8,630 \\
8,380\end{array}$ & $\left|\begin{array}{r}4.30 \\
-4.58 \\
-4.56\end{array}\right|$ & $\begin{array}{r}7,400 \\
8,130 \\
8,130\end{array}$ \\
\hline
\end{tabular}

\begin{tabular}{|c|c|c|c|c|c|c|c|c|c|c|c|c|}
\hline & \multicolumn{2}{|c|}{ Aug. 29} & \multicolumn{2}{|c|}{ Aug. 30} & \multicolumn{2}{|c|}{ Aug. 31} & \multicolumn{2}{|c|}{ Sept. 1} & \multicolumn{2}{|c|}{ Sept. 2} & \multicolumn{2}{|c|}{ Sept. 3} \\
\hline $\begin{array}{l}1 \\
2 \\
3 \\
4 \\
5 \\
6\end{array}$ & $\begin{array}{l}1.50 \\
1.48 \\
1.48 \\
1.48 \\
1.48 \\
1.47\end{array}$ & $\begin{array}{l}2,020 \\
2,020 \\
2,020 \\
2,020 \\
2,020 \\
1,940\end{array}$ & $\begin{array}{l}1.85 \\
1.88 \\
1.94 \\
2.02 \\
2.09 \\
2.14\end{array}$ & $\begin{array}{l}2,600 \\
2,680 \\
2,760 \\
2,850 \\
3,020 \\
3,100\end{array}$ & $\begin{array}{l}7.57 \\
6.95 \\
6.30 \\
5.80 \\
5.40 \\
5.10\end{array}$ & $\begin{array}{r}16,800 \\
14,800 \\
12,700 \\
11,300 \\
10,200 \\
9,410\end{array}$ & 3.50 & 5,650 & & & & \\
\hline $\begin{array}{r}7 \\
8 \\
9 \\
10 \\
11 \\
\text { N }\end{array}$ & $\begin{array}{l}1.46 \\
1.45 \\
1.45 \\
1.48 \\
1.52 \\
1.54\end{array}$ & $\begin{array}{l}1,940 \\
1,940 \\
1,940 \\
2,020 \\
2,020 \\
2,100\end{array}$ & $\begin{array}{l}2.19 \\
2.30 \\
2.47 \\
2.54 \\
2.55 \\
2.59\end{array}$ & $\begin{array}{l}3,190 \\
3,370 \\
3,640 \\
3,820 \\
3,820 \\
3,910\end{array}$ & $\begin{array}{l}4.88 \\
4.76 \\
4.81 \\
5.00 \\
5.17 \\
5.14\end{array}$ & $\begin{array}{l}8,890 \\
8,630 \\
8,630 \\
9,150 \\
9,670 \\
9,410\end{array}$ & 3.30 & 5,250 & 2.54 & 3,820 & 2.15 & 3,100 \\
\hline $\begin{array}{l}1 \\
2 \\
3 \\
4 \\
5 \\
6\end{array}$ & $\begin{array}{l}1.55 \\
1.55 \\
1.55 \\
1.55 \\
1.54 \\
1.58\end{array}$ & $\begin{array}{l}2,100 \\
2,100 \\
2,100 \\
2,100 \\
2,100 \\
2,180\end{array}$ & $\begin{array}{l}2.65 \\
2.74 \\
2.91 \\
3.13 \\
3.30 \\
3.46\end{array}$ & $\begin{array}{l}4,000 \\
4,180 \\
4,470 \\
4,950 \\
5,250 \\
5,650\end{array}$ & $\begin{array}{l}5.03 \\
4.87 \\
4.68 \\
4.52 \\
4.39 \\
4.30\end{array}$ & $\begin{array}{l}9,150 \\
8,890 \\
8,380 \\
7,880 \\
7,640 \\
7,400\end{array}$ & 3.09 & $4,850^{-}$ & - & & & \\
\hline $\begin{array}{r}7 \\
8 \\
9 \\
10 \\
11 \\
12\end{array}$ & $\begin{array}{l}1.60 \\
1.64 \\
1.68 \\
1.72 \\
1.78 \\
1.84\end{array}$ & $\begin{array}{l}2,180 \\
2,260 \\
2,340 \\
2,340 \\
2,510 \\
2,600\end{array}$ & $\begin{array}{l}4.05 \\
5.70 \\
7.10 \\
7.90 \\
8.15 \\
8.02\end{array}$ & $\begin{array}{r}6,720 \\
11,000 \\
15,200 \\
17,700 \\
18,700 \\
18,000\end{array}$ & $\begin{array}{l}4.25 \\
4.18 \\
4.09 \\
4.00 \\
3.91 \\
3.84\end{array}$ & $\begin{array}{l}7,170 \\
7,170 \\
6,940 \\
6,720 \\
6,500 \\
6,280\end{array}$ & $\overline{2} . \overline{8} \overline{6}$ & $\overline{4}, \overline{380}$ & $\overline{2} . \overline{3} 1$ & 3,370 & 2.00 & 2,850 \\
\hline
\end{tabular}

Supplemental RECORD.-Aug. 14, 9:30 a.m., gage height, 18.80 feet; discharge, 68,800 second-feet. 


\section{HOLSTON RIVER NEAR ROGERSVILLE, TENN.}

LOCATION.-Lat. $36^{\circ} 22^{\prime} 13^{\prime \prime}$, long. $82^{\circ} 59^{\prime} 58^{\prime \prime}, 300$ feet downstream from bridge on State Highways 66 and 70, half a mile upstream from Southern Railway bridge, half a mile downstream from Dodson Creek, and 3 miles south of Rogersville, Hawkins County. Datum of gage is $1,054.83$ feet above mean sea level, datum of 1929 , supplementary adjustment of 1936 .

Drainage AREA.- 3,035 square miles.

GAGE-HEIGHT RECORD.-Water-stage recorder graph.

DISCHARGE RECORD.-Stage-discharge relation defined by current-meter measurements up to 56,700 second-feet. Gage heights used to half-tenths between 1.1 and 2.8 feet; hundredths below and tenths above these limits.

Maxima.-1940: Discharge, 59,000 second-feet 6:00 a.m. Aug. 15 (gage height, 17.76 feet).

1902-39: Discharge, 70,900 second-feet Jan. 29, 1918 (gage height, 20.0 feet, former site and datum), from rating curve extended above 35,000 second-feet.

Stage known, 38.4 feet Mar. 10, 1867, former site and datum (discharge not determined).

Remarks.-Flood runoff not appreciably affected by artificial storage.

Mean discharge, in second-feet, 1940

\begin{tabular}{|c|c|c|c|c|c|c|c|c|c|c|c|}
\hline Day & Aug. & Sept. & Day & Aug. & Sept. & Day & Aug. & Sept. & Day & Aug. & Sept. \\
\hline 1 & 13,300 & 870 & 9 & 2,88 & 290 & 17 & 15 , & 1,60 & 25 & 3,8 & 1,2 \\
\hline 2 & & & 10 & & & 1 & & & & & 1,3 \\
\hline 3 & 5,870 & 4,730 & 11 & 1,9 & 2,2 & 19 & 9,7 & 1,4 & 2 & 3, & 1,460 \\
\hline 4 & 4,200 & 3,8 & 12 & 1,7 & 2,3 & 2 & 10 , & & & 2,8 & 1,390 \\
\hline 5 & 3,230 & $\mathbf{3}, 2$ & 13 & 1,9 & 2,0 & 2 & 7,9 & 1,3 & & 2, & 1,270 \\
\hline 6 & 2,960 & 3,050 & 14 & 25,1 & 1,880 & 22 & 5,9 & 1,3 & 30 & 5,8 & 1,200 \\
\hline 7 & 2, & 2,7 & 15 & 54,7 & 1,7 & 23 & & 1,300 & 31 & 13,700 & \\
\hline 8 & 3,140 & 2,450 & 16 & 28,100 & 1,670 & 24 & 4,620 & 1,250 & & & \\
\hline \multicolumn{12}{|c|}{\begin{tabular}{r|r|r} 
& 8,676 & 2,408 \\
\end{tabular}} \\
\hline
\end{tabular}

Gage height, in feet, and discharge, in second-feet, at indicated time, 1940

\begin{tabular}{|c|c|c|c|c|c|c|c|c|}
\hline \multirow{2}{*}{ Hour } & \multicolumn{2}{|c|}{ Aug. 14} & \multicolumn{2}{|c|}{ Aug. 15} & \multicolumn{2}{|c|}{ Aug. 16} & \multicolumn{2}{|c|}{ Aug. 17} \\
\hline & $\begin{array}{l}\text { Gage } \\
\text { height }\end{array}$ & Discharge & $\begin{array}{l}\text { Gage } \\
\text { height }\end{array}$ & Discharge & $\begin{array}{l}\text { Gage } \\
\text { height }\end{array}$ & Discharge & $\begin{array}{l}\text { Gage } \\
\text { height }\end{array}$ & Discharge \\
\hline $\begin{array}{l}1 \\
2 \\
3 \\
4 \\
5 \\
6\end{array}$ & $\begin{array}{l}1.50 \\
2.20 \\
3.00 \\
3.64 \\
4.11 \\
4.48\end{array}$ & $\begin{array}{l}2,790 \\
4,100 \\
5,870 \\
7,360 \\
8,710 \\
9,870\end{array}$ & $\begin{array}{l}17.26 \\
17.50 \\
17.62 \\
17.71 \\
17.74 \\
17.76\end{array}$ & $\begin{array}{l}57,100 \\
57,800 \\
58,200 \\
58,600 \\
58,600 \\
59,000\end{array}$ & $\begin{array}{l}13.70 \\
13.25 \\
12.80 \\
12.31 \\
11.85 \\
11.40\end{array}$ & $\begin{array}{l}43,200 \\
41,300 \\
39,700 \\
37,800 \\
35,900 \\
34,400\end{array}$ & $\begin{array}{l}6.90 \\
6.81 \\
6.72 \\
6.64 \\
6.57 \\
6.50\end{array}$ & $\begin{array}{l}17,800 \\
17,400 \\
17,100 \\
16,800 \\
16,800 \\
16,400\end{array}$ \\
\hline $\begin{array}{r}7 \\
8 \\
9 \\
10 \\
11 \\
\mathrm{~N}\end{array}$ & $\begin{array}{l}4.74 \\
5.00 \\
5.26 \\
5.64 \\
6.28 \\
7.24\end{array}$ & $\begin{array}{l}10,500 \\
11,400 \\
\mathrm{r} 2,400 \\
13,400 \\
15,700 \\
18,800\end{array}$ & $\begin{array}{l}17.74 \\
17.71 \\
17.64 \\
17.54 \\
17.40 \\
17.26\end{array}$ & $\begin{array}{l}58,600 \\
58,600 \\
58,200 \\
57,800 \\
57,500 \\
57,100\end{array}$ & $\begin{array}{r}10.98 \\
10.54 \\
10.18 \\
9.80 \\
9.50 \\
9.20\end{array}$ & $\begin{array}{l}32,900 \\
31,000 \\
29,900 \\
28,300 \\
27,200 \\
26,100\end{array}$ & $\begin{array}{l}6.43 \\
6.37 \\
6.30 \\
6.24 \\
6.20 \\
6.13\end{array}$ & $\begin{array}{l}16,100 \\
16,100 \\
15,700 \\
15,400 \\
15,400 \\
15,100\end{array}$ \\
\hline $\begin{array}{l}1 \\
2 \\
3 \\
4 \\
5 \\
6\end{array}$ & $\begin{array}{r}8.35 \\
9.58 \\
10.75 \\
11.80 \\
12.68 \\
13.50\end{array}$ & $\begin{array}{l}23,100 \\
27,600 \\
32,100 \\
35,900 \\
39,400 \\
42,400\end{array}$ & $\begin{array}{l}17.08 \\
16.89 \\
16.66 \\
16.40 \\
16.16 \\
15.93\end{array}$ & $\begin{array}{l}56,300 \\
55,500 \\
54,700 \\
53,600 \\
52,800 \\
51,600\end{array}$ & $\begin{array}{l}8.93 \\
8.66 \\
8.45 \\
8.25 \\
8.05 \\
7.86\end{array}$ & $\begin{array}{l}25,000 \\
24,200 \\
23,100 \\
22,400 \\
21,700 \\
21,300\end{array}$ & $\begin{array}{l}6.11 \\
6.06 \\
6.00 \\
5.94 \\
5.88 \\
5.81\end{array}$ & $\begin{array}{l}15,100 \\
15,100 \\
14,700 \\
14,400 \\
14,400 \\
14,100\end{array}$ \\
\hline $\begin{array}{r}7 \\
8 \\
9 \\
10 \\
11 \\
12 \\
\end{array}$ & $\begin{array}{l}14.30 \\
15.00 \\
15.60 \\
16.20 \\
16.63 \\
17.00\end{array}$ & $\begin{array}{l}45,400 \\
48,100 \\
50,400 \\
52,800 \\
54,300 \\
55,900 \\
\end{array}$ & $\begin{array}{l}15.67 \\
15.40 \\
15.13 \\
14.79 \\
14.45 \\
14.08\end{array}$ & $\begin{array}{l}50,800 \\
49,700 \\
48,500 \\
47,300 \\
45,800 \\
44,700\end{array}$ & $\begin{array}{l}7.68 \\
7.54 \\
7.40 \\
7.26 \\
7.14 \\
7.02 \\
\end{array}$ & $\begin{array}{l}20,600 \\
19,900 \\
19,500 \\
19,200 \\
18,500 \\
18,100 \\
\end{array}$ & $\begin{array}{l}5.75 \\
5.69 \\
5.63 \\
5.56 \\
5.50 \\
5.44 \\
\end{array}$ & $\begin{array}{l}14,100 \\
13,700 \\
13,400 \\
13,400 \\
13,100 \\
12,700\end{array}$ \\
\hline
\end{tabular}


TENNESSEE RIVER BASIN

Gage height, in feet, and discharge, in second-feet, at indicated time, 1940-Con.

\begin{tabular}{r|r|r|r|r|r|r}
\hline & \multicolumn{2}{|c|}{ Aug. 18 } & \multicolumn{2}{|c|}{ Aug. 19 } & \multicolumn{2}{c}{ Aug. 20 } \\
\cline { 2 - 7 } Hour & $\begin{array}{c}\text { Gage } \\
\text { height }\end{array}$ & Discharge & $\begin{array}{c}\text { Gage } \\
\text { height }\end{array}$ & Discharge & $\begin{array}{r}\text { Gage } \\
\text { height }\end{array}$ & Discharge \\
\hline 2 & 5.30 & 12,400 & 4.33 & 9,280 & 4.28 & 9,280 \\
4 & 5.18 & 12,100 & 4.46 & 9,870 & 4.39 & 9,570 \\
6 & 5.06 & 11,800 & 4.58 & 10,200 & 4.56 & 10,200 \\
8 & 4.97 & 11,400 & 4.69 & 10,500 & 4.70 & 10,500 \\
10 & 4.87 & 11,100 & 4.70 & 10,500 & 4.76 & 10,800 \\
N & 4.78 & 10,800 & 4.63 & 10,200 & 4.76 & 10,800 \\
2 & 4.68 & 10,500 & 4.53 & 9,870 & 4.71 & 10,500 \\
4 & 4.58 & 10,200 & 4.42 & 9,570 & 4.66 & 10,500 \\
6 & 4.48 & 9,870 & 4.31 & 9,280 & 4.61 & 10,200 \\
8 & 4.38 & 9,570 & 4.24 & 8,990 & 4.55 & 10,200 \\
10 & 4.30 & 9,280 & 4.20 & 8,990 & 4.48 & 9,870 \\
12 & 4.27 & 9,280 & 4.21 & 8,990 & 4.39 & 9,570 \\
\hline
\end{tabular}

\section{HOLSTON RIVER NEAR MORRISTOWN, TENN.}

Location.-Lat. $36^{\circ} 15^{\prime} 42^{\prime \prime}$, long. $83^{\circ} 17^{\prime} 18^{\prime \prime}$, at Morristown power house, just downstream from bridge on U.S. Highway $25 \mathrm{E}, 300$ feet upstream from Turkey Creek, and 3.3 miles north of Morristown, Hamblen County. Datum of gage is 964.02 feet above mean sea level, datum of 1929, supplementary adjustment of 1936.

DRAINAGE AREA. - 3,244 square miles.

GAGE-HEIGHT RECORD.--Water-stage recorder graph.

DISCHARGE RECORD.-Stage-discharge relation defined by current-meter measurements up to 27,300 second-feet and extended to crest gage height on basis of maximum discharge at Rogersville and Jefferson City. Gage heights used to half-tenths between 5.3 and 7.0 feet; hundredths below and tenths above these limits.

Maxima.-1940: Discharge, 58,900 second-feet 2 to $2: 30$ p.m. Aug. 15 (gage height, 26.70 feet).

1937-39: Discharge, 27,300 second-feet Oct. 29, 1937 (gage height, 16.59 feet).

Flood of Mar. 27, 1935, reached a stage of 28.4 feet, from floodmark (discharge, 65,000 second-feet).

REMARKs.-Flood runoff not materially affected by artificial storage.

Mean discharge, in second-feet, 1940

\begin{tabular}{|c|c|c|c|c|c|c|c|c|c|c|c|}
\hline Day & Aug. & Sept. & Day & Aug. & Sept. & Day & Aug. & Sept. & Day & Aug. & Sept. \\
\hline $\begin{array}{l}1 \\
2 \\
3 \\
4 \\
5 \\
6 \\
7 \\
8\end{array}$ & $\begin{array}{r}17,400 \\
9,700 \\
6,500 \\
4,600 \\
3,510 \\
3,080 \\
2,920 \\
3,000\end{array}$ & $\begin{array}{r}10,600 \\
7,100 \\
5,170 \\
4,140 \\
3,420 \\
3,080 \\
2,920 \\
2,600\end{array}$ & $\begin{array}{r}9 \\
10 \\
11 \\
12 \\
13 \\
14 \\
15 \\
16\end{array}$ & $\begin{array}{r}3,170 \\
2,600 \\
2,220 \\
2,010 \\
1,990 \\
13,100 \\
54,800 \\
35,600\end{array}$ & $\begin{array}{l}2,370 \\
2,220 \\
2,300 \\
2,440 \\
2,220 \\
2,000 \\
1,890 \\
1,780\end{array}$ & $\begin{array}{l}17 \\
18 \\
19 \\
20 \\
21 \\
22 \\
23 \\
24\end{array}$ & $\begin{array}{r}16,600 \\
11,500 \\
9,640 \\
9,550 \\
8,320 \\
6,110 \\
5,500 \\
4,980\end{array}$ & $\begin{array}{l}1,680 \\
1,620 \\
1,590 \\
1,560 \\
1,470 \\
1,430 \\
1,410 \\
1,340\end{array}$ & $\begin{array}{l}25 \\
26 \\
27 \\
28 \\
29 \\
30 \\
31\end{array}$ & $\begin{array}{r}4,140 \\
3,600 \\
3,340 \\
3,000 \\
2,920 \\
5,360 \\
11,800\end{array}$ & $\begin{array}{l}1,370 \\
1,410 \\
1,500 \\
1,520 \\
1,410 \\
1,300\end{array}$ \\
\hline & & & & & & & & & & $\begin{array}{r}8,792 \\
3.12\end{array}$ & $\begin{array}{r}2,562 \\
0.88\end{array}$ \\
\hline
\end{tabular}


390 FLOODS OF AUGUST 1940 IN THE SOUTHEASTERN STATES

Gage height, in feet, and discharge, in second-feet, at indicated time, 1940

\begin{tabular}{|c|c|c|c|c|c|c|c|c|}
\hline \multirow{2}{*}{ Hour } & \multicolumn{2}{|c|}{ Aug. 14} & \multicolumn{2}{|c|}{ Aug. 15} & \multicolumn{2}{|c|}{ Aug. 16} & \multicolumn{2}{|c|}{ Aug. 17} \\
\hline & $\begin{array}{c}\text { Gage } \\
\text { height }\end{array}$ & Discharge & $\begin{array}{c}\text { Gage } \\
\text { height }\end{array}$ & Discharge & $\begin{array}{l}\text { Gage } \\
\text { height }\end{array}$ & Discharge & $\begin{array}{l}\text { Gage } \\
\text { height }\end{array}$ & Discharge \\
\hline $\begin{array}{l}1 \\
2 \\
3 \\
4 \\
5 \\
5\end{array}$ & $\begin{array}{l}5.38 \\
5.46 \\
5.51 \\
5.58 \\
5.61 \\
5.63\end{array}$ & $\begin{array}{l}2,070 \\
2,140 \\
2,220 \\
2,370 \\
2,370 \\
2,440\end{array}$ & $\begin{array}{l}22.00 \\
22.74 \\
23.40 \\
24.05 \\
24.60 \\
25.10\end{array}$ & $\begin{array}{l}43,600 \\
45,800 \\
48,100 \\
50,000 \\
52,000 \\
53,600\end{array}$ & $\begin{array}{l}24.74 \\
24.40 \\
24.00 \\
23.58 \\
23.10 \\
22.61\end{array}$ & $\begin{array}{l}52,300 \\
51,300 \\
50,000 \\
48,700 \\
47,100 \\
45,500\end{array}$ & $\begin{array}{l}13.75 \\
13.56 \\
13.34 \\
13.18 \\
13.05 \\
12.86\end{array}$ & $\begin{array}{l}20,300 \\
19,800 \\
19,100 \\
18,800 \\
18,300 \\
18,100\end{array}$ \\
\hline $\begin{array}{r}7 \\
8 \\
9 \\
10 \\
11 \\
\mathrm{~N}\end{array}$ & $\begin{array}{l}5.64 \\
5.82 \\
6.62 \\
7.73 \\
8.55 \\
9.11\end{array}$ & $\begin{array}{l}2,440 \\
2,680 \\
4,050 \\
6,120 \\
7,930 \\
9,020\end{array}$ & $\begin{array}{l}25.50 \\
25.82 \\
26.10 \\
26.30 \\
26.45 \\
26.56\end{array}$ & $\begin{array}{l}55,000 \\
55,900 \\
56,900 \\
57,600 \\
57,900 \\
58,600\end{array}$ & $\begin{array}{l}22.06 \\
21.50 \\
20.90 \\
20.30 \\
19.65 \\
19.05\end{array}$ & $\begin{array}{l}43,900 \\
42,000 \\
40,100 \\
38,200 \\
36,000 \\
34,200\end{array}$ & $\begin{array}{l}12.72 \\
12.59 \\
12.49 \\
12.35 \\
12.25 \\
12.15\end{array}$ & $\begin{array}{l}17,600 \\
17,400 \\
17,100 \\
16,900 \\
16,400 \\
16,400\end{array}$ \\
\hline $\begin{array}{l}1 \\
2 \\
3 \\
4 \\
5 \\
6\end{array}$ & $\begin{array}{r}9.58 \\
10.10 \\
10.62 \\
11.62 \\
12.80 \\
14.30\end{array}$ & $\begin{array}{l}10,200 \\
11,400 \\
12,600 \\
15,000 \\
17,800 \\
21,600\end{array}$ & $\begin{array}{l}26.65 \\
26.70 \\
26.68 \\
26.63 \\
26.55 \\
26.42\end{array}$ & $\begin{array}{l}58,600 \\
58,900 \\
58,900 \\
58,600 \\
58,600 \\
57,900\end{array}$ & $\begin{array}{l}18.40 \\
17.84 \\
17.30 \\
16.85 \\
16.35 \\
15.90\end{array}$ & $\begin{array}{l}32,400 \\
30,700 \\
29,300 \\
27,900 \\
26,900 \\
25,600\end{array}$ & $\begin{array}{l}12.05 \\
11.96 \\
11.88 \\
11.80 \\
11.70 \\
11.62\end{array}$ & $\begin{array}{l}15,900 \\
15,900 \\
15,700 \\
15,400 \\
15,200 \\
15,000\end{array}$ \\
\hline $\begin{array}{r}7 \\
8 \\
9 \\
10 \\
11 \\
12 \\
\end{array}$ & $\begin{array}{l}15.60 \\
16.95 \\
18.10 \\
19.12 \\
20.30 \\
21.15 \\
\end{array}$ & $\begin{array}{l}24,800 \\
28,400 \\
31,500 \\
34,500 \\
38,200 \\
41,000 \\
\end{array}$ & $\begin{array}{l}26.28 \\
26.08 \\
25.88 \\
25.64 \\
25.38 \\
25.06 \\
\end{array}$ & $\begin{array}{l}57,600 \\
56,900 \\
56,300 \\
55,300 \\
54,600 \\
53,600 \\
\end{array}$ & $\begin{array}{l}15.50 \\
15.15 \\
14.85 \\
14.55 \\
14.25 \\
14.04 \\
\end{array}$ & $\begin{array}{l}24,600 \\
23,800 \\
22,800 \\
22,300 \\
21,300 \\
20,800 \\
\end{array}$ & $\begin{array}{l}11.54 \\
11.46 \\
11.39 \\
11.32 \\
11.21 \\
11.12 \\
\end{array}$ & $\begin{array}{l}14,700 \\
14,700 \\
14,500 \\
14,200 \\
14,000 \\
13,800\end{array}$ \\
\hline
\end{tabular}

\begin{tabular}{|c|c|c|c|c|c|c|}
\hline \multirow{2}{*}{ Hour } & \multicolumn{2}{|c|}{ Aug. 18} & \multicolumn{2}{|c|}{ Aug. 19} & \multicolumn{2}{|c|}{ Aug. 20} \\
\hline & $\begin{array}{l}\text { Gage } \\
\text { height }\end{array}$ & Discharge & $\begin{array}{l}\text { Gage } \\
\text { height }\end{array}$ & Discharge & $\begin{array}{c}\text { Gage } \\
\text { height }\end{array}$ & Discharge \\
\hline $\begin{array}{r}2 \\
4 \\
6 \\
8 \\
10 \\
\mathrm{~N}\end{array}$ & $\begin{array}{l}10.94 \\
10.77 \\
10.60 \\
10.43 \\
10.26 \\
10.11\end{array}$ & $\begin{array}{l}13,300 \\
13,000 \\
12,600 \\
12,100 \\
11,800 \\
11,400\end{array}$ & $\begin{array}{l}9.32 \\
9.27 \\
9.18 \\
9.23 \\
9.35 \\
9.48\end{array}$ & $\begin{array}{l}9,470 \\
9,470 \\
9,240 \\
9,240 \\
9,700 \\
9,930\end{array}$ & $\begin{array}{l}9.01 \\
8.96 \\
8.97 \\
9.05 \\
9.22 \\
9.41\end{array}$ & $\begin{array}{l}8,800 \\
8,800 \\
8,800 \\
8,800 \\
9,240 \\
9,700\end{array}$ \\
\hline $\begin{array}{r}2 \\
4 \\
6 \\
8 \\
10 \\
12 \\
\end{array}$ & $\begin{array}{r}10.01 \\
9.86 \\
9.74 \\
9.58 \\
9.46 \\
9.38 \\
\end{array}$ & $\begin{array}{r}11,100 \\
10,900 \\
10,400 \\
10,200 \\
9,930 \\
9,700 \\
\end{array}$ & $\begin{array}{l}9.58 \\
9.59 \\
9.50 \\
9.38 \\
9.23 \\
9.11 \\
\end{array}$ & $\begin{array}{r}10,200 \\
10,200 \\
9,930 \\
9,700 \\
9,240 \\
9,020 \\
\end{array}$ & $\begin{array}{l}9.56 \\
9.66 \\
9.65 \\
9.60 \\
9.53 \\
9.46 \\
\end{array}$ & $\begin{array}{r}10,200 \\
10,400 \\
10,200 \\
10,200 \\
9,930 \\
9,930 \\
\end{array}$ \\
\hline
\end{tabular}

SuPplemental RECORD.-Aug. 15, 2:30 p.m., gage height, 26.70 feet; discharge, 58,900 second-feet.

HOLSTON RIVER NEAR JEFFERSON CTTY, TENN.

Location.-Lat. $36^{\circ} 10^{\prime} 07^{\prime \prime}$, long. $83^{\circ} 30^{\prime} 10^{\prime \prime}$, 250 feet upstream from bridge on State Highway 92, 0.4 mile downstream from Mossy Creek, and 3 miles north of Jefferson City, Jefferson County. Datum of gage is 920.02 feet above mean sea level, datum of 1929, supplementary adjustment of 1936 .

DRAINAGE AREA. - 3,429 square miles.

GAGE-HEIGHT RECORD.-Water-stage recorder graph.

DISCHARGE RECORD.-Stage-discharge relation defined by eurrent-meter measurements up to 57,700 second-feet. Gage heights used to half-tenths between 2.1 and 4.0 feet; hundredths below and tenths above these limits.

Maxima.-1940: Discharge, 58,700 second-feet 9 p.m. Aug. 15 (gage height, 21.80 feet).

1937-39: Discharge, 27,600 second-feet Oct. 29, 1937 (gage height, 12.86 feet).

REMARKs.-Flood runoff not appreciably affected by artificial storage. 
TENNESSEE RIVER BASIN

Mean discharge, in second-feet, 1940

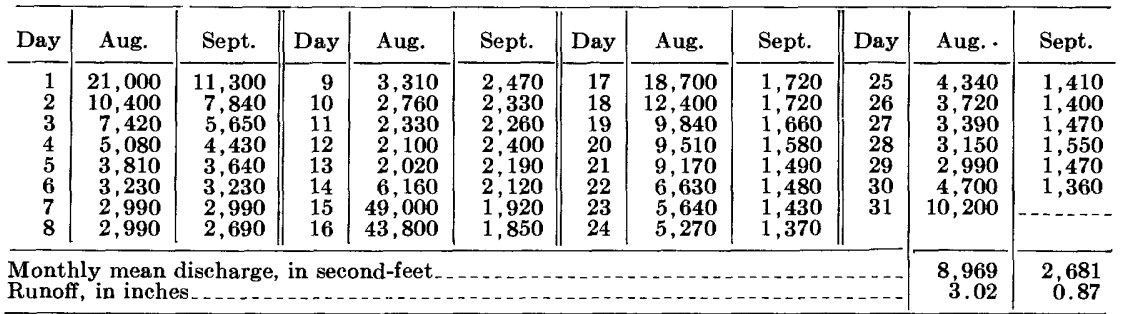

Gage height, in feet, and discharge, in second-feet, at indicated time, 1940

\begin{tabular}{|c|c|c|c|c|c|c|c|c|}
\hline \multirow{2}{*}{ Hour } & \multicolumn{2}{|c|}{ Aug. 14} & \multicolumn{2}{|c|}{ Aug. 15} & \multicolumn{2}{|c|}{ Aug. 16} & \multicolumn{2}{|c|}{ Aug. 17} \\
\hline & $\begin{array}{l}\text { Gage } \\
\text { height }\end{array}$ & Discharge & $\begin{array}{l}\text { Gage } \\
\text { height }\end{array}$ & Discharge & $\begin{array}{l}\text { Gage } \\
\text { height }\end{array}$ & Discharge & $\begin{array}{l}\text { Gage } \\
\text { height }\end{array}$ & Discharge \\
\hline $\begin{array}{l}1 \\
2 \\
3 \\
4 \\
5 \\
6\end{array}$ & 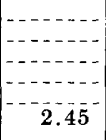 & 2,050 & $\begin{array}{l}13.00 \\
14.00 \\
14.95 \\
15.80 \\
16.60 \\
17.40\end{array}$ & $\begin{array}{l}27,900 \\
31,000 \\
34,200 \\
36,800 \\
39,400 \\
42,100\end{array}$ & $\begin{array}{l}21.54 \\
21.40 \\
21.22 \\
21.00 \\
20.79 \\
20.50\end{array}$ & $\begin{array}{l}57,500 \\
57,100 \\
56,300 \\
55,500 \\
54,700 \\
53,500\end{array}$ & $\begin{array}{l}12.00 \\
11.70 \\
11.39 \\
11.11 \\
10.87 \\
10.62\end{array}$ & $\begin{array}{l}24,900 \\
24,000 \\
23,100 \\
22,200 \\
21,600 \\
20,700\end{array}$ \\
\hline $\begin{array}{r}7 \\
8 \\
9 \\
10 \\
11 \\
\mathrm{~N}\end{array}$ & $\mid \begin{array}{c}-\ldots-\cdots \\
----\cdots \\
-\cdots \\
--\cdots \\
-\overline{2} . \overline{70}\end{array}$ & \begin{tabular}{c}
$-\ldots \ldots \ldots$ \\
$-\cdots$ \\
\hdashline-400
\end{tabular} & $\begin{array}{l}18.03 \\
18.60 \\
19.10 \\
19.55 \\
20.00 \\
20.34\end{array}$ & $\begin{array}{l}44,100 \\
46,300 \\
48,100 \\
50,000 \\
51,500 \\
52,700\end{array}$ & $\begin{array}{l}20.17 \\
19.85 \\
19.45 \\
19.10 \\
18.63 \\
18.15\end{array}$ & $\begin{array}{l}52,300 \\
50,700 \\
49,200 \\
48,100 \\
46,300 \\
44,800\end{array}$ & $\begin{array}{r}10.40 \\
10.23 \\
10.06 \\
9.90 \\
9.75 \\
9.62\end{array}$ & $\begin{array}{l}20,100 \\
19,500 \\
19,200 \\
18,600 \\
18,300 \\
17,800\end{array}$ \\
\hline $\begin{array}{l}1 \\
2 \\
3 \\
4 \\
5 \\
6\end{array}$ & $\begin{array}{l}2.75 \\
2.93 \\
3.65 \\
4.80 \\
5.65 \\
6.30\end{array}$ & $\begin{array}{l}2,470 \\
2,760 \\
3,900 \\
6,030 \\
7,620 \\
9,160\end{array}$ & $\begin{array}{l}20.66 \\
20.92 \\
21.15 \\
21.33 \\
21.50 \\
21.61\end{array}$ & $\begin{array}{l}54,300 \\
55,100 \\
56,300 \\
56,700 \\
57,500 \\
57,900\end{array}$ & $\begin{array}{l}17.75 \\
17.23 \\
16.74 \\
16.17 \\
15.60 \\
15.09\end{array}$ & $\begin{array}{l}43,400 \\
41,400 \\
39,700 \\
38,100 \\
36,100 \\
34,500\end{array}$ & $\begin{array}{l}9.50 \\
9.38 \\
9.29 \\
9.19 \\
9.09 \\
9.00\end{array}$ & $\begin{array}{l}17,500 \\
17,200 \\
16,900 \\
16,700 \\
16,400 \\
16,100\end{array}$ \\
\hline \multirow[t]{2}{*}{$\begin{array}{r}7 \\
8 \\
9 \\
10 \\
11 \\
12 \\
\end{array}$} & $\begin{array}{r}6.90 \\
7.60 \\
8.50 \\
9.57 \\
10.74 \\
11.90 \\
\end{array}$ & $\begin{array}{l}10,600 \\
12,400 \\
14,700 \\
17,800 \\
21,000 \\
24,600 \\
\end{array}$ & $\begin{array}{l}21.70 \\
21.76 \\
21.80 \\
21.78 \\
21.74 \\
21.69 \\
\end{array}$ & $\begin{array}{l}58,300 \\
58,700 \\
58,700 \\
58,700 \\
58,300 \\
58,300 \\
\end{array}$ & $\begin{array}{l}14.59 \\
14.09 \\
13.60 \\
13.15 \\
12.74 \\
12.37 \\
\end{array}$ & $\begin{array}{l}32,900 \\
31,300 \\
29,700 \\
28,500 \\
27,000 \\
26,100 \\
\end{array}$ & $\begin{array}{l}8.92 \\
8.83 \\
8.75 \\
8.68 \\
8.61 \\
8.57 \\
\end{array}$ & $\begin{array}{l}15,800 \\
15,500 \\
15,500 \\
15,300 \\
15,000 \\
15,000 \\
\end{array}$ \\
\hline & \multicolumn{2}{|c|}{ Aug. 18} & \multicolumn{2}{|c|}{ Aug. 19} & \multicolumn{2}{|c|}{ Aug. 20} & \multicolumn{2}{|c|}{ Aug. 21} \\
\hline $\begin{array}{r}2 \\
4 \\
6 \\
8 \\
10 \\
\mathrm{~N}\end{array}$ & $\begin{array}{l}8.38 \\
8.23 \\
8.07 \\
7.92 \\
7.75 \\
7.60\end{array}$ & $\begin{array}{l}14,400 \\
13,900 \\
13,700 \\
13,100 \\
12,900 \\
12,400\end{array}$ & $\begin{array}{l}6.75 \\
6.66 \\
6.57 \\
6.49 \\
6.43 \\
6.39\end{array}$ & $\begin{array}{r}10,400 \\
10,100 \\
9,880 \\
9,640 \\
9,400 \\
9,400\end{array}$ & $\begin{array}{l}6.49 \\
6.38 \\
6.27 \\
6.19 \\
6.16 \\
6.18\end{array}$ & $\begin{array}{l}9,640 \\
9,400 \\
9,160 \\
8,940 \\
8,940 \\
8,940\end{array}$ & $\begin{array}{l}6.72 \\
6.67 \\
6.60 \\
6.52 \\
6.43 \\
6.35\end{array}$ & $\begin{array}{r}10,100 \\
10,100 \\
9,880 \\
9,640 \\
9,400 \\
9,400\end{array}$ \\
\hline $\begin{array}{r}2 \\
4 \\
6 \\
8 \\
10 \\
12 \\
\end{array}$ & $\begin{array}{l}7.45 \\
7.30 \\
7.17 \\
7.05 \\
6.93 \\
6.81 \\
\end{array}$ & $\begin{array}{l}11,800 \\
11,600 \\
11,300 \\
10,800 \\
10,600 \\
10,400\end{array}$ & $\begin{array}{l}6.41 \\
6.52 \\
6.63 \\
6.69 \\
6.68 \\
6.60 \\
\end{array}$ & $\begin{array}{r}9,400 \\
9,640 \\
9,880 \\
10,100 \\
10,100 \\
9,880\end{array}$ & $\begin{array}{l}6.26 \\
6.41 \\
6.58 \\
6.71 \\
6.77 \\
6.77 \\
\end{array}$ & $\begin{array}{r}9,160 \\
9,400 \\
9,880 \\
10,100 \\
10,400 \\
10,400\end{array}$ & $\begin{array}{l}6.23 \\
6.11 \\
5.99 \\
5.87 \\
5.75 \\
5.63 \\
\end{array}$ & $\begin{array}{l}8,940 \\
8,720 \\
8,500 \\
8,280 \\
8,060 \\
7,620 \\
\end{array}$ \\
\hline
\end{tabular}

HOLSTON RIVER AT STRAWBERRY PLAINS, TENN.

Location.—Lat. $36^{\circ} 03^{\prime} 29^{\prime \prime}$, long. $83^{\circ} 42^{\prime} 18^{\prime \prime}$, 100 feet downstream from concrete highway bridge, 1 mile west of Strawberry Plains, Jefferson County, and 17 miles upstream from confluence with French Broad River. Datum of gage is 838.39 feet above mean sea level, datum of 1929, supplementary adjustment of 1936.

DrainaGe AREA.-3,626 square miles.

GAGE-HEIGHT RECORD.-Water-stage recorder graph.

DISCHARGE RECORD.- Stage-discharge relation defined by current-meter measurements 
up to 57,100 second-feet. Gage heights used to half-tenths between 1.9 and 3.9 feet; hundredths below and tenths above these limits.

Maxima.-1940: Discharge, 57,100 second-feet 9 a.m. Aug. 16 (gage height, 18.62 feet).

1930-39: Discharge, 62,900 second-feet Mar. 28, 1935 (gage height, 20.20 feet).

REMARKs.-Flood runoff not affected appreciably by artificial storage.

Mean discharge, in second-feet, 1940

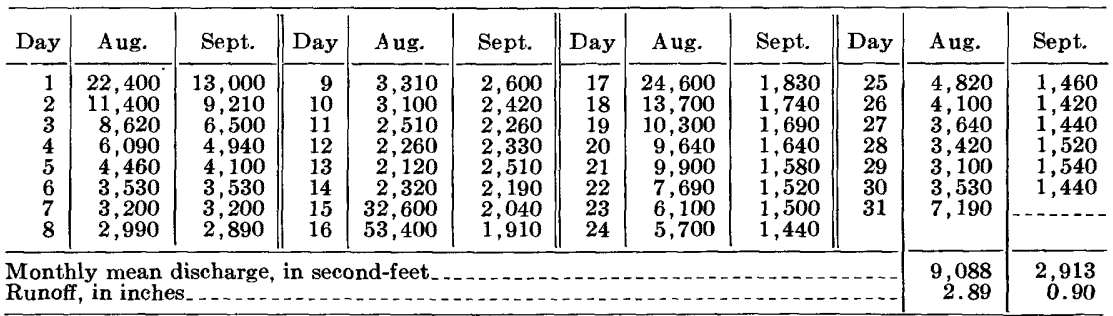

Gage height, in feet, and discharge, in second-feet, at indicated time, 1940

\begin{tabular}{|c|c|c|c|c|c|c|c|c|}
\hline \multirow{2}{*}{ Hour } & \multicolumn{2}{|c|}{ Aug. 14} & \multicolumn{2}{|c|}{ Aug. 15} & \multicolumn{2}{|c|}{ Aug. 16} & \multicolumn{2}{|c|}{ Aug. 17} \\
\hline & $\begin{array}{l}\text { Gage } \\
\text { height }\end{array}$ & Discharge & $\begin{array}{l}\text { Gage } \\
\text { height }\end{array}$ & Discharge & $\begin{array}{l}\text { Gage } \\
\text { height }\end{array}$ & Discharge & $\begin{array}{c}\text { Gage } \\
\text { height }\end{array}$ & Discharge \\
\hline $\begin{array}{l}1 \\
2 \\
3 \\
4 \\
5 \\
6\end{array}$ & $\mid \begin{array}{l}1.2 \\
1.84\end{array}$ & (2, 310 & $\begin{array}{l}3.60 \\
4.50 \\
5.30 \\
6.15 \\
6.95 \\
7.75\end{array}$ & $\begin{array}{r}6,360 \\
8,910 \\
11,400 \\
14,300 \\
17,100 \\
20,100\end{array}$ & $\begin{array}{l}17.59 \\
17.80 \\
18.05 \\
18.22 \\
18.35 \\
18.45\end{array}$ & $\begin{array}{l}53,600 \\
54,300 \\
55,000 \\
55,700 \\
56,400 \\
56,400\end{array}$ & $\begin{array}{l}13.19 \\
12.70 \\
12.10 \\
11.50 \\
10.93 \\
10.40\end{array}$ & $\begin{array}{l}39,700 \\
38,200 \\
36,300 \\
34,400 \\
32,200 \\
30,300\end{array}$ \\
\hline $\begin{array}{r}7 \\
8 \\
9 \\
10 \\
11 \\
\mathrm{~N}\end{array}$ & 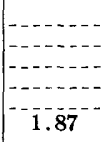 & 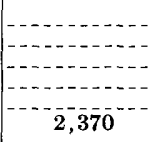 & $\begin{array}{r}8.52 \\
9.23 \\
9.90 \\
10.52 \\
11.26 \\
11.83\end{array}$ & $\begin{array}{l}22,800 \\
25,600 \\
28,400 \\
30,700 \\
33,700 \\
35,300\end{array}$ & $\begin{array}{l}18.55 \\
18.60 \\
18.62 \\
18.60 \\
18.55 \\
18.50\end{array}$ & $\begin{array}{l}57,100 \\
57,100 \\
57,100 \\
57,100 \\
57,100 \\
56,700\end{array}$ & $\begin{array}{l}9.92 \\
9.48 \\
9.12 \\
8.79 \\
8.48 \\
8.24\end{array}$ & $\begin{array}{l}28,400 \\
26,800 \\
25,200 \\
24,000 \\
22,800 \\
21,600\end{array}$ \\
\hline $\begin{array}{l}1 \\
2 \\
3 \\
4 \\
5 \\
6\end{array}$ & $1.8 \overline{3}^{-\cdots}$ & $\left(\begin{array}{c}2,290 \\
-2,220\end{array}\right.$ & $\begin{array}{l}12.43 \\
13.10 \\
13.75 \\
14.30 \\
14.80 \\
15.27\end{array}$ & $\begin{array}{l}37,300 \\
39,400 \\
41,500 \\
43,000 \\
44,600 \\
46,200\end{array}$ & $\begin{array}{l}18.35 \\
18.21 \\
18.00 \\
17.70 \\
17.40 \\
17.05\end{array}$ & $\begin{array}{l}56,400 \\
55,700 \\
55,000 \\
54,000 \\
53,000 \\
51,600\end{array}$ & $\begin{array}{l}8.03 \\
7.80 \\
7.68 \\
7.52 \\
7.39 \\
7.26\end{array}$ & $\begin{array}{l}20,800 \\
20,100 \\
19,700 \\
18,900 \\
18,600 \\
18,200\end{array}$ \\
\hline \multirow[t]{2}{*}{$\begin{array}{r}7 \\
8 \\
9 \\
10 \\
11 \\
12 \\
\end{array}$} & $\begin{array}{c}1.81 \\
-1.55^{-1} \\
-2.5 \\
\end{array}$ & 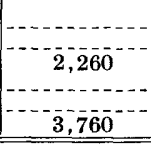 & $\begin{array}{l}15.69 \\
16.05 \\
16.40 \\
16.75 \\
17.05 \\
17.33 \\
\end{array}$ & $\begin{array}{l}47,400 \\
48,400 \\
49,700 \\
51,000 \\
51,600 \\
52,600 \\
\end{array}$ & $\begin{array}{l}16.64 \\
16.16 \\
15.60 \\
15.03 \\
14.40 \\
13.76 \\
\end{array}$ & $\begin{array}{l}50,300 \\
49,000 \\
47,100 \\
45,200 \\
43,300 \\
41,500 \\
\end{array}$ & $\begin{array}{l}7.15 \\
7.03 \\
6.95 \\
6.86 \\
6.78 \\
6.71 \\
\end{array}$ & $\begin{array}{l}17,800 \\
17,100 \\
17,100 \\
16,700 \\
16,400 \\
16,000 \\
\end{array}$ \\
\hline & \multicolumn{2}{|c|}{ Aug. 18} & \multicolumn{2}{|c|}{ Aug. 19} & \multicolumn{2}{|c|}{ Aug. 20} & \multicolumn{2}{|c|}{ Aug. 21} \\
\hline $\begin{array}{r}2 \\
4 \\
6 \\
8 \\
10 \\
N\end{array}$ & $\begin{array}{l}6.58 \\
6.45 \\
6.32 \\
6.22 \\
6.12 \\
6.01\end{array}$ & $\begin{array}{l}15,700 \\
15,000 \\
14,600 \\
14,300 \\
14,000 \\
13,600\end{array}$ & $\begin{array}{l}5.32 \\
5.23 \\
5.14 \\
5.05 \\
5.00 \\
4.94\end{array}$ & $\begin{array}{l}11,400 \\
11,000 \\
10,700 \\
10,400 \\
10,400 \\
10,100\end{array}$ & $\begin{array}{l}4.89 \\
4.91 \\
4.91 \\
4.87 \\
4.80 \\
4.72\end{array}$ & $\begin{array}{r}10,100 \\
10,100 \\
10,100 \\
10,100 \\
9,810 \\
9,510\end{array}$ & $\begin{array}{l}4.82 \\
4.91 \\
4.97 \\
4.97 \\
4.97 \\
4.91\end{array}$ & $\begin{array}{r}9,810 \\
10,100 \\
10,400 \\
10,400 \\
10,400 \\
10,100\end{array}$ \\
\hline $\begin{array}{r}2 \\
4 \\
6 \\
8 \\
10 \\
12\end{array}$ & $\begin{array}{l}5.90 \\
5.80 \\
5.69 \\
5.58 \\
5.50 \\
5.40\end{array}$ & $\begin{array}{l}13,300 \\
13,000 \\
12,600 \\
12,300 \\
12,000 \\
11,700\end{array}$ & $\begin{array}{l}4.87 \\
4.82 \\
4.78 \\
4.76 \\
4.77 \\
4.83\end{array}$ & $\begin{array}{r}10,100 \\
9,810 \\
9,810 \\
9,810 \\
9,810 \\
9,810\end{array}$ & $\begin{array}{l}4.66 \\
4.61 \\
4.59 \\
4.59 \\
4.62 \\
4.71\end{array}$ & $\begin{array}{l}9,510 \\
9,210 \\
9,210 \\
9,210 \\
9,210 \\
9,510\end{array}$ & $\begin{array}{l}4.87 \\
4.81 \\
4.77 \\
4.69 \\
4.61 \\
4.52\end{array}$ & $\begin{array}{r}10,100 \\
9,810 \\
9,810 \\
9,510 \\
9,210 \\
8,910\end{array}$ \\
\hline
\end{tabular}


MIDDLE FORK HOLSTON RIVER NEAR MEADOWVIEW, VA.

LOCATION.-Lat. $36^{\circ} 42^{\prime} 47^{\prime \prime}$, long. $81^{\circ} 49^{\prime} 08^{\prime \prime}$, at highway bridge three-quarters of a mile upstream from Cedar Creek and 4 miles southeast of Meadowview, Washington County. Datum of gage is $1,820.22$ feet above mean sea level, datum of 1929 , supplementary adjustment of 1936 .

DRAINAGE AREA.-211 square miles.

GAGE-HEIGHT RECORD.-Water-stage recorder graph.

DISCHARGE RECORD. - Stage-discharge relation defined by current-meter measurements up to 4,500 second-feet. Gage heights used to half-tenths between 3.7 and 6.0 feet; hundredths below and tenths above these limits.

Maxima.-1940: Discharge, 4,570 second-feet 8 p.m. Aug. 14 (gage height, 8.00 feet).

1931-39 : Discharge, 5,360 second-feet Jan. 23, 1935 (gage height, 8.59 feet).

Mean discharge, in second-feet, 1940

\begin{tabular}{|c|c|c|c|c|c|c|c|c|c|c|c|}
\hline Day & Aug. & Sept. & Day & Aug. & Sept. & Day & Aug. & Sept. & Day & Aug. & Sept. \\
\hline $\begin{array}{l}1 \\
2 \\
3 \\
4 \\
5 \\
6 \\
7 \\
8\end{array}$ & $\begin{array}{r}1,420 \\
518 \\
326 \\
246 \\
230 \\
197 \\
222 \\
182\end{array}$ & $\begin{array}{l}262 \\
228 \\
203 \\
186 \\
174 \\
161 \\
163 \\
130\end{array}$ & $\begin{array}{r}9 \\
10 \\
11 \\
12 \\
13 \\
14 \\
15 \\
16\end{array}$ & $\begin{array}{r}167 \\
150 \\
122 \\
143 \\
164 \\
2,600 \\
2,390 \\
1,480\end{array}$ & $\begin{array}{l}157 \\
154 \\
152 \\
139 \\
130 \\
124 \\
103 \\
133\end{array}$ & $\begin{array}{l}17 \\
18 \\
19 \\
20 \\
21 \\
22 \\
23 \\
24\end{array}$ & $\begin{array}{r}999 \\
1,370 \\
1,870 \\
1,230 \\
701 \\
608 \\
492 \\
393\end{array}$ & $\begin{array}{r}120 \\
112 \\
108 \\
105 \\
109 \\
83 \\
112 \\
105\end{array}$ & $\begin{array}{l}25 \\
26 \\
27 \\
28 \\
29 \\
30 \\
31\end{array}$ & $\begin{array}{l}318 \\
.288 \\
264 \\
237 \\
240 \\
258 \\
300\end{array}$ & $\begin{array}{r}98 \\
102 \\
106 \\
104 \\
70 \\
105\end{array}$ \\
\hline \multicolumn{10}{|c|}{$\begin{array}{l}\text { Monthly mean discharge, in second-feet } \\
\text { Runoff, in inches. }\end{array}$} & $\begin{array}{r}649 \\
3.55\end{array}$ & $\begin{array}{r}135 \\
0.71\end{array}$ \\
\hline
\end{tabular}


394 FLOODS OF AUGUST 1940 IN THE SOUTHEASTERN STATES

Gage height, in feet, and discharge, in second-feet, at indicated time, 1940

\begin{tabular}{|c|c|c|c|c|c|c|c|c|c|c|}
\hline \multirow{2}{*}{ Hour } & \multicolumn{3}{|c|}{ Aug. 14} & \multicolumn{2}{|c|}{ Aug. 15} & \multicolumn{3}{|c|}{ Aug. 16} & \multicolumn{2}{|c|}{ Aug. 17} \\
\hline & $\begin{array}{c}\text { Gage } \\
\text { height }\end{array}$ & \multicolumn{2}{|c|}{ Discharge } & $\begin{array}{c}\text { Gage } \\
\text { height }\end{array}$ & Discharge & $\begin{array}{c}\text { Gage } \\
\text { height }\end{array}$ & \multicolumn{2}{|c|}{ Discharge } & $\begin{array}{c}\text { Gage } \\
\text { height }\end{array}$ & Discharge \\
\hline \multirow{4}{*}{$\begin{array}{l}1 \\
2 \\
3 \\
4 \\
5 \\
6\end{array}$} & \multirow{4}{*}{$\begin{array}{l}2.40 \\
2.90 \\
3.38 \\
3.71 \\
4.02 \\
4.43\end{array}$} & \multicolumn{2}{|c|}{179} & & & & \multirow{2}{*}{\multicolumn{2}{|c|}{1,560}} & & \\
\hline & & \multirow{3}{*}{\multicolumn{2}{|c|}{$\begin{array}{r}366 \\
596 \\
775 \\
955 \\
1,250\end{array}$}} & 6.80 & 3,300 & 4.92 & & & 4.40 & 1,220 \\
\hline & & & & 6.52 & 3,000 & 4.88 & & & 4.32 & $1, \overline{150}$ \\
\hline & & & & 6.34 & $2, \overline{8} 0 \overline{0}$ & 4.89 & & & 4.26 & 1,120 \\
\hline \multirow{4}{*}{$\begin{array}{r}7 \\
8 \\
9 \\
10 \\
11 \\
\mathrm{~N}\end{array}$} & \multirow{4}{*}{$\begin{array}{l}4.68 \\
4.85 \\
5.15 \\
5.47 \\
5.76 \\
6.07\end{array}$} & \multirow{4}{*}{\multicolumn{2}{|c|}{$\begin{array}{l}1,420 \\
1,520 \\
1,750 \\
2,000 \\
2,280 \\
2,600\end{array}$}} & & & & & & & \\
\hline & & & & 6.12 & 2,600 & 4.86 & & & 4.22 & 1,080 \\
\hline & & & & 5.95 & 2,460 & $4.8 \overline{3}$ & & 0 & 4.10 & 1,020 \\
\hline & & & & 5.81 & 2,320 & 4.80 & & & 4.05 & $98 \overline{8}$ \\
\hline \multirow{4}{*}{$\begin{array}{l}1 \\
2 \\
3 \\
4 \\
5 \\
6\end{array}$} & \multirow{4}{*}{$\begin{array}{l}6.43 \\
6.84 \\
7.20 \\
7.52 \\
7.70 \\
7.88\end{array}$} & \multirow{4}{*}{\multicolumn{2}{|c|}{$\begin{array}{l}2,900 \\
3,300 \\
3,700 \\
4,020 \\
4,240 \\
4,460\end{array}$}} & & & & & & & \\
\hline & & & & 5.61 & 2,140 & 4.79 & & & 3.98 & 955 \\
\hline & & & & 5.46 & 2,000 & 4.75 & & & 3.89 & $\overline{89} \overline{5}$ \\
\hline & & & & $5 . \overline{3}$ & $1, \overline{9} 20$ & $4.72^{--}$ & & 0 & 3.85 & $-\overrightarrow{86} 5$ \\
\hline \multirow{4}{*}{$\begin{array}{r}7 \\
8 \\
9 \\
10 \\
11 \\
12 \\
\end{array}$} & \multirow{4}{*}{$\begin{array}{l}7.96 \\
8.00 \\
7.96 \\
7.84 \\
7.63 \\
7.30 \\
\end{array}$} & \multirow{4}{*}{\multicolumn{2}{|c|}{$\begin{array}{l}4,570 \\
4,570 \\
4,570 \\
4,350 \\
4,130 \\
3,800 \\
\end{array}$}} & & & & & & & \\
\hline & & & & 5.21 & 1,790 & 4.64 & & & 3.85 & 865 \\
\hline & & & & 5.06 & 1,670 & 4.55 & & & 3.79 & 835 \\
\hline & & & & $4 . \overline{98}$ & 1,630 & 4.44 & & & 3.65 & $\overline{7} \overline{4} \overline{5}$ \\
\hline \multirow[b]{2}{*}{ Hour } & \multicolumn{4}{|c|}{ Aug. 18} & \multicolumn{3}{|c|}{ Aug. 19} & \multicolumn{3}{|c|}{ Aug. 20} \\
\hline & \multicolumn{2}{|c|}{$\begin{array}{l}\text { Gage } \\
\text { height }\end{array}$} & \multicolumn{2}{|c|}{ Discharge } & $\begin{array}{c}\text { Gage } \\
\text { height }\end{array}$ & \multicolumn{2}{|c|}{ Discharge } & \multicolumn{2}{|c|}{$\begin{array}{c}\text { Gage } \\
\text { height }\end{array}$} & Discharge \\
\hline $\begin{array}{r}2 \\
4 \\
6 \\
8 \\
10 \\
\mathrm{~N}\end{array}$ & \multicolumn{2}{|c|}{$\begin{array}{l}3.72 \\
5.30 \\
5.85 \\
5.67 \\
5.03 \\
4.63\end{array}$} & \multicolumn{2}{|c|}{$\begin{array}{r}775 \\
1,870 \\
2,260 \\
2,180 \\
1,670 \\
1,380\end{array}$} & $\begin{array}{l}4.66 \\
4.95 \\
5.06 \\
5.17 \\
5.25 \\
5.35\end{array}$ & \multicolumn{2}{|c|}{$\begin{array}{l}1,380 \\
1,600 \\
1,670 \\
1,750 \\
1,830 \\
1,920\end{array}$} & & & $\begin{array}{l}1,670 \\
1,520 \\
1,460 \\
1,380 \\
1,250 \\
1,180\end{array}$ \\
\hline $\begin{array}{r}2 \\
4 \\
6 \\
8 \\
10 \\
12\end{array}$ & & & & $\begin{array}{r}, 150 \\
, 080 \\
988 \\
988 \\
, 120 \\
, 180\end{array}$ & $\begin{array}{l}5.60 \\
5.68 \\
5.70 \\
5.62 \\
5.45 \\
5.24\end{array}$ & $\begin{array}{l}2,1 \\
2,2 \\
2,2 \\
2,1 \\
2,0 \\
1,8\end{array}$ & & & & $\begin{array}{r}1,080 \\
1,050 \\
988 \\
955 \\
895 \\
775\end{array}$ \\
\hline
\end{tabular}

Supplemental Records.-Aug. 18, 1 a.m., gage height, 3.60 feet; discharge, 715 second-feet; 6:30 a.m., gage height, 5.87 feet; discharge, 2,260 second-feet.

WATAUGA RIVER NEAR SUGAR GROVE, N. C.

Location.-Lat. $36^{\circ} 14^{\prime} 18^{\prime \prime}$, long. $81^{\circ} 49^{\prime} 22^{\prime \prime}$, 300 feet downstream from Cove Creek and $2 \frac{1}{2}$ miles southwest of Sugar Grove, Watauga County. Datum of gage is 2,607.66 feet above mean sea level, datum of 1929, supplementary adjustment of 1936.

Drainage AREa. -90.8 square miles.

GAGE-HEIGHT RECORD.-Water-stage recorder graph Aug. 1 to 4:30 p.m. Aug. 13 (recorder was inundated Aug. 13) and 5 p.m. Aug. 17 to Sept. 30. Gage heights for period 4:30 to 12 p.m. Aug. 13 obtained from erest gage height determined from flood profiles, and estimated discharge.

DISCHARGE RECORD. - Stage-discharge relation defined by current-meter measurements up to 1,300 second-feet and extended logarithmically to slope-area measurement at erest gage height. Gage heights used to half-tenths between 3.4 and 5.3 feet; hundredths below and tenths above these limits. Discharge for period of no gageheight record is based on records for stations at Stump Knob and Butler, Tenn., and nearby streams.

Maxima.-1940: Discharge, 50,800 second-feet 7:30 p.m. Aug. 13 (gage height, 29.6 feet, from profile based on floodmarks).

The flood of July 1916 reached a stage of about 22.1 feet, from flood reference 
marks on barn a quarter of a mile above station, as witnessed by local resident (discharge, 28,000 second-feet).

REMARKs.-Flood runoff not affected by artificial storage.

Mean discharge, in second-feet, 1940

\begin{tabular}{|c|c|c|c|c|c|c|c|c|c|c|c|}
\hline Day & Aug. & Sept. & Day & Aug. & Sept. & Day & Aug. & Sept. & Day & Aug. & Sept. \\
\hline $\begin{array}{l}1 \\
2 \\
3 \\
4 \\
5 \\
6 \\
7 \\
8\end{array}$ & $\begin{array}{l}246 \\
176 \\
145 \\
129 \\
136 \\
234 \\
377 \\
212\end{array}$ & $\begin{array}{l}662 \\
452 \\
357 \\
318 \\
340 \\
258 \\
230 \\
222\end{array}$ & $\begin{array}{r}9 \\
10 \\
11 \\
12 \\
13 \\
14 \\
15 \\
16\end{array}$ & $\begin{array}{r}164 \\
140 \\
164 \\
836 \\
15,900 \\
4,570 \\
2,190 \\
1,050\end{array}$ & $\begin{array}{l}217 \\
202 \\
184 \\
165 \\
148 \\
141 \\
132 \\
125\end{array}$ & $\begin{array}{l}17 \\
18 \\
19 \\
20 \\
21 \\
22 \\
23 \\
24\end{array}$ & $\begin{array}{l}622 \\
503 \\
401 \\
326 \\
285 \\
261 \\
227 \\
204\end{array}$ & $\begin{array}{r}117 \\
110 \\
108 \\
104 \\
100 \\
96 \\
94 \\
92\end{array}$ & $\begin{array}{l}25 \\
26 \\
27 \\
28 \\
29 \\
30 \\
31\end{array}$ & $\begin{array}{r}194 \\
194 \\
172 \\
192 \\
212 \\
4,440 \\
1.340\end{array}$ & $\begin{array}{r}110 \\
106 \\
94 \\
90 \\
86 \\
85\end{array}$ \\
\hline $\begin{array}{l}\text { on } \\
\text { un }\end{array}$ & & & & & & & & & & $\begin{array}{l}1,169 \\
14.84\end{array}$ & $\begin{array}{r}185 \\
2.27\end{array}$ \\
\hline
\end{tabular}

Gage height, in feet, and discharge, in second-feet, at indicated time, 1940

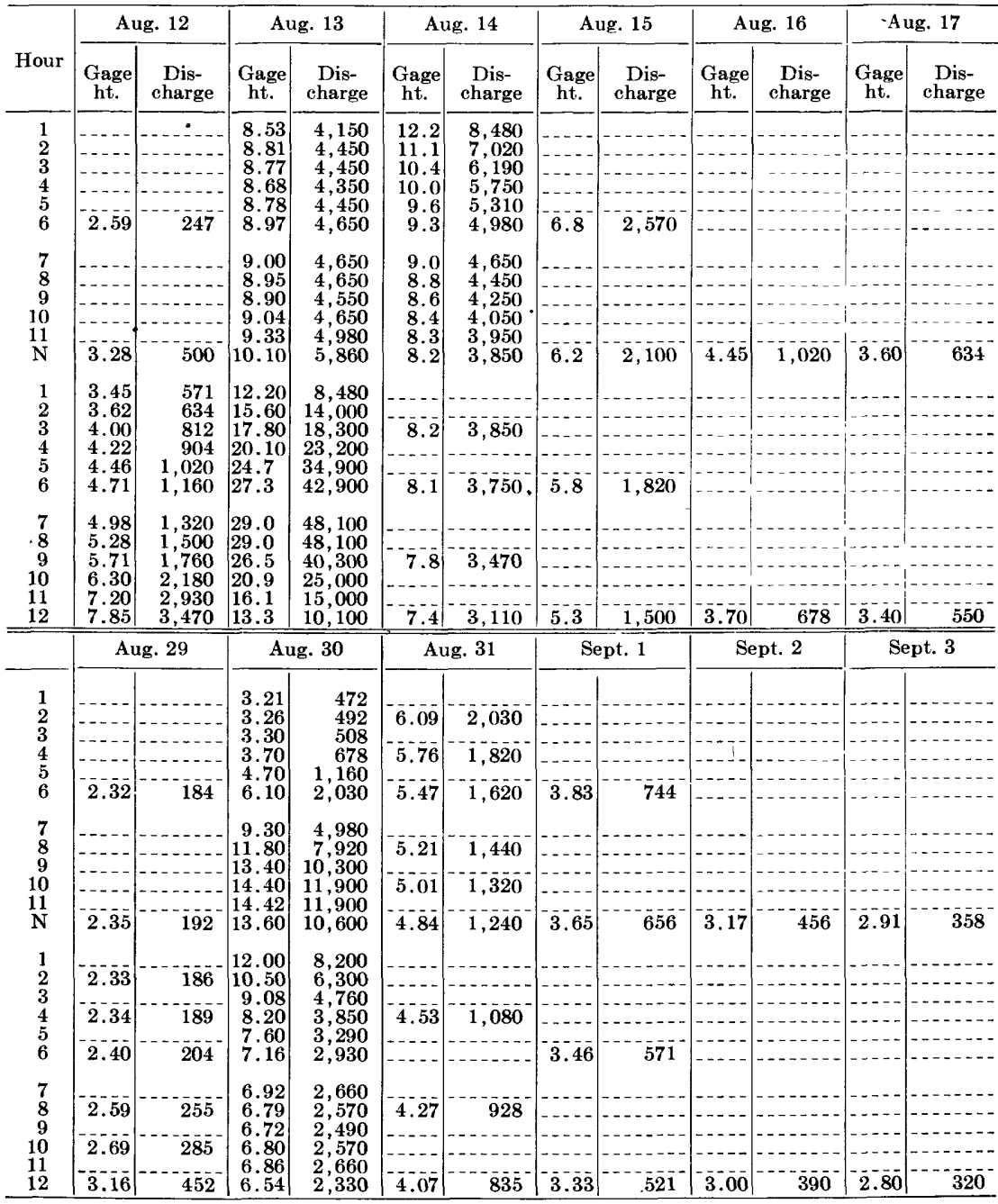

SUPPLEMENTAL RECORDs.-Aug. 13, 7:30 p.m., gage height, 29.6 feet; discharge, 50,800 second-feet. Aug. 30, 10:20 a.m., gage height, 14.63 feet; discharge, 12,300 second-feet. 


\section{WATAUGA RIVER AT STUMP KNOB, TENN.}

Location.-Lat. $36^{\circ} 18^{\prime} 36^{\prime \prime}$, long. $81^{\circ} 57^{\prime} 39^{\prime \prime}$, at former post office at Stump Knob, 1,000 feet downstream from Dugger Bridge, 21/4 miles upstream from Elk Creek, and $4 \frac{1}{2}$ miles upstream from Butler, Johnson County. Datum of gage is $1,869.03$ feet above mean sea level, datum of 1929, supplementary adjustment of 1936 .

Drainage AREa.-171 square miles.

GAGE-HEIGHT RECORD.-Aug. 1-15, from graph based on floodmark and shape of stage graphs for nearby stations; Aug. 16 to Sept. 30 from graph based on two or more staff gage readings daily.

DischARGE RECORD. - Stage-discharge relation defined by eurrent-meter measurements up to 4,050 second-feet and extended to crest gage height on basis of a study of the peak discharge at Butler. Gage heights used to half-tenths from 2.7 to 5.5 feet; hundredths below and tenths above these limits.

Maxima.-1940: Discharge, about 50,000 second-feet 8:30 p.m. Ang. 13 (gage height, 24.0 feet, from floodmark).

1927-31, 1934-39: Discharge, 16,100 second-feet Jan. 9, 1935. (gage height, 12.44 feet).

On May 21, 1901, a stage of about 19.5 feet was reached, discharge 34,400 second-feet.

REMARKS.-Flood runoff not affected by storage.

Mean discharge, in second-feet, 1940

\begin{tabular}{|c|c|c|c|c|c|c|c|c|c|c|c|}
\hline Day & Aug. & Sept. & Day & Aug. & Sept. & Day & Aug. & Sept. & Day & Aug. & Sept. \\
\hline $\begin{array}{l}1 \\
2 \\
3 \\
4 \\
5 \\
6 \\
7 \\
8\end{array}$ & $\begin{array}{l}780 \\
460 \\
320 \\
255 \\
240 \\
250 \\
460 \\
330\end{array}$ & $\begin{array}{r}1,040 \\
680 \\
519 \\
461 \\
508 \\
361 \\
315 \\
282 \\
\end{array}$ & $\begin{array}{r}9 \\
10 \\
11 \\
12 \\
13 \\
14 \\
15 \\
16 \\
\end{array}$ & $\begin{array}{r}240 \\
230 \\
245 \\
341 \\
14,800 \\
8,570 \\
3,800 \\
1,980 \\
\end{array}$ & $\begin{array}{l}268 \\
301 \\
284 \\
259 \\
233 \\
218 \\
207 \\
200\end{array}$ & $\begin{array}{l}17 \\
18 \\
19 \\
20 \\
21 \\
22 \\
23 \\
24 \\
\end{array}$ & $\begin{array}{r}1,120 \\
899 \\
690 \\
538 \\
460 \\
406 \\
361 \\
332 \\
\end{array}$ & $\begin{array}{l}182 \\
168 \\
168 \\
164 \\
161 \\
154 \\
148 \\
142 \\
\end{array}$ & $\begin{array}{l}25 \\
26 \\
27 \\
28 \\
29 \\
30 \\
31\end{array}$ & $\begin{array}{r}310 \\
328 \\
288 \\
297 \\
279 \\
4,420 \\
2,390\end{array}$ & $\begin{array}{l}161 \\
175 \\
145 \\
138 \\
138 \\
132\end{array}$ \\
\hline \multicolumn{10}{|c|}{$\begin{array}{l}\text { Monthly mean discharge, in second-feet } \\
\text { Runoff, in inches }\end{array}$} & $\begin{array}{l}1,497 \\
10.10\end{array}$ & $\begin{array}{r}277 \\
1.81\end{array}$ \\
\hline
\end{tabular}


TENNESSEE RIVER BASIN

Gage height, in feet, and discharge, in second-feet, at indicated time, 1940

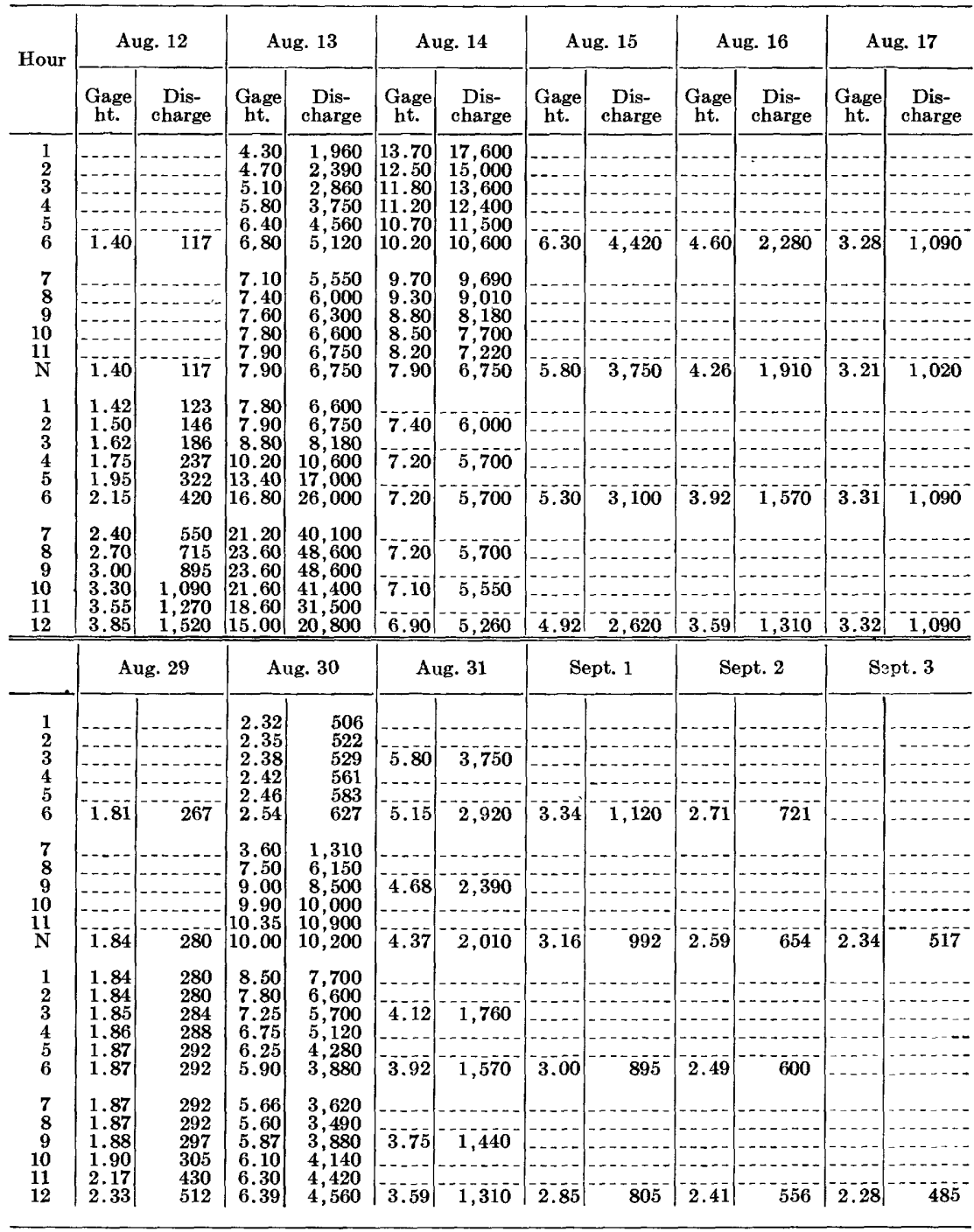


WATAUGA RIVER AT BUTLER, TENN.

Location.-Lat. $36^{\circ} 19^{\prime} 59^{\prime \prime}$, long. $82^{\circ} 00^{\prime} 16^{\prime \prime}$, at Butler, Johnson County, 1,000 feet downstream from highway bridge and 1,100 feet downstream from Roan Creek. Datum of gage is $1,809.38$ feet above mean sea level, datum of 1929 , supplementary adjustment of 1938 .

DrainaGe AREA.-427 square miles.

GAGE-HEIGHT RECORD.-Water-stage recorder graph except for period 7 p.m. Aug. 13 to noon Aug. 15, record for which was based on floodmarks and shape of graphs at nearby stations.

DISCHARGE RECORD.--Stage-discharge relation defined by current-meter measurements up to 14,200 second-feet and extended to crest gage height on basis of determination of peak flows by contracted-opening method, verified by runoff comparison with other stations in the Watauga River Basin. Gage heights used to half-tenths between 2.0 and 5.1 feet; hundredths below and tenths above these limits.

Maxima.-1940: Discharge, 71,500 second-feet 10 p.m. Aug. 13 (gage height, 25.4 feet).

1920-39: Discharge, 18,500 second-feet Jan. 9, 1935 (gage height, 11.85 feet).

The flood of May 21, 1901, reached a stage of 16.27 feet, former site and datum (discharge not determined).

Remarks.-Flood runoff not affected by artificial storage.

Mean discharge, in second-feet, 1940

\begin{tabular}{|c|c|c|c|c|c|c|c|c|c|c|c|}
\hline Day & Aug. & Sept. & Day & Aug. & Sept. & Day & Aug. & Sept. & Day & Aug. & Sept. \\
\hline $\begin{array}{l}1 \\
2 \\
3 \\
4 \\
5 \\
5 \\
7 \\
8\end{array}$ & $\begin{array}{r}1,820 \\
1,060 \\
734 \\
592 \\
539 \\
568 \\
1,260 \\
720\end{array}$ & $\begin{array}{r}1,940 \\
1,330 \\
1,010 \\
836 \\
902 \\
692 \\
\mathbf{6 1 4} \\
\mathbf{5 5 0}\end{array}$ & $\begin{array}{r}9 \\
10 \\
11 \\
12 \\
13 \\
14 \\
15 \\
16\end{array}$ & $\begin{array}{r}545 \\
469 \\
484 \\
838 \\
18,500 \\
17,100 \\
6,810 \\
3,900\end{array}$ & $\begin{array}{l}518 \\
592 \\
580 \\
460 \\
425 \\
397 \\
379 \\
361\end{array}$ & $\begin{array}{l}17 \\
18 \\
19 \\
20 \\
21 \\
22 \\
23 \\
24\end{array}$ & $\begin{array}{r}2,740 \\
2,060 \\
1,660 \\
1,300 \\
1,070 \\
954 \\
810 \\
707\end{array}$ & $\begin{array}{l}338 \\
325 \\
321 \\
302 \\
291 \\
284 \\
268 \\
268\end{array}$ & $\begin{array}{l}25 \\
26 \\
27 \\
28 \\
29 \\
30 \\
31\end{array}$ & $\begin{array}{r}640 \\
682 \\
586 \\
592 \\
560 \\
6,020 \\
3,800\end{array}$ & $\begin{array}{l}284 \\
317 \\
368 \\
258 \\
255 \\
246\end{array}$ \\
\hline \multicolumn{10}{|c|}{$\begin{array}{l}\text { Monthly mean discharge, in second-feet } \\
\text { Runoff, in inches }\end{array}$} & $\begin{array}{r}2,585 \\
6.98\end{array}$ & $\begin{array}{r}524 \\
1.37\end{array}$ \\
\hline
\end{tabular}


TENNESSEE RIVER BASIN

Gage height, in feet, and discharge, in second-feet, at indicated time, 1940

\begin{tabular}{|c|c|c|c|c|c|c|c|c|c|c|c|c|}
\hline \multirow{2}{*}{ Hour } & \multicolumn{2}{|c|}{ Aug. 12} & \multicolumn{2}{|c|}{ Aug. 13} & \multicolumn{2}{|c|}{ Aug. 14} & \multicolumn{2}{|c|}{ Aug. 15} & \multicolumn{2}{|c|}{ Aug. 16} & \multicolumn{2}{|c|}{ Aug. 17} \\
\hline & $\begin{array}{c}\text { Gage } \\
\text { ht. }\end{array}$ & $\begin{array}{c}\text { Dis- } \\
\text { charge }\end{array}$ & $\begin{array}{c}\text { Gage } \\
\text { ht. }\end{array}$ & $\begin{array}{l}\text { Dis- } \\
\text { charge }\end{array}$ & $\begin{array}{c}\text { Gage } \\
\text { ht. }\end{array}$ & $\begin{array}{l}\text { Dis- } \\
\text { charge }\end{array}$ & $\begin{array}{c}\text { Gage } \\
\text { ht. }\end{array}$ & $\begin{array}{c}\text { Dis- } \\
\text { charge }\end{array}$ & $\begin{array}{c}\text { Gage } \\
\text { ht. }\end{array}$ & $\begin{array}{c}\text { Dis- } \\
\text { charge }\end{array}$ & $\begin{array}{c}\text { Gage } \\
\text { ht. }\end{array}$ & $\begin{array}{c}\text { Dis- } \\
\text { charge }\end{array}$ \\
\hline $\begin{array}{l}1 \\
2 \\
3 \\
4 \\
5 \\
6\end{array}$ & 1.28 & $-\overline{469}$ & $\begin{array}{l}3.92 \\
4.25 \\
4.52 \\
4.88 \\
5.44 \\
5.94\end{array}$ & $\begin{array}{l}2,800 \\
3,280 \\
3,670 \\
4,350 \\
5,250 \\
6,200\end{array}$ & $\begin{array}{l}19.05 \\
17.00 \\
15.60 \\
14.50 \\
13.70 \\
12.70\end{array}$ & $\begin{array}{l}41,000 \\
33,700 \\
29,100 \\
25,800 \\
23,600 \\
20,900\end{array}$ & 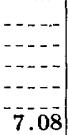 & 8,160 & & & & \\
\hline $\begin{array}{r}7 \\
8 \\
9 \\
10 \\
11 \\
\mathrm{~N}\end{array}$ & 1.34 & 501 & $\begin{array}{l}6.29 \\
6.48 \\
6.64 \\
6.86 \\
7.00 \\
7.03\end{array}$ & $\begin{array}{l}6,960 \\
7,340 \\
7,530 \\
8,120 \\
8,320 \\
8,320\end{array}$ & $\begin{array}{r}12.10 \\
11.50 \\
10.90 \\
10.40 \\
9.90 \\
9.40\end{array}$ & $\begin{array}{l}19,400 \\
17,900 \\
16,500 \\
15,400 \\
14,200 \\
13,100\end{array}$ & 6.40 & 6,740 & 4.84 & 3,880 & 4.07 & 2,700 \\
\hline $\begin{array}{l}1 \\
2 \\
3 \\
4 \\
5 \\
6\end{array}$ & $\begin{array}{l}1.41 \\
1.50 \\
1.55 \\
1.64 \\
1.83 \\
2.06\end{array}$ & $\begin{array}{l}539 \\
592 \\
624 \\
681 \\
811 \\
975\end{array}$ & $\begin{array}{r}7.00 \\
7.12 \\
7.38 \\
7.90 \\
10.20 \\
13.30\end{array}$ & $\begin{array}{r}8,320 \\
8,520 \\
9,120 \\
10,100 \\
15,000 \\
22,500\end{array}$ & $\left|\begin{array}{r}8.40 \\
\hdashline 7.60\end{array}\right|$ & 10,900 & 5.79 & 5,560 & $\cdots$ & & $\cdots$ & \\
\hline $\begin{array}{r}7 \\
8 \\
9 \\
10 \\
11 \\
12 \\
\end{array}$ & $\begin{array}{l}2.40 \\
2.65 \\
2.88 \\
3.13 \\
3.40 \\
3.65 \\
\end{array}$ & $\begin{array}{l}1,265 \\
1,490 \\
1,725 \\
1,970 \\
2,225 \\
2,500 \\
\end{array}$ & $\begin{array}{l}16.20 \\
19.50 \\
23.30 \\
25.40 \\
24.20 \\
21.20\end{array}$ & $\begin{array}{l}31,000 \\
43,000 \\
60,600 \\
71,500 \\
65,200 \\
50,400\end{array}$ & \begin{tabular}{|}
$-\overline{7} .50$ \\
7.50 \\
\end{tabular} & 9,000 & 5.34 & 4,640 & 4.43 & 3,260 & $|3.72|$ & 2,270 \\
\hline
\end{tabular}

\begin{tabular}{|c|c|c|c|c|c|c|c|c|c|c|c|c|}
\hline . & \multicolumn{2}{|c|}{ Aug. 29} & \multicolumn{2}{|c|}{ Aug. 30} & \multicolumn{2}{|c|}{ Aug. 31} & \multicolumn{2}{|c|}{ Sept. 1} & \multicolumn{2}{|c|}{ Sept. 2} & \multicolumn{2}{|c|}{ Sept. 3} \\
\hline $\begin{array}{l}1 \\
2 \\
3 \\
4 \\
5 \\
6\end{array}$ & $\begin{array}{l}-\cdots . \\
-1.72\end{array}$ & & $\begin{array}{l}2.48 \\
2.66 \\
2.71 \\
2.73 \\
2.81 \\
3.14\end{array}$ & $\begin{array}{l}1,080 \\
1,200 \\
1,250 \\
1,300 \\
1,340 \\
1,670\end{array}$ & $\begin{array}{l}6.24 \\
6.04 \\
5.74 \\
5.54 \\
5.36 \\
5.22\end{array}$ & $\begin{array}{l}6,340 \\
5,940 \\
5,370 \\
5,000 \\
4,820 \\
4,470\end{array}$ & - & - & -- & & $\ldots$ & $\begin{array}{l}-- \\
-- \\
-- \\
-- \\
--\end{array}$ \\
\hline $\begin{array}{r}7 \\
8 \\
9 \\
10 \\
11 \\
\text { N }\end{array}$ & 1.75 & 532 & $\begin{array}{l}3.44 \\
3.86 \\
5.63 \\
8.33 \\
9.33 \\
9.85\end{array}$ & $\begin{array}{r}1,980 \\
2,450 \\
5,180 \\
10,700 \\
12,900 \\
14,000\end{array}$ & $\begin{array}{l}5.10 \\
4.97 \\
4.87 \\
4.77 \\
4.69 \\
4.61\end{array}$ & $\begin{array}{l}4,300 \\
4,040 \\
3,880 \\
3,720 \\
3,640 \\
3,480\end{array}$ & 3.40 & 1,930 & 2.80 & 1.340 & 244 & 1040 \\
\hline $\begin{array}{l}1 \\
2 \\
3 \\
4 \\
5 \\
6 \\
6\end{array}$ & $\begin{array}{l}1.72 \\
1.73 \\
1.74 \\
1.79 \\
1.80 \\
1.82\end{array}$ & $\begin{array}{l}532 \\
538 \\
544 \\
574 \\
580 \\
592\end{array}$ & $\begin{array}{l}9.73 \\
9.23 \\
8.37 \\
7.38 \\
6.78 \\
6.25\end{array}$ & $\begin{array}{r}13,800 \\
12,700 \\
10,900 \\
8,790 \\
7,540 \\
6,340\end{array}$ & $\begin{array}{r}4 . \overline{3} 8 \\
4.16\end{array}$ & $\begin{array}{r}3,180 \\
2,840\end{array}$ & & & - & & $\ldots$ & - \\
\hline $\begin{array}{r}7 \\
8 \\
9 \\
10 \\
11 \\
12 \\
\end{array}$ & $\begin{array}{l}1.85 \\
1.84 \\
1.83 \\
1.85 \\
1.90 \\
1.93\end{array}$ & $\begin{array}{l}610 \\
604 \\
598 \\
610 \\
640 \\
658\end{array}$ & $\begin{array}{l}5.88 \\
5.58 \\
5.34 \\
5.31 \\
5.83 \\
6.15\end{array}$ & $\begin{array}{l}5,750 \\
5,180 \\
4,640 \\
4,640 \\
5,560 \\
6,340\end{array}$ & $\begin{array}{r}4.00 \\
3.85\end{array}$ & $\begin{array}{r}2,640 \\
2,450\end{array}$ & 2.99 & 1,520 & 2.54 & 1,120 & 2.26 & $\mid$\begin{tabular}{l}
-1 \\
\hdashline \\
\hdashline \\
\hdashline 88
\end{tabular} \\
\hline
\end{tabular}

WATAUGA RIVER AT HORSESHOE DAM, AT WILBUR, TENN.

Location.-Lat. $36^{\circ} 20^{\prime} 28^{\prime \prime}$, long. $82^{\circ} 07^{\prime} 26^{\prime \prime}$, at dam of East Tennessee Power \& Light Co., at Wilbur, Carter County, and $7 \frac{1}{2}$ miles upstream from Doe River and

Elizabethton. Datum of gage is $1,640.0$ feet above mean sea level.

Drainage ARea.-471 square miles.

GAGE-HEIGHT RECORD.-Hourly head-water readings 1 a.m. to 8 p.m. Aug. 13 .

DISCHARGE RECORD.-Peak discharge based on determination of flow over dam. Hourly discharges computed on basis of records of Watauga River at Elizabethton and Doe River at Elizabethton adjusted for difference in drainage areas and time interval.

Maxima.-1940: Discharge, 73,800 second-feet 11:30 p.m. Aug. 13 (gage height, 17.47 feet, from floodmark). 


\section{FLOODS OF AUGUST 1940 IN THE SOUTHEASTERN STATES}

1903-8: Discharge, 10,100 second-feet July 12, 1905 (gage height, 8.4 feet at site near Elizabethton and datum then in use).

REMARKs.-Crest of dam is 0.0 foot gage height, and top of flashboards is 3.5 feet gage height.

Gage height, in feet, and discharge, in second-feet, at indicated time, 1940

\begin{tabular}{|c|c|c|c|c|c|c|c|c|c|c|}
\hline \multirow{2}{*}{ Hour } & \multicolumn{2}{|c|}{ Aug. 13} & \multicolumn{2}{|c|}{ Aug. 14} & \multicolumn{2}{|c|}{ Aug. 15} & \multicolumn{2}{|c|}{ Aug. 16} & \multicolumn{2}{|c|}{ Aug. 17} \\
\hline & $\begin{array}{l}\text { Gage } \\
\text { height }\end{array}$ & $\begin{array}{l}\text { Dis- } \\
\text { charge }\end{array}$ & $\begin{array}{l}\text { Gage } \\
\text { height }\end{array}$ & $\begin{array}{l}\text { Dis- } \\
\text { charge }\end{array}$ & $\begin{array}{c}\text { Gage } \\
\text { height }\end{array}$ & $\begin{array}{l}\text { Dis- } \\
\text { charge }\end{array}$ & $\begin{array}{c}\text { Gage } \\
\text { height }\end{array}$ & $\begin{array}{l}\text { Dis- } \\
\text { charge }\end{array}$ & $\begin{array}{c}\text { Gage } \\
\text { height }\end{array}$ & $\begin{array}{l}\text { Dis- } \\
\text { charge }\end{array}$ \\
\hline $\begin{array}{l}1 \\
2 \\
3 \\
4 \\
5 \\
6\end{array}$ & $\begin{array}{l}4.2 \\
5.4 \\
5.8 \\
5.8 \\
5.8 \\
5.8\end{array}$ & $\begin{array}{r}994 \\
1,010 \\
1,190 \\
2,100 \\
2,570 \\
2,930\end{array}$ & 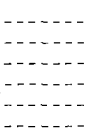 & $\begin{array}{l}54,000 \\
44,000 \\
36,100 \\
30,600 \\
28,200\end{array}$ & 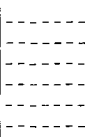 & $\begin{array}{l}13,400 \\
13,400 \\
13,100 \\
12,700 \\
12,400 \\
11,800\end{array}$ & |- & $\begin{array}{r}5,750 \\
5,540 \\
5,330\end{array}$ & 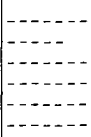 & $\begin{array}{r}3,710 \\
3,750 \\
3,610\end{array}$ \\
\hline $\begin{array}{r}7 \\
8 \\
9 \\
10 \\
11 \\
\mathrm{~N}\end{array}$ & $\begin{array}{l}6.1 \\
6.4 \\
6.6 \\
6.8 \\
7.1 \\
7.2\end{array}$ & $\begin{array}{l}3,440 \\
3,930 \\
4,460 \\
5,400 \\
6,460 \\
7,170\end{array}$ & $\begin{array}{l}--1 \\
--- \\
--- \\
--- \\
---\end{array}$ & $\begin{array}{l}25,800 \\
23,400 \\
22,200 \\
20,400 \\
18,600 \\
17,300\end{array}$ & $\begin{array}{l}--- \\
--- \\
---\end{array}$ & $\begin{array}{r}11,300 \\
10,700 \\
10,100 \\
9,900 \\
9,300 \\
9,110\end{array}$ & 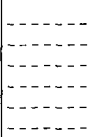 & $\begin{array}{r}4,940 \\
4,950 \\
4,740\end{array}$ & 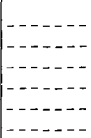 & $\begin{array}{r}3,470 \\
-\overline{3}, 340 \\
-\overline{3}, 210\end{array}$ \\
\hline $\begin{array}{l}1 \\
2 \\
3 \\
4 \\
5 \\
6\end{array}$ & $\begin{array}{l}7.3 \\
7.4 \\
7.4 \\
7.5 \\
7.6 \\
7.7\end{array}$ & $\begin{array}{l}7,630 \\
7,990 \\
8,070 \\
8,000 \\
7,860 \\
7,900\end{array}$ & 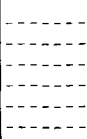 & $\begin{array}{l}16,100 \\
15,300 \\
14,500 \\
13,800 \\
13,500 \\
13,200\end{array}$ & $\mid \begin{array}{c}--1 \\
-\cdots \\
-\cdots \\
-\cdots\end{array}$ & $\begin{array}{l}8,540 \\
8,290 \\
8,030 \\
7,780 \\
7,510 \\
7,280\end{array}$ & 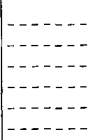 & $\begin{array}{r}4,540 \\
4,520 \\
4,240\end{array}$ & 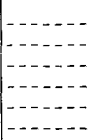 & $\begin{array}{r}3,080 \\
3, \overline{0} 40 \\
-\overline{2}, \overline{9} 0\end{array}$ \\
\hline $\begin{array}{r}7 \\
8 \\
9 \\
10 \\
11 \\
12\end{array}$ & $\begin{array}{r}8.9 \\
10.0 \\
\hdashline-0 .- \\
\hdashline-1 .-\end{array}$ & $\begin{array}{r}7,580 \\
12,100 \\
25,600 \\
48,500 \\
70,000 \\
70,500\end{array}$ & -- & $\begin{array}{l}12,900 \\
12,900 \\
13,300 \\
13,000 \\
13,300 \\
13,100\end{array}$ & - & $\begin{array}{r}7,050 \\
6,820 \\
6,600 \\
6,380 \\
6,160 \\
6,170\end{array}$ & 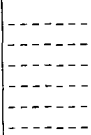 & $\begin{array}{r}3,950 \\
3,970 \\
4,020\end{array}$ & - & $\mid \begin{array}{r}2, \overline{800} \\
-\overline{2}, \overline{760} \\
-\overline{2}, \overline{6} \overline{0}\end{array}$ \\
\hline$\overline{\text { Mean }}$ & $\overline{1-\ldots \ldots}$ & 12,000 & $\bar{\ldots}$ & 24,100 & $\overline{\ldots \ldots}$ & 9,470 & $1-\ldots$ & 4,800 & $-\ldots$ & 3,250 \\
\hline
\end{tabular}

SuPPLEMENTAL RECORD.-Aug. 13, 11:30 p.m., gage height, 17.47 feet; discharge, 73,800 second-feet

WATAUGA RIVER AT ELIZABETH'TON, TENN.

Location.-Lat. $36^{\circ} 21^{\prime} 21^{\prime \prime}$, long. $82^{\circ} 13^{\prime} 26^{\prime \prime}$, between bridge on U. S. Highway $19 \mathrm{E}$ and Southern Railway bridge at Élizabethton, Carter County, 0.6 mile downstream from Doe River. Datum of gage is $1,486.23$ feet above mean sea level, datum of 1929 , supplementary adjustment of 1936 .

DRAINAGE AREA.-692 square miles.

GAGE-HEIGHT RECORD.-Water-stage recorder graph except for the period 3 to 6 a.m. Aug. 14, record for which was based on the shape of graph at beginning and end of period.

DISCHARGE RECORD.--Stage-discharge relation defined by current-meter measurements up to 28,500 second-feet and extended to crest gage height on basis of flood determination by contracted-opening method, and flow over Horseshoe Dam, at Wilbur, 7 miles upstream. Gage heights used to half-tenths between 3.6 and 6.3 feet; hundredths below and tenths above these limits.

Maxima.-1940: Discharge, 75,100 second-feet 12:30 a.m. Aug. 14 (gage height, 20.87 feet).

1926-39: Discharge, 25,700 second-feet Mar. 26, 1935 (gage height, 12.97 feet).

Stage known, 22.0 feet Feb. 27 or 28, 1902; discharge, 83,700 second-feet. Flood of July 16, 1916, reached a stage of 15.6 feet (discharge, 40,000 secondfeet).

REMARKS.-Flood runoff affected slightly by Horseshoe Dam, at Wilbur, 7 miles upstream. Flashboards on dam swept out sometime before crest of flood on August 14; no regulation thereafter. 
TENNESSEE RIVER BASIN

Mean discharge, in second-feet, 1940

\begin{tabular}{|c|c|c|c|c|c|c|c|c|c|c|c|}
\hline Day & Aug. & Sept. & Day & Aug. & Sept. & Day & Aug. & Sept. & Day & Aug. & Sept. \\
\hline 1 & 2,980 & 2,720 & 9 & 816 & 781 & 17 & 4,260 & 567 & 25 & 986 & 516 \\
\hline 2 & 1,780 & 1,850 & 10 & 674 & 864 & 18 & 2,960 & 538 & 26 & 1,030 & 538 \\
\hline 3 & 1,270 & 1,440 & 11 & 704 & 904 & 19 & 2,440 & 510 & 27 & 915 & 488 \\
\hline 4 & 978 & $\begin{array}{l}1,220 \\
1,00\end{array}$ & 12 & & 737 & 20 & $\begin{array}{l}1,940 \\
1,610\end{array}$ & 510 & 28 & 849 & 446 \\
\hline $\begin{array}{l}5 \\
6 \\
\end{array}$ & $\begin{array}{l}949 \\
862\end{array}$ & $\begin{array}{l}1,200 \\
1,020\end{array}$ & $\begin{array}{l}13 \\
14\end{array}$ & $\begin{array}{l}10,900 \\
28,400\end{array}$ & $\begin{array}{l}687 \\
638\end{array}$ & $\begin{array}{l}21 \\
22\end{array}$ & $\begin{array}{l}1,610 \\
1,450\end{array}$ & $\begin{array}{l}488 \\
467\end{array}$ & $\begin{array}{l}29 \\
30\end{array}$ & $\begin{array}{r}900 \\
6.970\end{array}$ & $\begin{array}{l}368 \\
354 \\
354\end{array}$ \\
\hline 7 & 1,430 & 913 & 15 & 10,900 & 608 & 23 & 1,230 & 467 & & 5,450 & \\
\hline 8 & 1,170 & 834 & 16 & 5,890 & 579 & 24 & 1,090 & 494 & & & . \\
\hline \multicolumn{10}{|c|}{$\begin{array}{l}\text { Monthly mean discharge, in second-feet. } \\
\text { Runoff, in inches }\end{array}$} & $\begin{array}{r}3,372 \\
5.62\end{array}$ & $\begin{array}{r}792 \\
1.28\end{array}$ \\
\hline
\end{tabular}

Gage height, in feet, and discharge, in second-feet, at indicated time, 1940

\begin{tabular}{|c|c|c|c|c|c|c|c|c|c|c|c|c|}
\hline \multirow{2}{*}{ Hour } & \multicolumn{2}{|c|}{ Aug. 12} & \multicolumn{2}{|c|}{ Aug. 13} & \multicolumn{2}{|c|}{ Aug. 14} & \multicolumn{2}{|c|}{ Aug. 15} & \multicolumn{2}{|c|}{ Aug. 16} & \multicolumn{2}{|c|}{ Aug. 17} \\
\hline & $\begin{array}{c}\text { Gage } \\
\text { ht. }\end{array}$ & $\begin{array}{c}\text { Dis- } \\
\text { charge }\end{array}$ & & $\begin{array}{c}\text { Dis- } \\
\text { charge }\end{array}$ & $\begin{array}{c}\text { Gage } \\
\text { ht. }\end{array}$ & $\begin{array}{c}\text { Dis- } \\
\text { charge }\end{array}$ & $\begin{array}{c}\text { Gage } \\
\text { ht. }\end{array}$ & $\begin{array}{r}\mathrm{Di} \\
\text { chat }\end{array}$ & $\begin{array}{c}\text { Gage } \\
\text { ht. }\end{array}$ & $\begin{array}{c}\text { Dis- } \\
\text { charge }\end{array}$ & $\begin{array}{c}\text { Gage } \\
\text { ht. }\end{array}$ & $\begin{array}{c}\text { Dis- } \\
\text { charge }\end{array}$ \\
\hline $\begin{array}{l}1 \\
2 \\
3 \\
4 \\
5 \\
6\end{array}$ & \begin{tabular}{|l|}
3.48 \\
3.47 \\
3.18 \\
2.84 \\
2.62 \\
2.48
\end{tabular} & & $\begin{array}{l}4.28 \\
4.29 \\
4.29 \\
4.50 \\
5.34 \\
5.70\end{array}$ & $\begin{array}{l}1,540 \\
1,540 \\
1,540 \\
1,720 \\
2,620 \\
3,100\end{array}$ & \begin{tabular}{|}
20.80 \\
19.90 \\
18.50 \\
16.95 \\
15.70 \\
14.74
\end{tabular} & $\begin{array}{l}74,300 \\
67,500 \\
57,200 \\
46,800 \\
38,600 \\
33,000\end{array}$ & \begin{tabular}{|l|}
10.65 \\
10.67 \\
10.67 \\
10.60 \\
10.50 \\
10.40
\end{tabular} & $\begin{array}{l}14, \\
14, \\
14, \\
13, \\
13,\end{array}$ & 7.60 & 6,310 & 6.71 & $4,640^{-}$ \\
\hline $\begin{array}{r}7 \\
8 \\
9 \\
10 \\
11 \\
\mathrm{~N}\end{array}$ & $\left|\begin{array}{l}2.40 \\
2.34 \\
2.30 \\
2.90 \\
3.50 \\
3.52\end{array}\right|$ & $\begin{array}{l}273 \\
250 \\
235 \\
510 \\
883 \\
897\end{array}$ & $\begin{array}{l}5.96 \\
6.28 \\
6.70 \\
7.12 \\
7.65 \\
8.12\end{array}$ & $\begin{array}{l}3,480 \\
4,000 \\
4,640 \\
5,330 \\
6,310 \\
7,400\end{array}$ & $\begin{array}{l}14.22 \\
13.67 \\
13.20 \\
12.86 \\
12.50 \\
12.12\end{array}$ & $\begin{array}{l}30,400 \\
27,900 \\
25,400 \\
24,000 \\
22,100 \\
20,300\end{array}$ & $\mid \begin{array}{r}10.22 \\
10.00 \\
9.80 \\
9.65 \\
9.50 \\
9.33\end{array}$ & $\begin{array}{l}13,000 \\
12,400 \\
11,800 \\
11,200 \\
11,000 \\
10,400\end{array}$ & 7.31 & 5,710 & 6.42 & 4,160 \\
\hline $\begin{array}{l}1 \\
2 \\
3 \\
4 \\
5 \\
6\end{array}$ & \begin{tabular}{|l|}
3.80 \\
3.90 \\
3.95 \\
3.94 \\
3.95 \\
3.90
\end{tabular} & $\begin{array}{l}1,100 \\
1,180 \\
1,230 \\
1,230 \\
1,230 \\
1,180\end{array}$ & $\begin{array}{l}8.36 \\
8.58 \\
8.77 \\
8.95 \\
9.15 \\
9.40\end{array}$ & $\begin{array}{r}8,110 \\
8,600 \\
9,100 \\
9,620 \\
10,200 \\
10,700\end{array}$ & $\left|\begin{array}{l}11.80 \\
11.50 \\
11.26 \\
11.12 \\
10.92 \\
10.80\end{array}\right|$ & $\begin{array}{l}18,900 \\
17,700 \\
16,900 \\
16,100 \\
15,300 \\
15,000\end{array}$ & $\begin{array}{r}9.03 \\
8.80 \\
8.5 \overline{7}\end{array}$ & $\begin{array}{r}9,620 \\
9,100 \\
8600\end{array}$ & 710 & 5 & 6.19 & 3 \\
\hline $\begin{array}{r}7 \\
8 \\
9 \\
10 \\
11 \\
12 \\
\end{array}$ & \begin{tabular}{|l|}
3.52 \\
3.07 \\
2.90 \\
2.87 \\
2.96 \\
4.15 \\
\end{tabular} & $\begin{array}{r}897 \\
608 \\
510 \\
494 \\
544 \\
1,400 \\
\end{array}$ & $\begin{array}{r}9.65 \\
10.00 \\
11.60 \\
14.40 \\
18.00 \\
20.13\end{array}$ & $\begin{array}{l}11,200 \\
12,400 \\
18,100 \\
31,400 \\
53,700 \\
69,000\end{array}$ & $\left|\begin{array}{l}10.70 \\
10.65 \\
10.65 \\
10.66 \\
10.65 \\
10.66\end{array}\right|$ & $\begin{array}{l}14,600 \\
14,300 \\
14,300 \\
14,600 \\
14,300 \\
14,600 \\
\end{array}$ & {$\left[\begin{array}{r}8.36 \\
-8.18 \\
-8.00 \\
\end{array}\right.$} & $\begin{array}{r}8,110 \\
-7,630 \\
7,170\end{array}$ & 7.00 & 5,150 & 5.96 & 3,480 \\
\hline
\end{tabular}

\begin{tabular}{|c|c|c|c|c|c|c|c|c|c|c|c|c|}
\hline & & 29 & & g. 30 & & g. 31 & & ot. 1 & & t. 2 & & pt. 3 \\
\hline 1 & & & 4.40 & & & & & & & & & \\
\hline 2 & & & 4.39 & 1,630 & 7.72 & & & & & & & \\
\hline & & & $\begin{array}{l}4.45 \\
4.56\end{array}$ & $\begin{array}{l}1,680 \\
1,770\end{array}$ & $\begin{array}{l}8.10 \\
8.30\end{array}$ & $\begin{array}{l}7,400 \\
7,870\end{array}$ & & & & & & $\therefore-$ \\
\hline 5 & & & 4.65 & 1,870 & 8.27 & 7,870 & & & & & & $\cdots$ \\
\hline 6 & 3.41 & 822 & 4.72 & 1,920 & 8.05 & 7,170 & 5.65 & 3,030 & & & & \\
\hline 7 & 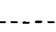 & & 5.07 & 2,280 & 7.80 & 730 & & & & & & \\
\hline $\begin{array}{l}8 \\
9\end{array}$ & & & $\begin{array}{l}5.42 \\
5.61\end{array}$ & $\begin{array}{l}2,680 \\
2,960\end{array}$ & $\begin{array}{l}7.62 \\
7.45\end{array}$ & $\begin{array}{l}6,310 \\
5,910\end{array}$ & & & & & & \\
\hline 10 & 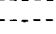 & 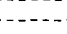 & 5.76 & 3,180 & 7.30 & 5,710 & $\cdots-1$ & -1 & & & & 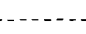 \\
\hline $\mathrm{N}$ & 3.40 & $8 \overline{1} \overline{5}$ & $\begin{array}{l}0.89 \\
6.80\end{array}$ & 4,800 & 7.06 & $\begin{array}{l}5,330 \\
5,330\end{array}$ & 5.37 & 2,620 & $4.6 \overline{6}$ & 1,820 & $4.1 \overline{1}$ & 1,400 \\
\hline 1 & 3.41 & 822 & 9.00 & 9,620 & & & & & & & & \\
\hline $\begin{array}{l}2 \\
3\end{array}$ & $\begin{array}{l}3.41 \\
3.41\end{array}$ & 822 & $\left|\begin{array}{l}10.80 \\
11.35\end{array}\right|$ & 17 & $\cdots$ & & & & & & & \\
\hline 4 & 3.44 & 842 & 11.30 & & -- & & $\cdots$ & & & & & 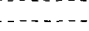 \\
\hline 6 & $\begin{array}{l}. .40 \\
3.49\end{array}$ & $\begin{array}{l}830 \\
876\end{array}$ & $\mid \begin{array}{l}10.93 \\
10.40\end{array}$ & $\begin{array}{l}10,600 \\
13,600\end{array}$ & -6.47 & 4,320 & 5.14 & 2,380 & & & & -. \\
\hline 7 & 3.50 & 883 & 9.74 & 11 & & & & & & & & \\
\hline 8 & $\begin{array}{l}3.54 \\
3.58\end{array}$ & 912 & 9.18 & 10 & & & & & & & & \\
\hline 10 & o. & 1,070 & 8.25 & 7, &.- & $\cdots$ & & & & & & \\
\hline 12 & $\begin{array}{l}4.31 \\
4.42\end{array}$ & $\begin{array}{l}1,540 \\
1,630\end{array}$ & $\begin{array}{l}7.94 \\
7.70\end{array}$ & $\begin{array}{l}6,950 \\
6,520\end{array}$ & -5.99 & 3,550 & $-\overline{4} . \overline{1} 1$ & 2,120 & 4.38 & 1,630 & 4.06 & 1,320 \\
\hline
\end{tabular}

SUPPLEMENTAL RECORDs.-Aug. 14, 12:30 a.m., gage height, 20.87 feet; discharge, 75,100 second-feet. Aug. 30, 3:30 p.m., gage height, 11.38 feet; discharge, 17,300 second-feet. 


\section{ELK CREEK NEAR ELK PARK, N. C.}

Location.-Lat. $36^{\circ} 11^{\prime} 10^{\prime \prime}$, long. $81^{\circ} 57^{\prime} 40^{\prime \prime}$, 1 mile downstream from Little Elk Creek, 2 miles northeast of Elk Park, Avery County, and 3 miles upstream from State line.

Drain AGe AREA.- 42.0 square miles.

GAGE-HEIGHT RECORD.-The water-stage recorder was lost in the flood of Aug. 13 and not recovered. Water-stage recorder graph available only to 12:30 p.m. Aug. 1. One staff-gage reading daily to hundredths Aug. 3, 9, and staff-gage readings twice daily to hundredths Aug. 18-24, 28-29, and Sept. 1-30. Graph based on two readings was used Aug. 29. No gage-height record for remaining period.

DischaRGE RECORD.-Stage-discharge relation defined by current-meter measurements up to 1,300 second-feet and extended to erest gage height on basis of peak flow determination by slope-area method. Gage heights used to half-tenths between 2.4 and 3.9 feet; hundredths below and tenths above these limits. Discharge for periods of no-gage height record is based on weather records and records for nearby streams.

Maxima.-1940: Discharge, 27,500 second-feet 6:30 p.m. Aug. 13 (gage height, 17.8 feet, from floodmarks).

1934-39:Discharge, 3,640 second-feet Jan. 9, 1935 (gage height, 7.15 feet).

Surveys by the Tennessee Valley Authority show that the floods of May 1901 and July 1916 probably were exceeded by the flood of August 1940.

REMARKs.-Flood runoff not affected by artificial storage.

Mean discharge, in second-feet, 1940

\begin{tabular}{l} 
Day \\
\hline 1
\end{tabular}

ROAN CREEK AT BUTLER, TENN.

Location.-Lat. $36^{\circ} 20^{\prime} 22^{\prime \prime}$, long. $81^{\circ} 59^{\prime} 36^{\prime \prime}$, half a mile northeast of Butler, Johnson County, and 0.7 mile upstream from mouth. Datum of gage is $1,826.78$ feet above mean sea level, datum of 1929, supplementary adjustment of 1936 . Drain AGE AREA.-166 square miles.

GAGE-HEIGHT RECORD.-Water-stage recorder graph.

DISCHARGE RECORD.-Stage-discharge relation defined by current-meter measurements up to 2,500 second-feet. Station affected by backwater from Watanga River 7 p.m. Aug. 13 to 1 a.m. Aug. 14; discharge computed from effective gage heights obtained from graph based on shape of graph at beginning and end of period. Gage heights used to half-tenths from 2.6 to 4.6 feet; hundredths below and tenths above these limits.

Maxima.-1940: Discharge, 3,920 second-feet 4 a.m. Aug. 14; gage height, 10.09 feet $9: 50$ p.m. Aug. 13 .

1934-39: Discharge, 4,940 second-feet Mar. 26, 1935 (gage height, 7.68 feet). REMARKs.-Flood runoff not appreciably affected by storage. 
TENNESSEE RIVER BASIN

Mean discharge, in second-feet, 1940

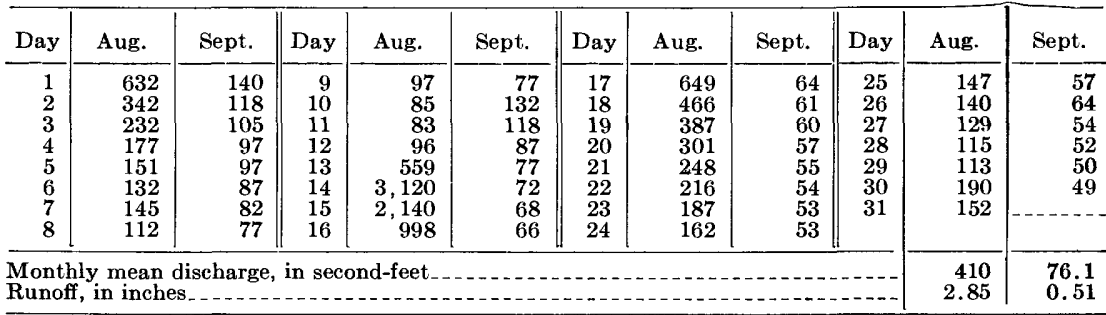

Gage height, in feet, and discharge, in second-feet, at indicated time, 1940

\begin{tabular}{|c|c|c|c|c|c|c|c|c|c|c|c|c|}
\hline \multirow{2}{*}{ Hour } & \multicolumn{2}{|c|}{ Aug. 13} & \multicolumn{2}{|c|}{ Aug. 14} & \multicolumn{2}{|c|}{ Aug. 15} & \multicolumn{2}{|c|}{ Aug. 16} & \multicolumn{2}{|c|}{ Aug. 17} & \multicolumn{2}{|c|}{ Aug. 18} \\
\hline & $\begin{array}{c}\text { Gage } \\
\text { ht. }\end{array}$ & $\begin{array}{c}\text { Dis- } \\
\text { charge }\end{array}$ & $\begin{array}{c}\text { Gage } \\
\text { ht. }\end{array}$ & $\begin{array}{l}\text { Dis- } \\
\text { charge }\end{array}$ & $\begin{array}{c}\text { Gage } \\
\text { ht. }\end{array}$ & $\begin{array}{l}\text { Dis- } \\
\text { charge }\end{array}$ & $\underset{\text { ht. }}{\text { Gage }}$ & $\begin{array}{c}\text { Dis- } \\
\text { charge }\end{array}$ & $\underset{\text { ht. }}{\text { Gage }}$ & $\begin{array}{l}\text { Dis- } \\
\text { charge }\end{array}$ & $\begin{array}{c}\text { Gage } \\
\text { ht. }\end{array}$ & $\begin{array}{c}\text { Dis- } \\
\text { charge }\end{array}$ \\
\hline 1 & 1 & & 8 & & & & & & & & & \\
\hline 2 & $\begin{array}{l}1.20 \\
1.19\end{array}$ & & 10 & & & & & & & & & \\
\hline 3 & 1.18 & 15 & 60 & & & & - & 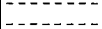 & -- & -1 & & - \\
\hline 4 & 1.16 & 15 & 6.61 & 20 & & & -- & - & -3 & -1 & -- & -- \\
\hline 5 & 1.15 & 1 & 6.53 & 30 & & & $\begin{array}{l}---1 \\
----\end{array}$ & 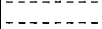 & $\mid \begin{array}{l}---\infty \\
--\cdots--\end{array}$ & -- & -- & $\begin{array}{ll}-2-\infty \\
-1-1\end{array}$ \\
\hline 6 & 1.13 & 1 & 6.35 & 40 & 5.16 & 2,670 & ---- & $---1-1$ & $-\cdots-\cdots$ & $-\cdots$ & -- & \\
\hline 7 & 1.13 & 145 & 6.29 & & & & & & & & & \\
\hline 8 & 1.15 & 149 & 6.13 & 3,470 & & - & -- & -- & -- & - & $\ldots$ & $\ldots \ldots$ \\
\hline 9 & 1.19 & 158 & 5.99 & $\mathbf{3}, \mathbf{3 8 0}$ & - & - & -- & 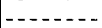 & -- & $\ldots$ & $-\ldots$ & $\ldots \ldots$ \\
\hline 10 & 1.27 & 177 & 5.84 & 3,200 & $-\ldots$ & $-\ldots$ &.--- & $\ldots$ &.- & $\ldots$ & $-\ldots$ & --- \\
\hline 11 & 1.38 & 205 & 5.65 & 3,020 & $----\overline{10}$ & $---1---$ & & $----1---$ & & $-----=--$ & & 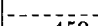 \\
\hline $\mathbf{N}$ & 1.36 & 200 & 5.54 & 30 & 4.43 & 2,040 & 2.99 & 990 & 2.40 & 645 & 2.01 & 450 \\
\hline 1 & 1.34 & 194 & 5.35 & 2,840 & - & $-\cdots$ & ---- & - & $-\cdots$ & & - . & ----- \\
\hline 2 & 1.40 & 210 & 5.23 & 2,670 & $-1--$ & 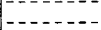 & 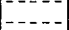 & 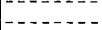 & 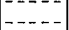 & --- & 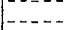 & - \\
\hline 3 & 1.45 & 224 & 5.13 & 2 , & 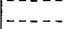 & ---2 & $\mid \begin{array}{l}----1 \\
--1--\end{array}$ & 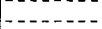 & - & $-10-1$ & $-\ldots$ & $0-10-1$ \\
\hline 4 & 1.50 & 238 & 5.04 & 00 & $\ldots$ & $-\ldots$ & $-\ldots$ & $\ldots$ & - - - - & $-\ldots-\ldots$ & $\ldots$ & $\ldots \ldots$ \\
\hline 5 & 1.65 & 284 & 5.00 & 00 & & $\ldots$ & $\ldots--$ & $\ldots$ & $\ldots \ldots$ & - & $-\ldots$ & 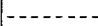 \\
\hline 6 & 2.05 & 437 & 4.92 & 20 & 3.87 & 1,570 & $-\ldots$ & & $-\ldots--$ & $-\ldots-\ldots$ & $-\ldots$ & $\ldots$ \\
\hline 7 & 2.70 & 664 & 4.86 & 2 , & & & - - - - & & & & $---\infty$ & \\
\hline 8 & 5.50 & 1,020 & 5.02 & 2, & $\ldots$ & $\ldots$ & ---- & $\ldots$ & $\ldots \ldots$ & 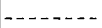 & $-\ldots$ & $---\cdot$ \\
\hline 9 & 8.60 & 1,660 & 5.33 & 2,760 & $-\ldots$ & - - - - - & $\ldots-$. & - - - - & ----- & $-\ldots-\ldots$ & ---- & ----- \\
\hline 10 & 10.07 & 2,080 & 5.57 & 3,020 & $---\ldots$ & $-\ldots \ldots$ & ----- & $---\ldots$ &.--- & $--\ldots$ & ---- & $---\cdots$ \\
\hline $\begin{array}{l}11 \\
12\end{array}$ & 9.10 & 2,760 & $\begin{array}{l}5.70 \\
5.89\end{array}$ & 3,110 & $\overline{3} . \overline{46}$ & $-\overline{1} 8 \overline{0}$ & $-\overline{2}-\overline{67}$ & $---\overline{7} 82^{--}$ & $-\overline{2} \overline{17}$ & $--\overline{5} \overline{5}$ & $-\overline{1.95}$ & $---\overline{426}$ \\
\hline & & & & & & & & & & & & \\
\hline
\end{tabular}

DOE RIVER AT ELIZABETHTON, TENN.

Location.-Lat. $36^{\circ} 20^{\prime} 40^{\prime \prime}$, long. $82^{\circ} 12^{\prime} 37^{\prime \prime}$, 0.2 mile upstream from covered highway bridge at Elizabethton, Carter County, and 1 mile upstream from mouth. Datum of gage is 1,524.73 feet above mean sea level, datum of 1929, supplementary adjustment of 1936 .

DRAINAGE AREA.-137 square miles.

GAGE-HEIGHT RECORD.-Water-stage recorder graph.

DISCHARGE RECORD.-Stage-discharge relation defined by current-meter measurements up to 3,800 second-feet. Gage heights used to half-tenths between 3.0 and 5.4 feet; hundredths below and tenths above these limits.

Maxima.-August, 1940: Discharge, 4,830 second-feet 9.p.m. Aug. 13 (gage height, 5.48 feet).

1932 to July 1940: Discharge, 7,300 second-feet July 30, 1940 (gage height, 6.75 feet).

REMARKs.-Flood runoff not appreciably affected by storage. 
Mean discharge, in second-feet, 1940

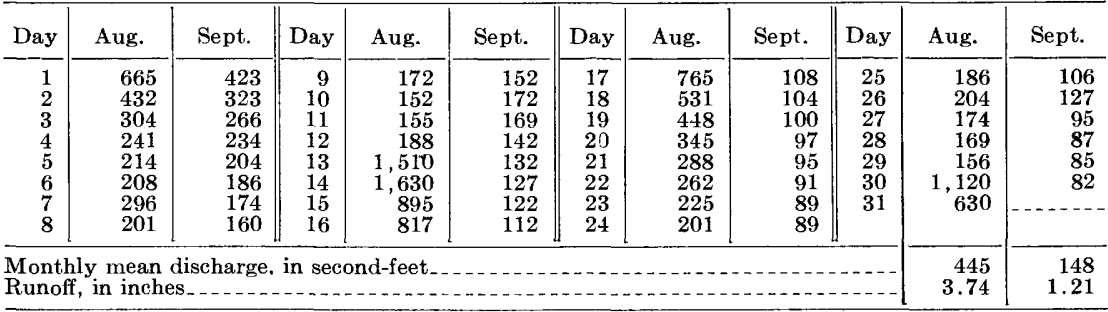

Gage height, in feet, and discharge, in second-feet, at indicated time, 1940

\begin{tabular}{|c|c|c|c|c|c|c|c|c|c|c|c|c|}
\hline \multirow{2}{*}{ Hour } & \multicolumn{2}{|c|}{ Aug. 12} & \multicolumn{2}{|c|}{ Aug. 13} & \multicolumn{2}{|c|}{ Aug. 14} & \multicolumn{2}{|c|}{ Aug. 15} & \multicolumn{2}{|c|}{ Aug. 16} & \multicolumn{2}{|c|}{ Aug. 17} \\
\hline & $\begin{array}{c}\text { Gage } \\
\text { ht. }\end{array}$ & $\begin{array}{l}\text { Dis- } \\
\text { charge }\end{array}$ & $\begin{array}{c}\text { Gage } \\
\text { ht. }\end{array}$ & $\begin{array}{l}\text { Dis- } \\
\text { charge }\end{array}$ & $\begin{array}{c}\text { Gage } \\
\text { ht. }\end{array}$ & $\begin{array}{l}\text { Dis- } \\
\text { charge }\end{array}$ & $\begin{array}{c}\text { Gage } \\
\text { ht. }\end{array}$ & $\begin{array}{l}\text { Dis- } \\
\text { charge }\end{array}$ & $\begin{array}{c}\text { Gage } \\
\text { ht. }\end{array}$ & $\begin{array}{l}\text { Dis- } \\
\text { charge }\end{array}$ & $\begin{array}{c}\text { Gage } \\
\text { ht. }\end{array}$ & $\begin{array}{l}\text { Dis- } \\
\text { charge }\end{array}$ \\
\hline 1 & --1 & $-\infty$ & 88 & ? & & & & $-n$ & -- & 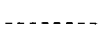 & & -- \\
\hline 2 & & & 1.84 & 437 & 4.32 & 2,790 & & - & $-\ldots$ & $-1-0$ & $-\ldots$ & 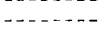 \\
\hline 3 & & & 1.82 & 427 & & & & -- & $-\ldots$ & 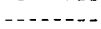 & $\ldots$. &.---1 \\
\hline 4 & &.- & 1.81 & 423 & 3.94 & 2,270 & -- & $\sim-\ldots$ & $-\ldots$ & $-\ldots-\ldots$ & $-\ldots$ & $\ldots \ldots$ \\
\hline 5 & $-\overline{1}-\overline{3}$ & $+--\overrightarrow{1} \overrightarrow{0}^{-}$ & 1.80 & 418 & 366 & - $80-$ & & $-\cdots-\overline{3} \overline{3}$ & & $-\cdots-\overline{7}-\overline{6}$ & & $----\frac{8}{80}$ \\
\hline 6 & 1.03 & 142 & 1.81 & 42 & 3.66 & 1,880 & 2.69 & 933 & 2.47 & 786 & 2.55 & 838 \\
\hline 7 & -- & $\ldots$ & 1.84 & 437 & & & & -- & - & - & 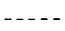 & --- \\
\hline 8 & -- & --- & 1.87 & 451 & 3.49 & 1,700 & $-\cdots$ & $\ldots$ & ---- & $-\cdots$ & $-\rightarrow-$ & $\ldots-\cdots$ \\
\hline $\begin{array}{r}9 \\
10\end{array}$ & ---- & -------- & 2.10 & 568 & 00 & 1400 & $\ldots$ & -- & ---- & --- & ----- & $-\cdots-\cdots$ \\
\hline $\begin{array}{l}10 \\
11\end{array}$ & $-\ldots-$ & $--\cdots---$ & $\begin{array}{l}2.32 \\
2.38\end{array}$ & 695 & 3.29 & 1,480 & ----- & $-\cdots$ & $--\cdots$ & --- & --- & $\ldots+\cdots$ \\
\hline $\mathrm{N}$ & 1.04 & 144 & $\begin{array}{l}2.38 \\
2.42\end{array}$ & $\begin{array}{r}731 \\
755\end{array}$ & 3.16 & 1,330 & 2.62 & 884 & 2.44 & 768 & $\overline{2} . \overline{4} \overline{4}$ & $-\overline{768}$ \\
\hline 1 & & & 2.42 & 755 & & & & & 2.45 & 77 & & $\ldots$ \\
\hline 2 & & & 2.45 & 774 & & & & & 2.45 & 77 & & -- \\
\hline 3 & 1.07 & 152 & 2.63 & 891 & 3.09 & 1,280 & & & 2.46 & 780 & & $-\ldots$ \\
\hline 4 & --- & $\ldots----$ & 3.04 & 1,240 & -- & $\ldots$ & $\ldots$ & & 2.48 & 79 & & - \\
\hline 5 & & & 3.57 & 1,760 & & & & & 2.49 & 79 & & \\
\hline 6 & 1.13 & 169 & 3.94 & 2,270 & 2.99 & 1,180 & 2.60 & 870 & 2.52 & 818 & 2.32 & 695 \\
\hline 7 & & & 4.21 & 2,640 & & & & --- & 2.60 & 870 & $\cdots$ & -- \\
\hline 8 & & & 4.95 & 3,860 & & & & & 2.61 & 877 & -- & - \\
\hline 9 & 1.53 & 304 & 5.48 & 4,830 & 2.89 & 1,090 & $-\ldots--$ & - & 2.72 & 956 & $\ldots$ & - . \\
\hline 10 & ----- & $\ldots+\ldots$ & 5.39 & 4,650 & $-\ldots-$ & $\ldots \ldots$ & $\ldots$. & $-\ldots----$ & 2.75 & 980 & ---- & $-\ldots \ldots$ \\
\hline 11 & $-\overline{1}-\overline{0}$ & $----\bar{d}-\overline{0}$ & 5.14 & 4,200 & & $--\overline{1}-\overline{0}-5$ & & 805 & 2.71 & 948 & & $---\overline{6}-1$ \\
\hline 12 & 1.89 & 460 & 4.79 & 3,600 & 2.79 & 1,010 & 2.50 & 805 & 2.67 & 919 & 2.20 & 624 \\
\hline
\end{tabular}

\section{NORTH FORK HOLSTON RIVER NEAR SALTVILLE, VA.}

Location.-Lat. $36^{\circ} 53^{\prime} 48^{\prime \prime}$, long. $81^{\circ} 44^{\prime} 47^{\prime \prime}$, half a mile upstream from Cedar Branch Bridge, 11/2 miles northeast of Saltville, Smyth County, and $4 \frac{1}{2}$ miles upstream from McHenry Creek. Datum of gage is $1,703.53$ feet above mean sea level, datum of 1929, supplementary adjustment of 1936 .

Dratnage AREa.-222 square miles.

GAGE-HEIGHT RECORD.-Water-stage recorder graph.

DISCHARGE RECORD.-Stage-discharge relation defined by current-meter measurements up to 5,100 second-feet. Gage heights used to half-tenths between 2.9 and 5.2 feet; hundredths below and tenths above these limits.

Maxima.-1940: Discharge, 5,840 second-feet 10 p.m. Aug. 14 (gage height, 6.23 feet).

1907-8, 1920-39: Discharge observed, 8,220 second-feet Feb. 3, 1923 (gage height, 13.97 feet, site and datum then in use). 
Mean discharge, in second-feet, 1940

\begin{tabular}{|c|c|c|c|c|c|c|c|c|c|c|c|}
\hline Day & Aug. & Sept. & Day & Aug. & Sept. & Day & Aug. & Sept. & Day & Aug. & Sept. \\
\hline $\begin{array}{l}1 \\
2 \\
3 \\
4 \\
5 \\
6 \\
7 \\
8\end{array}$ & $\begin{array}{r}478 \\
330 \\
211 \\
-\quad 161 \\
136 \\
124 \\
131 \\
118\end{array}$ & $\begin{array}{r}198 \\
168 \\
148 \\
126 \\
116 \\
107 \\
100 \\
95\end{array}$ & $\begin{array}{r}9 \\
10 \\
11 \\
12 \\
13 \\
14 \\
15 \\
16\end{array}$ & $\begin{array}{r}95 \\
85 \\
78 \\
74 \\
103 \\
3,510 \\
3,530 \\
1,530\end{array}$ & $\begin{array}{r}91 \\
95 \\
100 \\
91 \\
82 \\
78 \\
74 \\
72\end{array}$ & $\begin{array}{r}17 \\
-18 \\
19 \\
20 \\
21 \\
22 \\
23 \\
24\end{array}$ & $\begin{array}{r}984 \\
828 \\
1,270 \\
1,000 \\
618 \\
547 \\
408 \\
314\end{array}$ & $\begin{array}{l}68 \\
66 \\
64 \\
61 \\
59 \\
57 \\
55 \\
51\end{array}$ & $\begin{array}{l}25 \\
26 \\
27 \\
28 \\
29 \\
30 \\
31\end{array}$ & $\begin{array}{l}252 \\
219 \\
190 \\
170 \\
162 \\
207 \\
255\end{array}$ & $\begin{array}{r}57 \\
66 \\
61 \\
55 \\
53 \\
-\quad 51 \\
\end{array}$ \\
\hline \multicolumn{10}{|c|}{$\begin{array}{l}\text { Monthly mean discharge, in second-feet } \\
\text { Runoff, in inches. }\end{array}$} & $\begin{array}{r}584 \\
3.03\end{array}$ & $\begin{array}{l}85.5 \\
0.43\end{array}$ \\
\hline
\end{tabular}

Gage height, in feet, and discharge, in second-feet, at indicated time, 1940

\begin{tabular}{|c|c|c|c|c|c|c|c|c|}
\hline \multirow{2}{*}{ Hour } & \multicolumn{2}{|c|}{ Aug. 13} & \multicolumn{2}{|c|}{ Aug. 14} & \multicolumn{2}{|c|}{ Aug. 15} & \multicolumn{2}{|c|}{ Aug. 16} \\
\hline & $\begin{array}{l}\text { Gage } \\
\text { height }\end{array}$ & Discharge & $\begin{array}{l}\text { Gage } \\
\text { height }\end{array}$ & Discharge & $\begin{array}{l}\text { Gage } \\
\text { height }\end{array}$ & Discharge & $\begin{array}{l}\text { Gage } \\
\text { height }\end{array}$ & Discharge \\
\hline $\begin{array}{r}2 \\
4 \\
6 \\
8 \\
10 \\
\mathrm{~N} \\
\\
2 \\
4 \\
6 \\
8 \\
10 \\
12 \\
\end{array}$ & $\begin{array}{r}.91^{1} \\
.93 \\
.96 \\
.99 \\
1.06 \\
1.15 \\
1.34 \\
1.62 \\
\end{array}$ & $\begin{array}{r}74 \\
78 \\
85 \\
91 \\
107 \\
128 \\
183 \\
299 \\
\end{array}$ & $\begin{array}{l}2.07 \\
2.73 \\
3.42 \\
4.06 \\
4.60 \\
5.00 \\
5.34 \\
5.68 \\
5.99 \\
6.20 \\
6.23 \\
6.10 \\
\end{array}$ & $\begin{array}{r}556 \\
1,050 \\
1,690 \\
2,460 \\
3,210 \\
3,810 \\
4,290 \\
4,960 \\
5,480 \\
5,840 \\
5,840 \\
5,660 \\
\end{array}$ & $\begin{array}{l}5.92 \\
5.69 \\
5.47 \\
5.20 \\
4.95 \\
4.68 \\
4.44 \\
4.25 \\
4.07 \\
3.86 \\
3.73 \\
3.62 \\
\end{array}$ & $\begin{array}{l}5,300 \\
4,960 \\
4,620 \\
4,130 \\
3,740 \\
3,360 \\
\\
3,000 \\
2,720 \\
2,460 \\
2,210 \\
2,090 \\
1,910 \\
\end{array}$ & $\begin{array}{c}3.46 \\
3.34 \\
3.2 \overline{3}^{-} \\
3.13 \\
-3.0 \overline{2}^{-} \\
2.9 \overline{2}^{--} \\
\end{array}$ & $\begin{array}{r}1,740 \\
1,640 \\
1,540 \\
1,440 \\
1,290 \\
1,200\end{array}$ \\
\hline & \multicolumn{2}{|c|}{ Aug. 17} & \multicolumn{2}{|c|}{ Aug. 18} & \multicolumn{2}{|c|}{ Aug. 19} & \multicolumn{2}{|c|}{ Aug. 20} \\
\hline $\begin{array}{r}2 \\
4 \\
6 \\
8 \\
10 \\
\mathrm{~N} \\
\\
2 \\
4 \\
6 \\
8 \\
10 \\
12\end{array}$ & $\mid \begin{array}{c}-\overline{2.82} \\
-\overline{2} . \overline{3} \\
-2.6 \overline{4}^{--} \\
-2 . \overline{5} \\
-\overline{2} . \overline{47} \\
-2 . \overline{4} \overline{7}^{--}\end{array}$ & $\begin{array}{r}1,130^{-} \\
1,050 \\
972 \\
900 \\
836 \\
836\end{array}$ & $\begin{array}{l}2.71 \\
2.68 \\
2.58 \\
2.48 \\
2.42 \\
2.37 \\
\\
2.33 \\
2.35 \\
2.34 \\
2.33 \\
2.35 \\
2.62\end{array}$ & $\begin{array}{r}1,030 \\
1,000 \\
924 \\
844 \\
796 \\
759 \\
\\
731 \\
745 \\
738 \\
731 \\
745 \\
956\end{array}$ & $\begin{array}{l}2.71 \\
2.75 \\
2.82 \\
2.88 \\
2.95 \\
3.05 \\
\\
3.10 \\
3.15 \\
3.16 \\
3.15 \\
3.10 \\
3.04\end{array}$ & $\begin{array}{l}1,030 \\
1,060 \\
1,130 \\
1,180 \\
1,240 \\
1,340 \\
1,390 \\
1,440 \\
1,440 \\
1,440 \\
1,390 \\
1,340\end{array}$ & $\begin{array}{l}2.89 \\
-2.76 \\
-2.65 \\
2.54 \\
2.45 \\
2.36\end{array}$ & $\begin{array}{r}1,190 \\
1,070 \\
980 \\
892 \\
820\end{array}$ \\
\hline
\end{tabular}

\section{NORTH FORK HOLSTON RIVER NEAR GATE CITY, VA.}

Location.-Lat. $36^{\circ} 36^{\prime} 31^{\prime \prime}$, long. $82^{\circ} 34^{\prime} 05^{\prime \prime}$, at highway bridge $11 / 2$ miles downstream from Big Moccasin Creek and 2 miles southeast of Gate City, Scott County. Datum of gage is 1,197.56 feet above mean sea level, datum of 1929, supplementary adjustment of 1936 .

Drainage AREA. - 672 square miles.

GAGE-HEIGHT RECORD.-Water-stage recorder graph.

DISCHARGE RECORD.-Stage-discharge relation defined by current-meter measurements up to 21,000 second-feet. Gage heights used to half-tenths between 3.0 and 5.0 feet; hundredths below and tenths above these limits.

Maxima.-1940: Discharge, 23,700 second-feet 10 p.m. Aug. 14 (gage height, 14.75 feet).

1931-39: Discharge, 13,400 second-feet Jan. 30, 1932, Mar. 26, 1935 (gage height, 10.6 feet). 
FLOODS OF AUGUST 1940 IN THE SOUTHEASTERN STATES

Mean discharge, in second-feet, 1940

\begin{tabular}{|c|c|c|c|c|c|c|c|c|c|c|c|}
\hline Day & Aug. & Sept. & Day & Aug. & Sept. & Day & Aug. & Sept. & Day & Aug. & Sept. \\
\hline $\begin{array}{l}1 \\
2 \\
3 \\
4 \\
5 \\
6 \\
7 \\
8\end{array}$ & $\begin{array}{r}1,840 \\
1,500 \\
942 \\
634 \\
486 \\
402 \\
381 \\
621\end{array}$ & $\begin{array}{r}2,400 \\
1,380 \\
940 \\
730 \\
589 \\
515 \\
446 \\
407\end{array}$ & $\begin{array}{r}9 \\
10 \\
11 \\
12 \\
13 \\
14 \\
15 \\
16\end{array}$ & $\begin{array}{r}435 \\
335 \\
273 \\
234 \\
315 \\
10,600 \\
13,900 \\
5,410\end{array}$ & $\begin{array}{l}360 \\
360 \\
365 \\
340 \\
310 \\
282 \\
246 \\
242\end{array}$ & $\begin{array}{l}17 \\
18 \\
19 \\
20 \\
21 \\
22 \\
23 \\
24\end{array}$ & $\begin{array}{l}2,740 \\
\mathbf{1}, 880 \\
2,330 \\
3,020 \\
1,930 \\
1,660 \\
1,580 \\
1,150\end{array}$ & $\begin{array}{l}228 \\
216 \\
204 \\
200 \\
192 \\
180 \\
177 \\
173\end{array}$ & $\begin{array}{l}25 \\
26 \\
27 \\
28 \\
29 \\
30 \\
31\end{array}$ & $\begin{array}{r}898 \\
758 \\
647 \\
564 \\
536 \\
1,600 \\
2,630\end{array}$ & $\begin{array}{l}177 \\
196 \\
212 \\
196 \\
180 \\
162\end{array}$ \\
\hline \multicolumn{10}{|c|}{$\begin{array}{l}\text { Monthly mean discharge, in second-feet } \\
\text { Runoff, in inches. }\end{array}$} & $\begin{array}{r}2,007 \\
3.45\end{array}$ & $\begin{array}{r}420 \\
0.70\end{array}$ \\
\hline
\end{tabular}

Gage height, in feet, and discharge, in second-feet, at indicated time, 1940

\begin{tabular}{|c|c|c|c|c|c|c|c|c|c|c|c|c|}
\hline \multirow{2}{*}{ Hou } & \multicolumn{2}{|c|}{ Aug. 13} & \multicolumn{2}{|c|}{ Aug. 14} & \multicolumn{2}{|c|}{ Aug. 15} & \multicolumn{2}{|c|}{ Aug. 16} & \multicolumn{2}{|c|}{ Aug. 17} & \multicolumn{2}{|c|}{ Aug. 18} \\
\hline & $\begin{array}{l}\text { Gage } \\
\text { ht. }\end{array}$ & $\begin{array}{c}\text { Dis- } \\
\text { charge }\end{array}$ & $\begin{array}{c}\text { Gage } \\
\text { ht. }\end{array}$ & $\begin{array}{c}\text { Dis- } \\
\text { charge }\end{array}$ & $\begin{array}{c}\text { Gage } \\
\text { ht. }\end{array}$ & $\begin{array}{c}\text { Dis- } \\
\text { charge }\end{array}$ & $\begin{array}{c}\text { Gage } \\
\text { ht. }\end{array}$ & $\begin{array}{c}\text { Dis- } \\
\text { charge }\end{array}$ & $\begin{array}{c}\text { Gage } \\
\text { ht. }\end{array}$ & $\underset{\text { cha }}{\mathrm{D}}$ & $\begin{array}{l}\text { Gage } \\
\text { ht. }\end{array}$ & $\begin{array}{c}\text { Dis- } \\
\text { charge }\end{array}$ \\
\hline \multirow{4}{*}{$\begin{array}{l}1 \\
2 \\
3 \\
4 \\
5 \\
6\end{array}$} & & & \multirow{4}{*}{$\begin{array}{l}2.70 \\
2.85 \\
3.05 \\
3.21 \\
3.39 \\
3.65\end{array}$} & \multirow{4}{*}{$\begin{array}{r}800 \\
912 \\
1,070 \\
1,190 \\
1,360 \\
1,590\end{array}$} & \multirow{4}{*}{$\begin{array}{l}14.00 \\
13.50 \\
12.95 \\
12.45 \\
12.05 \\
11.65\end{array}$} & \multirow{4}{*}{$\begin{array}{l}21,700 \\
20,400 \\
19,200 \\
17,800 \\
16,800 \\
15,800\end{array}$} & 799 & & & & & \\
\hline & & $\ldots$ & & & & & 7.99 & 7,950 & & & & \\
\hline & & 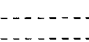 & & & & & 7.61 & 7,190 & & & & \\
\hline & 1.87 & $22 \overline{4}$ & & & & & 7.30 & 6,620 & & & & \\
\hline \multirow{4}{*}{$\begin{array}{r}7 \\
8 \\
9 \\
10 \\
11 \\
\mathrm{~N}\end{array}$} & & & \multirow{4}{*}{$\begin{array}{l}3.90 \\
4.05 \\
4.50 \\
5.70 \\
6.85 \\
8.23\end{array}$} & \multirow{4}{*}{$\begin{array}{l}1,840 \\
1,990 \\
2,470 \\
3,920 \\
5,720 \\
8,350\end{array}$} & \multirow{4}{*}{$\begin{array}{l}11.35 \\
11.13 \\
10.90 \\
10.74 \\
10.60 \\
10.46\end{array}$} & \multirow{4}{*}{$\begin{array}{l}15,400 \\
14,700 \\
14,200 \\
13,800 \\
13,500 \\
13,300\end{array}$} & & & & & & \\
\hline & & & & & & & 6.97 & 080 & & & & \\
\hline & & & & & & & 6.65 & 5,360 & & & & \\
\hline & 1.87 & 224 & & & & & $6 . \overline{38}$ & 5,020 & 4.70 & 2,690 & 3.90 & 1,840 \\
\hline \multirow{4}{*}{$\begin{array}{l}2 \\
3 \\
4 \\
5 \\
6\end{array}$} & 1 & & \multirow{4}{*}{$\mid \begin{array}{r}9.35 \\
10.40 \\
11.40 \\
12.20 \\
13.00 \\
13.65\end{array}$} & \multirow{4}{*}{$\begin{array}{l}10,900 \\
13,100 \\
15,400 \\
17,300 \\
19,200 \\
20,700\end{array}$} & \multirow{4}{*}{$\begin{array}{r}10.33 \\
10.20 \\
10.05 \\
9.87 \\
9.72 \\
9.54\end{array}$} & \multirow{4}{*}{$\begin{array}{l}12,800 \\
12,600 \\
12,200 \\
12,000 \\
11,500 \\
11,100\end{array}$} & & & & & & \\
\hline & 1.92 & 246 & & & & & 6.15 & 4,680 & & & & \\
\hline & 2.01 & 287 & & & & & 5.97 & 4,360 & & & & \\
\hline & 2.26 & 413 & & & & & 5.77 & 4,060 & & & & \\
\hline \multirow{4}{*}{$\begin{array}{r}7 \\
8 \\
9 \\
10\end{array}$} & & & \multirow{4}{*}{$\begin{array}{r}14.10 \\
144.45 \\
14.65 \\
144.75 \\
14.65 \\
14.38 \\
\end{array}$} & \multirow{4}{*}{$\begin{array}{l}22,000 \\
22,700 \\
23,200 \\
23,700 \\
23,200 \\
22,700 \\
\end{array}$} & \multirow{4}{*}{\begin{tabular}{|l|}
9.37 \\
9.18 \\
8.98 \\
8.78 \\
8.59 \\
8.39 \\
\end{tabular}} & \multirow{4}{*}{$\begin{array}{r}10,900 \\
10,400 \\
10,000 \\
9,580 \\
9,160 \\
8,750 \\
\end{array}$} & & & & & & \\
\hline & 2.44 & 515 & & & & & 5.61 & 3,780 & & & & \\
\hline & 2. & 558 & & & & & 5.48 & 3,6 & & & 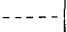 & -1 \\
\hline & 2.60 & 614 & & & & & 5.36 & 3,520 & 4.27 & 2,200 & 3.84 & 1,790 \\
\hline
\end{tabular}

\begin{tabular}{|c|c|c|c|c|c|c|c|c|c|c|c|c|}
\hline & & g. 29 & & . 30 & & g. 31 & & pt. 1 & & pt. 2 & & t. 3 \\
\hline 2 & & & 2.68 & 786 & 4.26 & 2,200 & & & & & & \\
\hline 6 & 2.28 & 521 & 3.37 & $\begin{array}{l}1,320 \\
\end{array}$ & 4.24 & 2,200 & 4.81 & 2,800 & & & & - \\
\hline 8 & & & $\begin{array}{l}3.57 \\
3\end{array}$ & 1,500 & 4.21 & 2,140 & & & & & & \\
\hline $\mathrm{N}$ & 2.25 & 504 & 3.77 & 1,690 & 4.88 & 2,920 & 4.47 & 2,420 & 3.39 & 1,360 & 2.88 & 935 \\
\hline 2 & 2.25 & 504 & 3.81 & 1,740 & 5.00 & 3,040 & & & & & & \\
\hline 6 & 2.32 & $\begin{array}{l}504 \\
545\end{array}$ & $\begin{array}{l}3.98 \\
4.07\end{array}$ & $\begin{array}{l}1,940 \\
1,990\end{array}$ & $\begin{array}{l}4.82 \\
4.87\end{array}$ & $\begin{array}{l}2,920 \\
2,860\end{array}$ & 4.09 & 2,040 & & & $\ldots$ & \\
\hline 8 & 2.37 & 576 & 4.10 & 2,040 & 4.98 & 3,040 & & & & & & \\
\hline 12 & 2.53 & 681 & 4.21 & 2,140 & 4.88 & 2,920 & 3.80 & 1,740 & 3.10 & 1,110 & 2.71 & 808 \\
\hline
\end{tabular}

\section{LITTLE RIVER NEAR WALLAND, TENN.}

LOCATION.-Lat. $35^{\circ} 45^{\prime} 48^{\prime \prime}$, long. $83^{\circ} 51^{\prime} 00^{\prime \prime}$, half a mile upstream from bridge on State Highway 73, 1 mile upstream from Ellejoy Creek, and 3 miles downstream from Walland, Blount County. Datum of gage is 877.36 feet above mean sea level, datum of 1929 , supplementary adjustment of 1936.

Drainage AREa.-192 square miles.

GAGE-HEIGHT RECORD.-Water-stage recorder graph.

DISCHARGE RECORD.-Stage-discharge relation defined by current-meter measurements up to 8,540 second-feet. Gage heights used to half-tenths between 3.3 and 5.3 feet; hundredths below and tenths above these limits.

Maxima.-1940: Discharge, 2,900 second-feet 6 a.m. Aug. 30 (gage height, 4.86 feet). 
1931-39: Discharge, 16,200 second-feet Feb. 4, 1936 (gage height, 13.18 feet), from rating curve extended above 9,000 second-feet.

REMARKs.-Flood runoff affected slightly by small dams above station.

Mean discharge, in second-feet, $1 \dot{9} 40$

\begin{tabular}{|c|c|c|c|c|c|c|c|c|c|c|c|}
\hline Day & Aug. & Sept. & Day & Aug. & Sept. & Day & Aug. & Sept. & Day & Aug. & Sept. \\
\hline 1 & 381 & 598 & 9 & 147 & 174 & 17 & 490 & 120 & 25 & 198 & 114 \\
\hline 2 & 222 & 413 & 10 & 142 & 175 & 18 & 379 & 117 & 26 & 181 & 159 \\
\hline 3 & 188 & 329 & 11 & 133 & 185 & 19 & 412 & 109 & 27 & 169 & 112 \\
\hline 4 & 172 & 280 & 12 & 141 & 156 & 20 & 359 & 109 & 28 & 159 & 125 \\
\hline 5 & 159 & 243 & 13 & 331 & 144 & 21 & 312 & 107 & 29 & 257 & 94 \\
\hline 6 & 156 & 218 & 14 & 1,000 & $\begin{array}{l}136 \\
132\end{array}$ & 22 & 278 & $\begin{array}{l}99 \\
09\end{array}$ & 30 & 1,400 & \\
\hline 8 & $\begin{array}{l}191 \\
153\end{array}$ & $\begin{array}{ll}201 \\
186\end{array}$ & $\begin{array}{l}15 \\
16\end{array}$ & $\begin{array}{r}1,560 \\
749\end{array}$ & 125 & $\begin{array}{l}23 \\
24\end{array}$ & $\begin{array}{l}243 \\
212\end{array}$ & $\begin{array}{l}99 \\
99\end{array}$ & & & \\
\hline \multicolumn{10}{|c|}{$\begin{array}{l}\text { Monthly mean discharge, in second-feet } \\
\text { Runoff }\end{array}$} & $\begin{array}{r}389 \\
2.33\end{array}$ & 175 \\
\hline
\end{tabular}

Gage height, in feet, and discharge, in second-feet, at indicated time, 1940

\begin{tabular}{|c|c|c|c|c|c|c|c|c|c|c|c|c|}
\hline \multirow{2}{*}{ Hour } & \multicolumn{2}{|c|}{ Aug. 13} & \multicolumn{2}{|c|}{ Aug. 14} & \multicolumn{2}{|c|}{ Aug. 15} & \multicolumn{2}{|c|}{ Aug. 16} & \multicolumn{2}{|c|}{ Aug. 17} & \multicolumn{2}{|c|}{ Aug. 18} \\
\hline & $\begin{array}{l}\text { Gage } \\
\text { ht. }\end{array}$ & $\begin{array}{c}\text { Dis- } \\
\text { charge }\end{array}$ & $\begin{array}{c}\text { Gage } \\
\text { ht. }\end{array}$ & $\begin{array}{c}\text { Dis- } \\
\text { charge }\end{array}$ & $\begin{array}{l}\text { Gage } \\
\text { ht. }\end{array}$ & $\begin{array}{c}\text { Dis- } \\
\text { charge }\end{array}$ & $\begin{array}{l}\text { Gage } \\
\text { ht. }\end{array}$ & $\begin{array}{c}\text { Dis- } \\
\text { charge }\end{array}$ & $\begin{array}{c}\text { Gage } \\
\text { ht. }\end{array}$ & $\begin{array}{c}\text { Dis- } \\
\text { charge }\end{array}$ & $\begin{array}{c}\text { Gage } \\
\text { ht. }\end{array}$ & $\begin{array}{c}\text { Dis- } \\
\text { charge }\end{array}$ \\
\hline \multirow{4}{*}{$\begin{array}{l}1 \\
2 \\
3 \\
4 \\
5 \\
6\end{array}$} & & & 3.02 & 968 & & & & & & & & \\
\hline & & & $\begin{array}{l}2.94 \\
2.87\end{array}$ & 841 & & & & & & & & $\cdots$ \\
\hline & & & $\frac{2}{2} .82$ & 801 & & & & & & & & - \\
\hline & 1.54 & 142 & 2.72 & 725 & $\overline{3} . \overline{9}$ & 1,920 & & & & & & \\
\hline \multirow{4}{*}{$\begin{array}{r}7 \\
8 \\
9 \\
10 \\
11 \\
\text { N }\end{array}$} & & & 2.66 & 681 & & & & & & & & \\
\hline & & & $\begin{array}{l}2.64 \\
2.64\end{array}$ & $\begin{array}{l}667 \\
667\end{array}$ & $\ldots$ & & & & & & & \\
\hline & & - & 2.77 & $\begin{array}{l}762 \\
9924\end{array}$ & $\cdots$ & . & -- & - & . & $\cdots$ & 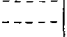 & - \\
\hline & 1.61 & 162 & 2.96 & 916 & $\overline{3} . \overline{3}$ & 1,460 & 2.74 & 740 & 2.37 & 491 & 2.16 & 381 \\
\hline \multirow{4}{*}{$\begin{array}{l}1 \\
2 \\
3 \\
4 \\
5 \\
6\end{array}$} & 1.63 & 169 & 2.92 & 882 & & & & & & & & $\ldots$ \\
\hline & \begin{tabular}{|l|l|}
$\mathbf{1 . 6 4}$ \\
1
\end{tabular} & $\begin{array}{l}172 \\
178\end{array}$ & $\begin{array}{r}2.89 \\
2.88\end{array}$ & $\begin{array}{l}857 \\
849\end{array}$ & & & & & & & & \\
\hline & 1.67 & 181 & 2.89 & 857 & $\cdots$ & & & & & & & -. \\
\hline & \begin{tabular}{|l|}
1.67 \\
1.65
\end{tabular} & $\begin{array}{l}181 \\
175\end{array}$ & $\begin{array}{l}2.90 \\
2.93\end{array}$ & $\begin{array}{l}865 \\
890\end{array}$ & 3.24 & $\mathbf{1}, 170$ & & & & & $\ldots$ & $\cdots$ \\
\hline 7 & & & 3.02 & 968 & 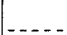 & & & & & & & 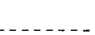 \\
\hline 8 & 3.03 & $\begin{array}{l}97 \\
\end{array}$ & \begin{tabular}{|}
3.37 \\
3.70
\end{tabular} & & & & & & & & & \\
\hline $\begin{array}{r}5 \\
10\end{array}$ & & & 3.83 & & & & & & & & & \\
\hline 11 & \begin{tabular}{|l|}
3.13 \\
3.09
\end{tabular} & $\begin{array}{l}1,070 \\
1,030\end{array}$ & $\begin{array}{r}4.05 \\
4.35\end{array}$ & 2,300 & $\mid-13.02$ & 968 & 2.51 & $577^{-}$ & $2 . \overline{2} 2$ & 410 & 2.13 & $36 \overline{6}$ \\
\hline
\end{tabular}

\begin{tabular}{|c|c|c|c|c|c|c|c|c|c|c|c|c|}
\hline & \multicolumn{2}{|c|}{ Aug. 29} & \multicolumn{2}{|c|}{ Aug. 30} & \multicolumn{2}{|c|}{ Aug. 31} & \multicolumn{2}{|c|}{ Sept. 1} & \multicolumn{2}{|c|}{ Sept. 2} & \multicolumn{2}{|c|}{ Sept. 3} \\
\hline & & & 2.62 & & 4.20 & 2,140 & & & & & & \\
\hline 2 & & & 2.73 & & 4.05 & 1,980 & & & & & & \\
\hline $\begin{array}{l}3 \\
4\end{array}$ & & & $\begin{array}{r}2.78 \\
3.08\end{array}$ & 770 & $\begin{array}{l}3.84 \\
3.68\end{array}$ & $\begin{array}{l}1,770 \\
1,20\end{array}$ & & & & & & \\
\hline 5 & & & $\begin{array}{l}4.10 \\
4.10\end{array}$ & $\begin{array}{l}1,030 \\
2,030\end{array}$ & 3.55 & $\begin{array}{l}1,460 \\
0\end{array}$ & & & & & & \\
\hline & 1.57 & 150 & & 2,900 & & 1,370 & 2.65 & 674 & & & & \\
\hline 78 & & & 4.50 & 2,480 & 3.35 & 1,270 & & & & & & \\
\hline 9 & $\ldots$ & 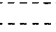 & 3.79 & 1,720 & 3.21 & 1,140 & $\ldots$ & & & & & \\
\hline 10 & & & $\begin{array}{l}3.57 \\
3.42\end{array}$ & $\begin{array}{l}1,460 \\
\end{array}$ & $\begin{array}{l}3.17 \\
3.13\end{array}$ & $\begin{array}{l}1,100 \\
1,070\end{array}$ & & & & & & \\
\hline $\mathrm{N}$ & $\overline{1} . \overline{1} \overline{1}$ & $\overline{1} \overline{6} \overline{2}$ & $\begin{array}{l}3.30 \\
3.30\end{array}$ & 1,220 & $\begin{array}{l}0.10 \\
3.10\end{array}$ & 1,040 & 2.56 & $6 \overline{11}$ & 2.23 & $41 \overline{6}$ & 2.05 & 330 \\
\hline 1 & & & 3.20 & 1,130 & 3.07 & 1,010 & & & & & & \\
\hline 3 & & 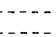 & $\begin{array}{l}3.12 \\
3.04\end{array}$ & , ${ }_{986}^{060}$ & $\begin{array}{l}3.02 \\
3.00\end{array} \mid$ & $\begin{array}{l}968 \\
950\end{array}$ & $\cdots$ & -1 & $\cdots$ & & & \\
\hline 4 & $\ldots$ & & 2.97 & 924 & 2.96 & 916 & & & & & & \\
\hline 0 & $1 . \overline{7}$ & $21 \overline{6}$ & 2.91 & 874 & 2.90 & 865 & 2.40 & $\overline{50} \overline{8}$ & & & & \\
\hline 7 & 1.87 & 253 & 2.97 & 924 & & & 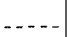 & & & & & \\
\hline 9 & & $\frac{2}{6}$ & $\begin{array}{l}2.99 \\
3.30\end{array}$ & $\begin{array}{r}942 \\
1.220\end{array}$ & $\begin{array}{l}2.85 \\
2.82\end{array}$ & 801 & & & & & & \\
\hline 10 & 2.72 & & & 2360 & 2.80 & & & & & & & \\
\hline 12 & $\left|\begin{array}{|}2.00 \\
2.62\end{array}\right|$ & $\begin{array}{l}6.4 \\
652\end{array}$ & $\begin{array}{l}4.44 \\
4.32\end{array}$ & $\begin{array}{l}2,400 \\
2,250\end{array}$ & 2.75 & 748 & $2.3 \overline{3}$ & 469 & $2.1 \overline{3}$ & $3 \overline{6} \overline{6}$ & $1 . \overline{9}$ & $299^{-}$ \\
\hline
\end{tabular}

$804331-49-28$ 
LITTLE TENNESSEE RIVER AT IOTLA, N. C.

Location.-Lat. $35^{\circ} 14^{\prime} 05^{\prime \prime}$, long. $85^{\circ} 23^{\prime} 35^{\prime \prime}$, 1,000 feet upstream from State highway bridge at Iotla, Macon County, and 1,100 feet upstream from Iotla Creek. Datum of gage is $1,958.62$ feet above mean sea level, datum of 1929, supplementary adjustment of 1936 .

DRAINAGE AREA.-323 square miles.

GAGE-HEIGHT RECORD.-Water-stage recorder graph except for period 9 p.m. Aug. 29 to 2 p.m. Aug. 31, where a graph based on floodmarks, records of Aluminum Company of America power plant $2 \frac{1}{2}$ miles upstream, and records for nearby streams was used and Sept. 6-12 for which there is no gage-height record.

DISCHARGE RECORD.-Stage-discharge relation defined by current-meter measurements up to 6,300 second-feet and extended to erest gage height on basis of computation of flood flow over the dam of the Aluminum Company of America power plant $2 \frac{1}{2}$ miles upstream. Gage heights used to half-tenths between 2.9 and 5.3 feet; hundredths below and tenths above these limits. Discharge for period of no gage-height record is based on records for station at Judson and for nearby streams.

Maxima.-1940: Discharge, 19,600 second-feet 10 a.m. Aug. 30 (gage height, 13.5 feet, from floodmarks).

1929-39: Discharge, 10,900 second-feet Sept. 30, 1936 (gage height, 8.84 feet).

The flood of October 1898 reached a stage of 13 feet (from survey by the Tennessee Valley Authority) discharge, 18,600 second-feet, from 1940 rating. REMARKs.-Flood runoff practically unaffected by artificial storage.

Mean discharge, in second-feet, 1940

\begin{tabular}{|c|c|c|c|c|c|c|c|c|c|c|c|}
\hline Day & Aug. & Sept. & Day & Aug. & Sept. & Day & Aug. & Sept. & Day & Aug. & Sept. \\
\hline $\begin{array}{l}1 \\
2 \\
3 \\
4 \\
5 \\
6 \\
7 \\
8\end{array}$ & $\begin{array}{l}274 \\
316 \\
267 \\
234 \\
246 \\
246 \\
294 \\
266\end{array}$ & $\begin{array}{r}2,010 \\
1,480 \\
1,260 \\
1,100 \\
1,020 \\
950 \\
900 \\
850\end{array}$ & \begin{tabular}{r|}
9 \\
10 \\
11 \\
12 \\
13 \\
14 \\
15 \\
16
\end{tabular} & $\begin{array}{r}270 \\
257 \\
255 \\
469 \\
4,590 \\
5,120 \\
2,000 \\
1,240\end{array}$ & $\begin{array}{l}800 \\
750 \\
700 \\
650 \\
636 \\
590 \\
576 \\
552\end{array}$ & $\begin{array}{l}17 \\
18 \\
19 \\
20 \\
21 \\
22 \\
23 \\
24\end{array}$ & $\begin{array}{l}950 \\
828 \\
762 \\
678 \\
593 \\
607 \\
546 \\
530\end{array}$ & $\begin{array}{l}530 \\
494 \\
524 \\
488 \\
476 \\
456 \\
454 \\
445\end{array}$ & $\begin{array}{l}25 \\
26 \\
27 \\
28 \\
29 \\
30 \\
31\end{array}$ & $\begin{array}{r}470 \\
463 \\
426 \\
415 \\
1,960 \\
12,300 \\
4,220\end{array}$ & $\begin{array}{l}540 \\
455 \\
409 \\
403 \\
392 \\
396\end{array}$ \\
\hline \multicolumn{10}{|c|}{$\begin{array}{l}\text { Monthly mean discharge, in second-feet } \\
\text { Runoff, in inches }\end{array}$} & $\begin{array}{l}1,358 \\
4.84\end{array}$ & $\begin{array}{r}710 \\
2.46\end{array}$ \\
\hline
\end{tabular}


TENNESSEE RIVER BASIN

Gage height, in feet, and discharge, in second-feet, at indicated time, 1940

\begin{tabular}{|c|c|c|c|c|c|c|c|c|c|c|c|c|}
\hline \multirow{2}{*}{ Hour } & \multicolumn{2}{|c|}{ Aug. 12} & \multicolumn{2}{|c|}{ Aug. 13} & \multicolumn{2}{|c|}{ Aug. 14} & \multicolumn{2}{|c|}{ Aug. 15} & \multicolumn{2}{|c|}{ Aug. 16} & \multicolumn{2}{|c|}{ Aug. 17} \\
\hline & $\begin{array}{c}\text { Gage } \\
\text { ht. }\end{array}$ & Dis- & $\begin{array}{c}\text { Gage } \\
\text { ht. }\end{array}$ & $\begin{array}{l}\text { Dis- } \\
\text { charge }\end{array}$ & $\begin{array}{c}\text { Gage } \\
\text { ht. }\end{array}$ & $\begin{array}{l}\text { Dis- } \\
\text { charge }\end{array}$ & $\begin{array}{c}\text { Gage } \\
\text { ht. }\end{array}$ & $\begin{array}{c}\text { Dis- } \\
\text { charge }\end{array}$ & $\begin{array}{c}\text { Gage } \\
\text { ht. }\end{array}$ & $\begin{array}{l}\text { Dis- } \\
\text { charge }\end{array}$ & $\begin{array}{c}\text { Gage } \\
\text { ht. }\end{array}$ & \\
\hline \multirow{4}{*}{$\begin{array}{l}1 \\
2 \\
3 \\
4 \\
5 \\
6\end{array}$} & & & \multirow{4}{*}{$\begin{array}{l}3.38 \\
3.45 \\
3.59 \\
3.86 \\
3.90 \\
4.00\end{array}$} & \multirow{4}{*}{$\begin{array}{l}1,510 \\
1,560 \\
1,710 \\
1,960 \\
2,010 \\
2,120\end{array}$} & \multirow{4}{*}{\begin{tabular}{|l|}
7.01 \\
6.95 \\
6.60 \\
6.48 \\
6.47 \\
6.45
\end{tabular}} & \multirow{4}{*}{$\begin{array}{l}6,680 \\
6,680 \\
5,960 \\
5,790 \\
5,790 \\
5,620\end{array}$} & & & & & & \\
\hline & & & & & & & 4.88 & 3,260 & 3.24 & 1,380 & 2.78 & 974 \\
\hline & & & & & & & 4.40 & 2,600 & 3.24 & 1,380 & $-\overline{2} . \overline{4} \mid$ & 942 \\
\hline & $|-\overline{1} .52|$ & 232 & & & & & 4.23 & 2,410 & 3.24 & 1,380 & $-\overline{2} . \overline{7} \mid$ & $942^{-}$ \\
\hline \multirow{4}{*}{$\begin{array}{r}7 \\
8 \\
9 \\
10 \\
11 \\
\mathrm{~N}\end{array}$} & & & \multirow{4}{*}{$\begin{array}{l}4.35 \\
4.65 \\
4.81 \\
4.85 \\
5.25 \\
5.73\end{array}$} & \multirow{4}{*}{$\begin{array}{l}2,540 \\
2,920 \\
3,120 \\
3,190 \\
3,760 \\
4,460\end{array}$} & \multirow{4}{*}{\begin{tabular}{|l|}
6.44 \\
6.43 \\
6.40 \\
6.28 \\
6.28 \\
6.27
\end{tabular}} & \multirow{4}{*}{$\begin{array}{l}5,620 \\
5,620 \\
5,620 \\
5,450 \\
5,450 \\
5,450\end{array}$} & & & & & & \\
\hline & & & & & & & 3.95 & 2,060 & 3.00 & 1,150 & 2.74 & 942 \\
\hline & & & & & & & $\overline{3.94}$ & 2,060 & 3.08 & 1,240 & 2.78 & 974 \\
\hline & $1 . \overline{8}$ & 252 & & & & & $3 . \overline{8}$ & 1,810 & $\overline{3.10}$ & $1, \overline{240}$ & 2.86 & 1,040 \\
\hline \multirow{4}{*}{$\begin{array}{l}1 \\
2 \\
3 \\
4 \\
5 \\
6\end{array}$} & & 252 & \multirow{4}{*}{$\begin{array}{l}6.03 \\
6.36 \\
6.55 \\
6.90 \\
7.09 \\
7.20\end{array}$} & \multirow{4}{*}{$\begin{array}{l}4,940 \\
5,620 \\
5,960 \\
6,500 \\
6,860 \\
7,040\end{array}$} & \multirow{4}{*}{$\begin{array}{l}6.12 \\
6.05 \\
5.90 \\
5.80 \\
5.79 \\
5.75\end{array}$} & \multirow{4}{*}{$\begin{array}{l}5,110 \\
4,940 \\
4,780 \\
4,620 \\
4,620 \\
4,620\end{array}$} & & & & & & \\
\hline & & $27 \overline{4}$ & & & & & 2.97 & 1,110 & 3.10 & 1,240 & 2.78 & 974 \\
\hline & $\begin{array}{l}1.90 \\
1.98\end{array}$ & $\begin{array}{l}392 \\
436\end{array}$ & & & & & $\overline{3} . \overline{1}$ & 2,010 & 3.09 & 1,240 & $2.6 \overline{6}$ & 882 \\
\hline & & $\begin{array}{l}447 \\
524\end{array}$ & & & & & 341 & 1.510 & 293 & 1,110 & 2.66 & 882 \\
\hline \multirow{4}{*}{$\begin{array}{r}7 \\
8 \\
9 \\
10 \\
11 \\
12 \\
\end{array}$} & 2.30 & 633 & \multirow{4}{*}{\begin{tabular}{|l|}
7.41 \\
7.47 \\
7.58 \\
7.60 \\
7.47 \\
7.23
\end{tabular}} & \multirow{4}{*}{$\begin{array}{l}7,400 \\
7,580 \\
7,770 \\
7,770 \\
7,580 \\
7,040\end{array}$} & \multirow{4}{*}{$\begin{array}{l}5.52 \\
5.51 \\
5.30 \\
5.24 \\
5.05 \\
4.99\end{array}$} & \multirow{4}{*}{$\begin{array}{l}4,140 \\
4,140 \\
3,840 \\
3,760 \\
3,470 \\
3,400\end{array}$} & & & & & & \\
\hline & & & & & & & 3.24 & 1,380 & $2 . \overline{9}$ & 1,110 & 2.66 & 882 \\
\hline & & & & & & & $\overline{3} . \overline{2}$ & 1,380 & 2.93 & 1,110 & $2 . \overline{6}$ & $9 \overline{8}$ \\
\hline & $\begin{array}{l}3.2 \\
3.2\end{array}$ & 80 & & & & & & & .93 & 10 & 2.68 & 896 \\
\hline & & & & & & & & & & & & \\
\hline
\end{tabular}

\begin{tabular}{|c|c|c|c|c|c|c|c|c|c|c|c|c|}
\hline & \multicolumn{2}{|c|}{ Aùg. 29} & \multicolumn{2}{|c|}{ Aug. 30} & \multicolumn{2}{|c|}{ Aug. 31} & \multicolumn{2}{|c|}{ Sept. 1} & \multicolumn{2}{|c|}{ Sept. 2} & \multicolumn{2}{|c|}{ Sept. 3} \\
\hline \multirow{5}{*}{$\begin{array}{l}1 \\
2 \\
3 \\
4 \\
5 \\
6\end{array}$} & 1.96 & 425 & 7.3 & 7,220 & 6.9 & 6,500 & & & & & & \\
\hline & 1.96 & 4 & 7.8 & 8,15 & 6.7 & & $4 . \overline{38}$ & 2,600 & $3.5 \overline{2}$ & 1,610 & & \\
\hline & 1.96 & 425 & 8.4 & 9,290 & 6.6 & 5 & & 0230 & 307 & 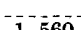 & & \\
\hline & $\begin{array}{l}1.97 \\
1.98\end{array}$ & $\begin{array}{l}430 \\
436\end{array}$ & $\begin{array}{r}9.1 \\
10.0\end{array}$ & $\begin{array}{l}10,600 \\
12,400\end{array}$ & $\begin{array}{l}6.4 \\
6.1\end{array}$ & $\begin{array}{l}5,620 \\
5,110\end{array}$ & 4.12 & 2,230 & 3.47 & 1,560 & & \\
\hline & 1.98 & 436 & 10.7 & 13,800 & $\begin{array}{l}0.1 \\
5.8\end{array}$ & 4,620 & 3.82 & 1,910 & $3 . \overline{4} 6$ & 1,560 & 3.19 & 330 \\
\hline \multirow{4}{*}{$\begin{array}{r}7 \\
8 \\
9 \\
10 \\
11 \\
\mathrm{~N}\end{array}$} & 1.97 & 430 & 11.8 & 00 & 5.5 & 4,140 & & & & & & \\
\hline & 1.97 & 430 & 2.7 & & 5.6 & & 3.82 & 1,910 & 3.24 & 1,380 & & \\
\hline & $\begin{array}{l}2.25 \\
2.54\end{array}$ & $\begin{array}{l}600 \\
798\end{array}$ & $\begin{array}{l}13.2 \\
13.5\end{array}$ & $\begin{array}{l}19,000 \\
19,600\end{array}$ & $\begin{array}{l}5.8 \\
5.8\end{array}$ & $\begin{array}{l}4,620 \\
4,620\end{array}$ & $\overline{3} . \overline{4}$ & 2,060 & $\overline{3} . \overline{24}$ & $\overline{1}, \overline{380}$ & & \\
\hline & $\begin{array}{l}3.40 \\
3.33\end{array}$ & $\begin{array}{l}1,510 \\
1,460\end{array}$ & $\begin{array}{l}13.3 \\
12.5\end{array}$ & $\begin{array}{l}19,200 \\
17,500\end{array}$ & $\begin{array}{l}5.8 \\
5.8\end{array}$ & $\begin{array}{l}4,620 \\
4,620\end{array}$ & 395 & 2,060 & 3.41 & 1,510 & 3.18 & 1,330 \\
\hline \multirow{4}{*}{$\begin{array}{l}1 \\
2 \\
3 \\
\mathbf{4} \\
5 \\
6\end{array}$} & 3.80 & 10 & 1.7 & & & & & & & & & \\
\hline & 4.20 & 350 & 11.1 & 00 & 5.3 & 3,840 & 3.80 & 1,910 & 3.41 & 1,510 & & \\
\hline & $\begin{array}{l}4.31 \\
4.50\end{array}$ & $\begin{array}{l}2,470 \\
2,730\end{array}$ & $\begin{array}{r}10.4 \\
9.9\end{array}$ & $\begin{array}{l}0 \\
00 \\
00\end{array}$ & 5.00 & 3,400 & 3.68 & 1,810 & 3.41 & 1,510 & & \\
\hline & $\begin{array}{r}4.72 \\
4.75 \\
\end{array}$ & 2,990 & 9.3 & 11,000 & 500 & 3400 & 69 & 1810 & $3 \overline{3}$ & 510 & 208 & 150 \\
\hline & & & & & & & & & & & & \\
\hline 8 & $\begin{array}{l}4.80 \\
4.89\end{array}$ & $\begin{array}{l}3,120 \\
3,260\end{array}$ & $\begin{array}{l}8.3 \\
7.9\end{array}$ & 8,340 & 4.62 & 2,860 & 3.69 & $1, \overline{8} \overline{0}$ & 3.21 & $1, \overline{3} 30$ & & \\
\hline $\begin{array}{r}9 \\
10\end{array}$ & $\begin{array}{l}5.3 \\
5.8\end{array}$ & & $\begin{array}{l}7.7 \\
7.5\end{array}$ & $\begin{array}{l}7,960 \\
7,580\end{array}$ & $-\overline{4} 38$ & 2600 & $-\overline{3} 8$ & 1.810 & 3.19 & 1,330 & & \\
\hline 11 & 6.3 & 5,450 & 7.3 & 7,220 & & & & & & & & \\
\hline 12 & 6.8 & 6,320 & 7.1 & 6,860 & 4.38 & 2,600 & 3.66 & 1,760 & 3.19 & 1,330 & 2.98 & 1,150 \\
\hline
\end{tabular}

SUPPLEM FNTAL RECORD.-Aug. 13, $9: 30$ p.m., gage height, 7.63 feet; discharge, 7,770 second-feet.

\section{LITMLE TENNESSEE RIVER AT JUDSON, N. C.}

Location.-Lat. $35^{\circ} 24^{\prime} 20^{\prime \prime}$, long. $83^{\circ} 33^{\prime} 45^{\prime \prime}$, a quarter of a mile downstream from highway bridge at railroad station at Judson, Swain County, and a quar'er of a mile upstream from Sawyer Branch. Datum of gage is 1,521.76 feet above mean sea level, datum of 1929 , supplementary adjustment of 1936 .

Drainage area.-664 square miles.

GAGE-HEIGHT RECORD.-Water-stage recorder graph.

DISCHARGE RECORD.--Stage-discharge relation defined by current-meter measurements up to 14,500 second-feet and extended logarithmically to crest gage height. Shifting-control method used Sept. 1-30, 1940. The 1902 rating at former site 


\section{FLOODS OF AUGUST 1940 IN THE SOUTHEASTERN STATES}

and datum was defined by current-meter measurements up to 22,000 secondfeet. Gage heights used to half-tenths between 18.4 and 20.7 feet; hundredths below and tenths above these limits.

Maxima.-1940: Discharge, 22,100 second-feet 3:30 p.m. Aug. 30 (gage height, 27.62 feet).

1896-1939: Discharge, 40,800 second-feet Feb. 28, 1902 (gage height, 16.19 feet, former site and datum). The available field data indicate that the 1902 maximum at present site and datum was from 3 to 5 feet higher than that of 1940 .

Surveys by the Tennessee Valley Authority show that the flood of March 1917 reached a stage of 32 feet, present site and datum, from flood profile.

REMARKs.-Flood runoff not affected by artificial storage.

Mean discharge, in second-feet, 1940

\begin{tabular}{|c|c|c|c|c|c|c|c|c|c|c|c|}
\hline Day & Aug. & Sept. & Day & Aug. & Sept. & Day & Aug. & Sept. & Day & Aug. & Sept. \\
\hline $\begin{array}{l}1 \\
2 \\
3 \\
4 \\
5 \\
6 \\
7 \\
8\end{array}$ & $\begin{array}{l}691 \\
628 \\
656 \\
596 \\
552 \\
576 \\
663 \\
628\end{array}$ & $\begin{array}{l}3,590 \\
2,590 \\
2,170 \\
1,860 \\
1,750 \\
1,640 \\
1,480 \\
1,420\end{array}$ & $\begin{array}{r}9 \\
10 \\
11 \\
12 \\
13 \\
14 \\
15 \\
16\end{array}$ & $\begin{array}{r}895 \\
628 \\
596 \\
619 \\
5,920 \\
8,540 \\
4,180 \\
2,390\end{array}$ & $\begin{array}{l}1,300 \\
1,280 \\
1,240 \\
1,120 \\
1,100 \\
1,040 \\
1,010 \\
1,000\end{array}$ & $\begin{array}{l}17 \\
18 \\
19 \\
20 \\
21 \\
22 \\
23 \\
24\end{array}$ & $\begin{array}{l}1,880 \\
1,580 \\
1,420 \\
1,300 \\
1,170 \\
1,110 \\
1,070 \\
1,050\end{array}$ & $\begin{array}{l}928 \\
902 \\
936 \\
894 \\
860 \\
836 \\
804 \\
804\end{array}$ & $\begin{array}{l}25 \\
26 \\
27 \\
28 \\
29 \\
30 \\
31\end{array}$ & $\begin{array}{r}979 \\
920 \\
860 \\
836 \\
2,160 \\
16,800 \\
7,610\end{array}$ & $\begin{array}{l}920 \\
936 \\
780 \\
750 \\
720 \\
720\end{array}$ \\
\hline \multicolumn{10}{|c|}{$\begin{array}{l}\text { Monthly mean discharge, in second-feet } \\
\text { Runoff, in inches }\end{array}$} & $\begin{array}{r}2,242 \\
3.90\end{array}$ & $\begin{array}{r}1,246 \\
2.10\end{array}$ \\
\hline
\end{tabular}


Gage height, in feet, and discharge, in second-feet, at indicated time, 1940

\begin{tabular}{|c|c|c|c|c|c|c|c|c|c|c|c|c|}
\hline \multirow{2}{*}{ Hour } & \multicolumn{2}{|c|}{ Aug. 12} & \multicolumn{2}{|c|}{ Aug. 13} & \multicolumn{2}{|c|}{ Aug. 14} & \multicolumn{2}{|c|}{ Aug. 15} & \multicolumn{2}{|c|}{ Aug. 16} & \multicolumn{2}{|c|}{ Aug. 17} \\
\hline & $\begin{array}{c}\text { Gage } \\
\text { ht. }\end{array}$ & $\begin{array}{c}\text { Dis- } \\
\text { charge }\end{array}$ & $\begin{array}{c}\text { Gage } \\
\text { ht. }\end{array}$ & $\begin{array}{c}\text { Dis- } \\
\text { charge }\end{array}$ & $\begin{array}{c}\text { Gage } \\
\text { ht. }\end{array}$ & $\begin{array}{c}\text { Dis- } \\
\text { charge }\end{array}$ & $\begin{array}{c}\text { Gage } \\
\text { ht. }\end{array}$ & $\begin{array}{c}\text { Dis- } \\
\text { charge }\end{array}$ & $\begin{array}{c}\text { Gage } \\
\text { ht. }\end{array}$ & $\begin{array}{c}\text { Dis- } \\
\text { charge }\end{array}$ & $\begin{array}{c}\text { Gage } \\
\text { ht. }\end{array}$ & $\begin{array}{c}\text { Dis- } \\
\text { charge }\end{array}$ \\
\hline $\begin{array}{l}1 \\
2\end{array}$ & $\mathbf{1 7 . 7 6}$ & 750 & $\begin{array}{l}3.38 \\
.39\end{array}$ & 0 & 23.78 & 10,800 & 21.49 & 5,820 & 19.61 & 2,720 & & \\
\hline $\begin{array}{l}3 \\
4 \\
\end{array}$ & $\overline{17} . \overline{6}$ & $65 \overline{6}^{-}$ & $\begin{array}{l}9 \\
4 \\
9\end{array}$ & 30 & 23.70 & 10,600 & 21.26 & 5,440 & 19.45 & $\overline{2}, \overline{5} 20$ & & \\
\hline $\begin{array}{l}5 \\
6\end{array}$ & $\overline{17} \overline{\overline{5}} \overline{3}$ & $590^{-}$ & $\left|\begin{array}{l}18.65 \\
19.34\end{array}\right|$ & $\begin{array}{l}1,580 \\
2,380\end{array}$ & 23.49 & 10,100 & $\overline{2} \overline{1} . \overline{0}$ & $5,080^{-}$ & $\overline{19} . \overline{4} \overline{1}$ & $2, \overline{450}$ & $\overline{19.00}$ & 1,970 \\
\hline $\begin{array}{l}7 \\
8\end{array}$ & $1 \overline{7} . \overline{4}$ & 552 & $\begin{array}{l}19.47 \\
19.54\end{array}$ & $\begin{array}{l}2,520 \\
2,650\end{array}$ & 23.15 & 9,430 & 20.97 & $4,900^{-}$ & 19.40 & 2,450 & & \\
\hline $\begin{array}{r}9 \\
10\end{array}$ & $\overline{17} . \overline{4}$ & $534^{-}$ & $\begin{array}{l}19.71 \\
20.04\end{array}$ & $\begin{array}{l}2,860 \\
3,360\end{array}$ & $2 \overline{2} . \overline{4}$ & 8,300 & 20.68 & 4,390 & 19.38 & 2,450 & & \\
\hline $\mathrm{N}$ & $1 \overline{7} . \overline{40}$ & $510^{-}$ & $\left|\begin{array}{l}20.68 \\
21.13\end{array}\right|$ & $\begin{array}{l}4,390 \\
5,080\end{array}$ & $2 \overline{2} . \overline{60}$ & 8,080 & $2 \overline{0} \overline{4}$ & 3,980 & $\overline{19} . \overline{37}$ & 2,380 & $\overline{18} \cdot \overline{8} \overline{6}$ & $1, \overline{800}$ \\
\hline $\begin{array}{l}1 \\
2\end{array}$ & $|\overline{17} . \overline{39}|$ & 504 & & & 22.53 & 7,860 & 20.28 & $3,740^{-}$ & & & & \\
\hline $\begin{array}{l}3 \\
4\end{array}$ & 17.42 & 522 & 22.84 & 0 & 22.38 & 7,640 & 20.12 & 3,440 & & & & \\
\hline $\begin{array}{l}5 \\
6\end{array}$ & $\overline{17.44}$ & 534 & 23.57 & $\begin{array}{r}9,430 \\
10,400\end{array}$ & $\overline{22.28}$ & 7,430 & 19.97 & 3,220 & 19.16 & 2,140 & 18.85 & 1,800 \\
\hline $\begin{array}{l}7 \\
8 \\
9\end{array}$ & $17 . \overline{1} 1$ & $576^{-}$ & $\begin{array}{l}23.81 \\
23.95 \\
24\end{array}$ & 11,3 & 22.09 & 7,010 & 19.83 & 3,070 & & & & \\
\hline 10 & 17.68 & 691 & 24.15 & & $2 \overline{1} . \overline{8}$ & $6,600^{-}$ & 19.52 & $2,580^{-}$ & & & & \\
\hline 11 & $\overline{18} . \overline{24}$ & 1,160 & $\left|\begin{array}{l}24.12 \\
24.01\end{array}\right|$ & 11,300 & $|\overline{2} \overline{1} . \overline{6}|$ & $6,010^{-}$ & 19.85 & $3,070^{-}$ & 19.14 & 2,140 & $\overline{18} \overline{8} \overline{8}$ & $1, \overline{750}$ \\
\hline
\end{tabular}

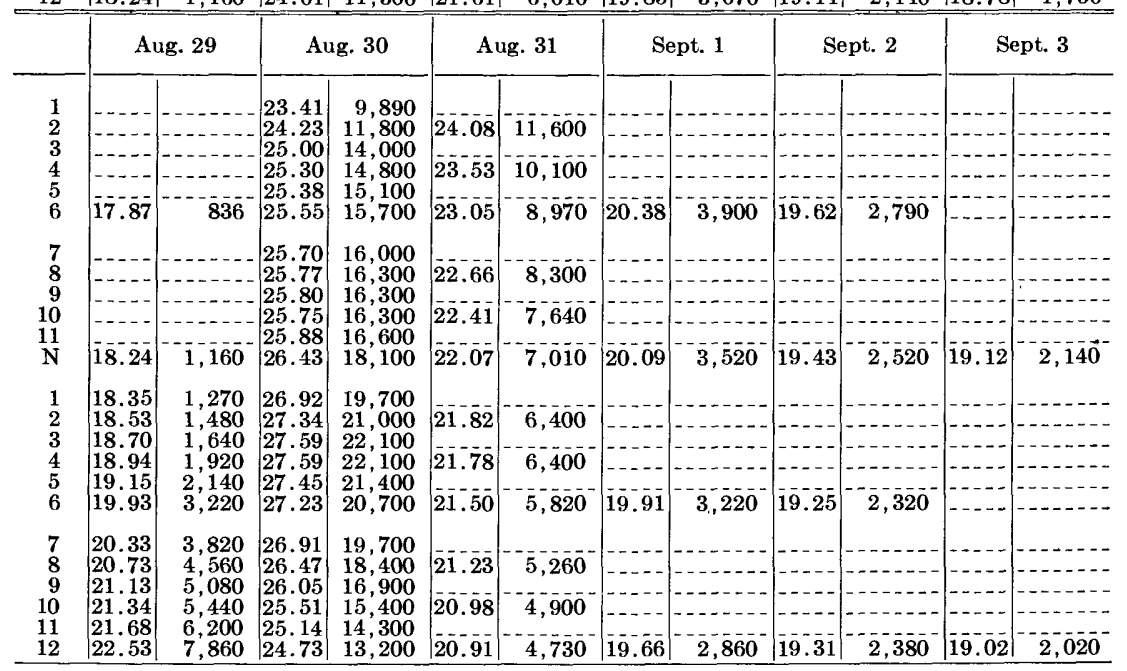

Supplemental ReCords.-Aug. 13, 10:30 p.m., gage height, 24.16 feet; discharge, 11,800 second-feet. Aug. 15, 10:15 p.m., gage height, 19.49 feet; discharge, 2,580 second-feet. Aug. 30, 3:30 p.m., gage height, 27.62 feet; discharge, 22,100 second-feet.

\section{LITTLE TENNGSSEE RIVER NEAR FONTANA, N. C.}

Location.-Lat. $35^{\circ} 26^{\prime} 50^{\prime \prime}$, long. $83^{\circ} 48^{\prime} 25^{\prime \prime}, 0.7$ mile downstream from Payne Branch and 1.1 miles southwest of Fontana, Swain County. Datum of gage is $1,275.09$ feet above mean sea level, datum of 1929, supplementary adjustment of 1936 .

Drainage AREA.-1,571 square miles (1943 revision).

GAGE-HEIGHT RECORD.-Water-stage recorder graph.

DISCHARGE RECORD.-Stage-discharge relation defined by current-meter measurements up to 21,000 second-feet and extended to erest gage height on basis of determination of flood flow at Cheoah Dam below the gage, computed by the Aluminum 


\section{FLOODS OF AUGUST 1940 IN THE SOUTHEASTERN STATES}

Company of America, and adjusted to flow at the gage on basis of the square root of the ratio of the drainage areas. Shifting-control method used Aug. 31 to Sept. 30. Gage heights used to half-tenths between 5.1 ard 8.1 feet; hundredths below and tenths above these limits.

Maxima.-1940: Discharge, 71,200 second-feet 4:15 p.m. Aug. 30 (gage height, 15.94 feet).

1938-39: Discharge, 37,000 second-feet Feb. 15, 1939 (gage height, 11.02 feet).

Surveys by the Tennessee Valley Authority show that the floods of May 1840 and March 1867 reached stages of 21 feet and 23 feet, respectively, from flood profiles, and that these floods exceeded those of March 1886 and March 1917.

REMARKs.-Flood runoff not affected by artificial storage.

Mean discharge, in second-feet, 1940

\begin{tabular}{|c|c|c|c|c|c|c|c|c|c|c|c|}
\hline Day & Aug. & Sept. & Day & Aug. & Sept. & Day & Aug. & Sept. & Day & Aug. & Sept. \\
\hline 1 & 1,820 & 9,310 & 9 & 1,800 & 3,260 & 17 & 4,730 & 2,360 & 25 & 2, & 2,080 \\
\hline 2 & 1,660 & & 10 & & & 18 & & & & & 2,2 \\
\hline 3 & 1,610 & 5,660 & 11 & 1,43 & 3,260 & 19 & 3,6 & 2,3 & 2 & 2,1 & 1,930 \\
\hline 4 & 1,4 & 4,9 & 12 & 1,4 & 2,8 & 20 & 3,2 & 2,2 & 2 & 2,0 & 1,840 \\
\hline 5 & 1,430 & 4,580 & 13 & 9,480 & 2,7 & 21 & 2,8 & 2,120 & 2 & 2,6 & 1,800 \\
\hline 6 & 1,430 & 4,110 & 14 & 23,600 & 2,650 & 22 & 2,730 & 2,040 & 30 & 40,900 & 1,760 \\
\hline 7 & 1,520 & 3,810 & 15 & 11,100 & 2,5 & 2 & 2,630 & 1,980 & 31 & 20,500 & \\
\hline 8 & 1,590 & 3,520 & 16 & 6,200 & 2,460 & 24 & 2,480 & 1,970 & & & \\
\hline \multicolumn{10}{|c|}{$\begin{array}{l}\text { Monthly mean discharge, in second-feet } \\
\text { Runoff, in inches }\end{array}$} & $\begin{array}{r}5,433 \\
3.99\end{array}$ & $\begin{array}{r}3,160 \\
2.24\end{array}$ \\
\hline
\end{tabular}


TENNESSEE RIVER BASIN

Gage height, in feet, and discharge, in second-feet, at indicated time, 1940

\begin{tabular}{|c|c|c|c|c|c|c|c|c|c|c|c|c|}
\hline \multirow{2}{*}{ Hour } & \multicolumn{2}{|c|}{ Aug. 13} & \multicolumn{2}{|c|}{ Aug. 14} & \multicolumn{2}{|c|}{ Aug. 15} & \multicolumn{2}{|c|}{ Aug. 16} & \multicolumn{2}{|c|}{ Aug. 17} & \multicolumn{2}{|c|}{ Aug. 18} \\
\hline & $\begin{array}{c}\text { Gage } \\
\text { ht. }\end{array}$ & $\begin{array}{c}\text { Dis- } \\
\text { charge }\end{array}$ & $\begin{array}{c}\text { Gage } \\
\text { ht. }\end{array}$ & $\begin{array}{c}\text { Dis- } \\
\text { charge }\end{array}$ & $\begin{array}{c}\text { Gage } \\
\text { ht. }\end{array}$ & $\begin{array}{c}\text { Dis- } \\
\text { charge }\end{array}$ & $\begin{array}{c}\text { Gage } \\
\text { ht. }\end{array}$ & $\begin{array}{c}\text { Dis- } \\
\text { charge }\end{array}$ & $\begin{array}{c}\text { Gage } \\
\text { ht. }\end{array}$ & $\begin{array}{c}\mathrm{D} \\
\text { cha }\end{array}$ & $\begin{array}{c}\text { Gage } \\
\text { ht. }\end{array}$ & $\begin{array}{c}\text { Dis- } \\
\text { charge }\end{array}$ \\
\hline \multirow{4}{*}{$\begin{array}{l}1 \\
2 \\
3 \\
4 \\
5 \\
6\end{array}$} & 4.36 & 1,480 & \multirow{4}{*}{$\begin{array}{l}10.98 \\
11.09 \\
11.04 \\
10.89 \\
10.67 \\
10.39\end{array}$} & \multirow{4}{*}{$\begin{array}{l}35,200 \\
35,900 \\
35,200 \\
34,500 \\
33,100 \\
31,000\end{array}$} & & & & & & & & \\
\hline & 4,39 & & & & 7.60 & & & & & & & \\
\hline & & & & & 7.69 & & & & & & & \\
\hline & 4.45 & 1,620 & & & - & - & 6.34 & 6,900 & $\ldots$ & & & \\
\hline \multirow{4}{*}{$\begin{array}{r}7 \\
8 \\
9 \\
10 \\
11 \\
\mathrm{~N}\end{array}$} & & & \multirow{4}{*}{$\mid \begin{array}{r}10.20 \\
10.00 \\
9.80 \\
9.58 \\
9.33 \\
9.08\end{array}$} & \multirow{4}{*}{$\begin{array}{l}29,600 \\
28,200 \\
26,800 \\
25,400 \\
23,300 \\
21,900\end{array}$} & & & & & & & & \\
\hline & 4.68 & 2,040 & & & 7.76 & 13,300 & & & & & & \\
\hline & $\overline{5} . \overline{58}$ & 4,260 & & & & & & & & & & \\
\hline & 6.30 & 6,700 & & & $7.3 \overline{7}$ & 11,200 & 6.13 & 6,120 & $5.7 \overline{4}$ & 4,740 & 5.47 & 3,810 \\
\hline \multirow{4}{*}{$\begin{array}{l}1 \\
2 \\
3 \\
4 \\
5 \\
6\end{array}$} & & & \multirow{4}{*}{\begin{tabular}{|l|}
8.89 \\
8.69 \\
8.55 \\
8.46 \\
8.36 \\
8.28
\end{tabular}} & \multirow{4}{*}{$\begin{array}{l}20,500 \\
19,100 \\
18,400 \\
17,800 \\
17,200 \\
16,500\end{array}$} & & & & & & & & \\
\hline & 6.58 & 7,900 & & & & & & & & & & \\
\hline & 6.88 & 9,150 & & & $\cdots$ & & & & & & & \\
\hline & 7.63 & 12,800 & & & 6.83 & 8,920 & 6.05 & 5,780 & & & & \\
\hline \multirow{5}{*}{$\begin{array}{r}7 \\
8 \\
9 \\
10 \\
11 \\
12 \\
\end{array}$} & 8.90 & 20,500 & \multirow{4}{*}{$\begin{array}{l}8.21 \\
8.12 \\
8.04 \\
7.88 \\
7.86 \\
7.90 \\
\end{array}$} & \multirow{4}{*}{$\begin{array}{l}15,900 \\
15,300 \\
14,700 \\
14,200 \\
13,900 \\
14,200 \\
\end{array}$} & & & & & & & & \\
\hline & & 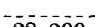 & & & & & & & & & & \\
\hline & 10.02 & & & & & & & & & & & \\
\hline & $10 . \overline{7}$ & 33,800 & & & 6.48 & 7,500 & 5.91 & 5,250 & 5.60 & 4,260 & 5.40 & 3,660 \\
\hline & \multicolumn{2}{|c|}{ Aug. 29} & \multicolumn{2}{|c|}{ Aug. 30} & \multicolumn{2}{|c|}{ Aug. 31} & \multicolumn{2}{|c|}{ Sept. 1} & \multicolumn{2}{|c|}{ Sept. 2} & \multicolumn{2}{|c|}{ Sept. 3} \\
\hline \multirow{4}{*}{$\begin{array}{r}2 \\
4 \\
6 \\
8 \\
10 \\
\mathrm{~N}\end{array}$} & $\ldots$ & $\ldots \ldots$ & \multirow{4}{*}{$\begin{array}{r}6.81 \\
7.47 \\
9.50 \\
11.13 \\
11.98 \\
12.65\end{array}$} & \multirow{4}{*}{$\begin{array}{r}8,700 \\
11,800 \\
24,700 \\
35,900 \\
42,200 \\
46,400\end{array}$} & \multirow{4}{*}{$\begin{array}{r}10.66 \\
10.02 \\
9.52 \\
9.12 \\
8.77 \\
8.50\end{array}$} & & - & & & & & \\
\hline & 4.66 & 2,000 & & & & 25 & 7.10 & 10,300 & & & & \\
\hline & & & & & & & & 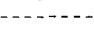 & & $\cdots$ & $\cdots$ & \\
\hline & $\mathbf{4} .7 \overrightarrow{4}$ & 2,160 & & & & 18,400 & 6.82 & 9,150 & 6.26 & 6,900 & $5 . \overline{9}$ & 5,600 \\
\hline 2 & 4.81 & 2,300 & 13.75 & 55 & 8.26 & & & & & & & \\
\hline $\begin{array}{l}4 \\
6\end{array}$ & $\begin{array}{l}4.90 \\
5.02\end{array}$ & $\begin{array}{l}2,480 \\
2,730\end{array}$ & $\begin{array}{l}15.87 \\
15.25\end{array}$ & & $\begin{array}{l}8.07 \\
7.78\end{array}$ & & 6.60 & 8,100 & & & & \\
\hline 8 & 5.23 & & 14.12 & & 7.74 & & & & & & & \\
\hline 10 & 5.74 & 4,740 & 12.80 & 47 & 7.60 & & & & & & & \\
\hline 12 & 605 & 30 & $|11.62|$ & 39,400 & 7.40 & 11,800 & 6.49 & 7,700 & 6.06 & 6,120 & 5.84 & 5,250 \\
\hline
\end{tabular}

SUPPLEMENTAL RECORDs.-Aug. 15, 6:30 a.m., gage height, 7.87 feet discharge, 13,900 second-feet. Aug. 30, 3:30 p.m., gage height, 15.70 feet, discharge, 69,600 second-feet; 4:15 p.m., gage height, 15.94 feet, discharge, 71,200 second-feet.

\section{LITTLE TENNESSEE RIVER AT CALDERWOOD, TENN.}

Location.-Lat. $35^{\circ} 30^{\prime} 24^{\prime \prime}$, long. $84^{\circ} 00^{\prime} 14^{\prime \prime}$, at Scona Lodge Ferry, two-thirds of a mile west of Calderwood, Blount County, and $2 \frac{1}{2}$ miles downstream from Calderwood Dam. Datum of gage is 861.41 feet above mean sea level, datum of 1929, supplementary adjustment of 1936 .

Drainage AREA.- $-1,862$ square miles.

GAGE-HEIGHT RECORD.-Water-stage recorder graph.

DISCHARGE RECORD.-Stage-discharge relation defined by current-meter measurements up to 60,300 second-feet. Gage heights used to half-tenths between 2.0 and 4.2 feet; hundredths below and tenths above these limits.

MAXIMA.-1940: Discharge, 63,900 second-feet 3:30 p.m. Aug. 30 (gage height, 9.70 feet).

1912-18, 1921-39: Discharge 82,000 second-feet Mar. 4, 1917 (gage height, 10.97 feet), from rating curve extended above 40,000 second-feet.

Gage height observed, 11.75 feet Mar. 4, 1917, before breaking of levee near gage.

REMARKS.-Flood runoff affected by power plants upstream. 
Mean discharge, in second-feet, 1940

\begin{tabular}{|c|c|c|c|c|c|c|c|c|c|c|c|}
\hline Day & Aug. & Sept. & Day & Aug. & Sept. & Day & Aug. & Sept. & Day & Aug. & Sept: \\
\hline 1 & 1,900 & 9,590 & 9 & 2,770 & 3,920 & 17 & 6,510 & 3,980 & 25 & 2,210 & 2,610 \\
\hline 2 & 2,190 & 7,0 & 10 & 1,910 & 4 & 18 & & & 26 & & 2,470 \\
\hline 3 & 1,620 & 6,760 & 11 & 1,760 & 4,360 & 19 & 4,560 & 3,410 & 27 & 2,860 & 2,500 \\
\hline 4 & 1,400 & 5,290 & 12 & 2,860 & 4,360 & 20 & 4,030 & 3,380 & 28 & 2,780 & 1,520 \\
\hline 5 & 1,760 & 4,880 & 13 & $\begin{array}{l}10,600 \\
10\end{array}$ & $\begin{array}{l}4,290 \\
,\end{array}$ & 21 & 3,300 & 3,930 & 29 & $\begin{array}{r}4,620 \\
27\end{array}$ & 1,070 \\
\hline$\frac{6}{7}$ & 2,010 & $\begin{array}{r}5,090 \\
4,080\end{array}$ & 14 & 19,300 & 3,890 & 22 & $\begin{array}{l}3,600 \\
3,770\end{array}$ & $\begin{array}{l}1,610 \\
, 040\end{array}$ & 30 & 37,700 & 2,310 \\
\hline 8 & $\begin{array}{l}2,300 \\
2,370\end{array}$ & 3,330 & $\begin{array}{l}10 \\
16\end{array}$ & $\begin{array}{r}10,820 \\
\end{array}$ & $\begin{array}{l}3,430 \\
4,030\end{array}$ & 24 & $\begin{array}{l}3,120 \\
3,120\end{array}$ & 2,780 & & & \\
\hline \multicolumn{10}{|c|}{$\begin{array}{l}\text { Monthly mean discharge, in second-feet } \\
\text { Runoff, in inches }\end{array}$} & $\begin{array}{r}5,622 \\
3.48\end{array}$ & $\begin{array}{r}3,900 \\
2.34\end{array}$ \\
\hline
\end{tabular}

Gage height, in feet, and discharge, in second-feet, at indicated time, 1940

\begin{tabular}{|c|c|c|c|c|c|c|c|c|}
\hline \multirow{2}{*}{ Hour } & \multicolumn{2}{|c|}{ Aug. 13} & \multicolumn{2}{|c|}{ Aug. 14} & \multicolumn{2}{|c|}{ Aug. 30} & \multicolumn{2}{|c|}{ Aug. 31} \\
\hline & $\begin{array}{l}\text { Gage } \\
\text { height }\end{array}$ & Discharge & $\begin{array}{l}\text { Gage } \\
\text { height }\end{array}$ & Discharge & $\begin{array}{c}\text { Gage } \\
\text { height }\end{array}$ & Discharge & $\begin{array}{c}\text { Gage } \\
\text { height }\end{array}$ & Discharge \\
\hline $\begin{array}{l}1 \\
2 \\
3 \\
4 \\
5 \\
6\end{array}$ & $\begin{array}{c}-1 . \overline{12} \\
-1.21\end{array}$ & $\begin{array}{r}1,850 \\
-2,060\end{array}$ & $\begin{array}{l}6.56 \\
6.57 \\
6.20 \\
5.82 \\
5.51 \\
5.46\end{array}$ & $\begin{array}{l}32,200 \\
32,200 \\
28,900 \\
25,700 \\
23,300 \\
23,300\end{array}$ & $\begin{array}{l}3.85 \\
3.55 \\
4.00 \\
5.10 \\
6.15 \\
6.57\end{array}$ & $\begin{array}{l}12,500 \\
10,900 \\
13,300 \\
20,300 \\
28,900 \\
32,200\end{array}$ & $\begin{array}{l}6.15 \\
5.60 \\
5.57 \\
5.42 \\
5.32 \\
5.19\end{array}$ & $\begin{array}{l}28,900 \\
24,100 \\
24,100 \\
22,500 \\
21,800 \\
21,000\end{array}$ \\
\hline $\begin{array}{r}7 \\
8 \\
9 \\
10 \\
11 \\
\mathrm{~N}\end{array}$ & \begin{tabular}{l}
1.66 \\
\hdashline 1.95
\end{tabular} & ${ }^{3,320}$ & $\begin{array}{l}5.56 \\
5.23 \\
5.06 \\
4.81 \\
4.77 \\
4.53\end{array}$ & $\begin{array}{l}24,100 \\
21,000 \\
20,300 \\
18,200 \\
18,200 \\
16,200\end{array}$ & $\begin{array}{l}6.75 \\
7.00 \\
7.30 \\
7.60 \\
7.62 \\
7.76\end{array}$ & $\begin{array}{l}34,000 \\
35,700 \\
38,400 \\
41,200 \\
41,200 \\
43,200\end{array}$ & $\begin{array}{l}4.95 \\
4.67 \\
4.67 \\
4.53 \\
4.69 \\
4.50\end{array}$ & $\begin{array}{l}19,500 \\
17,500 \\
17,500 \\
16,200 \\
17,500 \\
16,200\end{array}$ \\
\hline $\begin{array}{l}1 \\
2 \\
3 \\
4 \\
5 \\
6\end{array}$ & $\begin{array}{l}2.03 \\
2.81 \\
2.85 \\
2.85 \\
4.32 \\
4.80\end{array}$ & $\begin{array}{r}4,600 \\
7,440 \\
7,660 \\
7,660 \\
15,000 \\
18,200\end{array}$ & $\begin{array}{l}4.53 \\
4.53 \\
4.37 \\
4.35 \\
4.24 \\
4.10\end{array}$ & $\begin{array}{l}16,200 \\
16,200 \\
15,600 \\
15,600 \\
14,500 \\
13,900\end{array}$ & $\begin{array}{l}8.50 \\
9.15 \\
9.62 \\
9.55 \\
9.16 \\
8.30\end{array}$ & $\begin{array}{l}50,400 \\
58,100 \\
62,700 \\
62,700 \\
58,100 \\
48,400\end{array}$ & $\begin{array}{l}4.23 \\
4.23 \\
4.23 \\
4.10 \\
3.73 \\
3.78\end{array}$ & $\begin{array}{l}14,500 \\
14,500 \\
14,500 \\
13,900 \\
12,000 \\
12,200\end{array}$ \\
\hline $\begin{array}{r}7 \\
8 \\
9 \\
10 \\
11 \\
12\end{array}$ & $\begin{array}{l}5.69 \\
6.00 \\
6.36 \\
6.60 \\
6.62 \\
6.62\end{array}$ & $\begin{array}{l}24,900 \\
27,300 \\
30,600 \\
32,200 \\
32,200 \\
32,200\end{array}$ & $\begin{array}{l}4.10 \\
4.10 \\
3.94 \\
3.85 \\
3.67 \\
3.75\end{array}$ & $\begin{array}{l}13,900 \\
13,900 \\
13,100 \\
12,500 \\
11,500 \\
12,000\end{array}$ & $\begin{array}{l}8.20 \\
7.80 \\
7.15 \\
7.06 \\
6.45 \\
6.34\end{array}$ & $\begin{array}{l}47,300 \\
43,200 \\
37,500 \\
36,600 \\
30,600 \\
29,700\end{array}$ & $\begin{array}{l}3.82 \\
3.89 \\
3.89 \\
3.80 \\
3.79 \\
3.71\end{array}$ & $\begin{array}{l}12,200 \\
12,800 \\
12,800 \\
12,200 \\
12,200 \\
11,700\end{array}$ \\
\hline
\end{tabular}

Supplemental REcord.-Aug. 30, 3:30 p.m., gage height, 9.70 feet; discharge, 63,900 second-feet.

\section{LITTLE TENNESSEE RIVER AT MeGHEE, TENN.}

Location.-Lat. $35^{\circ} 36^{\prime} 16^{\prime \prime}$, long. $84^{\circ} 12^{\prime} 43^{\prime \prime}$, at mouth of Tellico River, 100 feet upstream from bridge on State Highways 33 and $72,0.3$ mile upstream from Louisville \& Nashville Railroad bridge, and 0.5 mile south of MeGhee, Monroe County. Datum of gage is 760.18 feet above mean sea level, datum of 1929 , supplementary adjustment of 1936 .

Drainage ARea.--2,443 square miles, including that of Tellico River.

GAGE-HEIGHT RECORD.-Water-stage recorder graph, except for period 1 a.m. Sept. 24 to 3 p.m. Sept. 25, record for which was based on range in stage and a study of normal regulation at this station.

DISCHARGE RECORD.-Stage-discharge relation defined by eurrent-meter measurements up to 65,900 second-feet. Gage heights used to half-tenths between 4.1 and 5.5 feet; hundredths below and tenths above these limits.

Maxima.-1940: Discharge, 52,100 second-feet 11 p.m. Aug. 30 (gage height, 21.56 feet).

1904-39: Discharge observed, 92,000 second-feet Apr. 2, 1920 (gage height, 30.5 feet, at site and datum then in use).

Stage known, 39.0 feet (original site and datum) March 1867 (discharge not determined). 
REMARKs.-Flood runoff subject to some regulation from power developments upstream.

Mean discharge, in second-feet, 1940

\begin{tabular}{|c|c|c|c|c|c|c|c|c|c|c|c|}
\hline Day & Aug. & Sept. & Day & Aug. & Sept. & Day & Aug. & Sept. & Day & Aug. & Sept. \\
\hline $\begin{array}{l}1 \\
2 \\
3 \\
4 \\
5 \\
6 \\
7 \\
8\end{array}$ & $\begin{array}{l}2,010 \\
2,460 \\
2,100 \\
1,690 \\
1,770 \\
2,210 \\
1,940 \\
2,210\end{array}$ & $\begin{array}{r}11,900 \\
7,240 \\
6,670 \\
6,130 \\
4,550 \\
5,470 \\
4,670 \\
3,600\end{array}$ & $\begin{array}{l}9 \\
10 \\
11 \\
12 \\
13 \\
14 \\
15 \\
16\end{array}$ & $\begin{array}{r}2,980 \\
2,480 \\
2,100 \\
2,580 \\
4,540 \\
22,800 \\
12,600 \\
7,540\end{array}$ & $\begin{array}{l}3,890 \\
4,480 \\
4,480 \\
4,590 \\
4,590 \\
4,150 \\
3,710 \\
4,040\end{array}$ & $\begin{array}{l}17 \\
18 \\
19 \\
20 \\
21 \\
22 \\
23 \\
24\end{array}$ & $\begin{array}{l}6,820 \\
4,330 \\
4,130 \\
4,820 \\
3,630 \\
3,590 \\
3,940 \\
3,500\end{array}$ & $\begin{array}{l}4,040 \\
3,820 \\
3,600 \\
3,400 \\
4,370 \\
1,940 \\
2,780 \\
2,680\end{array}$ & $\begin{array}{l}25 \\
26 \\
27 \\
28 \\
29 \\
30 \\
31\end{array}$ & $\begin{array}{r}2,780 \\
2,980 \\
3,180 \\
2,880 \\
4,010 \\
27,600 \\
27,400\end{array}$ & $\begin{array}{r}2,780 \\
2,780 \\
2,640 \\
1,960 \\
1,410 \\
1,750 \\
\end{array}$ \\
\hline \multicolumn{10}{|c|}{$\begin{array}{l}\text { Monthly mean discharge, in second-feet } \\
\text { Runoff, in inches }\end{array}$} & $\begin{array}{r}5,794 \\
2.73\end{array}$ & $\begin{array}{r}4,137 \\
1.89\end{array}$ \\
\hline
\end{tabular}

Gage height, in feet, and discharge, in second-feet, at indicated time, 1940

\begin{tabular}{|c|c|c|c|c|c|c|c|c|}
\hline \multirow{2}{*}{ Hour } & \multicolumn{2}{|c|}{ Aug. 13} & \multicolumn{2}{|c|}{ Aug. 14} & \multicolumn{2}{|c|}{ Aug. 15} & \multicolumn{2}{|c|}{ Aug. 16} \\
\hline & $\begin{array}{c}\text { Gage } \\
\text { height }\end{array}$ & Discharge & $\begin{array}{c}\text { Gage } \\
\text { height }\end{array}$ & Discharge & $\begin{array}{c}\text { Gage } \\
\text { height }\end{array}$ & Discharge & $\begin{array}{c}\text { Gage } \\
\text { height }\end{array}$ & Discharge \\
\hline $\begin{array}{l}1 \\
2 \\
3 \\
4 \\
5 \\
6\end{array}$ & 4.59 & ${ }^{\mathbf{3}, 710}$ & $\begin{array}{l}12.40 \\
13.50 \\
14.10 \\
14.59 \\
14.90 \\
15.07\end{array}$ & $\begin{array}{l}22,700 \\
25,600 \\
27,200 \\
28,500 \\
29,200 \\
29,800\end{array}$ & $\begin{array}{l}9.25 \\
9.10 \\
8.91 \\
8.66 \\
8.53 \\
8.52\end{array}$ & $\begin{array}{l}14,500 \\
14,300 \\
13,800 \\
13,300 \\
12,800 \\
12,800\end{array}$ & $6 . \overline{38}$ & ${ }^{7}, \mathbf{7 3 0} 0^{-1}$ \\
\hline $\begin{array}{r}7 \\
8 \\
9 \\
10 \\
11 \\
\text { N }\end{array}$ & 3.90 & 2,290 & $\begin{array}{l}14.99 \\
14.67 \\
14.22 \\
13.78 \\
13.37 \\
12.98\end{array}$ & $\begin{array}{l}29,500 \\
28,700 \\
27,400 \\
26,400 \\
25,300 \\
24,300\end{array}$ & $\begin{array}{l}8.63 \\
8.78 \\
8.88 \\
8.90 \\
8.89 \\
\mathbf{8 . 8 9}\end{array}$ & $\begin{array}{l}13,000 \\
13,500 \\
13,800 \\
13,800 \\
13,800 \\
13,800\end{array}$ & 6.18 & 7,040 \\
\hline $\begin{array}{l}1 \\
2 \\
3 \\
4 \\
5 \\
6\end{array}$ & $\begin{array}{l}3.87 \\
3.92 \\
4.02 \\
4.21 \\
4.36 \\
4.51\end{array}$ & $\begin{array}{l}2,230 \\
2,330 \\
2,520 \\
2,880 \\
3,180 \\
3,500\end{array}$ & $\begin{array}{l}12.59 \\
12.13 \\
11.70 \\
11.25 \\
10.90 \\
10.62\end{array}$ & $\begin{array}{l}23,300 \\
22,000 \\
20,900 \\
19,600 \\
18,800 \\
18,100\end{array}$ & $\begin{array}{l}8.87 \\
8.78 \\
8.64 \\
8.33 \\
8.03 \\
7.78\end{array}$ & $\begin{array}{l}13,800 \\
13,500 \\
13,000 \\
12,300 \\
11,500 \\
11,100\end{array}$ & 6.44 & $7,7 \mathbf{3 0}$ \\
\hline $\begin{array}{r}7 \\
8 \\
9 \\
10 \\
11 \\
12 \\
\end{array}$ & $\begin{array}{r}4.88 \\
5.62 \\
6.35 \\
7.95 \\
9.65 \\
11.25 \\
\end{array}$ & $\begin{array}{r}4,370 \\
5,910 \\
7,730 \\
11,500 \\
15,500 \\
19,600 \\
\end{array}$ & $\begin{array}{r}10.42 \\
10.20 \\
9.92 \\
9.73 \\
9.51 \\
9.38 \\
\end{array}$ & $\begin{array}{l}17,500 \\
17,000 \\
16,300 \\
15,800 \\
15,300 \\
15,000 \\
\end{array}$ & $\begin{array}{l}7.69 \\
7.58 \\
7.42 \\
7.31 \\
7.21 \\
7.05 \\
\end{array}$ & $\begin{array}{r}10,800 \\
10,600 \\
10,100 \\
9,860 \\
9,620 \\
9,140 \\
\end{array}$ & 6.03 & $6,810^{-1}$ \\
\hline & \multicolumn{2}{|c|}{ Aug. 29} & \multicolumn{2}{|c|}{ Aug. 30} & \multicolumn{2}{|c|}{ Aug. 31} & \multicolumn{2}{|c|}{ Sept. 1} \\
\hline $\begin{array}{l}1 \\
2 \\
3 \\
4 \\
5 \\
5 \\
6\end{array}$ & 4.45 & 3,400 & $\begin{array}{l}5.80 \\
6.07 \\
6.30 \\
6.41 \\
6.68 \\
7.22\end{array}$ & $\begin{array}{l}6,350 \\
7,040 \\
7,500 \\
7,730 \\
8,420 \\
9,620\end{array}$ & $\begin{array}{l}21.13 \\
20.62 \\
19.96 \\
19.17 \\
18.26 \\
17.39\end{array}$ & $\begin{array}{l}50,100 \\
48,100 \\
45,800 \\
42,800 \\
39,500 \\
36,500\end{array}$ & $8 . \overline{3}$ & 12,500 \\
\hline $\begin{array}{r}7 \\
8 \\
9 \\
10 \\
11 \\
\mathrm{~N}\end{array}$ & 3.91 & 2,310 & $\begin{array}{r}7.82 \\
9.18 \\
11.12 \\
12.64 \\
13.88 \\
14.75\end{array}$ & $\begin{array}{l}11,100 \\
14,500 \\
19,400 \\
23,300 \\
26,600 \\
29,000\end{array}$ & $\begin{array}{l}16.47 \\
15.58 \\
14.77 \\
14.04 \\
13.26 \\
12.62\end{array}$ & $\begin{array}{l}33,700 \\
31,100 \\
29,000 \\
26,900 \\
25,100 \\
23,300\end{array}$ & 7.56 & 10,600 \\
\hline $\begin{array}{l}1 \\
2 \\
3 \\
4 \\
5 \\
6\end{array}$ & 5.60 & 5,910 & $\begin{array}{l}15.56 \\
16.20 \\
16.82 \\
17.45 \\
18.12 \\
18.90\end{array}$ & $\begin{array}{l}31,100 \\
32,800 \\
34,600 \\
36,500 \\
38,800 \\
41,700\end{array}$ & $\begin{array}{l}12.02 \\
11.58 \\
11.28 \\
10.97 \\
10.60 \\
10.26\end{array}$ & $\begin{array}{l}21,700 \\
20,700 \\
19,900 \\
19,100 \\
18,100 \\
17,300\end{array}$ & 8.78 & 13,500 \\
\hline $\begin{array}{r}7 \\
8 \\
9 \\
10 \\
11 \\
12\end{array}$ & 5.72 & 6,130 & $\begin{array}{l}19.82 \\
20.52 \\
21.12 \\
21.47 \\
21.56 \\
21.46\end{array}$ & $\begin{array}{l}45,000 \\
47,700 \\
50,100 \\
51,700 \\
52,100 \\
51,700\end{array}$ & $\begin{array}{l}9.98 \\
9.74 \\
9.43 \\
9.10 \\
8.95 \\
8.93\end{array}$ & $\begin{array}{l}16,500 \\
15,800 \\
15,000 \\
14,300 \\
14,000 \\
13,800\end{array}$ & $\begin{array}{l}0 . \\
6.39\end{array}$ & $7, \overline{730}$ \\
\hline
\end{tabular}


CULLASA.JA CREEK AT HIGHLANDS, N. C.

Location.-Lat. $35^{\circ} 03^{\prime} 55^{\prime \prime}$, long. $83^{\circ} 13^{\prime} 30^{\prime \prime}$, a quarter of a mile downstream from Highlands municipal dam, half a mile downstream from Big Creek, and 2 miles northwest of Highlands, Macon County. Datum of gage is $3,373.63$ feet above mean sea level.

DRAINAGE AREA.-14.9 square miles.

GAGE-HEIGHT RECORD.-Water-stage recorder graph.

DISCHARGE RECORD.-Stage-discharge relation defined by current-meter measurements up to 700 second-feet and extended to crest gage height on basis of computation of flood flow over municipal dam. This rating verifies that used in 1928. Shifting-control method used Aug. 16 to 11 a.m. Aug. 29, 1940. Gage heights used to half-tenths between 3.0 and 4.6 feet; hundredths below and tenths above these limits.

Maxima.-1940: Discharge, 5,100 second-feet 3 a.m. Aug. 30 (gage height, 9.35 feet).

1927-39: Discharge, 2,420 second-feet Aug. 15, 1928 (gage height, 5.13 feet, former site and datum) from rating curve extended logarithmically above 170 second-feet.

The flood of July 1916 reached a stage of 7 feet, present site and datum (from survey by the Tennessee Valley Authority); discharge, 3,200 second-feet, from 1940 rating.

REMARKS.-Flood runoff affected only slightly by storage in Sequoyah Lake created by Highlands municipal dam.

Mean discharge, in second-feet, 1940

\begin{tabular}{r|r|r||r|r|r||r|r|r|r|r|r}
\hline Day & Aug. & Sept. & Day & Aug. & Sept. & Day & Aug. & Sept. & Day & Aug. & Sept. \\
\hline 1 & 17 & 231 & 9 & 33 & 84 & 17 & 121 & 46 & 25 & 54 & 54 \\
2 & 24 & 172 & 10 & 22 & 76 & 18 & 101 & 46 & 26 & 50 & 36 \\
3 & 20 & 143 & 11 & 21 & 70 & 19 & 88 & 47 & 27 & 46 & 32 \\
4 & 20 & 124 & 12 & 253 & 64 & 20 & 79 & 42 & 28 & 44 & 31 \\
5 & 19 & 120 & 13 & 1,460 & 60 & 21 & 72 & 39 & 29 & 428 & 28 \\
6 & 15 & 105 & 14 & 433 & 56 & 22 & 71 & 38 & 30 & 1,560 & 30 \\
7 & 19 & 95 & 15 & 233 & 53 & 23 & 61 & 35 & 31 & 354 & $-\ldots$ \\
8 & 20 & 88 & 16 & 155 & 51 & 24 & 58 & 38 & & \\
\hline
\end{tabular}


TENNESSEE RIVER BASIN

Gage height, in feet, and discharge, in second-feet, at indicated time, 1940

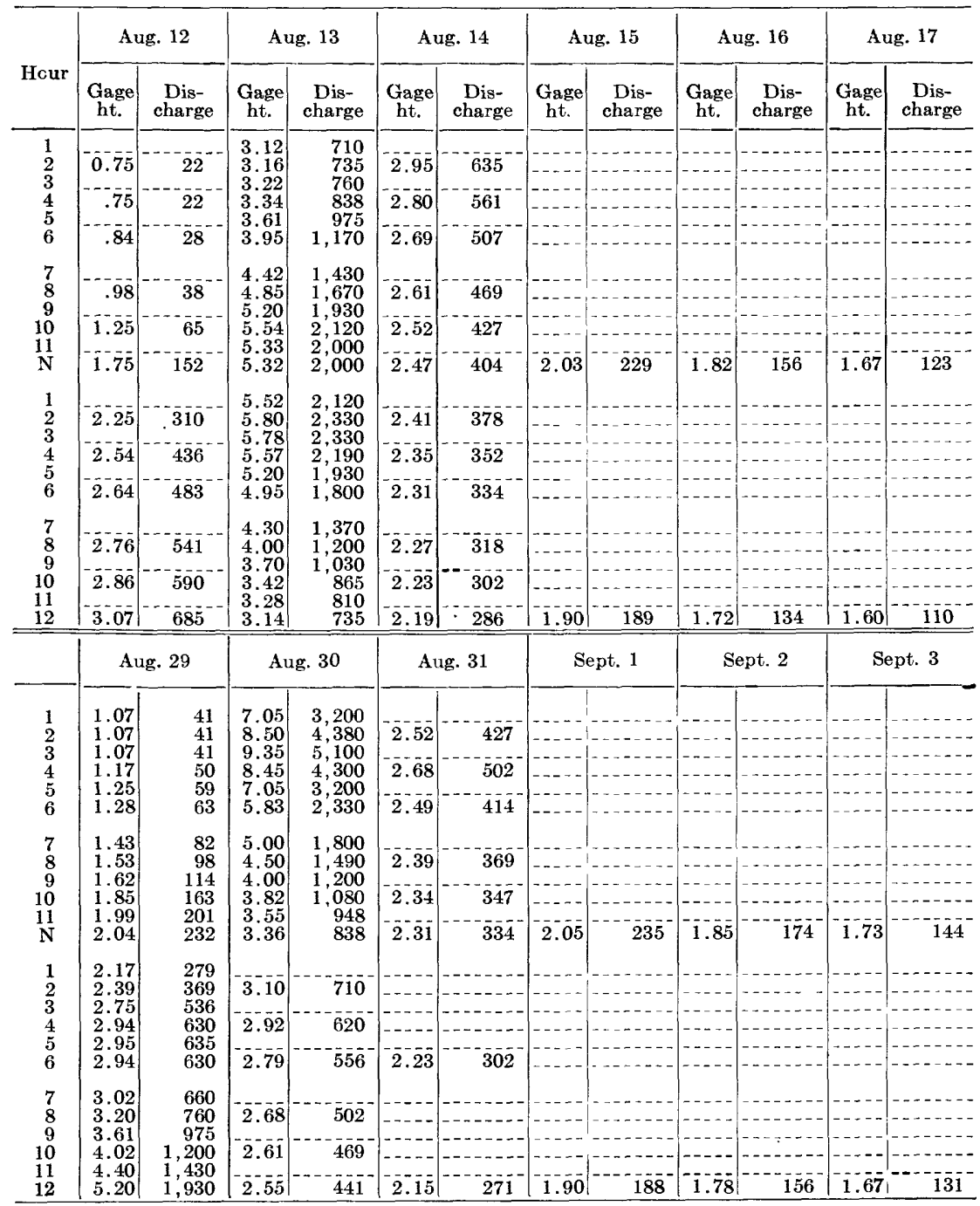

SUPPLEMENTAL RECORDs.-Aug. 13, 2:30 p.m., gage height, 5.92 feet; discharge, 2,400 second-feet.

CULLASAJA CREEK A'T CULLASAJA, N. C.

Location.-Lat. $35^{\circ} 10^{\prime} 05^{\prime \prime}$, long. $83^{\circ} 19^{\prime} 25^{\prime \prime}$, at Cullasaja, Macon Ċounty, 1 mile downstream from Ellijay Creek and $3 \frac{1 / 2}{2}$ miles upstream from mouth. Datum of gage is $2,023.37$ feet above mean sea level, datum of 1929, supplementary adjustment of 1936 .

Drainage AREa.—86.5 square miles.

GAGE-HEIGHT RECORD.-Water-stage recorder graph.

DISCHARGE RECORD.-Stage-discharge relation defined by current-meter measurements up to 2,200 second-feet and extended to crest gage height on basis of flood flow determination by slope-area method. Shifting-control method used Aug. 15 


\section{FLOODS OF AUGUST 1940 IN THE SOUTHEASTERN STATES}

to noon Aug. 29. Gage heights used to half-tenths between 2.4 and 4.4 feet; hundredths below and tenths above these limits.

Maxima.-1940: Diseharge, 19,300 second-feet 3:30 a.m. Aug. 30 (gage height, 20.83 feet).

1907-9, 1921-39: Discharge, 11,800 second-feet Aug. 15, 1928 (gage height, 17.04 feet, from floodmarks).

Records of North Carolina State Highway Commission show a stage of 17.2 feet, from floodmarks, for the flood of July 1916 (diseharge, 12,200 second-feet, from 1940 rating) and show that this stage was exceeded a few years prior to 1916 and again between 1916 and Feb. 12, 1920.

REMARKs.-Flood runoff practically unaffeeted by artificial storage.

Mean discharge, in second-feet, 1940

\begin{tabular}{|c|c|c|c|c|c|c|c|c|c|c|c|}
\hline Day & Aug. & Sept. & Day & Aug. & Sept. & Day & Aug. & Sept. & Day & Aug. & Sept. \\
\hline $\begin{array}{l}1 \\
2 \\
3 \\
4 \\
4 \\
5 \\
6 \\
7 \\
8\end{array}$ & $\begin{array}{l}68 \\
83 \\
67 \\
63 \\
62 \\
65 \\
64 \\
70\end{array}$ & $\begin{array}{l}701 \\
551 \\
459 \\
421 \\
381 \\
342 \\
305 \\
277\end{array}$ & $\begin{array}{r}9 \\
10 \\
11 \\
12 \\
13 \\
14 \\
15 \\
16\end{array}$ & $\begin{array}{r}82 \\
71 \\
65 \\
399 \\
4,970 \\
1,190 \\
604 \\
433\end{array}$ & $\begin{array}{l}255 \\
242 \\
225 \\
209 \\
198 \\
190 \\
180 \\
169\end{array}$ & $\begin{array}{l}17 \\
18 \\
19 \\
20 \\
21 \\
22 \\
23 \\
24\end{array}$ & $\begin{array}{l}333 \\
277 \\
242 \\
211 \\
194 \\
185 \\
168 \\
157\end{array}$ & $\begin{array}{l}162 \\
169 \\
164 \\
151 \\
143 \\
138 \\
133 \\
133\end{array}$ & $\begin{array}{l}25 \\
26 \\
27 \\
28 \\
29 \\
30 \\
31\end{array}$ & $\begin{array}{r}148 \\
138 \\
130 \\
122 \\
1,370 \\
7,550 \\
1,080\end{array}$ & $\begin{array}{l}171 \\
136 \\
124 \\
119 \\
114 \\
113\end{array}$ \\
\hline \multicolumn{10}{|c|}{$\begin{array}{l}\text { Monthly mean discharge, in second-feet } \\
\text { Runoff, in inches }\end{array}$} & $\begin{array}{r}666 \\
8.88\end{array}$ & $\begin{array}{r}236 \\
3.05\end{array}$ \\
\hline
\end{tabular}


TENNESSEE RIVER BASIN

Gage height, in feet, and discharge, in second-feet, at indicated time, 1940

\begin{tabular}{|c|c|c|c|c|c|c|c|c|c|c|c|c|}
\hline \multirow{2}{*}{ Hour } & \multicolumn{2}{|c|}{ Aug. 12} & \multicolumn{2}{|c|}{ Aug. 13} & \multicolumn{2}{|c|}{ Aug. 14} & \multicolumn{2}{|c|}{ Aug. 15} & \multicolumn{2}{|c|}{ Aug. 16} & \multicolumn{2}{|c|}{ Aug. 17} \\
\hline & $\begin{array}{c}\text { Gage } \\
\text { ht. }\end{array}$ & $\begin{array}{c}\text { Dis- } \\
\text { charge }\end{array}$ & $\begin{array}{c}\text { Gage } \\
\text { ht. }\end{array}$ & $\begin{array}{c}\text { Dis- } \\
\text { charge }\end{array}$ & $\begin{array}{c}\text { Gage } \\
\text { ht. }\end{array}$ & $\begin{array}{c}\text { Dis- } \\
\text { charge }\end{array}$ & $\begin{array}{c}\text { Gage } \\
\text { ht. }\end{array}$ & D & $\begin{array}{c}\text { Gage } \\
\text { ht. }\end{array}$ & $\begin{array}{c}\mathrm{D} \\
\mathrm{ch}\end{array}$ & $\begin{array}{c}\text { Gage } \\
\text { ht. }\end{array}$ & $\begin{array}{c}\text { Dis- } \\
\text { charge }\end{array}$ \\
\hline $\begin{array}{l}1 \\
2 \\
3 \\
4 \\
5 \\
6\end{array}$ & \begin{tabular}{|c|}
$-\cdots$ \\
\hdashline 1.02
\end{tabular} & $7 \overline{2}$ & $\begin{array}{l}5.43 \\
5.75 \\
6.10 \\
6.37 \\
6.66 \\
7.30\end{array}$ & $\begin{array}{l}1,310 \\
1,480 \\
1,620 \\
1,760 \\
1,900 \\
2,200\end{array}$ & $\begin{array}{l}7.20 \\
6.75 \\
6.40 \\
6.10 \\
5.82 \\
5.64\end{array}$ & $\begin{array}{l}2,150 \\
1,950 \\
1,760 \\
1,620 \\
1,480 \\
1,400\end{array}$ & & & & & & \\
\hline $\begin{array}{r}7 \\
8 \\
9 \\
10 \\
11 \\
N\end{array}$ & 1.32 & 110 & $\mid \begin{array}{r}8.90 \\
10.70 \\
12.00 \\
13.10 \\
13.90 \\
14.23\end{array}$ & $\begin{array}{l}3,100 \\
4,280 \\
5,350 \\
6,410 \\
7,290 \\
7,640\end{array}$ & $\begin{array}{l}5.46 \\
5.27 \\
5.11 \\
4.94 \\
4.82 \\
4.73\end{array}$ & $\begin{array}{l}1,350 \\
1,270 \\
1,190 \\
1,110 \\
1,070 \\
1,030\end{array}$ & 3.45 & 605 & 2.89 & 404 & 2.54 & \\
\hline $\begin{array}{l}1 \\
2 \\
3 \\
4 \\
5 \\
6\end{array}$ & $\begin{array}{l}1.43 \\
1.65 \\
2.10 \\
2.95 \\
4.00 \\
4.60\end{array}$ & $\begin{array}{l}127 \\
162 \\
248 \\
462 \\
782 \\
998\end{array}$ & $\mid \begin{array}{l}14.42 \\
14.63 \\
14.90 \\
15.28 \\
15.00 \\
14.42\end{array}$ & $\begin{array}{l}7,880 \\
8,120 \\
8,480 \\
9,020 \\
8,600 \\
7,880\end{array}$ & $\begin{array}{r}4.54 \\
4.40 \\
4.27\end{array}$ & $\begin{array}{r}962 \\
9926 \\
872\end{array}$ & & & & & & \\
\hline $\begin{array}{r}7 \\
8 \\
9 \\
10 \\
11 \\
12 \\
\end{array}$ & $\begin{array}{l}4.75 \\
4.68 \\
4.67 \\
4.72 \\
4.83 \\
5.10\end{array}$ & $\begin{array}{l}1,070 \\
1,030 \\
1,030 \\
1,030 \\
1,070 \\
1,190 \\
\end{array}$ & $\mid$\begin{tabular}{r|}
13.45 \\
12.25 \\
10.90 \\
9.65 \\
8.60 \\
7.78
\end{tabular} & $\begin{array}{l}6,740 \\
5,530 \\
4,420 \\
3,520 \\
2,920 \\
2,480 \\
\end{array}$ & $\begin{array}{r}4.12 \\
4.00 \\
-3.90\end{array}$ & $\begin{array}{l}818 \\
782 \\
748 \\
\end{array}$ & 3.10 & 504 & 2.65 & 368 & $2 . \overline{2}$ & \\
\hline & \multicolumn{2}{|c|}{ Aug. 29} & \multicolumn{2}{|c|}{ Aug. 30} & \multicolumn{2}{|c|}{ Aug. 31} & \multicolumn{2}{|c|}{ Sept. 1} & \multicolumn{2}{|c|}{ Sept. 2} & \multicolumn{2}{|c|}{ Sept. } \\
\hline $\begin{array}{l}1 \\
2 \\
3 \\
4 \\
5 \\
6 \\
6\end{array}$ & $\begin{array}{l}1.44 \\
1.47 \\
1.47 \\
1.49 \\
1.56 \\
1.64\end{array}$ & $\begin{array}{l}119 \\
124 \\
124 \\
127 \\
138 \\
151\end{array}$ & $\begin{array}{l}16.90 \\
19.00 \\
20.50 \\
20.60 \\
19.95 \\
19.00\end{array}$ & $\begin{array}{l}11,600 \\
15,500 \\
18,600 \\
18,800 \\
17,500 \\
15,500\end{array}$ & $\begin{array}{r}5.55 \\
\overline{5} . \overline{34} \\
5.4 \overline{8}\end{array}$ & $\begin{array}{l}1,400 \\
1,270 \\
1, \overline{3} 50\end{array}$ & & & & & & \\
\hline $\begin{array}{r}7 \\
8 \\
9 \\
10 \\
11 \\
\mathrm{~N}\end{array}$ & $\begin{array}{l}1.75 \\
1.90 \\
2.20 \\
3.50 \\
4.20 \\
4.52\end{array}$ & $\begin{array}{l}169 \\
198 \\
261 \\
605 \\
854 \\
962\end{array}$ & $\begin{array}{l}18.05 \\
16.95 \\
15.82 \\
14.35 \\
12.60 \\
10.98\end{array}$ & $\begin{array}{r}11,800 \\
9,780 \\
7,880 \\
5,900 \\
4,500\end{array}$ & $\begin{array}{r}5.14 \\
-4.87 \\
4.69\end{array}$ & $\begin{array}{l}1,190 \\
1,110\end{array}$ & 3.78 & 714 & 3.29 & 560 & 2.96 & $462^{-}$ \\
\hline $\begin{array}{l}1 \\
2 \\
3 \\
4 \\
5 \\
6\end{array}$ & $\begin{array}{l}4.65 \\
4.98 \\
5.30 \\
5.68 \\
5.70 \\
5.75\end{array}$ & $\begin{array}{r}998 \\
1,150 \\
1,270 \\
1,440 \\
1,440 \\
1,480\end{array}$ & $\begin{array}{l}9.82 \\
9.00 \\
8.37 \\
7.88 \\
7.45 \\
7.09\end{array}$ & $\begin{array}{l}3,160 \\
2,800 \\
2,530 \\
2,260 \\
2,100\end{array}$ & $\begin{array}{r}-\overline{4.50} \\
\hdashline 4 . \overline{32}\end{array}$ & 890 & & & & & -- & -- \\
\hline $\begin{array}{r}7 \\
8 \\
9 \\
10 \\
11 \\
12\end{array}$ & $\begin{array}{r}6.02 \\
6.60 \\
7.85 \\
10.75 \\
13.35 \\
15.00\end{array}$ & $\begin{array}{l}1,580 \\
1,850 \\
2,480 \\
4,350 \\
6,740 \\
8,600\end{array}$ & $\begin{array}{l}6.80 \\
6.55 \\
6.33 \\
6.13 \\
5.96 \\
5.80\end{array}$ & $\begin{array}{l}1,950 \\
1,850 \\
1,710 \\
1,620 \\
1,580 \\
1,480\end{array}$ & $\begin{array}{r}4.18 \\
4.08\end{array}$ & 854 & 3.46 & 605 & 3. $\overline{0}$ & 490 & 2.80 & 421 \\
\hline
\end{tabular}

SuPPLEMENTAL RECORD.-Aug. 30, 3:30 a.m., gage height, 20.83 feet; discharge, 19,300 second-feet.

\section{NANTAHALA RIVER AT ALMOND, N. C.}

Location.-Lat. $35^{\circ} 22^{\prime} 35^{\prime \prime}$, long. $83^{\circ} 33^{\prime} 55^{\prime \prime}$, at highway bridge at Almond, Swain County, about a quarter of a mile upstream from mouth. Datum of gage is $1,596.53$ feet above mean sea level, datum of 1929, supplementary adjustment of 1936.

DRAINAGE AREA. - 174 square miles.

GAGE-HEIGHT RECORD.-Water-stage recorder graph except for periods of partly obstructed intake, noon Aug. 13 to 8 a.m. Aug. 14 and 5 p.m. Ang. 29 to 10 a.m.

Aug. 30, for which a graph based on recorder record and floodmarks was used. DISCHARGE RECORD.-Stage-discharge relation defined by current-meter measurements 
up to 5,500 second-feet. Gage heights used to half-tenths between 2.3 and 4.5 feet; hundredths below and tenths above these limits.

Maxima.-1940: Discharge, 4,000 second-feet 6 p.m. Aug. 13 (gage height, 6.30 feet, from floodmarks).

1913-17, 1921-39: Stage, probably occurred Mar. 4, 1917 (record of erest stage not available; daily mean discharge, 15,200 second-feet, from records furnished by Knoxville Power Co.).

REMARKs.-Flood runoff not affected by artificial storage.

Mean discharge, in second-feet, 1940

\begin{tabular}{|c|c|c|c|c|c|c|c|c|c|c|c|}
\hline Day & Aug. & Sept. & Day & Aug. & Sept. & Day & Aug. & Sept. & Day & Aug. & Sept. \\
\hline 1 & 281 & 613 & 9 & 244 & 336 & 17 & 603 & 259 & 25 & 329 & 296 \\
\hline 2 & 247 & 531 & 10 & 207 & 336 & 18 & 526 & 256 & 26 & 312 & 259 \\
\hline 3 & 232 & 471 & 11 & 201 & 322 & 19 & 485 & 253 & 27 & 306 & 226 \\
\hline 4 & 223 & 432 & 12 & 258 & 306 & 20 & 423 & 247 & 28 & 296 & 218 \\
\hline 5 & 221 & $\begin{array}{l}419 \\
300\end{array}$ & 13 & 2,210 & $\begin{array}{l}300 \\
300\end{array}$ & 21 & 390 & 241 & 29 & 867 & \begin{tabular}{l}
215 \\
\hdashline 00
\end{tabular} \\
\hline $\begin{array}{l}6 \\
7\end{array}$ & $\begin{array}{l}226 \\
247\end{array}$ & $\begin{array}{l}390 \\
377\end{array}$ & 14 & 1,670 & 290 & 22 & 371 & 235 & 30 & 1,680 & \\
\hline 8 & 229 & 353 & $\begin{array}{l}15 \\
16\end{array}$ & $\begin{array}{l}\begin{array}{l}994 \\
740\end{array} \\
740\end{array}$ & $\begin{array}{l}281 \\
271\end{array}$ & $\begin{array}{l}2.3 \\
24\end{array}$ & $\begin{array}{l}5.53 \\
364\end{array}$ & $\begin{array}{l}229 \\
229\end{array}$ & & & \\
\hline \multicolumn{10}{|c|}{$\begin{array}{l}\text { Monthly mean discharge, in second-feet } \\
\text { Runoff, in inches }\end{array}$} & $\begin{array}{r}533 \\
3.53\end{array}$ & $\begin{array}{r}313 \\
2.01\end{array}$ \\
\hline
\end{tabular}

Gage height, in feet, and discharge, in second-feet, at indicated time, 1940

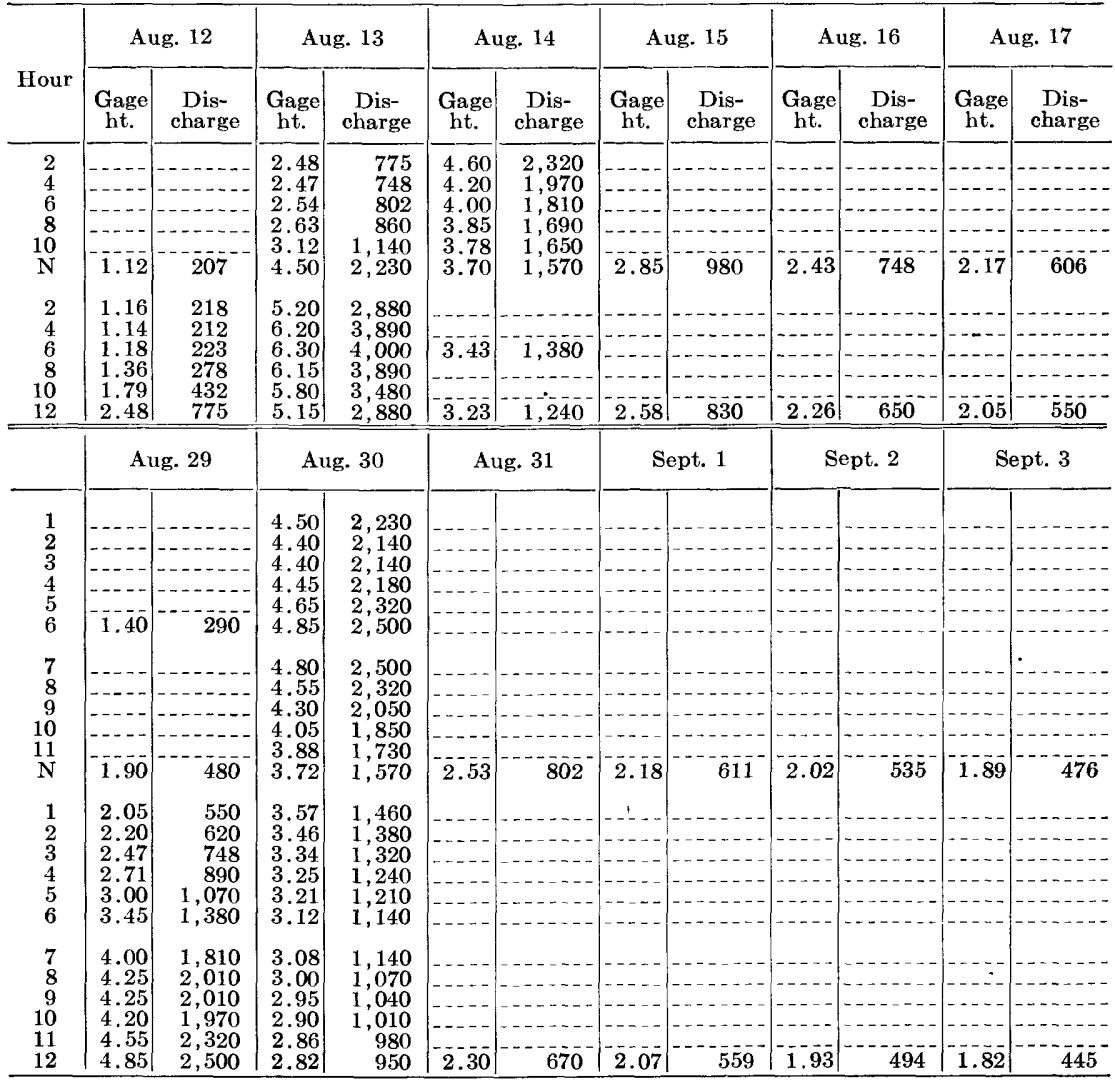


TUCKASEGEE RIVER AT TUCKASEGEE, N. C.

Location.-Lat. $35^{\circ} 16^{\prime} 45^{\prime \prime}$, long. $83^{\circ} 07^{\prime} 50^{\prime \prime}, 1$ mile downstream from confluence of East and West Forks and from Tuckasegee, Jackson County. Datum of gage is 2,125.16 feet above mean sea level, datum of 1929, supplementary adjustment of 1936.

Drainage AREA.-143 square miles.

GAGE-HEIGHT RECORD.-Water-stage recorder graph Aug. 1 to 2 a.m. Aug. 30 ; the recorder house was tipped over by the flood of Aug. 30. From 2 a.m. to 3:30 a.m. Aug. 30 a graph based on recorder record and floodmarks was used. No gage-height record from 3:30 a.m. Aug. 30 to Sept. 6; gage heights in table at indicated time were derived from estimated discharge. Twice-daily gage readings to hundredths used Sept. 7-30.

DISCHARGE RECORD.--Stage-discharge relation defined by eurrent-meter measurements up to 5,000 second-feet and extended to crest gage height on basis of determinations of the Aug. 13 and Aug. 30 flood flows by slope-area method. Stagedischarge relation unstable because of flood debris Sept. 9-30; discharge based on two discharge measurements and records for stations at Dillsboro and Bryson. Discharge for periods of no gage-height record is based on records for stations at Dillsboro and Bryson and for nearby streams. Gage heights used to half-tenths between 3.0 and 4.4 feet; hundredths below and tenths above these limits.

Maxima.-1940: Discharge, 40,800 second-feet 3:30 a.m. Aug. 30 (gage height, 21.1 feet, from floodmarks).

1934-39 : Discharge, 6,330 second-feet Sept. 30, 1936 (gage height, 8.83 feet).

Surveys by the Tennessee Valley Authority show the following flood stages: 18 feet May 1840, 16 feet June 1876, 14 feet August 1928. These stages applied to the 1940 rating give discharges of $23,100,17,100$, and 13,200 secondfeet, respectively.

REMARKs.-Flood runoff not affected by artificial storage.

Mean discharge, in second-feet, 1940

\begin{tabular}{|c|c|c|c|c|c|c|c|c|c|c|c|}
\hline Day & Aug. & Sept. & Day & Aug. & Sept. & Day & Aug. & Sept. & Day & Aug. & Sept. \\
\hline $\begin{array}{l}1 \\
2 \\
3 \\
4 \\
5 \\
6 \\
7 \\
8\end{array}$ & $\begin{array}{l}155 \\
152 \\
142 \\
135 \\
135 \\
132 \\
168 \\
180\end{array}$ & $\begin{array}{r}1,520 \\
1,200 \\
1,000 \\
900 \\
800 \\
750 \\
698 \\
649\end{array}$ & $\begin{array}{r}9 \\
10 \\
11 \\
12 \\
13 \\
14 \\
15 \\
16\end{array}$ & $\begin{array}{r}176 \\
142 \\
148 \\
1,190 \\
8,470 \\
2,720 \\
1,410 \\
1,020\end{array}$ & $\begin{array}{l}650 \\
600 \\
550 \\
480 \\
460 \\
440 \\
420 \\
400\end{array}$ & $\begin{array}{l}17 \\
18 \\
19 \\
20 \\
21 \\
22 \\
23 \\
24\end{array}$ & $\begin{array}{l}808 \\
684 \\
607 \\
540 \\
489 \\
458 \\
440 \\
446\end{array}$ & $\begin{array}{l}380 \\
380 \\
380 \\
360 \\
340 \\
320 \\
300 \\
300\end{array}$ & $\begin{array}{l}25 \\
26 \\
27 \\
28 \\
29 \\
30 \\
31\end{array}$ & $\begin{array}{r}434 \\
376 \\
342 \\
321 \\
2,420 \\
14,900 \\
2,400\end{array}$ & $\begin{array}{l}340 \\
300 \\
280 \\
260 \\
260 \\
240\end{array}$ \\
\hline \multicolumn{10}{|c|}{$\begin{array}{l}\text { Monthly mean discharge, in second-feet } \\
\text { Runoff, in inches }\end{array}$} & $\begin{array}{l}1,359 \\
10.96\end{array}$ & $\begin{array}{r}532 \\
4.15\end{array}$ \\
\hline
\end{tabular}


FLOODS OF AUGUST 1940 IN THE §OUTHEASTERN STATES

Gage height, in feet, and discharge, in second-feet, at indicated time, 1940

\begin{tabular}{|c|c|c|c|c|c|c|c|c|c|c|c|c|}
\hline \multirow[b]{2}{*}{ Hour } & \multicolumn{2}{|c|}{ Aug. 12} & \multicolumn{2}{|c|}{ Aug. 13} & \multicolumn{2}{|c|}{ Aug. 14} & \multicolumn{2}{|c|}{ Aug. 29} & \multicolumn{2}{|c|}{ Aug. 30} & \multicolumn{2}{|c|}{ Aug. 31} \\
\hline & $\begin{array}{c}\dot{b} \\
\text { Gage } \\
\text { ht. }\end{array}$ & $\begin{array}{c}\text { Dis- } \\
\text { charge }\end{array}$ & $\begin{array}{c}\text { Gage } \\
\text { ht. }\end{array}$ & $\begin{array}{c}\text { Dis- } \\
\text { charge }\end{array}$ & $\begin{array}{c}\text { Gage } \\
\text { ht. }\end{array}$ & $\underset{\text { char }}{\mathrm{Di}}$ & $\begin{array}{c}\text { Gage } \\
\text { ht. }\end{array}$ & $\underset{\text { cha }}{\mathrm{Di}}$ & $\begin{array}{c}\text { Gage } \\
\text { ht. }\end{array}$ & $\begin{array}{c}\text { Dis- } \\
\text { charge }\end{array}$ & $\begin{array}{c}\text { Gage } \\
\text { ht. }\end{array}$ & ch \\
\hline \multirow{5}{*}{$\begin{array}{l}1 \\
2 \\
3 \\
4 \\
5 \\
6\end{array}$} & & & & & & & \multirow{4}{*}{2.06} & \multirow{4}{*}{$3 \overline{32}$} & \multirow{5}{*}{$\begin{array}{l}14.60 \\
17.70 \\
20.0 \\
21.1 \\
20.4 \\
19.7\end{array}$} & \multirow{5}{*}{$\begin{array}{l}14,200 \\
22,000 \\
33,000 \\
40,500 \\
36,000 \\
31,000\end{array}$} & & \\
\hline & & & & & -6.69 & 4,160 & & & & & & \\
\hline & 1.73 & 180 & & & & & & & & & & \\
\hline & & & & $\begin{array}{l}3,9 \\
4,3\end{array}$ & 6.16 & & & & & & & \\
\hline & 1.80 & 207 & 8. & 5 & 5.70 & 3,200 & 2.14 & $37 \overline{6}$ & & & 5.1 & 700 \\
\hline \multirow{4}{*}{$\begin{array}{r}7 \\
8 \\
9 \\
10 \\
11 \\
\mathrm{~N}\end{array}$} & & & 9. & 7 , & & & & & \multirow{4}{*}{$\begin{array}{l}18.7 \\
17.7 \\
16.6 \\
15.5 \\
14.2 \\
12.8\end{array}$} & \multirow{4}{*}{$\begin{array}{l}26,000 \\
22,000 \\
18,500 \\
16,000 \\
13,500 \\
11,500\end{array}$} & & \\
\hline & 1.96 & 280 & 12.88 & 9,9 & 5.37 & & $\overline{2} . \overline{2} \overline{7}$ & 452 & & & & \\
\hline & & & 13.99 & & 5.13 & 2,660 & & & & & & \\
\hline & 2.30 & 470 & 14.05 & $\begin{array}{l}13 \\
13\end{array}$ & 4.84 & 00 & 2.57 & 649 & & & $4 . \overline{7}$ & 2,300 \\
\hline \multirow{5}{*}{$\begin{array}{l}1 \\
2 \\
3 \\
4 \\
5 \\
6\end{array}$} & \multirow{5}{*}{$\begin{array}{l}2.49 \\
2.60 \\
2.90 \\
3.26 \\
3.97 \\
4.67\end{array}$} & \multirow{5}{*}{$\begin{array}{r}593 \\
670 \\
885 \\
1,150 \\
1,700 \\
2,320\end{array}$} & \multirow{5}{*}{\begin{tabular}{|l|}
13.70 \\
13.50 \\
13.26 \\
12.87 \\
12.30 \\
11.56
\end{tabular}} & \multirow{5}{*}{$\begin{array}{r}12,800 \\
12,500 \\
12,200 \\
11,700 \\
10,800 \\
9,930\end{array}$} & & & \multirow{5}{*}{\begin{tabular}{|l|}
2.71 \\
3.11 \\
4.10 \\
4.37 \\
4.66 \\
5.65
\end{tabular}} & \multirow{5}{*}{$\begin{array}{r}747 \\
1,040 \\
1,820 \\
2,020 \\
2,320 \\
3,110\end{array}$} & \multirow[b]{2}{*}{10.7} & \multirow[b]{2}{*}{8,800} & & \\
\hline & & & & & 4.65 & 2,230 & & & & & & \\
\hline & & & & & 4.51 & 2,140 & & & 9.0 & 6,700 & & \\
\hline & & & & & & & & & & & & \\
\hline & & & & & 4.36 & 2,020 & & & 7.8 & 5,300 & 4.4 & 2,100 \\
\hline 7 & 5.16 & 2,750 & 10. & & & & 6. & & & & & \\
\hline $\begin{array}{l}8 \\
9\end{array}$ & $\begin{array}{l}5.57 \\
5.90\end{array}$ & & & & 4.24 & 1,940 & $\begin{array}{l}8.85 \\
0.90\end{array}$ & & 6.9 & 4,400 & & \\
\hline 10 & 6.1 & & & & 4.14 & 1,860 & 10.41 & & 6.4 & 3,900 & & \\
\hline 12 & $\begin{array}{l}6.1 \\
6.1\end{array}$ & & $\begin{array}{l}7.92 \\
7.46\end{array}$ & 5,010 & 4.04 & $\overline{1}, \overline{80}$ & 12.30 & 10,800 & 5.9 & 3,400 & 4.1 & 1,800 \\
\hline
\end{tabular}

Supplemental ReCORD.-Aug. 30, 3:30 a.m., gage height, 21.1 feet; discharge, 40,800 second-feet.

TUCKASEGEE RIVER AT DILLSBORO, N. C.

Location.-Lat. $35^{\circ} 21^{\prime} 50^{\prime \prime}$, long. $83^{\circ} 15^{\prime} 30^{\prime \prime}$, at county footbridge, half a mile downstream from Seott Creek and Dillsboro, Jackson County. Datum of gage is $1,950.15$ feet above mean sea level, datum of 1929, supplementary adjustment of 1936.

DRAinage AREA.-347 square miles.

GAGE-HEIGHT RECORD.-Water-stage recorder graph except 12 m. to 3 p.m. Aug. 13, where graph based on partial record and recorded range in gage height was used and Aug. 26 to Sept. 5, Sept. 13-19, 26, 27, for which there is no gageheight record; gage heights in table at indicated time were derived from estimated discharge.

DISCHARGE RECORD.--Stage-discharge relation defined by current-meter measurements up to 8,400 second-feet and extended to erest gage height on basis of determinations of flood flow by slope-area method and computation of flow over power plant dam just above the station. Gage heights used to half-tenths between 3.6 and 5.9 feet; hundredths below and tenths above these limits. Discharge for periods of no gage-height record is based on floodmarks, weather records, records for station at Bryson and for nearby streams.

Maxima.-1940: Discharge, 52,600 second-feet 6 a.m. Aug. 30 (gage height, 21.96 feet, from floodmark).

1928-39: Discharge, 14,000 second-feet Aug. 15, 1928 (gage height, 11.2 feet, from graph based on twice-daily gage readings, former site and datum).

REMARKS.-Flood runoff not affected by artificial storage. 
TENNESSEE RIVER BASIN

Mean discharge, in second-feet, 1940

\begin{tabular}{r|r|r||r|r|r|r|r|r|r|r|r}
\hline Day & Aug. & Sept. & Day & Aug. & Sept. & Day & Aug. & Sept. & Day & Aug. & Sept. \\
\hline 1 & 380 & 2,820 & 9 & 446 & 1,160 & 17 & 1,440 & 700 & 25 & 787 & 634 \\
2 & 370 & 2,270 & 10 & 370 & 1,120 & 18 & 1,280 & 700 & 26 & 700 & 580 \\
3 & 340 & 1,920 & 11 & 335 & 1,050 & 19 & 1,120 & 700 & 27 & 650 & 540 \\
4 & 330 & 1,700 & 12 & 794 & 891 & 20 & 1,010 & 670 & 28 & 600 & 508 \\
5 & 326 & 1,550 & 13 & 10,900 & 850 & 21 & 926 & 640 & 29 & 2,240 & 502 \\
6 & 339 & 1,450 & 14 & 4,900 & 800 & 22 & 884 & 622 & 30 & 21,700 & 490 \\
7 & 375 & 1,320 & 15 & 2,350 & 750 & 23 & 821 & 598 & 31 & 4,450 & $-\ldots$ \\
8 & 420 & 1,240 & 16 & 1,730 & 750 & 24 & 807 & 580 & \\
\hline
\end{tabular}

Gage height, in feet, and discharge, in second-feet, at indicated time, 1940

\begin{tabular}{|c|c|c|c|c|c|c|c|c|c|c|c|c|}
\hline \multirow{2}{*}{ Hour } & \multicolumn{2}{|c|}{ Aug. 12} & \multicolumn{2}{|c|}{ Aug. 13} & \multicolumn{2}{|c|}{ Aug. 14} & \multicolumn{2}{|c|}{ Aug. 15} & \multicolumn{2}{|c|}{ Aug. 16} & \multicolumn{2}{|c|}{ Aug. 17} \\
\hline & $\begin{array}{c}\text { Gage } \\
\text { ht. }\end{array}$ & $\begin{array}{c}\text { Dis- } \\
\text { charge }\end{array}$ & $\begin{array}{c}\text { Gage } \\
\text { ht. }\end{array}$ & $\begin{array}{c}\text { Dis- } \\
\text { charge }\end{array}$ & $\begin{array}{c}\text { Gage } \\
\text { ht. }\end{array}$ & $\begin{array}{c}\text { Dis- } \\
\text { charge }\end{array}$ & $\begin{array}{c}\text { Gage } \\
\text { ht. }\end{array}$ & $\begin{array}{c}\text { Dis- } \\
\text { eharge }\end{array}$ & $\begin{array}{c}\text { Gage } \\
\text { ht. }\end{array}$ & $\begin{array}{c}\text { Dis- } \\
\text { charge }\end{array}$ & $\begin{array}{c}\text { Gage } \\
\text { ht. }\end{array}$ & $\begin{array}{c}\text { Dis- } \\
\text { charge }\end{array}$ \\
\hline $\begin{array}{l}1 \\
2\end{array}$ & 2.76 & 365 & $\begin{array}{l}6.36 \\
6.64\end{array}$ & $\begin{array}{l}3,540 \\
3,800\end{array}$ & 9.37 & 8,400 & & & & & & \\
\hline 3 & & & 6.81 & 4,060 & & & & & & & & \\
\hline$\frac{4}{5}$ & 2.78 & 375 & 6.90 & $\begin{array}{l}4,200 \\
4,200\end{array}$ & 8.47 & 6,690 & & & & & & \\
\hline 6 & $\overline{2} . \overline{1}$ & 390 & 6.98 & 4,340 & 7.90 & 5,700 & & & & & & \\
\hline $\begin{array}{l}7 \\
8\end{array}$ & 2.86 & 415 & $\begin{array}{l}7.08 \\
7.24\end{array}$ & $\begin{array}{l}4,480 \\
4,630\end{array}$ & 7.44 & 4,930 & & & & & & \\
\hline 10 & 2.90 & 435 & $\begin{array}{l}7.59 \\
8.20\end{array}$ & $\begin{array}{l}5,230 \\
6,180\end{array}$ & 7.16 & 4,630 & & & & & & \\
\hline 11 & 3.08 & 538 & $\begin{array}{r}9.10 \\
10.70\end{array}$ & $\begin{array}{r}7,800 \\
11,200\end{array}$ & 6.92 & 4,200 & 5.32 & 2,300 & 4.69 & 1,740 & 4.36 & 1,450 \\
\hline 1 & & & 12.50 & 15,700 & & & & & & & & \\
\hline 2 & & 468 & 13.45 & 18,200 & & & & & & & & \\
\hline 4 & $\overline{3} . \overline{27}$ & 652 & 14.28 & 20,900 & -1 & - & & & & & & - \\
\hline 6 & 3.61 & 877 & 13.62 & $\begin{array}{l}20,000 \\
18,800\end{array}$ & $6 . \overline{2} 8$ & 3,420 & & & & & & \\
\hline 7 & & & 10 & 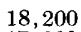 & & & & & & & & \\
\hline $\begin{array}{l}8 \\
9\end{array}$ & 4.16 & 280 & $\left|\begin{array}{l}12.98 \\
12.43\end{array}\right|$ & $\begin{array}{l}17,000 \\
15,400\end{array}$ & & & & & & & & \\
\hline 10 & $4 . \overline{9}$ & 1,960 & 12.00 & 14,400 & - - & $\cdots$ & & & & & & $\cdots$ \\
\hline $\begin{array}{l}11 \\
12\end{array}$ & 6.06 & 3,180 & $\left|\begin{array}{l}11 \\
10.53\end{array}\right| .10$ & 10,700 & $\overline{5.92}$ & $2, \overline{9} \overline{0}$ & $4 . \overline{9}$ & 1,920 & $4 . \overline{4} \overline{6}$ & $1,5 \overline{3} 0$ & $4 . \overline{2} \overline{1}$ & $1, \overline{3} 20$ \\
\hline
\end{tabular}

\begin{tabular}{|c|c|c|c|c|c|c|c|c|c|c|c|c|}
\hline \multirow{5}{*}{$\begin{array}{l}1 \\
2 \\
3 \\
4 \\
5 \\
6\end{array}$} & \multicolumn{2}{|c|}{ Aug. 29} & \multicolumn{2}{|c|}{ Aug. 30} & \multicolumn{2}{|c|}{ Aug. 31} & \multicolumn{2}{|c|}{ Sept. 1} & \multicolumn{2}{|c|}{ Sept. 2} & \multicolumn{2}{|c|}{ Sept. 3} \\
\hline & 318 & & 11.7 & 13,600 & & & & & & & & \\
\hline & 3.18 & 600 & $\begin{array}{l}13.1 \\
14.9\end{array}$ & $\begin{array}{l}17,400 \\
23,000\end{array}$ & & & & & & & & \\
\hline & 3.20 & 610 & 16.7 & 29,400 & & & $\ldots$ & & & & -. & \\
\hline & $3 . \overline{2} 8$ & 660 & $\left|\begin{array}{l}19.3 \\
21.96\end{array}\right|$ & $\begin{array}{l}40,000 \\
52,600\end{array}$ & 7.4 & 5,000 & & & & & & \\
\hline 7 & & & 21.3 & 49,200 & & & & & & & & \\
\hline 8 & 3.41 & 740 & 20.0 & 43,200 & & & - & & & & & \\
\hline 10 & $3 . \overline{6}$ & 900 & 17.2 & 31,200 & & & & & & & & \\
\hline N & 3.9 & 1,100 & $\begin{array}{l}16.1 \\
14.9\end{array}$ & $\begin{array}{l}27,000 \\
23,000\end{array}$ & 6.9 & 4,200 & 5.75 & 2,800 & 5.25 & 2,250 & 4.9 & 1,900 \\
\hline 1 & 4.1 & 1,250 & & & & & & & & & & \\
\hline 2 & 4.4 & 1,500 & 13.0 & 17,000 & & & & & & & & \\
\hline $\begin{array}{l}0 \\
4\end{array}$ & $\begin{array}{l}4.75 \\
5.05\end{array}$ & $\begin{array}{l}1,800 \\
2,050\end{array}$ & $11 . \overline{5}$ & 13,200 & - & & & & & & & \\
\hline 5 & 5.45 & 2,450 & ? 2 & & 6 & 3700 & & & & & & \\
\hline 6 & 5.9 & 2,900 & 10.2 & 10,000 & 6.5 & 3,700 & & & & & & \\
\hline 7 & 6.3 & 3,400 & & & & & & & & & & \\
\hline 8 & $\begin{array}{l}6.9 \\
7.6\end{array}$ & $\begin{array}{l}4,200 \\
5,200\end{array}$ & 9.4 & 90 & & & & & & & & \\
\hline 10 & 8.3 & 6,400 & 8.8 & 7,200 & & & & & & & & \\
\hline $\begin{array}{l}11 \\
12\end{array}$ & $\begin{array}{r}9.2 \\
10.4\end{array}$ & $\begin{array}{r}8,000 \\
10,600\end{array}$ & $8.4^{-}$ & 6,500 & 6.2 & 3,300 & 5.45 & 2,450 & 5.1 & 2,100 & $4.7 \overline{5}$ & 1,800 \\
\hline
\end{tabular}

Supplemental ReCond.-Aug. 13, 3:30 p.m., gage height, 14.32 feet; 20,900 second-feet. $804331-49-29$ 
TUCKASEGGE RIVER AT BRYSON CTTY, N. C.

Location.-Lat. $35^{\circ} 25^{\prime} 45^{\prime \prime}$, long. $83^{\circ} 27^{\prime} 10^{\prime \prime}$, 400 feet downstream from bridge on State Highway 288 in Bryson City, Swain County, and half a mile downstream from Deep Creek. Datum of gage is $1,716.54$ feet above mean sea level, datum of 1929, supplementary adjustment of 1936 .

DRAINAGE AREA.—655 square miles.

GAGE-HEIGHT RECORD.-Water-stage recorder graph.

DISCHARGE RECORD.-Stage-discharge relation defined by current-meter measurements up to 25,000 second-feet and extended to crest gage height on basis of logarithmic plotting and determination of flood flow by slope-area method. Gage heights used to half-tenths between 2.3 and 4.1 feet; hundredths below and tenths above these limits.

Maxima.-1940: Discharge, 61,600 second-feet 10:30 a.m. Aug. 30 (gage height, 15.96 feet).

1897-1939 : Discharge observed, 40,300 second-feet Nov. 19, 1906 (gage height, 13.2 feet).

The flood of May 1840 reached a stage of 21 feet (from survey by the Tennessee Valley Authority), discharge not determined.

REMARKs.-Flood runoff not affected by artificial storage.

Mean discharge, in second-feet, 1940

\begin{tabular}{|c|c|c|c|c|c|c|c|c|c|c|c|}
\hline Day & Aug. & Sept. & Day & Aug. & Sept. & Day & A ug. & Sept. & Day & Aug. & Sept. \\
\hline $\begin{array}{l}1 \\
2 \\
3 \\
4 \\
5 \\
6 \\
7 \\
8\end{array}$ & $\begin{array}{l}769 \\
714 \\
670 \\
640 \\
630 \\
630 \\
692 \\
681\end{array}$ & $\begin{array}{l}4,450 \\
3,460 \\
2,870 \\
2,510 \\
2,350 \\
2,120 \\
1,920 \\
1,770\end{array}$ & $\begin{array}{r}99 \\
10 \\
11 \\
12 \\
13 \\
14 \\
15 \\
16\end{array}$ & $\begin{array}{r}769 \\
650 \\
600 \\
753 \\
10,400 \\
8,750 \\
4,810 \\
2,960\end{array}$ & $\begin{array}{l}1,660 \\
1,640 \\
1,610 \\
1,420 \\
1,350 \\
1,290 \\
1,220 \\
1,180\end{array}$ & $\begin{array}{l}17 \\
18 \\
19 \\
20 \\
21 \\
22 \\
23 \\
24\end{array}$ & $\begin{array}{l}2,290 \\
1,930 \\
1,800 \\
1,550 \\
1,400 \\
1,330 \\
1,250 \\
1,210\end{array}$ & $\begin{array}{r}1,110 \\
1,120 \\
1,150 \\
1,050 \\
996 \\
984 \\
936 \\
924\end{array}$ & $\begin{array}{l}25 \\
26 \\
27 \\
28 \\
29 \\
30 \\
31\end{array}$ & $\begin{array}{r}1,150 \\
1,080 \\
1,010 \\
948 \\
2,130 \\
27,400 \\
6,920\end{array}$ & $\begin{array}{l}972 \\
996 \\
888 \\
850 \\
850 \\
800\end{array}$ \\
\hline \multicolumn{10}{|c|}{$\begin{array}{l}\text { Monthly mean discharge, in second-feet } \\
\text { Runoff, in inches }\end{array}$} & $\begin{array}{r}2,855 \\
5.03\end{array}$ & $\begin{array}{r}1,548 \\
2.63\end{array}$ \\
\hline
\end{tabular}


TENNESSEE RIVER BASIN

Gage height, in feet, and discharge, in second-feet, at indicated time, 1940

\begin{tabular}{|c|c|c|c|c|c|c|c|c|c|c|c|c|}
\hline \multirow{2}{*}{ Hour } & \multicolumn{2}{|c|}{ Aug. 12} & \multicolumn{2}{|c|}{ Aug. 13} & \multicolumn{2}{|c|}{ Aug. 14} & \multicolumn{2}{|c|}{ Aug. 15} & \multicolumn{2}{|c|}{ Aug. 16} & \multicolumn{2}{|c|}{ Aug. 17} \\
\hline & $\begin{array}{c}\text { Gage } \\
\text { ht. }\end{array}$ & $\begin{array}{l}\text { Dis- } \\
\text { charge }\end{array}$ & $\begin{array}{c}\text { Gage } \\
\text { ht. }\end{array}$ & $\begin{array}{l}\text { Dis- } \\
\text { charge }\end{array}$ & $\begin{array}{c}\text { Gage } \\
\text { ht. }\end{array}$ & $\begin{array}{l}\text { Dis- } \\
\text { charge }\end{array}$ & $\begin{array}{c}\text { Gage } \\
\text { ht. }\end{array}$ & $\begin{array}{l}\text { Dis- } \\
\text { charge }\end{array}$ & $\begin{array}{c}\text { Gage } \\
\text { ht. }\end{array}$ & $\begin{array}{l}\text { Dis- } \\
\text { charge }\end{array}$ & $\begin{array}{c}\text { Gage } \\
\text { ht. }\end{array}$ & $\begin{array}{l}\text { Dis- } \\
\text { charge }\end{array}$ \\
\hline $\begin{array}{l}1 \\
2 \\
3 \\
4 \\
5 \\
6\end{array}$ & 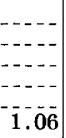 & - & $\begin{array}{l}2.03 \\
2.50 \\
2.89 \\
3.12 \\
3.31 \\
3.43\end{array}$ & $\begin{array}{l}1,950 \\
2,780 \\
3,560 \\
3,970 \\
4,390 \\
4,720\end{array}$ & $\begin{array}{l}7.72 \\
7.27 \\
6.76 \\
6.26 \\
5.85 \\
5.48\end{array}$ & $\begin{array}{l}17,400 \\
16,000 \\
14,300 \\
12,600 \\
11,100 \\
10,200\end{array}$ & $\begin{array}{l}4.40 \\
4.32 \\
4.25 \\
4.16 \\
4.02 \\
3.90\end{array}$ & $\begin{array}{l}7,040 \\
6,780 \\
6,520 \\
6,520 \\
6,020 \\
5,770\end{array}$ & $\mid$\begin{tabular}{c}
----- \\
----- \\
----- \\
\hdashline---- \\
---- \\
-----
\end{tabular} & 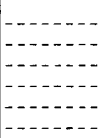 & $\left|\begin{array}{c}-\cdots- \\
---- \\
---- \\
-\cdots- \\
---- \\
----\end{array}\right|$ & 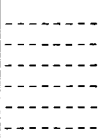 \\
\hline $\begin{array}{r}7 \\
8 \\
9 \\
10 \\
11 \\
\mathrm{~N}\end{array}$ & 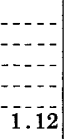 & \begin{tabular}{c}
-1 \\
\hdashline-1 \\
\hdashline 692
\end{tabular} & $\begin{array}{l}3.52 \\
3.59 \\
3.66 \\
3.78 \\
3.99 \\
4.36\end{array}$ & $\begin{array}{l}4,830 \\
5,060 \\
5,180 \\
5,530 \\
6,020 \\
7,040\end{array}$ & $\begin{array}{l}5.22 \\
5.02 \\
4.91 \\
4.80 \\
4.69 \\
4.57\end{array}$ & $\begin{array}{l}9,270 \\
8,690 \\
8,410 \\
8,130 \\
7,850 \\
7,580\end{array}$ & $\begin{array}{l}3.79 \\
3.72 \\
3.67 \\
3.29 \\
3.34 \\
3.34\end{array}$ & $\begin{array}{l}5,530 \\
5,290 \\
5,180 \\
4,390 \\
4,500 \\
4,500\end{array}$ & $\mid$\begin{tabular}{c}
.--- \\
$-\cdots-$ \\
$-\cdots-$ \\
\hdashline$-\overline{5}$ \\
2.5
\end{tabular} & ${ }_{2}, \overline{97} \overline{0}$ & $\mid \begin{array}{c}----- \\
----- \\
---- \\
-\overline{2} . \overline{2}\end{array}$ & 2,290 \\
\hline $\begin{array}{l}1 \\
2 \\
3 \\
4 \\
5 \\
6\end{array}$ & $\begin{array}{r}1.14 \\
1 . \overline{15} \\
1.2 \overline{1}\end{array}$ & \begin{tabular}{r}
$\mathbf{7 1 4}$ \\
\hdashline$\overline{725}$ \\
$-\overline{792}$
\end{tabular} & $\begin{array}{l}4.78 \\
5.32 \\
6.40 \\
6.60 \\
7.10 \\
8.00\end{array}$ & $\begin{array}{r}8,130 \\
9,560 \\
13,000 \\
13,600 \\
15,300 \\
18,500\end{array}$ & $\begin{array}{l}4.44 \\
4.32 \\
4.22 \\
3.80 \\
3.91 \\
3.94\end{array}$ & $\begin{array}{l}7,040 \\
6,780 \\
6,520 \\
5,530 \\
5,770 \\
5,900\end{array}$ & $\begin{array}{l}3.30 \\
3.25 \\
3.20 \\
3.16 \\
3.10 \\
2.82\end{array}$ & $\begin{array}{l}4,390 \\
4,280 \\
4,180 \\
4,080 \\
3,970 \\
3,360\end{array}$ & $\mid$\begin{tabular}{c}
---- \\
----- \\
---- \\
\hdashline--- \\
----- \\
----
\end{tabular} & 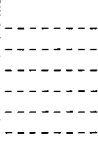 & $\mid \begin{array}{c}---- \\
----- \\
---- \\
---- \\
---\cdots- \\
----\end{array}$ & מ-1 \\
\hline $\begin{array}{r}7 \\
8 \\
9 \\
10 \\
11 \\
12 \\
\end{array}$ & $\begin{array}{r}1 . \overline{24} \\
1 . \overline{4} \\
1.76 \\
\end{array}$ & $\begin{array}{r}828 \\
1, \overline{0} 0^{-} \\
1,520\end{array}$ & $\begin{array}{l}8.35 \\
8.72 \\
9.05 \\
8.89 \\
8.62 \\
8.30\end{array}$ & $\begin{array}{l}20,100 \\
21,300 \\
22,500 \\
22,100 \\
20,900 \\
19,700\end{array}$ & $\begin{array}{l}3.88 \\
3.81 \\
3.76 \\
3.73 \\
3.87 \\
4.15\end{array}$ & $\begin{array}{l}5,770 \\
5,530 \\
5,410 \\
5,410 \\
5,650 \\
6,520 \\
\end{array}$ & $\begin{array}{l}2.98 \\
2.98 \\
2.95 \\
2.92 \\
2.87 \\
2.84\end{array}$ & $\begin{array}{l}3,760 \\
3,760 \\
3,660 \\
3,560 \\
3,460 \\
3,460\end{array}$ & $\left|\begin{array}{c}\cdots \cdots \\
\cdots \cdots \\
\hdashline-\cdots \\
\hdashline-\overline{3} \overline{7}\end{array}\right|$ & 2,510 & $\mid$\begin{tabular}{c}
$-\cdots-$. \\
$-\cdots--$ \\
$-\cdots-$ \\
\hdashline$\overline{2} .0 \overline{8}$
\end{tabular} & ${ }^{2}, 040$ \\
\hline
\end{tabular}

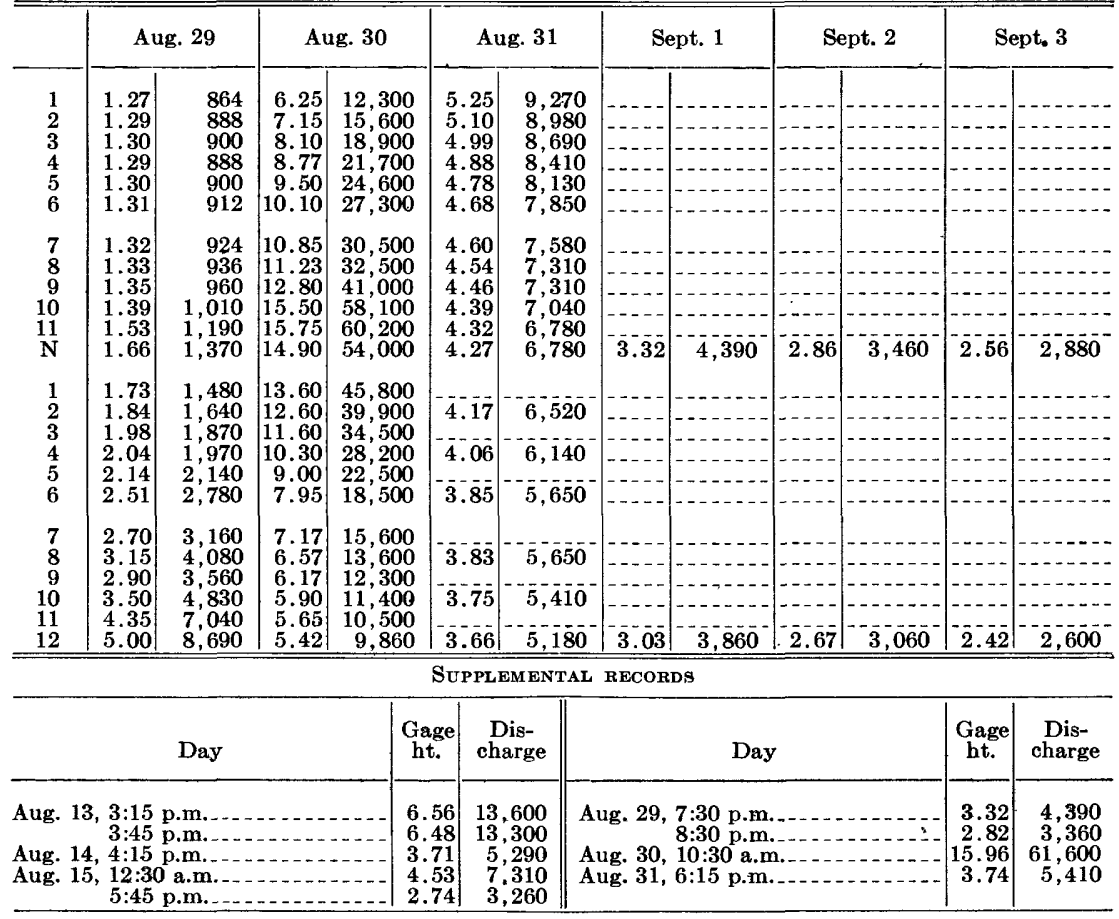

SCOTT CREEK AT SYLVA, N. C.

Location.-Lat. $35^{\circ} 22^{\prime} 25^{\prime \prime}$, long. $83^{\circ} 13^{\prime} 05^{\prime \prime}$, just downstream from Gunter Creek at Sylva, Jackson County. Datum of gage is 2,033.23 feet above mean sea level, datum of 1929 , supplementary adjustment of 1936 . 


\section{FLOODS OF AUGUST 1940 IN THE SOUTHEASTERN STATES}

Drainage AREA. - 55.0 square miles.

GAGE-HEIGHT RECORD.-Water-stage recorder graph, adjusted for partly obstructed intake 5-10 a.m. Aug. 12, 3-7 p.m. Aug. 29, and 10 a.m. Aug. 30 to Sept. 6 .

DISCHARGE RECORD.-Stage-discharge relation defined by current-meter measurements up to 800 second-feet and extended to crest gage height on basis of determination of flood flow by slop-area method. The extension of the 1929 rating was revised on basis of that for 1940. Gage heights used to half-tenths between 3.1 and 3.5 feet prior to Aug. 30 and between 3.4 and 4.7 feet subsequently; hundredths below and tenths above these limits.

Maxima.-1940: Discharge, 3,360 second-feet 4 a.m. Aug. 30 (gage height, 8.61 feet).

1928-39: Discharge, 2,200 second-feet July 10, 1929 (gage height, 6.00 feet). The flood of 1840 probably exceeded that of August 1910 (from survey by Tennessee Valley Authority).

Remarks.-Flood runoff not affected by artificial storage.

Mean discharge, in second-feet, 1940

\begin{tabular}{|c|c|c|c|c|c|c|c|c|c|c|c|}
\hline Day & Aug. & Sept. & Day & Aug. & Sept. & Day & Aug. & Sept. & Day & Aug. & Sept. \\
\hline 1 & 66 & 320 & 9 & 74 & 126 & 17 & 198 & 85 & 25 & 103 & 88 \\
\hline 2 & 6 & & 13 & & & & & & & & 74 \\
\hline 3 & 6 & 20 & 11 & 58 & 11 & 18 & & 8 & 27 & 91 & 71 \\
\hline 4 & 58 & 199 & 12 & 139 & 101 & 20 & 143 & 80 & 28 & 89 & 71 \\
\hline 5 & 58 & 172 & 13 & 659 & 98 & 21 & 13 & 7 & 29 & 322 & 68 \\
\hline 6 & 60 & 159 & 14 & 44 & 91 & 22 & 12 & 7 & 30 & 1,190 & 63 \\
\hline 7 & 70 & 147 & 15 & 299 & 88 & 23 & 12 & 7 & 31 & 407 & \\
\hline 8 & 76 & 13 & 16 & 232 & 8 & 24 & 110 & 74 & & & \\
\hline \multicolumn{10}{|c|}{$\begin{array}{l}\text { Monthly mean discharge, in second-feet } \\
\text { Runoff, in inches }\end{array}$} & $\begin{array}{r}192 \\
4.03\end{array}$ & $\begin{array}{r}117 \\
2.37\end{array}$ \\
\hline
\end{tabular}


TENNESSEE RIVER BASIN

Gage height, in feet, and discharge, in second-feet, at indicated time, 1940

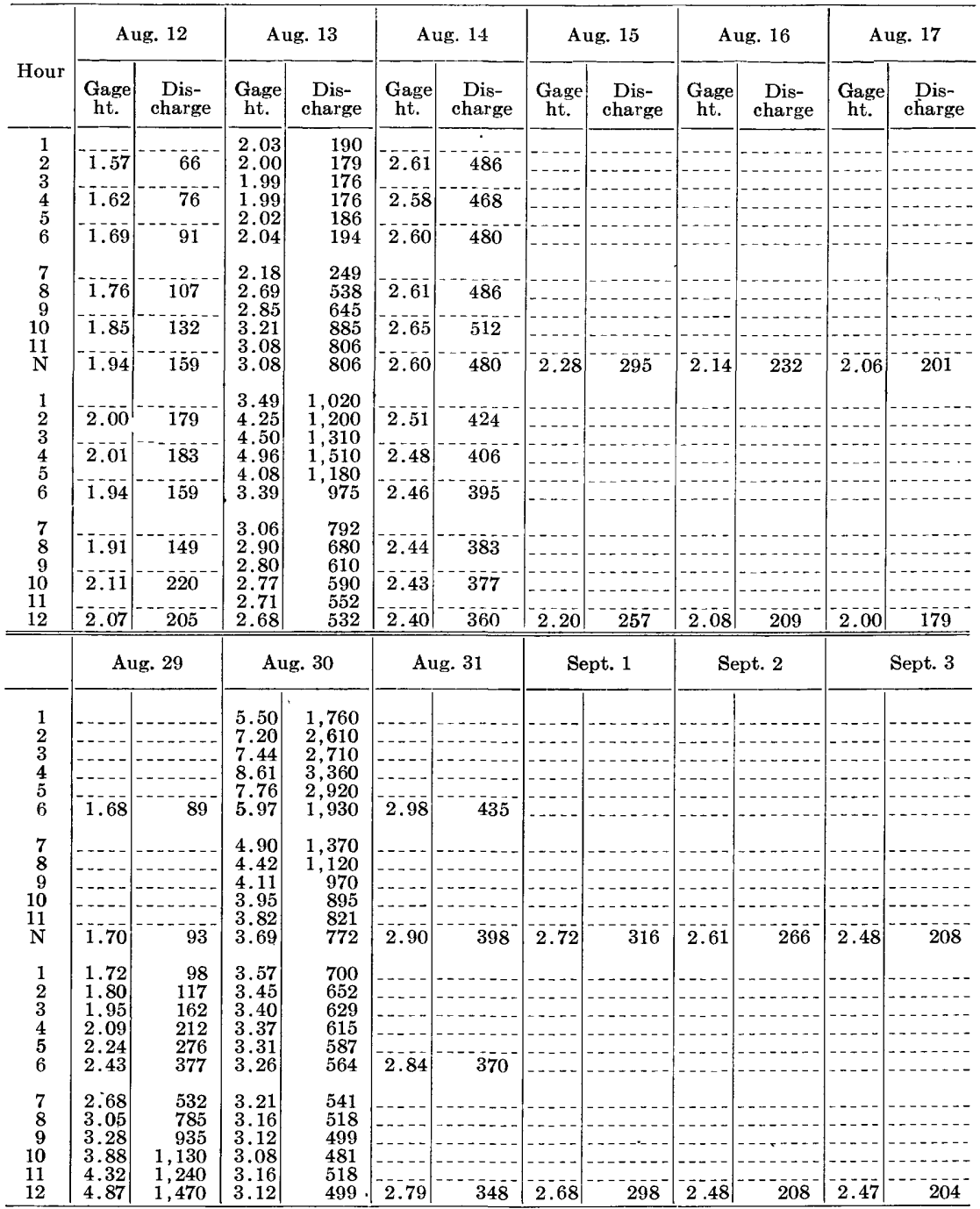

SUPPLEMENTARY RECORD.-Aug. 30, 2:30 a.m., gage height, 6.90 feet, discharge 2,460 second-feet.

\section{OCONALUF"TY RIVER AT CHEROKEE, N. C.}

Location.-Lat. $35^{\circ} 29^{\prime} 15^{\prime \prime}$, long. $83^{\circ} 18^{\prime} 45^{\prime \prime}$, on State Highway 107 , at cable footbridge in Cherokee Indian Reservation, three-quarters of a mile north of Cherokee, Swain County, and 2 miles upstream from Soco Creek. Datum of gage is $1,938.37$ feet above mean sea level, datum of 1929 , supplementary adjustment of 1936 .

DraiN AGE AREA.-131 square miles.

GAGE-HEIGHT RECORD.-Water-stage recorder graph.

DISCHARGE RECORD.-Stage-discharge relation defined by current-meter measurements up to 3,800 second-feet and extended logarithmically to erest gage height of 


\section{FLOODS OF AUGUST 1940 IN THE SOUTHEASTERN STATES}

1936 flood and verified by a slope-area determination of the discharge of the August 1940 flood. Shifting-control method used Aug. 1 to 3 p.m. Aug. 13. Gage heights used to half-tenths between 4.8 and 6.9 feet; hundredths below and tenths above these limits.

Maxima.-1940: Discharge, 6,310 second-feet 4 a.m. Aug. 30 (gage height, 8.84 feet).

1921-39: Discharge, 8,760 second-feet Apr. 6, 1936 (gage height, 10.25 feet). Surveys by the Tennessee Valley Authority show that the flood of March 1867 probably exceeded that of Apr. 6, 1936, and that the flood of November 1906 reached a stage of 12 feet (discharge not determined).

REMARKs.-Flood runoff not affected by artificial storage.

Mean discharge, in second-feet, 1940

\begin{tabular}{|c|c|c|c|c|c|c|c|c|c|c|c|}
\hline Day & Aug. & Sept. & Day & Aug. & Sept. & Day & Aug. & Sept. & Day & Aug. & Sept. \\
\hline $\begin{array}{l}1 \\
2 \\
3 \\
4 \\
5 \\
6 \\
7 \\
8\end{array}$ & $\begin{array}{l}223 \\
192 \\
179 \\
166 \\
159 \\
152 \\
174 \\
152\end{array}$ & $\begin{array}{l}565 \\
456 \\
387 \\
340 \\
308 \\
281 \\
261 \\
244\end{array}$ & $\begin{array}{r}9 \\
10 \\
11 \\
12 \\
13 \\
14 \\
15 \\
16\end{array}$ & $\begin{array}{r}163 \\
138 \\
138 \\
169 \\
1,320 \\
1,610 \\
1,370 \\
652\end{array}$ & $\begin{array}{l}228 \\
281 \\
265 \\
221 \\
206 \\
198 \\
188 \\
177\end{array}$ & $\begin{array}{l}17 \\
18 \\
19 \\
20 \\
21 \\
22 \\
23 \\
24\end{array}$ & $\begin{array}{l}475 \\
424 \\
424 \\
349 \\
312 \\
295 \\
261 \\
244\end{array}$ & $\begin{array}{l}170 \\
184 \\
174 \\
157 \\
151 \\
151 \\
141 \\
141\end{array}$ & $\begin{array}{l}25 \\
26 \\
27 \\
28 \\
29 \\
30 \\
31\end{array}$ & $\begin{array}{r}232 \\
217 \\
206 \\
194 \\
520 \\
2,460 \\
796\end{array}$ & $\begin{array}{l}154 \\
154 \\
135 \\
129 \\
127 \\
124\end{array}$ \\
\hline \multicolumn{10}{|c|}{$\begin{array}{l}\text { Monthly mean discharge, in second-feet } \\
\text { Runoff, in inches }\end{array}$} & $\begin{array}{r}463 \\
4.07\end{array}$ & $\begin{array}{r}223 \\
1.90\end{array}$ \\
\hline
\end{tabular}


TENNESSEE RIVER BASIN

Gage height, in feet, and discharge, in second-feet, at indicated time, 1940

\begin{tabular}{|c|c|c|c|c|c|c|c|c|c|c|c|c|}
\hline \multirow{2}{*}{ Hour } & \multicolumn{2}{|c|}{ Aug. 12} & \multicolumn{2}{|c|}{ Aug. 13} & \multicolumn{2}{|c|}{ Aug. 14} & \multicolumn{2}{|c|}{ Aug. 15} & \multicolumn{2}{|c|}{ Aùg. 16} & \multicolumn{2}{|c|}{ Aug. 17} \\
\hline & $\begin{array}{c}\text { Gage } \\
\text { ht. }\end{array}$ & $\begin{array}{c}\text { Dis- } \\
\text { charge }\end{array}$ & $\begin{array}{c}\text { Gage } \\
\text { ht. }\end{array}$ & $\begin{array}{c}\text { Dis- } \\
\text { charge }\end{array}$ & $\begin{array}{c}\text { Gage } \\
\text { ht. }\end{array}$ & $\begin{array}{c}\text { Dis- } \\
\text { charge }\end{array}$ & $\begin{array}{c}\text { Gage } \\
\text { ht. }\end{array}$ & $\begin{array}{c}\text { Dis- } \\
\text { charge }\end{array}$ & ht. & $\begin{array}{c}\text { Dis- } \\
\text { charge }\end{array}$ & ht. & $\begin{array}{c}\text { Dis- } \\
\text { charge }\end{array}$ \\
\hline $\begin{array}{l}1 \\
2 \\
3 \\
4 \\
5 \\
6\end{array}$ &.- & & $\begin{array}{l}3.77 \\
3.82 \\
3.85 \\
\mathbf{3 . 8 8} \\
\mathbf{3 . 9 2} \\
\mathbf{3 . 9 5}\end{array}$ & $\begin{array}{l}311 \\
338 \\
353 \\
370 \\
392 \\
409\end{array}$ & $\begin{array}{l}\mathbf{5 . 4 0} \\
5.32 \\
5.25 \\
5.24 \\
5.38 \\
5.57\end{array}$ & $\begin{array}{r}1,410 \\
1,360 \\
1,360 \\
1,510 \\
1,680\end{array}$ & $\begin{array}{r}6.19 \\
5.80 \\
5.52\end{array}$ & $\begin{array}{c}\overline{2}, \overline{4} 60^{-} \\
\overline{1}, \overline{9} \overline{0} \\
\overline{1}, \overline{6} \overline{0} 0^{-}\end{array}$ & & & & \\
\hline $\begin{array}{r}7 \\
8 \\
9 \\
10 \\
11 \\
\mathbf{N}\end{array}$ & $\overline{3} . \overline{4}$ & 152 & $\begin{array}{l}3.99 \\
4.05 \\
4.10 \\
4.16 \\
4.35 \\
4.63\end{array}$ & $\begin{array}{l}432 \\
468 \\
498 \\
540 \\
670 \\
887\end{array}$ & $\begin{array}{l}5.63 \\
5.60 \\
5.53 \\
5.44 \\
5.35 \\
5.27\end{array}$ & $\begin{array}{r}1,800 \\
1,740 \\
1,680 \\
1,560 \\
1,460 \\
1,360\end{array}$ & $\begin{array}{r}5.30 \\
-5.15 \\
5.02\end{array}$ & $\begin{array}{l}1, \overline{4} 10^{-} \\
1,260 \\
1,130\end{array}$ & $4 . \overline{38}$ & $648^{--}$ & 4.11 & \\
\hline $\begin{array}{l}1 \\
2 \\
3 \\
4 \\
5 \\
6\end{array}$ & $3 . \overline{4}$ & $1 \overline{6} \overline{3}-$ & $\begin{array}{l}4.91 \\
5.34 \\
5.67 \\
6.37 \\
6.77 \\
6.74\end{array}$ & $\begin{array}{l}1,150 \\
1,510 \\
1,860 \\
2,680 \\
3,200 \\
3,200\end{array}$ & $\begin{array}{l}5.22 \\
5.17 \\
5.14 \\
5.09 \\
5.04 \\
5.00\end{array}$ & $\begin{array}{r}1,310 \\
1,260 \\
1,260 \\
1,220 \\
1,180 \\
1,130\end{array}$ & $\begin{array}{r}4.92 \\
4 . \overline{83} \\
4 . \overline{7} \overline{5}\end{array}$ & $\begin{array}{r}1,040^{-} \\
9984 \\
920^{-1}\end{array}$ & & & $\begin{array}{l}-\cdots \\
-\cdots \\
-\cdots\end{array}$ & \\
\hline $\begin{array}{r}7 \\
8 \\
9 \\
10 \\
11 \\
12\end{array}$ & $\mathbf{3 . 5 3}$ & 196 & $\begin{array}{l}6.52 \\
6.29 \\
6.04 \\
5.84 \\
5.67 \\
5.52\end{array}$ & $\begin{array}{l}2,850 \\
2,590 \\
2,280 \\
2,040 \\
1,800 \\
1,620\end{array}$ & $\begin{array}{l}4.99 \\
5.47 \\
5.97 \\
6.39 \\
6.58 \\
6.56\end{array}$ & $\begin{array}{l}1,130 \\
1,560 \\
2,160 \\
2,720 \\
2,990 \\
2,920\end{array}$ & $\begin{array}{r}4.70 \\
4.65 \\
4.6 \overline{0}\end{array}$ & $\begin{array}{c}880^{-} \\
842^{-} \\
805\end{array}$ & $4 . \overline{0}$ & $\mathbf{5 3 3}$ & $\mathbf{3} .99$ & $41 \overline{4}^{-}$ \\
\hline
\end{tabular}

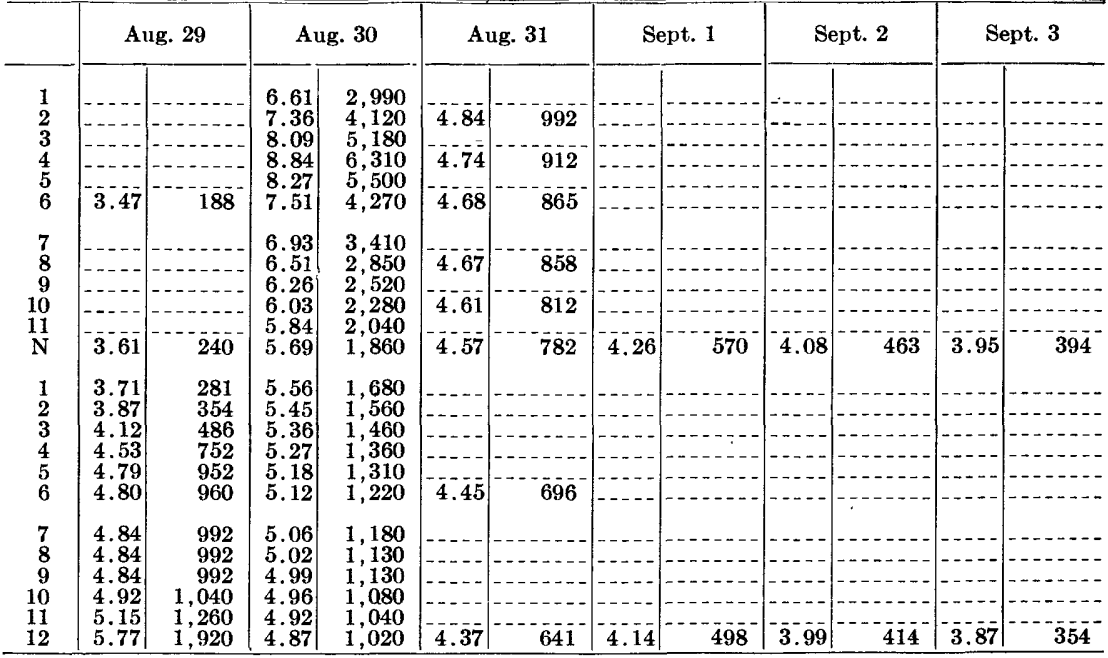

Supplemental ReCorDs.-Aug. 13, 5:30 p.m., gage height, 6.80 feet, discharge, 3,270 second-feet. Aug. 14, $11: 30$ p.m., gage height, 6.59 feet, discharge, 2,990 second-feet.

\section{NOLAND CREEK NEAR BRYSON CITY, N. C.}

Location.-Lat. $35^{\circ} 29^{\prime} 06^{\prime \prime}$, long. $83^{\circ} 30^{\prime} 15^{\prime \prime}, 1.1$ miles downstream from Mill Creek, 1.2 miles south of Great Smoky Mountains National Park, and 5 miles northwest of Bryson City, Swain County.

DRAINAGE AREA.-13.8 square miles.

GAGE-HEIGHT RECORD.-Water-stage recorder graph.

DISCHARGE RECORD.-Stage-discharge relation defined by current-meter measurements up to 270 second-feet and extended to erest gage height on basis of determination of flood flow by eritical-depth section method. Gage heights used to halftenths above 3.9 feet and hundredths below. The rating curve used in 1936 was revised on basis of that used for 1940 . 
Maxima.-1940: Discharge, 1,530 second-feet 12:15 a.m. Aug. 30 (gage height, 4.87 feet).

1935-39: Discharge, 1,060 second-feet Apr. 6, 1936 (gage height, 4.44 feet). Surveys by the Tennessee Valley Authority show that the floods of Mareh 1867 and November 1906 probably exceeded that of Aug. 30, 1940.

REMARKS.-Flood runoff not affected by artificial storage.

Mean discharge, in second-feet, 1940

\begin{tabular}{r|r|r||r|r|r||r|r|r|r|r|r}
\hline Day & Aug. & \multicolumn{1}{|c|}{ Sept. } & Day & Aug. & Sept. & Day & Aug. & Sept. & Day & Aug. & Sept. \\
\hline 1 & 24 & 79 & 9 & 17 & 29 & 17 & 50 & 20 & 25 & 25 & 18 \\
2 & 22 & 62 & 10 & 16 & 36 & 18 & 43 & 19 & 26 & 23 & 16 \\
3 & 20 & 52 & 11 & 16 & 28 & 19 & 42 & 19 & 27 & 22 & 15 \\
4 & 19 & 46 & 12 & 16 & 25 & 20 & 36 & 18 & 28 & 21 & 14 \\
5 & 18 & 41 & 13 & 204 & 24 & 21 & 34 & 17 & 29 & 203 & 14 \\
6 & 17 & 37 & 14 & 219 & 23 & 22 & 31 & 16 & 30 & 343 & 13 \\
7 & 18 & 34 & 15 & 114 & 22 & 23 & 28 & 16 & 31 & 114 & -16 \\
8 & 17 & 32 & 16 & 63 & 20 & 24 & 27 & 16 & \\
\hline
\end{tabular}

Gage height, in feet, and discharge, in second-feet, at indicated time, 1940

\begin{tabular}{|c|c|c|c|c|c|c|c|c|c|c|c|c|}
\hline \multirow{2}{*}{ Hour } & \multicolumn{2}{|c|}{ Aug. 13} & \multicolumn{2}{|c|}{ Aug. 14} & \multicolumn{2}{|c|}{ Aug. 15} & \multicolumn{2}{|c|}{ Aug. 16} & \multicolumn{2}{|c|}{ Aug. 29} & \multicolumn{2}{|c|}{ Aug. 30} \\
\hline & $\begin{array}{c}\text { Gage } \\
\text { ht. }\end{array}$ & $\begin{array}{l}\text { Dis- } \\
\text { charge }\end{array}$ & $\begin{array}{l}\text { Gage } \\
\text { ht. }\end{array}$ & $\begin{array}{l}\text { Dis- } \\
\text { charge }\end{array}$ & $\begin{array}{l}\text { Gage } \\
\text { ht. }\end{array}$ & $\begin{array}{c}\text { Dis- } \\
\text { charge }\end{array}$ & $\begin{array}{c}\text { Gage } \\
\text { ht. }\end{array}$ & $\begin{array}{c}\text { Dis- } \\
\text { charge }\end{array}$ & $\begin{array}{c}\text { Gage } \\
\text { ht. }\end{array}$ & $\begin{array}{l}\text { Dis- } \\
\text { charge }\end{array}$ & $\begin{array}{c}\text { Gage } \\
\text { ht. }\end{array}$ & $\begin{array}{c}\text { Dis- } \\
\text { charge }\end{array}$ \\
\hline $\begin{array}{l}1 \\
2 \\
3 \\
4 \\
5 \\
6\end{array}$ & $\begin{array}{l}1.12 \\
1.13 \\
1.15 \\
1.16 \\
1.17 \\
1.22\end{array}$ & $\begin{array}{l}19 \\
19 \\
20 \\
20 \\
21 \\
23\end{array}$ & $\begin{array}{l}2.49 \\
2.49 \\
2.68 \\
3.15 \\
3.15 \\
2.96\end{array}$ & $\begin{array}{l}184 \\
184 \\
237 \\
395 \\
395 \\
326\end{array}$ & 2.36 & 153 & & & $\begin{array}{l}1.23 \\
1.23 \\
1.24 \\
1.26 \\
1.29 \\
1.29\end{array}$ & $\begin{array}{l}20 \\
20 \\
21 \\
22 \\
24 \\
24\end{array}$ & $\begin{array}{l}4.42 \\
3.80 \\
3.57 \\
3.37 \\
3.22 \\
3.11\end{array}$ & $\begin{array}{r}1,130 \\
720 \\
588 \\
486 \\
422 \\
380\end{array}$ \\
\hline $\begin{array}{r}7 \\
8 \\
9 \\
10 \\
11 \\
\mathrm{~N}\end{array}$ & $\begin{array}{l}1.30 \\
1.40 \\
1.48 \\
1.63 \\
2.10 \\
2.50\end{array}$ & $\begin{array}{r}26 \\
31 \\
36 \\
46 \\
100 \\
187\end{array}$ & $\begin{array}{l}2.79 \\
2.70 \\
2.59 \\
2.51 \\
2.45 \\
2.41\end{array}$ & $\begin{array}{l}271 \\
243 \\
211 \\
190 \\
174 \\
164\end{array}$ & 2.19 & 116 & 1.82 & 63 & $\begin{array}{l}1.32 \\
1.34 \\
1.37 \\
1.47 \\
1.72 \\
2.42\end{array}$ & $\begin{array}{r}25 \\
26 \\
28 \\
35 \\
54 \\
167\end{array}$ & $\begin{array}{l}3.02 \\
2.93 \\
2.85 \\
2.79 \\
2.73 \\
2.67\end{array}$ & $\begin{array}{l}347 \\
316 \\
290 \\
271 \\
252 \\
234\end{array}$ \\
\hline $\begin{array}{l}1 \\
2 \\
3 \\
4 \\
5 \\
6\end{array}$ & $\begin{array}{l}3.40 \\
3.48 \\
3.35 \\
3.27 \\
3.24 \\
3.15\end{array}$ & $\begin{array}{l}500 \\
540 \\
478 \\
443 \\
430 \\
395\end{array}$ & $\begin{array}{l}2.38 \\
2.36 \\
2.33 \\
2.30 \\
2.30 \\
2.35\end{array}$ & $\begin{array}{l}157 \\
153 \\
146 \\
139 \\
139 \\
150\end{array}$ & 2.01 & $8 \overline{6}$ & 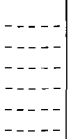 & & $\begin{array}{l}3.02 \\
2.78 \\
2.59 \\
2.46 \\
2.41 \\
2.79\end{array}$ & $\begin{array}{l}347 \\
268 \\
211 \\
177 \\
164 \\
271\end{array}$ & $\begin{array}{l}2.62 \\
2.57 \\
2.54 \\
2.50 \\
2.48 \\
2.47\end{array}$ & $\begin{array}{l}220 \\
206 \\
198 \\
187 \\
182 \\
180\end{array}$ \\
\hline $\begin{array}{r}7 \\
8 \\
9 \\
10 \\
11 \\
12\end{array}$ & $\begin{array}{l}3.11 \\
2.97 \\
2.82 \\
2.71 \\
2.62 \\
2.53\end{array}$ & $\begin{array}{l}380 \\
330 \\
280 \\
246 \\
220 \\
195\end{array}$ & $\begin{array}{l}2.52 \\
2.62 \\
2.68 \\
2.74 \\
2.78 \\
2.67\end{array}$ & $\begin{array}{l}192 \\
220 \\
237 \\
255 \\
268 \\
234\end{array}$ & $\begin{array}{r}1.95 \\
1.9 \overline{2}\end{array}$ & 75 & $1.7 \overline{3}$ & & $\begin{array}{l}2.75 \\
2.72 \\
3.19 \\
3.50 \\
3.87 \\
4.77\end{array}$ & $\begin{array}{r}258 \\
249 \\
410 \\
550 \\
762 \\
1,440\end{array}$ & $\begin{array}{l}2.47 \\
2.45 \\
2.42 \\
2.39 \\
2.36 \\
2.34\end{array}$ & $\begin{array}{l}180 \\
174 \\
167 \\
160 \\
153 \\
148\end{array}$ \\
\hline
\end{tabular}

Supplemental Reconds.-Aug. 14, 4:15 a.m., gage height, 3.22 feet, discharge, 422 second-feet. Aug. $29,12: 45 \mathrm{p} . \mathrm{m}$, gage height, 3.06 feet, discharge, 362 second-feet; $5: 30 \mathrm{p.m}$., gage height, 2.40 feet, discharge, 162 second-feet. Aug. 30, 12:15 a.m., gage height, 4.87 feet, discharge, 1,530 second-feet.

\section{TELLICO RIVER AT TELLICO PLAINS, TENN.}

Location.-Lat. $35^{\circ} 21^{\prime} 42^{\prime \prime}$, long. $84^{\circ} 16^{\prime} 44^{\prime \prime}$, 200 feet upstream from bridge on Tellico Plains-Rafter road, 0.4 mile downstream from Laurel Creek, and 0.8 mile east of Tellico Plains, Monroe County. Datum of gage is 846.64 feet above mean sea level, datum of 1929, supplementary adjustment of 1936 .

DRAINAGE AREA. - 118 square miles.

GAGE-HEIGHT RECORD.-Water-stage recorder graph.

DISCHARGE RECORD.-Stage-discharge relation defined by current-meter measurements up to 6,530 second-feet. Gage heights used to half-tenths between 2.7 and 4.3 feet; hundredths below and tenths above these limits.

Maxima.-August 1940: Discharge, 750 second-feet 4 p.m. Aug. 13 and 9 p.m. Aug. 14 (gage height, 2.99 feet). 
1925 to July 1940 : Discharge, 10,900 second-feet Aug. 5, 1938 (gage height, 11.39 feet).

REMARKs.-Flood runoff not affected by artificial storage.

Mean discharge, in second-feet, 1940

\begin{tabular}{|c|c|c|c|c|c|c|c|c|c|c|c|}
\hline Day & Aug. & Sept. & Day & Aug. & Sept. & Day & Aug. & Sept. & Day & Aug. & Sept. \\
\hline $\begin{array}{l}1 \\
2 \\
3 \\
4 \\
5 \\
6 \\
7 \\
8\end{array}$ & $\begin{array}{l}79 \\
76 \\
64 \\
60 \\
58 \\
56 \\
66 \\
61\end{array}$ & $\begin{array}{r}100 \\
86 \\
77 \\
72 \\
81 \\
68 \\
64 \\
61\end{array}$ & $\begin{array}{r}9 \\
10 \\
11 \\
12 \\
13 \\
14 \\
15 \\
16\end{array}$ & $\begin{array}{r}58 \\
70 \\
56 \\
57 \\
301 \\
558 \\
346 \\
184\end{array}$ & $\begin{array}{l}60 \\
61 \\
77 \\
58 \\
55 \\
53 \\
52 \\
49\end{array}$ & $\begin{array}{l}17 \\
18 \\
19 \\
20 \\
21 \\
22 \\
23 \\
24\end{array}$ & $\begin{array}{r}135 \\
112 \\
131 \\
102 \\
90 \\
87 \\
80 \\
85\end{array}$ & $\begin{array}{l}47 \\
46 \\
46 \\
45 \\
45 \\
44 \\
42 \\
41\end{array}$ & $\begin{array}{l}25 \\
26 \\
27 \\
28 \\
29 \\
30 \\
\mathbf{3 1}\end{array}$ & $\begin{array}{r}76 \\
70 \\
66 \\
64 \\
168 \\
209 \\
151\end{array}$ & $\begin{array}{l}61 \\
84 \\
47 \\
44 \\
42 \\
\mathbf{4 1} \\
-\end{array}$ \\
\hline \multicolumn{10}{|c|}{$\begin{array}{l}\text { Monthly mean discharge, in second-feet. } \\
\text { Runoff, in inches }\end{array}$} & $\begin{array}{r}122 \\
1.19\end{array}$ & $\begin{array}{l}58.3 \\
0.55\end{array}$ \\
\hline
\end{tabular}

Gage height, in feet, and discharge, in second-feet, at indicated time, 1940

\begin{tabular}{|c|c|c|c|c|c|c|}
\hline \multirow{2}{*}{ Hour } & \multicolumn{2}{|c|}{ Aug. 13} & \multicolumn{2}{|c|}{ Aug. 14} & \multicolumn{2}{|c|}{ Aug. 15} \\
\hline & $\begin{array}{c}\text { Gage } \\
\text { height }\end{array}$ & Discharge & $\begin{array}{l}\text { Gage } \\
\text { height }\end{array}$ & Discharge & $\begin{array}{c}\text { Gage } \\
\text { height }\end{array}$ & Discharge \\
\hline $\begin{array}{l}1 \\
2 \\
3 \\
4 \\
5 \\
6\end{array}$ & 1.07 & 61 & $\begin{array}{l}2.36 \\
2.30 \\
2.24 \\
2.22 \\
2.32 \\
2.48\end{array}$ & $\begin{array}{l}442 \\
415 \\
590 \\
382 \\
424 \\
498\end{array}$ & $\begin{array}{l}2.66 \\
2.56 \\
2.47 \\
2.40 \\
2.34 \\
2.28\end{array}$ & $\begin{array}{l}585 \\
537 \\
494 \\
460 \\
433 \\
407\end{array}$ \\
\hline $\begin{array}{r}7 \\
8 \\
9 \\
10 \\
11 \\
\end{array}$ & $1.3 \overline{2}$ & 112 & $\begin{array}{l}2.55 \\
2.55 \\
2.53 \\
2.50 \\
2.49 \\
2.46\end{array}$ & $\begin{array}{l}532 \\
532 \\
522 \\
508 \\
503 \\
489\end{array}$ & $\begin{array}{l}2.23 \\
2.18 \\
2.14 \\
2.10 \\
2.06 \\
2.02\end{array}$ & $\begin{array}{l}386 \\
367 \\
352 \\
338 \\
325 \\
312\end{array}$ \\
\hline $\begin{array}{l}1 \\
2 \\
3 \\
4 \\
5 \\
6\end{array}$ & $\begin{array}{l}1.34 \\
1.44 \\
2.90 \\
2.99 \\
2.97 \\
2.92\end{array}$ & $\begin{array}{l}117 \\
143 \\
701 \\
750 \\
726 \\
701\end{array}$ & $\begin{array}{l}2.46 \\
2.50 \\
2.65 \\
2.81 \\
2.87 \\
2.89\end{array}$ & $\begin{array}{l}489 \\
508 \\
580 \\
652 \\
676 \\
701\end{array}$ & 1.85 & 260 \\
\hline \begin{tabular}{r|}
7 \\
8 \\
9 \\
10 \\
11 \\
12
\end{tabular} & $\begin{array}{l}2.83 \\
2.76 \\
2.63 \\
2.55 \\
2.49 \\
2.42\end{array}$ & $\begin{array}{l}676 \\
628 \\
570 \\
532 \\
503 \\
470\end{array}$ & $\begin{array}{l}2.92 \\
2.97 \\
2.99 \\
2.96 \\
2.88 \\
2.76\end{array}$ & $\begin{array}{l}701 \\
726 \\
750 \\
726 \\
701 \\
628\end{array}$ & 1.72 & 221 \\
\hline
\end{tabular}

CLINCH RIVER AT CLEVELAND, VA.

Location.-Lat. $36^{\circ} 56^{\prime} 41^{\prime \prime}$, long. $82^{\circ} 09^{\prime} 18^{\prime \prime}$, 500 feet upstream from highway bridge at Cleveland, Russell County, 0.5 mile downstream from Muddy Hollow, and 2.3 miles downstream from Weaver Creek. Datum of gage is $1,500.24$ feet above mean sea level, datum of 1929, supplementary adjustment of 1936.

Drainage AREa. - 528 square miles.

GAGE-HEIGHT RECORD.-Water-stage recorder graph.

DISCHARGE RECORD.-Stage-discharge relation defined by current-meter measurements up to 8,800 second-feet and extended to crest gage height by logarithmic plotting on basis of comparisons of flood records with those for Clinch River at Speers Ferry. Gage heights used to half-tenths between 2.9 and 5.2 feet; hundredths below and tenths above these limits.

Maxima.-1940: Discharge, 22,500 second-feet 8 a.m. Aug. 14 (gage height, 20.60 feet).

1920-39: Discharge, 22,500 second-feet Dec. 22, 1926 (gage height observed, 21.1 feet, site and datum then in use). 
FLOODS OF AUGUST 1940 IN THE SOUTHEASTERN STATES

Mean discharge, in second-feet, 1940

\begin{tabular}{|c|c|c|c|c|c|c|c|c|c|c|c|}
\hline Day & Aug. & Sept. & Day & Aug. & Sept. & Day & Aug. & Sept. & Day & Aug. & Sept. \\
\hline $\begin{array}{l}1 \\
2 \\
3 \\
4 \\
5 \\
6 \\
7 \\
8\end{array}$ & $\begin{array}{r}2,760 \\
1,150 \\
643 \\
461 \\
367 \\
353 \\
901 \\
461\end{array}$ & $\begin{array}{r}2,090 \\
1,050 \\
724 \\
555 \\
470 \\
405 \\
355 \\
322\end{array}$ & $\begin{array}{r}9 \\
10 \\
11 \\
12 \\
13 \\
14 \\
15 \\
16\end{array}$ & $\begin{array}{r}322 \\
259 \\
226 \\
206 \\
371 \\
14,400 \\
5,960 \\
3,310\end{array}$ & $\begin{array}{l}296 \\
330 \\
338 \\
299 \\
259 \\
232 \\
216 \\
201\end{array}$ & $\begin{array}{l}17 \\
18 \\
19 \\
20 \\
21 \\
22 \\
23 \\
24\end{array}$ & $\begin{array}{r}2,130 \\
1,730 \\
2,560 \\
2,160 \\
1,410 \\
1,300 \\
1,010 \\
792\end{array}$ & $\begin{array}{l}195 \\
190 \\
176 \\
170 \\
163 \\
160 \\
148 \\
143\end{array}$ & $\begin{array}{l}25 \\
26 \\
27 \\
28 \\
29 \\
30 \\
31\end{array}$ & $\begin{array}{r}658 \\
574 \\
519 \\
470 \\
412 \\
522 \\
2,450\end{array}$ & $\begin{array}{r}160 \\
193 \\
187 \\
173 \\
150 \\
143 \\
\end{array}$ \\
\hline & & & & & & & & & & $\begin{array}{r}1,640 \\
3.58\end{array}$ & $\begin{array}{r}350 \\
0.74\end{array}$ \\
\hline
\end{tabular}

Gage height, in feet, and discharge, in second-feet, at indicated time, 1940

\begin{tabular}{|c|c|c|c|c|c|c|c|c|c|c|c|c|}
\hline \multirow{2}{*}{ Hour } & \multicolumn{2}{|c|}{ Aug. 13} & \multicolumn{2}{|c|}{ Aug. 14} & \multicolumn{2}{|c|}{ Aug. 15} & \multicolumn{2}{|c|}{ Aug. 16} & \multicolumn{2}{|c|}{ Aug. 17} & \multicolumn{2}{|c|}{ Aug. 18} \\
\hline & $\begin{array}{c}\text { Gage } \\
\text { ht. }\end{array}$ & $\begin{array}{c}\text { Dis- } \\
\text { charge }\end{array}$ & $\begin{array}{c}\text { Gage } \\
\mathrm{ht} .\end{array}$ & $\begin{array}{c}\text { Dis- } \\
\text { charge }\end{array}$ & $\begin{array}{c}\text { Gage } \\
\text { ht. }\end{array}$ & $\begin{array}{c}\text { Dis- } \\
\text { charge }\end{array}$ & $\begin{array}{c}\text { Gage } \\
\text { ht. }\end{array}$ & $\begin{array}{c}\text { Dis- } \\
\text { charge }\end{array}$ & $\begin{array}{c}\text { Gage } \\
\text { ht. }\end{array}$ & $\begin{array}{c}\text { Dis- } \\
\text { charge }\end{array}$ & $\begin{array}{c}\text { Gage } \\
\text { ht. }\end{array}$ & $\begin{array}{c}\text { Dis- } \\
\text { charge }\end{array}$ \\
\hline \multirow{4}{*}{$\begin{array}{l}1 \\
2 \\
3 \\
4 \\
5 \\
6\end{array}$} & & & \multirow{4}{*}{$\begin{array}{r}7.75 \\
10.90 \\
13.40 \\
18.05 \\
18.10 \\
19.40\end{array}$} & \multirow{4}{*}{$\begin{array}{r}4,790 \\
8,390 \\
11,500 \\
15,200 \\
18,400 \\
20,500\end{array}$} & & & & & & & & \\
\hline & & & & & 10.00 & 7,310 & & & & & & \\
\hline & & & & & 9.73 & 6,950 & $\ldots$ & $\ldots$ & & $\ldots$ & . & - \\
\hline & 1.79 & 198 & & & 9.48 & 6,710 & 6.73 & 3,680 & 5.33 & 2,340 & $\overline{4} . \overline{4} \mathbf{1}$ & 1,600 \\
\hline \multirow{4}{*}{$\begin{array}{r}7 \\
8 \\
9 \\
10 \\
11 \\
\mathrm{~N}\end{array}$} & & & \multirow{4}{*}{$\begin{array}{l}20.25 \\
20.60 \\
20.50 \\
20.10 \\
19.50 \\
18.70\end{array}$} & \multirow{4}{*}{$\begin{array}{l}21,800 \\
22,500 \\
22,300 \\
21,600 \\
20,600 \\
19,400\end{array}$} & & & & & & & & \\
\hline & & & & & 9.23 & 6,350 & & & & & & \\
\hline & & & & & 8.98 & 6,110 & & & & & & - \\
\hline & 1.79 & 198 & & & 8.77 & 5,890 & 6.18 & 3,180 & 5.04 & 2,120 & 4.23 & 1,500 \\
\hline \multirow{3}{*}{$\begin{array}{l}1 \\
2 \\
3 \\
4 \\
5 \\
6\end{array}$} & 1.79 & $19 \overline{8}$ & \multirow{3}{*}{$\left|\begin{array}{l}17.75 \\
16.75 \\
15.40 \\
15.00 \\
14.05 \\
13.30\end{array}\right|$} & \multirow{3}{*}{$\begin{array}{l}17,900 \\
16,400 \\
14,300 \\
13,700 \\
12,300 \\
11,400\end{array}$} & 8.62 & 5,670 & & & & & & \\
\hline & $|\overline{1} . \overline{8}|$ & 204 & & & $8 . \overline{4}$ & 5,450 & $\ldots$ & -- & & $-\alpha$ & 4.13 & $1,420^{-}$ \\
\hline & 1.92 & 239 & & & 8.21 & 5,230 & $5.8 \overline{7}$ & 2,880 & $=\overline{4} . \overline{0}$ & 1,920 & & \\
\hline \multirow{5}{*}{$\begin{array}{r}7 \\
8 \\
9 \\
10 \\
11 \\
12 \\
\end{array}$} & & & \multirow{4}{*}{$\mid \begin{array}{l}12.60 \\
12.00 \\
11.57 \\
11.22 \\
10.93 \\
10.60\end{array}$} & \multirow{4}{*}{$\begin{array}{r}10,500 \\
9,710 \\
9,230 \\
8,750 \\
8,390 \\
8,030 \\
\end{array}$} & & & & & & & & \\
\hline & 2.18 & 334 & & & 7.95 & 5,010 & - & & & & 5.47 & 2,520 \\
\hline & 3.30 & 880 & & & $7.6 \overline{7}$ & 4,680 & & & & & & \\
\hline & 5.55 & 2,610 & & & {$\left[\begin{array}{r}7 \\
\end{array}\right.$} & 4,380 & 5.62 & 2,610 & $\begin{array}{r}4 \\
4\end{array}$ & 1,760 & 5.00 & 2,080 \\
\hline & \multicolumn{2}{|c|}{ Aug. 19} & \multicolumn{2}{|c|}{ Aug. 20} & \multicolumn{2}{|c|}{ Aug. 31} & \multicolumn{2}{|c|}{ Sept. 1} & \multicolumn{2}{|c|}{ Sept. 2} & \multicolumn{2}{|c|}{ Sept. 3} \\
\hline \multirow{4}{*}{$\begin{array}{l}1 \\
2 \\
3 \\
4 \\
5 \\
\mathbf{5}\end{array}$} & & & & & 2.66 & 542 & & & & & & \\
\hline & & & & & \begin{tabular}{|}
2.65 \\
2.64
\end{tabular} \mid & 32 & & & & & & \\
\hline & 4.85 & 1,960 & $\ldots$ & -1 & 2.63 & 528 & 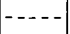 & -1 & & & $\cdots$ & \\
\hline & & & 5.38 & 2,430 & 2.63 & 528 & 5.49 & $2,520^{-}$ & & & & \\
\hline 8 & 5.73 & 2.700 & & & $\begin{array}{l}2.68 \\
3.23\end{array}$ & & & & & & & \\
\hline $\begin{array}{r}9 \\
10\end{array}$ & & & & & $\begin{array}{l}3.63 \\
3.05\end{array}$ & 1,0 & & & & & & \\
\hline$\frac{11}{N}$ & 5.93 & 2,880 & 5 & 2160 & 4.48 & $\begin{array}{l}1,680 \\
1,60\end{array}$ & 483 & 1 & 354 & 1030 & 30 & $810^{-}$ \\
\hline 1 & & & & & & & & & & & & \\
\hline$\stackrel{2}{3}$ & & & & & & & & & & & 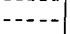 & \\
\hline 4 & & & $\cdots$ & & $\begin{array}{l}0.03 \\
7.05\end{array}$ & & & & & & & \\
\hline 6 & 5.68 & 2,700 & 4.75 & 1,880 & 8.05 & $\begin{array}{l}4,080 \\
5,010\end{array}$ & 4.35 & $1,560^{-}$ & $\ldots$ & 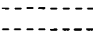 & $\cdots$ & $\cdots$ \\
\hline 7 & & & & & 8.22 & $\mathbf{5}$ & & & & & & \\
\hline 9 & & & & & $\begin{array}{l}8.10 \\
7.80\end{array}$ & & & & & & & \\
\hline $\begin{array}{l}10 \\
11\end{array}$ & & & & - & 7.42 & 4, & $\cdots$ & & & & $\ldots$ & \\
\hline 12 & 5.68 & 2,700 & $|-\overline{4} \mathbf{5} 1|$ & $1,680^{-}$ & 6.65 & 3,580 & $|4.00|$ & 1,320 & $3.2 \overline{3}$ & $850^{-}$ & $\mid 2.84$ & 628 \\
\hline
\end{tabular}

CLINCH RIVER AT SPEERS FERRY, VA.

LOCATION.-Lat. $36^{\circ} 38^{\prime} 55^{\prime \prime}$, long. $82^{\circ} 45^{\prime} 02^{\prime \prime}$, at highway bridge half a mile down- 
stream from Copper Creek, three-quarters of a mile northwest of Speers Ferry, Scott County, and 2 miles downstream from Clinchport. Datum of gage is 1,196.52 feet above mean sea level, datum of 1929, supplementary adjustment of 1936.

DraiNAGE AREA.-1,126 square miles.

GAGE-HEIGHT RECORD.-Water-stage recorder graph.

DISCHARGE RECORD.-Stage-discharge relation defined by current-meter measurements up to 18,000 second-feet. Gage heights used to half-tenths between 3.0 and 4.6 feet; hundredths below and tenths above these limits.

Maxima.--1940: Discharge, 25,100 second-feet 4 a.m. Aug. 15 (gage height, 20.98 feet).

1920-39: Discharge observed, 37,200 second-feet Feb. 3, 1923 (gage height, 24.35 feet datum then in use, 25.85 feet present datum).

Mean discharge, in second-feet, 1940

\begin{tabular}{|c|c|c|c|c|c|c|c|c|c|c|c|}
\hline Day & Aug. & Sept. & Day & Aug. & Sept. & Day & Aug. & Sept. & Day & Aug. & Sept. \\
\hline $\begin{array}{l}1 \\
2 \\
3 \\
4 \\
5 \\
6 \\
7 \\
8\end{array}$ & $\begin{array}{r}1,900 \\
3,030 \\
1,500 \\
1,020 \\
750 \\
630 \\
1,730 \\
1,900\end{array}$ & $\begin{array}{r}5,910 \\
3,040 \\
2,010 \\
1,520 \\
1,180 \\
988 \\
842 \\
722\end{array}$ & $\begin{array}{r}9 \\
10 \\
11 \\
12 \\
13 \\
14 \\
15 \\
16\end{array}$ & $\begin{array}{r}1,030 \\
700 \\
538 \\
443 \\
448 \\
8,970 \\
17,900 \\
6,640\end{array}$ & $\begin{array}{l}656 \\
658 \\
698 \\
638 \\
548 \\
480 \\
428 \\
400\end{array}$ & $\begin{array}{l}17 \\
18 \\
19 \\
20 \\
21 \\
22 \\
23 \\
24\end{array}$ & $\begin{array}{l}3,770 \\
2,790 \\
3,870 \\
4,350 \\
2,970 \\
2,750 \\
2,230 \\
1,700\end{array}$ & $\begin{array}{l}364 \\
346 \\
334 \\
314 \\
296 \\
292 \\
271 \\
271\end{array}$ & $\begin{array}{l}25 \\
26 \\
27 \\
28 \\
29 \\
30 \\
31\end{array}$ & $\begin{array}{r}1,380 \\
1,170 \\
1,010 \\
901 \\
860 \\
2,410 \\
3,470\end{array}$ & $\begin{array}{c}279 \\
274 \\
298 \\
306 \\
290 \\
266 \\
-\ldots\end{array}$ \\
\hline \multicolumn{10}{|c|}{$\begin{array}{l}\text { Monthly mean discharge, in second-feet } \\
\text { Runoff, in inchess }\end{array}$} & $\begin{array}{r}2,734 \\
2.80\end{array}$ & $\begin{array}{r}831 \\
0.82\end{array}$ \\
\hline
\end{tabular}

Gage height, in feet, and discharge, in second-feet, at indicated time, 1940

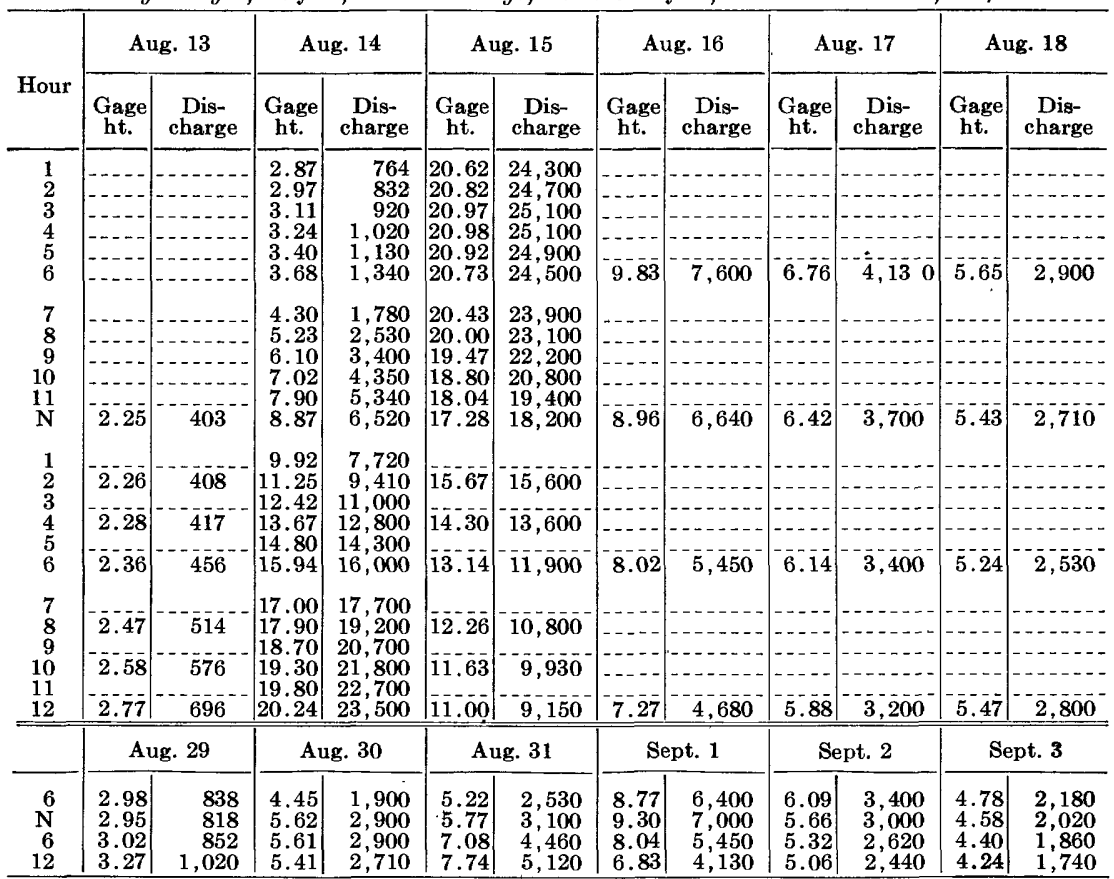

SUPPLEMENTAL RECORD.-Sept. 1, 11 a.m., gage height, 9.33 feet, discharge, 7,000 second-feet.

CLINCH RIVER ABOVE TAZEWELL, TENN.

LoCATION.-Lat. $36^{\circ} 25^{\prime} 30^{\prime \prime}$, long. $83^{\circ} 23^{\prime} 54^{\prime \prime}$, 0.4 mile upstream from Grissom Island, 4.6 miles downstream from Big War Creek, and 10 miles east of Taze- 


\section{FLOODS OF AUGUST 1940 IN THE SOUTHEASTERN STATES}

well, Claiborne County. Datum of gage is 1,060.7 feet above mean sea level, datum of 1929, supplementary adjustment of 1936 .

DRAINAGE AREA.-1;474 square miles.

GAGE-HEIGHT RECORD.-Water-stage recorder graph.

DischaRGE RECORD.-Síage-discharge relation defined by current-meter measurements up to 25,600 second-feet. Gage heights used to half-tenths between 2.1 and 4.2 feet; hundredths below and tenths above these limits.

Maxima.-1910: Discharge, 24,300 second-feet 5 p.m. Aug. 15 (gage height, 13.29 feet).

1927-39 : Discharge, 37,800 second-feet Jan. 31, 1932 (gage height, 14.90 feet, site and datum then in use).

Stage known, about 24 feet (present site and datum) in 1862, from information supplied by local resident (discharge not determined).

REMARKs.-Flood runoff not affected by artificial storage.

Mean discharge, in second-feet, 1940

\begin{tabular}{|c|c|c|c|c|c|c|c|c|c|c|c|}
\hline Day & Aug. & Sept. & Day & Aug. & Sept. & Day & Aug. & Sept. & Day & Aug. & Sept. \\
\hline $\begin{array}{l}1 \\
2 \\
3 \\
4 \\
5 \\
6 \\
7 \\
8\end{array}$ & $\begin{array}{r}2,420 \\
2,660 \\
2,300 \\
1,310 \\
942 \\
751 \\
766 \\
2,100\end{array}$ & $\begin{array}{r}5,920 \\
5,290 \\
2,720 \\
1,890 \\
1,450 \\
1,170 \\
987 \\
857\end{array}$ & $\begin{array}{r}9 \\
10 \\
11 \\
12 \\
13 \\
14 \\
15 \\
16\end{array}$ & $\begin{array}{r}1,450 \\
910 \\
683 \\
565 \\
558 \\
1,360 \\
18,500 \\
12,500\end{array}$ & $\begin{array}{l}770 \\
728 \\
728 \\
728 \\
676 \\
610 \\
548 \\
503\end{array}$ & $\begin{array}{l}17 \\
18 \\
19 \\
20 \\
21 \\
22 \\
23 \\
24\end{array}$ & $\begin{array}{l}5,510 \\
3,210 \\
3,100 \\
4,790 \\
3,810 \\
3,030 \\
2,540 \\
2,010\end{array}$ & $\begin{array}{l}472 \\
436 \\
413 \\
407 \\
386 \\
365 \\
354 \\
334\end{array}$ & $\begin{array}{l}25 \\
26 \\
27 \\
28 \\
29 \\
30 \\
31\end{array}$ & $\begin{array}{r}1,540 \\
1,310 \\
1,120 \\
984 \\
941 \\
2,260 \\
3,440\end{array}$ & $\begin{array}{r}360 \\
375 \\
344 \\
354 \\
365 \\
354 \\
-\end{array}$ \\
\hline iun & & & & & & & & & & $\begin{array}{r}2,883 \\
2.25\end{array}$ & $\begin{array}{r}1,030 \\
0.78\end{array}$ \\
\hline
\end{tabular}

Gage height, in feet, and discharge, in second-feet, at indicated time, 1940

\begin{tabular}{|c|c|c|c|c|c|c|c|c|c|c|c|c|}
\hline \multirow{2}{*}{ Hour } & \multicolumn{2}{|c|}{ Aug. 14} & \multicolumn{2}{|c|}{ Aug. 15} & \multicolumn{2}{|c|}{ Aug. 16} & \multicolumn{2}{|c|}{ Aug. 17} & \multicolumn{2}{|c|}{ Aug. 18} & \multicolumn{2}{|c|}{ Aug. 19} \\
\hline & $\begin{array}{c}\text { Gage } \\
\text { ht. }\end{array}$ & $\begin{array}{c}\text { Dis- } \\
\text { charge }\end{array}$ & $\begin{array}{c}\text { Gage } \\
\text { ht. }\end{array}$ & $\begin{array}{c}\text { Dis- } \\
\text { charge }\end{array}$ & $\begin{array}{c}\text { Gage } \\
\text { ht. }\end{array}$ & $\begin{array}{c}\text { Dis- } \\
\text { charge }\end{array}$ & $\begin{array}{c}\text { Gage } \\
\text { ht. }\end{array}$ & $\begin{array}{c}\text { Dis- } \\
\text { charge }\end{array}$ & $\begin{array}{c}\text { Gage } \\
\text { ht. }\end{array}$ & $\begin{array}{l}\text { Dis- } \\
\text { charge }\end{array}$ & $\begin{array}{c}\text { Gage } \\
\text { ht. }\end{array}$ & $\begin{array}{l}\text { Dis- } \\
\text { charge }\end{array}$ \\
\hline \multirow{3}{*}{$\begin{array}{l}1 \\
2 \\
3 \\
4 \\
5 \\
6\end{array}$} & & & $\begin{array}{l}6.15 \\
6.80\end{array}$ & $\begin{array}{l}6,670 \\
7,740\end{array}$ & 11.70 & 19,500 & & & & & & \\
\hline & 1.71 & 813 & $\begin{array}{l}7.48 \\
8.17\end{array}$ & $\begin{array}{r}9,100 \\
10,500\end{array}$ & 11.06 & 17,800 & & & & & & \\
\hline & $\ldots-$ & n & $\begin{array}{l}8.82 \\
9.50\end{array}$ & 11,900 & 10.40 & 15.800 & 6.01 & 6.330 & 4.40 & 3,760 & 3.64 & 780 \\
\hline \multirow{4}{*}{$\begin{array}{r}7 \\
8 \\
9 \\
10 \\
11 \\
\mathrm{~N}\end{array}$} & & & 10.07 & 15,100 & & & & & & & & \\
\hline & 1.84 & 918 & 10.68 & 16,700 & 9.76 & 14,300 & & & $\cdots$ & & -- & \\
\hline & & & 11.22 & $\begin{array}{l}18,100 \\
19,500\end{array}$ & 9.10 & 12,600 & & & & & & 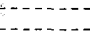 \\
\hline & 1.91 & $\overline{9} \overline{\overline{5}}$ & $\left|\begin{array}{l}12.11 \\
12.46\end{array}\right|$ & $\begin{array}{l}20,700 \\
21,900\end{array}$ & 8.54 & 11,200 & 5.44 & $\overline{5}, \overline{3} 10$ & $4 . \overline{17}$ & 3,420 & 3.70 & 2,840 \\
\hline \multirow{5}{*}{$\begin{array}{l}1 \\
2 \\
3 \\
4 \\
5 \\
6\end{array}$} & 1.92 & 984 & 12.75 & 22,800 & & & & & & & & \\
\hline & 1.92 & 984 & 12.37 & 23,400 & 8.10 & 10,300 & & & & & $-\cdots$ & - \\
\hline & $\begin{array}{l}1.93 \\
1.96\end{array}$ & $\begin{array}{r}992 \\
1,020\end{array}$ & $\left|\begin{array}{l}13.13 \\
13.25\end{array}\right|$ & $\begin{array}{l}23,700 \\
24,000\end{array}$ & 7.72 & 9,500 & & & & & --- & \\
\hline & 2.01 & 1,060 & 13.29 & 24,300 & & & & & & & & \\
\hline & 2.08 & 1,120 & 13.28 & 24,300 & 7.42 & 8,900 & 4.98 & 4,670 & 3.95 & 3,160 & 4.09 & 3,350 \\
\hline \multirow{6}{*}{$\begin{array}{l}8 \\
9\end{array}$} & 2.21 & 1,220 & 13.24 & 24,000 & & & & & & & & \\
\hline & $\begin{array}{l}2.52 \\
3.33\end{array}$ & 1,500 & $\begin{array}{|cc|}13.13 \\
12 & .98\end{array}$ & 23,700 & 7.14 & 8,300 & & & & & & \\
\hline & 4.10 & 3,350 & 12.78 & 22,800 & $6 . \overline{8}$ & 7,920 & - & & & & & \\
\hline & 4.85 & 4,350 & 12.54 & 21,900 & & & & & & & & \\
\hline & 5.50 & 5,480 & $\mid 12.30$ & 21,300 & 6.65 & 7,380 & 4.65 & 4,050 & 3.78 & 2,960 & 4.55 & 4,050 \\
\hline & \multicolumn{2}{|c|}{ Aug. 29} & \multicolumn{2}{|c|}{ Aug. 30} & \multicolumn{2}{|c|}{ Aug. 31} & \multicolumn{2}{|c|}{ Sept. 1} & \multicolumn{2}{|c|}{ Sept. 2} & \multicolumn{2}{|c|}{ Sept. 3} \\
\hline 6 & & & 2.50 & 1,500 & 4.35 & 3,760 & 5.14 & 4.830 & 6.13 & 6,500 & 3.82 & 2,960 \\
\hline $\mathrm{N}$ & 1.85 & 926 & $\begin{array}{l}3.32 \\
3.79\end{array}$ & 2,360 & 4.26 & & 5.61 & 5, & 5.26 & 5,150 & 3.56 & 2,660 \\
\hline 12 & 2.06 & 1,100 & $\begin{array}{l}3.12 \\
4.25\end{array}$ & $\begin{array}{l}2,840 \\
3,480\end{array}$ & $\begin{array}{l}3.95 \\
4.15\end{array}$ & $\begin{array}{l}3,100 \\
3,420\end{array}$ & $\begin{array}{l}0.40 \\
6.69\end{array}$ & 7,560 & $\begin{array}{l}4.0 \\
4.1\end{array}$ & $\begin{array}{l}4,000 \\
3,420\end{array}$ & 3.17 & 2,180 \\
\hline
\end{tabular}

SUPPLEMENTAL RECORDs.-Aug. 31, 2 a.m., gage height, 4.34 feet, discharge, 4.620 second-feet; 4 a.m., gage height, 4.37 feet, discharge, 3,760 second-feet. Sept. 1, 10:30 p.m., gage height, 6.72 feet, discharge, 7,560 second-feet. 


\section{CLINCH RIVER NEAR TAZEWELL, TENN.}

Location.-Lat. $36^{\circ} 23^{\prime} 57^{\prime \prime}$, long. $83^{\circ} 27^{\prime} 35^{\prime \prime}$, 600 feet downstream from bridge on U. S. Highway 25E, 3.5 miles upstream from Indian Creek, 7 miles southeast of Tazewell, Claiborne County, and 72 miles upstream from Norris Dam. Datum of gage is $1,013.5$ feet above mean sea level, datum of 1929 , supplementary adjustment of 1936 .

DRAINAGE AREA.- 1,482 square miles.

GAGE-HEIGHT RECORD.-Water-stage recorder graph.

Maxima.-1940: Gage height, 10.62 feet at 8 p.m. Aug. 15.

1937-39: Gage height, 18.58 feet Feb. 10, 1937.

The flood of March 1917 reached a stage of about 21.5 feet; flood of '186? reached a stage of about 24.5 feet.

REMARKS.-Station is in backwater from Norris Dam.

Mean gage height, in feet, 1940

\begin{tabular}{r|r|r||r|r|r||r|r|r||r|r|r}
\hline Day & Aug. & \multicolumn{1}{|c|}{ Sept. } & Day & \multicolumn{1}{|c|}{ Aug. } & Sept. & Day & Aug. & Sept. & Day & Aug. & Sept. \\
\cline { 2 - 8 } & 3.31 & 4.87 & 9 & 2.72 & 2.08 & 17 & 5.14 & 1.74 & 25 & 2.72 & 1.57 \\
2 & 3.31 & 4.94 & 10 & 2.20 & 2.02 & 18 & 4.01 & 1.70 & 26 & 2.50 & 1.60 \\
3 & 3.33 & 3.58 & 11 & 1.96 & 2.02 & 19 & 3.62 & 1.66 & 27 & 2.35 & 1.55 \\
4 & 2.54 & 3.00 & 12 & 1.81 & 2.02 & 20 & 4.49 & 1.64 & 28 & 2.23 & 1.55 \\
5 & 2.21 & 2.68 & 13 & 1.77 & 1.98 & 21 & 4.22 & 1.63 & 29 & 2.19 & 1.58 \\
6 & 2.02 & 2.43 & 14 & 2.15 & 1.91 & 22 & 3.68 & 1.59 & 30 & 3.04 & 1.57 \\
7 & 2.01 & 2.27 & 15 & 8.46 & 1.84 & 23 & 3.40 & 1.57 & 31 & 3.91 & $-\cdots$ \\
8 & 2.86 & 2.16 & 16 & 7.90 & 1.77 & 24 & 3.06 & 1.55 & & & \\
\hline
\end{tabular}

\section{NORRIS RESERVOIR AT NORRIS DAM, TENN.}

Location.-Lat. $36^{\circ} 13^{\prime} 29^{\prime \prime}$, long. $84^{\circ} 05^{\prime} 29^{\prime \prime}$, at Norris Dam on Clineh River, Anderson County, $2 \frac{1}{2}$ miles northwest of Norris, and $3 \frac{1}{2}$ miles east of Lake City (formerly known as Coal Creek). Datum of gage is mean sea level, adjustment of 1912, and 0.11 foot above mean sea level, datum of 1929 , supplementary adjustment of 1936 .

Drainage AREA.-2,912 square miles.

GAGE-HEIGHT RECORD.-Water-stage recorder graph.

REMARKs.-Controlled storage, 2,020,000 acre-feet between elevations 954.5 and 1,034.0 feet. During extreme floods the elevation of the water surface in the reservoir may reach $1,052.0$ feet, owing to the limited capacity of the spillway section. The total storage capacity at this elevation is $3,370,000$ acre-feet. Records furnished by the Tennessee Valley Authority. 
Elevation and contents, at midnight, 1940

\begin{tabular}{|c|c|c|c|c|c|c|c|c|c|}
\hline \multirow[b]{2}{*}{ Day } & \multicolumn{2}{|c|}{ August } & \multicolumn{2}{|c|}{ September } & \multirow[b]{2}{*}{ Day } & \multicolumn{2}{|c|}{ August } & \multicolumn{2}{|c|}{ September } \\
\hline & $\begin{array}{l}\text { Eleva- } \\
\text { tion } \\
\text { (feet) }\end{array}$ & $\mid \begin{array}{c}\text { Contents } \\
\text { (thousand } \\
\text { acre-feet) }\end{array}$ & $\begin{array}{c}\text { Eleva- } \\
\text { tion } \\
\text { (feet) }\end{array}$ & $\begin{array}{l}\text { Contents } \\
\text { (thousand } \\
\text { acre-feet) }\end{array}$ & & $\begin{array}{c}\text { Eleva- } \\
\text { tion } \\
\text { (feet) }\end{array}$ & $\begin{array}{l}\text { Contents } \\
\text { (thousand } \\
\text { acre-feet) }\end{array}$ & $\begin{array}{c}\text { Eleva- } \\
\text { tion } \\
\text { (feet) }\end{array}$ & $\begin{array}{l}\text { Contents } \\
\text { (thousand } \\
\text { acre-feet) }\end{array}$ \\
\hline $\begin{array}{l}1 \\
2 \\
3 \\
4 \\
5\end{array}$ & $\begin{array}{l}1,005.00 \\
1,005.19 \\
1,005.39 \\
1,005.51 \\
1,005.60\end{array}$ & $\begin{array}{l}1,578 \\
1,584 \\
1,589 \\
1,593 \\
1,595\end{array}$ & $\begin{array}{r}1.011 .80 \\
1,012.20 \\
1,012.39 \\
1,012.53 \\
1,012.63\end{array}$ & $\begin{array}{l}1,781 \\
1,793 \\
1,799 \\
1,803 \\
1,806\end{array}$ & $\begin{array}{l}16 \\
17 \\
18 \\
19 \\
20\end{array}$ & $\begin{array}{l}1,008.40 \\
1,008.84 \\
1,009.13 \\
1,009.35 \\
1,009.67\end{array}$ & $\begin{array}{l}1,677 \\
1,690 \\
1,699 \\
1,706 \\
1,715\end{array}$ & $\begin{array}{l}1,012.15 \\
1,011.89 \\
1,011.63 \\
1,011.31 \\
1,011.00\end{array}$ & $\begin{array}{l}1,792 \\
1,784 \\
1,776 \\
1,766 \\
1,756\end{array}$ \\
\hline $\begin{array}{r}6 \\
7 \\
8 \\
9 \\
10\end{array}$ & $\begin{array}{l}1,005.68 \\
1,005.72 \\
1,005.84 \\
1,005.94 \\
1,006.01\end{array}$ & $\begin{array}{l}1,598 \\
1,599 \\
1,602 \\
1,605 \\
1,607\end{array}$ & $\begin{array}{l}1,012.72 \\
1,012.79 \\
1,012.85 \\
1,012.90 \\
1,012.94\end{array}$ & $\begin{array}{l}1,809 \\
1,812 \\
1,813 \\
1,815 \\
1,816\end{array}$ & $\begin{array}{l}21 \\
22 \\
23 \\
24 \\
25\end{array}$ & $\begin{array}{l}1,009.99 \\
1,010.20 \\
1,010.41 \\
1,010.56 \\
1,010.67\end{array}$ & $\begin{array}{l}1,725 \\
1,731 \\
1,738 \\
1,742 \\
1,746\end{array}$ & $\begin{array}{r}1,010.59 \\
1,010.20 \\
1,009.87 \\
1,009.63 \\
1,009.36\end{array}$ & $\begin{array}{l}1,743 \\
1,731 \\
1,721 \\
1,714 \\
1,706\end{array}$ \\
\hline $\begin{array}{l}11 \\
12 \\
13 \\
14 \\
15\end{array}$ & $\begin{array}{l}1,006.07 \\
1,006.11 \\
1,006.24 \\
1,006.36 \\
1,007.43\end{array}$ & $\begin{array}{l}1,609 \\
1,610 \\
1,614 \\
1,617 \\
1,648\end{array}$ & $\begin{array}{r}1,012.97 \\
1,013.00 \\
1,012.90 \\
1,012.64 \\
1,012.48\end{array}$ & $\begin{array}{l}1,817 \\
1,818 \\
1,815 \\
1,807 \\
1,802\end{array}$ & $\begin{array}{l}26 \\
27 \\
28 \\
29 \\
30 \\
31\end{array}$ & $\begin{array}{r}1,010.78 \\
1,010.85 \\
1,010.89 \\
1,010.99 \\
1,011.16 \\
1,011.38\end{array}$ & $\begin{array}{l}1,749 \\
1,751 \\
1,753 \\
1,756 \\
1,761 \\
1,768\end{array}$ & $\begin{array}{r}1,008.92 \\
1,008.49 \\
1,008.04 \\
1,007.60 \\
1,007.17\end{array}$ & $\begin{array}{r}1,693 \\
1,680 \\
1,666 \\
1,653 \\
1,641 \\
- \\
\end{array}$ \\
\hline \multirow{2}{*}{\multicolumn{8}{|c|}{ Change in contents, equivalent, in second-feet }} & August & September \\
\hline & & & & & & & & $+3,155$ & $-2,134$ \\
\hline
\end{tabular}

CLINCH RIVER BELOW NORRIS DAM, TENN.

Location.-Lat. $36^{\circ} 12^{\prime} 56^{\prime \prime}$, long. $84^{\circ} 04^{\prime} 56^{\prime \prime}$, 0.5 mile upstream from Clear Creek, 0.9 mile downstream from Norris Dam, Anderson County, and 11/2 miles north of Norris. Datum of gage is 819.11 feet above mean sea level, datum of 1929, supplementary adjustment of 1936 .

Drain AGE AREA.-2,913 square miles.

GAGE-HEIGHT RECORD.-Water-stage recorder graph.

DISCHARGE RECORD.-Stage-discharge relation defined by current-meter measurements up to 41,300 second-feet. Gage heights used to half-tenths between 2.9 and 5.0 feet; hundredths below and tenths above these limits.

Maxima.-August 1940: Discharge, 4,260 second-feet 3:30 a.m. Aug. 22 (gage height, 4.09 feet).

1927 to July 1940: Discharge, 70,000 second-feet Mar. 23, 1929 (gage height, 33.7 feet at site near Coal Creek).

REMARKs.-Flood runoff completely regulated by storage in Norris Reservoir.

Mean discharge, in second-feet, 1940

\begin{tabular}{r|r|r||r|r|r||r|r|r||r|r|r}
\hline Day & Aug. & Sept. & Day & Aug. & Sept. & Day & Aug. & Sept. & Day & \multicolumn{1}{c|}{ Aug. } & Sept. \\
\hline 1 & 622 & 62 & 9 & 366 & 62 & 17 & 285 & 4,790 & 25 & 57 & 5,120 \\
2 & 97 & 62 & 10 & 288 & 249 & 18 & 271 & 4,680 & 26 & 57 & 6,820 \\
3 & 84 & 420 & 11 & 72 & 53 & 19 & 78 & 5,460 & 27 & 259 & 7,080 \\
4 & 70 & 62 & 12 & 66 & 53 & 20 & 62 & 5,460 & 28 & 558 & 7,280 \\
5 & 62 & 62 & 13 & 72 & 2,590 & 21 & 62 & 6,820 & 29 & 293 & 7,080 \\
6 & 353 & 62 & 14 & 78 & 4,790 & 22 & 403 & 6,310 & 30 & 272 & 6,560 \\
7 & 274 & 62 & 15 & 66 & 3,180 & 23 & 269 & 5,120 & 31 & 69 & - \\
8 & 299 & 62 & 16 & 91 & 5,580 & 24 & 171 & 4,790 & & & \\
\hline
\end{tabular}

POWELL RIVER NEAR JONESVILLE, VA.

LocAtion.-Lat. $36^{\circ} 39^{\prime} 43^{\prime \prime}$, long. $83^{\circ} 05^{\prime} 42^{\prime \prime}$, at highway bridge 2 miles southeast of Jonesville, Lee County, and 10 miles upstream from Wallen Creek. Datum of gage is 1,259.08 feet above mean sea level, datum of 1929, supplementary adjustment of 1936 .

Drainage AREA.-319 square miles.

GAGE-HEIGHT RECORD.-Water-stage recorder graph. 
DischaRgE RECORD.-Stage-discharge relation defined by current-meter measurements up to 17,000 second-feet. Gage heights used to half-tenths between 3.3 and 4.4 feet; hundredths below and tenths above these limits.

Maxima.-August 1940: Discharge, 1,140 second-feet $12 \mathrm{~m}$. Aug. 15 (gage height, 3.89 feet).

1931 to July 1940; Discharge, 22,900 second-feet (revised) Jan. 30, 1932 (gage height, 25.64 feet).

Mean discharge, in second-feet, 1940

\begin{tabular}{r|r|r|r|r|r||r|r|r|r|r|r}
\hline Day & \multicolumn{1}{c|}{ Aug. } & \multicolumn{1}{c|}{ Sept. } & Day & \multicolumn{1}{c|}{ Aug. } & Sept. & Day & Aug. & Sept. & Day & Aug. & Sept. \\
\hline 1 & 982 & 780 & 9 & 140 & 99 & 17 & 399 & 64 & 25 & 151 & 55 \\
2 & 506 & 429 & 10 & 113 & 110 & 18 & 280 & 62 & 26 & 129 & 70 \\
3 & 293 & 287 & 11 & 99 & 129 & 19 & 765 & 59 & 27 & 121 & 78 \\
4 & 204 & 218 & 12 & 89 & 106 & 20 & 731 & 57 & 28 & 108 & 60 \\
5 & 160 & 169 & 13 & 89 & 88 & 21 & 414 & 54 & 29 & 114 & 54 \\
6 & 137 & 142 & 14 & 438 & 78 & 22 & 291 & 53 & 30 & 632 & 49 \\
7 & 184 & 123 & 15 & 1,050 & 74 & 23 & 230 & 50 & 31 & 890 & $-\ldots$ \\
8
\end{tabular}

Gage height, in feet, and discharge, in second-feet, at indicated time, 1940

\begin{tabular}{|c|c|c|c|c|c|c|c|c|c|c|c|c|}
\hline \multirow{2}{*}{ Hour } & \multicolumn{2}{|c|}{ Aug. 14} & \multicolumn{2}{|c|}{ Aug. 15} & \multicolumn{2}{|c|}{ Aug. 16} & \multicolumn{2}{|c|}{ Aug. 30} & \multicolumn{2}{|c|}{ Aug. 31} & \multicolumn{2}{|c|}{ Sept. 1} \\
\hline & $\begin{array}{l}\text { Gage } \\
\text { ht. }\end{array}$ & $\begin{array}{c}\text { Dis- } \\
\text { charge }\end{array}$ & $\begin{array}{c}\text { Gage } \\
\text { ht. }\end{array}$ & $\begin{array}{c}\text { Dis- } \\
\text { charge }\end{array}$ & $\begin{array}{c}\text { Gage } \\
\text { ht. }\end{array}$ & $\begin{array}{c}\text { Dis- } \\
\text { charge }\end{array}$ & $\begin{array}{l}\text { Gage } \\
\text { ht. }\end{array}$ & $\begin{array}{c}\text { Dis- } \\
\text { charge }\end{array}$ & $\begin{array}{c}\text { Gage } \\
\text { ht. }\end{array}$ & $\begin{array}{c}\text { Dis- } \\
\text { charge }\end{array}$ & $\begin{array}{c}\text { Gage } \\
\text { ht. }\end{array}$ & $\begin{array}{c}\text { Dis- } \\
\text { charge }\end{array}$ \\
\hline \multirow{3}{*}{$\begin{array}{r}2 \\
4 \\
6 \\
8 \\
10 \\
\mathrm{~N}\end{array}$} & 1.67 & 148 & 3.66 & 998 & 3.38 & 860 & 2.14 & 272 & $\begin{array}{l}3.65 \\
3.52 \\
3.42\end{array}$ & $\begin{array}{l}998 \\
915 \\
860\end{array}$ & $\begin{array}{l}3.74 \\
3.62 \\
3.50\end{array}$ & $\begin{array}{r}1,050 \\
970 \\
915\end{array}$ \\
\hline & $1 . \overline{9}$ & $22 \overline{6}$ & $\overline{3} . \overline{8}$ & 1,110 & $\overline{3} . \overline{2} \overline{3}$ & $7 \overline{8}$ & $\overline{2} . \overline{4} \overline{7}$ & $\overline{3} \overline{8} \overline{1}$ & $\begin{array}{l}3.42 \\
3.35 \\
0\end{array}$ & 830 & $\begin{array}{l}3.00 \\
3.40\end{array}$ & 860 \\
\hline & $2 . \overline{5}$ & 407 & $\overline{3} . \overline{8}$ & 1,140 & $3 . \overline{10}$ & 680 & 2.96 & $\overline{5} \overline{8}$ & $\begin{array}{l}3.52 \\
3: 26\end{array}$ & $\begin{array}{l}800 \\
776\end{array}$ & $\begin{array}{l}5.01 \\
3.23\end{array}$ & $\begin{array}{l}800 \\
758\end{array}$ \\
\hline \multirow{3}{*}{$\begin{array}{r}2 \\
4 \\
6 \\
8 \\
10 \\
12\end{array}$} & 2.63 & 442 & 3.81 & 1,080 & $2.9 \overline{7}$ & 604 & 3.28 & $78 \overline{8}$ & $\begin{array}{l}3.19 \\
3.19 \\
3\end{array}$ & $\begin{array}{l}734 \\
734\end{array}$ & $\begin{array}{l}3.15 \\
3.08 \\
3.09\end{array}$ & $\begin{array}{l}710 \\
668\end{array}$ \\
\hline & 3.32 & 800 & $3.6 \overline{7}$ & 998 & 2.86 & 545 & 3.88 & 1,140 & $\begin{array}{l}3.36 \\
3.68\end{array}$ & $\begin{array}{r}830 \\
1,020\end{array}$ & $\begin{array}{l}3.02 \\
2.97\end{array}$ & $\begin{array}{l}632 \\
604\end{array}$ \\
\hline & $3.6 \overline{1}$ & 970 & 3.52 & 915 & $2 . \overline{7}$ & 497 & 3.77 & 1,050 & $\begin{array}{l}.0 .00 \\
3.83\end{array}$ & $\begin{array}{l}1,110 \\
1,10\end{array}$ & $\begin{array}{l}2.91 \\
2.86\end{array}$ & 545 \\
\hline
\end{tabular}

\section{GMORY RIVER AT OAKDALE, TENN.}

Location.-Lat. $35^{\circ} 58^{\prime} 59^{\prime \prime}$, long. $84^{\circ} 33^{\prime} 29^{\prime \prime}$, at Oakdale, Morgan County, 1,000 feet downstream from highway bridge and 1,100 feet downstream from Mud Lick Creek. Datum of gage is 763.38 feet above mean sea level, datum of 1929 , supplementary adjustment of 1936.

Drainage AREA.- 764 square miles.

GAGE-HEIGHT RECORD.-Water-stage recorder graph.

DISCHARGE RECORD.-Stage-discharge relation defined by current-meter measurements up to 80,000 second-feet. Gage heights used to half-tenths between 4.2 and 6.0 feet; hundredths below and tenths above these limits.

Maxima.-August 1940: Discharge, 6,900 second-feet 1:30 a.m. Aug. 30 (gage height, 8.84 feet).

1929 to July 1940: Discharge, 100,000 second-feet Feb. 3, 1939 (gage height, 30.9 feet, from floodmarks).

Stage known, about 42.3 feet, from floodmarks at highway bridge, Mar. 23, 1929 (discharged, 195,000 second-feet).

RemarKs.-Flood runoff not affected by storage. 
Mean discharge, in second-feet, 1940

\begin{tabular}{|c|c|c|c|c|c|c|c|c|c|c|c|}
\hline Day & Aug. & Sept. & Day & Aug. & Sept. & Day & Aug. & Sept. & Day & Aug. & Sept. \\
\hline 1 & 495 & 1,980 & 9 & 307 & 149 & 17 & 75 & 45 & 25 & & \\
\hline 2 & 299 & 1,130 & 10 & 208 & 101 & 18 & 64 & 40 & 26 & 208 & 18 \\
\hline 3 & $\begin{array}{l}225 \\
220\end{array}$ & 719 & 11 & 192 & 97 & 19 & 66 & 35 & 27 & 158 & 17 \\
\hline $\begin{array}{l}4 \\
5\end{array}$ & $\begin{array}{l}228 \\
167\end{array}$ & $\begin{array}{l}490 \\
358\end{array}$ & $\begin{array}{l}12 \\
13\end{array}$ & $\begin{array}{l}138 \\
117\end{array}$ & $\begin{array}{l}81 \\
70\end{array}$ & $\begin{array}{l}20 \\
21\end{array}$ & $\begin{array}{r}97 \\
108\end{array}$ & $\begin{array}{l}31 \\
28\end{array}$ & $\begin{array}{l}28 \\
29\end{array}$ & $\begin{array}{r}110 \\
1.110\end{array}$ & $\begin{array}{l}15 \\
16\end{array}$ \\
\hline 6 & 125 & 277 & $\begin{array}{l}14 \\
14\end{array}$ & 108 & 63 & 22 & 78 & 24 & 30 & 4,940 & 22 \\
\hline $\begin{array}{l}7 \\
8\end{array}$ & 553 & 218 & 15 & 105 & 55 & 23 & 93 & 22 & 31 & 4,540 & \\
\hline 8 & 516 & 180 & 16 & 95 & 52 & 24 & 281 & 20 & & & \\
\hline \multicolumn{10}{|c|}{$\begin{array}{l}\text { Monthly mean discharge, in second-feet } \\
\text { Runoff, in inches }\end{array}$} & $\begin{array}{r}517 \\
0.78\end{array}$ & $\begin{array}{r}213 \\
0.31\end{array}$ \\
\hline
\end{tabular}

HIWASSEE RIVER BELOW HAYESVILLE, N. C.

Location.-Lat. $35^{\circ} 04^{\prime} 30^{\prime \prime}$, long. $83^{\circ} 49^{\prime} 55^{\prime \prime}$, three-quarters of a mile downstream from Tusquitee Creek and $21 / 4$ miles (revised) northwest of Hayesville, Clay County. Datum of gage is $1,760.33$ feet above mean sea level, datum of 1929 , supplementary adjustment of 1936 .

DrainaGe AREA. - 252 square miles (1943 revision).

GAGE-HEIGHT RECORD.-Water-stage recorder graph.

DISCHARGE RECORD.- Stage-discharge relation defined by current-meter measurements up to 10,200 second-feet. Gage heights used to half-tenths between 3.5 and 5.3 feet; hundredths below and tenths above these limits.

Maxima.-1940: Discharge, 4,610 second-feet 4:30 p.m. Aug. 13 (gage height, 7.97 feet).

1934-39: Discharge, 10,600 second-feet Apr. 21936 (gage height, 12.42 feet).

Stage known, 16.1 feet Oct. 3, 1898, from flood reference mark cut in tree by gage observer shortly after the flood.

REMARKs.-Flood runoff not affected by artificial storage.

Mean discharge, in second-feet, 1940

\begin{tabular}{|c|c|c|c|c|c|c|c|c|c|c|c|}
\hline Day & Aug. & Sept. & Day & Aug. & Sept. & Day & Aug. & Sept. & Day & Aug. & Sept. \\
\hline 1 & 250 & 658 & 9 & 192 & 350 & 17 & 546 & 259 & 25 & 308 & 318 \\
\hline 2 & 237 & 550 & 10 & 181 & 340 & 18 & 475 & 259 & 26 & 295 & 250 \\
\hline 3 & 212 & 483 & 11 & 177 & 331 & 19 & 455 & 254 & 27 & 286 & 233 \\
\hline 4 & 204 & 445 & 12 & 328 & 308 & 20 & 395 & 250 & 28 & 272 & 221 \\
\hline 5 & 196 & 440 & 13 & 3,240 & $\begin{array}{l}00 \\
300\end{array}$ & 21 & $\begin{array}{l}370 \\
370\end{array}$ & 242 & $\begin{array}{l}28 \\
29\end{array}$ & 1,080 & 216 \\
\hline 6 & 208 & 435 & 14 & 1,590 & 290 & 22 & 355 & 233 & 30 & 1,690 & 212 \\
\hline 7 & 221 & 390 & 15 & 903 & 282 & 23 & 340 & 225 & 31 & 878 & \\
\hline 8 & 204 & 365 & 16 & 668 & 272 & 24 & 345 & 250 & & & \\
\hline \multicolumn{10}{|c|}{$\begin{array}{l}\text { Monthly mean discharge, in second-feet } \\
\text { Runoff, in inches }\end{array}$} & $\begin{array}{r}552 \\
2.52\end{array}$ & $\begin{array}{r}322 \\
1.43\end{array}$ \\
\hline
\end{tabular}


TENNESSEE RIVER BASIN

Gage height, in feet, and discharge, in second-feet, at indicated time, 1940

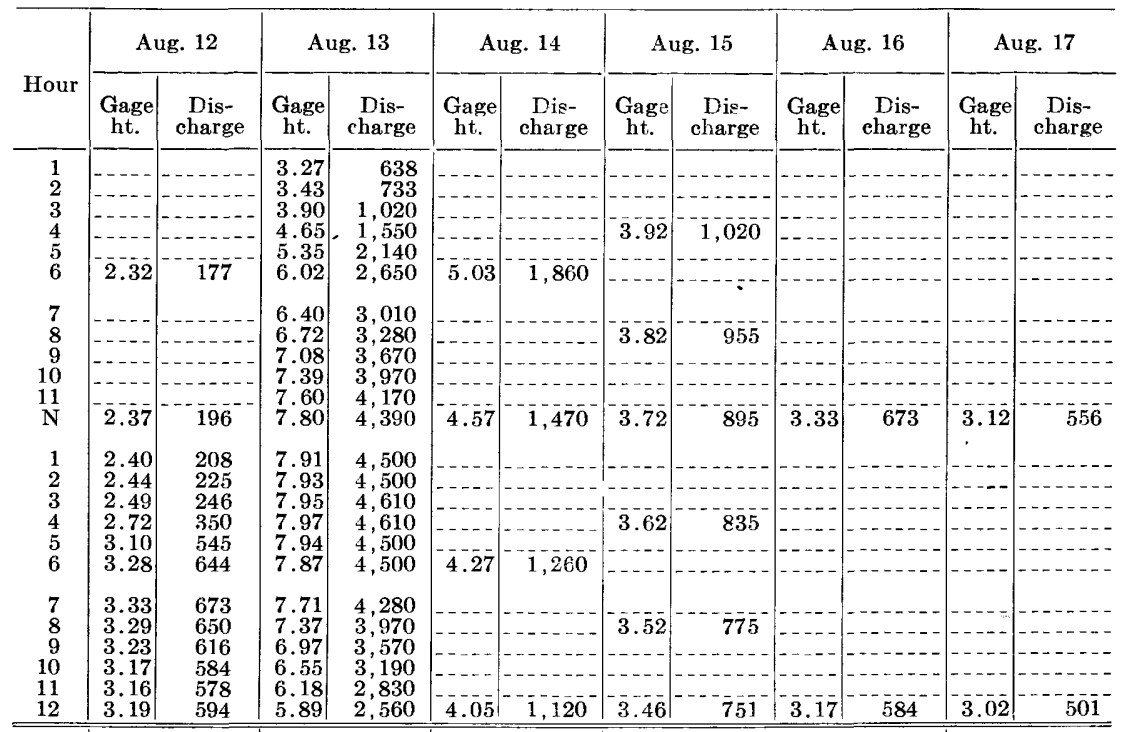

\begin{tabular}{|c|c|c|c|c|c|c|c|c|c|c|c|c|}
\hline & & g. 29 & & g. 30 & & 31 & & & & & & \\
\hline 1 & & & 5.66 & 2,380 & & & & & & & & \\
\hline 2 & & & $\begin{array}{r}5.73 \\
5.81\end{array}$ & $\begin{array}{l}2,380 \\
2\end{array}$ & & & & & & & & \\
\hline $\begin{array}{l}3 \\
4 \\
\end{array}$ & 2.52 & $2 \overline{59}{ }^{-}$ & $\begin{array}{l}0.81 \\
5.82 \\
-7\end{array}$ & $\begin{array}{l}2,400 \\
2,470\end{array}$ & & & & & & & & \\
\hline $\begin{array}{l}5 \\
6\end{array}$ & & & $\begin{array}{l}5.77 \\
5.60\end{array}$ & $\begin{array}{l}2,470 \\
2,300\end{array}$ & & & & & & & & \\
\hline 7 & & & 5.39 & 2,140 & & & & & & & & \\
\hline 8 & 2.70 & 340 & $\begin{array}{r}5.20 \\
5\end{array}$ & 1,980 & & & & & -1 & & & \\
\hline 10 & . & - & $\begin{array}{r}-3.03 \\
4.86\end{array}$ & $\begin{array}{l}1,000 \\
1,700\end{array}$ & & - & $\ldots$ & & - & & & $\ldots$ \\
\hline $\mathrm{N}$ & $3 . \overline{3} \overline{8}$ & 703 & 4.62 & 1,510 & 3.67 & $8 \overline{6} \overline{5}$ & $3 . \overline{2}$ & $6 \overline{6} \overline{7}$ & 3.13 & 562 & 3.00 & 490 \\
\hline 1 & 3.58 & 835 & & & & & & & & & & \\
\hline${ }_{3}^{2}$ & $\begin{array}{l}3.92 \\
4.27\end{array}$ & $\begin{array}{l}1,020 \\
1,260\end{array}$ & & & & & & & & & $-\cdots$ & ..- \\
\hline $\begin{array}{l}4 \\
5\end{array}$ & $\begin{array}{l}4.56 \\
4.75\end{array}$ & $\begin{array}{l}1,470 \\
1,620\end{array}$ & 4.27 & 1,260 & & & $-0-$ & & $\ldots$ & & & 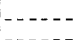 \\
\hline 6 & $\begin{array}{r}4.130 \\
5.30\end{array}$ & $\begin{array}{l}1,020 \\
2,060\end{array}$ & & & & & & & & & & \\
\hline 7 & 5.77 & 0 & & & & & & & & & & \\
\hline$\stackrel{8}{9}$ & $\begin{array}{l}5.83 \\
5.76\end{array}$ & 2,470 & 4.12 & 1,150 & & & & & & & & 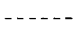 \\
\hline 10 & 5.63 & 2, & $\ldots$ & & & & & & & & $\cdots$ & 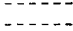 \\
\hline $\begin{array}{l}11 \\
12\end{array}$ & $\left|\begin{array}{l}5.38 \\
5.61\end{array}\right|$ & $\begin{array}{l}2,300 \\
2,300\end{array}$ & $3 . \overline{9}$ & 1,050 & -3.42 & 727 & 3.17 & 584 & 3.01 & 496 & 2.91 & 445 \\
\hline
\end{tabular}

SUPPLEM ENTAL RECORD.-Aug. 13, 4:30 p.m., gage height, 7.97 feet; discharge, 4,610 second-feet.

HIWASSEE RIVER ABOVE MURPHY, N. C.

Location.-Lat. $35^{\circ} 04^{\prime} 50^{\prime \prime}$, long. $84^{\circ} 00^{\prime} 10^{\prime \prime}$, on U. S. Highway 64,600 feet upstream from Will Scott Creek and 2 miles east of Murphy, Cherokee County. Datum of gage is $1,538.23$ feet above mean sea level, datum of 1929 , supplementary adjustment of 1936 .

Drainage AREA.- 404 square miles.

GAGE-HEIGHT RECORD.-Water-stage recorder graph except Sept. 22-30, for which period there is no record.

DISCHARGE RECORD.--Stage-diseharge relation defined by current-meter measurements up to 5,000 second-feet. Gage heights used to half-tenths between 3.6 and 5.5 


\section{FLOODS OF AUGUST 1940 IN THE SOUTHEASTERN STATES}

feet; hundredths below and tenths above these limits. Discharge for period of no gage-height record is based on records for station below Hayesville.

Maxima.-1940: Discharge, 5,940 second-feet 7 p.m. Aug. 13 (gage height, 7.88 feet).

1896-1917, 1918-39: Discharge observed, 23,100 second-feet Mar. 19, 1899 (gage height, 18.4 feet, site and datum then in use).

REMARKs.-Flood runoff. not affeeted by artificial storage.

Mean discharge, in second-feet, 1940

\begin{tabular}{rl|} 
Day \\
\hline A
\end{tabular}


TENNESSEE RIVER BASIN

Gage height, in feet, and discharge, in second-feet, at indicated time, 1940

\begin{tabular}{|c|c|c|c|c|c|c|c|c|c|c|c|c|}
\hline \multirow{2}{*}{ Hour } & \multicolumn{2}{|c|}{ Aug. 12} & \multicolumn{2}{|c|}{ Aug. 13} & \multicolumn{2}{|c|}{ Aug. 14} & \multicolumn{2}{|c|}{ Aug. 15} & \multicolumn{2}{|c|}{ Aug. 16} & \multicolumn{2}{|c|}{ Aug. 17} \\
\hline & $\begin{array}{c}\text { Gage } \\
\text { ht. }\end{array}$ & $\begin{array}{c}\text { Dis- } \\
\text { charge }\end{array}$ & $\begin{array}{c}\text { Gage } \\
\text { ht. }\end{array}$ & $\begin{array}{c}\text { Dis- } \\
\text { charge }\end{array}$ & $\begin{array}{c}\text { Gage } \\
\text { ht. }\end{array}$ & $\begin{array}{c}\text { Dis- } \\
\text { charge }\end{array}$ & $\begin{array}{c}\text { Gage } \\
\text { ht. }\end{array}$ & $\begin{array}{c}\text { Dis- } \\
\text { charge }\end{array}$ & $\begin{array}{c}\text { Gage } \\
\text { ht. }\end{array}$ & $\begin{array}{l}\text { Dis- } \\
\text { charge }\end{array}$ & $\begin{array}{c}\text { Gage } \\
\text { ht. }\end{array}$ & $\begin{array}{c}\text { Dis- } \\
\text { charge }\end{array}$ \\
\hline $\begin{array}{l}1 \\
2\end{array}$ & & & $\begin{array}{l}3.40 \\
3.54\end{array}$ & $\begin{array}{l}845 \\
952\end{array}$ & 6.52 & 4,020 & & & & & & \\
\hline $\begin{array}{l}3 \\
4\end{array}$ & & & $\begin{array}{l}3.52 \\
3.54\end{array}$ & $y$ & $\overline{6} . \overline{12}$ & $3, \overline{5} 0$ & & & & & & \\
\hline $\begin{array}{l}5 \\
6\end{array}$ & $\overline{2} \cdot \overline{3} \overline{7}$ & $\overline{2} 1 \overline{2}^{--}$ & $\begin{array}{l}3.65 \\
3.83\end{array}$ & $\begin{array}{l}1,040 \\
1,200\end{array}$ & $\overline{5.64}$ & 2,930 & 4.31 & $\overline{1}, \overline{590}$ & & & & \\
\hline $\begin{array}{l}7 \\
8\end{array}$ & & & $\begin{array}{l}4.07 \\
5.40\end{array}$ & $\begin{array}{l}1,360 \\
2,710\end{array}$ & 5.35 & 2,660 & & & & & & \\
\hline $\begin{array}{r}9 \\
10\end{array}$ & & & $\begin{array}{l}6.10 \\
6.92\end{array}$ & $\begin{array}{l}3,520 \\
4,540\end{array}$ & 5.24 & $\overline{2}, \overline{540}$ & & & & & & \\
\hline 11 & $2 . \overline{5} \overline{1}$ & $27 \overline{8}$ & $\begin{array}{l}6.43 \\
7.05\end{array}$ & $\begin{array}{l}3,890 \\
4,680\end{array}$ & 4.75 & 2,020 & 412 & 1410 & 3.62 & 10 & $3 \overline{6}$ & \\
\hline 1 & & & 7.11 & 4,8 & & & & & & & & \\
\hline 2 & & & 7.13 & 4,8 & $4 . \overline{8}$ & 2,120 & & & & & & \\
\hline 4 & $\overline{2} . \overline{5} \overline{5}$ & $299^{--}$ & 7.45 & $\begin{array}{l}5,380 \\
5,380\end{array}$ & $4 . \overline{9}$ & $2, \overline{2} 7 \overline{0}^{-}$ & & & & & & \\
\hline $\begin{array}{l}3 \\
6\end{array}$ & & & $\begin{array}{l}7.55 \\
7.32\end{array}$ & $\begin{array}{l}5,520 \\
5,100\end{array}$ & 4.94 & 2,220 & $\overline{3} . \overline{9} \overline{3}$ & $1, \overline{280}$ & & & & \\
\hline $\begin{array}{l}7 \\
8\end{array}$ & $2 . \overline{70}$ & 381 & $\begin{array}{l}7.88 \\
7.25\end{array}$ & $\begin{array}{l}5,94 \\
4,96\end{array}$ & 4.47 & $1, \overline{7} \overline{0}$ & & & & & & \\
\hline $\begin{array}{r}9 \\
10\end{array}$ & $\ldots$ & $\ldots$ & $\begin{array}{l}7.30 \\
7.50\end{array}$ & $\begin{array}{l}5,100 \\
5,380\end{array}$ & $46 \overline{1}$ & 1.870 & & & & & & \\
\hline $\begin{array}{l}11 \\
12\end{array}$ & $3.1 \overline{1}$ & $-\overline{00}--$ & 7.22 & 4,960 & & 770 & 90 & & ת & & & \\
\hline & 181 & 00 & & & .48 & 1,770 & 3.901 & & 3.5 & 38 & 3.31 & 782 \\
\hline
\end{tabular}

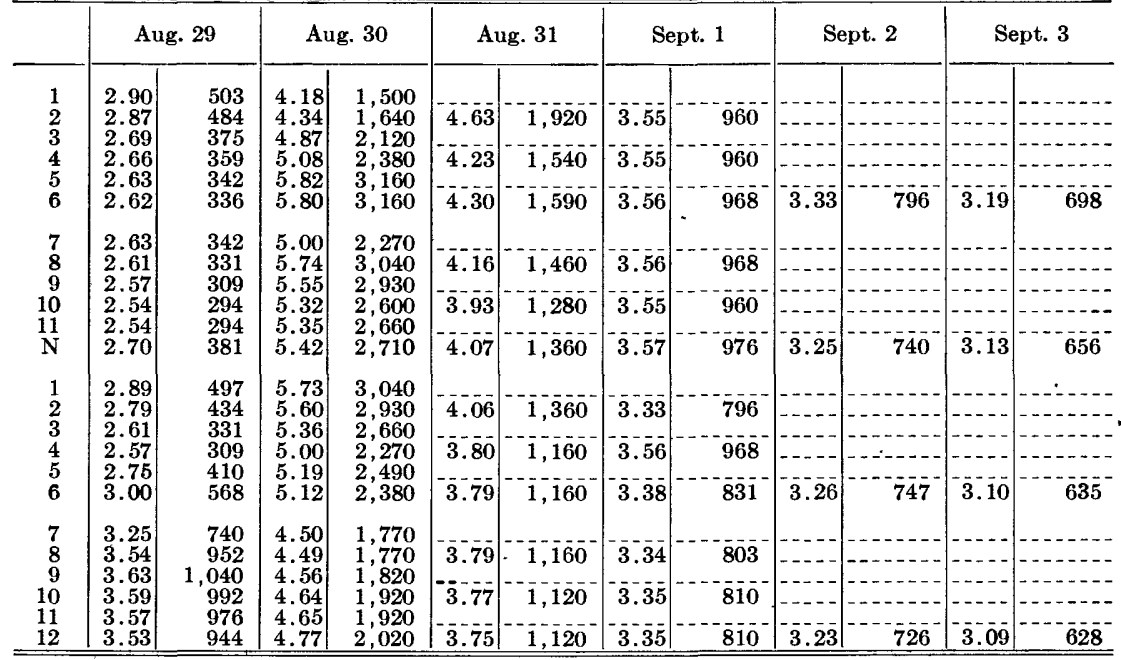

Supplemental ReCords

\begin{tabular}{|c|c|c|c|c|c|}
\hline Day & $\begin{array}{l}\text { Gage } \\
\text { height }\end{array}$ & Discharge & Day & $\begin{array}{l}\text { Gage } \\
\text { height }\end{array}$ & Discharge \\
\hline 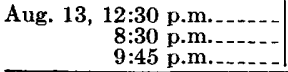 & $\begin{array}{l}7.16 \\
7.12 \\
7.58\end{array}$ & $\begin{array}{l}4,960 \\
4,820 \\
5,520\end{array}$ & $\begin{array}{r}\text { Aug. 13, 10:30 p.m.... } \\
11: 30 \text { p.m. }\end{array}$ & $\begin{array}{l}6.95 \\
7.35\end{array}$ & $\begin{array}{l}4,680 \\
5,240\end{array}$ \\
\hline
\end{tabular}

HIWASSEE RESERVOIR AT HIWASSEE DAM, N. C.

Location.—Lat. $35^{\circ} 09^{\prime} 05^{\prime \prime}$, long. $84^{\circ} 10^{\prime} 40^{\prime \prime}$, at Hiwassee Dam on Hiwassee River, one-third of a mile northwest of village of Hiwassee Dam, Cherokee County, and about 3.9 miles upstream from Shoal Creek. Datum of gage is mean sea level, datum of 1929 , preliminary adjustment. Subtract 0.63 foot from all ele- 
vations to reduce to datum of 1929 , supplementary adjustment of 1936 .

Drainage AREA.—968 square miles.

GAGE-HEIGHT RECORD.-Water-stage recorder graph.

Maxima.-August 1940: Midnight elevation, 1,523.68 feet Aug. 18 (contents, 420,600 acre-feet).

October 1939 to July 1940: Elevation, 1,524.44 feet 7 a.m. July 22 (contents, 425,200 acre-feet).

Remarks.-Flow of Hiwassee River has been regulated at Hiwassee Dam by this reservoir since Apr. 13, 1939; only slight regulation Apr. 13, 1939, to Jan. 14, 1940 , but complete regulation thereafter. Normal available capacity is 364,700 acre-feet between elevations 1,415.0 feet (minimum pool level) and 1,526.5 feet (top of gates). Additional capacity available is 35,600 acre-feet between elevations 1,526.5 and 1,532.0 (maximum high-water level). Records furnished by the Temnessee Valley Authority.

Elevation and contents, at midnight, 1940

\begin{tabular}{|c|c|c|c|c|c|c|c|c|c|}
\hline \multirow[b]{2}{*}{ Day } & \multicolumn{2}{|c|}{ August } & \multicolumn{2}{|c|}{ - September } & \multirow[b]{2}{*}{ Day } & \multicolumn{2}{|c|}{ August } & \multicolumn{2}{|c|}{ September } \\
\hline & $\begin{array}{c}\text { Eleva- } \\
\text { tion } \\
\text { (feet) }\end{array}$ & $\begin{array}{c}\text { Contents } \\
\text { (thousand } \\
\text { acre-feet) }\end{array}$ & $\begin{array}{c}\text { Eleva- } \\
\text { tion } \\
\text { (feet) }\end{array}$ & $\left|\begin{array}{c}\text { Contents } \\
\text { (thousand } \\
\text { acre-feet) }\end{array}\right|$ & & $\begin{array}{c}\text { Eleva- } \\
\text { tion } \\
\text { (feet) }\end{array}$ & $\begin{array}{l}\text { Contents } \\
\text { (thousand } \\
\text { acre-feet) }\end{array}$ & $\begin{array}{c}\text { Eleva- } \\
\text { tion } \\
\text { (feet) }\end{array}$ & $\begin{array}{l}\text { Contents } \\
\text { (thousand } \\
\text { acre-feet) }\end{array}$ \\
\hline $\begin{array}{l}1 \\
2 \\
3 \\
4 \\
5\end{array}$ & $\begin{array}{l}1,520.30 \\
1,520.09 \\
1,520.26 \\
1,520.43 \\
1,520.08\end{array}$ & $\begin{array}{l}400.4 \\
399.2 \\
400.2 \\
401.2 \\
399.2\end{array}$ & $\begin{array}{l}1,523.91 \\
1,524.28 \\
1,524.34 \\
1,524.06 \\
1,523.81\end{array}$ & $\begin{array}{l}422.0 \\
424.2 \\
424.5 \\
422.9 \\
421.4\end{array}$ & $\begin{array}{l}16 \\
17 \\
18 \\
19 \\
20\end{array}$ & $\begin{array}{l}1,523 \cdot 10 \\
1,523 \cdot 32 \\
1,523 \cdot 68 \\
1,523 \cdot 48 \\
1,523 \cdot 27\end{array}$ & $\begin{array}{l}417.1 \\
418.4 \\
420.6 \\
419.4 \\
418.1\end{array}$ & $\begin{array}{l}1,520.85 \\
1,520.37 \\
1,519.92 \\
1,519.42 \\
1,518.86\end{array}$ & $\begin{array}{l}403.6 \\
400.8 \\
398.2 \\
395.4 \\
392.2\end{array}$ \\
\hline $\begin{array}{r}6 \\
7 \\
8 \\
9 \\
10\end{array}$ & $\begin{array}{l}1,520.08 \\
1,520.20 \\
1,520.18 \\
1,520.20 \\
1,520.37\end{array}$ & $\begin{array}{l}399.2 \\
399.9 \\
399.8 \\
399.9 \\
400.8\end{array}$ & $\begin{array}{l}1,523.55 \\
1,523.81 \\
1,524.06 \\
1,523.71 \\
1,523.31\end{array}$ & $\begin{array}{l}419.8 \\
421.4 \\
422.9 \\
420.8 \\
418.4\end{array}$ & $\begin{array}{l}21 \\
22 \\
23 \\
24 \\
25\end{array}$ & $\begin{array}{l}1,522.98 \\
1,522,78 \\
1,522.50 \\
1,522.59 \\
1,522.80\end{array}$ & & $\begin{array}{l}1,518.03 \\
1,517 \cdot 18 \\
1,516.36 \\
1,515 \cdot 50 \\
1,514.71\end{array}$ & $\begin{array}{l}387.5 \\
382.7 \\
378.2 \\
373.4 \\
369.2\end{array}$ \\
\hline $\begin{array}{l}11 \\
12 \\
13 \\
14 \\
15\end{array}$ & $\begin{array}{l}1,520.53 \\
1,520.34 \\
1,522.13 \\
1,522.93 \\
1,523.19\end{array}$ & $\begin{array}{l}401.8 \\
400.6 \\
411.3 \\
416.1 \\
417.6\end{array}$ & $\begin{array}{l}1,522.89 \\
1,522.44 \\
1,522.03 \\
1,521.61 \\
1,521.31\end{array}$ & $\begin{array}{l}415.8 \\
413.1 \\
410.7 \\
408.2 \\
406.4\end{array}$ & $\begin{array}{l}26 \\
27 \\
28 \\
29 \\
30 \\
31\end{array}$ & $\begin{array}{l}1,522.43 \\
1,522.09 \\
1,521.63 \\
1,521.81 \\
1,522.79 \\
1,523.46\end{array}$ & $\begin{array}{l}413.1 \\
411.0 \\
408.3 \\
409.4 \\
415.2 \\
419.3\end{array}$ & $\begin{array}{l}1,513.78 \\
1,512.77 \\
1,511.82 \\
1,510.88 \\
1,509.89\end{array}$ & $\begin{array}{r}364.1 \\
358.8 \\
353.8 \\
348.9 \\
343.8 \\
\end{array}$ \\
\hline \multirow{2}{*}{\multicolumn{8}{|c|}{ Change in conten }} & August & September \\
\hline & & & & & & & & +276 & $-1,269$ \\
\hline
\end{tabular}

\section{HIWASSEE RIVER AT HIWASSEE DAM, N. C.}

Location.-Lat. $35^{\circ} 08^{\prime} 44^{\prime \prime}$, long. $84^{\circ} 11^{\prime} 09^{\prime \prime}, 3,500$ feet downstream from Hiwassee Dam and Reservoir, Cherokee County, and 3.2 miles upstream from Shoal Creek. Datum of gage is $1,263.40$ feet above mean sea level, datum of 1929 , supplementary adjustment of 1936.

Drainage AREa.- 968 square miles.

GAGE-HEIGHT RECORD.-Water-stage recorder graph.

DISCHARGE RECORD.-Stage-discharge relation defined by current-meter measurements up to 42,800 second-feet. Gage heights used to half-tenths above 4.4 feet and hundredths blow.

Maxima.-August 1940: Discharge, 3,430 second-feet 6 p.m. Aug. 16 (gage height, 5.21 feet).

1934 to July 1940 : Discharge, 42,800 second-feet Feb. 4, 1936 (gage height, 13.41 feet).

ReMarks.-Flow completely regulated by Hiwassee Reservoir. Monthly mean dis charge adjusted for storage. 
TENNESSEE RIVER BASIN

Mean discharge, in second-feet, 1940

\begin{tabular}{r|r|r||r|r|r|r|r|r|r|r|r}
\hline Day & Aug. & Sept. & Day & Aug. & Sept. & Day & Aug. & Sept. & Day & Aug. \\
\hline 1 & 1,690 & 31 & 9 & 526 & 1,820 & 17 & 555 & 1,970 & 25 & Sept. \\
\hline 2 & 1,240 & 31 & 10 & 33 & 1,960 & 18 & 38 & 1,950 & 26 & 1,820 & 3,000 \\
3 & 38 & 805 & 11 & 34 & 1,970 & 19 & 1,580 & 2,050 & 27 & 1,670 & 3,330 \\
4 & 33 & 1,760 & 12 & 1,140 & 2,000 & 20 & 1,500 & 2,230 & 28 & 2,000 & 3,090 \\
5 & 1,550 & 1,710 & 13 & 742 & 1,880 & 21 & 1,680 & 2,940 & 29 & 1,760 & 3,090 \\
6 & 548 & 1,770 & 14 & 1,800 & 1,860 & 22 & 1,410 & 3,000 & 30 & 742 & 3,120 \\
7 & 310 & 31 & 15 & 1,380 & 1,500 & 23 & 1,560 & 2,870 & 31 & 33 \\
8 & 620 & 31 & 16 & 1,850 & 1,960 & 24 & 481 & 2,980 & & \\
\hline
\end{tabular}

\section{HIWASSEE RIVER NEAR RELIANCE, TENN.}

LOCATION.-Lat. $35^{\circ} 13^{\prime} 20^{\prime \prime}$, long. $84^{\circ} 31^{\prime} 34^{\prime \prime}$, on State Highway 40 just upstream from notch between rock bluffs, half a mile downstream from Spring Creek, 3 miles downstream from highway bridge at Reliance, Polk County, and 31 miles downstream from Hiwassee Dam. Datum of gage is 718.34 feet above mean sea level, datum of 1929, supplementary adjustment of 1936 .

Drainage AREA.-1,223 square miles.

GAGE-HEIGHT RECORD.-Water-stage recorder graph.

DISCHARGE RECORD.-Stage-discharge relation defined by current-meter measurements up to 42,200 second-feet. Gage heights used to half-tenths between 3.7 and 6.0 feet; hundredths below and tenths above these limits.

Maxima.-August 1940: Discharge, 3,630 second-feet 6:45 p.m. Aug. 13 (gage height, 6.25 feet).

1926 to July 1940: Diseharge, 45,300 second-feet Feb. 4, 1936 (gage height, 23.01 feet).

REMARKS.-Flood runoff regulated by storage in Hiwassee Reservoir since Jan. $14,1940$.

Mean discharge, in second-feet, 1940

\begin{tabular}{r|r|r||r|r|r||r|r|r||r|r|r}
\hline Day & Aug. & \multicolumn{1}{|c|}{ Sept. } & Day & Aug. & Sept. & Day & Aug. & Sept. & Day & Aug. & Sept. \\
\cline { 2 - 7 } & 2,010 & 245 & 9 & 688 & 378 & 17 & 1,290 & 2,050 & 25 & 524 & 3,030 \\
2 & 1,560 & 161 & 10 & 606 & 2,080 & 18 & 672 & 2,030 & 26 & 562 & 3,320 \\
3 & 1,110 & 142 & 11 & 176 & 2,060 & 19 & 620 & 2,060 & 27 & 1,890 & 3,370 \\
4 & 224 & 1,340 & 12 & 493 & 2,070 & 20 & 1,560 & 2,130 & 28 & 1,790 & 3,200 \\
5 & 515 & 1,890 & 13 & 1,500 & 2,050 & 21 & 1,620 & 3,030 & 29 & 2,180 & 3,110 \\
6 & 1,300 & 1,770 & 14 & 1,260 & 1,900 & 22 & 1,730 & 3,040 & 30 & 1,560 & 3,170 \\
7 & 549 & 1,220 & 15 & 1,740 & 1,880 & 23 & 1,500 & 2,970 & 31 & 917 & $\ldots$ \\
8 & 424 & 210 & 16 & 1,730 & 1,720 & 24 & 1,340 & 3,030 & & \\
\hline
\end{tabular}

VALLEY RIVER AT TOMOTLA, N. C.

Location.-Lat. $35^{\circ} 08^{\prime} 30^{\prime \prime}$, long. $83^{\circ} 58^{\prime} 45^{\prime \prime}$, at highway bridge at Tomotla, Cherokee County, half a mile upstream from Rodgers Creek. Datum of gage is $1,556.46$ feet above mean sea level, datum of 1929, supplementary adjustment of 1936.

Drainage ARea.-104 square miles.

GAGE-HEIGHT RECORD.--Water-stage recorder graph.

DISCHARGE RECORD.-Stage-discharge relation defined by current-meter measurements up to 5,000 second-feet and extended to the 1906 crest gage height. Gage heights used to half-tenths between 3.1 and 4.4 feet; hundredths below and tenths above these limits. 
Maxima.-August 1940: Discharge, 482 second-feet 3 p.m. Aug. 13 (gage height, 3.21 feet).

1904-9, 1914-17, 1918 to July 1940: Discharge observed, 9,030 second-feet Nov. 19, 1906 (gage height, 17.3 feet).

REMarKs.-Flood runoff not affected by artificial storage.

Mean discharge, in second-feet, 1940

\begin{tabular}{|c|c|c|c|c|c|c|c|c|c|c|c|}
\hline Day & Aug. & Sept. & Day & Aug. & Sept. & Day & Aug. & Sept. & Day & Aug. & Sept. \\
\hline $\begin{array}{l}1 \\
2 \\
3 \\
4 \\
5 \\
6 \\
7 \\
8\end{array}$ & $\begin{array}{l}66 \\
63 \\
61 \\
59 \\
58 \\
57 \\
64 \\
59\end{array}$ & $\begin{array}{l}85 \\
75 \\
69 \\
64 \\
62 \\
59 \\
56 \\
55\end{array}$ & $\begin{array}{r}9 \\
10 \\
11 \\
12 \\
13 \\
14 \\
15 \\
16\end{array}$ & $\begin{array}{r}75 \\
59 \\
57 \\
59 \\
278 \\
232 \\
140 \\
103\end{array}$ & $\begin{array}{l}52 \\
55 \\
55 \\
49 \\
49 \\
49 \\
48 \\
46\end{array}$ & $\begin{array}{l}17 \\
18 \\
19 \\
20 \\
21 \\
22 \\
23 \\
24\end{array}$ & $\begin{array}{l}86 \\
76 \\
75 \\
69 \\
66 \\
66 \\
61 \\
61\end{array}$ & $\begin{array}{l}45 \\
45 \\
48 \\
46 \\
45 \\
45 \\
44 \\
44\end{array}$ & $\begin{array}{l}25 \\
26 \\
27 \\
28 \\
29 \\
30 \\
31\end{array}$ & $\begin{array}{r}59 \\
56 \\
55 \\
53 \\
209 \\
173 \\
106\end{array}$ & $\begin{array}{r}52 \\
49 \\
46 \\
44 \\
42 \\
42 \\
-\end{array}$ \\
\hline \multicolumn{10}{|c|}{$\begin{array}{l}\text { Monthly mean discharge, in second-feet } \\
\text { Runoff, in inches }\end{array}$} & $\begin{array}{l}89.1 \\
0.99\end{array}$ & $\begin{array}{l}52.0 \\
0.56\end{array}$ \\
\hline
\end{tabular}

Gage height, in feet, and discharge, in second-feet, at indicated time, 1940

\begin{tabular}{|c|c|c|c|c|c|c|c|c|}
\hline \multirow{2}{*}{ Hour } & \multicolumn{2}{|c|}{ Aug. 13} & \multicolumn{2}{|c|}{ Aug. 14} & \multicolumn{2}{|c|}{ Aug. 29} & \multicolumn{2}{|c|}{ Aug. 30} \\
\hline & $\begin{array}{c}\text { Gage } \\
\text { height }\end{array}$ & Discharge & $\begin{array}{c}\text { Gage } \\
\text { height }\end{array}$ & Discharge & $\begin{array}{c}\text { Gage } \\
\text { height }\end{array}$ & Discharge & $\begin{array}{c}\text { Gage } \\
\text { height }\end{array}$ & Discharge \\
\hline $\begin{array}{l}1 \\
2\end{array}$ & 1.93 & 68 & & & $\begin{array}{l}1.81 \\
1.82\end{array}$ & $\begin{array}{l}52 \\
53\end{array}$ & & \\
\hline $\begin{array}{l}5 \\
4\end{array}$ & 2.00 & 78 & 2.63 & 266 & $\begin{array}{l}1.82 \\
1.82\end{array}$ & $\begin{array}{l}53 \\
53\end{array}$ & 2.53 & 227 \\
\hline $\begin{array}{l}5 \\
6\end{array}$ & 2.12 & 100 & 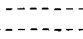 & & $\begin{array}{l}1.83 \\
1.84\end{array}$ & $\begin{array}{l}55 \\
56\end{array}$ & 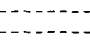 & 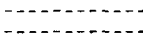 \\
\hline $\begin{array}{l}7 \\
8\end{array}$ & 2.36 & 165 & 2.58 & 246 & 1.95 & $\begin{array}{r}70 \\
162\end{array}$ & 242 & 185 \\
\hline $\begin{array}{r}9 \\
10\end{array}$ & 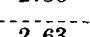 & 96 & & & 2.84 & 351 & $\ldots . .$. & $\ldots$ \\
\hline $\begin{array}{l}10 \\
11\end{array}$ & 2.63 & 266 & & & 2.77 & $\begin{array}{l}323 \\
287\end{array}$ & $\cdots$ & $\ldots$ \\
\hline $\mathrm{N}$ & 2.93 & 385 & 2.55 & 234 & 2.62 & 262 & 2.33 & 155 \\
\hline $\begin{array}{l}1 \\
2\end{array}$ & 3.17 & 464 & & & $\begin{array}{l}2.53 \\
2.48\end{array}$ & $\begin{array}{l}227 \\
208\end{array}$ & & $\ldots$ \\
\hline 3 & & & & & 2.52 & 223 & $-\cdots--$ & --1 \\
\hline 4 & 3.15 & 464 & 2.47 & 204 & 2.63 & 266 & 2.27 & 137 \\
\hline 6 & 3.02 & 418 & & & 2.69 & 291 & - & $\cdots$ \\
\hline .7 & $2-05=-$ & & & & 2.77 & 323 & & \\
\hline $\begin{array}{l}8 \\
9\end{array}$ & 2.95 & 392 & 2.45 & 196 & 2.77 & $\begin{array}{l}323 \\
307\end{array}$ & 2.25 & 132 \\
\hline 10 & 2.83 & 347 & & & 2.75 & 315 & 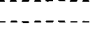 & - \\
\hline 12 & 2.75 & 315 & 2.39 & 175 & 2.67 & 283 & 2.22 & 123 \\
\hline
\end{tabular}

Supplemental ReCord.-Aug. 13, 3 p.m., gage height, 3.21 feet; discharge, 482 second-feet.

NOTTELY RIVER NEAR IVYLOG, GA.

LoCATION.-Lat. $34^{\circ} 55^{\prime} 32^{\prime \prime}$, long. $84^{\circ} 03^{\prime} 39^{\prime \prime}$, just downstream from Ivylog Creek and $2 \frac{1}{2}$ miles south of Ivylog, Union County. Datum of gage is $1,680.47$ feet above mean sea level, datum of 1929 .

DRAINAGE AREA. - 191 square miles.

GAGE-HEIGHT RECORD.-Water-stage recorder graph.

DISCHARGE RECORD.- Stage-discharge relation defined by current-meter measurements up to 6,300 second-feet and extended to 1938 crest gage height on basis of determination of flood flow by slope-area method. Gage heights used to halftenths between 3.3 and 4.9 feet; hundredths below and tenths above these limits.

Maxima.-August 1940: Discharge, 3,380 second-feet 1 p.m. Aug. 13 (gage height, 4.19 feet). 
1936 to July 1940: Discharge, 11,500 second-feet July 22, 1938 (gage height, 12.25 feet).

REMARKs.-Flood runoff not affected by artificial storage.

Mean discharge, in second-feet, 1940

\begin{tabular}{|c|c|c|c|c|c|c|c|c|c|c|c|}
\hline Day & Aug. & Sept. & Day & Aug. & Sept. & Day & Aug. & Sept. & Day & Aug. & Sept. \\
\hline 1 & 138 & 338 & 9 & 146 & 188 & 17 & 287 & 146 & 25 & 165 & 216 \\
\hline 2 & 165 & 277 & 10 & 119 & 178 & 18 & 248 & 142 & 26 & 157 & 165 \\
\hline$\overline{3}$ & 126 & 242 & 11 & 108 & 178 & 19 & 260 & 142 & 27 & 153 & 146 \\
\hline 4 & 119 & 238 & 12 & 183 & 165 & 20 & 210 & 142 & 28 & 146 & 134 \\
\hline 5 & 116 & $\begin{array}{l}262 \\
268\end{array}$ & 13 & 2,340 & 165 & 21 & 196 & 138 & 29 & 727 & 130 \\
\hline 6 & 175 & 288 & 14 & 839 & 161 & 22 & 192 & 134 & 30 & 663 & \\
\hline 8 & $\begin{array}{l}161 \\
130\end{array}$ & $\begin{array}{l}210 \\
196\end{array}$ & 16 & $\begin{array}{l}483 \\
350\end{array}$ & $\begin{array}{l}153 \\
149\end{array}$ & $\begin{array}{l}23 \\
24\end{array}$ & $\begin{array}{l}183 \\
174\end{array}$ & $\begin{array}{l}130 \\
165\end{array}$ & & & \\
\hline \multicolumn{10}{|c|}{$\begin{array}{l}\text { Monthly mean discharge, in second-feet } \\
\text { Runoff in inches }\end{array}$} & 321 & 182 \\
\hline
\end{tabular}

Gage height, in feet, and discharge, in second-feet, at indicated time, 1940

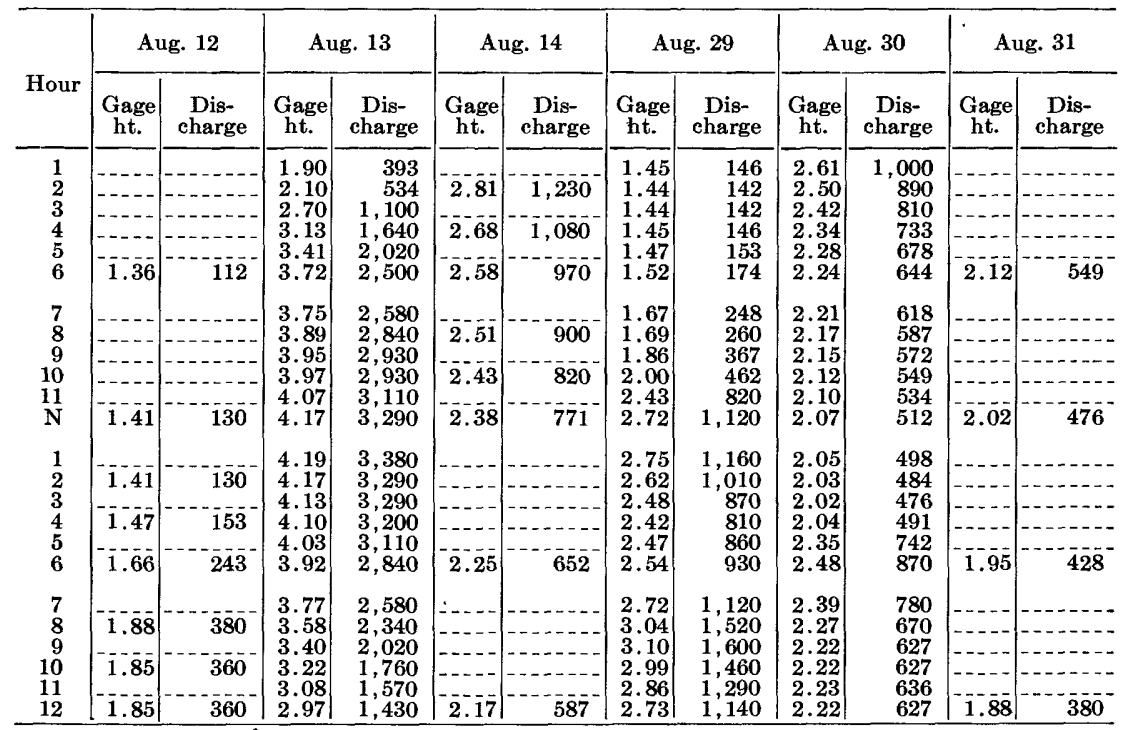

SupPLEMENTAL RECónds.-Aug. 29, 12:30 p.m., gage height, 2.77 feet, discharge, 1,180 second-feet; 8:30 p.m., gage height, 3.11 feet, discharge, 1,610 second-feet.

NOTTELY RIVER NEAR RANGER, N. C.

Location.-Lat. $35^{\circ} 01^{\prime} 40^{\prime \prime}$, long. $84^{\circ} 07^{\prime} 00^{\prime \prime}, 200$ feet upstream from highway bridge, half a mile downstream from Ranger, Cherokee County, and 71/2 miles southwest of Murphy. Datum of gage is 1,544.28 feet above mean sea level, datum of 1929, supplementary adjustment of 1936.

DRAINAGE AREA.-272 square miles.

GAGE-HEIGHT RECORD.-Water-stage recorder graph.

DISCHARGE RECORD.-Stage-discharge relation defined by current-meter measurements up to 11,100 second-feet. Shifting-control method used Aug. 1-12. Gage heights used to half-tenths between 2.6 and 4.1 feet prior to Aug. 13, and between 2.6 and 3.6 subsequently; hundredths below and tenths above these limits.

Maxima.-August 1940: Discharge, 3,190 second-feet 7-8 p.m. Aug. 13 (gage height, 9.30 feet). 
1901-5, 1914-17, 1918 to July 1940: Discharge observed, 14,100 second-feet

Feb. 28, 1902 (gage height, 21.0 feet, site and datum then in use).

REMARKs.-Flood runoff not affected by artificial storage.

Mean discharge, in second-feet, 1940

\begin{tabular}{|c|c|c|c|c|c|c|c|c|c|c|c|}
\hline Day & Aug. & Sept. & Day & Aug. & Sept. & Day & Aug. & Sept. & Day & Aug. & Sept. \\
\hline $\begin{array}{l}1 \\
2 \\
3 \\
4 \\
5 \\
6 \\
7 \\
8\end{array}$ & $\begin{array}{l}177 \\
196 \\
152 \\
137 \\
134 \\
140 \\
227 \\
156\end{array}$ & $\begin{array}{l}421 \\
332 \\
287 \\
274 \\
279 \\
358 \\
254 \\
232\end{array}$ & $\begin{array}{r}9 \\
10 \\
11 \\
12 \\
13 \\
14 \\
15 \\
16\end{array}$ & $\begin{array}{r}168 \\
140 \\
132 \\
141 \\
1,890 \\
1,330 \\
630 \\
438\end{array}$ & $\begin{array}{l}226 \\
218 \\
215 \\
198 \\
198 \\
192 \\
187 \\
178\end{array}$ & $\begin{array}{l}17 \\
18 \\
19 \\
20 \\
21 \\
22 \\
23 \\
24\end{array}$ & $\begin{array}{l}346 \\
290 \\
307 \\
260 \\
234 \\
232 \\
223 \\
220\end{array}$ & $\begin{array}{l}173 \\
170 \\
170 \\
170 \\
167 \\
162 \\
162 \\
167\end{array}$ & $\begin{array}{l}25 \\
26 \\
27 \\
28 \\
29 \\
30 \\
31\end{array}$ & $\begin{array}{l}201 \\
192 \\
187 \\
184 \\
490 \\
947 \\
663\end{array}$ & $\begin{array}{l}254 \\
206 \\
176 \\
170 \\
164 \\
159\end{array}$ \\
\hline \multicolumn{10}{|c|}{$\begin{array}{l}\text { Monthly mean discharge, in second-feet } \\
\text { Runoff, in inches. }\end{array}$} & $\begin{array}{r}360 \\
1.52\end{array}$ & $\begin{array}{r}217 \\
0.89\end{array}$ \\
\hline
\end{tabular}

Gage height, in feet, and discharge, in second-feet, at indicated time, 1940

\begin{tabular}{|c|c|c|c|c|c|c|c|c|c|c|c|c|}
\hline \multirow{2}{*}{ Hour } & \multicolumn{2}{|c|}{ Aug. 13} & \multicolumn{2}{|c|}{ Aug. 14} & \multicolumn{2}{|c|}{ Aug. 15} & \multicolumn{2}{|c|}{ Aug. 29} & \multicolumn{2}{|c|}{ Aug. 30} & \multicolumn{2}{|c|}{ Aug. 31} \\
\hline & $\begin{array}{c}\text { Gage } \\
\text { ht. }\end{array}$ & $\begin{array}{l}\text { Dis- } \\
\text { charge }\end{array}$ & $\begin{array}{c}\text { Gage } \\
\text { ht. }\end{array}$ & $\begin{array}{l}\text { Dis- } \\
\text { charge }\end{array}$ & $\begin{array}{c}\text { Gage } \\
\text { ht. }\end{array}$ & $\begin{array}{c}\text { Dis- } \\
\text { charge }\end{array}$ & $\begin{array}{c}\text { Gage } \\
\text { ht. }\end{array}$ & $\begin{array}{l}\text { Dis- } \\
\text { charge }\end{array}$ & $\begin{array}{c}\text { Gage } \\
\text { ht. }\end{array}$ & $\begin{array}{l}\text { Dis- } \\
\text { charge }\end{array}$ & $\begin{array}{c}\text { Gage } \\
\text { ht. }\end{array}$ & $\begin{array}{l}\text { Dis-" } \\
\text { charge }\end{array}$ \\
\hline 1 & 1.84 & 180 & & & & & & & 5.40 & 1,280 & & \\
\hline 2 & 1.93 & 208 & 7.92 & 2,370 & & & & & 5.78 & 1,430 & 4.18 & $\overline{87} \overline{8}$ \\
\hline 3 & 2.22 & 300 & & & & & 1.87 & 190 & 5.92 & 1,470 & & \\
\hline 4 & 2.52 & 396 & 7.00 & 1,940 & & & 1. - & & 5.82 & 1,430 & 3.90 & 784 \\
\hline 5 & 2.66 & 438 & & & & & & & 5.61 & 1,350 & & --- \\
\hline 6 & 2.74 & 470 & $6.2 \mathrm{i}$ & 1,590 & 3.61 & 694 & 1.88 & 192 & 5.32 & 1,240 & 3.76 & 739 \\
\hline 7 & 2.83 & 502 & & & & & & 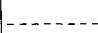 & 5.00 & 1,140 & & \\
\hline 8 & 3.05 & 566 & 5.65 & 1,350 & & & & $x=-$ & 4.69 & 1,040 & 3.66 & 709 \\
\hline 9 & 4.35 & 1,030 & & & & & 1.96 & 215 & 4.42 & 942 & & $5=-$ \\
\hline 10 & 6.00 & 1,650 & 5.25 & 1,210 & $\ldots$ & --- & ----- & $\ldots \ldots$ & 4.18 & 878 & 3.56 & 679 \\
\hline 11 & $\begin{array}{l}7.15 \\
7.82\end{array}$ & 2,160 & $-\overline{4} \overline{9}$ & $-\overline{1}, \overline{10}$ & $-\overline{3}-\overline{3} 6$ & $\cdots-\overline{6} \bar{g}^{-}$ & $-\overrightarrow{2}-\overrightarrow{8}$ & $-\overline{304}$ & $\begin{array}{l}4.00 \\
3.83\end{array}$ & $\begin{array}{l}814 \\
754\end{array}$ & $3 . \overline{45}$ & $\cdots-\overline{6} \overrightarrow{4} \bar{a}$ \\
\hline & . & 2,470 & & 1,100 & 0.00 & & & & & & & \\
\hline 1 & 8.30 & 2,690 & & & & & 2.34 & 322 & 3.70 & 724 & & $\vec{a}$ \\
\hline 2 & 8.60 & 2,840 & 4.67 & 1,040 & & & 2.44 & $35 \overline{1}$ & 3.60 & 694 & 3.34 & 619 \\
\hline 3 & 8.85 & 2,940 & & $-0=-$ & & & 2.62 & 397 & 3.52 & 664 & & $----\overline{-r}$ \\
\hline 4 & 9.01 & 3,040 & 4.46 & 974 & & -- & 3.00 & 514 & 3.45 & 649 & 3.25 & 589 \\
\hline 5 & 9.14 & 3,090 & $----\overline{-}$ & $-\vec{a}-$ & & 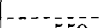 & 3.95 & 814 & 3.44 & 649 & & $----\bar{\sigma}=-$ \\
\hline 6 & 9.24 & 3,140 & 4.27 & 910 & 3.17 & 559 & 4.60 & 1,010 & 3.44 & 649 & 3.17 & 559 \\
\hline 7 & 9.30 & 3,190 & & & $\sim$ & $\ldots$ & 4.83 & 1,070 & 3.70 & 724 & & \\
\hline 8 & 9.30 & 3,190 & 4.13 & 846 & $\cdots$ & -1 & 4.77 & 1,070 & 3.92 & 784 & 3.10 & 544 \\
\hline 9 & 9.29 & 3,190 & & & & $\ldots$ & 4.64 & 1,010 & 3.99 & 814 & & -- \\
\hline 10 & 9.24 & 3,140 & 4.00 & 814 & & 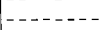 & 4.55 & 1,010 & 3.98 & 814 & 3.02 & 514 \\
\hline 11 & 9.11 & 3,090 & & & & $--x^{-1}$ & 4.59 & 1,010 & 4.02 & 814 & &.--- \\
\hline 12 & 8.80 & 2,940 & 3.87 & 784 & 3.00 & 514 & 4.87 & 1,100 & 4.20 & 878 & 2.96 & 499 \\
\hline
\end{tabular}

\section{BLUE RIDGE RESERVOIR NEAR BLUE RIDGE, GA.}

Location.-Lat. $34^{\circ} 52^{\prime} 52^{\prime \prime}$, long. $84^{\circ} 16^{\prime} 49^{\prime \prime}, 400$ feet above Blue Ridge Dam on Toccoa River, 2 miles west of Morganton, and $2 \frac{1}{2}$ miles northeast of Blue Ridge, Fannin County. Datum of gage is 0.12 foot below mean sea level, datum of 1929, supplementary adjustment of 1936 .

Drainage AREA.—233 square miles.

GAGE-HEIGHT REC0RD.-Water-stage recorder graph. Gage readings have been reduced to mean sea level.

Remarks.-Controlled storage, 183,000 acre-feet. Records furnished by the Tennessee Valley Authority. 
TENNESSEE RIVER BASIN

Elevation and contents, at midnight, 1940

\begin{tabular}{|c|c|c|c|c|c|c|c|c|c|}
\hline \multirow[b]{2}{*}{ Day } & \multicolumn{2}{|c|}{ August } & \multicolumn{2}{|c|}{ September } & \multirow[b]{2}{*}{ Day } & \multicolumn{2}{|c|}{ August } & \multicolumn{2}{|c|}{ September } \\
\hline & $\begin{array}{c}\text { Eleva- } \\
\text { tion } \\
\text { (feet) }\end{array}$ & $\begin{array}{l}\text { Contents } \\
\text { (thousand } \\
\text { acre-feet) }\end{array}$ & $\begin{array}{c}\text { Eleva- } \\
\text { tion } \\
\text { (feet) }\end{array}$ & $\begin{array}{l}\text { Contents } \\
\text { (thousand } \\
\text { acre-feet) }\end{array}$ & & $\begin{array}{c}\text { Eleva- } \\
\text { tion } \\
\text { (feet) }\end{array}$ & $\begin{array}{l}\text { Contents } \\
\text { (thousand } \\
\text { acre-feet) }\end{array}$ & $\begin{array}{c}\text { Eleva- } \\
\text { tion } \\
\text { (feet) }\end{array}$ & $\begin{array}{l}\text { Contents } \\
\text { (thousand } \\
\text { acre-feet) }\end{array}$ \\
\hline $\begin{array}{l}1 \\
2 \\
3 \\
4 \\
5\end{array}$ & $\begin{array}{l}1,680.49 \\
1,680.30 \\
1,680.48 \\
1,680.60 \\
1,680.41\end{array}$ & $\begin{array}{l}168.4 \\
167.8 \\
168.3 \\
168.7 \\
168.1\end{array}$ & $\begin{array}{l}1,679.79 \\
1,679.83 \\
1,679.67 \\
1,679.70 \\
1,679.50\end{array}$ & $\begin{array}{l}166.3 \\
166.4 \\
165.9 \\
166.0 \\
165.4\end{array}$ & $\begin{array}{l}16 \\
17 \\
18 \\
19 \\
20\end{array}$ & $\begin{array}{l}1,680.97 \\
1,680.97 \\
1,681.05 \\
1,680.94 \\
1,680.76\end{array}$ & $\begin{array}{l}169.8 \\
169.8 \\
170.0 \\
169.7 \\
169.2\end{array}$ & $\begin{array}{l}1,676.29 \\
1,675.87 \\
1,675.45 \\
1,675.00 \\
1,674.53\end{array}$ & $\begin{array}{l}156.2 \\
154.9 \\
153.8 \\
152.5 \\
151.2\end{array}$ \\
\hline $\begin{array}{r}6 \\
7 \\
8 \\
9 \\
10\end{array}$ & $\begin{array}{l}1,680.08 \\
1,679.89 \\
1,679.66 \\
1,679.40 \\
1,679.25\end{array}$ & $\begin{array}{l}167.1 \\
166.6 \\
165.9 \\
165.1 \\
164.7\end{array}$ & $\begin{array}{l}1,679.32 \\
1,679.23 \\
1,679.27 \\
1,679.03 \\
1,678.66\end{array}$ & $\begin{array}{l}164.9 \\
164.7 \\
164.7 \\
164.1 \\
163.0\end{array}$ & $\begin{array}{l}21 \\
22 \\
23 \\
24 \\
25\end{array}$ & $\begin{array}{l}1,680.59 \\
1,680.42 \\
1,680.08 \\
1,680.03 \\
1,680.03\end{array}$ & $\begin{array}{l}168.7 \\
168.2 \\
167.1 \\
167.0 \\
167.0\end{array}$ & $\begin{array}{l}1,674.08 \\
1,673.61 \\
1,673.08 \\
1,672.51 \\
1,671.91\end{array}$ & $\begin{array}{l}149.9 \\
148.5 \\
147.1 \\
145.5 \\
143.8\end{array}$ \\
\hline $\begin{array}{l}11 \\
12 \\
13 \\
14 \\
15\end{array}$ & $\begin{array}{l}1,679.21 \\
1,679.06 \\
1,680.48 \\
1.681 .05 \\
1,681.07\end{array}$ & $\begin{array}{l}164.6 \\
164.2 \\
168.3 \\
170.0 \\
170.1\end{array}$ & $\begin{array}{l}1,678.27 \\
1,677.86 \\
1,677.44 \\
1,677.05 \\
1,676.67\end{array}$ & $\begin{array}{l}161.9 \\
160.7 \\
159.4 \\
158.4 \\
157.2\end{array}$ & $\begin{array}{l}26 \\
27 \\
28 \\
29 \\
30 \\
31\end{array}$ & $\begin{array}{r}1,679.74 \\
1,679.39 \\
1,679.07 \\
1,679.11 \\
1,679.21 \\
1,679.56\end{array}$ & $\begin{array}{l}166.1 \\
165.1 \\
164.2 \\
164.3 \\
164.6 \\
165.6\end{array}$ & $\begin{array}{r}1,671.15 \\
1,670.25 \\
1,669.51 \\
1,668.78 \\
1,668.04 \\
\end{array}$ & $\begin{array}{r}141.8 \\
139.3 \\
137.3 \\
135.4 \\
133.5 \\
\\
\end{array}$ \\
\hline \multirow{2}{*}{\multicolumn{10}{|c|}{ September }} \\
\hline & & & & & & & & -56.9 & -53 \\
\hline
\end{tabular}

PARKSVILLE RESERVOIR AT PARKSVILLE, TENN.

Location.-Lat. $35^{\circ} 05^{\prime} 44^{\prime \prime}$, long. $84^{\circ} 38^{\prime} 51^{\prime \prime}$, at Parksville Dam on Ocoee River at Parksville, Polk County, $13 \%$ miles east of Cleveland. Datum of gage is 7.00

feet above mean sea level, datum of 1929, supplementary adjustment of 1936 . DRAINAGE AREA. - 595 square miles.

GAGE-HEIGHT RECORD.-Gage read hourly to tenths. Gage readings have been reduced to elevation above mean sea level.

REMARKs.-Controlled storage, 32,900 acre-feet. Elevations and capacity tables furnished by the Tennessee Valley Authority.

Elevation and contents, at midnight, 1940

\begin{tabular}{|c|c|c|c|c|c|c|c|c|c|}
\hline \multirow[b]{2}{*}{ Day } & \multicolumn{2}{|c|}{ August } & \multicolumn{2}{|c|}{ September } & \multirow[b]{2}{*}{ Day } & \multicolumn{2}{|c|}{ August } & \multicolumn{2}{|c|}{ September } \\
\hline & $\begin{array}{c}\text { Eleva- } \\
\text { tion } \\
\text { (feet) }\end{array}$ & $\begin{array}{l}\text { Contents } \\
\text { (thousand } \\
\text { acre-feet) }\end{array}$ & $\begin{array}{c}\text { Eleva- } \\
\text { tion } \\
\text { (feet) }\end{array}$ & $\begin{array}{l}\text { Contents } \\
\text { (thousand } \\
\text { acre-feet) }\end{array}$ & & $\begin{array}{c}\text { Eleva- } \\
\text { tion } \\
\text { (feet) }\end{array}$ & $\begin{array}{l}\text { Contents } \\
\text { (thousand } \\
\text { acre-feet) }\end{array}$ & $\begin{array}{c}\text { Eleva- } \\
\text { tion } \\
\text { (feet) }\end{array}$ & $\begin{array}{l}\text { Contents } \\
\text { (thousand } \\
\text { acre-feet) }\end{array}$ \\
\hline $\begin{array}{l}1 \\
2 \\
3 \\
4 \\
5 \\
5\end{array}$ & $\begin{array}{l}834.6 \\
834.1 \\
834.1 \\
834.1 \\
833.2\end{array}$ & $\begin{array}{l}85.4 \\
84.5 \\
84.5 \\
84.5 \\
82.8\end{array}$ & $\begin{array}{l}836.3 \\
836.4 \\
836.4 \\
835.7 \\
835.2\end{array}$ & $\begin{array}{l}88.6 \\
88.7 \\
88.7 \\
87.4 \\
86.5\end{array}$ & $\begin{array}{l}16 \\
17 \\
18 \\
19 \\
20 \\
21\end{array}$ & $\begin{array}{l}834.1 \\
833.9 \\
833.5 \\
833.6 \\
833.8 \\
833.9\end{array}$ & $\begin{array}{l}84.5 \\
84.1 \\
83.4 \\
83.6 \\
83.9 \\
84.1\end{array}$ & $\begin{array}{l}833.1 \\
832.8 \\
832.6 \\
832.0 \\
831.1 \\
831.7\end{array}$ & $\begin{array}{l}82.7 \\
82.1 \\
81.8 \\
80.7 \\
79.1 \\
80.2\end{array}$ \\
\hline $\begin{array}{r}6 \\
7 \\
8 \\
9 \\
10\end{array}$ & $\begin{array}{l}833.2 \\
833.1 \\
832.9 \\
833.1 \\
833.5\end{array}$ & $\begin{array}{l}82.8 \\
82.7 \\
82.3 \\
82.7 \\
83.4\end{array}$ & $\begin{array}{l}834.9 \\
835.0 \\
835.1 \\
834.4 \\
833.7\end{array}$ & $\begin{array}{l}86.0 \\
86.1 \\
86.3 \\
85.0 \\
83.8\end{array}$ & $\begin{array}{l}22 \\
23 \\
24 \\
25 \\
26\end{array}$ & $\begin{array}{l}834.4 \\
834.6 \\
834.9 \\
835.0 \\
834.5\end{array}$ & $\begin{array}{l}85.0 \\
85.4 \\
86.0 \\
86.1 \\
85.2\end{array}$ & $\begin{array}{l}832.5 \\
831.8 \\
831.2 \\
830.5 \\
829.9\end{array}$ & $\begin{array}{l}81.6 \\
80.4 \\
79.3 \\
78.1 \\
77.1\end{array}$ \\
\hline $\begin{array}{l}11 \\
12 \\
13 \\
14 \\
15\end{array}$ & $\begin{array}{l}833.6 \\
833.4 \\
834.6 \\
834.5 \\
834.2\end{array}$ & $\begin{array}{l}83.6 \\
83.2 \\
85.4 \\
85.2 \\
84.7\end{array}$ & $\begin{array}{l}833.1 \\
832.7 \\
832.1 \\
832.8 \\
833.5\end{array}$ & $\begin{array}{l}82.7 \\
82.0 \\
80.9 \\
82.1 \\
83.4\end{array}$ & $\begin{array}{l}27 \\
28 \\
29 \\
30 \\
31\end{array}$ & $\begin{array}{l}834.4 \\
834.5 \\
835.4 \\
836.0 \\
836.3\end{array}$ & $\begin{array}{l}85.0 \\
85.2 \\
86.9 \\
88.0 \\
88.6\end{array}$ & $\begin{array}{r}829.8 \\
829.6 \\
830.6 \\
830.0\end{array}$ & $\begin{array}{r}76.9 \\
76.6 \\
78.3 \\
77.2 \\
\end{array}$ \\
\hline \multirow{2}{*}{\multicolumn{8}{|c|}{ s, equ }} & August & September \\
\hline & & & & & & & & +45.5 & -192 \\
\hline
\end{tabular}

OCOEE RIVER AT PARKSVILLE, TENN.

LOCATION.-Lat. $35^{\circ} 05^{\prime} 48^{\prime \prime}$, long. $84^{\circ} 39^{\prime} 15^{\prime \prime}$, 0.4 mile downstream from dam and Ocoee No. 1 power plant of Tennessee Valley Authority at Parksville, Polk 


\section{FLOODS OF AUGUST 1940 IN THE SOUTHEASTERN STATES}

County. Datum of gage is 717.09 feet above mean sea level, datum of 1929 , supplementary adjustment of 1936 .

Drain AGE AREA. - 595 square miles.

GAGE-HEIGHT RECORD.-Water-stage recorder graph.

Discharge RECORD.-Obtained by use of discharge integrator, Stage-discharge relation defined by current-meter measurements up to 14,900 second-feet.

Maxima.-August 1940: Discharge, 3,080 second-feet 4 p.ml. Aug. 15 (gage height, 6.37 feet).

1911-16, 1921 to July 1940 : Discharge, 19,000 second-feet Apr. 6, 1936 (gage height, 18.32 feet).

REMARKs.-Flood runoff affected by storage in Blue Ridge and Parksville Reservoirs. Water-stage recorder inspected by employee of Tennessee Valley Authority.

Mean discharge, in second-feet, 1940

\begin{tabular}{|c|c|c|c|c|c|c|c|c|c|c|c|}
\hline Day & Aug. & Sept. & Day & Aug. & Sept. & Day & Aug. & Sept. & Day & Aug. & Sept. \\
\hline $\begin{array}{l}1 \\
2 \\
3 \\
4 \\
5 \\
6 \\
7 \\
8\end{array}$ & $\begin{array}{r}1,000 \\
1,260 \\
296 \\
204 \\
1,010 \\
985 \\
1,120 \\
1,040\end{array}$ & $\begin{array}{r}198 \\
194 \\
732 \\
1,190 \\
1,210 \\
1,040 \\
600 \\
227\end{array}$ & $\begin{array}{r}99 \\
11 \\
11 \\
13 \\
13 \\
15 \\
15 \\
16\end{array}$ & $\begin{array}{r}650 \\
374 \\
198 \\
959 \\
394 \\
850 \\
1,110 \\
1,010\end{array}$ & $\begin{array}{r}1,360 \\
1,550 \\
1,480 \\
1,410 \\
1,490 \\
410 \\
224 \\
1,380\end{array}$ & $\begin{array}{l}17 \\
18 \\
19 \\
20 \\
21 \\
22 \\
23 \\
24\end{array}$ & $\begin{array}{r}1,060 \\
762 \\
753 \\
654 \\
708 \\
292 \\
610 \\
696\end{array}$ & $\begin{array}{r}1,340 \\
1,090 \\
1,640 \\
1,800 \\
464 \\
246 \\
1,680 \\
1,680\end{array}$ & $\begin{array}{l}25 \\
26 \\
27 \\
28 \\
29 \\
30 \\
31\end{array}$ & $\begin{array}{r}208 \\
1,220 \\
1,020 \\
870 \\
554 \\
640 \\
308\end{array}$ & $\begin{array}{r}2,040 \\
2,020 \\
1,570 \\
1,750 \\
424 \\
1,840\end{array}$ \\
\hline \multicolumn{11}{|c|}{ onthly mean discharge, in second-feet 736} & 1,143 \\
\hline
\end{tabular}

SOUTH CHICKAMAUGA CREEK NEAR CHICKAMAUGA, TENN.

LoCATION.-Lat. $35^{\circ} 00^{\prime} 50^{\prime \prime}$, long. $85^{\circ} 12^{\prime} 27^{\prime \prime}$, a third of a mile upstream from bridge on U. S. Highway 11, 11/2 miles south of Chickamauga, Hamilton County, 6 miles east of Chattanooga, and 12 miles upstream from mouth. Datum of gage is 651.12 feet above mean sea level, datum of 1929 .

DRAINAGE AREA. - 428 square miles.

GAGE-HEIGHT RECORD.-Water-stage recorder graph except Aug. 29 to Sept. 11, and Sept. 26-29. Gage heights for Aug. 29, 30, Sept. 11, 26-29 were estimated on basis of partial record.

DISCHARGE RECORD.-Stage-discharge relation defined by current-meter measurements up to 17,600 second-feet. Gage heights used to half-tenths between 2.2 and 3.4 feet; hundredths below and tenths above these limits. Discharge for period of no gage-height record, Aug. 31 to Sept. 10, computed on basis of records for station on Sequatehie River near Whitwell.

Maxima.-August 1940: Discharge, 1,190 second-feet 3 p.m. Aug. 30 (gage height, 4.02 feet).

1928 to July 1940: Discharge, 20,000 second-feet Feb. 5, 1936 (gage height, 18.47 feet).

REMARKs.-Flood runoff not affected by storage. 
Mean discharge, in second-feet, 1940

\begin{tabular}{|c|c|c|c|c|c|c|c|c|c|c|c|}
\hline Day & Aug. & Sept. & Day & Aug. & Sept. & Day & Aug. & Sept. & Day & Aug. & Sept. \\
\hline $\begin{array}{l}1 \\
2 \\
3 \\
4 \\
5 \\
6 \\
7 \\
8\end{array}$ & $\begin{array}{l}266 \\
144 \\
125 \\
114 \\
114 \\
152 \\
342 \\
316\end{array}$ & $\begin{array}{l}447 \\
307 \\
212 \\
144 \\
118 \\
110 \\
104 \\
100\end{array}$ & $\begin{array}{r}9 \\
10 \\
11 \\
12 \\
13 \\
14 \\
15 \\
16\end{array}$ & $\begin{array}{l}152 \\
134 \\
122 \\
120 \\
147 \\
258 \\
184 \\
142\end{array}$ & $\begin{array}{r}100 \\
104 \\
104 \\
96 \\
98 \\
90 \\
94 \\
84\end{array}$ & $\begin{array}{l}17 \\
18 \\
19 \\
20 \\
21 \\
22 \\
23 \\
24\end{array}$ & $\begin{array}{l}127 \\
125 \\
112 \\
112 \\
114 \\
135 \\
136 \\
108\end{array}$ & $\begin{array}{l}94 \\
90 \\
80 \\
86 \\
84 \\
94 \\
77 \\
88\end{array}$ & $\begin{array}{l}25 \\
26 \\
27 \\
28 \\
29 \\
30 \\
31\end{array}$ & $\begin{array}{r}96 \\
100 \\
104 \\
114 \\
464 \\
922 \\
713\end{array}$ & $\begin{array}{r}88 \\
90 \\
88 \\
86 \\
84 \\
77 \\
\end{array}$ \\
\hline \multicolumn{10}{|c|}{$\begin{array}{l}\text { Monthly mean discharge, in second-feet } \\
\text { Runoff, in inches }\end{array}$} & $\begin{array}{r}204 \\
0.55\end{array}$ & $\begin{array}{r}117 \\
0.31\end{array}$ \\
\hline
\end{tabular}

\section{MAXIMUM DISCHARGES AT STREAM-MEASUREMENT STATIONS FOR THE FLOODS OF AUGUST 1940}

Water-Supply Paper 847 contains a summary of maximum flood discharges through September 1938 at all stream-measurement stations in the country; the summary of flood discharges in this report is prepared with a view to its use as a supplement to Water-Supply Paper 847. The index numbers used in tables 12,13 , and 14 and on plate 20 are the same index numbers used for the corresponding stream-measurement points in tables 1, 2, 3, 1-A, 2-A, and 3-A of Water-Supply Paper 847. Where additional points have been added, index numbers have been assigned using the same decimal system.

Tables 12, 13, and 14 summarize the flood discharges given elsewhere in this report. They also give discharges at miscellaneous points where the discharge was obtained by special methods, such as those noted under "Measurement of flood discharge" (pp. 61-62). The headings of the various columns are nearly self-explanatory. Period of record refers to the inclusive calendar years for which gaging-station records are available. The maximum flood previously known may include a flood outside the period of record, the general aim being to list the highest flood for which the discharge was known. When that flood was less than any during August 1940 and the stage is known for another flood greater than any during August 1940, the highest previous flood was listed giving the stage only. For the maximum during the present flood the discharge is the momentary peak discharge, unless otherwise noted, and the time is the time of its occurrence. The gage height is the gage height of the maximum discharge unless it is indicated as occurring at some other time.

The maximum discharge during the present flood was obtained as part of the record at a gaging station, unless otherwise indicated in the tables by letter symbol; it was usually obtained from a stagedischarge relation. The special methods, such as a slope-area measurement $(S)$, contracted-opening measurement $(C)$, computed flow through a tube $(\boldsymbol{T})$, or over a dam $(D)$, were used at gaging stations as well as at miscellaneous points. The use of such methods is considered to be more reliable when made in connection with a gaging-station record 
than when made for some other point, owing to the additional information available at a gaging station. In any event, the method used is given as part of the gaging-station records on pages $81-448$. The symbol $R$, used for stage-discharge relation, indicates that the peak discharge was obtained as a single isolated value, from a relation defined by previous measurements, by means of a gage height obtained from floodmarks. In connection with reservoir records the computed outflow $(O)$ represents the maximum value of the combined discharge as computed for the various spillways, outlet gates, and valves, turbines, or other outlet works. The computed inflow $(I)$ is the maximum value of the sum of computed outflow plus the rate of increase in contents expressed in second-feet.

The locations of all the stream-measurement points have been plotted on plate 20 . 
TABLE 12.-Summary of flood discharges in Potomac, Rappahannock, and York River Basins for the flood of August 1940 [Maximum discharges for flood of August 1940 were obtained from gaging-station records]

\begin{tabular}{|c|c|c|c|c|c|c|c|c|c|c|c|}
\hline \multirow{3}{*}{$\begin{array}{c}\text { No. } \\
\text { on } \\
\text { pl. } 20\end{array}$} & \multirow{3}{*}{ Stream and place of determination } & \multirow{3}{*}{$\begin{array}{c}\text { Drainage } \\
\text { area } \\
\text { (square } \\
\text { miles) }\end{array}$} & \multirow{3}{*}{$\begin{array}{l}\text { Period of } \\
\text { record }\end{array}$} & \multicolumn{4}{|c|}{ Maximum flood previously known } & \multicolumn{4}{|c|}{ Maximum during present flood } \\
\hline & & & & \multirow[b]{2}{*}{ Date } & \multirow[b]{2}{*}{$\begin{array}{c}\text { Gage } \\
\text { height } \\
\text { (feet) }\end{array}$} & \multicolumn{2}{|c|}{ Discharge } & \multirow[b]{2}{*}{ Time } & \multirow[b]{2}{*}{$\begin{array}{c}\text { Gage } \\
\text { height } \\
\text { (feet) }\end{array}$} & \multicolumn{2}{|c|}{ Discharge } \\
\hline & & & & & & Second- & $\begin{array}{l}\text { Second- } \\
\text { feet per } \\
\text { square } \\
\text { mile }\end{array}$ & & & $\begin{array}{l}\text { Second- } \\
\text { feet }\end{array}$ & $\begin{array}{c}\text { Second- } \\
\text { feet per } \\
\text { square } \\
\text { mile }\end{array}$ \\
\hline & Potomac River Basin & & & & & & & & & & \\
\hline $\begin{array}{l}883 \\
885\end{array}$ & North River near Burketown, Va.. & $\begin{array}{r}375 \\
1,076\end{array}$ & $\begin{array}{l}1926-40 \\
1930-40\end{array}$ & $\begin{array}{l}\text { Mar. 17, } 1936 \\
\text { Mar. 18, } 1936\end{array}$ & $\begin{array}{r}126.70 \\
26.57\end{array}$ & $\begin{array}{l}32,300 \\
77,000\end{array}$ & $\begin{array}{r}284.8 \\
71.5\end{array}$ & $\begin{array}{l}\text { Aug. } 16,7 \text { p.m. } \\
\text { Aug. } 17,2 \text { a.m. }\end{array}$ & $\begin{array}{l}10.14 \\
19.86\end{array}$ & $\begin{array}{r}5,370 \\
33,100\end{array}$ & $\begin{array}{l}14.3 \\
30.8\end{array}$ \\
\hline 886 & $\begin{array}{l}\text { wood, Va. } \\
\text { South Fork Shenandoah River near Luray, }\end{array}$ & 1,377 & $\left\{\begin{array}{l}1925-30 \\
1938-40\end{array}\right.$ & - do & ${ }^{323.6}$ & 81,600 . & 59.3 & Aug. 17, 11 a.m. & 17.87 & 341,100 & 29.8 \\
\hline 887 & $\begin{array}{l}\text { Va. Fork Shenandoah River at Front } \\
\text { South }\end{array}$ & 1,638 & $\left|\begin{array}{l}1938-40 \\
1899-1906 \\
1930-40\end{array}\right|$ & $\left\{-d_{-1}\right.$ & 26.01 & 398,000 & 59.8 & Aug. 17, 10:30 p.m. & 15.86 & $40,40 \theta$ & 24.7 \\
\hline 888 & $\begin{array}{l}\text { Royal, Va. } \\
\text { Shenandoah River at Millville, W.Va....... }\end{array}$ & 3,040 & $\left\{\begin{array}{l}1930-40 \\
1895-1909 \\
1928-40\end{array} \mid\right.$ & $\left\{-\mathrm{do}^{4}-\right.$ & 26.4 & 150,000 & 49.4 & Aug. 18, 11 a.m. & 13.7 & 40,100 & 13.2 \\
\hline $\begin{array}{l}890 \\
892\end{array}$ & $\begin{array}{l}\text { Middle River near Grottoes, Va......... } \\
\text { South River at Waynesboro, Va.......... }\end{array}$ & $\begin{array}{l}360 \\
144\end{array}$ & $\left\{\begin{array}{l}1928-40 \\
1925-40 \\
1905-6 \\
1928-40\end{array}\right.$ & Mar. 17,1936 & $\begin{array}{l}28.57 \\
13.9\end{array}$ & $\begin{array}{l}324,500 \\
{ }^{3} 10,500\end{array}$ & $\begin{array}{l}68.1 \\
72.9\end{array}$ & $\begin{array}{l}\text { Aug. } 16,11 \text { p.m. } \\
\text { Aug. } 16,12: 30 \text { p.m. }\end{array}$ & $\begin{array}{l}19.81 \\
13.9\end{array}$ & $\begin{array}{l}512,500 \\
310,500\end{array}$ & $\begin{array}{l}34.7 \\
72.9\end{array}$ \\
\hline $\begin{array}{l}893 \\
897\end{array}$ & South River at Harriston, Va.... & $\begin{array}{l}222 \\
215\end{array}$ & $\begin{array}{r}1928-40 \\
1925-40 \\
1925-40\end{array}$ & $\begin{array}{l}\text { Mar. 18, } 1936 \\
\text { Mar. 17, } 1936\end{array}$ & $\begin{array}{l}13.07 \\
23.25\end{array}$ & $\begin{array}{r}12,600 \\
340,500\end{array}$ & $\begin{array}{l}56.7 \\
188\end{array}$ & $\begin{array}{l}\text { Aug. } 16,6 \text { p.m. } \\
\text { Aug. } 16\end{array}$ & 12.91 & $\begin{array}{l}12,100 \\
61,000\end{array}$ & 54.5 \\
\hline 898 & $\begin{array}{l}\text { Store, Va. } \\
\text { North Fork Shenandoah River near Stras- } \\
\text { burg, Va. }\end{array}$ & 772 & $1925-40$ & Mar. 18, 1936 & 30.21 & 389,000 & 115 & Aug. 17,8 p.m. & 6.73 & 3,500 & 4.5 \\
\hline $\begin{array}{l}899.5 \\
900\end{array}$ & $\begin{array}{l}\text { Cedar Creek near Winchester, Va......... } \\
\text { Passage Creek at Buckton, Va............. }\end{array}$ & $\begin{array}{r}101 \\
87\end{array}$ & $\left\{\begin{array}{l}1937-40 \\
1905-6 \\
1932-40\end{array}\right.$ & Mar. 17,1936 & $\begin{array}{l}{ }^{7} 25 \\
{ }_{114.29}\end{array}$ & $\begin{array}{r}718,000 \\
12,300\end{array}$ & $\begin{array}{l}178 \\
141\end{array}$ & $\begin{array}{l}\text { Aug. } 17,1 \text { p.m. } \\
\text { Aug. } 17,4 \text { a.m. }\end{array}$ & $\begin{array}{l}2.00 \\
4.52\end{array}$ & $\begin{array}{r}78 \\
195\end{array}$ & 2.8 \\
\hline & RaPPAHANNOCK River Basin & & & & & & & & & & \\
\hline $\begin{array}{l}917 \\
918 \\
920\end{array}$ & $\begin{array}{l}\text { Rappahannock River at Kellys Ford, Va. } \\
\text { RappahannockRivernear Fredericksburg, Va. } \\
\text { Rapidan River near Culpeper, Va.... }\end{array}$ & $\begin{array}{r}641 \\
1,599 \\
465\end{array}$ & $\begin{array}{l}1925-40 \\
1907-40 \\
1930-40\end{array}$ & \begin{tabular}{l} 
Apr. 26,1937 \\
\hdashline do
\end{tabular} & $\begin{array}{l}29.22 \\
25.14 \\
28.03\end{array}$ & $\begin{array}{r}369,800 \\
3134,000 \\
50,000\end{array}$ & $\begin{array}{l}109 \\
83.8 \\
108\end{array}$ & $\begin{array}{l}\text { Aug. } 17,9: 30 \text { a.m. } \\
\text { Aug. } 17,11 \text { p.m. } \\
\text { Aug. } 17,11 \text { a.m: }\end{array}$ & $\begin{array}{r}8.49 \\
7.33 \\
15.36\end{array}$ & $\begin{array}{r}4,510 \\
17,300 \\
10,400\end{array}$ & $\begin{array}{r}7.0 \\
10.8 \\
22.4\end{array}$ \\
\hline & YoRK RIVER BASIN & & & & & & & & & & \\
\hline $\begin{array}{l}922 \\
924\end{array}$ & $\begin{array}{l}\text { North Anna River near Doswell, Va........ } \\
\text { South Anna River near Ashland, Va..... }\end{array}$ & $\begin{array}{l}439 \\
393\end{array}$ & $\begin{array}{l}1929-40 \\
1930-40 \\
\end{array}$ & Apr. $28,1937^{-1}$ & $\begin{array}{l}33.58 \\
22.77 \\
\end{array}$ & $\begin{array}{l}18,300 \\
13,700 \\
\end{array}$ & $\begin{array}{l}41.7 \\
34.9 \\
\end{array}$ & $\begin{array}{l}\text { Aug. } 17,6 \text { p.m. } \\
\text { Aug. } 18,12 \text { m. }\end{array}$ & $\begin{array}{r}10.40 \\
7.69 \\
\end{array}$ & $\begin{array}{l}3,320 \\
1,770 \\
\end{array}$ & $\begin{array}{l}7.6 \\
4.5 \\
\end{array}$ \\
\hline
\end{tabular}

1 Site and datum then in use.

2 Based on drainage area at site then in use.

4 Flood of about same magnitude occurred in 1870 .

5 Previously unpublished revision; supersedes figures published in Water-Supply Paper 891.

Daily mean discharge. 
TABLE 13.-Summary of flood discharges in south Atlantic slope and eastern Gulf of Mexico basins for the floods of August 1940 [Maximum discharges for the floods of August 1940 were obtained from gaging-station records, except as otherwise indicated by the following symbols: $C$, Contracted open-
ing measurement; $D$, Computed flow over dam; $I$, Computed inflow to reservoir; $O$, Computed outflow from reservoir; $S$, Slope-area measurement; $T$, Computed flow

\begin{tabular}{|c|c|c|c|c|c|c|c|c|c|c|c|}
\hline \multirow{3}{*}{$\begin{array}{c}\text { No. } \\
\text { on } \\
\text { pl. } 20\end{array}$} & \multirow{3}{*}{ Stream and place of determination } & \multirow{3}{*}{$\begin{array}{c}\text { Drainage } \\
\text { area } \\
\text { (square } \\
\text { miles) }\end{array}$} & \multirow{3}{*}{$\begin{array}{l}\text { Period of } \\
\text { record }\end{array}$} & \multicolumn{4}{|c|}{ Maximum flood previously known } & \multicolumn{4}{|c|}{ Maximum during present flood } \\
\hline & & & & \multirow[b]{2}{*}{ Date } & \multirow[b]{2}{*}{$\begin{array}{c}\text { Gage } \\
\text { height } \\
\text { (feet) }\end{array}$} & \multicolumn{2}{|c|}{ Discharge } & \multirow[b]{2}{*}{ Time } & \multirow[b]{2}{*}{$\begin{array}{c}\text { Gage } \\
\text { height } \\
\text { (feet) }\end{array}$} & \multicolumn{2}{|c|}{ Discharge } \\
\hline & & & & & & $\begin{array}{l}\text { Second- } \\
\text { feet }\end{array}$ & $\begin{array}{l}\text { Second- } \\
\text { feet per } \\
\text { square } \\
\text { mile }\end{array}$ & & & $\begin{array}{l}\text { Second- } \\
\text { feet }\end{array}$ & $\begin{array}{l}\text { Second- } \\
\text { feet per } \\
\text { square } \\
\text { mile }\end{array}$ \\
\hline & James RIver Basin & & & & & & & & & & \\
\hline $\begin{array}{l}1 \\
2 \\
3 \\
5 \\
7\end{array}$ & $\begin{array}{l}\text { Jackson River at Falling Spring, Va.. } \\
\text { James River at Lick Run, Va.- } \\
\text { James River at Buchanan, Va. } \\
\text { James River at Holcombs Rock, Va. } \\
\text { James River at Bent Creek, Va. }\end{array}$ & $\begin{array}{r}409 \\
1,369 \\
2,084 \\
3,250 \\
3,671\end{array}$ & $\begin{array}{l}1925-40 \\
1925-40 \\
1895-1940 \\
1926-40 \\
1925-40\end{array}$ & $\begin{array}{l}\text { Mar. 17, } 1936 \\
\text { November } 1877 \\
\text { March 1913 } \\
\text { Mar. 18, } 1936\end{array}$ & 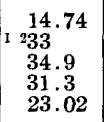 & $\begin{array}{r}124,700 \\
23120,000 \\
2125,000 \\
23118,000 \\
3115,000\end{array}$ & $\begin{array}{l}60.4 \\
87.7 \\
60.0 \\
36.3 \\
31.3\end{array}$ & $\begin{array}{l}\text { Aug. 16, } 4 \text { a.m. } \\
\text { Aug. 16, 10 a.m. } \\
\text { Aug. 15, 12 m. } \\
\text { Aug. 16, } 3 \text { p.m. } \\
\text { Aug. } 16,4: 30 \text { p.m. }\end{array}$ & $\begin{array}{r}8.72 \\
13.22 \\
16.00 \\
24.25 \\
19.63\end{array}$ & $\begin{array}{r}4,030 \\
18,700 \\
37,600 \\
66,800 \\
486,200\end{array}$ & $\begin{array}{r}9.9 \\
13.7 \\
18.0 \\
20.6 \\
23.5\end{array}$ \\
\hline $\begin{array}{r}8 \\
9 \\
10 \\
11 \\
12\end{array}$ & $\begin{array}{l}\text { James River at Scottsville, Va..... } \\
\text { James River at Cartersville, Va... } \\
\text { James River near Richmond, Va.. } \\
\text { Dunlap Creek near Covington, Va... } \\
\text { Potts Creek near Covington, Va. }\end{array}$ & $\begin{array}{r}4,571 \\
6,242 \\
6,757 \\
166 \\
158\end{array}$ & $\begin{array}{l}1925-40 \\
1899-1940 \\
1934-40 \\
1928-40 \\
1928-40\end{array}$ & $\begin{array}{l}\text { October } 1870 \\
\text { Mar. } 19,1936 \\
\text { Mar. 17, } 1936 \\
\text { Jan. 23, } 1935\end{array}$ & $\begin{array}{l}30.7 \\
28.77 \\
23.42 \\
10.52 \\
10.10\end{array}$ & $\begin{array}{r}2230,000 \\
3166,000 \\
3175,000 \\
8,370 \\
9,710\end{array}$ & $\begin{array}{l}50.3 \\
26.6 \\
25.9 \\
50.4 \\
61.5\end{array}$ & $\begin{array}{l}\text { Aug. 16, } 12 \text { p.m. } \\
\text { Aug. 17, } 3 \text { p.m. } \\
\text { - Aug. 18, 8:30 a.m. } \\
\text { Aug. 14, } 7 \text { p.m. } \\
\text { Aug. 14, 11 p.m. }\end{array}$ & $\begin{array}{l}25.84 \\
28.34 \\
21.80 \\
10.3 \\
7.90\end{array}$ & $\begin{array}{r}3130,000 \\
145,000 \\
151,000 \\
8,050 \\
5,800\end{array}$ & $\begin{array}{l}28.4 \\
23.2 \\
22.3 \\
48.5 \\
36.7\end{array}$ \\
\hline 12.5 & Cowpasture River at State Highway 629 , & 254 & & & & 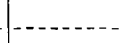 & & & & $7,700 S$ & 30 \\
\hline 13 & $\begin{array}{l}7 \text { miles east of Warm Springs, Va. } \\
\text { Cowpasture River near Clifton Forge, Va.- }\end{array}$ & 456 & $\left\{\begin{array}{l}1907-8 \\
1925-40\end{array}\right.$ & March 1913 & 20.8 & 2345,000 & 98.7 & Aug. 16, 3 p.m. & 8.21 & ${ }^{4} 6,120$ & 13.4 \\
\hline $\begin{array}{l}14 \\
15 \\
16\end{array}$ & $\begin{array}{l}\text { Craig Creek at Parr, Va. } \\
\text { Meadow Creek at Newcastle, Va. } \\
\text { Johns Creek at Newcastle, Va... }\end{array}$ & $\begin{array}{c}331 \\
13.8 \\
106\end{array}$ & $\begin{array}{r}1925-40 \\
1929-40 \\
1926-40\end{array}$ & $\begin{array}{l}\text { Jan. } 23,1935 \\
\text { Oct. } 2,1929 \\
\text { Jan. } 23,1935\end{array}$ & $\begin{array}{r}15.85 \\
53.64 \\
10.80\end{array}$ & $\begin{array}{r}16,700 \\
242 \\
38,000\end{array}$ & $\begin{array}{l}50.4 \\
17.5 \\
75.5\end{array}$ & $\begin{array}{l}\text { Aug. 15, } 5 \text { a.m. } \\
\text { Aug. 16, } 8 \text { a.m. } \\
\text { Aug. } 15,1: 30 \text { a.m. }\end{array}$ & $\begin{array}{r}15.02 \\
4.80 \\
9.53\end{array}$ & $\begin{array}{r}15,200 \\
700 \\
34,640\end{array}$ & $\begin{array}{l}45.9 \\
50.7 \\
43.8\end{array}$ \\
\hline 17.5 & $\begin{array}{l}\text { Calfpasture River above Mill Creek at } \\
\text { Goshen, Va. }\end{array}$ & 147 & $1939-40$ & May 31,1940 & 9.03 & 7,010 & 47.7 & Aug. 16, 8 p.m. & 8.00 & 5,370 & 36.5 \\
\hline $\begin{array}{l}19 \\
20 \\
20.5 \\
22\end{array}$ & $\begin{array}{l}\text { North River at Rockbridge Baths, Va. } \\
\text { North River near Lexington, Va. } \\
\text { North River near Buena Vista, Va. } \\
\text { Kerrs Creek near Lexington, Va... }\end{array}$ & $\begin{array}{r}329 \\
487 \\
649 \\
34\end{array}$ & $\begin{array}{l}1928-40 \\
1925-40 \\
1939-40 \\
1927-40\end{array}$ & $\begin{array}{l}\text { Mar. } 17,1936 \\
\text { Mar. 18, } 1936 \\
\text { Mar. 18,19,1936 } \\
\text { Mar. 17, 1936 }\end{array}$ & $\begin{array}{l}13.07 \\
23.58 \\
22 \\
12.82\end{array}$ & $\begin{array}{c}133,000 \\
140,000 \\
(6) \\
17,600\end{array}$ & $\begin{array}{r}100 \\
82.1 \\
-224\end{array}$ & $\begin{array}{l}\text { Aug. } 16,5 \text { p.m. } \\
\text { Aug. } 16,9: 30 \mathrm{a} . \mathrm{m} . \\
\text { Aug. } 16,10: 30 \mathrm{a.m} . \\
\text { Aug. } 14,10 \text { p.m. } \\
\text { Aug. } 31,4 \text { p.m. }\end{array}$ & $\begin{array}{r}8.45 \\
12.33 \\
13.36 \\
7.40 \\
10.07\end{array}$ & $\begin{array}{r}39,200 \\
10,600 \\
114,700 \\
41,200 \\
33,660\end{array}$ & $\begin{array}{r}28.0 \\
21.8 \\
22.7 \\
35.3 \\
108\end{array}$ \\
\hline 23.5 & Buffalo River near Norwood, Va. & $\begin{array}{r}360 \\
40\end{array}$ & 1940 & Apr. $\quad 9,1940$ & 4.77 & 2,900 & 8.1 & Aug. $16,12 \mathrm{~m}$. & 15.25 & $\underset{5,200 \mathrm{~S}}{25,600}$ & 71.1 \\
\hline 24.5 & $\begin{array}{l}\text { north of Massies Mill, Va. } \\
\text { Tye River near Lovingston, Va...- } \\
\text { Rockfish River at dam of Alberene Stone } \\
\text { Corporation, at Schuyler, Va. }\end{array}$ & $\begin{array}{r}92 \\
189\end{array}$ & $1938-40$ & Aug. 19, 1939 & 11.13 & 6,900 & 75.0 & $\begin{array}{l}\text { Aug. } 16,1: 30 \text { p.m. } \\
\text { Aug. } 15,5 \text { p.m. }\end{array}$ & 11.94 & $\begin{array}{c}7,700 \\
14,000 D\end{array}$ & 83.7 \\
\hline
\end{tabular}




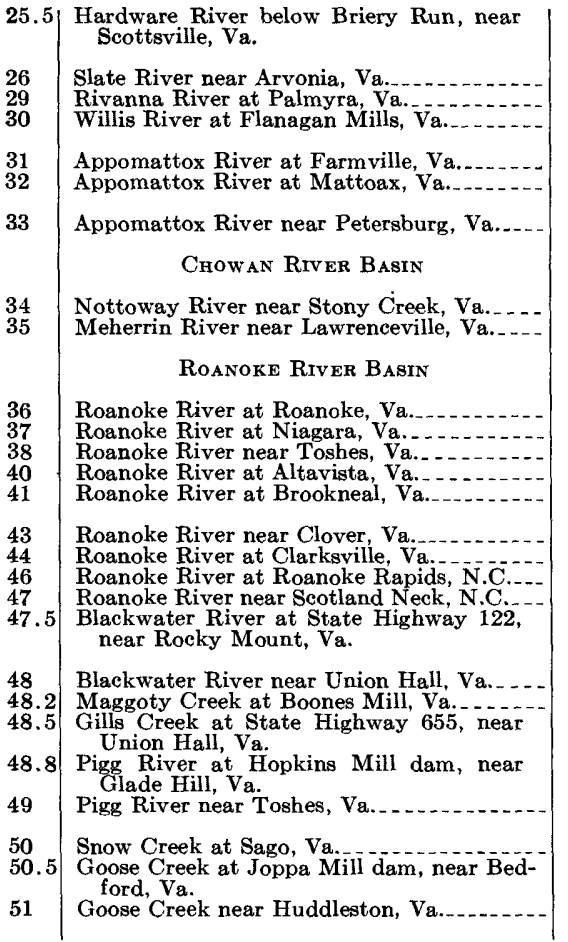

Revised; see Water-Supply Paper 952. 2 About.

3 Revised; see Water-Supply Paper 972.

4 Revised; supersedes figure published in Water-Supply Paper 892 5 Datum then in use.

${ }^{6}$ Discharge not determined.

\begin{tabular}{|c|c|c|c|c|c|c|c|c|c|}
\hline 116 & $1938-40$ & Feb. 11, 1939 & 10.04 & 1,370 & 11.8 & Aug. 16,11 p.m. & 13.73 & 74,250 & 36.6 \\
\hline $\begin{array}{l}235 \\
675 \\
247\end{array}$ & $\begin{array}{r}1926-40 \\
1934-40 \\
\{1926-35 \\
1936-40\end{array}$ & $\begin{array}{l}\text { Sept. } 6,1935 \\
\text { Apr. 26, } 1937 \\
\text { Apr. 27, } 1937\end{array}$ & $\begin{array}{l}22.18 \\
33.35 \\
23.86\end{array}$ & $\begin{array}{l}13,600 \\
56,700 \\
39,580\end{array}$ & $\begin{array}{l}57.9 \\
84.0 \\
38.8\end{array}$ & $\begin{array}{l}\text { Aug. } 16,12 \mathrm{~m} . \\
\text { Aug. } 17,3: 30 \mathrm{p} . \mathrm{m} . \\
\text { Aug. } 17,12 \mathrm{~m} .\end{array}$ & $\begin{array}{l}13.62 \\
21.78 \\
21.94\end{array}$ & $\begin{array}{r}5,880 \\
16,300 \\
37,380\end{array}$ & $\begin{array}{l}25.0 \\
24.1 \\
29.9\end{array}$ \\
\hline $\begin{array}{l}306 \\
729\end{array}$ & $\left\{\begin{array}{l}1926-40 \\
1900-1905 \\
1926-40\end{array}\right.$ & $\begin{array}{l}\text { Aug. 12, } 1928 \\
\text { Apr. 28, } 1937\end{array}$ & $\begin{array}{l}21.10 \\
29.97\end{array}$ & $\begin{array}{r}313,900 \\
20,100\end{array}$ & $\begin{array}{l}45.4 \\
27.6\end{array}$ & $\begin{array}{l}\text { Aug. } 15,4 \text { p.m. } \\
\text { Aug. } 18,8 \text { a.m. }\end{array}$ & $\begin{array}{l}23.60 \\
35.3\end{array}$ & $\begin{array}{l}21,000 \\
35,000\end{array}$ & $\begin{array}{l}68.6 \\
48.0\end{array}$ \\
\hline, 335 & $\begin{array}{l}1920-40 \\
1927-40\end{array}$ & Apr. 30,1937 & 14.85 & 18,800 & 14.1 & Aug. 20,10 am to $12 \mathrm{~m}$ & 18.15 & 28,000 & 21.0 \\
\hline $\begin{array}{l}586 \\
553\end{array}$ & $\begin{array}{l}1930-40 \\
1928-40\end{array}$ & $\begin{array}{l}\text { Apr. } 28,1937 \\
\text { Apr. } 27,1937\end{array}$ & $\begin{array}{l}20.00 \\
30.92\end{array}$ & $\begin{array}{l}11,500 \\
17,300\end{array}$ & $\begin{array}{l}19.6 \\
31.3\end{array}$ & $\begin{array}{l}\text { Aug. } 17,9 \text { a.m. } \\
\text { Aug. } 17,2 \text { a.m. }\end{array}$ & $\begin{array}{l}23.66 \\
42.0\end{array}$ & $\begin{array}{l}25,200 \\
38,000\end{array}$ & $\begin{array}{l}43.0 \\
68.7\end{array}$ \\
\hline $\begin{array}{r}388 \\
511 \\
1,020 \\
1,802 \\
2,420\end{array}$ & $\begin{array}{l}1896-1940 \\
1926-40 \\
1925-40 \\
1930-40 \\
1923-40\end{array}$ & $\begin{array}{lr}\text { Aug. } & 6,1901 \\
\text { Aug. } & 16,1928 \\
\text { Oct. } 19,1937 \\
\text { Oct. } 20,1937 \\
\text { Aug. } 12,1928\end{array}$ & $\begin{array}{l}14.34 \\
17.36 \\
20.45 \\
31.27 \\
37.15\end{array}$ & $\begin{array}{r}816,900 \\
934,400 \\
1029,500 \\
957,000 \\
976,300\end{array}$ & $\begin{array}{l}43.5 \\
67.3 \\
28.9 \\
31.6 \\
31.5\end{array}$ & $\begin{array}{l}\text { Aug. } 14,10: 30 \text { p.m. } \\
\text { Aug. 14, about } 8-10 \mathrm{pm} \\
\text { Aug. 15, 1:30 a.m. } \\
\text { Aug. 15, } 6 \text { a.m. } \\
\text { Aug. 15, } 7 \text { p.m. }\end{array}$ & $\begin{array}{l}18.25 \\
17.5 \\
27.36 \\
40.08 \\
46.0\end{array}$ & $\begin{array}{r}28,000 \\
35,000 \\
70,000 \\
105,000 \\
130,000\end{array}$ & $\begin{array}{l}72.2 \\
68.5 \\
68.6 \\
58.3 \\
53.7\end{array}$ \\
\hline $\begin{array}{r}3,230 \\
7,320 \\
8,410 \\
8,700 \\
119\end{array}$ & $\begin{array}{c}1929-40 \\
1934-40 \\
1911-40 \\
1940\end{array}$ & $\begin{array}{c}\text { Mar. } 19,1936 \\
\text { Jan. } 21,1936 \\
\text { Mar. } 18,1912 \\
1877\end{array}$ & $\begin{array}{c}23.49 \\
16.88 \\
-\overline{3} \overline{7} .8\end{array}$ & $\begin{array}{r}56,400 \\
114,000 \\
10158,000 \\
\left({ }^{6}\right)\end{array}$ & $\begin{array}{l}17.5 \\
15.6 \\
18.8\end{array}$ & $\begin{array}{l}\text { Aug. } 16,6 \text { p.m. } \\
\text { Aug. 17,6 a.m. } \\
\text { Aug. 18, 10:30 a.m. } \\
\text { Aug. 19, } 8 \text { a.m. } \\
\text { Aug. } 14, \text { about } 8-9 \text { pm }\end{array}$ & $\begin{array}{r}37.15 \\
26.66 \\
39.0 \\
1141.98\end{array}$ & $\begin{array}{c}160,000 \\
280,000 \\
261,000 \\
260,000 \\
17,000 S\end{array}$ & $\begin{array}{r}49.5 \\
38.3 \\
31.0 \\
29.9 \\
140\end{array}$ \\
\hline $\begin{array}{r}208 \\
14 \\
40\end{array}$ & $1925-40$ & Aug. 19,1939 & 18.50 & ${ }^{9} 17,900$ & $\$ 6.1$ & $\begin{array}{l}\text { Aug. 14, 8:30 p.m. } \\
\text { Aug. } 14 \text {, abt10-11 a.m. }\end{array}$ & 19.52 & $\begin{array}{c}19,700 \\
2,900 \mathrm{~S} \\
12,000 \mathrm{~S}\end{array}$ & $\begin{array}{l}94.7 \\
210 \\
300\end{array}$ \\
\hline 118 & & & & & & Aug. 14, abt 9-11 a.m. & & $7,600 D$ & 64 \\
\hline 394 & $1930-40$ & Oct. 20,1937 & 22.23 & ${ }^{3} 15,400$ & 39.1 & Aug. 15,8 a.m. & 32.5 & 334,300 & 87.1 \\
\hline $\begin{array}{r}60 \\
102\end{array}$ & $1934-40$ & Jan. 19,1936 & & 12131,700 & 28.3 & $\begin{array}{l}\text { Aug. } 14,5 \text { p.m. } \\
\text { Aug. } 15,4 \text { p.m. }\end{array}$ & 22.98 & $\begin{array}{l}312,000 \\
2,400 D\end{array}$ & $\begin{array}{r}200 \\
24\end{array}$ \\
\hline 187 & $1930-40$ & Oct. 19,1937 & 25.75 & ${ }^{9} 17,200$ & 92.0 & Aug. 14,5 p.m. & 21.90 & 12,700 & 67.9 \\
\hline
\end{tabular}

${ }^{8}$ Maximum observed.

${ }^{9}$ Revised; see Water-Supply Paper 892.

10 Revised; see Water-Supply Paper 1032.

${ }_{11}^{11}$ Occurred at 2 p.m.

12 Daily mean discharge. 


\begin{tabular}{|c|c|c|c|c|c|c|c|c|c|c|c|}
\hline \multirow{3}{*}{$\begin{array}{c}\text { No. } \\
\text { on } \\
\text { pl. } 20\end{array}$} & \multirow{3}{*}{ Stream and place of determination } & \multirow{3}{*}{$\begin{array}{l}\text { Drainage } \\
\text { area } \\
\text { (square } \\
\text { miles) }\end{array}$} & \multirow{3}{*}{$\begin{array}{c}\text { Period of } \\
\text { record }\end{array}$} & \multicolumn{4}{|c|}{ Maximum flood previously known } & \multicolumn{4}{|c|}{ Maximum during present flood } \\
\hline & & & & \multirow[b]{2}{*}{ Date } & \multirow[b]{2}{*}{$\begin{array}{c}\text { Gage } \\
\text { height } \\
\text { (feet) }\end{array}$} & \multicolumn{2}{|c|}{ Discharge } & \multirow[b]{2}{*}{ Time } & \multirow[b]{2}{*}{$\begin{array}{c}\text { Gage } \\
\text { height } \\
\text { (feet) }\end{array}$} & \multicolumn{2}{|c|}{ Discharge } \\
\hline & & & & & & $\begin{array}{l}\text { Second- } \\
\text { feet }\end{array}$ & $\begin{array}{l}\text { Second- } \\
\text { feet per } \\
\text { square } \\
\text { mile }\end{array}$ & & & $\begin{array}{c}\text { Second- } \\
\text { feet }\end{array}$ & $\begin{array}{l}\text { Second- } \\
\text { feet per } \\
\text { square } \\
\text { mile }\end{array}$ \\
\hline 51.5 & $\begin{array}{l}\text { Otter River at U. S. Highway } 460 \text {, near } \\
\text { Pedford, Va. }\end{array}$ & 116 & & & $\ldots$ & 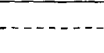 & 年 & $\begin{array}{l}\text { Aug. } 15 \text {, about } 12 \mathrm{~m} \text {. } \\
\text { to } 1 \text { p.m. }\end{array}$ & & $9,700 S$ & 84 \\
\hline 52 & Otter River near Evington, Va.............. & 325 & $1936-40$ & $\left\{\begin{array}{l}\text { Oct. } 19,1937 \\
\text { Aug. } 19,1939\end{array}\right.$ & 23.1 & ${ }^{9} 27,500$ & 84.6 & Aug. 14, 5 p.m. & 22.42 & ${ }^{4} 24,400$ & 75.1 \\
\hline 53.5 & $\begin{array}{l}\text { Little Otter River at U. S. Highway } 460 \text {, } \\
\text { near Bedford, Va. }\end{array}$ & 21 & & & & & 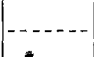 & $\begin{array}{l}\text { Aug. } 15 \text {, about } 12 \mathrm{~m} \text {. } \\
\text { to } 1 \text { p.m. }\end{array}$ & & $2,400 S$ & 110 \\
\hline $\begin{array}{l}54 \\
55 \\
59 \\
61.5\end{array}$ & $\begin{array}{l}\text { Falling River near Naruna, Va... } \\
\text { Falling River near Brookneal, Va. } \\
\text { Dan River near Francisco, N.C. } \\
\text { Dan River near Wentworth, N.C. }\end{array}$ & $\begin{array}{r}172 \\
228 \\
124 \\
1,050\end{array}$ & $\begin{array}{l}1929-35 \\
1935-40 \\
1924-40 \\
1939-40\end{array}$ & $\begin{array}{l}\text { Dec. } 1,1934 \\
\text { Mar. } 17 \text { or } 18,36 \\
\text { Oct. } 19,1937\end{array}$ & $\begin{array}{l}14.78 \\
28.00 \\
12.45\end{array}$ & $\begin{array}{r}4,500 \\
920,400 \\
12,400\end{array}$ & $\begin{array}{r}26.2 \\
89.5 \\
100\end{array}$ & $\begin{array}{l}\text { Aug. 15, 3 a.m. } \\
\text { Aug. 14, 10:30 a.m. } \\
\text { Aug. 15, 10-12 a.m. }\end{array}$ & $\begin{array}{l}26.5 \\
29.35 \\
9.40 \\
26.9\end{array}$ & $\begin{array}{l}22,000 S \\
23,000 \\
7,630 \\
50,200\end{array}$ & $\begin{array}{l}130 \\
101 \\
61.5 \\
47.8\end{array}$ \\
\hline $\begin{array}{l}62 \\
63 \\
64\end{array}$ & $\begin{array}{l}\text { Dan River at Leaksville, N.C. } \\
\text { Dan River at Danville, Va... } \\
\text { Dan River at South Boston, Va.. }\end{array}$ & $\begin{array}{l}1,150 \\
2,050 \\
2,730\end{array}$ & $\mid \begin{array}{l}1929-40 \\
1934-40 \\
\{1900-1907 \\
1923-40\end{array}$ & $\begin{aligned} & \text { Oct. } 20,1937 \\
& \text { Oct. } 21,1937 \\
& \text { Jan. } 21,1936\end{aligned}$ & $\begin{array}{l}27.90 \\
18.34 \\
28.5\end{array}$ & $\begin{array}{r}\left.{ }^{(6)}\right) \\
54,100 \\
351,000\end{array}$ & $\begin{array}{l}26.4 \\
18.7\end{array}$ & $\begin{array}{l}\text { Aug. } 15,12-2 \text { p.m. } \\
\text { Aug. } 15,6: 30 \text { p.m. } \\
\text { Aug. } 16,12 \text { p.m. }\end{array}$ & $\begin{array}{l}1428.26 \\
20.96 \\
31.8\end{array}$ & $\begin{array}{r}243,000 \\
75,000 \\
81,000\end{array}$ & $\begin{array}{l}37.4 \\
36.6 \\
29.7\end{array}$ \\
\hline $\begin{array}{l}65 \\
66\end{array}$ & $\begin{array}{l}\text { Mayo River near Price, N. C.. } \\
\text { North Mayo River near Spencer, Va.. }\end{array}$ & $\begin{array}{l}260 \\
108\end{array}$ & $\begin{array}{l}1929-40 \\
1928-40^{15}\end{array}$ & Oct. 19,1937 & $\begin{array}{l}14.00 \\
14.33\end{array}$ & $\begin{array}{l}30,000 \\
14,300\end{array}$ & $\begin{array}{l}115 \\
132\end{array}$ & $\begin{array}{l}\text { Aug. 14, } 5 \text { p.m. } \\
\text { Aug. 14, } 3 \text { p.m. }\end{array}$ & $\begin{array}{l}11.00 \\
10.11\end{array}$ & $\begin{array}{r}19,000 \\
6,800\end{array}$ & $\begin{array}{l}73.1 \\
63.0\end{array}$ \\
\hline $\begin{array}{l}66.5 \\
67 \\
67.5 \\
68 \\
69\end{array}$ & $\begin{array}{l}\text { Smith River at Passett, Va. } \\
\text { Smith River at Martinsville, Va. } \\
\text { Smith River at Spray, N. C. } \\
\text { Leatherwood Creek near Old Liberty, Va..- } \\
\text { Sandy River near Danville, Va.. }\end{array}$ & $\begin{array}{r}253 \\
374 \\
538 \\
68 \\
113\end{array}$ & $\begin{array}{l}1939-40 \\
1929-40 \\
1939-40 \\
1925-34 \\
1929-40\end{array}$ & $\begin{array}{l}\text { Oct. 20,1937 } \\
\text { Aug. 11, 1928 } \\
\text { Sept. } 7,1934\end{array}$ & $\begin{array}{c}222.9 \\
21.50 \\
-14.37 \\
11.60\end{array}$ & $\begin{array}{r}38,200 \\
39,000 \\
33,000 \\
122,970 \\
37,140\end{array}$ & $\begin{array}{c}151 \\
104 \\
61.3 \\
43.7 \\
63.2\end{array}$ & $\begin{array}{l}\text { Aug. 14, } 5 \text { p.m. } \\
\text { Aug. } 14,9 \text { p.m. } \\
\text { Aug. } 15,1 \text { a.m. } \\
\text { Aug. } 14,9 \text { p.m. }\end{array}$ & $\begin{array}{r}18.28 \\
19.50 \\
19.28 \\
-17.38\end{array}$ & $\begin{array}{l}26,600 \\
34,200 \\
45,600 \\
9,900 S \\
23,000\end{array}$ & $\begin{array}{l}105 \\
91.4 \\
84.8 \\
150 \\
204\end{array}$ \\
\hline 69.5 & $\begin{array}{l}\text { Banister River at State Highway 607, near } \\
\text { Riceville, Va. }\end{array}$ & 267 & 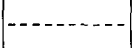 & 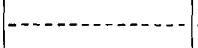 & & & & & & $48,000 S$ & 180 \\
\hline $\begin{array}{l}70 \\
72\end{array}$ & $\begin{array}{c}\text { Banister River at Halifax, Va. } \\
\text { Hyco River near Omega, Va... } \\
\text { PamLico RIver Basin }\end{array}$ & $\begin{array}{l}552 \\
338\end{array}$ & $\begin{array}{l}1928-40 \\
1934-40\end{array}$ & $\begin{array}{l}\text { June } 22,1938 \\
\text { Sept. 8, } 1934\end{array}$ & $\begin{array}{l}31.22 \\
27.50\end{array}$ & $\begin{array}{l}319,000 \\
311,000\end{array}$ & $\begin{array}{l}34.4 \\
32.5\end{array}$ & $\begin{array}{l}\text { Aug. 16, } 9 \text { a.m. } \\
\text { Aug. 17, } 8: 30 \text { a.m. }\end{array}$ & $\begin{array}{l}37.8 \\
25.65\end{array}$ & $\begin{array}{r}334,000 \\
39,280\end{array}$ & $\begin{array}{l}61.6 \\
27.5\end{array}$ \\
\hline $\begin{array}{l}72.5 \\
73 \\
74\end{array}$ & $\begin{array}{l}\text { Tar River near Tar River, N. C. } \\
\text { Tar River near Nashville, N. C.. } \\
\text { Tar River at Tarboro, N. C. }\end{array}$ & $\begin{array}{r}161 \\
701 \\
2,100\end{array}$ & $\mid \begin{array}{c}1939-40 \\
1928-40 \\
\{1896-1900 \\
1931-40\end{array}$ & $\begin{array}{r}\text { May 25, } 1940 \\
\text { Dec. 3,1934 } \\
\text { July 27, 1919 }\end{array}$ & $\begin{array}{l}11.9 \\
20.8 \\
34.2\end{array}$ & $\begin{array}{r}35,550 \\
16,900 \\
852,800\end{array}$ & $\begin{array}{l}34.5 \\
24.1 \\
25.1\end{array}$ & $\begin{array}{l}\text { Aug. 16, 10-10:30 a.m. } \\
\text { Aug. 18, } 8 \text { a.m. } \\
\text { Aug. 20, 6-8 p.m. }\end{array}$ & $\begin{array}{r}7.38 \\
17.37 \\
31.77\end{array}$ & $\begin{array}{r}32,050 \\
11,700 \\
37,200\end{array}$ & $\begin{array}{l}12.7 \\
16.7 \\
17.7\end{array}$ \\
\hline 74.5 & $\begin{array}{l}\text { Tar River at Greenville, N. C.- } \\
\text { Fishing Creek near Enfield, N. C.- }\end{array}$ & $\begin{array}{r}2,680 \\
462\end{array}$ & $\left\{\begin{array}{l}1931-40 \\
1918-23^{16} \\
1923-40\end{array} \mid\right.$ & $\begin{array}{ll}\text { July } & 28,1919 \\
\text { July } & 24,1919^{17}\end{array}$ & $\begin{array}{l}24.5 \\
19.6\end{array}$ & 20,300 & $4 \overline{3} . \overline{9}$ & $\begin{array}{l}\text { Aug. 22, 6-8 a.m. } \\
\text { Aug. 18, 1-4 a.m. }\end{array}$ & $\begin{array}{l}22.07 \\
17.72\end{array}$ & $\begin{array}{l}36,500 \\
12,600\end{array}$ & $\begin{array}{l}13.6 \\
27.3\end{array}$ \\
\hline
\end{tabular}




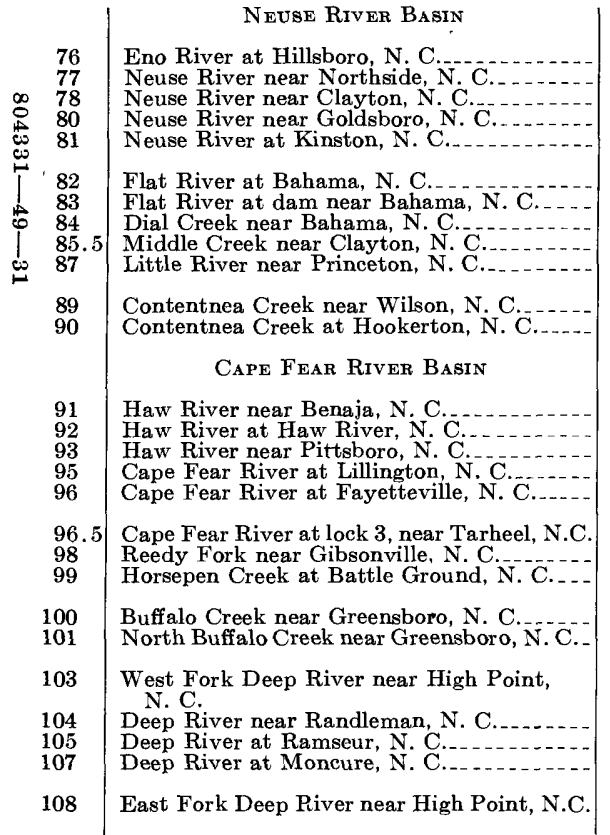

\begin{tabular}{|c|c|c|}
\hline $\begin{array}{c}66.5 \\
526\end{array}$ & $\begin{array}{l}1927-40 \\
1927-40\end{array}$ & $\begin{array}{lr}\text { Oct. } & 2,1929 \\
\text { Oct. } & 3,1929\end{array}$ \\
\hline $\begin{array}{l}1 \\
370 \\
690\end{array}$ & $\begin{array}{l}1930- \\
1930-\end{array}$ & $\begin{array}{l}\text { Oct. } 5,1929 \\
\text { July } 1919\end{array}$ \\
\hline $\begin{array}{c}150 \\
21171 \\
4.9 \\
80.7 \\
229\end{array}$ & $\begin{array}{l}1925-40 \\
1927-40 \\
1925-40 \\
1939-40 \\
1930-40\end{array}$ & $\begin{array}{l}\text { July } 26,1938 \\
\text { July } 26,1938 \\
\text { May } 24,1940 \\
\text { Apr. } 22,1940 \\
\text { Dec. } \quad 2,1934^{22}\end{array}$ \\
\hline $\begin{array}{l}236 \\
789\end{array}$ & $\begin{array}{l}1930-40 \\
1928-40\end{array}$ & $\begin{array}{l}\text { Sept. } 1924 \\
\text { Oct. } \quad 6,1929^{23}\end{array}$ \\
\hline $\begin{array}{r}168 \\
599 \\
1,310 \\
3,440 \\
4,370\end{array}$ & $\begin{array}{l}1928-40 \\
1928-40 \\
1928-40 \\
1923-40 \\
1889-1917 \\
1928-40\end{array}$ & $\begin{array}{l}\text { July } 1916 \\
\text { Feb. 28, } 1929 \\
\text { August } 1908^{24} \\
\text { Oct. 2, 1929 } \\
\text { Aug. 29, } 1908\end{array}$ \\
\hline $\begin{array}{c}4,810 \\
133 \\
15.9\end{array}$ & $\begin{array}{r}1928-40 \\
1937-40 \\
1928-40 \\
\{1925-31\end{array}$ & $\begin{array}{l}\text { July } 28, \\
\text { Jan. } 20 \text {, } \\
\text { Jan. 19, }\end{array}$ \\
\hline $\begin{array}{l}32.8 \\
36.4\end{array}$ & $\begin{array}{r}1934-40 \\
1928-40 \\
1928-40\end{array}$ & $\begin{array}{l}\text { Feb. } 28,1929 \\
\text { Jan. } 19,1936\end{array}$ \\
\hline 32. & & do \\
\hline $\begin{array}{r}{ }^{21} 124 \\
346 \\
1,410\end{array}$ & $\begin{array}{r}1928 \\
1922 \\
\{1898\end{array}$ & $\begin{array}{l}\text { Feb. } 28,1929 \\
\text { August } 1901 \\
\text { Apr. 7, 1936 }\end{array}$ \\
\hline 14.2 & 19 & $\left\{\begin{array}{l}\text { Jan. } \\
\text { Aug. }\end{array}\right.$ \\
\hline
\end{tabular}

\begin{tabular}{|c|c|c|c|c|c|c|}
\hline $\begin{array}{c}18.0 \\
28.64 \\
21.62 \\
1925.3 \\
25.0\end{array}$ & $\begin{array}{r}106,750 \\
1826,600 \\
1022,000 \\
38,600 \\
239,000\end{array}$ & $\begin{array}{c}102 \\
50.6 \\
19.3 \\
16.3 \\
14.5\end{array}$ & $\begin{array}{l}\text { Aug. } 14,5 \text { p.m. } \\
\text { Aug. } 18,3 \text { a.m. } \\
\text { Aug. } 16 \\
\text { Aug. } 22,4 \text { a.m. } \\
\text { Aug. } 25,6 \text { a.m. }\end{array}$ & $\begin{array}{r}10.90 \\
16.50 \\
14.6 \\
2019.18 \\
16.14\end{array}$ & $\begin{array}{r}1,680 \\
4,050 \\
11,500 \\
11,400 \\
10,900\end{array}$ & $\begin{array}{r}25.3 \\
7.7 \\
10.1 \\
4.8 \\
4.1\end{array}$ \\
\hline $\begin{array}{r}19.50 \\
7.60 \\
6.51 \\
12.68\end{array}$ & $\begin{array}{r}16,000 \\
18,600 \\
1,270 \\
1577 \\
4,030\end{array}$ & $\begin{array}{c}107 \\
109 \\
259 \\
7.1 \\
17.6\end{array}$ & $\begin{array}{l}\text { Aug. } 14,8: 30 \text { p.m. } \\
\text { Aug. } 16,3 \text { a.m. } \\
\text { Aug. } 14,3: 30 \text { p.m. } \\
\text { Aug. } 18,5: 30 \text { a.m. } \\
\text { Aug. } 19,9 \text { a.m. }\end{array}$ & $\begin{array}{r}6.97 \\
9.28 \\
3.22 \\
5.07 \\
11.70\end{array}$ & $\begin{array}{r}4,000 \\
3,020 \\
130 \\
360 \\
3,270\end{array}$ & $\begin{array}{r}26.7 \\
17.7 \\
26.5 \\
4.5 \\
14.3\end{array}$ \\
\hline $\begin{array}{r}224.3 \\
18.9\end{array}$ & $\begin{array}{l}(6) \\
11,100\end{array}$ & 14.1 & $\begin{array}{l}\text { Aug. } 17,6: 30 \text { p.m. } \\
\text { Aug. } 21,8 \text { p.m. }\end{array}$ & $\begin{array}{l}13.80 \\
15.23\end{array}$ & $\begin{array}{l}4,830 \\
6,100\end{array}$ & $\begin{array}{r}20.5 \\
7.7\end{array}$ \\
\hline $\begin{array}{c}{ }^{2} 17.5 \\
23.96 \\
{ }^{2} 32.1 \\
27.55 \\
{ }^{2} 68.0\end{array}$ & $\begin{array}{r}(6) \\
17,000 \\
98,090 \\
101,000 \\
2133,000\end{array}$ & $\begin{array}{l}28.4 \\
74.8 \\
29.4 \\
30.4\end{array}$ & $\begin{array}{l}\text { Aug. } 15,11 \text { p.m. }{ }^{1} \\
\text { Aug. } 16,5 \text { a.m. } \\
\text { Aug. } 14,11 \text { p.m. } \\
\text { Aug. } 17,8 \text { a.m. } \\
\text { Aug. } 17,5 \text { p.m. }\end{array}$ & $\begin{array}{l}13.7 \\
20.37 \\
14.68 \\
13.87 \\
32.25\end{array}$ & $\begin{array}{r}5,200 \\
12,700 \\
18,900 \\
29,600 \\
28,500\end{array}$ & $\begin{array}{r}31.0 \\
21.2 \\
14.4 \\
8.6 \\
6.5\end{array}$ \\
\hline $\begin{array}{l}24.0 \\
13.28 \\
7.07\end{array}$ & $\begin{array}{l}(6) \\
4,390 \\
980\end{array}$ & $\begin{array}{l}33.0 \\
61.6\end{array}$ & $\begin{array}{l}\text { Aug. } 18,2 \text { a.m. } \\
\text { Aug. } 15,4 \text { p.m. } \\
\text { Aug. } 14,11: 30 \text { a.m. }\end{array}$ & $\begin{array}{r}16.49 \\
12.70 \\
6.64\end{array}$ & $\begin{array}{l}{ }^{(6)} \\
4,130 \\
820\end{array}$ & $\begin{array}{l}31.1 \\
51.6\end{array}$ \\
\hline $\begin{array}{r}8.74 \\
11.38\end{array}$ & $\begin{array}{l}2,680 \\
1,750\end{array}$ & $\begin{array}{l}81.7 \\
48.1\end{array}$ & $\begin{array}{l}\text { Aug. } 14,10 \text { p.m. } \\
\text { Aug. } 14,1 \text { p.m. }\end{array}$ & $\begin{array}{l}7.32 \\
8.89\end{array}$ & $\begin{array}{l}1.060 \\
1,200\end{array}$ & $\begin{array}{l}32.3 \\
33.0\end{array}$ \\
\hline 13.84 & 2,880 & 89.7 & Aug. 14, 8:30 a.m. & 12.74 & 2,370 & 73.8 \\
\hline $\begin{array}{l}23.9 \\
28.75 \\
10.47\end{array}$ & $\begin{array}{r}8,470 \\
30,000 \\
27,000\end{array}$ & $\begin{array}{l}68.3 \\
86.7 \\
19.1\end{array}$ & $\begin{array}{l}\text { Aug. } 15,3 \text { a.m. } \\
\text { Aug. 14,5 p.m. } \\
\text { Aug. } 16,11 \text { p.m. }\end{array}$ & $\begin{array}{r}19.88 \\
14.53 \\
6.64\end{array}$ & $\begin{array}{r}5,590 \\
9,050 \\
11,500\end{array}$ & $\begin{array}{r}45.1 \\
26.2 \\
8.2\end{array}$ \\
\hline 265.1 & 2,170 & 153 & Aug. $14,7: 45$ a.m. & 5.84 & 2,520 & 177 \\
\hline
\end{tabular}

${ }^{17}$ Greater flood occurred Apr. 19, 1910; gage height 21.0 feet. ${ }_{10}$ Possibly in error.

${ }^{19}$ Former site and datum.

20 Occurred at 11 a.m.
21 Affected by storage.

${ }^{22}$ Greater flood occurred September 1924; gage height 14.90 feet. ${ }^{23}$ Greater flood occurred September 1928; gage height 23.3 feet. ${ }_{25}^{24}$ Flood of 1865 believed to have been 1 foot higher.

25
26
26 Areater flood occurred July $1916 ;$; dis sharge, 8, 640 sec ond-feet.

4 Revised; supersedes figure published in Water-Supply Paper 892.

9 Revised; see Water-Supply Paper 892.

2 Daily mean discharge.

14 Occurred at $6: 30$ a.

16. In North Carolina Department of Conservation and Development Bulletin 39. 


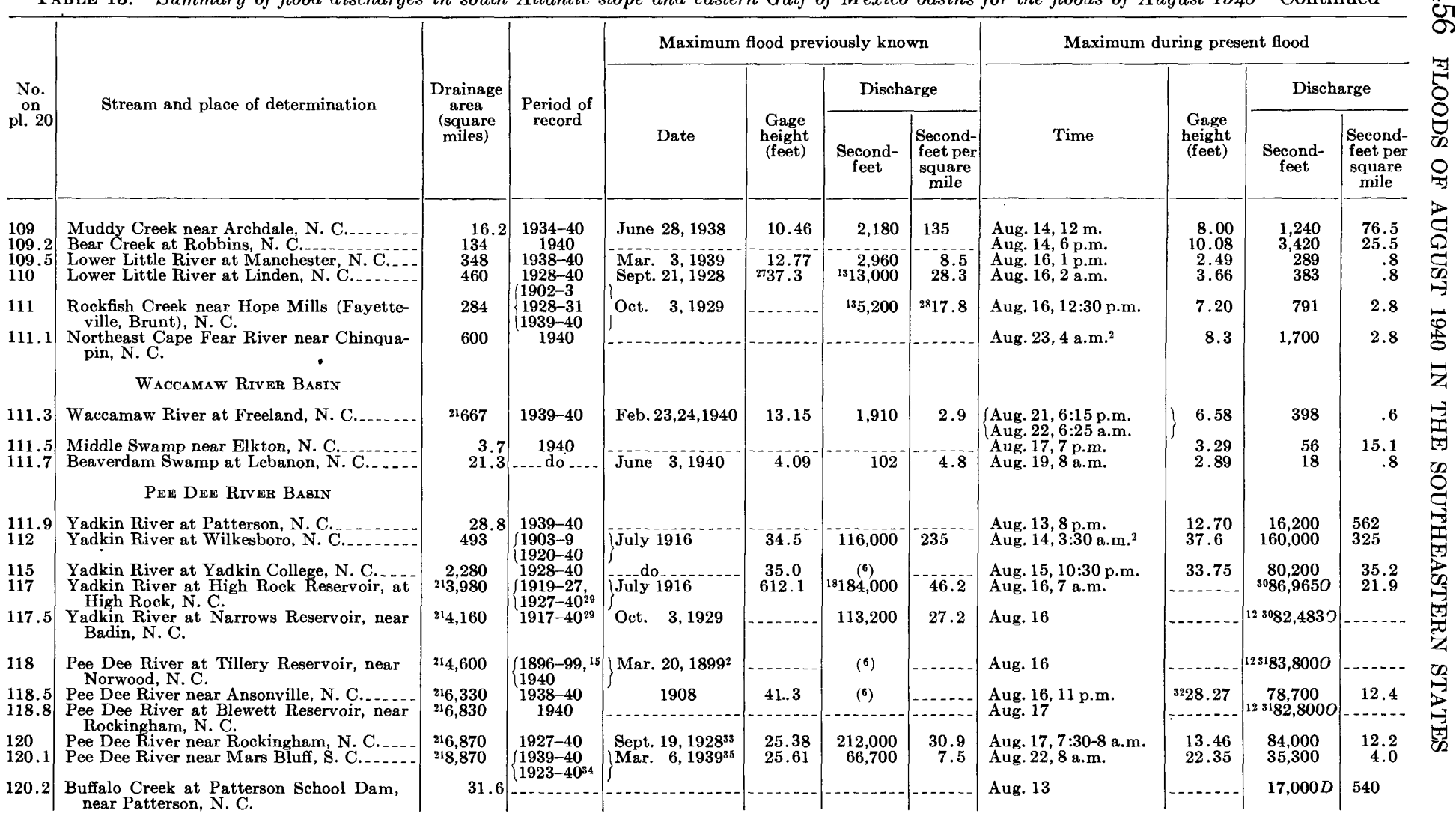




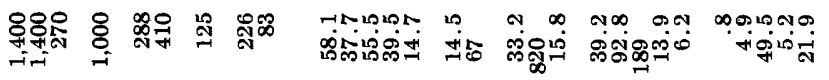

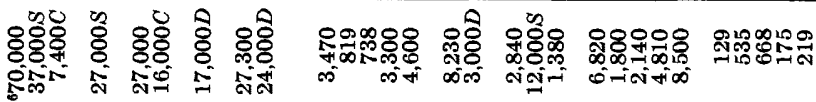

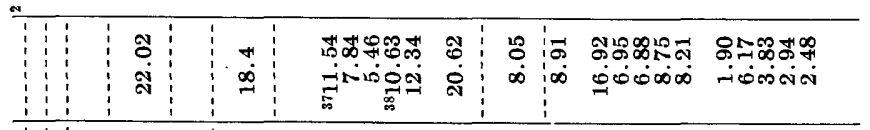

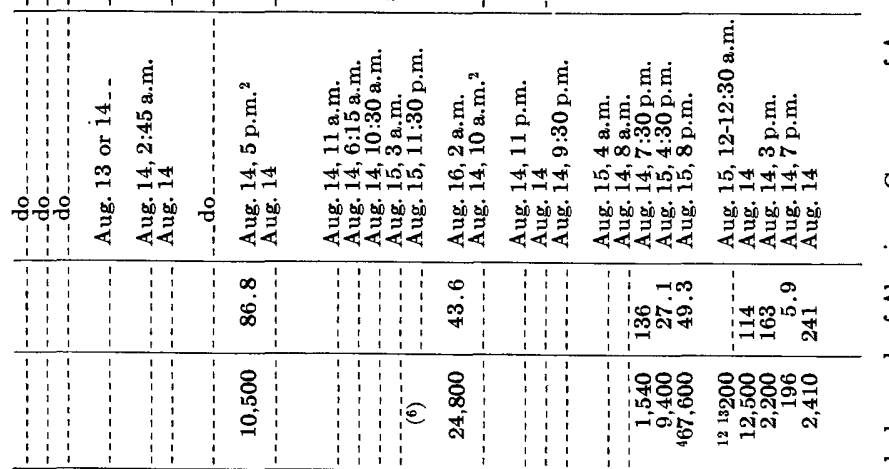

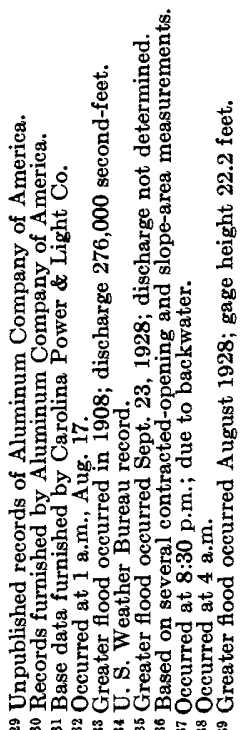

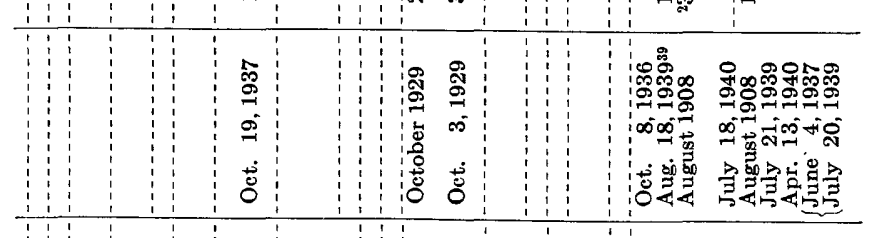

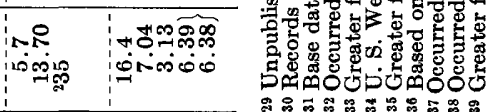

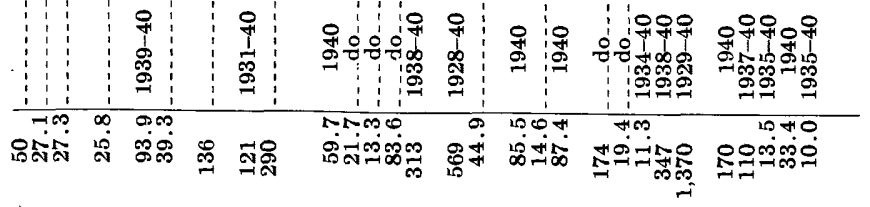
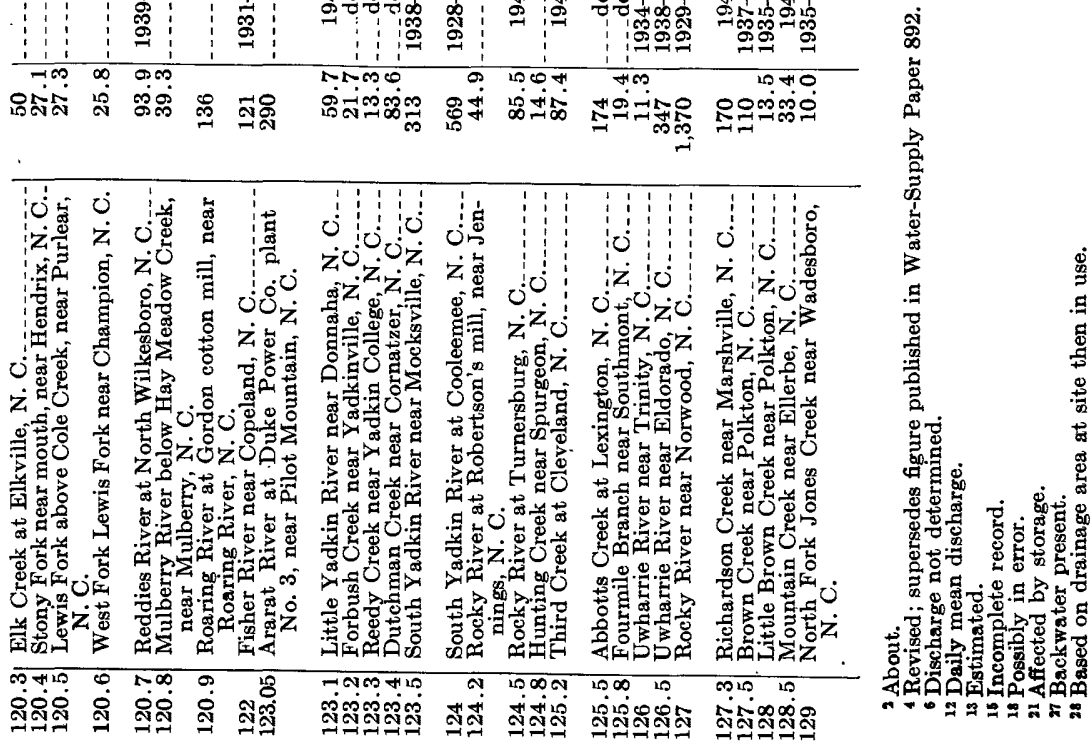


\begin{tabular}{|c|c|c|c|c|c|c|c|c|c|c|c|}
\hline \multirow{3}{*}{$\begin{array}{c}\text { No. } \\
\text { on } \\
\text { pl. } 20\end{array}$} & \multirow{3}{*}{ Stream and place of determination } & \multirow{3}{*}{$\begin{array}{c}\text { Drainage } \\
\text { area } \\
\text { (square } \\
\text { miles) }\end{array}$} & \multirow{3}{*}{$\begin{array}{l}\text { Period of } \\
\text { record }\end{array}$} & \multicolumn{4}{|c|}{ Maximum flood previously known } & \multicolumn{4}{|c|}{ Maximum during present flood } \\
\hline & & & & \multirow[b]{2}{*}{ Date } & \multirow[b]{2}{*}{$\begin{array}{c}\text { Gage } \\
\text { height } \\
\text { (feet) }\end{array}$} & \multicolumn{2}{|c|}{ Discharge } & \multirow[b]{2}{*}{ Time } & \multirow[b]{2}{*}{$\begin{array}{c}\text { Gage } \\
\text { height } \\
\text { (feet) }\end{array}$} & \multicolumn{2}{|c|}{ Discharge } \\
\hline & & & & & & $\begin{array}{c}\text { Second- } \\
\text { feet }\end{array}$ & $\begin{array}{c}\text { Second- } \\
\text { feet per } \\
\text { square } \\
\text { mile }\end{array}$ & & & $\begin{array}{l}\text { Second- } \\
\text { feet }\end{array}$ & $\begin{array}{l}\text { Second- } \\
\text { feet per } \\
\text { square } \\
\text { mile }\end{array}$ \\
\hline $\begin{array}{l}129.5 \\
130\end{array}$ & $\begin{array}{l}\text { Juniper Creek near Cheraw, S. C. } \\
\text { Lynches River at Effingham, S. C. }\end{array}$ & $\begin{array}{r}64 \\
21,030\end{array}$ & $\begin{array}{c}1940 \\
1891-1940^{34} \\
1929-40\end{array}$ & Aug. 30,1908 & 20.0 & 18,000 & 17.5 & $\begin{array}{l}\text { Aug. 16, } 4-7 \text { a.m. } \\
\text { Aug. 18, } 10 \text { p.m. }\end{array}$ & $\begin{array}{l}1.06 \\
9.43\end{array}$ & $\begin{array}{r}256 \\
1,980\end{array}$ & $\begin{array}{l}4.0 \\
1.9\end{array}$ \\
\hline $\begin{array}{l}130.3 \\
130.7 \\
131\end{array}$ & $\begin{array}{l}\text { Little Pee Dee River near Dillon, S. C..- } \\
\text { Drowning Creek near Hoffman, N. C. } \\
\text { Lumber River at Boardman, N. C.. }\end{array}$ & $\begin{array}{r}524 \\
178 \\
1,220\end{array}$ & $\left|\begin{array}{c}1939-40 \\
1939-40 \\
1929-40\end{array}\right|$ & $\begin{array}{l}\text { July } 24,1939 \\
\text { Feb. 22, } 1940 \\
\text { August } 1928\end{array}$ & $\begin{array}{r}10.18 \\
5.28 \\
11.8\end{array}$ & $\begin{array}{r}2,910 \\
435 \\
1325,000\end{array}$ & $\begin{array}{r}5.6 \\
2.4 \\
20.5\end{array}$ & $\begin{array}{l}\text { Aug. 19, } 6 \text { p.m. } \\
\text { Aug. 18, } 9 \text { a.m. } \\
\text { Aug. } 20,12 \mathrm{~m} .\end{array}$ & $\begin{array}{l}7.94 \\
5.07 \\
4.00\end{array}$ & $\begin{array}{l}797 \\
354 \\
763\end{array}$ & $\begin{array}{r}1.5 \\
2.0 \\
.6\end{array}$ \\
\hline $\begin{array}{l}131.3 \\
131.7 \\
132\end{array}$ & $\begin{array}{l}\text { Deep Creek near Roseland, N. C.- } \\
\text { Little Raft Swamp at Red Springs, N. C.. } \\
\text { Black River at Kingstree, S. C.. } \\
\text { SANTEE RIVER BAsIN }\end{array}$ & $\begin{array}{r}18.9 \\
23.1 \\
101,260\end{array}$ & $\mid$\begin{tabular}{c}
1940 \\
\hdashline $1929-40$ \\
$1893-1940^{34}$
\end{tabular} & Sept. 21,1928 & 18.0 & 1041,600 & 33.0 & $\begin{array}{l}\text { Aug. } 15,11 \text { p.m. } \\
\text { Aug. } 13,2 \text { a.m. } \\
\text { Aug. } 25,11 \text { p.m. }\end{array}$ & $\begin{array}{l}2.79 \\
2.14 \\
4.03\end{array}$ & $\begin{array}{r}47 \\
32 \\
376\end{array}$ & $\begin{array}{r}2.5 \\
1.4 \\
.3\end{array}$ \\
\hline 133.5 & $\begin{array}{l}\text { Catawba River at U. S. Highway 221, near } \\
\text { Marion, N. C. }\end{array}$ & 170 & & & & & & Aug. 13 & & $71,000 C$ & 418 \\
\hline 133.8 & $\begin{array}{l}\text { Catawba River at Bridgewater Reservoir, } \\
\text { near Bridgewater, N. C.40 }\end{array}$ & 380 & & & & & & $\left\{\begin{array}{l}\text { Aug. } 13,8-9 \text { p.m. } \\
\text { Aug. } 14,2-3 \text { a.m. }\end{array}\right.$ & & $\begin{array}{r}41141,760 I \\
43,7000\end{array}$ & 373 \\
\hline $\begin{array}{l}134.9 \\
135.3\end{array}$ & $\begin{array}{l}\text { Catawba River at Rhodhiss Reservoir, at } \\
\text { Rhodhiss, N. C. } 40 \\
\text { Catawba River at Oxford Reservoir, near }\end{array}$ & $\begin{array}{l}1,088 \\
1,310\end{array}$ & & & & & & $\begin{array}{l}\text { Aug. } 13,11-12 \text { p.m. } \\
\text { Aug. } 14,4 \text { a.m. } \\
\text { Aug. } 14,3-4 \text { a.m. }\end{array}$ & & $\left|\begin{array}{r}4167,740 I \\
104,000 O \\
41183,620 I\end{array}\right|$ & 154 \\
\hline 135.7 & $\begin{array}{l}\text { Taylorsville, N. C.40 } \\
\text { Catawba River at Lookout Shoals Reservoir, } \\
\text { near Catawba, N. C.40 }\end{array}$ & 1,449 & $1915-40^{42}$ & July 16,1916 & & ${ }^{43} 180,000$ & 124 & $\begin{array}{l}\text { Aug. 14, } 5 \text { a.m. } \\
\text { Aug. 14, 5-6 a.m. } \\
\text { Aug. 14, } 6 \text { a.m. }\end{array}$ & & $\begin{array}{r}158,0600 \\
4191,230 I \\
177,400 O\end{array}$ & 132 \\
\hline 136 & Catawba River at Catawba, N. C....... & 1211,535 & $\left\{\begin{array}{l}1896-1902 \\
1934-40\end{array}\right.$ & )--- do- & 4444.1 & $(6)$ & & Aug. 14, 11:30 a.m. & 36.8 & 177,000 & 115 \\
\hline 136.5 & $\begin{array}{l}\text { Catawba River at Mountain Island Reser- } \\
\text { voir, near Mountain Holly, N. C. } 40\end{array}$ & 1,860 & & & & & & $\left\{\begin{array}{l}\text { Aug. } 15,12-1 \text { a.m. } \\
\text { Aug. } 15,6 \text { a.m. }\end{array}\right.$ & & $\begin{array}{r}4124,230 I \\
117,200 O\end{array}$ & 66.8 \\
\hline 137 & Catawba River at Catawba Reservoir, near & 3,020 & & & & & & $\begin{array}{l}\text { Aug. } 15,8-9 \text { a.m. } \\
\text { Aug. } 15,2 \text { p.m. }\end{array}$ & & $41169,160 I$ & 56.0 \\
\hline 138.2 & $\begin{array}{l}\text { Catawba River at Fishing Creek Reservoir, } \\
\text { near Great Falls, S. C.40 }\end{array}$ & 3,810 & & & & & & $\begin{array}{l}\text { Aug. } 16,4-5 \text { a.m. } \\
\text { Aug. } 16,7 \text { a.m. }\end{array}$ & & $\begin{array}{r}4110,180 I \\
115,4900\end{array}$ & 28.9 \\
\hline 138.5 & $\begin{array}{l}\text { Catawba River at Rocky Creek Reservoir, } \\
\text { near Great Falls, S. C.40 }\end{array}$ & 4,360 & $1909-40^{42}$ & July 1916 & & 382,000 & 87.6 & $\begin{array}{l}\text { Aug. } 16,8-10 \text { a.m. } \\
\text { Aug. } 16,7 \text { a.m. }\end{array}$ & & $\begin{array}{r}4114,940 I \\
115,3100\end{array}$ & 26.4 \\
\hline 138.8 & $\begin{array}{l}\text { Wateree River at Wateree Reservoir, near } \\
\text { Camden, S. C. }{ }^{40}\end{array}$ & 4,750 & & & & & & $\left\{\begin{array}{l}\text { Aug. } 16,7-8 \text { a.m. } \\
\text { Aug. } 16,3 \text { p.m. }\end{array}\right.$ & $\ldots$ & $\begin{array}{r}4132,200 I \\
85,040 O\end{array}$ & 27.8 \\
\hline
\end{tabular}




\begin{tabular}{|c|c|c|c|c|c|c|c|c|c|c|c|}
\hline 139 & Wateree River near Camden, S. C. & ${ }^{1215,070}$ & $\begin{array}{ll}10 \\
40 \\
940^{84}\end{array}$ & July 18,1916 & ${ }^{19} 40.4$ & & & Aug. 16, 11 p.m. & 30.50 & 89,000 & 17.6 \\
\hline & $\begin{array}{l}\text { Santee River at Ferguson, S. C. } \\
\text { Mill Creek at Old Fort, N. C. }\end{array}$ & ${ }^{72114,600} 20.7$ & $1907-40$ & $\begin{array}{r}\text { July } 22,1916 \\
\text { Apr. } 4,1931\end{array}$ & $\begin{array}{c}24.5 \\
3.08\end{array}$ & $\begin{array}{r}8368,000 \\
248\end{array}$ & $\begin{array}{l}25.2 \\
12.0\end{array}$ & $\begin{array}{l}\text { Aug. } 21,10 \text { a.m. } \\
\text { Aug. } 13\end{array}$ & $\begin{array}{l}14.07 \\
10.1\end{array}$ & $\begin{array}{c}56,000 \\
7,900 S\end{array}$ & $380^{3.8}$ \\
\hline 11.2 & Buck Creek at Lake Tahoma, near Marion, & 22.7 & & & & & & Aug. 13,7 p.m. & & $6,200 D$ & 270 \\
\hline 41.5 & $\begin{array}{l}\text { North Fork Catawba River at Linville Cav- } \\
\text { erns, near Asheford, N. C. }\end{array}$ & 5.2 & & & & & & Aug. 13 & & ${ }^{45} 15,000$ & 2,900 \\
\hline 1.8 & $\begin{array}{l}\text { North Fork Catawba River above Sevier, } \\
\text { near Woodlawn, N. C. }\end{array}$ & 41.8 & & & & & & do_. & & $55,000 S$ & 1,300 \\
\hline 4.1 & Linville River at Branch, N. C. & $\begin{array}{c}65 \\
8.0\end{array}$ & $1922-40$ & July 1916 & 211.0 & 34,600 & 532 & $\begin{array}{l}\text { Aug. } 13,5 \text { p.m. } \\
\text { Aug. } 13\end{array}$ & 11.4 & $\begin{array}{l}\mathbf{3 9 , 5 0 0} \\
\mathbf{9 , 7 0 0 S}\end{array}$ & $\begin{array}{r}608 \\
1,200\end{array}$ \\
\hline & $\begin{array}{l}\text { Upper Creek above Steels Creek, near Table- } \\
\text { rock, N. C. }\end{array}$ & 20.2 & & & & & & & & $0 \mathrm{C}$ & 1,200 \\
\hline 14.5 & $\begin{array}{l}\text { ork below Worry, near Morgan- } \\
\text { C. }\end{array}$ & 80.5 & & & & & & Aug. 13, 11:30 p.m. & & $38,000 S$ & 470 \\
\hline .7 & Steels Creek near Tableroek, N. C. & $\begin{array}{l}16.0 \\
21.7\end{array}$ & & & & & & $\begin{array}{l}\text { Aus } \\
\text { Aus }\end{array}$ & & $\begin{array}{l}24,000 S \\
14,000 T\end{array}$ & $\begin{array}{r}1,500 \\
650\end{array}$ \\
\hline & $\begin{array}{l}\text { Johns River at Collettsville, N. C. } \\
\text { Little Mulberry Creek near Collettsville, N.C. }\end{array}$ & $\begin{array}{l}69.1 \\
27.3\end{array}$ & & & & & & $\begin{array}{l}\text { Aug } \\
\text { Aug }\end{array}$ & & & $\begin{array}{l}450 \\
510\end{array}$ \\
\hline $\begin{array}{l}7 \\
7.2 \\
7.5\end{array}$ & $\begin{array}{l}\text { ko, N. C. } \\
\text { N. C. } \\
\text { an Power Co. Gun- }\end{array}$ & $\begin{array}{l}66.0 \\
47.6 \\
34.9\end{array}$ & $1921-22$ & July 1916 & 27.0 & ${ }^{46} 52,500$ & 795 & $\begin{array}{l}\text { Aug. } 13,6 \text { p.m. } \\
\text { Aug. } 13 \\
\text { Aug. } 13,11 \text { p.m. }\end{array}$ & 36.5 & & $\begin{array}{r}1,500 \\
420 \\
370\end{array}$ \\
\hline 47.8 & & 69.9 & & & & & & & & & \\
\hline 18 & Taylorsville, N. C. & 80.0 & $1925-31$ & 1916 & & 20,700 & 259 & 11 p.m. & 29 & $31,000 D$ & 390 \\
\hline $\begin{array}{ll}3.3 \\
3.7 \\
1\end{array}$ & $\begin{array}{l}\text { t HighShoals, N.C. } \\
\text { tory, N. C. } \\
\text { harlotte, N. C. } \\
\text { y Rock, N. C. } \\
\end{array}$ & $\begin{array}{l}506 \\
69.3 \\
41.4 \\
97\end{array}$ & $1924-40$ & $\begin{array}{l}\text { October } 1929 \\
\text { Apr. } 6,1936 \\
\text { Aug. } 15,1928\end{array}$ & $\begin{array}{l}16.2 \\
16.8\end{array}$ & $\begin{array}{r}31,900 \\
9,920 \\
8,370 \\
926,000\end{array}$ & $\begin{array}{r}63 \\
143 \\
202 \\
268\end{array}$ & $\begin{array}{l}\text { Aug. 15, } 2: 30 \text { a.m. } \\
\text { August } \\
\text { Aug. 14, } 4 \text { a.m. } \\
\text { Aug. 13, } 2 \text { p.m. }\end{array}$ & $\begin{array}{r}8.75 \\
12.20\end{array}$ & $\begin{array}{c}22,000 D \\
6,000 D \\
42,230 \\
17,300\end{array}$ & $\begin{array}{c}43 \\
87 \\
53.9 \\
178\end{array}$ \\
\hline 153 & Broad & 864 & $1925-40$ & Aug. 16 & 24.3 & ${ }^{973,300}$ & 84.8 & Aug. $14,12: 30-1$ p.m. & 22.10 & 60,400 & 69.9 \\
\hline 54 & Broad River near Gaffney, S. C........ & $s 1,490$ & $\left\{\begin{array}{l}1896-99 \\
1938-40\end{array}\right.$ & Mar. 19, 1899 & 4712.20 & 825,400 & 17.0 & $14,7: 30$ p.m. & 19.78 & 119,000 & 79.9 \\
\hline \multicolumn{12}{|c|}{ 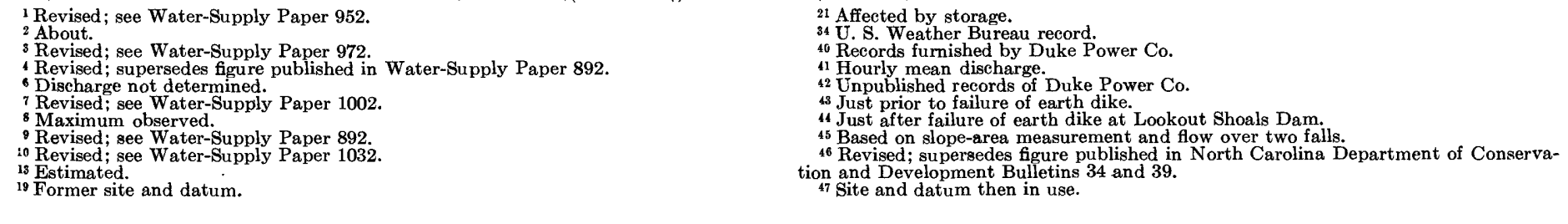 } \\
\hline
\end{tabular}




\begin{tabular}{|c|c|c|c|c|c|c|c|c|c|c|c|}
\hline \multirow{3}{*}{$\begin{array}{c}\text { No. } \\
\text { on } \\
\text { pl. } 20\end{array}$} & \multirow{3}{*}{ Stream and place of determination } & \multirow{3}{*}{$\begin{array}{c}\text { Drainage } \\
\text { area } \\
\text { (square } \\
\text { miles) }\end{array}$} & \multirow{3}{*}{$\begin{array}{l}\text { Period of } \\
\text { record }\end{array}$} & \multicolumn{4}{|c|}{ Maximum flood previously known } & \multicolumn{4}{|c|}{ Maximum during present flood } \\
\hline & & & & \multirow[b]{2}{*}{ Date } & \multirow[b]{2}{*}{$\begin{array}{c}\text { Gage } \\
\text { height } \\
\text { (feet) }\end{array}$} & \multicolumn{2}{|c|}{ Discharge } & \multirow[b]{2}{*}{ Time } & \multirow[b]{2}{*}{$\begin{array}{c}\text { Gage } \\
\text { height } \\
\text { (feet) }\end{array}$} & \multicolumn{2}{|c|}{ Discharge } \\
\hline & & & & & & $\begin{array}{l}\text { Second- } \\
\text { feet }\end{array}$ & $\begin{array}{c}\text { Second- } \\
\text { feet per } \\
\text { square } \\
\text { mile }\end{array}$ & & & $\begin{array}{l}\text { Second- } \\
\text { feet }\end{array}$ & $\begin{array}{l}\text { Second- } \\
\text { feet per } \\
\text { square } \\
\text { mile }\end{array}$ \\
\hline $\begin{array}{l}154.5 \\
156 \\
157.5 \\
158\end{array}$ & $\begin{array}{l}\text { Broad River near Carlisle, S. C. } \\
\text { Broad River at Richtex, S. C. } \\
\text { Green River near Mill Spring, N. C. } \\
\text { Second Broad River at Cliffide, N. C. }\end{array}$ & $\begin{array}{r}92,790 \\
34,850 \\
21174 \\
9211\end{array}$ & $\begin{array}{l}1938-40 \\
1925-40 \\
1939-40 \\
1925-40\end{array}$ & $\begin{array}{l}\text { Mar. } 1,1939 \\
\text { Oct. } 3,1929 \\
\text { July } 1916 \\
\text { Aug. } 16,1928\end{array}$ & $\begin{array}{l}16.27 \\
30.7 \\
24.2 \\
17.26\end{array}$ & $\begin{array}{r}34,900 \\
228,000 \\
(6) \\
{ }^{9} 14,500\end{array}$ & $\begin{array}{r}12.5 \\
47.0 \\
--\overline{8} . \overline{7}\end{array}$ & $\begin{array}{l}\text { Aug. } 15,4: 30 \text { p.m. } \\
\text { Aug. 16, } 8 \text { a.m. } \\
\text { Aug. 13, 8:30 p.m. } \\
\text { Aug. 14, 1 p.m. }\end{array}$ & $\begin{array}{l}29.41 \\
21.08 \\
22.15 \\
17.93\end{array}$ & $\begin{array}{r}103,000 \\
120,000 \\
10,800 \\
15,000\end{array}$ & $\begin{array}{l}36.9 \\
24.7 \\
62.1 \\
71.1\end{array}$ \\
\hline $\begin{array}{l}159.2 \\
159.5 \\
159.8 \\
161 \\
162\end{array}$ & $\begin{array}{l}\text { First Broad River near Gambles Store, N. C. } \\
\text { First Broad River near Lawndale, N. C.. } \\
\text { Buffalo Creek at Stubbs, N. C. } \\
\text { North Pacolet River at Fingerville, S. C.. } \\
\text { Pacolet River near Fingerville, S. C. } \\
\end{array}$ & $\begin{array}{r}25.1 \\
1198 \\
53.8 \\
116 \\
21212\end{array}$ & 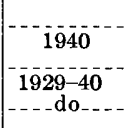 & 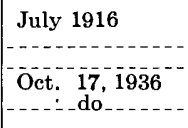 & $\begin{array}{l}21.23 \\
13.63\end{array}$ & $\begin{array}{r}7,290 \\
11,300\end{array}$ & $\begin{array}{l}62.8 \\
53.3\end{array}$ & $\begin{array}{l}\text { Aug. } 13,9: 30 \text { p.m. } \\
\text { Aug. 14, } 6 \text { a.m. } \\
\text { Aug. } 14,4 \text { a.m. } \\
\text { Aug. } 14,1: 15 \text { a.m. } \\
\text { Aug. } 14,1: 45 \text { a.m. }\end{array}$ & $\begin{array}{l}(48) \\
37.8 \\
-27.13 \\
22.43\end{array}$ & $\begin{array}{c}14,000 \mathrm{~S} \\
32,500 \\
8,800 \mathrm{D} \\
12,500 \\
22,800\end{array}$ & $\begin{array}{l}560 \\
164 \\
160 \\
108 \\
108\end{array}$ \\
\hline $\begin{array}{l}162.5 \\
164 \\
165 \\
165.5 \\
166\end{array}$ & $\begin{array}{l}\text { Pacolet River near Clifton, S. C. } \\
\text { North Tyger River near Moore, S. C. } \\
\text { Tyger River near Woodruff, S. C. } \\
\text { Middle Tyger River at Lyman, S. C. } \\
\text { South Tyger River near Reidville, S. C. }\end{array}$ & $\begin{array}{c}21320 \\
162 \\
351 \\
68.3 \\
106\end{array}$ & $\begin{array}{r}1940 \\
1934-40 \\
1929-40 \\
1938-40 \\
1934-40\end{array}$ & $\begin{array}{l}\text { Apr. } 7,1936 \\
\text { Sept. } 1929^{49} \\
\text { Aug. } 18,1939 \\
\text { Apr. } \quad 6,1936\end{array}$ & $\begin{array}{r}6.15 \\
14.65 \\
9.28 \\
13.66\end{array}$ & $\begin{array}{r}8,640 \\
19,600 \\
2,730 \\
6,080\end{array}$ & $\begin{array}{l}53.3 \\
55.8 \\
40.0 \\
57.4\end{array}$ & $\begin{array}{l}\text { Aug. } 14,12 \mathrm{~m} . \\
\text { Aug. } 14,3: 45 \text { p.m. } \\
\text { Aug. } 14,4 \text { p.m. } \\
\text { Aug. } 14,12: 30 \text { a.m. } \\
\text { Aug. } 13,8: 30 \text { p.m. }\end{array}$ & $\begin{array}{r}21.19 \\
7.15 \\
13.27 \\
16.16 \\
12.68\end{array}$ & $\begin{array}{r}26,800 \\
12,300 \\
19,200 \\
4,800 \\
5,510\end{array}$ & $\begin{array}{l}83.8 \\
75.9 \\
54.7 \\
70.3 \\
52.0\end{array}$ \\
\hline $\begin{array}{l}167 \\
167.5 \\
168 \\
170 \\
170.5\end{array}$ & $\begin{array}{l}\text { South Tyger River near Woodruff, S. C. } \\
\text { Fair Forest Creek near Union, S. C. } \\
\text { Enoree River near Enoree, S. C. } \\
\text { Saluda River near Pelzer, S. C.. } \\
\text { Saluda River near Ware Shoals, S. C. }\end{array}$ & $\begin{array}{l}174 \\
183 \\
307 \\
405 \\
569\end{array}$ & $\begin{array}{c}1940 \\
1929-40 \\
1939-40\end{array}$ & $\begin{array}{l}\text { Oct. } 2,1929 \\
\text { Apr. } 7,1936 \\
\text { Aug. } 18,1939\end{array}$ & $\begin{array}{l}9.78 \\
10.5 \\
10.26 \\
14.29\end{array}$ & $\begin{array}{l}9,510 \\
30,000 \\
13,300 \\
10,500\end{array}$ & \begin{tabular}{r|}
54.7 \\
$-97 . \overline{7}$ \\
32.8 \\
18.5
\end{tabular} & $\begin{array}{l}\text { Aug. 14, } 1: 45 \text { p.m. } \\
\text { Aug. 14, 9:15 a.m. } \\
\text { Aug. 14, } 12 \mathrm{~m} . \\
\text { Aug. 14, } 6 \text { a.m. } \\
\text { Aug. } 13,2: 30 \text { p.m. }\end{array}$ & $\begin{array}{r}8.18 \\
7.15 \\
6.86 \\
8.31 \\
20.48\end{array}$ & $\begin{array}{r}6,960 \\
7,520 \\
12,800 \\
9,920 \\
20,600\end{array}$ & $\begin{array}{l}40.0 \\
41.1 \\
41.7 \\
24.5 \\
36.2\end{array}$ \\
\hline 172 & Saluda River at Chappells, S. C. & 3501,350 & $\left\{\begin{array}{l}1927-40 \\
1905-40^{34}\end{array}\right.$ & Oct. $2,1929^{51}$ & 31.5 & 63,700 & 47.2 & Aug. 14,6 p.m. & 28.66 & 49,700 & 36.8 \\
\hline $\begin{array}{l}173 \\
175 \\
176\end{array}$ & $\begin{array}{l}\text { Saluda River near Silverstreet, S. C. } \\
\text { Saluda River near Columbia, S. C. } \\
\text { Reedy River near Ware Shoals (Prince- } \\
\text { ton), S. C. } \\
\text { Edisto RIver BAsin }\end{array}$ & $\begin{array}{r}3501,620 \\
351,620 \\
32,510 \\
53228\end{array}$ & $\left\{\begin{array}{r}1927-40 \\
1925-40 \\
1929-31 \\
1939-40\end{array}\right.$ & $\begin{array}{l}\text { Oct. } \quad 3,1929 \\
\text { Oct. } \quad 2,1929 \\
\text { August } 1908\end{array}$ & $\begin{array}{r}33.97 \\
15.22 \\
1934.6\end{array}$ & $\begin{array}{r}83,800 \\
67,000 \\
228,000\end{array}$ & $\begin{array}{r}51.7 \\
26.7 \\
28135\end{array}$ & $\begin{array}{l}\text { Aug. 15, 2:30 a.m. } \\
\text { Aug. 28, } 1: 15 \text { p.m. } \\
\text { Aug. } 14,5 \text { a.m. }\end{array}$ & $\begin{array}{r}30.29 \\
5.95 \\
13.32\end{array}$ & $\begin{array}{r}58,300 \\
9,950 \\
7,750\end{array}$ & $\begin{array}{r}36.0 \\
4.0 \\
34.0\end{array}$ \\
\hline 176.5 & $\begin{array}{l}\text { South Fork Edisto River near Montmorenci, } \\
\text { S. C. }\end{array}$ & 10198 & 1940 & & & & 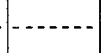 & Aug. 15, 8 a.m. & 8.81 & 2,460 & 12.4 \\
\hline $\begin{array}{l}177 \\
177.3 \\
177.7\end{array}$ & $\begin{array}{l}\text { South Fork Edisto River near Denmark, S.C. } \\
\text { Edisto River near Givhans, S. C.-.-... } \\
\text { North Fork Edisto River at Orangeburg, } \\
\text { S. C. }\end{array}$ & $\begin{array}{r}720 \\
102,730 \\
10683\end{array}$ & $\begin{array}{l}1931-40 \\
1939-40 \\
1938-40\end{array}$ & $\begin{array}{l}\text { Apr. } 11,1936 \\
\text { Mar. } 6,1939 \\
\text { Mar. } 3,1939\end{array}$ & $\begin{array}{r}10.91 \\
14.68 \\
9.98\end{array}$ & $\begin{array}{r}13,500 \\
16,900 \\
3,910\end{array}$ & $\begin{array}{r}18.8 \\
6.2 \\
5.7\end{array}$ & $\begin{array}{l}\text { Aug. } 19,4: 45 \text { a.m. } \\
\text { Aug. } 15,12: 15 \text { a.m. } \\
\text { Aug. } 19,10 \text { a.m. }\end{array}$ & $\begin{array}{r}7.92 \\
13.03 \\
8.59\end{array}$ & $\begin{array}{r}2,060 \\
12,600 \\
2,340\end{array}$ & $\begin{array}{l}2.9 \\
4.6 \\
3.4\end{array}$ \\
\hline
\end{tabular}




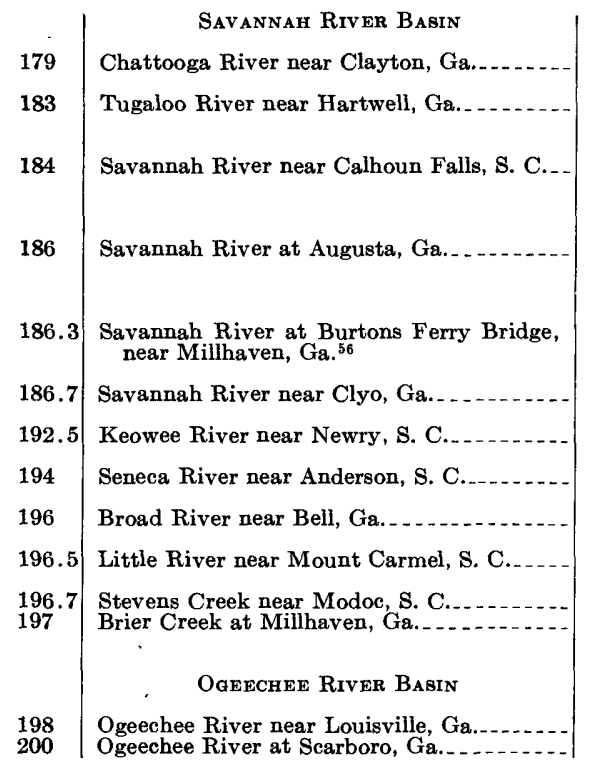

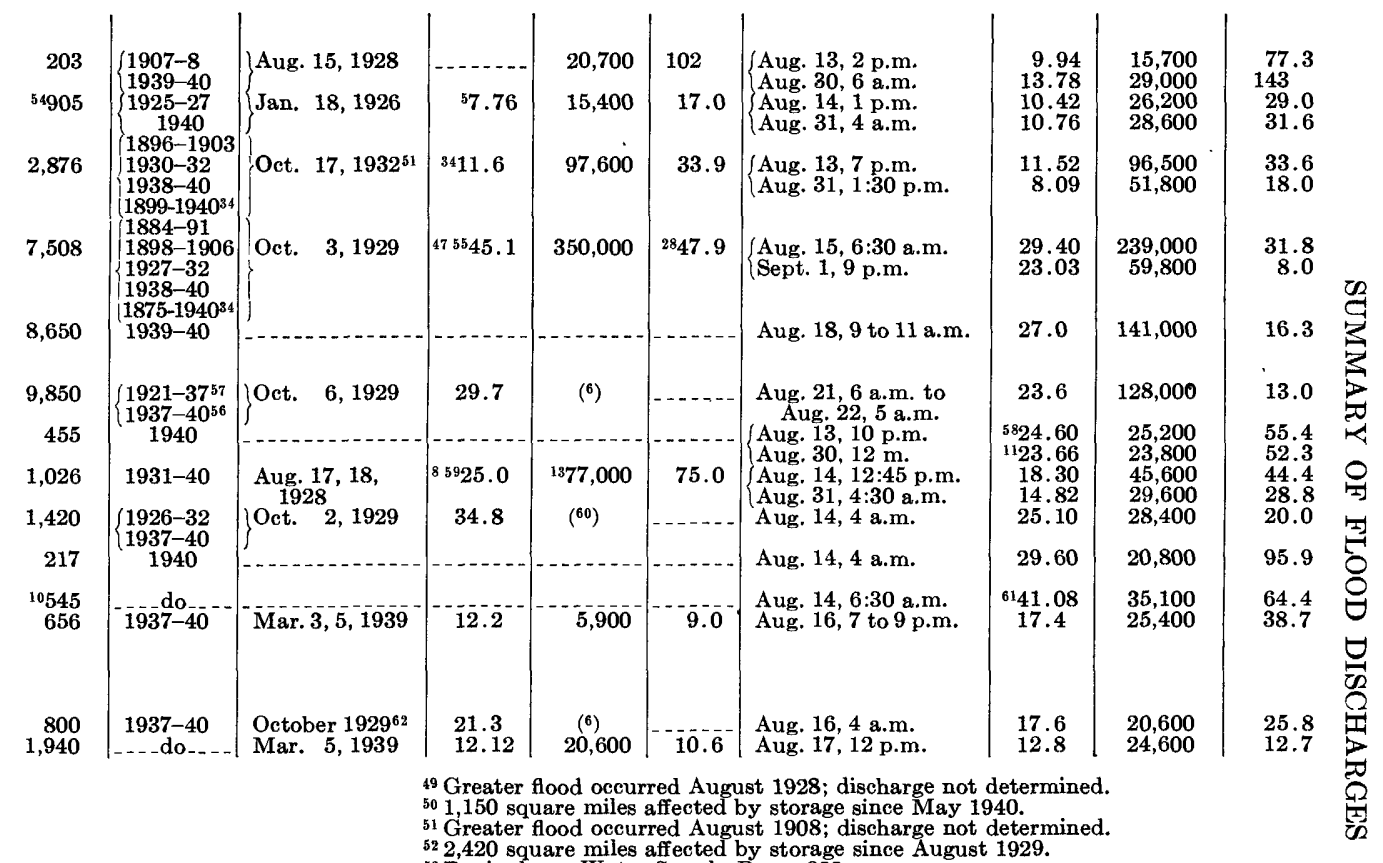

1 Revised; see Water-Supply Paper 952. 2 About.

Revised; see Water-Supply Paper 972. - Datum then in use.

Discharge not determined.

9 Revised; see Water-Supply Paper 892.

${ }^{1}$ Revised; see Water-Supply Paper 1032

1 Occurred at 2 p.m.

13 Estimated.

19 Former site and datum.

21 Affected by storage.

${ }^{28}$ Based on drainage area at site then in use.

47 . S. Weather Bureau record.

48 Flood of August 1940 reached a stage 3 feet higher than flood of July 1916.

${ }^{55}$ A stage of 46.3 feet occurred Sept. 27, 1929.

${ }^{56}$ Base data furnished by Corps of Engineers, War Department. ${ }^{57}$ U. S. Weather Bureau record; 1921-32 unpublished. 58 Occurred at 12 p.m. ${ }^{59}$ Records of Corps of Engineers, War Department. ${ }_{61}^{60}$ Discharge uncertain.

62 Data furnished by Central of Georgia Railway. 
TABLE 13.-Summary of flood discharges in south Atlantic slope and eastern Gulf of Mexico basins for the floods of August 1940-Continued

\begin{tabular}{|c|c|c|c|c|c|c|c|c|c|c|c|}
\hline \multirow{3}{*}{$\begin{array}{c}\text { No. } \\
\text { on } \\
\text { pl. } 20\end{array}$} & \multirow{3}{*}{ Stream and place of determination } & \multirow{3}{*}{$\begin{array}{l}\text { Drainage } \\
\text { area } \\
\text { (square } \\
\text { miles) }\end{array}$} & \multirow{3}{*}{$\begin{array}{l}\text { Period of } \\
\text { record }\end{array}$} & \multicolumn{4}{|c|}{ Maximum flood previously known } & \multicolumn{4}{|c|}{ Maximum during present flood } \\
\hline & & & & \multirow[b]{2}{*}{ Date } & \multirow[b]{2}{*}{$\begin{array}{c}\text { Gage } \\
\text { height } \\
\text { (feet) }\end{array}$} & \multicolumn{2}{|c|}{ Discharge } & \multirow[b]{2}{*}{ Time } & \multirow[b]{2}{*}{$\begin{array}{c}\text { Gage } \\
\text { height } \\
\text { (feet) }\end{array}$} & \multicolumn{2}{|c|}{ Discharge } \\
\hline & & & & & & $\begin{array}{l}\text { Second- } \\
\text { feet }\end{array}$ & $\begin{array}{l}\text { Second- } \\
\text { feet per } \\
\text { square } \\
\text { mile }\end{array}$ & & & $\begin{array}{l}\text { Second- } \\
\text { feet }\end{array}$ & $\begin{array}{l}\text { Second- } \\
\text { feet per } \\
\text { square } \\
\text { mile }\end{array}$ \\
\hline 201 & Ogeechee River near Eden, Ga........... & 2,650 & $1937-40$ & Mar. 8, 9 & 14.2 & 23,700 & 8.9 & Aug. 23,11 a.m. & 13.78 & 20,200 & $\overline{7.6}$ \\
\hline 203 & $\begin{array}{l}\text { Canoochee River near Claxton, Ga... } \\
\text { Altamaha River Basin }\end{array}$ & 555 & -..-_do-..- & $\begin{array}{c}\text { Feb. } 28, \text { Mar. } 1 \\
1939\end{array}$ & 13.8 & 7,980 & 14.4 & $\begin{array}{l}\text { Aug. } 16,10 \text { p.m. to } \\
\text { Aug. } 17,4 \text { a.m. }\end{array}$ & 12.9 & 5,910 & 10.6 \\
\hline 220 & Oconee River near Greensboro, Ga....... & 1,090 & $\left\{\begin{array}{l}1903-23 \\
1924-31^{59} \\
1937-40\end{array} \mid\right.$ & Aug. 26, 1908 & 35.4 & $(60)$ & & Aug. 14,4 a.m. & 19.0 & 12,200 & 11.2 \\
\hline 222 & $\begin{array}{c}\text { Oconee River at Milledgeville (Fraley's } \\
\text { I erry), Ga...... }\end{array}$ & 2,950 & $\left\{\begin{array}{l}1937-40 \\
1903-23 \\
1924-31^{59} \\
1937-40 \\
1904-40^{34} \\
1898-1913 \\
1929-31^{39}\end{array}\right.$ & Aug. $16,1928^{28}$ & 32.97 & 1877,500 & 26.3 & Aug. 19, 10 a.m. & 24.4 & 27,400 & 9.3 \\
\hline 224.5 & Oconee River near Mount Vernon, Ga....-- & 5,110 & $\begin{array}{l}1931-40 \\
1937-40\end{array}$ & Mar. 6,1939 & 20.4 & 48,300 & 9.5 & Aug. 21,8 p.m. & 15.9 & 20,000 & 3.9 \\
\hline 225 & Middle Oconee River near Athens, Ga.. & 404 & $\left\{\begin{array}{l}1901-2 \\
1929-32^{59}\end{array}\right.$ & Feb. 28, 1902 & ${ }^{47} 25.5$ & 819,600 & 48.5 & Aug. 14,10 p.m. & 20.3 & 5,930 & 14.7 \\
\hline 227 & $\begin{array}{l}\text { Ohoopee River near Reidsville, Ga... } \\
\text { Apalachicola River Basin }\end{array}$ & 1,110 & $\left\{\begin{array}{l}1937-40 \\
1903-7 \\
1937-40\end{array}\right.$ & Mar. 3, 1939 & 19.8 & ${ }^{8} 15,100$ & 13.6 & Aug. $16,12-2$ p.m. & $\begin{array}{l}19.7 \\
:\end{array}$ & 14,900 & 13.4 \\
\hline 273.5 & Chattahoochee River near Leaf, Ga....... & 150 & $\left\{\begin{array}{l}1907 \\
1940\end{array}\right.$ & . & & $\cdots$ & - . . & Aug. 13, 2 p.m. & 11.75 & 11,200 & 74.7 \\
\hline 274 & Chattahoochee River near Gainesville, Ga..- & ${ }^{53} 559$ & $\{1901-3$ & Dec. 29, 1901 & ${ }^{47} 28.4$ & $(64)$ & $\mid-\ldots$ & Aug. 14,3 a.m. & 18.74 & 30,500 & 54.6 \\
\hline 277 & Chattahoochee River'near Vinings, Ga.... & 1,450 & $1928-31$ & Sept. 28, 1929 & 18.84 & 28,700 & 19.8 & Aug. 15, 8 p.m. & 17.48 & 24,200 & 16.7 \\
\hline 278.5 & $\begin{array}{l}\text { Chattahoochee River near Whitesburg, Ga.-- } \\
\text { Chattahoochee River at West Point, Ga.-- }\end{array}$ & $\begin{array}{l}2,430 \\
3,550\end{array}$ & $\left\{\begin{array}{l}1938-40 \\
1896-1910 \\
1912-40\end{array}\right.$ & $\left\{\begin{array}{l}\text { Feb. } 28,1939 \\
\text { Dec. } 10,1919\end{array}\right.$ & $\begin{array}{l}15.7 \\
30.0\end{array}$ & $\begin{array}{r}23,300 \\
134,000\end{array}$ & $\begin{array}{r}9.6 \\
37.8\end{array}$ & $\begin{array}{l}\text { Aug. 16, 7-8 p.m. }{ }^{65} \\
\text { Aug. } 17,4-6 \text { p.m. }\end{array}$ & $\begin{array}{l}14.5 \\
11.60\end{array}$ & $\begin{array}{l}20,800 \\
20,300\end{array}$ & $\begin{array}{l}8.6 \\
5.7\end{array}$ \\
\hline 284 & Soque River near Demorest, Ga...... & 156 & $\left\{\begin{array}{l}1904-9 \\
1929-31 \\
1940\end{array}\right.$ & \}$_{1938}^{J u l y ~} 21$ or 22 & 22.8 & 14,400 & 92.3 & Aug. $13,12 \mathrm{~m}$. & 20.04 & 11,900 & 76.3 \\
\hline
\end{tabular}




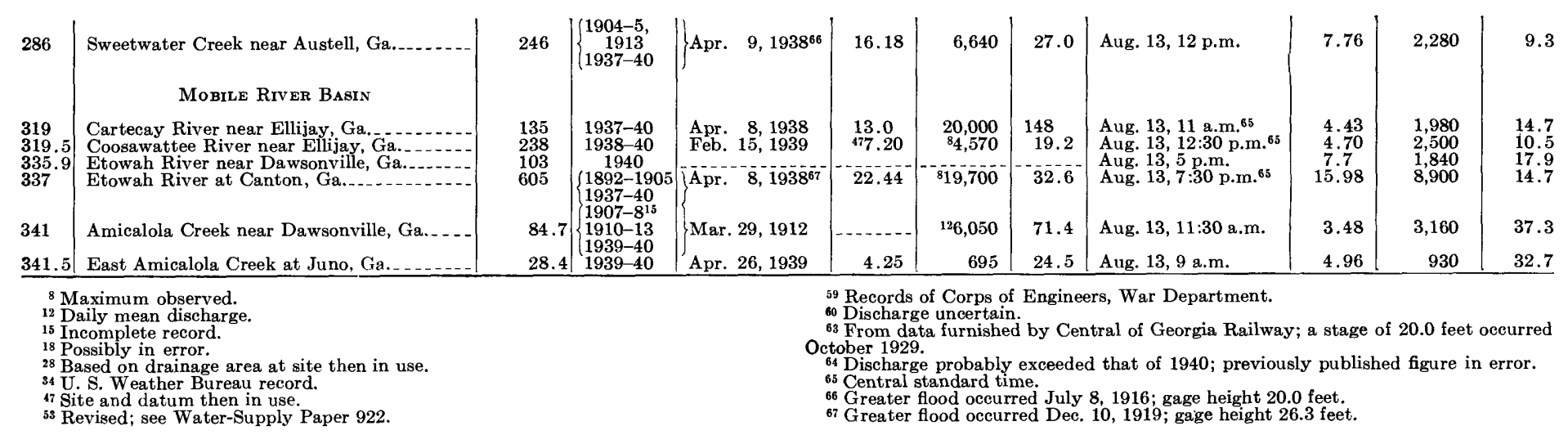

53 Revised; see Water-Supply Paper 922. 
TABLE 14.-Summary of flood discharges in Kanawha, Big Sandy, and Tennessee River Basins for the floods of August 1940 [Maximum discharges for the floods of August 1940 were obtained from gaging-station records, except as otherwise indicated by the following symbols: $C$, Contracted-opening measurement; $D$, Computed flow over dam; $R$, Stage-discharge relation; $S$, Slope-area measurement]

\begin{tabular}{|c|c|c|c|c|c|c|c|c|c|c|c|}
\hline \multirow{3}{*}{$\begin{array}{c}\text { No. } \\
\text { on } \\
\text { pl. } 20\end{array}$} & \multirow{3}{*}{ Stream and place of determination } & \multirow{3}{*}{$\begin{array}{c}\text { Drainage } \\
\text { area } \\
\text { (square } \\
\text { miles) }\end{array}$} & \multirow{3}{*}{$\begin{array}{l}\text { Period of } \\
\text { record }\end{array}$} & \multicolumn{4}{|c|}{ Maximum flood previously known } & \multicolumn{4}{|c|}{ Maximum during present flood } \\
\hline & & & & \multirow{2}{*}{ Date } & \multirow{2}{*}{$\begin{array}{c}\text { Gage } \\
\text { height } \\
\text { (feet) }\end{array}$} & \multicolumn{2}{|c|}{ Discharge } & \multirow{2}{*}{ Time $^{1}$} & \multirow[b]{2}{*}{$\begin{array}{c}\text { Gage } \\
\text { height } \\
\text { (feet) }\end{array}$} & \multicolumn{2}{|c|}{ Discharge } \\
\hline & & & & & & $\begin{array}{l}\text { Second- } \\
\text { feet }\end{array}$ & $\begin{array}{l}\text { Second- } \\
\text { feet per } \\
\text { square } \\
\text { mile }\end{array}$ & & & $\begin{array}{l}\text { Second- } \\
\text { feet }\end{array}$ & $\begin{array}{l}\text { Second- } \\
\text { feet per } \\
\text { square } \\
\text { mile }\end{array}$ \\
\hline & Kanawha River Basin & & & & & & & & & & \\
\hline 176.8 & $\begin{array}{l}\text { Middle Fork, South Fork New River about } \\
3.3 \text { miles below Blowing Rock, N. C. }\end{array}$ & 9.2 & & & & & & Aug. 13 & & $5,100 C$ & 550 \\
\hline 177 & South Fork New River near Jefferson, N. C. - & 207 & $\left\{\begin{array}{l}1924-26 \\
1928-40\end{array}\right.$ & July 15, 1916 & 18.0 & 35,200 & 170 & Aug. 14, 3 a.m. & 22.50 & 52,800 & 255 \\
\hline 180 & New River near Galax, Va.... & 1,131 & $1929-40$ & Oct. $\quad 2,1929$ & 9 & 233,100 & 29.3 & $\left\{\begin{array}{l}\text { Aug. } 14,9: 30 \text { a.m. } \\
\text { Aug. } 30,5 \text { p.m. }\end{array}\right.$ & 25.7 & $\begin{array}{r}141,000 \\
28,400\end{array}$ & $\stackrel{125}{25.1}$ \\
\hline 182 & New River at Ivanhoe, Va... & 1,340 & .... do & Sept. 6,1935 & 13.22 & 25,200 & 18.8 & Aug. $14,12 \mathrm{~m}$ & 38.1 & $\begin{array}{r}155,000 \\
35,700\end{array}$ & 116 \\
\hline 183 & New River at Allisonia, Va..... & 2,202 & $|-1898-1906|$ & Oct. $\quad 2,1929$ & 11.14 & 59,800 & 27.2 & $\left\{\begin{array}{l}\text { Aug. } 14,3 \text { p.m. } \\
\text { Aug. } 30,10 \text { p.m. }\end{array}\right.$ & $\begin{array}{r}23.42 \\
9.77\end{array}$ & $\begin{array}{r}185,000 \\
47,600\end{array}$ & $\begin{array}{l}84.0 \\
21.6\end{array}$ \\
\hline 184 & 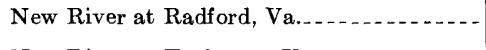 & 2,748 & $\left\{\begin{array}{l}1907-15 \\
1939-40\end{array} \mid\right.$ & Sept. 15, 1878 & 337.4 & (4) & & $\left\{\begin{array}{l}\text { Aug. 14, } 4 \\
\text { Aug. 31, } 4\end{array}\right.$ & 6 & 218 & $\begin{array}{l}79.3 \\
19.7\end{array}$ \\
\hline 185 & New River at Eggleston, Va....... & 2,941 & $1914-40$ & 1878 & 40 & 209,000 & 71.1 & 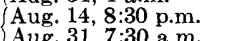 & 41.16 & $\begin{array}{r}219,000 \\
55,200\end{array}$ & 74.5 \\
\hline 186 & New River at Glenlyn, Va.................. & 3,768 & $1927-40$ & Oct. $3,1929^{5}$ & 16.75 & 94,400 & 25.1 & Aug. 14,12 p.m. & 27.50 & 226,000 & 60.0 \\
\hline 187 & New River near Hinton, W. Va............ & 4,600 & $1923-40$ & $\left\{\begin{array}{l}\text { Apr. } 21 \text { and } \\
\text { May } 23,1901^{5}\end{array}\right.$ & 24.2 & 234,000 & 50.8 & Aug. 15, 4:45 a.m. & & 232,000 & 50.4 \\
\hline 188 & New River at Caperton, W. Va............ & 6,826 & $1928-40$ & Jan. $23,1935^{5}$ & 23.60 & 142,000 & 20.8 & Aug. 15, 9 a.m. & 36.0 & 244,000 & 35.7 \\
\hline $\begin{array}{l}190 \\
190.2 \\
190.4 \\
190.6 \\
190.8\end{array}$ & $\begin{array}{l}\text { Kanawha River at Kanawha Falls, W. Va.-- } \\
\text { Kanawha River at Charleston, W. Va. } \\
\text { Kanawha River at Point Pleasant, W. Va.-- } \\
\text { Howard Creek near mouth, near Boone, N.C. } \\
\text { Rittle Creek at mouth, near Boone, N. C..-- }\end{array}$ & $\begin{array}{r}8,367 \\
10,420 \\
12,240 \\
11.6 \\
3.5\end{array}$ & \begin{tabular}{|c|}
$1877-1940$ \\
$1939-40$ \\
\hdashline-10 \\
-
\end{tabular} & Sept. 14,1878 & ${ }^{6} 37.8$ & 7320,000 & 38.2 & $\begin{array}{l}\text { Aug. } 15,11: 30 \text { a.m. } \\
\text { Aug. } 15,8 \text { p.m. } \\
\text { Aug. } 15,11 \text { p.m. } \\
\text { Aug. } 13\end{array}$ & $\begin{array}{r}29.60 \\
838.25 \\
-.2-\end{array}$ & $\begin{array}{c}248,000 \\
216,000 \\
9164,000 \\
7,000 \mathrm{~S} \\
1,900 \mathrm{~S}\end{array}$ & $\begin{array}{l}29.6 \\
20.7 \\
13.4 \\
600 \\
540\end{array}$ \\
\hline 192 & North Fork New River at Crumpler, N. C.-- & 277 & $\left\{\begin{array}{l}1908-16 \\
1928-40\end{array}\right.$ & 1878 & 17.6 & 51,000 & 184 & Aug. 14, 2 a.m. & 723.0 & 79,400 & 287 \\
\hline 192.2 & $\begin{array}{l}\text { Buffalo Creek near mouth, near West Jeffer- } \\
\text { son, N. C. }\end{array}$ & 12.6 & & & & & & Aug. 13 & & $-8,400 S$ & 670 \\
\hline 192.4 & $\begin{array}{l}\text { Horse Creek at N\&W RR trestle, near } \\
\text { T'uckerdale, N. C. }\end{array}$ & 32 & & & & & & - & & $8,100 \mathrm{~S}$ & 250 \\
\hline $\begin{array}{l}192.6 \\
192.8\end{array}$ & $\begin{array}{l}\text { Horse Creek at Lansing, N. C. } \\
\text { Chestnut Creek at Galax, Va. }\end{array}$ & $\begin{array}{l}58 \\
39\end{array}$ & & & & & & Aug. $14,8: 30 \mathrm{a} . \mathrm{m}$ & & $\begin{array}{l}18,000 \mathrm{~S} \\
11,000 \mathrm{C}\end{array}$ & $\begin{array}{l}310 \\
280\end{array}$ \\
\hline
\end{tabular}


Reed Creek at Grahams Forge, Va....... Big Reed Island Creek near Allisonia, Va. Little Reed Island Creek at Sylvatus, Va.. Little River near Coyd, Va.---...-... Little River at Graysonton, Va. Walker Creek at Bane (Staffordsville), Va. Wolf Creek near Narrows, Va. Bluestone River at Lilly, W. Va.......... Greenbrier River at Alderson, W. Va.....

Elk River at Queen Shoals, W. Va. Big Sandy River Basin

Russell Fork at Haysi, Va Pound River near Haysi, Va. Tennessee River Basin

French Broad River at Rosman, N. C..... French Broad River at Calvert, N. C...... French Broad River at Blantyre, N. C..... French Broad River at Bent Creek, N. C... French Broad River at Asheville, N. C..... French Broad River at Hot Springs, N. C.-1 See plate 20 for time zone location. 2 Revised; see Water-Supply
3 Site and datum then in use.

4 Discharge of 175,000 second-feet published in Water-Supply Paper 847 probably in error.

Greater flood probably occurred in 1878; discharge not determined. Corps of Engineers, War Department, or navigation gage, site then in use, present 7 Revised; supersedes figure published in Water-Supply Paper 893. 8 Occurred at 9 p.m.

${ }^{9}$ Flow of Ohio River at Pomeroy minus flow at Point Pleasant.

\begin{tabular}{|c|c|c|c|c|c|}
\hline$\left\{\begin{array}{l}1908-16 \\
1927-40 \\
1908-16 \\
1939-40\end{array}\right.$ & $\left\{\begin{array}{l}\text { July } 16,1916 \\
\text { do }\end{array}\right.$ & $\begin{array}{r}12.1 \\
{ }^{3} 14.8\end{array}$ & $\mid \begin{array}{r}107,110 \\
10 \quad 118,000\end{array}$ & $\begin{array}{r}28.8 \\
1227.5\end{array}$ & $\begin{array}{l}\text { Aug. 14, } 10 \text { p.m. } \\
\text { Aug. 14, } 7: 45 \text { a.m. }\end{array}$ \\
\hline $1908-16$ & July $15,1916^{13 a}$ & 9.07 & 4,500 & $18.8^{-}$ & \\
\hline$\{192\}$ & $\begin{array}{l}\text { Oct. } 2,1929 \\
\text { Mar. } 27,1913^{5}\end{array}$ & $\begin{array}{l}{ }^{3} 12.84 \\
315.8\end{array}$ & $\begin{array}{l}13,500 \\
12,100\end{array}$ & $\begin{array}{r}44.7 \\
1243.7\end{array}$ & $\begin{array}{l}\text { Aug. } 14,10 \\
\text { Aug. } 14,12\end{array}$ \\
\hline & July 16,1916 & 13.00 & ${ }^{10} 5,320$ & 23.9 & Aug. 15 or 16 \\
\hline$\left\{\begin{array}{l}1908 \\
1928\end{array}\right.$ & Mar. 25, 1935 & 11.0 & 14,400 & 32.9 & Aug. 14,8 p.m. \\
\hline $\begin{array}{l}189 \\
193 \\
192\end{array}$ & $\begin{array}{l}\text { Mar.13, } \\
\text { Mar. 18, } \\
\text { July 5, }\end{array}$ & $\begin{array}{l}22.0 \\
21.85 \\
28.60\end{array}$ & $\begin{array}{r}77,500 \\
60,800 \\
105,000\end{array}$ & $\begin{array}{l}57.1 \\
37.4 \\
79.8\end{array}$ & $\begin{array}{l}5,4 \text { a.m. } \\
5,9 \text { a.m. } \\
5,10: 30 \text { a.n }\end{array}$ \\
\hline $1928-40$ & . . . . do & 29.2 & 91,300 & 79.7 & $\begin{array}{l}\text { Aug. } 15,11 \text { p.m. } \\
\text { Aug. 26, } 9 \text { p.m. }\end{array}$ \\
\hline $\begin{array}{l}1926 \\
1926\end{array}$ & Mar. 23, & $\begin{array}{r}17.96 \\
\$ 16.50\end{array}$ & $\begin{array}{r}71533,000 \\
30,000\end{array}$ & $\begin{array}{r}115 \\
12138\end{array}$ & a.m. \\
\hline & July 1 : & 13.9 & (16) & & \\
\hline & Aug. & 13. & 16,100 & 156 & Aug. 30,6 a.m. \\
\hline $1920-40$ & Aug. $16,1928^{18}$ & 22.9 & 26,500 & 89.5 & 14,9 \\
\hline $1934-40$ & July 15,1916 & 27.3 & $(16$ & & $\begin{cases}A 1 \\
A\end{cases}$ \\
\hline$\left\{\begin{array}{l}1895-1901 \\
1903-40\end{array}\right.$ & July 16, 1916 & 23.1 & 110,000 & 116 & $\left\{\begin{array}{l}\text { Aug. } 30,1 \text { p.m. } \\
\text { Aug. } 14,1 \text { a.m. } \\
\text { Aug. } 30,12 \mathrm{~m} \text {. }\end{array}\right.$ \\
\hline 1934 & July 1916 & 19.3 & $(16)$ & & $\left\{\begin{array}{l}\text { Aug. 14, } 6 \text { a.m. } \\
\text { Aug. 30, } 7: 30 \text { a.m. }\end{array}\right.$ \\
\hline
\end{tabular}

\begin{tabular}{|c|c|c|}
\hline 4.82 & 3,730 & 15.1 \\
\hline 11.70 & 20,900 & 75.2 \\
\hline & $\begin{array}{r}8,100 \mathrm{~S} \\
15,000 \mathrm{~S} \\
14,000 \mathrm{~S}\end{array}$ & $\begin{array}{r}120 \\
78 \\
59\end{array}$ \\
\hline $\begin{array}{l}16.44 \\
10.08\end{array}$ & $\begin{array}{r}17,700 \\
4,660\end{array}$ & $\begin{array}{l}58.6 \\
15.3\end{array}$ \\
\hline 7.2 & 2,820 & 12.6 \\
\hline 7.05 & 6,400 & 14.6 \\
\hline $\begin{array}{r}8.83 \\
11.34 \\
7.07 \\
9.25 \\
3.96 \\
7.78\end{array}$ & $\begin{array}{r}16,100 \\
18,100 \\
9,830 \\
16,200 \\
164 \\
3,380\end{array}$ & $\begin{array}{r}11.9 \\
11.1 \\
7.5 \\
12.3 \\
.1 \\
3.0\end{array}$ \\
\hline $\begin{array}{r}10.20 \\
6.94\end{array}$ & $\begin{array}{r}{ }^{7} 11,900 \\
1,880\end{array}$ & $\begin{array}{r}41.6 \\
8.9\end{array}$ \\
\hline $\begin{array}{l}11.78 \\
11.86 \\
11.66 \\
10.83 \\
21.89 \\
19.32 \\
12.6 \\
11.08 \\
11.65 \\
12.15\end{array}$ & $\begin{array}{r}\mathbf{9 , 0 4 0} \\
\mathbf{9 , 4 1 0} \\
12,300 \\
\mathbf{9 , 3 8 0} \\
720,800 \\
710,900 \\
23,600 \\
18,900 \\
31,800 \\
34,800\end{array}$ & $\begin{array}{c}133 \\
139 \\
119 \\
91.1 \\
70.3 \\
36.8 \\
34.9 \\
28.0 \\
33.7 \\
36.8\end{array}$ \\
\hline & & \\
\hline
\end{tabular}

Daily mean discharge.

11 Possibly in error.

13 Based on drainage area at site then in use

Gersedes erroned. Greater flood occurred in 1900; gage height about 13 feet. Data furnished by Corps of Engineers, War Department. 16 Discharge not determined.

${ }^{17}$ Greater flood occurred July 1916; gage height 18.3 feet. 18 Greater flood occurred July 1916; gage height 27.1 feet. 


\begin{tabular}{|c|c|c|c|c|c|c|c|c|c|c|c|}
\hline \multirow{3}{*}{$\begin{array}{c}\text { No. } \\
\text { on } \\
\text { pl. } 20\end{array}$} & \multirow{3}{*}{ Stream and place of determination } & \multirow{3}{*}{$\begin{array}{c}\text { Drainage } \\
\text { area } \\
\text { (square } \\
\text { miles) }\end{array}$} & \multirow{3}{*}{$\begin{array}{l}\text { Period of } \\
\text { record }\end{array}$} & \multicolumn{4}{|c|}{ Maximum flood previously known } & \multicolumn{4}{|c|}{ Maximum during present flood } \\
\hline & & & & \multirow[b]{2}{*}{ Date } & \multirow[b]{2}{*}{$\begin{array}{c}\text { Gage } \\
\text { height } \\
\text { (feet) }\end{array}$} & \multicolumn{2}{|c|}{ Discharge } & \multirow[b]{2}{*}{ Time $^{1}$} & \multirow[b]{2}{*}{$\begin{array}{c}\text { Gage } \\
\text { height } \\
\text { (feet) }\end{array}$} & \multicolumn{2}{|c|}{ Discharge } \\
\hline & & & & & & $\begin{array}{l}\text { Second- } \\
\text { feet }\end{array}$ & $\begin{array}{l}\text { Second- } \\
\text { feet per } \\
\text { square } \\
\text { mile }\end{array}$ & & & $\begin{array}{l}\text { Second- } \\
\text { feet }\end{array}$ & $\begin{array}{l}\text { Second- } \\
\text { feet per } \\
\text { square } \\
\text { mile }\end{array}$ \\
\hline $\begin{array}{l}461 \\
462 \\
463\end{array}$ & $\begin{array}{l}\text { French Broad River near Newport, Tenn. -- } \\
\text { French Broad River at Dandridge, Tenn.-- } \\
\text { Tennessee River at Knoxville, Tenn..... }\end{array}$ & $\begin{array}{l}1,858 \\
4,446 \\
8,934\end{array}$ & $\begin{array}{l}\left\{\begin{array}{l}1900-1905 \\
1907 \\
1920-40 \\
1918-40\end{array}\right. \\
1899-1940\end{array}$ & $\begin{array}{l}\text { Feb. } 28,1902 \\
\text { Apr. } \quad 2,1920^{19} \\
\text { Mar. } \quad 1,1902^{20}\end{array}$ & $\begin{array}{l}23 \\
18.7 \\
36.0\end{array}$ & $\begin{array}{r}101,000 \\
1584,500 \\
15195,000\end{array}$ & $\begin{array}{l}54.4 \\
19.0 \\
21.8\end{array}$ & $\left\{\begin{array}{l}\text { Aug. } 14,7: 30 \text { a.m. } \\
\text { Aug. } 30,12 \mathrm{~m} . \\
\text { Aug. 15, } 7 \text { a.m. } \\
\text { Aug. } 31,1 \text { a.m. } \\
\text { Aug. 16, } 2 \text { a.m. } \\
\text { Aug. } 31,7 \text { p.m. }\end{array}\right.$ & $\begin{array}{l}12.59 \\
19.25 \\
18.73 \\
20.93 \\
23.90 \\
20.28\end{array}$ & $\begin{array}{r}38,000 \\
76,300 \\
81,400 \\
95,600 \\
118,000 \\
98,000\end{array}$ & $\begin{array}{l}20.5 \\
41.1 \\
18.3 \\
21.5 \\
13.2 \\
11.0\end{array}$ \\
\hline 464 & Tennessee River at Loucion, Tenn.... & 12,220 & $1922-40$ & Mar. $5,1917^{21}$ & 32.9 & 225,000 & 18.4 & $\left\{\begin{array}{l}\text { Aug. } 16,4 \text { p.m. } \\
\text { Sept. } 1,7 \text { a.m. }\end{array}\right.$ & $\begin{array}{l}19.86 \\
18.66\end{array}$ & $\begin{array}{l}123,000 \\
113,000\end{array}$ & $\begin{array}{r}10.1 \\
9.2\end{array}$ \\
\hline 465 & Tennessee River at Breedenton, Tenn... & 17,460 & $1934-40$ & Mar. 29, 1936 & 27.70 & 205,000 & 11.7 & Aug. $17,5-8$ a.m. & $\begin{array}{r}18.66 \\
-\cdots\end{array}$ & 113,000 & 6.5 \\
\hline 466 & Tennessee River at Chattanooga, Tenn.... & 2221,400 & $1874-1940$ & Mar. 11, 1867 & 2857.9 & 459,000 & 21.4 & $\left\{\begin{array}{l}\text { Aug. } 16,4 \text { p.m. } \\
\text { Sept. } 2,10 \text { a.m. }\end{array}\right.$ & $\begin{array}{r}\overline{19 . \overline{8}} \\
2421.07\end{array}$ & $\begin{array}{r}117,000 \\
81,500 \\
89,400\end{array}$ & $\begin{array}{l}6.7 \\
3.8 \\
4.2\end{array}$ \\
\hline 478 & Davidson River near Brevard, N. C........ & 40.4 & $1920-40$ & Aug. 15, $1928^{25}$ & 11.8 & 8,400 & 208 & Aug. $13,10: 30$ a.m. & $\begin{array}{r}9.20 \\
7.68\end{array}$ & $\begin{array}{r}6,100 \\
4,310\end{array}$ & 151 \\
\hline 480 & $\begin{array}{l}\text { South Fork Mills River at The Pink Beds, } \\
\text { N. C. }\end{array}$ & 9.99 & $1926-40$ & ............... & 8.0 & 2,220 & 222 & $\left\{\begin{array}{l}\text { Aug. } 13,2 \text { p.m. } \\
\text { Aug. 30, } 4 \text { a.m. }\end{array}\right.$ & $\begin{array}{l}7.16 \\
6.34\end{array}$ & $\begin{array}{l}4,610 \\
1,610 \\
1,110\end{array}$ & 161 \\
\hline 482 & Mills River near Mills River, N. C....... & 66.7 & $\left\{\begin{array}{l}1924-26 \\
1934-40\end{array}\right.$ & August 1928 & 13.5 & (16) & & $\left\{\begin{array}{l}A \\
A\end{array}\right.$ & 13 & $\begin{array}{r}269,440 \\
2610\end{array}$ & $\begin{array}{l}142 \\
150\end{array}$ \\
\hline 484 & Mud Creek at Naples, N. C..... & 109 & $\left\{\begin{array}{c}1907 \\
1938-40\end{array}\right.$ & July 1916 & 21 & (16) & & $\begin{array}{l}\text { Aug. } 13,11-12 \text { p.m. } \\
\text { Aug. } 30,5 \text { p.m. }\end{array}$ & $\begin{array}{l}13.07 \\
10.99\end{array}$ & $\begin{array}{r}2610,800 \\
264,800\end{array}$ & $\begin{array}{r}99.1 \\
44.0\end{array}$ \\
\hline $\begin{array}{l}484.1 \\
484.2\end{array}$ & $\begin{array}{l}\text { Hominy Creek above Candler, N. C. C. } \\
\text { Hominy Creek below Candler, N. C. }{ }^{27} \ldots\end{array}$ & $\begin{array}{l}28.9 \\
67.7\end{array}$ & & Feb. 28,1902 & $(28)$ & & & Aug. 30 & & $12,400 \mathrm{~S}$ & $\begin{array}{l}429 \\
189\end{array}$ \\
\hline 484.4 & $\begin{array}{l}\text { Hominy Creek at American Enka Corpora- } \\
\text { tion rayon plant at Enka, N. C. }{ }^{27}\end{array}$ & 86.4 & & - & & & & Aug. 30,5 a.m. & & ${ }^{29} 12,800$ & 148 \\
\hline 484.5 & $\begin{array}{l}\text { North Hominy Creek at mouth, near Can- } \\
\text { ton, N. C. }{ }^{27}\end{array}$ & 7.8 & & & & & & Aug. 30 & & $5,000 S$ & 641 \\
\hline 484.6 & $\begin{array}{l}\text { South Hominy Creek above Stony Fork, } \\
\text { near Candler, N. C.7 }\end{array}$ & 5.1 & & & & & & do & & $1,500 \mathrm{~S}$ & 294 \\
\hline 484.8 & $\begin{array}{l}\text { South Hominy Creek above Beaverdam } \\
\text { Creek, at Candler, N. C.27 }\end{array}$ & 29.2 & & & & & & ...do_ & & $5,500 S$ & 188 \\
\hline $\begin{array}{l}484.9 \\
486\end{array}$ & $\begin{array}{l}\text { Stony Fork near mouth, near Candler, N.C. }{ }^{27} \\
\text { Swannanoa River at Biltmore, N. C. }\end{array}$ & $\begin{array}{r}4.1 \\
130\end{array}$ & $\left\{\begin{array}{l}1920-26 \\
1934-40\end{array}\right.$ & July 1916 & 21.5 & $(16)$ & & $\begin{array}{l}\text { do. } \\
\text { Aug. } 13,7: 30 \text { p.m. } \\
\text { Aug. } 30,1: 30 \text { p.m. }\end{array}$ & 19.00 & $\begin{array}{l}1,300 S \\
18,400 \\
11,200\end{array}$ & $\begin{array}{l}317 \\
142 \\
86.2\end{array}$ \\
\hline 487 & $\begin{array}{l}\text { North Fork Swannanoa River near Black } \\
\text { Mountain, N. C. }\end{array}$ & 23.8 & & Aug. 15, 1928 & 7.04 & 5,050 & 212 & $\left\{\begin{array}{l}\text { Aug. } 13,12 \mathrm{~m} . \mathrm{m} \\
\text { Aug. 30, } 6: 30 \mathrm{a} . \mathrm{m}\end{array}\right.$ & $\begin{array}{r}8.55 \\
7.72\end{array}$ & $\begin{array}{r}8,200 \\
6,560\end{array}$ & $\begin{array}{l}345 \\
276\end{array}$ \\
\hline
\end{tabular}


487.5 Right Hand Fork of North Fork Swannanoa River at Ashevi"e water system intake. 488 Beetree Creek near Swannanoa, N

488.2 Beaverdam Creek at dam near mouth, near 488.4 Newfound Creek below Dix Creek, near Leicester, N. C.

488.6 Reems Creek at Weaverville, N. C

488.8 Sandymush Creek above Turkey Creek,

489 near Marshall, N. C.

490 Big Laurel Creek near Stackhouse, N. C. .

490.2 Spring Creek at Hot Springs, N. C.

490.5 West Fork Pigeon River at Spruce, near

490.8 West Fork Pigeon River at Lake Logan dam,

491 near Waynesville, N. C. 27

Pigeon River at Canton, N. C.

493

495

Pigeon River near Hepco, N. C.............

Pigeon River at Hartford, Tenn. .........

496

Pigeon River at Newport, Tenn

496.2 Middle Prong, West Fork Pigeon River near

greek at Lake Logan, near Waynes-

496.6 Big Creek at Lake Logan, near Waynes-

496.8 Big Branch (tributary to Little East Fork

497 Jonathan Creek near Cove Creek, N. C.....

1 See plate 20 for time zone location,

2 Revised; see Water-Supply Paper 893.

15 Maximum observed.

16 Discharge not determined.

${ }^{19}$ Greater flood occurred May 21, 1901; gage height 28.0 feet.

${ }^{20}$ Greater flood occurred Mar. 10, 1867; estimated discharge 270,000 second-feet. ${ }^{21}$ Greater floods occurred in 1867, 1875, and 1886; discharges not determined.

22 Affected by storage.

${ }^{23}$ At Walnut Street, present datum

24 Occurred at 12:15 p.m.

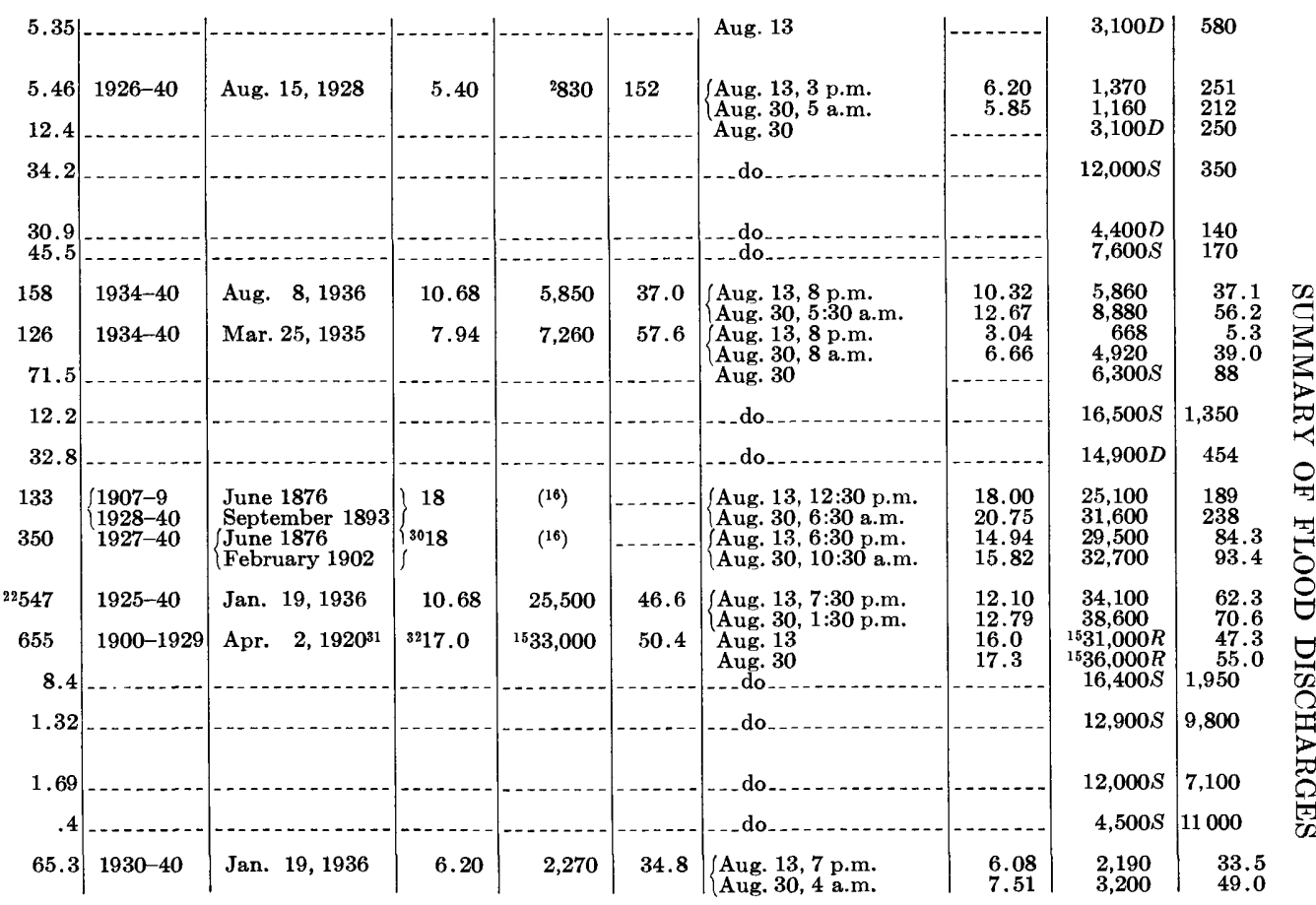

${ }^{25}$ Greater flood occurred June 1876; gage height 11.9 feet.

${ }_{26}$ Revised; supersedes figure published in Water-Supply Paper 893

${ }_{27}$ From "Floods of August 1940 in Tennessee River Basin," issued by T.V.A. as

supplement to "Precipitation in Tennessee River Basin October 1940"

${ }^{28} 8$ inches below that of August 1940, according to local residents.

${ }^{29}$ Estimated from best available data.

${ }_{31}^{30}$ From Tennessee Division of Geology Bulletin 34.

32 Site then in use. 
TABLe 14.-Summary of flood discharges in Kanawha, Big Sandy, and Tennessee River Basins for the floods of August 1940-Continued

\begin{tabular}{|c|c|c|c|c|c|c|c|c|c|c|c|}
\hline \multirow{3}{*}{$\begin{array}{c}\text { No. } \\
\text { on } \\
\text { pl. } 20\end{array}$} & \multirow{3}{*}{ Stream and place of determination } & \multirow{3}{*}{$\begin{array}{c}\text { Drainage } \\
\text { area } \\
\text { (square } \\
\text { miles) }\end{array}$} & \multirow{3}{*}{$\begin{array}{l}\text { Period of } \\
\text { record }\end{array}$} & \multicolumn{4}{|c|}{ Maximum flood previously known } & \multicolumn{4}{|c|}{ Maximum during present flood } \\
\hline & & & & \multirow[b]{2}{*}{ Date } & \multirow[b]{2}{*}{$\begin{array}{c}\text { Gage } \\
\text { height } \\
\text { (feet) }\end{array}$} & \multicolumn{2}{|c|}{ Discharge } & \multirow[b]{2}{*}{ Time' } & \multirow[b]{2}{*}{$\begin{array}{c}\text { Gage } \\
\text { height } \\
\text { (feet) }\end{array}$} & \multicolumn{2}{|c|}{ Discharge } \\
\hline & & & & & & $\begin{array}{c}\text { Second- } \\
\text { feet }\end{array}$ & $\begin{array}{c}\text { Second- } \\
\text { feet per } \\
\text { square } \\
\text { mile }\end{array}$ & & & $\begin{array}{l}\text { Second- } \\
\text { feet }\end{array}$ & $\begin{array}{l}\text { Second- } \\
\text { feet per } \\
\text { square } \\
\text { mile }\end{array}$ \\
\hline 498 & Cataloochee Creek near Cataloochee, N. C.-- & $\overline{49.2}$ & $1934-40$ & Jan, 19,1936 & 6.64 & 2,700 & 54.9 & $\left\{\begin{array}{l}\text { Aug. } 13,3: 30 \text { p.m. } \\
\text { Aug. 30, } 3 \text { a.m. }\end{array}\right.$ & $\begin{array}{l}5.12 \\
7.01\end{array}$ & $\begin{array}{l}1,360 \\
3,390\end{array}$ & $\begin{array}{r}27.6 \\
68.9\end{array}$ \\
\hline 499 & North Toe River at Altapass, N. C. . & ${ }^{33} 104$ & $1934-40$ & July 1916 & 24 & ${ }^{(16)}$ & & $\left\{\begin{array}{l}\text { Aug. } 13,9 \text { p.m. } \\
\text { Aug. } 30,11 \text { a.m. }\end{array}\right.$ & $\begin{array}{l}19.5 \\
10.07\end{array}$ & $\begin{array}{r}22,200 \\
6,620\end{array}$ & $\begin{array}{r}213 \\
63.0\end{array}$ \\
\hline 500.5 & $\begin{array}{l}\text { North Toe River at Toecane, N. C. } \\
\text { Nolichucky River at Poplar, N. C. }\end{array}$ & $\begin{array}{l}233 \\
608\end{array}$ & $1925-40$ & 1901 and 1916 & 21 & $(16)$ & & $\begin{array}{l}\text { Aug. } 13 \\
\text { Aug. } 13,7 \text { p.m. }\end{array}$ & 19.7 & $\begin{array}{l}51,000 \mathrm{~S} \\
74,500 \\
32,500\end{array}$ & $\begin{array}{l}220 \\
123 \\
53,5\end{array}$ \\
\hline 502 & Nolichucky River at Embreeville, Tenn. .. & 805 & $1920-40$ & Mar. 26, 1935 & 10.69 & 236,600 & 45.5 & $\begin{array}{l}\text { Aug. } 13,8 \text { a.m. } \\
\text { Aug. } 13,9: 30 \text { p.m. } \\
\text { Aug. } 30,10 \text { a.m. }\end{array}$ & $\begin{array}{l}13.07 \\
18.57 \\
11.23\end{array}$ & $\begin{array}{l}32,000 \\
82,500 \\
39,500\end{array}$ & $\begin{array}{c}53.5 \\
102 \\
49.1\end{array}$ \\
\hline 504 & $\begin{array}{l}\text { Nolichucky River at Greeneville Dam, near } \\
\text { Greeneville, Tenn. }\end{array}$ & 1,183 & $\left\{\begin{array}{l}1903-8^{34} \\
1919-25^{34} \\
1940\end{array}\right.$ & Jan. 23, 1906 & 31519.3 & $\begin{array}{l}303134 \\
73,500\end{array}$ & 64.5 & Aug. 14,8 a.m. & 80.0 & $73,500 D$ & 62.1 \\
\hline 505 & Nolichucky River near Morristown, Tenn... & 1,686 & $1920-40$ & Mar. 26, 1935 & 22.00 & 56,600 & 33.6 & $\left\{\begin{array}{l}\text { Aug. } 14,8 \text { p.m. } \\
\text { Aug. } 31,5 \text { a.m. }\end{array}\right.$ & $\begin{array}{l}22.68 \\
19.79\end{array}$ & $\begin{array}{l}61,900 \\
40,900 \\
0,4009\end{array}$ & $\begin{array}{l}36.7 \\
24.3\end{array}$ \\
\hline $\begin{array}{c}505.3 \\
505.7\end{array}$ & $\begin{array}{l}\text { Crabtree Creek above Roaring Branch, near } \\
\text { Estatoe, N. C. } \\
\text { South Toe River above Locust Creek, near }\end{array}$ & $\begin{array}{l}15.4 \\
32.8\end{array}$ & & & & & & Aug. 13 & & $\begin{array}{r}3,400 S \\
18,000 S\end{array}$ & $\begin{array}{l}220 \\
550\end{array}$ \\
\hline 06 & $\begin{array}{l}\text { Busick, N.C. } \\
\text { South Toe River at Newdale, N. C........ }\end{array}$ & 60.8 & $1934-40$ & July 1916 & 14 & 20,300 & 334 & $\left\{\begin{array}{l}\text { Aug. } 13,4 \text { p.m. } \\
\text { Aug. } 30,10 \text { a.m. }\end{array}\right.$ & $\begin{array}{l}17.4 \\
10.52\end{array}$ & $\begin{array}{l}29,400 \\
12,200\end{array}$ & $\begin{array}{l}484 \\
201\end{array}$ \\
\hline 06.3 & $\begin{array}{l}\text { Cane River above Falling Water Branch, } \\
\text { near Pensacola, N. C. }\end{array}$ & 18.1 & & & & & & Aug. 13 & & $15,000 S$ & 830 \\
\hline 507.7 & $\begin{array}{l}\text { Cane River at dam, near Burnsville, N. C.- } \\
\text { Cane River near Sioux, N. C...-......... }\end{array}$ & 157 & $1934-40$ & $\left\{\begin{array}{l}\text { August } 1893 \\
\text { May } 1901\end{array}\right.$ & $\overline{16}$ & 21,700 & $13 \overline{8}$ & $\left\{\begin{array}{l}\text { Aug. } 13,4: 30 \text { p.m. } \\
\text { Aug. } 30,7: 45 \text { a.m. }\end{array}\right.$ & $\begin{array}{l}17.8 \\
10.84\end{array}$ & $\begin{array}{l}18,000 D \\
27,300 \\
8,780\end{array}$ & $\begin{array}{l}490 \\
174 \\
55.9\end{array}$ \\
\hline 508 & Little Pigeon River at Sevierville, Tenn....- & 353 & $1920-40$ & June 29, 1928 & 15.4 & 32,000 & 90.7 & $\begin{array}{l}\text { Aug. } 14,12 \text { p.m. } \\
\text { Aug. } 30,6 \text { a.m. }\end{array}$ & $\begin{array}{l}9.17 \\
7.85\end{array}$ & $\begin{array}{l}8,760 \\
6,940\end{array}$ & $\begin{array}{l}24.8 \\
19.7\end{array}$ \\
\hline 510 & South Fork Holston River at Vestal, Va... & 301 & $1931-40$ & Mar. 26, 1935 & 13.26 & 10,700 & 35.5 & Aug. 14,6 to 7 a.m. & 13.25 & 10,600 & 35.2 \\
\hline 511 & $\begin{array}{l}\text { South Fork Holston River at Bluff City, } \\
\text { Tenn. }\end{array}$ & 813 & $1900-1940$ & May 22, 1901 & 3215.0 & 28,000 & 34.4 & $\left\{\begin{array}{l}\text { Aug. } 14,4 \text { p.m. } \\
\text { Aug. } 15,4 \text { a.m. }\end{array}\right.$ & 11.60 & 18,200 & 22.4 \\
\hline 512 & $\begin{array}{l}\text { South Fork Holston River at Kingsport, } \\
\text { Tenn. }\end{array}$ & 1,931 & $1925-40$ & · Mar. 26, 1935 & 15.18 & 45,200 & 23.4 & $\begin{array}{l}\text { Aug. } 14,9.30 \text { a.m. } \\
\text { Aug. } 30,11 \text { p.m. }\end{array}$ & $\begin{array}{r}18.80 \\
8.15\end{array}$ & $\begin{array}{l}68,800 \\
18,700\end{array}$ & $\begin{array}{r}35.6 \\
9.7\end{array}$ \\
\hline $\begin{array}{l}513 \\
513.3 \\
513.7\end{array}$ & $\begin{array}{l}\text { Holston River near Rogersville, Tenn....... } \\
\text { Holston River near Morristown, Tenn...-.. } \\
\text { Holston River near Jefferson City, Tenn.... }\end{array}$ & $\begin{array}{l}3,035 \\
3,244 \\
3,429\end{array}$ & \begin{tabular}{|l}
$1902-40$ \\
$1937-40$ \\
-
\end{tabular} & $\begin{array}{l}\text { Jan. } 29,1918^{35} \\
\text { Mar. } 27,1935 \\
\text { Oct. } 29,1937\end{array}$ & \begin{tabular}{|l}
320.0 \\
3628.4 \\
12.86
\end{tabular} & $\begin{array}{l}70,900 \\
65,000 \\
27,600\end{array}$ & $\begin{array}{r}23.4 \\
20.0 \\
8.0\end{array}$ & $\begin{array}{l}\text { Aug. } 15,6 \text { a.m. } \\
\text { Aug. } 15,2 \text { to } 2: 30 \text { p.m } \\
\text { Aug. } 15,9 \text { p.m. }\end{array}$ & $\begin{array}{l}17.76 \\
26.70 \\
21.80\end{array}$ & $\begin{array}{l}59,000 \\
58,900 \\
58,700\end{array}$ & $\begin{array}{l}19.4 \\
18.2 \\
17.1\end{array}$ \\
\hline
\end{tabular}



\begin{tabular}{l|l}
514 & Holston River at Strawberry Plains, Tenn.-- \\
516 & Middle Fork Holston River near Meadow-
\end{tabular} view, Va.

517.2 Watauga River below Laurel Fork, near 517.5 Watauga River above

517.8 Sugar Grove, N. C. 27

Watauga River near Sugar Grove, N. C...

518 Watauga River at Stump Knob, Tenn.....

519 Watauga River at Butler, Tenn.

520 Watauga River at Horseshoe Dam, at Wil-

521 bur (near Elizabethton), Tenn.

521.1 .

521.3 Dútch Creek at $\cdot$ Valle Crucis, N. C. 27

521.5 Craborchard Creek near Valle Crucis, N. ${ }^{27}$

521.7 Cove Creek near Surar Grove $N$ Cis,

521.9 Linville Creek near Sugar Grove, N. C.27--

522 Elk Creek near Banner Elk, N. C.

523 Elk Creek near Elk Park, N. C.

524 Roan Creek at Butler, Tenn.---

527 Doe River at Elizabethton, Tenn.........

North Fork Holston River at and near Saltville, Va.

530 North Fork Holston River near Gate City,

534 Little River near Walland, Tenn.........

537 Little Tennessee River at Iotla, N. C......

540 Little Tennessee River at Judson, N. C....

540.5 Little Tennessee River near Fontana, N. C.-

\begin{tabular}{|c|c|c|c|}
\hline $\begin{array}{r}3,626 \\
211\end{array}$ & $\begin{array}{l}1930-40 \\
1931-40\end{array}$ & $\begin{array}{l}\text { Mar. 28, } 1935 \\
\text { Jan. 23, } 1935\end{array}$ & $\begin{array}{r}20.20 \\
8.59\end{array}$ \\
\hline 33.1 & & & \\
\hline 55.1 & & & \\
\hline 90.8 & 1940 & July 1916 & 22.1 \\
\hline 171 & $\{1927-31$ & May 21, 1901 & 3719.5 \\
\hline 427 & $1900-01^{39}$ & Jan. $9,1935^{40}$ & 11.85 \\
\hline 471 & $1903-8^{41}$ & July 12,1905 & 8.4 \\
\hline 692 & $1926-40$ & $\begin{array}{c}\text { Feb, } 27 \text { or } 28, \\
1902\end{array}$ & ${ }^{36} 22.0$ \\
\hline 2.42 & & & \\
\hline $\begin{array}{r}10.6 \\
2.09 \\
17.7 \\
4.8\end{array}$ & & & \\
\hline $\begin{array}{l}17.8 \\
42.0\end{array}$ & $\begin{array}{l}1934-40 \\
\text { do }\end{array}$ & Jan. 9,1935 & $\begin{array}{l}7.34 \\
7.15\end{array}$ \\
\hline 166 & $-\ldots$ do & Mar. 26, 1935 & 7.68 \\
\hline $\begin{array}{l}137 \\
222\end{array}$ & $\left\{\begin{array}{l}1932-40 \\
1907-8 \\
1920-40\end{array}\right.$ & $\begin{array}{r}\text { July } 30,1940 \\
\text { Feb. } \quad 3,1923\end{array}$ & $\begin{array}{r}6.75 \\
{ }^{3} 13.97\end{array}$ \\
\hline 672 & $1931-40$ & $\left\{\begin{array}{l}\text { Jan. } 30,1932 \\
\text { Mar. 26, } 1935\end{array}\right.$ & 10.6 \\
\hline 192 & - . _do_... & Feb. $\quad 4,1936$ & 13.18 \\
\hline 323 & $1929-40$ & October 1898 & 13 \\
\hline 664 & $1896-1940$ & Feb. 28, 1902 & ${ }^{3} 16.19$ \\
\hline${ }^{33} 1,571$ & $1938-40$ & March 1867 & 23 \\
\hline
\end{tabular}

\begin{tabular}{r}
262,900 \\
5,360 \\
\hline 28,000 \\
34,400 \\
18,500 \\
4110,100 \\
83,700 \\
\\
\hline 16 \\
\hline $2,, 860$ \\
3,940 \\
7,300 \\
8,220 \\
13,400 \\
16,200 \\
18,600 \\
1540,800 \\
$(16)$ \\
\end{tabular}

17.3 Aug. 16, 9 a.m.

\begin{tabular}{|c|c|c|}
\hline \multirow[t]{2}{*}{$\begin{array}{r}18.62 \\
8.00\end{array}$} & $\begin{array}{r}57,100 \\
4,570\end{array}$ & $\begin{array}{l}15.7 \\
21.7\end{array}$ \\
\hline & $38,000 \mathrm{~S}$ & 1,100 \\
\hline & $41,000 \mathrm{~S}$ & 744 \\
\hline 29.6 & 50,800 & 559 \\
\hline${ }^{36} 24.0$ & 3050,000 & 292 \\
\hline${ }^{38} 10.35$ & 10,900 & 63.7 \\
\hline 25.4 & 71,500 & 167 \\
\hline $\begin{array}{r}9.85 \\
17.47\end{array}$ & $\begin{array}{l}14,000 \\
73,800 D\end{array}$ & 157.8 \\
\hline 20.87 & 75,100 & 109 \\
\hline 11.38 & $\begin{array}{c}17,300 \\
9,200 \mathrm{~S}\end{array}$ & $3,800.0$ \\
\hline & $16,000 \mathrm{~S}$ & 1,51 \\
\hline$\cdots$ & $6,000 \mathrm{~S}$ & 2,870 \\
\hline & $12,000 \mathrm{~S}$ & $\begin{array}{l}678 \\
875\end{array}$ \\
\hline 16.9 & $22,000 \mathrm{~S}$ & 1,200 \\
\hline 17.8 & 27,500 & 655 \\
\hline 4210.09 & 3,920 & 23.6 \\
\hline $\begin{array}{l}b .48 \\
6.23\end{array}$ & $\begin{array}{l}4,830 \\
5,840\end{array}$ & $\begin{array}{l}35.3 \\
26.3\end{array}$ \\
\hline 14.75 & 23,700 & 35.3 \\
\hline 4.49 & & \\
\hline 4.86 & 2,900 & 15.1 \\
\hline 7.63 & 7,770 & 24.1 \\
\hline $\begin{array}{l}13.5 \\
04.16\end{array}$ & $\begin{array}{l}19,600 \\
11,00\end{array}$ & 60.7 \\
\hline 27.62 & 22,100 & 33.3 \\
\hline 09 & 35,90 & 22 \\
\hline 15.94 & 71,200 & 45.3 \\
\hline
\end{tabular}

1 See plate 20 for time zone location.

2 Revised; see Water-Supply Paper 893.

15 Maximum observed.

16 Mischarme not determined.

${ }^{27}$ From "Floods of August 1940 in Tennessee River Basin," issued by T.V.A. as supplement to "Precipitation in Tennessee River Basin October 1940."

30 About.

31 From Tennessee Division of Geology Bulletin 34.

s3 Revised; see Water-Supply Paper 973

${ }^{34}$ At site upstream; drainage area 1,141 square miles, revised.

${ }^{35}$ Greater flood occurred March 1867; discharge not determined.

${ }_{37}^{36}$ From floodmark.

${ }^{37}$ From floodmark by Tennessee Valley Authority.

${ }^{38}$ From graph based on gage readings.

40 Greater flood occurred May 21, 1901, but did not exceed 1940 flood; discharge not determined.

${ }^{41}$ At site downstream; drainage area 475 square miles.

42 Occurred at 9:50 p.m. Aug. 13. 
TABLE 14.- Summary of flood discharges in Kanawha, Big Sandy, and Tennessee River Basins for the floods of August 1940 -Continued

\begin{tabular}{|c|c|c|c|c|c|c|c|c|c|c|c|}
\hline \multirow{3}{*}{$\begin{array}{c}\text { No. } \\
\text { on } \\
\text { pl. } 20\end{array}$} & \multirow{3}{*}{ Stream and place of determination } & \multirow{3}{*}{$\begin{array}{c}\text { Drainage } \\
\text { area } \\
\text { (square } \\
\text { miles) }\end{array}$} & \multirow{3}{*}{$\begin{array}{l}\text { Period of } \\
\text { record }\end{array}$} & \multicolumn{4}{|c|}{ Maximum flood previously known } & \multicolumn{4}{|c|}{ Maximum during present flood } \\
\hline & & & & \multirow{2}{*}{ Date } & \multirow[b]{2}{*}{$\begin{array}{c}\text { Gage } \\
\text { height } \\
\text { (feet) }\end{array}$} & \multicolumn{2}{|c|}{ Discharge } & \multirow{2}{*}{ Time $^{1}$} & \multirow[b]{2}{*}{$\begin{array}{c}\text { Gage } \\
\text { height } \\
\text { (feet) }\end{array}$} & \multicolumn{2}{|c|}{ Discharge } \\
\hline & & & & & & $\begin{array}{c}\text { Second- } \\
\text { feet }\end{array}$ & $\begin{array}{c}\text { Second- } \\
\text { feet per } \\
\text { square } \\
\text { mile }\end{array}$ & & & $\begin{array}{c}\text { Second- } \\
\text { feet }\end{array}$ & $\begin{array}{l}\text { Second- } \\
\text { feet per } \\
\text { square } \\
\text { mile }\end{array}$ \\
\hline 541 & Little Tennessee River at Calderwood, Tenn. & 221,862 & $\left\{\begin{array}{l}1912-18 \\
1921-40\end{array}\right.$ & \}$^{\text {Mar. } 4,1917}$ & 10.97 & 82,000 & 44.0 & $\left\{\begin{array}{l}\text { Aug. } 13,11 \text { to } 12 \text { p.m. } \\
\text { Aug. } 30,3: 30 \text { p.m. }\end{array}\right.$ & $\begin{array}{l}6.62 \\
9.70\end{array}$ & $\begin{array}{l}32,200 \\
63,900\end{array}$ & $\begin{array}{l}17.3 \\
34.3\end{array}$ \\
\hline 542 & Little Tennessee River at McGhee, Tenn. & 222,443 & $1904-40$ & Apr. $\quad 2,1920^{35}$ & ${ }^{3} 30.5$ & 1592,000 & 37.7 & $\left\{\begin{array}{l}\text { Aug. } 14,6 \text { a.m } \\
\text { Aug. } 30.11 \text { p. }\end{array}\right.$ & $\begin{array}{l}15.07 \\
21.56\end{array}$ & $\begin{array}{l}29,800 \\
\mathbf{5 2}, 100\end{array}$ & ${ }_{21.3}^{12.2}$ \\
\hline 543 & Cullasaja Creek at Highlands, N. C....-- & 14.9 & $1927-40$ & July 1916 & 7 & 3,200 & 215 & Aug. $13,2: 30$ p.m. & $\begin{array}{l}5.92 \\
9.35\end{array}$ & 2,400 & 161.0 \\
\hline 544 & Cullasaja Creek at Cullasaja, N. C. & 86.5 & $\left\{\begin{array}{l}1907-9 \\
192-40\end{array}\right.$ & \}....do..... & ${ }^{48} 17.2$ & 12,200 & 141 & Aug. 13,4 p.m. & $\begin{array}{l}15.28 \\
15.83\end{array}$ & $\begin{array}{r}0,100 \\
9,020\end{array}$ & $\begin{array}{l}-542 \\
104 \\
223\end{array}$ \\
\hline 546 & Nantahala River at Almond, N. C......... & 174 & $\left\{\begin{array}{l}1921-40 \\
1921-17 \\
1921-40\end{array}\right.$ & Mar. 4, 1917 & & 1015,200 & 87.4 & $\begin{array}{l}\text { Aug. } \\
\text { Aug. } 13,6 \text {, p.m.m. } \\
\text { Aug. } 30,6 \text { a.m. }\end{array}$ & $\begin{array}{r}6.00 \\
4.85\end{array}$ & $\begin{array}{r}19,000 \\
4,000\end{array}$ & $\begin{array}{r}23.0 \\
14.4\end{array}$ \\
\hline 546.5 & $\begin{array}{l}\text { East Fork Tuckasegee River near Tuckase- } \\
\text { gee, N. C. }\end{array}$ & 80.3 & $(102-40$ & & & & & Aug. 30 & & $30,000 \mathrm{~S}$ & 370 \\
\hline 547 & Tuckasegee River at Tuckasegee, N. C.... & 143 & $1934-40$ & May 1840 & 18 & 23,000 & 160 & $\left\{\begin{array}{l}\text { Aug. } 13,11 \text { a.m. } \\
\text { Aug. } 30,3: 30 \text { a.m. }\end{array}\right.$ & $\begin{array}{l}14.32 \\
21.1\end{array}$ & $\begin{array}{l}13,700 \\
40,800\end{array}$ & $\begin{array}{r}95.8 \\
285\end{array}$ \\
\hline 549 & Tuckasegee River at Dillsboro, N.C. & 347 & $1928-40$ & Aug. 15,1928 & ${ }^{3} 11.2$ & 14,000 & 40.3 & Aug. $13,3: 30$ p.m. & $\begin{array}{l}21.1 \\
14.32 \\
21.96\end{array}$ & $\begin{array}{l}40,900 \\
52,900\end{array}$ & $\begin{array}{l}60.2 \\
152\end{array}$ \\
\hline 550 & Tuckasegee River at Bryson City, N. C. . & 655 & $1897-1940$ & May 1840 & 21 & (16) & & Aug. $13,9 \mathrm{pm}$. & $\begin{array}{r}9.05 \\
15.96\end{array}$ & $\begin{array}{l}22,500 \\
61,600\end{array}$ & $\begin{array}{r}34.4 \\
94.0\end{array}$ \\
\hline $\begin{array}{l}550.2 \\
550.4\end{array}$ & $\begin{array}{l}\text { Wolf Creek near Tuckasegee, N. C.27 } \\
\text { West Fork Tuckasegee River above Glen- } \\
\text { ville Dam, near Glenville, N. C. }{ }^{27}\end{array}$ & 26.8 & & & & & & 然 & & $\begin{array}{l}14,500 \mathrm{~S} \\
10,300 \mathrm{~S}\end{array}$ & $\begin{array}{l}1,030 \\
384\end{array}$ \\
\hline 550.6 & $\begin{array}{l}\text { West Fork Tuckasegee River at Glenville } \\
\text { Powerhouse, near Tuckasegee, N. C. } .^{27}\end{array}$ & 52.5 & & & & & & $\ldots$ do. & & $14,000 \mathrm{~S}$ & 267 \\
\hline $\begin{array}{l}550.8 \\
550.9\end{array}$ & $\begin{array}{l}\text { Caney Fork near East Laport, N. C. } \\
\text { Do. }{ }^{27}\end{array}$ & $\begin{array}{r}38.1 \\
4439.4\end{array}$ & & & & & & -.-do_- & $=$ & $\begin{array}{l}17,000 S \\
21,700 S\end{array}$ & $\begin{array}{l}450 \\
551\end{array}$ \\
\hline 551 & Scott Creek at Sylva, N. C. & 55.0 & $\left\{\begin{array}{l}1921-22 \\
1928-40\end{array}\right.$ & July 10,1929 & 6.00 & 2,200 & $40.0^{-}$ & $\left\{\begin{array}{l}\text { Aug. } 13,4 \text { p.m. } \\
\text { Aug. } 30,4 \text { a.m. }\end{array}\right.$ & $\begin{array}{l}4.96 \\
8.61\end{array}$ & $\begin{array}{l}1,510 \\
3,360\end{array}$ & $\begin{array}{r}27.5 \\
61.1\end{array}$ \\
\hline 552 & Oconalufty River at Cherokee, N. C. & 131 & $1921-40$ & Apr. $6,1936^{45}$ & 10.25 & 8,760 & 66.9 & $\begin{array}{l}\text { Aug. } 13,5: 30 \text { p.m. } \\
\text { Aug. } 30,4 \text { a.m. }\end{array}$ & $\begin{array}{l}6.80 \\
8.84\end{array}$ & $\begin{array}{l}-5,270 \\
3,310\end{array}$ & $\begin{array}{l}25.0 \\
48.2\end{array}$ \\
\hline 553 & Noland Creek near Bryson City, N. C..--- & 13.8 & $1935-40$ & ..-do_ & 4.44 & 1,060 & 76.8 & $\begin{array}{l}\text { Aug. } 13,2 \text { p.m. } \\
\text { Aug. } 30,12: 15 \text { a.m. } \\
\text { Aug. } 13,4 \text { p.m. }\end{array}$ & $\begin{array}{l}3.48 \\
4.87 \\
2.99\end{array}$ & $\begin{array}{r}540 \\
1,530 \\
750\end{array}$ & $\begin{array}{r}39.1 \\
111 \\
6.4\end{array}$ \\
\hline 556 & Tellico River at Tellico Plains, Tenn.- & 118 & $1925-40$ & Aug. 5,1938 & 11.39 & 10,900 & 92.4 & $\begin{array}{l}\text { Aug. 14, } 9 \text { p.m. } \\
\text { Aug. 29, 4:15 p.m. }\end{array}$ & 2.62 & & 4.8 \\
\hline
\end{tabular}




\begin{tabular}{|c|c|c|c|c|}
\hline $\begin{array}{l}557 \\
558 \\
559\end{array}$ & $\begin{array}{l}\text { Clinch River at Cleveland, } \mathrm{Va} \\
\text { Clinch River at Speers Ferry, Va. } \\
\text { Clinch River above (near) Tazewell, Tenn. }\end{array}$ & $\begin{array}{r}528 \\
1,126 \\
1,474\end{array}$ & $\mid \begin{array}{l}1920-40 \\
1927-40\end{array}$ & $\begin{array}{l}\text { Dec. } 22,1926 \\
\text { Feb. } 3,1923 \\
\text { Jan. } 31,1932^{46}\end{array}$ \\
\hline 562 & $\begin{array}{l}\text { Clinch River below Norris Dam (near Coal } \\
\text { Creek), Tenn. }\end{array}$ & ${ }^{472}, 913$ & $1927-40$ & Mar. 23, 1929 \\
\hline 567 & Powell River near Jonesville, Va & 319 & $1931-40$ & Jan. 30,1932 \\
\hline $\begin{array}{l}572 \\
582 \\
583\end{array}$ & $\begin{array}{l}\text { Emory River at Oakdale, Tenn. } \\
\text { Hiwassee River below Hayesville, N. C. } \\
\text { Hiwassee River above (at) Murphy, N. C.- }\end{array}$ & $\begin{array}{r}764 \\
33252 \\
404\end{array}$ & $\begin{array}{l}1929-40 \\
1934-40 \\
\{1896-1917 \\
1918-40\end{array}$ & $\begin{array}{l}\text { Feb. } 3,1939^{49} \\
\text { Apr. } 2,1936^{50} \\
\text { Mar. } 19,1899\end{array}$ \\
\hline $\begin{array}{l}584 \\
587\end{array}$ & $\begin{array}{l}\text { Hiwassee River at Hiwassee Dam, N. C... } \\
\text { Hiwassee River near Reliance, Tenn. }\end{array}$ & $\begin{array}{r}51968 \\
511,223\end{array}$ & $\begin{array}{l}1934-40 \\
1926-40\end{array}$ & Feb. 4 , \\
\hline 591 & Valley River at Tomotla, N. C. & 104 & & Nov. 19,1906 \\
\hline 592 & Nottely River near Ivylog, Ga....- & 191 & 10 & July 22,1938 \\
\hline 593 & Nottely River near Ranger, N. C. & 272 & & Feb. 28, 1902 \\
\hline 600 & Ocoee River at Parksville, Tenn.... & 22595 & & Apr. 6,1936 \\
\hline 603 & $\begin{array}{l}\text { South Chickamauga Creek near Ch } \\
\text { mauga, Tenn. }\end{array}$ & 428 & & Feb. $\quad 5,1936$ \\
\hline
\end{tabular}

\begin{tabular}{|c|r|}
321.1 & 22,500 \\
25.85 & 1537,200 \\
314.90 & 37,800 \\
& \\
333.7 & 70,000 \\
25.64 & 18 \\
& 482,900 \\
3630.9 & 100,000 \\
12.42 & 10,600 \\
318.4 & 1523,100 \\
& \\
13.41 & 42,800 \\
23.01 & 45,300 \\
17.3 & 159,030 \\
12.25 & 11,500 \\
321.0 & 1514,100 \\
& \\
18.32 & 19,000 \\
18.47 & 20,000 \\
&
\end{tabular}

\begin{tabular}{r|l}
42.6 & Aug. 14, 8 a.m. \\
33.0 & Aug. 15, 4 a.m. \\
1225.5 & Aug. 15, 5 p.m. \\
& Sept. 1, 10:30 p.m. \\
24.0 & Aug. 22, 3:30 a.m. \\
71.8 & Aug. 15, 12 m. \\
131 & Aug. 30, 8 p.m. \\
42.1 & Aug. 30, 1:30 a.m. \\
Aug. 13, 4:30 p.m. \\
Aug. 13, 7 p.m. \\
44.2 & Aug. 16, 6 p.m. \\
37.0 & Aug. 13, 6:45 p.m. \\
86.8 & Aug. 13, 3 p.m. \\
60.2 & Aug. 13, 1 p.m. \\
51.8 & Aug. 13, 7-8 p.m. \\
31.9 & Aug. 15, 4 p.m. \\
46.7 & Aug. 30, 3 p.m.
\end{tabular}

\begin{tabular}{|r|r|r|}
20.60 & 22,500 & 42.6 \\
20.98 & 25,100 & 22.3 \\
13.29 & 24,300 & 16.5 \\
6.72 & 7,560 & 5.1 \\
4.09 & 4,260 &.-- \\
3.89 & 1,140 & 3.6 \\
3.88 & 1,140 & 3.6 \\
8.84 & 6,900 & 9.0 \\
7.97 & 4,610 & 18.3 \\
7.88 & 5,940 & 14.7 \\
& & \\
5.21 & 3,430 & 3.5 \\
6.25 & 3,630 & 3.0 \\
3.21 & 482 & 4.6 \\
4.19 & 3,380 & 17.7 \\
9.30 & 3,190 & 11.7 \\
. & & \\
6.37 & 3,080 & 5.2 \\
4.02 & 1,190 & 2.8 \\
\hline
\end{tabular}

1. See plate 20 for time zone location.

3 Site and datum then in use.

12 Based on drainage area at site then in use.

${ }^{36}$ From floodmark.

16 Mischarm observed.

${ }_{22}$ Affected not determ

${ }^{43}$ Greater stage occurred a few years prior to 1916 and again between 1916 and 1920

${ }_{45}^{4}$ Greater flood occurred in November 1906; gage height 12 feet.

${ }_{27}$ From "Floods of August 1940 in Tennessee River Basin," issued by T.V.A. as Greater floods occurred

supplement to "Precipitation in Tennessee River Basin October 1940."

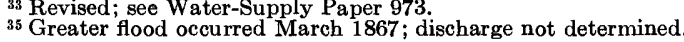

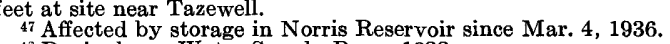

48 Revised; see Water-Supply Paper 1033.

${ }^{49}$ Greater flood occurred Mar. 23, 1929; discharge 195,000 second-feet.

${ }^{50}$ Greater flood occurred October 1898; gage height 16.1 feet.
${ }^{51}$ Affected by storage in Hiwassee Reservoir since Jan. 14,1940 


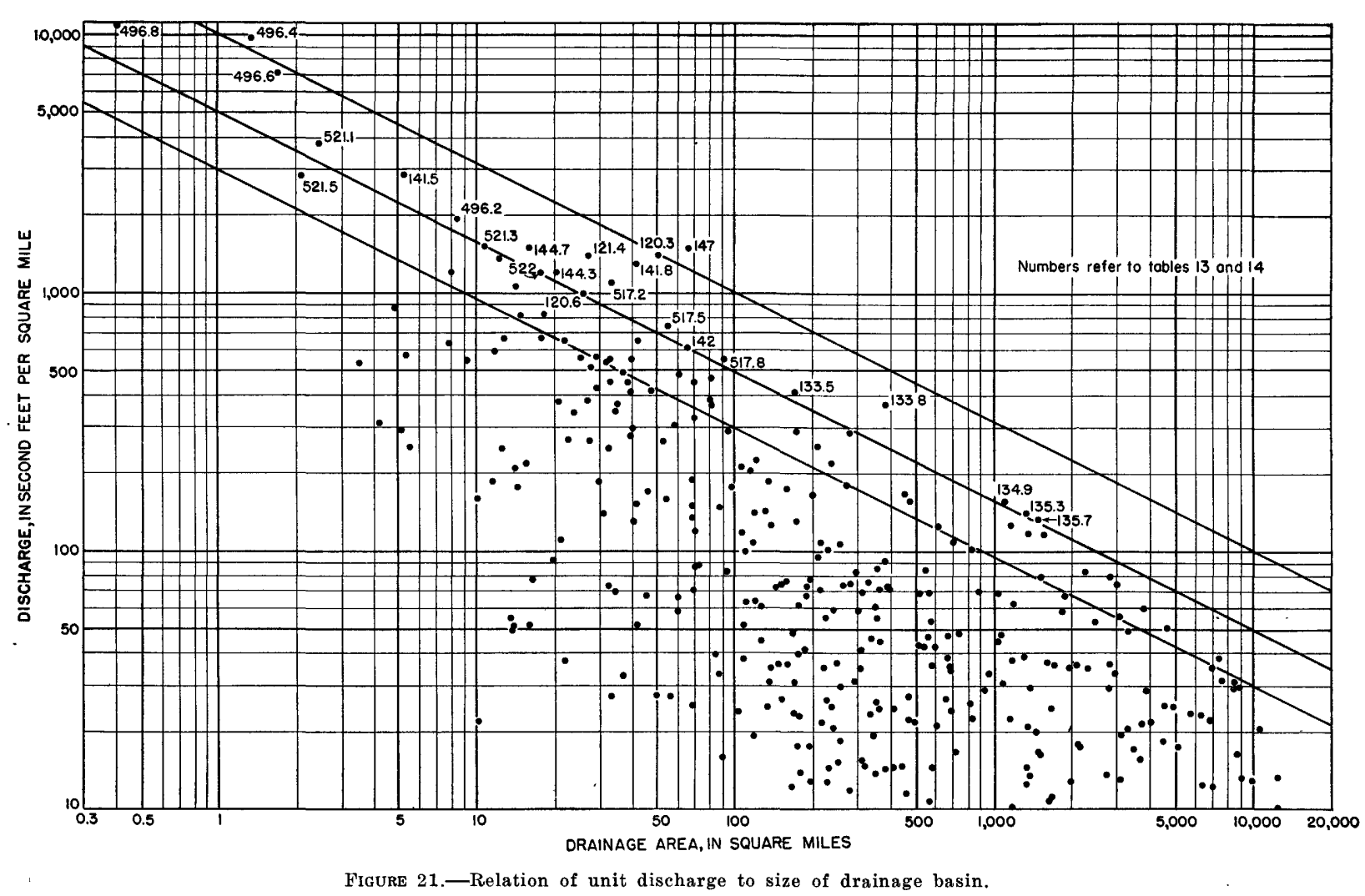

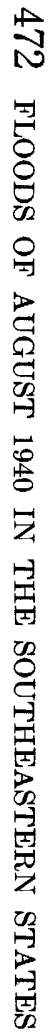

FIGURE 21.-Relation of unit discharge to size of drainage basin. 


\section{UNIT DISCHARGES}

The maximum discharge in second-feet per square mile has been plotted against the tributary drainage area in square miles in figure 21. Size of drainage basin, though a major factor influencing the magnitude of flood discharge, is only one of the factors. The comparative influence of such basin characteristics as slope, shape, and swamps are not brought out in a study such as that illustrated in figure 21, nor is the effect of artificial storage segregated. The figure is designed merely to provide a convenient method for comparing flood discharges from drainage areas that differ widely in size, and in its use the influence of factors other than drainage area should be kept in mind.

As an aid to those who use a flood formula expressing the discharge in terms of the square root of the drainage area, guide lines representing different values of this relation are drawn on figure $21 .{ }^{12}$

The highest unit rate of discharge measured was 11,000 second-feet per square mile for an area of 0.4 square mile tributary to Little East Fork Pigeon River. There are six discharges shown in tables 12-14 in excess of 2,000 second-feet per square mile for streams draining less than 10 square miles. Of these, three in the Pigeon River Basin occurred in late August. The other three occurred during the mid-August storm. Two of the latter were in the Watauga River Basin, and one was in the headwaters of Santee River. None of these outstanding rates of unit discharge occurred at regular gaging stations, and associated volumes of runoff are unknown.

Considering the size of drainage area, the greatest unit discharge occurred during the mid-August storm on Wilson Creek near Adako, N. C. (the site of a discontinued gaging station), one of the headwater streams of Santee River. (See pl. 5.) This area of 66 square miles received about 12 inches of rainfall and discharged at a maximum rate of 99,000 second-feet, or 1,500 second-feet per square mile.

Relatively high unit discharges also occurred on Catawba River, a tributary of Santee River, where there were discharges of about 150 second-feet per square mile from areas over 1,000 square miles.

Roanoke River produced the greatest unit discharges for large streams. At Clarksville, where the drainage area is 7,320 square miles, there was a discharge of 38.3 second-feet per square mile. The total discharge at Clarksville, 280,000 second-feet, also was greater than the discharge recorded at any other gaging station.

\section{STORAGE}

Runoff of some of the streams in the flood area was considerably affected by storage. The storage reservoirs, which served to reduce the

\footnotetext{
12 For other flood formulas see Jarvis, C. S., and others, Floods in the United S:ates, magnitude and frequency: U. S. Geol. Survey Water-Supply Paper 771, pp. 33-41, 1936.
} 


\section{FLOODS OF AUGUST 1940 IN THE SOUTHFASTERN STATES}

flood runoff, were located principally in the Pee Dee and Santee River Basins on the Atlantic slope, and in the Tennessee River Basin in the Ohio River Basin. Most of the reservoirs in the first two basins were built by private power companies, primarily for the generation of hydroelectric power, whereas most of the reservoirs in the Tennessee Valley were constructed as multiple-purpose projects, with storage for flood control. Both types of storage reservoirs were effective in reducing the flood peaks, particularly where the reservoirs were located near the headwaters of streams on which extreme unit discharges occurred. Table 15 lists by drainage basins the reservoirs for which storage records have been collected for publication in this report.

TABLE 15.-Principal storage reservoirs in the indicated drainage basins

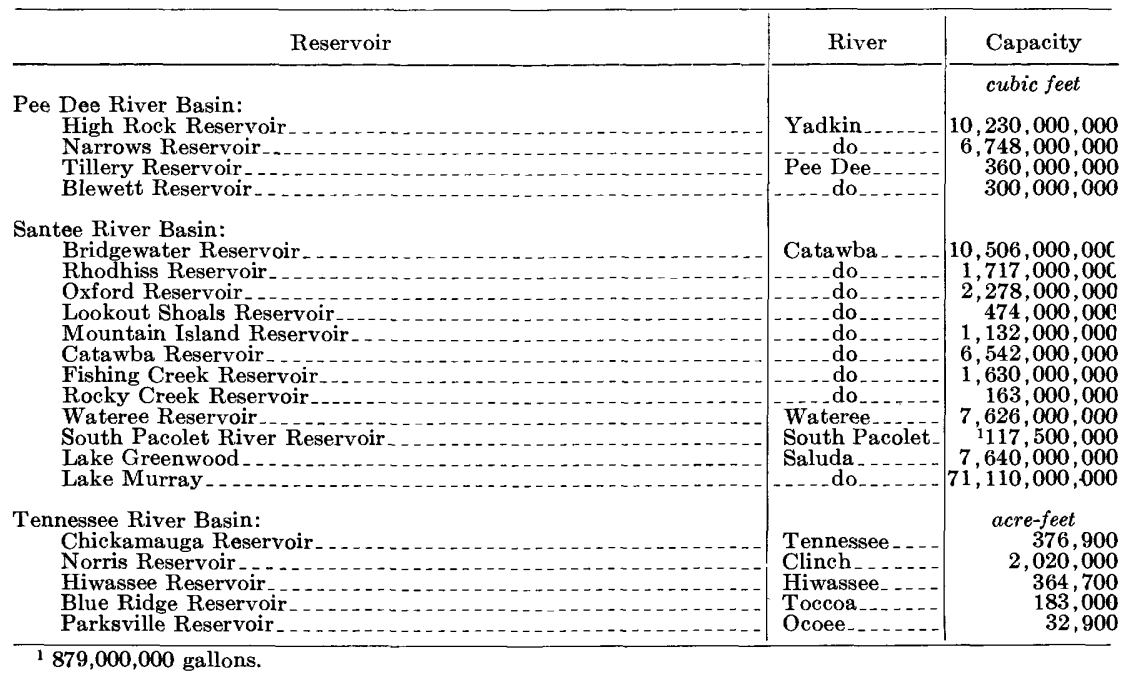

The four reservoirs listed for Yadkin-Pee Dee River are operated by the Aluminum Company of America and the Carolina Power \& Light Co. for the generation of electric power. Owing to the subnormal streamflow conditions prior to the flood, there was available in the four reservoirs listed 5,930,000,000 cubic feet (136,000 acre-feet) of storage below the tops of the various outlet gates, out of a total capacity under normal operation of $17,638,000,000$ cubic feet. During the period from midnight August 12 to midnight August 17, 6,165,000,000 eubic feet of water was stored in the reservoirs. This amounted to a mean reduction of approximately 14,000 second-feet for the 5-day period. The retaining of water at the various dams reduced the volume of the floodwaters downstream, which probably had the beneficial result of lowering the crest stages on the lower reaches of the river.

The reservoirs in the Santee River Basin stored 29,200,000,000 eubic feet between midnight August 12 and midnight August 17, amounting to a mean detention of 67,600 second-feet for the 5-day period, with 
favorable moderating effect on flood discharges in the river reaches downstream.

Figure 22 illustrates the details of operation of the storage in Bridge-

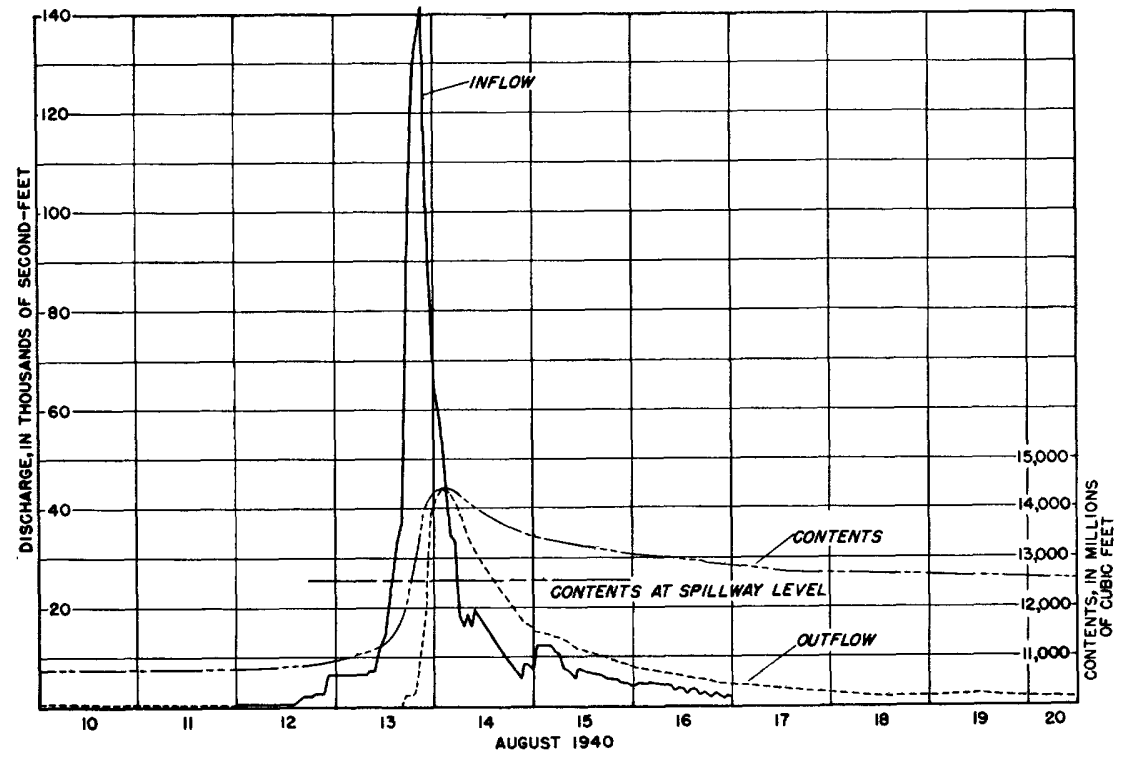

FIGURE 22.-Diagram showing contents, outflow, and computed inflow at Bridgewater Reservoir, near Bridgewater, N. C.

water Reservoir on Catawba River. The graphs of outflow and contents are based on observed or measured data. The graph of inflow into the reservoir approximates the flow at the reservoir site under natural conditions. This graph was computed by adjusting the graph of measured outflow for increments or decrements in measured storage. Similar

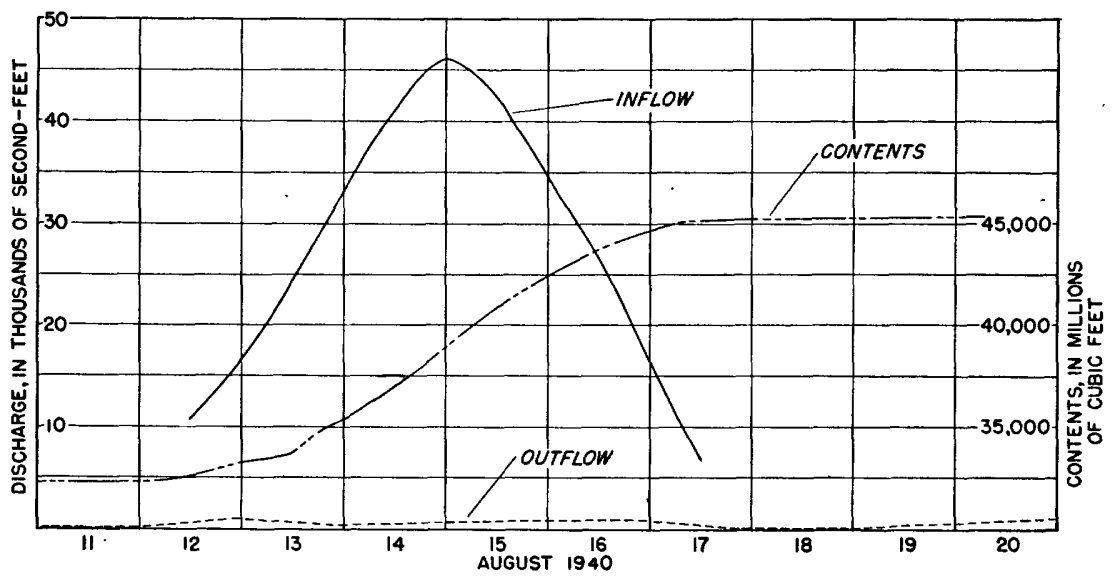

Figure 23.-Diagram showing contents, outflow, and computed inflow at Lake Murray, near Columbia, S. C. 
graphs are shown on figure 23 for Lake Murray on Saluda River near Columbia, S. C.

The five reservoirs in the upper Tennessee River Basin that are listed stored 126,000 acre-feet in the 5-day period from midnight August 12 to midnight August 17. This gain in storage is equivalent to a mean discharge of 12,700 second-feet. Only parts of the areas above the reservoirs listed were in flood, and flood inflow was accordingly moderate. With regard to the operation of Chickamauga R servoir the Tennessee Valley Authority reports that the maximum discharge downstream at Chattanooga was reduced from 136,000 second-feet to 80,000 second-feet, and the flood height was reduced 7 feet.

\section{RAINFAILL AND RUNOFF STUDIES METHODS OF ANALYSIS}

The floods of August 1940 had their eause in storm rainfall, of which a portion reached the streams in excessive rates and volumes, producing serious overflow. The conversion from storm rainfall into flood runoff, although apparent, is not readily definable in quantitative terms, and yet to a very considerable extent the satisfactory solution of the flood problem depends on an understanding and evaluation of the relations between rainfall and runoff. An analysis of past storms and floods can advance such an understanding.

The plan of study to this end with respect to the floods of August 1940 was, briefly, to compute mean areal rainfall over the basins above the several gaging stations, to compute the volume of direct runoff attributable to such rainfall, and finally to compare the values of rainfall and associated direct runoff.

Mean areal rainfall during the two storms over the several basins for which flood-discharge records are available has been computed by means of isohyetal maps of total storm precipitation reproduced as plates 16 and 17. The areas between the lines of equal rainfall and the basin outlines were measured by planimeter, and these partial areas were each multiplied by the average rainfall between the respective isohyetal lines. The sum of such products when divided by the total area of the basin is equal to the mean areal rainfall over the basin. The results of the determinations are listed in table 16 .

The accuracy of the determinations of mean rainfall over any given basin depends on the number of rain gages in and near the basin and their adequacy in defining the variation in rainfall. No general estimate of the accuracy of the figures published herein can be given; the accuracy depends on the particular conditions pertaining to the several basins. The density of rain gagcs is an important factor in this regard. With the average spread of rain gages it is likely that mean areal rainfall ean be determined with greater accuracy for a large basin than for a particular small one. It is also likely that determinations of mean areal 
rainfall for small basins within or near storm centers are least reliable.

The area covered by the mid-August storm is about 130,000 square miles, within which area there are 679 rain gages, equivalent to an average of 0.0052 rain gage per square mile. The rain-gage density when expressed in this way was greatest in the upper Tennessee Basin, where it was 0.0135 , and in general, determinations of rainfall should be fairly reliable in that part of the storm, again excepting the small headwater streams near the storm centers. The density of rain gages was least in the Savannah Basin, where there was a ratio of 0.0025 rain gage per square mile.

The records of flood discharge at the stream-gaging stations published herein have been used as the basis for determining the direct runoff and base runoff associated with the two storms. Discharge hydrographs based on data published in this report have been constructed for each storm, generally covering the dates of August 10-20 for the first and August 28-September 5 for the second. The method used is shown by figures 24 and 25, which illustrate stream behavior in different parts of the region

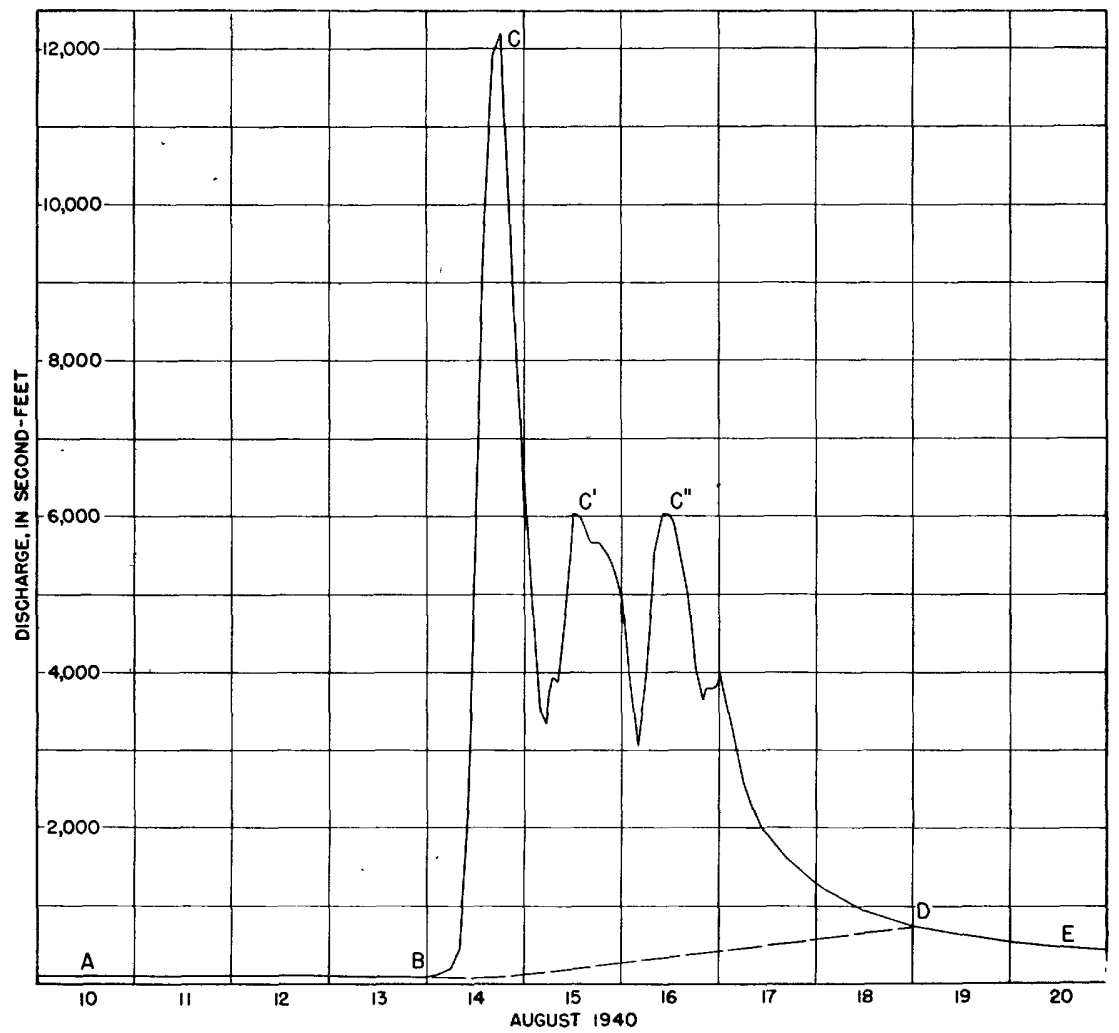

Figure 24.-Discharge hydrograph of Goose Creek near Huddleston, Va., August 10-20, 1940, showing method of analysis used to obtain runoff associated with storm of August 10-17, 1940. 

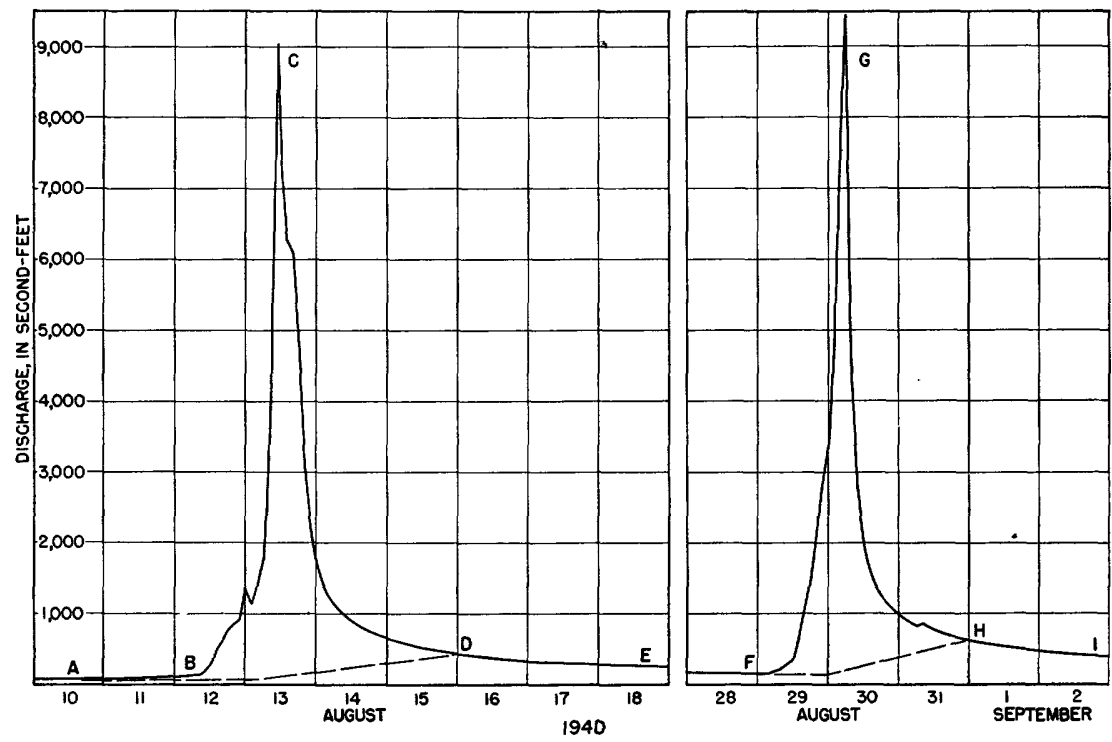

FIGURe 25.-Discharge hydrograph of French Broad River at Rosman, N. C., August 1940, showing method of analysis used to obtain runoff associated with storms of August 1940.

affected by the storm. Although the details of the hydrographs varied, similar methods were employed for all.

On August 10, when the rains began, the streams were low (point A on figs. 24 and 25). The flow on August 10 was largely composed of ground-water drainage. For a day or more, the rainfall was sufficient only to arrest the slow decline in stream flow; there was little, if any, increase in discharge. This period, identified by the segment $A B$ on the hydrographs, represents that initial part of a storm in which rainfall is taken up by vegetal interception, ground wetting, and similar abstractions. During this part of the storm, rainfall was not notably intense. As the storm continued and rainfall became more intense, the runoff generated caused the streams to rise in flood.

On small streams the differences in rainfall distribution resulted in flood hydrographs of corresponding differences in shape. Two kinds are illustrated by figures 24 and 25. In Virginia and parts of North Carolina the rise in stream flow was abrupt, and there were multiple peaks, identified by $\mathrm{C}, \mathrm{C}^{\prime}, \mathrm{C}^{\prime \prime}$ on figure 24 . The first peak was generally the greatest. In other parts of the storm area there was only one peak, generally on August 13, shown by the letter $\mathrm{C}$ on figure 25. On the larger streams these details of distribution were obscured in a single rounded peak. After the cessation of rainfall the streams receded to points $D$ and E. On August 18 or 20 the streams had again returned to a low stage, point $\mathrm{E}$, largely outflow from ground water, but a rate of flow above that of 10 days previous. 
There were scattered and infrequent rains of variable amount and intensity over all the region between August 17 and 28. These rains produced small rises in some streams, but in general there was a decline in stream flow until August 28 (point $\mathrm{F}$ on fig. 25), when stream flow was composed of ground-water outflow, at a rate lower than on August 20 but still greater than on August 10. The concentrated rains of August 28-31 produced a single peak, point $G$. The rise on the smaller streams during this flood was slower than the recession. The rains ended sharply so that the smaller streams receded quickly and had returned to baseflow rates by September 1 .

The water represented by the hydrographs had its origin in rainfall. Before entering the streams and reaching the gaging station, rain water may collect and flow to the streams along innumerable paths. At present one can do little more than speculate as to the course of the water represented by the hydrographs; there is no direct evidence. According to a widely held theory, some of the rain water falls directly on the river channels and thus becomes an immediate accretion to river discharge; some is shed by the ground and reaches the streams very promptly; some may infiltrate, a portion to reappear soon as wet-weather seeps or springs and a portion reaching the ground water reservoir, from which it drains slowly. The rain water, following different paths, as suggested, then collecting in and flowing through river channels of varying length and size, presents an integrated result when registered at a gaging station. The hydrograph by itself is merely a register of the magnitude of the discharge at given times; it conveys no information as to the courses of flow or the media through which the water flowed (other than the river channel in which the gage is located). The hydrograph might be duplicated in shape or form as a result of any number of hydraulic postulates; in this report, therefore, runoff will be classified only as to its time characteristies. Two elassifications are recognized, (1) direct runoff, or that flow which enters the streams with great promptness during and following a rainstorm, and (2) base runoff, or that flow which rises slowly as a result of rainfall and recedes even more slowly after the rain ends. It is the base runoff that accounts for the flow of streams during dry-weather periods; this has its origin mainly in ground-water outflow, and is therefore widely called ground-water runoff.

The separation of the discharge during floods into direct and base components can be made only with difficulty, especially in sluggish streams or where persistent rains keep the streams at flood levels for long periods. The manner of making the separation for the floods of August 1940 is illustrated on figures 24 and 25. It seems evident that point $\mathrm{B}$, before the flood rise, represents base flow. On the recession side, discharge after point $\mathrm{D}$ is assumed to be base flow. Point $\mathrm{D}$ was selected 
by inspection of the hydrograph, by identifying a point of change in curvature, and generally for a discharge below 10 second-feet per square mile. This point on many hydrographs was obscure, and different analysts might reach different conclusions as to its position, but the result of such differences in judgment would be relatively small in comparison with the magnitude of the direct runoff as a whole. On some hydrographs, as for example that for Tar River (see fig. 10), the change from rapidly receding direct runoff to stable base flow was abrupt.

$A$ line was drawn in the manner illustrated connecting points $B$ and $\mathrm{D}$ to represent the base-flow contribution during the flood. The position of this line is, of course, only approximate. The area enclosed within the hydrograph above the line $\mathrm{BD}$ is equivalent to the volume of direct runoff. This volume has been computed for the several stations and listed for their respective drainage basins in table 16. A similar analysis was made for the flood of August 28-31, 1940.

Base runoff was also computed for many streams and in the following manner: The volume of runoff below the graph $\mathrm{ABDE}$ was computed; from this was subtracted the total volume under a base-flow depletion graph extended from point $A$. The sum of the direct runoff and base runoff is equal to the total runoff discharged through the stream channels as a result of the storm and this sum is unaffected by the position of the line BD. 
TABLE 16.-Rainfall and associated direct runoff of floods of August 1940

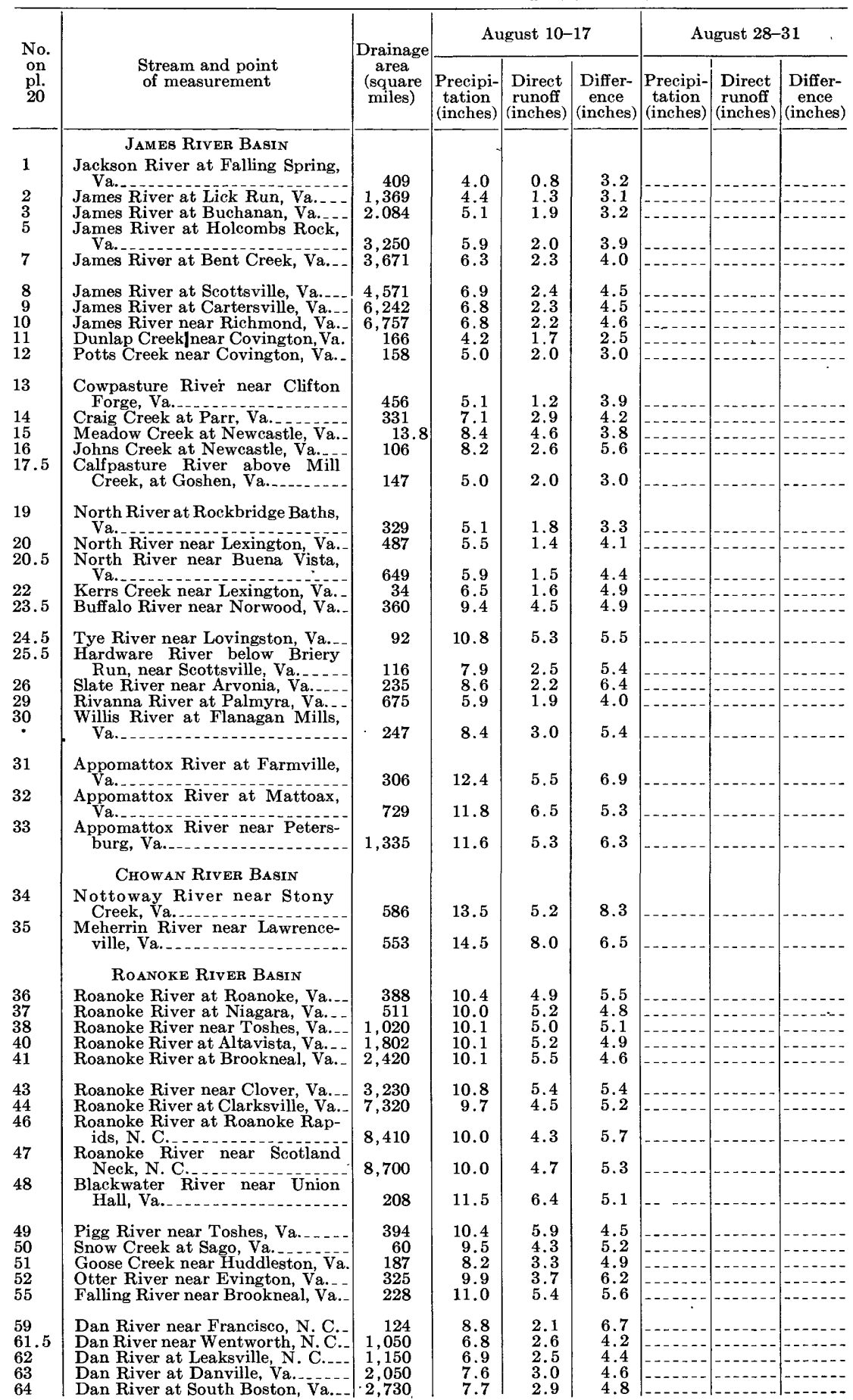


TABLE 16.-Rainfall and associated direct runoff of floods of August 1940-Continued

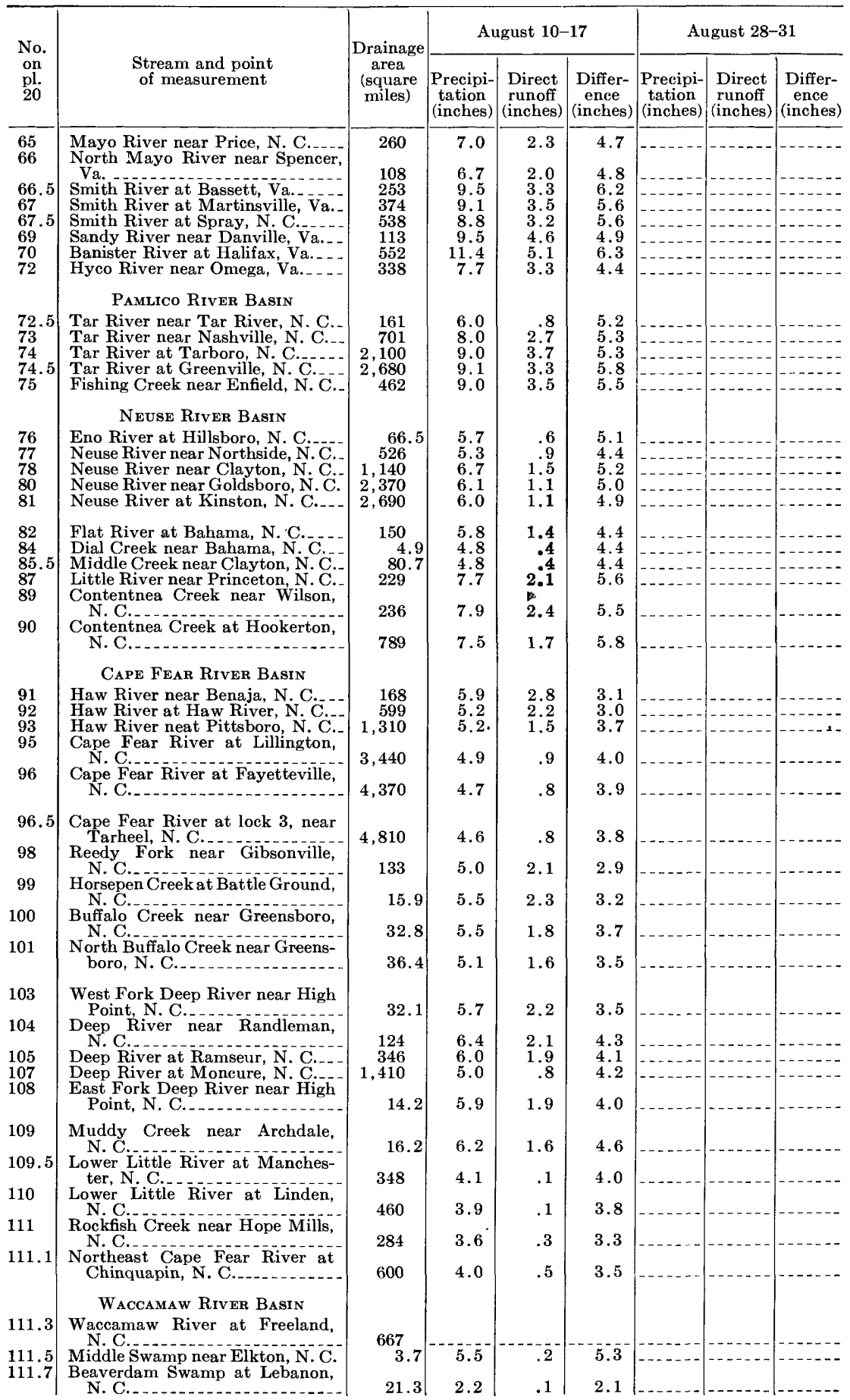


TABLE 16.-Rainfall and associated direct runoff of floods of August 1940-Continued

\begin{tabular}{|c|c|c|c|c|c|c|c|c|}
\hline \multirow{2}{*}{$\begin{array}{l}\text { No. } \\
\text { on } \\
\text { pl. } \\
20\end{array}$} & \multirow{2}{*}{$\begin{array}{l}\text { Stream and point } \\
\text { of measurement }\end{array}$} & \multirow{2}{*}{$\begin{array}{l}\text { Drainage } \\
\text { area } \\
\text { (square } \\
\text { miles) }\end{array}$} & \multicolumn{3}{|c|}{ August $10-17$} & \multicolumn{3}{|c|}{ August 28-31 } \\
\hline & & & $\begin{array}{c}\text { Precipi- } \\
\text { tation } \\
\text { (inches) }\end{array}$ & $\begin{array}{c}\text { Direct } \\
\text { runoff } \\
\text { (inches) }\end{array}$ & $\begin{array}{c}\text { Differ- } \\
\text { ence } \\
\text { (inches) }\end{array}$ & $\begin{array}{c}\text { Precipi- } \\
\text { tation } \\
\text { (inches) }\end{array}$ & $\begin{array}{c}\text { Direct } \\
\text { runoff } \\
\text { (inches) }\end{array}$ & $\begin{array}{l}\text { Differ- } \\
\text { ence } \\
\text { (inches) }\end{array}$ \\
\hline $\begin{array}{l}111.9 \\
112 \\
115\end{array}$ & $\begin{array}{l}\text { Pee Dee RIver Basin } \\
\text { Yadkin River at Patterson, N. C.- } \\
\text { Yadkin River at Wilkesboro, N. C.- } \\
\text { Yadkin River at Yadkin College, }\end{array}$ & 493.8 & $\begin{array}{l}12.5 \\
12.7\end{array}$ & $\begin{array}{l}4.5 \\
6.5\end{array}$ & $\begin{array}{l}8.0 \\
6.2\end{array}$ & & & \\
\hline 117 & $\begin{array}{l}\text { N. C. } \\
\text { Yakin River at High Rock Res- } \\
\text { ervoir, at High Rock, N. C. }\end{array}$ & $\begin{array}{l}2,280 \\
3,980\end{array}$ & 8.0 & 2.3 & 5.7 & & & \\
\hline 117.5 & $\begin{array}{l}\text { Yadkin River at Narrows Reser- } \\
\text { voir, near Badin, N. C. }\end{array}$ & 4,160 & & & & & & \\
\hline 118 & $\begin{array}{l}\text { Pee Dee River at Tillery Reser- } \\
\text { voir, near Norwood, N. C. }\end{array}$ & 4,600 & & & & & & \\
\hline 118.5 & Pee Dee River near Ansonville, & 6,330 & 6.4 & 1.1 & 5.3 & & & \\
\hline 118.8 & $\begin{array}{l}\text { Pee Dee River at Blewett Reser- } \\
\text { voir, near Rockingham, N. C. }\end{array}$ & 6,600 & & & & & & \\
\hline 120 & Pee Dee River near Rockingham, & 6,870 & 6.4 & 1.2 & 5.2 & & & \\
\hline 120.1 & $\begin{array}{l}\text { Pee Dee River near Mars Bluff, } \\
\text { S. C. }\end{array}$ & 8,870 & 6.2 & 1.0 & 5.2 & & & \\
\hline 120.7 & $\begin{array}{l}\text { Reddies River at North Wilkes- } \\
\text { boro, N. C. }\end{array}$ & 93.9 & 12.9 & 4.5 & 8.4 & & & \\
\hline $\begin{array}{l}122 \\
123.1\end{array}$ & $\begin{array}{l}\text { Fisher River near Copeland, N. C. } \\
\text { Little Yadkin River near Don- } \\
\text { naha, N. C. }\end{array}$ & $\begin{array}{c}121 \\
59.7\end{array}$ & $\begin{array}{r}6.4 \\
5.6\end{array}$ & 2.4 & $\begin{array}{l}.9 . \\
4.0 \\
3.7\end{array}$ & & & \\
\hline 123.2 & Forbush Creek near Yadkinville, & 09.8 & 0.0 & 1.0 & 5.0 & & & \\
\hline 123.3 & $\begin{array}{l}\text { Reedy Creek near Yadkin Col- } \\
\text { lege, N. C. }\end{array}$ & 13.3 & 5.0 & 1.3 & 3.7 & & & \\
\hline 123.4 & Dutchman Creek near Cornatzer, & 83.6 & 4.8 & 1.7 & 3.1 & & & \\
\hline 123.5 & $\begin{array}{l}\text { South Yadkin River near Mocks- } \\
\text { ville, N. C. }\end{array}$ & 313 & 7.4 & 1.3 & 6.1 & & & \\
\hline 124 & $\begin{array}{l}\text { South Yadkin River at Coolee- } \\
\text { mee, N. C. }\end{array}$ & 569 & 7.0 & 1.4 & 5.6 & & & \\
\hline $\begin{array}{l}124.5 \\
125.2\end{array}$ & $\begin{array}{l}\text { Rocky River at Turnersburg, } \\
\text { N. C. } \\
\text { Third Creek at Cleveland, N. C. }\end{array}$ & $\begin{array}{l}85.5 \\
87.4\end{array}$ & $\begin{array}{l}7.6 \\
6.0\end{array}$ & $\begin{array}{l}1.4 \\
1.1\end{array}$ & $\begin{array}{l}6.2 \\
4.9\end{array}$ & & & \\
\hline $\begin{array}{l}125.5 \\
125.8\end{array}$ & $\begin{array}{l}\text { Abbotts Creek at Lexington, N.C. } \\
\text { Fourmile Branch near South- } \\
\text { mont, N. C. }\end{array}$ & $\begin{array}{c}174 \\
19.4\end{array}$ & $\begin{array}{l}6.5 \\
7.5\end{array}$ & 2.1 & 4.4 & & & \\
\hline $\begin{array}{l}126 \\
126.5\end{array}$ & $\begin{array}{l}\text { Uwharrie River near Trinity, N. C. } \\
\text { Uwharrie River near Eldorado, }\end{array}$ & 11.3 & 9.0 & $\begin{array}{l}1.5 \\
2.0\end{array}$ & $\begin{array}{l}6.0 \\
5.1 \\
6.0\end{array}$ & & & \\
\hline 127 & Rocky River near Norwood, N. C. & $\begin{array}{r}347 \\
1,370\end{array}$ & $\begin{array}{l}6.0 \\
4.5\end{array}$ & .7 & $\begin{array}{l}5.3 \\
4.0\end{array}$ & & & \\
\hline $\begin{array}{l}127.3 \\
127.5\end{array}$ & $\begin{array}{l}\text { Richardson Creek near Marsh- } \\
\text { ville, N. C.. } \\
\text { Brown Creek near Polkton, N. C.- }\end{array}$ & $\begin{array}{l}170 \\
110\end{array}$ & $\begin{array}{l}3.5 \\
5.0\end{array}$ & $\begin{array}{r}0.1 \\
.4\end{array}$ & $\begin{array}{l}3.4 \\
4.6\end{array}$ & & & \\
\hline 128 & Little Brown Creek near Polkton, & 13.5 & $\begin{array}{l}0.0 \\
5.3\end{array}$ & .4 & 4.9 & & & \\
\hline 128.5 & $\begin{array}{l}\text { Mountain Creek near Ellerbe, } \\
\text { N. C. }\end{array}$ & 33.4 & 6.0 & .3 & 5.7 & & & \\
\hline 129 & $\begin{array}{l}\text { North Fork Jones Creek near } \\
\text { Wadesboro, N. C. }\end{array}$ & 10.0 & 4.9 & .4 & 4.5 & & & \\
\hline $\begin{array}{l}130 \\
130.3\end{array}$ & $\begin{array}{l}\text { Lynches River at Effingham, S. C. } \\
\text { Little Pee Dee River near Dillon, }\end{array}$ & 1,030 & 4.5 & .5 & 4.0 & & & \\
\hline 130.7 & $\begin{array}{l}\text { S. C. } \\
\text { Drowning Creek near Hoffman, }\end{array}$ & 524 & 5.8 & .3 & 5.5 & & & \\
\hline $\begin{array}{l}131 \\
131.3\end{array}$ & $\begin{array}{l}\text { Lumber River at Boardman, N. C. } \\
\text { Deep Creek near Roseland, N. C.- }\end{array}$ & $\begin{array}{r}1,220 \\
18.9\end{array}$ & $\begin{array}{l}5.3 \\
4.8 \\
5.3\end{array}$ & $\begin{array}{r}.4 \\
1.4 \\
.3\end{array}$ & $\begin{array}{l}4.9 \\
4.4 \\
5.0\end{array}$ & & & \\
\hline 131.7 & $\begin{array}{l}\text { Little Raft Swamp at Red } \\
\text { Springs, N. C. }\end{array}$ & 23.1 & 3.0 & .2 & 2.8 & & & \\
\hline 132 & $\begin{array}{l}\text { Black River at Kingstree, S. C. } \\
\text { SANTEe RIver Basin }\end{array}$ & 1,260 & 5.0 & 1.2 & 4.8 & & & \\
\hline 133.8 & Catawba River near Bridgewater, & & 18 & 7.2 & 4.8 & & & \\
\hline $\begin{array}{l}136 \\
139 \\
140\end{array}$ & $\begin{array}{l}\text { Catawba River at Catawba, N. C.- } \\
\text { Wateree River near Camden, S.C. } \\
\text { Santee River at Ferguson, S. C..- }\end{array}$ & $\begin{array}{r}1,535 \\
5,070 \\
14,600\end{array}$ & $\begin{array}{r}11.9 \\
6.8 \\
6.7\end{array}$ & $\begin{array}{l}5.0 \\
2.1 \\
1.9\end{array}$ & $\begin{array}{l}6.9 \\
4.7 \\
4.8\end{array}$ & & & \\
\hline 142 & e River at Branch, & & 14.1 & 11.0 & 3.1 & & & \\
\hline
\end{tabular}

1 Includes base flow. 


\section{FLOODS OF AUGUST 1940 IN THE SOUTHEASTERN STATES}

TABLE 16.-Rainfall and associated direct runoff of floods of August 1940-Continued

\begin{tabular}{|c|c|c|c|c|c|c|c|c|}
\hline \multirow{2}{*}{$\begin{array}{l}\text { No. } \\
\text { on } \\
\text { pl. } \\
20\end{array}$} & \multirow[b]{2}{*}{$\begin{array}{l}\text { Stream and point } \\
\text { of measurement }\end{array}$} & \multirow{2}{*}{$\begin{array}{l}\text { Drainage } \\
\text { area } \\
\text { (square } \\
\text { miles) }\end{array}$} & \multicolumn{3}{|c|}{ August $10-17$} & \multicolumn{3}{|c|}{ August $28-31$} \\
\hline & & & $\begin{array}{c}\text { Precipi- } \\
\text { tation } \\
\text { (inches) }\end{array}$ & $\begin{array}{c}\text { Direct } \\
\text { runoff } \\
\text { (inches) }\end{array}$ & $\begin{array}{c}\text { Differ- } \\
\text { ence } \\
\text { (inches) }\end{array}$ & $\begin{array}{c}\text { Precipi- } \\
\text { tation } \\
\text { (inches) }\end{array}$ & $\begin{array}{l}\text { Direct } \\
\text { runoff } \\
\text { (inches) }\end{array}$ & $\begin{array}{l}\text { Differ- } \\
\text { ence } \\
\text { (inches) }\end{array}$ \\
\hline 151 & $\begin{array}{l}\text { Little Sugar Creek near Char- } \\
\text { lotte, N. C. }\end{array}$ & 41.4 & 4.6 & 0.7 & 3.9 & & & \\
\hline 152 & $\begin{array}{l}\text { Broad River near Chimney Rock, } \\
\text { N. C. }\end{array}$ & 97 & 9.5 & 3.0 & 6.5 & & & \\
\hline 153 & $\begin{array}{l}\text { Broad River near Boiling Springs, } \\
\text { N. C. }\end{array}$ & 864 & 9.1 & 3.0 & 6.1 & & & \\
\hline $\begin{array}{l}154 \\
154.5\end{array}$ & $\begin{array}{l}\text { Broad River near Gaffney, S. C. } \\
\text { Broad River near Carlisle, S. C.-- }\end{array}$ & $\begin{array}{l}1, \stackrel{004}{490} \\
2,790\end{array}$ & $\begin{array}{l}8.4 \\
7.7\end{array}$ & $\begin{array}{l}2.0 \\
2.9\end{array}$ & $\begin{array}{l}0.1 \\
5.5 \\
5.6\end{array}$ & & & \\
\hline $\begin{array}{l}156 \\
157.5\end{array}$ & $\begin{array}{l}\text { Broad River at Richtex, S. C.-- } \\
\text { Green River near Millspring, } \\
\quad \text { N. C. }\end{array}$ & $\begin{array}{r}4,850 \\
174\end{array}$ & $\begin{array}{l}7.2 \\
9.7\end{array}$ & 1.9 & 5.3 & & & \\
\hline 158 & $\begin{array}{l}\text { Second Broad River at Cliffside, } \\
\text { N. C. }\end{array}$ & 211 & 8.4 & 2.9 & 5.5 & & & \\
\hline 159.5 & $\begin{array}{l}\text { First Broad River near Lawndale, } \\
\text { N. C. }\end{array}$ & 198 & 8.8 & 4.4 & 4.4 & & & \\
\hline 161 & $\begin{array}{l}\text { North Pacolet River at Finger- } \\
\text { ville, S. C. }\end{array}$ & 116 & 10.4 & 3.1 & 7.3 & & & \\
\hline 162 & $\begin{array}{l}\text { Pacolet River near Fingerville, } \\
\text { ville, S. C. } \\
\text { North Tyger River near Moore. }\end{array}$ & 212 & 10.4 & 3.4 & 7.0 & & & \\
\hline $\begin{array}{l}164 \\
165\end{array}$ & $\begin{array}{l}\text { North Tyger River near Moore, } \\
\text { S. C. } \\
\text { Tyger River near Woodruff, S. C. }\end{array}$ & $\begin{array}{l}162 \\
351\end{array}$ & $\begin{array}{l}9.7 \\
9.4\end{array}$ & $\begin{array}{l}3.3 \\
2.7\end{array}$ & $\begin{array}{l}6.4 \\
6.7\end{array}$ & & & \\
\hline 165.5 & $\begin{array}{l}\text { Middle Tyger River at Lyman, } \\
\text { S. C. }\end{array}$ & 68.3 & 9.6 & 2.8 & 6.8 & & & \\
\hline 166 & $\begin{array}{l}\text { South Tyger River near Reid- } \\
\text { ville, S. C. }\end{array}$ & 106 & 9.3 & 2.1 & 7.2 & & & \\
\hline $\begin{array}{l}167 \\
167.5\end{array}$ & $\begin{array}{l}\text { South Tyger River near Wood- } \\
\text { ruff, S. C. } \\
\text { Fair Forest Creek near Únion, }\end{array}$ & 174 & 9.2 & 2.1 & 7.1 & & & \\
\hline 107.0 & Farr Forest Creek near Umon, & 183 & 6.5 & 2.0 & 4.5 & & & \\
\hline $\begin{array}{l}168 \\
170\end{array}$ & $\begin{array}{l}\text { Enoree River near Enoree, S. C. } \\
\text { Saluda River near Pelzer, S. C.- }\end{array}$ & $\begin{array}{l}307 \\
405\end{array}$ & $\begin{array}{l}7.6 \\
9.6\end{array}$ & $\begin{array}{l}2.5 \\
1.8\end{array}$ & $\begin{array}{l}5.1 \\
7.8\end{array}$ & & & \\
\hline 170.5 & $\begin{array}{l}\text { Saluda River near Ware Shoals, } \\
\text { S. C. }\end{array}$ & 569 & 9.1 & 2.5 & 6.6 & & & \\
\hline $\begin{array}{l}172 \\
173\end{array}$ & $\begin{array}{l}\text { Saluda River at Chappells, S. C. - } \\
\text { Saluda River near Silverstreet, }\end{array}$ & 1,350 & 9.3 & & & & & \\
\hline $\begin{array}{l}175 \\
176\end{array}$ & $\begin{array}{l}\text { S. C. } \\
\text { Saluda River near Columbia, S.C. } \\
\text { Reedy River near Ware Shoals, }\end{array}$ & $\begin{array}{l}1,620 \\
2,510\end{array}$ & $\begin{array}{l}9.2 \\
8.3\end{array}$ & 2.8 & 5.5 & & & \\
\hline & $\begin{array}{l}\text { S. C. } \\
\text { Edisto River Basin }\end{array}$ & 228 & 7.9 & 2.7 & 5.2 & & & \\
\hline 176.5 & $\begin{array}{l}\text { South Fork Edisto River near } \\
\text { Montmorenci, S. C. }\end{array}$ & 198 & 4.8 & .8 & 4.0 & & & \\
\hline $\begin{array}{l}179 \\
183\end{array}$ & $\begin{array}{l}\text { Savannah River Basin } \\
\text { Chattooga River near Clayton, } \\
\text { Ga. } \\
\text { Tugaloo River near Hartwell, Ga. }\end{array}$ & $\begin{array}{l}203 \\
905\end{array}$ & $\begin{array}{r}11.6 \\
9.8\end{array}$ & $\begin{array}{l}2.3 \\
2.2\end{array}$ & $\begin{array}{l}9.3 \\
7.6\end{array}$ & $\begin{array}{r}11.2 \\
7.2\end{array}$ & $\begin{array}{l}3.0 \\
1.5\end{array}$ & $\begin{array}{l}8.2 \\
5.7\end{array}$ \\
\hline 84 & Savannah River near Calhoun & & & & & & & \\
\hline 86 & Savannah River at Augus & $\begin{array}{l}2,876 \\
7,508\end{array}$ & $\begin{array}{l}9.0 \\
8.8\end{array}$ & $\begin{array}{l}2.3 \\
3.0\end{array}$ & $\begin{array}{l}6.7 \\
5.8\end{array}$ & 5 & 0 & 5 \\
\hline & $\begin{array}{l}\text { Savannah } \mathbf{F} \\
\text { Bridge, } \mathbf{n}\end{array}$ & 8,650 & 8.5 & 2.8 & 5.7 & & & \\
\hline 86.7 & Sava & 9,850 & g. & 2.6 & 5.9 & & & \\
\hline 94 & $\begin{array}{l}\text { Anderson, S. C. } \\
\text { Bell, Ga. }\end{array}$ & $\begin{array}{l}1,026 \\
1,420\end{array}$ & $\begin{array}{r}11.0 \\
7.8\end{array}$ & $\begin{array}{l}2 . \\
1 .\end{array}$ & 6 & 6.7 & 1.5 & 5.2 \\
\hline 197 & Brier Creek at Millhaven, Ga... & 656 & 9.2 & 3.6 & 5.6 & & & \\
\hline 198 & $\begin{array}{l}\text { Ogaraher River Basin } \\
\text { Ogeechee River near Louisville, } \\
\text { Ga. }\end{array}$ & & 9 & & 78 & & & \\
\hline $\begin{array}{l}200 \\
201\end{array}$ & Ogeechee Riv & 1,940 & & & & & & \\
\hline 203 & Canoochee River near Claxton, & & & & & & & \\
\hline & KaNAWHA RIVER Bas & 555 & 5.6 & 1.4 & 4.2 & & & \\
\hline 177 & $\begin{array}{l}\text { South Fork New River near Jeffer- } \\
\text { son, N. C. }\end{array}$ & 207 & & 8.0 & & & 3.0 & 4.0 \\
\hline $\begin{array}{l}180 \\
182\end{array}$ & $\begin{array}{l}\text { New River near Gal } \\
\text { New River at Ivanh }\end{array}$ & $\begin{array}{l}1,131 \\
1,340\end{array}$ & $\begin{array}{r}9.7 \\
9.2\end{array}$ & $\begin{array}{l}4.4 \\
3.9\end{array}$ & $\begin{array}{l}5.3 \\
5.3\end{array}$ & $\begin{array}{l}4.3 \\
4.2\end{array}$ & $\begin{array}{l}1.1 \\
1.1\end{array}$ & $\begin{array}{l}3.2 \\
3.1\end{array}$ \\
\hline & New River at Allisonia, Va.... & 2,20 & 8.0 & & 5.1 & 3.6 & .9 & 2.7 \\
\hline & New River at Radford, Va.. & 2,748 & 8.0 & 2.7 & 5.3 & & & \\
\hline
\end{tabular}


TABLE 16.-Rainfall and associated direct runoff of floods of August 1940-Continued

\begin{tabular}{|c|c|c|c|c|c|c|c|c|}
\hline \multirow{2}{*}{$\begin{array}{l}\text { No. } \\
\text { on } \\
\text { pl. } \\
20\end{array}$} & \multirow{2}{*}{$\begin{array}{l}\text { Stream and point } \\
\text { of measurement }\end{array}$} & \multirow{2}{*}{$\begin{array}{l}\text { Drainage } \\
\text { area } \\
\text { (square } \\
\text { miles) }\end{array}$} & \multicolumn{3}{|c|}{ August $10-17$} & \multicolumn{3}{|c|}{ August 28-31 } \\
\hline & & & $\begin{array}{c}\text { Precipi- } \\
\text { tation } \\
\text { (inches) }\end{array}$ & $\begin{array}{c}\text { Direct } \\
\text { runoff } \\
\text { (inches) }\end{array}$ & $\begin{array}{l}\text { Differ- } \\
\text { ence } \\
\text { (inches) }\end{array}$ & $\mid \begin{array}{c}\text { Precipi- } \\
\text { tation } \\
\text { (inches) }\end{array}$ & $\begin{array}{c}\text { Direct } \\
\text { runoff } \\
\text { (inches) }\end{array}$ & $\begin{array}{l}\text { Differ- } \\
\text { ence } \\
\text { (inches) }\end{array}$ \\
\hline 185 & $\begin{array}{l}\text { New River at Eggleston, Va.. } \\
\text { New River at Glenlyn, Va. }\end{array}$ & $\begin{array}{l}2,941 \\
3,768\end{array}$ & $\begin{array}{l}7.9 \\
7.3\end{array}$ & $\begin{array}{l}2.6 \\
2.3\end{array}$ & $\begin{array}{l}5.3 \\
5.0\end{array}$ & 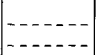 & & $-\cdots-1$ \\
\hline 192 & $\begin{array}{l}\text { North Fork New River at Crump- } \\
\text { ler, N. C. }\end{array}$ & 277 & 10.1 & 6.9 & 3.2 & 3.2 & 0.4 & 2.8 \\
\hline 194 & $\begin{array}{l}\text { Reed Creek at Grahams Forge, } \\
\text { Va. }\end{array}$ & 247 & 4.5 & .8 & 3.7 & 1.2 & .1 & 1.1 \\
\hline 195 & $\begin{array}{l}\text { Big Reed Island Creek near Alli- } \\
\text { sonia, Va. }\end{array}$ & 278 & 8.4 & 2.3 & 6.1 & 4.1 & .6 & 3.5 \\
\hline $\begin{array}{l}198 \\
199 \\
201\end{array}$ & $\begin{array}{l}\text { Graysonton, Va..- } \\
\text { Bane, Va.- } \\
\text { Narrows, Va...- }\end{array}$ & $\begin{array}{l}302 \\
305\end{array}$ & $\begin{array}{r}10.0 \\
4.3 \\
3.8\end{array}$ & $\begin{array}{l}3.3 \\
1.0\end{array}$ & $\begin{array}{l}6.7 \\
3.3 \\
2.7\end{array}$ & & & $\ldots$ \\
\hline 454 & $\begin{array}{l}\text { Tennessee River Basin } \\
\text { French Broad River at Rosman, } \\
\text { N. C. }\end{array}$ & 67.9 & 10.9 & 2.8 & 8.1 & 9.1 & 2.2 & 6.9 \\
\hline 455 & $\begin{array}{l}\text { French Broad River at Calvert, } \\
\quad \text { N. C. }\end{array}$ & 103 & 11.3 & 2.9 & 8.4 & 8.5 & 1.9 & 6.6 \\
\hline 456 & $\begin{array}{l}\text { French Broad River at Blantyre, } \\
\text { N. C. }\end{array}$ & 296 & 11.2 & 4.3 & 6.9 & 7.7 & 2.5 & 5.2 \\
\hline 458 & $\begin{array}{l}\text { French Broad River at Bent } \\
\text { Creek, N. C. }\end{array}$ & 676 & 9.6 & 2.9 & 6.7 & 7.5 & 2.2 & 5.3 \\
\hline 459 & $\begin{array}{l}\text { French Broad River at Asheville, } \\
\quad \text { N. C. }\end{array}$ & 945 & 9.3 & 2.6 & 6.7 & 7.6 & 2.3 & 5.3 \\
\hline 460 & French Broad River at Hot & 1,567 & 7.1 & 1.8 & 5.3 & 6.9 & 2.1 & 4.8 \\
\hline 461 & $\begin{array}{l}\text { French Broad River near New- } \\
\text { port, Tenn: }\end{array}$ & & 6.5 & 1.6 & 4.9 & 6.5 & 2.0 & 4.5 \\
\hline 478 & $\begin{array}{l}\text { Davidson River near Brevard, } \\
\text { N. C }\end{array}$ & 40.4 & 11.0 & 2.8 & 8.2 & 7.8 & 1.8 & 6.0 \\
\hline $\begin{array}{l}480 \\
482\end{array}$ & $\begin{array}{l}\text { South Fork Mills River at The } \\
\text { Pink Beds, N. C. } \\
\text { Mills River near Mills River, N. C. }\end{array}$ & $\begin{array}{c}9.99 \\
66.7\end{array}$ & $\begin{array}{r}12.1 \\
9.7\end{array}$ & $\begin{array}{l}5.4 \\
3.4\end{array}$ & $\begin{array}{l}6.7 \\
6.3\end{array}$ & $\begin{array}{l}8.8 \\
8.9\end{array}$ & $\begin{array}{l}2.5 \\
2.4\end{array}$ & $\begin{array}{l}6.3 \\
6.5\end{array}$ \\
\hline $\begin{array}{l}484 \\
486\end{array}$ & $\begin{array}{l}\text { Mud Creek at Naples, N. C. } \\
\text { Swannanoa River at Biltmore, }\end{array}$ & 109 & 8.4 & 3.2 & 5.2 & 6.7 & 2.5 & 4.2 \\
\hline 400 & N. C.- & 130 & 9.9 & 3.5 & 6.4 & 7.1 & 2.1 & 5.0 \\
\hline 488 & tain, N.C.... & 23.8 & 5 & 8.9 & 3.6 & 8.2 & 4.4 & 3.8 \\
\hline $\begin{array}{l}400 \\
489\end{array}$ & Ivy River near Marshall, N. C..- & $158^{56}$ & $\begin{array}{r}10.0 \\
4.9\end{array}$ & $\begin{array}{l}4.9 \\
1.0\end{array}$ & $\begin{array}{l}5.1 \\
3.9\end{array}$ & $\begin{array}{l}7.0 \\
5.2\end{array}$ & $\begin{array}{l}4.1 \\
1.1\end{array}$ & $\begin{array}{l}2.9 \\
4.1\end{array}$ \\
\hline 490 & urel Creek near Stack- & 126 & 2.8 & & 2.3 & 4.4 & 1.0 & \\
\hline $\begin{array}{l}491 \\
493 \\
495 \\
497\end{array}$ & $\begin{array}{l}\text { Pigeon River at Canton, N. C. } \\
\text { Pigeon River near Hepco, N. C.-- } \\
\text { Pigeon River at Hartford, Tenn. }\end{array}$ & $\begin{array}{l}133 \\
350 \\
547\end{array}$ & $\begin{array}{r}10.6 \\
7.3 \\
6.4\end{array}$ & $\begin{array}{l}5.3 \\
2.7 \\
1.7\end{array}$ & $\begin{array}{l}5.3 \\
4.6 \\
4.7\end{array}$ & $\begin{array}{l}9.4 \\
7.3 \\
6.5\end{array}$ & $\begin{array}{l}3.6 \\
1.9 \\
1.6\end{array}$ & $\begin{array}{l}58 \\
5.4 \\
4.9\end{array}$ \\
\hline 497 & $\begin{array}{l}\text { Jonathan Creek near Cove Creek, } \\
\text { N. C. }\end{array}$ & 65.3 & 5.4 & 1.1 & 4.3 & 5.4 & 1.0 & 4.4 \\
\hline 498 & Cataloochee Creek near Cataloo- & 49.2 & 5.8 & 1.0 & 4.8 & 5.3 & 1.0 & 4.3 \\
\hline 499 & $\begin{array}{l}\text { North Toe River at Altapass, } \\
\text { N. C. } \\
\text { Nolichucky River at Poplar, N. C. }\end{array}$ & $\begin{array}{l}104 \\
608\end{array}$ & $\begin{array}{r}10.9 \\
8.8\end{array}$ & $\begin{array}{l}5.0 \\
3.8\end{array}$ & $\begin{array}{l}5.9 \\
5.0\end{array}$ & $\begin{array}{l}5.5 \\
5.8\end{array}$ & $\begin{array}{l}1.5 \\
1.7\end{array}$ & $\begin{array}{l}4.0 \\
4.1\end{array}$ \\
\hline 506 & South Toe River at Newdale, N. C. & $\begin{array}{r}805 \\
60.8\end{array}$ & $\begin{array}{r}7.7 \\
14.5\end{array}$ & $\begin{array}{r}3.1 \\
11.0\end{array}$ & $\begin{array}{l}4.6 \\
3.5\end{array}$ & $\begin{array}{l}5.3 \\
9.6\end{array}$ & $\begin{array}{l}1.5 \\
5.2\end{array}$ & $\begin{array}{l}3.8 \\
4.4\end{array}$ \\
\hline $\begin{array}{l}507 \\
508\end{array}$ & $\begin{array}{l}\text { ux, N. C. } \\
\text { t Sevierville, }\end{array}$ & 157 & 7.3 & 3.9 & 3.4 & 5.3 & 1.4 & 3.9 \\
\hline 510 & $\begin{array}{l}\text { Tenn } \\
\text { South Fork Holston River at }\end{array}$ & 353 & 2.3 & .7 & 1.6 & & & \\
\hline 511 & River at & 301 & 5.6 & 1.4 & 4.2 & & & \\
\hline 512 & $\begin{array}{l}\text { Bluff City, Tenn. } \\
\text { South Fork Holston River at } \\
\text { Kingsport, Tenn. }\end{array}$ & $\begin{array}{r}813 \\
1,931\end{array}$ & $\begin{array}{l}4.6 \\
5.2\end{array}$ & $\begin{array}{l}1.4 \\
1.3\end{array}$ & $\begin{array}{l}3.2 \\
3.9\end{array}$ & & & \\
\hline 516 & $\begin{array}{l}\text { Holston River near } \\
\text { va. Va. }\end{array}$ & 211 & 3.9 & .7 & 3.2 & & & \\
\hline 517.8 & Watauga River near Sugar Grove, & 90.8 & 12.2 & 7.9 & 4.3 & 6.5 & 2.0 & 4.5 \\
\hline 518 & Watauga River at Stump Knob, & 17 & 0.1 & & 5 & 5.0 & 1.2 & 3.8 \\
\hline 519 & $\begin{array}{l}\text { Watauga River at Butler, Tenn.- } \\
\text { Watauga River at Horseshoe Dam, } \\
\text { at Wilbur, Tenn. }\end{array}$ & 471 & 7.7 & $\begin{array}{l}3.2 \\
3.0\end{array}$ & 4.7 & 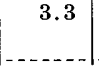 & 7 & 6 \\
\hline
\end{tabular}


TABLE 16.--Rainfall and associated direct runoff of floods of August 1940-Continued

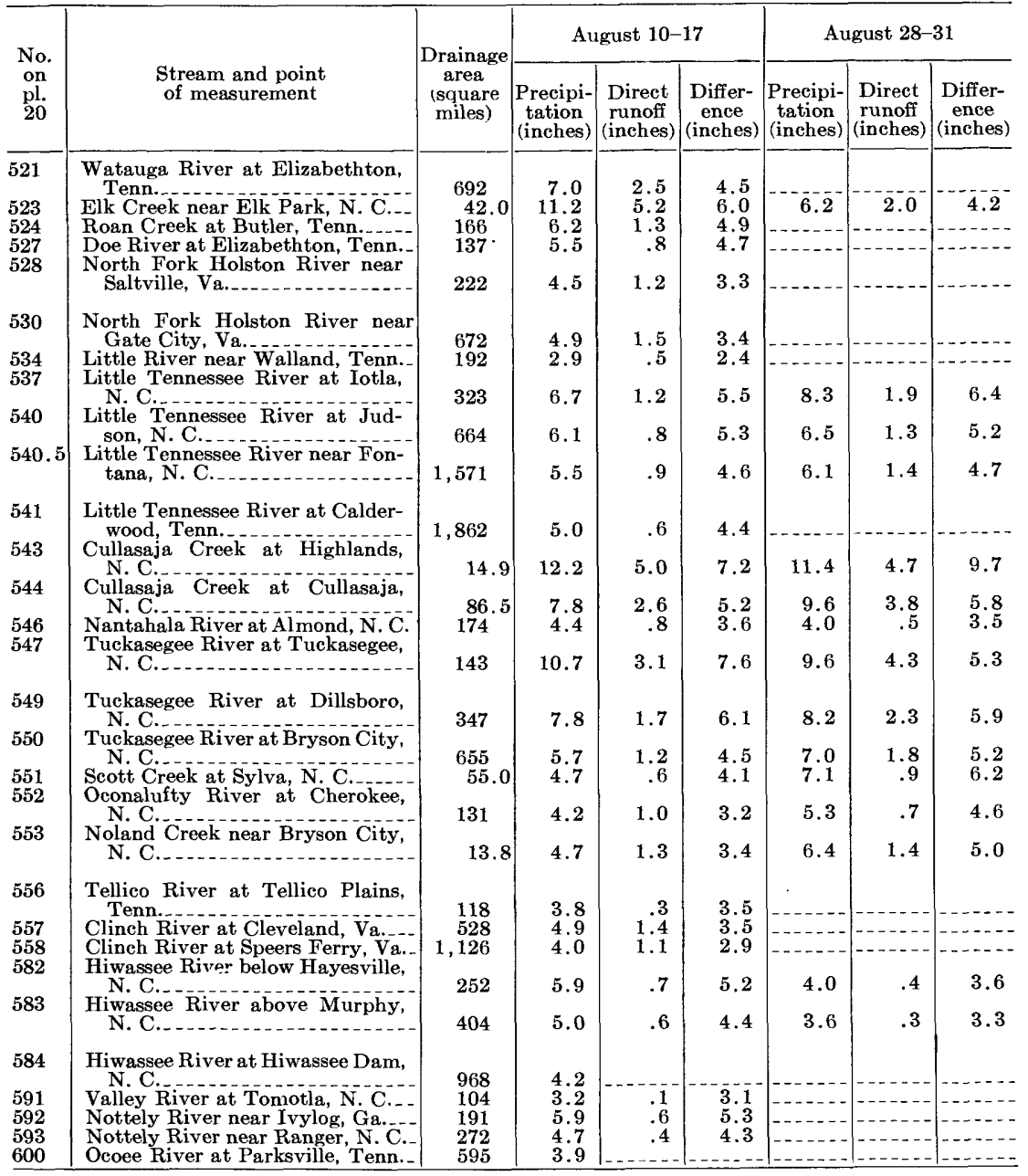

The volume of runoff varies with a number of factors, such as moisture condition of the soil and intensity of rainfall, but the volume of rainfall seems to be the dominant factor. Accordingly, volumes of direct runoff have been plotted against total rainfall on figures 26 and 27 . In order to compare the relative plotting of the several points, lines of equal infiltration index, ${ }^{13}$ in inches per hour, have been drawn on figures 26 and 27. By definition, the infiltration index is a rate of rainfall such that the volume of rainfall at greater rates equals the volume of direct runoff. It is intended to serve as a measure of the absorptive capacity of the ground.

\footnotetext{
13 For methods of computing infiltration index, see Langbein, W. B., and others, Major winter and non-winter floods in selected basins in New York and Penusylvania: U. S. Geol. Survey Water-Supply Paper 915, pp. 11-13.
} 


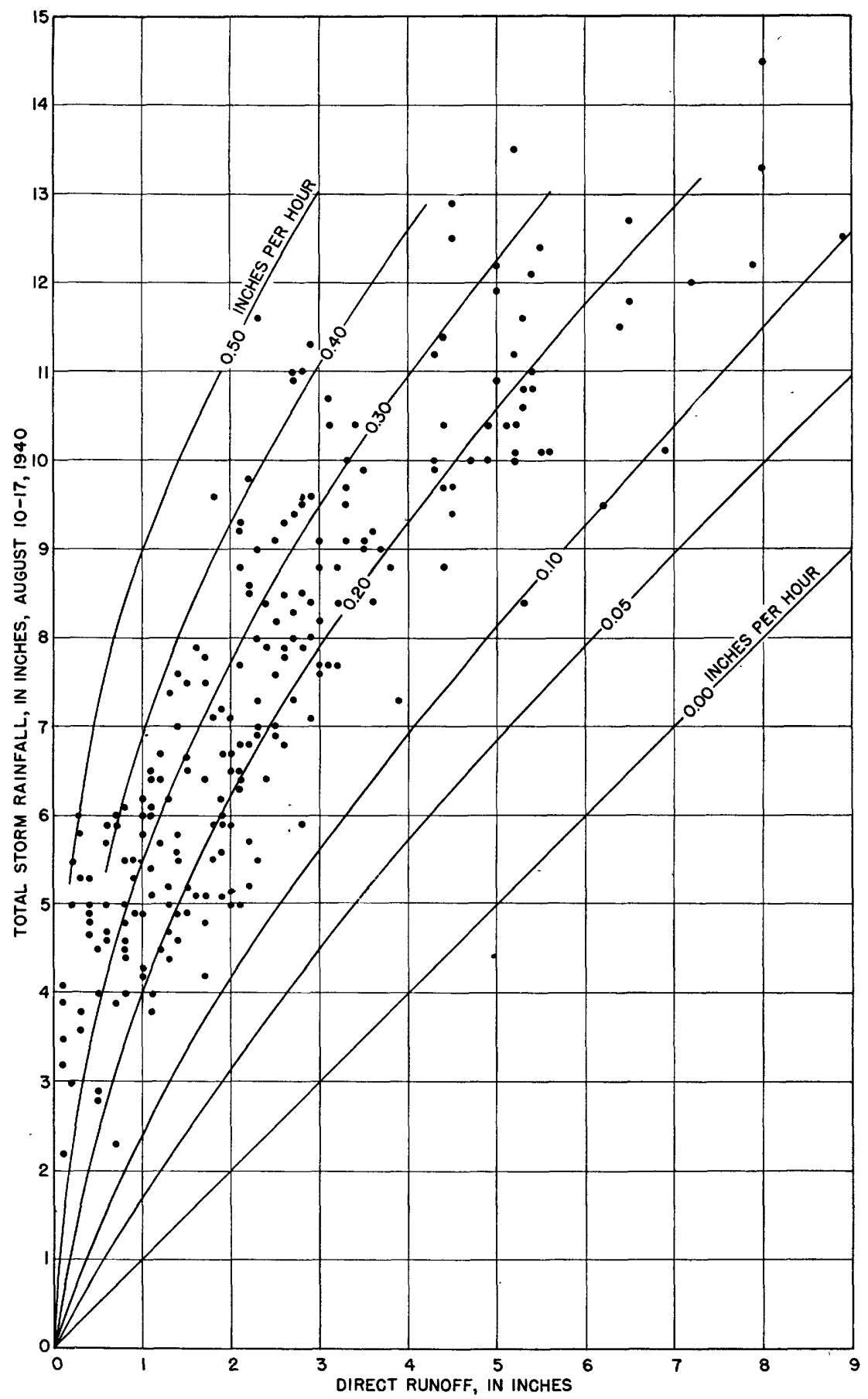

FIguRe 26. - Chart showing total rainfall and direct runoff for mid-August storm, in relation to indicated infiltration indices. 


\section{FLOODS OF AUGUST 1940 IN THE SOUTHEASTERN STATES}

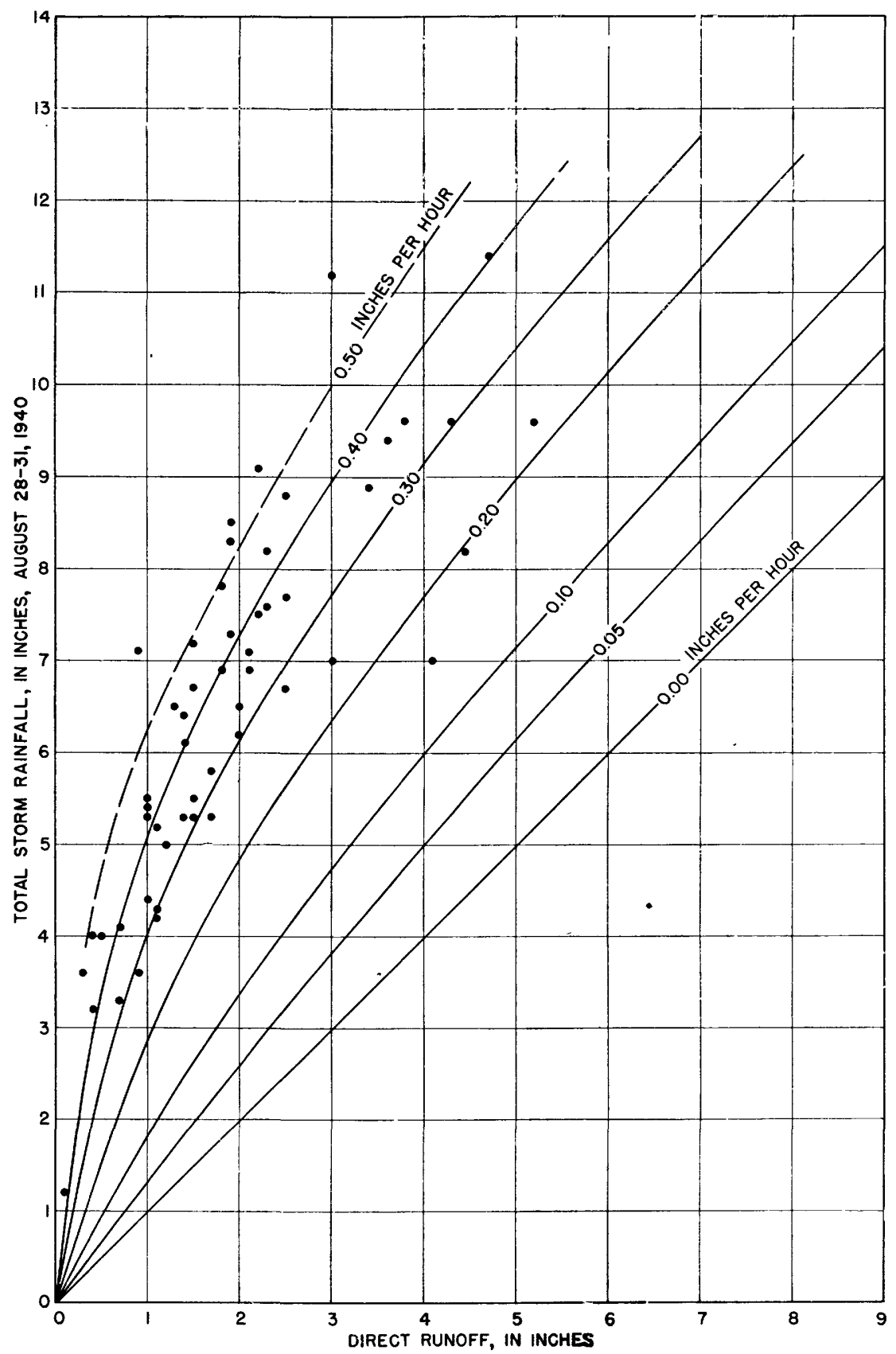

Figure 27,-Chart showing total rainfall and direct runoff for late-August storm, in relation to indicated infiltration indices.

It has been found that during a given storm empirical relations exist between the total storm rainfall and the volume of rainfall in excess of 


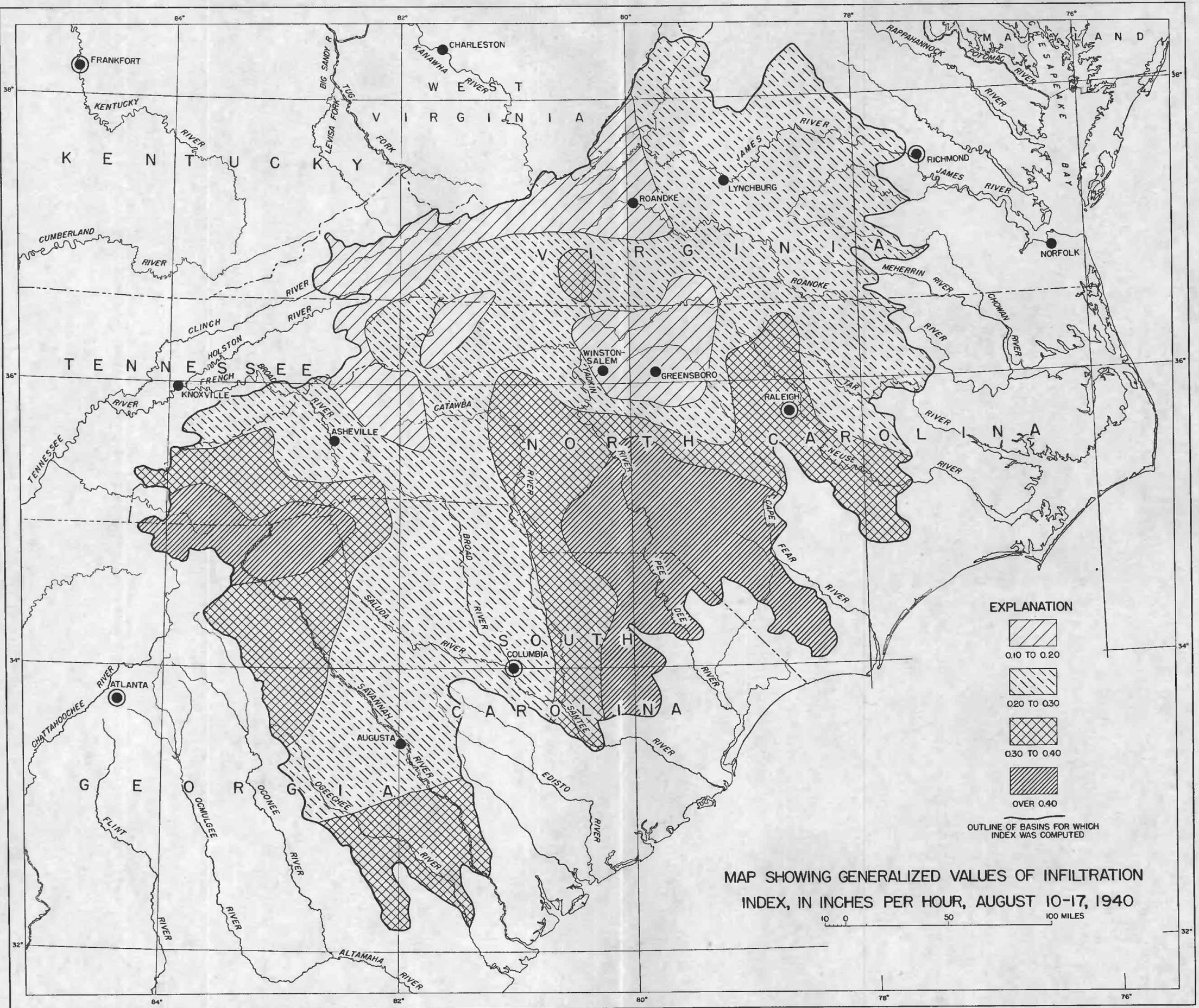


selected rates. The lines of figures 26 and 27 express this relation for the mid-August and late-August storms, respectively. Total storm rainfall is given as ordinate, and if by definition the lines representing the selected rainfall rates are interpreted as the infiltration index, the rainfall excess is equivalent to the volume of direct runoff shown as the abscissa.

These lines have been used for computing values of the infiltration index for the several plotted points representing the precipitation and direct runoff for each basin listed in table 16.

\section{DISCUSSION OF RESULTS}

There are about 250 computations of mean areal rainfall and associated direct runoff listed in table 16 for the mid-August storm and 55 for the late-August storm. Basin-wide precipitation averages of 10 inches or more were common, and there were three for which mean areal rainfall during the mid-August storm exceeded 14 inches. Two of these basins adjoin the Atlantic-Gulf divide between the Tennessee and Santee River Basins, South Toe River being a tributary of Tennessee River and Linville River a tributary of Santee River. Each of these tributaries drains about 65 square miles and discharged a direct-runoff volume of 11 inches, which was greater than the runoff of any other stream listed in table 16. Eleven inches of direct runoff is an extraordinary amount and closely approaches a limit of storm runoff experienced in this region, especially in the nonwinter season. The previous maximum 5-day runoff (approximately equivalent to the direct runoff) on record of any stream in the storm region was 9.18 inches measured on Daddy Creek near Grissy Cove, Tenn., March 22-26. 1929.

The third basin having mean areal rainfall in excess of 14 inches was Meherrin River above Lawrenceville, Va. The runoff from this basin, 553 square miles in area, was 8 inches, greater than that of any other basin of comparable size. In point of size of area, Roanoke River discharged the greatest flood volume. The runoff at Scotland Neck, N. C. $(8,700$ square miles), was 4.7 inches.

On figure 26 have been plotted volumes of direct runoff against associated amounts of mean areal rainfall, as listed for the mid-August storm in table 16. On this graph, as previously explained, have been drawn lines of equal infiltration index. It is assumed, therefore, that points conforming to a constant infiltration index represent basins of equal "runoff potentiality." For example, the mean areal rainfall of Rivanna River at Palmyra, Va., August 10-17 was 5.9 inches, and the associated direct runoff was 1.9 inches, indicating an infiltration index of 0.20 inch per hour. It is assumed that if the precipitation were 10.8 inches (as on Tye River in Virginia) then the direct runoff would be 5.3 inches. There is no rigorous way in which this theory can be tested. The following, however, was developed to check the shape of the lines 
on figure 26 . The basins listed in table 16 were grouped by precipitation amounts during the mid-August storm, and the direct runoff for groups of basins of equal precipitation was averaged, with the results shown on figure 28. These points represent basins with essentially equal precipitation but with different absorptive capacities, due either to differences in initial soil moisture or to factors inherent in the basin. The range of conditions in each precipitation group may be assumed to be the same, and therefore the several points may be said to represent the

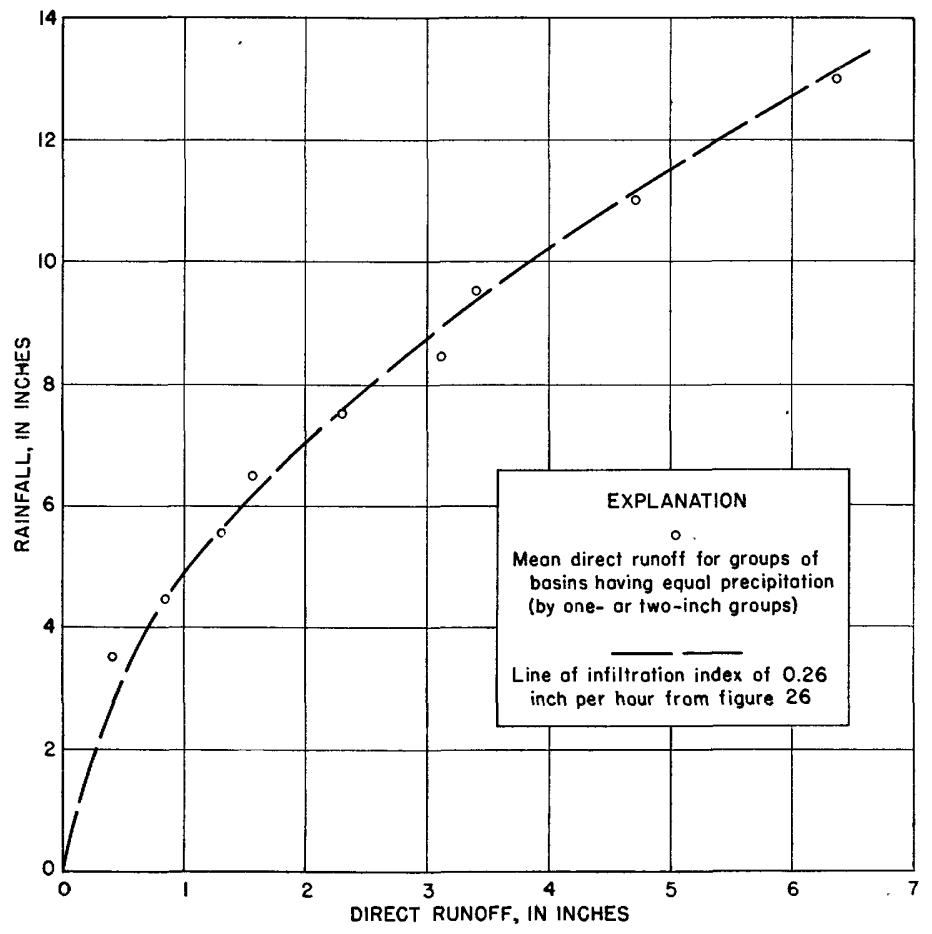

Figure 28.-Mean rainfall-runoff relation, mid-August storm.

runoff from a hypothetical "average" basin but with different amounts of rainfall. On this graph has been drawn a line representing an infiltration index of 0.26 inch per hour interpolated from figure 26. This line conforms quite well to the points as plotted.

Figure 26 suggests a curvilinear relation of rainfall to runoff, and such a relation would have an effect on the significance of the figures of "mean areal rainfall" when used in comparison with runoff. The method used assumes a linear or proportional relation of rainfall to runoff. This is in error to an extent depending on the range in rainfall within the basin and on the shape of the rainfall-runoff relation.

Again referring to figure 26 , it will be noted that most points are located within lines representing infiltration indices of 0.10 and 0.50 
inch per hour. The infiltration index for each plotted point was read by interpolation and entered on a map, with the plotting in the center of the basin. It is thought that erratic variations in the infiltration index between adjoining or nearby basins are not logical. Therefore the values of the infiltration index of adjoining or nesting basins were examined with the view to detecting irregularities or possible errors. Some of these seeming inconsistencies remain in the record and must be ascribed either to deficiency of the method of analysis or to errors of base data not apparent. Erratic variations seemed greatest between basins of 100 square miles or less in area, for which determinations of rainfall were not supported by measurements within the basin.

A tendency toward geographic grouping of values of the infiltration index was sufficiently well marked to permit the preparation of a map of generalized values during the mid-August storm. This map is reproduced in reduced scale as plate 21 . The values of the infiltration index had the following distribution according to area:

Infiltration index

Over 0.40 inch per hour

Between 0.30 and 0.40 inch per hour

Between 0.20 and 0.30 inch per hour

Between 0.10 and 0.20 inch per hour
Area
(square miles)

11,500

20,500

41,000

10,500

Total area (average $=0.29$ inch per hour)

83,500

The map indicates that low values of infiltration index (under 0.20) seem to be limited to the northern and higher parts of the region, whereas high values, indicative of good absorptive conditions (over 0.40 ), seem to occur only in the southern and lower parts of the region. There are some groups of basins for which the values of the infiltration index are consistent among themselves yet differ greatly from values in nearby groups that seem to be not greatly different in character. For example, the infiltration index in the upper Savannah and Hiwassee River Basins ranged between 0.40 and 0.50 inch per hour. Northward along the divide, in the upper Catawba and Nolichucky River Basins, the infiltration index was less than 0.20 inch per hour. According to available data, amounts of precipitation in these regions were of comparable magnitude, yet volumes of runoff in the latter were twice to three times that of the former. Differences of this extent reflect either inherent differences in the structure of these basins, differences in antecedent soil conditions as they affect the generation of direct runoff, or systematic or regional errors in base data or their interpretation.

The rainfall and runoff during the late-August storm were studied in the same fashion. Figure 27 is a plot of the total storm rainfall and direct runoff. Lines of equal infiltration index have also been drawn on this graph from a study of the rates of rainfall at recording rain 
gages within the storm region. Most of the points plot within the indices of 0.5 and 0.3 inch per hour. If figures 26 and 27 are compared it will be noted that the lines of equal infiltration index in figure 27 are farther to the right than those in figure 26. This is due to the shorter duration and generally higher rainfall rates of the lateAugust storm as compared with the mid-August storm. For the same precipitation and volume of direct runoff the infiltration index would be higher during the late-August storm than during the mid-August storm.

Plate 22 shows the generalized areal distribution of infiltration indices during the late-August storm. An area of high infiltration index ( $>0.40$ inch per hour) is shown in the southern part of the storm region, whereas in the northern part the infiltration index was generally less than 0.40 inch per hour.

This manner of distribution was comparable to that during the mid-August storm. The general average over the whole area was 0.37 inch per hour.

For comparable volume of rainfall, direct runoff during the lateAugust storm was about the same as during the mid-August storm. This is shown by figure 29. A mean rainfall-runoff relation during the

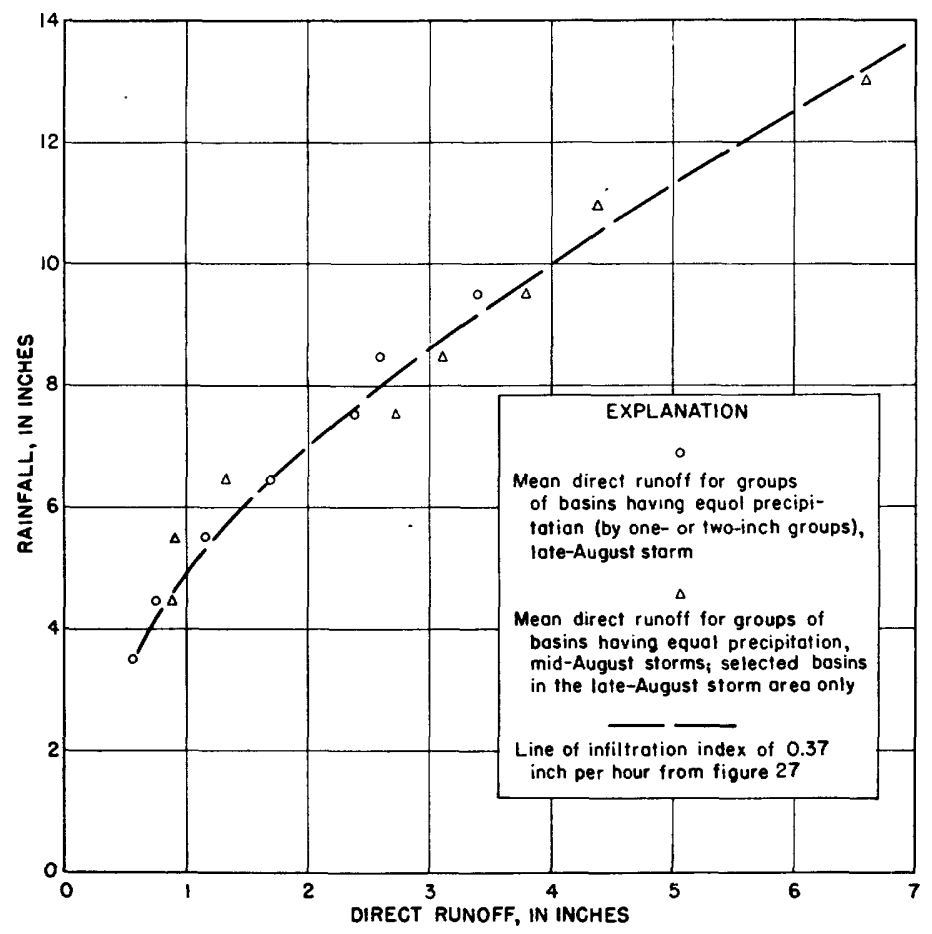

FIGURE 29.-Mean rainfall-runoff relation, late-August storm, and comparison with midAugust storm. 
late-August storm was prepared by averaging the direct runoff for groups containing basins with approximately equal rainfall (by 1- or 2 -inch intervals), and the mean rainfall and mean direct runoff for each group is plotted on figure 29. A line conforming to an infiltration index of 0.37 inch per hour as interpolated from figure 27 is drawn on figure 29 and averages the plotted points. Also plotted on figure 29 are averages of the direct runoff during the mid-August storm of groups of basins having approximately the same precipitation, but within the area of the late-August storm only. Thus the two series of points on figure 29 represent the same group of basins. Although there is some scattering, the points for the mid-August storm in general conform to those during the late-August storm. In this sense the dashed line on figure 29 also corresponds to an infiltration index of 0.26 inch per hour during the mid-August storm. The difference between 0.26 inch per hour during the mid-August storm and 0.37 inch per hour during the late-August storm for the same general rainfall-runoff relation is due entirely to difference in rainfall intensities during the two storms as they affect the computation of the infiltration index.

It is somewhat surprising that the volumes of direct runoff for the two storms were so nearly comparable. It might be expected that for equivalent amounts of precipitation the runoff volumes of the lateAugust storm would exceed those of the mid-August storm, for two reasons: (1) The retention from the first storm would tend to increase soil moisture, unless the drying out between storms was sufficient to deplete this retention; however, the base flow of the rivers was uniformly greater on August 28 than on Angust 10. (2) Rainfall intensities were greater during the late-August storm than during. the mid-August storm, but the agreement between volumes of runoff during the two storms suggests a uniformity of the rainfall-runoff relation.

\section{VARIATION OF RAINFALL-RUNOFF RELATIONS DURING}

\section{MID-AUGUST STORM}

The curve representing the relation of total storm rainfall to total direct runoff for the mid-August storm indicates a greater proportional conversion of rainfall into runoff for large amounts than for small amounts. A similar condition existed with respect to time, that is, as the storm continued there was an increase in the proportional amount of rainfall that was converted into runoff.

The smaller streams in Virginia and parts of North Carolina had two or more distinct peaks associated with distinct periods of rainfall, permitting division into separate storm periods. The volume of rainfall and direct runoff associated with each of the peaks during the mid- 


\section{FLOODS OF AUGUST 1940 IN THE SOUTHEASTERN STATES}

August storm has been estimated for six selected streams in the James, Roanoke, and Pamlico River Basins. The results are given in table 17.

TABLE 17.-Rainfall and associated direct runoff on selected streams having several peak flows during the mid-August flood

\begin{tabular}{|c|c|c|c|c|c|c|c|c|c|}
\hline \multirow{2}{*}{$\begin{array}{l}\text { No. } \\
\text { on } \\
\text { pl. } \\
20\end{array}$} & \multirow{2}{*}{ Stream and location } & \multicolumn{2}{|c|}{$\begin{array}{l}\text { Initial } \\
\text { period }\end{array}$} & \multicolumn{2}{|c|}{$\begin{array}{l}\text { First } \\
\text { peak }\end{array}$} & \multicolumn{2}{|c|}{$\begin{array}{l}\text { Second } \\
\text { peak }\end{array}$} & \multicolumn{2}{|c|}{ Total } \\
\hline & & $\begin{array}{l}\text { Rain- } \\
\text { fall }\end{array}$ & $\begin{array}{c}\text { Run- } \\
\text { off }\end{array}$ & $\begin{array}{l}\text { Rain- } \\
\text { fall }\end{array}$ & $\begin{array}{c}\text { Run- } \\
\text { off }\end{array}$ & $\begin{array}{l}\text { Rain- } \\
\text { fall }\end{array}$ & $\begin{array}{c}\text { Run- } \\
\text { off }\end{array}$ & $\begin{array}{l}\text { Rain- } \\
\text { fall }\end{array}$ & $\begin{array}{c}\text { Run- } \\
\text { off }\end{array}$ \\
\hline $\begin{array}{l}11 \\
24.5 \\
31 \\
51 \\
66.5 \\
72.5\end{array}$ & $\begin{array}{l}\text { Dunlap Creek near Covington, Va..- } \\
\text { Tye River near Lovingston, Va. } \\
\text { Appomattox River at Farmville, Va.- } \\
\text { Goose Creek near Huddleston, Va. } \\
\text { Smith River at Bassett, Va. } \\
\text { Tar River near Tar River, N. C..- }\end{array}$ & $\begin{array}{r}0.5 \\
.8 \\
.4 \\
.3 \\
1.3 \\
.8\end{array}$ & $\begin{array}{l}0.0 \\
0.0 \\
0.0 \\
0.0 \\
.1 \\
0.0\end{array}$ & $\begin{array}{l}2.5 \\
7.0 \\
9.1 \\
4.9 \\
5.8 \\
2.8\end{array}$ & $\begin{array}{l}1.1 \\
3.1 \\
3.0 \\
1.6 \\
2.1 \\
.25\end{array}$ & $\begin{array}{l}1.2 \\
3.0 \\
2.9 \\
1.9 \\
2.4 \\
2.4\end{array}$ & $\begin{array}{r}0.6 \\
2.2 \\
1.6 \\
.9 \\
1.1 \\
.50 \\
\end{array}$ & $\begin{array}{r}4.2 \\
10.8 \\
12.4 \\
18.2 \\
9.5 \\
6.0\end{array}$ & $\begin{array}{r}1.7 \\
5.3 \\
5.5 \\
13.3 \\
3.3 \\
.75 \\
\end{array}$ \\
\hline
\end{tabular}

1 Includes a third peak with rainfall 1.1 inches, runoff 0.8 inch.

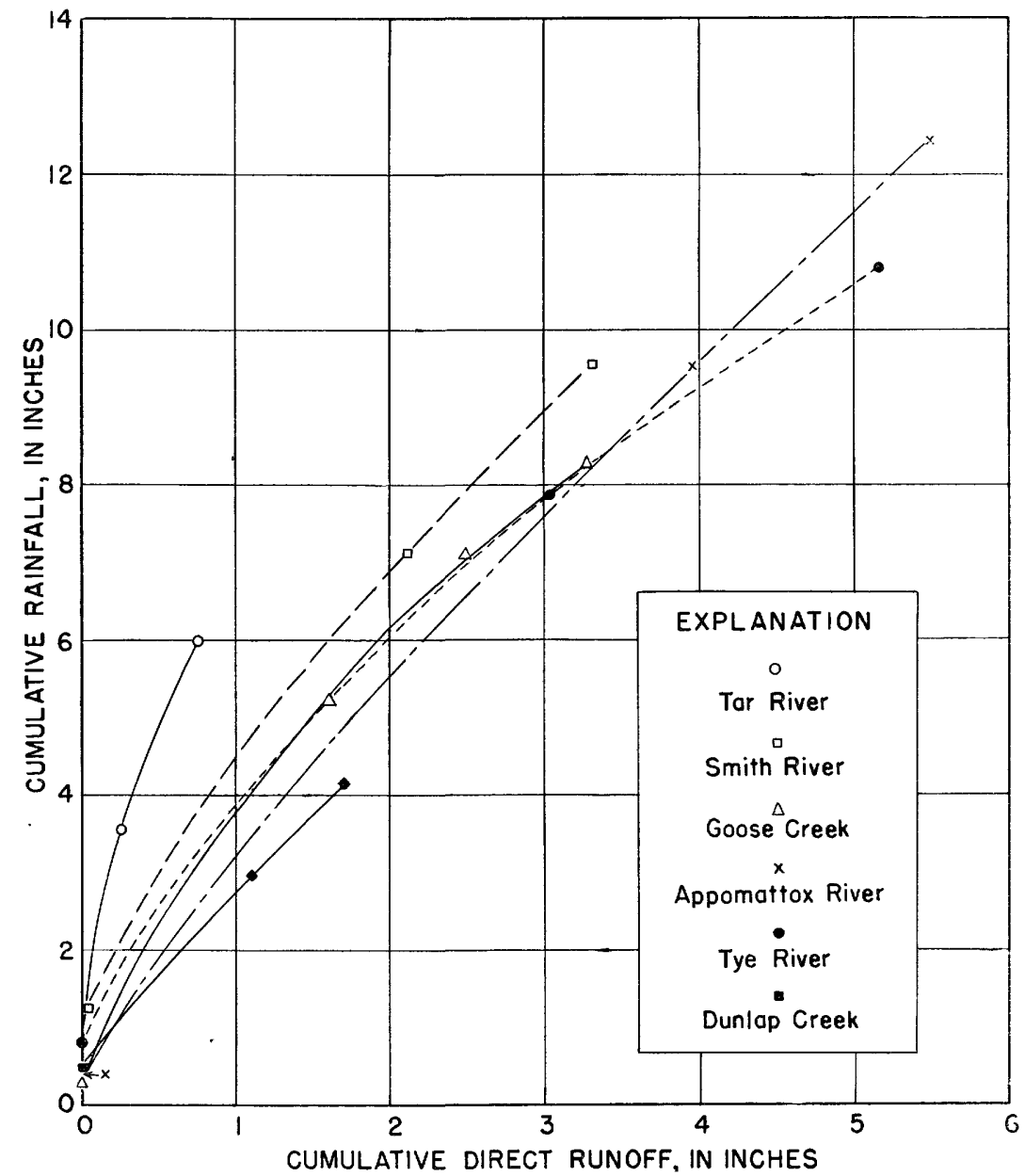

Figure 30.-Cumulative direct runoff in relation to cumulative rainfall for selected basins in Virginia and North Carolina, mid-August storm. 
The initial period includes rainfall that preceded any significant rise in stream flow. This rain, averaging about 0.6 inch, supplied losses by interception; ground wetting, and similar abstractions, which were satisfied before runoff began. On most streams in this area the rainfall producing the first peak, generally August 14-15, was greater than during the subsequent periods, and direct runoff was likewise greater. But it will be noted that the proportion of rainfall converted into runoff increased from one period to the next, a result of the effect of rainfall on the retention of subsequent rainfall. Figure 30 is a graphical presentation of the data given above. Curves drawn through the plotted points are concave to the right and similar in shape to the curves of infiltration index on figure 26 .

\section{CONCENTRATION OF DISCHARGE}

The degree to which direct runoff was concentrated with respect to time as measured by the ratio between the peak discharge above base flow, in second-feet, and the total direct runoff, in second-footdays, varied widely. The factors that are believed to be of greatest influence upon these concentration ratios involve such storm variables as duration and intensity of storm and direction of storm movement, and such inherent basin characteristies as channel hydraulies, tributary arrangement, and shape and slope of drainage basins. The lag in days between centers of mass of effective rainfall and the direct runoff as estimated by analysis of the recession graph $^{14}$ is a convenient measure of the inherent basin characteristics insofar as they affect the concentration of runoff. Figure 31 is a study of the concentration ratios for several basins in relation to the lag. The product of the concentration ratio and the lag (which product is dimensionless) for points in this figure shows a variation on the average from about 0.4 for streams with long lag to about 0.7 for streams with short lag. Departures from the line on figure 31 may be ascribed in part to differences in characteristies of rainfall in the various parts of the region. Basins in which storm rainfall was more concentrated than the average would plot above the line; points below the line represent basins in which rainfall was more spread out, and in some was so distributed as to produce two separate flood peaks.

Another measure of the concentration of discharge with respect to time is provided by the rate of rise in discharge in response to rainfall. Little Sugar Creek near Charlotte, N. C. (drainage area, 41.4 square miles), rose from 26 second-feet to 2,230 second-feet in 3 hours on August 14. Kanawha River at Kanawha Falls, W. Va. (drainage area, 8,367 square miles), increased in flow from 31,200 second-feet to

\footnotetext{
14 Langbein, W. B., Ohannel storage and unit-hydrograph studies: Am. Geophys. Union Trans. 1940, pt. 2, pp. 620-627.
} 


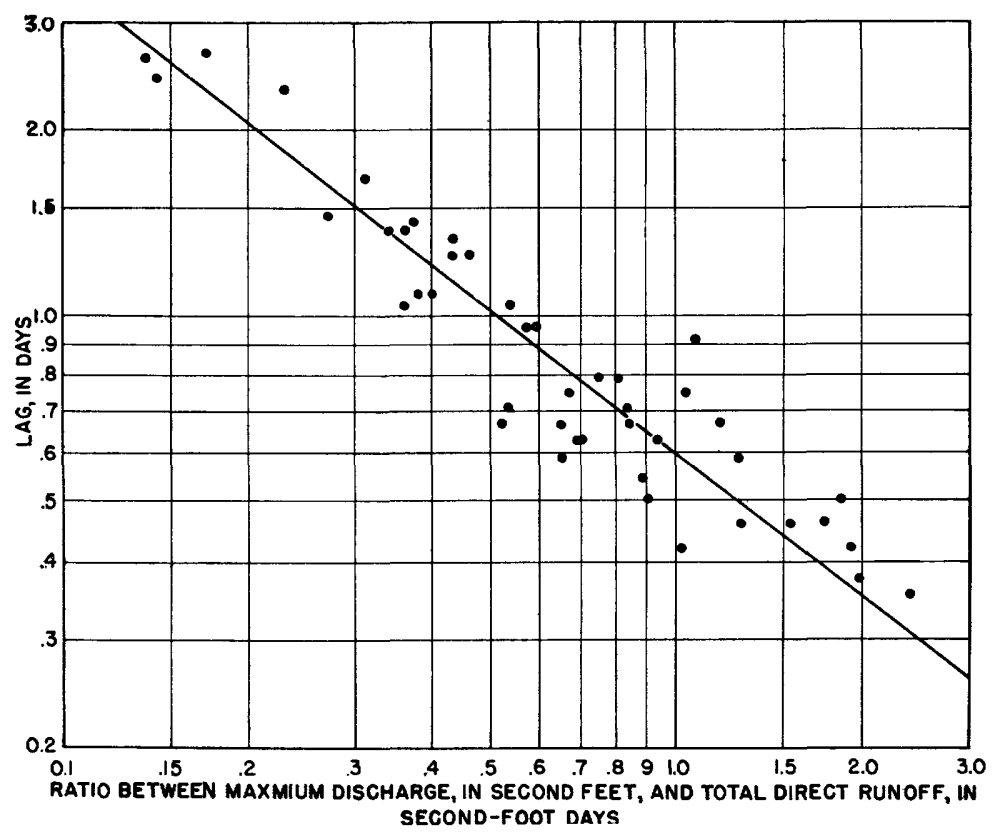

Figure 31.-Relation between concentration ratio and lag, mid-August flood.

208,000 second-feet in 4 hours on August 15. The above are "flashy" streams. Tar River in eastern North Carolina is an example of a sluggish stream. This river required 6 days to rise from 1,200 second-feet to a peak of 37,200 second-feet at Tarboro, N. C. (drainage area, 2,100 square miles).

Most hydrograph shapes were normal in appearance and were such as might be simply explained by details of rainfall distribution, inflow from tributaries, and like effects. But there were a few anomalies of special interest. The hydrographs at some of the downstream stations on the larger streams, especially the James, Neuse, Cape Fear, and Pee Dee Rivers, were somewhat odd in shape. It can be noted on figures $7,8,11$, 12 , and 13 that the recession in discharge was unusually rapid in comparison with the slow rise, the rounded peaks, and the lag between rainfall and time of peak discharge of these streams. Normally a stream that is long in reaching the crest would require a longer time to recede. On some streams the rate of recession after the peak appeared to be greater at downstream points than at upstream points. For example, the discharge of James River at Bent Creek, Va., decreased by 46 percent during the first calendar day following the peak; downstream at Richmond, Va., the discharge decreased by 58 percent during the first calendar day following the peak at Richmond, which occurred 2 days later than that at Bent Creek. 


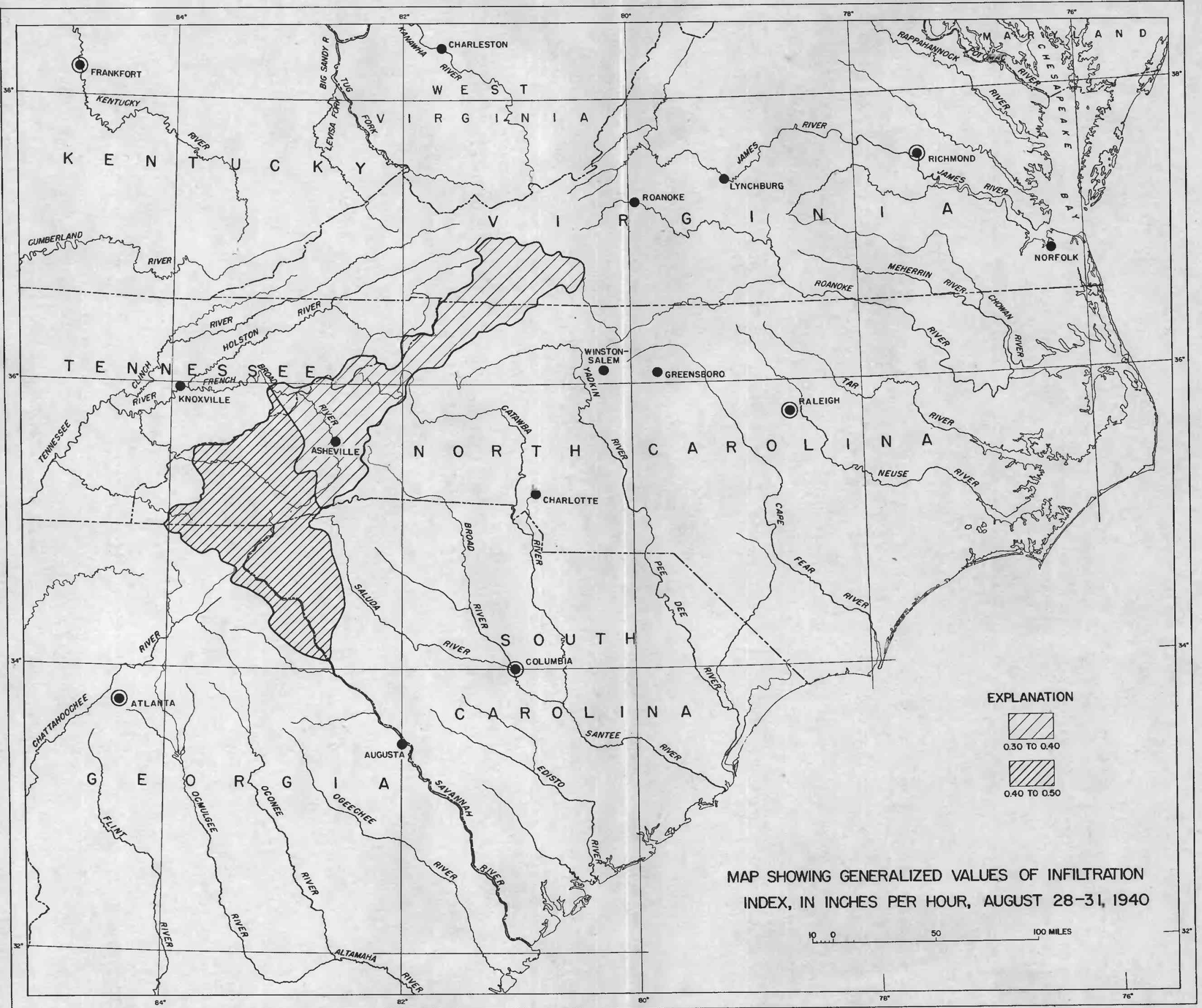




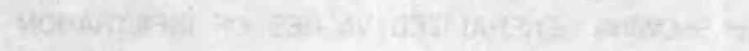

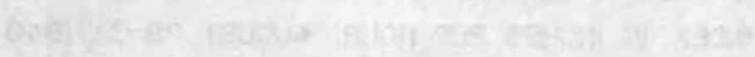


Figure 10 shows the hydrograph of Tar River near Nashville, N. C., a stream unaffected by artificial storage. This stream rose rapidly on August 14, apparently as a result of local inflow. Then for the next 4 days the discharge rose very slowly until noon of the 18 th ; rainfall had ended on August 16. The discharge then slowly receded from noon of the 18th to noon of the 20th. During the 4-day period August 15-19 the hydrograph was characteristic of a sluggish stream. Then during the afternoon of August 20 the stream abruptly receded, reaching baseflow level by midnight. The recession part of the hydrograph seems inconsistent with the remainder.

Sweetwater Creek (an unregulated stream), as shown by figure 32, rose from 80 second-feet at noon of August 12 to 2,100 second-feet at midnight. Then for 36 hours until noon of August 14 the discharge remained nearly constant, rising only to a maximum of 2,280 secondfeet. At noon of August 14 the stream receded in a common recession curve. The hydrograph in appearance is that of a common hydrograph truncated at about 2,150 second-feet. Examination of other flood hydrographs indicates that this behavior is normal for this stream.

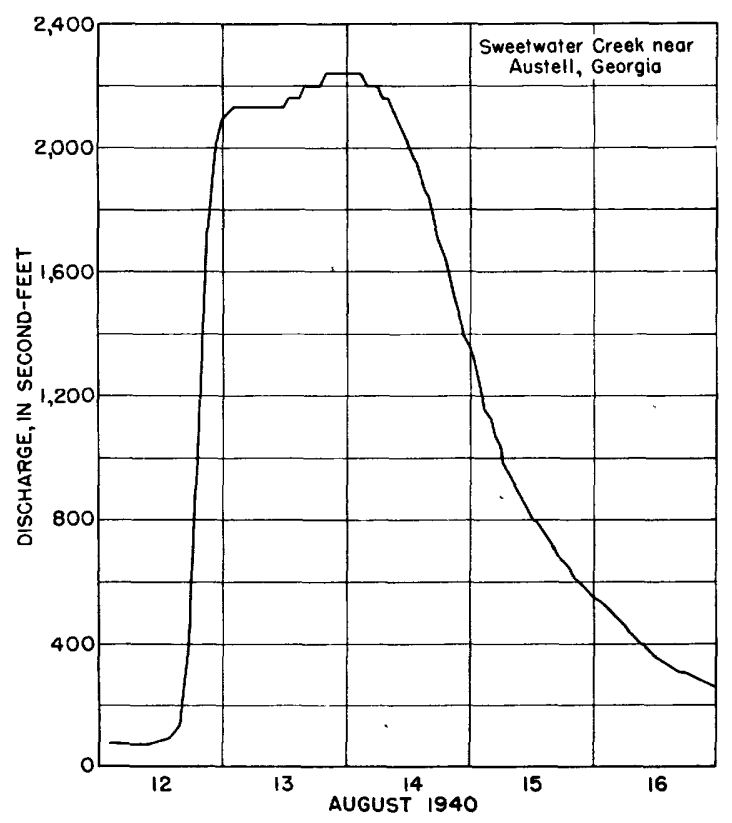

F'IgURE 32.-Hydrograph of Sweetwater Creek near Austell, Ga., August 12-16, 1940.

\section{INVENTORY}

The amounts of rainfall and their disposal by basins during the midAugust flood are summarized in table 18. This table lists the number of gaging stations operated in the basins indicated and for which rainfall and runoff data are given in table 16 . The table also gives the 
number of rain gages per square mile of area as an indication of the reliability of the amount of rainfall. The next two columns give mean rainfall and mean runoff expressed in inches. These two quantities are the averages of the corresponding quantities for the gaging stations in the indicated basins as given in table 16. Base runoff in inches was computed as explained in the section on "Methods of analysis" ( $p$. 476) for several rivers in each basin and the average listed in table 18.

TABLE 18.-Inventory of rainfall and runoff, mid-August flood

\begin{tabular}{|c|c|c|c|c|c|c|c|}
\hline Basin & $\begin{array}{c}\text { Number } \\
\text { of } \\
\text { gaging } \\
\text { stations }\end{array}$ & $\begin{array}{c}\text { Number of } \\
\text { precipitation } \\
\text { stations } \\
\text { (per square } \\
\text { mile) }\end{array}$ & $\begin{array}{c}\text { Precipi- } \\
\text { tation } \\
\text { (inches) }\end{array}$ & $\begin{array}{l}\text { Direct } \\
\text { runoff } \\
\text { (inches) }\end{array}$ & $\begin{array}{c}\text { Base } \\
\text { runoff } \\
\text { (inches) }\end{array}$ & $\begin{array}{c}\text { Net } \\
\text { reten- } \\
\text { tion }{ }^{1} \\
\text { (inches) }\end{array}$ & $\begin{array}{l}\text { Infiltra- } \\
\text { tion } \\
\text { index } \\
\text { (inches } \\
\text { per hour) }\end{array}$ \\
\hline James $_{-}$ & 28 & 0.0063 & 7.6 & 2.7 & 0.9 & 4.0 & 0.21 \\
\hline Roanoke & 28 & .0037 & 9.3 & 4.0 & 1.0 & 4.3 & .20 \\
\hline Pamlico & 5 & .0052 & 8. & 2.8 & .5 & 5.0 & .25 \\
\hline Neuse & 12 & .0055 & & 1.1 & .3 & & .32 \\
\hline Cape Fear & 20 & .0061 & 5.1 & 1.3 & 4 & 3.4 & .23 \\
\hline Pee Dee & 34 & .0047 & 6.4 & 1.4 & 5 & 4.5 & .30 \\
\hline Sar & 2 & .0056 & 8. & 2. & 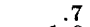 & 5.2 & .27 \\
\hline Savanı & 9 & .0025 & 9 . & 2. & 1.0 & 5.8 & .34 \\
\hline Ogeech & 4 & .0028 & 8 & & 8 & & .28 \\
\hline Upper $\mathrm{K}$ & 13 & .0085 & 8 & 3 & & 3 & .20 \\
\hline ennessee & 62 & .0135 & & 2. & 1.8 & 3.2 & \\
\hline
\end{tabular}

${ }^{1}$ Except for initial losses this quantity mainly represents the accretion in soil moisture and ground water, which is subsequently lost through processes of evapotranspiration.

Of the 5 to 9 inches of rainfall, from 1.1 to 4.0 inches was discharged during or soon after the cessation of rain, as direct runoff. Volumes of direct runoff were greatest in the Roanoke River Basin for two reasons, namely, high rainfall and low infiltration index. It is estimated that from 0.3 inch to 1.8 inches was discharged as base runoff, of which the greater part appeared as stream flow after the cessation of the rainstorm. The quantity of base runoff was least in the Neuse, Cape Fear, and Pee Dee Basins and greatest in the Kanawha and upper Tennessee Basins. There seems to be no apparent proportional relation of base runoff to direct runoff or to the volume of net retention. In the upper Tennessee River Basin the volume of base runoff nearly equaled the volume of direct runoff, and in some rivers in that region the base runoff exceeded the direct runoff. On the average, the volumes of rainfall and runoff in the upper Tennessee Basin were not greatly different from those in the James Basin, yet the base runoff in the latter averaged only 42 percent of the base runoff in the Tennessee Basin. The reason for this does not seem to be explained by the small difference in the infiltration index of these two basins as given in the last column of table 18 .

The average amounts of the net retention given in table 18 include about 0.5 inch of rainfall that fell during the initial periods of the storm prior to any significant rise in stream flow and was mainly intercepted by vegetation. The remainder first became an increment to soil moisture and to ground water and was subsequently lost through processes of transpiration and evaporation. Losses through these processes during the rainstorms were probably not great. 
A summary of the basin-wide averages of rainfall and runoff involved in the areas affected during the late-August flood is given in table 19. In general the amounts are less than during the mid-August flood: Base runoff, however, is notably greater in relation to the amount of direct runoff, reflecting the higher base flow during the later flood. The amounts of net retention noted in the next to the last column are also less than the retentions during the first storm. However, total net retention during August in the upper Savannah, Kanawha, and Tennessee River Basins ranged between 5 and 10 inches, sufficient to maintain soil moisture at more than average amounts during the following September and October, when precipitation was greatly deficient.

TABLE 19.-Inventory of rainfall and runoff, late-A ugust flood

\begin{tabular}{|c|c|c|c|c|c|c|c|}
\hline Basin & $\begin{array}{c}\text { Number } \\
\text { of } \\
\text { gaging } \\
\text { stations }\end{array}$ & $\begin{array}{c}\text { Number of } \\
\text { precipitation } \\
\text { stations } \\
\text { (per square } \\
\text { mile) }\end{array}$ & $\begin{array}{l}\text { Precipi- } \\
\text { tation } \\
\text { (inches) }\end{array}$ & $\begin{array}{c}\text { Direct } \\
\text { runoff } \\
\text { (inches) }\end{array}$ & $\begin{array}{c}\text { Base } \\
\text { runoff } \\
\text { (inches) }\end{array}$ & $\begin{array}{l}\text { Net } \\
\text { reten- } \\
\text { tion } \\
\text { (inches) }\end{array}$ & $\begin{array}{l}\text { Infiltra- } \\
\text { tion } \\
\text { index } \\
\text { (inches } \\
\text { per hour) }\end{array}$ \\
\hline $\begin{array}{l}\text { Upper Savannah. } \\
\text { Upper Kanawha, } \\
\text { Upper Tennessee }\end{array}$ & $\begin{array}{r}4 \\
7 \\
44\end{array}$ & 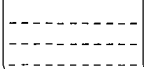 & $\begin{array}{l}7.5 \\
4.0 \\
6.9\end{array}$ & $\begin{array}{r}1.7 \\
.9 \\
2.1\end{array}$ & $\begin{array}{r}1.5 \\
.9 \\
1.8\end{array}$ & $\begin{array}{l}4.3 \\
2.2 \\
3.0\end{array}$ & $\begin{array}{r}0.48 \\
.32 \\
.37\end{array}$ \\
\hline
\end{tabular}

The infiltration indices during the late-August flood are greater than those over the same areas during the mid-August flood. This mainly reflects the difference in rates of rainfall during the two rainstorms. It may be noted that the infiltration indices during the late-August storm for the three basins noted are in the same proportion to one another as the infiltration indices for the same basins during the midAugust storm.

\section{COMPARISONS OF MAXIMUM RAINFALL RATES AND VOLUMES WITH MAXIMUM FLOOD DISCHARGES AND VOLUMES}

Flood-control works are usually designed on the basis of maximum observed or theoretically possible rates and volumes of rainfall and discharge. In addition to reviewing records of outstanding rainfall and floods, it is often of value with respect to such design to consider how the observed magnitudes might reasonably have been greater had the events occurred under more adverse conditions.

In the section on "Meteorologic and hydrologic conditions," results of studies of rainfall depth, area, and duration of the mid-August storm are presented in the form of tables of maximum observed rainfall of given duration and over given areas. (See pp. 59,60.) Also listed in this report are many records of flood discharge and volume. It is the purpose of this discussion to compare the amounts of rainfall and discharge to find which seem to approximate limiting value. For example, high rainfall may be recorded in a region in which no observations of stream flow were made, and, conversely, stream-flow data may be available in a region not adequately covered by rain gages. Thus extremes 
of discharge or rainfall may be inferred if one or the other is known.

The data of maximum rainfall have been converted into rates of discharge on the basis of the most adverse conditions by the following method:

The basic formula used is $q_{p}=S \frac{\mathrm{vol}}{\mathrm{lag}}$, in which $q_{\mathrm{p}}$ is peak discharge in second-feet per square mile; $S$ is the ordinate of the unit hydrograph and is dimensionless; vol is the volume of direct runoff per square mile expressed in second-foot-days; and the lag is the time interval, in days, between centers of mass of effective rainfall and direct runoff. If quantities representing the critical or the most adverse combinations are inserted in this formula, the result should indicate the limiting discharge under the given conditions in the storm area.

The value of $S$ is a function of the duration and distribution of rainfall and of the hydrograph shape. For the storm as a whole, it was computed that the value of $S$ was about 0.5 (see section on "Concentration of discharge," pp. 495-497), but studies of many unit hydrographs indicate that it varies from 0.45 for storms of long duration to 0.9 for storms of short duration.

A computation of lag intervals for the basins in the mid-August storm area indicates that the shortest lag for an area of 10 square miles would be about 1.5 hours ( $=0.062$ day). Maximum rainfall over 10 square miles, based on the list of maximum observed point rainfalls in table 10, was as follows: 1 hour, 2.75 inches; 2 hours, 3.90 inches; 3 hours, 4.6 inches. Maximum short-period rainfall during the late-August storm is indefinite. A study of the infiltration index with respect to drainage area indicates that the lowest or most adverse values ranged from about 0.10 inch per hour for 10 square miles to 0.20 inch per hour for areas of 10,000 square miles, and the amounts of rainfall will be reduced accordingly.

It will be noted that for lengthening storm duration the volume of supply increases, whereas the value of $S$ decreases. The critical or maximum values of peak discharge for an area of 10 square miles can be computed as follows:

\begin{tabular}{|c|c|c|c|c|c|c|c|}
\hline \multirow{2}{*}{$\begin{array}{c}\text { Duration } \\
\text { (hours) }\end{array}$} & \multirow{2}{*}{$\begin{array}{l}\text { Rainfall } \\
\text { (inches) }\end{array}$} & \multirow{2}{*}{$\begin{array}{c}\text { Retention } \\
\text { (inches) }\end{array}$} & \multicolumn{2}{|c|}{ Net } & \multirow[b]{2}{*}{$S$} & \multirow{2}{*}{$\underset{\text { (days) }}{\operatorname{Lag}}$} & \multirow{2}{*}{$\begin{array}{c}\text { Peak } \\
\text { discharge } \\
\text { (second-feet per } \\
\text { square mile) }\end{array}$} \\
\hline & & & Inches & $\begin{array}{l}\text { Second-foot- } \\
\text { days per } \\
\text { square mile }\end{array}$ & & & \\
\hline $\begin{array}{l}1 \\
2 \\
3\end{array}$ & $\begin{array}{l}2.75 \\
3.9 \\
4.6\end{array}$ & $\begin{array}{r}0.10 \\
.20 \\
.30\end{array}$ & $\begin{array}{l}2.65 \\
3.70 \\
4.3\end{array}$ & $\begin{array}{r}71 \\
99 \\
115\end{array}$ & $\begin{array}{r}0.82 \\
.63 \\
.48\end{array}$ & $\begin{array}{r}0.062 \\
.062 \\
.062 \\
\end{array}$ & $\begin{array}{r}940 \\
1,000 \\
890\end{array}=\max$. \\
\hline
\end{tabular}

Similarly for an area of 10,000 square miles the shortest lag would be about 48 hours, and, basing the retention on an infiltration index of 0.20 inch per hour, the maximum discharge is computed as follows : 


\begin{tabular}{|c|c|c|c|c|c|c|c|}
\hline \multirow{2}{*}{$\begin{array}{l}\text { Duration } \\
\text { (hours) }\end{array}$} & \multirow{2}{*}{$\begin{array}{l}\text { Rainfall } \\
\text { (inches) }\end{array}$} & \multirow{2}{*}{$\begin{array}{c}\text { Retention } \\
\text { (inches) }\end{array}$} & \multicolumn{2}{|c|}{ Net } & \multirow[b]{2}{*}{$S$} & \multirow{2}{*}{$\underset{\text { (days) }}{\text { Lag }}$} & \multirow{2}{*}{$\begin{array}{c}\text { Peak } \\
\text { discharge } \\
\text { (second-feet per } \\
\text { square mile) }\end{array}$} \\
\hline & & & Inches & $\begin{array}{l}\text { Second-foot- } \\
\text { days per } \\
\text { square mile }\end{array}$ & & & \\
\hline $\begin{array}{l}24 \\
48 \\
72\end{array}$ & $\begin{array}{r}6.3 \\
9.5 \\
10.8\end{array}$ & $\begin{array}{r}2.1 \\
3.8 \\
4.8\end{array}$ & $\begin{array}{l}4.2 \\
5.7 \\
6.0\end{array}$ & $\begin{array}{l}113 \\
153 \\
161\end{array}$ & $\begin{array}{r}0.85 \\
.69 \\
.59\end{array}$ & $\begin{array}{l}2 \\
2 \\
2\end{array}$ & $\begin{array}{l}48 \\
53 \\
48\end{array}=\max$. \\
\hline
\end{tabular}

Similar computations for 100 square miles and 1,000 square miles indicate discharges of about 425 and 180 second-feet per square mile, respectively.

In tables 12-14 and plotted on figure 21 are many recorded discharges of 1,000 second-feet or more per square mile for areas of 10 square miles or thereabouts. It may thus be inferred that rainfall of short-period intensity oecurred that was greater than any recorded.

By reference to figure 21 it will be seen that the greatest discharge for areas of 10,000 square miles is about 30 second-feet per square mile. As there are gaging stations in operation on all the principal rivers in the region, it is probable that the maximum discharge was measured in every river draining as much as 10,000 square miles. The highest recorded was on Roanoke River. However, the axis of the storm lay in a direction generally at right angles to the rivers so that no drainage basin with an area of 10,000 square miles was so located as to be critical with respect to the areal distribution of rainfall. A different storm position might have produced on the larger streams a discharge nearly 50 percent greater than recorded, although such transposition may not be meteorologically possible.

On figure 33 have been plotted depths of runoff during the midAugust flood with respect to size of drainage area. Only outstanding depths are plotted, as the graph was designed to delimit the maximum volume of runoff experienced during the flood. There are only four points available to define an enveloping curve-two at about 60 square miles, one at 550 square miles, and one at 8,700 square miles, the last being the Roanoke River. It is therefore only poorly defined.

On figure 33 there is also drawn a line showing maximum total storm rainfall over indicated areas, taken from figure 6 . The two graphs are nearly parallel, the maximum rainfall graph being about 7.5 inches above the enveloping graph of runoff. This difference between rainfall and runoff is about the same as the difference at the upper limits of the line of infiltration index of 0.30 inch per hour on figure 26, close to an average value, but there was a considerable area with lower or more adverse infiltration indices. The enveloping curve then does not represent the most unfavorable condition that might have prevailed with a more eritical combination of storm rainfall and low infiltration indices. There are several areas of about 100 square miles with infiltration indices of 0.10 inch per hour, but none lower. With this value of 


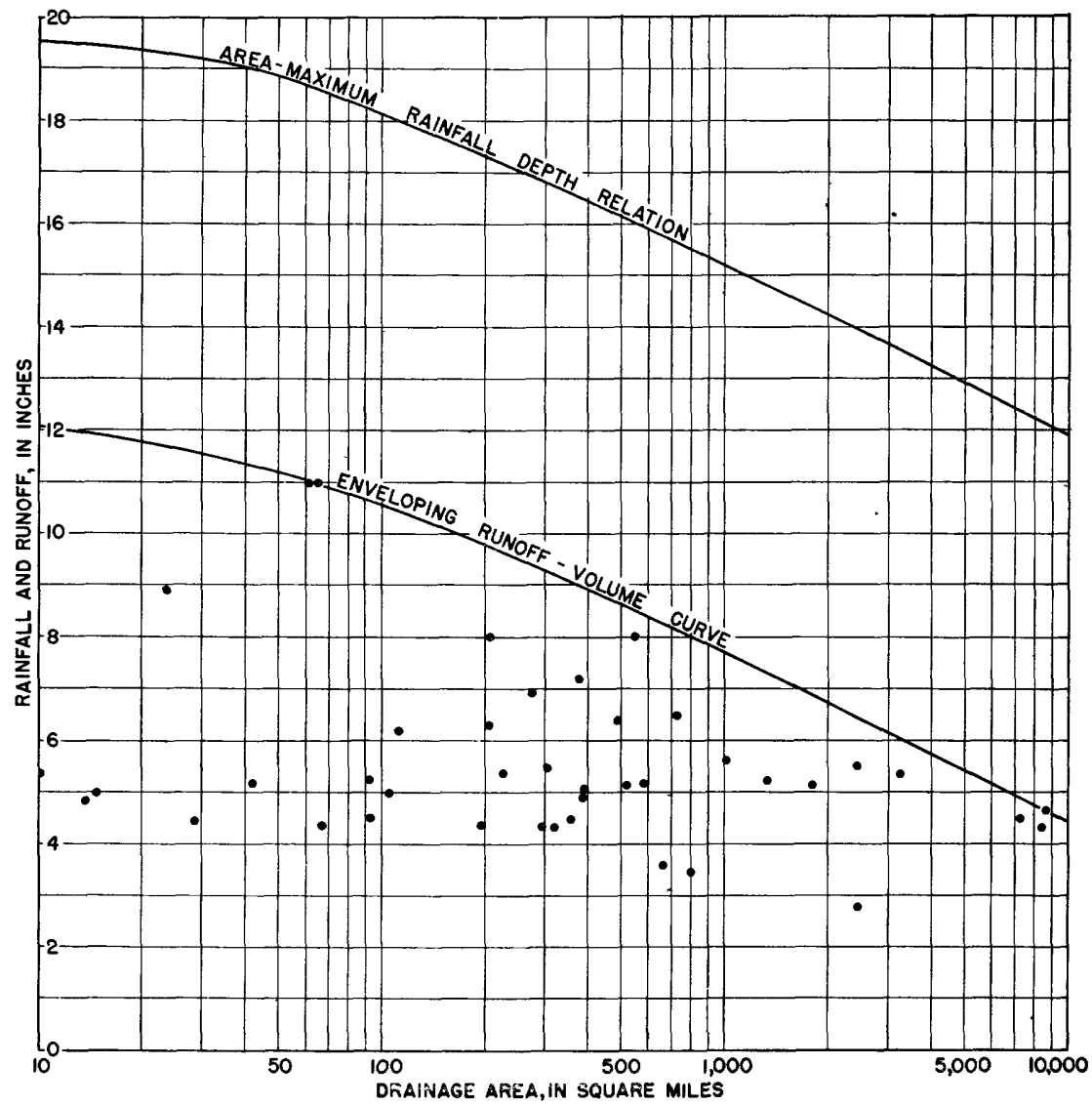

FIGURE 33.-Chart showing volume of runoff, in inches, in relation to drainage area and in relation to maximum rainfall, mid-August flood.

the infiltration index the retention would be about 3.5 inches for the high rainfall amounts, leaving a runoff of $18.1-3.5=14.6$ inches, in comparison with 10.6 inches, according to the enveloping curve of figure 33. For an area of 10,000 square miles the most adverse infiltration index experienced was 0.20 inch per hour, indicating a runoff volume of 6.2 inches, in comparison with about 4.5 inches discharged by the Roanoke River. A direct runoff volume of 6.2 inches essentially represents a transposition of the storm over a basin of about 10,000 square miles having an infiltration index of 0.20 inch per hour as did the Roanoke Basin. The transposition of the storm may not be meteorologically possible.

\section{BASE FLOW AND GROUND-WATER LEVELS}

Flood discharge is chiefly associated with the runoff that reaches the streams during the rainstorm or soon thereafter. This runoff has been 
termed direct runoff, its sharp concentration with respect to time being its identifying characteristic. The flood-peak discharges listed in tables 12,13 , and 14 are representative of direct flow. Volumes of direct runoff are reported in table 16.

Base flow, on the other hand, is the persistent constituent of river discharge. It is that component which maintains river discharge during rainless periods and consequently has great economic value. Base flow is composed largely of ground-water effluent, and the rate of such flow is an indication of the state of the ground-water levels and associated storage. An increment in base flow as a result of a rainstorm is indicative of ground-water recharge, drainage from which will sustain flow. for some days at a rate above the antecedent rates. Base flow rose in all basins as a result of the rainstorm of August 10-17. The increment was especially large in the James, Savannah, and Kanawha River Basins, where base flow rose, respectively, 2.0, 2.7, and 2.5 second-feet per square mile. From an analysis of several base-flow depletion hydrographs it was computed that such increments were sufficient to maintain river flow at rates above that of August 10 for about 25 days, even if there were no subsequent rain. This rise in stream flow also represents increment in ground-water storage of about $0.7,0.9$, and 0.8 inch in the three river basins. Total base runoff in these basins, as reported in table 18 , was greater by an amount equal to the base flow during the interval August 10-21.

A study of the increment in base flow and of the total base runoff in the several basins discloses a marked tendency to increase with storm precipitation and with initial rate of base flow, that is, the base flow on August 10 in second-feet per square mile. Base flow to a less extent also is indicative of soil moisture, although in those areas where the ground-water table is deep relative to soil-moisture penetration, the relationship might be very tenuous.

The flow of the rivers on August 10, 20, 28, and September 5 (respectively corresponding approximately to points A, E, F, and I on fig. 25) was composed almost entirely of ground-water outflow. In order to aid comparisons, the discharges on these dates at the several gaging stations have been converted into second-feet per square mile. The average flow at these gaging stations, grouped by drainage basins, is shown in table 20. Regulated streams are excluded from these averages.

The depletion in base flow following the mid-August storm was rapid, and on August 28, in the basins affected by the late-August storm, it was less than half what it was on August 20, though somewhat greater than on August 10. The increment due to the rainfall of August 28-30 was not so great as that due to the mid-August storm, so that base flow on September 5 was less than on August 20. 
TABLE 20.-Average base flow in second-feet per square mile, by drainage basins

\begin{tabular}{|c|c|c|c|c|}
\hline Basin & Aug. 10 & Aug. $20^{1}$ & Aug. 28 & Sept. 5 \\
\hline $\begin{array}{l}\text { James } \\
\text { Roanoke } \\
\text { Pamlico } \\
\text { Neuse } \\
\text { Cape Fear } \\
\text { Pee Dee } \\
\text { Santee } \\
\text { Savannah } \\
\text { Ogeechee } \\
\text { Kanawha } \\
\text { Upper Tennessee }\end{array}$ & $\begin{array}{r}0.6 \\
.7 \\
.5 \\
.2 \\
.2 \\
.3 \\
.4 \\
.6 \\
.2 \\
1.0 \\
1.10\end{array}$ & $\begin{array}{l}2.6 \\
2.1 \\
1.3 \\
.6 \\
.75 \\
.9 \\
1.3 \\
3.2 \\
2.1 \\
3.5 \\
2.9\end{array}$ & $\begin{array}{cc}1.1 \\
1.65 \\
1.4 \\
1\end{array}$ & 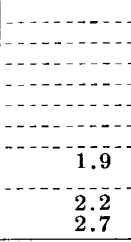 \\
\hline
\end{tabular}

${ }^{1}$ On some large streams a discharge corresponding to point $\mathrm{D}$ of fig. 25 was taken where this occurred after August 20.

Records of ground-water levels during the flood are available only in North Carolina. A summary is given in table 21.

TABLE 21.-Water levels in wells in North Carolina during flood periods

\begin{tabular}{|c|c|c|c|c|c|c|c|}
\hline & $\begin{array}{l}\text { Approximate } \\
\text { depth below } \\
\text { ground } \\
\text { surface to } \\
\text { water level } \\
\text { Aug. } 9\end{array}$ & $\begin{array}{c}\text { Stage } \\
\text { on } \\
\text { Aug. } 9 \\
\text { (feet) }\end{array}$ & $\begin{array}{c}\text { Precipi- } \\
\text { tation } \\
\text { Aug. 10-17 } \\
\text { (inches) }\end{array}$ & $\begin{array}{c}\text { Stage } \\
\text { on } \\
\text { Aug. } \\
17 \\
\text { (feet) }\end{array}$ & \begin{tabular}{|c|} 
Stage \\
on \\
Aug. \\
28 \\
(feet)
\end{tabular} & \begin{tabular}{|c|} 
Precipi- \\
tation \\
Aug. 28-31 \\
(inches)
\end{tabular} & $\begin{array}{l}\text { Stage } \\
\text { on } \\
\text { Sept. 1 } \\
\text { (feet) }\end{array}$ \\
\hline $\begin{array}{l}\text { Freuler well near Roanoke Rapids } \\
\text { Kurfee well at Mocksville } \\
\text { Brick Pit well near Goldsboro... } \\
\text { Baldwin well at Blantyre } \\
\text { Alston well near Nashville. } \\
\text { Governor Holt well at Haw River } \\
\text { McCauley well near Chapel Hill } \\
\text { Terrell well near Copeland }\end{array}$ & $\begin{array}{r}7.8 \\
23.0 \\
-34.5 \\
10.6 \\
23.8 \\
41.0 \\
47.7\end{array}$ & $\begin{array}{r}4.60 \\
7.42 \\
2.74 \\
5.49 \\
10.81 \\
5.17 \\
4.95 \\
1.30\end{array}$ & $\begin{array}{r}10.0 \\
5.8 \\
7.2 \\
9.7 \\
11.5 \\
6.0 \\
5.0 \\
5.7\end{array}$ & $\begin{array}{r}9.47 \\
8.77 \\
23.30 \\
5.46 \\
17.00 \\
9.17 \\
4.91 \\
2.07 \\
\end{array}$ & $\begin{array}{r}7.60 \\
8.76 \\
4.2 \\
5.18 \\
15.38 \\
7.89 \\
4.70 \\
1.75\end{array}$ & 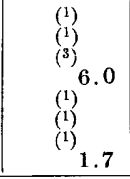 & $\begin{array}{r}7.72 \\
8.66 \\
4.4 \\
5.26 \\
14.11 \\
7.53 \\
4.64 \\
1.74\end{array}$ \\
\hline
\end{tabular}

${ }^{1}$ Less than 2 inches.

2 Possibly affected by surface inflow.

3 Less than 1 inch.

Ground-water levels on August 9 were below normal for August. The storm rainfall of August 10-17 produced a substantial rise in all wells in areas where there was more than 5 inches of rain except in the Baldwin well near Blantyre, N. C., in the upper French Broad River Basin. The water level in the Baldwin well is deep, and it responds very slowly to rainfall, as noted below.

After August 17 the water levels receded. None of the wells listed, except the Baldwin well, was in the area affected by the storm of August 28-30, so that the recession of the water levels was not interrupted by the late-August rainfall; but on September 1 the levels were above those of August 9. The rise in water level cannot readily be translated into volume of recharge for lack of sufficient water-level data and information as to specific yield.

The fluctuations of water level in the Freuler well during August are shown in figure 34. The water level rose sharply in this shallow well owing to the mid-August rainstorm and then slowly receded. The recession was interrupted by light rains on August 25 and 28. Rainfall during September and October was light and was insufficient to produce any significant rise in the water level, which receded from a stage of 7.84 feet on August 31 to 6.06 feet on September 30 and 5.17 feet on 
October 31. The recharge during the period August 10-17 was sufficient therefore to maintain the water level above that on August 10 for at least 2 months.

The deep Baldwin well at Blantyre, N. C., in the upper French Broad Basin, exhibited a different kind of behavior, as shown in figure 35 .

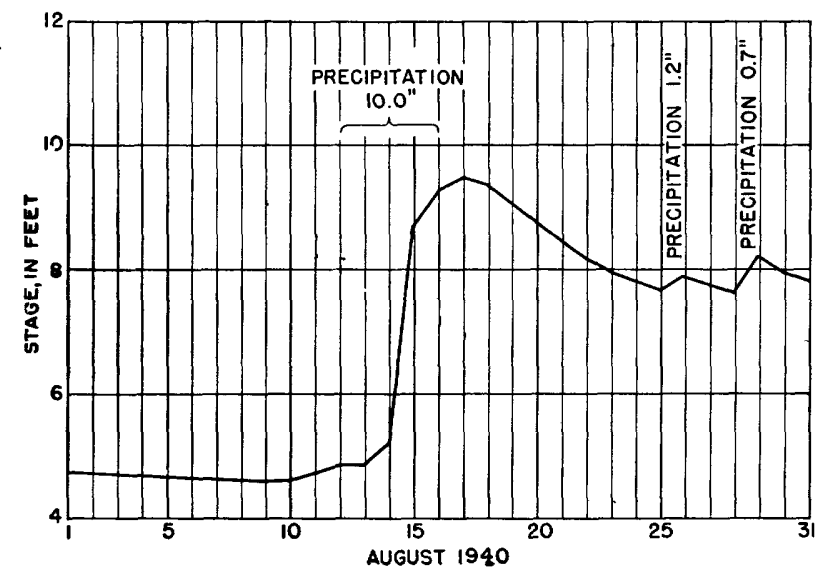

Figure 34.-Hydrograph of watêr level in Freuler well near Roanoke Rapids, N. C., August 1940.
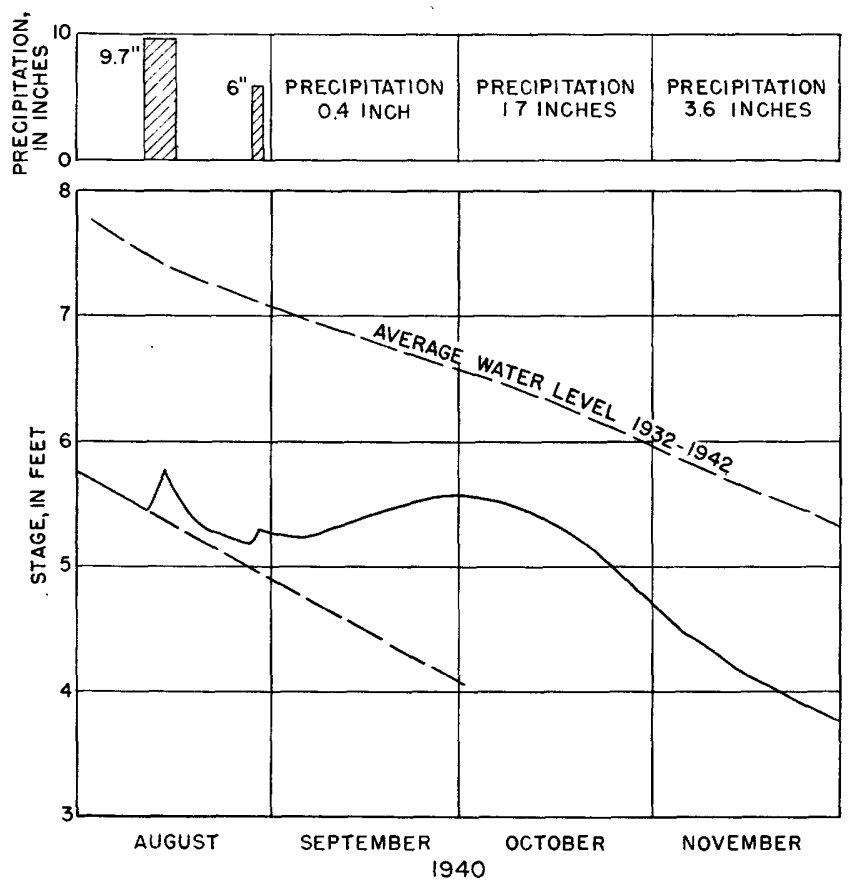

Figure 35.-Hydrograph of water level in Baldwin well at Blantyre, N. C., AugustNovember 1940 . 
There was a sharp but minor rise after the mid-August rains, followed by a nearly equally rapid recession; this minor fluctuation is suggestive of local inflow and drainage from the well. But the water level rose slowly during September, and on September 30 reached a peak of 5.56 feet. As the September rainfall was less than 1 inch, this rise must be attributed to the August rainfall. The September peak was only 0.07 foot higher than the water level on August 9, but the recharge from the August rainfall was doubtless greater than that, because without such recharge the water level would possibly have receded to nearly 4 feet. The fact that the heavy August rainfall was followed by 2 months of deficient precipitation provides an opportunity to study the delayed rise and recession of the Baldwin well, unobscured by recharge by subsequent rains.

Differences in time required for outflow of ground water are illustrated by the Freuler and Baldwin wells. Some ground-water aquifers respond relatively promptly to rainfall as illustrated by the water level in the shallow Freuler well. Deeper ground-water aquifers lag greatly behind the causative rainfall. The base flow in rivers therefore represents an integration of the outflow from many ground-water aquifers of a wide range in hydraulic behavior.

\section{FLOOD CRESTS}

Records of flood-crest stages were collected in the Tennessee River Basin by the Tennessee Valley Authority and in the James, Chowan, Roanoke, and Pee Dee River Basins by the Corps of Engineers, War Department. These data, together with crest stages obtained at Geological Survey gaging stations, are given in tables 22 and 23 . Such records are of special interest in presenting a limiting factor with respect to future developments along rivers and in furnishing basic information as to velocity of transmission of flood crests, valley or channel storage, the effects of natural or artificial channel constrictions, and other aspects of river behavior.

The tables describe the observation points by reference to local features and river distances above the mouth. The date and time of crest are given where known and the elevation of the crest at the observation point. It has been found that the crests of floods within the building limits of cities and towns and at other places more or less distant from a river may be materially different from those along the main river channel, as a result of various factors. Consequently, inconsistencies may occasionally appear to exist between local information and the records herein published. Flood erests on opposite banks of a stream are frequently at different elevations owing to the effect of bends and obstructions in the channel. 
TABLE 22.-Flood-crest stages of mid-August flood

Stream and location

\section{JAMES RIVER BASIN ${ }^{2}$}

James River:

Lick Run, Va., U. S. Geological Survey gage

Buchanan, Va. U. S. Geological Survey gage

Holcombs Rock, Va., U. S. Geological Survey gage -

Lynchburg, Va., U. S. Weather Bureau gage

Lynchburg, Va., at Lynchburg Iron and Metal Co. on left bank.

Mount Athos, Va., near Norfolk \& Western Ry. bridge, on right bank.

Galts Mill, Va., 4.5 miles upstream from, near Chesapeake \& Ohio Ry. bridge, on left bank.

Galts Mill, Va., on left bank

Stapleton, Va., on left bank

Walkerford $V$

Riverville, Va., 2.1 miles SW. of, on left bank

Riverville, Va., on left bank..

Gladstone, Va., at pump house of Chesapeake \& Ohio Ry., on left bank.

Gladstone, Va., at loading pen of Chesapeake \& Ohio Ry., on left bank.

Bent Creek, Va., U. S. Geological Survey gage......

Greenway, Va., on left bank ... . . .

Buffalo Station, Va., on left bank

Worwood, Va., on left bank

Winginia, Va., on left bank

Manteo, Va., Chesapeake \& Ohio Ry. depot, on lef bank.

Highland, Va., near Chesapeake \& Ohio Ry., depot, on left bank.

Howardsville, Va., on left bank

Warren, Va., 1.7 miles upstream from, on left bank

Warren, Va., 300 feet upstream from Chesapeake \& Ohio Ry. depot, on left bank.

Hatton, Va., at loading pen of Chesapeake \& Ohio Ry., on left bank.

Scottsville, Va., 1,200 feet upstream from bridge on Va. Highway 20 , on left bank.

Scottsville, Va., U.' S. Geological Survey gage

Scottsville, Va., 2.0 miles downstream from, on left bank.

Hardware, Va., 60 feet E. of Chesapeake \& Ohio Ry. depot, on left bank.

Strathmore, Va., at coal elevator of Chesapeake \& Ohio Ry., on left bank.

Bremo Bluff, Va., 200 feet SE. of post office, on left bank.

Bremo Bluff, Va., U. S. Weather Bureau gage

Bremo Bluff, Va., 2.2 miles downstream from, on left bank.

Bremo Bluff, Va., 4.2 miles downstream from, at dairy building, on left bank.

Rivana, Va., 80 feet north of Chesapeake \& Ohio Ry. depot, on left bank.

Columbia, Va., U. S. Weather Bureau gage

Elk Hill, Va., at loading pen of Chesapeake \& Ohio Ry., on left bank.

Pemberton, Va., 3.0 miles upstream from, on left bankPemberton, Va., 150 feet NW. of Chesapeake \& Ohio Ry. depot, on left bank.

Cartersville, Va., U. S. Geological Survey gage -.... Stokes, Va., 60 feet $N$. of Chesapeake \& Ohio Ry. depot, on left bank.

Rock Castle, Va., at Chesapeake \& Ohio Ry. depot, on left bank.

Rock Castle, Va., 2.0 miles downstream from, on left bank.

Irwin, Va., 2.0 miles upstream from, on left bank

Irwin, Va., at loading pen of Chesapeake \& Ohio Ry., on left bank.

Maidens, Va., 600 feet upstream from Chesapeake \& Ohio Ry. depot, on left bank.

1 Eastern standard time except as noted.

2 Furnished by Corps of Engineers, War Department.

\begin{tabular}{|c|c|c|}
\hline $\begin{array}{l}\text { Miles } \\
\text { above } \\
\text { mouth }\end{array}$ & Day and hour ${ }^{1}$ & $\begin{array}{c}\text { Elevation } \\
\text { (feet) }\end{array}$ \\
\hline $\begin{array}{l}338.9 \\
301.22 \\
263.17 \\
251.70 \\
251.00\end{array}$ & $\begin{array}{l}\text { Aug. } 16,10 \text { a.m } \\
\text { Aug. } 15,12 \text { m.- } \\
\text { Aug. } 16,3 \text { p.m. } \\
\text { Aug. } 16,4 \text { p.m. }\end{array}$ & $\begin{array}{l}991.5 \\
818.6 \\
572.8 \\
517.4 \\
521.0\end{array}$ \\
\hline 246.03 & & 492.3 \\
\hline 243.07 & & 478.7 \\
\hline $\begin{array}{l}238.53 \\
235.55 \\
232.87 \\
230.40 \\
228.10 \\
224.45\end{array}$ & & $\begin{array}{l}462.5 \\
450.0 \\
442.7 \\
430.2 \\
421.9 \\
409.5\end{array}$ \\
\hline 224.22 & & 408.0 \\
\hline $\begin{array}{l}222.90 \\
218.72 \\
215.62 \\
213.74 \\
211.10 \\
209.03 \\
205.97 \\
201.5\end{array}$ & Aug. 16, $4: 30$ p.m. & $\begin{array}{l}401.0 \\
385.4 \\
375.2 \\
368.4 \\
358.4 \\
353.2 \\
345.1 \\
334.4\end{array}$ \\
\hline 199.03 & & 323.8 \\
\hline $\begin{array}{l}196.53 \\
192.77 \\
191.09\end{array}$ & & $\begin{array}{l}316.1 \\
302.8 \\
295.3\end{array}$ \\
\hline 188.35 & & 287.2 \\
\hline 184.90 & & 279.4 \\
\hline $\begin{array}{l}184.65 \\
182.72\end{array}$ & Aug. 16, 12 p.m & $\begin{array}{l}279.0 \\
272.8\end{array}$ \\
\hline 178.00 & & 255.7 \\
\hline 173.68 & & 230.8 \\
\hline 171.50 & & 226.1 \\
\hline $\begin{array}{l}171.0 \\
169.25\end{array}$ & & $\begin{array}{l}224.9 \\
221.8\end{array}$ \\
\hline 167.37 & & 218.5 \\
\hline 164.57 & & 213.0 \\
\hline $\begin{array}{l}161.80 \\
157.08\end{array}$ & Aug. 17,10 a.m. & $\begin{array}{l}208.4 \\
201.5\end{array}$ \\
\hline $\begin{array}{l}155.42 \\
152.47\end{array}$ & & $\begin{array}{l}198.3 \\
192.6\end{array}$ \\
\hline $\begin{array}{l}152.36 \\
149.37\end{array}$ & Aug. 17, 3 p.m. & $\begin{array}{l}189.9 \\
185.8\end{array}$ \\
\hline 145.25 & & 178.1 \\
\hline 142.65 & & 173.2 \\
\hline $\begin{array}{l}139.81 \\
137.79\end{array}$ & & $\begin{array}{l}168.1 \\
166.0\end{array}$ \\
\hline 135.08 & & 161.6 \\
\hline
\end{tabular}

517.4

521.0

492.3

78.7

30.2

409.5

408.04

01.0

68.4

58.4

. 1

4

23.8

95.3

87.2

279.4

272.8

255.7

30.8

226.1

221.8

218.5

13.0

98.3

89.9

185.8

173.2

168.1

161.6 
TABLE 22.-Flood-crest stages of mid-August flood-Continued

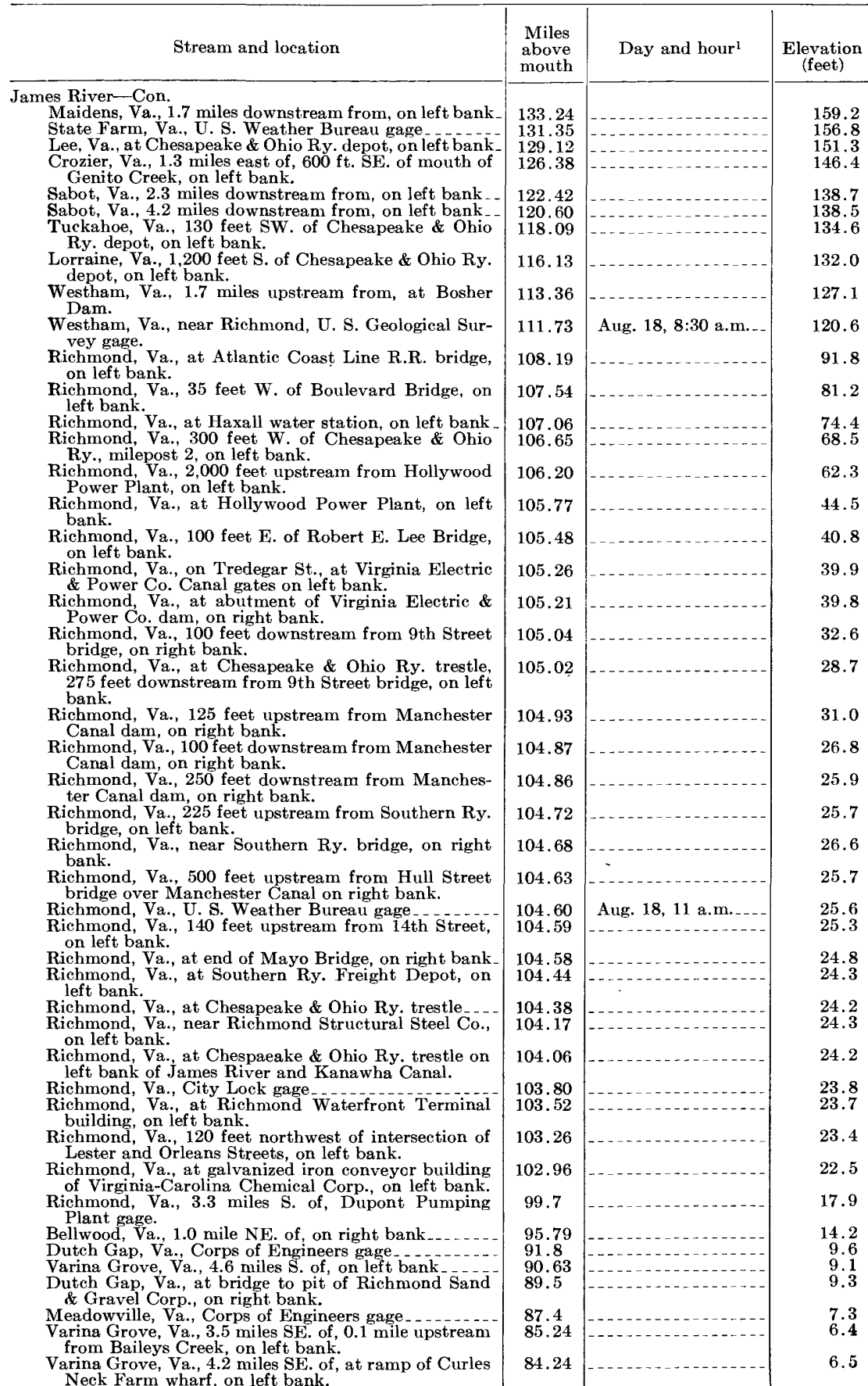

Eastern standard time except as noted. 
TABLE 22.-Flood-crest stages of mid-August flood-Continued

Stream and location

James River-Con.

Meadowville, Va., 0.7 mile SE. of, Corps of Engineers gage.

Bermuda Hundred, Va., 1.0 mile NW. of, 0.5 mile upstream from Turkey Island Cutoff, on right bank.

Bermuda Hundred, Va., 3.1 miles N. of, 0.6 mile upstream from Turkey Island Creek, on left bank.

Bermuda Hundred, Va., Corps of Engineers gage.

Appomattox River:

Farmville, Va., at W. C. Newman Ice Co., on right bank.

Farmville, Va., 30 feet north of Virginia Public Service Co. building, on right bank.

Farmville, Va., U. S. Geological Survey gage

Farmville, Va., 20 feet $\mathrm{S}$. of building of Kilkare Laundry on left bank.

Farmville, Va., 75 feet E. of Norfolk \& Western Ry. trestle, on left bank.

Farmville, Va., 2.7 miles NE. of, on left bank.

Rice, Va., 3.1 miles NW. of, at bridge of Norfolk and Western Ry., on left bank.

Angola, Va., 2.2 miles S. of, on left bank

Stony Point Mills, Va., 0.6 miles $\mathrm{S}$. of, 500 feet NW of Stony Point Bridge, on left bank.

Clementown Mills, Va., at bridge on Va. Highway 38 , on right bank.

Mattoax, Va., U. S. Geological Survey gage

Skinquarter, Va., 6.0 miles SW. of, on left bank

Rowlet Mill, Va., 2.2 miles E. of, 400 feet NE. of bridge on U. S. Highway 360 , on left bank.

Springfield Church, Va., 1.5 miles SE. of, at bridge over Wipponock Creek on Va. Highway 623, on right bank.

Sutherland, Va., 3.0 miles NE. of, on right bank . -

Petersburg, Va., 7.0 miles W. of, U. S. Geological Survey gage.

Petersburg, Va., at mouth of Indian Town Creek, on right bank.

Petersburg, Va., 1,200 feet upstream from Belt Line Bridge, on right bank.

Petersburg, Va., 50 feet downstream from Belt Line Bridge, on right bank.

Petersburg, Va., on Bocslee Street, 100 feet north of Norfolk \& Western Ry. track, on right bank.

Petersburg, Va., 1,100 feet upstream from Fleet Street Bridge, on right bank.

Petersburg, Va., at upstream side of Fleet Street., on right bank.

Petersburg, Va., 200 feet downstream from Fleet Street Bridge, on right bank.

Petersburg, Va., at intersection of Squaw Alley and Pigmingo Street, on right bank.

Petersburg, Va., at Virginia Electric \& Power Co. Harvell Plant, on right bank.

Petersburg, Va., 1,400 feet upstream from bridge on U. S. Highway 1 , on right bank.

Petersburg, Va., at bridge on U. S. Highway 1, on right bank.

Petersburg, Va., at intersection of River and Fifth Streets on right bank of Navigation Channel.

Petersburg, Va., at Atlantic Coast Line R.R. bridge, on right bank.

Petersburg, Va., on Magazine Road, near old powder magazine, on right bank.

Petersburg, Va., at riverward toe of Pocohontas Levee, 200 feet downstream from old foundation of Veteran Club house, on right bank.

Petersburg, Va., 50 feet downstream from end of Pocohontas Levee, on right bank.

\section{Chowan River Basiv 2}

Nottoway River:

Blackstone, Va., 7.5 miles SE. of, 100 feet NE. of Jonesboro Bridge on Va. Highway 46 , on left bank.

Blackstone, Va., 7.5 miles SE. of, Kennedy Bridge, on Va. Highway 46 , on left bank.

Ordsburg, Va., 2.5 miles W. of, on right bank

1 Eastern standard time except as noted.

2 Furnished by Corps of Engineers, War Department.

\begin{tabular}{|c|c|c|}
\hline $\begin{array}{l}\text { Miles } \\
\text { above } \\
\text { mouth }\end{array}$ & Day and hour ${ }^{1}$ & $\begin{array}{c}\text { Elevation } \\
\text { (feet) }\end{array}$ \\
\hline 82.4 & & 6.5 \\
\hline 80.26 & & 5.8 \\
\hline 76.87 & & 5.1 \\
\hline 73.3 & & 4.5 \\
\hline
\end{tabular}

109.9

306.7

304.2

305.5

304.4

302.0

296.7

298.2

277.9

267.4

248.3

209.8

200.8

195.1

151.2

23.7

(

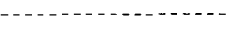

20.2

19.76

Aug. 20, 10-12 a.m.

136.1

134.4

49.4

46.0

43.8

38.9

34.3

29.9

20.4

20.3

18.3

17.7

16.6

9.1

14.1

13.3

10.9

115.9

238.8

114.9

232.5

109.6

215.2 


\section{FLOODS OF AUGUST 1940 IN THE SOUTHEASTERN STATES}

TABLE 22.-Flood-crest stages of mid-A ugust flood-Continued

\begin{tabular}{|c|c|c|c|}
\hline Stream and location & $\begin{array}{l}\text { Miles } \\
\text { above } \\
\text { mouth }\end{array}$ & Day and hour ${ }^{1}$ & $\begin{array}{c}\text { Elevation } \\
\text { (feet) }\end{array}$ \\
\hline $\begin{array}{l}\text { Nottoway River-Con. } \\
\text { Ordsburg, Va.. } 3.0 \text { miles NE. of, } 900 \text { feet south of }\end{array}$ & 107.42 & & 206.3 \\
\hline $\begin{array}{l}\text { Ordsburg, Va., } 3.0 \text { miles } \mathrm{NE} \text {. of, } 900 \text { feet south of } \\
\text { Gills Bridge on Va. Highway } 613 \text {, on right bank. }\end{array}$ & 107.42 & & 206.3 \\
\hline $\begin{array}{l}\text { Concord, Va., } 2.0 \text { miles N. of, } 600 \text { feet NW. of Har- } \\
\text { pers Bridge on Va. Highway } 612 \text {, on left bank. }\end{array}$ & 104.73 & & 198.9 \\
\hline Rawlings, Va., 2.0 miles NE. of, 125 feet SE. of Sea- & 100.5 & & 186.4 \\
\hline $\begin{array}{l}\text { MeKenney, Va., } 2.8 \text { miles S. of, } 400 \text { feet } \mathrm{N} \text {. of bridge } \\
\text { on U. S. Highway } 1 \text {, on left bank. }\end{array}$ & 98.39 & & 185.8 \\
\hline Warfield, Va., 6.4 miles E. of, on right bank -100 feet $\mathrm{NE}$. of & $\begin{array}{l}95.7 \\
92.7\end{array}$ & & $\begin{array}{l}180.8 \\
175.8\end{array}$ \\
\hline Concord Church, Va., 2.0 miles $S$. of, 300 feet $\mathrm{N}$. of & 82.31 & & 124.2 \\
\hline $\begin{array}{l}\text { Jarratt, Va., } 3.1 \text { miles NW. of, } 1,100 \text { feet } N \text {. of Smith's } \\
\text { Bridge on Va. Highway } 630 \text { on left bank. }\end{array}$ & 77.9 & & 99.0 \\
\hline $\begin{array}{l}\text { Stony Creek, Va., } 6.5 \text { miles } S \text {. of, } 0.3 \text { mile } N W \text {. of } \\
\text { Atlantic Coast Line } R, R \text { crossing right bank. }\end{array}$ & 73.6 & & 90.0 \\
\hline $\begin{array}{l}\text { Stony Creek, Va., } 3.5 \text { miles S. of, U. S. Geological } \\
\text { Survey gage. }\end{array}$ & 69.5 & & 82.1 \\
\hline Stony Creek, Va., 0.8 miles SE. of, 900 feet W. of & 66.3 & & 71.8 \\
\hline $\begin{array}{l}\text { Stony Creek, Va., } 4.0 \text { miles NE. of, on right bank- } \\
\text { Stony Creek, Va., } 7.6 \text { miles NE. of, } 30 \text { feet NE. of }\end{array}$ & $\begin{array}{l}63.0 \\
59.15\end{array}$ & & $\begin{array}{l}69.8 \\
66.6\end{array}$ \\
\hline $\begin{array}{l}\text { Nibletts Mill, Va., } 4.0 \text { miles W. of, on left bank } \\
\text { Homeville, Va., } 3.4 \text { miles NW. of, at bridge on Va. } \\
\text { Highway } 35 \text { over Nibletts Run Creek, on left bank. }\end{array}$ & $\begin{array}{l}56.67 \\
51.25\end{array}$ & & $\begin{array}{l}62.0 \\
52.6\end{array}$ \\
\hline 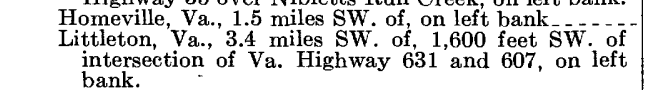 & $\begin{array}{l}47.3 \\
41.91\end{array}$ & & $\begin{array}{l}49.2 \\
43.4\end{array}$ \\
\hline Sebrell, Va., 3.9 miles NW. of, on left bank & 36.2 & & 38.2 \\
\hline $\begin{array}{l}\text { Sebrell, Va., } 2.3 \text { miles } \mathrm{SW} \text { of, } 200 \text { feet } \mathrm{W} \text {. of bridge } \\
\text { on Va. Highway } 653 \text { on right bank. }\end{array}$ & 32.4 & & 35.3 \\
\hline Sebrell, Va., 1.5 miles $S$. of, on left bank & 30.5 & & 32.5 \\
\hline $\begin{array}{l}\text { Courtland, Va., } 0.8 \text { mile } N \text {. of, on Va. Highway } 35, \\
350 \text { feet } W \text {. of county home, on left bank. }\end{array}$ & 25.2 & & 27.1 \\
\hline $\begin{array}{l}\text { Courtland, Va., } 2.9 \text { miles SE. of, } 1.0 \text { mile S. of inter- } \\
\text { section of Va. Highway } 674 \text { and U. S. Highway } 58, \\
\text { on left bank. }\end{array}$ & 20.1 & & 23.0 \\
\hline $\begin{array}{l}\text { Courtland, Va., } 4.0 \text { miles SE. of, at bridge on U. S. } \\
\text { Highway } 58 \text { over a swamp, on left bank. }\end{array}$ & 17.3 & & 21.5 \\
\hline $\begin{array}{l}\text { Courtland, Va., } 6.0 \text { miles } \mathrm{SW} \text {. of, } 2.5 \text { miles S. along } \\
\text { Va. Highway } 650 \text { from its intersection with U. S. } \\
\text { Highway } 58 \text {, on left bank. }\end{array}$ & 14.7 & & 21.3 \\
\hline $\begin{array}{l}\text { Franklin, Va., } 6.0 \text { miles SW. of, on left bank of stream- } \\
\text { Franklin, Va., } 8.4 \text { miles SW. of, } 1.5 \text { miles } S \text {. along Va. } \\
\text { Highway } 687 \text { from its intersection with Va. High- } \\
\text { way } 684 \text {, on left bank. }\end{array}$ & $\begin{array}{r}11.8 \\
8.5\end{array}$ & & $\begin{array}{l}18.1 \\
16.8\end{array}$ \\
\hline $\begin{array}{l}\text { Chowan River: } \\
\text { Winton, N. C., at bridge on N. C. Highway } 30\end{array}$ & 37.7 & & 5.2 \\
\hline Blackwater River: & & & \\
\hline $\begin{array}{l}\text { New Bohemia, Va., } 2.0 \text { miles } N \text {. of, } 50 \text { feet upstream } \\
\text { from bridge on Va. Highway } 630 \text {, on right bank. }\end{array}$ & 86.6 & & 111.7 \\
\hline $\begin{array}{l}\text { Prince George, Va., } 2.6 \text { miles SE. of, } 200 \text { feet upstream } \\
\text { from bridge on Va. Highway } 638 \text {, on right bank. }\end{array}$ & 83.0 & & 97.8 \\
\hline $\begin{array}{l}\text { New Bohemia, Va., } 5.5 \text { miles E. of, } 150 \text { feet down- } \\
\text { stream from bridge on Va. Highway } 635 \text {, on right } \\
\text { bank. }\end{array}$ & 79.9 & & 89.9 \\
\hline $\begin{array}{l}\text { Disputanta, Va., } 1.2 \text { miles NE. of, } 100 \text { feet upstream } \\
\text { from bridge on Va. Highway } 154 \text {, on right bank. }\end{array}$ & 76.9 & & 82.8 \\
\hline Waverly, Va., 5.8 miles NW. of, on left bank & 71.3 & & 74.7 \\
\hline $\begin{array}{l}\text { Waverly, Va., } 3.0 \text { miles NE. of, } 100 \text { feet upstream from } \\
\text { bridge on Va. Highway } 40 \text {, on right bank. }\end{array}$ & 65.01 & & 64.2 \\
\hline $\begin{array}{l}\text { Wakefield, Va., } 5.6 \text { miles N. of, } 200 \text { feet } \mathrm{S} \text {. of bridge } \\
\text { on Va. Highway } 603 \text { on right bank. }\end{array}$ & 60.31 & & 57.9 \\
\hline $\begin{array}{l}\text { Dendron, Va., } 2.0 \text { miles SW. of, on left bank } \\
\text { Sexton, Va., } 3.1 \text { miles SW. of, at Walls Bridge on Va. } \\
\text { Highway } 196 \text {, on left bank. }\end{array}$ & $\begin{array}{l}56.5 \\
50.3\end{array}$ & & $\begin{array}{l}50.2 \\
44.1\end{array}$ \\
\hline $\begin{array}{l}\text { Ivor, Va., } 6.2 \text { miles } \mathrm{N} \text {. of, at Proctors Bridge on Va. } \\
\text { Highway } 621 \text { on left bank. }\end{array}$ & 44.9 & & 39.9 \\
\hline Ivor, Va., 3.7 miles $\mathrm{E}$. of, at Broadwater Bridge on & 37.9 & & 33.1 \\
\hline 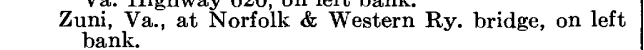 & 33.8 & & 30.9 \\
\hline $\begin{array}{l}\text { Burdette, Va., } 3.0 \text { miles NE. of, at bridge on Va. } \\
\text { Highway } 603 \text {, on left bank. }\end{array}$ & 27.15 & & 27.2 \\
\hline
\end{tabular}

' Eastern standard time except as noted. 
TABLE 22.-Flood-crest stages of mid-August flood-Continued

Stream and location

Blackwater River-Con.

Burdette, Va., 3.0 miles NE. of; from flood mark at U. S. Geological Survey gage established in 1941.

Burdette, Va., 2.2 miles $E$. of, 35 feet upstream from bridge on Va. Highway 619 , on right bank.

Franklin, Va., 3.2 miles upstream from, on right bank

Franklin, Va., near lumber yard office of Camp Manufacturing Co., on left bank.

Franklin, Va., near Franklin Peanut Co., on right bank

Franklin, Va., 500 feet SW. of bridge on U. S. Highway 58, on right bank.

Franklin, Va., at Warehouse of Pretlow Peanut Co., on right bank.

Franklin, Va., near J. C. Whitley Lumber Co., on right bank.

Franklin, Va., 3.5 miles E. of, at bridge on Va. Highway 189 , on left bank.

South Quay, Va., 5.4 miles downstream from, on left bank.

Meherrin River:

Brodnax, Va., 6.3 miles $\mathrm{N}$. of, 0.5 miles $\mathrm{W}$. of intersection of U. S. Highway 1 and Va. Highway 657 , on right bank.

Grandy, Va., 2.4 miles SW. of, 400 feet SW. of Gees Bridge, on right bank.

Lawrenceville, Va., 6.5 miles $\mathrm{SW}$. of, near bridge of Southern Ry., on right bank.

Lawrenceville, Va., 3.0 miles $\dot{\mathrm{S}}$. of, 380 feet NW. of bridge on Va. Highway 686 , on left bank.

Lawrenceville, Va., 4.3 miles SE. of, near U. S. Geological Survey gage.

Fitzhugh, Va., 4.2 miles N. of, 110 feet W. of bridge over Little Cove Creek, on Va. Highway 683, on right bank.

Independence Church, Va., 1.9 miles $\mathrm{N}$. of, on right bank.

Durand, Va., 1.3 miles SE. of, on left bank of stream

Emporia, Va., headwater gage of Va. Public Service Co.

Emporia, Va., tailwater gage of Va. Public Service Co.

Emporia, Va., at Atlantic Coast Line R.R. trestle, on left bank.

Emporia, Va., 75 feet downstream from bridge on Lee Street, on right bank.

Emporia, Va., 5.0 miles SE. of, on right bank

Lanes Corner, Va., 4.0 miles SE. of, on right bank.--

Claresville, Va., 1.0 miles $\mathrm{N}$. of, on right bank

Bryants Corner, Va., 2.5 miles NW. of, on right bank

Bryants Corner, Va., 4.8 miles SE. of, on right bank

Margarettsville, N. C., 2.0 miles NE. of, on right bank

Branches Bridge, N. C., 100 feet E. of bridge, on left bank.

Branches Bridge, N. C., 4.1 miles downstream from, on right bank.

Severn, N. C., 2.5 miles N. of, on left bank

Severn, N. C., 1.5 miles N. of, on right bank

Severn, N. C., 2.5 miles NE. of, 0.2 miles $\mathrm{SW}$. of Boon's Bridge, on right bank.

Murfreesboro, N. C., 5.0 miles NW. of, on right bank

Murfreesboro, N. C., 0.4 mile NE. of, 100 feet SW. of bridge on U. S. Highway 158 , on right bank.

Mapleton, N. C., 4.0 miles NE. of, 600 feet SW. of Cutoff Canal, on right bank.

Winton, N. C., 4.2 miles NW. of, 25 feet NE. of highway at Parker's Ferry, on right bank.

Roanoke River:

\section{Roanoke River Basin ${ }^{2}$} Salem, Va., about a mile SW. of, on right bank

Salem, Va., 1,000 feet upstream from highway bridge, on right bank.

Salem, Va., near highway bridge, on right bank

Salem, Va., a quarter of a mile upstream from bridge on U. S. Highway 11 , on right bank.

Salem, Va., about 300 feet upstream from bridge on U. S. Highway 11 , on right bank.

Salem, Va., at bridge on U. S. Highway 11, on SE. abutment.

1 Eastern standard time except as noted.

${ }^{2}$ Furnished by Corps of Engineers, War Department.

\begin{tabular}{|c|c|c|}
\hline $\begin{array}{l}\text { Miles } \\
\text { above } \\
\text { mouth }\end{array}$ & Day and hour ${ }^{1}$ & $\begin{array}{c}\text { Elevation } \\
\text { (feet) }\end{array}$ \\
\hline 27.15 & & 26.5 \\
\hline 24.1 & & 22.8 \\
\hline $\begin{array}{l}19.4 \\
13.6\end{array}$ & & $\begin{array}{l}19.6 \\
18.4\end{array}$ \\
\hline $\begin{array}{l}13.4 \\
13.2\end{array}$ & & $\begin{array}{l}17.8 \\
17.0\end{array}$ \\
\hline 12.6 & & 16.3 \\
\hline 12.4 & & 16.3 \\
\hline 8.3 & & 13.7 \\
\hline 2.9 & & 12.5 \\
\hline 115.4 & & 221.6 \\
\hline 111.1 & & 207.9 \\
\hline 105.15 & & 191.9 \\
\hline 97.55 & & 181.4 \\
\hline 95.65 & Aug. 17. & 178.6 \\
\hline 91.8 & & 168.5 \\
\hline 82.6 & & 135.1 \\
\hline $\begin{array}{l}79.3 \\
76.8\end{array}$ & & $\begin{array}{l}123.0 \\
120.0\end{array}$ \\
\hline $\begin{array}{l}76.8 \\
75.60\end{array}$ & & $\begin{array}{r}104.5 \\
98.4\end{array}$ \\
\hline 75.3 & & 97.1 \\
\hline $\begin{array}{l}71.7 \\
67.40 \\
63.20 \\
55.80 \\
52.40 \\
48.90 \\
43.30\end{array}$ & & $\begin{array}{l}81.8 \\
74.8 \\
64.8 \\
55.4 \\
48.9 \\
47.1 \\
42.3\end{array}$ \\
\hline 39.40 & & 39.3 \\
\hline $\begin{array}{l}35.0 \\
32.00 \\
28.05\end{array}$ & & $\begin{array}{l}35.6 \\
30.0 \\
24.9\end{array}$ \\
\hline $\begin{array}{l}16.70 \\
11.96\end{array}$ & & $\begin{array}{l}20.9 \\
18.2\end{array}$ \\
\hline 6.2 & & 10.7 \\
\hline 0.4 & & 6.9 \\
\hline $\begin{array}{l}370.90 \\
370.70 \\
370.30\end{array}$ & & $\begin{array}{l}1,017.66 \\
1,015.67 \\
1,011.30\end{array}$ \\
\hline $\begin{array}{l}370.10 \\
369.80\end{array}$ & & $\begin{array}{l}1,006.74 \\
1,004.84\end{array}$ \\
\hline 369.60 & & $1,002.58$ \\
\hline 369.54 & & 999.29 \\
\hline
\end{tabular}


TABLE 22.-Flood-crest stages of mid-A ugust flood-Continued

Stream and location

Roanoke River-Con.

Salem, Va., a quarter of a mile downstream from bridge on U. S. Highway 11 , on right bank.

Salem, Va., about 1.5 miles SE. of, about 100 feet upstream from bridge on U. S. Highway 11, on right bank.

Salem, Va., about 2.5 miles SE. of, on bridge on U. S. Highway 11.

Roanoke, Va., at pump house of Norfolk \& Western Ry. on left bank.

Roanoke, Va., about 1,000 feet upstream from Virginian Ry. bridge, on left bank.

Roanoke, Va., NE. end of Virginian Ry. bridge

Roanoke, Va., about 500 feet downstream from Virginian Ry. bridge, on right bank.

Roanoke, Va., about 2,000 feet downstream from Virginian Ry. bridge, on right bank.

Roanoke, Va., SE. abutment of bridge on Va. Highway 709 .

Roanoke, Va., at Harris Lumber Co., on right bank Do

Roanoke, Va., near Roanoke Cinder Block Co., on left bank.

Roanoke, Va., at foot of 18th Street, on left bank - -

Roanoke, Va., at Woods Lumber \& Supply Co., on left bank.

Roanoke, Va., near Woods Lumber \& Supply Co., on left bank.

Roanoke, Va., at bridge on U. S. Highway 11

Roanoke, Va., about 500 feet downstream from bridge on U. S. Highway 11, at Sam E. Finley Asphalt Co. on right bank.

Roanoke, Va., about 2,000 feet downstream from bridge on U. S. Highway 11, in Skyline Lumber Yard, on left bank.

Roanoke, Va., about 2,000 feet upstream from bridge on U. S. Highway 221, in Wasena Park, on right bank.

Roanoke, Va., about 1,000 feet upstream from bridge on U. S. Highway 221, in Wasena Park, on right bank.

Roanoke, Va., at Virginian Ry. track-scale house, on left bank.

Roanoke, Va., near Roanoke Ice \& Cold Storage Co., about 550 feet south of bridge on U. S. Highway 221 on right bank.

Roanoke, Va., Virginian Ry. pumphouse, on left bank

Roanoke, Va., at bridge on U. S. Highwav 220 .

Roanoke, Va., about 200 feet downstream from bridge on U. S. Highway 220 , on left bank.

Roanoke, Va., at Maher Field, on left bank

Roanoke, Va., Pleasant Avenue, fence of athletic field on left bank.

Roanoke, Va., 425 feet upstream from Norfolk \& Western Ry. bridge, in athletic field.

Roanoke, Va., about 100 feet upstream from Jefferson Avenue bridge, on right bank.

Roanoke, Va., at Pittsburgh Plate Glass Co., on left bank.

Roanoke, Va., opposite Metropolitan Flour Mills, on right bank.

Roanoke, Va., about 250 feet upstream from Walnut Street bridge, on right bank.

Roanoke, Va., Dominion Metal \& Culvert Corp., on left bank.

Roanoke, Va., U. S. Geological Survey gage, at Walnut Street bridge.

Roanoke, Va., about 350 feet downstream from Walnut Street bridge, in yard of Roanoke Iron \& Bridge Co., on left bank.

Roanoke, Va., about 800 feet downstream from Walnut Street bridge, at Roanoke Iron \& Bridge $\mathrm{Co}$. . bldg., on left bank.

Roanoke, Va., L. E. Pagahardt Garage, on right bank. Roanoke, Va., on right bank......... Do .

Roanoke, Va., 0.4 mile upstream from American Viscose Corp., on right bank.

Roanoke, Va., 0.2 mile upstream from bridge of American Viscose Corp., on right bank.

\begin{tabular}{l|c|r}
$\begin{array}{c}\text { Miles } \\
\text { above } \\
\text { mouth }\end{array}$ & Day and hour ${ }^{1}$ & \multicolumn{1}{|c|}{$\begin{array}{c}\text { Elevation } \\
\text { (feet) }\end{array}$} \\
\hline 369.30 & & 997.98 \\
368.70 & & 991.67
\end{tabular}

365.30

365.30

365.10

364.92

364.80

364.60

364.45

364.30

364.20

363.95

363.90

363.8

363.75

363.55

363.45

363.20

363.00

362.80

362.60

362.40

361.70

361.53

361.50

361.40

361.20

361.20

361.11

360.90

360.80

360.65

360.57

360.57

Avg. 14, 10.30 p.m.

963.12

961.43

960.39

957.58

954.85

954. 07

953.07

952.53

951.40

950.83

950.21

949.59

948.71

949.70

946.80

945. 36

942.79

941.09

938.61

932.03

931.96

931.44

930.77

930.58

930.53

929.76

928.22

927.59

926. 62

925.32

925.09

360.53

924.72

360.40

924.23

360.25

360.05

359.90

359.85

359.60

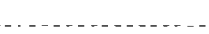

923.88

921.93

919.27

919.85

917.74

1 Eastern standard time except as noted. 
TABLE 22.-Flood-crest stages of mid-August flood-Continued

oanoke River-Con

Roanoke, Va., about 150 feet upstream from bridge of American Viscose Corp., on left bank.

Roanoke, Va., near American Viscose Corp., on right bank.

Roanoke, Va., about 300 feet downstream from bridge of American Viscose Corp., on right bank.

Roanoke, Va.., about 500 feet downstream from bridge of American Viscose Corp., on left bank.

Roanoke, Va., about 550 feet downstream from bridge of American Viscose Corp., on right bank.

Roanoke, Va., near American Viscose Corp., on left bank.

Roanoke, Va., about 0.2 mile upstream from highway bridge, at R. M. Hodges grocery store, on right bank.

Roanoke, Va., at Eastover service station, at highway bridge, on right bank.

Roanoke, Va., mouth of Tinker Creek

Niagara, Va., at dam of Appalachian Electric Power Co.

Niagara, Va., at power plant of Appalachian Electric Power Co.

Niagara, Va.. U. S. Geological Survey gage

Blackwater Ford, Va., 75 feet upstream from Back Creek, on right bank.

Hardys Ford, Va., 75 feet north of Hardys Ford Bridge on Va. Highway 634 , on lef t bank.

Webbs Ford, Va., on left bank.

Lynnville Ford, Va., 35 feet downstream from Lynnville Creek, on right bank.

Carters Island Ford, Va., 0.4 mile downstream from, on left bank.

Turners Ford, Va., 300 feet downstream from Indian Creek, on right bank.

Hales Ford, Va., 1,000 feet upstream from bridge on Va. Highway 122 , on right bank.

Radford Ford, Va., 700 feet downstream from, on right bank.

Greers Ford, Va., 0.9 mile downstream from, on left bank.

Shallow Ford, Va., on right bank

Anthonys Ford, Va., 2.1 miles downstream from, 0.5 mile downstream from Craddock Creek, on left bank.

Toshes, Va., 5 miles NW. of, U. S. Geological Survey

Tolers Ferry, Va., at bridge on Va. Highway 608 , on left bank.

Taylors Ford, Va., 2.3 miles upstream from, on right bank.

Chells Ford, Va., on left bank

Millers Ford, Va., on left bank-

Leesville, Va., 450 feet upstream from Virginian $\mathbf{R y}$. trestle, on right bank.

Leesville, Va., at Virginian $\mathrm{Ry}$. trestle, on right bank

Leesville, Va., 700 feet downstream from Virginian Ry. trestle, on left bank.

Leesville, Va., 3.3 miles downstream from, on right bank.

Altavista. Va., 0.5 mile upstream from, near Virginian Ry. trestle, on left bank.

Altavista, Va., U. S. Geological Survey gage

Altavista, Va., 500 feet NW. of bridge on Va. Highway 634 , on left bank.

Altavista, Va., 400 feet north of Lynch Creek, on left bank.

Altavista, Va., at Lane Co., on left bank

Altavista, Va., 0.2 mile downstream from silk mill, on lef $t$ bank.

Mansion, Va., at Wards Bridge on Va. Highway 640 , on left bank.

Mansion, Va.. 3.7 miles downstream from, on left bank

Taber, Va., on left bank...

Taber, Va., 3.2 miles downstream from, at Virginian Ry. bridge over Mill Creek, on left bank.

Seneca, Va., at Virginian Ry. bridge over Seneca River, on left bank.

Long Island, Va., at bridge on Va. Highway 126, on left bank.

Melrose, Va., at Virginian Ry. depot, on left bank

Melrose, Va., 2.6 miles downstream from, on left bank

\begin{tabular}{|c|c|c|}
\hline $\begin{array}{l}\text { Miles } \\
\text { above } \\
\text { mouth }\end{array}$ & Day and hour ${ }^{1}$ & $\begin{array}{c}\text { Elevation } \\
\text { (feet) }\end{array}$ \\
\hline 359.44 & & 916. \\
\hline 359.43 & & 916.10 \\
\hline 359.34 & & 915 . \\
\hline 359.30 & & 915.31 \\
\hline 359.30 & & 914.6 \\
\hline
\end{tabular}

359.25

358.15

357.95

357.24

355.40

355.32

355.28

352.26

347.87

345.08

340.97
340.97

337.80

335.76

331.35

328.00

325.90

322.29

319.17

313.11

309.29

304.40

299.99

296.66

293.82

293.68

293.50

290.02

287.00

286.45

286.10

285.88

285.60

285.20

281.81

278.18

914.84

904. 71

903.85

899.32

892.53

835.70

837.65

810.7

784.5

765.5

737.7

732.6

732.3

699.6

681.2

672.0

653.4

646.3

Aug. 15. 1:30 a.m.-

616.4

609.7

587.5

577.1

562.1

560.3

558.6

559.9

551.6

544.2

Aug. 15, 6 a.m..._ $\quad 543.3$

543.3
541.8

541.1

541.2

541.4

532.4

522.4

512.9

499.3

477.6

266.20

463.6

263.10

260.55

443.6

418.6

1 Eastern standaid time except as noted. 
TABLE 22,-Flood-crest stages of mid-August flood-Continued

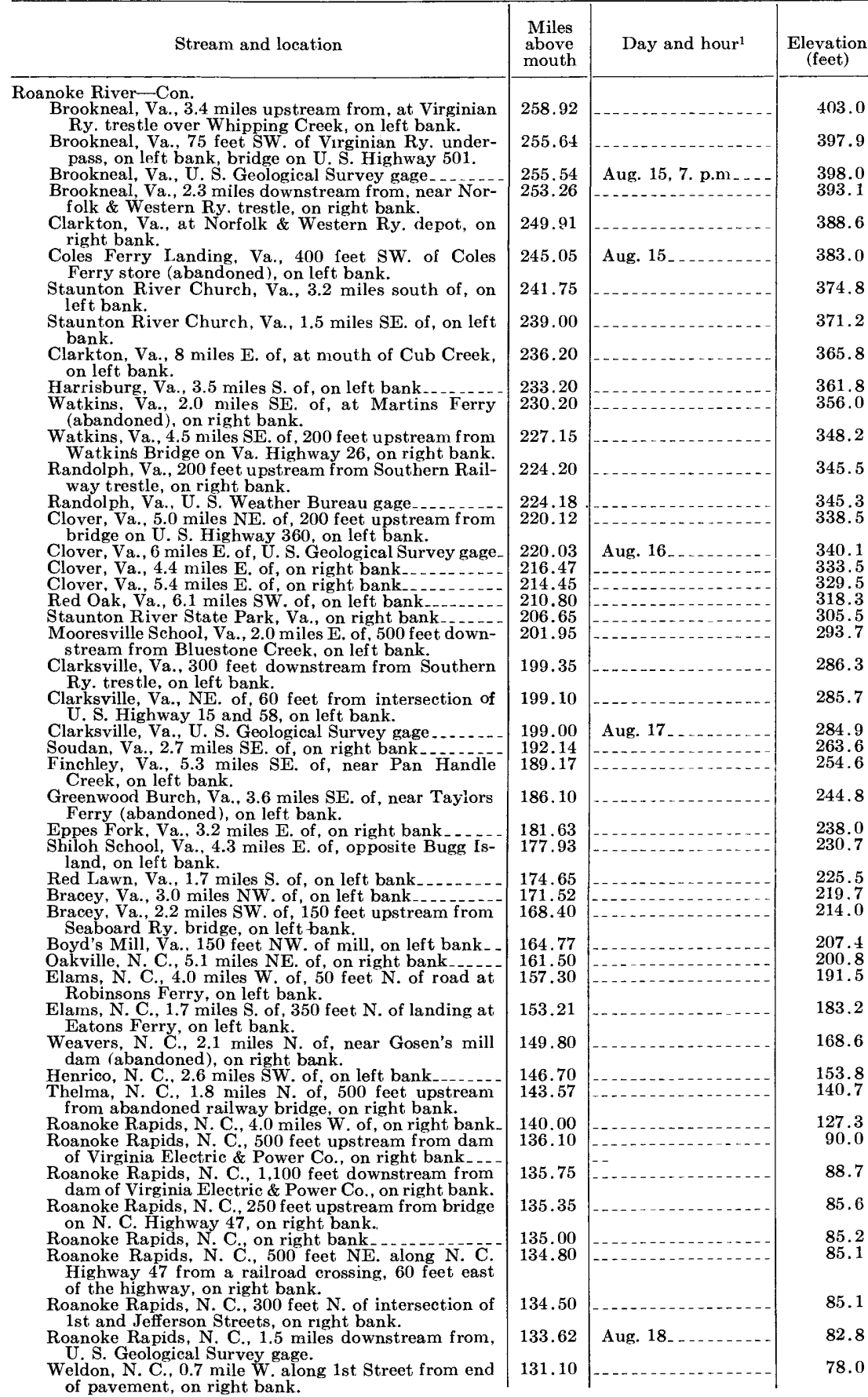

1 Eastern standard time except as noted. 
TABLE 22.-Flood-crest stages of mid-August flood-Continued

Stream and location

Roanoke River-Con.

Weldon, N. C., 500 feet $W$. along 1st Street from end of pavement, on right bank.

Weldon, N. C., 400 feet $W$. of schoolhouse along 1st Street, on right bank.

Weldon, N. C., 300 feet N. of Eddie \& Brothers Store on 1st Street, on right bank.

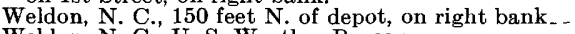

Weldon, N. C., U. S. Weather Bureau gage ........

Weldon, N. C., 500 feet east of U.S. Highway 158 , on right bank.

Weldon, N. C., 3.4 miles SE. of, on right bank . . .

Mud Castle, N.C., on left bank . .

Halifax, N. C., on right bank

Halifax, N. C., 350 feet $E$. of a gravel pit, on right bank

Halifax, N. C., 3.6 miles SE. of, near Little Zion Church, on right bank.

Caledonia State Prison Farm, N. C., 1.9 miles NW. of the farm office, on right bank.

Boones Crossroads, N. C., 1.4 miles SW. of, on left bank.

Tillery, N. C., 0.8 mile north of, on right bank

Tillery, N. C., 3.7 miles E. of, on right bank

Scotland Neck, N. C., 5.7 miles N., of U. S. Weather

Bureau gage.
Scotland Neck, N. C., 4.3 miles NE. of, 600 feet NE. along U. S. Highway 258 from its intersection with $\mathrm{N}$. C. Highway 561 , on right bank.

Norfleet, N. C., 4.4 miles NW. of, on right bank . . .

Norfleet, N. C., 2.3 miles $W$. of, on right bank

Roxodel, N. C., 2.4 miles SW. of, on left bank

Kelford, N. C., 2.8 miles SW. of, temporary gage of Corps of Engineers.

Kelford, N. C., 2.8 miles SW. of, at main trestle of Atlantic Coast Line R. R., on left bank.

Woodville, N. C., 4.1 miles SW. of, on left bank .... Palmyra, N. C., on right bank . . Woodville, N. C., 3.9 miles $S$. of, on left bank

Cahaba, N. C. 2.5 miles SW of, on left bank

Hamilton, $N$. C., 1.7 miles $N$. of, on right bank

Hamilton, N. C., at landing, on right bank ......

Quitsna, N. C. . 1.1 miles SW of, on left bank

Quitsn $N$ C. 25 miles SE of, near rogd to Coniot Landing, on left bank.

Williamston, N. C., at 117 Thelma Street, on right bank.

Williamston, N. C., at U. S. Highway 17 near Standard Oil Co.'s plant, on right bank.

Williamston, N. C., U. S. Weather Bureau gage.

Williamston, N. C., 4.6 miles SE. of, on right bank.

Jamesville, N. C., 2.0 miles $W$. of, 175 feet NW. of bridge on U. S. Highway 64 over Gardners Creek, on right bank.

Jamesville, N. C., on right bank

Dardens, N. C., 1.2 miles NW. of, on right bank...

Plymouth, N. C. 1.8 miles upstream from, at Hampton's Fishery, on right bank.

Plymouth, N. C., at west end of West Water Street, on right bank.

Plymouth, N. C., at Dare's Cut Rate Store on West Water Street, on right bank.

Plymouth, N. C., at eity pump house on right bank

Plymouth, N. C., at Plymouth Board \& Box Co., on right bank.

Dan River:

Francisco, N. C., 2.0 miles E. of, U. S. Geological Survey gage.

Wentworth, N. C., 3.0 miles NW. of, U. S. Geological Survey gage.

Leaksville, N. C., U. S. Geological Survey gage

Leaksville, N. C., 2.5 miles S. of, 400 feet downstream from Fishing Ċreek, on right bank.

Draper, N. C., 1.0 mile S. of, 160 feet NE. of bridge on N. C. Highway 700, on left bank.

Berry Hill, Va., 1,000 feet SW. of Danville \& Western Ry. flag station, on left bank.

Buford, Va., on left bank

\begin{tabular}{c|c|c}
$\begin{array}{c}\text { Miles } \\
\text { above } \\
\text { mouth }\end{array}$ & Day and hour ${ }^{1} \quad \begin{array}{c}\text { Elevation } \\
\text { (feet) }\end{array}$ \\
\hline &
\end{tabular}

130.77

130.55

77.7

130.30

130.10

130.02

129.90

127.25

124.05

120.75

120.55

117.60

113.44

111.31

108.50

105.90

102.49

102.18

99.63

97.57

95.00

93.79

93.60

85.70

79.25

72.04

69.50

66.10

62.07

59.10

55.05

51.55

37.85

37.63

37.48

31.95

28.30

17.92

12.55

9.30

7.50

7.24

7.11

6.50

Aug. 18, 2-5 p.m.

76.3

76.2

75.8

74.0
72.9

71.7

65.8

65.0

$\begin{array}{ll} & 64.8 \\ & 63.6\end{array}$

58.8

56.0

54.9

53.4
47.75

Aug $19,2 \mathrm{p}$

47.75

47.8

45.7

41.6

42.1

40.6

40.2

36.7

35.1

32.5

31.9

28.7

28.9

27.0

25.2

22.3

18.1

17.8

17.7

15.5

14.3

13.1

11.4

8.0

7.1

6.9

6.8

159.06

Aug. 14, 10:30 a.m.

39.4

103.74

Aug. 15, 10-12 a.m.

${ }^{3} 26.9$

93.56 Aug. 15, 6:30 a.m.-- 518.6

92.40 _... 515.7

87.81

504.1

81.60

487.1

77.40

478.2

${ }^{1}$ Eastern standard time except as noted.

$s$ Local gage datum; elevation above mean sea level not determined. 


\section{FLOODS OF AUGUST 1940 IN THE SOUTHEASTERN STATES}

TABLE 22.-Flood-crest stages of mid-August flood-Continued

Stream and location

Dau River-Con.

Powell, Va., 900 feet S. of Danville \& Western Ry. flag station, on left bank.

Schoolfield, Va., 400 feet upstream from Schoolfield powerhouse, on right bank.

Schoolfield, Va., 300 feet downstream from Schoolfield powerhouse, 50 feet upstream from bridge on U. S. Highway 58 , on right bank.

Schoolfield, Va., 300 feet downstream from bridge on Va. Highway 125 , on right bank.

Schoolfield, Va., at old city waterworks, on right bank

Danville; Va., at intersection of Union and Randolph Streets, on right bank.

Danville, Va., at intersection of Union and Floyd Streets, on right bank.

Danville, Va., 25 feet SW. of Union Street Bridge on U. S. Highway 58, on right bank.

Danville, Va., 300 feet downstream from Main Street bridge on U. S. Highway 58 , on right bank.

Danville, Va., U. S. Geological Survey gage

Danville, Va., 100 feet downstream from Southern Ry. bridge, on right bank.

Danville, Va., 2.0 miles downstream from, on right bank.

Blanche, N. C., 2.5 miles NW. of, at Walters Mill on Hogan Creek, on right bank.

Blanche, N. C., at Southern Ry. depot, on right bank

Blanche, N. C., 3.0 miles E. of, on right bank

Milton, N. C., at Southern Ry. depot, on right bank.

Jerdens Mill, Va., on left bank.

Jerdens Mill, Va., 0.7 mile NE. of, on left bank

Barksdale, Va., 75 feet S. of Southern Ry. flag station

Paces, Va., 400 feet E. of highway bridge, on right bank.

Tubeville, Va., 2.0 miles $\mathrm{N}$. of, on right bank

Stovers Mill, Va., 100 feet E. of Hupps Mill (abandoned), on right bank.

South Boston, Va., 4.0 miles upstream from, on left bank.

South Boston, Va., 1.2 miles W. of, at bridge on U. S. Highway 58 over Lawson Creek, on right bank.

South Boston, Va., U. S. Geological Survey gage

South Boston, Va., near intersection of U. S. Highways 58 and 501 , on right bank.

South Boston, Va., 1,200 feet E. of intersection of U. S. Highways 58 and 501 , on right bank.

South Boston, Va., 1,500 feet downstream from Southern Ry. depot, on left bank.

South Boston, Va., on right bank

South Boston, Va., 3.5 miles $E$. of, on left bank

Nelsons Ferry, Va., on left bank ...

Buffalo Lithia Springs, Va., 4 miles NW. of, at mouth of Hyco River, on left bank.

Buffalo Lithia Springs, Va., 31/2 miles NW. of, 0.5 mile downstream from mouth of Hyco River, on right bank.

Gravel Hill Church, Va., 2.1 miles NE. of, on right bank.

Saint Johns Church, Va., 1.7 miles NW. of, near bridge on Va. Highway 722 over Big Buffalo Creek, on right bank.

Occaneechee Island, Va., on left bank

Clarksville, Va., 200 feet NW. of Southern Ry. depot, on right bank.

Smith River:

Union Church, Va., 350 feet upstream from bridge on Va. Highway 623 , on right bank.

Jameson's Mill, Va., 1.5 miles downstream from, on left bank.

Jameson's Mill, Va., 4.0 miles downstream from, on left bank.

Philpott, Va., 3.6 miles upstream from, on left bank

Philpott, Va., 60 feet downstream from bridge on Va. Highway 674 , on right bank.

Bassett, Va., U. S. Geological Survey gage

Bassett, Va., on right bank.

Bassett, Va, at end of Fourth Street, on left bank

Bassett, Va., 200 feet $\mathrm{S}$. of end of First Street, on left bank.

\begin{tabular}{|c|c|c|}
\hline $\begin{array}{l}\text { Miles } \\
\text { above } \\
\text { mouth }\end{array}$ & Day and hour ${ }^{1}$ & $\begin{array}{c}\text { Elevation } \\
\text { (feet) }\end{array}$ \\
\hline 73.28 & & 463.6 \\
\hline 66.02 & & 441.8 \\
\hline 65.87 & & 425.5 \\
\hline 65.69 & & 424.9 \\
\hline $\begin{array}{l}65.6 \\
64.4\end{array}$ & & $\begin{array}{l}424.5 \\
417.3\end{array}$ \\
\hline 63.74 & & 413.5 \\
\hline 63.6 & & 412.7 \\
\hline 63.1 & & 401.5 \\
\hline $\begin{array}{l}62.74 \\
62.62\end{array}$ & Aug & $\begin{array}{l}400.4 \\
399.7\end{array}$ \\
\hline 60.5 & & 396.1 \\
\hline 58.45 & & 394.9 \\
\hline $\begin{array}{l}55.25 \\
52.1 \\
49.45 \\
45.4 \\
42.4 \\
41.0 \\
35.85\end{array}$ & & $\begin{array}{l}385.9 \\
379.9 \\
374.4 \\
368.8 \\
365.7 \\
363.2 \\
355.4\end{array}$ \\
\hline $\begin{array}{l}31.3 \\
28.15\end{array}$ & & $\begin{array}{l}347.7 \\
342.4\end{array}$ \\
\hline 26.51 & & 336.6 \\
\hline 23.50 & & 332.7 \\
\hline $\begin{array}{l}22.61 \\
22.49\end{array}$ & Aug. 16, 12 p.m. & $\begin{array}{r}331.9 \\
.330 .1\end{array}$ \\
\hline 22.25 & & 330.0 \\
\hline 22.13 & & 329.9 \\
\hline $\begin{array}{l}21.97 \\
20.10 \\
16.70 \\
12.15\end{array}$ & & $\begin{array}{l}329.6 \\
325.5 \\
321.6 \\
314.4\end{array}$ \\
\hline 11.7 & & 309.6 \\
\hline 8.4 & & 306.7 \\
\hline 5.3 & & 299.7 \\
\hline $\begin{array}{r}2.10 \\
.12\end{array}$ & & $\begin{array}{l}290.5 \\
285.2\end{array}$ \\
\hline 53.56 & & 925.2 \\
\hline 50.3 & & -877.0 \\
\hline 47.85 & & 856.0 \\
\hline $\begin{array}{l}44.65 \\
41.07\end{array}$ & & $\begin{array}{l}836.7 \\
796.4\end{array}$ \\
\hline $\begin{array}{l}38.05 \\
37.84 \\
37.55 \\
37.35\end{array}$ & Aug. 14, 5 p.m. & $\begin{array}{l}771.4 \\
772.1 \\
769.7 \\
768.0\end{array}$ \\
\hline
\end{tabular}

1 Eastern standard time except as noted. 
TABLE 22.-Flood-crest stages of mid-August flood-Continued

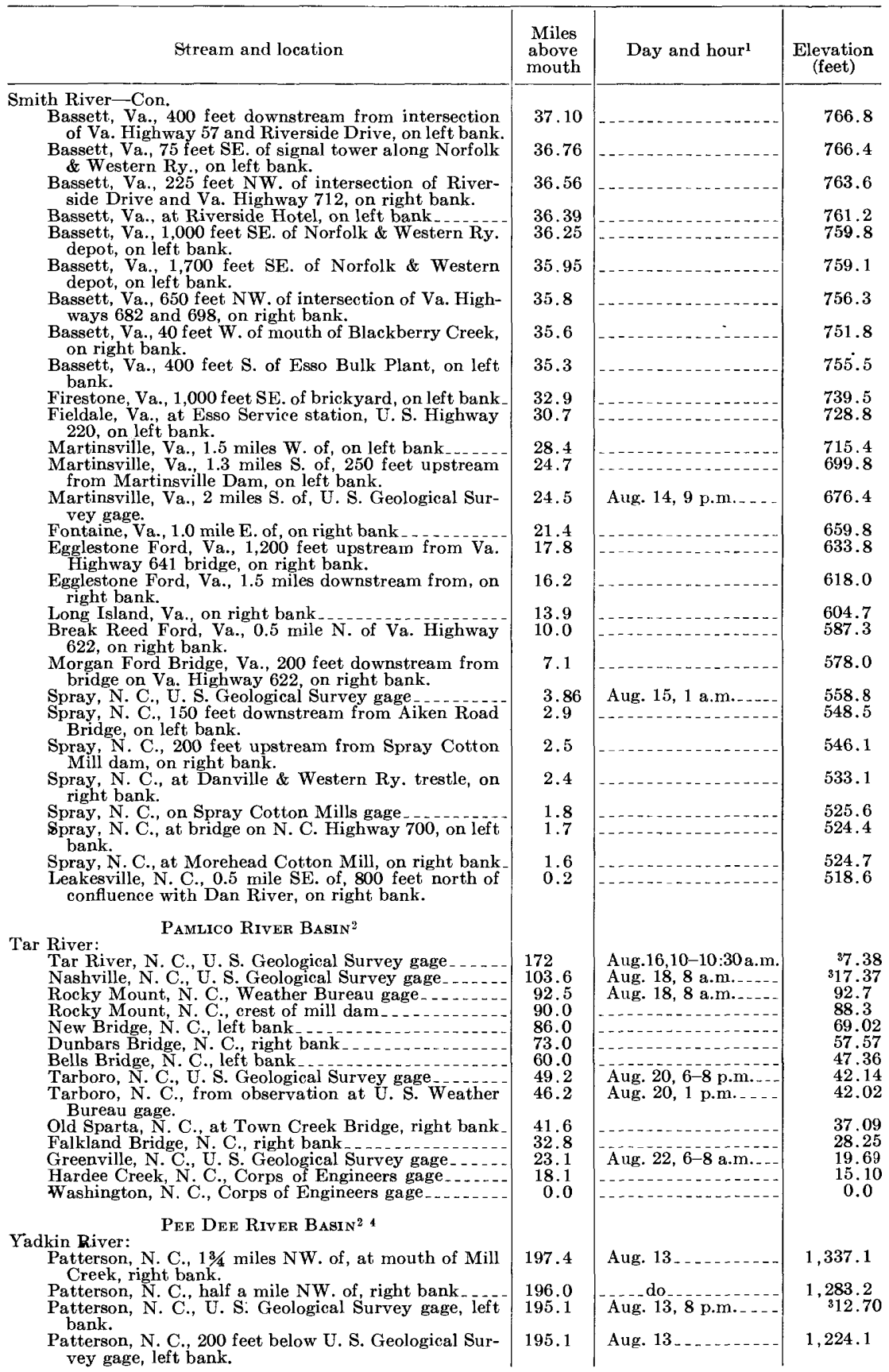

1 Eastern standard time except as noted.

2 Furnished by Corps of Engineers, War Department.

3 Local gage datum; elevation above mean sea level not determined.

4 Elevations are above mean sea level, datum of 1929 , supplementary adjustment of 1936 , except as noted. 
$\mathrm{T}_{\mathrm{ABLE}} 22$.-Flood-crest stages of mid-August flood-Continued

\begin{tabular}{|c|c|c|c|}
\hline Stream and location & $\begin{array}{l}\text { Miles } \\
\text { above } \\
\text { mouth }\end{array}$ & Day and hour ${ }^{1}$ & $\begin{array}{c}\text { Elevation } \\
\text { (feet) }\end{array}$ \\
\hline $\begin{array}{l}\text { Yadkin River-Con. } \\
\text { Patterson, N. } \text { C. } 3 \text { miles E. of, at mouth of Buffalo }\end{array}$ & & & \\
\hline $\begin{array}{l}\text { Patterson, N. C., } 3 \text { miles E. of, at mouth of } \mathrm{B} \\
\text { Creek, left bank. }\end{array}$ & 191.1 & Aug. 13 & $1,161.5$ \\
\hline $\begin{array}{l}\text { Patterson, N. C., } 5 \text { miles NE. of, near bridge on N. C. } \\
\text { Highway } 268 .\end{array}$ & 188.5 & do & $1,139.6$ \\
\hline Elkville, N. C., $21 / 2$ miles SW. of, at Caldwell dam site. & 186.4 & & 1,131 \\
\hline $\begin{array}{l}\text { Elkville, N. C., half a mile SW. of, on Kings Creek } \\
\text { Road, } 250 \text { feet S. of river, right bank. }\end{array}$ & 184.5 & & $1,107.2$ \\
\hline Elkville, N. C., 100 feet E. of Elk Creek, left bank - - & 181.9 & 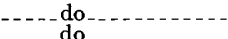 & $1,096.3$ \\
\hline $\begin{array}{l}\text { Elkville, N. C., about } 1 \text { mile NE. of, at Reedy Branch, } \\
\text { left bank. }\end{array}$ & 180.5 & & 8 \\
\hline Elkville, N. C., 2 miles NE. of, at Ferguson & 178.9 & $-\ldots$ do & $1,082: 7$ \\
\hline $\begin{array}{l}\text { Goshen, } N \text {. C., about } 3 \text { miles W. of, about } 1 \text { mile } \\
\text { below Stony Fork, right bank. }\end{array}$ & 175.2 & Aug. 1 & $1,060.0$ \\
\hline $\begin{array}{l}\text { Goshen, N. C., } 21 / 4 \text { miles W. of, at Marley Ford bridge, } \\
\text { right bank. }\end{array}$ & 174.0 & do & $1,046.4$ \\
\hline $\begin{array}{l}\text { Goshen, N. C., about } 3 / 4 \text { mile W. of, on Warrior Creek } \\
\text { Road, right bank. }\end{array}$ & 170.6 & 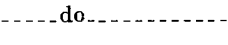 & $1,014.7$ \\
\hline $\begin{array}{l}\text { Goshen, N. C., right bank } \\
\text { Goshen, N. C., 3/4 mile east of, above Whites Creek, }\end{array}$ & $\begin{array}{l}169.8 \\
168.9\end{array}$ & _._. . do & $\begin{array}{l}1,010.0 \\
1,008.3\end{array}$ \\
\hline $\begin{array}{l}\text { Goshen, N. C., } 11 / 4 \text { miles NE. of, half a mile below } \\
\text { Smitthies Creek, right bank. }\end{array}$ & 168.3 & & $1,006.6$ \\
\hline $\begin{array}{l}\text { Goshen, } N \text {. C., } 31 / 2 \text { miles } \mathrm{NE} \text {. of, } 3 / 4 \text { mile above Mil- } \\
\text { lers Creek, right bank. }\end{array}$ & 165.6 & do & 990.2 \\
\hline $\begin{array}{l}\text { Wilkesboro, N. C., } 2 \text { miles W. of, } 3 / 4 \text { mile below Mil- } \\
\text { lers Creek, right bank. }\end{array}$ & 164.1 & do & 988.0 \\
\hline $\begin{array}{l}\text { Wilkesboro, N.C., } 11 / 2 \text { miles W. of, near mouth of } \\
\text { Moravian Creek, right bank. }\end{array}$ & 163.4 & . & 984.6 \\
\hline $\begin{array}{l}\text { Wilkesboro, N. C., } 11 / 4 \text { miles W. of, road leading to } \\
\text { Curtis Bridge. }\end{array}$ & 162.6 & Aug. 1 & 980.0 \\
\hline $\begin{array}{l}\text { Wilkesboro, N. C., U. S. Geological Survey gage, right } \\
\text { bank. }\end{array}$ & 161.0 & $\begin{array}{l}\text { Aug. } 14 \\
3: 30\end{array}$ & 979.9 \\
\hline $\begin{array}{l}\text { North Wilkesboro, N. C., Southern Ry. depot, left } \\
\text { bank. }\end{array}$ & 160.7 & Aug. & 979.4 \\
\hline $\begin{array}{l}\text { North Wilkesboro, N. C., 21/4 miles NE. of, Southern } \\
\text { Ry, bridge over Mulberry Creek, left bank. }\end{array}$ & 157.5 & do & 965.4 \\
\hline $\begin{array}{l}\text { North Wilkeshoro, N. C., } 41 / 4 \text { miles NE. of, Southern } \\
\text { Ry. bridge over Rock Creek, left bank. }\end{array}$ & 155.0 & & 961.0 \\
\hline $\begin{array}{l}\text { Roaring River, N. C., Southern Ry. bridge over Roar- } \\
\text { ing River, left bank. }\end{array}$ & 151.9 & & 948.7 \\
\hline $\begin{array}{l}\text { Ronda, N. C., left bank } \\
\text { Elkin, N. C., } 21 / 2 \text { miles W. of, Southern Ry. trestle }\end{array}$ & $\begin{array}{l}144.2 \\
140.1\end{array}$ & & $\begin{array}{l}923.3 \\
911.3\end{array}$ \\
\hline $\begin{array}{l}\text { over Little Elkin River, left bank. } \\
\text { Elkin, N. C., Southern Ry. bridge over Elkin River, } \\
\text { left bank. }\end{array}$ & 137.4 & & 904.9 \\
\hline $\begin{array}{l}\text { Elkin, N. C., } 2.3 \text { miles NE. of, on Highway 268, left } \\
\text { bank. }\end{array}$ & 135.2 & & 894.6 \\
\hline $\begin{array}{l}\text { Crutchfield, N. C., } 21 / 2 \text { miles W. of, Southern Ry. tres- } \\
\text { tle over Mitchell River, left bank. }\end{array}$ & 131.3 & $\mathrm{Au}$ & 886.0 \\
\hline eld, N. C., Southern Ry. depot, left bank & $\begin{array}{l}127.0 \\
125.4\end{array}$ & & $\begin{array}{l}868.3 \\
864.6\end{array}$ \\
\hline $\begin{array}{l}\text { Crutchfield, N. C., 18/4 miles E. of, Southern Ry. } \\
\text { bridge over Fisher River, left bank. }\end{array}$ & & & \\
\hline Rockford, N. C., So & 120.8 & $--8,8$ & 838.0 \\
\hline $\begin{array}{l}\text { Siloam, N. C., } 2 \text { miles W. of, highway intersection } 1 / 4 \\
\text { mile E. of Limerock railroad depot, left bank. }\end{array}$ & & & \\
\hline Siloam, N. C., Southern Ry. depot, left bank & 113.9 & & 816.7 \\
\hline $\begin{array}{l}\text { Shoals, N. C., } 0.4 \text { mile E. of, N. of Southern Ry. } \\
\text { tracks, left bank, }\end{array}$ & & & \\
\hline $\begin{array}{l}\text { Shoals, N. C., } 21 / 4 \text { miles E. of, Southern Ry. depot at } \\
\text { Boyden, left bank. }\end{array}$ & 107.2 & - & $\mathbf{7 7 3 . 3}$ \\
\hline $\begin{array}{l}\text { Donnaha, N. C., } 2 \text { miles NW, of, Southern Ry, trestle } \\
\text { over Little Yadkin River, left bank. }\end{array}$ & 105.5 & & 766.0 \\
\hline $\begin{array}{l}\text { Donnaha, N. C., Southern Ry. depot, left bank } \\
\text { Donnaha, N. C., } 6 \text { miles S. of, E. of bridge on U. S. } \\
\text { Highway } 421 \text {, lef } t \text { bank. }\end{array}$ & $\begin{array}{r}103.9 \\
96.3\end{array}$ & & $\begin{array}{l}763.4 \\
737.5\end{array}$ \\
\hline $\begin{array}{l}\text { Huntsville, N. C., } 1 \text { mile NE. of, near highway bridge } \\
\text { Clemmons, N. C., } 51 / 2 \text { miles } \mathrm{NW} \text {. of, Styers dam site. } \\
\text { Clemmons, N. C., } 21 \% 4 \text { miles NW. of, U. S. Highway }\end{array}$ & $\begin{array}{l}90.8 \\
83.4 \\
79.9\end{array}$ & & $\begin{array}{l}724.1 \\
710.6 \\
702.7\end{array}$ \\
\hline $\begin{array}{l}\text { Advance, N. C., } 2 \text { miles NE. of, Idols hydrostation } \\
\text { Advance, N. C., } 2 \text { miles E. of, on Baileys Ferry road.- } \\
\text { Advance, N. C., } 21 / 2 \text { miles SE. of, near Muddy Creek- } \\
\text { Advance, N. C., } 4 \text { miles S. of, on Highway } 801 \text { at Ful- }\end{array}$ & $\begin{array}{l}76.2 \\
73.7 \\
72.3 \\
65.9\end{array}$ & & $\begin{array}{l}693.8 \\
688.2 \\
686.1 \\
676.6\end{array}$ \\
\hline $\begin{array}{l}\text { Yadkin College, N. C., U. S. Geological Survey gage, } \\
\text { left bank. }\end{array}$ & 62.9 & Aug. 15, 10:30 p.m. & $\begin{array}{l}5672.4 \\
333.75\end{array}$ \\
\hline
\end{tabular}

1 Eastern standard time except as noted.

3 Local gage datum; elevation above mean sea level not determined.

5 From levels by Corps of Engineers to floodmark on gage well. 
TABLE 22.-Flood-crest stages of mid-August flood-Continued

Stream and location

\begin{tabular}{|c|c|c|}
\hline $\begin{array}{l}\text { Miles } \\
\text { above } \\
\text { mouth }\end{array}$ & Day and hour ${ }^{1}$ & $\begin{array}{c}\text { Elevation } \\
\text { (feet) }\end{array}$ \\
\hline 60.4 & Aug. $15 \ldots$ & 668.3 \\
\hline 57.9 & Aug. 15 or 16 & 662.3 \\
\hline 52.2 & do & 651.2 \\
\hline 46.6 & -do & 636.9 \\
\hline 0.0 & & \\
\hline $\begin{array}{l}87 \\
80 \\
73 \\
66.1\end{array}$ & Aug. $15,4: 45$ a. & $\begin{array}{c}21,486.4 \\
a 21,465.0 \\
a 21,430.4 \\
a 1,392.57\end{array}$ \\
\hline 62.6 & Aug. 15,5 a.m. & a1, 374.15 \\
\hline $\begin{array}{l}62.5 \\
60.5 \\
57 \\
54 \\
53 \\
49 \\
47 \\
45 \\
40 \\
39\end{array}$ & $\begin{array}{l}\text { Aug. } 15,3 \text { a.m. } \\
\text { Aug. 15, } \\
\\
\\
\\
\text { do do do do }\end{array}$ & $\begin{array}{l}1,370.54 \\
a b 1,353.1 \\
a b 1,335.4 \\
a b 1,301.4 \\
a b 1,290.2 \\
a b 1,266.4 \\
a b 1,247.1 \\
a b 1,239.7 \\
a b 1,198.8 \\
a b 1,179.7\end{array}$ \\
\hline 35 & $\ldots$ _. do & ${ }^{a b} 1,151,9$ \\
\hline $\begin{array}{l}30 \\
27 \\
25 \\
21 \\
18 \\
17.5 \\
12.5\end{array}$ & 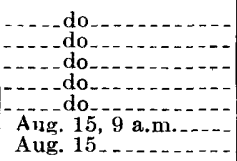 & $\begin{array}{c}a b 1,101.7 \\
a b 1,071.6 \\
a b 1,060.1 \\
a b 1,018.6 \\
a b 993.2 \\
a 974.44 \\
881.9\end{array}$ \\
\hline $\begin{array}{l}7 \\
6 \\
3 \\
1\end{array}$ & 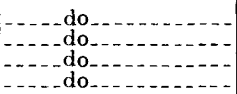 & $\begin{array}{l}a b 820.4 \\
a b 774.2 \\
a b 708.6 \\
a b 671.3\end{array}$ \\
\hline $\begin{array}{l}97.0 \\
97.0 \\
97.0\end{array}$ & Aug. 15 & $\begin{array}{l}6668.64 \\
6668.61\end{array}$ \\
\hline $\begin{array}{l}94.6 \\
94.4 \\
82.8\end{array}$ & $\begin{array}{l}\text { Aug. } 15,11: 30 \text { a.m. } \\
\text { Aug. 15, } 2 \text { p.m. }\end{array}$ & $\begin{array}{l}654.48 \\
6652.38 \\
9623.3\end{array}$ \\
\hline 82.8 & Aug. 15, 1:30 p.m.-- & 9622.9 \\
\hline 67.7 & Aug. 15, 4:30 p.m..- & 9601.4 \\
\hline 67.7 & _ _ do do & 9600.8 \\
\hline 58.5 & Aug. $15,9: 30$ p.m... & 89590.0 \\
\hline 57.8 & Aug. 15,9 p.m... & 9589.48 \\
\hline 54.3 & - _. do do . & 9586.36 \\
\hline 31.1 & Aug. 16, 3 a.m..... & 9568.4 \\
\hline 31.1 & _. do_- $^{-}$ & 9567.6 \\
\hline 0.0 & 15,11 & 11537.3 \\
\hline
\end{tabular}
Yadkin College, N. C., $21 / 2$ miles SW. of, near Harles-
ton Ferry road, right bank.

Yadkin College, N. C., 4 miles SW. of, $23 / 4$ miles above

Dutehman Creek, right bank.

Yadkin College, N. C., $6 \frac{1}{2}$ miles SW. of, at Hartleys Ferry, right bank.

Spencer, N. C., $41 / 2$ miles $N$. of, about 1 mile above South Yadkin River, site of proposed Junction Dam, right bank.

Mouth, confluence with Uwharrie River to form Pee Dee River.

\section{Kanawha River Basin}

New River:

Dickerson Mill, Va., just above West Virginia Stateline

Lick Creek, mouth of

Buffalo Creek, mouth of

Hinton, W. Va., U. S. Geological Survey recording gage above.

Hinton, W. Va., U. S. Geological Survey recording gage at.

Hinton, W. Va., U. S. Weather Bureau gage at ${ }^{7}$

Tug Branch, mouth of

Mill Branch,

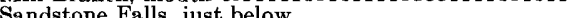

Sandstone Falls, just below

Meadow Creek, mouth of

Camp Branch, mouth of

Glades, W. Va., above railroad bridge at depot.....

Quinnimont, W. Va., mouth of Laurel Creek.

Prince, W. Va., at right bank abutment of railroad bridge at

Stretchers Neck tunnel, $400 \mathrm{ft}$. downstream from lower portal.

Buffalo Creek, $250 \mathrm{ft}$. above mouth of ...........

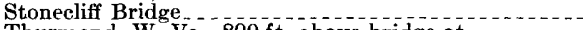

Thurmond, W. Va., $800 \mathrm{ft}$. above bridge at. . . .

Ephraim Creek, mouth of

Sewell, W. Va., above railroad bridge at.
Caperton, W. Va., U. S. Geological Survey gage.

Fayette, W. Va., site of U. S. Geological Survey gage, average of flood marks on left and right banks.

Hawks Nest, W. Va., at E. abutment of railway bridge-

Cotton Hill, W. Va., at Highway bridge (Laurel Creek)

At light signal tower of Chesapeake \& Ohio Ry.....

Cane Branch, W. Va.......................

Kanawha River:

Confluence of New and Gauley Rivers.

Gauley Bridge, W. Va., Bracken's restaurant

Gauley Bridge, W. Va., garage 100 feet below Bracken's restaurant.

Kanawha Falls, W. Va., navigation gage

Kanawha Falls, U.S. Geological Survey recording gage

London Dam, upper pool, U. S. Geological Survey recording gage.

London Dam, lower pool, U. S. Geological Survey recording gage.

Marmet, upper pool, U. S. Geological Survey recording gage.

Marmet, lower pool, U. S. Geological Survey recording gage.

Charleston, South Side Bridge, U. S. Weather Bureau gage. ${ }^{10}$

Charleston, mouth of Elk River, Corps of Engineers recording gage.

South Charleston, old lock 6, Corps of Engineers recording gage.

Winfield, upper pool, U. S. Geological Survey recording gage.

Winfield, lower pool, U. S. Geological Survey record-

ing gage.
Point Pleasant, at mouth, Corps of Engineers recording gage.

a Datum of 1929

- Furnished by Electro-Metallurgical Co., Glen

Ferris, W. Va.

1 Eastern Standard time except as noted.

- Sea-level datum, adjustment of 1912.

$804931-49-35$

${ }^{7}$ Furnished by U. S. Weather Bureau.

8 Maximum observed.

- Winfield datum, Corps Department.

10 Furnished by R. W. Jackson.

1 Sandy Hook datum. 
TABLE 22.-Flood-crest stages of mid-August flood-Continued

Stream and location

\section{Tennessee River Basin ${ }^{12}$}

French Broad River:

Rosman, N. C., U. S. Geological Survey gage, left bank.

Calvert, N. C., U. S. Geological Survey gage, right bank.

Calvert, N. C., at bridge 1.2 miles below gage, right bank.

Selica, N. C., 1.05 miles below Catheys Creek, right bank.

Brevard, N. C., 0.7 mile above bridge on U. S. Highway 276 , left bank.

Brevard, N. C., 0.35 mile below bridge on U. S. Highway 276 , right bank.

Brevard, N. C., at first bridge below U. S. Highway 276 , right bank.

Brevard, N. C., 0.4 mile below crossing of transmission line from Cascade Lake, right bank.

Pisgah Forest, N. C., 1.1 miles above Davidson River, right bank.

Pisgah Forest, N. C., 100 feet upstream from mouth of Davidson River, left bank.

Davidson River, N. C., 1.5 miles below Calhoun highway bridge, left bank.

Penrose, N. C., left bank

Blantyre, N. C., U. S. Geological Survey gage at BlanBlantyre, N. C., 1.5 miles below Blantyre bridge,

right bank.

Blantyre, N. C., 2.2 miles below Blantyre bridge at Little Willow Creek, right bank.

Bowman Bluff, N. C., 2,500 feet above Willow Creek, right bank.

Bowman Bluff, N. C., 1.9 miles above bridge on U. S. Highway 64 , right bank.

Etowah, N. C., 1 mile above bridge on U.S. Highway 64 , right bank.

Etowah. N. C., 450 feet above bridge on U. S. Highway 64 , right bank.

Horseshoe, N. C., 0.9 mile above bridge, right bank

Horseshoe, N. C., 0.2 mile below bridge, left bank --

Rugby, N. C., 0.6 mile above bridge on N. C. Highway 191 , left bank.

Rugby, N. C., 1,400 feet below bridge on N. C. Highway 191, left bank.

Rugby, N. C right bank of Mills River

Brickton, N. C., at Butlers Bridge, 1 mile below $\mathrm{Mu}$ Creek, left bank.

Fletcher, N. C., at Fanning Bridge, 1.5 miles below Cane Creek, left bank.

Arden, N. C., 1,600 feet above Glenn Bridge, right bank.

Arden, N. C., 600 feet above Glenn Bridge, left bank

Skyland, N. C., 25 feet above Long Shoals Bridge on N. C. Highway 280 , right bank.

Bent Creek, N. C., 1.7 miles below Long Shoals Bridge, right bank.

Bent Creek, N. C., U. S. Geological Survey gage, left bank.

Bent Creek, N. C., 1.5 miles above Dingle Creek, right bank.

Bent Creek, N. C., at Dingle Creek, right bank - -

Biltmore Forest, N. C., 2.7 miles above Hominy Creek, right bank.

Biltmore Forest, N. C., 1.2 miles above Hominy Creek, right bank.

Asheville, N. C., 0.6 mile above West Asheville viaduct, right bank.

Asheville, N. C., at West Asheville viaduct, left bank

Asheville, N. C., 1,300 feet below Southern Ry. bridge, right bank.

Asheville, N. C., U. S. Geological Survey gage, right bank.

Hot Springs, N. C., U. S. Geological Survey gage, right bank.

\begin{tabular}{|c|c|c|}
\hline $\begin{array}{l}\text { Miles } \\
\text { above } \\
\text { mouth }\end{array}$ & Day and hour ${ }^{1}$ & $\begin{array}{c}\text { Elevation } \\
\text { (feet) }\end{array}$ \\
\hline 216.3 & Aug. 13, 11 & $2,185.61$ \\
\hline 213.9 & Aug. 13,1 & $2,166.29$ \\
\hline 212.7 & Aug. 13. & $2,159.0$ \\
\hline 207.2 & . do & $2,135.5$ \\
\hline 197.2 & Aug. 14 & $2,111.2$ \\
\hline 196.2 & do & $2,109.4$ \\
\hline 195.4 & . do_. & $2,106.4$ \\
\hline 194.6 & - do_. & $2,103.5$ \\
\hline 192.8 & _.. do_ & $2,098.8$ \\
\hline 191.8 & $\ldots$ do & $2,098.2$ \\
\hline 189.2 & - - do_ & $2,089.8$ \\
\hline $\begin{array}{l}186.9 \\
183.7\end{array}$ & Aug. 14,9 & $\begin{array}{l}2,088.3 \\
2,082.21\end{array}$ \\
\hline 182.2 & Aug. 14 & $2,078.0$ \\
\hline 181.5 & $\ldots$. . do & $2,077.6$ \\
\hline 180.2 & $\ldots$ do_ & $2,076.9$ \\
\hline 179.1 & - $\ldots$ do & $2,075.1$ \\
\hline 178.2 & $\ldots$ do & $2,074.0$ \\
\hline 177.2 & -_do_. & $2,071.8$ \\
\hline $\begin{array}{l}174.2 \\
173.0 \\
171.2\end{array}$ & 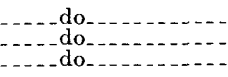 & $\begin{array}{l}2,067.4 \\
2,062.7 \\
2,059.4\end{array}$ \\
\hline 170.4 & $\ldots d$ & $2,058.6$ \\
\hline $\begin{array}{l}169.2 \\
167.4\end{array}$ & - _ do do & $\begin{array}{l}2,056.4 \\
2,054.9\end{array}$ \\
\hline 165.4 & $\ldots$. . do $\ldots$ & $2,049.6$ \\
\hline 163.2 & $\ldots$. . do & $2,043.1$ \\
\hline $\begin{array}{l}162.8 \\
160.6\end{array}$ & _. do do... & $\begin{array}{l}2,041.4 \\
2,027.4\end{array}$ \\
\hline 158.9 & _ _ do_. & $2,015.5$ \\
\hline 157.7 & Aug. 14, 6 & $2,008.55$ \\
\hline 157.1 & Aug. $14 \ldots$ & $2,005.2$ \\
\hline $\begin{array}{l}155.6 \\
154.2\end{array}$ & _. do do & $\begin{array}{l}1,999.0 \\
1,994.5\end{array}$ \\
\hline 152.7 & $\ldots$ do $\ldots$ & $1,988.7$ \\
\hline 148.2 & . do_ & $1,976.4$ \\
\hline $\begin{array}{l}147.65 \\
146.9\end{array}$ & $\ldots$. $\mathrm{do}_{\ldots} \ldots$ & $\begin{array}{l}1,973.8 \\
1,970.1\end{array}$ \\
\hline 145.7 & Aug. 14, 1 a.m. & $1,961.93$ \\
\hline 109.1 & Aug. 14, 6 a.m...... & $1,320.62$ \\
\hline
\end{tabular}

1 Eastern standard time except as noted.

11 From tabulations and surveys by Tennessee Valley Authority, sea-level datum of 1929, supplementary a djustment of 1936, except as noted. 
French Broad River-Con.

Newport, Tenn., U. S. Geological Survey gage

Dandridge, Tenn., U. S. Geological Survey gage, right bank.

Shady Grove, Tenn., 1.3 miles above Duncan Branch, right bank.

Shady Grove, Tenn., 0.4 mile above head of Ernest Fox Island, right bank.

Shady Grove, Tenn., Island Ford Mill, right bank Shady Grove, Tenn., 1 mile above foot of Zimmerman Island, right bank.

Catlettsburg, Tenn., 1 mile above Kykers Ferry, right bank.

Catlettsburg, Tenn., at Kykers Ferry, left bank

Revils, Tenn., at Hodges Ferry, right bank

Boyds Creek, Tenn., 500 feet below Boyds Creek, left bank.

Boyds Creek, Tenn., opposite middle of Bryant Island, left bank.

Kodak, Tenn., opposite mouth of Dumplin Creek, left bank.

Kodak, Tenn., 500 feet below foot of Cain Island, right bank.

Boyds Creek, Tenn., in point of Horseshoe Bend, left bank.

Boyds Creek, Tenn., opposite lower island of Seven Islands, right bank.

Kimberlin Heights, Tenn., 0.4 mile above head of Johnson Island, right bank.

Riverdale, Tenn., at Riverdale Ferry, left bank . . . .

Tennessee River:

Knoxville, Tenn., U. S. Geological Survey gage, right bank.

London, Tenn., U. S. Geological Survey gage, bridge pier.

Watts Bar Dam, Tenn., TVA headwater gage.

Watts Bar Dam, Tenn., TVA tailwater gage, right bank (head of Chickamauga Reservoir).

Breedenton, Tenn., U. S. Geological Survey gage, left bank.

Washington, Tenn., TVA gage at Armstrong's Ferry, right bank.

Sale Creek, Tenn., TVA gage at Doughty's Ferry, right bank.

Birchwood, Tenn., TVA gage at TVA safety harbor, left bank.

Chickamauga Reservoir, Tenn., TVA gage

Chickamauga Dam, Tenn. TVA tailwater gage

Chattanooga, Tenn., U. S. Geological Survey base gage at Meadow Lake, right bank.

Chattanooga, Tenn., U. S. Geological Survey auxiliary gage of Citico Bar, left bank.

Chattanooga, Tenn., U. S. Weather Bureau Walnut Street gage, left bank.

Davidson River:

Brevard, N. C., 0.9 mile above Avery Creek, right bank

Brevard, N. C., above Avery Creek, 400 feet below site of former U. S. Geological Survey gage known as Davidson River near Davidson River, N. C., right bank.

Brevard, N. C., 0.55 mile below Avery Creek, right bank.

Brevard, N. C., U. S. Geological Survey gage, right bank.

Pisgah Forest, N. C., at Ecusta Paper Corp. plant, right bank.

Pisgah Forest, N. C., at bridge on U. S. Highway 64 , left bank.

Mills River:

Mills River, N. C., 11/2 miles downstream from confluence of North and South Forks, U. S. Geological Survey gage, right bank.

Mills River, N. C.., 30 feet below bridge on N. C. Highway 191, right bank.

Mills River, N. C., left bank

\begin{tabular}{|c|c|c|}
\hline $\begin{array}{l}\text { Miles } \\
\text { above } \\
\text { mouth }\end{array}$ & Day and hour ${ }^{1}$ & $\begin{array}{c}\text { Elevation } \\
\text { (feet) }\end{array}$ \\
\hline $\begin{array}{l}77.4 \\
45.3\end{array}$ & $\begin{array}{l}\text { Aug. } 14,7: 30 \text { a.m. } .^{13}- \\
\text { Aug. } 15,7 \text { a.m. }{ }^{13}\end{array}$ & $\begin{array}{r}1,024.20 \\
922.06\end{array}$ \\
\hline 39.3 & Aug. 15 $\ldots$ & 906.6 \\
\hline 36.3 & . & 900.1 \\
\hline $\begin{array}{l}35.1 \\
33.9\end{array}$ & 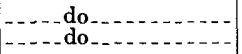 & $\begin{array}{l}896.5 \\
893.9\end{array}$ \\
\hline 29.7 & - & 885.8 \\
\hline $\begin{array}{l}28.8 \\
26.3 \\
24.0\end{array}$ & 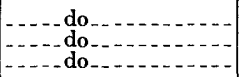 & $\begin{array}{l}882.4 \\
876.7 \\
874.2\end{array}$ \\
\hline 22.0 & - $\ldots$ do_... & 869.3 \\
\hline 19.9 & _... do do & 864.2 \\
\hline 18.9 & -...do_.. & 862.2 \\
\hline 16.4 & . . do do & 858.4 \\
\hline 14.6 & _..... do... & 853.8 \\
\hline 11.1 & $\ldots$..... do....... & 845.1 \\
\hline 7.4 & - - - do-_. & 837.7 \\
\hline 648.4 & Aug. 16, 2 a.m. ${ }^{13}$. & 821.58 \\
\hline 591.5 & Aug. 16, 4 p.m. ${ }^{13}$. & 746.15 \\
\hline $\begin{array}{l}530.2 \\
529.5\end{array}$ & $\begin{array}{l}\text { Aug. } 17,7 \text { a.m.13 } \\
\text { Aug. } 17,8 \text { a.m. }{ }^{13}-\ldots\end{array}$ & $\begin{array}{l}691.0 \\
687.8\end{array}$ \\
\hline 523.1 & Aug. $17,3-6$ p.m. ${ }^{13}-$ & 685.54 \\
\hline 503.8 & Aug. 18,9 p.m. ${ }^{13}--$ & 682.9 \\
\hline 497.2 & - do do & 682.8 \\
\hline 488.5 & Aug. 18,8 p.m. ${ }^{13}$ & 682.7 \\
\hline $\begin{array}{l}471.0 \\
471.0 \\
467.6\end{array}$ & $\begin{array}{l}\text { Aug. } 18,9 \text { p.m. }{ }^{13} \\
\text { Aug. } 16,3 \text { p.m. }{ }^{13} \\
\text { Aug. } 16,4 \text { p.m. }{ }^{13}-\end{array}$ & $\begin{array}{l}682.5 \\
642.3 \\
640.97\end{array}$ \\
\hline 465.4 & $-\cdots \mathrm{do}^{13}-\ldots$ & 640.0 \\
\hline 464.2 & $\ldots \mathrm{do}^{13} \ldots$ & 639.5 \\
\hline $\begin{array}{l}5.2 \\
4.3\end{array}$ & Aug. 13..... & $\begin{array}{l}2,204.3 \\
2,177.4\end{array}$ \\
\hline 3.5 & -... do do....... & $2,154.3$ \\
\hline 2.05 & Aug. $13,10: 30$ a.m.- & $2,124.33$ \\
\hline 1.1 & Aug. 13 ... & $2,114.0$ \\
\hline .35 & . . . do_. & $2,100.0$ \\
\hline 4.4 & Aug. 13, 4 p.m.... & $2,101.62$ \\
\hline 2.4 & Aug. $13 \ldots \ldots$ & $2,076.8$ \\
\hline 1.35 & - do do........... & $2,063.1$ \\
\hline
\end{tabular}

1 Eastern standard time except as noted.

18 Central standard time.

$804331-49-36$ 
TABLE 22.-Flood-crest stages of mid-August flood-Continued

Stream and location

Mud Creek:

Hendersonville, N. C., at highway bridge at mouth of Shephard Creek, right bank.

Hendersonville, N. C., near bridge on U. S. Highway 25 , right bank.

Hendersonville, N. C., at bridge on U. S. Highway 176 , right bank.

Hendersonville, N. C., at bridge on U. S. Highway 64 , left bank.

Balfour, N. C., near Smyth Station bridge, right bank

Balfour, N. C., at Balfour quarry, 0.6 mile below Clear Creek, left bank.

Mountain Home, N. C., left bank

Mountain Home, N. C., Southern Ry. fill, left bank

Naples, N. C., U. S. Geological Survey gage, left bank

Naples, N. C., at bridge on U. S. Highway 25 , right bank.

Naples, N. C., 0.4 mile above first highway bridge above mouth, right bank.

Naples, N. C., 1,500 feet below first highway bridge above mouth, right bank.

Cane Creek:

Fairview, N. C., 0.3 mile above Fairview, right bank

Fairview, N. C., 0.4 mile below Fairview, right bank

Fairview, N. C., 0.3 mile above Shoal Creek, left bank

Fairview, N. C., 0.2 mile above Gap Creek, right bank-

Fairview, N. C., 0.7 mile below Gap Creek, right bank.

Fletcher, N. C., 0.5 mile above Robinson Creek, right bank.

Fletcher, N. C., at first highway bridge above Fletcher, left bank.

Brickton, N. C., 0.4 mile below Kimsey Creek, right bank.

Hominy Creek:

Candler, N. C., 100 feet above lower highway bridge, left bank.

Candler, N. C., 0.7 mile below Candler, left bank

Enka, N. C., at American Enka Corp. intake dam, right bank.

Swannanoa River:

Swannanoa, N. C., 275 feet above street bridge, right bank.

Swannanoa, N. C., at bridge on U. S. Highway 70, left bank.

Swannanoa, N. C., 0.9 mile below bridge on U. S. Highway 70, left bank.

Swannanoa, N. C., near Asheville Farm School, right bank.

Swannanoa, N. C., 0.5 mile below Bull Creek, right bank.

Azalea, N. C., 1.5 miles above bridge on U. S. Highway 70 , left bank.

Azalea, N. C., 0.5 mile above bridge on U. S. Highway 70, left bank.

Azalea, N. C., near bridge on U. S. Highway 70, left bank.

Azalea, N. C., at Azalea Woodworking Co. plant, left bank.

Otteen, N. C., just above Lake Craig Dam.

Oteen, N. C., just below Lake Craig Dam

Oteen, N. C., 230 feet below bridge on U. S. Highway 74, right bank.

Biltmore, N. C., 150 feet above bridge at Sayles Biltmore Bleacheries, right bank.

Biltmore, N. C., 130 feet below bridge about 0.3 mile below Haw Creek, left bank.

Biltmore, N. C., U. S. Geological Survey gage, left bank.

Biltmore, N. C., at gate entrance to Biltmore Estate, left bank.

Asheville, N. C., 3,500 feet above mouth, right bank

Ivy River:

Barnardsville, N. C., left bank

Barnardsville, N. C., about 0.15 mile below Whittemore Creek, right bank.

\begin{tabular}{|c|c|c|}
\hline $\begin{array}{l}\text { Miles } \\
\text { above } \\
\text { mouth }\end{array}$ & Day and hour ${ }^{1}$ & $\begin{array}{l}\text { Elevation } \\
\text { (feet) }\end{array}$ \\
\hline 9.9 & Aug. 13. & $2,091.6$ \\
\hline 9.4 & $\ldots \mathrm{do}_{-}$ & $2,087.9$ \\
\hline 8.8 & $\ldots$ do & $2,084.5$ \\
\hline 7.7 & _. do_ & $2,079.7$ \\
\hline $\begin{array}{l}6.3 \\
5.0\end{array}$ & $\mid$\begin{tabular}{l} 
- do do \\
\hdashline- do $_{-}$
\end{tabular} & $\begin{array}{l}2,072.8 \\
2,070.7\end{array}$ \\
\hline $\begin{array}{l}3.0 \\
2.5 \\
2.2 \\
1.7\end{array}$ & $\begin{array}{l}\text { do } \\
\text { Aug. 13, 11-12 p.m. } \\
\text { Aug. 13. }\end{array}$ & $\begin{array}{l}2,063.7 \\
2,062.8 \\
2,060.55 \\
2,058.8\end{array}$ \\
\hline 1.0 & - . . do do & $2,057.4$ \\
\hline .3 & $\ldots$ do & $2,056.2$ \\
\hline $\begin{array}{c}12.5 \\
11.85 \\
10.95 \\
10.2 \\
9.2 \\
5.5\end{array}$ & \begin{tabular}{|c|} 
\\
\hdashline \\
\end{tabular} & $\begin{array}{l}2,213.2 \\
2,197.3 \\
2,179.0 \\
2,164.8 \\
2,149.0 \\
2,100.7\end{array}$ \\
\hline 3.8 & _do & $2,081.0$ \\
\hline .4 & -... do_ & $2,054.1$ \\
\hline 11.1 & _._. do & $2,097.0$ \\
\hline $\begin{array}{r}10.3 \\
8.0\end{array}$ & $\mid$\begin{tabular}{l} 
- do \\
\hdashline- do $_{-}$
\end{tabular} & $\begin{array}{l}2,081.3 \\
2,057.9\end{array}$ \\
\hline 15.5 & $\ldots \mathrm{do}_{-\ldots}$ & $2,188.4$ \\
\hline 14.8 & -..._do_. & $2,175.0$ \\
\hline 13.9 & -. _. do do_. & $2,154.1$ \\
\hline 12.4 & - _ do & $2,127.2$ \\
\hline 10.5 & $-\ldots \mathrm{do}_{-}$ & $2,097.2$ \\
\hline 9.1 & -....do_- & $2,079.2$ \\
\hline 8.1 & $\ldots \mathrm{do}_{-}$ & $2,069.0$ \\
\hline 7.6 & - . do & $2,063.6$ \\
\hline 6.9 & $-\ldots$ do & $2,052.5$ \\
\hline $\begin{array}{l}5.1 \\
5.1 \\
4.3\end{array}$ & 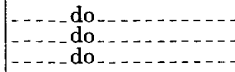 & $\begin{array}{l}2,043.43 \\
2,030.1 \\
2,021.5\end{array}$ \\
\hline 3.6 & ......do do & $2,014.6$ \\
\hline 2.6 & - & $2,003.5$ \\
\hline 1.6 & Aug. $13,7: 30$ p.m. & $1,995.58$ \\
\hline 1.4 & Aug. 13 - & $1,992.6$ \\
\hline .7 & $\ldots \mathrm{do}_{-.}$ & $1,984.1$ \\
\hline $\begin{array}{l}18.2 \\
17.2\end{array}$ & $\mid \begin{array}{l}-1 \\
-2 \text { do }\end{array}$ & $\begin{array}{l}2,187.7 \\
2,138.9\end{array}$ \\
\hline
\end{tabular}

'Eastern standard time except as noted. 
TABLE 22.-Flood-crest stages of mid-August flood-Continued

Stream and location

Ivy River-Con.

Democrat, N. C., 100 feet below bridge on N. C. Highway 695 , left bank.

Democrat, N. C., 0.4 mile above Morgan Branch, left bank.

Democrat, N. C., at highway bridge 0.3 mile below Morgan Branch.

Forks of Ivy, N. C., 1.3 miles above Middle Fork, right bank.

Marshall, N. C., U. S. Geological Survey gage, right bank.

Marshall, N. C., 100 feet above Laurel Branch, right bank.

Marshall, N. C., 0.5 mile below Laurel Branch, right bank.

West Fork Pigeon River:

Sunburst, N. C., mouth of Little East Fork, right bank

Sunburst, N. C., near Cecil School, 0.1 mile above Nick Creek, right bank.

Retreat, N. C., 0.6 mile below Nick Creek, right bank

Retreat, N. C., 1.4 miles below Nick Creek, right bank

Retreat, N. C., 2.0 miles below Nick Creek, left bank

Retreat, N. C., 0.6 mile by highway NE. of Retreat, left bank.

Woodrow, N. C., 0.3 mile above Bird Creek, left bank

Woodrow, N. C., 1,000 feet above confluence of West and East Forks, right bank.

Pigeon River:

Woodrow, N. C., 1 mile below confluence of East and West Forks, left bank.

Canton, N. C., U. S. Geological Survey gage, left bank Canton, N. C., 2,000 feet above Beaverdam Creek,

Canton, N. C., at mouth of Beaverdam Creek, right

bank.
Canton, N. C., 0.8 mile below Beaverdam Creek, right bank.

Canton, N. C., 2,000 feet above Cogburn Ford, right bank.

Clyde, N. C., 0.5 mile below highway bridge in Clyde, left bank.

Clyde, N. C., 0.4 mile above Richland Creek, left bank

Clyde, N. C., 1.0 mile below Richland Creek, left bank

Crabtree, N. C., at bridge on N. C. Highway 209, 2.5 miles below Richland Creek, right bank, site of former U. S. Geological Survey gage.

Crabtree, N. C., 0.8 mile above Crabtree Creek, right

Crabtree, N. C., 0.9 mile below Crabtree Creek, right bank.

Crabtree, N. C., 1,000 feet below first highway bridge below Crabtree Creek, left bank.

Cove Creek, N. C., 1.1 miles above Jonathan Creek, right bank.

Cove Creek, N. C., near mouth of Jonathan Creek, left bank.

Hepco, N. C., 0.8 mile below Jonathan Creek, U. S. Geological Survey gage, left bank.

Hepco, N. C., left bank

Waterville, N. C., at Waterville power plant, left bank

Browns, Tenn., left bank

Hartford, Tenn., U. S. Geological Survey gage, right bank.

Bluff ton, Tenn., left bank

Denton, Tenn., right bank

Wilton Springs, Tenn., near first footbridge below Woods Island, left bank.

Newport, Tenn., 3 miles above at Edwina, right bank-

Newport, Tenn., at mouth of English Creek, left bank

Newport, Tenn., U. S. Weather Bureau gage, right bank.

Newport, Tenn., Deep Ford Bridge, left bank

\begin{tabular}{|c|c|c|}
\hline $\begin{array}{l}\text { Miles } \\
\text { above } \\
\text { mouth }\end{array}$ & Day and hour' & $\begin{array}{l}\text { Elevation } \\
\text { (feet) }\end{array}$ \\
\hline 16.1 & Aug. 13. & $2,099.3$ \\
\hline 15.0 & $\ldots \mathrm{do}_{-}$ & $2,067.1$ \\
\hline 14.2 & . do & $.2,046.2$ \\
\hline 13.1 & $\ldots$ do $_{--}$ & $2,009.0$ \\
\hline 1.8 & Aug. 13, 8 & $1,710.73$ \\
\hline 1.3 & Aug. 13. & $1,695.3$ \\
\hline .9 & $\ldots$-..._do_- & $1,685.8$ \\
\hline $\begin{array}{l}6.4 \\
5.5\end{array}$ & - & $\begin{array}{l}2,840.1 \\
2,804.8\end{array}$ \\
\hline $\begin{array}{l}4.7 \\
3.9 \\
3.3 \\
2.15\end{array}$ & $\begin{array}{l}\text { do } \\
- \\
-\end{array}$ & $\begin{array}{l}2,771.7 \\
2,742.2 \\
2,722.6 \\
2,693.4\end{array}$ \\
\hline .7 & - & $\begin{array}{l}2,664.5 \\
2,654.1\end{array}$ \\
\hline 68.5 & - . _ do & $2,637.1$ \\
\hline $\begin{array}{l}64.0 \\
63.1\end{array}$ & $\begin{array}{l}\text { Aug. 13, } 12: 30 \text { p.m.- } \\
\text { Aug. } 13-\end{array}$ & $\begin{array}{l}2,590.22 \\
2,580.3\end{array}$ \\
\hline 62.8 & _...-do_. & $2,577.6$ \\
\hline 62.0 & - - - do do & $2,569.7$ \\
\hline 59.4 & - do do & $2,542.5$ \\
\hline 58.2 & - & $2,533.8$ \\
\hline $\begin{array}{l}55.4 \\
54.0 \\
52.2\end{array}$ & $\begin{array}{l}\ldots \text { do } \\
\ldots \\
-\end{array}$ & $\begin{array}{l}2,508.2 \\
2,493.6 \\
2,479.0\end{array}$ \\
\hline 50.6 & $\ldots \mathrm{do}_{--\ldots}$ & $2,462.7$ \\
\hline 48.8 & $\ldots \mathrm{do}_{-\ldots} \ldots$ & $2,439.1$ \\
\hline 48.1 & $\ldots$ - do $\ldots$ & $2,432.6$ \\
\hline 47.2 & .....do do & $2,409.9$ \\
\hline 45.9 & _... do do . . . & $2,370.5$ \\
\hline 45.1 & Aug. 13, 6:30 p.m.- & $2,350.89$ \\
\hline $\begin{array}{l}42.8 \\
38.0\end{array}$ & $\begin{array}{l}\text { Aug. } 13 \\
\text { Aug. } 12,12 \text { p.m., to } \\
\text { Aug. } 20,9 \text { a.m. }\end{array}$ & $\begin{array}{l}2,271.6 \\
2,258.00\end{array}$ \\
\hline $\begin{array}{l}25.8 \\
24.7 \\
21.4\end{array}$ & Aug. 13. & $\begin{array}{c}1,406.0 \\
1,364.9 \\
141,257.94\end{array}$ \\
\hline $\begin{array}{l}19.3 \\
15.9 \\
13.9\end{array}$ & 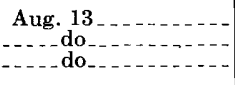 & $\begin{array}{l}1,231.4 \\
1,163.6 \\
1,130.0\end{array}$ \\
\hline $\begin{array}{r}10.8 \\
8.5 \\
6.8\end{array}$ & 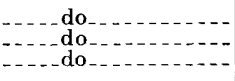 & $\begin{array}{l}1,091.8 \\
1,068.7 \\
1,056.7\end{array}$ \\
\hline 2.1 & _. do do & $1,026.5$ \\
\hline
\end{tabular}

${ }^{1}$ Eastern standard time except as noted.

14 Tennessee River Survey datum. 


\section{FLOODS OF AUGUST 1940 IN THE SOUTHEASTERN STATES}

TABLE 22.-Flood-crest stages of mid-August flood-Continued

Stream and location

\begin{tabular}{|c|c|c|}
\hline $\begin{array}{l}\text { Miles } \\
\text { above } \\
\text { mouth }\end{array}$ & Day and hour' & $\begin{array}{c}\text { Elevation } \\
\text { (feet) }\end{array}$ \\
\hline $\begin{array}{l}8.45 \\
7.5 \\
6.85\end{array}$ & \begin{tabular}{c} 
Aug. 13 \\
\hdashline do \\
\end{tabular} & $\begin{array}{l}2,934.4 \\
2,884.8 \\
2,856.8\end{array}$ \\
\hline 6.8 & do & $2,855.4$ \\
\hline $\begin{array}{l}5.9 \\
5.5\end{array}$ & - do do_ & $\begin{array}{l}2,816.6 \\
2,798.2\end{array}$ \\
\hline 4.6 & do. & $2,771.7$ \\
\hline 4.0 & ....do do & $2,758.1$ \\
\hline 3.6 & do. & $2,739.5$ \\
\hline 2.0 & _ do & $2,698.6$ \\
\hline 1.0 & -... do. & $2,672.7$ \\
\hline 31.6 & - do_ & $2,512.8$ \\
\hline $\begin{array}{l}29.6 \\
27.9 \\
26.7 \\
25.7 \\
25.4\end{array}$ & 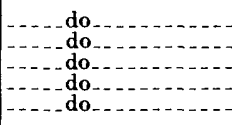 & $\begin{array}{l}2,486.9 \\
2,457.5 \\
2,450.3 \\
2,425.1 \\
2,423.8\end{array}$ \\
\hline 23.0 & do. & $2,386.7$ \\
\hline 21.4 & do. & $2,347.1$ \\
\hline $\begin{array}{l}19.2 \\
17.0\end{array}$ & - do_ & $\begin{array}{l}2,320.2 \\
2,273.5\end{array}$ \\
\hline $\begin{array}{l}14.9 \\
14.2\end{array}$ & - do do & $\begin{array}{l}2,254.1 \\
2,250.2\end{array}$ \\
\hline 11.7 & ..... do & $2,178.5$ \\
\hline 8.0 & - do & $2,147.5$ \\
\hline 6.6 & ..... do & $2,135.5$ \\
\hline 4.2 & - _ do & $2,092.6$ \\
\hline 3.8 & ..... do_- & $2,089.7$ \\
\hline $\begin{array}{r}1.3 \\
.6\end{array}$ & - do & $\begin{array}{l}2,056.6 \\
2,051.6\end{array}$ \\
\hline $\begin{array}{l}106.7 \\
103.4 \\
103.0 \\
102.5 \\
101.2 \\
100.9 \\
100.6\end{array}$ & \begin{tabular}{|c} 
Aug. 13, 7 p.m. \\
Aug. 13_. \\
\\
\\
\\
\\
\end{tabular} & $\begin{array}{l}1,991.66 \\
1,854.4 \\
1,851.1 \\
1,836.1 \\
1,780.8 \\
1,779.1 \\
1,769.3\end{array}$ \\
\hline 99.7 & _. do do_. & $1,741.4$ \\
\hline $\begin{array}{l}98.0 \\
95.7 \\
93.9\end{array}$ & {$\left[\begin{array}{l}\text { do } \\
\hdashline- \text { do }_{-} \\
\hdashline- \text { do }_{-}\end{array}\right.$} & $\begin{array}{l}1,694.5 \\
1,645.6 \\
1,611.6\end{array}$ \\
\hline $\begin{array}{l}93.0 \\
89.0\end{array}$ & Aug. $13,9: 30$ p.m. & $\begin{array}{l}1,591.5 \\
1,537.87\end{array}$ \\
\hline 88.6 & Aug. 13 & $1,532.8$ \\
\hline $\begin{array}{l}86.9 \\
86.0\end{array}$ & {$\left[\begin{array}{l}\text { do } \\
\hdashline-\mathbf{d}_{-}\end{array}\right.$} & $\begin{array}{r}1,509.8 \\
1,498.0\end{array}$ \\
\hline
\end{tabular}

Cruso, N. C., right bank

Cruso, N. C., right bank - - Cold Creek, left bani

Springdale, N. C., 0.9 mile below Cold Creek, right bank.

Springdale, N. C., $\mathbf{0 . 9 5}$ mile below Cold Creek, left bank.

Springdale, N. C., 0.4 mile below, right bank

Springdale, N. C., 0.45 mile above Burnett Creek, right bank.

Springdale, N. C., 0.4 mile below Burnett Creek, right bank.

Springdale, N. C., at new bridge on N. C. Highway 284, right bank.

Springdale, N. C., at new bridge on N. C. Highway 284, left bank.

Silver Bluff, N. C., near mouth of Dicks Creek, left bank.

Silver Bluff, N. C., 0.8 mile above Silver Bluff, right bank.

North Toe River:

Spruce Pine, N. C., 1,000 feet above bridge on N. C. Highway 19 , right bank.

Ninpo, N. C., right bank

Penland, N. C right bank

Wing Station, N. C., 1.0 mile above

Wing Station, N. C., right bank.

Wing Station, N. C., 0.6 mile above Crabtree Creek, right bank.

Boonford, N. C., at bridge on N. C. Highway 104, left bank.

Kona, N. C., 0.15 mile below South Toe River, right bank.

Bandana Station, N. C., right bank

Toecane, N. C., near mouth of Rose Branch, 3.0 miles above Cane Creek, right bank.

Toecane, N. C., 1.0 mile above Cane Creek, right bank

Toecane, N. C., at highway bridge, 0.3 mile above Cane Creek, right bank.

Forbes, N. C., at bridge on N. C. Highway 197, left bank.

Green Mountain, N. C., 1,000 feet above highway bridge, left bank.

Green Mountain, N. C., 1.2 miles below, at mouth of Jacks Creek, left bank.

Relief, N. C., 0.6 mile above, at mouth of Bee Branch, left bank.

Relief, N. C., 1,200 feet above highway bridge, right bank.

Huntdale, N. C., 0.6 mile above, right bank.

Huntdale, N. C., 1,000 feet above bridge on N. C. Highway 26 , left bank.

Nolichucky River:

Poplar, N. C., U. S. Geological Survey gage, right bank

Lost Cove, N. C., 2.0 miles above, left bank . . . . -

Lost Cove, N. C., 1.5 miles above, leff bank

Lost Cove, N. C., 1.0 mile above, left bank

Lost Cove, N. C., near, left bank

Lost Cove, N. C., 1,500 feet above State line, left bank

Lost Cove, N. C., near mouth of Devils Creek, left bank.

Unaka Springs, Tenn., 0.5 mile above Long Branch, left bank.

Unaka Springs, Tenn., left bank

Erwin, Tenn., bridge at Riverview, right bank

Erwin, Tenn., 500 feet above Garland Cemetery, right bank.

Erwin, Tenn., 1,500 feet above Stony Point, right bank

Embreeville, Tenn., U. S. Geological Survey gage, left bank.

Embreeville, Tenn., 200 feet below highway bridge, right bank.

Garber, Tenn., opposite mouth of Dry Creek, left bank

Garber, Tenn., Taylor Bridge, left bank

${ }^{1}$ Eastern standard time except as noted. 


Stream and location

Nolichucky River-Con.

Conklin, Tenn., 100 feet below Jackson Bridge, left bank.

Mount Carmal, Tenn., 150 feet below Bailey Bridge, left bank.

Limestone, Tenn., Snapp Bridge, right bank

Limestone, Tenn., Glaze Bridge, left bank.

Tusculum, Tenn, 150 feet above Brown Bridge, right bank.

Greeneville, Tenn., Jones Bridge, left bank_........

Bird Bridge, Tenn., right bank.

Greeneville Dam, Tenn., right bank, headwater

Greeneville Dam, Tenn right bank, tailwater

Cedar Creek, Tenn., Allen Bridge, left bank

Caney Branch, Tenn., 200 feet above Love Bridge, left bank.

Caney Branch, Tenn., near mouth of Dry Branch, left bank.

Bright Hope, Tenn., Easterly Bridge, right bank . . .

Bright Hope, Tenn., near Hale Bridge, left bank

Warrensburg, Tenn., Conway Bridge, left bank.

Morristown, Tenn. Susong Bridge right bank

Morristown, Tenn., U. S. Geological Survey gage near, left bank.

Morristown, Tenn., opposite Thomas Island, near, right bank.

White Pine, Tenn., Solomon Ferry, right bank

Leadvale, Tenn., opposite foot of Clark Island, right bank.

Leadvale, Tenn., 100 feet above bridge near mouth, right bank.

Cane River:

Burnsville, N. C., at Northwest Carolina Utilities Dam, right bank.

Riverside, N. C., at bridge on U. S. Highway $19 \mathrm{E}$, left bank.

Riverside, N. C., 800 feet above Phipps Creek, left

bank.
Cane River, N. C., 500 feet above Bald Creek, left bank.

Higgins, N. C., 1.9 miles above, left bank

Higgins, N. C., 0.8 mile below, right bank

Lewisburg, N. C., 300 feet above Little Hensley Branch, 1.0 mile above Lewisburg, left bank.

Lewisburg, N. C., 1.05 miles below bridge on $U$. S. Highway 23, right bank.

Ramsaytown, N. C., 1,000 feet above Pounding Mill Cove, right bank.

Sioux, N. C., 0.25 mile above bridge on U. S. Highway 23, right bank.

Sioux, N. C., U. S. Geological Survey gage, right bank

South Fork Holston River:

Bluff City, Tenn., U. S. Geological Survey gage, right bank.

Holston, Tenn., 0.75 mile below Bowman Ford, left bank.

Watauga River, mouth of, left bank

Fordtown, Tenn., 0.5 mile below Smith Shoal Bridge, left bank.

Fordtown, Tenn., 0.9 mile below Smith Shoal Bridge, 200 feet below falls, right bank.

Fordtown, Tenn., 400 feet below Sinking Creek, left bank.

Samuel, Tenn., 0.9 mile below Brown Creek, right bank.

Hemlock, Tenn., opposite island, right bank

Pactolus, Tenn., 0.2 mile above foot of Wexler Island, right bank.

Kingsport, Tenn., U. S. Geological Survey gage, left bank.

Kingsport, Tenn,, 0.5 mile above highway bridge at Long Island, right bank.

Kingsport, Tenn., 0.7 mile below highway bridge at Long Island, right bank.

\begin{tabular}{|c|c|c|}
\hline $\begin{array}{l}\text { Miles } \\
\text { above } \\
\text { mouth }\end{array}$ & Day and hour' & $\begin{array}{l}\text { Elevation } \\
\text { (feet) }\end{array}$ \\
\hline 81.6 & Aug. $13 \ldots$ & $1,459.7$ \\
\hline 77.1 & Aug. $14 \ldots$ & $1,420.4$ \\
\hline $\begin{array}{l}74.0 \\
70.0 \\
66.7 \\
59.8\end{array}$ & 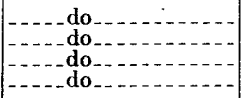 & $\begin{array}{l}1,393.4 \\
1,361.3 \\
1,336.5 \\
1,290.4\end{array}$ \\
\hline $\begin{array}{l}54.1 \\
50.3 \\
45.9 \\
45.9 \\
42.1 \\
36.8\end{array}$ & $\begin{array}{l}\text { Aug. 14, } 8 \text { a.m. }{ }^{13} \ldots \\
\text { Aug. 14. do } \\
- \text { do }\end{array}$ & $\begin{array}{l}1,264.7 \\
1,257.0 \\
1,255.9 \\
1,199.5 \\
1,180.4 \\
1,150.6\end{array}$ \\
\hline 34.8 & $\ldots+\ldots$ do $\ldots \ldots \ldots$ & $1,139.0$ \\
\hline $\begin{array}{l}32.1 \\
28.0 \\
20.8 \\
14.0 \\
10.6\end{array}$ & \begin{tabular}{|c|} 
do \\
Aug. 14,8 p.m. $^{13}$
\end{tabular} & $\begin{array}{r}1,121.8 \\
1,096.9 \\
1,063.2 \\
1,037.8 \\
11,027.08\end{array}$ \\
\hline 8.8 & Aug. $14 \ldots$ & $1,022.2$ \\
\hline $\begin{array}{l}3.2 \\
1.2\end{array}$ & - do do & $\begin{array}{r}1,004.9 \\
991.0\end{array}$ \\
\hline .3 & - & 984.0 \\
\hline 22.9 & Aug. $13 \ldots$ & $2,597.4$ \\
\hline 21.6 & 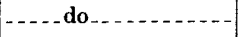 & $2,529.7$ \\
\hline 20.0 & $\ldots$.... do $\ldots . .$. & $2,501.6$ \\
\hline 18.7 & $\ldots \ldots$ do $\ldots \ldots \ldots$ & $2,493.2$ \\
\hline $\begin{array}{l}14.7 \\
12.0 \\
11.0\end{array}$ & 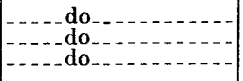 & $\begin{array}{l}2,420.5 \\
2,363.2 \\
2,325.4\end{array}$ \\
\hline 8.8 & -... do do _........ & $2,248.2$ \\
\hline 4.7 & - $\ldots$ do $o_{-} \ldots \ldots \ldots$ & $2,126.9$ \\
\hline 3.8 & $\mid \ldots$ do $\ldots \ldots \ldots+\ldots$ & $2,113.65$ \\
\hline 1.2 & Aug. 13, 4:30 p.m.- & $2,063.0$ \\
\hline $\begin{array}{l}34.4 \\
21.9\end{array}$ & $\begin{array}{l}\text { Aug. 14, } 4 \text { p.m. } \\
\text { Aug. 15, } 4 \text { a.m. } \\
\text { Aug. 14, }\end{array}$ & $\begin{array}{l}1,379.95 \\
1,288.8\end{array}$ \\
\hline $\begin{array}{l}20.0 \\
16.1\end{array}$ & {$\left[\begin{array}{l}\text { do } \\
-y_{2}\end{array}\right.$} & $\begin{array}{l}1,288.6 \\
1,265.7\end{array}$ \\
\hline 15.7 & - $-\mathrm{do}_{-}$ & $1,263.0$ \\
\hline 14.1 & $-\ldots+\ldots$ do $\ldots$ & $1,252.5$ \\
\hline 12.7 & - _._do__._ & $1,244.8$ \\
\hline $\begin{array}{r}10.4 \\
7.6\end{array}$ & - & $\begin{array}{l}1,229.8 \\
1,214.1\end{array}$ \\
\hline 5.7 & Aug. 14, 9:30 a.m... & $1,203.11$ \\
\hline 5.1 & Aug. $14 \ldots$ & $1,199.7$ \\
\hline 3.9 & 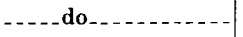 & $1,191.7$ \\
\hline
\end{tabular}

1 Eastern standard time except as noted.

13 Central standard time.

14 Tennessee River Survey datum. 
TABLE 22.-Flood-crest stages of mid-August flood-Continued

Stream and location
South Fork Holston River-Con.
Kingsport, Tenn., on city boundary at mouth of
Reedy Creek, right bank.
Kingsport, Tenn., 0.9 mile above North Fork Holston
River, 900 feet below small branch, right bank.

Holston River:

Click, Tenn., 0.2 mile below Parker Creek, right bank

Church Hill, Tenn., near mouth of Laurel Run, left bank.

Church Hill, Tenn., 0.3 mile above highway bridge, left bank.

New Canton, Tenn., 0.2 mile above head of Hord Islands, left bank.

Stony Point, Tenn., in point of Hord Bend, left bank

Stony Point, Tenn., between Christian Islands, left bank.

Stony Point, Tenn., near point of Christian Bend, left bank.

Stony Point, Tenn., 0.8 mile below Stony Point Creek, left bank.

Surgoinsville, Tenn., 0.8 mile above Terrill Creek, right bank.

Surgoinsville, Tenn., 0.5 mile above county ferry, right bank.

Surgoinsville, Tenn., county ferry, left bank . . . . . .

Surgoinsville, Tenn., county ferry, right bank .....

Burem, Tenn., 0.1 mile above head of Miller Island, left bank.

Burem, Tenn., 0.5 mile above Honeycutt Creek, left bank.

Burém, Tenn., 0.2 mile above Sensabaugh Branch, right bank.

Burem, Tenn., 1.1 mile below Beech Creek, left bank

McCloud, Tenn., left bank.

Rogersville, Tenn., McDonald mill, right bank

Rogersville, Tenn., U. S. Geological Survey gage, right bank.

Rogersville, Tenn., 50 feet above Southern Ry. bridge, right bank.

Rogersville, Tenn., 0.25 mile below Southern Ry.

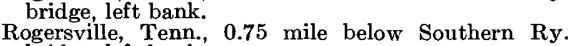
bridge left bank.

Rogersville, Tenn., transmission line crossing, 1.2 miles above Robertson Creek, left bank.

Rogersville, Tenn., 0.3 mile above Robertson Creek, left bank.

Rogersville, Tenn., near mouth of Robertson Creek, left bank.

Rogersville, Tenn., 0.5 mile below Robertson Creek, right bank.

St. Clair, Tenn., 0.6 mile below Crockett Creek, near Marble School, right bank.

St. Clair, Tenn., 0.4 mile above Price Island, right bank

Mooresburg, Tenn., Galbraith School, right bank

Mooresburg, Tenn., 100 feet below highway bridge, at Anderson Bend, left bank.

Russellville, Tenn., 0.2 mile below Bright Ferry, left bank.

Morristown, Tenn., U. S. Geological Survey gage, left bank.

Noeton, Tenn., 0.5 mile below German Creek, right bank.

Turley Island, Tenn., 1,000 feet below foot of, right bank.

Mayes Islands, Tenn., at foot of right bank.

May Springs, Tenn., 0.2 mile below Lambdin Branch,

right bank.
May Springs, Tenn., 0.6 mile above May Springs Branch, left bank.

May Springs, Tenn., mouth of May Springs Branch, right bank.

May Springs, Tenn., 0.55 miles above head of Tarr Island, right bank.

Jefferson City, Tenn., U. S. Geological Survey gage, right bank.

Jefferson City, Tenn., at bridge on Tenn. Highway 92 , right bank.

\begin{tabular}{|c|c|}
\hline $\begin{array}{l}\text { Miles } \\
\text { above } \\
\text { mouth }\end{array}$ & Day and hour \\
\hline 2.0 & Aug. 14 \\
\hline .9 & $\ldots$. $\mathrm{do}_{-}$ \\
\hline $\begin{array}{l}137.9 \\
134.2\end{array}$ & _. do do \\
\hline 131.8 & . _do_ \\
\hline 128.5 & $\ldots \ldots$ do \\
\hline $\begin{array}{l}127.2 \\
126.0\end{array}$ & _-_.do_- \\
\hline 124.1 & $\ldots$ do... \\
\hline 122.3 & $\ldots$... do_ \\
\hline 120.2 & Aug. 15_ \\
\hline 118.9 & $\ldots$.... do_. \\
\hline $\begin{array}{l}118.4 \\
118.4 \\
115.1\end{array}$ & 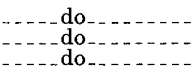 \\
\hline 113.5 & $\ldots$. do_ \\
\hline 110.2 & _. do_. \\
\hline $\begin{array}{l}107.7 \\
105.7 \\
104.6 \\
104.3\end{array}$ & $\begin{array}{l}\text { do do } \\
\text { Aug. 15, } 6 \text { a }\end{array}$ \\
\hline 103.8 & Aug. 15 \\
\hline 103.5 & _. do . . \\
\hline 103.0 & . do \\
\hline 102.5 & $\mathrm{do}_{-}$ \\
\hline 101.6 & _ do _. \\
\hline 101.2 & _..._do \\
\hline 100.7 & - _- _do_- \\
\hline 99.1 & . do \\
\hline 94.0 & _. . do_. \\
\hline $\begin{array}{l}91.2 \\
87.3\end{array}$ & - do do \\
\hline 79.8 & _....do_. \\
\hline 75.2 & Aug. 15, 2-2:30 \\
\hline 69.8 & Aug. 15 \\
\hline 65.0 & - $\ldots$ do \\
\hline $\begin{array}{l}63.1 \\
62.0\end{array}$ & _...do do \\
\hline 58.1 & $\ldots$. do \\
\hline 57.6 & . do \\
\hline 55.2 & $\ldots$ do $\ldots . . . . . .$. \\
\hline 52.0 & Aug. 15,9 p.m. ${ }^{18}$ \\
\hline 51.9 & Aug. 15. \\
\hline
\end{tabular}

Elevation (feet)

$1,184.6$

$1,178.1$

$1,162.6$

$1,148.6$

$1,142.2$

$1,134.4$

1, 131.0

$1,126.9$

$1,121.4$

$1,117.3$

$1,111.8$

$1,107.8$

$1,105.8$

$1,106.2$

1,099.2

$1,094.4$

1,086.1

$1,081.2$

$1,076.8$

$1,074.8$

$1,072.59$

$1,072.1$

1,071.4

$1,069.2$

$1,069.1$

$1,065.4$

$1,064.0$

$1,062.7$

1,056.2

$1,039.5$

$1,034.0$

$1,022.0$

$1,001.5$

990.72

977.3

967.5

963.6

961.5

953.5

952.4

943.5

941.82

941.4

1 Eastern standard time except as noted.

13 Central standard time. 
TABLE 22.-Flood-crest stages of mid-August flood-Continued

Stream and location

Holston River-Con.

Jefferson City, Tenn., 0.7 mile below bridge on Tenn . Highway 92, right bank.

Tampico, Tenn., 0.8 mile above West Branch, right bank.

Tampico, Tenn., mouth of West Branch, right bank -

Tampico, Tenn., in point of Horse Shoe Bend, right bank.

Tampico, Tenn., upper end of Vineyard Bend, right bank.

Tampico, Tenn., lower end of Vineyard Bend, right bank.

Tampico, Tenn., Indian Cave, right bank . . . . . .

Tampico, Tenn., 1.1 miles below Indian Cave, left bank.

Mule Shoe Bend, Tenn., upper end, right bank

Mule Shoe Bend, Tenn., mouth of Buck Hollow Branch, left bank.

East Hodges, Tenn., lower end of Mule Shoe Bend, right bank.

East Hodges, Tenn., mouth of Perrin Hollow Branch, right bank.

East Hodges, Tenn., Nances Ferry, left bank

Hodges, Tenn., near mouth of Beaver Creek, left bank

Hodges, Tenn., 0.25 mile above foot of Snaggy Island, left bank.

Hodges, Tenn., opposite center of McKinney Islands, right bank.

Strawberry Plains, Tenn., 0.2 mile above head of Trent Island, right bank.

Strawberry Plains, Tenn., 1.3 miles above Southern Ry. bridge, right bank.

Strawberry Plains, Tenn., 0.1 mile above Southern Ry. bridge, left bank.

Strawberry Plains, Tenn., U. S. Geological Survey gage, left bank.

Mascot, Tenn., 0.9 mile below McBee Bridge, right bank.

Mascot, Tenn., mouth of Flat Creek, right bank

Mascot, Tenn., 0.5 mile above Roseberry Creek, left bank.

Mascot, Tenn., 0.5 mile below Roseberry Creek, right bank.

Mascot, Tenn., 0.6 mile above Turkey Creek, right bank.

McMillan, Tenn., 0.4 mile below Turkey Creek, left bank.

McMillan, Tenn., 0.2 mile above Strong Creek, right bank.

John Sevier, Tenn., near reservoir, right bank

John Sevier, Tenn., 0.4 mile above head of Cabbage Island, left bank.

John Sevier, Tenn., 0.2 mile below foot of Cabbage Island, right bank.

Knoxville, Tenn., 100 feet above Inman Branch, left bank.

Knoxville, Tenn., mouth of Swanpond Creek, left bank

Knoxville, Tenn., 0.4 mile above Boyd Bridge, right bank.

Knoxville, Tenn., 1,200 feet below head of Boyd Island, left bank.

Knoxville, Tenn., 1,000 feet below foot of Boyd Island, left bank.

Watauga River:

Butler, Tenn., mouth of Gregg Branch, left bank ... -

Butler, Tenn., U. S. Geological Survey gage at Stump Knob, right bank.

Butler, Tenn., Blue Springs, right bank

Butler, Tenn., 0.2 mile above Roan Creek, left bank

Butler, Tenn., 200 feet above highway bridge, left bank

Butler, Tenn., 0.1 mile above gaging station, right bank.

Butler, Tenn., U. S. Geological Survey gage, right bank.

Butler, Tenn., 0.3 mile below gaging station, left bank

Butler, Tenn., 2.0 miles below gaging station, left bank

Fish Springs, Tenn., a mile above, at highway bridge, left bank.

\begin{tabular}{|c|c|c|}
\hline $\begin{array}{l}\text { Miles } \\
\text { above } \\
\text { mouth }\end{array}$ & Day and hour ${ }^{1}$ & $\underset{\text { Eleet })}{\text { Elevation }}$ \\
\hline 51.2 & Aug. 15.. & 940.1 \\
\hline 49.0 & .....do do & 938.9 \\
\hline $\begin{array}{l}48.2 \\
45.9\end{array}$ & $\mid \begin{array}{l}\text { _._. do do } \\
\ldots \text { do }\end{array}$ & $\begin{array}{l}932.0 \\
925.2\end{array}$ \\
\hline 42.9 & .....do... & 917.5 \\
\hline 40.9 & Aug. $16 \ldots$ & 911.5 \\
\hline $\begin{array}{l}40.0 \\
38.9\end{array}$ & - & $\begin{array}{l}907.0 \\
908.1\end{array}$ \\
\hline $\begin{array}{l}38.1 \\
37.2\end{array}$ & 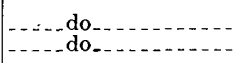 & $\begin{array}{l}902.0 \\
902.7\end{array}$ \\
\hline 36.1 & .....do_. & 897.5 \\
\hline 34.5 & _.do_. & 894.0 \\
\hline $\begin{array}{l}33.2 \\
30.4 \\
27.0\end{array}$ & 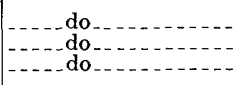 & $\begin{array}{l}890.1 \\
884.8 \\
877.6\end{array}$ \\
\hline 25.0 & _. do & 874.0 \\
\hline 22.1 & .....do & 867.7 \\
\hline 19.2 & $\ldots$ do & 861.5 \\
\hline 18.0 & -.... do & 859.4 \\
\hline 17.0 & Aug. 16,9 a.m. & 857.01 \\
\hline 16.1 & Aug. $16 \ldots$ & 856.0 \\
\hline $\begin{array}{l}14.1 \\
13.4\end{array}$ & $\begin{array}{l}\ldots \text { do } \\
\ldots \ldots \text { do }\end{array}$ & $\begin{array}{l}852.6 \\
851.7\end{array}$ \\
\hline 12.4 & .....do_.. & 848.8 \\
\hline 11.5 & .... do do..... & 846.7 \\
\hline 10.5 & $\ldots$. $\mathrm{do}_{\ldots} \ldots$ & 844.2 \\
\hline 10.1 & $\ldots \ldots$ do $\ldots . .$. & 844.1 \\
\hline $\begin{array}{l}8.1 \\
6.7\end{array}$ & $\mid$\begin{tabular}{l} 
- do do \\
\hdashline$-\ldots$ do
\end{tabular} & $\begin{array}{l}840.3 \\
838.7\end{array}$ \\
\hline 5.7 & ...... do & 836.7 \\
\hline 4.6 & 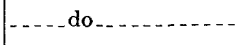 & 834.0 \\
\hline $\begin{array}{l}3.3 \\
2.2\end{array}$ & [... do & $\begin{array}{l}832.9 \\
831.3\end{array}$ \\
\hline 1.4 & -.....do do & 830.3 \\
\hline .3 & ...._do_... & 827.2 \\
\hline $\begin{array}{l}47.9 \\
47.6\end{array}$ & $\begin{array}{l}\text { Aug. } 13 \\
\text { Aug. } 13,8: 30 \text { p.m. }\end{array}$ & $\begin{array}{l}1,899.4 \\
1,893.0\end{array}$ \\
\hline $\begin{array}{l}46.5 \\
44.0 \\
43.8 \\
43.7\end{array}$ & \begin{tabular}{|l} 
Aug. 13 \\
\\
\end{tabular} & $\begin{array}{l}1,876.6 \\
1,837.4 \\
1,836.3 \\
1,835.0\end{array}$ \\
\hline 43.6 & Aug. 13, 10 p.m. & $1,834.8$ \\
\hline $\begin{array}{l}43.3 \\
41.6 \\
40.5\end{array}$ & \begin{tabular}{|l} 
Aug. 13 \\
do
\end{tabular} & $\begin{array}{l}1,830.3 \\
1,805.0 \\
1,787.0\end{array}$ \\
\hline
\end{tabular}


TABLE 22.-Flood-crest stages of mid-August flood-Continued

\begin{tabular}{|c|c|c|c|}
\hline Stream and location & & Day and hour ${ }^{1}$ & $\begin{array}{c}\text { Elevation } \\
\text { (feet) }\end{array}$ \\
\hline 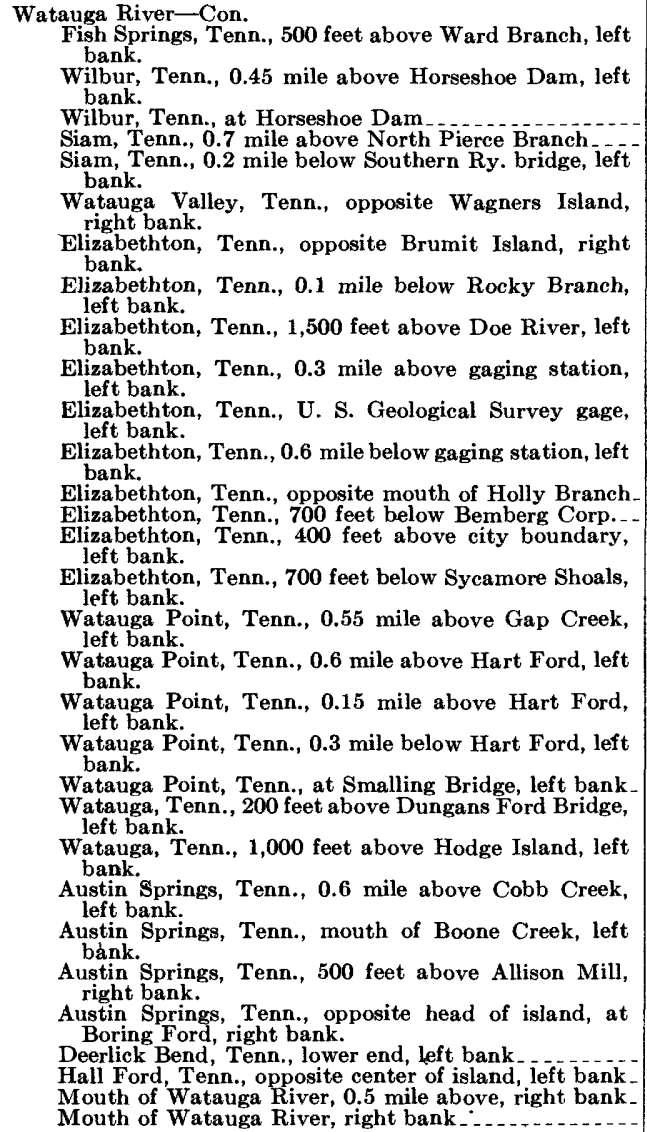 & $\begin{array}{l}39.5 \\
33.4 \\
32.95 \\
31.7 \\
30.7 \\
30.1 \\
27.4 \\
26.5 \\
26.0 \\
25.3 \\
25.0 \\
24.4 \\
24.0 \\
23.5 \\
22.9 \\
22.5 \\
22.0 \\
21.0 \\
20.55 \\
20.1 \\
19.5 \\
16.9 \\
14.4 \\
11.2 \\
8.3 \\
5.8 \\
3.7 \\
1.5 \\
.9 \\
.0\end{array}$ & $\begin{array}{l}\text { Aug. 13 } \\
\text { Aug. 13, } 11 \\
\text { Aug. 13, 11: } \\
\text { Aug. 13. } \\
\text { Aug. 14 }\end{array}$ & $\begin{array}{l}1,776.8 \\
1,658.2 \\
1,657.5 \\
1,592.3 \\
1,579.9 \\
1,573.9 \\
1,537.9 \\
1,525.9 \\
1,520.5 \\
1,514.3 \\
1,507.10 \\
1,502.7 \\
1,496.5 \\
1,492.4 \\
1,484.7 \\
1,484.2 \\
1,480.6 \\
1,472.8 \\
1,468.3 \\
1,462.4 \\
1,454.4 \\
1,424.0 \\
1,398.9 \\
1,382.1 \\
1,358.8 \\
1,338.8 \\
1,318.7 \\
1,300.7 \\
1,295.3 \\
1,290.4 \\
1,288.6\end{array}$ \\
\hline $\begin{array}{l}\text { ittle Tennessee River: } \\
\text { Iotla, N. C., U.S. Geological Survey gage, right bank- } \\
\text { Judson, N. C., U. S. Geological Survey gage, } 0.6 \text { mile } \\
\text { above Southern Ry. trestle, right bank. } \\
\text { Fontana, N. C., U. S. Geological Survey gage, right } \\
\text { bank. }\end{array}$ & $\begin{array}{c}109.7 \\
81.4 \\
62\end{array}$ & $\begin{array}{l}\text { Aug. 13, 9:30 p.m. } \\
\text { Aug. } 13,10: 30 \text { p.m. } \\
\text { Aug. 14, } 2 \text { a.m. }\end{array}$ & $\begin{array}{l}1,966.5 \\
1,545.92 \\
1,286.18\end{array}$ \\
\hline $\begin{array}{l}\text { ackasegee River: } \\
\text { Tuckasegee, N. C., near bridge on N. C. Highway 106, } \\
\text { left bank. } \\
\text { Tuckasegee, N. C., U. S. Geological Survey gage, right } \\
\text { bank. } \\
\text { Tuckasegee, N. C., } 0.25 \text { mile above county road } \\
\text { bridge, right bank. } \\
\text { East Laport, N. C., 1,000 feet above Caney Fork, left } \\
\text { bank. } \\
\text { East Laport, N. C., } 1.0 \text { mile below East Laport, left } \\
\text { bank. } \\
\text { East Laport, N. C., 1,000 feet below bridge on N. C. } \\
\text { Highway 106, right bank. } \\
\text { Cullowhee, N. C., near mouth of Wayehutta Creek, } \\
\text { right bank. } \\
\text { Cullowhee, N. C., } 0.4 \text { mile below Cane Creek, left bank- } \\
\text { Cullowhee, N. C., at highway bridge, } 1.9 \text { miles below } \\
\text { Cane Creek, right bank. }\end{array}$ & $\begin{array}{l}49.2 \\
48.1 \\
47.1 \\
46.0 \\
44.4 \\
43.4 \\
41.5 \\
38.7 \\
37.1\end{array}$ & $\begin{array}{l}\text { Aug. } 13 \\
\text { Aug. } 13,11 \text { a.m. } \\
\text { Aug. } 13\end{array}$ & $\begin{array}{c}2,148.3 \\
62,138.93 \\
2,131.5 \\
2,121.0 \\
2,101.9 \\
2,091.2 \\
2,074.7 \\
2,051.0 \\
2,038.9\end{array}$ \\
\hline
\end{tabular}

\footnotetext{
1 Eastern standard time except as noted.
}

- Sea level datum, adjustment of $\mathbf{1 9 1 2}$. 
TABLE 22.-Flood-crest stages of mid-August flood-Continued

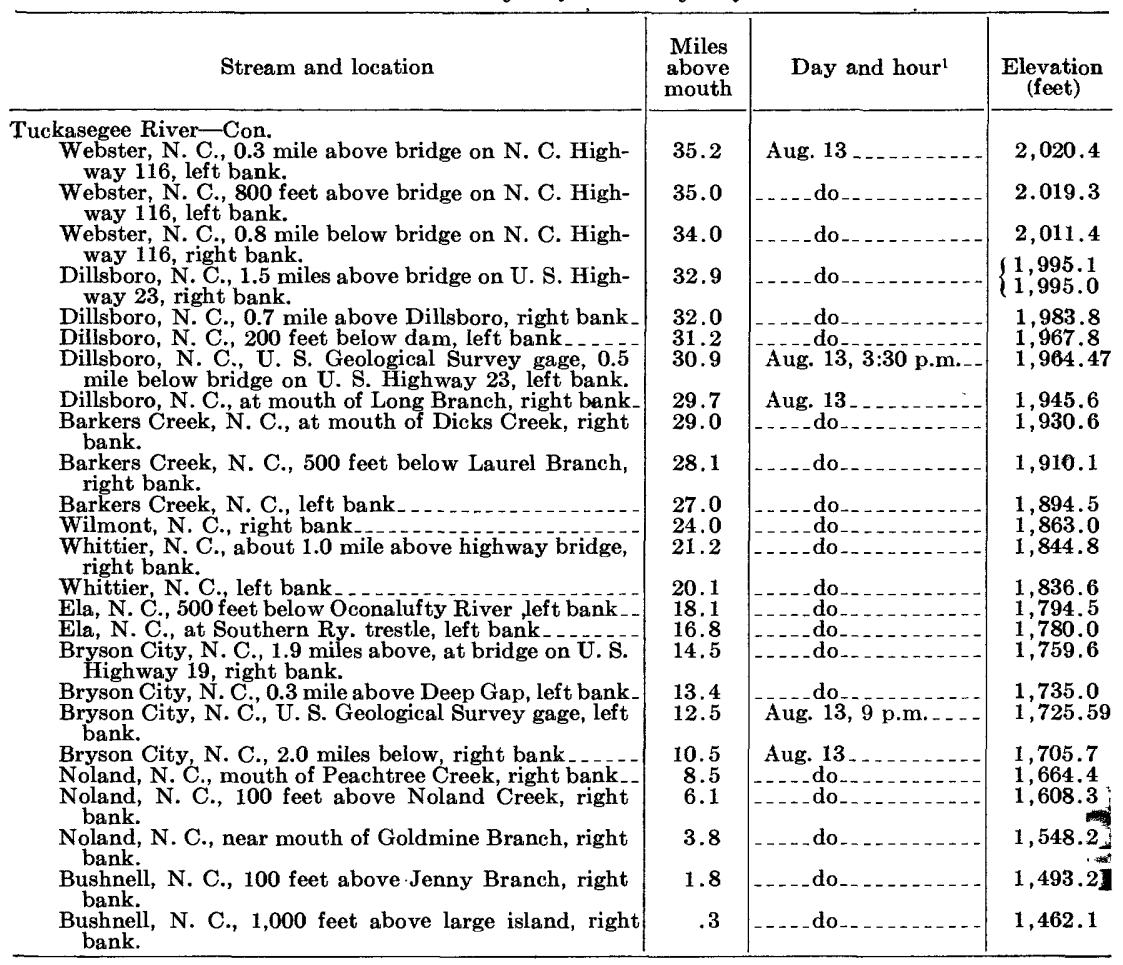

\footnotetext{
1 Eastern standard time except as noted.
} 
TABLE 23.-Flood-crest stages of late-August flood ${ }^{1}$

Stream and location

Tennessee River Basin

French Broad River:

Rosman, N. C., U. S. Geological Survey gage, left bank Calvert, N. C., U. S. Geological Survey gage, right bank.

Blantyre, N. C., U. S. Geological Survey gage, left bank.

Bent Creek, N. C., U. S. Geological Survey gage, left bank.

Asheville, N. C., mouth of Swannanoa River, right bank.

Asheville, N. C., 0.6 mile above West Asheville viaduct, right bank.

Asheville, N. C., 800 feet above Smith Street Bridge, right bank.

Asheville, N. C., 1,300 feet below Southern Ry. bridge, right bank.

Asheville, N. C., U. S. Geological Survey gage, right bank.

Craggy, N. C., near mouth of Beaverdam Creek, right bank.

Alexander, N. C., 0.6 mile below Newfound Creek, left bank.

Alexander, N. C., at highway bridge, left bank

Alexander, N. C. near nouth of Flat Creek, right bank

French Broad, N. C., opposite mouth of Sandymush Creek, right bank.

Marshall, N. C., at mouth of Allman Branch, right bank.

Marshall, N. C., 0.25 mile above Ivy River, left bank

Marshall, N. C., 0.45 mile below Ivy River, right bank

Marshall, N. C., at mouth of Hayes Creek, right bank

Marshall, N. C., 125 feet above lower bridge, right bank

Marshall, N. C., 1.1 miles below Southern Ry. station, right bank.

Marshall, N. C., 50 feet below first highway bridge below Redmon Dam, right bank.

Marshall, N. C., opposite Nocona railroad siding, left bank.

Walnut, N. C., 1 mile below Walnut Creek, right bank

Barnard, N. C., right bank .

Barnard, N. C., 1.2 miles below highway bridge, right bank.

Sandy Bottoms, N. C., right bank

Stackhouse, N. C., at mouth of Woolsey Creek, right bank.

Hot Springs, N. C., U. S. Geological Survey gage, right bank.

Paint Rock, N. C., left bank

Wolf Creek, Tenn., near mouth of Wolf Creek, left bank.

Del Rio, Tenn., 0.1 mile above Big Creek, left bank

Bridgeport, Tenn., 0.3 mile above head of Huff Island, right bank.

Bridgeport, Tenn., near mouth of Good Hope Branch, right bank.

Newport, Tenn., U. S. Geological Survey gage, left bank.

Rankin, Tenn., 0.1 mile above Pigeon River, left bank

Rankin, Tenn., 1.1 miles above Nolichucky River, left bank.

Dandridge, Tenn., U. S. Geological Survey gage, right bank.

Tennessee River:

Knoxville, Tenn., U. S. Geological Survey gage, right bank.

Loudon, Tenn., U. S. Geological Survey gage, bridge pier.

Watts Bar Dam, TVA headwater gage ...........

Watts Bar Dam, TVA tailwater gage (head of Chickamauga Reservoir).

Breedenton, Tenn., U. S. Geological Survey gage, left bank.

Washington, Tenn., near, at Armstrong's Ferry, TVA gage, right bank.

Sale Creek, Tenn., TVA gage at Doughty's Ferry, right bank.

${ }^{1}$ From tabulations and surveys by Tennessee Valley Authority, sea-level datum of 1929, supplementary adjustment of 1936, except as noted.

${ }^{2}$ Eastern standard time except as noted.

$s$ Central standard time.

\begin{tabular}{|c|c|c|}
\hline $\begin{array}{l}\text { Miles } \\
\text { above } \\
\text { mouth }\end{array}$ & Day and hour ${ }^{2}$ & $\begin{array}{c}\text { Elevation } \\
\text { (feet) }\end{array}$ \\
\hline $\begin{array}{l}216.3 \\
213.9\end{array}$ & $\begin{array}{l}\text { Aug. 30, } 6 \text { a.m.. } \\
\text { Aug. 30, } 6: 30 \text { a.m }\end{array}$ & $\begin{array}{l}2,185.69 \\
2,165.46\end{array}$ \\
\hline 183.7 & Aug. 31, 8 & $2,079.64$ \\
\hline 157.7 & Aug. 30,6 I & $2,007.03$ \\
\hline 149.0 & Aug. $30_{-}$ & $1,981.2$ \\
\hline 148.2 & do & $1,977.2$ \\
\hline 147.5 & - do do & $1,973.8$ \\
\hline 146.9 & $\ldots$ do & $1,970.6$ \\
\hline 145.7 & Aug. 30,12 & $1,962.43$ \\
\hline 142.2 & Aug. $30_{-}$ & $1,934.4$ \\
\hline 138.9 & . do & $1,856.2$ \\
\hline $\begin{array}{l}136.4 \\
135.3 \\
131.9\end{array}$ & 等 & $\begin{array}{l}1,787.3 \\
1,765.5 \\
1,727.1\end{array}$ \\
\hline 129.7 & do & $1,708.3$ \\
\hline $\begin{array}{l}128.1 \\
127.2 \\
126.0 \\
125.1 \\
124.2\end{array}$ & 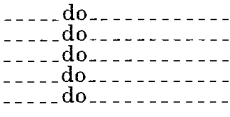 & $\begin{array}{l}1,680.9 \\
1,670.8 \\
1,656.5 \\
1,644.6 \\
1,638.5\end{array}$ \\
\hline 122.5 & $\ldots \mathrm{do}_{-}$ & $1,598.1$ \\
\hline 120.7 & . do_- & $1,575.0$ \\
\hline $\begin{array}{l}119.0 \\
117.4 \\
116.1\end{array}$ & $\begin{array}{l}\text { L do } \\
\ldots \text { do }\end{array}$ & $\begin{array}{l}1,554.1 \\
1,523.4 \\
1,502.0\end{array}$ \\
\hline $\begin{array}{l}114.5 \\
113.2\end{array}$ & (ndo do & $\begin{array}{l}1,457.2 \\
1,410.3\end{array}$ \\
\hline 109.1 & Aug. 30, 7:30 a.m.-- & $1,327.6$ \\
\hline $\begin{array}{r}103.1 \\
96.8\end{array}$ & Aug. $30_{-}$ & $\begin{array}{l}1,265.7 \\
1,188.3\end{array}$ \\
\hline $\begin{array}{l}90.6 \\
84.6\end{array}$ & $\ldots$-... do.- & $\begin{array}{l}1,138.5 \\
1,077.1\end{array}$ \\
\hline 80.1 & $\ldots \ldots$ do $\ldots \ldots \ldots$ & $1,045.8$ \\
\hline $\begin{array}{l}77.4 \\
74.1 \\
70.3\end{array}$ & $\begin{array}{l}\text { Aug. } 30,12 \mathrm{~m} .^{3} \\
\text { Aug. } 30 \\
\text { do }\end{array}$ & $\begin{array}{l}1,030.86 \\
1,012.4 \\
992.5\end{array}$ \\
\hline 45.3 & Aug. 31, 1 a.m. ${ }^{3}-\ldots$ & 924.26 \\
\hline
\end{tabular}

648.4

Aug. 31, 7 p.m. $.^{3}-\ldots$

817.96

744.95

691.2

688.2

686.26

683.3

683.1 
TABLE 23.-Flood-crest stages of late-August flood ${ }^{1}$-Continued

Stream and location

Tennessee River-Con.

Birchwood, Tenn., TVA gage at TVA Safety Harbor, left bank

Chickamauga Reservoir, Tenn., TVA gage

Chickamauga Dam, Tenn., TVA tailwater gage

Chattanooga, Tenn., U. S. Geological Survey base gage at Meadow Lake, right bank.

Chattanooga, Tenn., U. S. Geological Survey auxiliary gage at Citico Bar, left bank.

Chattanooga, Tenn., U. S. Weather Bureau Walnut Street gage, left bank.

South Fork Mills River:

Mills River, N. C., 2.1 miles above confluence with North Fork, right bank.

Mills River

Mills River, N. C., 0.4 mile below confluence of North and South Forks, left bank.

Mills River, N. C., U. S. Geological Survey gage, 0.75 mile above Foster Creek, right bank.

Mills River, N. C., 0.25 mile below Foster Creek, left bank.

Mills River, N. C. 30 feet below bridge on N.C. Highway 191, right bank.

Mills River, N. C., 2,500 feet below bridge on N. C. Highway 191, left bank.

Mills River, N.C., left bank

Mills River, N. C., 2,000 feet above first highway bridge above mouth, right bank.

Mills River, N. C., 1,200 feet below first highway bridge above mouth, right bank.

North Fork Mills River:

Mills River, N. C., 2,000 feet above confluence with South Fork, left bank.

Mud Creek:

Hendersonville, N. C., at bridge on U. S. Highway 64, left bank.

Balfour, N. C, at Balfour quarry, 0.6 mile below Clear Creek, left bank.

Mountain Home, N. C., left bank

Naples, N. C., U. S. Geological Survey gage, left bank

Naples, N. C., at bridge on U. S. Highway 25, right bank.

\section{Cane Creek}

Fairview, N. C., 0.3 mile above, right bank

Fairview, N. C., 0.2 mile above Gap Creek, right bank

Fairview, N. C., 0.5 mile above Gravel Creek

Fairview, N. C., mouth of Gravel Creek, right bank

Fairview, N. C., 0.3 mile above Miller Creek

Fletcher, N. C., at bridge just below mouth of Limestone Creek.

Fletcher, N. C., 0.5 mile above Robinson Creek, right bank.

Fletcher, N. C., 0.4 mile below Robinson Creek, left bank.

Fletcher, N. C., at first highway bridge above Fletcher, left bank.

Fletcher, N. C., 500 feet above Hooper Creek, right bank.

Fletcher, N. C., at bridge on U. S. Highway 25, right bank.

Brickton, N. C., 0.2 mile above Fletcher Creek, left bank.

Brickton, N. C., 0.2 mile below Kinsey Creek, right bank.

Hominy Creek:

Candler, N. C., 100 feet above lower highway bridge, left bank.

Candler, N. C., 0.7 mile below, left bank

Enka, N. C., 0.7 mile above highway bridge, right bank

Enka, N. C., at American Enka Corp. intake dam, right bank.

Enka, N. C., 0.4 mile below railroad bridge, left bank

Enka, N. C., 25 feet below first highway bridge below Enka, right bank.

\begin{tabular}{|c|c|c|}
\hline $\begin{array}{l}\text { Miles } \\
\text { above } \\
\text { mouth }\end{array}$ & Day and hour ${ }^{2}$ & $\begin{array}{l}\text { Elevation } \\
\text { (feet) }\end{array}$ \\
\hline 488.5 & Sept. 2,9 p.m. ${ }^{3} \ldots$ & 683.1 \\
\hline $\begin{array}{l}471.0 \\
471.0 \\
467.6\end{array}$ & $\begin{array}{l}\text { Sept. 2, } 10 \text { p.m. } \\
\text { Sept. 2, } 12 \text { m. }{ }^{3}- \\
\text { Sept. 2, } 10 \text { a.m. } .^{3}-\end{array}$ & $\begin{array}{l}682.8 \\
643 \cdot 4 \\
642.19\end{array}$ \\
\hline 465.4 & Sept. $2,12 \mathrm{~m} .^{3} \ldots \ldots$ & 641.2 \\
\hline 464.2 & $\ldots-\ldots \mathrm{do}^{3} \ldots \ldots$ & 640.7 \\
\hline 8.0 & Aug. $30 \ldots \ldots$ & $2,154.3$ \\
\hline 5.4 & $\ldots$ do $\ldots$. & $2,114.3$ \\
\hline 4.4 & Aug. 30,7 a.m.... & $2,102.09$ \\
\hline 3.5 & Aug. $30 \ldots \ldots$ & $2,090,2$ \\
\hline 2.4 & - $\ldots$ do $\ldots \ldots \ldots$ & $2,077,0$ \\
\hline 1.9 & - $\ldots$ do do $_{-} \ldots \ldots \ldots$ & $2,071.3$ \\
\hline $\begin{array}{l}1.35 \\
1.25\end{array}$ & $\left(\begin{array}{l}\mathrm{do}_{-} \\
-\ldots\end{array}\right.$ & $\begin{array}{l}2,064.1 \\
2,062.0\end{array}$ \\
\hline .6 & $\ldots \ldots$ do $\ldots \ldots \ldots \ldots$ & $2,056.7$ \\
\hline 6.25 & - $\ldots$ do $\ldots \ldots . . . . .$. & $2,128.5$ \\
\hline 7.7 & $\ldots$ do $\ldots \ldots \ldots \ldots$ & $2,078.9$ \\
\hline 5.0 & - $\ldots$ do do $_{-} \ldots \ldots$ & $2,069.7$ \\
\hline $\begin{array}{l}3.0 \\
2.2 \\
1.7\end{array}$ & $\begin{array}{l}\text { do } \\
\text { Aug. } 30,5 \text { p.m. } \\
\text { Aug. } 30\end{array}$ & $\begin{array}{l}2,062.5 \\
2,058.47 \\
2,056.8\end{array}$ \\
\hline $\begin{array}{r}12.5 \\
10.2 \\
8.5 \\
8.0 \\
7.3 \\
6.1\end{array}$ & 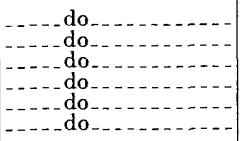 & $\begin{array}{l}2,212.2 \\
2,163.8 \\
2,139.7 \\
2,131.4 \\
2,121.9 \\
2,109.9\end{array}$ \\
\hline 5.5 & -... do do........... & $2,102.7$ \\
\hline 4.5 & $\ldots \mathrm{do}_{-\ldots} \ldots \ldots . . .$. & $2,088.5$ \\
\hline 3.8 & -... do do.......... & $2,081.6$ \\
\hline 3.4 & -...do-- & $2,075.5$ \\
\hline 2.7 & $\ldots$ do $_{-\ldots} \ldots \ldots \ldots$ & $2,071.1$ \\
\hline $\begin{array}{r}1.6 \\
.6\end{array}$ & $\mid$\begin{tabular}{l} 
do $_{2}$ \\
\hdashline$\ldots$ do
\end{tabular} & $\begin{array}{l}2,061.9 \\
2,054.2\end{array}$ \\
\hline 11.1 & - $\ldots$ do $\ldots \ldots \ldots$ & $2,103.5$ \\
\hline $\begin{array}{r}10.3 \\
9.1 \\
8.0\end{array}$ & 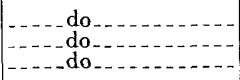 & $\begin{array}{l}2,088.0 \\
2,074.25 \\
2,061.4\end{array}$ \\
\hline $\begin{array}{l}7.2 \\
6.6\end{array}$ & ( & $\begin{array}{l}2,056.9 \\
2,048.7\end{array}$ \\
\hline
\end{tabular}

1 From tabulations and surveys by Tennessee Valley Authority, sea-level datum of 1929, supplementary adjustment of 1936 , except as noted.

2 Eastern standard time except as noted.

8 Central standard time. 
TABLE 23.-Flood-crest stages of late-August flood ${ }^{\perp}$-Continued

Stream and location

Hominy Creek-Con.

Enka, N. C., $0 . \dot{5}$ mile above second highway bridge below Enka, right bank.

Enka, N. C., 100 feet below second highway bridge below Enka, right bank.

Asheville, N. C., at third bridge above N. C. Highway 191, left bank.

Asheville, N. C., at second bridge above N. C. Highway 191 , left bank.

Asheville, N. C., 0.5 mile below second bridge above N. C. Highway 191 , right bank.

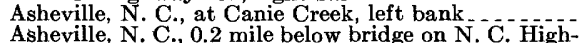
way 191 .

South Hominy Creek:

Candler, N. C., 0.27 mile above mouth, left bank

Swannanoa River:

Swannanoa, N. C., at garage near street bridge

Swannanoa, N. C., at bridge on U. S. Highway 70, left bank.

Azalea, N. C., 1.5 miles above bridge on U. S. Highway 70 , left bank.

Azalea, N. C., at Azalea Woodworking Co. plant, left bank.

Oteen, N. C., just above Lake Craig dam.

Oteen, N. C., just below Lake Craig dam, left bank--

Oteen, N. C., 230 feet below bridge on U. S. Highway 74 , right bank.

Biltmore, N. C., 150 feet above bridge at Sayles Biltmore Bleacheries, right bank.

Biltmore, N. C., 130 feet below bridge about 0.3 mile below Haw Creek, left bank.

Biltmore, N. C., U. S. Geological Survey gage, left bank.

Biltmore, N. C., at gate entrance to Biltmore Estate, left bank.

Asheville, N. C., 3,500 feet above mouth, right bank

Asheville, N. C., 25 feet above mouth.

Ivy River:

Barnardsville, N. C., left bank way 695 , left bank.

Democrat, N. C., at highway bridge 0.3 mile below Morgan Branch.

Forks of Ivy, N. C., at bridge on U. S. Highways 19 and 23.

Jupiter, N. C., at highway bridge 0.5 mile below Gabriels Creek, right bank.

Jupiter, N. C., opposite mouth of Eller Branch, right bank.

Sexton, N. C., 0.7 mile above Bull Creek, right bank

Sexton, N. C., at highway bridge 100 feet below Bull Creek.

Sexton, N. C., 0.7 mile below Bull Creek, left bank

Sexton, N. C., 1.5 miles above abandoned power dam, left bank.

Marshall, N. C., at highway bridge 0.2 mile below abandoned power dam, right bank.

Marshall, N. C., U. S. Geological Survey gage, right bank.

Marshall, N. C., 100 feet above Laurel Branch, right bank.

Marshall, N. C., 0.5 mile below Laurel Branch, right bank.

West Fork Pigeon River:

Sunburst, N. C., near mouth of Big Creek, left bank

Sunburst, N. C., bridge over Lake Logan, left bank

Sunburst, N. C., 0.6 mile above Lake Logan dam, right bank.

Sunburst, N. C., Lake Logan dam, right bank .

Sunburst, N. C., 200 feet below Lake Logan dam, right bank.

Sunburst, N. C., at mouth of Little East Fork Pigeon River right bank.

\begin{tabular}{|c|c|c|}
\hline $\begin{array}{l}\text { Miles } \\
\text { above } \\
\text { mouth }\end{array}$ & Day and hour ${ }^{2}$ & $\begin{array}{l}\text { Elevation } \\
\text { (feet) }\end{array}$ \\
\hline 5.5 & Aug. $30_{-}$ & $2,064.2$ \\
\hline 5.0 & $\ldots \mathrm{do}_{-}$ & $2,040.5$ \\
\hline 4.1 & -....do_. & $2,034.6$ \\
\hline 3.2 & -....do. & $2,017.9$ \\
\hline 2.6 & ..... do & $2,016.2$ \\
\hline $\begin{array}{r}1.7 \\
.7\end{array}$ & -...do.- & $\begin{array}{l}2,007.4 \\
1,995.6\end{array}$ \\
\hline 11.3 & $\ldots$ do & $2,102.6$ \\
\hline $\begin{array}{l}15.5 \\
14.8\end{array}$ & - do do.. & $\begin{array}{l}2,186.7 \\
2,172.5\end{array}$ \\
\hline 9.1 & $\ldots$ do & $2,076.2$ \\
\hline 6.9 & -... do.. & $2,050.4$ \\
\hline $\begin{array}{l}5.1 \\
5.1 \\
4.3\end{array}$ & 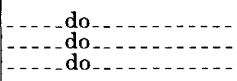 & $\begin{array}{l}2,040.08 \\
2,028.8 \\
2,018.4\end{array}$ \\
\hline 3.6 & -.... do do.. & $2,012.3$ \\
\hline 2.6 & ..... do & $2,001.3$ \\
\hline 1.6 & Aug. 30, 1:30 p.m.-- & $1,991.92$ \\
\hline 1.4 & Aug. $30_{-}$ & $1,989.8$ \\
\hline 0.7 & - & $\begin{array}{l}1,983.6 \\
1,981.5\end{array}$ \\
\hline $\begin{array}{l}18.2 \\
16.1\end{array}$ & - - do do._- & $\begin{array}{l}2,187.2 \\
2,098.8\end{array}$ \\
\hline 14.2 & -.... do & $2,045.3$ \\
\hline 11.8 & -...-do-. & $1,965.0$ \\
\hline 8.4 & -....do.. & $1,881.5$ \\
\hline 7.3 & ..... do_..... & $1,859.8$ \\
\hline $\begin{array}{l}6.1 \\
5.35\end{array}$ & - & $\begin{array}{l}1,827.6 \\
1,812.1\end{array}$ \\
\hline $\begin{array}{l}4.6 \\
3.7\end{array}$ & - & $\begin{array}{l}1,803.1 \\
1,796.6\end{array}$ \\
\hline 2.1 & - & $1,718.0$ \\
\hline 1.8 & Aug. 30, 5:30 a.m.-- & $1,713.08$ \\
\hline 1.3 & Aug. $30_{-}$ & $1,697.6$ \\
\hline .9 & ..... do do...... & $1,687.4$ \\
\hline $\begin{array}{l}8.9 \\
8.0 \\
7.6\end{array}$ & 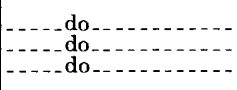 & $\begin{array}{l}2,971.3 \\
2,914.4 \\
2,912.1\end{array}$ \\
\hline $\begin{array}{l}7.0 \\
7.0\end{array}$ & - & $\begin{array}{l}2,912.0 \\
2,866.4\end{array}$ \\
\hline 6.4 & 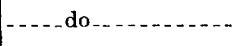 & $2,843.9$ \\
\hline
\end{tabular}

1 From tabulations and surveys by Tennessee Valley Authority, sea-level datum of 1929, supplementary adjustment of 1936 , except as noted.

2 Eastern standard time except as noted. 
TABLE 23.-Flood-crest stages of late-August flood ${ }^{1}-$ Continued

Stream and location

West Fork Pigeon River-Con.

Sunburst, N. C., near Cecil School, 0.1 mile above Nick Creek, right bank.

Retreat, N. C., 0.6 mile below Nick Creek, right bank Retreat, N. C., 1.4 miles below Niok Creek, right bank. Retreat, N. C., 2.0 miles below Nick Creek, left bank Retreat, N. C., 0.6 mile by highway NE. of Retreat, left bank.

Woodrow, N. C., 0.3 mile above Bird Creek, left bank

Woodrow, N. C., 1,000 feet above confluence of West and East Forks, right bank.

Pigeon River:

Woodrow, N. C., 1 mile below confluence of East and West Forks, left bank.

Woodrow, N. C., 0.6 mile above Stamey Cove Creek, left bank. Woodrow, N. C., 0.7 mile below Stamey Cove Creek,
left bank.

Canton, N. C., U. S. Geological Survey gage, left bank

Canton, N. $C_{.,}$on upper highway bridge in Canton

Canton, N. C., 2,000 feet above Beaverdam Creek, right bank.

Canton, N.C., mouth of Beaverdam Creek, right bank

Canton, N. C., 0.8 mile below Beaverdam Creek, right bank.

Canton, N. C., 2,000 feet above Cogburn Ford, right bank.

Clyde, N. C., 0.5 mile below highway bridge in Clyde, left bank.

Clyde, N. C., 0.4 mile above Richland Creek, left bank

Clyde, N. C., 1.0 mile below Richland Creek, left bank-

Crabtree, N. C., 1,500 feet below bridge on N. C. Highway 209, right bank.

Crabtree, N. C., 0.9 mile below Crabtree Creek, right bank.

Crabtree, N. C., 1,000 feet below first highway bridge below Crabtree Creek, left bank.

Cove Creek, N. C., 1.1 miles above Jonathan Creek, right bank.

Hepco, N. C., U. S. Geological Survey gage, 0.8 mile below Jonathan Creek, left bank.

Hepco, N. C., Waterville Lake at Waterville Dam....

Waterville, N. C., at Waterville power plant, left bank

Naillontown, Tenn., above, at old Tennessee \& North Carolina Ry. trestle, right bank.

Hartford, Tenn., U. S. Geological Survey gage, right bank.

Bluffton, Tenn., opposite, right bank

Denton, Tenn., 200 feet below toe of Brown Island, right bank.

Wilton Springs, Tenn., opposite Woods Island, right

Pleasant Grove, Tenn., opposite Vinson Island, right bank.

Newport, Tenn., 3 miles above at Edwina, right bank

Newport, Tenn., 800 feet below English Creek, left

bank. bank.

Newport, Tenn., 1,000 feet below lower bridge, left bank.

Newport, Tenn., 0.5 mile below lower bridge, left bank

Newport, Tenn., Deep Ford Bridge, left bank

East Fork Pigeon River:

Cruso, N. C., 0.3 mile below Cold Creek, left bank

Springdale, N. C., 0.4 mile below Springdale, right bank.-

Silver Bluff, N. C., 0.8 mile above Silver Bluff, right bank.

Little Tennessee River:

Franklin, N. C., on downstream side of bridge on U. S.

Highway 64.

Franklin, N. C., 0.9 mile below bridge on U. S. Highway 64 , left bank.

Franklin, N. C., 0.5 mile below Nantahala Power \& Light Co. dam, left bank.

\begin{tabular}{|c|c|c|}
\hline $\begin{array}{l}\text { Miles } \\
\text { above } \\
\text { mouth }\end{array}$ & Day and hour ${ }^{2}$ & $\begin{array}{l}\text { Elevation } \\
\text { (feet) }\end{array}$ \\
\hline 5.5 & Aug. 30 & $2,807.4$ \\
\hline $\begin{array}{l}4.7 \\
3.9 \\
3.3 \\
2.15\end{array}$ & $d d$ & $\begin{array}{l}2,775.2 \\
2,746.2 \\
2,723.8 \\
2,698.2\end{array}$ \\
\hline $\begin{array}{l}.7 \\
.2\end{array}$ & $\begin{array}{l}\text { - do } \\
\text { - - do }\end{array}$ & $\begin{array}{l}2,666.5 \\
2,655.6\end{array}$ \\
\hline 68.5 & do & $2,640.1$ \\
\hline 67.1 & -do & $2,627.8$ \\
\hline 65.8 & -_do & $2,609.2$ \\
\hline $\begin{array}{l}64.0 \\
63.7 \\
63.1\end{array}$ & $\begin{array}{l}\text { Aug. 30, } \\
\text { Aug. } 30^{-}\end{array}$ & $\begin{array}{l}2,592.97 \\
2,589.4 \\
2,583.0\end{array}$ \\
\hline $\begin{array}{l}62.8 \\
62.0\end{array}$ & $-d$ & $\begin{array}{l}2,581.3 \\
2,573.9\end{array}$ \\
\hline 59.4 & - do & $2,544.7$ \\
\hline 58.2 & do & $2,535.4$ \\
\hline $\begin{array}{l}55.4 \\
54.0 \\
51.9\end{array}$ & do & $\begin{array}{l}2,511.0 \\
2,496.5 \\
2,479.6\end{array}$ \\
\hline 48.8 & 9 & $2,442.4$ \\
\hline $4 \dot{8} .1$ & _do_ & $2,435.8$ \\
\hline 47.2 & do & $2,411.1$ \\
\hline 45.1 & Aug. 30 & $2,351.7$ \\
\hline 38.0 & Aug. 3 & $2,258.0$ \\
\hline $\begin{array}{l}25.8 \\
23.4\end{array}$ & Aug. 3 & $\begin{array}{l}1,407.3 \\
1,321.8\end{array}$ \\
\hline 21.4 & :30 p.m.. - & ${ }^{4} 1,258.63$ \\
\hline $\begin{array}{l}19.2 \\
16.8\end{array}$ & Aug. 3 & $\begin{array}{l}1,227.9 \\
1,179.2\end{array}$ \\
\hline 14.4 & _. do_ & $1,139.7$ \\
\hline 12.5 & $1-$ & $1,115.4$ \\
\hline $\begin{array}{r}10.8 \\
8.4\end{array}$ & do & $\begin{array}{l}1,093.7 \\
1,070.6\end{array}$ \\
\hline 6.8 & do & $1,058.0$ \\
\hline 5.4 & -_do.. & $1,050.4$ \\
\hline $\begin{array}{l}5.1 \\
2.1\end{array}$ & . do & $\begin{array}{l}1,043.9 \\
1,028.1\end{array}$ \\
\hline $\begin{array}{l}7.5 \\
5.9 \\
1.0\end{array}$ & _.....do_. & $\begin{array}{l}2,882.8 \\
2,814.6 \\
2,671.5\end{array}$ \\
\hline 115.8 & - do & $2,011.5$ \\
\hline 114.8 & do & $2,006.3$ \\
\hline 111.7 & $d$ & $1,984.3$ \\
\hline
\end{tabular}

1 From tabulations and surveys by Tennessee Valley Authority, sea-level datum of 1929, supplementary adjustment of 1936 , except as noted.

2 Eastern standard time except as noted.

4 Tennessee River Survey datum. 
TABLE 23.-Flood-crest stages of late-August flood ${ }^{1}$-Continued

Iotla, N. C., U. S. Geological Survey gage, right bank

Iotla, N. C., on bridge on N. C. Highway 286,500 feet below Iotla Creek.

Cowee, N. C., 1.0 mile above Cowee, left bank

Cowee, N. C., right bank

Etna, N. C., 0.4 mile below McCoy Ford, right bank

Etna, N. C., 900 feet above Dean Island, 1.5 miles above Burningtown Creek, left bank.

Needmore, N. C., 1,000 feet above Rattlesnake Creek, left bank.

Needmore, N. C., at dam, left bank

Needmore, N. C., 1,000 feet above Wiggins Creek, left bank.

Needmore, N. C., 200 feet above Sawmill Creek, 1.9 miles above bridge on U. S. Highway 19 , right bank.

Needmore, N. C., 100 feet above Sawmill Creek, 1.9 miles above bridge on U. S. Highway 19 , right bank.

Almond, N. C., 1.1 miles above highway bridge, right bank.

Almond, N. C., at highway bridge, near site of former U. S. Geological Survey gage, right bank.

Judson, N. C.. U. S. Geological Survey gage, 0.6 mile above Southern Ry. trestle, right bank.

Fontana, N. C., U. S. Geological Survey gage, right bank.

Tuckasegee River:

Tuckasegee, N. C., near bridge on N. C. Highway 106 , left bank.

Tuckasegee, N. C., U. S. Geological Survey gage, right bank.

East Laport; N. C., 1,000 feet above Caney Fork, left bank.

East Laport, N. C., 1.0 mile below, left bank

East Laport, N. C., 0.45 mile above bridge on N. C. Highway 106 , right bank.

East Laport, N. C., 1,000 feet below bridge on N. C. Highway 106, right bank.

Cullowhee, N. C., near mouth of Wayehutta Creek, right bank.

Cullowhee, N. C., 800 feet below bridge on N. C. Highway 106 , left bank.

Cullowhee, N. C., 0.4 mile below Cane Creek, left bank.

Cullowhee, N. C., at highway bridge, 1.9 miles below Cane Creek, right bank.

Webster, N. C., 0.3 mile above bridge on N. C. Highway 116 , left bank.

Dillsboro, N. C., 1.5 miles above bridge on U. S. Highway 23 , right bank.

Dillsboro, N. C. 0.7 mile above, right bank

Dillsboro, N. C., U. S. Geological Survey gage, left bank.

Dillsboro, N. C., 1.0 mile below bridge on U. S. Highway 23 , right bank.

Barkers Creek, N. C., 0.9 mile above highway bridge, left bank.

Barkers Creek, N. C., left bank.

Wilmont, N. C., right bank ........

Whittier, N. C., about 1 mile above highway bridge, right bank.

Whittier N.C. left bank

Ela, N. C., 200 feet above highway bridge, right bank

Ela, N. C., at Southern Ry. trestle, left bank.

Bryson City, N. C., at bridge on U. S. Highway 19 right bank.

Bryson City, N. C., 0.3 mile above Deep Creek, left bank.

Bryson City, N. C., U. S. Geological Survey gage, left bank.

Bryson City, N. C., 2.0 miles below, right bank ....

Noland, N. C., at mouth of Peachtree Creek, right bank.

Noland, N. C., 100 feet above Noland Creek, right bank.

Noland, N. C., near mouth of Goldmine Branch, right

Bushnell, N. C., 100 feet above Jenny Branch, right bank.

Bushnell, N. C., 1,000 feeta bove large island, right bank.

\begin{tabular}{|c|c|c|}
\hline $\begin{array}{l}\text { Miles } \\
\text { above } \\
\text { mouth }\end{array}$ & Day and hour? & $\begin{array}{c}\text { Elevation } \\
\text { (feet) }\end{array}$ \\
\hline $\begin{array}{l}109.7 \\
109.4\end{array}$ & $\begin{array}{l}\text { Aug. 30, } 10 \text { a.m. } \\
\text { Aug. } 30\end{array}$ & $\begin{array}{l}1,972.4 \\
1,970.3\end{array}$ \\
\hline $\begin{array}{l}107.4 \\
106.4 \\
102.8 \\
100.8\end{array}$ & 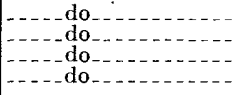 & $\begin{array}{l}1,958.6 \\
1,954.7 \\
1,932.8 \\
1,906.8\end{array}$ \\
\hline 95.8 & $\ldots \mathrm{do}_{-}$ & $1,817.1$ \\
\hline $\begin{array}{l}94.3 \\
92.2\end{array}$ & 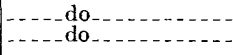 & $\begin{array}{l}1,791.9 \\
1,766.1\end{array}$ \\
\hline 89.4 & .....do & $1,716.9$ \\
\hline 89.4 & - do. & $1,715.3$ \\
\hline 86.0 & $\ldots$ do & $1,610.6$ \\
\hline 84.9 & .... do & $1,600.1$ \\
\hline 81.4 & Aug. $30,3: 30$ & $1,549.38$ \\
\hline 62 & Aug. 30, $4: 15$ & $1,291.03$ \\
\hline 49.2 & Aug. $30_{-}$ & $2,154.7$ \\
\hline 48.1 & Aug. 30, 3:30 a.m. - & ${ }^{5} 2,145.7$ \\
\hline 46.0 & Aug. $30_{-}$ & $2,129.3$ \\
\hline $\begin{array}{l}44.4 \\
44.0\end{array}$ & do & $\begin{array}{l}2,112.9 \\
2,105.4\end{array}$ \\
\hline 43.4 & ... do & $2,103.0$ \\
\hline 41.5 & do & $2,083.8$ \\
\hline 40.5 & ... do_. & $2,074.3$ \\
\hline $\begin{array}{l}38.7 \\
37.1\end{array}$ & - & $\begin{array}{l}2,060.3 \\
2,048.5\end{array}$ \\
\hline 35.2 & ..... do & $2,028.8$ \\
\hline 32.9 & $-\ldots .00-1$ & $2,001.5$ \\
\hline $\begin{array}{l}32.0 \\
30.9\end{array}$ & Aug. 30,6 a.m. & $\begin{array}{l}1,990.0 \\
1,972.11\end{array}$ \\
\hline 30.4 & Aug. 30_ & $1,967.5$ \\
\hline 27.9 & $\ldots$ do $\ldots$ & $1,917.0$ \\
\hline $\begin{array}{l}27.0 \\
24.0 \\
21.2\end{array}$ & 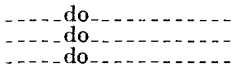 & $\begin{array}{l}1,901.8 \\
1,870.8 \\
1,851.5\end{array}$ \\
\hline $\begin{array}{l}20.1 \\
17.5 \\
16.8 \\
14.5\end{array}$ & {$\left[\begin{array}{l}{[} \\
\ldots\end{array}\right.$} & $\begin{array}{l}1,842.2 \\
1,795.2 \\
1,787.5 \\
1,766.5\end{array}$ \\
\hline 13.4 & - do do & $1,743.2$ \\
\hline 12.5 & Aug. 30, 10:30 a.m. & $1,732.50$ \\
\hline $\begin{array}{r}10.5 \\
8.5\end{array}$ & Aug. 30 & $\begin{array}{l}1,710.9 \\
1,670.7\end{array}$ \\
\hline 6.1 & _- do & $1,613.5$ \\
\hline 3.8 & -... do & $1,556.8$ \\
\hline 1.8 & $\ldots$ do & $1,498.9$ \\
\hline .3 & _... do do ........ & $1,468.0$ \\
\hline
\end{tabular}

${ }^{1}$ From tabulations and surveys by Tennessee Valley Authority, sea-level datum of 1929 , supplementary adjustment of 1936, except as noted.

2 Eastern standard time except as noted.

5 Adjustment of 1912 . 


\section{RECORDS OF PREVIOUS FLOODS}

Man's vision seems commonly to be seriously inadequate in foreseeing the potentialities of floods and in providing protection or remedies for lessening their destructive consequences. Foresight in such matters is greatly aided by the widest possible knowledge of great floods of the past. The longer the records bearing upon the magnitude and frequency of great floods the more enlightened and adequate will be the solution of flood problems.

Systematic observations of the stages and discharges of rivers in the United States cover a relatively short period of time; few exceed 50 years in length. In recent years information regarding many floods has been published currently in the water-supply papers of the Geological Survey. Water-Supply Paper 771, Floods in the United States-magnitude and frequency, contains an extensive compilation, from watersupply papers and other sources, of records of floods on some of the rivers covered in this report, for which, in general, the periods of systematic observation exceed 25 or 30 years.

The present report does not attempt to present records of previous floods in an exhaustive manner. This section is intended to afford a general view of some of the great floods of the past and to furnish references to data that will be helpful in the pursuance of more detailed investigations of the subject.

Records of historic floods and references to flood information are given in reports prepared by the Corps of Engineers, War Department, under provisions of House Document 308, 69th Congress, 1st session, enacted into law with modifications in the River and Harbor Act of January 21, 1927. Reports published for the various drainage basins are listed below, page references being given for the sections on historic floods.

James River, Va., 73d Cong., 2d sess., Appendix 2.15

Meherrin River, Va. and N. C., 71st Cong., 2 d sess., H. doe. 446, pp. 32-34.

Roanoke River, Va. and N. C., 74th Cong., 1st sess., H. doe. 65, pp. 63-66.

Neuse River, N. C., 72d Cong., 2 d sess., H. doe. 500, p. 31.

Cape Fear River, N. C., 73d Cong., 2d sess., H. doc. 193, p. 36.

Santee River, N. C. and S. C., 73d Cong., 1st sess., pp. 96-100.

Savannah River, Ga., S. C., and N. C., 74th Cong., 1st sess., H. doc. 64, pp. 36-37. Kanawha River, W. Va. and N. C., 74th Cong., 1st sess., H. doe. 91, pp. 63-65.

Tennessee River and tributaries, N. C., Tenn., Ala., and Ky., 71st Cong., 2d sess., H. doc. 328 , pp. 148-157, 187-189.

Publications of the Tennessee Valley Authority, particularly "Flood

15 Unpublished, but photostatic copy can be procured, at cost of reproduction, from the District Engineer, U. S. Engineer Office, Norfolk, Va. An abstract of this report is given in Floods of March 1936, pt. 3, Potomac, James, and upper Ohio Rivers; U. S. Geological Survey Water-Supply Paper 800, pp. 335-340, 1937. 
Control for upper French Broad River and tributaries," ${ }^{, 16}$ also contain much information on previous floods, as do many official State reports of agencies and departments that are concerned with the use of water.

Detailed information concerning floods, in satisfactory form for significant comparisons, is relatively searce for floods antedating the period of systematic observation, which began generally within the last 50 years. It is natural, however, that records of the more outstanding early floods should have been preserved through the years and comparisons made with later floods.

Although flood records are invaluable, it must be emphasized that the experience diselosed even by 100- or 200-year records may not be sufficient for establishing reliable long-time conclusions with relation to the magnitude and frequency of outstanding floods. A broad knowledge of practical meteorology, hydrology, and hydraulies is essential to the most effective interpretation of the records in respect to the occurrence of rare floods.

Records of previous floods are generally compiled only for the major rivers; ordinarily, little definite information is available regarding floods on the smaller streams. However, the occurrences of floods on such smaller streams, except those caused by cloudbursts, undoubtedly is associated more or less closely with the occurrence of the floods on the neighboring larger streams.

Information regarding some notable floods at gaging stations in the Roanoke, Kanawha, and Tennessee River Basins, including floods that occurred prior to the comparatively short period of systematic observations, is given on succeeding pages. This information has been assembled in connection with the preparation of the report on the floods of August 1940. Variations in the nature and origin of the information obtained from different sources have necessitated variation in the form of presentation for different basins.

\section{ROANOKE RIVER BASIN}

Outstanding flood stages and discharges on Roanoke River at Old Gaston, N. C., are given below. Old Gaston was the site of the former gaging station, 9 miles upstream from the present station at Roanoke Rapids. The discharges here given were obtained from a revised rating curve based on measurements made during the floods of August 1940 at Roanoke Rapids and subsequent studies; they supersede other values previously published, including revised records for the flood of 1912 published in Water-Supply Paper 782.

1877 : A stage of about 19 feet was reached (discharge, 212,000 secondfeet, revised); from statements made by local residents in 1912 .

${ }^{16}$ Flood control for upper French Broad River and tributaries, a preliminary report: TVA Water Control Planning Dept. Rept. 0-3075, Appendix A, Past floods in upper French Broad River Basin, August 1942. [Processed.] 
1889 : A stage of about 15 feet was reached (discharge, 137,000 secondfeet) ; from statements made by local residents in 1912 .

1912 : Maximum discharge during flood of March 18, 158,000 secondfeet (gage height $\mathbf{1 6 . 2}$ feet) ; from graph based on several readings daily of chain gage.

1936: Flood of January 23 reached a stage of 13.94 feet (discharge, 118,000 second-feet); from floodmarks.

1940: Flood of August 18 reached a stage of 21.48 feet (discharge, 261,000 second-feet); from floodmarks.

\section{KANAWHA RIVER BASIN}

Continuous records of stage and discharge in the Kanawha River Basin are relatively long, those on Kanawha River extending back to 1877. As a result of the flood of August 1940, however, studies were made which show that the published discharges for some previous floods should be revised. The revised figures are given in tables 24 and 25 and supersede those previously published.

TABLE 24.-Annual maximum daily mean and momentary peak discharges at gaging stations on New River, $W . V a$.

\begin{tabular}{|c|c|c|c|c|c|c|c|c|}
\hline \multirow[b]{2}{*}{ Year } & \multicolumn{4}{|c|}{ Near Hinton (above Greenbrier River) } & \multicolumn{4}{|c|}{ Caperton } \\
\hline & Day & $\begin{array}{l}\text { Daily } \\
\text { mean } \\
\text { (second- } \\
\text { feet) }\end{array}$ & Day & $\begin{array}{c}\text { Peak } \\
\text { (second- } \\
\text { feet) }\end{array}$ & Day & $\begin{array}{l}\text { Daily } \\
\text { mean } \\
\text { (second- } \\
\text { feet) }\end{array}$ & Day & $\underset{\substack{\text { Peak } \\
\text { (second- } \\
\text { feet) }}}{\text { - }}$ \\
\hline 1924 & Sept. 30 & 48,600 & Jan. 17 & 55,400 & & $\ldots$ & - & \\
\hline 1925 & Jan. 12 & 21,800 & Jan. 12 & 22,400 & & & & \\
\hline 1926 & Dec. 22 & 45,400 & Dec, 22 & 48,600 & & & & \\
\hline 1927 & Feb. 23 & 41,600 & Apr. 23 & 44,600 & & & & \\
\hline 1928 & Aug. 17 & 00 & Aug. 17 . & 48,600 & & & & \\
\hline $1929_{-}$ & Oet. 3 & 00 & Oct. 3 & 105,000 & Oet. & 86,400 & Oet. & 121,000 \\
\hline $1930_{-}$ & Feb. & 00 & Feb. & 26,000 & Feb. & 39,000 & Feb. & 46,400 \\
\hline $1931 \ldots$ & Apr. 5 & 21 , & Apr. & 23,000 & Apr. & 37,500 & Apr. & 43,400 \\
\hline $1932--$ & Dec. 29 & 0 & Dec. 29 & 37,000 & Feb. & 68,300 & Feb. & 79,500 \\
\hline 3 & Feb. 9 & 0 & Feb. 9 & 24,200 & Mar. 20 & 54,800 & Mar. 20 & $\mathbf{5 9}, 600$ \\
\hline & Mar. 5 & 0 & Mar. 5 & 53,600 & Mar. 5 & 109,000 & Mar. 5 & 114,000 \\
\hline & Jan. 2 & & Jan. 23 & 76,700 & Jan. 23 & 115,000 & Jan. 23. & 142,000 \\
\hline & Feb. 15 & & Feb. 15 & 62,800 & Mar. 18 & 122,000 & Mar. 18 & 135,000 \\
\hline $1937 \ldots$ & Oct. 2 & & Jan. 20 & 55,400 & Jan. 21 & 97,300 & Jan. $21 \ldots$ & 102,000 \\
\hline 1938 & July 2 & & July 24 & 44,600 & July 24 & 52,100 & July 24 & 61,900 \\
\hline 19 & Feb. 1 & & Feb. 1 & 27,300 & Jan. 31 & 59,600 & Jan. 31 & 71,500 \\
\hline & Aug. 1 & & Aug. & 232,000 & Aug. 15 & 177,000 & Aug. 15 & 244,000 \\
\hline
\end{tabular}

NoTE.-Figures of discharge in this table supersede those previously published.

Table 25, for Kanawha River at Kanawha Falls, W. Va., is based on a similar table in Water-Supply Paper 838. ${ }^{17}$ The discharges have been revised as a result of studies made since the floods of August 1940. Gage heights have been added, using those given in Water-Supply Paper 771. ${ }^{18}$ Gage heights prior to 1928 refer to the navigation gage of the Corps of Engineers, War Department, about a quarter of a mile above the Geological Survey recording gage. Gage heights at the recording gage site for floods prior to 1928 were obtained from a curve of relation between the navigation and recording gages.

17 Floods of Ohio and Mississippi Rivers, January-February 1937: U. S. Geol. Survey Water-Supply Paper 838, p. 647, 1938.

18 Jarvis, C. S., and others, Floods in the United States, magnitude and frequency: U. S. Geol. Survey Water-Supply Paper 771, p. 181, 1936. 
538 FLOODS OF AUGUST 1940 IN THE SOUTHEASTERN STATES

TABLE 25.-Annual maximum daily mean and momentary peak gage heights and discharges for Kanawha River at Kanawha Falls, W. Va.

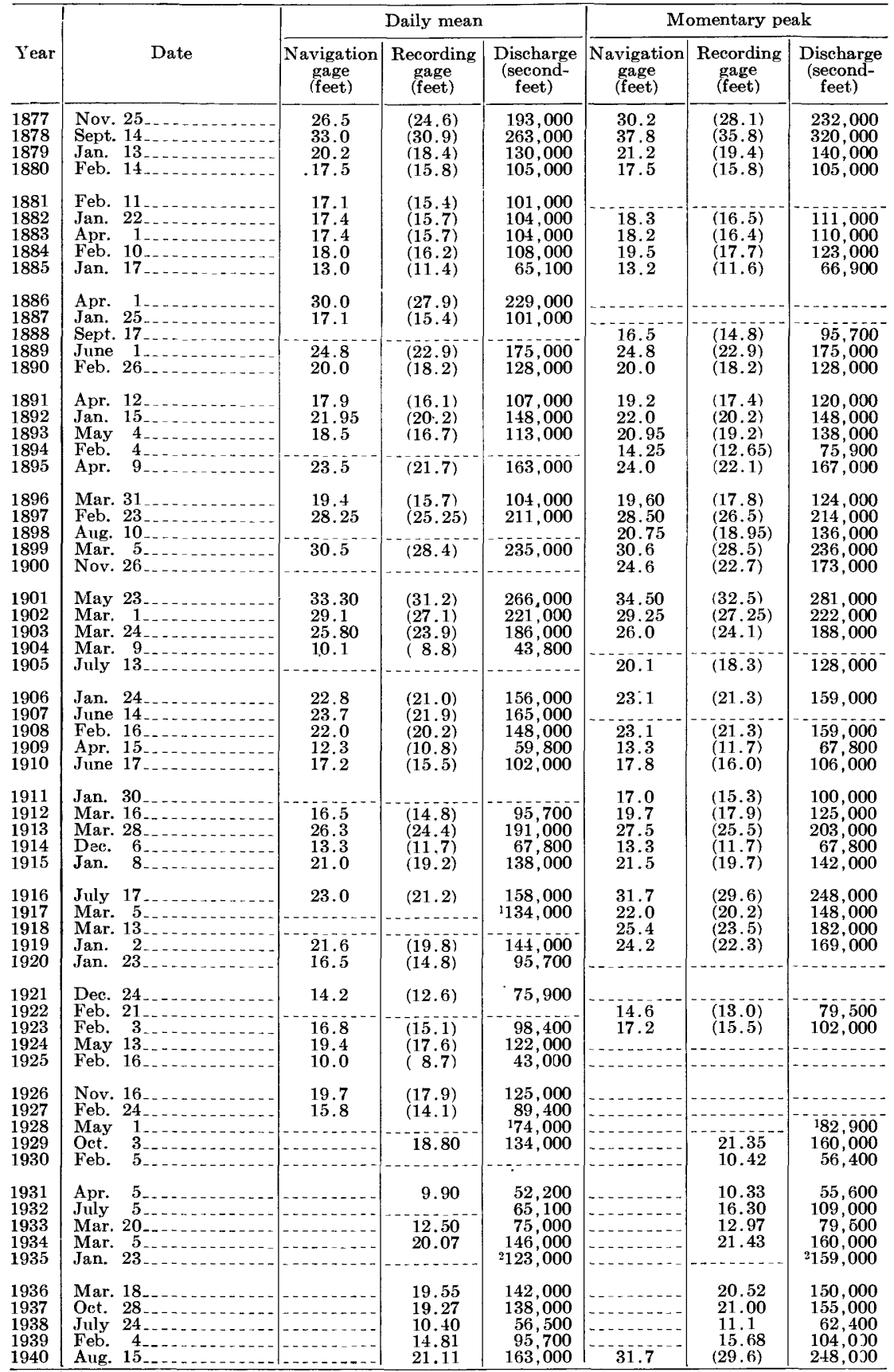

1 Discharge at lock 2, 9 miles downstream.

2 Discharge computed from flow of New River at Caperton and Gauley River above Belva.

NotE.-Figures of discharge in this table supersede those previously published. Gage heights in parenthesis were derived by relation curves from the navigation gage. 


\section{TENNESSEE RIVER BASIN}

Crest gage heights at gaging stations on French Broad, Tennessee, Nolichucky, Holston, Watauga, Little Tennessee, Hiwassee, Clinch, Toccoa, and Ocoee Rivers are given in tables 26 to 33 . In each table the gage heights are given for those floods that exceeded an arbitrarily chosen gage height at a key station.

TABLE 26.-Flood-crest stages, in feet, at stations on French Broad River when stage was 12 feet or more at Dandridge, Tenn.

\begin{tabular}{|c|c|c|c|c|c|c|c|}
\hline Year & Date & $\begin{array}{c}\text { French } \\
\text { Broad } \\
\text { River } \\
\text { at } \\
\text { Newport } \\
\text { (Oldtown), } \\
\text { Tenn. }\end{array}$ & $\begin{array}{c}\text { French } \\
\text { Broad } \\
\text { River } \\
\text { at } \\
\text { Dandridge. } \\
\text { Tenn.2 }\end{array}$ & Year & Date & $\begin{array}{c}\text { French } \\
\text { Broad } \\
\text { River } \\
\text { at } \\
\text { Newport } \\
\text { (Oldtown), } \\
\text { Tenn.1. }\end{array}$ & $\begin{array}{c}\text { French } \\
\text { Broad } \\
\text { River } \\
\text { at } \\
\text { Dandridge. } \\
\text { Tenn.2 }\end{array}$ \\
\hline 1867 & March & & ${ }^{3} 40$ & 1927 & Feb. $23-24$ & 7.5 & 13.0 \\
\hline 1875 & May & & 432 & 1928 & June $30 \ldots$ & 9.40 & 13.9 \\
\hline or & & & & & Aug. 16,17 & 13.45 & 517.2 \\
\hline 1876 & & & & 1929 & Mar. 24 & 6.91 & 12.3 \\
\hline 1901 & May 21 & 5610.5 & ${ }^{4} 28$ & 1932 & Dec. 28,29 & 9.12 & 14.65 \\
\hline 1902 & Feb & 4723.0 & & 1933 & Feb. 15 & 8.00 & 13.83 \\
\hline 1906 & Jan & & 15.0 & 1934 & Mar. 3,4 & 8.65 & 12.5 \\
\hline 1909 & June 5 & 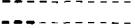 & 12.0 & 1935 & Mar. 26,27 & 9.15 & 16.63 \\
\hline 1913 & $\mathrm{Ma}$ & & 512.5 & 1936 & Jan. 19,20 & 13.38 & 18.49 \\
\hline & $\mathrm{Ma}$ & & 16.0 & & Feb. 4,5 & 9.10 & 12.70 \\
\hline $\begin{array}{l}1915 \\
1916\end{array}$ & Dec. 19 & & 13.0 & & Mar. 25. & 8.31 & 12.13 \\
\hline 1916 & July & & ${ }^{5} 12.0$ & & Mar. 26-28 & 11.13 & 15.15 \\
\hline & Jul & 422 . & 521.0 & & Apr. 2 & 10.84 & 13.28 \\
\hline $\begin{array}{l}1917 \\
1918\end{array}$ & Mar. 5_ & $\ldots$ & 516.0 & & Apr. $6-$ & 12.32 & 16.38 \\
\hline 18 & Jan & & 15 & & Oct. 16,17 & 10.80 & 12.33 \\
\hline & $\mathrm{Oct}$ & & & 1937 & Jan & 11.43 & 15.28 \\
\hline $\begin{array}{l}1920 \\
1921\end{array}$ & Apr. 2 & & 18.7 & 1940 & Aug. 14,15 & 12.60 & 18.73 \\
\hline $\begin{array}{l}1921 \\
1922\end{array}$ & Feb. 10 & 59.4 & 513.4 & & Aug. 30,31 & 19.25 & 20.93 \\
\hline 1922 & Jan. 21-22=- & ${ }^{5} 6.9$ & ${ }^{5} 12.6$ & & & & \\
\hline
\end{tabular}

1 Datum of gage is 1,011.61 feet above mean sea level, datum of 1929 , supplementary adjustment of 1936.

2 Datum of gage is 903.33 feet above mean sea level, datum of 1929 , supplementary adjustment of 1936; prior to Dec. 6, 1916, gage was 300 feet upstream at same datum. Records prior to 1931 by U. S. Weather Bureau.

3 Traditional stage.

4 From floodmark.

5 Maximum observed.

6 From gage with datum approximately 1,010.3 feet above nean sea level, datum of 1929, supplementary adjustment of 1936 .

7 Maximum stage known. 
TABLE 27.-Flood-crest stages, in feet, at stations on Tennessee River during years in which stage was 35.0 feet or more at Chattanooga, Tenn.

\begin{tabular}{|c|c|c|c|c|c|c|}
\hline Year & Date & $\begin{array}{l}\text { Tennessee } \\
\text { River } \\
\text { at } \\
\text { Knoxville, } \\
\text { Tenn.1 }\end{array}$ & $\begin{array}{l}\text { Tennessee } \\
\text { River } \\
\text { at } \\
\text { Loudon, } \\
\text { Tenn.? }\end{array}$ & $\begin{array}{l}\text { Tennessee } \\
\text { River } \\
\text { near } \\
\text { Rockwood, } \\
\text { Tenn. }\end{array}$ & $\begin{array}{c}\text { Tennessee } \\
\text { River } \\
\text { at } \\
\text { Breedenton, } \\
\text { Tenn. }\end{array}$ & $\begin{array}{c}\text { Tennessee } \\
\text { River } \\
\text { at } \\
\text { Chattanooga, } \\
\text { Tenn. }\end{array}$ \\
\hline $\begin{array}{l}1867 \\
1875 \\
1879 \\
1880 \\
1881\end{array}$ & $\begin{array}{l}\text { Mar. } 10-11 \\
\text { Feb. } 27-M a r .1 \\
\text { Jan. } 15 \\
\text { Mar. } 18 \\
\text { Jan. } 19\end{array}$ & 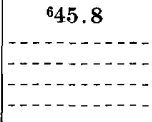 & 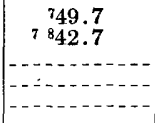 & 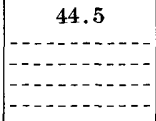 & 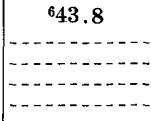 & $\begin{array}{l}657.9 \\
853.8 \\
838.0 \\
838.3 \\
840.2\end{array}$ \\
\hline $\begin{array}{l}1883 \\
1884\end{array}$ & $\begin{array}{l}\text { Jan. } 23 \\
\text { Feb. } 10-111 \\
\text { Mar. } 7-10\end{array}$ & $\begin{array}{c}816.1 \\
822.3\end{array}$ & & $\begin{array}{ll}--- \\
--- \\
---\end{array}$ & -- & $\begin{array}{l}838.2 \\
836.8 \\
842.8\end{array}$ \\
\hline $\begin{array}{l}1886 \\
1890\end{array}$ & $\begin{array}{l}\text { Mar. 31-Apr. } 3 \\
\text { Feb. } 28-\text { Mar. } 2\end{array}$ & $\begin{array}{l}829.6 \\
823.0\end{array}$ & $\begin{array}{l}834.9 \\
825.0\end{array}$ & $---8 \overline{29} 6$ & -- & $\begin{array}{l}852.2 \\
842.5\end{array}$ \\
\hline 1891 & $\begin{array}{l}\text { Feb. } 11-14 \\
\text { Mar. } 10-11\end{array}$ & $\begin{array}{l}{ }^{8} 21.9 \\
816.9\end{array}$ & $\begin{array}{l}823.0 \\
820.9\end{array}$ & $\begin{array}{l}825.1 \\
826.0\end{array}$ & -10-0- & $\begin{array}{l}837.5 \\
838.9\end{array}$ \\
\hline $\begin{array}{l}1892 \\
1896 \\
1897\end{array}$ & $\begin{array}{l}\text { Jan. } 15-17 \\
\text { Apr. } 3-5 \\
\text { Mar. 11-15 }\end{array}$ & $\begin{array}{l}823.3 \\
828.7 \\
822.5\end{array}$ & $\begin{array}{c}{ }^{8} 26.0 \\
-\end{array}$ & $\begin{array}{l}825,0 \\
831 \cdot 4 \\
826.4\end{array}$ & 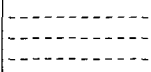 & $\begin{array}{l}837.9 \\
840.5 \\
837.9\end{array}$ \\
\hline 1899 & $\begin{array}{l}\text { Feb. } \quad 7-9 \\
\text { Mar. 16-17 } \\
\text { Mar. 20-22 }\end{array}$ & $\begin{array}{l}8923.1 \\
8919.8 \\
8928.2\end{array}$ & & $\begin{array}{ll}--- \\
--- \\
--\end{array}$ & & $\begin{array}{l}838.3 \\
836.7 \\
840.0\end{array}$ \\
\hline 1902 & $\begin{array}{l}\text { Dec. } 31,1901-J a n .2 \\
\text { Mar. } 1-4\end{array}$ & $\begin{array}{r}81031.0 \\
836.0\end{array}$ & - & 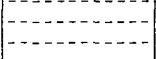 & 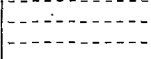 & $\begin{array}{r}840.8 \\
838.0\end{array}$ \\
\hline $\begin{array}{l}1917 \\
1918 \\
1920 \\
1922 \\
1926\end{array}$ & $\begin{array}{l}\text { Mar. } 5-7 \\
\text { Jan. } 29 \text { Feb. } 2 \\
\text { Apr. } 3-5 \\
\text { Jan. } 22-24 \\
\text { Dec. } 26-29\end{array}$ & $\begin{array}{r}828.2 \\
24.2 \\
826.7 \\
819.0 \\
14.8\end{array}$ & $\begin{array}{l}32.9 \\
823.5 \\
827.5 \\
821.2 \\
820.70\end{array}$ & $8 \overline{25} \cdot 2$ & 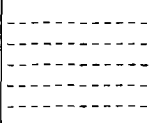 & $\begin{array}{l}847.7 \\
842.5 \\
843.6 \\
835.8 \\
38.45\end{array}$ \\
\hline $\begin{array}{l}1929 \\
1932 \\
1936\end{array}$ & $\begin{array}{l}\text { Mar. } 24-26 \\
\text { Dec. } 29-31 . \\
\text { Mar. } 28-29 \\
\text { Apr. } 7-9\end{array}$ & $\begin{array}{l}17.20 \\
20.15 \\
23.80 \\
21.69\end{array}$ & $\begin{array}{l}821.50 \\
24.73 \\
25.75 \\
24.30\end{array}$ & $\mid$\begin{tabular}{c}
827.6 \\
824.6 \\
\hdashline$-\ldots . . .-$ \\
\end{tabular} & $\begin{array}{c}27.70 \\
25.60\end{array}$ & $\begin{array}{l}38.50 \\
37.50 \\
37.08 \\
35.40\end{array}$ \\
\hline
\end{tabular}

${ }^{1}$ Records from 1883 to 1889 by U. S. Signal Service; 1890 to August 1925 by U. S. Weather Bureau; August 1925 to date by U. S. Geological Survey. All readings are comparable unless otherwise noted. Datum of gage is 797.68 feet above mean sea level, datum of 1929, supplementary adjustment of 1936

2 Datum of gages, 726.29 feet above mean sea level, datum of 1929 , supplementary adjustment of 1936. Oct. 1, 1922, to Sept. 30, 1929, staff gage 4.5 miles downstream, datum 726.0 feet above mean sea level. Records prior to Oct. 1, 1922, by U. S. Weather Bureau at Southern Ry. bridge 1,600 feet downstream; datum of gages Dec. 1, 1883, to June 28, 1907, 727.7 feet above mean sea level, 1929 general adjustment; June 29, 1907, to Sept. 30, 1922, 724.6 feet above mean sea level.

${ }^{3}$ Gage heights obtained from Daily river stages of U. S. Weather Bureau without attempt to correlate datum of various gages used.

4 Datum of gage, 666.22 feet above mean sea level, datum of 1929, supplementary adjustment of 1936.

5 Datum of gage, 621.12 feet above mean sea level, general adjustment of 1929 . Records prior to June 16, 1926, from Water-Supply Paper 353 and Daily river stages published by $U$. S. Weather Bureau; subseqt ent to June 16, 1926, from recorder charts furnished by U. S. Weather Bureau. The datum is believed to have remained the same for the period of use.

6 From floodmark.

7 Traditional stage.

8 Maximum observed.

9 Read on temporary gage about 2,000 feet downstream from original gage with datum 0.42 foot lower. No comparative readings available.

10 Read on gage about 2,600 feet downstream from original gage with datum 2.3 feet lower. Comparative readings at stage 23.6 feet on this gage indicate a minus correction of about 2 feet is required to make readings at that stage comparable with previous and subsequent readings. 
TABLE 28. - Flood-crest stages, in feet, at stations on Nolichucky River when stage was 7.5 feet or more at Embreeville, Tenn.

\begin{tabular}{|c|c|c|c|c|}
\hline Year & Date & $\begin{array}{l}\text { Nolichucky River } \\
\text { at } \\
\text { Embreeville, Tenn. }{ }^{1}\end{array}$ & $\begin{array}{c}\text { Nolichucky River } \\
\text { near } \\
\text { Greeneville, Tenn. }{ }^{23}\end{array}$ & $\begin{array}{l}\text { Nolichucky River } \\
\text { near } \\
\text { Morristown, Tenn. }\end{array}$ \\
\hline $\begin{array}{l}1905 \\
1906 \\
1908\end{array}$ & $\begin{array}{l}\text { July } 12 \\
\text { Jan. } 23 . \\
\text { Sept. } 19 \\
\text { Nov. } 19.12 \\
\text { Jan. } 12\end{array}$ & 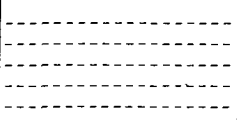 & $\begin{array}{l}8.65 \\
519.3 \\
58.20 \\
13.60 \\
59.10\end{array}$ & 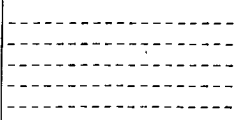 \\
\hline $\begin{array}{l}1921 \\
1922 \\
1923\end{array}$ & $\begin{array}{l}\text { Feb. 10-11 } \\
\text { Aug. } 3-4 \\
\text { Jan. 21-22 } \\
\text { Mar. 16-17 } \\
\text { May 29-30. }\end{array}$ & $\begin{array}{ll}5 & 8.75 \\
11.0 \\
5 & 9.03 \\
5 & 7.80 \\
5 & 7.64\end{array}$ & $\begin{array}{ll}5 & 8.5 \\
5 & 14.10 \\
5 & 7.9 \\
5 & 9.25 \\
5 & 7.25\end{array}$ & $\begin{array}{r}514.45 \\
514.57 \\
515.10 \\
513.10 \\
- \\
\end{array}$ \\
\hline $\begin{array}{r}1924 \\
1926 \\
1927\end{array}$ & $\begin{array}{l}\text { Mar. } 6-7 \\
\text { Sept. 29. } \\
\text { Jan. } 18-199 \\
\text { Nov. } 16 \\
\text { Feb. 23-24. }\end{array}$ & $\begin{array}{ll}5 & 7.65 \\
5 & 7.82 \\
5 & 7.58 \\
5 & 8.40 \\
5 & 7.69\end{array}$ & 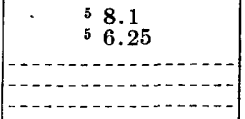 & $\begin{array}{r}513.30 \\
59.70 \\
10.64 \\
13.56 \\
17.11\end{array}$ \\
\hline $\begin{array}{l}1928 \\
1929\end{array}$ & 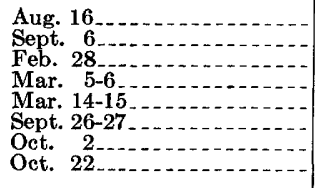 & 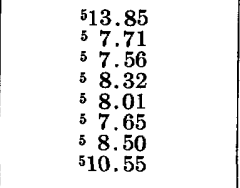 & 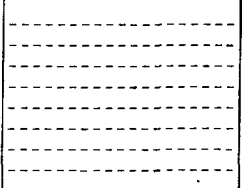 & $\begin{array}{r}18.90 \\
11.63 \\
13 . \overline{83} \\
11.87 \\
10.51 \\
11.50 \\
16.99\end{array}$ \\
\hline $\begin{array}{l}1934 \\
1935 \\
\\
1936 \\
\\
1940\end{array}$ & $\begin{array}{l}\text { July } 15-16 \\
\text { Jan. } 8,9 \\
\text { Mar. } 26 \\
\text { Jan. } 19-20 \\
\text { Oct. } 16-17 \\
\text { Aug. } 13-14 \\
\text { Aug. } 30-31\end{array}$ & $\begin{array}{r}10.30 \\
10.23 \\
10.69 \\
8.76 \\
8.80 \\
18.57 \\
11.23\end{array}$ & 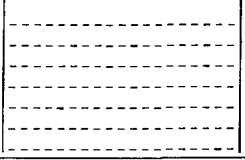 & $\begin{array}{l}16.14 \\
17.15 \\
22.00 \\
18.97 \\
16.04 \\
22.68 \\
19.79\end{array}$ \\
\hline
\end{tabular}

1 Datum of gage is 1,519.30 feet above mean sea level, datum of 1929 , supplementary adjustment of 1936. Prior to Oct. 1, 1931, from chain gage 2,000 feet downstream; datum of gage 1,512.97 feet above mean sea level, datum of 1929 , supplementary adjustment of 1936 .

2 Datum unknown. Prior to Apr. 7, 1908, gage was located on opposite side of bridge with datum 2.04 feet higher than present gage.

3 Prior to 1919 , flood erests tabulated for stages 6.0 feet or over.

4 Datum of gage is 1,004.40 feet above mean sea level, Tennessee River Survey datum.

5 Maximum observed. 


\section{FLOODS OF AUGUST 1940 IN THE SOUTHEASTERN STATES}

TABLE 29.-Flood-crest stages, in feet, at stations on Holston River when stage was 18.0 feet or more at Rogersville, Tenn.

\begin{tabular}{|c|c|c|c|c|c|c|c|}
\hline Year & Date & $\begin{array}{c}\text { South Fork } \\
\text { Holston } \\
\text { River at } \\
\text { Bluff City, } \\
\text { Tenn. }\end{array}$ & $\begin{array}{c}\text { South Fork } \\
\text { Holston } \\
\text { River at } \\
\text { Kingsport, } \\
\text { Tenn. }{ }^{2}\end{array}$ & $\begin{array}{c}\text { Holston } \\
\text { River } \\
\text { near } \\
\text { Rogersville, } \\
\text { Tenn. }^{3}\end{array}$ & \begin{tabular}{|c|} 
Holston \\
River \\
near \\
Morristown, \\
Tenn.4
\end{tabular} & \begin{tabular}{|} 
Holston \\
River \\
near \\
Jefferson \\
City, Tenn.
\end{tabular} & $\begin{array}{c}\text { Holston } \\
\text { River } \\
\text { at Straw- } \\
\text { berry Plains, } \\
\text { Tenn. }{ }^{6}\end{array}$ \\
\hline 1867 & ar. 10 & & $-----\ldots-n$ & 738.4 & $-\cdots-\infty-\infty$ & 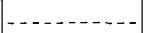 & $---\infty-\ldots$ \\
\hline 1901 & $\begin{array}{l}\text { May } 22 \\
\text { Dec. } 29\end{array}$ & $\begin{array}{l}8915.0 \\
8912.6\end{array}$ & 年 & $\ldots \ldots$ & - & - & - $-\cdots-\cdots$ \\
\hline $\begin{array}{l}1902 \\
1903\end{array}$ & $\begin{array}{l}\text { Feb. } 28 \\
\text { Feh. } 17 \\
\text { Mar. } 23-24\end{array}$ & $\begin{array}{r}891.4 \\
89.4 \\
87.5\end{array}$ & $\begin{array}{l}---1 \\
---- \\
---- \\
\cdots--\end{array}$ & $\begin{array}{r}817.0 \\
814.3\end{array}$ & \begin{tabular}{|c|}
--- \\
--- \\
--- \\
---
\end{tabular} & 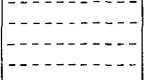 & 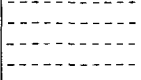 \\
\hline 1906 & $\begin{array}{l}\text { Jan. } 23 \ldots \\
\text { Nov. } 20\end{array}$ & $\begin{array}{r}11.6 \\
85.8\end{array}$ & & $\begin{array}{r}17.5 \\
813.5\end{array}$ & $--\infty$ & - & -1 \\
\hline 1907 & June $14-15$ & 811.7 & $\begin{array}{ll}----1 \\
----1\end{array}$ & 814.0 & 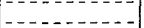 & 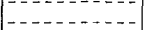 & 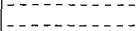 \\
\hline 1912 & Apr. 3 & 88.1 & - & 814.4 & 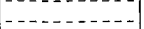 & 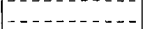 & 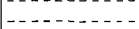 \\
\hline 1913 & Mar. 27-2 & 10.9 & $x^{-1}$ & 819.1 & $-\cdots----\cdots$ & $-\cdots-\cdots-\cdots$ & $\ldots \ldots \ldots$ \\
\hline 1915 & Dec. 18 & 10.0 & & 15.3 & - & & --- \\
\hline $\begin{array}{l}1916 \\
1917\end{array}$ & $\begin{array}{l}\text { July } 17 \\
\text { Mar. } 5\end{array}$ & $\begin{array}{r}86.3 \\
9.3\end{array}$ & & $\begin{array}{l}{ }^{815.4} \\
817.1\end{array}$ & --- & - & - \\
\hline 1918 & Jan. 29 & 89.1 & 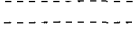 & 20.0 & $\begin{array}{ll}---1 \\
-\cdots-1\end{array}$ & 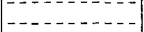 & 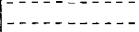 \\
\hline 1920 & Apr. 2- & 8.2 & $-\ldots$ & 15 & 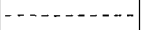 & $--\cdots+----$ & $\ldots-\ldots$ \\
\hline 1922 & Jan. 20-22 & 88.9 & & 13 & - & -- & $\ldots$ \\
\hline & Apr. $28-29$ & & -- & ${ }^{813}$ & --1 & $-\ldots-$ & $\ldots \ldots$ \\
\hline 1923 & $\begin{array}{l}\text { Feb. } 3-4 \\
\text { Feb. 13-14 }\end{array}$ & $\begin{array}{r}11.3 \\
8.4\end{array}$ & $\ldots \ldots$ & $\begin{array}{r}17.0 \\
813.0\end{array}$ & $\ldots \ldots$ & $\mid-\cdots+-1$ & - - - - \\
\hline 1926 & Dec. $22-23$ & 10.0 & 9.1 & 13.6 & $-\ldots-$. & 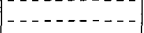 & -..- \\
\hline 1927 & Feb. 23-2 & 11.4 & 13.9 & 17.0 & & & - \\
\hline 1932 & Feb. 4-5 & $\begin{array}{r}0.4 \\
10.0\end{array}$ & 12.6 & 14 & & & $16 . \overline{6}$ \\
\hline 1935 & Mar. 26-28 & 12.5 & 15.2 & & 728.4 & - - - - - - - & 20.2 \\
\hline 1936 & Jan. 19 & 8.6 & 11.0 & & $\mid-\ldots-\infty,-$ & $\mid-\ldots+-\infty$ & $14 . \overline{2}$ \\
\hline 1940 & $\begin{array}{l}\text { Apr. } \quad 6-8 \\
\text { Aug. } 13-16\end{array}$ & $\begin{array}{r}8.8 \\
11.6 \\
\end{array}$ & $\begin{array}{l}10.8 \\
18.8 \\
\end{array}$ & $\begin{array}{l}13.0 \\
17.8\end{array}$ & 26.7 & $\mid---\overline{2} 1 . \overline{8}$ & $\begin{array}{l}14.3 \\
18.6 \\
\end{array}$ \\
\hline
\end{tabular}

1 Datum of gage is 1,368.35 feet above mean sea level, datum of 1929 , supplementary adjustment of 1936.

2 Datum of gage is $1,184.31$ feet above mean sea level, datum of 1929 , supplementary adjustment 0 1936.

${ }_{3}$ Prior to Oct. 26, 1923, gage located at railroad bridge about $1 / 2$ mile downstream from present site; records by U. S. Weather Bureau; datum of gage 1,052.42 feet above mean sea level, datum of 1929 , supplementary adjustment of 1936; October 1923 to May 1934, gages at highway bridge 300 feet upstream, datum of gages, 1,054.80 feet above mean sea level, datum of 1929 , supplem $m$ nary adjustment of 1936 ; since May 1934, datum of gage 1,054.83 feet above mean sea level, datum of 1929 , supplementary adjustment of 1936 .

4 Datum of gage is 964.02 feet above mean sea level, datum of 1929, supplementary adjustment of 1936 .

5 Datum of gage is 920.02 feet above mean sea level, datum of 1929 , stuplementary adjustment of 1936 .

6 Datum of gage is 838.39 feet above mean sea level, datum of 1929, supplementary adjustment of 1936 .

7 From floodmark.

8 Maximum observed.

- No records available at Rogersville for this rise. 
TABLE 30.-Flood-crest stages, in feet, at stations on Watauga River when stage was 10.0 feet or more at Elizabethton, Tenn.

\begin{tabular}{|c|c|c|c|c|}
\hline Year & Date & $\begin{array}{l}\text { Watauga River } \\
\text { at } \\
\text { Stump Knob, } \\
\text { Tenn. }\end{array}$ & $\begin{array}{l}\text { Watauga River } \\
\text { at } \\
\text { Butler, Tenn.2 }\end{array}$ & $\begin{array}{l}\text { Watauga River } \\
\text { at } \\
\text { Elizabethton, } \\
\text { Tenn. }\end{array}$ \\
\hline $\begin{array}{l}1900 \\
1901 \\
1902 \\
1913\end{array}$ & $\begin{array}{l}\text { Oet. } 23 \\
\text { May } 21 \\
\text { Feb. } 27 \text { or } 28 \\
\text { Mar. } 14 \\
\text { Mar. } 27\end{array}$ & 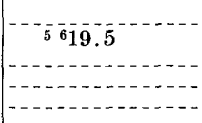 & \begin{tabular}{rl}
4 & 515.00 \\
4 & 516.27 \\
\hdashline & -1.2
\end{tabular} & $\begin{array}{r}22.0 \\
10.4 \\
710.0\end{array}$ \\
\hline $\begin{array}{l}1916 \\
1918 \\
1920 \\
1924 \\
1927\end{array}$ & 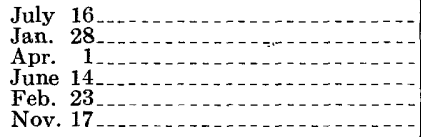 & $\mid-\frac{1}{3} 9.20$ & $\begin{array}{rll}7 & 8 & 5.30 \\
7 & 8 & 7.55 \\
7 & 9 & 8.60\end{array}$ & $\begin{array}{r}715.6 \\
11.1 \\
10.2 \\
710.9 \\
11.1 \\
10.39\end{array}$ \\
\hline $\begin{array}{l}1932 \\
1935\end{array}$ & 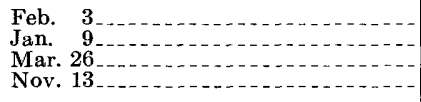 & $\begin{array}{r}12.44 \\
8.05 \\
9.2\end{array}$ & $\begin{array}{r}9.70 \\
11.85 \\
10.80 \\
8.40\end{array}$ & $\begin{array}{l}11.8 \\
12.32 \\
12.97 \\
10.23\end{array}$ \\
\hline $\begin{array}{l}1936 \\
1940\end{array}$ & 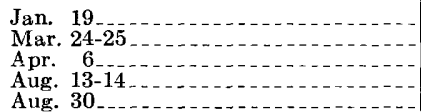 & $\begin{array}{r}5.91 \\
5.80 \\
6.50 \\
624.0 \\
1010.35\end{array}$ & $\begin{array}{r}7.45 \\
7.51 \\
7.85 \\
625.40 \\
9.78\end{array}$ & $\begin{array}{l}10.79 \\
10.96 \\
10.62 \\
20.87 \\
11.37\end{array}$ \\
\hline
\end{tabular}

1 Datum of gage is $1,869.03$ feet above mean sea level, datum of 1929 , supplementary adjustment of 1956 .

${ }^{2}$ Datum of gage is $1,809.38$ feet above mean sea level, datum of. 1929 , supplementary adjustment of 1936.

3 Datum of gage is $1,486.23$ feet above mean sea level, datum of 1929 , supplementary adjustment of 1936.

4 From staff gage 200 feet below highway bridge. Datum unknown.

5 No records available at Elizabethton for this rise.

6 From floodmarks.

7 Maximum observed.

8 From chain gage at highway bridge. Datum was 2.88 feet higher than present gage.

From staff gage at highway bridge; same datum as chain gage.

10 From graph based on observer's readings. 


\section{FLOODS OF AUGUST 1940 IN THE SOUTHEASTERN STATES}

TABLE 31.-Flood-crest stages, in feet, at stations on Little Tennessee and Hiwassee Rivers when stage was 20.0 feet or more on Little Tennessee River at McGhee, Tenn.

\begin{tabular}{|c|c|c|c|c|c|}
\hline Year & Date & $\begin{array}{c}\text { Little Tennessee } \\
\text { River at } \\
\text { Calderwood, } \\
\text { Tenn. }\end{array}$ & $\begin{array}{c}\text { Little Tennessee } \\
\text { River at } \\
\text { McGhee, Tenn. }{ }^{1}\end{array}$ & $\begin{array}{c}\text { Hiwassee River } \\
\text { at } \\
\text { Charleston, } \\
\text { Tenn. }\end{array}$ & $\begin{array}{c}\text { Hiwassee River } \\
\text { near } \\
\text { Reliance, Tenn.4 }\end{array}$ \\
\hline $\begin{array}{l}1867 \\
1884 \\
1886 \\
1899\end{array}$ & $\begin{array}{l}\text { March } \\
\text { Mar. } 31 \\
\text { Mar. 16 } 20\end{array}$ & 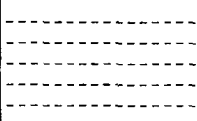 & $\begin{array}{l}539.0 \\
538.5 \\
-\end{array}$ & $\begin{array}{rl}6 & 734.0 \\
5 & 727.3 \\
5 & 727.6\end{array}$ & 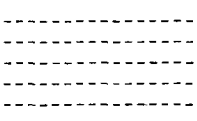 \\
\hline $\begin{array}{l}1906 \\
1913 \\
1917 \\
1918 \\
1920\end{array}$ & $\begin{array}{l}\text { Nov. } 19-20 \\
\text { Mar. } 27-28 \\
\text { Mar. } 4-5 \\
\text { Jan. } 29-31 . \\
\text { Apr. } 2-3 .\end{array}$ & $\begin{array}{r}8748.27 \\
6911.75 \\
\end{array}$ & $\begin{array}{l}530.0 \\
521.5 \\
527.2 \\
520.15 \\
530.5\end{array}$ & $\begin{array}{r}30.0 \\
520.0 \\
28.3 \\
521.5 \\
530.5\end{array}$ & $\begin{array}{c}515.20 \\
58.6 \\
513.90\end{array}$ \\
\hline $\begin{array}{l}1922 \\
1926 \\
1932 \\
1933\end{array}$ & $\begin{array}{l}\text { Jan. } 20-22 \\
\text { Dec. } 25-26-29 \\
\text { Jan. } 30-31 \\
\text { Dec. } 28-29 \\
\text { Feb. } 15\end{array}$ & $\begin{array}{c}746.3 \\
7.14 \\
9.80 \\
6.72\end{array}$ & $\begin{array}{l}23.7 \\
20.9 \\
20.6 \\
27.0 \\
20.7\end{array}$ & $\begin{array}{l}628.2 \\
24.4 \\
22.1 \\
28.58 \\
21.98\end{array}$ & $\begin{array}{c}511.56 \\
1015.1 \\
14.63 \\
22.0 \\
13.53\end{array}$ \\
\hline $\begin{array}{l}1934 \\
1936\end{array}$ & $\begin{array}{l}\text { Mar. } 3-4 \\
\text { Jan. } 19-20 \\
\text { Feb. } 4-5 \\
\text { Mar. } 28 \\
\text { Apr. } 2-3 . \\
\text { Apr. } 6-7 . \\
\end{array}$ & $\begin{array}{r}8.07 \\
8.60 \\
8.77 \\
6.60 \\
7.69 \\
10.03\end{array}$ & $\begin{array}{l}21.97 \\
23.5 \\
24.9 \\
21.1 \\
20.7 \\
25.78\end{array}$ & $\begin{array}{l}23.5 \\
24.86 \\
27.19 \\
21.67 \\
25.5 \\
27.12\end{array}$ & $\begin{array}{l}17.9 \\
18.49 \\
23.01 \\
15.00 \\
21.40 \\
19.88\end{array}$ \\
\hline $\begin{array}{l}1937 \\
1939 \\
1940\end{array}$ & $\begin{array}{l}\text { Jan. } 3 \\
\text { Feb. } 15-16-1 \\
\text { Aug. } 30\end{array}$ & $\begin{array}{l}7.66 \\
7.11 \\
9.70\end{array}$ & $\begin{array}{l}20.55 \\
20.13 \\
21.56\end{array}$ & $\begin{array}{r}22.17 \\
22.94 \\
2\end{array}$ & $\begin{array}{r}16.16 \\
16.18 \\
116.08 \\
\end{array}$ \\
\hline
\end{tabular}

1 Datum of gage, 760.18 feet above mean sea level, datum of 1929 , supplementary adjustment of 1936 ; Sept. 18, 1925, to Sept. 5, 1929, staff gage 100 feet downstream was used, same datum; Oct. 1, 1918, to Sept. 17, 1925, U.S. Weather Bureau gages 0.3 mile downstream were used, same datum; Dec. 1,1905 , to Sept. 30,1918 , U. S. Weather Bureau gage 0.3 mile downstream was used; datum of gage 0.79 feet higher than present gage; Nov. 29, 1904, to Nov. 30, 1905, U. S. Weather Bureau gage 0.4 mile downstream was used, datum of gage 0.3 feet lower than succeeding gage. Records prior to 1904 from U. S. Weather Bureau.

${ }^{2}$ Datum of gage 861.41 feet above mean sea level, datum of 1929 , supplementary adjustment of 1936; June 1,1923 , to Sept. 30,1927 , datum of gage was 122.41 feet above mean sea level, datum of 1929 , supplementary adjustment of 1936 . Jan. 1, 1921, to May 31, 1923, gages at highway bridge 2,000 feet upstream were used; datum was 863.56 feet above mean sea level, datum of 1929 , supplementary adjustment of 1936. Jan. 1, 1914, to Dec. 31, 1918, gage 1 mile downstream was used; datum of gage $122.4^{\mathrm{l}}$ feet above mean sea level, datum of 1929 , supplementary adjustment of 1936 . Jan 1,1912 , to Dec, 31 , 1913, gage at present site was used; datum of gage 122.41 feet above mean sea level, datum of 1929 , supplementary adjustment of 1936 .

3 Datum of gage 665.56 feet above mean sea level, datum of 1929 , supplementary adjustment of 1936 . Prior to Sept. 7, 1926, gages 250 feet downstream were used; datum of gages 667.32 feet above mean sea level, general adjustment of 1929 . Records prior to 1899 and from 1903 to 1919 , from U. S. Weather Bureau.

4 Datum of gage 718.34 feet, datum of 1929 , supplementary adjustment of 1936 . Prior to Oct. 1,1926 , gage 3 miles upstream, published as Hiwassee River at Reliance, was used; datum of gage 748.36 feet above mean sea level, datum of 1929 , supplementary adjustment of 1936.

5 Maximum observed.

${ }^{6}$ Present datum.

7 No records available at $\mathrm{McGhee}$ for this rise.

8 Daily mean gage height.

${ }^{9}$ Before breaking of levee.

10 From graph based on observer's readings.

11 Flow regulated by storage in Hiwassee Reservoir. 
TABLE 32.-Flood-crest stages in feet, at stations on Clinch River when stage was 30 feet or more at Clinton, 10 feet or more near Tazewell, or 12 feet or more above Tazewell

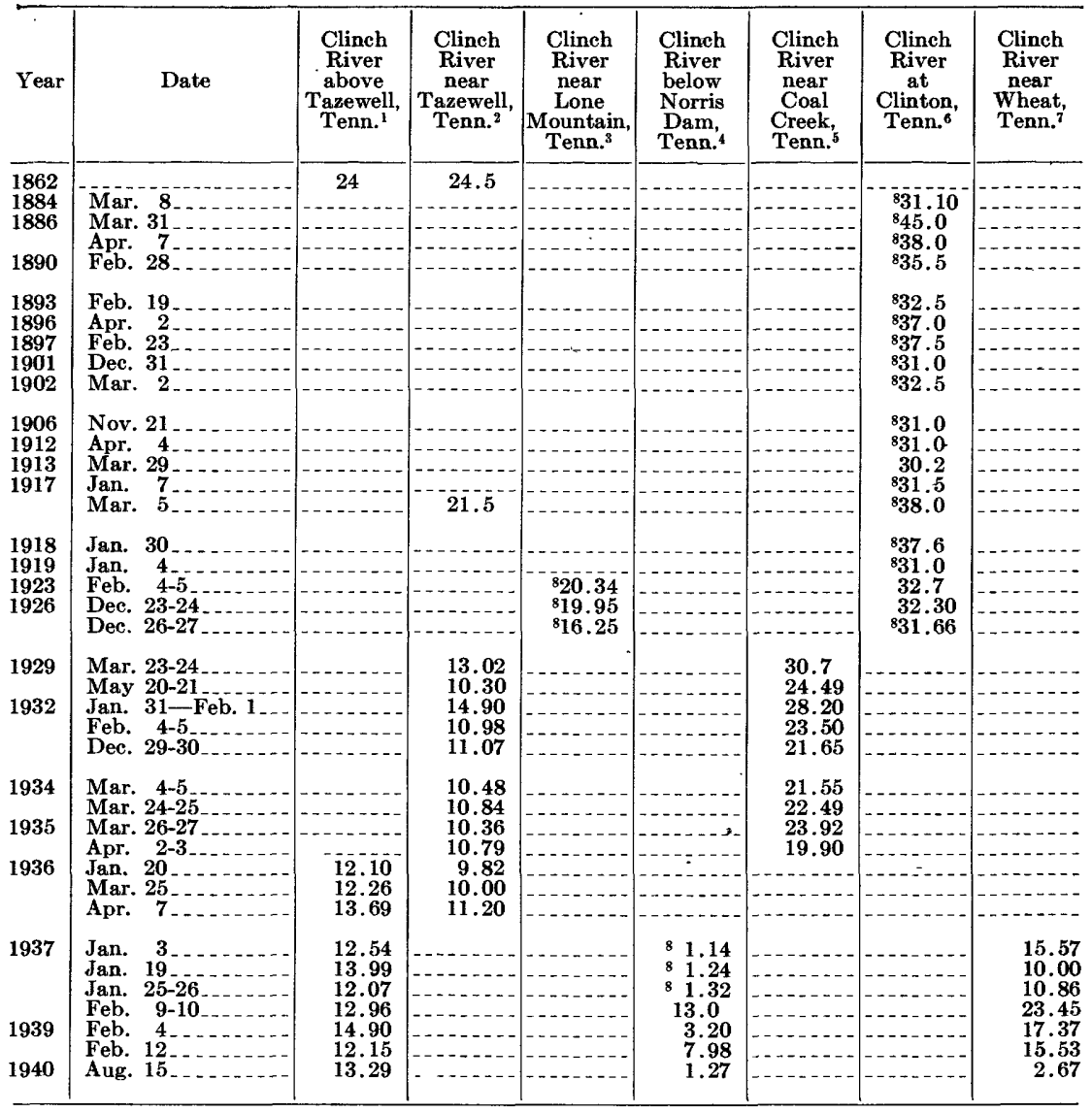

1 Datum of gage, 1,060.7 feet above mean sea level, datum of 1929, supplementary adjustment of 1936 . 2 Datum of gage, 1,012.55 feet above mean sea level, Tennessee River Survey datum. Affected by backwater from Norris Dam after December 1936.

Datum of gage, 958.19 feet above mean sea level.

4 Datum of gage, 819.11 feet above mean sea level, datum of 1929 , supplementary adjustment of 1936 . Flow regulated by storage in Norris Reservoir.

5 Datum of gage, 805.61 feet above mean sea level, datum of 1929 , supplementary adjustment of 1936 . Prior to Aug. 24, 1935, datum of gage was 3.00 feet higher than present datum. Flow regulated by storage in Norris Reservoir after.June 1935.

6 Datum of gage, 776.96 feet above mean sea level, general adjustment of 1929 . Prior to July 1920 datum of gage was 777.1 feet above mean sea level, general adjustment of 1929 ; records by U. S. Weather Bureau.

7 Datum of gage, 717.36 feet above mean sea level, datum of 1929 , supplementary adjustment of 1936 .

Flow regulated by storage in Norris Reservoir.

Maximum observed. 


\section{FLOODS OF AUGUST 1940 IN THE SOUTHEASTERN STATES}

TABLE 33.-Flood-crest stages, in feet, at stations on Toccoa and Ocoee Rivers, when stage exceeded 7.0 feet at Dial, Ga.

\begin{tabular}{|c|c|c|c|c|c|c|c|}
\hline Year & Date & $\begin{array}{c}\text { Toccoa } \\
\text { River } \\
\text { near } \\
\text { Dial, Ga. }{ }^{1}\end{array}$ & $\begin{array}{c}\text { Toccoa } \\
\text { River } \\
\text { near } \\
\text { Blue Ridge, } \\
\text { Ga. }\end{array}$ & \begin{tabular}{|c|} 
Ocoee \\
River \\
at \\
Copperhill, \\
Tenn.
\end{tabular} & $\begin{array}{c}\text { Ocoee } \\
\text { River } \\
\text { at } \\
\text { McHarg, } \\
\text { Tenn. }{ }^{4}\end{array}$ & $\begin{array}{c}\text { Ocoee } \\
\text { River } \\
\text { at } \\
\text { Emf, Tenn. }{ }^{5}\end{array}$ & $\begin{array}{c}\text { Ocoee } \\
\text { River } \\
\text { at } \\
\text { Parksville, } \\
\text { Tenn. }\end{array}$ \\
\hline $\begin{array}{l}1906 \\
1908 \\
1915 \\
1916 \\
1918\end{array}$ & $\begin{array}{l}\text { Nov. } 19 \\
\text { Feb. } 15 \\
\text { Dec. } 29 \\
\text { July } 9-10 \\
\text { Dec. } 22\end{array}$ & $\begin{array}{r}77.6 \\
97.1 \\
10.0 \\
97.6\end{array}$ & $\begin{array}{r}13.0 \\
98.3\end{array}$ & $\begin{array}{c}7818.5 \\
76.50\end{array}$ & 79.6 & $\begin{array}{r}10.0 \\
13.7 \\
910.4\end{array}$ & 15.75 \\
\hline $\begin{array}{l}1920 \\
1921 \\
1922 \\
1929 \\
1931\end{array}$ & $\begin{array}{l}\text { Apr. } 2 \\
\text { Feb. } 10 \\
\text { Jan. } 21 \\
\text { Sept. } 25-26 \\
\text { Dec. 13-14 }\end{array}$ & $\begin{array}{l}7.20 \\
9.25 \\
8.0 \\
7.05 \\
8.05\end{array}$ & $\begin{array}{r}811.9 \\
11.7 \\
10.4 \\
7.52 \\
2.44\end{array}$ & \begin{tabular}{rl} 
& \\
7 & 11.74 \\
7 & 7.4 \\
7 & 7.9 \\
- & - \\
\hdashline & -
\end{tabular} & 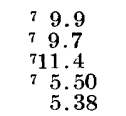 & $\begin{array}{c}12.40 \\
10.75 \\
12.5 \\
7.85 \\
7.94\end{array}$ & $\begin{array}{l}6.71 \\
7.90\end{array}$ \\
\hline $\begin{array}{l}1932 \\
1934 \\
1936\end{array}$ & $\begin{array}{l}\text { Dec. } 28 \\
\text { Mar. } 3 \\
\text { Feb. } 4-5 . \\
\text { Apr. } 2 \\
\text { Apr. } 6 \\
\text { Apr. } 8\end{array}$ & $\begin{array}{l}8.10 \\
7.05 \\
8.3 \\
9.60 \\
7.3 \\
8.28\end{array}$ & $\begin{array}{r}7.40 \\
1.31 \\
4.93 \\
7.22 \\
8.04 \\
104.05\end{array}$ & 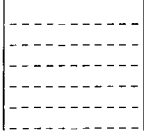 & $\begin{array}{l}7.20 \\
4.70 \\
8.95 \\
8.10 \\
8.80 \\
7.51\end{array}$ & $\begin{array}{l}9.71 \\
7.7 .4 \\
11.7 \\
10.4 \\
11.95 \\
10.07\end{array}$ & $\begin{array}{r}15.3 \\
6.70 \\
9.58 \\
12.60 \\
18.32 \\
6.53\end{array}$ \\
\hline
\end{tabular}

1 Records prior to 1925 by Tennessee Electric Power Co. Datum of gage is 1,781.13 feet above mean sea level, datum of Tennessee Electric Power Co.

${ }_{2}^{2}$ Datum of gage is $1,538.77$ feet above mean sea level, datum of 1929 , supplementary adjustment of 1936. Flow regulated by storage in Blue Ridge Reservoir after December 1930. Prior to Apr. 1, 1931, gage 800 feet upstream set to datum 0.56 foot lower was used.

3 Datum of gage not known.

4 Datum of present gage is $1,427.16$ feet above mean sea level, datum of 1929 , supplementary adjustment of 1936. Prior to Oct. 10,1931, datum of gage was $1,430.00$ feet above mean sea level, same datum. Flow regulated by storage in Blue Ridge Reservoir after December 1930 .

${ }_{5}$ Datum of gage is 838.15 feet above mean sea level, general adjustment of 1929 . Flow regulated by storage in Blue Ridge Reservoir after December 1930.

6 Datum of gage is 717.58 feet above mean sea level, Tennessee River Survey datum. Flow regulated by storage in Parksville Reservoir from beginning of record, and in Blue Ridge Reservoir after December 1930 .

7 Maximum gage height observed.

8 No record at Dial, Ga.

9 Maximum daily mean gage height.

10 Estimated. 
Administration and pèrsonnel..... Allisonia, Va., Big Reed Island Creek

$$
\text { near .........316-317 }
$$

New River at............ 305-306 Almond, N. C., Nantahala River at. .419-420 Altamaha River Basin, records for..289-292 Altapass, N. C., North Toe River at..371-372 Altavista, Va., Roanoke River at....121-122 Anderson, S. C., Seneca River near. .281-282 Ansonville, N. C., Pee Dee River near ...........189-190

Antecedent conditions ........ 17-20

Apalachicola River Basin, records for ..........292-300

Appomattox River, at Farmville, Va..111-112

at Mattoax, Va. ........112-113

near Petersburg, Va........113-114

Archdale, N. C., Muddy Creek near. . 175 Area-depth-duration relations, records of ...... 56-61

Arvonia, Va., Slate River near.....107-108

Asheville, N. C., French Broad River at $\ldots \ldots \ldots \ldots \ldots 333-334$

Athens, Ga., Middle Oconee River near . . . . . . . .291-292

Augusta, Ga., Savannah River at...276-277 Austell, Ga., Sweetwater Creek near.299-300

\section{B}

Badin, N. C., Yadkin River at Nar-

rows Reservoir near. .186-187

Bahama, N. C., Dial Creek near....164-165

Flat River at and near......163-164

Bane, Va., Walker Creek at.......319-320

Banister River, at Halifax, Va....153-154

Base flow ..............476-480 See also Ground water.

Bassett, Va., Smith River at. . . . . 148-149 Battle Ground, N. C., Horsepen Creek at

Bear Creek, at Robbins, N. C.....175-176 Beaverdam Swamp, at Lebanon,

N. C. ........179-180

Beetree Creek, near Swannanoa,

N. C. $\ldots \ldots \ldots \ldots \ldots 357-358$

Bell, Ga., Broad River near. . . . . . 283-284

Belva, W. Va., Gauley River above..324-325

Benaja, N. C., Haw River near..... 167

Bent Creek, N. C., French Broad

River at ........331-332

Bent Creek, Va., James River at... 86-87

Big Laurel Creek, near Stackhouse,

N. C. .............

361

Big Reed Island Creek, near

Allisonia, Va. ......316-317

Biltmore, N. C., Swannanoa River at.353-354
Swannanoa River near.355-356

Black River at Kingstree, S. C.... 218

Blackwater River near Union Hall,

Va. ..........130-131

Blantyre, N. C., French Broad

River at .........329-330

Blue Ridge, Ga., Blue Ridge Reser-

voir near .......446-447

Blue Ridge Reservoir, near Blue

Ridge, Ga. . .....446-447

Bluestone River, at Lilly, W. Va....322-323

Bluff City, Tenn., South Fork Holston

River at . . . . . 385-386

Boardman, N. C., Lumber River at.. $\quad 217$

Boiling Springs, N. C., Broad River

near $\ldots \ldots \ldots \ldots 243-244$

Branch, N. C., Linville River at....240-241

Brevard, N. C., Davidson River

near ..........345-346

Bridgewater, N. C., Catawba River

near ........219-220

Brier Creek, at Millhaven, Ga.....286-287

Broad River, at Richtex, S. C.....246-247 near Bell, Ga........... . 283-284 near Boiling Springs, N. C. . . . 243-244 near Carlisle, , S. C. . . . . . . 245-246 near Chimney Rock, N. C.....242-243 near Gaffney, S. C.........244-245

Brookneal, Va., Falling River near..137-138

Roanoke River at.........123-124

Brown Creek, near Polkton, N. C....211-212 Bryson City, N. C., Noland Creek

near .........4429-430

Tuckasegee River at........424-425

Buchanan, Va., James River at.... 83-84

Buena Vista, Va., North River near.101-102 Buffalo Creek, near Greensboro,

$$
\text { N. C. } \ldots \ldots \ldots \ldots \ldots \quad 172
$$

Buffalo River, near Norwood, Va...104-105 Butler, Tenn., Roan Creek at......402-403 Watauga River at........ 398-399

\section{C}

Calderwood, Tenn., Little Tennessee River at .......413-414

Calfpasture River, above Mill Creek, at Goshen, Va........

Calhoun Falls, S. C., Savannah River near .........274-275

Calvert, N. O., French Broad River at $\ldots \ldots \ldots \ldots \ldots \ldots 328-329$

Camden, s. C., Wateree River near. .237-239 Cane River, near Sioux, N. C......381-382 Canoochee River, near Claxton, Ga... $\quad 289$ Canton, N. C., Pigeon River at..... 362-363 Cape Fear River, at Fayettesville, N. C. . . . . . 169-170 at Lillington, N. C.......... 169 near Tarheel, N. C......... 170 
Cape Fear River Basin, records for. .167-178 Caperton, W. Va., New River at. . . .311-312 Carlisle, S. C., Broad River near. . . 245-246 Cartersville, Va., James River at.... 88-89 Cataloochee, N. C., Cataloochee Creek near ..........369-370

Cataloochee Creek, near Cataloochee, N. C. ..........369-370

Catawba, N. C., Catawba River at and near ..........225-228

Catawba River, at and near, Catawba,

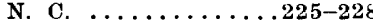

at Rhodhiss, N. C..........221-222 near Bridgewater, N. C.. . . . 219-220 near Great Falls, S. C........233-236 near Mount Holly, N. C.......229-230 near Rock Hill, s. C.........231-232 near Taylorsville, N. C... . . . . 223-224

Chappells, S. C., Lake Greenwood near ........263-264

Saluda River at...........264-265

Charleston, W. Va., Kanawha River at $\ldots \ldots \ldots \ldots \ldots \ldots \ldots \ldots+314$

Charlotte, N. C., Little Sugar Creek near .........241-242

Chattahoochee River, at West Point,

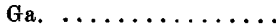

near Gainesville, Ga........293-294 near Leaf, Ga............. 292-293 near Vinings, Ga........... 295 near Whitesburg, Ga......... 296

Chattanooga, Tenn., Chichamauga Reservoir near .....343-344

Tennessee River at.........344-345 Chattooga River, near Clayton, Ga...271-272 Cheraw, S. C., Juniper Creek near. .214-215 Cherokee, N. C., Oconalufty River at.427-429 Chickamauga, Tenn., South Chickamauga Creek near...448-449

Chickamauga Reservoir, near Chatta. nooga, Tenn. .......343-344

Chimney Rock, N. C., Broad River near ..........242-243

Chinquapin, N. C., Northeast Cape Fear River near......

Chowan River Basin, records for. ...114-117 Clarksville, Va., Roanoke River at. . 126-127 Claxton, Ga., Canoochee River near. . 289 Clayton, Ga., Chattooga River near..271-272 Clayton, N. C., Middle Creek near... 165

Neuse River near........... 162 Cleveland, N. C., Third Creek at.... 205 Cleveland, Va., Clinch River at....431-432 Cliffside, N. C., Second Broad River at $\ldots \ldots \ldots \ldots \ldots 248-249$

Clifton Forge, Va., Cowpasture River near .......... 93-94

Clifton, S. C., Pacolet River near...

Clinch River, above Tazewell, Tenn..433-434

at Cleveland, Va..........431-432

at ISpeers Ferry, Va.........432-433

below Norris Dam, Tenn...... 436

near Tazewell, Tenn......... 435

Clover, Va., Roanoke River near....124-125

Clyo, Ga., Savannah River near....278-279
Columbia, S. C., Lake Murray near . 266-267

Saluda River near......... 267-268

Contentnea Creek, at Hookerton,

N. C. .........166-167

near Wilson, N. C.......... 166

Cooleemee, N. C., South Yadkin River

at $\ldots \ldots \ldots \ldots \ldots 201-203$

Copeland, N. C., Fisher River near..195-196

Cornatzer, N. C., Dutchman Creek near ..........199-200

Cove Creek, N. C., Jonathan Creek near ..........367-368

Covington, Va., Dunlap Creek near. 91-92

Potts Creek near.......... 92-93

Cowpasture River, near Clifton Forge, Va. ........... 93-94

Craig Creek, at Parr, Va......... 95

Crumpler, N. C., North Fork New River at ........314-315

Cullasaja, N. C., Cullasaja Creek at . .417-419

Cullasaja Creek, at Cullasaja, N. C..417-419 at Highlands, N. C.........416-417

\section{D}

Damage from floods.......14-15; pls. 3-15 Dan River, at Danville, Va........142-143 at Leaksville, N. C..........140-141 at South Boston, Va......... 144-145 near Francisco, N. C.........138-139 near Wentworth, N. C........ 139-140 Dandridge, Tenn., French Broad

River at ........339-340

Danville, Va., Dan River at....... 142-143 Sandy River near. . . . . . . . 152-153

Data, explanation of . . . . . . . 62-80 Davidson River, near Brevard, N. C..345-346

Deep Creek, near Roseland, N. C..... $\quad 217$

Deep River, at Moncure, N. C....... 174 at Ramseur, N. C......... 174

near Randleman, N. C......... 173

Definitions of terms.......... 62-63 Demorest, Ga., Soque River near. . .298-299 Denmark, S. C., South Fork Edisto

River near ......269-270

Díal Creek near Bahama, N. C......164-165 Dillon, S. C., Little Pee Dee River near . . . . . . . 215-216

Dillsboro, N. C., Tuckasegee River at.422-423

Discharge, at indicated times...... 66-80 concentration of $\ldots \ldots \ldots \ldots \ldots$ 495-497 maximum, compared with maximum rainfall ....499-502 mean ............... 66 volumes, compared with maximum rainfall .....4499-502 Doe River, at Elizabethton, Tenn....403-404 Donnaha, N. C., Little Yadkin River near ...........196-197

Drowning Creek, near Hoffman

N. C. $\ldots \ldots \ldots \ldots \ldots 20216$

Dublin, Ga., Oconee River at......290-291

Dunlap Creek, near Covington, Va... 91-92 Dutchman Creek, near Cornatzer,

N. C. . . . . . . 199-200 


\section{$\mathbf{E}$}

East Fork Deep River, near High

Point, N. O....... 175

Eden, Ga., Ogeechee River near. ...288-289

Edisto River, near Givhans, S. C.... 270

Edisto River Basin, records for....269-271

Effingham, S. C., Lynches River at... 215

Eggleston, Va., New River at.....308-309

Eldorado, N. O., Uwharrie River

near ..........208-209

Elizabethton, Tenn., Doe River at..403-404

Watauga River at........400-401

Elk Creek, near Elk Park, N. C.... 402

Elk Park, N. C., Elk Creek near... 402

Elk River, at Queen Shoals, W. Va... 325

Elkton, N. O., Middle Swamp near... 179

Ellerbe, N. O., Mountain Oreek near.213-214

Embreeville Tenn., Nolichucky River

at $\ldots \ldots \ldots \ldots \ldots \ldots \ldots+375-376$

Emory River, at Oakdale; Tenn.....437-438

Enfield, N. O., Fishing Oreek near... 160

Eno River, at Hillsboro, N. O...... 161

Enoree, .S. O., Enoree River near. . . 260-261

Enoree River, near Enoree, S. C. . . .260-261

Evington, Va., Otter River near. ...135-136

\section{$\mathbf{F}$}

Fair Forest Creek, near Union, S. C..259-260 Falling River, near Brookneal, Va...137-138 Falling Spring. Va., Jackson River at $\ldots \ldots \ldots \ldots \ldots$

Farmville, Va., Appomattox River at.111-112

Fayetteville, N. C., Cape Fear River

at $\ldots \ldots \ldots \ldots \ldots 169-170$

Ferguson, S. C., Santee River at...239-240

Fingerville, S. C., North Pacolet

River at............

251

Pacolet River near.........251-252

South Pacolet River Reservoir

near ..........253-254

First Broad River, near Lawndale,

N. C. . . . . . . 249-250

Fisher River, near Copeland, N. C..195-196

Fishing Creek, near Enfield, N. C... 160

Flanagan Mills, Va., Willis River at.109-110

Flat River, at and near Bahama,

N. C. . . . . . 163-164

Flood crests, records of ........ 506-534

Flood-crest stages, of late-August

flood ...........530-534

of mid-August flood....... 507-529

Flood discharges, measurements

of $\ldots \ldots \ldots \ldots 61-62 ;$ pl. 18

summary of . . . . .

Fontana, N. C., Little Tennessee

River near .......441-413

Forbush Creek, near Yadkinville,

N. C. . . . . . 197-198

Fourmile Braneh, near Southmont,

N. C. . . . . 206-207

Francisco, N. C., Dan River near. . 138-139

Freeland, N. C., Waccamaw River at 178

French Broad River, at Asheville,

N. C. .........333-334
French Broad River-Continued

Page

at Bent Creek, N. C.........331-332

at Bantyre, N. C.......... 329-330

at Calvert, N. C..........328-329

at Dandridge, Tenn. . . . . . . 339-340

at Hot Springs, N. C........335-336

at Rosman, N. C..........326-327

near Newport, Tenn. .......337-338

\section{G}

Gaffney, S. C., Broad River near. . . 244-245

Gaging-station records......63-80; pl. 19

Gainesville, Ga., Chattahoochee River

near ..........293-294

Galax, Va., New River near.......301-302

Gate City, Va., North Fork Holston

River near ......405-406

Gauley River, above Belva, W. Va...324-325

Gibsonville, N. C., Reedy Fork near. $\quad 171$

Givhans, S. C., Edisto River near.... 270

Glenlyn, Va., New River at.......309-310

Goldsboro, N. C., Neuse River near. .162-163

Goose Creek, near Huddleston, Va...134-135

Goshen, Va., Calfpasture River above

Mill Creek at....... 98

Grahams Forge, Va., Reed Creek at.315-316

Graysonton, Va., Little River at...318-319

Great Falls, S. C., Catawba River

near ..........233-236

Green River, near Mill Spring, N. C. 247-248

Greenbrier River, at Hilldale, W. Va.. 323-324

Greeneville, Tenn., Nolichucky River

near .........376-377

Greensboro, Ga., Oconee River near. 289-290

Greensboro, N. O., Buffalo Creek near 172

North Buffalo Oreek near...... 172

Greenville, N. O., Tar River at. ..... 159

Ground water, recorded data on ...502-506

$\mathbf{H}$

Halifax, Va., Banister River at....153-154

Hardware River, near Scottsville,

Va. ..........106-107

Hartford, Tenn., Pigeon River at. . 365-366

Hartwell, Ga., Tugaloo River near. . 272-273

Haw River, at Haw River, N. C.... 168 near Benaja, N. C.......... 167 near Pittsboro, N. C. . . . . . 168-169

Haw River, N. C., Haw River at.... 168

Hayesville, N. C., Hiwassee River

below ........4 438-439

Hepco, N. C., Pigeon River near. . . 364-365

High Point, N. C., East Fork Deep

River near ........ 175

West Fork Deep River near.... 173

Highlands, N. O., Cullasaja Creek at.416-417

High Rock, N. O., Yadkin River at. 183-186 Hilldale, w. Va., Greenbrier River

at $\ldots \ldots \ldots \ldots \ldots \ldots 323-324$

Hillsboro, N. C., Eno River at..... 161

Hinton, W. Va., New River near....310-311 
Hiwassee Dam, N. C., Hiwassee Reservoir at .......441-442

Hiwassee River at. . . . . . . . 442-443

Hiwassee Reservoir, at Hiwassee Dam, N. C.......441-442

Hiwassee River, above Murphy, N. C. . . . . . . 439-441

at Hiwassee Dam, N. C....... .442-443

below Hayesville, N. C. . . . . . 438-439

near Reliance, Tenn. ........ 443

Hoffman, N. C., Drowning Creek

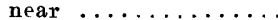

Holcombs Rock, Va., James River at Holston River, at Strawberry Plains, Tenn. ..........391-392

near Jefferson City, Tenn... . . .390-391

near Morristown, Tenn.........389-390

near Rogersville, Tenn........ . 388-389

Hookerton, N. C., Contentnea Creek at $\ldots \ldots \ldots \ldots \ldots 166-167$

Hope Mills, N. C., Rockfish Creek

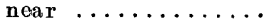

Horsepen Creek, at Battle Ground,

Hot Springs, N. C., French Broad River at ........335-336

Huddleston, Va., Goose Creek near. 134-135

Hyco River, near Omega, Va... . . . 154-155

Hydrographs of August flood.66-80, 477, 478 I

Infiltration index.......... pl. 21, 22 Iotla, N. C., Little Tennessee River

at $\ldots \ldots \ldots \ldots \ldots 408-409$

Ivanhoe, Va., New River at.......303-304 Ivy River, near Marshall, N. C.... 359-360 Ivylog, Ga., Notteley River near. . . 444-445

J

Jackson River at Falling Spring, Va. James River, at Bent Creek, Va.....

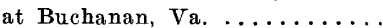

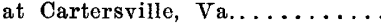

at Holcombs Rock, Va........

at Lick Run, Va............

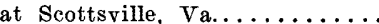

near Richmond, Va...........

James River \& Kanawha Canal, near Richmond, Va. ......

Tames River Basin, records for.... 81-114

Jefferson, N. C., South Fork New River near ........300-301

Jefferson City, Tenn., Holston River near ..........390-391

Johns Creek, at Newcastle, Va......

Jonathan Creek, near Cove Creek,

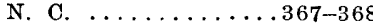

Jonesville, Va., Powell River near. . .436-437 Judson, N. C., Little Tennessee River at ...........409-411

Juniper Creek, near Cheraw, S. C..214-215

\section{$\mathbf{K}$}

Kanawha Falls, W. Va, Kanawha

River at .........312-313
Kanawha River, at Charleston,

$$
\text { W. Va. . . . . . . 313-314 }
$$

at Kanawha Falls, W. Va.....312-313

Kanawha River Basin, previous floods

in $\ldots \ldots \ldots \ldots \ldots \ldots 537-538$

records for ............300-325

Keowee River, near Newry, S. C...279-280

Kerrs Creek, near Lexington, Va....102-104 Kingsport, Tenn., South Fork Hol-

ston River at......386-387

Kingstree, S. C., Black River at.... 218

Kinston, N. C., Neuse River at..... $\quad 163$

Knoxville, Tenn., Tennessee River at.341-342

\section{I.}

Lake Greenwood, near Chappells,

S. C. . . . . . . 263-264

Lake Murray, near Columbia, S. C. . 266-267

Late-August flood, features of . . . . 12-13; pls. 10, 11, 12, 13A

Late-August storm, description of records of....45-56; pl. 17

general features of..........

Lawndale, N. C., First Broad River near ........249-250

Lawrenceville, Va., Meherrin River

near ........116-117

Leaf, Ga., Chattahoochee River near. 292-293

Leaksville, N. C., Dan River at.....140-141

Lebanon, N. C., Beaverdam Swamp at $\ldots \ldots \ldots \ldots \ldots \ldots$ 179-180

Lexington, N. C., Abbotts Creek at. .205-206 Lexington, Va., Kerrs Creek near...102-104 North River near............100-101

lick Run, Va., James River at..... 82-83 Lillington, N. C., Cape Fear River at. $\quad 169$ Lilly, W. Va., Bluestone River at. . . 322-323 Linden, N. C., Lower Little River at.176-177 Linville River, at Branch, N. C. . . . 240-241 Little Brown Creek, near Polkton,

N. C. . . . . . . 212-213

Little Pee Dee River, near Dillon,

S. ก. .........215-216

Little Pigeon River, at Sevierville, Tenn. ...........383-384

Little Raft Swamp at Red Springs,

N. C. ........ 218

Little River, at Graysonton, Va... . 318-319

Little River, near Mount Carmel,

S. C. ........284-285

Little River, near Princeton, N. C...165-166

Little River, near Walland, Tenn....406-407

Little Sugar Creek, near Charlotte,

N. C. . . . . . . 241-242

Little Tennessee River, at Calderwood, Tenn. .....413-414

at Iotla, N. C. . . . . . . .408-409

at Judson, N. C..........409-411

at McGhee, Tenn.........414-415

near Fontana, N. C.........411-413

Little Yadkin River, near Donnaha,

N. C. . . . . . 196-197

Loudon, Tenn., Tennessee River at. .342-343 Louisville, Ga., Ogeechee River near. $\quad 287$ 
Lovingston, Va., Tye River near....105-106 Lower Little River, at Linden, N. C. 176-177 at Manchester, N. C......... 176 Lumber River, at Boardman, N. C... $\quad 217$ Lyman, S. C., Middle Tyger River at 257 Lynches River, at Effingham, S. C...

215

\section{$\mathbf{M}$}

McGhee, Tenn., Little Tennessee

River at ........4414-415

Manchester, N. C., Lower Little River at ...........

Mars Bluff, s. C., Pee Dee River near ........... 193-194

Marshall, N. C., Ivy River near.... 359-360

Marshville, N. C., Richardson Creek

near ..........210-211

Martinsville, Va., Smith River at...149-150

Mattoax, Va., Appomattox River at. .112-113

Mayo River, near Price, N. C. . . . . 145-146

Meadow Creek, at Neweastle, Va..... 96

Meadowview, Va., Middle Fork

Holston River near...393-394

Maherrin River, near Lawrenceville, Va. ...........116-117

Meteorologic and hydrologic conditions during floods of August $1940 \ldots \ldots$. 15-61

Mid-August flood, features of..... 8-12 ; pls. $3,4,5,6,7,8,9$

Mid-August storm, distribution of precipitation in .... $42-45$ general features of ........ $7-8$ recorded precipitation of. $20-41 ;$ pl. 16 Middle Creek, near Clayton, N. C.... 165 Middle Fork Holston River, near Meadowview, Va. ...393-394

Middle Oconee River, near Athens,

Ga. ............291-392

Middle Swamp, near Elkton, N. C... 179

Middle Tyger River, at Lyman, S. C. . $\quad 257$

Mill Spring, N. C., Green River near. 247-248

Milledgeville, Ga., Oconee River at. . 290

Millhaven, Ga., Brier Creek at. ...286-287

Savannah River near........277-278

Mills River, near Mills River, N. C. . 349-350

Mills River, N. C., Mills River near.349-350 Mocksville, N. O., South Yadkin River near ..........200-201

Modoc, S. C., Stevens Creek near. .285-286

Moncure, N. C., Deep River at.... $\quad 174$

Montmorenci, S. C., South Fork Edisto River near....

Moore, S. C., North Tyger River near 255

Morristown, Tenn., Holston River

near . . . . . . 389-390

Nolichucky River near......377-378

Mount Carmel, S. C., Little River near ........284-285

Mount Holly, N. C., Catawba River near .........229-230

Mount Vernon, Ga., Oconee River near ...................

Mountain Creek, near Ellerbe, N. C..213-214
Mud Creek, at Naples, N. C.... . . 351-352

Muddy Creek, near Archdale, N. C... 175

Murphy, N. C., Hiwassee River

above ........4439-441

\section{$\mathbf{N}$}

Nantahala River, at Almond, N. C. .419-420 Naples, N. C., Mud Creek at. . . . . . 351-352 Narrows, Va., Wolf Creek near... . . 321-322 Nashville, N. C., Tar River near..... 157 Neuse River, at Kinston, N. C...... 163 near Clayton, N. C......... 162 near Goldsboro, N. C........162-163 near Northside, N. C......... 161

Neuse River Basin, records for.....161-167 New River, at Allisonia, Va... . . . 305-306 at Caperton, W. Va.........311-312 at Eggleston, Va..........308-309 at Glenlyn, Va............309-310 at Ivanhoe, Va............303-304 at Radford, Va...........306-307 near Galax, Va..........301-302 near Hinton, W. Va........ 310-311 Newcastle, Va., Johns Creek at..... 97 Meadow Creek at........... 96 Newdale, N. C., South Toe River at. 379-381) Newport, Tenn., French Broad River near ..........337-338

Newry, S. C., Keowee River near. . . 279--280

Niagara, Va., Roanoke River at..... 119 Noland Creek, near Bryson City, N. C. ........429-430

Nolichucky River, at Embreeville, Tenn. . . . . . . 375-376

at Poplar, N. C........... 373-374

near Greeneville, Tenn....... 376-377

near Morristown, Tenn.... . . 377-378

Norris Dam, Tenn., Clinch River below .......... 436

Norris Reservoir at.......435-436 Norris Reservoir, at Norris Dam, Tenn. . . . . . 435-436

North Buffalo Creek, near Greensboro, N. C..........

North Fork Edisto River, at Orangeburg, s. C..........

North Fork Holston River, near Gate City, Va. ......405-406

near Saltville, Va..........404-405

North Fork Jones Creek, near Wadesboro, N. C.........

North Fork New River, at Crumpler, N. C. .........314-315

North Fork Swannanoa River, near Black Mountain, N. C. 355-356

North Mayo River, near Spencer, Va..146-147 North Pacolet River, at Fingerville,

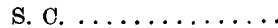

North River, at Rockbridge B.ths,

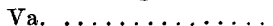

near Buena Vista, Va.......101-102 near Lexington, Va.......... 100-101 North Toe River, at Altapass, N. C.. 371-372 North Tyger River, near Moore, S. C. 255 
North Wilkesboro, N. C., Reddies

River at .........194-195

Northeast Cape Fear River, near

Chinquapin, N. C...... 178

Northside, N. C., Neuse River near.. 161

Norwood, N. C., Pee Dee River near.187-189

Rocky River near..........209-210

Norwood, Va., Buffalo River near. . 104-105

Notteley River, near Ivylog, Ga... . 444-445

near Ranger, N. C......... 445-446

Nottoway River, near Stony Creek,

Va. ..........114-115

\section{$\mathbf{0}$}

Oakdale, Tenn., Emory River at. . . .437-438

Ocoee River, at Parksville, Tenn....447-448

Oconalufty River, at Cherokee, N. C. .427-429

Oconee River, at Dublin, Ga....... 290-291

at Milledgeville, Ga......... 290

near Greensboro, Ga......... 289-290

near Mount Vernon, Ga....... 291

Ogeechee River, at Scarboro, Ga..... $\quad 288$

near Eden, Ga.............288-289

near Louisville, Ga......... 287

Ogeechee River Basin, records for. . 287-289

Ohoopee River, near Reidsville, Ga...

Omega, Va., Hyco River near....154-155

Orangeburg, S. C., North Fork Edisto

River at ...........

Otter River, near Evington, Va. ....135-136

\section{$\mathbf{P}$}

Pacolet River, near Clifton, S. C.... near Fingerville, S. C. . . . . 251-252

Palmyra, Va., Rivanna River at... . 108-109

Pamlico River Basin, records for....156-160

Parksville, Tenn., Ocoee River at. .447-448 Parksville Reservoir at.......

Parksville Reservoir, at Parksville,

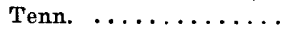

Parr, Va., Craig Creek at......... 447

Patterson, N. C., Yadkin River at...180-181

Pee Dee River, near Ansonville, N. C..189-190 near Mars Bluff, S. C......... 193-194 near Norwood, N. C......... 187-189 near Rockingham, N. C....... 191-193

Pee Dee River Basin, records for. . . 180-218 Pelzer, S. C., Saluda River near.....261-262 Petersburg, Va., Appomattox River near ..........113-114

Pigeon River, at Canton, N. C.....362-363 at Hartford, Tenn.......... . 365-366 near Hepco, N. C. . . . . . . . . . 364-365

Pigg River, near Toshes, Va.......131-132

Pittsboro, N. C., Haw River near...168-169

Polkton, N. C., Brown Creek near...211-212 Little Brown Creek near.......212-213

Poplar, N. C., Nolichucky River at..373-374 Potts Creek, near Covington, Va..... 92-93 Powell River, near Jonesville, Va...436-437 Precipitation, records of ........ 20-61 Previous floods, records of. See under name of basin.
Price, N. C., Mayo River near.....145-146 Princeton, N. O., Little River near. .165-166

\section{$\mathbf{Q}$}

Queen Shoals, W. Va., Elk River at.

\section{$\mathbf{R}$}

Radford, Va., New River at......306-307

Rainfall and associated direct runoff. 481-488

Rainfall rates, maximum, compared with maximum discharges ......4499-502

Rainfall volumes, maximum, compared with maximum discharges ......4499-502

Rainfall-runoff relations, discussion of data from. . . . . .489-493 inventory of $\ldots \ldots \ldots \ldots \ldots \ldots 497-499$ methods of analysis of . . . . .476-488; pls. 16,17

variation in, during mid-August storm .........493-495

Ramseur, N. C., Deep River at..... 174 Randleman, N. C., Deep River near.. 173 Ranger, N. C., Notteley River near. 445-446 Red Springs, N. C., Little Raft Swamp at $\ldots \ldots \ldots \ldots \ldots$

Reddies River, at North Wilkesboro,

N. C. . . . . . . 194-195

Reed Creek, at Grahams Forge, Va...315-316

Reedy Creek, near Yadkin College,

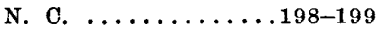

Reedy Fork, near Gibsonville, N. C. 171 Reedy River, near Ware Shoals,

S. C. . . . . . 268-269

Reidsville, Ga., Ohoopee River near. 292 Reidsville, S. C., South Tyger River near .......257-258

Reliance, Tenn., Hiwassee River near 443 Reservoirs, storage in........473-476 Rhodhiss, N. C., Catawba River at...221-222 Richardson Creek, near Marshville,

N. C. $\ldots \ldots \ldots \ldots \ldots 210-211$

Richmond, Va., James River \&

Kanawha Canal near.

111

James River near. . . . . . . . . 90-91

Richtex, S. C., Broad River at.....246-247

Rivanna River, at Palmyra, Va......108-109 Roan Creek, at Butler, Tenn........402-403

Roanoke, Va., Roanoke River at...117-118 Roanoke Rapids, N. C., Roanoke

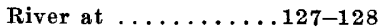

Roanoke River, at Altavista, Va.....121-122 at Brookneal, Va..........123-124 at Clarksville, Va..........126-127 at Niagara, Va........... 119 at Roanoke, Va...........117-118 at Roanoke Rapids, N. C. . . . 127-128 near Clover, Va...........124-125 near Scotland Neck, N. C.......128-129 near Toshes, Va...........120-121

Roanoke River Basin, previous floods.536-537 records for ..........117-155 
Rob,oins, N. C, Bear Creek at..... 175-176

Rock Hill, S. C., Catawba River near. 231-232

Rockbridge Baths, Va., North River at $\ldots \ldots \ldots \ldots \ldots$.

Rockfish Creek, near Hope Mills, N. C. . . . . . . . 99

Rockingham, N. C., Pee Dee River near ..........191-193

Rocky River, at Turnersburg, N. O..203-204

near Norwood, N. C. . . . . . . 209-210

Rogersville, Tenn., Holston River near ..........388-389

Roseland, N. C., Deep Creek near... 217

Rosman, N. C., French Broad River at $\ldots \ldots \ldots \ldots \ldots 326-327$

Sago, Va., Snow Creek at........

Saltville, Va., North Fork Holston

River near .......404-405

Saluda River, at Chappells, S. C...264-265

near Columbia, S. C.........267-268

near Pelzer, S. C..........261-262

near Silverstreet, S. C...... 265-266

near Ware Shoals, S. C.......262-263

Sandy River, near Danville, Va....152-153

Santee River, at Ferguson, S. C... . .239-240

Santee River Basin, records for. . . .219-269

Savannah River, at Augusta, Ga....276-277

near Calhoun Falls, S. C......274-275

near Clyo, Ga...........278-279

near Millhaven, Ga........277-278

Savannah River Basin, records for . 271-287

Scarboro, Ga., Ogeechee River at....

288

Scotland Neck, N. C., Roanoke River near ........128-129

Scott Creek, at Sylva, N. C.......425-427

Scottsville, Va., Hardware River

near ..........106-107

James River at. . . . . . . . 87-88 Second Broad River, at Cliffside,

N. C. . . . . . . .248-249

Seneca River, near Anderson, S. C...281-282 Sevierville, Tenn., Little Pigeon River

at $\ldots \ldots \ldots \ldots \ldots 383-384$

Silverstreet, S. C., Saluda River near , 265-266

Sioux, N. C., Cane River near. . . . 381-382

Slate River near Arvonia, Va......107-108

Slides, features of ........14, pl. 13B,

Smith River, at Bassett, Va........148-149

at Martinsville, Va.........149-150

at Spray, N. C.............150-151

Snow Creek, at Sago, Va........ 133

Soque River, near Demorest, Ga.... 298-299

South Boston, Va., Dan River at... 144-145

South Chickamauga Creek, near

Chickamauga, Tenn. . .448-449

uth Fork Edisto River, near

Denmark, S. C.....269-270

near Montmorenci, S. C....... 269

nuth Fork Holston River, at Bluff

City, Tenn. ......385-386

at Kingsport, Tenn......... 386-387

at Vestal, va............384-385
South Fork Mills River, at The Pink

Beds, N. C. . . . . 347-348

South Fork New River, near Jefferson,

N. C. ..........300-301

South Pacolet River Reservoir, near

Fingerville, S. C....253-254

South Toe River, at Newdale, N. C...379-380

South Tyger River, near Reidville,

S. C. ........257-258

near Woodruff, S. C........258-259

South Yadkin River, at Cooleemee,

N. C. . . . . . . 201-203

near Mocksville, N. C.......200-201

Southmont, N. C., Fourmile Branch

near ........206-207

Speers Ferry, Va., Clinch River at..432-433

Spencer, Va., North Mayo River near.146-147

Spray, N. C., Smith River at. ......150-151

Stackhouse, N. C., Big Laurel Oreek near .......... 361

Station description, form described. . 65-66 Stevens Creek, near Modoc, S. C....285-286 Stony Creek, Va., Nottoway River near .........114-115

Strawberry Plains, Tenn., Holston River at .........391-392

Stump Knob, Tenn., Watauga River at $\ldots \ldots \ldots \ldots \ldots 396-397$

Sugar Grove, N. O., Watauga River near ..........394-395

Swannanoa, N. C., Beetree Creek near ..........357-358

Swannanoa River, at Biltmore, N. C..353-354 Sweetwater Creek, near Austell, Ga..299-300 Sylva, N. C., Scott Creek at. . . . 425-427

\section{$\mathbf{T}$}

Tar River, at Greenville, N. C...... 159

at Tarboro, N. C.......... 158

near Nashville, N. C........ 157

near Tar River, N. C........ 156

Tar River, N. C., Tar River near. ... 156

Tarboro, N. C., Tar River at...... 158

Tarheel, N. C., Cape Fear River near. $\quad 170$

Taylorsville, N. C., Catawba River near .........223-224

Tazewell, Tenn., Clinch River above and near .......433-435

Tellico Plains, Tenn., Tellico River at $\ldots \ldots \ldots \ldots 430-431$

Tellico River, at Tellico Plains, Tenn. . . . . . . 430-431

Tennessee River, at Chattanooga Tenn. ..........344-345

at Knoxville, Tenn.........341-342

at Loudon, Tenn........... . 342-343

Tennessee River Basin, previous floods in ........539-546

records for ........... 326-449 The Pink Beds, N. O., South Fork Mills River at. . . . . 347-348

Third Creek, at Cleveland, N. C.... 205 Tomotla, N. C., Valley River at. . . . 443-444 Toshes, Va., Pigg River near......131-132

Roanoke River near.........120-121 
Trinity, N. C., Uwharrie River near.207-208 Tuckasegee, N. C., Tuckasegee River

$$
\text { at .........421-422 }
$$

Tuckasegee River, at Bryson City,

N. C. . . . . . . . 424-425

at Dillsboro, N. C.........422-423

at Tucksegee, N. C. . . . . . .421-422

Tugaloo River, near Hartwell, Ga... .272-273

Turnersburg, N. C., Rocky River at. .203-204

Tye River, near Lovingston, Va.... 105-106

Tyger River, near Woodruff, S. C...

256

\section{U}

Union, S. C., Fair Forest Creek near.259-260

Union Hall, Va., Blackwater River near ..........130-131

Unit discharges, features of ....... 473

Uwharrie River, near Eldorado, N. C..208-209 near Trinity, N. C.........207-208

\section{V}

Valley River, at Tomotla, N. C. . . . 443-444

Vestal, Va., South Fork Holston River at $\ldots \ldots \ldots \ldots \ldots 384-385$

Vinings, Ga., Chattahoochee River near ............. 295

$\mathbf{W}$

Waccamaw River, at Freeland, N. C.. 178

Waccamaw River Basin, records for.178-180 Wadesboro, N. C., North Fork Jones Creek near ......... 214

Walker Creek, at Bane, Va........319-320

Walland, Tenn., Little River near...406-407
Ware Shoals, S. C., Reedy River near. $26 \frac{7}{2}$

Saluda River near.........262,

Watanga River, at Butler, Tenn.....398-3. ,

at Elizabethton, Tenn. ......400-41.

at Horseshoe Dam, at Wilbur,

Tenn. ........399-400

at Stump Knob, Tenn........396-397

near Sugar Grove, N. C. . . . . 394-395

Wateree River near Camden, S. C. . .237-239

Wentworth, N. C., Dan River near. . 139-14n

West Fork Deep River, near High

Point, N. C..........

West Point, Ga., Chattahoochee River at $\ldots \ldots \ldots \ldots \ldots$.

Whitesburg, Ga., Chattahoochee River

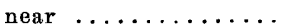

Wilbur, Tenn., Watauga River at Horseshoe Dam at. . .399-46:

Wilkesboro, N. C., Yadkin River at..181-18: Willis River, at Flanagan Mills, Va..109-11) Wilson, N. C., Contentnea Creek near 166 Wolf Creek, near Narrows, Va... . 321-322 Woodruff, S. C., South Tyger River near .........258-259

Tyger River near......... 256

\section{$\mathbf{Y}$}

Yadkin College, N. C., Reedy Creek near ..........198-199 Yadkin River at. . . . . . . 182-183 Yadkin River, at High Rock, N. C. . 183-186 at Patterson, N. C..........180-181 at Wilkesboro, N. C........181-182 at Yadkin College, N. C.......182-183 near Badin, N. O.......... 186-187 Yadkinville, N. C., Forbush Creek near .........197-198 





